\title{
Global Food Value Chains and Competition Law BRICS Draft Report
}

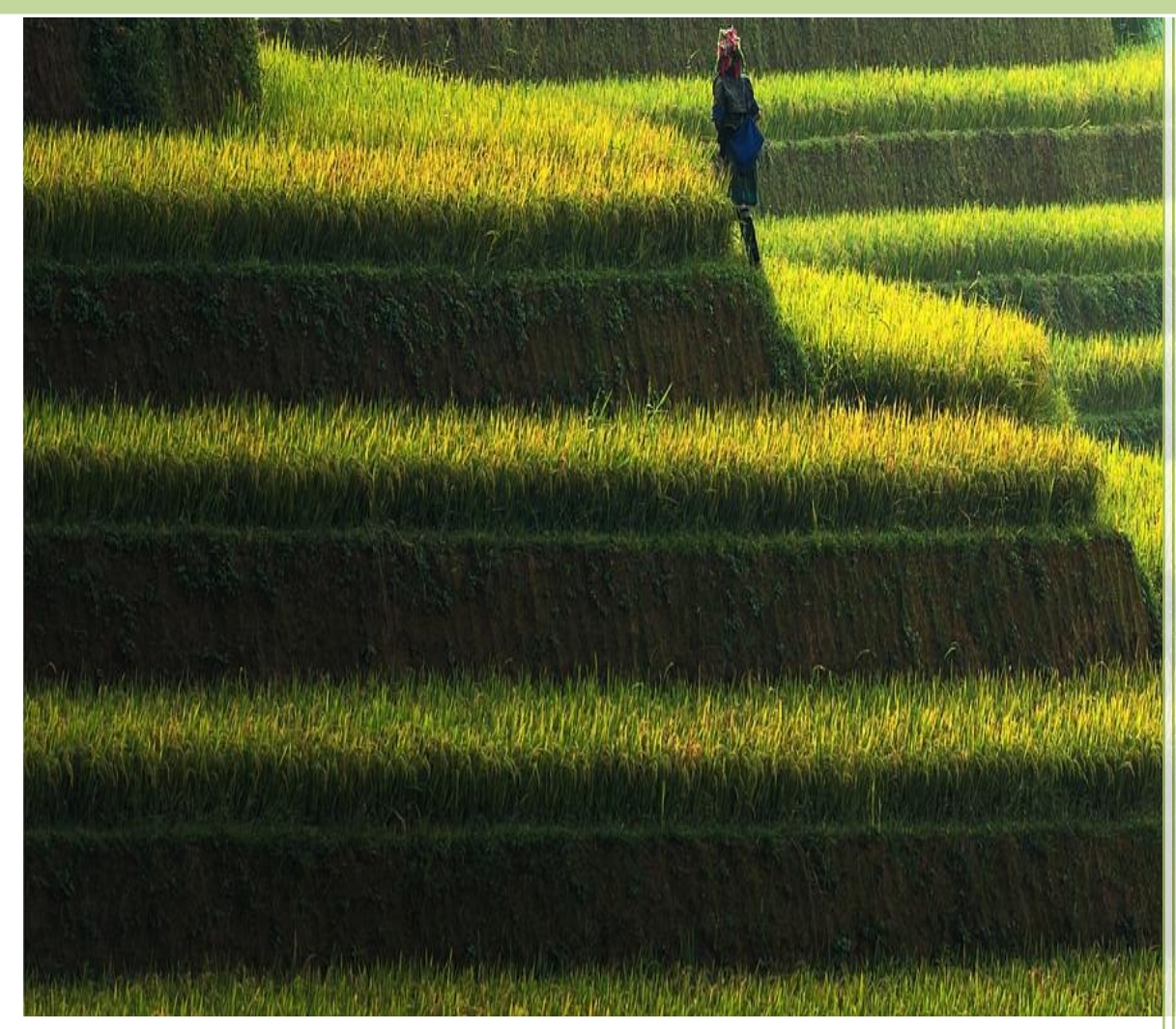

Principal

Investigator:

Professor Ioannis

Lianos 


\section{Work in progress}

Do not cite or use without prior explicit authorisation for each use by the contact author

For citations and further questions please first contact the Principal Investigator Prof. Ioannis Lianos (UCL, HSE Skolkovo), i.lianos@ucl.ac.uk

Updated versions of the Report will be available at https://www.ucl.ac.uk/cles/cles-research paper-series 
Centre for Law, Economics and Society

\author{
CLES \\ Faculty of Laws, UCL
}

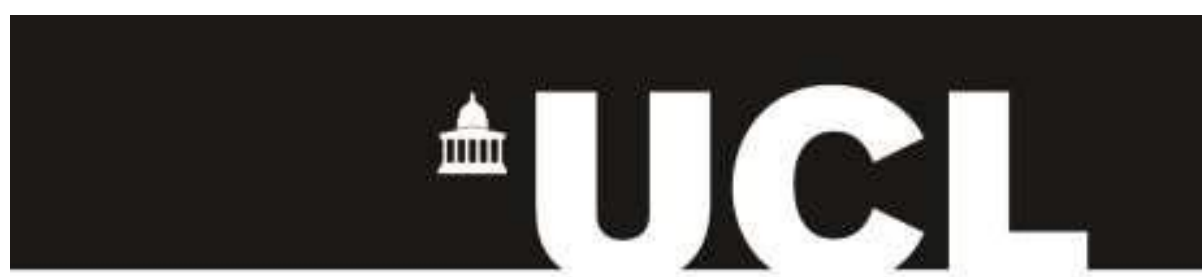

\title{
LAW, ECONOMICS \& SOCIETY
}

HSE Skolkovo Institute for Law and Development Higher School of Economics

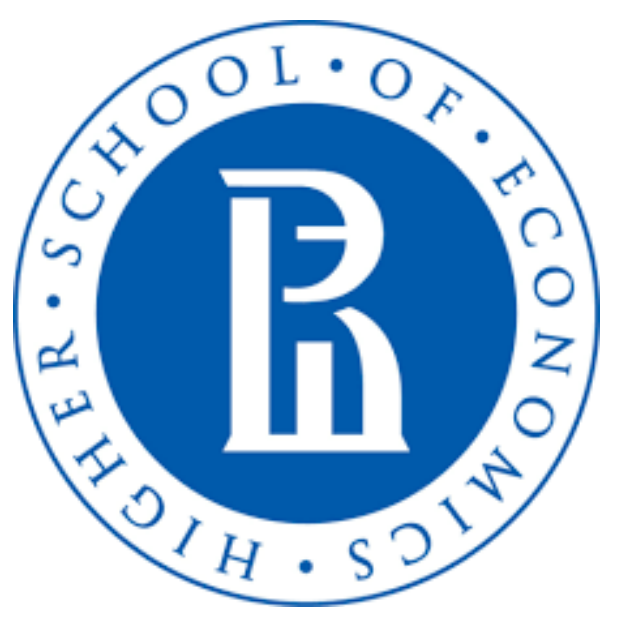

November 2017, updated January 2018 
Ioannis Lianos et al @ 2017 


\section{Table of Contents}

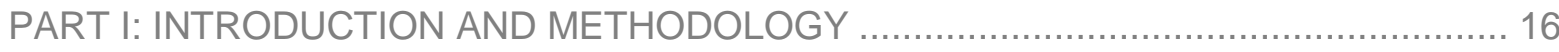

CHAPTER 1: DEVELOPING TOOLS TO DEAL WITH THE COMPLEXITY OF THE FOOD SECTOR....................28

1.1. Introducing the Global Value Chain concept in Competition Law and Policy.................. 30

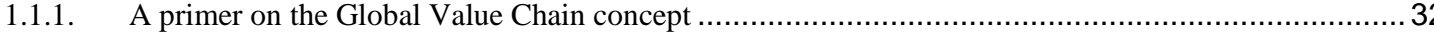

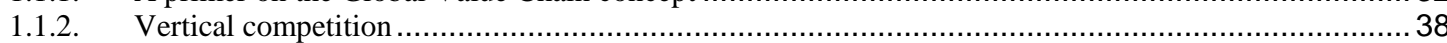

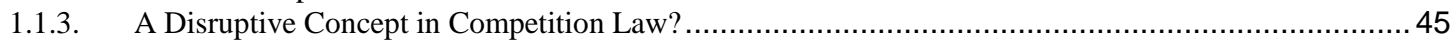

1.1.3.1. The received view on vertical integration/quasi-integration........................................... 46

1.1.3.2. The disruptive potential of GVCs for competition law \& policy on vertical restraints ...............52

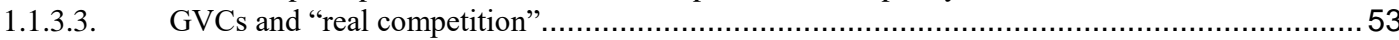

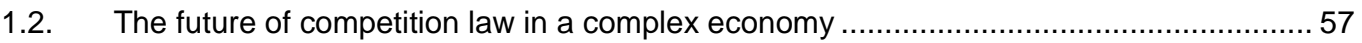

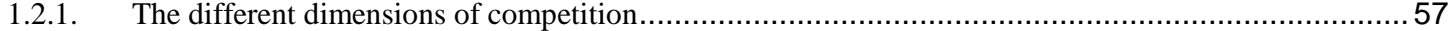

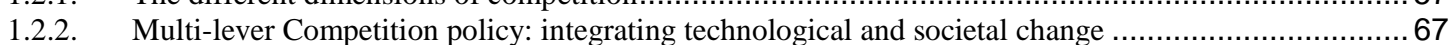

Chapter 2: The Transformations of the Global Food Value Chains: Technology and Societal

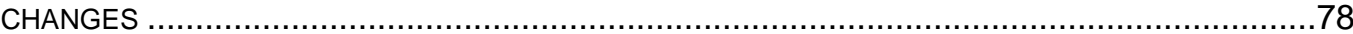

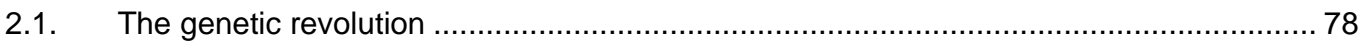

2.2. Digital revolution in food production and the convergence of genetics and digital technologies: the emergence of FoodTech

2.3. The emergence of new consumer trends and technologies: fair trade, organic food, e and mcommerce.

88

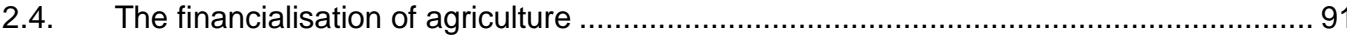

PART II: GLOBAL FOOD VALUE CHAIN(S): GENERAL PRESENTATION ................... 102

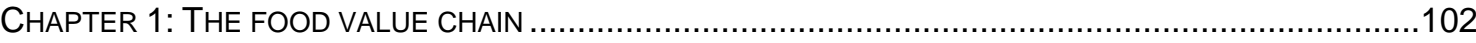

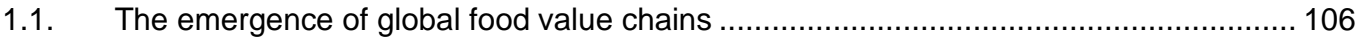

1.2. Specific sectors (examples and discussion per jurisdiction) ..................................... 107

1.3. Global/transnational value chains, power relations and the need for advanced network analysis 110

CHAPTER 2: THE VARIOUS SEGMENTS OF THE FOOD VALUE CHAIN: A GENERAL ACCOUNT

120

2.1. Cost structure and global food value chains ......................................................... 120

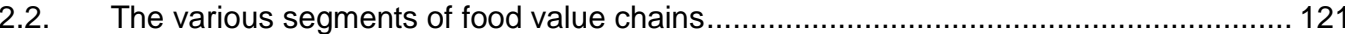

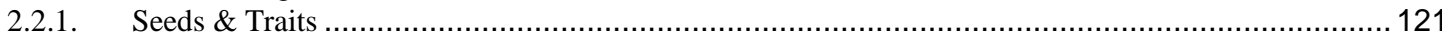

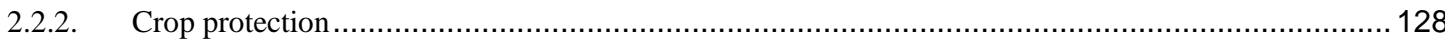

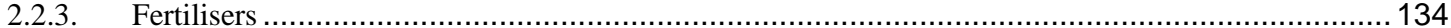

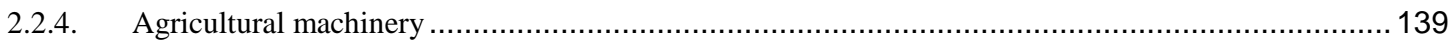

2.2.4.1. The evolution of the agricultural machinery market................................................... 139

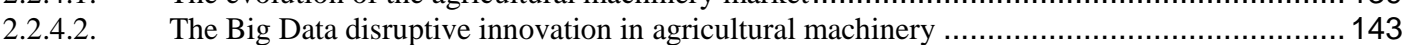

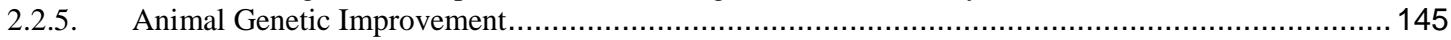

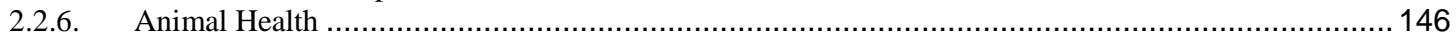

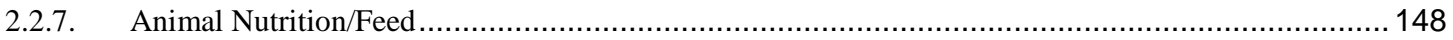

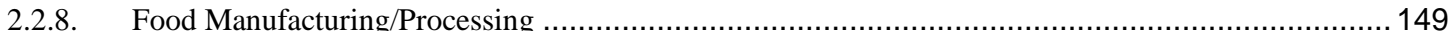

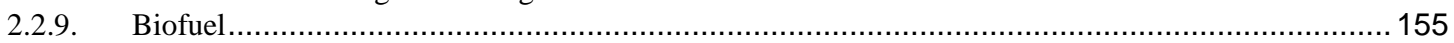

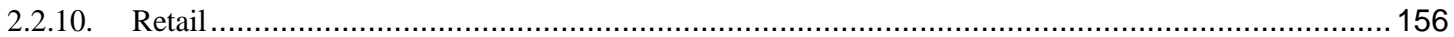

2.3. Economic concentration and the emergence of industry global leaders ..................... 168

2.3.1. Business Strategy: a focus on the factors of production segment of the food value chain................. 168

2.3.2. The emergence of global actors across the food value chain .................................................. 173 
1.1. Polycentric competition law ........................................................................... 190

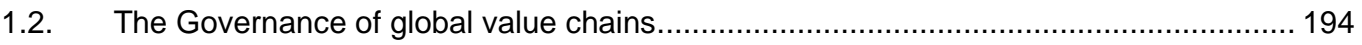

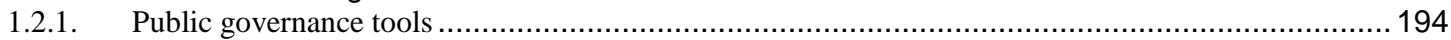

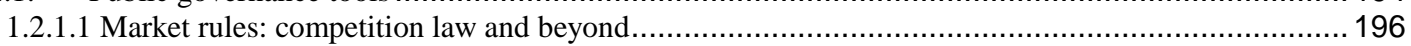

1.2.1.2. Self-regulation or mixed public-private regulation, standard setting ........................................... 198

1.2.1.3. Planning law, restrictions concerning trading hours and paternalistic regulation............................. 201

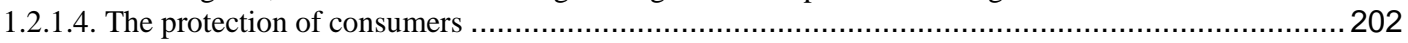

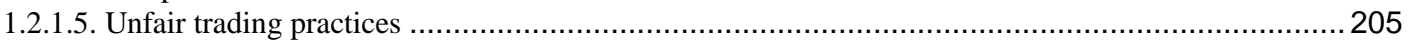

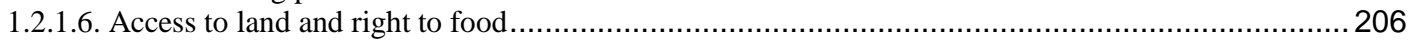

1.2.1.7. Sustainability, environmental protection and biodiversity .................................................. 212

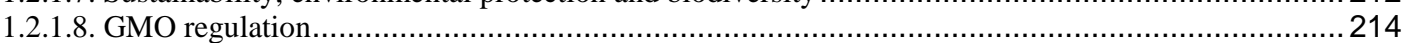

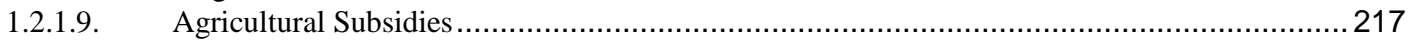

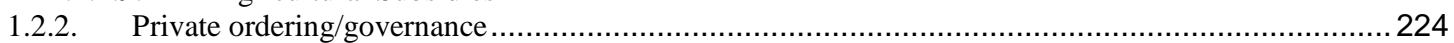

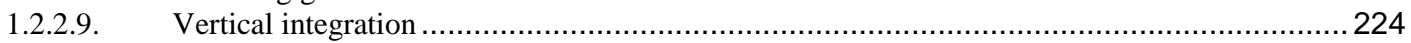

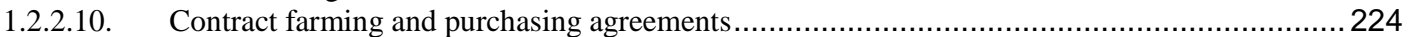

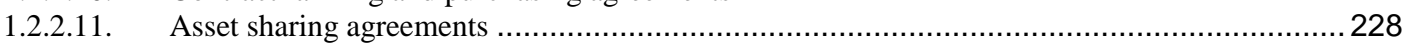

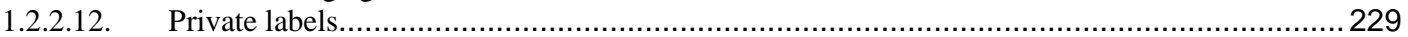

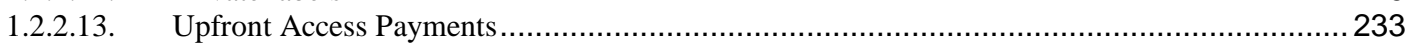

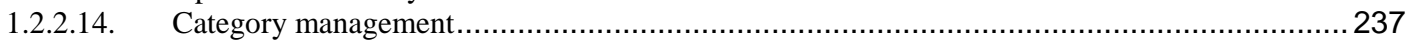

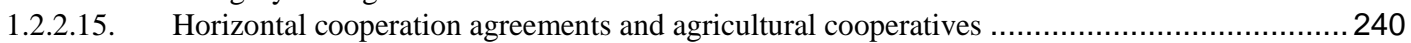

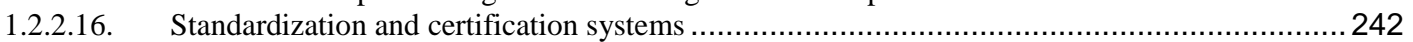

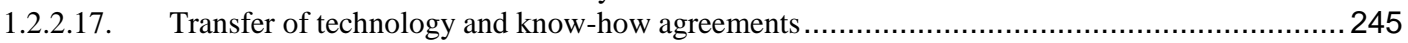

\section{CHAPTER 2: COMPETITION LAW ENFORCEMENT ACTIVITY IN BRICS AND THE FOOD VALUE CHAIN .....255}

2.1. The enforcement activity of the BRICS competition authorities in the food sector.............. 255

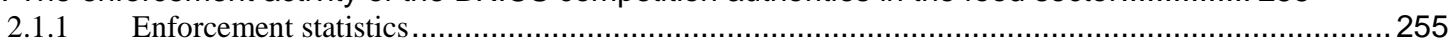

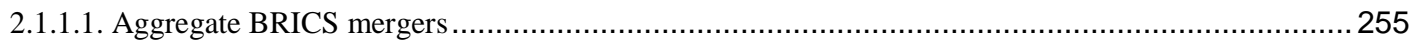

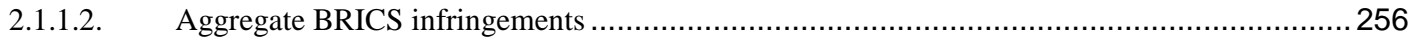

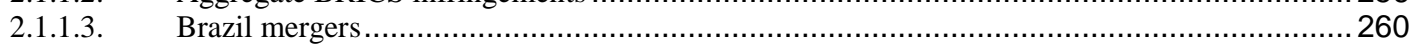

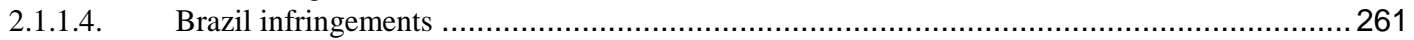

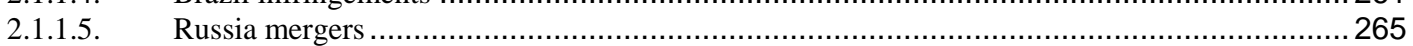

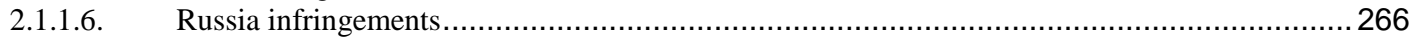

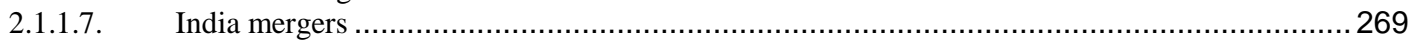

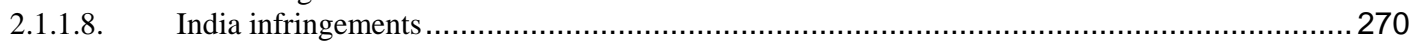

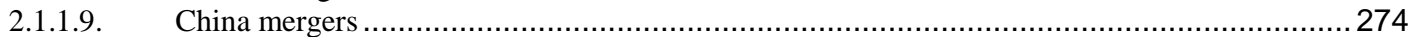

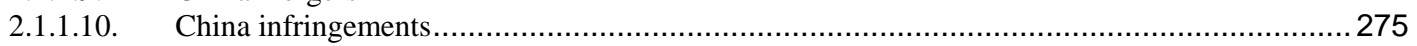

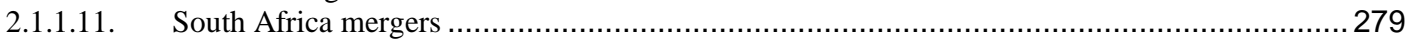

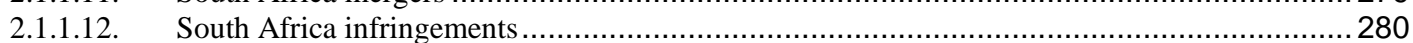

2.1.2. A bestiary of competition law enforcement interventions in the food sector in BRICS ....................... 283

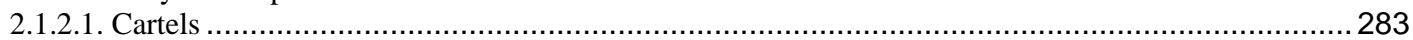

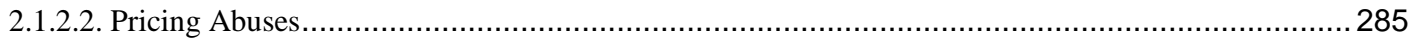

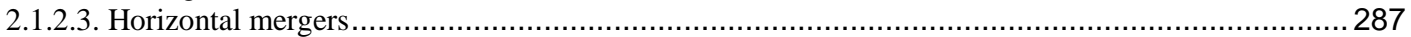

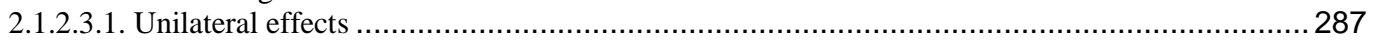

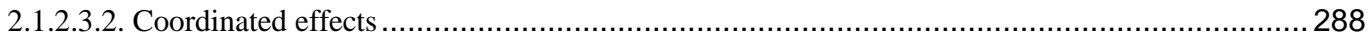

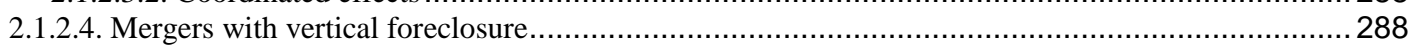

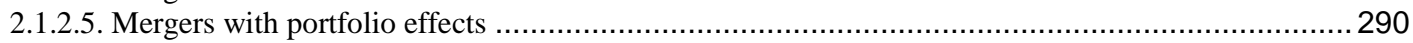

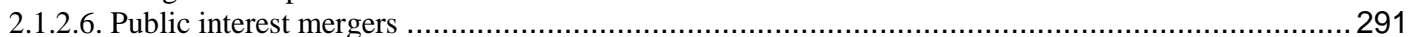

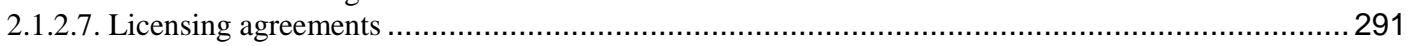

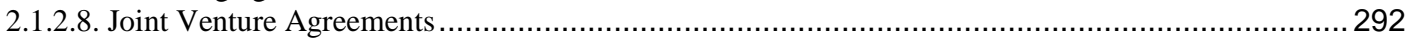

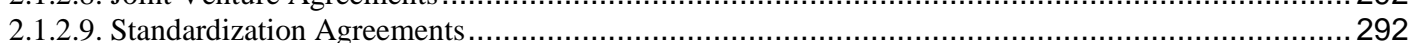

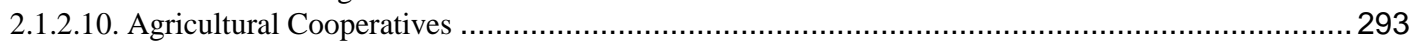

2.2. A comparative analysis of the competition assessment of some recent merger transactions in the

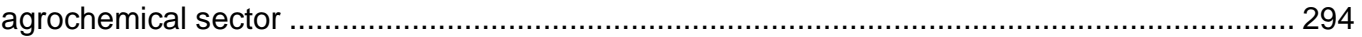

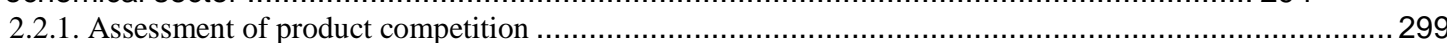

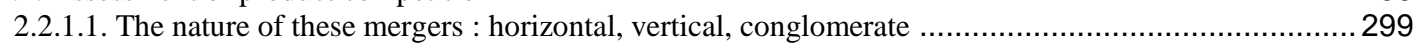

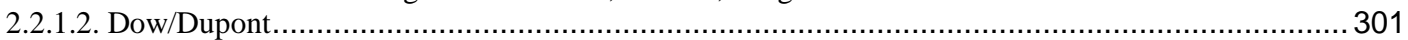

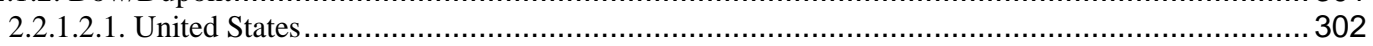

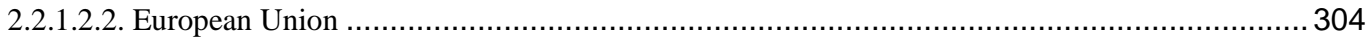

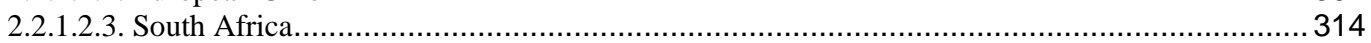

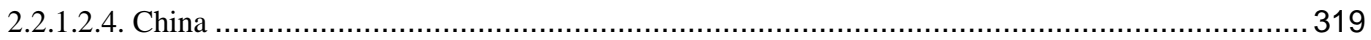

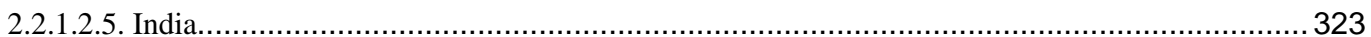

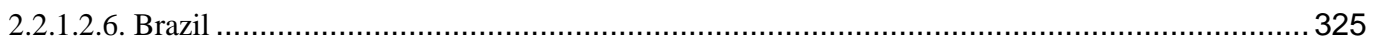

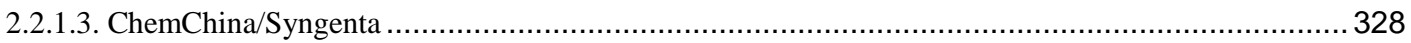




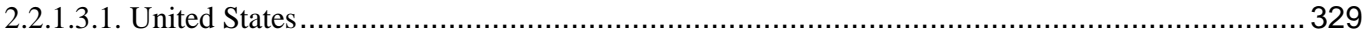

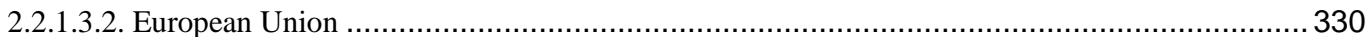

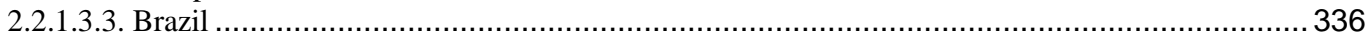

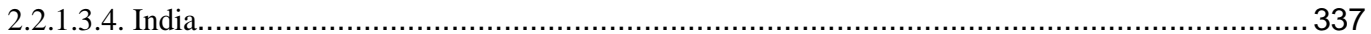

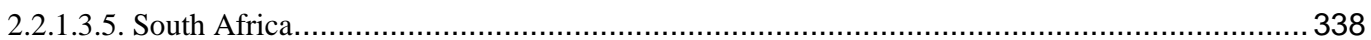

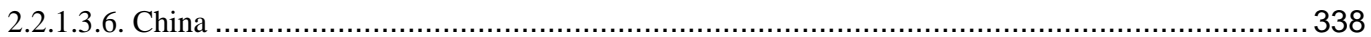

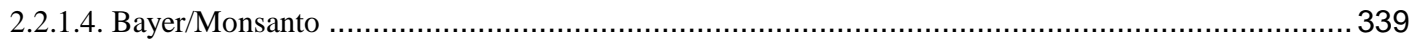

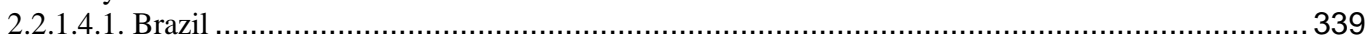

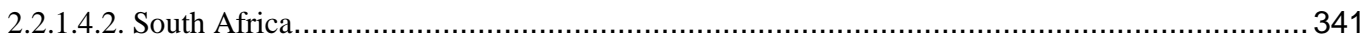

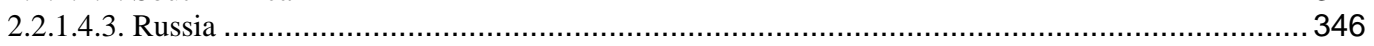

2.2.2. Non-conventional merger assessment: Innovation competition and broader public interest concerns ........ 348

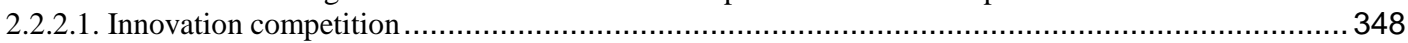

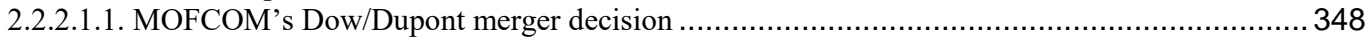

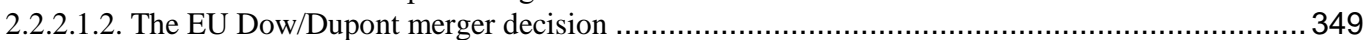

2.2.2.1.3. The Competition Commission's of South Africa Bayer/Monsanto case .............................. 357

2.2.2.1.4. The Russian FAS Bayer/Monsanto decision ................................................................. 358

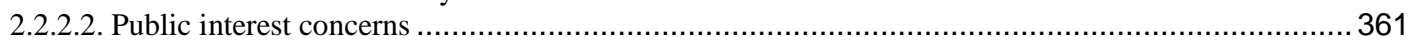

2.3. Case study: The Dow Chemical Company/DuPont merger case in Brazil: anatomy of a competition assessment .... 362

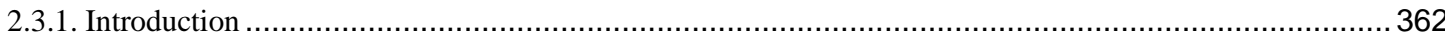

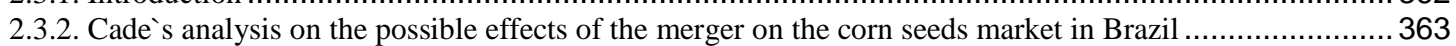

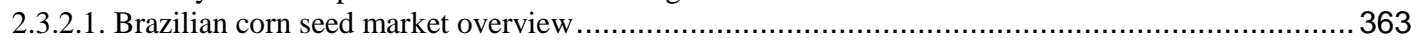

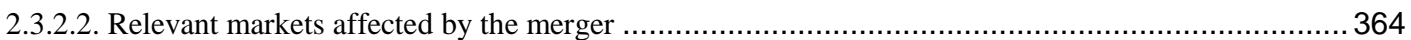

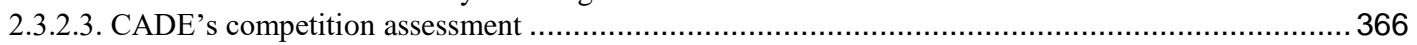

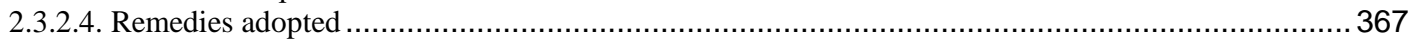

CHAPTER 3: SUPERIOR BARGAINING POWER AND THE BOUNDARIES OF COMPETITION LAW ..............369

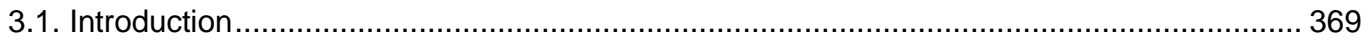

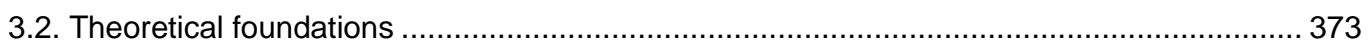

3.3. Superior bargaining power and competition law and policy in the food sector.................. 384

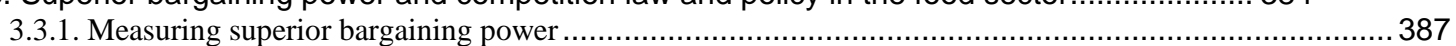

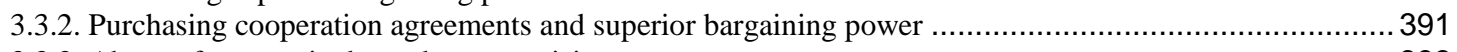

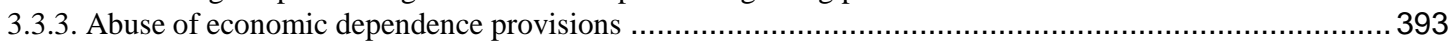

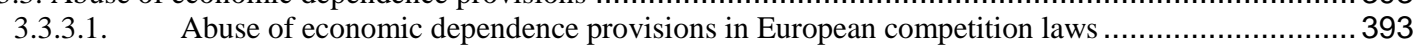

3.3.3.2. Abuse of economic dependence in BRICS ............................................................. 398

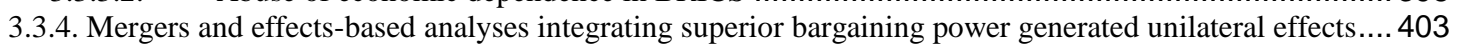

3.3.5. Dealing with Superior Bargaining power outcomes (price discrimination) via specific legislation of general

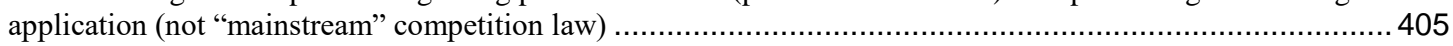

3.3.6. Opening up the floodgates? Unfair commercial practices as a competition law issue .......................... 410

3.3.7. Status-based protections of specific groups from superior bargaining power competition law ............... 416

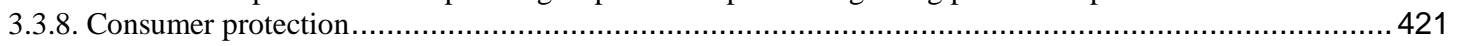

3.4. Beyond competition law: Superior bargaining power and the food value chain (contract law, unfair

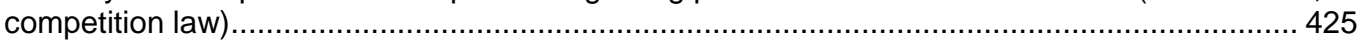

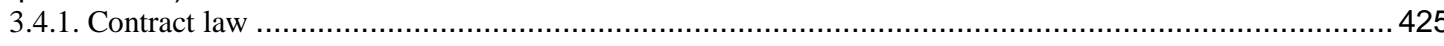

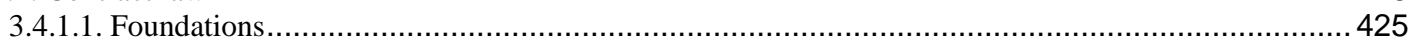

3.4.1.2. The many facets of superior bargaining power in contract law .......................................... 427

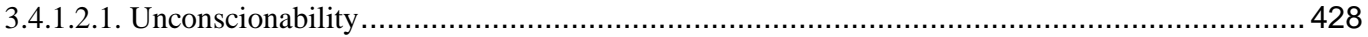

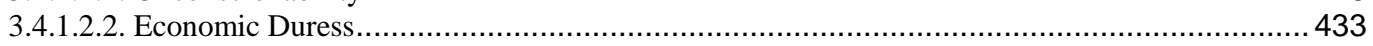

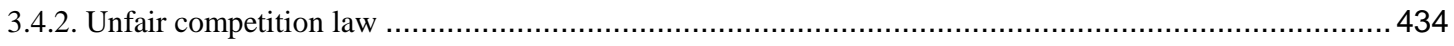

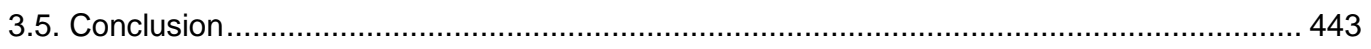

CHAPTER 4: FINANCIALISATION OF THE FOOD CHAIN, COMMON OWNERSHIP AND COMPETITION LAW ..454

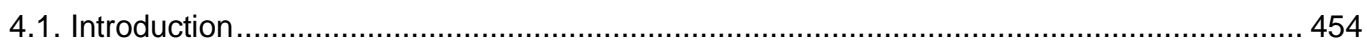

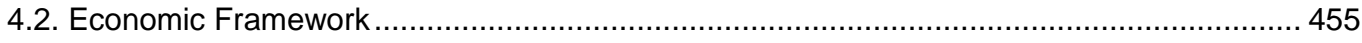

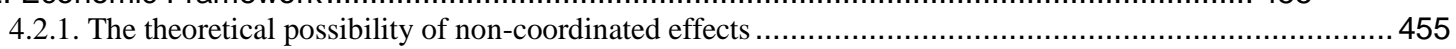

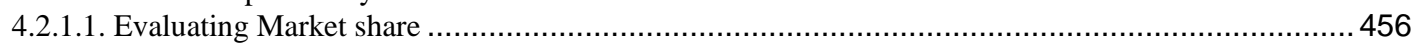

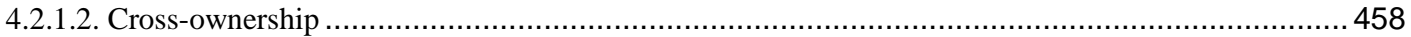

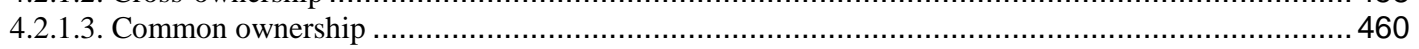

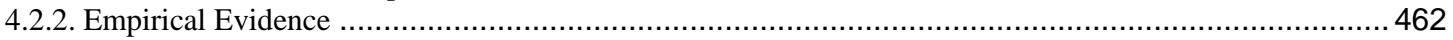

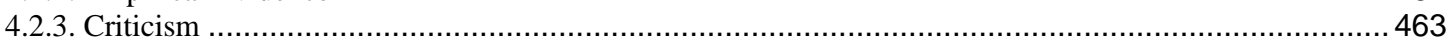

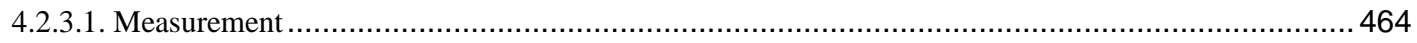

4.2.3.2. Methodology of the empirical estimation of links between common ownership and prices .............. 464 
4.2.3.3. Possibility of the undecoordinated effect of common ownership feeding into the coordinated effect on

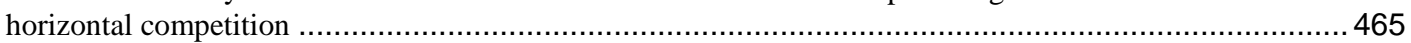

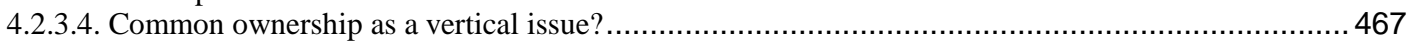

4.2.3.4.1 Mechanisms of a classic foreclosure in vertical market structure ..................................... 468

4.2.3.4.2 Empirical evidence on possible vertical exploitation from the food value chain .................... 473

4.2.3.4.3. Effect of margin squeeze on long-term sustainability ............................................... 474

4.2.3.4.4. Evaluating the effects of financialisation on the economy: evidence and controversy .......... 476

4.2.3.5. Common ownership and coordinated effects........................................................... 479

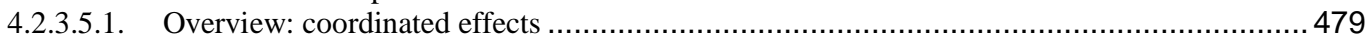

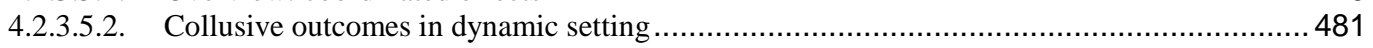

4.2.3.5.3. Challenges to the model of collusive outcome ...................................................... 482

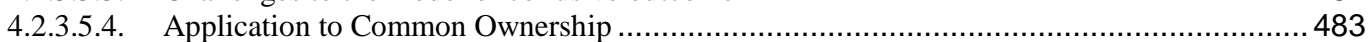

4.2.3.5.5. Partial Ownership Increasing the Parameter of Attractiveness of Long-Run Collusive Outcome 484

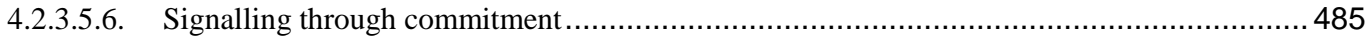

4.2.3.5.7. Application of signalling through commitment to common ownership .......................... 486

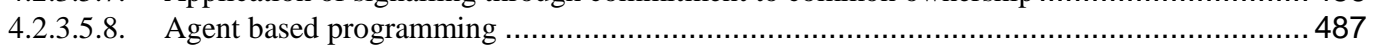

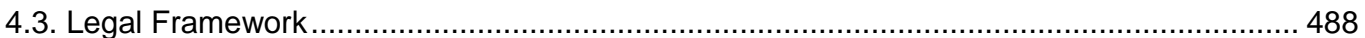

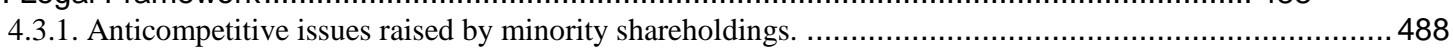

4.3.2. The competition law framework for common ownership: a work in progress ................................... 496

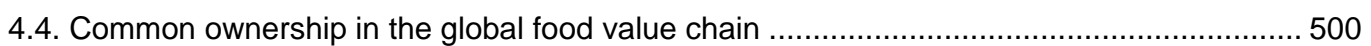

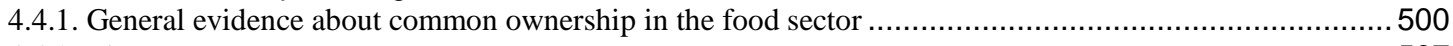

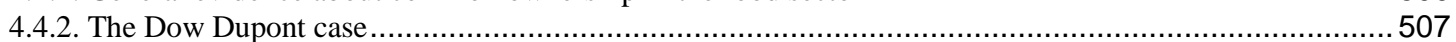

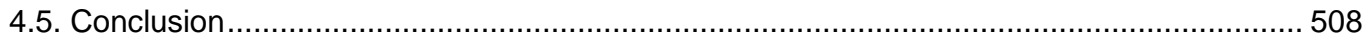

PART IV: INNOVATION AND COMPETITION IN AGRICULTURE ............................ 516

CHAPTER 1: THE INTERACTION BETWEEN COMPETITION LAW AND IP RIGHTS ..................................516

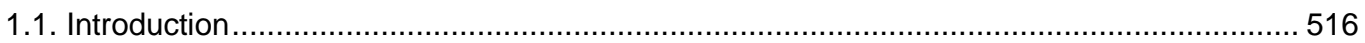

1.2. The expansion of intellectual property rights and the food value chain ............................5 516

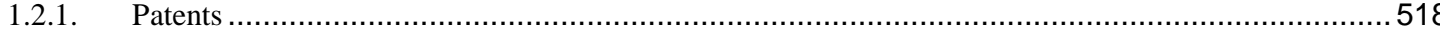

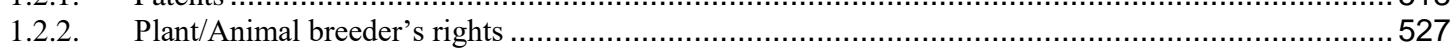

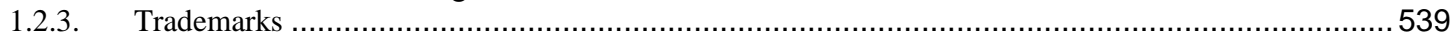

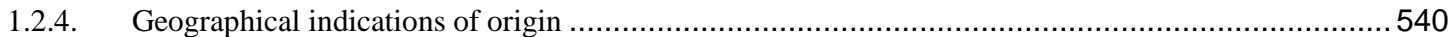

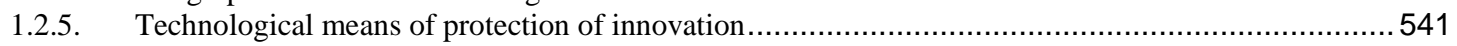

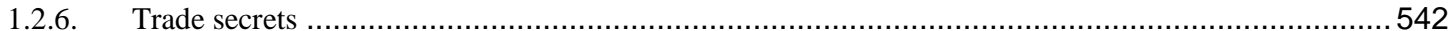

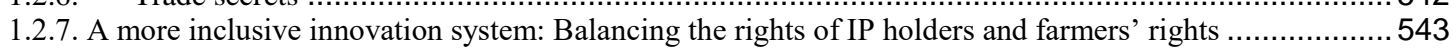

1.2.8. The rise of patents versus other forms of IP protection for private investment in agricultural research .....549

1.2.9. The governance of the innovation process: inter-business arrangements ....................................551

1.2.10. The governance of the innovation process: knowledge commons ..........................................555

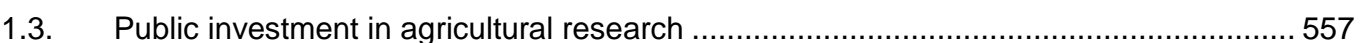

1.4. The interaction between competition law and IP: how much room do competition law enforcers have in the innovation space? 560

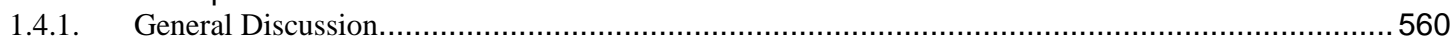

1.4.2. General principles on the interaction between competition law and IP law ................................567

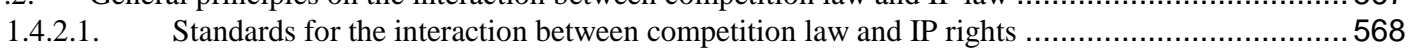

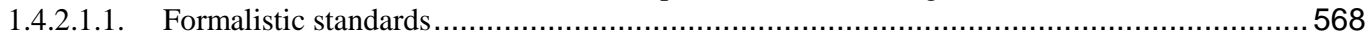

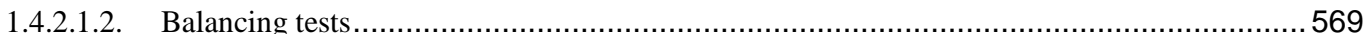

1.4.2.1.3. New standards for restrictions to innovation competition? ....................................... 571

1.4.3. The interaction between competition law and IP rights in BRICS ......................................... 582

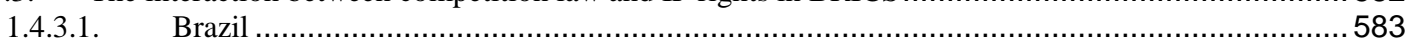

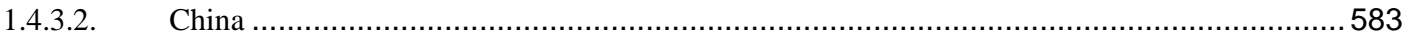

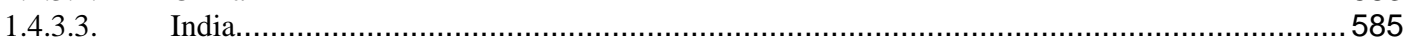

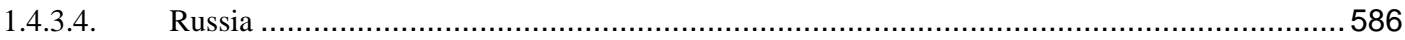

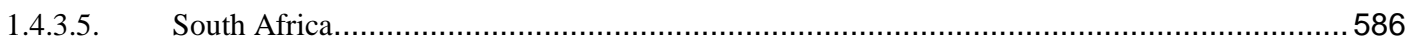

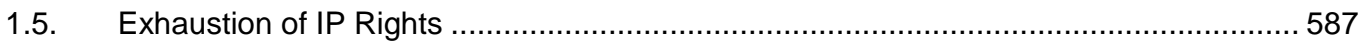

ChaPter 2: MERgers ANd Product InNOVATION: SEEdS AND GM Crops ...............................602

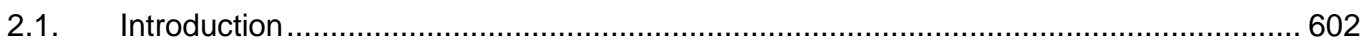

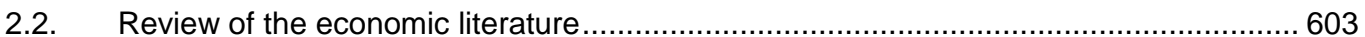




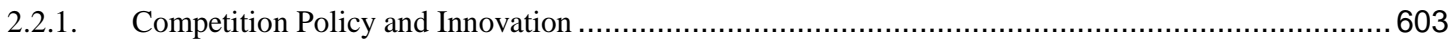

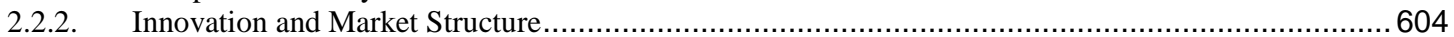

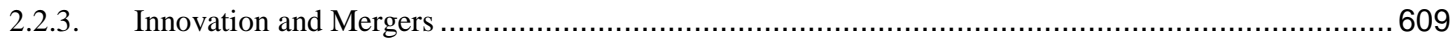

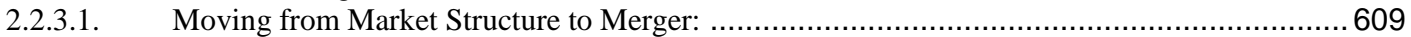

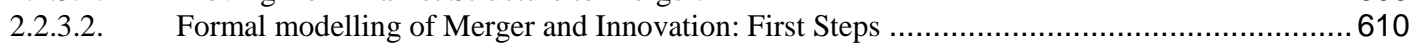

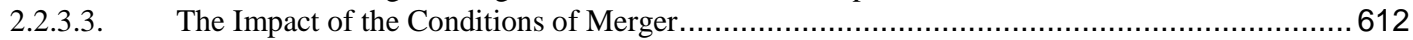

2.2.3.4. The Ambiguous Results of the Empirical Work on Merger and Innovation ..........................613

2.2.3.5. Which market should competition policy be concerned about? .....................................614

2.2.4. Approaching Merger and Innovation with Some Key Principles............................................... 614

2.3. Main economic effects and a proposed typology .................................................. 616

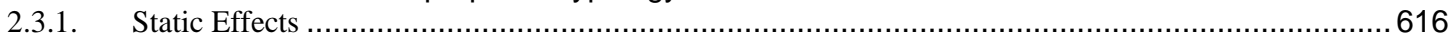

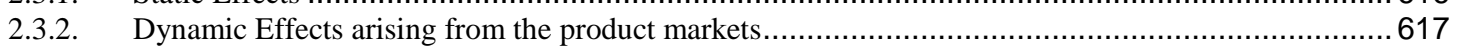

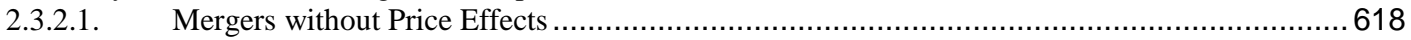

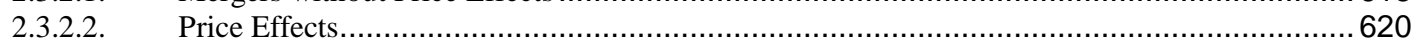

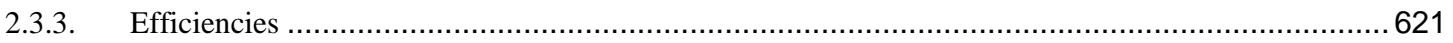

2.3.3.1. Economies of scale and Complementarities in the Innovation Markets ..............................621 621

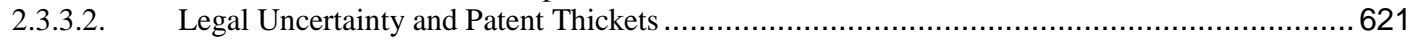

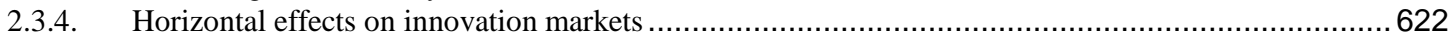

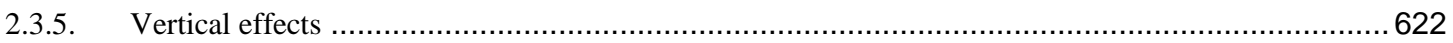

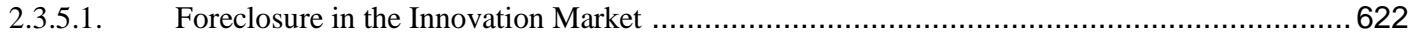

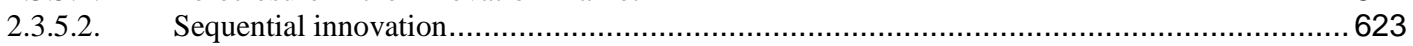

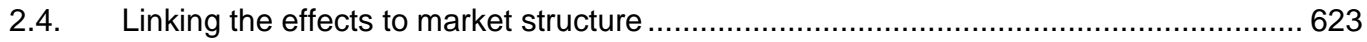

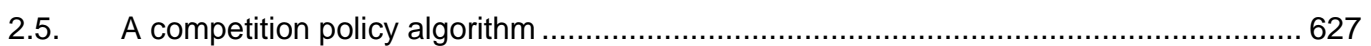

2.6. The GM crops and seed industries: main features and past mergers....................... 628

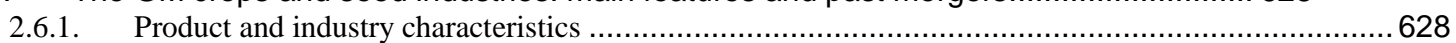

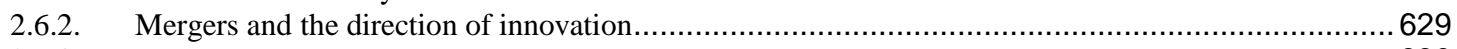

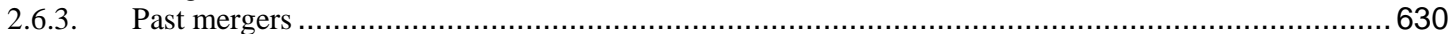

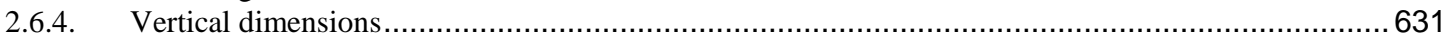

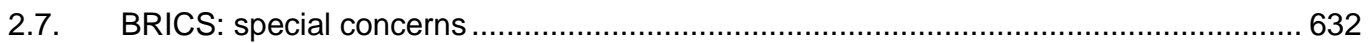

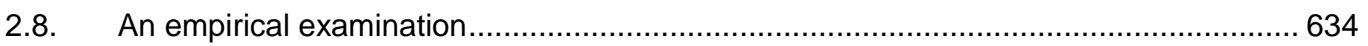

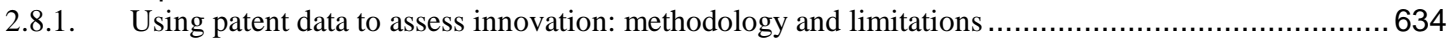

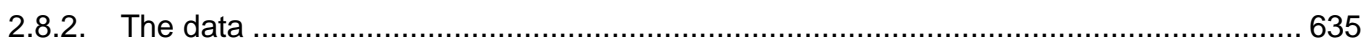

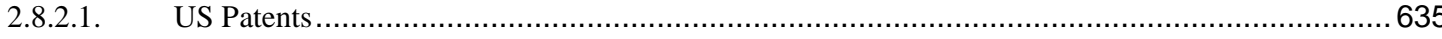

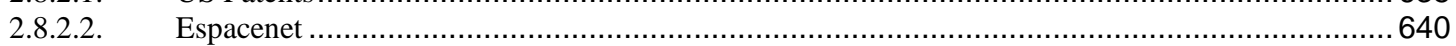

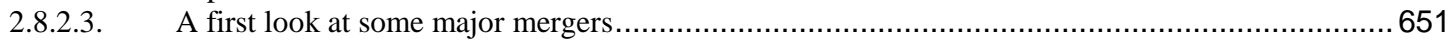

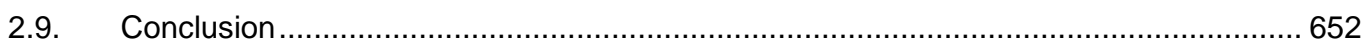

Appendix A: formal analysis of the innovation effects of a merger ...................................6 660

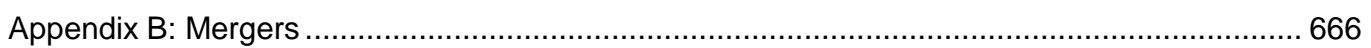

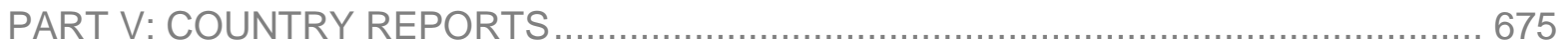

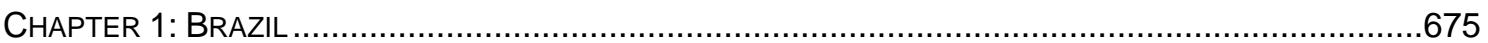

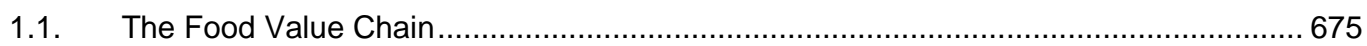

1.2. Regulatory Framework of the Food Sector in Brazil ........................................... 677

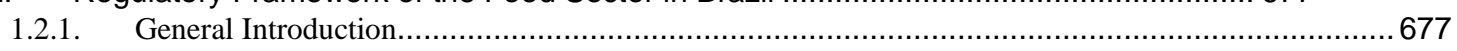

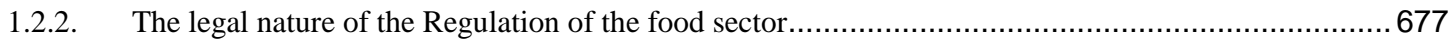

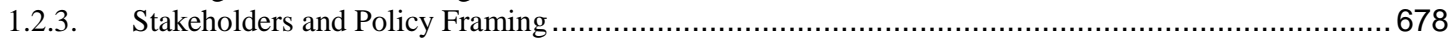

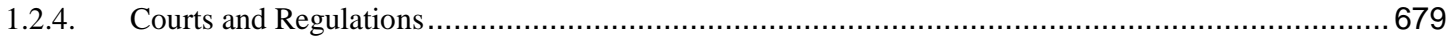

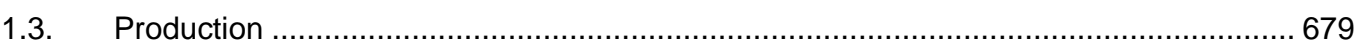

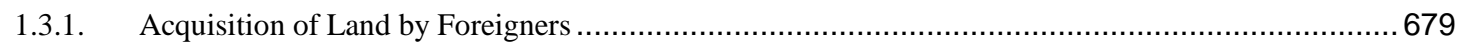

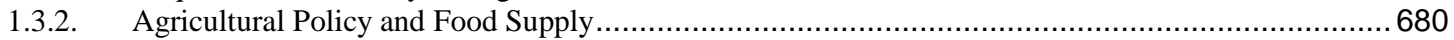

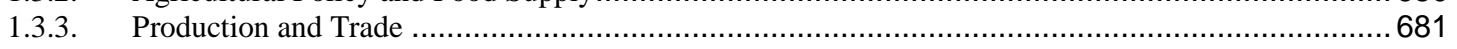

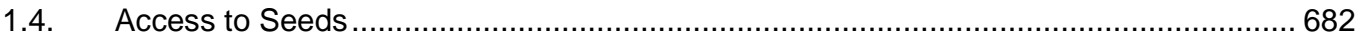

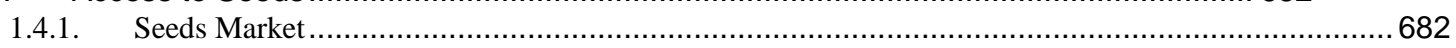

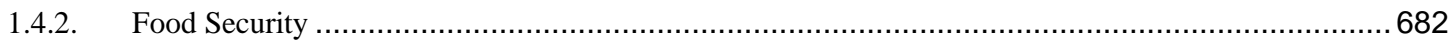

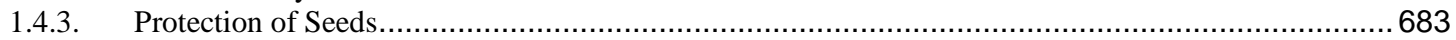

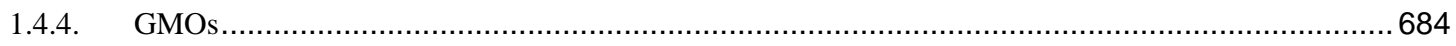


1.5. Consumers' interests.......

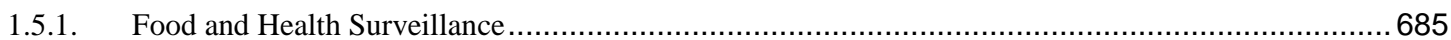

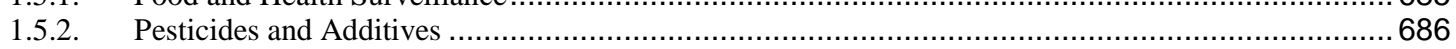

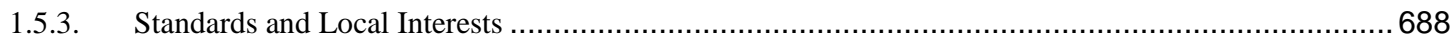

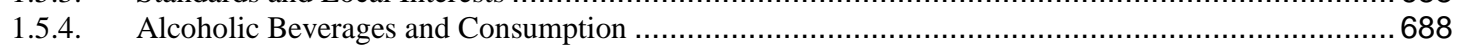

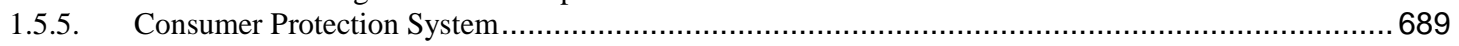

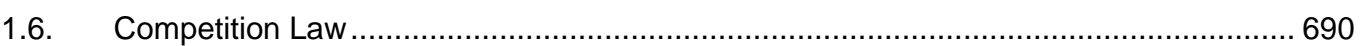

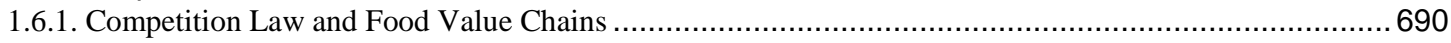

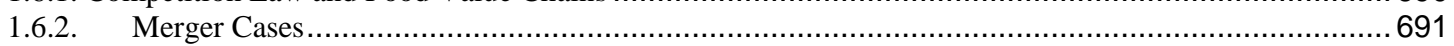

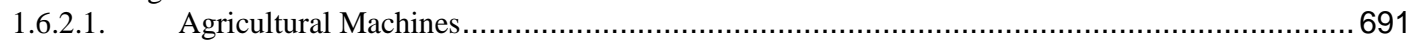

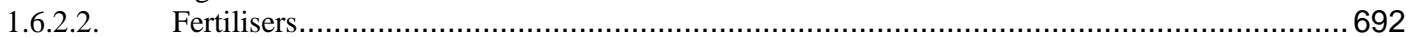

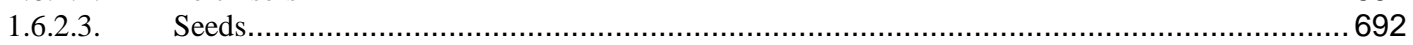

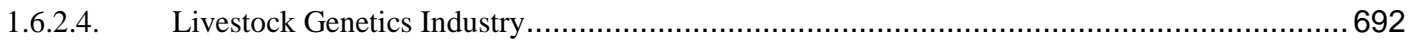

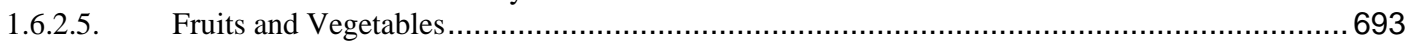

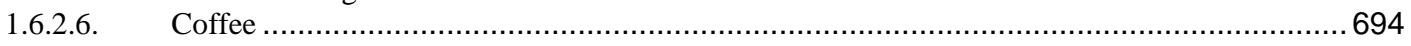

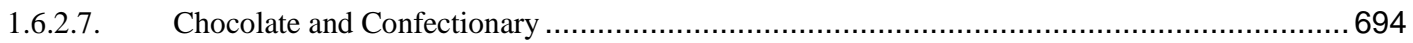

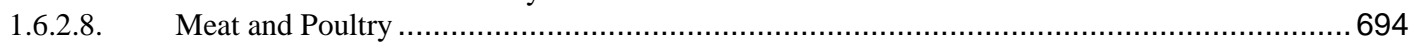

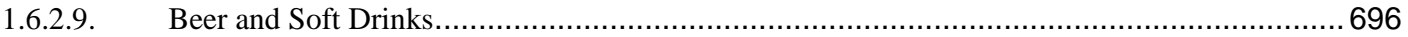

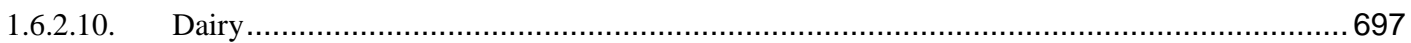

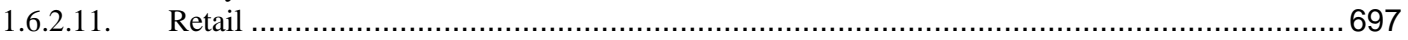

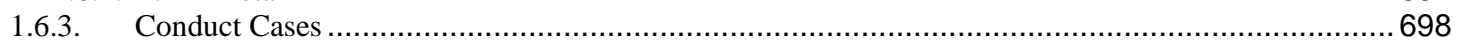

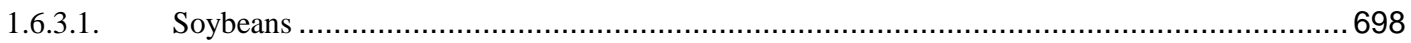

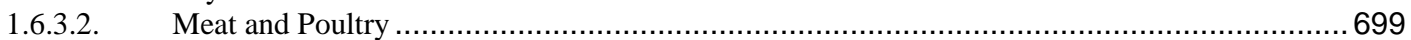

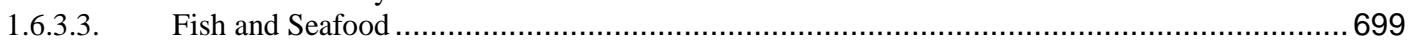

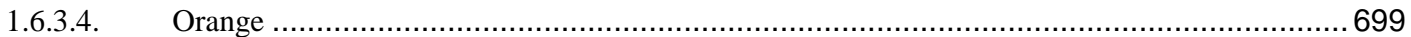

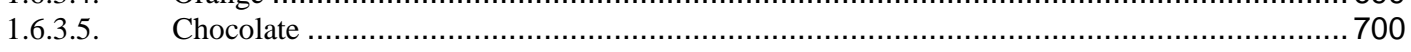

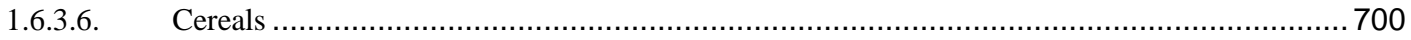

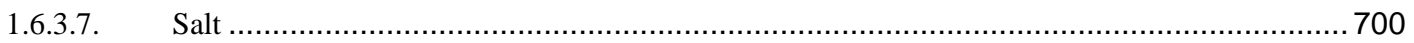

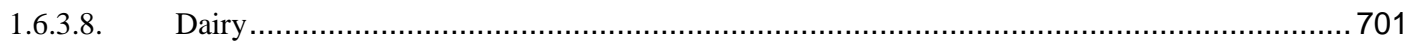

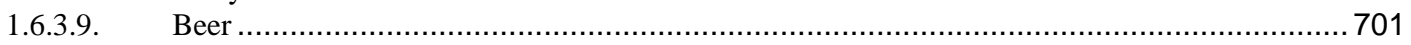

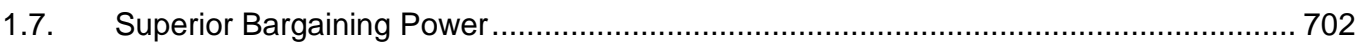

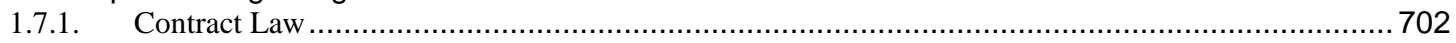

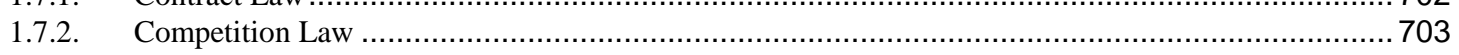

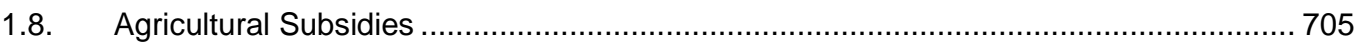

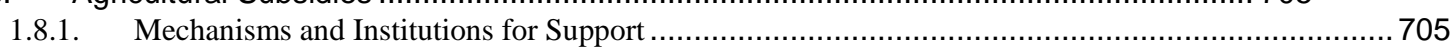

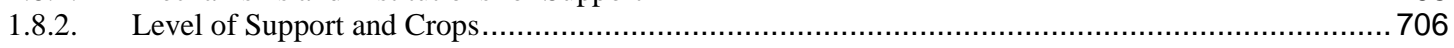

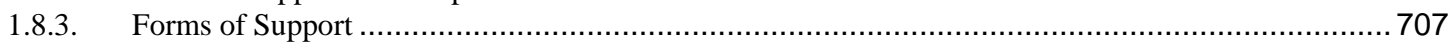

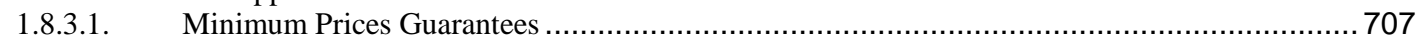

1.8.3.2. Agriculture Insurance and Environmental Requirements ......................................... 708

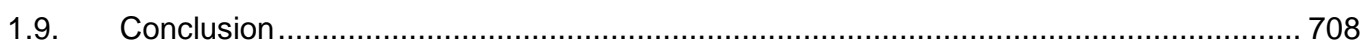

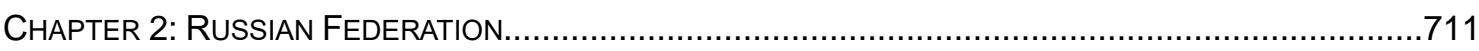

2.1. General Overview and Legal Framework ........................................................... 711

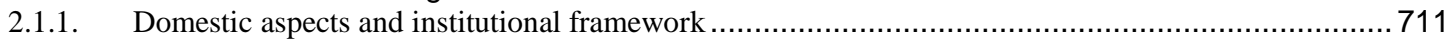

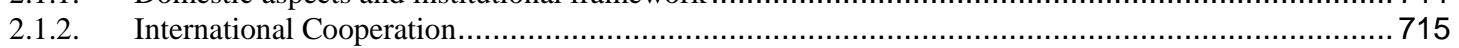

2.2. Competition Issues on Different Levels of the Food Supply Chain .......................... 716

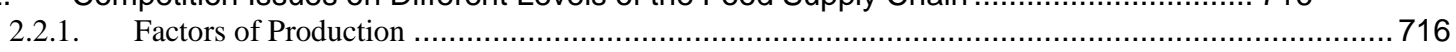

2.2.2.1. Right of Access of Farmers to the Plant Varieties and Animal Breeds in Russia .......................718

2.2.2.2. Markets of Fertilisers in Russia .............................................................................. 720

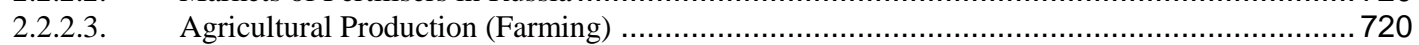

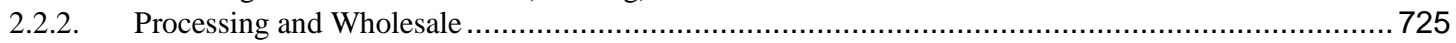

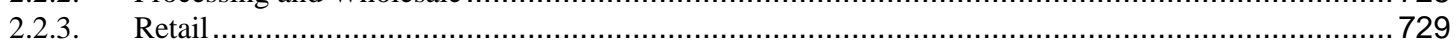

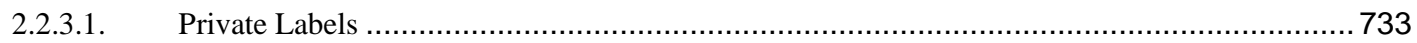

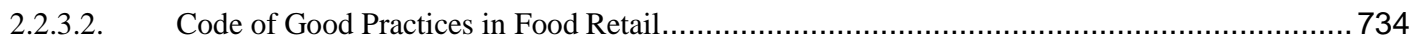

2.2.3.3. Regulation of Retail Prices and Mark-Up for Food Products ........................................ 735

2.3. State Regulation of Food Supply Value Chains in Russia ......................................... 735

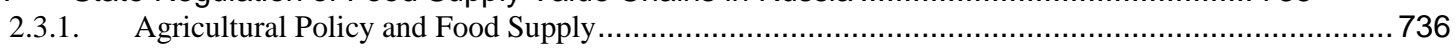

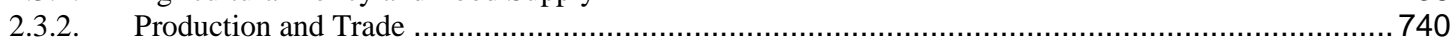

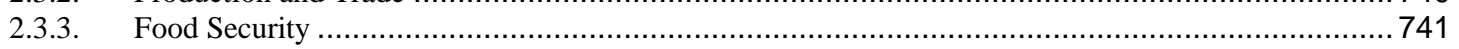

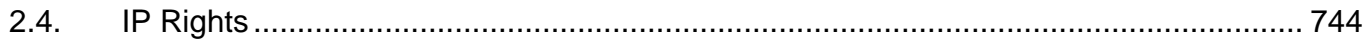

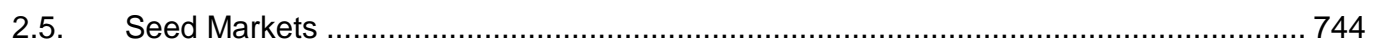




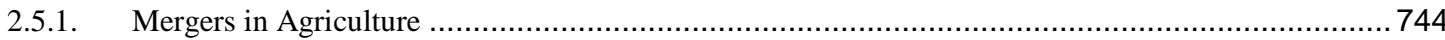

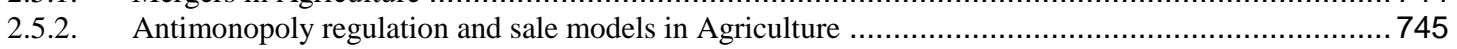

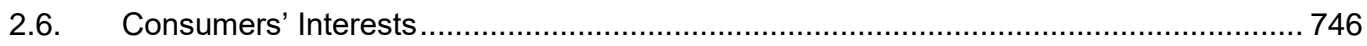

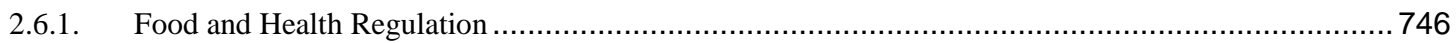

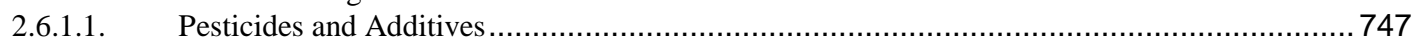

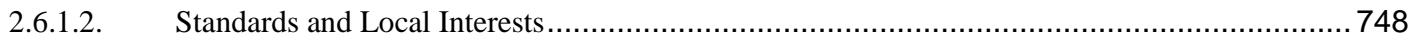

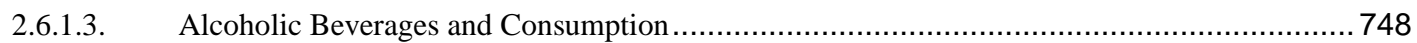

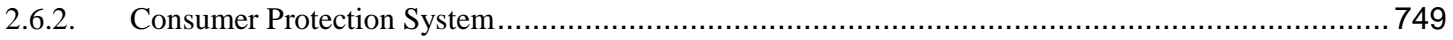

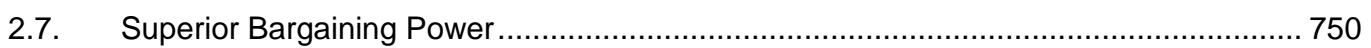

2.7.1. Superior Bargaining Power in Russian Contract Law .................................................... 750

2.7.2. Superior Bargaining Power under Competition Law ........................................................ 754

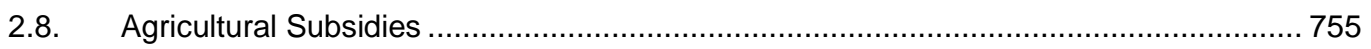

2.8.1. Federal Law dated 29 December 2006 N 264-FZ "On Development of the Agriculture".................. 755

2.8.2. State programmes aimed at subsidising agricultural producers: ........................................756

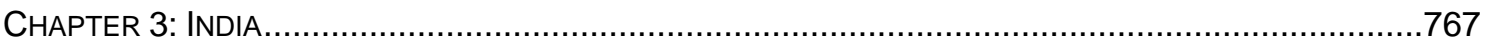

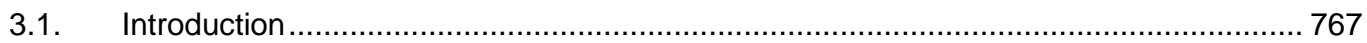

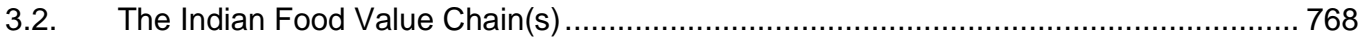

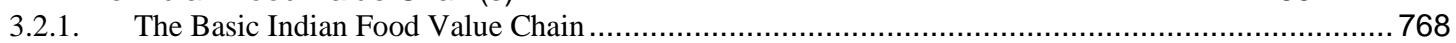

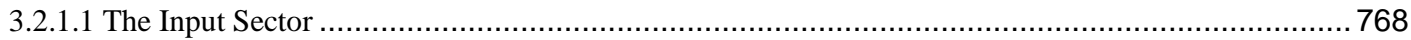

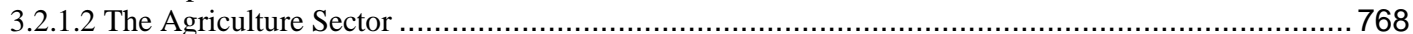

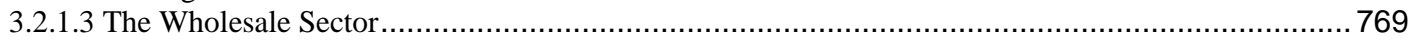

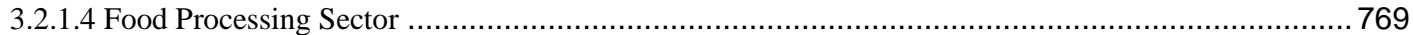

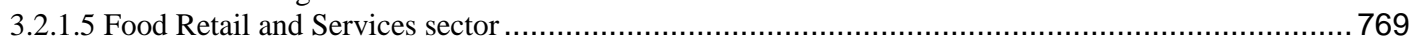

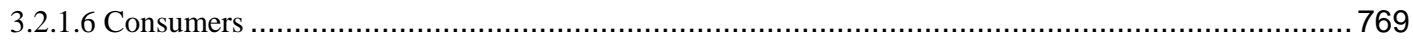

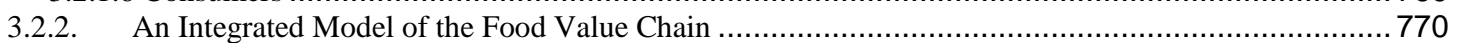

3.3 The Legal and Regulatory Framework for Food Value Chain(s) ................................... 771

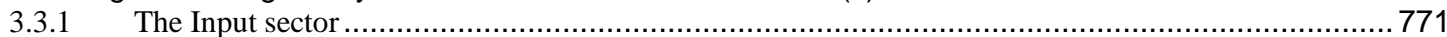

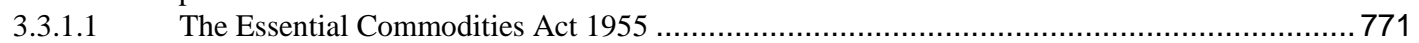

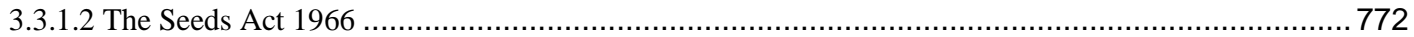

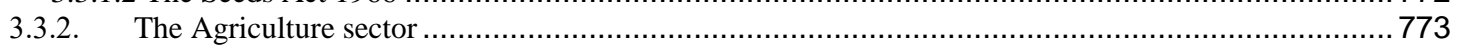

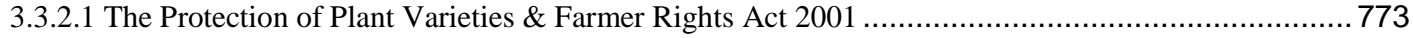

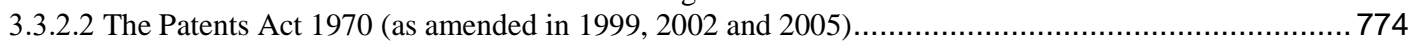

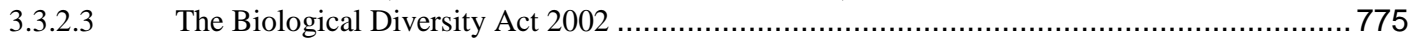

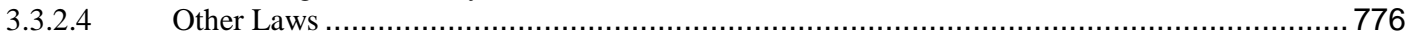

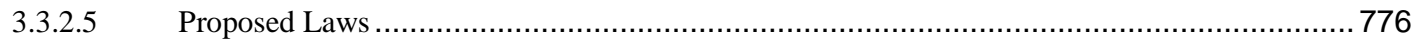

3.3.3. The Wholesale, Food Processing and Food Retail and Services sectors................................... 776

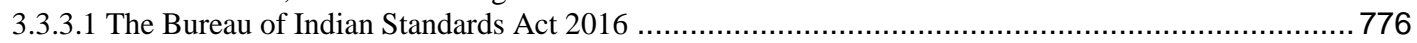

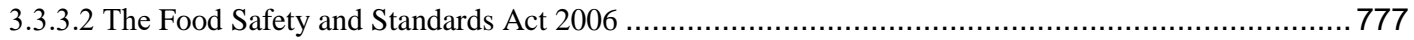

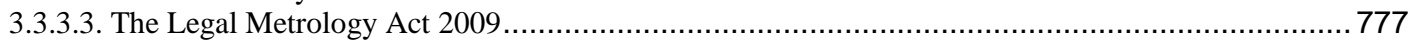

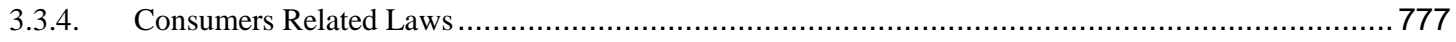

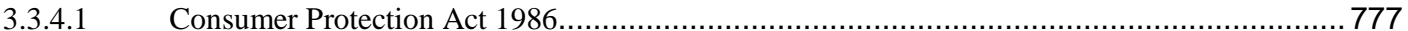

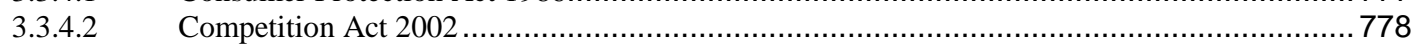

3.4 Relevant Government Ministries, Departments and Regulatory Bodies ....................... 778

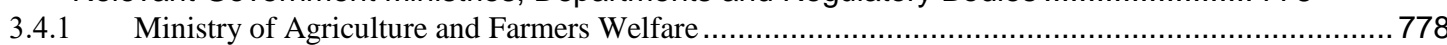

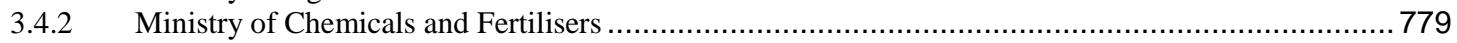

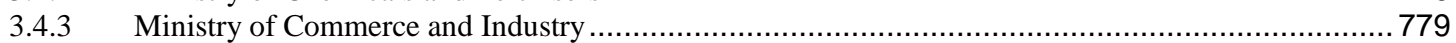

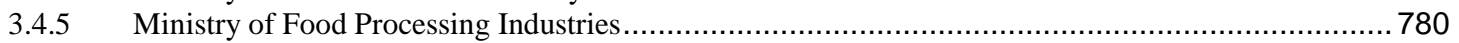

3.4.6 Ministry of Consumer Affairs, Food and Public Distribution ................................................. 781

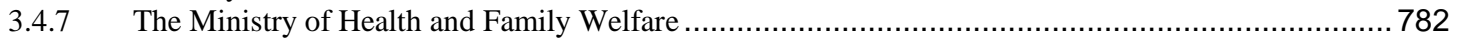

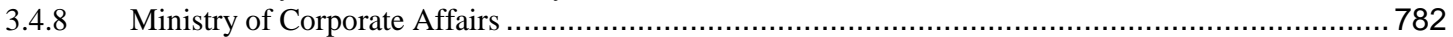

3.5. Categories of Regulation and their Impact.......................................................... 782

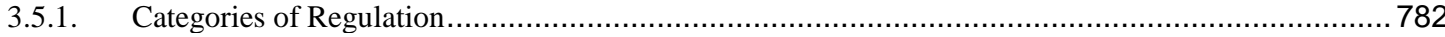

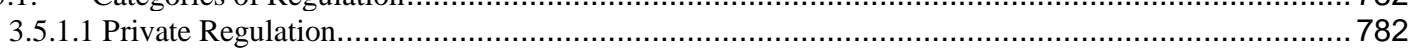

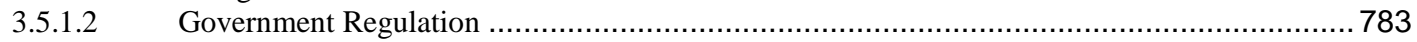

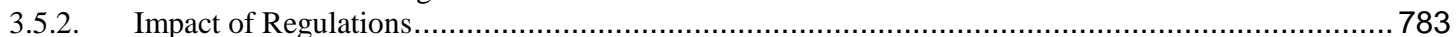

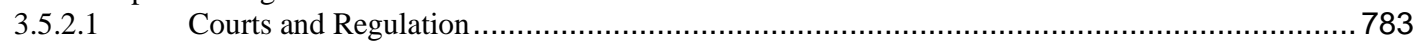

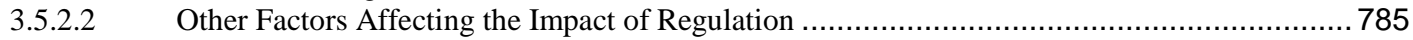

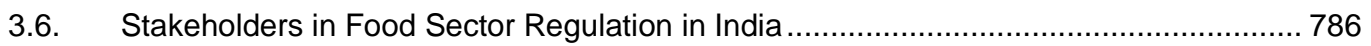

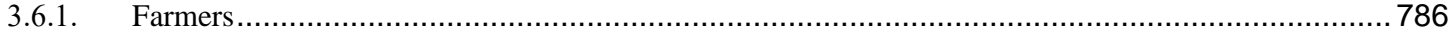

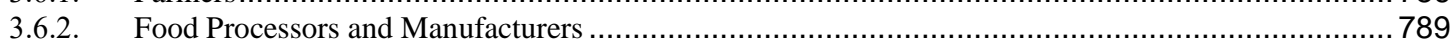




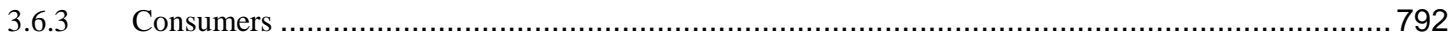

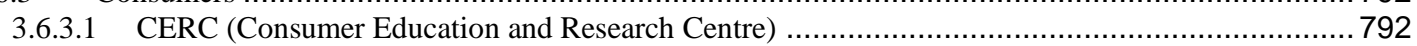

3.6.3.2 FEDCOT (Federation of Consumer Organisations in Tamil Nadu) ..................................... 792

3.6.3.3 Citizen Consumer and Civic Action Group (CAG) ........................................................ 792

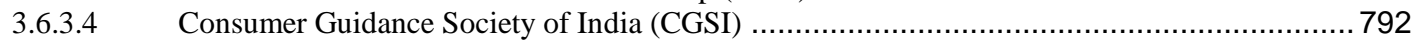

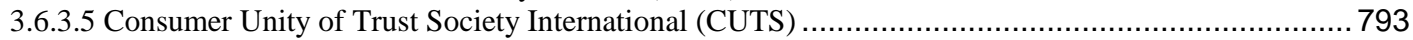

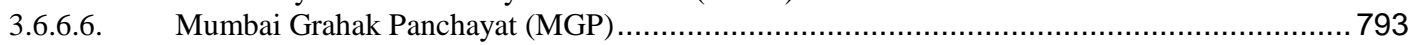

3.7 Intellectual Property Rights and the Agriculture Sector in India ............................... 794

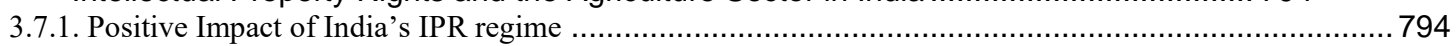

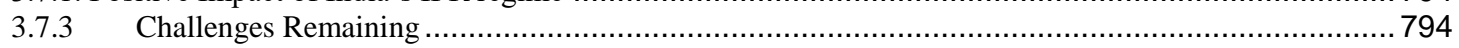

3.8 Competition Law and the Indian Food Value Chain ................................................ 795

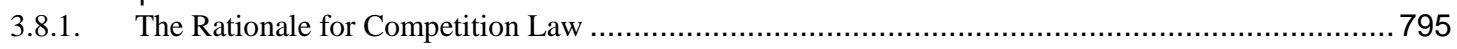

3.8.2. Landmark Cases relating to the Food Value Chain(s) ...................................................... 796

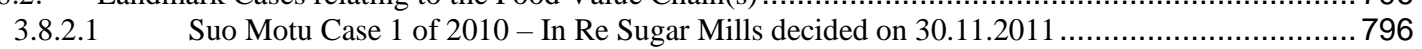

3.8.2.2 Suo Motu Case 1 of 2011 - In Re Rise in Onion Prices decided on 10.04.2012 .................... 798

3.8.2.3 Suo Motu case No. 2 of 2011-Re Aluminum Phosphide Tablets Manufacturers order dated

23.04.2012 798

3.9. Unfair Trading Practices 799

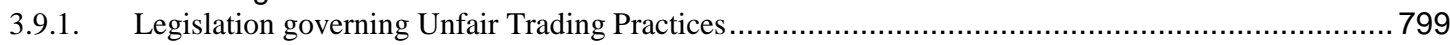

3.9.2. Instances of Unfair Trading Practices in Food Processing Industry ......................................... 800

3.10. Superior Bargaining Power. 801

3.11. Interface between Competition Law, IP Rights, Unfair Trading Practices and Superior Bargaining Position 802

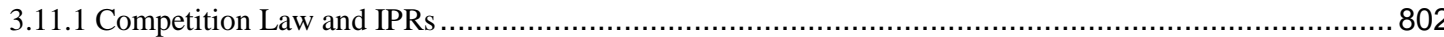

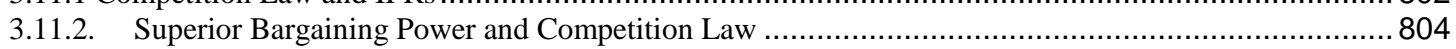

3.11.3. Dealing with Unfair Trade Practices under Competition Law.............................................. 806

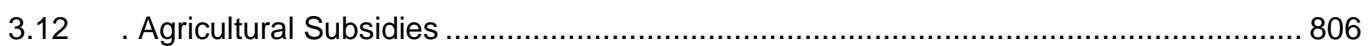

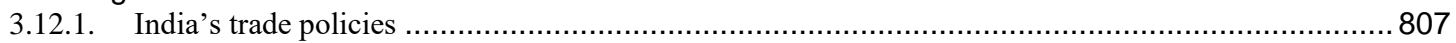

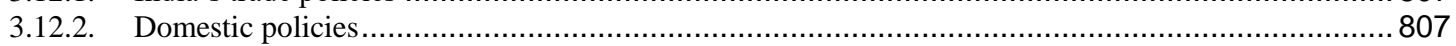

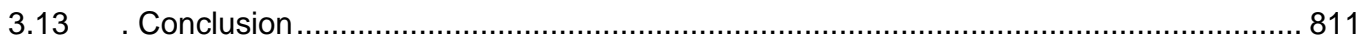

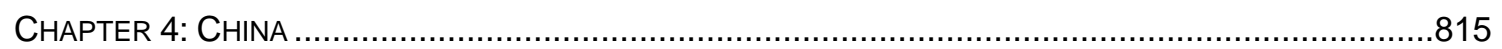

4.1. China's agricultural policy and food value chain ............................................... 815

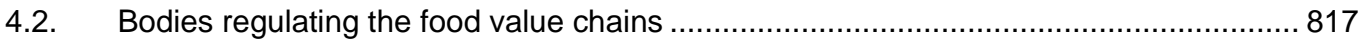

4.3. Regulatory framework for the food value chains.............................................. 824

4.3.1. National policy regarding the supply segments of the food value chains.................................... 824

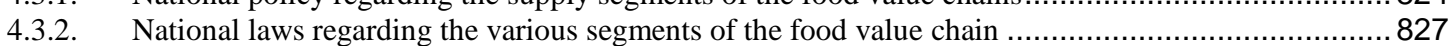

4.3.2.1. Basic laws for the production and supply segments of the food value chain ........................ 827

4.3.2.1.1. Agriculture Law of the People's Republic of China 1993(中华人民共和国农业法)............8 827

4.3.2.1.2. Fisheries Law of the People's Republic of China 1986 (FLPRC)( 中华人民共和国渔业法) and Animal Breeding Law of the People's Republic of China 2006 (AHLPRC)( 中华人民共和国畜牧法) ... 833 4.3.2.1.3. Land Administration Law of the People's Republic of China (LALPRC) 1986(中华人民共和国 土地管理法), Law of the People's Republic of China on Land Contract in Rural Areas 2002 (LPRCLCRA) (中华人民共和国农村土地承包法), Grassland Law of the People's Republic of China 2002 (GLPRC) (中 华人民共和国草原法), Seed Law of the People's Republic of China 2015 (SLPRC)(中华人民共和国种子 法) 834

4.3.2.1.4. Grain Law of the People's Republic of China (draft for public comments) 2015 (GLPRCdpc)(

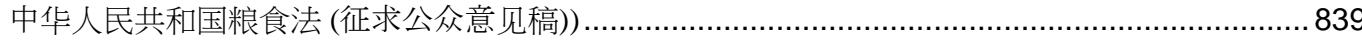

4.3.2.2. Basic laws for the distribution and consumption segments of the food value chains ..................843

4.3.2.2.1.1. Price Law of the People's Republic of China (PLPRC) 1998 (中华人民共和国价格法) ... 844

4.3.2.2.1.2. Law of the People's Republic of China on the Protection of Consumer Rights and Interests

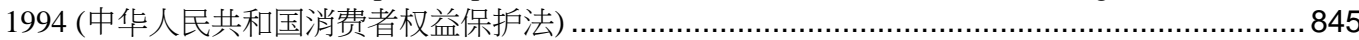

4.3.2.1.3. Foreign Trade Law of the People's Republic of China (1994) (中华人民共和国对外贸易法) 845

4.4. Protection of Intellectual Property Rights ....................................................... 846

4.5. Competition law, superior bargaining power, and food value chains ......................... 849

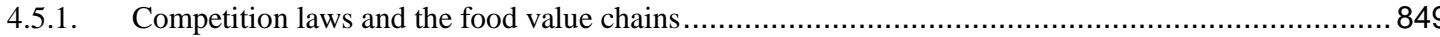

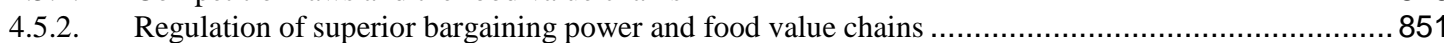


4.6. Competition Law Enforcement in specific segments of the food value chain......

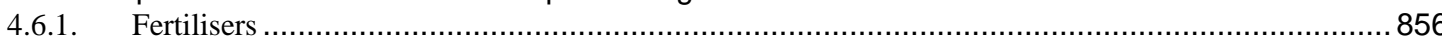

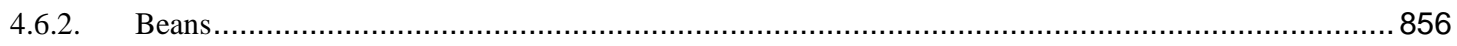

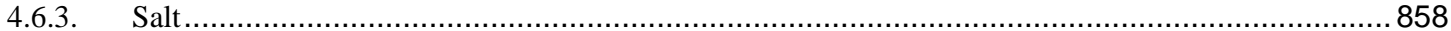

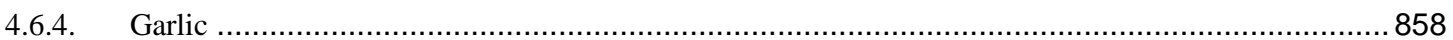

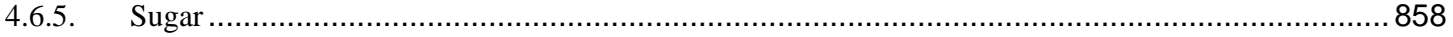

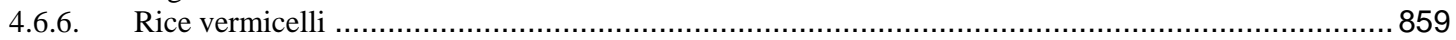

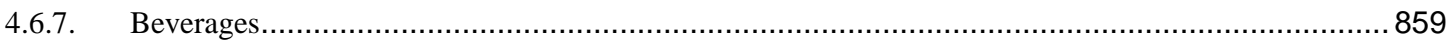

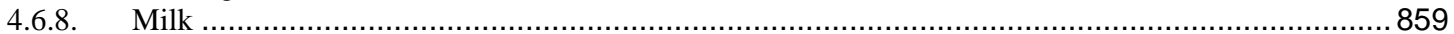

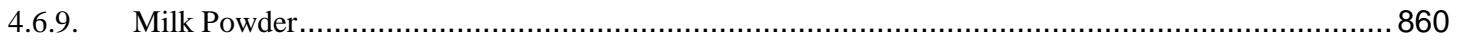

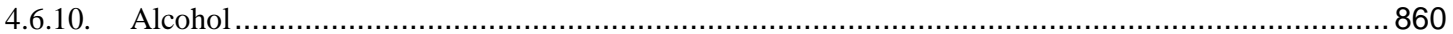

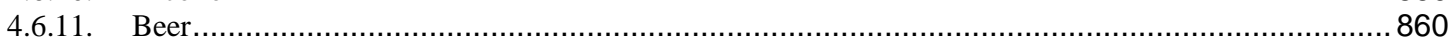

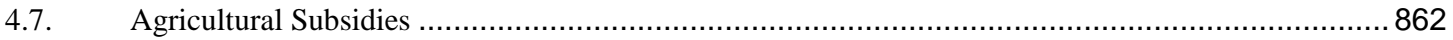

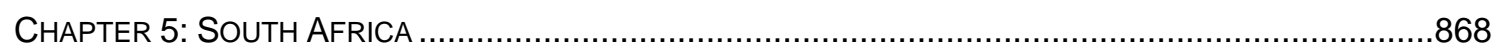

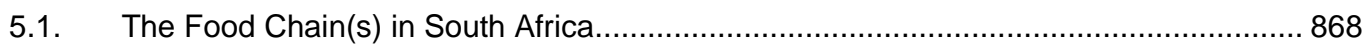

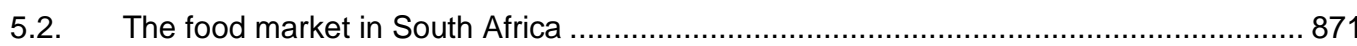

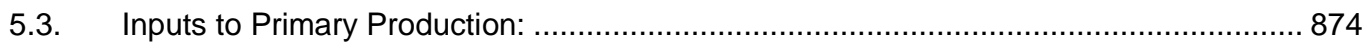

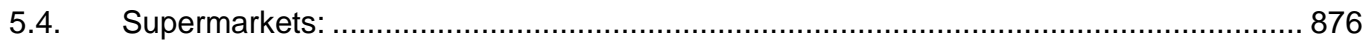

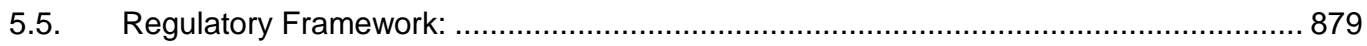

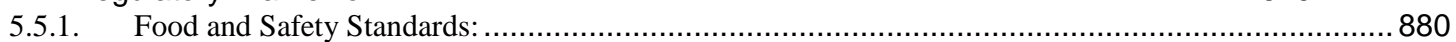

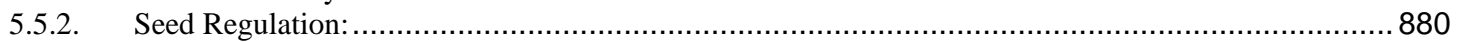

5.5.3. Regulating contracts between retailers and SMEs through legislation: ..................................... 882

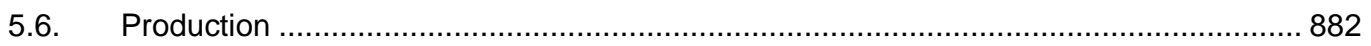

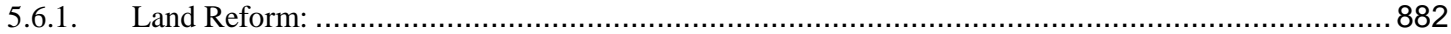

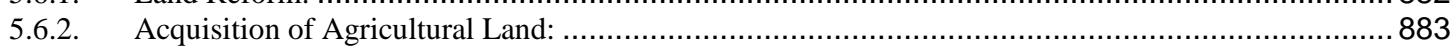

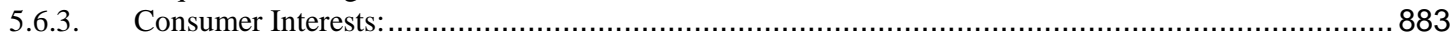

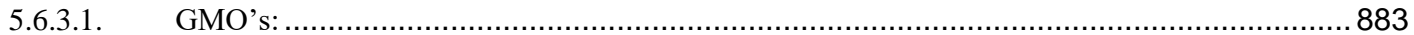

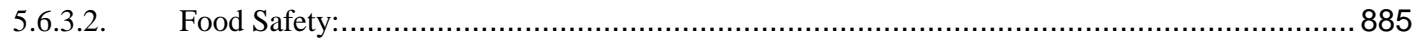

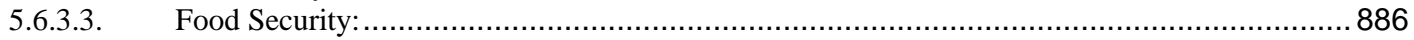

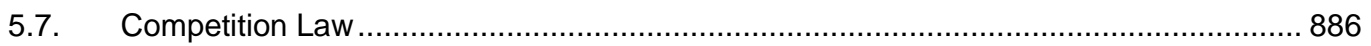

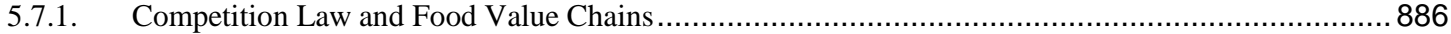

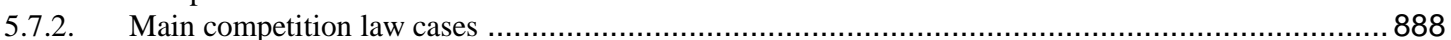

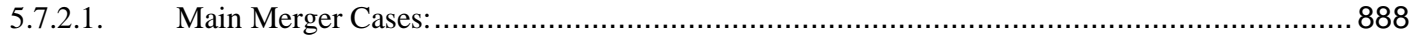

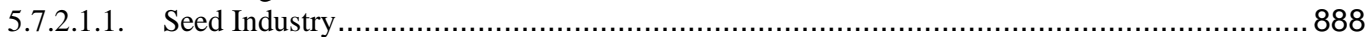

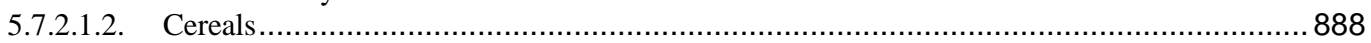

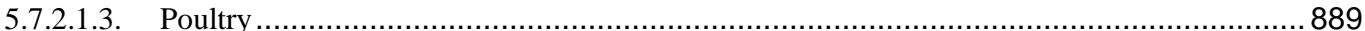

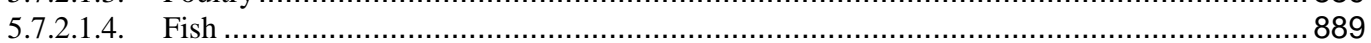

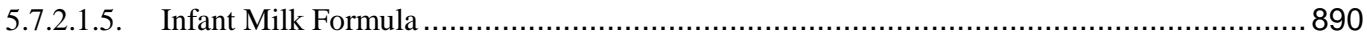

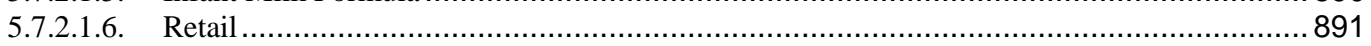

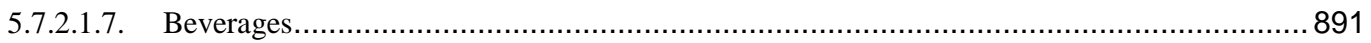

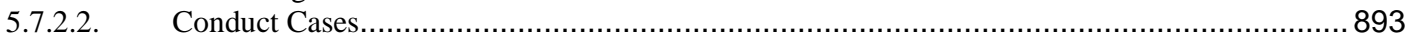

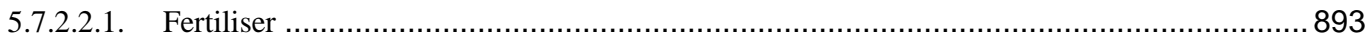

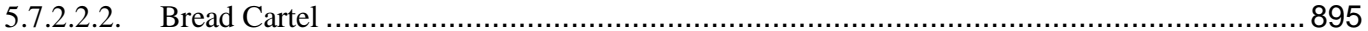

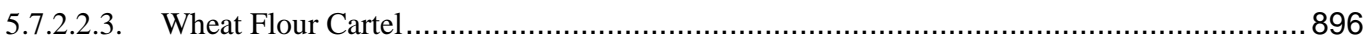

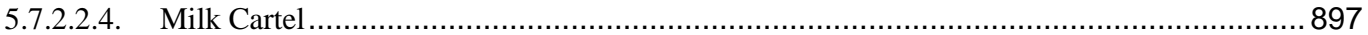

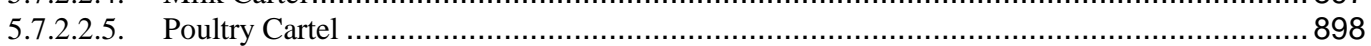

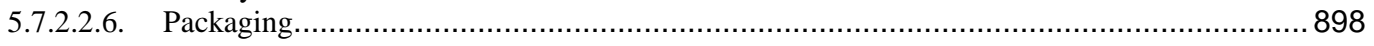

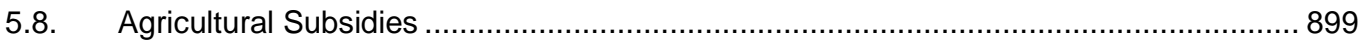

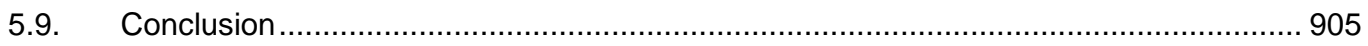

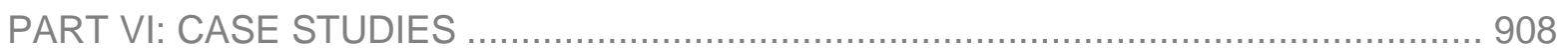

CHAPTER 1: INSIGHTS FROM SELECTED VALUE CHAINS IN SOUTH AFRICA .................................908

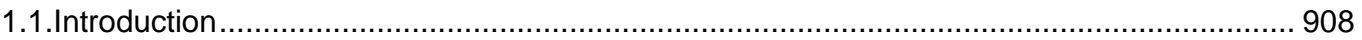

1.2. A value chain approach in conjunction with industrial organisation principles .............. 909

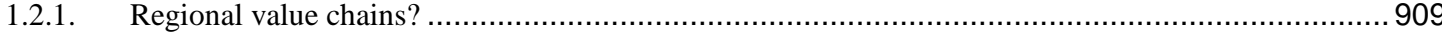

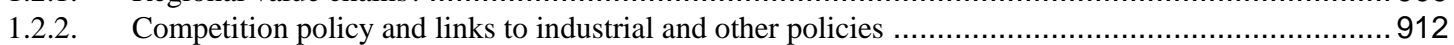

1.3. Brief background on the history and evolution of food sectors in South Africa ............. 913 


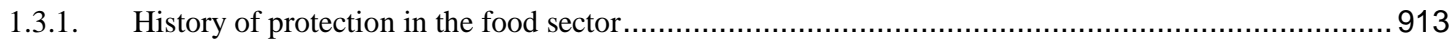

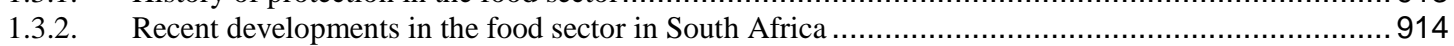

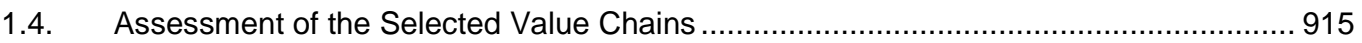

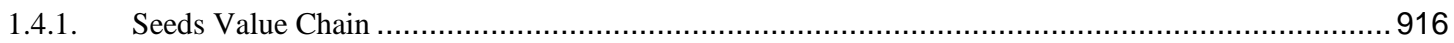

1.4.1.1. A mapping of the key players and ownership structures ........................................... 916

1.4.1.2. Regulation and barriers to entry ........................................................................ 918

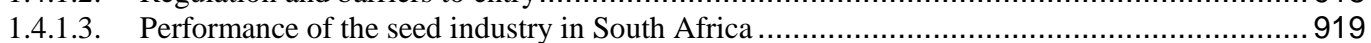

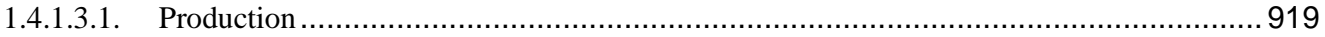

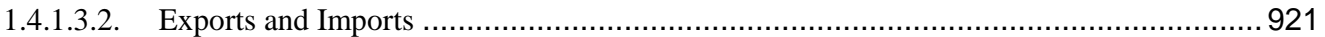

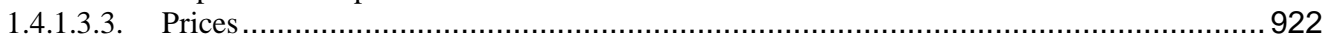

1.4.1.4. Trends in concentration and outcomes of key competition cases ................................... 923

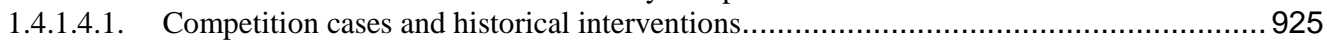

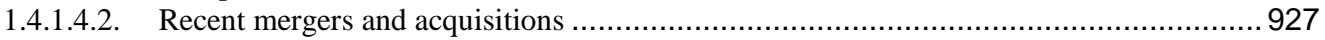

1.4.2. Fertiliser Value Chain....................................................................................... 929

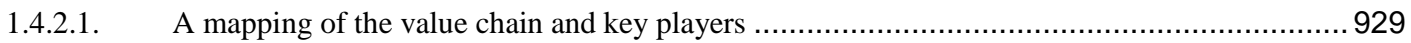

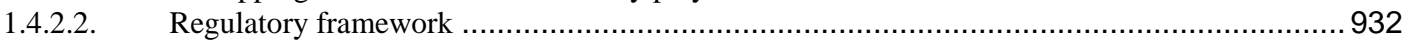

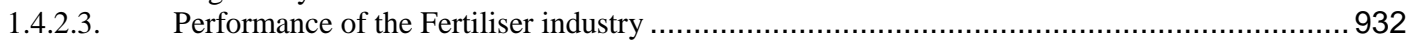

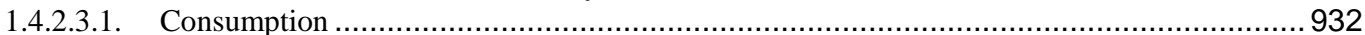

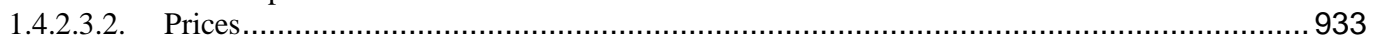

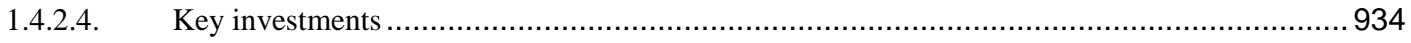

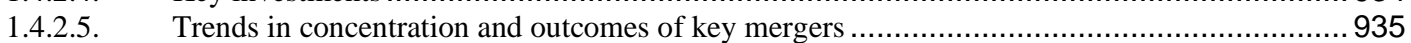

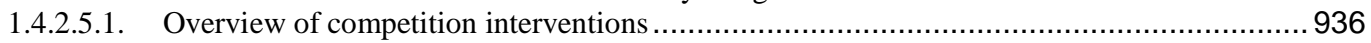

1.4.2.5.2. Ex-post assessment of the Competition Commission's intervention in 2009 ....................937

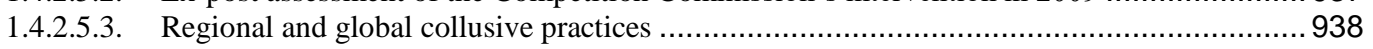

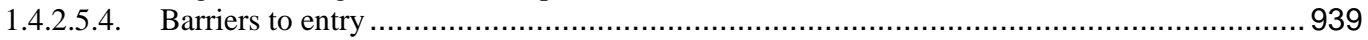

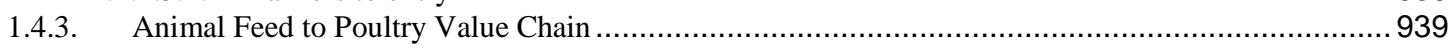

1.4.3.1. A mapping of the key players and ownership structures ........................................... 939

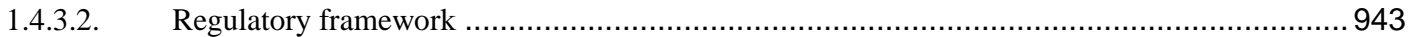

1.4.3.3. Performance of the South African poultry industry .............................................. 943

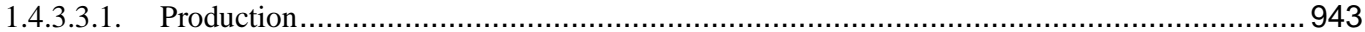

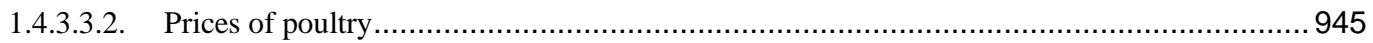

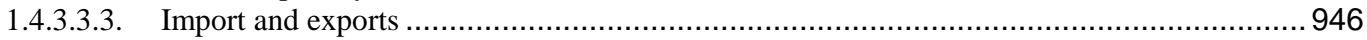

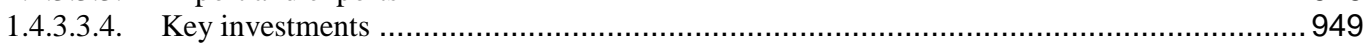

1.4.3.4. Trends in concentration and outcomes of key cases in South Africa .................................950

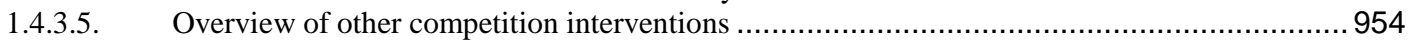

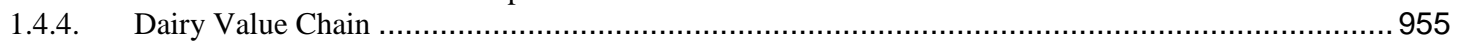

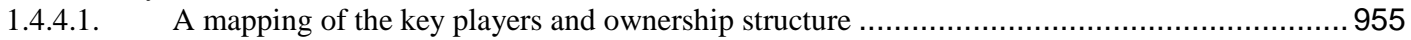

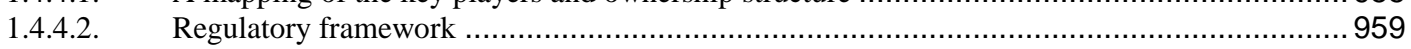

1.4.4.3. Performance of the South African dairy sector .......................................................... 960

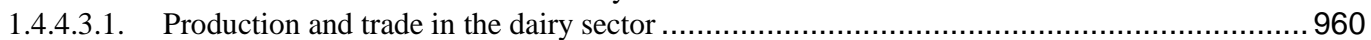

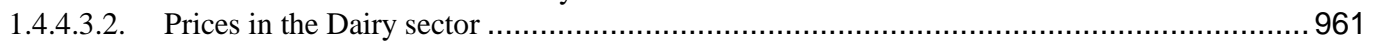

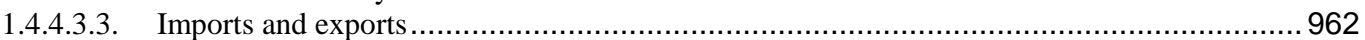

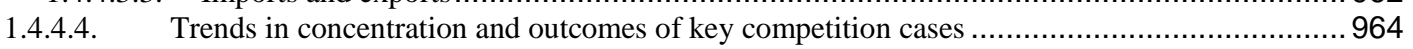

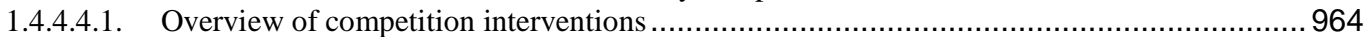

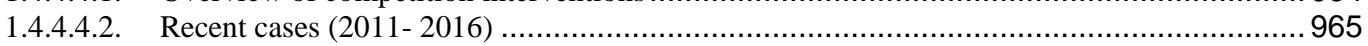

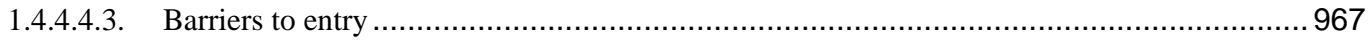

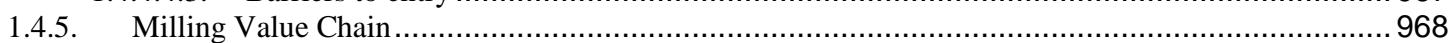

1.4.5.1. A mapping of the key players and ownership structures ........................................ 968

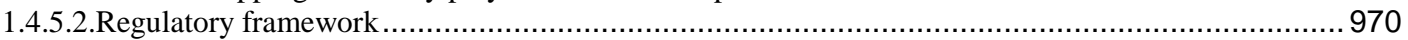

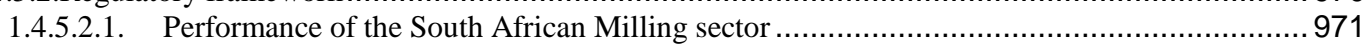

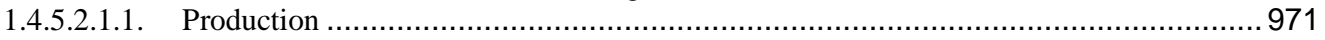

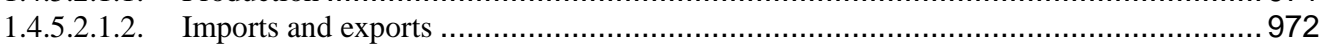

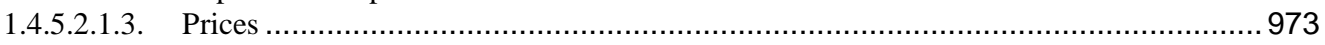

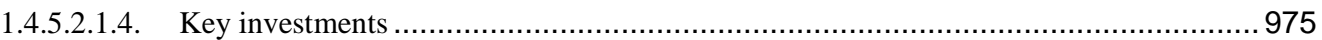

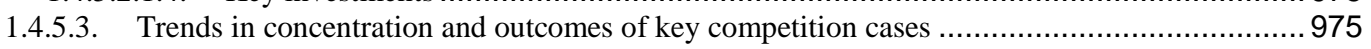

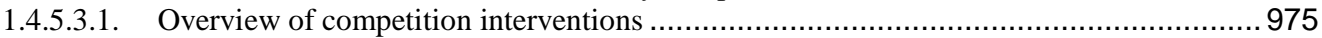

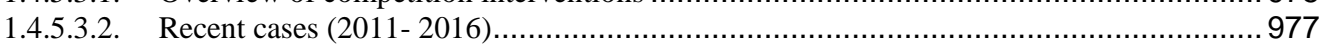

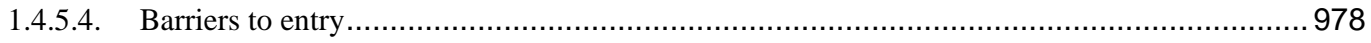

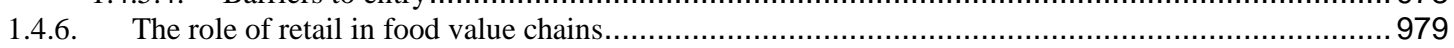

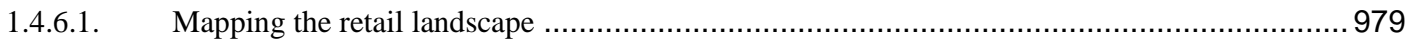

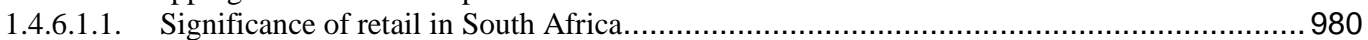

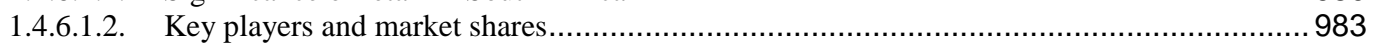

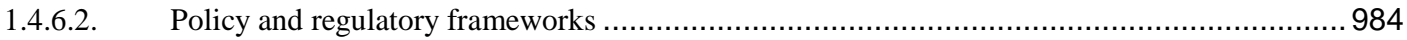

1.4.6.2.1. Nature of competitive rivalry and a review of competition concerns in South Africa ............984

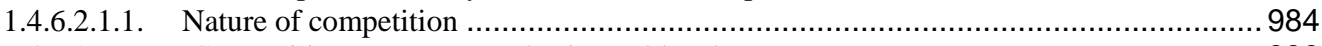

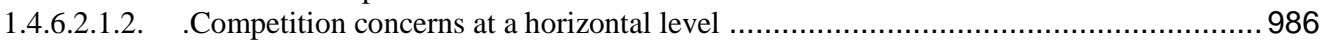


1.4.6.2.1.3. Implications on suppliers - main vertical competition concerns ............................988

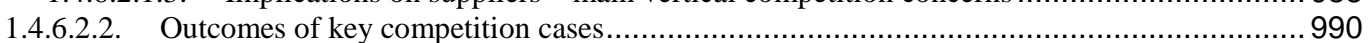

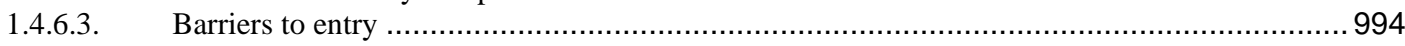

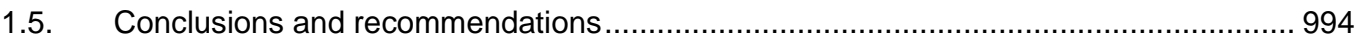

ChAPTER 2: GM COtTON SEEdS: EMERGING JURISPRUDENCE VIS--À-VIS COMPETITION, PRICE CONTROL AND

PATENT LICENSING IN INDIA................................................................1005

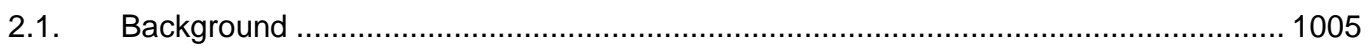

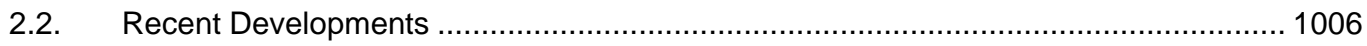

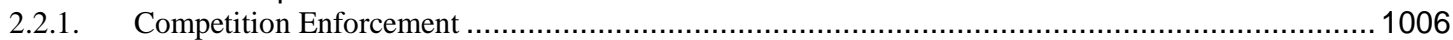

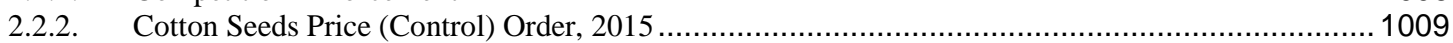

2.2.3. Licensing and Formats for GM Technology Agreement Guidelines ....................................... 1011

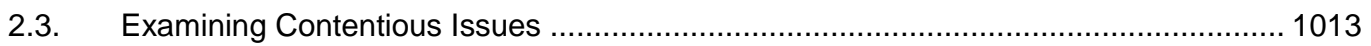

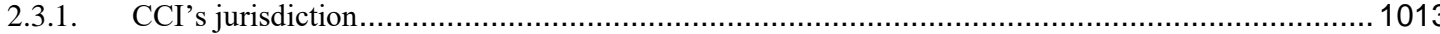

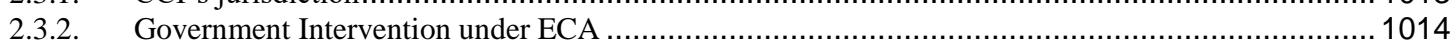

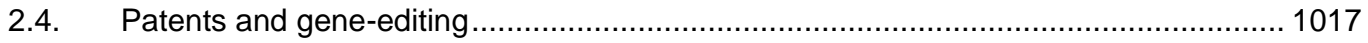

CHAPTER 3: NEW FORMS OF FINANCING THE AGRICULTURAL SECTOR IN BRAZIL: THE EXPERIENCE OF THE

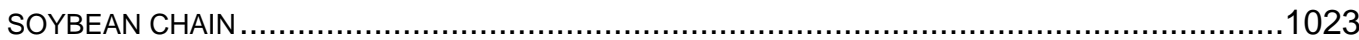

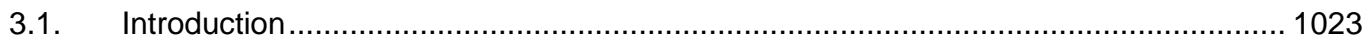

3.2. Structural change in Brazilian agriculture ......................................................... 1023

3.2.1. The effects of the Brazilian crisis of the 1980s on rural credit ............................................. 1023

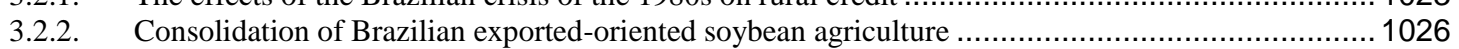

3.3. New organizational forms of Brazilian soybean chains ..................................... 1029

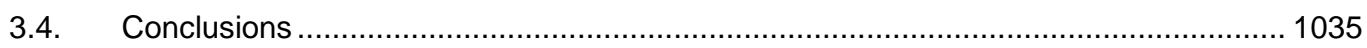




\section{Part I: Introduction and Methodology}

\section{Ioannis Lianos}

\section{Aims of the research}

The research project aims to provide the first in-depth analysis of the regulation, from a competition policy perspective, of the food industry by the BRICS countries, and selected developed countries (European Union, United States). Our aim has been to map the structure of the food value chain globally, as well as in the various jurisdictions we examine, focusing on the balance of power between the various actors in the value chain: retailers, farmers, processors and suppliers, traders, agro-industry, consumers, in the current context of technological and societal transformation, as well as the impact of these power relations on the governance of these global food value chains. Our aim was to understand the broader contours of public action in the various segments of global food value chains, in particular when this takes the form of competition law, and the various values that seem to animate public authorities when interfering with the private governance regimes put in place, or more broadly the activity of global food value chains . Our understanding is that competition law, and more broadly competition policy, constitutes a tool, among a larger set of institutional options at the disposal of public authorities, in order to deal with the economic, social and political costs flowing from the exercise of economic power. The way it will be used, and the scope of competition law intervention, is highly dependent on the capability and incentives of the various formal and informal institutions managing the competitive activity in global food value chains. It is our belief that the forms this competitive activity takes place in the short, medium and long run cannot only be described through the sole perspective of price theory.

Although we strive to take a broader perspective than price theory in the conceptualization of competitive interactions between economic actors involved in food production and commercialisation, we have chosen not to incorporate in this analysis the broader macroperspective of "food regimes"1. We recognize that this theoretical framework may offer useful insights in understanding the important structural changes of the governance of food systems the last decades, with the rise of the globalization of food production and consumption (the denationalisation of food systems and the emergence of an international food order which largely operates on the basis of transnational food value chains) and the increasing financialisation of

\footnotetext{
1 This term denotes a'rule-governed structure of production and consumption of food on a world scale: $\mathrm{H}$. Friedmann, 'The political economy of food: a global crisis'. (1993) 197 New Left Review 29. On "food regimes" see also, H. Friedman, International regimes of food and agriculture since 1870. In: T. Shanin, (ed.) Peasants and peasant societies (Oxford: Basil Blackwell, 1987), p. 258; H. Friedman, From colonialism to green capitalism: social movements and the emergence of food regimes. In: F.H. Buttel \& P. McMichael, (eds.) New directions in the sociology of global development. Research in rural sociology and development (Vol. 11, Oxford: Elsevier, 2005), p. 229; Ph. McMichael, 'A food regime genealogy',(2009) 36(1) Journal of Peasant Studies 139. For a critical review, see H. Bernstein, 'Agrarian political economy and modern world capitalism: The contributions of food regime analysis'. (2016) 43 Journal of Peasant Studies 3.
} 
food with the emergence of a "corporate food regime"2 Although we recognize that the quest for "food sovereignty" may be an important driving force for the action of various public authorities involved in the regulation of economic activities in the food sector, we consider that if we had prominately integrated this concern in a competition law and policy setting, the clash of sovereigns that will have surely emerged would have made more difficult our effort to develop common understandings and practices among competition law authorities in BRICS and around the world. That said, we recognize that "food sovereignty" concerns may, in reality, at least influence the enforcement activity of competition law authorities, in particular with regard to global mergers and conduct that further internationalises the food production and commercialisation system, away from its domestic "roots", and that it might explain some of their enforcement priorities, and one may also argue, the design of remedies imposed for competition law infringements, for instance with regard to global mergers. We can therefore consider it as a useful background information and a possible independent variable, although we have not taken it systematically into account in this study.

Our starting point is that as all markets, food markets cannot be analysed abstractly without realising that they are embedded in social relations ${ }^{4}$, not only between consumers and producers or retailers, but also between other sociological categories of actors that are present in various fields of life, sometimes invisible from the specific market where the economic exchange about food took place and the price was presumably formed ${ }^{5}$. These could even go beyond the economic sphere and touch upon the political or the cultural fields ${ }^{6}$. Furthermore, the social importance of food render these markets, and their regulation, particularly sensitive to politics. For instance, farmers and their struggle for land re-distribution and economic

\footnotetext{
${ }^{2} \mathrm{Ph}$. McMichael, Global Development and the Corporate Food regime, in F.H. Buttel and P. McMichael (eds). New directions in the sociology of global development (Oxford: Elsevier Press, Volume 11, 2005), 269.

${ }^{3}$ On "food sovereignty" see, inter alia, Ph. McMichael, 'Historicizing food sovereignty' (2014) 41 The Journal of Peasant Studies', 933; Ph. McMichael, 'Commentary: Food regime for thought', (2016) 43 The Journal of Peasant Studies 648; (noting that food sovereignty "is about reorganizing international political economy, modeling social struggle around democratic principles, gender equity, producer rights, ecological practices and rebalancing the urban/rural divide").

${ }^{4}$ On the social embeddedness of markets and more generally economic activity, see M. Granovetter, Economic Action and Social Structure: The problem of Embededness, (1985) 91(3) American Journal of Sociology 481; M. Callon, Introduction: The Embeddedness of Economic Markets in Economics", in M. Callon (ed.), The Laws of the Markets (Oxford: Blackwell, 1998), 1-57; B. Jessop, The Social Embeddedness of the Economy and its Implications for Economic Governance, in F. Adaman \& P. Divine (eds.), The Socially Embedded Economy (Black Rose Books, Montreal, 2001); . This approach questions the assumption of neoclassical price theory that the market forms a clearly delimited, socially disembedded sphere of economic relations, in which the various actors only pursue their material interest in order to satisfy their wants, exchange being entirely driven by the optimizing, economizing behaviour of pre-constituted rational individuals with pre-given and stable preference functions, their incentives and subsequent action being "managed" by the invisible hand of the price mechanism. ${ }^{5}$ In reality, the process of price formation is quite complex, the global price of a food staple being set not by actual exchange on a market (actual prices), but also by "futures" and "prosthetic" prices, such as different global price indexes that also take into account subsidies and the expectations of financial investors, which structure the various exchanges and become the actual world price of the food staple, in question. For a fascinating analysis with regard to global cotton markets, see K. Çalişkan, Market Threads: How Cotton Farmers and Traders Create a Global Commodity (Princeton Univ. press 2010), Chap. $1 \& 2$ in particular.

${ }^{6}$, See N. Fligstein, The Architecture of Markets - An Economic Sociology of Twenty-First-Century Capitalist Societies (Princeton University press, 2001), highlighting the importance of studying markets also as political and cultural fields, markets being social constructions that require extensive institutional support. One may also add that in some cultural contexts, certain types of food may have both nutritional and sacralization functions (or only the second).
} 
independence has profoundly influenced the political and economic constitution of modern capitalist societies ${ }^{7}$ and to a large extent explains the emergence of antitrust law, the last decades of the $20^{\text {th }}$ century ${ }^{8}$.

We consider that the (global) food value chain and its regulation constitutes an important area of study for competition policy. First, the food supply chain connects three economically important sectors: the agricultural sector, the food processing industry and the distribution sectors. As the food processing industry and the distribution sectors have many interactions with other sectors, market malfunctioning along the food supply chain can have significant repercussions. Second, the important mutations that have characterized this industry in recent years, in particular technological development at the food production, processing and distribution, as well as important changes in the preferences of consumers, in particular those of the BRICS jurisdictions which have seen their disposable income rise significantly in recent years, but also more general societal trends (e.g. healthy food, organic food, e-commerce, mcommerce) have inevitably affected the structure of the industry and the strategies of the different actors. We believe that competition law and policy should take that into account. We also consider that, despite the important socio-economic differences between BRICS jurisdictions as to the organization and functioning of this industry and the import or export orientation of their economies, there is a significant value in exploring possible synergies in the regulation of the competition in the global food value chains, including the prevalent position of multi-national corporations in various segments of the value chain, eventually with the development of common perceptions over the adequate competition policy options on offer.

The original hypothesis explored in this study is that power relations shape the structure of the market and its regulatory framework, including competition law. Economic power may take different forms and may draw from various sources ${ }^{9}$, including market power, that is the ability to raise process profitably or reduce output, or to affect another valuable parameter of competition, such as quality, innovation and variety, which may result from the high concentration of food markets, situations of relational power in view of the bargaining position that some market actors dispose, leading to asymmetrical power, either because of the presence of global networks managed by powerful actors or because of situations of economic dependence, and situations of exclusionary power that again some market actors dispose, enabling them to marginalise actual or potential competitors and raise barriers to entry in food markets, because of "unfair" or anticompetitive commercial practices. This conduct may have

\footnotetext{
${ }^{7}$ K. Polanyi, The Great Transformation: The political and economic origins of our time (first published 1944, Beacon press, 2001). According to Polanyi, the disembededness of th market from other spheres of social activity has been achieved only because it has been followed by a counter movement, various social groups (or society) attempting to re-embed market forces in social institutions and thereby to regulate the market mechanism (the so called "double movement"). Social movements, such as those initiated by farmers have played an important role in this respect.

${ }^{8}$ In the US, the so called "Granger movement" was established in 1867 by Oliver Hudson Kelley, with the aim to unite the farmers against the monopolistic practices of railroads and elevators and to institute for themselves cooperative methods of buying and selling: S.J. Buck, The Granger Movement - A study of agricultural organization and its political, economic, and social manifestations 1870-1880 (Harvard Univ. Press, 1913); T.J. DiLorenzo, The Origins of Antitrust: An Interest Group Perspective (1985) 5 International Review of Law and Economics 73

${ }^{9}$ On a discussion about economic power, see M. Granovetter, Society and Economy - Framework and Principles (Harvard Univ. Press, 2017), Chapter 4.
} 
been generated and maintained either because of the use of legitimate tools provided by the state (e.g. property rights) or because of the links that associate these economic powerful actors with other spheres of power (e.g. political power). The research project aimed to understand how these various sources of power operate in this economic sector and in particular to explore how the transformative innovation in the methods of production and distribution in the food industry the last decade, can change, or has the potential to change, the existing power relations in the food industry. The role of the broader institutional design (e.g. property rights. commons, regulation) in empowering some actors in this transformative process has been an important theme in this study.

It also becomes crucial to understand that competition law is a tool, among many others, with the aim to control economic power, in order to ensure that food markets operate in the short, medium and long term benefit of consumers and of the general public. The competition law tool has a number of advantages and disadvantages in achieving this purpose, in comparison to other governance tools, public and private. Our starting point is that it is difficult to establish in abstracto when competition law may be a superior tool than the other tools at our disposal, before making a comparative institutional analysis of the advantages and disadvantages of the other tools in the specific jurisdiction ${ }^{10}$. To do that, it becomes essential to understand the political economy of the governance of the food sector in this specific jurisdiction, including if the other tools may be, or may not be, the least imperfect alternatives in order to promote the values that drive public interest.

The analysis will, first, aim to uncover the most common commercial practices that occur across various jurisdictions in the food industry, including specific forms of distribution contracts, strategies of expansion and capacity building, and to unveil the complex governance framework, public and private, of global food value chains. We will then explore the market situation in the various segments of the global food value chains, examining the level of concentration, the main economic actors, data with regard to prices, consumer choice, quality and innovation, before turning to examining how the competition law tool was employed in order to ensure affordability of prices, but also broader aims, such as innovation, protection of smallholders and farmers etc.. We will focus on the regulations/norms that may apply to the food sector in each jurisdiction (including international norms), such as competition law, unfair competition statutes, IP laws, codes of conduct, contract law, planning law, self-regulatory initiatives etc. Our aim will be to explore how national (and international) legal regimes have coped with the complexity of this sector, the various interests that need to be balanced (those of consumers for cheap products, those of the government to limit inflation and promote innovation and consumer choice, those of farmers for adequate compensation, those of small

10 N. Komesar, Law's Limits (Cambridge: Cambridge University Press , 2001); N. Komesar, Imperfect Alternatives: Choosing Institutions in Law, Economics and Public Policy (University of Chicago press, 1994). Neil Komesar has advanced a theory of comparative institutional analysis emphasizing the primary role of institutional choice. By institutional choice Komesar means the selection of the social decision-making process that would dispose the residual right of decision-making in a specific context. Komesar distinguishes between legislatures (the political realm), courts (adjudicators) and markets. It is, however, possible to break his categories and apply his analysis to various other intermediary social decision-making processes, such as the State bureaucracy, independent regulators, private standard setting/self-regulation bodies, or, in our case, competition authorities 
retailers and groceries stores for sustainability, those of business actors for greater efficiency and profitability etc.) and how this balancing has occurred in each jurisdiction examined. We will aim to understand the reasons of regulatory divergence in the policy mix used and reflect on policies that will enhance economic development and promote transformative innovation in this context.

Our emphasis will not only be on the consumer side (and the need to guarantee affordability, enhance consumer choice and innovation) but also the supply side (the integration of the factors of production segment of agriculture, the presence of large retailers and their competitive interaction with smaller grocery stores, e-commerce and $\mathrm{m}$-commerce) in these jurisdictions, in particular in view of the need to enhance market access to global food value chains in conditions favouring investment, employment and productivity, while fulfilling objectives of sustainable development. Similarly, we will focus on the existence of significant FDI in the food industry in each jurisdiction examined. We will explore the governance aspects of transnational networks linking big distribution to food suppliers and farmers, the relations between food distribution and food supply, the need to take into account these transnational contractual networks when envisaging the enforcement of competition law, the adequacy of self-regulation and soft law to protect the public interest in this context, or the need for international cooperation and convergence, among BRICS, but also beyond.

The team has engaged with a number of competition authorities (those of the BRICS but also other emergent jurisdictions), international organizations (e.g. UNCTAD, OECD), as well as a number of international and local experts (economist and lawyers). Because of their importance in the global economy and the political capital and ambition they dispose, in terms of promoting different paths and models for development globally, the BRICS countries have constituted the main focus of our research. There is also a lack of work on the issues raised by the food value chain and competition policy for developing and emergent jurisdictions, and the BRICS countries in particular. Although there is a lot of work on the regulation of the food value chain in the EU and the US, we consider that the same considerations may not apply in BRICS, with the result that it is difficult to transpose the solutions promoted for the European or the US markets. By promoting an in-depth discussion over these issues, and taking a political economy and comparative perspective, this research project has the ambition to create a knowledge base that will be particularly helpful for competition and other authorities in these jurisdictions in charge of policy in the food sector area, independent from the existing resources from the US and EU, and to develop cooperation between the competition and other authorities in BRICS on this issue.

More importantly, we consider that an in-depth analysis of the competition policy issues in the food industry may provide a blueprint for rethinking competition law and policy and the interaction between competition law and other tools that have been used to manage relations of economic power, such as unfair competition, IP laws, contract law, regulation and selfregulation, in order to promote a plurality of objectives that are often put forward by public authorities in this area: economic efficiency, innovation and consumer welfare, distributive justice and the fight against inequalities, right to food, the increase of national productivity, industrial and agricultural policy concerns, employment, sustainable development etc. The existence of various market actors (agribusiness, processors, distributors at the wholesale and 
retail levels), different forms of commerce competing with each other (modern and more traditional), different means of self-regulation including standard setting and certification, various groups of consumers (some focusing on price, while others on quality, including organic and fair trade food), various forms of suppliers (e.g. industrial, farmers), presents a complex web of societal relations built in order to guarantee the production and distribution of food. Because of the societal importance of the sector, this social web of actors is intrinsically linked with politics, either at the national (democracy, political stability) or the global level (the new geopolitics of food). Indeed, as some have commented, "( $\mathrm{t}$ )he world is in transition from an era of food abundance to one of scarcity. Over the last decade, world grain reserves have fallen by one third. World food prices have more than doubled, triggering a worldwide land rush and ushering in a new geopolitics of food. Food is the new oil. Land is the new gold"11. Our aim is to develop a "holistic" competition law and policy perspective that will aim to integrate the multi-dimensional reality of global food value chains in the assessment of specific commercial practices or sectors. Hence, we have strived to provide the grammar for this more holistic perspective on competition law and policy in this crucial sector for the national and the global economy.

The project had four central operational objectives/aims:

1. Form a complete picture of the legal framework applying to the food industry in BRICS and other selected jurisdictions, as well as international efforts of convergence. We have focused on all aspects of competition law (antitrust, mergers, market inquiries) and the interaction of competition law with other tools employed to regulate economic power in the food sector in order to promote the public interest, including unfair competition, contract law, IP laws, regulatory and self-regulatory initiatives. An important aim of this work has been to understand how the different tools employed to regulate the activity of this specific sector interacted with each other and to determine the policy mix chosen by each of the examined jurisdictions.

2. Understand the characteristics of the food industry and its link to food value chain at the level of the BRICS jurisdictions, selected emergent, developing economies and globally. We have focused on the actors involved, their relations, the institutions that "regulate" their activity at the local, national and global level, in order to understand the broader societal context in which these economic relations are embedded. This aim has been achieved by collecting information published on the organization of the food industry in the selected jurisdictions. This part is nevertheless uncomplete. We plan to conduct in the next few months some additional interviews and qualitative research in order to understand the strategies of the actors involved and their interaction with each other, the possible transnational links that exist between different actors, the role of politics and geopolitics and their effect, and the role of symbols, such as brands, in structuring these forms of social interaction.

3. Explore the interplay between the characteristics of the food industry and the wider economic eco-system in each jurisdiction. This has been achieved by exploring the structural characteristics of the national and the global markets (in particular

\footnotetext{
${ }^{11}$ L.R. Brown, Empty Planet, Empty Plates (Norton \& Company, 2011), 3.
} 
collecting data on market concentration, prices, quality, consumer choice and innovation to the extent these were publicly available and they been compiled and relied upon by the public authorities or trusted (non-biased by material interests) private actors.

4. Examine the interaction between the legal and regulatory framework relating to the food industry in the selected jurisdictions (and globally) and the broader societal and economic context we have identified, as parts of aims 1 and 2 . We have been particularly interested in understanding if the economic and social transformations that have characterized the evolution of this economic sector the last few decades, and in particular since 2005, have led to the development of new types of legal tools in competition law (or more broadly), or of different ways to understand traditional legal concepts, or of different methods/processes for adjudicating legal disputes and making trade-offs between the values, interests or rights protected

\section{Contributors to the research}

The project was initiated and designed by professor Ioannis Lianos, chair of global competition law and public policy at UCL Laws and chief researcher of the HSE-Skolkovo Institute for Law and Development, who conceptualized the project and was its principal investigator from its starting date in April 2015, inviting academic colleagues from BRICS jurisdictions to contribute to the project, managing the various research teams involved in the project at different times and generating support for the project among the various BRICS competition authorities. Professor Lianos is also the main drafter of this Report. In his capacity as the Director of the Centre for Law, Economics and Society at UCL Laws, professor Lianos ensured the coordination of the UCL team contributing to this project, in particular the research staff and administrative staff involved in the organisation of the various workshops and colloquia so as to engage with the stakeholders in the research and to promote public impact. In his capacity as the chief researcher of the HSE Skolkovo Institute for Law and Development, professor Lianos also coordinated the HSE research team involved in this project.

The research project benefitted from the important contribution of professor Alexey Ivanov, Director of the HSE Skolkovo Institute for Law and Development, who provided comments and feedback on the initial research proposal prepared by professor Lianos, but also contributed to the project at various stages, in the context of the presentations of the project to various audiences, individually or with professor Lianos, bringing a great deal of local knowledge in the way the food industry operates in BRICS countries and also, more crucially, ensuring the support of the Federal Antimonopoly Service of the Russian Federation and of its chairman, professor Igor Artemiev, to this project. Professor Ivanov also made a considerable contribution in bringing the project to the attention of the BRICS competition authorities' working group on the food sector that was established in May 2016, with the aim to coordinate the BRICS competition activity in this sector and generate more cooperation between the BRICS competition authorities. In his capacity as the Director of the HSE Institute for Law and Development, professor Ivanov ensured the coordination of the HSE Skolkovo Institute team involved in this project, in particular the administrative staff involved in the organisation 
of the various workshops and colloquia. . We would like to thank him for his important contribution to this project, from its inception.

The project benefitted from the material, and intellectual, support of the Competition Commission of South Africa, which funded part of this study, and in particular of Commissioner Tembinkosi Bonakele and deputy commissioner Hardin Ratshisusu, who have provided insightful feedback at various occasions following the presentations of the project and in the various preparatory workshops and have been very supportive of the initiative.

The project's research team was expanded by the active participation of various researchers and research teams from BRICS countries and beyond.

First, the team of the Centre for Competition, Regulation and Economic Development (CCRED), and in particular professor Simon Roberts and Reena Das Nair, Teboho Bosiu and Anthea Paelo, who participated to the various workshops organized in order to discuss the methodology and the intermediate results of our research, but also drafted a number of case studies on a number of food value chains in South Africa included in Part V of this report. Judge Dennis Davis has provided intellectual leadership. His unparalleled experience in adjudicating competition law cases in South Africa as well as his conceptualization of global food value chains have been an important source of inspiration for this work.

Second, the team of the Centre for Organization Studies (CORS) at the University of Sao Paulo in Brazil, and in particular professor Sylvia Saes who contributed to some of the preparatory workshops and also contributed with case studies on food value chains in Brazil and her colleagues Rodrigo Lanna F. da Silveira (from Unicamp, Brazil), and Beatriz Saes (from the University of Sao Paulo) who contributed to the report with a case study. We would also like to acknowledge the great support we have received from the Administrative Council for Economic Defence (CADE), the Brazilian competition authority, and its former chair professor Marcio de Oliveira Junior, currently advisor at the Brazilian Senate, who has contributed to the various preparatory workshops, as well as in reviewing the country report for Brazil, together with professor Caio Mario da Silva Pereira Neto of the FGV Law School in Sao Paulo, who has also contributed to the various preparatory workshops.

Third, the team of the Consumer Unity \& Trust Society (CUTS) International, and in particular his chairman Pradeep S. Mehta who has contributed to the preparatory workshops and Ujwal Kumar, who has also contributed with a case study on the issues rising out of BT cotton in India. We are also particularly thankful to an anonymous reviewer and Dr. Seema Gaur, Senior Economic Adviser at the Ministry of Economics and Information Technology of the Governent of India for their insightful contributions to the various preparatory workshops, as well as for providing their feedback on the country report for India.

Fourth, the team of the Koguan Law School at Shanghai Jiao Tong University, and in particular professors Wang Xianlin and Liyang Hou, who have also contributed to the various preparatory workshops organized and have also provided feedback for the country report on China.

Fifth, professor Pierre Regibeau from CRA, Imperial College and CLES@UCL and professor Katherine Rockett from the Department of Economics at the University of Essex, who have actively participated to the various preparatory workshops and have also contributed 
to the report providing economic and empirical insights on the effects of mergers on innovation in the agro-chem sector.

The project was officially launched at the first BRICS Competition Law Forum, organised by the HSE Skolkovo Institute for Law and Development, with the support of UCL in St Petersburg in May 2015 ${ }^{12}$. The workshop participants were asked to provide feedback to an exploratory report co-drafted by professor Ioannis Lianos with the assistance of Dr. Claudio Lombardi, senior researcher at the time at the HSE Skolkovo Institute for Law and Development.

The next step was the organization of a preparatory workshop in cooperation with the University of Cape Town and Judge Dennis Davis, which took place in Cape Town in November 2015, following up the annual BRICS competition law conference organised by the South African Competition Commission ${ }^{13}$. Professor Ioannis Lianos and Dr. Claudio Lombardi presented in this workshop an updated version of the exploratory report and asked partcipants to develop specific themes of interest in order to promote reflection on the various themes touched upon the food value chain project.

This work continued with the Second BRICS Competition Law Forum organised in May 2016 in St Petersburg, organised by the HSE Skolkovo Institute for Law \& Development and the Centre for Law, Economics and Society at UCL, a workshop that was entirely dedicated to the issue of global food value chains ${ }^{14}$. Some of the first results of this research work have been published at a special issue of the competition law journal Concurrences and appeared in January and April 2016 ${ }^{15}$.

Professor Lianos presented some of the results of this work at a conference organised by the Forum for Law and Markets at the University of Haifa Faculty of Law, a conference also supported by the Loyola Institute for Consumer Antitrust Studies in June 2016. Professors Ioannis Lianos, Alexey Ivanov, and Dr. Claudio Lombardi have also presented about the food value chains project in various conferences organised by the Russian Federal Antimonopoly Service (FAS) and the Skolkovo Foundation in December 2015, September 2016 and December 2016.

It became essential at this point of time to explore in more detail the concept of global value chains and its possible contribution to competition law. For this reason, a workshop was organised in London by the Centre for Law, Economics and Society at UCL in February 2017, where a number of participants commented on a concept note prepared by professor Lianos ${ }^{16}$.

\footnotetext{
${ }^{12} \mathrm{See}$, https://www.ucl.ac.uk/cles/research_initiatives/gcl-economic/brics-competition-law-and-policy-forum .

13 See, https://www.ucl.ac.uk/cles/research_initiatives/gcl-economic/index/edit/brics-competition-law-andpolicy-academic-workshop

${ }^{14}$ See http://www.ucl.ac.uk/cles/research_initiatives/gcl-economic/global-food-supply-chains-and-competitionlaw

${ }^{15}$ I. Lianos \& C. Lombardi, Competition law and policy and the food value chain, January 2016, Concurrences Review $N^{\circ} 1-2016$, Art. $N^{\circ} 78014,22-35$; I. Lianos, D. Katalevsky \& A. Ivanov, The global seed market, competition law and intellectual property rights: Untying the Gordian knot, May 2016, Concurrences Review $\mathrm{N}^{\circ}$ 2-2016, Art. No 78807, 62-80.

${ }^{16}$ See, https://www.laws.ucl.ac.uk/event/global-value-chains-in-competition-law/ .
} 
The first preliminary draft of the food report was presented at a the third BRICS Competition Law Forum organised in May 2017 in St Petersburg, with the participation of a number of competition law officials and scholars from BRICS countries and beyond ${ }^{17}$.

Drafts of the various chapters of the report were circulated in September and October 2017 and a number of external reviewers were involved, with regard to the country reports and the data collected on the enforcement activity of BRICS competition authorities in this sector, as well as with regard to the other, more conceptual, parts of the report.

We are happy to have received comments by two anonymous reviewers on Part V of the report, in particular regarding Chapter II on Innovation and mergers. Particular care has been taken to integrate the most recent decisional practice of the BRICS and other competition authorities, in particular as the mega-mergers on seeds, traits and plant protection were coming to be assessed by the competition authorities in 2016 and 2017.

The report benefited from a dedicated team of senior and junior scholars that have spent time to gather information, analysing it and also contributing to various extens in the drafting of the report.

At the HSE Skolkovo Institute for Law and Development, the contribution of Dr. Claudio Lombardi has been quite significant. Dr. Lombardi assisted professor Lianos in the conceptualization of some of the themes touched upon by the research project, and has also assisted professor Lianos in the drafting of the exploratory report and of its updated version presented in November 2015, having worked on this project from March 2015 to January 2017. Dr. Dimitry Katalevsky has provided the research team with his important expertise on the business side of the food industry and has contributed to the methodology of the financialisation study, regarding the visualisation of the common and cross-ownership links in the various segments of the food value chain, jointly with George Ovchinikov and professor Lianos. Mr Maksim Bashkatov, Ms. Katya Semenova \& Mr. Georgy Tyulyaev have contributed to the country report on the Russian federation. Dr. Qiang Yu has contributed to the drafting of the country report on China as well as to the coding of the decisional practice of the Chinese competition authorities in this sector.

At the Centre for Law, Economics and Society at UCL, Dr. Amber Darr has contributed, jointly with professor Lianos, to the analysis of the implications of the right to food in competition law and, on her own, to the country report on India. Dr. Matthew Strader has contributed to the coding of the cases in South Africa and also helped with research on some aspects relating to price discrimination in the superior bargaining power chapter, in particular concerning US law. Mr Murilo Lubambo de Melo has drafted the country report for Brazil and has been dealing with the coding of the decisional practice of the Brazilian competition authority. Mr Wang Bo and Ms Ye Huilin have contributed to the drafting of the country report on China as well as to the coding of the food-industry related competition law cases in China. Mr Theodore Alysandratos and Mr George Poquillon have assisted professor Lianos with the statistical analysis of the data collected on the enforcement activity of the BRICS competition authorities in this sector. Ms Averil Campion has assisted professor Lianos with the industry analysis parts of the research and contributed to part of these Sections. Mr Justin Lindeboom

\footnotetext{
${ }^{17}$ See, https://www.laws.ucl.ac.uk/event/global-antitrust-brics-style/ .
} 
and Ms Christina Kanakari have contributed, together with professor Lianos, to the part of the research relating to the concept of superior bargaining power. Mr Lindeboom has also contributed to the drafting of sections of Part III, Chapter 1 of the report. Mr Igor Nicolic and Mr Riccardo Savona Siemens assisted professor Lianos with the drafting of the legal analysis chapter in the Innovation part of the report. Ms Alina Velias helped professor Lianos with the data collection and significantly contributed to the conceptualization and drafting of the Financialisation Section of the report.

The research would not have been possible without the funding provided by the HSE Skolkovo Institute for Law and Development, the Centre for Law, Economics and Society at UCL and the Competition Commission of South Africa. Professor Lianos would like to thank the Leverhulme Trust for its financial support in particular with regard to replacement teaching costs and research assistance. The project aims to present a different perspective on the role of economics and social science literature in competition law, and apply it in an important economic sector, a theme intrinsically linked to the study of the role of economists and economics in competition law that forms part of professor Lianos' research programme funded by the Leverhulme Trust.

\section{Structure of the Report}

This draft report is divided in six parts.

Part I introduces the methodology and the conceptual framework of this study, in particular the concepts of "global value chain", "vertical competition", "multi-lever competition policy" and "polycentric competition law", which constitute some of the theoretical innovations brought by this study.

Part II engages with a description of the industry structure and of the major economic and technological transformations that have marked global food value chains in recent decades. This part will be updated and reviewed in order to include additional data and discussion when we will dispose of the final decisions of all the BRICS competition authorities on the recent seed and agrochem mergers and we have a clearer picture over the new structure of the industry, following the most recent merger wave.

Part III engages with the legal framework. We start by exploring the competition law enforcement activity of BRICS competition authorities in general, before turning to the recent agrochem and seed mergers, the process of review being still ongoing. Then we turn our attention to the concept of superior bargaining power, which we think needs to be reconceptualised and be used more systematically, also in competition law enforcement, depending on the comparative institutional analysis performed as to the institutional capabilities of the various institutions and also other legal fields to deal with instances of superior bargaining power. This Section is still a work in progress and needs substantial theoretical work, which we hope to complete in the next couple of months. The next Section deals with an issue that, we believe, should become center-stage in competition law enforcement, in view of the prevalence of common ownership by the same institutional investors of the various economic actors at the different segments of the food value chain. We consider that this raises important competition law issues that competition authorities need to 
tackle, not only on the basis of well-accepted theories of harm, such as unilateral effects, coordinated effects, vertical foreclosure, but also specific theories of harm focusing on the preservation of "vertical competition".

Part IV explores the issues raised by the need to adopt competition law enforcement that promotes innovation and works in tandem with other legal regimes having a similar objective. The first Chapter focuses on the legal framework and explores in more detail the interaction of competition law and intellectual property rights. The second Chapter explores the way these concerns may play out in assessing mergers, from an innovation perspective. Competition authorities increasingly worry about the impact that concentrations might have on innovation. Until recently, a common view was that, because of the well-documented "inverted U-shape" relationship between innovation and market concentration, mergers were only likely to have an adverse effect on innovation if market concentration is already quite high. New cases and new economic papers have challenged this orthodoxy, arguing that a refutable presumption that mergers lead to less innovation might make for better policy. We review this debate and propose a typology of effects to help decide whether or not such a presumption is actually warranted. We then apply these principles to the case of mergers in the seed/GM crops industry, which is of particular significance for BRICS countries. Finally we present a first illustrative empirical exploration of this typology and the economic principles that underlie it by examining how previous mergers in the industry have affected the merged parties' propensity to patent in various jurisdictions. Because the economic needs of BRICS countries can be distinct, we emphasise not only the effect of mergers on total patent counts but also possible effects on the specific areas where research takes place

Part V includes country reports from the BRICS jurisdictions. We have tried to include in these reports information on the legal framework structuring food markets and food value chains, not only in the area of competition law, but also other areas of law that exercise an important impact on the competitive interactions in this economic sector. We consider that this holistic perspective is essential if one is to understand the constraints and challenges faced by competition authorities when framing their intervention in food markets. We have a Section for each BRICS jurisdictions, starting with Brazil, Russia, India, China and South Africa.

Part VI delves into a number of case studies of specific food value chains. We have six case studies from South Africa (on seeds, fertilisers, animal feed to poultry, dairy, milling and retail), one case study from India (GM cotton), and one from Brazil (soybean). These case studies provide insightful analysis on the challenges that competition authorities face in specific economic sectors and also constitute excellent illustrations of the descriptive and operational power of the value chain concept. 


\section{Chapter 1: Developing tools to deal with the complexity of the food sector}

\section{Ioannis Lianos}

The last few decades competition law around the globe has been firmly geared towards the paradigm of consumer surplus/welfare as the main analytical framework in assessing alleged restrictions of competition. Consumer welfare has traditionally focused on the ability of consumers to benefit from lower prices and higher output. Competition authorities have developed tools and methodologies in order to assess when business conduct may have nefarious effects to consumer welfare/surplus. Different forms of business transactions, such as determining its own prices, providing rebates, subjecting the sale of a product to the condition that the buyer also purchases a different product, or at least agrees he will not purchase the product from any other supplier, concluding agreements with other firms for the licensing of technology or the definition of a common technical standard, proceeding to a merger and acquisition transaction, may fall under competition law scrutiny when there is some likelihood that the specific conduct will harm consumer welfare or consumer surplus. This assessment is, in principle, done in the context of a relevant market.

Economists of the neoclassical paradigm defined the market by reference to a single seller or buyer and including in it all considerations he/she took into account in determining his/her business policies and practices. The market was therefore seen as a group of firms that are significant competitors to the single firm in question. This specified even more the classical economic notion of market as an "area within which price tends to uniformity, allowance being made for transportation costs" 18 . U.S. economist Jo Bain developed the concept by setting the boundaries of the market as relating to the group of products that are not only "identical or perfect substitutes" to each other, but also alternatively "close substitute products", close substitutability therefore becoming the general criterion for inclusion in the market ${ }^{19}$. This concept is based on cross-price elasticity of demand. U.S. economist Fritz Machlup added the cross price elasticity of supply dimension as a factor for determining market boundaries, noting the importance of significant interdependence between the firms included within the boundary of the market ${ }^{20}$.

The usefulness of the concept of relevant market in order to analyse the effects on consumers of specific forms of business conduct has been frequently questionned. Gregory Werden comments that "hostility to market delineation was particularly intense from the early 1930s to the mid-1950s, in view of the perception shared by economists at the time that product differentiation enabled each firm to a certain extent to behave as a monopolist on a particular market, at least to a certain extent ${ }^{21}$. However, even to the proponents of the imperfect competition school for whom product differentiation could be a source of market power, it was

${ }^{18}$ G. Stigler, The Theory of Competitive Price (New York: Macmillan, 1942) p. 92, cited by G. J. Werden, The History of Antitrust Market Delineation, (1992) 76(1) Marquette Law Review 123-215, 15.

${ }^{19}$ J. S. Bain, Price Theory (New York: John Wiley \& Sons, 1952), pp. 24-25

${ }^{20}$ F. Machlup, The Economics of Sellers' Competition (Baltimore: Johns Hopkins University Press, 1952), pp. 213-214.

${ }^{21}$ G. J. Werden, The History of Antitrust Market Delineation, (1992) 76(1) Marquette Law Review 123-215, 125. 
clear that assessing the welfare effects of a conduct at the industry level was not very useful and were quick to recognize that "(q)uestions relating to competition, monopoly and oligopoly must be considered in terms of markets" 22 . Most recent salvos against market definition were initiated by proponents of a more "direct" form of assessment of marker power" ${ }^{23}$.

Despite these criticisms, the tool of market definition offers a relatively simple analytical framework in order to analyse and, more importantly measure, the effects of a restriction of competition on the welfare of consumers (or consumer surplus), in particular with regard to the price parameter of competition. Indeed, these effects are almost always assessed with regard to their impact on the price mechanism. Conduct restricting rivalry between competing undertakings (economic entities) that may lead to higher prices, which could not be compensated in the short and medium term by lower prices (or more rarely some other benefit, such as higher quality, innovation) may constitute a restriction of competition and lead to competition law sanctions and remedies (depending on the competition law system in question).

Although useful, the tool of market definition does not, however, provide a full picture of the competitive interactions taking place in a field of economic activity. Competitive interactions do not only take place in the context of a market, but may also arise in the context of a hierarchy or a network, if one adopts the classic categorisation by Oliver Williamson of economic organizations ${ }^{24}$. It is possible that various departments in the same undertaking may compete for resources and attention by the senior management. It is also possible that an undertaking member of a distribution network competes not only with other distributors, as to the amount of sales/market it can capture and consequently increase its profits, but also with its own suppliers as to the share of the joint profit generated by their cooperation.

Although the analytical framework of the relevant market works generally well in order to assess competition between undertakings present at the same market and competing for a higher market share (in this market), and the welfare effects of this restriction of competition on price and output, it works less well the more one moves away from effects on price to consider the effect of such restriction of competition on innovation, variety and consumer choice. This study also contends that the concept of relevant market does not offer the proper analytical framework to assess the effect of restrictions of "vertical competition" that may be of concern for competition authorities in BRICS and other emergent and developing countries for reasons that we will explain in the subsequent Sections of this report. Competition authorities may not only be interested in assessing the effects of a specific restriction of competition on the welfare of the consumers situated in their jurisdiction but they may also want to understand how a specific conduct may affect the share of the total surplus value

\footnotetext{
22 J. Robinson, The Industry and the Market, (1956) 66(262) The Economic Journal 360-361, 361. See also, E. Chamberlin, Product Heterogeneity and Public Policy, (1950) 40 American Economic Review Papers \& Proceedings 85-92, 86-87 noting that “(i)ndustry' or 'commodity' boundaries are a snare and a delusion - in the highest degree arbitrarily drawn, and wherever drawn, establishing at once wholly false implications both as to competition of substitutes within their limits, which supposedly stops at their borders, and as to the possibility of ruling on the presence or absence of oligopolistic forces by the simple device of counting the number of producers included".

${ }^{23}$ See, inter alia, L. Kaplow, Market Definition: Impossible and Counterproductive, (2013) 79(1) Antitrust Law Journal 361-379

${ }^{24}$ O Williamson, The Mechanisms of Governance (OUP, 1996).
} 
generated by the value chain and captured by the undertakings (producers and distributors), consumers and other stakeholders. To the extent that enhancing productivity and promoting innovation become important aims for competition law, beyond the traditional focus of competition law on allocative efficiency, the last type of assessment becomes particularly important.

Competition law assessment in a globalised world needs to engage with the "global value chain revolution" that has been the hallmark of the second phase of globalization unleashed by the ICT revolution in the $1990 \mathrm{~s}^{25}$. According to Richard Baldwin, a feature of this second phase of globalization is the unbundling of the physical location of factories and manufacturing from places of consumption, as "radically better communications made it possible to coordinate complex activities at distance" and led to a considerable amount of offshoring to low-wages nations. This also led to a considerable transfer of marketing, managerial and technical know-how redrawing the contours of global industrial competitiveness, as these are now defined "by the outlines of international production networks rather than the boundaries of nations" 26 . The food sector has been one of those particularly affected by this second phase of globalization, to the extent that for a considerable period of human history, production and consumption were situated at the same territory, probably in view of the sensitivity of food that is not propice to long transport distances, perishable waste being quite important in the food supply chains ${ }^{27}$, and the high transportation costs. Elites were able to benefit from international commerce on food, but the transportation costs and the important risk of food waste made it less likely that trans-national commerce of food could reach the masses of consumers. The quite important drop in transportation costs since the $19^{\text {th }}$ century (and the coresponding increase in transportation capacity), investments in intelligent food logistics, and the organization of the food production and distribution along global food value chains, controlled by international corporations, either in the form of contractual governance, or through Foreign Direct Investments (FDI) and ownership, have considerably increased the scope of international competition for what was, until recently, a more localised to a defined territory set of competitive interactions. One neds therefore new concepts that could account for this important paradigm shift. We will first introduce the concept of global value chain, before focusing on its disruptive potential in competition law.

\subsection{Introducing the Global Value Chain concept in Competition Law and Policy}

During the last two decades we have witnessed the emergence of a "new economy" driven by important technological changes and the rise of a new kind of infrastructure

\footnotetext{
${ }^{25}$ R. Baldwin, The Great Convergence (Harvard Univ. press, 2016).

${ }^{26}$ Ibid., 6.

27 J. Gustavsson, C. Cederberg, U. Sonesson, Rv. Otterdijk, A. Meybeck, Global food losses and food waste: extent, causes and prevention. In Interpack 2011. Rome, Italy: Food and Agriculture Organization of the United Nations (noting that roughly one-third of food produced for human consumption is lost or wasted globally, this statistict being based on an analysis of the data from the FAO statistical yearbook)' J. Parfitt, M. Barthel, S. Macnaughton, Food waste within food supply chains: quantification and potential for change to 2050, (2010) Phil. Trans. R. Soc. B 365, 3065-3081 (noting that average losses vary between 14\% and 70\% per product); FAO, Food Wastage Footprint: Impacts on Natural Resources (2013) available at http://www.fao.org/docrep/018/i3347e/i3347e.pdf (estimating food waste to 1.3 billion tons of food globally).
} 
technology, the Internet. As sociologist Manuel Castells noted, this economy is global in nature, not just international:

"A global economy is a historically new reality, distinct from a world economy. A world economy, that is an economy in which capital accumulation proceeds throughout the world, has existed in the West at least since the sixteenth century [...] A global economy is something different: it is an economy with the capacity to work as a unit in real time on a planetary scale" 28 .

This is largely possible because of the organisation of economic production in the context of global supply or value chains. GVCs are prevalent in the global economy. As a recent joint OECD, WTO and World bank report indicates, “(b)etween $30 \%$ and $60 \%$ of G20 countries' exports consist of intermediate inputs traded within GVCs" ${ }^{29}$. Economic production is increasingly structured around GVCs, which permit the simultaneous and coordinated transnational production and distribution of a very large array of products that each stage of the supply chain has to manage effectively, without this involving vertical integration by ownership. ${ }^{30}$ GVCs as typically coordinated by transnational corporations, which manage the cross-border trade of production inputs and outputs occurring in the context of their "networks of affiliates, contractual partners (in non-equity modes of international production) and arm'slength suppliers" 31 . The global markets of various food commodities are therefore embedded in these transnational networks of businesses that expand in both develop and developing countries. The image of a global market has therefore to be completed with the analysis of these social networks, Kevin Sobel-Read going as far as arguing that " $(\mathrm{t})$ he most important paradigm for understanding the global economy, and the political and social relationships that both guide it and stem from it, is no longer the template of the market but rather the role of global value chains", corporate action, in the form of global value chains not only driving but also defining, and therefore creating, the market ${ }^{32}$. GVCs do not only concern cross-border trade of product inputs (components) and outputs, but may also englobe transfer of technology and know-how, and from this perspective are particulalry important for the oerganisation of the generation and diffusion of innovation globally.

Legal scholarship has been trying to analyse this phenomenon, leading even to the development of a new legal field, transnational legal studies. But as Kevin Sobel-Read rightly notes,

"(t)he paradigm of the world political economy has shifted dramatically over the past twenty years. Legal scholarship, however, lags significantly behind. Existing legal scholarship is calibrated to an outdated model that suggests that multinational corporations - either individually or through one-to-one supplier relationships - create,

\footnotetext{
${ }^{28}$ M. Castells, The Information Age: Economy, Society and Culture - The Rise of the Network Society (Wiley, 1996), p. 92.

${ }^{29}$ OECD, WTO and World Bank group, Global Value Chains; Challenges, Opportunities and Implications for Policy (2014), available at https://www.oecd.org/tad/gvc_report_g20_july_2014.pdf , p. 13. See also UNCTAD, World Investment Report 2013, available at http://unctad.org/en/PublicationsLibrary/wir2013_en.pdf .

${ }^{30}$ K. De Backer and S. Miroudot, Mapping Global Value Chains, European Central Bank, (2014) Working Paper Series No. 1677.

${ }^{31}$ UNCTAD, World Investment Report 2013 (UN, 2013), 122.

${ }^{32}$ K. B. Sobel-Read, Global Value Chains: A Framework for Analysis, (2014) 5(3) Transnational Legal Theory 364-407, 367.
} 
manufacture, and sell a given product. But in today's world, in what have been termed "global value chains," the research, design, production, and retail of most products take place through coordinated chain components that stretch systemically across multiple - from a few to a few thousand - firms" ${ }^{\prime 3}$.

These global value chains (GVCs) are characterised by their "systemic, coordinationdriven nature", as they rely on various systems of transnational governance and different sorts of linkages, some traditional such as contract law, others novel and relying on corporate law, property law or some more informal mechanisms ${ }^{34}$. For instance, "global value chains are becoming a primary conduit for the transfer of intellectual property globally", as "( $t$ )he creators of intellectual products are relying less on traditional intellectual property regimes to enable them to limit access to their material, and more on a combination of contractual rights and technological protections" 35 .

Although this concept has so far been used in order to describe the operation of off shore expansion and organization of production, which are relevant concerns for public authorities involved in the context of industrial policy, we believe that it may be a quite useful tool in order to conceptualize the various forms of competitive interaction and the complexity of the social structure on which economic transactions in the food sector are embedded. In particular, the concept of global value chains calls attention to the process of vertical competition, which is as important as that of horizontal competition if one focuses not only on economic efficiency, but also on fairness in the allocation of the total surplus value generated by cooperation between independent economic actors to the extent that this may have pervasive effects on the increase in productivity and performance of the various segments of the value chain.

\subsubsection{A primer on the Global Value Chain concept}

The GVC approach provides a theoretical framework enabling us to understand how the global division and integration of labour in the world economy has evolved over time and, more importantly, how the distribution of awards, from the total surplus value, is allocated between the various segments of the chain. ${ }^{36}$ The GVC framework aims to explain how global industries are organized by examining the structure and dynamics of different actors involved in a given industry. In the words of its initiator, Professor Gary Gereffi,

“(i)n today's globalized economy with very complex industry interactions, the GVC methodology is a useful tool to trace the shifting patterns of global production, link geographically dispersed activities and actors within a single industry, and determine the roles they play in developed and developing countries alike. The GVC framework focuses on the sequences of value added within an industry, from conception to

\footnotetext{
33 Ibid., 364.

${ }^{34}$ Ibid, 365.

35 Ibid, 392.

${ }^{36}$ On the GVC framework and its predecessor Global Commodity Chains, see G. Gereffi and M. Korzienewicz (eds.), Commodity Chains and Global Capitalism (Westport: Praeger, 1994); G. Gereffi, J. Humphrey and T. Sturgeon, The governance of global value chains, (2005) 12(1) Review of International Political Economy 78 104.
} 
production and end use. It examines the job descriptions, technologies, standards, regulations, products, processes, and markets in specific industries and places, thus providing a holistic view of global industries both from the top down and the bottom up" 37 .

A tool aiming to map the inter-firm networks on a global scale, the GVC approach enables the consideration of a number of factors that may influence competitive interactions. Although the tool was initially framed so as to help policy-makers to design industrial strategies geared towards a greater participation of firms, active in their jurisdiction, to the global economy, we think that its descriptive potential is wider than that. By exploring the sequences of tangible and intangible value adding activities, "from conception and production to end use", GVC analysis offers a picture of global industries both "from the top-down", by examining for instance "how 'lead firms 'govern' their global-scale affiliate and supplier networks", but also from "the bottom-up", asking "how these business decisions affect the trajectory of economic and social 'upgrading' or 'downgrading' in specific countries" 38 .

This mapping approach examines various dimensions: (i) the input-output structure of a GVC, by focusing on the process of transformation of raw materials and factors of inputs of production to final products, (ii) the geographic scope of GVCs which explains the degree of global dispersion of the chain, (iii) the governance structure of the GVC, which delves into the issue of control of the chain, (iv) the upgrading, which describes "the dynamic movement within the value chain" and "how producers shift between different stages of the chain", (v) the local (or global) institutional context in which the value chain is embedded, including regulation and self-regulation, (vi) industry stakeholders that may be various local (but also global) actors of the value chain that interact to achieve industry upgrading. These may not only be companies, but also industry associations, workers, educational or research institutions, government agencies and ministerial departments. All these actors are involved to a certain degree in the operation of the global value chains and influence their development.

The starting point for the development of this analytical framework was the growing importance of new global buyers (big retail) constituting "buyer-driven global commodity chains." Initially, research in the GVC tradition highlighted the power and important role of large retailers, such as Walmart and Tesco, but also successful brand merchandisers and/or designers of products or middlemen and facilitators, such as Nike, Reebok, Google etc, in "dictating the way the chains operate by requiring suppliers to meet certain standards and protocols, despite limited or no production capabilities" "39, but also by largely determining "the location of high-value activities and the conditions under which other firms participate in GVCs" 40 and sometimes through forcing un unfair balance of risks to suppliers. In reaction to these "buyer driven" commodity chains or GVCs, "producer-driven chains" are more vertically integrated along all segments of the supply chain and leverage the technological or scale advantages of integrated suppliers and from this perspective are characterised by higher

\footnotetext{
${ }^{37}$ G. Gereffi and K. Fernandez-Stark, Global value Chain Analysis: A Primer (CGGC: $2^{\text {nd }}$ ed., 2016), p. 7.

${ }^{38}$ Ibid.

${ }^{39}$ Ibid, p. 10.

${ }^{40}$ OECD, WTO and World Bank Group, Global value Chains: Challenges, Opportunities and Implications for Policy (2014), 21.
} 
barriers to entry. Classic examples of producer-driven chains are the automobile and aeronautical industries, or some parts of the computer industry (e.g. Apple).

The framework shares Michael Porter's emphasis on "value systems" a concept that has been used in order to describe a set of inter-firm linkages through which different economic actors (and their value chains) are interconnected. ${ }^{41}$ GVC's "holistic view" of global industries focuses on the governance of the value chain, that is, how some actors can shape the distribution of profits and risks in the chain. Taking a political economy perspective, the GVC approach explores the way economic actors may maintain or improve ("upgrade") their position in the global value chain, "economic upgrading" being defined as "the process by which economic actors-firms and workers- move from low-value to relatively high-value activities in GVC." 42 There are different types of upgrading: some relate to the entry in the value chain, where firms participate for the first time in national, regional or global value chains, others to "end-market upgrading", firms moving into more sophisticated markets that require compliance with new, more rigorous quality standards, or into larger markets that call for investments in production scale ${ }^{43}$.

Governance analysis, which aims to identify "the lead firms in the sector, their location, how they interact with their supply chain and their sources of influence and power over them" 44 , constitutes an essential step in mapping GVCs. Hence, contrary to traditional neoclassical price theory (NPT) analysis, and more in vogue with transaction cost economics (TCE) and economics of organization, the GVC approach does not mainly focus on issues of horizontal market power and concentration at each segment of the chain, but engages with the vertical links between the various actors. However, in contrast to TCE, it aims to understand how and whether "lead" actors can capture "value". Hence, its focus is on the distribution of the value generated by the chain, rather than the maximization of the surplus (efficiency) as such. A typology of GVC governance structures was elaborated with the aim to describe and explain the driving forces for the constitution of global value chains. According to Gereffi et al., there are "three key determinants of value chain governance patterns: complexity of transactions, codifiability of information; and capability of suppliers." ${ }^{45}$ His framework is broader than the framework often employed by TCE in order to explain the prevalence of certain forms of organization (hierarchy versus the market system), as the latter focuses only on the determinants of asset specificity and the frequency of the transactions as the driving forces for organizational choice. ${ }^{46}$

\footnotetext{
${ }^{41}$ M. Porter, Competitive Advantage: Creating and Sustaining Superior Performance (New York: Free Press, 1985).

${ }^{42}$ G. Gereffi, Global value chains in a post-Washington Consensus world, (2014) 21(1) Review of International Political Economy 9-37, 18.

${ }^{43}$ G. Gereffi and K. Fernandez-Stark, Global value Chain Analysis: A Primer (CGGC: $2^{\text {nd }}$ ed., 2016), p. 12.

${ }^{44}$ Ibid, p. 10.

${ }^{45}$ G. Gereffi, J. Humphrey and T. Sturgeon, The Governance of Global Value Chains, (2005) 12(1) Review of International Political Economy 78-104, 84.

${ }^{46}$ In a nutshell, the more there is asset specificity and the interaction is long-term, the more it is justifiable to invest resources in order to build a hierarchy form of organization.
} 
The GVC framework draws inspiration from the resource-based or competences-based view of the firm, ${ }^{47}$ according to which firms as path-dependent entities characterised by heterogeneous competence bases and operating under conditions of genuine uncertainty, their existence being justified by the development of productive competencies and learning for a specific cognitive community that forms the firm's core. Contrary to what TCE predicts, firms will not necessarily develop specific capabilities and learning in order to engage in certain value activities, because, for instance, of economies of scale and the frequency of transactions, as they may be unable to develop the capabilities which are necessary for them to participate in certain value chain activities; they will be thus obliged to appeal to external resources. ${ }^{48} \mathrm{In}$ contrast to the contract theory of the firm, pioneered by TCE, the competence-base view of the firm enquires into the sources of the competitive advantage and the path-dependent process of accumulation of such capabilities. Although the GVC framework adopts the markets and hierarchy categories of TCE, it perceives them as part of a continuum, the network category, which it then analyses as three distinct types of governance regime. The three variables mentioned above (complexity, codifiability and capabaility) act as parameters in predicting how the value chain governance shifts in different situations.

In a nutshell, the GVC framework advances the following five governance categories:

- Markets where the costs of switching to new partners is very low. These "arms-length exchanges" require little or no cooperation between the actors, hence explaining the low switching costs. Here, "( $\mathrm{t}$ )he central governance mechanism is price rather than a powerful lead firm" 49 .

- Modular value chains where suppliers make products to a customer's specifications, without however making transaction-specific investments that will generate a situation of mutual dependence or just dependence. Modular governance occurs when complex transactions can be easily codified. This keeps switching costs relatively low as transaction-specific investments are limited. However, "linkages (or relationships) are more substantial than in simple markets because of the high volume of information flowing across the inter-firm link" 50 .

- Relational value chains where complex interactions between buyers and sellers often create mutual dependence and high levels of asset specificity. This merely occurs if buyers and sellers rely on complex information that may not be easily transmitted or learned, leading to more frequent interaction, information exchange and knowledge sharing between parties. These relations require a high degree of trust between business partners that needs to be built over a significant period of time. This makes switching to a new partner relatively difficult, the company having invested considerable resources on the specifications of the specific value chain to which it has so far

\footnotetext{
${ }^{47}$ G. Gereffi, J. Humphrey and T. Sturgeon, The governance of global value chains, (2005) 12(1) Review of International Political Economy 78-104, 81.

${ }^{48}$ The competence or resource-bases view of the firm draws on work by E. Penrose, The Theory of the Growth of the Firm (Oxford University Press, 1959). See, more generally, N. J. Foss, The Theory of the Firm: Contractual and Competence Perspectives, (1993) 3 Journal of Evolutionary Economics 127-144; G. M. Hodgson, Evolutionary and competence-based theories of the firm, (1998) 25(1) Journal of Economic Studies 25-56.

${ }^{49}$ G. Gereffi \& K. Fernandez-Stark, Global value Chain Analysis: A Primer (CGGC: $2^{\text {nd }}$ ed., 2016), p. 10.

50 Ibid, p. 10.
} 
participated to. These value chains are more frequently used by suppliers of differentiated products based on quality, geographic origin, or some other unique characteristics $^{51}$.

- Captive value chains where relatively small suppliers face significant switching costs and are "captive" to large buyers, such networks being characterized by a high degree of monitoring and control by lead firms. These networks are characterized by power asymmetry between the parties, which forces thick ties and high switching costs. Lad firms will usually tend to have competence in areas outside of production.

- Hierarchy which denotes situations of vertical integration with the exercise of managerial control, lead firms developing and manufacturing products in-house. ${ }^{52}$ This is usually the case when product specifications cannot be codified, products are complex or highly competent suppliers cannot be found ${ }^{53}$.

The operation of the key determinants of global value chain governance is described in the following table.

Table 1: Governance types in GVC

\begin{tabular}{|l|l|l|l|l|}
\hline $\begin{array}{l}\text { Governance } \\
\text { type }\end{array}$ & $\begin{array}{l}\text { Complexity of } \\
\text { transactions }\end{array}$ & $\begin{array}{l}\text { Ability to } \\
\text { codify } \\
\text { transactions }\end{array}$ & $\begin{array}{l}\text { Capabilities in } \\
\text { the supply-base }\end{array}$ & $\begin{array}{l}\text { Degree of } \\
\text { explicit } \\
\text { coordination } \\
\text { and power } \\
\text { asymmetry }\end{array}$ \\
\hline Market & Low & High & High & Low \\
\hline Modular & High & High & High & \\
\hline Relational & High & Low & High & \\
\hline Captive & High & High & Low & High \\
\hline Hierarchy & High & Low & Low & \\
\hline
\end{tabular}

Source: G. Gereffi, J. Humphrey and T. Sturgeon $(2005)^{54}$

Of particular interest for the purposes of competition law is the category of captive and relational value chains where power is exercised by "lead firms". For instance, these may be modern retailers and supermarkets controlling the agri-food chain, linking daily groceries' consumers with small farmers around the world. In this context, supplier's capabilities are relatively low, the complexity of product specifications being high and amenable to codification. In the face of complex products and specifications, the "lead" firms have important incentives and abilities to intervene and to control the chain, thus building up

\footnotetext{
${ }^{51}$ Ibid, p. 11.

${ }^{52}$ G. Gereffi, J. Humphrey and T. Sturgeon, The governance of global value chains, (2005) 12(1) Review of International Political Economy 78-104, 84.

${ }^{53}$ G. Gereffi and K. Fernandez-Stark, Global value Chain Analysis: A Primer (CGGC: $2^{\text {nd }}$ ed., 2016).

${ }^{54}$ G. Gereffi, J. Humphrey and T. Sturgeon, The governance of global value chains, (2005) 12(1) Review of International Political Economy 78-104, 87.
} 
transactional dependence and locking in suppliers. The latter are confined to a narrow set of tasks (for instance, provide raw products or simple assembly) and are dependent on the "lead firm" for complementary value adding activities, such as branding, marketing, commercialisation, advertising. As a consequence of this configuration, "lead firms" are able to reap the overwhelming part of the total surplus-value of the chain. In the context of relational value chains, the power balance between retailers and suppliers is more symmetrical, as suppliers' capabilities are high, thus each firm is contributing key competencies leading to a situation of mutual dependence. Trust rather than power may constitute in this case the main mechanism of coordination of the value chain and eventually the allocation of the total surplus value of the chain may appear more symmetric.

This classification of various forms of organization of the value chain highlights the importance of conducting a careful analysis of the power relations along the supply chain, the aim being to unveil value extraction bottlenecks affecting the distribution of the total surplus value. ${ }^{55}$ This analysis cannot be undertaken by the traditional NPT framework which mainly focuses on horizontal competition and its effects on consumers or total welfare and assesses the competitive interactions between firms within a specific relevant market. In contrast, the GVC perspective has a distributive focus and may be particularly helpful if one aims to understand real business strategies and how the design of the value chain may determine who profits from the collective innovation and other surplus value generated, the inter-country distribution of the total surplus value, in the case of transnational networks, if one takes a political economy perspective, and more broadly the impact of value extraction bottlenecks on the competitive process, the latter concept being intrinsically linked to an evolutionary perspective on economic change. GVC analysis may question the mechanistic view of the countervailing bargaining theory argument, claiming, for instance, that the consolidation and increasing concentration at the supplier level may curtail the rising power of retailers, by emphasizing the risk of the development of "bilateral oligopolies" of consolidated producers and retailers and subsequently of double marginalisation that may harm consumers and the competitive process. ${ }^{56}$

We consider that such an approach is particularly helpful. Not uniquely in the context of global value chains affecting developing or emergent economies ${ }^{57}$, which is a topic that has attracted some attention, if one wants to promote a political economy framework that will enable local firms to participate to global value chains and thus to "upgrade" existing capabilities and to create "domestic" added value, but also in the context of a developed countries' club, such as the EU. Indeed, it becomes easy to observe a large heterogeneity of

\footnotetext{
${ }^{55}$ R. L. Steiner, Intrabrand Competition-Stepchild of Antitrust, (1991) 36 The Antitrust Bulletin 155-200, has also emphasized the role of "vertical competition" and "vertical market power" in his "dual-stage model" of competition law assessment. However, he does not offer an analytical competition law framework which will go beyond the classic NPT focus on horizontal concentration and the possibility of vertical market power to transform itself to horizontal market (selling or procurement) power.

${ }^{56}$ J. Lee, G. Gereffi and J. Beauvais, Global value chains and agrifood standards: Challenges and possibilities for smallholders in developing countries, (2012) 109(31) Proceedings of the National Academy of Science 12326$12331,12329$.

${ }^{57}$ See, for instance, R. Kaplinsky, Competitions Policy and the Global Coffee and Cocoa Value Chains, Paper prepared for the United Nations Conference for Trade and Development (Brighton: Institute of Development Studies, Sussex, 2004), available at https://www.ids.ac.uk/files/RKaplinskycocoacoffee05.pdf.
} 
productive capabilities between the North and the South/Eastern part of the Continent and the establishment of value chains with "lead" firms (mostly based in the Northern part of Europe) extracting an important share of the total surplus value produced. Article 3(3) of Regulation 1/2003 offers some policy space by explicitly authorizing Member States to adopt and apply provisions of national law that predominantly pursue an objective different from that pursued by Articles 101 and 102 TFEU, for instance, legislation that "prohibits undertakings from imposing on their trading partners, obtaining or attempting to obtain from them terms and conditions that are unjustified, disproportionate or without consideration." 58

\subsubsection{Vertical competition}

The concept of global value chains has been employed by economic sociologists and business economists with the aim to describe the way trade flows are organized in the modern economy and to guide the action of public authorities eager to upgrade the productive activities in their jurisdiction to higher added activities. This is not what is sought by the use of this concept in competition law. The aim here is different: it consists in emphasising the importance of vertical competition in the process of producing and distributing products for end-consumers. We consider that focusing on horizontal competition in the context of a relevant market and with regard to substitutable goods and services only tells part of the story about competitive interactions, as the undertakings' incentives and strategy and that of their management is often influenced even more significantly by the constraints imposed by the vertical competition that opposes it to other undertakings in each value chain with the aim to attract the higher percentage of the total surplus value generated by the value chain. This "surplus value" may result from sales in various relevant markets in the various segments of the value chain, the use of inputs for the in-house production and sale of outputs when this process of transformation adds value, or value generated by the presence of the various undertakings in financial markets, where specific decisions are made by investors as to the market value of a company, on the basis of expectations about future returns on investment. We will explore this competition for capital which is an important characteristic of the modern financialised economy, often ignored by competition law, in Section 1.1.3.3.

Firms operating in each of the layers of a value chain face an important dilemma: they want to maximise their market power, as this will enable them to increase their profits, to the extent that they are able to charge higher prices to consumers in their segment of the value chain, but their ability to do so may be limited by the need to take into account the effect that this price increase may have on the overall competitive position of the value chain they are participating to, as increasing prices at one segment of the chain may hurt other firms operating in other parts of the chain, which may then react and increase prices as well, should they have the ability to do so without taking into account the joint interest of the various companies members to the value chain. Hence, a winning strategy may be to increase competition in other parts of the chain by promoting entry and fragmenting supply, while maintaining their monopoly position in their segment of the chain, or to cooperate with other monopolised

\footnotetext{
${ }^{58}$ Recital 9 and Article 3(3) of Regulation 1/2003.
} 
segments of the value chain, thus sharing between them the profits arising out of the joint activities of the chain (co-opetition or the so called frenemies situation).

\section{Figure 1: A general view of the Food Value Chain}

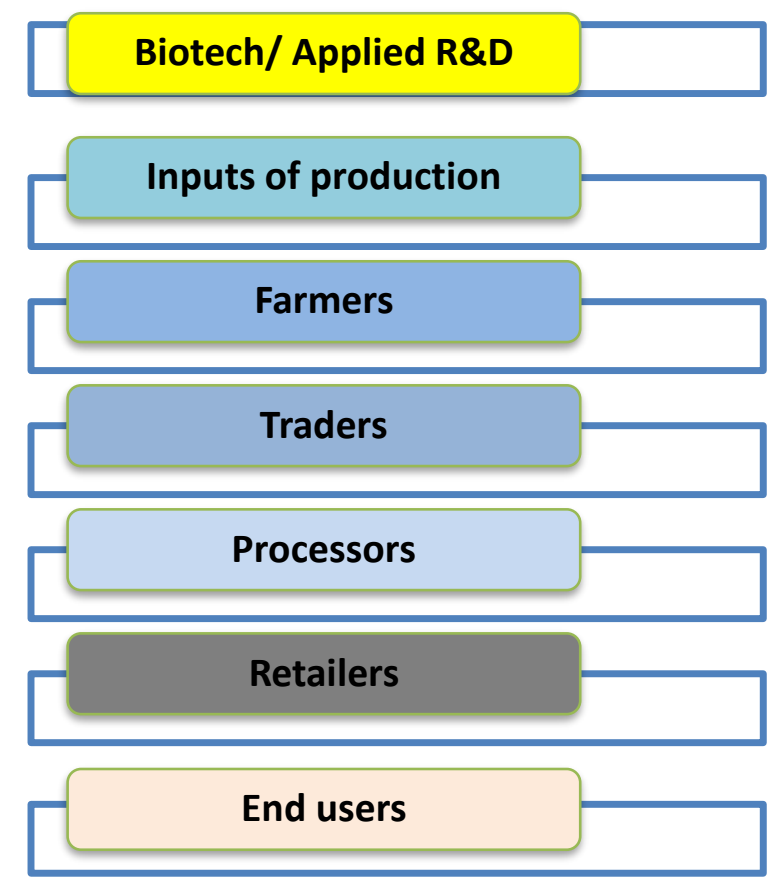

\section{Source: Author's compilation}

It becomes clear that intervention, or non-intervention, at one segment of the vertical value chain may lead to adverse unintended consequences at other parts of the chain. It becomes therefore necessary to internalize the complexity of the value chain as an integral part of the overall economic and legal context, and avoid any localized silo-based competition law assessment of a particular segment that would only take into account horizontal competition and not vertical competition.

The Global Value Chain approach enables competition authorities to focus not only on issues of horizontal market power and concentration at each segment of the chain, but also to engage with the vertical links between the various actors with the aim to understand how and whether "lead" actors can capture value. Competition authorities may therefore focus on the distribution of the surplus value generated by the chain, rather than just on the maximization of the surplus (economic efficiency) as such. This may be important, should fairness, inequality or distributive justice considerations constitute an important aim to be pursued by competition law ${ }^{59}$. Focusing on pecuniary externalities, that is the creation of third-party eflects through changes in relative prices may be irrelevant if one focuses on economic efficiency (which takes into account only technological externalities) and assumes away distributive justice concerns, on the basis of the existence of possible transfers (through progressive taxation, subsidies etc)

\footnotetext{
${ }^{59}$ On a more detailed analysis of the role of different forms of inequality in competition law, see I. Lianos, The Poverty of Competition Law, CLES Research paper series 2/2018.
} 
that may mitigate these effects, according to the Second Fundamental Theorem of Welfare Economics $^{60}$. It is thought that these pecuniary externalities should be left to the political process to sort out. However, one may not assume that this is always the case in reality, as it might be that the political process does not function well in the sense of taking seriously into account the compensation of losers, or that the State in question cannot afford the transfer of the appropriate level of resources to compensate the losers, in particular as those that benefit from the restrictions of competition may be outside the reach of its tax authorities and there is an inter-jurisdictional transfer of wealth. Hence, it is possible that the source of these pecuniary externalities could be better dealt with by competition law. It may also be possible, in particular in jurisdictions with weak institutions and quite significant wealth disparities, that the resource misallocations that may result, should these pecuniary externalities be taken into consideration by competition law, could be less severe than those generated by the transfers that would be required to ensure the specific fairness objectives pursued by the specific jurisdiction

Transfers may become a permanent feature of the specific political economy, with serious effects as to the incentives of the various economic actors. In the long run it may also be more efficient to deal directly through the tool of competition law with the structural position of the lead firms that led to the structural weakness of these economic actors at the first place, rather than delegate the task to wealth transfers decided by the political process, in particular if the later has proven so far ineffective to deal with the "losers". One may not also exclude the costs of political turmoil in the presence of a widespread perception by the public opinion and the participants to the value chain that they do not have equal opportunities to benefit from the joint surplus of the value chain, generated by the increased amount of trade made possible by this coordination of economic activity at the global scale through these value chains (equality of opportunity).

It may not also be excluded that the allocation of the total surplus value of the chain may have important implications on the investment and innovation incentives of the various segments of the value chain, but also more generally affect those of the overall global value chain. It has become quite uncontroversial to examine the distribution of financial value from innovation in the global supply chains, precisely because innovation needs to be nurtured by the development of technological capabilities across the various segments of the value chain and subsequent levels of investment by the various economic actors ${ }^{61}$. Independent actors pursuing different avenues of innovation through the constitution of $R \& D$ poles may also enhance the likelihood that innovation will be successfully diffused to farmers and the rest of the economy. The economic effects of a significantly higher extraction capacity at one level of the chain, because of the presence of a lead firm, may also have negative effects on growth, as

${ }^{60}$ See, M. Blaug, 'The Fundamental Theorems of Modern Welfare Economics, Historically Contemplated', (2007) History of Political Economy 39(2) 185-207 :

"The First Fundamental Theorem of Welfare Economics: Assume that all individuals and firms are selfish price takers. Then a competitive equilibrium is Pareto optimal.

The Second Fundamental Theorem of Welfare Economics: Assume that all individuals and producers are selfish price takers. Then almost any Pareto optimal equilibrium can be supported via the competitive mechanism, provided appropriate lump sum taxes and transfers are imposed on individuals and firms"

${ }^{61}$ See, J. Dedrick, K. L. Kraemer \& G. Linden, Who profits from innovation in global value chains?: a study of the iPod and notebook PCs, (2010) 19(1) Industrial and Corporate Change, 81-116, (examining the allocation of the profits of iPods and notebook computers value chain and the role of bargaining power in this context). 
this could lead to inequalities in the distribution of innovation income ${ }^{62}$. These may be expected if the other economic actors involved in the value chain, in particular small holders and small and medium undertakings (SMEs), see their margins squeezed by the restriction of vertical competition. The role of SMEs in the development of innovative activity is quite important.

It is frequently argued that lead firms have a special responsibility to organize innovative activity when strategically designing their value chains and that they have the incentive and the ability to use strategies in order to "encourage and enable their supplying farmers to adopt technologies that meet the firms' needs (product attributes, transaction specifications, and so on), and their use of contracts to both enforce the requirements and include provisions for inputs and services for farmers to adopt the needed technologies (and commercial practices)"63. Relying on a Schumpeterian approach, these studies argue that the "the implementation of innovations leads to non-competitive behaviour or market structure" and that policy makers should be flexible and develop "a degree of tolerance to noncompetitive behaviour associated with implementing new innovations" as "(i)mplementation of policies that aim to preserve competitive market structures may diminish the innovative spirit" ${ }^{\prime}$. "Interlinked contracting" or outright vertical integration between farmers, processors and/or technology firms enable technology transfers and finance provision to occur, while preserving investors from situations of ex post opportunism and hold up. Hence, value chains operate as "engines for technological adoption" in the presence of imperfect credit markets and access to finance, the existence of important relation specific investments, in particular for the adoption of firm-specific technologies and in the presence of weak institutions of contract enforcement ${ }^{65}$.

These studies assume that lead firms will have the incentive to organize the diffusion of innovation along the various segments of the value chain. This may be true under specific circumstances, where there is competition between various value chains, and the switching costs of the various suppliers to other value chains are not prohibitive, although it is also argued that when competition is very strong this may affect contract enforcement, and consequently impact on innovation incentives ${ }^{66}$. The underlying assumption is that market size constitutes a major determinant of innovation incentives and the amount and type of technological change, a classic feature in Schumpeterian approaches to innovation. As Aghion and Howitt put it, when exploring whether market competition is good or bad for growth, "( $\mathrm{t}$ )he Schumpeterian answer to this question, appears to be one- sided: to the extend that monopoly rent is what

\footnotetext{
${ }^{62}$ See, E. Dabla-Norris, K. Kochhar, N. Suphaphiphat, F. Ricka, E. Tsounta, Causes and Consequences of Income Inequality: A Global Perspective (IMF, June 2015), available at https://www.imf.org/external/pubs/ft/sdn/2015/sdn1513.pdf .

${ }^{63}$ T. Reardon, L. Lu \& D. Zilberman, Links among innovation, food system transformation, and technology adoption, with implications for food policy: Overview of a special issue, Food Policy (2017), https://doi.org/10.1016/j.foodpol.2017.10.003 .

${ }^{64}$ D. Zilberman, L. Lu \& T. Reardon, Innovation-induced food supply chain design, Food Policy (2017), http://dx.doi.org/10.1016/jfoodpol.2017.03.010

${ }^{65}$ J. Swinnen \& R. Kuijpers, Value chain innovations for technology transfer in developing and emerging economies: Conceptual issues, typology, and policy implications, Food Policy (2017), http://dx.doi.org/10.1016/j.foodpol.2017.07.013

${ }^{66}$ J.F.M. Swinnen, A. Vandeplas \& M. Maertens, Liberalization, Endogeneous institutions, and growth: a comparative analysis of agricultural reforms in Africa, Asia, and Europe, (2010) 24(3) World Bank Econ. Rev. $412-445$.
} 
induces firms to innovate and thereby makes the economy grow, product market competition can only be detrimental to growth ${ }^{67}$. However, empirical works by Nickell, Blundell, Griffith \& Van Reenen, among others, point to a positive correlation between product market competition (as measured either by the number of competitors in the same industry or by the inverse of a market or profitability index) and productivity growth within a firm or industry ${ }^{68}$. In a competitive environment firms innovate in order to survive (the so called "Darwinian view") ${ }^{69}$.

One may further advance that lead firms may undertake strategic investments (in technological innovations such as enhanced traceability, brand building, or product differentiation) to make their products more attractive. If the incentives for these endogenous sunk costs are sufficient, then it is possible that industry structure remains concentrated even in the presence of a substantial increase of demand and output ${ }^{70}$. Hence, high concentration in these markets may persist because of the fact that firms in the industry decide to incur, in addition to the exogenous sunk costs which are costs that any firm will have to incur upon entry into the market, endogenous fixed sunk costs (.e.g. advertising, $R \& D$, process innovations), with the aim to increase their price-cost margin. Sutton shows that the size of these endogenous sunk costs does not depend on the level of output and that as market size grows and demand increases in industries with significant endogenous sunk costs, there will be "a lower bound to industry concentration" and an increase in sales may cause the number of firms to shrink. The reason provided for this is that all firms will invest in endogenous sunk costs and in the long run this investment will produce little or no profit in view of the fact that the competitive advantage gained by each firm's investment will be largely ineffective if all other firms may do the same investment. Industry profitability may fall in the long term in such expanding market if the additional profit gained from the increased volume of sales is exceeded by the increase in investment in exogenous sunk costs. Consequently, there will be less entrants in the market and more concentration. Sunk, fixed $R \& D$ investments can jointly determine both the levels of concentration and innovation activity.

It becomes therefore important to analyze whether the consolidation of the inputs of production food sector is consistent with an endogenous sunk costs framework. There have been various studies undertaken within the endogenous sunk costs framework in this sector. Oehmke, Wolf, and Raper show an endogenous, cyclical relationship between industry concentration and R\&D intensity ${ }^{71}$. Magnier, Kalaitzandonakes, and Miller described the decreasing product life cycles associated with increasing innovation in corn seed ${ }^{72}$, while

\footnotetext{
${ }^{67}$ P. Aghion Philippe \& P. Howitt, Endogenous Growth Theory (Cambridge, Mass., MIT Press, 1998), 305.

${ }^{68}$ R. Blundell, R. Griffith \& J. Van Reenen, Dynamic Count Data Models of Technological Innovation (1995) 105 (429) Economic Journal 333; S. Nickell, Competition and Corporate Performance, 104(4) Journal of Political Economy 724.

${ }^{69}$ M. Porter The Competitive Advantage of Nations, (New York: Free Press, 1990).

70 J. Sutton, Sunk Costs and Market Structure: Price Competition, Advertising, and the Evolution of Concentration, (MIT Press, 1991).

${ }^{71}$ J. Oehmke, C. Wolf, \& K. Raper, On Cyclical Industry Evolution in Agricultural Biotechnology R\&D, (2005) 3(2) Journal of Agricultural and Food Industrial Organization, https://doi.org/10.2202/1542-0485.1107 .

72 A. Magnier, N. Kalaitzandonakes \& D.J. Miller, Product Life Cycles and Innovation in the US Seed Corn Industry, (2010) 13(3) International Food and Agribusiness Management Review, available at http://ageconsearch.umn.edu/bitstream/93557/2/2.pdf .
} 
Kalaitzandonakes and Bjornson explained the endogenous relationship between firm innovation strategies, including complementary intellectual assets, and industry consolidation characteristics $^{73}$. Fulton and Giannakas ${ }^{74}$ claimed that R\&D expenses to obtain regulatory approvals should be considered as sunk costs. Sunk costs potentially prevent new entrants to enter a market niche. Taking an endogenous sunk costs approach, Anderson and Sheldon's research supports the hypothesis that the GM corn, cotton, and soybean seed markets are characterized by endogenous fixed costs to $R \& D$ with the theoretical lower bounds to $R \& D$ concentration ranging from $54.8 \%$ for corn, $47.3 \%$ for cotton, and $78.6 \%$ for soybeans ${ }^{75}$. They find that in the markets for GM corn, cotton, and soybean seeds endogenous R\&D investments are mainly responsible for the rising levels of concentration. The authors find little to no evidence that accounting for mergers and acquisitions significantly increases the lower bound to $\mathrm{R} \& \mathrm{D}$ concentration.

However, this research does not account for the possibility that innovation may come from within the various segments of the existing value chain, and that lead firms may behave strategically and block new avenues of innovation that may challenge their strong structural positioning and the share of the total surplus value they are able to extract from the value chain (vertical innovation competition) ${ }^{76}$. Vertical innovation competition constitutes to a certain extent one of the most frequent ways entrenched dominant positions resulting from the control of general purpose technologies (GPTs) may come to an end. Going back to the history of the GPT of individual productivity computing, the industry was for a long time dominated by a hardware manufacturer, IBM initially manufacturing mainframes before moving to the production of personal computer ${ }^{77}$. In this process, IBM contracted with a software firm, Microsoft, delegating to it the task to come up with an operating system for PCs. Microsoft came to appreciate the importance of the computer's operating system, which was akin to its nervous system as it does the logistical work that allows the central processing unit to compute: shifting from program to programme, allocating storage to files, moving data to and from modems and disk drives and printers. In order to understand the operating system, of course one needs to have access to the source code. Microsoft concluded a non-exclusive contract with IBM for the operating system of IBM PCs (the DOS operating system), maintaining the ability

\footnotetext{
${ }^{73}$ N. Kalaitzandonakes \& B. Bjornson 'Vertical and Horizontal Coordination in the Agro-biotechnology Industry: Evidence and Implications', (1997) 29(1) Journal of Agricultural and Applied Economics, 129-39.

${ }^{74}$ M. Fulton \& K.Giannakas. Agricultural biotechnology and industry structure. AgBioForum 4(2), 2001. pp. 137151.

${ }^{75}$ B.C. Anderson \& I.M. Sheldon, R\&D Concentration under Endogenous Fixed Costs: Evidence from the Agricultural Biotechnology Industry (mimeo, 2015)

76 To a certain extent, these various possibility theorems are common to all forms of vertical integration in the presence of a concentrated market structure: see T. Bresnahan \& J. Levin, Vertical Integration and Market Structure, NBER Working Paper No. 17889, available at http://www.nber.org/papers/w17889

${ }^{77}$ See, T. Bresnahan \& S. Greenstein, Technological Competition and the Structure of the Computer Industry, Working $\quad$ Paper 1997, available at http://citeseerx.ist.psu.edu/viewdoc/download?doi=10.1.1.598.252\&rep=rep1\&type=pdf 33 (noting that "(t)he simple framework [of contractual theories of vertical integration on the basis of transaction cost economics or property rights approaches] suggests a relationship between horizontal concentration and vertical integration that is driven by efficiency considerations --- the size of scale economies relative to the size of the market. What it neglects is the possibility that firms might make strategic efforts to limit competition. An industry can be very concentrated and feature considerable market power because of scale economies or because business strategy limits the number of active firms, for instance by affecting the potential for entry".
} 
to sell DOS to other companies. This would eventually make Microsoft's MS-DOS the standard and set the stage not only for Microsoft becoming the leading PC software company, as it provided Microsoft the rights to sell DOS for other machines, but also to end up as the lead firm in the PC value chain for years, as hardware (PCs) was increasingly commoditized and subject to intense international competition. To the extent that the operating system and software became the most valuable "commodity" in the PC value chain, Microsoft replaced IBM as the lead firm in this value chain, and this guaranteed the considerable profits and high rates of return Microsoft made during the first two decades of the individual computer industry. With the exception of the integrated model followed by Apple, which tightly integrated software and hardware with the aim to ensure control of the user experience end to end, all other hardware producers saw a decreasing percentage of the total surplus value generated by the PC value chain ${ }^{78}$.

Economic theory accepts that "a market form of organization may have considerable value when there is substantial uncertainty about the optimal direction of technical progress, or about the source of that progress"79. Although there are important benefits in the coordination of innovative activity, it is possible that potential inventors may have different views about the appropriate direction of innovation on the basis of their private information, thus making it worthwhile to enhance vertical competition as a source of innovation variety, in particular if the sector is already highly concentrated.

Of course, in order to become of interest for competition law intervention, restrictions of vertical competition need to be pervasive and not temporary, and should lead to significant pecuniary externalities, at least in the medium term. There should also be a high possibility that these may be converted to strong structural positions in other value chains in which the lead firm may be involved, thus renewing the cycle of total surplus value capture. The aim of competition law is not to micro-manage the allocation of profits between the various segments of the value chain but to ensure that the basics of vertical competition are sound and that there is no entrenched superior bargaining power situation that may lead to misallocation of resources in the medium and long term.

Competition is not also the only tool available in order to ensure the right degree of vertical competition. In the context of the food supply chain, various legal tools may be used to ensure this, such as provisions of contract law on superior bargaining power, limits to appropriability of intellectual property rights on which lad firms may rely to exercise bargaining power, such as laws ensuring access to seeds, price regulation. The optimal choice among these tools is not fixed and may depend on the remedies each of them provides, the capabilities of the specific institutions to assess restrictions of vertical competition and more generally the political economy of the specific jurisdiction.

\footnotetext{
${ }^{78}$ J. Dedrick, K. L. Kraemer \& G. Linden, Who profits from innovation in global value chains?: a study of the iPod and notebook PCs, (2010) 19(1) Industrial and Corporate Change, 81-116, (noting that "that Apple has captured a great deal of value from the innovation embodied in the iPod, while notebook makers capture a more modest share of the value from PC innovation").

${ }^{79}$ T. Bresnahan \& J. Levin, Vertical Integration and Market Structure, NBER Working Paper No. 17889, available at http://www.nber.org/papers/w17889 38.
} 


\subsubsection{A Disruptive Concept in Competition Law?}

With some exceptions GVCs have not been explored systematically by competition law scholars $^{80}$. The concept offers an important descriptive and analytical potential. The most obvious one relates to the transnational dimension it brings forward, calling for a "transnational coordination" between "destination states" and "producer states", this coordination being pursued at global, regional or bilateral levels ${ }^{81}$. The concept may provide a wider and much needed canvass in order to better conceptualize issues emerging in the enforcement of more than 130 competition laws now in a globalized economy.

We turn to the normative potential of the concept. The concept may accommodate a refocus of competition law from a unitary emphasis on consumer welfare to include other considerations, such as improving productivity and eventually pursuing other broader public interest considerations, to the extent their realisation may be affected by the restriction of competition. It could form part of a competition policy that is not only aimed at market fixing but also market shaping, this being crucial in the context of emergent economies, such as the BRICS. We also think that it has the potential to put forward a more holistic picture of competitive interactions, englobing the important but often ignored by mainstream competition law analysis, competition on attracting capital investment, which is particularly significant in the era of financialisation. The concept may require going beyond the assessment of price competition and the use of the "traditional" concepts of market definition and market power. In essence, we believe it may have the same transformative potential as the concept of multisided markets, although it might play out differently, as it may renew the focus of competition law on vertical market power and vertical competition

More specifically, by bringing the focus back to governance and power within the value chains, we believe that the concept of GVC may potentially alter the direction of competition policy towards vertical contractual restraints, and break with the quasi-forbearance regime this category of restraints benefits from, in the absence of a prima facie indication of horizontal market power. This may imply a renewed interest for theories of "relational market power" or "superior bargaining power" in competition law enforcement (see our analysis in Part III, Chapter 3). The holistic perspective that the GVC methodology offers for conceptualizing competitive interactions and the social context to which these are embedded may also provide competition authorities a more complete picture of the way restrictions of horizontal and/or vertical competition may affect the structural position of various economic actors and could also endanger the realisation of various public interest objectives, beyond consumer welfare/surplus.

\footnotetext{
${ }^{80}$ See, I. Lianos and C. Lombardi, Superior Bargaining Power and the Global Food Value Chain: The Wuthering Heights of Holistic Competition Law?, Concurrences I-2016 22-35; D. Gerber, Competition Law and Global Supply Chains, (2016). Available at SSRN: http://ssrn.com/abstract=2807154; I. Lianos, Global Value Chains and Competition Law, (2017) CLES Research Paper Series 3/2017; D. Davis, R. Kalpinsky and M. Morris, Rents, Power and Governance in Global Value Chains, in I. Lianos, A. Ivanov and D. Davis (eds.), Global Food Value Chains and Competition Law (forth. 2017).

81 D. Gerber, Competition Law and Global Supply Chains, (2016). Available at SSRN: http://ssrn.com/abstract=2807154, 24-26.
} 


\subsubsection{The received view on vertical integration/quasi-integration}

It is well accepted in Industrial Organization (IO) theory that vertical control may take different forms, going from a rigid mechanism of control within a hierarchy (vertical integration), which is based on control through the exercise of power, to more loose forms of coordination of economic activity (vertical control through contractual arrangements) ${ }^{82}$ and 'take it or leave-it exchange', that are only based on trust, rather than a binding commitment. ${ }^{83}$

Hierarchy

Vertical Integration

\begin{abstract}
Quasi-integration
\end{abstract}
Market

$\begin{array}{ll}\text { Vertical } & \text { Take-it-or- } \\ \text { contractual } & \text { leave-it } \\ \text { arrangements } & \text { exchange } \\ \text { (vertical } & \\ \text { cooperation) } & \end{array}$

There might be different reasons explaining the choice between vertical integration and vertical contractual arrangements. The starting point is transaction costs economics (TCE), in particular the work of Ronald Coase, Oliver Williamson and Paul Joskow ${ }^{84}$. According to TCE, the coordination of economic activities may take place either through the market or through some form of hierarchical control imposed by the entrepreneur within the boundaries of a hierarchy. One of the main reasons for incurring the costs of organization within a hierarchy are the costs that are imposed by employing the market mechanism, due to a number of market imperfections, such as the absence of perfect information that would enable the economic operator to select the best available partner (as an example of transaction costs). ${ }^{85}$ The governance of these costly (if one uses the market mechanism) transactions would require either the constitution of a hierarchical organisation under the control of the entrepreneur, who will integrate these activities in its existing hierarchy, or the selection of (independent) partners, their relation being managed by (long-term) contractual arrangements. Relying on vertical control, instead of the pure market exchange mechanism, may also be explained by the bounded rationality of economic agents. US economist Herbert Simon once explained that it is only

\footnotetext{
${ }^{82}$ M. K. Perry, Vertical Integration: Determinants and Effects, in R. Schmalensee and R. D. Willig (eds.), Handbook of Industrial Organization (Vol 1, Amsterdam: North Holland Publishing, 1989) p. 183, 186. A vertical control 'arises from a contract between two firms at different stages which transfers control of some, but not all, aspects of production or distribution'.

${ }^{83}$ Ibid, p. 188, 'these are exchanges which require no negotiations or governance of a continuing relationship. Rather they are take-it-or-leave-it exchanges in which the price, quantity and other dimensions of the good are each set by one firm or the other'. The distinction between power and trust as the defining characteristic of the opposition between hierarchy and market is inspired by N. Luhmann, Trust and Power (Chichester: Wiley, 1979). ${ }^{84}$ R.H. Coase, The Nature of the Firm, (1937) 16(4) Economica 386; O. Williamson, The Economic Institutions of Capitalism (Free Press, 1985); P. Joskow, The New Institutional Economics: Alternative Approaches, (1995) 151(1) Journal of Institutional and Theoretical Economics, 248; P. Joskow, Transaction Cost Economics, Antitrust Rules and Remedies, (2002) 18(1) Journal of Law, Economics and Organization 95; For a brief discussion, see Chapter 2.

${ }^{85}$ E.G. Furubont and R Richter, Institutions and Economic Theory-The Contribution of the New Institutional Economics (The Univ. of Michigan Press, Ann Arbor, 1999)
} 
because individual human beings are limited in knowledge, foresight, skill, and time that organizations are useful investments for the achievement of human purpose' ${ }^{86}$

Transaction costs economics and the bounded rationality of economic agents explain the constitution of different forms of organization of economic activity promoting efficiencyenhancing collaboration. One option is to vertically integrate, in order to achieve a durable integration of the assets of different economic agents. Another option would be to put in place a flexible form of coordination that avoids any risk of opportunistic behaviour by the agents.

In some cases, the realization of the objectives of the economic agents will require the elaboration of a long term agreement. A long term agreement may create a risk of opportunism as each party will commit some specific assets necessary for the completion of the common objective ("asset specificity") and will thus incur a sunk cost, that is, a cost that could not be recovered if the company exited the market. Whenever a firm has to make an investment in something that has no other equally valuable use, it needs contractual protection from opportunistic behaviour by its suppliers. The costs sunk in the investment create an inequality in bargaining power and hence allow unilateral appropriation of the benefit of that investment ("hold up") unless the investor protects himself by a contract that is enforceable. This is a major justification for imposing contractual vertical control. There are different tools ensuring vertical control in relations of vertical cooperation. These arrangements may impose 'vertical restraints', that is, 'agreements and contractual provisions between vertically related firms' ${ }^{87}$

Markets and Hierarchies are not distinct concepts but different poles of a continuum. This led Williamson to introduce a third category in his taxonomy, falling between Markets and Hierarchies, for organizational forms that do not correspond to the characteristics of those two forms. He called this category 'Hybrids' ${ }^{88}$ This term, still highly imprecise, covers a variety of organizational forms, such as alliances, collective trademarks, networks, partnerships and relational contracts ${ }^{89}$ which do not institute hierarchies, as each of the participants retains its autonomy, and do not institute markets, as there are formal or informal mechanisms that are set in order to facilitate a long-term coordination and cooperation between the different entities forming the hybrid..$^{90}$

According to Williamson, each of these organizational forms presents different characteristics and is supported by different forms of contract law. ${ }^{91}$ The identity of the parties is irrelevant in transactions in spot markets and the price mechanism is the only way to allocate tasks and rights of control. However, it becomes an important element if the transaction involves specific investments, since its long duration creates uncertainty regarding the ex post

\footnotetext{
${ }^{86}$ HA Simon, Models of Man (Wiley, New York, 1957) 199.

${ }^{87}$ M Motta, Competition Policy - Theory and Practice (CUP, 2004) 302.

${ }^{88}$ O. Williamson, Comparative Economic Organization: The Analysis of Discrete Structural Alternatives, (1991) 36 Administrative Science Quarterly 269-296.

${ }^{89}$ S. Deakin, C. Lane and F. Wilkinson, 'Trust' or Law? Towards an Integrated Theory of Contractual Relations Between Firms, (1994) 21 Journal of Law and Society 329-349, 334-335; I. R. MacNeil, Contracts: Adjustment of Long-Term Economic Relations Under Classical, Neoclassical, and Relational Contract Law (1978) 72 Northwestern University Law Review 854-905, 857.

${ }^{90}$ C. Ménard, The Economics of Hybrid Organizations, (2004) 160 Journal of Institutional and Theoretical Economics 345-376, 347-350.

${ }^{91}$ O. Williamson, The Economic Institutions of Capitalism - Firms, Markets, Relational Contracting (New York: Free Press, 1985), p. 68-72; O. Williamson, The Mechanisms of Governance (Oxford University Press, 1996), p. 93.
} 
sharing of joint profits, which induces the risk of opportunistic behaviour from the parties. Because of the difficulty of considering ex ante all the possible 'consequential disturbances' that may happen in the future, the contract will inevitably be incomplete. ${ }^{92}$ 'Long term incomplete contracts require special adaptive mechanisms to effect realignment and restore efficiency when beset by unanticipated disturbances'. ${ }^{93}$ Although these adaptive mechanisms perfect the contract between the parties at the same time, they impose important restrictions on their autonomy in the market. If the specific investments are important and there is an important risk of opportunism, the transaction costs will be important and a hierarchy will emerge. Economic literature has relied on the transaction costs framework in order to analyse agricultural supply chains ${ }^{94}$.

Property rights theories of the firm acknowledge the importance of vertical restraints as control mechanisms for complementary assets ${ }^{95}$, even in the absence of asset specificity. As Hart pointed out,

'in a world of transaction costs and incomplete contracts, ex post residual rights of control will be important because through their influence in asset usage, they will affect ex post bargaining power and the division of ex post surplus in a relationship', division which will, in turn, 'affect the incentives of actors to invest in that relationship'. ${ }^{96}$

The degree of control (ownership versus contractual commitment) will of course depend on a number of variables.

For the proponents of TCE, the legal regime should take account of the specificities of each of these forms of organization and the existence of transaction costs that would justify a more integrated form of control and coordination between the parties to the transaction. Accordingly, the law applicable to the internal organization of the firm or hierarchy should be forbearance. Williamson explains

'whereas courts routinely grant standing to contracts between firms should there be disputes over prices, the damages to be ascribed to delays, failures of quality, and the like, the courts have the good sense to refuse to hear disputes between one internal division and another over identical technical issues. Access to the courts being denied, the parties must resolve their differences internally, which is to say that the firm becomes its own court of ultimate appeal' ${ }^{97}$

There are two reasons that mainly justify the law of forbearance:

'(1) parties to an internal dispute have deep knowledge - both about the circumstances surrounding a dispute as well as the efficiency properties of alternative solutions - that

\footnotetext{
${ }^{92}$ O. Williamson, Comparative Economic Organization: The Analysis of Discrete Structural Alternatives, (1991) 36 Administrative Science Quarterly 269-296, 271.

${ }^{93}$ O. Williamson, The Mechanisms of Governance (Oxford University Press, 1996), p. 96.

${ }^{94}$ See, for instance, J.E. Hobbs, Measuring the importance of transaction costs in cattle marketing, (1997) 79(4) Am. J. Agr. Econ. 1083-1095; R.E. Goodhue, Broiler production contracts as a multi-agent problem: common risks, incentives and heterogeneity, (2000) 82(3) Am. J. Agr. Econ. 645-676

${ }^{95}$ O. Hart and J. Moore, Property Rights and the Nature of the Firm, (1990) 98 Journal of Political Economy 11191158 .

${ }^{96}$ O. Hart, An Economist's Perspective on the Theory of the Firm, (1989) 89 Columbia Law Review 1757-1774, 1766.

${ }^{97}$ O. Williamson, The Economics of Govenance, (2005) 95 American Economic Review 1-18, 10.
} 
can be communicated to the court at great cost, and (2) permitting the internal disputes to be appealed to the court would undermine the efficacy an integrity of hierarchy'. ${ }^{98}$

The identification of these different forms of organization and of their corresponding regimes of contract law has important implications for competition law analysis. Vertical restraints may be considered as governance tools that are used in order to avoid organizational failures that arise in situations of hierarchy or hybrid (networks). In the absence of significant market power, competition law should not intervene in a situation of hierarchy, as this will compromise the internal organization of this form of governance. The scope of competition law intervention will be more important in the situation of a network.

The distinction between network and hierarchies should not, however, be overstated. Networks may evolve towards a loose form of hierarchy as they are subject to cyclical developments following which the most powerful participants may bring the network itself under control and create a situation of hierarchy. ${ }^{99}$ Consequently, it is important for competition law to recognize the specificities of these different organizational forms and adopt a flexible approach, which will not affect the choice of the most efficient organizational structure by the parties to the transaction, in the absence of significant market power. ${ }^{100}$

In its survey of the American business history in 1977, Chandler noted that vertical integration was the result of the nineteenth-century technical change in transportation and communication that made possible the collapse of geographical barriers and the emergence of larger markets. ${ }^{101}$ This, in turn, increased economies of scale that led to mass distribution with the emergence of department stores, mail-order houses and chain stores. ${ }^{102}$ The position of the distributors in the value chain changed: independent wholesalers were increasingly replaced by in-house purchasing and marketing units. First, producers demanded increasingly higher volumes, thus eliminating 'one of the primary raisons d'être of wholesalers, the ability to work at higher volumes than one's customers'. ${ }^{103}$ Second, the standardization of inputs and outputs required a relative specialization, rather than a more general ability to deal with a diverse set or products. Also, 'standardization of inputs and outputs militated against another of the merchant's comparative advantages, the ability to deal with a diverse set of products'. ${ }^{104}$ This period of vertical integration has been followed by a period of vertical disintegration. Large vertically integrated firms were becoming less significant and were joining a richer mix of new organizational forms (eg franchise agreements, alliances, sub-contracting). ${ }^{105}$ This followed the need for further specialization of functions coupled with the generalization of the capabilities of managers, which became detached from the specific product as their main function became to manage risks. This evolution is also linked to the emergence of a modular

\footnotetext{
${ }^{98} \mathrm{O}$. Williamson, The Mechanisms of Governance (Oxford University Press, 1996), p. 100.

${ }^{99}$ H. B. Thorelli, Networks: Between Markets and Hierarchies, [1986] 7 Strategic Management Journal 37-51.

${ }^{100}$ C. Ménard, Maladaptation of Regulation to Hybrid Organizational Forms, (1999) 18 International Review Law and Economics 403-417, 414-416.

101 A. D. Chandler, The Visible Hand - The Managerial Revolution in American Business (Harvard University Press, 1977), p. 79.

${ }^{102}$ Ibid, ch. 7.

${ }^{103}$ R. N, Langlois, The Vanishing Hand: The Changing Dynamics of Industrial Capitalism, (2003) 12 Industrial and Corporate Change 351-385, 369.

${ }^{104}$ Ibid.

${ }^{105}$ Ibid.
} 
system of production, which relied on a vertically disintegrated production system and thus required looser forms of vertical control than ownership. The concept of network perfectly captures these intermediate forms of vertical control. The case law on franchise and selective distribution illustrates that EU competition law has recognized the importance of this form of organization of the transactions, alongside the specific competition law regime for hierarchies, and the neutrality of competition law towards the choice of different forms of organization of the transactions.

Technological changes in the ICT sector have played an important role in the revision of the EU rules on distribution agreements in mid-1990s, arguably as important as the role played by the change of policy paradigm with the advent of the 'more economic approach' and the increasing influence of economics in determining the scope of intervention of competition authorities concerning 'vertical' restraints. ${ }^{106}$

First, they significantly decreased organisation and monitoring costs, improving the level of communication between the various business units of a vertically integrated firm, while at the same time they decrease transaction costs at the marketplace, for instance by considerably limiting search costs. This may affect the incentives of firms for vertical integration and also leads to the development of network economic structures, where independent economic entities form long-term relationships with other companies, sharing resources and jointly developing strategies. These networks may take different forms: strategic alliances and partnerships, supply webs interconnecting various strategic alliances and complex outsourcing contracts, electronic marketplaces and portals. These networks form industry value chains, sometimes long, sometimes short, always oriented towards the final consumer and enclosing a series of primary (identify customers, design, purchase inputs, manufacture, market and sell, deliver, provide after-sales services and support) and supportive activities (finance and administration, human resources, technology development activities).

Second, the possibilities offered by tracking technology and the wider availability of personal data, on the online and market behaviour of consumers, have led a number of companies to develop, more effectively, commercial practices that discriminate between different market segments, divided according to the customers' characteristics (gender, age, geographic location, income level, personality, approach to life etc), leading to different forms of market segmentation. This is particularly important for focused advertising and e-marketing, eventually also pricing the products or offering specific tailored-made to these segments, versions of them. This may of course enable these firms to extract more revenue out of the various market segments, if they are able to prevent arbitrage between the different groups of customers. This market segmentation may be achieved either unilaterally or with the cooperation of the other parts of the supply chain, through specific agreements ensuring the

\footnotetext{
${ }^{106}$ Already at the Green Paper on Vertical Restraints in EC Competition Law (1997), available at http://ec.europa.eu/competition/antitrust/others/96721en_en.pdf paras. 40-43, the Commission noted that the '[w] hole nature of distribution has been changed by the Information Technology Revolution', citing Just in Time principles in the organisation of manufacturing and distribution, quick response logistics, Electronic Data Interchange, bar coding, laser scanners as important innovations 'involving a shift from the traditional arms-length relationship between manufacturers, wholesalers and retailers towards a relationship of co-operation particularly in the area of logistics'.
} 
effectiveness of the segmentation, which could eventually give rise to different forms of vertical restraints.

Third, through technology supply chain management becomes more effective and less expensive, enabling companies to achieve higher quality at a lower production cost. Firms find it crucial to enter into long-term agreements with partners in other segments of the chain, in order to create the necessary relation of trust that is required by the importance of relationspecific investments that need to be undertaken in setting the supply chain management. This may lead to disintermediation and vertical integration but also to deconcentration through the constitution of networks or supply alliances that are managed by supply chain councils. These various forms of supply chain management share the common characteristic that they are all ultimately consumer-orientated, as any segment of the chain directs its efforts towards meeting the needs of the next member of the chain, the perception being that all segments of the chain do not constitute separate islands of activity but essential ingredients for the formation of the total value of the chain. For instance, brand-building takes the wider perspective, that of the whole value chain, leading to the elaboration of labels and standards to which the various segments of the chain abide. Issues relating to the distribution of the total surplus value of the chain also take a prominent role in the relation between the various economic actors participating to the supply chain, in particular as supply chain management, even if it is flexible, crystallizes more easily their position (and total surplus value share). Alternatively, the possibilities offered by private electronic marketplaces and portals, such as AmazonSupply which also operates as an actual distributor, with warehouses and products stocked on shelves, may lead firms to opt for a spot-market method of organisation of their economic activity, if the nature of their products and other considerations does not justify the cost of elaborating long-term supply relationships.

Fourth, Internet and the advent of digital economy profoundly change the organisation and the revenue models of the industry. Long gone are the days where distribution was organised as a web of conflicting interests, each of the actors (manufacturer, wholesaler and retailer) acting in order to defend their interests and develop independent strategies, sometimes to the detriment of the chain. Online commerce enables manufacturers to bypass intermediaries by proceeding to a direct distribution of their product through the Internet. This can take the form of the conventional catalogue revenue model, with the difference that the catalogue is now online, consumers placing orders through the manufacturer's website. Internet also empowers discount retailers to lower down their costs and thus to take advantage of the fact that their website operates as a hub for discount offers from different manufacturers. Marketing channels are also diversified, with the development of omni-channel strategies, where manufacturers operate their own website, while also distributing through traditional retailers, online retailers and discounters. These different online forms of distribution and the corresponding revenue models are also expanding in the food sector.

Among the various models, advertising-supported revenue models have been on the rise. These business models usually rely on multi-sided platform strategies, bringing together two or more interdependent groups of consumers, information technology and the possibilities offered by Big Data technology and the social Web to collect personal data making it an extremely valuable business method for advertisers. This provides incentives to the various 
economic actors to strategically design platforms that appeal to multiple sides, thus increasing the instances of platform competition.

These various models may co-exist in the same industry but also within the same supply chain. They are often implemented through vertical restraints, which aim to ensure the profitability of the whole supply chain, as opposed to the profitability of just the specific segment of the chain, by institutionalising procedures for the distribution of profit margins along the chain. This alters the usual understanding that each economic transaction should be assessed at the level of the chain it intervenes, without any consideration to other sides of the platform or other segments of the value chain. Competition authorities cannot therefore assume that the conflicting web of interests will lead the various levels of the chain to police each other (the so called self-policing character of vertical restraints) which have led many competition authorities to abandon the area of vertical restraints in setting their enforcement priorities, deciding instead to focus on cartels. These important economic and technological transformations and the increasing importance of supply chain management may call for new operational concepts in competition law and the development of a more 'holistic' approach that engages more fully with value chains.

\subsubsection{The disruptive potential of GVCs for competition law \& policy on vertical restraints}

The various forms of organization of global value chains highlight the importance of conducting a careful analysis of the power relations along the supply chain, the aim being to unveil value extraction bottlenecks affecting the distribution of the total surplus value. This analysis cannot be undertaken by the traditional NPT framework which mainly focuses on horizontal competition and its effects on consumers or total welfare and assesses the competitive interactions between firms within a specific relevant market. In contrast, the GVC perspective has a distributive focus and may be particularly helpful if one aims to understand real business strategies and how the design of the value chain may determine who profits from the collective innovation and other surplus-value generated.

A focus on GVCs will enable a re-conceptualization of the way competition law deals with vertical integration or quasi-integration. Traditionally, the relation between the different levels of a vertical supply chain has been thought as complementary, competition authorities rarely seeing any reason to intervene, unless one of the segments disposes of considerable market power and engages in acts of exclusion by, for instance, raising the costs of its rivals upstream or downstream. This approach tends to ignore the allocation of the revenues engendered by the supply chain between the various partners ("vertical competition") as an issue external to the exclusive focus of competition law on economic efficiency. In contrast, the GVC approach recognizes that issues relating to the distribution of the total surplus value of the chain also take a prominent role in the relation between the various economic actors participating to the supply chain. By dissecting the chain-wide coordination of various economic activities, the GVC approach also better describes the systemic nature of GVCs, each part of the chain impacting on the others.

Such view is of course anathema for the proponents of the received view on vertical restraints. As it was made clear by Advocate General Van Themaat in Pronuptia, the seminal 
EU case regarding franchising, a precedent setting the new direction of EU competition law on vertical restraints towards a more Chicago-oriented approach, "the question whether or not a franchise agreement results in a fair division of costs and benefits as between franchisor and franchisee is not in itself relevant to the question whether Article [101(1) TFEU] is applicable ${ }^{107}$ However, we consider that for reasons we will explain in the following Section, modern competition law cannot afford ignoring issues of total surplus allocation between the various segments of the chain, as this may greatly affect productivity, which should be an important concern for competition law enforcement.

Concerns over global competitiveness, employment, investment in quality competition and long-term consumer interest may also weigh in the decision of competition authorities to explore the dynamics of global value chains and the way issues of distribution of the total surplus produced by the chain may be included in competition law assessment.

We consider that the GVC approach provides a theoretical framework enabling us to understand how the global division and integration of labour in the world economy has evolved over time and, more importantly, how the distribution of awards, from the total surplus value, is allocated between the various segments of the chain. Contrary to traditional NPT analysis, and more in vogue with transaction cost economics (TCE) and economics of organization, the GVC approach enables competition authorities to focus not only on issues of horizontal market power and concentration at each segment of the chain, but also to engage with the vertical links between the various actors with the aim to understand how and whether "lead" actors can capture value. Their focus is on the distribution of the value generated by the chain, rather than just on the maximization of the surplus (efficiency) as such. We think that such an approach will more truthfully reflect the various forms of competitive interaction taking place in the marketplace and within global value chains.

\subsubsection{GVCs and "real competition"}

In his recent work on Capitalism: Competition, Conflict, Crises, Anwar Shaikh provides an alternative picture of competitive activity, heavily relying on the "classical" school of economics of Adam Smith, David Ricardo and Karl Marx, to which he also adds the work of Piero Sraffa ${ }^{108}$. Shaikh argues that the profit motive, not making things or carrying out services, is seen as the driving force of capitalism: "Capital is a particular social form of wealth driven by the profit motive. With this incentive comes a corresponding drive for expansion, for the

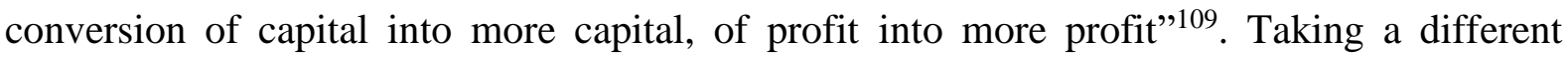
perspective than neoclassical economics, both the perfect competition view and the imperfect competition paradigm, he argues that the capitalist economy should not be viewed as a "perfect" market economy with accompanying "imperfections", but as individual capitals in competition to gain profit and market share ${ }^{110}$. What he calls, "real competition" is a struggle to lower costs per unit of output in order to gain more profit and market share and thus raise

\footnotetext{
${ }^{107}$ Case C-161/84 Pronuptia de Paris GmbH v Pronuptia de Paris Irmgard Schillgallis [1986] ECR 414.

108 A. Shaikh, Capitalism: Competition, Conflict, Crises (Oxford University Press, 2016).

${ }^{109}$ Ibid, p. 259.

110 Ibid.
} 
the rate of return of the capital invested. Competition within an industry compels individual producers to set prices that keep them in the game, forcing them to lower costs so that they can compete effectively, and producing a persistent differential in costs as new capitals enter and oldest ones are retired. In this context, competition within an industry turbulently equalizes selling prices and therefore dis-equalizes profit margin and profit rates. Competition between industries comes about through inter-industrial investment flows which focus on the lowest cost techniques that are generally reproducible and providing higher rates of return for the capital invested, the capital moving from one industry to another in search of higher profits, thus bringing about the equalization of profit rates between industries ("regulating capitals") 111 .

Contrary to what was advanced by mainstream economic theorists, Shaikh also argues that that the profit rates will not necessarily raise with new technology, but may well fall. ${ }^{112}$ Indeed, if one looks to empirical data, the profit rates have been decreasing considerably the last few decades in what has been considered by some as a productivity crisis for modern capitalism $^{113}$. Despite the fact that the cost of capital is "close to zero and that companies may take up almost free liquidity on markets", large and global MNE governing global value chains use their record surplus liquidity for other purposes rather than turning it into working capital $^{114}$. Some have talked about "the weakened capitalist ethos", the firms being "worn out in their capacity for using and combining labor and capital in more productive ways", advancing the increasing bureaucratization of the firms and their opaque ownership by institutional investors, rather than by virulent entrepreneurs as the main cause ${ }^{115}$. Others have put forward the lower increase of total factor productivity brought by the most recent waves of technology revolutions ${ }^{116}$. Finally, some have argued that the fall of real wages and overindebtedness, as well as the rising levels of inequality of income, has eaten the purchasing power of consumers/workers and led to decreasing levels of profitability for capital overall. ${ }^{117}$

This phase of capitalism largely coincides with the financialisation movement starting in the early to mid-1970s and taking unprecedented proportions until the 2008 economic

\footnotetext{
${ }^{111}$ Ibid, p. 34.

${ }^{112}$ This is also argued by Clark, see G. Clark, Winter Is Coming: Robert Gordon and the Future of Economic Growth, (2016) 106(5) American Economic Review: Papers \& Proceedings 68-71. Moreover see, R. Gordon, The Rise and Fall of American Growth (Princeton University Press, 2016).

${ }^{113}$ See, for instance, R. Gordon, The Rise and Fall of American Growth (Princeton University Press, 2016); F. Erixon and B. Weigel, The Innovation Illusion (Yale University Press, 2016).

${ }^{114}$ F. Erixon and B. Weigel, The Innovation Illusion (Yale University Press, 2016), p. 20.

${ }^{115} \mathrm{~F}$. Erixon and B. Weigel, The Innovation Illusion (Yale University Press, 2016). The decrease of virulent entrepreneurship and dynamism is also supported by the falling numbers of innovative business startups in the last few decades, see R. Decker et al., The Role of Entrepreneurship in US Job Creation and Economic Dynamism, (2014) 28(3) Journal of Economic Perspectives 3-24, and J. Haltiwanger, I. Hathaway and J. Miranda, Declining business dynamism in the U.S. High-Technology sector, (2014). Available at SSRN: https://papers.ssrn.com/sol3/papers.cfm?abstract_id=2397310.

${ }^{116} \mathrm{R}$. Gordon, The Rise and Fall of American Growth (Princeton University Press, 2016). However, the relationship between technology growth and a productivity slowdown is not as obvious as it may seem, as pointed out by D. M. Byrne, M. B. Reinsdorf and J. G. Fernald, Does the United States have a Productivity Slowdown or a Measurement Problem?, (2016) Federal Reserve Bank of San Francisco Working Paper 2016-03. Available at http://www.frbsf.org/economic-research/publications/working-papers/wp2016-03.pdf.

${ }^{117}$ W. Streeck, How Will Capitalism End? (Verso, 2016). ${ }^{117}$ On the forecast of a slowing growth in disposable median income per person, see R. Gordon, Perspectives on The Rise and Fall of American Growth, (2016) 106(5) American Economic Review: Papers \& Proceedings 1-7, and more broadly R. Gordon, The Rise and Fall of American Growth (Princeton University Press, 2016).
} 
crisis $^{118}$. During this period productivity growth has gone down in all Western economies ${ }^{119}$. According to Shaihk, the real cause of this drop in productivity is the movement in profitability - the dominant factor under capitalism. The profitability of corporate capital in the Western world has been in "secular decline" 120 since the end of the Second World War with only a moderate stabilisation from the early 1980s, although dropping in the $2000 \mathrm{~s}^{121}$. Suppressed wage growth and reduced wage share stabilised the rate of profit as well as an enormous fall in the interest rate in the 1980s, which fuelled credit expansion and massive debt finance, ultimately raising the net (or enterprise) rate of profit. These policies led to phenomenal leveraging and excessive financialisation, which reduced the rate of return of working capital in relation to other forms of capital investment. This expansion of liquid assets does not correspond with operational costs, or working capital. Companies have excess liquidity, which leads to excess corporate savings, the typical multinational being a net contributor of savings, rather than a net user of savings ${ }^{122}$.

Cash hoarding is seen as a defensive act in order for the companies and their management to protect their current stock of technology, innovation. As a result they do not invest as much in new technology/innovation (for instance new network infrastructure which would require enormous amounts of fixed capital). Business investment is down and has declined since the late 1970s as measures as a share of GDP indicate ${ }^{123}$. There is increasing evidence that the economy has moved from capital intensive to less capital intensive sectors. Companies prefer to retain earnings and distribute them to shareholders and the management rather than invest them in $R \& D^{124}$. Investments in $R \& D$ are increasingly concentrated in a few sectors across most of the mature economies ${ }^{125}$. The concept of research has also changed $-\mathrm{a}$ lot of money is actually spent on product adaptation, design and development, copying a feature

\footnotetext{
${ }^{118}$ J. Montgomerie and K. Williams, Financialised Capitalism: After the Crisis and Beyond Neoliberalism, (2009) 13(2) Competition \& Change 99-107. For a historical and explanatory analysis of the concept financialisation, with regards to profitability, shareholder value and shifted incentives on innovation, see N. van der Zwan, State of the Art: Making Sense of Financialisation, (2014) 12 Socio-Economic Review 99-129.

${ }^{119}$ See, F. Erixon and B. Weigel, The Innovation Illusion (Yale University Press, 2016), pp. 24-25. See also Cette, Fernald and Mojon that study how both the US and EU productivity slowdown has its roots in a period prior to the 2008 financial crisis and subsequent recession, G. Cette, J. G. Fernald and B. Mojon, The Pre-Great Recession Slowdown in Productivity, (2016) Federal Reserve Bank of San Francisco Working Paper 2016-08. Available at http://www.frbsf.org/economic-research/publications/working-papers/wp2016-08.pdf.

${ }^{120}$ L Summers, 'The Age of Secular Stagnation: What It Is and What to Do About It', (March-April 2016) Foreign Affairs, available at https://www.foreignaffairs.com/articles/united-states/2016-02-15/age-secular-stagnation .

${ }^{121}$ A. Shaikh, Capitalism: Competition, Conflict, Crises (Oxford University Press, 2016), pp. 243-256.

${ }^{122}$ F. Erixon and B. Weigel, The Innovation Illusion (Yale University Press, 2016), ch. 2.

${ }^{123}$ Ibid, p. 29.

${ }^{124}$ See, for instance, some recent research on big pharma: W. Lazonick, Profits without prosperity, (2014) 92(9) Harvard Business Review 46-55; W. Lazonick and M. Mazzucato, The risk-reward nexus in the innovationinequality relationship: Who takes the risks? Who gets the rewards?, (2013) 22(4) Industrial and Corporate Change 1093-1128; P. Gleadle et al., Restructuring and innovation in pharmaceuticals and biotechs: The impact of financialisation, (2014) 25 Critical Perspectives on Accounting 67-77. At a broader level, it can also be seen how financialisation alters a firm's incentives away from investment and in favour of short-term shareholder's return: see O. Orhangazi, Financialization and Capital Accumulation in the Nonfinancial Corporate Sector: A Theoretical and Empirical Investigation on the US Economy, 1973-2004, (2007) MPRA Paper No. 7724. Available at: https://mpra.ub.uni-muenchen.de/7724/; M. Mazzucato, Financing innovation: creative destruction vs. destructive creation, (2013) 22(4) Industrial and Corporate Change 851-867.

${ }^{125}$ See for example G. Clark, Winter Is Coming: Robert Gordon and the Future of Economic Growth, (2016) 106(5) American Economic Review: Papers \& Proceedings 68-71.
} 
or add on from another product or adjusting the product stock to local demands, the D, and little is spent to the $\mathrm{R}^{126}$. Growth in real investment on R\&D is declining, the US National Science Foundation reporting that its measure of R\&D intensity has flatlined since $1995^{127}$. Many companies have reacted to problems with their R\&D strategy by outsourcing $R \& D$ to smaller firms that can take bigger risks ${ }^{128}$. Once the $R \& D$ investments have begun to mature into innovative products, large companies have acquired them and integrated them into their global value chains ${ }^{129}$. This may affect the innovation and entrepreneurial ethos. Companies also spend their money in defensive ways by buying competition with a considerable acceleration of M\&A activity. From 1997 to 2012, 8327 delists out of which 4957 were due to M\&A activity as companies intended to consolidate rather than invest in more competitive products and services or reward efficient staff and workers ${ }^{130}$. Recent research on innovation has put forward the full picture of the innovation value chain, and highlighted the important role of the State in funding fundamental R\&D that ripened to highly successful commercial innovation leading to important private returns and profits ${ }^{131}$.

One of the main reasons advanced for this lack of risky investments is the lower profitability of R\&D research ${ }^{132}$. Indeed, as economist James Bessen recently noted the higher aggregate profits in what he calls the 'rent-seeking sector', such as pharma/chemicals, petroleum refining, transportation equipment/defense, utilities, communication, in comparison to sectors that are less regulated, noting that for each dollar spent lobbying for a tax break, firms received returns in excess of $\$ 220^{133}$. This makes rent seeking and lobbying the second most important driver of firms' profitability, before even R\&D spending. In other words, corporations achieve more returns per dollar if this is spent on lobbying and rent seeking regulation than on R\&D. These empirical findings may of course be related to the specific US

\footnotetext{
${ }^{126}$ F. Erixon and B. Weigel, The Innovation Illusion (Yale University Press, 2016), p. 33.

${ }^{127} \mathrm{R} \& \mathrm{D}$ intensity, measured as the share of industry-level R\&D expenditure to sales, increased in the seed sector from $11.0 \%$ in 1994 to $15.0 \%$ in 2000 before falling back to $10.5 \%$ in 2009 .

${ }^{128}$ See for instance, P. Gleadle et al., Restructuring and innovation in pharmaceuticals and biotechs: The impact of financialisation, (2014) 25 Critical Perspectives on Accounting 67-77

${ }^{129}$ Comanor and Scherer point out to how M\&A may have been used as a safety net for companies against the uncertain prospects of innovation projects or to acquire synergies in R\&D, W. S. Comanor and F. M. Scherer, Mergers and innovation in the pharmaceutical industry, (2013) 32 Journal of Health Economics 106-113. Similar analyses can also be found in P. Gleadle et al., Restructuring and innovation in pharmaceuticals and biotechs: The impact of financialisation, (2014) 25 Critical Perspectives on Accounting 67-77.

${ }^{130}$ F. Erixon and B. Weigel, The Innovation Illusion (Yale University Press, 2016), p. 38

${ }^{131}$ M. Mazzucato, The Entrepreneurial State (Anthem, 2013); W. H. Janeway, Capitalism in the Innovation Economy: Markets, Speculation and the State (Cambridge University Press, 2012). See also Lazonick and Tulum who show how the US biopharmaceutical industry is sustainable in part through a favourable governmental investment and institutional framework, W. Lazonick and Ö. Tulum, US biopharmaceutical finance and the sustainability of the biotech business model, (2011) 40 Research Policy 1170-1187.

132 See P. Gleadle et al., Restructuring and innovation in pharmaceuticals and biotechs: The impact of financialisation, (2014) 25 Critical Perspectives on Accounting 67-77. This point is also clearly illustrated by Clark when using investment in healthcare as an example. The improvement in life expectancy means that the investment costs of adding life-years are set to increase incrementally in the future, see G. Clark, Winter Is Coming: Robert Gordon and the Future of Economic Growth, (2016) 106(5) American Economic Review: Papers \& Proceedings 68-71, 70.

${ }^{133}$ J. Bessen, Accounting for Rising Corporate Profits: Intangibles or Regulatory Rents? (2016) Boston University School of Law, Law and Economics Research Paper No. 16-18. Available at SSRN: ssrn.com/abstract=2778641.
} 
context, but arguably the situation may not be that different in Europe ${ }^{134}$. If profit in capitalism is what drives growth profit then it is necessary to raise the net rate of profit of working capital.

How is the above discussion relevant for competition law and policy, and also with regard to our topic of Global Value Chains? The hypothesis we advance is that the constitution of global value chains, in particular of the captive sort, leads to a profit squeezing of the various actors in the chain controlled by the lead firm. Lead firms seek to increase their share of the total surplus value produced by the chain. This is the normal effect of restricting vertical competition across the various segments of the chain. However, one may assume that this will decrease the profitability of productive activities along the chain, the effect of which may be a fall in overall productivity, generating a fall in profitability in a never ending and mutually reinforcing cycle, for the following reasons. Often lead firms exercise control through strategic assets (brands, IP rights) relying on past investments and without necessarily facing the competitive pressure to increase their profitability by productive investments, in view of the declining rate of profitability and therefore the declining "real competition" between capitals. They may prefer to distribute their profits to their management and shareholders, or to defend their position by buying out actual or potential competition. Large lead firms may also have less incentives to invest in an increase of productivity than small and medium firms, to the extent that they prefer to invest in strategies that lock in the other firms in their value chains.

\subsection{The future of competition law in a complex economy}

\subsubsection{The different dimensions of competition}

New technologies require important investments and fixed costs for their development, which often lead to network effects, as use of a product or service by any user increases the product's value for other users (sometimes even all users). In other words, the value of the product to one user is positively affected when another user joins and enlarges the network (positive network externalities). For instance, an additional user of a search engine may increase the quality of search provided by this search engine, therefore benefitting all users, in view of the additional queries that this may direct to the search engine and consequently the increase in the stock of data/information the specific search engine disposes about users and their preferences which can help search engines to offer better search services to all consumers. This positive feedback loop mechanism explains why these markets are tippy and are characterized by 'winner takes it all' competition. For instance, there might be fierce competition to conquer a market share advantage over rivals, with regard to the specific technology or standard applying in the industry, as the market may switch almost completely to the winner (competition for the market). ${ }^{135}$

\footnotetext{
${ }^{134}$ Tori and Onaran, for example, analysed firm-data in Europe and found that the increased financialisation by nonfinancial companies can be seen as resulting in lower physical investment due to altered incentives: D. Tori and O. Onaran, The effects of financialisation and financial development on investment: Evidence from firm-level data in Europe, (2017) Greenwich Papers in Political Economy, University of Greenwich No 44.

${ }^{135}$ Usual examples include the videotape format war between VHS and Sony's BETAMAX, or the competition between Windows and Intel from one side and Apple from the other for the microcomputer market. For an analysis
} 
Quite often, these products or services constitute a package of complementary products and technologies, which form a system competing with other systems ('system competition'). ${ }^{136}$ The value of the product does not always depend directly on the number of adopters, but on the adoption of some complementary products that are bundled/packaged with the first product (think about a book reader and the content of the book). Network effects lead to collective switching costs and lock-in effects, which reduced competition and may entrench the dominant position of the winner for a significant period of time. Firms are quite imaginative in their business models, sometimes distributing the product for free in one side of the market, thus inducing more users to join the network and therefore increasing the value of the product for other users situated at the paying side of the market, the platform facilitating the interaction between two different groups of customers (multi or two-sided market platforms). They may also use various business practices, such as penetration pricing where they charge low prices (even below their costs) to gain market share, or strategically bundling their products so as to take hold of another market and then expand. In these markets, it is possible that firms may incur losses for a significant period of time in order to invest in acquiring market share (either through natural growth or by buying out actual or potential competitors) in order to constitute one stop shop solutions or essential platforms for various groups of customers. ${ }^{137}$ Competition between firms takes unexpected forms, such as competing for consumers' attention (or eyeballs), eventually profiling them and using algorithms in order to predict and possibly manipulate their behaviour. ${ }^{138}$ These developments thus require a renewal of the theoretical frameworks so far used by economics for traditional markets, as well as a clear understanding of business strategy, thus widening the sources of wisdom for competition law beyond neoclassical price theory economics. ${ }^{139}$

Similarly, one may criticize the relatively narrow perspective of the mainstream neoclassical price theory economics, which is based on methodological individualism, the idea that social action and the ensuing order are perceived as generated by objective economic interests of the individual actor, the latter behaving in an instrumental (rational) way in order to maximize his welfare. What is absent from such analysis is the role that social relations and social institutions play in the economy, the latter being considered as distinct configurations of interests and social relations. Work in political economy and economic sociology may provide the bigger picture we need in order to understand the full dimension of competitive interactions.

The various forms of competitive struggle are not only taking place in the context of product markets. Competition becomes a struggle to lower costs per unit of output with the aim

\footnotetext{
of competition in open and closed systems see, CMA \& Autorité de la Concurrence, The Economics of Open and Closed Systems (December 16th, 2014).

136 M L Katz \& C Shapiro, 'Systems Competition and Network Effects' [1994] 8(2) Journal of Economic Perspectives 93.

${ }^{137}$ For an example of this strategy see, LM Khan, ‘Amazon's Antitrust Paradox’ [2017] 126(3) Yale Law Journal 564.

${ }^{138}$ F Pasquale, The Black Box Society - The Secret Algorithms That Control Money and Information (Harvard University press, 2015).

${ }^{139}$ On the importance, for instance, of other fields than economics see, among others, the special issues of the Antitrust Bulletin on Entrepreneurship and Antitrust [2016, Vol. 61(4)]; and on Antitrust as a Multi-disciplinary field [2014 Vol. 59(4].
} 
to gain more profit and market share and thus raise the rate of return of the capital invested ${ }^{140}$. Some have distinguished between competition within an industry, which forces individual producers to set prices that keep them in the game and compels them to lower costs so that they can compete effectively, thus leading to a turbulent equalization of selling prices but a disequalization of profit margin and profit rates, and competition between industries, the capital moving from one industry to another in search of higher profits, thus bringing about the equalization of profit rates between industries. ${ }^{141}$ The financialisation movement, that is the increasing influence of global financial markets in the real economy, started in the early to mid1970s and has since taken unprecedented proportions. ${ }^{142}$ It has led to phenomenal leveraging, which has allegedly reduced the rate of return of working capital in relation to other forms of capital investment, such as lobbying, rent-seeking activities or short-term investments in financial assets. ${ }^{143}$ One should also take into account the level of development of capital markets as part of the overall economic context, when examining competitive strategies, and explore if firms have multiple source of finance beyond traditional bank lending.

The rising concentration of the different levels of the food value chain has certainly attracted the attention of the public, but one should not overestimate its importance as a factor indicating the level of competition in a market. Already in 2009, the European Commission noted that the high concentration of the retail sector did not lead to a higher profitability, observing that "on average in 2006, the average net profit margins of European retailers were around $4 \%$, whereas these same margins in the case of The Coca-Cola Company and the Group Danone were around $20 \%$ and $11 \%$, respectively" 144 . The negotiations occurring between retailers and large multinational suppliers, who are often producers of a portfolio of goods which are in some cases must-carry brands and have significant market power, may offset in some cases the buyer power of even the largest retailers. More recently, the Harper review in Australia noted that

"(a)lthough concentration is relevant, it is not determinative of the level of competition in a market. [... ]"145.

The attraction of consumers to specific brands and product differentiation may also be a source of market power for suppliers, although it is also possible that low cost "no frills" brands may enhance competition and lead to lower prices for consumers. The complex

\footnotetext{
${ }^{140}$ A Shaikh, Capitalism: Competition, Conflict, Crises (Oxford University Press, 2016).

${ }^{141}$ Ibid., p 34.

${ }^{142}$ J. Montgomerie \& K. Williams, 'Financialised Capitalism: After the Crisis and Beyond Neoliberalism' (2009) 13(2) Competition \& Change 99. For a historical and explanatory analysis of the concept financialisation, with regards to profitability, shareholder value and shifted incentives on innovation, see N van der Zwan, 'State of the Art: Making Sense of Financialisation' (2014) 12 Socio-Economic Review 99.

${ }^{143}$ J Bessen, 'Accounting for Rising Corporate Profits: Intangibles or Regulatory Rents?'(2016) Boston University School of Law, Law and Economics Research Paper No. 16-18. Available at SSRN: ssrn.com/abstract=2778641; O Orhangazi, Financialisation and the US Economy (Edward Elgar, 2008) (showing that investment in financial assets crowds out investment in real assets, companies preferring to make investor pay outs through dividends or stock buybacks, rather than investing in $\mathrm{R} \& \mathrm{D}$ or in promoting productivity).

144 Commission Staff Working Paper, Competition in the Food Supply Chain, SEC(2009) 1449.

145 Ian Harper, Peter Anderson, Su McCluskey, Michael O’Bryan QC, Competition Policy Review, Final Report (March 2015), available at http://competitionpolicyreview.gov.au/files/2015/03/Competition-policy-reviewreport_online.pdf , pp. 283-284.
} 
interrelation between low-cost and 'quality-focused' brands has not yet been thoroughly considered.

There have also been some significant changes at the upstream level of the food value supply chain. First, farmland consolidation resulted in a considerable increase of farm size the last four decades, with important purchasers including private-equity firms and sovereign wealth funds ${ }^{146}$. Second, the development of new technologies has led to the emergence of a diverse group of players: "crop protection and seed companies, equipment companies, fertiliser companies, retail distributors, and pure-play digital start-ups", which seek to develop an "integrated offering of equipment and services for farmers" enabling them to "gradually build a compelling one-stop solution that will allow them to compete for the lion's share of the market"147. Consequently, these companies develop strategies in order to develop new capabilities and exploit different sources of revenue by "applying new technology or by expanding across the value chain or geographically"148. An illustration of such strategies is offered by Monsanto:

"Having already transformed itself from a chemical company into a seeds company, Monsanto moved into crop-planting technology by acquiring Precision Planting, a manufacturer of precision equipment and software used to tailor planting to different parts of a field. Monsanto likewise moved into data science by acquiring Climate Corporation, a provider of hyperlocal weather monitoring, agronomic data modelling, and high-resolution weather simulations. Finally, Monsanto developed FieldScripts, a high-tech service that applies field data to increase planting efficiency and yield potential. The company is expected to further expand into variable-rate fertilization and crop protection. Through these efforts, Monsanto is building an integrated, 'beyind the seeds' solution that will allow it to exploit new sources of revenue relating to equipment, fertiliser, crop protection, and even software" $" 149$.

Of particular importance is also the need to enhance dynamic efficiency and innovation at each stage of the food value chain. A careful balancing of competition law and intellectual property law should be performed. These regimes employ different means to the same ends of enhancing long-term consumer welfare and promoting innovation. The competition laws preserve the competitive spur to innovation, and the intellectual property laws create incentives for innovation. Market players should therefore make the choice of positioning themselves as fully integrated providers, or the orhestrators of a network, or partners of an established network $^{150}$.

Finally, the role of state intervention in the form of ownership, more or less intrusive regulation of the various dimensions of competition, eventually price competition, or subsidies needs also to be taken into account. Competition law is one among various tools for state intervention in markets, and its contours must be defined with regard to other forms of state

\footnotetext{
${ }^{146}$ Boston Consulting Group, Crop Farming 2030 - The Reinvention of the Sector (April 2015), available at https://www.bcgperspectives.com/content/articles/process-industries-innovation-crop-farming-2030reinvention-sector/, p. 11.

147 Ibid., p. 10.

148 Ibid., p. 12.

149 Ibid., p. 12.

150 Ibid., p. 15.
} 
intervention, such as regulation ${ }^{151}$. Governments intervene widely in markets to achieve various policy goals. Sometimes these policy goals align with one another and sometimes they conflict and require various trade-offs in policy responses, such as to pursue efficiency, to correct market failures, or to ensure equity and distributive justice.

The broader competition policy (which includes not only competition law but also other measures to address issues of competition in the economy) interfaces with state activity across many different levels of how government organizes economic behaviour. Government organizes economic activity in part through the shape and nature of regulation and overall state involvement. Understanding the distinction between competition law and policy clarifies competition authorities' capabilities and limitations when it comes to promoting competition in situations of a broader regulatory overlay. When considering the question of institutional design, how countries design optimal competition policy involves three choices: what to leave to the jurisdiction of competition law (and competition agencies and judges), what to assign to noncompetition authorities (such as sector regulators) exclusively as part of their jurisdiction, and how to establish concurrent jurisdiction among the competition authority and two or more regulatory authorities.

Government intervention may take different forms, depending on the policy area and the dimension of government action with the preservation of some form of market competition $^{152}$. For example, governments may intervene as market makers: they might decide to use competitive tendering to introduce competition for goods and services that were previously supplied solely by the public sector; they might introduce more choice in the provision of public services by opening access to private or voluntary sector providers; or they might make tradable permits accessible in such a way as to most efficiently allocate among private providers the costs of engaging in an activity that is harmful to society. The state may operate to create or facilitate markets, or in some cases to act as a market participant. Governments can affect markets through direct participation as a supplier to provide public goods and services that free markets are unlikely to supply at an adequate level. Governments also act as significant buyers of goods and services from the private sector to deliver public services and perform their normal functions. In dispensing public services the government may establish a state-owned enterprise (SOE) or a public-private partnership (a relatively recent phenomenon), or it may decide to procure services through a competitive tendering process. Alternatively, the state may act as a deregulator in which it removes regulation to unleash market forces within various parts of the economy.

A possible way of intervention in the economy by the State is through State Owned Enterprises. In some jurisdictions, such as in the European Union (for national SOEs) and China (for regional and local administrative monopolies) these are generally subject to some form of competition law scrutiny. Likewise, governments may intervene indirectly by influencing private markets when they create either negative or positive impacts on consumer

${ }^{151}$ There is a massive literature on this distinction between competition and regulation, perceived as separate spheres but still in constant interaction with each other. We note some recent contributions in Europe: N Dunne, Competition law and Economic Regulation - Making and Managing Markets (CUP, 2015); J Drexl \& F DiPorto (eds.), Competition Law as Regulation (Edward Elgar, 2015).

${ }^{152}$ For an introduction to the interaction between competition and government action, see T Cheng, I Lianos \& D Sokol, Competition and the State (SUP, 2014). 
or total welfare. In this case, command and control regulation or more market-based incentive forms of regulation might be other venues for taxes and subsidies to influence the incentives and behaviours of private firms. Sometimes, governments deliberately try to influence consumer behaviours in a variety of ways - for example, by providing information on hidden costs associated with certain types of consumption (eg, advertising campaigns against tobacco or alcohol), or by nudging consumers to adopt a behaviour that will protect their self-interest. They might also attempt to indirectly influence businesses by coordinating private-sector activities to generate the appropriate amount of information for the adoption of public policies or by promoting self-regulation by business, as this generally saves implementation costs. In some situations, government intervention may be the by-product of corruption, may be captured by special interests, or it may be following the right objectives but be badly designed - what is called 'government failure. In this case it will be, in general, welfare reducing. In other instances, however, government intervention is justified by legitimate public interest objectives. Of course, it is not the aim of competition law to correct any form of government failure if that failure does not impact the competitive process. Competition law may supplement other areas of law in an effort to improve government action and increase efficiency. Yet, the role of competition law is also relevant in the context of legitimate state action, depending on the forms that the latter may take, some of which may affect the competitive process more than others.

Conflicts between competition law and regulation may be direct, if regulation affects the core parameters of competitive markets by restricting competition on price, entry and quantity, as it is often the case for economic regulation, or lateral, in case these core dimensions of competition are not directly targeted, but regulation may nevertheless indirectly affect them, as it may be the case in situations of social or technical regulation. Economic regulation denotes the government intervention in a sector to correct a market failure arising from e.g. a natural monopoly (telecom, energy), or asymmetric information. It acts a priori, requires continuous monitoring and is intrusive in management. In contrast, competition law consists in a set of rules for market operation that prevents and sanctions abuses of market power, across all sectors. It acts a posteriori, once behavior is observed and mostly relies on the dissuasive power of sanctions. From this perspective, it is a less intrusive tool for market management in comparison to regulation.

Economic regulation's role is often complementary to competition law since regulation controls monopolies that would never function efficiently under competition, its main function being to adopt measures that can control monopoly pricing. By ensuring non-discriminatory access to necessary inputs, e.g. network infrastructure, economic regulation may also facilitate competition in markets, thus enabling a greater scope of intervention for competition law. The less the regulatory regime interferes with the workings of the market, the more room for competition law. Expanded confidence in competition and markets may lead some previously regulated sectors to towards a specific competition law regime, taking into account the specificities of the economic sector, and even leading to the application of general competition law rules. This movement across the regulation/competition continuum may be observed in various sectors, such as airlines, maritime transports, telecoms, and can also be observed in the food sector, by the transition of the sector to private markets from a regime of administered 
economy or state-owned enterprises in some of the jurisdictions examined, in particular during the 1990s. However, it may also be substitutable to competition law, as experience has shown that when markets or segments of the industries become competitive, or there is a political decision to move to competitive markets as the main mechanism of organizing economic activity in this sector/segment, then state-ownership, administrated economy or sector-specific regulation may often be substituted by competition law. Indeed, this may happen when the interaction of competition law and regulation could prove problematic, in particular if the regulatory regime aims to control prices, restrict entry, give incumbents a competitive advantage, or requires or permits some practice that competition law prohibits. These risks of substantive conflict may be exacerbated if different institutions are in charge of competition law enforcement from those in charge of regulating the specific economic sector. The rules regulating the interaction between competition law and regulation may vary from jurisdiction to jurisdiction: some prefer a cumulative application of competition law and economic regulation so that ex ante regulation by a Regulatory Authority does not prevent the ex post intervention on the basis of competition rules, others opt for a regime of substitution, the choice being between regulation or competition law.

It therefore becomes important to examine the interaction of the various competitive forces in operation and their impact on the incentives of the actors to innovate and compete on price/quality/variety. Taking the example of genetically modified seeds, the structure of the industry has changed considerably the last few decades, in view the expansion of IP rights and technological development. Diana Moss notes that

"[...] the organization of the transgenic seed industry has shifted fundamentally over the past two decades from separate ownership of agricultural biotechnology and seed assets to integrated platforms. These platforms comprise three major levels: (1) innovation involving genetic transformation technologies and genomics; (2) genetic traits that are expressed in plant agronomics, including insect resistance (Bt) and herbicide tolerance $(\mathrm{Ht})$; and (3) state-of-the-art seeds containing genetic traits, for which seed companies are the major distribution channel for ultimate sales to farmers. Most current-generation transgenic seeds contain multiple or "stacked" genetic trait"153. These seed platforms may be established for benign reasons, for instance the prospect of economies of coordination that potentially arise from complementarities between complex research and development. However, seed platforms may also result from a strategy to create or enhance market power though control of patented technology and distribution channels for delivering transgenic seeds to farmers, in particular through a wave of merger and acquisitions by the dominant players in the market ${ }^{154}$. This has occurred partly because of the expansion of IP rights in this sector, as instead of negotiating for the rights to a competitor's technology, it was simpler, cheaper, or more advantageous to acquire the competitor outright.

The trade-offs are further complicated by the variety of competition models characterizing the industry. As it is reported by Diana Moss,

153 Diana L. Moss, Transgenic Seed Platforms: Competition Between a Rock and a Hard Place?, American Antitrust Institute (AAI) Submission, October 23, 2009, p. $2 .$.

${ }^{154}$ Ibid., p. 2.. 
"[...] two non-mutually exclusive models of competition characterize rivalry in transgenic seed--inter-platform and intra-platform competition. In the first case, rivalry is between transgenic seed platforms. Seed containing traits that are exclusive to a single firm are the product of such platforms. Intra-platform competition involves rivalry within platforms whereby firms develop new transgenic seed products, in part, by obtaining access to rivals' patented traits. [...] What model of competition is likely to produce the greatest benefits for competition and consumers poses key a question for antitrust enforcement" ${ }^{\prime 155}$.

Moreover, firms have the choice to either opt for an open system in which different complementary assets (such as genetic traits and seed germplasm) interoperate well with rival technology, or to develop "closed" platforms. This choice involves "fundamental decisions to promote open source versus proprietary technologies, "plug-and-play" versus nonstandardized components, and tactics that are designed to frustrate rivals' access to needed technology" 156 . Although traditional breeding methods required important resources and a considerable investment of time (because of long breeding cycles) and hence economies of scale and large market players, the latest genome-editing technologies, particularly CRISPR/Cas, may constitute more efficient and less resource intensive and time-consuming breeding methods, that offer opportunities for the emergence of a more competitive and less integrated market structures relating to seeds. Indeed, as a recent Nuffield Council on Bioethics report observes, "the potential of genome editing techniques (in terms of decreased cost and technical difficulty, and increased speed) may revive the opportunities for small and mediumsized biotech companies in the agricultural area and unlock development of a wider variety of traits" ${ }^{\prime 157}$. This likely emergence of a more competitive market structure, in view of reduced endogenous sunk costs, may be blocked by the business strategies of integrated agro-chem corporations that may try to establish one-shop platforms, combining traits, seeds, pesticides and smart agriculture or digital solutions for farmers in order to raise barriers to the independent entry of small and medium-sized start-ups in the various segments of the value chain.

One may thus advance that competition in this context may occur between platforms and within platforms. Competition authorities should make efforts to promote inter-platform competition, but also intra-platform competition, in view of the consolidation of the industry and the significant competitive position of Monsanto which controls large, totally closed platforms in transgenic seed that may be challenged only by the unlikely emergence of rival platforms. This may lead to single-firm dominance and the foreclosure of competitors from the access to technology that is critical for intra-platform competition. Diana Moss explains that as the dominant player in the market for genetic trait, Monsanto acquired numerous independent seed companies between the mid-1990s to late 2000s, beefing up its presence in downstream markets for traited seed with the effect that it has been to create vertically integrated platforms of genetic traits and traited seed. In order to stack, a developer must combine its own traits with those of Monsanto or another rival. In view of Monsanto's important share in genetic trains, the number of possible traits combinations that could be created between non-Monsanto

\footnotetext{
${ }^{155}$ Ibid, p. 12.

156 Ibid., p. 12

${ }^{157}$ Nuffield Council on Bioethics, Genome Editing: An Ethical Review (September 2016), p. 62.
} 
developers is limited, with the result that the majority of stacked trait combinations contain a Monsanto trait. The possibility of generic competition in transgenic seed, following the end of some Monsanto patents is also limited, without the development of an institutional structure for promoting and managing generic competition and incentives for the dominant player in this market to facilitate the development of generic products ${ }^{158}$. According to Diana Moss, "(a) myriad of adverse effects potentially flow from this, including reduced or lower quality innovation in transgenic seed, higher seed prices to farmers (i.e., "technology fees"), fewer transgenic seed choices, and higher commodity prices than what would have prevailed under competitive market conditions"159.

Similar complex trade-offs involving static and dynamic competition across different platforms should also be performed at the retail segment of the market. Supermarkets may also be perceived as platforms providing services both to consumers, who have a wider choice of products/brands to buy at one stop shop service (thus practising one-homing), and grocery brands, which offers them access to its shelf-space as well as a wide array of remunerated services, which condition access to as many supermarket platforms as possible (thus practising multi-homing $)^{160}$. Sometimes these fees may become a more important source of revenue for multi-product retailers than retail margins ${ }^{161}$.

It is important to pause a little here in order to understand that demand substitutability and cross-price elasticity of demand and supply are not the only ways to delineate spaces where competition takes place, other routes being also open. The point we want to make is that market definition is as much a legal construct as an economic one. What is clear is that there is no clear-cut boundary of the market, so long as this identifies an arena/field for competition. Some have considered that the market can be "the smallest area within which it is possible to be a viable competitor" 162 . One may take a strategic approach, starting from the perspective of the firm, which either focuses on its potential consumers whose needs and functions it tries to satisfy (demand side), or ignores demand by focusing on comparable (and competing) firms (supply side). If one focuses on the supply side, it may be possible to consider as competitors and thus forming part of the "relevant market" for the purposes of competition law analysis, firms with resources similar to the firm under investigation, which in all likelihood may pose a competitive threat to its competitive position. These resources may include physical capital, such as an industrial plant, equipment, technology, geographical location, but also human capital resources (managerial skills, innovation capabilities), organisational resources as well as important assets for production (for instance, crucially important for the competitive process personal data) that may sustain the competitive advantage of the firm ${ }^{163}$. Firms following

\footnotetext{
${ }^{158}$ Diana L. Moss, Transgenic Seed. The High Technology Test for Antitrust?, Competition Policy International, Competition Policy International Spring 2010, 10(2).

${ }^{159}$ Diana L. Moss, Transgenic Seed Platforms: Competition Between a Rock and a Hard Place?, AAI Submission, October 23, 2009, p.12.

${ }^{160}$ Javier, Berasategi, Supermarket Power: Serving Consumers or Harming Competition (February 2014), pp. 3644.

${ }^{161}$ Ibid.,p. 40.

162 P.A. Geroski, Thinking creatively about markets, (1998) 16(6) International Journal of Industrial Organization 677.

163 J.B. Barney, Firm resources and sustained competitive advantage, (1991) 17(1) Journal of Management 99B. Wernerfelt, A resource-based view of the firm, (1984) Strategic Mangement Journal 171.
} 
similar strategies, thus constituting a "strategic group"164, disposing of similar resources, and serving the same customers' needs ${ }^{165}$, may thus, under such an approach, be considered as competitors, constraining the action of each other, even if their products do not overlap in the same relevant market. In a period of convergence of physical, biological and digital worlds, as a result of the recent transformations of industrial production, and the dislocation of boundaries between markets, one may find that such an approach fits better the economics of the fourth industrial revolution than the narrower market definition based on the principle of cross-price elasticity between products, from the point of view of the consumer. How could one proceed to market delineation in a world in which personalisation of production means that consumers become the designers of the individually customised products they will consume, the products being produced by 3-D printing and robots, firms competing mainly on the market for personal information, which will serve as the raw material on which personalised production will take place?

The focus on innovation also raises important questions as to the locus of competition assessment to the extent that the concept of "innovation market" that has been employed in order to assess the effect on future effects on innovation competition may not provide an appropriate framework to the extent that it does not take into account the possibility of drastic innovation and the possible entry of undertakings that are not presently active in the specific industry or market, but may have some technological capabilities that could enable it to constitute a possible competitive constraint in innovation competition. In some recent merger cases concering the seed/agrochem sector, the European Commission took a broader perspective and employed the concept of "innovation space" and the "industry" when assessing the possible effect of the merger transaction on innovation ${ }^{166}$. According to the Commission, when analysing the effects on innovation it becomes important to to assess the impact of the transaction "at the level of innovation efforts by the Parties and its competitors" 167 . The assessment of innovation competition follows three steps:

"(349) First, the assessment of innovation competition requires the identification of those companies which, at an industry level, do have the assets and capabilities to discover and develop new products which, as a result of the R\&D effort, can be brought to the market.

(350) Secondly, it is also relevant to identify and analyse those spaces in which innovation competition occurs in the crop protection industry. The R\&D players do not innovate for all the product markets composing the entire crop protection industry at

\footnotetext{
164 According to M.E. Porter, Competitive strategy. Techniques for analysing industries and competitors (Free Press, 1980), 129 defines "strategic groups" as a "group of firms in an industry following the same or similar strategy along the strategic dimensions", the firms within a "strategic group" competing more intensely with each other than with firms outside this core group. See, K.G. Smith, C.M. Grimm, S. Wally \& G. Young, Strategic groups and rivalrous firm behaviour: Towards a reconciliation, (1997) 18(2) Strategic Management Journal 149; R.K. Reger \& A.S. Huff, Strategic groups: A cognitive perspective, (1993) 14(2) Strategic Management Journal 103 (emphasising the need to take into account psycho-sociological factors influencing manager's cognitive perception about their competitors).

${ }_{165}$ M. Bergen \& M.A. Peteraf, Competitor identification and competitor analysis: A broad-based managerial approach, (2002) 23(4/5) Managerial and Decision Economics 157.

${ }^{166}$ EU Commission Decision, CASE M.7932 Dow/Dupont (2017), paras 348-352

${ }^{167}$ Ibid., para. 348.
} 
the same time. They also do not innovate randomly without targeting specific spaces within that industry. When setting up their innovation capabilities and conducting their research R\&D players have specific discovery targets ([...]).

(351)A given discovery target is based on lead crops and lead pests and may thus comprise AIs that can be used in several downstream formulated product markets (for example chewing Lepidopteran insecticides, broadleaf herbicides). The spaces where innovation competition takes place are thus broader than an individual downstream crop protection market, but are nonetheless small. In fact, in light of increasing regulatory hurdles, which require crop protection products to be ever more selective, the innovation spaces in the crop protection industry are getting ever smaller: the innovation output tends to be confined to ever narrower spaces from which it is more difficult to adapt the innovation to other purposes.

(352) In conclusion, in order to assess innovation competition, the Commission will both consider metrics of innovation taking place at industry level, as well as innovation taking place in spaces consisting of groupings of crop/pest combinations [...]" [areas where the parties' activities overlapped] ${ }^{168}$.

The concept may also affect the way we proceed to the definition of the geographic boundaries in which competitive interactions take place ${ }^{169}$. In its assessment of the Dow/Dupont merger the Commission focused both on innovation competition "at the level of innovation spaces within the crop protection industry and on innovation competition at the industry level"170. More specifically, the Commission focused on the line of research the merging companies weer active, the latter concept comprising "the set of scientists, patents, assets, equipment and chemical class(es) which are dedicated to a given discovery target whose final output are successive pipeline [products] targeting a given innovation space" ${ }^{\text {"171. It }}$ therefore becomes clear that which of the various approaches on offer is chosen depends greatly on the type of competition/tournament taking place in the specific "field" of economic/social activity $^{172}$.

\subsubsection{Multi-lever Competition policy: integrating technological and societal change}

Science and technology studies (STS) and sociology literature emphasises the need to uncover the various social processes at play composing the field of the food industry, before proceeding to any conclusion with regard to the manifestation of economic power ${ }^{173}$. It becomes therefore important to unearth the socio-technical agencements that characterize the specific industry. As actors in these markets invent new products and technologies, they transform these markets

\footnotetext{
168 Ibid., paras 349-352.

${ }^{169}$ Ibid., para. 361.

${ }^{170}$ Ibid., para. 1956.

${ }^{171}$ Ibid., para. 1958.

172 On the concept of "field" and its possible contribution to address complex competitive interactions, see P. Bourdieu, Principles of an Economic Anthropology, in P. Bourdieu, The Social Structures of the Economy, (Cambridge, Polity press, 2005), 193; N. Fligstein \& D. McAdam, Toward a General Theory of Strategic Action Fields, (2011) 29 Sociological Theory 1.

${ }^{173}$ P. Bourdieu, The Social Structures of the Economy, (Cambridge, Polity press, 2005), 193; N. Fligstein \& D. McAdam, Toward a General Theory of Strategic Action Fields, (2001) 29 Sociological Theory, 1-26
} 
beyond recognition and add new value chains to the existing ones, thus leading to disruptive innovation. This is a process that usually takes a considerable period of time and may lead to situations of entrenched economic (and market) power for a significant period. Founded for one objective, markets often end up serving an entirely different purpose after a certain time. This constructive action takes place furthermore in hybrid collectives based on economic actors conceptualized as socio-technical agencements that not only denote collectives of human beings but also abstract collectives incorporating technical devices, tools and algorithms ${ }^{174}$. These sociotechnical arrangements provide the capacity to act but also to give meaning to action. Their ontology does not possess inherent or fixed properties but is variable and largely dependent on adaptive behaviours and reflexive agencies. Financial market models, methods and tools can thus be made to work if the corresponding agencement is constructed and actors are configured in such a way that the postulates may be found to have empirical validity.

In the era of genetically modified and edited food, technologies play an increasingly important role in forming the core of the socio-technical agencement of global food supply chains and of their finance, which is increasingly automated through algorithmic configurations in global financial markets. Financial markets for agricultural commodities and futures markets grow in abstraction as they tend to organize encounters between distant and desynchronised supplies and demands, seemingly decoupled from the ordinary economy of production and consumption. The increased level of technical complexity of these agencements, as well as the dehumanization and variability of global food supply markets this implies create important challenges for competition authorities. To our knowledge, this financial dimension of the interconnectedness between various food systems has rarely been encountered in legal scholarship about food supply chains. The following graph represents the various units of analysis we would like to bring together in exploring this issue ${ }^{175}$.

\footnotetext{
${ }^{174}$ M. Callon, The Law of the Markets (Blackwell, 1998) ; M. Callon, Y. Millo, F. Muniesa (eds.), Market Devices (Blackwell, 2007); M. Callon \& F. Muniesa, "Les marchés économiques comme dispositifs collectives de calcul," Réseaux (2003) 21(122): 189-234.

175 The framework is inspired by the classic four layer model of Koppenjan \& Groenewegen on institutional design for complex technological systems with our addition of a fifth layer focusing on the nature and potential uses of technology, the risks involved, as perceived by the actors and the current biophysical conditions possibly restricting its use and further development: J. Koppenjan, \& J. Groenewegen, Institutional design for complex technological systems. (2005) 5(3) International Journal of Technology, Policy and Management, 240-257,
} 


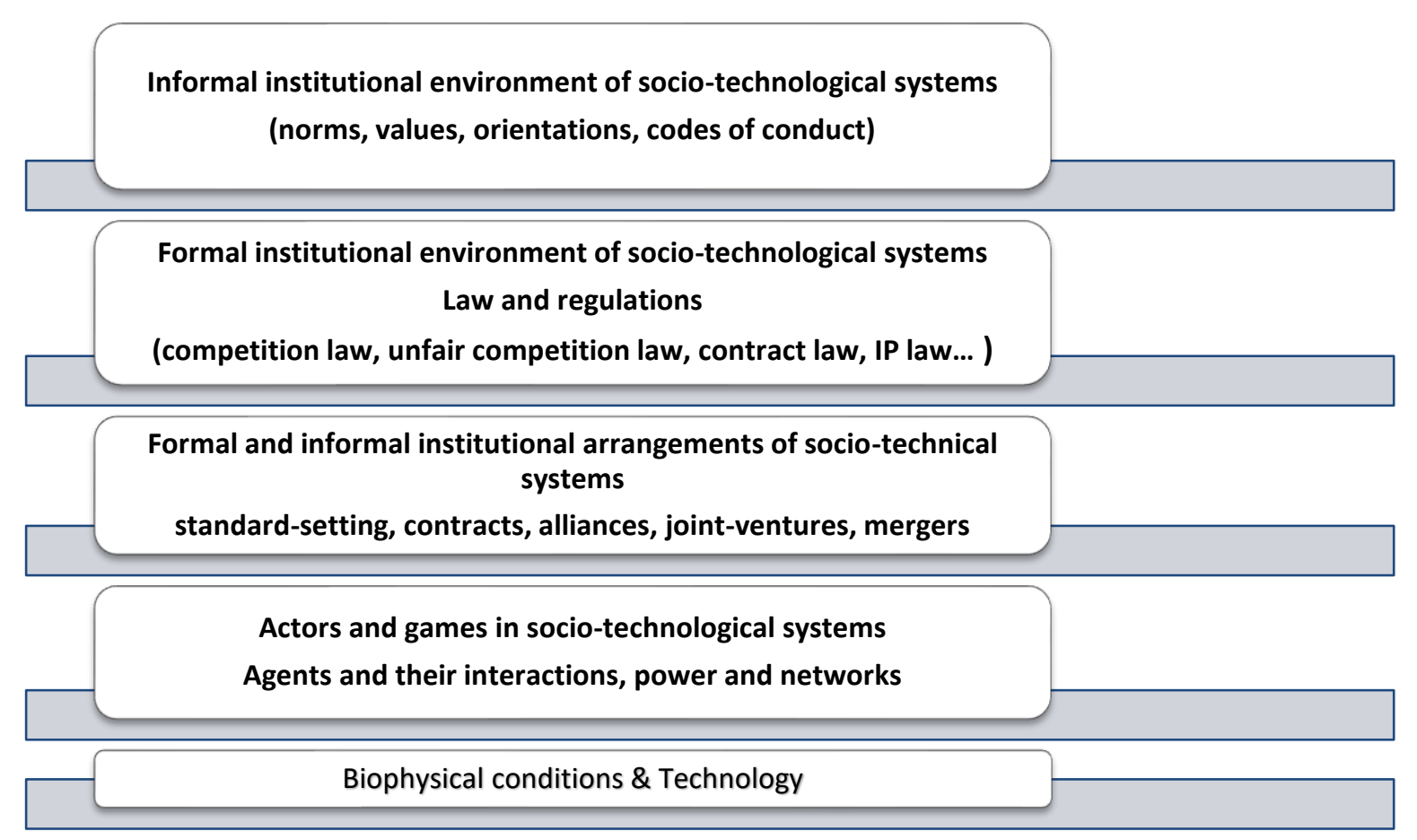

Competition authorities constitute part of the formal institutional environment of sociotechnical systems in the food sector, along with other areas of law, such as intellectual property, unfair competition law, contract law, with which competition law interacts and occasionally is in tension. All of these areas of law deal with broader dimensions of the public interest, going beyond lower prices and higher output to the benefit of consumers, or promoting consumer choice and innovation, which form the core of the tasks of competition authorities. They represent the plurality of values usually taken into account in setting regulatory goals for food systems. Among them one may identify the right to food, biodiversity and sustainability in the era of the Anthropocene, security of supply, which becomes essential in a period of rapid and eventually catastrophic climatic change for food production in various regions of the world, as well as more general geopolitical concerns in the control of the factors of production for food and the promotion of the competitiveness of the local industry.

One may distinguish between various conceptions of the role of competition authorities: (i) the core, where there is a large agreement among jurisdictions, (ii) a grey area, where there is a significant number of jurisdictions, developed and developing economies that, either explicitly, or implicitly, integrate these concerns in their competition law, and (iii) what has been characterised as 'public policy concerns', which are areas where there is some strong disagreement between competition authorities as to possibility to integrate them among the aims of their action. 

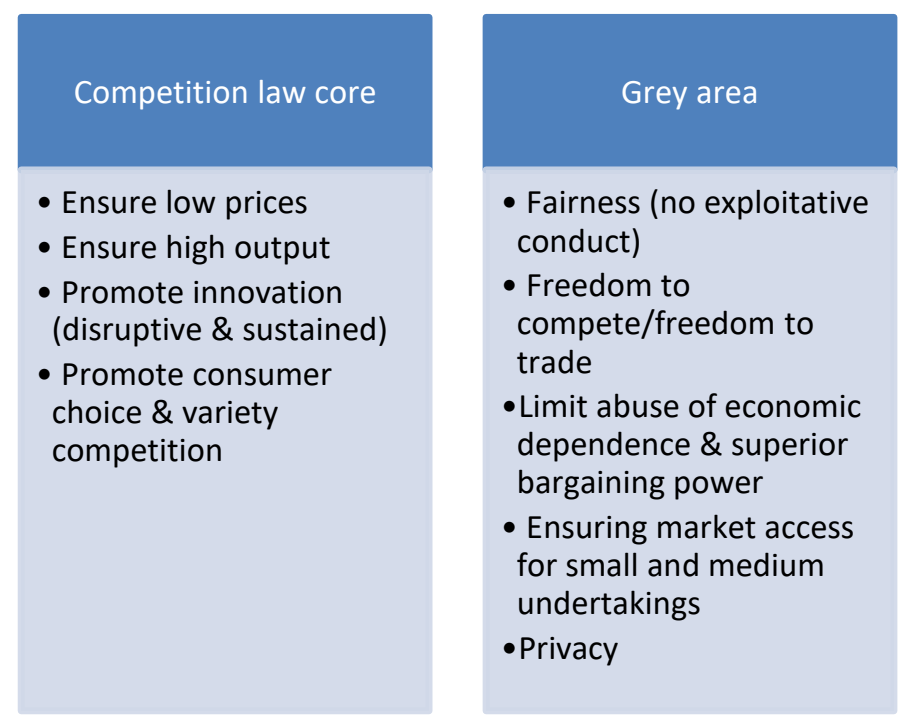

Normally outside the

competition law core

Public policy interests

- Security of supply

- Right to food

- Biodiversity and sustainability

- Competitiveness of the local industry

- Geopolitical concerns \& national security

- Promote employment \& social welfare

- Promoting human

happiness or capabilities

There is little to no work on the way these broader concerns may be integrated in a sound way in the assessment performed by the various public authorities in charge in conducting competition policy in this field, although there is a clear trend recently to focus on the contribution of competition law and policy to inclusive growth ${ }^{176}$.

Various BRICS authorities include public interest concerns in the criteria usually taken into account when assessing the compatibility to competition law of mergers and acquisitions, and eventually also cooperative agreements. For instance, the Anti-Monopoly law of the Republic of China identifies among its objectives not only "protecting fair competition in the market" and "the interests of consumers" but also protecting the "lawful business operations" of undertakings in industries "controlled by the State-owned economy and concerning the lifeline of national economy and national security". The "Anti-Monopoly Law of the People's Republic of China" and "Interim Provisions on Assessing the Impact of Concentration of Business Operators on Competition" regulate the factors to be considered when examining business operators, and it is clear that the public interest should be considered comprehensively ${ }^{177}$.

The South African competition legislation takes into account not only how a specific merger may produce anticompetitive effects or provide pro-competitive synergies, but also how it may promote the efficiency, adaptability and development of the economy, promote employment and advance the social and economic welfare of South Africans, or ensure that small and medium-size enterprises have an equitable opportunity to participate in the economy and promote a greater spread of ownership, in particular to increase the ownership stakes of historically disadvantaged persons ${ }^{178}$.

\footnotetext{
${ }^{176}$ See J. Furman, Beyond Antitrust: The Role of Competition Policy in Promoting Inclusive Growth, Searle Center Conference on Antitrust Economics and Competition Policy (September 2016), available at https://obamawhitehouse.archives.gov/sites/default/files/page/files/20160916_searle_conference_competition_f urman_cea.pdf ; A. Dierx, F. Iljkovitz, B. Pataracchia, M. Ratto, A. Thum-Thyssen, J. Varga, Does EU Competition Policy Support Inclusive Growth?, (2017) 13(2) Journal of Competition Law and Economics 225260.

${ }^{177}$ Submission Questionnaire PRC.

${ }^{178}$ Submission Questionnaire, South Africa indicates that Section 12 of the South African Competition Act, sets out that in considering mergers, the competition authorities have to "determine whether or not the merger is likely to substantially lessen or prevent competition" taking into account the following factors:
} 
In a similar fashion the Russian Federal Law on the Protection of Competition (article 13) allows some forms of anticompetitive conduct as well as agreements and mergers to be authorized by the authority if such anticompetitive acts help with substantial modernization of the related industries or increase in innovation activities and technological advance in Russia or lead to an expansion of the Russian products' share in the global markets. In the context of a wave of mega-mergers that have changed the competitive architecture of the industry, it becomes important to understand how these public interest concerns have already been integrated in merger law, identify best practices and devise a methodology for their inclusion in the competition policy assessment, while preserving the rights of due process and the legal certainty of the parties to the transaction, and the possibility of all affected interests to be represented. There is little work that goes beyond accepting that these concerns may play a role and which explores thoroughly the way these concerns and values may be taken into account, eventually measured and evaluated, in a way that is compatible with legal certainty and could facilitate compliance by corporations.

One may distinguish between situations of lateral conflict which may occur because competition law enforcement can jeopardise the aims followed by these various regulatory tools, from what we can call situations of regulatory osmosis, that is, the absorption of regulatory aims in the enforcement of competition law. This process may occur as a result of the pressure to interpret and enforce competition law principles in congruence to the aims and the structure of the entire legal system to which competition law is integrated. Without the need to refer to the concept of law as integrity of philosopher Ronald Dworkin, it is we think uncontroversial to argue that a competition authority or a judge enforcing competition law should strive to interpret the law in accordance to the broader moral and legal principles underpining the legal system ${ }^{179}$ One may distinguish two situations. First, it is possible that competition law includes among its own objectives the consideration of public policy (as the previous examples indicated) or that sector-specific regulators that have concurrent jurisdiction to apply competition law may have more than one aims in their mission statement and they often need to take into account and satisfy all these objectives. Second, even if one does not integrate these concerns as 'objectives' to be followed by the competition legislation, one needs to 'take into account' the broader principles of the legal system when interpreting the law, focusing on the way these are transcribed in its legal and institutional context, in particular for

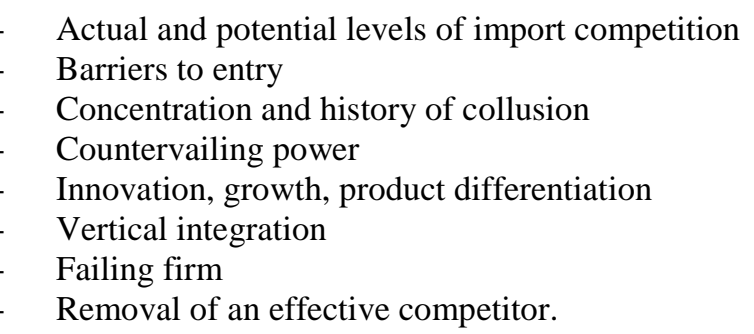

The Competition Act also requires that competition authorities have regard for the following public interest factors:

Impact on a particular industrial sector or region

Employment

- Ability of small businesses controlled or owned by historically disadvantaged people to compete

- Ability of national industries to compete in international markets

${ }^{179}$ See, generally, R Dworkin, Law's Empire (Harvard Univ. Press, 1986). 
areas like competition law, where the legal rules do not provide much detail on the way one should interpret them, and statutory interpretation plays an important role. Hence, one may distinguish between various degrees of the 'duty' to take into account public interest concerns followed by social and technical regulation. A strong and extensive in scope duty if these are listed among the objectives of competition law or in the mission statement of regulators enforcing competition law, which means that the decision-maker should maximise all the objectives or to the extent there is some hierarchy between them prioritise some objectives. A weaker one, in all other circumstances, when these objectives must be taken to a certain degree into account so that the legal system does not create conflicting demands from economic actors, and, more broadly, the values integrity of the legal system does not suffer.

It is important to acknowledge here that competition law should intervene whenever there is a restriction of the competitive process ${ }^{180}$, and the decision to intervene, or not to intervene, needs to be justified, as scarce enforcement resources are used and chilling effects may be created for welfare-enhancing conduct. The process of justification may involve arguments in favour of such restriction of competition and thus of the decision not to intervene on the basis of economic efficiency considerations, but also arguments relating to the need to intervene against this restriction of competition, these taking into account all the social costs engendered by such restriction, including the social costs of the increase of prices on the market, less consumer choice, but also restrictions on privacy, to the extent that these are important parameters of competition and could be considered as providing content to the concept of competition on quality. It is possible that regulation may offer a superior institutional alternative than competition law in order to alleviate these concerns. This requires a careful comparative institutional analysis, the final choice to act through a specific tool (competition or some form of transparency regulation) being at the end between imperfect institutional alternatives. For instance, it is possible that the extent of remedial action and possibly the continuous supervision of data markets this may entail could be considered as outside the traditional remit of competition law and the technical competences of competition authorities and may require the intervention of regulation, in particular in view of the reticence of competition authorities to intervene in this sector. But it cannot be excluded that it might make more sense to focus on the practices of the undertakings having a significant structural/lead position in data markets and/or value chains and not on the conduct of all undertakings. To the extent that competition law disposes of the tools to engage with economic power more than data protection legislation, it could provide in this context a superior alternative.

\footnotetext{
${ }^{180}$ A Edlin \& J Farrell, Freedom to Trade and the Competitive Process, in R Blair \& DD Sokol (eds.), The Oxford Handbook of International Antitrust Economics, Vol. I (OUP, 2014), Chap. 13, define the competitive process as "the process of sellers and buyers forming improving coalitions", they argue that "[competition law] protects the potential beneficial trades between competitors and consumers. Since both consumers and competitors gain from such trade, this view can explain why both consumers and thwarted competitors have antitrust rights, even though antitrust protects 'competition and not competitors'. Consumers are not protected from all high prices, but only from those that a competitor would be happy to beat but for some thwarting action; this explains why a pure monopoly does not violate the law simply, but only from tactics such as moving he goalposts that block them from giving customers a better deal than a monopoly does". Such an approach may dispense, to a certain extent, with focusing on all practices that reduce consumer welfare in equilibrium and may provide a useful starting point for the competition assessment.
} 
A similar analysis may take place with regard to other considerations of "public interest". For instance, promoting biodiversity may constitute an important aim pursued by public authorities, eager to ensure a higher quality of nutrition and to preserve food safety, biodiversity being the best way to guarantee a healthy eco-system and consequently resilience in the face of the uncertainty associated with climate change ${ }^{181}$. One may also want to take into account the gerater impact on wealth inequality of cartels, anticompetitive merger activity and other anti-competitive prices in the food sector, in particular if this affects markets of staple food products $^{182}$.

\section{References}

Anderson, B.C., Sheldon, I.M. R\&D Concentration under Endogenous Fixed Costs: Evidence from the Agricultural Biotechnology Industry, (mimeo, 2015).

Argent, J \& T. Begazo, Competition in Kenyan markets and its impact on income and poverty: a case study on sugar and maize, (World Bank Policy Research Working Group 7179, January 2015).

Barney, J.B. Firm resources and sustained competitive advantage, (1991) 17(1) Journal of Management 99B.

Bergen , M.,Peteraf, M.A. Competitor identification and competitor analysis: A broad-based managerial approach, (2002) 23(4/5), Managerial and Decision Economics, 157.

Bernstein, H., 'Agrarian political economy and modern world capitalism: The contributions of food regime analysis'. (2016) 43 Journal of Peasant Studies 3

Bessen, J. Accounting for Rising Corporate Profits: Intangibles or Regulatory Rents? (2016) Boston University School of Law, Law and Economics Research Paper, No. 16-18.

Berasategi, J. Supermarket Power: Serving Consumers or Harming Competition (February 2014), pp. 36-44.

Blaug, M. 'The Fundamental Theorems of Modern Welfare Economics, Historically Contemplated', (2007) History of Political Economy 39(2) 185-207.

Blundell, R, R Griffith \& J. Van Reenen, Dynamic Count Data Models of Technological Innovation (1995) 105 (429) Economic Journal 333.

Bresnahan, T., Levin, J. Vertical Integration and Market Structure, NBER Working Paper No. 17889.

Çalişkan, K, Market Threads: How Cotton Farmers and Traders Create a Global Commodity (Princeton Univ. press 2010).

${ }^{181}$ T.C.H. Sunderland, Food security: Why is biodiversity important?, (2011) International Forestry Review 13(3): 265-274.

${ }^{182}$ See, for instance, G. Porto, N. Depetris Chauvin \& M. Olarreaga, Supply Chains in Export Agriculture, Competition, and Poverty in Sub-Saharan Africa (World Bank \& CEPR, 2011) (exploring a number of case studies in Africa with regard to crops on cotton, coffee, tobacco and cocoa); J. Argent \& T. Begazo, Competition in Kenyan markets and its impact on income and poverty : a case study on sugar and maize, (World Bank Policy Research Working Group 7179, January 2015); and the examples included in World Bank \& OECD, A Step Ahead : Competition Policy for Shared Prosperity and Inclusive Growth. Trade and Development (World Bank, 2017). 
Callon, M. The Law of the Markets (Blackwell, 1998);

Callon, M., Y. Millo, F. Muniesa (eds.), Market Devices (Blackwell, 2007).

Callon, M., Muniesa, F. "Les marchés économiques comme dispositifs collectives de calcul," Réseaux (2003) 21(122): 189-234.

Castells, M. The Information Age: Economy, Society and Culture - The Rise of the Network Society (Wiley, 1996), p. 92.

Chandler, A.D. The Visible Hand - The Managerial Revolution in American Business (Harvard University Press, 1977).

Cheng, T. , Lianos, I. \& Sokol, D., Competition and the State (SUP, 2014).

Clive, J. Global Status of Biotech/GM Crops, (Ithaca, NY, 2014) ISAAA Brief No. 49.

Coase, R. The Nature of the Firm, (1937) 16(4), Economica, 386.

Dabla-Norris, E., Kochhar, K., Suphaphiphat, N., Ricka, F., Tsounta, E. Causes and Consequences of Income Inequality: A Global Perspective (IMF, June 2015).

Davis, D., Kalpinsky, R., Morris, M. Rents, Power and Governance in Global Value Chains, in I. Lianos, A. Ivanov and D. Davis (eds.), Global Food Value Chains and Competition Law (forth. 2018).

De Backer, K., Miroudot, S., Mapping Global Value Chains, European Central Bank, (2014) Working Paper Series No. 1677.

Dedrick, J., Kraemer, J.K., Linden, G. Who profits from innovation in global value chains?: a study of the iPod and notebook PCs, (2010) 19(1), Industrial and Corporate Change, 81-116.

Dunne, N., Competition law and Economic Regulation - Making and Managing Markets (CUP, 2015).

Drexl, D. \& DiPorto, F. (eds.), Competition Law as Regulation (Edward Elgar, 2015).

Erixon, F., Weigel, B. The Innovation Illusion (Yale University Press, 2016).

Friedmann, H., 'The political economy of food: a global crisis'. (1993) 197 New Left Review 29.

International regimes of food and agriculture since 1870. In: T. Shanin, (ed.) Peasants and peasant societies. (Oxford: Basil Blackwell, 1987), p. 258.

Fulton, M., Giannakas, K. Agricultural biotechnology and industry structure. AgBioForum 4(2), 2001, pp. 137-151.

Furubont, E.G. Richter, R. Institutions and Economic Theory-The Contribution of the New Institutional Economics (The Univ. of Michigan Press, Ann Arbor, 1999).

Furman, J. Beyond Antitrust: The Role of Competition Policy in Promoting Inclusive Growth, Searle Center Conference on Antitrust Economics and Competition Policy, (September 2016).

Gerber, D. Competition Law and Global Supply Chains, (2016).

Gereffi, G., Fernandez-Stark, K. Global value Chain Analysis: A Primer (CGGC: $2^{\text {nd }}$ ed., 2016),

Gereffi, G., Humphrey, J., Sturgeon, T. The governance of global value chains, (2005) 12(1) Review of International Political Economy 78-104, 84. 
Geroski, P.A. Thinking creatively about markets, (1998) 16(6) International Journal of Industrial Organization 677.

Gordon, R. The Rise and Fall of American Growth (Princeton University Press, 2016).

Hart, O. An Economist's Perspective on the Theory of the Firm, (1989) 89, Columbia Law Review 1757.

Hart, O., Moore, J. Property Rights and the Nature of the Firm, (1990) 98 Journal of Political Economy 1119.

Joskow, P. The New Institutional Economics: Alternative Approaches, (1995) 151(1) Journal of Institutional and Theoretical Economics, 248.

Joskow, P. Transaction Cost Economics, Antitrust Rules and Remedies, (2002) 18(1), Journal of Law, Economics and Organization 95.

Kaplinsky, R. Competitions Policy and the Global Coffee and Cocoa Value Chains, Paper prepared for the United Nations Conference for Trade and Development (Brighton: Institute of Development Studies, Sussex, 2004).

Kalaitzandonakes, N., Bjornson , B., (1997) 29(1) Vertical and Horizontal Coordination in the Agro-biotechnology Industry: Evidence and Implications Journal of Agricultural and Applied Economics, 129.

Katz, M.L., Shapiro, C. 'Systems Competition and Network Effects' [1994] 8(2) Journal of Economic Perspectives 93.

Langlois, R.N. The Vanishing Hand: The Changing Dynamics of Industrial Capitalism, (2003) 12 Industrial and Corporate Change 351.

Lianos, I., Lombardi, C. Superior Bargaining Power and the Global Food Value Chain: The Wuthering Heights of Holistic Competition Law?, Concurrences I-2016 22.

Lianos, I. Global Value Chains and Competition Law, (2018) CLES Research Paper Series $3 / 2017$.

Lianos, I., The poverty of Competition Law (2018) CLES Research Paper Series 2/2018.

Lee, J., Gereffi, G., Beauvais, J. Global value chains and agrifood standards: Challenges and possibilities for smallholders in developing countries, (2012) 109(31) Proceedings of the National Academy of Science 12326.

Magnier, A., Kalaitzandonakes, N., Miller, D.J., Product Life Cycles and Innovation in the US Seed Corn Industry, (2010) 13(3), International Food and Agribusiness Management Review 17.

McMichael, Ph., Global Development and the Corporate Food regime, in F.H. Buttel and P. McMichael (eds). New directions in the sociology of global development (Oxford: Elsevier Press, Volume 11, 2005), 269.

'A food regime genealogy',(2009) 36(1) Journal of Peasant Studies 139.

'Historicizing food sovereignty' (2014) 41 The Journal of Peasant Studies', 933; Ph. McMichael, 'Commentary: Food regime for thought', (2016) 43 The Journal of Peasant Studies 648.

Global Development and the Corporate Food regime, in F.H. Buttel and P. McMichael (eds). New directions in the sociology of global development (Oxford: Elsevier Press, Volume 11, 2005), 269. 
Ménard, C. The Economics of Hybrid Organizations, (2004) 160, Journal of Institutional and Theoretical Economics 345.

Montgomerie, J., Williams, K. Financialised Capitalism: After the Crisis and Beyond Neoliberalism, (2009) 13(2) Competition \& Change 99.

Moss, D. Transgenic Seed Platforms: Competition Between a Rock and a Hard Place?, AAI Submission, October 23, 2009.

Motta, M. Competition Policy - Theory and Practice (CUP, 2004).

Nickell, S, Competition and Corporate Performance, 104(4) Journal of Political Economy 724.

Nuffield Council on Bioethics, Genome Editing: An Ethical Review (September 2016)

OECD, WTO and World Bank group, Global Value Chains; Challenges, Opportunities and Implications for Policy (2014).

Oehmke, J., Wolf, C., Raper, K. On Cyclical Industry Evolution in Agricultural Biotechnology R\&D, (2005), 3(2), Journal of Agricultural and Food Industrial Organization.

Pasquale, M. The Black Box Society - The Secret Algorithms That Control Money and Information (Harvard University Press, 2015).

Perry, M.K. Vertical Integration: Determinants and Effects, in R. Schmalensee and R. D. Willig (eds.), Handbook of Industrial Organization (Vol 1, Amsterdam: North Holland Publishing, 1989) p. 183

Philippe, P, Howitt, P. Endogenous Growth Theory (Cambridge, Mass., MIT Press, 1998).

Porter, M. Competitive Advantage: Creating and Sustaining Superior Performance (New York: Free Press, 1985).

Porto, G, N. Depetris Chauvin \& M. Olarreaga, Supply Chains in Export Agriculture, Competition, and Poverty in Sub-Saharan Africa (World Bank \& CEPR, 2011)

Reardon, T., Lu, L., Zilberman, D. Links among innovation, food system transformation, and technology adoption, with implications for food policy: Overview of a special issue, Food Policy (2017).

Shaikh, A. Capitalism: Competition, Conflict, Crises (Oxford University Press, 2016).

Simon, H.A. Models of Man (Wiley, New York, 1957).

Sobel-Read, B. Global Value Chains: A Framework for Analysis, (2014) 5(3) Transnational Legal Theory 364.

Streeck, W. How Will Capitalism End? (Verso, 2016).

Sunderland, T.C.H., 'Food security: Why is biodiversity important?', (2011) 13(3) International Forestry Review 265.

Sutton, J. Sunk Costs and Market Structure: Price Competition, Advertising, and the Evolution of Concentration, (MIT Press, 1991).

Swinnen, J.F.M., Vandeplas, A., Maertens, M. Liberalization, Endogeneous institutions, and growth: a comparative analysis of agricultural reforms in Africa, Asia, and Europe, (2010) 24(3) World Bank Econ. Rev. 412.

Swinnen, J.F.M., Kuijpers, R. Value chain innovations for technology transfer in developing and emerging economies: Conceptual issues, typology, and policy implications, Food Policy (2017). 
Thorelli, H.B. Networks: Between Markets and Hierarchies, [1986] 7, Strategic Management Journal 37.

Williamson, O. The Economic Institutions of Capitalism (Free Press, 1985).

Williamson, O. The Economics of Govenance, (2005) 95 American Economic Review 1.

Williamson, O. The Mechanisms of Governance (Oxford University Press, 1996).

\section{Tables and Figures}

Table 1: Governance Types in GVC....................33

Figure 1: A General View of the Food Value Chain.......36 


\section{Chapter 2: The Transformations of the Global Food Value Chains: Technology and Societal changes}

\section{Ioannis Lianos}

\subsection{The genetic revolution}

For a significant part of human history the manipulation of the process of natural variation by humans made possible the selection and the retention of organisms suitable for agricultural use in cultivating land and breeding livestock. It is well-known that genetic variety results from a process of mutation generated by natural selection, different traits resulting from genetic variety being expressed as the organism's phenotype ${ }^{183}$. With this process, “useful traits appearing spontaneously in nature were bred into certain crops or animals by human (rather than natural) selection"184, and led to the development of modern agriculture.

Domestication, breeding and non-natural selection has led to the development, roughly 10000 years ago, of major crop plants that constitute our staple foods today, such as corn (maize), wheat, rice, potato, tomatoes, grape, peach, various other fruits and vegetable, from wild plant varieties to the ones we are familiar now, during a period of non-natural selection over the span of several hundred years. A similar process took place in domesticating, breeding and artificially selecting phenotypic traits and a vast number of phenotypically different breeds with desirable traits during an evolutionary short time period. The domestication of cattle from their wild ancestors, but also the transition from the ancient Siberian wolves to the domesticated dog constitute landmark successes of humanity in its effort to control and manage nature to its own benefit, leading to the emergence of institutions, such as property rights, that led to the development of political communities ${ }^{185}$. Manipulating microbes, bacteria and yeasts, and other micro-organisms, to produce different varieties of wine, beer, bread, cheese and yogurt, or in order to serve in food fermentation and in preventing food spoilage, has been an important feature of the food systems that emerged at the time of the First Agricultural Revolution between 10000 and $2000 \mathrm{BC}$. This process "has exerted a tremendous evolutionary constraint that has left almost nothing that is commonly eaten today (except perhaps fish) biologically unaltered by human intervention and has rendered many wild antecedents extinct"186.

The discovery of the laws of inheritance by George Mendel and Charles Darwin's discovery of the process of natural selection in the $19^{\text {th }}$ century, as well as the implementation of the process of increased mutagenesis in the 1920s, led to an acceleration of the alteration of

\footnotetext{
183 European Commission, Explanatory Note, New Techniques in Agricultural Biotechnology (2017), 24. "Phenotype" refers to the "visible appearance of an organism (with respect to one or more traits) which reflects the interaction of a given genotype with a given environment". A "genotype" "corresponds to the DNA sequence of a cell, and therefore of an organism or individual, which determines, together with epigenetic and environmental factors, stable and heritable characteristics (phenotype) specific for that cell/organism/individual".: European Commission, Explanatory Note, New Techniques in Agricultural Biotechnology (2017), Annex 4.

${ }^{184}$ European Commission, Explanatory Note, New Techniques in Agricultural Biotechnology (2017), 24.

185 See, for instance, the role the domestication of the dog played for the emergence of the institution of private property rights: see . D. Friedman, Law's Order (Princeton Univ. Press, 2000), 118-119.

${ }^{186}$ Nuffield Council on Bioethics, Genome Editing: An Ethical Review (September 2016), 58.
} 
the genotypes and phenotypes of plants and animals by selective non-natural breeding for purposes of increasing genetic diversity. Indeed, domestication is highly dependent on mutagenesis, "as random or induced genomic mutations are fixed, giving rise to desirable traits, such as high yield" 187 , while reducing genetic diversity.

The multiplication of hybridization experiments transformed conventional farming to "agricultural science", with a variety of conventional breeding techniques emerging during this period, techniques that are still in use for various crops in different parts of the world ${ }^{188}$. These include, for plants, the process of simple selection, which as we explained above led to the development of all widely used modern crops, the practice of sexual crossing through hybridization, that can occur intraspecies or interspecies, its aim being to develop novel hybrid cultivars that feature traits that do not occur within a single species, bridge crossing through a third species if a direct cross is not possible, embryo rescue, somatic hybridisation through chromosome engineering in order to combine genes from varieties which are sexually incompatible, induced mutagenesis by exposing plants or seeds to physical (e.g. X-rays, gamma rays) or chemical [e.g. diethyl sulfate (dES), ethyl methanesulfonate (EI)] manipulation or mutation-inducing agent so as to trigger random changes in the plant's genetic composition, translocation breeding, and doubled haploids or polyploidy induction ${ }^{189}$. One of the tools widely chosen to ensure crossing, at least since the mid-1970s, is marker-assisted selection, which is based "on the molecular detection of genomic markers closely associated to the specific trait" "190. Progress in computing technology have made marker-assisted quicker and more precise. For animals, modern breeding programmes on the basis mostly of artificial insemination, but also embryo transfer technology and in vitro production of embryos, have replaced simple selection, a process starting at least six decades ago. Mutagenesis and selection is also the most widely used technique to generate and select microbes and other microorganisms with preferred characteristics, these been enriched with the assistance of physical or chemical agents ${ }^{191}$.

The progress of molecular biology in isolating and sequencing DNA and a more complete understanding of the molecular mechanisms of genetic inheritance, led to the emergence of recombinant DNA technology in the early 1970s and other established techniques of genetic modification. This enabled scientists to insert genetic information into the genome of another unrelated organism, thus making possible transgenic animals and plants. Boyer and Cohen employed recombinant nucleic acids in bacteria in 1973, leading the way to the application of genetic engineering in animals and plants in the late 1970s-early 1980s. In 1983, the first genetically engineered plants consisted in tobacco to which was inserted antibiotic resistance genes. The first commercial Genetically Modified (GM) crops were commercialised in 1992 (tobacco), the first insect and herbicide resistant crops being approved in 1995-1996 ${ }^{192}$. GM crops are now constituting a sizable, although still not the most significant in terms of arable land, part of agricultural production of seeds, with, in 2014, a "reported 18

\footnotetext{
187 Ibid, 57.

${ }^{188}$ P. Enriquez, CRISPR GMOs, (2017) 18(4) North Carolina Journal of Law \& Technology 432.

${ }^{189}$ European Commission, Explanatory Note, New Techniques in Agricultural Biotechnology (2017), 29-35.

190 Ibid., 30.

191 Ibid., 44.

192 P. Enriquez, CRISPR GMOs, (2017) 18(4) North Carolina Journal of Law \& Technology 432, 457.
} 
million farmers in twenty-eight countries across the world" devoting "181,5 million hectares" of arable land for cultivation of GM crops. However, in terms of value, it is estimated that more than half of the global seed market consists in GM seeds ${ }^{193}$. GM seeds account for $83 \%$ of the soybean, $29 \%$ of the production of cotton, and $24 \%$ of the canola grown worldwide ${ }^{194}$.

This geographic expansion of GM seeds varies from region to region. Although worldwide the cultivation of genetically modified plants has increased " 100 -fold in the last 17 years", the total area of cultivation of GM plants in Europe was "a mere 129000 hectares in 2012) ${ }^{195}$. One also needs to take into account that commercial seeds (GM or conventional) do not form the only two categories of seed used in agriculture, but that one should also account for "farmers' seed systems" which "result from the breeding efforts of farmers in their fields to obtain seeds that they expect to be better suited to their soil, practices and needs" that still constitute "a substantial part of the seeds sown in less-developed countries" and "farm-saved seeds, which "are sown and harvested from conventional seeds purchased in the previous year", only a small fraction of these being sown "the next season after sorting and cleaning"196. To our knowledge, their value is not accounted for in the previous statistics, which, in any case as Sylvie Bonny notes is underestimated, "given the extent of partial or biased analyses, as well as a lack of data on certain aspects", economic data being "heterogeneous and sometimes "nonconcordant"197.

A variety of techniques are available for genetic transformation of plant cells or animals, the most common, for plants, being the transformation by a gene vector of the soil bacterium Agrobacterium tumefaciens, other techniques being the particle bombardment method (biolistics) or gene gun, microinjenction, polyethylene Glycol and electroporationbased propoplast transformation, laser microbeams, vaccum infiltrationultrasoundm electrophoresis and agrolistic transformation ${ }^{198}$.

Biotechnology engineering may also genetically alter animals. The first transgenic livestock was reported in 1985. The most typical methods include microinjenction, which has been used for more than 20 years, and which is currently replaced by more efficient protocols based on somatic cell nuclear transfer (SCNT) ${ }^{199}$. Dolly was the first mammal cloned from an adult body cell, using the process of somatic cell nuclear transfer (traditional cloning), where researchers remove the genetic material from an egg and replace it with the nucleus of some other body cell, this becoming a factory to produce an embryo that develops into an offspring.

193 S. Bonny, Corporate Concentration and Technological Change in the Global Seed Industry, (2017) 9 Sustainability 1632, Table 1, referring to a study by Philips McDougall, bringing the total of the global seed market to $\$ 35$ billion, although she also notes that these figures account for approximately only three quarters of global commercial seed sales, the global market of seeds purchased being evaluated to around $\$ 48.5$ billion.

${ }^{194}$ European Commission, Explanatory Note, New Techniques in Agricultural Biotechnology (2017), 51 (citing a study by J. Clive, Executive Summary: Global Status of Commercialized Biotech/GM Crops: 2014 - ISAA Brief 51-2015.

${ }^{195}$ F. Hartung \& J. Schiemann, Precise plant breeding using new genome editing techniques: opportunities, safety and regulation in the EU, (2014) 78 Plant Journal 742-752, 743 (citing research by the International Service for the Acquisition of Agri-biotech Applications).

${ }^{196}$ Bonny (2017), Section 2.2.1.

${ }^{197}$ Bonny (2017), Section 1.

198 P. Enriquez, CRISPR GMOs, (2017) 18(4) North Carolina Journal of Law \& Technology 432, 465-472; European Commission, Explanatory Note, New Techniques in Agricultural Biotechnology (2017), 49-51.

${ }^{199}$ European Commission, Explanatory Note, New Techniques in Agricultural Biotechnology (2017), 52. 
These methods aim to increase fecundity, for instance by genetically engineering chicken that will only produce female offspring for egg-laying, or cattle which better converts feed to muscle. However, to date, "the only example of a GM animal being approved for direct human consumption is the AquaAdvatage salmon, which was approved by the US FDA in late 2015, almost 20 years after the initial application", and following an extensive review ${ }^{200}$. In contrast, there are no GM animals or derived products on the EU market, nor have there been any applications for GM animals in the EU. In microorganisms, a large variety of end products result from genetic engineering, producing DNA constructs and transferring them into another microorganism, using methods such as electroporation, introduction via conjugation or transduction $^{201}$.

GM seeds are at the centre of the innovative effort in modern agriculture, the plant science industry being one of the world's most R\&D intensive industries. The plant biotechnology R\&D industry consists of a handful of large firms (around 8-9 global firms, four of which are particularly strong competitors), a varying number of smaller firms (around 7500 of different sizes from around the world producing conventional seeds) ${ }^{202}$, and public-sector research organizations such as land-grant universities. The degree of consolidation of this industry is remarkable if one takes into account that in the early 1980s there were more than two hundred different seed and trait companies and that many agricultural chemical companies included units in both seeds and agricultural chemicals. The process of consolidation has been described as following:

"At first, pharmaceutical and chemical companies sold off their bulk chemicals businesses and bought up or merged with other pesticide and pharmaceutical companies. The major life-sciences companies each purchased smaller biotechnology companies that had promising new genes and seed companies that owned efficient seed distribution networks and/or traditional varieties into which novel genes could be inserted" 203 .

This concentration is not only limited in seeds. It is also reported that the 10 biggest pesticide firms now control $90 \%$ of the global pesticide market, that 10 companies control $76 \%$ of the animal pharmaceutical sales, 10 animal feed firms control 52\% of the global animal market $^{204}$. A lot of these companies control IPRs. In the seed business IPRs consist of patents, plant variety rights and trade secrets. In view of the possibilities of replication through reverse engineering trade secrets are not the most optimal way to protect products sold on the open market.

GM seeds and crops also led to various ethical and environment-focused concerns, vocally expressed by civil society, and which led to the establishment of strict regulatory regimes and standards specifically focusing biotechnology and genetic engineering, eventually also the prohibition of GMOs in a number of jurisdictions.

\footnotetext{
${ }^{200}$ Nuffield Council on Bioethics, Genome Editing: An Ethical Review (September 2016), 63.

${ }^{201}$ European Commission, Explanatory Note, New Techniques in Agricultural Biotechnology (2017), 54.

202 Bonny (2017), 2.2.1.

${ }^{203}$ Carl Pray, James Ohmhke \& Anwar Naseem, Innovation and Dynamic Efficiency in Plant Biotechnology: An Introduction to the Researchable Issues, (2005) 8(2\&3) AgBioForum 52, 59.

204 ETC, Who will Control the Green Economy? (November 2011), available at http://www.etcgroup.org/sites/www.etcgroup.org/files/publication/pdf_file/ETC_wwctge_4web_Dec2011.pdf
} 
In the EU, a key distinction is made between genetically modified organisms (GMOs), where alteration was made "in a way that does not occur naturally by mating and/or natural recombination" and requiring the use of a listed to Annex I A, part 1 of Directive 2001/18/EC ${ }^{205}$, and food that does not fall within this classification and has not been subject to genetic alteration. Although non-GM food and feed is subject to the General Food Law Regulation which provides general safety standards and is regulated by the European Food Safety Authority ${ }^{206}$, GM food and feed is subject to specific regulation in relation to containment and environmental risks ${ }^{207}$. According to Directive 2001/18/EC, a "Genetically Modified Organism (GMO) means an organism, with the exception of human beings, in which the genetic material has been altered in a way that does not occur naturally by mating and/or natural recombination" ${ }^{208}$. The current approval process for GM plants is time-consuming (around 4-6 years) and expensive (around €7-15 million), and does not ensure EU-wide distribution of the approved plant/seed, as the safeguard clause enables Member States to reject already approved GMOs in case of new scientific information about adverse effects.

A different regulatory approach is followed in the US, where a "Coordinated Framework for the Regulation of Biotechnology" was put in place in $1986^{209}$, assigning broad federal jurisdiction over biotechnology products to three federal agencies: the US Department of Agriculture (USDA), the Food and Drug Administration (FDA), and the Environmental Protection Agency (EPA). Each of these agencies derives its power to regulate from different legislative frameworks: the USDA relies on the Plant Protection $\mathrm{Act}^{210}$, the FDA relies on the Federal Food, Drug, and Cosmetic Act, and in particular its provisions on food adulteration and food additives ${ }^{211}$, and the EPA mainly on the Federal Insecticide, Fungicide, and Rodenticide $\mathrm{Act}^{212}$. Their approach for the regulation of GMOs is products-based, rather than process-based, as it in the EU, as regulation focuses on the nature of the products, their

\footnotetext{
205 Art. 2(2) Directive 2001/18/EC of the European Parliament and of the Council of 12 March 2001 on the deliberate release into the environment of genetically modified organisms, [2001] OJ L 106/1.

${ }^{206}$ Regulation (EC) No 178/2002 laying down the general principles and requirements of food law, establishing the European Food Safety Authority and laying down procedures in matters of food safety, [2002] OJ L31/1.

${ }^{207}$ Directive 2001/18/EC of the European Parliament and of the Council of 12 March 2001 on the deliberate release into the environment of genetically modified organisms, [2001] OJ L 106/1, amended by Directive (EU) 2015/412 as regards the possibility for the Member States to restrict or prohibit the cultivation of GMOs in their territory, [2015] OJ L 68/1; and Regulation (EC) No 1946/2003 on transboundary movements of genetically modified organisms, [2003] OJ L 287/1; Regulation (EC) 1829/2003 on genetically modified food and feed, [2003] OJ L 268/1; Regulation (EC) 1830/2003 concerning the traceability and labelling of genetically modified organisms and the traceability of food and feed products produced from genetically modified organisms, [2003] OJ L 268/24. On EU Food law, see A. Alemanno \& S. Gabbi (eds.), Foundations of EU Food Law and Policy (Routledge, 2016); B. Jack, Agriculture and EU Environmental Law (Routledge, 2009, paperback ed., 2016 ); M. Lee, EU Regulation of GMOs - Law and Decision Making for a New Technology (Edward Elgar, 2008. 208 Art. 2(2) Directive 2001/18/EC.

209 Coordinated Framework, 51 Fed. Reg. 23,302 (June 26, 1986), available at https://www.aphis.usda.gov/brs/fedregister/coordinated_framework.pdf .

2107 U.S.C. $\$ \S 7701-86(2012)$.

21121 U.S.C. $\$ 402$ (food adulteration) and $\S 409$ (food additives). Under the FFDCA, substances added to food can be classified either as "food additives," which require approval from the FDA that they are safe before they can be marketed, and substances added to food classified as "generally recognized as safe" (GRAS), as to which preapproval is not needed.

2127 U.S.C. $\S \S 136-136 y$ (2012).
} 
characteristics and intended use, rather than the process in which they are produced ${ }^{213}$. An important scientific and social debate is currently ongoing with regard to the regulation of GMOs, in view of some recently published research ${ }^{214}$, but of course the issue of GMO regulation is broader than just addressing environmental and safety concerns, and relates to the wider economy and governance of agriculture and the control of food production systems. Contrary to the EU regulation of GMOs, the US one does not require the labelling of GM food.

Most recently, "gene-editing" techniques have enabled targeted interventions at the molecular level of DNA or RNA function, thus making it possible to shear DNA with tremendous precision. These New Breeding Techniques (NBT) followed earlier generation genetic engineering techniques that most often involved the transfer of cloned genes from one organism to another in order to produce a transgenic organism. The aim was to use genetic engineering so as to give rise to a phenotype that may be radically novel in the engineered strain and reproduce this effect in populations. This research came out of dissatisfaction with recombinant DNA technologies that were quite time-consuming, expensive, highly inefficient at times and that required a special skill-set and important investments in specialised personnel and laboratories. NBTs were enabled by advances in genome sequencing and DNA assembly, following important progress in various fields, such as molecular biology, bioinformatics and data technologies ${ }^{215}$.

These NBTs made it possible to introduce changes to the genome without introducing genes or sequences from another species. Oligonucleotide Directed Mutagenesis (ODM) is a gene-editing technique, where short DNA (or DNA-RNA) fragments (oligonucleotides) are introduced into cells so as to trigger the cell to modify its own DNA to match the introduced DNA fragments. Alternative gene targeting technologies emerged with genome modification becoming possible via the development of site-directed nucleases (SDN), that operate as molecular scissors. These took first the form of zinc finger nucleases (ZFN) first used in 2005 and the transcription activator-like effector nucleases (TALENs), first used in 2010. They consist in proteins which are engineered to both recognise specific DNA sequences and to cut DNA in the region of such sequences. They require some considerable effort to produce a pair of proteins for every editing procedure. The clustered regularly interspaced short palindromic repeat (CRISPR/Cas) system, was discovered in 2012. CRISPR is an adaptive immune system that uses complementary single-guide RNA (sgRNA) to recognize and cleave select foreign DNA, neutralising the ability of a pathogen to wreak havoc in the host ${ }^{216}$. It comprises two elements: a clustered regularly interspaced short palindromic repeat (CRISPR) RNA and the

\footnotetext{
213 See, M.T. Roberts, Food Law in the United States (Cambridge University Press, 2016); Chris A. Wozniak, Alan McHughen (eds.), Regulation of Agricultural Biotechnology: The United States and Canada (Springer, 2012).

${ }^{214}$ See, National Academy of Science and Engineering, and Medicine, Genetically Engineered Crops: Experiences and Prospects (2016); European Commission, A Decade of EU-Funded GMO Research (2001-2010) (European Union, 2010), available at https://ec.europa.eu/research/biosociety/pdf/a_decade_of_eufunded_gmo_research.pdf ; European Academies Science Advisory Council, Planting the future: opportunities and challenges for using crop genetic improvement technologies for sustainable agriculture (EASAC Policy Report 21, June 2013), available at http://www.easac.eu/fileadmin/Reports/Planting_the_Future/EASAC_Planting_the_Future_FULL_REPORT.pd f.

${ }^{215}$ Nuffield Council on Bioethics, Genome Editing: An Ethical Review (September 2016), 57.

${ }^{216}$ P. Enriquez, CRISPR GMOs, (2017) 18(4) North Carolina Journal of Law \& Technology 432, 509
} 
CRISPR-associated protein 9 (Cas 9), which is an endonuclease. CRISPR-Cas9 and other geneediting technologies, such as the "more precise" CRISPR-Cpf1, allow scientists to manipulate the genetic makeup of an organism by de-activating or knocking out a gene function, eventually without the need to introduce genes from other organisms, as this is the case for classical GMO genetic engineering.

Compared to the previous technologies of genetic editing, CRISPR is much more efficient ("in terms of successes per attempt"), and cheaper as "the components are trivial to produce", they can be "synthesized with commercially available kits" and the "system functions with a universal Cas9 protein framework that dispenses with the need to design a different protein for each DNA target" ${ }^{217}$. New Breeding Techniques, such as CRISPR, which enable the production of a specific and targeted mutation, "avoid the need to screen hundreds of thousands of crosses [...] to identify those with the desired traits", thus significantly reducing "the time and numbers of plants involved in achieving a desired mutation that might otherwise be sought by using methods of random mutation and selection" 218 . To the difference of conventional breeding techniques, gene editing makes it possible to reduce the time needed to generate the desired genetic characteristics in a plant population from 7-25 years to as few as 2-3 years as well as to bypass "the need to go through a number of plant generations to achieve a particular genetic combination" 219 . By allowing multiple editing simultaneously in various parts of DNA able to inactivate up to tens of targets at once ${ }^{220}$, CRISPR also allow much faster products development. This complies with the finding of a recent study published by the US National Academy of Sciences that with the CRISPR breakthrough "the scope, scale, complexity, and tempo of biotechnology products are increasing"221.

Another advantage of using CRISPR editing techniques consists in the recent USDA regulation suggesting that CRISPR modified seeds may not need regulatory approval as GMOs, since in some cases gene manipulations may involve only deletions or modifications with existing $\mathrm{DNA}^{222}$. The competitive advantage of such genome-editing technologies, should these not be subject to the existing restrictions of conventional GMO regulation, in comparison to conventional breeding methods, may significantly alter the market structure and industry dynamics. Of course, the way GMOs are defined for regulatory purposes is different in Europe, which raises the question whether these New Breeding Technologies, such as OFT and CIRPR, could fall within the scope of the existing EU Regulations on GMOs ${ }^{223}$.

\footnotetext{
${ }^{217}$ Nuffield Council on Bioethics, Genome Editing: An Ethical Review (September 2016), 9.

218 Ibid., 58.

${ }^{219}$ See, Nuffield Council on Bioethics, Genome Editing: An Ethical Review (September 2016), 56-62.

${ }^{220} \mathrm{~L}$. Yang et al. Genome-wide inactivation of porcine endogenous retroviruses (PERVs) //Science. -2015 . - T. 350. - №. 6264. - C. 1101-1104.

${ }^{221}$ National Academy of Sciences, Engineering, and Medicine. Preparing for Future Products of Biotechnology. Washington, DC: The National Academies Press. doi: 10.17226/24605. 2017, p. 53

${ }^{222}$ See, for instance, the recent controversy over the anti-browning mushroom developed by plant pathologist Yinong Yang at Pennsylvania State University using CRISPR-Cas9, which was not considered by the USDA as integrating any introduced genetic material and thus not regulated as a GMO (see https://www.aphis.usda.gov/biotechnology/downloads/reg_loi/15-321-01_air_response_signed.pdf ).

223 See European Parliament, Briefing, New plant-breeding techniques (May 2016), http://www.europarl.europa.eu/RegData/etudes/BRIE/2016/582018/EPRS_BRI(2016)582018_EN.pdf and the expected intervention of the Court of Justice of the EU in pending Case C-528/16 (judgment expected in 2018)
} 
Genome editing techniques, such as CRISPR, may be used in plant breeding in order to enhance pesticide resistance (e.g. bacterial-blight resistant rice), induce draught tolerance and improve yield or nutritional benefit and appearance ${ }^{224}$. Application of CRISPR technologies for biofuels with the development of plant-based industrial bioproducts may also decrease dependence on oil-based products ${ }^{225}$. In animal genetics, gene-editing technologies "made possible research that had been previously unfeasible" 226 , as the technology may apply to animals having long reproduction cycle and CRISPR/Cas9 doesn't require knowing the entire genetic blueprint of the organism, as it is the case with more "traditional" biotechnology methods.

The impact of these revolutionary technologies on food production is still a matter of speculation. However, the technology trend makes it plausible that the most valuable productive asset in agricultural production will not anymore be the control of genetic material (e.g. seeds) but the control of genetic information (e.g. DNA sequences), the next generation biotech leading to revolutionary changes in bioengineering tools, enabling the systematic design of phenotypes by manipulation of genotypes. The economic actor that will control this strategically essential abstract information, for instance through Intellectual Property (IP) Rights, may finish by controlling physical living DNA designs. This may engender profound structural changes in the industry, as gene-editing technologies may be cheaper and less regulated to develop, therefore leading to lower endogenous sunk costs, which provide more opportunities for new entry in the seeds/traits/animal genetics markets. Indeed, as a recent Nuffield Council on Bioethics report recognizes, "the potential of genome editing techniques (in terms of decreased cost and technical difficulty, and increased speed) may revive the opportunities for small and medium-sized biotech companies in the agricultural area and unlock development of a wider variety of traits" ${ }^{227}$. These developments may be blocked either by regulatory burdens similar to those imposed to GMOs, or by the business strategies of incumbent agro-chem corporations that may try to establish one-shop platforms, combining traits, seeds, pesticides and smart agriculture or digital products in order to erase barriers to the independent entry of small and medium-sized start-ups in the various segments of the value chain, licensing or a merging with the agro-chem behemoths being the only options on the table. One needs therefore to look closer to the development of digital revolution in agriculture.

\subsection{Digital revolution in food production and the convergence of genetics and digital technologies: the emergence of FoodTech}

Collaboration is at the forefront of the next Green Revolution. With the Internet comes the creation of a new scale of interconnectedness that serves to link networks in more intricate and efficient ways than ever before witnesseed in history. The global agricultural value chain

\footnotetext{
${ }^{224}$ Nuffield Council on Bioethics, Genome Editing: An Ethical Review (September 2016), 61.

${ }^{225}$ Ibid., 61.

${ }^{226}$ Ibid, 62.

227 Ibid., 62.
} 
can be transformed into an ecosystem of closely tied players as the IoT increases ${ }^{228}$. In particular, this could entail "farmers, food manufactureres, distributors, retailers, technology companies, the public sector, and NGOs working together to alleviate the bottlenecks to information flow as they arise" 229 . Digital techniques will place the quantity and quality of agricultural output, cost savings, less input utilization as the aim of its intention ${ }^{230}$. Precision agriculture and its ability to use technologies to produce more with less will benefit large farms the most, resulting in farm size increases due to the large investments needed for these technological implementations.

Farmers are often required to secure lending in order to fund the high input costs derived from Fertilisers, seeds, and volitbale export sales. The 2016 growing season in the United States, for example, saw corn prices halved ${ }^{231}$ and the USDA reported net farm income was down 55 percent in the past year ${ }^{232}$. From an economic incentives standpoint, this presents a worrying landscape. Consequently, the next Green Revolution could mean small farms face a lack of economic incentives and financial challenges due to the «thin profit margins and relatively long payback periods» for those in the agricultural sector ${ }^{233}$. Whie offering numerous benefits, the emergence of FoodTech requires a more skilled workforce of farmers, but could also decrease the number of jobs on farms because of greater use of these technologies ${ }^{234}$.

As farmers begin to implement these technologies, the vast amount of data that will be generated through the use of smart sensors and connected farm equipment will raise questions of ownership and control of these agronomic and equipment insights ${ }^{235}$. Consequently, policy makers and businesses must answer what data management, data ownership, and access to open data should look like throughout the food value chain in terms of standards for exchange, exploitation, and abuse. Experts convey that "making farmers the owners of their data and providing opportunities to control the flow of their data to stakeholders should help build trust with farmers for exchanging data" to encourage an egalitarian approach to big data analysis ${ }^{236}$. Others reinforce the argument that information is thus the revolutionary aspect of the Green Revolution and not genetic tinkering or new plant breeds ${ }^{237}$.

\footnotetext{
${ }^{228}$ W. Sarni, J. Mariani \& J. Kaji, From dirt to data: The second green revolution and the Internet of Things, (2016) Deloitte Review Issue 18, available at https://dupress.deloitte.com/dup-us-en/deloitte-review/issue18/second-green-revolution-and-internet-of-things.html .

229 Ibid.

${ }^{230}$ European Parliament, Precision Agriculture and the Future of Farming in Europe, IP/G/STOA/FWC/20131/Lot 7/SC5 (December 2016), available at http://www.europarl.europa.eu/RegData/etudes/STUD/2016/581892/EPRS_STU(2016)581892_EN.pdf .

${ }^{231}$ Wall Street Journal 2016. Available at: https://www.wsj.com/articles/corn-sinks-following-usda-report1459442761

${ }^{232}$ See Reuters https://www.reuters.com/article/us-usa-agriculture-bankruptcy/fearing-wave-of-bankruptcies-u-scorn-belt-wants-new-debt-cap-idUSKCNOUU003

${ }^{233}$ See W. Sarni, J. Mariani \& J. Kaji, From dirt to data: The second green revolution and the Internet of Things, (2016) Deloitte Review Issue 18.

${ }^{234}$ See European Parliament, Precision Agriculture and the Future of Farming in Europe, IP/G/STOA/FWC/20131/Lot 7/SC5 (December 2016), available at http://www.europarl.europa.eu/RegData/etudes/STUD/2016/581892/EPRS_STU(2016)581892_EN.pdf .

${ }^{235}$ See Tech Crunch 2016, Available at: https://techcrunch.com/2016/07/06/the-land-grab-for-farm-data/

${ }^{236}$ European Parliament, Precision Agriculture and the Future of Farming in Europe, IP/G/STOA/FWC/20131/Lot 7/SC5 (December 2016).

237 Harvard (2017), available at https://news.harvard.edu/gazette/story/2017/04/the-future-of-food-will-beproactive-efficient-and-digitized-or-else/
} 
The hope is that with increased insights, decision making will become simpler, more intelligent, and more focused by fusing instinct with technology. In particular, argricultural giants like Bayer aim to supply the tools needed for "improved decision making". Other key actors such as Monsanto intend to build a "network of in-field sensors to expand the scope of soil, weather and other data flwoing in its digitial agriculture tools" which could combine open source software development to enable relevant application creation ${ }^{238}$. Overall, it would appear that the future is geared towards these Amazon-styled eco system models for agricultural products.

Additional pushes for the adoption of FoodTech are that the modern farmer deserves less time consuming ways to inspect crops that conventional methods and should have access to the prosperity produced by digital agricultural services ${ }^{239}$. Furthermore, precision agriculture will use machine learning to detect biotic stress for effective crop protection. For example, the use of non-invasive high resolution sensors can provide information that is calculated in linear and nonlinear models and used to successfully detect plant disease and weeds very early on ${ }^{240}$. Delving even deeper into the components of FoodTech reveals that products and applications for food production, processing, preservation packaging and all aspects of the food value chain will experience new opportunties for innovation. Technology can turn farms into lab-like settings, to more efficiently approach high-value but thirsty crops such as almonds, pistachios and grapes through smart farming ${ }^{241}$.

Fueling the framing of the digital revolution in agriculture is to define farmers as businessmen who urgently need the capacity to make rapid decisions with customizable options they cannot do with their own instinct: like choosing the right crop variety and "applying exactly the right fertiliser dose"242. Emerging markets involve small holder farmers still entrenched by antiquated farming practices, overusing macro Fertilisers or missing preventable pest infestations ${ }^{243}$. Not without moral and ethical questions, the digital revolution in agriculture means acknowledging that these 500 million smallholder farms will likely depend on the social responsibility of corporations and governments in their transition towards the IoT adoption and sensor dispersal ${ }^{244}$.

This further exemplifies the need for a skilled workforce capable of utilizing the technology to effectively reap its benefits. Of course, it is the younger generations who must re-engage with rural areas to better understand how food is produced and inspire innovation

\footnotetext{
238 Reuters (2016) https://www.reuters.com/article/us-monsanto-farming-data/monsantos-climate-corp-toexpand-digital-farming-platform-idUSKCN10S1Q4 .

239 Accenture Digital Agriculture: Improving Profitability, available at https://www.accenture.com/_acnmedia/Accenture/Conversion-

Assets/DotCom/Documents/Global/PDF/Digital_3/Accenture-Digital-Agriculture-Point-of-View.pdf .

240 J. Behmann, T. Mahlein, et al, A review of advanced machine learning methods for the detection of biotic stress in precision crop protection. (2015) 16(3) Precision Agriculture 239-260.

241 The Economist 2016, Technology Quarterly. Available at: http://www.economist.com/technologyquarterly/2016-06-09/factory-fresh

${ }^{242}$ Bayer Scientific Magazine. Available at https://www.research.bayer.com/en/digital-farming.aspx https://www.research.bayer.com/en/digital-farming.aspx

${ }^{243}$ Accenture Digital Agriculture: Improving Profitability.

${ }^{244}$ W. Sarni, J. Mariani \& J. Kaji, From dirt to data: The second green revolution and the Internet of Things, (2016) Deloitte Review Issue 18.
} 
and improved food security ${ }^{245}$. Ultimately, consumers can drive the demand for change in the industry by engaging with the connectedness the IoT provides to encourage more locally sourced food access or more sustainable shipping routes through improved mapping technology. This need of global food value chains to track and trace, starting from the farm level, leads to communication improvements for consumers about the origin, production, processes and carbon footprints. Consumers should be able to trust the agri-food sector founded "upon greater transparency and traceability along the whole value chain" 246.

\subsection{The emergence of new consumer trends and technologies: fair trade, organic food, $e$ and m-commerce}

Although the digital revolution with e and $\mathrm{m}$-commerce have introduced major changes in the distribution of products, less than $1 \%$ of food and beverage sales currently occur online ${ }^{247}$. This slow introduction of e and m-commerce in food retail is due to factors such as costs, the complexity of logistics, shipping fees, the quality and freshness of the products; Yet, it is estimated that between 2013 and 2018, online grocery sales will grow at a compound annual growth rate (CAGR) of $21.1 \%$, reaching nearly $\$ 18$ billion by the end of the forecast period in the US, while in comparison, offline grocery sales will rise by $3.1 \%$ annually during the same period $^{248}$. The market has seen the emergence of new intermediaries, such as online grocery delivery services, concierge shopping and subscription prepared meals start-ups offering services that really are differentiated from traditional supermarket shopping and do not necessarily require home delivery of food items but enable also offer "click and collect" services. Organic food constitutes one of the most fast-growing areas of e-commerce in both developed and developing economies ${ }^{249}$. Omnichannel retailing, that is, the use of all physical channels (offline) and digital channels (online) offering a seamless, customer-centered experience may be the new frontier in food retail. Although supermarkets and big brick and mortar stores have been attempting to integrate digital commerce in their model, this is still at its infancy. Public policy makers have been increasingly looking closely to e-commerce. In particular in the EU, following the recent adoption of the Digital Single Market Strategy, the Commission announced an e-commerce sector inquiry in order to address contractual restrictions in distribution agreements that prevent retailers from selling goods or services purchased online or cross-border to customers located in another EU country. Although the

\footnotetext{
${ }^{245}$ European Parliament, Precision Agriculture and the Future of Farming in Europe, IP/G/STOA/FWC/20131/Lot 7/SC5 (December 2016).

${ }^{246}$ European Commission, Digitising the Agri-food Sector: a research agenda for Horizon 2020 (European Commission - Directorate General for Agriculture and Rural Development November 2016).

${ }^{247} \mathrm{See}, \mathrm{http}: / / \mathrm{www} \cdot$ businessinsider.com/e-commerce-disrupting-huge-grocery-market-2014-12

${ }^{248} \mathrm{See}$, http://www.businessinsider.com/e-commerce-disrupting-huge-grocery-market-2014-12, citing a report by BI Intelligence.

${ }^{249}$ See, for instance, Organic Shop, India's largest online organic marketplace of organic products. It was also reported that an implication of the consumers' increasing preference for organic food, "[...] the amount of organically cultivated land in the $27 \mathrm{EU}$ member countries grew by 6 percent per year from 2002 through 2011, when the total organic planted area represented 5.4 percent of total agricultural land": Boston Consulting Group, Crop Farming 2030 - The Reinvention of the Sector (April 2015), available at https://www.bcgperspectives.com/content/articles/process-industries-innovation-crop-farming-2030reinvention-sector/, p. 6.
} 
food sector and more generally perishable products may not be the primary focus of such inquiry, the boost to intra-EU e-commerce that may result from such sector inquiry may also benefit this sector.

The Digital revolution is also revolutionizing the food industry through a more systematic use of Bog Data. The Industry may take advantage of the same big data services as financial firms and marketing departments to better understand their consumer, increase efficiency and create new products ${ }^{250}$. Companies believe that big data may create a more customized, customer-centric experience, where specific customer profiles may be collected and used in order to enhance more relevant marketing efforts. It was reported that Starbacks which has 13 million mobile payment app users representing $16 \%$ of total transactions, uses this data to track what individual customers like, or what makes someone different from other customers $^{251}$. Several supermarkets may use data from their loyalty cardholders to personalize the shopping experience and target rewards and new promotions. Data aggregation technology may also be used in farming. It was reported that Monsanto bought several farm data analytics companies between May 2012 and February 2014:

"Monsanto acquired Precision Planting, a maker of hardware and software that assists farmers with seed space, depth, and root systems in fields, in early 2012. In October 2013, the company bought Climate Corporation, a weather data analysis startup in San Francisco, for almost a billion dollars. Then, in February 2014, Climate Corporation bought Solum, a soil testing service based in San Francisco. Monsanto's primary software product, Filed Scripts, works with all of these systems to determine soil productivity and yield" 252 .

Monsanto's acquisition of Climate Corp. shows the potential applications that big data may have in agri-business. Climate Corp. offers insurance against weather-related incidents which goes beyond what has traditionally been the federal crop insurance in the U.S. which protects farmers against the costs of their inputs - fertiliser, seed - during hard times but does not do more than just assist them in breaking even on these costs. Climate Corp. offers insurance covering the profit. Using weather data to measure temperature and rainfall and other factors it guarantees to a farmer that bought a policy that covered drought and his land didn't receive the specified amount of rain covered by the policy, that he will be paid out automatically by Climate Corp. (for his lost profit) based on the measurements ${ }^{253}$. The era of "Smart" or "Precision agriculture" has begun.

$\mathrm{Ag}$ analytics and technology-aided farming aim to develop new sensors to monitor and make farms more efficient or better manage resources and constitute a dynamic emergent market, with the involvement of agri-tech start-ups and larger agricultural corporations ${ }^{254}$. Cheap sensors constantly monitor the moisture and nutrients in soil, while satellite images may assist farmers to measure the yields of crops. Big data may also become important in order to establish global networks of information-sharing among players in supply chains which can

\footnotetext{
${ }^{250}$ See, http://www.wired.com/2014/02/big-data-revolutionizing-food-industry/ .

${ }^{251}$ See, http://www.wired.com/2014/02/big-data-revolutionizing-food-industry/

${ }^{252} \mathrm{See}$, http://www.techrepublic.com/article/how-big-data-is-going-to-help-feed-9-billion-people-by-2050/

${ }^{253}$ See http://www.bloomberg.com/bw/articles/2013-10-02/monsanto-buys-climate-corporation-for-930-millionbringing-big-data-to-the-farm .

${ }^{254}$ See http://www.greenbiz.com/article/can-ex-googler-use-big-data-help-farmers-grow-more-food
} 
result in significant cost reductions, reliability and sustainability benefits and ultimately guarantee the security of food supplies at a time when climate change may lead to situations of food scarcity and disruption ${ }^{255}$. Further applications may include the use of data on food purchases, along other social activities in order to identify health risks, which although controversial has already occurred ${ }^{256}$. These technologies will change the way farming operates and the need for labour in this sector. As it was noted in a recent report,

"(i)nstead of sitting on equipment outdoors, (the farmer) and a handful of associates operate all the equipment for a farm covering thousands of hectares from a control room. GPS-guided autonomous drones constantly provide the data required for the algorithms, and other GPS-guided equipment works the fields with precision, sometimes even at the level of the individual plant. The crops have been genetically engineered to resist most fungi, viruses and insects and are highly efficient in their uptake and use of nutrients. As a result, the farm needs less fertiliser, water, and crop protection than it did in the past" 257 .

Finally, an important societal development is the emergence and increasing popularity of organic food and fair trade, in particular in Europe. Both constitute strategies of quality product differentiation that occur not only at the food processing level, but also at the retail level with specific retailers specializing in the distribution of organic and fair trade products. Contrary to traditional product differentiation relying on branding and advertising for specific products, these constitute generic categories of product differentiation and labelling, based on perceived attributes of particular types of products, in particular relating to the inputs used and the process of their production (e.g. natural, recyclable, eco-friendly, low energy, recycled content, non-toxic etc.). This market for quality-product differentiation is regulated by private or government run certification process. Such public and private certification systems may raise similar competition concerns to technology standard-setting ${ }^{258}$.

Market definition may also be quite challenging in this context of generic categories product differentiation. In Federal Trade Commission v. Whole Foods Inc., the court of appeal reversed the decision of the district court, which had rejected the demand for a restraining order and preliminary injunction brought by the FTC in order to block a merger between two premium, natural and organic (PNO) supermarkets ${ }^{259}$. The government's case was based on the theory of unilateral effects, advancing that the merger will create a monopoly in eighteen cities where the two merging companies were the only PNO supermarkets. This contention was based on internal business documents that demonstrated the closeness of competition between

\footnotetext{
255 See, http://www.theguardian.com/sustainable-business/2015/jun/16/big-data-sensors-satellites-map-risksfood-supply-chain

${ }^{256}$ It was reported that Aviva ran a trial with 60,000 individuals in the US in 2010, showing that online data detailing food purchases and social activities could be as effective in identifying potential health risks as blood and urine tests: Boston Consulting Group, The Value of our Digital Identity (November 2012), available at http://www.libertyglobal.com/PDF/public-policy/The-Value-of-Our-Digital-Identity.pdf

${ }^{257}$ Boston Consulting Group, Crop Farming 2030 - The Reinvention of the Sector (April 2015), available at https://www.bcgperspectives.com/content/articles/process-industries-innovation-crop-farming-2030reinvention-sector/, p. 3.

${ }^{258}$ P. Karolyczk, Product Certification - the next big standard-setting debate? (March 14, 2013), available at http://kluwercompetitionlawblog.com/2013/03/14/product-certification-the-next-big-standard-setting-debate/ ${ }^{259}$ Federal Trade Commission v. Whole Foods Inc., 548 F.3d 1028 (2008).
} 
the two merging companies and direct evidence (based on diversion ratios) showing that entry by other PNO supermarkets had greater impact on PNOs prices than entry by conventional supermarkets. The district court rejected these arguments, as they focused on the effect of the merger to consumers that were buying only organic food. The district court chose instead a market definition that considered important the role of marginal consumers, thus including conventional supermarkets in the same relevant market as the PNO supermarkets: "because so many people are cross-shopping for natural and organic foods and are marginal rather than core customers, the actual loss from a SSNIP would exceed the critical loss", that is, it will be unprofitable. The court of appeal agreed with the district court on the need to define a relevant market but it also emphasized that core consumers, demanding exclusively a particular product or package of products, are in some situations "worthy of antitrust protection5", therefore leading to the definition of a distinct submarket of PNO supermarkets. The Court found that these consumers "may be captive to the sole supplier, which can then, by means of price discrimination, extract monopoly profits from then while competing for the business of marginal consumers" 260 .

\subsection{The financialisation of agriculture}

The process of financialisation of the global economy has been described as a recurrent trend affecting a number of markets ${ }^{261}$. Following up the transformation of corporate control since the 1970s with the development of the multiproduct firm, in which managers sought to spread risks across various product lines in order to achieve greater profitability and to grow through mergers financed by leveraged buyouts, private equity investing financed by junk bonds and other innovative financial techniques, the level of corporate (but also household) debt has considerably increased. The financialisation of the modern corporation has been a marking feature of this evolution, with the prevalence of the shareholder value principle, the focus on short-term share price, leveraging through debt and various hybrid financial instruments as well as the important role of institutional investors, in particular financial institutions but also sovereign wealth funds.

The financialisation of agricultural commodities trade is an episode of this ongoing expansion of financialisation of agricultural markets. Financial speculation on agricultural commodities has been facilitated by the creation of new financial devices with the aim to establish private insurance markets through forward trading that would substitute for existing public price-control mechanisms set in order to protect farmers from market price fluctuations. For instance, The Food Corporation of India is a public body, established in 1964, with the aim

\footnotetext{
${ }^{260}$ Federal Trade Commission v. Whole Foods Inc., 548 F.3d 1028, 1038 (2008).

${ }^{261}$ More generally, see, G.A. Epstein, Financialization and the World Economy, (Northampton, MA: Edward Elgar, 2005); R.J. Shiller, R. J., The New Financial Order. Risk in the 21st Century, (Princeton: Princeton University Press, 2003); Johnna Montgomerie \& Karel Williams, Financialised Capitalism: After the Crisis and beyond Neoliberalism, Competition \& Change (June 2009) 13: 99-107; Ewald Engelen, The Case for Financialization, Competition \& Change (June 2008) 12: 111-119; N. van der Zwan, Making sense of financialization, Socio-econ Rev (2014) 12 (1): 99-129; R. Solow, How to Save American Finance from Itself Has Financialisation gone too far?, New Republic (April 8, 2013), available at http://www.newrepublic.com/article/112679/how-save-american-finance-itself .
} 
to act as a cross between a marketing board, a food bank and a subsidy scheme, intervening with the aim to protect farmers from market prices' volatility, thus acting as a public insurance mechanism ${ }^{262}$. Yet the development of such commodity futures trade triggers through selfreinforcing speculation price fluctuations, thus putting the farmers at the mercy of big market actors, such as one-stop shop solution corporations providing farmers insurance with regard to their yields. As it was explained by Ghosh,

"The declared purpose of forward trading and of futures markets is to allow for hedging against price fluctuations, whereby the selling of futures contracts would exceed the demand for them. This implies that futures prices would be lower than spot prices, or what is known as backwardation. However, throughout much of the period from January 2007 to June 2008, the markets were actually in contango, in which futures prices were higher than spot prices. This cannot reflect the hedging function and must imply the involvement of speculators who are expecting to profit from rising prices"263. An important step in this process of financialisation is the creation of a tradable commodity price index, the first one in the Unites States being the Bureau of Labor Statistics Spot Commodity Index, extablished in the early 1940s, followed in 1991 by the creation of the Goldman Sachs Commodity Index (SP-GSCI), thus enabling investors to bet on commodities, simply buying a swap contract from Goldman Sachs, "without having to participate in formal futures markets with their position limit restrictions"264. The following step in this financial innovation was the creation of the Exhange Traded Funds (ETFs), which enabled institutional and retail investors to add commodities to portfolios, therefore transforming commodities to a new asset class ${ }^{265}$. The financialisation of commodity markets culminated with the passage of the Commodity Futures Modernization Act (CFMA) of 2000, which led to a phenomenal increase of the swaps market. In order to avoid price manipulation, the CFMA required that all agricultural futures be traded on a CFTC-regulated exchange. However, it also allowed for the possibility of an exemption if this "would be consistent with the public interest" 266 . On the understanding that financial investments would not influence spot prices, such exemption was widely interpreted and that led to a "tremendous flow of funds" into commodities ${ }^{267}$. Hence, CFMA led to a deregulation of futures trading for agricultural commodities, financial interests dominating now futures trading and accounting for 70-80 percent of open interest in many markets ${ }^{268}$.Following the 2008 commodity price bubble, the CFTC proposed the establishment of speculative position limits for a number of previously exempted agricultural commodity futures and option contracts, adopting these new posiiton limits rules in October 2011. However, these rules were successfully challenged in court, which interpreted the Dodd-Frank Act, the statutory legal basis for the CFTC action, as requiring the CFTC, when establishing

\footnotetext{
${ }^{262}$ Luigi Russi and Tomaso Ferrando, Capitalism a Nuh' Wi Frien' - the Formatting of Farming into an Asset, from Financial Speculation to International Aid, Catalyst - A Social Justice Forum, Vol. 6, issue 1, 3.

263 Jayati Ghosh, "The Unnatural Coupling: Food and Global Finance" Journal of Agrarian Change (2010) 10 (1): 72-86, 78-79.

${ }^{264}$ T.P. Schmidt, The Political Economy of Food and Finance (Routledge, 2016), 60.

${ }^{265}$ Ibid., 63.

${ }^{266}$ Ibid., 65 .

${ }^{267}$ Ibid.

${ }^{268}$ Ibid.
} 
new position limits, to prove that speculative limits were necessary in order to avoid excessive speculative positions that could lead to higher prices in interstate commerce. CFTC had to propose new limits in 2013.

The intricacies of commodity futures trading are explored in the following article, of which we include extended excerpts.

\section{Luigi Russi and Tomaso Ferrando, Capitalism a Nuh' Wi Frien' - the Formatting of Farming into an Asset, from Financial Speculation to International Aid, Catalyst - A Social Justice Forum, Vol. 6, issue 1 (2015) (excerpts - references and footnotes omitted)}

"[...] The consequences (of commodity futures trading), for farmers, are particularly challenging, and often sufficient to push many off the land. For instance, they might decide to err on the side of caution and sow more from one year to the next, so as to preserve their overall income even in the case of falling prices (by selling more). The sad irony of this strategy is that, as many farmers simultaneously do the same, they can create a glut that depresses prices even further, producing the very conditions they are trying to shelter themselves against. Desperate to secure sales for their crops, farmers will also accept whatever prices will get them an income. In other words, they will be more eager to bend to the dictates of more concentrated brokers and processors further along the food supply chain. In the absence of a public insurance system like the FCI, in fact, those who can-typically farmers more integrated in global commodity chains, leaning towards extensive mechanization and scale of agricultural production-are left with the option of purchasing private insurance. And that private insurance, when it comes to crops, is called a future. Futures are agreements for the sale or purchase of commodities (like many food staples, e.g. grains) at a fixed price, for future delivery. These agreements are in turn exchanged as standardized positions on regulated exchanges, the largest of which are located in the US. Because they are traded on regulated and centralized exchanges, futures prices are considered reliable indicators of the conditions of the markets for the concerned commodities, even by operators who trade those commodities on spot exchanges (i.e. everyone who buys and sells agricultural produce, such as wholesalers), since futures prices are meant to reflect information more complete than would be available on fragmented spot markets. In this sense, even if only a few farmers can directly transact in futures, all farmers are affected by fluctuations in the prices of these instruments.

The fact that futures are exchanged in standardized form means that one does not directly enter into an agreement with a specific party. Instead, buy and sell orders are matched by a clearinghouse. Indeed, one way to think of the functioning of futures markets is to think of them as like the more familiar stock exchange where, however, what is exchanged is not stocks, but rather commodities with a pre-determined delivery date. This means that there are as many different 'prices' as there are available delivery dates to choose from. Like a stock exchange, futures markets can also be subject to endogenous dynamics (i.e. patterns of trading emerging from the combination of motives, institutional arrangements, and the technological and analytical equipment of market participants, rather than from exogenous factors such as the available supply or demand of the goods being traded) that can - under certain conditionsmake their functioning a ticking time-bomb. 
Indeed, economists like Hyman Minsky have, for instance, long suggested that a lot of what happens in a financial market need not necessarily be explained by appealing to fluctuations in supply and demand, understood as external variables that are simply reflected in price dynamics.

Sometimes, instead, markets cause by their own functioning the problems that neoclassically-trained economists subsequently try to pin on fluctuations in demand and supply.

In the case of commodity futures, the beginning of the story lies in the changing structure of commodity futures markets after the approval of the Commodity Futures Modernization Act in the US in the year 2000. A commodity future, as anticipated above, is a contract for the sale or purchase of a standardized commodity (including many food staples) with a future delivery date. The regulated markets for commodity futures basically generate a price for a given maturity date, by matching standardized buy and sell orders. The effect of opening a position on the futures market is not - like on a stock exchange - to acquire ownership of the underlying asset, but simply to freeze the price at the level it stands, for a given future delivery date. This is where the original insurance function stems from, since an open futures position insulates the transaction from the dynamics of the spot (immediate delivery) market because, on maturity, the exchange will be performed at the previously agreed price, not at the spot (current) price. An alternative to holding a futures position till maturity, however, is to determine one's exposure before taking delivery, by opening at a later time the opposite position (for the same delivery date), presumably for a different price than had been previously fixed on the original order. This means that opening and closing positions on the futures market, for a given delivery date, at different moments in time can result in profits or losses. Because standardized futures contracts are not entered into with a specific party, if one submits a 'buy' order it is always possible for that investor to determine his or her exposure, by putting in a 'sell' order for that same delivery date, and vice versa. Of course, if 'buy' and 'sell' orders for a particular delivery date are put in at different moments in time prior to delivery, it might be that one might sell for more than he or she bought (a profit-making strategy called 'going long'), or that they will buy for less than they originally sold (a strategy called 'going short'). Prior to the 2000 Act coming into force, participants in this market (especially when it came to agricultural commodities) were either commercial operators who needed to insure themselves against price fluctuations, or arbitrageurs, who merely sought to profit from temporary price variations, while being subject to precise position limits. After 2000, however, the Commodity Futures Modernization Act allowed unregulated over-the-counter derivative transactions on commodities (thereby opening a market for financial products indexed to the price of commodity futures, as described below), as well as containing the so-called 'swapdealer loophole', whereby parties hedging a financial position could trade on the futures market like 'commercial' operators engaging in it for operational needs (such as to insure their produce against price fluctuations), thereby being exempt from the stricter position limits for speculators. Both of these are relevant for what was to follow.

As a consequence, in fact, after 2000 a new type of investment scheme became ubiquitous, which has since become known as 'commodity index speculation'. In its original OTC form, it consists of a swap contract between the swap dealer (typically an investment 
bank, like Goldman Sachs) and an institutional investor, like a pension fund, with money to invest. The swap would be used to simulate (financially) the (actual) ownership of commodities. This would initially require the institutional investor to pay the dealer a lump sum. In exchange for it, they would be credited at contractually-stipulated dates with the variations in value of their simulated investment in commodities. The way this 'virtual' ownership of commodities would be simulated is by taking as a point of reference the value of a commodity index. This is a figure obtained through a mathematical formula that averages the price of different commodity futures, weighted by the percentage of different commodities that have been included in the index.

Let's take for instance a hypothetical index including grain, gas and oil futures in equal percentages. This would translate into a number that would track over time-in equal measure relative to one another - the price of gas, grain and oil. The reason for choosing the futures price specifically stems from the assumption that futures prices are a reliable indicator of the proximate fluctuations in spot prices, so that investing in commodity futures is more or less equivalent to buying the commodities themselves, if all one is looking for is to simulate commodity ownership from a purely financial standpoint.

To return to the swap contract, the dealer would then - at fixed dates - have to transfer the variation in the value of the index between any two contractually stipulated settlement dates.

However, once the dealer takes the obligation upon him-/herself to deliver a cash flow that reproduces ownership of a basket of commodities, it would then make sense for them to procure insurance against fluctuations in the prices of those commodities. And the way to do so is to join commercial operators (trying to insure themselves against risks related to their business, e.g. as grain traders or producers) on the futures market: this is how the link between an OTC derivative transaction - the swap - and the futures market is first established. What is significant to note, here, is that swap dealers enter the same insurance market as commercial operators, to cover themselves against the fluctuation of commodity prices. This entails, in turn, that their trading strategies will be responsive (not to events pertaining to the actual production and exchange of commodities, but) to the peculiar characteristics of the financial risks they are insuring themselves against, as illustrated below.

This, in fact, is where a crucial issue arises, namely that, while a futures contract by definition has a time-limited duration (because it is subject to a delivery date), the sort of obligation that the swap dealer enters into with the institutional investor can in theory be openended. In other words, the swap dealer can synthesize 'ownership' of commodities over an unspecified length of time, and they would 'insure' themselves against the risk entailed by this financial obligation by opening futures positions, which however expire at a certain date in the future. So the tool (commodity future) used to insure the swap dealers' financial risks is not built to cover the entire span of the risks - from indefinite exposure to commodity price fluctuations - that they are trying to shield themselves against.

This creates a discrepancy between:

1. The length of the obligation of the swap dealer towards the institutional investor through the swap contract on the one hand, and 
2. The length of a standardised futures contract on the other, through which the swap dealer may try to insure their financial risk.

This discrepancy poses the need for periodical rollover of any futures positions that have been opened by the dealer to hedge the swap. In other words, it's as though the swap dealers had to keep renewing their insurance coverage, upon its expiry date. The way they do so is through a particular trade called a rollover, which involves closing one's exposure on futures nearing maturity, and opening an interest in the next-expiring batch.

A rollover requires first of all to open the opposite position (say 'sell') on a given maturity date, to the one that an operator already holds. In this way, the original undertaking (for example, 'buy') cancels out with the new one. This is followed by opening a new position (e.g. 'buy') for a later delivery date. So, if I enter into a commitment to buy grain for delivery on the 2nd of February, I can later enter into another one to sell grain for delivery on the 2nd of February, so that my two positions cancel out and I don't actually have to take physical delivery. Subsequent to that, I may then wish to 'roll over' my exposure to the futures market by submitting another commitment to buy grain for delivery on March 2nd.

This, in fact, is what a swap dealer would be doing, since they would typically hold a number of positions containing the undertaking to buy for delivery at a fixed date into the future (say February 2nd). As that date approaches, the swap dealer would undertake to sell the same amount for delivery on February 2nd, so that its obligations would cancel out. When this happens, however, what a third-party observer would see would be a sudden surge in 'sell' orders for the given commodity as the delivery date of February 2nd approaches. For these 'sell' orders to clear with matching 'buy' orders, it is likely that the price they will attract will be lower than it would otherwise have been outside of the rollover period.

Symmetrically, as the swap dealer rolls its position over into a later-expiring future, it would issue a 'buy order' with a later expiry date (say March 2nd). For this surge in 'buy' orders to clear with matching 'sell' orders, the commodity will draw a higher price than it otherwise would outside the rollover period, when sudden surges in 'buy' orders would not normally occur.

The fact that these rollovers happen at regular intervals, for contractual reasons (insuring the risks stemming from a commodity index swap) and not to reflect fundamentals in the underlying commodity market muddles the informational value of futures prices. Furthermore, the periodical price-depression of near-expiring futures (as swap dealers close expiring future positions) and price-inflation of later-expiring futures (as swap dealers open new positions on the buy side) tilts the structure of futures prices towards contango.

Many commentators of neoclassical formation have denied that this sort of price structure - even if induced by the activity of commodity index speculation - could ever have any repercussions on spot prices, which they suggest only reflect present (not anticipated) scarcity of a commodity, based on standard demand and supply interaction. On this reading, the rise of grain prices becomes something to ascribe exclusively to increased meat consumption, draughts, and competition between edible crops and biofuels, all of which directly affect supply of the relevant commodities.

However, as buyers and sellers on spot markets take into account the signals coming from the futures market, those sellers with access to storage facilities might decide to hoard, 
whereas interested buyers, anticipating a rise in prices, might try to stockpile today to shelter themselves from rising prices in the future. Hence, a price structure induced by the periodical rollover of futures contracts seems capable to affect spot prices as well, even though any ownership on the part of the swap dealers themselves would never be more than 'virtual' as they close off their positions and never take delivery. As a consequence of contango in the futures market, instead, 'real' scarcity could and did in fact ensue on spot markets in the 200708 period (during which time futures markets were precisely in contango), sparking protests and 'hunger revolutions' around the world: this - as mentioned at the beginning of this section - is because, while the main futures markets are centralized in the United States, they are used worldwide as a reference for spot trading as well.

Add to this that commodity-indexed financial products became particularly attractive as investment opportunities, particularly after the dotcom and subprime bubbles. [...]

The increase in the percentage of futures trades being undertaken in connection with speculation would eventually cause a self-reinforcing loop whereby, as more and more commodity investors engage in 'automatic' rollovers, the contango-inducing dynamics that these rollovers perpetuate would become stronger. This drives up futures prices even further, increasing the appeal of commodities as an investment, and eventually leading to an increasing amount of trading that takes place to hedge commodity index-linked products, thereby giving rise to a self- reinforcing loop of investment driving futures prices higher through contangoinducing rollovers, and higher futures prices begetting more investment. In addition to this, contango-inducing dynamics were further exacerbated by other speculators, such as money managers, who positioned themselves so as to profit from the rollover. If, in fact, market participants who are not involved in hedging commodity indexed products anticipate that the near-expiring future will trade for less in response to a predicted surge in 'sell' orders from swap dealers during the rollover period, they may adopt a strategy of 'going long', by selling before the rollover period and buying (for less) during that subsequent phase.

However, as several operators simultaneously trade in anticipation of the rollover, this can create another 'mini-surge' of sell orders that lengthens the span and breadth of contango inducing trading.

If, as the authors contend, the commodity futures market leads to a dissociation of the price formation from the present standard demand and supply interaction, thus reflecting the preferences of the consumers, and is intrinsically linked to the perceptions of investors about future evolution of demand (which may be irrational), it is hard to imagine how a competition law ignoring the formation of commodity prices could operate if it did not find a way to integrate in the analysis the contango-inducing dynamics of commodities future trading and the externalities that such pseudo-market configuration may produce on the different economic actors involved (farmers, final consumers, processors).

A second illustration of the increasingly important role of financialisation is the growing role of institutional investors and private equity in the food industry. Schmidt reports that from the 281 deals reported in 2013 in the Food and Beverage Industry, investment firms and banks 
were involved in 47 , or $15 \%$ of all activity ${ }^{269}$. A number of the largest companies in the various segments of the value chain are privately held corporations, most notably grain companies, with a number of companies at the retail level having a mixed ownership structure ${ }^{270}$. Moreover, a number of institutional investors, including sovereign wealth funds, but also privately held grain corporations are investing in agricultural land, in particular global farmland investments. This has led to backclash from some quarters that raised the problem of global fam land grab as a main public policy concern ${ }^{271}$.

Broadening the horizon of competition authorities to envision tools and frameworks that respond to such crucial developments, such as financialisation, constitutes an important challenge we need to take into account. This is particularly important as to the visible economic concentration of some of the segments of the food value chain, one should also add the "stealth concentration" arising out of the investment of the same institutional investors in various companies active in the multiple segments of the food value chain. Chapter 4 of Part III examines in more detail the role of large institutional investors in the food sector, the possible effects this may have on competition, and the different tools at the disposal of competition law authorities.

\section{References}

Accenture. Digital Agriculture: Improving Profitability. (2015).

Backer, K., Miroudot, S. Mapping Global Value Chains (OECD, 2013).

Biscarini, F, Nicolazzi, E. Challenges and opportunities in genetic improvement of local livestock breeds. (2015), Frontiers in Genetics, 6(33).

Bekakers, R.,Duysters, G., Verspagen, B. Intellectual property rights, strategic technology agreements and market structure: the case of GSM, (2002) 31(7) Research Policy 1141-1161.

Behmann, J, Mahlein, T, et al. A review of advanced machine learning methods for the detection of biotic stress in precision crop protection. (2015), Precision Agriculture. 16(3), 239260.

Bonny, S. Corporate Concentration and Technological Change in the Global Seed Industry, (2017).

Boston Consulting Group, The Value of our Digital Identity (November 2012).

Boston Consulting Group, Crop Farming 2030 - The Reinvention of the Sector (April 2015).

Competition Commission of India, Competitive Assessment of Onion Markets in India, (2012).

Cotterill, R. 'Market Power in the Retail Food Industry: Evidence from Vermont,' (1986), The Review of Economics and Statistics, 379.

Enriquez P., CRISPR GMOs, (2017) 18(4) North Carolina Journal of Law \& Technology 432. ETC, Who will Control the Green Economy? (November 2011).

269 T.P. Schmidt, The Political Economy of Food and Finance (Routledge, 2016), 111.

270 Ibid., 114.

${ }^{271} \mathrm{Ph}$. McMichael, The land grab and corporate food regime restructuring, (2012) 39 (3-4) The Journal of Peasant Studies 681. 
ETC Group, Breaking Bad: Big Ag Mega-Mergers in Play, (December 2015), Communique 115.

European Commission, Digitising the Agri-food Sector: a research agenda for Horizon 2020 (European Commission - Directorate General for Agriculture and Rural Development November 2016).

European Commission, Explanatory Note, New Techniques in Agricultural Biotechnology (2017), 24.

European Parliament, Precision Agriculture and the Future of Farming in Europe, IP/G/STOA/FWC/2013-1/Lot 7/SC5 (December 2016).

Evenson, R. Government Policy and Technological Progress in U.S. Agriculture, in R. Nelson (ed.). Government Support of Technological Progress: A Cross Industry Analysis (New York: Pergamon Press, 1982).

Food and Agriculture Organization (FAO) of the United Nations, Commission on Genetic Resources for Food and Agriculture (2015). The Second Report on the State of the World's Animal Genetic Resources for Food and Agriculture.

Fuglie, K. Research Investments and Market Structure in the Food Processing, Agricultural Input, and Biofuel Industries Worldwide, USDA-ERS Economic Research Report No. 130 (2011) 11

Gereffi, G., Christian, M. Trade, Transnational Corporations and Food Consumption: A Global Value Chain Approach, in C. Hawkes, C. Blouin, S. Henson, N. Drager, L. Dubé (eds.), Trade, Food, Diet and Health Perspectives and Policy Options, (Wiley-Blackwell, 2010). 3.

Ghosh, J. The Unnatural Coupling: Food and Global Finance, (2010) 10(1) Journal of Agrarian Change 72-86, 78-79.

Gataulina, E.A., Vertical Integration in an Agroindustrial Complex: Agrofirms and Agroholdings in Russia, The dynamics of vertical coordination in agrifood chains in Eastern Europe and Central Asia: case studies. Working Paper 45 (2006).

Hartung, F., Schiemann, J. Precise plant breeding using new genome editing techniques: opportunities, safety and regulation in the EU, (2014) 78 Plant Journal 742-752, 743.

Harris, J The US Food Marketing System: Competition, Coordination, and Technological Innovations Into the 21st Century, (2002), USDA Economic Research Service 1.

Howard, P. Visualizing Consolidation in the Global Seed Industry: 1996-2008, (2009) 1(4) Sustainability 1266-1287.

Humphrey, J., Memedovic, O. 'Global Value Chains in the Agrifood Sector' (2006) UNIDO 5 .

Karolyczk, P. Product Certification - the next big standard-setting debate? (March 14, 2013).

Kaufman, P., Handy, C. U.S. Fresh Produce Markets: Marketing Channels, Trade Practices, and Retail Pricing Behavior (US Dept of Agriculture, Economic Research Service 1989).

Krijn, P, Wolfert, S, Verdouw, C.N. A European Perspective on the Economics of Big Data: (OECD, 2015).

Kneafsey, M. Short Food Supply Chains and Local Food Systems in the EU (2013) Report EUR 25911 EC. 
KPMG International, The agricultural and food value chain: entering a new era of cooperation (2013).

Lianos, I.,Katalevsky, D., Ivanov, A.The global seed market, competition law and intellectual property rights: untying the Gordian knot. Concurrences , 2016 (2), Article 78807.

Lyneis, J. System dynamics for business strategy: a phased approach, (1999) 15 System Dynamics Review 37-70.

MacDonald, J. 'Contracts, Markets, and Prices: Organizing the Production and Use of Agricultural Commodities' (2004) USDA-ERS Agricultural Economic Report.

$\mathrm{Ph}$. McMichael, The land grab and corporate food regime restructuring, (2012) 39 (3-4) The Journal of Peasant Studies 681

Meade, B, Puricelli, E, McBride, W et al. (2016). Corn and soybean production costs and export competitiveness in Argentina, Brazil, and United States (USDA report summary for Economic Research Service).

Ministry of Agriculture, Government of India, Report on Agricultural Marketing, 2007.

Nordås, H., Grosso, M., Pinali, E. Market Structure in the Distribution Sector and Merchandise Trade (OECD 2008) 14.

Nuffield Council on Bioethics, Genome Editing: An Ethical Review (September 2016).

Pray, C., Ohmhke, J., Naseem, A. Innovation and Dynamic Efficiency in Plant Biotechnology: An Introduction to the Researchable Issues, (2005) 8(2\&3) AgBioForum 52, 59.

Rama, R. Foreign Multinational Enterprises in the Food and Beverages Industries of the BRICS, in W. Naude, A. Szirmai, \& N. Haraguchi (eds.), Structural Change and Industrial Development in the BRICS. (OUP, 2015) p. 300

Reardon. T., Chen K. The quiet revolution in Asia's rice value chains. (2014), Annals of the New York Academy of Sciences., p 110.

Roberts, M.T., Food Law in the United States (Cambridge University Press, 2016).

Russi, L., Ferrando, T. Capitalism a Nuh' Wi Frien' - the Formatting of Farming into an Asset, from Financial Speculation to International Aid, Catalyst - A Social Justice Forum, Vol. 6, issue 1, 3 (2015).

Sarni, W., J. Mariani \& J. Kaji, From dirt to data: The second green revolution and the Internet of Things, (2016) Deloitte Review Issue 18

Schmidt T.P., The Political Economy of Food and Finance (Routledge, 2016)

Swinnen, J. Global Supply Chains, Standards and the Poor How the Globalization of Food Systems and Standards Affects Rural Development and Poverty (CABI 2007) 1.

Tiwari, B, Norton, T, Holden, $M$ et al (2013). Current Concepts and Applied Research in Sustainable Food Processing. John Wiley \& Sons. 12-14.

Wandel, J. 'Business Groups and Competition in Post-Soviet Transition Economies: The Case of Russian "agroholdings"” (2011) 24 The Review of Austrian Economics, 403.

Warren, K. Why has Feedback Systems Thinking Struggled to Influence Strategy and Policy?, (2004) 21 Systems Research and Behavioral Science 1-17.

Warren, K. Strategic Management Dynamics (Wiley, 2008).

World Bank, Agriculture for Development (World Bank 2008). 
World Bank and others, The Dynamics of Vertical Coordination in Agrifood Chains in Eastern Europe and Central Asia: Implications for Policy and World Bank Operations (The World Bank 2005).

Wolstenholme, Qualitative vs quantitative modelling: the evolving balance, (1999) 50 Journal of Operational Research Society, 422-428.

Wolfert, S, Ge, L. "Big Data in Smart Farming-A Review”. (2017) 153 Agricultural Systems, 69-80.

Wozniak, M.T., McHughen A. (eds.), Regulation of Agricultural Biotechnology: The United States and Canada (Springer, 2012).

Zhang,Y.,Xudong, R. Organization, technology and management innovations through acquisition in China's pork value chains: The case of Smithfield acquisition by Shuanghui. (2017) Food Policy. 


\title{
Part II: Global Food Value Chain(s): General Presentation
}

\author{
Chapter 1: The food value chain
}

\section{Ioannis Lianos \& Claudio Lombardi}

\subsection{General Presentation on Food Value Chains}

The food supply chain is generally depicted as composed by three main levels: agricultural production, industrial processing and wholesale or retail distribution. At a closer look, however, the food supply chain becomes more complex than this tripartition, involving a number of other stages and links that add value to the chain either in the form of goods or services inputs. ${ }^{272}$ At each level of the supply chain, firms as well as other organizational forms perform specific activities supplying goods or services. Moreover, at the same level there may be one or more firms performing the same or complementary activities, adding specific value at their stage of activity.

\section{Figure 1: Total Food Supply Chain}

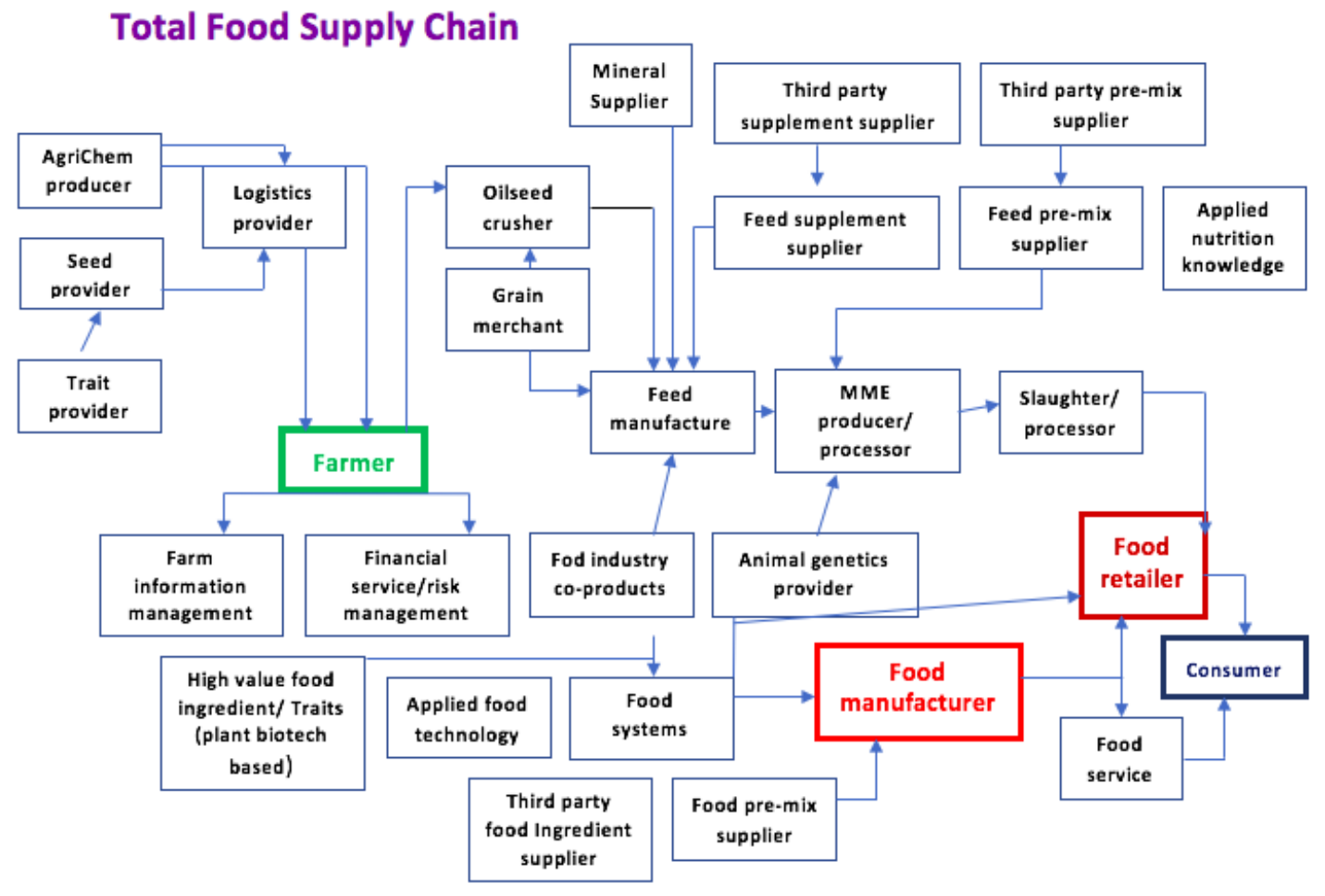

Source:Moniqa ${ }^{273}$

\footnotetext{
${ }^{272}$ The accent on the activity that at each stage of the supply chain one or more subjects perform adding certain value, generated the definition of value-added chain. Initially defined by Bruce Kogut, 'Designing Global Strategies: Comparative and Competitive Value Added Chains' (1985) 26 Sloan management review. For later development see Gary Gereffi, John Humphrey and Timothy Sturgeon, 'The Governance of Global Value Chains' (2005) 12 Review of international political economy 78.

273 See http://www.ineffableisland.com/2010/06/eu-funded-moniqa-tracks-edible-safety.html\#!/2010/06/eufunded-moniqa-tracks-edible-safety.html .
} 
The food supply chain, as a whole, originates therefore even before the agricultural sector, ${ }^{274}$ with the factors of production market (for example the seed and traits provider, fertlisers, agricultural machinery, plant protection agents) and ends with the final consumer.

The agricultural commodities generally undergo a processing stage before being distributed. However, in some cases they are sold directly to consumers (direct chain) or through the sole mediation of the wholesale industry (short supply chain). The length of the supply chain depends therefore on how many stages of transformation or commercialiation the product undergoes before reaching the final consumer.

\section{Figure 2: The Long and Short Supply Chains}

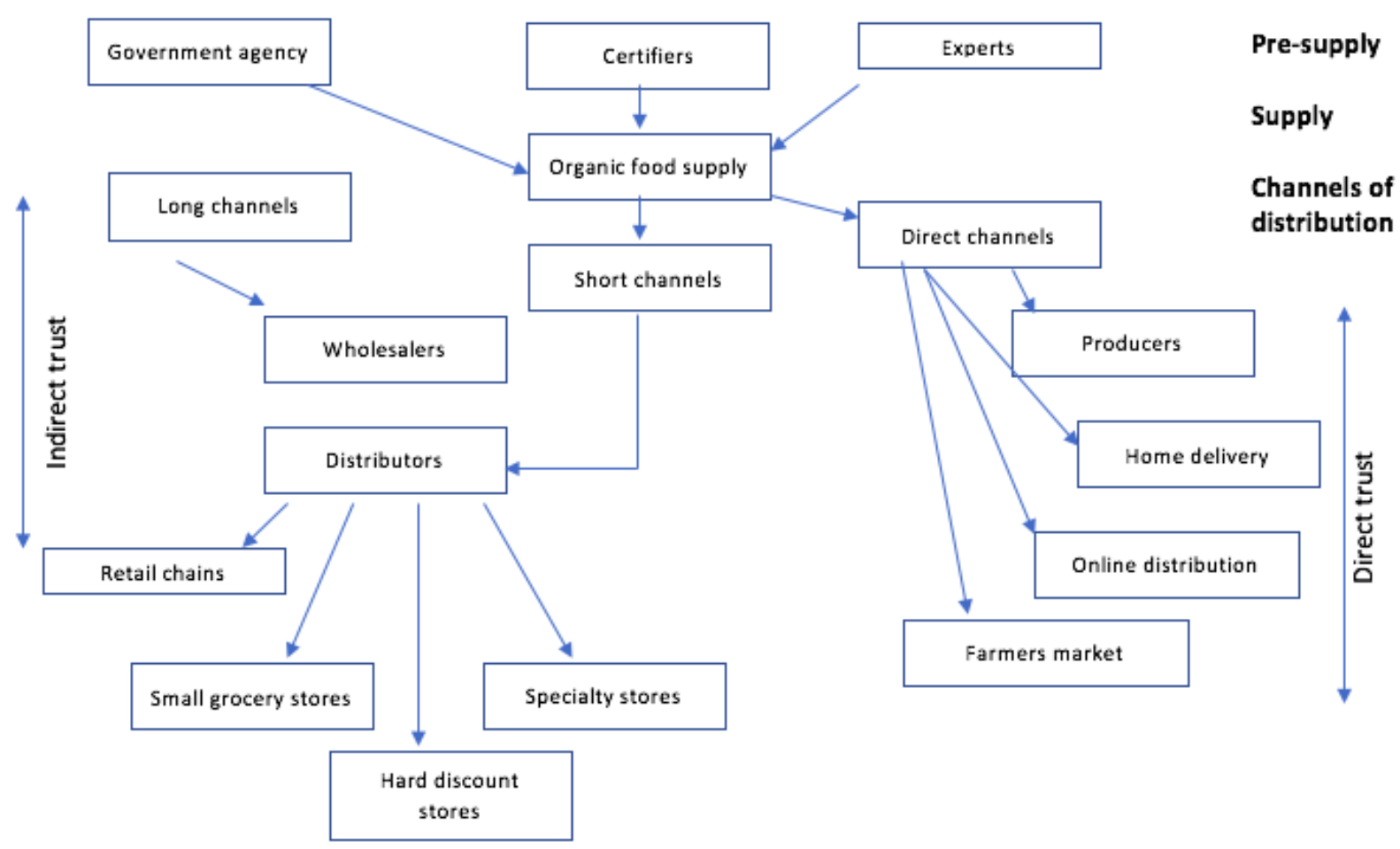

Source: Europea Commission, Joint Research Center $2013^{275}$

A simplified description of the structural organization of the supply chain is generally based on the relationships between producers and suppliers, on one hand, and suppliers and retailers, on the other. ${ }^{276}$

\footnotetext{
${ }^{274}$ The agricultural sector is in this paper intended as comprising both crop production and raising of livestock. ${ }^{275}$ M. Kneafsey and others, 'Short Food Supply Chains and Local Food Systems in the EU' (2013) Report EUR $25911 \mathrm{EC}$, available at http://ipts.jrc.ec.europa.eu/publications/pub.cfm?id=6279.

${ }^{276}$ Food supply chains are generally presented as characterised by a structure characterized by two bottlenecks, one at supply level and the second at retail level, see for instance South Centre, 'Rebalancing the Supply Chain: Buyer Power, Commodities and Competition Policy' (2008) South Centre.
} 
Typically, at production level, the relationship between market actors spans from a spot market exchange to a full ownership integration. ${ }^{277}$ Within this range, there are different types of contractual relationships, which contribute to the definition of the governance model adopted by the supply chain. In particular, marketing agreements and production agreements are the categories under which different relationships between contractors and growers are defined. ${ }^{278}$

At distribution level, instead, there are generally three types of wholesalers around which the supply chain is structured: a) merchant wholesalers; b) manufacturers' branches and offices; and c) brokers and agents. ${ }^{279}$

\section{Figure 3: Food distribution channels}

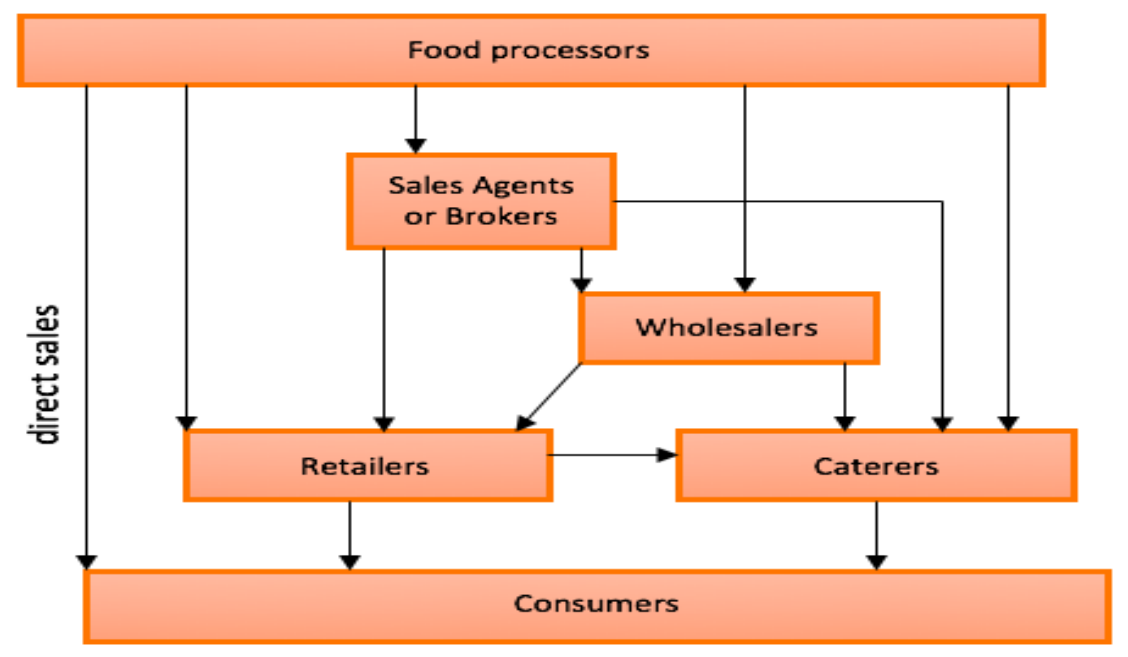

Source: Harris et al., $2002^{280}$

Along the food supply chain, firms perform their activities together with and in compliance to governmental agencies and NGOs-managed regulatory regimes and certifications. In this perspective, production, services and monitoring activities, all bundle in the same value chain that brings the product to the final consumer. Consequently, one may add to the concept of 'length' of the supply chain that of 'width', aiming to describe the situation in which actors that are situated at the same level of the value chain perform similar or complementary activities, adding specific value at their stage of activity. However, some of the actors may simultaneously perform the same activity for different levels of the supply chain. This is the case, for instance, of the certification agencies, which verify the activity of both suppliers and sub-processors, thus blurring the significance of the distinction between width and length. The

\footnotetext{
277 J.M. Harris and others, 'The US Food Marketing System: Competition, Coordination, and Technological Innovations Into the 21st Century' USDA Economic Research Service (2002) 1.

${ }^{278}$ James M MacDonald and others, 'Contracts, Markets, and Prices: Organizing the Production and Use of Agricultural Commodities' [2004] USDA-ERS Agricultural Economic Report <http://papers.ssrn.com/sol3/papers.cfm?abstract_id=754986> accessed 22 May 2015.

279 .M. Harris and others, 'The US Food Marketing System: Competition, Coordination, and Technological Innovations Into the 21st Century' USDA Economic Research Service (2002) 1.

${ }^{280}$ Ibid.
} 
characteristics and number of firms involved in the different segments of the food value chain also vary considerably:

The profitability and structure of the various segments of the value chain vary. Some segments are characterised by intense levels of competition and consequently lower profitability, while others are more concentrated (see Figures 4 and 5).

Figure 4: Key profitability metrics of the agribusiness value chain

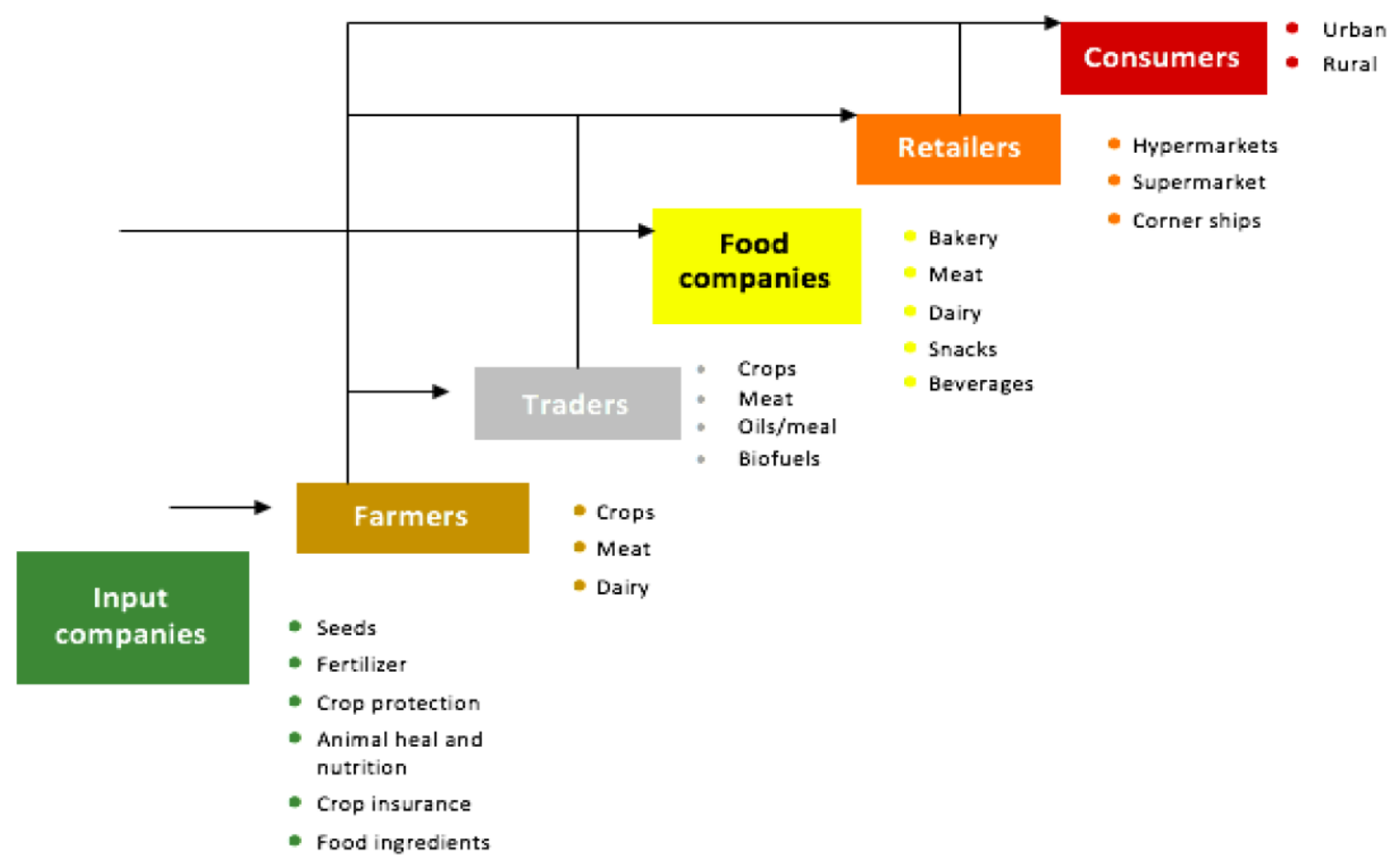

Figure 5: Key profitability metrics

\begin{tabular}{|c|c|c|c|c|c|}
\hline Sector & Input & Farmers & Traders & $\begin{array}{c}\text { Food } \\
\text { companies }\end{array}$ & Retailers \\
\hline $\begin{array}{l}\text { Sales: USSbn } \\
\text { [approx.] }\end{array}$ & 400 & 3,000 & 1,000 & 3,500 & 5,400 \\
\hline Number of players & $100 \mathrm{~s}$ & 450 million & Tens & Thousands & Millions \\
\hline EBIT \% & $15 \%$ & Variable & $2-5 \%$ & $10-20 \%$ & $5 \%$ \\
\hline R\&D $\%$ sales & $\begin{array}{l}<1 \% \text { (fertilizers)- } \\
10 \% \text { (seeds) }\end{array}$ & $0 \%$ & $<1 \%$ & $1-2 \%$ & $<1 \%$ \\
\hline R\&D spend: USSbn & 10 & - & Low & 8 & Low \\
\hline $\begin{array}{l}\text { Composition/Sub- } \\
\text { sectors }\end{array}$ & $\begin{array}{l}\text { - Seed } \\
\text { - Fertilizer } \\
\text { - Crop protection } \\
\text { - Machinery } \\
\text { - Animal health } \\
\text { and nutrition } \\
\text { - Crop insurance } \\
\text { - Food } \\
\text { ingredients }\end{array}$ & $\begin{array}{l}\text { - Grains } \\
\text { - Fruitland } \\
\text { - Vegetables } \\
\text { - Meat } \\
\text { - Dairy }\end{array}$ & $\begin{array}{l}\text { - Handling } \\
\text { - Primary } \\
\text { processing } \\
\text { - Secondary } \\
\text { processing }\end{array}$ & $\begin{array}{l}\text { - Bakery } \\
\text { - Meat } \\
\text { - Dairy } \\
\text { - Snacks } \\
\text { - Ready meals } \\
\text { - Beverages }\end{array}$ & $\begin{array}{l}\text { - Multiples } \\
\text { - Discounters } \\
\text { - Wholesalers } \\
\text { - Independents }\end{array}$ \\
\hline Range & $\begin{array}{l}\text { R\&D based majors } \\
\text { to generic } \\
\text { manufacturers }\end{array}$ & $\begin{array}{l}\text { Smallholders to } \\
\text { agroholdings }\end{array}$ & $\begin{array}{l}\text { Global } \\
\text { agribusiness } \\
\text { to local } \\
\text { middlemen }\end{array}$ & $\begin{array}{l}\text { SMEs to } \\
\text { multinationals }\end{array}$ & $\begin{array}{l}\text { Corner shops to } \\
\text { hypermarkets }\end{array}$ \\
\hline
\end{tabular}


Source: KPMG International (2013) 281

\subsection{The emergence of global food value chains}

The structure of the food value chain and the relationship between the firms operating in it has changed drastically the last two decades. ${ }^{282}$ Agriculture and agri-food production has taken advantage of technological innovation becoming more industrialised ${ }^{283}$ and globalised. ${ }^{284}$ This resulted in a constant increase of global agricultural trade during the last three decades ${ }^{285}$, the volume of trade passing from 230 billion US dollars in 1980 to 1,100 billion in $2010 .{ }^{286}$ At the same time, markets have witnessed the development of new technologies at the production stage, for instance through the optimization of processes, and at the distribution level, because of ICT advances. Modern information systems enable suppliers to receive directly signals over the preferences of consumers for higher quality products, the private sector responding by creating "value chains" with the aim to reduce, through the exercise of control, the uncertainty emerging out of their interaction with a number of economic actors present in different market segments (and for which they do not dispose sufficient information).

The globalisation of the economy has led to the development of a transnational mode of production, with a number of production facilities dispersed in various jurisdictions, thus increasing the need to put in place transnational value chains reducing the resulting uncertainty of dealing with foreign economic actors. One may also trace the development of value chains in the expansion of national and international regulations regarding consumer protection, food safety and quality, for instance regulation imposing the traceability of food, feed, at all stages of production, processing and distribution (e.g. EU Regulation 178/2002 287 , the WTO sanitary and phytosanitary standards, Codex Alimentarius). The private sector complies with such regulations by establishing standards (e.g. organic agriculture ISO-9000) and specific codes of conduct managed by industry associations or non-governmental organizations (e.g. Global gap, a NGO that sets voluntary standards for the certification of agricultural products around the globe, in particular the Integrated farm Assurance (IFA), the international gold standard in farm certification). The coexistence of public and private regulation in supply chains leads to a double interdependence, when the regulatory framework contributes to shape supply chains adopting private regulation, which, in turn, affects public regulatory strategies.

\footnotetext{
${ }^{281}$ KPMG International, The agricultural and food value chain: entering a new era of cooperation (2013), 5

282 Johan FM Swinnen, Global Supply Chains, Standards and the Poor How the Globalization of Food Systems and Standards Affects Rural Development and Poverty (CABI 2007) 1.

283 John Humphrey and Olga Memedovic, 'Global Value Chains in the Agrifood Sector' [2006] UNIDO 5 <Available at http://agris.fao.org/agris-search/search.do?recordID=GB2013202293> accessed 15 May 2015.

${ }^{284}$ Gary Gereffi and Michelle M Christian, 'Trade, Transnational Corporations and Food Consumption: A Global Value Chain Approach', Trade, Food, Diet and Health Perspectives and Policy Options, C. Hawkes, C. Blouin, S. Henson, N. Drager, L. Dubé, eds (2010) 3 <Available at: http://papers.ssrn.com/sol3/papers.cfm?abstract_id=1564948> accessed 8 May 2015.

${ }^{285}$ World Bank, Agriculture for Development (World Bank 2008).

${ }^{286}$ FAOStat, 2013, http://faostat3.fao.org/home/E.

${ }^{287}$ Regulation 178/2002 of the European Parliament and the European Council laying down the general principles and requirements of food law, establishing the European Food Safety Authority and laying down procedures in matters of food safety [2002] OJ L 31/1.
} 
As a result of these developments, the food value chain is increasingly structured around "global value chains" (GVCs). ${ }^{288}$ Global value chains permit the simultaneous production and distribution of a very large array of products that each stage of the supply chain has to manage effectively. In this regard, information technology plays a fundamental role especially in those 'small conduits' of the supply chain where few actors organize a large number of activities and operations. For instance, the OECD acknowledges that "the average number of items in a sold in a typical grocery store in the US has increased from about 6000 in 1960 to about 45000 in 2006". 289

In this context, the interplay or even combination of local and global supply chains may structure the value chain in different ways, depending on the interaction between the two.

Figure 6: Example of Interaction of Global Value Chain and Local Value Chain in the Wheat Market

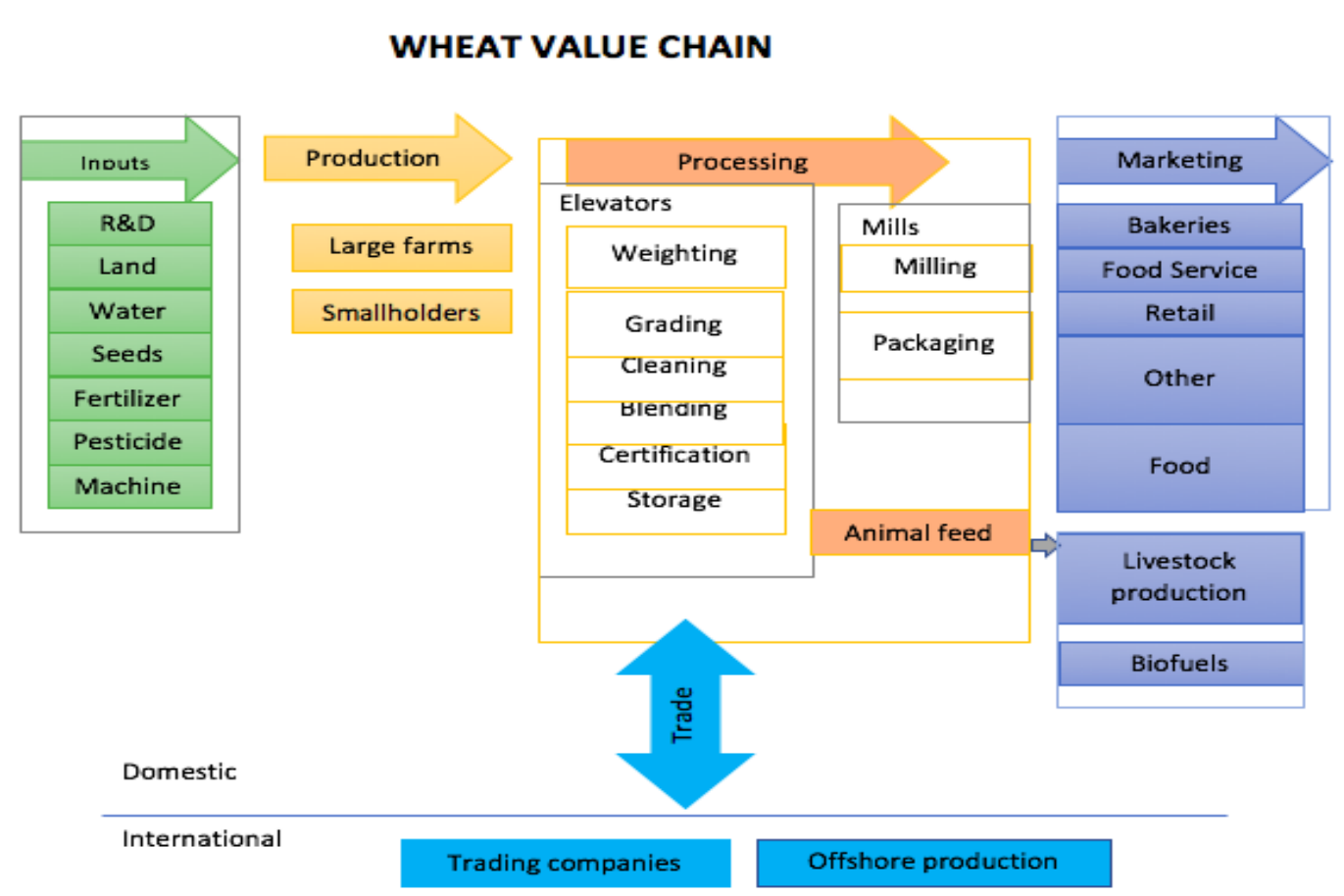

\begin{tabular}{|lll|}
\hline & \multicolumn{1}{c}{$\begin{array}{c}\text { Institutions } \\
\text { Government Regulations }\end{array}$} & $\begin{array}{l}\text { Futures Trading } \\
\text { Trade Policies }\end{array}$ \\
\hline
\end{tabular}

Source: Duke Minerva ${ }^{290}$

1.2.Specific sectors (examples and discussion per jurisdiction)

${ }^{288}$ Koen Backer and Sébastien Miroudot, Mapping Global Value Chains (OECD, 2013).

${ }^{289}$ Hildegunn Kyvik Nordås, Massimo Geloso Grosso and Enrico Pinali, Market Structure in the Distribution Sector and Merchandise Trade (OECD 2008) 14.

${ }^{290} \mathrm{http}: / /$ sites.duke.edu/minerva/the-global-value-chain/ 
The interplay between global value chains and local markets is fundamental in order to understand the structure of the different food supply chains in the BRICS countries. The opening of internal economies to the global market have, indeed, deeply changed the structure of the food supply chain in these countries. ${ }^{291}$ However, BRICS jurisdictions reacted to this changes in different ways.

For instance, the Russian agri-food industry, prior to 1993, was based on a system governed by the Ministry of Trade and supervised by a number of State agencies. The commodity was transferred from producer to wholesale intermediaries that distributed the goods to industrial processors or to territorial departments.

\section{Figure 7: The system of wholesale in Russia prior to 1993}

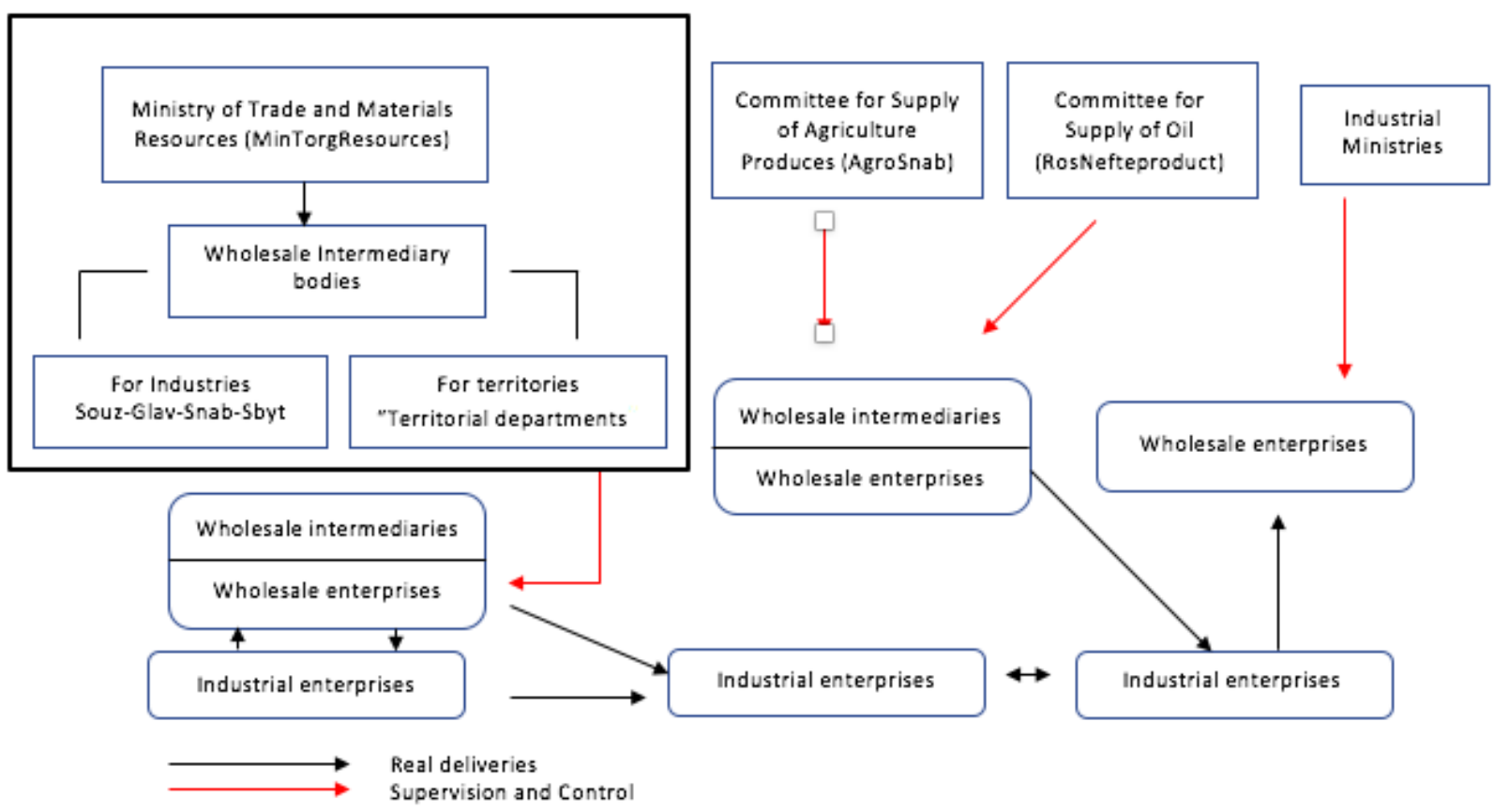

The System of Wholesale Trade in Russia prior to 1993

Source: Gataulina et al. $(2006)^{292}$

The opening up to the world market and the dissolution of the Soviet regime brought a number of consequences, including the 1998 financial crisis. The agricultural sector reacted by consolidating under the aegis of few national incumbents. In particular, Gazprom became the largest agricultural holding, controlling 91 agricultural firms through 25 of its subsidiaries. ${ }^{293}$ Orel Niva is one of them:

\footnotetext{
291 Johan FM Swinnen, Global Supply Chains, Standards and the Poor How the Globalization of Food Systems and Standards Affects Rural Development and Poverty (CABI 2007) 1.

${ }^{292}$ EA Gataulina and others, 'Vertical Integration in an Agroindustrial Complex: Agrofirms and Agroholdings in Russia' [2006] The dynamics of vertical coordination in agrifood chains in Eastern Europe and Central Asia: case studies. Working Paper 45.

${ }^{293}$ World Bank and others, The Dynamics of Vertical Coordination in Agrifood Chains in Eastern Europe and Central Asia: Implications for Policy and World Bank Operations (The World Bank 2005) 91.
} 


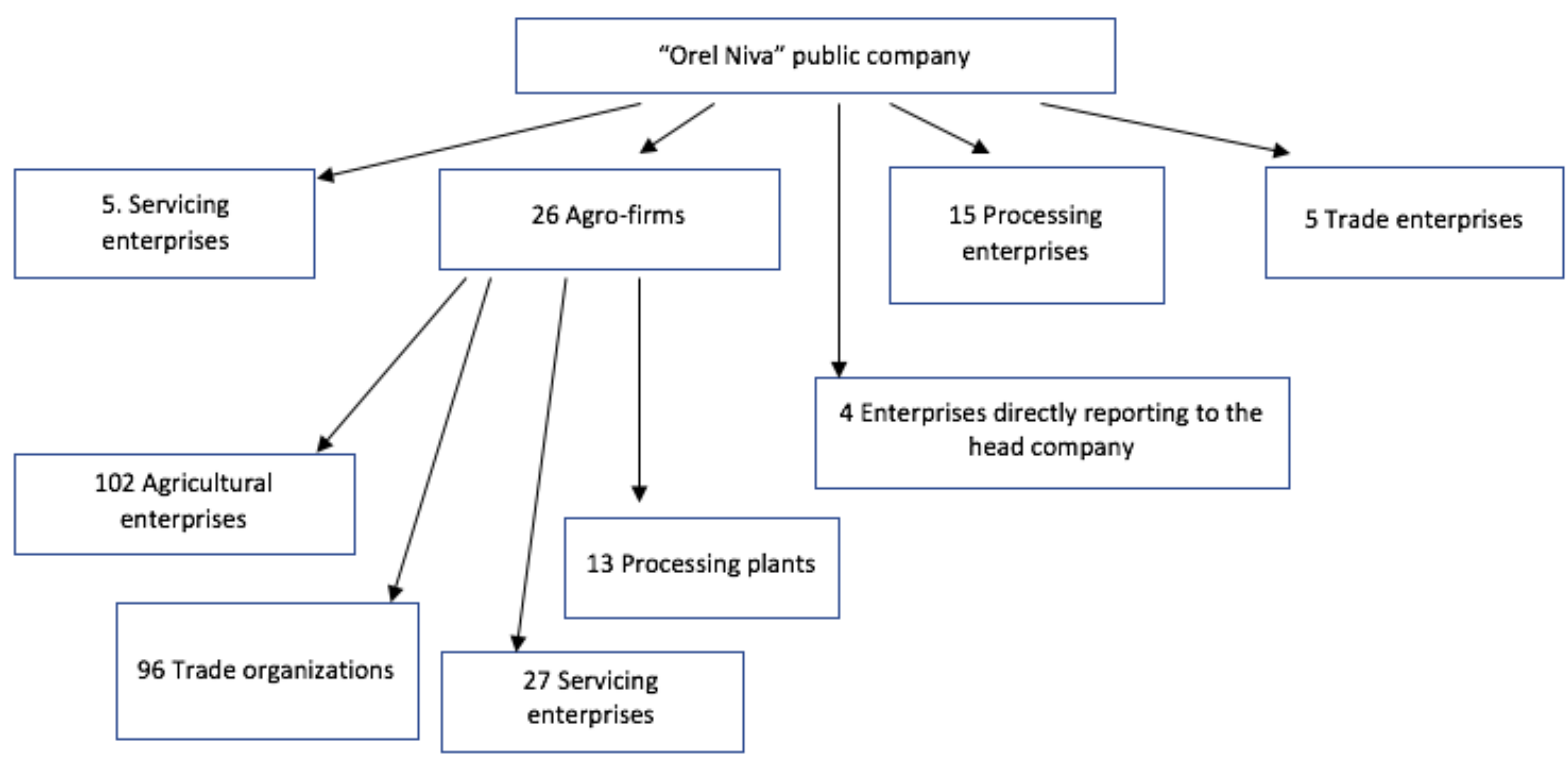

Source: Gatualina et al (2004)

The leading motive of the regional authorities in Orel for assisting in the creation of agrofirms and large regional holdings was "to actively employ methods of state control to preserve and develop the agroindustrial sector of the region, to rehabilitate bankrupt agricultural enterprises, to provide the enterprises with fixed and current assets, and to restore the broken integration links". ${ }^{294}$ The Orel region was to become a model for developing a regional agricultural sector under market conditions but with a strong controlling role of the state. The creation of huge agroholdings in Russia has significantly affected the performance of the farms. Interestingly, the results appear to be quite mixed. ${ }^{295}$ Gataulina et al.'s (2004) study finds that vertical integration has contributed to:

- A better supply of inputs to farms.

- Growth in output and productivity.

- Poor financial results.

- "Important heterogeneity among the farms. Some of the integrated farms with good management seem to have performed very well" 296 .

However, on the other hand, Gataulina et al found out that the profitability of such agroholding worsened almost 20 percentage points in the period 1999-2002. The negative trend on profitability affected at the same time also the other vertically integrated agricultural enterprises to the extent that, for instance, on 149 agriholdings in the Belgorod region only 39 were profitable in $2002^{297}$.

\footnotetext{
${ }^{294}$ World Bank and others (n 21).

295 ibid.

296 ibid; Gataulina and others (n 20).

297 World Bank and others (n 21).
} 
In contrast, in India, contract farming has found 'fertile ground' in regulating the relationships between agricultural producers and suppliers or wholesalers, in some cases even as a solution to offset cartels at wholesale level created by national legislation.

In 1963, the Agricultural Produce Marketing Committee (APMC) passed the APMC Act with the aim of regulating marketing of agricultural produce. The Act fully regulated the relationship between farmers and suppliers to the extent that only licensed intermediaries could trade the commodities on the market. The outcome of this regulatory framework did not solely ended up in the creation of monopolies and high entry barriers, but also of a highly cartelized wholesale market. ${ }^{298}$ Since 2007 , this regulatory framework has been changed by a number of amendment laws aiming at a more liberalized agricultural market. In a 2012 market study on the onion market, the Indian competition authority observes that the solution for managing the liberalization of the market lies also in the use of contract farming. ${ }^{299}$

The onion market is paradigmatic of the Indian agricultural production. The producers are generally small farmers scattered throughout the country. They sell the produce mainly through arm's length agreements at the local markets where traders fix rates comparing the local rates to the other national markets' rates. ${ }^{300}$ Finally, market traders are often vertically integrated with wholesalers and retailers. As in other sectors of agricultural production ${ }^{301}$ the Indian authorities envisaged contract farming, in line with what was also put forward by the APMC 2007 Amendment Act, as one of the main viable solutions to the problems affecting the market, especially to fight cartels. With contract farming the supplier agrees with the farmer not only on price, quantity and time of the performance, but establishes also the standards that the farmers have to follow in production. The authority can therefore monitor parties' behaviour on the market, encouraging the adoption of high international safety standards and, at the same time, leaving to the market some degree of contractual freedom.

\subsection{Global/transnational value chains, power relations and the need for advanced network analysis}

National governments cannot ignore transnational value chains in the food sector. The food prices are a sensitive issue largely due to the proportion of income spent on food and also the potentially regressive effect it has on lower income households. The share of household income spent on food varies substantially, a recent OECD study reporting for the OECD countries that it may range from around 22 per cent in Turkey and Mexico to less than 10 per cent in the US, Canada and the $\mathrm{UK}^{302}$. However, even in countries where the aggregate share is relatively low, since the lower income groups spend a greater proportion of their income on food, the rise in food prices can have a regressive effect on the less well-off.

\footnotetext{
${ }^{298}$ Competition Commission of India, Competitive Assessment of Onion Markets in India, 2012, available at http://www.cci.gov.in/images/media/completed/AO.pdf.

299 Ibid.

300 Ibid., 41.

${ }^{301}$ For instance in the tea and paddy markets, see respectively Annexes IV and V regarding two examples of contracts in these sectors.

302 OECD
} 
The power relations in the global food value chain are characterized by international actors and local producers operating within the geographic area determined by the logistics of the product. Additionally, the whole value chain goes through continuous reshapes, as to meet consumer changing demand. The market power of a firm, in the food as in any other industry, generally triggers the attention of competition watchdogs, if it corresponds to the notion of dominance, intended as "a position of economic strength enjoyed by an undertaking which enables it to prevent effective competition being maintained on the relevant market by affording it the power to behave to an appreciable extent independently of its competitors, customers and ultimately of its consumers" ${ }^{303}$. This notion of dominance leaves therefore, at least partially, undisclosed the relative power ${ }^{304}$ of the company on its trading partners.

Globalized markets are the result of a complex nexus of interconnections between firms, where the relative power of a firm and its market power are deeply intertwined, to the extent that, in some cases, the relative power of a firm, rather than its market share and concentration, may explain better the causes of markets distortions. Several studies have tried to find a correlation between the level of concentration of modern retailers and the ratio of passing on of price benefits or the creation of market efficiency ${ }^{305}$, on one hand, or the creation of inefficiencies, on the other. The creation of a negative externality associated to the high level of concentration, would indeed presume an abuse of superior bargaining power having distorting effects on the market. However, the research findings on the point are mixed, as while some papers find a connection between levels of retail concentration and higher consumer prices ${ }^{306}$, others state that there is no empirical basis to find such correlation, but that in many cases the opposite is true $\mathrm{e}^{307}$.

In global value chains, the effects of the use of bargaining power through contracting and technology transfer are equally debated ${ }^{308}$. Some scholars have found positive effects of contracting in situation of unbalanced bargaining power, in particular with regard to the development of quality standards in developing and transition economies, also through technology and know-how transfer ${ }^{309}$ and income stability and food security of participating

\footnotetext{
303 Judgment of the European Court of Justice, Case 27/76, United Brands v. Commission, [1978] E.C.R. 207 at para. 65 and Judgment of the European Court of Justice, Hoffmann La Roche v. Commission, 85/76, [1979] E.C.R.-461 at para. 38.

${ }^{304}$ Here for relative power, we intend the power exerted by a firm on a commercial partner.

${ }^{305}$ See for instance the USDA Report discussing some of them, Sharad Tandon and others, The Expansion of Modern Grocery Retailing and Trade in Developing Countries (US Dept of Agriculture, Economic Research Service 2011) <Available at http://purl.fdlp.gov/GPO/gpo17052> accessed 21 August 2015.

${ }^{306}$ Ronald W Cotterill, 'Market Power in the Retail Food Industry: Evidence from Vermont' [1986] The Review of Economics and Statistics 379; Ronald W Cotterill and C David Harper, Market Power and the Demsetz Quality Critique: An Evaluation for Food Retailing (University of Connecticut, Department of Agriculture and Resource Economics 1995).

${ }^{307}$ Phil R Kaufman and C Handy, U.S. Fresh Produce Markets: Marketing Channels, Trade Practices, and Retail Pricing Behavior (US Dept of Agriculture, Economic Research Service 1989); James K Binkley and John M Connor, 'Market Competition and Metropolitan-Area Grocery Prices' [1996] Available at SSRN 1238553 <http://papers.ssrn.com/sol3/papers.cfm?abstract_id=1238553> accessed 21 August 2015.

308 Johan FM Swinnen, 'Global Agricultural Value Chains, Standards, and Development' (2014) 30 Robert Schuman Centre for Advanced Studies Research Paper No. RSCAS <available at http://papers.ssrn.com/sol3/Papers.cfm?abstract_id=2434532> accessed 8 May 2015.

309 Johan FM Swinnen and Anneleen Vandeplas, 'Quality, Efficiency Premia, and Development' < Available at http://papers.ssrn.com/sol3/papers.cfm?abstract_id=1106101> accessed 21 August 2015.
} 
households ${ }^{310}$. By contrast, others have denounced the repeated abuse of such superior bargaining power of multinational organizations exploiting poor countries, extracting rents through unfair contract terms ${ }^{311}$.

Another important issue to consider is the difficulties of the relevant market concept and traditional NPT analysis to represent the power relations between the various economic actors involved in the food value chain, in particular if this is of trans-national dimension and their possible welfare effects on final consumers or other economic actors. Global seed producers (Monsanto, Syngenta, DuPoint Pioneer, BASF, etc.) continue to increase their global presence have recently acquired critical market influence in key food exporting regions. Some global players have gained such an influence on national markets which is already not under control by national legislative and executive powers. Combined with the natural complexity of global food production-supply chains, any disruption in seeds supply may cause a systemic food shock of a global magnitude.

\section{Figure 9: Seed Industry Structure}

\footnotetext{
310 Bart Minten, Lalaina Randrianarison and Johan FM Swinnen, 'Global Retail Chains and Poor Farmers: Evidence from Madagascar' (2009) 37 World Development 1728; Christina Handschuch, Meike Wollni and Pablo Villalobos, 'Adoption of Food Safety and Quality Standards among Chilean Raspberry producers-Do Smallholders Benefit?' (2013) 40 Food Policy 64; Solomon Asfaw, Dagmar Mithöfer and Hermann Waibel, 'EU Food Safety Standards, Pesticide Use and Farm-Level Productivity: The Case of High-Value Crops in Kenya' (2009) 60 Journal of Agricultural Economics 645; Julie Subervie and Isabelle Vagneron, 'A Drop of Water in the Indian Ocean? The Impact of GlobalGap Certification on Lychee Farmers in Madagascar' (2013) 50 World Development 57.

311 Catherine Dolan and John Humphrey, 'Governance and Trade in Fresh Vegetables: The Impact of UK Supermarkets on the African Horticulture Industry' (2000) 37 Journal of development studies 147; Thomas Reardon and others, 'The Rise of Supermarkets in Africa, Asia, and Latin America' (2003) 85 American journal of agricultural economics 1140; Matthew Warning and Nigel Key, 'The Social Performance and Distributional Consequences of Contract Farming: An Equilibrium Analysis of the Arachide de Bouche Program in Senegal' (2002) 30 World Development 255.
} 


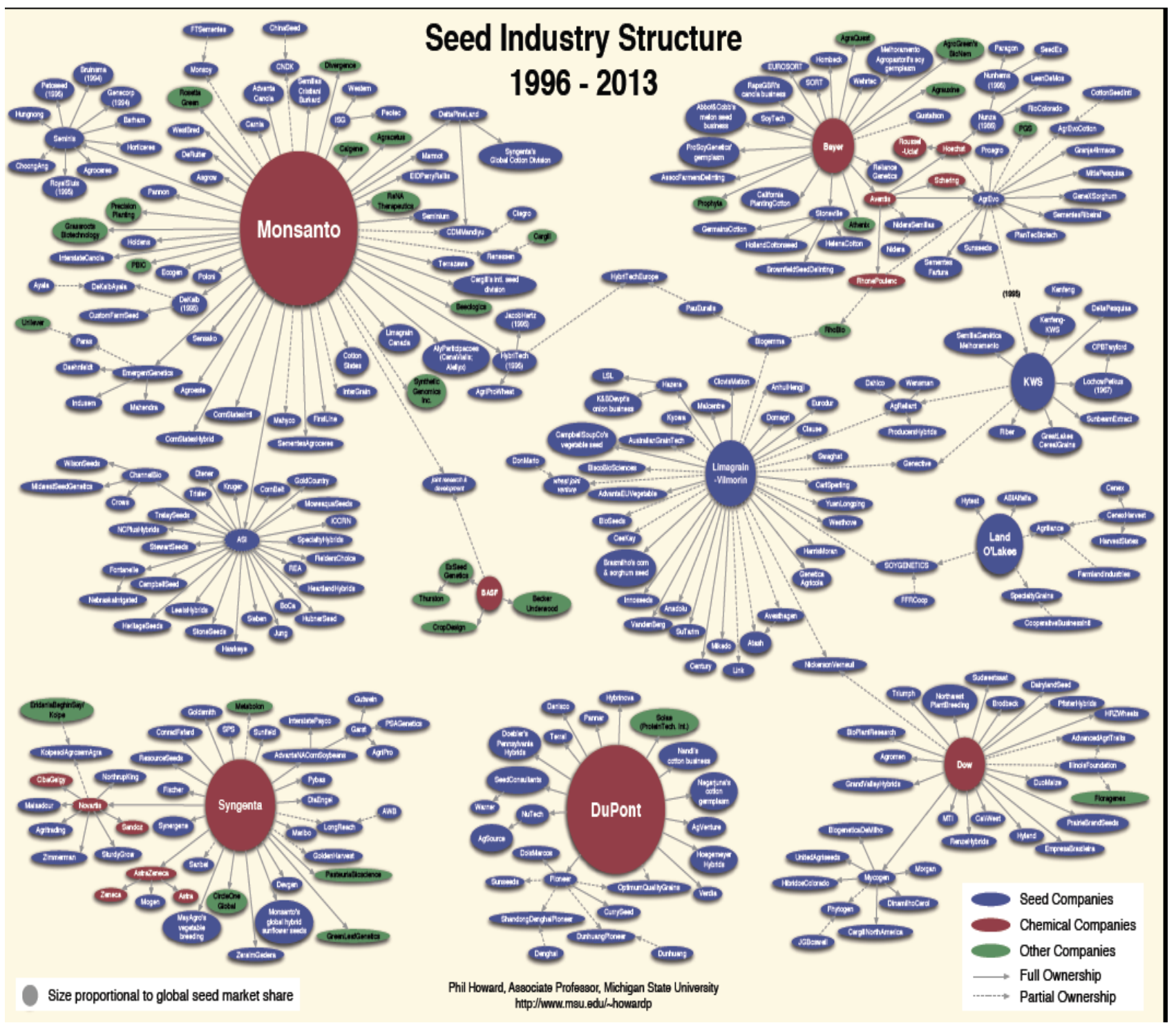

Source: Philip H. Howard, (2009) ${ }^{312}$

It is also important to take into account of the specific local competitive conditions, which may provide to an undertaking significant power over price that may impact a large group of consumers, even in the absence of a large presence in the national market. A recent submission by the Israeli competition authority to an OECD Report on Competition Issues in the Food Chain Industry advances the concept of "competition groups" in the assessment of the competition interactions between various retail stores in a geographic area.

\section{Textbox 1: Constructing a Store's Competition Group}

OECD, Report on Competition Issues in the Food Chain Industry, DAF/COMP(2014)16, 239-241

312 Philip H. Howard, Visualizing Consolidation in the Global Seed Industry: 1996-2008, Sustainability 2009, 1(4), 1266-1287. 
To support the implementation of the Food Act, the antitrust authority developed a model that defines geographical markets in the grocery retail sector and establishes a demand area and competition group for each store of a major retailer. The application of the model consists of three stages:

1. Defining the demand area - a demand area is defined from the perspective of each store as a collection of statistical regions in its vicinity that account for a significant portion of the store's sales. This area will be defined based on the characteristics of consumer 114ehaviour in the area (or at the national level) such as preference for certain store characteristics (size, amenities, variety, etc.) and average travel time to a store. 2. Defining the competition group - a store's competition group is comprised of a collection of rival stores that compete over a significant number of consumers with the store in question. That is, any rival store for which the number of consumers existing in both the demand area of the rival store and the demand area of the store in question is above a certain threshold will be included in the competition group. The underlying assumption is that for the rival store to serve as a competitive restraint on the 114ehaviour of the store in question there needs to be a critical mass of consumers both stores compete over. The threshold corresponding to this critical mass is determined by the director general ("the determined rate"). Three main points regarding the determination of the competition group call for clarification:

A. A rival store may be located outside a store's demand area but included in its competition group as long as there is overlap between the demand areas of the two stores. For example, as shown in the figure below, stores B and C compete with store A despite the fact that they are not in store A's demand area. Store B is in store A's competition group because these two stores share statistical regions 1 and 4 and the population in these two regions constitutes $40 \%$ of the total population of store A's demand area (statistical regions 1 to 5). Hence store B constrains store A's incentive to raise prices, as then store A stands to lose $40 \%$ of its potential customers. A similar reasoning shows that store $\mathrm{C}$ too is in store A's competition group.

B. Not every rival store in the demand area of the store under examination is necessarily included in the store's competition group. For example: store D in the figure below is not in competition with store A despite being in store A's demand area. Store D attracts only consumers from statistical region 5. Hence, if store A raises prices, the highest number of consumers it could lose to store $\mathrm{D}$ is the population of statistical region 5 , which constitutes only $15 \%$ of the population in store A's demand area.

C. The relationship of being in one's competition group is not necessarily symmetric. For example, a high revenue store located near a low revenue store may be in the competition group of the low revenue store, but not vice versa. To illustrate, as noted, store A does not see store D as a competitor (only 15\% of store A's potential customers come from store D's demand area). Nevertheless, store D sees store A as a competitor: $100 \%$ of store D's potential customers (the population of statistical region 5) are also in store A's demand area. When store D raises prices, it might lose all of its potential customers to store A. 
3. A store is determined to be "concentrated" if the total revenues of all stores in its competition group that belong, along with the store in question, to the same chain constitute more than $30 \%$ of the total revenue of all stores in the competition group.

区 There are four stores: A, B, C, D

X The demand area of each store consists of the statistical areas as follows:

- The demand area of store $A$ includes statistical region 1-5;

- The demand area of store $B$ includes statist:

- The demand area of store $\mathrm{C}$ includes statistical region 1,2,9-11;

- The demand area of store $\mathrm{D}$ includes statistical region 5 .

区 Constructing competition groups (assuming an overlap threshold of $30 \%$ :

\begin{tabular}{||l|l|l|l|}
\hline $\begin{array}{c}\text { Store under } \\
\text { Examination }\end{array}$ & $\begin{array}{c}\text { Potential } \\
\text { Competitor }\end{array}$ & Overlap Rate & Rival Store? \\
\hline A & B & $40 \%$ & Yes \\
\hline A & C & $50 \%$ & Yes \\
\hline A & D & $15 \%$ & No \\
\hline D & A & $100 \%$ & Yes \\
\hline
\end{tabular}

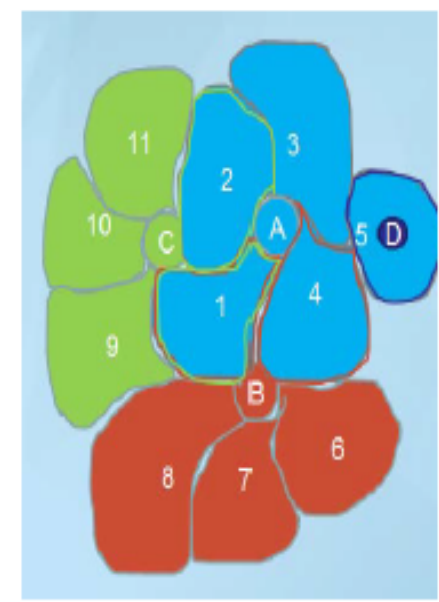

区 This results in the following competition groups for stores $A$ and $D$ :

\begin{tabular}{|l|l|}
\hline Store & $\begin{array}{l}\text { Competition } \\
\text { Group }\end{array}$ \\
\hline A & B,C \\
\hline D & A \\
\hline
\end{tabular}

In the UK, in the private ophthalmology investigation of Chapter I CA98/101 TFEU infringement the CMA focused on local areas ${ }^{313}$. The CMA has also used catchment areas in market definition of various merger cases ${ }^{314}$. Finally, the CMA also used catchment areas for market definition purposes on the private healthcare market investigation ${ }^{315}$. The European Commission has used catchment areas in merger cases especially involving airline companies $^{316}$ and some cases involving maritime conferences ${ }^{317}$.

The recent SIA Maxima Latvija case of the CJEU may provide an additional example of the consideration of the local competition conditions when assessing vertical restraints and the possibility of local market power. The case concerned a non-compete clause concerned

\footnotetext{
${ }^{313}$ Conduct in the ophthalmology sector, Case CE/9784-13 (2015), paras 3.46-3.48.

314 eg. Completed acquisition by Lafarge Tarmac Holdings Limited of Tarmac Building Products Limited, available at https://assets.publishing.service.gov.uk/media/53760e58ed915d0ff1000005/Lafarge.pdf and more recently see Celesio / Sainsbury's Pharmacy Business merger inquiry (2016), available at https://assets.publishing.service.gov.uk/media/579b817540f0b64974000014/sainsbury_s-celesio-finalreport.pdf.

${ }^{315}$ Final Report, Private Healthcare Market Investigation (April 2014, CMA25), paras 5.62 and onwards. It readopted the approach also in its provisional findings report in the Private Healthcare remittal, (November 2015), para 3.34.

316 e.g. Case No COMP/M.6447 -IAG/ BMI (2012), Case No COMP/M.6447 -IAG/ BMI (2015) and Case No COMP/M.4439- Ryanair / Aer Lingus (2007).

317 Commission Decision 94/980/EC, (IV/34.446 - Trans-Atlantic Agreement), [1994] OJ L 376/1, paras 67 onwards; See also, Commission Decision 1999/243/EC, (IV/35.134 - Trans-Atlantic Conference Agreement), [1999] OJ L 95/1, para 84 in relation to Northern Europe ports.
} 
included in a commercial lease agreement between a major retailer and the owner of a shopping centre. ${ }^{318}$ The Court considered that this was a vertical agreement and applied the Delimitis cumulative effect approach in order to assess the possible foreclosure effect, focusing on the various catchment areas affected by the agreement. According to the Court, the first part of the test consists 'in the examination of all the factors affecting the access to the relevant market for the purposes of assessing whether, in the catchment areas where the shopping centres which are covered by those agreements are located, there are real concrete possibilities for a new competitor to establish itself'. ${ }^{319}$ The second part of the test explores 'the conditions under which competitive forces operate on the relevant market', which includes 'not only the number and the size of operators present on the market, but also the degree of concentration of that market and customer fidelity to existing brands and consumer habits'. ${ }^{320}$

\footnotetext{
${ }^{318}$ Case C-345/14 SIA Maxima Latvija v Konkurences padome [2015] ECLI:EU:C:2015:784.

319 ibid, para 27.

${ }^{320} \mathrm{ibid}$, para 28.
} 


\section{References}

Asfaw S, Mithöfer D and Waibel H, 'EU Food Safety Standards, Pesticide Use and Farm-Level Productivity: The Case of High-Value Crops in Kenya', (2009), 60 Journal of Agricultural Economics, 645.

Backer K and Miroudot S, Mapping Global Value Chains (OECD, 2013).

Binkley J K and Connor J M, 'Market Competition and Metropolitan-Area Grocery $\begin{array}{lllll}\text { Prices', } 1996 . & \text { Available } & \text { at } & \text { SSRN } & 1238553\end{array}$ <http://papers.ssrn.com/sol3/papers.cfm?abstract_id=1238553>.

Competition Commission of India, 'Competitive Assessment of Onion Markets in India', 2012. Available at <http://www.cci.gov.in/images/media/completed/AO.pdf > .

Cotterill R W, 'Market Power in the Retail Food Industry: Evidence from Vermont', 1986, The Review of Economics and Statistics, 379.

Cotterill R W and Harper C D, 'Market Power and the Demsetz Quality Critique: An Evaluation for Food Retailing', (University of Connecticut, Department of Agriculture and Resource Economics, 1995).

Dolan C and Humphrey J, 'Governance and Trade in Fresh Vegetables: The Impact of UK Supermarkets on the African Horticulture Industry' (2000) 37 Journal of development studies 147.

Duke University, Global Value Chains. Available at http://sites.duke.edu/minerva/theglobal-value-chain/

FAOStat, 2013. Available at <http://faostat3.fao.org/home/E>

Gataulina EA and others, 'Vertical Integration in an Agroindustrial Complex: Agrofirms and Agroholdings in Russia', 2006, The dynamics of vertical coordination in agrifood chains in Eastern Europe and Central Asia: case studies. Working Paper 45.

Gereffi G, Hymphrey J and Sturgeon T, 'The Governance of Global Value Chains', 2005, 12 Review of International Political Economy, 78.

Gereffi G and Christian M, 'Trade, Transnational Corporations and Food Consumption: A Global Value Chain Approach', in C. Hawkes, C. Blouin, S. Henson, N. Drager, L. Dubé (eds.) Trade, Food, Diet and Health Perspectives and Policy Options (Wiley Blackwell, 2010) 3.

Handschuch C, Wollni M and Villalobos P, 'Adoption of Food Safety and Quality Standards among Chilean Raspberry producers-Do Smallholders Benefit?', (2013), 40 Food Policy, 64.

Harris J M and others, The US Food Marketing System: Competition, Coordination and Technological Innovations Into the 21st Century', (USDA Economic Research Service, 2002).

Howard P, 'Visualizing Consolidation in the Global Seed Industry: 1996-2008', (2009), Sustainability 1(4), 1266-1287. 
Humphrey J and Memedovic O, 'Global Value Chains in the Agrifood Sector', 2006, UNIDO 5. Available at http://agris.fao.org/agris-search/search.do?recordID=GB2013202293>

Kaufman P R and Handy C, U.S. Fresh Produce Markets: Marketing Channels, Trade Practices, and Retail Pricing Behavior, (US Dept of Agriculture, Economic Research Service, 1989).

Kogut B, 'Designing Global Strategies: Comparative and Comperative Value Added Chains', (1985), 26 Sloan Management Review.

Kneafsey M and others, 'Short Food Supply Chains and Local Food Systems in the EU', (2013, Report EUR 25991 European Commission).

KPMG International, 'The agricultural and food value chain: entering a new era of cooperation', 2013.

South Centre, 'Rebalancing the Supply Chain: Buyer Power, Commodities and Competition Policy', 2008, South Centre.

MacDonald M J and others, Contracts, Markets, and Prices: Organizing the Production and Use of Agricultural Commodities, (USDA-ERS Agricultural Economic Report, 2004).

Minten B, Randrianarison L and Swinnen J, 'Global Retail Chains and Poor Farmers: Evidence from Madagascar', (2009), 37 World Development, 1728.

Nordås H K, Grosso M G and Pinali E, 'Market Structure in the Distribution Sector and Merchandise Trade', (OECD, 2008).

OECD, Report on Competition Issues in the Food Chain Industry, DAF/COMP, 2014 (16), 239-241.

Reardon T and others, 'The Rise of Supermarkets in Africa, Asia, and Latin America', (2003) 85 American Journal of Agricultural Economics, 1140.

Swinnen J, 'Global Supply Chains, Standards and the Poor How the Globalization of Food Systems and Standards Affects Rural Development and Poverty', (CABI , 2007) 1.

Swinnen J, 'Global Agricultural Value Chains, Standards, and Development', 2014, 30 Robert Schuman Centre for Advanced Studies Research Paper No. RSCAS. Aavailable at http://papers.ssrn.com/sol3/Papers.cfm?abstract_id=2434532> ).

Swinnen J and Vandeplas A, 'Quality, Efficiency Premia, and Development', 2008,

LICOS Discussion Paper No. 184/2007. Available at
http://papers.ssrn.com/sol3/papers.cfm?abstract_id=1106101> .

Subervie J and Vagneron I, 'A Drop of Water in the Indian Ocean? The Impact of GlobalGap Certification on Lychee Farmers in Madagascar', (2013) 50 World Development, 57.

Tandon S and others, 'The Expansion of Modern Grocery Retailing and Trade in Developing Countries', (US Dept of Agriculture, Economic Research Service, 2011)

Warning M and Key N, 'The Social Performance and Distributional Consequences of Contract Farming: An Equilibrium Analysis of the Arachide de Bouche Program in Senegal', (2002), 30 World Development, 255.

World Bank, Agriculture for Development, (World Bank 2008). 
World Bank, The Dynamics of Vertical Coordination in Agrifood Chains in Eastern Europe and Central Asia: Implications for Policy and World Bank Operations, (The World Bank, 2005).

\section{Figures}

Figure 1: Total Food Supply Chain .......89

Figure 2: The Long + Short Supply Chain....90

Figure 3: Food distribution channels....91

Figure 4: Key profitability metrics of the agribusiness value chain...92

FIgure 5: Key profitability metrics...92

Figure 6: Example of Interaction of Global Value Chain and Local Value CHain in the Wheat Market......94

Figure 7: The System of WHolesale in Russia prior to $1993 \ldots . .95$

Figure 8: Structure of Orel Niva Public Company...96

FIgure 9: Seed Indsutry Structure...99 


\title{
Chapter 2: The various segments of the food value chain: a general account
}

\author{
Ioannis Lianos with Averill Campion \& Dmitry Katalevsky
}

\subsection{Cost structure and global food value chains}

The market for factors of production comprises different segments, the largest in terms of sales being fertilisers and animal feed (not including medicated seeds, which form part of the animal health sector $)^{321}$. These two markets consist of mostly bulk inputs not involving much of R\&D and account for 60 percent of total agricultural input sales ${ }^{322}$. Farm machinery and equipment account for 21 percent, crop protection chemicals for around 9,5\%, while crop seeds for 5,5\% of inputs purchased by farmers. Animal health and animal breeding materials account for the remaining 4 percent $^{323}$. In China, the cost of buying seed account for $25 \%$ of the total cost of fertiliser, farmyard manure, agricultural pesticides and agricultural mulch ${ }^{324}$.

Historically farmers have met their proportion of demand for crop seed and animal breeding stock through self-supply or by obtaining these inputs through informal markets or from neighbouring farms. These methods of procurement however declined since the emergence of private seed companies and about $2 / 3$ of the crop used globally now is supplied by private seed companies ${ }^{325}$. The situation is however different in developing countries, where " $80 \%-90 \%$ of the seed planted by farmers in the global South comes from the so-called "informal sector" - that is, farm-saved seeds (including seed exchange with neighbouring farms and seed sales from local markets or seed fairs)" and "(j)ust 10\%- $20 \%$ of seed requirements in developing countries is met by the "formal sector" - that is, seed companies, government seed sources or other institutions" 326 .

If one looks to growth, only the markets for farm machinery and seeds have grown significantly in recent decades ${ }^{327}$. In recent years there has been significant investment in $\mathrm{Ag}$ Biotechnology (with an increase of almost 150\% from 2014 to 2016), in farm management software, sensing and Internet of Things applications in agriculture (with an increase of investment of $3.7 \%$ during the same period), novel farming systems (an increase of $63 \%$ the same period) and supply chain technologies (an increase of 3\% during the same period) ${ }^{328}$. Investment in Robotics mechanization and other hardware, such as drone technologies applied in agriculture, has also increased in 2015 although it suffered a pullback in 2016. The sector's funding is, however, dominated by investments in food marketing/food e-commerce which

\footnotetext{
${ }^{321}$ K. Fuglie et al, Research Investments and Market Structure in the Food Processing, Agricultural Input, and Biofuel Industries Worldwide, USDA-ERS Economic Research Report No. 130 (2011) 11.

322 Ibid.

${ }^{323}$ Ibid.

${ }^{324}$ Survey questionnaire completed by the Chinese competition authorities for the purposes of this Study.

${ }^{325}$ K. Fuglie et al, Research Investments and Market Structure in the Food Processing, Agricultural Input, and Biofuel Industries Worldwide, USDA-ERS Economic Research Report No. 130 (2011) 11.

${ }^{326}$ ETC Group, Putting the Cartel before the Horse ....and Farm, Seeds, Soil, Peasants, etc. - Who Will Control Agricultural Inputs, 2013?, Communiqué no 111 (September 2013).

${ }^{327}$ K. Fuglie et al, Research Investments and Market Structure in the Food Processing, Agricultural Input, and Biofuel Industries Worldwide, USDA-ERS Economic Research Report No. 130 (2011) 11.

${ }^{328}$ AgTech Investing Report, Year in Review 2016 (January 31 ${ }^{\text {st }}, 2017$ ), 17.
} 
account for $40 \%$ of the total funding, the category of food and agtech being valued to at least $\$ 60$ billion $^{329}$. Biotechnology startups come next, attracting almost $22 \%$ of funding ${ }^{330}$.

\subsection{The various segments of food value chains}

\subsubsection{Seeds \& Traits}

The seeds industry is an example of industries that changed dramatically over the last 50 years from post-harvest seeds savings practice by farmers to purchasing of seeds from a few global industrial giants. Crops are usually classified in eight broader groupings: corn, cereals, soybean, vegetables, rice, diverse field crops, sugar cane, and specialty crops ${ }^{331}$. The industry evolved through a number of major biotech advancements and legal enhancements of intellectual property rights (IPRs). Technology-driven growth has not been the only major transformation of this economic sector. Its consolidation, in particular in the factors of production segment, has been particularly important in recent years. The various segments of the factors of production markets have been progressively consolidated in (most frequently tight) oligopolies. In the seeds sector, a number of merger waves, starting in the 1980s, have led to the emergence of a relatively concentrated market structure of 6 big players thirty years later (Monsanto, Syngenta, DuPont, BASF, Bayer, Dow, the so called 'Big Six').

The first merger wave occurred in the mid-1980s, swiping aside a market structure dominated until then by commercial seed companies that were formed in the 1930s following the introduction of the first hybridized crops. Until then farmers have been cultivating new plant varieties for thousands of years through selective breeding by cross-pollinating two different, but related plants over 6 to 10 plant generations, eventually creating a new plant variety. The introduction of a method of controlled crossing (marker-assisted breeding) that can create these desired traits within just one generation led to the development of a special kind of hybrid crops, the so called F1 hybrid seeds, which combine characteristics of two related plants, thus following the process of cross-pollination. Second generation hybrids do not however 'reproduce true', thus they may not share the desired characteristics as selected in the first generation. A farmer cannot expect the next generation of plants to be identical to the first, which may lead farmers to purchase seeds rather than save the seeds and replant them the next season, as they have done for generations.

Following the discovery in 1973 by Cohen and Boyer of the basic technique for creating recombinant DNA, enabling the development of bacterial enzymes capable of cutting DNA at specific sites and splicing DNA segments into foreign DNA in order to create recombinant molecules with altered functions, crop scientists were able to identify and isolate desired traits, modify the relevant genes, for instance knocking out a gene to produce a desirable characteristic (for instance resistance to a specific disease), or eventually adding one or more new genes that are not already found in that organism (transgenic genetic engineering) and then incorporate these traits into new crop varieties via transplantation with greater

\footnotetext{
329 Ibid., 14.

330 Ibid.

${ }^{331}$ Syngenta, Our Industry 2016, 49.
} 
precision and more quickly than traditional marker-assisted breeding for native (non-biotech or non-genetically engineered) traits. The traits are engineered by insertion of foreign genes into the plants, that cross different biological groups (bacteria and plants). These genes may be single or stacked and usually confer a desirable attribute to the seed, for instance herbicide or insect resistance.

Traditional marker-assisted breeding enables breeders to select plants with desirable combinations of genes by using genetic markers to identify the versions of the specific genes associated with the desirable trait. Markers allow breeders to guide performance at the early stages of breeding, leading to the development of plants with new properties without incorporating undesirable genes generally found in the original organism. Although markerassisted breeding and traditional hybridization creates seed varieties with greater yield potential and more desirable biological characteristics, from those already found in the organism, genetic engineering provides the possibility to add new traits that it would not have been possible to develop using marker-assisted breeding, thus greatly enhancing breeding productivity.

Genetically-engineered seeds may also limit the possibility of farmers to save the seeds and replant them the next season. In a meta-analysis of 147 studies $^{332}$ about the impacts of these genetically-engineered seeds, it was found that overall GM technology adoption has reduced chemical pesticide use by $37 \%$, increased crop yields by $22 \%$, and increased farmer profits by $68 \%$. Consequently, the benefits in terms of productivity of genetically-engineered seeds appear to be significant.

By finding in Diamond vs Chakrabarty (1980) that a bacterium breaking down crude oil qualifies as patentable subject matter as a "non-naturally occurring manufacture or composition of matter" and a "product of human ingenuity" the US Supreme Court opened the door to the patentability of engineered plant breeds ${ }^{333}$. In 1985, the USPTO expanded patent protection to genetically modified traits in Ex Parte Hibberd ${ }^{334}$, adding to the existing IP protection of newly developed plant breeds through the Plant Patent Act of 1930 (providing patent rights for developers of new varieties of asexually propagated plants propagated by cutting pieces of the stem rather than germinating seeds) or the Plant Variety Protection Act of 1970 (protecting developers of new varieties of seed-propagated plants). In 2001, the US Supreme Court held for the first time in J. E. M. Ag Supply, Inc. v. Pioneer that utility patents may be issued for crops and other flowering (sexually reproducing) plants and can be combined with plant variety rights protection and/or plant patents ${ }^{335}$. With a utility patent, patent-holders can sue farmers and rivals for patent infringement and pursue litigation to enforce licensing agreements. Utility patents are routinely used for genetically modified traits, traditional germplasm and biotechnology research tools and provide a higher degree of protection than

\footnotetext{
${ }^{332}$ See Klumper, W, Qaim M (2014). A Meta-Analysis of the Impacts of Genetically Modified Crops. PLoS ONE 9(11): e111629.

${ }^{333}$ Diamond v. Chakrabarty, 447 U.S. 303 (1980).

334227 U.S.P.Q. 443 (Board of Patent Applications and Interferences, 1985).

335 J. E. M. Ag Supply, Inc. v. Pioneer Hi-Bred International, Inc., 534 U.S. 124 (2001). This overlapping protection was significant as U.S. Plant variety protection legislation [7 U.S.C. $\$ \S 2543-2544$ ] conferred "less robust protection than utility patents" as it allows farmers to save seeds for replanting and provides for a research exception for private, non-commercial uses of protected seed. See, D. Lim, Living with Monsanto, (2015) Michigan State Law Review 559, 567.
} 
plant variety rights as there is no exemption for farmers or plant breeders to use materials protected by the utility patent. We examine the role of IP rights in this sector at Part IV, Chapter 1 .

Intellectual property protection first permitted small biotech start-ups to receive funding from venture capital and other sources of funding in order to progress in the applied segment of their research, while it also enabled them, at the second stage, to be targeted by a wave of merger and acquisitions with large agri-chemical corporations that started investing in the development and large scale commercialisation of the products emerging out of the research efforts, thus guaranteeing a greater dissemination of these new technologies and products in food production. Already in the 1970s and the development of plant variety protection rights, a number of chemical and pharmaceutical companies had acquired a number of small and medium sized regional seed companies, but a number of larger seed companies (e.g. Pioneer, DeKalb) and smaller regional seed companies remained in the market.

The second wave of M\&As occurred in the mid-1990s/early 2000s where a number of seed companies were either acquired or entered into joint ventures with a number of large multinational with investments and research capacity in biotechnology. At the same time, large pharmaceutical companies, such as AstraZeneca, Novartis, and American Home Products, which collectively controlled about 26 percent of the global agricultural market, chose to divest their seed germplasm assets and concentrate on core their pharmaceutical businesses. This led to the re-structuring of the sector with the combination of biotechnology know how, genetic research assets and IP rights with seed germplasm, as this would have facilitated the commercial introduction of new GM or biotech seeds. As agro-chemical firms and other diversified firms vertically integrated into the seed business and seed genetics, new global players emerged. For instance, before the mid-1980s, Monsanto was primarily active in the production of chemicals and optoelectronics, while Syngenta was created in 1999 as a spin-off, following the merger between the agrochemical business of pharmaceutical corporation AstraZeneca and the seeds and crop protection business of Novartis. The result of this extensive merger activity is that in the number of independent seed companies has passed from 600 in 1996 to 100 in 2009.

The most recent merger wave was initiated in July 2014 when Monsanto made a number of acquisition offers to Syngenta. These offers were rejected, but the Monsanto bid triggered a number of other M\&A transactions that were announced in 2015 and 2016 between the various market leaders in the factors of production segment. In November 2015, Syngenta accepted the offer of ChemChina (which owns ADAMA, one of the largest agrochemical companies in the world). In December 2015, Dupont and Dow announced their merger, which was cleared with conditions by the European Commission in March 2017336. In September 2016, Bayer put forward a merger deal with Monsanto, triggering an in-depth investigation ${ }^{337}$ by the European Commission due to concerns over reduced competition, especially in the seeds

\footnotetext{
${ }^{336}$ European Commission, IP/17/772 (2017), available at http://europa.eu/rapid/press-release_IP-17-772_en.htm 337 European Commission, IP/17/2762 (2017) available at http://europa.eu/rapid/press-release_IP-172762_en.htm
} 
area. One year later, BASF is now set to acquire Bayer's seed business ${ }^{338}$ which will result in an even denser market shrinkage. However, until October 2017 BASF had not initiated any specific actions to consolidate, leading its speculative chess board open to the possibility to buy up smaller companies, or sell, because it would not have the strength to take on the concentrated power of its competitors ${ }^{339}$. If all the proposed megamergers are approved, these three companies (ChemChina-Syngenta, DuPont-Dow, Bayer-Monsanto) will own and sell about $60 \%$ of the world's patented seeds and pesticides/herbicides (AgriPortal, 2016).

The global commercial seed market is valued at around USD 38.5 billion (some estimates putting this at USD 48.5billion) ${ }^{340}$, with Monsanto possessing the highest seeds market share of 23\%, followed by DuPont at 15\%, and Syngenta at 9\%. in 2016

Table 1: The twelve main global seed companies ranked by their global seed sales in billions USD in 2016

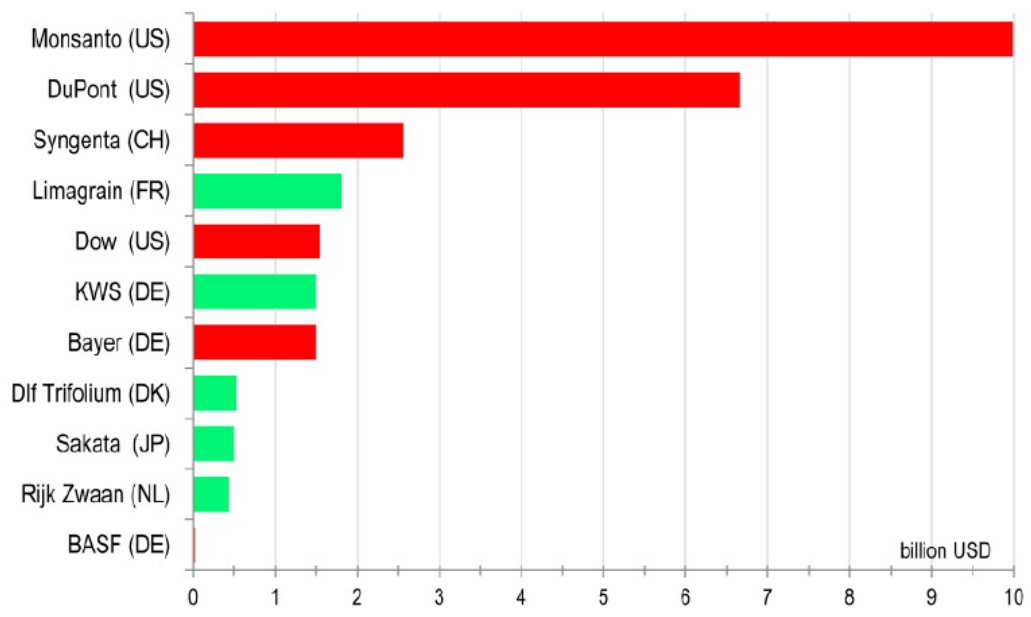

Source: S. Bonny (2017) ${ }^{341}$

The size of the seed market is relatively small in comparison to the rest of the food value chain, and in particular retail, mainly "because the added value is much higher at the end of the agrifood chain than at its beginning" ${ }^{342}$. Most of the big companies in the sector come from the chemical industry, only Limagrain and KWS being from the agricultural and seed sector. Monsanto and DuPont have a high share of seeds in their total agricultural sales, while Syngenta, Bayer, Dow and BASF mainly sell pesticides, while Limagrain and KWS only focus

\footnotetext{
338 See Financial Times (2017), available at: https://www.ft.com/content/1d5ca16b-412d-3ed2-8899$7185 f 5308009$ ? mhq5j=e5 .

${ }^{339}$ ETC Group. 2016. The Monsanto-Bayer tie-up is just of seven: Mega-mergers and big data domination threaten seeds and food security. [Online] Available: http://www.etcgroup.org/content/monsanto-bayer-tie-just-onesevenmega-mergers-and-big-data-domination-threaten-seeds-food .

${ }^{340}$ See the comparative table by S. Bonny, Corporate Concentration and Technological Change in the Global Seed Industry, (2017) 9 Sustainability 1632, Table 1.

341 Ibid., Figure 3 (noting that "( $(\mathrm{t})$ he total size of seed market is not well known due to the difficulty of assessing the value of seeds saved by farmers and the total value of the commercial seed market").

342 Ibid., at 1632 (noting in comparison that the food distribution segment of the value chain weighs USD 834 billion, while the food processing segment USD 507 billion).
} 
on seeds. The recent merger consolidation will however establish integrated platforms in both seeds and plant protection agents.

There exist various kinds of seeds that may be used by the farmers. Bonny distinguishes four categories:

“ - Conventional' seeds are supplied by approximately 7500 companies of different sizes from around the world.

- GM seeds are usually created by big companies. However, smaller companies can also sell GM crops through license agreements on genetic traits.

- Farmers' seed systems result from the breeding efforts of farmers in their fields to obtain seeds that they expect to be better suited to their soil, practices, and needs. While these have become less important in industrialized countries because of the development of hybrid seeds for some crops, they can constitute a substantial part of the seeds sown in less-developed countries.

- Farm saved seeds are sown and harvested from conventional seeds purchased in the previous year. Seeds from a small fraction of this harvest are sown the next season after sorting and cleaning. It is essential to differentiate these seeds from the farmers' seed systems mentioned above, since these saved seeds are a kind of "copy" of purchased seeds rather than newly-bred ones.

- Seeds from public research are rarely sold as end-user seeds to farmers since public research generally works upstream in plant breeding" 343 .

Genetically modified (GM) seeds' share in the global commerce of seeds has been growing from $9 \%$ in 2001 to $33 \%$ in 2016. The seed and traits value chain is primarily guided by the Big Six (Monsanto, Bayer, DuPont, Sygenta, Dow, and BASF) and consists two primary crucial inputs: the germplasm pool and advanced breeding technologies. Plant germplasm refers to the genetic base of a specific crop ranging from the "elite" germplasm of modern plant improvement to more wild plants that can potentially provide useful genes for improvements or for future domestication. As living genetic resources, germplasms are stored in seed banks to be used for plant research, breeding, and preservation and play a critical role in maintain the diversity needed to sustain genetic improvements for polygenic traits like yield, responding to pathogen pressures, and for providing genetic buffering. The second major input, advanced breeding technologies, involves using gene-editing technologies such as DuPont Pioneer's CRISPR-Cas to increase the productivity and sustainability of these seeds ${ }^{344}$. CRISPR-Cas advanced breeding technology can improve seeds with the creation of elite corn hybrids that use native characteristics found in a target crop, resulting in a five-bushel-per-acre increase in grain yield. This is particularly useful for water limited environments.

\section{Table 2: Seed and traits value chain}

343 S. Bonny, Corporate Concentration and Technological Change in the Global Seed Industry, (2017) 9 Sustainability 1632.

344 See SeedWorld (2016). DuPont Pioneer Establishes a CRISPR-Cas Advanced Breeding Platform. Available at: http://seedworld.com/dupont-pioneer-establishes-crispr-cas-advanced-breeding-platform/ 


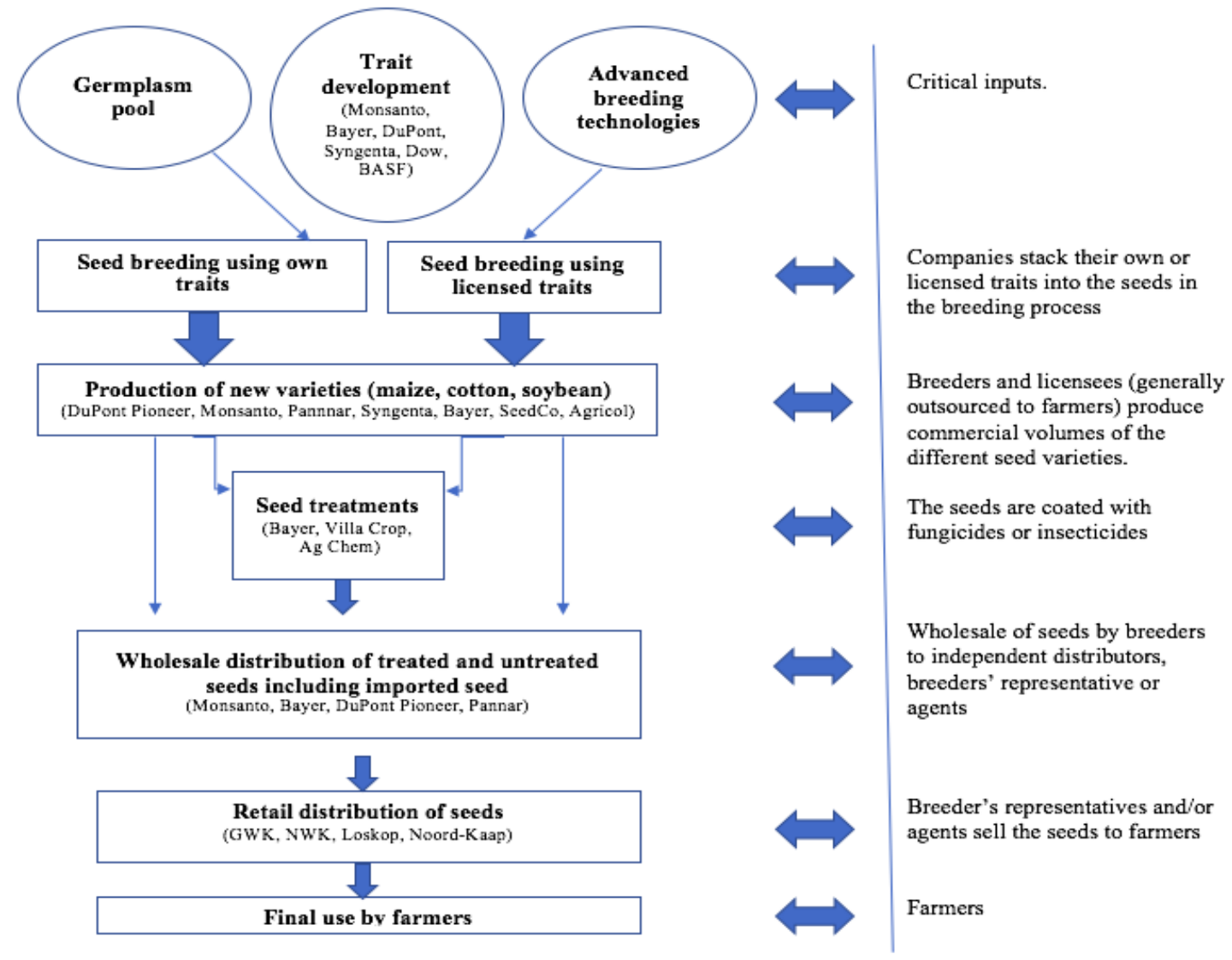

Source: Competition Commission of South Africa (2017) $)^{345}$

The interconnected and interdependent relationships amongst actors in the second and third stages of the seed and traits value chain has resulted in a highly integrated relationship between agbiotechnology and seed firms ${ }^{346}$. Specifically, the second stage consists of germplasm pools to breed seeds using their own traits or companies that infuse their own patented traits into the seeds and breeding process.. As a result, the commercialization of these GM traits has raised major strategic issues for agbiotechnology and seed firms involved at this stage as to whether it is better to release their own varieties of traits or to license the seed firms. These licensing agreements between seed firms and agbiotechnology firms allow trait development for the portfolio, but not for commercial output. The third stage in the seed \& traits value chain is the production of new varieties of seeds which are produced in commercial sized volumes. Next in the value chain, seeds receive treatments and are coated with fungicides or insecticides.

The South African DAFF reports that the formal seed system was worth USD 3.6 billion in 2010-11 with maize as the largest seed sector in 59\% of the total seed market by value. In May 2017, the Competition Commission of South Africa conditionally approved a Bayer and Monsanto transaction whereby Bayer intends to acquire Monsanto. While the new

\footnotetext{
${ }^{345}$ Competition Commission of South Africa, Case 2017Feb004 (Bayer/Monsanto) (May 3, 2017), p. 34, para. 76 (figure based on third parties and merging parties' submissions).

${ }^{346}$ W. Wilson \& Huso, S, Trait Stacking, Licensing, and Seed Firm Acquisitions in Genetically Modified Grains. (2008) 33(3) Journal of Agricultural and Resource Economics. 383.
} 
company will control $20 \%$ of the commercial seed market and agrochemical market ${ }^{347}$, the most concerning area of competition are GM cotton seeds, as $84.6 \%$ of cotton seeds varieties in South Africa are owned by Monsanto. In addition to GM cotton seeds, Monsanto also employs $80 \%$ of private sector breeders in maize and and $100 \%$ of the breeders in soybean and sunflowers ${ }^{348}$. Although the merger would create a monopoly and eliminate competition in the development and production of seed traits and herbicides, it is argued that the consolidation of these forces is beneficial to the scaling of research and development budgets ${ }^{349}$ so that greater innovation can take place. With a shift from the Big Six to the Big Three, the power and control over R\&D risks being focused more on high-profit products that benefit the mergers versus targeting the most appropriate products needed by South African farmers. A 2016 South African Grain Seeds Analysis report conveys that " a competitive seed sector is key to ensuring timely availability of appropriate and high quality seeds and affordable prices to farmers in South Africa." The South African seed industry has matured into a sector with 107 seed companies and has seen exports of around USD 73 mill from the years 2012-2013. Currently, four companies dominate ownership of maize seeds: Monsanto, Pioneer Hi-Breed, Pannar, and Klein Karoo Seed ${ }^{350}$, which is differentiated from the market share due to variety types.

On the other hand, it is further suggested that due to the interlinkage of this stage, the elimination of competition actually remedies the situation since the SA Commission will require Bayer to divest and sell the entire global Liberty Link trait technology and associated branded business and require the future purchaser to commercialize it in South Africa or license out to a third party as to enable the country to benefit from this divestiture. As both Monsanto and Bayer possess technological systems for seed trait production and accompanying herbicides used on those seeds, cross licensing agreements could enhance the merger. Nonetheless, less competition and more oligopoly could lead to a path dependency, locking farmers into a narrow input model of producing just three main crops: maize, soya, cotton ${ }^{351}$ instead of a variety that could feed and benefit the food security of the South African population. There are also expressed concerns that the reduced competition trend undermines the emergency of alternative systems more inclusive of smallholder farmers to promote a more egalitarian agricultural economy. Moreover, implications of increased input costs and reduced choices for farmers and consumers could reinforce that the South African market is a dumping ground for the unsuccessful, old GM technologies in which Monsanto has incurred deep sunk costs from development ${ }^{352}$. Regardless, South Africa is strategically important for both companies in terms of sales as Bayer holds (206) patents on transgenic plant traits and Monsanto holds (119). Consequently, this merger is advantageous as means of access to proprietary knowledge of each company and expected costs savings towards the next big shift in genome editing technology CRISPR.

\footnotetext{
347 See All Africa (2017) "Agribusiness Giants on Merger Path". Available at: http://www.allafrica.com/stories/201702270838.html

${ }^{348}$ African Center for Biodiversity available at http://www.acbio.org.za

${ }^{349}$ ACBIO (2017). The Three Agricultural Input Mega-Mergers: Grim Reapers of South Africa's Food and Farming Systems.

${ }^{350}$ Department of Agriculture, Forestry and Fisheries, Republic of South Africa (2016).

${ }^{351}$ Ibid

352 Ibid
} 
A number of seed firms are now actively investing in $R \& D$ in gene-editing technologies, such as CRISPR and TALEN:

"Bayer: Bayer CropScience entered into collaboration with Cellectis in 2006 for access to Cellectis' proprietary meganuclease technology for use in plant research and product development. Bayer extended the partnership in 2014 to access the TALENs technology for gene stacking and targeted mutagenesis applications and for collaborating to develop commercial canola traits. Bayer also has collaboration with Precision BioSciences around meganucleases and has successfully used the technology for trait stacking in cotton.

Calyxt. Calyxt uses TALENs technology developed by Cellectis and at the University of Minnesota and is currently conducting field testing on improved starch potato seeds as of 2015 .

Cibus. Cibus is a US-based company that has developed the Rapid Trait Development System (RTDS), a plant and microbial platform for precision gene editing and advanced non-transgenic breeding. RTDS enables site-specific edits of native traits with no introduction of foreign DNA. Cibus has launched its first commercial crop, SU Canola, a non-transgenic canola tolerant to sulfonylurea herbicides in the US.

Limagrain. In 2009, Cellectis and Limagrain entered into a non-exclusive licence agreement on the use of the I-Scel meganuclease, an engineered nuclease, in plants.

Monsanto. Monsanto has access to the TALENs technology from the Two Blades Foundation and has generated TALENs recombinase hybrids for targeted transgene insertion in crops.

Syngenta. On 30 April 2016, Precision BioSciences announced that it has been working with Syngenta to develop advanced agricultural products using its proprietary ARCUS technology, a fully-synthetic engineered nuclease. Researchers at Syngenta have successfully used ARCUS to insert genes into desired locations in the corn genome Moreover, Syngenta entered into a non-exclusive license agreement with the Two Blades Foundation in 2012 to access the TALENs technology for commercial use in certain crop plants" ${ }^{353}$.

Other actors include Precision BioSciences, The Broad Institute, Cibus, Calyxt, Two Blades, etc. Who are actively trying to license their technology. For instance, the Broad Institute recently licensed its CRISPR technology to Monsanto.

Finally, the sixth stage is the retail distribution of the seeds, which eventually ends up in their final use by farmers as the last stage in the value chain.

\subsubsection{Crop protection}

Crop protection aims to protect crops by avoiding the occurrence of diseases, controlling weeds and protecting from insects. Their use has been an essential feature of the

${ }^{353}$ Commission Decision, Case M.7932 - Dow/DuPont (2017), paras 3427-3432. 
Green Revolution, leading to a staggering increase in yield productivity the last forty years ${ }^{354}$. The industry grew considerably in recent years ${ }^{355}$. Plant protection products include herbicides, fungicides, insecticides, seed treatment by chemical or biological substances or physical processes applied to seeds or seedings. A significant feature of this industry is that it is heavily regulated in order to mitigate the risk of residues or, in case the residues occur, ensure that these are below the approved Maximum Residue Level (MRL). As it is explained in a recent report by Syngenta, '(a) significant amount of time and money must be invested into the registration of a crop protection product. The chance of a discovery compound passing all the many safety and efficacy tests on the way to market is about 1 or 2 in $100000[\ldots]^{356}$.

This market is dominated by companies based in 4 countries - Germany, the US, Switzerland and Japan, which account for almost $83 \%$ of global sales of agricultural chemicals

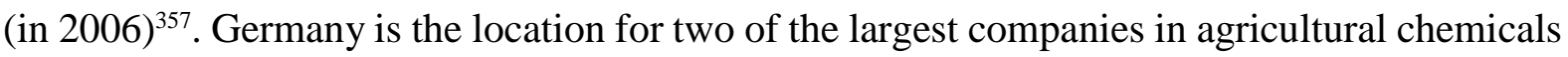
(Bayer and BASF) which represent $40 \%$ of total global R\&D in the sector. The industry provides crop protection through a combination of using agricultural chemicals with seeds with GM traits but not all firms are integrated in both chemical and genetic research. Some firms, such as Monsanto are mostly active in genetic research, although the company has developed the herbicide glyphosate, which has been used widely in agriculture, in conjunction with Monsanto seeds. BASF is presently only active in agricultural chemicals and is not present in the seeds segment of the market, focusing its research on chemical and biological trait discovery. In 2007, BASF and Monsanto agreed to jointly develop new crop technologies, with Monsanto concentrating in marketing products issued from the collaboration and both companies sharing net profits. More details about the market structure of the industry are provided below.

\section{Figure 1: Schematic representation of the agrochemicals supply chain}

\footnotetext{
${ }^{354}$ See, S. Ling Wang, P. Heisey, D. Schimmelpfennig \& E. Ball, Agricultural Productivity Growth in the United States: Measurement, Trends, and Drivers (USDA Economic Research Report 189, July 2015).

355 For a thorough analysis, see K. Fuglie et al., Research Investments and Market Structure in the Food Processing, Agricultural Input, and Biofuel Industries Worldwide, USDA-ERS Economic Research Report No. 130 (2011).

${ }^{356}$ Syngenta, Our Industry 2016, 70.

${ }^{357}$ K.O. Fuglie et al, Research Investments and Market Structure in the Food Processing, Agricultural Input, and Biofuel Industries Worldwide (USDA, Economic Research Report Number 130 December 2011), 49.
} 


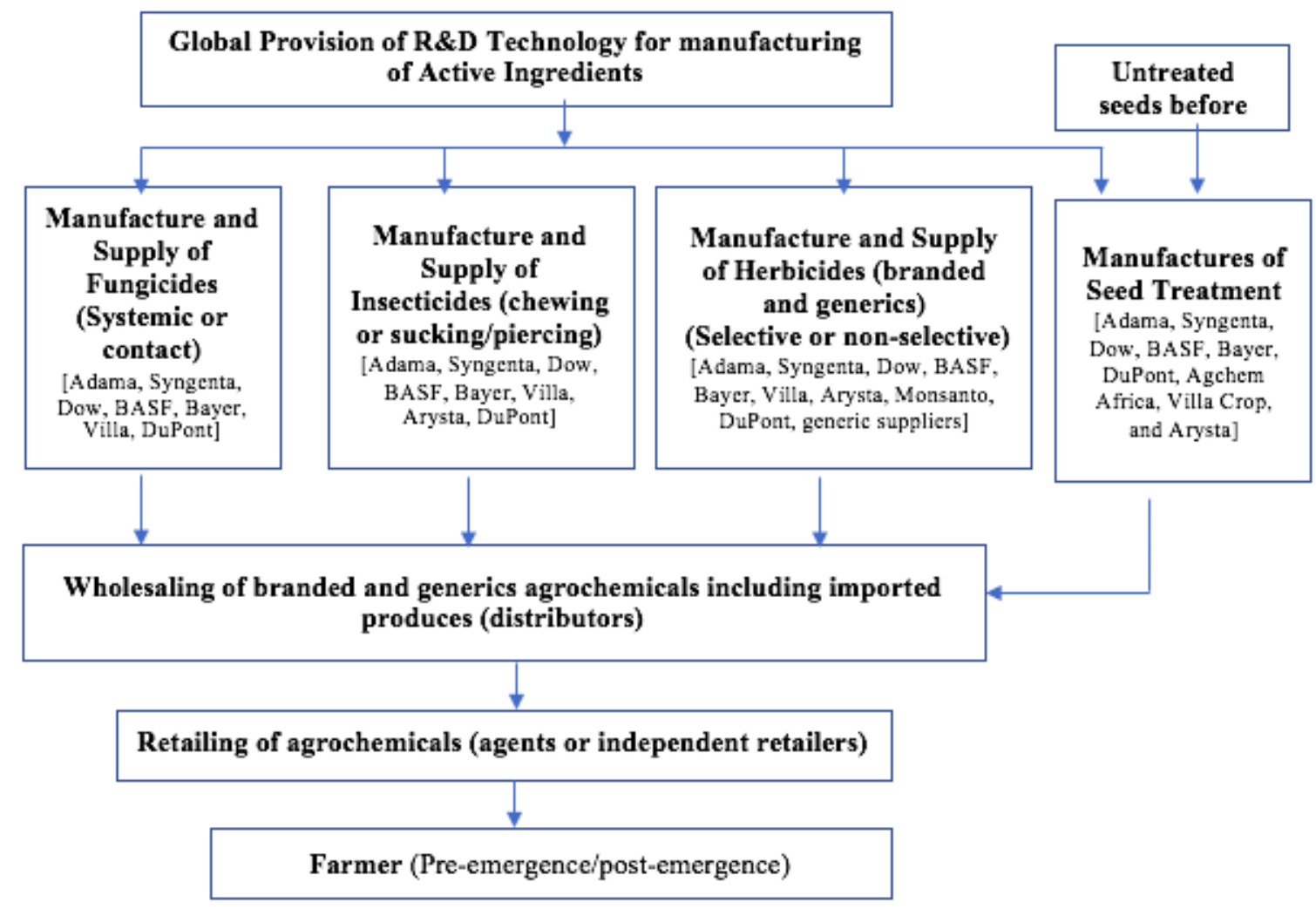

Source: Competition Commission of South Africa (2017) 358

The plant variety protection value chain begins with the global provision of $R \& D$ technology for manufacturing active ingredients. Bayer reports that planned R\&D investment in this field will be approximately EUR 1 billion in 2017 with efforts to bring over 15 new products to farmers in the next five years ${ }^{359}$. Due to tight European regulations, these key players have focused their $\mathrm{R} \& \mathrm{D}$ efforts on meeting the stringent regulatory measures.

While the second stage of the value chain has been focused on four main protection areas: fungicides, insecticides, herbicides, and seeds treatments, there is growing interest in biological crop protection solutions (such as Bayer's Poncho 2.0), and complementary bacterium that can increase the productivity of soil around plant roots for better nutrient rich feeding. However, the main pathogens which cause plant diseases are often fungi ${ }^{360}$ as well as bacteria and viruses. The global fungicides market is estimated to be valued at USD 14.49 billion in 2016 with projections to reach USD 19.17 billion by 2022. The most common fungal infections that impact agricultural productivity include: powdery mildew (wheat, barley rye), stripe rust (wheat and barley) and ergot (wheat, barley and rye. The fungicides market is led by: triazoles, strobilurins, and chloronitriles, but the phenylamides segment is the fasted

\footnotetext{
${ }^{358}$ Competition Commission of South Africa, Case 2017Feb004 (Bayer/Monsanto) (May 3, 2017), p. 40, para. 92 (figure based on third parties and merging parties' submissions).

${ }^{359}$ Bayer (2017). Crop Science Division of Bayer well positioned to fulfill future customer, market and social needs., available at http://www.press.bayer.com/baynews/baynews.nsf/id/Crop-Science-Division-of-Bayer-wellpositioned-to-fulfill-future-customer-market-and-societal-needs .

360 European Crop Protection Association, Pesticides and Biodiversity, (ECPA, 2010), available at http://www.ecpa.eu/sites/default/files/7584\%2BBiodiversity_V04_b\%C3\%A0t.pdf .
} 
growing type in the market ${ }^{361}$. Regional sales performance for Adama ${ }^{362}$ in the India, Middle East and Africa markets for 2015 was around USD \$289.5 million in comparison to USD \$ 983.9 million for crop protection. BASF's crop protection division saw more than EUR 5.8 billion in sales for 2015 .

The third stage in the plant variety protection value chain moves from the manufacturing of fungicides, herbicides, and insecticides towards the wholesale of these branded agrochemicals, which are then sent to retailers in order to end up in the last stage with farmers. Last spring, Bayer agreed to divest its herbicide Liberty for antitrust approval purposes to meet conditions imposed the South Africa Competition Commission ${ }^{363}$. Without such a divestiture, the merger would mean Monsanto and Bayer could combine their Liberty and RoundUp Ready seeds brands, which would have reduced the level of competition in this market. Further implications for South Africa mean that just three corporations would control $64 \%$ of the agrochemical market with Bayer-Monsanto controlling 25\% of this share, making it the world's largest supplier of seeds and chemicals ${ }^{364}$. South Africa also play a key role in the future expansion for the two companies and its dominant position over traits-germplasm crop protection products in the country. In fact, South Africa uses more agrochemicals that any other African country and farmers in South Africa have spent USD 2.3 billion on agrochemicals in the $2014 / 15$ season $^{365}$.

The process of product development of crop protect begins with active ingredients (AI) which are formulated into granules or emulsifieable concentrates designed for potency and efficiency purposes that are sold to distributors and farmers ${ }^{366}$. These active ingredients that are essential to crop protection are based on five areas of need: the chemical class, the plant to be protected, the molecule itself, the mode of action, or the pests against which the substances act. In total, the lifecycle process for AIs can be around 30 years, involving pharmaceutical companies and academic institutions which initially provide thousands of molecules that are synthesized each year ${ }^{367}$.

In terms of the lifecycle of AIs used for crop protection, the R\&D company normally spends an 11 year period for discovery and development ${ }^{368}$. During the discovery process, candidate molecules are assessed based on a combination of company aims and other porperties in which patents are developed for these new AIs, formulations, mixtures, and process technologies ${ }^{369}$. Next, the development stage begins with field studies to meet regulation criteria and the trial preparation can move forward, which is generally a 5-6 year development

\footnotetext{
$361 \quad$ See http://www.marketsandmarkets.com/Market-Reports/fungicides356.html?gclid=CjwKCAjw64bPBRApEiwAJhG-fhu8BBRoHxfKKtXCxg1rCWZ7bQYoOFzLi2vzM6vA0XvF5t3525B2BoC2HcQAvD_BwE

362 Adama See: https://www.adama.com/en/media/press-releases/adama-performance-q3-2015.html

363 See Business Insider (2017). Available at: http://markets.businessinsider.com/news/stocks/r-bayer-to-sellliberty-crop-protection-brands-to-get-merger-nod-2017-5-1001989110

364 ACBIO (2017). The Bayer-Monsanto merger: Implications for South Africa's Farmers. Available at http://acbio.org.za/wp-content/uploads/2017/02/Bayer-Monsanto-report.pdf

365 Ibid.

366 Commission Decision, Case M.7932 - Dow/DuPont (2017), para. 159.

${ }^{367}$ Ibid., para. 173.

${ }^{368}$ Ibid., para. 161.

${ }^{369}$ Ibid., para. 163.
} 
process $^{370}$. In order for the AI to be profitable, the commercialization stage involves finding uses for the product or combing it with other components and $\mathrm{AIs}^{371}$. Other strategic measures used to extend the life of AIs include more supplementary patents for its compositions or formulations ${ }^{372}$. Moreover, patenting strategies aim to tackle generic competition through combining forces with other AI mixtures that are also patented ${ }^{373}$.

Because of the long time period for discovery and development combined with the high cost of around USD 286 million $^{374}$, it is common for firms to partner in the early stages with licensing, technical sales, or reciprocal arrangements to mitigate economies of scale and manufacturing $\operatorname{costs}^{375}$. Other costs are found in the later stages of approval which can be USD 33 million $^{376}$ before the product is finally authorized as being safe for people, animal, and environmental health. The importance of the approval and authorization stage is to ensure that the health jeopardizing components are regulated ${ }^{377}$. Overall, the AI must go through a strict assessment in the EU before it is approved and registered on a list which currently exceeds 400 approved active ingredients for crop protection ${ }^{378}$. This analysis monitors residues and effects to monitor carcinogens, endocrine disruptors, and mutagenics taking around 2.5-3.5 additionaly years for approval and requiring additional preparation before the application can be started ${ }^{379}$. As such, in order for farmers in the EU to access the crop protection, the AI must have received two types of authorisation before they can be sold to farmers in the EEA ${ }^{380}$. First, the crop protection products with the AI must have been authorised by the Commission, upon the advice of European Food Safety Authority ("EFSA"). Second, the crop protection product incorporating the AI (alone or as part of a mixture of AIs) must have been authorised by the competent authority in the Member State(s) where it will be sold. ${ }^{381}$. Both registration of the final product and commercialization take place in the national markets.

Marketing to farmers is another strategic step that takes place several years before the $\mathrm{AI}$ is launched using communication with growers, advertising, and branding ${ }^{382}$. However, generic companies can impose competitive constraints since the development period is several years shorter for a generic ${ }^{383}$. The elaborate web of AI patents means generic players deal mostly with off-patent technologies, meaning they have a limited ability to address farmer

\footnotetext{
${ }^{370}$ Ibid., paras 166-167.

${ }^{371}$ Ibid., para. 169.

372 Ibid., para. 199.

${ }^{373}$ Ibid., para. 170.

${ }^{374}$ Ibid., para. 197.

${ }^{375}$ Ibid., para. 204.

376 Ibid., para. 189.

${ }^{377}$ Ibid., paras 178 \& 180.

${ }^{378}$ Ibid., para. 185.

${ }^{379}$ Ibid., paras 184 \& 186.

${ }^{380}$ Regulation 1107 sets the rules for (i) the approval of the AI contained in formulated products (referred to as plant protection products in that regulation) and (ii) the authorisation of plant protection products at Zonal and Member State level: Commission Regulation (EU) No 546/2011 of 10 June 2011 implementing Regulation (EC) No 1107/2009 of the European Parliament and of the Council as regards uniform principles for evaluation and authorisation of plant protection products, [2011] OJ L 155/127.

${ }^{381}$ Commission Decision, Case M.7932 - Dow/DuPont (2017), para. 181.

382 Ibid., para. 207.

${ }^{383}$ Ibid., para. 210
} 
needs ${ }^{384}$. Usual complaints about generics are about the fact that their products are aged, the lack of innovative capabilities, and inadequate consultancy for customers. Currently, Adama leads the generic players in crop protection products ${ }^{385}$. As such, generic companies focus less on discovery and original development and leverage advantage from selling different mixes or formulations ${ }^{386}$. Especially, because resistance is a major problem for crop protection products, there is a need for new innovative insecticides and fungicides and AIs which are mostly developed through non-generic R\&D focused companies, which can offer more competitive products of high quality ${ }^{387}$.

Generic players find it hard to compete against such massive R\&D players and are left with portfolios of low margin AIs that large R\&D companies do not want ${ }^{388}$. The complexities and costs of registering in multiple EU countries can also deter generic players from commercializing off-patent AIs and a general lack of technical expertise makes that their production processes (and costs) will usually not be as efficient as those of the R\&D player ${ }^{389}$. Nonetheless, generic products represent an important competitive constraint on the market leaders as analysis shows that customers typically switch to generic suppliers more than amongst the large multinationals. Yet, the crop protection sector is characterized by high entry barriers to knowledge and expertise, financial resources, and capital.

Among the generics, Adama is a lead developer in crop protection products and is the leader in the off-patent active ingredients in terms of sales, with a dominant international presence in over 100 countries. This places Adama at a rank of number seven amongst all global companies engaged in the field. Due the aforementioned constraints listed previously for generic companies, such as overcoming expensive regulatory issues and innovation, Adama nonetheless utilizes a competitive strategic business model that has managed to overcome these weaknesses worldwide. In 2011, Adama became part of ChemChina, a major conglomerate controlled by the Chinese government, and has since penetrated the Chinese market in terms of commercial and operational infrastructure to solidify its commercial platform with numerous agreements with other Chinese government-owned agricultural companies that have resulted in Adama being the exclusive distributor for these Chinese companies (Adama 2016 financial report). For example, crop protection represented 93.7 percent of the company's sales in 2016 with segment revenues in crop protection at USD 287 million for 2016. The company reports that registration requirements prove to be the biggest barrier to entry in a country, often consisting of renewed compliance and testing.

Due to macro trends, the top conglomerates often maintain diversified portfolios to ensure they have products at various stages in the lifecycle due to the high costs of discovery, development, and commercialization. Adama has a dominant presence in emerging markets with Latin America being 26.2 percent of its market distribution and Asia 27.7 percent.

Overall entry and exit barriers include general reputation and knowledge accumulation in the sector, financial resilience, access to stable funding sources, technological knowledge

\footnotetext{
${ }^{384}$ Ibid., para. 451.

385 Ibid., para. 230.

${ }^{386}$ Ibid., para. 231.

${ }^{387}$ Ibid., para. 452.

${ }^{388}$ Ibid., para. 497.

${ }^{389}$ Ibid., paras $463 \& 464$
} 
and successful off-patent product development, raw material supply chain efficiency, and obtaining regulatory approval and permits for their products. Herbicides are 49.3 percent of Adama's revenue in 2016, almost double in comparison to insecticides and fungicides.

FMC, another generic products player, operates with a low-cost, flexible manufacturing and supply chain model. It completed the acquisition of Cheminova in 2015 for an aggregate purchase of USD 1.8 billion. The acquisition is nearing full integration, enabling FMC to access new direct market channels and expand its product lines and technology. In 2016, FMC reported USD 3.3 billion in annual sales. Recently, FMC announced the acquisition of a large proportion of DuPont's crop protection business in response to the European Commission's decision that required DuPont to be divested due to its recent merger with The Dow Chemical Company. Direct operations for FMC in Europe take place in Poland, the Czech Republic and Slovakia with R\&D investments representing 5.8 percent of total revenue in 2016.

Nufarm is a generic player competing worldwide in crop protection and prioritizes its investments on a small number of important crops in four geographical regions. In 2016 Nufarm experienced around USD 2.7 billion in sales revenue with profits at around USD 27.5 million in 2016.

Japanese companies, such as Sumitomo, are more R\&D.focused. Other companies include Agro-Kanesho, Hokko, Ishihara Sangyo Kaisha (ISK), Kumiai, Kyoyu Agri, Mitsui Chemicals, Nihon Nohyaku, Nippon Soda and Nissan Chemical. These companies have a regional focus, mostly targeting domestic crops and pests ${ }^{390}$. Furthermore, in case a new active has promising applications in other markets it is often developed by or in cooperation with one of the largest R\&D-integrated players ${ }^{391}$. The Japanese companies individually are also much smaller than the Big 5 as concerns global sales, an important proportion of their sales being generated in $\operatorname{Japan}^{392}$.

\subsubsection{Fertilisers}

Fertilisers can be inorganic (or mineral) and organic. Inorganic Fertilisers are manufactured by firms in the agro-chemical industry, and can either include one macronutrient (simple nutrient Fertilisers, such as urea) or made of compounds mixtures (mineral Fertilisers containing NP, NK, and NPK, such as diammonium phosphate). Organic Fertilisers include instead, for example, manure or compost and they are not generally associated with the agro-chemical industry. Inorganic Fertilisers constitute a critical ingredient in the global food economy. There are three main agricultural fertiliser nutrients: nitrogen $(\mathrm{N})$, phosphate (P2O5), and potash ( $\mathrm{KCl}$, or potassium). Nitrogen accounts for the larger part of the total tonnage of Fertilisers (around 63\%), while phosphate and potassium for $21 \%$ and $15 \%$ respectively ${ }^{393}$. World fertiliser nutrient $(\mathrm{N}+\mathrm{P} 2 \mathrm{O} 5+\mathrm{K} 2 \mathrm{O})$ consumption is estimated to reach 186,900,000 tonnes in 2014, up by 2.0 percent over 2013, world demand for total fertiliser nutrients being estimated

\footnotetext{
390 Ibid., para. 2275.

${ }^{391}$ Ibid., para. 2276.

392 Ibid., para. 2283.

${ }^{393}$ K.O. Fuglie et al, Research Investments and Market Structure in the Food Processing, Agricultural Input, and Biofuel Industries Worldwide (USDA, Economic Research Report Number 130 December 2011), 66.
} 
to grow at 1.8 percent per annum from 2014 to $2018^{394}$. The use of fertilisers raises environmental concerns as it may affect surface and groundwater quality, and, for nitrogen, it may vaporize into the atmosphere in the form of nitrous oxide that constitutes a greenhouse gas. The industry developed considerably post-Second World War, in particular because of heavy investment by the public sector. Since the 1980s, fertiliser markets have been liberalized, although government-owned or controlled production still accounts for the largest part of global nitrogen production and a significant part of the phosphate production ${ }^{395}$.

With regard to economic concentration, one needs to distinguish between nitrogen, whose supply is the least concentrated as its production is associated with the availability and cost of natural gas, the main ingredient for synthesizing ammonia, and phosphorus or potassium, whose supply is concentrated, as these fertilisers are primarily mined from underground deposits from only a handful of countries. In particular, for potash, only three countries in the world (Canada, Belarus and Russia) account for more than $80 \%$ of the world reserves.

With regard to the supply of potash, the Canadian company PotashCorp is the world's largest potash manufacturer but also produces significant amounts of all three primary fertilisers. Together with another Canadian firm Agrium and the U.S. firm Mosaic (which sources most of its potash from mines in Canada), it conducts its offshore marketing of potash through a common trading consortium Canpotex, which controls more than one-third of global potash production, and accounts for almost $2 / 3$ of world potash trade, including trade by other potash companies in which PotashCorp has significant ownership. The competing trading consortium in this industry is a cabal of three companies, Belaruskali, Silvinit, and Uralkali, which operate through their marketing consortium, the Belarusian Potash Company (BPC) with regard to exports, which accounts for 1/3 of world potash trade. In 2013 Uralkali quitted BPC heralding a price war that led to an important drop in the price of potash.

The phosphate segment is oligopolistic with the government-owned Moroccan company, the OCP group, being the largest global producer of phosphates. OCP controls 36 percent of the global raw phosphate market and 51 percent of the global phosphoric acid sales, providing phosphate rock to both PotashCorp and Agrium ${ }^{396}$.

Yara International, based in Norway, is one of the world's biggest nitrogen fertiliser producer, but also present in all other fertilisers, being the industry leader in the production of inorganic Fertilisers globally, in terms of value of sales, followed by Agrium, Mosaic and Potash Corp ${ }^{397}$. Although the overall fertiliser market, if nitrogen is included, does not seem to be overly concentrated, the Top 10 of Fertilisers firms controlling approximately two fifths of the global market in 2011 , for a CR4 of less than $25 \%{ }^{398}$, the level of concentration is quite high with regard to potash and phosphorus. Nitrogen-phosphorus-potash nutrients do not substitute for each other in plant growth, but are all necessary to biosynthesize basic building blocks of plants, animals, and other life forms so therefore are complementary inputs to crop

\footnotetext{
${ }^{394}$ FAO, World Fertiliser Trends and Outlook to 2018 (FAO, 2015).

${ }^{395}$ C.L. Taylor \& D. Moss, The Fertiliser Oligopoly: the Case for Global Antitrust Enforcement, (AAI, 2013 ), 11 (governments control 57 percent of nitrogen, 47 percent of phosphorus, and 19 percent of potash).

396 Ibid., 17.

${ }^{397}$ European Parliament, Overview of the Agricultural Sectors in the EU Study (2015), 62.

398 Ibid., 62.
} 
production. One should also account of the fact that many of the major phosphorus producers also manufacture nitrogen fertiliser, partly because a source of nitrogen is required to stabilize phosphorus, and partly because many fertiliser manufacturers sell blended nitrogenphosphorus-potash fertiliser at wholesale and retail.

Although real fertiliser prices were relatively stable from the late 1980s until 2004, this period was followed by another where fertiliser prices have risen considerably between 2005 and $2008^{399}$ and 2010-2012. They have since been going down, rather considerably $y^{400}$. It has been alleged, with regard to the previous price hikes that global fertiliser producers have acted in a coordinated fashion to raise prices, to the detriment of competitors and consumers, forming a global potash cartel $^{401}$. There is indeed some history of collusive agreements between fertiliser producers on prices and market shares dating back to the $1880 \mathrm{~s}^{402}$. The industry is comprised largely of a small, close-knit group of executives and closed trade associations, which may facilitate collusion ${ }^{403}$. Allegedly the potash cartel collapsed when a Russian company, Uralkali, quitted BTC in $2013^{404}$.

The exercise of buyer power by large users such as India and China, fertiliser contracts for these countries being now negotiated by a single entity, or only a few entities for each country ${ }^{405}$, and the drop in demand following the high fertiliser prices during the period from the early 2000s to 2008, may also signal a fundamental change in fertiliser market dynamics ${ }^{406}$. Consumption of fertilisers has been declining in the EU-27, most probably for environmental regulation related reasons and probably as demand from farmers declined in reaction to the price hikes observed between 2004 and 2012. The farmers temporarily reduced the application of phosphorus and potash, as the prices of these two commodities have considerably risen, the decline in consumption of $\mathrm{N}$-based products being less marked than for $\mathrm{K}$ and $\mathrm{P}^{407}$. The share

\footnotetext{
${ }^{399}$ In 2008 , prices of phosphorus rock rose by $700 \%$ in a little over a year, contributing to increases in fertiliser prices: $\operatorname{COM}(2013) 517$ final.

400 Fertilisers Price Index is at a current level of 71.16, down from 150.41 in May 2012: https://ycharts.com/indicators/Fertilisers_index_world_bank .

401 For a discussion, see C.L. Taylor \& D. Moss, The Fertiliser Oligopoly: the Case for Global Antitrust Enforcement, (AAI, 2013), 9.

402 A 1949 report by the Federal Trade Commission (FTC), for example, documents cartels in nitrogen, phosphorus, and potash from before World War I to just after World War II: FTC, Annual Report, 18-21 (1949). ${ }^{403}$ C.L. Taylor \& D. Moss, The Fertiliser Oligopoly: the Case for Global Antitrust Enforcement, (AAI, 2013$), 40$. ${ }^{404}$ See https://www.wsj.com/articles/how-the-belarusian-potash-company-re-gained-its-footing-1450098821 .

${ }^{405}$ India has historically imposed price controls on fertilisers, the difference between the total delivered price at the farm gate and the maximum retail price being made up for by a government subsidy to farmers, manufacturers, or importers. Although prices of phosphate and potash were deregulated in April 2010, they are subject to maximum retail prices (MRP). Urea is still the only controlled fertiliser, sold at statutory notified uniform sale price. The problems faced by the manufactures in earning a reasonable return on their investment with reference to controlled prices, are mitigated by providing support under the New Pricing Scheme for Urea units and the concession Scheme for decontrolled Phosphatic and Potassic Fertilisers. The statutorily notified sale price and indicative MRP is generally less than the cost of production of the irrespective manufacturing unit. The difference between the cost of production and the selling price/MRP is paid as subsidy/concession to manufacturers. As the consumer prices of both indigenous and imported Fertilisers are fixed uniformly, financial support is also given on imported urea and decontrolled Phosphatic and Potassic Fertilisers. See http://fert.nic.in/page/fertiliser-policy

${ }^{406}$ C.L. Taylor \& D. Moss, The Fertiliser Oligopoly: the Case for Global Antitrust Enforcement, (AAI, 2013), 3336.

${ }^{407}$ European Parliament, Overview of the Agricultural Sectors in the EU Study (2015), 55.
} 
of fertilisers costs over total specific cost has also followed a positive but declining trend over time.

The industry is characterized by important barriers to entry, in particular for phosphorus and potash production, as dominant firms or governments control most known reserves, and activity is subject to strict environmental regulations. Large fertiliser producers also have similar cost structures, with substantially lower costs than smaller, non-integrated rivals. The competitive fringe is dependent on the dominant firms for raw materials necessary for phosphorus and potash fertiliser production, or for mixing product for wholesale and retail sales, and consequently, its expansion seems limited. In September 2016 a deal was announced between two of the leaders in the market for fertilisers, Potash Corp and Agrium for US\$30 billion. The deal is expected to close in mid-2017 and will create the largest fertiliser company in the world; it also plans to expand into seeds and crop chemicals.

The fertiliser industry spends relatively little in research, relative to company sales, with R\&D spending to represent less than $0.25 \%$ of sales. Most of the innovations in the industry are spill-overs from either the public sector or private R\&D effort in other chemical and energy industries or a result of "learning-by-doing" within the fertiliser industry" ${ }^{408}$. There are various reasons explaining the low level of $R \& D$ spending and innovation in the industry. First, "fertiliser is a large-volume and low-value commodity with few opportunities to develop differentiated products" ${ }^{\prime 409}$. Second, the industry involves high costs related to environmental regulation or raw resources procurement, with the result that it is quite capital intensive and there are few opportunities to develop more efficient manufacturing processes ${ }^{410}$. Third, the industry may suffer from low incentives to innovate in view of the difficulty to claim intellectual property over improvement of manufacturing technology and therefore recoup returns to research investment ${ }^{411}$. Fourth, the oligopoly structure of the industry may also reduce the competitive pressure on firms to innovate. A lot of research is jointly funded by the industry, which has constituted an International Plant Nutrition Institute (IPNI), a non-profit, science-based organization supporting research and education for better fertiliser utilisation. The International Fertiliser Development Center (IFDC), a public non-profit R\&D centre focuses on developing and transferring fertiliser technology to developing countries, including the "Virtual Fertiliser Research Center," a global initiative initiated in 2010 which combines the work of multiple research institutions around the world cooperating to advance a unified research agenda in order to create a new generation of more efficient Fertilisers and soil fertiliser management technologies.

The action of competition authorities in this segment of the value chain has been relatively limited. In 2010, the European Commission fined $€ 175647000$ nine animal feed phosphate companies for manipulating phosphorus prices from 1969 through 2004, their aim being to share a large part of the European feed phosphates sales by allocating sales quotas and

\footnotetext{
${ }^{408}$ K.O. Fuglie et al, Research Investments and Market Structure in the Food Processing, Agricultural Input, and Biofuel Industries Worldwide (USDA, Economic Research Report Number 130 December 2011), 69.

409 ibid

${ }^{410}$ Ibid.

${ }^{411}$ Ibid.
} 
coordinating prices, as well as coordinating sale conditions when and to the extent necessary for those purposes ${ }^{412}$.

In 2011, the Russian FAS approved the proposed merger of Uralkali and Silvinit considering the fact that Uralkali and Silvinit export about $85-90 \%$ of produced potash, with just remaining $10-15 \%$ going for domestic consumption, in view of the positive effects the merger would have had on the competitiveness of Russian producers on the global market and a number of conditions imposed on market pricing and treatment of customers. In 2011, FAS opened an investigation into Uralkali's potash pricing, noting that "there are signs that the prices are 'monopolistically' high. The case started following a customer complaint that carnallite prices were excessive. In October 2015, FAS found that Uralkali's prices did not generate supra-competitive profits and were thus not abusive ${ }^{413}$.

In 2005, the Competition Commission of South Africa (CCSA) opened an investigation against Sasol regarding the collusion between the company and its competitors, Omnia and Yara, to divide markets and fix prices in South Africa and in 2007 another investigation for a cartel between Sasol and Foskor in the phosphoric acid industry. Sasol, Omnia and Yara, are the main suppliers of fertiliser in South Africa, and had set up various committees to coordinate business practices, derive forecasted market shares and ensure balance of supply and demand. These arrangements between these competitors resulted in Sasol becoming the sole wholesale supplier of an important fertiliser product, limestone ammonium nitrate (LAN). The CCSA settled the case for R188 million, the settlement being approved by the Competition Tribunal and covering the collusion investigations against Sasol, first with Omnia and Yara and then with Foskor, without however covering any abuse of dominance issues ${ }^{414}$.

In 2012, the Consumer Unity \& Trust Society (CUTS), approached the India Competition Commission to investigate what they maintain is a global potash cartel operated by PotashCorp, Mosaic, Agrium, and the Russian producers requesting the Competition omissionn of India (CCI) to undertake an investigation under Section 19 of the Competition Act for an act taking place outside India that has or is likely to have an appreciable adverse effect on competition in India vide Section 32 of the Competition Act (the "effects doctrine") against the global potash cartel ${ }^{415}$. Although the US FTC has not initiated any enforcement action against fertiliser producers, deciding instead to approve the PhosChem export cartel under the Webb-Pomerene Act, there were some private actions in the US, alleging that potash producers operated a cartel through which they fixed prices in Brazil, China, and India, and that inflated prices in those markets influenced the price of potash in the U.S. Defendants moved to dismiss, arguing that the district court lacked jurisdiction under the Foreign Trade Antitrust Improvements Act, 15 U.S.C. 6a, but the district court denied the motion and the Seventh Circuit affirmed ${ }^{416}$. Following this judgment the parties settled damages for $\$ 110$ million for direct and indirect purchasers.

\footnotetext{
${ }^{412}$ Commission Decision, Case COMP/38866 - Animal Feed Phosphates (2010) confirmed by the General Court (case T-456/10) and the Court of Justice of the EU (case C-411/15 P).

${ }^{413}$ See http://solutions.fas.gov.ru/ca/upravlenie-kontrolya-promyshlennosti/ats-62537-15

414 See, http://www.compcom.co.za/wp-content/uploads/2014/09/06-May-09-Sasol-settles-fertiliser-case-withCompetition-Commission-to-pay-R188-million.pdf .

${ }^{415}$ See http://www.cuts-ccier.org/pdf/CUTS_Preliminary_Information_Report_Submitted_to_CCI.pdf .

${ }^{416}$ Minn-Chem, Inc. v. Agrium, Inc., No. 10-1712 (7th Cir. 2012).
} 


\subsubsection{Agricultural machinery}

\subsubsection{The evolution of the agricultural machinery market}

World demand for agricultural equipment is expected to grow 6.8 percent per year through 2016 to $\$ 175$ billion, with particular growth in China, Brazil, and India. The U.S.-based company John Deere is the world's largest manufacturer of farm machinery, followed by CNH Industrial (following the integration of Fiat Industrial and CNH Global)) and AGCO. The next tier consists of the following large producers: Kubota, Yanmar and Iseki; CLAAS, Caterpillar, Same Deutz-Fahr (SDF), Mahindra \& Mahindra and Bucher Industries. There are 1,500 firms making agricultural equipment around the world, but less than 12 large multinationals are present in this market. Most of the large players offer a broad array of agricultural equipment to achieve economies of scale, but several focus on a few select lines such as irrigation products or milking machines. There are also large firms that cut across several industrial machinery categories, and for some, their involvement is quite limited in agricultural equipment. Three of the four leading manufacturers produce nonfarm machinery, such as earth-moving and construction equipment or machines for home-gardening and lawn care.

The manufacture of high-end farm machinery requires heavy capital investment and a concomitant need to achieve economies of scale and scope. The advent of 'smart agriculture' has led to increasing technical complexity of such equipment with emphasis on electronic controls and sensors. That has considerably increased the threshold level for entry into the industry on a worldwide scale and increasing consolidation of the industry. Small and mediumsized firms (as well as individual inventors and farmers) have historically been a source of innovation in farm machinery, but their share of the global market appears to have significantly declined the last two decades ${ }^{417}$. Consolidations and mergers have led to fewer and larger companies producing for global markets. Between 1994 and 2009, the market share of the four largest farm machinery manufacturers rose from 28 to 50 percent of total global sales ${ }^{418}$.

Farm tractors make up the largest share of the market, accounting for nearly 30 percent of global sales of new farm equipment, with harvesting and haying machinery making up another 22 percent of the global market, while equipment for such uses as planting, fertilizing, plowing, cultivating, irrigating, and spare parts accounting for the remainder ${ }^{419}$.

Large multinational firms account for most of the formal R\&D by the farm machinery industry, but small and medium-sized firms' contribution to innovation has been significant, some studies noting that the farm machinery industry is one in which large firms have concentrated on making refinements and achieving economies of scale in the manufacture of innovations originating from small-sized entrepreneurs, some of which have been bought by larger firms, offering them the necessary economies of scale in manufacturing and

\footnotetext{
${ }^{417}$ K.O. Fuglie et al, Research Investments and Market Structure in the Food Processing, Agricultural Input, and Biofuel Industries Worldwide (USDA, Economic Research Report Number 130 December 2011).

418 Ibid.

419 Ibid.
} 
distribution ${ }^{420}$ The large firms spend relatively little on $R \& D$, with a reported $R \& D$ to sales ratio that does not exceed 4 percent and for some is less than 1 percent ${ }^{421}$.

A recent game-changer in this industry is the development of precision agriculture and innovative high-speed precision planting systems. These systems enable farmers to plant seeds at substantially higher speeds than conventional planters without sacrificing accuracy. By allowing farmers to plant crops more quickly and accurately within the optimal planting window, high-speed precision planting systems can substantially improve crop yields. This high speed planting is expected to become standard in the next few years. High-speed precision planting technology takes several years to develop and important investments. This industry has recently been the focus of competition law activity with the recent challenge by the US DOJ of the John Deere-Precision Planting merger in August 2016 and the subsequent abandonment of the merger by the parties in May 2017.

Precision Planting, which forms part of The Climate Corporation, a digital agriculture company acquired by Monsanto in 2013, was first to develop a high speed planting system, called SpeedTube, in 2014. Its main competitor Deere developed the ExactEmerge high-speed precision planting system, also in 2014. The business model followed by each company was different, as unlike Deere, which sold its high-speed precision planting technology bundled into new planters, Precision Planting first offered SpeedTube as a set of components that could be purchased at a relatively low cost and retrofitted onto existing planters made by planter manufacturers, including John Deere. This posed a formidable challenge to Deere and its profitable sales of new planters. The two companies have remained the dominant providers of high-speed precision planting systems in the United States - accounting for at least $86 \%$ of all U.S. sales. In November 2015, Deere announced that it had agreed with The Climate Corporation (Monsanto) to acquire Precision Planting, for $\$ 190$ million, subject to a carve-out of some assets and adjustments, thus leading Deere to control nearly every method through which American farmers can acquire effective high speed precision planting systems. Head to head competition between Deere and Precision Planting had largely benefitted farmers so far through lower prices and more innovative high-speed precision planting systems in the marketplace, the firms offering a series of discounts and aggressive financial packages. Deere and Precision Planting have also competed intensely for farmers' business through advertising campaigns and industry events.

Concurrently, Deere announced that it has entered into an into an exclusive data-sharing agreement with The Climate Corporation, providing The Climate Corporation near real-time access to data collected from Deere equipment (the Digital Ag Connectivity agreement). This data-sharing agreement offered Monsanto considerable value in addition to the $\$ 190$ million that it would have received from Deere.

Indeed, high-speed precision planting systems enable farmers to plant accurately at up to twice the speed at which they would otherwise be able to plant with conventional systems, thus leading in spacing that allows for ideal plant growth. Planting at higher speeds, while

420 R. Evenson, Government Policy and Technological Progress in U.S. Agriculture, in R. Nelson (ed.). Government Support of Technological Progress: A Cross Industry Analysis (New York: Pergamon Press, 1982).

${ }^{421}$ K.O. Fuglie et al, Research Investments and Market Structure in the Food Processing, Agricultural Input, and Biofuel Industries Worldwide (USDA, Economic Research Report Number 130 December 2011). 
maintaining precision, is valuable because it better enables farmers to plant crops within the optimal planting window - the narrow set of days each season when planting conditions are most likely to produce high crop yields. Farmers can acquire high-speed precision planting systems by purchasing a retrofit kit to update their conventional planter, or by purchasing a new planter with a high-speed precision planting system factory-installed.

Deere was particularly concerned about Precision Planting's technology because of its retrofit solutions that would have enabled farmers to upgrade their conventional planters with the latest high-speed planting technology without purchasing a new planter. Deere was also concerned that Precision Planting's technology could commoditize the planter toolbar. Indeed, because Precision Planting's high-speed precision planting retrofit components can be attached to existing planter toolbars, they would foster farmers' indifference to the brand of the planter toolbar and exert competitive pressure on Deere's planter sales.

In its complaint ${ }^{422}$, the US DOJ argued that the relevant market included both highspeed precision planting systems that are factory-installed on new planters, and systems that are retrofitted onto new and used conventional planters, noting that no reasonably interchangeable substitutes exist for high-speed precision planting systems. Indeed, wider conventional planters are not effective substitutes for planters equipped with high-speed precision planting systems because wider planters are less manoeuvrable, are more expensive to purchase, operate, and maintain, have lower resale value and may have other detrimental effects on the planting process.

The complaint noted that Deere and Precision Planting were the only two meaningful providers of high-speed precision planting systems in the United States. Although Kinze and Horsch Maschinen GmbH claim to offer comparable solutions in the United States, their planters' use of a conventional seed tube instead of a seed-delivery cartridge made them incapable of delivering the same accuracy at high speeds as Deere's and Precision Planting's high-speed precision technology. Even counting Kinze's and Horsch's systems that lack seeddelivery cartridges as high-speed precision planting systems, their shares of the high-speed precision planting systems market in 2015 were approximately $12 \%$ and $2 \%$, respectively, while Deere's share of the market was approximately 44\%, and Precision Planting's was approximately $42 \%$. As a result, should the merger be authorised Deere would control $86 \%$, or nearly all of the relevant market post-merger, if Kinze and Horsch are not included. Even accounting for Kinze's and Horsch's shares, the HHI for the highspeed precision planting systems market exceeds 3800, and with the acquisition the HHI would exceed 7600, thus indicating, according to the US horizontal merger guidelines that the merger will be presumptively anticompetitive.

In addition, the US DOJ noted that the merger would have averted the need for Deere to reduce ExactEmerge pricing by $5-15 \%$ to maintain ExactEmerge's market share, and thus the 'strategic value' of the acquisition, that it would retain from not having to compete with Precision Planting, would range between $\$ 70$ million and $\$ 210$ million. It was also alleged by the US DOJ that the proposed acquisition was also likely to reduce the quality of some of the highspeed precision planting options in the market, as post-acquisition, Deere would likely

${ }^{422}$ See https://www.justice.gov/opa/pr/justice-department-sues-block-deere-s-acquisition-precision-planting . 
seek to reposition Precision Planting's offerings to maximize the profitability of Deere's highspeed precision planters and to reduce competition between Deere's and Precision Planting's retrofit solutions, thus 'tempering' both Deere's growing retrofit business and Precision Planting's growing factory-install business with Case and AGCO, both of which would cannibalize Deere's high-speed precision planters business. According to the DOJ, the extensive intellectual property rights held by both Deere and Precision Planting, would have also prevented other firms from adopting important aspects of their respective high-speed precision planting systems, further inhibiting entry.

Following this development, The Climate Corporation announced Monsanto's termination of their agreement with Deere \& Company for the acquisition of the Precision Planting LLC equipment business, and expressed its intention to sell the Precision Planting equipment business ${ }^{423}$. The digital collaboration agreement between Deere and Climate and a distribution deal with farm data management company Ag Leader has also been terminated.

When describing the value chain of farm machinery, the most important aspect to note is that the final customers and users of agricultural equipment are farmers. First, farm machinery is cyclical ${ }^{424}$ with correlations related to rises in commodity prices and demand for equipment. At the same time, experts argue that "trends in commodity prices cannot explain long-term structural changes within the farm machinery industry" such as the "entire range of famous tractor brands: Lanz, FAR, Ford, Citroën, Röhr, BMB gradually disappeared in the $20^{\text {th }}$ century due to the industrial landscape ${ }^{425}$." This is exemplified through the increasing adoption of strategic growth instruments such as M\&A, JVs, and cooperative agreements to increase market shares in "turf" with the future expansion of new geographic markets.

It is expected that in the near future profit pools for the farm machinery value chain will shift from Europe towards China, but with high industry consolidation, only 75 to 80 percent of machine manufactures see opportunities for organic growth in market share gains ${ }^{426}$. The position of companies across the machinery value chain takes several archetype forms: component specialists, machine manufacturers, equipment \& machine system providers, aftersales providers, and software/system providers. In particular, component specialist focus on the development of components for industrial machines. Next, the sale of single machines places a focus on the development and production of these single machines like milling and grinding machines. Third, equipment and machine system providers focus on assembly and integration of combined machinery systems, lines and equipment lik, wuch as processing machinery equipment and packaging lines. The aftersales providers are active in the aftersale business of parts and services. Finally, the software development providers focus on the high price, country specific segment.

Farming equipment consists of a variety of machinery and tools that help carry out a number of "processes to upgrade the quality and quantity of production such as using

\footnotetext{
${ }^{423}$ See http://www.agprofessional.com/news/industry/john-deere-terminates-acquisition-precision-planting

${ }^{424}$ G. Dryancour, The Agricultural Machinery Market \& Industry in Europe: An analysis of the most important structural trends \& why EU regulation of the sector needs to change (Report for CEMA, 2016).

${ }^{425}$ Ibid

${ }^{426}$ McKinsey \& Company. "How to succeed: Strategic options for European machinery. Shifting growth patterns, increasing pace of digitization and organizational change."
} 
machinery for multiple purposes like :harrowing, ploughing, tilling, and planting ${ }^{427}$. For example, sugar beet production involves machinery for seeding, harvesting, short-term storage, load and cleaning, transport and return of by products. In emerging economies such as India and Brazil, governments are escalating subsidies on agricultural machinery which is encouraging for multinationals hoping to expand their global operations. However, there are reports that these central government sponsored schemes are failing to make an impact at the grassroots level in several Indian districts ${ }^{428}$. For example, the central government of India has subsidized over 20 types of farm machinery for the Pilibhit district through the use of online registration for the purchase of this machinery.

With falling commodity prices, farmers are nonetheless encouraged to invest in more expensive, bigger, and more productive machinery and technology. This expenditure is mostly funded by cheap debt and high tax allowances ${ }^{429}$. France, the biggest crop producer in the EU has suffered from poor grain harvests and market prices which negatively affects farmers' ability to invest in more machinery ${ }^{430}$. This further indicates that the customer base is shrinking, but the reliance on mechanisation is not. Thus, from a strategical standpoint the key is to convince farmers that they need new innovation and technology to increase production since it is more difficult to expand the customer base within the EU and US markets. As such, the incorporation of monitoring systems, GPS, systems, and self-driven mechanism will fuel the desired material/economic increase $\mathrm{e}^{431} \mathrm{~s}$ for machinery suppliers.

\subsubsection{The Big Data disruptive innovation in agricultural machinery}

It is expected that five main drivers of big data in farming will disrupt conventional farm equipment technologies: precision agriculture, sensors, Internet of Things, smartphone usage, and cloud computing ${ }^{432}$. The Big Six are quickly delving into investments in this area, with Bayer planning to put at least EUR 200 million in their Digital Farming business by 2020. The framing of digital solutions is often geared towards the desire to help smallholder framers reach their potential and productivity levels. For example, venture capital is saturating the ag tech space with investment increasing $80 \%$ annually ${ }^{433}$.

First, farming machinery already employs precision agriculture features to use one or more sources of data like soils, crops, nutrients, and pests for optimization purposes. For

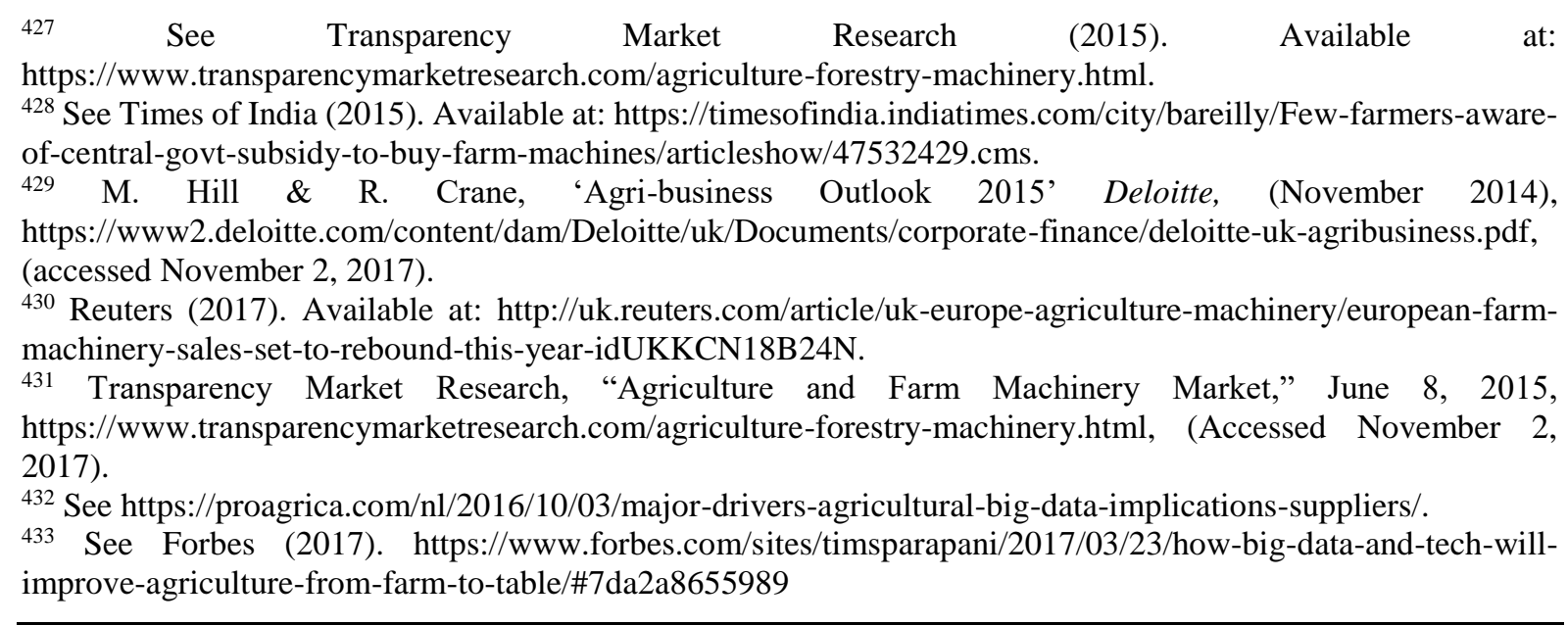


example, these tools can aid farmers with increasing inputs like crop protection agents and fertiliser to improve yields and quality. Additionally, real time data can help farmers adapt their growing conditions. Second, sensors (both remote such as satellite technology, UAVs/drones) and in-field sensors (monitory anything from seed applications to yield) are building blocks for transforming ag systems as a mechanism for collecting the vast volumes of information. These sensors on crops can provide data points on soil condition as well as information about wind requirements or water availability. Third the IoT creates linkages with external data sources so that analytics can be used to prevent spoilage, for example. The already established popularity of smart phones will provide numerous apparatuses for farmer's to download and use apps to reap the uses of big data. This, coupled with cloud computing, can create structures for big data projects and as a way to deal with the capacity requirements associated with big data.

Examples of data exchange platforms in agriculture include Monsanto's fieldscripts, the Farm Business Network, and Farm mobile. ${ }^{434}$ There are also aspirations to integrate suppliers and food processors with cloud platforms that create connectivity with many businesses at once for data exchange. Ultimately, this means that agriculture will undergo its third major revolution, but there are still issues over information storage, processing, and the extent to which the data generated can actually be used effectively to enhance farmer productivity. Yet, the future of digital agriculture is not limited to these main ideas. "Modern information-based technologies, such as self-driving tractors, GPS (global positioning systems), robot milking machines, automated egg production, drones, satellite data and social media, will change farm practices and agricultural structures," according to the USDA. From an optimistic viewpoint, a more data driven agricultural sector should lead to improved sustainability, food safety, resource efficiency, and waste reduction ${ }^{435}$. As such, governments are providing funding to support these efforts, with a recent announcement by the USDA for $\$ 1.35$ million for data driven farm management practices ${ }^{436}$.

"Smart Farming" is also expected to incorporate robots and more artificial intelligence in farming in coming years ${ }^{437}$. Consequently, the stakeholder landscape will entail power shifts with the emergence of new actors, such as tech companies, venture capitalists and new entrants. Scholars also point out that these power shifts should inevitably change relations among "different players in current food supply chain networks." Ensuring open data and privacy protection will be the biggest challenge for public institutions and smart farming could "unravel two extreme scenarios 1) closed, proprietary systems in which the farmer is part of a highly integrated food supply chain or 2) open, collaborative systems in which the farmer and every other stakeholder in the chain network is flexible in choosing business partners as well for the technology as for the food production side ${ }^{438}$."

\footnotetext{
${ }^{434} \mathrm{~K}$. Poppe, 'Big opportunities for big data in food and agriculture' (LEI Wageningen UR), OECD Workshop, (2016).

${ }^{435}$ K. P, Wolfert, S, Verdouw, C.N. (2015). A European Perspective on the Economics of Big Data: OECD. Available at: https://www.oecd.org/tad/events/Autumn15_Journal_Poppe.et.al.pdf

${ }^{436}$ See USDA (2017). Available at https://nifa.usda.gov/announcement/usda-announces-135-million-supportdata-driven-farm-management-practices

${ }^{437}$ S. Wolfert, L. Ge, C. Verdough, M.J. Bogaardt, Big Data in Smart Farming-A Review (2017) 153 Agricultural Systems 69-80.

438 Ibid
} 


\subsubsection{Animal Genetic Improvement}

The global animal genetics market is estimated to be worth around $\$ 4$ billion by 2020 from $\$ 3.68$ billion in $2016^{439}$. With more diverse genetic pools, live-stock production systems are more resilient to shock, have improved productivity, and are better adapted to changing environmental conditions. Drivers of change in the animal genetics resources management stem from increased demands for livestock products, marketing infrastructure and access, retailing, climate, disease, and lifestyle factors, just to name a few ${ }^{440}$. The next 50 years will foresee an increase in meat production by 75 million tonnes in developing countries alone, totalling at an average of 175 million tonnes. Developed countries already experience an average of 75 million tonnes of meat produced in 2017 and that figure is expected to level off in coming years, placing the emphasis on the Global South. Moreover, the increasing demand in animal protein consumption further drives the growth of the animal genetics market as farmers are incentivizes to adopt "advanced genetic technology for larger-scale production and quality breeds."

Genetic diversity remains under threat due to known risks and breed distinction. These threats include: indiscriminate cross-breeding, introduction/increased use of exotic breeds, lack of profitability/competitiveness, diseases/disease management, loss of pasture or production environment and poor control of inbreeding ${ }^{441}$. However, genetic food engineering first began in 1994 with the debut of a GM tomato, the first food licensed by the FDA for human consumption. Genetic modification of animal specifies is largely used for research purposes ${ }^{442}$ with reports of animal breeding and genetics $R \& D$ expenditures at around $\$ 339$ million in $2010^{443}$.

Advances in technology are most intense within the area of genomics. Although this has helped define the genetic basis of heritable traits, its advantages are restrained to only a few breeds widely used. Additionally, there are strict regulations surrounding animal genetic engineering, in addition to its high costs and time consuming $R \& D$ activities.

The major players of the animal genetics market are Genus Plc, Topigs, Envigo, CRV Holding B.V., Hendrix Genetics BV. The market is segmented by product, testing service and region $^{44}$ and is further segmented into live animals and genetic materials. Additionally, the live animals segment is further categorized into canine, equine, poultry, porcine, bovine etc. and the genetic materials segment is further categorized into semen and embryo. Europe is the

\footnotetext{
${ }^{439}$ See Market and Markets (2016). Available at: http://www.marketsandmarkets.com/Market-Reports/animalgenetic-market-12462093.html

${ }^{440}$ Food and Agriculture Organization of the United Nations, Commission on Genetic Resources for Food and Agriculture (2015). The Second Report on the State of the World's Animal Genetic Resources for Food and Agriculture.

${ }^{441}$ Ibid, 5

${ }^{442}$ G. Rangel, From Corgis to Corn: A Brief Look at the Long History of GMO Technology. (Harvard, 2015)., available at: http://sitn.hms.harvard.edu/flash/2015/from-corgis-to-corn-a-brief-look-at-the-long-history-of-gmotechnology/

${ }^{443}$ K.O. Fuglie et al, Research Investments and Market Structure in the Food Processing, Agricultural Input, and Biofuel Industries Worldwide (USDA, Economic Research Report Number 130 December 2011).

444 See Market Watch (2016). Available at: http://www.marketwatch.com/story/animal-genetics-market-to-see84-cagr-to-2021-driven-by-advanced-genetic-technologies-2016-07-20-122034555
} 
largest regional segment of the global animal genetics market. Nonetheless, the rising populations and urbanization in BRICS will shift these countries into the fastest growing markets.

Hendrix Genetics BV operates in the layer, hybrid turkey, pig, aquacultulre, and traditional breed activities as a multi-species animal breeding company. Major breeding centers are in the Netherlands, France and Canada and it provides genetics for animal proteins such as eggs and salmon ${ }^{445}$. Its annual revenues were $\$ 436$ million, while Tyson Foods earned around $\$ 25.6$ billion in annual revenues in 2015 . Another key player in animal genetic improvement, Genus PLC, enables farmers to more efficiently produce animal protein, meat and milk, totalling \$398 million in revenue for 2015. The company sells genetics directly and through distributors in more than 70 countries with Latin American containing 29\% of the revenue. The two main markets are the porcine market, which sells genetically superior boars and sows to produce offspring, the dairy and beef markets where the primary product is bull semen and is delivered with artificial insemination.

The current trend is for "reduced genetic variation both within and across breeds" 446 . This has led to a technological focus on the high-output of international transboundary breeds and the loss of smaller ones, neglecting the benefits of local, smaller breeds. Genomics has experience successful application in the dairy cattle breads ${ }^{447}$, but the genetic selection of animal breeding dates back for thousands of years.

Often, genetic improvement in livestock sectors involves extremely organized systems with selection based on : visual appraisal, pedigree information, performance data, genetic metric values and accuracy, genomic/DNA markers enhanced genetic merit values. Since 1957, poultry growth has increased by $85-90 \%$. In dairy, for example, in the 1940s $25 \mathrm{M}$ cows produced $4500 \mathrm{lbs}$. per lactation, and in 2008 9.2M cows produce 22,000 lbs. per lactation. As such, there is a 2.7 fold reduction in cow numbers and 4.9 fold milk yield per cow increase due to genetic improvements as 1940s cows required 4.5 times more land and produced 2.6 times more methane $e^{448}$.

\subsubsection{Animal Health}

The global animal health market is expected to reach $\$ 58.4$ billion by 2025 , primarily driven by technological advancements to combat a rise in zoonotic and food-borne diseases internationally ${ }^{449}$. The projected population increased, coupled with the expansion of required livestock mean that animal based food products should increase in demand. Feed additives are

\footnotetext{
445 See Bloomberg (2017). Available at: https://www.bloomberg.com/research/stocks/private/snapshot.asp?privcapid=22105742.

${ }^{446}$ F. Biscarini, E. Nicolazzi, A. Stella, P. Boetcher, G. Gandini,. Challenges and opportunities in genetic improvement of local livestock breeds.(2015) 6 Frontiers in Genetics. 33.

447 Ibid

448 Ibid

${ }^{449}$ See Grand View Research (2017). Available at: http://www.grandviewresearch.com/industry-analysis/animalhealth-market.
} 
segmented into nutritional and medicinal with a $46.7 \%$ market share of products in $2015^{450}$. Food additives are used to increase muscle growth to increase feed utilization.

Because commercial animals including livestock and poultry enter the human food chain, the "prevention and eradication of disease is a vital ongoing concern" driving the demand for animal healthcare products as a necessary expense ${ }^{451}$. The nutritional chemical segments are set to remain key, while the faster growing segments in animal health appear to be vaccines and diagnostics, according to the report.

Furthermore, this market also undergoes extensive collaboration research initiatives like the recent "Zoetis agreement with the University of Nottingham to conduct a research on maximizing muscle growth and feed efficiency in pig farming." Zoetis (as a part of Pfizer) possess around $20 \%$ of the animal health market share, making it the largest company in the segment. The company delivers quality medicines and vaccines, complemented by diagnostic products, genetic tests, biodevices and a range of services.For 2016, the company reported shares of $\$ 1.3$ billion with a $5 \%$ operational growth driven by the launch of new products. Operating in the U.S. and internationally, the company delivers a portfolio of products for livestock and companion animals with sales of livestock products flat operationally at the international level.

For example, Draxxin is an injectable anti-infective used to help treat respiratory disease in swine and cattle and has expanded its Fostera swine vaccine franchise. Other key actors include Merck Animal Health whicih operates in more than 150 countries with global sales reported at $\$ 3.5$ billion in $2016^{452}$, Merial (Sanofi) at a $\$ 2.7$ billion revenue, and Elanco (Eli Lilly subsidiary) which competes closely with Merck in the swine flu and aquaculture markets recently acquired Boehringer Ingelheim Vetmedica in 2017, expanding its vaccine portfolio $^{453}$. Additionally, there is Bayer Animal Health, Novartis Animal Health and Virbac S.A.

Major products driving the performance of the animal health segment include aquaculture products to maximize fish survival and growth (salmon, tilapia, trout) and swine products to help in the production of safe and high quality pork. Vaccines tend to be given to animals at different life stages and vaccinating these groups can protect against herd immunity ${ }^{454}$. Dairy, beef cattle and sheep face a constant threat from a range of soil dwelling bacteria, prompting the frequent use of vaccines to fight these bacterial diseases.

Antibiotics resistance is facing growing concerns for public officials as its use in agricultural settings has received relatively low attention ${ }^{455}$. Human consumption of antibiotic treated animals threatens human health due to "pathogenic-resistant organisms propagated in these livestock" as the bacteria found in livestock meat can harbour resistant genes ${ }^{456}$. However,

\footnotetext{
450 Ibid

${ }^{451}$ Available at: https://www.freedoniagroup.com/industry-study/animal-health-products-2990.htm

${ }^{452}$ Yahoo Finance (2017). Available at: https://finance.yahoo.com/quote/MRK/.

${ }^{453}$ See https://finance.yahoo.com/news/elanco-animal-health-completes-acquisition-190000148.html

${ }^{454}$ National Office of Animal Health, Antibiotics Resistance, https://www.noah.co.uk/medicine-topics/antibioticsfor-animals/resistance/, (accessed 2 November 2017).

455 T. Landers and B. Cohen, T.E. Wittum, E.L. Larson, A Review of Antibiotic Use in Food Animals. (2012) 127(1) Public Health Reports. 4-22.

${ }^{456}$ Ibid
} 
the overall impact from antibiotic use in food animals has not been adequately assessed due to a lack of research. The World Health Organization reports that Norway is intentionally reducing its antibiotic use in salmon ${ }^{457}$, a major export for the country and highly consumed. This is in a large part due the increase in salmon farming, which was developed by the Scottish in the early 1970s as an alternative to river fishing. When antibiotics are overused, especially in farming, bacteria will become resistant to the treatment and can have profound effects on future animal health if widespread.

\subsubsection{Animal Nutrition/Feed}

In the United States, corn is the most commonly produced feed grain at more than 95 percent of total production and is the main energy ingredient in livestock feed ${ }^{458}$. Sorghum, barley, and oats make up the other major feed grains. Competiveness in the commodity market can be summarized as following: Brazil has the lowest production cost of soybeans per bushel at 8.5 percent under the U.S. cost, while the average cost per bushel for corn remains lowest in the United States ${ }^{459}$. Geographically, Parana in Brazil's coast benefits from its location and is the lowest cost exporter of corn and soybeans, followed by the U.S. Heartland, which has a larger production capacity than Parana. However, only 25 percent of soybean and corn production in Brazil comes from Parana, while $75 \%$ is from the Heartland ${ }^{460}$. Other factors such as low land costs and improvements to inland transportation costs in Brazil improve the competitive position of the country.

The animal nutrition market can be divided by nutrition type (amino acids, minerals, vitamins etc.), by livestock, and by administration method (oral, topical, injection) and will hit $\$ 18.8$ billion by $2020^{461}$. Increasing demands for food mean farmers "must have access to reliable feed for the livestock with proper nutrition for health and reproductive purposes." For example, amino acids substitute to protein sources and have a major share in the market. Evonik, an animal nutrition amino acid provider, reports that their amino acid feed can even minimize nitrogen excretion. The biggest shares of the nutrition market are Amino acids, followed by prebiotics for the poultry industry.

The top feed producers include: CP Group with annual production of 27,650 metric tons, Cargill with 17,900 metric tons of annual feed produced, New Hope Liuhe, Purina Animal Nutrition, Wen's Food Group, Tyson Foods, and BRF. Overall the global animal feed market is highly competitive and contains a large number of players with its strongest markets in North America and Europe. Remaining at the forefront of feed nutrient development, Cargill Inc. has traditionally acquired regional companies in different locations to "get easy entry in that

\footnotetext{
${ }^{457}$ See http://www.who.int/features/2015/antibiotics-norway/en/

${ }^{458}$ USDA (2017). Available at https://www.ers.usda.gov/topics/crops/corn/

${ }^{459}$ B. Meade, E. Puricelli, W. McBride, C. Valdes, L. Hoffman, Linda Foreman, and E. Dohlman, Corn and Soybean Production Costs and Export Competitiveness in Argentina, Brazil, and the United States, EIB-154, U.S. Department of Agriculture, Economic Research Service, June 2016.

460 Ibid

461 WattAgNet Report (2017). Available at http://www.wattagnet.com/articles/26463-report-animal-nutritionmarket-to-hit--b-by--
} 
particular market to benefit from the customer base ${ }^{462}$." In this industry, market shares are stabilized with the introduction of novel ingredients. Therefore, companies tend to focus on research expansion and facilities and new investment opportunities in Latin America and Asia.

The animal feed market plays a lead role as an enabler of economic production of animal proteins and is the largest element in creating affordable and profuse animal proteins ${ }^{463}$. Global commercial manufacturers generate over $\$ 400$ billion per year with compound feed production at 1 billion tonnes annually. Feed grain prices dropped during the 2016/17 marketing year in the U.S. while global supplies increased ${ }^{464}$. The planted acreage of 8 major U.S. crops is reported to be 257 million acres in the past several years with anticipated declining acreage. On a global scale, 33 percent of the world's land (ice-free) is used for croplands used for livestock feed production ${ }^{465}$. Increases in livestock density could entail growing risks for human proximity as 66 percent of emerging human diseases originate from animals.

Main players of the animal feed market include: Evonik, DuPont, Adisseo, BASF, ADM, and Nutreco. Evonik's annual sales for 2016 were $\$ 12.9$ billon with $30 \%$ of sales taking place in Europe. In terms of nutrition, the company produces specialty chemicals with rising prosperity in emerging markets while the leading market positions in superasorbents and DLmethionine. DuPont's Danisco Animal Nutrition is an industry leader in feed enzymes due to the innovation of carbohydrase products 25 years earlier. DuPont's Danisco also competes in betaine, which increases lean meat yield, probiotics which reduce antibiotic dependence, and essential oils to stimulate feed intake and improve bodyweight gain in feed animals.

Divestitures in the pharmaceuticals business caused BASF's 2016 animal nutrition seeds to fall by $3 \%$ and declined by EUR 66 million in this division. Europe is BASF's largest market for animal nutrition sales at $40 \%$ with South America, Africa, and the Middle East at $10 \%$.

Challenges and implications for the sector consist of competition for raw materials between food, feed, and energy as it is believed animal protein production will double in an already food insecure world (for humans) ${ }^{466}$.

\subsubsection{Food Manufacturing/Processing}

The global food processing industry faces several challenges related to global inequalities, rising costs of ingredients, and social responsibility that can affect how they design products integrated into sustainable diets. At the beginning of the twentieth century, food security issues were addressed through solutions of food and crop production, but modern times require food processing to be integrated more sustainable into the production, distribution and retailing

\footnotetext{
${ }^{462}$ Tim Kilgore, "Cargill swung to an operating profit in the second quarter as sales rose," MarketWatch, July 13, 2017, https://www.marketwatch.com/story/cargill-swung-to-an-operating-profit-in-the-second-quarter-as-salesrose-2017-07-13, (accessed November 2, 2017).

463 International Feed Industry Federation (2017). Available at: http://www.ifif.org/pages/t/The+global+feed+industry.

${ }_{464}$ Office of the Chief Economist, World Agricultural Outlook Board, U.S. Department of Agriculture, USDA Agricultulral Projections to 2026, 2017, Pub. OCE-2017-1, 106, Washington D.C.

${ }^{465}$ Food and Agriculture Organization of the United Nations, "Livestock and Landscapes," Sustainability Pathways, http://www.fao.org/docrep/018/ar591e/ar591e.pdf, (accessed November 2, 2017).

466 Ibid., 3.
} 
components of supplied food ${ }^{467}$. For example, the food processing sector can benefit from designing more efficient supply chains that deliver safer perishables, design foods that provide high nutrition and low environmental impacts, and aligning their manufacturing processes with policy guidance ${ }^{468}$.

Not without scandal, the food processing industry has faced several meat scandals in recent years, which has exposed how companies tamper with compliance regulations, like the poor hygienic standards poultry processing plants and horsemeat scandals in the $\mathrm{EU}^{469}$ and tainted meat issues at Brazil's largest food processing giants ${ }^{470}$. The food processing industry involves the processing and packaging of produce, meats, fish, animal feeds, fruit juices, and dairy products ${ }^{471}$. Additionally, the industry includes grain milling, crop cleaning, grading and packaging, animal slaughtering, seafood processing, freezing, canning operations, coffee, and tea, but excludes primary crop growers. As a mature sector with consistently positive investment returns, companies generate their revenue from the sale of food and ingredients to a variety of customers ranging from supermarkets, restaurants, and other players down the chain. This industry is valued at over $\$ 2$ trillion globally with over 400,000 businesses ${ }^{472}$.

Geographically, the EU leads the global food processing production with a $44 \%$ turnover behind the US at $20 \%$ and China at 19\%, according the EU Food and Drink Industry. Moreover, the complexity and length of food supply chains entangles food processing with numerous food safety risks, especially with consumer demand for more knowledge about food origins and more sustainable food production. The developing world is the biggest growth engine, as nations like China, India, Brazil and Russia change their eating habits like buying more packaged foods and consuming more meat due to wealth increases. Innovative technologies will continue to transform the food processing and packaging markets with the food processing equipment industry (processing machinery and equipment and packaging machinery and equipment) could reach $\$ 25.7$ billion and $\$ 31.5$ billion by 2020 with compounded annual growth rates of 4.2 percent $^{473}$.

Key actors are: Tyson, Smithfield, JBS/Swift, Shaungui, Pilgrim's Pride, Butterball, Sara Lee, Perdue, National Beef and Sanderson. In particular, JBS with USD 53.5 billion in revenue in 2016 is the world's largest meat producer, while Pilgrim's Pride as its chicken processor foreign subsidiary reaching USD 10 billion in revenue last year. Tyson Foods commands $24 \%$ of the beef market and produces and distributes other protein products such as

467 B. Tiwari, Norton, T, Holden, M (eds.), Current Concepts and Applied Research in Sustainable Food Processing. (John Wiley \& Sons, 2013), 12-14.

468 Ibid

469 See The Guardian (2017) https://www.theguardian.com/business/2017/oct/01/the-chicken-scandal-and-adysfunctional-food-industry

${ }^{470}$ New York Times (2017). Brazil's Largest Food Companies Raided in Tainted Meat Scandal. Available at: https://www.nytimes.com/2017/03/17/world/americas/brazil-food-companies-bribe-scandal-salmonella.html

471 Business Day Markets, "Food Processing," New York Times, http://markets.on.nytimes.com/research/markets/usmarkets/industry.asp? industry=54122, (accessed November 2, 2017).

${ }^{472}$ Rentokil, 'Food processing: global trends' https://www.rentokil.com/food-processing/global-trends/, (accessed November 2, 2017).

473 BCC Research, 'Innovation Key to Growth of Global Food Processing and Packaging Market' https://www.bccresearch.com/pressroom/fod/innovation-key-to-growth-of-global-food-processing-andpackaging-market, (accessed November 2, 2017). 
chicken, pork, and prepared foods with a total market cap of $\$ 13.2$ billion. Its major facilities are in the US, India, China, Brazil, and Mexico. 42 percent of Tyson's revenue came from the beef segment, 30 percent from the chicken segment, 14 percent from pork, and 10 percent from prepared foods during the fiscal year $2014^{474}$. In the US beef packaging industry, just four producers control $75 \%$ of the market share: Tyson, JBS USA, Cargill, and National Beef.

As consumer preference for individual food product packaging remains substantial, companies are producing packaged options in response with different materials. In addition, automated equipment and robotics are being introduced for efficiency and consistency reasoning like higher volume production potential. Recently, automation is changing the food processing industry even further solutions designed to improve productivity and drive profits ${ }^{475}$. Traceability and operating simplicity are two areas of specialty for automation like Omron's Vision and Sensor Technology's visual inspection system that "can avert product recalls, eliminate human error, reduce waste." CSIRO's shockwave can disrupt the structure of food, while its forward osmosis innovation is more gentle and cost effective than evaporation.

Nestle holds operations in 191 countries in seven categories of their product portfolio totalling 89 billion in sales in 2016: Powdered and Liquid Beverages ( $\$ 19.8$ billion in sales); Nutrition and Health Science ( $\$ 15$ billion in sales); Milk products and Ice cream ( $\$ 14.3$ billion); Prepared dishes and Cooking aids ( $\$ 12$ billion); PetCare ( $\$ 12$ billion); Confectionery ( $\$ 8.7$ billion); and Water ( $\$ 7.4$ billion). Activities in Asia include USD 22 billion in revenue, with USD 40 billion in the Americas, and USD 26 billion in Europe. It includes 19\% of activities related to powdered liquid beverages; $15 \%$ for nutrition, $14 \%$ for milk products and ice cream, $12 \%$ for prepared dishes and cooking aids, $12 \%$ for pet care..

Unilever operates in more than 100 countries with over 70 percent of its volume in emerging markets, which provide the industry with strong growth. Through selling products in more than 190 countries, Unilever sells GBP 1 billion or more from its 13 brands: Axe, Dirt is Good (e.g. Omo), Dove, Family Goodness (e.g. Rama), Heartbrand (e.g. Wall's), Hellmann's, Knorr, Lipton, Lux, Magnum, Rexona, Sunsilk, Surf, but contains over 400 brands in total to operate globally and locally on an efficient scale. Due to intense competition, Unilever invests $€ 1$ billion annually on research and development and frequently collaborates with academia and suppliers. Unilever is organized into four categories: the largest is Personal Care (also its fastest growing area of the market), then Foods followed by Home Care, and Refreshment. Unilever is one of the big three global players in Personal Care. Personal care accounts for 38 percent of its total business, and Unilever has invested in increasing participation in Egypt and China. Personal Care had a turnover of GBP 20 billion in 2016, with a focus on non-premium segments of the market. Recent acquisitions in this category include: Dollar Shave Club in the male grooming segment and Living Proof, the premium hair care business. In 2016 Food generated a turnover of GBP 12.5 billion which is 24 percent of its turnover. Foods brands include global brands like Knorr and Hellmann, and local brands like Bango in Indonesia, Robertson's in South Africa and Kissan in India. Sales were expanded in emerging markets at over 7 percent with strong growth in Latin America,

\footnotetext{
${ }^{474}$ A. Jones, 'Tyson Foods Revenue Segments' Market Realist, (December 11, 2014), https://beta.marketrealist.com/2014/12/tyson-foods-revenuesegments?utm_source=redirect5\&utm_medium=auto, (accessed November 2, 2017).

${ }^{475}$ See Food\&Beverage https://foodmag.com.au/how-automation-is-changing-the-food-processing-industry/
} 
Africa, and South East Asia. Home Care, generated a turnover of GBP 10 billion in 2016 which is 19 percent of its turnover. This includes brands like: Surf and Dirt is Good, and Sunglight and generates 80 percent of its sales in emerging markets. Refreshments generated a turnover of GBP 10 billion in 2016, which accounts for 19 percent of turnover. Major brands are: Heartbrand (e.g. Wall's), Magnum and Lipton.

Danone's products are available in 130 countries across 5 continents with a particular focus in emerging markets. The categories of Danone products include: medical nutrition, waters, early life nutrition, and fresh dairy products. 53 percent of group sales were in emerging markets in 2016 with strong positions in Indonesia, China, Russia, Mexico and Brazil. For example, the income from fresh dairy was around EUR 518 million, EUR 322 million for waters, EUR 403 million for early life, and EUR 137 million for medical nutrition. Danone operates frequently through acquisitions and partnerships to expand its portfolio of business and views Africa as the continent for future expansion. At the same times, North America is still a major growth market in all four categories with a heavy emphasis on dairy products, especially yogurt, in addition to water high water bottle consumption in the US. Brand innovation in waters resulted in a 2.9 percent increase in this category with consumers switching to healthier hydration options. Danone experiences over 80 percent of its sales in Africa, driven by a need for dairy products that can support limited refrigeration infrastructure. Finally, the fastest growing area of Medical Nutrition is baby food brands which experienced a 30 percent growth in 2016.

This year, Mars, part of Procter \& Gamble Company, experienced USD 35 billion in global sales of consumer packaged goods in five segments: Beauty; Grooming; Health Care; Fabric Care and Home Care; and Baby, Feminine and Family Care. Products are sold in over 180 countries through mass merchandisers, grocery stores, membership club stores, drug stores, department stores, salons, e-commerce and high-frequency stores In particular, sales to Walmart represent 14 percent of the total revenue, and net sales in the U.S. are around 35 percent of the total net sales globally, with Europe at 39 percent, Asia at 18 percent, and Latin America at 10 percent.

Associated British Foods sells in more than 100 countries with operations in 50 countries across Europe southern Africa, the Americas, Asia and Australia. It experienced GBP 13.4 billion in revenue in five business segments: Grocery; Sugar; Agriculture; Ingredients; Retail. Grocery accounted for GBP 3,274 million in sales with major international brands being: Twinings and Ovaltine. The sugar category accounted for GBP 1,798 million in sales with the beet sugar factories in the UK which produce one million tons of sugar per year and Azucarera in Spain at 400,000 tons, with two beet sugar factories in northeast China at 160,000 tons, while Africa's Illova possess production facilities in six African countries and produces 1.7 million tons. The agriculture category accounted for GBP 1,084 million in sales, while the ingredients possessed GBP 1, 294 million in sales with a focus on yeast and bakery ingredients with 49 plants in 26 countries. Retail accounted for GBP 5, 949 in sales with Primark as the major retail group with stores in UK, Ireland, Spain, Portugal, Germany the Netherlands, Belgium, Austria, France, Italy, and the US.

Cargill operates in the food ingredients and applications segment, animal nutrition \& protein, origination and processing, and industrial and financial services with earnings of 
around USD 1.64 billion. Animal nutrition was a strong global performer with a focus on valueadded protein and poultry in many regions with good results in grain and oil seeds in China and South America. The Food Ingredients \& Applications segment saw improvements in the edible oils, malt and starches with acquisition in the chocolate business. Animal Nutrition \& Protein was strong win turkey and value added protein in North America with an additional acquisition of salmon nutrition leader EWOS and another $\$ 500$ million in acquisitions in the protein business. Origination \& Processing performed strongly in South America and China, forming a joint venture to build a grain terminal in Ukraine on the Black Sea and expansions of oilseed processing facilities in Brazil. The Industrial \& Financial Services consist of ocean shipping, energy, metals.

Modes of entry for food and beverage processors in the BRICS is varied with Russia containing the most amount (10) successful greenfield projects from 2007-09 in the food and beverage sector and no recorded M\&A deals, accounting for 8 percent of new industrial plant creation in the industry ${ }^{476}$. However, in Brazil, India, and South Africa joint ventures and M\&A were more common modes of entry in the industry as they still stimulate linkages between the foreign investors and local partners. Because of cultural differences in food consumption, market penetration strategies for large MNEs like Kellogg's and Unilever in Asia countries and India has been to leverage mass advertising campaigns to expand the product market which successfully began to displace the traditional substitute products ${ }^{477}$. For example, as breads, breakfast cereals and margarine are not readily consumed, in addition to low consumption of animal products in India due to cultural and religious reasons, foreign investors used marketing to re-shape the habits of consumers. Overall, the MNEs are attracted to these emerging economies that promise new "dynamic demographic trends" and large internal markets and urban population, since developed countries show signs of stagnating demographics and competition from cheap retailers through private labels ${ }^{478}$.

Of particular interest is the active role retailers play in some processing markets amd/or markets for fresh food in BRICS and other emergent/developing economies. Modern retail supermarket chains face barriers particular to India, such as maintaining a fresh supply of perishable produce in stores, which can be extremely challenging. Yet, the mere presence of these retailers in the Indian retail market can create modernizing effects for farmers and agricultural production through the supermarkets' need to ensure that new supply chains exist for quality standards purposes ${ }^{479}$. This in turn can create a mixture of combing traditional trading systems with the establishment of supply chains for the daily supply of very perishable products. In India, Future Group is the leading corporate retailer, but possesses a low share of food sales, and purchases 80 percent of its fresh produce through a system of farm collection and distribution centers ${ }^{480}$. Next, the retailer Reliance contains a greater share of fresh food

\footnotetext{
${ }^{476}$ R. Rama. Foreign Multinational Enterprises in the Food and Beverages Industries of the BRICS, in W. Naude, A. Szirmai, \& N. Haraguchi (eds.), Structural Change and Industrial Development in the BRICS (OUP, 2015), 300-310.

477 Ibid, p 305.

478 Ibid.

${ }^{479}$ A. Trebbin, Linking small farmers to modern retail through producer organizations-experiences with producer companies in India. (2014) 45 Food Policy 45, 35-44.

480 Ibid.
} 
sales and uses a system of collection centers from farmers for $60 \%$ of its requirements, while the rest comes from AMPC markets ${ }^{481}$. Selling exclusively fruits and vegetables, Mother Dairy supplies its outlets SAFL by procuring $60 \%$ of fruit supplies from farmer associations and $20 \%$ from village aggregators and $20 \%$ from AMPC markets. Indian supermarkets face low sales in fresh food, but still require higher standards of quality than traditional supply chains, although the low volumes needed limit the procurement relationship.

The demand for higher quality product from supermarkets can encourage Indian farmers to adopt agricultural technology to improve hygienic practices, use better feed, and create higher yielding livestock ${ }^{482}$. Institutional innovations must nevertheless first take place before the system can change as a whole. For example, increased demand for products in dairy does not automatically trigger improved quality of those products in the value chains. Thus, the main implication is investing in costly upgrades to infrastructure to create better supply systems for dairy companies in India that enable better closer-farm processor links ${ }^{483}$. As such, the Indian dairy industry will need to focus on improving livestock quality and veterinary infrastructures and breeding practices for more productive milk yield ${ }^{484}$. Other imperatives are found to be: more available cattle feed inputs, increased credit flow e.g. working capital loans for fodder and feed to transition the dairying from traditional agri-residue, product innovation, and overcoming distribution challenges related to poor infrastructure. For the meat industry in India, this might entail revising the prices of inputs for feed, which have increased significantly in recent years, followed by clarity in the regulation of cattle slaughter (which is banned in most states), and more efficient livestock markets that are still based on traditional procurement from cattle brokers that operate once a week in unregulated markets ${ }^{485}$.

Changes in diet and increasing demands for pork are also driving transformations for China's pork industries, which are highly undeveloped in terms of technology, labor conduct, and low market concentration ${ }^{486}$. As an emerging economy, China's pork value chain is deeply tied to small hog producers, and small scale operations in all areas such as butchers, breeders, finishers and processors. Therefore, the acquisition of Shuanghui, China's largest pork processor, by Smithfield represents a modernization opportunity for the processor to increase its domestic standards, set by the multinational, and incorporate its strengths of stable and safe hog supplies, multiplying self-owned hog farms, and expanding contracts with large-scale commercial farms or pork sourced from the U.S. ${ }^{487}$ Shuanghui must decide whether increasing hog production in China is a sustainable solution in terms of environmental and space related costs and limitations, or if imported carcasses from the U.S. is a more viable solution. This also

\footnotetext{
${ }^{481}$ AMPC markets are markets in agricultural products that are regulated under the Agricultural Produce Market Committee (APMC) Act enacted by State Governments. It is estimated that there are about 2477 principal regulated markets based on geography (the APMCs) and 4843 sub-market yards regulated by the respective APMCs in India. See http://www.indiabudget.nic.in/es2014-15/echapvol1-08.pdf .

${ }^{482}$ E. Janssen \& J Swinnen, Technology adoption and value chains in developing countries: Evidence from dairy in India. (2017) Food Policy https://doi.org/10.1016/j.foodpol.2017.08.005

${ }^{483}$ Ibid, p 10

${ }^{484}$ Boston Consulting Group, Indian Agribusiness (BCG, July 2012).

485 Ibid p 41

${ }^{486}$ Y. Zhang, \& R. Xudong, et al, Organization, technology and management innovations through acquisition in China's pork value chains: The case of Smithfield acquisition by Shuanghui. (2017) Food Policy, https://doi.org/10.1016/j.foodpol.2017.08.004

${ }^{487}$ Ibid p 10
} 
means Shuanghui may adopt a largely American concept for high processed pork products to consumers with plans to open two new processing plants, and one American style processor that will produce Smithfield brand products ${ }^{488}$.

The knowledge and strategic transfer from the acquisition places Shuanghui in a position to create better management teams and leverage the already deeply vertically integrated pork value chain Smithfield operates, as vertical integration in the pork value chain is nonexistent in China. However, the new infusion of Smithfield imports into the Chinese market is not without reactions and could face some public policy concerns. In particular, China bans pork with ractopamine a feed additive very common in the U.S., but it is uncertain whether pork imports will ever fully meet these regulatory standards since Smithfield is the largest certified exporter to China. In order to compete with the acquisition, other leading Chinese pork processors are focusing on improving their brand image and adopting American style marketing concepts to keep the interest of the changing Chinese consumers' preferences. Ultimately, the transformations taking place in China's agrifood system may have important implications as the traditional village trader role will continue to be reduced and undermined in many areas and replaced with urban wholesale markets and supermarkets ${ }^{489}$. Moreover, consolidation and a more dynamic market creating rapid development in various segments is both revolutionary for the country, and undoubtedly private-sector led.

\subsubsection{Biofuel}

Biofuels refer to liquid transportation fuels derived from agricultural, forest, or other organic materials (like feedstock) and turned into ethanol and biodiese ${ }^{490}$. The history of commercial interest in biofuels began in the 1970s as a response to OPECs oil export embargo and was pushed heavily in Brazil and the United States. ${ }^{491}$ A renewed interest for energy independence has compelled countries to combat fossil fuel prices and GHG emissions through the development of alternative energy sources. In the past forty years, Brazil has prioritized its ethanol programmes to incorporate it as part of the country's fuel supply (moreso than in comparison to the U.S.). Biochemical and thermochemical processes create biomass that is used as the biofuel ${ }^{492}$. While Brazil and the U.S. lead in biofuel production worldwide, the European Union is in third place with Germany and France as its largest producers. In Europe, biofuel commercial production is based on sugar beet, wheat and rapeseed which are converted to bioethanol/ETBE and biodiesel ${ }^{493}$.

First generation biofuels are produced from crops, which has "caused greater emphasis to be placed on $2^{\text {nd }}$ generation biofuels" produced from lingo-cellulosic feedstocks ${ }^{494}$, which

\footnotetext{
488 Ibid p 5

${ }^{489}$ T. Reardon \& K. Chen et al, The quiet revolution in Asia's rice value chains. (2014) Annals of the New York Academy of Sciences. p 110.

${ }^{490}$ UNCTAD, The Biofuels Market: Current Situation and Alternative Scenarios (UNCTAD, 2009), 1-14

491 Ibid

${ }^{492}$ M. Balat, An Overview of Biofuels and Policies in the European Union. (2007) 2(2) Energy Sources 167-181.

${ }^{493}$ Ibid

${ }^{494}$ R.E. Sims, W. Mabee, J.N. Saddler \& M. Taylor, An overview of second generation biofuel technologies. (2010) 101(6) Bioresource Technology 1570.
} 
haven't yet realized their full commercial deployment and still face challenges. Second generation biofuels are appealing in that, instead of using food for humans (food crops), production comes from feedstock. This plays into the sustainability value system in that waste can be used as fuel and re-cycled in the system e.g. using "waste vegetable oil" vs. virgin vegetable oil. Consequently, each generation of production requires a different extraction technology.

The current global biofuels market was reported to reach $\$ 6.6$ billion dollars in $2016^{495}$. Drivers are favourable regulations and investments in the market for renewable energy, but production process limitations still exist. Key actors are: A2BE Carbon Capture LLC, Abengoa bioenergy, Algenol Biofuels, Bankchak Petroleum, Chemtex group, Clariant Produkte, GmbH, and Dupont Industrial Biosciences. A2BE Carbon Capture is focused on developing algae production systems through offering photo-bioreactor algae cultivation and technologies that can turn industrial $\mathrm{CO} 2$ emissions into algal biomass, and biofuels. Algenol Biofuels (as U.S. based company $\$ 3.1$ million in sales) also specialized in low cost ethanol made from $\mathrm{CO} 2$ and seawater using algae which can produce over 6,000 gallons of ehtanal per acre per year compared to corn at $400^{496}$ and has begun developing projects throughout Southern China. Next, DuPont Industrial Sciences reported revenue of $\$ 392$ million in 3Q16 at a $4.8 \%$ rise annually.

The growing international interest in biofuels is correlated with increased demands in feedstocks ${ }^{497}$. In terms of imports, Canada and the EU are the world's largest with Brazil specializing in sugarcane-based ethanol exports. This new sweet spot for Brazil leverages its position as the world's top sugar producer to diversify even more deeply into the biofuel industry ${ }^{498}$

In fact, a favourable market climate such as reduced feed costs and falling prices of crops in the U.S. are providing incentives for expansion ${ }^{499}$. Further innovations can reduce the cost of biofuel production in coming decades, but may remain under competitive with nonrenewable alternatives without a price on carbon emissions ${ }^{500}$. However, as the demand for electric cars rises, the forces of renewable energy could gain more momentum. Positive news is that a range of feedstocks can be turned into liquid biofuels creating a diverse playing field for the sector.

\subsubsection{Retail}

Several factors are driving food retailers towards trategic options like M\&As such as stiff competition, challenging growth environment, and changing consumer preferences ${ }^{501}$. The latter has also encouraged the testing of "new concept to retain market share." Online retailers,

\footnotetext{
495 J. Lamb, “Advanced Biofuels Market Size, Share, Report, Analysis, Trends \& Forecast to 2023,” Reuters, July 24, 2017, http://www.reuters.com/brandfeatures/venture-capital/article?id=13343,.

496 USEPA 2009

${ }^{497}$ USDA long-term projections 2017

${ }^{498}$ BBC 2015 Available at http://www.bbc.co.uk/news/business-33114119

${ }^{499}$ USDA long-term projections 2017

${ }^{500}$ International Renewable Energy Agency (IRENA) 2016. Innovation Outlook.

${ }^{501}$ See Duff and Phelps Food Retail Industry Insights 2016-2017
} 
warehouse clubs, mass retailers and grocery delivery services are re-shaping the way food retail market competition has taken place in modern times. In fact, many grocery chains have failed to adapt to a shift in consumer preferences towards more intimate shopping and less supermarket styled models in the developed world ${ }^{502}$.

The sector has also been marked by increasing global consolidation. This wave of consolidation includes the acquisition of Roundy's by Kroger (the largest pure play grocery in the U.S) and Pace Food Retails acquisition of Dean \& DeLuca, and Amazon's \$13 billion acquisition of Whole Foods, indicating speciality food interests are gaining momentum. An even deeper analysis might convey that modern food markets are active at the local level of response to consumer wants which vary, based on income and cultural preferences in the scope of a more global food industry ${ }^{503}$.

The EU has seen increases in national level grocery retailing in the past 15 years ${ }^{504}$. The top grocery retailers in the EU are Schwarz Group, Aldi, Edeka, Rewe, Tesco, Carrefour which means 10 food retailers have accounted for 26 percent of the market share. In particular, Carrefour reached net sales of EUR 746 billion for 2016, while Tesco was at EUR 48 billion, and Aldi EUR 7.6 billion $^{505}$ with a 12 percent increase. Wal-Mart wins $\$ 800$ billion and possesses a 21 percent supermarket share in the U.S.

Currently, India has one of the world's fastest growing economies and food retail sector was valued at \$600billion in 2015 with estimated retail food sales at around \$360billion or 60 percent of the total retail sales ${ }^{506}$. However, grocery retail tends to be dominated by local players in most countries. It has even been argued that "every grocery retailer that has ventured overseas has failed as often as succeeded," e.g. some industries face more difficulty internationalizing than others, although of course there are exceptions ${ }^{507}$.

BRICS jurisdictions show rather different situations with reference to retail concentration. The importance of modern large retailers ${ }^{508}$ varies widely across these countries. While large retails have, for instance, recently surpassed local small groceries in terms of volumes of sales in Russia and Brazil, in India and China, by contrast, these modern retailers still hold a small share of the food sold on the market.

\section{Figure 2: Modern versus Traditional retail in BRICS}

\section{Russia Brazil}

\footnotetext{
502 Ibid

${ }^{503}$ See M. Gehlar \& A. Regmi, Factors Shaping Global Food Markets, New Directions in Global Food Markets / AIB-794 (Economic Research Service, USDA, 2002).

${ }^{504}$ R. Bell, R. Davies et al., 'The changing structure of food retailing in Europe: the implications for strategy', (1997) 30(6) Long Range Planing 853.

505 A. Felsted, 'Foreign grocers struggle in fast-moving China retail market' Financial Times, (April 29, 2015), https://www.ft.com/content/99139f00-ee52-11e4-88e3-00144feab7de .

506 USDA Foreign Agricultural Service, India Retail Foods 2015, December 28, 2015, Pub. IN5164, New Delhi.

${ }^{507}$ M. Corstjens \& R. Lal, Retail Doesn't Cross Borders: Here's Why and What to Do About It, Harvard Business Review (April 2012).

${ }^{508}$ Expressed in volumes of fresh and packaged food sold.
} 

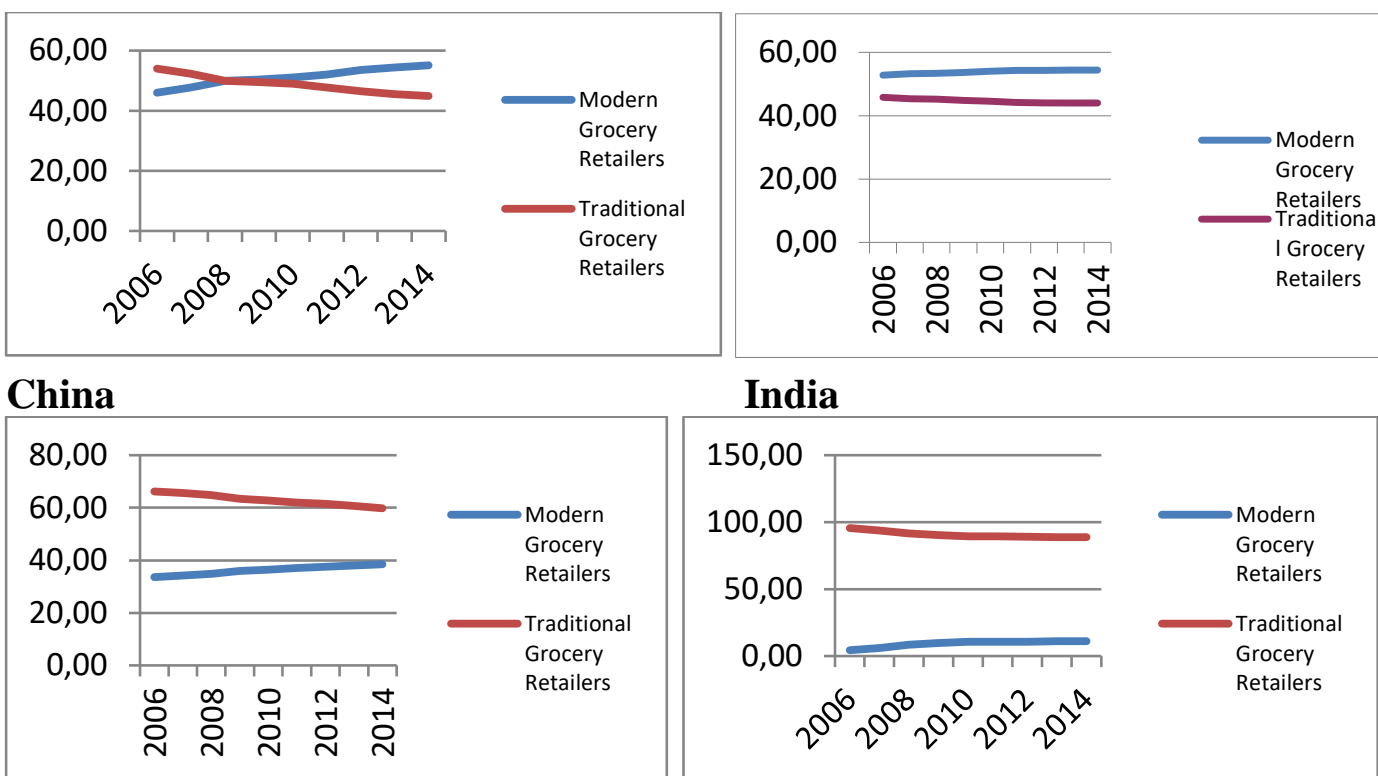

India

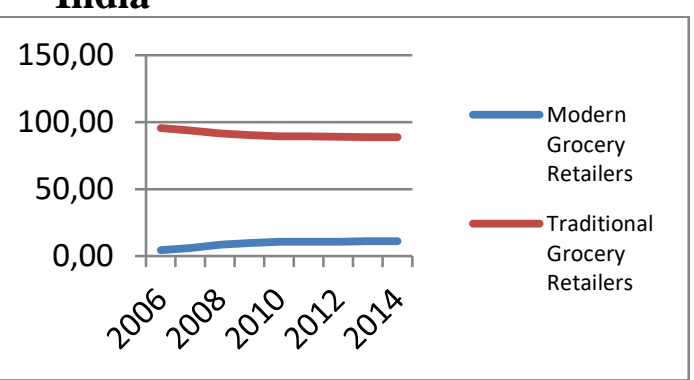

\section{South Africa}

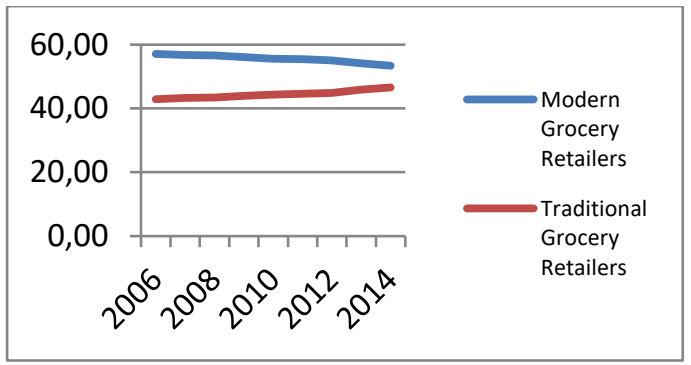

Source: our elaboration of data from Euromonitor

BRICS supply chains also show other bottlenecks, such as 'agroholdings' in Russia ${ }^{509}$ and State regulated markets in India. ${ }^{510}$ Consequently, their policy responses have been adapted to local conditions.

With regard to global MNEs, Walmart's empire consists of supercenters, discount stores, neighborhood markets and other small formats and Sam's Clubs with in the U.S. and international properties consisting of the following: Africa (408 properties), Argentina (108), Brazil (499), Central America (709), China (432), India (21), Japan (346), and Mexico $(2,360)^{511}$. International competition takes place in several ways through merchandise price setting, locations, and even store hours against retailers operating in department, drug, solar stores, supermarkets, hypermarkets, home-improvement stores, and cash \& carry operators. Internationally, Walmart has undergone an inorganic approach to geographic expansion via selective acquisitions and strategic alliances to accumulate new stores or to open new units. It

509 J. Wandel, 'Business Groups and Competition in Post-Soviet Transition Economies: The Case of Russian "agroholdings"” (2011) 24 The Review of Austrian Economics 403; J. Swinnen, K. Herck and others, 'Food Security: Challenges and Opportunities for Eastern Europe and Central Asia' (2012) 9 Asian Journal of Agriculture and Development 37.

510 Ministry of Agriculture, Government of India, Report on Agricultural Marketing, 2007, available at http://agricoop.nic.in/AnnualReport06-07/AGRICULTURAL\%20MARKETING.pdf.

${ }^{511}$ See: https://www.sec.gov/Archives/edgar/data/104169/000010416916000079/wmtform10-kx1312016.htm 
is also standard to introduce new formats for the new units like supercenters that have not previously operated in those markets. A variety of factors determines Walmart's ability to effectively expand its international segment, such as local laws for building acquisition and site location, the ability to hire, train, and retain qualified personnel, and the availability of certain goods and local suppliers needed to expand products where there is an emphasis on locally sourced items. Nonetheless, as the world's largest retailer, it has more overseas stores than it does in the United States with a reported total of 6,189 stores in the international segment versus the 4,987 in the US.

There are also a variety of barriers to geographic expansion related to cultural penetration and differences that make it difficult for Walmart's concepts to connect with the consumer in some countries, in addition to foreign investment laws inhibiting market entry and the general legal and business environment of these markets. This raises concerns about Walmart's ability to expand both inorganically and organically in the International segment, which is key to growing the business. As such, inorganic growth could face severe road blocks for the corporation if suitable acquisition candidates and prices are not identified consistently in the future. Inorganic expansion has worked well in the past due to the local knowledge existing operations already possess, but future successful integration of these acquisitions or alliances into Walmart's existing operations depends largely on timing. Potentially, Walmart's International segment will be adversely affected in terms of future financial performance because of this inability to effectively acquire operations.

Wholly-owned subsidiaries operating in retails are situated in Argentina, Brazil, Canada, Chile, China, India, Japan and the UK, while majority-owned subsidiaries are operating in Africa, Central America and Mexico with joint ventures in China. Interestingly, 26 percent of the consolidated net sales for the fiscal year 2016 came from Walmart International operations. However, the company faces challenges from the different regulatoy structures and frameworks in each jurisdiction. For example, Brazil is a federal state with complex local laws with multiple interpretations which make Walmart's Brazilian subsidiaries subject to inherent uncertainty and materially adversity in terms of financial performance. Walmart also operates smaller units at around 2,400 square feet such as drugstores and convenience stores, the wholesale category containing the largest units at around 35,000 square feet to 70,000 square feet. The segment's net sale for 2016 was USD 123.4 billion which has fallen from the previous years of 2015 and 2014. There are 176 distribution facilities in Argentina, Brazil, Canada, Central America, Chile, China, Japan, Mexico, South Africa, and the United Kingdom with 77 percent of the International segment's purchases passing through these facilities in 2016. Walmart's major international competition is from multinationals and local supermarket chains like Carrefour SA, Metro AG, and Tesco, for example.

Despite the numerous barriers than can adversely affect future financial performance, Walmart's international revenue grew at a CAGR of 7.3 percent from 2009-2014, but the profitability is lower due to high front-end costs related to expansion efforts. Walmart has announced a strategic review of its global assets, closing down 60 locations in Brazil of its Maxxi brand cash and carry stores and some supercenters for restructuring purposes ${ }^{512}$.

512 Forbes 2017. Available at: https://www.forbes.com/sites/greatspeculations/2017/03/16/why-wal-mart-isinvesting-more-in-brazil/\#6d0558e620b4 . 
Originally, Walmart entered Brazil in 1995 with the acquisition of two retailers: Bompreço S.A. Supermercados do Nordeste and Sonae Distribuição Brasil S.A. which expanded operations in northeast and south Brazil resulting in a variety of brands-nine different store banners in total in Brazil.

Costco Wholesale Corporation engages in the operation of membership warehouse in the U.S., Candad, U.K., Mexico, Japan, Australia, Spain and majority-owned subsidiaries in Taiwan and Korea. Membership warehouses operate based on the concept of offering low prices to members on private-label products and a selection of nationally branded merchandise which produces high sales volumes and rapid inventory turnover. This combines with volume purchasing, efficient distribution, and reduced handling in merchandise in warehouse facilities to create profitability at lower gross margins that other retailers $^{513}$. The online business front operates websites in the U.S. Canada, U.K., and Mexico to provide customers with additional products not available in warehouses resulting in 3 percent of net sales attributed to online business for the past three years. There are a total of 686 warehouses: with (480) in the U.S., (89) in Mexico, (36) in the U.K., (27) in Japan, (12) in Korea, and (11) in Taiwan.

International competition is with global, national, and regional wholesalers and retailers like supermarkets, supercenters, department and specialty stores, gasoline stations, and internet retailers and is based on price, merchandise quality, and location and selection. Total revenue for 2015 was $\$ 84$ billion in the US and $\$ 14$ billion internationally with food representing 22 percent, sundrieds 21 percent, and hardlines 16 percent of sales. As such, Costco has largely focused on organic expansion through the operation of membership warehouses in the U.S., Canada, Mexico, U.K. Japan, Australia and Spain with majority owned subsidiaries in Taiwan and Korea.

In 2013, Costco expanded its operation organically by opening over 150 warehouse clubs globally to accelerate growth with an initial customer responses in these markets better than that in the U.S. ${ }^{514}$ In particular, the Asian market has seen an average of 30,00040,000 signups in the first eight to twelve weeks for its new warehouses while those figures were around 3,000-12,000 for the U.S. As such, net sales increased by 45 percent from 2010-2014 which is immense in comparison to similar multinational competitors such as Walmart which experienced 21 percent growth during this same period ${ }^{515}$. Recent geographic expansion is taking place in France and Iceland ${ }^{516}$. In Iceland's capital city, 20 percent of households are now members of Costco's local warehouse, a concept enjoyed in a country like Iceland where food and consumer goods prices are 70 percent higher than in the U.S., especially gasoline prices.

https://www.sec.gov/Archives/edgar/data/909832/000090983215000014/cost10k83015.htm\#sEFD5A5B9D552 FE15471ED3EF135E51A1

${ }^{514}$ Forbes 2015. Available at: https://www.forbes.com/sites/greatspeculations/2015/04/17/costcos-internationalexpansion-plans-will-boost-growth/\#34b52f063a9e

515 Ibid

516 Bloomberg 2017. Available at: https://www.bloomberg.com/news/articles/2017-08-24/costco-is-playing-adangerous-game-with-the-web 
Thus, Costco has been able to capture the interest of consumers in various national markets in offering price comparison points, for example. Costco intends to open 15 units in France by 2025, with its first French store opening with 30,000 members hoped for, but currently only 10,000 have been sold ${ }^{517}$. Due to the annual fee, French customers experience prices that are 20 to 40 percent lower than standard supermarkets. Strategically, Costco is raising annual membership fees in the U.S. and Canada.

Kroger is one of the largest retailers in the world in terms of annual sales and operates over 2,800 stores across the US. This takes places through consumer product purchase in stores, fuel centers and online platforms. Last year, Kroger generated USD 4 billion in sales from its convenience stores ${ }^{518}$. The company is active in inorganic growth expansion with several recent acquisitions such as a merger with Roundy's, a chain with 151 stores and 101 pharmacies across the US for $\$ 800$ million in 2015, and a 2014 acquisition of Harris Teeter a regional chain with 200 stores in the Southeastern US and mid-Atlantic markets for $\$ 2.4$ billion. Thus, its expansion has been primarily in the US in terms of geography. In terms of online retail, Kroger merged with Vistacost.com in 2014 which is a leader in online nutrition and healthy living with plans to growth its online space market through purchasing 10 percent of its common stock. Other recent mergers include: ModernHEALTH in 2016 for $\$ 407$ million through the purchase of 100 perc ent of its outstanding shares that will enable Kroger to expand its specialty pharmacy services in terms of geographic reach.

Kroger reported a total sales increase of 1.3 percent for 2015 due to supermarket sales and the inclusion of Roundy's sales., with an increase of total sales in 2016 at 5 percent due to the merger with ModernHEALTH. Currently, Kroger operates directly or through subsidiaries with 2,796 supermarkets with local banner names in which 2,255 had pharmacies and 1,445 had fuel centers ${ }^{519}$. In addition to supermarkets, Kroger operates through its subsidiaries consisting of 784 convenience stores, 319 fine jewelry stores and online retailers with 56 percent of convenience stores operated in company owned facilities. However, there are 4,000 owned or leased supermarkets, convenience stores, fine jewelry stores, distribution warehouses, food production plants via divisions, subsidiaries or affiliates located in the US, illustrating that the majority of the properties of its businesses are leased. In the US, Kroger operates 38 food production plants that consist of 17 dairies, 10 delis or bakery plants, 5 grocery production plants, two meat plants and two cheese plants with the food production plants producing 45 percent of the grocery units sold in supermarkets.

Lidl, a German food-retailing chain, has experienced success in its international organic expansion in recent years, offering mostly own-brand goods and no premiumpriced products ${ }^{520}$.Lidl is owned by the Schwarz Groupand is Europe's biggest retailer that keeps prices low with limited inventory and a slim selection of private label items. The

\footnotetext{
${ }^{517}$ Forbes 2017. Available at: https://www.forbes.com/sites/walterloeb/2017/05/30/costco-exceeds-expectationsin-sales-and-earnings-will-open-15-units-in-france/\#199a60f947b6

${ }^{518}$ Financial Times (2017). Available at: https://www.ft.com/content/787923be-ae99-11e7-aab9-abaa44b1e130

${ }^{519}$ See http://ir.kroger.com/sec-filings

520 The Economist 2015. Available at: https://www.economist.com/news/business/21646224-germandiscounters-successful-business-model-only-stretches-so-far-tomorrow-not-quite
} 
chain has expanded into the UK over the past several years, adversely affect the UK's biggest supermarket chains by spurring price wars ${ }^{521}$. Other geographic expansion is taking place in the US with 12 cities already leased along the East Coast from New Jersey to Georgia. Currently, Lidl possess 10,000 stores in 26 European countries. In 2015, Lidl acquired grocery delivery start-up Kochzauber which will provide knowledge in delivery fresh grocery items to compete with Amazon Fresh and the online grocery market concept. In the UK Lidl offers a network of 600 stores.

Aldi, which is divided into two legally separate but co-operating companies: Aldi Nord and Aldi Sud, is a Dutch-Belgian retailer that also runs U.S. supermarket chains Stop $\&$ Shop, Giant, Hannaford, and Food Lion ${ }^{522}$. For example, there are 1,100 Food Lion shops across the US and is furthering its inorganic expansion in the US with the acquisition of all 66 stores from Delhaize Group's Bottom Dollar chain. Currently, it has 1,600 stores in 45 US states. Aldi reported increased sales by 22.6 percent in the past year in Britain with 600 stores in the $\mathrm{UK}^{523}$.

Tesco currently has around 6,8099 shops globally is the world' third largest retailer. It operates more than 3,000 stores across the UK and contains 25 percent of the UK market share, but is struggling to find new avenues for growth on the home turf leading to future geographic expansion abroad ${ }^{524}$. Tesco's profits fell by 8.3 percent in the UK in 2016, resulting in a new focus on opening local convenience stores with plans to open 160 new ones in the UK. Competition concerns are raised over Tesco's recent acquisition of wholesaler Booker Group from GBP for $£ 3.7$ billion which supplies hundreds of convenience stores that compete with Tesco's small front shops ${ }^{525}$. Booker supplies from that 5,000 stores under the Premier, Londis, Bugdens, and Family shopper brands, thus resulting in Tesco as a new major supplier serving 125,00 convenience stores and 468,000 pubs and restaurants across Britain.

International geographic expansion has been inorganic and largely in the form of joint ventures. In 2014, Tesco completed a joint venture with China Resources Enterprise Limited to create the largest food retailer in China. This results in the combination of Tesco's 131 outlets in the country with CRE's 3,000 stores called Vanguard in which CRE has 80 percent of the new chain with Tesco investing around GBP 85 million $^{526}$. In addition, Tesco formed a joint venture with a unit of Tata Group in India and invested USD 140 million to be the first foreign supermarket in India ${ }^{527}$. The India JV will operate in the hypermarket and Star Bazaar retail business in India. Strategically, the distribution

521 Business Insider 2016. Available at: http://uk.businessinsider.com/lidls-expansion-plans-in-the-us-2016-9

${ }^{522}$ See Reuters 2014. Available at: http://uk.reuters.com/article/us-tesco-india/tesco-confirms-joint-venture-withtata-in-india-idUKBREA2K0U020140321

523 The Economist 2015. Available at: https://www.economist.com/news/business/21646224-germandiscounters-successful-business-model-only-stretches-so-far-tomorrow-not-quite

${ }^{524}$ Financial Times 2017. Available at: https://www.ft.com/content/c49977ca-e460-11e6-8405-9e5580d6e5fb

525 Ibid

${ }^{526}$ BBC 2014. Available at: http://www.bbc.co.uk/news/business-27615404

${ }^{527}$ Reuters 2014. Available at: http://uk.reuters.com/article/us-tesco-india/tesco-confirms-joint-venture-with-tatain-india-idUKBREA2K0U020140321 
center will provide wholesale products to traditional India retailers, restaurants, and kirana stores as well as small farmers and other suppliers with a new channel in the local market. Next, in 2002 Tesco launched in Malaysia and has 47 stores totaling GBP 937 in revenue which is its biggest overseas operated with 11 percent of the market share and is engaged in a partnership with Sime Darby. In South Korea, Tesco has 520 stores totaling in GBP 5.3 billion in revenue and is the second largest grocer and is its most successful, especially its homeplush chain which has utilized virtual stores for customers. In Japan, Tesco possesses 121 stores that have now all been sold due to a difficult market.

Metro Group, a Germany multi-channel food service provider, generates sales of EUR 59 billion in international retailing with operations in over 2,000 location in 29 countries. Metro's brands contribute to the performance of sales such as Metro/Makro Cash \& Carry a leader in self-service wholesale trade, Media Markt and Saturn a leader in electronics retailing and Real hypermarkets. Metro Group uses inorganic geographic expansion such as the 2017 acquisition of Pro à Pro to penetrate deeper into the food service distribution in France which provides direct food delivery to a variety of customer groups with around 42,000 French customers and generates EUR 670 million in 2015. According to the annual report, geographic expansion has extended into the Middle East and major Asian cities with the take-over of Classic Fine Foods group, a leading Asian company in food delivery that directly supplies hotels, restaurants, and catering sectors with food products.

The Metro Cash \& Carry is its biggest international business and is focusing on value creation in its national subsidiaries. In fact, the 2016 acquisition of RUNGIS by Metro group expanded its premium food supplier portfolio across six countries, especially the premium segment in Germany. RUNGIS' acquisition will be executed in that Metro will allow RUNGIS to operate independently, but Metro will benefit from the extension of delivery business with direct contacts in premium foods for customers in hotels, restaurants, and catering sectors and various trading and logistic entities. Other countries involved in the RUNGIS acquisition are: Austria, Poland, Portugal, Switzerland and Spain.

Target Corp. currently posses 1,802 stores in the US with sales generated USD 69 million in 2016, a 5.8 percent decrease from the prior year. It is one of North America's largest discount retailers with over USD 73 billion in annual revenue. California, Texas, Florida, Minnesota, and Illinois are the top give sales generating states. Geographic expansion into Canada was largely unsuccessful and resulted in a full exit in 2015 and certain other wholly owned subsidiaries of Target. Target has engaged in a variety of geographic expansion, with India operations in Embassy Manyata Tech Park and Embassy Golf Links. Other acquisitions include the CHEFS Catalog and assets of cooking.com to expand its e-commerce presence in the kitchenware market. Target allows both business to operate under their brand names, but combined to create a new, wholly owned subsidiary of Target.

Recently, Target acquired a San Francisco transportation technology company called Grad Junction to enhance its same day delivery business and is testing out new concepts in next-day delivery to compete with Amazon Prime Pantry, for example. 
Therefore, inorganic expansion across the US is well suited for these ambitions ${ }^{528}$. Further focus on organic expansion of CityTarget locations in big cities across the US will allow growth for the smaller format stores that have been unexposed to Target in general ${ }^{529}$. Specifically, this will entail 11 new small format stores in New York, Chicago, Los Angeles, Philadelphia, and Minneapolis and is opening 32 new stores in 2017 in total.

French retailer Auchan is a privately held hypermarket operator which is present in 17 countries, making 75 percent of its revenue outside of France. Auchan is accelerating its inorganic geographic expansion with the 2017 acquisition of Karavan a local Ukrainian retailer, despite the fact it already possesses 11 hypermarkets in five Ukrainian cities. In 2012 Auchan acquired Metro AG's Real hypermarkets in eastern Europe for USD 1.4 billion which has resulted in 18.7 percent of its global turnover ( $\$ 52$ billion) for central and eastern Europe in 2017.

Carrefour operates in a multi-formal, omni channel model in food retail which enjoys global inorganic expansion through acquisitions. These operations include 12,000 stores and e-commerce sites in more than 30 countries, with total sales of around EUR 103 billion in 2016. Moreover, there has been an organic increase in sales by 3 percent with renewed growth in France. There are 5,670 stores in France, 3,873 in Europe (excluding France), 348 stores in Asia, and 1,092 stores in other countries. The formats of operation include: hypermarkets under the Carrefour banner for major shopping trips, supermarkets under the Carrefour Market, Bairro and Supeco banners, convenience stores like Carrefour Express, City, Contact, Bio, and Cash \& carry for food service professionals for products at wholesale prices.

Its most recent acquisition was Spain's Eroski stores which includes 26 hypermarkets, 8 shopping centers, 22 adjoining petrol stations, and will extend its presence in 27 new cities. Recent organic geographic expansion is the opening of Carrefour's first hypermarket in Kazakhstan with franchisee Majid Al Futtaim Group in addition to Kenya's first hypermarket store in Nairobi under the same franchisee. Within Europe, Carrefour has acquired Rue de Commerce a key player in non-food e-commerce, has acquired 86 Billa supermarkets in Romania. In Brazil, it opened 12 new stores with a presence in all of the country's states (134 stores in total for 2016), and is launching e-commerce business in the country as well.

China is a host to a variety of food retail expansion, as multinationals identify the Chinese market as a means of stronger and faster penetration. For example, Walmart plans to open 30 to 40 new stores in China and will upgrade over 50 stores currently there with net sales growing 5.4 percent in the past year. Walmart already opened 21 hypermarket stores, 3 Sam's Clubs and 24 new stores in 2016 $6^{530}$. Already, Walmart operates in 117 cities across 25 provinces, but is finding it challenging to implement the right product mix. The challenges of expansion are related to supply chain efficiency, logistics, and physical

\footnotetext{
${ }^{528}$ Techcrunch 2017. Available at: https://techcrunch.com/2017/08/14/target-acquires-transportation-companygrand-junction-to-expand-same-day-delivery-services/

${ }_{529}$ See Reuters 2015. Available at: https://www.reuters.com/article/us-target-canada-usa/after-canada-exit-targetthinks-small-with-u-s-expansion-plans-idUSKBNOKO2Q820150115
}

${ }^{530}$ See http://www.marketing-interactive.com/walmart-china-plans-massive-2017-expansion/ 
infrastructure ${ }^{531}$. In terms of strategic importance, China is also a key market for Tesco which has utilized a joint venture to combine its retail practices with CRE's local knowledge, buying GBP 2 billion worth of goods and services from China for Tesco ${ }^{532}$. China's e-commerce food retail front is also of interest to Metro Group which partnered with Alibaba in 2015 to expand into China. Metro Group opened a cross border e-shop on Alibaba Group's Small Global platform to offer Chinese customers German products, according to an annual report. In addition, Metro operates in over 80 wholesale markets in China under METRO Cash \& Carry, and will use the e-commerce to sell its private labels in dairy, coffee, chocolate and cosmetic goods. Auchan operates hypermarkets in China under the Auchan Hypermarket China Group.

It is estimated that the size of the South African food and general retail industry is valued at R215 billion per year. Within this market, large players tend to benefit from economies of scale, so that discounts with suppliers are secured, resulting in major barriers to entry. As such, a South African Competition Commission inquiry into whether these barriers of entry are negatively impacting competition in the grocery retail sector of South Africa is currently ongoing ${ }^{533}$. The inquiry will further assess whether small businesses and independent retailers can develop in this environment of competitive constraints within the supply chain. Thus, the concern is that larger players in the grocery retail supply chain place strong competitive constraints on smaller players.

The grocery retail supply chain of South Africa is made up of a level of manufacturers, processors, and suppliers made up of well-known international brands such as British American Tobacco in addition to smaller manufacturers. The grocery manufacturers and suppliers penetrate the market through grocery retailers, wholesalers, and buyer groups via: (1) direct supply by grocery manufacturers and processors or (2) through wholesalers and independent grocery retailers that independently procure their products, providing an alternative route for the market and protection for smaller suppliers, and (3) through national supermarket chain internal distribution of grocery products to their stores ${ }^{534}$. The main buyer groups in South Africa are Unitrade Management Services ("UMS"), the Buying Exchange Company ("BEC"), the Independent Buying Consortium ("IBC"), the Independent Cash \& Carry Group ("ICC") and Elite Star Trading ("EST"). Buyer groups use collective buying power to secure cost savings and aggregate volume purchases by combing resources to make supply purchases. In short, buyer groups are a form of cooperation between buyers in terms of price, diversity, quality.

Major grocery retail chains in South Africa have invested in and use distribution centers that enable grocery manufacturers, processors, and suppliers to send their products to these

\footnotetext{
$531 \quad$ Forebes 2016. Available at:

https://www.forbes.com/forbes/welcome/?toURL=https://www.forbes.com/sites/dougyoung/ https://www.ft.com/content/85103bcc-ee24-11e4-987e-00144feab7de2016/01/25/wal-mart-talks-up-chinacommitment/\&refURL=https://www.google.co.uk/\&referrer=https://www.google.co.uk/

${ }^{532}$ Financial Times 2017. Available at: https://www.ft.com/content/c49977ca-e460-11e6-8405-9e5580d6e5fb

533 Competition Commission South Africa, “Retail Market Inquiry,” May 26, 2016, http://www.compcom.co.za/retail-market-inquiry/

534 Ibid
} 
centers, which are then sent to the chains' individual stores. Next, national supermarket chains in South Africa use the format of serving customers in more rural and township areas. Here, 80 to 90 percent of the food retail market is owned by the five largest players with Pick n Pay as the largest national grocery supermarket, followed by the SPAR Group, Woolsworths, Walmart owned Massmart, and Fruit and Veg City and include hypermarkets, convenience stores, and express stores. Independent grocery retailers operate in both the formal and informal sectors and provide access to low income consumers for grocery retail products ${ }^{535}$. The end users of grocery products are the consumers, which in South Africa means that large social inequalities exist with over 21 percent still living in extreme poverty unable to pay for basic nutrition.

India's retail food market is placed within one of the fastest growing large economies with estimates that it will be the world's third largest economy by 2025 . This potential for growth is resulting in an increase of higher land or rental spaces, more stringent food and labeling laws, and rising capital costs for retail growth in the country, resulting in industry members devising different formats to ensure economies of scale ${ }^{536}$. A recent analysis shows that India's total food and non-food retail sector is valued at USD 600 billion with retail food sales at around USD 360 billion at 60 percent of the total retail sales. The Government of India aims to protect its 12 million shopkeepers, who are responsible for 97 percent of all retail sales, through disabling foreign supermarkets to open shops in the country ${ }^{537}$. However, individual states possess the authority to deny or approve retail FDI.

Although European grocers are enticed by the fast rising consumer spending in emerging economies like India and stagnant, blanketed markets in their home countries in terms of supermarkets and hypermarkets, traditional trade is proving to remain the consumers' preferred choice ${ }^{538}$. This is largely due to multinational grocers' reliance on European grocery formats, which have not rooted well in emerging economies due to inherent barriers related to a lack of good road networks, car ownership, and a small middle class with less means for storing bulk groceries ${ }^{539}$. Therefore, emerging markets have a distinct identity that differentiates them from developed markets. Understanding how these demand and supply side factors shape the retail environment in these countries would enable the development of better suited food retail formats. Moreover, India's government has clearly signalled protectionist public policies aimed to limit the growth of FDI retail ${ }^{540}$. Nonetheless, 85 percent of private consumption in India is on food, with food grains being the largest share ${ }^{541}$. Regional preferences for food also dominate the Indian market with over 10 kinds of rice that are tied strongly to these regional preferences.

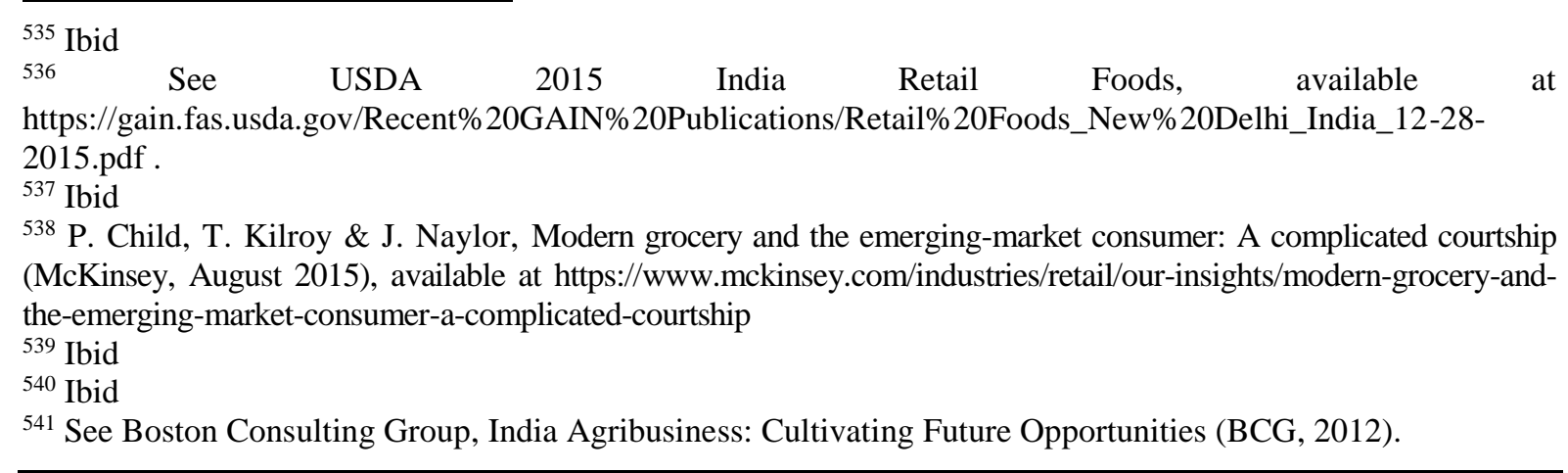


Table 3: Largest retail chains in the world (in terms of revenue and countries in operation)

\begin{tabular}{|c|c|c|c|}
\hline Name of the Chain & $\begin{array}{l}\text { Retail } \\
\text { Revenue } \\
\text { (2014) US\$B }\end{array}$ & $\begin{array}{l}\text { Countries in } \\
\text { Operation }\end{array}$ & $\begin{array}{l}\text { Retail Revenue (2016) US } \\
\text { \$B }\end{array}$ \\
\hline & 476 & 28 & 482 \\
\hline & 112 & 10 & 118 \\
\hline & 98 & 1 & 109 \\
\hline & - & 26 & - \\
\hline & 63 & 13 & 53 \\
\hline & 76 & 34 & 78 \\
\hline & - & 17 & - \\
\hline & 11 & 32 & 12.7 \\
\hline
\end{tabular}




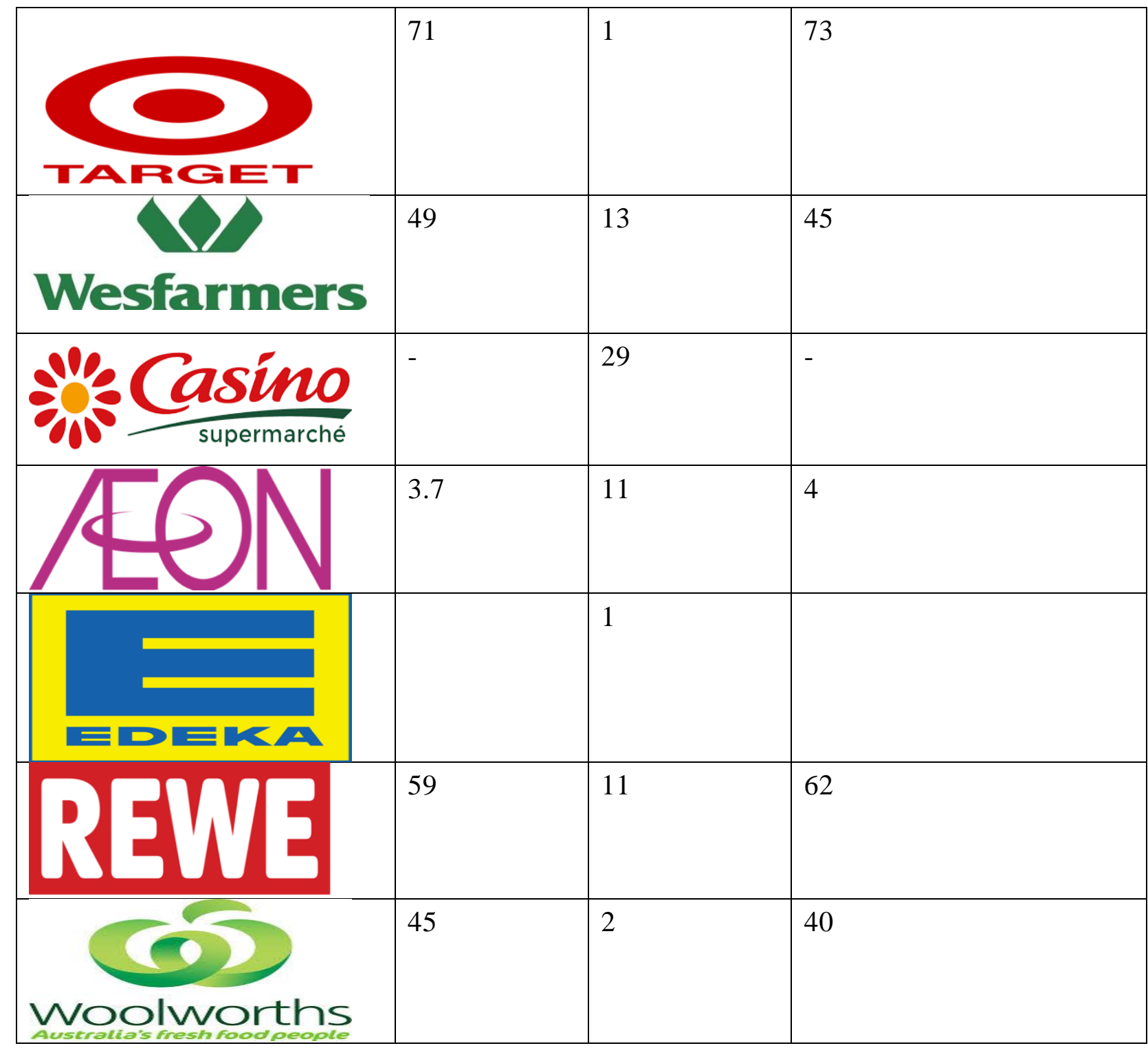

Source: Authors' compilation of data

\subsection{Economic concentration and the emergence of industry global leaders}

Having described the various global actors in the different segments of the value chain, we will explore in this Section the business strategies followed for international expansion and dominance of the food value chain (in terms of attracting the highest percentage of the total surplus produced by the specific food value chain) and the way M\&As and investment in technology may fit in this strategy. We will focus on the factors of production segment.

\subsubsection{Business Strategy: a focus on the factors of production segment of the food value chain}

The results of the conducted analysis of M\&A activity, in particular in the factors of production segment of the food value chain show a shift in strategy from seeds acquisitions to acquisitions in the biotech and IT sectors. In biotech, the companies are rapidly developing microbial 
products which can either become complementary to the existing products or serve as a replacement of traditional chemistry (i.e., pesticides products) ${ }^{542}$. The global pesticides industry accounts for USD 54,2bn (2013) and continues to grow steadily up to USD 75.9bn by $2019^{543}$. Microbial products are a new opportunity and potentially a game changer and a disrupting technology at the global scale. Although currently the industry is still in its infancy (less than USD 2 bn of global sales in 2014), going forward it represents a huge potential, especially given the growing demand for organic farming globally. Realizing this, in 2014 Monsanto announced an alliance known as BIOAG Alliance with Novozymes, one of leaders in biotech industry. Novozymes is responsible for the production of the microbial products while Monsanto serves as the lead for field testing, registration, and commercialization for the Alliance's products ${ }^{544}$.

A clear diversification move for global leaders is happening in the so-called "digital agriculture" market. Precision agriculture (or "precision farming") is a global trend that is rapidly growing. By precision farming experts understand a data analysis at the level of the square meter or even smaller to optimize the consumption of inputs (seeds, water, Fertilisers, pesticides, etc.), and to monitor the actual process of production. ${ }^{545}$ Precision agriculture, for instance, may use sensors to collect information from soil (various parameters such as the level of moisture, Fertilisers and pesticides, soil organic matter, various soil properties such as bulk density, texture, compaction, etc.), and satellite images about crop growth progress. It then would combine all information and use big data algorithms to analyse it, applying sophisticated mathematical models to plan and adjust in real-time for needed inputs to maximize the eventual crop yield.

Precision agriculture is expected to revolutionize farming on a global scale within the next 10-15 years. The leading companies are rapidly enhancing this competency. A recent acquisition of the Climate Corporation by Monsanto is a bet to diversify beyond the traditional seeds and pesticides business model. The software developed by the Climate Corporation is aimed to become a powerful decision-support system and a crop progress monitoring tool for a typical farmer ${ }^{546}$. Combined with the existing product portfolio of Monsanto (seeds, traditional and bio-pesticides, etc.), the data analysis and recommendation tool of the Climate Corporation will enable Monsanto to become an ultimate one stop-shop opportunity for a farmer. Monsanto intends to sell subscription to the software as a stand-alone service on a global scale. The other "big six" of the seeds industry - Syngenta, DuPont Pioneer, Bayer, BASF, and Dow - are rapidly catching up by developing their own IT-platforms ${ }^{547}$.

\footnotetext{
542 R. Fraley, Citi 2014 Basic Materials Conference, (3 December 2014), available at http://www.monsanto.com/investors/documents/2015/2014.12.03_citi_fraley.pdf.

${ }^{543}$ Christina Xie, Global Agrochemical Market will Continue to Maintain Steady Growth, (28 October 2014), available at http://news.agropages.com/News/NewsDetail---13349.htm.

544 BIOAG Alliance Fact Sheet, available at http://www.novozymes.com/en/aboutus/brochures/Documents/BioAg-Alliance-factsheet.pdf.

545 Boston Consulting Group, Crop farming 2030: the reinvention of the sector, (2015), available at https://www.bcgperspectives.com/content/articles/process-industries-innovation-crop-farming-2030reinvention-sector/.

546 D. Friedberg, The Climate Corporation Platform Update (21 August 2014), available at http://www.monsanto.com/investors/documents/whistle\%20stop\%20tour\%20vii\%20aug\%202014/the_climate_ corporation_update.pdf.

${ }^{547}$ ETC Group, Breaking Bad: Big Ag Mega-Mergers in Play, (December 2015),Communique 115.
} 
The growth engine of a corporation (how companies grow, what causes rapid growth) has long been one of the most fascinating topics for scholars studying corporate strategy and general management, although its lessons are still relatively unclear. One of the possible explanations of corporate growth engine worth studying was proposed by Achi et al. and is known as "growth cycles / accelerators" $" 548$. Achi et al. studied 9450 publicly listed companies to find 41 companies that have grown dramatically over the previous ten years (growth rates in excess of 20 percent). They suggested that increasing returns driven by positive feedback loops are at the core of successfully growing companies. A number of generic self-reinforcing feedback loops common to the companies that experienced superior growth rates over a long time period was identified. The authors suggested that corporate management needs to combine several growth accelerators to win market share, lock-in customers, and eventually to get sustainable performance over a long timescale. The topic of corporate growth mechanisms through feedback loops and its implications for strategic management was discussed in the works of Morecroft (1985) $)^{549}$, Lyneis (1999) $)^{550}$, Sterman (2000) $)^{551}$, Warren $\left(2004^{552}, 2008^{553}\right)$, Casadesus-Masanell, and Ricart $\left(2007^{554}\right)$, among others.

In our opinion, this is a useful methodology for the analysis of the emergence of the global seed leaders over the last three decades. We think that considering the active mergers and acquisitions policy conducted by the "Big Six" as the only explanation of their rapid development is insufficient. Top factors that shaped the seed industry include: (1) consolidation, (2) R\&D spending, (3) early adoption of the use of new promising genetics technology (i.e., RNA inhibition allowing selective control and the expression of individual genes), (4) vertical integration, (5) network externalities (sale of complementary products in addition to seeds - i.e., Monsanto's corn seeds and "Roundup Ready"), (6) economies of scale from market expansion, and (7) product differentiation (seeds, pesticides, IT cloud-based decision support systems). Such factors are the core growth accelerators based on reinforcing feedback loops. Other accelerators fuelling the corporate engine of global seed and agriculture chemistry producers include IP rights protection, patent alliances to swap traits, market power resulting from increasing lobbying opportunities, etc.

A mechanism of gaining a competitive advantage through key growth accelerators is examined in more detail below (Pictures 1-3) using a methodology of casual loops diagrams of system dynamics ${ }^{555}$.

\section{Figure 3: System dynamics (General)}

\footnotetext{
${ }^{548}$ Z. Achi et al., The Paradox of Fast Growth Tigers, (1995) 3McKinsey Quarterly 4-17.

549 J. Morecroft, The Feedback View of Business Policy and Strategy, (1985) 1(1) System Dynamics Review 419.

${ }^{550}$ J. M. Lyneis, System dynamics for business strategy: a phased approach, (1999) 15 System Dynamics Review 37-70.

551 J. Sterman, Business Dynamics: Systems Thinking and Modelling for Complex World (McGraw Hill, 2000).

552 K. Warren, Why has Feedback Systems Thinking Struggled to Influence Strategy and Policy?, (2004) 21 Systems Research and Behavioral Science 1-17.

${ }^{553}$ K. Warren, Strategic Management Dynamics (Wiley, 2008).

${ }^{554}$ R. Casadesus-Masanell \& J.E. Ricart, Competing Through Business Models, (November, 2007) IESE Business School Working Paper No. 713, available at http://ssrn.com/abstract=1115201.

555 E. F. Wolstenholme, Qualitative vs quantitative modelling: the evolving balance, (1999) 50 Journal of Operational Research Society 422-428.
} 


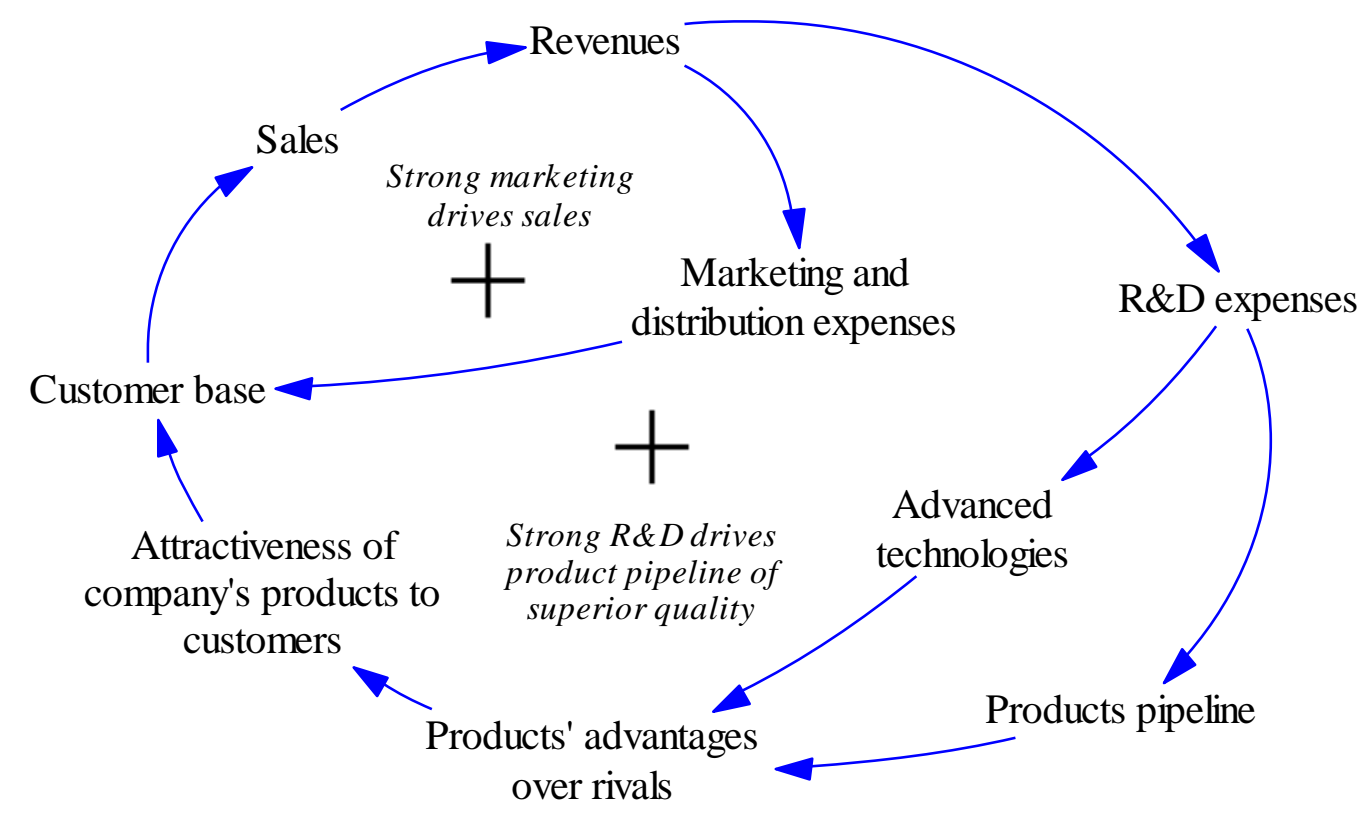

Source: I. Lianos, D. Katalevsky \& A. Ivanov $(2016)^{556}$

The most common growth accelerators for leading seed companies come from state-of-the-art research and development efforts resulting in advanced technologies (i.e., RNA inhibition, etc.), and products with a superior quality over competitors (i.e., seeds with higher yields or advanced resistance to insects), as well as substantial spending on marketing \& distribution channels (Figure X). A diversified pipeline of high quality products increases the attractiveness of a company's products to customers, thus increasing customer base, driving sales and revenues. Higher revenues allow strong R\&D and marketing budgets, thus forming a powerful feedback loop based on the economic concept of increasing returns.

Figure 4: System dynamics (Specific)

${ }^{556}$ I. Lianos, D. Katalevsky \& A. Ivanov, The global seed market, competition law and intellectual property rights: untying the Gordian knot. 2016 (2) Concurrences, Article 78807. 


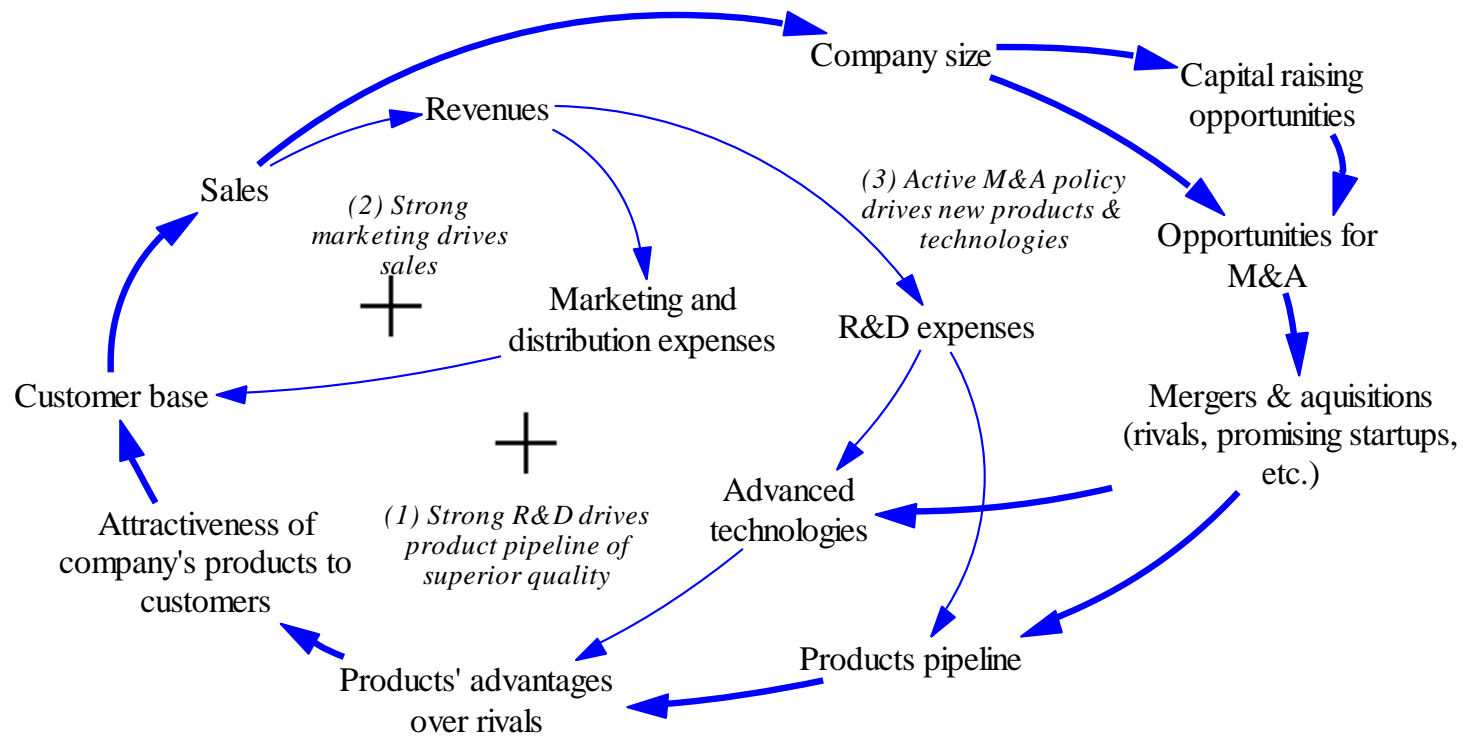

Source: I. Lianos, D. Katalevsky \& A. Ivanov $(2016)^{557}$

As a company grows in size, it gets access to favorable capital raising options, thus enhancing opportunities for M\&A (Figure X). Through acquisitions of promising start-ups or rivals with high potential products or advanced technologies the company adds to the existing product pipeline, driving further sales and revenues. This is another self-reinforcing growth cycle that was successfully employed by global seed and agrochemical companies over the last 20 years.

The market power of the "Big Six" (to become the Mighty Three) is further enhanced by the cross-licencing agreements for genetically modified seed traits between Monsanto, Syngenta, Bayer, DuPont, BASF and Dow ${ }^{558}$. This enables them to create additional barriers to entry for new market players by enhancing intellectual property and trait licensing agreements (i.e, swap of traits, generic trait agreement to manage regulatory regime after expiration of patents) between them as well as litigating the expiration of patents (i.e., peaceful resolution of patent litigation between Monsanto and DuPont in 2013). The results obtained by Vergote and Grandjean ${ }^{559}$ suggest that in some cases such cooperation between rivals may lead to increased barriers to entry for those who are not part of the network. An example of such a case has been documented by Bekkers et al. ${ }^{560}$ through the analysis of Motorola's successful attempt to create a group of dominant players in the GSM industry in 1980s through cross-licencing agreements.

Figure 6: System dynamics (Close up)

\footnotetext{
557 Ibid..

${ }^{558} \mathrm{Ph}$. H. Howard, Intellectual Property and Consolidation in the Seed Industry, (2015) 55(6) Crop Science 1-7, available at http://www.apbrebes.org/files/seeds/files/Howard_seed_industry_patents_concentration_2015.pdf. ${ }^{559}$ W. Vergote \& G. J. Grandjean, Network formation among rivals, (2015) CEREC Working Papers 2014/9. ${ }^{560}$ R. Bekakers, Geert Duysters, and Bart Verspagen, Intellectual property rights, strategic technology agreements and market structure: the case of GSM, (2002) 31(7) Research Policy 1141-1161.
} 


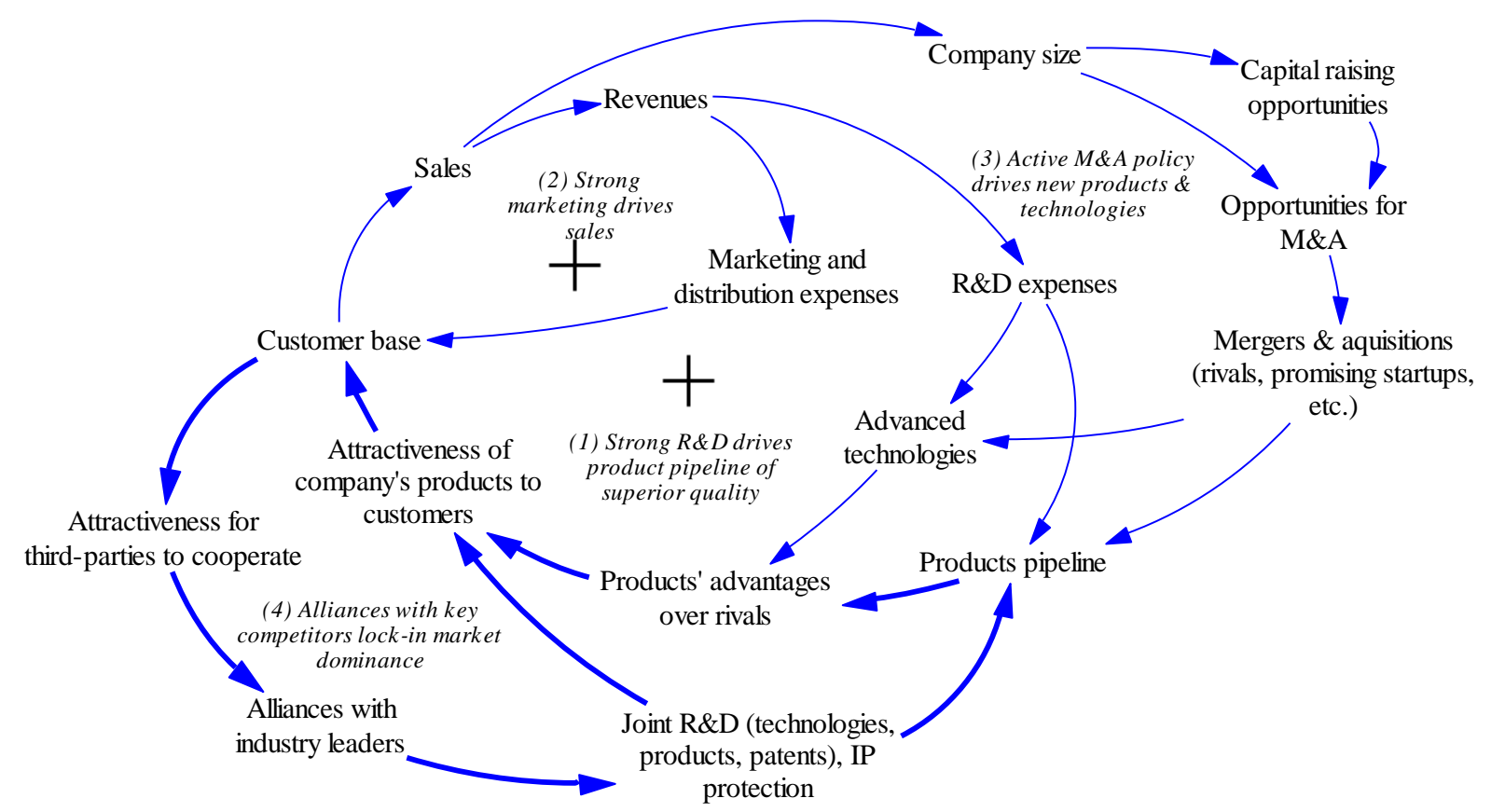

Source: I. Lianos, D. Katalevsky \& A. Ivanov $(2016)^{561}$

An established customer base serves as an attractiveness anchor for third-parties (i.e., competitors, leading NGOs, etc.) to cooperate (Picture 3). The companies become engaged in alliances and networks for joint R\&D opportunities (research for new technologies, products a good example is Monsanto-Novozymes alliance), IP-protection issues (cross-licensing agreements, joint patents, competitive framework after patent expiration policy, etc.), or major industry initiatives (i.e., construction of Svalbard Global Seed Vault).

As the area under GMO plants continues to expand, ${ }^{562}$ the area under biotech crops increased every year from 1996 to 2014 and accounted for more than 180 million hectares in 2014 , leading seed production companies increasingly to gain market power. Eventually, a combination of several powerful positive feedback loops helps industry leaders to de facto lock-in sustainable competitive advantage and market dominance. Lobbying opportunities as well as sponsoring of NGOs, various interest groups, and the scientific community helps to shape a positive corporate image and to sustain market power, thus further maintaining the status quo. Combined altogether, the self-reinforcing feedback loops that drive growth accelerators for global seed industry leaders help them to create a superior competitive advantage over other industry rivals.

\subsubsection{The emergence of global actors across the food value chain}

The ongoing and projected mergers in the seed and agro-chem industry will greatly affect the future control of food production and innovation, which is essential in order to improve yields and feed the world. On the basis of 2015 pro-forma sales, the agro-chem

\footnotetext{
${ }^{561}$ I. Lianos, D. Katalevsky \& A. Ivanov, The global seed market, competition law and intellectual property rights: untying the Gordian knot, 2016 (2) Concurrences, Article 78807.

${ }^{562}$ C. James, Global Status of Biotech/GM Crops, (Ithaca, NY, 2014) ISAAA Brief No. 49.
} 
industry being valued at approximately $85 € \mathrm{bn}$, Bayer/Monsanto will be the market leader with 23.1€bn, followed by Syntenta/ChemChina Ag with $14.8 € \mathrm{bn}$ in the second position, Dow Ag and Dupont Ag with 14.6€bn in the third position, and in fourth position BASF Ag with 5.8€bn. Note that, with the exception of BASF, which is only present in crop protection, all other market leaders are present in both crop protection as well as seeds and traits ${ }^{563}$. The following Figure provides a picture of the agrochem industry prior and after the mega merger process:

\section{Figure 7: Comparison before and after the most recent mega merger wave in agrochem}

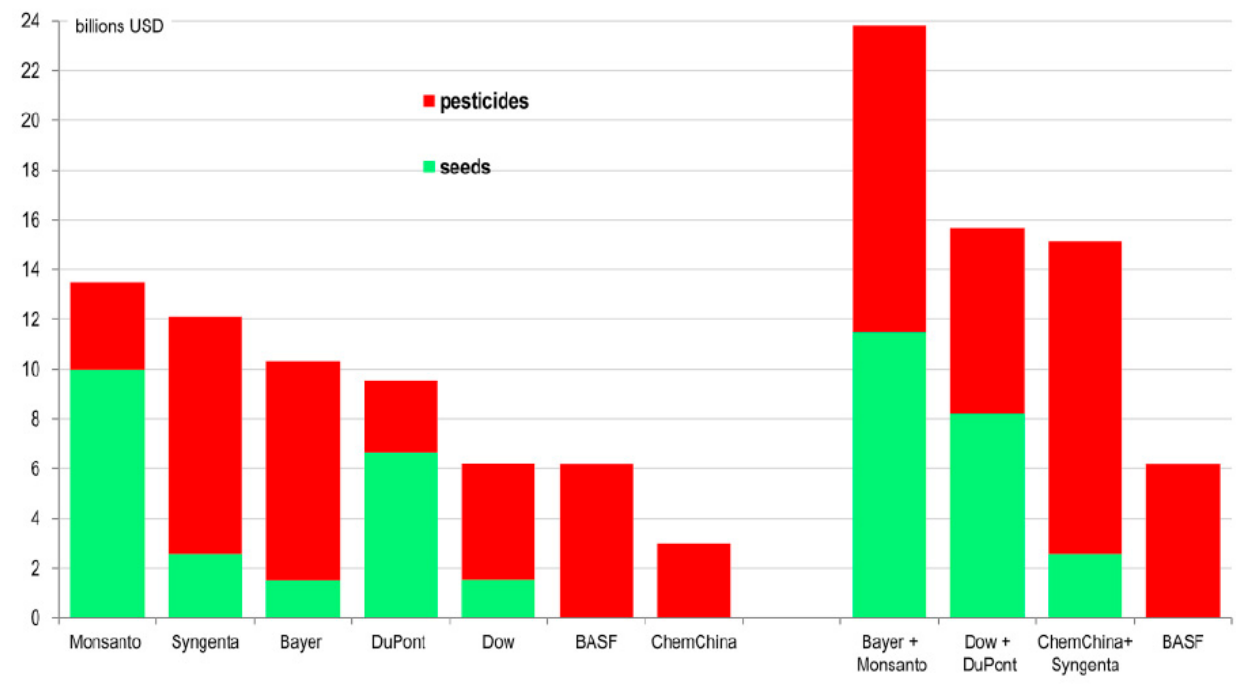

(1) Previous situation (2002-2014) with six large groups, "The Big Six": Monsanto, Syngenta, DuPont, Bayer, Dow, and BASF.
(2) Possible situation in 2017, following the 20152016 concentrations leading to four main groups, "The Big Four": Bayer + Monsanto, DowDupont, Syngenta + ChemChina, and BASF.

Source: S. Bonny $(2017)^{564}$

We discuss the activity of the main global leaders that have dominated the factors of production segment of the global food value chain and constitute the firms with the most developed technological capabilities to take advantage of the opportunities offered by the fourth industrial revolution in this sector.

Germany-headquartered Bayer $\boldsymbol{A} \boldsymbol{G}$ is a "life science" company with core competences in the areas of health care and agriculture. Bayer has proceeded to a number of mergers and acquisitions in recent years. Although Bayer's strength is in agrochemicals, it is present in seeds as well, in particular since its acquisition of Aventis and its AgrEvo subsidiary in 2002.

\footnotetext{
${ }^{563}$ Bayer, Acquisition of Monsanto to Create a Global Leader in Agriculture, Investor Presentation, June 2016, 13.

564 S. Bonny, Corporate Concentration and Technological Change in the Global Seed Industry, (2017) 9 Sustainability 1632, Figure 9. Total sales in seeds and pesticides in 2016 in billion USD. Note that the figure does not take into account the recently announced acquisition of the seeds and non-selective pesticides business of Bayer by BASF.
} 
Bayer is present in rice, cotton, oilseed rape / canola, and vegetable seeds, but also, at least before the merger transaction, it aimed to gain competitive positions in wheat and soybeans. Bayer controls popular seed brands, such as Arize for rice, Credenz for soybeans, Fibermax for cotton, InVigor for canola seeds, Nunhems for vegetable seeds, Stoneville for cotton seeds, seed treatment solutions, such as Gaucho, glyfosinate-ammomium based herbicides like Liberty and Basta, and fungicides, like Nativo. Since its acquisition of US organic pest control company AgraQuest in August 2012, Bayer Crop Science has heavily invested in establishing a Biologics (crop protection) platform. Bayer is also present in "digital farming", projecting to at least invest $€ 200 \mathrm{~m}$ in this area between 2015 and 2020, and currently selling and testing products in ten countries ${ }^{565}$.

US-based Monsanto is an agrochemical and agricultural biotechnology corporation. Its Seed and Genomic segment produces germplasm, in particular row crop seeds (hybrid varieties and foundation seed) of corn, soybean, cotton, canola and other row crop seeds, as well as vegetable seeds, in particular open field and protected-culture seed for tomato, pepper, melon, cucumber, squash, beans, broccoli, onions and lettuce. Monsanto is a leader in germplasm positions in corn, soybeans, cotton and vegetables ${ }^{566}$. Furthermore, it disposes of a unique and patented seed chipping technology, which enables it to test improved seeds at the lab before the seed is even planted, thus reducing the time it takes to produce a new variety by more than two years ${ }^{567}$. Monsanto controls leading brands, such as Dekalb and Channel for corn, Asgrow for soybeans, Deltapine for cotton, Seminis and De Ruiter for vegetable seeds. Monsanto also develops biotechnology traits enabling crops to protect themselves from borers and rootworm and therefore assisting farmers in controlling insects and weeds. These products are distributed in various brands, such as SmartStax, YieldGard, YieldGard VT triple, VT triple PRO for corn, Intacta RR2 PRO for soybeans, Bollgard and Bollgard II for cotton. Its biotechnology traits enable crops, such as corn, soybeans, cotton and canola to be tolerant of Roundup branded and other glyphosate-based herbicides or dicamba herbicides and include brands such as Roundup Ready, RoundupReady 2 Yield, Roundup Ready 2 Xtend and Intacta RR2 PRO (for soybeans), and Genuity. It disposes of advanced technologies for better control of weeds, insects and viruses with its RNA (genetic) ${ }^{568}$ spray technology (BioDirect Technology), without any "tinkering" with the plants' genes being necessary, for instance with the use of a transgenic approach that would create a plant to deliver the RNA, and just with a topical application of

\footnotetext{
565 Bayer, Bayer's commitment to innovation and sustainability will help shape the future of farming (Sept. 7 2016), available at http://www.press.bayer.com/baynews/baynews.nsf/id/Bayers-commitment-to-innovationand-sustainability-will-help-shape-the-future-of-farming .

${ }^{566}$ Monsanto is $\mathrm{n}^{\circ} 1$ in the US and Brazil with at least a 50\% market share, $\mathrm{n}^{\circ} 1$ in Argentina with $60 \%$ and $\mathrm{n}^{\circ} 2$ in the EU with $20 \%$ market share for corn with its DeKalb brand. Monsanto also controls a $40 \%$ market share in the US for soybean through its Asgrow brand, $40 \%$ in the US for cotton germplasm through its brand Deltapine and is the global market leader with a $20 \%$ market share in vegetable seeds with its brands DeRuiter and Seminis : Monsanto, Accelerating the Future of Agriculture, Monsanto's 8thWhistle Stop Investor Field Tour (August 1718, 2016) 16-20, available at https://monsanto.com/app/uploads/2017/05/whistle_stop_viii_day-1session_materials.pdf

567 C. Patterson, Monsanto's Seed Chipping Technology, AgAdvance (January 2013), available at http://www.agadvance.com/issues/jan-2013/monsantos-seed-chipping-technology.aspx .

${ }^{568}$ RNA interference (or RNAi) is a biological process where ribonucleic acid molecules inhibit gene expression or translation enabling the transfer of information from a gene to produce a protein.
} 
the $R N A^{569}$. Monsanto licences genetic material to other seed companies for their seed and forms the central node of a spider web of cross-licensing agreements between the 'Big Six'.

Monsanto has considerably expanded its activity through a number of M\&As the last two decades. More recently, Monsanto acquired The Climate Corporation, which may omen a possible future integration strategy towards precision agricultural machinery equipment. "Precision farming" makes use of sensors to collect information from soil (various parameters such as the level of moisture, Fertilisers and pesticides, soil organic matter, various soil properties such as bulk density, texture, compaction, etc.), and satellite images about crop growth progress. It then combines all information using big data algorithms to analyse it, in order to plan and adjust in real-time the need for inputs (e.g. pesticides). It is promised that this may improve the crop yield, but it may also have the effect to lock in farmers in the Monsanto value chain, making them technologically dependent as Monsanto owns or controls the data generated.

The recent acquisition of the Climate Corporation by Monsanto is a bet to diversify beyond the traditional seeds and pesticides business model. The software developed by the Climate Corporation is aimed to become a powerful decision-support system and a crop progress monitoring tool for a typical farmer ${ }^{570}$. The idea is also to use the power of analytics (Big Data) and advanced marker technology to accelerate yield gains and digitize field testing ${ }^{571}$. The combination of big data metagenomics, bio-informatics, machine learning, and predictive analytics may lead to the development of next-generation insect-control solutions by retargeting proteins ${ }^{572}$. Combined with the existing product portfolio of Monsanto (seeds, traditional and bio-pesticides, etc.), the data analysis and recommendation tool of the Climate Corporation will enable Monsanto to build an integrated 'beyond the seeds' platform to farmers, enabling it to exploit new sources of revenue relating to equipment, fertiliser, pesticides, and even software, providing "optimized seeding and fertility" insights to farmers through Climate FieldView and other products ${ }^{573}$. Monsanto intends to sell subscription to the software as a stand-alone service on a global scale. The other "big six" of the seeds industry Syngenta, DuPont Pioneer, Bayer, BASF, and Dow - are rapidly catching up by developing their own IT-platforms ${ }^{574}$.

US- based DowDuPont is a holding company formed through the merger of equals between The Dow Chemical Company and E. I. du Pont de Nemours and Company, effective

\footnotetext{
569 A. Regalado, The Next Great GMO Debate (August, 11, 2015), MIT Technology Review, available at https://www.technologyreview.com/s/540136/the-next-great-gmo-debate/ .

570 D. Friedberg, The Climate Corporation Platform Update (21 August 2014), available at http://www.monsanto.com/investors/documents/whistle\%20stop\%20tour\%20vii\%20aug\%202014/the_climate_ corporation_update.pdf..

571 W. Vogt, Soybean Breeding Takes on Big Data (November 16, 2016), available at http://www.farmindustrynews.com/soybeans/soybean-breeding-takes-big-data ; Monsanto, Accelerating the Future of Agriculture, Monsanto's 8thWhistle Stop Investor Field Tour (August 17-18, 2016) 59, available at https://monsanto.com/app/uploads/2017/05/whistle_stop_viii_day-1-session_materials.pdf

572 Monsanto, Press Release (Sept. 6, 2016), available at http://news.monsanto.com/pressrelease/corporate/monsanto-collaborates-second-genome-use-microbiome-technology-platform-accel .

573 Boston Consulting Group, Crop Farming 2030 (2015) p. 12; J. Jansen, Unlocking Digital Ag and Seed Technology 6, available at http://files.constantcontact.com/fe439c1b001/3be810cd-551f-4ca4-8e4df812e2aef91a.pdf?ver=1474384793000

${ }^{574}$ ETC Group, Breaking Bad: Big Ag Mega-Mergers in Play, (December 2015), Communique 115.
} 
31 August 2017. The business divisions at DowDuPont include the Agriculture division, Material Science division, and a Specialty Products division. The Agriculture division comprises of both products and technologies, in germplasm, seeds traits and crop protection.

The seed solutions are present in alfalfa, canola, cereals, corn, cotton, rice, silage inoculants, sorghum, soybeans, sunflowers and wheat. DowDuPont crop protection offers a variety of solutions in areas such as cereals herbicides, corn and soybean herbicides, fungicides, insecticides, rice, seed-applied technologies, specialty crop herbicides, structural pest management. Some of the popular crop protection brands include Arylex Active, Enlist Duo, herbicide with Colex-D, Lumisena seed treatment, Vessarya disease control, Inatreq, Pyraxalt insect control, Rinskor Active and Zorvec. DowDuPont has seed offerings such as Enlist Corn, Enlist Cotton, Leptra insect protection in Latin America, Omega-9 Reduced Saturate Sunflower, ProPound Advanced Canola Meal, Stewarded, limited commercial launch of Pioneer brand Qrome products and Plenish Soybeans, Enlist E3 Conkesta, Soybean, Enlist E3 Soybean and Enlist Soybean.

One of the merging companies of DowDuPont is US- headquartered Dow Chemical Company, a multinational chemical corporation operating in five segments: Agricultural Sciences, Consumer Solutions, Infrastructure Solutions, Performance Materials \& Chemicals and Performance Plastics. The agricultural sciences segment was present in both the crop protection and seeds. Popular seed brands included Agromen (under license from Agromen Sementes Agricolas Ltda), ${ }^{575}$ Brodbeck Seeds, Dairyland Seed, Dow Seeds, Myco-Gen Seeds, Nexera, Omega-9. The Dow solutions in the area of crop protection included insecticides, fungicides and herbicides. Insecticides brands comprised of Isoclast, Lorsban, Radiant, Sentricon, Tracer. Fungicides solutions included Dithane, Inatreq; popular herbicides brands consisted of: Arylex, Broadway, Clincher, Durango, Fencer, Garlon, Lontrel, Milestone.

Dow also invested in technologies and seed traits in conjunction with other companies such as Monsanto. The products in this area included the popular Enlist, Enlist Duo, Exzact Precision Technology, POWERCORE Insect Trait Technology, Refuge Advanced Powered By Smartstax, Smartstax Insect Trait Technology. The Smartstax and POWERCORE were multi-event technology developed by Dow AgroSciences LLC with Monsanto. The Smartstax, the Smartstax logo, POWERCORE and the POWERCORE logo all belong to Monsanto Technology, LLC. ${ }^{576}$

As a result of the DowDupont merger, Dow had to divest certain assets to gain regulatory approval in a number of countries. In Brazil for example, Dow sold to CITIC Agri Fund part of its local corn seed business for \$1.1B, including seed processing plants and research centers, the Morgan seed brand, and license for the Dow Sementes Brand. ${ }^{577}$

\footnotetext{
575 The Dow Chemical Company, Security and Exchange Commission form 10-K (31 December 2016), http://www.dow-dupont.com/investors/dowdupont-filings-and-reports/sec-filingsdetails/default.aspx?FilingId=11834973

576 The Dow Chemical Company, Security and Exchange Commission form 10-K (31 December 2016), http://www.dow-dupont.com/investors/dowdupont-filings-and-reports/sec-filingsdetails/default.aspx?FilingId=11834973

577 http://www.dow.com/en-us/news/press-releases/dow-to-divest-a-portion-of-its-corn-hybrid-seed-business-inbrazil-to-citic-agri-fund
} 
The other merging company in the DowDuPont merger is US- E. I. du Pont de Nemours and Company. The company consisted of six reportable segments: Agriculture, Electronics \& Communications, Industrial Biosciences, Nutrition \& Health, Performance Materials and Protection Solutions. DuPont's agricultural businesses included DuPont Pioneer and DuPont Crop Protection.

DuPont Pioneer expertise was in producing, developing and marketing a variety of seeds (hybrid corn seed and soybean seed varieties). DuPont Pioneer's research and development was directed at "integrating high yielding germplasm with ...proprietary and/or licensed native" ${ }^{, 578}$ In 2016, DuPont invested 57 percent of the company's total research and development expense. ${ }^{579}$ Crop Protection served agriculture companies through a variety of products including herbicides and insecticides, as well as protection for field crops such as wheat, corn, soybean and rice and specialty crops such as fruit, nut, vine and vegetables. The main insecticide in the DuPont portfolio was DuPont Rynaxypyr.

Regulatory approval for the DowDuPont merger in countries like the EU, US and Canada was conditional on the sale of certain assets including DuPont's cereal broadleaf herbicides portfolio, DuPont's insecticides portfolio consisting of Rynaxypyr, Cyazypyr and Indoxacarb, and DuPont's Crop Protection R\&D development pipeline and organization, with the exclusion of seed treatment, nematicides, and late-stage R\&D programs. ${ }^{500}$ The approval was granted after DuPont divested these assets to FMC Corporation, in exchange of its Health $\&$ Nutrition business, including food ingredients and pharmaceutical excipients and $\$ 1.6 \mathrm{~B}$ in consideration of the difference in the asset value of the swap. ${ }^{581}$

Aside from the DowDuPont merger, other recent transactions by DuPont included the acquisition of San Francisco-based Granular, Inc., a provider of farm software and analytics tools through its products AcreValue and Farm Management Software, and the owner of AcreValue.com, the leading digital marketplace for farmland real estate. The acquisition marked further investments by DuPont in Digital Agriculture, with new tools to complement DuPont's agronomic software business (Encirca services). ${ }^{582}$

German-headquartered $\boldsymbol{B} \boldsymbol{A S F}$, is a global company that operates in five segments including chemicals; performance products; functional materials and solutions; agricultural solutions; oil and gas. BASF's agricultural solutions focuses primarily on crop protection.

\footnotetext{
578 DuPont, Security and Exchange Commission form 10-K (31 December 2016), http://www.dowdupont.com/investors/dowdupont-filings-and-reports/sec-filings-details/default.aspx?FilingId=11819730.

579 DuPont, Security and Exchange Commission form 10-K (31 December 2016), http://www.dowdupont.com/investors/dowdupont-filings-and-reports/sec-filings-details/default.aspx?FilingId=11819730.

${ }^{580}$ DuPont, 'Summary of Transactions with FMC: Divestiture of Certain Crop Protection Assets and Acquisition of FMC's Health \& Nutrition Business" (31 March 2017), http://s2.q4cdn.com/752917794/files/doc_presentations/2017/mar/DuPont-FMC-Transactions-Presentation.pdf. ${ }^{581}$ DuPont, 'Summary of Transactions with FMC: Divestiture of Certain Crop Protection Assets and Acquisition of FMC's Health \& Nutrition Business" (31 March 2017), http://s2.q4cdn.com/752917794/files/doc_presentations/2017/mar/DuPont-FMC-Transactions-Presentation.pdf; Reuters, 'DuPont, FMC win EU antitrust approval for asset swap deal' (27 July 2017) https://www.reuters.com/article/us-fmc-m-a-du-pont-eu/dupont-fmc-win-eu-antitrust-approval-for-asset-swapdeal-idUSKBN1AC1F0.

582 http://www.dupont.com/corporate-functions/media-center/press-releases/dupont-acquires-ag-softwarecompany-granular-to-accelerate-digital-ag-strategy.html;

http://s21.q4cdn.com/813101928/files/doc_presentations/2017/09/DowDuPont-Inc.-Special-Call-transcript.pdf
} 
Among its fertilisers, one of the popular products is Limus, an additive for urea-based Fertilisers. BASF's herbicide solutions include the herbicide Engenia, an important component of dicamba and glyphosate-tolerant cropping systems for soy and cotton. A new series of products to cater for crop protection needs includes insecticides Inscalis and broflanilide, and new fungicide, Revysol. ${ }^{583}$ In recent years BASF has actively invested into functional crop care solutions and technologies. These include the Seltima formulation that ensures precise release of its fungicide active ingredient on rice crops and exclusively on the rice leaf's surface and Cultivance production system, a combination of genetically modified soybeans and the corresponding herbicide. In 2016, BASF developed a digital platform (Maglis), which provides support to farmers in collecting, interpreting and monitoring a range of agricultural data. This complements collaborations with companies such as John Deere, to develop integrated IT applications for precision agriculture. For instance, farmers in Brazil can already make use of the DigiLab application for plant disease diagnostics and treatment. ${ }^{584}$ The focus by BASF on digital agriculture can also be seen by its recent acquisition of US-based company ZedX. This firm develops agronomic models that analyze weather, plant growth and infestation, and will also complement BASF's online platform Maglis. ${ }^{585}$

US-headquartered Deere \& Company is a manufacturing company that has operations in three major business segments: agriculture and turf, construction and forestry, and financial services. The agriculture and turf segment products are categorized in five product platforms: crop harvesting (combines, cotton pickers \& cotton strippers, sugarcane harvesters, related front-end harvesting equipment, sugarcane loaders and pull-behind scrapers); turf and utility; hay and forage (self-propelled forage harvesters and attachments, balers and mowers); crop care (tillage, seeding and application equipment, including sprayers, nutrient management and soil preparation machinery); and tractors. Deere has developed increasingly integrated agricultural management systems, which rely on advanced data collection and analytics in conjunction with GPS technologies. ${ }^{586}$ These technologies allow farmers control over soil management, and input costs and yields, while also providing interaction between owners of equipment and dealers in the field. In light of the key role of new technologies in precision farming, Deere has acquired Blue River Technology - a firm that has applied a combination of computer vision, robotics, and machine learning to agricultural spraying equipment. The acquisition for $\$ 305 \mathrm{M}$ replicates previous Deere's strategic choices in precision farming, such as the acquisition of GPS technology firm NavCom Technology in 1999. ${ }^{587}$ Other recent acquisitions by Deere include the $80 \%$ interest in Hagie Manufacturing Company LLC in the

\footnotetext{
${ }^{583}$ BASF Group, Annual Report 2016, http://report.basf.com/2016/en/

${ }^{584}$ BASF Group, Annual Report 2016, http://report.basf.com/2016/en/

585 John Vogel, 'Pennsylvania-based ZedX boosts BASF's digital ag intelligence' (11 May 2017) American Agriculturalist, http://www.americanagriculturist.com/business/pennsylvania-based-zedx-boosts-basf-s-digitalag-intelligence;

https://www.basf.com/en/company/news-and-media/news-releases/2017/04/p-17-192.html

586 Deere \& Company, Security and Exchange Commission form 10-K (31 December 2016) http://d18rn0p25nwr6d.cloudfront.net/CIK-0000315189/b4e24d59-e4fe-4bd4-be0d-e245e947d601.pdf

${ }^{587}$ https://www.deere.com/en/our-company/news-and-announcements/news-releases/2017/corporate/2017sep06blue-river-technology/
} 
US, Monosem in France, and Mazzotti in Italy. ${ }^{588}$ Hagie Manufacturing Company is a U.S. market leader in high clearance sprayers while Monosem is a European market leader in precision planters. ${ }^{589}$

Swiss-based Syngenta, is a leading pesticide supplier worldwide. ${ }^{590}$ Syngenta's range of products includes herbicides, insecticides, fungicides, seedcare and seeds. In terms of sales, the popular brands include VIBRANCE, a fungicide for cereals, corn, diverse field crops, rice, soybean, specialty crops, vegetables; ELATUS \& SOLATENOL, a fungicide for cereals, corn, diverse field crops, soybean, specialty crops, vegetables; FORTENZA \& MINECTO, seedcare treatments for cereals, corn, diverse field crops, rice, soybean, specialty crops, vegetables; ADEPIDYN, a fungicide for cereals, corn, soybean, specialty crops, vegetables.

In seeds, Syngenta introduced the largest number of genetically modified (GM) trait introductions in the industry between 2010 and 2014. ${ }^{591}$ New GM traits for soybean and corn are in the process for regulatory approval, and consist of $\mathrm{OH} 2$ soybean and corn molecular stacks for herbicide tolerance and corn rootworm. The largest crop for Syngenta is corn; its popular hybrid in this area is AGRISURE ARTESIAN, which offers drought protection and high yield in normal conditions. Syngenta has also developed methods of combining seeds and crop protection protocols, as can be seen both in the Water+ Intelligent Irrigation approach and in the GROMORE program for rice. In light of the development of technologies in crop protection, Syngenta has recently developed MAXVEG, a platform that combines chemistry and agronomy to maximize yields through safe, effective use of crop protection. In terms of mergers and acquisitions, Syngenta was the subject of a $\$ 43 \mathrm{~B}$ takeover by Chemchina. The Chinese-based company is active in the pesticide markets in Europe through Adama, a whollyowned Israel-based subsidiary. ${ }^{592}$ As a result of regulatory approval processes ChemChina had to divest a number of assets in the herbicides and fungicides areas to avoid overlap in market. In the US, the divestiture has taken place through the acquisition by American Vanguard Corporation of Adama Agricultural Solutions' US assets relating to crop protection product lines - Abamectin, Chlorothalonil and Paraquat. ${ }^{593}$ A similar divestiture has taken place in Mexico, through the acquisition by American Vanguard Corporation's Mexican subsidiary of Syngenta's selective herbicides for sugar cane and contact fungicide brands. ${ }^{594} \mathrm{In}$ terms of postacquisitions plans, it would seem that Chemchina's strategy might be the redistribution of crop

\footnotetext{
588 Deere \& Company, Security and Exchange Commission form 10-K (31 December 2016) http://d18rn0p25nwr6d.cloudfront.net/CIK-0000315189/b4e24d59-e4fe-4bd4-be0d-e245e947d601.pdf

${ }^{589}$ Chloe Cornish, 'John Deere ploughs a new furrow with algorithmic acquisition', (11 September 2017) Financial Times, https:/www.ft.com/content/3c7c84c4-94f3-11e7-a9e6-11d2f0ebb7f0; https://www.deere.com/en/our-company/news-and-announcements/news-releases/2017/corporate/2017jun27corporaterelease.html

${ }^{590}$ Syngenta, Annual Report 2016, https://www4.syngenta.com/annualreport2016

${ }^{591}$ Syngenta, Annual Report 2015, https://www4.syngenta.com/annualreport2015

592 EU Commission Press Release, 'Mergers: Commission clears ChemChina acquisition of Syngenta, subject to conditions' (5 April 2017) http://europa.eu/rapid/press-release_IP-17-882_en.htm.

${ }^{593}$ Business Wire, 'American Vanguard Enters into Agreement with Adama to Acquire Certain Crop Protection Assets in the U.S' (5 April 2017) http://www.businesswire.com/news/home/20170405005411/en/AmericanVanguard-Enters-Agreement-Adama-Acquire-Crop.

$594 \quad$ See,

http://www.americanvanguard.com/NewsMedia/PressReleases/2017PressReleases/August23,2017PressRelease/tabid/427/Default.asp $\mathrm{X}$.
} 
protection assets to its Adama subsidiary in order to compensate for the subsidiary's antitrust related divestitures. ${ }^{595}$

Table 4 - Companies in the agroindustry and their presence in the segments of the value chain

\begin{tabular}{|l|l|l|l|l|l|l|}
\hline & SEEDS & $\begin{array}{l}\text { HERBICID } \\
\text { ES AND }\end{array}$ & $\begin{array}{l}\text { MACHIN } \\
\text { FUNGICID } \\
\text { ES }\end{array}$ & $\begin{array}{l}\text { FERTILIS } \\
\text { ERS }\end{array}$ & $\begin{array}{l}\text { PESTICI } \\
\text { DES }\end{array}$ & $\begin{array}{l}\text { BIG DATA/ } \\
\text { DIGITAL } \\
\text { AGRICULT } \\
\text { URE }\end{array}$ \\
\hline DOW & & & & & \\
\hline DUPONT & & & & & \\
\hline $\begin{array}{l}\text { DOWDUPO } \\
\text { NT (since } \\
\text { 31.08.17 ) }\end{array}$ & & & & & \\
\hline BASF & & & & & \\
\hline DEERE & & & & & \\
\hline $\begin{array}{l}\text { CHEMCHIN } \\
\text { A- } \\
\text { SYGENTA }\end{array}$ & & & & & \\
\hline BAYER & & & & & \\
\hline MONSANTO & & & & & \\
\hline
\end{tabular}

Source: Authors' compiled data

595 Andrew Marc Noel, ChemChina Said to Plan to Move New Assets to Adama Post-Syngenta, (10 April 2017) Bloomberg https://www.bloomberg.com/news/articles/2017-04-10/chemchina-said-to-plan-to-move-new-assetsto-adama-post-syngenta. 


\section{References}

Achi Z et al., 'The Paradox of Fast Growth Tigers', (1995) McKinsey Quarterly 3.

ACBIO, 'The Bayer-Monsanto merger: Implications for South Africa's Farmers', 2017. Available at http://acbio.org.za/wp-content/uploads/2017/02/Bayer-Monsanto-report.pdf.

ACBIO, 'The Three Agricultural Input Mega-Mergers: Grim Reapers of South Africa's Food and Farming Systems', 2017.

Adama. Adama Delivers Robust Volume Growth Despite Difficult Market and Currency Conditions, 2015. Available at https://www.adama.com/en/media/press-releases/adama-performance-q3-2015.html

AgTech Investing Report, Year in Review 2016, 2017, 17.

AllAfrica, 'Agribusiness Giants on Merger Path, 2017. Available at http://www.allafrica.com/stories/201702270838.html

BASF Group, 'BASF to strengthen digital farming offer with acquisition of ZedX Inc', 2017. Available at https://www.basf.com/en/company/news-and-media/news-releases/2017/04/p-17-192.html.

BASF Group, Annual Report 2016. Available at http://report.basf.com/2016/en/.

Bayer, 'Bayer's commitment to innovation and sustainability will help shape the future of farming', 2016. Available at http://www.press.bayer.com/baynews/baynews.nsf/id/Bayers-commitment-toinnovation-and-sustainability-will-help-shape-the-future-of-farming .

Bayer, Acquisition of Monsanto to Create a Global Leader in Agriculture, Investor Presentation, June 2016.

Bekakers R, Duysters G, and Verspagen B, 'Intellectual property rights, strategic technology agreements and market structure: the case of GSM', (2002) 31(7) Research Policy 1141-1161.

Bell, R., Davies, R., The changing structure of food retailing in Europe: the implications for strategy (1997) 30(6) Long Range Planning 853.

Boston Consulting Group, Indian Agribusiness, (BCG, 2012).

Bonny S, 'Corporate Concentration and Technological Change in the Global Seed Industry', 2017, 9 Sustainability, 1632.

BBC, 'Tesco and China Resources Enterprise reach retail deal', 2014. Available at: http://www.bbc.co.uk/news/business-27615404

Biscarini, F, Nicolazzi, E et al., 'Challenges and opportunities in genetic improvement of local livestock breeds', 2015 Frontiers in Genetics 6 (33).

Bloomberg, 'Costco Is Playing a Dangerous Game With the Web', 2017. Available at: https://www.bloomberg.com/news/articles/2017-08-24/costco-is-playing-a-dangerous-game-with-theweb

Bonny S, Corporate Concentration and Technological Change in the Global Seed Industry, (2017) 9(9) Sustainability 1632. 
Brodholt A, 'Major drivers of agricultural big data - implications for suppliers, 2016. Available at https://proagrica.com/nl/2016/10/03/major-drivers-agricultural-big-data-implications-suppliers/

Business Insider, 'Bayer to sell Liberty crop protection brands to get merger nod', 2017. Available at http://markets.businessinsider.com/news/stocks/r-bayer-to-sell-liberty-crop-protection-brands-to-getmerger-nod-2017-5-1001989110.

Business Wire, 'American Vanguard Enters into Agreement with Adama to Acquire Certain Crop Protection Assets in the U.S', 5 April 2017. Available at http://www.businesswire.com/news/home/20170405005411/en/American-Vanguard-EntersAgreement-Adama-Acquire-Crop.

Casadesus-Masanell R and Ricart J.E., 'Competing Through Business Models', 2007, IESE Business School Working Paper No. 713. Available at http://ssrn.com/abstract=1115201.

Child P, Kilroy T, and Naylor J, 'Modern grocery and the emerging-market consumer: A complicated courtship', 2015, McKinsey. Available at: https://www.mckinsey.com/industries/retail/ourinsights/modern-grocery-and-the-emerging-market-consumer-a-complicated-courtship.

Clive J, ‘Global Status of Biotech/GM Crops', 2014, ISAAA Brief No. 49, Ithaca, NY.

Cornish C, 'John Deere ploughs a new furrow with algorithmic acquisition', 2017, Financial Times. Available at https://www.ft.com/content/3c7c84c4-94f3-11e7-a9e6-11d2f0ebb7f0; https://www.deere.com/en/our-company/news-and-announcements/newsreleases/2017/corporate/2017jun27-corporaterelease.html

Corsini L, Wagner K et al, 'Crop Farming 2030: The Reinvention of the Sector', 2015, Boston Consulting Group. Available at https://www.bcgperspectives.com/content/articles/process-industriesinnovation-crop-farming-2030-reinvention-sector/

Corstjens M, Lal R, 'Retail Doesn't Cross Borders: Here's Why and What to Do About It', 2012, Harvard Business Review. Available at: https://hbr.org/2012/04/retail-doesnt-cross-borders-hereswhy-and-what-to-do-about-it

Deere \& Company, Security and Exchange Commission form 10-K, 2016. Available at http://d18rn0p25nwr6d.cloudfront.net/CIK-0000315189/b4e24d59-e4fe-4bd4-be0de245e947d601.pdf.

Deere \& Company, 'Deere to Advance Machine Learning Capabilities in Acquisition of Blue River Technology', 2017. Available at https://www.deere.com/en/our-company/news-andannouncements/news-releases/2017/corporate/2017sep06-blue-river-technology/.

Dryancour G, 'The Agricultural Machinery Market \& Industry in Europe: An analysis of the most important structural trends \& why EU regulation of the sector needs to change', 2016 (report for CEMA).

ECPA, 'Pesticides and Biodiversity', 2010. Available at http://www.ecpa.eu/sites/default/files/7584\%2BBiodiversity_V04_b\%C3\%A0t.pdf

ETC Group, 'Putting the Cartel before the Horse ....and Farm, Seeds, Soil, Peasants, etc. - Who Will Control Agricultural Inputs, 2013?', 2013, Communiqué no 111.

ETC Group, ‘Breaking Bad: Big Ag Mega-Mergers in Play’, 2015, 115 Communique. 
European Commission, IP/17/772, 2017. Available at http://europa.eu/rapid/press-release_IP-17772_en.htm

ETC Group, 'The Monsanto-Bayer tie-up is just of seven: Mega-mergers and big data domination threaten seeds and food security', 2016. Available at http://www.etcgroup.org/content/monsanto-bayertie-just-one-sevenmega-mergers-and-big-data-domination-threaten-seeds-food

European Commission, IP/17/2762, 2017. Available at http://europa.eu/rapid/press-release_IP-172762_en.htm

European Commission Press Release, 'Mergers: Commission clears ChemChina acquisition of Syngenta, subject to conditions', 5 April 2017. Available at http://europa.eu/rapid/press-release_IP-17882_en.htm.

European Parliament, Overview of the Agricultural Sectors in the EU Study (European Parliament, 2015).

Evenson R, 'Government Policy and Technological Progress in U.S. Agriculture', in R. Nelson (ed.). Government Support of Technological Progress: A Cross Industry Analysis, (New York: Pergamon Press, 1982).

Deloitte, 'Agri-business Outlook 2015', 2014. Available at https://www2.deloitte.com/content/dam/Deloitte/uk/Documents/corporate-finance/deloitte-ukagribusiness.pdf.

Department of Justice, Press statement 'Justice Department Sues to Block Deere's Acquisition of Precision Planting', 2016. Available at https://www.justice.gov/opa/pr/justice-department-sues-blockdeere-s-acquisition-precision-planting.

Duff and Phelps, 'Food Retail Industry Insights 2016-2017'. Available at https://www.duffandphelps.com/assets/pdfs/publications/mergers-and-acquisitions/industryinsights/consumer/food-retail-industry-insights-2016.pdf

DuPont, 'Summary of Transactions with FMC: Divestiture of Certain Crop Protection Assets and DowDuPont Inc, S\&P Capital IQ, McGraw Hill Financial, 2017. Available at http://s21.q4cdn.com/813101928/files/doc_presentations/2017/09/DowDuPont-Inc.-Special-Calltranscript.pdf.

DuPont, 'DuPont Acquires Ag Software Company Granular to Accelerate Digital Ag Strategy and Help Farmers Operate More Profitable Businesses', 2017. Available at http://www.dupont.com/corporatefunctions/media-center/press-releases/dupont-acquires-ag-software-company-granular-to-acceleratedigital-ag-strategy.html

Federal Trade Commission (FTC), Annual Report, 1949, 18-21.

Fertilisers Price Index, 2017. Available at https://ycharts.com/indicators/Fertilisers_index_world_bank

Financial Times, 'BASF to pay $€ 5.9 \mathrm{bn}$ to buy 'significant parts' of Bayer seed business', 2017. Available at: https://www.ft.com/content/1d5ca16b-412d-3ed2-8899-7185f5308009?mhq5j=e5

Financial Times, 'Tesco swoops on food supplier Booker in £3.7bn deal', 2017. Available at: https://www.ft.com/content/c49977ca-e460-11e6-8405-9e5580d6e5fb 
Financial Times, 'Kroger weighs up options including sale of convenience stores', 2017. Available at https://www.ft.com/content/787923be-ae99-11e7-aab9-abaa44b1e130

Food and Agriculture Organisation of the United Nations, 'World Fertiliser Trends and Outlook to 2018', 2015, FAO.

Food \& Beverage, 'How automation is changing the food processing industry', 2016. Available at https://foodmag.com.au/how-automation-is-changing-the-food-processing-industry/

Forbes, 'How Big Data And Tech Will Improve Agriculture, From Farm To Table', 2017. Available at https://www.forbes.com/sites/timsparapani/2017/03/23/how-big-data-and-tech-will-improveagriculture-from-farm-to-table/\#7da2a8655989

Forbes, 'Why Wal-Mart Is Investing More In Brazil', 2017. Available at https://www.forbes.com/sites/greatspeculations/2017/03/16/why-wal-mart-is-investing-more-inbrazil/\#6d0558e620b4

Forbes, 'Costco's International Expansion Plans Will Boost Growth', 2015. Available at: https://www.forbes.com/sites/greatspeculations/2015/04/17/costcos-international-expansion-planswill-boost-growth/\#34b52f063a9e

Forbes, 'Costco Exceeds Expectations In Sales and Earnings -- Will Open 15 Units In France', 2017. Available at: https://www.forbes.com/sites/walterloeb/2017/05/30/costco-exceeds-expectations-insales-and-earnings-will-open-15-units-in-france/\#199a60f947b6

Fraley R, Basic Materials Conference, 2014. Available at http://www.monsanto.com/investors/documents/2015/2014.12.03_citi_fraley.pdf.

Friedberg D, The Climate Corporation Platform Update, 2014. Available at http://www.monsanto.com/investors/documents/whistle\%20stop\%20tour\%20vii\%20aug\%202014/the climate_corporation_update.pdf.

Freedonia, Animal Health Products. Available at: https://www.freedoniagroup.com/industrystudy/animal-health-products-2990.htm

Fuglie K et al, 'Research Investments and Market Structure in the Food Processing, Agricultural Input, and Biofuel Industries Worldwide', 2011, USDA-ERS Economic Research Report No. 130, 11.

Gallas D, 'Brazil's biofuel industry finds new sweetspot', 2015, BBC. Available at http://www.bbc.co.uk/news/business-33114119

Government of India, Department of Fertilisers, Report on Fertilisers, 2015. Available at http://fert.nic.in/page/fertiliser-policy

Howard P, 'Intellectual Property and Consolidation in the Seed Industry', (2015), 55(6) Crop Science 1-7. Available at http://www.apbrebes.org/files/seeds/files/Howard_seed_industry_patents_concentration_2015.pdf.

International Renewable Energy Agency (IRENA), Innovation Outlook, 2016

Iyer A, Singhi A, 'India Agribusiness: Cultivating Future Opportunities', 2012, Boston Consulting Group. Available at https://www.bcg.com/en-in/perspectives/28844. 
Jansen J, 'Unlocking Digital Ag and Seed Technology', Constant Contact, 6. Available at http://files.constantcontact.com/fe439c1b001/3be810cd-551f-4ca4-8e4d-

f812e2aef91a.pdf?ver=1474384793000.

Jürgen Wandel, 'Business Groups and Competition in Post-Soviet Transition Economies: The Case of Russian "agroholdings", 2011, 24 The Review of Austrian Economics, 403

Keshav Agrawal, 'Few farmers aware of central govt subsidy to buy farm machines', Times of India, 2015. Available at: https://timesofindia.indiatimes.com/city/bareilly/Few-farmers-aware-of-centralgovt-subsidy-to-buy-farm-machines/articleshow/47532429.cms

Klumper, W, Qaim M 'A Meta-Analysis of the Impacts of Genetically Modified Crops.', 2014, PLoS ONE 9(11): e111629.

Krijn, P, Wolfert, S, Verdouw, 'A European Perspective on the Economics of Big Data: OECD', 2015. Available at: https://www.oecd.org/tad/events/Autumn15_Journal_Poppe.et.al.pdf

Landers, T, Cohen, B et al, 'A Review of Antibiotic Use in Food Animals, (2012) 127 Public Health Reports, 4-2.

Lianos, Katalevsky D. \& Ivanov A., 'The global seed market, competition law and intellectual property rights: untying the Gordian knot', 2016, 2 Concurrences, Article 78807.

Lim D, Living with Monsanto, (2015) Michigan State Law Review 559.

Lyneis J, System dynamics for business strategy: a phased approach, (1999) 15(1) System Dynamics $37-70$.

MacDonald A, 'How a Potash Cartel Collapsed', The Wall Street Journal, 2015.

Available at https://www.wsj.com/articles/how-the-belarusian-potash-company-re-gained-its-footing1450098821.

Meade, B, Puricelli, E, McBride, W et al. 'Corn and soybean production costs and export competitiveness in Argentina, Brazil, and United States', 2016, USDA report summary for Economic Research Service.

Marketing Interactive, 'Walmart China plans massive 2017 expansion', 2017. Available at http://www.marketing-interactive.com/walmart-china-plans-massive-2017-expansion/

Market Watch, 'Animal Genetics Market to See 8.4\% CAGR to 2021 Driven by Advanced Genetic Technologies', 2016. Available at http://www.marketwatch.com/story/animal-genetics-market-to-see84-cagr-to-2021-driven-by-advanced-genetic-technologies-2016-07-20-122034555

Markets and Markets, Fungicides Market by Type (Benzimidazoles, Dithiocarbamates, Phenylamides, Chloronitriles, Strobilurins, and Triazoles), Crop Type (Cereals \& Grains, Oilseeds \& Pulses), Form (Liquid, Wettable powder), Mode of Application - Global Forecast to 2022. Available at Http://www.marketsandmarkets.com/Market-Reports/fungicides-

356.html?gclid=CjwKCAjw64bPBRApEiwAJhG-

fhu8BBRoHxfKKtXCxg1rCWZ7bQYoOFzLi2vzM-6vA0XvF5t3525B2BoC2HcQAvD_BwE

Market and Markets, 'Animal Genetics Market by Type (Canine, Poultry, Porcine, Bovine), Genetic Material (Semen (Bovine Porcine Equine), Embryo (Bovine Equine)), Testing Services (DNA Testing, DNA Typing, Genetic Disease Testing) - Global Forecast to 2021', 2016. Available at: http://www.marketsandmarkets.com/Market-Reports/animal-genetic-market-12462093.html. 
McKinsey \& Company, 'How to succeed: Strategic options for European machinery. Shifting growth patterns, increasing pace of digitization and organizational change', 2016. Available at https://www.mckinsey.de/files/vdma_european_machinery_2016.pdf.

Ministry of Agriculture, Government of India, Report on Agricultural Marketing, 2007. Available at http://agricoop.nic.in/AnnualReport06-07/AGRICULTURAL\%20MARKETING.pdf

Monsanto, 'Accelerating the Future of Agriculture', Monsanto's 8th Whistle Stop Investor Field Tour 2016, 16-20, Available at https://monsanto.com/app/uploads/2017/05/whistle_stop_viii_day-1session_materials.pdf.

Morecroft J, 'The Feedback View of Business Policy and Strategy', (1985) 1(1) System Dynamics Review, 4-19.

Noel A, 'ChemChina Said to Plan to Move New Assets to Adama Post-Syngenta', 10 April 2017, Bloomberg. Available at https://www.bloomberg.com/news/articles/2017-04-10/chemchina-said-toplan-to-move-new-assets-to-adama-post-syngenta.

Peterson H, 'Lidl is about to invade the US', 2016, Business Insider. Available at: http://uk.businessinsider.com/lidls-expansion-plans-in-the-us-2016-9

Patterson C, 'Monsanto's Seed Chipping Technology', 2013, AgAdvance,. Available at http://www.agadvance.com/issues/jan-2013/monsantos-seed-chipping-technology.aspx.

Perez S, 'Target acquires transportation company Grand Junction to expand same-day delivery services', 2017, Techcrunch. Available at https://techcrunch.com/2017/08/14/target-acquirestransportation-company-grand-junction-to-expand-same-day-delivery-services/

Rangel G, 'From Corgis to Corn: A Brief Look at the Long History of GMO Technology', 2015, Harvard University. Available at: http://sitn.hms.harvard.edu/flash/2015/from-corgis-to-corn-a-brieflook-at-the-long-history-of-gmo-technology/.

Rama R, 'Chapter 11: Foreign Multinational Enterprises in the Food and Beverages Industries of the BRICS; Structural Change and Industrial Development in the BRICS, 2015, 300-310.

Reardon T\& Chen K et al, 'The quiet revolution in Asia's rice value chains', (2014) Annals of the New York Academy of Sciences, 110.

Regalado A, 'The Next Great GMO Debate', 2015, MIT Technology Review. Available at https://www.technologyreview.com/s/540136/the-next-great-gmo-debate.

Reuters, 'European farm machinery sales set to rebound this year', 2017. Available at: http://uk.reuters.com/article/uk-europe-agriculture-machinery/european-farm-machinery-sales-set-torebound-this-year-idUKKCN18B24N.

Reuters, 'Tesco confirms joint venture with Tata in India', 2014. Available at: http://uk.reuters.com/article/us-tesco-india/tesco-confirms-joint-venture-with-tata-in-indiaidUKBREA2K0U020140321.

Reuters, 'After Canada exit, Target thinks small with U.S. expansion plans', 2015. Available at: https://www.reuters.com/article/us-target-canada-usa/after-canada-exit-target-thinks-small-with-u-sexpansion-plans-idUSKBNOKO2Q820150115. 
Reuters, 'DuPont, FMC win EU antitrust approval for asset swap deal', 2017. Available at https://www.reuters.com/article/us-fmc-m-a-du-pont-eu/dupont-fmc-win-eu-antitrust-approval-forasset-swap-deal-idUSKBN1AC1F0.

Rentokil, 'Food processing: global trends'. Available at https://www.rentokil.com/foodprocessing/global-trends.

Schikorra R, 'Dow to Divest a Portion of Its Corn Hybrid Seed Business in Brazil to CITIC Agri Fund', 2017, The Dow Chemical Company. Available at http://www.dow.com/en-us/news/pressreleases/dow-to-divest-a-portion-of-its-corn-hybrid-seed-business-in-brazil-to-citic-agri-fund.

SeedWorld, 'DuPont Pioneer Establishes a CRISPR-Cas Advanced Breeding Platform', 2016, Available at http://seedworld.com/dupont-pioneer-establishes-crispr-cas-advanced-breeding-platform/.

Sims, R, Saddler, J, Mabee, W et al., An overview of second generation biofuel technologies, (2010) 101(6) Bioresource Technology 1570

Sterman J, Business Dynamics: Systems Thinking and Modelling for Complex World (McGraw Hill, 2000).

Swinnen J, 'Technology adoption and value chains in developing countries: Evidence from dairy in India', (2017) Food Policy. Available at https://doi.org/10.1016/j.foodpol.2017.08.005

Swinnen J, K van Herck and others, 'Food Security: Challenges and Opportunities for Eastern Europe and Central Asia', (2012) 9 Asian Journal of Agriculture and Development, 37.

Syngenta, Annual Report 2016. Available at https://www4.syngenta.com/annualreport2016.

Syngenta, Annual Report 2015. Available at https://www4.syngenta.com/annualreport2015.

Taylor C and Moss D, The Fertiliser Oligopoly: the Case for Global Antitrust Enforcement, (American Antitrust Institute, 2013).

Tiwari, B, Norton, T, Holden, M et al, 'Current Concepts and Applied Research in Sustainable Food Processing', 2013.

Trebbin, A, Linking small farmers to modern retail through producer organizations-experiences with producer companies in India, (2014) 45 Food Policy , 35-44.

UNFAO, 'Livestock and Landscapes'. Available at http://www.fao.org/docrep/018/ar591e/ar591e.pdf

United States Department of Agriculture (USDA), National Institute of Food and Agriculture, 2017. Available at https://nifa.usda.gov/announcement/usda-announces-135-million-support-data-drivenfarm-management-practices.

United States Department of Agriculture (USDA), 2017. Available at https://www.ers.usda.gov/topics/crops/corn/

United States Department of Agriculture (USDA), Long Term Projections 2017. Available at https://www.usda.gov/oce/commodity/projections/

UNCTAD, The Biofuels Market: Current Situation and Alternative Scenarios, (2009). 
Balat, M, 'An Overview of Biofuels and Policies in the European Union', (2007) 2(2). Energy Sources 167-181.

Vergote W and Grandjean G, 'Network formation among rivals', (CEREC Working Papers 2014/9).

Wang S L, Heisey P, Schimmelpfennig D \& Ball E, Agricultural Productivity Growth in the United States: Measurement, Trends, and Drivers, (USDA Economic Research Report, 2015)

Warren K, 'Why has Feedback Systems Thinking Struggled to Influence Strategy and Policy?', (2004), 21 Systems Research and Behavioral Science, 1-17.

Warren K, Strategic Management Dynamics, (Wiley, 2008)

Wilson W, 'S Trait Stacking, Licensing, and Seed Firm Acquisitions in Genetically Modified Grains', Journal of Agricultural and Resource Economics, (2008) 33(3), 383.

Wolfert, S, Ge, L, et al, 'Big Data in Smart Farming-A Review', (2017) 153 Agricultural Systems 153, 69-80.

Wolstenholme E, 'Qualitative vs quantitative modelling: the evolving balance', (1999) 50 Journal of Operational Research Society, 422-428.

Zhang $\mathrm{Y}$, \& Xudong $\mathrm{R}$, et al, 'Organization, technology and management innovations through acquisition in China's pork value chains: The case of Smithfield acquisition by Shuanghui' (2017), Food Policy. Available at https://doi.org/10.1016/j.foodpol.2017.08.004

\section{Tables and Figures}

Table 1: The twelve main global seed companies ranked by their global seed sales in billions USD in 2016. 107

Table 2: Seed and traits value chain....108

Table 3: Largest retail chains in the world (in terms of revenue and countries in operation). 149

Table 4 -Companies in the agroindustry and their presence in the segments of the value chain...163

Figure 1: Schematic representation of the agrochemicals supply chain....112

Figure 2: Modern versus Traditional retail in BRICS....140

Figure 3: System dynamics (General)......153

Figure 4: System dynamics (Specific).....154

Figure 6: System dynamics (Close up)....155

Figure 7: Comparison before and after the most recent mega merger wave in...156 


\title{
PART III: Legal Analysis
}

\section{Chapter 1: An holistic perspective on the relevant legal framework}

\author{
Ioannis Lianos, Justin Lindeboom, Claudio Lombardi \& Amber Darr
}

Public policy makers involved in the regulation of the global food value chain are confronted to a quite complex task, in view of the various legal and economic frameworks to which their action has to be integrated and the variety of governance tools at their disposal. The following sections provide the beginning of a competition law analysis that aims to integrate the variety of considerations competition law authorities are really confronted at when assessing their enforcement priorities and when exploring the type of analysis they will resort to in their competition law cases so that these become relevant for the specific institutional, economic and social context of their own jurisdiction. We think that such context-aware competition law analysis becomes essential if the aim of the authority is not just to promote some abstract principle of economic efficiency, but to ensure that the decisions reached have a broader claim of legitimacy than the community of competition law and economics experts, and that the authority maintains its influence and consequently its independence. This may be a day-to-day struggle in emerging and developing countries, which usually offer weaker institutional guarantees, in comparison to developed countries, as to the independence of competition authorities. These may also be subject to various social pressures, in particular in view of the fact that most of these jurisdictions have only recently adopted competition law.

\subsection{Polycentric competition law ${ }^{596}$}

Mainstream competition law has developed tools to study markets, or broader industrial sectors (e.g. the market investigation reference regime in the UK and in South Africa or sector enquiries in the EU), by making a conscious effort to analyse them as an insulated sector of activity, with its own rules, operating in a, more or less, competitive mode, and remaining largely aloof from politics or culture. This approach is not only justified by reasons of political or professional ideology, but may also have to do with the need of predictability and consistency, which are considered as forming the hallmarks of the rule of law. The latter could be jeopardised if competition authorities benefitted from a larger degree of discretion and values considered as external to competition law's focus on allocative efficiency and price competition could form part of the analysis. Of course, things are not so simple as the boundaries of what can be considered as being within the normal scope of competition law or being outside of it, is a matter of social consensus. For instance, for a long period of time innovation was absent from the competition law assessment, which focused primarily on the protection of the competitive process or allocative efficiency. This trend seems to have changed the last two decades, with the adoption in 1995 of the US DOJ and FTC Guidelines for the

\footnotetext{
596 This Section partly draws on I. Lianos, Polycentric Competition Law (Current Legal Problems, forth. 2017).
} 
licensing of $\mathrm{IP}^{597}$, the US Merger Guidelines, the EU Merger Guidelines and some recent decisions in the EU regarding the recent seed merger transactions (see Part IV). Dynamic analysis and the focus on innovation has become infused in the DNA of modern competition law. The complex assessment of the innovation incentives of the parties to the merger and the possible evolution of the industry seems to open the possibility to a more "polycentric" approach to the extent that this considers the effects of mergers and/or other conduct on the process of innovation, beyond the potential output and price effects on consumers (actual or future) in the affected relevant markets..

In the context of an economic sector of strategic social importance, such as food, competition law forms part of a broader institutional framework, whose purpose is to cater for a number of public policy concerns, going beyond just ensuring the affordability of staple food and low prices. These could relate to the promotion of competition on quality, which is correlative to food safety, the adequate provision of national markets in food, in this case involving security of food supply concerns, free and fair market access for smallholders, thus guaranteeing public order and economic democracy, or the preservation of the ability of future generations to enjoy at least the same level of variety of food we currently benefit from, which brings forward the objective of biodiversity, of particular significance in the era of the Anthropocene. Furthermore, in the current context of climate change, sudden financial crises followed by cycles of economic depression and political turmoil High-impact, low-probability events (HILP) ${ }^{598}$, or "black swans, according to Nassim Taleb ${ }^{599}$, become an important element in the policy equation. One needs to recognize the increasing interconnectivity between social, economic, political and environmental spheres of life. Important 'cascade effects' may easily be divulged across the various spheres of economic activity, but also to the political and cultural spheres. The danger with the functionalist archetype of mainstream competition law is that it shapes the cognition of its actors in a way that makes them unable to engage with the wider picture, as they operate in the specific schema of price competition.

This choice of cognitive closure is justified by the difficulty to develop legal institutions/instruments that would be easily administrable in view of the available resources so as to take into account broader concerns. It is also frequently contended that other areas of law, and forms of governance, such as regulation may be better suited to take into account these concerns. These arguments rely on the assumption that the only way these broader concerns may be taken into account is some form of quantitative and qualitative balancing. These are not, however, the only decision procedures available, as capping or lexicographic priority ${ }^{600}$ may offer some adequate options. Some of these decision procedures are less demanding in

\footnotetext{
597 “Antitrust Guidelines for the Licensing of Intellectual Property" issued on April 6, 1995, by the U.S. Department of Justice and the Federal Trade Commission, recently updated by the Antitrust Guidelines for the Licensing of Intellectual Property issued on January 12, 2017 by the US Department of Justice and the US Federal Trade Commission.

${ }^{598}$ Bernice Lee, Felix Preston \& Gemma Green, Preparing for High-Impact, Low Probability Events (Chatham House, 2012) available

at https://www.chathamhouse.org/sites/files/chathamhouse/public/Research/Energy,\%20Environment\%20and\%20 Development/r0112_highimpact.pdf

${ }^{599}$ Nassim Nicholas Taleb, The Black Swan: The Impact of the Highly Improbable (Penguin, 2008).

${ }^{600}$ For a more in depth analysis of these decision procedures and their possible application in compettion law, see I. Lianos, Polycentric Competition Law, CLES Research paper 1/2018 (forth.).
} 
terms of information gathering and processing than balancing. The additional assumption made is also that other institutional alternatives may be better suited for the task. This may well be true but it has to be confirmed after a careful comparative institutional analysis, which will assess the least imperfect option. It may also be possible that the relative weakness of other institutional alternatives may call for a more active role for competition authorities.

This brings forward systemic resilience as the principal aim to be pursued by public authorities, and welcomes some holistic thinking in the traditionally compartimented approach followed by competition law. It becomes therefore important to go beyond established institutional "logics" and pre-established institutional moorings. At an abstract level, there are various strategies in order to organize this interplay and ensure effective problem-solving. "Framing struggles" recognize that there may be alternative approaches from different institutional arenas that could be relevant in a problem-solving activity, in particular when activities are situated at the intersection of multiple institutional spheres ${ }^{601}$. One may expect a clash of institutional logics, to the extent that the solution to the problem may be different, not necessarily diverging, should one choose one or another of these logics, thus rendering the issue "ripe" for a "framing struggle". The object of this framing contest is clear: determine the dominant logic which will prevail in the specific context when the decision-maker takes a decision. It cannot always be assumed that competition law will emerge victorious from these framing contests. "Cross-institutional isomorphism" provides a different perspective ${ }^{602}$. The idea here is that in view of the alterity of the problem to be solved, for the specific institutional setting, it might make sense to borrow instruments and/or the overall logic from a different institutional realm and transplant them back, "repurposing them for the occasion". Competition law can borrow from other areas of law, such as data protection, consumer protection or environmental law tools, repurposing them accordingly so as to fit the competition law field. For instance, it is possible to "Multiple performance" aims to allow for the integration of multiple frameworks that speak in many languages and articulate and maintain alternative conceptions of what is valuable or worthy ${ }^{603}$. As Granovetter observes, these multiple institutional frameworks can be used as resources for pragmatic actors, which may benefit from some degree of ambiguity and ambivalence when frames collide as part of conflicting visions and interests. It is important to offer to the actors some room for manoeuvre and to enable a discursive space to open where multiple principles of evaluation will be in play and benefit from productive friction. There are therefore many benefits in providing actors a "portfolio" of value frames from which they can draw creative and innovative solutions in a pragmatic way.

Again here, there are two possible options. One would be to resort to alchemy and the subsequent transmutation of various values and tools coming from different legal fields. This may eventually lead to the integration of various "spheres" or "economies of worth" into a single theoretical framework, eventually facilitating commensurability and weighing. This is not an easy task and often requires a great level of abstraction and axiomatisation that may not necessarily be implemented by existing institutions, as it may demand new forms of combined expertise. A second approach would be to reconceptualise competition law in a way that would

${ }^{601}$ M. Granovetter, Society and the Economy: Framework and Principles (Harvard Univ. Press, 2017), Ch. 5 ${ }^{602}$ Ibid.

${ }^{603}$ Ibid. 
better reflect its polycentric character, by introducing concepts and tools that engage more effectively with the complexity of economic interactions, a complex economy characterized by the overlapping and interpenetrating domains of economic networks, political networks, and social networks, whose functional domains of activity are linked to the extent that they are composed by multifunctional people participating in multiple networks. Networks act as catalysts for each other and enable actors to develop an ecology of strategies that may be deployed across the various networks in which these actors interact with each other. These may affect the structural position of the actors, in specific fields or overall. One needs therefore to take into account of these multi-networks strategies and focus on the connectedness between the various actors in different spheres of activity. Networks may also be affected by, what Brian Arthur calls, "sudden percolation", to the extent that "a change occurring in one field may be propagated and continue to propagate in other fields as long as the various networks are densely connected"604. Important changes that appear localised and impact on just a few individual nodes may be felt right across the economy and other spheres of social activity. Interactions between closely connected networks may have a self-reinforcing effect and lead to the development of new structures and path dependencies that could give rise to non-linear systems. Third, to the extent that there is interaction between various agents and nonlinear feedback between the actors and their environment, the system of interactions that emerges is reflexive as agents frame their strategies observing the broader environment, assess their position in it and determine their actions in order to alter the environment according to their aims (e.g. improve their structural position across networks).

To provide an example, a polycentric competition law approach would require a more holistic framework for the assessment of economic power, the trigger for any form of competition law intervention, to the extent that we want to take into account all the social costs (or benefits) engendered by a restriction of the competitive process, including effects on innovation, on privacy or on the protection of the environment, and to the extent that there is evidence that economic power is indispensable for these benefits or costs to occur. It is clear that the current analysis of market power, using the proxy of market shares and performed in the context of a relevant market, is inappropriate for analysing the competitive process in industries with dynamic competition. As Marc Granovettter discusses in his recent book on Economy and Society, economic power can be also based on dependence, on the control of legitimate authority and on the ability to control the agenda and the overall discourse ${ }^{605}$. Resource-dependence theories may complement our understanding of market power relations that are for the moment only focusing on direct economic power over consumers, and that the development of state capitalism in various parts of the world raise important questions as to the adequacy of our current narrow metrics in assessing economic power and bring forward the need to also account for power emerging out of control exercised by a State authority. Finally, one should take into account the power emerging out of central positioning in "structural holes", and consider the social structure of competition ${ }^{606}$. Indeed, having ties that provide the only route through which resources or information can be transfered between network

${ }^{604}$ B. Arthur, Complexity Economics: A Different Framework for Economic Thought (OUP, 2015), 1

${ }^{605}$ M. Granovetter, Society and the Economy: Framework and Principles (Harvard Univ. Press, 2017), chap. 4.

${ }^{606}$ R.S. Burt, Structural Holes - The Social Structure of Competition (Harvard Univ. Press, 1995 (. 
segments that are otherwise disconnected from each other, in particular if this is within various spheres of activity, may provide invaluable strategic advantages over actors having few or no alternatives, and may easily convert this strategic positioning to economic power.

In envisioning the way polycentric competition law may apply to global food value chains, the first step in the analysis would be to understand the complex governance of these value chains by public and private actors.

\subsection{The Governance of global value chains}

\subsubsection{Public governance tools}

The globalization of food supply chains introduced a multilevel governance system, ${ }^{607}$ relying on supranational organizations (such as the EU), international treaties and State regulation but also comprising private regulatory governance mechanisms that are complementary or alternative to public legislation. Indeed, private actors, including NGOs, play a fundamental role in the governance of the food value chain, in particular as they focus on the regulation of the organizational dimension of the supply chain. As a result, both public and private regulation have moved from regulating product standards to regulating process. ${ }^{608}$

Regulators may intervene in the food market regulating specific links of the supply chain, for instance through urban planning and opening hours for the retail, or products labelling and food safety for the producers. They may also adopt macro-solutions insisting on the whole national economy, such as labour market regulation and competition policy. ${ }^{609}$ Regulation raises compliance costs for firms. ${ }^{610}$ Such costs are partly passed-on to consumer and partly remain on the farmers. ${ }^{611}$ Regulation may also increase market fragmentation, thus diminishing the overall level of competitiveness. ${ }^{612}$

Although the role of public governance is relatively limited in the global good value chain, private transnational regulation assumes a more fundamental coordinating role. International regulatory frameworks tend to be relatively limited in their effectiveness, as in some cases they are designed as soft law instruments and in many others they are limited to certain geographical regions. Businesses obviate to this lack of transnational state regulation designing more sophisticated contractual networks operating as private governance regimes. ${ }^{613}$

\footnotetext{
607 For a definition of multi-level governance systems, see Liesbet Hooghe and Gary Marks, Multi-Level Governance and European Integration (Rowman \& Littlefield Publishers 2001).

${ }^{608}$ Fabrizio Cafaggi and Paola Iamiceli, Private Regulation and Industrial Organisation: The Network Approach (European University Institute 2012) <available at: http://cadmus.eui.eu/bitstream/handle/1814/23264/WP-LAW2012-21.pdf?sequence $=1>$.

${ }^{609}$ Lina Bukeviciute, Adriaan H Dierx and F Ilzkovitz, The Functioning of the Food Supply Chain and Its Effect on Food Prices in the European Union (EC, Directorate-General for Economic and Financial Affairs 2009) <available at http://ec.europa.eu/economy_finance/publications>.

610 ibid 27.

${ }^{611}$ OECD, Competition in the Food Chain (n 143); Vavra and Goodwin (n 143).

612 Nordås, Grosso and Pinali (n 17). This study identified three main types of regulations as potentially problematic for the functioning of the food supply chain: regulations creating entry barriers, regulations limiting price competition and regulations restricting shop opening hours.

${ }^{613}$ Fabrizio Cafaggi and Paola Iamiceli, Private Regulation and Industrial Organisation: The Network Approach (European University Institute 2012) <available at: http://cadmus.eui.eu/bitstream/handle/1814/23264/WP-LAW-
} 
Public and private regulation often intervenes in specific sectors of the economy in order to offset or overcome market inefficiencies with various legal measures. There are different types of market inefficiency that may affect the global food value chain: i) insufficient competition manifested by the market dominance of one or more firms at a segment of the food value chain (bottleneck) affecting, for instance, the speed and magnitude of price changes transmission along the chain and/or innovation ; ii) informational asymmetry; iii) generation of significant negative externalities with regard to broader public policy objectives, in particular involving public goods such as environment and land surface, public health, consumer rights; and iv) 'unfair' effects, as deemed by policymakers, on the basis of their conception of appropriate distributional justice or allocative efficiency. ${ }^{614}$ For instance, agriculture becomes increasingly technology driven (biotech, crop protection, microbial solutions, big data and analytics software) capturing the significant part of the value added along the whole food pipeline (bottleneck distortion). To remain competitive and to stay in business farmers have to adapt the latest technologies including seeds. This makes farmers to become critically dependent on global agriculture technology providers with "in or out" consequences for farmers. At the same time, farmers labor is increasingly commoditized causing social tensions (i.e., a wave of India farming suicides claiming the reason for it on Monsanto GMO cotton seeds). ${ }^{615}$

Policy responses have taken different forms with each State adopting a range of them, according to its own socio-economic context and institutional capabilities. Allan Fels and Matthew Lees distinguish four categories of policy responses in order to deal with situations of market dominance:

Table 1: Policy responses to market dominance

2012-21.pdf?sequence=1>; Fabrizio Cafaggi and Horatia Muir Watt, The Regulatory Function of European Private Law (Edward Elgar 2009).

${ }^{614}$ AI Ogus, Regulation: Legal Form and Economic Theory (Hart 2004) 30-54.

${ }^{615}$ I. Lianos \& A. Ivanov, Global Food Value Chains and Competition Law, Presentation, September 2016, Competition Law day (Moscow). 


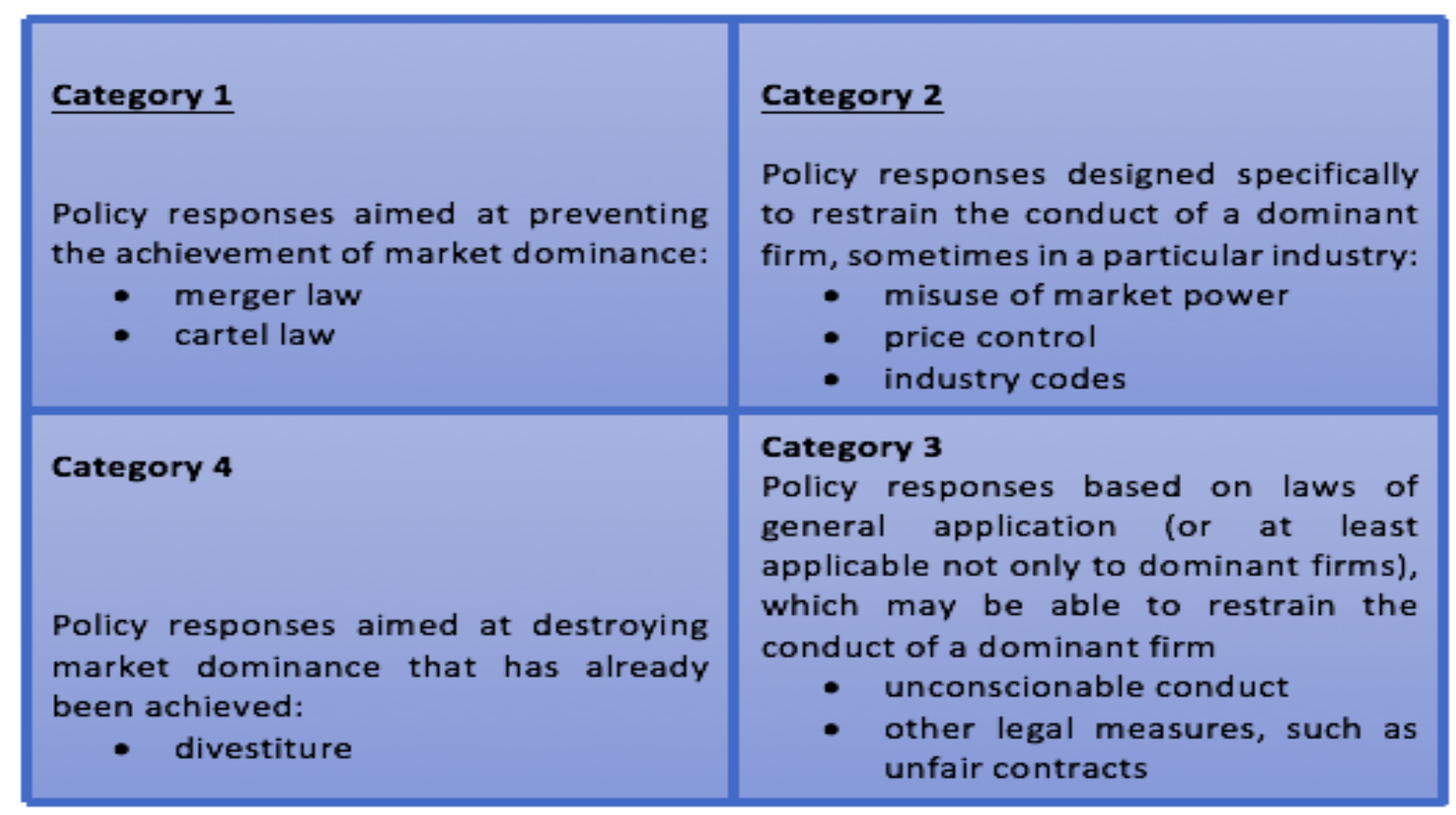

Source: Fels \& Lees $(2015)^{616}$

\subsubsection{Market rules: competition law and beyond}

Competition authorities have been active on all fronts, using the various categories of legal measures set out above. The European Commission published in 2009 its Communication on 'A better functioning food supply chain in Europe' ${ }^{617}$ that gave the way to a series of market studies aimed at assessing the degree of competitiveness in the European food market. A number of investigations by national competition authorities followed. ${ }^{618}$ Similarly, the informational asymmetry existing between consumers and suppliers has been a long time concern, legislators choosing to strengthen the requirements for product labelling in order to reduce this gap. ${ }^{619}$

The high volatility of agri-food commodity prices and food prices has also been a matter for concern. As it has been shown by a number of studies, the price transmission of these fluctuations is not evenly distributed along the supply chain. ${ }^{620}$ In particular, it has been observed that cost shocks are only partly passed through the supply chain. ${ }^{621}$ Furthermore, a

\footnotetext{
616 A. Fels \& M. Lees, Unconscionable conduct in the context of competition law with special reference to retailer/supplier relationships within Australia, Paper presented to the $10^{\text {th }}$ ASCOLA Conference, 21-23 May 2015, p. 28.

${ }^{617}$ Communication of the European Commission: A better functioning food supply chain in Europe (COM(2009) 591).

${ }^{618}$ See for instance ECN, Report on Competition Law Enforcement and Market Monitoring Activities by European Competition Authorities in the Food Sector (2012).

${ }^{619}$ See, for instance, the Regulation (EU) No 1169/2011 on food product labelling.

${ }^{620}$ Pavel Vavra and Barry Goodwin, Analysis of Price Transmission Along the Food Chain (OECD Publishing 2005); Henry W Kinnucan and Olan D Forker, 'Asymmetry in Farm-Retail Price Transmission for Major Dairy Products' (1987) 69 American journal of agricultural economics 285; Backer and Miroudot (n 16); OECD, Competition in the Food Chain, vol DAF/COMP(2013)15 (OECD 2013).

${ }^{621}$ OECD, Competition in the Food Chain (n 143) 23.
} 
fall in commodity prices does not necessarily lead to a correspondent decline of retail prices. ${ }^{622}$ This asymmetric price pass-through is often completed at the expenses of farmers, who receive a lower share of the 'food dollar', ${ }^{623}$ and bear most of the risks related to price volatility. Although it has been suggested that the cause of this asymmetry lies mainly in the unbalanced market power generated by the high concentration at retail level, drawing such conclusion for policy reasons may conceal many other potential causes for the asymmetric price transmission in operation. ${ }^{624}$ For instance, it has been alleged that government intervention may contribute, in some instances, to generate an asymmetric transmission of prices ${ }^{625}$. The asymmetry of the transmission of price changes along the supply chain may also raise issues of fairness in the food supply chain ${ }^{626}$ justifying regulatory intervention based on reasons of distributional justice.

In the course of the last decade, national and supranational competition authorities of the EU, US and to a certain extent, BRICS jurisdictions, have carried out a series of investigations into the food market. ${ }^{627}$ Many of these investigations have focused especially on the retail sector whose rapid consolidation process, occurring in the last two decades, has been considered to be a relevant factor for a possible abuse of dominant position. ${ }^{628}$ Although national competition authorities have examined the possible negative effects to competition from the high concentration and consolidation of the retail sector, in particular in groceries, ${ }^{629}$ there is no systematic empirical evidence of a systemic threat to the competitiveness of markets originating from high levels of concentration at retail level. ${ }^{630}$

\section{Table 2: Overview of the main practices that may give rise to competition concerns}

\footnotetext{
${ }^{622}$ Ibid.

623 Ibid 6.

624 Pavel Vavra and Barry Goodwin, Analysis of Price Transmission Along the Food Chain (OECD Publishing 2005).

${ }^{625}$ Bruce L Gardner, 'The Farm-Retail Price Spread in a Competitive Food Industry' (1975) 57 American Journal of Agricultural Economics 399; Kinnucan and Forker (n 143); Vavra and Goodwin (n 624).

${ }^{626}$ OECD, Competition in the Food Chain (n 143) 21.

${ }^{627}$ EC (n 166); Communication of the European Commission: A better functioning food supply chain in Europe (n 140); EC, High Level Forum for a Bet-ter Functioning Food Supply Chain - Final Report (2014) <available at http://ec.europa.eu/growth/tools-databases/newsroom/cf/itemdetail.cfm?item_id=7838\&lang=en>; OECD, Competition in the Food Chain (n 143); OECD, 'Competition Issues in the Food Supply Chain - Note by the United States' DAF/COMP/WD(2013)123; USDA, 'Competition and Agriculture: Voices from the Workshops on Agriculture and Antitrust Enforcement in Our 21st Century Economy and Thoughts on the Way Forward' [2012] U.S. Department of Justice.

628 OECD, Competition in the Food Chain (n 143).

${ }^{629}$ See, for instance, the Reports by the UK Competition Commission, Final Report of the supply of groceries in the UK market investigation, 30 April 2008 and Comisión Nacional de la Competencia, Report on the relations between manufacturers and retailers in the food sector, October 2011. The UK Competition Commission have identified 52 different practices 26 of which resulted to create potential "uncertainty for suppliers regarding their revenues or costs as a result of the transfer of excessive risks or unexpected costs to suppliers". The Spanish Competition Authority detected 18 practices, falling into three categories: (i) commercial payments (e.g., fees for carrying and placing of products); (ii) contributions to ancillary activities carried out by the retailer (e.g., promotion fees); (iii) atypical payments. See also ECN (n 141). See also the Harper review in Australia: Ian Harper, Peter Anderson, Su McCluskey, Michael O’Bryan QC, Competition Policy Review, Final Report (March 2015), available at http://competitionpolicyreview.gov.au/files/2015/03/Competition-policy-reviewreport_online.pdf

${ }^{630}$ OECD, Competition Issues in the Food Chain Industry DAF/COMP(2014)16.
} 


\begin{tabular}{|c|c|c|}
\hline Practice & Description & Main competition risk \\
\hline Cartels & $\begin{array}{l}\text { Agreements among competitors relating } \\
\text { inter alia to price fixing, output } \\
\text { restriction and market partitioning }\end{array}$ & $\begin{array}{l}\text { Maintenance of high prices and stalling } \\
\text { of innovation to the detriment of } \\
\text { consumers. Cartels constitute very } \\
\text { serious anti-competitive behaviour }\end{array}$ \\
\hline Purchasing agreements & $\begin{array}{l}\text { Agreements concluded by competing } \\
\text { buyers for the purpose of jointly buying } \\
\text { certain inputs }\end{array}$ & $\begin{array}{l}\text { Under certain conditions, tool for } \\
\text { foreclosing rivals' access to essential } \\
\text { inputs at competitive conditions; } \\
\text { collusive behaviour between } \\
\text { competitors on downstream markets }\end{array}$ \\
\hline Resale price maintenance & $\begin{array}{l}\text { Restriction of the buyer's ability to } \\
\text { determine the sale price to end } \\
\text { consumers }\end{array}$ & Reduction of price competition \\
\hline Single branding & $\begin{array}{l}\text { Obligation or incentive scheme which } \\
\text { makes the buyer purchase practically all } \\
\text { of his requirements on a particular } \\
\text { market from only one supplier, for a } \\
\text { certain duration }\end{array}$ & $\begin{array}{l}\text { Possible restriction of in-store inter- } \\
\text { brand competition and/or foreclosure of } \\
\text { the market to competing and potential } \\
\text { suppliers }\end{array}$ \\
\hline Private label products & $\begin{array}{l}\text { Products made by third parties upstream } \\
\text { in the supply chain and sold under } \\
\text { retailers' brand }\end{array}$ & $\begin{array}{l}\text { Possible foreclosure of suppliers' } \\
\text { competing goods; restriction of in-store } \\
\text { inter-brand competition }\end{array}$ \\
\hline Tying & $\begin{array}{l}\text { Purchase of a product (tying product) } \\
\text { made conditional on purchase of other } \\
\text { product (tied product) }\end{array}$ & $\begin{array}{l}\text { Possible foreclosure on the market of } \\
\text { tied product, and indirectly of the tying } \\
\text { product }\end{array}$ \\
\hline Exclusive supply agreements & $\begin{array}{l}\text { Direct or indirect obligation causing a } \\
\text { supplier to sell a good only to one buyer }\end{array}$ & $\begin{array}{l}\text { Possible foreclosure of other buyers / } \\
\text { retailers }\end{array}$ \\
\hline Certification schemes & $\begin{array}{l}\text { Requirement to comply with a number } \\
\text { of conditions set by individual buyers }\end{array}$ & $\begin{array}{l}\text { Potential risks of foreclosing competing } \\
\text { buyers }\end{array}$ \\
\hline
\end{tabular}

Source: European Commission (2008) $)^{631}$

Some jurisdictions have also targeted superior bargaining power, irrespective of the existence of structural market power, when transactions on a competitive market are not mutually beneficial for the parties but one party is coerced into entering the transaction, because of a lack of economic alternative. Furthermore, some jurisdictions have chosen imaginative instruments to deal with some of the competition problems arising out of the power of multibrand retailers, even if these do not dispose of market power. We will focus on the various forms of addressing superior bargaining power in Chapter 3 of this Part.

\subsubsection{Self-regulation or mixed public-private regulation, standard setting}

Self-regulation gained momentum with the advancement of globalization and the development of new technologies and processes when the pace of change and the global nature of supply chains generated, by consequence, an informal delegation of power to private

${ }^{631}$ Communication from the Commission to the European Parliament, the Council, the European Economic and Social Committee and the Committee of the Regions _ Food Prices in Europe, COM(2008) 821 final. 
actors. ${ }^{632}$ Self-regulation originates from firms and industry groups active along the supply chain, as well as from NGOs and other civil society groups promoting specific policies in the market. ${ }^{633}$ Self-regulation may also manage the risks created by the supply chain, ${ }^{634}$ such as food safety or price shocks. ${ }^{635}$ Private governance solutions range from ex ante regulatory mechanisms (for example certifications) to ex post remedies to infringements of private standards.

Self-regulatory provisions may establish rules, practices or processes ${ }^{636}$ addressing specific issues arising along the supply chain, in particular dealing with environmental and safety standards, as well as with social standards. The coexistence of public and private regulation in supply chains resolves therefore in a double interdependence, when the regulatory framework contributes to shape supply chains that adopt private regulation, which, in turn, affects public regulatory strategies. ${ }^{637}$

The reasons for the increasing importance of national and transnational private contracting in food markets are numerous. Among them we can list:

a) differences in the bargaining power and the size of firms (sometimes translated in terms of market concentration, although the two things do not always correspond) between market actors; ${ }^{638}$

b) market consolidation;

c) changes in technology of commodities;

d) improved transportations;

e) changes in consumer demand;

f) crises connected to product safety; ${ }^{639}$

g) "the inability of States to deal with cross-boundary risk management". 640

Self-regulation allows private actors to swiftly adapt their relationship to the changing market conditions. Moreover, especially in the case of transition countries, private regulation constitutes the means through which private businesses import higher regulatory standards in those jurisdictions.

Standard setting leads to an important involvement of public and private actors and constitutes an example of hybrid public/private regulation. With regard to standard-setting

${ }^{632}$ Fabrizio Cafaggi and Paola Iamiceli, Private Regulation and Industrial Organisation: The Network Approach (European University Institute 2012) <available at: http://cadmus.eui.eu/bitstream/handle/1814/23264/WP-LAW2012-21.pdf?sequence $=1>1$.

${ }^{633}$ For instance, international organizations or associations (such as standards setters) and epistemic communities.

${ }^{634}$ Bridget M Hutter, 'Understanding the New Regulatory Governance: Business Perspectives' (2011) 33 Law \& Policy 459.

${ }^{635}$ See the table below for an overview of the private standards in food safety and environmental protection adopted in BRICS countries.

${ }^{636}$ Fabrizio Cafaggi, 'New Foundations of Transnational Private Regulation' [2010] EUI Working Paper Series RSCAS 2010/531.

${ }^{637}$ G. Gereffi \& J. Lee, 'A Global Value Chain Approach to Food Safety and Quality Standards' [2009] Global Health Diplomacy for Chronic Disease Prevention Working Paper Series.

${ }^{638}$ Gereffi and Christian (n 13); Gereffi, Humphrey and Sturgeon (n 3).

${ }^{639}$ G. Gereffi \& J. Lee, 'A Global Value Chain Approach to Food Safety and Quality Standards' [2009] Global Health Diplomacy for Chronic Disease Prevention Working Paper Serie

${ }^{640}$ Fabrizio Cafaggi and Paola Iamiceli, Private Regulation and Industrial Organisation: The Network Approach (European University Institute 2012) <available at: http://cadmus.eui.eu/bitstream/handle/1814/23264/WP-LAW2012-21.pdf?sequence=1>, 1 . 
organisations and standards related to plant protection, these are regulated either by international standards, set by intergovernmental organisations, or by governmental standards, set by national governments. On an international level, plant protection standards are set by the Commission on Phytosanitary Measures (CPM), which is established pursuant to the International Plant Protection Convention (IPPC) from 1951, and deposited with the Food and Agriculture Organization of the United Nations (FAO). IPPC consists of 183 parties, which includes 180 United Nations member states, the Cook Islands, Niue, and the European Union. The Convention is recognized by the WTO's Agreement on the Application of Sanitary and Phytosanitary Measures as the only international standard setting body for plant health. ${ }^{641}$ The strategic objectives of the CPM are the following:

- protecting sustainable agriculture and enhancing global food security through the prevention of pest spread;

- protecting the environment, forests and biodiversity from plant pests;

- facilitating economic and trade development through the promotion of harmonized scientifically based phytosanitary measures, and

- developing phytosanitary capacity for members to accomplish the preceding three objectives. ${ }^{642}$

The IPPC also provides for establishment of Regional Plant Protection Organizations (RPPO). RPPOs are inter-governmental organisations that coordinate the working of National Plant Protection Organisations (NPPOs) on a regional level and cooperate with the CPM in developing international standards for plant protection products. ${ }^{643}$ The functions of RPPOs include:

- coordination and participation in activities among their NPPOs in order to promote and achieve the objectives of the IPPC

- cooperation among regions for promoting harmonized phytosanitary measures

- gathering and dissemination of information, in particular in relation with the IPPC

- cooperation with the CPM and the IPPC Secretariat in developing and implementing international standards for phytosanitary measures. ${ }^{644}$

There are currently 9 RPPOs:

- Asia and Pacific Plant Protection Commission ${ }^{645}$

- Comunidad Andina ${ }^{646}$

- Comite de Sanidad Vegetal del Cono Sur ${ }^{647}$

- European and Mediterranean Plant Protection Organization ${ }^{648}$

- Inter-African Phytosanitary Council ${ }^{649}$

\footnotetext{
${ }^{641}$ https://www.ippc.int/en/structure/

${ }^{642}$ Ibid.

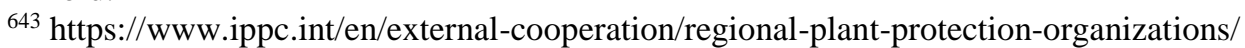

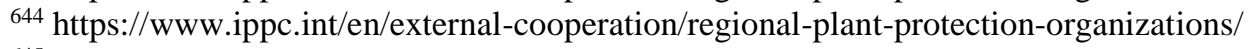

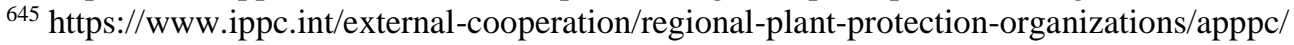

${ }^{646} \mathrm{https}: / / \mathrm{www} . i p p c . i n t /$ external-cooperation/regional-plant-protection-organizations/comunidadandina

${ }^{647} \mathrm{https}$ ://www.ippc.int/external-cooperation/regional-plant-protection-organizations/cosave

${ }^{648} \mathrm{https} / / / \mathrm{www}$. ippc.int/external-cooperation/regional-plant-protection-organizations/eppo

649 https://www.ippc.int/external-cooperation/regional-plant-protectionorganizations/interafricanphytosanitarycouncil
} 
- Near East Plant Protection Organization ${ }^{650}$

- North American Plant Protection Organization ${ }^{651}$

- Organismo Internacional Regional de Sanidad Agropecuaria ${ }^{652}$

- Pacific Plant Protection Organization ${ }^{653}$

Finally, each country generally has its own legislation regulating and implementing international standards on plant protection products. The EU, for example, has extensive pesticides database that are available for use in the EU. ${ }^{654}$

With regard to seeds, seed standards generally relate to quality, safety and marketing of seeds. Seed standards are set by and international organisations, on an international level, and governments on a national level,

At the international level, the Organisation of Economic Cooperation and Development (OECD) issues certification standards related to following types of plants: Grasses and Legumes; Crucifers and other Oil or Fibre species; Cereals; Maize and Sorghum; Sugar and Fodder Beet; Subterranean clover and similar species; and Vegetables. ${ }^{655}$ These standards are aimed to ensure varietal identity and purity of seeds through appropriate requirements and controls throughout the cropping, seed processing and labelling operations. Seeds complying with OECD standards are certified as "quality-guaranteed" and the aim is to facilitate international trade in seeds and removals of technical barriers to entry. ${ }^{656}$ To date, 58 countries participate in the OECD seed standardisation process. ${ }^{657}$

On a national level, each country generally regulates its own requirements for quality, safety and marketing of seeds. In the EU, there is extensive legislation governing the registration, certification and marketing of seeds. Before placing on the market, seeds should first be registered and certified (certification should guarantee the identity, health and quality of seeds and propagating material before marketing). ${ }^{658}$ The EU also regulates marketing of seeds and provides for specific requirements for packaging, sealing, labelling and documentation. ${ }^{659}$ The US similarly has its own standards related to quality, ${ }^{660}$ and marketing of seeds. ${ }^{661}$

1.2.1.3. Planning law, restrictions concerning trading hours and paternalistic regulation

\footnotetext{
${ }^{650} \mathrm{https}: / / \mathrm{www}$. ippc.int/external-cooperation/regional-plant-protection-organizations/neppo

${ }^{651} \mathrm{https}: / / \mathrm{www} . \mathrm{ippc}$. int/external-cooperation/regional-plant-protection-organizations/nappo

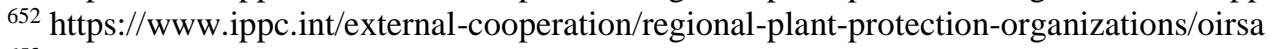

653 https://www.ippc.int/external-cooperation/regional-plant-protectionorganizations/pacificplantprotectionorganisation

${ }^{654}$ see: http://ec.europa.eu/food/plant/pesticides/eu-pesticides-database/public/?event=homepage\&language=EN

${ }^{655} \mathrm{http}: / / \mathrm{www}$. oecd.org/tad/code/abouttheoecdseedschemes.htm

${ }^{656}$ Ibid.

${ }^{657}$ see: http://www.oecd.org/tad/code/countriesparticipatingintheoecdseedschemes.htm

${ }^{658}$ see: https://ec.europa.eu/food/plant/plant_propagation_material/legislation/eu_marketing_requirements_en

${ }^{659}$ Ibid.

${ }^{660} \mathrm{https} / / / \mathrm{www} . g i p s a . u s d a . g o v /$ fgis/usstandards.aspx

${ }^{661} \mathrm{https}: / /$ www.ams.usda.gov/rules-regulations/fsa
} 
The European Commission regards planning restrictions and opening hours as potential competition inhibitors, therefore worthy of careful analysis. ${ }^{662}$ From this perspective, planning regimes, by limiting the attribution of construction permits, may hinder the establishment of new stores hampering competition in the specific geographic area. ${ }^{663}$ Moreover, entry regulations in the retail sector may have a negative repercussion on the labour markets. A study conducted in Italy showed empirical evidence that regions adopting tight restrictions on opening of large stores benefit from less employment growth than geographical regions with less restrictions. ${ }^{664}$ Furthermore, an informal survey of the European Commission concluded that "planning regimes place more limited constraints on the extension of existing stores by retailers compared with new entry". ${ }^{665}$ Most recently, the Australian Competition Policy Review, observed that "(r)emoving barriers to entry and other regulatory barriers would strengthen competition in the supermarket sector", noting that "(p)lanning and zoning restrictions are limiting the growth of new entrants [...] (and) more broadly affect the ability of independent supermarkets to compete" ${ }^{\prime 666}$. However, the negative impact on the performance of the retail and employment sectors, in some cases may be counterbalanced by objectives of environmental protection underlying the local planning policies. One could finally add paternalistic regulation limiting the distribution of certain categories of food products, for instance, state monopolies in the wholesaling or retailing of some or all categories of alcoholic beverages.

\subsubsection{The protection of consumers}

The development of consumer rights and of the legal field of consumer protection law constitutes one of the major legal innovations of the last five decades, starting with the Consumer Bill of Rights adopted by President Kennedy in 1962 in the US and the four basic rights recognized for consumers (the right to safety, the right to be informed, the right to choose, the right to be heard). The UN Guidelines for Consumer Protection, adopted by a UN General Assembly resolution in 1985, expanded the number of consumer rights to eight (adding the right to basic needs, including the right to food and water, the right to redress, the right to consumer education, the right to a healthy environment, a list that is continuously updated in order to correspond to evolving consumer needs and new technology). At the EU, a Council Resolution in 1975 set a preliminary programme for an EU consumer protection and information policy, providing for basic consumer rights. In 1985, the first consumer protection directives were adopted, following the introduction of a specific EU competence for consumer protection at the Maastricht Treaty in 1992. The protection of consumers figures also as an

\footnotetext{
${ }^{662}$ EC, 'Commission Staff Working Document - The Functioning of the Food Supply Chain and Its Effects on Food Prices' 20.

663 ibid.

${ }^{664}$ Eliana Viviano, 'Entry Regulations and Labour Market Outcomes: Evidence from the Italian Retail Trade Sector' (2008) 15 Labour Economics 1200.

${ }^{665}$ Bukeviciute, Dierx and Ilzkovitz (n 152) 29.

${ }^{666}$ Ian Harper, Peter Anderson, Su McCluskey, Michael O’Bryan QC, Competition Policy Review, Final Report (March 2015), available at http://competitionpolicyreview.gov.au/files/2015/03/Competition-policy-reviewreport_online.pdf, pp. 88-89.
} 
important objective of the Union, following the Treaty of Lisbon. Article 12 TFEU provides that "consumer protection requirements shall be taken into account in defining and implementing other Union policies and activities". This article may be interpreted as requiring that the protection of the interest of the consumer should be an integral part of EU competition law and policy. Similar legislation granting rights to consumers, including the right to food and water exist in a number of jurisdictions ${ }^{667}$.

Consumer protection in the food sector is mainly enacted by the establishment of safety standards. These safety standards cover: i) farmers' production, including processes adopted and substances used for growing plants and feeding animals; ii) food processing; iii) food distribution; iv) labelling and information to consumers. Public regulation generally provides the legal framework in which private parties set an important number of private standards.

\section{Table 3: Consumer protection in BRICS}

\begin{tabular}{|l|l|}
\hline Brazil & Consumer protection \\
\hline Legislation & Consumer Protection Code, Law 8.078/90 \\
\hline Institutions & $\begin{array}{l}\text { Consumer Protection and Defense Authority, Ministry of } \\
\text { Justice }\end{array}$ \\
\hline Standards & $\begin{array}{l}50 \quad \text { standards regulating production, processing and } \\
\text { retailing. }{ }^{668}\end{array}$ \\
\hline
\end{tabular}

\begin{tabular}{|l|l|}
\hline Russia & Consumer protection \\
\hline Legislation & Law N 2300-1 as of 07.02.1992 \\
\hline
\end{tabular}

\footnotetext{
${ }^{667}$ Although it is quite rare that constitutional texts refer to the consumer. See, for instance, Art. 51(1) of the Spanish Constitution of 1978 providing that "the public authorities shall guarantee the protection of consumers and users and shall by means of effective measures, safeguard their safety, health, and legitimate economic interests".

${ }^{668}$ See http://www.standardsmap.org.
} 


\begin{tabular}{|l|l|}
\hline Institutions & $\begin{array}{l}\text { Federal Service on Customers' Rights Protection and Human } \\
\text { Well-Being Surveillance }\end{array}$ \\
\hline Standards & $\begin{array}{l}25 \text { standards regulating production, processing and } \\
\text { retailing. }{ }^{669}\end{array}$ \\
\hline
\end{tabular}

\begin{tabular}{|l|l|}
\hline India & Consumer protection \\
\hline Legislation & Consumer Protections Act, 1986 \\
& $\begin{array}{l}\text { Department } \\
\text { http://consumeraffairs.nic.in/consumer/index.php }\end{array}$ \\
\hline Institutions & 48 standards regulating production, processing and retailing. ${ }^{670}$ \\
\hline Standards & Affairs \\
\hline
\end{tabular}

\begin{tabular}{|l|l|}
\hline China & Consumer protection \\
\hline Legislation & $\begin{array}{l}\text { Law of the People's Republic of China on Protection of } \\
\text { Consumer Rights and Interests (02-06-2006) }\end{array}$ \\
\hline Institutions & State Administration of Industry and Commerce \\
& \\
\hline
\end{tabular}

${ }^{669}$ See http://www.standardsmap.org.

${ }^{670}$ See http://www.standardsmap.org. 


\begin{tabular}{|c|c|}
\hline $\begin{array}{l}\text { South } \\
\text { Africa }\end{array}$ & Consumer protection \\
\hline $\begin{array}{l}\text { Legislatio } \\
\mathrm{n}\end{array}$ & $\begin{array}{l}\text { Consumer Protection Act (Act } 68 \text { of 2008) } \\
\text { https://www.westerncape.gov.za/other/2011/3/consumer_protection_act.p } \\
\underline{\text { df }}\end{array}$ \\
\hline $\begin{array}{l}\text { Institution } \\
\mathrm{S}\end{array}$ & $\begin{array}{l}\text { Consumer Affairs Committee of The Department of Trade and Industry } \\
\text { http://www.thedti.gov.za/ }\end{array}$ \\
\hline Standards & 44 standards regulating production, processing and retailing. ${ }^{672}$ \\
\hline
\end{tabular}

\subsubsection{Unfair trading practices}

According to a European 'High Level Forum on Better Functioning of the Supply Chain' (HLF) report, a number of European national competition authorities discovered the existence of unfair practices in the food supply chain linked to imbalances of bargaining power between stakeholders. ${ }^{673}$ As it is reported by the HLF, "NCAs found that most of these practices do not fall within the scope of competition rules at EU level or in most Member States, as they did not affect consumer welfare. A few NCAs have proposed alternative solutions to tackle them, such as the application of national laws against unfair trading practices, or the adoption of codes of conduct or good practices with effective enforcement mechanisms. A few NCAs have also expressed concerns about the potential anti-competitive effects that some of these practices may have in the long term, should they ultimately negatively affect the competitive process in the supply chain or consumer welfare by reducing investment and innovation or limiting consumer choice". ${ }^{674}$ In Europe, these concerns have resulted in the launch of the Supply Chain Initiative, under the auspices of the EU, which endorses the principles of fair contracting contained in the HLF Report and in the Green Paper on Unfair trading practices in the food and non-food supply chain in Europe, ${ }^{675}$ with the aim to establish a set of principles of good practice

\footnotetext{
${ }^{671}$ See http://www.standardsmap.org.

${ }^{672}$ See http://www.standardsmap.org.

${ }^{673} \mathrm{EC}(\mathrm{n} \mathrm{171).}$

674 ibid.

${ }^{675}$ Green Paper on Unfair trading practices in the food and non-food supply chain in Europe (COM/2013/037).
} 
for the food supply chain. ${ }^{676}$ The regulatory framework related to unfair competition in the food sector of the BRICS countries is instead rather diverse but may play a significant role in the future.

\subsubsection{Access to land and right to food}

The right to food is proclaimed and protected by international law. Article 25(1) of the Universal declaration of Human rights stipulates that "(e)veryone has the right to a standard of living adequate for the health and well-being of himself and of his family, including food". Article 11(1) of the International Covenant on Economic Social and Cultural Rights also requires the States Parties to the Covenant to recognize "the right of everyone to an adequate standard of living for himself and his family, including adequate food". Similar obligations are proclaimed by Articles 24 and 27 of the Convention on the Rights of the Child. The right to food is also protected by a number of regional treaties (e.g. and Article 11 of the American Declaration on the Rights and Duties of Man) and national constitutions (e.g. for instance, in South Africa, in the landmark case Government of the Republic of South Africa v. Irene Grootboom and others concerning housing, the court rules that the Government had violated the Constitution by not making "reasonable" provision for persons in desperate need, the right to food enjoying a similar constitutional protection ${ }^{677}$ ). The World Summit organized by the Food and Agriculture Organization of the United Nations (FAO) in 1996 emphasized the need to clarify the obligations arising from the right to food, as provided for under international human rights law. In response, the Committee on Economic, Social and Social Rights issued its general comment No. 12 (1999), providing a definition of the right to adequate food ${ }^{678}$.

The right to food is about the way in which individuals may access food markets for the purpose inter alia of providing food for oneself. ${ }^{679}$ Right to food [is]...the right to have regular, permanent and unobstructed access, either directly or by means of financial purchases, to quantitatively and qualitatively adequate and sufficient food. ${ }^{680}$ In terms of United Nation's General Comment $12^{681}$ economic accessibility applies 'to any acquisition pattern or entitlement through which people procure their food'. Accessibility also 'implies that personal and household financial costs associated with the acquisition of food for an adequate diet should be at a level such that the attainment and satisfaction of other basic needs are not threatened or compromised. ${ }^{682}$ Under Article 2 of the International Convention of Economic, Social and Cultural Rights (ICESCR), the right to adequate food is a relative standard, subject

\footnotetext{
${ }^{676}$ See http://www.supplychaininitiative.eu/.

${ }^{677}$ Government of the Republic of South Africa and Others v Grootboom and Others (CCT11/00) [2000] ZACC 19; 2001 (1) SA 46; 2000 (11) BCLR 1169 (4 October 2000).

${ }^{678}$ Committee on Economic, Social and Cultural Rights, General Comment 12, Right to adequate food (Twentieth session, 1999), U.N. Doc. E/C.12/1999/5 (1999), reprinted in Compilation of General Comments and General Recommendations Adopted by Human Rights Treaty Bodies, U.N. Doc. HRI/GEN/1/Rev.6 at 62 (2003).

${ }^{679}$ Tristan Feunteun, 'Cartels and the Right to Food: An Analysis of States' Duties and Options' [2015] Journal of International Economic Law. 342.

680 ibid. 343.

${ }^{681}$ United Nations Economic and Social Council E/C.12/1999/5 12 May 1999 'The right to adequate food (art. 11)'.

${ }^{682}$ Tristan Feunteun, 'Cartels and the Right to Food: An Analysis of States' Duties and Options' [2015] Journal of International Economic Law. 342, 349.
} 
to progressive realization according to the available resources of the state. ${ }^{683}$ The term "progressive realization" was interpreted and explained in General Comment No. 3:

"... the fact that realization over time, or in other words progressively, is foreseen under the Covenant should not be misinterpreted as depriving the obligation of all meaningful content. It is on the one hand a necessary flexibility device, reflecting the realities of the real world and the difficulties involved for any country in ensuring full realization of economic, social and cultural rights. On the other hand, the phrase must be read in the light of the overall objective, indeed the raison d'être, of the Covenant which is to establish clear obligations for States parties in respect of the full realization of the rights in question. It thus imposes an obligation to move as expeditiously and effectively as possible towards that goal. Moreover, any deliberately retrogressive measures in that regard would require the most careful consideration and would need to be fully justified by reference to the totality of the rights provided for in the Covenant and in the context of the full use of the maximum available resources"

Further in terms of General Comment No. 3, there was a 'minimum core obligation' upon every state party to the ICESCR 'to ensure the satisfaction of, at the very least, minimum essential levels of each of the rights'. The minimum core obligation in respect of the right to food is the right to be provided essential foodstuffs. In order for a State party to be able to attribute its failure to meet at least its minimum core obligations to a lack of available resources it must demonstrate that every effort has been made to use all resources that are at its disposition in an effort to satisfy, as a matter of priority, those minimum obligations. ${ }^{685}$

The way the right to food may relate to competition law enforcement has become progressively apparent, but initially competition law was not considered as part of the toolbox that could lead to the realization of this largely programmatic right ${ }^{686}$. A number of developing countries, namely, Cuba, Dominican Republic, El Salvador, Haiti, Honduras, Kenya, Nicaragua, Pakistan, Sri Lanka, Uganda and Zimbabwe, had submitted a proposal calling for a "food security box", which recognized the specific food security needs and special situations of developing countries, although it did not mention the right to food. The proposal also asked for specific policy instruments including (a) choice of which products may be liberalized; (b) Re-evaluation of tariffs; (c) Flexibility in levels of domestic subsidies; (d) Protection against dumping and most importantly, (e) Protection against monopolies. Developing countries

\footnotetext{
${ }^{683}$ Article 2(1) of the ICESCR

"1. Each State Party to the present Covenant undertakes to take steps, individually and through international assistance and co-operation, especially economic and technical, to the maximum of its available resources, with a view to achieving progressively the full realization of the rights recognized in the present Covenant by all appropriate means, including particularly the adoption of legislative measures." [emphasis added]

${ }^{684}$ UN Committee on Economic, Social and Cultural Rights (CESCR), General Comment No. 3: The Nature of States Parties' Obligations (Art. 2, Para. 1, of the Covenant), 14 December 1990, E/1991/23, available at: http://www.refworld.org/docid/4538838e10.html [accessed 29 August 2016] Para 9.

685 ibid para 10.

${ }^{686}$ On the legal nature of the right to food and the contribution of competition law to its realization, see Amber Darr \& Ioannis Lianos, The 'Hunger Games': Competition Law and the Right to Food, CLES Research paper 4/2017 (forthcoming).
} 
argued that they must be given an easily accessible mechanism to protect themselves against the abuse of monopoly power and to seek compensation. ${ }^{687}$

Competition Policy increasingly came under discussion in the post 2000 discussion of the Millennium Development Goals, because it was believed that even though it was not mentioned explicitly, it was of considerable importance for the MDGs. ${ }^{68}$ This brought attention to competition law as a possible tool in order to achieve the broader aims of the right to food. But, of course, a lot of conceptual work had to be done in order to build this possible connection.

In 2000, the Commission on Human Rights appointed a Special Rapporteur on the right to food with the mandate, among others, to present recommendations on possible steps to achieve the full realization of the right to food, by the submission of annual reports to the Human Rights Council and the UN General Assembly and by preparing thematic reports. The Special Rapporteur may also lead country missions in order to examine the right to food in the country and propose recommendations to improve the situation. In 2004, FAO also adopted voluntary guidelines to support the progressive realization of the right to adequate food in the context of national food security, providing practical guidance to States in order to implement the right to adequate food $^{689}$. All FAO member States have accepted the Guidelines by adopting them at the FAO Council in November 2004. In 2006, the Right to Food Unit was created to support members with the implementation of the Guidelines. In 2006, the UN General Assembly also decided that the Human Rights Council will undertake a universal periodic review of the fulfilment by each UN Member State of its human rights obligations and commitments, each country being reviewed every four years.

The World Development Report 2008 'Agriculture for Development' highlighted the need for competition policy and the establishment of regulatory institutions as priority areas for public action. In particular, the Report noted that greater access to assets for smallholders, level playing fields, and strong producer organizations to achieve scale and market power are necessary elements and that the opportunities offered by major changes in markets will work for the poor only if these complementary policies are in place. ${ }^{690}$

Olivier de Schutter, the United Nations Special Rapporteur on the Right to Food from 2008 to 2014 has played an important role in bringing competition to the forefront of the RTF debate. Arriving on the scene at a time of heightened awareness about the impact of concentration, particularly in the agribusiness sector, de Schutter advocated a rights approach for competition policy.

A Fact Sheet on the Right to Adequate Food was published by the Office of the United Nations High Commissioner for Human Rights in 2010 ${ }^{691}$. This Fact Sheet clarifies that food must be available, accessible and adequate, the latter concept requiring that food must satisfy dietary needs and being safe from adverse substances, such as contaminants from industrial or

\footnotetext{
${ }^{687}$ United Nations General Assembly A/56/210 23rd July 2001 'Preliminary report of the Special Rapporteur of the Commission on Human Rights on the right to food, Jean Ziegler', para 85

${ }^{688}$ David Satterthwaite ed. 'The Millennium Development Goals and Local Processes: Hitting the target or missing the point?' "Policy coherence and the Millennium Development Goals" iscepi!Maryanne Grieg-Gran p. 135 ${ }^{689}$ Available at ftp://ftp.fao.org/docrep/fao/meeting/009/y9825e/y9825e.pdf

${ }^{690}$ World Development Report 2008: 'Agriculture for Development', p. 134

${ }^{691}$ Office of the High Commissioner for Human Rights, The Right to Adequate Food, Factsheet no. 34, available at http://www.ohchr.org/Documents/Publications/FactSheet34en.pdf
} 
agricultural processes, including residues from pesticides, hormones or veterinary drugs. The right to food also implies that States should provide an enabling environment in which a person will live in conditions allowing him or her to produce food or to buy it (that is, land, seeds, water and other resource for production and money and access to the market for consumption purposes). The right to food provides entitlements to individuals to access adequate food and to the resources necessary for the sustainable enjoyment of food and imposes obligations to States to overcome hunger and malnutrition and realize food security for all. It is distinguished from the concept of food sovereignty, which is recognized under some national laws ${ }^{692}$, according to which peoples should be able to define their own mode of food production and determine the extent to which they want to be self-reliant and protect domestic food production and regulate trade in order to achieve sustainable development objectives. The FAO Fact Sheet also details the implications of the right to food for specific groups of people, such as people living in rural and urban areas, indigenous peoples, women, and children.

Among the various legal obligations that the right to food imposes on States, an important one is the duty of States to protect individuals' enjoyment of the right to food against violations by third parties (including private enterprises and other entities), which involves the protection of sources of food from destruction and environmental damage, but also the obligation to ensure that food put on the market is safe and nutritious, States being required to develop and enforce food quality and safety standards and to ensure "fair and equal market practices". States should also be active in fulfilling the right to food, including by the implementation of agrarian reform programs. Of particular interest is also the extent of the obligations imposed, as according to the first special rapporteur on the right to food, "to comply fully with their obligations [...] States must also respect, protect and support the fulfilment of the right to food of people living in other territories" ${ }^{\$ 93}$, thus not only their citizens but also third parties subject to their jurisdiction, such as private companies that may violate the right to food in other countries. International law also imposes on States obligations to take steps to ensure an equitable distribution of world food supplies (Article 11(2) of the International Covenant on Economic, Social and Cultural Rights). The High Commissioner's Factsheet also adds that there is an increasing recognition by the Human Rights Council and its regional and international soft-law instruments that corporations themselves have a responsibility to respect human rights, including the right to food, which means that they should not infringe on the enjoyment of human rights and that effective remedies for victims should be in place.

The high level of concentration in food supply chains and the bargaining power that ensues has been examined by a briefing note of the special rapporteur on the right to food, that is of particular interest for our study in view of the emphasis put on the "direct link between the ability of competition regimes to address abuses of buyer power in supply chains and the enjoyment of the right to adequate food" ${ }^{\prime 64}$. The special rapporteur highlighted the important concerns over agribusiness concentration that affect according to him the effective realization

\footnotetext{
6922008 Constitution of Ecuador. 2008 Organic Law of Food Security and Food Sovereignty of Venezuela; 2007 Constitution of Bolivia.

${ }^{693}$ Office of the High Commissioner for Human Rights, The Right to Adequate Food, Factsheet no. 34, p. 19.

${ }^{694}$ Olivier de Schutter, Addressing Concentration in Food Supply Chains, Briefing Note 03, December 2010, p. 1.
} 
of the right to adequate food. He noted that this concentration is not only limited to the retail sector, which has attracted a lot the attention of competition authorities eager to deal with the bargaining power of large supermarkets, in both developed and developing countries, but also extends to the production of agricultural commodities. The report provides some examples of the latter:

"[...] (T)here are around 500 million consumers of coffee. Yet, just four firms carry out $45 \%$ of all coffee roasting, and only four firms carry out $40 \%$ of all international coffee trading. Similarly, just three companies control over $80 \%$ of the world's tea markets, and four companies control $40 \%$ of international trading in cocoa, $51 \%$ of cocoa grinding and $50 \%$ in confectionary manufacturing. There are additional examples: in the Brazilian soybean market, roughly 200,000 farmers attempt to sell to five main commodity traders; in the Ivorian cocoa industry, three large transnational commodity buyers (ADM, Cargill and Barry Callebaut) dominate; and in 1996, two transnational food and beverage companies (Nestlé and Parmalat) controlled 53\% of the Brazilian dairy processing market, driving off a large number of cooperatives, which had to sell their facilities to these companies" ${ }^{\prime 95}$.

According to the report, the downward pressure to producers' income forces less efficient producers to merge, without however any cost savings arising out of these mergers and the consequent economies of scale being passed on to consumers, in view of the gatekeeping role of large commodity buyers and processors, as well as retailers. For instance, despite the fall in the farm prices for coffee beans by $80 \%$, retail prices for coffee only dropped by $27 \%$, while at the same time the profits of Starbucks and Nestlé, the main coffee retailer and coffee processor, increased considerably. The report also noted the practice of large retailers in the developed world to pass the cost of compliance with the retailer's standards on hygiene, food safety and traceability to the coffee producers, thus increasing the costs of smaller farms and leading to the increase of large farms (horizontal concentration) as well as of those farms controlled directly by the coffee exporters (vertical integration).

The social consequences of this concentration and of the downward pressure on farm prices are quite significant, with agricultural wages being depressed, child labour employed and proper environmental precautions dispensed with. Faced with a reality of decreasing revenues, small farmers are pressed to produce even more agricultural commodities in order to earn short-term income in an attempt to meet daily expenses, which leads to oversupply and the vicious circle of further depression of prices,, sometimes even below the average cost of production. Large buyers in developed countries also demand high volume discounts, obliging the suppliers to raise the prices for other buyers, thus exacerbating the comparative competitive advantage of large retailers and leading to more concentration at the retail side of the market (the waterbed effect). Final consumers are also ultimately harmed by reductions in quality or choice and decreased levels of innovation by producers without enjoying the benefit, because of the gatekeeper effect of large supermarkets and industrial processors, of significantly lower prices. Consumer sovereignty also suffers from the ability of dominant buyers to dictate to consumers the choice of the products that come to market.

${ }^{695}$ Ibid., p. 2. 
The special rapporteur recommended that "competition law regimes should be improved to comport with general human rights principles of equality and non-discrimination, and to facilitate the realization of human rights, including among others the right to food, the right to work and the right to development" ${ }^{\prime 69}$. More concretely this implies that countries exporting agricultural commodities should not adopt "competition laws focused on consumer welfare on the model proposed by the OECD", but should instead seek to "ensure that, in the competition law regime that they set up, they offer a sufficient high level of protection of their producers against abuses of dominant positions by commodity buyers, food processors or retailers, as part of their obligation to protect the right to food under their jurisdiction"697. For the special rapporteur, "substantive competition laws should recognize that consumer harms arising from excessive buyer concentration are incipient and therefore indeterminate in character, but that this indeterminacy should not be a reason for failing to control such conduct", a "more enriched conception of consumer welfare" being needed, "one that takes account of consumers' interests in sustainability - rather than focusing purely upon short-term price changes $"{ }^{\prime 98}$. In view of the inability of major developed countries competition authorities to control excessive buyer power, because of the remoteness of the effects of such power on their consumers, according to the effects doctrine ${ }^{699}$, developing jurisdictions, in which the majority of impoverished farmers are located, should set up "credible competition authorities of their own". Developed countries should also design competition law regimes that address

\footnotetext{
${ }^{696}$ Ibid., p. 4.

${ }^{697}$ Ibid., p. 5.

698 Ibid., p. .5

${ }^{699}$ The rapporteur notes that Section 6(a) of the Foreign Trade Antitrust Improvements Act (FTAIA) provides that jurisdiction of the US Sherman Act can be established only where extraterritorial conduct has "direct, substantial and reasonably foreseeable effect" on trade or commerce in the US, these concepts being interpreted restrictively by the US courts. Hence, conduct by large buyers leading that has remote effects on consumers may escape the scope of the Sherman Act. He gives the example of a $9^{\text {th }}$ Circuit court of appeals case in U.S. v. LSL Biotechnologies, 379 F.3d 672 ( $9^{\text {th }}$ Cir. 1945), in which the defendant, a US corporation, had imposed a foreign supplier-developer of tomato seeds, a contractual clause preventing it from supplying any other buyer in the U.S. According to the US DOJ Antitrust Division, such clause would have made less likely possible innovations from the foreign supplier-developer in the creation of heartier tomato seeds that would allow consumers to enjoy higher quality, better tasting winter tomatoes. The judge dismissed these arguments noting that the "delay of possible innovations does not have a direct effect on American commerce". The special rapporteur notes that the EU effects doctrine may catch this type of behavior as the EU courts have interpreted the requirement of the immediate and substantial effect in the EU broadly "to pertain not so much to economic effects, but to the structure of the market". With regard to the US, it is well known that the $9^{\text {th }}$ circuit in earlier cases had adopted a strict standard for directness of the effect on American commerce, as the effect must follow as "an immediate consequence of the defendant's activity" [US v LSL Biotechnologies, 379 F.3d 672 (9th Cir. 2004]. In 2012 the seventh circuit took a different approach in Minn-Chem Inc. v. Agrium Inc., 683 F.3d 845 (7th Cir. 2012), where it introduced the " "reasonably proximate causal nexus'" standard, which enables a more expansive interpretation of Section 6(a) of the Foreign Trade Antitrust Improvements Act (FTAIA). This more expansive view was confirmed in the recent Motorola II judgment of the seventh circuit, Motorola Mobility v. AU Optrronics Corp., 773 F.3d 826 (7th Cir. 2014), petition for cert. filed, 83 U.S.L.W. 3745 (U.S. March 16, 2015), where the seventh circuit revisited a more restrictive interpretation of Section 6(a) in Motorola I, Motorola Mobility v. AU Optronics Corp., 746 F.3d 842 (7th Cir. 2014) in which the court rejected the existence of a "direct" effect on U.S. commerce because of the fact that the anti-competitive behaviour was affecting intermediary and not final products. The second circuit has also adopted the more expansive "reasonably proximate causal nexus" standard in Lotes Co. v. Hon Hai Precision Indus. Co., 753 F.3d 395 (2d Cir. 2014) (conduct was considered as within the scope even if it affected intermediary products). In a recent judgment the Ninth circuit nevertheless insisted on the restrictive approach of "the immediate consequence test": US v. Hui Hsiung, 778 F.3d 738 (9th Cir. 2015), petition for cert. filed, 83 U.S.L.W. 3745 (U.S. March 16, 2015).
} 
the negative effects of high concentration and buyer power. According to the special rapporteur,

"Developed countries [...] should avoid creating high barriers to assert jurisdiction, as well as substantive rules of competition law that leave abusive buyer behaviour in developing countries unchecked. Reductions of consumer welfare resulting from abuses of buyer power occur only in the long-term, and as an indirect consequence of the appropriation of producer welfare. It is therefore inappropriate to focus competition regimes on consumer protection alone. Instead, developed countries, especially those where dominant agribusiness buyers are domiciled, should be more active in addressing the creation, maintenance and abuse of such buyer power, with a view not only to protecting the suppliers, particularly in developing countries, from the impacts of abuses of dominant positions, but also to ensuring the longer term stability of supply for consumers.

Developing countries where food insecurity is widespread in the rural areas and where violations of the right to adequate food of small-scale farmers are common, may wish to create competition regimes that impose on buyers specific duties, or subject them to specific types of control, in certain supply chains or for certain commodities that are particularly important to the revenues of small-scale farmers, with a view to preventing types of conduct which result in harms to the welfare of producers"700.

\subsubsection{Sustainability, environmental protection and biodiversity}

Legal obligations arising out of environmental protection laws and sustainability norms included in international treaties and national constitutions also frame public action relating to the preservation of competition in the context of the food value chain. For instance, the EU treaties include a general integration clause at Article 7 TFEU, according to which " $(\mathrm{t})$ he Union shall ensure consistency between its policies and activities, taking all of its objectives into account and in accordance with the principle of conferral of powers". Sustainable development constitutes a fundamental objective pursued by the European Union, according to the Treaty of Lisbon. With regard to environmental protection, Article 11 TFEU provides that "(e)nvironmental protection requirements must be integrated into the definition and implementation of the Union's policies and activities". The inclusion of these provisions should have led the Commission and arguably the Courts to grant more importance to broader public interest concerns in some circumstances, although these expectations have not been fulfilled by current practice.

There is a variety of practices among jurisdictions. Some jurisdictions, including the EU, seem to prefer not to aggregate effects across markets and to balance competition with other public interests, to the extent that these public interest objectives cannot be taken into account in the competition assessment. For instance, in the EU, the Commission takes into account the positive welfare effects of an agreement as long as "the group of consumers affected by the restriction and benefiting from the efficiency gains are substantially the same"701. Yet, it also

\footnotetext{
700 Olivier de Schutter, Addressing Concentration in Food Supply Chains, Briefing Note 03, December 2010, p.6. ${ }^{701}$ Commission, Notice - Guidelines on the application of article 81(3) [2004] OJ C 101/7, para. 43
} 
accepts that such aggregation is possible for related relevant markets, such as downstream markets, where one can assume that the consumers affected would be substantially the same. The EU courts' position on this issue seems more liberal. With regard to the application of Article 101(3) TFEU the General Court indicated in a case that it has regard to advantages arising from the agreement, not only for the specific relevant market but also for "every other market on which the agreement in question might have beneficial effects"702. Public interest objectives have occasionally outweighed the finding of a restriction of competition in the context of Article 101(1) TFEU, when an activity is (self-)regulated and the restraints are ancillary for its organization and operation ${ }^{703}$ Environmental policy aims have also been taken into account in the enforcement of Article 101(3) TFEU in a number of cases ${ }^{704}$. The European Merger Control Regulation also allows for the consideration of public interest objectives ${ }^{705}$. Based on the horizontal integration clauses of the Treaty, perceived as indicating the preferences of EU citizens, the competition law decision-makers may also devise a social welfare function that takes into account additional dimensions of welfare, than price and quality, in case benefits brought for the public interests are quantifiable, but also beyond ${ }^{706}$. Other competition law regimes are also confronted with similar concerns relating to the choice between a more general framework of cost benefit analysis across markets or only within a relevant market.

Biological diversity is protected at the international level by the Convention on Biological Diversity adopted in 1992. The Convention aims, among others, to achieve a fair and equitable sharing of benefits arising from genetic resources and regulates access to genetic sources and traditional knowledge. GMs are further regulated by the Carthagena Protocole on Biosafety, adopted in January 2000, which makes it clear that products from new technologies must be based on the precautionary principle. The aim to guarantee a fair and equitable sharing of benefits arising from genetic resources is further implemented by the Nagoya Protocol on Access to Genetic Resources, a supplementary agreement to the Convention on Biological Diversity, adopted in 2010 (entry into force in 2014). The Nagoya Protocol sets out core obligations for States contracting parties, including domestic-level access measures with the aim to create conditions to promote and encourage research contributing to biodiversity conservation and sustainable use and benefit-sharing obligations for the benefits arising from the utilization of genetic resources as well as subsequent applications and commercialization,

\footnotetext{
702 Case T-86/95, Compagnie générale maritime and others v. Commission [2002] ECR II-2011, para. 130.

${ }^{703}$ Case C-309/99, Wouters and Others [2002] ECR I-1557; Case C-519/04, Meca-Medina and Majcen [2006] ECR I-6991.

${ }^{704}$ See, Commission Decision no. 94/986/EC, Philips/Osram [1994] OJ L 378/37, para. 27 "The use of cleaner facilities will result in less air pollution, and consequently in direct and indirect benefits for consumers from reduced negative externalities"; Commission Decision no. 2000/475/EC, CECED [1999] OJ L187/47, para. 5557; Commission Decision 2001/837/EC, DSD [2001] L 319/1, para. 148: "consumers will likewise benefit as a result of the improvement in environmental quality sought, essentially the reduction in the volume of packaging". ${ }^{705}$ Council Regulation (EC) No 139/2004 on the control of concentrations between undertakings [2004] OJ L 24/1, recital 23 (requiring the Commission to place its appraisal within the general framework of the fundamental objectives of the Treaties), thus allowing broader public interest concerns to be taken inton account in the appraisal process) .

${ }^{706}$ See, Commission Decision no. 2000/475/EC, CECED [1999] OJ L187/47, para. 55-57, taking into account collective benefits to the environment and balancing them against the restriction to competition, thus extending the competition assessment outside of the boundaries of the specific relevant market.
} 
subject to mutually agreed terms (monetary or non-monetary). According to the Protocol, "(e)ach Party shall take legislative, administrative or policy measures, as appropriate, with the aim of ensuring that benefits arising from the utilization of genetic resources that are held by indigenous and local communities, in accordance with domestic legislation regarding the established rights of these indigenous and local communities over these genetic resources, are shared in a fair and equitable way with the communities concerned, based on mutually agreed terms $" 707$. Indigenous and local communities may thus derive rights blocking the propertisation and commercialisation of indigenous genetic resources by multi-national corporations.

\subsubsection{GMO regulation}

Since the 1990s, many jurisdictions have put in place specific regulation of genetically modified organisms (GMOs), though they are widely diverging in strictness and complexity.

In the European Union, GMOs are regulated with a comprehensive legal framework, ${ }^{708}$ which is aimed at (1) protecting human and animal health and the environment by introducing a safety assessment of the highest possible standards; (2) harmonising efficient, time-limited and transparent procedures for risk assessment and authorisation of GMOs; (3) ensuring clear labelling of GMOs placed on the market so that consumers and professionals (e.g. farmers) can make an informed choice; and (4) ensuring the traceability of GMOs placed on the market. ${ }^{709}$ In accordance with the Cartagena Protocol on Biosafety to the Convention on Biological Diversity which was signed on 15 May 2000 and came into effect on 11 September 2003, the EU legislative framework is based on the precautionary principle. The precautionary principle reflects a risk management strategy whereby the possibility that a given policy or action might cause harm to the public or the environment and the lack of scientific consensus on the issue is sufficient reason for not pursuing the policy or action in question, at least until more scientific knowledge becomes available. ${ }^{710}$

Authorization for GMOs are available for cultivation and for food and feed purposes under Regulation 1829/2003 (food and feed) ${ }^{711}$ and Regulation 2001/18 (cultivation). ${ }^{712}$ Applications for authorization for food and feed are sent to the relevant national authority, which forwards the application to the European Food Safety Authority (EFSA) for a risk

\footnotetext{
${ }^{707}$ Article 5 of the Nagoya Protocol.

${ }^{708}$ Directive 2001/18/EC on the deliberate release of GMOs into the environment; Regulation (EC) $1829 / 2003$ on genetically modified food and feed; Directive (EU) 2015/412 amending Directive 2001/18/EC as regards the possibility for the Member States to restrict or prohibit the cultivation of GMOs in their territory; Regulation (EC) 1830/2003 concerning the traceabilityand labelling of genetically modified organisms and the traceability of food and feed products produced from genetically modified organisms; Directive 2009/41/EC on contained use of genetically modified micro-organisms; Regulation (EC) 1946/2003 on transboundary movements of GMOs.

${ }^{709} \mathrm{https}: / /$ ec.europa.eu/food/plant/gmo/legislation_en.

${ }^{710}$ See Article 191 TFEU. See further Anne I. Myhr, 'The Precautionary Principle in GMO Regulations' in Terje Traavik and Lim Li Ching (eds), Biosafety First - Holistic Approaches to Risk and Uncertainty in Genetic Engineering and Genetically Modified Organisms (Third World Network and GenØk 2009).

${ }^{711}$ Regulation (EC) No 1829/2003 of the European Parliament and of the Council of 22 September 2003 on genetically modified food and feed [2003] OJ L268/1.

712 Directive 2001/18/EC of the European Parliament and of the Council of 12 March 2001 on the deliberate release into the environment of genetically modified organisms and repealing Council Directive 90/220/EEC [2001] OJ L106/1.
} 
assessment. EFSA evaluates the application based on risks for the environment, human health and animal safety, and may give recommendations on labelling or other conditions. On the basis of EFSA's opinion, the European Commission will advise the Member States to either approve or reject the application. The Member States decide on the application in the Standing Committee on Plants, Animals, Food and Feed by qualified majority. When the Committee fails to reach an approval or rejection decision (because of abstentions), the European Commission can convene an Appeal Committee which also decides by qualified majority. For authorization applications concerning GMO cultivation, EFSA defers the risk assessment to the relevant national authority of the country where the application is filed. If however at least one other Member State objects against the assessment report, EFSA will itself undertake a risk assessment. Both cultivation and food and feed authorizations are valid for a maximum of 10 years, and are renewable. ${ }^{713}$

Between 2009 and 2011, the EU legislative framework for GMO regulation was evaluated by two consultancy firms. While the relevant authorities and other stakeholders showed support for the main objectives of the EU's GMO regulation, it was also reported that GMO cultivation would benefit from more flexibility in the authorization process, that the authorization system could be more efficient, and that risk assessment should be more harmonized. ${ }^{714}$

Decision-making within the GMO authorization system has indeed been inefficient and ineffective, and has been described by Shaffer and Pollack as 'a record of persistent conflict, bargaining from fixed positions, formal votes on nearly every proposed decision, substantial numbers of abstentions (representing a refusal to take a position) and ultimate deadlock' ${ }^{715}$ In 2013, the General Court of the European Union forced the European Commission to proceed in the authorization process of maize 1507, an insect-resistant genetically modified maize, after several years of delays, U-turns and inaction since the initial application in 2001. ${ }^{716}$

In the United States, regulation of GMOs is divided between the Food and Drug Administration (FDA), the Environmental Projection Agency (EPA), and the Department of Agriculture (USDA)'s Animal and Plant Health Inspection Service. ${ }^{717}$ The FDA is responsible for food and feed safety and has the authority to remove foods from the market that are a threat to public health, ${ }^{718}$ and regulates food additives, which must be approved by the FDA before market access, unless the additive is 'generally recognized as safe'. ${ }^{719}$ Genetically modified

\footnotetext{
${ }^{713}$ See, https://ec.europa.eu/food/plant/gmo/authorisation_en.

${ }^{714}$ See, https://ec.europa.eu/food/plant/gmo/authorisation_en.

${ }^{715}$ M. Pollack and G. Shaffer, 'Risk regulation, GMOs, and the limits of deliberation' in D. Naurin and H. Wallace (eds), Unveiling the Council of the European Union: Games Governments Play in Brussels (Palgrave MacMillan, 2008), 161.

${ }^{716}$ Case T-164/10, Pioneer Hi-Bred International, Inc. v European Commission, EU:T:2013:503.

${ }^{717}$ See generally e.g., Diahanna Lynch \& David Vogel, The Regulation of GMOs in Europe and the United States: A Case-Study of Contemporary European Regulatory Politics, Council on Foreign Relations (5 April 2013); K. Gostek, 'Genetically Modified Organisms: How the United States' and the European Union's Regulations Affect the Economy' (2016) 24 Michigan State International Law Review 761;

${ }^{718}$ Section 402(a)(1) of the FD\&C Act, 21 U.S.C. 342(a)(1).

${ }^{719}$ Section 409 of the FD\&C Act, 21 U.S.C. 348.
} 
foods generally do not require pre-approval by the FDA as they are classified as presumptively generally recognized as safe. ${ }^{720}$ There are no separate labelling requirements for GMO foods. ${ }^{721}$

The EPA regulates pesticides and microorganism developed through genetic engineering, regarding manufacture, sale and use. The USDA regulates the planting, importation, or transportation of GMO plants pursuant to the Plant Protection $\mathrm{Act}^{722}$ through an authorization system, whereby most GMO plants are classified as 'regulated articles' which require prior approval of the USDA before it may be introduced. ${ }^{723}$

Russia has prohibited domestic sales and import of genetically modified organisms in 2016. ${ }^{724}$ The cultivation and breeding of genetically modified plants and animals is prohibited, except in cases where they will be used in testing and scientific research ${ }^{725}$. Current legislation had allowed the use of genetically modified seeds in agriculture and required special labeling of food that was produced with GMOs. Because the introduction of GMO registration procedures had been postponed until July 2017, however, there was a de facto moratorium on production of genetically modified. ${ }^{726}$

China ratified the Cartagena Protocol on Biosafety on 8 June 2005, effective from 6 September 2005. China has traditionally cautiously reviewed the introduction and development of Genetically Modified Organisms (GMOs) and GM products. The authorities actively promote fundamental research but strictly control the planting of GM crops. In its 2011 Five Year Plan for Development of Agricultural Science and Technology, the Ministry of Agriculture proposed to strengthen research involving genetically modified organisms (GMOs). ${ }^{727}$ In theory, crops that pass the safety tests are considered safe and can be planted. To date, China has approved seven GM crops: a varieties of tomato (1997), cotton (1997), petunia (1999), sweet pepper and chili pepper (1999), papaya (2006), rice (2009), and corn (2009). ${ }^{728}$ In addition, China has approved four imported GM crops (cotton, soybean, corn and canola) as raw materials for processing but they cannot be imported as seeds.

\footnotetext{
${ }^{720}$ https://www.loc.gov/law/help/restrictions-on-gmos/usa.php\#Foodstuffs.

${ }^{721}$ https://www.loc.gov/law/help/restrictions-on-gmos/usa.php\#Foodstuffs.

7227 U.S.C. $\$ \S 7701-7786$ (2012).

${ }^{723} \mathrm{https} / / / \mathrm{www} \cdot$ loc.gov/law/help/restrictions-on-gmos/usa.php.

724 Putin signed the law on GMO prohibition // RBC. 2016. URL: http://www.rbc.ru/politics/04/07/2016/577aa7bb9a794761a21c8d57.

${ }^{725}$ Moscow Bans GMO: Russia, the World's Largest GMO-free Territory, Platform for the Development of Organic Agriculture // Global Research. 2016. URL: http://www.globalresearch.ca/moscow-bans-gmo-russia-theworlds-largest-gmo-free-territory-platform-for-the-development-of-organic-agriculture/5548448; Russian State Duma Passes Total Ban on GMO Crops and Animals // Sustainable Pulse. 2016. URL: http://sustainablepulse.com/2016/06/25/russian-parliament-passes-total-ban-on-gmo-crops-and-

animals/\#.WPoJRxFZdp1; Where are GMOs grown and banned? // GMO FAQ. Agricultural biotechnology frequently asked questions. URL: https://gmo.geneticliteracyproject.org/FAQ/where-are-gmos-grown-andbanned/.

${ }^{726}$ Russia: Full Ban on Food with GMOs // Library of Congress. 2016. URL: http://www.loc.gov/law/foreignnews/article/russia-full-ban-on-food-with-gmos/; Law Proposal № 714809-6. On amending of the certain enactments on genetic engineering // ASOZD (the Automated System for Legislative Procedures). URL: http://asozd2.duma.gov.ru/main.nsf/\%28SpravkaNew\%29?OpenAgent\&RN=714809-6\&02.

${ }^{727}$ 中华人民共和国国民经济和社会发展第十二个五年规划纲要 [12th Five-Year Plan], Central Government of the People's Republic of China website (Mar. 16, 2011), http://www.gov.cn/2011lh/content_1825838.htm (in Chinese); https://www.loc.gov/law/help/restrictions-on-gmos/china.php.

${ }^{728} \mathrm{https}: / / \mathrm{www}$. loc.gov/law/help/restrictions-on-gmos/china.php.
} 
Brazil is the second largest producer of genetically modified (GM) crops in the world after the US: in the 2014/2015 planting season, around 90\% of the soybean and corn crops was genetically modified. ${ }^{729}$ Law 11,105 of 24 March, 2005, ${ }^{730}$ sets out authorization, inspection and monitoring procedures for research and commercial release, production and marketing rules, cultivation regimes and restrictions on GMOs in foodstuffs. Article 6, VII, sole paragraph, prohibits the development and sale of seeds genetically modified to become sterile after the second generation, although there have been multiple legislative proposals to eliminate or condition this prohibition.

South Africa's GMO regulatory regime includes regulation of contained use, trial release, commercial release, and transboundary movement. The primary legislation is the Genetically Modified Organisms Act of 1997, which was amended in 2006 in part to give effect to the Cartagena Protocol on Biodiversity which South Africa ratified in 2003. ${ }^{731}$ Additional laws which impose further rules on GMO-related activities include the National Environmental Management: Biodiversity Act, the Consumer Protection Act, and the Foodstuffs, Cosmetics and Disinfectants Act. ${ }^{732}$ The Department of Agriculture, Forestry and Fisheries (DAFF) is responsible for promoting responsible GMO-related activities; limiting harm to the environment as well as to human and animal health; and establishing standards for conducting risk assessments for GMO-related activities. ${ }^{733}$

South Africa was the first country in Africa to approve commercial production of genetically modified crops. The first approval for the commercial use of a genetically modified crop was in 1997 for Monsanto's MON810 Yield Guard insectresistant maize. ${ }^{734}$ According to the United Nations, South Africa currently has 2.3 million hectares of GM crops under cultivation of which 4.3 per cent in GM cotton, 17.7 per cent is GM soybean and 78.0 per cent is GM maize. ${ }^{735}$ South Africa is the ninth largest producer of GM crops in the world. ${ }^{736}$ It is a requirement that foodstuffs obtained through certain techniques of genetic modification be labelled as such before they are put on sale in the marketplace. The Consumer Protection Act imposes additional labelling requirements. It requires that "[a]ny person who produces, supplies, imports or packages any prescribed goods must display on, or in association with the package or those goods, a notice in the prescribed manner and form that that discloses the presence of any genetically modified ingredients or components of those in accordance with applicable regulations."

\subsubsection{Agricultural Subsidies}

\footnotetext{
729 http://www.soybeansandcorn.com/news/Dec11_14-20145-Brazilian-Soybean-Crop-is-91-GMO-Corn-88GMO

${ }^{730}$ Available at: http://www.planalto.gov.br/ccivil_03/_ato2004-2006/2005/lei/111105.htm

731 https://www.loc.gov/law/help/restrictions-on-gmos/south-africa.php\#_ftn6

$732 \mathrm{https}$ ://www.loc.gov/law/help/restrictions-on-gmos/south-africa.php\#_ftn6

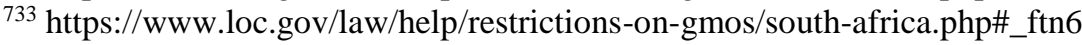

734 http://www.biowatch.org.za/list.php?cat=GM\%20crops FINAL.pdf

http://unscn.org/files/Publications/Country_Case_Studies/UNSCN-Country-Case-Study-South-Africa-

${ }^{736}$ African Centre for Biodiversity, The Bayer-Monsanto merger: Implications for South Africa's agricultural future and its smallholder farmers. " February 2017.
} 
Agricultural production is heavily subsidised in developed countries, in particular the European Union, United States and Japan. Philip H. Howard reports that direct subsidies globally amount to 1 billion US dollars per day usually weighted to the largest farms ${ }^{737}$. To this direct support, one should add indirect government subsidies for funding research and development to increase production, including university extension services for the promotion of new technologies, purchasing excess production, subsidies for insputs, such as fuel, irrigation, fertilisers, regulations that enable the externalisation of the cost of pollution or soil loss, and import tariffs increasing barriers to trade for competitors ${ }^{738}$. These large scale subsidization led to overproduction in certain cases. This led the European Union to reform its common agricultural policy in 1992 (the "MacSharry" reforms), 2003 (introducing a single payment scheme that does not proceed to payments according to a particular line of production of crop and livestock) and 2013 (integrating a more land-based approach and sustainable agriculture with 'green' direct payments), progressively shifting the common agricultural policy of the EU from product support (through prices) to producer support (through income support, direct payments and therefore decoupling subsidies from production, moving instead to subsidizing environmental protection, rural development (agro-tourism) and food safety and quality. There have been continuing discussions at the WTO level to reach agreement on the reduction or elimination of subsidies, but all efforts have failed so far, the latest one being the Doha Round in 2008.

In the EU, support for farmers is primarily financed by the European Agricultural Guarantee Fund (EAGF), which takes roughly $80 \%$ of the total budget of the Common Agricultural Policy (CAP). The other $20 \%$ of the CAP budget goes into the European Agricultural Fund for Rural Development (EAFRD), aims to help farmers modernise their farms and become more competitive through rural development measures.

The EAGF subsidizes farmers through (1) direct support and (2) market regulation measures. Direct support subsidies account for over $90 \%$ of the EAGF budget and roughly $70 \%$ of the total budget of the CAP.

On average, direct payments amount to $€ 267$ per eligible hectare. ${ }^{739}$ In 2016 the total budget for the EAGF was $€ 42220.3$ million, of which $€ 39445.7$ million was foreseen for direct payments to farmers. ${ }^{740}$

Direct support is provided by direct payments to farmers which take the form of a basic income support based on the number of hectares farmed (basic payments) ${ }^{741}$ In addition, specific

\footnotetext{
${ }^{737}$ Philip H. Howard, Concentration and Power in the Food System (Bloomsbury 2016) 90.

${ }^{738}$ Ibid.

739 'Direct payments', available at https://ec.europa.eu/agriculture/direct-support/direct-payments_en.

${ }^{740}$ Commission Staff Working Document accompanying the document report from the Commission to the European Parliament and the Council 10th financial report from the Commission to the European Parliament and the Council on the European Agricultural Guarantee Fund 2016 Financial Year, SWD/2017/0285 final.

741 Regulation (EU) No 1307/2013 of the European Parliament and of the Council of 17 december 2013 establishing rules for direct payments to farmers under support schemes within the framework of the common agricultural policy and repealing Council Regulation (EC) No 637/2008 and Council Regulation (EC) No 73/2009 [2013] OJ L347/608; 'Direct support', available at https://ec.europa.eu/agriculture/direct-support_en
} 
support schemes are available for 'green farming' or 'greening', ${ }^{742}$ and young farmers. ${ }^{743}$ Basic payments, green farming subsidies, and young farmers subsidies are mandatory part of the Member States' allocated budget. Additionally, there are four subsidy schemes which are voluntary for Member States: (4) redistributive payments aimed at small and middle-size farms, whereby farmers may be granted additional support for the first hectares of farmland; (5) additional income support for farming in areas with natural constraints, such as mountain areas; (6) simplified payment scheme for small farmers replacing the other schemes, offering payments up to $€ 1250$; and (7) support coupled to production for certain areas or sectors undergoing difficulties. ${ }^{744}$

Direct payments are independent of the quantity of output. Under the cross-compliance scheme, however, farmers have to comply to certain qualitative requirements as to public, animal and plant health, environment, and animal welfare. ${ }^{745}$ The requirements of crosscompliance comprise (1) statutory management requirements (SMRs), which consist of 13 legislative standards regarding environment, food safety, animal and plant health and animal welfare; and (2) good agricultural and environmental conditions (GAECs) which consist of standards related to soil protection, maintenance of soil organic matter and structure, avoiding the deterioration of habitats, and water management. ${ }^{746}$ The system of cross-compliance aims to 'contribute to the development of sustainable agriculture through better awareness on the part of beneficiaries of the need to respect those basic standards' and to make the CAP 'more compatible with the expectation of society through improving consistency of that policy with the environment, public health, animal health, plant health and animal welfare policies'. ${ }^{747}$

Green farming subsidies account for $30 \%$ of the direct payments budgets of the EU Member States. The green farming scheme aims to support farmers 'in the transition towards more sustainable agricultural production models'. ${ }^{748}$ Farmers are eligible for green direct

\footnotetext{
742 'Greening', available at https://ec.europa.eu/agriculture/direct-support/greening_en; Recital 37 of Regulation (EU) No 1307/2013 of the European Parliament and of the Council of 17 december 2013 establishing rules for direct payments to farmers under support schemes within the framework of the common agricultural policy and repealing Council Regulation (EC) No 637/2008 and Council Regulation (EC) No 73/2009 [2013] OJ L347/608 : 'One of the objectives of the new CAP is the enhancement of environmental performance through a mandatory "greening" component of direct payments which will support agricultural practices beneficial for the climate and the environment applicable throughout the Union'.

743 'Young farmers', available at https://ec.europa.eu/agriculture/cap-funding/young-farmers_en.

744 'Direct payments', available at https://ec.europa.eu/agriculture/direct-support/direct-payments_en.

745 'Cross compliance', available at https://ec.europa.eu/agriculture/direct-support/cross-compliance_en.

746 Arts. 93 and 94 of and Annex II to Regulation (EU) No 1306/2013 of the European Parliament and of the Council of 17 December 2013 on the financing, management and monitoring of the common agricultural policy and repealing Council Regulations (EEC) No 352/78, (EC) No 165/94, (EC) No 2799/98, (EC) No 814/2000, (EC) No 1290/2005 and (EC) No 485/2008 [2013] OJ L347/549. See also Commission Implementing Regulation (EU) No 809/2014 of 17 July 2014 laying down rules for the application of Regulation (EU) No 1306/2013 of the European Parliament and of the Council with regard to the integrated administration and control system, rural development measures and cross compliance [2014] OJ L227/69; Commission Delegated Regulation (EU) No 640/2014 of 11 March 2014 supplementing Regulation (EU) No 1306/2013 of the European Parliament and of the Council with regard to the integrated administration and control system and conditions for refusal or withdrawal of payments and administrative penalties applicable to direct payments, rural development support and cross compliance [2014] OJ L181/48.

${ }^{747}$ Recital 54 Regulation (EU) No 1306/2013.

${ }^{748}$ European Commission, Commission Staff Working Document: Review of greening after one year, SWD(2016) 218 final.
} 
payments when they meet obligations regarding crop diversification, ${ }^{749}$ maintaining permanent grassland, ${ }^{750}$ and maintaining 'ecological focus areas' which are areas dedicated to ecologically benificial elements such as fallow land, hedges and trees. ${ }^{751}$

In the US, the United States' federal farming subsidy scheme aims at helping farmers to manage the fluctuations in agricultural production and profitability while ensuring stable food supply. In practice support is highly biased in favour of the five major commodities: corn, soybeans, wheat, cotton, and rice. Dairy and sugar are separately regulated through price and market controls. ${ }^{752}$

Agricultural support can be tracked back to the nineteenth century, with the Morrill Act of 1862 and the Hatch Act of 1887. In the 1930s, direct support for farmers was introduced as part of the New Deal, including the Agricultural Adjustment Act of 1933. At their lowest in 1974, farm subsidies accounted for $2 \%$ of total farm income, and at their highest made up $47 \%$ of total farm income in $2000 .^{753}$

Historically, the US farming subsidy system has included direct payments and countercyclical payments which were activated when market prices fell below a certain threshold. Direct payments were introduced in 1996 with the Freedom to Farm Act. Direct payments were initially introduced as a transition measure to make farmers less dependent on government subsidies. In 2002 the transitional character of direct payments was made permanent, and counter-cyclical payment were introduced. The Agricultural Act of 2014 eliminated direct payments ${ }^{754}$ and counter-cyclical payments, ${ }^{755}$ as well as the Average Crop Revenue Election

\footnotetext{
${ }^{749}$ Art. 44(1) Regulation (EU) No 1307/2013: 'Where the arable land of the farmer covers between 10 and 30 hectares and is not entirely cultivated with crops under water for a significant part of the year or for a significant part of the crop cycle, there shall be at least two different crops on that arable land. The main crop shall not cover more than $75 \%$ of that arable land. Where the arable land of the farmer covers more than 30 hectares and is not entirely cultivated with crops under water for a significant part of the year or for a significant part of the crop cycle, there shall be at least three different crops on that arable land. The main crop shall not cover more than 75 $\%$ of that arable land and the two main crops together shall not cover more than $95 \%$ of that arable land'.

${ }^{750}$ Art. 45(1) Regulation (EU) No 1307/2013: 'Member States shall designate permanent grasslands which are environmentally sensitive in areas covered by Directives 92/43/EEC or 2009/147/EC [...] Farmers shall not convert or plough permanent grassland situated in areas designated by Member States under the first subparagraph and, where applicable, the second subparagraph'.

751 Art. 46(1) Regulation (EU) No 1307/2013: 'Where the arable land of a holding covers more than 15 hectares, the farmer shall ensure that, from 1 January 2015, an area corresponding to at least $5 \%$ of the arable land of the holding that the farmer declared [...] is ecological focus area'. According to Art. 46(2), Member States must decide that one or more of the following are considered to be ecological focus areas: (a) land lying fallow; (b) terraces; (c) landscape features, including such features adjacent to the arable land of the holding which, by way of derogation from Article 43(1) of this Regulation, may include landscape features that are not included in the eligible area in accordance with point (c) of Article 76(2) of Regulation (EU) No 1306/2013; (d) buffer strips, including buffer strips covered by permanent grassland, provided that these are distinct from adjacent eligible agricultural area; (e) hectares of agro-forestry that receive, or have received, support under Article 44 of Regulation (EC) No 1698/2005 and/or Article 23 of Regulation (EU) No 1305/2013; (f) strips of eligible hectares along forest edges; ( $g$ ) areas with short rotation coppice with no use of mineral fertiliser and/or plant protection products; (h) afforested areas referred to in point (b)(ii) of Article 32(2) of this Regulation; (i) areas with catch crops, or green cover established by the planting and germination of seeds, subject to the application of weighting factors referred to in paragraph 3 of this Article; (j) areas with nitrogen-fixing crops..

752 'Farm subsidy primer', Environmental Working Group, available at https://farm.ewg.org/subsidyprimer.php. 753 'Farm subsidies over time', The Washington Post, 2 July 2006, available at http://www.washingtonpost.com/wp-dyn/content/graphic/2006/07/02/GR2006070200024.html.

${ }^{754}$ Section 1101 Agricultural Act of 2014, H.R. 2642; P.L. 113-79

${ }^{755}$ Section 1102 Agricultural Act of 2014, H.R. 2642; P.L. 113-79.
} 
Program (ACRE), which guaranteed eligible farmers a minimum total revenue. Under ACRE, farmers could give up $20 \%$ of their direct payment entitlements and some measure of price support, in exchange for payments which were only provided when revenue declined more than $10 \%$ relative to a five-year average. ${ }^{756}$

Since the introduction of the 2014 Act, all federal agricultural support now consists of variable payments. The Act covers over $\$ 950$ billion in spending over 10 years, of which crop insurance accounts for $\$ 89.8$ billion, commodity programmes account for $\$ 44.4$ billion, and conservation subsidies accounts for $\$ 56$ billion.

Under the 2014 Act the primary source of farm subsidies is crop insurance under the Federal Crop Insurance Program. The 2014 Act also introduced a commodity programme comprising Agricultural Risk Coverage (ARC), Price Loss Coverage (PLC), and marketing assistance loans (MAL), and provides additional farmer support through conservation programmes, and disaster aid. ${ }^{757}$

The Federal Crop Insurance Program subsidizes farmers to purchase crop insurances from approved private insurers. Subsidies cover about $60 \%$ of the premium costs, reimburse insurance companies for their adinistrative and operating costs, and cover part of the payments for farmers to compensate yield or revenue losses. Farmers can choose among different insurance programmes including (1) yield protection, where a percentage the expected yieldper-acre is insured based on certain market price); (2) revenue protection, where a percentage of the expected revenue-per-acre is insured based on market prices; and (3) revenue protection with harvest price option, where a percentage of the expected revenue-per-acre is insured either based on market prices or harvest prices, whichever is higher. ${ }^{758}$ According to the Congressional Research Service, corn, cotton, soybeans and wheat account for over two-thirds of all acres enrolled in crop insurance programmes. ${ }^{759}$

The three commodity programmes of the 2014 Act together are projected at $\$ 44.4$ billion over a 10-year period. Farmers must choose between PLC and ARC payments. PLC payments are triggered when the national average price of a covered crop ${ }^{760}$ falls below the fixed reference price for that crop. The PLC payment is equal to the difference between the national average price and the reference price. ARC payments are triggered when a covered crop's estimated average revenue (based on the crop yield multiplied by the national average price) falls below its guaranteed level, which is $86 \%$ of the historical average revenue per acre based on the last five years.

\footnotetext{
${ }^{756}$ Roman Keeney, 'The End of the Direct Payment Era in US Farm Policy', Purdue Extension, EC-7774-W, available at https://www.extension.purdue.edu/extmedia/ec/ec-774-w.pdf.

${ }^{757}$ See e.g., Dennis A. Shields, 'Farm Commodity Provisions in the 2014 Farm Bill (P.L. 113-79)' (Congressional Research Service, 28 March 2014); Chris Edwards, 'Agricultural Subsidies' (7 October 2016), available at https://www.downsizinggovernment.org/agriculture/subsidies\#_edn8.

758 See e.g., 'Crop insurance primer', Environmental Working Group, available at https://farm.ewg.org/crop_insurance_analysis.php; Caroline Kitchens, 'Making farm support a safety net again', $R$ Street Policy Study No 92 (April 2017).

${ }^{759}$ Dennis A. Shield, 'Federal Crop Insurance: Background and Issues',Congressional Research Service (17 April 2009).

${ }^{760}$ The national average price is reported by the USDA National Agriculture Statistical Service.
} 
In addition, MALs are 9-month loans at harvest time which farmers can apply for in order to meet cash flow requirements without having to sell their crops when prices are at their lowest.

The 2014 Act has introduced a $\$ 125000$ per farm cap on subsidies from the commodity programmes PLC, ARC and MAL combined. ${ }^{761}$ PLC and ARC not available to upland cotton producers, for which there is a specific insurance programme under the Stacked Income Protection Plan.

Agricultural subsidies are also quite prominent in Japan. The objectives of Japan's agricultural policy are laid down in the Basic Law on Food, Agriculture and Rural Areas. ${ }^{762}$ The Law aims to stabilize and improve people's lifestyle and develop the national economy (Article 1); secure a stable food supply at reasonable prices (Article 2(1)); maintain the multifunctional roles of agriculture, i.e. a stable production in ruralareas, conservation of land, water, and the formation of good landscape, etc (Article 3); promote sustainable agricultural development (Article 4); and develop rural areas through improvements of production conditions and infrastructure (Article 5).

One of the key problems of Japanese agriculture is that $98 \%$ of all farms are smaller than 5 hectares. Fragmentation, small-scale farming and inefficient production have long been supported by regulations within a gentan system, under which farmers were subsidized to reduce rice crops, so as to increase the price of rice. ${ }^{763}$ 'About $70 \%$ of Japan's farmers grow rice, but the crop represents only $20 \%$ of the total value of the country's agricultural output. This is due to the nation's declining rice consumption and falling rice prices. The majority of Japan's rice farmers are small operators with 1 or 2 hectares of paddies. Their average age is above 70 . This means many rice farmers are past retirement age, and their profession in Japan is at risk of dying out'. ${ }^{764}$

In 2005, the Farm Management Stabilization Programme aimed to promote more efficient and stable farming by providing payments to individual farmers managing at least 4 hectare of land and community-based farm cooperatives managing more than 20 hectares. $^{765}$

In 2007, the Law on Farm Income Stabilization introduced three new direct payments for farmers as part of the Farm Management Stabilization Programme: (1) payments based on historical area planted; (2) payments based on commodity output, which seeks to encourage quality improvement of domestic products by differentiating the payment rate according to the product quality, like (1) only targeted at wheat, barley, soybeans, sugar beet and starch potatoes; and (3) payments compensating for $90 \%$ of the loss of income compared with the average income of the preceding five years for which rice is also eligible. ${ }^{766}$ The 2007 reform followed the guidelines of the WTO on trade-distorting subsidies. \#

In 2010, however, previous reforms were overturned by the new Democratic Party of Japan (DPJ) government and substituted for new direct payment programme called the Income

\footnotetext{
${ }^{761}$ Section 1603 Agricultural Act 2014.

${ }^{762}$ English translation: http://www.maff.go.jp/e/basic_law/basiclaw_agri/basiclaw_agri.html.

763 'Rice farming in Japan: Political staple', The Economist, 2 December 2013.

764 'Japan to stop coddling its rice farmers' (15 January 2017), available at https://asia.nikkei.com/PoliticsEconomy/Policy-Politics/Japan-to-stop-coddling-its-rice-farmers.

${ }^{765}$ Ibid., p. 74.

${ }^{766}$ Ibid., p. 72.
} 
Compensation Program (ICP). Under the ICP, fixed payments are provided to farmers per acre farmed. The ICP also provides subsidies if market prices drop below production costs. ${ }^{767} \mathrm{In}$ 2010 the Japanese Government estimated an annual budget of 560 billion yen for ICP for rice, ${ }^{768}$ with an extention of ICP to other major crops adding an extimated 440 billion yen. ${ }^{769}$ 'The LDP criticized the DPJ's direct income compensation payments system calling it a scattering of subsidies and pledged that it would abolish it. The DPJ granted direct income compensation payments even to small-scale part-time farmers who had very little agricultural income'. 770

In 2013, when the Liberal Democratic Party (LDP) had again gained power, it was announced that the gentan system would be abolished in 2018. In 2014, direct income compensation payments were already cut in half. In 2014, trade-distorting agricultural support was $8 \%$ lower than in 2012, still however amounting to $¥ 900$ billion (US\$9 billion at historical exchange rates for that period). ${ }^{771}$ Moreover, "two-thirds of the trade-distorting support provided by Tokyo counted towards its ceiling on the aggregate measure of support (AMS). This refers to highly trade-distorting payments such as input and output subsidies or market price support, dubbed "amber box" under WTO rules'. ${ }^{772}$ Government support further included "¥75 billion in "blue box" payments. This refers to production-limiting payments that are considered less trade-distorting than the amber box, and therefore not currently subject to any limit under WTO rules'. ${ }^{773}$

In 2018, production targets for rice acreage reduction will be completely abolished. However, cuts in these subsidies are compensated by an increase in other 'gentan-type' subsidies provided if rice as staple food is replaced with rice as animal feed. ${ }^{774}$

Simiilar machanisms of support either through minimum agricultural prices, or support through agricultural insurance are also provided in BRICS countries. These various forms of support are detailed in the country reports.

\footnotetext{
767 Yoshihisa Godo, Evaluation of Japanese Agricultural Policy Reforms Under the WTO Agreement on Agriculture, Selected Poster prepared for presentation at the International Association of Agricultural Economists (IAAE) Triennial Conference, Foz do Iguaçu, Brazil, 18-24 August, 2012, available at https://ageconsearch.umn.edu/bitstream/125102/2/20120609GodoIAAE_AESPoster.pdf.

768 Yoshihisa Godo and Daisuke Takahasi, 'Japan', in David Orden, David Blandford and Tim Josling (eds.), WTO Disciplines on Agricultural Support: Seeking a Fair Basis for Trade (Cambridge University Press 2011), p. 166.

769 Ibid., p. 167.

${ }^{770}$ Kazuhito Yamashita, 'Rather than being abolished, the Gentan System was strengthened. - We need to abolish the gentan policy even if we are not pushed by the United States to do so' (Canon Institute for Global Studies, 12 January 2017), available at http://www.canon-igs.org/en/column/macroeconomics/20170112_4095.html.

771 'Japan Reports Fall in Trade-Distorting Farm Subsidies in New WTO Figures' (Bridges, 13 July 2017), available at https://www.ictsd.org/bridges-news/bridges/news/japan-reports-fall-in-trade-distorting-farmsubsidies-in-new-wto-figures.

772 'Japan Reports Fall in Trade-Distorting Farm Subsidies in New WTO Figures' (Bridges, 13 July 2017), available at https://www.ictsd.org/bridges-news/bridges/news/japan-reports-fall-in-trade-distorting-farmsubsidies-in-new-wto-figures.

773 'Japan Reports Fall in Trade-Distorting Farm Subsidies in New WTO Figures' (Bridges, 13 July 2017), available at https://www.ictsd.org/bridges-news/bridges/news/japan-reports-fall-in-trade-distorting-farmsubsidies-in-new-wto-figures.

${ }^{774}$ Kazuhito Yamashita, 'Rather than being abolished, the Gentan System was strengthened. - We need to abolish the gentan policy even if we are not pushed by the United States to do so' (Canon Institute for Global Studies, 12 January 2017), available at http://www.canon-igs.org/en/column/macroeconomics/20170112_4095.html.
} 


\subsubsection{Private ordering/governance}

Particular commercial arrangements have developed so as to enhance cooperation at the horizontal and vertical level in the various segments of the food value chain. The emergence of commercial practices, such as slotting allowances and category management agreements are also illustrations of this increasing importance of retailer bargaining power that started to characterize the evolution of the distribution sector since the 1980s.

\subsubsection{Vertical integration}

The integration of small scale farmers into global value chains often happens through different forms of vertical coordination with commodity buyers. The level of vertical coordination between firms in the market may arrive to its extreme when one of the businesses vertically integrates the other business, or part of the economic activity related to that business. Vertical integration generally takes three alternative forms: i) backward integration; ii) forward integration; and iii) full vertical integration. ${ }^{775}$ Especially for BRICS jurisdictions, vertical integration has often been envisaged as a solution to the difficulties encountered by global producers or wholesalers in importing standards through coordination. ${ }^{776}$ Differently, in other cases, full integration has been promoted by national incumbents, as for instance, agro-holdings in Russia.

\subsubsection{Contract farming and purchasing agreements}

Contract farming is a relatively recent contractual scheme linking farmers and commodity buyers with the objective to regulate their relationship. ${ }^{777}$ Developing and transition economies are fostering through state legislation the adoption of this type of contract, as they aim at ensuring small farmers the access to global markets and guarantee higher standards and consistent supply to buyers. ${ }^{778}$ Contract farming aims at finding a middle way between spot market transactions, which often entails high transaction costs, and vertical integration, which might lead to high management costs. ${ }^{779}$ Two types of contract farming are usually distinguished between: production contract (PC) and marketing contract (MC). ${ }^{780}$ Under production contract farming, farmers provide land, labour and capital, while the contractor provides credit and technical assistance, and controls key management decisions, in

\footnotetext{
${ }^{775}$ Charles WL Hill and Gareth R Jones, Strategic Management: Theory: An Integrated Approach (2014).

${ }^{776}$ Jon H Hanf, 'Processor Driven Integration of Small-Scale Farmers into Value Chains in Eastern Europe and Central Asia' <http://www.fao.org/fileadmin/user_upload/Europe/documents/Publications/PDI/EECA_en.pdf > accessed 17 June 2015.

${ }^{777}$ For a general description of contract farming, see Caterina Pultrone, 'An Overview of Contract Farming: Legal Issues and Challenges’ (2012) 17 Uniform law review Uniform Law Review 263.

778 ibid 263.

${ }^{779}$ K. Otsuka, Y. Nakano and K. Takahashi, 'Contract Farming in Developed and Developing Countries' (2016) 8 Annual Review of Resource Economics 353-376.

780 J.M. MacDonald et al, 'Contracts, markets, and prices: organizing the production and use of agricultural commodities’ (2004) Agric. Econ. Rep. 837, Econ. Res. Serv., Dep. Agric., Washington, DC.
} 
exchange for agreements of quantity and quality of the products. Market contract farming is a looser form of contract farming where only the quantity and quality are agreed upon. ${ }^{781}$ The legal framework introduced by these contracts involves different levels of regulation, especially in global value chains. When foreign buyers are involved, domestic legislation on private contract law applies together with the United Nations Convention on Contracts for the International Sale of Goods (CISG) and the UNIDROIT Principles of International Commercial Contracts (UNIDROIT), in most of the developing and transition countries as well as in developed countries. Domestic legislation may regulate contract farming through the general rules on contract law or on the basis of specific legislation on agricultural contracts. ${ }^{782}$ Finally, some jurisdictions, such as Spain, provide a typified contractual arrangement, through specific legislation defining in particular contract farming. ${ }^{783}$

Local governments have a fundamental role as facilitators of these agreements, as they have to help farmers to reach the contractual objectives by facilitating their access to land and agricultural inputs. $^{784}$ On the other hand, local governments monitor the "correct implementation of the contract or the financial institutions that extend credit to farmers". 785

Contract farming, in particular PC, is capable of mitigating market failures by providing high-quality technology and other inputs which particularly in developing countries would otherwise be unavailable. Contract farming is generally understood to improve production efficiency and farmers' income, although it is less clear to what extent it improves net profit and farmers' welfare because contract farming is usually applied to labour-intensive crops and products. $^{786}$

Contract farming might also increase inequality between larger and smaller suppliers, as there are concerns that it is biased towards larger firms because of smaller transaction costs in large-scale contracts, leading to the exclusion of smallholder farms. ${ }^{787}$ While empirical studies on potential exclusion of smallholder farms by contract farming is inconclusive, it has been argued that public sector support and NGO support in the form of training programmes is

\footnotetext{
${ }^{781}$ K. Otsuka, Y. Nakano and K. Takahashi, 'Contract Farming in Developed and Developing Countries' (2016) 8 Annual Review of Resource Economics 353, 354.

${ }^{782}$ In France, for instance, there is a rural code regulating, inter alia, contract farming. Differently, an instance regarding state legislation dealing with contract farming regards India, where the Indian Contract Act of 1872 regulates also contract farming. However, here, secondary legislation, such as the APMC Act of 2003, provides strict regulation specifically on contract farming. See ibid 271; Debashis Chakraborty, 'Contract Farming in India' (2009) 1 Review of Market Integration 83; Sukhpal Singh, 'Contract Farming for Agricultural Development and Diversification in Punjab: Problems and Prospects' (2005) 12 Journal of Punjab Studies 251.

${ }^{783}$ See Ley (L.) 2/2000 (7 Jan.), Reguladora de los Contratos Tipo de Productos Agroalimentarios, 8 BOE 881 (2000).

${ }^{784}$ Pultrone (n 212) 277.

785 ibid.

${ }^{786}$ Ibid, 369.

787 N. Key and D. Runsten, 'Contract farming, smallholders, and rural development in Latin America: the organization of agroprocessing firms and the scale of outgrower production' (1999) 27 World Development 27 381-401; J. Swinnen, Global Agricultural Value Chains, Standards, and Development, EUI Working Papers RSCAS 2014/30, 2; T. Reardon, C.P. Timmer, C.B. Barrett and J. Berdegué, 'The rise of supermarkets in Africa, Asia, and Latin America' (2003) 85 American Journal of Agriculture Economics 1140-1146; J. Kirsten and K. Sartorius, 'Linking agribusiness and small-scale farmers in developing countries: Is there a new role for contract farming?' (2002) 19 Dev. South. Afr. 503-529; C. Poulton A. Dorward and J. Kydd, 'The future of small farms: new directions for services, institutions, and intermediation' (2010) 38 World Development 1413-1428.
} 
indispensable in order to create significant benefits of contract farming for smallholder farmers. ${ }^{788}$

Another concern with regard to contract farming is the effect of superior bargaining power of large downstream companies. Buyers need to ascertain that specific standards of production are respected, and may do so not only through monitoring activity but also by training farmers on the specific standards. It has been observed that the high degree of control enjoyed by the buyer may resemble, in some cases, to an employer-employee relationship, rather than to one between two independent contractors. ${ }^{789}$ The buyer has generally a higher bargaining power determined not only by concentration and the size of the firm, but also by information regarding formation of commodity prices on the market, which is often not available to farmers. ${ }^{790}$ It has been argued that superior bargaining power, in particular in contract farming models in which decision-making capacity is transferred to the contractors, increases the capability of contractors to extract rents from the value chain to the detriment of the farmers. ${ }^{791}$ Moreover, in contrast to spot market transactions, contract farming could make it easier for buyers to discriminate among their suppliers, in particular in the context of superior bargaining power and/or monopsony, as the buyer can negotiate individual contracts with different terms in conjunction with secret-keeping obligations. ${ }^{792}$ For example, '[i]n a case involving American cattle, a jury determined that the ability to offer individual contracts, combined with secrecy, resulted in a multibillion dollar reduction in revenue for disfavored sellers' ${ }^{793}$ Lastly, contract farming in combination with unequal bargaining power may create additional lock-in effects as a result of specific investments or long-term contracts. Local governments, may remedy to some of these imbalances, without, however, hampering the freedom of contracting of the parties, if any real freedom is present. Discrimination among farmers might also be remedied by authorising farmers to consult advisors on their contract negotiations. ${ }^{794}$

Nonetheless, empirical research suggests that contract farming brings about noticeable benefits both for buyers/contractors as well as farmers. For example, India has had a long history of regulation limiting private investment and trade in various aspects of agriculture, which is only now being slowly removed. Until 2003, when reforms of the Agricultural

\footnotetext{
${ }^{788}$ K. Otsuka, Y. Nakano and K. Takahashi, 'Contract Farming in Developed and Developing Countries' (2016) 8 Annual Review of Resource Economics 353, 370.

789 ibid 278.

790 S. Singh, 'Contract Farming for Agricultural Development and Diversification in Punjab: Problems and Prospects’ (2005) 12 Journal of Punjab Studies 251.

${ }^{791}$ M. Warning and N. Key, 'The social performance and distributional consequences of contract farming: an equilibrium analysis of the arachide de bouche program in Senegal' (2002) 30 World Development 255-263.

792 P.C. Carstensen, Competition Policy and the Control of Buyer Power: A Global Issue (Edward Elgar 2017), 46, with reference to C. Morison, 'Contract Poultry Farming', American Agriculture Movement Newsletter (November 2001): 'The pay for a contract farmer is based on what growers call "artificial competition shrouded in secrecy."'.

793 P.C. Carstensen, Competition Policy and the Control of Buyer Power: A Global Issue (Edward Elgar 2017), 46-47, referring to Pickett v. Tyson Fresh Meats, Inc., 315 F. Supp. 2d 1172 (M.D. Ala. 2004), aff'd, 420

F. 3d 1272 (11th Cir. 2005) (denying liability despite the plaintiffs' losses).

${ }^{794}$ Cf. Packers and Stockyards Act of 1921, 7 U.S.C. § 229(b) (2016).
} 
Produce Market Committee Act was initiated in many states, ${ }^{795}$ it was illegal in most states for businesses to purchase agricultural produce directly from farmers. Today, contract farming is emerging as a preferred mechanism through which agri-businesses can directly engage with farmers. The growth of contract farming in India in recent years has led authorities to regulate relationships between agricultural producers and suppliers or wholesalers. An expanding urban middle class and increasing commercial investment in agricultural retailing and processing are creating demand for more standardized, higher-quality agricultural produce. But underdeveloped supply chains and small farm sizes make sourcing such produce difficult. ${ }^{796}$

PepsiCo was one of the earliest promoters of the contract-farming model in India. In 1997, it set up a tomato processing plant in Punjab, not a traditional tomato growing area, and started tying up with local farmers to grow tomato varieties needed for ketchup. Independent studies confirmed increased yields and incomes for farmers partnering with PepsiCo. Studies also found that once better seed varieties, new technology and growing practices were introduced to a select group of farmers through contract farming, such practices spread to other farmers who were not directly involved in such efforts.

Swinnen also points at empirical studies which demonstrate that once farmers are included in contract farming schemes they benefit significantly, not only from increased household income, decline in poverty and income stability, but also from production quality and innovation: ${ }^{797}$

"The demand for higher quality products requires buyers to assist farmers in order to improve the quality of production, for example by providing the farmer with inputs on credit. In a context of weak contract enforcement, which is likely in many developing countries, this creates holdup opportunities for the farmer, who can decide to use the inputs but sell the high-value product to another buyer without paying back the credit that the first buyer offered him. In order to prevent this, buyers are forced to offer attractive contract terms in order to secure their returns to investment, for example by offering the farmer a price premium. Hence, poor suppliers can benefit from the introduction of quality standards in a weak contract enforcement context, even if all bargaining power lies with the buyer". 798

\footnotetext{
795 Agriculture in India is a matter for the states or provinces, rather than for the centre. Although several states had adopted APMC Acts in the '50s and '60s - the most notable being the Maharashtra APMC Act 1963-the system established for market regulation remained deeply flawed. Under this regime, money lender, traders, bankers etc. were often one person. This all in one role of middleman resulted in perpetual indebtness of farmer as well as creation of monopolies. http://www.insightsonindia.com/2014/11/20/agriculture-marketing-apmc-actrelated-issues/ (Accessed $15^{\text {th }}$ may 2017).

${ }^{796}$ https://blogs.wsj.com/indiarealtime/2011/07/20/india-journal-the-rise-of-contract-farming/ (accessed $15^{\text {th }}$ May 2017)

797 J. Swinnen, Global Agricultural Value Chains, Standards, and Development, EUI Working Papers RSCAS 2014/30, 4, with references to empirical research in Senegalese horticulture, vegetable export production in Madagascar, and fruit and vegetable production in Chile, Kenya and Madagascar.

${ }^{798}$ Ibid. See further J. Swinnen and A. Vandeplas, 'Rich consumers and poor producers: quality and rent distribution in global value chains' (2011) 2 Journal of Globalization and Development 1-30.
} 
Further empirical research should clarify income effects on farmers and the sustainability of these effects, as there might be a publication bias towards successful instances of contract farming. ${ }^{799}$

\subsubsection{Asset sharing agreements}

The ownership of assets as well as of the business activities of a firm, involves at the same time the right to earn the profits and the responsibility for the risk that the business may incur in. Business owners have indeed the advantage of controlling the economic activity in each phase and earn the profits that the same activity generates. However, in some cases the level of risk may outweigh the benefits, to the extent that the owner prefers sharing risks and profits of the business. Parties may decide to establish through private contracting different forms of co-ownerships, depending of the risk distribution they intend to set up. In the agri-food supply chain the forms of co-ownership and asset sharing are several. Rent and wages paid for the management of assets, for instance, are a typical example of assets sharing in the chain ${ }^{800}$. Swinnen and Kuijpers have identified four models of institutional innovations of the value chain for technology transfer so as to share risks and profits. ${ }^{801}$ The first model is farm processor/retailer contracting, where the buyer of the farm's product finances the necessary technology as part of a contract that typically contains obligations for the farmer concerning the buyer's standards. The technology that is provided can be rather simple, e.g. Fertilisers or animal feed - or involve more complex technological systems including advice and extension services. ${ }^{802}$ The second model is farm - technology company contracting and leasing, which means that technology companies themselves transfer their technology to farmers through credit schemes or leasing arrangements. ${ }^{803}$ Another model involves a more complex 'triangular structure', where risks are shared among multiple partners who are setting up joint programmes to set up technology or investment loans to farmers. These triangular structures are used with more complex or expensive technologies requiring more finance. For example, a processing company may provide a payment guarantee to a technology company which will sell a technology to a farmer, so as to enable the farmer to sell its products to the processing company. ${ }^{804}$ Lastly, according to the fourth model which uses special purpose verhicles (SPVs), a stand-alone company is joint owned by several actors, for example a processor and a financial institution and/or a technology company. This SPV will then contract with the farmers so as to allow multiple partners to share the risks and assets involved in trading with the farmer. ${ }^{805}$

\footnotetext{
${ }^{799}$ M.F. Bellemare, 'Contract farming: What's in it for smallholder farmers in developing countries?' (2015) 30(3) Choices $1-4$.

${ }^{800}$ Food and Agriculture Organization of the United Nations, Leasing Agricultural Land. (Food and Agriculture Organization of the United Nations 2004).

${ }^{801}$ J. Swinnen and R. Kuijpers, " Value Chain Innovations for Technology Transfer in Developing and Emerging Economies: Conceptual Issues, Typology, and Policy Implications (2017) Food Policy 1.

${ }^{802}$ Ibid, 4-5.

${ }^{803}$ Ibid 5.

${ }^{804}$ Ibid 5-6.

${ }^{805} \mathrm{Ibid}, 6-7$.
} 


\subsubsection{Private labels}

Retailer power manifests itself increasingly with the use of private labels, which compete directly with leading manufacturers' brands and other national brands and illustrate this shift in balance of power between retailers and suppliers ${ }^{806}$. However, empirical evidence of the negative welfare effects of private labels is lacking and is, at best, ambiguous, thus not giving clear directions to competition authorities for action ${ }^{807}$.

Private label is a term referring to all products sold under a retailer's brand, which could be the retailer's own name (store brands) or a brand created by a manufacturer exclusively for the retailer, who defines the characteristics of the product (generic brands). Private label products are generally exclusively distributed by the retailer along with national brand products, which are marketed by manufacturers throughout the national market, not only in the specific retailers' outlets. This brings a horizontal dimension in the relationship between suppliers and retailers, as private labels may compete for market share with national brands ${ }^{808}$.

Private label brands' market share has been constantly growing, in particular in the food sector ${ }^{809}$ and represents a significant volume of retail sales in Europe. Private labels are generally perceived by consumers of being of lower price and quality than national brands. In addition, national labels benefit from a 'reputation premium', as a result of more extensive advertising than private labels and brand loyalty building. This leads to lower prices for private labels than equivalent, in terms of quality, national brand products. Despite this retail price differential, retailer's gross margins for private labels are more important in comparison to

\footnotetext{
${ }^{806}$ Ariel Ezrachi, Unchallenged Market Power? The Tale of Supermarkets, Private Labels, and Competition Law, (2010) 33(2) World Competition 257-274; Albert Foer, Introduction to Symposium on Buyer Power and Antitrust, 72 Antitrust L.J. 505 (2005); Louis Vogel, Competition Law and Buying Power, 19(1) European Competition Law Rev 4 (1998).

${ }^{807}$ For a more detailed analysis of the literature on the welfare effects of private labels see, Ioannis Lianos, Some Reflections on the Vertical Restraints Antitrust Category, (2008) 4 Concurrences 17-26, available at http://www.concurrences.com/IMG/pdf/Colloque_UCL-IDC_Paris_230508_EN-2.pdf and Ariel Ezrachi, supra. ${ }^{808}$ Although the issue of private labels being in the same market than national brands depends on a number of circumstances, recent case law has not excluded that private labels may be in the same relevant market than national brands at the retail level but not at the wholesale level because of differences in the functioning of the markets for national and private labels: Case IV/M.623, January 16, 1996; Case COMP/M.2097, SCA / Metsä Tissue, January 31, 2001, available at http://ec.europa.eu/comm/competition/mergers/cases/decisions/m2097_en.pdf , para 20-28

${ }^{809}$ M B Ward and others, "Effects of the Private-Label Invasion in Foods Industries" [2002] 844 American Journal of Agricultural Economics 961-973; This is also highlighted in the recent UK Competition Commission report into

the grocery sector: UK Competition Commission, Final report, Grocery's Market Investigation 30.4.2008, available at http://www.competitioncommission.org.uk/rep_pub/reports/2008/538grocery.htm (hereinafter, Grocery's Market Report). Some retailers have also developed a strong private-label identity as they sell only own-label goods (e.g. Aldi, Marks \& Spencer) and the development of private labels constitutes an important aspect of their commercial strategy against other retailers. It seems that the development of private labels is an important aspect of horizontal competition between retailers: Grocery's Market Report, at p. 71, footnote 2, ('Morrisons told us that whilst the key elements of competition between grocery retailers might manifest themselves in stores competing for customers at a local level, these elements were determined at a national level. In particular, Morrisons noted that the national elements of competition included pricing, purchasing, product range selection, range of own-label products, store format, branding and most advertising, new openings, distribution, in-store marketing and promotions, and service and ethos'). See also Appendix 9.10 ('consumer research indicates that around 20 per cent of shoppers choose their grocery retailer on the basis of own-label ranges').
} 
national brand products. It follows that the commercialisation of is thus more profitable for the retailers compared to that of national brands. This constitutes the main reason for the introduction of private labels by retailers and leads often to the exclusion of second-tier national brands from the market ${ }^{810}$. Two reasons explain the higher retail gross margins for retailers. Steiner notes that retailers with strong private labels have more leverage with manufacturers and this helps them to increase their gross margins ${ }^{811}$. Private labels may also enhance consumer loyalty to retail brands and therefore reinforce the horizontal market power of the retailers. This will in turn strengthen the retailers' vertical bargaining power against national brand manufacturers and will enable them to obtain better deals that will increase their profits $^{812}$. These distributional outcomes are ambiguous from the point of view of the consumers.

The commercialization of private labels obviously increases consumer choice by offering a lower price substitute to the consumers. The system may also introduce an effective countervailing power for retailers against the market power of national brand owners. Nevertheless, private labels may also produce important anti-competitive effects, in particular if they finish by dominating the market. Consumer choice and product variety may be affected if private labels exclude all but the leading national brand. This may also increase retail prices for consumers. Private labels will increase search costs for consumers and will therefore offer the opportunity for a higher mark-up at the supply or retail level.

Empirical studies have also showed that competition from private labels might not lead to lower prices for national brand products ${ }^{813}$. Consumers with a high degree of loyalty to the manufacturer's brand will not benefit from the introduction of private label products:

"( $\mathrm{t}$ )he trade-off for the national brand producer facing a private label is between exploiting the loyal consumers with a high price and competing for the switching consumers with a lower price. When the fraction of loyals is high, the national brand will concentrate on the loyal segment and a private label will be introduced at a lower price. On the other hand, when the fraction of loyals is relatively low, the national brand finds it optimal to offer an exclusivity contract to the retailer at a low price and no private label is introduced ... If the national brand producer serves both loyal and switching consumers initially, the price of the national brand will be relatively low. In such a situation private label competition would lead to an increase in the price of the national brand. The reason is that the national brand producer decides not to serve the switching consumers to which the private label is offered and instead sets a high price to serve only loyal consumers ... Loyal consumers are worse off due to a higher price on the national brand, while switching consumers are better off when offered a low-

\footnotetext{
${ }^{810}$ M B Ward and others, 'Effects of the Private-Label Invasion in Foods Industries' [2002] 84 American Journal of Agricultural Economics 961, at 963.

${ }^{811}$ R L Steiner, 'The Nature and Benefi ts of National Brand/Private Label Competition' [2004] 24 Review of Industrial Organization 105, at 113-114.

${ }^{812}$ Ibid., at 112-113.

813 T Staahl Gabrielsen and L Sørgard, 'Private Labels, Price Rivalry, and Public Policy' [2007] 51 European Economic Review 403, 404
} 
price private label. It turns out that in some cases consumers on aggregate benefit from private label introduction, in other cases they are worse off" $" 14$.

It follows that the effect of private labels on consumers is ambiguous and largely depends on the characteristics of consumer demand for the specific product. Restricting the commercial freedom of retailers may have, depending on the circumstances, a positive or a negative welfare effect for consumers.

Consumer choice and product variety would also be affected if private labels exclude all but the leading national brand. The gatekeeper role of the retailers may lead to the exclusion of some national brands. As the European Commission remarked in its merger decision Procter \& Gamble/Gillette,

"(i)f a retailer refused to carry a brand of the parties, the brand would risk disappearing from the customers' awareness. As a consequence, it would be detrimental to a leading brand of the parties to be excluded from a major retailer for a longer period, as it would entail significant losses in customer awareness, whilst the costs would be relatively minor for the retailer (whose sales with this brand represent only a small fraction of its turnover). It should also be noted that the parties' overall sales represent on average not more than $2 \%$ of the retailers' sales, while for the parties certain retailers represent $10 \%$ and more of the sales in a given country".

The Commission, however, also noted that this is unlikely to happen in practice as leading national brands ("must-stock brands") may play a role of quality certification for the retailer in inter-store competition. Private labels change the power relation between suppliers and retailers to the benefit of the later. The retailers establish their control over the suppliers, which see no reason to develop their own brands and finally are marginalised as independent players in the market (they could still supply goods for the retailers' private labels). It is not also clear what will be the effects of private labels for innovation. Copycat packaging is an important concern for suppliers of national brands and may lead to fewer investments for R\&D and less innovation. Private labels may also be a source of buyer power, which in certain circumstances, if it is associated with selling power, may produce anticompetitive effects.

The EU Block Exemption Regulation 330/2010 on vertical agreements applies only in situations where the undertakings are competing distributors, for example independent retailers competing with supplier-owned outlets, but does not cover the situations where the supplier and the retailer are competing manufacturers. This excludes from the scope of the block exemption situations where the retailer sells private labels that compete with the national brand of a supplier, except in circumstances where the distributor provides specifications to a manufacturer to produce particular goods under the distributor's brand name and both parties conclude a sub-contracting agreement

Private labels are also mentioned at Paragraph 116 of the Guidelines on Vertical restraints: the existence of own brands including private labels and the brand image of the undertaking concerned amongst final consumers are elements to be considered in assessing if one of the undertaking's customers possess buyer power. Buyer power is viewed positively, as

${ }^{814}$ Ibid., at 406. 
it "may prevent the parties from exercising market power and thereby solve a competition problem that would otherwise have existed", which "is particularly so when strong customers have the capacity and incentive to bring new sources of supply on to the market in the case of a small but permanent increase in relative prices". Private labels are also mentioned a second time with regard to category management agreements that may lead to distortions of competition, According to Paragraph 210, "in most cases the distributor may not have an interest in limiting its choice of products, when the distributor also sells competing products under its own brand (private labels), the distributor may also have incentives to exclude certain suppliers, in particular intermediate range products".

In Russia, the share of private labels in the line of products of retailers has been growing steadily in recent years. In 2017 the share of private labels of the big retailers has reached 10$17 \%$ in their overall turnover, ${ }^{815}$ although this is still less than the share of private labels in many foreign countries $(30-35 \%) .{ }^{816}$ The difference in price between private labels and analogous brands reaches $20-30 \%$ and many consumers switch to private labels in the low price categories where the brand is not of the utmost importance (sugar, cereals, milk, soft drinks, etc) ${ }^{817}$ Russian competition law and law on trading activities do not contain direct prohibition against private labels. However, this practice has attracted some attention of the competition authority. Back in 2011 during the expert panel on retail industry, FAS announced that it was planning to investigate the practice of the "brand squeezing", by which it referred to the use of private labels as leverage to force independent producers to drop prices of their brands. ${ }^{818}$ The outcome of the investigation is unclear.

Also South Africa has seen the growth of private label products in supermarkets. Every major supermarket has a range of their own brand/private label products. ${ }^{819}$ The majority of Woolworths' products are private labels. Shoprite has 'Ritebrand' and 'Housebrand' ranges in Checkers, which cover approximately 300 products. ${ }^{820}$ Pick n Pay's private label is "No Name" brand and it is looking to expand its private label range. Food Lover's Market has "Freshers" and "Food Lovers Signature". SPAR has its own private label products. SPAR does not allow major suppliers to manufacture its own private label products but rather allows new and smaller suppliers to enter the supermarket supply chain. ${ }^{821}$

\footnotetext{
815 According to RBK and Kommersant the share of private labels of "Piatorochka" amounts to $17 \%$ of its turnover; "Diksi" - 15,5\%; "Lenta" - 12\%; "Magnit" - 11\%; "Metro Cash and Carry" - 10,9\% (Anastasiya Demidova, 'Food retail chains are selling their names' (23.03.2017, RBK) accessed at http://www.rbc.ru/newspaper/2017/03/23/58d267cb9a7947df5d18c78d; Julia Bezrukova, 'The retail chains use private labels to increase their income' (09.08.2016, Kommersant), https://www.kommersant.ru/doc/3059373 accessed 20 April 2017.

816 ibid.

${ }^{817}$ Kommersant (n 2577).

818 FAS press release dated 28.10.2011, accessed at http://fas.gov.ru/press-center/fas-inmedia/detail.html?id=9994.

${ }^{819}$ Das Nair and Chisoro, "The expansion of regional supermarket chains and implications for local suppliers", WIDER Working Paper 2017/26. The data available is incomplete and what follows is based on the best available data.

${ }^{820}$ Das Nair and Chisoro, "The expansion of regional supermarket chains and implications for local suppliers", WIDER Working Paper 2017/26.

${ }^{821}$ Das Nair and Chisoro, "The expansion of regional supermarket chains and implications for local suppliers", WIDER Working Paper 2016/169.
} 
Morris and Kaplan note that Shoprite Checkers currently has about $8 \%$ of turnover as private label and this will soon double. ${ }^{822}$ South African supermarkets are moving in the direction of private labels as it is seen as key to their competitive edge in that it develops brand loyalty. ${ }^{823}$ Moreover, this furnishes supermarkets with more leverage with the large suppliers who have branded products. ${ }^{824}$ This is manifest in a recent example where Pick n Pay's branded tomato sauce which within a few weeks of introduction claimed $15 \%$ of the overall local market. ${ }^{825}$

Private labels operate differently for large and smaller volume producers. ${ }^{826}$ The use of private label by Pick n Pay and Shoprite, for example, often involves engaging large brand manufacturers to supply a specific large volume order which will be packaged in accordance with the private label specifications. ${ }^{827}$ Large supermarkets have sufficient influence to negotiate optimal deals under such circumstances. However, they are dependent on large brand manufacturers to supply the best quality. ${ }^{828}$ For small supermarkets, such as Food Lovers Markets, order sizes are limited - "if they use a large branded manufacturer it would be on the basis of picking up over runs, and the power relations then are too asymmetric." ${ }^{829}$ As a result, small supermarkets opt for engaging with, and seeking out, small specialist manufacturers supplying their private label products. ${ }^{830}$

\subsubsection{Upfront Access Payments}

This category includes practices, such as slotting allowances, pay-to-stay fees, payments to have access to a distributor's campaigns.

There are conflicting stories on the rationale of upfront access payments and its potential anti-competitive or pro-competitive effects. Moreover, there is reportedly a high variability across product categories in the likelihood of paying fees and their magnitude. ${ }^{831}$ For example, '[p]roducts that must be refrigerated (where shelf space is more scarce and product

\footnotetext{
${ }^{822}$ Kaplan, D \& Morris, M, Potential for Developing Local Suppliers in the Retail Sector Report for Trade and Industrial Policy Strategies (TIPS), May 2017.

${ }^{823}$ Kaplan, D \& Morris, M, Potential for Developing Local Suppliers in the Retail Sector Report for Trade and Industrial Policy Strategies (TIPS), May 2017.

${ }^{824}$ Kaplan, D \& Morris, M, Potential for Developing Local Suppliers in the Retail Sector Report for Trade and Industrial Policy Strategies (TIPS), May 2017.

${ }^{825}$ Kaplan, D \& Morris, M, Potential for Developing Local Suppliers in the Retail Sector Report for Trade and Industrial Policy Strategies (TIPS), May 2017.

${ }^{826}$ Kaplan, D \& Morris, M, Potential for Developing Local Suppliers in the Retail Sector Report for Trade and Industrial Policy Strategies (TIPS), May 2017.

${ }^{827}$ Kaplan, D \& Morris, M, Potential for Developing Local Suppliers in the Retail Sector Report for Trade and Industrial Policy Strategies (TIPS), May 2017.

${ }^{828}$ Kaplan, D \& Morris, M, Potential for Developing Local Suppliers in the Retail Sector Report for Trade and Industrial Policy Strategies (TIPS), May 2017.

${ }^{829}$ Kaplan, D \& Morris, M, Potential for Developing Local Suppliers in the Retail Sector Report for Trade and Industrial Policy Strategies (TIPS), May 2017.

${ }^{830}$ Kaplan, D \& Morris, M, Potential for Developing Local Suppliers in the Retail Sector Report for Trade and Industrial Policy Strategies (TIPS), May 2017.

${ }^{831}$ Federal Trade Commission, Slotting Allowances in the Retail Grocery Industry: Selected Case Studies in Five Product Categories (November 2003).
} 
introductions more common) are more likely to pay fees and to pay higher fees. Products that are distributed through direct store delivery are less likely to pay fees and to pay lower fees. ${ }^{832}$

Some authors have advanced anti-competitive theories. Slotting fees might be a mechanism for manufacturers to raise rivals' costs: dominant suppliers aim to secure a sufficient amount of shelf space in order to increase the costs and impose barriers to entry to potential upstream competitors ${ }^{833}$. Upfront payments provide dominant manufacturers an instrument to leverage their power against potential competitors by raising their cost of entry. Economies of scale or scope must of course be present at the supplier level and the shelf space should be foreclosed for a significant amount of time for the raising rivals' costs strategy to succeed $^{834}$. Small manufacturers are also disadvantaged in comparison to large manufacturers because they lack adequate access to capital markets and thus may not be able to pay the large upfront fees that are demanded by the retailers. It has been argued that "the dominant firm prefers to pay for scarce shelf space with slotting allowances rather than with wholesale price concessions because the former go directly to the retailers' bottom line, whereas the latter are mitigated by retail price competition"; "by paying retailers with lump-sum money, the dominant firm can compensate retailers for their scarce shelf space without having to lower its wholesale price, which would reduce the overall available profit to be split". ${ }^{835}$ Slotting allowances make exclusion by dominant firms of their competitive fringe profitable: "if the dominant firm had to pay for exclusion by offering retailers lower wholesale prices, exclusion would not be profitable" 836 . These theories of harm focus on the abuse of retailers' buying power by dominant manufacturers that aim to exclude their smaller rivals in the upstream market. A possible generalization would be that upfront payments are welfare reducing if they are initiated by dominant manufacturers and unlikely to lead to exclusion, when they are initiated by powerful buyers. However, other theories emphasize the role of downstream market power in excluding competitors and limiting the distribution of small manufacturers' products. Marx and Shaffer have recently argued that upfront payments may allow a retailer with bargaining power to earn positive profits while it prevents small manufacturers from obtaining distribution from another retailer: "the manufacturer will not want to trade with the rival retailer because of fears that if it did, the dominant retailer would cut back on some or all of its planned purchases" $" 837$. The welfare implications are that retail prices will be higher, because there is less competition at the retail level, and with fewer retailers buying from the small manufacturer, the choice in the marketplace will be reduced. Policy makers should thus be concerned also when slotting allowances are initiated by powerful retailers and should in this case not just

\footnotetext{
832 Ibid, 64.

${ }^{833}$ For an overview see, Paul N. Bloom, Gregory T. Gundlach \& Joseph P. Cannon, Slotting Allowances and Fees: Schools of Thought and the Views of Practising Managers, (2000) 64(2) The Journal of Marketing 92-108, 96-97.

${ }^{834}$ Benjamin Klein \& Joshua D. Wright, The Economics of Slotting Contracts , note however that "most slotting arrangements involve relatively short-term retailer shelf space commitments", usually a period of six months to a year. They also note that some large retailers, such as Wal-Mart prefer receiving the single best wholesale price that suppliers can offer instead of slotting fees.

${ }^{835}$ Greg Shaffer, Slotting Allowances and Optimal Product Variety, (2005) 5(1) Advances in Economic Analysis \& Policy, Article 3, at 3.

836 Ibid., at 23.

${ }^{837}$ Leslie M. Marx \& Greg Shaffer, Upfront Payments and Exclusion in Downstream Markets, (2007) 38 (3) Rand Journal of Economics 823-843, at 838.
} 
prohibit slotting allowances, but also other means to achieve exclusion, such as an explicit exclusive dealing provision.

Some jurisdictions indeed adopt a strict approach to slotting allowances in the food retail market. In Russia, for example, Article 9(13)(1) of the Federal law 'On the Basic Principles of State Regulation of Trading Activities in the Russian Federation', which regulates relationships between food retail chains and food suppliers, prohibits food retail chains to require from their suppliers payment for the right to supply food products to the existing or newly opened retail facilities. According to FAS, prohibition of slotting allowances covers not only explicit cases, but also payments for any services delivered by the retail chain, which are imposed on suppliers by the retails chain and do not have the economic justification other than payment for access to the shelf space. Additional services rendered by the food retail chain to its suppliers (like promotional, marketing, logistics, packaging services) are subject to stringent rules: (i) they should be rendered on the basis of the separate agreement, and (ii) the aggregate amount of payment for such services together with payment for the purchase by a retailer from its suppliers certain quantities of the food products should not exceed $5 \%$ (earlier 10\%) of the price of the purchased goods. ${ }^{838}$

In the US, slotting allowances and other access payments are generally widespread particularly in the food retail industry. ${ }^{839}$ However, slotting fees and other 'pay-to-play' fees are prohibited in the retail sale of alcoholic beverages since $1995 .{ }^{840}$

Other authors advance the view that retailers employ three-part tariffs that combine slotting allowances (negative upfront payments made by the manufacturer even if the retailer does not buy anything afterwards) with two part-tariffs (the supplier charges wholesale prices and the retailers pay conditional fixed fees on actual trade) in order to achieve a monopolistic outcome and reduce retail competition ${ }^{841}$. This is not possible with a two-part tariff structure if the retailer has bargaining power, as in this case each retailer has an incentive to free-ride on it rival's revenue by reducing its own prices. The story goes as follows:

"(w)holesale prices above costs maintain retail prices at the monopoly level, while large conditional payments (corresponding to the retailers' anticipated variable profits) protect retailers against opportunistic moves by their rivals: any price-cutting by one retailer would lead the others to 'opt out'; upfront payments by the manufacturer (slotting allowances) can then be used to give ex ante each retailer its full contribution to the industry profits" $" 842$.

Slotting allowances do not lead to the exclusion of efficient retailers but they allow firms to maintain monopoly prices in a situation in which competing manufacturers offer contracts to a common retailer.

\footnotetext{
${ }^{838}$ Article 9(4) and (11) of the Federal law "On the Trading Activities".

${ }^{839}$ Federal Trade Commission, Slotting Allowances in the Retail Grocery Industry: Selected Case Studies in Five Product Categories (November 2003); 'The hidden war over grocery shelf space' (22 November 2016), https://www.vox.com/2016/11/22/13707022/grocery-store-slotting-fees-slotting-allowances.

${ }^{840}$ Alcohol and Tobacco Tax and Trade Bureau, Guidance Regarding Industry Members' Participation in Retail Programs, available at https://www.ttb.gov/industry_circulars/archives/2012/12-01.html. See also Gregory T. Gundlach and Paul N. Bloom, 'Slotting Allowances and the Retail Sale of Alcohol Beverages' (1998) 17 Journal of Public Policy \& Marketing 173-184.

${ }^{841}$ Patrick Rey, Jeanine Thal \& Thibaud Vergé, Slotting Allowances and Conditional Payments (July 4, 2006)

842 Ibid., at 4-5.
} 
Other authors have argued that slotting fees constitute a facilitating practice to increase profit levels at the expense of suppliers and final consumers ${ }^{843}$. As Shaffer explains,

"(i)n providing a means for retailers to commit contractually to high prices, a manufacturer indirectly raises retailer profits by eliminating their incentive for aggressive downstream pricing. Although manufacturers would prefer lower retail prices and hence greater sales, the competition among themselves for the scarce shelf space provides the incentive for such contracts" 844 .

Some authors noted, however, that empirical evidence does not support this theory as retailer profits and prices did not increase, following the introduction of slotting allowances, and manufacturer profits did not fall, as they would have if retailers have been using slotting allowances to price discriminate ${ }^{845}$.

To these anticompetitive stories for slotting allowances one could oppose an efficiency rationale. Slotting allowances enable retailers to manage efficiently a scarce resource, shelf space, and allocate it to its best possible use. They might serve as a signaling device for new products and "a basis for achieving efficient cost sharing and risk shifting among manufacturers and retailers" $"$ "Slotting allowances moderate the risks of new product introductions and compensate retailers for the increasing costs of introducing and managing new products: they help equate an oversupply of new products with a less-than commensurate consumer demand for them ${ }^{847}$. Finally, some authors have advanced "the promotional services theory of slotting contracts" $" 848$. Retail shelf space is thought as a means to create incremental or promotional sales that would not occur otherwise and for which infra-marginal consumers would not be willing to pay, as they will purchase the product without promotional shelf space. The manufacturers want greater retailer promotional shelf space supplied for their products but retailers have sub-optimal incentives to provide it, as they would not take into account of the manufacturer's profit margin on the incremental sales produced by the promotional shelf space, which is particularly problematic if the manufacturer is supplying a differentiated product. Upfront fees can thus be thought as a way to incentivize retailers to supply the optimal promotional shelf space and also as targeted discounts to marginal consumers, thereby increasing the marginal elasticity of demand. Manufacturers with the greatest profitability from incremental sales will be able to pay the most for shelf space and thus win the competition between suppliers for obtaining superior promotional shelf space. But why choose upfront payments, instead of a wholesale price reduction, that could arguably achieve a similar result and provide more information on the value of the shelf space provided by the retailer? Klein

\footnotetext{
${ }^{843}$ Greg Shaffer, Slotting Allowances and Resale Price Maintenance: A Comparison of Facilitating Practices, (1991) 22 Rand Journal of Economics 120-136.

844 Ibid., at 121.

${ }^{845}$ Mary W. Sullivan, Slotting Allowances and the Market for New Products, 40 Journal of Law \& Economics 461-493 (1997), at 490.

${ }^{846}$ Leslie M. Marx \& Greg Shaffer, Upfront Payments and Exclusion in Downstream Markets, (2007) 38 (3) Rand Journal of Economics, at 93.

${ }^{847}$ Mary W. Sullivan, Slotting Allowances and the Market for New Products, 40 Journal of Law \& Economics 461-493 (1997).

${ }^{848}$ Benjamin Klein \& Joshua D. Wright, The Economics of Slotting Contracts, 50(3) Journal of Law \& Economics 421-454 (2007) ; Joshua D. Wright, Slotting Contracts and Consumer Welfare, 74(2) Antitrust Law Journal 439473.
} 
and Wright explain that in the presence of inter-retailer price competition, retailers will be obliged to decrease their price more than they will increase incremental sales for the manufacturer, as they are selling to both marginal and infra-marginal consumers, the latter being ready to switch retailers if they find the product cheaper elsewhere, and thus any shelf payment through a lower wholesale price will be eroded ${ }^{849}$. The manufacturer will thus have to reduce even more considerably its wholesale price in order to create the equilibrium shelf space rental return. However, if the retailer competition is intense, Klein and Wright argue that there will be a point where a lower wholesale price will be an inappropriate way for a manufacturer to compensate retailers for the supply of promotional shelf space and the manufacturers will thus employ upfront payments.

\subsubsection{Category management}

Category management is a vertical partnership in which previously confidential information is shared between manufacturers and retailers in order to cut costs in distribution and increase the margin of both parties. The major impetus for this type of arrangement came from the supermarket industry as a response to the intense competition of warehouses and discounts stores. The category captain presents a plan-o-gram to the retailer suggesting a layout and a promotional plan for the entire category.

In the agricultural value chain, category management are perceived as a form of modular linkage, as transaction-specific investments are generally low and the information shared can be codified relatively easily: 'suppliers can be plugged into and taken out of value chains with ease'. ${ }^{850}$ There are different forms of category management arrangements, going from strong ones, when the category captain has joint responsibility with the retailer for category development and is entrusted all category decisions, to loose forms of category management, where the retailer also received second opinions and recommendations from other category captains or the role of the category captain is an advisory one ${ }^{851}$.

Category management is efficiency-enhancing: it reduces the risk of retailers' out of stock and inventories, speeds up delivering times, enables the retailers to plan their production schedules. Suppliers and retailers have complementary information on consumers' needs and category management is a way to pool this information together for the benefit of consumers ${ }^{852}$. Alongside these various justifications, Klein and Wright have also advanced that category management is a way to ensure that the distributor provides a sufficient level of promotion

\footnotetext{
${ }^{849}$ Ibid.

${ }^{850}$ J. Humphrey and O. Memdovic, 'Global Value Chains in the Agrifood Sector', United Nations Industrial Development Organization Working Paper, Vienna 2006, 11.

${ }^{851}$ Debra M. Desrochers, Gregory T. Gundlach \& Albert A. Foer, Analysis of Antitrust Challenges to Category Captain Arrangements, 22(2) Journal of Public Policy \& Marketing 201-215, at 204 (2003).

${ }^{852}$ See, FTC Report, Workshop on Slotting Allowances and Other marketing Practices in the Grocery Industry 46-55 (2001), "the manufacturers may know things like the times of year when a product will best sell, the kind of promotion that are most effective in moving the product or the kinds of complementary goods that might be advantageously displayed in adjacent markets". Retailers have point of sale data and knowledge of their promotional efforts. However, because retail outlets carry thousands of categories of products, the retailer cannot be expected to understand detailed aspects pertinent to the marketing of each category.
} 
desired by the supplier ${ }^{853}$. The story is similar than the promotional services theory advanced for slotting contracts. The distributors do not supply the sufficient level of promotion desired by the supplier because they do not take into account of the supplier's marginal profit when deciding what level of promotion to supply. Shelf space is a particular type of promotional service. Klein and Wright argue that category management is a substitute contractual device to a limited exclusivity provision in the distribution contract. The fundamental limitation on the degree of exclusivity is that the category captain is obliged to place rival brands on its plan-ograms and that the final decision regarding listing and the allocation of shelf space belongs to the retailer and not the category captain. The retailer has the incentive to hold up the manufacturer by providing insufficient shelf space and promotional effort. The suppliers provide payment to ensure sufficient shelf space, either by reducing their wholesale prices, or by paying upfront access fees (slotting allowances) or through the premium earned by the retailers because of an RPM clause. Category management allows the supplier to prevent retailer hold up, for example by selling the same shelf space twice, and ensures some return to the supplier in the form of a limited exclusive distribution for their products. There is, indeed, an implicit understanding that category captaincy is intended to privilege the brands of the category captain. This conceptualization of category management as a limited form of exclusive distribution has gained acceptance in the recent JT International South Africa (Pty) Ltd and BAT South Africa case of the South African Competition Tribunal ${ }^{854}$.

The European Commission's guidelines on vertical restraints do not embrace this conceptualization when they examine the possible positive effects of category management. It is certainly noted in the guidelines that category management is generally positive and can produce anti-competitive effects only in specific circumstances ${ }^{855}$. A similar positive assessment of the effects of such agreements on consumers was made by the Commission in its Procter \& Gamble case in the context of EU merger control ${ }^{856}$. The Commission also notes in the vertical restraints guidelines that category management arrangements might also bring a number of efficiency gains: they may allow distributors to achieve economies of scale as they ensure that the optimal quantity of products is presented timely and directly on the shelves ${ }^{857}$. They may also enable suppliers to achieve economies of scale by allowing them to better

\footnotetext{
${ }^{853}$ Benjamin Klein \& Joshua D. Wright, Antitrust Analysis of Category Management: Conwood v. United States Tobacco, (2006) available at http://www.justice.gov/atr/public/hearings/single_firm/docs/219951.htm . See also, Joshua D. Wright, An Antitrust Analysis of Category Management: Conwood Co. v. United States Tobacco Co., 17 Supreme Court Economic Review 311 (2009).

${ }^{854}$ Case No:05/CR/Feb05, The Competition Commission, JT International South Africa (Pty) Ltd and British American Tobacco South Africa (Pty) Ltd, available at http://www.saflii.org/za/cases/ZACT/2009/46.html , para. 77.

855 EU Vertical Restraints Guidelines, available at http://ec.europa.eu/competition/antitrust/legislation/guidelines_vertical_en.pdf, para. 210 ("in most cases category management agreements will not be problematic").

856 Case No COMP/M.3732 - Procter \& Gamble/ Gillette, (2005) available at http://ec.europa.eu/competition/mergers/cases/decisions/m3732_20050715_20212_en.pdf, para. 151 “category management policy appears to provide an advantage to leading brands in general, and not only to the parties. This may be seen as largely pro-competitive, as it makes it easier for retailers to stock the most-demanded brands and easier for consumers to find them in sufficient quantities on the shelves. Hence, there is no elimination of competition".

${ }^{857}$ Vertical Restraints Guidelines, para. 209.
} 
anticipate demand and to tailor their promotions accordingly ${ }^{858}$. However, no effort was made to develop a more holistic view of this practice, such as the "the promotional services theory" advanced by Klein and Wright. The reason might be that accepting this theory could provide room for a more lenient approach towards RPM, another mechanism of retailer promotional services compensation ${ }^{859}$, which is something the European Commission did not want to pursue in this revision of the Block exemption regulation on vertical agreements.

Category management may "sometimes distort competition between suppliers, and finally result in anticompetitive foreclosure of other suppliers, where the category captain is able, due to its influence over the marketing decisions of the distributor, to limit or disadvantage the distribution of products of competing suppliers" ${ }^{\prime 860}$. This comes essentially from the conflict of interest between the supplier and the retailers, although the Commission notes that "in most cases the distributor may not have an interest in limiting its choice of products" ${ }^{\text {" }}$. Category managemement might, however, produce exclusionary effects to other suppliers, in particular when the category captain is able, due to its influence over the marketing decisions of the distributor, to limit or disadvantage the distribution of products of competing suppliers. The US litigation in Conwood v. US Tobacco Co.provides an illustration of this risk fo anticompetive effects, although one should note that the factual circumstances of this case are exceptional $^{862}$. This conflict of interest is particularly acute when the distributor also sells private labels, in which case he has incentives to exclude certain suppliers, in particular intermediate national brands, as this is also noted in the Commission's vertical restraints guidelines $^{863}$. The Commission will assess this upstream foreclosure effect by analogy to the assessment of single branding obligations, and will integrate factors such as the market coverage of these agreements, the market position of competing suppliers and the possible cumulative use of such agreements ${ }^{864}$.

The Commission also examined the possible collusive effects of category management agreements at the upstream and downstream level. This was an important concern in the UK Competition Commission (CoCo) supply of groceries in the UK market investigation ${ }^{865}$. The CoCo acknowledged that category management may provide increased opportunities to exchange information between suppliers, whether directly or indirectly via retailers. The report

\footnotetext{
${ }^{858}$ See also, Case No COMP/M.3732 - Procter \& Gamble/ Gillette, (2005), above, para. 150.

${ }^{859}$ See, most recently, Benjamin Klein, Competitive Resale Price Maintenance in the Absence of Free Riding, 76 Antitrust L. J. 431 (2009).

${ }^{860}$ Vertical Restraints Guidelines, para. 210.

861 Ibid.

${ }^{862}$ Conwood Company, L.P. v. United States Tobacco Co., , 290 F.3d 768 (6thCir. 2002) (finding maintenance of monopoly power through exclusionary conduct, including the destruction of competitors' promotional stands, payments for exclusive product display space).

${ }^{863}$ Vertical Restraints Guidelines, para. 210. See, however, the more positive for category management analysis of the Commission in Case No COMP/M.3732 - Procter \& Gamble/ Gillette, (2005), above, para. 143-145, where the Commission notes that there is little likelihood that category managers would provide biased recommendations to retailers, as "the market investigation has shown that there is no significant information asymmetry between retailers and suppliers which could be abused" and that "most of the parties. competitors and some of the retailers, through their private labels, provide a full range of oral care products, sometimes similar or even broader than the parties. range, which prevents the parties from forcing retailers to buy a full line of their own branded products". ${ }^{864}$ Ibid, referring to para. 132-141 (single branding obligations).

${ }^{865}$ UK Competition Commission, The Supply of groceries in the UK market investigation (April 30, 2008), available at http://www.competition-commission.org.uk/rep_pub/reports/2008/538grocery.htm .
} 
reviewed category management in two product categories - fresh fruit and yogurt - and found varying degrees of supplier interaction as a result of category management relationships ${ }^{866}$. The Commission concluded that "the degree of interaction among suppliers arising from category management is a cause for concern" $" 867$. The European Commission also recognizes in the vertical restraints guidelines that "category management may also facilitate collusion between suppliers through increased opportunities to exchange via retailers sensitive market information, such as for instance information related to future pricing, promotional plans or advertising campaigns" $" 868$. The risk might be more significant if the retailers sell private labels and are thus competitors to the supplier/category captain.

Furthermore, the Commission acknowledged in the vertical restraints guidelines that category management agreements may facilitate collusion between distributors when the same supplier serves as a category captain for all or most of the competing distributors on a market and provides these distributors with a common point of reference for their marketing decisions ${ }^{869}$. One could question the possibility of this anticompetitive effect happening, unless there is a widespread adoption of the same category captain by all retailers. The category captain may also only provide advice about stocking and presentation of the category and is not involved in setting the retail selling price. As the UK Competition Commission noted in its report in the groceries market investigation, this concern might be overstated as there was no evidence, from the case studies that category management activities were being used to facilitate, or had the effect of facilitating, collusion between grocery retailers ${ }^{870}$.

\subsubsection{Horizontal cooperation agreements and agricultural cooperatives}

Small and medium enterprises at any level of the supply chain may sometimes enter agreements although not optimal for their interests, for the sole reason that the other party has effectively exerted its higher bargaining power. Some SMEs often seek horizontal coordination in order to gain a better bargaining position and extract better contractual terms.

Horizontal cooperation agreements can have various degrees of integration. In the context of agricultural cooperatives, transaction cost economists distinguish between bargaining associations, marketing cooperatives, new generation cooperatives, and horizontal integration, where the most cost-effective form of cooperation depends on the specific transaction characteristics. ${ }^{871}$ Bargaining associations are the most simple form of horizontal coordination, where farmers take a collective bargaining position vis-à-vis suppliers (e.g. suppliers of

\footnotetext{
${ }^{866}$ Appendix 8.1. of the UK Competition Commission's Report (ibid.).

${ }^{867}$ Competition Commission, The Supply of groceries in the UK market investigation (April 30, 2008), at 151 noting that "there were also some examples where suppliers offered information to grocery retailers regarding the future plans of competitors" and at p. 155, observing that "(o)ur review of the conditions necessary for tacit coordination to arise and be sustainable suggested that these conditions may be present in UK grocery retailing". ${ }^{868}$ Vertical Restraints Guidelines, para. 212.

${ }^{869}$ Vertical Restraints Guidelines, para. 211.

${ }^{870}$ Competition Commission, The Supply of groceries in the UK market investigation (April 30, 2008), Appendix 8.1 , para. 25. See also, para. 8.19 of the main report.

${ }^{871}$ F. Chaddad, 'Advancing the theory of the cooperative organization: The cooperative as a true hybrid' (2012) 83 Annals of Public and Cooperative Economics 445-461; K. Sartorius and J. Kirsten, 'A framework to facilitate institutional arrangements for smallholder supply in developing countries: an agribusiness perspective’ (2007) 32 Food Policy 640-655.
} 
Fertilisers and seeds) or buyers (e.g. manufacturers) to increase their relative bargaining strength. Bargaining association are loose structures which involve little to no pooling of assets or significant control. Marketing cooperatives, in contrast, are engaged in storing, transporting, or processing as well, so as to counterbalance relative bargaining power more actively and meet requirements of buyers. ${ }^{872}$ As a result, marketing cooperatives require some degree of shared ownership of the shared activities, and require more investments from individual farmers. ${ }^{873}$ New generation cooperatives refer to larger-scale cooperatives which are more centralized and regulated, and membership is closed ${ }^{874}$ Finally, in the case of horizontal integration, farmers have unified assets in a single firm.

The most diffuse form of horizontal coordination in the food value chain is the cooperative system among agricultural producers. This form of voluntary organization among producers receives large incentives from national and supra-national regulators, as a way to re-balance the food supply chain and foster its competitiveness. ${ }^{875}$ The European Commission launched a large study, called "Support for Farmers' Cooperatives (SFC)", ${ }^{876}$ where these objectives are systematized and has also provided guidance to farmers. However, horizontal cooperation in the food industry is not only taking place exclusively at the farm level. BRICS jurisdictions, again provide meaningful instances of different uses of such contractual networks. For example, in Brazil horizontal coordination has for a long time been used by small retailers in order to constitute buying groups and offset the high bargaining power of concentrated wholesalers. The effects of the creation of buying groups are double. On one hand, horizontal coordination raises the bargaining power of the group participants that will thus be able to obtain more favourable prices, which is presumed to be beneficial for consumers long term, because it preserves consumer choice. ${ }^{877}$ On the other hand, the interaction between horizontal and vertical effects of such coordination, may create a so-called "waterbed" effect. Here, the advantage acquired by the buying group which is able to bargain lower prices may bring the upstream supplier to raise costs for other weaker competitors in order to offset the loss. ${ }^{878}$

Other jurisdictions have also actively supported farmers to establish horizontal cooperatives so as to counterbalance market power upstream or downstream, either through immunity from competition law enforcement or other legislative and/or regulatory support. In 1922, the United States Congress authorized a farmers' producer cartel by allowing farmers to establish cooperatives that would negotiate prices with the buyers of farming products. ${ }^{879}$ Likewise, industry-wide collective bargaining has been legalized in 1935 after industry-wide labour agreements had been previously subject to antitrust litigation. ${ }^{880}$

\footnotetext{
${ }^{872}$ C. Poulton and M.C. Lyne, 'Coordination for market development' in Institutional economics perspectives on African agricultural development, 135-184

${ }^{873}$ F. Chaddad, 'Advancing the theory of the cooperative organization: The cooperative as a true hybrid' (2012) 83 Annals of Public and Cooperative Economics 445-461.

874 Ibid.

875 Jos Bijman and others, Suppport for farmers' cooperatives: final report (LEI 2012).

876 ibid.

877 OECD, Competition Law and Policy in the Russian Federation (n 193) 29.

${ }^{878}$ Ibid; Roman Inderst and Tommaso M Valletti, 'Buyer Power and the "Waterbed Effect"' (2011) 59 The Journal of Industrial Economics 1.

${ }^{879}$ Capper-Volstead Act, 7 USC $\S \S 291-292$ (2016); Peter C. Carstensen, 'Agricultural Cooperatives and the Law: Obsolete Statutes in a Dynamic Economy’ (2013) 58 S.D. L. R EV . 46.

${ }^{880}$ National Labor Relations Act, 29 USC $\S \S 151-169$ (2016); Peter C. Carstensen, Competition Policy and the
} 
In Russia, development of agricultural cooperations has been consistently declared as one of the priorities of the state agricultural policies in general, as well as of the FAS priorities in agricultural sector. ${ }^{881}$ Agricultural cooperatives receive state support in the form of subsidies provided from the federal and regional budgets for development of technical infrastructure, acquisition of equipment, organising of distributing and logistics centers, etc.

\subsubsection{Standardization and certification systems}

Both horizontal and vertical coordination have the object of regulating the process or the quality level of the production. In this case, parties often agree upon these aspects setting specific quality standards. Private standards have direct impact on the structure of the supply chain, as they define the relationships among the participants. ${ }^{882}$ In facilitating coordination of the agri-food value chain, standards transmit credible information on the quality and other characteristics of products. ${ }^{883}$ Standards may be the result of an agreement, also facilitated by specific organizations or NGOs, or may be imposed by a dominant firm (de facto standards). Private standards may thus be set alternatively by a lead firm or by agents external to the network. ${ }^{884}$

Global value chain literature distinguishes between two motives for explicit coordination in value chains through private standard-setting: risk management and product differentiation. Standardization of factors including product quality, safety, processes, etc, allows firms to control risk. Secondly, firms can aim at lowering buyers' information costs through standardsetting, thereby differentiating their products. ${ }^{885}$ The impact of private standards thus also depends on the function they perform. In general, however the private standards set a new regulatory regime between the parties, which works in parallel to state legislation. Private standard-setting may go beyond public standardization regulations either by introducing additional parameters, for example by introducing a more stringent standard, or by introducing additional enforcement mechanisms to improve the achievement of the goals set by public regulation. ${ }^{886}$ Especially in developing and transition countries, private regulation stops being a mere complement to public standards, becoming the main source of regulation, especially when public regulation on product safety is particularly lax. The private regulation provides

Control of Buyer Power: A Global Issue (Edward Elgar 2017) 48-49.

881 'Strategy of the Sustainable Development of the Agricultural Territories of the Russian Federation to 2030" adopted by the Decree of the Government of the Russian Federation dated 02 February 2015 N151-r; FAS press release dated 27.02.2017 at http://fas.gov.ru/press-center/news/detail.html?id=49039.

${ }^{882} \mathrm{See}$, for instance, the QS system in Germany, a private certification for meat that had the effect of lowering the vertical coordination in the relevant market; EC (n 171) 33.

${ }^{883}$ S. Henson and J. Humphrey, 'Understanding the Complexities of Private Standards in Global Agri-Food Chains as They Impact Developing Countries' (2010) Journal of Development Studies 1628-1646, 1633.

${ }^{884}$ John Humphrey and Hubert Schmitz, 'Governance in Global Value Chains', The Value of Value Chains, vol 32 (IDS 2001).

885 S. Henson and J. Humphrey, 'Understanding the Complexities of Private Standards in Global Agri-Food Chains as They Impact Developing Countries' (2010) Journal of Development Studies 1628-1646; see further M. Aragrande et al, Food Supply Chains Dynamics and Quality Certification (EU/DG Joint Research Centre, Brussels 2005).

${ }^{886}$ S. Henson and J. Humphrey, 'Understanding the Complexities of Private Standards in Global Agri-Food Chains as They Impact Developing Countries’ (2010) Journal of Development Studies 1628-1646, 1633-1634. 
also remedial solutions to the infringement of such standards, through the enforcement of contract and codes of conduct. Some authors see in the growth of private regulation also the effect of "increasing wealth transfer, shifting the value downstream while placing the costs of safety regulation further upstream on the supply chain". ${ }^{887}$ Private standards may also have repercussions on the competitiveness of the market. Depending on how they are used, standards can indeed foster product differentiation or, on the opposite, bring product standardization.

Private standards may be introduced by individual firms (e.g. Tesco's 'Nature's Choice' and Carrefour's 'Filières Qualité'), national collective organizations (e.g. the British Retail Consortium Global Standard), or international collective organizations (e.g. GlobalGAP, Marine Stewardship Council, and Forest Stewardship Council). ${ }^{888}$ Private standards may also pursue different goals and levels of protection depending on market circumstances and level of development. For example, in India private regulation emerged both in consortia and the efforts of NGOs and civil society groups. However, these private regulations are primarily designed to address the level of economic development in the country. For example, while regulations governing the Indian wet retail market may not be adequate according to US consumption standards, however, from the point of view of Indian consumers these regulations are adequate because anything more stringent would render the products too expensive for consumption. ${ }^{889}$

A variety of third-party certification bodies are found in the food ecosystem. They establish standards for produce and grant compliant members particular benefits in the commercialisation of food (including for instance through labels). ${ }^{890}$ Third-party certification schemes normally refer to standards that range across the social, environmental and safety spheres (ie food safety, organic or fair trade and so forth). ${ }^{891}$ The certification providers that are discussed below feature strongly in the discussion on food standards, and have acquired recognition both among consumers and producers notwithstanding their generally voluntary nature.

Fairtrade International is a non-profit organisation formed of 23 member organizations (three producer networks and 20 national Fairtrade organizations). ${ }^{892}$ Fairtrade offers the FAIRTRADE Certification Mark, in cases where an independent certifier (Flocert) finds compliance with Fairtrade Standards in social, environmental and economic factors. ${ }^{893}$

\footnotetext{
${ }^{887}$ Fabrizio Cafaggi, 'New Foundations of Transnational Private Regulation' [2010] EUI Working Paper Series RSCAS 2010/53 1.

${ }^{888}$ S. Henson and J. Humphrey, 'Understanding the Complexities of Private Standards in Global Agri-Food Chains as They Impact Developing Countries' (2010) Journal of Development Studies 1628-1646, 1632-1633.

${ }^{889}$ See further International Food Safety Standards and India's Food Exports- An Analysis Based on Gravity Model Using Three-Dimensional Data, Rajesh Mehta, September 2010, Research and Information System for Developing Countries.

${ }^{890}$ See, for example, K. H. Eller, Private governance of global value chains from within: lessons from and for transnational law, (2017) Transnational Legal Theory 1-34.

${ }^{891}$ K. H. Eller, Private governance of global value chains from within: lessons from and for transnational law, (2017) Transnational Legal Theory 1-34. See also UNIDROIT, FAO and IFAD, UNIDROIT/FAO/IFAD Legal Guide on Contract Farming (Rome, 2015).

${ }^{892}$ Fairtrade, The Fairtrade System available at https://www.fairtrade.net/about-fairtrade/fairtrade-system.html

893 ECOLABEL Index, Fairtrade, available at http://www.ecolabelindex.com/ecolabel/fairtrade; Fairtrade, Certifying Fairtrade, available at https://www.fairtrade.net/about-fairtrade/certifyingfairtrade.html?utm_medium=email\&utm_campaign=Fairtrade $\% 252525252525252525252520 \operatorname{Insider} \% 2525252$ 52525252525252520June\%2525252525252525252525202016\&utm_content=Fairtrade\%252525252525252525 252520Insider\%252525252525252525252520June\%2525252525252525252525202016\%252525252525252525
} 
Participation is voluntary and there are currently Fairtrade Standards in relation to small producer organisations, hired labour, contract production, as well as trading, climate and textile. ${ }^{894}$ Flocert provides an online platform (named Fairtrace) that allows to track certified products throughout the supply chain, ${ }^{895}$ and an online tool to verify compliance with the Fairtrade Standards. ${ }^{896}$

GLOBALG.A.P is a "private sector food safety certification" involved in the establishment and maintenance of good practices and standards in such areas as food safety and traceability, environment, workers' safety, and animal welfare. ${ }^{897}$ Participation is voluntary and three certification products are available, namely GLOBALG.A.P.; localg.a.p; and GLOBALG.A.P.+ Add-on. GLOBALG.A.P. provides 40 standards in three areas: crops, livestock and aquaculture. ${ }^{898}$ GLOBALG.A.P. maintains a database system where certified producers can be identified on the basis of a unique code and reviewed in terms of compliance with the certification audits. ${ }^{899}$ Moreover, GLOBALG.A.P. offers access to a network of 140 certification bodies $^{900}$ that in turn must have received ISO 17065 accreditation. ${ }^{901}$

UTZ Certified is a non-profit organisation that provides certification when certain conditions contained in its Code of Conduct and the Chain of Custody guidelines are met. ${ }^{902}$ The UTZ standard applies, among others, to coffee, tea, cocoa and hazelnuts. The UTZ Certified Code of Conduct deals primarily with growth and harvest (building on issues such as safety, farm management, employee/environmental protection ${ }^{903}$ while the Chain of Custody guidelines follow the whole supply chain process. ${ }^{904}$ Compliance is ensured through regular audits performed by independently accredited auditors, and a traceability system (the Good Inside Portal) allows to track all sales of certified products and each step involved in the production. ${ }^{905}$ UTZ Certified has recently announced a merger with another major global thirdparty certifier, the Rainforest Alliance, which will eventually lead to a single global standard and certification body. ${ }^{906}$

\footnotetext{
252520CID_39e5d6f30910742c748f16e668614e3a\&utm_source=\&utm_term=Find $\% 252525252525252525252$ 520out\%252525252525252525252520more\%252525252525252525252520about\%25252525252525252525252 0these $\% 252525252525252525252520$ Projects

${ }^{894}$ Fairtrade, Our standards, available at https://www.fairtrade.net/standards/our-standards.html.

${ }^{895}$ Ana Ionova, How fair is our food? Big companies take reins on sourcing schemes, Reuters (3 September 2017) available at https://www.reuters.com/article/us-food-fairtrade-sustainability-insight/how-fair-is-our-food-bigcompanies-take-reins-on-sourcing-schemes-idUSKCN1BE0GI.

${ }^{896} \mathrm{https}: / / \mathrm{www}$.flocert.net/solutions/fairtrade-resources/compliance-criteria/

${ }^{897}$ GLOBALG.A.P, What We Do, available at http://www.globalgap.org/uk_en/what-we-do/; GLOBALG.A.P, Cultivating the Future of the Planet available at http://www.globalgap.org/uk_en/what-we-do/globalg.a.p.certification/globalg.a.p./

${ }^{898}$ GLOBALG.A.P, What We Do, available at http://www.globalgap.org/uk_en/what-we-do/.

${ }^{899}$ GLOBALG.A.P, For Buyers, available at http://www.globalgap.org/uk_en/buyers/.

${ }^{900}$ GLOBALG.A.P, For Buyers, available at http://www.globalgap.org/uk_en/buyers/.

${ }^{901}$ GLOBALG.A.P, $\quad$ GLOBALG.A.P. $\quad$ TOURSTOP $2016, \quad$ available at https://www.globalgap.org/export/sites/default/.content/.galleries/Pictures/TOUR2016/TOUR2016_Ethiopia_Pr esentations/Introduction-to-GLOBALG.A.P.-Christi-Venter.pdf

${ }^{902}$ UTZ Certified, The UTZ Standard, available at https://utz.org/what-we-offer/certification/the-standard/

${ }^{903}$ UTZ Certified, The UTZ Standard, available at https://utz.org/what-we-offer/certification/the-standard/

${ }^{904}$ UTZ Certified, The UTZ Standard, available at https://utz.org/what-we-offer/certification/the-standard/

${ }^{905}$ ECOLABEL Index, UTZ Certified, available at http://www.ecolabelindex.com/ecolabel/utz-certified.

${ }^{906}$ UTZ Certified, The Rainforest Alliance and UTZ to merge, forming a new, stronger organization, available at https://utz.org/merger/.
} 
The Marine Stewardship Council (MSC) is a global non-profit organisation involved primarily in the certification of fishing and seafood supplies. ${ }^{907}$ The MSC label is granted to fisheries that have been found to be compliant with the MSC Fisheries Standard as well as Chain of Custody Standard. ${ }^{908}$ Each fishery that meets the standard will have proven that it engages in a sustainable level of fishing activity (ie avoiding the overexploitation of the fish stocks), while minimising the impact on environmental biodiversity and maintaining effective management. ${ }^{909}$ Participation is voluntary and compliance with the required standard and criteria is assessed by independent certification bodies. ${ }^{910}$

Private standard-setting is present in all segments of the value chain. For instance, with regard to seeds, the International Seed Testing Association (ISTA) is private, nongovernmental standard-setting organisation, that consists of laboratories and sampling entities and industry members from approximately 80 countries across the world. ${ }^{911}$ The objectives of ISTA are development, adoption and publication of standard procedures for sampling and testing seeds, and to promote uniform application of these procedures for evaluation of seeds moving in international trade. ${ }^{912}$ ISTA also works on promotion of research in the area of food science and technology, including sampling, testing, storing, processing, and distributing seeds. ${ }^{913}$ ISTA publishes International Rules for Seed Testing, that provide for harmonised and uniform seed testing methods.

\subsubsection{Transfer of technology and know-how agreements}

Transfer of technology refers to the transfer of tangible property itself and of technology rights such as patents, plant breeder's certificates, trademarks and topographies of semiconductor products which allows the right holder to produce a particular product. Know-how can be defined as a package of practical information resulting from experience and teting, which is secret, substantial, i.e. significant and useful for the production of a particular product, and can be identified in manuals or another written form. ${ }^{914}$

Technology transfers and know-how agreements can be used as mechanisms to ensure that agricultural research innovations reach farmers and have an impact on production processes. Spreading innovation within global value chains from advanced (international) companies to SMEs is widely thought to be beneficial for production growth through learning

\footnotetext{
${ }^{907}$ MSC, About us, available at https://www.msc.org/about-us.

${ }^{908}$ MSC, What does the blue MSC label mean?, available at https://20.msc.org/what-we-are-doing/ourapproach/what-does-the-blue-msc-label-mean.

${ }^{909}$ MSC, Annual Report 2016-2017, available at https://www.msc.org/documents/msc-brochures/annual-reportarchive/annual-report-2016-17-english.

${ }^{910}$ MSC, Annual Report 2016-2017, available at https://www.msc.org/documents/msc-brochures/annual-reportarchive/annual-report-2016-17-english.

911 See https://www.seedtest.org/en/about-ista-_content---1--1011.html .

912 Ibid.

913 Ibid.

914 Cf. Article 1(1)(i) of Commission Regulation No 316/2014 on the application of Article 101(3) TFEU to categories of technology transfer agreements [2014] OJ L93/17.
} 
and increasing skill sets. ${ }^{915}$ Developing countries generally do not have strong private innovate sectors that are prevalent in developed countries, so that public research organizations are a more important source of innovation. ${ }^{916}$ Moreover, private sector technology transfers might only be feasible for certain (high-value) market segments, because safeguards and contract compliance are often costly. Also, it is more likely that technologies that are non-specific to the relationship between the farmer and the technology supplier will be diverted after the transfer, making transfers of non-specific technology more risky than that of specific technologies. ${ }^{917}$ Macro-economic stability is also key in efficient functioning of technology transfers, as instability increases the risk of hold-up and investment risks. ${ }^{918}$ Notwithstanding these conditions for successful technology transfers, private technology transfers have become increasingly popular in developing countries also as a form of value chain development programmes. Special purpose vehicles which are owned by multiple partners in the value chain can be used to mitigate and spread assets and risks, among other models of value chain innovations. $^{919}$

Technology licensing generally provides incentives for further innovation on part of the buyer. ${ }^{920}$ Buyers of technology have an incentive to reduce production costs, improve the final product or develop new products using the licensed technology. ${ }^{921}$ Uncertainty, risk aversion and seller anticipations influence the incentives for further innovation; higher buyer risk aversion is for example associated with a reduction in the buyer's innovation incentives, while levels of future innovation are higher when the technology seller anticipates opportunities for future innovation. ${ }^{922}$ Risk aversion and innovation expectations are thus likely to affect the levels of future innovation through modification of the licensing agreement terms. ${ }^{923}$

Technology licensing in the agricultural biotechnology industry have some unique elements in comparison with other kinds of license agreements. ${ }^{924}$ One single technology or product in agri-biotech often is often covered by multiple property types, such as utility patents, plant patents, plant breeder's rights, trade secrets, trademarks and tangible biological property. Also, defining the freedom to operate must be clearly stated, for example whether the licensee

\footnotetext{
${ }^{915}$ See e.g., OECD and World Bank, Inclusive Global Value Chains Policy options in trade and complementary areas for GVC Integration by small and medium enterprises and low-income developing countries, Report prepared for submission to G20 Trade Ministers Meeting Istanbul, Turkey, 6 October 2015.

916 A.B. Bennett, R. Rajalahti and A. Pape-Christiansen, 'Technology Transfer Offices: Facilitating Intellectual Property Protection for Agricultural Innovation', available at http://siteresources.worldbank.org/INTARD/Resources/335807-1330620492317/84783711330712171692/Module5-TN5.pdf.

917 J. Swinnen and R. Kuijpers, Value Chain Innovations for Technology Transfer in Developing and Emerging Economies: Conceptual Issues, Typology, and Policy Implications (2017) Food Policy 1, 8.

918 Ibid, 10.

${ }^{919}$ See section 1.2.2.3. above.

920 B.A. Larson and M. Anderson, 'Technology Transfer, Licensing Contracts, and Incentives for Further Innovation' (1994) 76 American Journal of Agricultural Economics 547-556.

${ }^{921}$ Ibid, 548; H. Katrak, 'Payments for Imported Technologies, Market Rivalry and Adaptive Activity in the Newly Industrializing Countries' (1988) 25 Journal of Development Studies 43-53; T. Blumenthal, 'Japan's Technological Strategy' (1976) 3 Journal of Development Economics 245-255.

${ }_{922}$ B.A. Larson and M. Anderson, 'Technology Transfer, Licensing Contracts, and Incentives for Further Innovation' (1994) 76 American Journal of Agricultural Economics 547-556, 555.

${ }^{923}$ Ibid.

${ }^{924}$ R.S. Cahoon, 'Licensing Agreements in Agricultural Biotechnology' in IP Handbook of Best Practices, chapter 11.2, available at www.iphandbook.org/handbook/ch11/po2/.
} 
has the right to make crosses of a particular product, and how this affects royalty rates. These questions often lead to anti-royalty-stacking provisions in licensing agreements. Thirdly, agribiotech licensing agreements often contain philanthropic and humanitarian use clauses particularly if they concern crop that are important food staples in developing countries. Lastly, technology transfers often give rise to stewardship provisions which establish some form of ongoing oversight of commercial development and dissemination of the new technology. ${ }^{925}$

Public research institutions may be used to assist with technology transfers, including IP protection and licensing and transfer of tangible property rights. Such public/private partnerships can be organized in various ways, depending on the institutional objectives, type of technology involved, and local needs and resources. Bennett, Rajalahti and PapeChristiansen distinguish between four models of Technology Transfer Office (TTO) models in public institutions to assist innovation in agricultural innovation: (1) an independent TTO department within the research institution, which is mainly useful for institution with sufficient resources to carry the necessary investment requirements; (2) network-based TTOs where multiple institutions share costs and expertise so as to reach the necessary critical mass for technology transfer activity; (3) a subsidiary company where knowledge resources within an institution are sufficient but institutional culture is not conductive for entrepreneurial activity, and a subsidiary can take advantage of the available knowledge while maintaining its own operational flexibility; and (4) outsourcing of technology transfer, which minimizes investments but which also reduces revenue to the institution and which is particularly suitable for technology that can be used for high-value opportunities. ${ }^{926}$ These specific characteristics of technology licensing in the agricultural biotechnology industry require each license agreement to be unique and contain specific mechanism to safeguard the various interests and mutual agreement of both parties.

Technology transfer and know-how agreements can have both pro- and anticompetitive effects. They can promote production efficiency and innovation by allowing innovators to earn returns that (partially) cover their research and development costs. They also foster the spread of technology and know-how so as to allow licencees to reduce production costs and develop new or improved products. Moreover, technology licensing agreements allow the technology of the licensor to be combined with the technology and the assets of the licensee. On the other hand, technology transfer and know-how agreements are capable of reducing intra- or inter-technology competition, for example when two companies crosslicense their technologies in combination with a market sharing agreement, or when a licensing agreement between non-competitors contains vertical price fixing clauses.

In EU competition law, technology transfer and know-how agreements are assessed under the Technology Transfer Block Exemption Regulation. ${ }^{927}$ The Guidelines on the application of Article 101 TFEU to technology transfer agreements recognizes that 'the vast

\footnotetext{
925 Ibid.

${ }_{926}$ A.B. Bennett, R. Rajalahti and A. Pape-Christiansen, 'Technology Transfer Offices: Facilitating Intellectual Property Protection for Agricultural Innovation', 407ff.

${ }^{927}$ Commission Regulation No 316/2014 on the application of Article 101(3) TFEU to categories of technology transfer agreements [2014] OJ L93/17.
} 
majority of those agreements are indeed pro-competitive' ${ }^{928}$ The Block Exemption Regulation contains a general exemption from Article 101 TFEU for technology transfer agreements between competitors where their combined market share does not exceed $20 \%$ of the relevant market, ${ }^{929}$ and for technology transfer agreements between non-competitors where the market share of each of the parties does not exceed $30 \%$ on the respective relevant markets. ${ }^{930}$ Such agreements are deemed to benefit from the exemption in Article 101(3) TFEU. Where the market share of the parties exceeds the thresholds set out in Article 3 of the Block Exemption Regulation, the agreement must be assessed individually under Article 101(3) TFEU. Further, the Block Exemption Regulation is not applicable to agreements which contain the hardcore restrictions listed in Article 4, including market allocations, output limitation and vertical price restrictions.

It also seems that merger control has been recently used by the Russian FAS in order to organize a technology transfer to Russia-based agritech companies in the context of its merger remedy in the Bayer/Monsanto case ${ }^{931}$.

\footnotetext{
${ }^{928}$ Guidelines on the application of Article 101 of the Treaty on the Functioning of the European Union to technology transfer agreements, [2014] OJ C89/3, para. 17.

${ }^{929}$ Article 2(1) and 3(1) Commission Regulation No 316/2014 on the application of Article 101(3) TFEU to categories of technology transfer agreements [2014] OJ L93/17.

930 Article 2(1) and 3(2) Commission Regulation No 316/2014 on the application of Article 101(3) TFEU to categories of technology transfer agreements [2014] OJ L93/17.

${ }^{931}$ This case and the remedies imposed are discussed in Chapter 2 of Part IV in this Report.
} 


\section{References}

Aragrande, M., et al, Food Supply Chains Dynamics and Quality Certification (EU/DG Joint Research Centre, Brussels 2005).

Bellemare, M.F., 'Contract farming: What's in it for smallholder farmers in developing countries?' (2015) 30(3) Choices 1-4.

Bloom, P.N. \& Gregory T. Gundlach \& Joseph P. Cannon, Slotting Allowances and Fees: Schools of Thought and the Views of Practising Managers, (2000) 64(2) The Journal of Marketing 92-108.

Blumenthal, T., 'Japan's Technological Strategy' (1976) 3 Journal of Development Economics 245-255.

Bukeviciute, L., Adriaan H Dierx and F Ilzkovitz, The Functioning of the Food Supply Chain and Its Effect on Food Prices in the European Union (EC, Directorate-General for Economic and Financial Affairs 2009) available at <http://ec.europa.eu/economy_finance/publications>

Burt, R.S., Structural Holes - The Social Structure of Competition (Harvard Univ. Press, 1995).

Cafaggi, F., 'New Foundations of Transnational Private Regulation' (2010) EUI Working Paper Series RSCAS 2010/53 1.

Cafaggi, F. and Iamiceli, P., Private Regulation and Industrial Organisation: The Network Approach (European University Institute 2012), available at <http://cadmus.eui.eu/bitstream/handle/1814/23264/WP-LAW-2012-21.pdf?sequence=1>

Cafaggi, F. and Watt, H.M., The Regulatory Function of European Private Law (Edward Elgar 2009).

Cahoon, RS, 'Licensing Agreements in Agricultural Biotechnology' in IP Handbook of Best Practices, chapter 11.2, available at <www.iphandbook.org/handbook/ch11/po2/>.

Carstensen, P.C., 'Agricultural Cooperatives and the Law: Obsolete Statutes in a Dynamic Economy’ (2013) 58 S.D. L. R EV . 46.

Carstensen, P.C., Competition Policy and the Control of Buyer Power: A Global Issue (Edward Elgar 2017).

Chaddad, F., 'Advancing the theory of the cooperative organization: The cooperative as a true hybrid' (2012) 83 Annals of Public and Cooperative Economics 445-461. 83.

Chakraborty, D., 'Contract Farming in India' (2009) 1 Review of Market Integration

Darr, A. \& Ioannis Lianos, The 'Hunger Games': Competition Law and the Right to Food, CLES Research paper 4/2017 (forth.).

Das Nair N. and Chisoro, "The expansion of regional supermarket chains and implications for local suppliers", WIDER Working Paper 2017/26.

Das Nair N. and Chisoro, "The expansion of regional supermarket chains and implications for local suppliers”, WIDER Working Paper 2016/169. 
de Schutter, O., Addressing Concentration in Food Supply Chains, Briefing Note 03, December 2010, p. 1.

Desrochers, D.M., Gregory T. Gundlach \& Albert A. Foer, Analysis of Antitrust Challenges to Category Captain Arrangements, (2003) 22(2) Journal of Public Policy \& Marketing 201-215.

Diahanna L. \& David Vogel, The Regulation of GMOs in Europe and the United States: A Case-Study of Contemporary European Regulatory Politics, Council on Foreign Relations (5 April 2013).

ECN, Report on Competition Law Enforcement and Market Monitoring Activities by European Competition Authorities in the Food Sector (2012).

Eller, K-H., Private governance of global value chains from within: lessons from and for transnational law, (2017) Transnational Legal Theory 1-34.

European Commisssion, Communication of the European Commission: A better functioning food supply chain in Europe, $\operatorname{COM}(2009) 591$.

European Commission, High Level Forum for a Better Functioning Food Supply Chain - Final Report (2014), available at <http://ec.europa.eu/growth/toolsdatabases/newsroom/cf/itemdetail.cfm?item_id=7838\&lang=en $>$.

Ezrachi, A., 'Unchallenged Market Power? The Tale of Supermarkets, Private Labels, and Competition Law', (2010) 33(2) World Competition 257-274.

Federal Trade Commission, Slotting Allowances in the Retail Grocery Industry: Selected Case Studies in Five Product Categories (November 2003).

Fels, A. \& M. Lees, Unconscionable conduct in the context of competition law with special reference to retailer/supplier relationships within Australia, Paper presented to the 10th ASCOLA Conference, 21-23 May 2015, p. 28.

Feunteun, T, 'Cartels and the Right to Food: An Analysis of States' Duties and Options' (2015) Journal of International Economic Law. 342.

Foer, A., Introduction to Symposium on Buyer Power and Antitrust, (2005) 72 Antitrust L.J. 505.

Gardner, B.L., 'The Farm-Retail Price Spread in a Competitive Food Industry' (1975) 57 American Journal of Agricultural Economics 399.

Gereffi, G. \& Lee, J. 'A Global Value Chain Approach to Food Safety and Quality Standards' (2009) Global Health Diplomacy for Chronic Disease Prevention Working Paper Series.

Gostek, K, 'Genetically Modified Organisms: How the United States' and the European Union's Regulations Affect the Economy' (2016) 24 Michigan State International Law Review 761.

Granovetter, M., Society and the Economy: Framework and Principles (Harvard Univ. Press, 2017).

Gundlach, G.T. and N. Bloom, 'Slotting Allowances and the Retail Sale of Alcohol Beverages’ (1998) 17 Journal of Public Policy \& Marketing 173-184. 
Henson J. and J. Humphrey, 'Understanding the Complexities of Private Standards in Global Agri-Food Chains as They Impact Developing Countries' (2010) Journal of Development Studies 1628-1646. (2014).

Hill, CW and Gareth R Jones, Strategic Management: Theory: An Integrated Approach

Hooghe, L. and Gary Marks, Multi-Level Governance and European Integration (Rowman \& Littlefield Publishers 2001).

Humphrey, J. and Memdovic, O. 'Global Value Chains in the Agrifood Sector', United Nations Industrial Development Organization Working Paper, Vienna 2006.

Humphrey, J. and Schmitz, H. 'Governance in Global Value Chains', The Value of Value Chains, vol 32 (IDS 2001).

Hutter, B.M., 'Understanding the New Regulatory Governance: Business Perspectives' (2011) 33 Law \& Policy 459.

Inderst, R. and Tommaso M Valletti, 'Buyer Power and the "Waterbed Effect"' (2011) 59 The Journal of Industrial Economics 1.

Kaplan, D \& Morris, M, Potential for Developing Local Suppliers in the Retail Sector Report for Trade and Industrial Policy Strategies (TIPS), May 2017.

Katrak, H, 'Payments for Imported Technologies, Market Rivalry and Adaptive Activity in the Newly Industrializing Countries' (1988) 25 Journal of Development Studies 4353.

Key, N. and Runsten, D. 'Contract farming, smallholders, and rural development in Latin America: the organization of agroprocessing firms and the scale of outgrower production' (1999) 27 World Development 27 381-401.

Kinnucan, HW and Olan D Forker, O.D., 'Asymmetry in Farm-Retail Price Transmission for Major Dairy Products' (1987) 69 American Journal of Agricultural Economics 285.

Kirsten, J. and K. Sartorius, 'Linking agribusiness and small-scale farmers in developing countries: Is there a new role for contract farming?' (2002) 19 Dev. South. Afr. 503-529.

Klein, B., Competitive Resale Price Maintenance in the Absence of Free Riding, (2009) 76 Antitrust L. J. 431.

Klein, B. \& Joshua D. Wright, The Economics of Slotting Contracts, (2007) 50(3) J. of Law \& Economics 421-454.

Larson, B.A. and M. Anderson, 'Technology Transfer, Licensing Contracts, and Incentives for Further Innovation' (1994) 76 American Journal of Agricultural Economics 547556.

Lee, B. Felix Preston \& Gemma Green, Preparing for High-Impact, Low Probability Events (Chatham House, 2012) available at https://www.chathamhouse.org/sites/files/chathamhouse/public/Research/Energy,\%20Enviro nment\%20and\%20Development/r0112 highimpact.pdf.

Lianos, I., 'Polycentric Competition Law' (Current Legal Problems, forth. 2018), CLES Research paper $1 / 2018$ (forth.) 
Lianos, I., Some Reflections on the Vertical Restraints Antitrust Category, (2008) 4 Concurrences 17-26.

Lianos, I, 'Some reflections on the question of the goals of EU competition law' in Lianos, I \& Geradin, D (eds.), Handbook on European Competition Law-Substantive issues (Edward Elgar, 2013), 1-84.

MacDonald, J.M. et al, 'Contracts, markets, and prices: organizing the production and use of agricultural commodities' (2004) Agric. Econ. Rep. 837, Econ. Res. Serv., Dep. Agric., Washington, DC.

Marx, L.M. \& Greg Shaffer, Upfront Payments and Exclusion in Downstream Markets, (2007) 38 (3) Rand Journal of Economics 823-843.

Myhr, A, 'The Precautionary Principle in GMO Regulations' in Terje Traavik and Lim Li Ching (eds), Biosafety First - Holistic Approaches to Risk and Uncertainty in Genetic Engineering and Genetically Modified Organisms (Third World Network and GenØk 2009).

OECD, Competition in the Food Chain, vol DAF/COMP(2013)15 (OECD 2013).

OECD, Competition Issues in the Food Chain Industry DAF/COMP(2014)16.

OECD and World Bank, Inclusive Global Value Chains Policy options in trade and complementary areas for GVC Integration by small and medium enterprises and low-income developing countries, Report prepared for submission to G20 Trade Ministers Meeting Istanbul, Turkey, 6 October 2015.

Ogus, A., Regulation: Legal Form and Economic Theory (Hart 2004).

Otsuka, K., Y. Nakano and K. Takahashi, 'Contract Farming in Developed and Developing Countries' (2016) 8 Annual Review of Resource Economics 353-376.

Pollack, M. and G. Shaffer, 'Risk regulation, GMOs, and the limits of deliberation' in D. Naurin and H. Wallace (eds), Unveiling the Council of the European Union: Games Governments Play in Brussels (Palgrave MacMillan, 2008), 161.

Poulton, C. A. Dorward and J. Kydd, 'The future of small farms: new directions for services, institutions, and intermediation' (2010) 38 World Development 1413-1428.

Poulton, C. and M.C. Lyne, 'Coordination for market development' in Institutional economics perspectives on African agricultural development, 135-184.

Pultrone, C. 'An Overview of Contract Farming: Legal Issues and Challenges' (2012) 17 Uniform law review Uniform Law Review 263.

Reardon, C.P. Timmer, C.B. Barrett and J. Berdegué, 'The rise of supermarkets in Africa, Asia, and Latin America' (2003) 85 American Journal of Agriculture Economics 11401146.

Rey, R., Jeanine Thal \& Thibaud Vergé, Slotting Allowances and Conditional Payments (July 4, 2006).

Sartorius, K. and J. Kirsten, 'A framework to facilitate institutional arrangements for smallholder supply in developing countries: an agribusiness perspective' (2007) 32 Food Policy 640-655.

Shaffer, G., Slotting Allowances and Optimal Product Variety, (2005) 5(1) Advances in Economic Analysis \& Policy, Article 3.. 
Shaffer, G., Slotting Allowances and Resale Price Maintenance: A Comparison of Facilitating Practices, (1991) 22 Rand Journal of Economics 120-136.

Shield, D.A., Federal Crop Insurance: Background and Issues,Congressional Research Service (17 April 2009).

Singh, S., 'Contract Farming for Agricultural Development and Diversification in Punjab: Problems and Prospects’ (2005) 12 Journal of Punjab Studies 251.

Staahl Gabrielsen, T. and L Sørgard, 'Private Labels, Price Rivalry, and Public Policy' [2007] 51 European Economic Review 403, 404.

Steiner, S.T, 'The Nature and Benefits of National Brand/Private Label Competition' (2004) 24 Review of Industrial Organization 105.

Sullivan, M.W., Slotting Allowances and the Market for New Products, (1997) 40 Journal of Law \& Economics 461-493.

Swinnen, J., Global Agricultural Value Chains, Standards, and Development, EUI Working Papers RSCAS 2014/30.

Swinnen, J. and R. Kuijpers, 'Value Chain Innovations for Technology Transfer in Developing and Emerging Economies: Conceptual Issues, Typology, and Policy Implications (2017) Food Policy 1.

Swinnen, J. and A. Vandeplas, 'Rich consumers and poor producers: quality and rent distribution in global value chains' (2011) 2 Journal of Globalization and Development 130 .

Taleb, N.N., The Black Swan: The Impact of the Highly Improbable (Penguin, 2008).

UK Competition Commission, The Supply of groceries in the UK market investigation (April 30, 2008), available at http://www.competitioncommission.org.uk/rep_pub/reports/2008/538grocery.htm.

USDA, 'Competition and Agriculture: Voices from the Workshops on Agriculture and Antitrust Enforcement in Our 21st Century Economy and Thoughts on the Way Forward' [2012] U.S. Department of Justice.

Vavra, P. and Barry Goodwin, Analysis of Price Transmission Along the Food Chain (OECD Publishing 2005).

Viviano, E, 'Entry Regulations and Labour Market Outcomes: Evidence from the Italian Retail Trade Sector' (2008) 15 Labour Economics 1200. Law Rev 4.

Vogel, L., Competition Law and Buying Power, (1998) 19(1) European Competition

Ward, M.B. and others, "Effects of the Private-Label Invasion in Foods Industries" (2002) 844 American Journal of Agricultural Economics 961-973.

Warning \& N. Key, 'The social performance and distributional consequences of contract farming: an equilibrium analysis of the arachide de bouche program in Senegal' (2002) 30 World Development 255-263.

Wright, JD, An Antitrust Analysis of Category Management: Conwood Co. v. United States Tobacco Co., 17 Supreme Court Economic Review 311 (2009).

Wright, J.D., Slotting Contracts and Consumer Welfare, 74(2) Antitrust Law Journal 439-473. 


\section{Tables and Figures}

Table 1: Policy responses to market dominance....170

Table 2: Overview of the main practices that may give rise to competition concerns...172 Table 3: Consumer protection in BRICS...178 
Chapter 2: Competition Law enforcement activity in BRICS and the food value chain

Ioannis Lianos, Matthew Strader, Amber Darr, Justin Lindeboom, Christina Kanakari, Murilo Lubambo, Bo Wang, Patricia Semensato Cabral, Yedda Beatriz Seixas, Mariane Cortat de Campos Melo

\subsection{The enforcement activity of the BRICS competition authorities in the food sector}

\subsubsection{Enforcement statistics}

We have collected and coded 1105 merger cases and 282 infringement cases from the five BRICS jurisdictions during the period 2004-2017 concerning the various segments of the food value chain. Most of these cases concern the period between 2008-2017 (first quarter): 181 infringement cases and 529 merger cases. In particular, for the period 2008-2017 we have coded 137 merger cases from South Africa, 47 merger cases from Russia, 78 merger cases from India, 20 merger cases from China, 247 merger cases from Brazil. For the same period, we have coded 60 infringement cases from South Africa, 48 infringement cases from Russia, 18 infringement cases from India, 23 infringement cases from China, and 32 infringement cases from Brazil.

Our results are still provisional as we are to finalize some additional coding and we expect to receive feedback from the BRICS competition authorities. However, we include these provisional statistics in order to provide the bigger picture on antitrust enforcement priorities and the segments of the food value chain that have attracted the interest of the BRICS competition authorities the last decade.

\subsubsection{Aggregate BRICS mergers}

Table 1: Distribution of supply chain types BRICS aggregate mergers

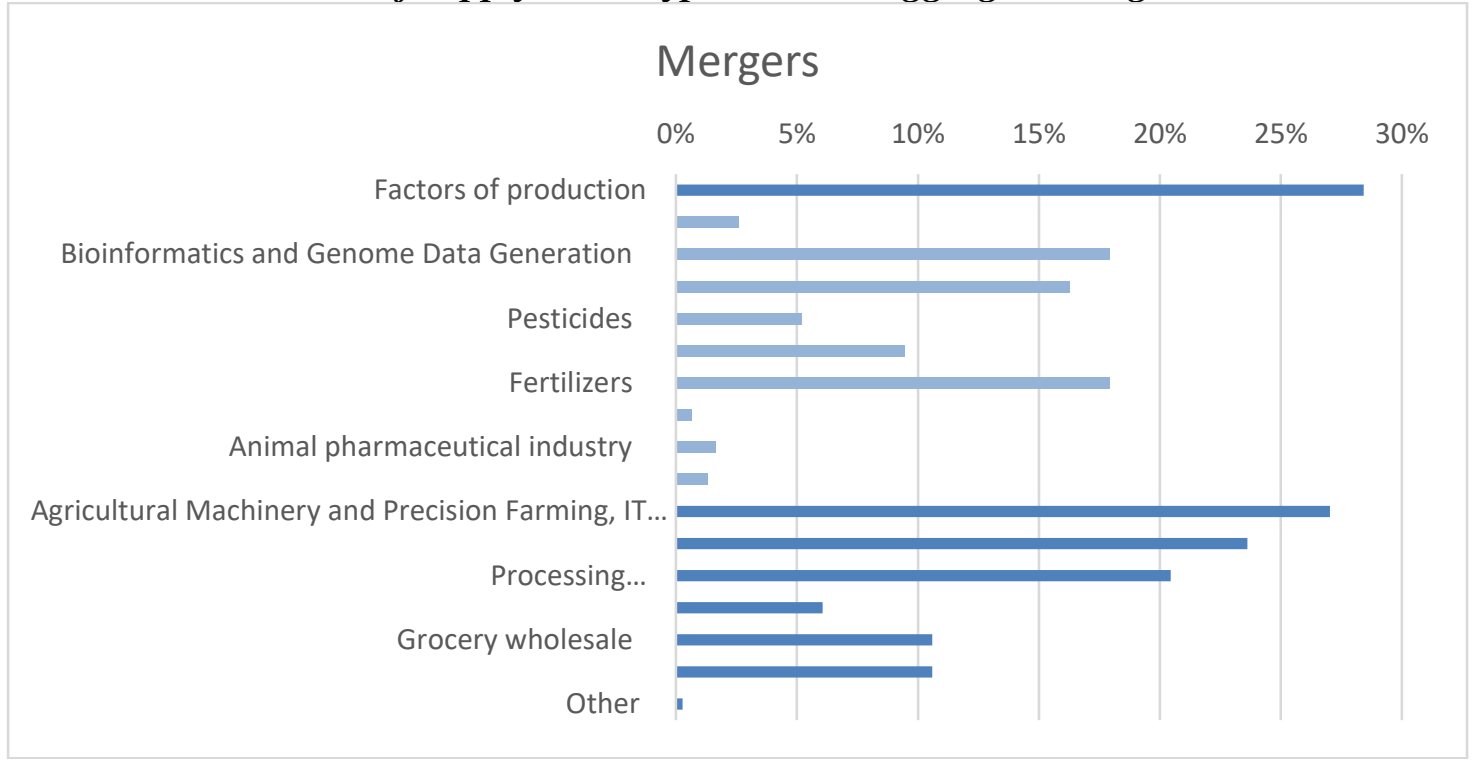

Source: authors' compiled statistics 
Table 1 visualizes the distribution of supply chain types in all merger cases concerning the food sector in the BRICS countries. Taking all BRICS countries into account, most merger cases concerned the processing supply chain level (24\%) followed by retail $(21 \%)$, factors of production $(21 \%)$ and manufacturing $(20 \%)$. Significantly fewer merger cases have been reported in the farming and grocery wholesale levels.

\section{Table 2: Distribution of products BRICS aggregate mergers}

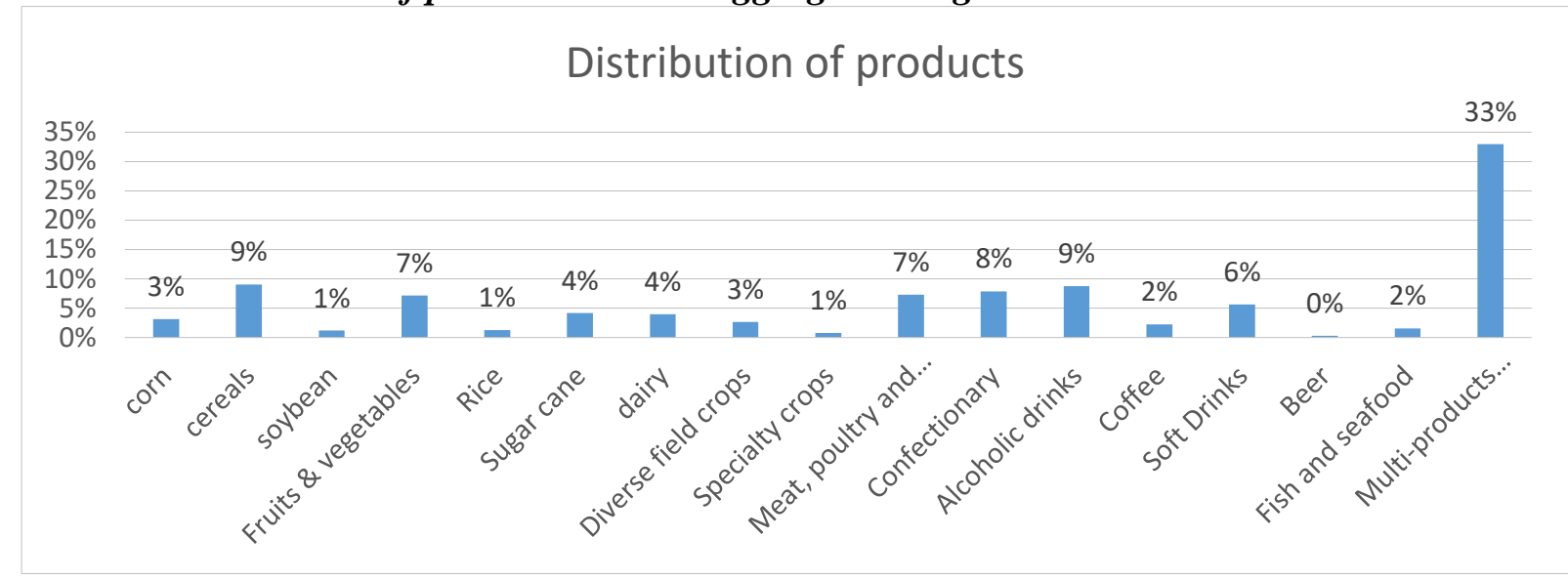

Source: authors' compiled statistics

In table 2, the merger cases in the BRICS countries concerning the food sector are classified according to the type of products involved. As we can see, most of the single-product mergers concerned cereals $(9 \%)$, alcoholic drinks $(9 \%)$, confectionary $(8 \%)$, meat, poultry and eggs $(7 \%)$, and $6 \%$ soft drinks. Others single-product mergers are significantly less prevalent. The largest category of merger cases in the food sector, however, concerned multi-product activities and/or other product types $(33 \%)$.

\subsubsection{Aggregate BRICS infringements}

Table 3: distribution of supply chain types BRICS aggregate infringements 


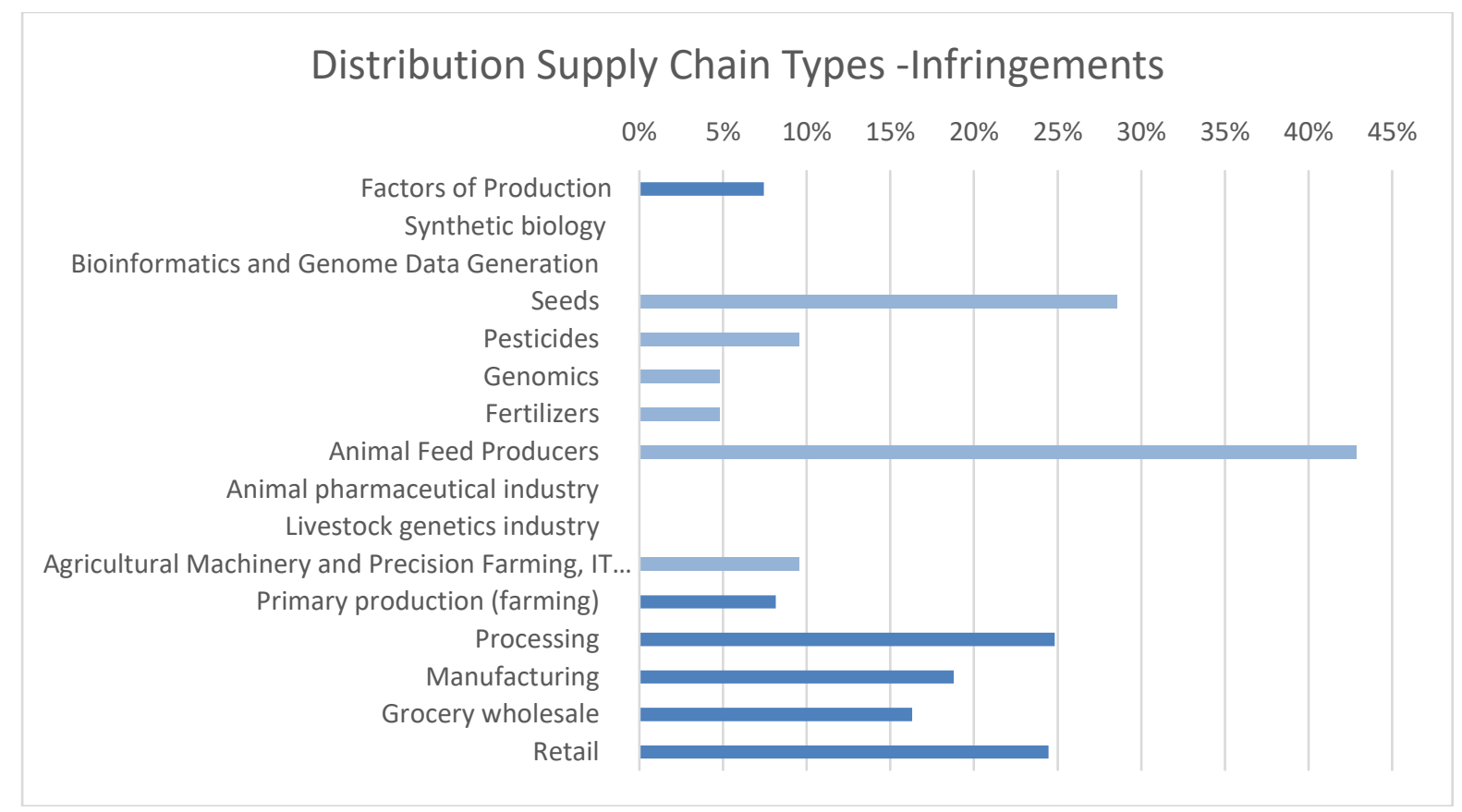

\section{Source: authors' compiled statistics}

Table 3 describes the distribution of infringement cases (antitrust) concerning the food sector in all BRICS countries combined according to the level of the supply chain involved. As we can see, almost half of all infringement cases concerned either the processing level $(25 \%)$ or the retail level (24\%). Only $15 \%$ of the infringement cases dealt with the factors of production (7\%) and primary production (farming) (8\%), while the overwhelming majority of infringement cases concerned supply chain levels more downstream.

\section{Table 4: distribution of infringement types by products BRICS aggregate infringements}

\section{Distribution of infringement types by products}

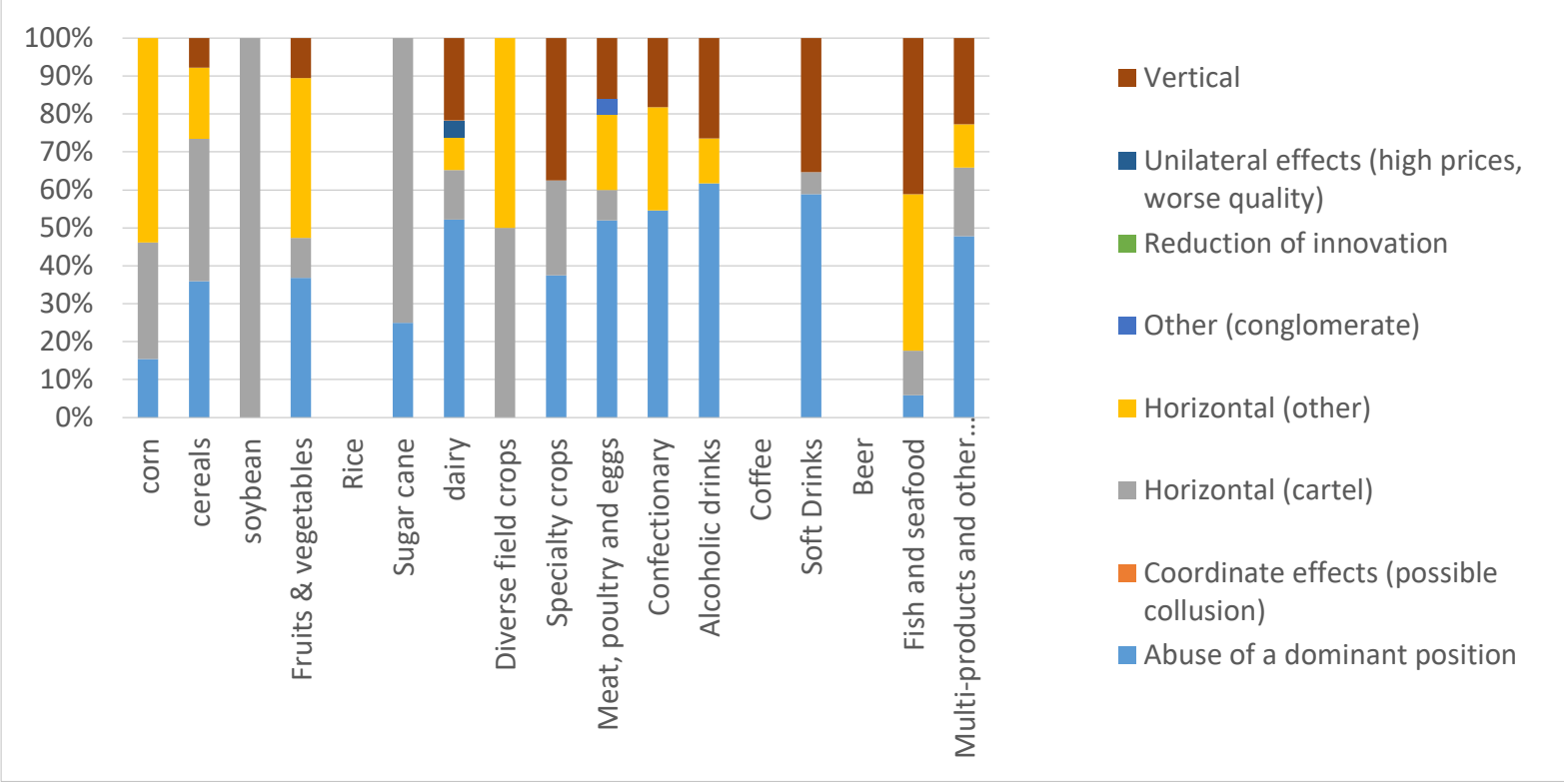

Source: authors' compiled statistics 
Table 4 describes the various infringement types for each product category in the aggregate BRICS food sector infringement cases. While there is substantial variety among the product categories in the types of infringements, abuse of a dominant position cases are prevalent in most of the product categories (with the exception of e.g. corn, and fish and seafood). Notably vertical infringements are also a substantial part of the dairy, specialty crops, meat, poultry and eggs, confectionary, alcoholic drinks, soft drinks, fish and seafood, and multi-products / other products categories, accounting for roughly 15 to $40 \%$. For some product categories, cartel infringements take up a very significant share of total infringements, for example in soybeans (only cartel infringement), sugar cane, and diverse field crops, whereas in other product categories there have been virtually no cartel cases (for example soft drinks and fish and seafood).

\section{Table 5: distribution of products BRICS aggregate infringements}

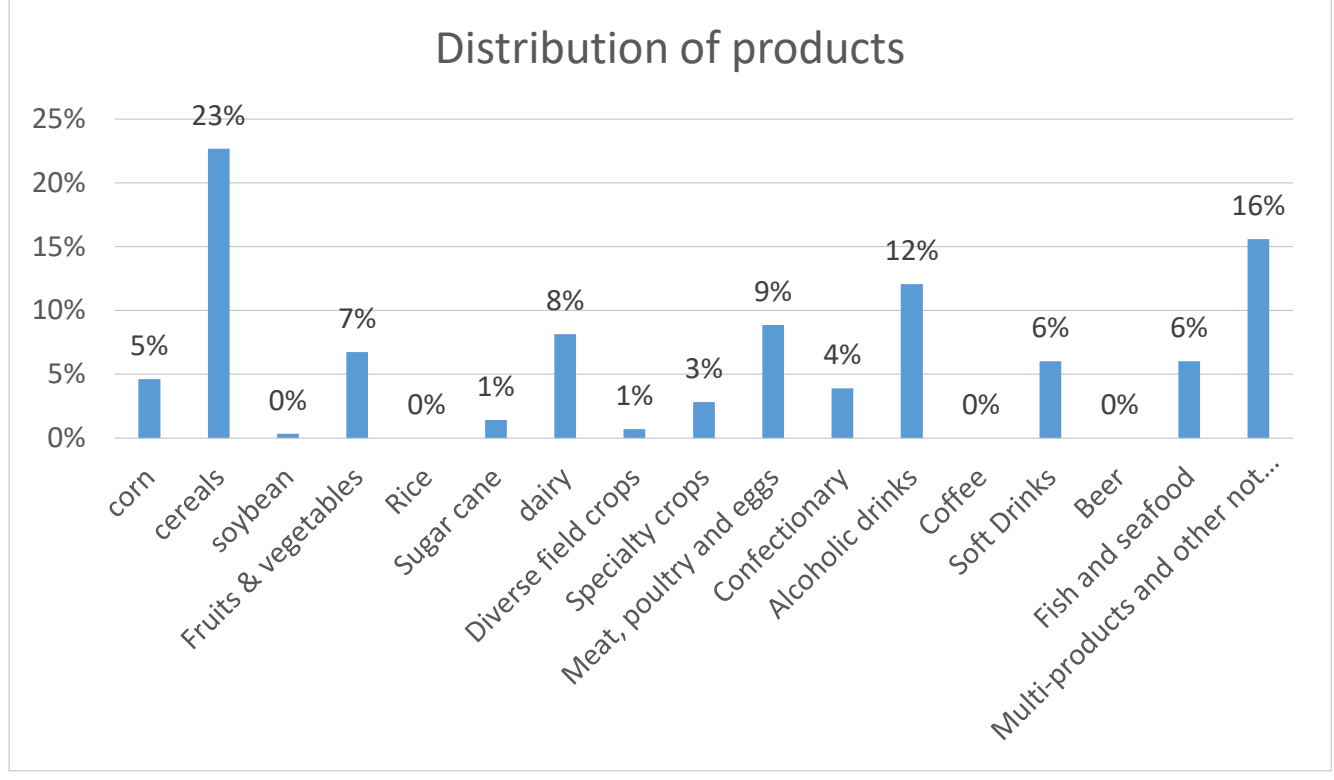

Source: authors' compiled statistics

Table 5 describes the aggregate BRICS infringement cases (antitrust) categorised according to product type. Compared with the aggregate BRICS merger cases (see Table 2), a substantially lower percentage of cases concerns multi-products and miscellaneous products (16\% compared with $33 \%$ for merger cases). The largest product category is cereals which reflects almost a quarter $(23 \%)$ of all infringement cases. Alcoholic drinks (12\%), meat, poultry and eggs (9\%) and dairy $(8 \%)$ are far less prevalent in the infringement statistics, with the other product types taking an even lower share. Notably, there were no infringements in the soybean, rice, coffee, and beer product categories.

Table 6: distribution of reasons for proceeding by infringement types BRICS aggregate 


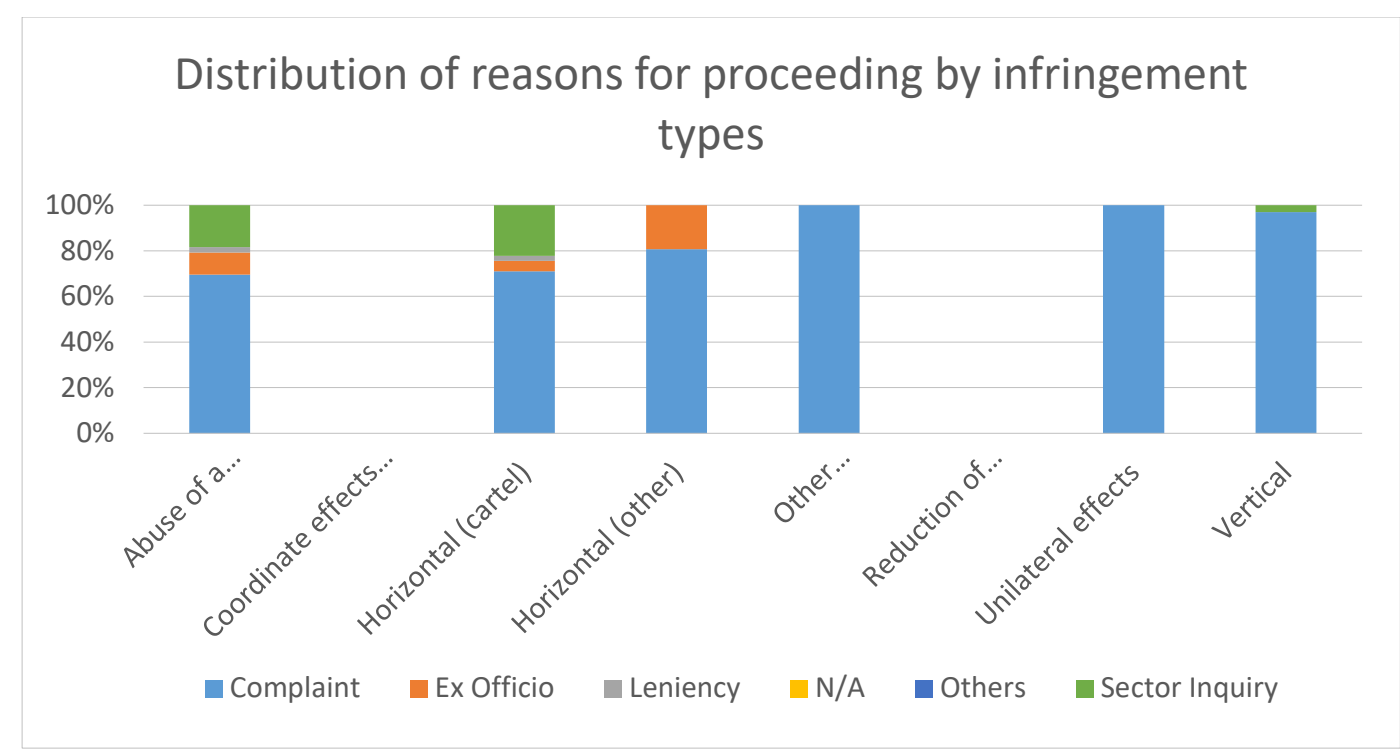

Source: authors' compiled statistics

Table 6 provides a distribution of the reasons for starting infringement proceedings in the BRICS countries for each infringement type. For all types of infringements, complaints have been the most prevalent reason for starting the procedure. All unilateral effects infringements procedures have been started because of a complaint, as well as almost vertical infringement cases. Sector inquiries have been a comparatively important reason for proceedings in abuse of a dominant position and cartel cases. Leniency is (virtually) excluded as a reason for starting proceedings for all infringement types.

\section{Table 7: infringement proceedings by infringement type BRICS aggregate}

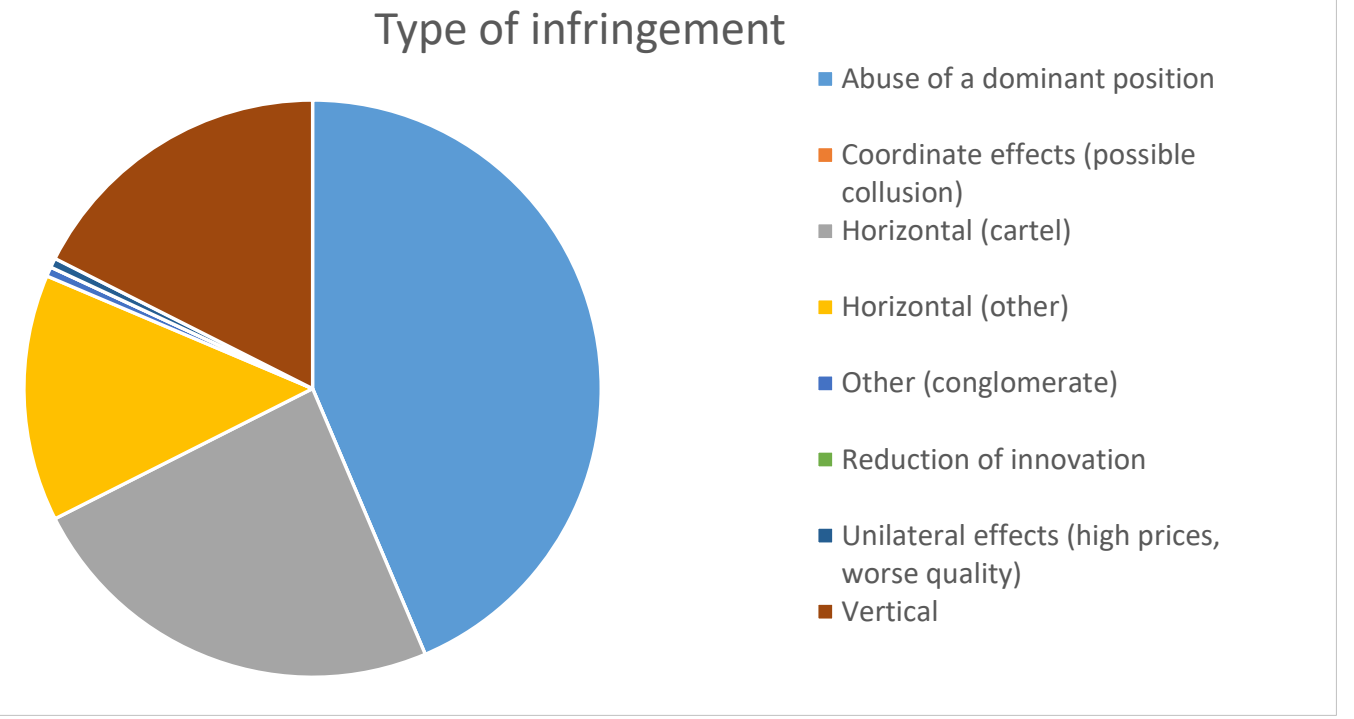

Source: authors' compiled statistics

Table 7 provides a pie chart of the infringement proceedings in the BRICS countries according to the type of infringement. The primary reason for starting infringement proceedings has been abuse of a dominant position. Horizontal cartel cases, horizontal non-cartel cases, and vertical 
restrictions are the other main reasons for starting proceedings. Other types of infringement have only sparsely given rise to infringement proceedings.

\section{Table 8: distribution of infringement types BRICS aggregate infringements}

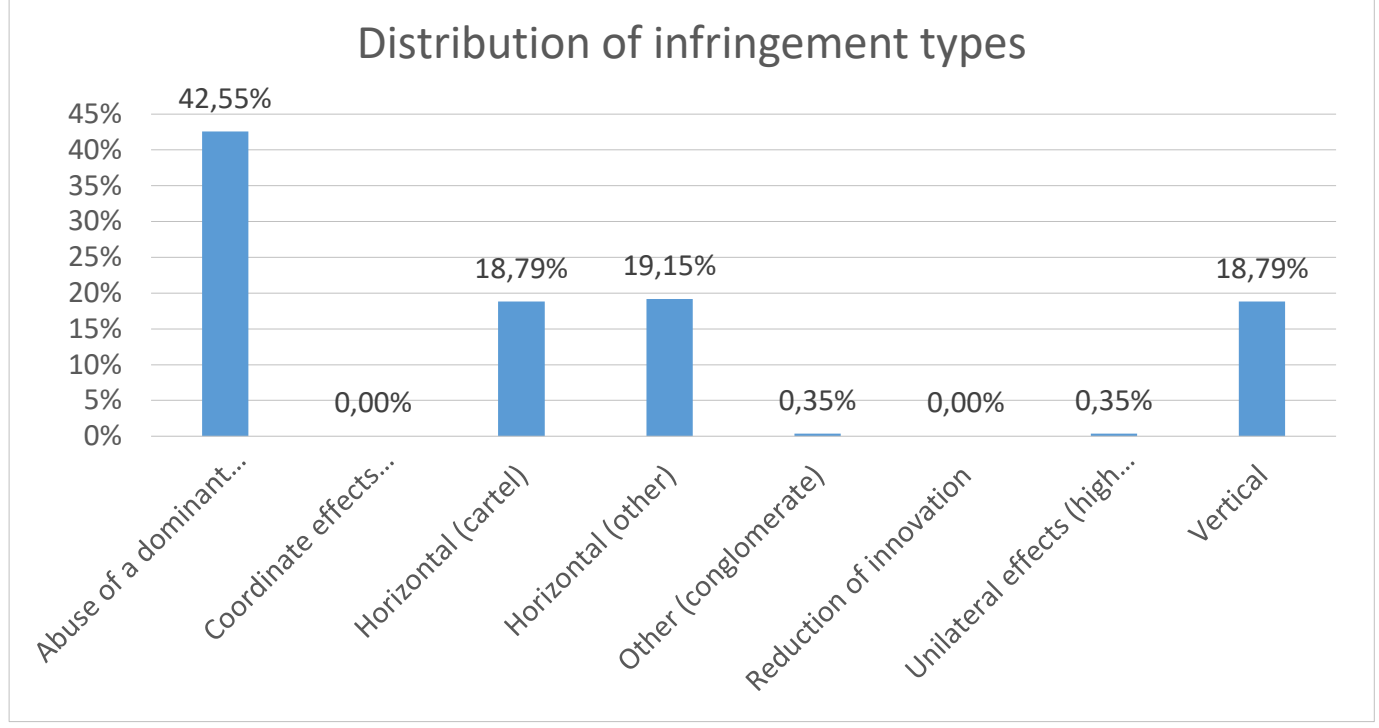

Source: authors' compiled statistics

Table 8 describes a categorization of the aggregate infringements in BRICS based on infringement types. Most infringements that were established concerned abuse of a dominant position $(42.55 \%)$. Horizontal cartel infringements, horizontal non-cartel infringements, and vertical restrictions each account for just under $20 \%$ of total infringements in BRICS.

\subsubsection{Brazil mergers}

Table 9: distribution of supply chain types Brazil mergers

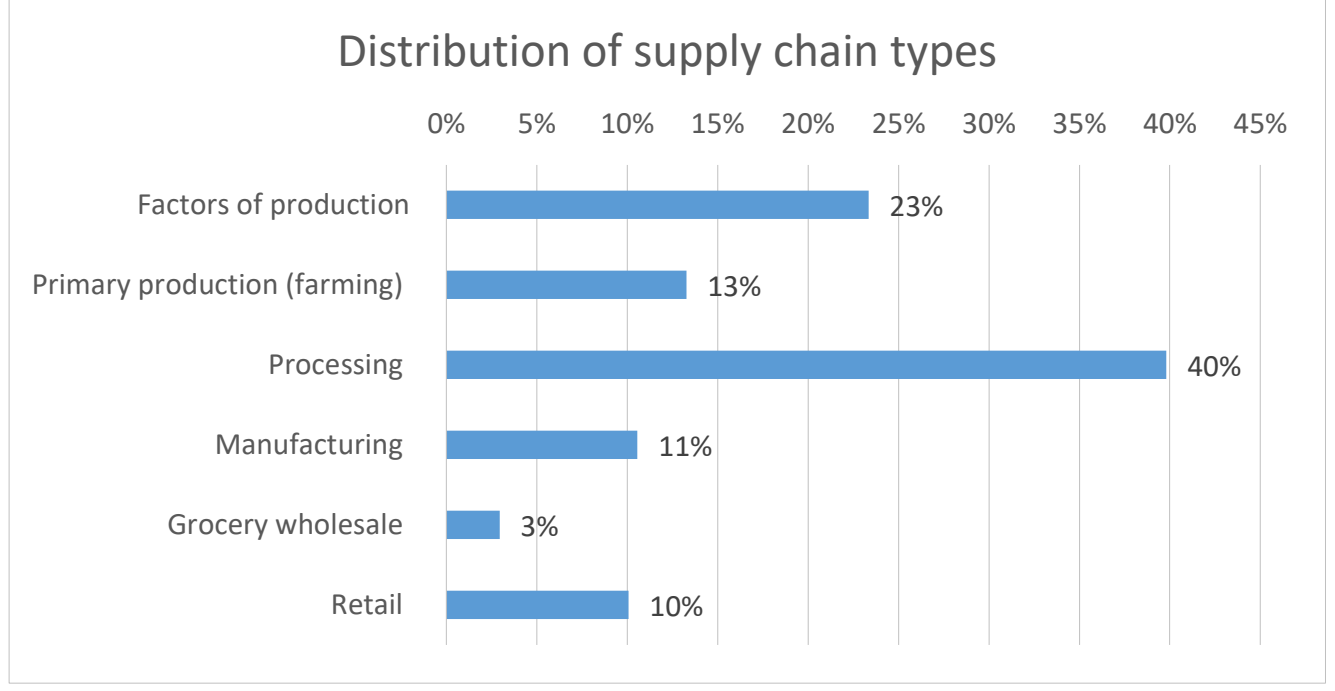

Source: authors' compiled statistics 
Table 9 visualizes the distribution of supply chain types in all merger cases concerning the food sector in Brazil. Of these merger cases, $40 \%$ applied to the processing level of the supply chain. This share of the processing level is substantially higher than that of the cases concerning factors of production. The other levels of the supply chain are far less prevalent, with grocery wholesale only accounting for $3 \%$ of the cases.

\section{Table 10: distribution of products Brazil mergers}

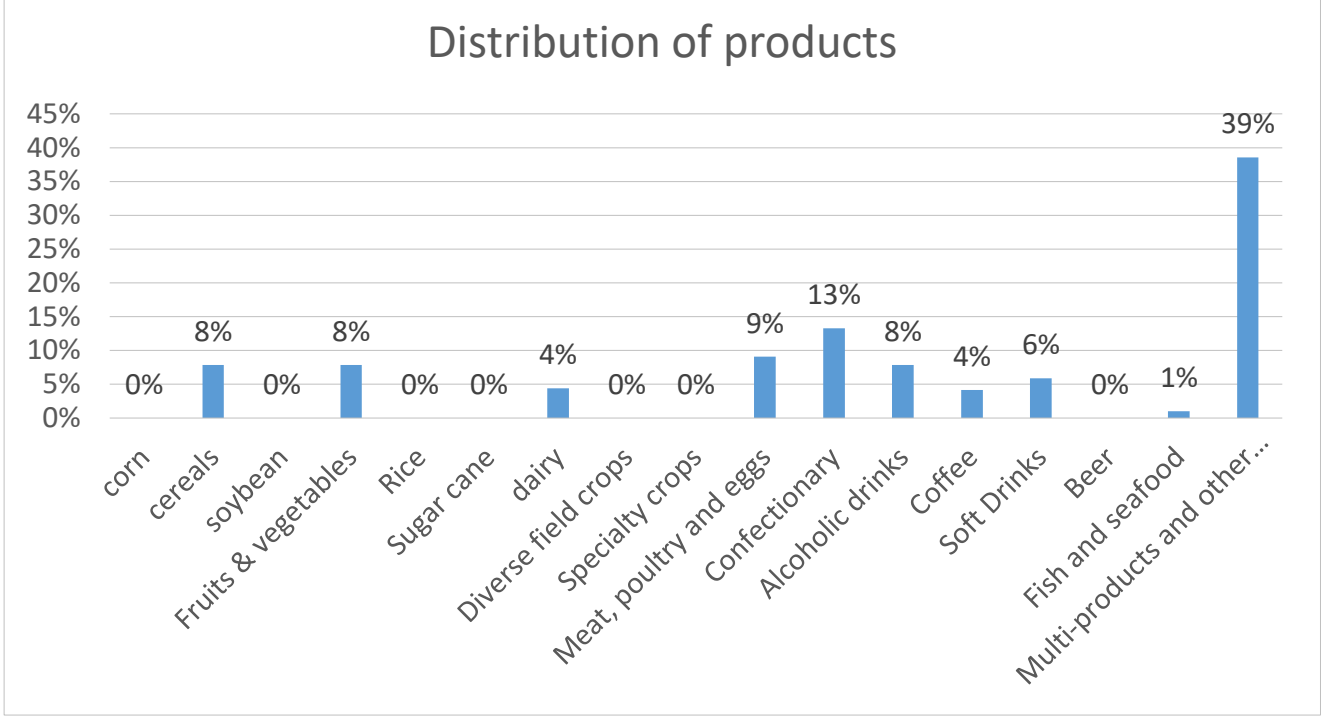

Source: authors' compiled statistics

In table 10, the merger cases in Brazil concerning the food sector are classified according to the type of products involved. Among single-product related mergers, confectionary (13\%)and meat, poultry and eggs (9\%) are most prevalent, with cereals, fruits and vegetables, and alcoholic drinks following with $8 \%$ each. However, the largest category of products is, by far, multi-products and other products, counting for 39\% of all merger cases in Brazil.

\subsubsection{Brazil infringements}

Table 11: distribution of supply chain types Brazil infringements 


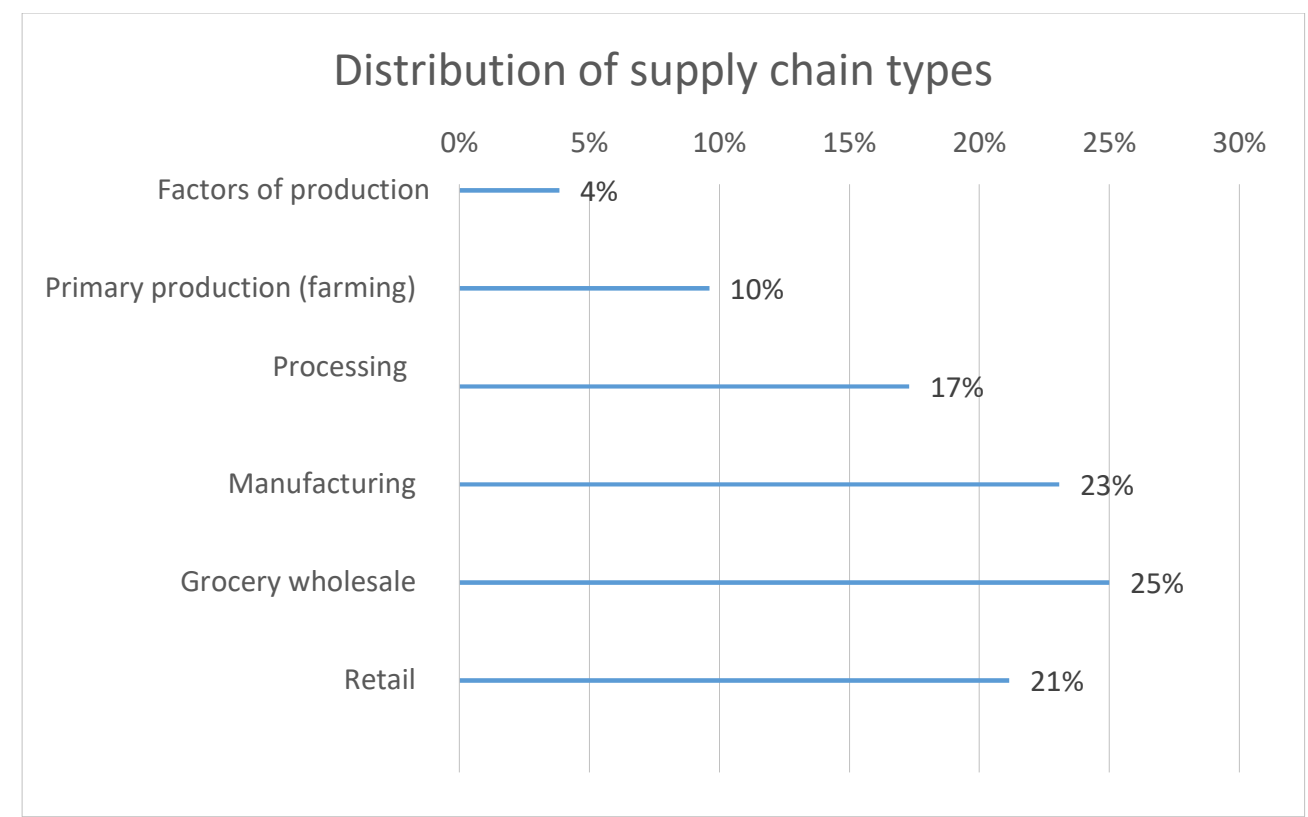

Source: authors' compiled statistics

Table 11 describes the distribution of infringement cases (antitrust) concerning the food sector in Brazil according to the level of the supply chain involved. Most infringement cases are situated in the more downstream levels of the supply chain, in particular grocery wholesale (25\%), manufacturing (23\%) and retail (21\%). In contrast, factors of production and primary production (farming) have experienced significantly fewer antitrust enforcement cases with $4 \%$ and $10 \%$ of the total number of infringements cases respectively.

\section{Table 12: distribution of infringement types by products Brazil infringements}

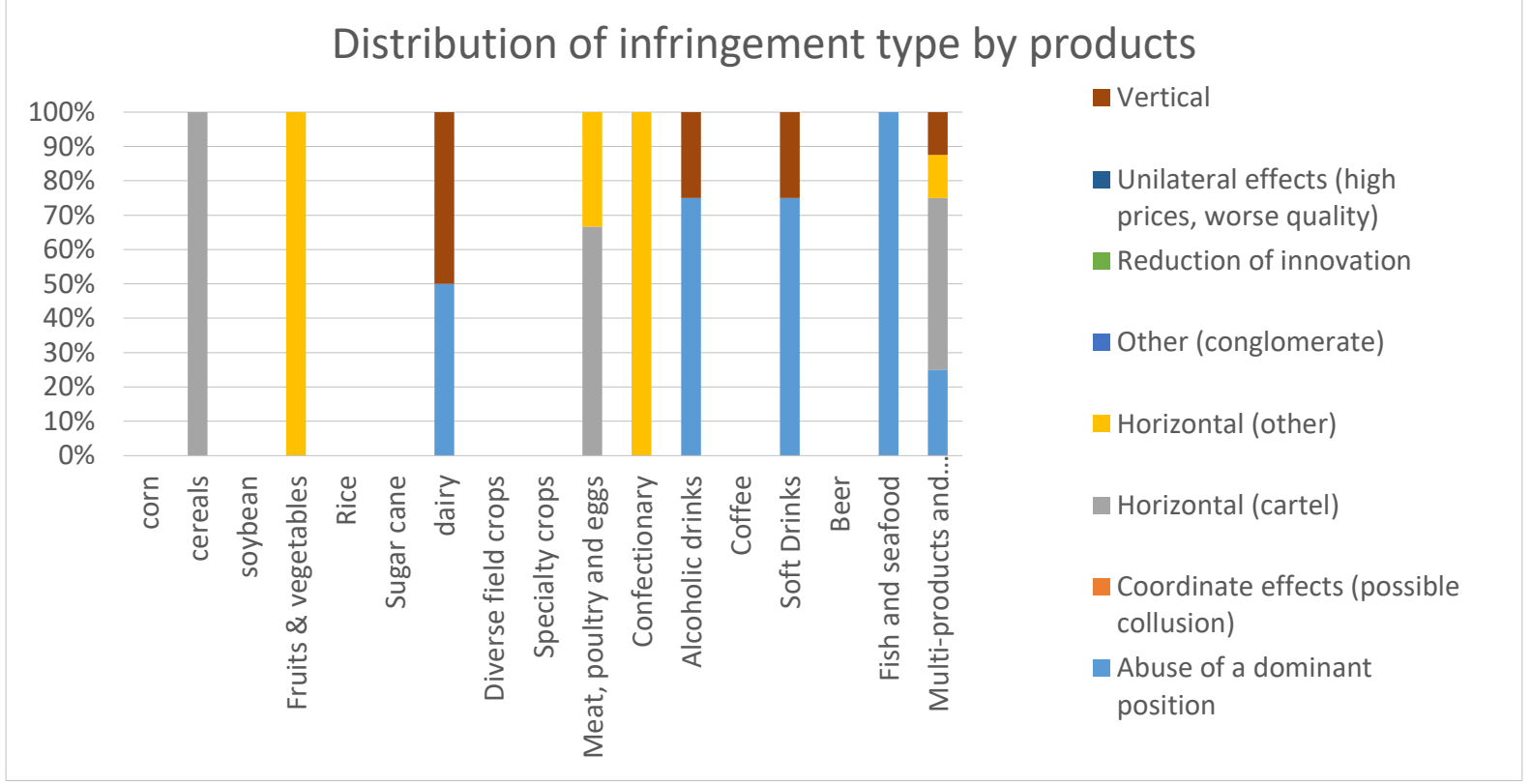

Source: authors' compiled statistics 
Table 12 describes the various infringement types for each product category in Brazil's infringement cases (antitrust) concerning the food sector. Among the product types there is wide divergence as to the types of infringement cases. Whereas for example there have only been non-cartel horizontal infringements in the fruits and vegetables ( 1 case) and confectionary product type (3 cases), the fish and seafood segment has only had 1 abuse of a dominant position case while there have only been cartel cases ( 4 in total) in cereals.

\section{Table 13: distribution of products Brazil infringements}

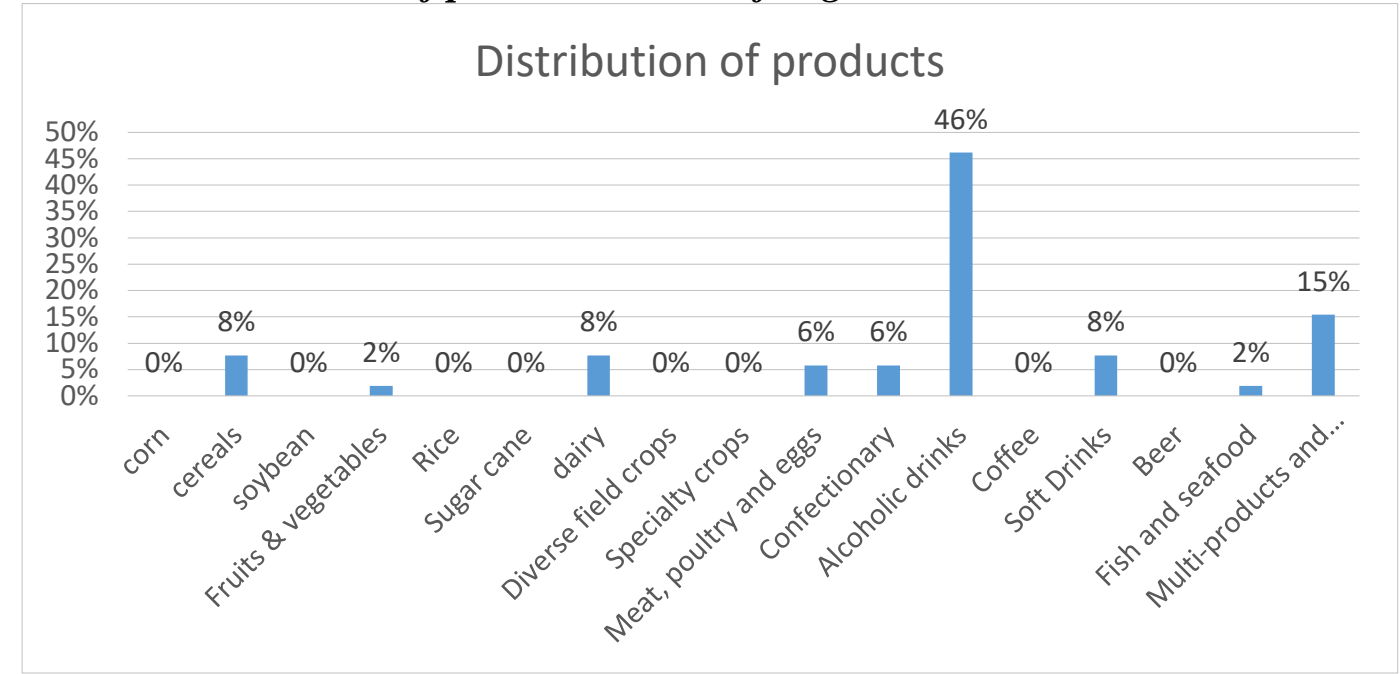

Source: authors' compiled statistics

Table 13 describes the infringement cases (antitrust) in Brazil categorised according to product type. Particularly notable is that almost half of all infringement cases concerned alcoholic drinks (18 cases, i.e. $46 \%$ ). This percentage is far above that of any other single-product type. Cereals, dairy, and soft drinks each count for $8 \%$ (4 cases), and $15 \%$ of the cases ( 8 in total) concerned infringements regarding multi-products or other products not included.

\section{Table 14: distribution of reasons for proceeding by infringement types Brazil}

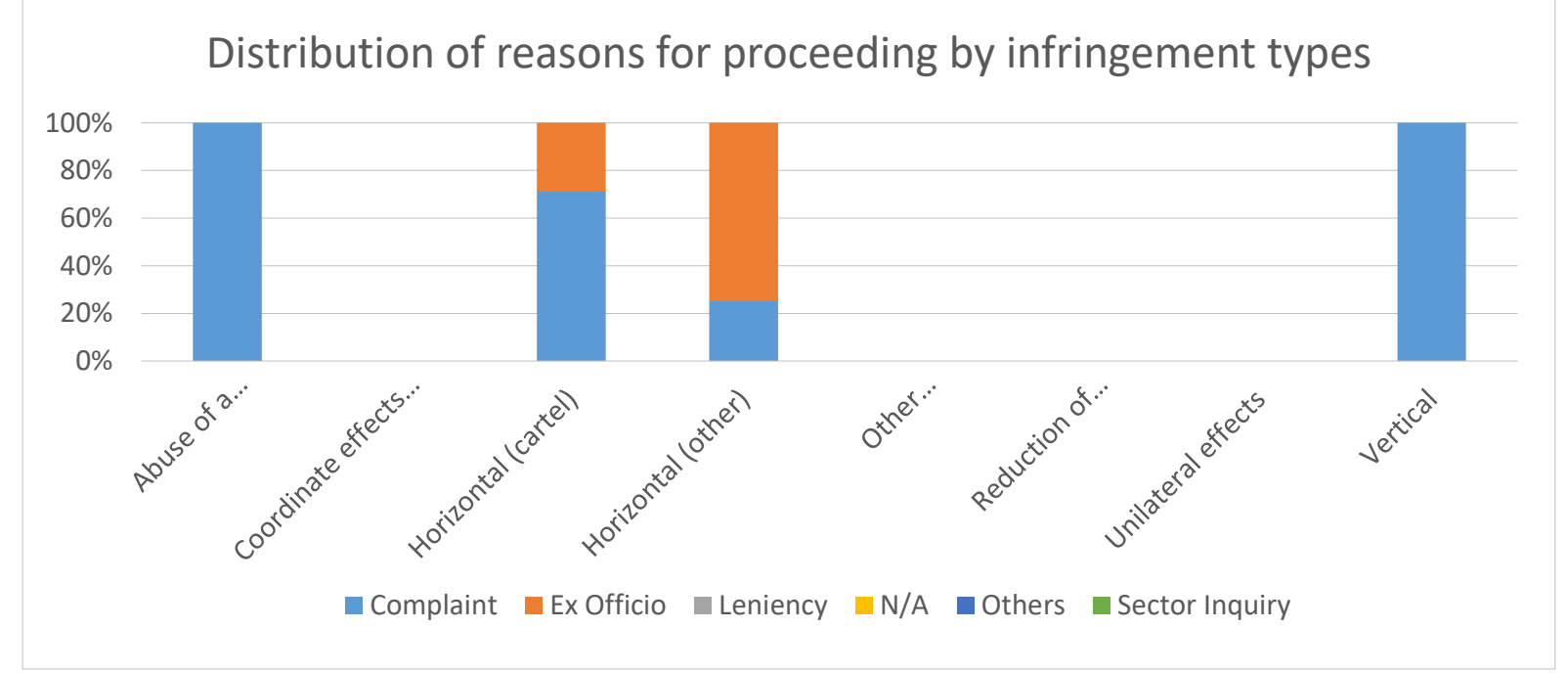

Source: authors' compiled statistics 
Table 14 provides a distribution of the reasons for starting infringement proceedings in Brazil for each infringement type. Cases concerning abuse of a dominant position and vertical restraints were all initiated following complaints, which was also the case in the majority of cartel cases. By contrast, non-cartel horizontal infringements have been instigated mostly ex officio.

Table 15: infringement proceedings by infringement type Brazil

Type of infringement

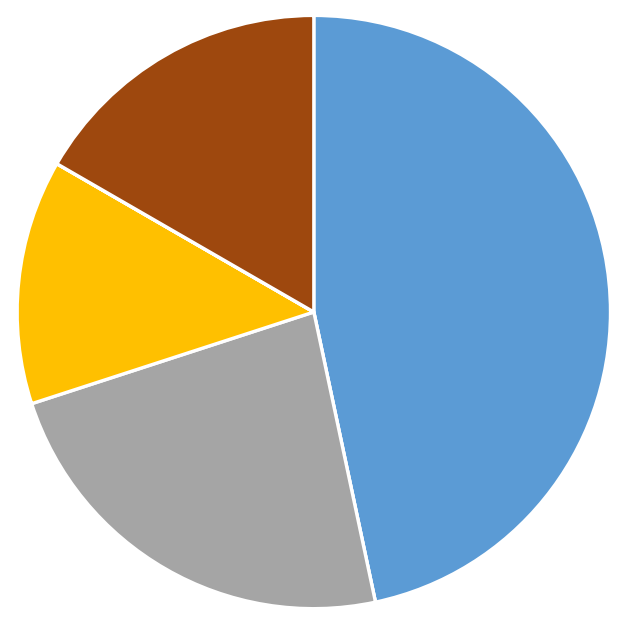

- Abuse of a dominant position

- Coordinate effects (possible collusion)

- Horizontal (cartel)

- Horizontal (other)

- Other (conglomerate)

- Reduction of innovation

- Unilateral effects

vertical

Source: authors' compiled statistics

Table 15 provides a pie chart of the infringement proceedings in Brazil according to the type of infringement. In Brazil, almost half of the total infringement proceedings concerned abuse of a dominant position. The second-largest category of infringement proceedings concerned horizontal cartel cases, and the other proceedings dealt with horizontal non-cartel cases and vertical restrictions.

Table 16: distribution of infringement types Brazil infringements 


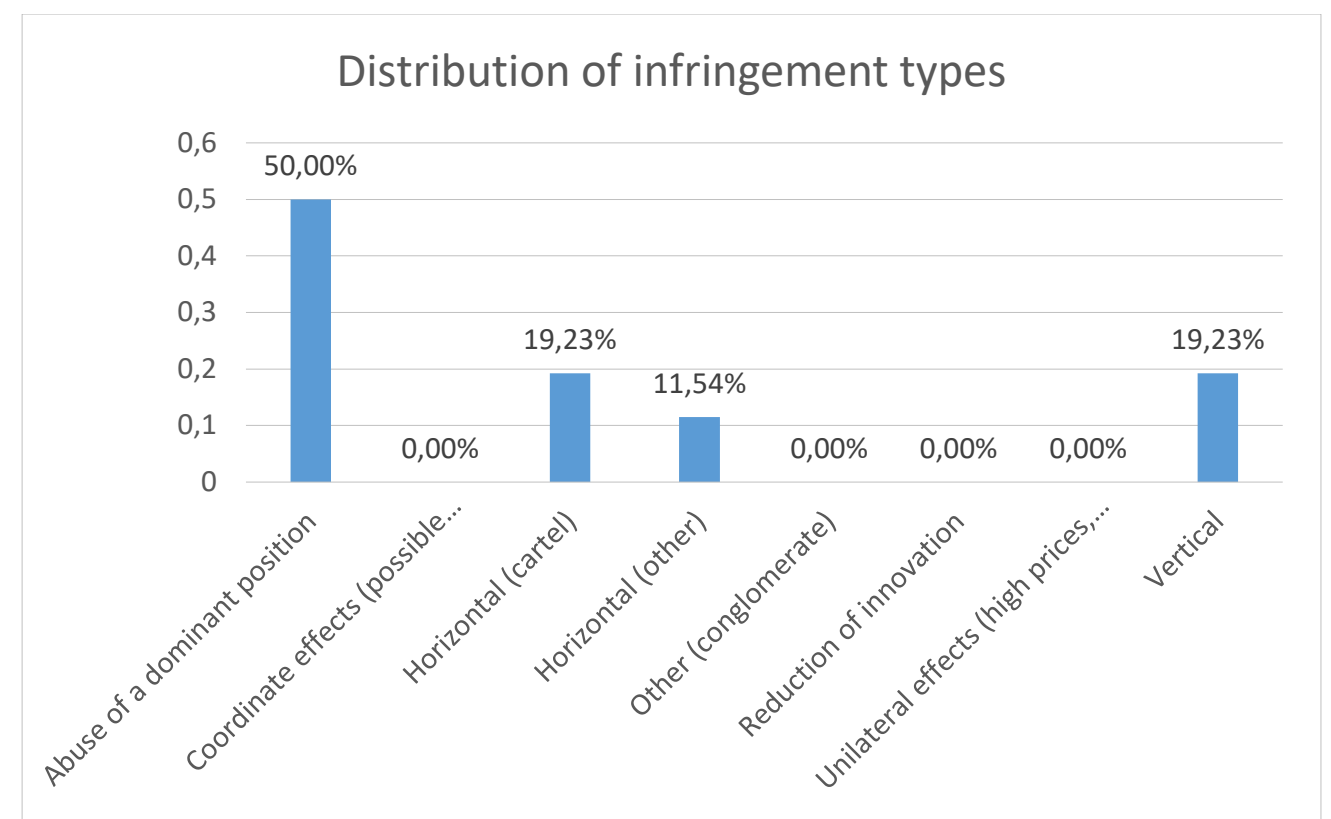

Source: authors' compiled statistics

Table 16 describes a categorization of the infringements in Brazil based on infringement types. Exactly half of the total number of infringements was an abuse of a dominant position $(50.00 \%)$. Horizontal cartels infringements and vertical restraints each represented $19.23 \%$ of the total number of infringements, and horizontal non-cartel cases accounted for $11.54 \%$. No other types of infringements have been found.

\subsubsection{Russia mergers}

Table 17: distribution of supply chain types Russia mergers

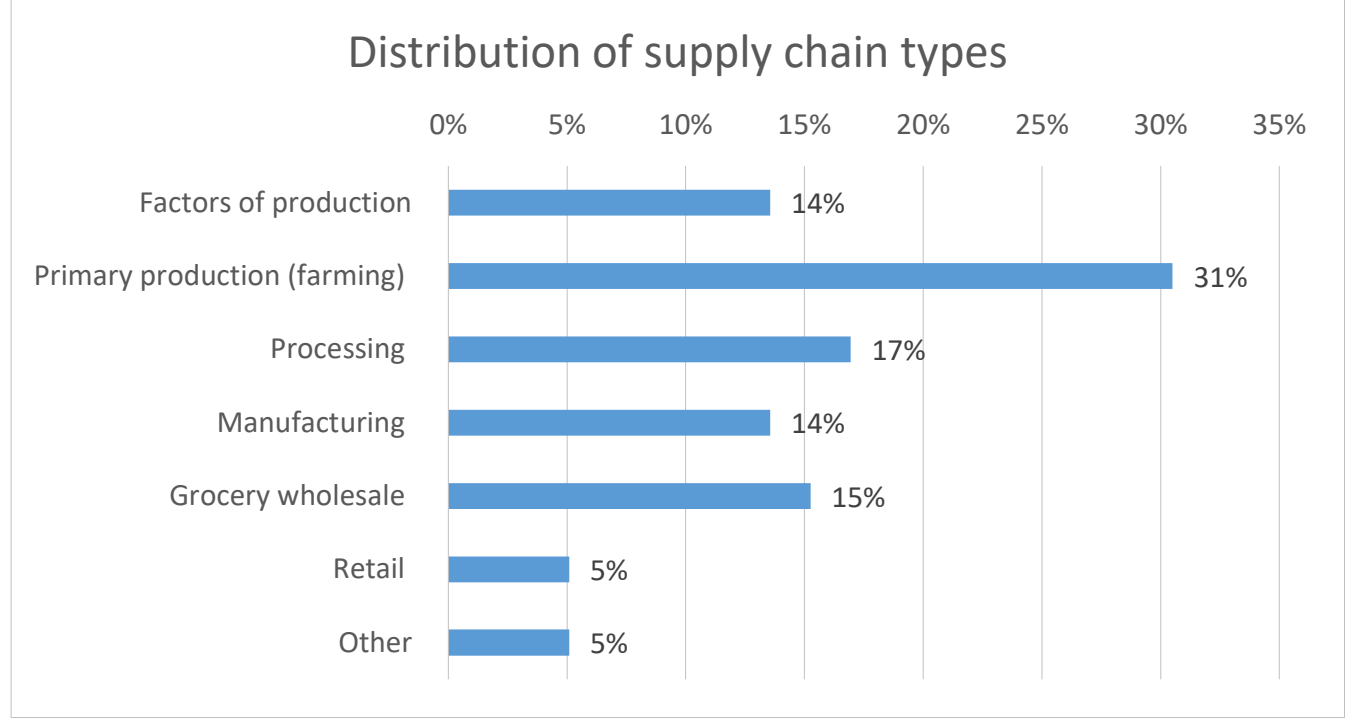

Source: authors' compiled statistics

Table 17 visualizes the distribution of supply chain types in all merger cases concerning the food sector in Russia. The largest number of food sector mergers took place within primary 
production (farming) (31\%). With factors of production, processing, manufacturing and grocery wholesale levels each counting for $14 \%$ to $17 \%$, the retail level had appreciably fewer merger activity with only $5 \%$ of the total number.

\section{Table 18: distribution of products Russia mergers}

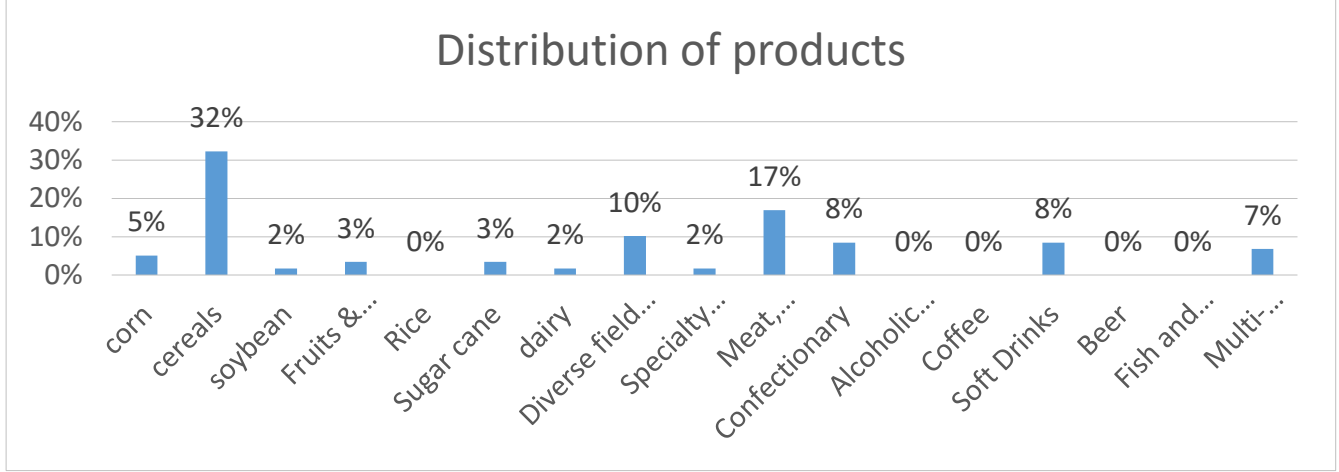

Source: authors' compiled statistics

In table 18, the merger cases in Russia concerning the food sector are classified according to the type of products involved. Almost one-third of food sector mergers concerned the cereals market (32\%), followed by meat (17\%) and diverse field crops (10\%). Only $7 \%$ of mergers in Russia concerned multi-products or other product, which is very low in comparison with the other BRICS jurisdictions (compare with table 10 (Brazil), table 26 (India), table 34 (China) and table 42 (South Africa)).

\subsubsection{Russia infringements}

Table 19: distribution of supply chain types Russia infringements

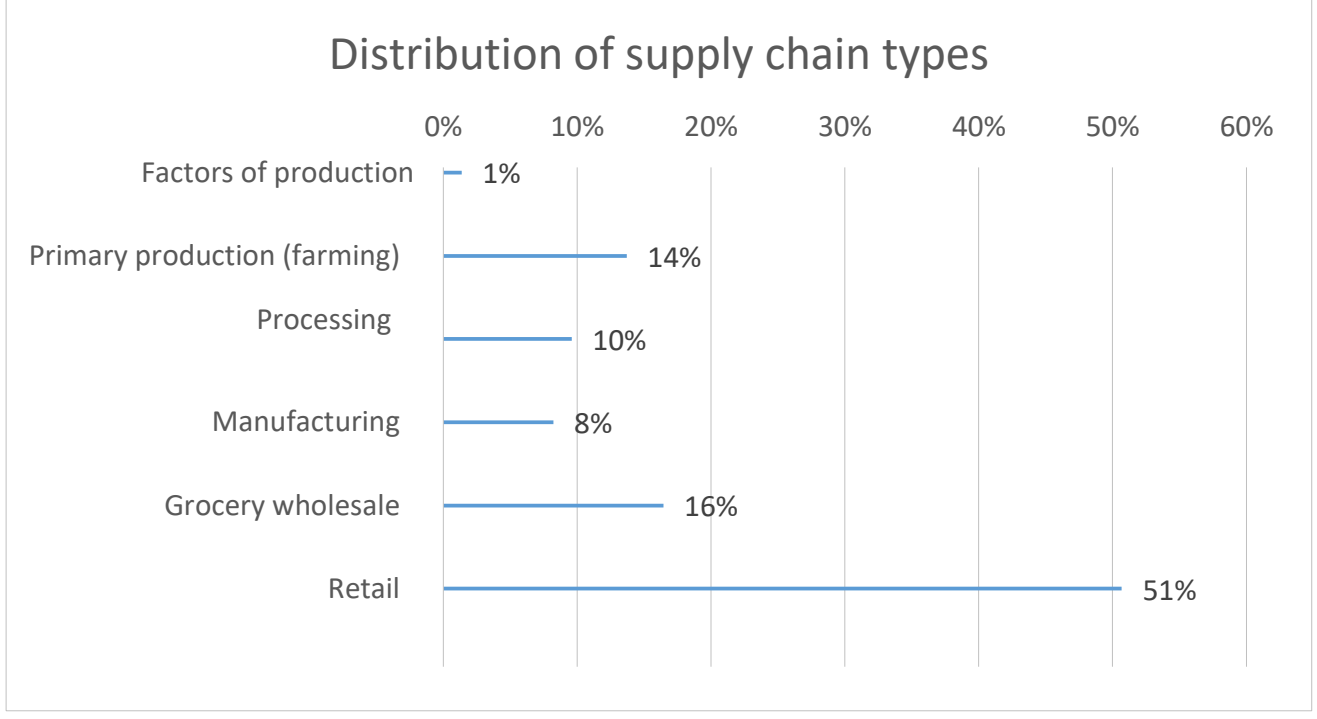

Source: authors' compiled statistics

Table 19 describes the distribution of infringement cases (antitrust) concerning the food sector in Russia according to the level of the supply chain involved. What is particularly notable is 
that over half of all infringements concerned the retail level (51\%). Grocery wholesale (16\%) and primary production (14\%) have been far less subject to antitrust enforcement. There has been only 1 infringement case on the factors of production level (genomics), representing only slightly over $1 \%$.

\section{Table 20: distribution of infringement types by products Russia infringements}

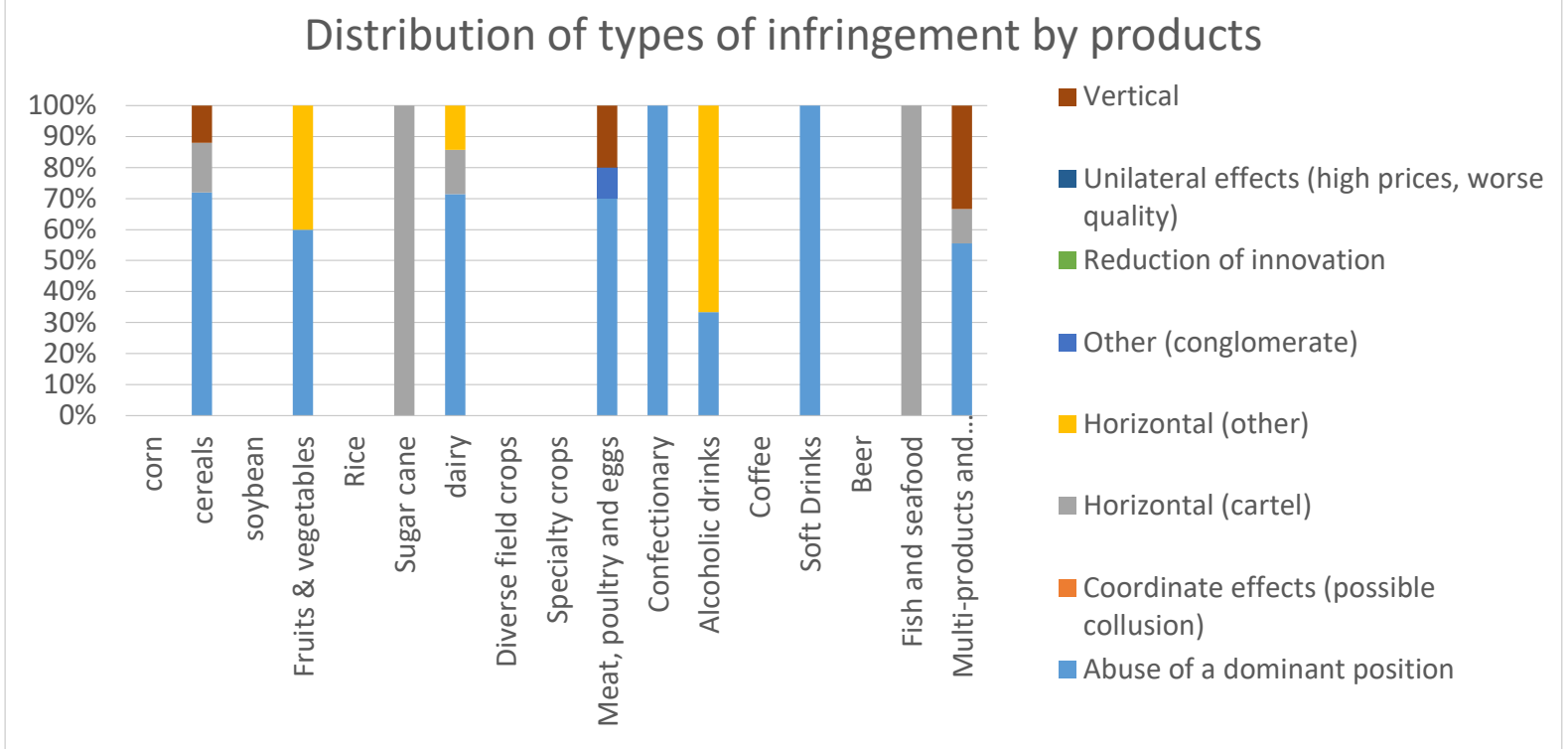

Source: authors' compiled statistics

Table 20 describes the various infringement types for each product category in Russia's infringement cases (antitrust) concerning the food sector. As for the other BRICS countries, there is wide variety among the product types in terms of the infringement types. For example, while non-cartel horizontal infringements take up a substantial share of infringements in the alcoholic drinks category, and to a lesser degree in fruits and vegetables, in other product types they are (almost) non-existent. By contrast, there have only cartel infringements in the sugar cane and fish and seafood product categories. Abuse of a dominant position is prevalent in other product types, including cereals, confectionary, and soft drinks.

\section{Table 21: distribution of products Russia infringements}

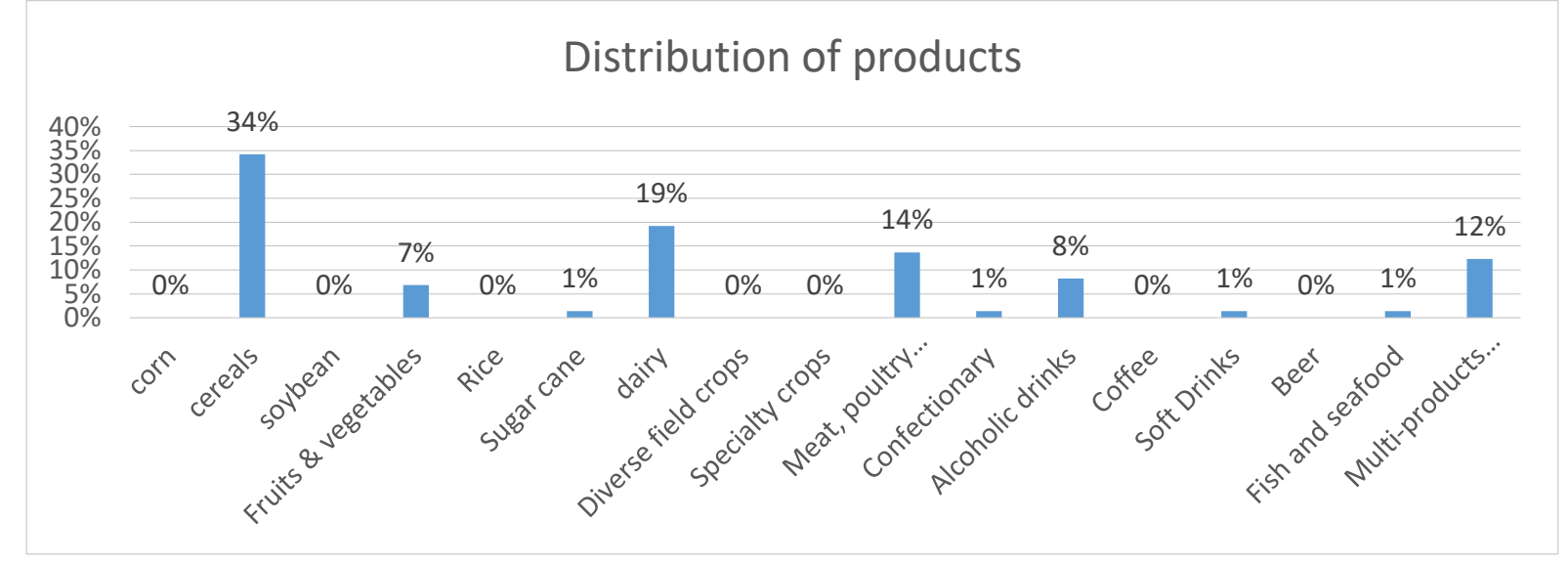


Source: authors' compiled statistics

Table 21 describes the infringement cases (antitrust) in Russia categorised according to product type. Most infringements took place in the cereals segment (34\%), which is considerably more than in dairy (19\%), meat, poultry and eggs (14\%) and multi-products and other products (12\%) categories. Multiple product types have not been subject to antitrust enforcement, including corn, rice, and coffee.

\section{Table 22: distribution of reasons for proceeding by infringement types Russia}

\section{Distribution of reasons for proceeding by infringement types}

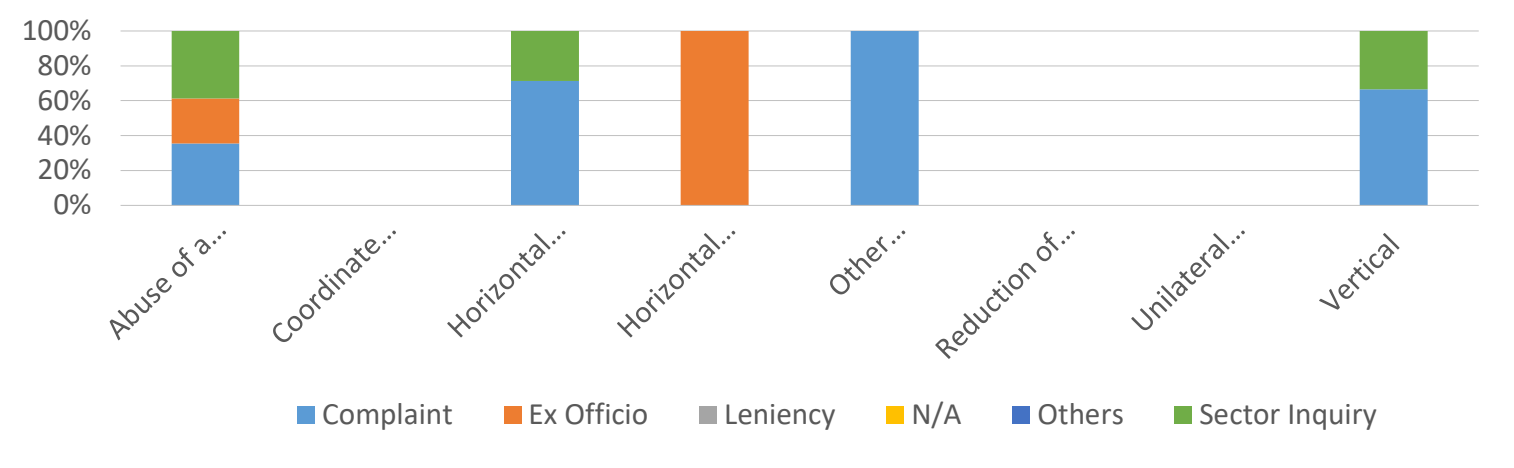

Source: authors' compiled statistics

Table 22 provides a distribution of the reasons for starting infringement proceedings in Russia for each infringement type. Both of the two horizontal non-cartel infringement proceedings were instigated ex officio, while the only conglomerate (other) infringement proceedings was based on a complaint. Horizontal cartel and vertical infringement proceedings were based on a mix of complaints and sector inquiries, while the abuse of dominance cases were the result of complaints (11 cases), sector inquiries (12 cases) but also ex officio proceedings ( 8 cases).

Table 23: infringement proceedings by infringement type Russia

Type of infringement
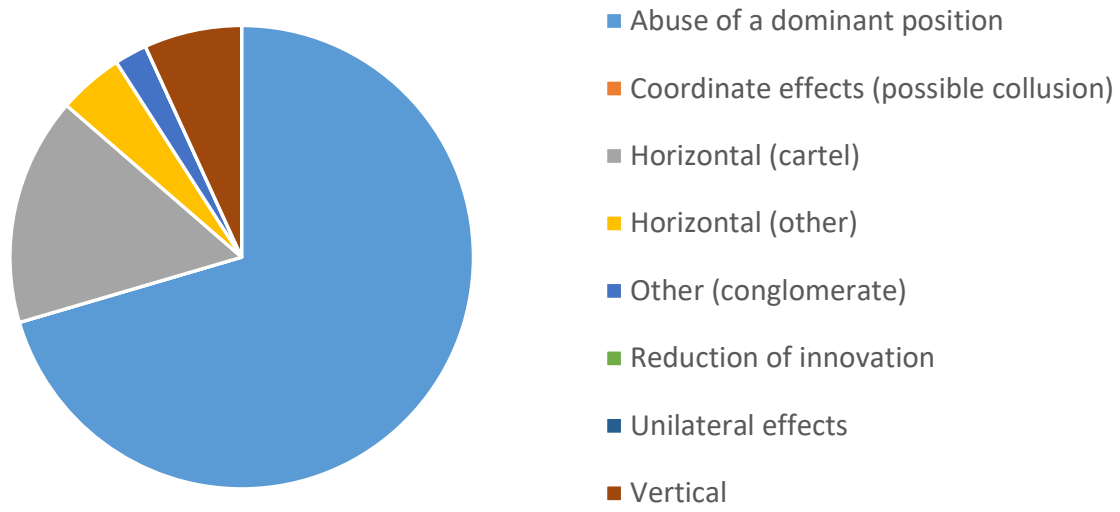

Source: authors' compiled statistics 
Table 23 provides a pie chart of the infringement proceedings in Russia according to the type of infringement. Almost three-quarters of the infringement proceedings were directed at abuse of dominance. Horizontal cartel cases are the second-largest category of infringement proceedings, with horizontal non-cartel, vertical restrictions and conglomerate cases having a significantly smaller share in enforcement activity. There have been no enforcement proceedings against coordinated effects, reduction of innovation, and unilateral effects infringements.

\section{Table 24: distribution of infringement types Russia infringements}

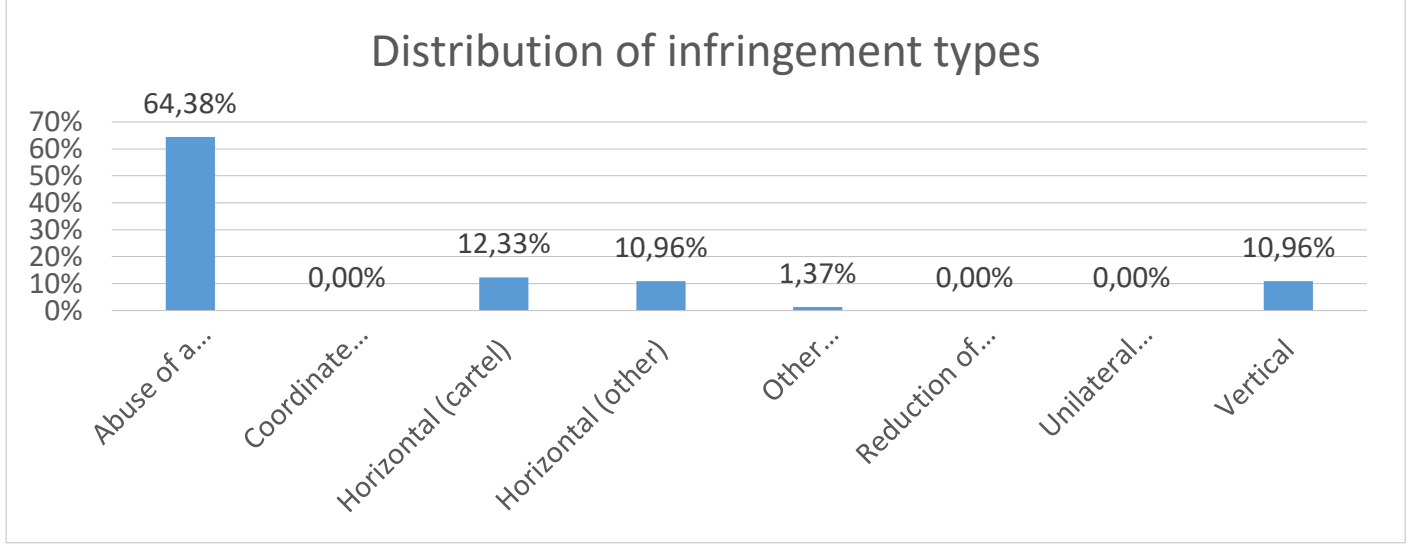

Source: authors' compiled statistics

Table 24 describes a categorization of the infringements in Russia based on infringement types. Almost two-thirds of the infringements were abuses of a dominant position. Horizontal cartel cases represented $12.33 \%$ of total infringements found, and horizontal non-cartel and vertical infringements each $10.96 \%$.

\subsubsection{India mergers}

Table 25: distribution of supply chain types India mergers

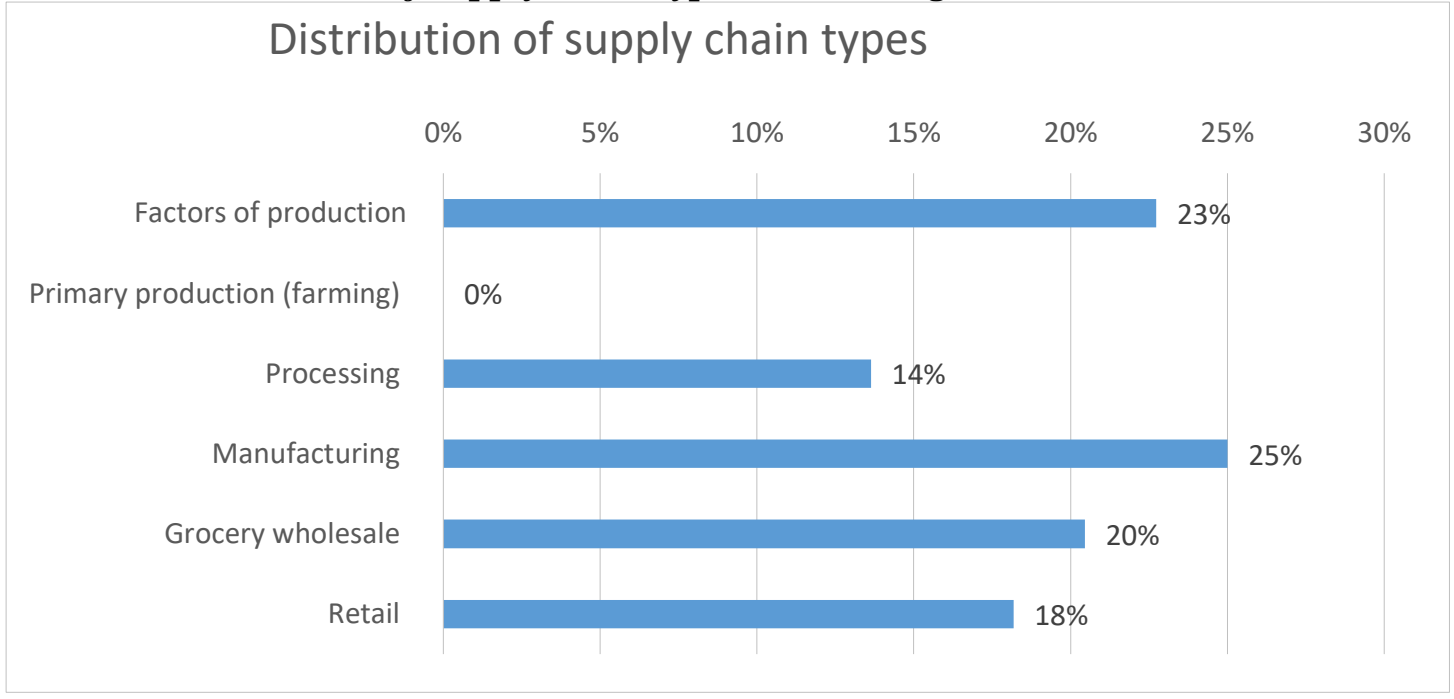

Source: authors' compiled statistics 
Table 25 visualizes the distribution of supply chain types in all merger cases concerning the food sector in India. There have been no merger cases at the primary production (farming) level of the supply chain. Mergers are spread rather equally among the manufacturing (25\%), factors of production (23\%), grocery wholesale $(20 \%)$ and retail (18\%) levels, while the remaining $14 \%$ took place at the processing level.

\section{Table 26: distribution of products India mergers}

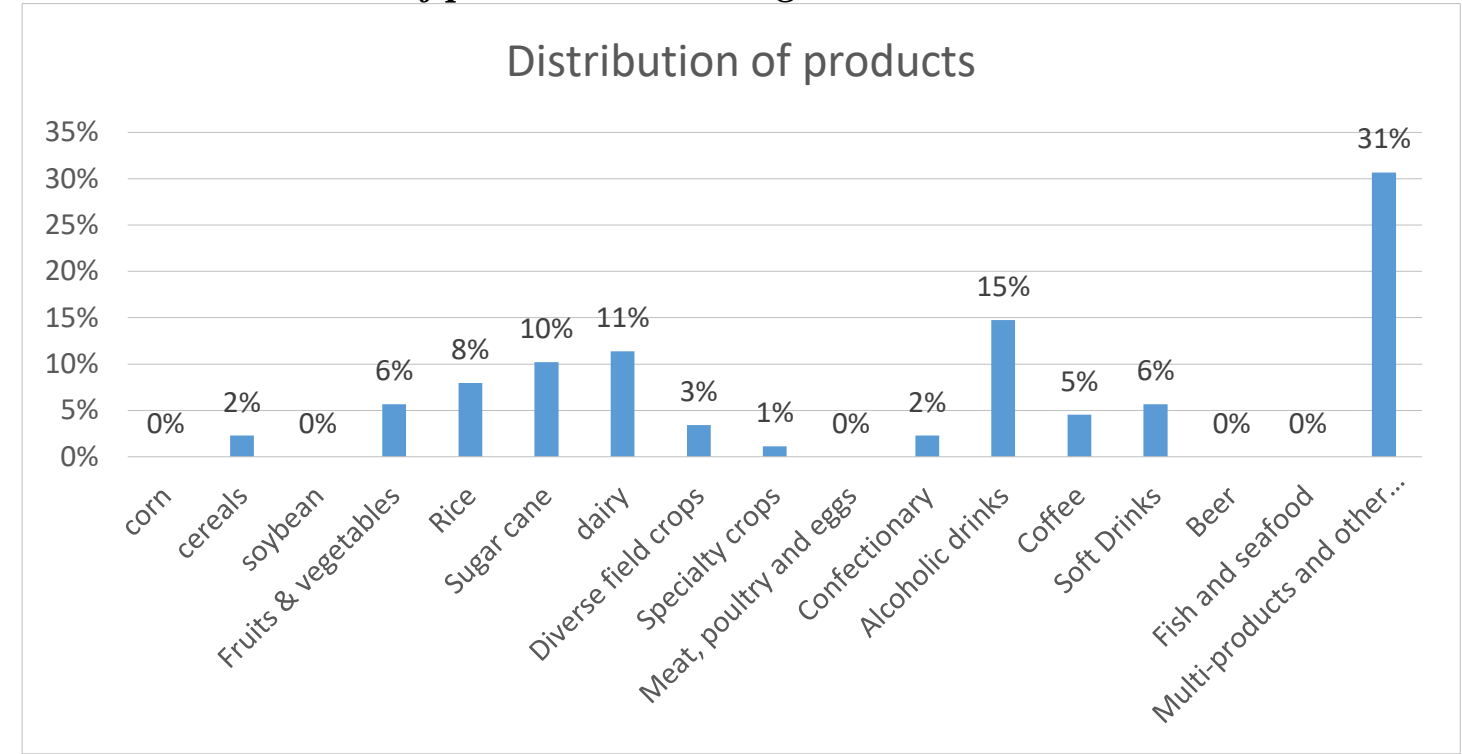

Source: authors' compiled statistics

In table 26, the merger cases in India concerning the food sector are classified according to the type of products involved. Most mergers concerned multi-product or products not included (31\%). Alcoholic drinks were involved in $15 \%$ of the cases, followed by dairy (11\%), sugar cane $(10 \%)$, and rice $(8 \%)$. No mergers took place in corn, soybean, meat, poultry and eggs, beer and fish and seafood product categories.

\subsubsection{India infringements}


Table 27: distribution of supply chain types India infringements

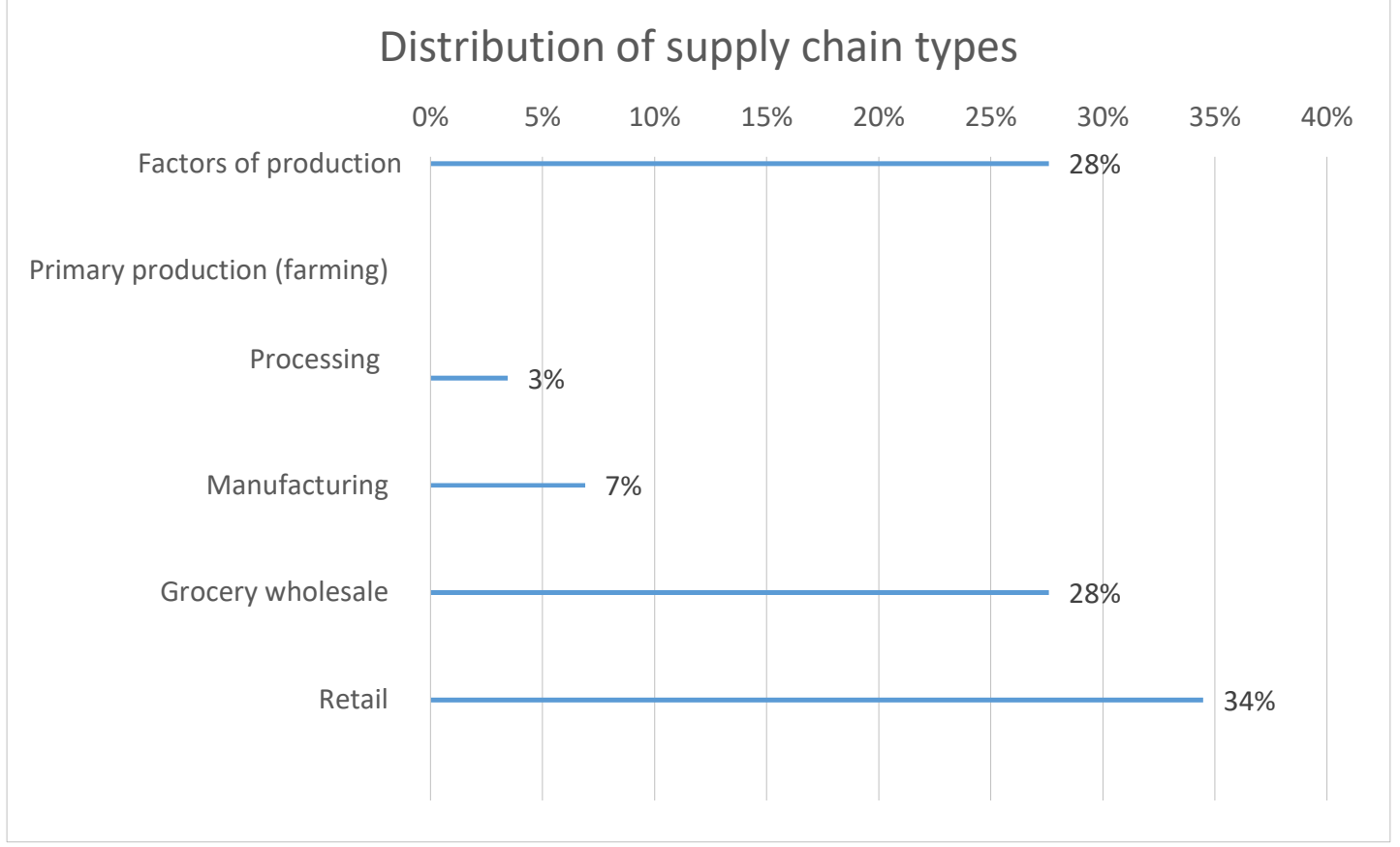

Source: authors' compiled statistics

Table 27 describes the distribution of infringement cases (antitrust) concerning the food sector in India according to the level of the supply chain involved. The division among supply chain levels is rather unequal, with more than a third of infringements taking place in retail (34\%), in contrast to only $7 \%$ in manufacturing, $3 \%$ in processing and $0 \%$ in primary production. At the factors of production level as well as the grocery wholesale level, $28 \%$ of infringements took place.

Table 28: distribution of types of infringement by product India infringements 


\section{Distribution of types of infringement by product}

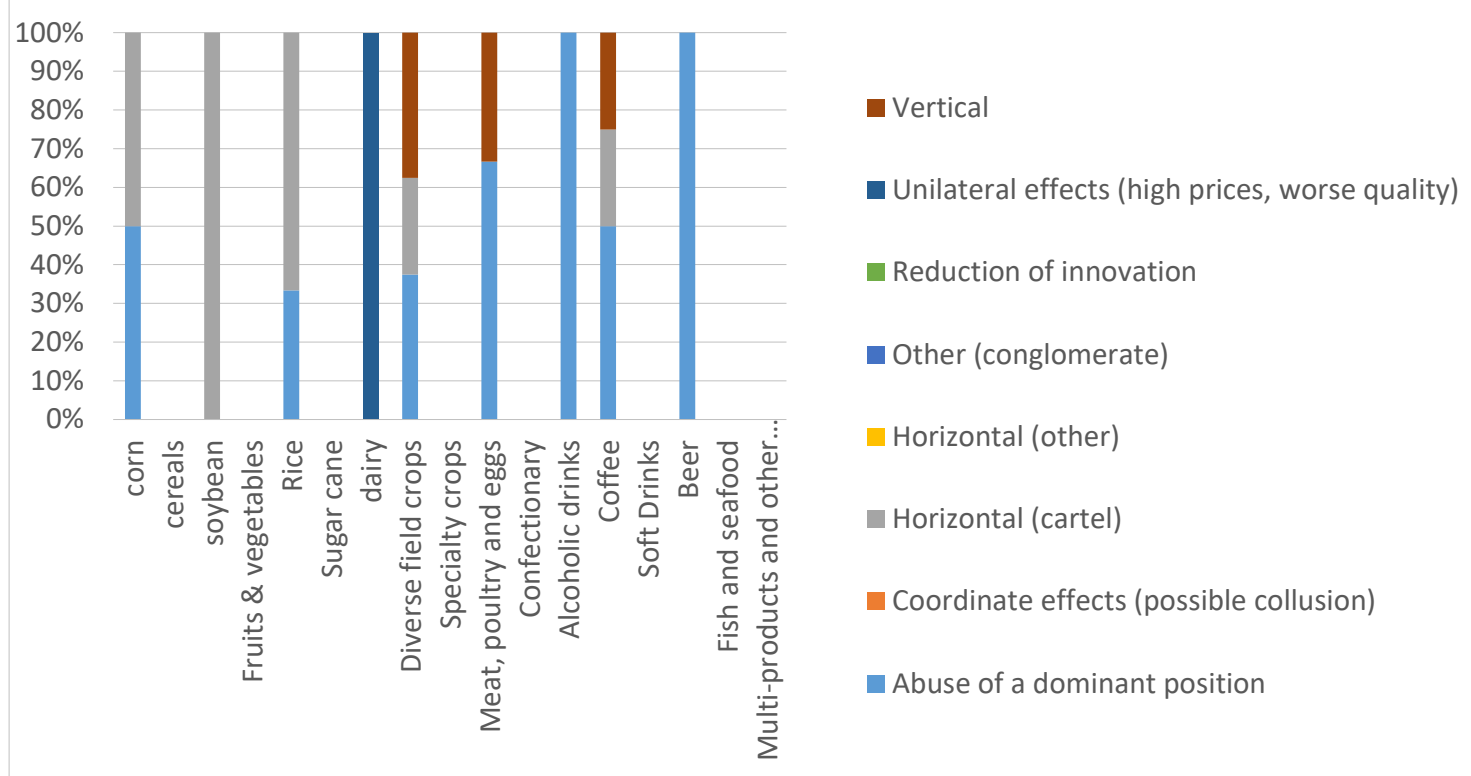

Source: authors' compiled statistics

Table 28 describes the various infringement types for each product category in India's infringement cases (antitrust) concerning the food sector. Horizontal cartel cases have been predominant in corn, soybean and rice products types. Most infringements in the meat, poultry and eggs, alcoholic drinks and beer concerned abuse of a dominant position. There has been one infringement regarding dairy products, which concerned unilateral effects.

\section{Table 29: distribution of products India infringements}

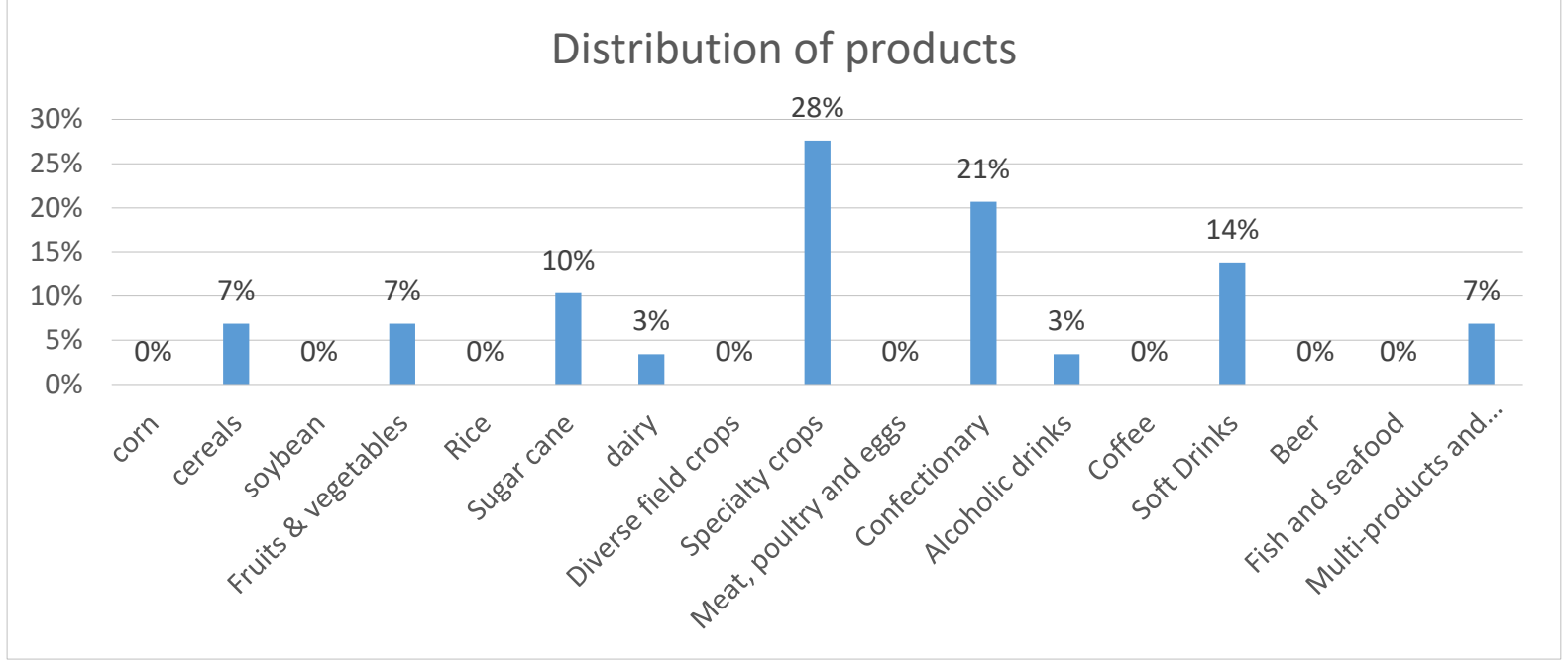

Source: authors' compiled statistics

Table 29 describes the infringement cases (antitrust) in India categorised according to product type. Specialty crops count for the largest share of infringements with $28 \%$, followed by confectionary (21\%) and soft drinks (14\%). 


\section{Table 30: distribution of reasons for proceeding by infringement types India}

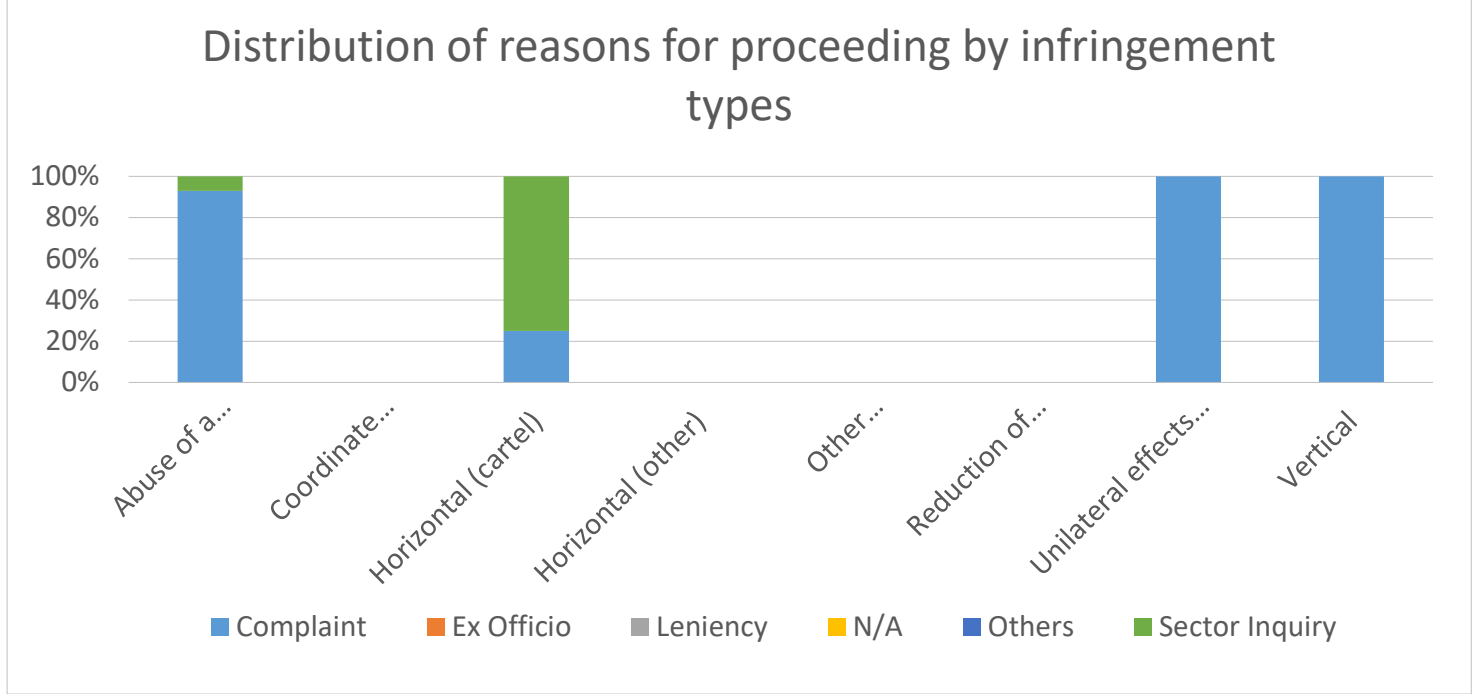

Source: authors' compiled statistics

Table 30 provides a distribution of the reasons for starting infringement proceedings in India for each infringement type. Horizontal cartel infringement proceedings have been initiated prominently after sector inquiries and in some cases after complaints. Abuse of dominance, unilateral effects, and vertical restraints proceedings were almost exclusively the result of complaints. No leniency or ex officio proceedings have been reported.

\section{Table 31: infringement proceedings by infringement type India}

\section{Type of infringement}

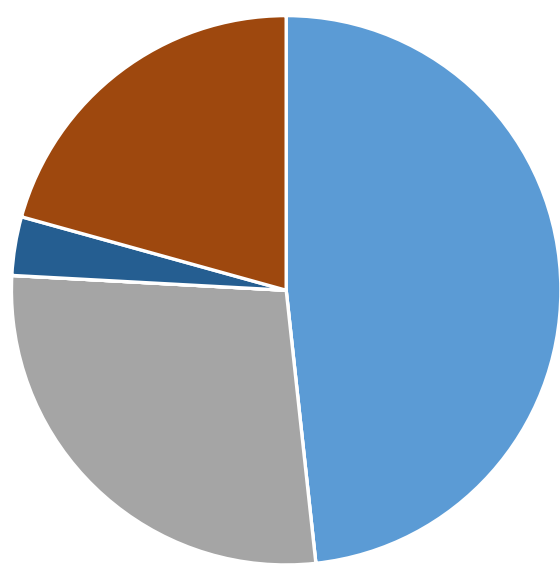

- Abuse of a dominant position

- Coordinate effects (possible collusion)

- Horizontal (cartel)

- Horizontal (other)

- Other (conglomerate)

- Reduction of innovation

- Unilateral effects (high prices, worse quality)

- Vertical

Source: authors' compiled statistics

Table 31 provides a pie chart of the infringement proceedings in India according to the type of infringement. Just under half of all infringement proceedings dealt with abuse of a dominant position. More than a quarter of the proceedings concerned horizontal cartel cases, and vertical 
restrictions were subject of just under a quarter of the proceedings. Notably, a small share of the infringement proceedings dealt with unilateral effects.

\section{Table 32: distribution of infringement types India infringements}

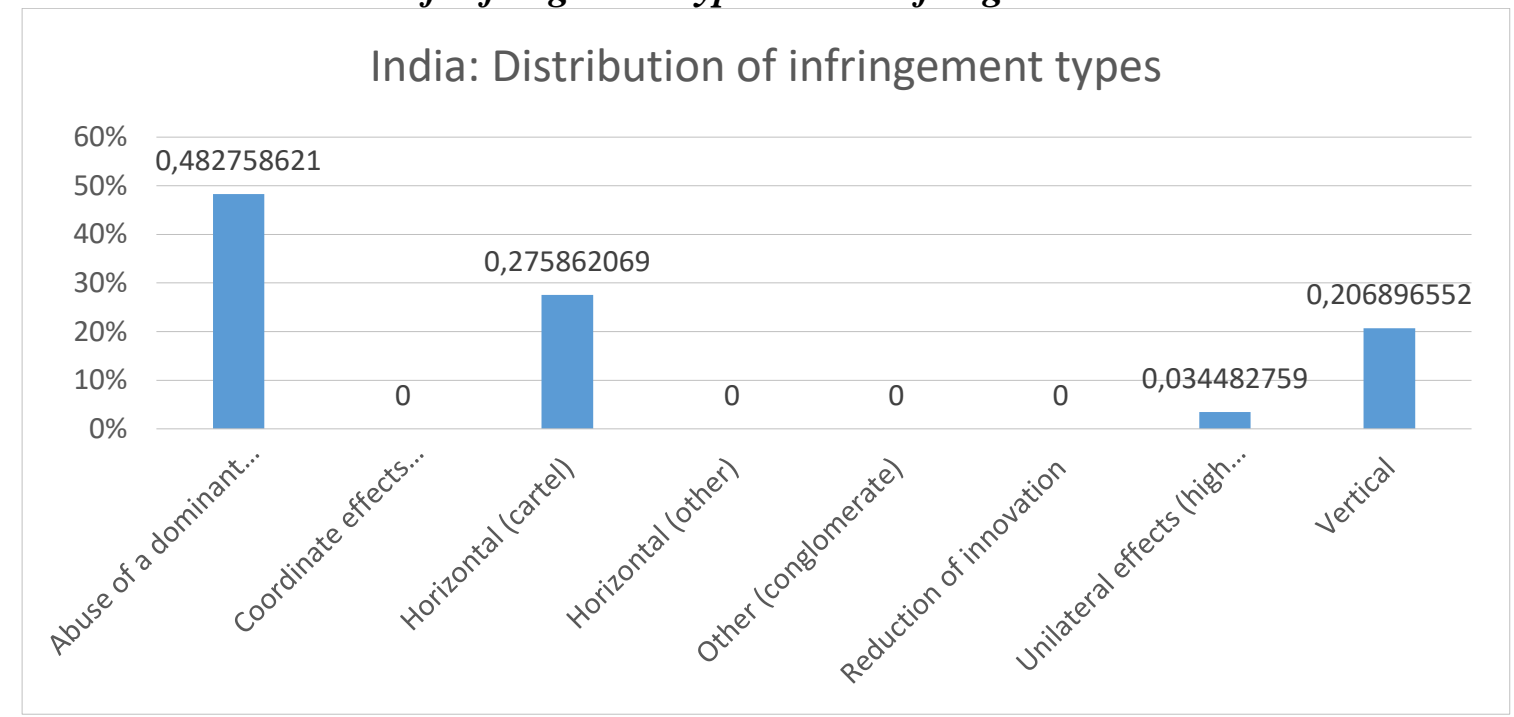

Source: authors' compiled statistics

Table 32 describes a categorization of the infringements in India based on infringement types. $48.27 \%$ of the infringements established in India concerned abuse of a dominant position. Horizontal cartel cases were the subject of $27.59 \%$ of all infringements, and $20.69 \%$ dealt with vertical restrictions. Infringements related to unilateral effects, i.e. high prices and worse quality, were also (small) part of total infringements found.

\subsubsection{China mergers}

Table 33: distribution of supply chain types China mergers

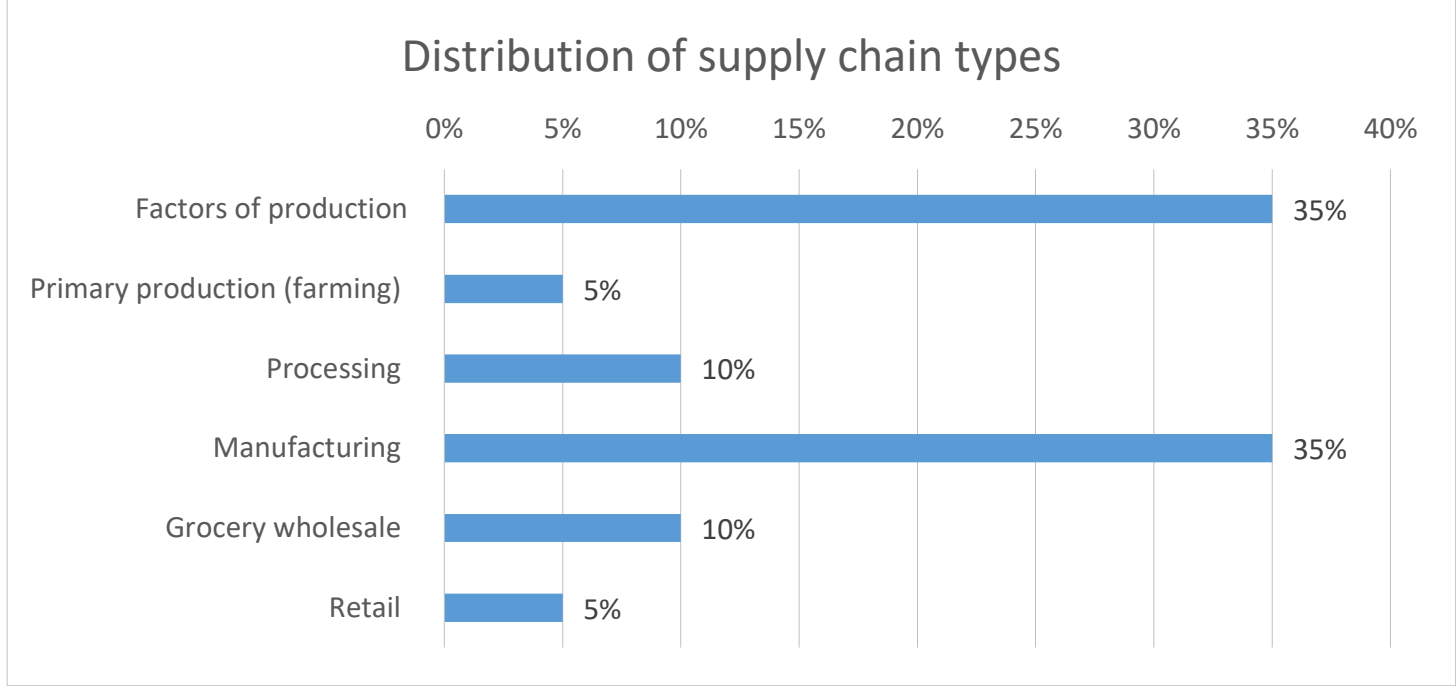

Source: authors' compiled statistics 
Table 33 visualizes the distribution of supply chain types in all merger cases concerning the food sector in China. Close to three-quarters of mergers concerned either the factors of production level or the manufacturing level (35\% each). Primary production and retail levels each counted for only $5 \%$ of merger cases, and processing and grocery wholesale both having a $10 \%$ share.

\section{Table 34: distribution of products China mergers}

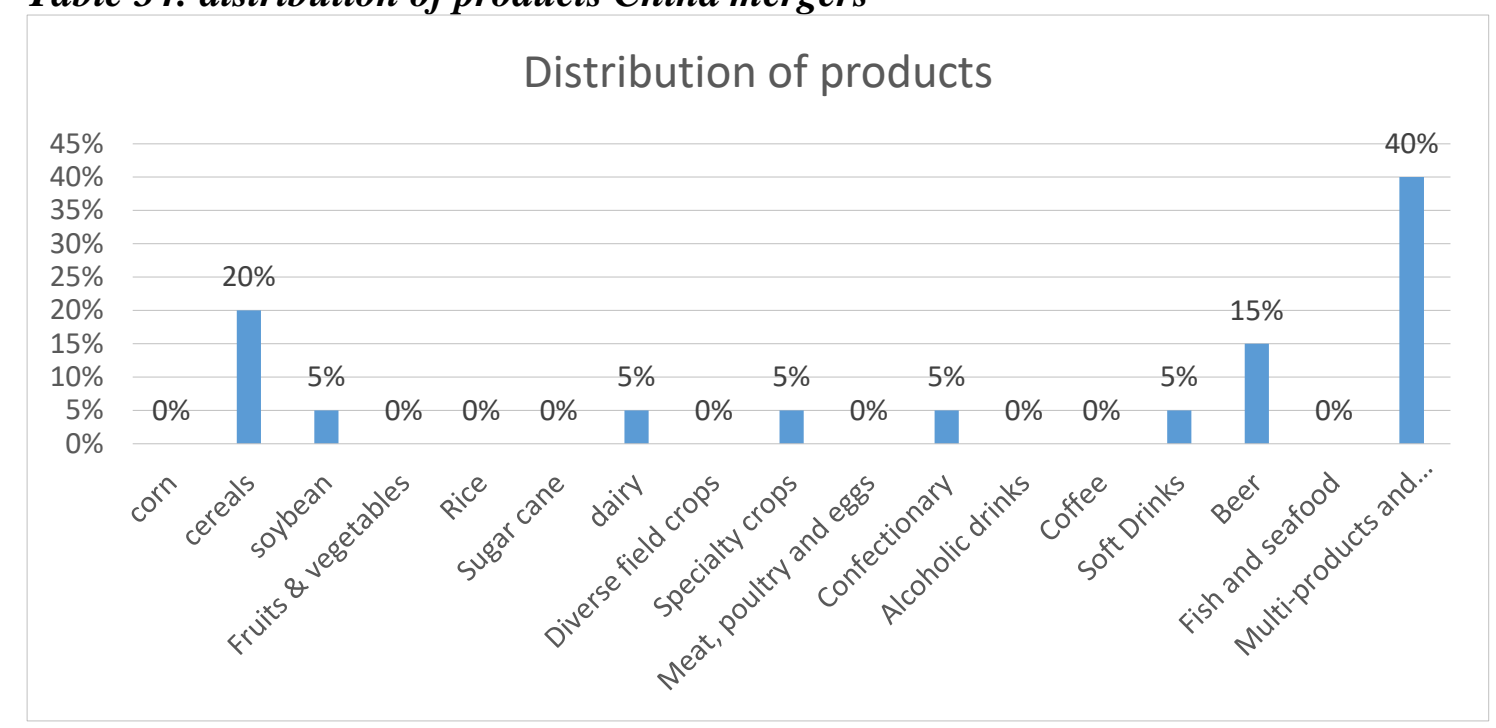

Source: authors' compiled statistics

In table 34, the merger cases in China concerning the food sector are classified according to the type of products involved. The largest share of mergers dealt with multiple products or other products not listed specifically (40\%). Of single-product mergers, the largest share is taken by cereals $(20 \%)$, followed by beer $(15 \%)$. There were no single-product mergers in the majority of product categories, including corn, sugar cane, coffee and fish and seafood.

\subsubsection{China infringements}

Table 35: distribution of supply chain types China infringements 


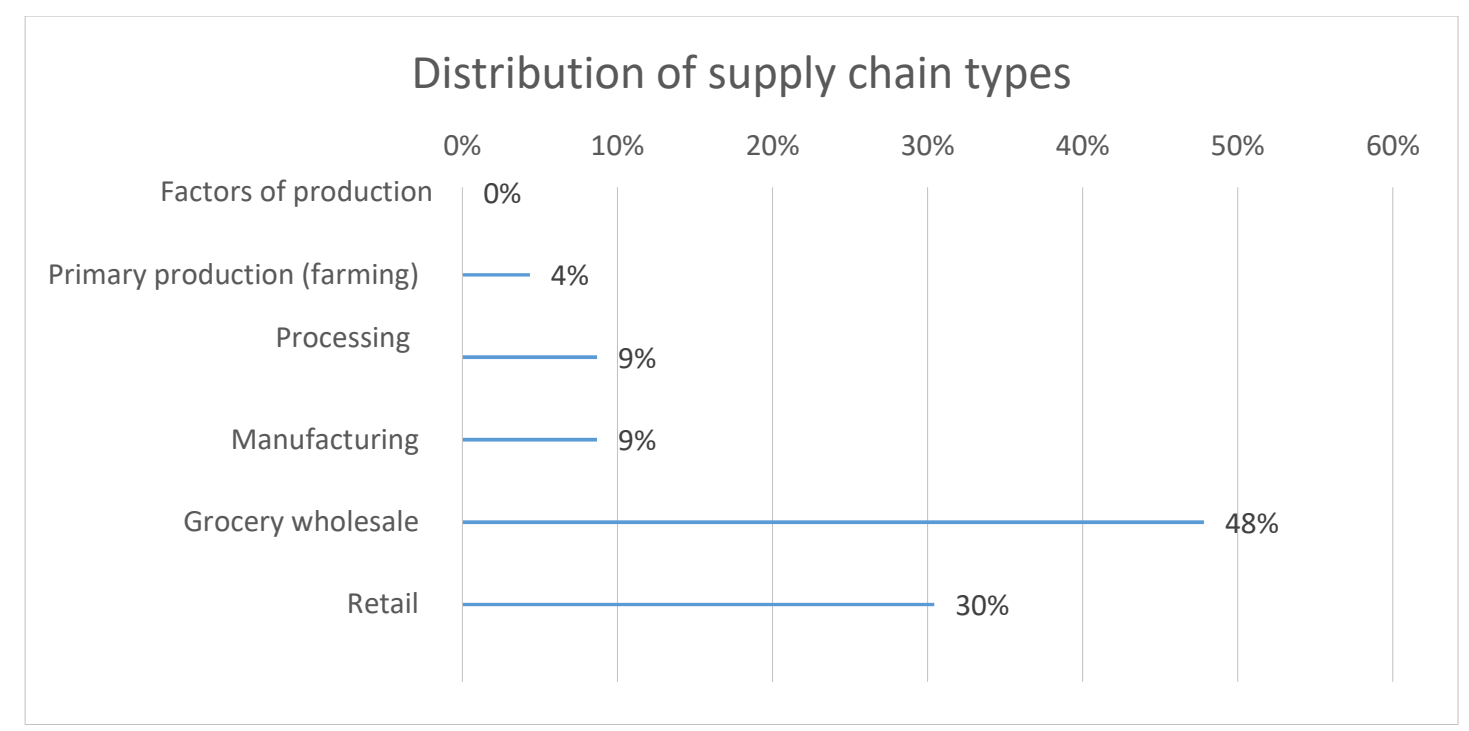

Source: authors' compiled statistics

Table 35 describes the distribution of infringement cases (antitrust) concerning the food sector in China according to the level of the supply chain involved. Almost half of all infringements concerned the grocery wholesale level of the supply chain (48\%). The retail level follows with $30 \%$, with the other supply chain levels having only a small share of between $4 \%$ and $9 \%$. Notably, there have been no infringements at the factors of production level.

\section{Table 36: distribution of types of infringements by product China infringements}

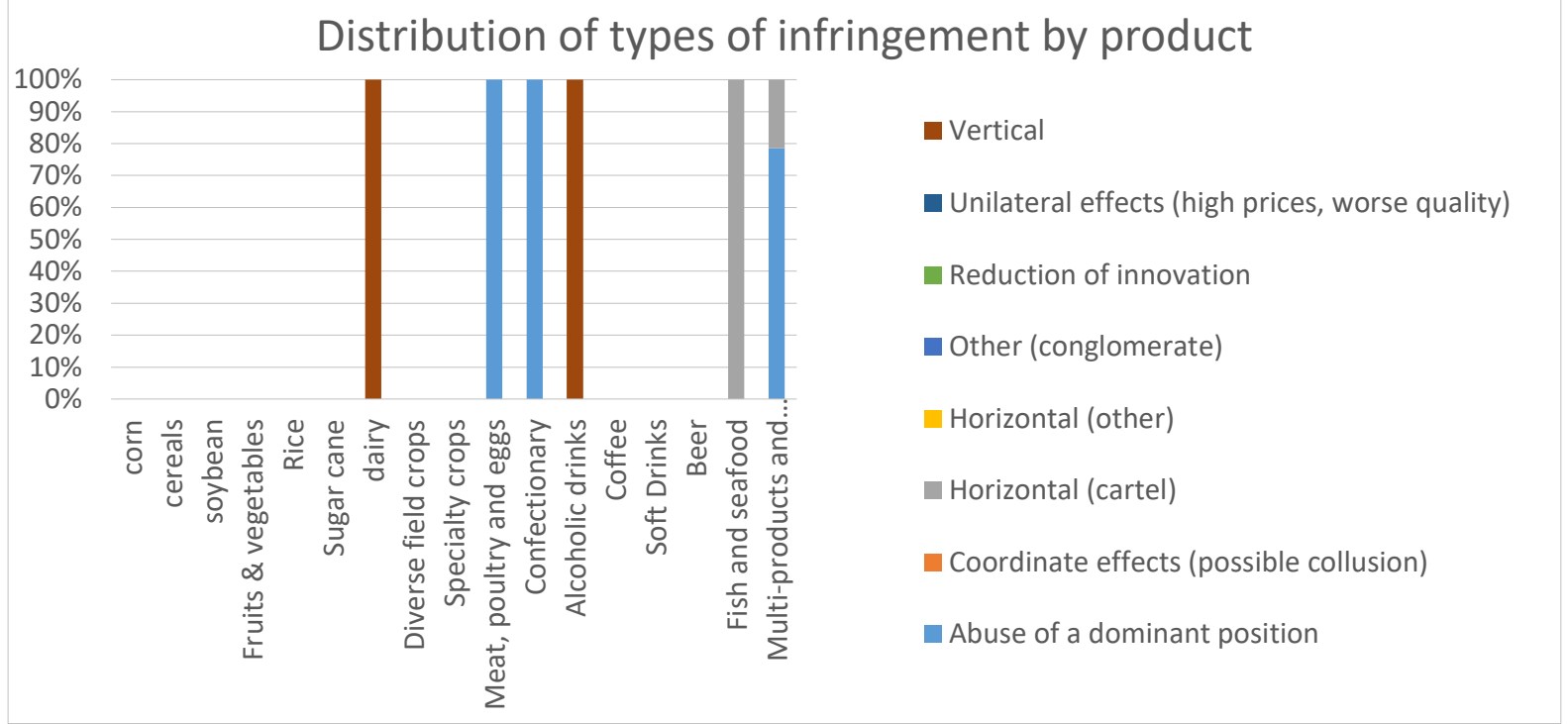

Source: authors' compiled statistics

Table 36 describes the various infringement types for each product category in China's infringement cases (antitrust) concerning the food sector. Only vertical infringements were found in the dairy and alcoholic drinks product category, and only abuse of dominance in the meat, poultry and eggs, and the confectionary types. Horizontal cartel infringements have been 
reported in the fish and seafood as well as, for a small part, in the multi-products and other products category.

\section{Table 37: distribution of products China infringements}

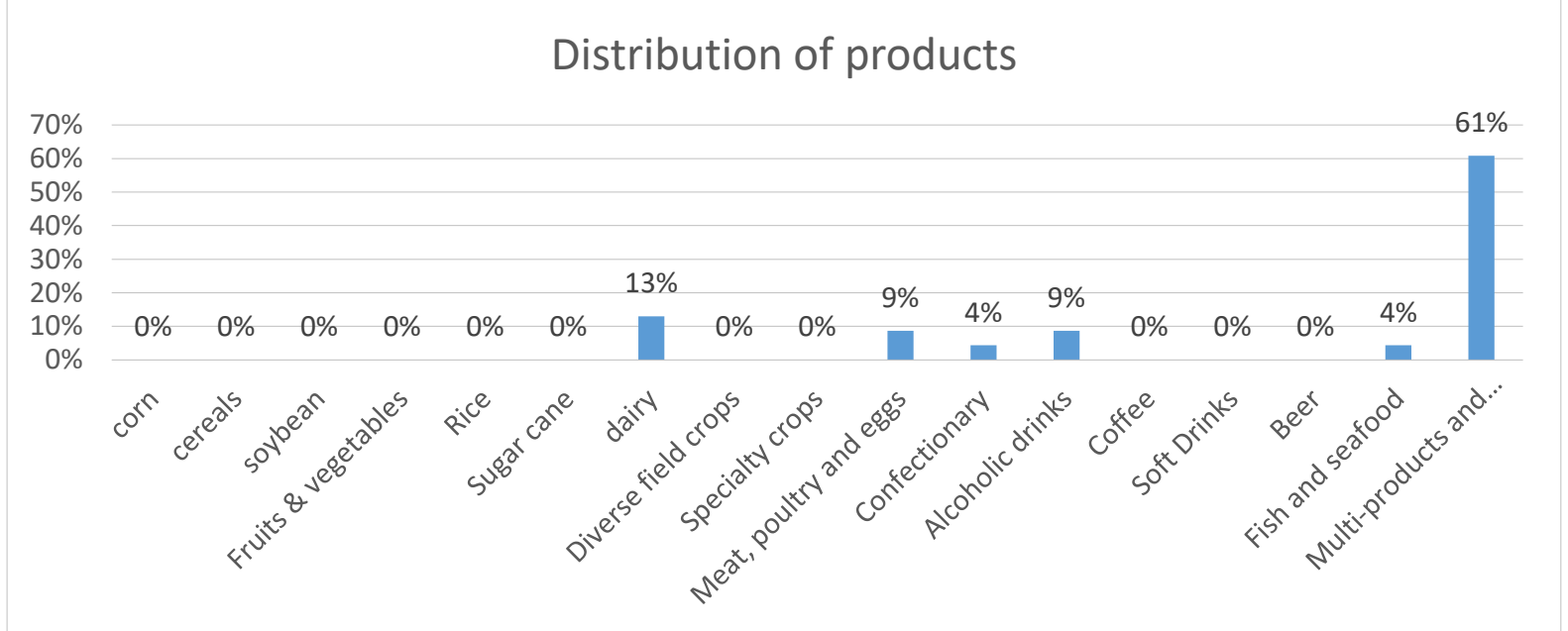

Source: authors' compiled statistics

Table 37 describes the infringement cases (antitrust) in China categorised according to product type. Multi-products and other products not listed in the table take up the largest share of infringements with $61 \% .13 \%$ of the infringements pertained to dairy, $9 \%$ to meat, poultry and eggs, also $9 \%$ to alcoholic drinks. Confectionary and fish and seafood product categories each counted for $4 \%$ of total infringements.

\section{Table 38: distribution of reasons for proceedings by infringement type China}

\section{Distribution of reasons for proceedings by infringement type}

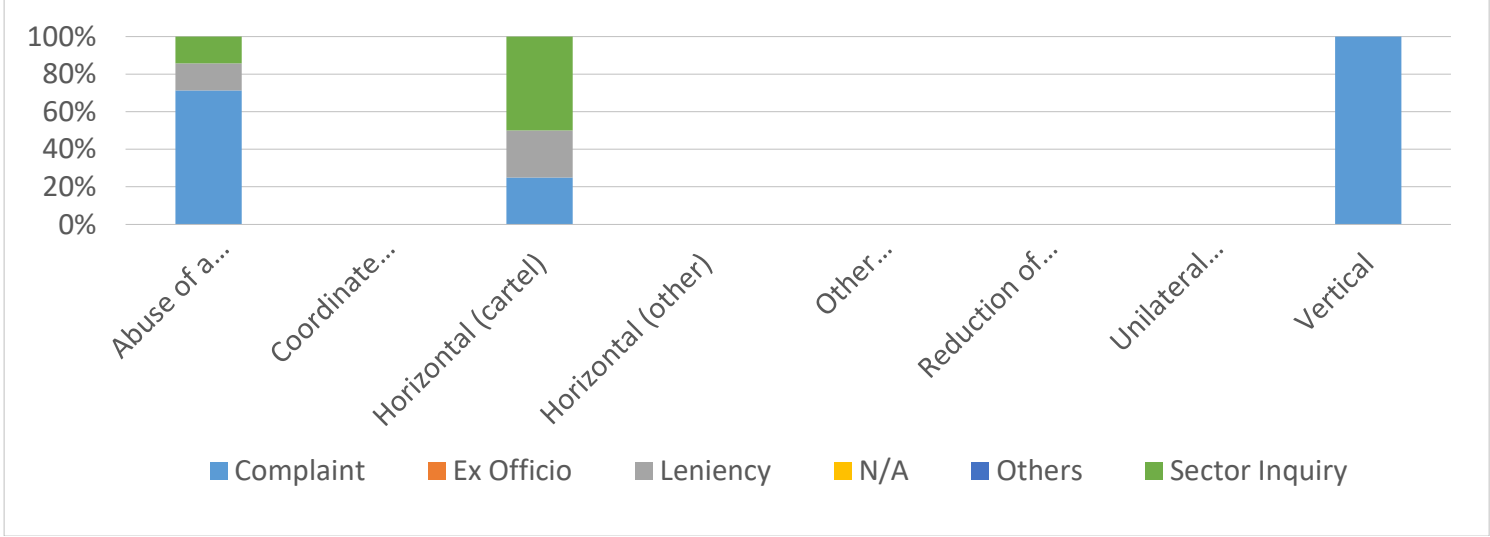

Source: authors' compiled statistics

Table 38 provides a distribution of the reasons for starting infringement proceedings in China for each infringement type. All 5 vertical infringement proceedings were based on complaints. In the abuse of dominance and horizontal cartel cases, reasons for proceedings were a mix of complaints, leniency applications and sector inquiries. 


\section{Table 39: infringement proceedings by infringement type China}

\section{Type of infringement}

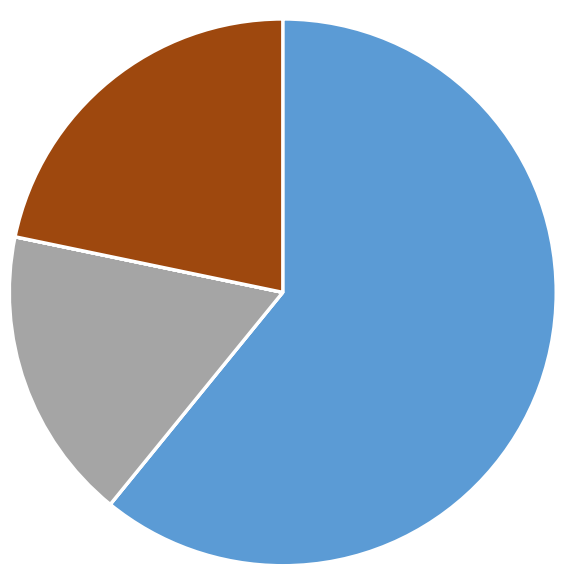

$$
\begin{aligned}
& \text { - Abuse of a dominant } \\
& \text { position } \\
& \text { - Coordinate effects } \\
& \text { (possible collusion) } \\
& \text { - Horizontal (cartel) } \\
& \text { - Horizontal (other) } \\
& \text { - Other (conglomerate) } \\
& \text { - Reduction of innovation } \\
& \text { - Unilateral effects (high } \\
& \text { prices, worse quality) } \\
& \text { - Vertical }
\end{aligned}
$$

Source: authors' compiled statistics

Table 39 provides a pie chart of the infringement proceedings in China according to the type of infringement. A majority of the infringement proceedings were initiated against alleged abuse of a dominant position. The rest of the proceedings were targeted at either horizontal cartel cases or vertical restrictions. There have been no infringements proceedings against coordinated effects, horizontal non-cartel cases, conglomerate infringements, reductions of innovation and unilateral effects.

\section{Table 40: distribution of infringement types China infringements}

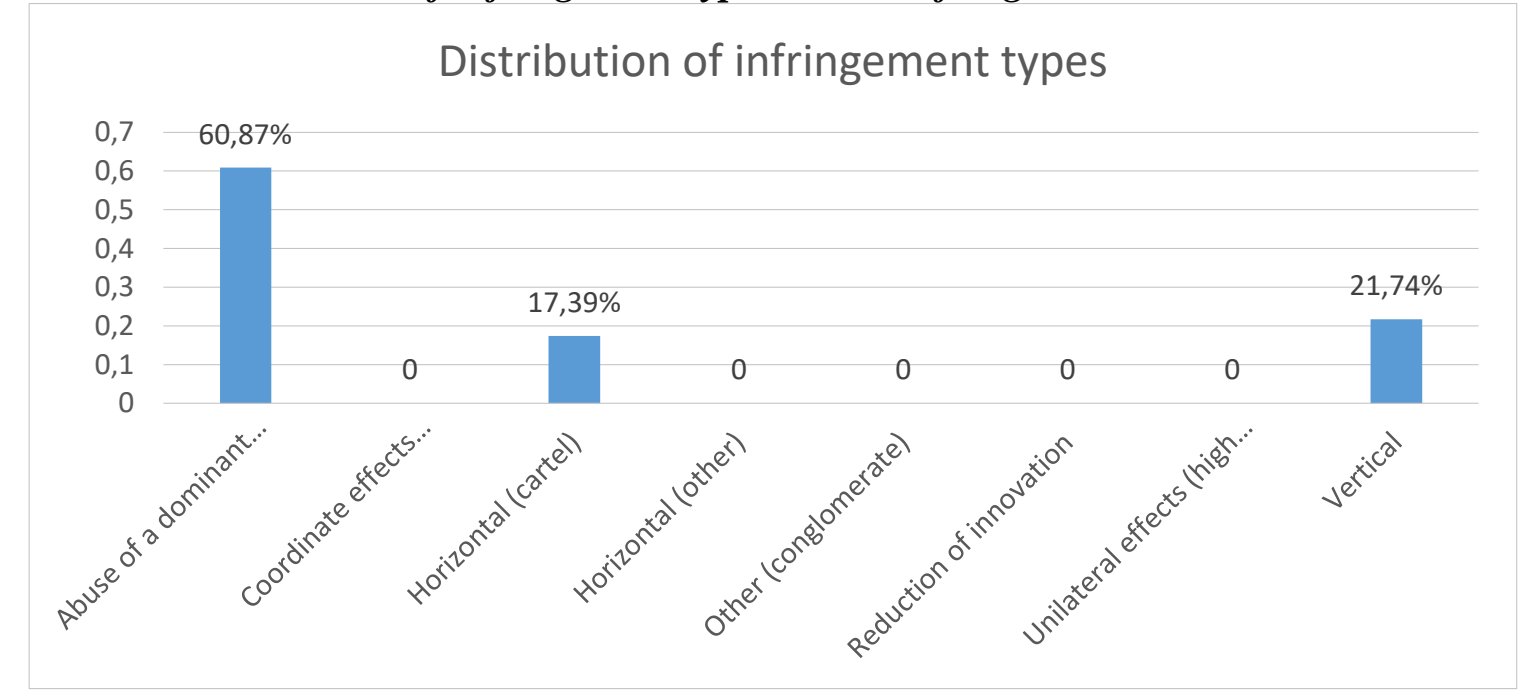

Source: authors' compiled statistics

Table 40 describes a categorization of the infringements in China based on infringement types. A majority of $60.87 \%$ of total infringements concerned abuses of a dominant position. Vertical restrictions account for $21.74 \%$, and horizontal cartel cases for $17.39 \%$ of total infringements in China. 


\subsubsection{South Africa mergers}

\section{Table 41: distribution of supply chain types South Africa mergers}

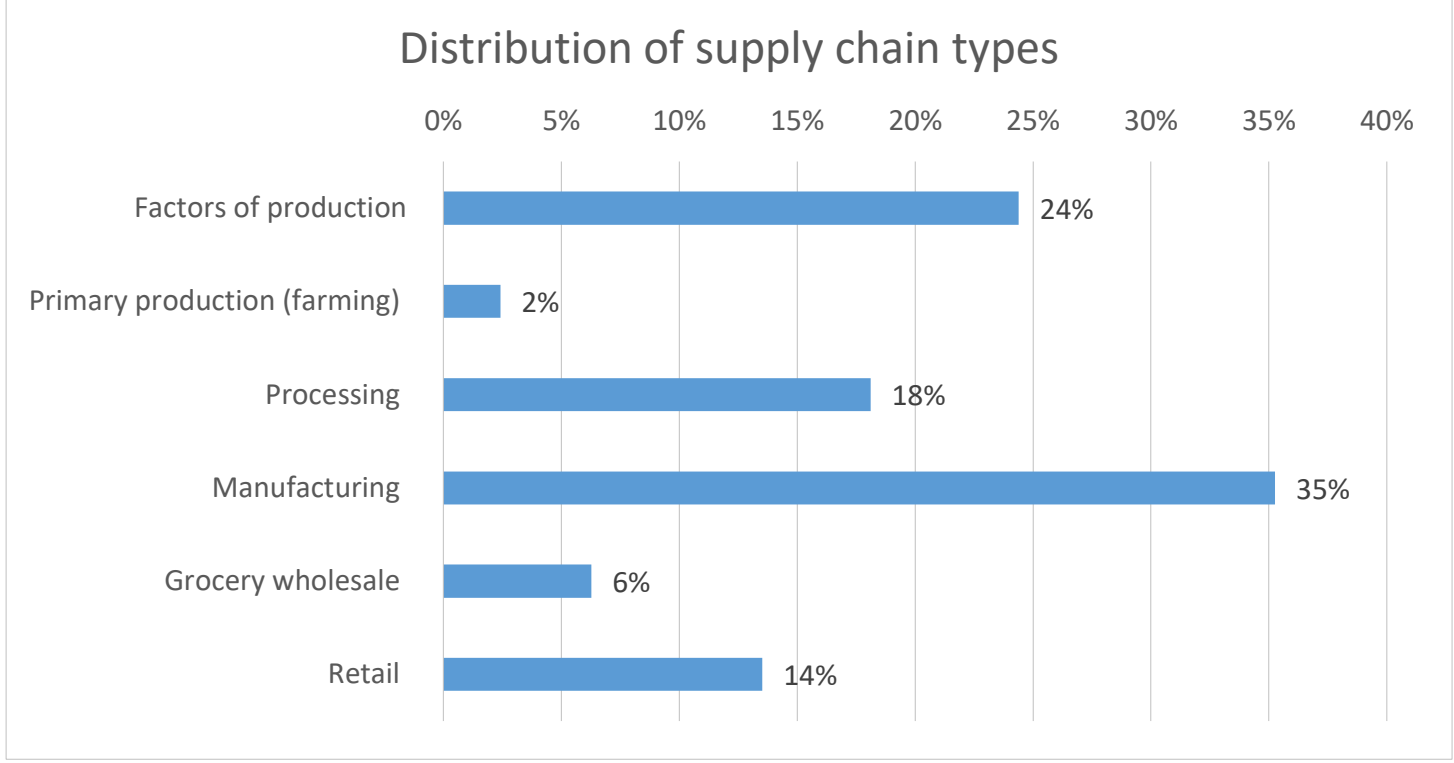

Source: authors' compiled statistics

Table 41 visualizes the distribution of supply chain types in all merger cases concerning the food sector in South Africa. Slightly over one-third of food sector merger cases took place at the manufacturing level of the supply chain $(35 \%)$. The factors of production level accounted to $24 \%$, followed by processing (18\%) and retail (14\%). Merger cases have been comparatively limited in primary production $(2 \%)$ and grocery wholesale $(6 \%)$.

Table 42: distribution of products South Africa mergers

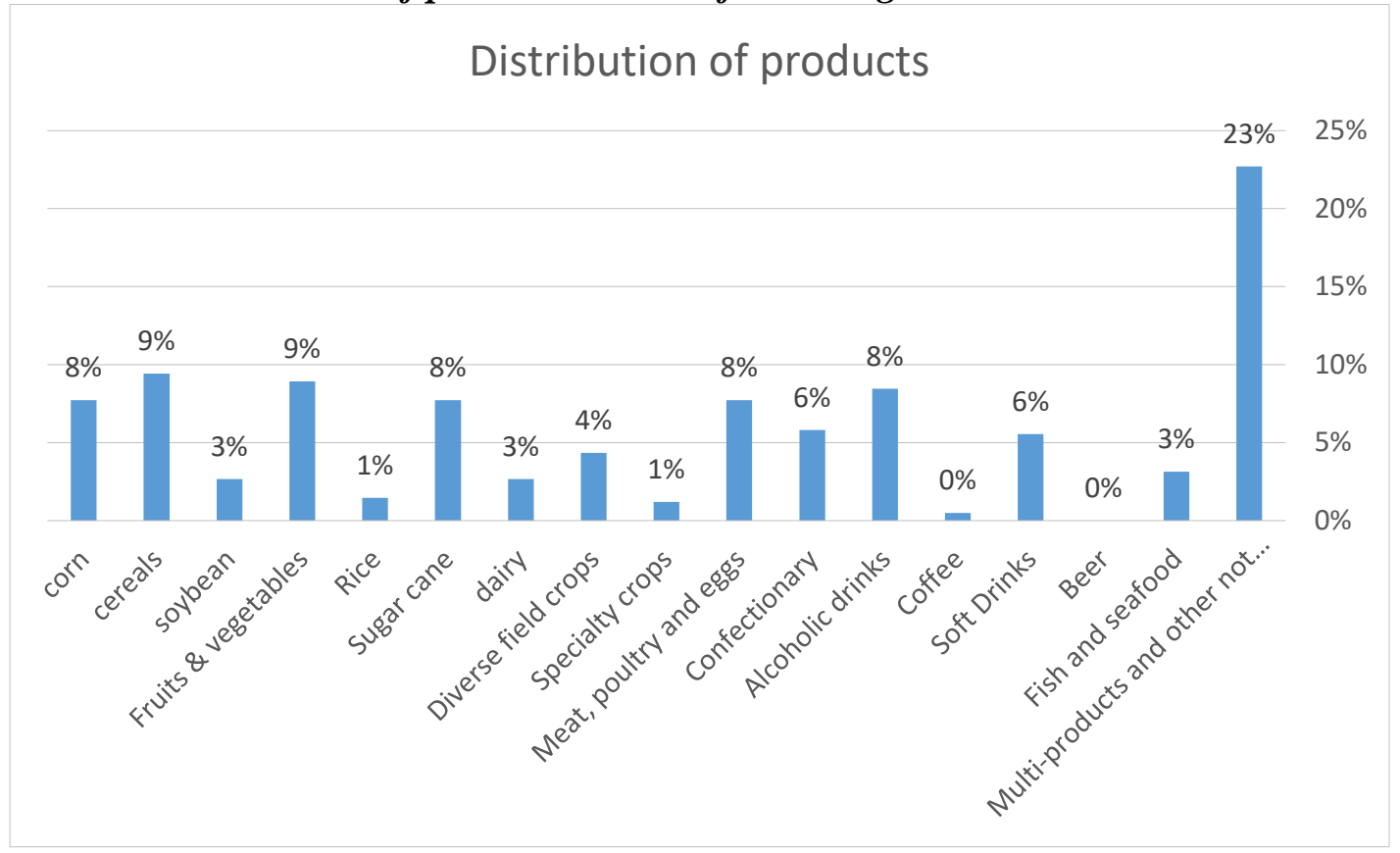


Source: authors' compiled statistics

In table 42, the merger cases in South Africa concerning the food sector are classified according to the type of products involved. Compared with the other BRICS countries, distribution of product type mergers is relatively equal, with $9 \%$ share for cereals and fruits and vegetables each, and $8 \%$ for corn, sugar cane, meat, poultry and eggs, and alcoholic drinks each. Just under a quarter of merger cases concerned multi-products or other products not listed (23\%).

2.1.1.12. South Africa infringements

Table 43: distribution of supply chain types South Africa infringements

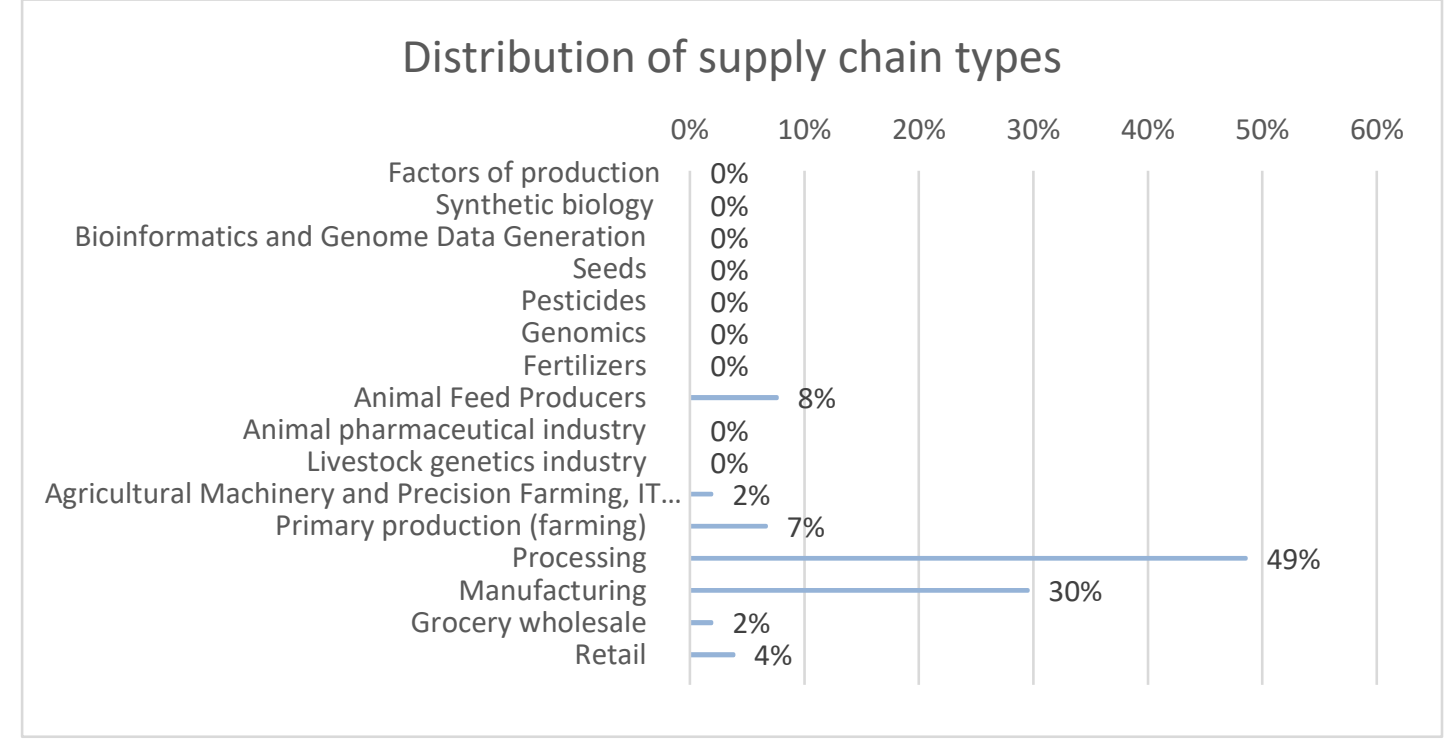

Source: authors' compiled statistics

Table 43 describes the distribution of infringement cases (antitrust) concerning the food sector in South Africa according to the level of the supply chain involved. $49 \%$ of all food sector related infringements took place at the processing level, followed by the manufacturing level which accounts for $30 \%$. The other supply chain levels are significantly less represented in antitrust enforcement, with for example the grocery wholesale and the retail levels only having $2 \%$ and $4 \%$ of infringement cases respectively.

Table 44: distribution of infringement type by products South Africa infringements 


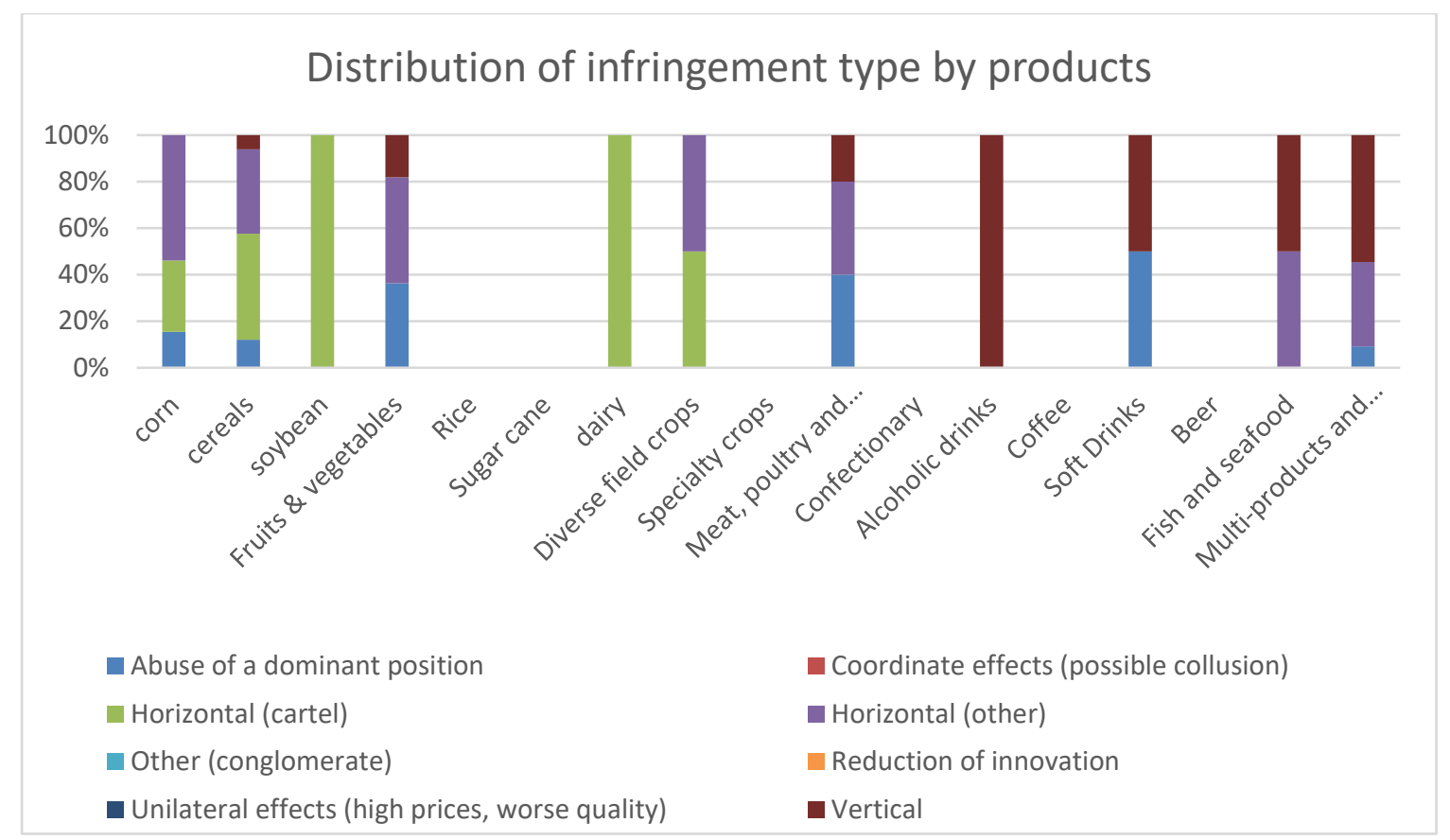

Source: authors' compiled statistics

Table 44 describes the various infringement types for each product category in South Africa's infringement cases (antitrust) concerning the food sector. Vertical infringements were relatively prevalent in the categories of alcoholic drinks, soft drinks, fish and seafood, and other (multi-) products. Horizontal cartel infringements took a considerable share in the infringements in the soybean, dairy, and diverse field crops categories.

\section{Table 45: distribution of products South Africa infringements}

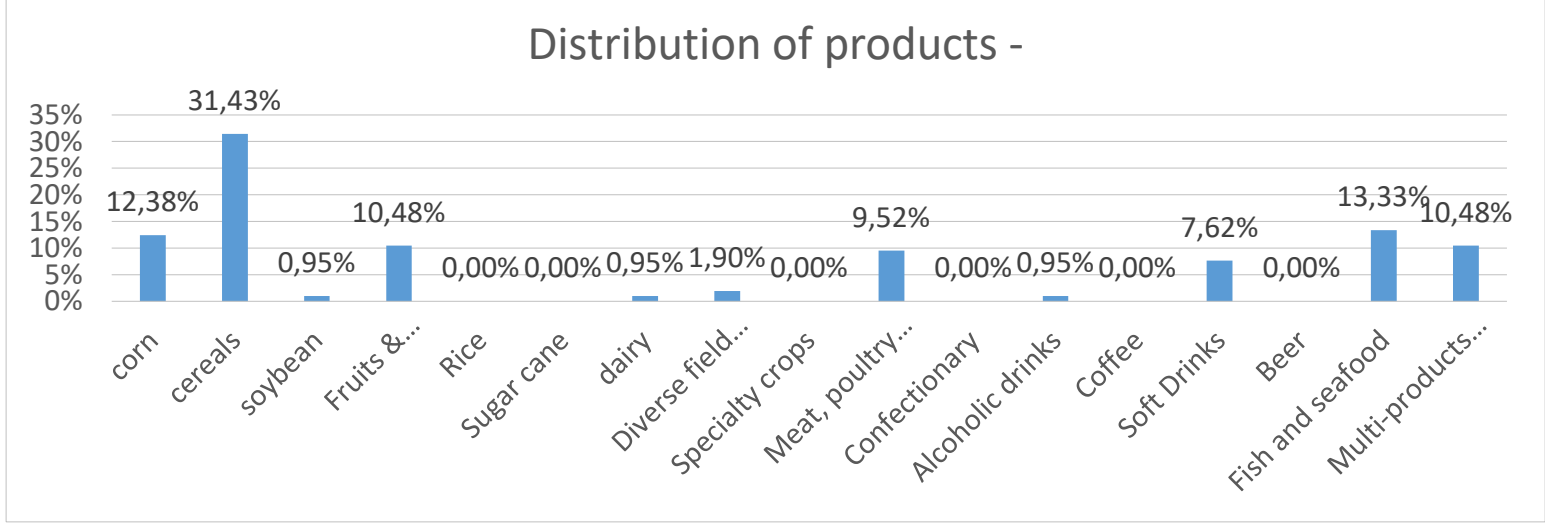

\section{Source: authors' compiled statistics}

Table 45 describes the infringement cases (antitrust) in South Africa categorised according to product type. Among the single-product type infringements, most infringements concerned cereals (31.43\%). Other substantial shares of infringements are taken by the product categories of corn, fruits and vegetables, meat, poultry and eggs, and fish and seafood. There have been no infringements in several product categories, including rice, sugar cane, coffee and beer. 
Table 46: reasons for proceeding by infringement types South Africa

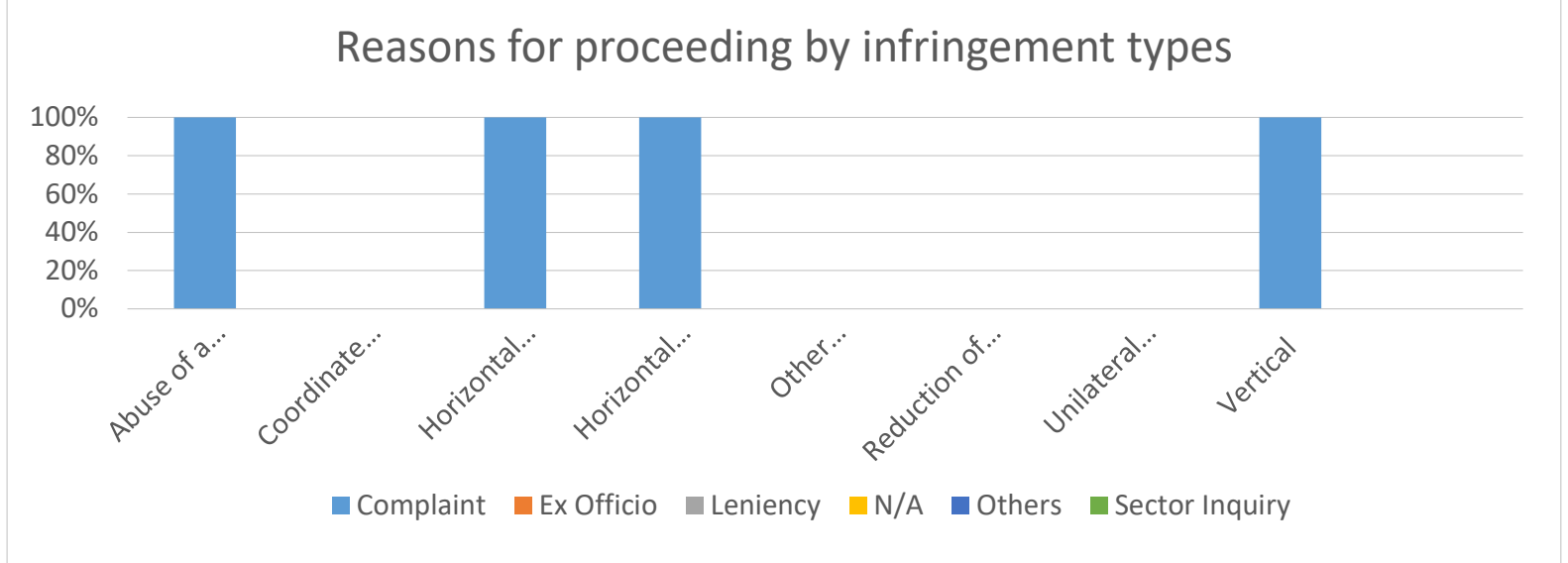

Source: authors' compiled statistics

Table 46 provides a distribution of the reasons for starting infringement proceedings in South Africa for each infringement type. All proceedings have been initiated on the basis of complaints.

Table 47: infringement proceedings by infringement type South Africa

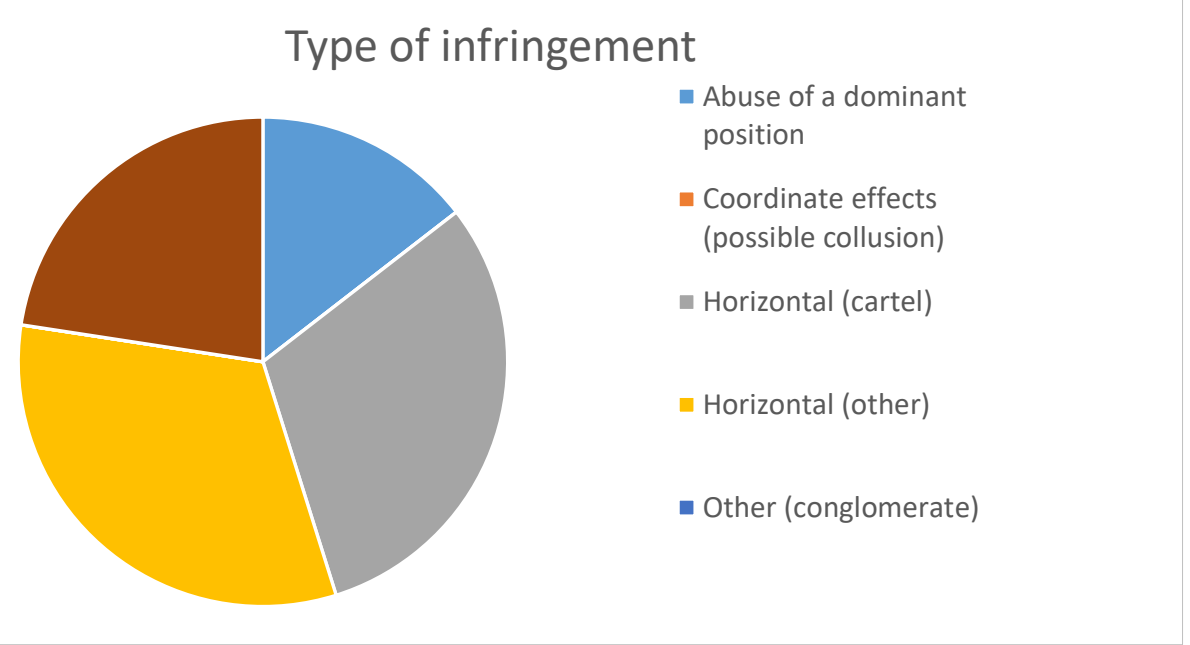

Source: authors' compiled statistics

Table 47 provides a pie chart of the infringement proceedings in South Africa according to the type of infringement. In comparison with the other BRICS jurisdictions, abuse of dominance cases have been only a minor part of total infringement proceedings. The majority of infringement proceedings were targeted at horizontal infringements (cartel and non-cartel). Just under a quarter of proceedings dealt with vertical restrictions. There have been no infringement proceedings against other types of infringements, including reduction of innovation and unilateral effects.

Table 48: distribution of infringement types South Africa infringements 


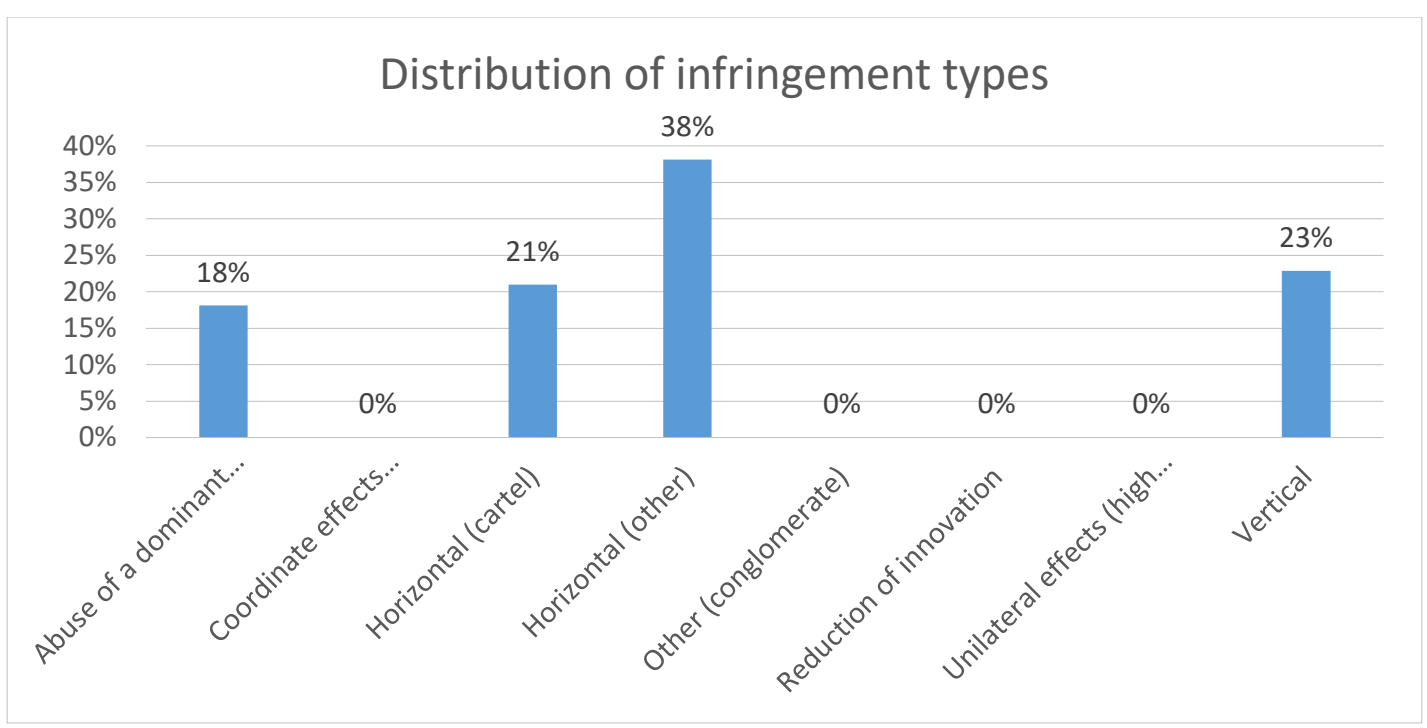

Source: authors' compiled statistics

Table 48 describes a categorization of the infringements in South Africa based on infringement types. Horizontal infringements account for $59 \%$ of the total infringements found, with $21 \%$ cartel infringements and 38\% non-cartel infringements. Vertical restrictions (23\%) and abuse of a dominant position (18\%) also take up an appreciable share of total infringements in the food sector.

\subsubsection{A bestiary of competition law enforcement interventions in the food sector in BRICS}

\subsubsection{Cartels}

All BRICS countries have investigated cartels in the food sector. These cartels operated at different levels of the supply chain: for instance, in the cases considered for these sections, the Russian, Chinese, and South African competition authorities, investigated and penalized cartels at the manufacturing level, although cartels were also uncovered in Russia at the grocery wholesale level. Cartels prosecuted by the Competition Commission of India operated in the pesticides market, whereas those investigated by CADE operated at the processing level as well as the retail level. Interestingly, however, the majority of these cartels dealt with downstream food items, which may directly be transferred from shop to table: bread in Brazil and Russia, rice vermicelli in China and fish in South Africa. Only one Indian cartel case dealt with the upstream factors of production market (pesticides). Brazil, South Africa and Russia initiated the investigations into these cartels on the basis of complaints, whereas India and China led the enquiries into the cartels on their own initiative. Regardless, however, in each of the cases considered here, the investigations and proceedings led to a finding of guilt and culminated in fines against the cartelists. In a number of instances, these fines were also accompanied by cease and desist orders.

More specifically, CADE suspected a cartel in the Bread industry in the town of Sobradinho, located in the surroundings of Brasilia. In 2001, CADE had received a complaint 
from the local police and, after thorough investigations and hearings, in 2013 CADE arrived at the conclusion that several bakeries in the area had formed a cartel to fix the price of bread and to align their market practices generally. CADE consequently, fined 18 bakeries and their owners (totaling 19 individuals) in the sum of Brazilian Reals 650,000,000.00. ${ }^{932}$ FAS also uncovered a cartel in the bread industry and in a 2016 decision held that the Joint stock company "Project "Svezhiy Khleb", open joint stock company "Kurskkhleb" and closed joint stock company "Zheleznogorskiy khlebozavod", which were competitors in the market of bread in the Kurskiy region, had entered into an oral agreement for sharing the product market, volume of sales, range of products and composition of buyers. They had also refused to enter into agreement with certain sellers and had created barriers to entry for other economic entities (eg LLC "Vash Khleb") in the region. Accordingly, FAS fined each of these entities. ${ }^{933}$

In 2012, the Competition Commission of India held that of the four manufacturers of Aluminum Phosphide Tablets in India, which are used for the purpose of storing grains and act as insecticides, three, namely United Phosphorous Limited (UPL), Sandhya Organic Chemicals Private Limited (SOCL), and Excel Crop Care Limited (ECCL) who were supplying these tablets to the Food Corporation of India (FCI) had engaged in collusive bidding. In the tender floated by FCI, these companies had quoted the same price and on negotiation reduced it by the same margin. In the process, they had also doubled the price of these tablets. Investigation into the matter revealed that the parties had been quoting identical prices not only in FCI tenders but also in tenders floated by other government agencies. CCI, therefore, held that the companies had abused their dominant position and had also formed a cartel for the purpose of collusive bidding, which had led to appreciable adverse economic effects. CCI imposed penalty at a rate of $9 \%$ on average of three years turnover on the three parties and directed them to 'cease and desist' from engaging in practices of manipulating process of bidding in any manner. ${ }^{934}$

In 2014, China investigated and found a cartel between Nanning Xianyige Food Factory in the Guangxi region and 18 rice vermicelli manufacturers, which raised the price of rice vermicelli in the region. The case was decided by the National Development and Reform Commission of the region, which directed the parties to cease and desist their illegal practices and imposed a fine of $1 \%$ on the turnover of the preceding year. The NDRC also issued a warning to other rice vermicelli manufacturers. This was the first case to be decided under China's new Anti-monopoly Law. ${ }^{935}$

The South African Competition Commission carried out a very thorough investigation of the South African Pelagic Fish Processors Association for price fixing and market allocation

\footnotetext{
932 Administrative Council for Economic Defence - CADE, Administrative Proceedings n 08012.004039/200168, Defendants: Panificadora e Confeitaria Eulálio - ME and others. Final Decision, Reporting Commissioner: Ana Frazão, 23 May 2012.

${ }^{933}$ Decisions by FAS of Kurskiy region, 21/07/2016, case №03-05/21-2016A with regard to Joint stock company "Project "Svezhiy Khleb" and case № 03-05/22-2016A with regard to Closed joint stock company "Zheleznogorskiy khlebozavod".

${ }^{934}$ Order of the Competition Commission of India in Suo Motu Case no. 2/2011 in Re Aluminum Phosphide Tablets Manufacturers dated 23/04/2012

935 Although NDRC did not publish its full decision online, it released an announcement relating to this case, which summarized the basic facts and Guangxi DRC's findings. The Chinese version of the announcement is available at NDRC's website at http://www.ndrc.gov.cn/fzgggz/jgjdyfld/fjgld/201402/t20140228_588558.html.
} 
of pelagic fish, and for entering into exclusive supply agreements with trawlers to supply pelagic fish. The price fixing allegation stemmed from the Association implementing an industry-wide formula that linked payments to boat owners, skippers, and crew to the average annual fishmeal price that the industry reached. From 1999 to 2010, all industry participants utilized the formula whether they attended the Association's meetings or not, where participants exchanged competitively sensitive information. The Association admitted to and agreed to cease committing the challenged conduct. It agreed to cooperate with the Commission and to implement a competition law compliance program. The Association finally agreed to pay an administrative penalty of South African Rand 16,800.00, which equaled nearly $8 \%$ of the subscriptions that it collected from its members in 2010. The Commission also investigated and penalized individual members of the Associations under different orders. The settlement between the Competition Commission and the South African Pelagic Fish Processors Association was incorporated in an agreement filed before the South African Competition Tribunal. ${ }^{936}$

\subsubsection{Pricing Abuses}

There are several interesting cases relating to pricing abuses. In 2010 in Brazil, CADE initiated an ex officio enquiry of excessive pricing abuse in the Poultry Farming sector after discovering from published reports, that the president of the Brazilian Association of Poultry Farming had recommended that the sector reduce its production by approximately $20 \%$ in order to avoid a decrease in prices. CADE considered the conduct to be illegal and fined the Association and its president to cease and desist from this conduct and to pay a fine of approximately Brazilian Real 1,000,000.00 only. ${ }^{937}$

In 2014, FAS in Russia received a complaint that an open joint stock company 'Zernoproduct' was engaging in excessive pricing abuse in the grain and cereal sector by rendering the services of keeping and offloading the grains from the stocks of the interventional reserve created by the Ministry of Agriculture at an artificially high price which exceeded the prices of analogous services in other regions. After investigations and economic analysis, FAS established that the price for services of keeping and offloading the grains from the stocks of the interventional reserve set by OJSC "Zernoproduct" was monopolistically high. However, FAS did not impose a fine and merely obtained from it a commitment that it would reduce the price at which it was offering services. ${ }^{938}$

In a 2016 decision, the Competition Commission of India (CCI) held that members of the Indian Jute Mills Association had indulged in an excessive pricing abuse. CCI had initiated the investigation on the basis of a complaint received from the Indian Sugar Mills Association and others who were the primary consumers of bags produced by the Indian Jute Mills

\footnotetext{
${ }^{936}$ Decision of the Competition Tribunal Republic of South Africa Case No. CR213Mar14/SA066Jul16 In the matter of the Competition Commission v. The South African Pelagic Fish Processors Association dated 29/07/2016.

937 BRAZIL, Administrative Council for Economic Defence - CADE, Administrative Proceedings $n$ 08012.003623/2009-53 and Request n 08700.002933/2009-01, Defendants: União Brasileira de Avicultura (UBA) and Ariel Antônio Mendes. Final Decision, Reporting Commissioner: Carlos Ragazzo, 09 June 2010. ${ }_{938}$ Decision of Ivanovo FAS, 17/04/2014, case №02-08/2013-003 Open joint-stock company “Zernoproduct”.
} 
Association. The complainants had argued that the Indian Jute Mills Association and its members was in the practice of fixing the price of jute packaging material by issuing a daily price bulletin. It was further argued that the prices imposed by the Jute Mills Association and its members were unfair and excessive price and limited technical development of market. After an investigation CCI found the Jute Mills Association and its members guilty of abusing their dominant position and engaging in anti-competitive behaviour. CCI directed the parties to cease and desist from indulging in these acts and imposed a penalty of 5\% of the average turnover of the mills and the association in the last three years. ${ }^{939}$

In 2012, the NDRC of the Guizhou and Sichuan region in China provided information about a pricing abuse in the liquor sector. It reported that Moutai had issued a price limiting order to its distributors and had subsequently penalized six distributors for acting contrary to the price limiting order. In 2013, the Price Supervision and Anti-Monopoly Bureau of NDRC and Guizhou Price Bureau commenced joint investigation of Moutai and Wuliangye. Subsequently, Moutai and Wuliangye cancelled relevant marketing policies that violated the antimonopoly law. Moutai also withdrew relevant penalty decisions and refunded the deposits of its distributors. Finally, by its decision of 22 February 2013, Guizhou Provincial Pricing Administration imposed a penalty of RMB 247 million (approximately USD 39.8 million) on Kweichow Moutai, the most famous Chinese state-owned producer of premium liquor, for administering resale price maintenance. On the same day, Sichuan PDRC released its decision to penalize Wuliangye, another state-owned premium liquor producer, in an amount of RMB 202 million (about USD 32.6 million) for RPM as well. ${ }^{940}$

On 22 February 2013, Guizhou Provincial Pricing Administration released the decision to impose a penalty on Kweichow Moutai, the most famous Chinese state-owned producer of premium liquor, for administering resale price maintenance. ${ }^{941}$ In more detail, on 18 December 2012, Moutai issued a price limiting order regarding the lowest retail price and bulk price of Moutai liquor. On 5 January 2013, Moutai internally announced penalty to six distributors for disobeying the lowest guidance prices. Of the six distributors, three Chongqing distributors were penalized by suspension of relevant contractual arrangement, retention of deposits and yellow-card warning, etc. Such distributors shall also resume the guidance prices. On 13 January 2013, the Bureau of Price Supervision and Anti-Monopoly Bureau of NDRC and Guizhou Price Bureau commenced joint investigation on Moutai and Wuliangye. NDRC held that Moutai's RPM violated AML and required it to (a) cancel relevant marketing policies and rules that violate antimonopoly law (b) withdraw penalties to relevant distributors and (c) refund the retained deposits. Unlike other prior large ticket, this one was issued by the local Guizhou Price Bureau. Guizhou Price Bureau issued a 247 million ticket to Moutai and a 202

\footnotetext{
${ }^{939}$ Competition Commission Of India Case No. 38 of 2011 Indian Sugar Mills Association and others v. Indian Jute Mills Association and others order dated 31/10/2014.

${ }^{940}$ The NDRC did not publish the full contents of these two sanctions. However, the case number and rulings may be deduced from the companies' announcements since both Moutai and Wuliangye are listed companies. Those sanctions are: Guizhou Price Bureau's administrative sanction (Qian Jia Chu [2013] No.1) against Kweichow Moutai; Sichuan DRC's administrative sanction (Chuan Fa Gai Jia Jian [2013] No.1) against Wuliangye.

${ }^{941}$ Kweichow Moutai case, 22 February 2013
} 
million ticket for $\mathrm{Wu}$ Liangye which is the largest Anti-trust ticket. The total amount of Moutai and Wuliangye ticket is the biggest fine in antitrust enforcement practice.

In South Africa, in 2011, the Animal feed producers notified the Competition Commission of South Africa (CCSA) of the possibility of an abuse on the part of Foskor by charging excessive prices for the sale of phosphoric acid, which constitutes an input to both livestock and poultry feed. The Commission determined that Foskor possessed the ability to sustain prices "substantially in excess" of the competitive level, to "the very limit" of its monopolistic power in the local market, and that the price that Foskor charged was "excessive and detrimental to consumers". To respond to the Commission's concerns, Foskor eliminated the $75 \%$ shipping rate from the local phosphoric acid price, thereby substantially lowering prices. Foskor additionally committed to adopt a competition law compliance program. The settlement between the Competition Commission and Foskor was recorded in an agreement filed before the Competition Tribunal. ${ }^{942}$

\subsubsection{Horizontal mergers}

\subsection{Unilateral effects}

The BRICS competition authorities have reviewed numerous horizontal merger cases relating to all segments of the agro-food industry, involving both domestic and international firms.

In Brazil, in 2008, CADE reviewed the acquisition by Monsanto, a market leader in all types of corn seeds, of Agroeste Sementes ${ }^{943}$. The report of the authority indicated some horizontal concentration in the market for hybrid corn, involving the technology, the incorporation into the seeds, the multiplication and the sale. Although barriers to entry were high and the variation of HHI level was significant, the authority considered that rivalry in the market (Syngenta, Pioneer and Dow) was enough to curb any anticompetitive effects. The final decision was approval of the transaction with the condition of restricting the non-competition clause to five years. Of course, unilateral effects were also raised in the context of the proposed purchase of Monsanto Co. by Bayer AG, two of the largest competitors in the world for soybean seeds and transgenic cotton, which is explored in another Section of this report ${ }^{944}$

Turning to Russia, in 2017, the Federal Antimonopoly Service (FAS) granted the application of JSC "United Confectioners", the largest confectionary holding in Russia and Eastern Europe, to acquire 42,43\% of voting shares of the OJSC Moscow Confectionary Factory "Krasniy Octyabr" specialised in production of confectionary. ${ }^{945}$ "United Confectioners" is a vertically integrated holding including 19 factories, 8 logistic centers and the agro-holding cluster producing raw materials for the factories. Upon the acquisition, $100 \%$ of capital share of "Krasniy Octyabr" would belong to the entities constituting the same group with "United Confectioners".

\footnotetext{
${ }^{942}$ Decision of the Competition Tribunal of the Republic of South Africa in Case no. 43/CR/2010 in the matter between the Competition Commission of South Africa v. Foskor (Pty) Ltd order dated 28/02/2011. 943 Agroeste Sementes

${ }^{944}$ Monsato/Bayer, Administrative Council for Economic Defence - CADE, Administrative Proceedings n AC 08700.001097/2017-49, final decision pending as of 31 August 2017.

9452017 /M/ United Confectioners. JSC, FAS of Russia, No ЦA/6182/17, 2 February 2017.
} 
With regard to China, MOFCOM conditionally approved in 2009 Pfizer's proposed acquisition of Wyeth. ${ }^{946}$ MOFCOM concluded that Pfizer's acquisition of Wyeth would substantively change the structure of market competition for swine mycoplasma pneumonia vaccine, resulting in restrictions on or elimination of competition. To support its conclusion, MOFCOM used specific data to demonstrate that the market share of the merged company and the resulting concentration in the market of swine mycoplasma pneumonia vaccine, which would be significantly increased and, consequently, render it more difficult for other companies to enter the relevant market. Thus, clearance of the proposed merger was conditional on the divestment of the business of Mycoplasma pneumoniae pneumonia vaccine

The Competition Commission's of South Africa analysis of the merger between Dow and Dupont in 2017 also greatly relied on the non-coordinated (unilateral) effects of the merger, following the existence of various horizontal overlaps between the merging companies in fungicides, herbicides, and insecticides. ${ }^{947}$ The decision is examined in more detail at a different Section of this Report.

\subsection{Coordinated effects}

Coordinated effects were brought forward by the Competition Commission of South Africa when it provisionally cleared the proposed merger by Dow of Dupont in 2017. ${ }^{948}$ The CCSA considered whether the merger would have produced coordinated effects in the maize seed market. The prevalence of cross-licensing agreements necessary to breed and develop traits would have facilitated coordination among the market participants. The agrochemical market further had undergone tremendous consolidation in the recent past. However, the Tribunal determined that the heterogeneity of traits and seeds materially would have inhibited coordination, as the market produced constant innovation. Additionally, licensing agreements normally do not indicate the costs of the licensee or otherwise reveal the prices of downstream products. The CCSA also considered unilateral and coordinated theories of harm on the sunflower market. As for the coordinated effects, the CCSA also conducted an extended analysis of the possibility that the merger would produce coordinated effects. As in the maize seed market, the relevant products were not homogenous, weakening the potential for coordination. Market participants competed in several markets and commonly met at CropLife, an industry association, factors that increased opportunities to exchange information and detect and punish deviations from agreed actions. Yet as the parties constantly innovated, the heterogeneity of fungicides rendered coordination untenable. Again, this decision is examined in greater detail in another Section of the report.

\subsubsection{Mergers with vertical foreclosure}

In Brazil, CADE has been exploring vertical foreclosure in various merger cases. Most notably, in 2011, CADE was notified of the proposed merger between Sadia and Perdigão, two Brazilian

\footnotetext{
${ }^{946}$ Pfizer/Wyeth, MOFCOM, 29 September 2009

${ }^{947}$ Competition Tribunal of South Africa, Case No: LM030May16, DowDuPont Inc., 30 June 2017. 948 Ibid.
} 
top players in the food industry -and historical rivals- into Brasil Foods. ${ }^{949}$ They represented together between $50 \%$ and more than $80 \%$ of sales in the Brazilian market of processed food in each market. CADE undertook an extensive analysis of all the relevant markets. The report indicated that the operation could lead to high horizontal concentration, especially in the markets of margarine, sausages, ham, hamburgers, lasagnas, frozen pizza, kebabs and meatballs. There was also vertical integration and concerns on the increase of the purchase bargaining power. Entry and rivalry were not capable of compensating the market power created. The claimed efficiencies were not sufficient. The reporting Commissioner voted for the prohibition of the merger. The other Commissioners (majority) voted for its approval with several restrictions. During the same year, CADE also examined the proposed acquisition by Fresenius of Hosp Pharma. ${ }^{950}$ The report of the authority indicated that there was vertical integration in the market of parenteral nutrition and its components. Although Fresenius held a dominant position, there was no possibility of vertical foreclosure given that competitors could provide inputs and import products. Nonetheless, agreements included a non-competition clause requiring adjustment as to its geographical scope. The transaction was approved with the condition of restricting the clause to the a distance of $200 \mathrm{~km}$ from Sao Paulo. In 2006, CADE reviewed the proposed agreements for cooperation and licensing for the use of hybrid corn between Monsanto and Agromen. ${ }^{951}$ The report of the authority indicated that there was no horizontal concentration or vertical integration. The merger was approved without restrictions.

Turning to India, in 2016, the CCI unconditionally approved the proposed acquisition of Anik Industries Limited by BSA International S.A ${ }^{952}$. The Acquirer proposed to acquire the Target's dairy business by way of slump sale. The Acquirer was a company incorporated in Belgium and functions in India through its subsidiary, Tirumala Milk Foods Pvt. Ltd. (Tirumala), which is engaged in the production and manufacture of liquid milk and milk products. The Target is engaged in three sectors i.e. dairy, power production and trading of coal and agro goods. The CCI held that there was a horizontal overlap between the parties in the (a) liquid milk and (b) ghee activities. In the Ghee market, the CCI recognized that the market comprised of organized and unorganized players and the geographic market was the entire territory of India. It was further observed that the players were unlikely to raise concerns and thus further market delineation was not required. The market shares of the parties were insignificant and vertical foreclosure was unlikely to occur.

With regard to China, in 2006, MOFCOM conditionally approved the proposed acquisition of SAB Miller by Anheuser-Busch InBev pending on the divestment of $49 \%$ shares of China Resources Breweries CO., Ltd. ${ }^{953}$ In its competition analysis, MOFCOM considered four factors, including (a) the deal will further enhance ABI's market controlling power, (b)

\footnotetext{
${ }^{949}$ Sadia/ Perdigão, Administrative Council for Economic Defence - CADE, Administrative Proceedings n AC 08012.004423/2009-18, 13 July 2011.

${ }^{950}$ Fresenius/Hosp Pharma, Administrative Council for Economic Defence - CADE, Administrative Proceedings n AC 012.008526/2009-57, 29 June 2011.

${ }^{951}$ Monsanto/Agromen, Administrative Council for Economic Defence - CADE, Administrative Proceedings n AC 08012.009265/2005-69, 05 April 2006.

952 B.S.A. International S.A./Anik Industries Ltd, CCI, C-2016/04/386, 23 June 2016.

953 Anheuser-Busch InBev / SAB Miller, MOFCOM, 29 July 2016.
} 
the deal between the two closely competing beer makers will lead to reduced competition, (c) the deal will increase barriers to entry, and (d) the deal will hurt downstream distributors. MOFCOM's decision analysed the market structure and possible harm to downstream distributors. It found that most beer distributors are small in scale with limited coverage, and lack significant bargaining power. Post-merger, the undertaking would have the incentive and power to control the distribution channel and customers in order to raise the entry barriers to beer market. Due to reduced competition between ABI and CR Snow, the distributors' bargaining power would be further weakened. Thus, the distributors would have less access to ABI's incentive programs, and thereby their interests will be harmed.

Vertical foreclosure was also an issue raised by the Competition Commission of South Africa in the analysis of the acquisition of Little Green beverages, a supplier of branded private label soft drinks in South Africa, by Main Street, a private investment fund that owned a shareholding in a corrugated packaging company. ${ }^{954}$ The CCSA expressed concerns that the merger raised some vertical foreclosure issues, in that LGB purchased packaging materials from Main Street's packaging company. After LGB assured the Tribunal that it did not intend to shift its procurement to this company completely, the Tribunal held that the transaction was unlikely to produce input or customer foreclosure. The Tribunal approved the transaction and concluded that it was unlikely to substantially prevent or lessen competition in any relevant market.

\subsubsection{Mergers with portfolio effects}

In Brazil, CADE examined portfolio effects in 2009, when considering the acquisition by Recofarma (a company owned by the multinational corporation Coca Cola) of Leao Junior, which is a company active in the tea and guarana business. ${ }^{955}$ The authority found high horizontal concentration in the markets of ready-to-drink tea (mate) and iced teas. Entry and rivalry would not be sufficient to curb anticompetitive effects, especially because of the brand loyalty observed in this market. The report analysed the specificities of the distribution chain for cold teas, in which a duopoly was established. Efficiencies were presented but they were not sufficient to dispel the competitive concerns. Given the portfolio power of Coca-Cola, CADE decided to propose structural restrictions which were, in the end, agreed by the parties. The final decision was approval with the condition of the sale of the brand Nestea from CocaCola.

In India, portfolio effects came up in the context of the assessment of the Dow/Dupont merger ${ }^{956}$. The CCI considered that the proposed merger had a conglomerate dimension, raising issues in several markets, such as crop protection products, $\mathrm{R} \& \mathrm{D}$ in crop protection products, seeds, purified CMC and material science. Whilst CCI was of the view that the merger did not have an adverse effect on competition in seeds and purified CMC, but it found potential adverse

\footnotetext{
${ }_{954}$ Competition Tribunal of South Africa, Case No: LM168Nov16, Main Street 1438 (Pty) Ltd, 19 Jan. 2017.

${ }^{955}$ Recofarma (Coca-Cola)/Leao Junior, Administrative Council for Economic Defence - CADE, Administrative Proceedings n AC 08012.001383/2007-91, 17 June 2009.

${ }^{956}$ Dow Chemical Company Ltd, Case No C-2016/05/400, 08 June 2017.
} 
effect on competition in relation to crop protection products, $\mathrm{R} \& \mathrm{D}$ in crop protection products, and material science. Consequently, CCI recommended modifications to the merger, which were accepted by the parties. The decision is examined in more detail in a separate Section of the report.

\subsubsection{Public interest mergers}

The parallel consideration of public interest concerns in the merger control of South Africa is of course a well-known feature of South African regime ${ }^{957}$. One of the many examples of the consideration of public interest concerns in food sector mergers is the 2016 acquisition of Anheuser-Busch by SABMiller, the CCSA conditionally approving the proposed acquisition. ${ }^{958}$ In South Africa, AB InBev supplies beer products and SABMiller is the largest producer of beer products. The CCSA found that the proposed merger raised several competition and public interest concerns. To satisfy public interest concerns, the parties agreed to pay one billion rand mostly for agricultural development, but also for enterprise development and other objectives. The parties also agreed for five years to generally maintain the same employment level at SABMiller, and to meet benchmarks for local input purchases.

\subsubsection{Licensing agreements}

In 2015, CADE unconditionally approved the proposed licensing agreement granted by Monsanto to Embrapa, through which the latter would develop and sell corn seeds with the VTPro2 technology. ${ }^{959}$ The report of the authority indicates that there was no risk that the agreement would be detrimental to the competition in the market, since there was no exclusivity involved.

Of particular interest is also CADE's approval with restrictions in 2014 of four operations involving licensing agreements through which Monsanto do Brasil Ltda authorized other companies to develop, produce and sell, in Brazil, soybean seeds with Intact RR2 PROTM technology, owned by Monsanto ${ }^{960}$. CADE conditioned the approval of the transactions to the change of clauses that gave Monsanto the possibility to influence the strategic decisions of the licensee companies. This influence did not only reach seed production with Intact technology but also extended to the total production of the licensee companies. The contractual provisions established a compensation mechanism for the licensee companies, based on sales of the Intact product and on the sales of certified seeds of Monsanto's competitors. Had a licensee company chosen to expand its production by also using a patent

\footnotetext{
${ }^{957}$ For an excellent study, see A. A. Raslan, Mixed Policy Objectives in Merger Control: What Can Developing Countries Learn from South Africa?, (2016) 39(4) World Competition 625 and the analysis provided in the country report on South Africa.

958 Anheuser-Busch InBev SA/NV \& SABMiller plc, Competition Tribunal of South Africa, Case No: LM211Jan16, 4 August 2016.

${ }^{959}$ Monsanto/Embrapa, Administrative Council for Economic Defence - CADE, Administrative Proceedings $n$ AC 08700.001226/2015-37, 24 March 2015.

960 See CADE's press release http://www.cade.gov.br/noticias/cade-aprova-com-restricoes-contrato-delicenciamento-entre-monsanto-e-bayer .
} 
from a competing product, the compensation from what had been produced with Intact technology would have been reduced accordingly. Monsanto's competitor should have then counterbalanced the offer by paying for the correspondent profit reduction.

\subsubsection{Joint Venture Agreements}

In 2015, the Competition Commission of South African brought three complaints against Astral Operations, having found that it was a dominant undertaking. ${ }^{961}$ In the Elite Complaint, it alleged that Astral entered a joint venture with a horizontal competitor, Country Bird, that foreclosed other suppliers of parent stock chicken by forcing Country Bird to source $90 \%$ of its requirements from the joint venture undertaking, Elite. The contract between the parties also restricted Country Bird from entering the upstream breeder market. The Commission finally alleged that the joint venture forced Elite to purchase feed requirements from a certain source, which foreclosed other suppliers of feed. Astral admitted that the joint venture violated competition law by preventing Country Bird from expanding within the broiler market and offering an alternative parent stock breed. Astral subsequently bought-out Country Bird's interest in Elite. The Commission refrained from imposing a penalty for this offense. In a second complaint, termed Poultry Products, Astral admitted to price fixing and attempting to raise the price of fresh poultry in the Western Cape from 2003 to 2007. Astral undertook not to commit similar acts in the future and to pay an administrative penalty which represented $3 \%$ of its fresh poultry turnover in the Western Cape for 2008. In a third Complaint, entitled Breeding Stock, the Commission alleged that an association which included Astral allocated markets, exchanged sensitive information, and arranged for exclusive supply agreements and tying. The Commission accepted undertakings by Astral to submit information to the association in a certain format and to cooperate with ongoing investigations related to the above complaints.

\subsubsection{Standardization Agreements}

The Competition Commission of South Africa examined standardization agreements in a case brought in 2011, concerning the activities of an industry association for grain storage, a committee of which was staffed by representatives of most competitors. The CCSA alleged that the defendant Grain Silo Indus (GSI), exchanged cost information and recommended daily storage rates to another industry association, SAFEX ${ }^{962}$. SAFEX set a price benchmark for grain storage and sales transactions in the physical grain market on which participants in these separate markets relied. GSI also aggregated on a yearly basis the cost information that its members regularly submitted to it to facilitate circulating an annual average cost of running a grain storage business. While GSI argued that SAFEX needed uniform tariffs to function properly, the CCSA considered that having competitors providing grain storage services jointly determine the SAFEX tariffs through GSI amounted to horizontal price fixing. GSI admitted that it provided a forum where its members could share detailed cost information related to the

${ }^{961}$ Astral Operations Ltd, Comp. Trib. of S. Africa, Case No: 015891, 12 November 2013.

962 Grain Silo Indus (Pty) Ltd, Case No: 43/CR/Jun11, Comp. Trib. of S. Africa, 9 November 2011. 
cost of operating a silo and of storing grain, that it therefore facilitated the joint determination of proposed SAFEX tariffs. GSI agreed to pay an administrative penalty of 94,556 rand, to cooperate in the prosecution of other conspiracy participants, and to implement a competition law compliance program.

\subsubsection{Agricultural Cooperatives}

Starting with China, in 2016, an abuse of dominance case was brought by the Huazhou Chen Yawang Farming Cooperative to the High People's Court of Guangdong Province, alleging that Huazhou Bayberry Food Ltd refused to continue to offer slaughter and wholesale facilities to Chen, because Huazhou Chen Yawang Farming Cooperative failed to get the requisite permission by the government ${ }^{963}$, although Huazhou Chen Yawang Farming Cooperative alleged that it had assured a business licence from the Huazhou Administration of Industry and Commerce. Maoming Intermediate Court held that the dispute concerned an abuse of dominant market position over which the Court did not have jurisdiction, and thus declined to hear the case. In the subsequent appeal, the High Court of the Guangdong province upheld that judgment.

The Competition Commission of South Africa also examined agricultural cooperatives when it was seized in 2002, by a farmer's complaint alleging that the Patensie cooperative, a packing and distribution association of farmers, prevented him from procuring packing services from another vendor. ${ }^{964}$ The CCSA alleged that the defendant's Articles of Association constituted a horizontal agreement between farmers that fixed trading conditions and fined noncompliance, including a requirement not to deal with competing packing and marketing vendors. According to the CCSA, this conduct qualified as collusion and abuse of dominance.

The Competition Tribunal proceeded only with the abuse of dominance claim. It found that the individual members of the association could not control its business decisions, as no farmer held more than a $6 \%$ share of the association. The absence of a profit above costs also did not create a single economic entity. The Tribunal determined that the relevant product market consisted of farmers and the association exchanging services as buyers and sellers for the packing and marketing of citrus fruit. It identified a geographic market of the Gamtoos River Valley because of the significant costs associated with transporting fruit. The Tribunal held that the association dominated this market, holding at least a 70\% share, which surpassed the $45 \%$ floor required to prove dominance. The South African Competition Act explicitly provides that companies may not "require or induce" customers or suppliers to cease or avoid dealing with competitors. The association's Articles required members to supply their entire output to the association for packing and marketing, completely precluding farmers from dealing with other purveyors of these services. The Tribunal characterized this provision as a "naked restraint of trade" and an exclusionary act regardless of whether the Commission could establish anticompetitive effects; the Tribunal presumed effects based on dominance and the

\footnotetext{
${ }^{963}$ Huazhou Chen Yawang Farming Cooperative v. Huazhou Food Ltd., Huazhou Bayberry Food Ltd., The High People's Court of Guangdong Province, 23 December 2016.

${ }^{964}$ Patensie Sitrus, Case No: 37/CR/Jun01, Comp. Trib. of S. Africa, 8 April 2002.
} 
act itself. However, the Tribunal did not impose an administrative penalty. It rather voided the Articles of Association that compelled the exclusionary practice.

\subsection{A comparative analysis of the competition assessment of some recent merger transactions in the agrochemical sector}

The recently notified mergers in the seed and agro-chem industry, as well as those contemplated in other related sectors raise difficult questions that competition authorities around the world. Because of the importance of their market size, the decision reached by US and EU competition authorities were important for the merging parties, but the perspective of a number of other competition authorities in emerging and developing economies', in particular in the BRICS, the BRICS competition authorities in some cases assessing the merger transactions before the EU and the US competition authorities had the chance to finalize their assessment. Hence, their decisions played an increasingly important role for the transactions, in particular with the adoption of some global remedies that took care of some of the most controversial competition law concerns raised by these transactions.

The most recent merger wave started in July 2014 when Monsanto made a number of acquisition offers to Syngenta. These offers were rejected, but the Monsanto bid triggered a number of other M\&A transactions that were announced in 2015 and 2016 between the various market leaders in the factors of production segment. In November 2015, Syngenta accepted the offer of ChemChina (which owns ADAMA, one of the largest agrochemical companies in the world). In December 2015, Dupont and Dow announced their merger. In September 2016, Bayer put forward a merger deal with Monsanto. During the same month, a deal was announced between two of the leaders in the market for Fertilisers, Potash Corp and Agrium. In November 2015, it was reported that Deere \& Co. (the leader in agricultural machinery) has agreed to buy Monsanto's precision farming business. This deal was opposed by the US Department of Justice as it would have led Deere to control a significant part of the already highly concentrated US high-speed precision planting systems market ${ }^{965}$.

The global consolidation of the crop seeds \& biotechnology, agricultural chemical, animal health and breeding industries, as well as agricultural machinery has been the focus of economic research, including, Hart (2000) ${ }^{966}$, King (2001) ${ }^{967}$, MacDonald et al. $(2004)^{968}$, Fernandez-Cornejo ${ }^{969}$, Fuglie et al. $(2011)^{970}$, Moss $(2013)^{971}$, the European Parliament

\footnotetext{
965 See, https://www.justice.gov/atr/case-document/file/905571/download .

966 N. E. Hart, The Age of Contract Agriculture: Consequences of concentration in Input Supply, (2000) 18(1) Journal of Agribusiness 115-127.

967 J. King, Concentration and Technology in Agricultural Input Industries, USDA, Agriculture Information Bulletin no. 763.

968 J. MacDonald et al., Contracts, Markets, and Prices: Organizing the Production and Use of Agricultural Commodities, (2004) Agricultural Economic Report No. 837, 9.

969 J. Fernandez-Cornejo, The Seed Industry in U.S. Agriculture, U.S. Dep't of Agric., Econ. Res. Serv., Agric. Info. Bull. No. 786 (2004), 4.

${ }^{970}$ K. Fuglie et al, Research Investments and Market Structure in the Food Processing, Agricultural Input, and Biofuel Industries Worldwide, USDA-ERS Economic Research Report No. 130 (2011).

${ }^{971}$ D. L. Moss, Competition, Intellectual Property Rights, and Transgenic Seed, (2013) 58 South Dakota Law Review 543-559
} 
$(2014)^{972}$, Boston Consulting Group $(2015)^{973}$, the ETC Group $\left(2011^{974}, 2015^{975}\right.$ ), the European Commission (2015) $)^{976}$, US National Academy of Sciences (2015) $)^{977}$, Howard (2009 ${ }^{978}$, $2016)^{979}$. High concentration in the food industry is not unusual. This phenomenon has been extensively studied over the last several years. Howard argues that the rapid consolidation of the seed industry led to global dominance by a few companies, with Monsanto, Syngenta and DuPont being the most powerful ${ }^{980}$. At the time the mergers were notified it was estimated that "the Big Six" (Monsanto, Syngenta, DuPont, BASF, Bayer, Dow) collectively controlled more than $75 \%$ of the global agrochemical market, $63 \%$ of the commercial seed market, and almost three quarters of $R \& D$ expenses in the seeds and pesticides sector (as the combined $R \& D$ budget of the Big Six was 15 times more than the USDA crop science research budget in $2013)^{981}$. More in depth analysis of the structure of the seeds and agrochemical markets was provided in Part II.

These mergers raised quite interesting questions as to the possible theories of harm analysed, the way the various competition authorities employed the relevant market tool for their assessment or price competition, and the extent to which they ignored it when examining other possible effects of the merger, the way markets were defined for different types of products, the role, if any, of public interest considerations, but also significant differences in the economic and legal context of each jurisdiction, the relevant product markets in some jurisdictions being less concentrated than in others, sometimes being linked to the fact that some markets are conventional seed markets, the commercialization of genetically modified or edited book being limited by extensive regulation, while other jurisdictions are more GMOfriendly and one may observe a higher concentration of their market.

It has been alleged that the large agrochemical companies that have initiated this merger wave are seeking to develop an "integrated offering of equipment and services for farmers," enabling them to "gradually build a compelling one-stop solution that will allow them to compete for the lion's share of the market. It is increasingly clear that market players in this industry have made the choice of positioning themselves as fully integrated providers, or the orchestrators of a network, or partners of an established network ${ }^{982}$, which may lead to the

972 I. Mammana, Concentration of Market Power in the EU Seed Market, (January 2014), Study commissioned by the Greens/EFA Group in the European Parliament.

973 Boston Consulting Group, Crop Farming 2030 - The Reinvention of the Sector (April 2015), available at https://www.bcgperspectives.com/content/articles/process-industries-innovation-crop-farming-2030-

reinvention-sector/

974 ETC Group, Who will control the Green Economy? (November 2011), available at http://www.etcgroup.org/sites/www.etcgroup.org/files/publication/pdf_file/ETC_wwctge_4web_Dec2011.pdf.

975 ETC Group, Outsmarting Nature, November 2015;

976 European Commission, Overview of the Agricultural Sectors in the EU Study (2015).

${ }^{977}$ M. M. Nesheim, M. Oria and P. Tsai Yin (eds.), A Framework for Assessing Effects of the Food System, National Academy of Sciences (2015), p. 54

${ }_{978} \mathrm{Ph}$. H. Howard, Visualizing consolidation in the global seed industry: 1996-2008, (2009) Sustainability 1(4):1266-1287.

${ }^{979} \mathrm{Ph}$. Howard, Concentration and Power in the Food System (Bloomsbury, 2016).

$980 \mathrm{Ph}$. H. Howard, Visualizing consolidation in the global seed industry: 1996-2008, (2009) Sustainability 1(4):1266-1287; Ph. H. Howard, Seed industry structure, (2014), available at https://msu.edu/ howardp/seedindustry.html.

${ }^{981}$ ETC Group, Breaking Bad: Big Ag Mega-Mergers in Play, (December 2015), Communique 115, available at http://www.etcgroup.org/content/breaking-bad-big-ag-mega-mergers-play, p.4.

${ }^{982}$ Id., p. 15. 
development of bottlenecks in the food supply chain affecting consumers and other market actors, such as farmers. This is particularly the case in the seed sector, where companies have been offering a package of genetic transformation technology and genomics, traits, seeds and chemicals ${ }^{983}$. As we have examined in Part I, it is possible to argue that this package of 'complementary' products and technologies may form a system competing with other systems ('systems competition'). ${ }^{984}$

Hence, a question that had to be tackled, when determining the relevant markets affected by the mergers is if research, breeding and development/marketing of the various kinds of seeds be considered as part of the same or of different relevant markets? The answer to this question was not clear at the time these mergers were first assessed. For instance in the EU, the question has been left open in the Commission's decision in Limagrain/KWS/Genective $J V^{985}$, while in Syngenta/Monsanto's sunflower seeds business, the Commission considered that breeding and commercialisation are two separate markets ${ }^{986}$, and in Syngenta CP/Advanta the Commission included both stages of the seed industry in one single relevant product market ${ }^{987}$. What about seed-herbicide packages, the seed/agrochem company selling cultivars with special tolerance to the parent agro-chem company's herbicides? Would the Commission proceed to the same approach it employs in the context of tying cases, where the existence of independent suppliers in the manufacture and sale of the tied product may constitute serious evidence of the existence of a separate market for that product ${ }^{988}$ ? Of course, market definition issues will also concern the question of GM seed markets being defined as a separate market than conventional seeds, the Commission noting in Limagrain/KWS/Genective $J V$ that "it is difficult to predict how the breeding and commercialisation of conventional and GM [...] seeds will interact in the future", substitutability depending "to a large degree on the future deregulation and overall regulatory environment for GM maize seeds in the EEA" $" 989$.

One may also argue that the emergence of integrated technology/traits/seeds/chemicals platforms may place barriers to new entry, as companies wishing to enter the market(s) would need to offer an integrated solution to farmers. This may stifle disruptive innovation, if in the absence of the merger, firms were able to enter one or two segments of the market (e.g. research and breeding) without the need to offer an "integrated" platform product that would offer significant economies of scale, but would also require high fixed costs. Although traditional breeding methods required important resources and a considerable investment of time (because of long breeding cycles) and thus provided large economies of scale leading to the emergence of large market players, the latest genome-editing technologies, particularly CRISPR/Cas, may constitute more efficient and less resource intensive and time-consuming breeding methods, that offer opportunities for the emergence of more competitive and less integrated market

\footnotetext{
983 D. L. Moss, Transgenic Seed Platforms: Competition Between a Rock and a Hard Place?, AAI Submission, October 23, 2009, p. 2.

${ }^{984}$ M L Katz \& C Shapiro, 'Systems Competition and Network Effects' [1994] 8(2) Journal of Economic Perspectives 93.

985 Case No COMP/M.6454 - LIMAGRAIN / KWS / GENECTIVE JV (2013), para. 23.

986 Case No COMP/M.5675-Syngenta/Monsanto's Sunflower Seed Business, C(2010) 7929 final, paras 76-89.

${ }^{987}$ Case No COMP/M.3465 - SYNGENTA CP / ADVANTA (2004), para. 12.

${ }^{988}$ Case T-201/04, Microsoft v. Commission, [2007] ECR II-3601, paras 917 \& 922.

${ }^{989}$ Case No COMP/M.6454 - LIMAGRAIN / KWS / GENECTIVE JV (2013), para. 30.
} 
structures in the traits/seeds segment(s). Competition in this context may also occur between platforms and within platforms. Competition authorities should make efforts to promote interplatform competition, but also intra-platform competition. But in this case, how to define the relevant market, or the space where competition takes place, in order to complete the analysis of the possible effects of an actual or potential restriction of competition?

The mergers also raised quite important questions as to the level of concentration one needs to take into account when assessing the effect of a series of mergers affecting the same industry. The issue came forward in particular in the EU case concerning Dow/Dupont and will certainly also come up with the ongoing Bayer/Monsanto transaction.

Market structure and concentration is, of course, just one step in the assessment of mergers and is followed by a more thorough analysis of the possible anticompetitive effects and efficiencies, if the level of concentration resulting from the merger raises concerns, in view of the specific thresholds in each jurisdiction triggering a more careful scrutiny. In the EU, the assessment as to whether a merger would give rise to a Significant Impediment of Effective Competition (SIEC) is based on a counterfactual analysis where the post-merger scenario is compared to a hypothetical scenario absent the merger in question. The latter is normally taken to be the same as the situation before the merger is consummated. ${ }^{990}$ However, the Commission may take into account future changes to the market that can "reasonably be foreseen". ${ }^{991}$ The identification of the proper counterfactual can be complicated by the fact that there can be more than one merger occurring in parallel in the same relevant market. Under the mandatory notification regime, the Commission does not factor into the counterfactual analysis the merger notified after the one under assessment. ${ }^{992}$ On the basis of the identified counterfactual, the Commission then proceeds with the definition of the relevant product and geographic market. ${ }^{993}$ The Commission tackled the issue in the Dow/Dupont merger, as following the notification of the transaction, the Commission received notification of the acquisition of Syngenta by ChemChina and Bayer announced that it had reached agreement to acquire Monsanto. At the time of the review of the merger the Commission's review of the acquisition of Syngenta by ChemChina was still ongoing. In a manner "consistent with its previous practice" the Commission assessed the transaction "according to a priority principle ('first come, first served approach') based on the date of notification ${ }^{994}$. Citing its previous decisional practice on this issue ${ }^{995}$, the Commission noted:

\footnotetext{
${ }^{990}$ Horizontal Merger Guidelines [2004] OJ C31/6, para 9.

991 Ibid.

992 See, eg, TUI/First Choice Case COMP/M.4600 [2007], paras 66-68; TomTom/Tele Atlas Case COMP/M.4854 [2008], paras 187 and 188.

${ }_{993}$ EU Horizontal Merger Guidelines [2004] OJ C31/6, para 10.

${ }^{994}$ Commission Decision, Case M.7932 - Dow/DuPont (2017), para. 136.

995 Commission Decisions in Case M.6214 - Seagate/HDD Business of Samsung (2011); Case M.6203 - Western Digital/Viviti Technologies (2011); Case M.4942 - Nokia/Navteq (2008); Case M.4854 - TomTom/Tele Atlas (2008); Case M.4601 - Karstadtquelle/My Travel (2007) and Case M.4600 - TUI/First Choice (2007). See also, Case T-342/99, Airtours v. Commission, EU:T:2002:146, para.82 ("the level of competition obtaining in the relevant market at the time when the transaction is notified is a decisive factor in establishing whether a collective dominant position has been created for the purposes of Regulation No 4064/89"), as well as Case T-2/93, Air France v. Commission, EU:T:1994:55, paras 70-72;Case C-347/00, Verband der freien Rohrwerke and Others $v$. Commission, EU:T:2003:188, para. 170.
} 
"(137) It should be recalled that assessing the competitive effects of a proposed transaction under the Merger Regulation involves a comparison of the competitive conditions that would result from the notified merger with the conditions that would have prevailed in absence of the merger. The competitive conditions existing at the time of notification constitute, as a general rule, the relevant framework for evaluating the effects of a transaction.

However, in some circumstances the Commission may take into account future changes to the market that can reasonably be predicted.

(138) The Commission considers from these principles and the general scheme of the Merger Regulation that a party that is the first to notify a transaction should have it assessed on its own merits as to whether it would significantly impede effective competition in the internal market or in a substantial part thereof. This first to notify a transaction should therefore be entitled to have its operation decided first (for example, declared compatible with the internal market) within the applicable time limits of the Merger Regulation. It is therefore not necessary or appropriate to take into account future changes to the market conditions resulting from subsequently notified transactions that require approval from the Commission.

(139) Therefore, in the circumstances of this Decision, the Transaction, which was notified to the Commission first, should be assessed in the light of the competitive situation that prevailed at the time of its notification, disregarding the potential changes that may be brought by the proposed ChemChina/Syngenta and Bayer/Monsanto transactions".996

This issue has not been addressed in the decisions of the other competition authorities we have been able to identify and process.

We will structure the discussion in two sub-Sections. The first will delve into the more conventional competition law analysis performed by the competition authorities of the BRICS countries, EU and the US on these mergers regarding the effects of the notified transactions on price (the so called product competition). As it will become clear, with regard to this more conventional competition law analysis, the authorities seem to take a similar approach, implementing well-known principles of market definition and competition assessment, or for the analysis of efficiencies, even if, of course, one may expect some limited differences, due, for instance, to the specificity of the product and geographic markets explored, the level of concentration in each jurisdiction and their overal perception on the contestability of these markets. In contrast, the approach followed by the competition authorities in question with regard to the assessment of the effect on innovation is quite different (innovation competition). Some authorities have engaged in depth with the possible effects on innovation and explored new approaches in dealing with these effects, some have flagged up the issue but preferred not to take a specific standpoint for this case, while others have preferred, for various reasons, to focus their analysis on the more conventional competition law issues of product competition, sometimes even ignoring possible effects on innovation.

${ }^{996}$ Commission Decision, Case M.7932 - Dow/DuPont (2017), paras 137-139. 


\subsubsection{Assessment of product competition}

As the mergers involved different segments of the value chain, the competition authorities, the mergers raised a number of concerns, horizontal, vertical and conglomerate. The analysis

\subsubsection{The nature of these mergers : horizontal, vertical, conglomerate}

The three mergers led to significant overlaps between the merging entities, restricting competition between competitors, and raising mainly risks for unilateral (non-coordinated) effects in various product markets. Connnected to this horizontal dimension, the mergers also raised issues of vertical and/or conglomerate nature.

To take the example of the Bayer/Monsanto merger, the existence of horizontal overlaps between Bayer and Monsanto, raises important risks for actual and potential competition.

Firstly, both companies compete in the seeds sector for various crops, in view of Bayer's presence in the seeds segment, since its acquisition of Aventis in 2002. For instance, the two companies compete "head-to-head" in seed and traits for cottonseed and soybeans ${ }^{997}$.

Secondly, there are considerable overlaps in the pesticides segment of the value chain. Monsanto manufactures the glyphosate-based Roundup Ready brand herbicides and other herbicides, such as the Harness ${ }^{\circledR}$ brand for cotton and corn. Bayer produces Liberty, a glyfosinate-ammonium based pesticide that not only directly competes with Roundup, but also constitutes the main challenger in this market, in view of the recent concerns raised by the World Health Organization's International Agency for Research on Cancer (IARC), that reclassified glyphosate as "probably carcinogenic to humans" and the difficulties to extend the authorisation of glyphosate in the $\mathrm{EU}^{998}$. These overlaps may give rise to an important degree of horizontal consolidation, when two companies compete in the same relevant geographic markets.

Thirdly, although pesticides and seed treatment may be considered as complements to seeds and traits, and hence forming separate product markets, the development of genetically modified (GM) seeds with traits will lead to some form of substitution between GM seeds and pesticides. For example, this substitution effect becomes clear if one takes into account that Btcorn varieties are registered as pesticides with the US Environmental Protection Agency $(\text { EPA })^{999}$. The development of GM plant varieties resistant to certain diseases may also lead to a substitution effect between GM-plants and certain herbicides that aim to control weeds that are usually harbouring diseases. To this extent, the merger could be considered as limiting a source of actual and potential competition for pesticide firms.

\footnotetext{
997 AAI, Food \& Water Watch, National Farmers Union, Proposed Merger of Monsanto and Bayer, (2017, July $\left.26^{\text {th }}\right), 6 \& 12$, available at https://nfu.org/2017/07/26/aai-fww-and-nfu-say-monsanto-bayer-merger-puts-competition-farmers-and-consumers-at-risk/ ${ }^{998}$ For a summary see European Parliament, Renewing authorisation for glyphosate, (April 7, 2016), available at http://www.europarl.europa.eu/RegData/etudes/ATAG/2016/580894/EPRS_ATA\%282016\%29580894_EN.pdf. ${ }^{999}$ See, https://www3.epa.gov/pesticides/chem_search/reg_actions/pip/smartstax-factsheet.pdf.
} 
Fourthly, the two companies may have or develop overlaps in "digital farming", both disposing of leading innovation capabilities and R\&D technology platforms ${ }^{1000}$. Monsanto is quite active in tools for precision planting and high-tech weather prediction through its subsidiary Climate Corporation ${ }^{1001}$, while Bayer's "digital farming" unit is active in soil analytics and decision support tools for farmers, such as weather analytics, crop yield models, pest and disease models, product data (mode of action, genetics) ${ }^{1002}$. The situation in this emerging but crucial, from a strategic perspective, market is even more complex in view of the links between the merging entities and their competitors in this segment of the agricultural value chain, following the global licensing agreement in October 2016 between Monsanto and Dow AgroSciences on the Exzact Precision Technology Genome-Editing Platform for research and commercial development of new crop solutions across Monsanto Company's research portfolio $^{1003}$.

The non-horizontal dimension of the merger refers to the fact that the merging entity may have the ability and the incentive to foreclose competitors in upstream or downstream situated markets in the seeds, as well as in the crop protection value chain, and to produce exclusionary "portfolio effects" arising from the combination of the complementary businesses of Monsanto and Bayer in traits, seeds, pesticides, herbicides, and digital farming to the detriment of final consumers, in this case farmers.

Vertical integration is conventionally seen more positively than on horizontal overlaps in view of the belief that vertical integration may lead to efficiencies. However, vertical integration may be problematic for competition, if it enables the new entity to strategically foreclose competitors ${ }^{1004}$, by offering packaged solutions in the seed and traits value chain and in the agrochemical supply chain, therefore increasing prices and/or reducing consumer choice. Looking, more specifically, to the seed and traits value chain, to the extent that there is an upstream market for the development and commercialisation of traits and a downstream market for the breeding of traited seeds, and that the treatment of seeds can be considered as an upstream market to the downstream supply of seeds, the merging entity may have the incentive to engage in a foreclosure strategy against rivals downstream and/or upstream. As each trait offers "unique characteristics to the particular seeds", it cannot be excluded that "each company would have a monopoly on the trait developed", in particular as this is also protected by patents

\footnotetext{
1000 AAI, Food \& Water Watch, National Farmers Union, Proposed Merger of Monsanto and Bayer, (2017, July $\left.26^{\text {th }}\right), 6$; Bayer, Investor Handout (Septemebr 14, 2016), 14.

1001 Fortune, Monsanto's Climate Corp to Expand Digital Farming Platform (August 17, 2016), http://fortune.com/2016/08/17/monsantos-climate-corp-to-expand-digital-farming-platform/ ; M. Stern, Digital Agriculture, (Speech, 2015), available at https://monsanto.com/app/uploads/2017/05/digital-agstern_2015.11.17.pdf . Monsanto has a significant presence in digital farming in Europe with the acquisition in November 2016 of Vitafields, a European farm management software company based in Tallinn, Estonia and present in seven European countries: Monsanto, The Climate Corporation Acquires VitalFields to Expand Digital Agriculture Innovation for European Farmer (November 21, 2016), available at http://news.monsanto.com/pressrelease/climate/climate-corporation-acquires-vitalfields-expand-digital-agriculture-innovation 1002 For more information, see http://www.digitalfarming.bayer.com/ .

${ }^{1003}$ Dow AgroSciences Press Release, Monsanto and Dow AgroSciences Announce Global Licensing Agreement on Exzact Precision Technology Genome-Editing Platform (October 3, 2016), available at https://www.dowagro.com/en-us/newsroom/pressreleases/2016/10/monsanto-dow-agrosciences-globallicensing-agreement-exzact\#.WY2qwoVOKUk .

${ }^{1004}$ M. Whinston, Lectures on Antitrust Economics (MIT, 2007).
} 
and that other companies can only obtain access to it through licensing agreements ${ }^{1005}$. Monsanto has a strong position in traits and, as highlighted above, forms the central node of the network of licensing agreements between the Big Six. The new entity will therefore have the ability to foreclose rivals from access to the traits licensed, and its incentive to foreclose will depend on a comparison of the revenues derived from foreclosure strategies with the foregone revenues derived from licensing to its downstream competitors.

It is also possible to conceive the two value chains as forming in reality one: a technological platform/system consisting of, for instance, a non-selective herbicide tolerant traited seed and a corresponding non-selective herbicide, which are used in combination in order to provide farmers the best protection against weeds. When farmers make decisions on which seeds to plant they make their choice on the basis of the various systems available for the specific crop, after which they are locked in the specific "technological pathway" provided by this system ${ }^{1006}$. For instance, a Liberty herbicide is formulated to work in conjunction with the Liberty Link traits, which is the glufosinate ammonium tolerate trait. Hence, seed companies and crop protection firms will not be able to compete with the merging entity's platform "unless they are vertically integrated seed and crop protection firms who develop traits, breed seeds and develop active ingredients for herbicides" and they develop "their own traits for non-selective herbicide tolerance or license traits from the merging parties"1007.

The merger finally includes a conglomerate dimension, in view of Monsanto's and Bayer's presence in the seeds, crop protection and digital agriculture/smart farming value chains. In particular developing a new value chain, possibly integrating the three value chains on the basis of Big Data appears one of the main reasons motivating the merger transaction. It is clear that the acquisition of the Climate Corporation's data science engine and extensive field research networks was Bayer's principal drive to the merger ${ }^{1008}$. The aim is to transform its core business from producing seeds, herbicides/pesticides and other products to providing an inclusive package of services to farmers, guiding their choice in the " 40 interlocked decisions that inexorably a grower is going to make every single year" ${ }^{\text {1009. }}$

\subsubsection{Dow/Dupont}

Dow and DuPont signed an agreement on December 11, 2015, stipulating that the two companies will combine in a "merger of equals", and name the new company being named DowDuPont Inc. The existing shareholders of Dow and DuPont will hold approximately 50\% equity, respectively of the new entities emerging after the merger. The merged entity would have a market capitalisation of approximately USD 130 billion. At a later stage, Dow and

\footnotetext{
1005 Competition Commission of South Africa, Case 2017Feb004 (Bayer/Monsanto) (May 3, 2017), p. 117, para. 364.

1006 Competition Commission of South Africa, Case 2017Feb004 (Bayer/Monsanto) (May 3, 2017), p. 105, para. 317

1007 Ibid., p. 106, para. 320.

1008 On the importance of Big Data for "smart farming" and agricultural production, see S. Wolfert, L. Ge, C. Verdouw, M.-J. Bogaardt, Big Data in Smart Farming: A Review, (2017) 153 Agricultural Systems 69.

${ }^{1009}$ A. Murray, Why Bayer Wants Monsanto, Fortune (May 19 ${ }^{\text {th }}, 2016$ ) quoting an interview with Monsanto's CEO Hugh Grant.
} 
DuPont declared their intention to create from their combined activities three separate publicly traded companies focusing on agriculture, material science and specialty products respectively. In agriculture, the merged entity would become the number 1 global integrated crop protection and seeds player and the number 2 global seeds player.The Dow/Dupont merger was examined in depth in the United States, the European Union, South Africa, China and Brazil. The Russian FAS approved the merger without conditions and it was not possible to identify any specific analytical framework was used so as to arrive to this decision. The Brazilian case is examined in depth in a case study, which also explores the remedial part of the case, an issue that we have not yet systematically examined in this report, as we are still waiting final decisions on these mergers from all the authorities involved. The parties were arguing that the merger would create value, efficiencies, and synergies worth $\$ 3$ billion annually, and growth synergies worth $\$ 1$ billion, as the parties had complementary product offerings. The parties also pointed to corporate synergies that reduced leverage service costs and that would enable procurement synergies, together amounting to $\$ 3.5$ to $\$ 4.1$ billion.

\begin{tabular}{|l|l|l|}
\hline Dow/DuPont merger transaction & Decision date \\
\hline Country & $\begin{array}{l}\text { Notification/Investigation } \\
\text { date }\end{array}$ & 15 June 2017 \\
\hline United States & 22 June 2016 2017 \\
\hline European Union & 12 August 2016 & 27 Mar. 2017 \\
\hline Brazil & NA & 17 Mayb 2017 \\
\hline Russia & 19 May 2016 & 27 July 2017 \\
\hline India & 21 March 2016 & 8 June 2017 \\
\hline China & 10 May 2016 & 29 April 2017 \\
\hline South Africa & & 7 Mar. 2017 \\
\hline
\end{tabular}

\subsection{United States}

In June 2017, the Department of Justice, along with the offices of three state attorneys general, the States of Iowa, Mississippi and Montana, filed a civil antitrust lawsuit in the U.S. District Court for the District of Columbia to enjoin the merger transaction between Dow and Dupont, and to accept the settlement reached ${ }^{1010}$. Following an investigation of the merger starting in April 2017, the DOJ Antitrust division considered that, absent the remedies agreed, the merger would have likely reduced competition between two of only a handful of chemical companies that manufacture certain types of crop protection chemicals, potentially harming U.S. farmers and consumers. In addition, the merger would have given the merged company a monopoly over ethylene derivatives known as acid copolymers and ionomers, which are also used to manufacture many products, including food packaging. The Complaint alleged that the acquisition would likely reduce or eliminate competition in the markets for broadleaf

${ }^{1010}$ Complaint, U.S. v. Dow Chem.-Dupont, Case 1:17-cv-01176 (15 June 2017) [U.S. Dow Complaint]. For the discussion on the settlement, see https://www.justice.gov/opa/press-release/file/973941/download. 
herbicides for winter wheat and chewing pest insecticides, and would tend to create a monopoly in the markets for acid copolymers and ionomers, in the United States in violation of Section 7 of the Clayton Act. That loss of competition likely would result in increased prices and a reduction in service and innovation for the consumers. ${ }^{1011}$

The DOJ's complaint alleged that Dow and DuPont are two of only a few significant competitors in the markets for broadleaf herbicides for winter wheat and insecticides for chewing pests. In particular, DuPont's Finesse-formulated herbicide products (active ingredients Metsulfuron Methyl and Chlorsulfuron Methyl), is the market leading broadleaf herbicide for winter wheat, and Dow had recently introduced a new broadleaf herbicide called Quelex to compete with Finesse. DuPont's Rynaxypyr line of products, which are marketed in the United States under the brand names Altacor, Coragen, and Prevathon, are also the top selling insecticides for chewing pests, and compete with Dow's methoxyfenozide products, sold in the United States under the Intrepid brand, and Dow's spinetoram products, sold under the Delegate and Radiant brands. The complaint alleged that the loss of competition between Dow and DuPont would result in higher prices, less favorable contractual terms, and a reduced incentive to innovate for each of these products. ${ }^{1012}$

The DOJ separated Crop protection chemicals into three broad categories that have different qualities and attributes: herbicides (to combat weeds); insecticides (to combat insect pests); and fungicides (to combat microbial disease). The following relevant markets were defined:

- the development, manufacture, and sale of broadleaf herbicides sold in the United States labelled and registered for use on winter wheat is a line of commerce and relevant market within the meaning of Section 7 of the Clayton Act

- the development, manufacture, and sale of chewing pest insecticides sold in the United States is a line of commerce and relevant market within the meaning of Section 7 of the Clayton Act ${ }^{1013}$

When assessing the anticompetitive effects of the merger, the DOJ found that Dow Chemical and DuPont compete head-to-head for the development, manufacture, and sale of broadleaf herbicides for winter wheat. Competition between Dow and Dupont has benefited farmers through lower prices, more effective solutions, and superior service, and has also spurred research, development, and marketing of new and improved broadleaf herbicides for winter wheat. It was found that the merger would substantially lessen competition, leading to higher prices, less favorable contractual terms, and a reduced incentive to spend significant resources in developing new products. ${ }^{1014}$

Similar effects would take place in the insecticides for chewing pests market, in particular as the combined company would control nearly seventy-five percent of the market in the United States. It was further noted that Dow Chemical and DuPont's closest competitor sells competing products that are mixed with DuPont's Rynaxypyr, for which the competitor has a license. As a result, specialty crop farmers would have little alternative but to accept

\footnotetext{
1011 U.S. Dow Compl., ๆ甲 4-5, 66.

1012 Ibid., 19 22, 25-26.

1013 Ibid., 9 甲 29, 32.

1014 Ibid., 9 ๆ 33, 35.
} 
increased prices post-merger. A combined Dow Chemical and DuPont would have the incentive and ability to eliminate or restrict financial and other incentives to customers, extinguishing this competition and those tangible and valuable benefits to customers. The difficulty of entry in these markets was duly highlighted, in particular the barriers to entry resulting from the discovery, development, testing, registration, and commercial launch of a new herbicide or insecticide can take ten to fifteen years and can cost well over $\$ 150$ million dollars. ${ }^{1015}$

A settlement was reached involving the divestiture of DuPont's market-leading Finesse and Rynaxypyr crop protection products, so as to preserve vigorous competition in the sale of these products and benefit farmers and consumers. Under the proposed Final Judgment, DuPont was required to divest its Finesse-formulated herbicide products (active ingredients Metsulfuron Methyl and Chlorsulfuron Methyl), and its Rynaxypyrformulated insecticide products, along with the assets used to develop, manufacture, and sell those products. Dow Chemical was required to divest some of its ionomers manufacturing units and associated assets. ${ }^{1016}$

Interestingly, the DOJ press release noted the close cooperation between the Antitrust Division of the DOJ and the European Commission in the course of their respective investigations. At the time the DOJ considered the case, the European Commission had already approved the merger on the condition of certain divestitures including several products also divested in the US DOJ Antitrust Division's proposed settlement, as well as Dupont's assets used for research and development of new crop protection chemicals. The US DOJ press release mentions that "(1)ike the European Commission, the Antitrust Division examined the effect of the merger on development of new crop protection chemicals but, in the context of this investigation, the market conditions in the United States did not provide a basis for a similar conclusion at this time" ${ }^{\text {"1017. }}$.

\subsection{European Union}

When examining the Dow/Dupont merger, the European Commission focused on several general factors in assessing competitive effects, including market shares, whether the merger eliminated a significant and close competitor (rather than the closest competitor), entry barriers, and the existence and strength of alternative suppliers. Producers in this industry have maintained pricing power despite patent expiry or generic entry ${ }^{1018}$.

With regard to herbicides, the Commission noted how regulation influences the ability of alternative crop protection products to substitute for existing products, since the Commission must authorize the AI used in a product, and each member state separately must authorize the crop protection product incorporating the AI. The relevant crops for this market examined in the EU case were cereals, rice, pastures, oilseed, rape, sunflower, beets, and corn. The

\footnotetext{
1015 Ibid., $9 \uparrow$ 37, 40.

1016 Proposed Final Judgment, U.S. v. Dow Chem.-Dupont, Case 1.17-cv-01176-APM, ๆ A, p. 10 (28 Sept. 2017).

1017 See https://www.justice.gov/opa/pr/justice-department-requires-divestiture-certain-herbicides-insecticidesand-plastics .

1018 See Commission Decision, Case M.7932 - Dow/DuPont (2017), paras 423-24, 433, 522
} 
Commission segmented this market according to selection and non-selective crop protection products, by crop, by the specific weed targeted, and by the timing of when farmers apply the herbicide. The Commission found that products with different Modes of Action (MoA) and different chemical classes still directly competed ${ }^{1019}$.

For cereal herbicides, and more specifically post-emergence broadleaf selective cereal herbicides, the combined market share of the parties would exceed 50\% in many EEA countries. The parties would have commanding positions in France (60-70\%), Germany (60$70 \%$ ), and the UK (50-60\%). In the pre-emergence broadleaf selective cereal herbicide market, the parties would control 30-40\% of combined sales at the EEA level, and have high shares in certain EEA countries. The Commission found noteworthy that the relevant market share levels may have underestimated the parties' strength in these markets because they did not incorporate the impact of new products that likely would reach the market. The Commission specifically highlighted the expected success of Dow's new Arylex AI. The Commission additionally found that Dow and Dupont were close and important competitors in these markets, even if not closest competitors, as determined by market participants. The Commission considered the degree of closeness as a relevant, though not decisive, factor in the competitive analysis. As an additional factor assessed to determine market strength, the Commission found that Dow and Dupont offered the main AIs that farmers used in the latter stages of the growing season. The Commission also separately analysed the competitive restraints imposed by rivals in the herbicide market, finding that no other leading crop protection rivals focused on broadleaf weed herbicides for cereals. Rivals further had limited pipeline products that would be able to exert competitive pressure on Dow/Dupont in the foreseeable future. The Commission concluded that the transaction likely would produce a significant impediment to effect competition in the cereal herbicide market, segmenting this conclusion into several categories. In the post-emergence broadleaf selective cereal herbicides market, the Commission found the transaction would create a dominant position in several member states. The Commission separately determined that the transaction would strengthen a dominant position in Norway (70-80\%), the Netherlands (50-60\%), and Lithuania (50-60\%). The Commission lastly stated that the transaction would eliminate an important competitive restraint in Romania (40-50\%), Hungary (40-50\%), Bulgaria (40-50\%), and Spain (40-50\%) ${ }^{1020}$. The Commission continued to draw the same distinctions for the pre-emergence broadleaf selective cereal herbicide market, the post-emergence cross-spectrum selective cereal herbicides market, and the pre-emergence cross-spectrum selective cereal herbicide market ${ }^{1021}$.

The Commission next assessed the rice herbicide market, focusing on Italy, Spain, Greece, and Portugal. Dow produced the leading rice herbicide worldwide, Penoxsulam. The Commission noted that more customers viewed BASF and Bayer as Dow's closest rival in rice herbicides compared to Dupont, though market participants acknowledged that the parties were close competitors that exerted some competitive pressure on each other. The transaction would produce high combined market shares in selective cross-spectrum post-emergence rice herbicides, with pipeline products strengthening the parties' position. The resistance of pests

1019 Ibid., $\uparrow \uparrow$ 577, 581, 643, 655.

${ }^{1020}$ Ibid, paras 657, 702-704, 707, 730, 746, 770-71, 783, 791, 808, 810-812

${ }^{1021}$ Ibid., paras 818, 820, 824-25, 830, 834 . 
to herbicides posed problems for producers in this segment, causing them commonly to mix AIs. Few rice herbicides competed with the parties' offerings, and rivals would not exert competitive pressure on Dow/Dupont due to pipeline products ${ }^{1022}$.

In the pasture herbicide market, Dow sold products in most EEA countries, while Dupont produced only in Germany and Poland. Customers opined that three other rivals, Nufarm, Bayer, or BASF, constituted Dow's closest competitor rather than Dupont, and the parties argued that they faced competition from generics given that the relevant AIs were off-patent. The Commission determined that the transaction would produce high market shares throughout the EEA of at least 50-60\% in all countries except France (20-30\%) and Austria (20-30\%), and market participants acknowledged that the parties represented close competitors. Competitors exerted limited restraint in this market, both in terms of actual and potential competition, which mainly derived from generic substitutes. The parties' closest rival had only a 5-10\% market share. The Commission concluded that the transaction either would create or strengthen a dominant position ${ }^{1023}$.

In the oilseed rape herbicide market, a defining characteristic consisted of the fact that farmers had to target weeds at an early stage. Dow sold three existing products and had a fourth potential blockbuster product scheduled to hit the market soon. Dupont had an effective AI that it sold under two brand names. BASF sold the leading product, no longer patent-protected. The parties argued that generics exerted competitive restraint in this market. Customers viewed BASF, Syngenta, or Bayer as Dow's closest competitor. Yet the parties offered alternative products or solutions, and market participants considered that the parties were close competitors. Several market participants stated that the parties each sold an indispensable product in this segment, and market information suggested that both contributed significant innovation, as few other rivals had new products in their pipelines. The Commission decided that competitive restraints were limited, particularly from other R\&D-integrated players, none of which had a market share greater than 5\%. Contrary to the parties' claims, generic rivals did not restrain the parties' market power materially, since the largest had only a 5-10\% market share. The Commission concluded that the transaction would lead to a strengthening of Dow's dominant position because it eliminated Dupont as a potential competitor in all EEA countries except for Austria ${ }^{1024}$.

In the market for sunflower herbicides, the parties argued that their combined market shares would not exceed 10-20\%. The Commission stated that Dupont held 90-100\% of the market for selective broadleaf post-emergence sunflower herbicides in the EEA. The Commission also identified the threat that Dupont was leveraging its market power in sunflower seeds to gain a benefit in the sunflower herbicide market. In addition to their corresponding low market shares in the specific market identified by the Commission, the parties' rivals had few new products in their pipelines that might exert pricing pressure within a few years. The leading generic had only a $0-5 \%$ market share, and after the transaction, it would constitute the only competitor

1022 Ibid., paras 839, 844, 862, 868, 870, 879, 887, 893, 896-97, 901.

1023 Ibid., paras 928, 952-53, 959, 971, 976, 981, 983-84, 988, 994-95, 998.

1024 Ibid., paras 1003, 1006-1010, 1013, 1020-21, 1048-49, 1051-52, 1061, 1063, 1077. 
with a 5-10\% market share in just six of the twelve EEA countries where Dupont had a dominant position ${ }^{1025}$.

As the parties' combined market share in the beet herbicide market amounted to only 20$30 \%$ in Austria, France, Germany, and the Netherlands respectively, the Commission determined that the transaction unlikely would significantly impede effective competition ${ }^{1026}$.

In the corn herbicide market, Dow had a small corn herbicide portfolio prior to the transaction, and the Commission determined that the transaction raised the potential for anticompetitive effects only in the Austrian market, where the parties would attain a 30-40\% market share. It nevertheless concluded that the transaction unlikely would significantly impede effective competition ${ }^{1027}$.

With regard to insecticides, the Commission distinguished between older and newer insecticides, as the older products had a more indiscriminate effect on insects, in some cases harming beneficial insects such as bees. Dow's insecticide portfolio consisted of four products; Dupont sold two products. Syngenta constituted the largest insecticide producer in the EEA, holding a $20-30 \%$ market share. Bayer represented the second largest insecticide producer in the EEA, having a 10-20\% market share. The Commission decided to segment insecticides primarily by crop, but also as to whether they had foliar or soil application, and finally according to the pests targeted. Respondents to the Commission's market investigation recommended this approach. Farmers chose insecticides based on their effectiveness in controlling the targeted pest, and based on the relevant crop. The Commission stated that market share figures for insecticides did not accurately portray market power, underestimating the parties' positions, since both Dow and Dupont immediately after the decision were scheduled to introduce new insecticides throughout the EEA.

The Commission projected that both Dow and Dupont likely would gain significant market share from rivals over the following two years due to the success of two products launched by Dow and one product launched by Dupont. Conversely, the Commission also found that the leading rivals to the merging parties were planning to withdraw several AIs because of regulatory reasons. Bayer and Syngenta, particularly, likely would lose market share. Aside from these developments, the transaction would enable the parties to become the leading insecticide producer for several specialty crops, including fruits and vegetables, which represented the largest markets in the EEA for insecticides. The Commission determined that the parties were important and close competitors, and that market participants perceived a material overlap in the spectrum of pests that the parties' portfolios targeted. Despite the market share figures, the Commission argued that after the transaction, the parties would have the strongest insecticide portfolio across the EEA, in terms of controlling the newest and most effective AIs. This advantage risked enabling the parties to raise and control prices. The leading market producers targeted different pests, and in the case of Bayer, which did compete with two products in the same market, both faced regulatory issues. Similarly, while Syngenta also targeted some of the same pests, most of its products were old, suffered from curtailed effectiveness due to resistance, and were under regulatory pressure. Examining the leading

1025 Ibid. paras 1094, 1101, 1113, 1126-1127, 1133.

1026 Ibid., paras 1144, 1146.

${ }^{1027}$ Ibid., paras 1154, 1157-1159. 
producers' product pipelines, the Commission found that because third-parties would introduce only one AI designed to combat the pests that the merging parties targeted, the parties would face insufficient competitive restraint post-transaction. While some of the parties' product utilized off-patent AIs, registration costs across insecticide markets would prevent generics from competing in the multitude of different insecticide markets ${ }^{1028}$.

At the specific crop level in national markets, starting with pome fruit, the combined entity would become a market leader in several EEA countries with market shares significantly larger than those of the other R\&D-integrated players. Related to this finding, the parties were important and close competitors, and rivals imposed limited restraint. The only rival that attained a significant market share, Bayer in Slovakia, confronted regulatory pressure and an expiring registration in $2018^{1029}$.

In the insecticide market for stone fruits, the transaction would enable the merging parties to become a market leader in Greece with a 30-40\% market share, and notwithstanding Dupont's absence on the Spanish market, Dow then controlled 80-90\% of the market, suggesting it offered the only effective product for this pest. The Commission found the parties were close and important competitors since both the parties' main AIs effectively targeted the same pests in this segment, while Syngenta offered a less effective alternative. Notably, the Commission determined that the transaction likely would cause a significant impediment to effective competition in Spain on this segment notwithstanding the fact that, pre-transaction, only Dow offered products. The transaction presented no market share accretion ${ }^{1030}$.

In the insecticide market for citrus fruit, the transaction would enable the parties to exercise a leading position in Italy, and in Spain where Dow possessed a dominant position holding 60$70 \%$ of the market, the transaction would strengthen Dow's dominant position, as the parties were scheduled to introduce new products in both markets. The Commission determined that the parties were important and close competitors, pointing to the fact that in Italy the transaction combined the two leading suppliers of insecticides for a certain pest in citrus. For another pest, Syngenta sold a rival product burdened from severe regulatory pressure. Rivals in this category held low and fragmented market shares ${ }^{1031}$.

In the insecticide market for grapes, the transaction would enable the parties to exercise market power in the Czech Republic (90-100\%), Austria (70-80\%), Hungary (50-60\%), and Greece (50-60\%). In Germany, Italy, and Spain, the merged entity would be competing against only one other major rival. The transaction would enable the parties to significantly increase their market shares due to introducing new products in France, Italy, Greece, Poland, Germany, and Spain. As the parties directly competed on this market, the Commission found they were close and important competitors. Rivals held low and fragmented market shares, and the parties restrained each other pre-transaction more than rivals constrained them. The Commission recognized that Syngenta's offering yielded inferior results compared to the parties' products, and the AI supporting BASF's alternative product faced severe regulatory pressure, suggesting

\footnotetext{
${ }^{1028}$ Ibid., paras 1172-73, 1177, 1192, 1205, 1217-1218, 1220-21, 1224, 1233, 1236, 1238, 1243, 1250, 1271-73, $1276,1308-9,1313,1340-41,1345$.

${ }^{1029}$ Ibid., paras 1351, 1353, 1364, 1367, 1371.

${ }^{1030}$ Ibid., paras 1374, 1376-78, 1384, 1390, 1395

${ }^{1031}$ Ibid., paras 1398, 1400, 1402, 1409-10.
} 
BASF's market share in France and Germany overstated its position. The Commission concluded that the transaction likely would significantly impede effective competition in Hungary, Greece, France, Italy, Spain, Germany, and that the transaction would create dominant positions in Austria and the Czech Republic ${ }^{1032}$.

In the insecticide market for vegetables (solanacea), despite a $20-30 \%$ market share posttransaction, the Commission determined that the transaction would allow the parties to achieve a leading market position targeting lepidoptera, and it would significantly impede effective competition. The parties planned to introduce a product that the Commission determined would substantially increase their market share, while the Commission expected the shares of rivals to fall because their products featured AIs under regulatory pressure. The Commission found that the parties were important and close competitors, while rivals held low and fragmented market shares and offered less effective products. In Italy, the transaction joined the only main competitors to Syngenta offering insecticides for lepidoptera. The Commission concluded that the transaction significantly would impede effective competition for insecticides targeting lepidoptera, diptera, hemiptera, and thrips ${ }^{1033}$.

In the insecticide market for vegetables (leafy/legumes), the Commission reached a similar conclusion concerning Spain based on similar facts. The transaction would enable the parties to attain a leading position selling insecticides targeting lepidoptera, with a 40-50\% market share. Rivals held low and fragmented shares on that market. Based on this evidence, the Commission concluded that the transaction would significantly impede effective competition ${ }^{1034}$.

In the insecticide market for vegetables (brassicas), the transaction affected the Spanish and French markets. In Spain, it would create a leading position targeting lepidoptera, enabling a market share of $80-90 \%$. Syngenta would represent the only main competitor, and it would have a mere $20-30 \%$ of the market. In France, the transaction would place the combined entity in the number two position behind Syngenta, the market leader. The Commission found the parties were close and important competitors: In France, the parties represented the second and third leading producers in the market pre-transaction. Other rivals than Syngenta held low and fragmented market shares in both markets. The Commission determined that the transaction would significantly impede effective competition in France because it eliminated an important competitive restraint, and in Spain because it created a dominant position ${ }^{1035}$.

In the last insecticide market for vegetables (other), the Commission found the parties were important and close competitors in this segment, while rivals imposed limited competitive restraints as they had low and fragmented market shares. Concerning insecticide for hemiptera in Italy, Bayer represented the only other main player, with generics weakened by significant competitive pressure. Despite a combined market share of just 20-30\%, the Commission determined that the transaction would significantly impede effective competition because it would join two of three main R\&D-integrated producers and thus eliminate an important competitive restraint. The Commission also found that the transaction would significantly

\footnotetext{
1032 Ibid., paras 1425-27, 1435-37, 1440-41

1033 Ibid., paras 1449-51, 1465-66, 1468, 1473

1034 Ibid., paras 1479, 1482, 1487.

1035 Ibid., paras 1491, 1493, 1497, 1501.
} 
impede effective competition in Spain, Greece (both markets), the Netherlands, and the Czech Republic in insecticides targeting other pests. The Commission again found liability in Greece despite no overlap between the parties' offerings pre-transaction, on the basis that Dupont's products were the main effective choice for eliminating lepidoptera ${ }^{1036}$.

In the insecticide market for potatoes, the Commission determined that the parties were important and close competitors, and that rivals exercised weak competitive restraints as reflected in their low and fragmented market shares. It concluded that the transaction likely would significantly impede effective competition in Greece, the UK, Bulgaria, and Spain, where existing producers were losing market share due to regulatory pressure on their products $^{1037}$.

In the insecticide market for corn in Austria, Hungary, and the Czech Republic, the Commission determined that competitors held low and fragmented market shares and thus imposed limited restraints, and ultimately concluded that the transaction would significantly impede effective competition, particularly where the transaction would strengthen a dominant position in the Czech Republic (80-90\%) and in Austria (90-100\%) ${ }^{1038}$.

In the insecticide market for oilseed rape, the Commission determined that the transaction would not significantly impede effective competition ${ }^{1039}$.

In the insecticide market for cotton, the Commission found that the combined entity would be able to exercise market power in Greece after attaining a 50-60\% market share. It further found that the parties were important and close competitors pre-transaction, and that rivals exerted weak competitive restraints, as demonstrated by their low and fragmented market shares. The transaction would significantly impede effective competition ${ }^{1040}$.

The Commission then turned to the analysis of the market for nematicides. Nematicides target nematodes, which are agricultural pests, specifically microscopic roundworms or parasites. In the EEA, nematodes mainly pose a problem for potatoes, fruits \& vegetables, flowers, and tobacco, as well as cereals, and thus implicate markets in Spain, Italy, and the UK. Fumigants sterilize the soil, killing diseases, other insects and weeds as well as nematodes. As they can kill crops, farmers apply nematicides before planting. Non-fumigant chemical nematicides constitute an alternative that target only nematodes, that farmers can apply to the crop, that work less effectively, yet that cost less than fumigants. Farmers usually select this class of nematicides below certain levels of infestation and for lower-value crops. The Commission uses the terms "nematistatics" and "nematistats" to refer to chemicals that paralyze rather than kill nematodes, thus neutralizing their ability to target crops. The Commission stated that the EEA has made available only a few AIs for nematode control, that many of the parties' AIs face regulatory pressure such as a risk of substitution, and that the EEA likely will restrict AI use or remove many from the market in subsequent years. Dow sold an expensive soil fumigant, AI 1,3-dichloropropene, long off-patent and no longer approved in the EEA, though it receives Emergency Use Permits (EUPs) regularly in EEA countries such

\footnotetext{
${ }^{1036}$ Ibid., paras 1508, 1513, 1515, 1518-19.

${ }^{1037}$ Ibid., paras 1526, 1531, 1536, 1538-40.

${ }^{1038}$ Ibid., paras 1548 \& 1552.

1039 Ibid., para 1557.

1040 Ibid., paras 1560, 1563, 1566.
} 
as Belgium, France, Spain, and Italy. Dupont sold the non-fumigant chemical nematicide AI oxamyl, which paralyzes nematodes, costs less, and works less effectively. A rival supplied a generic version of AI 1,3-dichloropropene ${ }^{1041}$.

The Commission defined the relevant market by looking at the specific crop-pest combination that corresponded to a specific treatment need for the farmer. The Commission attempted to group all chemical solutions available to a farmer to address a specific nematode problem as applied to a certain crop, which can vary with nematode species. The Commission included soil fumigants and non-fumigants in the nematicide market, finding them differentiated products. The relevant market shares were unreliable and indeterminate as an indicator of market power. Dow controlled $40-50 \%$ of fumigant nematicides, making it the leader in this category. The Commission credited a market participant's view that Dow's fumigant represented an indispensable product because of its efficacy. Dupont held 40-50\% of the non-fumigant chemical nematicide category in the EEA. The Commission determined that these elements were insufficient for finding that the transaction significantly impeded effective competition $^{1042}$.

The Commission proceeded to assess proof that rivals imposed limited competitive restraint. Minor market players owned the main competing products, which exhibited lower efficacy and operated in niche segments. The parties argued that regulatory pressure would create an opening for innovation and competition, yet the Commission stated that it would consider as relevant only AIs with a high likelihood of reaching the market. Taken together, these elements again were insufficient to support liability ${ }^{1043}$.

The Commission also explored the effect of the merger with regard to the production of fungicides. Fungicides constitute agrochemicals that control diseases, particularly fungi. In the EEA, fungicides mainly target cereals, fruits \& vegetables, and rice. Concerning fruits \& vegetables, grapes and vines require fungicides the most. Fungicides implicate the timing of application, since different diseases attack different crops at different growth stages, on which the effectiveness of an AI might depend. Most products can work effectively for limited junctures when applied to each crop. Due to both the timing issue and resistance management, fungicide producers, for most products, mixed several AIs with different Modes of Action (MoAs). This practice aimed to limit resistance development and to broaden spectrum to address the maximum number of disease problems given the few available treatment opportunities. Producers also rotated AIs. Picoxystrobin constituted Dupont's most important and effective fungicide. Yet overall the parties maintained a limited portfolio of fungicide AIs and thus sought to cooperate with more dominant companies, particularly by securing thirdparty AIs for mixtures. Generics operated in this market but did not constrain the global R\&Dintegrated players because of limited market reach and relatively weak product portfolios ${ }^{1044}$.

In defining markets for agrochemicals, the Commission started by examining the specific crop-pest combination corresponding to the specific treatment that the farmer needs. From the demand-side, different disease patterns attack different cereal crops. A decision to account for

\footnotetext{
${ }^{1041}$ Ibid., paras 1569, 1576-77, 1583, 1585-86, 1588-89, 1595-96, 1601.

1042 Ibid., paras 1612, 1615, 1617, 1652-53, 1656, 1658-59, 1664.

1043 Ibid., paras $1671,1673,1680,1681$.

${ }^{1044}$ Ibid., paras 1702, 1704-5, 1707, 1716-17, 1727, 1732, 1747, 1750.
} 
the type of disease by defining the market according to the crop-disease combination is appropriate because this factor determines the farmer's need for treatment. Distinct diseases afflicting a crop generally demand different treatments. Crop protection stakeholders responding to the Commission's market investigation approved of distinguishing between fungicides by crops and by disease ${ }^{1045}$.

Turning specifically to cereals, as resistance to fungicide has become commonplace even for newer products, the leading fungicides typically combine at least two AIs. Yet the leading producers have no products with new MoAs in their pipeline, except for Dow and Dupont. The merger thus eliminated the potential competition that would have existed when the parties released their new products, giving them prospective pricing power. The Commission also acknowledged that the present market leaders would have the incentive and ability to preserve their positions, rendering the likelihood of future dominance difficult to discern. To demonstrate a significant impediment of effective competition based on pipeline products, the Commission needed to establish both that those products materially would have enhanced the parties' market power, and that the greater market power adversely would have affected competition rather than enabling the parties to compete more effectively against the market leaders. While the parties had reason to believe that their pipeline products would have generated considerable sales and would have exhibited good efficacy, identifying the exact level of resistance pressure on forthcoming AIs raises immense uncertainty, as resistance can evolve differently based on how the relevant chemicals react in different environments and geographies. Regulatory uncertainty also would complicate the analysis. The Commission instead relied on a more conventional assessment: For the downstream grouping of cereal septoria, wheat, and barley fungicides, both Dow and Dupont had limited market shares. The Commission found that this evidence insufficiently established that the transaction likely would significantly impede effective competition, and reached an overall conclusion that accorded with this result ${ }^{1046}$.

The Commission next assessed cereal powdery mildew fungicides in the Czech Republic, Slovakia, and the UK, where the parties' combined market share would not have amounted to more than 20-30\%. The Commission noted that Dow's quinoxyfen likely would lose its regulatory approval in the EEA. Based on this evidence, the Commission determined that the transaction unlikely would significantly impede effective competition in these markets ${ }^{1047}$.

Examining the cereal fungicide market in Slovenia, the Commission found that the transaction would enable the parties to hold a mere 20-30\% market share. This evidence did not support finding that the transaction would significantly impede effective competition ${ }^{1048}$.

In the rice blast market, given its diminutive size relative to larger markets in Asia, particularly Japan, the cost of registering a product relative to projected sales often did not justify significant investment within the EEA, which explained the availability of few AIs in the EEA, despite the existence of many more in Asia. The Commission found that Dow had dominance in the EEA prior to the transaction, especially in Greece and Italy, and that Syngenta

\footnotetext{
1045 Ibid., paras 1758-59, 1761-63, 1765, 1769.

1046 Ibid., paras 1773, 1775, 1781-84, 1795, 1810, 1812, 1823, 1825-26, 1828, 1832.

1047 Ibid., paras 1837-1839.

1048 Ibid., paras 1841, 1843.
} 
placed a distant second in a duopoly market. Dow exerted less dominance in Spain. In 2015, Dow controlled $60-70 \%$ of the market in Italy and $80-90 \%$ of the market in Greece, while in Spain it had a 40-50\% market share. The parties argued that the merger did not affect the EEA market since Dupont did not sell rice blast fungicides in 2014 and 2015. Dow's leading product, tricyclazole, benefitted from EUPs every year when requested because it constituted an indispensable fungicide to combat rice blast, the standard treatment worldwide, with no other AI providing a similar level of protection. Dow also sold a less effective fungicide used in the EEA rice blast market. Dupont registered picoxystrobin in 2015/2016, and the Commission found that the product would have enabled Dupont to build a strong market position. The combined entity would have two of the three effective molecules then available. The transaction thus strengthened Dow's dominant position, by both eliminating potential competition and by permitting the parties to mix their AIs, further increasing the efficacy of their products. The Commission concluded that the transaction would significantly impede effective competition in Italy, Greece, and Spain, where the parties represented important and close actual competitors ${ }^{1049}$.

In the markets for rice sheath blight in Italy, Spain, and Greece, the parties did not have a presence and Dupont did not sell at all in these markets. Competitors had dominant positions. The Commission concluded that the transaction unlikely would substantially impede effective competition ${ }^{1050}$.

In the markets for vegetable and flower fungicides in the Czech Republic and Slovakia, with the transaction creating market shares of 30-40\% in the Czech Republic and 50-60\% in Slovakia, the Commission determined that the transaction unlikely would significantly impede effective competition ${ }^{1051}$.

In the markets for grape/vine fungicides in Austria, Hungary, and the UK, with the transaction enabling the parties to attain market shares of 20-30\% in both Austria and Hungary, and possibly $60-70 \%$ in the UK based on conflicting sources, the Commission still found that the transaction unlikely would significantly impede effective competition ${ }^{1052}$.

With regard to vertical effects, the first issue concerned the definition of the relevant markets, in view of the fact that in its Syngenta/Monsanto sunflower seed business merger, the Commission had made a distinction between (i) the upstream market for the trading, usually through exchanges and licences, of seed varieties (parental lines and hybrids) and (ii) the downstream market for the trading of seeds, also identifying separate relevant product markets for each crop seed so that, for example, sunflower seeds constitute a product market separate from those for other seeds ${ }^{1053}$. The Commission distinguished two levels: the upstream market for the trading of seed varieties, where the main players are seed companies and breeders and the downstream market for the commercialisation of seeds, with a further segmentation for each type of crop seeds, distributors or farmers being there the key stakeholders ${ }^{1054}$. The Commission left open the question whether the market could be further segmented on the basis

\footnotetext{
1049 Ibid., paras 1848, 1850-52, 1857-59, 1869, 1872, 1877, 1879, 1881, 1889, 1897. 1910-11, 1914-15, 1918-19.

1050 Ibid., paras 1923-1925.

${ }^{1051}$ Ibid., paras 1928, 1930.

1052 Ibid., paras 1932, 1933, 1935.

1053 Commission Decision in Case M.5675 - Syngenta/Monsanto's Sunflower Seed Business (2010), para. 76.

1054 Ibid., para. 3301
} 
of whether seeds are genetically modified, as this was not relevant for the case, in view of the fact that the merging entities' activities do not overlap in the sale of GM seeds, only DuPont selling a limited amoung of GM maize seeds in Europe ${ }^{1055}$ The relevant geographic markets was the trading of seed varieties at the EEA level and the markets for the commercialisation of seeds at the national level ${ }^{1056}$. An analysis of the position of the parties in various crops, such as maize, sunflower, cotton did not raise any specific concerns. Nonetheless, the Commission examined issues arising from the vertical overlap between Dow and DuPont, which are active both in the upstream market for the trading of seed varieties as well as in the downstream market for the trading of seeds, in particular for each of cotton, maize, oilseed rape, and sunflower seeds. According to the Commission "(s)uch affected markets would be susceptible to raise competition concerns should they be likely to lead to a material foreclosure of competitors in the upstream market for the licensing of seed varieties or in the downstream market for the trading of seeds" 1057 .

In order to assess the existence of an eventual foreclosure effect, the Commission examined the existence of input or customer foreclosure. With regard to input foreclosure, the Commission found that Dow and DuPont are not significant licensors of seed varieties to third parties in Europe and that a number of seed competitors that are currently licensing to third parties their seed varieties. The breeder exception rule in the EU also allows seed companies to rely on the germplasm of competitors for crossing and selection so that the need to in-license is often limited to the instances in which finished varieties are needed to fill a portfolio gap ${ }^{1058}$. Furthermore, the Commission found that "seed companies tend to rely on their own seed varieties more than in the past, with the possible exception of sunflower seeds, and aim at inlicensing seed varieties only to meet specific needs" ${ }^{1059}$. Similar conclusions were reached with regard to customer foreclosure ${ }^{1060}$. The vertical relations between the merging parties between the upstream markets for the trading of seed varieties and the downstream markets for the trading of seeds were not found to raise any concerns as to the existence of a significant impediment of effective competition.

\subsection{South Africa}

In South Africa, Dow distributed sunflower seeds and agrochemicals, such as insecticides, herbicides, and fungicides. The target, DuPont, distributed maize and sunflower seeds and agrochemicals. In its decision, the CCSA identified horizontal overlap in fungicides, herbicides, and insecticides ${ }^{1061}$. In the national maize seed market, the CCSA determined that the transaction would prevent competition in the breeding, production, and supply of commercial maize seeds that would have occurred in South Africa absent the merger, since

\footnotetext{
1055 Ibid., para. 3303.

1056 Ibid., para. 3304.

${ }^{1057}$ Ibid., para. 3388.

1058 Ibid., para. 3394.

1059 Ibid., para. 3395.

1060 Ibid., para. 3405.

1061 Competition Commission of South Africa, Case No: LM030May16, DowDuPont Inc., (30 June 2017), Executive Summary paras 4-8.
} 
Dow had tangible plans to enter this market and would have competitively restrained Monsanto and DuPont. In the national market for the distribution of sunflower seeds, the merger would create an entity with a market share of $54.3 \%$ and an accretion of $53.9 \%$. The CCSA did not find anticompetitive effects because the merger did not change the structure of the market. In the national market for the distribution of purified CMC, the merged entity would hold $22.8 \%$ of the market, a gain of $6.6 \%$. The CCSA similarly concluded that the merger did not change the structure of the market. In regional markets for the distribution of insecticides, and specifically chewing insects, the merged entity would have a market share of $97.4 \%$, with an accretion of $90.2 \%$. The CCSA determined that this result would enable the joined entity to exercise market power, as no viable alternatives would remain in the market. ${ }^{1062}$.

The CCSA also considered whether the merger would have produced coordinated effects in the maize seed market, which is examined in the following Section on non-horizontal aspects. The prevalence of cross-licensing agreements necessary to breed and develop traits would have facilitated coordination among the market participants. The agrochemical market further had undergone tremendous consolidation in the recent past. However, the CCSA determined that the heterogeneity of traits and seeds materially would have inhibited coordination, as the market produced constant innovation. Additionally, licensing agreements normally do not indicate the costs of the licensee or otherwise reveal the prices of downstream products $^{1063}$.

The CCSA first focused on the maize seed market. Dupont constituted the largest provider of genetically-modified (GM) seeds in South Africa, having attained a market share of $50 \%$. Maize seed breeding requires three components: a multiplicity of robust genetics (germplasm), advanced breeding technologies, and biotechnology traits. A germplasm encapsulates the material in a seed, consisting of DNA that determines its characteristics, including the yield of the crop. Developing traits involves inserting foreign genes into a seed so that, during the breeding process, the seed ultimately yields desired characteristics. Companies often register traits as intellectual property. Only after the development and regulatory approval of seeds do companies multiply the seed paradigm for the market. The last stage of production involves selling the seeds either directly or through independent agricultural businesses to farmers. The merger would contract the trait development market from six companies to four. Due to the desirability and prevalence of stacked traits, companies often cross-license their trait portfolios. The CCSA recognized two stages that comprised maize seed production: (1) development \& breeding and (2) production and distribution. At the breeding stage of maize seeds the parties' activities did not overlap in the relevant geographic market, South Africa ${ }^{1064}$.

The maize seeds markets supported little demand-side substitutability. In conducting business, maize farmers focused on seed performance and the price they would receive for their crop. Seed prices exerted much fainter influence on their purchase decisions. Between seeds of the same variety, moreover, competition proceeded more on performance than price. South African farmers did substitute sunflower seed for maize hybrid seed, and while substitution proceeded between GM and non-GM hybrid maize, $80 \%$ of all hybrid maize that South African

1062 Ibid., Executive Summary paras 11-12, 15-16, 19-21.

1063 Ibid., paras 107, 114, 117-118, 123.

${ }^{1064}$ Ibid., paras 32, 35-36, 38-39, 41, 44, 46, 50, 73. 
farmers grew consisted of GM seed. By contrast, on the supply-side, producers could not easily substitute between GM and non-GM hybrid maize seed, since the GM market featured a specific regulatory framework, and producing GM seeds required significant investment on the development side, in terms of producing traits that often rely on foreign organisms ${ }^{1065}$.

The CCSA recognized a theory of harm in the maize seed market that centered on removing a potential entrant. No other viable entrants could have constrained the incumbents in this instance. Dow had begun planning since 2001 to enter the South African maize seed market and introduce hybrids and biotechnology traits as it surmised that its South American germplasm would function effectively in South Africa, given that the two regions shared similar climatic conditions, and that it could achieve a market share of $20 \%$. Dow even tested its hybrids containing PowerCore and Enlist traits. It would have been a credible competitor to Monsanto and Dupont; instead, the merger produced an entity with a market share of nearly $60 \%$, far ahead of rivals ${ }^{1066}$.

The CCSA next evaluated the distribution level of the sunflower seed market at the national level. Dupont distributed sunflower seeds in South Africa, while Dow did not develop or breed sunflower seeds in South Africa but imported them through a joint-venture relationship. The price difference between sunflower seeds and other agronomic crops ranged from $11 \%$ to $45 \%$, suggesting sunflower seeds constituted its own market. Yet on the supply-side, producers readily could substitute between sunflower seeds and alternatives ${ }^{1067}$.

The CCSA considered unilateral and coordinated theories of harm on the sunflower market. While the merger would produce a market share of $54.3 \%$ and an accretion of $53.9 \%$, Dow held less than $1 \%$ of the market pre-merger. Such shares did not reflect adverse unilateral effects. As in the maize seed market, the relevant products were not homogenous, weakening the potential for coordination ${ }^{1068}$.

Turning to the purified CMC (carboxymethylecellulose) market, the CCSA stated that agrichemical companies used this semi-synthetic powder to control the viscosity and rheology (the study of the flow of matter) of fluids "as a thickener, stabilizer, or suspending agent". While the CCSA would not opine on demand-side substitutability between purified CMC and guar, it found limited demand-side substitutability between technical grade CMC and purified CMC. The CCSA further determined that chemical companies could not manufacture CMC and guar concurrently, nor could they substitute between purified CMC and technical grade CMC beyond a limited extent. The parties' activities overlapped only in the narrow national market for the distribution of purified CMC. Unilateral effects were not significant as the merged entity held about one-fifth of the market in 2014, and the market did not materially change due to the merger ${ }^{1069}$.

The CCSA then assessed the agrochemicals market, predominantly referring to the following pesticides: herbicides, insecticides and fungicides. According to the CCSA, research and development costs in this market were high, comparable to the pharmaceutical industry,

\footnotetext{
1065 Ibid., paras 58-62.

${ }^{1066}$ Ibid., paras 74, 77, 81-82, 88, 97, 102, 104.

1067 Ibid., paras 133, 137-138, 141, 143, 145, 151.

1068 Ibid., paras 154, 158, 164.

${ }^{1069}$ Ibid., paras 166, 177, 179, 181, 184, 188, 193, 198, 200.
} 
and complying with regulatory requirements was expensive. Pesticides posed health risks such as toxicity to humans and animals. By the time a pesticide hit the market in South Africa, patent rights would extend for only seven years. Registering a pesticide for a certain crop could take five to seven years at a cost of 4 million rand. Entering the pesticide market also would require the dominant undertaking to license downstream rivals knowing that they would compete directly with its own operations. The merger would produce the second largest global agrochemical company. The CCSA found the following characteristics of pesticides important. Companies produced insecticides targeting pests, such as sucking or chewing insects. Sucking insects feed on sap, while chewing insects deconstruct and digest plant components. This difference is relevant because insecticide companies have more difficulty controlling sucking insects. With herbicides, non-selective herbicides clear fields of weeds, while selective herbicides can kill weeds amidst crops. Of the parties' insecticides, only Runner 240 SC, belonging to Dupont, competed with Dow's four products on the pest-chewing segments ${ }^{1070}$.

Considering demand-side substitutability, farmers can use pesticides only for the crops for which producers registered them, and producers design pesticides for specific pests and crops. Further hindering demand-side substitutability, producers have designed pesticides for different stages of the crops' life cycle. Farmers additionally must implement resistance management, given that pests develop resistance to single pesticides when used for extended periods. As a result, farmers use different pesticides which often complement each other rather than compete. Demand substitutability can occur only at a market definition based on insect per crop $^{1071}$.

As to supply-side substitutability, it did not occur between broad spectrum insecticides and narrow spectrum insecticides. The parties additionally applied different chemistry to produce insecticides, as Dow, for example, used "old chemistry" to target all insects within a narrow category, while Dupont utilized "new chemistry" to target specific insects. Due to these dynamics, the Commission limited its analysis of insecticides to the market for chewing insecticides applied to fruits (citrus and deciduous) and vegetables. The CCSA also defined regional markets in crops ${ }^{1072}$.

The leading theory of harm in the agrochemicals market again consisted of unilateral effects focused on higher prices. The merger would create an entity with a market share of $97.4 \%$, increasing Dow's share of the chewing insecticide market for fruits and vegetables by $90.2 \%$. The CCSA stated that because of this figure alone, the merged entity likely would exert significant market power, and could increase prices unilaterally; the merger essentially created a monopoly ${ }^{1073}$.

In the market for herbicides, the CCSA assessed competitive effects for oil seeds and winter cereals, which supported regional market definitions. The CCSA focused on whether the merger would enable the combined entity to increase the prices for herbicides. The parties would attain a $14.3 \%$ market share for oilseeds and a $23.4 \%$ market share for winter cereals.

\footnotetext{
1070 Ibid., paras 205-209, 213, 219, 221, 232, 266-267.

1071 Ibid., paras 234-236, 240-241.

1072 Ibid., paras 242, 244, 248, 255.

${ }^{1073}$ Ibid., paras 256-257, 261-262, 272.
} 
The market share figures convinced the CCSA that adequate competition would persist in the market post-merger ${ }^{1074}$.

In the market for fungicides, the CCSA stated that it would assess competitive effects in regions on a crop by crop basis. The parties' activities overlapped in supplying fungicides to fruits and vegetables, specifically grapes, oilseeds, tomatoes, and cucurbits. Post-merger, the joined-entity would have $10.6 \%$ of the grape fungicide market, $25.0 \%$ of the oilseed fungicide market, $17.5 \%$ of the tomato fungicide market, $29.4 \%$ of the cucurbits fungicide market. The CCSA found the merger would not significantly weaken competition. The CCSA considered entry barriers only at the distribution level. In addition to the entry barriers associated with registering new fungicides, entry barriers also consisted of relationships that distributors and agents had built with farmers, as farmers rarely switched between distributors, even when distributors switched fungicide manufacturers. Taken together, the CCSA viewed the entry barriers as "insurmountable" 1075 .

The CCSA also noted that the merger could produce conglomerate effects that could harm competition, as the merged entity could bundle insecticides with other products such as seeds. In regional markets for the distribution of herbicides, the merger would create a $14.3 \%$ market share in oilseed herbicides and a $23.4 \%$ market share for herbicides in winter cereals, a result with which the CCSA did not express concern. In regional markets for the distribution of fungicides, the merger would produce a $10.6 \%$ market share for grape fungicides, $25 \%$ for oilseed fungicides, $17.5 \%$ for tomato fungicides, and $29.4 \%$ for cucurbits fungicides. These market shares did not raise competitive concerns. In the national market for the distribution of HiPEDs (High Pressurized Ethylene Derivatives), the parties would acquire a 1.2\% market share from the merger ${ }^{1076}$.

The CCSA also conducted an extended analysis of the possibility that the merger would produce coordinated effects. Market participants competed in several markets and commonly met at CropLife, an industry association, factors that increased opportunities to exchange information and detect and punish deviations from agreed actions. Yet as the parties constantly innovated, the heterogeneity of fungicides rendered coordination untenable ${ }^{1077}$.

Lastly, in the national market for HiPEDs, inputs used to produce plastic products, the merging parties supplied the South African market through imports, making the distribution level of the value chain relevant for assessing competitive effects. The CCSA narrowed the product analysis to LDPE and LDPE derivatives, which, given the varying prices that applied to these products, suggested the existence of separate markets. The CCSA concluded that each HiPED product constituted a separate market and were not substitutable, yet the CCSA determined that the merger would not produce competitive concerns regardless of how it defined the markets, given that the joined entity would have a market share of $1.2 \%$ postmerger ${ }^{1078}$.

\footnotetext{
${ }^{1074}$ Ibid., paras 282, 284, 286, 290.

1075 Ibid., paras 298, 300, 303, 307, 310, 314, 316.

1076 Ibid., paras 11-12, 15-16, 19-21, 23-24, 25, 30.

1077 Ibid., paras 317, 319, 325, 328, 330, 338.

1078 Ibid., paras 341-342, 348, 350-351, 354, 358, 365.
} 
As the primary condition to approving the merger, the parties agreed to divest the Divestment Business in South Africa which included pipeline, IP rights, personnel, and facilities used by Dupont for its R\&D activities worldwide. To address concerns in the commercial maize seed market, the CCSA accepted a proposed remedy to license to independent third parties all the hybrids that Dow had tested in South Africa since 2013, since the remedy improved the chances of discovering high yielding hybrids. The CCSA similarly accepted remedies that the parties proposed related to chewing insecticides for citrus and vegetables, which involved a Global Divestiture of DuPont's nine herbicide Als, its three insecticide Als, and its global research \& development organization. Furthermore, for three years after the completion of the merger, the parties could not sell any new products that matched or had substantially the same formulation composition as the products it divested. The Purchaser had to display the financial resources and expertise, and have the incentive to maintain and develop the Divestment Business as a viable competitor to the merging parties. It already must have operated in the crop protection industry and must be able to demonstrate a track record of discovering or developing new AIs ${ }^{1079}$.

\subsection{China}

The merger was also assessed by the Chinese competition authorities, in particular MOFCOM, which approved it with conditions, including diverstiture and additional transaction obligations, in April $2017^{1080}$. The competition law assessment included, in a nutshell, that the merger would eliminate and restrict competition in the market of selective herbicide for rice, and the market of pesticide for rice, as following the transaction, the two parties will account for almost $40 \%$ market share in the Chinese market of selective herbicide for rice. MOFCOM considered that selective herbicides are generally used for particular crops, therefore, those selective herbicides suitable for different crops constitute separate commodity markets ${ }^{1081}$. It also came to the decision that pesticides and germicides suitable for different crops constitute separate relevant product markets, because of the obvious differences between common pests and pathogenic bacteria of different crops ${ }^{1082}$. Referring to the high HHI following the merger, MOFCOM noted that the transaction would reduce or eliminate competition between two competitors among a few competitors in the global and Chinese market in agrochemical products $^{1083}$. MOFCOM also considered the entry barriers in the market, such as funds, technology, and R\&D capability, which would have made it difficult for new entrants to enter timely and impose efficient competitive pressure on the new entity ${ }^{1084}$. MOFCOM also found an adverse effect on the innovation market, as well as effects on the downstream distributors

\footnotetext{
1079 Ibid., Annexure A $9 \uparrow$ 3.2, 3.7, 3.16.2-3.16.3.

${ }^{1080}$ see 中华人民共和国商务部公告2017年 第25号MOFCOM Announcement No. 25 of 2017 (April 29, 2017), available at http://english.mofcom.gov.cn/article/policyrelease/buwei/201705/20170502577349.shtml.

${ }^{1081}$ Ibid., para 7.

1082 Ibid., paras 8-9.

1083 Ibid., paras 39-40.

1084 Ibid., paras 32, 36, 41, 44.
} 
of the parties, which would have been either integrated or could possibly have been eliminated altogether ${ }^{1085}$.

With regard to the definition of the relevant markets in the part of the decision concerning agrochemicals, MOFCOM found that Dow and DuPont had lateral overlaps in nine markets: selective herbicides for grain and rice, pesticides for vegetables, fruit trees, rice, and cotton, and germicides for vegetables, fruit trees and potatoes. MOFCOM distinguished selective herbicides from non-selective herbicides, as the former are suitable for different crops and constitute separate product markets. Similarly, with regard to pesticides, the authority noted the obvious difference between common pests of different crops, noting that pesticides for different crops contain different active ingredients and ratios thereof, which results in the limited effectiveness or even ineffectiveness of a pesticide suitable for a particular crop when applied to other crops. Consequently, MOFCOM found that pesticides suitable for different crops constitute separate relevant product markets. Similar findings also applied for germicides, as the germicides suitable for different crops contain different active ingredients and ratios, and may target particular pathogenic bacteria, hence the finding that germicides suitable for different crops constitute separate relevant product markets. ${ }^{1086}$

The Chinese authorities defined the market as being national, in view of the fact that selective herbicides for grain and rice, pesticides for vegetables, fruit trees, rice, and cotton, and germicides for vegetables, fruit trees and potatoes need have registered with the relevant authorities in China. Their composition and application methods also depend on the environment, climate, soil characteristics, topography and the way the farmers apply them, which can be quite specific to the jurisdiction. Chinese customers and agricultural platform companies usually procure their products in China, which is the relevant geographic market. 1087

MOFCOM reviewed the resulting economic concentration in terms of relevant market concentration rates, market share and market control of the undertakings participating in the merger, keeping an eye on the impact of the merger on market access and technological progress as well as consumers and other relevant undertakings in accordance with Article 27 of the Anti-monopoly Law. The authority came to the conclusion that the transaction could produce adverse effects eliminating and restricting competition in the Chinese market of selective herbicide for rice and pesticide for rice. ${ }^{1088}$ This was based on a number of findings by the authority. First, the global agrochemical market has a high degree of concentration, with six companies accounting for $77 \%$ market share. These firms are strong in $R \& D$, benefit from a rich portfolio of products and patents and show financial strength. In view of these characteristics and their focus on $\mathrm{R} \& \mathrm{D}$, they constitute a different business model from generics that have a more limited $R \& D$ capacity and are mainly engaged in the production and development of generic drugs, or from "pesticide preparation enterprises" which buy active

\footnotetext{
1085 Ibid., para 33. The merger would also have adverse effects on the global markets of acid copolymer and ionomers, but as this is not related to the global food value chain, we will not be exploring this part of the decision in this report.

1086 Ibid., paras 7-9.

1087 Ibid., paras 25-26.

1088 Ibid., para 27.
} 
components from the Big Six in order to produce their own products ${ }^{1089}$. Second, prior to the transaction, Dow has long been ranked first in the Chinese market of selective herbicide for rice, with the second to the seventh competitors accounting for less than 50\% market share on aggregate. The selective herbicide for rice penoxsulam launched by Dow in 2005 has been quite successful, achieving the largest ever sales volume in the Chinese market of selective herbicide for rice. There are no effective substitutes for Dow's selective herbicides for rice, hence the profit margins are much higher than the industry average. Third, DuPont is a major innovator in the Chinese market of selective herbicide for rice. It benefits from the advantage that its products are launched overseas and may enter the Chinese market. According to MOFCOM, following the completion of the transaction, both parties to the transaction will account for almost $40 \%$ of the Chinese market of selective herbicide for rice, their market forces and research and development capabilities will be integrated; and their market control will be further enhanced ${ }^{1090}$.

The authority also noted that in view of barriers to entry it would be difficult for a new competitor to enter the market in the short term. In particular, Funding and technology research and development capability are decisive factors for competing effectively in the market of selective herbicide for rice. Due to the declining new active ingredient screening success rates, and the increasing research and development costs, shortened patent protection periods and stricter requirements of environmental protection, in recent years, it becomes quite difficult to launch new products and the cycles of innovation are constantly extending. The ranking of the top seven undertakings in the market has been relatively stable, without new effective competitors coming in the market the last decade. This of courses reduces the competitive pressure on both parties after the concentration ${ }^{1091}$.

The authority also found that the transaction would have adverse effects in the market of pesticide for rice. DuPont has been steadily ranked first in the Chinese market of pesticide for rice between 2011 and 2015. Its market share was usually almost two times that of the second competitor and its "ultrahigh" profit margin that is much higher than the industry average over more than ten years were thought of as indicators of its economic power ${ }^{1092}$. Dow also shows strength in $R \& D$ in the Chinese market of pesticide for rice. It has been able to launch active ingredients and new product reserves are significantly more quickly than other competitors, showing its great market potential. Dow's pesticide product for rice sulfoxaflor is one of the major pesticides used for rice crops in China, no other product being available in China that can compete with it effectively. Dupont has developed Triflumezopyrim which has received the requisite authorisations and is about to be launched in the Chinese market. The experimental results show that the drug is "highly efficient and rapid at low dosage and environmentally friendly" ${ }^{1093}$. According to MOFCOM, following the transaction, both parties will be able to integrate their market and R\&D capabilities further consolidating their existing

\footnotetext{
1089 Ibid., para 28

1090 Ibid., paras 29-31

1091 Ibid., paras 32-33

1092 Ibid., para 35

${ }^{1093}$ Ibid., para 35
} 
leading position in the market, in particular with the combination of the product portfolio of sulfoxaflor and triflumezopyrim ${ }^{1094}$.

According to the Chinese merger watchdog, it will be quite unlikely for new competitors to enter the pesticides market for rice, in particular in view of the declining rate of success rates for new active ingredients, the increasing research and development costs, shortened patent protection periods and stricter requirements of environmental protection standards. As a result, the top seven competitors in the Chinese pesticides market for rice were basically stable during the period between 2011 and $2015^{1095}$.

With regard to vertical anticompetitive effects, MOFCOM found that the transaction could damage the interests of downstream distributors. Indeed, distributors of selective herbicides for rice rely on the merging parties in terms of product pricing, promotion input and technical services and are thus in a relatively weak bargaining position. In accordance with the revised Administrative Regulations on Agricultural Chemicals of the People's Republic of China, distributors will have to take responsibility for the quality (including safety) of agricultural chemicals. This increases the dependence of downstream distributors on producers and this makes them more willing to distribute products of well-known multinational corporations, such as the merging parties. Following completion of the transaction, the competition between Dow and DuPont in the market for selective herbicides for rice will be eliminated. As their distributors in major Chinese provinces did not overlap before the merger, their original distributors may be integrated or eliminated, hence the bargaining position of their distributors will be further weakened and their interests damaged ${ }^{1096}$. Similar findings were made with regard to pesticides for rice ${ }^{1097}$.

Given that the concentration of undertakings may have the effect of eliminating and restricting competition in the Chinese markets of selective herbicide for rice and pesticide for rice, MOFCOM conditionally approved the concentration, requiring Dow and DuPont to divest, with regard to herbicides for rice cultures, the active ingredients metsulfuron-methyl and azimsulfuron and cyantraniliprole, and regarding pesticides for rice, chlorantraniliprole and indoxacarb, including all related tangible and intangible assets as well as the employees involved. ${ }^{1098}$ Remedies also included the obligation on the new entity to provide access, within a period of five years since the closing of the transaction, and on a non-exclusive basis to the hybrid active ingerdients/active ingredients of bensulfuron methyl, bensulfuron methyl + carfentrazone ethyl, and pyrazosulfuron ethyl as well as DuPont's existing preparations that only contain the above hybrid active ingredients/active ingredients in China at reasonable prices (i.e. no higher than the average price over the past 12 months) to Chinese undertakings making such request, to the extent these conform to the Chinese regulatory framework, in particular regarding registration and authorisation of active ingredients. Similar requirements were provided for access to Dow's trifuralin (sulfoxaflor). With regard to the vertical concerns MOFCOM prohibited to the merged entity for a period of 5 years since the conditional approval

\footnotetext{
1094 Ibid., para 36

1095 Ibid.

1096 Ibid., para 34

${ }^{1097}$ Ibid., para 38

${ }^{1098}$ Ibid., paras 48-49, 53-56
} 
of the transaction, from imposing on Chinese distributors exclusive obligations to sell a number of pesticides and herbicides ${ }^{1099}$.

\subsection{India}

On 19 May 2016, the Competition CCI of India (CCI) received a joint notice of merger from Dow Chemical Company (Dow), E. I. du Pont de Nemours and Company (DuPont), DowDuPont Inc. (DowDuPont), Diamond Merger Sub Inc. (Diamond Merger Sub), and Orion Merger Sub Inc. (Orion Merger Sub) whereby the Parties informed the CCI that they had entered into a Merger Agreement on 11 December 2015 in order to merge the businesses of Dow and DuPont and to create three independent companies dealing in agriculture material sciences and specialty products. ${ }^{100}$ On 19 January 2017, the CCI, after considering the notice issued a show cause notice ( $\mathrm{SCN}$ ) to the parties to address potential competition concerns arising from the proposed merger. ${ }^{1101}$

The parties initially responded to the SCN on 20 February 2017 and amended their response on 1 and 2 March 2017. After examining the response, the CCI formed the view that the proposed merger was likely to have an appreciable adverse effect on competition (AAEC) in markets in India and, therefore, directed the parties to publish the proposed merger for the knowledge and information of persons likely to be affected by the proposed merger and of the public generally. ${ }^{1102}$ Accordingly, on 18 March 2017, the parties published the details of the merger and the CCI allowed until 10 April 2017 for receipt of comments. ${ }^{1103}$ In its meeting on 28 April 2017, the CCI evaluated the proposed merger in light of the initial application, the response of the parties and the comments of stakeholders and the general public. ${ }^{1104}$

In order to carry out its assessment of competition concerns arising from the proposed merger, the CCI noted that the Parties are involved in manufacture and sale of (a) crop protection products; ${ }^{1105}$ (b) research and development in crop protection products; ${ }^{1106}$ (c) seeds; ${ }^{1107}$ (d) specialty chemical; ${ }^{1108}$ and (e) material sciences. ${ }^{1109}$ In this case note we do not address the analysis of the material science markets.

\footnotetext{
1099 Ibid., paras 50-52

1100 Order dated 8 June 2017 in respect of Combination Registration No. C-2016/05/400), paras 1-2.

${ }^{1101}$ Ibid para 18.

1102 Ibid para 21.

1103 Ibid para 22.

1104 Ibid para 23.

1105 Ibid para 27(A). The CCI observed that Parties have a portfolio of insecticides, fungicides and herbicides effective on multiple pests / fungus / weeds, infesting many common crops (e.g. cereals, fruits, vegetables etc.). it also noted that the Parties have an overlap in insecticides, fungicides and herbicides.

1106 ibid para 27(B). The CCI noted that Dow and DuPont are engaged in R \& D and maintain facilities across the globe. The CCI also observed that this may have an effect on new products coming into India.

${ }^{1107}$ Ibid para 27 (C). The CCI observed that the operations of the parties overlap in the manufacture and sale of non-genetically modified corn seeds in India.

1108 Ibid para 27 (D). The CCI noted the overlap Purified carboxymethylcellulose (Purified CMC).

${ }^{1109}$ Ibid para 27 (E). The CCI observed that the activities of the parties overlap in certain hydrocarbonsandethylene derivatives products ('Co-polymers'), specifically Acid Copolymers, Acrylate Co-polymers, and MAH Grafted Polymers.
} 
Whilst the CCI identified the territory of India as the relevant geographic market for all products, ${ }^{1110}$ it identified the relevant product market as follows.

In relation to crop protection products, the CCI observed that the each specific combination of crop, class of insect and fungicides has its own separate relevant product market. It also noted that herbicides may be classified into selective and non- selective categories. ${ }^{1111}$ The CCI further observed that for analysis of substitutability of insecticides, fungicides, and herbicides, the application method to the crop, whether the product is patented or not, and active ingredients, formulation and mode of action of may also be relevant. ${ }^{112}$

In relation to seeds, the CCI identified an overlap in the non-GM corn seeds. It, therefore, stated that given seeds for different crops have different characteristics and differ in their intended use, non-GM corn seeds constitute a separate relevant product market. ${ }^{113}$

In respect of Purified CMC, the CCI noted that the product is used in food, pharmaceuticals and personal care products. However, it stopped short of defining the market due to the small presence of the parties in these products. ${ }^{114}$

The CCI carried out assessment of each of the overlapping relevant market(s). Considering factors such as low combined market shares of the Parties (market share of DuPont and Dow are 30-35 percent and 5-10 percent, respectively, for the year 2014); ${ }^{115}$ low increment as a result of the proposed combination (moderately concentrated with the premerger HHI of 1825-1830, increasing to 2205-2210, post-combination with increment of 375$380)^{1116}$ and presence of several competitors and other competing products of competitors (other competitors in the relevant market are distantly placed e.g. Syngenta (15-20 percent), Rallis (10-15 percent), UPL (5-10 percent), Nagarjuna (0-5 percent), Bayer (0-5 percent) $)^{1117}$ the CCI did not find competition concerns in any relevant market except in the market Fungicides for grapes which target fungus 'Ascomycota' in India'1118

In respect of the impact of the merger on $\mathrm{R} \& \mathrm{D}$ in crop protection products in India, the CCI observed that a considerable research and development activity of the Parties related to crop protection products occurs outside India which may lessen post-merger, and thereby, adversely affect the Indian crop protection market. ${ }^{1119}$ However, the CCI also noted that the parties have offered global divestiture to the European CCI relating to (i) herbicides, (ii) insecticides, and (iii) $\mathrm{R} \& \mathrm{D}^{1120}$ and observed that this remedy was sufficient to meet competition concerns relating to R \& D in these products in India. ${ }^{1121}$ The CCI directed the parties to keep it informed of the progress of or any changes to the divestment. ${ }^{1122}$

\footnotetext{
1110 Ibid. para 30.02 .

${ }^{1111}$ Ibid para 29.1.1.2.

1112 ibid para 29.1.1.3

1113 ibid para 29.1.2.1

1114 ibid para 29.1.3.1

1115 ibid para 30.1.2.

1116 ibid.

1117 ibid.

1118 ibid para 30.1.3.

1119 ibid para 30.1.4.

1120 ibid para 30.1.5.

1121 ibid para 30.1.8.

1122 ibid para 30.1.9.
} 
With regard to the competition assessment of seeds, the CCI had already noted that the only overlap in the activities of the parties in seeds was in relation to GM corn seeds in India where the combined market share of the parties was approximately 25-30 percent. However, the post-merger increment in these shares was negligible. The CCI also noted the presence of several other players such as Monsanto, Syngenta, Kaveri Seeds, Nuziveedu Seeds and CP Seeds in producing and supplying non-GM corn seeds in India. ${ }^{1123}$ The CCI further noted that the parties were not engaged in commercial licensing of the technology for producing GM corn seeds. ${ }^{1124}$ In relation to the interdependence of seeds and agrochemicals and the parties did not offer any crop seed, ${ }^{1125}$ which has a trait that would make it tolerant to a particular agrochemical in India. The CCI, therefore, concluded that the proposed merger was not likely to have AAEC in the seed market. ${ }^{1126}$

In respect of Purified CMC, the CCI noted that the Indian market is import based, in which the share of Dow is insignificant and there are also a number of other competitors. ${ }^{1127}$ Therefore, the proposed merger is not likely to have AAEC in the market for Purified CMC in India. ${ }^{1128}$

The CCI approved the merger on the basis of the following modifications, which the parties accepted unconditionally. With regard to the agrichem products, the CCI directed the parties to (i) provide an undertaking that they are not and will not re-enter the commercialization of Flusilasole AI and the products /formulations containing Flusilasole AI in India for specified period of from the date of the undertaking; ${ }^{1129}$ (ii) to file an application with the Central Insecticide Board \& Registration Committee (CIB \& RC) for immediate withdrawal of DuPont's registration of products/formulations containing Flusilasole AI, to immediately file CIB \& RC's acknowledgement of such communication with the CCI and to give an undertaking not to register with the CIB\&RC, and to give an undertaking that it would not register any such product for a specified period; ${ }^{1130}$ (iii) to file an application with the Trade Mark Registry in India, to cancel DuPont's trademark for NUSTAR and to surrender it and to immediately file Trade Mark Registry's acknowledgement of such communication with the CCI, ${ }^{1131}$ and (iv) to give an undertaking not to sell or export Flusilasole AI or any products/formulations containing Flusilasole AI in India either directly or indirectly through their affiliates. ${ }^{1132}$ Parties were also directed to bind their subsidiaries and affiliates and to inform all relevant government departments of their commitments. ${ }^{1133}$

\subsection{Brazil}

\footnotetext{
1123 ibid para 30.2.1.

1124 ibid para 30.2.2

1125 ibid para 30.2.3.

1126 ibid para 30.2.4.

${ }^{1127}$ Ibid para 30.3.1.

1128 ibid para 30.3.2.

${ }^{1129}$ Ibid para 34.1.2(i)

${ }^{1130}$ Ibid para 34.1.2(ii)

${ }^{1131}$ Ibid para 34.1.2(iii)

1132 Ibid para 34.1.2(iv)

${ }^{1133}$ Ibid para 34.1.2(v) and (vi).
} 
Given the complexity of the case, the case reached the in-depth second phase of analysis in merger control. Both companies had substantial activities in Brazil and CADE undertook an extensive analysis of all the relevant markets. ${ }^{1134}$

CADE reached the conclusion that the merger could lead to horizontal concentration in the markets of pesticides. These were divided into several relevant markets:

- pesticide inputs in the world market (including active ingredients, according to their uses, halopyridine and co-formulant propylene glycol);

- insecticides, according to their uses;

- herbicides, according to their uses;

- fungicides, according to their uses;

- acaricides, according to their uses;

- seed treatment;

- plant growth regulators.

While the markets of acaricides and plant growth regulators did not raise concerns, relevant horizontal concentration was found in the other markets. Barriers to entry were considered to be high, given the regulatory requirements, high investment in R \& D, brand power for consumers, scope economies and access to distribution channels. ${ }^{1135}$ As to rivalry, the analysis led to the conclusion that in the markets of fungicides (for potatoes, peach and grapes), no concerns arose. As to insecticides and herbicides, the analysis of the relevant market of insecticides for chewing insects (mainly, lepidoptera) and for apples revealed concerns but the global divestments package that was proposed was adequate to dispel them. ${ }^{1136}$ The vertical integration between pesticides and their inputs and ingredients was not considered problematic: a market foreclosure strategy would be ineffective, since DuPont acquired all Dow`s supply, which sold a small quantity to DuPont. ${ }^{1137}$

The authority undertook a more careful analysis of the seeds markets and developed jurisdiction-specific remedies. The analysis was carried out in the following alternative scenarios for the relevant markets: ${ }^{1138}$

- national market of corn seeds in general (conventional and GM) as well as more strict scenarios divided by the type of corn (simple, double and triple);

- national market of soybean seeds in general (conventional and GM) as well as more strict scenarios divided by the type of corn (simple, double and triple);

- national market of corn seeds divided by the type of corn (simple, double and triple) for grain production;

- national market of corn seeds divided by the type of corn (simple, double and triple) for ensilage;

\footnotetext{
1134 The merger did not raise competition concerns in the market of specialized products for health, nutrition, electronics and communication, where the two entities were present. Specifically, horizontal concentration and vertical integration had been identified in food fibres, food texturizers, semiconductor encapsulation technology, dry photo-resistant films, post recording waste removal products, but they did not lead to problems in Brazil. Ibid para 30-40.

${ }_{1135}$ Ibid para 82-85.

${ }^{1136}$ Ibid para 96-99.

${ }^{1137}$ Ibid para 104-108.

${ }^{1138}$ Ibid para 125.
} 
- national market for licencing of corn germplasm;

- world market of R\&D in GM corn seeds;

- world market of R\&D in GM soybean seeds;

- national market for licencing of GM corn seeds;

- National market for licencing of GM soybean seeds.

There was horizontal concentration in the markets of soybeans and corn seeds. CADE found that the market of soybeans seeds led to concentration; however, the combined entity's market share was no more than $10 \%$ and HHI variation not over 200 , thus, insufficient to raise concerns. ${ }^{1139}$ In the market for corn seeds (specifically, simple and triple hybrid corn), CADE found a high degree of horizontal concentration. It also decided that the destination (grain production or ensilage) should not be relevant for the analysis.

As to simple hybrid corn, the resulting market shares calculated by turnover were around 40-50\%. The HHI pre-operation was between 2600-3000 and the HHI variation was around $600-800 .{ }^{1140}$ As to triple hybrid corn, the resulting market shares calculated by turnover were between $70-80 \%$. The HHI pre-operation was around 3000-3200 and the HHI variation was around 600-800. ${ }^{1141}$ In those markets, CADE considered that barriers to entry were high due to: the need for investment in $\mathrm{R} \& \mathrm{D}$, in marketing and distribution to access the market and in the maintenance of an adequate improvement programme; the cost and time to fulfil regulatory procedures; the long cycle of investments; brand recognition and the requirement of staff expertise. ${ }^{1142}$

As to rivalry, most competitors could not deviate their supply in response to an increase in price. ${ }^{1143}$ The authority analysed the role of brands, the new entity's control of valuable germplasm banks, its research and development strength, including its patent portfolio and its presence in distribution to conclude that rivalry in the corn seeds market was not sufficient to dispel concerns. ${ }^{1144}$ Specific remedies were deemed to be necessary. There was no analysis of efficiencies since the parties proposed an agreement. As to the vertical integration between licensing, development and production of seeds, CADE did not however raise any concerns: a market foreclosure strategy either upstream or downstream would be ineffective. ${ }^{145}$

The reporting Commissioner voted in favour of conditionally approving the operation. Given the fact that the merger transaction was between foreign undertakings, it was reported in the decision that the remedies were coordinated with other jurisdictions. The remedies were mostly structural and involved (with regard to the part of the decision on agrochemical markets)

\footnotetext{
1139 Ibid para 129.

1140 Para 280 of the Superintendence Report. BRAZIL, Administrative Council for Economic Defence CADE, Merger Case $n$ 08700.005937/2016-61, Parties: The Dow Chemical Company and EI Du Pont de Nemours and Company. Superintendence Report on Seeds, 4 May 2017, available at < http://sei.cade.gov.br/sei/institucional/pesquisa/documento_consulta_externa.php?OCglvmlfNSHxzhPz7bTu2 U4F2xF5pnlCl11mtYJvYgGcDWM6PSuNvbj_mSM7E00vCyBQ44lmyaYJe-vk0hI-GQ,,> $\quad$ accessed 7 November 2017.

${ }^{1141}$ Ibid, para 336 and 351.

${ }^{1142}$ CADE Final Decision, see note above, para 135-137.

1143 Ibid para 143-144.

${ }^{1144}$ Ibid para 148-156.

${ }^{1145}$ Ibid para $157-159$.
} 
- the transfer of some herbicides and insecticides inputs ${ }^{1146}$ and products ${ }^{1147}$;

- the divestment of some R\&D assets;

- the transfer of germplasm banks of corn under certain limitations;

- the transfer of corn pipeline hybrids and commercial hybrids;

- the sale of corn industrial facilities;

- the transfer of corn R\&D centres;

- the transfer of brands, staff and sales force.

It was mentioned that the businesses should be transferred to an independent experienced market player with capacity to operate and to be an effective rival. More in depth analysis of CADE's decision is included in the Section of this report dealing with case study on agrochem mergers in Brazil.

\subsubsection{ChemChina/Syngenta}

This $\$ 43$ billion takeover deal, announced in February 2016, brings together Syngenta, one of one of the leading agriculture companies in the world and a major innovator in this sector, and ChemChina, a Chinese corporation with sole control of ADAMA Agricultural Solutions Ltd, an Israel-based corporation, manufacturing, formulating and selling agricultural chemical products in the U.S, constituting mostly generic supplier. The transaction was assessed by a number of jurisdictions, which approved it either conditionally or unconditionally. For instance, the merger was approved unconditionally in Russia, while in India Syngenta and ChemChina announced that their deal was "deemed approved" by the CCI, due to the expiry of the statutory maximum of the 210 day review period from merger filing. As of the date of writing, no decision or press release was found at the CCI's website.

\begin{tabular}{|c|c|c|}
\hline \multicolumn{3}{|c|}{ ChemChina/Syngenta merger transaction } \\
\hline Country & $\begin{array}{l}\text { Notification/Investigation } \\
\text { date }\end{array}$ & Decision date \\
\hline United States & N.A & N.A. \\
\hline European Union & 23 Sept. 2016 & 5 Apr. 2017 \\
\hline Brazil & 5 September 2016 & 24 February 2017 \\
\hline Russia & NA & 13 July 2016 \\
\hline India & $\begin{array}{ll}\text { C-2016/08/424 } & \text { (Date not } \\
\text { known) } & \\
\text { C-2016/03/380 } & \text { (Date not } \\
\text { known) } & \\
\end{array}$ & $\begin{array}{l}\text { Approved. Date not known } \\
\text { Pending }\end{array}$ \\
\hline China & N.A. & 12 April 2017 \\
\hline
\end{tabular}

\footnotetext{
${ }^{1146}$ Active ingredients of herbicides for cereals, oilseed rape, sunflower, rice and pasture: Thifensulfuron Methyl, Tribenuron Methyl, Metsulfuron Methyl, Chlorsulfuron Methyl, Triflusulfuron Methyl, Lenacil, Flupyrsulfuron Methyl, Ethametsulfuron Methyl and Azimsulfuron; Active Ingredients of Insecticides: Ciantraniliprole, Clorantraniliprole and Indoxacarbe.

1147 Herbicides: Ally (Dupont); Insecticides: ALTACOR ${ }^{\circledR} 35 \mathrm{WG}$, PREMIO ${ }^{\circledR}$ 20SC, BENEVIA ${ }^{\circledR} 100$ OD, VERIMARK® 200 SC, AVATAR, RUMO, AVAUNT 150.
} 


\subsection{United States}

Following a complaint by the US Federal Trade Commission, the FTC and the merging entities reached an agreement in April 2017 for the transaction to go forward with the imposition of a remedial package.

The complaint of the FTC defined the relevant market as formulated crop protection products based on the active ingredients paraquat, abamectin, and chlorothalonil. Paraquat is a non-selective "burndown" herbicide, which is a cheap solution in order to get rid of weeds at the end of the farming season. Abamectin is an insecticide used to kill mites, psyllid, and leafminers, merely used in citrus and tree nut crops, any alternatives to this product being significantly more expensive because they are patent-protected or less effective. Finally, Chlorothalonil is a broad-spectrum fungicide used primarily in peanuts and potatoes. The FTC's complaint noted that the markets for formulated crop protection products using the active ingredients paraquat, abamectin, and chlorothalonil in the United States are highly concentrated, with Syngenta being the market leader in each of the three product markets, while ADAMA being either the largest or the second largest generic supplier. In particular, the FTC estimated that the merged entity's market share following the transaction would be over $60 \%$ in formulated crop protection products with the active ingredient paraquat. The combined market would have reached $80 \%$ for the formulated crop protection products with the active ingredient abamectin share, ADAMA being the generic market leader in abamectin-based products. Finally, the combined market share post-transaction in formulated crop protection products with the active ingredient chlorothalonil would have been over 40\%, ADAMA being the second largest generic supplier in this market.

The FTC further noted the low likelihood of entry of new competitors that could effectively counteract the anticompetitive effects of the acquisition in the markets in the foreseeable future, referring to support this allegation to the relatively stable market shares of ADAM for an extended period of time.

According to the FTC, without the proposed remedial package, the transaction would have removed an important competitive constraint on ADAMA, thereby increasing the likelihood that the merged entity will unilaterally exercise market power in the relevant markets and that customers in the United States would be forced to pay higher prices or accept reduced service for crop protection formulations based on the abovementioned active ingredients. Indeed, Syngenta owns the branded version of each of the pesticide products based on the three active ingredients in question, giving it significant market shares in the United States, while ChemChina's subsidiary ADAMA focuses on generic pesticides and is either the first- or second-largest generic supplier in the United States for each of these products.

FTC and the merging companies convened a consent agreement requiring ChemChina to sell all rights and assets of ADAMA's U.S. paraquat, abamectin and chlorothalonil crop protection businesses to California-based agrochemical company AMVAC. 


\subsection{European Union}

The European Commission opened an in depth investigation of the merger in October 2016, considering that should the transaction as notified go ahead it would have reduced competition in a number of existing markets for pesticides (in particular fungicides, herbicides, insecticides and seed treatment products. The Commission also expressed concerns that the transaction would reduce competition for plant growth regulators, which are products used in agriculture to slow or stimulate a crop's growth and development. The Commission's investigation focused on competition for existing pesticides, since ChemChina does not compete with Syngenta for the development of new and innovative pesticides. Hence, the Commission did not assess the possible effects of the merger transaction on innovation, given that generic suppliers do not compete in innovation of new Active Ingredients (Ai) s or in formulations based on patented AIs. Instead they compete mainly in solo and mixture products based on off-patent AIs ${ }^{1148}$.

The Commission's investigation showed that the parties would have held high combined market shares for a number of pesticides and for certain plant growth regulators, with few other competitors remaining. This effect was reinforced by the fact that Adama is a close and important generic competitor of Syngenta in many of these markets. The Commission concluded that the takeover would have significantly impeded effective competition in a number of relevant markets.

Quite interestingly, the Commission referred in its decision to the "value chain" for crop protection products (including lawn and garden products), the chain englobing four stages: discovery, development, mixture/formulation, distribution. The Commission clearly distinguished between the integrated research and development ("R\&D") players that are active at all four stages of the value chain and have a global presence, and other players, including generic suppliers or undertakings only present in one of the segments of the crop protection value chain, noting that these two groups of economic actors are characterized by different capabilities in the production chain for crop protection products and are active at different stages of the value chain ${ }^{1149}$. Not only are generic players not present in the upstream discovery and development of new AIs and therefore do not compete in the discovery of new AIs, but also they are usually excluded from the patent strategies adopted by the major R\&D players, which at the early stages of the research process, commonly seek 'compound patent' on new AIs, providing the patentee the exclusive right to manufacture the AI, to incorporate that AI into formulated products and to put those formulated products on the market for the first time" ${ }^{1150}$. Generic players cannot therefore use patent-protected AIs to produce new formulations that compete with those of the patent holder. Furthermore, "R\&D companies commonly adopt a 'post-patent strategy', which involves employing tools to maximise the profitability of their AIs and avoid generic competition, even after the expiry of the compound patent" ".151. Hence, the space where generic suppliers compete with "R\&D companies" is fairly small and "even when generic companies appear to hold a substantial share of the market, that

\footnotetext{
1148 Ibid., para. 44.

${ }^{1149}$ Ibid., paras 29-37 and 41-49.

${ }^{1150}$ Ibid., para. 42.

${ }^{1151}$ Ibid., para. 43.
} 
share is dependent on access to AIs which tend to be originated by large R\&D players" ${ }^{1152}$. The Commission included various other categories of economic actors, than just generic, in its category of "other players":

- "pure" generic players (such as Sipcam, Gowan, Belchim), "which generally operate on specific regions or relatively few countries, focus primarily on selling 'me too'/copycat products or products which are relatively un-differentiated from the original product, either under their own name or as private label products for distributors" $" 1153$.

- "differentiated" generic players (such as, Adama, Nufarm, Arysta/Chemtura, FMC/Cheminova), which "operate globally and try to differentiate themselves from the ;pure' generic players by, in addition to producing 'me too' versions, also creating alternative mixtures which are not simply copies but attempt to offer differentiated benefits to existing products already available in the market"1154. The Commission notes that Adama constitutes the only generic player with a substantial geographic coverage across the $\mathrm{EEA}^{1155}$.

- "generic active ingredient producers" which are players based in India and Chin, and "which do not generally try to market or register products themselves outside their home countries" and they "only sell AIs to other players that carry out all the formulation, registration, and marketing"1156

- other agrochemical players that are active in the research of new AIs but do not engage in development (such as, Sumitomo Chemical Co. Ltd., Nihon Nohyaku Co. Ltd., Kumiai Chemical Industry Co. Ltd., Ishihara Sangyo Kaisha and Mitsui Chemicals Inc, which are "active in the discovery of new AIs in certain market segments, but do not compete across the board with the main integrated R\&D players and tend to focus on offering products based on off-patent AIs, like the generic players"

The Commission found that there are 7 main generic players active globally, with 6 generic players being active in the $\mathrm{EU}^{1158}$. The Commission noted the important barriers to entry in this industry, as the launch of a new AI requires significant time and financial resources due to the rigorous testing that the AI must undergo before being commercialised (the average costs being \$286 million and the development and commercialisation taking approximately 10 years) ${ }^{1159}$. According to the Commission, barriers to entry include "building inventive capability, regulatory costs, development skills, expense of research, cost of investment, risk, difficulty to obtain high enough market access, time for registration, and demanding technical

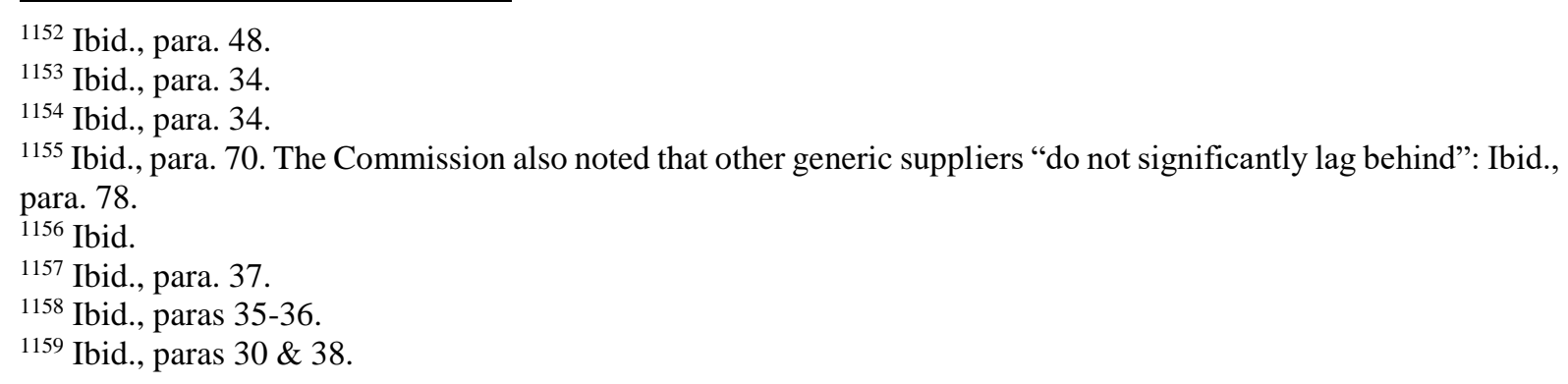


requirements"1160, which further delay the entry of a generic in a market, usually for a period between 1-5 years (sometimes longer), after a product becomes off patent ${ }^{1161}$.

Figure 1: Value Chain in the production of crop protection products: Key players

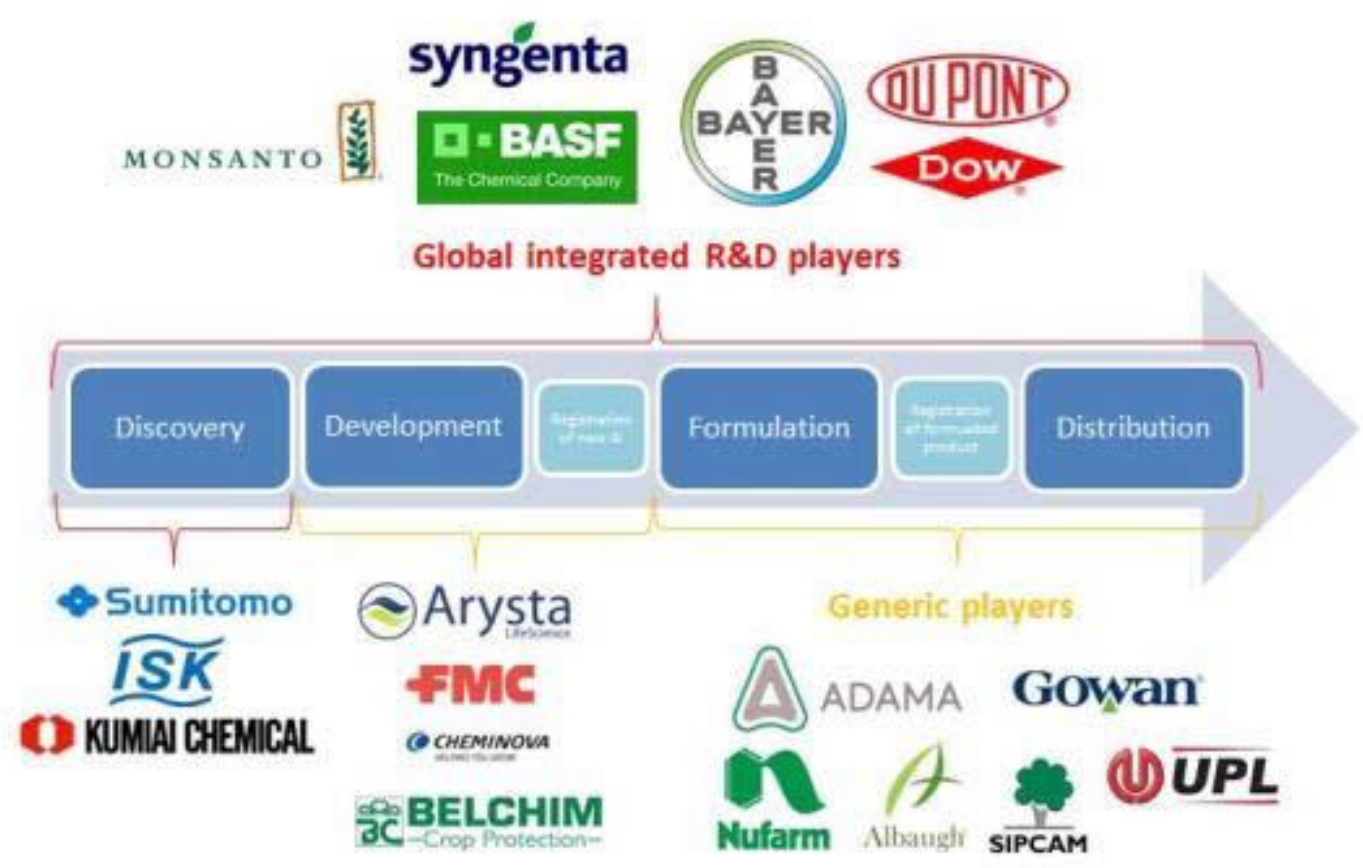

Source: Commission Decision, ChemChina/Syngenta $(2017)^{1162}$

Moving to the analysis of the economic concentration in the affected markets, the Commission noted that Syngenta was the leading integrated R\&D player in crop protection markets at the global level and the second biggest agrochemical company in the European market, with market shares of about 30-40\% in herbicides and fungicides, and 10-20\% in insecticides and seed treatment, with a leading crop protection portfolio and AIs ${ }^{1163}$.

Table 49: Share of crop protection economic actors (2015 EEA agrochemical sales by crop protection product)

\footnotetext{
${ }^{1160}$ Ibid., para. 39.

${ }^{1161}$ Ibid., para. 40.

1162 Ibid., para. 31.

${ }^{1163}$ Ibid., paras 52-57.
} 


\begin{tabular}{|c|c|c|c|c|c|c|c|c|}
\hline SECTOR & Adama & Syngenta & Dow & DuPont & Bayer & $\begin{array}{c}\text { Monsant } \\
\text { o }\end{array}$ & BASF & $\begin{array}{c}\text { Market } \\
\text { size ('000 } \\
\text { USD) }\end{array}$ \\
\hline Fungicides & {$[5-10] \%$} & {$[10-20] \%$} & {$[0-5] \%$} & {$[0-5] \%$} & {$[20-30] \%$} & {$[0-5] \%$} & {$[20-30] \%$} & {$[\ldots]$} \\
\hline Insecticides & {$[5-10] \%$} & {$[10-20] \%$} & {$[5-10] \%$} & {$[5-10] \%$} & {$[10-20] \%$} & {$[0-5] \%$} & {$[0-5] \%$} & {$[\ldots]$} \\
\hline $\begin{array}{l}\text { Non-selective } \\
\text { Herbicides }\end{array}$ & {$[5-10] \%$} & {$[5-10] \%$} & {$[5-10] \%$} & {$[0-5] \%$} & {$[10-20] \%$} & {$[20-30] \%$} & {$[0-5] \%$} & {$[\ldots]$} \\
\hline $\begin{array}{l}\text { Plant Growth } \\
\text { Regulators }\end{array}$ & {$[5-10] \%$} & {$[10-20] \%$} & {$[0-5] \%$} & {$[0-5] \%$} & {$[5-10] \%$} & {$[0-5] \%$} & {$[20-30] \%$} & {$[\ldots]$} \\
\hline $\begin{array}{l}\text { Seed } \\
\text { Treatment }\end{array}$ & {$[0-5] \%$} & {$[20-30] \%$} & {$[0-5] \%$} & {$[0-5] \%$} & {$[40-50] \%$} & {$[0-5] \%$} & {$[5-10] \%$} & {$[\ldots]$} \\
\hline $\begin{array}{l}\text { Selective } \\
\text { Herbicides }\end{array}$ & {$[5-10] \%$} & {$[10-20] \%$} & {$[10-20] \%$} & {$[5-10] \%$} & {$[20-30] \%$} & {$[0-5] \%$} & {$[10-20] \%$} & {$[\ldots]$} \\
\hline All sectors ${ }^{88}$ & {$[5-10] \%$} & {$[10-20] \%$} & {$[5-10] \%$} & {$[5-10] \%$} & {$[20-30] \%$} & {$[0-5] \%$} & {$[10-20] \%$} & {$[\ldots]$} \\
\hline
\end{tabular}

Source: Commission Decision, ChemChina/Syngenta (2017) $)^{1164}$

The case was also particularly interesting because of the fact that ChemChina is a state-owned undertaking. The Commission acknowledged that by virtue of Article 106 TFEU the principle of non-discrimination between public and private undertakings applies and that "undertakings making up an economic unit with independent power of decision, irrespective of the way in which their capital is held or of the rules of administrative supervision applicable to them" 1165 . The issue was raised because Chinese SOEs are managed in China by an administrative body named Central SASAC, which is the State-owned Assets Supervision and Administration Commission of the State Council through which the Central Government supervises and manages the state-owned assets of its State owned enterprises. The Commission did not decide on the issue as for the purpose of the Transaction, whether ChemChina is regarded as one economic entity with other companies owned by the Chinese Central Government or not, did not have an impact for the competitive assessment. The Commission left the question open and considered the most restrictive approach under which ChemChina is regarded as one economic entity with other companies owned by the Chinese Central Government ${ }^{1166}$.

In defining the relevant markets, because each raw material exhibited a different chemical structure, because each raw material specifically constituted an active ingredient (AI), and because each AI had to undergo a registration process, which authorizes only the exact AIs submitted, the Commission found distinct markets both for each raw material and for each AI. ${ }^{1167}$ The Commission went on to define markets in the various crop-protection products such as herbicides and fungicides largely based on crop and pest that farmers wished to target, in addition to the timing of application. ${ }^{1168}$ Concerning geographic markets, the Commission identified worldwide markets for raw materials and AIs, but national markets for the various crop-protection products. ${ }^{1169}$

\footnotetext{
${ }^{1164}$ Ibid., para. 52.

1165 Ibid., para. 81.

${ }^{1166}$ Ibid., para. 88 .

${ }^{1167}$ Ibid., paras 95-96, 101-102.

${ }^{1168}$ See, e.g., paras 108, 121, 143.

${ }^{1169}$ Ibid., paras 161, 166, 174.
} 
In undertaking a competitive assessment of horizontal overlap in the market for active ingredients, the Commission stated that in assessing competitive effects in all markets, it would consider whether the transaction eliminated important constraints that the parties previously had exerted both on each other and on remaining competitors. The Commission would look to whether the parties were close competitors in particular markets, meaning that anticompetitive effects could follow even if the parties were not closest competitors. ${ }^{1170}$ The Commission narrowed the analysis at the EEA level to seven AIs and determined the transaction would not significantly strengthen the parties' market position, noting low market shares, an incremental increase in market share of less than $5 \%$ for six AIs, and the presence of many alternative suppliers for each of the seven AIs. ${ }^{1171}$

The Commission next conducted a competitive assessment of the vertical relationship between AIs and crop protection products, and between raw materials and AIs. Starting with AIs and crop protection products, the Commission stated that input foreclosure requires a significant degree of market power in the upstream market, and that the parties unlikely would have sufficient dominance in the AIs where the parties' activities overlap. ${ }^{1172}$ The Commission reached the same conclusion concerning customer foreclosure because the transaction would not generate the market power necessary in the various crop protection products to support such an exclusionary strategy, and because ChemChina would not be able to purchase anywhere near Syngenta's share of worldwide demand in the AIs that it produced. ${ }^{1173}$ Turning to raw materials and AIs, the Commission excluded the possibility of both input and customer foreclosure, since Syngenta purchased only 5-10\% of its raw materials from ChemChina, and since Syngenta represented less than $1 \%$ of ChemChina's sales of the relevant raw materials. ${ }^{1174}$

After dismissing concerns in the lawn and garden markets, ${ }^{1175}$ the Commission extensively examined horizontal overlap in crop protection markets. It found 712 markets where the activities of the parties overlapped, and 464 where their combined market shares exceeded 20\%. ${ }^{1176}$ The Commission stated it would examine scores computed using the Herfindahl-Hirschmann Index (HHI), setting the benchmark for whether accretion raised competitive concern depending on whether the relevant market share fell above or below $50 \%$. In the actual assessment, however, the Commission did not make this factor determinative. As another broad set of criteria that the Commission considered as a type of safe harbour, the transaction would not raise competitive concern if the combined market shares of the parties fell below $30 \%$ and at least three other alternative competitors supplied the market. ${ }^{1177}$ Instead of exhaustively setting-out results for the many markets that the Commission considered, the following paragraphs briefly will discuss the varied factors that the Commission assessed in

\footnotetext{
${ }^{1170}$ Ibid., para. $178,182$.

${ }^{1171}$ Ibid., paras 198, 204, 210, 219.

1172 Ibid., paras 224, 230, 236.

1173 Ibid., para. 255, 262.

1174 Ibid., para. 282, 298.

1175 Ibid., paras 302, 306.

1176 Ibid., para. 320.

1177 Ibid., paras 322, 324.
} 
determining competitive effects, particularly emphasizing markets where low market share figures traditionally would end the analysis.

As the Commission said it would, it placed considerable weight on whether the parties competed head-to-head in the relevant market prior to the merger. ${ }^{1178}$ It also looked closely at the incremental increase in market share that the merger created, with shares below 5\% usually not raising competitive concern. Occasionally, the Commission did not find anticompetitive effects despite the transaction producing both high market shares and significant accretion. In the Cereals-Wheat-Fungicides-Leafspots market in Greece, for example, the merger permitted the parties to attain a 50-60\% market share, which had increased by 20-30\%. Yet the Commission noted that BASF held a sizable share as well (30-40\%), and that Bayer was also active on the market $(<5 \%)$. The presence of either or both integrated crop-protection companies and generics on a given market mitigated the effect of higher market shares. The Commission also placed considerable weight on potential barriers to entry and expansion, which were minor in this example because at least 5 companies held fungicide product registrations for wheat in Greece and thus could respond to price fluctuations without incurring the significant costs in terms of money and time to register new products. The parties in this example lastly did not share active ingredients, suggesting product differentiation. ${ }^{179}$

More frequently, the Commission found liability despite market share levels that, when viewed perhaps in other markets, would raise little concern. The relative position of rivals mattered to the Commission: In the Cereals-Barley-Fungicide-Leafspots market in Slovakia, the transaction created a market leader with a 40-50\% share, yet the nearest competitor had a share nearly $50 \%$ lower. ${ }^{1180}$ In the Cereals-Wheat-Insecticides-Foliar-Broad Spectrum market in Italy, the transaction generated a 30-40\% market share. While Bayer (10-20\%) and BASF (5-10\%) remained on the market, the Commission noted the combined entity would be twice as large as its nearest rival. The merger boosted the market share of the parties by $10-20 \%$, and left only one generic producer on the market. The Commission found that the transaction removed a "dynamic" rival from the market, Adama, which between 2013 and 2015 materially had increased sales. The Commission determined that the parties were close competitors, whose products were in the same chemical class, indicating a similar mode of action. Adama had planned to launch new formulations over the short-term and had products in its pipeline that suggested the combined entity's market share would not decrease. ${ }^{1181}$ The Commission thus found a significant impediment to effective competition based largely on the likely development of the market after the merger.

Most strikingly, in several instances the Commission determined that liability existed in markets where the combined entity's share fell below 30\%. Consider, for example, the market for Oilseed Rape-Fungicides-Leaves/Leafspots in Estonia. The merger created an entity with the third-largest share of the market, at 20-30\%, with Bayer (40-50\%) and BASF (30$40 \%$ ) retaining stronger positions. The transaction increased the combined entity's market share by $10-20 \%$ and eliminated the only generic company active on the market, Adama, which

\footnotetext{
1178 See, e.g., ibid., para. 341.

${ }^{1179}$ Ibid., para. 359-60, 362-64.

${ }^{1180}$ Ibid., para. 431.

${ }^{1181}$ Ibid., paras 507-508, 510-513.
} 
had recently entered the market. The Commission determined that the parties were close competitors that competed directly with several products, and that the parties were planning to launch new formulations and mixtures that would maintain or enhance their market position. ${ }^{182}$ The Commission acknowledged the low market share, but stated that between the closeness of the parties' products, pipeline products, and the growth plans of the entities, it considered that the market share levels did not fully incorporate the degree to which the parties restrained each other, and the future market strength of the combined entity. ${ }^{1183}$

\subsection{Brazil}

Syngenta had substantial activities in Brazil while ChemChina was less present in the country compared to other jurisdictions. CADE undertook an extensive analysis of all the relevant markets. In the sector of inputs for pesticides, CADE decided that each ingredient should considered a relevant market with a global scope. ${ }^{1184}$ The markets of pesticides were considered to be composed by several relevant markets: insecticides (divided by culture, type of application and pest group), non-selective and selective herbicides (divided by culture and type of herbs) and fungicides (divided by culture). ${ }^{1185}$ There was also the relevant market for insecticides and herbicides for seed treatment and pesticides for after-harvest treatment, according to the culture. ${ }^{1186}$ Urban and garden pest control products were also considered a relevant market in a national level. ${ }^{1187}$

CADE evaluated horizontal concentration in each of these relevant markets. In most of them, the resulting concentration was below $20 \%$ or between $20 \%$ and $30 \%$. Generally, CADE undertook further investigation in relation to the markets in which the resulting concentration was above $20 \%$ and the HHI variation was over 200 , as follows: ${ }^{1188}$

- cotton (selective herbicides);

- potatoes (selective herbicides);

- coffee (selective herbicides, and certain insecticides);

- sugarcane (selective herbicides);

- citric products (selective herbicides and after-harvest treatment);

- industrial vegetables (selective herbicides for beans);

- corn (certain insecticides, fungicides);

- other specialties (insecticides for peanuts and others);

- soybeans (insecticides);

- tomatoes (selective herbicides);

- wheat (insecticides, selective herbicides and fungicides).

\footnotetext{
1182 Ibid., paras 965, 966, 968-71.

${ }^{1183}$ Ibid., para. 972. For markets that resemble this one, see ibid., paras 981, 1002, 1010, 1048, 1090, 1105, 1344, 1464, 1619, 1939.

1184 Ibid para 58-67.

1185 Ibid para 76-101.

${ }^{1186}$ Ibid para 102-110.

${ }^{1187}$ Ibid para 116-129.

${ }^{1188}$ Ibid para 304.
} 
The analysis centred on whether a possible increase in price in those markets would be balanced by the presence of current or future rivals. Entry was not considered to be timely, given the necessary authorisation to offer pesticides in Brazil, which required extensive regulatory analysis. ${ }^{189}$ Moreover, CADE considered there were extensive barriers to entry, due to the fact that entry has to take place in several markets at the same time for it to be profitable. $^{1190}$

On the other hand, rivalry was deemed to be sufficient to displace concerns. Competitors could increase production at least in $10 \% .{ }^{1191}$ CADE considered that the companies had different profiles in terms of innovation. While Syngenta invested in research and development to develop new products, ChemChina mostly relied on inputs in the public domain. ${ }^{1192}$ Other competitors had a strong portfolio and could therefore effectively compete and have access to distributors. ${ }^{193}$ Syngenta had 20\%-30\% of the pesticides market in Brazil and ChemChina less than $10 \%$, the resulting market share would be less than $30 \%$ and the rivals, with different profiles, would have $70 \%$ of the market. ${ }^{1194}$ Eventual complaints could be dealt within the framework of the rules regarding anticompetitive conduct, and thus would not raise concerns in the context of the ex ante merger control. ${ }^{1195}$

The vertical integration between inputs and pesticides and between pesticides and seeds produced by Syngenta was not considered problematic: some of them were pre-existent and there would be no incentive for market foreclosure. ${ }^{1196}$ CADE`s Superintendence approved the operation without restrictions; hence there was no need for the CADE's Tribunal decision.

\subsection{India}

The CCI approved the merger ${ }^{197}$. CNAC is the agrochemical division of ChemChina, which manufactures and sells generic active ingredients and formulated products used for crop protection as well as non-agrochemical crop products for home and garden and pest control operations. Syngenta is a global concern, operating in the crop protection and seeds business. It is involved in the research, development, manufacture and marketing of agrochemical products, active ingredients sold on a standalone basis, and in flowers, turf and landscape, and professional pest management products. China National Chemical Corporation ("ChemChina"), through its subsidiary CNAC proposed to acquire shares and indirect sole control of Syngenta. The market for formulated products in India was identified as the relevant market for the proposed merger. China National Chemical Corporation (CNAC) and Syngenta

\footnotetext{
${ }^{1189}$ Ibid para 310-319.

${ }^{1190}$ Ibid para 330-332.

${ }^{1191}$ Ibid para 337.

1192 Ibid para 349-355.

1193 Ibid para 820-890.

${ }^{1194}$ Ibid para 888.

${ }^{1195}$ Ibid para 891.

${ }^{1196}$ Ibid para 140-157.

${ }^{1197}$ CCI, China National Agrochemical Corporation \& Syngenta AG, C-2016/08/424
} 
filed two merger notifications before CCI. The first of these applications stands approved due to the expiry of the statutory period ${ }^{1198}$ whilst the other is still pending before it. ${ }^{1199}$

CNAC is the agrochemical division of ChemChina, which manufactures and sells generic active ingredients and formulated products used for crop protection as well as nonagrochemical crop products for home and garden and pest control operations. Syngenta is a global concern, operating in the crop protection and seeds business. It is involved in the research, development, manufacture and marketing of agrochemical products, active ingredients sold on a standalone basis, and in flowers, turf and landscape, and professional pest management products. China National Chemical Corporation ("ChemChina"), through its subsidiary CNAC proposed to acquire shares and indirect sole control of Syngenta. In the notice filed before CCI, the relevant market was stated to be 'the market for formulated products in India' which may be deemed to refer to formulated products used for crop protection referred to elsewhere in the notice.

\subsection{South Africa}

The CCSA has conditionally approved the intermediate merger between China National Agrochemical Corporation ('ChemChina') and Syngenta. The CCSA found that ChemChina focuses on the discovery, development, manufacture and sale of broad and diversified line of agrochemicals or crop protection products and in South Africa it operates through Adama South Africa (Pty) Ltd which is involved in the testing and registration of agrochemical products. Syngenta is active in the agricultural sector, particularly in seed and crop protection products in over ninety countries. In South Africa, Syngenta has a formulation plant in Brits in the North West, where it manufactures agrochemicals. According to the CCSA, the proposed transaction was unlikely to substantially prevent or lessen competition in any of the affected markets. This was based on the fact that there were other suppliers of agrochemicals and seed treatment products that customers can turn to, post-merger. However, the CCSA was concerned that the merger may result in the merging parties importing all their products at the expense of using the manufacturing plant situated in North West in South Africa. This was considered as having an adverse effect on the agrochemicals sector and was also likely to lead to job losses. In order to address these concerns, the CCSA has imposed a condition that requires the merging parties not to relocate the manufacturing plant from North West for a certain period.

\subsection{China}

The merger was unconditionally approved by MOFCOM on April 12nd $2017^{1200}$.

\footnotetext{
${ }^{1198}$ CCI, China National Agrochemical Corporation \& Syngenta AG, C-2016/08/424. Section 31(11) of the Indian Competition Act 2002 states that if CCI does not, on the expiry of a period of ninety working days from the date of publication referred to in sub-section (2) of section 29, pass an order or issue direction in accordance with the provisions of sub-section (1) or sub-section (2) or sub-section (7), the combination shall be deemed to have been approved by CCI.

${ }^{1199}$ CCI, China National Agrochemical Corporation \& Syngenta AG C-2016/03/380

1200 MOFCOM，2017年第二季度无条件批准经营者集中案件列表，（April 12，2017)， available at http://fldj.mofcom.gov.cn/article/zcfb/201707/20170702603665.shtml .
} 


\subsubsection{Bayer/Monsanto}

The transaction brings together Germany-headquartered Bayer AG, a "life science" company with core competences in the areas of health care and agriculture, and US-based Monsanto is an agrochemical and agricultural biotechnology corporation in a merger that would create the global leader in Agriculture Industry. The merger was notified in a number of jurisdictions, some of which have already approved it with conditions, while the process of approval is still ongoing in other jurisdictions.

\begin{tabular}{|l|l|l|}
\hline Bayer/Monsanto merger transaction \\
\hline Country & $\begin{array}{l}\text { Notification/Investigation } \\
\text { date }\end{array}$ & Decision date \\
\hline United States & --N.A. & \\
\hline European Union & June 30, 2017 & N.A. \\
\hline Brazil & 21 February 2017 & pending \\
\hline Russia & NA & 8 November 2017 \\
\hline India & $\begin{array}{l}\text { C-2016/10/446, and C- } \\
2017 / 08 / 523 \quad \text { (dates not } \\
\text { known) }\end{array}$ & \\
\hline China & NA & pending \\
\hline South Africa & 1 Feb. 2017 & 3 May 2017 \\
\hline
\end{tabular}

\subsection{Brazil}

Upon notification of the merger transaction, on $21^{\text {st }}$ February 2017, CADE decided in a preliminary report in July 2017, that the merger was complex and started to undertake an extensive analysis of all the relevant markets. Both Bayer and Monsanto have substantial activities in Brazil. In October 2017, CADE`s Superintendence issued its report and recommended objections to the transaction. Based on market shares and HHI variation, the following relevant market were further investigated:

- Soybeans biotechnology (R \& D of GM varieties in the world and licensing of GM varieties in Brazil);

- Improvement, production and commercialisation of soybean seeds in Brazil;

- Cotton biotechnology (R \& D of GM varieties in the world and licensing of GM varieties in Brazil);

- Improvement, production and commercialisation of cotton seeds in Brazil;

- Improvement, production and commercialisation of melon seeds in Brazil;

- Improvement, production and commercialisation of tomato seeds in Brazil. ${ }^{1201}$

1201 See note above BRAZIL, Administrative Council for Economic Defence - CADE, Merger Case $n$ 08700.001097/2017-49, Parties: Bayer Aktiengesellschaft and Monsanto Company. Objection Recommendation, General Superintendence, $03 \quad$ October 2017, available at < http://sei.cade.gov.br/sei/institucional/pesquisa/documento_consulta_externa.php?hfmv1NAFovfv4EqNdKFi 
Entry was not considered to be timely in any of the markets. ${ }^{1202}$ Barriers to entry were considered high in all the relevant markets, due to the cost and time involved to engage in $\mathrm{R} \&$ $\mathrm{D}$, the need for specialized work and the presence of strict regulatory requirements. ${ }^{1203}$ Particularly, CADE's Superintendence considered that both companies had activities in other parts of the chain, such as the development of seeds, genomics and pesticides and also had extensive R\&D capabilities in pesticides. ${ }^{1204}$ This indicated that entry of competitors was quite difficult, given the portfolio power of the new entity and its extensive ties to distributors.

In the markets of melon and tomato seeds, there was effective rivalry capable of dispelling concerns. ${ }^{1205}$ In all the other markets related to cotton and soybeans, rivalry was not considered to be sufficient to counterbalance market power. Among the reasons, one can mention that (i) the parties are the only players capable of operating in an integrated way with biotechnology, production and commercialisation (ii) all the other players depend on the technology of other parties; (iii) the parties have stronger brands and capacity to invest in marketing compared to its rivals. ${ }^{1206}$

For example, in the market of soybeans seeds, although the HHI variation was not substantial and that Bayer had not obtained a relevant market share, the resulting market share is 30\%-40\%. While Monsanto is the largest player in both technology and seeds for soybeans in Brazil, there were indications that Bayer would increase its focus on the country. In the cotton market, although Monsanto had not obtained a relevant market share, it is the third player in the market and the resulting participation would be around 60-70\%. In any case, both parties had significant R \& D pipelines for improvement of cotton and soybeans.

As to the non-horizontal effects, a varied of vertical relations were identified by CADE's Superintendence. Among them, the cross-integration between the development of GM soybeans and cotton and the improvement, production and sale was considered to be harmful. ${ }^{1207}$ Both companies had the incentive to limit the access of rivals to its technology given the dominance of Monsanto in the soybeans technology and the high resulting market shares upstream and downstream in both cotton technology and seeds. ${ }^{1208}$

Conglomerate effects were also analysed. The need to enter the sector in two or more markets at the same time and the possibility by new entity of offering bundles of complementary products gave rise to concerns, which potentialised the horizontal effects. ${ }^{1209}$ The analysis of efficiencies was not published, but the Superintendence was of the opinion that they were not sufficient to balance the market power created. ${ }^{1210}$

Based on those considerations, CADE's Superintendence objected to the transaction and sent the case for a final decision by the CADE's Tribunal.

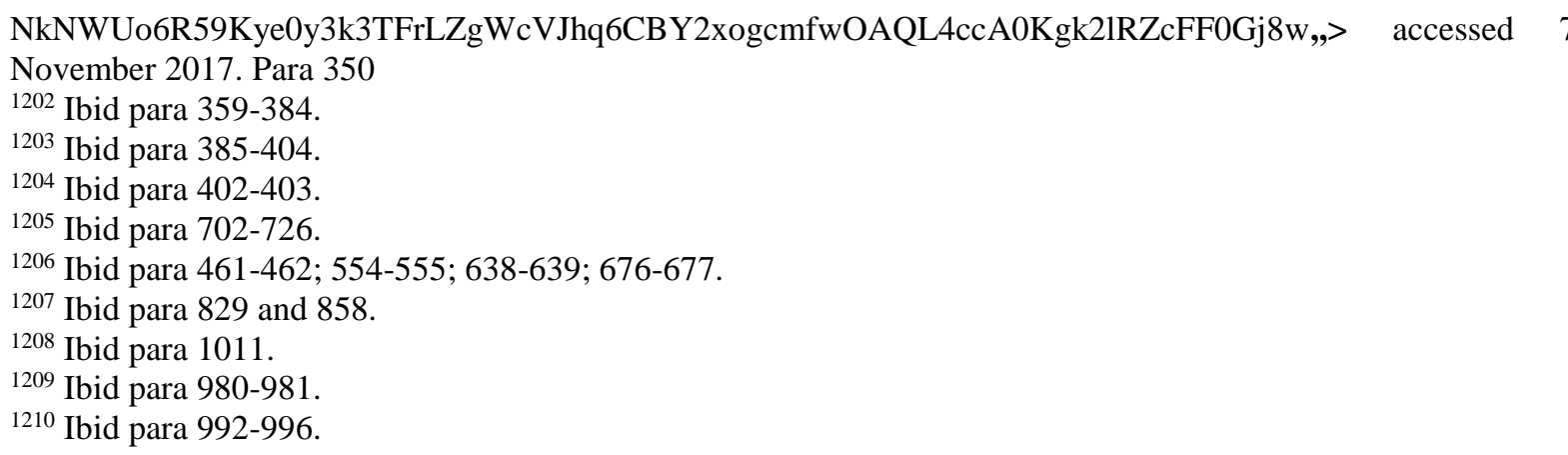




\subsection{South Africa}

The Competition Commission of South Africa (CCSA) was the first to be officially notified of this global transaction on 1 February 2017. The transaction was conditionally approved on 3 May 2017. The acquirer, Bayer, sold a variety of products that protected crops in South Africa, including fungicides, insecticides, herbicides, and seed treatment products. Bayer also sold vegetable seeds, cotton seeds, and canola. The target, Monsanto, supplied seeds, biotechnology traits, and crop-protection products in South Africa. Within the category of cropprotection, Monsanto sold only herbicides. Yet Monsanto sold a wide variety of seeds, such as vegetable seeds, maize seeds, soybean seeds, and cotton seeds. Both companies actively researched and developed bio-technology traits that serve as critical inputs to geneticallymodified (GM) seeds and agrochemicals.

The merger implicated both horizontal and vertical overlaps. Horizontally, both parties sold herbicides, GM cotton seeds, and vegetable seeds, and both parties developed bio-technology traits for cotton, maize, and soybean seeds. Vertically, Bayer manufactured herbicides for third parties utilizing a toll manufacturing arrangement, and it conducted a seed treatment business, coating seeds with insecticides and fungicides. Monsanto licensed maize, cotton, and soybean seed traits.

The CCSA arrived to a conclusion in May $2017^{1211}$. Quite interestingly, the CCSA took into account the value chain both for crop protection products and seeds/traits and considered that Bayer and Monsanto are potential competitors to each other pre-merger at various levels of the seed and crop protection value chain, and although they are not present at all levels of the seed and crop protection value chains in South Africa, they compete globally along the entire value chain in terms of seeds and herbicides.

The CCSA recognized the following horizontal markets: (1) a national market for the wholesale distribution of cotton seeds; (2) a national market for the distribution of vegetable seeds; (3) a national market for the supply of selective herbicides; and (4) a national market for the supply of non-selective herbicides for non-GM crops. The CCSA further recognized the following vertical markets: (1) an "upstream market for the development and commercialization of maize seed traits with global and national dynamics"; (2) an "upstream market for the development and commercialization of cotton seed traits with global and national dynamics"; (3) an "upstream market for the development and commercialization of soybean seed traits with global and national dynamics"; (4) an upstream national market for seed treatment; (5) a downstream national market for the supply of treated seeds; (6) an upstream national market for the toll manufacturing of herbicides; and (7) a downstream national market for the supply of herbicides.

The CCSA found unilateral effects in the cotton seed market but not in the vegetable seed market because of a minimal market share accretion and the strength of existing competitors. In the selective herbicide market, several viable alternatives negated potential unilateral effects. For a similar reason, specifically a low combined market share, the transaction did not raise

${ }^{1211}$ Competition Commission of South Africa, Case No: 2017Feb0004, Bayer Aktiengesellschaft, (3 May 2017). 
unilateral effects in the non-selective herbicide market for non-GM crops. The CCSA did determine that the transaction produced unilateral effects related to removing a potential competitor, in that Bayer's Liberty system exerted significant competitive constraint on Monsanto's system. The CCSA evaluated vertical effects in the seed treatment market, finding little concern since Bayer did not have a strong incentive to engage in input foreclosure. Customers of Bayer also could find alternative sources of supply in the market for toll manufacturing services. While Monsanto had the ability to foreclose access to traits postmerger, it would not have an incentive to do so, since the licensing of traits constituted a highly profitable business. The CCSA additionally held that the merger produced portfolio effects, enabling the parties to offer new bundled products and to develop new traits for their seeds that rivals could not compete against when offering alternative agrochemical products. Portfolio effects also enhanced entry barriers. As to coordinated effects, the heterogeneity of the products offered due to constant innovation ultimately made coordination difficult ${ }^{1212}$.

More specifically, with regard to the horizontal dimension of the merger, the CCSA found that to compete in the market for developing traits, an entity would have to incur a large upfront investment in the necessary technology, facilities, and personnel that acts as a material entry barrier. Similarly, active companies can seek intellectual property protection for traits that prevent duplication for twenty years in the case of patents. The registration process also constructs substantial entry barriers. To conduct a field trial, a party must request a release that takes 120 days, and field trials transpire over a minimum of two planting seasons. After a successful field trial, a party must seek a general release, a process that takes 270 days. The entity would have to pay 3,892 rand per GMO for a trial release, and 30,231 rand per GMO for a general release. Given recent consolidation in the industry, the trait development market will contain four rather than six viable entities. Parties wishing to compete in the seed breeding business often must license traits from the four producers. When stacking traits, a developer can register and license the stack to third parties. Technological systems or platforms represent common products in the agrochemical business and consist of seeds containing both herbicidetolerant traits and the corresponding herbicides to which the seed reacts. Such platforms enable a farmer to spray herbicide on a crop that otherwise would harm the crop. In the trait development market, Bayer did not breed seeds in South Africa, eliminating the possibility for horizontal overlap ${ }^{1213}$.

The parties did compete in distributing cotton and vegetable seeds in South Africa. In a national cotton seed geographic market, the parties competed in selling GM cotton seeds. The CCSA determined that demand-side substitutability between the different varieties of cotton seeds existed but depended on the region where the farmer planted the seeds. Due to the high entry barriers associated with trait development outlined above, the CCSA stated that agrochemical companies did not engage in supply-side substitutability ${ }^{1214}$.

Turning to vegetable seeds, the CCSA held that the parties competed in distributing various vegetable seeds and in producing and distributing onion seeds in a national South African market. Demand-side substitution did not occur because farmers used each seed for a specific

1212 Ibid., paras 4-20, 23, 25-27, 30, 32-33.

1213 Ibid., paras 43, 79, 82-83, 85, 87.

${ }^{1214}$ Ibid., paras 91, 107, 115, 123. 
purpose and could not substitute seed types, which translated into separate markets for each seed. Supply-side substitution did occur as agrochemical companies could sell any seed available, and farmers did switch between seed companies ${ }^{1215}$.

As to the herbicide market, the CCSA distinguished between non-selective herbicides that could clear entire fields of weeds and selective herbicides that killed only weeds but not the surrounding crops. Because of this functional difference, the two herbicides each constituted an individual market. With demand-side substitution, farmers could substitute between selective herbicides with the same active ingredients, using the products interchangeably. In terms of this transaction, the parties' selective herbicides featured different active ingredients that they registered for specific crops. The merger did not raise competitive concern on the market for selective herbicides ${ }^{1216}$.

In the market for non-selective herbicides, the CCSA noted that the parties' products each contained only one active ingredient. Bayer utilized Basta which employed glufosinate ammonium, and Monsanto supplied various RoundUp products that used glyphosate. The CCSA found that demand-side substitution generally did not exist between these two active ingredients, given that using them interchangeably would wipe-out the crops that they were supposed to protect. However, weed resistance to the glyphosate altered that conclusion to an extent, as farmers have switched between the ingredients to ameliorate the effects of resistance. Basta qualified as a contact herbicide that burned plants only where contact occurred, as compared to RoundUp, which killed plants that it contacted at the root. As an important distinguishing characteristic, Bayer charged a higher price for Basta relative to the price Monsanto changed for RoundUp. Because of this price difference, farmers applied Basta only when RoundUp proved ineffectual or harmful to crops. The CCSA ultimately found no horizontal overlap between non-selective herbicides for GM-seeds, since farmers generally did not use glufosinate ammonium herbicide for maize, cotton, or soybean crops. Horizontal overlap did exist between non-selective herbicides for non-GM seeds in the markets for fruits $\&$ grapes, sugarcane, and vegetables and flowers ${ }^{1217}$.

The CCSA evaluated systems of traits separately, as the decision of which GM seed to plant committed farmers to a particular "technological pathway" associated with a specific system. Between the merging parties, Bayer's Liberty herbicide constituted a glufosinate ammonium based herbicide that worked in conjunction with the Liberty Link traits and the corresponding glufosinate ammonium tolerate trait. Basta technically could perform the same function as Liberty since the active ingredients of the two herbicides performed the same function. Generic herbicides also competed in the systems market, and quality differences between the products were insignificant ${ }^{1218}$.

The CCSA defined the market for traits as the development of crop-specific traits. As to demand-side substitutability, agrochemical companies registered traits on a crop-specific basis, which supported a market on a per crop, per trait property basis. Due to the presence of multiple properties within a stacked seed, the CCSA only considered the market for traits on a per crop

\footnotetext{
1215 Ibid., paras 127-128, 130, 136.

${ }^{1216}$ Ibid., paras 145-146, 150-151, 153.

${ }^{1217}$ Ibid., paras 154, 156, 164, 167, 169, 171, 179.

${ }^{1218}$ Ibid., paras 183, 185, 187, 191.
} 
basis. Farmers dictated the demand for varieties of traits, which generally eliminated substitutability between seed traits for different crops. Maize seed traits, soybean seed traits, and cotton seed traits thus all constituted separate markets. From the perspective of supply-side substitutability, the technical skill, research, and time necessary to develop new traits significantly weakened the prospect of switching between developing traits for different crops. Companies more likely would license traits from competitors rather than developing alternative traits. Unlike many of the other relevant markets, the trait market had both global and national characteristics $^{1219}$.

The CCSA next assessed the various theories of harm, starting with unilateral effects, which produce higher prices or lower quality or variety. Removing a potential competitor counts as a unilateral effect. In markets where innovation exerts a competitive restraint, eliminating a rival with a small market share can harm competition if it has promising pipeline products. The CCSA applied this analysis to the removal of Bayer as a potential competitor in the market for developing traits. Bayer had traits that it had not registered and commercialized in South Africa, and the CCSA considered Bayer as a significant player in developing traits. Despite Bayer's absence from the market, Bayer acted as a potential competitor in the South African trait market due to the large sunk costs required to develop traits that already existed. While registration still constituted an entry barrier for Bayer, the CCSA asserted that Bayer's maize, cotton, and soybean traits still competed against Monsanto's alternative traits. In the trait system market, while Monsanto alone had registered its glyphosate-based system, glufosinate ammonium systems were available in other jurisdictions. Post-merger, the competitive restraint that Bayer could have exerted on Monsanto with its glufosinate ammonium system would no longer exist ${ }^{1220}$.

In the market for cotton seeds, Bayer and Monsanto were the only two entities supplying seeds to the market. By significantly reducing competitive restraints in this market, the CCSA determined that the merger would eliminate the incentive of the parties to supply cotton seeds of superior quality, and to produce superior innovation. The merger further would reduce buyer power by eliminating a significant competitor. In the vegetable seed market, on the other hand, several viable distributors remained in the market, neutralizing the possibility of unilateral effects. The CCSA reached a similar conclusion for the herbicide market, finding several viable alternatives in addition to the extensive use of generics that would weaken unilateral effects ${ }^{1221}$.

In assessing vertical effects related to the seed treatment market, the CCSA stated that market participants could procure seed treatment services from companies other than Bayer, and that Bayer would not have an incentive to forgo profitable business by foreclosing its services. The CCSA also considered whether the transaction might foreclose competitors of Bayer that supplied seed treatment to Monsanto. The CCSA did not find customer foreclosure likely. It then assessed the effects of the merger on the toll manufacturing of herbicide market, inquiring whether the transaction would enable Bayer to restrict access to toll manufactured

${ }^{1219}$ Ibid., paras 229-230, 232-233, 237-238, 244.

${ }^{1220}$ Ibid., paras 246, 249-250, 308, 312, 317, 319, 323.

${ }^{1221}$ Ibid., paras 262, 269, 274, 281, 288-289, 292. 
herbicides for third parties. The CCSA discounted the possibility of input foreclosure because other upstream toll manufacturers sufficiently would restrain Bayer ${ }^{1222}$.

The CCSA further evaluated potential vertical effects in the trait market for maize and soybeans, where developing traits occurred upstream, and breeding traited seeds occurred downstream. The first issue involved determining whether Monsanto had the ability to foreclose downstream rivals from access to its maize traits, and the CCSA found that it did. As to whether Monsanto had an incentive to block access to its traits, the CCSACCSA concluded that it did not. As Bayer did not license traits in South Africa prior to the merger, Monsanto would not be gaining any market share accretion due to the merger that might have justified a foreclosure strategy. Licensing traits constituted a lucrative business for Monsanto. Concerning the cotton trait market, Bayer and Monsanto were the only two companies supplying cotton seeds to South Africa. This meant that the merger could not foreclose downstream rivals because no other breeders needed to license cotton seed traits from the merged entity ${ }^{1223}$.

The CCSA also considered portfolio effects that the merger might produce. Portfolio effects consist of how a merger changes the incentives of the merged entity to offer tied or bundled products post-merger due to an expansion in the company's product range. Portfolio effects most often occur when a merger joins complementary products of which the merged entity has market power in at least one product. This merger implicated possible portfolio effects because of the complementarity between seeds and agrochemicals. The CCSA determined that the merged entity would have the ability to exercise portfolio effects due to its market power in the development of traits used as complements to the agrochemicals that both parties produced. The parties' internal documents had detailed a strategy to provide integrated crop solutions to farmers, and the parties offered technological platforms consisting of three distinct products or services — biotechnology traits, seed production, and agrochemicals — used together and designed to increase yield and produce more sophisticated plant varieties. Competing with such platforms would require entering both the traits and agrochemical markets, which would demand perhaps prohibitive capital investment. Portfolio effects also could entail offering new bundled input packages by stacking traits. The CCSA argued that generic competitors in the non-selective herbicide market were particularly at risk, as the merged entity likely would bundle its dominant traits with herbicide to foreclose generics. Portfolio effects ultimately would harm farmers by enabling higher seed prices, jeopardizing the ability of small farmers to remain competitive ${ }^{1224}$.

The CCSA lastly evaluated the potential for coordinated effects. Factors enabling coordination included cross licensing agreements between all major rivals, high entry barriers, recent consolidation, and multi-market contact. Yet the relevant products were not homogeneous; rather, they embodied constant and significant innovation that would make agreeing to terms and monitoring difficult. The CCSA concluded that the merger unlikely would produce coordination ${ }^{1225}$.

\footnotetext{
1222 Ibid., paras 334, 338, 342, 346, 351, 355.

${ }^{1223}$ Ibid., paras 362, 370, 375-376, 378, 381-383.

${ }^{1224}$ Ibid., paras 393-394, 406, 411, 414, 417, 425, 433, 437

1225 Ibid., paras 446, 455, 458-459, 461-462.
} 
As to remedies, the CCSA ordered Bayer to divest its cotton business, and to sell its Liberty Link trait business and its Liberty business. It was thought that this global divestiture remedy for the Liberty Link traits business (including the divestment of the corresponding Liberty herbicide) and Liberty business (the system) will address the removal of a potential competition concern and the exclusionary portfolio effects of the merger ${ }^{1226}$. This remedy would also ensure that the cross licensing between Bayer and Monsanto and other entities will not perpetuate, as a new purchaser will fill the position of Bayer in all existing business operations ${ }^{1227}$. The buyer would have to commit to commercialize the Liberty Link and Liberty products in South Africa or license a third-party to commercialize the products in South Africa ${ }^{1228}$.

\subsection{Russia}

The Russian FAS took notice of the importance of the merging entities as two of the main global competitors in a variety of areas of the factors of production segment of the food value chain. FAS noted that Bayer has business activities in pharmaceuticals, consumer health, and crop science, the company being a world leader in production of insecticides and fungicides. The agricultural sector represents a significant part of the total profits of the company. Bayer also offers a platform based solution for pesticides integrated with biotechnology seeds (Liberty Link). In 2002 Bayer acquired two agro tech companies, Aventis and Nunhems, and became one of the world leading companies in the selection of new crop varieties and seed suppliers for agricultural producers. In recent years Bayer has also been actively involved in smart agriculture. In 2015, Bayer purchased the digital agricultural platform Zoner, and in 2016, it acquired ProPlant. Bayer has also recently announced the commercial launch in 2018 of complex digital solutions in the agricultural sector, named Xarvio. Furthermore, Bayer is a vertically integrated company which is also involved in different partnerships with equipment manufacturers, such as Bosch.

As for Monsanto, FAS noted that it is present in crop protection, digital farming, crop production, science research in farming and agrochemicals. In 1996 Monsanto acquired Agrocetus and Dekalb, and between 2005 and 2008, it also acquired Seminis and De Ruiter. In 2012, Monsanto acquired Precision Planting, and in 2013, it acquired Climate Corporation. In 2016, Monsanto acquired Vital Fields. Between 2013 and 2016 Monsanto acquired TargetGene, RossetaGene and GrassRobots. Currently, Monsanto is a world leading high tech company in the production of corn and soya seeds, including other vegetable crops. The company also provides services on paid access to plant genetic information. These business segments represent a significant part of the total profits of the company. Monsanto is also a leading producer of the universal herbicide glyphosate and its digital solutions in agricultural sector (FieldView) is considered as one of the best in the world.

The FAS considered that the merger transaction would affect markets of high tech products for agro manufactures. Interestingly, in assessing the merger the Russian competition watchdog did not follow a static approach focusing on market definition in the various product

${ }^{1226}$ Ibid., para. 531.

${ }^{1227}$ Ibid., para. 526

${ }^{1228}$ Ibid., paras 497, 500, 502, 506-507, 526, 529, 531, 534. 
markets, but took a dynamic perspective defining as the affected markets the "integrated agritech markets" because separate seeds, agrochemicals and digital solutions are not any more that important for the competitive dynamic in this sector due to ongoing technological change. Hence, it seems that the FAS's decision is more focused on the effect of the merger transaction on innovation competition, than on the sole impact of the merger on product competition. This aspect of the decision of the FAS is further explored in the Section on innovation competition.

This dynamic perspective notwithstanding, the FAS proceeded to analyse the markets of seeds, agricultural chemistry, and digital farming, while noting the fact that the emerging market is integrated agro tech solutions. All these markets were considered by the FAS Russia in the context of the global value chain approach, with a particular focus on the effects of the merger on Russian agro manufactures (consumers of agricultural products) (vertical competition), as well as on potential competitors of Bayer and Monsanto in the field of supplying such products to agro manufactures (horizontal competition). According to the authority, in view of the dynamic perspective taken it was important to analyse the transformation dynamics of such markets, taking a global perspective, in view of the effect of the global transformation of the sector to the alteration of the competitive environment in Russia in the short and medium term.

In particular, FAS Russia found that the merger affected the Russian market of highlyproductive seeds material, which depends on the latest technologies and involves access to big data about genetics (data and data analytics). The merger had also effects on the crop protection market, as well as on the market for digital solutions for agriculture. We will analyze these effects in the Section dedicated to innovation competition.

According to FAS, the merger transaction would create the world leading company in the markets of plant protection, seeds and genetic traits. On the basis of 2015, the consolidated company would become the largest in the world for herbicides and insecticides, as well as for seeds and genetic materials, and the second largest in the world for fungicides. According to FAS, as a result of the transaction, there will be a higher degree of concentration in the seed market in particular for certain types of crops will also vary, the new entity reaching a significant market share in the market for cotton, in the market for soybean, in the market for vegetables in the market for corn. This market position indicates, according to FAS, the possible emergence of a dominant position of the consolidated company in these markets in the near future. The share of vegetable seeds was also found significant and could indicate the existence of considerable market power.

In analysing the merger transaction, the FAS did not only take into account the current position of the merging companies in the relevant markets, but also the most likely changes in the structure of these market as well as to the state of competition in a short and medium term perspective, in view of the technological and social transformations occurring in the food sector. Hence, the authority considered that the analysis of the merger transaction should not only be based on the consideration of combined shares of companies at the relevant markets, but also factor in the unique opportunities for the new entity to significantly increase its market power presented by the ongoing changes in the industry, transformation which is partly framed by the strategies followed by the various economic actors, including the merged entity. This 
part of the decision will also be analysed in the Section on innovation competition and nonhorizontal effects.

FAS examined the following possible theories of harm: (i) the "probable" foreclosure of potential and existing rivals who do not dispose of the ability to operate in the integrated agritech platform markets on the global scale, (ii) a substantial increase in the entry barriers and the probability of anticompetitive conduct within this tight oligopolistic market, (iii) an "increase in the probability" of collusion, in view of the limited number of players of global presence in the industry. The situation was made worse, with regard to the last two concerns, in view of the immunity IP rights benefit in Russia from antitrust enforcement with regard to both unilateral conduct and licensing agreements.

Turning back to the more "conventional" competition analysis of horizontal effects, FAS took into account the appearance of new and increasing barriers to entry in the market in view of the establishment of digital platforms integrating the supply of key agricultural inputs, as well as the increasing risks of collusion in view of the fact that the market will become a tight oligopoly dominated by a few (three) global actors offering the full range of modern agricultural technologies and an integrated platform for farmers. FAS also considered that these companies were also closely linked by mutual licensing agreements on intellectual property and other partnership agreements, thus raising the risk of possible anticompetitive agreements or concerted actions that would suppress possible potential competitors by closing their access to certain key technologies or data, ultimately leading to the exploitation of consumers. As there were three global actors, it would be more difficult to track collusive arrangements. We explore the remedies imposed in the relevant Section of the Report dealing with innovation competition as these mostly aim to address these concerns.

\subsubsection{Non-conventional merger assessment: Innovation competition and broader public interest concerns}

\subsubsection{Innovation competition}

The recent merger cases also offered the opportunity to competition authorities to test more dynamic approaches in assessing possible restrictions on innovation competition, going beyond a simple analysis of the effect of the merger on product market competition, technology market competition, or even innovation market competition. Innovation competition concerns took a prominent role in the MOFCOM's Dow/DuPont merger case, the EU's Dow/Dupont merger case, the CCSA's Bayer/Monsanto case and in the FAS's Bayer/Monsanto case. Although recognizing the innovation competition concerns raised by the mergers, other authorities did not focus that much in their decision on this issue may be in view of the fact that there were few $R \& D$ activities of the merging parties taking place in their jurisdiction.

\subsection{MOFCOM's Dow/Dupont merger decision}


MOFCOM considered that the transaction could have an adverse impact on technological progress in the market of selective herbicide for rice ${ }^{1229}$. Prior to the merger, Dow and DuPont were respectively major innovation forces in the market of selective herbicide for rice and pesticides for rice. They competed in their research and development fields, made large investments in research and development and had a relatively strong innovation capability and rich product reserves. It was considered that the merger transaction would eliminate the basis for competition between both parties, and thus lead to a reduction in technological research and development expenses, to a decrease in their innovative efforts in the fields where there was parallel innovation (with the same target products), and to delays in the launch of new products. Hence, it would produce adverse effect on the "market of technological progress" for the relevant products. The remedial package included an obligation to divest DuPont's research and development products for selective herbicide for rice, as well as a divestiture of DuPont's global technology departments and regional development departments related to selective herbicide for rice. It was further ordered that DuPont divests global technology departments and regional development departments related to pesticide for rice.

\subsection{The EU Dow/Dupont merger decision}

In the EU Dow/Dupont case, the Commission focused its assessment both on innovation competition at the level of innovation spaces within the crop protection industry and on innovation competition at the industry level. In particular, the Commission looked

"(1) At the level of innovation spaces, the overlaps between the Parties' lines of research and early pipeline products as well as between lines of research and early pipeline products of a Party that will compete in a market where the other Party is an existing or potential supplier; and

(2) At the industry level, the overlap between the Parties' respective global R\&D organisations, that is the resources, personnel, facilities, and other tangible and intangible assets dedicated to research, development and registration of new active ingredients (including lines of research, field testing facilities, registration capabilities)" ${ }^{\prime 1230}$.

The Commission also distinguished between lines of research, which comprise the set of scientists, patents, assets, equipment and chemical class(es) which are dedicated to a given discovery target whose final output are successive pipeline AIs targeting a given innovation space, early pipeline products, that is, products which are intermediate results of lines of research, which have already been selected among leads, but with a lower likelihood of success than development products and still in the discovery or predevelopment stage and pipeline products in the development stage whose likelihood of being successfully launched is between 80 to $90 \%{ }^{1231}$.

\footnotetext{
${ }^{1229}$ 中华人民共和国商务部公告2017年 第25号MOFCOM Announcement No. 25 of 2017 (April 29, 2017).

1230 Ibid., para. 1957.

1231 Ibid., paras 1958-1960.
} 
The Commission dedicated several hundred pages of its lengthy decision on innovation competition. Referring to paragraphs 8, 24 and 38 of the EU Horizontal Merger Guidelines (HMG), the Commission held that

"(1989) The Merger Regulation sets up a legal framework that is not limited to the assessment of price effects, but under which the Commission is bound to conduct an appraisal of the likely effect of concentration in light of a number of criteria [...]

(1990) Innovation is an important criterion relevant in order to conduct the appraisal"1232.

The Commission derived from this focus on innovation competition that the framework in the HMG dealing with the non-coordinated (unilateral) effects of mergers could also apply in order to assess mergers affecting other parameters of competition than price, such as innovation competition $^{1233}$. Hence, the Commission needs to assess whether the transaction reduces important constraints on one or more sellers and significantly impede effective innovation competition considering both the loss of competition between the merging firms, and the reduction of competitive pressure on other non-merging firms. According to the Commission, "(o)verall, the loss of product variety brought about by less innovation harms consumers by depriving them of choice, and reducing competition on rival products". ${ }^{1234}$

This innovation-focused framework influenced of course one of the theories of harm put forward by the Commission in this case, harm to innovation. More importantly, the Commission linked the existence of rivalry/competition with the promotion of innovation. As it is tellingly put forward in the Commission's decision,

"(2000) [...] the Commission considers that the market features of the crop protection industry suggest that rivalry (or competition) is likely an important factor driving innovation, and that a merger between important rival innovators is likely to lead to a reduction in innovation" $" 1235$.

Many reasons were given for what could be characterized as the Commission's prior belief or starting point in this case, essentially linked to some of the "features" of the market.

"(i) individual crop protection product markets are contestable on the basis of innovation; (ii) given the strong Intellectual Property Rights (IPRs) in the crop protection industry, the original innovator can be expected to reap the benefits from its innovation, by preventing rivals from imitating the successful innovation (that is, appropriability is high); (iii) innovation is mostly based on product innovation; (iv) consolidation between rival innovators is unlikely to be associated with efficiencies ([...]); and (v) the fear of cannibalisation of own existing products is a disincentive to innovate which is likely to be reinforced by a merger between rival innovators" 1236 .

The Commission also relied on a body of theoretical and empirical economic literature that raised doubts over the Schumpeterian linkage between monopolistic profits and innovation (this literature is further examined and discussed in Part IV, Chapter 2 of this Report), and

\footnotetext{
1232 Ibid., paras 1989-1990.

1233 Ibid., para. 1994.

1234 Ibid., para. 1998.

1235 Ibid., para. 2000.

1236 Ibid., para. 2001.
} 
empirical evidence that "in the past, concentration in the industry was accompanied by a decrease in innovation" ${ }^{237}$. The Commission also found that concentration was not also high at the industry level, but also at the level of innovation spaces ${ }^{1238}$. The concept of "innovation space" constitutes an intermediate level of consideration of a space where competitive activity takes place, in addition to that of product relevant market downstream, technology market upstream, or at the level of the industry ${ }^{1239}$. According to the Commission,

“(2162) [...] (T)he R\&D players do not innovate for all the product markets composing When setting up their innovation capabilities and conducting their research, they target specific innovation spaces which are upstream of lucrative product markets and product markets which are of strategic interest for the R\&D player in question.1602 In order to assess innovation competition, it is thus important to consider the spaces in which this innovation competition occurs" $" 1240$.

The aim here is to delineate spaces where innovation competition takes place and to develop a structured approach that will enable the Commission to assess the existence of competitive constraints to the merging parties. This assessment requires:

"[...] (F)irst of all the identification of those companies which, at an industry level, have the assets and capabilities to discover and develop new products which, as a result of the R\&D effort, can be brought to the market. This analysis would identify the industry players who are capable to bring innovation to the crop protection markets overall. Against this background, it is possible to assess whether, through increased concentration and in light of high barriers to entry, the Transaction would be likely to reduce innovation output in the crop protection industry overall.

Secondly, and at another level, however, it is also relevant to identify and analyse those spaces in which innovation competition occurs in the crop protection industry, so as to assess whether the Transaction would significantly impede innovation competition in such spaces" $" 1241$.

These "innovation spaces" are getting smaller in the crop protection industry, in view of the increasing regulatory hurdles, which require crop protection products to be ever more selective, compared to the past ${ }^{1242}$. The Commission rejected the view of the parties that the choice was either focusing on the effect of the merger on specific relevant markets, such as upstream technology market and the relevant product markets or the assessment of innovation in the industry in general, noting that the early leads pursued do not indicate clearly what specific type of downstream product will materialise with the final Active Ingredient, which makes it necessary to assess innovation competition in innovation spaces, corresponding to small groupings of crop/pest combinations ${ }^{1243}$.

The Commission then noted the oligopolistic nature of the industry dominated by five integrated crop protection R\&D players, following an unprecedented wave of consolidation in

\footnotetext{
${ }^{1237}$ Ibid., para 2003. See also 2157-2158 and the discussion in Section 8.5. of the Commission's decision. 
the industry since the mid-1990s ${ }^{1244}$. In contrast to other industry players, these players have scale, assets, capabilities, disposing the possibility to access to markets to pursue R\&D globally and are integrated throughout the entire $R \& D$ pipeline ${ }^{1245}$. Although the Commission noted the existence of other companies that are active to some extent in $\mathrm{R} \& \mathrm{D}$, it found that these were not comparable to the five global R\&D-integrated players as regards innovation competition $^{1246}$. The Commission further noted that Monsanto was not a strong player in the crop protection industry as its most significant activity as regards crop protection innovation has been the introduction of one extremely successful AI (Glyphosate) more than thirty years ago, this "decades old innovation still constituting the core of its crop protection revenues, its patent share in the market being fairly insignificant ${ }^{1247}$. In contrast, Dow's herbicides patent share for new active ingredients was in the range of 30-40\%, Syngenta's patent share in the range of $20-30 \%$, Bayer's patent share in the range of 10-20 to 20-30\%, and DuPont's patent share in the range of $5-10$ to $10-20 \%^{1248}$. The Commission similarly proceeded to analyse the competitive constraint with regard to innovation brought by Isagro and a number of Japanese companies present in the industry, concluding that these were not active in the discovery and development of new AIs, or were distant competitors of the merging parties. Quantitative metrics on the basis of patent applications confirmed that the five global R\&D-integrated players play a predominant role in crop protection innovation ${ }^{1249}$.

The Commission further noted that industry shares tend to underestimate the expected non-coordinated effects of the merger given the significant cross shareholding between the main players, an issue that will be analysed in Chapter 4 of this Part ${ }^{1250}$.

Moving beyond the industry level, the Commission noted that concentration of R\&Dintegrated players at specific innovation spaces is even higher leading to tighter oligopolistic markets. Indeed, not all the R\&D integrated companies are present in each innovation space and are present in all the downstream markets for formulated products. Despite being active at an industry level, each R\&D player only competes in some markets for formulated products and therefore develops innovation efforts aiming at introducing new products in downstream markets for formulated products in some innovation spaces, but not all. As the Commission notes, "(o)therwise, they would be present with a product in all the downstream markets" This implies that at each innovation space level fewer than the Big 5 players are competing, and therefore concentration is likely to be higher at this level than at the overall industry level $^{1252}$.

On the basis of these findings the Commission held that the merger would bring together two competitors which pre-merger were more important innovation competitors at industry level than their downstream market shares and their R\&D expenditure shares

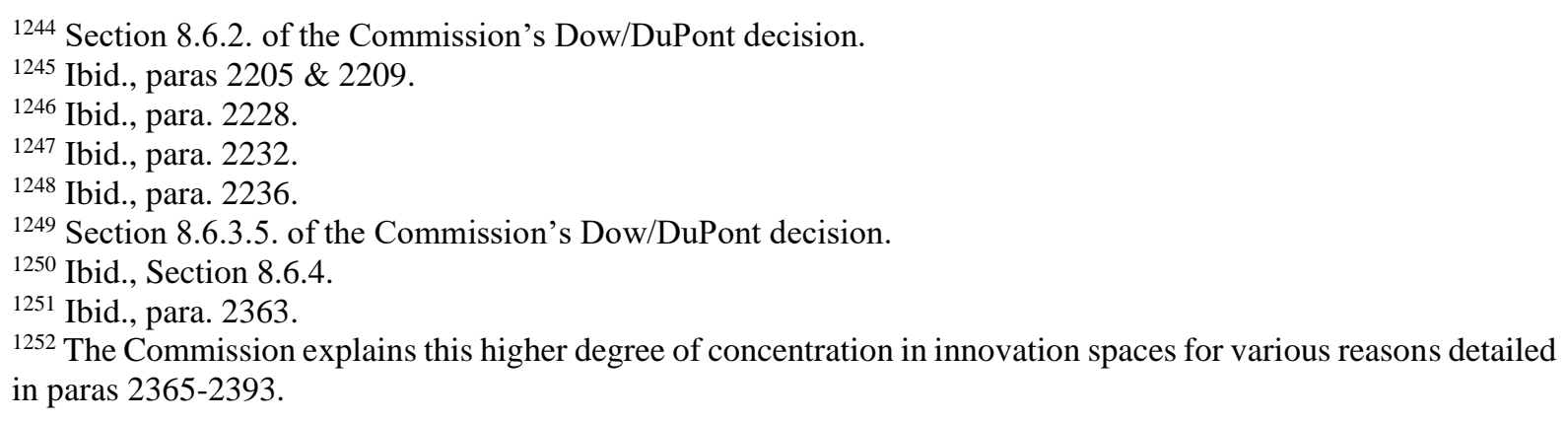


suggest ${ }^{1253}$. The Commission observed that the merging parties are important innovators in the crop protection industry with ambitious targets in terms the number and quality of new AIs and that their shares of patents (including citations of patents, which was thought as the most relevant criterion to assess the quality of patents) and new active ingredients shares (based on turnover on downstream markets), at industry level are higher than their downstream shares and their R\&D expenditure shares suggest ${ }^{1254}$.

The closeness of Dow and Dupont as competitors in several innovation spaces was also an element considered by the Commission. To determine closeness, in terms of competitive pressure for innovation competition, the Commission took into account current product overlaps as well as overlaps in their lines of research and early pipeline products ${ }^{1255}$. In doing so, the Commission explored the current lines of research and early pipeline products of the Parties which overlap and that could therefore risk being discontinued, deferred or redirect by the merged entity, thus leading to an effect on innovation. The Commission examined overlaps in a number of innovation spaces, such as broadleaf weed herbicides where Dow and DuPont were the only companies with a clear focus in this broader group of herbicides ${ }^{1256}$. The analysis of herbicide pipeline products from competitors that may reach the market beyond 2022 also confirmed that none of them had the potential to pose a serious threat to the market position of the merging parties in Europe ${ }^{1257}$. Similar findings were made for a series of insecticides ${ }^{1258}$ and fungicides ${ }^{1259}$.

The Commission next proceeded in exploring if the merged entity would have incentives to reduce innovation efforts on overlapping lines of research and early pipeline products on the innovation spaces where the merging parties currently compete ${ }^{1260}$. In order to assess these incentives the Commission referred to economics theory suggesting that a merger bringing together two competing early pipeline products (or lines of research) or an early pipeline product (or line of research) positioned to compete with an existing product may lead to a reduction on the efforts to continue with those overlapping early pipeline products (or lines of research) if the early pipeline product (or line of research) of one of the merging parties was likely to capture significant revenues from the competing product of the other merging party (be it another early pipeline product - or line of research - or products currently marketed), each company's research posing an externality to the other's ${ }^{1261}$. According to the Commission, " $(\mathrm{t})$ his adverse externality is internalized post-merger - from the perspective of each innovator, the expected loss of profits on the products of the other merging firm adds to the opportunity cost of innovating -, making it more likely that an early pipeline product (or line of research) is suppressed, deferred or re directed (particularly in the presence of significant development and commercialisation costs)" ${ }^{\prime 1262}$. Similar cannibalization concerns could also arise if a

\footnotetext{
1253 Section 8.7 of the Commission's Dow/DuPont decision.

${ }^{1254}$ Sections 8.7.1. \& 8.7.2. of the Commission's Dow/DuPont decision.

1255 Ibid., para. 2601.

${ }^{1256}$ Ibid., para. 2645.

${ }^{1257}$ Ibid., para. 2699.

1258 Ibid., para. 2729.

${ }^{1259}$ Ibid., para. 2842.

${ }^{1260}$ Section 8.9 of the Dow/DuPont decision.

${ }^{1261}$ Ibid., paras 3017-3018.

1262 Ibid., paras 3018 \& 3024.
} 
merging party's early pipeline product overlaps with an early pipeline product of the other merging party, the Commission concluding that this will reduce the incentives for the merged entity to continue with both lines of research and early pipeline products with the same intensity as each of the merging parties would in the absence of the merger ${ }^{1263}$. Consumers are harmed "by both the loss of product variety, and the reduced intensity of future product market competition in the markets where the discontinued/deferred/redirected early pipeline product would have been introduced but for the merger" ${ }^{\prime 264}$. Although the Commission was not be able to identify in this case precisely which early pipeline products or lines of research the merging parties would likely discontinue, defer or re-direct, it was considered probable that the early pipeline products and lines of research where the parties were close innovation competitors would be the those for which the merging parties would have less incentive to innovate ${ }^{1265}$. The Commission also noted that "discontinuation of an early pipeline product or line of research is more likely to occur the higher the expected sales which that early pipeline product from the merged entity would capture (if launched) from another existing or future product of the merged entity"1266.

In the same vein, the Commission noted that the merged entity would have lower incentives to achieve the same overall level of innovation as the merging parties pre-merger, in view of the fact that "rivalry at the innovation stage is a crucial driver of the incentives to innovate" 1267 . According to the Commission,

"[...] on highly concentrated innovation driven industries with very high barriers to entry such as the crop protection industry, the internalisation of the effects of innovation competition between the parties of a merger between important innovators would likely lead to noticeable reductions in the innovation efforts of the parties in relation to any future products that would otherwise be introduced in the absence of the transaction"1268.

This theory of harm goes beyond the "short-term" harm to innovation competition that would likely come with the discontinuation of overlapping lines of research and early pipeline products which target the same innovation spaces ${ }^{1269}$. It consists in a medium and long-term theory of harm that would result from the lower overall incentives of the merged entity to innovate as compared to the merging parties separately before the transaction and the "structural effect of the transaction", the merged entity the merged entity pursuing less discovery work, less lines of research, less development and registration work and ultimately bringing less innovative AIs to the market than the merging parties would have done absent the transaction ${ }^{1270}$. To the extent that "lowered innovation incentives can manifest themselves in (i) lower innovation efforts reflected for example in less financial resources, less scientists, less physical assets devoted to innovation, and (ii) lower internal innovation output targets",

\footnotetext{
1263 Ibid., para. 3022.

1264 Ibid., para. 3019.

1265 Ibid., para. 3025

1266 Ibid. \& 3053.

1267 Ibid., para. 3054.

1268 Ibid., para. 3055.

1269 Ibid., para. 3056.

${ }^{1270}$ Ibid., para. 3057.
} 
the Commission explored the parties' post-integration planning documents and the synergies put forward by the merging parties which were set from the beginning to be more focused on cost cutting than on creating value (as more than $70 \%$ of the announced synergies were costbased) ${ }^{1271}$.

The Commission also found unlikely a sufficiently strong countervailing reaction of innovation competitors as the combination of efforts of players with discovery capabilities and of players with development capability would not offset the reduction of output resulting from the transaction ${ }^{1272}$. It was not to be expected that third-party R\&D-integrated players would increase their $R \& D$ expenditure and $R \& D$ targets following a concentration, in particular in view of the finding that the past consolidation of the industry seems to have harmed innovation competition in the crop protection industry ${ }^{1273}$.

The efficiency gains put forward by the parties have not also been proved or substantiated. In particular, the Commission took issue with the claim of the parties that the loss of competition between tem would have increased their incentives to innovate. This argument was carefully distinguished from the separate issue that a reduction in imitation (or free-riding) by rival firms may generate an offsetting pro-innovation effect (by allowing the merging parties to internalise a positive externality that was not being internalised absent the merger), as in this case "a reduction in imitation risk does not automatically follow from a loss of competition between the merging parties and can - at least in principle - be achieved by strong (enforcement of) IPR, high degree of secrecy or other business strategies by the industry participants" 1274 .

The harm to innovation would be significant to the extent that unilateral (non-coordinated) effects are expected to be more pronounced if the merger brings together two out of a limited number of large, qualitatively and highly effective R\&D-integrated players" and "effects are also stronger if the merging parties are close competitors in terms of their likely innovation trajectories or in the product markets targeted with their innovation ${ }^{1275}$.

Because innovation is an important parameter of competition the Commission arrived to the conclusion that as a result of its non-coordinated effects on innovation, the transaction significantly impeded effective competition within the meaning of Article 2(3) of the Merger Regulation.

The Dow/Dupont merger also offered the opportunity to the Commission to analyse for the first time the emerging technology of gene-editing. Indeed, both Dow and DuPont are developing gene editing technologies, Dow the EXZACT Precision Technology (EXZACT), a zinc finger nuclease technology (ZFN), while DuPont is present in the CRISPR/Cas9 technology. DuPont has also been developing its CRISPR-Cas technology since 2012, on the basis of third party licenses and collaborations as well as proprietary IPRs ${ }^{1276}$.

The decision was also the first time the Commission had to assess market definition in relation to gene editing. Although the Commission noted that there are four main families of

\footnotetext{
${ }^{1271}$ Ibid., para. 3071.

1272 Section 8.10 .6 of the Dow/DuPont decision.

1273 Ibid., para. 3242.

1274 Ibid., para. 3275.

1275 Ibid., para. 3287.

${ }^{1276}$ Ibid., paras. 3408-3409.
} 
engineered nucleases being developed for application in crops: meganucleases, ZFNs, transcription activator-like effect or based nucleases (TALENs), and the CRISPR-Cas system, it considered that, for the purposes of the decision, the exact scope of the relevant product market for gene editing would be left open as the merger would not significantly impede effective competition in the internal market irrespective of whether the different families of engineered nucleases are considered to belong to the same relevant product market ${ }^{1277}$. The geographic dimension of the market of gene editing was also thought to be worldwide in scope although again the exact scope of the relevant geographic market for gene editing was left open $^{1278}$.

The Commission then proceeded to the assessment of non-coordinated effects in seed gene-editing. First it found that the merging parties' products are not close competitors and may even be considered complementary. The Commission accepted the merging parties' argument that CRISPR/Cas9 and EXZACT do not compete closely with each other, in that the former is a lower precision (and also lower cost) technology, used predominantly for gene deletion and modification, while EXZACT is a high precision (and high cost) technology used predominantly for gene stacking/trait insertion ${ }^{1279}$. Second, it held that there are several alternative gene editing tools available, with several seed companies developing gene editing technologies for agriculture ${ }^{1280}$. Hence, the Commission found that despite CRISPR/Cas9 being currently the best gene editing technology for seeds, there are several other alternatives that the merging parties' competitors have access to, including similar CRISPR/Cas9 technologies from other sources, and therefore the ZFN of Dow is not the only or even the best alternative available to DuPont's CRISPR/Cas $9^{1281}$. The Commission also found that there was no reason to worry about the merging parties' incentives to license gene editing technologies to rival seed companies or, in any event, to license them at terms that would be less attractive than those offered pre-merger.

It would also be unlikely that the merger strengthen the merging parties' IPR portfolio in relation to CRISPR/Cas technologies to the extent that Dow has no patents on the actual CRISPR enzymes, and therefore could not impede the development or use of the technology, and there has been an exponential proliferation of CRISPR patent filings, with many agricultural companies using CRISPR technology for the development of plant products without any need of licensing Dow's IP. The Commission concluded that there was no risk for a significant impediment of effective competition in gene-editing.

The Commission considered that the remedies it imposed in order to take into account the horizontal unilateral effects concerns in product market competition, and which involved the divestiture of an $\mathrm{R} \& \mathrm{D}$ division, were also able to deal with the innovation competition concerns, From this perspective the purchaser of the crop protection divested business will be able to replace DuPont as a global, fully R\&D integrated competitor in the crop protection industry, and in particular in the areas where Dow and DuPont overlap, thus maintaining the

\footnotetext{
1277 Ibid., para. 3414.

1278 Ibid., para. 3415.

1279 Ibid., para. 3418.

1280 Ibid., paras 3427 \& 3434.

${ }^{1281}$ Ibid., para. 3435.
} 
rivalry with Dow's R\&D activities that would otherwise have been eliminated by the merger ${ }^{1282}$. The divestiture will include all DuPont's assets and personnel dedicated to the discovery of new AIs as well as all patents, know-how and any other IP owned by DuPont related to its global R\&D Organisation and crop protection pipeline ${ }^{1283}$. The Crop Protection Divested Business will therefore be able to replicate the competitive constraint previously exerted by DuPont.

\subsection{The Competition Commission's of South Africa Bayer/Monsanto case}

The CCSA considered the fact that both Bayer and Monsanto are among the industry leaders in terms of global spend on R\&D for traits and concluded that this "reinforces the magnitude of R\&D development capabilities and initiatives that will not be consolidated within the merged entity" 1284 . The merger raised concerns with regard to the removal of potential competition at the level of platform or "system competition" ("as traits and herbicide tolerant traits are used as a 'system' to provide farmers with the best protection against weeds in order to generate high crop yields") ${ }^{1285}$. Indeed, the decision of farmers on which FM seed to plant "locks farmers into" a "technological pathway where only a specific system can be used" The CCSA found that other seed and crop protection forms will not be able to compete with the merging parties' platform "unless they are vertically integrated seed and crop protection firms who develop traits, breed seeds and develop active ingredients for herbicides" and that their only options are either "to develop their own traits for non-selective herbicide tolerance or license traits from the merging parties"1287. Hence, the CCSA concluded that the removal of a potential competitor which would have competed with Monsanto's dominant glyphosate based technological system could be problematic from a competition law perspective ${ }^{1288}$. Although this is not explicitly referred to in the decision, the main concern seems to be innovation competition in this market and the lock in of farmers to a specific technology.

Similar concerns, that implicitly raise an innovation competition issue, were raised with regard to the exclusionary portfolio strategies of the merged entity, in particular as it could have the ability to block rivals from becoming effective competitors in the "provision of technological platforms (or 'systems') to farmers in South Africa", given the market power of the merged entity in the development and production of traits ${ }^{1289}$. These technological indivisible packages of traits, seed and chemicals are marketed by firms to be sold and used together. By coupling this offer, the CCSA found that the merged entity could increase its rivals' "innovation costs" in the seed industry, as competitors will have to develop new technological platforms in response to any new bundled product offerings by the parties in

\footnotetext{
1282 Ibid., para. 4032.

1283 Ibid., para. 4035.

${ }^{1284}$ Competition Commission of South Africa, Case No: 2017Feb0004, Bayer Aktiengesellschaft, (3 May 2017).

1285 Ibid., para. 316.

${ }^{1286}$ Ibid., para. 317.

1287 Ibid., para. 320.

1288 Ibid., para. 324

${ }^{1289}$ Ibid., para. 407.
} 
order to be able to compete with the merged entity for the same customer base ${ }^{1290}$. At the same time, the exclusion of competitors from the market and the entrenchment of the dominant position of Monsanto's technological platform following the merger with Bayer, will reduce the merged entity's spending on innovation, therefore leading to a reduction of the level of innovation in the market, to the detriment of farmers ${ }^{1291}$. The fact that Monsanto's patent on glyphosate has expired and that it is possible for farmers to procure from generic herbicide manufacturers was not considered a sufficient consideration to question the bundling issue, as farmers still have strong incentives to continue to use Monsanto's glyphosate-based herbicide for Monsanto's tolerant traits, as in case they use generics they will lose any claims for compensation against Monsanto in case the seed underperforms ${ }^{1292}$. This further ties farmers to Monsanto's technological platform. Third parties certainly have the possibility to license the traits from the merging parties, but such licensing agreements have restrictions which limit their ability to become effective competitors in the provision of technological platforms ${ }^{1293}$. Despite the focus being partly on innovation competition, the CCSA emphasised the potential price increases the bundling of the new entity's offer could produce to the detriment of farmers as the principal competition concern raised by portfolio effects.

\subsection{The Russian FAS Bayer/Monsanto decision}

An important aspect of the FAS decision was the perception that merged entity will be capable to offer to farmers genetic material (seeds), a full range of plant protection products, as well as digital management solutions that simplify the process of organizing agricultural production. Although these products were, until recently, separate markets, following the first wave of economic concentration, which was held in the late 90's-early 2000's, many solutions in this area had become interdependent (package or system competition).

Bayer and Monsanto are vertically integrated high-tech companies, active in research and development, distribution and the sale of products to end consumers. According to FAS, the high intensity of innovation and the rapidly changing business models in the markets for these products require analysis, not only at the level of the various product markets affected by the merger, but also at the level of the "integrated market of agricultural technological solutions". With regard to the effect on innovation, FAS focused on the risks for competition in the market for digital solutions in agriculture. According to the FAS, the merger raises the risk of the emergence of a closed digital platform that will dominate the market and which will eventually reduce competition by squeezing out from the market alternative digital solutions from other companies. The control over the digital platform by the merging parties could influence the decision of agricultural producers to acquire other means of production (from seeds to agrochemicals). The decrease of innovative activity in the field of digital farming could also create barriers to entry into the market for digital platforms. It could also have the potential to cut down the research activity of competitors, as these will lose the incentive of competing

\footnotetext{
${ }^{1290}$ Ibid., paras 418-420 \& 424

1291 Ibid., para. 420.

1292 Ibid., para. 426.

${ }^{1293}$ Ibid., para. 430.
} 
with the industry leaders. A closed and dominant digital platform will also become an important barrier to entry for the emergence of new small innovative projects in the fields of selection or agro chemistry, which could have been integrated without difficulty into open digital platforms. The decision does not provide further details about the assessment of the incentives and of the ability of the leading digital platform to foreclose the access of smaller competitors in their platform.

According to FAS, the new entity resulting from the merger would have access to accumulated data on genetic information, and will control technologies of accelerated selection, including technologies of gene editing, which enable the accelerated selection of certain given characteristics by means of digital algorithms and big data, including historical data. The control of these technologies and the significant market share of the merging entities in the relevant product markets provide, according to the FAS, the merged entity with the power to influence the decisions of agriculture producers, raising strategic barriers to entry into these markets for other companies which do not dispose of the same access to technologies, and therefore to significantly increase its share on the full range of the relevant markets. Indeed, the creation of a digital platform integrating the supply of key agricultural inputs makes it "virtually impossible" for independent producers of agrochemicals or seeds to enter the market, as well as for individual agronomic digital services not integrated into such a platform to have access to a critical installed base of consumers. According to FAS, in markets that are heavily dependent on ongoing technological transformation and innovation competition, market power should be conceived as the projection of the innovation potential of the merging entity. The joint merged entity would become a dominant player in a number of global product markets like genomic markers for some crops, digital farming solutions and even some seeds markets as well and would get an ultimate advantage in the agritech markets as it would combine a complex technological capability of the global scale that other companies lack. The consolidation of the R\&D resources of Bayer and Monsanto and of their innovative potential will enable the merged entity to "dramatically increase" its market power in the relevant commodity markets, through various exclusionary strategies. In view of the established immunity from antitrust regulation for both the exercise of IP rights in the unilateral conduct context and also with regard to anticompetitive licensing agreements, this conduct could not be dealt ex post, by the antitrust law provisions, therefore, according to the FAS decision, making it necessary to deal with the possible situations of abuse of this market power ex ante through merger control.

Finding that the merger would lead to a substantial elimination of competition, FAS considered the adoption of remedies that would aim to ensure that the Russian agrotechnological companies and research centers would be guaranteed an effective access to key data and genetic information necessary for the creation of a more competitive offer in the agricultural production sector in Russia. The FAS decision imposes a number of access remedies (to the relevant genomic resources and the digital platforms data and algorithms) as well as compulsory technological transfer to the Russian agritech players with the aim to boost competition and make the competitive environment in this sector more dynamic and vibrant. The compulsory licensing remedies cover the crops where market competition in Russia is the least developed. Providing such a technological transfer and access of Bayer and Monsanto 
should be, according to the decision aimed at achieving the goal of overcoming the identified negative consequences for the state of competition created by the higher degree of economic concentration in this market and would aim to "compensate" the negative effects for competition resulting from the merger transaction.

The decision organized this "technology transfer" by establishing a monitoring mechanism that would be managed by a non-profit organization, the "Centre for Technological Transfer", established in the context of a Higher Education Institution, the "National Research University Higher School of Economics". This monitoring trustee would ensure the efficient transfer by the new entity of the newest technologies in the field of selective pesticides, as well as access to the relevant banks of genetic information (genetic markers) and the parent lines of the relevant crops to Russian business entities making such request, when this is necessary for the creation of new highly productive varieties/ hybrids of wheat, soybean, corn, sugar beet, tomatoes, cucumber, white cabbage. Russian business entities, selected by the Center of Technological Transfer on the basis of criteria agreed with the FAS Russia and on the basis of non-discriminatory conditions, should also benefit from a non-discriminatory access to the existing data files (on soil, climate, etc.), on the basis of which the forecast models of digital agronomic platforms for precision farming have been built, as well as to digital agronomical platforms for precision farming and provision of telematics services.

Non-discriminatory access principles will be elaborated by the merged entity together with the Center of Technological Transfer within one year after concluding the contract. These rules should be also agreed by the FAS Russia. Similar conduct remedies apply to the packaged solutions for agricultural producers, which were formed on the basis of digital agronomic platforms for precision farming, in terms of delivery of mineral Fertilisers, seeds, plant protection products and agricultural machinery. The scope, form and regulation of technology transfer in each specific case will be determined by an agreement between the merged entity and the Russian business entity, the recipient of technology, as well as the Center of Technological Transfer.

The fee for the transfer of technology protected by intellectual property rights will be paid from the revenue of the Russian business entity - recipient of technology - following the introduction of a new variety / hybrid. It is further specified that the fee should not exceed 50\% of the amount of the fee that is assigned in comparable market conditions. The volume and form of access to databases will be determined by the agreement between the merged entity, the Russian business entity - recipient of technology-and the Center of Technological Transfer in each specific case, and will be based on universal access protocols elaborated by the merged entity and agreed by the Center of Technological Transfer. The contract will also establish the rules of interaction between the Center of Technological Transfer and the merged entity, the contract including provisions on the responsibility of the parties in case of failure to fulfil their obligations, the imposition of penalties, the amount of which will bear a "preventive character"

It is further convened that the merged entity will finance the Centre of Technological Transfer in an amount comparable to the funding of such organizations at the territory of the European Union and will support the activities of the administrative and managing staff of the Centre of Technological Transfer, as well as providing the possibility of involving international 
experts with the necessary expertise to ensure the transfer of technology, access to the databases and telematics services.

\subsubsection{Public interest concerns}

The public interest assessment of mergers is a feature of the South African merger control and the seed mergers could not be an exception.

In the Dow/DuPont case in South Africa, the CCSA looked to public interest concerns with regard to the effects of the merger on employment, as well to its impact on a broader economic sector. The CCSA found that the parties did not contemplate job losses due to the transaction, as they did not plan to combine their South African businesses ${ }^{1294}$. With regard to the impact on an economic sector, the CCSA explored the effect of the merger transaction on warehousing and logistics companies and on R\&D activities in South Africa. With regard to the first, it found no impact. With regard to the second, the CCSA considered the issue as to whether the merged entity would shut-down the two breeding facilities it controlled in South Africa and import seeds from its operations located in other countries as important. The Commission's view was that "there may be change in incentives arising as a result of the merger in relation to the continuance of the existing R\&D facilities in South Africa" as Dow is "a large global company with research facilities elsewhere in the world" and "may have incentives to discontinue or relocate existing R\&D facilities currently operated in South Africa ${ }^{1295}$. The CCSA was particularly worried as some investments and upgrades made to one of the facilities were developed as a culmination of remedies imposed to DuPont in the context of another merger decision of the $\mathrm{CCSA}^{1296}$. As a condition to approving the merger, the parties committed to maintaining DuPont's two South African breeding facilities ${ }^{1297}$.

Public interest concerns were also raised in the Bayer/Monsanto case in South Africa. With regard to employment concerns, the CCSA found that the transaction likely would result in the retrenchment of twenty skilled employees, causing it to impose a condition that restricted any further retrenchments due to the merger for a period of three years ${ }^{1298}$. With regard to the effect of the merger on a particular industrial sector or region, the CCSA examined the effect of the merger on a number of various corporate responsibility projects, its impact on distributors and small scale farmers. As Monsanto had been involved in various development projects, the CCSA ordered that the merged entity continue with such initiatives for three years after the merger, and five years for projects that otherwise would have gone beyond the three-year period $^{1299}$.

In contrast, in the EU public interest concerns in particular about the protection of the environment and biodiversity were explicitly excluded from consideration in the pending

\footnotetext{
${ }^{1294}$ Competition Commission of South Africa, Case No: LM030May16, DowDuPont Inc., (30 June 2017), paras 371-372.

1295 Ibid., para. 384.

1296 Ibid., para. 385.

${ }^{1297}$ Ibid., paras 370, 373, 382-385.

1298 Competition Commission of South Africa, Case No: 2017Feb0004, Bayer Aktiengesellschaft, (3 May 2017). ${ }^{1299}$ Ibid., para. 502.
} 
assessment of the Bayer/Monsanto merger transaction, the European Commissioner releasing a letter in which it unequivocally declared that "( $\mathrm{t})$ he Commission's mandate under the European merger control rules is to assess the merger solely from a competition perspective" ${ }^{\prime 300}$.

\subsection{Case study: The Dow Chemical Company/DuPont merger case in Brazil: anatomy of a competition assessment ${ }^{1301}$}

Patricia Semensato Cabral ${ }^{1302}$, Yedda Beatriz Seixas ${ }^{1303}$, Mariane Cortat de Campos Melo ${ }^{1304}$

\subsubsection{Introduction}

The industry of products for crop protection and seeds has gone through consolidation waves in the last few years. Nowadays, we are witnessing another one of the mentioned waves; in the last few years, some important mega mergers between global competitors took place, such as Syngenta control acquisition by $\mathrm{CNAC}^{1305}$, the acquisition of Monsanto by Bayer ${ }^{1306}$ and the DuPont and Dow Chemical merger ${ }^{1307}$. The following paper aims to present a summary of the Administrative Council for Economic Defense - Cade's decision ${ }^{1308}$, the Brazilian competition authority, on the Dow and DuPont case, with special attention to the corn seeds market.

On December 2015, Dow and DuPont announced their intention to combine in a merger of equals. After the closing of the transaction, the new company would be named DowDuPont and would have a combined market capitalization of approximately $\$ 130$ billion at announcement ${ }^{1309}$. The Parties claimed that this would be a "highly synergistic transaction" expected to deliver "approximately $\$ 3$ billion in cost synergies, with 100 percent of the runrate cost synergies achieved within the first 24 months following the closing of the transaction" 1310 . The case was notified to CADE on October 2016, and the authority rendered

\footnotetext{
1300 http://europa.eu/rapid/press-release_IP-17-2762_en.htm .

1301 Merger case 08700.005937/2016-61. All opinions registered in this paper are personal, and should not be taken as Cade's official positioning.

1302 Masters in Economics, University of Brasilia, and antitrust specialist, Fundação Getúlio Vargas. Head of Merger and Antitrust Unity 1 at CADE’s General Superintendence. E-mail: patricia.cabral@cade.gov.br .

${ }^{1303}$ Masters in Business Administration, University of Brasilia. Deputy Head of Merger and Antitrust Unity 1 at CADE's General Superintendence. E-mail: Yedda.seixas@cade.gov.br .

${ }^{1304} \mathrm{PhD}$ candidate and Masters in Business Administration, University of Brasilia. Works as case handler at Merger and Antitrust Unity 1 at CADE's General Superintendence. E-mail: mariane.melo@cade.gov.br .

${ }^{1305}$ Merger case 08700.006269/2016-90, approved without restrictions by CADE on February 24th, 2017.

${ }^{1306}$ Merger case 08700.001097/2017-49, currently being analysed at Cade.

${ }^{1307}$ Merger case 08700.005937/2016-61, approved with restrictions by CADE on May 17th, h2017.

1308 The Administrative Council for Economic Defense - CADE is an agency with jurisdiction over the Brazilian territory, being composed by an Administrative Tribunal, a General Superintendence and a Department of Economic Studies.

1309 Available on http://www.dow.com/en-us/news/press-releases/DuPont-and-dow-to-combine-in-merger-ofequals . Last access on 13/9/2017.

1310 Available on http://www.dow.com/en-us/news/press-releases/DuPont-and-dow-to-combine-in-merger-ofequals . Last access on 13/9/2017
} 
its final decision on May 2017. Besides Brazil, at least another 24 jurisdictions around the world examined the transaction. ${ }^{1311}$

Despite the claim that the merger consisted of the "combination of two highly complementary global leaders"1312, there were several overlaps regarding Dow and DuPont activities, in the following segments: material science, agriculture (seeds and crop protection) and specialty products. Regarding the material science and crop protection markets, the parties presented substantial global remedies that were considered sufficient to address competition concerns expressed by several antitrust authorities. These remedies were also considered sufficient by Cade, addressing possible anticompetitive effects for the Brazilian market in crop protection and material science.

Notwithstanding, the transaction raised competition concerns in a specific market in Brazil, not being reached by the global remedies: the corn seeds market. This situation demanded additional remedies tailored to the Brazilian context. In the following sections, we will present the key points considered in the analysis (section 2.3.2) and the final remedies presented on Cade's decision (section 2.3.3.).

\subsubsection{Cade's analysis on the possible effects of the merger on the corn seeds market in Brazil}

\subsubsection{Brazilian corn seed market overview}

As is indicated in Cade's General Superintendence report on the case ${ }^{1313}$, corn is the most representative crop sale on the global commercial seeds market. The Seeds and Seedlings Brazilian Association (Abrasem, in its portuguese acronym) reports that Brazil is the third biggest global player on corn seeds production, with 4 million tons of seeds produced in the 2015/2016 cycle, amounting to R 10 billions per year ${ }^{1314}$.

Corn crops are widespread in Brazil, be it for its multiple functions in rural property (such as poultry, pork, meat and other animals' feeds) or for Brazilian farming tradition of this cereal. The seed is the main input for the corn crop, resulting that "farming characteristics, such as productive potential, stability, pest resistance and crop adequacy to the farming system and to climate and soil conditions must be taken into account, in order for the farming process to become more competitive ${ }^{1315}$.

\footnotetext{
${ }^{1311}$ According to the Parties in the files of the case.

1312 Available on http://www.dow.com/en-us/news/press-releases/DuPont-and-dow-to-combine-in-merger-ofequals . Last access on 13/9/2017.

1313 Parecer 2/2017/CGAA1/SGA1/SG, de 4/5/2017. According to the Brazilian competition Law (Law 12529/2011), the General Superintendence is responsible for the investigation phase in mergers and in anticompetitive conducts (both cartels and unilateral). At the end of the investigation, the Superintendence renders a reasoned opinion ("Parecer técnico"). If the Superintendence understands that a certain merger does not raise any competition concern, this opinion accounts for a final decision, unless that (i) third parties refers to CADE Administrative Tribunal or (ii) the Administrative Tribunal decides to review the Superintendence analysis. On the other hand, if the Superintendence understands that the case can not be approved without remedies, or that the merger should be blocked, the case is necessarily referred to the Tribunal, who will be responsible for the final decision.

${ }^{1314}$ Available on http://www.abrates.org.br/noticia/mercado-de-sementes-movimenta-r-10-bi-ao-ano-no-brasil. ${ }^{1315} \mathrm{Cuz}$ et al (2015). Available on https://ainfo.cnptia.embrapa.br/digital/bitstream/item/140279/1/doc-184.pdf.
} 
There are two processes employed, in the corn seeds segment, to generate more competitive seeds: (i) conventional breeding and (ii) transgenesis, or genetic engeneering. The conventional breeding technique employs crossbreeding among plants of the same species, in order to select specific aimed characteristics; in this process, a good quality germplasm - that is, a good collection of genetic material - is essential. When the transgenesis technique is chosen, the specimens receives, through genetic engineering, on or more genes from another organism. Examples of transgenesis are the Bt corn technique (Bacillus thuringiensis), which introduces the genetic material of this bacillus in the corn DNA, in order to acquire insect resistance. Genetically modified seeds represent more than $91 \%$ of the Brazilian corn seed market.

The picture bellow, provided by Dow and DuPont in the files of the merge case analysed by Cade, illustrates the corn seed industry organization:

\section{Figure 2: The corn seed industry organization}

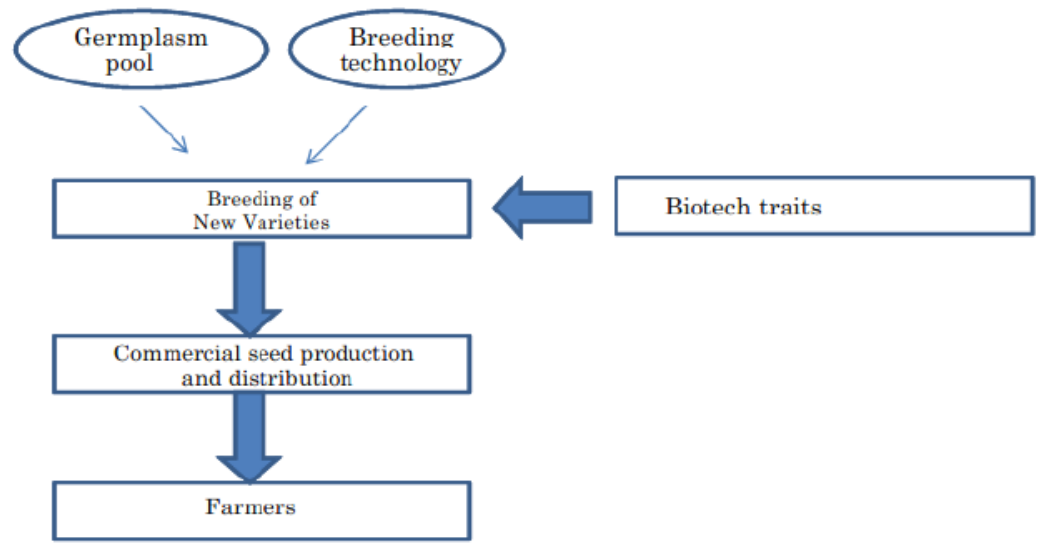

Source: Dow/DuPont in the files of the case 08700.005937/2016-61.

The first step, breeding of new varieties, consists of the development of new hybrids, and may last from seven to ten years ${ }^{1316}$. Regarding genetically modified seeds, biotech traits are introduced, to provide seeds with specific wanted characteristics, such as insects or herbicide resistance.

About commercial seeds production and commercialization, it is worthy to mention that, before a new hybrid (conventional or transgenic) can be marketed, it needs to register the hybrid and obtain sanitary authorization from the competent authorities. This registering process does not provide any sort of intellectual property rights. In addition, although plant specimens cannot be covered by patent per se, the Brazilian patenting system allows for the protection of technological inventions regarding transgenic events introduction.

2.3.2.2. Relevant markets affected by the merger

1316 Parecer 2/2017/CGAA1/SGA1/SG (4/5/2017), paragraph 24. 
Both Dow and Dupont are active in the corn seeds market in Brazil. DuPont develops and commercializes corn seeds under the brands Pioneer and BioGene. Dow markets corn seeds under the brands Dow Sementes, Morgan, Agromen and Coodetec.

CADE understood that the merger would not result in significant market concentration on transgenic events for corn seeds, since DuPont developed only the Hercules IR event, in partnership with Dow, and is not active in this segment in Brazil. DuPont informed that it has not commercialized any proprietary transgenic event for corn seeds in the country in the last 10 years. Furthermore, even though Dow is a relevant player in transgenic events for corn seeds in Brazil, no causal connection between the merger and market concentration was established. Therefore, the analysis of the horizontal effects of the transaction was focused on the corn seeds production and commercialization segment of the market, without further discussions on the transgenic events market. Some potential vertical relations were discussed $^{1317}$, but no competition concern arose from any of them.

When defining the relevant market, CADE did not distinguish between genetically modified and conventional corn seeds. An eventual differentiation would bring little practical effects for the analysis, for the Brazilian market is composed mostly of transgenic seeds (more than 90\%). However, other segmentations were considered, for the reasons explored bellow.

Hybrid corn seeds are created after the breeding of inbred lines. Often, hybrid corn seeds generate plants with high resistance and production, and with a uniform-sized spike. This can generate more productive and efficient corn crops.

There are three types of hybrid seeds: simple, double and triple. Simple hybrids are obtained after the breeding of two inbred lines, also known as "parental". Double hybrids are obtained from the breeding of two simple hybrids, and triple hybrids are the result of the breeding of one inbred line and a simple hybrid.

The Parties argued that the relevant market should include corn seeds in general, without any segmentation by kind of hybrid, because: (i) different hybrid types were substitutes both on supply and demand sides; (ii) farmers choose the seed type based on productivity, not on the breeding type employed to obtain that seed variety. It happens that several market players consulted by CADE pointed at important distinctions between hybrids. First, price differences were expressive: in average, simple hybrids prices are superior to the triple hybrids prices, which, for their turn, are superior to double hybrids prices. Also, simple hybrids are perceived as more productive and more sophisticated in terms of technological level.

Another segmentation considered in CADE's assessment was the distinction between hybrids for grain production or for ensilage. Some market players reported that seeds used for ensilage and for grains could be, in fact, diverse market niches which provide different results for farmers. Although this distinction was not sufficient to define relevant markets in a more restrictive way, concentration scenarios on grain and on ensilage were considered.

In sum, even though a precise relevant market definition was left open, the assessment of the Brazilian authority took into account the segmentations related above, which are: simple, double and triple corn hybrids, with further segmentation based on ensilage or grain production,

${ }^{1317}$ Namely, (i) germplasm licensing and corn seeds; (ii) biotech traits licensing and corn seeds; (iii) other potential relations involving pesticides and seeds. 
all in the national geographic scenario. In all of the scenarios considered, the merger raised competition concerns.

\subsubsection{CADE's competition assessment}

The merger generated substantial concentration on all the aforementioned scenarios. From Cade's assessment, considering the corn seeds market broadly defined, without further segmentation, both Dow and DuPont held 20\%-30\%, each, of the market in the year previous to the operation, resulting in a combined market share of 40-50\%. Concentration levels would be smaller regarding simple hybrids (Dow: 10-20\%; DuPont: 20-30\%; combined market share: 30-40\%), but considerably higher when considering the triple hybrids (Dow: 60-70\%; DuPont: 0-10\%; combined market share: $70-80 \%)^{1318}$. Scenarios where grains are split from ensilage resulted in shares similar to the previous mentioned, from $40-50 \%$ up to $70-80 \%$, in the case of triple hybrids for grains.

Besides Dow and DuPont, the corn seeds market (not segmented by hybrid type) in Brazil had only two more competitors with relevant market shares. The first is Monsanto, with a market share of $40-50 \%$ in the year previous to the merger. The second one is Syngenta, with a market share of $10-20 \%$ in the year previous to the merger. Other competitors do not have a relevant market share. Thus, based on public data made available on Cade`s decision, corn seed market C4 (without hybrid segmentation) would be of $90-100 \%$, and $\mathrm{C} 2,80-90 \%{ }^{1319}$, pointing a highly concentrated market.

Besides the evidence leading to a highly concentrated market, another factor was essential to Cade's assessment: Dow and DuPont strong positioning in corn seed breeding activities. Although there were relevant difficulties in establishing objective criteria that allowed comparisons between the Parties' germplasm banks, CADE considered there were enough elements to conclude that Dow and DuPont had a privileged position in both areas. Not all competitors, especially those without relevant market shares, own such high quality germplasm banks, in terms of size, variety and range. This context reinforces the fact that the Parties, especially after the operation, would hold considerable market power.

The markets discussed are characterized by relevant barriers to entry. The most important were the need for high investments in Research and Development, investment needs in order to gain market access (distribution and marketing), high investment need in order to maintain a breeding program, slow and expensive regulatory procedures, access to good germplasm and transgenic events, long term investment return, turnover capital needed to finance sales' deadlines, timeframe for brand recognition, specialized manpower needs.

Also, entry takes a considerable time, usually more than what is acceptable as a timely entry for the purpose of a competition assessment. As CADE's public decision shows, competitors estimated in more than 2 years the time needed to enter the market; if the competitor chooses to start its own breeding program, the timeframe goes up to 10 years. Therefore, considering the existence of entry barriers and the estimated timeframe for a new

1318 There is no overlap between Dow and DuPont on the double hybrids segment.

1319 Parecer técnico 2/2017/CGAA1/SGA1/SG, de 4/5/2017, paragraph 286. 
competitor entry, CADE concluded that new entries were not sufficient to counter Dow and DuPont joined market power after the operation.

\subsubsection{Remedies adopted}

As mentioned, Dow and DuPont proposed the divestments of a considerable set of assets worldwide. These divestments were sufficient to address the competition concerns of the material Science and crop protection markets, both in Brazil. ${ }^{1320} 1321$

In order to address Brazil's concerns, the Parties presented an additional remedy. This remedy consists, in general lines, in divestments of assets related to Dow's corn seed market, the most important being the transfer of a copy of the germplasm bank belonging to DAS Sementes, the transfer of a part of Dow's Pipeline and Commercial Hybrids, productive units, transfer of research centers, brands, manpower and sales team. According to Dow, "the assets being divested generated revenues in 2016 of approximately $\$ 287$ million"1322.

It is interesting to observe that concerns with innovation capabilities of the buyer are present in the design of the remedy for the Brazilian corn seeds market. In this sense, the package to be divested included, besides the transferring of present market share (commercial hybrids, brands, sales team and productive units), a set of assets considered by CADE as being sufficient to "allow the new competitor to maintain himself as a relevant competition force in the medium and long term"1323. Those assets necessary to sustain the new competitors position in the market consists in essential assets to build R\&D capacity, such as good quality germplasm bank, research centers and personnel.

On August $2^{\text {nd }} 2017$, CADE approved the buyer for the divested assets. The technical assessment that subsided Cade's decision ${ }^{1324}$ does not mention the buyer's identity due to confidentiality issues, but Dow has declared that part of the before mentioned assets was bought by the Chinese conglomerate CITIC Agri Fund. Cade's assessment concluded that the buyer meets the criteria established in the approved remedy, as follows: independency and no connections with the Parties and its affiliates; financial resources; proven experience in the

${ }^{1320}$ As stated by the European Commission (http://europa.eu/rapid/press-release_IP-17-772_en.htm), the parties offered a set of commitments. The parties proposed to divest a significant part of DuPont's existing pesticide business, including its R\&D organisation, in particular: (i) "globally, DuPont's herbicides for cereals, oilseed rape, sunflower, rice and pasture (thifensulfuron, tribenuron, metsulfuron, chlorsulfuron, triflusulfuron, lenacil, flupyrsulfuron, ethametsulfuron and azimsulfuron) and insecticides for chewing insect and sucking insect control for fruits and vegetables etc. (indoxacarb, cyazypyr and rynaxypyr). They will also divest all tangible and intangible assets underpinning the divested products (including the facilities where the products are manufactured) and relevant personnel"; (ii) "an exclusive license to DuPont's product for rice cultivation in the European Economic Area to address the more limited concerns relating to fungicides"; (iii) "DuPont's global R\&D organisation, with the exception of a few limited assets that support the part of DuPont's pesticide business, which is not being divested". In relation to Material Science (certain petrochemical products), Dow proposed to divest "its two manufacturing facilities for acid co-polymers in Spain and in the US, as well as the contract with a third party through which it sources ionomers that it sells to its customers."

1321 The crop protection business was acquired by FMC Corporation (merger case 08700.003377/2017-91, approved by CADE by 11/7/2017). The material Science bussiness was acquired by SK Global Chemical Co. LTD (merger case 08700.001886/2017-80 approved by CADE by 20/4/2017).

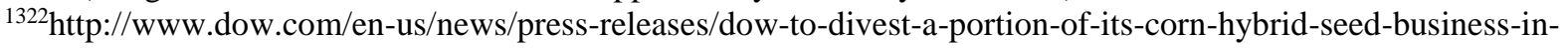
brazil-to-citic-agri-fund .

1323 Parecer técnico 2/2017/CGAA1/SGA1/SG, de 4/5/2017.

${ }^{1324}$ Parecer 85/2017/UCD/PFE-CADE-CADE/PGF/AGU, de 2/8/2017. 
corn seed market or similar; incentives to develop the Divested Venture as a competitive force, viable and active in the market; and no competitive concerns prima facie.

\section{Tables and Figures}

Table 1: Distribution of supply chain types BRICS aggregate

Table 2: No name or source.....255

Table 3: No name or source...280

Table 4: Share of crop protection economic actors (2015 EEA agrochemical sales by crop protection product)...284

Table 5:...no name/source ....287

Figure 1: Value Chain in the production of crop protection products: Key players..284

Figure 2: The corn seed industry organization.....3111 


\title{
Chapter 3: Superior Bargaining power and the Boundaries of Competition Law
}

\author{
Ioannis Lianos, Claudio Lombardi \& Justin Lindeboom with Christina Kanakari
}

\subsection{Introduction}

Two subsequent developments have ensured that food issues have recently gained prominence in the work of competition authorities. First, the considerable rise of the price of commodities, including food, in 2008, led to increasing demands for intervention from public authorities in order to curb the phenomenon of food inflation. ${ }^{1325}$ Food inflation trends seem, however, to have since been reversed, the prices of commodities decreasing sharply the last few months of 2015. ${ }^{1326}$ Second, additional concerns have been raised by the perception that retailers have gained considerable power over the upstream parts of the supply chain, in particular processors but also farmers. Individual or collective retailer power has been at the centre of the attention of public authorities in Europe, ${ }^{1327}$ with certain investigations being recently carried out at the national level. ${ }^{1328}$ As a recent study commissioned by the European Commission shows, the top 10 European retailers have seen their market share grow from $26 \%$ of total EU grocery in 2000 to almost $31 \%$ in 2011 , the overall concentration of retailers increasing in virtually all Member States. ${ }^{1329}$ The international expansion of some retail brands across Europe, but also in non-European markets, has led to a general decrease in the importance of home markets for top European retailers in terms of the domestic share of European grocery banner sales. ${ }^{1330}$ Retailer power also manifests itself increasingly with the use of private labels, which compete

\footnotetext{
${ }^{1325}$ It was reported that inflation from 2005 to 2011 saw food prices increase by around $22 \%$ on average across OECD countries. However, there has been substantial variation: relatively low levels of food inflation in the US (14\%) through to higher levels in Turkey (67\%) and Mexico (48\%). These variations even occur within countries participating to more homogeneous (from a trade perspective) blocks (e.g. EU): OECD, Competition in the Food Chain, vol. DAF/COMP(2013)15 (OECD 2013).

${ }^{1326}$ The FAO Food Price Index averaged 155.7 points in August 2015, down 8.5 points (5.2\%) from July, the sharpest monthly drop since December 2008: FAO, Food Price Index, available at http://www.fao.org/worldfoodsituation/foodpricesindex/en.

${ }^{1327}$ See the study commissioned by the OFT: P. Dobson, M. Waterson and A. Chu, The Welfare Consequences of the Exercise of Buyer Power, OFT, September 1998, Research Paper 16; OECD, Buying Power of Multiproduct Retailers, 1999; European Commission, Buyer Power and its Impact in the Food Retail Distribution Sector of the European Union, 1999; UK Competition Commission, Supermarkets: A report on the supply of groceries from multiple stores in the United Kingdom, 2000, Cm. 4842.

${ }^{1328}$ UK Competition Commission, The supply of groceries in the UK market investigation, April 2008; OFT, Grocery Market - Proposed Decision to Make a Market Investigation Reference, March 2006, at 42-49; A. Svetlicinii, The Croatian Competition Authority issues a report on competition on the food retail market in 2008, 16 July 2009, e-Competitions, No. 28749, www.concurrences.com; H. P. Nehl, The Austrian competition authority concludes general inquiry in the highly concentrated food distribution sector while highlighting indications of strong buyer power (Branchenuntersuchung Lebensmittelhandel), 18 June 2007, e-Competitions, No. 13981, www.concurrences.com;

${ }^{1329}$ European Commission, DG COMP, The Economic Impact of Modern Retail on Choice and Innovation in the EU Food Sector, (2014), available at http://ec.europa.eu/competition/publications/KD0214955ENN.pdf, 50-52. This is driven by higher concentration of modern retail.

${ }^{1330}$ European Commission, DG COMP, The Economic Impact of Modern Retail on Choice and Innovation in the EU Food Sector, (2014), available at http://ec.europa.eu/competition/publications/KD0214955ENN.pdf, 55.
} 
directly with leading manufacturers' brands and other national brands and illustrate this shift in the balance of power between retailers and suppliers. ${ }^{1331}$

Concerns over the rising power of retailers in the food sector have led many competition authorities to use existing rules or adopt new rules on superior bargaining power, these rules either forming part of competition law statutes or of other functional equivalents. ${ }^{1332}$ These different rules stay relatively opaque as to the definition of the concept of superior bargaining power, the common characteristic (and presumably) advantage of these provisions being that they may potentially impose competition law related duties to undertakings not disposing of a dominant position or a significant market power, for unilateral conduct, which would have otherwise not been subject to competition law related duties under the traditional rules of abuse of a dominant position. The concept of superior (or unequal) bargaining power is also a wellknown concept in the fields of contract law and unfair competition law, ${ }^{1333}$ where it has given rise to a considerable literature attempting to unveil its theoretical underpinnings. ${ }^{1334}$ Authors usually contrast the use of this concept in these areas of law, where the focus is on the unfairness of the process of exchange, with the efforts to integrate this rule in the field of competition law, where the emphasis is usually put on outcomes, such as efficiency or consumer welfare. The underlying objective of contract law or unfair competition statutes consists in regulating the contest between contracting parties and ensuring a relatively equalized landscape of bargaining capacity, bargaining power being interpreted as the interplay of the parties' actual power relationship in an exchange transaction. ${ }^{1335}$ On the contrary,

${ }^{1331}$ D. R. Desai, I. Lianos and S. Weber Waller, Brands, Competition Law and IP (CUP, 2015); A. Ezrachi and U. Bernitz, Private Labels, Branded Goods and Competition Policy: The Changing Landscape of Retail Competition (OUP 2009); A. Ezrachi, Unchallenged Market Power? The Tale of Supermarkets, Private Labels, and Competition Law, (2010) 33(2) World Competition 257-274; A. Foer, Introduction to Symposium on Buyer Power and Antitrust, 72 Antitrust L.J. 505 (2005); L. Vogel, Competition Law and Buying Power, 19(1) ECLR 4 (1998).

${ }^{1332}$ For a comparative analysis of rules on superior bargaining power, see ICN, Report on Abuse of Superior Bargaining Position (2008), available http://www.internationalcompetitionnetwork.org/uploads/library/doc386.pdf.

${ }^{1333}$ See, for instance, for contract law, at the EU level, Article 4:109 (ex -art. 6.109) of the Principles of European Contract Law 2002 on excessive benefit or unfair advantage because at the time of the conclusion of the contract "was dependent on or had a relationship of trust with the other party, was in economic distress or had urgent needs, was improvident, ignorant, inexperienced or lacking in bargaining skill"; Principle 10 of the Draft Common Frame of Reference (DCFR) concerning restrictions to the principle of the freedom of contract because of inequality of bargaining power (even in the context of B2B relations) and the contract law sub-doctrines that explicitly or implicitly incorporate bargaining power such as unconscionability, duress, undue influence, the parol evidence rule and public policy. On unfair competition, again at the E.U.E.U. level, see Green Paper on unfair trading practices in the business-to-business food and non-food supply chain in Europe COM(2013) 37; Communication of the Commission, Tackling unfair trading practices in the business-to-business food supply chain, $\operatorname{COM}(2014) 472$ final.

${ }^{1334}$ See in particular the seminal cases Lloyds Bank Ltd v. Bundy [1974] EWCA Civ 8 (EWCA (Civ)); Macaulay v. Schroeder Publishing Co Ltd [1974] 1 WLR; and the following critical and explanatory appraisal by S. N. Thal, Inequality of Bargaining Power Doctrine: The Problem of Defining Contractual Unfairness, (1988) 8 Oxford J. Legal Stud. 17; M. J. Trebilcock, The Doctrine of Inequality of Bargaining Power: Post-Benthamite Economics in the House of Lords [1976] University of Toronto L. J. 359; L. A. DiMatteo, Equity's Modification of Contract: An Analysis of the Twentieth Century's Equitable Reformation of Contract Law (1998) 33 New Eng. L. Rev. 265; and more recently A. Choi and G. Triantis, The Effect of Bargaining Power on Contract Design [2012] Va. L. Rev. 1665.

1335 Yet, it is important to note that regulatory interventions in order to rebalance contractual inequality are still designed as exceptions to the principle of the freedom of contract and the certainty of the contract, especially in 
competition law defines bargaining power more generally, in terms of the ability of an undertaking to introduce a deviation from the price or quantity obtained from the competitive situation in the market in which the transaction takes place. In this context, buying power denotes the ability of a buyer to achieve more favourable terms than those available to other buyers or what would otherwise be expected under normal competitive conditions. This approach emphasizes the gain resulting from the presence of bargaining power relative to a situation in which it is absent (not necessarily that of perfect competition), ${ }^{1336}$ focusing on market structure and concentration. ${ }^{1337}$

It is usually thought that superior (or unequal) bargaining power may constitute a competition law problem as long as it leads to negative welfare effects in terms of pricing, choice or innovation, these "competition law concerns" being carefully distinguished from "non-competition" law concerns. ${ }^{1338}$ Two views are usually advanced with regard to the interaction of provisions on superior bargaining power and competition law. First, considerable effort has been spent in order to mould the concept of superior bargaining power into the competition law and economics traditional framework by bringing adjustments to traditional competition law concepts such as relevant market and market power ${ }^{1339}$ or focusing competition law enforcement on "buying power." Second, new provisions on superior bargaining power or economic dependence, introduced in the competition law statutes by some jurisdictions, are typically examined from the perspective of efficiency and consumer welfare and usually relegated to the outer boundaries of competition law provisions on abuse of a dominant position, for instance on the basis of an error cost analysis, ${ }^{1340}$ or the perception that

B2B contracts, where a very limited power to rebalance the contractual arrangement is generally left to the discretion of the judge.

${ }^{1336}$ See, R. Clarke, S. Davies, P. W. Dobson and M. Waterson, Buyer Power and Competition in European Food Retailing (Edward Elgar 2002).

1337 J. T. Dunlop and B. Higgins, Bargaining Power and Market Structures, (1942) L(1) The Journal of Political Economy 1, 4-5; R. G. Noll, "Buyer Power" and Economic Policy, (2005) 72 Antitrust Law J. 589.

1338 Recent empirical work has relativized the impact of the superior bargaining power of retailers, as this is exemplified by rising consolidation and increasing concentration levels, on price: see E. Ciapanna and C. Rondinelli, Retail Market Structure and Consumer prices in the Euro Area, ECB Working Paper Series, No. 1744, December 2014 (observing that larger concentration of retailers on the purchasing side of the procurement market is associated with lower consumer prices). See also, European Commission, DG COMP, The Economic Impact of Modern Retail on Choice and Innovation in the EU Food Sector, (2014), available at http://ec.europa.eu/competition/publications/KD0214955ENN.pdf (noting that consumer choice was not affected by the rise of concentration levels at retail, although innovation may have been).

${ }^{1339}$ See, for instance, $\S 20$ of the German Act against Restraints of Competition on "relative and superior market power" (relative und absolute Marktmach).

${ }^{1340}$ See, for instance, F. Wagner von Papp, Unilateral conduct by non-dominant firms: a comparative reappraisal, ASCOLA Tokyo Conference (2015), (on file with the author, shortly available at the SSRN) conducting an "error cost analysis" and advancing the view that dominance, and consequently the definition of a relevant market, is a necessary condition for a superior bargaining power to be considered as a competition law problem and recognising the countervailing impact that subsidiary contract law enforcement would have on error costs. An error cost analysis conducted in abstracto may underestimate the transaction costs associated with the use of the specific legal process, which may vary from jurisdiction to jurisdiction and in some cases may be less important in the context of competition law enforcement than other alternatives. Error cost analysis may also lead to the "sin of single institutional analysis" see, K. N. Komesar Law's Limits, (Cambridge: Cambridge University Press, 2001) as it will emphasize the defects of one institutional alternative (e.g. competition law) on some aspects to argue for an expansive role of another, probably equally defective in some other aspects, institutional choice: contract law or unfair competition law statutes. 
fairness concerns have little role to play in modern competition law. ${ }^{1341}$ Provisions on superior bargaining power are examined from a public choice perspective as a by-product of the political pressure of organised interests of small and medium undertakings or farmers, leading to the adoption of mainly redistributive statutes that restrict competition and presumably economic efficiency. From this angle, the existence of a superior bargaining power of retailers in the procurement markets does not necessarily give rise to market power at the selling side, harming final consumers.

Price transmission from producer to consumer prices seems to have worked so far in favour of final consumers, as producer price increases during the period of the recent rise of commodity prices in 2008 have been partially absorbed by the food retail sector through a reduction of profit margins, at least in the old Member States. ${ }^{1342}$ It remains to be seen if the most recent decrease of food prices will also be passed on to consumers or if we will face a situation of asymmetric price transmission from producer to consumer food prices. ${ }^{1343}$ Similarly, the recent Modern Retail Study of the European Commission noted that the increase in the overall retail concentration has been counter-balanced to a certain extent by consolidation in the processing and manufacturing industries for certain products, such as coffee, frozen ready cooked meals, baby food ${ }^{1344}$. Finally, critics of the concept of superior bargaining power usually explain that the complexity of the problems raised by unequal bargaining power between retailers and suppliers cannot be solved by competition law and a more integrated framework is needed, combining the enforcement of competition law, when there is conduct that enters its scope, but also unfair trading practices laws, provisions of contract law and more generally civil law (tort law, European sales law), which aim to deal with abusive use of unequal bargaining power, and finally, soft law and self-regulatory initiatives by the industry that have emerged in several Member States. ${ }^{1345}$ The argument is often made that competition law may be less effective in dealing with the problem than these other areas of law, without, however, that conclusion being based on a thorough comparative institutional analysis that also examines the institutional and social norms related constraints that may limit the remedial potential of other areas of law to deal with the problem. ${ }^{1346}$

${ }^{1341}$ See, for instance, P. Akman, The Concept of Abuse in EU Competition Law (Hart Pub. 2012), Ch. 4.

${ }^{1342}$ L. Bukeviciute, A. Dierx and F. Ilzkovitz, The functioning of the food supply chain and its effect on food prices in the European Union, (2009) European Economy, Occasional Papers 47, 14.

${ }^{1343}$ Asymmetric transmission is often linked to the existence of market power at a level of the value chain: OECD, Food Price Formation, October 2015, available at http://www.oecd.org/site/agrfcn/meetings/agrfcn-7-food-priceformation-paper-october-2015.pdf; in a 2009 report for the European Commission, L. Bukeviciute, A. Dierx and F. Ilzkovitz, The functioning of the food supply chain and its effect on food prices in the European Union, (2009) European Economy, Occasional Papers 47, 18, noted that for the euro area, "the magnitude of the transmission is similar in the case of a price increase and a price decrease."

${ }^{1344}$ European Commission, DG COMP, The Economic Impact of Modern Retail on Choice and Innovation in the EU Food Sector, (2014), available at http://ec.europa.eu/competition/publications/KD0214955ENN.pdf, 218, 304-377.

${ }^{1345}$ On a discussion of the possible combinations between these different tools across Member States, see Final Report, Study on the Legal Framework Covering Business - to Business Unfair Trading Practices in the Retail Supply Chain, Final Report (26 February 2014), available at http://ec.europa.eu/internal_ market/retail/docs/140711-study-utp-legal-framework_en.pdf.

1346 These may, for instance, relate to inefficient judicial systems with few capabilities to engage with the economic underpinnings of superior bargaining power, in comparison to the more expert competition authorities, entrenched power relations that make it difficult for suppliers to bring contractual disputes against retailer networks and raise a contract law point based on economic duress or unconscionability against a partner with 


\subsection{Theoretical foundations}

Albeit the many attempts at a definition of bargaining power ${ }^{1347}$, bargaining power is one word but many things ${ }^{1348}$. For what it is concerned with the exercise of bargaining power in business relationships between agri-food market actors, bargaining power reveals in particular two relevant facets.

The first type of conduct interests the formation of the contract and its execution. The unbalance of bargaining power between market actors may help explaining why businesses, that traditional contract law presumes to be well informed and able to bargain, accept nonfavourable conditions ${ }^{1349}$.

The second aspect regards the market conditions preexisting to the conclusion of the contract. These market conditions may be referred to the whole relevant market ${ }^{1350}$, or to the specific business relationship affected by the agreement. The condition of dominance, indeed, originates from the economics of the market (market shares of the dominant firm) or as a consequence of relational ties.

superior bargaining power, a complaint to the competition authority offering in this case a better option, in view of the far-reaching remedies that a competition law violation may give rise to and that neither contract law nor unfair competition law offer. Even if private enforcement of competition law is more frequently used in these instances, competition authorities focusing on cartels as their enforcement priority, it might still be preferable from the point of view of the parties, in view of the general hostility of contract law judges to legal intervention in order to rebalance contractual inequality.

1347 See in particular the seminal cases Lloyds Bank Ltd v Bundy [1974] EWCA Civ 8 (EWCA (Civ)); Macaulay $v$ Schroeder Publishing Co Ltd [1974] 1 WLR; and the following critical and explanatory appraisal by Spencer Nathan Thal, 'Inequality of Bargaining Power Doctrine: The Problem of Defining Contractual Unfairness, The' (1988) 8 Oxford J. Legal Stud. 17; Michael J Trebilcock, 'The Doctrine of Inequality of Bargaining Power: PostBenthamite Economics in the House of Lords' [1976] University of Toronto Law Journal 359; Larry A DiMatteo, 'Equity's Modification of Contract: An Analysis of the Twentieth Century's Equitable Reformation of Contract Law' (1998) 33 New Eng. L. Rev. 265; and more recently Daniel D Barnhizer, 'Bargaining Power in Contract Theory' [2005] in Visions of Contract Theory Rationality, Bargaining, and Interpretation <Available at http://papers.ssrn.com/sol3/papers.cfm?abstract_id=578578> accessed 20 August 2015.

1348 See, inter alia, Albert Choi and George Triantis, 'The Effect of Bargaining Power on Contract Design' [2012] Virginia Law Review 1665 who report about some of the detractors of a broad spectrum use of the theory, in particular David A Lax and James Sebenius, Manager as Negotiator (Simon and Schuster 1987); Duncan Kennedy, 'Distributive and Paternalist Motives in Contract and Tort Law, with Special Reference to Compulsory Terms and Unequal Bargaining Power' (1981) 41 Md. L. Rev. 563; Richard A Posner, Economic Analysis of Law (Aspen Law \& Business 1986), who however, later smoothed his view using the concept of unequal bargaing power in business relationships, for instance here William M Landes and Richard A Posner, 'Should Indirect Purchasers Have Standing to Sue Under the Antitrust Laws? An Economic Analysis of the Rule of Illinois Brick' [1979] The University of Chicago Law Review 602, 833.

${ }^{1349}$ See, for instance, The Government Bill on the Amendment of the Finnish Competition Act, HE 197/2012, pp. 9-13, which, facing high levels of concentration of retailers, considers abuse of buying power conducts such as imposition of unreasonable contract terms, tying, bundling, exclusive dealing et similia. Similarly, Hungary, Germany, Italy, France, to cite only some, have adopted specific provisions tackling such type of abuses of superior bargaining power leading to unfair contract terms.

${ }^{1350}$ Here the common definition of dominance would find application. See, for instance, the one given by the CJEU in the United Brands and Hoffmann-La Roche cases as "a position of economic strength enjoyed by an undertaking which enables it to prevent effective competition being maintained on the relevant market by affording it the power to behave to an appreciable extent independently of its competitors, customers and ultimately of its consumers"; Judgment of the European Court of Justice, Case 27/76, United Brands v. Commission, [1978] E.C.R. 207 at para. 65 and Judgment of the European Court of Justice, Hoffmann La Roche v. Commission, 85/76, [1979] E.C.R.-461 at para. 38. 
The indefiniteness of the expression bargaining power is, at the same time, a critical problem and an advantage that several jurisdiction use to address issues crossing the boundaries of private law and competition regulation. The perception is that the abuse of contractual terms in a business relationship or the imposition of such terms creates conditions and effects in the market that should be addressed under a holistic approach, enabling the use of both contractual and competition law remedies ${ }^{1351}$.

The food market presents plenty of alternatives for holdup and anticompetitive behaviours ${ }^{1352}$. Farmers generally undertake specialized capital investments to provide the products at the local and international standards, under contractual arrangement with buyers. In particular, in markets of perishable products with few buyers, this contractual relationship easily turns into an economic dependence of the farmer to the buyer ${ }^{1353}$. Perishable products introduce a new element to the equation, that is, the holdup due to lack of alternatives for logistic reasons ${ }^{1354}$. Some products, such as chicken or sugar beets ${ }^{1355}$, have to be marketed locally, as they cannot be shipped far without losing much of their value. Processors and local buyers can therefore use this opportunity to impose low prices on the farmer on non favourable proprietary provisions. For instance, it has been reported that iin the U.S. "grower cares for the chickens, and usually provides land and housing facilities, utilities, labor, and other operating expenses, such as repairs and maintenance... The contractor provides chicks, feed, veterinary supplies and services, management services or field personnel, and transportation for the birds to and from the farm" ${ }^{1356}$. On the basis of this model, integrators own livestock, while farmers receive a rent for growing it ${ }^{1357}$. Integrators compete downstream, as retailers can easily shift

1351 This is, for instance, the vision endorsed by the Italian Legislator, who adopted specific laws on abuse of economic dependence affecting the market, and furthermore, strengthened the regulation fixing specific rules for contracts trading agricultural goods and foodstuffs.

1352 James M MacDonald and Penni Korb, 'Agricultural Contracting Update: Contracts In 2008' (2011) EIB-72. U.S. Dept. of Agriculture, Econ. Res. Serv.

${ }^{1353}$ At this regard, Swinnen and Valdeplas, explain that in some cases may be true the opposite, a situation where the firm dominant in the relevant market is subject to the holdup of small farmers in which the firm has invested. ${ }^{1354}$ M James M MacDonald and Penni Korb, 'Agricultural Contracting Update: Contracts In 2008' (2011) EIB72. U.S. Dept. of Agriculture, Econ. Res. Serv give several examples of opportunistic behaviours in the agricultural market. 1355 Ibid 3.

1356 USDA, Contracting in the Poultry Industry, 1999, available at http://www.ers.usda.gov/media/256039/aib748c_1_.pdf.

${ }^{1357}$ Purdue statement: "Our chickens and turkeys are raised on local farms by independent farmers under written contract with Perdue. (...) Perdue has been contracting with farmers since the 1950s, and currently has contracts with more than 2,200 farm partners. (...)Under the contract growing relationship, Perdue delivers day-old chicks to the farms and provides feed, veterinary care and advice. Producers, in turn, are responsible for providing housing that meets Perdue's standards for poultry welfare and biosecurity, and for caring for the birds on a daily basis. Our flock supervisors, veterinarians and poultry welfare officers - backed by an advanced team of scientists and laboratory technicians working with the industry's leading research and analytical equipment - assist our producers. (...) We do have high standards for how we expect our birds to be raised. That's the only way to consistently deliver a quality, wholesome product and to ensure the health and welfare of our birds and environmental sustainability across our supply chain. We work with our producers to ensure adherence to our strict standards for food safety, bird health, poultry welfare and environmental stewardship.

A poultry operation is like any other business in that producers need to reinvest in their operations to remain competitive. In addition, standards related to food safety, bird health and welfare and environmental stewardship change over time as a result of, among other things, advances in animal husbandry, changing consumer and customer expectations and new laws and regulations. However, Perdue often provides no-interest financing and other incentives to assist our producers with necessary upgrades", available at 
from a one to another, since there is few (if no) product differentiation ${ }^{1358}$. However, they do not compete upstream, as they impose similar contract to farmers.

It is a constant feature of all disciplines involved in the analysis of the operation of capitalist economies that the concept of power takes a primary role in understanding the logic of individual strategy as well as collective action. To the extent that this action takes place in the context of markets where various forms of exchange take place, it becomes essential to understand the constitutive elements and various dimensions of economic power as various forms of legal regulation have developed with the aim to sustain the performativity and legitimacy of the capitalist mode of production and exchange. This comparative analysis, across various legal spheres, is further complicated by the complexity of the concept of power, ${ }^{1359}$ confusion over its exact meaning in each context, and the different approaches employed by social scientists in analysing relations of economic power to the extent that these are manifested in situations of market exchange.

For instance, sociologists and economists have developed different approaches to the concept of power. If for economists, markets are primarily processes for price formation, the price helping to allocate scarce resources in an efficient manner, (market) power being the ability to increase prices and consequently to allocate scare resources in an inefficient manner, sociologists focus on social relations and institutions in markets, analysing the way market actors interact with each other when producing or exchanging products. ${ }^{1360}$

From a sociological perspective, in Max Weber's classic definition, power denotes a situation in which there is "probability that one actor within a social relationship will be in a position to carry out his own will despite resistance, regardless of the basis on which this probability rests". ${ }^{1361}$ This definition may present various problems in view of the focus on the volitional element, the "will" of a specific actor, as opposed to the "resistance" of another, thus indicating that some form of coercion is exercised on one actor by another. The concept of coercion is notoriously complex and ambiguous. Most theoretical accounts of coercion appear to be either over- or under-inclusive. Philosopher Robert Nozick has famously provided a conceptual framework for thinking about coercion, indicating a list of necessary and sufficient conditions for judging the truth of the claim that $P$ has coerced $Q$. According to Nozick, coercion occurs when

"1. $P$ aims to keep $\mathrm{Q}$ from choosing to perform action A;

2. $P$ communicates a claim to $Q$;

http://www.perduefarms.com/News_Room/Statements_and_Comments/details.asp?id=537\&title=Statement $\% 2$ 0on\%20Poultry\%20House\%20Contracts\#sthash.GlzhYvcG.dpuf.

1358 USDA, Contracting in the Poultry Industry, 1999, available at http://www.ers.usda.gov/media/256039/aib748c_1_.pdf.

${ }^{1359}$ See e.g., P. Morriss, Power: A Philosophical Analysis, 2nd edn (Manchester University Press 2002); S. Lukes, Power: A Radical View, 2nd edn (Palgrave Macmillan 2004); P. Bachrach and M.S. Baratz, 'The Two Faces of Power' (1962) 56 American Political Science Review 941; T. Wartenberg, The Forms of Power: From Domination to Transformation (Temple University Press 1990).

${ }^{1360}$ For a discussion, see M. Grannoveter, Society and Economy: Framework and Principles (Harvard University Press, 2017), 91; R. Swedberg, An Introduction and Agenda, in V. Nee \& R. Swedberg (eds.), The Economic Sociology of Capitalism (Princeton University Press, 2005), 4, 11.

${ }^{1361}$ M. Weber, The Theory of Economic and Social Organization (1947, Free Press, first published 1922), 152. 
3. $P$ 's claim indicates that if $Q$ performs A, then $P$ will bring about some consequence that would make $Q$ 's A-ing less desirable to $Q$ than $Q$ 's not A-ing;

4. $P$ 's claim is credible to $Q$;

5. $Q$ does not do $A$;

6. Part of $Q$ 's reason for not doing A is to lessen the likelihood that $P$ will bring about the consequence announced in (3)". 1362

Nozick associated coercion with proposals (conditional threats or offers), excluding direct uses of force or violence and considered that coercion takes place only when the coercee acquiesces to it, thus making coercion explicitly dependent on the coercee's choice to take, or not to take, a specific action A. The focus of his definition of coercion is therefore on how the coercee is affected by coercion, for instance through an alteration of its intentions or dispositions, rather than what the coercer does. For Nozick, coercion operates through the will of the coercee. However, if one is to take into account as coercion any alteration of the coercee's costs and benefits to acting, it is inevitable that the definition of "economic coercion" will be extremely vague, as one should have to perform a causation analysis for each alteration of costs and benefits in order to determine if the coercee's action would have occurred "but for" the action of the coercer. What is more, practically every form of action in markets is based at a minimum on implicit "coercion" in Nozick's sense by all participants: for instance in a cartel, typically all participants at least implicitly threaten to act competitively (or perhaps even 'hypercompetitively') if the others do not comply with the cartel agreement; and the implicit threat by the other cartel participants is the reason for each participant to abide by the cartel agreement. ${ }^{1363}$ A similar conclusion may also apply in a monopoly situation. A monopolist will not charge the higher prices he can get (an infinite price for his product), if this will have as a possible effect of reducing demand for his product leading only to consumers that have the highest willingness to pay to continue buying it. For instance, assuming that there is a state monopoly for selling beer with a high alcoholic content, and the monopoly decides to triple the price of beer, one may expect that many consumers will stop purchasing high alcoholic beer and switch to low alcoholic beer or another type of drink (thus exercising some form of implicit coercion to the monopolist). There is a point where pricing above will lead to a loss of customers that will be so large that it will outweigh the gain in profit from this specific transaction. So the sky is not the limit for monopoly price rises. A monopolist's power to charge a high price is ultimately function of the elasticity of demand for its product, that is, the possibility that his product may be substituted by another one (cross-price elasticity). Nozick's broad definition is therefore unhelpful.

Others have taken a more conventional view on coercion, considering that this occurs when it also takes the form of direct force, the coercee being acted upon. ${ }^{1364}$ However, it is also unclear if coercion may be limited to a specific action that was taken, or not taken, by the coercee. There might, indeed, be difficulties in identifying precisely the actions the description

\footnotetext{
${ }^{1362}$ R. Nozick, 'Coercion', in P. Suppes, and M. White (eds.), Philosophy, Science, and Method: Essays in Honor of Ernest Nagel, (Sidney Morgenbesser, New York: St. Martin's Press, 1969), 440-472, 441-445.

${ }^{1363}$ Cf. C. Beaton-Wells, 'The ACCC Immunity Policy for Cartel Conduct: Due for Review' (2013) 41 Australian Business Law Review 171, 184: "However, threats between rivals are common in the cut and thrust of business. Something more than a threat should be required."

${ }^{1364}$ See, G. Lamond, 'Coercion and the Nature of Law' (2001) 7 Legal Theory 35.
} 
of coercion will include, thus distinguishing between coerced acts from non-coerced ones. One may address this issue by taking a subjective perspective, focusing on how the coercee perceives her situation at the time of the exercise of coercion, which will however introduce further sources of uncertainty in determining the coerced acts, and thus would introduce further complications.

Another option would be to distinguish the different conditional threats or actions of the coercer by looking to the relationship these have to some baseline representing the situation of the coercee prior to the proposal, this being the "normal or natural expected course of events", the latter concept being interpreted either as a normative (moral) baseline, or as a nonnormative (predictive) one. But what is the "normal or natural expected course of events" in the course of a market? In the absence of a theoretical model on how markets should operate, the line distinguishing what constitutes coercion from what is "normal" behaviour becomes blurred. In case one focuses on economic efficiency, that is increasing the size of the economic pie, "normal" behaviour will be that which brings this precise effect. A similar consequentialist approach may be adopted if one takes a equality perspective that focuses on an equal or "fair" allocation of the economic pie between the various market actors. Defining "coercion" is a particularly complex endeavour, as various possible moral baselines may be constructed for judging whether a conditional threat/proposal "coerces" someone to adopt an action, and there are various ways to take into account what the recipient of the conditional threat/offer would want.

It is possible to adopt a narrower definition of coercion that would not only focus on the fact that someone threatens someone else in case his demand is denied, but also requiring that the coercer will make the alleged "coercee" worse off than he ought to be. But again, the criterion remains unclear as it is dependent on the moral baseline chosen. Some authors have, in addition, required for coercion to exist that the choice forced upon the coercee be such that he has no reasonable choice but to accept it. ${ }^{1365}$ The absence of another choice may provide a more workable definition of coercion, but again it would require some consideration of the relative bargaining positions of the parties, past imbalances of power, the eventual dependence of one party from another, that it may be impossible or undesirable to consider. Focusing on the level of pressure exerted to the alleged "coercee's" market autonomy, looking to the power, intention and activity of coercers, may also be problematic, as it is not a priori clear which is the boundary for compulsion to be considered sufficiently strong so as to make the "coercee's" choice involuntary ("coerced"). However, this scheme is also difficult to apply in practice as it can be interpreted in various ways leading either to an absurdly narrow understanding of coercion, or to one that is too broad as it would cover mutually beneficial business transactions.

The absence of alternative "reasonable choices" can easily entail a conception of coercion that is too narrow, particularly as applied to exercises of market power. It can be argued that in the absence of a threat that is genuinely life-threatening, the alleged coercee arguably always has the choice to resist the threat notwithstanding the fact that this choice might make him worse off. A series of hypothetical examples testing the demarcation between coercion and non-coercion would then lead to regress, leaving only direct threats to life and liberty as

1365 A. Wertheimer, Coercion (Princeton University Press, 1987). 
instances of coercion. Such a narrow understanding of coercion is advanced by Friedrich A. Hayek. Hayek takes the difference between a free man and a slave as his heuristic starting point in order to argue that “[c]oercion occurs when one man's actions are made to serve another man's will, not for his own but for the other's purpose [...] Coercion implies, however, that I still choose but that my mind is made someone else's tool, because the alternatives before me have been so manipulated that the conduct that the coercer wants me to choose becomes for

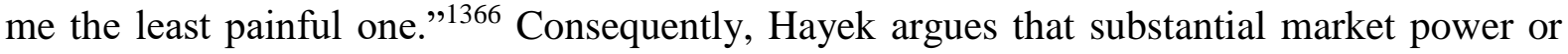
monopoly could rarely result in true coercion. A monopolist could only exercise true coercion if he where, for example, the owner of the only spring in an oasis, leaving other settlers no choice but to do whatever the spring owner required of them if they want to survive. ${ }^{1367}$ Hayek's conception of coercion is thus clearly unhelpful, as it would only cover threats to deny goods that are crucial to one's existence. ${ }^{1368}$

By contrast, a broader understanding of the absence of reasonable choices would entail that an extremely tempting offer, such as sharing the profits of a long-term joint venture, may be considered as exercising a pressure similar to a conditional threat by a monopolist of a scarce resource to deny access to this facility at a reasonable rate, to the extent that in both cases the presumed "coercer" is manipulating the incentives (or opportunity costs) that the presumed "coercee" associates with various courses of action, but one may not want that to be considered as a form of economic coercion, as this would eventually lead to a quite broad interpretation of the term, eventually including also situations of mutually beneficial cooperation.

To the extent that the voluntary, or not, character of an exchange may not constitute an adequate criterion to define (economic) power, it may be more relevant to focus on indirect methods of observing power, such as the process through which economic power is manifested as well as its various sources or various manifestations of power deemed relevant for the specific circumstances. Some conceptual presumptions about the nature of power are obviously inevitable in order to select the sources and manifestations that are deemed relevant. For example, Steven Lukes' influential "three dimensional" approach to power focuses on someone's ability to affect other people's conduct, taking the conflictual aspect of power as a starting point: A exercises power over B when A affects B in a manner contrary to B's interests. ${ }^{1369}$ Similarly, Michel Foucault argued that "if we speak of the structures or the mechanisms of power, it is only insofar as we suppose that certain persons exercise power over others", stressing the relational component of power. ${ }^{1370}$ In contrast, Peter Morriss argues that our primary understanding of power is the ability to effect outcomes, rather than the ability to affect other people. ${ }^{1371}$ The conceptual distinction between "power-over" and "power-to" affects the degree to which empirical facts are relevant in identifying the exercise of power. However, one can take also a more empirical, inductive approach focused on the extension

\footnotetext{
${ }^{1366}$ Friedrich A. Hayek, The Constitution of Liberty (University of Chicago Press 1960), 133.

1367 Ibid, 136.

1368 See e.g., Ellen Frankel Paul, "Hayek's Conception of Freedom, Coercion, and the Rule of Law" (1980) 6 Reason Papers 37-52.

1369 S. Lukes, Power: A Radical View, 2nd edn (Palgrave Macmillan 2005), 37.

${ }^{1370}$ M. Foucault, 'Afterword: The Subject and Power', in H. Dreyfus and P. Rabinow, Michel Foucault: Beyond Structuralism and Hermeneutics, 2nd edn (University of Chicago Press 1983), 217.

${ }^{1371}$ P. Morriss, Power: A Philosophical Analysis (Manchester University Press 2002), chapter 5.
} 
(reference) rather than the intension (meaning) of power. ${ }^{1372}$ Such as approach would, albeit of course not without any presumptions on "power-over" and "power-to" conceptions, focus on the properties of actors that affect their power to either influence other actors' conduct and/or to affect outcomes directly.

Process-based definitions of power focus on the bargaining process and aim to identify situations in which there is some form of asymmetry or inequality on the ability of the actors to influence each other's course of conduct. In economics, the analysis of bargaining power is intrinsically related to the issue of how actors may divide the joint gains resulting from their cooperation, the so called bargaining problem. Bargaining power will conventionally refer to the relative share of the total surplus gained by an actor in the bargaining problem. People enter into cooperation with other people to the extent that this cooperation my produce a joint surplus that would not be possible absent that cooperation. Assuming that individuals have the incentive to cooperate with others, and consequently limit their freedom of action to a certain extent, in order to increase their welfare, this joint surplus will be "the difference between the benefits (net of direct costs) each gains from the joint activity and the benefits each would receive in their next best alternative". ${ }^{1373}$ Each participant in a joint project should therefore receive benefits at least as great as in their next best alternative, so as to maintain their incentive to participate to the joint project (the so called participation constraint). ${ }^{1374} \mathrm{~A}$ long as the "participation constraints" of all participants to the cooperative project are satisfied, the question of distribution is settled in an economically efficient way. ${ }^{1375}$ What matters is not the distributive outcome as such, for instance that each participant enjoys an equal share of the joint profit, but the fact that each participant has been able to get a payoff equivalent to their next best alternative. Absent this rent from the joint surplus collected by the participants, these will have no incentive to enter into the joint activity at the first place.

It is possible to imagine that a single participant could gain the most important part of the joint profit if, for instance, he makes take-it or leave-it offers to the rest of the participants that are only "barely superior to their next best alternatives". ${ }^{1376}$ To the extent that the joint surplus is net of the participants' next best alternatives, the allocational outcome will be deemed Pareto optimal (economic efficient). However, this outcome may not be considered fair to the extent that it leads to an unequal allocation of the joint profit, should one consider that fairness requires that the joint surplus produced should be allocated equally between the participants. However, distributive justice concerns are not of essence to welfare economic analysis, which carefully separates questions of efficiency from questions of distributive justice. This separation is explained by number of crucial assumptions. The first is what has been called "the Second Fundamental Theorem of Welfare Economics", according to which if one assumes that all individuals and producers are selfish price takers, then almost any Pareto optimal equilibrium can be supported via the competitive mechanism, provided appropriate lump sum taxes and transfers are imposed on individuals and firms. The main idea is that in the long run

\footnotetext{
1372 E.g. K. Dowding, Power (Open University Press 1996).

1373 Ibid., 168

${ }^{1374}$ S. Bowles, Microeconomics - Behavior, Institutions, and Evolution (Princeton Univ. Press, 2004$), 171$.

1375 Ibid., 171.

1376 Ibid.
} 
the competitive process will eliminate any benefit from the joint surplus that is higher than the participation constraints of each of the participants. This further assumes that "only competitive equilibrium transactions take place", a quite heroic assumption which in the best case scenario only holds at the very long term. ${ }^{1377}$ A second assumption is that allocational outcomes may not have effect on distributional outcomes, which is also quite unlikely, as the existing allocation of resources determines the next best alternative for each of the participants and consequently the distribution of the joint surplus. Conversely, conflicts relating to the fair distribution of rents may contribute to inefficiency to the extent that resources may be spent on advancing distributional claims and rent-seeking deviating resources away from productive activities. Participants may also be driven in their selection for technologies and the organisation of their activity to activities that increase their share of the joint surplus, rather than those increasing the size of the joint surplus. A third assumption is that the participants to the cooperation are able to write complete and costlessly enforceable contracts regulating all aspects of their private interactions and consequently the costs and benefits of their cooperation. This is of course only possible in theory. Finally, it is possible that joint surplus generating activities may be blocked following intense conflicts over the distribution of the joint surplus and "bargaining breakdowns leading to foregone mutual beneficial opportunities". ${ }^{1378}$

The situation of economic dependence between two firms may precede their business relationship, coincide with the contract that incepts such relationship, or arise in the execution of the contract. The economic dependence can be defined as a situation of unbalance in the business relationship between two firms, which makes impossible or excessively difficult for one to continue with the business without the other. The abuse of economic dependence generally take the form of a refuse to purchase or sell, or the one of an arbitrary interruption of business relationships. Economic scholars have, since long, analysed these contractual dynamics, especially under the theory of 'incomplete contracts' ${ }^{1379}$. Inter alia, this theory explains that, since parties are not generally able to foresee all the possible evolution of their business relationship, when one of the parties gains a position of superior bargaining power, it will likely exploit this situation. Based on this theory, Klein, Crawford and Alchian, designed an economic model explaining that the intention of the opportunistic behaviour not necessarily preexist to the formation of the contract ${ }^{1380}$. This is the case where there is a competitive market where the two firms bargain the contract in power parity ${ }^{1381}$ but nonetheless the investments done by one of them turn this firm into economic dependence, exposing that firm to holdup

\footnotetext{
1377 Ibid., 172.

1378 Ibid., 173.

1379 Oliver Hart and John Moore, 'Incomplete Contracts and Renegotiation' [1988] Econometrica: Journal of the Econometric Society 755; Oliver Hart and John Moore, 'Foundations of Incomplete Contracts' (1999) 66 The Review of Economic Studies 115; Ian Ayres and Robert Gertner, 'Filling Gaps in Incomplete Contracts: An Economic Theory of Default Rules' [1989] Yale Law Journal 87; Jean Tirole, 'Incomplete Contracts: Where Do We Stand?' (1999) 67 Econometrica 741.

1380 Benjamin Klein, Robert G Crawford and Armen A Alchian, 'Vertical Integration, Appropriable Rents, and the Competitive Contracting Process' [1978] Journal of law and economics 297.

${ }^{1381}$ Hence, each of them decides choses the 'best option'.
} 
from the business partner. In these cases, it is argued that vertical integration is both a solution to opportunistic holdup ${ }^{1382}$ and a more convenient alternative to contracting ${ }^{1383}$.

We may have, on the other hand, an economic dependence created by market conditions precedent to the stipulation of the contract, which forced one of the parties to accept the terms imposed by the dominant firms and undertake specific investments. The abuse of economic dependence deriving from a superior market power may trigger the application of both contract law and competition law or other rules specifically designed to deal with situations of economic dependence.

The definition of an economic dependency situation is dependent on the dimension of economic power the specific regime puts forward.

Neoclassical price theory has focused on market power, that is, the ability of an undertaking to charge higer prices and reduce output profitably. This presupposes that the undertaking holds power over consumers, who are dependent on the specific undertaking's offer, as they cannot substitute this offer with one from another competing undertaking on the specific relevant market. Neoclassical price theory (NPT) provides the tools to determine the situations where substitution is possible, that is that there is cross price elasticity of demand between different products that will form part of the same relevant market. NPT therefore defines bargaining power more generally, in terms of the ability of an undertaking to introduce a deviation from the price or quantity obtained from the competitive situation in the market in which the transaction takes place. In this context, buying power denotes the ability of a buyer to achieve more favourable terms than those available to other buyers or it would otherwise be expected under normal competitive conditions. The approach emphasizes the gain resulting from the presence of bargaining power relative to a situation in which it is absent (not necessarily that of perfect competition) ${ }^{1384}$, thus focusing on the market structure and concentration $^{1385}$. A typical definition of buyer power in terms of concentration is the following one provided by Roger Noll:

"[B] uyer power" refers to the circumstances in which the demand side of a market is sufficiently concentrated that buyers can exercise market power over sellers. A buyer has market power if the buyer can force sellers to reduce price below the level that would emerge in a competitive market. Thus buyer power arises from monopsony (one buyer) or oligopsony (a few buyers), and is the mirror image of monopoly or oligopoly" ${ }^{\prime 386}$.

In the standard model of monopsony, the supply side of a market is perfectly competitive and is represented by an upward-sloping supply curve. As a mirror image of a monopolist's behaviour, a monopsonist can take advantage of his market power by reducing his demand. The lower price obtained by the buyer reflects the lower marginal cost of supply.

\footnotetext{
1382 Oliver Hart and Jean Tirole, 'Vertical Integration and Market Foreclosure' [1990] Brookings papers on economic activity. Microeconomics 205; Ronald H Coase, 'The Nature of the Firm' (1937) 4 Economica 386.

1383 As a response to a situation in which "quasi rents" are created, Klein, Crawford and Alchian (n 16).

${ }^{1384}$ See, Roger Clarke, Stephen Davies, Paul W. Dobson \& Michael Waterson, Buyer Power and Competition in European Food Retailing, 2 (2002).

1385 John T. Dunlop \& Benjamin Higgins, Bargaining Power and Market Structures, (1942) L(1) The Journal of Political Economy 1, 4-5.

${ }^{1386}$ Roger G. Noll, “Buyer Power” and Economic Policy, (2005) 72 Antitrust Law J. 589.
} 
One may nevertheless take a broader perspective on bargaining power. For instance, an OECD report in 1998 provided the following definition:

"[A] retailer is defined to have buyer power if, in relation to at least one supplier, it can credibly threaten to impose a long term opportunity cost (i.e. harm or withheld benefit) which, were the threat carried out, would be significantly disproportionate to any resulting long term opportunity cost to itself" ${ }^{\prime 1387}$.

The bargaining power in this context emanates from the ability of one side of the market to obtain a concession from the other side, by threatening to impose a cost, or withdrawing a benefit. Hence, here it is the threat and not the act (as for a monopsony) of reducing the quantities of purchase that gives rise to bargaining power. As it was also explained in a document prepared by the German Competition Authority, literature often interprets buyer power as bargaining power and examines it within the context of bargaining theory models, "with the consequence that, for instance, demand-side market power is not expressed by a strategic reduction of quantities, but in bilaterally negotiated individual prices and rebates as well as other purchase conditions" $" 1388$.

What are the competitive effects of monopsony power and bargaining power ${ }^{1389}$ ? With regard to the upstream side, as the monopsonist restricts its input purchases to reduce prices below competitive levels, there might be allocative inefficiency and the buyer may extract supplier surplus. With regard to the downstream side, there is no allocative inefficiency if the monopsonist discriminates perfectly. Consumers do not benefit though from reduced input prices as these do not lead to reduced output prices that are passed to output buyers, to the extent that "the monopsonist may control the price it pays for an input but cannot control the quantity of the input offered for sale at that price" ${ }^{1390}$. Although monopsony is considered as the mirror image of monopoly, buyer-side conduct is regularly treated more leniently than equivalent conduct on the selling side. This relies on the idea that serving large buyers may involve lower distribution costs and lower production costs, leading to important discounts, as the larger the buyer the more credible would be its threat to integrate backwards and produce the good itself ${ }^{1391}$.

One may also distinguish between buyer power, which denotes the ability of buyers to obtain advantageous terms of trade from their suppliers and countervailing power, which characterizes the presence of strong buyers mitigating or even fully averting adverse consequences for consumer surplus or total welfare that would otherwise arise from the exercise of market power at the supply side. Countervailing power on the buyer side may be

\footnotetext{
1387 OECD, Buyer Power of Large Scale Multiproduct Retailers, 6 (1998)

1388 Bundeskartellamt, Buyer Power in Competition law: Status and Perspectives, Meeting of the Working Group on Competition Law on 18 September 2008. See also, Paul W. Dobson, Exploiting Buyer Power: Lessons from the British Grocery Trade, 72 Antitrust Law J. 532 (2005), "(b)uyer power gives retailers more than just the ability to extract discounts and obtain low prices from suppliers; buyer power may manifest itself in the contractual obligations that retailers may be able to place on suppliers".

1389 For a detailed analysis, see Roger D. Blair \& Jeffrey L. Harrison, Monopsony in Law and Economics (Cambridge University Press, 2010).

${ }^{1390}$ Jeffrey L. Harrison, Complications in the Antitrust Reponse to Monopoly, in I. Lianos \& D. Sokol (eds.), The Global Limits of Competition Law (Stanford University press, 2012), 54, at 58.

1391 David Sheffman and Pablo Spiller, Buyers' strategies, entry barriers, and competition, (1992) 30 Economic Inquiry, 418.
} 
an important force offsetting suppliers' increased market power ${ }^{1392}$. The economic analysis of bilateral monopoly or oligopoly, the situation where a lawful monopolist confronts a lawful monopsony, does not offer clear directions. While some authors argue that bilateral monopoly produces welfare effects that are superior to those of monopoly or monopsony and that it does not raise any competition concerns ${ }^{1393}$, others doubt on the possibility of bilateral bargaining to reliably reach an efficient outcome, because of the pervasive presence of private information and incomplete contracts ${ }^{1394}$.

This theoretical discussion has practical interest for competition law enforcement. Although agricultural cooperatives may fall within the scope of competition law, joint purchasing agreements, such as cooperatives, are usually considered positively, as they usually aim at the creation of countervailing buying power which can lead to lower prices or better quality products or services for consumers.

With regard to the definition of the relevant concept of economic power, some scholars have tried to draw a clear boundary between bargaining power, which is considered a contract law issue, and monopoly power, which is viewed as a competition law issue, what we will call the separation thesis. In particular, Trebilcock believes that it is fundamental to differentiate 'situational monopolies' from 'structural monopolies' ${ }^{1395}$. Situational monopolies are transitory states of imbalance in the bargaining position of the parties to an agreement, which can be subject to exploitation. The 'situational monopolist' (in Trebilcock's terms) may take advantage of the business partner by charging prices that are higher than its 'reference price'. For instance, Trebilcock imagines a situation where 'A has violated his own reference price in opportunistically taking advantage of B's temporary dependency ${ }^{1396}$. For Trebilcock, these monopolies should be regulated by contract law. On the other hand, structural monopolies are those that antitrust law should target, as the dominance of the monopolist is market-wide and non-transitory. Here, the dominant firm enjoys a market power that precedes the negotiation of the specific bargain and that impacts on all the market actors ${ }^{1397}$. However, it has already been noted that when the relevant market is narrowly defined, as it may happen in EU competition law, the two situations are indistinguishable and therefore the distinction may lose significance ${ }^{1398}$. Trebilcock maintains that while the problem of competition law is to

${ }^{1392}$ The term was first coined by John Kenneth Galbraith to describe the power developed on one side of the market as a way to counter the market power on the other side of the market. John Kenneth Galbraith, American Capitalism: The Concept of Countervailing Power (1952). See also, Thomas von Ungern-Sternberg, Countervailing power revisited, (1996)14 International Journal of Industrial Organization 507; Paul W. Dobson \& Michael Waterson, Countervailing Power and Consumer Prices, (1997) 107 Economic Journal 418 ; and Zhiqi Chen, Dominant Retailers and Countervailing Power Hypothesis, (2003) 34 Rand Journal of Economics 612.

${ }^{1393}$ Tom Campbell, Bilateral Monopoly in Mergers, (2007) 74 Antitrust law Journal 521; Roger D. Blair \& Christina Depasquale, Bilateral Monopoly and Antitrust Policy, in Roger D. Blair \& Daniel Sokol (ed.), Oxford Handbook of International Antitrust Economics, volume 1 (Oxford University Press, 2015) 364, 377.

${ }^{1394}$ Jonathan B. Baker, Joseph Farrell \& Carl Shapiro, Merger to Monopoly to Serve a Single Buyer, (2008) 75 Antitrust Law Journal 637.

${ }^{1395}$ M J Trebilcock, The Limits of Freedom of Contract (Harvard University Press 1997); Michael J Trebilcock, 'The Doctrine of Inequality of Bargaining Power: Post-Benthamite Economics in the House of Lords' [1976] University of Toronto Law Journal 359.

${ }^{1396} \mathrm{M}$ Trebilcock, The Limits of Freedom of Contract, 94.

${ }^{1397}$ Id. 96.

${ }^{1398}$ P. Akman, 'The Relationship between Economic Duress and Abuse of a Dominant Position' [2014] Lloyd's Maritime and Commercial Law Quarterly 99, 113. 
determine and remedy to market failures, contract deals with contracting failures, which in the particular case of duress, relates to the coercion of voluntariness that may happen in 'situational monopolies'. This is particularly the case for long term contracts where exploitation of a 'bilateral monopoly' is likely to occur ${ }^{1399}$.

One may also attempt to define economic dependence more broadly, not only focusing on consumer, but also on other economic actors that may be subject to economic power and which need to be protected, for a public policy reason. One may think of farmers, small suppliers, or even specific categories of vulnerable consumers. In this context, one may refer to resource dependency theories of Emmerson and other sociologists, such as Cook, who focus on the network position of the economic actors in order to determine the power-dependence of one versus the other, the underlying idea being that "the power of A over B is equal to, and based upon, the dependence of B upon A" ${ }^{1400}$. These intellectual foundations of economic power will be related to the concept of relational market power that has been developed in some competition law literature and we aim in the final version of this paper to include a Section exploring the way this intellectual foundation of economic power may work, and the measurement tools it provides, for instance through advanced social network analysis. Social exchange theory based conceptualization of economic dependence have already been suggested by some scholars, in particular in the context of gauging economic power the food sector $^{1401}$, but the intellectual foundations have not been explored in depth and what remains to be done is to develop an overall theory of economic dependence, in particulal in a network context, that would assist us to determine the comparative institutional advantage (or disadvantage) of competition law, versus other areas of law (contract law, unfair competition, fairness-driven ad hoc legislative interventions to deal with situations of economic dependence.

\subsection{Superior bargaining power and competition law and policy in the food sector}

Several national antitrust authorities have recently delved into the concept of superior bargaining power in the food-retail sector and commissioned studies in order to better operationalize superior bargaining power in competition law enforcement and develop measurement tools. ${ }^{1402}$ Competition law does not only regulate the exercise of bargaining

\footnotetext{
${ }^{1399}$ Id. 111. In this connection, Akman recalls Hovenkamp arguing that "[s]imple bilateral monopoly is not an antitrust problem because bilateral monopoly has no consequences for market prices and output" in Herbert Hovenkamp, 'Harvard, Chicago, and Transaction Cost Economics in Antitrust Analysis' (2010) 57 The Antitrust Bulletin 613, 14.

${ }^{1400}$ R.M. Emmerson, Power-dependence relations, (1962) 27(1) American Sociological Review 31, 33; K.S. Cook \& R.M. Emerson, Power, equity and commitment in exchange networks, (1978) 43(5) American Sociological Review 721.

${ }^{1401}$ H.S. James, M.K. Hendrickson, Ph. H. Howard, Networks, power and Dependency in the Agrifood Industry, in In: James, Jr. H. (eds) The Ethics and Economics of Agrifood Competition. (The International Library of Environmental, Agricultural and Food Ethics, vol 20. Springer, Dordrecht, 2013).

${ }^{1402}$ See, for instance, Competition Commission, The Supply of Groceries in the UK Market Investigation, available at http://webarchive.nationalarchives.gov.uk/ 20140402141250/http://www.competition-commission.org.uk/assets/competitioncommission/docs/pdf/noninquiry/rep_pub/reports/2008/fulltext/538.

pdf; Italian Competition Authority, Indagine Conoscitiva Sul Settore Della GDO' (2013) IC43, available at http://www.agcm.it/indagini-conoscitive-db.html; Bundeskartellamt, Sektoruntersuchung Nachfragemacht Im

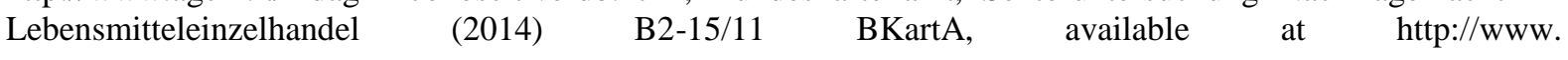


power in the context of a contractual relationship, bilateral or other looser forms of cooperation, but also when this is purely "unilateral", although only in situations where there is a dominant position. Certainly, the concept of 'dominant position' has been more and more assimilated to the concept of "market power", which hinges mainly on the calculation of market shares of the undertaking and its ability to raise prices and reduce output or other parameters of competition (innovation, quality, variety), as the outcomes-oriented definition of neoclassical price theory advanced. However, the way competition authorities define "dominant position" has been quite broad and may include situations of what has been characterized as "non-structural market power", including situations of superior bargaining power.

Indeed, both theory and practice that structural market power is often not necessary for having relative market power toward one or more trading partners. Market shares as low as 10$20 \%$ may be sufficient in some cases to maintain a superior bargaining position. ${ }^{1403}$ Research also suggests that superior bargaining positions of retailers are widespread particularly in the food sector, negatively affecting in particular upstream farmers and SMEs. ${ }^{1404}$ Farmers typically are confronted with high levels of concentration both upstream (input markets for agricultural production, e.g. seeds, Fertilisers and crops) and downstream (e.g. manufactoring and retailers, in particular vertically integrated multinationals), such that they face superior bargaining positions both ways. ${ }^{1405}$

The theory of non-structural market power has been criticized by some authors as not being sufficiently substantial to constitute market power under competition law, and that it should therefore be excluded from competition law assessment ${ }^{1406}$. Two reasons are advanced for this criticism: (i) enforcement agency budgets and judicial resources are scarce and thus, it does not make sense to squander them in attacks on market power over low sales volumes, as it is the case for relational market power and (ii) there are no procedures or specific methodology for measuring the extent of market imperfections, thus permitting the intervention of the competition authority in situations of significant relational market power.

bundeskartellamt.de/Sektoruntersuchung_LEH.pdf?_blob=publicationFile\&v=7; Autorité de la concurrence, Opinion 15-A-06 of 31 March 2015 Concerning the Joint Purchasing Agreements in the Food Retail Sector, available at http://www.autoritedelaconcurrence.fr/pdf/avis/15a06.pdf; Finnish competition authority, Study on Trade in Groceries - How Does Buyer Power Affect The Relations between the Trade and Industry?' (2012) 1 FCA reports, available at http://www.kkv.fi/globalassets/kkv-suomi/julkaisut/selvitykset/2012/en/fca-reports-12012-study-on-trade-in-groceries.pdf.

1403 See J.B. Kirkwood, 'Buyer Power and Exclusionary Conduct: Should Brooke Group Set the Standards for Buyer Induced Price Discrimination and Predatory Bidding?' (2005) 72 Antitrust Law Journal 625, 637-44; W.S. Grimes, 'Buyer Power and Retail Gatekeeper Power: Protecting Competition and the Atomistic Seller' (2005) 72 Antitrust Law Journal 563, 569; P.W. Dobson, 'Exploiting Buyer Power: Lessons from the British Grocery Trade' (2005) 72 Antitrust Law Journal 529, 535; Z. Chen, 'Buyer Power: Economic Theory and Antitrust Policy’ (2007) 22 Research in Law and Economics 17, 31;

${ }^{1404}$ Myriam Vander Stichele and Bob Young, The Abuse of Supermarket Buyer Power in the EU Food Retail Sector Preliminary Survey of Evidence (March 2009).

1405 E.g. OECD, 'Spotlight on Global Value Chains: Does it Mean Shutting Out Small Producers?' in Promoting Pro-Poor Growth: Agriculture (Paris, OECD, 2006), 58; U. Schwager, 'Competition Issues Affecting the Agricultural Sector in Selected Developing Countries: Key Findings From Selected UNCTAD Market Studies' in M. Gal, M. Bakhoum, J. Drexl, E. Fox and D.Gerber (eds.), Economic Characteristics of Developing Jurisdictions: Their Implications For Competiton Law (Edward Elgar 2015), 153-176.

${ }^{1406}$ B Klein, 'Market Power in Antitrust: Economic Analysis After Kodak' (1994) 3 Supreme Court Economic Review 43. 
Despite these criticisms, the concept of relational market power is integrated in modern competition law assessment in two ways. First, the competition law of some States takes directly into account the existence of a situation of 'economic dependency' in the enforcement of competition law, even in the absence of neoclassical market power. ${ }^{1407}$ For example, section 20(2) of the German Act against Restraints of Competition (Gesetz gegen Wettbewerbsbeschränkungen) (GWB) extends the prohibition of abuse of a dominant position to undertakings which do not possess market power in the structural, neoclassical sense, but do have "relative market power" (relative Marktmacht) in their contractual relationships with small and medium enterprises which depend on them. Thus, market power is defined within the bilateral relationship between suppliers and buyers. ${ }^{1408}$ Other juridictions having specific provisions on the abuse of economic dependence based on a concept of relative dominance / market power include France, ${ }^{1409}$ Italy, ${ }^{1410}$ Portugal, ${ }^{1411}$ Czechia $^{1412}$ and Greece. ${ }^{1413}$ In Japan $^{1414}$ and Korea, ${ }^{1415}$ traditional competition law provisions are supplemented with a prohibition of abuse of a superior bargaining position, which have a similar rationale. ${ }^{1416}$

Second, non-structural factors might be taken into account indirectly, in assessing the existence of a dominant position, either by narrowing down the relevant market definition (excluding the price constraints imposed on the specific after-sales services by competing manufacturers under the assumption that consumers take into account the cost of after-sales services when they purchase a product) or by considering it as an additional factor reinforcing the finding of a dominant position, even if the firm does not have high market shares. For instance, the incorporation of such non-structural factors can be seen in the theory of an obligatory partner in EU competition law. In Swiss competition law, Article 4 II of the Swiss Cartel Act defines dominance broadly which also includes a situation of relative dominance towards one or more suppliers or customers. Consequently, a distinction is made between a dominant position in de neoclassical sense and a situation in which a company has customers which are economically dependent upon it even though the company does not have market power vis-à-vis its competitors. ${ }^{1417}$ Other jurisdictions which include a broader concept of dominance not necessarily based on a neoclassical understanding of market power include China and India. ${ }^{1418}$

\footnotetext{
${ }^{1407}$ See generally and for discussion, M Bakhoum, 'Abuse without Dominance in Competition Law: Abuse of Economic Dependence and its Interface with Abuse of Dominance', Max Planck Institute for Innovation and Competition Research Paper No. 15-15.

${ }_{1408}$ Immenga/Mestmäcker, Wettbewerbsrecht. Band 2. GWB Kommentar zum Deutschen Kartellrecht (Beck 2007), § 20.

${ }_{1409}$ Article L 420-2 of the French Commercial Code.

${ }^{1410}$ Article 9 of the Italian Law on Industrial Subcontracting.

${ }^{1411}$ Article 12 Portuguese Competition Act.

1412 T. Fiala, 'Czech Republic: Anti-competitive Practices - Economic Dependence Act' (2014) 35 European Competition Law Review 5.

${ }^{1413}$ E. Truli, 'Relative Dominance and the Protection of the Weaker Party: Enforcing the Economic Dependence Provisions and the Example of Greece' (2017) Journal of European Competition Law \& Practice.

${ }^{1414}$ Article 2 (9)(v) of the Act on Prohibition of Private Monopolization and Maintenance of Fair Trade.

${ }^{1415}$ Article 23(4)(1) of the Monopoly Regulation and Fair Trade Act.

${ }^{1416}$ See further section 3.3.3. below.

${ }^{1417}$ See Swiss Competition Commission, Decision CoopForte [2005] RPW/DPC I 146, in which Coop, the second supermarket chain in Switzerland, demanded a sum equal to $0.5 \%$ of the billing value from its suppliers.

1418 See further section 3.3 .3 below.
} 
The debate over the inclusion or separation thesis notwithstanding, we will explore the various instances in which superior bargaining power considerations were included in competition law analysis, starting with the thorny issue of measuring superior bargaining power, the lack of appropriate, and predictable, measurement being one of the major concerns of those arguing that this concept should not be integrated in competition law.

\subsubsection{Measuring superior bargaining power}

The attention of the competition law enforcers historically lingers on size and market share or concentration of the negotiating parties in order to define their power relations. ${ }^{1419}$ However, scholarly studies on contracts and negotiations take a game/bargaining theory approach arguing that, for the outcome of negotiation, even more important than market shares or the size of negotiating parties is the existence of "threat points" enabling one of the parties to seek a "best alternative to a negotiated agreement" (BATNA). ${ }^{1420}$ Indeed, the negotiating party holding a BATNA has the possibility to resort to a valid alternative to the negotiation in progress or to the contract concluded, preventing hold-up and threats to cease negotiation. In conceiving the bargaining model one may take a Nash cooperative bargaining solution as the axiomatic starting point, ${ }^{1421}$ or resort to a non-cooperative or sequential bargaining model which will attempt to factor in the costs of the delay to agreement, and extend this analysis from bilateral bargaining to n-person bargaining. ${ }^{1422}$ Although it is not clear if the results will be the same under each of these models, their common feature, in contrast to industrial organization theory, is that bargaining power is perceived as a concept that can be measured with reference to a specific bargaining relation in a specific context and it is not dependent on structural analysis (for instance the existence of monopsony or oligopsony). Bargaining power may also impact on price as well as on non-price terms. ${ }^{1423}$ Measuring bargaining power is a difficult exercise that scholars and law enforcers have tried to engage with, adopting diverse approaches.

Attempts to measure bargaining power in the context of the food sector have focused particularly on the demand side bargaining power. Buyer power must not be conflated with monopsony and can take a variety of forms. Carstensen contends that " $\mathrm{t}] \mathrm{he}$ continuum of buyer power is a function of the following factors:

(1) the buyer's market options for its output;

(2) the producer's ease of switching outlets or product lines;

\footnotetext{
${ }^{1419}$ This is for instance the approach by the Commission in its last report for the HLF, European Commission, DG COMP, The Economic Impact of Modern Retail on Choice and Innovation in the EU Food Sector: Final Report, available at http://ec. europa.eu/competition/publications/KD0214955ENN.pdf.

${ }^{1420}$ A. Renda and others, Study on the Legal Framework Covering Business-to-Business Unfair Trading Practices in the Retail Supply Chain, Final Report (2014) DG MARKT/2012/049/E 25, available at http://ec.europa.eu/internal_market/

retail/docs/140711-study-utp-legal-framework_en.pdf; I. Ayres and B. J Nalebuff, Common Knowledge as a Barrier to Negotiation (1996) 44 UCLA L. Rev. 1631.

${ }^{1421}$ Most of these studies have relied on this type of model so far.

${ }^{1422}$ See, for instance, J. Sutton, Non-Cooperative Bargaining Theory: An Introduction, (1986) LIII Review of Economic Studies 709-724; K. Binmore, M. J. Osborne, A. Rubinstein, Non-Cooperative Models of Bargaining, Chapter 7 in Handbook of Game Theory with Economic Applications (Elsevier, 1992), 179-225.

${ }^{1423}$ A. Choi and G. Triantis, The Effect of Bargaining Power on Contract Design (2012) Va. L. Rev. 1665.
} 
(3) the quantities that the buyer takes from any one producer as a percentage of its purchases of that input; and

(4) the percentage of its own output that a producer sells to a single buyer."1424

In its report on the supply of groceries, the UK Competition Commission investigated the degree of buyer power of grocery retailers vis-à-vis suppliers. The Commission tries to define "buyer power" tautologically as being able to "obtain a better deal from its suppliers in terms of prices, product quality or purchasing terms, for example, compared with grocery retailers that do not have buyer power". In its assessment of the grocery sector, the possession of buyer power by grocery retailers is assessed by looking at four types of evidence:

(1) the relative size of grocery retailers compared to suppliers;

(2) the prices and margins that suppliers are able to negotiate with grocery retailers;

(3) the share of the retail price that is earned by grocery retailers and others; and

(4) a review of e-mail correspondence between two retailers and their suppliers, including e.g. evidence of below-cost selling by suppliers that would be difficult be difficult to explain in the absence of retailer buyer power.

In Japan, abuse of a superior bargaining position is prohibited by the Antimonopoly Act. ${ }^{1425}$ In its Guidelines Concerning Abuse of Superior Bargaining Position under the Antimonopoly Act, the Japan Fair Trade Commission defines a superior bargaining position as follows. Party A has a superior bargaining position over Party B in the following situation: (1) Party A makes a request that is substantially disadvantageous for Party B. and (2) Party B would be unable to avoid accepting such a request on the grounds that Party B has difficulty in continuing the transaction with Party A and thereby Party B's business management would be substantially impeded.

The existence of a superior bargaining position is determined by considering four sets of facts, taking into account both structural and non-structural factors:

1. The degree of dependence by Party B on the transactions with Party A, which if Party B is the supplier is measured with reference to the amount of sales by Party B to Party A, divided by Party B's total amount of sales;

2. The structural market position of Party A, i.e. its market share and ranking;

3. The possibility of Party $B$ to change its business by starting or increasing its transactions with another party other than Party A, for instance based on Party B's specific investments for its transactions with Party A;

4. Other factors indicating the need for Party B to carry out transactions with Party A, including for example the amount of transactions with Party A and the relative business size of Party A. ${ }^{1426}$

In 2014, the German Bundeskartellamt concluded an in-depth study in the food retail sector, where it attempted to measure superior bargaining power ("demand side power" -

${ }^{1424}$ Peter C. Carstensen, Competition Policy and the Control of Buyer Power. A Global Issue (Edward Elgar 2017), ch. 3.

${ }^{1425}$ Article 2 (9)(v) of the Act on Prohibition of Private Monopolization and Maintenance of Fair Trade.

${ }^{1426}$ Japan Fair Trade Commission, Guidelines Concerning Abuse of Superior Bargaining Position under the Antimonopoly Act (30 November 2010), p. 5-6, available at http://www.jftc.go.jp/en/legislation_gls/imonopoly_guidelines.files/101130GL.pdf. 
"Nachfragemacht") econometrically by exploring the conditions of its existence. ${ }^{1427}$ The conditions of bargaining power were converted into independent variables used for the econometric assessment. The selection of the independent variables was performed on the basis of a survey. In particular, the Bundeskartellamt looked into the procurement market of branded products for several reasons, including the fact that they form the core business of retailers, they are at the center of the majority of competition complaints and they are easier to compare and identify. ${ }^{1428}$ The authority initially divided the products object of negotiations into four categories: "product category," xxx“"must-stock items," "items listed at a discounter" and "high-turnover items." Furthermore, they identified seven procurement markets with different market structures. In order to identify and order the branded products forming the statistical population belonging to the sample, the authority used the European Article Number (EAN). The authority then interviewed the retailers and manufacturers about the results of their negotiations on each EAN article. In particular, the Bundeskartellamt inquired about the switching possibilities to alternative negotiating partners and about the overall competitive environment. The authority noted that negotiations between producers and merchants take place once a year. In these negotiations producers and merchants bargain over the conditions for the business relationships of the following year. Yet, the Bundeskartellamt also acknowledged that the sole focus on procurement volumes is not sufficiently differentiated to provide valid conclusions for the definition and measurement of demand-side bargaining power. For its econometric assessment, the Bundeskartellamt considered different determinants in order to describe the individual bargaining position of each party and did not base itself only on market concentration and the existence of a monopsony or an oligopsony. The bargaining model construed on the basis of this theoretical approach can be summarized as following:

$\mathrm{K}$ [conditions of superior bargaining power] $=\mathrm{f}\left(\mathrm{x}\right.$ [amount ordered]; $\mathrm{D}^{1-6}$ [bargaining determinants, which indicates the "Drohpunkte" (threat points), that is, the best alternative to negotiate ] $)^{1429}$.

These are the following:

\footnotetext{
${ }^{1427}$ Bundeskartellamt, Sektoruntersuchung Nachfragemacht Im Lebensmitteleinzelhandel (2014) B2-15/11 BKartA, available at http://www.bundeskartellamt.de/Sektoruntersuchung_LEH.pdf?_blob=publicationFile\&v=7 (hereinafter Bundeskartellamt Food Retail Report)

${ }^{1428}$ The other market identified by the Bundeskartellamt is the one of private labels, which the authority describes as characterized by a different "bargaining logic," although deeply influencing the negotiations for branded products. Private labels are usually bargained through tenders, while branded products are traded with annual negotiations. However, in its econometric study the Bundeskartellamt states that "private labels are actually considered in the assessment of the "competitive environment" of the branded products," see Bundeskartellamt, Summary of the Final Report of the Sector Inquiry into the Food Retail Sector, 8. In this connection the Bundeskartellamt observes that private labels are often considered as part of a different market with respect to branded products. However, they can be often used in negotiations to put pressure on manufacturers of branded products, at 11 .

${ }_{1429}$ Hence, the Bundeskartellamt especially focusses on the walk-away point in the specific negotiation and how it is influenced by different factors for each party.
} 
- Alternative distribution paths for producer $\mathrm{p}$ (other than with retailer $\mathrm{r}$ ) or even alternative production paths (switching to different product) $=$ outside options of producer; ${ }^{1430}$

- Outside options of retailer: importance of the product for the retailer (is delisting a credible threat?); ${ }^{1431}$

- Brand strength: if consumers expect certain brands, then delisting is improbable; ${ }^{1432}$

- Competition by other producers/brands which creates opportunities for $r$ to circumvent $\mathrm{p}{ }^{1433}$

- r's own brands ("Handelsmarken"): these must be substitutable for brands of $p$, and p must not be (by chance) the actual producer of r's own brands; the Report notes the trend towards private labels even in the premium segment; ${ }^{1434}$

- Buyer cooperation: bundling buying power ${ }^{1435}$.

The conditions adopted for this analysis were not only price terms but also non-price terms, such as deadline for payment and agreements on delivery. A fundamental stage of the Bundeskartellamt's assessment was the reckoning of the importance of a retailer for its suppliers and the evaluation of the "outside options" of both parties. The definition of "outside option" given by the authority resembles closely to the one of the BATNA, "the better a party's outside options, the better the conditions that party is able to negotiate." ${ }^{1436}$ Not surprisingly, the Bundeskartellamt concluded in this study that the purchasing volumes "have a decisive impact on the negotiating conditions, ${ }^{1437}$ and therefore constitute one of the main advantages of major retailers vis-à-vis their smaller competitors in negotiations. Furthermore, the authority determined that the well-known branded products "the delisting of which would most likely result in a disproportionate decline in turnover for that retail company, has the effect that its manufacturer is able to achieve better conditions." ${ }^{438}$ In such cases, the producer is in a stronger bargaining position, since the retailer has no BATNA. ${ }^{1439}$

\footnotetext{
${ }^{1430}$ Bundeskartellamt Food Retail Report, 321.

${ }^{1431}$ Bundeskartellamt Food Retail Report, 322.

${ }^{1432}$ Bundeskartellamt Food Retail Report, 323.

${ }^{1433}$ Bundeskartellamt Food Retail Report, 324. However the Bundeskartellamt states that this is only true if two conditions are assumed. Firstly the other brand has to pose a sufficient substitution to the article which is the subject of the negotiations and secondly that the producer of the relevant article is not also the producer of the alternative trade brand. The Bundeskartellamt measures the value of this influence with the help of a survey in which the undertakings were asked to assess the importance of alternative brands. Furthermore the survey asked for an assessment of the substitutability of the specific article through the alternative on a scale from $0 \%$ to 100 $\%$..

${ }^{1434}$ Bundeskartellamt Food Retail Report, 324-325.

1435 Membership in a buyer group reduces the outside-options of the supplier and thereby may lead to better conditions for the demand side. The impact of the membership is measured by adding a variable which is 1 for "yes" and 0 for "no". In a second step it is measured whether an undertaking is a "big" or a "small" member of such a group. Thereby a variable only gets the value one, when the undertaking is not the one with the highest turnover in the group.

${ }^{1436}$ Bundeskartellamt, Summary of the Final Report of the Sector Inquiry into the Food Retail Sector, 10.

${ }^{1437}$ Bundeskartellamt, Summary of the Final Report of the Sector Inquiry into the Food Retail Sector, 10.

${ }^{1438}$ Bundeskartellamt, Summary of the Final Report of the Sector Inquiry into the Food Retail Sector, 10.

${ }^{1439}$ However, these so-called "must-have" products accounted only to $6 \%$ of the sample adopted by the authority that, according to the same authority, can be reasonably taken as representative of the whole food-retail national market.
} 
In a 2012 sector inquiry, the Italian Competition Authority studied the bargaining power of retailers and suppliers on the basis of three different "clusters" of undertakings, reaching comparable results. ${ }^{1440}$ These "clusters" were obtained by comparing several data, including the overall turnover, the number of retailers supplied, the "strength" of the brand (especially in the specific geographic area). In particular, these three groups or "clusters" were: i) undertakings with high bargaining power; ii) undertakings with medium bargaining power and iii) undertakings with low bargaining power. ${ }^{1441}$ The data published by the ICA relatively differs from that of the Bundeskartellamt, but still shows a situation of prevalence of retailers' superior bargaining position, irrespective of market concentration levels. On the basis of their clusters, the ICA concluded that in the $23.4 \%$ of their sample, the supplier holds a strong bargaining position (not necessarily stronger than the retailer) and is not economically dependent on the retailer. In the $48.8 \%$ of cases, the suppliers showed an intermediate degree of dependence from the retailers. Finally, the $27.8 \%$ of the sample highlighted a high level of dependence. ${ }^{1442}$ It is worth observing that both the Italian and German retail sectors are moderately concentrated, if compared to others such as the Finnish, Latvian or Swedish. ${ }^{1443}$

Both studies by the German and the Italian competition authorities engage with what may be considered as captive value chains in the GVC approach terminology and attempt to develop appropriate measurement tools for superior bargaining power. Competition authorities have also attempted to gauge with superior bargaining power in exploring certain conduct that reinforces retail power vis-à-vis farmers or processors.

\subsubsection{Purchasing cooperation agreements and superior bargaining power}

Competition authorities around the world have increasingly looked into buying alliances and joint purchasing agreements concluded between major retail chains, these agreements becoming more common following the food crisis of 2008. Group purchasing organisations ("GPOs") may take different forms of governance structure depending on the level of integration they select, spanning from jointly controlled companies to looser forms of cooperation, collectively referred to as "joint purchasing arrangements" 1444 . From the point of view of the size of retailers, group purchasing organisations are generally of two types. The first type consists in a multilateral agreement formed by retailers of the same size which by bundling their purchase volumes intend to increase their bargaining power vis-à-vis the suppliers. Recently, however, antitrust authorities registered a tendency to form purchasing groups where there is one dominant retailer and several smaller retailers. ${ }^{1445}$ In this type of

\footnotetext{
${ }^{1440}$ Italian Competition Authority, Market Investigation in the Retail Sector (2012).

${ }^{1441}$ Italian Competition Authority, Market Investigation in the Retail Sector (2012), 162.

${ }^{1442}$ Italian Competition Authority, Market Investigation in the Retail Sector (2012), 162.

${ }^{1443}$ European Commission, The Economic Impact of Modern Retail on Choice and Innovation in the EU Food Sector, 131.

${ }^{1444}$ European Commission, Guidelines on the Applicability of Article 101 of the Treaty on the Functioning of the European Union to Horizontal Co-Operation Agreements, vol OJ [2011] C 11, 194, available at http://eurlex.europa.eu/LexUriServ/LexUriServ.do?uri=OJ:C:2011:011:0001:0072:EN:PDF.

${ }^{1445}$ See, for instance, Italian Competition Authority, Case I768 Centrale Italiana S.c a r.l; Bundeskartellamt, Summary of the Final Report of the Sector Inquiry into the Food Retail Sector, 5; Autorite de la concurrence, Opinion 15-A-06 of 31 March 2015 Concerning the Joint Purchasing Agreements in the Food Retail Sector.
} 
agreements, the smaller retailers generally issue mandate contracts to the "head" of the purchasing cooperation in order to negotiate the conditions of procurement for the whole organisation. These forms of cooperation generally include several other conditions in order to coordinate selling practices and share information, especially about procurement costs. ${ }^{1446}$

The findings of the national competition authorities corroborate the view that these purchasing cooperation agreements have, in many cases, an almost negligible effect on the bargaining power of the major retailers, while, in the short term, they improve the bargaining position of the smaller retailers. ${ }^{1447}$ This is true even when, as it is apparently the case, the head of the purchasing organisation does not pass on the benefit of the bargain in whole. ${ }^{1448}$ Yet these agreements may also lead to long-term forms of cooperation, including the sharing of sensitive information, and may create the conditions for the economic dependence of the smaller retailers that often structure their business model to the one dictated by the cooperation agreement. ${ }^{1449}$ In addition, the coordination of the selling practices may cause the "homogenization" of the assortments and of the services offered by the undertakings participating to the buying alliance, thus dampening competition. ${ }^{1450}$

In analysing these agreements the competition authorities had departed from a strict application of the concept of dominance and adopted a broad understanding of market distortions. Bargaining power does not necessarily depend on the market share owned by a specific firm in the relevant market, neither on the level of concentration. If a producer owns an important share of the market but, nonetheless, has to bargain with retailers disposing of valid alternatives to the negotiation, such as other substitutable brands or private label products, the bargaining power of that producer will most probably be limited. On the other hand, a concentrated local retail market, where a retailer holds an important share, may still be open to balanced negotiations, if the producers have valid "outside alternatives," both nationally and internationally, instead of negotiating with that retailer. For instance, the extent of the geographic presence at national and international level of the retail chain is able to considerably influence the negotiations, since its demand is difficult to be substituted and it is particularly relevant to reach economies of scale, possibly creating a situation of economic dependence of the supplier. ${ }^{1451}$ In France, the Autorité de la concurrence explored allegations of abuse of superior bargaining power when examining three different cooperation agreements among the six most important French retailers (Système U/Auchan, ITM/Casino, Carrefour/Cora). ${ }^{1452}$ The Autorité pointed out that these agreements may fall within the scope of the prohibition of anticompetitive agreements, in view of the exchange of sensitive information between competitors and/or can be addressed according to abuse of economic dependence provisions. With regard to the latter, the Autorité found that the narrow approach adopted so far with regard

\footnotetext{
${ }^{1446}$ This is for instance the situation described by the ICA in the Case Centrale Italiana S.c. a r.l.

${ }^{1447}$ Bundeskartellamt Food Retail Report; Italian Competition Authority Case Centrale Italiana S.c. a r.l.; Autorité de la concurrence, Opinion 15-A-06 of 31 March 2015 Concerning the Joint Purchasing Agreements in the Food Retail Sector.

${ }^{1448}$ Bundeskartellamt Food Retail Report; Case 1768 Centrale Italiana S.c. a r.l.

${ }^{1449}$ Bundeskartellamt, Summary of the Final Report of the Sector Inquiry into the Food Retail Sector, 19.

${ }^{1450}$ Case 1768 Centrale Italiana S.c. a r.l.

${ }^{1451}$ Italian Competition Authority, Market Investigation in the Retail Sector, 212.

${ }^{1452}$ Autorité de la concurrence, Opinion Concerning the Joint Purchasing Agreements in the Food Retail Sector.
} 
to the definition and measurement of economic dependence led to under-enforcement of these provisions and called for "an amendment to the procedure aimed at establishing the existence of abuses of economic dependency in order to make it more effective."1453

\subsubsection{Abuse of economic dependence provisions}

Competition authorities also focus on the implementation of specific provisions on abuse of economic dependence, which may emerge in various situations. In the first scenario, two firms bargain the contract in power parity and in a competitive market, but nonetheless the investments made by one of them put this firm into a situation of economic dependence, exposing it to hold-up from its business partner. In the second scenario, the economic dependence may result from market conditions pre-existing to the stipulation of the contract, which forced one of the parties to accept the terms imposed by the other party and to undertake specific investments. With regard to its causes, the situation of economic dependence may derive from the absence of "outside options" for one of the business parties, or from high switching costs. ${ }^{1454}$ The food market presents plenty of opportunities for hold-up and anticompetitive conduct engendered by situations of economic dependence. ${ }^{1455}$ Farmers generally undertake specialized capital investments to provide the products at the local and international standards, under contractual arrangement with buyers. In particular, in markets of perishable products with few buyers, this contractual relationship easily turns into an economic dependence of the farmer to the buyer. Moreover, the particular conditions of the market of perishable products may be the cause of hold-up due to lack of alternatives for logistic reasons. Indeed, some products, such as chicken or sugar beets, have to be marketed locally, as they cannot be shipped far without losing much of their value. Processors and local buyers can therefore use this opportunity to impose low prices on farmers or non-favourable conditions.

Provisions on abuse of a situation of economic dependence is a well-known feature of some competition law regimes in Europe and Japan/Korea, and to some extent the theory may have influenced EU competition law's theory of "obligatory trading partner". There are also provisions about abuse of economic dependence in some BRICS countries.

\subsubsection{Abuse of economic dependence provisions in European competition laws}

As mentioned above, Section 20(2) of the German Act against Restraints of Competition contains an extension of the prohibition of abuse of economic dependence. German law distinguishes between various forms of economic dependence, namely dependence based on a strongly branded product or range of products (sortimentsbedingte Abhängigkeit), business-related dependency arising out of a long-standing business

\footnotetext{
${ }^{1453}$ Autorité de la concurrence, Press Release: Opinion 15-A-06 of 31 March 2015 Concerning the Joint Purchasing Agreements in the Food Retail Sector, 7, available at http://www.autoritedelaconcurrence.fr/pdf/avis/15a06.pdf, xxxin French.

${ }^{1454}$ Italian Competition Authority, Market Investigation in the Retail Sector, 200.

${ }^{1455}$ J. M. MacDonald and P. Korb, Agricultural Contracting Update: Contracts in 2008 (2011) EIB-72. U.S. Dept. of Agriculture, Econ. Res. Serv. Economic Information Bulletin No. 72.
} 
relationship between the SME and the undertaking concerned (unternehmensbedingte Abhängigkeit), shortage dependence which pertains to the scarcity of a product (mangelbedingte Abhängigkeit) and technical dependence (technisch bedingte Abhängigkeit). ${ }^{1456}$ In an early case law on abuse of economic dependence, the German Federal Court of Justice (Bundesgerichtshof) observed that a situation of economic dependence is manifested by "insufficient and unacceptable means of switching to other undertakings", which may also be the case when there is "lively competition" on the market. ${ }^{1457}$

French law also contains specific rules concerning abuse of economic dependence. Article L 420-2 of the Commercial Code prohibits abusive exploitation by a company of a customer or supplier that is economically dependent on that company, whenever this abuse is susceptible to affect the functioning or structure of competition. However, the last condition indicates that the prohibition of abuse of economic dependence does not function fully independent of a neoclassical economic conception of competition law. As a result, enforcement of Article L 420-2 in vertical relationships is more difficult ${ }^{1458}$ and the provision cannot be equated with Article 20(2) GWB. The Autorite de la Concurrence applied the provision on abuse of economic dependence in the Carrefour case. ${ }^{1459}$ Food retailer Carrefour had created a network of contractual relationships with distributors with the effect of creating interlinked dependency relationships. Carrefour concluded franchise agreements with individual distributors lasting seven years, and with one month difference in signing date, agreements with the same distributors on the commercialization of Carrefour's products. These agreements contained several obligations for the individual distributors and other provisions allowing Carrefour to coordinate its distribution, including a one-year cancellation notice, the right of Carrefour to veto decisions including on capital cession, loyalty rebates and arbitration clauses. The Competition Authority however concluded that each of the agreement should be assessed individually and found no situation of economic dependence as the content of the agreements was part of the contractual freedom of the parties. ${ }^{1460}$

Italian law also contains a provision on the prohibition of abuse of economic dependence (abuso di dipendenza economica) which is however not formally part of Italian competition law. While the initial draft law qualified abuse of economic dependence as equal to abuse of a dominance position in the 'traditional' sense, any reference to dominance has been removed from the law, following a opposition by the Italian Antitrust Authority. ${ }^{1461}$ The scope of application of the provision is, moreover, still unclear with widely diverging interpretations in the case law; while some courts argued that abuse of economic dependence

\footnotetext{
${ }^{1456}$ P. Këllezi, 'Abuse below the Threshold of Dominance? Market Power, Market Dominance, and Abuse of Economic Dependence' in M.O. Mackenrodt, B.C. Gallego and S. Enchelmaier (eds), Abuse of Dominant Position: New Interpretation, New Enforcement Mechanisms? (Springer 2008), 61-62.

${ }^{1457}$ Bundesgerichtshof, Rossignol, BGH NJW 1976, 801 (1975).

${ }^{1458}$ Ibid., 63-65.

1459 Autorité de la Concurrence, Décision n 10-D-08 du 3 mars 2010 relative à des pratiques mises en œuvre par Carrefour dans le secteur du commerce d'alimentation générale de proximité.

${ }^{1460}$ For a critical analysis of the decision, see L. Boy, 'Abus de dépendance économique: Reculer pour mieux sauter?' [2010] $\mathrm{n}^{\circ}$ 23, Revue Lamy Concurrence, 93; and M. Bakhoum, 'Abuse without Dominance in Competition Law: Abuse of Economic Dependence and its Interface with Abuse of Dominance', Max Planck Institute for Innovation and Competition Research Paper No. 15-15, 6-7.

1461 AGCM, Opinion of 20 June 1995 on Industrial Subscontracting; and Opinion of 10 February 1998 on Industrial Subscontracting. See further Këllezi, 'Abuse below the Threshold of Dominance?', 68-69.
} 
is only applicable to subcontracting agreements, in light of its legislative context and literal meaning, other courts have held that the prohibition may apply to all kinds of interactions between undertakings or agreements that are similar to subcontracting agreements. ${ }^{1462}$ Focusing on the relations between supplier and buyer, the Italian competition authority identifies four broad categories of economic dependence: i) dependence on assortment of the retailer, typically linked to branded products, which defines the lack of alternatives to a particular product or group of products; ii) dependence for shortage of supply sources, where the economic dependence originates from a situation of temporary lack of the specific product on the market; iii) dependence of the supplier, due to the fact that the supplier produces a significant share of its sales with a single buyer; iv) dependence on trade relations, in which the dependence originates from the significant asset-specific investments made by a contractor in order to fulfil its commitments and the difficulty to redeploy those investments for other purposes. ${ }^{1463,1464}$

By contrast, in its study into the joint purchasing agreements in the food retail sector, the French competition authority considers four different criteria for determining a situation of economic dependence: i) the importance of the share of revenue generated by that supplier with the distributor; ii) the importance of the distributor in the marketing of the products concerned; iii) the absence of deliberate choice of supplier to concentrate its sales from the distributor; iv) the absence of alternative solutions supplier. ${ }^{1465}$

However, both authorities conclude that this situation of economic dependence often gives rise to opportunistic hold-ups from the party enjoying superior bargaining position. In particular, these authorities observe that often retailers request contract modifications or additions to dependent suppliers, threatening to delist the supplier's product or to impose other forms of retaliation. ${ }^{1466} \mathrm{In}$ its sector inquiry, the ICA observed that the $67 \%$ of the respondent suppliers reported requests of modifications or additions to the supply contracts during their executions. ${ }^{1467}$ In several cases, the request of the retailer to modify or add contract terms also regarded discount terms and expenditures, which were already been negotiated, having therefore a retroactive effect. ${ }^{1468}$ From the sample adopted, the authority stressed that the $74 \%$

\footnotetext{
${ }^{1462}$ For an overview of this case law, see Valeria Falce, 'The Italian Regulation against the abuse of economic dependence', paper presented at the 10th ASCOLA Conference (Tokyo 21-23 May 2015).

${ }^{1463}$ Italian Competition Authority, Market Investigation in the Retail Sector, 201.

${ }^{1464}$ See further, Valeria Falce, 'Abuse of Economic Dependence and Competition Law Remedies: A Sound Interpretation of the Italian Regulation' (2015) 36 European Competition Law Review 71.

${ }^{1465}$ Autorité de la concurrence, Opinion Concerning the Joint Purchasing Agreements in the Food Retail Sector, 72.

${ }^{1466}$ Autorité de la concurrence, Opinion Concerning the Joint Purchasing Agreements in the Food Retail Sector, 81; Italian Competition Authority, Market Investigation in the Retail Sector, 200.

${ }^{1467}$ Italian Competition Authority, Market Investigation in the Retail Sector, 163. In detail, the respondents replied that this coercive modification of the contract happens: for the $45 \%$ "sometimes," for the $18 \%$ "often", and for the 4\% "always."

${ }^{1468}$ In this regard, the ICA points out that "[i]t is particularly interesting to note that the majority of respondents (74\%) perceive, always or sometimes, these requests for unilateral modification of contract terms as binding for the supplier, which is exposed in the event of rejection, to specific retaliation, such as 'delisting' (that is, the exclusion from the list of suppliers), total or only for some products, or an unjustified worsening of the conditions for the following procurement period" (our translation). The ICA, therefore, acknowledges that $20 \%$ of respondents stated that they accept the requests "always," 37\% "often," 38\% said they accept them "sometimes," and only 5\% said they accept them "never," at 163 .
} 
of the respondents who refused to modify the contract accordingly to the retailer's request, reported having suffered retaliation, either by delisting ( $62 \%$ of respondents), or by "clear and unjustified worsening of contract terms for the following procurement period"1469 (59\% of respondents), or by adoption of both delisting and worsening of contract terms (47\% of respondents). Moreover, according to this study, framework procurement contracts are often stipulated after the start of the supply period, ${ }^{1470}$ and the following contracts detailing the procurement agreement are almost always negotiated during the supply period, ${ }^{1471}$ leaving therefore ample margin for the integration of the contract by the dominant party.

These findings seem to support those studies claiming that the adoption of incomplete agreements (such as framework contracts), which parties detail during the execution, exposes the economic dependent undertaking to opportunistic hold-ups. ${ }^{1472}$ In 2011 , the Spanish National Commission for Competition (now "CNMC"), published a report on the relations between manufacturers and retailers in the food sector, with the aim to describe the status quo of the relations between retailers and suppliers and analyse the impact on competition of the alleged bargaining power of large distributors. ${ }^{1473}$ The CNC found that the contracts linking suppliers with retail chains were occasionally left incomplete as for the consideration required, thus producing uncertainty, inefficient transfer of risk on the suppliers and a reduction of intrabrand competition. ${ }^{1474}$

Moving outside the EU, both Japan and Korea regulate the abuse of a superior bargaining position, serving goals similar to the provisions on abuse of economic dependence. The Korean Monopoly Regulation and Fair Trade Act prohibits unfair business practices including "making a trade with a transacting partner by unfairly taking advantage of his position in the business area". ${ }^{1475}$ The Korea Fair Trade Commission examines the possible

\footnotetext{
${ }^{1469}$ These procurement contracts were generally annual and subject to renegotiation every year.

${ }^{1470}$ In their sample, the $35 \%$ of respondents always negotiate the framework agreement before the start of the supply period, the $19 \%$ declared that this happens "often," and the $45 \%$ admitted that this happens only "sometimes"; see Italian Competition Authority, Market Investigation in the Retail Sector, 162.

${ }^{1471}$ Italian Competition Authority, Market Investigation in the Retail Sector, 163.

${ }^{1472}$ O. E Williamson, Transaction-Cost Economics: The Governance of Contractual Relations (1979) Journal of law and economics 233; B. Klein, R. G. Crawford and A. A. Alchian, Vertical Integration, Appropriable Rents, and the Competitive Contracting Process (1978) Journal of law and economics 297. Based on this theory, Klein, Crawford and Alchian designed an economic model explaining that the intention of an opportunistic behaviour does not necessarily preexist to the formation of the contract, as it may also result from an asset-specific investment of the business partner.

${ }^{1473}$ Comision Nacional de la Competencia, Report on the Relations between Manufacturers and Retailers in the Food Sector, available at: http://www.cncompetencia.es/Inicio/Informes/InformesyEstudiossectoriales/tabid/228/Default.aspx.

${ }^{1474}$ OECD, Latin American Competition Forum, Competition Issues in the Groceries Sector: Focus on Conduct Contribution from $\quad$ Spain, $3, \quad$ available at http://www.oecd.org/officialdocuments/publicdisplaydocumentpdf/?cote=DAF/COMP/LACF(2015)5\&docLang uage=En,. In the wake of the CNC's recommendations, the Spanish Parliament approved the Law 12/2013 on measures to improve the functioning of the food supply chain (LCA), with the threefold aim to detail the conditions and characteristics of contracts between retailers and suppliers, lay down a "black list" of prohibited "abusive" practices, and empower the newly created Food Industry Information and Control Agency (AICA) to fine undertakings that fail to comply with these requirements. The Spanish Competition authority is highly critical of this new system where its competence overlaps in some cases with that of the Ministry responsible in the specific sector and with the new competences of the AICA, alleging that this has created a futile duplication of norms and institutions.

${ }^{1475}$ Article 23(1)(4) of the Monopoly Regulation and Fair Trade Act.
} 
existence of a superior bargaining position mainly in light whether and how feasible the transaction counterparty may "find" a "replacement" for the current business relationship. Since revising its Guidelines in 2015, it has added that a superior bargaining position requires a continuing transaction relationship to emphasise a "lock-in" effect and "considerable" dependence of the opposite party on the party allegedly having a superior bargaining position. ${ }^{1476}$ Examples of abuse of superior bargaining position include forced purchases, imposing sales targets, imposing any disadvantages, and interference with business management. $^{1477}$

In Japan, Article 2(9)(v) of the Anti Monopoly Act (AMA) prohibits as unfair trade practices:

"engaging in any act specified in one of the following by making use of one's superior bargaining position over the counterparty unjustly, in light of normal business practices: (a) causing the counterparty in continuous transactions (including a party with whom one newly intends to engage in continuous transactions; the same applies in (b) below) to purchase goods or services other than those to which the relevant transactions pertain (b) causing the counterparty in continuous transactions to provide money, services or other economic benefits

(c) refusing to receive goods in transactions with the counterparty, causing the counterparty to take back such goods after receiving them from the counterparty, delaying payment to the counterparty or reducing the amount of payment, or otherwise establishing or changing trade terms or executing transactions in a way disadvantageous to the counterparty".

Certain other practices not listed under this section may also be designated as unfair trading practices. ${ }^{1478}$ Moreover, sector-specific designations have been made, for example for the newspaper section and large-scale retailers. ${ }^{1479}$ While abuse of a superior bargaining position is a longstanding part of Japanese competition law, its use and function is still widely debated. Most commentators seem to argue that it is anomaly in the Anti Monopoly Act that is not necessarily in line with the goals of competition law. ${ }^{1480}$ However, the regulation of superior bargaining power can be justified with reference to the specific characteristics of the Japanese legal system in which weaker contractual parties might not be able to protect themselves against opportunistic behavior by parties with greater bargaining power, thus

\footnotetext{
${ }^{1476}$ KFTC, Guidelines on the Review of Unfair Trade Practices. See also T.K. Cheng and M.S. Gal, 'Superior Bargaining power: Dealing with Aggregate Concentration Concerns', paper presented at the 10th ASCOLA conference (Tokyo, 21-23 May 2015).

1477 Ibid.

1478 Article 2(9)(vi) AMA.

1479 See further Florian Wagner-von Papp, 'Unilateral Conduct by Non-Dominant Firms: A Comparative Reappraisal', paper presented at the 10th ASCOLA conference (Tokyo, 21-23 May 2015).

1480 See e.g. M. Wakui and T.K. Cheng, 'Regulating Abuse of Superior Bargaining Position under the Japanese Competition Law: An Anomaly or a Necessity?' (2015) 0 Journal of Antitrust Enforcement 1; Shigekazu Imamura, Dokusen kinshi ho nyumon [Introduction to Antimonopoly Law] (Yuhikaku Publishing 1993).
} 
justifying the prohibition of abuse of superior bargaining power as a supplement to standard contract law. ${ }^{1481}$

\subsubsection{Abuse of economic dependence in BRICS}

As of current, none of the BRICS countries' general competition law frameworks contain specific provisions on abuse of economic dependence or superior bargaining power. However, at least in Brazil, India, Russia and China, the general competition law provisions on abuse of a dominant position could be applied to sanction abuse of economic dependence. A comparative analysis of these countries reveals diverse approaches to the issues of dominance and abuse of power or economic dependence. While some of them openly accept the use of the concepts of "bargaining power" and "economic dependence" as a possible alternative to market share/NPT inspired market power tests (for example India and China), other have adopted a NPT approach, based on the calculation of the market share in order to determine dominance on a relevant market (Russia and Brazil).

Brazilian law does not explicitly contemplate any rule on abuse of economic dependence, abuse of superior bargaining power or the concept of obligatory trading partner. ${ }^{1482}$ However, the CADE maintains that it would be possible to sanction an undertaking for abuse of superior bargaining power, as the "claim could be based on any of these effects / purposes, even though there is not a clear definition of the infraction". ${ }^{1483}$ Article 36 of the Brazilian Competition Act indeed provides a non-exhaustive list of violations, thus leaving room for miscellaneous infringements including abuse of economic dependence. ${ }^{1484}$ However, CADE has been careful to not intervene in the freedom of contract, in relation to conduct within the sphere of private relations. In 2009, for instance, CADE analysed whether AMBEV had imposed quotas, engaged in resale price maintenance with its distributors and sold directly to supermarkets, among other practices. ${ }^{1485} \mathrm{CADE}$ decided that there was no infringement related to the distribution network, since those were private matters and discontinued the proceedings.

Looking at the express violations in Article 36, it seems possible to subsume abuse of economic dependence under "arbitrary increase of profits" (indent III), since it operates independently of a "restraint of free competition" (indent I), control of the relevant market (indent II), or abuse of dominance (indent IV). In practice, however, CADE has been quite reluctant to refer to this indent to base infringements in general.

\footnotetext{
${ }^{1481}$ For this argument, see M. Wakui and T.K. Cheng, 'Regulating Abuse of Superior Bargaining Position under the Japanese Competition Law: An Anomaly or a Necessity?' (2015) 0 Journal of Antitrust Enforcement 1, 2731.

1482 ICN, 'Report on Abuse of Superior Bargaining Position' (2008) 10.

1483 ibid 12.

1484 "The acts which under any circumstance have as an objective or may have the following effects shall be considered violations to the economic order, regardless of fault, even if not achieved:

I - to limit, restrain or in any way injure free competition or free initiative;

II - to control the relevant market of goods or services;

III - to arbitrarily increase profits; and

IV - to exercise a dominant position abusively".

${ }^{1485}$ PA 08012.004363/2000-89, decided on 28 October 2009.
} 
Abuse of economic dependence could also be regarded as an abuse of a dominant position. However, the Brazilian Competition Act maintains a structural interpretation of dominance, ${ }^{1486}$ such that economic dependence or superior bargaining power vis-à-vis a trading partner alone seems insufficient. Correspondingly, while CADE has already examined cases dealing with abuse of economic dependence and has reasoned about the connection between dependency and market power, no infringement has ever been found based exclusively on economic dependence, devoid of general market conditions. As Berardo and Becker state, "CADE highlighted that dependency, i.e. one seller depending exclusively or almost exclusively on purchases made by one purchaser, does not in itself necessarily correspond to buying power, which obviously depends on aggregate market output and purchases". ${ }^{1487}$

Likewise, India has no specific rules on abuse of economic dependence or superior bargaining power. However, contrary to Brazil, Indian competition law give a broader definition of a dominant position, which includes non-structural factors. According to the Explanation of Article 4 of the Indian Competition Act, in considering a dominant position, the Competition Commission shall take into consideration, amongst other factors, the economic power of the enterprise including commercial advantages over competitors, the dependence of consumers on the enterprise, and countervailing buyer power. ${ }^{1488}$ Indeed, the CCI has clarified that "the market share of an enterprise is 'only one of the factors that decides whether an enterprise is dominant or not, but that factor alone cannot be decisive proof of dominance" 1489 . In a number of cases before it, the CCI has identified the existence of unequal bargaining power

${ }^{1486}$ Article $36 \S 2$ of the Brazilian Competition Act: "A dominant position is assumed when a company or group of companies is able to unilaterally or jointly change market conditions or when it controls $20 \%$ (twenty percent) or more of the relevant market, provided that such percentage may be modified by Cade for specific sectors of the economy".

1487 Jose Carlos da Matta Berardo, and Bruno Bastos Becker, in Pierre Kobel, Pranvera Këllezi and Bruce Kilpatrick (eds), Antitrust in the Groceries Sector \& Liability Issues in Relation to Corporate Social Responsibility (2015) 101.

${ }^{1488}$ Article 4 Explanation (a) defines dominant position as follows:

"a position of strength, enjoyed by an enterprise, in the relevant market, in India, which enables it to-

(i) operate independently of competitive forces prevailing in the relevant market; or

(ii) affect its competitors or consumers or the relevant market in its favour".

In considering dominance, the Competition Commission has to take into consideration, as for Art. 19(4), the following factors:

(a) market share of the enterprise;

(b) size and resources of the enterprise;

(c) size and importance of the competitors;

(d) economic power of the enterprise including commercial advantages over competitors;

(e) vertical integration of the enterprises or sale or service network of such enterprises;

(f) dependence of consumers on the enterprise;

(g) monopoly or dominant position whether acquired as a result of any statute or by virtue of being a Government company or a public sector undertaking or otherwise;

(h) entry barriers including barriers such as regulatory barriers, financial risk, high capital cost of entry, marketing entry barriers, technical entry barriers, economies of scale, high cost of substitutable goods or service for consumers;

(i) countervailing buying power;

(j) market structure and size of market;

(k) social obligations and social costs;

(I) relative advantage, by way of the contribution to the economic development, by the enterprise enjoying a dominant position having or likely to have an appreciable adverse effect on competition;

(m) any other factor which the Commission may consider relevant for the inquiry".

${ }^{1489}$ Mr Ramakant Kini v Dr L H Hiranandani Hospital, Powai, Mumbai, Case No.39 of 2012, 14. 
between parties to contracts, ${ }^{1490}$ whereas in several other cases parties themselves have pressed this principle. ${ }^{1491}$ Regardless, however, CCI has not specifically addressed superior bargaining power issues in its orders until now.

Somewhat similarly, Article 17 of the Chinese Anti-Monopoly Law (AML) (中华人民 共和国反垄断法) provides that the assessment of the existence of a dominant position depends on many factors, beyond market shares, such as the extent to which other undertakings rely on the undertaking in question, thus indirectly referring to situations of economic dependence ${ }^{1492}$. Until now, however, to our knowledge there have not been any cases implementing the dependence perspective in interpreting Article 18 AML.

Nonetheless, explicit incorporation of abuse of superior bargaining power provisions is debated currently both with respect to the AML as well as the Anti-Unfair Competition Law. ${ }^{1493}$ An amendment of the AML was initiated in 2015 by the National Development and Reform Commission; one of the main issues touched upon by the amendment is whether the provision on superior bargaining power should be added to the AML. The draft amendment (to which SAIC contributed) was published by the Legislative Affairs Office of the Administration in February 2016 for public consultation.

The inclusion of a provision to govern superior bargaining power into the AML has long been suggested by the majority of Chinese scholars and the recent amendments ignited again the debate. Most Chinese scholars support the view that superior bargaining power (SPB) should be regulated by Chinese Antimonopoly Law (AML), ${ }^{1494}$ although some are more critical. ${ }^{1495}$

With respect to the inclusion of abuse of economic dependency (or of superior bargaining power), Russian general competition law seems to follow an approach similar to Brazil. In principle, Article 10 of the Competition Act makes it possible to sanction certain forms of abuse of economic dependence by dominant undertakings, such as imposing contractual terms unprofitable for the counteragent, unjustified production reduction, and unjustified refusal to deal. ${ }^{1496}$

${ }^{1490}$ Belaire Owners' Association Vs. DLF Limited, HUDA \&Ors. (Case No. 19/2010) - Abuse of Dominant
Position in Real Estate Industry.
${ }^{1491} \mathrm{M} / \mathrm{s}$ Rajarhat Welfare Association \&Anr. v/s DLF Commercial Complexes Ltd. \&Ors. (Case No. 10 of 2011
, Dated: 25.05.2011) at Para 2.6; Case No. 13 \& 21 of 2010 and Case No. 55 of 2012 at par 5.24.
${ }^{1492}$ Article 10, SAIC Rules on Abuse of Dominance; Article 18, NDRC Rules on Anti-Price Monopoly Conduct.
${ }^{1493}$ With regard to the Anti-Unfair Competition Law, see section 3.3.6 below.
${ }^{1494}$ See, for instance, Prof. Yanbei MENG 孟雁北 : 《滥用相对经济优势地位行为的反垄断法研究》, 载《
法学家》2004 年第6 期; Prof. Shiying XU, http://qiduojun.csu.edu.cn/shichangguizhifa/512.html (explaining
that that Article 18 AML should offer the basis for relevant regulation); and Dr. Qiang YU
(http://www.cqvip.com/qk/89400a/201604/74909067504849544852484856.html), arguing that it is necessary to
apply anti-monopoly law to superior bargaining power because, firstly, abuse of a superior bargaining power
distorts the product value chain and, finally, leads to higher prices or a decline in product quality.
For example Prof.

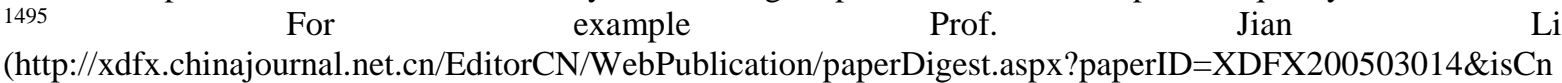
$\mathrm{ki}=\mathrm{ck} 01$ ) argued that the theory SPB has major defects, and its inclusion into competition law will produce negative implications to the theoretical analysis and legal practice for both antitrust law and unfair competition law, resulting in theoretical and practical chaos.

1496 Article 10 Competition Law:

"[...] 3) imposing contractual terms upon a counteragent which are unprofitable for the latter or not connected with the subject of agreement (economically or technologically unjustified and (or) not provided for directly by 
However, as in Brazil, the concept of dominance is to a large extent interpreted with respect to the structure of the market as a whole, taking market shares as a principal starting point. ${ }^{1497}$ Thus, the evaluation of bargaining power of market actors or the assessment of economic dependence that might be established between some of them, seems not to be a factor triggering the application of Russian competition law rules ${ }^{1498}$. Indeed, the Russian antitrust authority has confirmed that they reject the application of a notion of abuse of superior bargaining power of economic dependence independent from the analysis of the market power of the dominant firm, as "only a company(s) with substantial degree of market power can effectively exploit vertically integrated upstream and downstream trade partners and, therefore, general behavioral legal provisions for market dominant firms suffice"1499.

With respect to the food sector specifically, Article 13 of the Federal Law on the Basic Principles of State Regulation of Trading Activities in the Russian Federation of 25 December 2009 , seems to leave open the possibility of abuse of economic dependence or superior bargaining power. Article 13 deals exclusively with the supply of food products and provides a list of conducts that may fall foul of competition regulation, some of which, such as creating and imposing discriminatory conditions to contractual counterparties, seem to operate independently from the assessment imposed by Article 5 of the Antimonopoly law. ${ }^{1500}$ Hence,

the Federal Laws, statutory legal acts of the President of the Russian Federation, statutory legal acts of the Government of the Russian Federation, statutory legal acts of the authorized federal executive authorities or judicial acts, requirements for transferring financial assets, other property, including property rights, as well as consent to conclude a contract on conditions of including in it provisions, concerning the goods in which the counteragent is not interested and other requirements);

4) economically or technologically unjustified reduction or cutting off the production of goods if there is demand for the goods or orders for their delivery are placed and there is possibility of its profitable production, as well as if such reduction or cutting off the production of goods are not provided for directly by the Federal Laws, statutory legal acts of the President of the Russian Federation, statutory legal acts of the Government of the Russian Federation, statutory legal acts of the authorized federal executive authorities or judicial acts;

5) economically or technologically unjustified refusal or evasion form concluding a contract with individual purchasers (customers) in the case when there are possibilities for production or delivery of the relevant goods as well as if such a refusal or evasion is not provided for directly by the Federal Laws, statutory legal acts of the President of the Russian Federation, the Government of the Russian Federation, authorized federal executive authorities or judicial acts".

1497 Article 5 of the Russian Antimonopoly Law: "The position of an economic entity (except financial organizations) is recognized as dominant:

1) whose share in the certain goods market exceeds fifty per cent if only in the course of examination of the case of violation of the antimonopoly legislation or in the course of exercising state control over economic concentration it would be established that despite the excess of the aforementioned quantity position of the economic entity in the goods market is not dominant;

2) whose share in the certain goods market is less than fifty per cent in case the dominance of this economic entity was established by the antimonopoly body proceeding from stable or subjected to insignificant changes share of the economic entity in the market as compared to the shares of its competitors in this goods market, opportunities for access to this goods market of new competitors, or proceeding from other criteria characterizing goods market".

1498 At first glance, the Russian competition law seems to be solidly based on structural underpinnings of the analysis of dominance.

1499 ICN, 'Report on Abuse of Superior Bargaining Position' (2008) 17.

${ }^{1500}$ Article 13 of the Federal Law on the Basic Principles of State Regulation of Trading Activities in the Russian Federation:

"Antimonopoly Rules for Economic Entities Involved in Trading Activities and Economic Entities Supplying Food Products 
it may be possible to argue that, at least potentially, the FAS is enabled to deal with cases of abuse of economic dependence or superior bargaining power in the market of supply of food products.

South Africa does not have separate provisions on abuse of economic dependence, and maintains a structural definition of dominance based primarily on market shares. ${ }^{1501}$ However, merger assessment allows for a justification on public policy grounds. In considering whether a merger can or cannot be justified on public policy grounds, the South African Competition Commission must take into account "the effect that the merger will have on (a) a particular industrial sector or region; (b) employment; (c) the ability of small businesses, or firms controlled or owned by historically disadvantaged persons, to become competitive; and (d) the ability of national industries to compete in international markets." 1502

\section{Table 1: Abuse of economic dependence and abuse of superior bargaining power in BRICS}

1. Economic entities, involved in trading activities for sale of food products through organization of a trade network, and economic entities, supplying food products to trade networks, are forbidden to:

1) Create discriminatory conditions including:

a) Preventing entry/exit of other economic entity to/from the market;

b) Violating pricing procedures established by normative legal acts;

2) Impose conditions upon a counteragent:

a) On prohibiting the economic entity to enter into contracts for supply of food products with other economic entities involved in similar activities as well as other economic entities on similar or other conditions;

b) On liability for failure to honor the obligations of the economic entity for supplies of food products on conditions that are better than conditions for other economic entities involved in similar activities;

c) On providing information by the economic entity to the counteragent about contracts concluded by the economic entity with other economic entities involved in similar activities;

d) On paying the fee by the economic entity, supplying food products, for the right to supply such goods to the economic entity, involved in trading activities through organizing a trade network, in operational or newly opened trading facilities;

e) On paying the fee for changing the range of food products by the economic entity;

f) On reducing the prices by the economic entity, supplying food products, to the level, when with mark-up (surcharge) added, the price shall not exceed the minimum price for such goods in the trade by economic entities involved in similar activities;

g) On compensating damages by the economic entity, supplying food products, caused by loss of or damages to such goods after transfer of ownership for such goods, except when losses or damages were caused due to the fault of the economic entity, supplying such goods;

h) On compensating the costs, not related to execution of the contract for supply of food products and further sale of a particular consignment of such goods, by an economic entity;

i) On returning the food products that were not sold upon expiry of the designated period, to the economic entity that had supplied such goods, except when returning such goods is allowed or is provided for by the law of the Russian Federation;

j) Other conditions if they contain essential signs of the conditions provided for by sub-clauses "a" - "i" of this Clause;

k) Exercise wholesale trade under a commission agent agreement or a mixed agreement with elements of a commission agent agreement.

2. An economic entity can present evidence that its actions (omissions) specified in Part 1 of this Article (except actions specified in Clause 2 Part 1 Article 1 of this Article) can be allowed under Part 1 Article 13 of No.135-FZ Federal Law "On Protection of Competition" of 26th July 2006 (further on referred to as the Federal Law "On Protection of Competition")".

${ }^{1501}$ Article 7 of the Competition Act, which reads: "A firm is dominant in a market if - (a) it has at least $45 \%$ of that market; (b) it has at least $35 \%$, but less than $45 \%$, of that market, unless it can show that it does not have market power; or (c) it has less than $35 \%$ of that market, but has market power." Article 7 (c) could theoretically be understood as including instances of relative market power and superior bargaining power.

${ }^{1502}$ Article 12A(3) of the Competition Act. 


\begin{tabular}{|l|l|l|}
\hline & $\begin{array}{l}\text { Abuse of economic dependence } \\
\text { without structural market power }\end{array}$ & $\begin{array}{l}\text { Superior bargaining power / } \\
\text { Public policy }\end{array}$ \\
\hline Brazil & $\mathrm{No}$ & $\mathrm{No}^{1503}$ \\
\hline Russia & $\mathrm{No}$ & $\mathrm{No}^{1504}$ \\
\hline India & Yes (vis-à-vis consumers) & 1505 \\
\hline China & Potentially & $\mathrm{Yes}^{1506}$ \\
\hline South Africa & No & Potentially $^{1507}$ \\
\hline
\end{tabular}

Source: Author's compilation

\subsubsection{Mergers and effects-based analyses integrating superior bargaining power generated unilateral effects}

The criterion of a "significant impediment of effective competition" in merger control also offers some flexibility in order to assess unilateral effects that may be provoked by superior bargaining power. In the Edeka case, concerning the proposed acquisition of Kaiser's Tengelmann by Edeka, the Bundeskartellamt observed that although the target company had low market shares at the national level, in some regions, it was the strongest and closest competitor of the two major groups, Edeka and Rewe, with local and regional market shares between $10 \%$ and $30 \% .{ }^{1508}$ Moreover, on the procurement side the Bundeskartellamt researched 11 procurement markets in various groceries. Edeka's market share accounted for up to 35\% depending on the procurement market, with Kaiser's accounting for only 2-5\%. However, Edeka was the strongest competitor of the three leading retailer groups - Edeka, Rewe and Scharz - already having a strong bargaining position in the procurement market. The merger would lead to the elimination of one of the few independent competitors, further increasing concentration of the demand structure. The resulting loss of competitive pressure and the increase of economic dependency of suppliers on the three leading retailer groups would furthermore be reinforced by the fact that Kaiser's was a member of a purchasing cooperation which formed a direct alternative to the leading retailers for manufacturers. For these reasons, the Bundeskartellamt concluded that the acquisition of Kaiser by Edeka would have created a

\footnotetext{
1503 According to one of CADE's spokesman, it would be however possible to take into consideration a case of superior bargaining power under the present regulation, see ICN, 'Report on Abuse of Superior Bargaining Position' (2008) 12.

1504 Although Article 13 of the Federal Law "On the Basic Principles of State Regulation of Trading Activities in the Russian Federation" of 25 December 2009, available here: http://en.fas.gov.ru/legislation/legislation_50728.html, applies standards not directly related to market dominance.

1505 Article 4.2 (a)(f) Competition Act.

1506 Article 4.2 (a) of the Competition Act.

1507 Public policy exception, limited to mergers, see Article 12A.

${ }^{1508}$ Bundeskartellamt, Case B2-96/14 Edeka/Kaiser's Tengelmann, available at http://www.bundeskartellamt.de/SharedDocs/Entscheidung/DE/Entscheidungen/Fusionskontrolle/2015/B2-9614.pdf?_blob=publicationFile \&v=3.
} 
significant impediment to effective competition ("SIEC") despite the absence of dominance post-merger..

The SIEC test does not require market dominance, thus allowing the authority to impede a merger also in cases of non-coordinated or unilateral effects resulting from the dissolution of an important competitor. These effects have to be evaluated for both the downstream and the upstream markets. With particular reference to the procurement sector, the U.K. Competition Commission considered that the further imbalance of the bargaining positions created by the merger may lower the "levels of investment in new products or manufacturing techniques" and produce "adverse effects on product innovation and diversity." ${ }^{1509}$ Moreover, in more than one occasion, the EU Commission has warned against the possible anticompetitive effects that superior buyer power may create in the downstream sector, due to the discounts that the new merged entity is able to obtain to the detriment of competitors. ${ }^{1510}$

European antitrust authorities have engaged with several other potentially anticompetitive effects following an abuse of superior bargaining power, such as "waterbed effects" or "spiraling effects," 1511 or the foreclosure and collusive effects caused by category management ${ }^{1512}$ or by slotting allowances. ${ }^{1513}$ The recent study commissioned by the European Commission on The Economic Impact of Modern Retail also raises the possibility that retail concentration at local level may produce negative aggregate dynamic effects, through the reduction of the incentives of suppliers to innovate. ${ }^{1514}$

In the US, considerations of bargaining power have been paramount in several merger cases. For instance, in ProMedica the FTC blocked the merger between ProMedica, a major health care system in Ohio and a local community hospital. Post-merger ProMedica would have a market share of $58.3 \%$ in the acute-care inpatient service market and $80.5 \%$ in the inpatient obstetrical services market. The district court examined the effects on competition with significant emphasis to the bargaining leverage resulting from the merger, noting that "the respective degrees of bargaining leverage are determined by how each party would fare if no agreement were reached [...] Failure to reach an agreement depends on the hospital's and

${ }^{1509}$ UK Competition Comm, Safeway plc Inquiry, 2003, § 1.22(d).

${ }^{1510}$ See, for instance, EC Commission, Carrefour/Promodes, COMP M/16847, 2 December 1999; Kesko/Tuko IV/M.78420 November 1996.

${ }^{1511}$ Both analysed by the Bundeskartellamt Food Retail Sector Inquiry, 25; Autorité de la concurrence, Opinion Concerning the Joint Purchasing Agreements in the Food Retail Sector, 56. The "waterbed effects" may result from a merger downstream which leads to marginal costs reductions and lower input prices for the merged entity, which sees its output rising, while at the same time raising the input prices of the merged entity's competitors, leading to an adverse effect on final consumers. On the "waterbed effects," see, R. Inderst and T. Valletti, Buyer Power and the "Waterbed Effect" (2011) 59(1) Journal of Industrial Economics, 1-20; P. Dobson and R. Inderst, Differential Buyer Power and the Waterbed Effect: Do Strong Buyers Benefit or Harm Consumers? (2007) 28(7) ECLR, 393-400; A. Majumdar, Waterbed Effects and Buying Mergers, CCP Working Paper 05-7 (2007).

${ }^{1512}$ Finnish competition authority, Study on Trade in Groceries, 26.

${ }^{1513}$ Italian Competition Authority, Market Investigation in the Retail Sector, 133.

${ }^{1514}$ European Commission, DG COMP, The Economic Impact of Modern Retail on Choice and Innovation in the EU Food Sector, (2014), available at http://ec.europa.eu/competition/publications/KD0214955ENN.pdf, 36. However, the study also found that "a large imbalance away from suppliers and towards modern retailers was generally found to be associated with more innovation, reflecting in particular the finding that greater supplier concentration was associated with less innovation," although it was also noted that the Member States in the sample did not include those with the highest level of national retailer concentration. The methodology of measuring the level of innovation followed in this study was also quite narrow as innovation essentially referred to the introduction of "new EAN products" (EAN being European Article Number). 
health plan's respective "walk-away" points." 1515 It also considered the relevance of ProMedica's relative bargaining power toward particular trading partners, noting that "a hospital may have greater bargaining power with respect to some of its services by virtue of the attractiveness of its offerings and/or the lack of alternative providers for those services. [...] A hospital with enhanced bargaining power for certain services can also exploit the bargaining power across additional services, leading to higher rates for any number of the hospital's services." 1516 The $6^{\text {th }}$ Circuit Court of Appeals affirmed the anti-competitive effect of the merger and the FTC's divestiture order. ${ }^{1517}$

The SIEC test is not the only mechanism to integrate superior bargaining power in the assessment of mergers and acquisitions. In South Africa, superior bargaining power was taken into account in the Wal-Mart/Massmart case via the public interest provision in the Competition Act. ${ }^{1518}$ In September 2010, Wal-Mart announced that it intended to acquire a controlling interest in Massmart, a wholesaler and retailer in South Africa. Wal-Mart had no presence in South Africa and Massmort had a market share of at most $25 \%$ of certain segments of the relevant market and was smaller than the two key competitors, Checkers and Pick n Pay. While the South African Competition Commission initially cleared the merger without conditions, ${ }^{1519}$ on appeal the CAC identified several public interest concerns as a result of WalMart's enormous global purchasing power. The CAC considered there was a threat of loss of sales and employment by local supplies as Massmart would have incentive to make use of WalMart's global procurement network, substituting local supplies for imported supplies. Notwithstanding the limited structural market power, the global value chain dimension of the case would result in superior bargaining power of Massmart post-merger vis-à-vis small, medium and micro sized suppliers. The CAC held that the public interest provision in the Competition Act should not be used as a surrogate for industrial policy and subjected the merger to the condition that a solution should be identified to counteract the merger-specific risks of the transaction, particularly the impact on local small, medium and micro producers and their interactions with the global value chain of the merged entity. ${ }^{1520}$

In conclusion, distortion of negotiations via abuse of superior bargaining position may happen at any node of the value chain and may take different forms. The NCAs have started to analyse how and to what extent superior bargaining power can distort competition and to develop tools and methods for its measurement.

\subsubsection{Dealing with Superior Bargaining power outcomes (price discrimination) via specific legislation of general application (not "mainstream" competition law)}

\footnotetext{
1515 FTC v. ProMedica Health Sys., Inc., 2011-1 Trade Cas. (CCH) ๆ 77,395 (N.D. Ohio Mar. 29, 2011), paras 52-53.

1516 Ibid para 67.

1517 ProMedica Health System, Inc. v. F.T.C., 2014 WL 1584835 (6th Cir. Apr. 22, 2014).

1518 Article 12A of the 1998 Competition Act.

${ }^{1519}$ Commission case number: 2010Nov5445.

${ }^{1520}$ Competition Appeal Court: 110/CAC/Jun11 and 111/CAC/Jun11 (9 March and 9 October 2012).
} 
Vigorous competition can depend on charging different prices to customers. Buyer-induced price discrimination can harm consumer welfare by limiting choice, raising rivals' costs, lowering incentives to compete and serve consumers, and enhancing market power. Buyers can induce price discrimination without market power, to the extent that they have bargaining power in a particular transaction. Much of the discussion in the U.S. concerning price discrimination has centered on whether a plaintiff must allege injury to competition, and what that might entail. Courts may presume injury in vertical cases, and even when plaintiffs must establish the fact, they need only show the diversion of sales or profits. The Supreme Court has narrowed the claim by requiring rivals to compete for the same customer ${ }^{1521}$.

The Act June 19, $1936^{1522}$, also known as the Robinson-Patman Act (RP Act), introduced a ban on price discrimination in the American antitrust regulation. The Act forbids price differentiation for goods of like grade or quality sold to competing buyers. By the mid1930s the trend toward vertical integration was on the rise and the hostility against concentration, especially in the retail sector, raised in paralle ${ }^{1523}$. It was the eve of the Great Depression, which hit particularly hard on small businesses. This added to the fact that for many the Clayton Act was not well equipped to protect smaller retailers from the buying power of large concentrated retailers and, therefore, it was necessary to "curb and prohibit all devices by which large buyers gained discriminatory preferences over smaller ones by virtue of their greater purchasing power." 1524 . The U.S. Congress enacted the price discrimination laws in response to two perceived threats to competition. The first threat involved the ability of large suppliers to price discriminate on a regional basis and thereby underprice, weaken, and ultimately eliminate local competitors. The second threat focused on the ability of large buyers to negotiate materially lower prices from suppliers relative to smaller rivals, the result of which could suppress competition. ${ }^{1525}$ While Congress did not link fairness concerns to Neoclassical Price Theory, undertakings cannot price discriminate in perfectly competitive markets. ${ }^{1526}$

Paradoxically, while the Act was at least partially targeted at price discrimination induced by large buyers negotiating more favourable terms with their SME suppliers, the RP Act only contains one section on the liability of buyers. § 2(f) prohibits the knowing inducement or receipt of discriminatory prices, but this liability is generally derivative, requiring first a preliminary finding of seller liability. ${ }^{1527}$ For this reason, $\S 2$ (f) can hardly be used to combat industry-wide price discrimination where downstream companies possess superior bargaining power vis-à-vis all or most suppliers, as the supplier would typically have a meeting competition-defence. ${ }^{1528}$

\footnotetext{
1521 See infra ...

152215 USC 13 (2012) (unofficial date by which Act is current), http://www.law.cornell.edu/uscode/uscprint.html.

1523 Herbert Hovenkamp, The Opening of American Law: Neoclassical Legal Thought, 1870-1970 (Oxford University Press 2014) 222.

${ }^{1524}$ FTC v. Henry Broch \& Co., 363 U.S. 166, 168 (1960).

1525 Joseph P. Bauer \& Earl W. Kintner, The Robinson-Patman Act: A Look Backwards, A View Forward, 31 ANTITRUST BULLETIN 571, 579 (1986), http://ssrn.com/abstract=2335063.

1526 See Daniel J. Gifford \& Robert T. Kudrle, The Law \& Economics of Price Discrimination in Modern Economies: Time for Reconciliation? p. 16, Research Paper No. 08-21, http://ssrn.com/abstract=1188722.

${ }^{1527}$ D.E. Ray, 'Buyer Liability Under Section 2(f) of the Robinson-Patman Act' (1981) 15 University of Richmond Law Review 547.

${ }^{1528}$ Cf. Great Atl. \& Pac. Tea Co. v. FTC, 440 U.S. 69, 78 (1979).
} 
The Robinson-Patman Act purportedly filled a void left by the Sherman Act. ${ }^{1529}$ To apply, the Sherman Act requires an agreement between two or more persons, or the existence or likelihood of monopoly power. The RP Act can remedy and deter unilateral pricing that causes anticompetitive or unfair results in the absence of monopoly. ${ }^{1530}$ The Act does not aim solely to promote efficiency. Congress sought to help small businesses, as a source of social and political welfare in society. Yet the Act does not shield small businesses from the pricecuts that larger undertakings can effectuate because of scale economies or efficiencies in operation or distribution. ${ }^{1531}$ An undertaking will charge different prices because it can, due to market power, or because higher costs associated with conducting business dictate charging higher prices to a particular set of customers. ${ }^{1532}$

Courts have interpreted the RP Act to address price differences, not necessarily economic price discrimination, which occurs when an undertaking earns varying rates of return selling to distinct customers. The undertaking sets a different ratio of price to marginal cost on different sales. ${ }^{1533}$ American courts have carved out from the Act two different types of price differences. The firsts, also called primary-line cases, entail a differentiation of prices through discounts among competing sellers ${ }^{1534}$ and it is generally the result of predatory pricing ${ }^{1535}$. Secondary line cases are instead the result of a discrimination among the seller's customers, for which some are 'favored' and other 'disfavored' according to the pricing conditions of the seller ${ }^{1536}$.

The Act provides two affirmative defenses. $\S 2$ (a) sets-out a cost defense, while $\S 2$ (b) institutes a meeting competition defense. The cost defense arises more frequently because of its link to efficiency. The defense allows suppliers to pass-on to buyers cost savings realized due to the buyer's efficiency. A seller can avoid liability by demonstrating that it "had a higher

\footnotetext{
${ }^{1529}$ The RP Act does not address promotional services squarely. Plaintiffs have attempted to avoid the competitive injury requirement and defenses applicable under $\S 2$ (a) by arguing that courts should evaluate certain promotional services under $\S 2(\mathrm{e})$. The FTC has argued that for $\S 2(\mathrm{e})$ to apply, a "seller must offer [a] special package size primarily to convey a promotional message." Brief of Amicus Curiae the Federal Trade Commission in Support of Defendants-Appellants \& Reversal, Woodman's Food Market, Inc. v. The Clorox Co. \& Clorox Sales, No. 153001, pp. 3, 9 (7th Cir. 2015). The issue can arise under $\S 2$ (a) and the meeting competition defense, since companies might argue that they did not price discriminate and that they provided the same value to customers even if the company charged different prices, to the extent that promotional assistance accounted for the shortfall. See Richard M. Steuer, Crossing the Streams of Price \& Promotion Under the Robinson-Patman Act, 27(1) ANTITRUST 64, 65, 67 (Fall 2012), http://ssrn.com/abstract=2184291.

${ }^{1530}$ See Bauer \& Kintner, supra n.3 at 587-88.

${ }^{1531}$ Id. 588-89.

${ }^{1532}$ E. Thomas Sullivan, Herbert J. Hovenkamp, Howard A. Shelanski \& Christopher Leslie, Secondary-Line Differential Pricing \& the Robinson-Patman Act, Legal Studies Research Paper Series No. 2013-138, p. 15, http://ssrn.com/abstract=2319067.

${ }^{1533} I d$. at p. 1. For price discrimination to apply, § 2(a) states that different prices must apply to products of "like grade or quality". In FTC v. Borden Co., 383 U.S. 637 (1966), the U.S. Supreme Court held that the FTC can determine grade from product characteristics rather than consumer preferences. The Court found the requirement satisfied because Borden was selling identical milk at different prices simply based on whether the milk carried the Borden label or a private label. Sullivan et al., supra n.8 at pp. 35-36.

${ }^{1534}$ D Daniel Sokol, 'Analyzing Robinson-Patman' (2015) 83 The George Washington Law Review 264, 2070.

${ }^{1535}$ See Volvo Trucks N. Am., Inc. v. Reeder-Simco GMC, Inc., 546 U.S. 164, 176 (2006): "Primary-line cases entail conduct-most conspicuously, predatory pricing-that injures competition at the level of the discriminating seller and its direct competitors.".

${ }^{1536}$ Id.: "Secondary-line cases ... involve price discrimination that injures competition among the discriminating seller's customers ...; cases in this category typically refer to 'favored' and 'disfavored' purchasers."
} 
marginal cost with respect to the disfavored buyer than [it] did for the favored buyer." 1537 The defense creates an incentive for buyers to enhance productive efficiency, as they strive to earn individual discounts that might follow from such cost savings. ${ }^{1538}$

Courts have interpreted the Robinson-Patman (RP) Act to require a low threshold for competitive harm. A plaintiff can establish price discrimination with evidence of a mere price difference.

The existence of price discrimination does not extensively reveal the health of competition in a particular market, but only that perfect competition does not exist, which hardly indicates the presence of monopoly power. ${ }^{1539}$ Even if price discrimination weakens or excludes a rival, intensified competition can produce identical consequences. ${ }^{1540}$

The meeting competition defense may apply haphazardly or invite collusion, since a defendant first must ascertain whether a rival has offered a lower price. ${ }^{1541}$ A seller may call upon the defense only when it has a good faith belief that a rival has offered a discount below its asking price to a particular customer. Sellers cannot rely on mere rumors of price concessions. ${ }^{1542}$ The seller can establish a good faith belief by gathering documentary evidence, market data, and assessing the reasonableness of the claim in terms that include the seller's previous experience with particular buyers. ${ }^{1543}$ Courts do not want sellers verifying price quotes with rivals, since secrecy encourages competition and contributes a critical obstacle to rivals stabilizing industry prices. ${ }^{1544}$

Critics also have argued that the Act features disproportionate remedies. The Federal Trade Commission can secure "broad injunctive relief of long duration," and private parties can recover treble damages. ${ }^{1545}$ Non-dominant companies may respond by refraining from pricing activities that generally benefit consumers. ${ }^{1546}$

In particular, the Act likely inhibits three common instances of procompetitive price discrimination: (1) price reductions to select customers in oligopolistic markets; (2) price reductions offered in new territories to facilitate entry; and (3) discounts targeted at distributors that operate efficiently or that innovate. ${ }^{1547}$

With the first instance concerning oligopolistic markets, an undertaking might earn additional profits by offering lower prices to an individual customer to win its business. The incentive to provide a lower price would dissipate, however, if the undertaking had to offer a

\footnotetext{
${ }^{1537}$ Id., p. 38.

${ }^{1538}$ See Kirkwood, supra n.2, p. 38.

${ }^{1539}$ Cooper et al., supra n.44, p. 44.

${ }^{1540} I d$., p. 49. In a footnote, the U.S. Supreme Court once stated that a plaintiff can establish competitive injury from price discrimination by showing the favored buyer "passed on" the discount by offering a lower retail price. Yet the pass-through does not indicate concentration in the supplier market, and pass-through invariably would occur in a perfectly competitive buyer market. See Alexei Alexandrov \& Sergei Koulayev, Using the Economics of Pass Through in Proving Antitrust Injury in Robinson-Patman Cases, pp. 1, 13, (discussing J. Truett Payne, 451 U.S. at _ n.4 (pin-cite not provided)), https://papers.ssrn.com/sol3/papers.cfm?abstract_id=2555952.

${ }^{1541}$ See Bauer \& Kintner, supra n.3 at 582.

1542 See Sullivan et al., supra n.8 at pp. $43-44$ (quoting U.S. v. United States Gypsum Co., 438 U.S. 422, _ (1978) (pin-cite not provided)).

${ }^{1543}$ Id., pp. 44-45 (quoting U.S. Gypsum, 438 U.S. at _ (pin-cite not provided)).

${ }^{1544}$ Id., p. 45 (quoting U.S. Gypsum, 438 U.S. at __ (pin-cite not provided)).

1545 Id. 582-83.

1546 See id. 583

${ }^{1547}$ Id.
} 
general price reduction, because lower prices to all customers would curtail overall profits. ${ }^{1548}$ In any event, rivals likely would match a market-wide price reduction, blocking the undertaking from gaining new customers. Critics have asserted that absent the RP Act, companies more frequently would lower prices selectively, which would initiate the competitive responses that would reduce prices economy-wide. ${ }^{1549}$

In the second instance, to overcome brand loyalty and switching costs when entering a new market, an undertaking similarly may have to lower price below the market level or add promotional benefits, such as altering quantity or quality. The undertaking regularly could not recover the costs and reduced profits associated with lowering prices and altering product features across all markets in which it operates. In response to RP Act enforcement, the undertaking likely would expand more reticently. ${ }^{1550}$

Thirdly, the ability to reward efficient distribution promotes competition among distributors, and between brands. Prohibiting vertical price discrimination deters experimentation and promotional activities downstream. It also can increase final prices, assuming an adequate pass-through rate from distributors to consumers. ${ }^{1551}$

To bypass the prohibition on price discrimination and to ensure products qualify as differing grades and quality, undertakings wishing to expand production or to incentivize certain activities might differentiate their products inefficiently, ultimately placing upward pricing pressure on products. ${ }^{1552}$ Price discrimination laws allegedly further inhibit the bargaining process by preventing buyers from requesting price concessions that decrease retail prices. ${ }^{1553}$ A general consensus has formed in the United States that the RP Act often can shift the beneficiaries of enforcement "from consumers to less efficient competitors". ${ }^{1554}$ Because Congress may have intended for the Act to serve this objective, courts risk defying the explicit will of Congress by interpreting the Act differently. ${ }^{1555}$

Recognizing that the RP Act may not maximize societal welfare and to avoid conflict between the judiciary and the legislature, U.S. enforcement agencies precipitously have curtailed RP Act enforcement. During the Kennedy and Johnson administrations through 1968, RP allegations accounted for $64.7 \%$ of all non-merger cases. That percentage fell to $5.1 \%$ from 1968 to 1976 during the Nixon/Ford administrations, and has never increased again. Since the Reagan administration from 1981 to 1988 , the enforcement percentage has hovered at, or reached, zero. ${ }^{1556}$

\footnotetext{
1548 See id. 584; see also Kirkwood, supra n. 2 at p. 28 \& n.100 (quoting Monahan's Marine, Inc. v. Boston Whaler, Inc., 866 F.2d 525, 527-28 (1st Cir. 1989) (Breyer, J.) ("If suppliers must cut prices to all competing dealers or to none ... they may well decide not to cut prices at all.")).

${ }^{1549}$ Bauer \& Kintner, supra n.3 at 584.

1550 See id.

${ }^{1551}$ See id. 585. Price discounts to incentivize efficient dealer activity does not harm the less effective dealer and competition; rather, it structurally induces competition. Sullivan et al., supra n.8 at p. 25.

1552 See id. 585-86.

1553 Gifford \& Kudrle, supra n.4 at p. 13.

1554 Sokol, supra n.14 at 2066.

1555 Id. 2082.

${ }^{1556}$ Id. 2072 \& n.62 (citing Timothy J. Muris, How History Can Inform Practice in Modern U.S. Competition Policy, p. 10 (2004), http://www.law.gmu.edu/assets/files/publications/working-papers/04-20.pdf). As of the late 1980s, private litigants continued to file a multitude of Robinson-Patman claims, of which courts decided dozens of actions each year. Bauer \& Kintner, supra n.3 at 607-608.
} 
According to Hovenkamp "Almost any general policy of preventing price discrimination in oligopolistic markets would be socially harmful. Indeed, two of the most damaging effects of the Robinson-Patman Act are that it (1) makes cartel "cheating" more difficult by penalizing individual price cuts; and more generally, (2) destroys the incentive for oligopolists to compete more aggressively by pursuing marginal sales" ${ }^{\text {"1557 }}$. Moreover, he observes "A statute is not bad, however, simply because it manifests a distributive rather than an efficiency concern and requires consumers to pay the bill. Many statutes do that, and one function of the legislative process is to protect people whom the free market protects poorly". He points out that the Robinson-Patman has failed to filfil its own objectives as it does not effectively protect small businesses, which (paradoxically) sometimes run afoul of the act, and because the act is often "quite hostile toward economic competition" 1558 .

There are no specific statutes in the BRICS countries equivalent to the RobinsonPatman Act, but in Russia Article 13 of the Federal Law on Basic Principles of State Regulation of Trading Activities potentially could have a somewhat similar effect, although this is speculative.

\subsubsection{Opening up the floodgates? Unfair commercial practices as a competition law issue}

Section 5 of the Federal Trade Commission Act was introduced by the Congress in 1914 and declares that the FTC has the power to condemn "unfair methods of competition in or affecting commerce, and unfair or deceptive acts or practices in or affecting commerce" ${ }^{1559}$. In addition to this already broad prerogative, based on the same Section 5, the FTC is also "empowered and directed to prevent persons, partnerships, or corporations (...) from using unfair methods of competition in or affecting commerce and unfair or deceptive acts or practices in or affecting commerce" 1560 . Hence, Section 5 provides an open-ended enforcement mandate to the FTC, which can condemn and also prevent the use of unfair methods of competition.

The contingences of the first years of the $20^{\text {th }}$ century led the Congress to assign the FTC more extensive powers ${ }^{1561}$. The authority of the rule of reason as applied in Standard Oil was harshly questioned by members of the Congress that intended to remedy to the perceived shortcomings of the Sherman Act vesting the Commission with 'public policy' powers ${ }^{1562}$ on the ground of it being an "administrative body under the control of the legislature" 1563 . By examining the legislative history of Section 5, Averitt came to the conclusion that " $[\mathrm{t}] \mathrm{he}$

\footnotetext{
${ }^{1557}$ Herbert Hovenkamp, Federal Antitrust Policy: The Law of Competition and Its Practice (2016) 774.

1558 ibid 774-775.

155915 USC $\S 45(a)(1)$.

156015 USC $\S 45(a)(2)$.

1561 "There are many forms of combination, and many practices in business which have been so unequivocally condemned by the Supreme Court that as to them and their like the statute is so clear that no person can be in any doubt respecting what is lawful and what is unlawful; but as the statute is now construed there are ... many other practices that seriously interfere with competition, and are plainly opposed to the public welfare, concerning which it is impossible to predict with any certainty whether they will be held to be due or undue restraints of trade", S. REP, No. 1326, 63d Cong., 3d Sess., at xiv, see Neil W Averitt, 'The Meaning of Unfair Methods of Competition in Section 5 of the Federal Trade Commission Act' (1980) 21 BcL REv. 227, 232.

1562 ibid 277.

1563 ibid 299.
} 
language of the statute was therefore made deliberately broad to provide, in all instances, for adequate protection against harms to competition" ${ }^{1564}$. The Congress intended to design an instrument which would be broad enough to be used ex ante, to prevent the monopolization of a market, whereas under the Sherman Act remedies were actionable only when monopolization had already taken place. Several other commentators echo this view observing that "section 5 invites legislators to demand that the FTC attack conduct that escapes the reach of prevailing judicial interpretations of the other antitrust laws" $" 1565$.

However, the legislative intent of the draftsmen has had limited impact on the discussion over the future of Section 5, given the polarization of the approaches in two main factions.

Among to the advocates of the expansive approach to Section 5, there is who highlights the possibility to tackle 'incipient' harms to competition and other anticompetitive conducts which are now falling outside the Sherman Act. In particular, as for $\S 1$ of the Sherman Act, this broader power could be used to overcome the limitation of the existence of a "contract, combination, or conspiracy", leaving out of its scope other collusive practices such as parallel conducts in oligopolistic markets ${ }^{1566}$. Moreover, $\S 2$ may be interpreted more similarly to what Article 102 TFEU is in the EU, in order to prosecute abuses of dominant position, rather than being restricted to conducts that monpolise the market ${ }^{1567}$. Lande also proposed to expand the reach of Section 5 , however in a different way, which is by using the 'consumer choice approach' 1568 .

By contrast, an opposing view supports a restrictive interpretation of Section 5, mainly justified by the unpredictability of an otherwise too broad and undefined concept of unfairness. In particular, the then Commissioner Joshua Wright has in different instances proposed the adoption of an illegality test according to which, under Section 5, a practice "generates harm to competition as understood by the traditional antitrust laws and generates no cognizable efficiencies" 1569 . This author has urged the adoption of a principled approach to Section 5, warning against the danger that without a clarification on the interpretation, the FTC "can extract easy settlements whenever it desires by simply asserting that conduct is unfair" ${ }^{\prime 1570}$. In sum, he believes that the authority of the FTC under Section 5 should be confined within the limits of the Sherman and Clayton Acts, and should consider only economic efficiency effects within the consumer harm standard ${ }^{1571}$. However, the critics of such narrow interpretation of

\footnotetext{
1564 ibid 279.

1565 William E Kovacic and Marc Winerman, 'The Federal Trade Commission as an Independent Agency: Autonomy, Legitimacy, and Effectiveness' (2014) 100 Iowa L. Rev. 2085, 2093; Herbert Hovenkamp, 'The Federal Trade Commission and the Sherman Act' (2010) 62 Fla. L. Rev. 871, 3.

${ }^{1566}$ Hovenkamp, 'The Federal Trade Commission and the Sherman Act' (n 177) 5.

1567 ibid 12-14.

${ }^{1568}$ Robert H Lande, 'Should Section 5 Guidelines Focus on Economic Efficiency or Consumer Choice?' 4 <https://papers.ssrn.com/sol3/papers.cfm?abstract_id=2437966> accessed 21 July 2017; Neil W Averitt and Robert H Lande, 'Using the" Consumer Choice" Approach to Antitrust Law' (2007) 74 Antitrust Law Journal 175.

${ }^{1569}$ Joshua D Wright, 'Revisiting Antitrust Institutions: The Case for Guidelines to Recalibrate the Federal Trade Commission's Section 5 Unfair Methods of Competition Authority' (2013) 4 Concurrences 1.

1570 ibid.

${ }^{1571}$ Joshua Wright, 'Recalibrating Section 5: A Response to the CPI Symposium' (2013) 12 Antitrust Chronicle <https://ideas.repec.org/a/cpi/atchrn/12.2.2013i=13042.html> accessed 21 July 2017; Wright, 'Revisiting
} 
Section 5 observed that this would go against the legislative intent of the draftsmen ${ }^{1572}$ and that this would translate "the $\S 5$ proscription of "unfair methods of competition" into something like "methods of competition that fail to create even an iota of efficiency"1573.

The case law does not provide any clear guidance on the interpretation of Section 5 enforcement. While, for instance, in Brown Shoe the Supreme Court stated that the Commission has power to "arrest trade restraints in their incipiency"1574 and therefore had no obligation to prove future harm to competition ${ }^{1575}$, in $\mathrm{Gratz}_{\mathrm{z}}$ it gave central importance to the anticompetitiveness of the conduct ${ }^{1576}$.

Despite the broad formulation of the law, Section 5 cases are relatively scarce. Especially since the 1980s the FTC limited the application of Section 5 to conducts showing a strong deceptive, coercive or oppressive character ${ }^{1577}$. In other words, the FTC has exercised a high degree of self-restraint to the extent that some critics talked about under enforcement of the law and deviation from the Congress's original intent ${ }^{1578}$.

After a long debate over the meaning and interpretation of Section 5 FTC, in 2015 the Federal Trade Commission released the much-awaited Statement of Enforcement Principles Regarding "Unfair Methods of Competition" Under Section 5 of the FTC Act (Guidance paper) ${ }^{1579}$. The document is the result of a compromise ${ }^{1580}$ between those who wanted Section 5 to be limited to economic efficiency ${ }^{1581}$ and those who instead advocated for a more expansive approach ${ }^{1582}$. Proponents of opposing views, however, converged at least on one ground, which was the necessity of clarifying the interpretation of Section 5. The Guidance paper, although particularly brief in its formulation, attempted at a clarification of the norm stating that:

Antitrust Institutions: The Case for Guidelines to Recalibrate the Federal Trade Commission's Section 5 Unfair Methods of Competition Authority' (n 181); Jan M Rybnicek and Joshua D Wright, 'Defining Section 5 of the FTC Act: The Failure of the Common Law Method and the Case for Formal Agency Guidelines' (2014) 1287 George Mason Law Review <https://papers.ssrn.com/sol3/papers.cfm?abstract_id=2496748> accessed 21 July 2017.

1572 Lande (n 180).

1573 Albert Foer, 'On the Inefficiencies of Efficiency as the Single-Minded Goal of Antitrust' (2015) 60 The Antitrust Bulletin 103, 4-5.

${ }^{1574}$ FTC v Brown Shoe Co, Inc, 384 US 316, 322 (1966). For other 'expansionist decisions', see Hovenkamp, 'The Federal Trade Commission and the Sherman Act' (n 177) 5, footnote 24.

1575 Hovenkamp, 'The Federal Trade Commission and the Sherman Act' (n 177) 4-5; Richard A Posner, 'The Federal Trade Commission: A Retrospective’ (2005) 72 Antitrust Law Journal 761, 766.

${ }^{1576}$ FTC v Gratz, 253 US 421 (1920).

1577 Tim Wu, "Section 5 and "Unfair Methods of Competition": Testimony Before the Senate Antitrust Committee' (Columbia Public Law Research Paper No 14-508; Columbia Law and Economics Working Paper No 542 2016) ID 27601625 <https://papers.ssrn.com/abstract=2760162>.

1578 ibid 2.

${ }^{1579}$ Federal Register, Vol. 80, No. 182, September 21, 2015.

1580 Robert H Lande, 'Joshua Wright: Embodying the Spirit of Bipartisanship' <https://truthonthemarket.com/2015/08/25/joshua-wright-embodying-the-spirit-of-bipartisanship/>.

1581 Wright, 'Recalibrating Section 5' (n 183); Rybnicek and Wright (n 183); Joshua D Wright, 'Proposed Policy Statement Regarding Unfair Methods of Competition Under Section 5 of the Federal Trade Commission Act' (US FTC 2013); Joshua D Wright and Angela Diveley, 'Unfair Methods of Competition after the 2015 Commission Statement' [2015] WThe Antitrust Source (October 2015); George Mason Legal Studies Research Paper No. LS 15-25; George Mason Law \& Economics Research Paper No. 15-39. 〈https://ssrn.com/abstract=2664953>.

${ }^{1582}$ Lande (n 180). 
"In deciding whether to challenge an act or practice as an unfair method of competition in violation of Section 5 on a standalone basis, the Commission adheres to the following principles:

- the Commission will be guided by the public policy underlying the antitrust laws, namely, the promotion of consumer welfare;

- the act or practice will be evaluated under a framework similar to the rule of reason, that is, an act or practice challenged by the Commission must cause, or be likely to cause, harm to competition or the competitive process, taking into account any associated cognizable efficiencies and business justifications; and - the Commission is less likely to challenge an act or practice as an unfair method of competition on a standalone basis if enforcement of the Sherman or Clayton Act is sufficient to address the competitive harm arising from the act or practice.".Firstly, the Commission has clarified what kind of public policy concern can be considered in enforcing Section 5, limiting the scope to consumer welfare. This is not a negligible limitation, as Section 5 was initially envisaged also as an instrument designed to protect a wider array of public interest concerns. The congressional debates reveal indeed that under Section 5 the FTC has the power to consider social and political (public policy) issues, along with economic values ${ }^{1583}$. As reported by Averitt, the Commission was initially supposed to apply public policy powers by considering a number of legal, economic, commercial and social factors, such as courts decisions, academic papers, commercial customs and other 'habits of trade', ${ }^{1584}$ thereby constantly updating its understanding of 'unfair competition' under Section 5.

In this vein, Kovacic and Winerman observe that "[i]n theory, Section 5 had the potential to help make the Commission the preeminent vehicle for setting competition policy in the United States"1585. They indeed maintain that thanks to its distinctive research and data collection powers, and constant exposure to competition law problems, it would be the best placed to determine the "appropriate standards of liability", give guidance to courts on how to "frame and apply antitrust rules", and "develop apply and assess doctrine"1586. However, the actual formulation of the Guidance paper limits this power to set policy standards, tying the action of the FTC to the promotion of consumer welfare ${ }^{1587}$.

\footnotetext{
1583 Averitt (n 173) 283.

1584 The public policy standard includes a number of factors, some of which were already listed by Senator Cummins during the Congressional debates "It will be the duty of the [Commission] to consult the decisions of the courts, the learning of the time, the custom of' merchants, the habits of trade, the writings of studious and thoughtful men, all of which go to make up our understanding of the words 'unfair competition.' It will be the duty of the commission to apply those words in that sense precisely as it is now, the duty of the court to apply the words 'undue restraint of trade' in the sense in which we commonly understand that phrase" 51 Come. RFC. 13048 (1914).

1585 William E Kovacic and Marc Winerman, 'Competition Policy and the Application of Section 5 of the Federal Trade Commission Act' (2010) 76 Antitrust Law Journal 929, 932.

1586 ibid.

1587 Although this standard may potentially include a number of different economic and non-economic factors, see ICN, 'Discussion Document "Competition Enforcement and Consumer Welfare"," (2011) $<$ http://www.internationalcompetitionnetwork.org/uploads/library/doc857.pdf >; Albert A Foer and others, 'The
} 
Finally, the Guidance paper disposes that the Section 5 will be interpreted with an approach akin to the rule of reason, thus returning a central role to the harm to competition and to the competitive process ${ }^{1588}$.

The actual formulation of Section 5, as interpreted by the Guidelines, still leaves some leeway to the FTC to condemn conducts which are de facto assimilated to an abuse of superior bargaining power. Once established the presence of an anticompetitive harm, it would be still possible for the FTC to challenge an act or practice as an unfair method of competition on a standalone basis, if the Sherman or Clayton Acts cannot address the anticompetitive harm arising from that conduct.

At state level, there are a number of laws addressing specific abuses of superior bargaining power, such as the California's Franchise Investment Law ${ }^{1589}$ and the Vehicle Code ${ }^{1590}$, or the New York's Franchise Act $^{1591}$ and the Franchised Motor Vehicle Dealer Act ${ }^{1592}$. At Federal level, on the opposite, there are no specific laws specifically dealing with such abuses. Thanks to the still broad powers envisaged by Section 5, the FTC may prevent and condemn some of the unfair conducts characterised by such abuses. Determining when an act is unfair under Section 5 is not as straightforward and the recent Guidelines do not clarify this point. The interpretation of 'unfairness' has been changing throughout the decades also according to the policy and general sentiment of the FTC and courts. In 1964, for instance, in the Cigarette Rule SBP, the FTC stretching the meaning of the word through extensive interpretation, decided that "an act or practice is "unfair": (I) whether the practice "offends public policy" as set forth in "statutes, the common law, or otherwise"; (2) "whether it is immoral, unethical, oppressive, or unscrupulous"; (3) "whether it causes substantial injury to consumers (or competitors or other businessmen)."'1593 The following decades, however, saw a succession of decision tending to narrower interpretation of the term ${ }^{1594}$. Despite the remaining uncertainty around the definition of 'unfairness' under Section 5, if there is harm to competition, the Commission could condemn abuses

Goals of Antitrust: Thoughts on Consumer Welfare in the US' [2006] Chapters $<$ https://ideas.repec.org/h/elg/eechap/3692_21.html> accessed 29 July 2017; Gregory J Werden, 'Consumer Welfare and Competition Policy' in Josef Drexl, Wolfgang Kerber and Rupprecht Podszun (eds), Competition Policy and the Economic Approach, Cheltenham: Elgar (Edward Elgar Publishing 2011)..

1588 Despite the narrowing of the scope of Section 5, Commissioner (now Acting Chairman) Maureen K. Ohlhausen published a dissenting statement on the basis of the fact that the Guidelines still leave too much uncertainty in the application of Section 5.

http://leginfo.legislature.ca.gov/faces/codes_displayexpandedbranch.xhtml?tocCode=CORP\&division=5.\&title= 4.\&part $=\&$ chapter $=\&$ article $=$.

1590

At:

http://leginfo.legislature.ca.gov/faces/codes_displayexpandedbranch.xhtml?tocCde=VEH\&division=2.\&title=\& part $=\&$ chapter $=6 . \&$ article $=$.

${ }^{1591}$ New York General Business Law $\S \S 680-95$.

1592 New York Vehicle \& Traffic Law $\S \S 460-73$. See for a comment and report of these State laws, Yee Wah Chin, 'What Role for Abuse of Superior Bargaining Position Laws?' (2016) 256 NYLJ <https://papers.ssrn.com/sol3/papers.cfm?abstract_id=2806417> accessed 31 July 2017.

1593 J Howard Beales III, 'The Federal Trade Commission's Use of Unfairness Authority: Its Rise, Fall, and Resurrection' (2003) 22 Journal of Public Policy \& Marketing 192, 192-193.

${ }^{1594}$ Beales III (n 231). 
of superior bargaining power, disregarding the analysis of monopolisation of the relevant market and the strict requirements of the Sherman Act.

Based on this new 'hype' due to the discussion around its meaning, interpretation and enforcement, Section 5 may potentially find new life to complement the Sherman and Clayton Acts, covering anticompetitive conducts that they actually fail to oversee, including anticompetitive abuses of superior bargaining power.

In China, including of a prohibition of abuse of superior bargaining power in the AntiUnfair Competition Law of the People's Republic of China (AUCL) 中华人民共和国反不正 当竞争法 has been subject of recent discussion. On 25 February 2016, the Legislative Affairs Office of the State Council published the amended draft of the AUCL, in which the abuse of superior bargaining power as a prohibited act had been added.

The draft amendment defines superior bargaining power as where "in a certain transaction, a business operator holds a comparatively advantageous position as to capital, technology, market access, sales channel and raw material purchase etc., which renders the trading counterparty to be dependent on this business operator, (this manifested by) the difficulty (it has) to switch to other business operators". Article 6 of the draft AUCL also identified five forms of abuse of superior bargaining power as unfair trade: (1). restricting a trading counterparty to certain trading partners without any justifiable reasons; (2). restricting a trading counterparty to designated products without any justifiable reasons; (3). restricting a trading counterparty to certain trading conditions when dealing with other operators without any justifiable reasons; (4). charging unreasonable fees or unreasonably requesting other economic benefits from trading counterparties; and (5). imposing other unreasonable conditions.

However, most Chinese academics have argued against the incorporation of abuse of superior bargaining power into the AUCL, inter alia because this would fall under the scope of the AML and possible concerns about false positives. ${ }^{1595}$ In this regard, it is important to observe that the relations between the AUCL and the AML remain subtle at present. It seems unlikely that this amendment will ultimately become part of the revised AUCL. The proposed amendment of the AUCL was reviewed by the Chinese National People's Congress for the first time in February 2017. When the Congress subsequently published the bill for public comments after the first reading, the regulation of SPR in Article 6 had been deleted.

In India, unfair commercial practices may be taken into account in determining abuse of a dominant position. Article 4.2(a) of the 2002 Competition Act qualifies such abuse as imposing directly or indirectly unfair or discriminatory conditions or prices, which could address vertical restrictions of competition consisting of unfair contractual terms.

\footnotetext{
${ }^{1595}$ See e.g. the views $\quad$ of $\quad$ Guangyao (http://kns.cnki.net/KCMS/detail/detail.aspx?dbcode=CJFQ\&dbname=CJFDLAST2016\&filename=JGLS20160 5011\&v=MDA3ODNIZmJHNEg5Zk1xbzlFWllSOGVYMUx1eFITN0RoMVQzcVRyV00xRnJDVVJMMmZid VJwRkNyblY3M0xMeXI); Qiang

YU (http://www.cqvip.com/qk/89400a/201604/74909067504849544852484856.html); and Xiaoye WANG (http://law.chinalawinfo.com/fulltext_form.aspx?Gid=1510167962\&Db=qikan). See, by contrast, Xianli WANG, who is in favour of regulating superior bargaining power under the AUCL because "in practice it is hard to regulate SPB-abuse according to the clause of AML and SPB is basically the same with dominant position" (http://law.sjtu.edu.cn/Detail17930.aspx).
} 


\subsubsection{Status-based protections of specific groups from superior bargaining power competition law}

Farmers and SMEs are particularly affected by instances of superior bargaining power in light of global value chains, international distribution networks and high levels of concentration upstream as well as downstream. Based on three UNCTAD market studies of agricultural markets in developing countries, Ulla Schwager noted that the farming sector is fragmented, with only a few large and medium-sized producers and a large number of small businesses. High levels of concentration are present in downstream markets (manufacturing, distribution, and retail) and also in upstream input markets, such as fertiliser and crop suppliers. ${ }^{1596}$ It has been argued that competition law should specifically address the freedom of competition of farmers, particularly in developing countries, as this could be of higher relevance than just protecting consumer welfare. ${ }^{1597}$ However, protecting farmers and SMEs may be an objective of competition law also outside developing jurisdictions in light of various instances of superior bargaining power and economic dependence as noted in the sections above. High levels of concentration are reported in various input markets also in the EU. For instance, a single company controls 45 percent of the wheat market in the UK; while 5 companies control $95 \%$ of the EU vegetable seed market. The maize seed sector, a vital part of the EU seed market is controlled by 5 companies whose collective market share amounts to $51.4 \%$ : the maize varieties of DuPont Pioneer accounting for a $12.2 \%$ market share, Syngenta for $11.5 \%$, Limagrain for 9,7\%, Monsanto for 8,95\%, and KWS for 8,9\%, from a total of 4975 maize varieties registered in the European Common Catalogue. ${ }^{1598}$ Further merger activity in the seed and other inputs markets will further weaken the bargaining position of farmers vis-à-vis suppliers. The rise of "contract agriculture" ${ }^{" 599}$ has led farmers to enter into "take it or leave it" long-term exchanges with only a few companies controlling germplasm. This may reinforce their technological dependence vis-à-vis a small number of agro-chem companies, rendering switching to another (new) product or package of products particularly difficult, even if new entrants may offer more personalized service and products developed for local soils and climates. ${ }^{1600}$

\footnotetext{
${ }^{1596}$ U. Schwager, 'Competition Issues Affecting the Agricultural Sector in Selected Developing Countries: Key Findings From Selected UNCTAD Market Studies' in M. Gal, M. Bakhoum, J. Drexl, E. Fox and D.Gerber (eds.), Economic Characteristics of Developing Jurisdictions: Their Implications For Competiton Law (Edward Elgar 2015), 153-176, referring to tobacco cultivation in Malawi, rice production in Nicaragua and corn production in Mexico.

${ }^{1597}$ See e.g., J. Drexl, 'Consumer Welfare and Consumer Harm: Adjusting Competition Law and Policies to the Need of Developing Jurisdictions', in M. Gal, M. Bakhoum, J. Drexl, E. Fox and D. Gerber (eds.), Economic Characteristics of Developing Jurisdictions: Their Implications for Competition Law (Edward Elgar 2015), 265295.

${ }^{1598}$ I. Mammana, Concentration of Market Power in the EU Seed Market, (January 2014), Study commissioned by the Greens/EFA Group in the European Parliament.

${ }^{1599}$ N. E. Hart, 'The Age of Contract Agriculture: Consequences of Concentration in Input Supply' (2000) 18(1) Journal of Agribusiness 115-127; J. McDonald et al., 'Contracts, Markets, and Prices: Organizing the Production and Use of Agricultural Commodities' (2004) Agricultural Economic Report No. 837 9, available at http://www.ers.usda.gov/media/284610/aer8371.pdf.

${ }^{1600}$ See Ioannis Lianos with Dmitry Katalevsky, 'Merger Activity in the Factors of Production Segments of the Food Value Chain: A Critical Assessment of the Bayer/Monsanto Merger', CLES Policy Paper Series 2017/1.
} 
Indeed, in several jurisdictions specific solutions addressing the application of competition laws have been put in place for certain sectors and in order to protect specific groups with a significant potential for being harmed by an exercise of superior bargaining power, in particular in the food sector. These groups may be farmers, small and medium undertakings (SMEs) (in particular suppliers) or final consumers.

For instance, on the basis of Article 42 TFEU, the EU legislator set up an exception to the application of competition laws in the milk sector, allowing milk farmers to coordinate and act collectively in the market of supply, in order to improve their bargaining power ${ }^{1601}$. The Regulation also introduces specific safeguards which empower the NCAs and the Commission to intervene if these agreements have a negative impact on competition or SMEs in the dairy sector $^{1602}$. This regulation argues that the imbalance of bargaining power in the dairy supply chain can lead to unfair commercial practices and that this is documented by an uneven price transmission along the supply chain ${ }^{1603}$. This, in turn, may endanger the well-functioning of the internal market. Surprisingly, therefore, the EC draws market-wide conclusions regarding a problem otherwise described as a non-structural and therefore occasional.

Some jurisdictions have also chosen imaginative instruments to deal with some of the competition problems arising out of the power of multi-brand retailers, even if these do not dispose of market power.

In its 2000 Grocery Report, the UK Competition Commission found that five leading supermarkets, each having at least an $8 \%$ share of grocery purchases for resale had sufficient buying power for a number of their practices adversely distorting competition in the supplier mainly but also retail markets for the supply of groceries. The UK Competition Commission remedied this competition concern by requiring each supermarket meeting the $8 \%$ criterion to give undertakings to comply with a Code of Practice addressing the anticompetitive conduct identified and an independent dispute resolution system. ${ }^{1604}$ The Groceries Supply Code of Practice (GSCOP), published by the UK Competition Commission (now the Competition and Markets Authority, CMA) in August 2009, provides that retailers may not require suppliers to pay for shelf space, although payments may be allowable for promotions of new product listings, where the payments are proportional to the risk incurred by the retailer in stocking the new line. ${ }^{1605}$ The GSCOP is the result of the UK Competition Commission's investigation of the groceries market between May 2006 and April 2008. The Commission suggested the adoption of the GSCOP, an improved version of the existing Supply Code of Practice, together with an Ombudsman to ensure effective enforcement of the new provisions for suppliers and retailers.

The GSCOP came into force in February 2010 and imposes legally binding obligations on the UK's ten largest supermarket retailers - principally those with an annual £1 billion turnover (the so called 'Designated Retailers'). The Grocery Code Adjudicator Act 2013 came into force on 25 June 2013, formally establishing the role of the Grocery Code Adjudicator.

\footnotetext{
${ }^{1601}$ Regulation (EU) No 261/2012.

1602 Article $126 \mathrm{c}$

1603 Recital (5).

${ }^{1604}$ Competition Commission, Grocery Report 2000, Summary and Conclusions, paras 1.10-1.11.

1605 GSCOP, Part 5, 12. See also, Competition Commission, A Report on the supply of groceries from multiple stores in the United Kingdom (2000).
} 
The Adjudicator oversees the implementation and enforcement of the GSCOP, investigating whether a Designated Retailer has breached GSCOP and taking enforcement action by making recommendations, requiring information to be published, or imposing financial penalties if the investigation reveals a breach of GSCOP by a Designated Retailer and requiring a Designated Retailer to pay some or all of the costs of an investigation (including enforcement costs). Similar provisions have been added to the Irish draft code of Practice for Grocery Goods Undertakings, published in August 2009. ${ }^{1606}$ The Australian government has also recently announced that it had prescribed a new food and grocery code of conduct to address issues between grocery retailers and suppliers. ${ }^{1607}$

In Italy, the legislator has decided to regulate in detail the contractual relationship between agricultural producers and business buyers. In particular, Article 62 of the law 27/2012 establishes that business-to-business contracts of purchase of agricultural products have to be in written form and must contain a set of compulsory information about the parties and the object of the agreement. Article 62.8 of the law 27/2012 provides the Italian Antitrust Authority (ICA) the power to punish a conduct resulting in "an unwarranted exercise of bargaining power on the demand side at the expense of suppliers." 1608 Therefore, in addition to its power to intervene in cases of abuses of dominant position and economic dependence, the ICA can now intervene in commercial relationships of a vertical nature in the agro-food industry, even in the absence of a dominant position, provided that the contract produces an appreciable adverse effect on the market. Article 62.8, prohibits the stronger contracting party from imposing unfair conditions on the counterparty. This law, in particular, regards the form and content of contracts between undertakings in the food industry. Art. 62.8 targets indeed business to business contracts having as object the sale of agricultural products and foodstuff, prescribing that they "shall be in writing and shall indicate term, quantities, characteristics of the good, price, delivery mode and payment method". This provision also identifies a number of prohibited conducts in trade relations between operators, such as the imposition of unfair, retroactive and discriminatory contractual conditions ${ }^{1609}$. On July 9, 2015, the ICA concluded the first procedure based on the application of Article 62.8, against the retailer Eurospin, for

${ }^{1606}$ See, H Mullan, 'Banning payments for slotting and shelf-space: Ireland set to follow the United Kingdom's example' [2010] 31 ECLR 151.

${ }^{1607}$ B Billson (Minister for Small Business) 2015, Grocery Code to improve relationships between retailers, wholesalers and suppliers, media release 2 March, Canberra.

${ }^{1608}$ ICA, Agri-foodstuffs: according to the Antitrust, the market power of the organized mass distribution getting stronger, conflicting relationships with suppliers and uncertain effects on consumers, IC43, available at http://www.agcm.it/en/newsroom/press-releases/2101-ic43-agri-foodstuffs-according-to-the-antitrust-the-

market-power-of-the-organized-mass-distribution-getting-stronger-conflicting-relationships-with-suppliers-anduncertain-effects-on-consumers.html.

${ }^{1609}$ Article 62.2: The following commercial practices are expressively prohibited:

a) direct or indirect imposition of conditions on the purchase, on the sale or other conditions unduly burdensome or retroactive;

b) application of substantially different conditions to different counterparties for the provision of comparable goods and services;

c) subjecting continued business relations to the performance of obligations which have no connection, by nature or by commercial practice, with the objective of the contracts or relationships;

d) a request for undue and unilateral performance obligations, not justified by the nature or content of the business relations;

e) any other unfair commercial practice considered so taking into account the complex business relationships that characterise the food supply. 
allegedly imposing upon its suppliers the half-yearly payment of two unjustifiably large sums which did not correspond to any service provided to them by the group. ${ }^{1610}$ The ICA concluded, however, that the business conduct put in place by Eurospin did not constitute an infringement of Article 62.8. The contested contractual terms were indeed fairly negotiated and not imposed. Moreover, the ICA observed that the relative costs were proportioned to the service offered by Eurospin.

Therefore, the ICA, besides its power to intervene in cases of abuses of dominant position, can now intervene in commercial relationships of vertical nature in the agro-food industry, different from an abuse of dominant position, provided that the contract produces an appreciable adverse effect on the market.

In the context of the BRICS countries, most competition law regimes have no specific exemptions for the agro-food industry, with the exception of China. Competition law in Brazil does not include any a priori sectorial exclusions or exemptions. ${ }^{1611}$ Therefore, anticompetitive conduct in the food sector is analysed no differently from other sector and irrespective of the level of the chain or its vertical/horizontal nature. Also mergers in the food chain are scrutinised in the same way as all the other economic sectors, if they reach the turnover requirements of the law. Likewise, the Indian Competition Law Act does not contain any exemptions for the agro-food sector or agricultural co-operatives specifically. ${ }^{1612}$ While section 54 allows Central Government to exempt specific groups from the scope of the Act, this power has not been exercised in respect of agricultural co-operatives. Also Russian competition law currently does not set forth any specific exemptions from antitrust scrutiny for the agricultural sector. However, the FAS has explicitly pointed at the necessity of strengthening the bargaining position of farmers in contract negotiations. ${ }^{1613}$ Development of agricultural cooperations has been consistently declared as one of the priorities of the state agricultural policies in general, as well as of the FAS priorities in agricultural sector. ${ }^{1614}$ Agricultural cooperations are exempted from the restrictions imposed by Article 14 of the Federal law "On the Trading Activities" on dominant retail chains whose market share exceeds $25 \%$ in the relevant geographic market. ${ }^{1615}$ Agricultural cooperatives also receive state support

\footnotetext{
${ }^{1610}$ Italian Competition Authority Eurospin Italia S.p.A. decision No. 25551 of 9 July 2015.

1611 There are, however, some particularities of regulated sectors such as telecommunication; oil and gas; electricity; surface, civil and air transportation; and health. See OECD, Competition Law and Policy in Brazil - A Peer Review (OECD Pub 2010). In the case of banking, there is a pending discussion in the Supreme Court of whether the Central Bank would be the authority with exclusive competence to analyse mergers in the financial sector.

${ }^{1612}$ Agricultural co-operatives are included in the definition of 'person' in the Indian Competition Act. See Article 2(1)(v) 'an association of persons or a body of individuals, whether incorporated or not, in India or outside India; 2(1)(viii) 'a co-operative society registered under any law relating to cooperative societies'; and 2(l)(x) 'every artificial juridical person, not falling within any of the preceding sub-clauses'.
}

${ }^{1613} \mathrm{FAS}$ press release dated 20.05.2016, http://fas.gov.ru/press-center/news/detail.html?id=45796.

1614 'Strategy of the Sustainable Development of the Agricultural Territories of the Russian Federation to 2030' adopted by the Decree of the Government of the Russian Federation dated 02 February 2015 N151-r; FAS press release dated 27.02.2017 at http://fas.gov.ru/press-center/news/detail.html?id=49039.

${ }^{1615}$ Paragraph 1 Article 14 of the Federal law "On the Trading Activities". Article 14 prohibits food retail chain whose market share exceeds $25 \%$ of the volume of all food products sold during the previous year in the territory of the region or local district to acquire or lease additional premises for trading within the relevant territory on any ground, including commissioning of new objects. 
in the form of subsidies provided from the federal and regional budgets for development of technical infrastructure, acquisition of equipment, organising of distributing and logistics centers, etc. As a result, the number of agricultural cooperatives has increased from 2006 to 2013 by five times and as of 01 January 2014 amounted to $6913 .{ }^{1616}$

By contrast, China has a broad, though not unlimited, exemption for actors in the agrofood sector. Article 56 AML provides that the AML does not apply to the association or cooperation by agricultural producers or rural economic organizations "in their business activities of production, processing, sale, transportation, storage of farm products, etc". ${ }^{1617}$ The competition law exemption for agro-food sectors generally refers to the provisions included in Chapter 2 of the AML, including Article 13 on anti-competitive collaboration between competitors, Article 14 on anti-competitive collaboration between suppliers and dealers, and Article 16, which prohibits industrial organisations to organise concerted anticompetitive practices. In addition, the departmental regulation Provisions against Pricing Abuse ${ }^{1618}$ 反价 格垄断规, which was enacted pursuant to AML and primarily forbids anticompetitive pricing collaboration, price related administrative abuse, and pricing abuses, repeats Article 56 AML, negating the application of section 1 of Article 3: "a price fixing agreement reached by business operators". 1619

While Chinese competition law offers exemptions for "association or cooperation by agricultural producers or rural economic organizations in their business activities of production, processing, sale, transportation, storage of farm products, etc", ${ }^{1620}$ there is no exemption for the other three main areas that are governed by Chinese competition law, i.e. distribution cartels, merger control, and abuse of a dominant position. As regards superior bargaining power, as noted above it is not yet fully certain whether abuse of superior bargaining power to harm food production, distribution, and consumption constitutes an infringement of Chinese competition law in the first place, although the AML does not exclude this. Should abuse of superior bargaining power fall under the scope of Article 18 of the AML, it is also not yet known whether such abuse would also be subject to the competition law exemption for agro-food groups.

Notwithstanding the limited exemptions for agro-food groups provided in the BRICS countries, all in all the developments in various competition law jurisdictions indicate the emergence of a "fairness-driven competition law"1621, in particular in areas of social significance, such as the food sector, which breaks with the traditional apathy of competition law with vertical restraints. The allocation of the total surplus value of the vertical relation between the supplier(s) and the retailer(s) is usually considered by the proponents of the economic approach to competition law as a distributive justice issue that should not be of interest for competition law, but could eventually be dealt under other legal regimes, for

\footnotetext{
1616'Strategy of the Sustainable Development of the Agricultural Territories of the Russian Federation to 2030' (n $84)$.

1617 http://english.mofcom.gov.cn/article/policyrelease/Businessregulations/201303/20130300045909.shtml

$1618 \mathrm{http} / / / \mathrm{www} . \mathrm{gov} . \mathrm{cn} / \mathrm{flfg} / 2011-01 / 04 /$ content_1777969.htm

1619 http://www.gov.cn/flfg/2011-01/04/content_1777969.htm

1620 Article 54 of AML. http://www.china.org.cn/china/LegislationsForm2001-2010/201102/14/content_21917139.htm.

${ }^{1621}$ I. Lianos \& C. Lombardi, forth.
} 
instance contract law, unfair competition law etc. ${ }^{1622}$ Although it is clear that the competition policy followed with regard to vertical restraints has moved towards a more economic approach around the world, focusing on the effect vertical restraints have on economic efficiency, consumer welfare or the objective of market integration in the $\mathrm{EU}^{1623}$, some competition authorities have taken a broader perspective, espousing other goals than just economic efficiency and consumer welfare. ${ }^{1624}$ Our claim is that competition authorities should not only focus on restrictions on inter-brand or intra-brand competition, but also address restrictions of the vertical competition between the supplier(s) and the retailer(s), to the extent that a an unequal or unfair distribution of the surplus value across the various segments of the value chain may affect economic efficiency and the short-term as well as the long-term interests of the consumers, in particular if one of the parties disposes of a powerful market position upstream or downstream, even if this does not amount to a dominant position. Concerns over inequality and the role competition law could eventually play in this context ${ }^{1625}$ may also justify claims for a 'fairer' distribution of the total surplus value resulting from investments and innovation and for an increasing focus of competition law enforcement on the way the total value is allocated between the various segments of the vertical chain.

\subsubsection{Consumer protection}

Consumer protection in the food sector is mainly enacted by the establishment of safety standards. These safety standards cover: i) farmers' production, including processes adopted and substances used for growing plants and feeding animals; ii) food processing; iii) food distribution; iv) labelling and information to consumers. Public regulation generally provides the legal framework in which private parties set an important number of private standards. Surveillance of compliance with the legislation is generally assigned to public regulators.

For instance, in Brazil the Brazilian Health Regulatory Agency (ANVISA) exercises health surveillance on the production and marketing of products and services, including

\footnotetext{
1622 See, for instance, the position of AG Van Themaat in Case C-161/84 Pronuptia de Paris GmbH v Pronuptia de Paris Irmgard Schillgallis [1986] ECR 414, noting that the question whether or not a franchise agreement results in a fair division of costs and benefits as between franchisor and franchisee is not in itself relevant to the question whether Article [101(1) TFEU] is applicable'.

${ }_{1623}$ Guidelines on Vertical Restraints [2010] OJ C 130/1, para 7.

${ }^{1624}$ It is noteworthy that the protection of the 'buyer's freedom as regards choice of sources of supply" or the protection of competitors' access to the market, are also among the elements considered as among the objectives of EU Competition Law: Case C-209/10 Post Danmark A/S v Konkurrencerådet [2012] ECLI:EU:C:2012:172, para 26. See also, C-49/07 Motosykletistiki Omospondia Ellados NPID (MOTOE) v Elliniko Dimosio [2008] ECR I-4863, para 51 ('A system of undistorted competition, such as that provided for by the Treaty, can be guaranteed only if equality of opportunity is secured as between the various economic operators') and Opinion of AG J Kokott, Case C-49/07, para 100. In British Airways and Michelin II, confirmed by the European Courts, the European Commission's decisions both found that rebate schemes (as well as being exclusionary and discriminatory) were 'unfair' to the affected travel agents and dealers: Case C-95/04 P British Airways plc $v$ Commission [2007] ECR I-2331; See also, Opinion of AG Kokott in C-95/04P; Case T-203/01 Manufacture française des pneumatiques Michelin v Commission (Michelin II) [2003] ECR II-4071, paras 110 and 240 (noting that as a result of its loyalty- inducing character, the quantity rebate scheme 'limited the dealers' choice of supplier and made access to the market more difficult for competitors'). Although this case law mainly concerns the implementation of Article 102 TFEU, it indicates that EU competition law enshrines a multi-value system of competition law.

1625 See our analysis in Chapter 1.
} 
technologies, processes and ingredients that pose health risks. ${ }^{1626}$ It has the power to regulate the importation of products and to perform sanitary inspections at the points of entry to the territory, to issue general regulations in the form of Resolutions and individual decisions to prohibit the sale of products, and to determine the recollection from the market of unsafe foodstuffs. Regulation includes, inter alia Resolution 26/2015 for foodstuffs labelling (which entered into force in 2016). The industry is now under an obligation to include information in clear language on all ingredients which may produce allergies. There has also been a public consultation on labelling related to lactose and lactose diet ${ }^{1627}$ and also a related children's food, who may be oversensitive to some minerals. ${ }^{1628}$

In Russia, food and health surveillance in the Russian Federation is implemented by the Federal Service for Supervision of Consumer Rights Protection and Human Welfare (Rospotrebnadzor). As follows from Article 1 of the Provision on the Federal Service for Supervision of Consumer Rights Protection and Welfare Person, Rospotrebnadzor is responsible for the development and implementation of the state policy and normative legal regulation in the sphere of consumer protection, and for the development and approval of state sanitary epidemiological rules and hygienic standards. It is also responsible for the organization and implementation of the state sanitary-epidemiological surveillance and supervision in the field of consumer protection ${ }^{1629}$.

In South Africa, the Department of Health is responsible for ensuring food safety. As part of its functions, it oversees the administration of food legislation, which includes publicizing regulations for food safety, labelling food, and evaluating risk assessments for the DAFF that are related to agricultural chemicals and food produced through biotechnology. ${ }^{1630}$

South Africa's food regulation is particularly vigorous with regard to GMO use, including contained use, trial release, commercial release, and transboundary movement. The primary legislation is the Genetically Modified Organisms Act of 1997 and its Regulations in addition to miscellaneous laws that impose further rules on GMO-related activities, including the National Environmental Management: Biodiversity Act, the Consumer Protection Act, and the Foodstuffs, Cosmetics and Disinfectants Act. ${ }^{1631}$ The Department of Agriculture, Forestry and Fisheries is responsible for promoting responsible GMO-related activities; limiting harm to the environment as well as to human and animal health; and establishing standards for conducting risk assessments for GMO-related activities. ${ }^{1632}$ Foodstuffs obtained through certain techniques of genetic modification are required to be labelled as such before they are put on sale in the marketplace. The Consumer Protection Act imposes additional labelling requirements. It requires that "[a]ny person who produces, supplies, imports or packages any prescribed goods must display on, or in association with the package or those goods, a notice

\footnotetext{
${ }^{1626} \mathrm{http}: / /$ portal.anvisa.gov.br/contact-us

1627 http://www.brasil.gov.br/saude/2016/09/anvisa-ira-consultar-populacao-sobre-rotulagem-de-alimentos-come-sem-lactose

1628 http://www.brasil.gov.br/saude/2016/06/anvisa-abre-consulta-sobre-limite-toxicologico-em-comida

${ }^{1629}$ Decree of the Government of the Russian Federation of June 30, 2004 No. 322. URL: http://base.garant.ru/12136005/.

1630 https://www.loc.gov/law/help/restrictions-on-gmos/south-africa.php\#_ftn6

${ }^{1631} \mathrm{https} / / / \mathrm{www}$. loc.gov/law/help/restrictions-on-gmos/south-africa.php\#_ftn6

1632 https://www.loc.gov/law/help/restrictions-on-gmos/south-africa.php\#_ftn6
} 
in the prescribed manner and form that that discloses the presence of any genetically modified ingredients or components of those in accordance with applicable regulations."

Table 2: Overview of consumer protection standards in BRICS countries

\begin{tabular}{|l|l|}
\hline Brazil & Consumer protection \\
\hline Legislation & Consumer Protection Code, Law 8.078/90 \\
\hline Institutions & $\begin{array}{l}\text { Consumer Protection and Defense Authority, Ministry of } \\
\text { Justice }\end{array}$ \\
\hline Standards & $\begin{array}{l}50 \quad \text { standards regulating production, processing and } \\
\text { retailing. }{ }^{1633}\end{array}$ \\
\hline
\end{tabular}

\begin{tabular}{|l|l|}
\hline India & Consumer protection \\
\hline Legislation & Consumer Protections Act, 1986 \\
\hline Institutions & $\begin{array}{l}\text { Department } \\
\text { http://consumeraffairs.nic.in/consumer/index.php }\end{array}$ \\
\hline Standards & 48 standards regulating production, processing and retailing. ${ }^{1634}$ \\
\hline
\end{tabular}

China

${ }^{1633}$ See http://www.standardsmap.org.

${ }^{1634}$ See http://www.standardsmap.org. 


\begin{tabular}{|l|l|}
\hline Legislation & $\begin{array}{l}\text { Law of the People's Republic of China on Protection of } \\
\text { Consumer Rights and Interests (02-06-2006) }\end{array}$ \\
\hline Institutions & State Administration of Industry and Commerce \\
\hline Standards & 49 standards regulating production, processing and retailing. ${ }^{1635}$ \\
\hline
\end{tabular}

\begin{tabular}{|c|c|}
\hline $\begin{array}{l}\text { South } \\
\text { Africa }\end{array}$ & Consumer protection \\
\hline $\begin{array}{l}\text { Legislatio } \\
\mathrm{n}\end{array}$ & $\begin{array}{l}\text { Consumer Protection Act (Act } 68 \text { of } 2008) \\
\text { https://www.westerncape.gov.za/other/2011/3/consumer_protection_act.p } \\
\text { df }\end{array}$ \\
\hline $\begin{array}{l}\text { Institution } \\
\mathrm{s}\end{array}$ & $\begin{array}{l}\text { Consumer Affairs Committee of The Department of Trade and Industry } \\
\text { http://www.thedti.gov.za/ }\end{array}$ \\
\hline Standards & 44 standards regulating production, processing and retailing. ${ }^{1636}$ \\
\hline
\end{tabular}

\begin{tabular}{|l|l|}
\hline Brazil & Consumer protection \\
\hline Legislation & Consumer Defence Code, 1990 (Law No. 8,078) \\
& \\
\hline
\end{tabular}

1635 See http://www.standardsmap.org.

${ }^{1636}$ See http://www.standardsmap.org. 


\begin{tabular}{|l|l|}
\hline Institutions & Consumer and Protection Defense Department \\
\hline Standards & Standards regulating production, processing and retailing. ${ }^{1637}$ \\
\hline
\end{tabular}

Source: Author's compilation

\subsection{Beyond competition law: Superior bargaining power and the food value chain (contract law, unfair competition law)}

\subsubsection{Contract law}

\subsubsection{Foundations}

Classical contract law is based on the idea that each individual benefits from a private sphere in which its autonomy cannot be curtailed by the intervention of the state or other forms of coercion, no one having the authority to impose obligations or liabilities that have not been voluntarily assumed by the individual through contract. Freedom of contract assumed away power, the contract to which the individual expressly agreed to defining the contours of the individual's obligations. Formalism in the interpretation of the provisions of such contract was thus the natural extension of the crucial assumption of the absence of power, and the fact that the contractual provisions represented the preferences and choice of the individuals that had consented to it. Courts were therefore to mechanically apply formal contract rules, thus protecting the individual's right to voluntarily engage in contractual obligations vis-à-vis other individuals. Such theoretical construction of the concept of contract was based on the understanding that the individuals engaging in these economic transactions supported by the legal contractual form did not dispose of the ability to impose their will on their contractual partners, something that would have denied the voluntary character of the transaction and consequently the inference that the contractual provisions were the pure result of their choice to enter into the specific economic transaction, and expressed their preferences as to the type of relation they wish to establish with their partner. This assumption of correspondence between choice, preferences and contractual freedom was crucially necessary as all transactions in a capitalist economy involved the creation of value, the joint surplus generated by such exchange/cooperation (we do not distinguish between the two concepts for the time being), and consequently raised the issue of the allocation of such value between the parties to the (contractual) transaction. ${ }^{1638}$ Neoclassical economics gave rise to what has been characterized as the era of "neoclassical contract". 1639

\footnotetext{
${ }^{1637}$ See http://www.standardsmap.org.

1638 Adam Smith

1639
} 
Both civil law and common law jurisdictions recognise the importance of bargaining power in a transaction. It is possible that during the formation or the subsequent execution of a contract, the party enjoying a superior bargaining power may force its counterparty to accept or implement terms of the contract that are unfavourable to its interests. In the food-retail sector, for instance, it may happen that supermarkets impose conditions, such as slotting allowances, slotting fees, pay-to-stay fees, shelf-placement fees, exclusive distribution, restrictions of sale, etc., which are detrimental to the supplier but that are nonetheless accepted. If the contract and the factual situation fulfil a number of strict conditions described by the law, the common law judge can annul or modify the unlawful contract terms. By the same token, in civil law jurisdictions, the judge can annul or, in some cases, modify the terms of the contract accepted under vitiation of the original intent of the parties. Although there is hardly any grand theory of "unequal" or "superior" bargaining power in contract law, ${ }^{1640}$ at several instances the various legal systems examined (e.g. United States, United Kingdom, Germany, France and Italy) include

Table 2: Superior bargaining power theories in contract law

\begin{tabular}{|l|l|}
\hline Country & Theory \\
\hline U.S. & $\begin{array}{l}\text { Equitable doctrines (such as (Estoppel, Undue influence, } \\
\text { Unconscionability, Marshalling, Subrogation, Laches } \\
\text { Hotchpot Equitable conversion }{ }^{1641} \text { ) }\end{array}$ \\
\hline U.K. & $\begin{array}{l}\text { Equitable doctrines (Estoppel, Undue influence, } \\
\text { Unconscionability, Marshalling Subrogation Laches } \\
\text { Hotchpot Equitable conversion) }\end{array}$ \\
\hline Germany & $\begin{array}{l}\text { Good faith, mistake; duress; misrepresentation and the } \\
\text { exceptio doli generalis }\end{array}$ \\
\hline France & $\begin{array}{l}\text { Good faith, mistake; duress; misrepresentation and the } \\
\text { exceptio doli generalis, abuse of the right }\end{array}$ \\
\hline Italy & $\begin{array}{l}\text { Good faith, mistake; duress; misrepresentation and the } \\
\text { exceptio doli generalis, abuse of the right }\end{array}$ \\
\hline Brazil & $\begin{array}{l}\text { Good faith; public interest; abuse of the right; damages; } \\
\text { potestative clause; adjustment of a disproportional } \\
\text { obligation; equitable reduction of the penal clause; } \\
\text { excessive onerousness; enrichment- without cause; mistake } \\
\text { andignorance; duress; exceptio doli generalis }\end{array}$ \\
\hline Russia & $\begin{array}{l}\text { Good faith; abuse of the right; excessive onerousness } \\
\text { India }\end{array}$ \\
\hline
\end{tabular}

Source: Author's compilation

${ }^{1640}$ Daniel D. Barnhizer, 'Inequality of Bargaining Power', 76 U. Colo. L. Rev. 139 (2005).

${ }^{1641}$ See infra. 
It appears that contract laws generally set rules to determine which factors influence bargaining power. Courts tend to presume equality of bargaining power in B2B contracts, and also assume informational symmetry.

\subsubsection{The many facets of superior bargaining power in contract law}

Contractual freedom is a general and widely accepted principle ${ }^{1642}$. It follows that, any limitation to contractual freedom of private and public entities should be justified by specific public or private interests. For a contract to be valid, it is essential that the parties give their consent and that this consent is not vitiated by means of mistake, duress, undue influence, unsconscionable conduct, or any other illegal conduct that the law identifies as a vitiating factor ${ }^{1643}$. While the mistake is an erroneous belief at contracting that certain facts are true, the equitable remedies of duress, undue influence and unconscionability target a conduct that, transcending the fairness of the bargain, exploits a 'vantage position' at the expenses of the other contractual party. Often this conduct is made possible by a situation of unbalance in the bargaining power of the parties to the contract. But the normative and conceptual basis for the examination of these cases tend to widely differ throughout Europe, the United States and BRICS countries.

As mentioned above, the respective contract law in some BRICS countries such as Brazil, the Russian Federation and India sets out rules to determine which factors influence bargaining power. More specifically, Russian contract law deals with the superior bargaining power concept as part of the general mechanism to protect weaker parties in contracts. The protection of the weaker party has been primarily based on special legislation on consumer rights and Art. 428 of the Civil Code. Art. 428 of the Code is applicable also to contracts that are not contracts of adhesion but where conditions of such agreements are determined by one of the parties while the other party due to obvious inequality in bargaining power is put in a position that substantially prevents it from negotiating other content of certain contract terms. Russian legislation has also included traditional means to protect the weaker party that is affected by the monopolist such as Art. 10 of the Civil Code which refers to the general prohibition of abuse of rights and Art. 169 of the Civil Code which fixes the invalidity of a legal transaction made with a purpose contrary to the basis of the legal order and morality.

Russian contract law enables the assessment of the level of competition on a certain market in order to determine whether it is possible to apply the superior bargaining power concept. In certain cases, courts have used Art. 428 as an additional criterion to qualify the dominant position of the market actor. ${ }^{1644}$

However, it is worth noting that the enforcement of these rules has been relatively rare and mostly in cases when the adversely affected party is a consumer. Commercial courts interfere into B2B transaction on the basis of Art. 428 only in exceptional cases, that is when

\footnotetext{
${ }^{1642}$ In Europe it is enshrined in Article 16 of the Charter of Fundamental Rights of the European Union as part of the 'freedom to conduct a business'

1643 Generally, the remedy prescribed by law for vitiated contracts is the voidability of the contract concerned.

${ }^{1644}$ Case NoA53-16802/2010; Case NoA60-29999/2011; Case NoA60-816/2011; Case NoA51-5351/2010.
} 
the imbalance in superior bargaining power was clearly disproportional. Also, the party, claiming for the application of Art. 148, shall display initiative in negotiations.

With regards to Brazilian contract law, it is centred upon the principle of bargaining power, though limited to the application of general concepts such as good faith and public interest. ${ }^{1645}$ The objective good faith has the function of a general clause and serves as an interpretative tool. Generally, Brazilian courts intervene on the basis of the constitutional principle of social justice. Brazilian courts treat cases involving abuse of superior bargaining power using different provisions of contract law such as potestative clauses, the concept of damage, the abuse of right, the adjustment of a disproportional obligation equitable, reduction of the penal clause, excessive onerousness, enrichment without cause. The Roman law doctrine is also applicable namely mistake, ignorance, duress and exceptio doli generalis.

However, in cases of B2B contracts it is assumed that both parties enter the contract with the minimum knowledge available to avoid substantial mistakes, and thus, the Roman law doctrine is not applicable. Overall, the Administrative Council for Economic Defence ('CADE') has been careful to not intervene in the freedom of contract, in relation to conduct within the sphere of private relations.

When assessing bargaining power, Indian contract law provides for all the general remedies to the defects of consent, namely mistake, misrepresentation, fraud, coercion, undue influence. However, a situation of unequal bargaining power between parties does not affect the validity of the contract even if it results into an agreement containing provision disparity and the claimant has to prove that the contract was concluded in defect of consent. Thus, in case of unconscionability, undue influence must be proved, since mere unconscionability cannot avoid a contract. ${ }^{1646}$ However, evidence of the unconscionable conduct reverts the burden of proof on the party that has a "dominating position". In a number of cases, the Supreme Court of India has identified the existence of unequal bargaining power between parties to contracts. ${ }^{1647}$ Regardless, however, CCI has not specifically addressed superior bargaining power issues in its orders.

\subsection{Unconscionability}

This is a doctrine that is usually met in common law jurisdictions. The theory of unconscionability originated as an equitable relief in a contract suit in US law. As such, unconscionability is a discretionary bar that works as a 'safety net' that the judge generally uses when other remedies are not applicable ${ }^{1648}$. The UCC § 2-302, Restatement (Second) of Contracts $\S 208$ guarantees judicial protection against contracts that are "seriously unfair"1649,

\footnotetext{
1645 Lucia Iwasa

${ }^{1646}$ Kesavulu Naidu v. Arithulai Ammal (1912) 36 ILR Mad 533.

1647 Belaire Owners 'Association Vs. DLF Limited, HUDA \&Ors. (Case No. 19/2010) - Abuse of Dominant Position in Real Estate Industry.

1648 Arthur Allen Leff, 'Unconscionability and the Code. The Emperor's New Clause' (1967) 115 University of Pennsylvania Law Review 485; Richard A Epstein, 'Unconscionability: A Critical Reappraisal' (1975) 18 The Journal of Law \& Economics 293; Edward Allan Farnsworth, Farnsworth on Contracts (Little, Brown 1990) 188; Gareth Spark, Vitiation of Contracts (Cambridge 2013).

1649 The draftsman of the Uniform Commercial Code declares:
} 
and for many scholars this constitutes the normative basis for the application of unconscionability in the US ${ }^{1650}$. On this basis, American judges and scholars identified two types of unconscionability ${ }^{1651}$, procedural and substantive. The conceptualisation of this distinction is attributed to Arthur Leff, who first divided the concept of unconscionability defining procedural unconscionability as "bargaining naughtiness" and substantive unconscionability as "evils in the resulting of contract" 1652 .

Procedural unconscionability focuses on the circumstances that made excessively difficult for a party to protect herself ${ }^{1653}$, as for instance in case of a take-it-or-leave-it clause that had no chances to refuse ${ }^{1654}$. Therefore, it focuses on the formation of the contract and on the formation of the consent inherent to the conclusion of the contract. Procedural unconscionability may depend for instance on the absence of negotiation (as in cases of standards form contracts ${ }^{1655}$ ) or on the existence of a monopoly, ${ }^{1656}$ which leaves no bargaining alternative or leeway for substitution. American judges have extended this approach to all the situations where there is absence of competition or limited competition that translates into "absence of meaningful choice on the part of one of the parties with contract terms which are unreasonably favorable to the other party"1657.

\footnotetext{
"The basic test is whether, in the light of the general commercial background and the commercial needs of the particular trade or case, the clauses involved are so one- sided as to be unconscionable under the circumstances existing at the time of the making of the contract. (...) The principle is one of the prevention of oppression and unfair surprise and not of the disturbance of allocation of risks because of superior bargaining power", UCC $\S 2$ 302 (Official Uniform Comment). More broadly, the 'conundrum' of whether the (un)balance between the exchange values can determine the validity of a contract was already posed in Roman law. Under the Corpus Iuris Civilis the typical (limited contract types) Roman law approach to contracts was combined with the formality of the consensus. In particular, the stipulatio was valid also when the offer and the acceptance were not balanced, the express consent being the relevant requisite. However, the Roman law developed also the concept of 'bona fides' (good faith). Moreover, in the postclassical period the introduction of the laesio enormis signed a first important limitation to the freedom of contract. However, the modern conceptualization of the contract as a consensual agreement came only in the 18th Century with the 'Pandettistic' movement.

${ }^{1650}$ Peter Cane \& Mark V Tushnet, The Oxford Handbook of Legal Studies (Oxford University Press 2005) 10, 914.

${ }^{1651} \operatorname{Leff}(\mathrm{n} 2)$.

1652 ibid 487. Leff argued that the section 2-302 of the Uniform Commercial Code was ill drafted because it did not consider the fact that unconscionability, as all other contract law "defenses" (in particular he mentions fraud, duress, mistake, impossibility and illegality) can be classified by referring to the process of contracting or to the result of the contract . This distinction between procedural and subtantive, Leff believes, would have helped the draftsmen of the UCC to fully "appreciate the significance of the unconscionability concept's necessary procedure-substance dichotomy and that such failure is one of the primary reasons for section 2-302's final amorphous unintelligibility and its accompanying commentary's final irrelevance", Ibid., 488.

${ }^{1653}$ Nichols v. YJ USA Corp., 2009 U.S. Dist. LEXIS 22450 (D. Tex. 2009).

${ }^{1654}$ Melvin A. Eisenberg, Mistake in Contract Law, 91 CAL. L. REV. 1573, 1607-09 (2003); see also Jonathan E. Breckenridge, Bargaining Unfairness and Agreements to Arbitrate: Judicial and Legislative Application of Contract Defenses to Arbitration Agreements, 1991 ANN. SURV. AM. L. 925, 947- 48 (1991).

${ }^{1655}$ See Iwen v. U.S. West Direct, 977 P.2d 989, 996 (Mont. 1999), here the court observes that there was "no meaningful choice" on the part of the buyer, since the contract was presented on a take-it-or-leave-it basis.

1656 Epstein (n 2).

${ }^{1657}$ Williams v. Walker-Thomas Furniture, 350 F.2d 445,449 (D.C. Cir. 1965); Ezra Friedman, 'Competition and Unconscionability' [2013] American law and economics review 444; Russell B Korobkin, 'A'Traditional'and'Behavioral'Law-and-Economics Analysis of Williams v. Walker-Thomas Furniture Company' (2004) 26 University of Hawaii Law Review 441. Korobkin recalls also a labour law case where the the California Supreme Court found unconscionable a term in an employment contract because the job (the seller's product) was particularly important to the employee (the buyer), see Armendariz v. Found. Health Psychcare Servs. Inc., 6 P.3d 669690 (Cal . 2000).
} 
On the other hand, substantive unconscionability refers to the contractual terms that are "overly-harsh" or "one sided" 1658 . In other words, the terms have to be unfair, unreasonable or exploitative. Examples of unfair terms may be: unfair price ${ }^{1659}$, unfair disclaimers, promoting default, waiver of defences, acceleration of payments, repossession of goods without prior hearings and overall imbalance ${ }^{1660}$. In general, it is possible to say that a contract is substantively unconscionable if there is an imbalance in the contract caused by a gross disparity in the values exchanged.

However, substantive and procedural unconscionability are not as neatly separated as it may seem. Procedural unconscionability indeed is often used as a clue or a prerequisite to determine substantive unconscionability in contract terms. The Comment of the Restatement Second explicitly recognises the unbalance of power in the bargaining process as an indication of the existence of a possible defect in the contract. The "defects in the bargaining process" may therefore corroborate the gross disparity in contract terms to apply the remedy of unconscionability ${ }^{1661}$.

American scholars are divided on the function of unconscionability as a condition for the vitiation of the contract. While some scholars observe that one-sided contracts may arise in

\footnotetext{
${ }^{1658}$ Lemke v. Arrowood, 2000 WI App 32 (Wis. Ct. App. 1999).

${ }^{1659}$ In this respect, Browne and Biksacky report that "In unfair price unconscionability cases, one party asserts that the price to be paid is grossly disproportionate to the value of the good or service received in exchange. See, e.g., Murphy v. McNamara, 416 A.2d 170, 176 (Conn. Super. Ct. 1979). In Murphy, the court declared a contract was unconscionable because a buyer paid $\$ 1,268$ for a television worth $\$ 499$. !d. at 173. Another case affirmed it was unconscionable for a seller to charge $\$ 4,322$ for windows that only cost the seller $\$ 1,080.50$. Sho-Pro oflnd., Inc. v. Brown, 585 N.E.2d 1357, 1361 (Ind. Ct. App. 1992). In another case, a contract was orally negotiated in Spanish, but the contract was written in English. Frostifresh Corp. v. Reynoso, 274 N.Y.S.2d 757, 758 (Civ. Ct. 1966). The written contract charged the buyer three times the value of an appliance, and the court subsequently invalidated the contract on unconscionability grounds. Id. at 759. After an extensive empirical analysis of price unconscionability cases, Darr notes that high price alone is only a necessary condition. Darr, supra note 25 , at 1844. He explains: Neither process problems nor enforcement problems are sufficient in all cases to find unconscionability when price is high. If the contract price is high compared to the reference price the court selects, there is evidence of overreaching, and if market mechanisms are unlikely to rectify the situation, the courts are likely to intervene.

Absent any one of these factors, the opposite result appears likely.

Id. DiMatteo and Rich explain unfair price contracts are often referred to as '"per se unconscionab[le]"' because the imbalance in consideration is so severe as to be considered unconscionable on its face. Larry A. DiMatteo \& Bruce Louis Rich, A Consent Theory of Unconscionability: An Empirical Study of Law in Action, 33 FLA. ST. U. L. REV. 1067, 1091 (2006) (quoting M.P. Ellinghaus, In Defense of Unconscionability, 78 YALE L.J. 757,789 (1969)). The authors further explain that many state legislatures also use the principles of unconscionability to stop unfair price gouging in contracts and sales. Specifically, eighteen states, including New York and Florida, have anti-price-gouging statutes with sixteen triggered by a declaration of a state of emergency or natural disaster. See M Neil Browne and Lauren Biksacky, 'Unconscionability and the Contingent Assumptions of Contract Theory’ [2013] Mich. St. L. Rev. 211, 220 at footnote 52.

1660 ibid.

1661 The Comment $\mathrm{c}$ to $\$ 208$ reads: "Inadequacy of consideration does not of itself invalidate a bargain, but gross disparity in the values exchanged may be an important factor in a determination that a contract is unconscionable and may be sufficient ground, without more, for denying specific performance See $\S \S 79,364$. Such a disparity may also corroborate indications of defects in the bargaining process, or may affect the remedy to be granted when there is a violation of a more specific rule. Theoretically it is possible for a contract to be oppressive taken as a whole, even though there is no weakness in the bargaining process and no single term which is in itself unconscionable. Ordinarily, however, an unconscionable contract involves other factors as well as overall imbalance".
} 
competitive markets and that this one-sidedness induces efficient outcomes ${ }^{1662}$, others justify the application of the unconscionability doctrine arguing that 'sellers' have a profit incentive to take advantage of their position, and in some cases of the bounded rationality of the 'buyer', proposing inefficient contract terms ${ }^{1663}$.

Most US courts require both procedural and substantive unconscionability to be present, while for some others it suffices that either of the elements is established ${ }^{1664}$. Moreover, in some cases American courts have considered the inherent imbalance of market power in order to decide whether the one-sidedness of a contract made it unconscionable, stating that " $[\mathrm{t}] \mathrm{he}$ greater the ... inequality of bargaining power, the less unreasonable the risk reallocation which will be tolerated"1665. The point made here is that monopolist or monopsonist power can be used to exert pressure and impose unfavourable contract terms. In general, American courts tend to apply a balancing test based on the evaluation of the facts of each case ${ }^{1666}$. Arthur Corbin's test for substantive unconscionability, which asks whether the terms at issue are "so extreme as to appear unconscionable according to the mores and business practices of the time and place", has been widely influential with courts ${ }^{1667}$. In this regard, Radin admits that "[a]pplication of the doctrine of unconscionability is a process of relentless case-by-case adjudication, with many discretionary judgment calls in each case. Perhaps with the exception of truly egregious cases, outcomes are extremely unpredictable" 1668 . Also Oakley observes that the U.S. courts' ad hoc approach to unconscionability "makes it hard to know ahead of time which terms will be found fair and which will be deemed unfair" and "encourages contract drafters to take advantage of ambiguities" ${ }^{1669}$.

This discretionary power, allowed also to disentangle the evaluation of unconscionability from the examination of bargaining power. According to the Restatement, "[a] bar gain is not unconscionable merely because the parties to it are unequal in bargaining position .... But gross inequality of bargaining power, together with terms unreasonably

\footnotetext{
${ }^{1662}$ See for instance Lucian A Bebchuk and Richard A Posner, 'One-Sided Contracts in Competitive Consumer Markets' (2005) 104 Mich. L. Rev. 827, 827, observing that this one-sidedness induces "efficient outcomes, should contingencies arise during the performance of the contract, than a more "balanced" contract that because of imperfect enforcement could create costs as a consequence of consumers' enforcing protective provisions in the contract".

${ }^{1663}$ Korobkin (n 11). See also, on bounded rationality and the application of the unconscionability doctrine, Bubb, Ryan, and Alex Kauffman. 2009. "Consumer Biases and Firm Ownership", Working Paper. Available at: ttps://files.nyu.edu/rb165/public/papers/ BubbKaufman ConsumerBiasesandFirmOwnership.pdf, DellaVigna, Stefano, and Ulrike Malmendier. 2004. "Contract Design and Self- Control: Theory and Evidence," 119 Quarterly Journal of Economics, 353-402, Bar-Gill, Oren, and Rebecca Stone. 2012. "Pricing Misperception: Explaining Pricing Structure in the Cellular Service Market," 9 Journal of Empirical Legal Studies 430-56.

1664 Brian A Blum, Contracts (2013) 414.

1665 A \& M Produce Co. v. FMC Corp. 135 Cal.App.3d 473,487 (1982).

1666 See, e.g., Davis v. KB Home of S.C., Inc., 713 S.E.2d 799, 807 (S.C. Ct. App. 2011) ("There is no set rule as to what constitutes a waiver of the right to arbitrate; the question depends on the facts of each case." (quoting Liberty Builders, Inc. v. Horton, 521 S.E.2d 749, 753 (S.C. Ct. App. 1999)).

1667 See Nancy Kim, Evolving Business and Social Norms and Interpretation Rules: The Need for a Dynamic Approach to Contract Disputes, 84 NEB. L. REv. 506, 551 (2005) (quoting Arthur L. Corbin, Corbin on Contracts $\S 128(1952))$.

1668 Margaret Jane Radin, Boilerplate: The Fine Print, Vanishing Rights, and the Rule of Law (Princeton University Press 2013) 125.

1669 Robert L. Oakley, Fairness in Electronic Contracting: Minimum Standards for Non-Negotiated Contracts, 42 HOuS. L. REv. 1041, 1061 (2005).
} 
favorable to the stronger party" may support a finding of unconscionability in the bargaining process" $" 1670$. In other words, gross inequality of bargaining power is a factor contributing to procedural unconscionability, but it is rarely sufficient on its own.

In the UK the doctrine of unconscionability was developed as a concept of equity and does not hinge on a general and abstract norm as in the U.S. ${ }^{1671}$. The theory has been revisited by the courts ${ }^{1672}$, however it remains wrapped in a number of "unresolved issues" related to its definition ${ }^{1673}$.

The basic elements of the doctrine were set out in Alec Lobb (Garages) Ltd v Total Oil (Great Britain) Ltd, where Mr Peter Millett QC asserted that: "[f]irst, one party has been at a serious disadvantage to the other, whether through poverty, or ignorance, or lack of advice, or otherwise, so that circumstances existed of which unfair advantage could be taken ... Second, this weakness of the one party has been exploited by the other in some morally culpable manner . . . And third, the resulting transaction has been, not merely hard or improvident, but overreaching and oppressive." 1674 . However, there is no consensus or an authoritative statement as to what is the role of each element and if there is a hierarchy among them ${ }^{1675}$.

Although the role of substantive unfairness is debated, the unfairness of the transaction or of the relation caused by an unconscionable conduct is often posed in contract law disputes. The term unconscionable is therefore also a descriptor to define a certain conduct (the exploitative conduct) or situation (in particular the weakness in the complainant), and it can be adapted to disparate factual situations. For instance, English courts have declared unconscionable the improper and unethical use of commercially sensitive data ${ }^{1676}$, the liquidation of a sum for a breach of contract (deemed unconscionable and exorbitant) ${ }^{1677}$ and the failure to provide any assistance to the business partner, opposition to the scheme, and resort to forgery and false evidence ${ }^{1678}$. Moreover, the theory of unconscionability has been used to remedy to the exploitation of the weakness of one party to a contract ${ }^{1679}$.

\footnotetext{
1670 Restatement (Second) of Contracts $§ 208 \mathrm{cmt}$. d (1979).

${ }^{1671}$ However, an unconscionable conduct may be punished depending on the factual situation and the norm it violates. The doctrine of unconscionability was first introduced in England to protect in equity the expectant heirs and has been then extended to other contractual relationships in Fry v. Lane (1888) 40 ChD 312.

1672 See eg., Alec Lobb v. Total Oil [1985] 1 All ER 303, CA., Crédit Lyonnais v. Burch (1997) 29 HLR 513, CA and Portman BS v. Dusangh [2000] 2 All ER (Comm) 221, CA.

${ }^{1673}$ Spark (n 2) 279.

${ }^{1674}$ Fry v Lane (1888) 40 Ch D 312. Following literature has developed this theory by establishing four different elements: "(1) weakness in the complainant; (2) unconscionable conduct by the defendant; (3) substantive unfairness; and (4) absence of advice for the complainant", ibid.

1675 ibid. While, for instance, Chen-Wishart maintains that "[m]ere undervalue is insufficient, the contract must be overreaching and oppressive or entail such substantial undervalue that it "shocks the conscience of the court." (Mindy Chen-Wishart, 'The Nature of Vitiating Factors in Contract Law' [2015] Philosophical Foundations of Contract Law, Oxford University Press) therefore advocating for a central role of substantial unfairness, others, in contrast, believe that "substantive unfairness is not a prerequisite of the doctrine" (Spark (n 17) 209). Finally, other voices among jurists contend that unconscionability is mainly about "transactional imbalance" and that substantive unfairness is not a necessary requisite of the conduct, see David Capper, 'Undue Influence and Unconscionability: A Rationalisation'(1998)' 114 LQR 479, 486.

1676 Personal Management Solutions Ltd v Brakes Bros Ltd [2014] EWHC 3495 (QB).

1677 ParkingEye Ltd v Beavis [2015] EWCA Civ 402.

1678 Borrelli v Ting [2010] UKPC 21.

${ }^{1679}$ For instance, in the case Clark v. Malpas (1862) 4 De GF \& J 401, the court concluded that the contract was unconscionable because "a poor and illiterate man was induced to enter into a transaction of an unusual nature, without proper independent advice, and in great haste", see Alec Lobb v. Total Oil [1985] 1 All ER 303, CA.
} 
There is no unconscionability doctrine in civil law countries. However, the examination of the illegal conduct of the parties and the imbalance of bargaining power between them that brings to a severe distortion (vitiating factor) of their contractual relationship is generally analysed through the good faith criterion. Good faith, in its several facets, fulfils a similar function to the one of equity (and therefore also unconscionability) in common law. Good faith is indeed a limit to all those conducts trespassing the boundaries of 'fairness', which the judiciary can use in order to devoid or annul the contract and order compensation. Most civil law systems distinguish between objective and subjective good faith. Quite clearly, the latter refers to the state of mind (subjective) of the agent: in this case, ignorance of illegality of the action would save him from any accusation. Objective good faith refers instead to general standards of conduct that the contracting parties have to adopt during negotiations and in the execution of the contract. For instance, in Germany and Italy this theoretical framework has evolved into the formulation of two concepts of (respectively) "treu und glauben" and "correttezza". By contrast, the French legal system does not distinguish between subjective and objective good faith.

\subsection{Economic Duress}

The theory of duress originated as an equitable relief to protect a person that entered a contract or performed an action as a consequence of a threat (i.e. physical duress) ${ }^{1680}$. It was then developed to include also illegitimate threats (e.g. to breach an existing contract or to commit a tort) to a person that has no practical alternatives to the terms imposed ${ }^{1681}$. So, besides duress to persons and duress to goods, the common law developed a third type of duress called 'economic duress'. This type of duress "arises where one party uses his superior economic power in an 'illegitimate' way so as to coerce the other contracting party to agree to a particular set of terms"1682. In other words the relevant case law on economic duress shows that this remedy can be invoked subject to two conditions, the coercion of the will and the exertion of an illegitimate pressure on the victim of the 'wrong of duress'. With regard to the proof of duress, two main elements are required, causation and illegitimate pressure. The commercial pressure has to be causally linked to the decision of the victim to enter the contract or perform an action, that otherwise would have not entered or performed. Secondly, the pressure has to be illegitimate. This is generally a thorny aspect of the proof, but courts have provided guidance

\footnotetext{
1680 Skeate v Beale (1840) 11 Ad \& El 983, 113 ER 688.

1681 See Universe Tankships Inc. of Monrovia v International Transport Workers Federation [1983] 1 AC 366 (HL).

${ }^{1682}$ Ewan McKendrick, Contract Law (Palgrave Macmillan 2005) 358, interpreting the relevant jurisprudence. Kerr J first outlined and applied this doctrine in The Siboen and The Sibotre [1976] 1 Lloyd's Rep 293 where he stated "if I should be compelled to sign a lease or some other contract for a nominal but legally sufficient consideration under an imminent threat of having my house burnt down or a valuable picture slashed through without any threat of physical violence to anyone, I do not think that the law would uphold the agreement... The true question is ultimately whether or not the agreement in question is to be regarded as having been concluded voluntarily.". Later, in the case Privy Council in R v. Attorney-General for England and Wales [2003] UKPC 22 Lord Hoffmann detailed this doctrine stating that the economic duress contains two essential elements: a) pressure amounting to compulsion of the will of the victim; b) illegitimacy of the pressure.
} 
on the elements of the illegitimate pressure ${ }^{1683}$. However, no clear definition or principle of legitimacy has been developed. It has been noted that the legitimacy may refer to the conduct of the wrongdoer as well as to the adequacy of the consent ${ }^{1684}$.

\subsubsection{Unfair competition law}

According to a European 'High Level Forum on Better Functioning of the Supply Chain' (HLF) report, a number of European national competition authorities discovered the existence of unfair practices in the food supply chain linked to imbalances of bargaining power between stakeholders. ${ }^{1685}$ As it is reported by the HLF, "NCAs found that most of these practices do not fall within the scope of competition rules at EU level or in most Member States, as they did not affect consumer welfare. A few NCAs have proposed alternative solutions to tackle them, such as the application of national laws against unfair trading practices, or the adoption of codes of conduct or good practices with effective enforcement mechanisms. A few NCAs have also expressed concerns about the potential anti-competitive effects that some of these practices may have in the long term, should they ultimately negatively affect the competitive process in the supply chain or consumer welfare by reducing investment and innovation or limiting consumer choice". ${ }^{1686}$ In Europe, these concerns have resulted in the launch of the Supply Chain Initiative, under the auspices of the EU, which endorses the principles of fair contracting contained in the HLF Report and in the Green Paper on Unfair trading practices in the food and non-food supply chain in Europe, ${ }^{1687}$ with the aim to establish a set of principles of good practice for the food supply chain. ${ }^{1688}$ The regulatory framework related to unfair competition in the food sector of the BRICS countries is instead rather diverse.

For example, in the Russian Federation, the Federal Antimonopoly Service (FAS) plays a prominent role in monitoring and ensuring the protection of competition in the Russian food market. It now encompasses not only protection of competition, but also various spheres of economic regulations. FAS regulates and oversees the activities of natural monopolies; performs control over the public procurement procedures and foreign investments in the Russian Federation; oversees compliance with the regulations on advertising activities. In its activities FAS is subject to Russian competition law, which comprises two principal legal acts, the Federal law "On Protection of Competition" and the Federal law "On the Basic Principles of State Regulation of Trading Activities in the Russian Federation". With a view to defining priorities in promotion of competition in the Russian Federation, FAS has devised the "National Plan on Development of Competition in 2017-2018' with particular focus on a number of industries including agriculture.

Brazil has a wide network of regulations in the food sector which is spread in several levels of hierarchy, organs and autonomous agencies. Unfair competition in the food sector is

\footnotetext{
${ }^{1683}$ Carillion Construction Ltd v Felix (UK) Ltd [2001] B.L.R. 1; 74 Con. L.R. 144 , per Dyson, J.

1684 David Capper, ‘Undue Influence and Unconscionability: A Rationalisation'(1998)' 114 LQR 479, 172. 
assessed in the same way as all the other economic sectors. Competition law in Brazil has gone through some important changes in the past five years when the New Law 12,529 of 30 November, $2011^{1689}$ came into force on May 29, replacing the old Law 8,884, of 1994. Competition law is enforced by a single authority system under the umbrella of the Administrative Council for Economic Defence (CADE), with a subsidiary role by the Ministry of Finance in the promotion of competition. In general, the main regulatory bodies in the food sector include the Brazilian Health Regulatory Agency-ANVISA and the National Food Supply Company (CONAB) which regulates the supply of the Brazilian internal market. Also, the Ministry of Agriculture, Livestock and Food Supply (MAPA) regulates, classifies and inspects agricultural products in Brazil, including imported foodstuffs.

In Mainland China, the regulation of food value chains is particularly complex. The main bodies responsible for regulating unfair competition in the food sector are the National Development and Reform Commission (NDRC) and the State Administration for Industry and Commerce (SAIC). In a nutshell, NDRC is the competent authority for the macro control and regulation of the Chinese economy, whilst NDRC's affiliation, the Bureau of Price Supervision and Antimonopoly, is one of the three Chinese antitrust enforcement agencies and its jurisdiction covers unilateral and collective anticompetitive conduct cases concerning price. With regards to SAIC, it is the competent authority in charge of market supervision, regulation and related administrative law enforcement. The SAIC and its local subsidiaries are responsible for law enforcements in enterprise registration, antitrust and anti-unfair competition, advertising industry, consumer protection and trademark protection. The SAIC and local AIC system is responsible for enforcing Chinese Anti-Unfair Competition Law and Chinese AntiMonopoly Law with regard to monopolistic agreements, abuse of market dominant position, and practices to eliminate or restrict competition through abuse of administrative power.

The basic regulatory framework of food value chains has been set by several laws and national policies. As the food value chain is a novel concept to both Chinese academics and regulators, there is no specific law or policy that regulates it as an integrated phenomenon, and thus, the regulation of different segments of a food value chain differs substantially. The most significant competition law legislation is the Anti-monopoly Law of the People's Republic of China (AML) 2008. ${ }^{1690}$ Article 56 AML provides that the AML does not apply to the association or cooperation by agricultural producers or rural economic organizations in their business activities of production, processing, sale, transportation, storage of farm products, etc. ${ }^{1691}$ The competition law exemption for agro-food sectors generally targets the provisions included in AML Chapter 2, that is, Article 16 prohibiting industrial organisations from organising concerted anticompetitive practices, and Article 13 prohibiting competitors from concluding monopoly agreements. It is noted that although Chinese competition law offers these exemptions, competition law enforcement in the areas of distribution cartels, merger control, and abuse of a dominant position in the agricultural sector receive no exemption.

${ }^{1689}$ Available at: http://www.planalto.gov.br/ccivil_03/_ato2011-2014/2011/Lei/L12529.htm

1690 http://english.mofcom.gov.cn/article/policyrelease/Businessregulations/201303/20130300045909.shtml ${ }^{1691} \mathrm{http} / / /$ english.mofcom.gov.cn/article/policyrelease/Businessregulations/201303/20130300045909.shtml 
On 13 Oct 2006, MOFCOM, the Ministry of Public Security, the State Administration for Industry \& Commerce, the State Administration of Taxation, the State Development \& Reform Commission jointly enacted a department regulation entitled Administrative Measures for Fair Transactions between Retailers and suppliers which specifies some forms of abuse of superior bargaining power. ${ }^{1692}$ In 2011, MOFCOM issued a Work plan against large scale retailers and suppliers' illegal charge. ${ }^{1693}$ On 25 February 2016, the Legislative Affairs Office of the State Council published the amending draft of the Anti-Unfair Competition Law of the People's Republic of China (AUCL). The AUCL added the abuse of superior bargaining power as a prohibited act and no exemption for agro-food issues is mentioned in the draft amendment.

In India, the central government has vast powers to regulate the food sector. The Indian food sector is governed by multiple laws and regulations that govern different links in the food value chain. Unfair trading practices are covered under the Consumer Protection Act, 1986. Until 2002, the Monopolies and Restrictive Trade Practices Act (MRTP), which was enacted to prevent monopolies and restrictive trade practices, was the foremost legislation to deal with unfair trade practices in the country. In 2002, the Competition Act, repealed the MRTP Act, and cases pending before the MRTP Commission were transferred to the Competition Commission of India (CCI). However, the Competition Act did not contain any provision expressly dealing with unfair trading practices, and therefore, these were addressed under the provisions of the Consumer Protection Act, 1986, which was already dealing with unfair trade practices.

In South Africa, the agriculture industry has a long history of intense state intervention. The apartheid government extensively regulated the production and marketing of agricultural products through state sanctioned 'control boards' established by the Marketing Act of 1937 (consolidated in 1968). The Marketing Act instituted a system of controls which regulated the movement, pricing, quality standards and marketing supply of the majority of agricultural production. The first democratic government liberalised the sector and introduced a reformed competition legislation. Unfair competition in the food sector is assessed in the same way as all the other economic sectors. In general, the Competition Act applies a consumer welfare standard in the assessment of abuse of dominance and merger cases. In November 2015, the Competition Commission established a market into the grocery retail section which is designed to focus on the role of supermarket chains in townships, particularly in peri urban and rural areas. $^{1694}$

\section{Table 3: Unfair Competition Laws in BRICS}

\footnotetext{
1692 http://www.mofcom.gov.cn/article/b/c/200610/20061003442804.shtml

$1693 \mathrm{http}: / /$ www.mofcom.gov.cn/article/h/redht/201112/20111207899504

1694 The inquiry has conducted some public hearings but has produced no report as at the time of the completion of this paper. It has provided transcripts of the hearings conducted on the Competition Commission's website www.compcom.co.za/ retail market inquiry
} 


\begin{tabular}{|c|c|c|}
\hline Brazil $^{1695}$ & Unfair Competition & $\begin{array}{l}\text { Unfair Competition in Food } \\
\text { sector }\end{array}$ \\
\hline Legislation & $\begin{array}{l}\text { 1. Federal Constitution of } 1988 \text { (Art. 173, (4)) } \\
\text { 2. Law No. } 12,529 / 11 \text {, Art. } 36 \\
\text { 3. Law No. 9,279/96 (The Industrial Property } \\
\text { Law), Art. } 195 \\
\text { 4. Law No. } 8,078 / 90 \text { (Consumer Defence Code) }\end{array}$ & $\begin{array}{l}\text { No specific legislation on } \\
\text { unfair competition in the food } \\
\text { sector. }\end{array}$ \\
\hline Substance & $\begin{array}{l}\text { 1. Art. 173(4) of the Federal Constitution } \\
\text { provides that "the law shall repress the abuse } \\
\text { of economic power that aims at the } \\
\text { domination of markets, the elimination of } \\
\text { competition and the arbitrary increase of } \\
\text { profits" } \\
\text { 2. The Competition Law No.12,529/11 sets } \\
\text { forth the basic framework for anticompetitive } \\
\text { conduct (Art. 36). } \\
\text { 3. The Industrial Property Law defines the } \\
\text { crime of "Unfair Competition" which covers } \\
\text { commercial disparagement, false branding, } \\
\text { fraudulent diversion of trade, advertising } \\
\text { designed to cause brand confusion, violation } \\
\text { of trademark rights, commercial bribery, } \\
\text { illegitimate appropriation or disclosure of } \\
\text { trade secrets, false patent claims (Art. 195). } \\
\text { 4. The Consumer Defence Code regulates such } \\
\text { marketing practices as deceptive advertising, } \\
\text { false warranties, door to door sales, } \\
\text { telemarketing, abusive price increases. }\end{array}$ & $\begin{array}{l}\text { 1. The Brazilian } \\
\text { Competition Law No. } \\
12,529 / 2011 \text { does not } \\
\text { set forth any type of } \\
\text { sector-specific } \\
\text { exemptions or rules on } \\
\text { unfair competition. } \\
\text { 2. The Industrial Property } \\
\text { Law No. 9,279/96 } \\
\text { prohibits unfair } \\
\text { competition practices } \\
\text { and is also general in } \\
\text { scope without sector- } \\
\text { specific rules (Art.195). } \\
\text { As a result the general } \\
\text { rules on the prohibition } \\
\text { of unfair competition } \\
\text { and anticompetitive } \\
\text { practices apply } \\
\text { indistinctly to all } \\
\text { market sectors. }\end{array}$ \\
\hline Institutions & $\begin{array}{l}\text { 1. Administrative Council for Economic } \\
\text { Defence (CADE) } \\
\text { 2. Secretary for Economic Monitoring of the } \\
\text { Ministry of Finance (SEAE) } \\
\text { 3. Consumer Protection and Defence } \\
\text { Department (DPDC) }\end{array}$ & \\
\hline
\end{tabular}

1695 OECD \& Inter-American Development Bank, Competition Law and Policy in Latin America - p[eer reviews of Argentina, Brazil, Chile, Mexico and Peru (OECD \& IADB, 2006), 95-96; P. Kobel, P. Këllezi, Bruce Kilpatrick (eds.), Antitrust in the Groceries Sector \& Liability Issues in Relation to Corporate Social Responsibility (Springer, 2015), 96-97. 


\begin{tabular}{|c|c|c|}
\hline India ${ }^{1696}$ & Unfair Competition & $\begin{array}{l}\text { Unfair Competition in Food } \\
\text { sector }\end{array}$ \\
\hline Legislation & $\begin{array}{l}\text { 1. Consumer Protection Act, } 1986 \\
(\text { Art. 2(1)(r)) } \\
\text { 2. Competition Act, } 2002 \text { (Art. 4(2), Art. } \\
66(4) \text { ) }\end{array}$ & $\begin{array}{l}\text { Food Safety and Standards Act, } \\
2006\end{array}$ \\
\hline Substance & 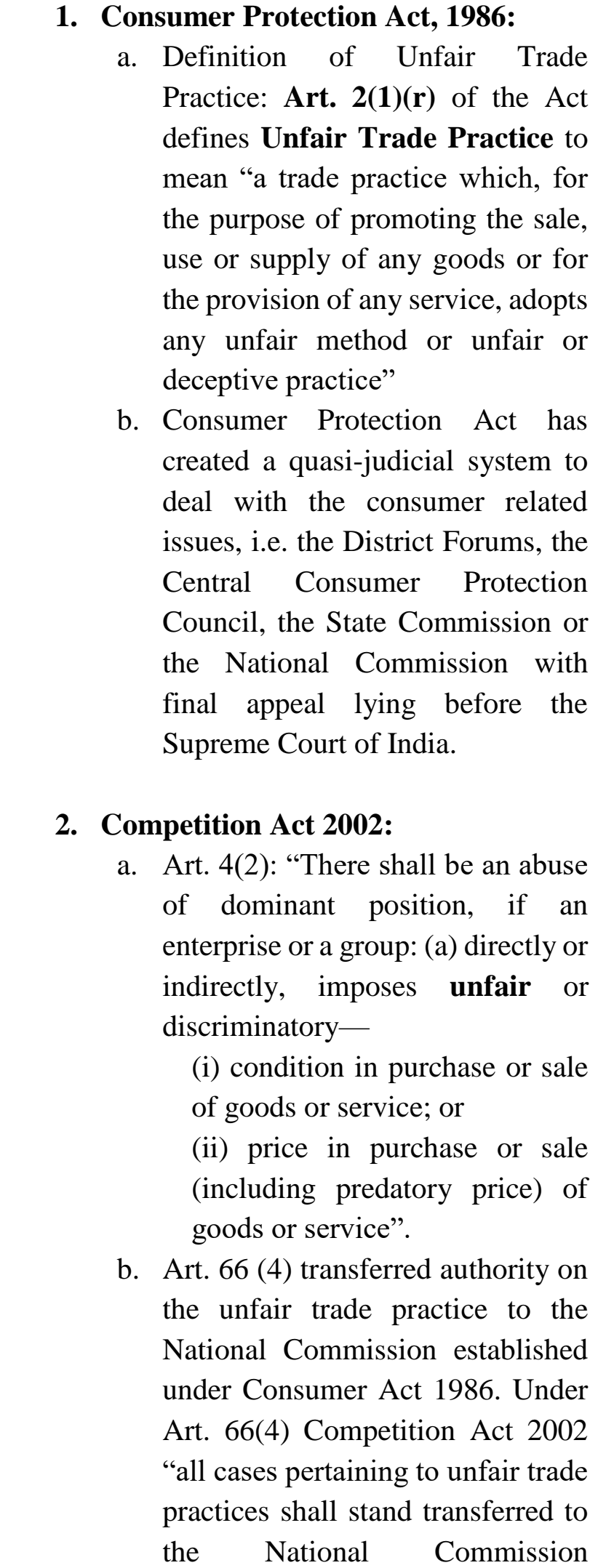 & 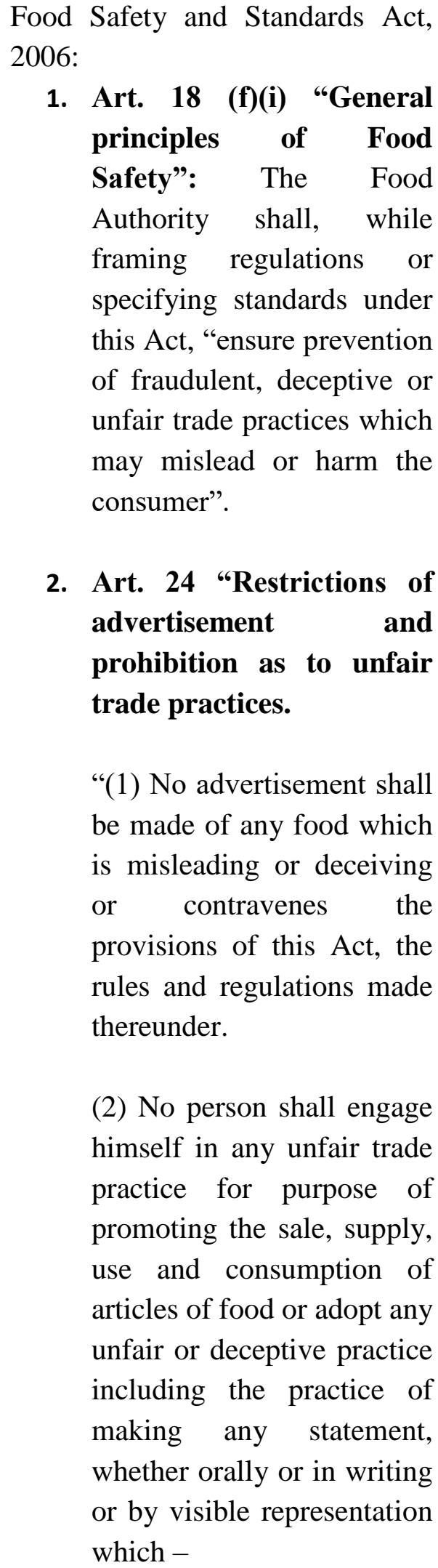 \\
\hline
\end{tabular}




\begin{tabular}{|c|c|c|}
\hline & $\begin{array}{l}\text { constituted under the Consumer } \\
\text { Protection Act, 1986". } \\
\text { c. One exception - "All cases } \\
\text { pertaining to unfair trade practices } \\
\text { referred to in clause (x) of } \\
\text { subsection (1) of section 36A of the } \\
\text { Monopolies and Restrictive Trade } \\
\text { Practices Act } 1969 \text { and pending } \\
\text { before the Monopolies and } \\
\text { Restrictive Trade Practices } \\
\text { Commission shall stand transferred } \\
\text { to the Appellate Tribunal". }\end{array}$ & $\begin{array}{l}\text { (a) falsely represents that } \\
\text { the foods are of a particular } \\
\text { standard, quality, quantity } \\
\text { or grade-composition; } \\
\text { (b) makes a false or } \\
\text { misleading representation } \\
\text { concerning the need for, or } \\
\text { the usefulness; } \\
\text { (c) gives to the public any } \\
\text { guarantee of the efficacy } \\
\text { that is not based on an } \\
\text { adequate or scientific } \\
\text { justification thereof." }\end{array}$ \\
\hline Institutions & $\begin{array}{l}\text { Consumer Protection Act 1986: } \\
\text { 1. District Consumer Forums (Art. } 9 \\
\text { (a), } 14(\mathrm{f})) \\
\text { 2. Central Consumer Protection } \\
\text { Council (Art. 6 (e)) } \\
\text { 3. State Commission (Art. 9(b)) } \\
\text { 4. National Commission (Art. 21) } \\
\text { Competition Act 2002: } \\
\text { 1. Competition Commission of India } \\
\text { (CCI) (Arts. 18, 19) } \\
\text { 2. Appellate Tribunal (Art. 66(4)) }\end{array}$ & $\begin{array}{l}\text { Food Safety and Standards } \\
\text { Authority of India } \\
\text { http://www.fssai.gov.in/AboutFSS } \\
\underline{\text { AI/FSSAct.aspx }}\end{array}$ \\
\hline
\end{tabular}

${ }^{1696}$ R. Mathur \& U. S. Mehta, Unfair Trade Practices and Institutional Challenges in India: An Analysis, GIZ Stakeholder Consultation Workshop (New Delhi, April 1-2, 2013). 


\begin{tabular}{|c|c|c|}
\hline Russia $^{1697}$ & Unfair Competition & $\begin{array}{l}\text { Unfair Competition in Food } \\
\text { sector }\end{array}$ \\
\hline Legislation & $\begin{array}{l}\text { Federal Law No. 135-FZ “On The Protection } \\
\text { of Competition", 2006 } \\
\underline{\text { http://en.fas.gov.ru/legislation/legislation } 5091} \\
\underline{\text { 5.html }}\end{array}$ & $\begin{array}{l}\text { General Provisions of the Federal } \\
\text { Law "On The Protection of } \\
\text { Competition", } 2006\end{array}$ \\
\hline Substance & $\begin{array}{l}\text { Federal Law "On The Protection of } \\
\text { Competition", } 2006 \\
\text { Article } 14 \text { "Prohibition of Unfair Competition": } \\
\text { "1. Unfair competition is not permitted, } \\
\text { including: } \\
\text { 1) dissemination of false, inaccurate, or } \\
\text { distorted information, which can inflict losses } \\
\text { on economic entity or cause damage to its } \\
\text { business reputation; } \\
\text { 2) misrepresentation concerning the nature, } \\
\text { method, and place of manufacture, consumer } \\
\text { characteristics, quality and quantity of a } \\
\text { commodity or concerning its producers; } \\
\text { 3) incorrect comparison of the products by an } \\
\text { economic entity, manufactured or sold by it, } \\
\text { with the products manufactured or sold by other } \\
\text { economic entities; } \\
\text { 4) sale, exchange or other way of input of a } \\
\text { commodity into circulation if there was illegal } \\
\text { use of the results of intellectual activity and } \\
\text { equalized to them means of individualization of } \\
\text { a legal person, means of individualization of } \\
\text { production, works, services; } \\
\text { 5) illegal receipt, use, and disclosure of } \\
\text { information constituting commercial, official or } \\
\text { of this Article concerning acquisition and use of } \\
\text { other protected by law secret. } \\
\text { 2. Unfair competition, related to acquisition and } \\
\text { use of exclusive rights for the means of } \\
\text { individualization of a legal person, means of } \\
\text { individualization of production, works, and } \\
\text { services is not permitted. }\end{array}$ & \\
\hline
\end{tabular}




\begin{tabular}{|l|l|l|}
\hline & $\begin{array}{l}\text { exclusive rights to a trademark is sent by an } \\
\text { interested Party to the federal executive } \\
\text { authority for intellectual property for } \\
\text { recognizing invalid the legal protection granted } \\
\text { to this trademark." }\end{array}$ & \\
\hline Institutions & $\begin{array}{l}\text { Federal Anti-Monopoly Service (FAS) - } \\
\text { established in 2004 }\end{array}$ & $\begin{array}{l}\text { Federal Anti-Monopoly Service } \\
\text { (FAS) }\end{array}$ \\
\hline
\end{tabular}

${ }^{1697}$ OECD, Competition Law and Policy in the Russian Federation (OECD, 2013). 


\begin{tabular}{|c|c|c|}
\hline China & Unfair Competition & $\begin{array}{l}\text { Unfair Competition in Food } \\
\text { sector }\end{array}$ \\
\hline Legislation & $\begin{array}{l}\text { Anti-monopoly Law of the People's Republic } \\
\text { of China (AML), } 2008\end{array}$ & $\begin{array}{l}\text { General Provisions of the Anti- } \\
\text { monopoly Law of the People's } \\
\text { Republic of China (AML), } 2008\end{array}$ \\
\hline Substance & $\begin{array}{l}\text { Chapter III Abuse of Market Dominance } \\
\text { Art. 17: "A business operator with a dominant } \\
\text { market position shall not abuse its dominant } \\
\text { market position to conduct following acts: } \\
\text { (1) selling commodities at unfairly high prices } \\
\text { or buying commodities at unfairly low prices; } \\
\text { (2) selling products at prices below cost without } \\
\text { any justifiable cause; } \\
\text { (3) refusing to trade with a trading party without } \\
\text { any justifiable cause; } \\
\text { (4) requiring a trading party to trade exclusively } \\
\text { with itself or trade exclusively with a designated } \\
\text { business operator(s) without any justifiable } \\
\text { cause; } \\
\text { (5) tying products or imposing unreasonable } \\
\text { trading conditions at the time of trading without } \\
\text { any justifiable cause; } \\
\text { (6) applying dissimilar prices or other } \\
\text { transaction terms to counterparties with equal } \\
\text { standing; } \\
\text { (7) other conducts determined as abuse of a } \\
\text { dominant position by the Anti-monopoly } \\
\text { Authority under the State Council". }\end{array}$ & $\begin{array}{l}\text { The Anti-monopoly Law } 2008 \\
\text { does not cover the agricultural } \\
\text { sector. } \\
\text { According to Art. } 56 \text { "This Law } \\
\text { does not govern the ally or } \\
\text { concerted actions of agricultural } \\
\text { producers and rural economic } \\
\text { organizations in the economic } \\
\text { activities such as production, } \\
\text { processing, sales, transportation } \\
\text { and storage of agricultural } \\
\text { products." }\end{array}$ \\
\hline Institutions & $\begin{array}{ll}\text { 1. } & \text { State Administration for Industry \& } \\
\text { Commerce (SAIC) } \\
\text { 2. National Development and Reform } \\
\text { Commission (NDRC) } \\
\text { 3. Bureau of Price Supervision and } \\
\text { Antimonopoly } \\
\text { 4. Local Administration for Industry \& } \\
\text { Commerce (AIC) }\end{array}$ & \\
\hline
\end{tabular}




\begin{tabular}{|c|c|c|}
\hline $\begin{array}{l}\text { South } \\
\text { Africa }\end{array}$ & Unfair Competition & $\begin{array}{l}\text { Unfair Competition in Food } \\
\text { sector }\end{array}$ \\
\hline Legislation & $\begin{array}{l}\text { 1. Competition Act, } 1998 \\
\text { 2. Consumer Protection Act No } 68 \\
\text { (CPA), } 2008\end{array}$ & \\
\hline Substance & $\begin{array}{l}\text { Competition Act, 1998: } \\
\text { Art 8: "Abuse of dominance prohibited It is } \\
\text { prohibited for a dominant firm to - } \\
\text { (a) charge an excessive price to the detriment of } \\
\text { consumers; } \\
\text { (b) refuse to give a competitor access to an } \\
\text { essential facility when it is economically } \\
\text { feasible to do so; } \\
\text { (c) engage in an exclusionary act, other than an } \\
\text { act listed in paragraph (d), if the anti- } \\
\text { competitive effect of that act outweighs its } \\
\text { technological, efficiency or other pro- } \\
\text { competitive gain; or } \\
\text { (d) engage in any of the following exclusionary } \\
\text { acts, unless the firm concerned can show } \\
\text { technological, efficiency or other pro- } \\
\text { competitive gains which outweigh the anti- } \\
\text { competitive effect of its act (...)". } \\
\text { Consumer Protection Act No } \mathbf{6 8 , 2 0 0 8} \\
\text { Section } \mathbf{4 8} \text { of the CPA deals with unfair, } \\
\text { unreasonable or unjust contract terms. } \\
\text { Section } 51 \text { sets out the prohibited transactions, } \\
\text { agreements, terms or conditions. }\end{array}$ & \\
\hline Institutions & $\begin{array}{l}\text { 1. National Consumer Commission (NCC) } \\
\text { 2. Competition Commission (Art. 21(1) of } \\
\text { the Competition Act) } \\
\text { 3. Competition Tribunal (Art. } 27 \text { of the } \\
\text { Competition Act) } \\
\text { 4. Competition Appeal Court (Art. } 37 \text { of } \\
\text { the Competition Act) }\end{array}$ & \\
\hline
\end{tabular}

Source: Authors' compilation

\subsection{Conclusion}

Our provisional conclusion is that there is need to develop a proper concept of superior bargaining power in competition law in order to deal with the situations of bargaining power 
and constrained choice that will emerge out of the increasing concentration of agrochem, seed and processing. It is possible that other areas of law may provide more adequate tools, but no presumption on their superiorioty as options should be made before a careful comparative institutional analysis. We believe that addressing the structural disparities of bargaining power is essential in order to ensure efficiency and fairness and that competition law may offer, in some cases, a better alternative than contract law, or unfair competition law, in order to deal with these situations.

1698 T. Hartzenberg, Competition Policy and Practice in South Africa: Promoting Competition for Development Symposium on Competition Law and Policy in Developing Countries, (2005-2006) 26 Northwestern Journal of International Law \& Business 667, 667-668. 


\section{References}

Akman P., The Concept of Abuse in EU Competition Law (Hart Publishing 2012).

Akman P., 'The Relationship between Economic Duress and Abuse of a Dominant Position' [2014] Lloyd's Maritime and Commercial Law Quarterly 99.

Alexandrov A. and S. Koulayev, 'Using the Economics of Pass Through in Proving Antitrust Injury in Robinson-Patman Cases' (2015) 60 Antitrust Bulletin 345.

Autorité de la concurrence, Opinion 15-A-06 of 31 March 2015 Concerning the Joint Purchasing Agreements in the Food Retail Sector (2015), available at http://www.autoritedelaconcurrence.fr/pdf/avis/15a06.pdf.

Averitt N.W., 'The Meaning of Unfair Methods of Competition in Section 5 of the Federal Trade Commission Act' (1980) 21 Boston College Law Review 227.

Averitt N.W. and R.H. Lande, 'Using the "Consumer Choice" Approach to Antitrust Law' (2007) 74 Antitrust Law Journal 175.

Ayres I. and R. Gertner, 'Filling Gaps in Incomplete Contracts: An Economic Theory of Default Rules' (1989) 99 Yale Law Journal 87.

Ayres I. and B.J. Nalebuff, 'Common Knowledge as a Barrier to Negotiation' (1996) 44 UCLA Law Review 1631.

Bachrach P. and M.S. Baratz, 'The Two Faces of Power' (1962) 56 American Political Science Review 941.

Baker J.B., J. Farrell and C. Shapiro, 'Merger to Monopoly to Serve a Single Buyer' (2008) 75 Antitrust Law Journal 637.

Bakhoum M., 'Abuse without Dominance in Competition Law: Abuse of Economic Dependence and its Interface with Abuse of Dominance', Max Planck Institute for Innovation and Competition Research Paper No. 15-15.

Bar-Gill, O. and R. Stone. 2012. 'Pricing Misperception: Explaining Pricing Structure in the Cellular Service Market' (2012) 9 Journal of Empirical Legal Studies 430.

Barnhizer D.D., 'Inequality of Bargaining Power' (2005) 76 University of Colorado Law Review 139.

Barnhizer D.D., 'Bargaining Power in Contract Theory', L.A. DiMatteo, R.A. Prentice, B.D. Morant and D.D. Barnhizer (eds.), Visions of Contract Theory. Rationality, Bargaining, and Interpretation (Carolina Academic Press 2007).

Bauer J.P. and E.W. Kintner, 'The Robinson-Patman Act: A Look Backwards, A View Forward' (1986) 31 Antitrust Bulletin 571.

Beaton-Wells A., 'The ACCC Immunity Policy for Cartel Conduct: Due for Review' (2013) 41 Australian Business Law Review 171.

Bebchuk L.A. and R.A Posner, 'One-Sided Contracts in Competitive Consumer Markets' (2005) 104 Michigan Law Review 827. 
Binmore K., M. J. Osborne and A. Rubinstein, 'Non-Cooperative Models of Bargaining', in R.J. Aumann and S. Hart (eds.), Handbook of Game Theory with Economic Applications (Elsevier 1992).

Blair R.D. and J.L. Harrison, Monopsony in Law and Economics (Cambridge University Press 2010).

Blair R.D. and C. Depasquale, 'Bilateral Monopoly and Antitrust Policy', in R.D. Blair and D. Sokol (eds.), Oxford Handbook of International Antitrust Economics, vol. 1 (Oxford University Press 2015).

Blum B.A., Contracts (Aspen Publishers 2013).

Bowles S., Microeconomics - Behavior, Institutions, and Evolution (Princeton University Press 2004).

Boy L., 'Abus de dépendance économique: Reculer pour mieux sauter?' [2010] n 23 Revue Lamy Concurrence 93.

Breckenridge J.E., 'Bargaining Unfairness and Agreements to Arbitrate: Judicial and Legislative Application of Contract Defenses to Arbitration Agreements' [1991] Annual Survey of American Law 925.

Bubb R. and A. Kauffman, 'Consumer Biases and Firm Ownership' (26 October 2009), available at: https://files.nyu.edu/rb165/public/papers/Bubb Kaufman ConsumerBiasesandFirmOwnership.pdf.

Bukeviciute L., A. Dierx and F. Ilzkovitz, The Functioning of the Food Supply Chain and its Effect on Food Prices in the European Union (2009) European Economy Occasional Papers 47.

Bundeskartellamt, Sektoruntersuchung. Nachfragemacht im Lebensmitteleinzelhandel (2014) B2-15/11 BKartA, available at bundeskartellamt.de/Sektoruntersuchung_LEH.pdf?_blob=publicationFile\&v=7.

http://www.

Campbell T., 'Bilateral Monopoly in Mergers' (2007) 74 Antitrust Law Journal 521.

Cane P. and M.V. Tushnet, The Oxford Handbook of Legal Studies (Oxford University Press 2005).

Capper D., 'Undue Influence and Unconscionability: A Rationalisation' (1998) 114 Law Quarterly Review 479

Carstensen P.C., Competition Policy and the Control of Buyer Power. A Global Issue (Edward Elgar 2017).

Chen Z., 'Dominant Retailers and Countervailing Power Hypothesis' (2003) 34 Rand Journal of Economics 612.

Chen Z., 'Buyer Power: Economic Theory and Antitrust Policy' (2007) 22 Research in Law and Economics 17.

Chen-Wishart M., 'The Nature of Vitiating Factors in Contract Law', in G. Klass, G. Letsas and P. Saprai, Philosophical Foundations of Contract Law (Oxford University Press 2015).

Cheng T.K. and M.S. Gal, 'Superior Bargaining power: Dealing with Aggregate Concentration Concerns', paper presented at the 10th ASCOLA conference (Tokyo, 21-23 May 2015).

Chin Y.W., 'What Role for Abuse of Superior Bargaining Position Laws?', New York Law Journal (6 July 2016).

Choi A. and G. Triantis, 'The Effect of Bargaining Power on Contract Design' [2012] Virginia Law Review 1665. Ciapanna E. and C. Rondinelli, 'Retail Market Structure and Consumer prices in the Euro Area' (December 2014) ECB Working Paper Series No. 1744. 
Clarke R., S. Davies, P.W. Dobson and M. Waterson, Buyer Power and Competition in European Food Retailing (Edward Elgar 2002).

Comision Nacional de la Competencia, Report on the Relations between Manufacturers and Retailers in the Food Sector, available

http://www.cncompetencia.es/Inicio/Informes/InformesyEstudiossectoriales/tabid/228/Default.aspx.

Coase R.H., 'The Nature of the Firm' (1937) 4 Economica 386.

Cook K.S. \& R.M. Emerson, Power, equity and commitment in exchange networks, (1978) 43(5) American Sociological Review 721.

Corbin A.L., Corbin on Contracts (West Publishing 1952).

DellaVigna S. and U. Malmendier, 'Contract Design and Self-Control: Theory and Evidence' (2004) 119 Quarterly Journal of Economics 353.

Desai D.R., I. Lianos and S. Weber Waller, Brands, Competition Law and IP (Cambridge University Press 2015). DiMatteo L.A., 'Equity's Modification of Contract: An Analysis of the Twentieth Century's Equitable Reformation of Contract Law' (1998) 33 New England Law Review 265.

DiMatteo L.A. and B.L. Rich, 'A Consent Theory of Unconscionability: An Empirical Study of Law in Action' (2006) 33 Florida State University Law Review 1067.

Dobson P.W. and M. Waterson, 'Countervailing Power and Consumer Prices' (1997) 107 Economic Journal 418.

Dobson P.W., M. Waterson and A. Chu, 'The Welfare Consequences of the Exercise of Buyer Power' (1998) OFT Research Paper 16.

Dobson P.W., 'Exploiting Buyer Power: Lessons from the British Grocery Trade' (2005) 72 Antitrust Law Journal 529.

Dobson P.W. and R. Inderst, 'Differential Buyer Power and the Waterbed Effect: Do Strong Buyers Benefit or Harm Consumers?' (2007) 28 European Competition Law Review 393.

Dowding K., Power (Open University Press 1996).

Drexl J., 'Consumer Welfare and Consumer Harm: Adjusting Competition Law and Policies to the Need of Developing Jurisdictions', in M. Gal, M. Bakhoum, J. Drexl, E. Fox and D. Gerber (eds.), Economic Characteristics of Developing Jurisdictions: Their Implications for Competition Law (Edward Elgar 2015).

Dunlop J.T. and B. Higgins, 'Bargaining Power and Market Structures' (1942) L(1) The Journal of Political Economy 1.

Eisenberg M.A., 'Mistake in Contract Law' (2003) 91 California Law Review 1573.

Ellinghaus M.P., 'In Defense of Unconscionability' (1969) 78 Yale Law Journal 757.

Emmerson R.M., Power-dependence relations, (1962) 27(1) American Sociological Review 31.

Epstein R.A., 'Unconscionability: A Critical Reappraisal' (1975) 18 Journal of Law \& Economics 293.

European Commission, Buyer Power and its Impact in the Food Retail Distribution Sector of the European Union (1999).

European Commission, Green Paper on unfair trading practices in the business-to-business food and non-food supply chain in Europe, COM(2013) 37 final.

European Commission [Renda A. et al.],, Study on the Legal Framework Covering Business-to-Business Unfair Trading Practices in the Retail Supply Chain, Final Report (European Commission, 26 February 2014), available at

market/retail/docs/140711-study-utp-legal-framework_en.pdf. http://ec.europa.eu/internal_ 
European Commission, The Economic Impact of Modern Retail on Choice and Innovation in the EU Food Sector (2014), available at http://ec.europa.eu/competition/publications/KD0214955ENN.pdf.

Ezrachi A. and U. Bernitz, Private Labels, Branded Goods and Competition Policy: The Changing Landscape of Retail Competition (Oxford University Press 2009).

Ezrachi A., 'Unchallenged Market Power? The Tale of Supermarkets, Private Labels, and Competition Law' (2010) 33 World Competition 257.

Falce V., 'Abuse of Economic Dependence and Competition Law Remedies: A Sound Interpretation of the Italian Regulation' (2015) 36 European Competition Law Review 71.

Falce V., 'The Italian Regulation against the abuse of economic dependence', paper presented at the 10th ASCOLA Conference (Tokyo 21-23 May 2015).

Farnsworth E.A., Farnsworth on Contracts (Little Brown 1990).

Fiala T., 'Czech Republic: Anti-competitive Practices - Economic Dependence Act' (2014) 35 European Competition Law Review 5.

Finnish Competition Authority, Study on Trade in Groceries - How Does Buyer Power Affect The Relations between the Trade and Industry? (2012) 1 FCA reports, available at http://www.kkv.fi/globalassets/kkvsuomi/julkaisut/selvitykset/2012/en/fca-reports-1-2012-study-on-trade-in-groceries.pdf.

Foer A., 'Introduction to Symposium on Buyer Power and Antitrust' (2005) 72 Antitrust Law Journal 505.

Foer A., 'On the Inefficiencies of Efficiency as the Single-Minded Goal of Antitrust' (2015) 60 Antitrust Bulletin 103.

Foer A. et al., 'The Goals of Antitrust: Thoughts on Consumer Welfare in the US', in P. Marsden (ed.), Handbook of Research in Trans-Atlantic Antitrust (Edward Elgar 2006).

Foucault M., 'Afterword: The Subject and Power', in H. Dreyfus and P. Rabinow (eds.), Michel Foucault: Beyond Structuralism and Hermeneutics, 2nd edn (University of Chicago Press 1983).

Frankel Paul E., 'Hayek's Conception of Freedom, Coercion, and the Rule of Law' (1980) 6 Reason Papers 37.

Friedman E., 'Competition and Unconscionability' [2013] American Law and Economics Review 444.

Galbraith J.F., American Capitalism: The Concept of Countervailing Power (Houghton Mifflin 1952).

Gifford D.J. and R.T. Kudrle, 'The Law \& Economics of Price Discrimination in Modern Economies: Time for Reconciliation?' (2008) Minnesota Legal Studies Research Paper No. 08-21.

Grannoveter M., Society and Economy: Framework and Principles (Harvard University Press, 2017).

Grimes W.S., 'Buyer Power and Retail Gatekeeper Power: Protecting Competition and the Atomistic Seller' (2005) 72 Antitrust Law Journal 563.

Harrison J.L., 'Complications in the Antitrust Reponse to Monopoly', in I. Lianos and D. Sokol (eds.), The Global Limits of Competition Law (Stanford University Press 2012).

Hart N.E., 'The Age of Contract Agriculture: Consequences of Concentration in Input Supply' (2000) 18 Journal of Agribusiness 115.

Hart O. and J. Moore, 'Incomplete Contracts and Renegotiation' [1988] Econometrica: Journal of the Econometric Society 755. 
Hart O. and J. Moore, 'Foundations of Incomplete Contracts' (1999) 66 Review of Economic Studies 115.

Hart O. and J. Tirole, 'Vertical Integration and Market Foreclosure' [1990] Brookings Papers on Economic Activity: Microeconomics 205.

Hayek F.A., The Constitution of Liberty (University of Chicago Press 1960).

Hovenkamp H., 'The Federal Trade Commission and the Sherman Act' (2010) 62 Florida Law Review 871.

Hovenkamp H., 'Harvard, Chicago, and Transaction Cost Economics in Antitrust Analysis' (2010) 57 Antitrust Bulletin 613.

Hovenkamp H., The Opening of American Law: Neoclassical Legal Thought, 1870-1970 (Oxford University Press 2014).

Hovenkamp H., Federal Antitrust Policy: The Law of Competition and Its Practice (West Publishing 2016).

Howard Beales III J., 'The Federal Trade Commission's Use of Unfairness Authority: Its Rise, Fall, and Resurrection' (2003) 22 Journal of Public Policy \& Marketing 192.

ICN, Report on Abuse of Superior Bargaining Position (2008), available at http://www.internationalcompetitionnetwork.org/uploads/library/doc386.pdf.

ICN, 'Discussion Document "Competition Enforcement and Consumer Welfare"' (2011), available at http://www.internationalcompetitionnetwork.org/uploads/library/doc857.pdf.

Imamura S., Dokusen kinshi ho nyumon [Introduction to Antimonopoly Law] (Yuhikaku Publishing 1993).Immenga U. and E.-J. Mestmäcker, Wettbewerbsrecht. Band 2. GWB Kommentar zum Deutschen Kartellrecht (Beck 2007).

Inderst R. and T. Valletti, 'Buyer Power and the "Waterbed Effect"' (2011) 59 Journal of Industrial Economics 1 .

Italian Competition Authority, 'Indagine Conoscitiva Sul Settore Della GDO' (2013) IC43, available at http://www.agcm.it/indagini-conoscitive-db.html.

James H.S., M.K. Hendrickson, Ph. H. Howard, Networks, power and Dependency in the Agrifood Industry, in In: James, Jr. H. (eds) The Ethics and Economics of Agrifood Competition. (The International Library of Environmental, Agricultural and Food Ethics, vol 20. Springer, Dordrecht, 2013).

Kennedy D., 'Distributive and Paternalist Motives in Contract and Tort Law, with Special Reference to Compulsory Terms and Unequal Bargaining Power' (1981) 41 Maryland Law Review 563.

Këllezi P., 'Abuse below the Threshold of Dominance? Market Power, Market Dominance, and Abuse of Economic Dependence', in M.O. Mackenrodt, B.C. Gallego and S. Enchelmaier (eds.), Abuse of Dominant Position: New Interpretation, New Enforcement Mechanisms? (Springer 2008).

Kim N., 'Evolving Business and Social Norms and Interpretation Rules: The Need for a Dynamic Approach to Contract Disputes' (2005) 84 Nebraska Law Review 506.

Kirkwood J.B., 'Buyer Power and Exclusionary Conduct: Should Brooke Group Set the Standards for Buyer Induced Price Discrimination and Predatory Bidding?' (2005) 72 Antitrust Law Journal 625. 
Klein B., 'Market Power in Antitrust: Economic Analysis After Kodak' (1994) 3 Supreme Court Economic Review 43.

Klein A., R.G. Crawford and A.A. Alchian, 'Vertical Integration, Appropriable Rents, and the Competitive Contracting Process' (1978) 21 Journal of Law and Economics 297.

Komesar K.N., Law's Limits, (Cambridge University Press 2001).

Korobkin R.B., "A "Traditional" and "Behavioral" Law-and-Economics Analysis of Williams v. Walker-Thomas Furniture Company' (2004) 26 University of Hawaii Law Review 441.

Kovacic W.E. and M. Winerman, 'Competition Policy and the Application of Section 5 of the Federal Trade Commission Act' (2010) 76 Antitrust Law Journal 929.

Kovacic W.E. and M. Winerman, 'The Federal Trade Commission as an Independent Agency: Autonomy, Legitimacy, and Effectiveness' (2014) 100 Iowa Law Review 2085.

Lamond G., 'Coercion and the Nature of Law' (2001) 7 Legal Theory 35.

Lande R.H., 'Should Section 5 Guidelines Focus on Economic Efficiency or Consumer Choice?’ (2014) 5 Competition Policy International 1.

Landes W.M. and R.A Posner, 'Should Indirect Purchasers Have Standing to Sue Under the Antitrust Laws? An Economic Analysis of the Rule of Illinois Brick' [1979] University of Chicago Law Review 602.

Lax D.A. and J. Sebenius, Manager as Negotiator (Simon and Schuster 1987).

Leff A.A., 'Unconscionability and the Code. The Emperor's New Clause' (1967) 115 University of Pennsylvania Law Review 485.

Lianos I. with D. Katalevsky, 'Merger Activity in the Factors of Production Segments of the Food Value Chain: A Critical Assessment of the Bayer/Monsanto Merger' (2017) CLES Policy Paper Series 2017/1.

Lukes S., Power: A Radical View, 2nd edn (Palgrave Macmillan 2004).

McDonald J. et al., 'Contracts, Markets, and Prices: Organizing the Production and Use of Agricultural Commodities' (2004) Agricultural Economic Report No. 837.

MacDonald J. and P. Korb, 'Agricultural Contracting Update: Contracts In 2008' (2011) USDA Economic Information Bulletin No. 72.

1. McKendrick E., Contract Law (Palgrave Macmillan 2005).

Majumdar A., 'Waterbed Effects and Buying Mergers' (2007) CCP Working Paper 05-7.

Mammana I., Concentration of Market Power in the EU Seed Market, Study commissioned by the Greens/EFA Group in the European Parliament (January 2014).

da Matta Berardo J.C. and B. Bastos Becker, 'Brazil', in P. Kobel, P. Këllezi and B. Kilpatrick (eds.), Antitrust in the Groceries Sector \& Liability Issues in Relation to Corporate Social Responsibility (Springer 2015).

Mullan H., 'Banning payments for Slotting and Shelf-space: Ireland set to Follow the United Kingdom's Example' (2010) 31 European Competition Law Review 151.

Morriss P., Power: A Philosophical Analysis, 2nd edn (Manchester University Press 2002).

Muris T.J., 'How History Can Inform Practice in Modern U.S. Competition Policy' (2004) George Mason Law \& Economics Research Paper No. 04-20. 
Nehl H.P., 'The Austrian competition authority concludes general inquiry in the highly concentrated food distribution sector while highlighting indications of strong buyer power (Branchenuntersuchung Lebensmittelhandel)', e-Competitions, No. 13981 (18 June 2007).

Neil Browne M. and L. Biksacky, 'Unconscionability and the Contingent Assumptions of Contract Theory' [2013] Michigan State Law Review 211.

Noll R.G., “"Buyer Power” and Economic Policy' (2005) 72 Antitrust Law Journal 589.

Nozick R., 'Coercion', in P. Suppes, and M. White (eds.), Philosophy, Science, and Method: Essays in Honor of Ernest Nagel, (St. Martin's Press 1969).

Oakley R.L., 'Fairness in Electronic Contracting: Minimum Standards for Non-Negotiated Contracts' (2005) 42 Houston Law Review 1041.

OECD, Buying Power of Multiproduct Retailers, DAFFE/CLP(99)21 (OECD 1999).

OECD, 'Spotlight on Global Value Chains: Does it Mean Shutting Out Small Producers?', in Promoting Pro-Poor Growth: Agriculture (OECD 2006).

OECD, Competition Law and Policy in Brazil - A Peer Review (OECD 2010).

OECD, Competition in the Food Chain, DAF/COMP(2013)15 (OECD 2013).

OECD, 'Food Price Formation' (October 2015), available at http://www.oecd.org/site/agrfcn/meetings/agrfen-7-food-price-formation-paper-october-

2015.pdf.

OECD, Latin American Competition Forum, Competition Issues in the Groceries Sector: Focus on Conduct Contribution from Spain, DAF/COMP/LACF(2015)5 (OECD 2015).

OFT, Grocery Market - Proposed Decision to Make a Market Investigation Reference (March 2006).

Posner R.A., Economic Analysis of Law (Aspen Law \& Business 1986).

Posner R.A., 'The Federal Trade Commission: A Retrospective' (2005) 72 Antitrust Law Journal 761.

Radin M.J., Boilerplate: The Fine Print, Vanishing Rights, and the Rule of Law (Princeton University Press 2013).

Ray D.E., 'Buyer Liability Under Section 2(f) of the Robinson-Patman Act' (1981) 15 University of Richmond Law Review 547.

Rybnicek J.M. and J.D. Wright, 'Defining Section 5 of the FTC Act: The Failure of the Common Law Method and the Case for Formal Agency Guidelines' (2014) 21 George Mason Law Review 1287.

Sheffman D. and P. Spiller, 'Buyers' Strategies, Entry Barriers, and Competition' (1992) 30 Economic Inquiry 418.

Svetlicinii A., 'The Croatian Competition Authority issues a report on competition on the food retail market in 2008', e-Competitions, No. 28749 (16 July 2009).

Schwager U., 'Competition Issues Affecting the Agricultural Sector in Selected Developing Countries: Key Findings From Selected UNCTAD Market Studies', in M. Gal, M. Bakhoum, J. Drexl, E. Fox and D.Gerber (eds.), Economic Characteristics of Developing Jurisdictions: Their Implications For Competiton Law (Edward Elgar 2015).

Sokol D., 'Analyzing Robinson-Patman' (2015) 83 George Washington Law Review 264.

Steuer R.M., 'Crossing the Streams of Price \& Promotion Under the Robinson-Patman Act' (2012) 27 Antitrust 64.

Sutton J., 'Non-Cooperative Bargaining Theory: An Introduction' (1986) 53 Review of Economic Studies 709. 
Schwager U., 'Competition Issues Affecting the Agricultural Sector in Selected Developing Countries: Key Findings From Selected UNCTAD Market Studies', in M. Gal, M. Bakhoum, J. Drexl, E. Fox and D.Gerber (eds.), Economic Characteristics of Developing Jurisdictions: Their Implications For Competiton Law (Edward Elgar 2015).

Spark G., Vitiation of Contracts (Cambridge University Press 2013).

Swedberg R., 'An Introduction and Agenda', in V. Nee and R. Swedberg (eds.), The Economic Sociology of Capitalism (Princeton University Press 2005).

Thal S. N., 'Inequality of Bargaining Power Doctrine: The Problem of Defining Contractual Unfairness' (1988) 8 Oxford Journal of Legal Studies 17.

Thomas Sullivan E. et al., 'Secondary-Line Differential Pricing \& the Robinson-Patman Act' (2013) Legal Studies Research Paper Series No. 2013-138.

Tirole J., 'Incomplete Contracts: Where Do We Stand?' (1999) 67 Econometrica 741.

Trebilcock M. J., 'The Doctrine of Inequality of Bargaining Power: Post-Benthamite Economics in the House of Lords' [1976] University of Toronto Law Journal 359.

Trebilcock M.J., The Limits of Freedom of Contract (Harvard University Press 1997).

Truli E., 'Relative Dominance and the Protection of the Weaker Party: Enforcing the Economic Dependence Provisions and the Example of Greece' (2017) Journal of European Competition Law \& Practice.

UK Competition Commission, Supermarkets: A report on the supply of groceries from multiple stores in the United Kingdom, Cm. 4842 (2000).

UK Competition Commission, The supply of groceries in the UK market investigation (April 2008).

von Ungern-Sternberg T., 'Countervailing Power Revisited' (1996) 14 International Journal of Industrial Organization 507.

USDA, Contracting in the Poultry Industry (1999), available at http://www.ers.usda.gov/media/256039/aib748c_1_.pdf.

Vander Stichele M. and B. Young, The Abuse of Supermarket Buyer Power in the EU Food Retail Sector Preliminary Survey of Evidence (March 2009).

Vogel L., 'Competition Law and Buying Power' (1998) 19 European Competition Law Review 4.

Wagner-von Papp F., 'Unilateral Conduct by Non-Dominant Firms: A Comparative Reappraisal', paper presented at the 10th ASCOLA conference (Tokyo, 21-23 May 2015).

Wakui M. and T.K. Cheng, 'Regulating Abuse of Superior Bargaining Position under the Japanese Competition Law: An Anomaly or a Necessity?' (2015) 0 Journal of Antitrust Enforcement 1.

Wartenberg T., The Forms of Power: From Domination to Transformation (Temple University Press 1990).

Weber M., The Theory of Economic and Social Organization (Free Press 1947 [1922]).

Werden G.J., 'Consumer Welfare and Competition Policy', in Josef Drexl, Wolfgang Kerber and Rupprecht Podszun (eds), Competition Policy and the Economic Approach, Cheltenham: Elgar (Edward Elgar 2011).

Wertheimer A., Coercion (Princeton University Press 1987).

Williamson O.E., 'Transaction-Cost Economics: The Governance of Contractual Relations' (1979) 22 Journal of Law and Economics 233. 
Wright J.D., 'Revisiting Antitrust Institutions: The Case for Guidelines to Recalibrate the Federal Trade Commission's Section 5 Unfair Methods of Competition Authority' (2013) 4 Concurrences 1.

Wright J.D., 'Recalibrating Section 5: A Response to the CPI Symposium' (2013) 12 Antitrust Chronicle 1.

Wright J.D., 'Proposed Policy Statement Regarding Unfair Methods of Competition Under Section 5 of the Federal Trade Commission Act' (US FTC 2013).

Wright J.D. and A. Diveley, 'Unfair Methods of Competition after the 2015 Commission Statement' [2015] Antitrust Source (October 2015), George Mason Legal Studies Research Paper No. LS 15-25, George Mason Law \& Economics Research Paper No. 15-39.

Wu T., 'Section 5 and "Unfair Methods of Competition": Testimony Before the Senate Antitrust Committee’ (2016) Columbia Public Law Research Paper No. 14-508..

\section{Tables and Figures}

Table 1. Superior bargaining power theories in contract law...373

Table 2: Unfair Competition Law in BRICS....383 


\title{
Chapter 4: Financialisation of the food chain, common ownership and competition law
}

\author{
Ioannis Lianos, Alina Velias, Dmitry Katalevsky \& George Ovchinikov
}

\subsection{Introduction}

The financialisation of the economy has led to an increasing role for institutional investors in the global economy. The possible anticompetitive incentives created by presence of cross ownership and common ownership in concentrated markets have been long recognised in theoretical literature (Rotemberg, 1984; Bresnahan and Salop, 1986; Reynolds and Snapp, 1986; Gordon, 1990; O’Brien and Salop, 2000; Gilo, 2000; Gilo et al., 2006) ${ }^{1699}$; but lacked sufficient empirical evidence ${ }^{1700}$. Recent empirical analyses of the U.S. airline industry (Azar, Schmalz, and Tecu 2016 ${ }^{1701}$; and banking industry (Azar, Raina, and Schmalz, 2016 ${ }^{1702}$ ) measured the potential (large) effect of the common ownership price levels rising above the competitive ones. Posner, Scott Morton and Weyl note that

'(i)nstitutional investors owned 70-80\% of the US stock market, up from 7\% in 1950. When combined, BlackRock, Vanguard, and State Street constitute the single largest shareholder of at least $40 \%$ of all public companies in the US. They constitute the largest owner in nearly 90\% of public companies in the S\&P 500, up from 25\% in 2000. The fraction of US public firms held by institutional investors who simultaneously hold large blocks of other same-industry firms increased from less than $10 \%$ in 1980 to about $60 \%$ in 2010,1703 .

Although the role of institutional investors is more limited in Europe, similar concerns may also be expressed. These findings resulted in even greater policy concern (Council of Economic

\footnotetext{
${ }^{1699}$ J J Rotemberg, 'Financial Transaction Costs and Industrial Performance', (1984) Mass. Inst. of Tech., Alfred P. Sloan Sch. of Mgmt., Working Paper No. 1554-84; T Bresnahan \& S C Salop, 'Quantifying The Competitive Effects of Production Joint Ventures', (1986) 4 Inter'1 J. Ind. Org. 155; R J Reynolds \& B R Snapp, 'The Competitive Effects of Partial Equity Interests and Joint Ventures', (1986) 4 Inter'l J. Ind. Org. 141; Roger H. Gordon, 'Do Publicly Traded Corporations Act in the Public Interest?', (1990). Nat'l Bureau of Econ. Research, Working Paper No. 3303; D P O’Brien \& S C Salop, 'Competitive Effects of Partial Ownership: Financial Interest and Corporate Control' [2000] 67 Antitrust L.J. 559; E A Posner, F Scott Morton, \& E Glen Weyl, 'A Proposal to Limit the Anti-Competitive Power of Institutional Investors' forth. Antitrust Law Journal; D Gilo, 'The Anticompetitive Effects of Passive Investment', (2000) 99 Mich. L. Rev. 1; D Gilo, YMoshe, \& Y Spiegel, 'Partial Cross Ownership and Tacit Collusion', (2006), 37 RAND J. Econ. 81;

${ }^{1700}$ See, the concerns expressed by S C Salop \& D P O'Brien, 'Competitive Effects of Partial Ownership: Financial Interest and Corporate Control' [2000] 67 Antitrust L.J. 559

${ }^{1701}$ J Azar, M C Schmalz, \& I Tecu, Isabel, ‘Anti-Competitive Effects of Common Ownership' (March 15, 2017). Journal of Finance, Forthcoming. Available at SSRN: https://ssrn.com/abstract=2427345 or http://dx.doi.org/10.2139/ssrn.2427345; further - AST(2016) 1702 J Azar, R Raina, \& M C Schmalz, 'Ultimate Ownership and Bank Competition'. (July 23, 2016). Available at SSRN: https://ssrn.com/abstract=2710252 or http://dx.doi.org/10.2139/ssrn.2710252; further - ARS(2016) ${ }^{1703}$ E A Posner, F Scott Morton, \& E Glen Weyl, 'A Proposal to Limit the Anti-Competitive Power of Institutional Investors', forth. Antitrust law Journal (November 29, 2016). University of Chicago Coase-Sandor Institute for Law \& Economics Research Paper No. 787. Available at SSRN: ssrn.com/abstract=2872754 .
} 
Advisors, 2016 ${ }^{1704}$; Elhauge, $2016^{1705}$ ), proposals for legislative intervention (Posner, Scott Morton and Weyl, 2017 ${ }^{1706}$ ), and criticism of the findings (Rock and Rubinfeld, 2017 $\mathrm{a}^{1707}$; Rock and Rubinfeld, 2017b ${ }^{1708}$ ).

\subsection{Economic Framework}

We consider four major mechanisms through which common ownership may be causing adverse effects to the economy, namely: (1) unilateral/non-coordinated effects; (2) coordinated effects (tacit collusion); (3) vertical foreclosure through raising rivals' costs strategies and (4) vertical exploitative behaviour (gaining higher profit margins at the expense of reduced margins for the competitive segment of the value chain).

The possible unilateral effects of the common ownership on the economy is an actively debated topic. We analyse it in-depth and also discuss the way it may be feeding into a possible effect on coordinated effects, exacerbating the possibility for tacit coordination in the market. We then move on to exploring whether the presence of institutional investors may be feeding into the third, wider area of exploitative behaviour across the entire value chain rather than within an individual segment of the market. Here we consider the established mechanisms of foreclosure available to the vertically integrated investors - and iscuss them in context of the recent evidence of increased financialisation of the food markets and negative effects on the farmer segment. We highlight the lack of insight into specifically the role of common ownership exploiting the same mechanisms and draw directions for further research.

\subsubsection{The theoretical possibility of non-coordinated effects}

In the first section of this chapter, we review the theoretical and the empirical evidence and the counterarguments that emerged in the current (heated) debate on the unilateral effects of common ownership. We conclude that there is acute need for research into other markets characterised by presence of financial investors and vital effects on consumers - such as food market. We also sympathise with the concerns raised about possible distortive nature of regulatory intervention, and argue for the need of better methodology and evaluation of thresholds at which regulators should intervene. We do dismiss the arguments that claim that the presence of financial investors does not pose a concern for anti-monopolistic regulation and we lay out why we think their arguments address problems which can be dealt with the

\footnotetext{
${ }^{1704}$ Council of Economic Advisors (2016): “Benefits of Competition and Indicators of Market Power," Available online

${ }^{1705}$ E Elhauge, 'Horizontal Shareholding', (2016). 129 Harv. L. Rev. 1267

${ }^{1706}$ E A Posner, F M Scott Morton, \& E G Weyl, 'A Proposal to Limit the Anti-Competitive Power of Institutional Investors' (March 22, 2017). Antitrust Law Journal, Forthcoming. Available at SSRN: https://ssrn.com/abstract=2872754 or http://dx.doi.org/10.2139/ssrn.2872754

${ }^{1707}$ E B Rock \& D L Rubinfeld, 'Defusing the Antitrust Threat to Institutional Investor Involvement in Corporate Governance' (March 1, 2017). NYU Law and Economics Research Paper No. 17-05. Available at SSRN: https://ssrn.com/abstract=2925855; further - RR(2017a)

1708 EB Rock \& DL Rubinfeld, 'Antitrust for Institutional Investors' (July 2017). NYU Law and Economics Research Paper No. 17-23; UC Berkeley Public Law Research Paper. Available at SSRN: https://ssrn.com/abstract=2998296; further - RR(2017b)
} 
improved methodology, but do not undermine the theoretical rooting of the problem per se. Our focus is the indications that only separate owners have interest in aggressive competitive strategy. Crowding them out of the most powerful shareholders can make the firm lose incentives and corporate support for the competitive strategy.

We then turn to the way competition authorities have engaged so far with the possible anticompetitive effects of minority shareholdings, and in particular common ownership by the same financial investors of competing firms in the same relevant market. We also examine the proposals made for legislative changes that would engage more seriously with the issues raised by common ownership.

The last part proceeds to an empirical analysis of the presence of financial investors and common ownership in the global food value chain. This is an area with considerable common ownership and this raises inevitably the question of the way competition authorities might take this into account when assessing merger activity. In the context of the seed and agrochem mergers, the issue was raised by the Competition Commission of South Africa, for the Dow/Dupont and Bayer/Monsanto cases, although the CCSA did not engage thoroughly with it, and in a more prominent way in the European Commission's decision in Dow/Dupont.

Policy makers' concern with common ownership is driven by it potentially leading to monopolistic outcomes, a deadweight loss for the economy, and particularly negative outcomes for the consumers. The legislation in its current state does not have an explicit measure for common ownership in prevention of monopolistic outcomes. However, recent developments in measurement of the market concentration attempt to incorporate the degree of common ownership into equation (AST, 2016; ARS, 2016) and there are calls for creating thresholds at which these concentrations should be considered anticompetitive (Posner, Scott Morton and Weyl, 2017) $)^{1709}$. Evidence based on these recent developments has already been applied on the markets.

\subsubsection{Evaluating Market share}

Competition authorities have long used commonly agreed measures of market concentration to evaluate between-company acquisitions.

The Herfindahl-Hirschman index (HHI) is a commonly accepted measure of market concentration. It is calculated by squaring the market share of each firm $\mathrm{j}$ competing in a market, and then summing the resulting numbers.

$$
H H I=\sum_{j} s_{j}^{2}
$$

\footnotetext{
${ }^{1709}$ J Azar, M C Schmalz, \& I Tecu, Isabel, ‘Anti-Competitive Effects of Common Ownership’ (March 15, 2017). Journal of Finance, Forthcoming. Available

SSRN: https://ssrn.com/abstract=2427345 or http://dx.doi.org/10.2139/ssrn.2427345; J Azar, R Raina, \& M C Schmalz, 'Ultimate Ownership and Bank Competition'. (July 23, 2016). Available at SSRN: https://ssrn.com/abstract=2710252 or http://dx.doi.org/10.2139/ssrn.2710252; EA Posner, FM Scott Morton, \& EG Weyl, 'A Proposal to Limit the Anti-Competitive Power of Institutional Investors' (March 22, 2017). Antitrust Law Journal, Forthcoming. Available at SSRN: https://ssrn.com/abstract=2872754 or http://dx.doi.org/10.2139/ssrn.2872754
} 
HHI can be close to zero when a market is comprised of many firms of small size and reaches a maximum of 10,000 when a market is controlled by a single firm.

The operational thresholds for the HHI are relatively well-defined. Under the US horizontal merger guidelines, the safe harbour threshold is an HHI below 1,500. For HHI levels between 1,500 and 2,500, a merger leading to an increase of more than 100 points normally warrants additional scrutiny. Above 2,500, an increase between 100 and 200 triggers additional scrutiny, whereas for increases above 200 points there is a rebuttable presumption of anticompetitive effects. In contrast, an increase below 100 points is generally considered unproblematic ${ }^{1710}$. The 200 points threshold also marks the point beyond which, if two parties intended to merge, the burden of proof that the merger does not lead to enhanced market power shifts to the merging parties (as opposed to the competition authority). Consequently, in the recent evidence, acquisitions of less than $25 \%$ but at least $15 \%$ have been judged to be in violation of the Clayton Act. (Salop and O'Brien, 2000) ${ }^{1711}$. The European Commission takes a similar perspective noting that 'while the absolute level of the HHI can give an initial indication of the competitive pressure in the market post-merger, the change in the HHI (known as the 'delta') is a useful proxy for the change in concentration directly brought about by the merger' ${ }^{1712} \mathrm{HHI}$ values are used to screen out mergers unlikely to give rise to anticompetitive concerns. According to the General Court in Sun Chemical Group BV and others v Commission, "the greater the margin by which those thresholds are exceeded, the more the HHI values will be indicative of competition concerns'. ${ }^{1713}$ In particular, the EU Horizontal Merger Guidelines stipulate that the Commission is unlikely to identify horizontal competition concerns in a market with a post-merger HHI below 1,000, these markets normally not requiring extensive analysis ${ }^{1714}$. The Commission is also unlikely to identify horizontal competition concerns in a merger with a post-merger HHI between 1,000 and 2,000 and a delta below 250, or a merger with a post-merger HHI above 2,000 and a delta below 150, with the exception of certain special circumstances, one of which being that there are significant cross-shareholdings among the market participants ${ }^{1715}$.

The HHI index in its current formulation only captures the shares of the market controlled by a single firm, and is agnostic to any cross ownership and common ownership aspects of such holding. Theoretical literature has long argued that shareholders with diversified portfolios have an interest in the maximization of joint portfolio profits as opposed to individual firm profits, thus predicting that diversification can reduce competition in product markets. Examples of mechanisms include: internalising between-firm (vertical or horizontal) externalities (Hansen and Lott, 1996 ${ }^{1716}$ ) risk-sharing considerations (Admati, Pfleiderer, and

\footnotetext{
${ }^{1710}$ See DoJ/FTC's 2010 US Horizontal Merger Guidelines, $\mathrm{p} 19$.

${ }^{1711}$ D P O'Brien \& S C Salop, 'Competitive Effects of Partial Ownership: Financial Interest and Corporate Control' [2000] 67 Antitrust L.J. 559;

${ }^{1712}$ See DoJ/FTC's 2010 US Horizontal Merger Guidelines, $\mathrm{p} 19$.

${ }^{1713}$ Case T-282/06 Sun Chemical Group Bv and others v Commission [2007] ECR II-2149, para 138.

${ }^{1714}$ EU Horizontal Merger Guidelines [2004] OJ C31/7

${ }^{1715}$ Ibid., para. 20.

${ }^{1716}$ R G Hansen \& JR Lott, (1996), 'Externalities and corporate objectives in a world with diversified shareholder/consumers', Journal of Financial and Quantitative Analysis, 31(1), 43-68.
} 
Zechner, $1994^{1717}$ ), legal ownership over companies being separated from its control (Berle and Means, $1991^{1718}$ ). Recent literature proposes methods for incorporating these consideration into the measurement indexes and resulting anti-monopolistic legislation.

\subsubsection{Cross-ownership}

O'Brien and Salop (2000), building on Bresnahan and Salop (1986) ${ }^{1719}$ define a framework where firms do not collude, either expressly or tacitly, yet the incentives driven by the cross ownership yield an anticompetitive outcome. In this framework, each firm sets its price independently and unilaterally, that is, on the assumption that its pricing decision will have no effect on the prices charged by its competitors. The key element of the framework is that the objective function of the firm's manager takes into account to which extent a firm's most powerful owners are also owners of natural competitors, and vice versa. The anticompetitive outcome in the framework is driven by the two aspects of the cross ownership: the financial and the control ones.

The financial mechanism is purely structural: cross ownership links the fortunes of actual or potential competitors, producing a positive correlation among their profits. The manager of the firm A thus has financial interest in other firms' profits that enters his incentives through the cross ownership, although this may warrant some more subtle analysis. For instance, if firm A owns some stock in firm B and the manager is judged on the total profit of firm A, then indeed A's manager will behave less aggressively with B. However if the stock in A is only owned by some of the owners in A, then A's manager only cares if these specific owners exert significant control on A. The linking of profits gives each firm an incentive to compete less vigorously and adopt behaviour more conducive to joint profit maximization than otherwise would be the case (for the full framework of financial interest and corporate control see Reynolds and Snapp, $1986^{1720}$ ).

A second reason the acquisition might diminish competition arises if the acquisition gives firm A some degree of corporate control over the management of other firms. This concerns situations where a firm would exercise its corporate governance powers in other firms in the market to restrain these firms' competitive actions against its profits (for detailed discussion, see O'Brien and Waehrer, $\left.2017^{1721}\right)$.

O'Brien and Salop (2000) formalise methodologies ${ }^{1722}$ for evaluating partial ownership acquisitions in application to both major models that describe individual firms incentives in

\footnotetext{
${ }^{1717}$ A R Admati, P Pfleiderer, \& J Zechner, (1994). 'Large shareholder activism, risk sharing, and financial market equilibrium'. journal of Political Economy, 102(6), 1097-1130.

1718 A A Berle \& G G C Means, (1991). The modern corporation and private property. Transaction publishers.

1719 D P O'Brien \& S C Salop, 'Competitive Effects of Partial Ownership: Financial Interest and Corporate Control' [2000] 67 Antitrust L.J. 559;; T Bresnahan \& S C Salop, 'Quantifying The Competitive Effects of Production Joint Ventures', (1986) 4 Inter'l J. Ind. Org. 155

${ }^{1720}$ R J Reynolds \& B R Snapp, 'The Competitive Effects of Partial Equity Interests and Joint Ventures', (1986) 4 Inter'1 J. Ind. Org. 141

${ }^{1721}$ D P O'Brien \& K Waehrer, 'The Competitive Effects of Common Ownership: We Know Less than We Think', (February 23, 2017). Available at SSRN: https://ssrn.com/abstract=2922677

1722 D P O'Brien \& S C Salop, 'Competitive Effects of Partial Ownership: Financial Interest and Corporate Control' [2000] 67 Antitrust L.J. 559;
} 
oligopolistic markets. Cournot model (competition on quantity) is addressed by modified HHI (or MHHI). Bertrand model (competition on price) is captured by the Price Pressure Index, or PPI (which builds on the past work on diversion ratios of the firm's sales to its merger partner, Shapiro, $\left.1995^{1723}\right)$.

The financial incentive is more striking from the point of view of the economic theory. It suggests that the cross ownership has the capability to distort the incentives of the firms away from competition towards maximising a weighted sum of the owners' financial returns through the returns from the firm itself but also through the returns from the other firms in the same market. This does not require any action from the cross owners ${ }^{1724}$.

The O'Brien and Salop (2000) model incorporates both financial and control incentives through the assumption that the firm's manager weighs the interests of the firm's owners in the way that incorporates both their financial interest and their control over the firm ${ }^{1725}$. The firm's manager then the objective function which includes the weighted owners' earnings. The weight on each owner's profit in the manager's objective function can be interpreted as a measure of the degree of control or influence the owner has over the firm's managers. For example, in a case where the owner has no control over the manager, her weight in the manager's objective function consists only of her financial interest. This weight is consequently lower than the weight of an owner with the same ownership percentage (i.e. the same financial interest) but also with control over the governance (i.e. voting shares).

O'Brien and Salop (2000) (building on Bresnahan and Salop (1986) ${ }^{1726}$ ) propose the MHHI (modified HHI) index to capture the above effects. The MHHI comprises the initial market share HHI and the MHHI increases (the "deltas") which caused by the partial ownership transactions. The newly acquired financial interest of firm $i$ in firm $j$ is defined by the fraction $\beta(\sim)$ of entitlement of firm $\mathrm{i}$ to the profits of firm $\mathrm{j}$. Analogously, the newly acquired corporate control is defined by the fraction $\gamma(\sim)$ gained by firm i over firm $\mathrm{j}$. Finally, these are weighted the pre-acquisition market shares of $\mathrm{Si}$ and $\mathrm{Sj}$ respectively.

The authors present a range of possible $\triangle \mathrm{MHHI}$ reflecting the cases from silent financial interest to total control. The general formula for the MHHI used in the subsequent literature is given without an assumption on the degree of control:

$$
\mathrm{MHHI}=H H I+\sum_{j} \sum_{k \neq j} s_{j} s_{k} \frac{\sum_{i} \gamma_{i j} \beta_{i k}}{\sum_{i} \gamma_{i j} \beta_{i j}}
$$

The MHHI is mentioned in footnote 25 of the EU Horizontal Merger Guidelines. It has also been presented in details in the context of the 2013 public consultation "Towards more

${ }^{1723}$ C Shapiro, 'Mergers with differentiated products', (1995), Antitrust, 10, 23.

${ }^{1724}$ Although one may also raise the question on why would a manager maximise such a weighted sum rather than care only about those in control.

1725 D P O’Brien \& S C Salop, 'Competitive Effects of Partial Ownership: Financial Interest and Corporate Control' [2000] 67 Antitrust L.J. 559;

${ }^{1726}$ D P O'Brien \& S C Salop, 'Competitive Effects of Partial Ownership: Financial Interest and Corporate Control' [2000] 67 Antitrust L.J. 559; T Bresnahan \& S C Salop, 'Quantifying The Competitive Effects of Production Joint Ventures', (1986) 4 Inter'l J. Ind. Org. 155 
effective EU merger control" and extensively referred to in the annex I to the Commission staff working document "Towards more effective EU merger control"1727. In Case M.6541 Glencore / Xstrata, the minority stake of Glencore in Xstrata was taken into account in measuring the increase in concentration in the EEA production of all grades of zinc metal, as well as in the concentration in their EEA supply ${ }^{1728}$. With regard to the case law, the MHHI, or implicitly referred to, has been used in Cases M.1383 - Exxon / Mobil78 and M.1715 Alcan / Pechiney ${ }^{1729}$, in which a series of equity cross-holding between the parties and their competitors affected the competitive assessment, in Case M.2283 - Schneider / Legrand ${ }^{1730}$, in order to assess the adverse effect on competition caused by Schneider's stake in Legrand, and in Case M.6576 - Munksjö / Ahlstrom ${ }^{1731}$, in order to assess the impact of common shareholders on control in relation to the design of the remedy proposal ${ }^{1732}$. The test was also referred to in the recent Dow/Dupont merger of the European Commission, which will be examined in the last Section of this Chapter ${ }^{1733}$.

Much of the debate in the subsequent sections concerns whether this is an appropriate measure to enforce. In our opinion, the value of this formulation lies primarily in capturing the mechanism of the possible effect of cross-ownership on market competition - whilst the exact measurement of the effect is open to debate.

\subsubsection{Common ownership}

Until recently, there has not been a theoretical framework for evaluating the common ownership effects on the market processes described above. The recent theoretical work by Azar (2017) attempts to fill this gap by developing a model of a firm behaviour in an oligopolistic setting where the firm aggregates and shareholder objectives, including the common ownership ${ }^{1734}$. The framework posits the following premise: a common shareholder with equal shares in all firms in the market cannot benefit from competition and therefore will not encourage it. The mechanisms supporting this premise are hypothesised as follows. If one firm competes aggressively for market share, this share comes at the expense of the other firms in the market. The decrease in revenues for the other firms is, however, greater than the increase in revenues for the aggressively competitive firm. For example, in a simplest version of oligopolistic market, two firms A and B are of equal size. If A undercuts B's price to attract customers from $\mathrm{B}$, it gains market share and many more products at this slightly reduced price. The average price on the market is lower, while the total number of customers remains the

\footnotetext{
${ }^{1727}$ Available online: http://ec.europa.eu/competition/publications/annual_report/2016/part2_en.pdf 
same. Hence, the effect on the total producer rents on the market is negative. Consequently, an investor holding equal-sized stakes in both $\mathrm{A}$ and $\mathrm{B}$ enjoys greater total (i.e. portfolio) profits when the firms set prices or quantities as if they were two divisions of a monopoly. The authors conclude that only separate owners have interest in aggressive competitive strategy. Crowding them out of the most powerful shareholders makes the firm lose support for the competitive strategy.

The measurement indexes developed in the paper follow premises similar to O'Brien and Salop (2000) ${ }^{1735}$ and consequently arrive at the same functional form. Since the MHHI in its original form ignores beneficial ownership by financial investors. AST(2016) modify the MHHI to take into account beneficial ownership by financial investors, which in most cases are industry outsiders ${ }^{1736}$. In this version of the index, all the holdings of the financial investors are included into "delta" part of the calculation of the index as follows.

For a firm $\mathrm{j}$ and its share of the market $s_{\mathrm{j}}$, the HHI is given by $\sum_{\mathrm{j}} \mathrm{s}_{\mathrm{j}}^{2}$. The total market concentration $\mathrm{MHHI}$ is then composed of the market share, HHI, and the common ownership concentration, $\triangle \mathrm{MHHI}$, as follows:

$$
\sum_{j} \sum_{k} s_{j} s_{k} \frac{\sum_{i} \gamma_{i j} \beta_{i k}}{\sum_{i} \gamma_{i j} \beta_{i j}}=\sum_{j} s_{j}^{2}+\sum_{j} \sum_{k \neq j} s_{j} s_{k} \frac{\sum_{i} \gamma_{i j} \beta_{i k}}{\sum_{i} \gamma_{i j} \beta_{i j}}
$$

where $\beta_{i j}$ is the ownership share of firm $j$ accruing to shareholder $i, \gamma_{i j}$ the control share of firm $j$ exercised by shareholder $i$, and $k$ indexes firm $j$ 's competitors. HHI captures the number and relative size of competitors; $\triangle \mathrm{MHHI}$ captures the density of the ownership network, i.e. to which extent these competitors are connected by common ownership and control links.

Note that in this model the economic incentive remains independent of any coordination or communications among the firms. The basic anticompetitive effects arise from the fact that interlocking shareholdings diminish each individual firm's incentives to cut prices or expand output by increasing the costs of taking away sales from rivals.

Also note that managers actively demanding reduced competition to drive up profit margins in the portfolio is not a single possible incentive and, this, not a necessary requirement for this model. In fact, managers may be driven by the desire for "quiet life" (Hicks, 1935; for recent empirical evidence see Bertrand and Mullainathan, 2003 ${ }^{1737}$ ). This can result in omission to explicitly demand or incentivize tougher competition between portfolio firms, thus also leading to an equilibrium with reduced competition and sustained high margins.

1735 D P O’Brien \& S C Salop, 'Competitive Effects of Partial Ownership: Financial Interest and Corporate Control' [2000] 67 Antitrust L.J. 559;

${ }^{1736}$ J Azar, M C Schmalz, \& I Tecu, Isabel, ‘Anti-Competitive Effects of Common Ownership' (March 15, 2017). Journal of Finance, Forthcoming. Available at SSRN: https://ssrn.com/abstract=2427345 or http://dx.doi.org/10.2139/ssrn.2427345

1737 Hicks, (1935). 'Annual survey of economic theory: the theory of monopoly'. Econometrica: Journal of the Econometric Society, 1-20; M Bertrand \& S Mullainathan, (2003). 'Enjoying the quiet life? Corporate governance and managerial preferences'. Journal of political Economy, 111(5), 1043-1075. 


\subsubsection{Empirical Evidence}

The emerging branch of empirical research has recently demonstrated links between common ownership and industry-level profit margins (Azar, 2012 ${ }^{1738}$ ) and firm-level profitability and market shares (He and Huang, 2014 ${ }^{1739}$ ). The two most concern-raising studies find effects of common ownership on product prices. AST(2016) ${ }^{1740}$ apply the commonownership adjusted MHHI to the U.S airline industry. They find (1) common ownership concentration at levels that they consider likely to yield regulatory concerns, and (2) the effect of the common ownership on the airfares estimated in the range of 3-12 percent. Similarly, $\operatorname{ARS}(2016)^{1741}$ use a generalised HHI (GHHI) that encompasses both cross ownership and common ownership in the U.S. banking sector and find a causal link between this measure and the higher prices for banking products.

The empirical evidence lends itself nicely to a split into two parts - evidence of concentrated common ownership in the industry, and the evidence of the link between such concentration and higher prices.

AST (2016) ${ }^{1742}$ demonstrate that, conversely, the ownership structure of most of the large US airlines (barring Virgin Airlines) shows that there are no owners with significant influence - the largest shares of stock a single investor would hold are under $20 \%$. The authors use this fact to support their claim that there are no owners with significant influence who are interested in competition between these airlines.

For the concentration of common ownership, AST (2016) ${ }^{1743}$ calculate that for the average airline route, the HHI has ranged over time from approximately 5000 to 5400 and $\triangle \mathrm{MHHI}$ has ranged from approximately 1000 to 2600, resulting in MHHIs ranging from approximately 6000 to 8000 . Authors then analyse their findings on the $\Delta \mathrm{MHHI}$ from the perspective if the same logic currently used towards HHI worldwide was applied to $\triangle \mathrm{MHHI}$. I.e., if the regulator were to consequentially apply this logic to changes of market concentration that are due to common ownership, asset managers would have to prove that the common ownership links that their holdings or acquisitions create do not affect market prices. If the proposition of identical mapping of the HHI guideline to the MHHI, the figures for the latter that study identifies are more than two to three times the federal guidelines' HHI threshold of 2500 and $\triangle \mathrm{MHHIs}$ that are five to thirteen times greater than the guidelines' $\Delta \mathrm{HHI}$ threshold

1738 J Azar, 'A New Look at Oligopoly: Implicit Collusion Through Portfolio Diversification' (November 8, 2011). Available at SSRN: https://ssrn.com/abstract=1993364 or http://dx.doi.org/10.2139/ssrn.1993364

$1739 \mathrm{~J}$ He \& J Huang, 'Product Market Competition in a World of Cross-Ownership: Evidence from Institutional Blockholdings' (January 13, 2016). Forthcoming in the Review of Financial Studies. Available at SSRN: https://ssrn.com/abstract=2380426 or http://dx.doi.org/10.2139/ssrn.2380426

${ }^{1740}$ J Azar, M C Schmalz, \& I Tecu, Isabel, ‘Anti-Competitive Effects of Common Ownership' (March 15, 2017). Journal of Finance, Forthcoming. Available at SSRN: https://ssrn.com/abstract=2427345 or http://dx.doi.org/10.2139/ssrn.2427345

${ }_{1741}$ J Azar, R Raina, \& M C Schmalz, 'Ultimate Ownership and Bank Competition'. (July 23, 2016). Available at SSRN: https://ssrn.com/abstract=2710252 or http://dx.doi.org/10.2139/ssrn.2710252

${ }^{1742}$ J Azar, M C Schmalz, \& I Tecu, Isabel, ‘Anti-Competitive Effects of Common Ownership’ (March 15, 2017). Journal of Finance, Forthcoming. Available at SSRN: $\underline{\text { https://ssrn.com/abstract=2427345 }}$ or http://dx.doi.org/10.2139/ssrn.2427345 ${ }^{1743}$ Ibid. 
of 200. The airline stock acquisitions that produced an average MHHI of 5000-5400 and average $\triangle \mathrm{MHHI}$ of $1000-2600$ should thus presumed highly likely to have anticompetitive effects.

ARS (2016) ${ }^{1744}$ show a similar common ownership pattern for the US banks. Among the top-five beneficial owners for all the six largest banks, three companies are always the same (Blackrock, Vanguard and State Street), and Berkshire Hathaway or Fidelity are present in most of the cases. Applying the GHHI index that accounts for the cross ownership and common ownership, ARS (2016) ${ }^{1745}$ show that considering ownership significantly increases countylevel banking concentration in the U.S. banking industry.

Whilst the acceptable levels of market concentration can be debated (and will be debated in the section below), the rise of industry prices above the competition level poses the main concern for the policy makers. AST (2016) ${ }^{1746}$ find that after controlling the market concentration captured by HHI and the other known determinants and relating common ownership and prices within the same firm, time, and industry (which reduces the amount of confounding variation) - the common ownership concentration, as measured by $\triangle \mathrm{MHHI}$, has explanatory power over the ticket prices, estimated at an increment of 3-12 percent of the price. In line with these effects, ARS (2016) ${ }^{1747}$ find that the GHHI has a positive and highly significant effect on fees and thresholds for interest-bearing checking accounts (but not on the interest rate spreads for the accounts). They estimate an \$0.80-\$1.16 higher average fee growth and a $\$ 900-\$ 1,200$ higher threshold growth for the top tercile countries in their dataset. These are the first empirical results that explicitly link common ownership and higher prices in two different industries.

\subsubsection{Criticism}

Extending the OS model to account for common ownership and the empirical application of this model posit serious challenges. We review three types of criticism directed at the (1) appropriateness of the choice of measure of common ownership, (2) methods of empirical estimation of the effect common ownership on prices, and (3) the mechanism linking common ownership with reduced incentives to compete. It is easy to note, that the (1) and (2) are methodological concerns that call for improvement of the models and estimation techniques, whereas the (3) casts doubt on the issue of common ownership per se. We agree with the need for further methodological improvements, but we are not convinced by the arguments that try to do away with the issue itself.

\footnotetext{
1744 J Azar, R Raina, \& M C Schmalz, 'Ultimate Ownership and Bank Competition'. (July 23, 2016). Available at SSRN: https://ssrn.com/abstract=2710252 or http://dx.doi.org/10.2139/ssrn.2710252 1745 Ibid.

${ }^{1746}$ J Azar, M C Schmalz, \& I Tecu, Isabel, ‘Anti-Competitive Effects of Common Ownership’ (March 15, 2017). Journal of Finance, Forthcoming. Available at SSRN: https://ssrn.com/abstract=2427345 or http://dx.doi.org/10.2139/ssrn.2427345

1747 J Azar, R Raina, \& M C Schmalz, 'Ultimate Ownership and Bank Competition'. (July 23, 2016). Available at SSRN: https://ssrn.com/abstract=2710252 or http://dx.doi.org/10.2139/ssrn.2710252
} 


\subsubsection{Measurement}

RR (2017a) $)^{1748}$ raise concern whether the proposed measurement is appropriate - i.e. whether common ownership element of the MHHI should be given the same weight as the market concentration HHI. They present an exercise on potential large differences arising from varying the way in which the common ownership enters the equation for market concentration. For two major institutional investors, each holding a 10 percent ownership share in all the airlines the MHHI $\Delta$ will equal 125 in the O'Brien-Salop framework. This calculation assumes that each airline will choose its output on the assumption that it will internalize 10 percent of the profits generated by each of the other airlines. Under an assumption that the institutional investors' stock holdings give them one-way control, the MHHI $\Delta$ would increase to 750 . By contrast, if the airline managers do not account for the effect of their strategy on institutional investors' other holdings, the MHHI $\Delta$ would be zero. RR (2017a) ${ }^{1749}$ thus state that the MHHI framework is extremely sensitive to the extent to which managers will take into account the effects on their shareholders other investments. Applying the O'Brien and Salop model to another example of one investor holding $30 \%$ compared to three investors each holding $10 \%$, they disagree that single ownership of $30 \%$ should be treated equally to 3 investors owning $10 \%$ each. The second example also raises the questions of endogeneity of the $30 \%$, but likely not the $10 \%$ holding - discussed in greater detail below.

Indeed, in their empirical test ARS (2017) ${ }^{1750}$ assume that the DOJ/FTC Merger Guidelines' emphasis on the importance of HHIs in investigation into potential anticompetitive effects maps directly to the MHHI framework. This is a very strong assumption to make, and further research is needed to develop informative measurement techniques. This criticism feeds directly into the methodological challenges for the policy making, whilst it does not undermine the model itself.

In summary, the value of the MHHI $\Delta$ in its current formulation is questionable and needs further improvement. In particular, to establish the extent to which it is capable of affecting the competition and whether same or lower threshold should be applied compared to market concentration, HHI.

4.2.3.2. Methodology of the empirical estimation of links between common ownership and prices

The multiple factors that can influence both common ownership and price-cost margins across firms or industries pose significant methodological challenges to interpreting the correlations between the two as causal links.

\footnotetext{
${ }^{1748}$ EB Rock \& DL Rubinfeld, 'Defusing the Antitrust Threat to Institutional Investor Involvement in Corporate Governance' (March 1, 2017). NYU Law and Economics Research Paper No. 17-05. Available at SSRN: $\underline{\text { https://ssrn.com/abstract=2925855 }}$ ${ }^{1749}$ Ibid.

17501750 J Azar, R Raina, \& M C Schmalz, 'Ultimate Ownership and Bank Competition'. (July 23, 2016). Available at SSRN: https://ssrn.com/abstract=2710252 or http://dx.doi.org/10.2139/ssrn.2710252
} 
O'Brien and Waehrer (2017) ${ }^{1751}$ raise the concern of possible endogeneity (or, reverse causality) of the MHHI. If factors other than common ownership affect both price and the MHHI, the empirical finding of the relationship between price and the MHHI would not reflect the relationship between price and common ownership, but both of these with the omitted variable. The authors argue that all three concentration measures of the MHHI equation are endogenous variables that depend on the same exogenous factors that affect equilibrium prices. For example, marginal cost reduction of a single firm in a symmetric oligopoly increases the market share of the firm that experiences the cost reduction and increases the HHI. However, the cost reduction typically reduces price. Thus, regressions of price on the MHHI are likely to show a relationship even if common ownership has no actual causal effect on price.

O'Brien and Waehrer (2017) ${ }^{1752}$ also challenge the inconsistency between the empirical specifications of the AST (2016) estimates for the MHHI and the economic theory. In particular, they show that, theoretically, MHHI may rise or fall with an increase in common ownership that is asserted to affect price. Therefore, a positive relationship between the MHHI and price does not necessarily imply a positive relationship between common ownership and price.

Gramlich and Grundl (2017) ${ }^{1753}$ attempt applying an alternative methodology which places fewer restrictions on the nature of competition. They directly analyse the weights that firms place on each other's' profits rather than measures of industry concentration (MHHI and GHHI) used in APS(2017) and ARS(2017) ${ }^{1754}$. The effects they find are somewhat consistent with the APS(2017) and ARS(2017) ${ }^{1755}$, but the sign of the effect is not robust, and implied magnitudes of the effects that are found are small.

We believe that these methodological concerns reflect the underlying need for continued examination of empirical data and refinement of methodologies that allow to produce robust, unbiased result, informative for relevant policy-making.

4.2.3.3. Possibility of the undecoordinated effect of common ownership feeding into the coordinated effect on horizontal competition

RR (2017a) $)^{1756}$ challenge 'the ability of shareholders to influence managers to soften competition so as to maximize investors' portfolio value'. The financial incentives mechanism cited extensively in the literature makes it clear that shareholders do not have to actively

${ }^{1751}$ D P O'Brien \& K Waehrer, 'The Competitive Effects of Common Ownership: We Know Less than We Think', (February 23, 2017). Available at SSRN: https://ssrn.com/abstract=2922677

${ }^{1752} \mathrm{Ibid}$.

1753 J Gramlich, \& S Grundl, 'Estimating the Competitive Effects of Common Ownership'. (April 21, 2017). FEDS

Working Paper No. 2017-029. Available at SSRN: https://ssrn.com/abstract=2940137 or http://dx.doi.org/10.17016/FEDS.2017.029r1

${ }^{1754}$ J Azar, R Raina, \& M C Schmalz, 'Ultimate Ownership and Bank Competition'. (July 23, 2016). Available at SSRN: https://ssrn.com/abstract=2710252 or http://dx.doi.org/10.2139/ssrn.2710252; J Azar, R Raina, \& M C Schmalz, 'Ultimate Ownership and Bank Competition'. (July 23, 2016). Available at SSRN: https://ssrn.com/abstract=2710252 or http://dx.doi.org/10.2139/ssrn.2710252

${ }^{1755} \mathrm{Ibid}$.

${ }^{1756}$ EB Rock \& DL Rubinfeld, 'Defusing the Antitrust Threat to Institutional Investor Involvement in Corporate Governance' (March 1, 2017). NYU Law and Economics Research Paper No. 17-05. Available at SSRN: https://ssrn.com/abstract=2925855 
influence the managers; common knowledge of their preferences is a sufficient condition.

RR (2017a) ${ }^{1757}$ also doubt feasibility of firm managers taking into account holdings of shareholders in their competitors. They deem this not feasible because of: (1) substantial heterogeneity among the holdings of the largest shareholders, (2) dynamic nature of the investor portfolios.

We are not convinced by this argument, since both heterogeneity of shareholders and dynamic portfolios appear commensurable with the model. Firstly, there is no consensus about the level of market concentration that triggers this incentive mechanism - thus "substantial heterogeneity" in the eyes of R\&R (2017a) ${ }^{1758}$ may well be enough concentration in the objective function of the firm's manager. The authors give a following example of differential incentives within a shareholder circle: 'At the end of 2016, PRIMECAP had differentially weighted holdings of the airlines: $2.85 \%$ of Delta, $11.78 \%$ of Southwest, $8.97 \%$ of American, $6.27 \%$ of United, $4.95 \%$ of Alaska Air and $5.91 \%$ of JetBlue. T. Rowe Price, by contrast, held $13.99 \%$ of American and $10.14 \%$ of Alaska Air, smaller holdings of $1.26 \%$ of Southwest and $2.25 \%$ of United, and nothing in Delta and JetBlue. PRIMECAP might argue for Southwest and JetBlue to undercut Delta and United if that would be in the unilateral interest of Southwest and JetBlue, respectively. T. Rowe Price, by contrast, would likely object were United Airlines management to take into account the effect of its strategy on Delta and JetBlue because it is only invested in United and Southwest.' We believe that the premises of this argument still boil down to the measurement of expected profits and the precise way they enter the PRIMECAP's incentives and, consequently, incentives of the firms in which it holds shares. To predict PRIMECAP strategy we need to understand which outcome (competitive or non-competitive) outweighs, considered both over the short and the long term.

As for dynamic portfolios, RR (2017a) ${ }^{1759}$ claim that 'holdings change quite dramatically over time, making it impossible to count on incentives of others'. To exemplify, they compare top ten shareholdings in Southwest as of March 31, 2013 with the shareholdings in Southwest as of 2016Q4. They highlight that while PRIMECAP was the largest shareholder at both times, Berkshire Hathaway acquired its $7 \%$ sometime between the two periods. T. Rowe Price, by contrast, reduced its holding from $5.3 \%$ to $1.26 \%$ while Fidelity increased its holding from $3 \%$ to $5.53 \%$. In our view, the overarching model applied by AST (2016) ${ }^{1760}$ assumes that the firm's manager maximises a weighted aggregate of investor interests - which can feasibly include dynamic expectations over fluctuations in shareholdings. Furthermore, we find it plainly surprising that in the current day markets largely driven by analytics, forecasting, and feasibility studies for potential scenarios $R \& R(2017 a)^{1761}$ consider complexity a feasible challenge.

\footnotetext{
1757 Ibid.

1758 Ibid.

1759 EB Rock \& DL Rubinfeld, 'Defusing the Antitrust Threat to Institutional Investor Involvement in Corporate Governance' (March 1, 2017). NYU Law and Economics Research Paper No. 17-05. Available at SSRN: https://ssrn.com/abstract=2925855

1760 J Azar, R Raina, \& M C Schmalz, 'Ultimate Ownership and Bank Competition'. (July 23, 2016). Available at SSRN: https://ssrn.com/abstract=2710252 or http://dx.doi.org/10.2139/ssrn.2710252

1761 EB Rock \& DL Rubinfeld, 'Defusing the Antitrust Threat to Institutional Investor Involvement in Corporate Governance' (March 1, 2017). NYU Law and Economics Research Paper No. 17-05. Available at SSRN: https://ssrn.com/abstract=2925855
} 
$R \& R(2017 a)^{1762}$ also refer to vertical integration as a potential source of complexity that interferes with manager's ability to aggregate investor interests. In their example, BlackRock, Vanguard and State Street also manage funds that own shares of the airlines' suppliers (e.g., Exxon, Boeing) and customers (e.g. GE, GM, and IBM). We see this not as a viable criticism of the model - the mechanisms affecting manager's decision-making can potentially allow for a more complex way of how the portfolio structure enters their objective function. We view it as another reason to conduct further research specifically into the mechanisms of common ownership in vertically integrated holdings.

This brings us to back to the broader picture of this debate. The policy makers are ultimately concerned about the possibility of anticompetitive outcomes arising from common ownership. The outcome the research in this area aims to define and prevent is ultimately the conditions under which 'firms may be able to collude with each other to create and abuse market power, for example by agreeing to raise prices or by restricting output (thereby raising prices) to consumers or by restricting wage growth for workers' 1763

Given the current state of the literature, we feel in the position to call for further empirical research and theoretical investigation into the complex structures of (horizontal and vertical) common ownership in market value chains and its effect on competitor firms, suppliers and consumers.

\subsubsection{Common ownership as a vertical issue?}

In addition to the horizontal collusion concerns that may arise out of common ownership by financial investors, one needs also to explore the risks that the presence of the same financial investors in all concentrated segments of the food value chain may create for the development of practices leading to the reduction of the margins of the only segment of the food value chain that is not overly concentrated, farming. One may argue that the transmission mechanism here is simpler, to the extent that squeezing farmers' margins is something that managers of firms situated upstream want to do anyway, so the issue of owners controlling managers is less important than in the context of horizontal non-coordinated effects. A manager of an upstream input supplier may also have more incentives to squeeze if he knows others will not try to steal its business by being "nicer".

The question one may ask is what would be the incentives of the common investors in case the restriction of vertical competition, that is competition between the various segments of the value chain for a larger share of the total surplus value produced by the value chain, could increase their profits to the detriment of the farmers' segment of the value chain? One may argue that there could be two types of concerns here. First, in case the financial investor is present in both the upstream input and the farming sector, as some of them undoubtedly are, this may raise vertical foreclosure effects which are similar to those expressed in the context of margin squeeze. Margin squeeze requires the ability to act directly in the downstream market, hence the financial investor should also be present in the farming segment. Second, in

\footnotetext{
1762 Ibid.

${ }^{1763}$ Council of Economic Advisors (2016): "Benefits of Competition and Indicators of Market Power," Available online
} 
case the financial investor is present only in the segments situated upstream and downstream from the farming segment, there might be an exploitative concern, with regard to the restriction of vertical competition over the total surplus value and the squeezing of the margins of the nonconcentrated framework, that of farmers. One should nevertheless bear in mind that the aim pursued here will be different, in comparison to the margin squeeze exclusionary context, as it will consist more in extracting/capturing a higher share of the joint profit of the cooperation between the different segments of the food value chain than in excluding a competitor upstream or downstream. One should therefore examine the incentives and the ability of financial investors to rely on their common ownership of the other segments of the value chain (in particular factors of production and processing) in order to extract this additional revenue and to marginalise vertical competition from the non-concentrated segment of the food value chain, thus reducing the profitability of farming.

\subsection{Mechanisms of a classic foreclosure in vertical market structure}

From an economic perspective, margin squeeze supposes the existence of a vertically integrated firm with a dominant position in an upstream market and which prevents its (nonvertically integrated) rival in a downstream market from achieving 'an economically viable price-cost margin' 1764 (see Figure 1). Margin squeeze may also result from a reduction of vertical competition, should, for instance

\section{Figure 1: Classic market structure in which a margin squeeze might $\operatorname{arise}^{1765}$}

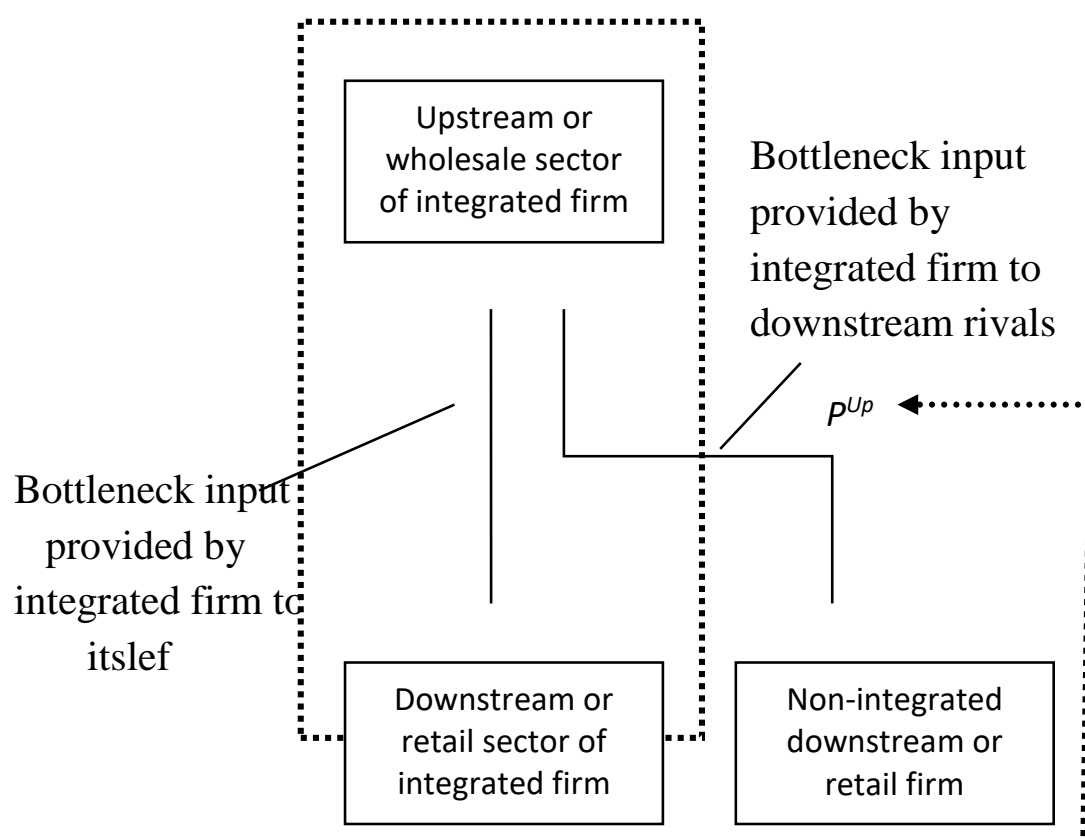

${ }^{1764}$ R O'Donoghue and J Padilla, The Law and Economics of Article 102 TFEU (Hart

Existence of a price squeeze depends on the relationship between the upstream input price and downstream price of the integrated firm 


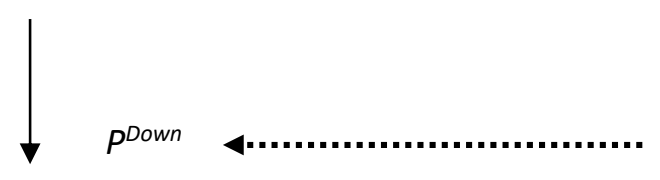

According to the EU case law, there is margin squeeze if the spread between the wholesale prices upstream and the retail prices to end users downstream practiced by the dominant undertaking were either negative or insufficient to cover the specific costs at the upstream level which the dominant undertaking has to incur in order to supply its own retail services to end users, so that that spread does not allow a competitor which is as efficient as that undertaking to compete for the supply of those services to end users ${ }^{1766}$. This margin squeeze leads the dominant underttaking's actual or potential equally efficient rivals to operate on the retail market only at a loss or at artificially reduced levels of profitability. Hence margin squeeze covers both situations of negative and positive margins.

Economists identify different rationales/theories of harm for (anticompetitive) margin squeeze.

First, the behaviour may be the result of an exclusionary practice, which may either be based on predation, or on anticompetitive foreclosure.

A predation theory of harm would involve a profit sacrifice in the first phase and recoupment in the second phase. This is the only available theory of harm in case the wholesale price is set by regulators on a strictly cost-basis. Application of a predatory pricing theory of harm would involve that the competition authority or court examine "whether the dominant firm's own downstream business would be profitable if it had to pay the same actual input prices as third parties', that is 'a test of downstream predatory pricing in the context of vertical integration' 1767

The focus here would be on the analysis of downstream competition between the dominant undertaking and its competitor(s). There are, however, also notable differences between margin squeeze and predatory pricing: first, although in predation cases competition authorities look to all costs of the dominant undertaking, they only look at the costs in the downstream market and the upstream price for margin squeeze; second, margin squeeze does not involve that the dominant undertaking is losing money overall, as it might be able to gain profits upstream rather than downstream and the margin squeeze may be overall profitable for the vertically integrated undertaking. Hence, it is not necessary to examine the recoupment of this 'sacrifice' by the dominant undertaking, as it may well be that the undertaking recoups its losses more or less simultaneously throughout the period of the abuse of margin squeeze. ${ }^{1768}$ The existence of a 'sacrifice' in margin squeeze cases may however take different forms, such as the opportunity cost for each unit not sold to downstream competitors, because of the high price of the bottleneck input, this opportunity cost being sometimes quite large if the wholesale price is above the upstream marginal cost (eg in presence of large economies of scale).

\footnotetext{
${ }^{1766}$ Case C-52/09 Konkurrensverket v TeliaSonera Sverige AB [2011] ECR I-527, paras 25-26, 32-34.

${ }^{1767}$ R O'Donoghue and J Padilla, The Law and Economics of Article 102 TFEU (Hart Pub, 2nd ed, 2013) 397.

${ }^{1768}$ Ibid., 398.
} 
An anticompetitive foreclosure theory of harm may involve a vertical foreclosure, which would arise when 'the bottleneck good is either used as an input (eg an infrastructure) by a potentially competitive downstream industry (input foreclosure) [...], or when the bottleneck is needed to access final consumers (customer foreclosure)". ${ }^{1769}$ A distinct possibility is horizontal foreclosure, which 'arises when the monopolized good is sold directly to customers, who use it in conjunction with complementary goods (eg system goods or aftersale services), involving scenarios in which the integrated undertaking attempts to protect its upstream monopoly or core market from potential competition by downstream customers or its market position in an adjacent market. Although most of the scenarios involving margin squeeze examined by EU and national competition authorities and courts involved vertical foreclosure, as 'margin squeeze allegations are typically made in network industries where a vertically integrated operator supplies access to its network to downstream competitors', one cannot exclude the horizontal foreclosure scenario as well. Vertical foreclosure may involve the leverage theory of harm, the margin squeeze being explained by the anticompetitive motive to monopolize the downstream market, or to dampen competition in the downstream market. The vertical foreclosure theory was subject to criticism by the Chicago school of antitrust economics, which argued that there is a single monopoly profit to be made overall from end to end in the vertically integrated structure, and that the bottleneck monopolist may earn the entire monopoly profit simply by charging the monopoly margin at the upstream (bottleneck input) level and, consequently, leveraging market power from the bottleneck input market to the downstream market is not the main rationale for adopting such practices, and that these may be explained by efficiency reasons. ${ }^{1770}$ The single monopoly profit theorem was criticized by post-Chicago antitrust economists, observing the very strict assumptions under which it may apply and the fact that in the absence of exclusionary practices the upstream monopolist cannot fully exert its monopoly power. ${ }^{1771}$ The horizontal foreclosure argument will often take the form of maintenance of monopoly theory of harm or defensive leveraging.

Second, margin squeeze may arise as 'a by-product of pure exploitation of upstream market power by a vertically integrated firm', the upstream monopolist raising prices above the competitive level in order to 'appropriate some of the value created by downstream firms'. ${ }^{1772}$ By raising its price upstream the bottleneck monopolist will reduce the profits of downstream competitors which will be captured by the monopolist upstream (excessive pricing theory of harm). Of course, the monopolist should never charge prices that are so high as to eliminate its downstream rivals, because this will eliminate the wholesale profits made by selling the bottleneck input to them, the vertically integrated undertaking deriving revenue from two sources: the wholesale level and the retail level. This exploitative strategy makes sense in particular when the downstream rivals are differentiated from the vertically integrated firm's

\footnotetext{
1769 B Jullien, P Rey and C Saavedra, The Economics of Margin Squeeze, IDEI mimeo (March 2014) 11.

1770 More on the 'single monopoly profit' argument, XXX.

${ }^{1771}$ See, our analysis, XXX.

1772 B Jullien, P Rey and C Saavedra, The Economics of Margin Squeeze, IDEI mimeo (March 2014) 19. In contrast, Chicago school of economics would disagree with the characterization of such conduct as abusive behavior. The single-monopoly profit theorem posits that the upstream monopolist can extract its rent by charging downstream rivals. Hence it is hard to claim this is about abuse of dominance to the extent that that is what they would expect a dominant operator to do.
} 
downstream unit. For example, downstream rivals may preside a niche market segment, or may offer better customer service, thus being able to sell at a premium compared to the vertically intergrated firm's downstream price. Yet, exploitative wholesale pricing may reduce the competitiveness of downstream competitors, thus providing the monopolist a 'price umbrella', enabling him to raise prices at the downstream level, or increase the profits of its downstream unit (raising rivals' costs theory).

In addition to these anticompetitive harm narratives, economists also acknowledge that a margin squeeze conduct may also generate plausible efficiency gains, such as dynamic pricing in markets with network effects and switching costs, promotional efforts for experience or credence goods, emergent markets, or even the motivation to use margin squeeze in order to meet competition. It is also often argued that the likelihood of error in identifying a margin squeeze is high as competition authorities and courts may not take into account other possible justification for the finding that downstream costs exceed the difference between upstream and downstream prices, such as industry shakeouts or temporary responses to bad market conditions, or the fact that the company may be undertaking legitimate investments in order to enhance its future profitability.

As it is not possible to always observe the price at which the firm sells its bottleneck input to its downstream sector, or because of the possibility of a fully integrated firm to shift apparent profits around within the upstream and downstream components of the same firm (through transactions or transfer pricing), the price at which the integrated firm sells its bottleneck input are inferred or imputed. The process is explained in the following excerpt:

"The most important element of a margin squeeze concerns the methodology to be applied to identify (or impute) an abuse. This raises several issues. First, what legal test should be applied to determine whether the dominant firm's upstream and downstream prices cause the activities of a downstream rival to be uneconomic, i.e. either lossmaking or insufficient to provide a "reasonable profit". The most commonly-applied test is whether the dominant firm's own downstream operations would make a profit if they had to pay the same input price as rivals. A second, related issue is whether a different test based on the costs of a "reasonably efficient entrant" can also be applied. Third, the relevant cost standard to be applied to the dominant firm's downstream operations needs to be identified. Fourth, because margin squeeze concerns the price spread, or margin, one must look not only at costs but also at profitability, and it is necessary to apply a specific methodology in this regard. Finally, it needs to be ensured that the compared inputs, costs, and downstream revenues are truly comparable. [...] A number of alternative tests could be envisaged in order to ascertain whether the dominant firm's prices would unlawfully exclude downstream rivals: (1) whether the dominant firm's own downstream operations could trade profitably on the basis of the wholesale price charged to third parties for the relevant input; (2) whether the dominant firm's downstream rivals could trade profitably on the basis of the wholesale price charged by the dominant firm; (3) whether some notional or hypothetical "reasonably 
efficient operator" could trade profitably on the basis of the dominant firm's input prices; or (4) a combination of some or all of the preceding tests"1773.

With regard to the above imputation tests, the one focusing on the dominant firm's own costs is only concerned with margin squeeze conduct that may exclude firms that are as efficient as the dominant undertaking, that it the excluded rivals have costs than the dominant firm (the Dominant undertaking's own costs test). The test is practical as the dominant firm cannot know its rivals' costs but only its own costs. ${ }^{1774}$ Another imputation test would focus on the costs of a reasonably efficient competitor, which will find abusive a margin that is insufficient to allow a reasonably efficient competitor to obtain a normal profit, for instance the downstream rival's costs (the reasonable efficient competitor test). The second test may lead to the application of competition law if the margin squeeze excludes a less efficient rival than the dominant firm, as long as this is a 'reasonably efficient' competitor. ${ }^{1775}$ Hence, the test involves a crucial choice as to the degree of efficiency it is reasonable to expect from rivals and emphasizes the competitive process, rather than efficiency as such, as the test facilitates the maintenance of competitors even less efficient than the dominant undertaking in the market.

The application of the equally efficient competitor test involves the consideration of all product-specific costs that the dominant firm incurs at the downstream market, exploring whether given these cost the dominant undertaking would remain profitable on the basis of the bottleneck input price it charges its competitors. Long-run average incremental costs constitute the most commonly applied cost benchmark in margin squeeze cases and refer to the productspecific costs linked with the total volume of output of the relevant product. As it is explained by the Commission, the choice of this cost benchmark

'[...] is in accordance with economic theory and the Commission's decisional practice where the ability of competitors to operate profitably in the long term was assessed. In order to assess whether the prices that the dominant firm applies over time are such that they can foreclose equally efficient competitors the costs considered must include the total costs which are incremental to the provision of the product/service. These are also the prices which form the basis of the firm's decision to invest'. ${ }^{1776}$

Finally, margin squeeze claims involve some profitability analysis, which 'entails assessing whether the vertically integrated dominant firm's own downstream operations could operate profitably on the basis of the upstream price charged to its competitors by its upstream operating arm'. ${ }^{1777}$ This is performed either by employing a 'period by period' approach, which 'compares for every year (or for shorter periods) the observed revenues and costs extracted

\footnotetext{
${ }^{1773}$ R O'Donoghue and J Padilla, The Law and Economics of Article 102 TFEU (Hart Pub, 2nd ed, 2013) 376

${ }^{1774}$ However, it could be argued that the Dominant undertaking can observe downstream rivals' prices. This may be relevant where the downstream rival is differentiated and able to seel at a premium compared to the downstream price charged by the Dominant undertaking. Under these circumstances, failure to pass the as-efficient competitor test might not necessarily establish exclusionary intent, as the higher wholesale price charged to the downstream rival might be aimed at extracting the premium thereof, thus being exploitative in nature.

1775 Where there are downstream economies of scale (ie, due to large fixed advertising costs) for example, the Dominant undertaking's downstream costs might be adjusted upward to reflect the fact that the rival is operating at a lower scale. However, this treatment of downstream scale economies may amount to consider them as an anticompetitive entry barrier, which may be contentious.

${ }^{1776}$ European Commission, Contribution to the OECD, Margin Squeeze, DAF/COMP/WP2/WD(2009)32, 6.

1777 Ibid., 6
} 
from the dominant firm's accounts in which investment expenditure have been amortised over appropriate periods', or by using a discounted cash flow ('DCF') approach, which 'consists in assessing the overall profitability over an adequate period (in general several years) in order to take account not only of current revenues but also of future revenues flowing from current investments'.

The question whether such foreclosure can be fuelled by the presence of institutional investors in most segments of the value chain is a truly underexplored area. We now review evidence from a range of papers analysing food (and several others) value chains with high concentrations of market power within many segments of the chain - and the correlated evidence of harm to the market.

\subsection{Empirical evidence on possible vertical exploitation from the food value chain}

Currently in the literature there is no clarity whether common ownership increase the opportunities for margin squeeze. There is however a number of studies that link general financialisation of the markets with shifting balance of power and, consequently, shifts of profit margins. Specifically for food industry, Isakson (2014) argues that financialisation of food markets led to (1) food retailers becoming the dominant players on the market, (2) food retailers activity being dictated by the finance capital, (3) exploitation of food workers and push down on the wages resulting from the financialisation, (4) small-scale farmers being most affected since they are the segment that remains most vulnerable to market volatility ${ }^{1778}$. The incentives the financialised segments create for the downstream segments make it economically unfeasible for the farmers to surpass interacting with them; at the same time, the costs of this financialisation have been (arguably) passed on to the farmers in the following segments of the value chain (for detailed overview see Isakson, 2014) ${ }^{1779}$.

Food retailing. Retailers provide an inventory management model which is attractive for the downstream clients. It poses low demand on funds for inventory and storage, as well as 1-3 months delay in payment to the supplying farmers - which frees up these funds for financial activities, that benefit shareholders. At the same time, retailers move the cost of providing this attractive model is shifted to the farmers, who receive late payments whilst having to comply with the "just in time" inventory demand.

Agricultural risk. Same patterns are observed in the market for agricultural risk. Bush (2012) ${ }^{1780}$ develops an interesting argument where the expectations created by the speculative derivatives market increase the volatility of the real market - which affects smaller-scale farmers directly, and also makes it more expensive for the farmers to hedge their risks ${ }^{1781}$.

\footnotetext{
1778 S R Isakson 'Food and finance: The financial transformation of agro-food supply chains'. (2014). Journal of Peasant Studies, 41(5), 749-775.

1779 S R Isakson 'Food and finance: The financial transformation of agro-food supply chains'. (2014). Journal of Peasant Studies, 41(5), 749-775.

${ }^{1781}$ S B Bush, 'Derivatives and development: a political economy of global finance, farming, and poverty'. (2012), New York: Palgrave Macmillan
} 
Food trade and processing. Murphy et al (2012) ${ }^{1782}$ highlight how foor retailers are increasingly engaged in a variety of financial activities where they leverage on their first-hand knowledge of the market conditions to drive profit for their clients. They provide an example of the world's four largest grain traders - Archer Daniels Midland (ADM), Bunge, Cargill and Louis Dreyfus (or, as they are collectively referred to, the ABCDs) - provide all established investment vehicles that allow external investors to speculate on agricultural commodities and other dimensions of food production. They state

'Due to their dominance of agricultural trade and their direct contact with food suppliers, the ABCDs are among the first to know about supply conditions, making their financial products particularly attractive to investors wishing to speculate on agricultural derivatives markets. Indeed, operating under the slogan 'monetize our expertise', Louis Dreyfus' hedge fund, the Alpha Fund, expanded rapidly, growing some 20-fold within its first two years and, ultimately, refusing to accept new investors because the fund had grown so large after a mere three years of operation.'

Given how profitable such hedge funds prove to be, Meyer (2009) ${ }^{1783}$ argues that the incentives in the market are currently shifter from the actual products to catering to speculators' interest in price movements.

Agricultural inputs and land. Market segments producing inputs such as land, seeds, fertilisers and machinery have seen an increasing inflow of investors over the past years (HiQuest, 2010) ${ }^{1784}$. Althought the 'price-cost squeeze' in this segment is the most understudies, it is argued that entrance of the investors was associated with raised prices, increased volatility, and greater barriers for the traditional farming models (e.g. moving from land-ownership to land-leasing) in these markets as well ${ }^{1785}$.

In our view the evidence above makes a strong case for need to investigate the role of financialisation of food markets and, specifically, to what extent the described 'profit-cost squeezes' may be inabled by presense of the same institutional investors in all segments of the value chain apart from the faming. Another important issue to note is that most (or even all) of the processes described above can be posited as efficiency gains enabled by the development of the market. However, this raises a question of whether such efficiency gains at the expense of agriculture are firstly, sustainable, and, secondly - normatively appropriate. We discuss these in the next section.

\subsection{Effect of margin squeeze on long-term sustainability}

These concerns may be raised not only by common ownership, but more broadly by the financialisation of agricultural production, as most of the food value chains have been

${ }^{1782}$ S Murphy, D Burch, J Clapp 'Cereal Secrets: The World's Largest Grain Traders and Global Agriculture'. (2012), Oxfam Research Reports. Oxford: Oxfam International.

1783 J Mayer, 'The growing interdependence between financial and commodity markets'. UNCTAD Discussion Paper No. 195. Geneva: United Nations Trade and Development Conference.

${ }^{1784}$ HighQuest Partners. 'Private Financial Sector Investment in Farmland and Agricultural Infrastructure'. (2010). OECD Food, Agriculture, and Fisheries Papers, No. 33, OECD Publishing.

${ }^{1785}$ S R Isakson 'Food and finance: The financial transformation of agro-food supply chains'. (2014). Journal of Peasant Studies, 41(5), 749-775. 
financialised over recent years - apart from the farming segment of them (at least, to a considerable extent). As we are witnessing major power concentration alongside the different segments of the value chain, there is a major issue rising on the entire vertical of this chain institutional investors having mechanisms that allow them to extract margins at every point of the food value chain, at the expense of the farming sector. Whilst this arrangement can be argued as optimal and efficient on the case-to-case basis, there are two issues with the overall picture. Firstly, whether such an arrangement poses a threat of negative effects on the farming industry in the long-term. Here we discuss the question of sharing the total surplus from the perspective of possibility to use this surplus to innovate, invest into sustainable practices and create buffers against economic shocks. The second issue is more normative: whether the system that creates instruments and incentives that allow institutional investors to gradually gain market power and extract the greater share of profit margins is a fair and sustainable system. We finally stress that the issue of the same investors being present in most segments of the chain is under researched, which makes it unclear to what extent it may be feeding into the presented adverse effects on the market.

The lack of reliable profit stream can be a disincentive to look for long-term sustainable investment. At the same time, it has been shown that institutional investors do not provide a replacement incentives for sustainability through their economic decision-making ${ }^{1786}$. For example, the public consultation by European Commission on how the institutional investors factor in the environmental, social and governance (ESG) information and performance of companies or assets into investment decisions showed that the majority of investors did not consider that their fiduciary duty regarding ESG was not clear enough, creating reasons to not consider it in investment decisions ${ }^{1787}$. Recent study of supply chains of four food commodities selected for global economic importance and their potentially adverse impact on the environment (tuna, shrimp, soy and beef) finds multiple ties between the major financial institutions holding shares in the chains - and shows that passive investors engage less in sustainability issues compared with active investors ${ }^{1788}$. Thus, part of the investor profits in the value chain may be obtain at the expense of withdrawing incentives and the profit margins required for long-term sustainable production.

Another sustainability question is whether the farming industry receives a sufficient share of the total surplus to be robust to economic shocks, if profit margins are (arguably) squeezed at the farmers' end, this can prevent them from building saving buffers that allow them to survive a year of bad weather shocks. There exist instruments such as impact investing designed to include the issues of sustainability into the set of incentives for the institutional investors (see a detailed discussion by Rogalska, 2016) ${ }^{1789}$. We believe there is a need for a policy-driven discussion on including such incentives on a regulatory basis.

\footnotetext{
${ }^{1786}$ A P van Duijn, R Beukers, R B Cowan, L O Judge, W van der Pijl, L Römgens,... \& t Steinweg, 'Financial value-chain analysis' (2016). (No. 2016-028). LEI Wageningen UR.

1787 European Commission (2016), "Summary of the responses to the public consultation on Long-term and sustainable investment”, Brussels, October 2016 JUST/A3

1788 Apart from the retail banks which often have developed sustainability policies. Authors, however, note that this financing is largely drawn on syndicated loans and this changes the dynamics of these banks' leverage

${ }^{1789}$ M Rogalska, "Globalisation and Financialisation of the Economy Impact Investing at Scale as a Promising Response". (2016) weatherhead Centre for International affairs, Harvard University
} 
In the current market, the firms and the investors are efficiently and rationally following their incentives, reaping off profits in the ways that caters to their client interests. Further evaluation is needed to understand whether this is a sustainable way forward, or whether the cost-cutting and other activities enabled my market power concentration reduce the incentives and the profit surplus available for the farmers to innovate, invest into sustainable practices and withstand economic shocks. This also raises a normative question: is it appropriate that most of the total surplus is extracted by the institutional investors, and what long-term effects it will have. Finally, the additional incentives present for the investors that hold shares in several segments of the market is the yet less researched issue.

\subsection{Evaluating the effects of financialisation on the economy: evidence and controversy}

The effects of financialisation of most of the segments of the value chain has been linked to a range of observable market trends which are argued to have a long-term adverse effect on the economy; the controversy of these effects being driven by firms pursuing their shareholder interests in an optimal way deserves a separate discussion we develop in the following section. We again stress that whilst it is not unlikely to expect the same incentive mechanisms of common ownership present in horizontal markets to play a role on vertical as well, the research in these area is needed.

Burch and Lawrence $(2009,2013)^{1790}$ analyse how private equity takeovers of supermarkets transform the food retail sector. They use a case-study of private equity consortium's takeover of the Somerfield Supermarkets (UK) to identify four strategies that financial actors are employing as a means of realizing shareholder value: (1) narrowing the retailer's product line and reducing the number of suppliers, thereby streamlining the sourcing process (including the closure of some distribution centers) and reducing costs; (2) reducing the number of employees (many of whom previously worked in the distribution centers) and increasing the workload (i.e. rate of exploitation) of the remaining workers; (3) disregarding previous commitments to environmental quality and the well-being of food producers in the global South, including Somerfield's withdrawal from the Ethical Trading Initiative (ETI), which sets labor standards for developing country suppliers, and (4) de-bundling and repackaging assets, including the introduction of an operating company/property company (opco/propco) arrangement, whereby Somerfield sold its real estate properties to a newly created subsidiary of itself that, in turn, leased the property back to Somerfield. These transformations are argued to worsen the economic situation of specific groups in the market (farmers, labour force), and create long-term threats to the country's economy (environmental sustainability); at the same time, however, these can be seen as efficient steps taken by the company to reduce costs and maximise its shareholders returns in the context of the current globalised market.

${ }^{1790}$ B Burch \& G Lawrence, 'Towards a third food regime: behind the transformation. Agriculture and Human Values', (2009). 26(4), 267-279; B Burch \& G Lawrence, Financialization in agri-food supply chains: private equity and the transformation of the retail sector'. (2013). Agriculture and Human Values 30(2), 247-258. 
There is a number of techniques that can provide measurements for the effects above; a more complex issue is, however, creating a framework for evaluating these longer-term effects against the shorter-term increases in investors profits that firms achieve through these activities. Specifically, studies use scanner and retail data measure prices at different stages of the value chain (for example, see Villas-Boas, 2007a; Villas-Boas, 2007b ${ }^{1791}$. Similar approach has been taken to measure changes in labour market that can be attributed to the increased saturation of common ownership. A greater challenge is, however, to evaluate these effects against the value driven by the institutional investors to their clients, which also include large parts of the society (e.g. pension funds). We thus believe there is a need for a coherent evaluative framework to allow quantifying and comparing such long-term effects for the economy against the shorter-term benefits for the shareholders against each other and make meaningful recommendations for regulative purposes.

Another important long-term effect of financialisation is the withdrawal of value added sectors from the economy. For example, Ashman, Mohamed and Newman (2013) explore the case study Anglo American PLC, by far the most important South African company ${ }^{1792}$. In the 1990s Anglo American had 100 subsidiaries in South Africa, manufacturing accounted for about 30 per cent of its revenues, and its activities collectively accounted for over 40 per cent of the Johannesburg Stock Exchange market capitalization. By 2007 however, following the process restructuring Anglo had either moved or sold a large number of its segments that were considered very important for the South African economy. Specifically, it shifted offshore the engineering and design segments of Boart Longyear (which produces tools and equipment and services for the international mining industry) - this was considered an important area of capital and transport equipment where South Africa had built a technological lead due to innovation in mining and minerals processing. Similarly, in 2012 Anglo shifted the high value-added and higher technology parts of its paper and packaging business to Europe leaving South Africa with low value-added production and exports and more reliant on importing higher value added manufactured products that had been produced in the country. Similarly to the previous example, these actions bring undeniable benefits to the market shareholders and, crucially, can be argued optimal in pursuing the investor interest. The longer-term threats that these actions pose to the overall competitiveness of the economy are much more difficult to quantify, posing a challenge for evaluating the two against each other.

A more short-term piece of evidence that can be helpful in identifying the path of the negative effect of financialisation on the market is the mismatch between the industry performance and the shareholder returns. Ashman, Mohamed and Newman (2013) refer to a recent study by PWC which highlights the trend for share prices of mining companies to not reflect changes in commodities prices (PWC 2012) ${ }^{1793}$. PWC reports that

\footnotetext{
${ }^{1791}$ S B Villas-Boas, 'Vertical relationships between manufacturers and retailers: Inference with limited data.' S. (2007). The Review of Economic Studies, 74(2), 625-652.; S B Villas-Boas, 'Using retail data for upstream merger analysis.' (2007). joclec, 3(4), 689-715.

1792 S Ashman, S Mohamed, \& S Newman, 'Financialisation of the South African economy: Impact on the economic growth path and employment'. (2013), Discussion Paper. United Nations Department of Economic and Social Affairs.

1793 Price Waterhouse Coopers, 'Mine: The Growing Disconnect'. (2012), PWC, London. http://www.pwc.com/gx/en/mining/publications/mining/mine-the-growingdisconnect.jhtml
} 
"2011 was a year of a growing disconnect for the mining industry. Mining company stocks significantly underperformed the broader markets and lost value despite record profits, and the disconnect between share values and many commodity prices widened (PWC, 2012, p. 1)."

Their report on global mining in 2012 shows even more problems, lower profits and lower share prices for the global mining industry (PWC, 2013). Such disconnect may be more readily observable in the food value chain: for example, if the shocks on the production side (e.g. reduction in crops) coexist with continuously high returns to the shareholders. - this may be a signal for the regulators to raise their concerns about how these shocks are absorbed within the value chain.

This brings us to the more general questions of market functioning in the modern world. The way we currently think about corporate governance does not fully account for the fact that most investors are diversified. This has already been seen as an issue in mergers and acquisitions. For example, in the context of common ownership, a company may not be incentivised to bargain over the split of the merger premium. A diversified investor holding a proportional amount of both companies' shares, does not care about the most competitive split, since it does not necessarily maximise the overall value of their holding. For example, if both companies act in the best interest of such an investor, they would minimise the expenses on legal and negotiating costs, avoid pushing one of the companies to raise debt to pay more, and not run the risk of one of the companies exiting the deal due to disagreement about the split of the benefits - because all these actions reduce the benefits of the diversified shareholder, compared to the benefits of a non-competitive merger. Additionally, the current management of the companies has been academically and professionally trained to think in the context of the modern portfolio theory. From this perspective, both economic and legal researchers need to incorporate this understanding into the way the market and its incentives are analysed and regulated.

The potential issues that institutional investors create for the less concentrated segments of the value chain, such as farmers, also raises a broader question. Diversified institutional investing offers many advantages and much of society relies on them. For one, pension funds are able to hedge the risks, benefit from the low-cost management for the capital, and guarantee its clients long-term returns. At the same time, there are multiple indications that there may be anticompetitive incentives inherent in this system. This raises a number of important research directions: what methods and what evidence we need to conclude whether it is indeed what is happening, what changes we can and should make while keeping the balance of the positives that institutional investment brings. To enable policy interventions, we need to establish whether the potential costs to the economy outweighs the well-established benefits of diversification. We also need to establish the method of quantifying the costs of possibly lowering the competition and squeezing the margins of more vulnerable players of the value chain (such as farmers). There is also need for value judgement on what is the fair allocation of the surplus in the market and whether it should be extracted by the party that is better placed to extract it - or shared more equally. Finally, there appears need to undertake further research into the way that uncoordinated effect of common ownership may be entering the incentives 
of institutional investors present in several segments of the value chain. Specifically, pursuing interests of same shareholders in more than a single segment of a value chain may lead to a greatly exacerbated scale of squeezing the margins, since firms may not have incentives to undercut each other not only horizontally but also vertically. Furthermore, the incentive to maximise the common owners' profit margins may lead individual sectors to neglect the activity that is optimal within the sector.

It is important to note that despite the argument about common ownership creating wrong incentives - within the system firms and shareholders are responding correctly to the current market incentives. Managers aren't acting against shareholders' interests, and shareholders are focused on the long-term returns. Managers are pursuing the best way of maximizing the value of their shareholders' portfolios. And those shareholders are investing rationally and correctly in diversified portfolios that maximize risk-adjusted return. Yet the functioning of this system in its current state created a negative externality for the wider economy. In our view this tension indicates the need for further thorough investigation into what incentives the current economic and legal framework creates, possible outcomes of these incentives and the ways to alter the framework to achieve the desired improvements.

\subsubsection{Common ownership and coordinated effects}

\subsection{Overview: coordinated effects}

Economic effects of minority shareholding on market competition have recently come into focus of regulatory bodies and academic research (Council of Economic Advisors, 2016 ${ }^{1794}$; Elhauge, 2016 ${ }^{1795}$; Azar, Schmalz, and Tecu 2016 ${ }^{1796}$; Azar, Raina, and Schmalz, $2016^{1797}$ ). Current antitrust rules provide limited guidance as to how agencies or courts should review the risks for competition associated with the acquisition of a passive minority interest $\left(\mathrm{OECD}, 2008^{1798}\right)$. The definition of common shareholding currently used for the purposes of corporate law and finance to evaluate threat to competition focuses on direct effects: corporate/economic control, or incentives as short-run unilateral effects. It largely ignores indirect and informal influence and incentives such as strategic effects and long-run market interactions (for a comprehensive overview, see Tzanaki, forth.) that have potential for fostering tacit collusion.

The main question of possible coordinated effects of common ownership can be formulated in lay terms as follows. The current assumption under which common ownership is of no concern to regulators posits that holding equity in a large proportion of largest players

\footnotetext{
1794 Council of Economic Advisors (2016): "Benefits of Competition and Indicators of Market Power," Available online

1795 E Elhauge, 'Horizontal Shareholding', (2016). 129 Harv. L. Rev. 1267

1796 J Azar, M C Schmalz, \& I Tecu, Isabel, 'Anti-Competitive Effects of Common Ownership' (March 15, 2017). Journal of Finance, Forthcoming. Available at SSRN: https://ssrn.com/abstract=2427345 or http://dx.doi.org/10.2139/ssrn.2427345; further - AST(2016)

1797 J Azar, R Raina, \& M C Schmalz, 'Ultimate Ownership and Bank Competition'. (July 23, 2016). Available at SSRN: https://ssrn.com/abstract=2710252 or http://dx.doi.org/10.2139/ssrn.2710252; further - ARS(2016)

${ }^{1798}$ OECD, ‘Antitrust Issues Involving Minority Shareholdings and Interlocking Directorates’ (n 15) 21
} 
of an oligopolistic market simply allows the institutional investors to hedge their risks over the outcomes of a standard oligopolistic competition. Individual firms in the portfolio undercut each other, yielding profits and losses to individual players, and on balance this portfolio yields an average constant stream of standard oligopoly-competition size profit for the institutional investors. The current concern is that an alternative state of the world is possible, where presence of institutional investors provides either incentives or mechanisms that distort the competitive behaviour of firms in a way that allows tacit collusion and, thus, collusive profits in the market. We present evidence supporting this concern - for both incentives, and mechanisms.

The next crucial step for a regulator is to define the set of parameters that facilitate these anticompetitive effects: features of the market in which they can arise, the relationship between the size of common ownership and the size of the coordinated effects on market price, role of the number, and comparative size of the firms in the market. After defining the potential coordinated effects we then go on to discussing such parameters that are crucial for regulatory attention and further research.

Passive ownership is associated with two main theories of harm ${ }^{1799}$ : Unilateral effects, and coordinated effects, which relate to a change in the market structure or nature of competition that enables independent competitors to coordinate their behaviour in order to reach and sustain collusion which in turn leads to higher prices. Theoretical frameworks are currently developed with a focus on cross ownership. However, Ezrachi and Gilo (2006) suggest that 'When a firm's controlling shareholder invests in this firm's competitor, the potential unilateral and coordinated anticompetitive effects are similar to those involving passive investment among the rivals themselves. Since the controlling shareholder partly identifies with the profits and losses of the rival firm, the controller tends to make his own firm compete less vigorously.'

For unilateral effects, Ezrachi and Gilo (2006) ${ }^{1800}$ give a following standard example. Suppose firm A passively invests in firm B. This passive investment could cause prices to go up relative to the case without passive investment. Absent passive investment, firm A would hesitate to raise the price of its brand, out of fear that such an increased price (although it would increase firm A's revenue per unit) would cause firm A to lose too many customers to firm B. However, if firm A passively invests in firm B, a price raise may become profitable. Although some of the customers may switch to firm B, firm A shares some of firm B's profits. Hence, the competitive constraints that prevented firm A from raising the price of its product diminish when firm A, through passive investment, absorbs part of firm B's profits. O'Brien and Salop (2000), building on Bresnahan and Salop (1986) ${ }^{1801}$ formulate how not only cross ownership

\footnotetext{
${ }^{1799}$ Guidelines on the Assessement of Horizontal Mergers under the Council Regulation on the Control of Concentrations between Undertakings [2004] OJ C 31/05 (“EU Horizontal Merger Guidelines”), para 22.

1800 Ezrachi, Ariel, and David Gilo. "EC competition law and the regulation of passive investments among competitors." Oxford Journal of Legal Studies 26, no. 2 (2006): 327-349.

${ }^{1801}$ D P O’Brien \& S C Salop, 'Competitive Effects of Partial Ownership: Financial Interest and Corporate Control' [2000] 67 Antitrust L.J. 559;; T Bresnahan \& S C Salop, 'Quantifying The Competitive Effects of Production Joint Ventures', (1986) 4 Inter'I J. Ind. Org. 155
} 
but crucially, common ownership can give rise to the same unilateral effects through creating interdependence between individual firms' objective functions.

Coordinated effects are less straight-forward and can occur through several different mechanisms we discuss in detail below. The general route of harm to competition is, however, making undercutting less desirable for a firm that would otherwise undercut. As Tzanaki (forth.) rightly points out, the repeated nature of the interaction between the firms is currently not taken into account by the regulatory assessment of the markets - whilst it has the power to drastically change the outcomes of the interaction, compared to the single stage equilibria.

The simples example would be a situation where, even if it is in firm's individual profitbased interest to undercut, the losses that this undercutting brings onto other firms are absorbed will be absorbed through held share in them. Here, the key question is what factors promote or discourage collusive outcome. We will argue that common ownership is a factor that facilitates collusive outcome.

All classic models of dynamic oligopoly ${ }^{1802}$ are affected by the folk theorem - any outcome from collusive to competitive (including all asymmetric ones) are outcomes of a Nash equilibrium if the discount factor in the industry is close enough to one (Kreps, 1990 ${ }^{1803}$ ) - i.e. if firms care enough about the future payoffs as well as the payoffs in the current period to make "punishment" for deviating from the agreed upon static equilibrium effective. It is nearly irrelevant whether it is prices or quantities that firms are choosing in a given round: each firm can pick the collusive price and threaten to drop it to Cournot price if one of the other firms deviates; similarly, rivals can be choosing quantities and still sustain prices a-la Bertrand equilibrium (Abreu, 1986 ${ }^{1804}$ ). We review two types of theories on tacit collusion enabled by partial acquisitions: 1) models of severe dissuasive punishment for deviating firms (prisoner dilemma); 2) models that contain mechanisms that allows for all firms to have no incentive to deviate (assurance game).

\subsection{Collusive outcomes in dynamic setting}

We first discuss a model that showcases how dynamic setting in general is more conducive to collusion. firms interact repeatedly, they may then be able to maintain higher prices by tacitly agreeing that any deviation from the collusive path would trigger some retaliation. For being sustainable, retaliation must be sufficiently likely and costly to outweigh the short-term benefits from "cheating" on the collusive path.

\footnotetext{
${ }^{1802}$ For respective-name models see Cournot (1838); Bertrand (1883); von Stackelberg (1934); and for kinked demand - Hall and Hitch (1939), and Sweezy (1939).

${ }^{1803}$ Kreps, D.M., 1990. A course in microeconomic theory (Vol. 41). Princeton, NJ: Princeton university press.
}

${ }^{1804}$ Abreu, D., 1986. Extremal equilibria of oligopolistic supergames. Journal of Economic Theory, 39(1), pp.191-225. 
Abreu, Pearce, and Stacchetti $\left(1986^{1805}\right)$ show possibility for collusive asymmetric equilibria that maximise the total profit in the industry. They extend this model to include an empirically plausible constraint of imperfect monitoring (Abreu, Pearce, and Stacchetti, $1990^{1806}$ ) showing that solutions for supergames (dynamic repetition of interaction over a number of periods) can be derived from the solutions of the static problems (interaction in a single period).

In this model firms cannot directly observe each others' output; they base their decisions on past period's market price, which has a stochastic element to it - thus, mot fully reflecting the aggregate output of the rivals. Firms produce some quantity $q$ lower than Cournot-Nash quantity, thus getting collusive profits. In this model, there are two reasons for the market price to be lower than expected when all firms abide by collusion. Price drops either due to the stochastic noise, which is outside of firms' control. Alternatively, at least one firm is chiselling at the agreement, producing quantities above $q$ and reaping larger profits at its profit increases by more than the market price drops. To prevent the chiselling from brining the equilibrium price to the Cournot-Nash level, the firms set a trigger price $\tilde{p}$. If the market price drops to this trigger price, firms enter the 'punishment' producing Cournot-Nash quantities for T periods. After T periods they revert to the collusive quantity $q$ until the market price drops to the trigger level again. The more noise there is on the market the more often the market price will fall beyond the trigger level despite all firms abiding by the agreement. Cartel members can choose the parameters q, $\tilde{p}$ and $\mathrm{T}$ that yield the greatest total discounted profit. The key principle for reaching the maximum - after every market iteration, the value of the remaining equilibrium must be the extreme point of the equilibrium value set. In layman terms, the expected collusive profits should be the highest, compared to profits from the alternative strategies. The value of the equilibrium depends on the parameters of the model: such as cost of monitoring, and the amount of noise. In application of this model to the common ownership setting we argue that is reduces the cost of monitoring and the level of noise, thus increasing the value of the collusive equilibrium.

\subsection{Challenges to the model of collusive outcome}

There are two main arguments challenging applicability of this model in practice. Firstly, multiplicity of equilibria in asymmetric markets (i.e. firms facing different marginal costs, and different levels of common ownership) raises a question of whether the firms can in practice coordinate on a single equilibrium, and sustain this equilibrium in a noisy market with imperfect information (i.e. where firms cannot directly observe each other's output or price, but only derive it from the market outcome). Theory predicts possibility of collusive outcomes, but does not spell out which ones will emerge (Tirole, 1988). The fact that dynamic models of infinitely repeated games produce no unique equilibrium posits problems for model-based

\footnotetext{
${ }^{1805}$ Abreu, D., Pearce, D. and Stacchetti, E., 1986. Optimal cartel equilibria with imperfect monitoring. Journal of Economic Theory, 39(1), pp.251-269.

${ }^{1806}$ Abreu, D., Pearce, D. and Stacchetti, E., 1990. Toward a theory of discounted repeated games with imperfect monitoring. Econometrica: Journal of the Econometric Society, pp.1041-1063.
} 
predictions and relevant legislation (Ayres, $1990^{1807}$ ). For folk theorem application for local equilibria need to know how equilibrium expectations move with changes in the parameters.

Secondly, some authors (e.g. Tzanaki, forthcoming) raise a question of whether the collusive equilibrium can be sustained by the threat of punishment. Individual firms always have an incentive to chisel at the agreement - to achieve higher individual profits. The greater the noise in the market, the higher their chances are to blame the deviations from the collusive agreement on this noise - the greater is the incentive to chisel. We now discuss these limitations in application to the common ownership. We also discuss potential strategies of defining parameters that can lead to robust collusive equilibria for specific markets in the section on agent-based modelling.

\subsection{Application to Common Ownership}

Transparency of information. Common ownership can be seen as an additional instrument allowing the firms to reduce the costs of monitoring the abiding by the agreement. If common investors are present in all firms in the market, the fluctuations in market price can be attributed to solely the exogenous shocks, reducing the need for punishment when price falls below the expectation due to such shock. Increased transparency due to presence of common ownership thus has potential to increase level of tacit collusion in the market by reducing the cost of monitoring and removing the need for trigger price. Specifically, in an asymmetric setting it is unclear which equilibria to look coordinate on. Additionally, for a firm which finds its profits lower than expected, it does not necessarily know whether it is a) noise outside of rivals' control, b) mistake of the rivals concerning the nature of the agreement (i.e. which of the equilibria the coordination is on); c) chiselling by the rivals. Common ownership can, arguably, reduce the amount of uncertainty in such a system. As Kreps (1990) states, one expects oligopolistic firms to collude as much as the circumstances permit. Everything else held equal, they will act more collusively when there is less noise, than when there is more. One would expect greater levels of collusion in the industries where institutions allow for more precise monitoring of rivals.

Evolution of the equilibrium, coordination on a single equilibrium in asymmetric setting. One could speculate that the common ownership could be the trigger for the evolution of the collusive equilibrium that is currently missing from the models that assume that this equilibrium is triggered exogenously but do not specify the path. It is plausible that changes in concentration of common ownership in the market could be used to model the shift in the market from a competitive to a collusive equilibrium. In fact, we discuss a model that has a flavour of this approach in the forthcoming section, considering share-buying as a signal of a change in firm's payoffs in the first, pre-collusive stage of the game.

Credibility of punishment. Features of the above model lend themselves nicely to the common ownership setting - since it allows to maximise total profit in the industry, which is in the interest of an investor holding equity across the firms. Question remains whether a firm finds it credible that its cheating on the collusive agreement will lead to other firms reverting

${ }^{1807}$ Ian Ayres, 'Playing Games with the Law' (1990) 42 Stanford Law Review 1291, 1310-1311 
to the competitive strategy for the rest of the game. Tzanaki (forth.) argues that the mechanism supporting collusion (severe punishments) may not be credible if post-deviation it is not in the self-interest of the undertaking threatening punishment against any deviating rival. In the following sections we discuss how in the context of common ownership the outcome must depend on the assumed strategies of the players, and the structure of the payoffs for the investors. Tzanaki (forth.) further presents the alternative conceptualisation of collusion in which firms signal to each other intentions to collude by acquiring shares in each other (common ownership, Gilo, 1997) which changes their payoff structure. We discuss the proposed way in which the conclusions from this model may be stretched to the case of common ownership.

\subsection{Partial Ownership Increasing the Parameter of Attractiveness of Long-Run Collusive Outcome}

Previous model assumed common shareholdings as given. We now discuss a model which treats shareholding acquisition is viewed as an "endogenous decision variable" in the preceding stage of the game. The crucial difference is that in this formulation a firm that conduct an acquisition alters its payoff structure in the way that leads to incurring a loss if other firms do not collude - making this new payoff structure public knowledge.

Consider a standard setup where each firm follows a tit-for-tat strategy: it charges monopoly price $p^{m}$ in any period $t$ if in every period preceding $t$ neither firm has deviated from $p^{m}$. If there was a deviation from $p^{m}$ in the preceding period, each firm reverts to charging $c$ (marginal cost) forever. Gilo (1997) proposes the following manner of treating partial ownership (PO) as an endogenous variable in this setting. At a first stage firms simultaneously select PO levels in one another - anticipating the effect of this cross ownership on the second stage. Second stage is an infinitely repeated price game (a la Bertrand). Consider a symmetric case, where Bertrand prediction is that two firms will split the market equally, at an equal price $p=p_{1}=p_{2}$ equal to marginal cost $c$. $\mathrm{PO}$ does not changing this static equilibrium - it enters the firm's strategy by affecting the dynamic repetition of this static game through affecting the discount factor in the industry.

Gilo (1997) argues that for cross ownership levels $\mathrm{x}$ and $\mathrm{y}$, the monopolist price $p^{m}$ is sustainable for the discount factor $\delta$ being above or equal the following threshold (critical discount factor) $\delta^{c}$

$$
\delta \geq \max \left\{\frac{1}{2}-\frac{x}{2(1-y)}, \frac{1}{2}-\frac{y}{2(1-x)}\right\} \equiv \delta^{c}
$$

In lay terms, PO affects the discount parameter which makes the short-term gain from the deviation smaller than the resulting long-term loss - imposing an incentive-compatible constraint on undercutting. Conversely, as each firm owns close to a half of another firm, the $\delta^{c}$ approaches zero - i.e. collusion is very sustainable. Note that without PO, $\delta^{c}=\frac{1}{2}$, i.e. as long as firms care enough about the future profits $\left(\delta \geq \frac{1}{2}\right)$ from the collusive outcome AND they believe those profits are not attainable unless they collude in the current period - collusive outcome is attainable without PO. PO makes it more attainable, lowering the extent of how 
much the firms need to care about the future profits from collusion.

Interestingly, this part of the argument does not seem resolve the issue of how enforceable retaliation is - since it holds under the assumption of the exogenously set commitment to the tit-for-tat strategy. What it does - is formulate how common ownership increases the attractiveness of the long-term collusive outcome over the short-term cheating outcome. From this perspective, discount factor is not the only way PO can be entering the firms' incentives. For example, we may choose to not assume ex ante that the repetition of the price-game stage is infinite, but instead assume that it is long enough for the firms to be attracted to the collusive outcome until the latter periods of the supergame (for finite horizon games with multiple equilibria in the stage game and cooperative or reputational equilibria see Benoit and Krishna (1985); for a theoretical formulation and an empirical example of finitely repeated prisoner dilemma, see Embrey, Fréchette, and Yuksel, 2015 ${ }^{1808}$ ). In this setting, PO may enter as a variable that increases the expected length of the horizon - i.e. if shares are bought in the firms, these firms are expected to interact longer than average.

\subsection{Signalling through commitment}

Gilo (1997) further assumes that acquiring PO involves a sunk transaction cost $c_{p}(x)$ for the level $\mathrm{x}$ of PO. Hence, if a firm incurs this sunk cost, it has an intention to coordinate on the collusive outcome. If it was planning to undercut, it would have not acquired the PO. If we denote price paid for acquisition of the PO as $\mathrm{T}(\mathrm{x})$, the firm will prefer to pay the price as long as the profit from the collusive outcome is greater or equal ${ }^{1809}$ this price, thus:

$$
T(x) \leq \frac{1}{1-\delta} \frac{\pi^{m}}{2} x
$$

This conclusion becomes even stronger when cost asymmetric scenarios are considered. It is not profitable for a lower cost (larger) firm to acquire part in larger cost (smaller) firm (Farrel and Shapiro, 1990) unless we allow for repeated interaction and tacit collusion - in which case even fully passive partial ownership of higher cost firm by the lower cost firm can be mutually beneficial (Gilo, ).

The preliminary condition of this model is that firm incurs a positive loss in deviating from the collusive price - but only firm 1 which initiates the acquisition: $s_{1}^{*} \phi_{1}^{*}+$ $x\left(1-s_{1}^{*}\right) \phi_{2}^{*}>k$. This preliminary condition is easier met with $\mathrm{PO}$, since without $\mathrm{PO} \mathrm{x}$ is zero.

For collusive profit $\phi_{i}^{*}$ and market shares $s_{i}^{*}$, without the CO collusive outcome is sustainable as long as:

$s_{1}^{*} \phi_{1}^{*}>k$

where $\mathrm{k}$ is firm's profit in a static (one period) Bertrand equilibrium and $\delta$ is large enough. These preliminary conditions guarantee that firm 1's loss from deviating from the collusive price is positive, authors show that it is possible to find a set of $(\mathrm{k}, \delta)$ pairs under which the collusive outcome is sustainable. Note: this condition may not be met when asymmetry is largei.e. one firms cost advantage is large enough for the static Bertrand result to outweigh the

${ }^{1808}$ Embrey, Matthew, Guillaume R. Fréchette, and Sevgi Yuksel. "Cooperation in the finitely repeated prisoner's dilemma." (2015).

${ }^{1809}$ See p.12 and fn 12 of Gilo (1997) for variations of perfectly functioning market (under strict equality) and positive profits 
collusive profit under any $\delta .{ }^{1810}$ If now allowing for PO, collusive outcome is still sustainable for a set of $(\mathrm{k}, \delta)$ pairs - PO lowers the critical discount factor $\delta^{c}$, as long as $\phi_{1}^{*}>k$. If $\phi_{1}^{*}<k$ preliminary condition will never be met - firm 1 would not be incurring a positive loss from the deviation, hence it will deviate under any $\delta$, with or without partial ownership. Generally, the smaller is firm 1's cost advantage (i.e. the lower the k) and the larger are the profits produced by firm 1 under collusion $\left(\phi_{1}^{*}\right)$ the more PO facilitates tacit collusion. Crucially, the authors show that the preliminary condition $s_{1}^{*} \phi_{1}^{*}+x\left(1-s_{1}^{*}\right) \phi_{2}^{*}>k$ is easier met for the higher levels of $\mathrm{x}$ - i.e. the more firms acquire each other's shares, the easier it is for the profits from the collusive outcome to outweigh gains from deviation. Since k correlates with firm 1's cost advantage, PO facilitates more sustainable tacit collusion under higher cost advantages.

Importantly, the acquisition in the initial stage signals the preference for collusive outcome at the first iteration of the price-game. This results in a more sustainable equilibrium, since if the first iteration of the price game is left to chance further assumptions need to be made on how many non-collusive stages a firm is prepared to tolerate before it defaults into competitive strategy for the rest of the game (e.g. in the first round firm 1 observes if the other one colludes- if yes, they continue colluding, if not-firm 1 gives the other firm another chance in the next period).

\subsection{Application of signalling through commitment to common ownership}

From the first glance, the model discussed above lends itself nicely for the extension from the cross ownership to common ownership (CO). Indeed, applying it to $\mathrm{CO}$ appears to remove the need for bilateral investment - i.e. for each major competitor to hold share in another competitor. Institutional investors will commonly hold shares in all the major firms. However, the assumption of the sunk cost of transaction (or, alternatively, legal constraints, imperfect financial and capital markets causing non-positive returns on investment ${ }^{1811}$ ) becomes more challenging. Arguably, it should be less costly for the institutional investors to switch ownership between the firms in the industry, than it is for the firms themselves. Whilst for the firms PO is a secondary activity, that they may choose to engage into on the side of operating in the market, for the investors acquisition of shares is their primary activity, costs for which should be expected to be optimised better than for the firms.

On the other hand, one could argue that a sunk cost is borne when the institutional investor enters the industry. This would create an even more extreme signalling case - as soon as the institutional investor enters the industry and common ownership commences, it signals commitment for collusion to the firms in the industry. This, in turn, raises a question about the parameters faced by the investors entering at later stages - which requires further dynamic analysis.

Tzanaki (forth.) makes an interesting point on distinction between the first and the second models discussed:

'i) the commitment model creates space for a superior mutually acceptable bargain, whereas the punishment model forces a collusive equilibrium via the threat of reverting to an inferior

1810 Tirole, 1988 (272-273)

${ }^{1811}$ See fn 11 in Gilo (1997) 
mutually destructive state; ii) in the bargaining model, the key is whether the acquirer's commitment is credible, whereas in the punishment model, the key is whether the threat of retaliation against the deviating rival is credible.'

I might be wrong but it is still not clear to me how the loss incurred in the first period introduces more credibility into the system; the greater commitment to collusion to me seems to be driven by the firms' commitment to the tit-for-tat strategy and the sequential formulation of the model - which makes either of the commitments credible. For example, one can devise a game where commitment to potential loss at the beginning comes not from acquiring a share of $\mathrm{PO}$, but from a costly punishment in the first several rounds of the price game - aimed to develop a reputation that will support the further collusive tit-for-tat equilibrium. The burden of credibility shifts to sticking with tit-for-tat - hence the certainty that once foregone payoff from the collusive action will not be attainable again. Perhaps what she has in mind is the range of the strategies that a firm is considering for the game - with and without the common ownership in the market.

The question remains - even if you publically committed to the tit-for-tat and incurred an ex ante loss, if the other players deviate, do you go through and charge a price equivalent of marginal cost for infinity? If firms are rational, they know that a firm that chiselled once and did not experience punishment will continue chiselling, making a collusive equilibrium not sustainable. If it is not sustainable, they will revert to the competitive equilibrium. Punishment in this case is really the withdrawal of the opportunity to obtain anything above the competitivelevel profit.

There are further questions that need to be clarified for this setup to be applicable, namely:

- Would we consider institutional investors to incur a potential 'loss' when acquiring equity? Given that they hedging is a major part of their operations, is this incentive quantitatively identical to that of cross-ownership or not?

- Should the expected higher profits (from the collusive outcome) be absorbed in the cost of acquiring the equity? Furthermore, how do costs of acquiring equity develop? For example, if the current set of institutional investors is making large profits due to tacit collusion - how does this affect the price faced by newly entering institutional investor?

- Do the long-term horizons of institutional investors match with the long-term horizons of firms in which these investors are acquiring equity? If they do not match, the transition of incentive mechanism from cross ownership to common ownership is less trivial.

- Firm that buys equity signals commitment to collusive outcome but also, potentially, effectively proposes the split of the surplus based on how much equity it is buying and, therefore, at what threshold of the market price it will revert to competitive outcome and incur a loss. This raises questions of what happens if more than one firm proposes different split.

\subsection{Agent based programming}

Agent-based modelling (an attractive way of finding equilibria in complex problems involving strategic behaviour) has been successfully used to gauge the effect of different 
market parameters on tacit collusion in general (Govender, 2016 ${ }^{1812}$ ), and specifically for oligopolistic market structures (Kimbrough and Murphy, 2009 ${ }^{1813}$ ) and even establish robust equilibria in complex strategies involving mark-up pricing specifically in oligopolistic electricity markets (Newbery, 2012 ${ }^{1814}$ ).

In the complex settings such as effect of common ownership in asymmetric settings, agent based programming can help derive critical parameters such as size of common ownership which, holding other market parameters constant, is capable of tilting the market outcome towards a collusive equilibrium. It may also have potential in exploring the further questions we discuss regarding the practical implications of the models - such as modelling the outcomes of entry of investors at different stages of the game, and potential further asymmetry in costs and profit splits driven by the common ownership.

Based on the theory discussed above, the conditions for a sustainable collusion in oligopolistic markets are likely to depend on:

- how attractive is collusive profit compared to the competitive equilibrium profit

- how much investors care about the long-term profits compared to the short-term

- the positive losses arising from deviation from collusive price are derived from the appropriate combinations of the first two points

Common ownership is likely to enter in these factors through:

- lowering the industry discount rate

- increasing the attractiveness of the collusive outcome profit

- extending expected interaction horizon

Conditions conducive to collusion that regulator may be incorporating into decision-making: non-extreme asymmetry, degree of common ownership, degree of transaction costs, horizon and discounting factor. Note that these effects are achievable for completely passive (no voting rights) PO - which are currently treated very leniently by the regulators (as compared to acquisitions of shares with voting rights which undergo antitrust scrutiny).

\subsection{Legal Framework}

Cross-shareholding and common ownership is often raised as a concern in order to indicate that the current concentration indicators based on control may not necessarily represent the potential restriction of competition that may occur through the action of passive investors controlling minority shareholdings in various companies in the relevant sector or market segment. We will first examine the anticompetitive issues raised by minority shareholdings, before turning to those raised by common ownership.

\subsubsection{Anticompetitive issues raised by minority shareholdings.}

In the EU, only those transactions that result in a lasting change in the structure of the market fall within the scope the substantive law provision of the EU Merger Regulation

\footnotetext{
1812 Govender, R., 2016. The detection of tacit collusion using agent-based modelling (Doctoral dissertation, University of Johannesburg)

1813 Kimbrough, S.O. and Murphy, F.H., 2009. Learning to collude tacitly on production levels by oligopolistic agents. Computational Economics, 33(1), pp.47-78.

${ }^{1814}$ Newbery, D., 2012. The roubstness of agent-based models of electricity wholesale markets.
} 
(EUMR) prohibiting a concentration in case it poduces a significant impediment of effective competition and satisfies the conditions of Article 3 EUMR. ${ }^{1815}$ There are primarily two types of concentrations: $i$ ) those arising from a proper M\&A transaction between previously independent firms; ${ }^{1816}$ and ii) those arising from the acquisition of control. ${ }^{1817}$ In the former case, either two or more firms merge and thus cease to exist as separate legal entities, or the target firm is absorbed, and thus ceases to exist as a legal entity, whilst the acquiring firm retains its legal identity. ${ }^{1818}$ In the latter case, whilst the target firm does not cease to exist as a separate legal entity, its control is transferred in a lasting way to another firm or to more firms jointly. ${ }^{1819}$

According to Article 3(2) EUMR, control means being able to exercise decisive influence on a firm, most commonly, by virtue of a controlling shareholding, which can be lower than $50 \%$ where the rest of the shareholders are dispersed. ${ }^{1820}$ Control can therefore be execised on a de jure basis, by virtue of a majority of voting rights, or on a de facto basis, where the remaining shareholdings are fragmented so unable to veto the relatively larger shareholder. ${ }^{1821}$ Hence, control does not cover only the case where the acquiring undertaking controls a majority of voting rights which confer the power to take strategic decisions, but also where it is merely possible to veto strategic decisions, the latter being labelled negative sole control. ${ }^{1822}$ Control can also be acquired on a contractual basis, provided there is a very long duration and the contract confers control over the management and the resources despite the fact that property rights or shares are not transferred. ${ }^{1823}$ The transfer of control can refer to just part of a firm, as long as it confers a market presence to which a market turnover can be clearly attributed. ${ }^{1824}$

In Anglo American Corporation/Lonrho, ${ }^{1825}$ AAC, a diversified South African company involved in mining, finance, commerce and industry, acquired a shareholding of $24.13 \%$ of Lonrho, a UK company active in mining, agriculture, trading and property. The Commission amalgamated the shareholding that AAC would acquire in Lonrho with that of two other shareholders, on account of the fact that the latter would vote their shares as instructed by AAC. In this light, it examined whether AAC would acquire on a de facto basis solely or jointly with these two shareholders the possibility to exercise decisive influence over Lonrho and therefore control it. The Commission concluded that AAC would acquire sole control of Lonrho, taking into account the following considerations that: $i$ ) a $27.47 \%$ shareholding would have amounted to a majority of the votes cast at past meeting; $i$ ) the next largest shareholder owned $3 \%$ of the shares, while it also had shares in AAC itself; iii) AAC was the only industrial or mining company having a significant shareholding in Lonrho, which added to the leverage AAC could exercise in it since it increased its influence over the board; and $i v$ ) Lonrho's directors who

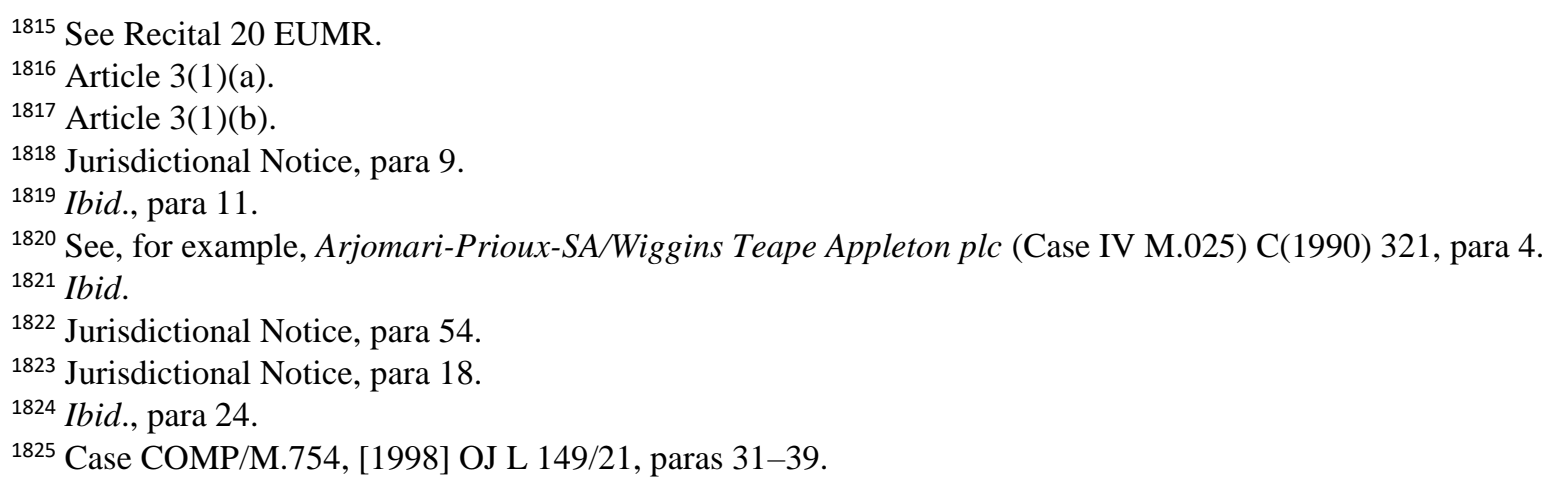


held a total of $0.12 \%$ of the shares in the company would not be expected to vote against AAC in its capacity of main shareholder.

Under the UK national merger legislation the definition of control is less strict, thus entailing a broader jurisdictional scope. Under the UK law (Enterprise Act 2002), minority shareholdings will be subject to merger control where 'material influence' can be exercised over the acquired business. The 'Merger Assessment Guidelines' ${ }^{\text {'1826, }}$, provide guidance on the authorities' assessment of 'material influence' focusing mainly on the importance of voting rights and board representation. Factors that may be relevant to an assessment of a particular shareholding include the distribution and holders of the remaining shares, in particular whether the acquiring entity's shareholding makes it the largest shareholder, patterns of attendance and voting at recent shareholders' meetings based on recent shareholder returns, the existence of any special voting or veto rights attached to the shareholding under consideration, the status and expertise of the acquirer and its corresponding influence with other shareholders. ${ }^{1827}$

$B S k y B / I T V$ is one of the leading cases on the issue of material influence. The OFT (the predecessor of the Competition and Markets Authority- CMA) considered the issue of material influence in relation to the acquisition by BskyB, by far the UK leading Pay-TV operator, of a $17.9 \%$ stake in ITV, the leading commercial Free-To-Air TV operator. The OFT concluded that the acquisition of this minority stake would give BSkyB material influence. The OFT found that, on the basis of evidence of attendance and voting at recent ITV shareholders' meetings, BSkyB's shareholding would be likely in practice to allow it to block special resolutions at ITV shareholders' meetings. The OFT found that turnout at ITV shareholders' meetings has ranged between $63-70 \%$. Therefore, BSkyB's $17.9 \%$ stake would have enabled it to exercise more than $25 \%$ of the votes cast at these meetings.

The OFT also made the following observations: a) BSkyB could obtain board representation as a result of its shareholding; $b$ ) BSkyB was the only significant trade shareholder and has substantial industry expertise; c) BSkyB was the largest individual shareholder and ITV's corporate governance policy was to hold frequent discussions with major shareholders; $d$ ) the remaining shareholdings in ITV were fragmented; and there was a number of other ITV shareholders that had cross-shareholdings in both merging firms. This approach was upheld by both the Competition Appeal Tribunal ${ }^{1828}$ and the Court of Appeal. ${ }^{1829}$

In Ryanair/Aer Lingus ${ }^{1830}$ the UK Competition Commission (now replaced by the CMA) focused its analysis on the obstacles which an unwelcome shareholder can pose to the company freely pursuing its own commercial objectives. The CC concluded that by limiting Aer Lingus's ability to pursue its independent commercial policy and strategy, Ryanair's minority shareholding would have led to a reduction in Aer Lingus's effectiveness as a competitor ${ }^{1831}$.

In the US, Section 7 of the Clayton Act, as amended by the Celler-Kefauver Antimerger Act of 1950 and then in 1980, adopted against a backdrop of increasing concern towards

\footnotetext{
${ }^{1826}$ Merger Assessment Guidelines, September 2010, paras 3.2.8-3.2.10

1827 Ibid., para 3.2.10.

${ }^{1828}$ BskyB v Competition Commission and the Secretary of State [2008] CAT 25.

${ }^{1829}$ BskyB v Competition Commission and the Secretary of State [2010] EWCA Civ 2.

${ }^{1830}$ Competition Commission Report, Ryanair Holdings plc/Aer Lingus Group plc [2013].

${ }^{1831}$ Ibid., paras 7.16-7.24.
} 
concentration of US businesses, prohibits not only acquisitions by one corporation of the stock of another, but also, more broadly acquisitions of assets where the 'effect of such acquisition may be substantially to lessen competition, or to tend to create a monopoly.' 1832 This provision captures acquisitions by natural persons, partnerships, as well as other unincorporated associations and business entities, and not just by corporations. There is no express shareholder percentage ownership trigger or a 'material influence' test but it is the value of the acquisition that may trigger a filing under the Hart-Scott Rodino (HSR) Act, which parties to a transaction must submit to the U.S. Federal Trade Commission and the U.S. Department of Justice if certain jurisdiction tests are met. The Clayton Act's coverage for partial acquisitions is however limited if the acquisition was made "solely for investment" 1833 . The HSR Act includes an exemption from filing for a partial acquisition if the acquirer shows that the acquisition was made solely for the purpose of investment and that it will result in ownership of $10 \%$ or less of the voting securities of the issuer ${ }^{1834}$, this percentage being $15 \%$ for institutional investors, as their intention is presumed not to be for investment only. Furthermore, to benefit from the exemption, the stock must not be used "by voting or otherwise to bring about, or in attempting to bring about, the substantial lessening of competition", the parties arguing for the exemption being required to prove that the purpose of the acquisition was not to gain control over the target company ${ }^{1835}$.

One may also note another type of structural link targeted by US merger control, "interlocking directorates," that is situations where an individual or entity serves on the Board or as an officer of two competing corporations, a situation that may emerge with the recent financialisation trend, with private equity and hedge funds often investing in various companies active in the same industry. Under Section 8(a)(1) of the Clayton Act, '[n]o person shall, at the same time, serve as a director or officer in any two corporations (other than banks, banking associations, and trust companies) that are. . . by virtue of their business and location of operation, competitors, so that the elimination of competition by agreement between them would constitute a violation of any of the antitrust laws . . . ${ }^{1836}$ The statute is interpreted as applying not only to natural "persons" or individuals, but also to a "firm". There are a number of exemptions however to the prohibition and liability (for banks, banking associations, and trust companies or when the "competitive" sales of the interlocked firms fail to meet some thresholds (de minimis exceptions).

It is therefore accepted in various competition law regimes regarding merger control, although not as such in the EU, that structural links occuring in transactions that do not meet the legal definition of acquisition of control or decisive influence, but in which, instead, the

\footnotetext{
183215 U.S.C. $\S 18$.

183315 U.S.C. $\S 18$.

1834 This presumption is narrowly construed and does not apply if the issuer whose stock is being acquired is a competitor of the acquirer.

1835 See, United States v. Dairy Farmers of America, 426 F.3d 850 (6th Cir. 2005), noting that "even without control or influence, an acquisition may still lessen competition" and constitute a violation of Section 8 Clayton Act.

${ }^{1836} 15$ U.S.C. $\S 19(4)$.
} 
acquirer of non-controlling minority shareholdings gains the possibility to exercise material influence over the target, may lead, potentially, to significant anti-competitive effects ${ }^{1837}$.

The literature distinguishes between full merger scenarios and partial concentration scenarios involing the acquisition of minority shareholdings:

'"'(i)n a full merger scenario, the acquiring firm obtains $100 \%$ of the following types of rights over the target: 1) 'control rights'; and ii) 'cash flow rights'. Control rights allow the acquirer to influence the target's strategic decisions; hence they provide the acquirer the ability to raise the target's prices. On the other hand, cash flow rights entitle the acquirer to have a financial interest- by means of its investment-and share in the profits of the target hence they give the acquirer the incentive to raise the target's prices. Importantly, in the case of partial share ownership these two type of rights do not necessarily coincide, and their relative proportions may be rather asymmetrical depending on the particularities of each commercial transaction, or may even change from time to time. It follows that partial share ownership leads to two variants of the above-mentioned usual merger situation: i) it either gives only one type of rights (e.g. financial interests) but not the other one (e.g. control/influence); or ii) it gives partially both types of rights. This is crucial because the existence and the degree of each type of rights in a partial share acquisition have distinct competition implications in that any combination of financial interests and control rights leads to different anticompetitive effects' ${ }^{1838}$.

Minority shareholdings can nevertheless be addressed, under the current European competition regime, with one of the following ways ${ }^{1839}$ :

- They may give 'decisive influence' in terms of the Merger Regulation, constituting a concentration.

- They can be part of the substantive analysis of a concentration, eg minority shareholdings relevant to the assessment of a Significant Impediment to Effective Competition.

- There have been cases where the merging parties have been willing to dispose of, or reduce, their stakes either before or during the phase I administrative proceedings, so as to obtain unconditional merger clearance ${ }^{1840}$; or to give formal commitments to

\footnotetext{
${ }^{1837}$ It has been noted that "(a)cquisitions of non-controlling minority shareholdings account for approximately $10-12 \%$ of all mergers notified in Germany and 5\% in the United Kingdom", the only jurisdictions (in addition to Austria) which currently have national merger control rules providing them the competence to review structural links, such as minority shareholdings. See, Commission Staff Working Document, Impact Assessment, SWD(2014) 217 final, para. 38. The Commission's "rough" estimates indicate that the number of cases of minority shareholdings that would meet the turnover thresholds of the Merger Regulation should be around 20-30 (or 7$10 \%$ of the merger cases currently examined by the Commission each year), which means that in case the jurisdiction of the EUMR was extended to these cases the Commission could intervene in another 1-2 cases per year (Ibid., para 46).

1838 A Tzanaki,'The legal treatment of minority shareholdings under EU competition law: Present and future' University of Piraeus - Essays in Honour of Professor Panayiotis I Kanellopoulos, (Sakkoulas Publications, 2015), 861-886.

1839 See, A Burnside, 'Minority Shareholdings: An overview of EU and national case law', e-Competitions, No 56676.

1840 Courtaulds/SNIA Cases M.113 [1991] (disposal of a 12\% stake in a competitor); Banco Santander/Abbey National M.3547 [2004] (modification of co-operation agreement between Santander and RBS, including
} 
divest, as a condition of clearance. ${ }^{1841}$ However, had the same stake(s) been acquired post-acquisition, the Commission would lack powers to intervene. ${ }^{1842}$

- Under the Commission's remedial powers, the Commission cannot order the unwinding of a non-controlling shareholding that was part of a failed takeover: (i) the remaining stake does not confer control over the target, and (ii) the proposed takeover has been prohibited and thus not fully implemented. The Ryanair/ Aer Lingus cases have identified this problem. Ryanair acquired shares in Aer Lingus on the stock exchange and in parallel launched a public bid. Although initially only notifying the bid, the European Commission asserted jurisdiction over the combined stake-plus-offer, treating these as a single concentration, and prohibiting that concentration. While the offer therefore fell away, the question remaining was as to the stake. Although this had been part of a prohibited concentration, the Commission took the view that, once standing in isolation, it could not be the subject of a sell-down order under Article 8(4) EUMR (unwinding of completed/prohibited concentrations), because by itself it did not confer control. This position was upheld by the General Court ${ }^{1843}$.

- Article 101 can apply to agreements by which a minority interest is acquired and Article 102 TFEU can apply to acquisitions by a dominant company. In the Philip Morris and the Gillette cases, Articles 101 and 102 TFEU have been specifically applied to minority shareholdings giving rise to 'some (informal) influence' over the target, which could be lower than the 'decisive influence' (control) threshold under the EUMR. However Article 101 cannot be invoked unless there is a finding of an 'agreement' and/or 'concerted practice' between two or more 'undertakings' linked to the minority share acquisition. Similarly, Article 102 is only applicable if there is a 'dominant' undertaking which is found to be 'abusive'.

In the Philip Morris judgment in $1984^{1844}$, the European Court of Justice held that although the mere acquisition of a minority stake could not of itself be said to amount to conduct restricting competition ( for the purposes of art.101), it could nevertheless serve as an instrument for influencing the commercial conduct of a competitor, thereby restricting or distorting competition, in particular where the agreement provided for commercial cooperation, or where it gave the acquiring shareholder the possibility of taking effective control of the target at a later stage. The Court emphasised the need to consider not just the immediate effects of the transaction, but also the longer term potential impact.

termination of reciprocal board representation and reduction of Santander's shareholding in RBS). [references taken by Burnside]

1841 VEBA/VIAG Case M.1673 [2000] (disposal of various minority stakes to address concerns about joint dominance); IPIC/MAN Ferrostaal Case M.5406 [2009] (divestment of MAN Ferrostaal's 30\% stake in Eurotecnica, a company involved in melamine production technology licensing and plant engineering, to address vertical concerns).[references taken by Burnside]

1842 M Friend, 'Regulating minority shareholdings and unintended consequences' (2012) 33 (6) ECLR 303, 304305.

1843 Case T-411/07 Aer Lingus Group Plc v European Commission [2011] ECR II-03691, paras 77-78, 84-85, 87.and corresponding Commission Decision Ryanair/Aer Lingus (Case COMP/M.4439)

${ }^{1844}$ Cases 142 and 156/84 British American Tobacco Co Ltd v Commission of the European Communities [1987] ECR 4487. 
Article 101 TFEU applies to a number of agreements by which a minority interest is acquired:

- 'Joint ventures, where formal 'joint' control in the EUMR sense is lacking. Typically these will involve parents with holdings in a common vehicle.

- Production-only joint ventures - with joint control, but lacking full-functionality.

- A shareholding anchoring a commercial relationship, e.g. supplier/customer, strategic alliances.

- Complex ownership structures contrived to achieve a merger while avoiding a transfer of 'control'

- Holding structures in which a company de facto neutralises a competitor.

- Simple acquisition of a shareholding when sold by a single vendor" ${ }^{\text {"1845 }}$.

As regards the possible application of Article 102 TFEU, the Court held that the acquisition of a minority shareholding in a competitor could only amount to an abuse where it resulted in effective control, or at least some influence, over the target's commercial policy, although the judgment offered no guidance on what level of influence would be problematic, or how the assessment was to be carried out. ${ }^{1846}$

In the Warner-Lambert $v$ Gillette ${ }^{1847}$ case, the Commission successfully challenged Gillette's acquisition of a $22 \%$ non-voting interest in the parent company of its major competitor, Wilkinson Sword, both as an infringement of art 101 and 102 TFEU. It is worth noting that there were various other commercial agreements in place, including an unsecured loan and the acquisition of certain trademarks outside the European Union and United States, but fell short of control.

Despite this relative ignorance of minority shareholdings in the EU competition law enforcement, it is expected that minority shareholdings may lead to a number of possible anticompetitive effects, horizontal, vertical and eventually conglomerate. As the Commission clearly explained in some preparatory work on the need to xpand the EU merger control regime to non-controlling minority shareholdings,

"22. (t)here are several types of anti-competitive concerns that can result from the acquisition of minority shareholdings. The economic effects of minority shareholdings on competition in the market significantly depend on the financial interests flowing from them and the corporate rights conferred by them. While financial interests refer to the acquiring firm's entitlement to a share of the profits of the target firm, corporate rights refer to the acquiring firm's ability to influence the target firm's strategic decisions.

\footnotetext{
${ }^{1845}$ A Burnside, 'Minority Shareholdings: An overview of EU and national case law', e-Competitions, No 56676, 2., who notes that although Article 101 TFEU seems not to apply when the minority shareholding is acquired through the stock exchange by buying a rival's shares from a number of unidentified counterparties, this is still an unsettled issue.

${ }^{1846}$ A few other examined similar cases are: Enichem/ICI Case IV/31.846 [1988] OJ L 50/18, BT/MCI Case IV/34.857 [1994] OJ L223/36, Olivetti/Digital Case IV/34.410 [1994] OJ L 309/24 and Phoenix/Global One Case IV/35.617 [199] OJ L 239/57 [references cited in Tzanaki, 'The legal treatment of minority shareholdings under EU competition law: Present and future' University of Piraeus - Essays in Honour of Professor Panayiotis I Kanellopoulos, (Sakkoulas Publications, 2015), 861-886].

1847 Warner-Lambert/Gillette Case IV/33.440.
} 
23. Structural links among competitors may lead to unilateral anti-competitive effects, since they may increase the ability and incentives of firms to unilaterally raise prices or restrict output. Intuitively, if firms have a financial interest in their competitors' profits, they 'internalise' the positive effects on their competitors' profits of a reduction in their own output or an increase in their own price. As a result, a firm with minority stakes in a competitor will have less of an incentive to compete vigorously and so will tend to reduce its competitive pressure, which will lead to price increases and output reductions in the market. This may occur irrespective of whether the minority shareholding is "passive", ie the minority shareholder has no influence on the target firm's decisions, or whether it is "active" and its holder may have some influence on the target firm's decisions.

24. In case of "active" minority stakes the potential anti-competitive effects can also occur when the acquirer gains material influence over the outcome of special resolution decisions in the shareholders' meeting which are needed to approve certain strategies, for example in relation to significant investments, product lines, geographical scope, raising capital, engaging in mergers and acquisitions. As regards the ability to implement such as strategy, this depends on the specificities of the market and notably on the market position of the companies involved. The practice of the Commission and the Member States has shown that competition concerns are more likely to be serious when a minority shareholding grants some degree of influence over the target firm's decisions $[\ldots]$

26. Competition concerns may also arise when the acquirer can use its minority shareholding position to limit the competitive strategies available to the target firm, thereby weakening it as a competitive force. [...]

29. Also, the most obvious way a minority shareholder can gain a competitive advantage in the market is through the ability to increase a rival's costs. In an extreme situation, if the costs of the target firm are sufficiently raised, this firm may actually decide to stop competing with the acquirer in the relevant market.

30. Horizontal minority participations may also lead to coordinated anti-competitive effects as they may impact on the ability and incentives of market participants to tacitly or expressly collude to achieve supra-competitive profits. The acquisition of a minority stake may enhance transparency as it typically offers the acquiring firm a privileged view on the commercial activities of the target. It may also make the threat of future retaliation more credible and severe in case a minority shareholder deviates from the collusive behaviour as firms may revert to a less collaborative behaviour in the jointly owned firm. Both effects will impact on the ability and incentives of market participants to coordinate.

31. Finally, non-horizontal transactions may lead to competition concerns, in particular in relation to input or customer foreclosure. The ability to implement a strategy based on foreclosing competitors from the target company's supply or demand depends on the influence resulting from the minority stake over business decision of the target company and on the ability to exercise this influence against the resistance of other stakeholders. Extensive information rights can also matter in this regard: The fear that 
commercially sensitive information ends up in the hands of a competitor, may deter companies from dealing with firms in which their competitors have minority stakes that entail such extensive information rights. In the case where the minority shareholding is purely "passive" and its holder has no influence on the target firm's decisions, the expected competition concerns will be more limited than in a full merger, given the smaller financial incentives to foreclose. On the other hand, when the minority shareholding is "active" and its holder has some influence on the target firm's decisions, the risk of foreclosure can actually be higher than what would occur with a fullyintegrated firm. This is because, in some circumstances, input or customer foreclosure may be more likely to occur since the company acquiring the minority shareholding only internalises a part, rather than all, of the target firm's profits while it receives the full benefit of foreclosure" 1848 .

In view of these potential anticompetitive effects, the acquisition of minority shareholdings has attracted attention ${ }^{1849}$, as the Commission has identified an 'enforcement gap' in respect of this type of acquisitions, especially with regards to non-controlling minority but influential (to business conduct) shareholdings in the context of merger control. The European Commission has explored the possibility of improving the effectiveness of the EU Merger Regulation by applying it to transactions that involve structural links ${ }^{1850}$.

\subsubsection{The competition law framework for common ownership: a work in progress}

The Merger regulation's jurisdictional notice recognizes that "[s]ole control can be acquired on a de jure and/or de facto basis" ${ }^{1851}$. With regard to de facto basis, the Commission's Jurisdictional Notice further stipulates that the Commission should assess whether "the [minority] shareholder is highly likely to achieve a majority at the shareholders' meetings, given the level of its shareholding and the evidence resulting from the presence of shareholders in the shareholders' meetings in previous years". Indeed, "[w]here, on the basis of its shareholding, the historic voting pattern at the shareholders' meeting and the position of other shareholders, a minority shareholder is likely to have a stable majority of the votes at the shareholders' meeting, then that large minority shareholder is taken to have sole control" 1852 .

A further element to take into account is the importance of shareholder fragmentation on effective control, in particular on the aspect resulting from voting, the Commission finding in the past that an institutional investor was able to exercise decisive influence over the target

\footnotetext{
${ }^{1848}$ Commission Staff Working Document, Impact Assessment, SWD(2014) 217 final.

1849 White Paper on Modernisation, Commission Programme No 99/027.

${ }^{1850}$ See, Commission Staff Working Document, Impact Assessment, SWD(2014) 217 final, Part 3; Support Study for Impact Assessment concerning the review of merger regulation regarding minority shareholdings, Final Report 92016), available at ec.europa.eu/competition/publications/reports/KD0416839ENN.pdf

${ }^{1851}$ Commission Consolidated Jurisdictional Notice under Council Regulation (EC) No 139/2004 on the control of concentrations between undertakings, para. 55

1852 Commission Consolidated Jurisdictional Notice under Council Regulation (EC) No 139/2004 on the control of concentrations between undertakings, OJ C95, 16.4.2008, para. 59.
} 
with only controlling 39\% shares, when the rest was spread among more than 100000 shareholders ${ }^{1853}$. In a similar vein, the Commission found that a capital participation of $25.96 \%$ was such as to lead to a change of ownership of control, in particular due to the participation in general meetings ${ }^{1854}$. A dispersion of voting rights among a large number of small shareholders, also led the Commission to accept that effective voting rights of $34 \%$ by RTL (although it held $48.39 \%$ of the shares, the voting rights were limited by regulation) could signal control, in particular on the basis of past record of shareholders' presence and the very unlikely possibility of their coalescence to reach a majority of the votes ${ }^{1855}$. A merger transaction may of course increase the level of participation of certain shareholders in the new entity, and eventually its possibility to establish control.

But more than just a story of a simple minority shareholding leading to an effective control of the company's strategy, the issue is if it is also possible to find an anticompetitive effect on the basis of the presence of common institutional investors in all significant players in a specific market, that is through a partial competitor ownership. It is accepted that cross ownership may give rise to anticompetitive effects, Paragraph 20(c) of the EU Horizontal Merger Guidelines state that

"[t]he Commission is [...] unlikely to identify horizontal competition concerns in a merger with a post-merger HHI between 1000 and 2000 and a delta below 250, or a merger with a post-merger HHI above 2000 and a delta below 150, except where special circumstances such as, for instance, one or more of the following factors are present: [...] (c) there are significant cross-shareholdings among the market participants [...]". Cross-shareholding is also mentioned as a possible facilitator of possible coordinated effects, in the sense that it provides an information channel amongst competitors ${ }^{1856}$, and that it provides "help in aligning incentives among the coordinating firms"1857. The causal mechanism is explained in the Commission's decision in Dow/DuPont Annex 5:

"For the sake of the argument, assume that a firm (the acquiring firm) acquires a minority share in a competitor (the partially acquired firm). When contemplating a price increase, the acquiring firm anticipates that part of its customers will react to this price increase by diverting their purchase to its competitors, which will see their sales increase, including the one in which it has a minority share. The extra profits generated by the diverted sales to the benefit of the partially acquired firm will, in turn, be partially redistributed to the acquiring firm. As a consequence, when holding a minority share in a competitor, the acquiring firm has higher incentives to increase its prices than in the absence of such a minority share" 1858 .

Hence, "( $(t)$ he impact on the acquired firm's incentives depends on how the transaction affects the governance of the acquired firm, that is on the acquiring firm's degree of

\footnotetext{
${ }^{1853}$ See, Case IV/M.025 - Arjomari/Wiggins Teape Appleton (OJ C 321, 21.12.1990), page 16; Case IV/M.764 - Saint Gobain/Poliet (OJ C225), page 8.

${ }^{1854}$ Case IV/M.343 - Société Générale de Belgique/Générale de Banque, (OJ C225, 20.08.1993), page 2.

1855 Case M.3330 - RTL/M6, (OJ C95, 20.4.2004), page 35.

${ }^{1856}$ Recital 47 of the EU Horizontal Merger Guidelines

${ }^{1857}$ Ibid., recital 48.

1858 Ibid., para. 43.
} 
control, which can range from no control at all (silent financial interest), to partial control, to total control"1859.

The Commission felt that it did not have adequate tools for dealing with anticompetitive acquisitions of minority shareholdings. In its White Paper - Towards more effective EU merger control released in 2014, it advocated for a targeted transparency system which will be well suited to capture such transactions and to prevent consumer harm arising from them. The White Paper put forward three procedural options for the control of minority shareholdings:

- 'A notification system, which would extend the current system of ex-ante merger control to acquisitions of non-controlling minority shareholdings under certain conditions.

- A transparency system, which would require parties to submit an information notice informing the Commission of acquisitions of non-controlling minority shareholdings. The information notice would enable the Commission to decide whether to further investigate the transaction, enable the Member States to consider a referral request, and enable potential complainants to come forward.

- A self-assessment system, which would not require parties to notify acquisitions of non-controlling minority shareholdings in advance of completion. The Commission could, however, initiate an investigation of potentially problematic minority shareholding acquisitions on the basis of its own market intelligence or complaints. ${ }^{1860}$

In order to provide parties with legal certainty, only a transaction which meets the following cumulative criteria would fall within the definition of a 'competitively significant link':

- 'acquisitions of a minority shareholding in a competitor or vertically related company (i.e. there needs to be a competitive relationship between acquirer and target); and

- the competitive link would be considered significant if the acquired shareholding is (1) around $20 \%$ or (2) between $5 \%$ and around $20 \%$, but accompanied by additional factors such as rights which give the acquirer a 'defacto' blocking minority, a seat on the board of directors, or access to commercially sensitive information of the target.' 1861

The parties would be required to self-assess whether a transaction creates a 'competitively significant link' and, if so, submit an information notice. In the event that an information notice is submitted, the Commission would then decide whether to investigate the transaction and the Member States would decide whether to make a referral request. ${ }^{1862}$ The theme of minority shareholdings was however omitted in the most recent merger control consultation launched by Commissionner Vestager, therefore bringing the process of reform of EUMR on this issue to a standstill ${ }^{1863}$.

\footnotetext{
1859 Ibid., para. 45.

${ }^{1860}$ European Commission, White Paper - 'Towards more effective EU merger control' (2014), available at ec.europa.eu/competition/consultations/2014_merger_control/mergers_white_paper_en.pdf, para 43.

${ }^{1861}$ Ibid., para 47

1862 Ibid., para 48.

1863 See, http://ec.europa.eu/competition/consultations/2016_merger_control/index_en.html .
} 
The literature discussed above has also triggered a number of proposals for legislative interventions, of varying levels of stringency. Elhauge (2016) ${ }^{1864}$ takes a radical stand claiming that stock acquisitions that create anticompetitive horizontal shareholdings should be considered illegal under current antitrust law. He thus calls for the break-up of the existing shareholdings, citing a range of negative outcomes such as corporate executives being rewarded for industry performance rather than individual corporate performance alone, corporations not using recent high profits to expand output and employment, and economic inequality rising in recent decades.

Posner, Scott Morton and Weyl (2017) ${ }^{1865}$ question whether direct application Section 7 of the Clayton Act would be a right measure, or would cause disruption on the markets whilst failing to eliminate most of the harms from common ownership. They present evidence from simulations of the market outcomes deriving the sufficient anti-monopolistic conditions for the model used in AST(2017) ${ }^{1866}$. Their simulation-driven evidence suggests that limiting investors to holding up to $1 \%$ of a company's equity per oligopoly or shares of a single company in any oligopoly is a sufficient condition. They, therefore, propose a public enforcement policy granting a safe harbour to the investors who voluntarily reduce their portfolio to either of the two conditions. Note, however, that picking a single company in a sector raises important market-definition questions. As conversely pointed out in recent media discussions: 'Can you invest in both Facebook and Google, or are they in the same industry?' ${ }^{1867}$ Should we rely on relevant markets, rather than industries, instead?

Rock and Rubinfeld (2017b) ${ }^{1868}$ propose a much wider safe harbour. They suggest protection from antitrust liability for the investors whose ownership share is below 15 percent, provides no board representation, and who only engage in "normal" corporate governance activities. Notably, this approach does not remove the financial incentive aspect of common ownership, concentrating purely on the corporate control. The proposed limitations on the voting right behind the shares also fails to address the concern that shareholders may simply fail to exercise their corporate governance rights in the way that prioritises a profit-maximising strategy for a single firm over the industry performance. Elhauge $(2016)^{1869}$ discusses such an example of DuPont's diversified shareholders rejected an activist effort to (arguably) compete harder against Monsanto. Besides, the institutional investors such as index funds would argue that they owe to their individual investors the protection of their interests, such demanding good governance from the firms that they invest into. Voting rights, thus, is the instrument they can use to exercise the interests of their investors.

\footnotetext{
${ }^{1864}$ E Elhauge, 'Horizontal Shareholding', (2016). 129 Harv. L. Rev. 1267.

${ }^{1865}$ E A Posner, F Scott Morton, \& E Glen Weyl, 'A Proposal to Limit the Anti-Competitive Power of Institutional Investors', forth. Antitrust law Journal (November 29, 2016). University of Chicago Coase-Sandor Institute for Law \& Economics Research Paper No. 787. Available at SSRN: ssrn.com/abstract=2872754 .

${ }^{1866}$ J Azar, M C Schmalz, \& I Tecu, Isabel, ‘Anti-Competitive Effects of Common Ownership' (March 15, 2017).

Journal of $\quad$ Finance, $\quad$ Forthcoming.
SSRN: $\underline{\text { https://ssrn.com/abstract=2427345 }}$ or http://dx.doi.org/10.2139/ssrn.2427345

${ }^{1867}$ M Levine (2015). Index Funds May Work a Little Too Well. Bloomberg View, 22.

1868 EB Rock \& DL Rubinfeld, 'Antitrust for Institutional Investors' (July 2017). NYU Law and Economics

Research Paper No. 17-23; UC Berkeley Public Law Research Paper. Available at SSRN: https://ssrn.com/abstract=2998296

${ }^{1869}$ E Elhauge, 'Horizontal Shareholding', (2016). 129 Harv. L. Rev. 1267
} 
There are also significant concerns about market distortions that can be caused by either form of legislative intervention. Posner, Scott Morton and Weyl (2017) ${ }^{1870}$ raise an important concern about potential interventions leading to a single investor's act of becoming a significant common owner without taking a direct action, but simply led by actions of other investors on the market. The authors warn that private litigation or unguided public litigation could cause problems because of the interactive nature of institutional holdings on competition. Given that the proposed MHHI indexes evaluate market concentrations through the relative weights of investor portfolios, the investment of one institutional investor in competing firms affects the amount by which another institutional investor "lessens competition" with its investments in the same industry. Consequently, institutions could become liable simply because other institutions changed their holdings and thereby made an industry less competitive. A stringent legislation that transfers responsibility onto institutional investors to determine other institutions' ownership shares and expected volatility, would put them into a difficult position lacking clarity about where they can legally invest.

Having reviewed the literature, we find the intuitions captured in Azar's (2012) (871 $^{18}$ mechanisms a reasonable concern about the effect of common ownership on market competition. Given the recent emergence of measurement techniques and empirical estimation methodology in this area, we are not very concerned with the criticisms expressed by some authors on this issue, although we acknowledge the need for improvement. What we do feel strongly about is the debate about the incentives of firms in the market being distorted away from competition by the presence of institutional investors - and here we do not find any sufficiently convincing counterarguments. Policy makers are ultimately agnostic as to whether common ownership undermines competition by altering the firm manager's incentives or via other routes. The policy maker concern remains about the eventual unilateral effects, or collusive outcomes. The main test therefore is - whether these collusive outcomes and anticompetitive effects are facilitated by the presence of financial investors.

\subsection{Common ownership in the global food value chain}

We first consider general evidence about common ownership in the food value chain, before exploring the way the European Commission dealt with this issue in its recent Dow/Dupont merger decision.

\subsubsection{General evidence about common ownership in the food sector}

Some of the competition authorities examining the recent seed mergers raised concerns over the common ownership that can be observed by the same financial investors in the various segments of the food value chain, and more specifically seeds and crop protection chemicals.

${ }^{1870}$ E A Posner, F Scott Morton, \& E Glen Weyl, ‘A Proposal to Limit the Anti-Competitive Power of Institutional Investors', forth. Antitrust law Journal (November 29, 2016). University of Chicago Coase-Sandor Institute for Law \& Economics Research Paper No. 787. Available at SSRN: ssrn.com/abstract=2872754 .

${ }^{1871}$ J Azar, 'A New Look at Oligopoly: Implicit Collusion Through Portfolio Diversification' (November 8, 2011). Available at SSRN: https://ssrn.com/abstract=1993364 or http://dx.doi.org/10.2139/ssrn.1993364 
In particular, the European Commission noted in its recent Dow/Dupont merger decision a significant level of common shareholdings across the BASF, Bayer, Dow, DuPont, Monsanto and Syngenta, the shareholding of these firms also been characterised by a tail of atomistic shareholders, most of the listed shareholders having less than $0.01 \%$ equity share ${ }^{1872}$. Such a tail of atomistic equity holders may be less likely to be able to exert influence over general assemblies and the companies' management, the Commission concluding that "the control exerted by large shareholders seems to be more important than their ownership equity share suggests" ${ }^{\prime 1873}$. Furthermore, according to Annex 5 included in the Dow/Dupont EU Commission decision, "Dow, DuPont and Monsanto seem to be the most 'consanguine' agrochemical firms, as they share a significant number of equity holders with, overall, large positions on all of these three firms" ${ }^{1874}$. Indeed, small number of common shareholders, collectively own around 21\% of BASF, Bayer and Syngenta and around 29\%-36\% of Dow, DuPont and Monsanto ${ }^{1875}$.

The Commission even went further and explored the shareholding structure outside the Big 6 and found that a significant number of shareholders listed in in the Big Six are also shareholders of FMC, a competitor that is no longer present in active R\&D discovery, thus taking the view that the conclusions reached for the integrated R\&D players and Monsanto on their concentrated shareholdings and on their common shareholdings also extend to some of the non-vertically integrated shareholdings ${ }^{1876}$.

We confirmed these findings by conducting our own research on the shareholding of these companies by institutional investors. We selected 33 publicly traded companies on NYSE, NASDAQ and LSE across various parts of the food value chain. The food value chain is presented by companies operating in such sectors as biotechnology Illumina, ILMN; Genus, GNS.L), agriculture seeds, crop protection producers (i.e., Monsanto, MON; E.I. Du Pont Nemours and Company, DD; the Dow Chemical Company, DOW; Agrium, AGU; American Vanguard Corporation, AVG), fertiliser producers (Potash Corporation of Saskatchevan Inc., POT; the Mosaic Company, MOS; CF Industries Holdings, CF), farm and construction machinery manufacturers (Deer and Company, DE; AGCO Corporation, AGCO; CNH Industrial, CNHI), food producers including major branded food diversified manufacturers (Archer Daniels Midland Company, ADM; Bunge Limited, BG; Tyson Foods, TSN; the Kraft Heinz Company, KHS; Conagra Brands, CAG, Pinnacle Foods, PF; Post Holdings, etc.), animal health medicines, vaccines and animal safety products (Zoetis, ZTS; Neogen Corporation, NEOG), pet products (Blue Buffalo Pet Products, BUFF) and some others. Our analysis covered the full value chain from leading biotechnology companies producing genome sequencing equipment to seeds and animal breeding companies, from fertiliser and pesticides manufacturers to farm equipment, from farmers and raw food manufacturers to major food diversified holdings.

\footnotetext{
1872 See Commission Decision, Case M.7932 - Dow/DuPont (2017), paras 2339, 2340 \& 2347.

${ }^{1873}$ Ibid., Annex 5, paras 32-33.

1874 Ibid., Annex 5, para. 13.

1875 Ibid., Annex 5, para. 80.

1876 Ibid. para. 18.
} 
The information about investors was taken from Bloomberg (date of analysis June 1213, 2017). Overall, we analysed investor profile of 33 public companies and 2,569 investors into these companies. Overall these investors account for 10,239 links (relationships) across 33 publicly traded agriculture and food companies. The results of our research are shown in the following Figure.

\section{Figure 2: Helicopter view of the investors into leading food value chain publicly traded companies}

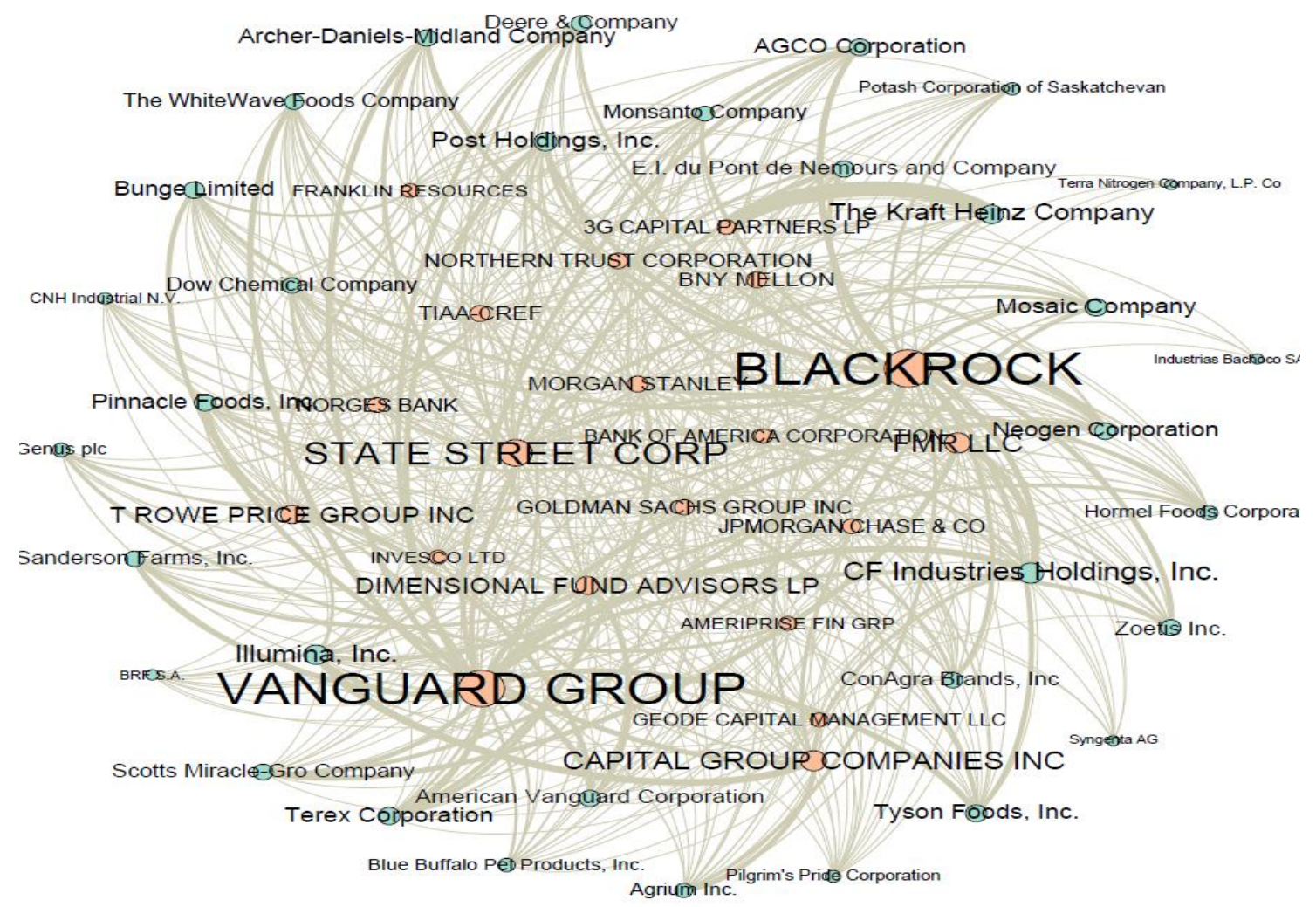

Source: Authors' calculations ${ }^{1877}$

The helicopter view shows a clear core group of top-20 investors. Using page-rank algorithm ${ }^{1878}$ we identified key investors (the importance/influence of the investor is indicated by the size of the node, the thickness of relationship between the investor and the investee is correlated with the percentage of shares owned).

The most active investors include the leading global investment \& wealth management corporations (Morgan Stanley, Goldman Sachs, UBS, Deutsche Banks and others), banks (BNY Mellon, Bank of New York, Bank of America Corporation, etc.), asset-managers and financial services providers (BlackRock, Vanguard Group, State Street, TIAA, Wells Fargo, etc.), pension and sovereign wealth funds, central banks (Norges Bank, the central bank of

1877 We include 33 public companies (blue color), 2569 investors (orange color) with 10239 links. The names of the major 15 investors representing an influential cluster are provided.

1878 S Brin \& L Page, 'The Anatomy of a Large-Scale Hypertextual Web Search Engine', Proceedings of the seventh International Conference on the World Wide Web (WWW1998):107-117 
Norway), investment funds (Dimentional Fund Advisors, Geode Capital Management) and other players.

Figure 3: The core investors in seed and traits

BNY MELLON

JPMORGANCHASE \& CO FRANKLIN RESOURCES

BAFEEU

\section{RTHERN TRUST CORPORATION}

TIAA-CREF

T ROWE PRICE GROUP INC

GOVMT PENSION INVST FUND JAPAN

STATE STREET CORP BANK OF AMERICA CORPORATION

CAPITAL GROUECOMPANIES INC

ANGUARD GROUP NORGES BANK

DIMENSIONAL FUND ADVISORS LP

UBS INVESCOLTD

MORGAN STANLEY

BLACKROCK

\section{FMRLLC}

DEUTSCHE BANK AG

SUN LIFE FINANCIAL INC

El. du Pont de Cenours and Com

Source: Authors' calculations

The top-20 investors from the list ranking by their activity (the number of companies they invested, maximum possible ties - 33) are presented in the Table below.

Table 1: top 20 investors

\begin{tabular}{lll}
\hline Investor & $\begin{array}{l}\text { Number } \\
\text { investees }\end{array}$ & $\begin{array}{c}\text { of of total } \\
\text { investees } \\
\text { covered }\end{array}$ \\
\hline MORGAN STANLEY & 30 & $91 \%$ \\
\hline BLACKROCK & 29 & $88 \%$ \\
\hline BNY MELLON & 29 & $88 \%$ \\
\hline $\begin{array}{l}\text { DIMENSIONAL } \\
\text { ADVISORS LP }\end{array}$ & FUND & 29 \\
\hline $\begin{array}{l}\text { GOLDMAN SACHS } \\
\text { INC GROUP }\end{array}$ & 29 & $88 \%$ \\
\hline STATE OF CALIFORNIA & 29 & $88 \%$ \\
\hline NORGES BANK & 28 & $88 \%$ \\
\hline $\begin{array}{l}\text { NORTHERN } \\
\text { CORPORATION }\end{array}$ & 28 & $85 \%$ \\
\hline STATE STREET CORP & 27 & $82 \%$ \\
\hline
\end{tabular}




\begin{tabular}{lll}
\hline TIAA-CREF & 27 & $82 \%$ \\
\hline $\begin{array}{l}\text { BANK OF AMERICA } \\
\text { CORPORATION }\end{array}$ & 25 & \\
\hline DEUTSCHE BANK AG & 25 & $76 \%$ \\
\hline $\begin{array}{l}\text { GEODE CAPITAL } \\
\text { MANAGEMENT LLC }\end{array}$ & 25 & \\
\hline UBS & 25 & $76 \%$ \\
\hline CHARLES SCHWAB & 24 & $76 \%$ \\
CORPORATION & 24 & \\
\hline VANGUARD GROUP & 22 & $73 \%$ \\
\hline AMERIPRISE FIN GRP & 22 & $67 \%$ \\
\hline INVESCO LTD & 22 & $67 \%$ \\
\hline WELLS FARGO \& COMPANY & 21 & $64 \%$ \\
\hline FMR LLC & & \\
\hline
\end{tabular}

Source: Authors' calculations

Note that each investment company or mutual fund holds several funds, each of which could be managed in a "passive" or in an "active" way. More details on share ownership of the most active investors into the global food value chain is presented in Table 2. 
Table 3: Share ownership of the most infuential investors into the global food value chain (sorted by page rank)

\begin{tabular}{|c|c|c|c|c|c|c|c|c|c|c|c|c|c|c|c|}
\hline \multirow{3}{*}{ Investor } & \multicolumn{15}{|c|}{ Percentage shares owned } \\
\hline & \multicolumn{2}{|c|}{$\begin{array}{l}\text { Animal } \\
\text { Safety }\end{array}$} & \multicolumn{2}{|c|}{$\begin{array}{l}\text { Biotech / } \\
\text { Animal } \\
\text { genomics } \\
\end{array}$} & \multicolumn{3}{|c|}{$\begin{array}{l}\text { Seeds \& } \\
\text { Protection }\end{array}$} & \multicolumn{2}{|c|}{ Fertilisers } & \multicolumn{2}{|c|}{$\begin{array}{l}\text { Farm } \\
\text { Machinery }\end{array}$} & \multicolumn{2}{|c|}{$\begin{array}{l}\text { Food, } \\
\text { companies }\end{array}$} & \multicolumn{2}{|c|}{ diversified } \\
\hline & $\stackrel{\mathscr{0}}{\stackrel{0}{0}}$ & 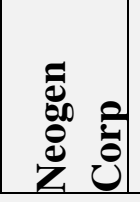 & 䮍 & 气̊ & 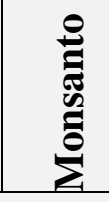 & 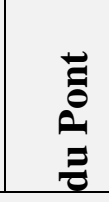 & 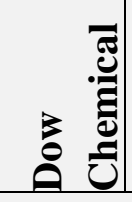 & 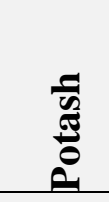 & 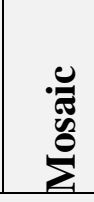 & 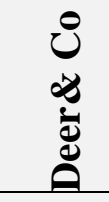 & 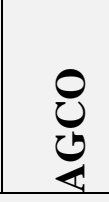 & 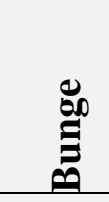 & 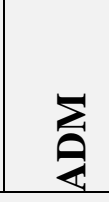 & ש்ֶ & $\begin{array}{ll}0 & 0 \\
0 & 0 \\
0 & 0 \\
& 0 \\
\end{array}$ \\
\hline BlackRock Inc & 7.35 & $\begin{array}{l}11.7 \\
2 \\
\end{array}$ & 7.33 & 4.56 & 5.97 & 6.31 & 6.58 & 4.75 & $\begin{array}{l}7.1 \\
2 \\
\end{array}$ & 5.23 & 8.21 & 5.69 & 6.91 & 6.34 & 6.61 \\
\hline Vanguard Group & 6.67 & 8.55 & 6.61 & 2.4 & 6.82 & 6.99 & 6.65 & 2.31 & $\begin{array}{l}7.1 \\
2 \\
\end{array}$ & 6.39 & 7.1 & $\begin{array}{l}10.0 \\
1 \\
\end{array}$ & 7.64 & $\begin{array}{l}10.8 \\
8 \\
\end{array}$ & 8.36 \\
\hline State Street Corp & 4.33 & 2.38 & 4.15 & 0.59 & 4.59 & 4.91 & 3.97 & 0.14 & $\begin{array}{l}5.5 \\
7 \\
\end{array}$ & 3.84 & 4.16 & 3.02 & 5.79 & 4.29 & 4.86 \\
\hline FMR LLC & 0.21 & 0.82 & 0.54 & 0 & 2.88 & 3.73 & 1.27 & 3.2 & $\begin{array}{l}1.4 \\
6 \\
\end{array}$ & 1.33 & 1.63 & 2.86 & 0.16 & 0.19 & 0.27 \\
\hline Capital Group Companies & 0 & 0 & $\begin{array}{l}10.5 \\
7 \\
\end{array}$ & 0 & 2.98 & $\begin{array}{l}10.2 \\
5 \\
\end{array}$ & 3.74 & 5.34 & $\begin{array}{l}5.1 \\
6 \\
\end{array}$ & 2.91 & 0 & 0 & 0 & 2.08 & 0 \\
\hline $\begin{array}{ll}\text { Dimensional } & \text { Fund } \\
\text { Advisors LP } & \\
\end{array}$ & 0.27 & 1.7 & 0.18 & 1.08 & 0.23 & 0.18 & 0.34 & 0.27 & $\begin{array}{l}1.0 \\
5\end{array}$ & 0.29 & 3.51 & 1.48 & 0.95 & 0.32 & 1.39 \\
\hline T Rowe Price & 8.19 & 0.03 & 4.33 & 1.42 & 0.33 & 2.29 & 0.17 & 0 & $\begin{array}{l}0.8 \\
1 \\
\end{array}$ & 0.19 & 1.44 & 6.76 & 2.11 & 2.29 & $\begin{array}{l}10.5 \\
7 \\
\end{array}$ \\
\hline Morgan Stanley & 2.99 & 0.38 & 3.02 & 0.34 & 0.54 & 0.51 & 0.53 & 0.45 & $\begin{array}{l}1.4 \\
6 \\
\end{array}$ & 0.43 & 1.44 & 0.58 & 0.42 & 1.56 & 0.39 \\
\hline
\end{tabular}




\begin{tabular}{|l|llllllllllllllll|}
\hline BNY Mellon & 1.11 & 1.39 & 0.85 & 0 & 0.9 & 1.04 & 1.35 & 0.39 & $\begin{array}{l}2.9 \\
9\end{array}$ & 0.8 & 1.13 & 0.36 & 1.35 & 1.92 & 1.8 \\
\hline TIAA - CREF & 1.99 & 0.44 & 0.93 & 0.12 & 0.73 & 0.47 & 1.07 & 0.15 & $\begin{array}{l}0.3 \\
7\end{array}$ & 0.55 & 2.03 & 1.43 & 0.47 & 2.42 & 1.21 \\
\hline Goldman Sachs & 1.03 & 0.3 & 0.96 & 0.15 & 0.7 & 0.83 & 0.47 & 0.22 & $\begin{array}{l}0.4 \\
9\end{array}$ & 0.32 & 0.91 & 1.59 & 0.66 & 1.4 & 1.66 \\
\hline $\begin{array}{l}\text { Share owned by top-11 } \\
\text { investors }\end{array}$ & $\mathbf{3 4 . 1}$ & $\mathbf{2 7 . 7}$ & $\mathbf{3 9 . 4}$ & $\mathbf{1 0 . 6}$ & $\mathbf{2 6 . 6}$ & $\mathbf{3 7 . 5}$ & $\mathbf{2 6 . 1}$ & $\mathbf{1 7 . 2}$ & $\mathbf{3 3}$ & $\mathbf{2 2 . 2}$ & $\mathbf{3 1 . 5}$ & $\begin{array}{l}\mathbf{3 3 . 7} \\
\mathbf{8}\end{array}$ & $\begin{array}{l}\mathbf{2 6 . 4} \\
\mathbf{6}\end{array}$ & $\begin{array}{l}\mathbf{3 3 . 6} \\
\mathbf{9}\end{array}$ & $\begin{array}{l}\mathbf{3 7 . 1} \\
\mathbf{2}\end{array}$ \\
\hline
\end{tabular}

Source: Authors' calculations on the basis of Bloomberg data (access date - June 12, 2017) 


\subsubsection{The Dow Dupont case}

The Commission examined in great detail the possible anticompetitive effects of common shareholding in the Dow/DuPont merger case, both in its decision and also in an Annex attached to its decision ${ }^{1879}$. The Commission's starting point was the industry shares tend to underestimate the expected non-coordinated effects of the merger given the significant cross shareholding between the main players. The Commission provided factual evidence on the significant level of common shareholding in the agrochemical industry and on the involvement of large minority shareholders which, despite some being labelled "passive investors" are as in fact "active owners". The Commission noted that presence of a significant level of common shareholding tends to lower rivalry. This finding was first based on the economic literature on cross-shareholdings, "which extends to common shareholding", and which "tends to show that common shareholding of competitors reduces incentives to compete as the benefits of competing aggressively to one firm come at the expense of firms that belong to the same investors' portfolio" ${ }^{1880}$. This literature has been discussed in great detail in the previous Sections of this Chapter.

The Commission further took into account some recent empirical studies ${ }^{1881}$ providing indications that the presence of significant common shareholding in an industry is "likely to have material consequences on the behaviour of the firms in such industries" ${ }^{1882}$, leading to the possibility of higher prices, in view of the fact that common shareholders tend to shape the monetary incentives of firms' executives in order to align them with industry performance, and not only their firm's specific performance $^{1883}$.

Quite interestingly, the Commission transposed this literature, which has focused on price effects to the situation of innovation competition, which allegedly may also be reduced by such crossand common ownership ${ }^{1884}$. The narrative goes as following:

"[...] by increasing its efforts in R\&D, a firm incurs a cost that decreases its current profits in expectation of future benefits brought by the resulting products of its innovation. Such future benefits would necessarily materialise through price competition of future products which, given the specificities of the agrochemical industry, in particular the fact that the total size of the crop protection industry is typically not related to innovation, is likely to be mainly at the expense of its competitors. In other words, the decision taken by one firm, today, to increase innovation competition has a downward impact on its current profits and is also likely to have a downward impact on the (expected future) profits of its competitors.

This, in turn, will negatively affect the value of the portfolio of shareholders who hold positions in this firm and in its competitors. Therefore, as for current price competition, the

\footnotetext{
${ }^{1879}$ Commission Decision, Case M.7932 - Dow/DuPont (2017).

1880 Ibid., para. 2348.

${ }^{1881}$ In particular, J. Azar, M. Schmalz \& I. Tecu, Anti-competitive effects of common ownership, (2016) Ross School of Business working paper 1235

1882 Commission Decision, Case M.7932 - Dow/DuPont (2017), para. 2349.

${ }^{1883}$ See, M. Anton, F. Ederer, M. Gine \& M. Schmalz, Common ownership, competition, and top management incentives, (2016) Ross School of Business working paper 1328.

${ }^{1884}$ Ibid., para. 2350.
} 
presence of significant common shareholding is likely to negatively affect the benefits of innovation competition for firms subject to this common shareholding" 1885 .

Hence, for the Commission, the concentration measures, such as market shares or the HerfindahlHirschman index ("HHI"), are likely to underestimate the level of concentration of the market structure and, thus, the market power of the merging parties. In view of the fact that common shareholding is a reality in the agrochemical industry, both in terms of the number of common shareholders as well as with respect to the level of shares possessed by these common shareholders, the Commission took this into account as an element of context in the appreciation of any significant impediment to effective competition, noting that in the context of innovation competition, such findings provide indications that innovation competition in crop protection should be less intense as compared with an industry with no common shareholding ${ }^{1886}$.

\subsection{Conclusion}

This Chapter of the Report examined the possibility that common ownership may constitute a competition concern, raising issues of unilateral effects, horizontal collusion and vertical exploitation. Many institutional investors are passive investors in various companies active at various segments of the food value chain. Although this Chapter merely focused on the seed/agrochem sector, it is possible to identify considerable common ownership in other parts of the food value chain as well, in particular its bits with the highest economic concentration. In view of the possible negative welfare effects of common ownership to competition, and its prevalence in the food sector, it looks advisable that BRICS competition authorities develop the adequate tools to deal with this issue, eventually resorting to the use of the MHHI tool. Other tools, probably based on advanced social network analysis, could also be developed in the future.

1885 Ibid., para. 2351 \& Annex 5, para. 59.

${ }^{1886}$ Ibid., para. 2352. 


\section{References}

Admati, A.R., P Pfleiderer, \& J Zechner, (1994). 'Large shareholder activism, risk sharing, and financial market equilibrium'. journal of Political Economy, 102(6), 1097-1130.

Ashman, S, Mohamed, \& S Newman, 'Financialisation of the South African economy: Impact on the economic growth path and employment'. (2013), Discussion Paper. United Nations Department of Economic and Social Affairs.

Azar, J., 'A New Look at Oligopoly: Implicit Collusion Through Portfolio Diversification'

(November 8, 2011). Available at

SSRN: https://ssrn.com/abstract=1993364 or http://dx.doi.org/10.2139/ssrn.1993364

Azar, J., R Raina, \& M C Schmalz, 'Ultimate Ownership and Bank Competition'. (July 23, 2016). Available

SSRN: https://ssrn.com/abstract=2710252 or http://dx.doi.org/10.2139/ssrn.2710252

Azar, J., M C Schmalz, \& I Tecu, Isabel, 'Anti-Competitive Effects of Common Ownership'

(March 15, 2017). Journal of Finance, Forthcoming. Available at SSRN: https://ssrn.com/abstract=2427345 or http://dx.doi.org/10.2139/ssrn.2427345

Berle, A.A. \& G G C Means, (1991). The modern corporation and private property. Transaction publishers.

Villas-Boas, S.B., 'Vertical relationships between manufacturers and retailers: Inference with limited data.' S. (2007). The Review of Economic Studies, 74(2), 625-652.

Villas-Boas, S.B.., 'Using retail data for upstream merger analysis.' (2007). joclec, 3(4), 689715.

Bertrand, M. \& S Mullainathan, (2003). 'Enjoying the quiet life? Corporate governance and managerial preferences'. Journal of political Economy, 111(5), 1043-1075.

Burch, B. \& G Lawrence, 'Towards a third food regime: behind the transformation. Agriculture and Human Values', (2009). 26(4), 267-279

Burch, B. \& G Lawrence, Financialization in agri-food supply chains: private equity and the transformation of the retail sector'. (2013). Agriculture and Human Values 30(2), 247-258.

Bush, S.B., 'Derivatives and development: a political economy of global finance, farming, and poverty'. (2012), New York: Palgrave Macmillan

Bresnahan, T., \& S C Salop, 'Quantifying The Competitive Effects of Production Joint Ventures', (1986) 4 Inter'1 J. Ind. Org. 155

Brin, S. \& L Page, 'The Anatomy of a Large-Scale Hypertextual Web Search Engine', Proceedings of the seventh International Conference on the World Wide Web (WWW1998):107-117

Burnside, A., 'Minority Shareholdings: An overview of EU and national case law', $e$ Competitions, No 56676.

Commission Staff Working Document, Impact Assessment, SWD(2014) 217 final.

Council of Economic Advisors (2016): "Benefits of Competition and Indicators of Market Power," Available online

van Duijn, A.P., R Beukers, R B Cowan, L O Judge, W van der Pijl, L Römgens,... \& t Steinweg, 'Financial value-chain analysis' (2016). (No. 2016-028). LEI Wageningen UR.

Elhauge, E., 'Horizontal Shareholding', (2016). 129 Harv. L. Rev. 1267

European Commission (2016), "Summary of the responses to the public consultation on Long-term and sustainable investment", Brussels, October 2016 JUST/A3 
European Commission, White Paper - 'Towards more effective EU merger control' (2014), available

ec.europa.eu/competition/consultations/2014_merger_control/mergers_white_paper_en.pdf, para 43.

M Friend, 'Regulating minority shareholdings and unintended consequences' (2012) 33 (6) ECLR 303, 304-305.

Gilo, D., 'The Anticompetitive Effects of Passive Investment', (2000) 99 Mich. L. Rev. 1

Gilo, D., YMoshe, \& Y Spiegel, 'Partial Cross Ownership and Tacit Collusion', (2006), 37 RAND J. Econ. 81

Gramlich, J., \& S Grundl, 'Estimating the Competitive Effects of Common Ownership'. (April 21, 2017). FEDS Working Paper No. 2017-029. Available at SSRN: https://ssrn.com/abstract=2940137 or http://dx.doi.org/10.17016/FEDS.2017.029r1

Green, E.J., R C Marshall, \& L M Marx, (2014). 'Tacit collusion in oligopoly'. The Oxford Handbook of International Antitrust Economics, 2, 464-497.

Hansen, R.G. \& JR Lott, (1996), 'Externalities and corporate objectives in a world with diversified shareholder/consumers', Journal of Financial and Quantitative Analysis, 31(1), 43-68.

He, J. \& J Huang, 'Product Market Competition in a World of Cross-Ownership: Evidence from Institutional Blockholdings' (January 13, 2016). Forthcoming in the Review of Financial Studies. Available

at

SSRN: https://ssrn.com/abstract=2380426 or http://dx.doi.org/10.2139/ssrn.2380426

Hicks, J, (1935). 'Annual survey of economic theory: the theory of monopoly'. Econometrica: Journal of the Econometric Society, 1-20

HighQuest Partners. 'Private Financial Sector Investment in Farmland and Agricultural Infrastructure'. (2010). OECD Food, Agriculture, and Fisheries Papers, No. 33, OECD Publishing.

Isakson, S.R., 'Food and finance: The financial transformation of agro-food supply chains'. (2014). Journal of Peasant Studies, 41(5), 749-775.

Ivaldi, M., B Jullien, P Rey, P Seabright, \& J Tirole, (2003). 'The economics of tacit collusion'. Final report for DG competition, European Commission, 4-5.; E J Green, R C Marshall, \& L M Marx, (2014). 'Tacit collusion in oligopoly'. The Oxford Handbook of International Antitrust Economics, 2, 464-497.

Jullien, B., P Rey and C Saavedra, The Economics of Margin Squeeze, IDEI mimeo (March 2014) 11.

Levine, L., (2015). Index Funds May Work a Little Too Well. Bloomberg View, 22.

Mayer, J., 'The growing interdependence between financial and commodity markets'. UNCTAD Discussion Paper No. 195. Geneva: United Nations Trade and Development Conference.

Murphy, S., D Burch, J Clapp 'Cereal Secrets: The World's Largest Grain Traders and Global Agriculture'. (2012), Oxfam Research Reports. Oxford: Oxfam International.

O’Brien, D.P. \& S C Salop, 'Competitive Effects of Partial Ownership: Financial Interest and Corporate Control' [2000] 67 Antitrust L.J. 559

O'Brien D.P., \& K Waehrer, 'The Competitive Effects of Common Ownership: We Know Less than We Think', (February 23, 2017). Available at SSRN: https://ssrn.com/abstract=2922677

O'Donoghue, R. and J Padilla, The Law and Economics of Article 102 TFEU (Hart Pub, 2nd ed, 2013) 366. 
Posner, E.A., F Scott Morton, \& E Glen Weyl, 'A Proposal to Limit the Anti-Competitive Power of Institutional Investors' forth. Antitrust Law Journal

Price Waterhouse Coopers , 'Mine: The Growing Disconnect'. (2012), PWC, London. http://www.pwc.com/gx/en/mining/publications/mining/mine-the-growingdisconnect.jhtml

Reynolds R.J. \& B R Snapp, 'The Competitive Effects of Partial Equity Interests and Joint Ventures', (1986) 4 Inter'1 J. Ind. Org. 141; Roger H. Gordon, 'Do Publicly Traded Corporations Act in the Public Interest?', (1990) Nat'1 Bureau of Econ. Research, Working Paper No. 3303

Rogalska, M., "Globalisation and Financialisation of the Economy Impact Investing at Scale as a Promising Response”. (2016) weatherhead Centre for International affairs, Harvard University

Rock E.B. \& D L Rubinfeld, 'Defusing the Antitrust Threat to Institutional Investor Involvement in Corporate Governance' (March 1, 2017). NYU Law and Economics Research Paper No. 17-05. Available at SSRN: https://ssrn.com/abstract=2925855

Rock E.B. \& DL Rubinfeld, ‘Antitrust for Institutional Investors' (July 2017). NYU Law and Economics Research Paper No. 17-23; UC Berkeley Public Law Research Paper. Available at SSRN: https://ssrn.com/abstract=2998296

Rotemberg, J.J., 'Financial Transaction Costs and Industrial Performance', (1984) Mass. Inst. of Tech., Alfred P. Sloan Sch. of Mgmt., Working Paper No. 1554-84

Tzanaki, A., 'The legal treatment of minority shareholdings under EU competition law: Present and future' University of Piraeus - Essays in Honour of Professor Panayiotis I Kanellopoulos, (Sakkoulas Publications, 2015), 861-886.

Tzanaki, A., The regulation of minority shareholdings and other structural links between competing undertakings: A law \& economics analysis (Phd thesis, UCL, September 2017) 


\section{References}

Admati, A.R., P Pfleiderer, \& J Zechner, (1994). 'Large shareholder activism, risk sharing, and financial market equilibrium'. journal of Political Economy, 102(6), 1097-1130.

Ashman, S, Mohamed, \& S Newman, 'Financialisation of the South African economy: Impact on the economic growth path and employment'. (2013), Discussion Paper. United Nations Department of Economic and Social Affairs.

Azar, J., 'A New Look at Oligopoly: Implicit Collusion Through Portfolio Diversification' (November 8, 2011). Available at SSRN: https://ssrn.com/abstract=1993364 or http://dx.doi.org/10.2139/ssrn.1993364

Azar, J., R Raina, \& M C Schmalz, 'Ultimate Ownership and Bank Competition'. (July 23, 2016). Available

at

SSRN: https://ssrn.com/abstract=2710252 or http://dx.doi.org/10.2139/ssrn.2710252

Azar, J., M C Schmalz, \& I Tecu, Isabel, 'Anti-Competitive Effects of Common Ownership' (March 15, 2017). Journal of Finance, Forthcoming. Available at SSRN: $\underline{\text { https://ssrn.com/abstract=2427345 } \text { or http://dx.doi.org/10.2139/ssrn.2427345 }}$

Berle, A.A. \& G G C Means, (1991). The modern corporation and private property. Transaction publishers.

Villas-Boas, S.B., 'Vertical relationships between manufacturers and retailers: Inference with limited data.' S. (2007). The Review of Economic Studies, 74(2), 625-652.

Villas-Boas, S.B.., 'Using retail data for upstream merger analysis.' (2007). joclec, 3(4), 689715.

Bertrand, M. \& S Mullainathan, (2003). 'Enjoying the quiet life? Corporate governance and managerial preferences'. Journal of political Economy, 111(5), 1043-1075.

Burch, B. \& G Lawrence, 'Towards a third food regime: behind the transformation. Agriculture and Human Values', (2009). 26(4), 267-279

Burch, B. \& G Lawrence, Financialization in agri-food supply chains: private equity and the transformation of the retail sector'. (2013). Agriculture and Human Values 30(2), 247-258.

Bush, S.B., 'Derivatives and development: a political economy of global finance, farming, and poverty'. (2012), New York: Palgrave Macmillan

Bresnahan, T., \& S C Salop, 'Quantifying The Competitive Effects of Production Joint Ventures', (1986) 4 Inter'l J. Ind. Org. 155

Brin, S. \& L Page, 'The Anatomy of a Large-Scale Hypertextual Web Search Engine', Proceedings of the seventh International Conference on the World Wide Web (WWW1998):107-117

Burnside, A., 'Minority Shareholdings: An overview of EU and national case law', e-Competitions, No 56676.

Commission Staff Working Document, Impact Assessment, SWD(2014) 217 final. 
Council of Economic Advisors (2016): "Benefits of Competition and Indicators of Market Power," Available online

van Duijn, A.P., R Beukers, R B Cowan, L O Judge, W van der Pijl, L Römgens,... \& t Steinweg, 'Financial value-chain analysis' (2016). (No. 2016-028). LEI Wageningen UR.

Elhauge, E., 'Horizontal Shareholding', (2016). 129 Harv. L. Rev. 1267

European Commission (2016), "Summary of the responses to the public consultation on Long-term and sustainable investment", Brussels, October 2016 JUST/A3

European Commission, White Paper - 'Towards more effective EU merger control' (2014), available at ec.europa.eu/competition/consultations/2014_merger_control/mergers_white_paper_en.pdf, para 43.

M Friend, 'Regulating minority shareholdings and unintended consequences' (2012) 33 (6) ECLR 303, 304-305.

Gilo, D., 'The Anticompetitive Effects of Passive Investment', (2000) 99 Mich. L. Rev. 1

Gilo, D., YMoshe, \& Y Spiegel, 'Partial Cross Ownership and Tacit Collusion', (2006), 37 RAND J. Econ. 81

Gramlich, J., \& S Grundl, 'Estimating the Competitive Effects of Common Ownership'. (April 21, 2017). FEDS Working Paper No. 2017-029. Available at SSRN: https://ssrn.com/abstract=2940137 or http://dx.doi.org/10.17016/FEDS.2017.029r1

Green, E.J., R C Marshall, \& L M Marx, (2014). 'Tacit collusion in oligopoly'. The Oxford Handbook of International Antitrust Economics, 2, 464-497.

Hansen, R.G. \& JR Lott, (1996), 'Externalities and corporate objectives in a world with diversified shareholder/consumers', Journal of Financial and Quantitative Analysis, 31(1), 43-68.

He, J. \& J Huang, 'Product Market Competition in a World of Cross-Ownership: Evidence from Institutional Blockholdings' (January 13, 2016). Forthcoming in the Review of Financial Studies. Available at SSRN: https://ssrn.com/abstract=2380426 or http://dx.doi.org/10.2139/ssrn.2380426

Hicks, J, (1935). ‘Annual survey of economic theory: the theory of monopoly'. Econometrica: Journal of the Econometric Society, 1-20

HighQuest Partners. 'Private Financial Sector Investment in Farmland and Agricultural Infrastructure'. (2010). OECD Food, Agriculture, and Fisheries Papers, No. 33, OECD Publishing.

Isakson, S.R., 'Food and finance: The financial transformation of agro-food supply chains'. (2014). Journal of Peasant Studies, 41(5), 749-775.

Ivaldi, M., B Jullien, P Rey, P Seabright, \& J Tirole, (2003). 'The economics of tacit collusion'. Final report for DG competition, European Commission, 4-5.; E J Green, R C Marshall, \& L M Marx, (2014). 'Tacit collusion in oligopoly'. The Oxford Handbook of International Antitrust Economics, 2, 464-497.

Jullien, B., P Rey and C Saavedra, The Economics of Margin Squeeze, IDEI mimeo (March 2014) 11.

Levine, L., (2015). Index Funds May Work a Little Too Well. Bloomberg View, 22.

Mayer, J., 'The growing interdependence between financial and commodity markets'. UNCTAD Discussion Paper No. 195. Geneva: United Nations Trade and Development Conference. 
Murphy, S., D Burch, J Clapp 'Cereal Secrets: The World's Largest Grain Traders and Global Agriculture'. (2012), Oxfam Research Reports. Oxford: Oxfam International.

O’Brien, D.P. \& S C Salop, 'Competitive Effects of Partial Ownership: Financial Interest and Corporate Control' [2000] 67 Antitrust L.J. 559

O'Brien D.P., \& K Waehrer, 'The Competitive Effects of Common Ownership: We Know Less than We Think', (February 23, 2017). Available at SSRN: https://ssrn.com/abstract=2922677

O'Donoghue, R. and J Padilla, The Law and Economics of Article 102 TFEU (Hart Pub, 2nd ed, 2013) 366 .

Posner, E.A., F Scott Morton, \& E Glen Weyl, 'A Proposal to Limit the Anti-Competitive Power of Institutional Investors' forth. Antitrust Law Journal

Price Waterhouse Coopers , 'Mine: The Growing Disconnect'. (2012), PWC, London. http://www.pwc.com/gx/en/mining/publications/mining/mine-the-growingdisconnect.jhtml

Reynolds R.J. \& B R Snapp, 'The Competitive Effects of Partial Equity Interests and Joint Ventures', (1986) 4 Inter'1 J. Ind. Org. 141; Roger H. Gordon, 'Do Publicly Traded Corporations Act in the Public Interest?', (1990) Nat'l Bureau of Econ. Research, Working Paper No. 3303

Rogalska, M., "Globalisation and Financialisation of the Economy Impact Investing at Scale as a Promising Response”. (2016) weatherhead Centre for International affairs, Harvard University

Rock E.B. \& D L Rubinfeld, 'Defusing the Antitrust Threat to Institutional Investor Involvement in Corporate Governance' (March 1, 2017). NYU Law and Economics Research Paper No. 17-05. Available at SSRN: https://ssrn.com/abstract=2925855

Rock E.B. \& DL Rubinfeld, 'Antitrust for Institutional Investors' (July 2017). NYU Law and Economics Research Paper No. 17-23; UC Berkeley Public Law Research Paper. Available at SSRN: https://ssrn.com/abstract=2998296

Rotemberg, J.J., 'Financial Transaction Costs and Industrial Performance', (1984) Mass. Inst. of Tech., Alfred P. Sloan Sch. of Mgmt., Working Paper No. 1554-84

Tzanaki, A., 'The legal treatment of minority shareholdings under EU competition law: Present and future' University of Piraeus - Essays in Honour of Professor Panayiotis I Kanellopoulos, (Sakkoulas Publications, 2015), 861-886.

Tzanaki, A., The regulation of minority shareholdings and other structural links between competing undertakings: A law \& economics analysis (Phd thesis, UCL, September 2017) 


\section{Tables and Figures}

Table 1: top 20 investors.......421

Table 2: Share ownership of the most infuential investors into the global food value chain (sorted by page rank)....423

Figure 1: Classic market structure in which a margin squeeze might arise....405

Figure 2: Helicopter view of the investors into leading food value chain publicly traded companies...419

Figure 3: The core investors in seed and traits....420 


\section{PART IV: Innovation and Competition in Agriculture}

Since the early to mid-1990s competition law has initiated the process of adding to its genetic code innovation, with the adoption of guidelines and subsequently case law, with the increasingly important role of competition law enforcement in technology sectors. A question emerged: how could this practically drive the action of competition authorities? These were not only supposed to care about the welfare of existing consumers on clearly defined relevant markets, but also now take into account innovation concerns in their enforcement activity. This is of course true also for BRICS competition authorities. The development of biotechnology, branding and marketing in the food sector has led to interesting encounters with Intellectual Property (IP) regimes. The first Chapter will explore this interaction. The second Chapter will delve into the analysis of mergers, in particular in the food sector, if one adopts an innovation perspective.

\section{Chapter 1: The interaction between competition law and IP rights}

\section{Ioannis Lianos with Igor Nikolic \& Riccardo Savona Siemens ${ }^{1887}$}

\subsection{Introduction}

This part of the report will explore the role of Intellectual Property (IP) rights and more generally different forms of protection of innovations in the enforcement of competition law in food value chains. We will examine the various approaches and methods chosen by the BRICS and other selected jurisdictions so as to promote innovation in this sector of activity, while also preserving other public policy interests, such as affordability, the protection of the environment and biodiversity, among others. The first Section will deal with the expansion of IP rights in the food value chain in recent decades, in particular following the development of the biotechnology industry. The second Section will delve into the way competition law enforcement has interacted with IP rights in the jurisdictions examined.

\subsection{The expansion of intellectual property rights and the food value chain}

The expansion of property rights has been a salient feature of the recent transformation of the economic structure of many BRICS jurisdictions and other developing countries. A particular manifestation of this phenomenon of the increasing role of private property has been the expansion of intellectual property rights or property rights in intangibles, at each level of the food value chain.

With regard to food production, historically, plant and seed material were regarded as communal resources to be freely shared. Farmers were incentivized to save, replant, and resell seeds to other farmers, the dominant paradigm for trait development being farmer sharing ${ }^{1888}$. Starting with the

1887 CLES\&UCL. The text accompanying the footnotes 1944-1972 was taken by a common project between Ioannis Lianos and Dimitry Katalevsky on the Bayer/Monsanto merger.

1888 M. Llewelyn, The Legal Protection of Biotechnological Inventions: An Alternative Approach, (1997) 19 European Intellectual Property Review 115, 117. 
mechanization and the use of tractors in the late $19^{\text {th }}$ century and most recently with the granting of the first plant biotechnology patent in 1992, IP rights have long been used in the agricultural sector in order to stimulate research and development and innovation. They also formed the basis for the emergence of a private seed industry following the Green revolution of the 1960s-1970s. Initially funded by the public sector, the Green revolution led to an important increase of productivity at a higher cost for the independence of farmers that have until then ensured the effort of innovation in the sector by developing crop diversity (decentralised and highly fragmented innovation environment). Farmers became dependent on external seeds, which led to the emergence of a private seed market. The new varieties introduced by the Green revolution required also sharp increases in the use of Fertilisers and pesticides, which added to the dependence of farmers on the private market and increased the need for credit. The development of biotech and genetic engineering in the 1990s had also profound implications on the development of the industry and the process of its privatization. Hybrid crops provide high yields but also lose this advantage the following generation, thus leading farmers to buy new seeds regularly.

Genetically modified (GM) seeds are at the centre of the innovative effort in modern agriculture, the plant science industry being one of the world's most R\&D intensive industries ${ }^{1889}$. The plant biotechnology R\&D industry now consists of six large firms, whose number following the ongoing merger wave might come down to four, a varying number of smaller firms, and public-sector research organizations such as land-grant universities (see Part II of this Report). The degree of consolidation of this industry is remarkable if one takes into account that in the early 1980s there were more than two hundred different seed companies and that many agricultural chemical companies had both seeds and agricultural chemicals. The process of consolidation has been described as following:

"At first, pharmaceutical and chemical companies sold off their bulk chemicals businesses and bought up or merged with other pesticide and pharmaceutical companies. The major lifesciences companies each purchased smaller biotechnology companies that had promising new genes and seed companies that owned efficient seed distribution networks and/or traditional varieties into which novel genes could be inserted" ${ }^{1890}$.

This concentration is not only limited in seeds. It is also reported that the 10 biggest pesticide firms now control $90 \%$ of the global pesticide market, that 10 companies control $76 \%$ of the animal pharmaceutical sales, 10 animal feed firms control $52 \%$ of the global animal market ${ }^{1891}$, three animal genetics firms control more than $90 \%$ of turkeys and broilers genetics markets, while 4 companies control the swine genetics market ${ }^{1892}$. A lot of these companies control IPRs. There is some causal link between the rise of IP rights protection in this industry and the higher levels of economic concentration observed.

\footnotetext{
1889 See, ETC Group, Who will control the Green Economy? (November 2011), available at http://www.etcgroup.org/sites/www.etcgroup.org/files/publication/pdf_file/ETC_wwctge_4web_Dec2011.pdf

1890 Carl Pray, James Ohmhke \& Anwar Naseem, Innovation and Dynamic Efficiency in Plant Biotechnology: An Introduction to the Researchable Issues, (2005) 8(2\&3) AgBioForum 52, 59.

1891 ETC, Who will Control the Greem Economy? (November 2011), available at http://www.etcgroup.org/sites/www.etcgroup.org/files/publication/pdf_file/ETC_wwctge_4web_Dec2011.pdf

1892 See, Chapter 2, Part II.. See also, P.H. Howard, Concentration and Power in the Food System (Bloomsbury, 2016), 116-120.
} 
In the seed business IPRs consist of patents, plant variety rights, trade secrets and trademarks. We will first comment on each of these rights, before discussing the balance between different forms of IP rights in the industry.

\subsubsection{Patents}

In 1930, U.S. Congress established a plant patent regime providing protection over asexually reproducing plants (where each generation is genetically identical to the preceding), with the exclusion of food tubers (such as potato or Jerusalem artichoke, which are considered staple food) ${ }^{1893}$. Asexual reproduction is the propagation of a plant without the use of fertilized seeds to assure an exact genetic copy of the plant being reproduced, with the aim to establish the uniformity and stability of the. The grant, which lasts for 20 years from the date of filing the application, protects the patent owner's right to exclude others from asexually reproducing the plant, and from using, offering for sale, or selling the plant so reproduced, or any of its parts, throughout the United States, or from importing the plant so reproduced, or any part thereof, into the United States. The criteria for the patent protection do not include a requirement that plants are useful, but that they are new (nonobvious) and distinct, that is, that the plant is shown to differ from known, related plants by at least one distinguishing characteristic, which is more than a difference caused by growing conditions or fertility levels,. To be patentable, it is also required that the plant was invented or discovered in a cultivated state, and asexually reproduced. Plant patents are mainly used by the horticulture industry.

\section{Figure 1: Top US plant patent holders}

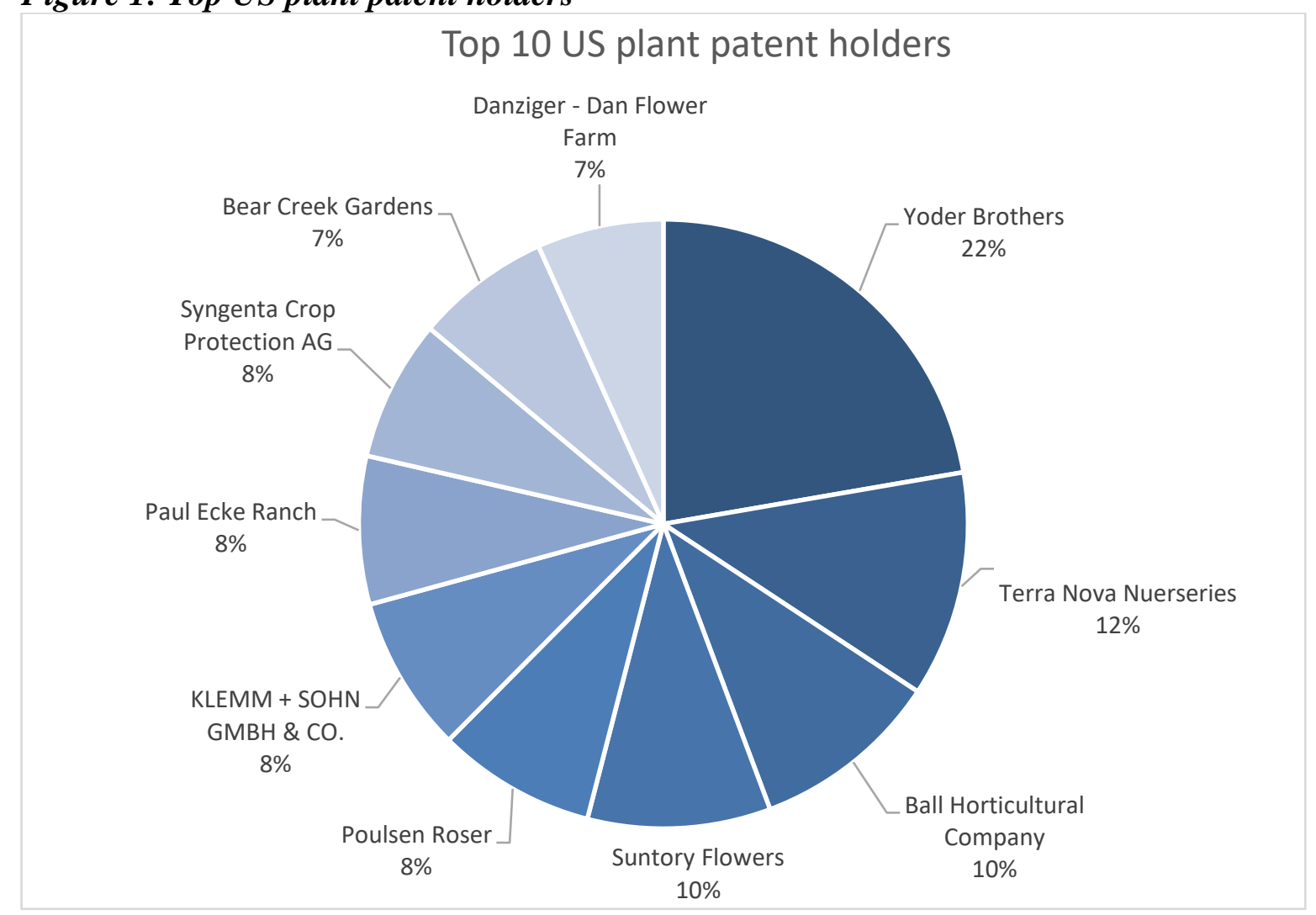

Source: Authors' compilation of data on the basis of USPTO data

${ }^{1893}$ Plant Patent Act 1930, 35 U.S.C. 161. 
The development of new traits via biotechnology is a quite costly process, the costs being associated with the discovery, development and authorisation of a new biotechnology derived crop trait being for the 2008-2012 timeframe estimated to \$136 million, out of which $\$ 31$ million are the costs of discovery, $\$ 28$ million the costs of introgression breeding and wide-area testing and more than $\$ 35$ million being spent on regulatory science and registration and regulatory affairs ${ }^{1894}$. This is quite substantial, although less than the cost of bringing a new conventional chemical crop protection product to the market, which was in the 2005-2008 period \$256 million. The mean value of the number of years required from the discovery of the trait to its first commercial sale for all crops is estimated to 13.1 years, this period being 11.7 years for canola, while for soybean this period is 16.3. years, and for corn 12 years ${ }^{1895}$. These considerable investments of resources and time may explain the reason biotechnology-based inventions in agriculture were considered a patentable subject matter.

In view of the prevalence of hybridisation and conventional breeding techniques, patents on living organisms were not recognized at least until the early 1980s. The expansion of cellular and molecular biology throughout the 1960s and 1970s, specifically the transplantation of genes between organisms by Cohen and Boyer in 1973, increased the ability of crop scientists to identify and isolate desired traits, modify the relevant genes, and to incorporate these traits into new crop varieties via transplantation with greater precision ${ }^{1896}$. These advances had two key implications for agricultural seed manufacturers and plant and animal scientists First, the ability to identify and isolate the relevant genetic traits greatly facilitated the transference of desirable characteristics through selective breeding. Second, the ability to incorporate genetic material from one species into the DNA of another organism allowed for previously infeasible or inconceivable transfers of specific traits.

In Diamond vs Chakrabarty, the US Supreme Court extended patent claims to life sciences, this leading to the emergence of the biotechnology industry ${ }^{1897}$. In 1985 , the court expanded patent protection to genetically modified plants in Ex Parte Hibberd ${ }^{1898}$. With a utility patent, patent-holders can sue farmers and rivals for patent infringement and pursue litigation to enforce licensing agreements. These decisions have led the agricultural biotechnology industry to rely heavily on utility patents for intellectual property (IP) protection. Utility patents are thus available for the protection of plant tissue and seeds, as well as for the whole plants. The emergence of IP protection led to a shift of the paradigm from public sector innovation to private sector innovation, particularly in plant technologies and molecular level agricultural biotechnology ${ }^{1899}$. It was reported that "the average annual growth rate in utility patents for plant biotechnology was about 20 percent for major field crops, higher than the average rate of growth across all innovation areas" ${ }^{\prime 1900}$.

Further in the US, patent laws protect distinct plant varieties that are asexually reproduced. Protection is received by the special Plant Patent Act of 1930 (PPA) which established specific type

\footnotetext{
1894 P. McDougall, The cost and time involved in the discovery, development and authorisation of a new plant biotechnology derived trait, (Phillips McDougall, 2011), 7, available at https://croplife.org/wpcontent/uploads/pdf_files/Getting-a-Biotech-Crop-to-Market-Phillips-McDougall-Study.pdf .

1895 Ibid., 10.

1896 ISAAA, 2010

${ }^{1897}$ Diamond v. Chakrabarty, 447 U.S. 303 (1980).

1898227 U.S.P.Q. 443 (Board of Patent Applications and Interferences, 1985).

${ }^{1899}$ Paul W. Heisey, John L. King, and Kelly Day Rubenstein, Patterns of Public-Sector and Private-Sector Patenting in Agricultural Biotechnology, (2005) 8 AGBIOFORUM 73.

1900 Diana L. Moss, Transgenic Seed Platforms: Competition Between a Rock and a Hard Place?, AAI Submission, October 23, 2009, p.25.
} 
of patent called 'plant patent'. As opposed to utility patent mentioned above, plant patents do not require utility. Instead, it requires distinctiveness, that the plan be a distinct new variety. According to the Section 161 of the PPA: "whoever invents or discovers and asexually reproduces any distinct and new variety of plant, including cultivated sports, mutants, hybrids, and newly found seedlings, other than a tuber propagated plant or a plant found in an uncultivated state, may obtain a patent therefor, subject to the conditions and requirements of this title."1901

Sexually reproduced plants, in contrast, are protected by the Plant Variety Protection Act of 1970, a specific type of IP right which is covered in more detail in section 4.2.1.2 below

Regarding genes, the US Supreme Court held that naturally occurring DNA segment is not patent eligible merely because it has been isolated. ${ }^{1902}$ According to the US Patent Act and in the light of US Supreme Court's judgment in Mayo, ${ }^{1903}$ laws of nature, natural phenomena, and abstract ideas are not patentable. ${ }^{1904}$ On the other hand, genes that are not naturally occurring can be patented. In that regard, the court held that synthetically created DNA, that omits portions of the natural DNA, is patent eligible because it is not a product of nature. ${ }^{1905}$ Therefore, as long as the genes are modified they would be eligible for patent protection in the US.

The scope of patentability is more delineated in Europe, where plant varieties and essential biological processes are excluded from patent protection ${ }^{1906}$, also in view of the need to avoid a double protection under patent law and the sui generis plant variety protection resulting from the UPOV (Union for the Protection of New Varieties of Plants) Convention ${ }^{1907}$.

However, the European Directive 98/44/EC on the legal protection of biotechnological inventions led to the possibility of patenting when the technical feasibility of the invention is not confined to a specific plant variety ${ }^{1908}$. In 1999, the Enlarged Board of Appeal of the European Patent Office stated that "(a) patent cannot be granted for a single plant variety but can be granted if varieties may fall within the scope of its claims" ${ }^{1909}$. Indeed, according to Recital 31 of the Biotechnology Directive, "a plant grouping which is characterised by a particular gene (and not its whole genome) is not covered by the protection of new varieties and is therefore not excluded from patentability even if it comprises new varieties of plants". Plant varieties may also fall within the scope of patent claims when they are the direct product of a patented non-biological technical process.

The most recent jurisprudence of the Enlarged Board of Appeal (EBA) of the EPO has reduced even further the patentability exception enshrined in Article 53(b) EPC, even for a patent claim for a product that is directly obtained and/or defined by an "essentially biological process". The EBA held that "the fact that the only method available at the filing date for generating the claimed subject-matter is an essentially biological process for the production of plants disclosed in the patent application does not render a patent claim directed to plants or plant material other than a plant variety

\footnotetext{
190135 U.S.C.A. $\S 161$.

1902 Association for Molecular Pathology v. Myriad Genetics, Inc., 133 S. Ct. 2107, 2109, 186 L. Ed. 2 d 124 (2013)

${ }^{1903}$ Mayo Collaborative Servs. v. Prometheus Labs., Inc., 566 U.S. 66, 132 S. Ct. 1289, 182 L. Ed. 2d 321 (2012)

190435 U.S.C.A. $\S 101$

1905 Association for Molecular Pathology v. Myriad Genetics, Inc., 133 S. Ct. 2107, 2109, 186 L. Ed. 2 d 124 (2013).

1906 Article 53(b) of the European Patent Convention.

${ }^{1907}$ International Convention of the Protection of New Varieties of Plants, Ger.-Neth.-U.K., Dec. 2, 1961, 815 U.N.T.S. 89 (revised Nov. 10, 1972, Oct. 23, 1978 and Mar. 19, 1991).

1908 Article 4(2) of Directive 98/44/EC of the European Parliament and of the Council of 6 July 1998 on the legal protection of biotechnological inventions, OJ 1998 L 213/13. According to Article 2 of Directive 98/44/EC, “(a) process for the production of plants or animals is essentially biological if it consists entirely of natural phenomena such as crossing or selection".

1909 Transgenic Plant/NOVARTIS II, G 001/98 [2000] OJ 111.
} 
unallowable". ${ }^{1910}$ In essence, the EBA found that the patentability exception in Article 53(b) EPC for "essentially biological processes for the production of plants" had to be interpreted narrowly and did not extend beyond the excluded processes in order to cover products defined or obtained by such processes. Hence, a product resulting from an "essentially biological process for the production of plants or animals" may be patented as long as (i) the patentability requirements (novelty, inventive step, industrial application) are satisfied, (ii) the claim defines the product to be covered, either in a product format or in a product-by-process format, and (iii) the patent does not claim a single plant variety, which is something that is explicitly excluded from the scope of patentability under Article 53(b) EPC.

This is a very favorable position for large agrochemical corporations ${ }^{1911}$ and contrasts with the more restrictive approach followed by some EU member States' patent legislation, which exclude product claims from patentability where the claimed products have been generated by an essentially biological process for the protection of plants ${ }^{1912}$.

On the other hand, the position of the EPO that patents can be granted for plants obtained from essentially biological processes is in contrast with the position of the European Commission (EC). Namely, the EC issued a Notice where it held that the EU legislator's intention when adopting the Biotechnology Directive was to exclude from patentability products (plants/animals and plant/animal parts) that are obtained by means of essentially biological processes. ${ }^{1913}$ Formally, however, the EPO is not bound by the EU legislation and the European Commission's interpretation. The patentability of plants obtained from essentially biological processes will depend on the future interpretations by the EPO.

Opportunities for access to proprietary knowledge through IP law are generally limited. The EU biotechnology directive includes the possibility of compulsory cross-licensing for non-exclusive use where a breeder cannot acquire or exploit a plant variety right without infringing a prior patent, inasmuch as the licence is necessary for the exploitation of the plant variety to be protected. This is subject to payment of an appropriate royalty on reasonable terms ${ }^{1914}$. Nevertheless, the conditions to apply for compulsory cross-licensing are quite restrictive, as applicants must show that "(a) they have

\footnotetext{
${ }^{1910}$ Enlarged Board of Appeal, EPO, Appeal number T 1242/06, Case G 0002/12, Tomato II (March 25, 2015); Enlarged Board of Appeal, EPO, Appeal number T 0083/05 - 3.3.04, Case G 0002/13, Broccoli II (March 25, 2015). It is noteworthy that the Enlarged Board of Appeal emphasized that "there is no general notion of an obligatorily restrictive construction of exceptions to patentability, for example, such as that adopted by the Court of Justice of the European Union (CJEU) when insisting on a narrow interpretation of exceptions to or derogations from fundamental EC Treaty principles embodied in the four freedoms" (case G002/13, p. 41). Hence, the exclusion of patentability incorporated in Article 53(b) EPC of "essentially biological processes for the production of plants" does not cover any product of such a process, but only excludes biological breeding processes sensu stricto.

${ }^{1911}$ See, the discussion in Timo Minssen \& Ana Nordberg, The Impact of Brocolli II \& Tomato II on European patents in conventional vreeding, GMO's and Synthetic Biology: The grand finale of a juicy patents tale?, (2015) 34 (3) Biotechnology Law Report 81-98.

${ }_{1912}$ Enlarged Board of Appeal, EPO, Appeal number T 0083/05 - 3.3.04, Case G 0002/13, Broccoli II (March 25, 2015), pp. 64-65 [Part VIII(2)6d] referring to recent amendments to this effect in the German Patent Act of 1936 (as amended in 2013) and in the Dutch Patent Act 1995 (as amended in 2014). However, as the EBA noted, "no such amendments have been made in [...] the United Kingdom, [...] France [...] Austria [...] and Switzerland". It remains to be seen if the Court of Justice of the EU will adopt such a narrow interpretation of the exclusion of patentability of products deriving from essentially biological processes, when interpreting the exclusion rule under Article 4(1) of the Biotechnology Directive, the CJEU not being bound by the EBA jurisprudence.

${ }^{1913}$ Commission Notice on certain articles of Directive 98/44/EC of the European Parliament and of the Council on the legal protection of biotechnological inventions, OJ 2016 C 411/03.

${ }^{1914}$ Article 12, Article 4(2) of Directive 98/44/EC of the European Parliament and of the Council of 6 July 1998 on the legal protection of biotechnological inventions, OJ 1998 L 213/13.
} 
applied unsuccessfully to the holder of the patent or of the plant variety right to obtain a contractual licence; (b) the plant variety or the invention constitutes significant technical progress of considerable economic interest compared with the invention claimed in the patent or the protected plant variety"1915.

With respect to patent protection in BRICS countries, the overall situation is the following:

- Brazil: patent protection is available only to transgenic microorganisms and the processes which lead to production of transgenic seeds, plants and its parts (organs, tissues or cells), not to the final product itself. ${ }^{1916}$ However, the definition of transgenic microorganism (bacteria, mildews, yeasts, funguses, viruses) does not extend to transgenic plants, cells or seeds. As such, plant parts, including plant cells and seeds, appear not to be entitled to receive patent protection; ${ }^{1917}$

- Russia: patent protection is available for cells of plants if they represent a technical solution that is novel, has inventive step and industrial application; ${ }^{1918}$

- India: patent protection is available for the biological material such as recombinant DNA, Plasmids and processes of manufacturing thereof provided they are produced by substantive human intervention. Gene sequences, DNA sequences without having disclosed their functions are not patentable for lack of inventive step and industrial application;

- China: patent protection is available for processes used in the manufacturing of animal and plant varieties. ${ }^{1919}$ Transgenic animals or transgenic plants obtained through DNA and generic engineering are not patentable. ${ }^{1920}$ Genes, however, under certain circumstances may be patentable. ${ }^{1921}$

- South Africa: patent protection is available only for animal, plant or any essentially biological process used in the production of animals or plants or the product of the process provided the process and products are not microbiological. ${ }^{1922}$ A patent examination is not required as is the case in other countries although the recommendation for its implementation has been included the 2013 South African Intellectual Property (SA IP) Draft Policy.

Below is the overview of patents granted in BRICS countries in during the period of 2010 to 2015 by the area of technology as collected by the WIPO Intellectual Property Statistics Data Centre:

\section{Table 1: Overview of patents granted in BRICS countries (2010-2015)}

\section{Organic Fine Chemistry}

\footnotetext{
1915 Article 12, Article 4(2) of Directive 98/44/EC of the European Parliament and of the Council of 6 July 1998 on the legal protection of biotechnological inventions, OJ 1998 L 213/13.

1916 See Brazil Food Country Fiche p. 10

1917 https://www.lifesciencesipreview.com/contributed-article/brazil-focus-protecting-plant-varieties-in-brazil-withoutip-law

0003? transitionType $=$ Default $\&$ contextData $=($ sc. Default $) \&$ firstPage $=$ true $\& b h c p=1$

1919 See: China Food Country Fiche, p. 31.

1920 Wei Li, 'Patenting Genes in China, U.S., and the EU: How Does it Differ? Can It Get Out of Control?' (2016) 35 Biotechology Law Report 165.

${ }^{1921}$ Ibid.

1922 Section 25(4)(b) of the Patents Act, No. 57 of 1978
} 


\begin{tabular}{|l|l|l|l|l|l|l|}
\hline & $\mathbf{2 0 1 0}$ & $\mathbf{2 0 1 1}$ & $\mathbf{2 0 1 2}$ & $\mathbf{2 0 1 3}$ & $\mathbf{2 0 1 4}$ & $\mathbf{2 0 1 5}$ \\
\hline Brazil & 230 & 185 & 143 & 277 & 262 & 354 \\
\hline Russia & 826 & 864 & 978 & 775 & 740 & 867 \\
\hline India & 141 & 143 & 157 & 141 & 166 & 1,858 \\
\hline China & 3,252 & 4,500 & 6,529 & 7,551 & 8,247 & 10,436 \\
\hline $\begin{array}{l}\text { South } \\
\text { Africa }\end{array}$ & 37 & 240 & 564 & 368 & 467 & 158 \\
\hline
\end{tabular}

\begin{tabular}{|l|l|l|l|l|l|l|}
\hline & \multicolumn{4}{|l}{ Biotechnology } & & \\
& $\mathbf{2 0 1 0}$ & $\mathbf{2 0 1 1}$ & $\mathbf{2 0 1 2}$ & $\mathbf{2 0 1 3}$ & $\mathbf{2 0 1 4}$ & $\mathbf{2 0 1 5}$ \\
\hline Brazil & 51 & 52 & 24 & 66 & 84 & 103 \\
\hline Russia & 493 & 537 & 506 & 483 & 566 & 676 \\
\hline India & 58 & 40 & 25 & 33 & 42 & 982 \\
\hline China & 2,197 & 3,292 & 5,409 & 6,986 & 6,595 & 6,465 \\
\hline $\begin{array}{l}\text { South } \\
\text { Africa }\end{array}$ & 373 & 129 & 422 & 311 & 342 & 124 \\
\hline
\end{tabular}

\begin{tabular}{|l|l|l|l|l|l|l|}
\hline & \multicolumn{3}{|l}{ Food Chemistry } & & & \\
& $\mathbf{2 0 1 0}$ & $\mathbf{2 0 1 1}$ & $\mathbf{2 0 1 2}$ & $\mathbf{2 0 1 3}$ & $\mathbf{2 0 1 4}$ & $\mathbf{2 0 1 5}$ \\
& & & & & & \\
\hline Brazil & 43 & 49 & 27 & 98 & 125 & 143 \\
\hline Russia & 4,064 & 4,165 & 2,844 & 3,352 & 4,961 & 2,461 \\
\hline India & 17 & 12 & 13 & 5 & 10 & 413 \\
\hline China & 1,930 & 2,943 & 7,371 & 8,950 & 6,843 & 7,952 \\
\hline $\begin{array}{l}\text { South } \\
\text { Africa }\end{array}$ & 187 & 65 & 175 & 136 & 203 & 67 \\
\hline
\end{tabular}

Source: Authors' compilation of data

Table 2: Granted patents (biotechnology) BRICS 2010-2015 


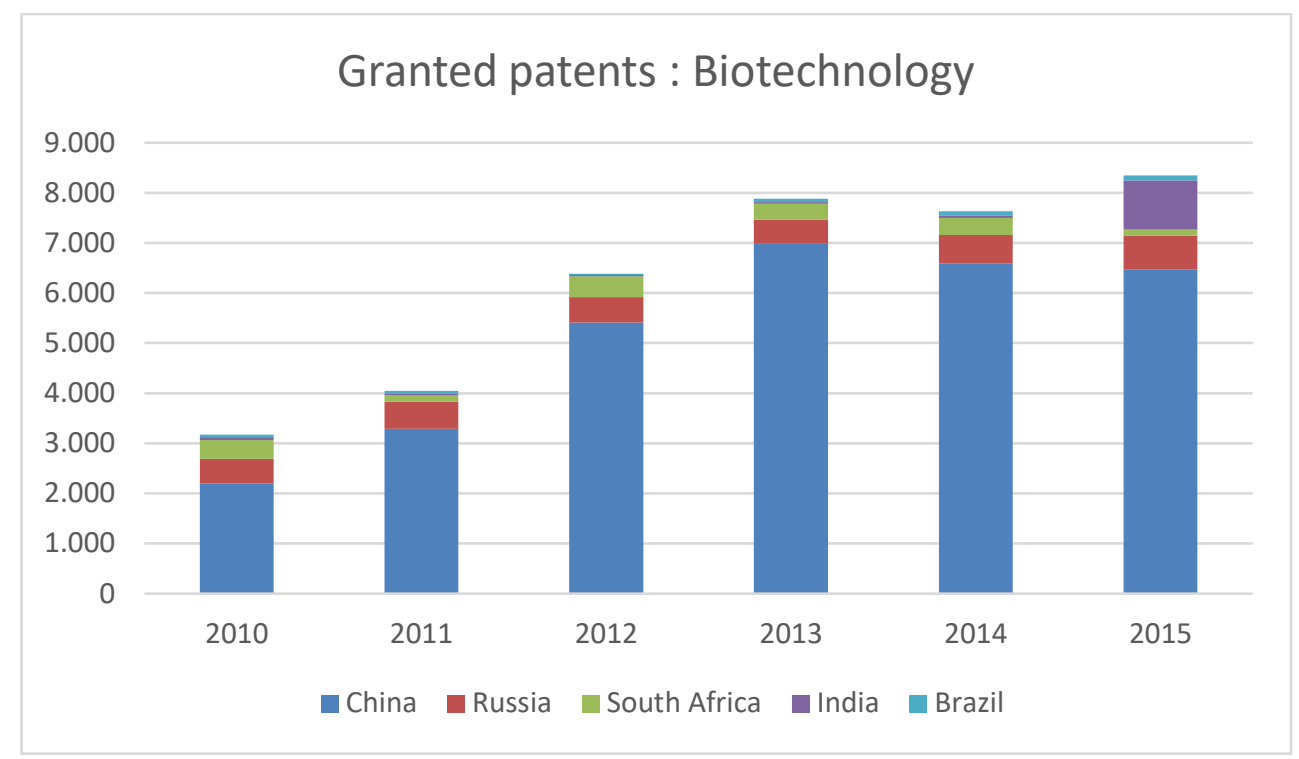

Source: Authors's calculation

Figure 2: Granted patents (food chemistry) BRICS 2010-2015

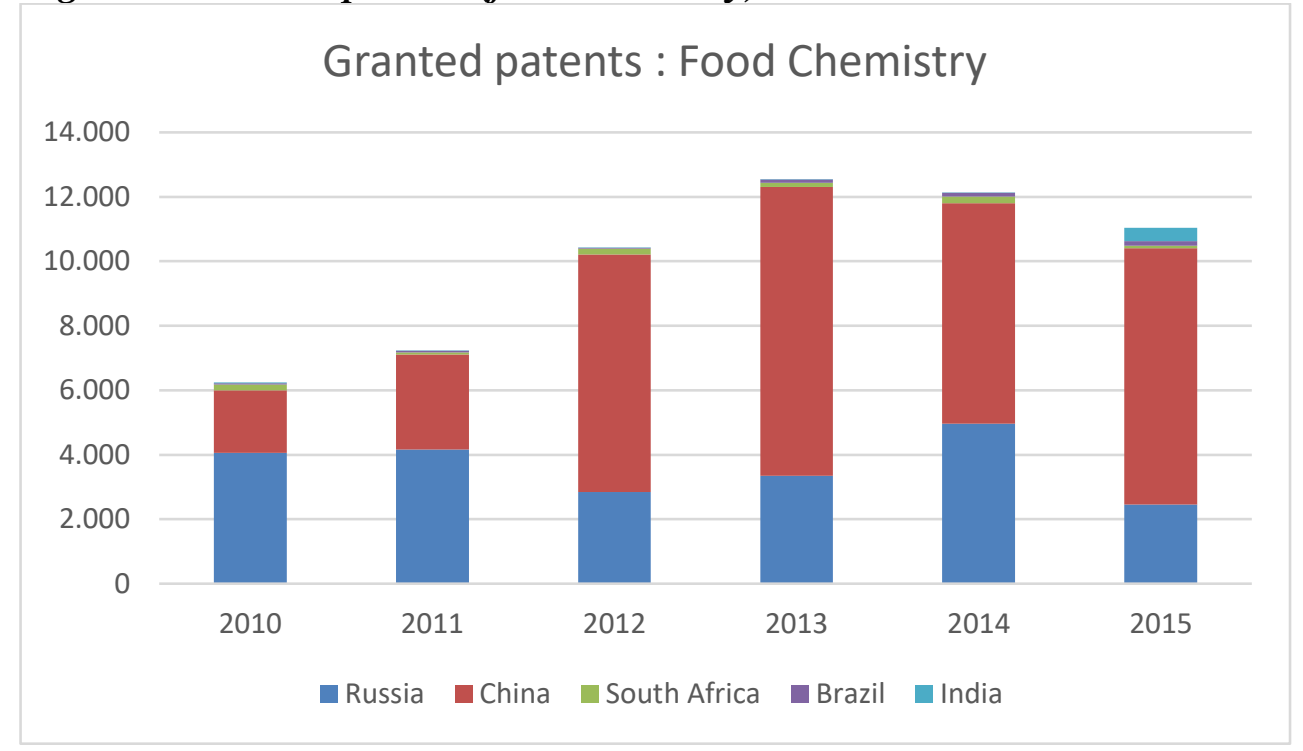

Source: Authors's calculation

The following figure also aggregates different technologies that could be relevant and all BRICS data (on the basis of the WIPO database)

Figure 3: Granted patents per year per technology group (BRICS) 


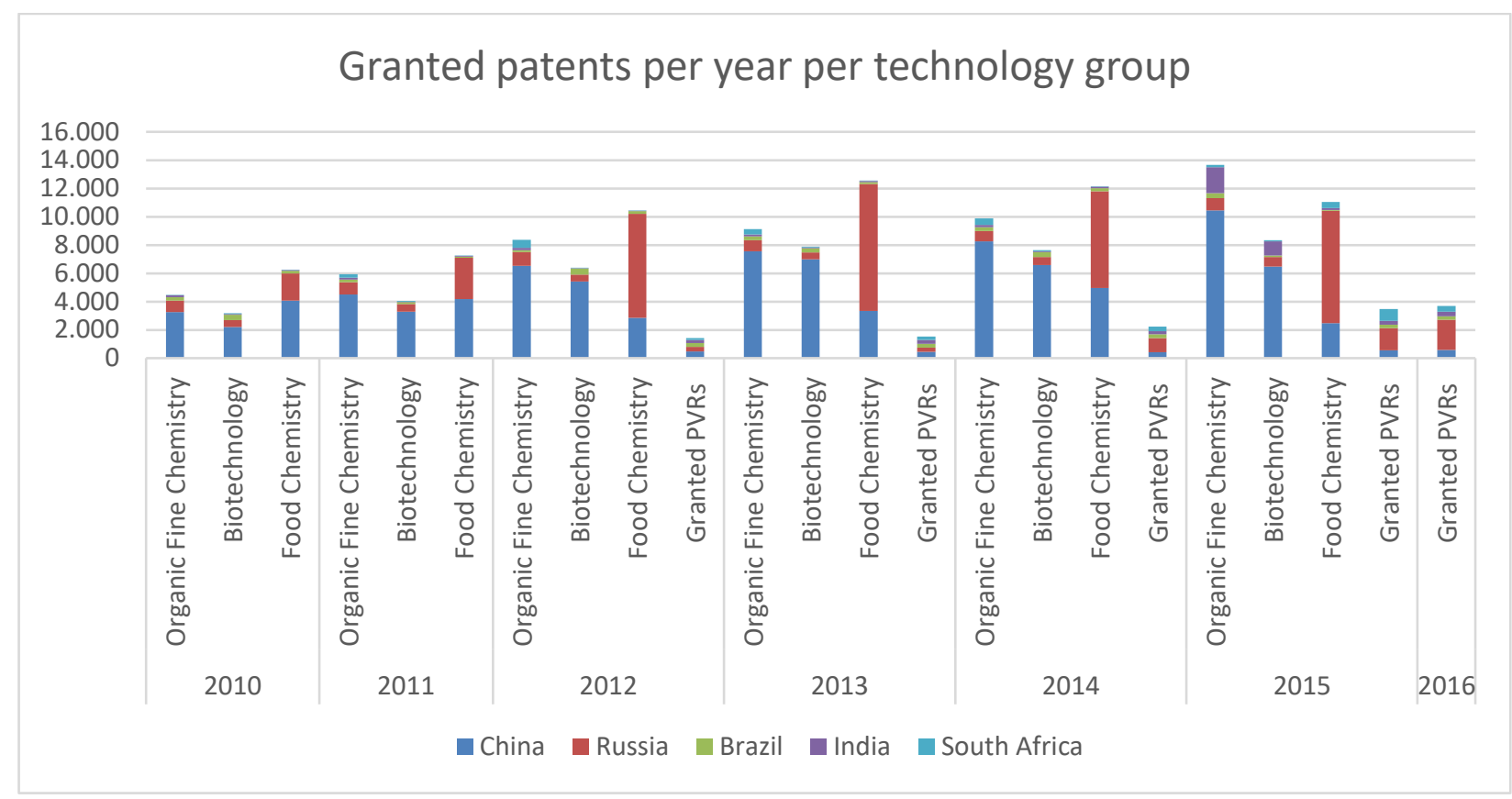

Source: Authors' data compilation

With regard to the respective strength of the Big 6 in terms of patents they have been granted, the following tables compile data from the EPO. It has not been possible to identify the patents related to the agrochem industry, so the statistics present the overall strength of these companies in terms of the number of patents granted.

Table 3: EPO - patents granted patents per year 2005-2016

Patents granted by the EPO between 2005-2016

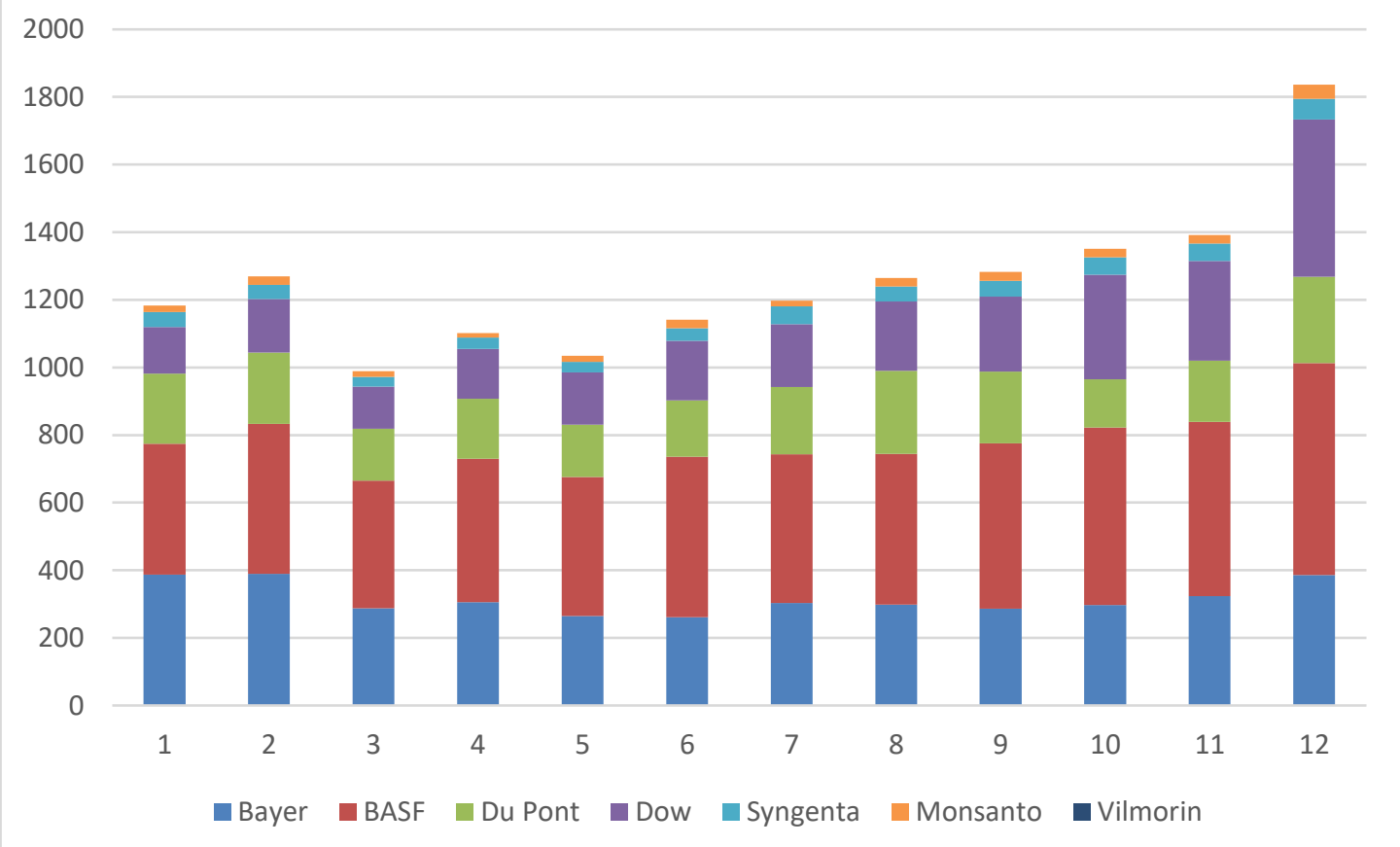

Source: Authors' calculations 
Most of the companies granted biotechnology patents are pharmaceutical companie, although DuPont, Bayer, BASF, DSM are also among the tiop applicants (although the figures refer to all life sciences related patents, including agricultural biotech).

\section{Figure 4: EPO top patent applicants in biotechnology in 2016}

\section{EPO top patent applicants in biotechnology in 2016 (top 10 companies)}

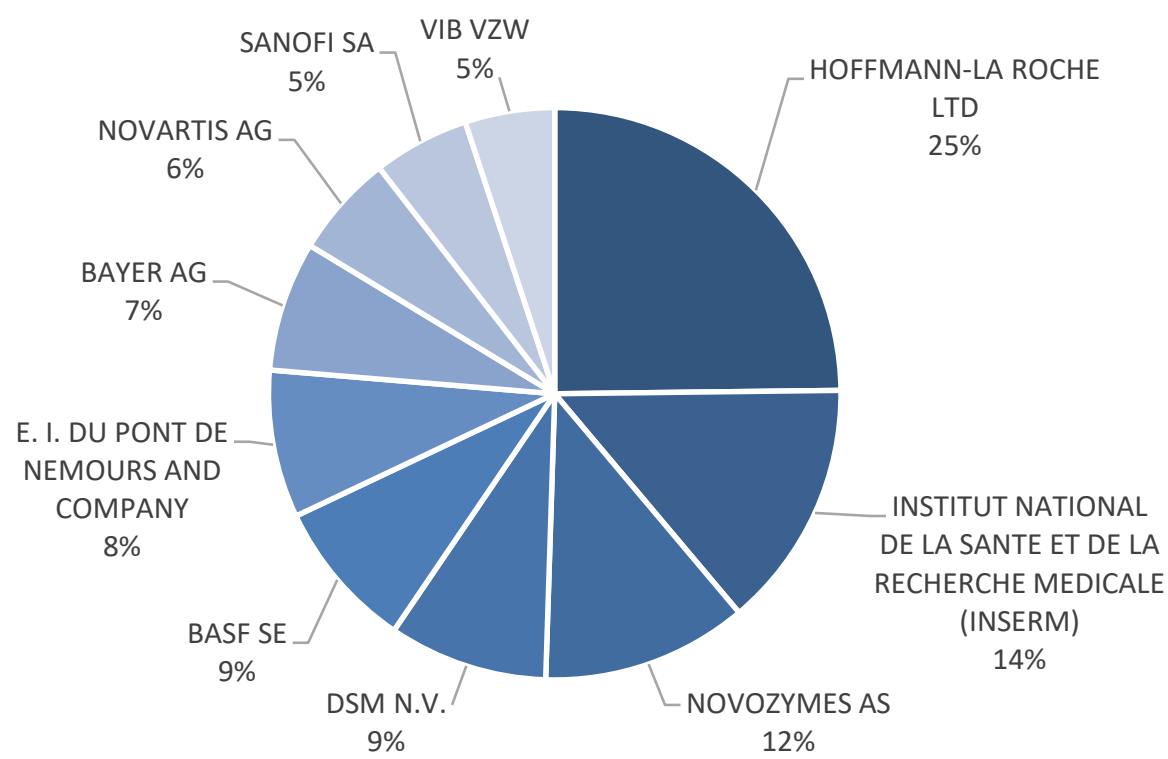

Source: Authors' calculations

This information of course provides little information as to the quality of these patents. Of course, measure of $R \& D$ concentration are issuance of patents.

With regard to the US, the following data compiled by the USPTO database may provide some insights over the innovative potential of some of the R\&D focused global corporations in agricultural biotech (although the patent figures do not only include agricultural biotech related patents). The figure also includes information on plant patents.

Figure 5: The innovative potential of the large $R \& D$ agrichem corporations: $U S$ 


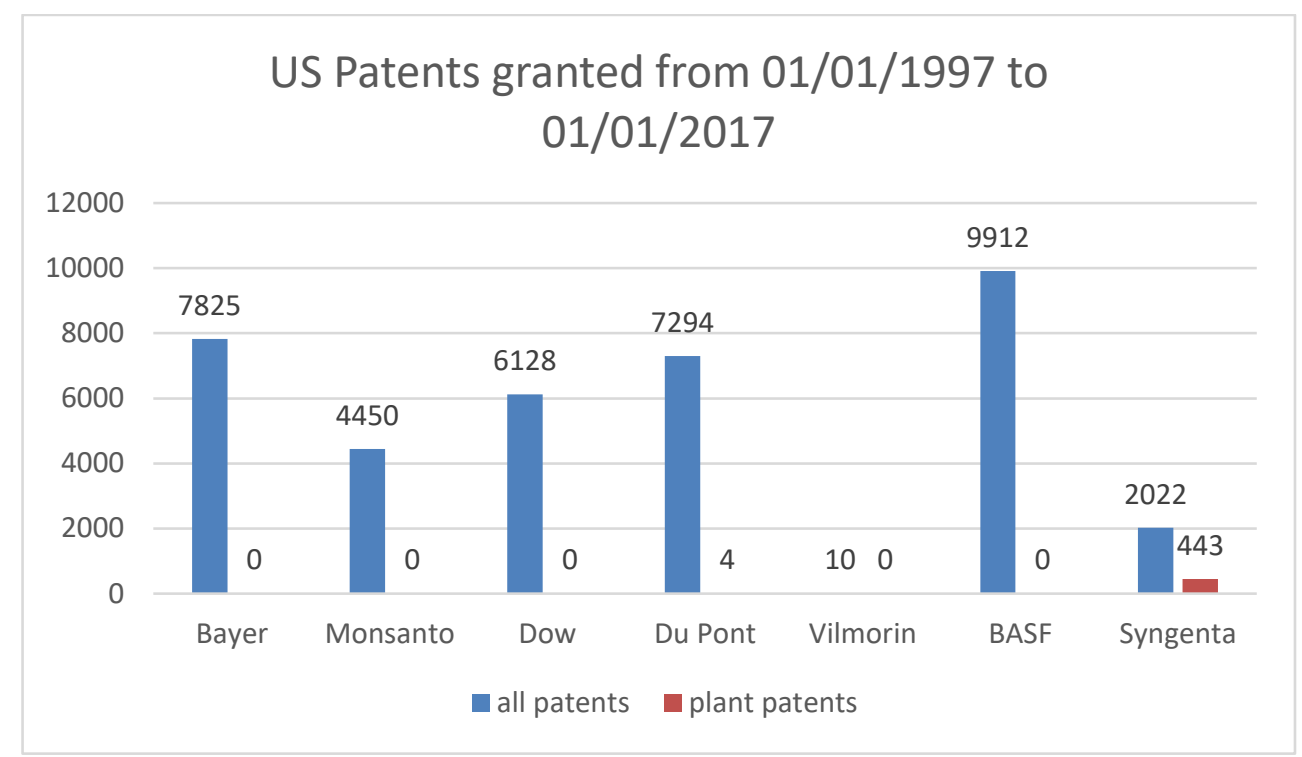

Source: Authors's data compilation

\subsubsection{Plant/Animal breeder's rights}

According to the TRIPS agreement, every country must have at least sui generis protection for plants. Article 27.3(b) allows WTO members to exclude "plants and animals other than microorganisms and essentially biological processes for the production of plants and animals other than micro-organisms and essentially biological processes for the production of plants and animals other than biological and microbiological processes", provided that they offer patents or establish "an effective sui generis system" of protection for plant varieties. Yet, the WTO stays short in defining precisely what constitutes an "effective sui generis system". Many jurisdictions protect plant varieties through the UPOV (Union for the Protection of New Varieties of Plants) Convention, which was adopted in 1961, in order to safeguards the interests of farmers and breeders with exemptions permitting farmers to save seed from one growing season to another and allowing breeders to use protected seeds for research purposes ${ }^{1923}$. UPOV is an intergovernmental organization, most of its members being developed industrialised countries, which administers common rules for the recognition and protection of plant variety protection globally.

Like patents, plant variety protection providing patent-like rights to plant breeders. These sui generis IPRs protect the genetic makeup of a specific plant variety, the criteria for protection being novelty, distinctness, uniformity and stability. PVP confers to the developer of a novel combination of genes manifested as a distinct, uniform and stable variety (the phenotype of the variety) a bundle of rights, without any need to prove an inventive step nor a specific utility, as title is provided solely on the evaluation of the variety's value in terms of genetic quality. Although plant variety protection laws can provide exemptions for breeders, allowing them to use protected varieties for further breeding and for farmers and allowing them to save seeds from their harvest, these exceptions are provided under highly restricted conditions and these regimes have become more and more similar to the protection provided by patents, in particular since the 1991 UPOV Convention.

${ }^{1923}$ International Convention of the Protection of New Varieties of Plants, Ger.-Neth.-U.K., Dec. 2, 1961, 815 U.N.T.S. 89 (revised Nov. 10, 1972, Oct. 23, 1978 and Mar. 19, 1991). 
Countries such as the US have pursued a system of concurrent protection of a plant variety through the grant of utility patents, plant patents and plant variety protections (the latter protected in adherence to the UPOV Convention 1991 Act). ${ }^{1924}$ US Supreme Court decisions in J.E.M. Ag Supply, Inc. v. Pioneer Hi-Bred ${ }^{1925}$ and more recently in Bowman v. Monsanto ${ }^{1926}$ have emphasized the importance of conceiving these different systems of IP rights (utility patents, plant patent, plant variety protection) as parallel to one another rather than mutually exclusionary. This complementarity is also supported by the lack of wording to the contrary in the relevant legislation (U.S. plant patent legislation, U.S. Plant Variety Protection Act) and the divergence of scope and requirements for each type of IP protection in this area. ${ }^{1927}$ The plant variety protection is seen as an encouragement for new varieties of sexually reproduced plants, protecting their breeders and developers. Its scope covers plants that are sexually reproduced, tuber propagated, and F1 hybrids. ${ }^{1928}$ In addition to compliance with the criteria of 'novelty, distinctness, uniformity and stability', the US provisions on plant variety protection require the deposit of propagation material for the purpose of preservation; the material deposited need not be accessible to the public. ${ }^{1929}$ The issuance of a certificate requires initial fees but no maintenance fees. ${ }^{1930}$

In the EU too there is an overlap of different systems of IP protection in relation to plant varieties. ${ }^{1931}$ The Community-wide plant variety protection exists under the Community Plant Variety Rights regime pursuant to Regulation 2100/94 (which rests on the UPOV Convention 1991 Act). The criteria to grant plant variety protection are the same as those identified above in other jurisdictions, including the addition of the fact that the variety under scrutiny must be designated by a denomination in accordance with the provisions of Article 63 of Regulation 2100/94. The Community-wide provisions coexists with national plant variety protection present in twenty-three EU member states. ${ }^{1932}$ Thus, breeders may choose to rely on a plant variety protection that extends its coverage to the whole EU, or alternatively to a specific number of member states. ${ }^{1933}$ In order to benefit from the Community-wide plant variety protection, fees have to be paid for registration and on annual basis for each year of protection.

The boundaries of these IP rights have also been broadly interpreted. In Erawu-Jacquery $v$ La Hesbignonne, the Court of Justice of the EU held that a prohibition on the sale or export of basic seeds by the IP right holder was not subject to Article 101 TFEU since considerable investment had been made in developing the basic seed. According to the Court, "a person who has made considerable efforts to develop varieties of basic seed which may be the subject-matter of plant

\footnotetext{
${ }^{1924}$ On this generally, see also Mark D. Janis, Non-obvious plants, in Duncan Matthews and Herbert Zech (eds), Research Handbook on Intellectual Property and the Life Sciences (Edward Elgar, 2017).

1925 J.E.M. Ag Supply, Inc. v. Pioneer Hi-Bred Int'l, Inc., 534 U.S. 124 (2001).

${ }^{1926}$ Bowman v. Monsanto Co., 133 S.Ct. 1761, 1767 (2013)

${ }^{1927}$ Mark D. Janis, Non-obvious plants, in Duncan Matthews and Herbert Zech (eds), Research Handbook on Intellectual Property and the Life Sciences (Edward Elgar, 2017), pp. 163-164.

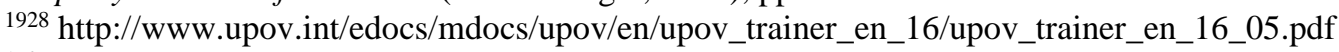

${ }^{1929}$ Mark D. Janis, Non-obvious plants, in Duncan Matthews and Herbert Zech (eds), Research Handbook on Intellectual Property and the Life Sciences (Edward Elgar, 2017).

$1930 \mathrm{http} / /$ www.upov.int/edocs/mdocs/upov/en/upov_trainer_en_16/upov_trainer_en_16_05.pdf.

${ }^{1931}$ On this, see for example Axel Metzger, Patents on native traits: what scope of protection?' in Duncan Matthews and Herbert Zech (eds), Research Handbook on Intellectual Property and the Life Sciences (Edward Elgar, 2017).

1932 Bart Kiewiet, The Community Plant Variety Protection System, (1 July 2009) CVPO available at: http://cpvo.europa.eu/sites/default/files/documents/articles/2009-07-10_Article_Italy.pdf.

1933 Bart Kiewiet, The Community Plant Variety Protection System, (1 July 2009) CVPO available at: http://cpvo.europa.eu/sites/default/files/documents/articles/2009-07-10_Article_Italy.pdf.
} 
breeders' rights must be allowed to protect himself against any improper handling of those varieties of seed" and "to that end, the breeder must be entitled to restrict propagation to the growers which he has selected as licensees"1934. In Bowman v. Monsanto, the US Supreme Court held that the sale of one generation of seed does not exhaust rights on later generations: a farmer who purchased seed to grow could not sow a new crop using the seeds produced by the fist crop - as that, the Court held, would constitute making the patented product and not reusing or selling the seed that had been purchased.

BRICS countries have implemented differently the plant variety protection rights, under direct or indirect pressure from developed countries, in the context of bilateral trade and investment agreements containing an obligation for developing countries to embrace UPOV rules.

India's Protection of Plant Varieties and Farmers' Rights Act, 2001 (PVPFR Act), which became fully operational in 2007, require that the breeder or any other person entitled to produce, market and sell the seeds of a registered variety must make such seeds or propagating materials available to farmers "in a timely manner" to "satisfy their requirements" and "at a reasonable market price"1935. A number of provisions in the PVPFR Act directly or indirectly recognize specific rights of, or grant entitlements to, farmers and farming community ${ }^{1936}$. Farmers have the right to 'save, use, sow, resow, exchange, share or sell' farm produce including seed of a protected variety in the same manner as they were entitled to prior to the Act, without however that involving the right to sell branded seed of a protected variety. Farmer are also entitled to recognition and reward in cases where the genetic material they preserved and improved is used in developing new varieties. Farmers have the right to claim compensation from the breeder, if the variety they purchased fails to perform as per the disclosure made by the breeder. Finally, they are immune from infringement legal action, if such infringement was innocent. Most importantly, the Authority in charge of the implementation of the Act is empowered to issue compulsory license after three years of registration, if the breeder fails to satisfy the reasonable requirements of the public for the seed or other propagating material or that the seed or propagating material has not been made available to the public at a reasonable price. The effects of UPOV protection on the quality or diversity of plant varieties is a matter for investigation, much commercial breeding being directed at cosmetic changes in order to serve market strategies.

China's protection of new plant varieties is provided for by the Regulations of the PRC on protection of New Varieties of Plants 1997 (amended on March 1, 2013) (the Regulations) and Seed Law of the People's Republic of China (Amended in 2015) (SLPRC). The first instrument is an administrative regulation and therefore at a hierarchical lower level; the second instrument, through its dedicated chapter on the Protection of New Varieties (chapter IV), therefore strengthens the plant variety protection by upgrading its standing on the basis of a law. ${ }^{1937}$ China is only a signatory to the UPOV Convention Act 1978 and not the UPOV Convention Act 1991. ${ }^{1938}$ The Regulations sets down a protection of plant varieties for botanical genus and species that are included in the National List of the Protected Plant, provided the usual criteria of novelty, distinctness, uniformity and stability and

\footnotetext{
${ }^{1934}$ Case 27/87 SPRL Louis Erauw-Jacquery v La Hesbignonne SC [1988] ECR 1919. See also, Case 258/78, Nungesser v. Commission [1982] ECR 2015, para. 10

1935 Protection of Plant Varieties and Farmers' Rights Rules, 2003 (as amended in 2012), Rule 36A.

${ }^{1936}$ For a description see, Sujith Koonan, India's sui generis system of plant variety protection (January 2014), available at http://www.quno.org/sites/default/files/resources/QUNO\%20India\%20-\%20plant\%20variety\%20protection\%20$\% 202014 . p d f$

1937 Cuicui Liu and Wenhui Zhang, Recent Advances in Protection of New Varieties of Plants, Lexology (19 July 2016).

$1938 \mathrm{http}: / /$ www.upov.int/en/publications/conventions/1991/act1991.htm.
} 
adequate denomination are respected. ${ }^{1939}$ Farmers are given a right of access to seeds and to propagate the protected variety material on their holdings when this was obtained by harvesting the material of protected variety on their own holdings in the first place. ${ }^{1940}$ Compulsory licensing may be granted by the Ministry of Agriculture for the implementation of varieties where national or public interest reasons may arise. ${ }^{1941}$

Brazil's Plant Variety Protection Act (Law 9,456 of 25 April, 1997) (PVPA) offers plant variety protection for conventional breeding techniques that would not qualify for patents under Brazilian law. ${ }^{1942}$ The PVPA incorporates into Brazilian law the provisions of the UPOV Convention Act $1978 .{ }^{1943}$ In order to avail of the protection the variety of plant genus or species would have satisfy UPOV criteria of eligibility as contained in the PVPA. Exceptions to the plant variety protection arise for farmers in certain cases, for example where they reserve and plant seeds for personal use in their own holding, or they use or sell products or the material obtained in their holding (except for reproduction), or where they multiply seeds for donation or exchange (only for small rural producers). ${ }^{1944}$ The revised Seeds Act 2003 also contains some provisions that recognise varieties that are connected to family farmers and indigenous people, whereby these categories benefit from an exemption of registration in the National System of Seeds and Plant Seedlings in instances of multiplication of seeds for "distribution, exchange or commercialization among themselves." 1945

The Russian law that provides for the protection of new plant varieties is the law "On Seed Breeding" of 17 December 1997 N 149-FZ (Russian Law "On Seed Breeding). The law is based on the UPOV Convention acceded by Russia on 24 April 1998. The new variety of plant has to satisfy the UPOV criteria of eligibility and be included in the State Register of the Plant Variety Admitted to Use. ${ }^{1946}$ The breeder of the new variety would have to be registered as well by State Commission of the Russian Federation for Testing and Preservation of Plant Varieties. ${ }^{1947}$ The Russian Federation Civil Code (Civil Code) prescribes that the exclusive right of plant varieties is protected through registration in the State Register of Protected Varieties of Plants and confirmed by subsequent patent. ${ }^{1948}$ The exceptions to the rights of the breeder are the usual ones set forth by the UPOV Convention, with some additional provisions for the protection of farmers granted by the Civil Code. Thus, for instance, farmers are allowed to the use of the products of the harvest in their own holding for a period of two years for propagating within their own holding, if the variety is found in the list

\footnotetext{
${ }^{1939}$ Li Jinguang, A view on Plant variety under china's Plant IP Protection system, (2011) 44 China Intellectual Property Magazine; Cuicui Liu and Wenhui Zhang, Recent Advances in Protection of New Varieties of Plants, Lexology (19 July 2016).

${ }^{1940}$ Regulations Art. 10; SLPRC 2015 Article 29; Li Jinguang, A view on Plant variety under china's Plant IP Protection system, (2011) 44 China Intellectual Property Magazine.

${ }^{1941}$ Regulations Art. 11; SLPRC 2015 Article 30.

1942 On this see also Marcelo Dias Varella, Intellectual Property and Agriculture: The Case on Soybeans and Monsanto, 18 (2013) J. Tech. L. \& Pol'y 59-82.

${ }^{1943}$ Renata Campello Afonso, Brazil focus: Protecting plant varieties — without IP law, Life Sciences Intellectual Property Review (16 June 2015).

${ }^{1944}$ Renata Campello Afonso, Brazil focus: Protecting plant varieties-without IP law, Life Sciences Intellectual Property Review (16 June 2015); Karine Peschard (2017) Seed wars and farmers' rights: comparative perspectives from Brazil and India, The Journal of Peasant Studies, 44:1, 144-168.

1945 Karine Peschard (2017) Seed wars and farmers' rights: comparative perspectives from Brazil and India, The Journal of Peasant Studies, 44:1, 144-168

${ }^{1946}$ Russian Law "On Seed Breeding" art. 6.

1947 'Provisions on the Registration of the Originator of the Variety of the Plant' adopted by the Decree of the Ministry of Agriculture and Food Production of the Russian Federation as of 10 February 1999 N 50, paras 1, 6.

${ }^{1948}$ Russian Federation Civil Code Article 1414.
} 
of varieties adopted by the Government of the Russian Federation. Compulsory licensing of protected varieties is also available after three years from the patent, where a person is prepared to use that variety but is refused by the patent holder. The action for compulsory licence is brought in the court, which then defines the conditions of the license and the amount of payment. ${ }^{1949}$

South Africa's law on plant variety protection is found in Plant Breeders' Rights Act 15 of 1976 (as amended), which reflects the additional steps undertaken by the country in its membership to the UPOV Convention. ${ }^{1950}$ The legislation provides for the conventional UPOV protection provided the criteria of eligibility to register a plant variety are satisfied. Rights are granted to farmers who use harvested material obtained on their holding from that propagating material with the objective of propagation. However, the harvested material cannot be used for propagation by anyone outside that farmer and thus farmers are only allowed to replant farm-saved seeds belonging to protected variety in their own holdings. ${ }^{1951}$

The tables below summarises the state of art of plant and animal breeders' rights in BRICS jurisdictions.

Table 4: Plant breeders' rights in BRICS

\begin{tabular}{|c|c|c|c|}
\hline & PVP laws & PVP conventions & Institutions \\
\hline Brazil & $\begin{array}{l}\text { a. Law No. } 9.456 \text { of April } \\
\text { 28, } 1997 \text { (Plant Variety } \\
\text { Protection Law); } \\
\text { b. Law No. } 11.105 \text { of } \\
\text { March 24, } 2005 \text { (Biosafety } \\
\text { Law); }\end{array}$ & $\begin{array}{l}\text { a. UPOV Convention for } \\
\text { the protection of new } \\
\text { varieties of plants }{ }^{1952} \text {; } \\
\text { b. Agreement on Trade- } \\
\text { Related Aspects of } \\
\text { Intellectual Property } \\
\text { Rights (TRIPS } \\
\text { Agreement). }\end{array}$ & $\begin{array}{l}\text { a. The National Plant } \\
\text { Varieties Protection } \\
\text { Service (SNPC) - Ministry } \\
\text { of Agriculture; }{ }^{1953} \\
\text { b. National Biosecurity } \\
\text { Council-CNBS. }{ }^{1954}\end{array}$ \\
\hline Russia & $\begin{array}{l}\text { a. General applicable IP } \\
\text { rights: Civil Code of the }\end{array}$ & $\begin{array}{l}\text { a. UPOV Convention for } \\
\text { the protection of new } \\
\text { varieties of plants }{ }^{1956} \text {; } \\
\text { b. Agreement on Trade- } \\
\text { Related Aspects of } \\
\text { Intellectual Property } \\
\text { Rights } \\
\text { Agreement). }\end{array}$ & Antimonopoly \\
\hline
\end{tabular}

\footnotetext{
1949 Russian Federation Civil Code Article 1423.

1950 Sileshi Bedasie, The Possible Overlap Between Plant Variety Protection And Patent: Approaches In Africa With Particular Reference To South Africa And Ethiopia, 1(1) (2012) Haramaya Law Review 125-136.

${ }^{1951}$ Plant Breeders' Rights Act 15 of 1976 (as amended) section 23; Netnou-Nkoana NC, Jaftha JB, Dibiloane MA, Eloff J. "Understanding of the farmers' privilege concept by smallholder farmers in South Africa", S Afr J Sci. 2015.

$1952 \mathrm{http}: / / \mathrm{www} . u p 0 v$. int/en/publications/conventions/1991/act1991.htm.

1953 Established with Article 44 Law No. 9.456 of April 28, 1997.

1954 Established by Article 8 Law No. 11.105 of March 24, 2005.

${ }^{1956} \mathrm{http}: / /$ www.upov.int/en/publications/conventions/1991/act1991.htm.
} 


\begin{tabular}{|c|c|c|c|}
\hline & $\begin{array}{l}\text { Russian Federation (as } \\
\text { amended up to 2014); }{ }^{1955} \\
\text { b. IP-related laws: } \\
\text { - Federal Law No. 135-FZ } \\
\text { of July 26, } 2006 \text { on the } \\
\text { Protection of Competition } \\
\text { (as last amended on } \\
\text { December 6, 2011); } \\
\text { - Federal Law No. 149-FZ } \\
\text { of December 17, 1997 on } \\
\text { Seed Culturing (as last } \\
\text { amended by Federal Law } \\
\text { No. 248-FZ of July 19, } \\
\text { 2011). }\end{array}$ & & \\
\hline India & $\begin{array}{l}\text { a. Protection of Plant } \\
\text { Varieties and Farmers' } \\
\text { Rights Act, 2001; } \\
\text { b. The Patents Act, } 1970 \\
\text { (as amended up to Patents } \\
\text { (Amendment) Act, 2005). } \\
\text { IP-related laws: } \\
\text { a. The Seeds } \\
\text { (Amendment) Act, } 1972 \\
\text { b. The Seeds Act } 1966 .\end{array}$ & $\begin{array}{l}\text { a. Agreement on Trade- } \\
\text { Related Aspects of } \\
\text { Intellectual Property } \\
\text { Rights } \\
\text { Agreement); } \\
\text { b. International Treaty } \\
\text { on Plant Genetic } \\
\text { Resources for Food and } \\
\text { Agriculture. }\end{array}$ & $\begin{array}{l}\text { a. Protection of Plant } \\
\text { Varieties and Farmers } \\
\text { Rights Authority }{ }^{1957} \text {; } \\
\text { b. The Appellate Board. }{ }^{1958}\end{array}$ \\
\hline China & $\begin{array}{l}\text { Regulations of the } \\
\text { People's Republic of } \\
\text { China, the Protection of } \\
\text { New Varieties of Plants of } \\
1 \text { October } 1997^{1959}\end{array}$ & $\begin{array}{l}\text { a. UPOV Convention for } \\
\text { the protection of new } \\
\text { varieties of plants; }{ }^{1960} \\
\text { b. Agreement on Trade- } \\
\text { Related Aspects of } \\
\text { Intellectual Property } \\
\text { Rights (TRIPS } \\
\text { Agreement). }\end{array}$ & $\begin{array}{l}\text { Ministry of Agriculture } \\
\text { (MOA): } \\
\text { - promulgated "The } \\
\text { Implementing Rules for the } \\
\text { Regulations of the People's } \\
\text { Republic }\end{array}$ \\
\hline
\end{tabular}

${ }^{1955}$ Part IV of the Civil Code "codifies fundamental rules and principles of intellectual property law and has for the first time introduced provisions relating to databases protected by copyright". For specific provisions on intellectual property, see Chapter 70 'Copyright', Chapter 71 'Related Rights', Chapter 72 'Patent Law', Chapter 73 'Selection Achievements', Chapter 74 'Topologies of Integrated Circuits', Chapter 75 'The Right to Trade Secret (Know-How), Chapter 76 'Rights to the Means of Individualization of Legal Entities, Goods, Works, Services and Enterprises, and Chapter 77 'Right of Using the Results of Intellectual Activity within a Unified Technology'; source wipolex database.

For other general provisions relating to intellectual property provided for in the Civil Code, see:

-Part I, Chapter 2, Articles 2, 8 \& 3; Chapter 3, Articles 18 \& 26; Chapter 4, Articles 64; Chapter 6, Articles 128 \& 129; Chapter 16, Article 256

-Part II, Chapter 38, Articles 769, 773 \& 772; Chapter 45, Article 855; Chapter 54, Article 1028.

${ }^{1957}$ Established by Chapter II Protection of Plant Varieties and Farmers' Rights Act, 2001.

${ }^{1958}$ As established by Art. 116 of the Patents Act, 1970.

${ }^{1959} \mathrm{http}: / /$ www.wipo.int/wipolex/en/text.jsp?file_id=360025.

$1960 \mathrm{http}: / / \mathrm{www} . u p o v \cdot$.int/en/publications/conventions/1991/act1991.htm. 


\begin{tabular}{|c|c|c|c|}
\hline & & & $\begin{array}{l}\text { of China on the Protection } \\
\text { of New Varieties of Plants } \\
\text { (Agriculture Part)". }{ }^{1961} \\
\text { - is responsible for the } \\
\text { protection of new varieties } \\
\text { of field crops, vegetables, } \\
\text { ornamental species and } \\
\text { fruit crops. }{ }^{1962} \\
\text { State Forestry } \\
\text { Administration (SFA): } \\
\text {-promulgated "The Rules } \\
\text { for the Implementation of } \\
\text { the Regulations of the } \\
\text { People's } \\
\text { Republic of China On the } \\
\text { Protection of New Varieties } \\
\text { of Plants (Forest Part)" } 1963 \text {; } \\
\text { - responsible for the } \\
\text { protection of new varieties } \\
\text { of forest trees, bamboo and } \\
\text { woody rattan, woody } \\
\text { ornamental plant (including } \\
\text { woody flower e.g. roses), } \\
\text { fruit tree (dry fruit), woody } \\
\text { oil-bearing plants, plants } \\
\text { used for beverage, plants } \\
\text { used for condiment and } \\
\text { woody herbs as well as } \\
\text { other plants which are in } \\
\text { conformity with Article } 2 \\
\text { of the Regulations. }\end{array}$ \\
\hline $\begin{array}{l}\text { South } \\
\text { Africa }\end{array}$ & $\begin{array}{l}\text { a. Plant Breeders' Rights } \\
\text { Amendment Act } 1996 \\
(\text { Act No. } 673 \text { of 1996) }\end{array}$ & $\begin{array}{l}\text { a. UPOV Convention for } \\
\text { the protection of new } \\
\text { varieties of plants }^{1965} \text {; }\end{array}$ & $\begin{array}{l}\text { The Registrar of Plant } \\
\text { Breeders' Rights. }{ }^{1966}\end{array}$ \\
\hline
\end{tabular}

1961 http://www.cnpvp.cn/en/index.html.

${ }^{1962}$ In October 2011, the protection of plant varieties under the authority of MOA covered 80 genera and species, see http://www.cnpvp.com/english/Introduction\%20of\%20the\%20Network.htm.

1963 http://www.cnpvp.net/index/index_en.aspx.

${ }^{1964}$ In October 2011, the protection of plant varieties under the authority of SFA covered 78 genera and species, see http://www.cnpvp.com/english/Introduction\%20of\%20the\%20Network.htm.

${ }^{1965} \mathrm{http}: / /$ www.upov.int/en/publications/conventions/1991/act1991.htm.

${ }^{1966}$ As established by the Plant Breeders' Rights Amendment Act 1996 (Act No. 673 of 1996). 


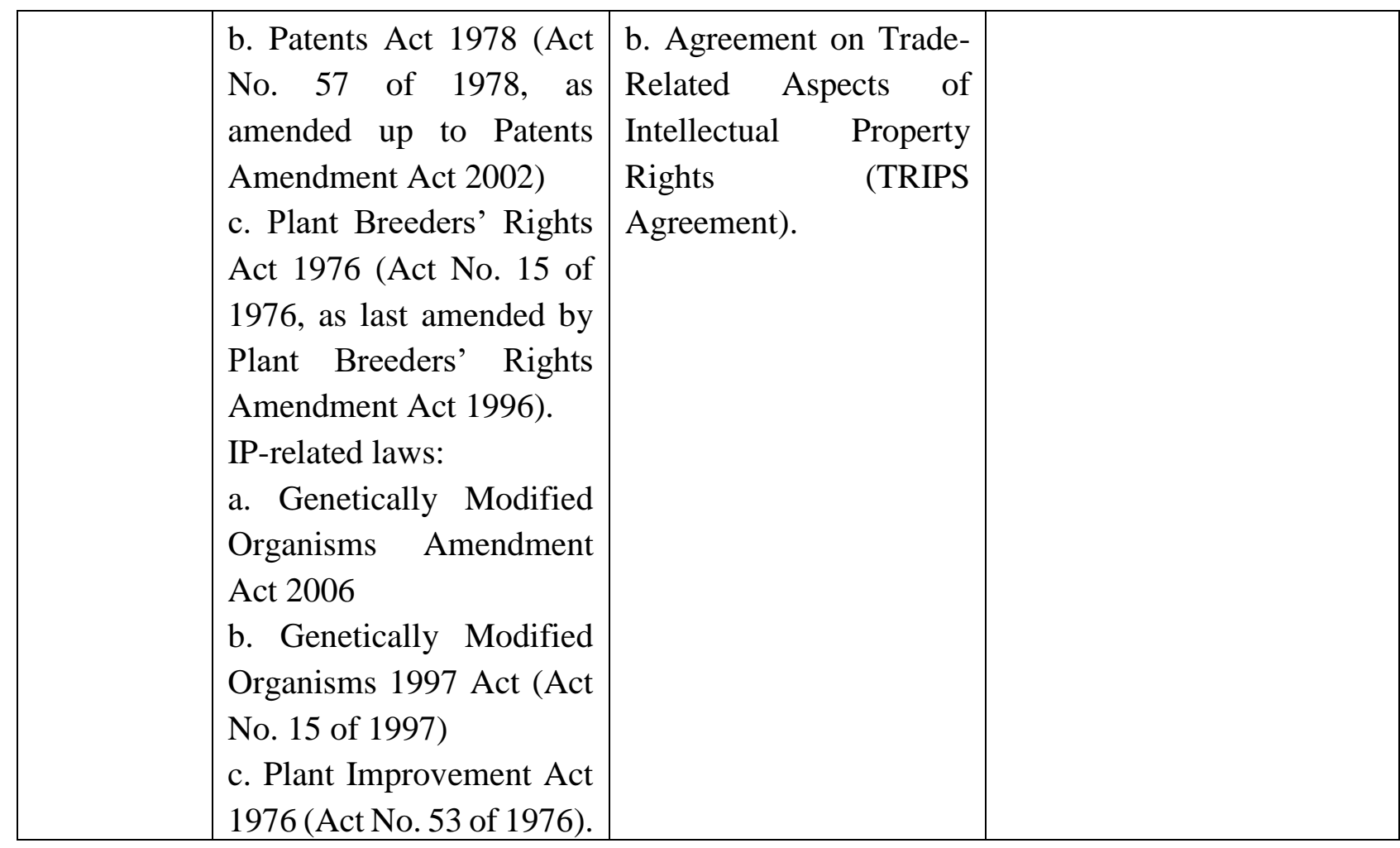

Source: Authors' compilation of data

Table 5: Animal breeders' rights in BRICS

\begin{tabular}{|c|c|c|c|}
\hline & ABR laws & ABR conventions & Institutions \\
\hline Brazil & $\begin{array}{l}\text { - The Brazilian } \\
\text { Forest Code, 1965; } \\
\text { - Brazilian federal } \\
\text { law on the scientific } \\
\text { use of animals, } 2008 \\
\text { (Law } \\
\text { 11794/2008); } 1967 \\
\text { - Brazil Regulation } \\
\text { of Industrial and } \\
\text { Health Inspection of } \\
\text { Products of Origin, } \\
\text { 2005; } \\
\text { - } \\
\text { Guideline 07, 1999; }\end{array}$ & $\begin{array}{l}\text { - Convention on } \\
\text { Biological Diversity, } \\
\text { 1992; }{ }^{1970} \\
\text { - The International } \\
\text { Treaty on Plant } \\
\text { Genetic Resources } \\
\text { on Food and } \\
\text { Agriculture, } 2001 \\
\text { (art. 9); }{ }^{1971} \\
\text { - The Agreement on } \\
\text { Trade-Related } \\
\text { Aspects } \\
\text { Intellectual Property } \\
\text { Rights (TRIPS), } \\
\text { 1994. }{ }^{1972}\end{array}$ & $\begin{array}{l}\text { - Ministry of agriculture, } \\
\text { livestock and food supply }\end{array}$ \\
\hline
\end{tabular}

$1967 \mathrm{http} / / / \mathrm{www}$. fiocruz.br/omsambiental/media/ArtigoILARv5201eFilipecki.pdf

${ }^{1970} \mathrm{https} / / / \mathrm{www} . c b d . i n t / d o c /$ legal/cbd-en.pdf

${ }^{1971} \mathrm{http} / / / \mathrm{www}$.planttreaty.org/content/texts-treaty-official-versions

$1972 \mathrm{https} / / /$ www.wto.org/english/tratop_e/trips_e/t_agm0_e.htm 


\begin{tabular}{|c|c|c|c|}
\hline & $\begin{array}{lr}-\quad \text { Decree } & 6.323, \\
2007 ; 1968 & \\
& \\
- & \text { Normative } \\
\text { Guideline } & 03 \quad- \\
\text { Humane } & \text { Slaughter, } \\
2000 ; & \\
& \\
-\quad \text { Decree } & 30.691- \\
\text { Sanitary } & \text { and } \\
\text { Industrial } & \text { Inspection } \\
\text { Regulation } & \text { of } \\
\text { Animal } & \text { Origin } \\
\text { Products, } & 1952 .{ }^{1969} \\
\end{array}$ & & \\
\hline Russia & $\begin{array}{l}\text { - Federal statute No } \\
123 \text { "On pure-strain } \\
\text { stock-breeding", } \\
\text { 1995; }{ }^{1973} \\
\text { - Government } \\
\text { regulation No } 244 \\
\text { "On measures of } \\
\text { federal statute "on } \\
\text { pure-strain stock- } \\
\text { breeding } \\
\text { realization", } \\
\text { 1996. }{ }^{1974}\end{array}$ & $\begin{array}{l}\text { - Decision of the } \\
\text { Council of Eurasian } \\
\text { Economic } \\
\text { Commission No } 94 \\
\text { "On regulation on } \\
\text { unified procedure of } \\
\text { joint verification of } \\
\text { objects and sampling } \\
\text { among goods } \\
\text { (products) come } \\
\text { under veterinary } \\
\text { control (inspection), } \\
\text { 2014; }{ }^{1975} \\
\text { - Convention on } \\
\text { Biological Diversity, } \\
\text { 1992; } \\
\text { - The International } \\
\text { Treaty on Plant } \\
\text { Genetic Resources }\end{array}$ & $\begin{array}{l}\text { - State stock-breeding } \\
\text { service. }\end{array}$ \\
\hline
\end{tabular}

\footnotetext{
${ }_{1968} \mathrm{http}: / /$ www.agricultura.gov.br/arq_editor/file/Desenvolvimento_Sustentavel/Organicos/Legislacao/Nacional/Ingles/ DECREE_N_06_323_guidelines_for_organic_agriculture_December_de_2007.pdf

1969 http://www.planalto.gov.br/ccivil_03/decreto/1950-1969/D30691.htm

1973 Федеральный закон от 3 августа 1995 г. «О племенном животноводстве» // СПС «КонсультантПлюс»

1974 Постановление Правительства РФ от 6 марта 1996 г. «О мерах по реализации Федерального закона «О племенном животноводстве» // СПС «КонсультантПлюс»

1975 Решение № 49 Совета Евразийской экономической комиссии «О Положении о едином порядке проведения проверок объектов и отбора проб товаров (продукции), подлежащих ветеринарному контролю (надзору) // СПС «КонсультантПлюс»
} 


\begin{tabular}{|c|c|c|c|}
\hline & & $\begin{array}{l}\text { on Food and } \\
\text { Agriculture, 2001; } \\
\text { - The Agreement on } \\
\text { Trade-Related } \\
\text { Aspects of } \\
\text { Intellectual Property } \\
\text { Rights (TRIPS), } \\
\text { 1994. }\end{array}$ & \\
\hline India & $\begin{array}{l}\text { India's Plant Variety } \\
\text { Protection and } \\
\text { Farmers' Rights Act, } \\
2001^{1976} \\
\text { The Patents } \\
\text { (Amendment) } \\
\text { Ordinance, 2004 of } \\
\text { the Indian Govt. on } \\
\text { December } \\
\text { 2004 } \\
\text { The Biological } \\
\text { Diversity Act, } \\
2002^{1978 \quad 27}\end{array}$ & $\begin{array}{l}\text { Convention on } \\
\text { Biological Diversity, } \\
1992 \\
\text { The International } \\
\text { Treaty on Plant } \\
\text { Genetic Resources } \\
\text { on Food and } \\
\text { Agriculture, } 2001 \\
\text { (art. 9) } \\
\text { The Agreement on } \\
\text { Trade-Related } \\
\text { Aspects } \\
\text { Intellectual Property } \\
\text { Rights (TRIPS), } \\
\text { 1994 }\end{array}$ & \\
\hline China & $\begin{array}{l}\text { The Patent Law, } \\
1993^{1979}\end{array}$ & $\begin{array}{l}\text { Convention on } \\
\text { Biological Diversity, } \\
1992 \\
\text { The Agreement on } \\
\text { Trade-Related } \\
\text { Aspects } \\
\text { Intellectual Property } \\
\text { Rights (TRIPS), } \\
1994\end{array}$ & $\begin{array}{l}\text { State Science and } \\
\text { Technology Commission } \\
\text { ("SSTC") } \\
\text { the China Food and Drug } \\
\text { Administration (CFDA) }\end{array}$ \\
\hline
\end{tabular}

1976 http://www.vakilno1.com/bareacts/ptplant2001/ptplant.html

1977 http://lawmin.nic.in/Patents\%20Amendment\%20Ordinance\%202004.pdf

$1978 \mathrm{http} / / / \mathrm{www}$.wipo.int/wipolex/en/details.jsp?id=6058

1979 http://www.wipo.int/wipolex/en/details.jsp?id=6503 


\begin{tabular}{|c|c|c|c|}
\hline South Africa & $\begin{array}{l}\text { Animal } \\
\text { Improvement Act, } \\
1998^{1980} \\
\text { The South African } \\
\text { Patents Act (Act No } \\
57 \text { of 1978) }\end{array}$ & $\begin{array}{l}\text { Convention on } \\
\text { Biological Diversity, } \\
1992\end{array}$ & $\begin{array}{l}\text { Department of Agriculture, } \\
\text { Forestry and Fisheries } \\
\text { The Agricultural Research } \\
\text { Council } \\
\text { National Advisory } \\
\text { Committee for Farm } \\
\text { Animal Genetic Resources }\end{array}$ \\
\hline
\end{tabular}

Source: Authors' compilation of data

Table 6: Plant Variety Rights Statistics

The following table presents the statistics on granted plant variety rights protection rights in BRICS countries for the period of 2012 to 2016 as provided by the official statistics of the UPOV: $:^{1982}$

\begin{tabular}{|l|l|l|l|l|l|}
\hline & $\mathbf{2 0 1 2}$ & $\mathbf{2 0 1 3}$ & $\mathbf{2 0 1 4}$ & $\mathbf{2 0 1 5}$ & $\mathbf{2 0 1 6}$ \\
\hline Brazil & 232 & 273 & 202 & 266 & 301 \\
\hline Russia & 466 & 458 & 426 & 544 & 592 \\
\hline India $^{1983}$ & 119 & 254 & 330 & 842 & 419 \\
\hline China & 336 & 296 & 996 & 1589 & 2132 \\
\hline South Africa & 259 & 255 & 273 & 233 & 247 \\
\hline
\end{tabular}

Source: Authors' compilation of data

Figure 6: Granted PVRs BRICS (2010-15)

\footnotetext{
${ }^{1980} \mathrm{http} / / / \mathrm{www}$.daff.gov.za/doaDev/sideMenu/animalAndAquacultureProduction/docs/Animal\%20improvement\%20act (2).pdf

1981 http://www.saflii.org/za/legis/consol_act/pa1978109/

$1982 \mathrm{http}: / /$ www.upov.int/edocs/mdocs/upov/en/c_51/c_51_7.pdf

${ }^{1983}$ Note that India is not a party to the UPOV Convention. The information on plant variety protection rights granted in India was obtained from annual reports of India's Protection of Plant Varieties and Farmers' Rights Authority, available at: http://plantauthority.gov.in/annualrpt.htm.
} 


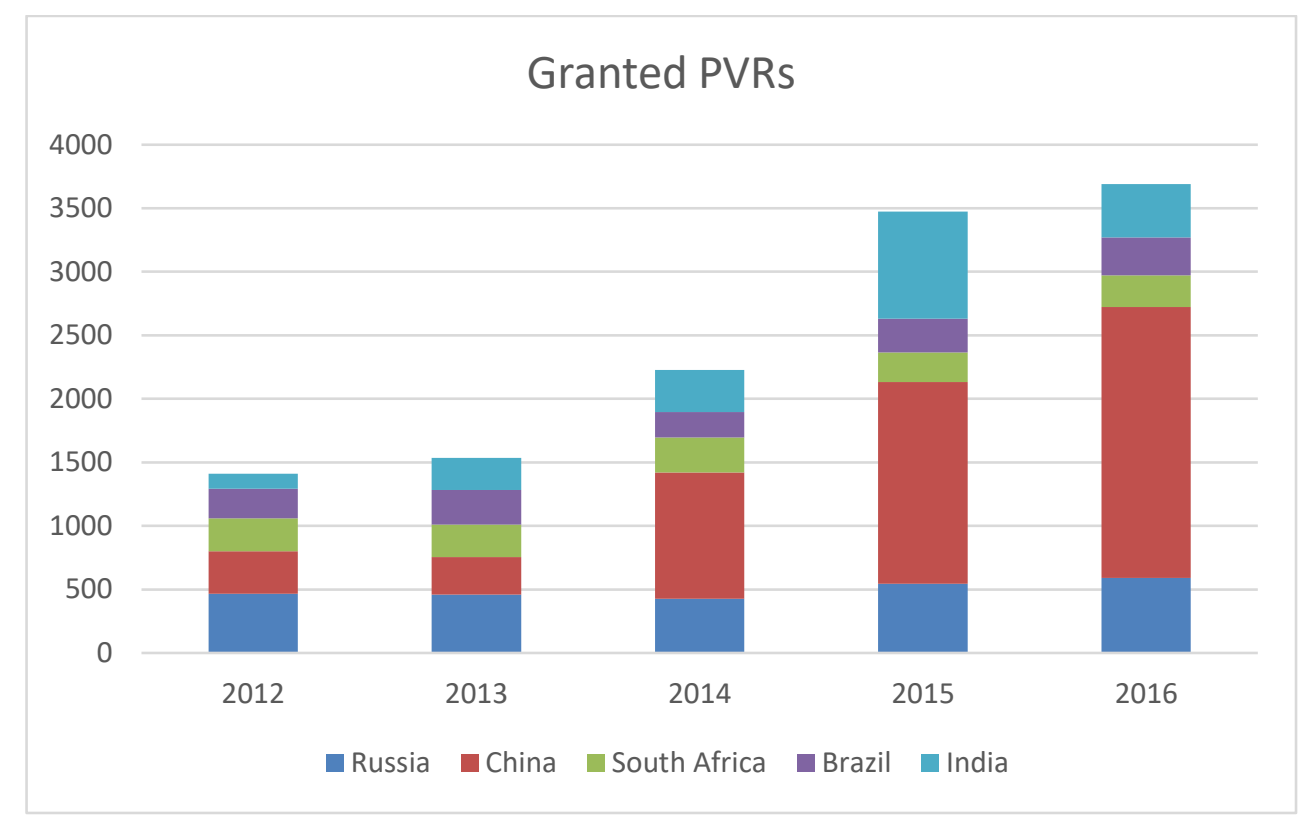

Authors' compilation

With regard to the importance of the Big 6 in plant variety protection the following figure may be helpful and indicated their relative importance with regard to the plant variety protection certificates granted by the EU Plant Variety Office and the relevant US data.

Figure 7: Top companies for EU Plan Variety Protection certificates issued by the Community Plant Variety Office

EU Plan Variety Protection certificates issued by the Community Plant Variety Office

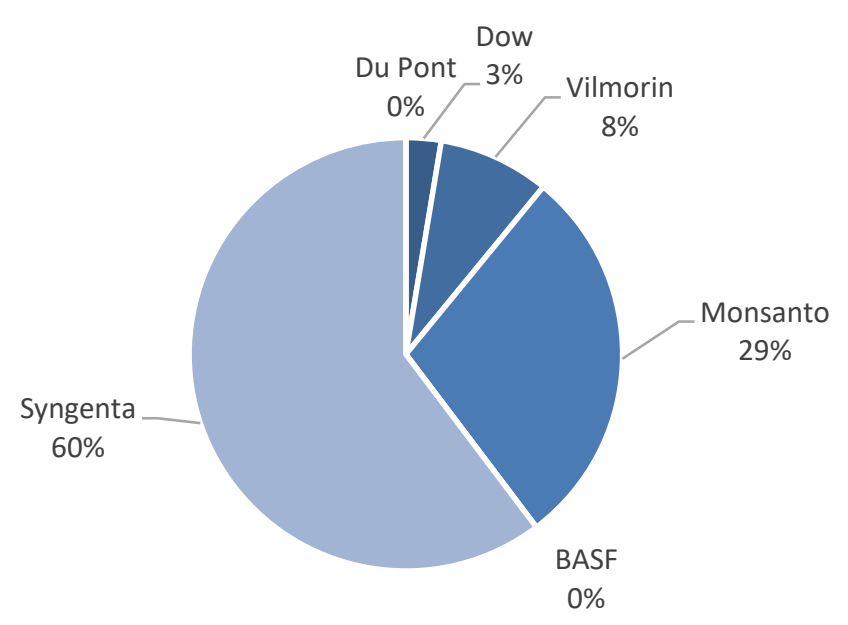

Source: Authors' compilation of data

Figure 8: Number of plant vvariety protection certificates issued by the US Marketing Service 


\section{Number of plant variety protection certificates (PVP) issued by the US Agricultural Marketing Service}

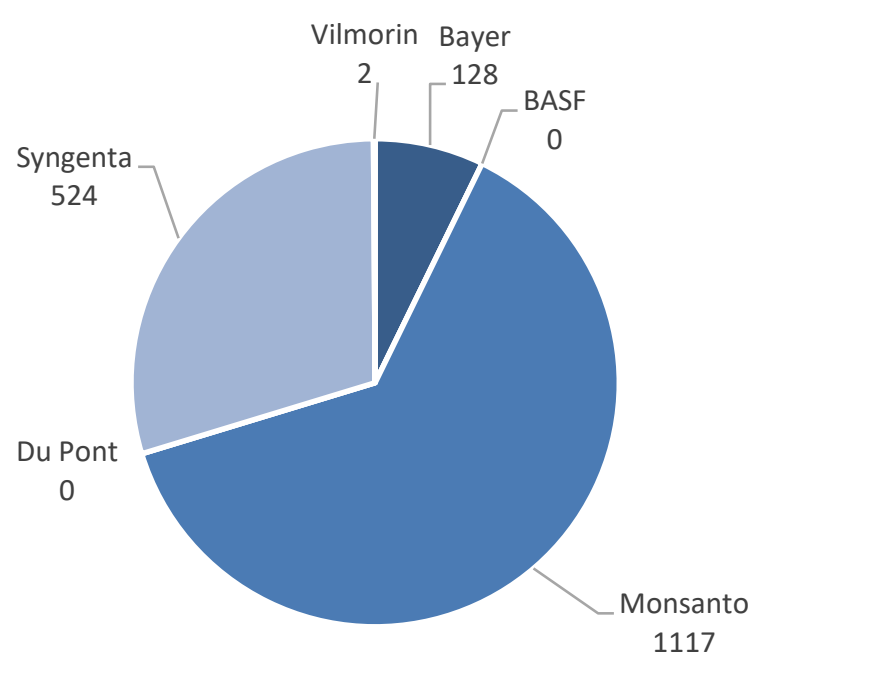

Source: Authors' compilation

\subsubsection{Trademarks}

Trademarks play and important role in the protection of one's visual identity and recognition. Trademarks on the one hand serve as an indication of origin of a product, and a guarantee of quality in the the eyes of consumers. Trademarks are also good advertising tool and, if successful, may represent a valuable commercial asset.

Various trademarks are tpresent in the processing segment of the food value chain, with a number of iconic global brands, enabling a higher degree of product heterogeneity. Brands also extend to more than product differentiation, as they may be used by brand-owners in order to reinforce the "emotional and cognitive appeal" of a certain brand to consumers, the identity that a brand confers on products giving a context to an individual act of consumption "which may increase its emotional impact and turn it into the basis of a continuing relationship" ${ }^{1984}$. For instance, Monsanto controls leading brands, such as Dekalb and Channel for corn, Asgrow for soybeans, Deltapine for cotton, Seminis and De Ruiter for vegetable seeds. It also develops biotechnology traits enabling crops to protect themselves from borers and rootworm and therefore assisting farmers in controlling insects and weeds. These products are distributed in various brands, such as SmartStax, YieldGard, YieldGard VT triple, VT triple PRO for corn, Intacta RR2 PRO for soybeans, Bollgard and Bollgard II for cotton. Its brand portfolio includes glyphosate-based herbicides or dicamba herbicides and include brands, such as Roundup Ready, RoundupReady 2 Yield, Roundup Ready 2 Xtend and Intacta RR2 PRO (for soybeans), and Genuity. Bayer controls popular seed brands, such as Arize for rice, Credenz for soybeans, Fibermax for cotton, InVigor for canola seeds, Nunhems for vegetable seeds, Stoneville for cotton seeds, seed treatment solutions, such as Gaucho, glyfosinate-ammomium based herbicides like Liberty and Basta, and fungicides, like Nativo.

${ }^{1984}$ Lianos, Ioannis, Brands, Product Differentiation and EU Competition Law (September 1, 2014). D. Desai, I. Lianos \& S. Weber Waller (eds.), Brands, Competition Law and IP (Cambridge University Press, 2015); CLES Research Paper No. 7/2014. Available at SSRN: http://ssrn.com/abstract=2542970 
Brand may also play a role further downstream in the food value chain. For instance, BRICS countries are experiencing the growth of private brand products in supermarkets. In South Africa, supermarkets are estimated to capture 90 percent of the South African food market. ${ }^{1985}$ A trend in South Africe is the incrase of supermaket's own private brands and every major supermarket chain has its own private brand. ${ }^{1986}$ This trend may allow new producers to enter the market via supermarket's own private brand. However, on the other hand, new entrants still have to supply at volume required by the large supermarkets which may make it hard for small producers to enter the market. ${ }^{1987}$

On the international level, trademark protection is guaranteed by TRIPS Agreement to which all BRICS countries are members. Subsequently, BRICS countries have implemented trade mark protection in their national statutes.

\subsubsection{Geographical indications of origin}

Last but not least, many jurisdictions have developed a system of geographical indications of origin (GIs), as a vehicle for product differentiation. These can either take the form of sui generis systems (i.e. special regimes of protection), or the use of collective or certification marks, or finally, administrative product approval schemes.

According to Article 22 of the TRIPS Agreement, geographical indications of origin are "indications which identify a good as originating in the territory of a Member, or a region or locality in that territory, where a given quality, reputation or other characteristic of the good is essentially attributable to its geographical origin." TRIPS Agreement also provides that all governments must provide legal opportunities in their own laws for the owner of a GI registered in that country to prevent the use of marks that mislead the public as to the geographical origin of the good.

Each country generally has its own laws providing for protection of GIs. In the EU, there is a distinction between: i) Protected Designations of Origins (PDO); ii) Protected Geographical Indications (PGI), and iii) Traditional Speciality Guaranteed (TSG).1988

A PDO is defined as a name which identifies a product: "(i) originating in a specific place, region or, in exceptional cases, a country; (ii) whose quality or characteristics are essentially or exclusively due to a particular geographical environment with its inherent natural and human factors; and (iii) the production steps of which all take place in the defined geographical area."1989 Therefore, it is necessary for a geographical name to qualify as a PDO that there is a clear link between the physical characteristics of the product with which the geographical name has been used and the geographical name.

PGI is defined as a name which identifies a product: “(i) as originating in a specific place, region or country; (ii) whose given quality, reputation or other characteristic is essentially attributable to its geographical origin; and (iii) at least one of the production steps of which take place in the

\footnotetext{
1985 South Africa Country Fitche p. 16.

1986 Reena Das Nair, 'Competition in Supermarkets: A South African Perspective' (2016) p. 17, available at: https://static1.squarespace.com/static/52246331e4b0a46e5f1b8ce5/t/56f130034d088e7b7cb6fef4/1458647047632/Reen a+das+Nair_Competition+in+Supermarkets+-+A+South+African+Perspective.pdf

1987 South Africa Country Fitche p. 10.

1988 Regulation (EU) No 1151/2012 of the European Parliament and of the Council of 21 November 2012 on quality schemes for agricultural products and foodstuffs OJ 202 L 343.

${ }^{1989}$ Ibid, Article 5(1).
} 
defined geographical area."1990 PGIs can be explained as a form of protection where there is not a clear link between the territory and the qualities of products, but reputational concerns of a given territory warrant protection.

TSG, in the end, is defined as a name which describes a specific product or foodstuff that: “(i) results from a mode of production, processing or composition corresponding to traditional practice for that product or foodstuff; or (ii) is produced from raw materials or ingredients that are those traditionally used." 1991 In this case, the qualities of products are not required to be related to a certain geographical area. What is required is tradition in terms of production methods and materials used.

A name may not be registered as a PDO or PGI "where it conflicts with a name of a plant variety or an animal breed and is likely to mislead the consumer as to the true origin of the product." 1992 This provision is inserted to ensure that a certain plant variety cannot be protected both by plant variety protection and by GI protection.

As BRICS countries are members of the TRIPS Agreement they are required to provide GI protection.

South Africa provides for GI protection in the Agricultural Product Standards Act of 1990 (APS Act). ${ }^{1993}$ GI protection is adminstred by the Ministry of Agriculture, Forestry and Fisheries. According to the APS Act, geographical name can be protected if its is: i) used in connection with an indication of the true origin of the product in question; ii) used in translation; or iii) used together with words such as "kind", "type", "style", "imitation" or similar words or expressions. Ammedments to the GI protection legislation are currently under developments which should further regulate the use of registered GI to agricultural products.

\subsubsection{Technological means of protection of innovation}

The seed industry has put in place biological tools to protect its IP rights by developing hybridization in the $1930 \mathrm{~s}$, in particular of corn that strengthened the ability of private actors to appropriate the value of new corn varieties through secrecy ${ }^{1994}$. Indeed, corn hybrids rely on crosspolinating two inbred lines in order to generate a hybrid, which displays superior productivity to the inbred lines. However, this vigor is lost in subsequent generations, making thus necessary for farmers to purchase seeds for every planting season ${ }^{1995}$. More recently this "technological protection" has been achieved through cytoplasmic male sterility, one of the most efficient ways to produce F1 hybrid seeds.

IP right holders may also take measures in order to avoid problems with regard to the implementation of their IP rights, in particular in developing jurisdictions with weak IP enforcement systems. Material Transfer Agreements between the IP right holders and farmers may specify the conditions under which a seed sample will be exchanged. Those holding utility patent rights in seed may sell subject to a contractual provision that bars the farmer from saving seed and using it to grow another generation of crops, thus controlling farmers through purchase agreements. An example is

\footnotetext{
1990 Ibid, Article 5(2).

${ }^{1991}$ Ibid, Article 18(1).

1992 Regulation (EU) No 1151/2012 of the European Parliament and of the Council of 21 November 2012 on quality schemes for agricultural products and foodstuffs OJ 202 L 343, Article 6(2).

1993 Act No. 119 of 1990.

1994 D.N. Duvick, Biotechnology in the 1930s: the development of hybrid maize, (2001) (2) Nature Reviews Genetics 69.

1995 R. Dixon, Hybrid Corn Revisited, (1980) 48(6) Econometrica 1451.
} 
Monsanto's Roundup Ready ${ }^{\circledR}$ Technology Agreement that usually provides that the farmer cannot save seed or any other part of the crop grown from the Monsanto seed for replanting and that the farmer is prohibited from supplying seed to any other person. Violation of these licenses may be regarded as a breach of contract subject to draconic sanctions, the farmer being obliged to pay 120 times the technology fee plus the legal fee if he/she is caught violating the agreement. Enforcement of these contractual clauses involves the continuous inspection of the farmers' fields by Monsanto staff. Binding arbitration constitutes the default dispute resolution mechanism for these agreements. One may consider these contractual limitations of traditional farmer seed saving and sharing practices as introducing a restriction to research and seed development by farmers and thus a restriction on innovation. Monsanto may advance that such restrictions are necessary in order to protect its own incentives to innovate, in view of its investment on R\&D in order to develop the technology and the need to recoup the costs by the appropriation of the profits arising out of the productivity improvements introduced due to its innovative effort.

The seed industry has also put in place biological tools to protect its IP rights through cytoplasmic male sterility, one of the most efficient ways to produce F1 hybrid seeds. Another biological protection is Genetic Use Restriction Technology (GURT), with the development of terminator technologies preventing farmers from saving seeds since the genetically engineered plants will not germinate in subsequent generations or will not express the specific trait (e.g. herbicide resistance) that is protected by IP rights unless the plant is sprayed with specific chemicals in order to activate the right gene. These biological protection instruments are particularly useful for the private seed industry in jurisdictions with weak enforcement of IPRs. These technologies are protected by patents, a great number of them being held by few global seed companies. This IP-based business environment makes it quite difficult for public institutions to assert themselves in the process of innovation in the seed industry and promote the open access and sharing ethos that was prevalent prior to the expansion of IPRs in this sector of activity.

\subsubsection{Trade secrets}

Trade secrets are confidential business information that provides companies with a certain competitive edge. ${ }^{1996}$ Unlike patents, trade secrets are not required to be registered to produce effects and they last indefinitely as long as they remain secret. However, once trade secret is made public anyone can use it and the holder of trade secret does not have the right to exclude other form using trade secret that has become public.

Trade secrets are internationally regulated by the TRIPS Agreements. Article 39 of the TRIPS Agreement defines trade secrets as information that: i) must be secret (i.e. it is not generally known among, or readily accessible to, circles that normally deal with the kind of information in question); ii) have commercial value because it is a secret; and iii) must have been subject to reasonable steps by the rightful holder of the information to keep it secret (e.g., through confidentiality agreements).

Similar definition of trade secret has been adopted in the U.S. and the EU. The U.S. Uniform Trade Secrets Act grants legal protection to trades secrets and protects their misappropriation. ${ }^{1997}$ On

\footnotetext{
${ }_{1997}^{1996}$ http://www.wipo.int/sme/en/ip_business/trade_secrets/trade_secrets.htm 
the EU level a Trade Secrets Directive was adopted in 2016 which intends to harmonise the national laws in EU countries against the unlawful acquisition, disclosure and use of trade secrets. ${ }^{1998}$

The EU Trade Secrets Directive defines trade secrets as the information that: i) is secret in the sense that it is not, as a body or in the precise configuration and assembly of its components, generally known among or readily accessible to persons within the circles that normally deal with the kind of information in question; ii) has commercial value because it is secret; and iii) it has been subject to reasonable steps under the circumstances, by the person lawfully in control of the information, to keep it secret. The EU established remedies from unlawful misappropriation of trade secrets, including: i) stopping the unlawful use and further disclosure of misappropriated trade secrets; ii) the removal from the market of goods that have been manufactured on the basis of a trade secret that has been illegally acquired; and iii) the right to damages.

BIRCS countries, as members of TRIPS Agreement, recognise the protection of trade secrets in their national statutes.

As demonstrated above, IP protection of plants may be achieved by: i) plant variety protection or ii) patent protection in certain circumstances. Gene modifications may also be patented in certain circumstances. This may appear to leave little role for trade secrets in plant protection. Nevertheless, the use of hybrids, at least since the 1920s, and the fact that hybrids do not truly self-replicate enable a private firm to retain control of the pure lines so that these remain the exclusive source for the superior hybrid offspring. One may also add here contractual arrangements between breeders and farmers that prohibit seed replanting and/or the seed being used by others' breeding programmes. Commonly referred to as bag tag licenses, these are routinely used to market seeds ${ }^{1999}$. These may be protected by trade secrets, although secrecy may be impossible for most crops other than corn varieties. A company may also gain valuable know-how that could be protected by trade secret rights. Farm data (mainly agronomic and equipment data collected by sensors and other precision ag technology) are particularly important for the development of the "Internet of farming", and can be collected in an anonymised form including information on yield and products used as well as GPS location information, without prior explicit authorisation by the farmer ${ }^{2000}$. These could be protected as a trade secret, in particular as there are no clear-cut guidelines regarding the privacy of the data, its ownership and control. This broad pool of real time data could be extremely valuable for traders in commodity markets as they could influence farmland values.

\subsubsection{A more inclusive innovation system: Balancing the rights of IP holders and farmers' rights}

As highlighted above, the different regimes regulating farmers' access to seeds derive from a combination between domestic and international intellectual property legal frameworks, including the overarching International Convention for the Protection of New Varieties of Plants (the "UPOV Convention"). The following analysis shows the interconnection and influence between domestic and

\footnotetext{
1998 Directive 2016/943 of the European Parliament and of the Council of 8 June 2016 on the protection of undisclosed know-how and business information (trade secrets) against their unlawful acquisition, use and disclosure, OJ $2016 \mathrm{~L}$ 157/1 (EU Trade Secrets Directive).

1999 M.S. Clancy \& G. Moschini, Intellectual Property Rights and the Ascent of Proprietary Innovation in Agriculture, Working Paper 17, WP 572 (January 2017), 6.

${ }^{2000}$ High-tech U.S. farm machines harvest Big Data, reap privacy worries (Reuters, April 10, 2014).
} 
international frameworks by comparing BRICS countries (Brazil, Russia, India, China and South Africa) among other international players.

The Trade-Related Aspects of Intellectual Property Rights (TRIPS), directs its members to arrange "for the protection of plant varieties either by patents or by an effective sui generis system or by any combination thereof"' (Article 27(3)(b)). The UPOV Convention is relevant in this regard, as this instrument created a sui generis protection for plant breeding, and in doing so shaped the domestic intellectual property legislation of most countries.

According to the UPOV Convention, a new plant variety (defined in Article 1(vi) of the UPOV Convention 1991) would be granted protection when the variety satisfies Article 12 UPOV Convention 1991 requirements of distinctiveness, uniformity and stability - the so-called DUS conditions:

- Distinctiveness refers to the fact that a variety must be clearly distinguishable from any other variety whose existence is a matter of common knowledge (Article 7 UPOV Convention 1991).

- Uniformity denotes a sufficient uniformity in the variety's relevant characteristics "subject to the variation that may be expected from the particular features of its propagation" (Article 8 UPOV Convention 1991).

- Stability is linked to the fact that a variety "must remain true to its description after repeated reproduction or propagation or, where the breeder has defined a particular cycle of reproduction or multiplication, at the end of each cycle" (Article 9 UPOV Convention 1991). ${ }^{2001}$

Finally, Article 6 UPOV Convention 1991 sets the element of novelty as applying where, within specific timeframes and localities, there has been no sale or disposal of propagating or harvested variety material from the date of filing for the protection. ${ }^{2002}$

The UPOV Convention's protections afforded to the plant breeder are found in Article 14 UPOV Convention 1991; in the absence of authorisation, the breeder is granted exclusive control over:

- Production

- Reproduction (multiplication)

- Conditioning for the purpose of reproduction

- Offering for sale

- Selling or other marketing

- Exporting, importing, stocking for any of the above purposes. ${ }^{2003}$

In certain cases protection is also granted over harvested material (Article 14(2) UPOV Convention 1991) or certain products from the harvested material (Article 14(3) UPOV Convention 1991).

The protection rights granted by the UPOV Convention 1991 are also subject to particular limitations found, for example, in Articles 15 and 16. Among these limitations, it is possible to see those that are aimed at regulating the access of farmers to seeds:

- Article 15(1)(i) UPOV Convention 1991 deals with activities in the private sector for noncommercial purposes, that may include for instance subsistence farming.

\footnotetext{
${ }^{2001}$ On this see G. Würtenberger, "Protection of plant innovations" in D. Matthews \& H. Zech (eds), Research Handbook on Intellectual Property and the Life Sciences (Edward Elgar, 2017).

2002 Ibid..

2003 Ibid..
} 
- Article 15(1)(ii) UPOV 1991 discusses activities that are conceived in the context of tests for ulterior cultivation.

- The use of plants, or parts thereof such as seeds, for the purpose of creating a new variety can also be a limitation to the protection rights (Article 15 (1)(iii) UPOV Convention 1991) (i.e. "breeder's exception")

- One of the most relevant provisions however is found in Article 15(2) UPOV Convention 1991, also known as farmer's privilege. As explained by Gert Würtenberger, this provision shields farmers who gained harvested material through the "the cultivation of legally produced propagating material of protected varieties [within their] own company and which [they] further use within [their] own company as propagating material... The farmer[s] may be allowed, without the consent of the plant variety right proprietor, to keep part of [their] harvest and to use the same in the following year on [their] fields as seed for the propagation of new plants." 2004

Other limitations on the UPOV protection may derive from the legal principle of exhaustion of rights (Article 16 UPOV Convention 1991) and on the basis of public interest arguments, including public morals, order and security, the health and life of humans, animals or plants, the environment, industrial and commercial property rights, restricting competition, trade or agricultural production (Articles 17(1) and 18 UPOV Convention 1991).

While the present analysis has focused on the general UPOV Convention thus far, the relevance of this framework is clear when one views the domestic legislative models dealing with plant varieties and farmers' access rights.

In the EU there is currently ongoing debate whether certain plant varieties, besides plant variety protection based on the UPOV Convention, may also be patented. Namely, the European Patent Convention excludes from patentability "plant varieties" and “"essentially biological processes for the production of plants". As mentioned in Section 4.2.1.1, the EPO in two cases in 2015 held that process for the production of plants is not patentable in principle if it involves conventional breeding, irrespective of additional technical steps such as marker assisted selection, which support conventional breeding. ${ }^{2005}$ However, it also ruled that products of such processes (cross breeding and selection) are patentable (e.g. plants with novel traits) provided they also fulfil the criteria for patentability. ${ }^{2006}$ In other words, new plant varieties obtained through biological processes may be patentable.

This has been viewed negatively by the EU institutions and some Member States. The European Parliament adopted in 2015 a Resolution communicating the view that the patentability of products obtained from essentially biological processes should be prohibited. ${ }^{2007}$ The European Commission followed with aNotice where it held that the EU legislator's intention when adopting the EU Biotechnology Directive was to exclude from patentability products (plants/animals and plant/animal parts) that are obtained by means of essentially biological processes. ${ }^{2008}$ However, such

\footnotetext{
2004 Ibid..

${ }^{2005}$ Enlarged Board of Appeal, EPO, Appeal number T 1242/06, Case G 0002/12, Tomato II (March 25, 2015); Enlarged Board of Appeal, EPO, Appeal number T 0083/05 - 3.3.04, Case G 0002/13, Broccoli II (March 25, 2015).

${ }^{2006}$ See also Houses of Parliament, Parliamentary Office of Science and Technology, Intellectual Property and Plants, (2016) Postnote 517.

${ }^{2007}$ European Parliament resolution of 17 December 2015 on patents and plant breeders' rights, 2015/2981(RSP)/

${ }^{2008}$ Commission Notice on certain articles of Directive 98/44/EC of the European Parliament and of the Council on the legal protection of biotechnological inventions, OJ 2016 C 411/03.
} 
interpretation of the European Commission is not formally binding on the EPO as EPO works pursuant to the European Patent Convention, and not the EU Biotechnology Directive. Therefore, the future of the patentability of plant varieties obtained from essentially biological processes will depend on the future interpretation by the EPO.

Next, some Member States have included in their patent statues specific plant breeder's exception. As seen above, UPOV allows others to use plants, or parts of plants such as seeds, for the purpose of creating a new variety. Some EU countries such as Germany, France, Switzerland and the Netherlands have gone further and introduced a breeding exception in their patent statutes - limiting the right of patent holders by allowing plant breeders to use freely patented biological material for creating new plant variety types. ${ }^{2009}$ The Unitary Patent Convention similarly provides an exemption from the unitary patent protection for "the use of biological material for the purpose of breeding, or discovering and developing other plant varieties"2010

BRICS countries constitute a revealing example of how the UPOV Convention provisions have been replicated to varying extents. Russia's law "On Seed Breeding" dated 17 December 1997 N 149-FZ and the IP part of the Russian Civil Code mirror the provisions on plant variety rights along the lines of the UPOV Convention. Interestingly however, the exclusive right to plants varieties is also provided confirmation by patent. ${ }^{2011}$ The situation is slightly different for countries such as Brazil, China and South Africa, which unlike Russia are signatories to the UPOV Convention 1978, and where there is a clearer separation between plant variety protection and patents. In Brazil, the Plant Variety Protection Act (Law 9,456 of 25 April, 1997) deals with conventional plant breeding techniques that would not fall within the remit of patent protection under the Industrial Property Law (Law 9,279 of 14 May, 1996). ${ }^{2012}$ The patent option would only be available to transgenic microorganisms and the processes which lead to production of transgenic seeds, plants and its parts (organs, tissues or cells), not to the final product itself. ${ }^{2013}$ Similarly in China, patent law may cover the production methods used in connection to plant varieties but not the protection of the plant variety ${ }^{2014}$ the protection of plant varieties is based on administrative regulations (which stand at a lower level than laws) such as Regulations of the PRC on protection of New Varieties of Plants 1997(amended on March 1, 2013) 2015 and the Seed Law of the People's Republic of China (SLPRC) (Amended in 2015). ${ }^{2016}$ In South Africa, the provisions pertaining to plant variety protections are contained in the Plant Improvement Act 53 of 1976 (as amended) and the Plant Breeders' Rights Act 15 of 1976 (as amended). In the present discussion, India offers a model that is different to the countries analysed so far; the country is not a member of the UPOV Convention and yet maintains certain characteristics from the UPOV protection through its Protection of Plant Varieties and

\footnotetext{
2009 Viola Prifti, 'The Breeding Exemption in Patent Law: Analysis of Compliance With Article 30 of the TRIPS Agreement' (2013) The Journal of World Intellectual Property 2018.

${ }^{2010}$ Article 27(c) of the Unitary Patent Convention.

${ }^{2011}$ Article 1414 of the Civil Code.

2012 Available at: http://www.planalto.gov.br/ccivil_03/leis/L9279.htm

${ }^{2013}$ Rodrigues, Roberta L, Lage, Celso L. S, \& Vasconcellos, Alexandre G. (2011). Intellectual property rights related to the genetically modified glyphosate tolerant soybeans in Brazil. Anais da Academia Brasileira de Ciências, 83(2), 719730. https://dx.doi.org/10.1590/S0001-37652011000200029.

2014 Patent Law of the People's Republic of China [Revised], 2008, see http://www.wipo.int/edocs/lexdocs/laws/en/cn/cn028en.pdf Article 25

2015 Regulations of the PRC on protection of New Varieties of Plants (hereinafter Regulations) see http://www.wipo.int/wipolex/en/details.jsp?id=15503

2016 see: http://www.npc.gov.cn/englishnpc/news/Legislation/2015-11/05/content_1950421.htm The full text of SLPRC2015 is not available from official source. The English edition of SLPRC in NPC database has not been revised.
} 
Farmers' Rights Act, 2001 (PVPFR Act). There are however also some similarities with the other jurisdictions analysed previously; for instance a method or process for modifying a plant can potentially be patented, and patents are "allowed on microorganisms, as well as on microbiological, biochemical and biotechnological processes." 2017 At the same time there is an exclusion from patentability for plants and parts "other than microorganisms, but including seeds, varieties, species and essentially biological processes for production or propagation of plants and animals."2018

In terms of farmers' access rights, the standard can vary across different jurisdictions. Countries like Russia and China, for example, provide for similar legislative provisions that follow UPOV frameworks, while India and Brazil have in place more balanced provisions for farmers, and South Africa seemingly offers lower prospects for farmers' access rights.

The Russian Civil Code at Article 1422 sets forth the exceptions to the UPOV rights contained in Article 15 UPOV Convention 1991 and discussed above. The Civil Code also adds specific conditions to the farmer's privilege provision to protect farmers' rights, including a two-year timelimit and the presence of the variety in the specified list of varieties adopted by the Government of the Russian Federation. Finally, Article 1423 of the Civil Code also allows for the compulsory licensing of the rights for varieties of plants upon application to court; so-far however such option has not been greatly availed of perhaps due to the conditions and the consideration due for the license agreement.

The Chinese framework for farmers' access rights follows similar lines, with Article 10 Regulations of the PRC on protection of New Varieties of Plants 1997(amended on March 1, 2013) granting farmers the possibility to harvest protected variety material and use it for propagating within their own concern; such farmers' rights however have to be viewed within the limitations imposed by the law, particularly in the Seed Law of the People's Republic of China (SLPRC) (Amended in 2015). One interesting difference between Russia and China in this area is the latter's provisions enabling the Ministry for Agriculture to grant compulsory licensing as opposed to requesting the intervention of the courts.

In comparison to the above, the Brazilian legislation would seem to be more accommodating towards farmers' access rights. While the Plant Variety Protection Act does not grant explicit recognition to farmers as breeders, the revised Seeds Act 2003 recognises varieties associated to certain categories such as family farmers and indigenous people. ${ }^{2019}$ These categories are exempted from registration in the National System of Seeds and Plant Seedlings when they "multiply seeds or seedlings for distribution, exchange or commercialization among themselves." ${ }^{2020}$ Other provisions that regulate the access rights of farmers, include the Plant Variety Protection Act section dealing with farmer's privilege. While certain parts of this section set strict conditions on seeds for "own use" on quantity and time limits, provisions are also made for small rural producers, who can multiply seeds for exchange but only in dealings with other similar producers. ${ }^{2021}$ The Brazilian provisions might explain the country's opposition to the UPOV Convention 1991, primarily because of the

${ }^{2017}$ Karine Peschard (2014) Farmers' rights and food sovereignty: critical insights from India, The Journal of Peasant Studies, 41:6, 1085-1108.

2018 Karine Peschard (2014) Farmers' rights and food sovereignty: critical insights from India, The Journal of Peasant Studies, 41:6, 1085-1108.

${ }^{2019}$ Karine Peschard (2017) Seed wars and farmers' rights: comparative perspectives from Brazil and India, The Journal of Peasant Studies, 44:1, 144-168.

${ }^{2020}$ Ibid..

${ }^{2021}$ Ibid.. 
restrictions on rights to seeds. The potential for saving seeds would in fact develop into an 'optional exemption', and be restricted to farmers' own use. ${ }^{2022}$ The obligation to 'safeguard the legitimate interests of the breeder', could result in larger farmers paying royalties to breeders to save seeds for their own use. ${ }^{2023}$

The position in India is similarly framed by one its objectives: offering safeguards to farmers' access. It is important to note the PVPFR Act has a broad definition of breeder, encompassing also farmers; this in turn means that farmers can register their varieties and are in theory placed at the same level as breeders. ${ }^{2024}$ The definition of farmer's varieties includes, for example, those that are traditionally cultivated or their wild relatives, and their registration is exempted from fees. The criteria for protection nevertheless remain the same DUS conditions identified at the outset of this discussion, except for novelty. ${ }^{2025}$ The PVPFR Act however also has other innovative provisions in terms of farmers' access rights, such as:

- the right "to save, use, sow, re-sow, exchange, share or sell seeds, including from protected varieties, as well as harvested materials, 'in the same manner as he was entitled before the coming into force of this Act"

- the limitation on farmer's liability for innocent infringement of breeder's rights.

- disclosure by seed companies to farmers of the expected yield for the protected variety, and compensation rights where non-performance arises.

Thus, the Indian law provisions in respect of farmers' rights of access seem to be more comprehensive and effective than their counterparts in the other countries analysed so far, including Brazil. Unlike the provisions in the Brazilian legislation, the PVPFR Act offers safeguards that go beyond basic rights to seeds, and its coverage applies to all farmers rather than solely small rural farmers. ${ }^{2026}$ Furthermore, the PVPFR Act would also seem to tilt in favour of farmers, in the event that they are shown not be aware of the protections granted to plant varieties. ${ }^{2027}$ At least in theory therefore, the PVPFR Act would suggest farmers being on the same level as private and public breeders in terms of entitlement to intellectual property protection, rather than just being entitled to rights of cultivation as offered in other jurisdictions such as Brazil. This, in turn, would benefit broadly the rights of access by farmers.

The legal framework in South Africa is more restrictive for farmers' access rights. The Plant Breeders' Rights Act is among one of the pieces of legislation that gives effect to South Africa's obligations under the UPOV Convention. Under this legislation, farmers are allowed access rights as per the usual UPOV provisions, including the farmer's privilege. The exchange of protected varieties among farmers is excluded, allowing farmers to only replant farm-saved seed from protected varieties on their own holdings. The South African provisions offer a stark contrast to the more flexible

\footnotetext{
2022 Ibid.

2023 Ibid.

2024 Sujith Koonan, India's sui generis system of plant variety protection (January 2014), available at http://www.quno.org/sites/default/files/resources/QUNO\%20India\%20-\%20plant\%20variety\%20protection\%20$\% 202014 . p d f$

2025 Karine Peschard (2014) Farmers' rights and food sovereignty: critical insights from India, The Journal of Peasant Studies, 41:6, 1085-1108; Sujith Koonan, India's sui generis system of plant variety protection (January 2014), available at http://www.quno.org/sites/default/files/resources/QUNO\%20India\%20-\%20plant\%20variety\%20protection\%20$\% 202014$.pdf

${ }^{2026}$ Karine Peschard (2017) Seed wars and farmers' rights: comparative perspectives from Brazil and India, The Journal of Peasant Studies, 44:1, 144-168

2027 Ibid.
} 
provisions on exchange found in the Brazilian and Indian legislation. It should be noted that two bills (the Plant Breeders' Rights Bill (PBR Bill) and the Plant Improvement Bill 2015) are being held at public hearing in the South Africa's Portfolio Committee on Agriculture. These bills will not necessarily improve access rights of farmers, as they allow for provisions including for "only certified seed to be sold on the commercial market" that thereby restrict rights concerning the re-use, exchange and sale of farm-saved seed. ${ }^{2028}$

The example of South Africa provides a reminder of the different levels of access rights granted to farmers across various jurisdictions. While the UPOV Convention sets down criteria at the international level for plant variety recognition and its limits, it is also important to examine national legislations replicating such provisions. Ultimately, the interaction between each country's provisions on the rights of access of farmers and the intellectual property rights legislation reveals not only how these property rights are conceived in the area of agricultural biodiversity but also how they are shaped by wider socio-economic factors.

\subsubsection{The rise of patents versus other forms of IP protection for private investment in agricultural research}

There has been a relatively higher increase in the use of utilities patent protection in agricultural filed in the US, in comparison to plant variety protection, although the trend for both has been in the ascendant the last three decades ${ }^{2029}$. This may be due to the higher effectiveness of utility patents in ensuring the appropriability of the innovation returns provided by the invention.

Appropriability under Plant Variety Protection is limited by the farmer's privilege and the breeders' exemption, which erode the ability of new variety developers to appropriate rent by selling seeds ${ }^{2030}$. It was reported that plant variety rights are only associated with low increase in value in comparison to seeds not protected by Plant Variety Rights, and that they are often not litigated, which indicates that they may not be expected to confer substantial market power ${ }^{2031}$. There is, however, evidence that Plant Variety Rights stimulate innovation and R\&D spending, as their establishment had led in general to an increase in R\&D spending for crops eligible for protection ${ }^{2032}$. Evidence that

${ }^{2028}$ Susan Isiko Strba, "Legal and institutional considerations for plant variety protection and food security in African development agendas: solutions from WIPO?” Journal of Intellectual Property Law \& Practice, 2017, Vol. 12, No. 3 191 205.

${ }^{2029}$ G. Moschini, Competition in the US Seed Industry and the Role of Intellectual Property. (2010) 25(2) Choices Mag 1.(providing evidence for the use of Plant Variety Protection rights and utility patents for corn and soybeans and noting that the number of utility patents on varieties exceeded that of PVP rights between 2005-2009); P. Pardey, B. Koo, J. Drew, J. Horwich, C. Nottenburg, The evolving landscape of plant varietal rights in the United States, 1930-2008. (2013) 1(1) Nature biotechnology 25

${ }^{2030}$.S. Clancy \& G. Moschini, Intellectual Property Rights and the Ascent of Proprietary Innovation in Agriculture, Working Paper 17, WP 572 (January 2017), 16.

${ }^{2031}$ W. Lesser, Valuation of Plant Variety Protection Certificates, (1994) 16(2) Rev. Agric. Econ. 231; M.D. Janis \& J.P. Kesan, Intellectual Property Protection: Sound and Fury?, (2002) 39 Houston Law Review 727; S. Clancy \& G. Moschini, Intellectual Property Rights and the Ascent of Proprietary Innovation in Agriculture, Working Paper 17, WP 572 (January 2017), 16-17.

${ }^{2032}$ R. Perrin, K. Kunnings, L. Ihnen, Some Effects of the U.S. Plant Variety Protection Act of 1970. Research Report No. 46, Department of Economics and Business Economics, (North Carolina State University, Raleigh, 1983); L. Butler \& B. Marion, The Impacts of Patent Protection on the U.S. Seed Industry and Public Plant Breeding. North Central Regional Research Publication 304 (1985); S. Malla \& R. Gra. An Analytical and Empirical Analysis of the Private Biotech R\&D Incentives. Selected Paper. Annual Conference of the Agricultural and Applied Economics Association, (Tampa, FL, 2000); S. Mall, R. Gray \& P. Phillips. Gains to research in the presence of intellectual property rights and 
their availability as mechanisms to protect plant varieties stimulated the rate of innovation in the industry is more ambiguous ${ }^{2033}$.

Plant patents do not have limits to appropriability, such as the farmer's privilege or a breeder's exemption, and from this perspective may be considered more valuable than Plant Variety Protection rights $^{2034}$. Some studies put the price premium provided to on average a level of $23.5 \%{ }^{2035}$, which declines with the age of the patent and disappears when the plants get of patent, thus showing that the price premium is not merely due to the higher quality of the protected plants ${ }^{2036}$. Some other studies indicate that the effect of plant patents on innovation is, similarly to that of plant variety rights, quite limited as there is no evidence that it led to increased commercial breeding. although one might not exclude that the lower impact of plant patents could be explained by other factors, such as widespread breeding by users ${ }^{2037}$.

Appropriability is quite high for utility patents, and there is evidence that biotechnology patents have one of the largest patent premiums of any industry ${ }^{2038}$. This may explain why half of utilities patents on varieties ever issues were granted during the period of 2011-2015 and that during this period there has been a considerable growth of the share of patented private varieties for corn, wheat, cotton and soybeans ${ }^{2039}$.

research subsidies. (2004) 26(1) Rev. Agric. Econ. 63 discussed by S. Clancy \& G. Moschini, Intellectual Property Rights and the Ascent of Proprietary Innovation in Agriculture, Working Paper 17, WP 572 (January 2017), 16-17.

2033 . Perrin, K. Kunnings, L. Ihnen, Some Effects of the U.S. Plant Variety Protection Act of 1970. Research Report No. 46, Department of Economics and Business Economics, (North Carolina State University, Raleigh, 1983); B. Babcock \& W. Foster Measuring the potential contribution of plant breeding to crop yields: flue-cured tobacco, 1954-87. (1991( 73 Amer. J. Agric. Econ. 850; A. Naseem, J. Oehmke, D. Schimmelpfennig, Does plant variety intellectual property protection improve farm productivity? Evidence from cotton varieties. (2005) 8 Agbioforum 100; J. Alston\& R.J. Venner, The effects of the US Plant Variety Protection Act on Wheat Genetic Improvement. (2002) 31 Res. Policy 527; D.E. Kolady \& W. Lesser, But are they Meritorious? Genetic Productivity Gains under Plant Intellectual Property Rights., (2009) 60(1) J. of Agric. Econ. 62; R. Thomson. The yield of plant variety protection, (2015) 97(3) Amer. J. Agric. Econ. 762, discussed by S. Clancy \& G. Moschini, Intellectual Property Rights and the Ascent of Proprietary Innovation in Agriculture, Working Paper 17, WP 572 (January 2017), 16-17.

${ }^{2034}$ Ibid., 17.

2035 J. Drew C. Yue, N. Anderson \& P. Pardey, Premiums and discounts for plant patents and trademarks used on ornamental plant cultivars: a hedonic price analysis, (2015) 50 HortScience 879.

2036 S. Clancy \& G. Moschini, Intellectual Property Rights and the Ascent of Proprietary Innovation in Agriculture, Working Paper 17, WP 572 (January 2017), 17.

2037 See, the work of J. Stallman, Impacts of the 1930 Plant Patent Act on Private Fruit Breeding Investment. (Pd.D. Dissertation, Michigan State University, 1986) cited by S. Clancy \& G. Moschini, Intellectual Property Rights and the Ascent of Proprietary Innovation in Agriculture, Working Paper 17, WP 572 (January 2017), 18. See also, P. Moser \& P.W. Rhode, Did Plant Patents Create the American Rose?, in J.Lerner \& S.Stern (eds.), The Rate and Direction of Inventive Activity Revisted, (Chicago, IL: University of Chicago Press, 2011) (showing that following the Plant Patent Act 1930 a large commercial breeding sector emerged, but this did not lead to an overall growth of new roses registsred with the American Rose Society, the overall rate falling. S. Clancy \& G. Moschini, Intellectual Property Rights and the Ascent of Proprietary Innovation in Agriculture, Working Paper 17, WP 572 (January 2017), 18, advance that this drop may be explained by the fact that only $16 \%$ of the new roses were patented and that there was a widespread breeding of roses by hobbyists.

${ }^{2038}$ A. Arora, M. Ceccagnoli \& W.M. Cohen, R\&D and the Patent Premium. (2008) 26 Int. J. Ind. Organ. 1153; W.M. Cohen Fifty years of empirical studies of innovative activity and performance, in B. Hall \& N. Rosenberg (eds.), Handbook of the Economics of Innovation Volume 1, (Oxford, UK: Elsevier Publishing, 2010) (finding that utility patents are the most valuable to life science and chemical industries, agricultural biotech presenting many similarities with these sectors).

2039 . Clancy \& G. Moschini, Intellectual Property Rights and the Ascent of Proprietary Innovation in Agriculture, Working Paper 17, WP 572 (January 2017), 19 , reporting that private corn varieties account for $100 \%$ of planted US acres (already since 1980 (this being facilitated by hybrid technology), while for wheat it rose from 5\% to $24 \%$ between 1980 and the late 1990 s, for cotton it rose from $72 \%$ to $93 \%$ over the same period and for soybeans it rose from $8 \%$ to $70-90 \%$ over the period. 
The type of IP protection preferred by the firms is not necessarily will not necessarily promote societal welfare if the specific type of innovation could be protected by less restrictive to competition instruments. As it has been shown by some recent research, patents may be best at promoting longrange research programs (such as the introduction of exotic germplasm), while Plant Variety Protection rights promote faster diffusion of genetic improvements across firms, hence, they can be a superior option to patents when the diffusion element of innovation dominates the incentives element $^{2040}$.

\subsubsection{The governance of the innovation process: inter-business arrangements}

The important number of M\&A transactions in the seed and crop protection industries the last thirty years constitutes the tip of a much bigger consolidation iceberg that has taken various forms ${ }^{2041}$. The extent of this cross-licensing activity is unknown as major competition law jurisdictions, such as the EU and the US, do not require a notification of cross-licensing agreements. In Brazil, while CADE's precedents suggests that cross-licensing agreements used to be of mandatory notification under the old CADE's ruling for associative agreements, after the enactment of CADE's Resolution $\mathrm{n}^{\mathrm{o}} 17$ in October 2016, there was no precedent that would signalize whether these arrangements should be of mandatory notification. It is important to point out that CADE's Resolution $\mathrm{n}^{\mathrm{o}} 17$ significantly changed criteria for mandatory notification of associative agreements. According to the new ruling, associative agreements are of mandatory notification provided that: (i) the involved parties are competitors and met the double turnover threshold criteria; (ii) with a term of 2 year or longer; (iii) the agreement aims to create a joint undertaking to pursue an economic activity; and (iv) the sharing of the risks and results of the economic activity ${ }^{2042}$.

- Joint ventures: In 2013, KWS and Limagrain acquired joint control of Genective SA, a company active in the research and marketing of transgenic traits to be used in the production of genetically modified ("GM") seeds, in particular "GM maize traits", with the aim to improve the plants' qualities in terms of herbicide tolerance, insect resistance and water use efficiency. These transgenic traits were protected by patents, the parties aiming to license their use between them (cross-licensing) as well as to interested customers. The European Commission cleared the joint venture ${ }^{2043}$. It found no competition concerns in the upstream market for the development and licensing of GM maize traits, as it noted that the joint venture would compete with Monsanto, the only strong competitor already active in the EEA market, and that other firms may enter this market, concluding that there would be four providers of GM maize traits in the European market in the future ${ }^{2044}$. The Commission also found no competition concerns in the downstream market for breeding and commercialization of conventional and GM maize seeds to customers in Europe. First, the parties conducted their breeding activities almost exclusively for internal use. Second, although the Commission found that the market shares of the parties were high at some national markets in the EEA, it

\footnotetext{
${ }^{2040}$ S.H. Lence, D.J. Hayes, J.M. Alston \& J.S. Smith, Intellectual property in plant breeding: comparing different levels and forms of protection, (2016) 43(1) Eur. Rev. Agric. Econ. 1.

${ }^{2041}$ ETC Group Communiqué 115, Breaking Bad (December 2015), 11.

2042 Submission Questionnaire Brazil.

${ }^{2043}$ Case No COMP/M.6454 - LIMAGRAIN / KWS / GENECTIVE JV (2013).

2044 Id., para. 40.
} 
did not find that a level of 30-40\% market share raised concerns and noted that the proposed transaction did not give rise to vertical links between the activities of the JV and the activities of the parties in the commercialization of conventional seeds. The European Commission made clear that the issue in this case was not the combination of the parties' activities in the breeding and commercialization of seeds, as their cooperation remained confined to the development and licensing of transgenic traits on the upstream market, leading to the creation of a new competitor in the development and licensing of GM maize traits. The European Commission also held that companies regularly offered seeds incorporating transgenic traits of their competitors to meet customer demand, and that therefore "trait developers normally do not have incentives to market GM seeds incorporating exclusively their own transgenic traits" ${ }^{2045}$. Monsanto, Du Pont and Syngenta have also invested and established four jointventure companies in China with Chinese seed enterprises.

- Cross-licensing and trait licensing agreements: Some recent research has documented a spider web of cross-licensing agreements of proprietary traits and technologies between the "Big Six"2046. This form of collaboration is particularly linked to the development of crops stacking multiple transgenic traits, some of them combining transgenic traits owned by different companies, within a single seed. By licensing traits to one another, companies can sell their own technologies as well as the technologies of their competitors. Monsanto's traits are the central node in this network of agreements, as it is the only firm to have agreements with each of the other 5 firms, with the result that, according to some estimations, "more than $80 \%$ of the land planted with major field crops in the US contained transgenic traits owned or licensed by Monsanto" 2047 . It is also quite difficult to understand the full implications of the existence of this web of cross-licensing agreements between the Big Six, but also more broadly, the network of all trait licensing agreements with third parties, in view of the fact that licensing information is rarely made public, patent owners being not legally required to disclose licensing data to the patent office, or the competition authority, the public only seeing "the information that a patent owner chooses to provide" ${ }^{2048}$. This may stifle innovation as "(a) young entrepreneur interested in that collection of patents could spend huge sums of lawyer's fees for investigating the true ownership of each patent or developing a freedom-tooperate analysis before even beginning to make a product for market"2049.

- Distribution agreements: In order to distribute their own products on the national and local markets, a large seed company can make a deal with smaller seed companies without owning them. This may dampen competition between them to the detriment of consumers.

- Collaborations, research agreements and $R \& D$ strategic alliances: A number of inter-firm alliances have also developed in recent years. BASF and Monsanto have collaborated since 2007 on R\&D partnerships worth $\$ 2.5$ billion in breeding, biotech, pesticides, ag microbials,

\footnotetext{
2045 Id., para. 53.

${ }^{2046} \mathrm{Ph}$. Howard, Intellectual Property and Consolidation in the Seed Industry, (2015) 55(6) Crop Science 1-7.

${ }^{2047} \mathrm{Ph}$. Howard, Visualizing Consolidation in the Global Seed Industry:1996-2008, (2009) 1 Sustainability $1266,1279$.

2048 O.A. Jefferson, D. Kôllhofer, T. H. Ehrich \& R.A. Jefforson, The ownership question of plant gene and genome intellectual properties, “(015) 33(1) Nature Biotechnology 1138, 1142.

2049 Id.
} 
ag biologicals, and precision agriculture ${ }^{2050}$. Microbial products are a new opportunity and potentially a game changer and a disrupting technology at the global scale. Although currently the industry is still in its infancy (less than USD 2bn of global sales in 2014), going forward it represents a huge potential, especially given the growing demand for organic farming globally. Realizing this, in 2014 Monsanto announced an alliance known as BIOAG Alliance with Novozymes, one of leaders in biotech industry. Novozymes is responsible for the production of the microbial products while Monsanto serves as the lead for field testing, registration, and commercialization for the Alliance's products ${ }^{2051}$.

- Patent litigation truces: Following a period of patent war about who controls the technology for making soybeans resistant to the weed-killer Roundup, known generically as glyphosate, DuPont and Monsanto agreed in 2013 to drop antitrust and patent claims against each other. DuPont agreed to pay Monsanto $\$ 1.75$ billion over 10 years for the rights to the technology of its herbicide-resistant soybean, sweeping away a US federal jury's decision that DuPont should pay Monsanto \$1 billion for infringing on the company's proprietary glyphosateresistance technology, and also an antitrust lawsuit that DuPont had brought against Monsanto. Commenting on the agreement, Brett D. Begemann, Monsanto's president and chief commercial officer, noted in a joint news release: “( $t$ )his signals a new approach to our companies doing business together, allowing two of the leaders in the industry to focus on bringing farmers the best products possible"2052. This culture of "doing business together" may increase risks of collusion or parallel exclusion of actual and/or potential competitors.

'Post-Patent' Generic trait agreements: One may also mention as an illustration of the extensive collaboration between the Big Six the generic trait agreement aiming to put in place a "post-patent" regulatory regime, laying down the rules for access to generic biotech traits at patent expiration ${ }^{2053}$. The expiration of some of the first biotech patents granted in the mid to late 1980s constitutes an important challenge for the industry, in particular as it is theoretically possible that generics may enter these markets and that the Big Six may attempt to delay such entry, using exclusionary strategies, such as failing to renew the regulatory approval of a biotech trait before expiration of the patent or of existing regulatory approvals ${ }^{2054}$. These patents' expiration may enable farmers to save commodity seed from the current year for planting the next year (brown bagging), a practice that seed companies have long sought to limit.

An example is Monsanto's Roundup Ready ${ }^{\circledR}$ Technology Agreement that usually provides that the farmer cannot save seed or any other part of the crop grown from the Monsanto seed for replanting and that the farmer is prohibited from supplying seed to any other person. Violation of these licenses may be regarded as a breach of contract subject to draconic sanctions, the farmer being obliged to pay 120 times the technology fee plus the legal fee if he/she is caught violating the

\footnotetext{
${ }^{2050}$ ETC Group Communiqué 115, Breaking Bad (December 2015).

2051 BIOAG Alliance Fact Sheet, available at http://www.novozymes.com/en/about-us/brochures/Documents/BioAgAlliance-factsheet.pdf.

2052 A, Pollack, Monsanto and DuPont Settle Fight Over Patent Licensing, New York Times (March 26, 2013).

${ }^{2053}$ ETC, Issue \# 110, Gene Giants Seek "Philanthrogopoly (March 2013).

2054 The issue was raised by Martin A. Lema \& Vanesa Lowenstein, Tit for Tat: Agbiotech Intellectual Property and Corporate Social Responsibility, 2 BRIDGES TRADE BIORES REV. 11, 11-12 (2008). See also, Norman W. Hawker, Competition Issues Arising from Generic Biotech Crops, (2013) 18(1) Drake Journal of Agricultural Law $137,138$.
} 
agreement. Enforcement of these contractual clauses involves the continuous inspection of the farmers' fields by Monsanto's staff. Binding arbitration constitutes a default dispute resolution mechanism.

The seed industry has also put in place biological tools to protect its IP rights by developing hybridization, or more recently through cytoplasmic male sterility, one of the most efficient ways to produce F1 (the first filial generation of offspring of distinctly different parental types) hybrid seeds. Another biological protection is Genetic Use Restriction Technology (GURT), with the development of terminator technologies preventing farmers from saving seeds since the genetically engineered plants will not germinate in subsequent generations or will not express the specific trait (e.g. herbicide resistance) that is protected by IP rights, unless the plant is sprayed with specific chemicals in order to activate the right gene. These biological protection instruments are particularly useful in jurisdictions with weak enforcement of IPRs.

As Monsanto's Roundup and Roundup Ready patent expired in 2015, competitors can now introduce a generic version of the trait. Monsanto has patented the Genuity ${ }^{\mathrm{TM}}$ Roundup Ready 2 Yield trait technology, these seeds being protected by a different utility patent which will not expire until the end of the next decade. It is estimated that around two dozen patents on first generation biotech crop traits and technologies will come off patent in the next 5-10 years. However, as with the pharma industry, which is also heavily regulated for human health and safety reasons, generic genetically engineered seeds and traits or chemicals must go through re-approval. One may add to these regulatory requirements those resulting from the UN Convention on Biological Diversity and the Cartagena Protocol on Biosafety, which would require from the breeders wanting to use these generic traits, to have biosafety approval from the government authorities, in particular where they plan to export the genetically engineered germplasm or cultivate the genetically engineered seeds ${ }^{2055}$. To satisfy these government approval processes and the subsequent registration requirements, the generics' producers will need legal access to the proprietary safety testing data initially submitted by the Big Six. Without access to this proprietary information the cost of bringing generic biotech crops to market may be quite prohibitive.

In order to pre-empt any regulatory or competition law initiative in this area, the industry leaders put in place a "unique private sector solution to address the transition of regulatory and stewardship responsibilities for biotech" 2056 , with the aim to ultimately control the terms of access to expired traits. Monsanto, in the context of the Biotechnology Industry Organization (BIO) and the American Seed Trade Association (ASTA), drafted the Generic Event Marketability and Access Agreement (GEMAA) which provides that companies that have developed proprietary regulatory information (the "Proprietary Regulatory Property (PRP) Holders") should provide access to the generics at patent expiration. PRP Holders are required to provide notice of patent expiration three years before the last patent on the biotechnology event expires. At the point of the notice of patent expiration, the PRP Holder may choose one of the following strategies: (i) independently maintain regulatory responsibility at no cost to users of the generic, thus providing access to the proprietary regulatory package for purposes of new product development, such as seed products containing proprietary stacks; (ii) share regulatory responsibility, in which case in which case the PRP Holder and interested Signatories to the GEMAA would begin negotiation of a "joint responsibility

2055 See our analysis in Part III, Chapter 1.

${ }^{2056}$ See, http://www.agaccord.org/ . 
agreement"; (iii) or discontinue regulatory responsibility leading to the negotiation of a "transition agreement" with the same timeline and process as the joint responsibility agreement, including binding arbitration for unresolved issues in the negotiation ${ }^{2057}$. The GEMAA entered into force in November 2012 and has 10 signatories, including the Big Six (with the exception of Syngenta) ${ }^{2058}$.

The Data Use and Compensation Agreement (DUCA) requires its signatories to provide three years in advance of patent expiration notification that a patent will expire. It also puts in place mechanisms for a 'good-faith' negotiation for pre-patent access, prior to patent expiration, if necessary, as well as an alternate mechanism for data compensation in return for access to proprietary regulatory property (PRP) at patent expiration ${ }^{2059}$. The DUCA opened for signature in December 2013 and will become operational once it is signed by six parties. It has so far been signed by four.

The speed of the entry of generics in this market will depend on the access generic seed companies may have to Monsanto's and other Big Six's data packages allowing them an advanced development and testing. This may raise equivalent competition issues than those routinely involved in the competition law enforcement in the pharma sector that led to jurisprudence such as FTC $v$. Actavis in the U.S., ${ }^{2060}$ and Astra Zeneca in the E.U with regard to strategies by incumbent IP holders to block the entry of generics, following the expiration of their IP rights ${ }^{2061}$.

\subsubsection{The governance of the innovation process: knowledge commons}

At the other side of the governance spectrum, one may think of organising the innovation activity in the form of "common pool resources" or "knowledge commons" 2062 . Crop genetic resources could be conceptualised as a form of commons, the relative open flows of germplasm making possible collective systems of conservation and innovation, as those self-managed by farmers from the dawn of agriculture ${ }^{2063}$. One may cite the example of the collective pooling and management of plant genetic resources for food and agriculture put in place by the International Treaty on Plant Genetic Resources for Food and Agriculture (PGRFA), adopted by the FAO in 2001 and which entered into force on 29 June 2004. Emergent and developing countries have vigorously campaigned to ensure that genetic material taken from their territories without permission would not be used to generate commercial applications that would benefit from IP rights internationally protected through the TRIPS agreement. By asserting territorial sovereignty over all genetic resources, the Convention on Biological Diversity (CBD) provided the possibility for an international regulation of access to these resources by scientists for research purposes and eventually farmers. The CBD provided regulations for access to genetic resources and transfer of relevant technologies on Mutually Agreed Terms (MAT) and based on Prior Informed Consent (PIC). The Nagoya Protocol on Access and Benefits

\footnotetext{
2057 See, http://www.agaccord.org/include/GEMAA-SecondAmendedEdition-Nov52015.pdf .

2058 These include the American Farm Bureau Federation, the American Seed Trade Association, the American Soybean Association, BASF Plant Science LP, Bayer CropScience, Dow AgroSciences LLC, Dupont Pioneer, Gro Alliance, LLC, Monsanto Company and the National Corn Growers Association.

${ }^{2059}$ See, http://www.agaccord.org/?p=DUCA.

${ }^{2060}$ Federal Trade Commission v. Actavis, 133 S.Ct. 2223 (2013).

${ }^{2061}$ Case C-457/10 P, AstraZeneca AB and AstraZeneca plc v European Commission, ECLI:EU:C:2012:770.

2062 E. Ostrom, Governing the Commons: The Evolution of Institutions for Collective Action. (New York: Cambridge University Press, 1990); C. Hess \& E. Ostrom, Understanding Knowledge as Commons (MIT press, 2006)

${ }^{2063}$ M. Halewood, I. López Noriega \& S. Louafi (eds.), Crop Genetic Resources as a Global Commons: Challenges in International Law and Governance (Routledge, 2013).
} 
Sharing, a 2010 supplement to the 1992 Convention on Biological Diversity, put forward a framework for ensuring that countries where seeds and microbes held in public collections originate, along with the relevant traditional knowledge, share in the profits and other benefits provided from their use. The Nagoya Protocol mainly focused on the creation of a mechanism for bilateral arrangements, but an additional option would have been a multilateral treaty establishing a transnational exchange and remuneration system.

The last option was taken with the PGRFA, with the establishment of public seed banks. The Treaty constitutes the follow up of an International Undertaking on Plant Genetic Resources in $1983^{2064}$ The Treaty's aims are the conservation and sustainable use of all plant genetic resources for food and agriculture and the fair and equitable sharing of the benefits arising out of their use, in harmony with the Convention on Biological Diversity, for sustainable agriculture and food security 2065 Article 9 of the PGRFA provides for farmer's rights, and in particular for "the right to equitably participate in sharing benefits arising from the utilization of plant genetic resources for food and agriculture" 2066 . The Treaty also puts in place a global system for access and benefit sharing in order to provide farmers, plant breeders and scientists with access to plant genetic materials and covering 64 of the most important crops. This easily accessible global pool of genetic resources in various public collections and seed banks is freely available to potential users in the Treaty's ratifying nations for research, breeding and training for food and agriculture. Those who access the materials must be from the Treaty's ratifying nations and they must agree to use the materials totally for research, breeding and training for food and agriculture.

The Treaty prevents the recipients of genetic resources from claiming intellectual property rights over those resources in the form in which they received them, and ensures that access to genetic resources already protected by international property rights is consistent with international and national laws. For those that want to make a commercial use of these resources, the Treaty puts in place a "take and pay" rule. If a plant cultivar put in a public collection is used for commercial purposes, they agree to share any benefits from their use through four benefit-sharing mechanisms established by the Treaty, the exchange of information, access to and transfer of technology and capacity building. They are also required to pay a small percentage of the resulting proceeds, a tithe, back to the Benefit Sharing Fund of the ITPGRFA. Facilitated access to this vast gene pool under the Treaty is provided under the terms and conditions of the Standard Material Transfer Agreement (SMTA). If the recipient commercializes a product (product that is a PGRFA and that incorporates material accessed under SMTA) and where such product is not available without restriction to others, the recipient is required to pay a fixed percentage of the sales of the commercialized product into the mechanism. This is specifically $1.1 \%$ of net sales less $30 \%$ or $0.77 \%$ of gross sales. However, if the recipient commercialises a product where product is available without restriction to others, the recipient is encouraged to make voluntary payments into the mechanism. After the expiry or abandonment of the protection period of an IPR on a product, the recipient is encouraged to place a sample of this product into a collection of the multilateral system. In case a recipient obtains IPR on any products developed from the material or its components and assigns such IPR to a third party, 
the benefit sharing obligations of the agreement is transferred to that third party. The Benefit Sharing Fund invests directly in high-impact projects such as supporting farmers in developing countries who conserve crop diversity in their fields and providing assistance to farmers and breeders who adapt crops to our changing needs and demands.

Other examples of international efforts to constitute commons are the recent proposals for establishing a commons regime for microbial genetic resources ${ }^{2067}$. One may also consider the quite sophisticated Transnational Open Knowledge Environments enabling the sharing of data

\subsection{Public investment in agricultural research}

Research and development in agriculture has been described as one of the main drivers of agricultural productivity and, in turn, of global food production to match increasing demand. ${ }^{2068}$

Public investment has featured in agricultural research to varying extents and under specified frameworks according to different countries. Different reasons arise for public investment in agriculture. For instance, some countries have different standards and costs associated to IP enforcement, making it hard to defend IP and thereby diminishing the returns of private research and development in this area. The development of technologies through public R\&D in agriculture has also been beneficial in aiding the relief of poverty and equity, and therefore tackling social issues. ${ }^{2069}$ In this regard, for example, public investment aimed at the productivity of smallholder farmers could target new varieties of crops and therefore increase self-sufficiency by reducing the price of crops. ${ }^{2070}$

Empirical studies conducted in some countries reveal how public investment in research can lead to long-term increase in crop productions consistently through different crops; ${ }^{2071}$ moreover productivity-based research can produce higher results than investment for example into irrigation. $^{2072}$

In terms of the relationship between public and private investment, the former could in certain circumstances also increase the profitability of the latter. This may occur, for example, where R\&D in crop varieties that produce higher yield increases the financial standing of agricultural enterprises, expands the opportunities for private actors and pushes in turn for more private investment. ${ }^{2073}$ At the same time it should be noted, macroeconomic consequences of public investment (for eg increases in

\footnotetext{
${ }^{2067}$ P.F. Uhlirch, Designing the Microbial Research Commons (National Academies Press, 2011); J. H. Reichman, P. F. Uhlir, \& T. Dedeurwaerdere, Governing Digitally Integrated Genetic Resources, Data, and Literature: Global Intellectual Property Strategies for a Redesigned Microbial Research Commons (Cambridge University press, 2016)

${ }^{2068}$ K.O Fuglie and A.A Toole, The evolving institutional structure of public and private agricultural research, (2014) Amer. J. Agr. Econ. 1-22.

2069 Tewodaj Mogues, Bingxin Yu, Shenggen Fan and Linden McBride, the impacts of public investment in and for agriculture: synthesis of the existing evidence, ESA Working paper No. 12-07 October 2012.

2070 Tewodaj Mogues, Bingxin Yu, Shenggen Fan and Linden McBride, the impacts of public investment in and for agriculture: synthesis of the existing evidence, ESA Working paper No. 12-07 October 2012.

${ }^{2071}$ See for example Rosegrant, M., F. Kasryno, and N. D. Perez., Output Response to Prices and Public Investment in Agriculture: Indonesian Food Crops., 55 (2) 1998 Perez Journal of Development Economics 333-352.

2072 Rosegrant, M., F. Kasryno, and N. D. Perez., Output Response to Prices and Public Investment in Agriculture: Indonesian Food Crops., 55 (2) 1998 Perez Journal of Development Economics 333-352. See more generally, Tewodaj Mogues, Bingxin Yu, Shenggen Fan and Linden McBride, the impacts of public investment in and for agriculture: synthesis of the existing evidence, ESA Working paper No. 12-07 October 2012

2073 Tewodaj Mogues, Bingxin Yu, Shenggen Fan and Linden McBride, the impacts of public investment in and for agriculture: synthesis of the existing evidence, ESA Working paper No. 12-07 October 2012 p. 40.
} 
interest rates) may increment the cost of borrowing and diminish the margins of profitability for private actors. $^{2074}$

In recent years, the relationship between public and private investment has come to the forefront of discussions on agricultural investment. In countries like the US, as a matter of fact, agricultural research has witnessed an emergence of trends that see a correlation between diminished public investment on one side and increased private investment on the other, with productivity in the area being increasingly propped up by the latter. ${ }^{2075}$ This trend is also reflected globally: in 2008 private investment amounted to $36 \%$ of the 54 billion USD spent on agricultural research. ${ }^{2076}$

Moving forward, the new private/public dichotomy has led to reconsider the interplay between governmental bodies (and spending) and private actors. Private actors have been pursuing projects that in the past would have been in the primary scope of public bodies, due to higher returns on social issues (environment, food nutrition etc) rather financial returns. ${ }^{2077}$ On the other hand, public bodies and institution can engage in a different allocation of public resources in their portfolio of public projects, creating new opportunities of collaboration between private and public and the possibility of technology transfer; as an example, public investment could focus on upstream research, with the market development and application being given to private actors. ${ }^{2078}$ Specifically, the collaboration could range from the simple research grant or patent licensing to joint venture or more complex research consortia involving a number of private and public actors. ${ }^{2079}$

This new paradigm requires appropriate legislative frameworks that create and foster technology transfer between public and private. Illustrations of such frameworks can be seen in many jurisdictions, for example in the US with the Technology Transfer Act 1986 or the Bayh-Dole Act 1980, or in South Africa with the Intellectual Property Rights from the Publicly Financed Research and Development Act (act no. 51 of 2008). The importance of legislative frameworks is crucial as they establish clear boundaries between public and private in the research and commercialisation efforts. In the absence of clarity, private actors could be disincentivised where they lack the financial returns to their investment, and equally public investment would lack the commercialisation needed to fully realise social benefits. ${ }^{2080}$

Institutional design is also crucial in determining public investment and collaboration with private actors. Brazil, for example, has been very successful in developing public research

\footnotetext{
${ }^{2074}$ Tewodaj Mogues, Bingxin Yu, Shenggen Fan and Linden McBride, the impacts of public investment in and for agriculture: synthesis of the existing evidence, ESA Working paper No. 12-07 October 2012 p. 40-41.

2075 K.O Fuglie and A.A Toole, The evolving institutional structure of public and private agricultural research, (2014) Amer. J. Agr. Econ. 1-22; on this, see also J.M. Alston and others, Persistence Pays: U.S. Agricultural Productivity Growth and the Benefits from Public R\&D Spending (2010, Springer Ed.).

New York: Springer.

2076 N. Bientema and others, ASTI Global Assessment of Agricultural R\&D Spending, (Washington DC: International Food Policy Research Institute, 2012).

2077 K.O Fuglie and A.A Toole, The evolving institutional structure of public and private agricultural research, (2014) Amer. J. Agr. Econ. 1-22.

${ }^{2078}$ K.O Fuglie and A.A Toole, The evolving institutional structure of public and private agricultural research, (2014) Amer. J. Agr. Econ. 1-22.

${ }^{2079}$ For an elaboration of this, see K.O Fuglie and A.A Toole, The evolving institutional structure of public and private agricultural research, (2014) Amer. J. Agr. Econ. 1-22, pp 8-9.

${ }^{2080}$ K.O Fuglie and A.A Toole, The evolving institutional structure of public and private agricultural research, (2014) Amer. J. Agr. Econ. 1-22.
} 
development in agriculture through EMBRAPA (Brazilian Entreprise for Agriculture Research), as can be seen by the country's enhanced productivity and economic efficiencies in agriculture, "strong export performance and geographic decentralization of growth." ${ }^{2081}$ EMBRAPA has the task of pursuing research and development activities and technology transfer in agriculture and livestock. ${ }^{2082}$ It is a public company that employs 10.000 people and has an annual budget of ca. 900 million USD. ${ }^{2083}$ EMBRAPA works in the development and marketing in seeds through collaborations with research centres and governments, and is the owner of relevant patents and software registers (in either sole or co-ownership). It is also in charge of coordinating federal state entities' participation in a wider national system of research.

The success of EMBRAPA can be illustrated through its work in the transformation of Cerrado's soil, in a central part of the country that is $22 \%$ of the country's total area. ${ }^{2084}$ The soil was originally highly acid and contained poor nutrients, leading to an unproductive use of the area. EMBRAPA tackled the issues by employing techniques, such as agricultural liming, developing varieties of bacterium rhizobium (adapted to the Cerrado soil), and cross-breeding African grass brachiaria with a native Cerrado grass to improve the yield of the grass feed. ${ }^{2085}$ As a result parts of Cerrado turned into a successful high-yield pasture.

The results of EMBRAPA are in part due to its collaborative efforts internationally. The breeding program dealing with short-photoperiod soybeans was in collaboration between EMBRAPA and USDA-ARS. The germplasm of grass feed bracharia (that was then adapted to for the Cerrado soil) was provided by the International Center for Tropical Agriculture. EMBRABA further maintains so-called Virtual Labs Abroad (Labex) for collaboration in the US and in Europe. ${ }^{2086}$

In South Africa, public research and development in agriculture is carried out by the Agricultural Research Council and nine provincial Departments of Agriculture. ${ }^{2087}$ This segregation of R\&D expenditures between different public entities has been criticised as not reflecting suitable agro-ecological boundaries to conceive and target agricultural R\&D. ${ }^{2088}$ From 2000 to 2009 South Africa's R\&D expenditure was on average 0.87 percent of GDP. ${ }^{2089}$ However, despite relatively high public $R \& D$ expenditure in agricultural sector, it has declined significantly since 2005 . The decline in public agricultural $R \& D$ expenditure was mainly attributed to the shifts in government funding model and budget cuts. ${ }^{2090}$

\footnotetext{
${ }^{2081}$ P. Correa and C. Schmidt, Public Research Organizations and Agricultural Development in Brazil: How Did Embrapa Get It Right?, World Bank Economic Premise (June 2014), p.8 available at: http://siteresources.worldbank.org/EXTPREMNET/Resources/EP145.pdf

${ }^{2082}$ Brazil Country Fiche, p.9

${ }^{2083}$ Available at: https://www.embrapa.br/en/quem-somos.

${ }^{2084}$ P. Correa and C. Schmidt, Public Research Organizations and Agricultural Development in Brazil: How Did Embrapa Get It Right?, World Bank Economic Premise (June 2014) available at: http://siteresources.worldbank.org/EXTPREMNET/Resources/EP145.pdf

${ }^{2085}$ P. Correa and C. Schmidt, Public Research Organizations and Agricultural Development in Brazil: How Did Embrapa Get It Right?, World Bank Economic Premise (June 2014) available at: http://siteresources.worldbank.org/EXTPREMNET/Resources/EP145.pdf

${ }^{2086}$ P. Correa and C. Schmidt, Public Research Organizations and Agricultural Development in Brazil: How Did Embrapa Get It Right?, World Bank Economic Premise (June 2014) available at: http://siteresources.worldbank.org/EXTPREMNET/Resources/EP145.pdf

${ }^{2087}$ Trade Research Niche Area, Faculty of Economic and Management Sciences, North West University, 'South Africa's Agricultural Trade Competitiveness Diagnostics (June 2013), p. 137.

${ }^{2088}$ Ibid.

${ }^{2089}$ Ibid, p. 138.

${ }^{2090}$ Ibid, p. 139.
} 
The figure below represents the agricultural $R \& D$ expenditure in South Africa and selected peer countries

\section{Table 7: Agricultural R\&D expenditure in South Africa}

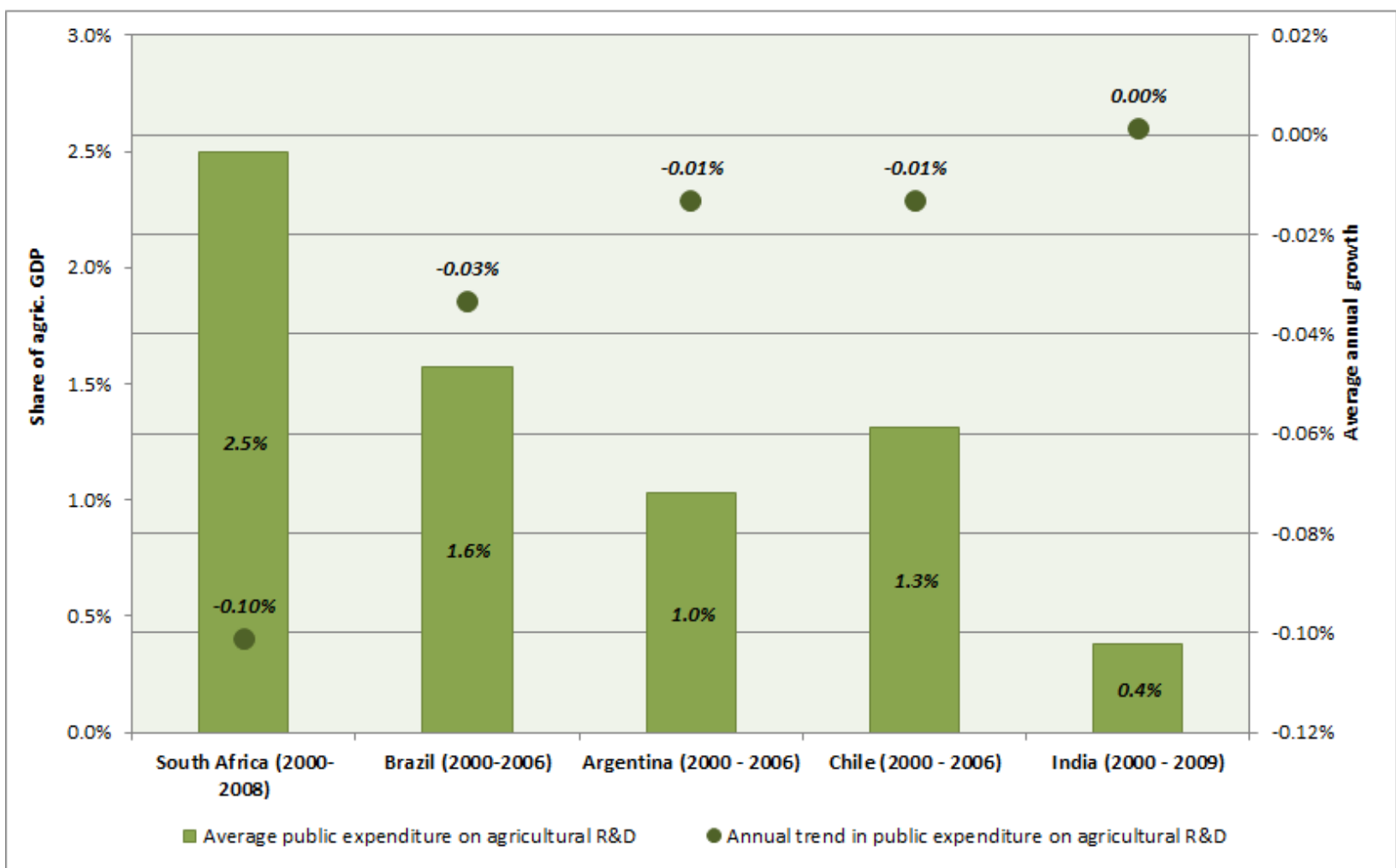

Source: Trade Research Niche Area, Faculty of Economic and Management Sciences, North West University, 'South Africa's Agricultural Trade Competitiveness Diagnostics (June 2013) p. 140.

To improve the productivity and efficiency in agricultural sector, it has been suggested that Brazil's EMBRAPA model shoud be introduced in South Africa as well. ${ }^{2091}$

\subsection{The interaction between competition law and IP: how much room do competition law enforcers have in the innovation space?}

\subsubsection{General Discussion}

As innovation is considered a major engine of growth, public authorities play a direct role in fostering innovation $^{2092}$, but also in supporting the emergence of an innovation-friendly market environment. Historical work has duly noted the role of institutions (formal and informal) in the promotion of

\footnotetext{
${ }^{2091}$ Trade Research Niche Area, Faculty of Economic and Management Sciences, North West University, 'South Africa's Agricultural Trade Competitiveness Diagnostics (June 2013), p. v.

${ }^{2092}$ This is either done through public investment in science and basic research, which can play an important role in developing general-purpose technologies and, hence, in enabling further innovation, as well as public support to innovative activity in the private sector, which is usually taking the form of a mix of direct and indirect instruments such as tax credits, soft loans, direct support etc. On the important role of the State in supporting innovation, see M Mazucatto, The Entrepreneurial State: debunking public vs. private sector myths (Anthem 2013).
} 
innovation and creativity. ${ }^{2093}$ The growth of Total Factor Productivity (TFP) ${ }^{2094}$ is often used as a measure of innovation ${ }^{2095}$. The intensity of R\&D expenses has also been used as an indirect measure of innovation, as it quantifies the resources used to promote innovation. Firm-level survey data may also provide information on innovation, the way firms introduce new products or processes in the market. But these do not constitute the only metrics, in particular as innovations may take different forms along the value chain if one is to approach the measurement topic from a value chain perspective. This involves agricultural inputs such as Fertilisers and seeds, at times coming from the chemical or the biotechnology sector; product innovations; and process or organizational innovations in the fields of payments, logistics, and distribution services. Specific innovation metrics may develop for each of these various forms of innovation. For instance, in the context of agricultural biotechnology, Moser, Ohmstedt, and Rhode compiled data on advances in yields, and other biological characteristics of patented corn hybrids, to measure the speed of biological innovation ${ }^{2096}$. These different measures may indicate that performance measures are impossible to construct in a manner that makes them comparable across industries ${ }^{2097}$. One also needs to bear in mind that in developing countries, agricultural activities and related innovations often take place at the farm or household level (especially in case of subsistence farming), not in private-sector firms as captured by most data collections, and that capturing activity in the informal sector may be statistically challenging.

Innovation has been traditionally defined as an 'economic change' or development that is not generated by the spontaneous evolution of consumers' needs but is instead engendered by the inventors. Schumpeter emphasized the role of the entrepreneur and opposed the active role she or he plays in the innovative process to the passive role of the consumer. ${ }^{2098}$ His point was that most innovation is entrepreneur-generated. This view accommodates the perception that the main actor in the innovation process is the inventor (or more broadly the entrepreneur) and that law should provide the right set of tools in order to enhance his or her inventive activity this involving the protection of Intellectual Property (IP) rights. One could compare this entrepreneur/inventor centred view of innovation to the increasing role of consumer-generated innovation.

Users, such as farmers, participate to the development of innovation in the market. Major advances in agricultural technology, let alone the process of single selection, found their sources in innovation performed by the farmers or agricultural, working individually or collectively in cooperatives. Their share in the innovation process has been declining since the development of the chemicals-based model of agriculture in the 1960s-1970s and then the biotech revolution, which increased the costs of innovation. This may change with the advent of cheaper technologies of genome-editing and the possibility to develop varieties with regional characteristics, which seem to

\footnotetext{
2093 J Mokyr, The Lever of Riches: Technological Creativity and Economic Progress (OUP, 1992).

2094 TFP corresponds to the growth of output that is not explained by the relative contributions of capital and labor and can be considered as "technical progress in its broadest sense". Its level is its level is determined by how efficiently and intensely the factors of production (labour, capital) are utilized in production: R.M. Solow, 'Technical change and the aggregate production function' (1957) 39 The Review of Economics and Statistics, 312-320.

${ }^{2095}$ R. Gordon, The Rise and Fall of American Growth (Princeton University Press, 2016).

${ }^{2096}$ P. Moser, J. Ohmstedt, \& PW. RhodePatent Citations - An Analysis of Quality Differences and Citing Practices in Hybrid Corn (March 5, 2016). Available at SSRN: https://ssrn.com/abstract=1888191 or http://dx.doi.org/10.2139/ssrn.1888191

${ }^{2097}$ P. Moser, Patents and Innovation in Economic History, (2016) 8 Annual Review of Economics 241.

2098 J Schumpeter, Capitalism, Socialism and Democracy (1942, published by Harper \& Bros. in 1950).
} 
require less specialisation and cheaper and more easily accessible instruments ${ }^{2099}$. The question of the ownership of farm data could also be quite relevant for a more active role of farmers in the process of innovation brought by "smart agriculture". A more active role of farmers in the process of innovation should presumably get them a better share of the total surplus value produced by innovation.

Traditionally the process of innovation has been conceived of as linear. According to this traditional model, innovation is thought to start 'upstream', with fundamental scientific insights, and moved 'downstream' through the discovery of technical applications of these insights, the development of commercial embodiments and manufacturing techniques, followed by arrangements for distribution, servicing, and sales. In Bush's view, upstream research—basic science—was too far removed from application to be an attractive target for commercial investment. At the same time, however, this work is the wellspring from which multiple technological prospects flow. The expectation was that robust competition would function as an 'engine', driving industry to adapt the advances, find applications, create new businesses and jobs, enhance productivity, and improve social welfare. $^{2100}$

Figure 9: The Innovation process

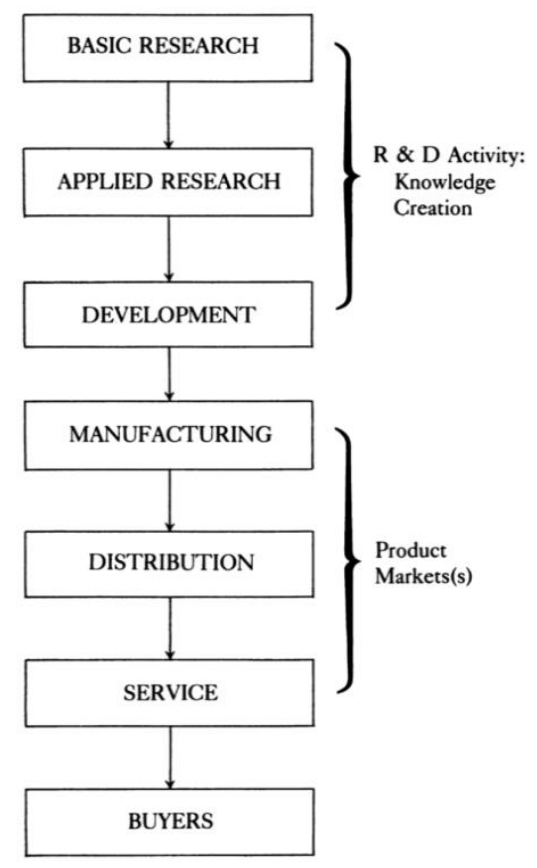

Source: J.A. Ordover (1984) $)^{2101}$

It has become clear that the traditional model and the laws that flowed from it do not capture many important aspects of the innovation process.

\footnotetext{
${ }^{2099}$ Nuffield Council on Bioethics, Genome Editing: An Ethical Review (September 2016), 9.

2100 J Schumpeter, The Theory of Economic Development (London, Transaction Pub 2005, first published by Harvard University Press in 1934) and Capitalism, Socialism and Democracy (1942, published by Harper \& Bros. in 1950).

${ }^{2101}$ JA Ordover, 'Economic Foundations and Considerations in Protecting Industrial and Intellectual Property' (1984) 53 Antitrust Law Journal 503, 515.
} 
Modern economists have questioned the linearity of innovation. Fundamental insights are not the exclusive domain of scientists. In fact, downstream players can have a significant role in identifying new prospects and finding commercial opportunities for their use. Conversely, upstream inventors are sometimes in the best position to guide the further development of fundamental insights. ${ }^{2102}$ Similarly, the emerging shift from vertical integration to value chain licensing recognizes that every participant in the innovation process brings its own expertise to bear in taking ideas and turning them into marketplace products. ${ }^{2103}$ Since intellectual property licenses serve to allocate rewards along the development path, rights holders require a high degree of flexibility in the manner in which they arrange their business dealings. ${ }^{2104}$

Dating back at least to William Nordhaus's work ${ }^{2105}$, an optimal intellectual property (eg patent) policy design has traditionally been conceived in terms of a trade-off between the benefit of providing incentives for the development of new technologies and the cost of deadweight loss from higher prices during the life of the patent or of the IP protection. ${ }^{2106}$ This influential approach has traditionally modeled innovations as isolated discoveries and predicted an unambiguously positive relationship between patent strength and the rate of innovation. This model is not however unanimously shared and has been criticized in recent years. In her work, Suzanne Scotchmer ${ }^{2107}$ has stressed that many or most innovations are cumulative - in the sense that any given discovery is also an input into later follow-on discoveries where successive innovations build upon earlier innovations. ${ }^{2108}$ In markets where innovation is cumulative in this sense, optimal patent policy design also depends on how patents on existing technologies affect follow-on innovation. There is a growing body of empirical evidence supporting that patents may hinder follow-on innovation. ${ }^{2109}$

Follow-on or cumulative innovation is particularly important for plant-related innovation to the extent that the value of a seed to a farmer is encapsulated in its genetics, which codes the accumulation of desirable traits from innumerable generations of breeding and selection activities, some of which date back to the dawn of agriculture, and that "production of an improved variety is not possible without physical access to the relevant germplasm", information per se, such as that disclosed by utility patents, being "just not enough to provide the blueprint for an improved variety without access to the relevant biological material" 2110 .

${ }^{2102}$ See, eg, F Murray and S O'Mahony, 'Exploring the Foundations of Cumulative Innovation: Implications for Organization Science' [2007] 18 Organization Science 1006.

${ }^{2103}$ SM O'Connor, 'IP Transactions as Facilitators of the Globalized Innovation Economy' in RC Dreyfuss, DL Zimmerman and H First (eds), Working Within the Boundaries of Intellectual Property-Innovation Policy for the Knowledge Society (Oxford University Press 2010) 203.

${ }^{2104}$ DJ Teece, G Pisano and A Shuen, 'Dynamic Capabilities and Strategic Management' (1997) 18 Strategic Management Journal 509, 516; DJ Teece, 'Profiting from Technological Innovation: Implications for Integration, Collaboration, Licensing and Public Policy' [1986] 15 Research Policy 285.

${ }^{2105}$ W Nordhaus, 'An Economic Theory of Technological Change' [1969] 59 The American Economic Review 18.

${ }^{2106} \mathrm{~K}$ Arrow, Economic Welfare and the Allocation of Resources for Invention in The Rate and Direction of Inventive Activity: Economic and Social Factors (NBER, 1962) 609.

${ }^{2107} \mathrm{~S}$ Scotchmer, Innovation and Incentives (MIT press, 2004).

${ }^{2108}$ This was well understood since the times of Isaac Newton who famously wrote in a letter to Robert Hooke that '[i]f I have seen further it is by standing on the shoulders of Giants". See R Andrews et al (eds), The Columbia World of Quotations No. 41418 (Columbia University Press 1996).

${ }_{2109}$ MA Heller \& RS Eisenberg, 'Can Patents Deter Innovation? The Anticommons in Biomedical Research' [1998] 280 Science 698; J Bessen \& E Maskin, 'Sequential innovation, patents, and imitation' [2009] 40 RAND Journal of Economics 611.

${ }^{2110}$ M.S. Clancy \& G. Moschini, Intellectual Property Rights and the Ascent of Proprietary Innovation in Agriculture, Working Paper 17, WP 572 (January 2017), 13. 
Closely related to the prevalence of cumulative innovation is the increasing importance of knowledge sharing as a fundamental source of innovation. ${ }^{2111}$ There is evidence of knowledge sharing taking place even between 'apparent competitors' in various industries, which facilitate innovation that builds cumulatively on previous advances. ${ }^{2112}$ There is considerable evidence that innovation in agriculture was particularly strong, even before the institution of property rights, such as plant variety protection rights or patents, and that it was shared between the various market participants, farmers freely sharing improved varieties or within the context of agricultural societies that disseminated knowledge via meetings and fairs, and facilitated the collection and dispersal of seeds ${ }^{2113}$. The rise of 'collective innovation ${ }^{2114}$, constitutes a defining moment in the new economics of innovation and indicates that it is inevitable that, at least at the initial stages of the development of a new technology, firms would cooperate, while competing in other aspects of their activity, in what has be described as 'soft rivalry' (or co-opetition). ${ }^{2115}$ It is important to rethink the interaction of competition law with IP rights, but also more specifically the framework of competition law enforcement in the era of 'collective innovation'.

It is clear that the pattern of technological advance is not the same in all fields. As Richard Nelson and Robert Merges have noted, 'at least four different generic models are needed. The first describes discrete invention. A second concerns 'cumulative' technologies. Chemical technologies have special characteristics of their own. Finally, there are 'science-based' technologies where technical advance is driven by developments in science outside the industry'. ${ }^{2116}$ A 'one size fits all' intellectual property system is therefore not appropriate. Specifically, because intellectual property law was first developed during the Industrial Revolution, it is largely based on stand-alone (discrete) mechanical inventions. Thus, it has few doctrines that permit one generation of innovators to 'stand on the shoulders' of those who went before. ${ }^{2117}$ Change is necessary to make the law resonate better with a science-based sector such as biotechnology. There exists many opportunities (or as professors Dan Burk and Mark Lemley would put it, 'levers') that can be used to tailor patent law to deal with these realities. ${ }^{2118}$

Classic intellectual property and innovation laws were developed with a single jurisdiction in mind. As borders have become more permeable, capital, firms, and expertise migrate to jurisdictions

\footnotetext{
${ }^{2111}$ J Bessen \& A Nuvolari, 'Knowledge Sharing Among Inventors: Some Historical Perspectives' in D Harhoff \& KL Lakhani (eds.), Revolutionizing Innovation (MIT press, 2016) 135.

${ }^{2112}$ E von Hippel, 'Cooperation between rivals: informal know-how trading' [1987] 16 Research Policy 291.

${ }^{2113}$ M.S. Clancy \& G. Moschini, Intellectual Property Rights and the Ascent of Proprietary Innovation in Agriculture, Working Paper 17, WP 572 (January 2017), 10; W.E. Huffman \& R.R. Evenson Science for Agriculture: A Long-Term Perspective. (Ames, IA: Blackwell Publishing, 2006).

${ }^{2114}$ RC Allen, 'Collective invention' [1983] 4 Journal of Economic Behaviour and Organization 24.

${ }^{2115}$ E von Hippel, 'Cooperation between rivals: informal know-how trading' (1987) 16 Research Policy 291, 299 explains this process of sharing by focusing on the 'competitive value' of the unit of knowledge that was revealed to a competitor. If the competitive advantage provided by this unit of knowledge is limited, information disclosure, in particular if reciprocated, may lead to more general welfare gains for all the firms in the industry that participate to this knowledge sharing. See also, J Bessen, 'The Two Faces of Innovation', Boston University School of Law Working Paper 10-35 (2011) available at SSRN: ssrn.com/abstract=1698802 (observing that as technology matures firms' willingness to share knowledge and their use of IP and patents change, knowledge-sharing being more prevalent in the early stages of technology or where local innovation has little effect on worldwide prices).

${ }^{2116}$ RP Merges and R Nelson, 'On the Complex Economics of Patent Scope' (1990) 90 Columbia Law Review 839, 880. ${ }^{2117}$ See, eg, S Scotchmer, 'Standing on the Shoulders of Giants: Protecting Cumulative Research and the Patent Law' [1991] 5 Journal of Economic Perspectives 29. The phrase, 'standing of the shoulders of giants', derives from a Isaac Newton's famous letter to Robert Hooke, supra n 2108.

218 DL Burk and MA Lemley, The Patent Crisis and How Courts Can Solve it (University of Chicago Press 2009).
} 
with the most favourable conditions. ${ }^{2119}$ Indeed, the promulgation of the TRIPS Agreement within the World Trade Organization is testament to this change. The global nature of the innovation enterprise and the emergence of a global marketplace for innovative products is a reality illustrated by the emergence of innovation value chains in various industries, where multiple firms acting in various segments of the chain innovate, thus contributing to the total surplus value of the chain. ${ }^{2120}$ The increasing number of jurisdictions worldwide having adopted and enforcing competition law statutes may nevertheless complicate the operation of these global IP rules, in view of the divergent positions various jurisdictions take on the intersection of competition law with IP rights and the absence of a global competition law framework, equivalent to the TRIPS agreement.

It has become evident that intellectual property laws are not the sole determinants of innovation. Firms appropriate the benefits of inventiveness in a variety of ways; for many firms, patent law is low on the list of strategies, alternative methods including lead time, secrecy and the development of complementary capabilities in sales and service or manufacturing ${ }^{2121}$. Economic research has shown that the role of property rights on information may be relevant only in a limited amount of circumstances, as small inventions are not imitated, medium inventions involve a form of "implicit licensing," and large inventions are protected primarily through secrecy when property rights are weak ${ }^{2122}$. Indeed, Edwin Mansfield's work suggests that the pharmaceutical sector is alone in relying principally on patent law to capture returns from innovation. ${ }^{2123} \mathrm{~A}$ similar evolution seems also happening in agricultural biotech to the extent that the largest companies active in the seeds \& traits value chain come from the chemical sector ${ }^{2124}$. But is this the only model for the future of agriclture? Once again, a 'one-size-fits-all' system makes little sense as it is clear that patent law can be manipulated to deal with differences that arise from the technical field in which innovation is taking place, changes that occur as an industry matures, and other variables.

The role of the competitive process in the promotion of innovation is well recognized and widely accepted. Certainly, research and development requires up front investments for uncertain rewards. Intellectual property rights were initially conceived as an exception to the rule of competitive markets. By providing some economic rents (, intellectual property rights ensure that the inventor has adequate incentives to innovate at the first place. ${ }^{2125}$ Although IP may provide some certainty over the ability of an undertaking to retain the benefits from the innovation it put in place (and internalise the positive

2119 P Samuelson, 'Intellectual Property Arbitrage: How Foreign Rules Can Affect Domestic Protections' [2004] 71 University of Chicago Law Review 223.

${ }^{2120}$ See for instance the studies on the global supply chains of iPods and notebook computers and the question of the distribution of financial value coming out of these chains: J Dedrick, 'Who profits from innovation in global value chains?: a study of the iPod and notebook PCs' [2010] 19 Industrial and Corporate Change 81.

${ }^{2121}$ W.M. Cohen R.P. Nelson \& J.P. Walsh, Protecting Their Intellectual Assets: Appropriability Conditions and Why U.S. Manufacturing Firms Patent (Or Not). (NBER Working Paper 7552, 2000).

2122 J.J. Anton \& D.A.Yao, Little Patents and Big Secrets: Managing Intellectual Property, (2004) 35 Rand J. Econ 1.

${ }^{2123}$ E Mansfield, 'Patents and Innovation: An Empirical Study' [1986] 32 Management Science 173. See generally A López, 'Innovation and Appropriability, Empirical Evidence and Research Agenda' in The Economics of Innovation (WIPO 2009), available at www.wipo.int/ip-development/en/economics/pdf/wo_1012_e_ch_1.pdf.

2124 S. Bonny, Corporate Concentration and Technological Change in the Global Seed Industry, (2017) 9 Sustainability 1632, Figure 3.

2125 This simple trade-off was already recognized by the UK Statute of Monopolies (1623) which declared 'all monopolies [...] for the sole buying, selling, making, working or using of anything within this realm, or of any other monopolies, or of power to give license or toleration to do, use or exercise anything against any law [...] are contrary to the laws of this realm, and so are and shall be utterly void [...]' but also recognized an exception from this prohibition for '[...] any letters patents and grants of privilege for the term of fourteen years or under, hereafter to be made, of the sole working or making of any manner of new manufactures within this realm, to the true and first inventor or inventors of such manufactures $[\ldots]$ '. 
externalities thus produced), the social return to innovation largely exceeds its private return. ${ }^{2126}$ In reality, imperfect IP protection may lead the competitors to gain some of the rewards from the rival's innovation (the problem of limited appropriability). ${ }^{2127}$ Technological spillovers and imitation across the industry or cross-industries may boost growth to a considerable extent, without being possible that these indirect benefits are appropriated by the IP holder, thus illustrating the inadequacy of a policy relying on intellectual property rights only to spur innovation and the importance of public funding of research. It has been argued that disruptive innovation may also challenge monopoly positions that become temporary (the process of 'creative destruction'). ${ }^{2128}$

With regard to the appropriate market structure for innovation two views oppose each other. ${ }^{2129}$ The Schumpeterian view alleges that large firms and monopolists may be more innovative than firms in competitive markets, in view of the head start they dispose, having a dominant position on a market, and the resources to fund large research and development. In contrast, economist Kenneth Arrow has challenged the incentives of a monopolist to invest on $R \& D$ in view of the fact that the new products may displace, partly or totally, the monopolist's products from the market (thus leading the monopolist to compete with himself). ${ }^{2130}$ Recent empirical economic studies have examined these claims attempting to link market concentration in an industry (on the basis of the Lerner index, thought of as a proxy for product market competition) to R\&D expenditures in the same industry. They found the existence of an 'inverted-U' relationship whereas the level of innovation rises in industries with oligopolistic market structures, being relatively more modest in industries having a more competitive market structure and industries dominated by monopolists (see the analysis in Chapter 2, Part IV) However, some other economists find these studies unconvincing. ${ }^{2131}$ Competition law may be aimed at fostering innovation in product markets as well as innovation and technology markets, by taking an industry-specific approach and prioritizing restrictions to competition that may impact the most on innovation. Jonathan Baker explains,

'[a competition law] enforcement program crafted to promote innovation would attack direct reductions in innovation competition; protect product market competition in winner-take most or winner-take-all markets; protect product market competition in markets in which probable technological or regulatory developments or rapid growth in demand largely determine the extent of future product market competition; challenge naked horizontal agreements to fix prices or allocate customers; prevent agreements among rivals to engage in conduct facilitating coordination with no plausible business justification; and challenge horizontal mergers likely to

\footnotetext{
${ }^{2126}$ This was highlighted by K Arrow, Economic Welfare and the Allocation of Resources for Invention in The Rate and Direction of Inventive Activity: Economic and Social Factors (NBER, 1962) 609.

${ }^{2127}$ Ibid., 619.

${ }^{2128}$ J Schumpeter, Capitalism, Socialism and Democracy (1942, published by Harper \& Bros. in 1950) 83, noting that 'The opening up of new markets, foreign or domestic, and the organizational development from the craft shop and factory to such concerns as U. S. Steel illustrate the same process of industrial mutation - if I may use that biological term - that incessantly revolutionizes the economic structure from within, incessantly destroying the old one, incessantly creating a new one. This process of Creative Destruction is the essential fact about capitalism. It is what capitalism consists in and what every capitalist concern has got to live in'.

${ }^{2129}$ For a critical analysis, see J Baker, 'Beyond Schumpeter vs. Arrow: How Antitrust Fosters Innovation' [2007] 74 Antitrust Law Journal 575; RJ Gilbert, 'Competition and Innovation' in WD Collins (ed) [2008] 1 ABA Section of Antitrust Law, Issues in Competition Law and Policy 573.

2130 The so called 'replacement effect' or 'Arrow effect': K Arrow, 'Economic Welfare and the Allocation of Resources for Invention in The Rate and Direction of Inventive Activity: Economic and Social Factors' (NBER, 1962) 619-625.

${ }^{2131}$ See, the discussion in J Baker, 'Beyond Schumpeter vs. Arrow: How Antitrust Fosters Innovation' (2007) 74 Antitrust Law Journal 575, 584-587 (suggesting some alternative measures of innovative activity).
} 
reduce product market competition. [...] There are other areas of [competition law] enforcement, including cases challenging vertical restraints, vertical mergers, and restrictions imposed by legitimate horizontal joint ventures in industries not characterized by winner-take-most competition, likely technological or regulatory change, or rapid growth. In these remaining areas, [competition law] intervention could, in theory, simultaneously enhance pre-innovation product market competition and reduce post-innovation competition, with the net effect on innovation incentives unclear. In practice, however, [competition law] enforcement in these other areas is, on the whole, measured. The great majority of such conduct will not be found to harm competition under current antitrust standards, so these kind of cases in the aggregate would present little threat to innovation in the economy even if the incentives at issue in the third and fourth economic principles turned out to be particularly important in the settings for those enforcement actions. Accordingly, it is unlikely that [competition law] enforcement to protect product market competition in areas outside those that would be emphasized by a policy focused on innovation would systematically affect the level of post-innovation competition reasonably anticipated by firms conducting R\&D throughout the economy'.

This discussion highlights not only the importance of intellectual property and competition law, but also the complexity of the various trade-offs to undertake between pre-innovation product competition, competition for the development of innovation and post-innovation product and technology innovation, as well as of the various interests to take into account (inventors, cumulative innovators, competitors, external or internal participants in value chains, actual consumers and future generations of consumers), which highlight the need for a governance system that stays abreast of technological, economic, and social developments, and which is steeped in the economic literature.

\subsubsection{General principles on the interaction between competition law and IP law}

Critics of competition law's intervention with IP rights often note its static focus on competitive outcomes in terms of competitive market structure, or, for more effects-based competition law regimes, on better economic performance (measured in terms of lower prices, better quality, and wider choice). Some authors have suggested a re-orientation of competition law towards a more dynamic approach that would incorporate innovation as an objective of competition law. ${ }^{2132}$ The concept of 'dynamic competition' regroups a number of theories that might be distinguished from the 'static competition model'. ${ }^{2133}$ A common characteristic of these different theories of 'dynamic

${ }^{2132}$ For a discussion of this literature, see, MA Carrier, Innovation for the 21st Century: Harnessing the Power of Intellectual Property and Antitrust Law (Oxford University Press 2011).

${ }^{2133}$ See, for this opposition, A Tepperman and M Sanderson 'Innovation and Dynamic Efficiencies in Merger Review' (Canada, Competition Bureau 2007), available at www.competitionbureau.gc.ca/eic/site/cb-bc.nsf/vwapj/cra-finalreport-on-efficiencies-2007-04-09-e.pdf/\$FILE/cra-final-report-on-efficiencies-2007-04-09-e.pdf, p 5, 'Competition based on the successive introduction of new or better products over time is called dynamic competition. Dynamic competition based on investment in R\&D may be thought of as a form of "competition for the market" in contrast to price competition which is "competition in the market." This characterization is overly simplistic, however. There are certainly many situations in which both forms of competition operate-firms may compete for customers' business by reducing price and improving quality for existing goods, and by pursuing innovation in an effort to introduce new goods to market. Nonetheless, this way of dichotomizing competitive rivalry serves to emphasize an important contrast. Static views of competition take the existing set of products and market participants as given, describing the outcome of competitive behaviour among those market participants using strategic instruments such as pricing or advertising that can be applied and varied in the "short term". Dynamic competition involves the creation of new products and potentially also new markets, along with the replacement or obsolescence of older products. It also implicitly or explicitly involves entry and 
competition' is that they all focus on innovation as a key component of the competitive process. ${ }^{2134}$ In both Europe and the US, IP rights traditionally fall under the scope of competition law. This is also increasingly the case for more mature but also younger competition law regimes, with the emergence of soft law managing the interaction between competition law and IP rights in a way that satisfies the aims of both these areas of law ${ }^{2135}$. There are different standards governing the interaction between competition law and IP rights.

\subsubsection{Standards for the interaction between competition law and IP rights}

Competition authorities have progressively moved from formalistic standards for the IP/Competition law interface to economic balancing standards. It is also possible to identify a new trend, observed in recent merger cases, to move beyond a simple economic balancing test, and take into account potential entrants in technology markets and innovation paths in the medium term.

\subsection{Formalistic standards}

With regard to formalistic standards, one may distinguish between standards focusing on the scope of the IP and standards focusing on the intent of the IP holder.

Standards focusing on the scope of the IP rights have taken different forms. First, the inherency doctrine, or scope of the patent doctrine, protects the practices inherent to the exercise of the IP right from the application of competition law. ${ }^{2136}$ Such standards were adopted at the initial steps of the interaction between competition law and IP rights. For instance, the Court of Justice of the EU

proceeded in its first cases regarding IP rights in competition law to the definition of the scope of the IP rights as linked to the 'subject matter' and the 'essential function' of the specific IP rights. The concept of the 'specific subject-matter' made it possible to determine what might be covered by the legal status of any industrial or intellectual property right without damaging the EU principles of competition or that of free movement (exhaustion). For instance, in the field of patents, the 'specific subject-matter' consists, in the Court of Justice's view, in 'the exclusive right to use an invention with a view to manufacturing industrial products and putting them into circulation for the first time [...]

exit by firms - there is no guarantee that today's successful firms will be able to offer the product attributes demanded by tomorrow's consumers'.

2134 J Ellig and D Lin, 'A Taxonomy of Dynamic Competition Theories' in J Ellig (ed), Dynamic Competition and Public Policy - Technology, Innovation and Antitrust Issues (Cambridge University Press 2011) 16-44 outline the principal strands of dynamic competition law scholarship.

2135 See, for instance, in Japan, the recently amended Guidelines for the Use of Intellectual Property under the Antimonopoly Act, January 2016 stipulates that “[...] when applying the Antimonopoly Act with respect to the restrictions pertaining to the use of technology, it is important for competition policy to insulate competition in technologies and products from any negative effect caused by any restrictions that deviate from the intent of the intellectual property systems, while making every effort to facilitate competition through the intellectual property systems"; for China (see footnote 4). Even in the South Korea and Taiwan competition law regimes that provide some form of immunity regime to the exercise of IP rights (article 59 of the Monopoly Regulation and the Fair Trade Act in South Korea and article 45 of the Fair Trade Act in Taiwan), competition authorities have enacted guidelines to distinguish a justifiable exercise of IP rights, entitled to competition law immunity, from unjustifiable acts going "beyond the purpose", or being "inappropriate use" of IP rights, which fall under the scope of competition law.

${ }^{2136}$ VB Venegas, 'Shifting Towards a Dynamic Efficiency Test?: Evaluating Licensing Agreements under Antitrust Law' in S Anderman and A Ezrachi (eds) Intellectual property and Competition Law - New Frontiers (Oxford University Press 2011) 461-485. 
as well as the right to oppose infringements'. ${ }^{2137}$ The Court referred to the purposive concept of 'essential function' in order to expand the specific subject matter beyond the core rights previously identified. The concepts of 'subject matter' and 'essential function' of IP rights have been used in various cases as a shield to competition law enforcement.

In other occasions the EU Courts went beyond a purely formalistic distinction between the 'existence', the core of the IP right, and its 'exercise' and considered the value of the IP right in envisioning the interaction between competition law and IP rights. In Erawu-Jacquery $v$ La Hesbignonne, the Court held that a prohibition on the sale or export of basic seeds was not within Article 101 TFEU since considerable investment had been made in developing the basic seed. ${ }^{2138}$ According to the Court, 'a person who has made considerable efforts to develop varieties of basic seed which may be the subject-matter of plant breeders' rights must be allowed to protect himself against any improper handling of those varieties of seed' and 'to that end, the breeder must be entitled to restrict propagation to the growers which he has selected as licensees'. ${ }^{2139}$

A possible alternative formalistic standard is to focus on the intent of the monopolist. ${ }^{2140}$ Some US courts have adopted standards based on anticompetitive intent, advancing the view that a monopolist should not 'rely upon a pretextual business justification to mask anticompetitive conduct'. ${ }^{2141}$ This might involve some analysis of the subjective intent of the undertaking, by looking to documents, emails or statements. However, it is unclear at what level of company management the decision-maker should look to find evidence of intent and it is quite common for executives to use language that suggests intent to exclude a competitor.

An alternative would be to examine objective intent as this is indicated by the behaviour of the undertaking. In its Preliminary Report of the Sector Inquiry on the Pharmaceutical Sector, the European Commission noted that 'intention can [...] be taken into account in competition law assessments', ${ }^{2142}$ although it is clear that the intent of the applicants does not form part of the assessment of patent claims. ${ }^{2143}$ The Astra Zeneca decision of the European Commission, confirmed by the General Court, acknowledged the importance of evidence of anticompetitive intent in demonstrating that a conduct is liable to have anticompetitive effects. ${ }^{2144}$ The General Court of the EU in its judgment in the same case found that while abuse is an objective concept, '[...] intention can still be taken into account to support the conclusion that the undertaking concerned abused a dominant position, even if the abusive conduct actually took place'. ${ }^{2145}$

\subsection{Balancing tests}

\footnotetext{
${ }^{2137}$ Case C-15/74 Centrafarm BV and Adriaan de Peijper v Sterling Drug Inc [1974] ECR 1147.

${ }^{2138}$ Case C-27/87 SPRL Louis Erauw-Jacquery v La Hesbignonne SC [1988] ECR 1919. See also, Case C-258/78 L.C. Nungesser KG and Kurt Eisele v Commission [1982] ECR 2015.

2139 Ibid., para 10.

${ }^{2140}$ MA Carrier, 'Unravelling the Patent-Antitrust Paradox' (2002) 150 University of Pennsylvania Law Review $761,793$.

${ }^{2141}$ Image Technical Services, Inc. v Eastman Kodak Co. 125 F.3d 1195 (9th Cir. 1997), 1219.

${ }^{2142}$ European Commission, Pharmaceutical Sector Inquiry, Final Report, fn 375 and 376.

${ }^{2143}$ For example, in the context of the DG Comp's Pharmaceutical sector inquiry, the European Patent Office argued against a scrutiny of the intent of applicants in applying for patent rights for purposes of competition law. See, Communication from the Commission, Executive Summary of the Pharmaceutical Sector Inquiry Report, available at ec.europa.eu/competition/sectors/pharmaceuticals/inquiry/communication_en.pdf, p 7

2144 Commission Decision, AstraZeneca, Annex A, para 13.

${ }^{2145}$ Case T-321/05 AstraZeneca AB v Commission [2010] ECR II-2805, para 334, although on appeal the Court of Justice did not explicitly confirmed this position: Case C-457/10P AstraZeneca AB v Commission (6 December, 2012).
} 
A significant episode in the interaction between competition law and IP rights, at least in Europe and the US, is the development of balancing tests.

Balancing tests weigh the restriction of allocative efficiency or other anticompetitive effects of the conduct involving IP rights from one side and the possible benefits of these IP rights in inducing innovation and dynamic efficiency on the other side. Innovation is considered positively as it enhances competition in the market and provides a variety of choice to consumers. Contrary to the formalistic analysis conducted under the scope or intent tests, balancing tests involve some consideration of the economic effects of the IP rights in the specific market configuration. Various balancing tests have been suggested in the law and economics literature, some intervening in the IP side of the equation, while others in the competition law side. ${ }^{2146}$

The EU Guidelines on Transfer of Technology Agreements (interpreting the Transfer of Technology Block Exception Regulation) seem to be inspired by the principle of an economic balancing test. ${ }^{2147}$ Their starting standpoint is that there is no inherent conflict between intellectual property rights and EU competition rules. According to the European Commission,

'[...] both bodies of law share the same basic objective of promoting consumer welfare and an efficient allocation of resources. Innovation constitutes an essential and dynamic component of an open and competitive market economy. Intellectual property rights promote dynamic competition by encouraging undertakings to invest in developing new or improved products and processes. So does competition by putting pressure on undertakings to innovate. Therefore, both intellectual property rights and competition are necessary to promote innovation and ensure a competitive exploitation thereof'. ${ }^{2148}$

The Guidelines refer to the concept of 'dynamic competition', ${ }^{2149}$ but it is important here to note that although there is no presumption that intellectual property rights and licence agreements as such give rise to competition concerns, any eventual anticompetitive concerns will be assessed with an eye on the possible pro-competitive efficiencies, which 'must be considered under Article 101(3) TFEU and balanced against the negative effects on competition'. ${ }^{2150}$ In the current version of the EU TTBER, the market share threshold to be applied for the purpose of the safe harbour depends on whether the agreement is concluded between competitors or non-competitors . Outside the safe harbour individual assessment is required, although this does not give rise to any presumption that the agreement is caught by Article 101 TFEU.

In the context of Article 102 TFEU, the European Commission seems to have been inspired by the balancing approach in its Microsoft decision. ${ }^{2151}$ The specific characteristics of intellectual property rights were not prima facie taken into account. The Commission observed that 'there is no persuasiveness to an approach that would advocate the existence of an exhaustive checklist of

${ }^{2146}$ For an example of the first see, the Kaplow's 'ratio test' [L Kaplow, 'The Patent-Antitrust Intersection: A
Reappraisal' (1984) 97 Harvard Law Review 1813] focusing on the IP side of the equation and suggesting an adjustment
of the scope and strength of IP rights as a possible solution to the problem. For an example of the second, see Ordover's
critical trade-off is 'between incentives for investment in knowledge creation and the overall efficiency with which this
investment is achieved' [JA Ordover, 'Economic Foundations and Considerations in Protecting Industrial and Intellectual
Property' (1984) 53 Antitrust Law Journal 503].
2147 European Commission, Guidelines on the application of Article 101 of the Treaty on the Functioning of the European
Union to technology transfer agreements, [2014] OJ C 89/3.
2148 Ibid., para 7.
2149 Ibid., paras 7- 8.
2150 Ibid., para 9.
$2151 \quad$ Microsoft/W2000 (Case COMP/C-3/37.792) Commission Decision $\quad$ [2004], available at
http://ec.europa.eu/competition/antitrust/cases/dec_docs/37792/37792_4177_1.pdf. 
exceptional circumstances and would have the Commission disregard a limine other circumstances of exceptional character that may deserve to be taken into account when assessing a refusal to supply'. ${ }^{2152}$ Microsoft has put forward the same justification as in the US litigation: the need to protect its own incentives to innovate by preserving its intellectual property rights. ${ }^{2153}$ The Commission rejected that claim by affirming that intellectual property rights 'cannot as such constitute a selfevident objective justification for Microsoft's refusal to supply'. ${ }^{2154}$ The Commission considered that innovation is an objective for both intellectual property and competition law $^{2155}$ and adopted a balancing test focused on innovation incentives of Microsoft and its competitors. ${ }^{2156}$ Because of the nature of the market, Microsoft's incentives to innovate were maintained, while those of its competitors were also preserved ${ }^{2157}$

In its Microsoft judgment, the General Court considered that prejudice to consumers may arise where there is limitation of technical development. ${ }^{2158}$ The Court did not however balance Microsoft's incentives to innovate with those of its competitors, thus focusing on a version of the balancing test that would compare static allocative inefficiencies to dynamic efficiency benefits. This version of the test may lead to an extension of the scope of Article 102 TFEU, as it takes into account only the incentives of the rivals of the dominant firm to innovate without considering those of the dominant firm.

The risk of the economic balancing approach is that in practice courts and competition authorities may emphasize more restrictions to allocative efficiency than dynamic efficiency benefits. The possibility that these economic balancing tests might lead in practice to weigh more static efficiency as opposed to dynamic effects has led to the view that competition law should turn to dynamic analysis and embrace the goal of innovation.

\subsection{New standards for restrictions to innovation competition?}

Competition authorities have been increasingly focusing on the possible effects of anticompetitive conduct activity on innovation. This is particularly the case in merger control which is quite forward-looking. The US DOJ \& FTC Horizontal Merger Guidelines of 2010 were the first to include a specific Section on competition harm to innovation and product variety and explicitly considering that "(a) merger enhances market power if it is likely to encourage one or more firms to raise price, reduce output, diminish innovation, or otherwise harm customers as a result of diminished

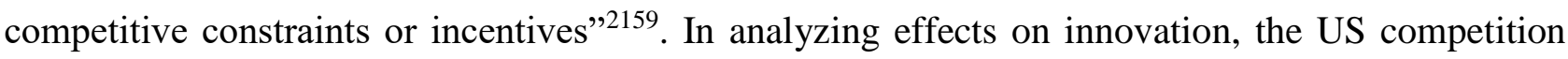
authorities have often taken an "innovation market" perspective ${ }^{2160}$, or as this has been reframed in the 2017 update of the US DOJ \& FTC Antitrust Guidelines for the Licensing of Intellectual Property, "research and development markets" 2161 . According to the 2017 US Licensing of IP Guidelines,

\footnotetext{
${ }^{2152}$ Ibid., para 555.

${ }^{2153}$ Ibid., para 709.

${ }^{2154}$ Ibid., para 710.

${ }^{2155}$ Supra n 2151, Microsoft Commission Decision, para 712.

${ }^{2156}$ Ibid., para 783.

${ }^{2157}$ Ibid., para 725.

${ }^{2158}$ Case T-201/04 Microsoft v Commission (2007) ECR II-3601, para 647.

${ }^{2159}$ USDOJ \& FTC, Horizontal Merger Guidelines (2010), p. 2. Emphasis added.

${ }^{2160}$ RJ Gilbert and SC Sunshine, 'Incorporating Dynamic Efficiency Concerns in Merger Analysis: The Use of Innovation Markets’ [1995] 63 Antitrust Law Journal 569.

${ }^{2161}$ US DOJ \& FTC Antitrust Guidelines for the Licensing of Intellectual Property, Section 3.2.3. (2017)
} 
"(a) research and development market consists of the assets comprising research and development related to the identification of a commercializable product, or directed to particular new or improved goods or processes, and the close substitutes for that research and development. When research and development is directed to particular new or improved goods or processes, the close substitutes may include research and development efforts, technologies, and goods that significantly constrain the exercise of market power with respect to the relevant research and development, for example by limiting the ability and incentive of a hypothetical monopolist to reduce the pace of research and development. The Agencies will delineate a research and development market only when the capabilities to engage in the relevant research and development can be associated with specialized assets or characteristics of specific firms. In assessing the competitive significance of current and potential participants in a research and development market, the Agencies will take into account all relevant evidence. [...] The Agencies may base the market shares of participants in a research and development market on their shares of identifiable assets or characteristics upon which innovation depends, for example, on shares of research and development expenditures, or on shares of a related product. When entities have comparable capabilities and incentives to pursue research and development that is a close substitute for the research and development activities of the parties to a licensing arrangement, the Agencies may assign equal market shares to such entities"2162.

The US authorities have employed "innovation markets" or "research and development markets" concepts in order to assess competition effects in a number of cases ${ }^{2163}$. According to this approach, the US Agencies will delineate research and development markets, only when the capabilities to engage in relevant research and development can be associated with specialized assets or characteristics of specific firms", the authorities seeking to identify three key effects: (i) the ability of the merged firm to reduce total market investments in $R \& D$, (ii) the incentive of the merged entity to reduce the innovative effort and (iii) the impact of the merger on the efficiency of the R\&D expenditure ${ }^{2164}$. This looks like a relatively demanding framework from an evidential perspective. In most recent cases, the US authorities seem to adopt a broader framework and have also challenged mergers for diminishing innovation even if the merger would eliminate potential competition from a relative small competitor, in particular when the smaller player has promising pipeline products. The theory of harm in these cases was the 'actual potential entrant' theory, a potential entrant merging with an existing competitor and thus leading to lessen future competition.

The European Commission's Horizontal Merger Guidelines includes as one of the effects to be analysed under merger control, the 'effect on innovation'2165. According to the Commission's Guidelines,

\footnotetext{
2162 Ibid.

2163 The FTC has identified and referred to research and development markets in the following matters: Complaint, Amgen Inc., 134 F.T.C. 333, 337-39 (2002) (identifying a research and development market for inhibitors of cytokines that promote the inflammation of human tissue); Wright Med. Tech., Inc., Proposed Consent Agreement with Analysis to Aid Public Comment, 60 Fed. Reg. 460, 463 (Jan. 4, 1995) (identifying a research and development market for orthopedic implants for use in human hands); Am. Home Prods. Corp., Proposed Consent Agreement with Analysis to Aid Public Comment, 59 Fed. Reg. 60,807, 60,815 (Nov. 28, 1994) (identifying a research and development market for, among other things, rotavirus vaccines).

${ }^{2164}$ E. Cefis et al, The Role of Innovation in Merger Policy: Europe's Efficiency Defence versus America's Innovation Markets Approach, Tjalling C. Koopmans Institute, Discussion paper series 07-21.

${ }^{2165}$ EU Horizontal Merger Guidelines [2004] OJ C31/5, para 8 (hereinafter EU HMG).
} 
"(i)n markets where innovation is an important competitive force, a merger may increase the firms' ability and incentive to bring new innovations to the market and, thereby, the competitive pressure on rivals to innovate in that market. Alternatively, effective competition may be significantly impeded by a merger between two important innovators, for instance between two companies with "pipeline" products related to a specific product market. Similarly, a firm with a relatively small market share may nevertheless be an important competitive force if it has promising pipeline products" 2166 .

The innovation potential of the merging firms, in particular if "one or more merging parties are important innovators in ways not reflected in market shares", is taken into account, irrespective of the levels of concentration that are usually considered by the Commission's Horizontal Guidelines as raising competition concerns ${ }^{2167}$. The Commission's Guidelines also recognize that efficiencies may bring forward positive innovation effects, and acknowledge that "consumers may also benefit from new or improved products or services, for instance resulting from efficiency gains in the sphere of $\mathrm{R}$ $\& \mathrm{D}$ and innovation" 2168 . However, as for other types of efficiency gains put forward, the parties need to demonstrate that (i) efficiencies are a direct consequence of the notified merger and cannot be achieved to a similar extent by less anticompetitive alternatives, and (ii) that efficiencies have to be verifiable such that the Commission can be reasonably certain that the efficiencies are likely to materialise, and be substantial enough to counteract a merger's potential harm to consumers ${ }^{2169}$. Similarly, the EU non-horizontal merger guidelines list the diminishing of innovation as a competition concern for vertical and conglomerate mergers ${ }^{2170}$ and also state that mergers involving innovative companies that are likely to expand significantly in the near future will be extensively investigated even when the post-merger market share is below $30 \%{ }^{2171}$.

A Competition Policy Brief published by the European Commission in 2016 explains that harm to innovation may justify the Commission to consider that a merger between a firm present in the relevant market with a firm that is not actually present in the relevant market could lead to a significant impediment of effective competition. According to this document,

"(f)or a merger with a potential competitor to raise serious competition concerns, it is in principle necessary to show, firstly, that the potential competitor currently acts as a significant competitive constraint, or there is a significant likelihood that, absent the merger, it would grow into an effective competitive force in the foreseeable future. This is more likely in particular when the market is already concentrated, as in a market with many actual competitors a potential entrant is, in principle, less likely to be a significant competitive constraint. Secondly, it needs to be established that there are not enough actual or potential competitors to maintain the necessary competitive pressure after the merger. In particular, barriers to entry must be high enough to exclude the existence of several other potential competitors, but the merging firm potentially entering the market must be well positioned to overcome these barriers, for instance as it is present in an adjacent or vertically related market or already has specific entry plans" ${ }^{2172}$.

\footnotetext{
2166 Ibid., para. 38.

${ }^{2167}$ Ibid., para. 20.

${ }^{2168}$ Ibid., para. 81 .

${ }^{2169}$ Ibid., paras 85-86.

${ }^{2170}$ EU Non Horizontal Merger Guidelines [2008] OJ C 265/7, para. 10.

${ }^{2171}$ Ibid., para. 26.

${ }^{2172}$ European Commission, Competition Policy Brief, 2016-01, p. 3.
} 
Members of the chief economist team of the European Commission have also recently published studies analysing the impact of a merger on firms' incentives to innovate and showing that in certain markets at least, mergers tend to reduce overall innovation, making consumers "always worse off after a merger and that the inverted-U relationship between innovation and some measure of competition is not applicable to a merger setting ${ }^{2173}$. In their paper they study three key channels for the effects of a merger on innovation: price coordination relates to "the elimination of product market competition between the merging firms", as, "( $\mathrm{t}$ )he merger internalizes the negative pricing externality that the merging firms exert on each other in the absence of the merger" and , according to the authors this affects the incremental profit of innovating and consequently the incentive to innovate.. While it is clear that a merger between competitors induces price coordination and thus harms consumers via higher prices, its effects on innovation incentives is ambiguous, but in general the reduction in the intensity of price competition following a merger tends to favour innovation. However, a merger will also produce an innovation externality reflecting the reduction of expected profits that innovation by one of the merging may produce to its merging partner (and vice-versa): either innovation by one of the merging firms cannibalizes the pre-innovation sales of the merging partner, or innovation by one of the merging firms diverts profitable post-innovation sales of the other merging firm. According to the authors, each of the merging firms internalizes this expected negative externality by reducing innovation, thus showing that the merger exerts a downward pressure on innovation incentive of the merging firms, at least via the innovation externality channel. This effect is more likely to be significant when (i) the merger brings together two out of a limited number of significant innovators and (ii) the merging firms, absent the merger, would have been likely to divert to a significant extent future sales from each other when introducing innovative products, which is particularly the case if the merging firms' existing and/on innovative products compete closely. Finally, the third channel consists in innovation-related efficiencies caused by the merger that increases the ability and/or incentive of the merging parties to innovate, in particular as it affects the ability by an innovator to prevent knowledge spillovers to other firms (appropriability). The authors argue that a merger leads to a reduction in the innovation effort of the merging parties in the absence of efficiencies, that the negative effect on innovation incentives tends to be stronger if the parties are close competitors, and finally that although non-merging parties increase their innovation effort postmerger, this increase does not compensate for the reduction of innovation effort by the merging firms. Their conclusion is that a merger between two out of a limited number of innovators is likely to depress innovation incentives, in the absence of innovation-related efficiencies.

The Commission has actively considered innovation effects in a series of recent merger cases, either exploring the possibility that a horizontal merger will lead to a loss of innovation by eliminating pipeline products that would likely have entered existing markets or that would have created entirely new value chains, thus preventing consumers from increased choice and variety ${ }^{2174}$, as well as non-

${ }^{2173}$ G. Federico, G. Langus, T. Valletti, A simple model of mergers and innov ation, (2017) 157 Economic Letters 136; . Federico, G. Langus, T. Valletti, Horizontal Mergers and Product Innovation: An Economic Framework, Federico, Giulio and Langus, Gregor and Valletti, Tommaso M., Horizontal Mergers and Product Innovation: An Economic Framework (July 10, 2017). Available at SSRN: https://ssrn.com/abstract=2999178 .

${ }^{2174}$ COMP/M. 5675 - Syngenta/Monsanto's Sunflower Seed Business, Commission decision of 17 November 2010, para. 248 and paras 200 and 207 (finding that farmers would have suffered from reduced choice); COMP/ M.6166 - Deutsche Börse/NYSE Euronext, Commission decision of 1 February 2012, section 11.2.1.3.4, confirmed by Case T-175/12, Deutsche Börse AG v Commission, ECLI:EU:T:2015:148; Case No COMP/ M.7326, Medtronic/Covidien, Commission decision of 28 November 2014; Case No COMP/M.7275, Novartis/GlaxoSmithKline's oncology business, Commission decision of 28 January 2015 ; Case No COMP/ M.7559, Pfizer/Hospira, Commission decision of 4 August 2015 Case 
horizontal vertical or conglomerate mergers that would have harmed the ability of the merged entity's rivals to innovate ${ }^{2175}$. It has been alleged that in several of these cases the Commission has proceeded to establish a novel theory of harm, that of a significant impediment to industry innovation (SIII), as it has not explored the existence of specific innovation markets that could have been affected by the merger, the Commission relying, in order to find the SIII, on several negative views about the merger gathered from third parties, without assessing if the merger would lead to a reduction in the R\&D spend/innovation incentives of the merged entity, its rivals and/or the whole industry ${ }^{2176}$. According to this view, the Commission's SIII theory is based on a presumption that regulatory intervention is warranted when a merger removes a "parallel path R\&D", this being not in line with the standard of proof in EU merger control ${ }^{2177}$.

These criticisms are far-fetched as, first, it is quite difficult to explain why the competition authority should not assess, when examining the merger, what would be the merger's effects on innovation incentives in the industry. This can be done, without necessarily defining a specific "innovation market". Indeed, in the context of the Transfer of Technology Guidelines, the Commission has put in place a filter that confines detailed analysis to cases "that are likely to present real competition concerns", not based on market shares but on the existence of "at least four independent technologies that may constitute a commercially viable alternative, in addition to the licensed technology controlled by the parties to the agreement" ${ }^{2178}$. According to the Commission, '(i)n assessing whether the technologies are sufficiently substitutable the relative commercial strength of the technologies in question must be taken into account. The competitive constraint imposed by a technology is limited if it does not constitute a commercially viable alternative to the licensed technology ${ }^{2179}$. Although if an agreement falls outside the safe harbour this does not create a presumption of incompatibility with Article 101 TFEU but simply leads to an individual assessment under the guidelines and Article 101(3) TFEU, the Commission's approach indicates that the main concern is the existence of sufficient choice in terms of independent technologies available in the market, thus showing that showing the emphasis put on the existence of various "independent" R\&D paths or, more generally, technologies. Limiting the focus on innovation to just the adoption of the "innovation markets" approach seems reductionist and certainly does not represent the most recent competition law thinking, also of US competition agencies ${ }^{2180}$. It is also important to take into account the patent portfolio strength of the merging parties, as well as the existence of licensing and crosslicensing agreements and internal strategy documents in order to assess the possible effects of a specific merger on innovation.

One should not limit this finding on situations of high market shares but it may be also be relevant to emphasise the need to keep an eye on technological developments and the possibility of potential

No COMP/ M.7278, General Electric/Alstom (Thermal Power- Renewable Power \& Grid Business), Commission decision of 8 September 2015

2175 Case COMP/ M.5984 - Intel/McAfee, Commission decision of 26 January 2011 ; Case COMP/ M.6564 ARM/GIESECKE \& DEVRIENT/GEMALTO JV, Commission decision of 6 November 2012; Case No COMP/M.7688 Intel/Altera, Commission decision of 14 October 2015.

${ }^{2176}$ N. Petit, Significant Impediment to Industry Innovation: A Novel Theory of Harm in EU Merger Control?, ICLE White paper 2017-1, 22.

2177 Ibid., p. 21.

${ }^{2178}$ Guidelines on the application of Article 101 of the Treaty on the Functioning of the European Union to technology transfer agreements [2014] OJ C 89/3, para. 157.

2179 Ibid.

${ }^{2180}$ See our analysis of the US merger cases above where innovation concerns were raised. 
competitors that rely on different technologies than the dominant undertaking, even if they are of a smaller size than the dominant undertaking, to challenge the competitive position of existing value chains and replace them with new ones. Competition law should take into account this form of disruptive competition, not only in relativizing the high market shares proxy, but also in assessing restrictions to the potential competition from these disruptors.

This may be particularly important in view of recent work raising questions over the effects of mergers and economic concentration on innovation in various industries. The market for agricultural biotechnology research and development is particularly concentrated, with the former "Big Six" accounting for a significant number of agricultural bio-technology patents issued in the US, as well as more than $80 \%$ of crop field trials for regulatory release in the US ${ }^{2181}$. There is empirical evidence of the inverse relationship between firm concentration in corn, cotton and soybean seed markets, and R\&D intensity in these markets, research finding that as the number of firms declined following the M\&A waves, the intensity of R\&D fell ${ }^{2182}$. Similar evidence exists for the effect of M\&As on innovation in the pharmaceutical industry ${ }^{2183}$. Although synergies and efficiencies were often put forward as the main rationale for mergers, the empirical evidence that these are effectively realized remains rather poor ${ }^{2184}$. The companies may argue that they will increase spending on $R \& D$. However, there may be doubts on these increases in $R \& D$ research materializing, in view of the fact that their R\&D expenses have been going down recently ${ }^{2185}$. Having three instead of six important market players may restrict the possibilities of joint collaboration on $R \& D$, in view of the prevalence of cross-licensing in this sector, thus increasing the risk of tacit collusion, in particular as most stacks are inter-firm stacks. Overlaps in biotech innovation could also lead to size down research capabilities and thus restrict the number of R\&D poles. Finally, a recent drop in research intensity in this sector may be related to the increasing consolidation of the industry, thus showing an inverse relation between market concentration and innovation and/or product quality ${ }^{2186}$. Ø. Solberg \& L. Breian (2015) studied five Nordic countries finding that consolidation (from 1950 to the present) has resulted in a decrease in the number of available cultivars, a shift in focus to crops and hybrids more profitable to companies, and termination of breeding programs for regionally relevant crops $^{2187}$.

\footnotetext{
${ }^{2181}$ J.L. King \& D. Schimmelpfenig, Mergers, acquisitions, and stocks of agricultural biotechnology intellectual property, (2005) 8(2\&3) AgBioForum, 83-88. Available: http://www.agbioforum.org (accessed May 29, 2017).

${ }^{2182}$ D. E. Schimmelpfennig et al, The impact of seed industry concentration on innovation: a study of US biotech market leaders, (2004) 30 Agricultural Economics 157-167.

${ }^{2183}$ W.S. Comanor \& F.M. Scherer, Mergers and innovation in the pharmaceutical industry, (2013) 3291) Journal of Health Economics, 106-113; J. Haucap \& J. Stiebale, How Mergers Affect Innovation:

Theory and Evidence from the Pharmaceutical Industry, DICE DISCUSSION PAPER 218 (2016), available at http://www.dice.hhu.de/fileadmin/redaktion/Fakultaeten/Wirtschaftswissenschaftliche_Fakultaet/DICE/Discussion_Pap er/218_Haucap_Stiebale.pdf .

${ }^{2184}$ For recent empirical evidence: see B.A. Blonigen \& J.R. Pierce, 'Evidence for the Effects of Mergers on Market Power and Efficiency' [2016] Finance and Economics Discussion Series 2016-082. Washington: Board of Governors of the Federal Reserve System, available at doi.org/10.17016/FEDS.2016.082.

${ }^{2185}$ For instance, Monsanto' expenses for R\&D have been going down in recent years: from $\$ 1,725$ million in 2014 to \$1,580 million in 2015 and \$1,512 million in 2016: Monsanto 2016 Annual Report, Form 10-K, p. 8. It therefore looks that, as a percentage of sales, $R \& D$ spending has actually slumped back down to mid-1990s levels. The level of R\&D in this sector (between $8.5-11.4 \%$ of sales) [Bayer, Acquisition of Monsanto to Create a Global Leader in Agriculture, Investor Presentation, June 2016, 17] is also much lower than the level of $R \& D$ in the pharmaceutical sector (between $16-20 \%$ of sales), even if the level of costs of launching an innovative product (including the costs associated to the regulatory approval pipeline) are comparable.

2186

${ }^{2187} \emptyset$. Solberg \& L. Breian, Commercial cultivars and farmer's access to crop diversity: a case study from the Nordic Region, (2015) 24 Agricultural and Food Science 150.
} 
Recent research has found that $R \& D$ intensity, measured as the share of industry-level $R \& D$ expenditure to sales, increased from $11.0 \%$ in 1994 to $15.0 \%$ in 2000 before falling back to $10.5 \%$ in $2009^{2188}$. There is a significant heterogeneity across firms as they vary by size and innovation strategy with the eight largest seed companies having an average R\&D intensity of $15.8 \%$ while accounting for $75.6 \%$ of the global R\&D share. The number of new active ingredients in the R\&D pipeline also decreased by $60 \%$ between 2000 and 2012. J. Fernandez-Cornejo \& D. Schimmelpfennig also note :

"[c]alculations for corn, soybeans, and cotton indicate that as the seed industry became more concentrated during the late 1990s, private research intensity dropped or slowed. Was there a connection between the concentrating industry and the slowing intensity? Further ERS analysis, using econometric methods, found a simultaneous self-reinforcing relationship. Those companies that survived seed industry consolidation appear to be sponsoring less research relative to the size of their individual markets than when more companies were involved. This finding runs counter to the hypothesis that dominant firms in consolidated industries conduct more new product research than they otherwise would in order to expand the size of their markets (because of less risk of being outcompeted during the long time periods required to bring new products to market)" 2189 .

A recent study by Jefferson et $\mathrm{al}^{2190}$ (2015) of ownership issue of agriculture seed-related patents concluded that "the restructuring of the crop agriculture industry in the 1980s and 1990s and the strategic use of patent rights enabled some large-scale patent holders to exclude or deter others from using critical research tools and materials. This legal and expected use .....allowed a few corporations to influence or control much of global agricultural innovation". R\&D spending of leading agriculture seeds may also constitute a way to assess innovation. The five companies (Monsanto, Syngenta, DuPont Pioneer, BASF and Bayer ${ }^{2191}$ ) had a combined R\&D budget accounted for more than USD 6 billion $^{2192}$ in 2015. Such concentration of industrial R\&D suggests potential barriers to entry for competitors. The industry leaders claim that the process of development of a new biotechnology trait is complex and time consuming. According to Syngenta, it takes about 13 years on average to develop a new GM trait and roughly USD $136 \mathrm{~m}$ of R\&D costs (excluding failures) ${ }^{2193}$. Another study brings this cost to $\$ 286$ million. The regulatory framework of GM plants is very stringent and typically requires about nine years of regulatory work assuming it is running in parallel to early development stages. Some researchers believe that $R \& D$ expenditures as well as expenditures on regulatory improvements should be considered sunk costs ${ }^{2194}$. Sunk costs are typically considered to be a characteristic of non-contestable markets (in other words, markets that do not behave in a competitive manner; although contestable markets have few companies competing, however due to a threat of new entrants such markets considered to behave in a competitive manner).

\footnotetext{
2188 B. Anderson \& I. M. Sheldon, R\&D concentration under Endogenous Fixed Costs: Evidence from Genetically Modified Corn Seed (2017) 99(5) American Journal of Agricultural Economics 1265.

${ }^{2189}$ J. Fernandez-Cornejo \& D. Schimmelpfennig, Have Seed Industry Changes Affected Research Effort?, Amber Waves (2004), available at https://www.ers.usda.gov/amber-waves/2004/february/have-seed-industry-changes-affectedresearch-effort/

2190 Jefferson, Osmat A., Köllhofer, Deniz, Ehrich, Thomas H., \& Jefferson, Richard A. The ownership question of plant gene and genome intellectual properties. Nature Biotechnology, 33(10), 2015. pp. 1138-1143.

${ }^{2191}$ Source: companies annual reports. For BASF and Bayer the numbers reflecting agriculture science departments R\&D spending were used.

2192 After currency exchange adjustments.

${ }^{2193}$ Syngenta. Our Industry 2016. http://www4.syngenta.com/ /media/Files/S/Syngenta/our-industry-syngenta.pdf

${ }^{2194}$ Fulton, M., and K. Giannakas. Agricultural biotechnology and industry structure. AgBioForum, 4(2), 137-151. 2001.
} 
An important literature has also covered the possible negative economic effects of the consolidation of this sector on consumer welfare and innovation, but also biodiversity. Stiegert et al. (2010) show that industry concentration can increase seed prices ${ }^{2195}$. A recent report by PricewaterhouseCoopers (2015) indicates that concentration in animal health market has had a negative impact on $R \& D$ and that low R\&D productivity led to mature portfolios with some of the key drugs on the market present for more than 20 years $^{2196}$. Some studies have also found that excessive market power and high concentration in animal genetics industry led to less biodiversity by (i.e., poultry) ${ }^{2197}$. Moser and Wong ${ }^{2198}$ (2015) analyzed completion dynamics in the US agricultural biotechnology industry before entrance of Monsanto into this market segment (1996) and after, showing that Monsanto's acquisitions triggered a patent war between Monsanto and Pioneer Hi-Bred, although it also led to important investments in R\&D. Roucan-Kane and Gray (2009) ${ }^{2199}$ explained that corn and soybean seed costs have been growing rapidly, as a percentage of farm costs, while farmers are almost completely reliant on commercial seed industry. It is reported that growth of commercial seed industry triggered growth of private R\&D spending which increased by 1300 percent (in real terms) between 1960 and 1996 (Fernandez-Cornejo 2004 ${ }^{2200}$ ). Since 1984 private research spending exceeded public spending in seed industry and has been almost completely privatized today. Rising costs of private R\&D spending on seeds were put on farmers: the rise in seed prices outperforming the general index of prices paid by US farmers by nearly $30 \%$ over the period of 1994-2008 (since the introduction of the GE seeds in 1996) ${ }^{2201}$. Studies on the adoption of innovations in agriculture (in particular, adoption by farmers of GE seeds) show that a superior control of a wide range of weeds (Scursoni et al, 2006), convenience, flexibility and relative simplicity of pest control that led to the reduction in managerial intensity compared to traditional methods (Marra and Pigott ${ }^{2202}$, 2006; Gardner and Nelson ${ }^{2203}$, 2007) were suggested as key causes that led to the acceptance of farmers of herbicide-resistance technology and GE seeds. Interestingly, the higher reliance of farmers on seeds through time leads to more inelastic demand: farmers become less sensitive to price increases in seed (Pigott and Marra ${ }^{204}$, 2008). Schiemmelpfennig et al. (2004)

\footnotetext{
${ }^{2195}$ K. Stiegert, S. Guanming, J.-P. Chavas, Innovation, Integration, and Biotech Revolution: The Case of U.S. Seed Markets, Choices 25(2) (2010).

${ }^{2196}$ PWC, Animal health: Strategy Playbook for an Evolving Industry, (August, 2015).

${ }^{2197}$ W.M. Muir et al, Genome-wide assessment of worldwide chicken SNP genetic diversity indicates significant absence of rare alleles in commercial breeds, (2008) 105(45) PNAS, 17312-17317.

${ }^{2198}$ P. Moser \& P.Wong, Competition and Innovation: Did Monsanto's Entry Encourage Innovation in GMO Crops? April 3, 2015.

${ }^{2199}$ M. Roucan-Kane \& A.Gray. The US Seed Industry: An Exploration of Statistics Highlighting the Economic Activity pf the US Row Crop Seed Industry, Purdue University, Department of Agricultural Economics, Working Paper \#09-08, 2009

2200 J. Fernandez-Cornejo. The seed industry in U.S. agriculture: An exploration of data and information on crop seed markets, regulation, industry structure, and research and development. Agriculture Information Bulletin No. 786. U.S. Department of Agriculture-Economic Research Service. Washington, DC. 2004. Available online at http://www.ers.usda.gov/publications/aib786/aib786.pdf

${ }^{2201}$ National Research Council. The Impact of Genetically. Engineered Crops on Farm Sustainability in the United States. Washington, DC: National Academies Press. 2010, p. 146, 148

${ }^{2202}$ M.C. Marra, \& N.E. Piggott. The value of non-pecuniary characteristics of crop biotechnologies: A new look at the evidence. In Regulating agricultural biotechnology:Economics and policy. eds. R.E. Just, J.M. Alston, and D. Zilberman, 2006. pp. 145-178. New York: Springer.

${ }^{2203}$ J.G. Gardner \& C.H. Nelson. Genetically modified crops and labor savings in US crop production. Paper presented at the 2007 Southern Agricultural Economics Association Annual Meeting (Mobile, AL, February 4-7, 2007). 2007

${ }^{2204}$ N.E.Piggott, N.E \& M.C. Marra. Biotechnology adoption over time in the presence of non-pecuniary characteristics that directly affect utility: A derived demand approach. AgBioForum 11(1), 2008. pp: 58-70.
} 
found that an increase in industry concentration produces negative effect on research intensity of agriculture biotechnology ${ }^{2205}$. Roucan-Kane and Gray $(2009)^{2206}$ showed that corn and soybean seed costs have been growing rapidly, as a percentage of farm costs, while farmers are almost completely reliant on commercial seed industry;

Rising costs of private R\&D spending on seeds by industry leaders were put on farmers: the rise in seed prices outperformed the general index of prices paid by US farmers by nearly $30 \%$ over the period of 1994-2008 (since the introduction of the GE seeds in 1996) ${ }^{2207}$. For some crops, after adjustments for inflation the price of cotton seeds almost tripled between 1996 and 2007 while growth in price of soybean seed increased by over 60\%. Stiegert et al. (2010) claimed that industry concentration can increase seed prices ${ }^{2208}$. Schiemmelpfennig et al. (2004) concluded that increase in industry concentration produces negative effect on research intensity of agriculture biotechnology ${ }^{2209}$; Industry concentration and market power of leaders in seed industry raise concerns of potential market manipulations from leading companies (i.e. by artificially lowering supply and variability of seeds being produced by the market combined with increased prices). This is important given the fact that farmers need to adapt seeding materials to the specific conditions of local environments ${ }^{2210}$;

A number of studies in other factors of production industries (animal health, animal genomics) provided similar conclusions in relation to negative effects of industry concentration. For instance, high concentration in animal genetics industry results in excessive market power of industry leaders and, more importantly, provides less biodiversity thus enables long-term negative consequences for the industry as a whole. A study conducted by PricewaterhouseCoopers in 2015 focusing on animal health market provided that concentration in animal health market has negative impact on $R \& D$ as low R\&D productivity lead to mature portfolios with key drugs on the market for more than 20 years $^{2211}$. Moreover, a patent power can frustrate competition in the market to the advantage of the market leader.

Another interesting academic study of negative effect of industry concentration in seeds sector was conducted by Moser and Wong ${ }^{2212}$ (2015). The researchers analyzed completion dynamics in the US agricultural biotechnology industry before entrance of Monsanto into this market segment (1996) and after. They found that between 1924 and mid-1990-ies Pioneer Hi-Bred used to dominate the US plant-breeding industry. However, the acquisition DeKalb Genetics by Monsanto in 1996-1998

${ }^{2205}$ D. E. Schimmelpfennig et al, The impact of seed industry concentration on innovation: a study of US biotech market leaders, (2004) 30 Agricultural Economics 157-167.

${ }^{2206}$ Maude Roucan-Kane and Allan Gray. The US Seed Industry: An Exploration of Statistics Highlighting the Economic Activity pf the US Row Crop Seed Industry, Purdue University, Department of Agricultural Economics, Working Paper \#09-08, 2009

${ }^{2207}$ National Research Council. The Impact of Genetically. Engineered Crops on Farm Sustainability in the United States. Washington, DC: National Academies Press. 2010, p. 146, 148

${ }^{2208}$ Stiegert, Kyle. W, Guangming Shi, and Jean-Paul Chavas. Innovation, Integration and the Biotechnology Revolution in the US Seed Markets. The Magazine of Food, Farm and Resource Issues. Quarter 2, 25 (2), 2010.

${ }^{2209}$ Schiemmelpfennig, D.E, Carl E. Pray, Margaret F. Brennan. The impact of seed industry concentration on innovation: a study of US biotech market leaders. Agricultural Economics. Volume 30, Issue 2. March 2004. Pp.157-167.

${ }^{2210}$ Shi, G. and J.-P.Chavas. On pricing and vertical organization of differentiated products. Staff Paper No. 535. University of Wisconsin-Madison. Madison, WI. 2009.Available online at http://www.aae.wisc.edu/pubs/sps/pdf/stpap543.pdf

2211 Animal Health: Strategy Playbook for an Evolving Industry. PWC Report, August 2015. Available at http://www.pwc.com/us/en/health-industries/our-perspective/animal-health-playbook.html

${ }^{2212}$ Petra Moser and Paul Wong, Competition and Innovation: Did Monsanto's Entry Encourage Innovation in GMO Crops? April 3, 2015. 
changed the volume of innovation by Pioneer (based on the analysis of field trials permits issued by the US Department of Agriculture for GMO crops). As a result of acquisition, Monsanto got access to elite combinations of corn and soy. As a field study conducted by Moser and Wong showed, field trials for soy conducted by Pioneer fell from 20.5 per year (1992-1995) to 2.9 per year in 1999-2005. Overall, all soy breeders performed fewer trials after Monsanto's acquisitions. In addition, Monsanto's acquisitions triggered a patent war between Monsanto and Pioneer Hi-Bred. Although field trials for soy declined, Pioneer and other soy breeders applied for almost 50 times more patents after 1998 in soy compared to other crops. This is also consistent with the view of Schumpeter on competition and economics who claimed that monopolies tend to spend more on R\&D.

However, there is no clear link established in the academic literature between market concentration and innovation ${ }^{2213}$. Although it is widely believed that R\&D is the main driver of innovation in agricultural biotechnology, some researchers note that $R \& D$ is not the only contributor to the innovative products. Some believe that the role of expenditures in improved machinery and capital equipment should not be underestimated (Piergiovanni and Santarelli, 2013 ${ }^{2214}$ ) while others claim that broader advancements in informatics sciences (bioinformatics), genomics, engineering and other fields of science should be taken into account while as a source of innovation as well ${ }^{2215}$. Moreover, agriculture is increasingly prone to potential disruptive shocks. For instance, Mitra et all conclude that both pharmaceutical and agricultural industries are susceptible to technology shocks as new technology discoveries significantly broaden new options for $R \& D^{2216}$. For instance, a recently discovered new effective way of genome editing named CRISPR/Cas9 has produced a revolution in genome editing and is a considered to be a good example of such technology disruption cases.

Innovation level is typically measured by such metrics as $R \& D$ expenses, $R \& D$ intensity (ratio of R\&D expenses to sales) ${ }^{2217}$, patent counts and patent citations. However, none of these indicators treated alone is a useful measure of the true innovation efforts as claimed by Petit (2017) ${ }^{2218}$. Instead, an industry wide context should be taken into account - i.e., like technology disruption, agriculture commodity price trends, specific policy regulations, etc.

Therefore, in our view a merger assessment should not only be limited to the assessment of the potential harm or usefulness to industry's overall innovation efforts, but should be viewed in a wider perspective and primarily from the potential of market power arising from industry concentration.

\footnotetext{
${ }^{2213}$ Petit, Nicolas. Significant Impediment to Industry Innovation: A Novel Theory of Harm in EU Merger Control? ICLE Antitrust \& Consumer Protection Research Program. White Paper, 2017-1.

2214 Piergiovanni, Roberta and Enrico Santarelli, The More You Spend, the More You Get? The Effects of R\&D and Capital Expenditures on the Patenting Activities of Biotechnology Firms, SCIENTOMETRICS, Volume 94, Issue 2 (2013), pages 497-521.

${ }^{2215}$ Philip G. Pardey, Connie Chan-Kang, Jason M. Beddow, and Steven P. Dehmer, Long-Run and Global R\&D Funding Trajectories: The U.S. Farm bill in a Changing Context, AMERICAN JOURNAL OF AGRICULTURAL ECONOMICS, Volume 97, Issue 5 (2015), pages 1312-1323

${ }^{2216}$ Mitra, James, Joyce Tait, and David Wield, From Maturity to Value-added Innovation: Lessons from the Pharmaceutical and Agro-biotechnology Industries, TRENDS IN BIOTECHNOLOGY, Volume 29, Issue 3. 2011. pp. 105-109.

${ }^{2217} \mathrm{R} \& \mathrm{D}$ expenses and intensity has been relatively stable over the last several years for the market leaders (Appendix 1).

2218 Petit, Nicolas. Significant Impediment to Industry Innovation: A Novel Theory of Harm in EU Merger Control? ICLE Antitrust \& Consumer Protection Research Program. White Paper, 2017-1.p.18
} 
Industry concentration increases a risk of oligopolistic pricing since coordination of few market players are possible thus exercising significant market power upon dispersed farmers ${ }^{2219}$.

Considering this, common concerns still to be addressed include:

- Potentially limited access to seeds (with or without GE traits) to farmers (especially access to seeds non GE-seeds of the same yield characteristics);

- Lack of farmer input and knowledge regarding which seed traits might be developed;

- Emerging alliances between large biotechnology, agriculture input providers as well as agribusiness firms that might reduce in the long-term diversity and availability of choice ${ }^{2220}$;

- Power relationship between biotechnology firms and farmers ${ }^{2221}$;

In addition, special attention should be paid to potential lobbying power by the seeds and other agriculture input industry leaders, which may affect innovation if it leads to barriers to entry for innovative firms in the market. Thus, there is evidence that sizeable amount of funding is used by market leaders for financing of political campaigns to influence public policy processes ${ }^{2222}$. It is worth mentioning that a study conducted by the US National Academy of Sciences on impact of genetically engineered crops on farm sustainability in the US produced a following conclusion on seed industry concentration:

"[...] Research has also identified the continuing consolidation of the seed industry and its integration with the chemical industry. The market power of firms that supply seed has not adversely affected farmers' economic welfare so far, but research is needed on how market structure may affect ongoing access to non-GE or single-trait seeds and future seed prices. Furthermore, there has been comparatively little research on how changes in farmer social networks and seed-industry concentration might be affecting farmers' planting decisions and options, overall yield benefits, crop genetic diversity, and economic returns" ${ }^{\text {"2223. }}$.

In other words, there is a clear lack of studies of the seed industry consolidation consequences and we still do not fully understand all potential implications.

Innovation has also been an important consideration in the competition law and policy at the retail sector. A recent study commissioned by the European Commission on The Economic Impact of Modern Retail raises the possibility that retail concentration at local level may produce negative aggregate dynamic effects, through the reduction of the incentives of suppliers to innovate. ${ }^{2224}$

2219 Carstensen, Peter. Comments for the United States Departments of Agriculture and Justice Workshops on Competition Issues in Agriculture. Legal Studies Research Paper Series, Paper No.1103. http://ssrn.com/abstract=1537191.

${ }^{2220}$ Impact of Genetically Engineered Crops on Farm Sustainability in the United States. The NAS report.

${ }^{2221}$ Phillipson, M. Agricultural Law: Containing the GM revolution. Biotechnology and Development Monitor (48): 2-5, 2001

2222 Renwick, Alan, Md. Mofakkarul Islam and Steven Thompson, Power in Global Agriculture: Economics, Politics, and Natural Resources. International Journal of Agricultural Management, Volume 2, Issue 1. 2012

${ }^{2223}$ Impact of Genetically Engineered Crops on Farm Sustainability in the United States. The US National Academy of Sciences Report. pp. 206-207

${ }^{2224}$ European Commission, DG COMP, The Economic Impact of Modern Retail on Choice and Innovation in the EU Food Sector, (2014), available at http://ec.europa.eu/competition/publications/KD0214955ENN.pdf, 36. However, the study also found that "a large imbalance away from suppliers and towards modern retailers was generally found to be associated with more innovation, reflecting in particular the finding that greater supplier concentration was associated with less innovation," although it was also noted that the Member States in the sample did not include those with the highest level of national retailer concentration. The methodology of measuring the level of innovation followed in this study was also quite narrow as innovation essentially referred to the introduction of "new EAN products" (EAN being European Article Number). 
In its recent decision on the Dow/Dupont merger ${ }^{2225}$, the European Commission found that the merger may have reduced innovation competition for pesticides by looking to the ability and the incentive of the parties to innovate. The Commission found that the fact that two parties were competing head-to-head in a number of important herbicide, insecticide and fungicide innovation areas may have affected, after the merger, the incentive of the new entity to innovate and may have led it to discontinue some of these costly development efforts. The Commission emphasised that this analysis was not general but was based on "specific evidence that the merged entity would have lower incentives and a lower ability to innovate than Dow and DuPont separately" and "that the merged entity would have cut back on the amount they spent on developing innovative products"2226. That said, the Commission also mentioned the following, which we think may be of relevance to the competition assessment of the other pending mergers:

"(o)nly five companies (BASF, Bayer, Syngenta and the merging parties) are globally active throughout the entire $R \& D$ process, from discovery of new active ingredients (molecules producing the desired biological effect), their development, testing and regulatory registration, to the manufacture and sale of final formulated products through national distribution channels. Other competitors have no or more limited R\&D capabilities (e.g. as regards geographic focus or product range). After the merger, only three global integrated players would remain to compete with the merged company, in an industry with very high barriers to entry. The number of players active in specific innovation areas would be even lower than at the overall industry level" 2227.

This type of assessment looks close to the filter of the existence of at least four independent technologies that constitute a commercially viable alternative, in addition to the licensed technology controlled by the parties to the agreement, that the Commission usually employs in its Transfer of Technology Guidelines in order to exclude the possibility that a licensing agreement may restrict competition and thus infringe Article $101 \mathrm{TFEU}^{2228}$. There is no reason why the Commission will apply a different approach in the context of merger control. The above indicate that the Commission may view more negatively mergers that lead to less than three or four independent technologies commercially available on the market. The Commission will also certainly look to effects on innovation in the context of its analysis of the Bayer/Monsanto merger.

\subsubsection{The interaction between competition law and IP rights in BRICS}

The interaction between competition law and IP rights in BRICS countries is mixed. On the one hand, there are countries like China and India that fully apply competition law to the exercise of IP rights. On the other hand, countries like Brazil, Russia and South Africa do not yet have a clear view on the role between competition law and IP law. Brazil appears to examine the exercise of IR right mainly through merger control provisions, Russia examines the exercise of IP right thought unfair competition law statute, while South Africa appear to have least developed practice in this respect.

\footnotetext{
${ }^{2225}$ European Commission, Case M.7932 Dow/Dupont (2017).

${ }^{2226}$ Commission's Press Release on Dow/Dupont, http://europa.eu/rapid/press-release_IP-17-772_en.htm. 2227 Id.

${ }^{2228}$ European Commission, Guidelines on the application of Article 101 of the Treaty on the Functioning of the European Union to technology transfer agreements, [2014] OJ C 89/3, para. 157. See Section 13.3.3.2.2.
} 
The following sections will provide a brief overview of the state of the interplay between competition law and IP rights in BRICS countries.

\subsubsection{Brazil}

Brazilian Competition Law is contained in the Law 12,529 of 30 November, which came into force on May 29, 2012. The Administrative Council for Economic Defence - CADE is in charge with the competition law enforcement. Decisions are subject to a broad scope of judicial review not only at the first instance but also with several instances of appeal. IP right are not subject to any tailored exemption and the Brazilian Competition Law is applicable to business practices involving such rights

CADE examined IP related issues in several merger decisions. For instance, in the 2017 DuPont/Dow merger, CADE cleared the transaction subject to certain remedies related to divestment of R\&D assets, transfer of corn R\& centres and brands (see Case Study xxx).

In 2014, CADE assessed the licensing agreement granted by Monsanto to Bayer, through which the latter would develop and sell soya seeds with the Intacta technology.92 The report of the authority indicated that there was the risk that Monsanto would exert undue control and influence on Bayer in the soya market. It considered that some clauses of the agreement would be detrimental to the competition and had to be changed. CADE imposed restrictions on the agreement such as the exclusion of a preference option and of provisions related to the exchange of commercial information. The transaction was approved with those restrictions.

In 2006, CADE analysed the agreement between Monsanto, FMT and Unisoja for the licensing and sale of soybean seeds with the gene Roundup Ready. The authority approved the transaction with the conditions of changing three clauses of the contract in order to allow the parties to carry out research and development independently and to produce seeds with technologies other than Monsanto's.

\subsubsection{China}

The Anti-Monopoly Law of the People's Republic of China (AML) 2008 provides for competition law protection in China. Chinese competition authorities have held that exercise of IP rights is not immune from competition law. For instance, the recent Order of the State Administration for Industry and Commerce (SAIC) No. 74, promulgated on April $7^{\text {th }}$, 2015, for the purposes of protecting fair market competition, stimulating innovation and prohibiting undertakings from abusing intellectual property rights to eliminate or restrict competition. These provisions became effective in August 2015. In a document released by SAIC on the interpretation of this Order it is recognized that protecting IPRs is important to encourage innovation and competition, but it also stipulated that SAIC will not hesitate to intervene where it considers that IPRs are being exercised in a manner that harms innovation and competition and thereby the consumer interest and social welfare in China. According to Article 2 of that Order, "the Antimonopoly Law shall apply if an undertaking abuses its intellectual property rights to eliminate or restrict competition" in particular for IP related practices involving "monopoly agreements or abuse of a dominant market position". According to Article 3, the impact of such practices on "intellectual property rights, innovation and other factors" has to be taken into consideration, not only in product markets, but also in technology markets. Article 7 of this Order 
stipulates that "(w)ithout justifiable reasons, an undertaking with a dominant position shall not refuse to license its intellectual property rights on reasonable terms to other undertakings for the purpose of eliminating or restricting competition, provided that such intellectual property rights constitute an essential facility for production or business operation". Hence, Chinese anti-monopoly law may apply to a refusal to license such intellectual property rights when this will result "in adverse effects on competition or innovation in the relevant market, and will impair consumer or public interests", under the condition of course that (compulsory) "(1)icensing its intellectual property rights will not cause unreasonable harm to the dominant undertaking". This amounts to a balancing exercise. According to Article 16 of this Order, a number of factors will be considered in performing this balancing:

"(1) Market position of the undertaking and of the trading parties,

(2) Market concentration degree in the relevant market,

(3) Entry barriers in the relevant market,

(4) Industry practice and stage of industry development,

(5) Duration and scope of the effects of the restrictions in relation to output, territories, consumers, etc.

(6) Effects on the promotion of innovation and technology,

(7) Innovation capacity of the undertakings concerned and speed of technological change, and

(8) Other factors relevant to determining the effects of exercising intellectual property rights on competition".

The Chinese example shows that a gradual approach may be developed in the application of competition law to IP rights. Article 55 of the Chinese Anti-Monopoly law (2007) provided that

“( $(\mathrm{t})$ his Law does not apply when an undertaking exercises its intellectual property rights in accordance with laws and administrative regulations on intellectual property rights; However, this Law shall apply if an undertaking abuses its intellectual property rights to eliminate or restrict competition".

This established the possibility that Anti-Monopoly Law may apply to IP rights related conduct. However, in the absence of published detailed guidance, competition law enforcement to IP rights remained largely theoretical. It was only after a long process of gestation, with a working group established by SAIC in 2009 with the task to develop detailed guidelines as to the implementation of Anti-Monopoly law to IP rights and after several years of consultations with stakeholders both within and outside China, that the move was finally made with the promulgation of SAIC's Order in 2015. It is also noted that in view of the separation of powers between the SAIC and the National Development and Reform Commission (NDRC), the Order does not consider pricing issues, including the question of excessive royalties. Further guidance is to be expected by the National Development and Reform Commission ("NDRC"). The Ministry of Commerce ("MOFCOM") will also adopt guidance on mergers involving IP rights. In addition, SAIC is in the process of adopting detailed guidance for monopoly agreements and abuse of dominance not relating to price. It is expected that the final guidelines will be formulated by the three Chinese Competition Agencies and will be released by their overarching authority, the Antimonopoly Commission of the State Council during 2016.

It is worthy of note that "cross-licensing agreements" between seed companies may violate relevant laws. Although Article 5 of China's anti-monopoly law rules that the law should not be applied to the behavior of business operator that follow intellectual property law and administrative 
rules and regulations, the law should could be applied to those who abuse of intellectual property to limit competition.

\subsubsection{India}

In terms of Section 3(5) of the Indian Competition Act 2002 (as amended in 2007), sections 3(1) to 3(4) may not be deemed to restrict the right of any person to restrain any infringement of, or to impose reasonable conditions, as may be necessary for protecting any of his rights which have been or may be conferred upon him under-

(a) the Copyright Act, 1957 (14 of 1957);

(b) the Patents Act, 1970 (39 of 1970);

(c) the Trade and Merchandise Marks Act, 1958 (43 of 1958) or the Trade Marks Act, 1999 (47 of 1999);

(d) the Geographical Indications of Goods (Registration and Protection) Act, 1999 (48 of 1999);

(e) the Designs Act, 2000 (16 of 2000);

(f) the Semi-conductor Integrated Circuits Layout-Design Act, 2000 (37 of 2000).

It is clear that this article does not provide a blanket immunity for anticompetitive conduct involving IP rights (as it exempts only "reasonable conditions" that are "necessary" for the protection of the right). In addition, Section 4 of the Act (dealing with abuse of dominance) does not include a similar provision, which indicates that even "reasonable" conditions imposed by IP holders, in the sense of Article 3(5), may be subject to the Competition Act, if they result in an abuse of a dominant position when there is an "appreciable adverse effect on competition". In Amir Khan Productions Private Limited v. Union of India ${ }^{2229}$, the Bombay High Court held that the Competition Commission of India (CCI) has jurisdiction to deal with competition cases involving IPRs. It seems that the CCI staff would favour an approach that would call for "a balance between abuse of monopoly and protection of the property holders' rights" 2230 .

The CCI referred to Section 3(5) in Shri Shamsher Kataria v. Honda Siel Cars India Limited \& Others. ${ }^{2231}$ In examining whether the three types of agreements entered into between Original Equipment Manufacturers (OEMs) and Original Equipment Suppliers (OESs) fell within the ambit of section 3(4), CCI held that:

(a) agreements between OEMs and their overseas suppliers did not fall within section 3(4) as these were internal agreements of a single economic entity;

(b) agreements between OEMs and local OESs were instances of refusal to deal and exclusive distribution agreements, and fell within the mischief of section 3. CCI analysed the AAEC of these agreements in light of factors listed in section 19(3). It also considered whether the defendant was entitled to an exemption under section 3(5)(i); $;^{2232}$

\footnotetext{
${ }^{2229}$ Amir Khan Productions Private Limited v. Union of India, 2010 (112) Bom LR 3778.

${ }^{2230}$ CCI, Intellectual Property Rights under the Competition Act, 2002, available at http://www.competition-commissionindia.nic.in/advocacy/Intellectual_property_rights.PDF .

${ }^{2231}$ Case 3/2011 decided 25.08.2014.

2232 ibid (para 20.6.7). CCI also referred to this reasoning in: (1) Case 3/2011 Shri Shamsher Kataria v. Honda Siel Cars Limited India \& others, decided 27.07.2015 and (2) In considering section 3(5) exemption in Case 107/2013 Association of Third Party Administrators v. General Insurers (Public Sector) Association of India \& others decided 04.01.2016 CCI clarified that joint ventures that enhanced efficiency even though horizontal, were not presumed to have an AAEC and
} 
(c) agreements between OEMs and their authorized dealers were also anti-competitive on the basis of an analysis similar to that in case of OEMs and local OESs (see (b) above).

\subsubsection{Russia}

Competition Law in Russia is based on the Federal law "On Protection of Competition" dated 26 July 2006 N 135-FZ (Federal law "On Protection of Competition"). The enforcement of competition law is entrusted to the The Federal Antimonopoly Service of the Russian Federation ( FAS)

The FAS's investigations are mainly based on the following provisions of the Federal law "On Protection of Competition":

(i) Article 10 - prohibition of abuse of dominant position;

(ii) Article 11 - prohibition of written or oral agreements between competitors (cartels) / "vertical" agreements, which lead or might lead to anticompetitive effects described in the said Article;

(iii) Article 11.1 - prohibition of concerted actions, which leads to restriction of competition;

(iv) Article 15 - prohibition of adoption of acts or performance of actions by state bodies, which lead or may lead to restriction or elimination of competition;

(v) Article 16 - prohibition of anticompetitive agreements or concerted actions by state authorities; between the state authorities and economic entities if they lead or may lead to restriction or elimination of competition.

However, with respect to IP rights, competition law in the Russian Federation lacks any efficient instruments, which can help to resist any negative consequences for competition resulting from the abuse of IP rights. For instance, under Article 10 of the Federal law "On protection of competition" abuse of IP rights by dominant households does not affect actions in respect of enforcement of exclusive rights on intellectual property and means of identification, individualizing food products or associated services. Moreover, in accordance with Article 11 of the Federal law "On protection of competition", anticompetitive agreements are prohibited. However, these legal provisions are not applied to agreements on assignment, alienation of rights of exploitation of IP assets or means on identification.

Instead, the developments concerning the interaction between IP and competition in Russia are mainly in the area of unfair competition law.

\subsubsection{South Africa}

The Competition Commission is in charge of enforcing competition law in South Africa. However, the interplay between competition and IP law is not specifically addressed in any statute or regulation., and the Competition Commission has not yet issued official guidelines addressing the overlap of IP and competition law

Nevertheless, the Competition Commission may apply provision of South Africa's Competition Act to firms holding intellectual property rights. For instance, Section 8(b) of the

their anti-competitive effects needed to be established. 'The question of them being per se anti-competitive does not arise...' (para 67). 
Competition Act prohibits a dominant firm from refusing to give a competitor access to an essential facility when it is economically feasible to do so. ${ }^{2233}$ Section $8(\mathrm{~b})$ of the Competition Act can therefore be used, in certain instances, as a means to grant compulsory licensing in situations where the firm has refused to license its IP right. The Competition Commission may also use Section 8(a) of the Competition Act prohibiting dominant firms from charging excessive prices and challenge patent holders that charge excessively high royalties for the use of their patented technology. ${ }^{2234}$

The Competition Commission may further apply other provisions of the Competiton Act, such as Section 5(1) that prohibits an agreement between parties in a vertical relationship if it has the effect of substantially preventing or lessening competition in a market and Section 8(c) that prohibits a dominant firm from engaging in conduct that impedes or prevents other firms from entering into, or expanding within a market. ${ }^{2235}$

In that regard, the Competition Commission investigated company HZPC Holland BV, ${ }^{2236}$ that enjoyed plant breeder's right over the Mondial seed potato variety in South Africa for 20 years. After the expiry of plant breeder's right, HZPC Holland BV entered into exclusive agreement with company Wesgrove Potatoes for the use of Mondial seed veriety and refusing access to seeds to others. The Competition Commission considered this exclusive agreement to be the means to exclude other South African potato seed growers from growing and selling the Mondial seed potato variety once the plant breeder's right has expired. ${ }^{2237}$

Table 8: Comparison Competition/IP in BRICS

\begin{tabular}{|l|l|l|l|l|l|}
\hline & Brazil & Russia & India & China & South Africa \\
\hline $\begin{array}{l}\text { Competition } \\
\text { law applies to } \\
\text { IP rights }\end{array}$ & Partly & No & Fully & Fully & Partly \\
\hline $\begin{array}{l}\text { Competition } \\
\text { Law and IP } \\
\text { Guidelines }\end{array}$ & No & No & Yes & Yes & No \\
\hline
\end{tabular}

Source: Authors' compilation of data

\subsection{Exhaustion of IP Rights}

\footnotetext{
${ }^{2233}$ Itumeleng Lesofe, 'Finding the Right Balance Between the Enforcement of Competition Law and The Protection of Intellectual Property Rights' (2017) p. 14, available at: http://www.compcom.co.za/wpcontent/uploads/2017/09/Paper_Competition-and-IP-Law_Itumeleng-Lesofe_Final_24082017.pdf

${ }^{2234}$ Itumeleng Lesofe, 'Finding the Right Balance Between the Enforcement of Competition Law and The Protection of Intellectual Property Rights' (2017) p. 15, available at: http://www.compcom.co.za/wpcontent/uploads/2017/09/Paper_Competition-and-IP-Law_Itumeleng-Lesofe_Final_24082017.pdf

${ }^{2235}$ Itumeleng Lesofe, 'Finding the Right Balance Between the Enforcement of Competition Law and The Protection of Intellectual Property Rights' (2017) p. 16, available at: http://www.compcom.co.za/wpcontent/uploads/2017/09/Paper_Competition-and-IP-Law_Itumeleng-Lesofe_Final_24082017.pdf

${ }^{2236}$ Itumeleng Lesofe, 'Finding the Right Balance Between the Enforcement of Competition Law and The Protection of Intellectual Property Rights' (2017) p. 15, available at: http://www.compcom.co.za/wpcontent/uploads/2017/09/Paper_Competition-and-IP-Law_Itumeleng-Lesofe_Final_24082017.pdf

${ }^{2237}$ Itumeleng Lesofe, 'Finding the Right Balance Between the Enforcement of Competition Law and The Protection of Intellectual Property Rights' (2017) p. 15-16, available at: http://www.compcom.co.za/wpcontent/uploads/2017/09/Paper_Competition-and-IP-Law_Itumeleng-Lesofe_Final_24082017.pdf
} 
While patents produce dynamic benefits by encouraging innovation, they also produce allocative inefficiencies. ${ }^{2238}$ An exclusive right holder seeking to maximize returns will tend to raise prices over the competitive price and decrease output. This produces a deadweight loss, in that there are potential consumers who forego purchase at the 'monopoly' price even though they could put the invention to good use (and thus raise social welfare). The patentee does not make the sale, and thus earns less than the full potential return. The exhaustion doctrine mitigates the first problem. Once a patentee sells an embodiment of the invention (or authorizes such a sale), his interest in that embodiment is deemed to be exhausted. From this perspective, IP rights exhaustion offers a way to limit the monopolistic rents of the IP rights holder. The buyer can resell, creating a secondary market where goods are available at lower cost. Those who would not pay the original price can purchase in the secondary market and enjoy the benefit of the invention. The exhaustion doctrine is also said to satisfy purchasers' expectations in that it limits restraints on alienation.

There are, however, numerous issues raised by the exhaustion doctrine. First, exhaustion can increase the patentee's loss in that the secondary market can compete with the primary market for the patentee's products. This exerts a downward pressure on price and reduces incentives to innovate. Patentees thus prefer to deal with deadweight loss by segmenting markets and charging differential prices, depending on what that market can pay. The exhaustion doctrine interferes with this strategy because buyers can purchase in the low-cost segment of the market and resell to the high-cost segment. In particular, patentees use international boundaries for this purpose. As a result, prices in some countries will be significantly lower than prices in other countries. Patentees do not believe that their interest in selling where the price is high is 'exhausted' by sale where the price is low. IP holders (in particular patent holders) also have other interests in the fate of the embodiments they sell. Some products are dangerous if not refurbished correctly. In these cases, the patent holder needs to control resale in order to assure quality (and protect itself from tort liability).

The principle of exhaustion or first sale in the US has been considered as a possible way to regulate the use of patents in self-replicating technologies, such as genetically engineered crops. In Bowman v. Monsanto, the US Supreme Court clarified that patent exhaustion doctrine applies to reusing or selling, but not to making the patented product, effectively indicating that the patent exhaustion doctrine does not apply to self-replicating technologies in the specific circumstances of the case, the intentional character of the self-replication and the fact that the purchaser exercised control over that replication having probably played a role in this case. The scope of the patent exhaustion doctrine was narrowed down, as the Supreme Court held that the sale of one generation of seed does not exhaust rights on later generations. A farmer who purchased seed to grow could not sow a new crop using the seeds produced by the fist crop - as that, the Court held, would constitute making the patented product and not reusing or selling the seed that had been purchased ${ }^{2239}$. Bowman was found to infringe two of Monsanto's patents because he "made" replicas of Monsanto's genetically modified, herbicide-resistant soybean seeds, by simply planting, cultivating, harvesting, saving, and then re-planting the patented seeds. IP rights on self-replicated seeds are thus not exhausted by the first authorized sale to a farmer. Seed companies that own the patent rights for genetically edited/modified plants may, in conjunction with license agreements, restrict a farmer's use of patented genetically-edited plants, this being also possible when a farmer plants seed that

${ }^{2238}$ On the complex economics of parallel trade, see KE Maskus, Private Rights and Public Problems - The Global Economics of Intellectual property in the $21^{\text {st }}$ Century (Peterson Institute for International Economics, 2012) $172-188$. ${ }^{2239}$ Bowman v. Monsanto Co., 133 S. Ct. 1761 (2013). 
contains the patented product. The Court was however careful to limit its holding to Bowman's particular situation, refusing to apply the holding to all cases involving self-replicating technologies

In a quite interesting recent judgment in Impression Products $v$ Lexmark, the US Supreme Court reiterated that the exhaustion doctrine in the US patent law means that when a "patentee sells an item, that product is no longer within the limits of the [patent] monopoly and instead becomes the private, individual property of the purchaser." ${ }^{2240}$ In other words, once a patentee sells patented product, it exhausts all of its patent rights in that product and cannot, from a patent law perspective, prohibit the future sale or re-use of the patented product. The parties cannot bargain around this rule by specifying conditions at the time of sale, even if these are clear. Hence, the rule of first sale (exhaustion) "is not merely presumptive, but absolute once a sale of the patented article has occurred"2241. In the case at hand, Lexmark wanted to prevent competitors, such as Impression Products, from buying used ink cartridges, refurbishing them, and selling them to its printer customer. Its aim was to keep this market for itself. The company imposed contractual terms to limit resale of ink cartridges obtained through its cartridge Return Program in the US also tried to prevent ink cartridges obtained abroad from being resold in the US through claimed patent rights. The practice that Lexmark was attempting to enforce amounts to a tying arrangement. The US Supreme Court held that Lexmark could not make a patent claim to ban Impression Products from importing in the US and re-selling Lexmark's toner cartridges which it obtained from Lexmark's customers from abroad and in the US, as having sold outside the US exhausts patent rights just as a sale inside the US. According to the Court, once a patented thing is sold, conditions imposed on that particular thing, such as an obligation to cannot be enforced via patent infringement suits. With this case the Supreme court reinforced the freedoms of device owners against the practice of IP holders to expand their power to the after-sales markets for repair and/or replacement parts and diagnostic tools. This may relate to "the importance of leaving buyers of goods free to compete with each other when reselling or otherwise disposing of those goods", which was recognised by Justice Breyer in Kirtsaeng ${ }^{2242}$.

This more expansive application of the exhaustion doctrine, and the underlying principle of protecting the freedom of buyers, may be particularly relevant for agriculture in view of the tendency of agricultural machinery companies to argue that the specialised software running tractors and other machines bought by farmers is protected by copyright and patent law and that allowing farmer's access to it would harm the companies' intellectual property rights ${ }^{2243}$. If agricultural machine manufacturers were recognised such a right, farmers would not be able to personalise, modify or improve the equipment they purchase. Farmers have reacted to this expansive interpretation of copyright and patent law, claiming of their "right to repair". It was reported that some US States have been considering legislation to legalise the right to repair electronics more generally, or tractors and other farm equipment, specifically ${ }^{2244}$. In view of the significance of big data and data analytics in "smart agriculture" and the development of the Internet of Things, it is expected that this issue will be particularly important and will raise questions as to the scope of the property rights of farmers when buying hardware and equipment, including their ability to repair and modify "their" equipment,

\footnotetext{
${ }^{2240}$ Impression Products v. Lexmark, 137 S. Ct. 1523 (2017)

${ }^{2241}$ H. Hovenkamp, Reasonable Patent Exhaustion, (August 22, 2017). Yale J Regulation (2017); U of Penn, Inst for Law \& Econ Research Paper No. 17-29. Available at SSRN: https://ssrn.com/abstract=2995751

${ }^{2242}$ Kirtsaeng v. John Wiley \& Sons, Inc., 568 U.S. 519, 538, 133 S. Ct. 1351, 1363 (2013)

${ }^{2243}$ See, https://motherboard.vice.com/en_us/article/kbgzgz/farmers-right-to-repair .

2244 See, https://motherboard.vice.com/en_us/article/mg7nbv/five-states-are-considering-bills-to-legalize-the-right-torepair-electronics
} 
and the extent to which the IP rights the companies have on software, through copyright or patent, (digital property) may limit the property rights of the farmers on the tangiles (machines, equipment $)^{2245}$. To a certain extent farmers may be thought to compete with the agricultural machinery companies in the market for the repair of the products they purchased from them, which may raise the possibility that the patent exhaustion could apply in this case, should this expansive interpretation of the doctrine prevail.

There is a great diversity in the exhaustion regimes chosen by various jurisdictions. A major distinction concerns between importing and exporting countries, ${ }^{2246}$ the latter usually adopting the international exhaustion regime, as this is more favorable to parallel trade. ${ }^{2247}$ It is also frequent that the exhaustion regime may change over time, or that the choice of policy remains undetermined by national legislation, thus leaving it up to national courts to determine what exhaustion rules to apply in specific cases. For instance, in the absence of any provision in the Chinese legislation, Chinese courts have generally avoided addressing the question directly. ${ }^{2248}$ In contrast, Indian law adopts international exhaustion for trade-marks, although it provides the trade-mark owner with the possibility of opposing parallel imports of trademarked products under limited circumstances, such that the conditions of the goods have been changed or impaired after they were put on the market. ${ }^{2249}$ The South African Trademarks Act adopts a similar position, stating in $\S 34$ (2) (d) of the Trade Marks Act that a trade mark registration is not infringed by 'the importation into, or distribution, sale or offering for sale in the Republic, of goods to which the trade mark has been applied by or with the consent of the proprietor'. 2250

Table 9: Comparison Exhaustion in BRICS

\begin{tabular}{|l|l|l|l|l|l|}
\hline $\begin{array}{l}\text { Exhaustion } \\
\text { regime }\end{array}$ & Brazil & Russia & India & China & $\begin{array}{l}\text { South } \\
\text { Africa }\end{array}$ \\
\hline
\end{tabular}

\footnotetext{
${ }^{2245}$ For an interesting discussion on this issue, see J.A.T. Fairfield, Owned (Cambridge Univ. press, 2017).

2246 "Exporting country" is the country out of the market of which a good is exported in parallel and "Importing country" is that where a good is imported in parallel.

2247 .G. Grigoriadis, Trademarks and Free Trade: A Global Analysis (Springer, 2014),, 60.

${ }^{2248}$ See, for instance, the discussion of Chinese law in D. Chow (2011), Exhaustion of Trademarks and Parallel Imports in China, (2011) 51(4) Santa Clara Law Review, 1283.

${ }^{2249}$ High Court of Delhi, Kapil Wadhwa \& Ors. vs Samsung Electronics Co. Ltd [decided on October 3, 2012], FAO(OS) 93/2012, where the High Court interpreted Section 30 (3) of the Indian Trade Marks Act 1999 to cover international exhaustion. Section 30(4) of the Indian Trademarks Act empowers a brand owner to have parallel imported goods declared infringing on the basis of any 'legitimate reason". The High Court recognized the wide scope of this exception enabling the trade-mark proprietor to oppose parallel imports by noting the following: (para. 68) "[...] it would be relevant to note that further dealing in the goods placed in the market under a trademark can be opposed where legitimate reasons exist to oppose further dealing and, in particular, where the condition of the goods has been changed or impaired. With respect to physical condition being changed or impaired, even in the absence of a statutory provision, the registered proprietor of a trademark would have the right to oppose further dealing in those goods inasmuch as they would be the same goods improperly so called, or to put it differently, if a physical condition of goods is changed, it would no longer be the same goods. But, sub-Section 4 of Section 30 is not restricted to only when the conditions of the goods has been changed or impaired after they have been put on the market. The section embraces all legitimate reasons to oppose further dealings in the goods. Thus, changing condition or impairment is only a specie of the genus of legitimate reasons, which genus embraces other species as well."

${ }^{2250}$ However, under the Consumer Protection Act, the parallel importer 'a person who markets any goods that bear a trade mark, but have been imported without the approval or licence of the registered owner of that trade mark, must apply a conspicuous notice to those goods in the prescribed manner and form.' See South African Consumer Protection Act, No 68 of 2008 (s. 25 (2)).
} 


\begin{tabular}{|l|l|l|l|l|l|}
\hline $\begin{array}{l}\text { International } \\
\text { Exhaustion } \\
\text { (General) }\end{array}$ & No & No & Yes & Yes & No \\
\hline $\begin{array}{l}\text { Regional } \\
\text { Exhaustion }\end{array}$ & N/A & Yes & N/A & N/A & N/A \\
\hline $\begin{array}{l}\text { National } \\
\text { exhaustion }\end{array}$ & Yes & Yes & Yes & Yes & Yes \\
\hline
\end{tabular}

Source: Authors's compilation of data

\section{Tables and Figures}

Table 1: Overview of patents granted in BRICS countries (2010-2015)...433

Table 2: Granted patents (biotechnology) BRICS 2010-2015...434

Table 3: EPO - patents granted patents per year 2005-2016....436

Table 4: Plant breeders' rights in BRICS........442

Table 5: Animal breeders' rights in BRICS.......445

Table 6: Plant Variety Rights Statistics..........448

Table 7: Agricultural R\&D expenditure in South Africa....471

Table 8: Comparison Competition/IP in BRICS....498

Table 9: Comparison Exhaustion in BRICS......502

Figure 1: Top US plant patent holders.....429

Figure 2: Granted patents (food chemistry) BRICS 2010-2015....435

Figure 3: Granted patents per year per technology group (BRICS)....435

Figure 4: EPO top patent applicants in biotechnology in 2016 .......437

Figure 5: The innovative potential of the large R\&D agrichem corporations: US.....437

Figure 6: Granted PVRs BRICS (2010-15)...448

Figure 7: Top companies for EU Plan Variety Protection certificates issued by the Community Plant Variety Office .....449

Figure 8: Number of plant vvariety protection certificates issued by the US Marketing Service.....449

Figure 9: The Innovation process....473

\section{References}

Animal Health: Strategy Playbook for an Evolving Industry. PWC Report, August 2015. Available at http://www.pwc.com/us/en/health-industries/our-perspective/animal-health-playbook.html

Allen R.C., 'Collective invention' (1983) 4 Journal of Economic Behaviour and Organization 24

Alston J.M., Andersen M.A., James J.S. and Pardey P.G., Persistence Pays: U.S. Agricultural Productivity Growth and the Benefits from Public R\&D Spending (Springer 2010) 
Alston J., Venner R.J., 'The Effects of the US Plant Variety Protection Act on Wheat Genetic Improvement' (2002) 31 Research Policy 527

Anderson B. and Sheldon I. M., 'R\&D Concentration Under Endogenous Fixed Costs: Evidence from Genetically Modified Corn Seed' (2017) 99 American Journal of Agricultural Economics 1265

Andrews R. (ed), The Columbia World of Quotations No. 41418 (Columbia University Press 1996)

Anton J.J. and Yao D.A., 'Little Patents and Big Secrets: Managing Intellectual Property’ (2004) 35 RAND Journal of Economics 1

Arora A., Ceccagnoli M and. Cohen W.M, 'R\&D and the Patent Premium' (2008) 26 International Journal of Industrial Organization 1153

Arrow K., Economic Welfare and the Allocation of Resources for Invention in The Rate and Direction of Inventive Activity: Economic and Social Factors (NBER 1962)

Babcock B. and Foster W., 'Measuring the Potential Contribution of Plant Breeding to Crop Yields: Flue-Cured Tobacco 1954 - 1987' (1991) 73 American Journal of Agricultural Economics 850

Baker J., 'Beyond Schumpeter vs. Arrow: How Antitrust Fosters Innovation' (2007) 74 Antitrust Law Journal 575

Bedasie S., 'The Possible Overlap Between Plant Variety Protection and Patent: Approaches in Africa With Particular Reference To South Africa And Ethiopia' (2012) 1 Haramaya Law Review 125

Bessen J., 'The Two Faces of Innovation' (2011) Boston University School of Law Working Paper 10-35, available at SSRN: ssrn.com/abstract $=1698802$

Bessen J. and Maskin E., 'Sequential innovation, patents, and imitation' (2009) 40 RAND Journal of Economics 611

Bessen J. and Nuvolari A., 'Knowledge Sharing Among Inventors: Some Historical Perspectives' in Harhoff D. and Lakhani K.L. (eds.), Revolutionizing Innovation (MIT press 2016)

Bientema N., Stads G.S., Fuglie K. and Heisey P, ASTI Global Assessment of Agricultural R\&D Spending (Washington DC: International Food Policy Research Institute 2012)

BIOAG Alliance, Fact Sheet, available at http://www.novozymes.com/en/aboutus/brochures/Documents/BioAg-Alliance-factsheet.pdf

Blonigen B.A. and Pierce J.R., 'Evidence for the Effects of Mergers on Market Power and Efficiency' (2016) Finance and Economics Discussion Series 2016-082, available at doi.org/10.17016/FEDS.2016.082

Bonny S., 'Corporate Concentration and Technological Change in the Global Seed Industry' (2017) 9 Sustainability 1632

Burk D.L. and Lemley M.A., The Patent Crisis and How Courts Can Solve It (University of Chicago Press 2009). 
Butler L. and Marion B., 'The Impacts of Patent Protection on the U.S. Seed Industry and Public Plant Breeding' (1985) North Central Regional Research Publication 304

Campello Afonso R., 'Brazil focus: Protecting plant varieties-Without IP law', Life Sciences Intellectual Property Review (16 June 2015)

Carrier M.A., Innovation for the 21st Century: Harnessing the Power of Intellectual Property and Antitrust Law (Oxford University Press 2011)

Carrier M.A., 'Unravelling the Patent-Antitrust Paradox' (2002) 150 University of Pennsylvania Law Review 761

Carstensen P., 'Comments for the United States Departments of Agriculture and Justice Workshops on Competition Issues in Agriculture' Legal Studies Research Paper Series, Paper No.1103. http://ssrn.com/abstract=1537191.

Cefis E., Grondsma M., Sabidussi A., Schenk E.J.J, 'The Role of Innovation in Merger Policy: Europe's Efficiency Defence Versus America's Innovation Markets Approach' (2007) Tjalling C. Koopmans Institute, Discussion Paper Series 07-21

Chow D., 'Exhaustion of Trademarks and Parallel Imports in China' (2011) 51 Santa Clara Law Review 1283

Clancy M.S. and Moschini G., 'Intellectual Property Rights and the Ascent of Proprietary Innovation in Agriculture' (2017) Working Paper 17-WP 572, available at https://www.card.iastate.edu/products/publications/pdf/17wp572.pdf

Cohen W.M., 'Fifty Years of Empirical Studies of Innovative Activity and Performance', in Hall B. and Rosenberg N. (eds.) Handbook of the Economics of Innovation Volume 1 (2010 Elsevier Publishing)

Cohen W.M., Nelson R.P. and Walsh J.P., 'Protecting Their Intellectual Assets: Appropriability Conditions and Why U.S. Manufacturing Firms Patent (Or Not)' (2000) NBER Working Paper 7552

Comanor W.S. and Scherer F.M., 'Mergers and Innovation in the Pharmaceutical Industry' (2013) 32 Journal of Health Economics 106

Correa P. and Schmidt C., 'Public Research Organizations and Agricultural Development in Brazil: How Did Embrapa Get It Right?' World Bank Economic Premise (June 2014) available at: http://siteresources.worldbank.org/EXTPREMNET/Resources/EP145.pdf

Das Nair R, 'Competition in Supermarkets: A South African Perspective' (2016) available at: https://static1.squarespace.com/static/52246331e4b0a46e5f1b8ce5/t/56f130034d088e7b7cb6fef4/14 58647047632/Reena+das+Nair_Competition+in+Supermarkets+-

+ A+South+African+Perspective.pdf

Dedrick J., 'Who Profits From Innovation in Global Value Chains? A Study of the iPod and Notebook PCs' (2010) 19 Industrial and Corporate Change 81 
Dias Varella M., 'Intellectual Property and Agriculture: The Case on Soybeans and Monsanto', 18 (2013) Journal of Tecnhology Law \& Policy 59

Dixon R., 'Hybrid Corn Revisited' (1980) 48 Econometrica 1451

Drew J., Yue C., Anderson N. and Pardey P., 'Premiums and Discounts for Plant Patents and Trademarks Used on Ornamental Plant Cultivars: a Hedonic Price Analysis', (2015) 50 HortScience 879

Duvick D.N., 'Biotechnology in the 1930s: The Development of Hybrid Maize' (2001) Nature Reviews Genetics 69

Ellig J. and Lin D., 'A Taxonomy of Dynamic Competition Theories' in J Ellig (ed), Dynamic Competition and Public Policy - Technology, Innovation and Antitrust Issues (Cambridge University Press 2011)

ETC Group, Breaking Bad: Big Ag Mega-Mergers In Play, Communiqué 115 (December 2015)

ETC Group, Gene Giants Seek “Philanthrogopoly”, Communique 110 (March 2013)

ETC Group, Who will control the Green Economy? (November 2011), available at http://www.etcgroup.org/sites/www.etcgroup.org/files/publication/pdf_file/ETC_wwctge 4web_De c2011.pdf

Fairfield, J.A.T., Owned (Cambridge Univ. press, 2017)

Federico G., Langus G., Valletti T., ‘A Simple Model of Mergers and Innovation' (2017) 157 Economic Letters 136

Federico G., Langus T., Valletti T., 'Horizontal Mergers and Product Innovation: An Economic Framework' (2017), available at SSRN: https://ssrn.com/abstract=2999178

Fernandez-Cornejo J. and Schimmelpfennig D., 'Have Seed Industry Changes Affected Research Effort?' (2014) Amber Waves, available at https://www.ers.usda.gov/amberwaves/2004/february/have-seed-industry-changes-affected-research-effort/

Fernandez-Cornejo J., 'The seed industry in U.S. agriculture: An exploration of data and information on crop seed markets, regulation, industry structure, and research and development. Agriculture Information Bulletin No. 786. U.S. Department of Agriculture-Economic Research Service' Washington, DC. 2004. Available online at http://www.ers.usda.gov/publications/aib786/aib786.pdf

Fuglie K.O. and Toole A.A., 'The Evolving Institutional Structure of Public and Private Agricultural Research' (2014) 96 American Journal of Agricultural Economics 862

Gardner J.G. and Nelson C.H., 'Genetically modified crops and labor savings in US crop production', paper presented at the 2007 Southern Agricultural Economics Association Annual Meeting (Mobile, AL, February 4-7, 2007)

Gilbert R.J., 'Competition and Innovation' in Collins W.D. (ed) Issues in Competition Law and Policy 1 (ABA Section of Antitrust Law 2008)

Gilbert R.J. and Sunshine S.C., 'Incorporating Dynamic Efficiency Concerns in Merger Analysis: The Use of Innovation Markets' (1995) 63 Antitrust Law Journal 569 
Gordon R., The Rise and Fall of American Growth (Princeton University Press 2016)

Grigoriadis G., Trademarks and Free Trade: A Global Analysis (Springer 2014)

Halewood M., López Noriega I. and Louafi S (eds.), Crop Genetic Resources as a Global Commons: Challenges in International Law and Governance (Routledge 2013)

Haucap J. and Stiebale J., 'How Mergers Affect Innovation: Theory and Evidence from the Pharmaceutical Industry' (2016) Dice Discussion Paper 218, available at http://www.dice.hhu.de/fileadmin/redaktion/Fakultaeten/Wirtschaftswissenschaftliche_Fakultaet/DI CE/Discussion_Paper/218_Haucap_Stiebale.pdf

Heller M.A. and. Eisenberg R.S, 'Can Patents Deter Innovation? The Anticommons in Biomedical Research' (1998) 280 Science 698

Hess C. and Ostrom E., Understanding Knowledge as Commons (MIT Press 2006)

Heisey P, King J. and Rubenstein K.D., 'Patterns of Public-Sector and Private-Sector Patenting in Agricultural Biotechnology' (2005) 8 AgBioForum 73

Hippel von E., 'Cooperation Between Rivals: Informal Know-How Trading' (1987) 16 Research Policy 291

Huffman W.E. and Evenson R.R., Science for Agriculture: A Long-Term Perspective (Blackwell Publishing 2006)

Hovenkamp H., 'Reasonable Patent Exhaustion' (2017) University of Pennsivalnia, Inst for Law \& Economics, Research Paper No. 17-29, available at SSRN: https://ssrn.com/abstract=2995751

Houses of Parliament, Parliamentary Office of Science and Technology, Intellectual Property and Plants (2016) Postnote 517

Howard P.H., Concentration and Power in the Food System (Bloomsbury 2016)

Howard P., 'Intellectual Property and Consolidation in the Seed Industry' (2015) 55 Crop Science 1

Howard P. 'Visualizing Consolidation in the Global Seed Industry:1996-2008' (2009) 1 Sustainability 1266

Janis M.D., 'Non-obvious plants', in Matthews D. and Zech H. (eds), Research Handbook on Intellectual Property and the Life Sciences (Edward Elgar 2017)

Janis M.D. and Kesan J.P., 'Intellectual Property Protection: Sound and Fury?' (2002) 39 Houston Law Review 727

Jinguang L., 'A View on Plant Variety Under China's Plant IP Protection System' (2011) 44 China Intellectual Property Magazine

Jefferson O.A., Kôllhofer D., Ehrich T. H. and Jefforson R.A., 'The Ownership Question of Plant Gene and Genome Intellectual Properties' (2015) 33 Nature Biotechnology 1138 
Kaplow L., 'The Patent-Antitrust Intersection: A Reappraisal' (1984) 97 Harvard Law Review 1813

Kiewiet B., 'The Community Plant Variety Protection System', (2009) CVPO available at: http://cpvo.europa.eu/sites/default/files/documents/articles/2009-07-10_Article_Italy.pdf

King J.L. and Schimmelpfenig D., 'Mergers, Acquisitions, and Stocks of Agricultural Biotechnology Intellectual Property' (2005) 8 AgBioForum 83

Kolady D.E. and Lesser W., 'But are they Meritorious? Genetic Productivity Gains under Plant Intellectual Property Rights' (2009) 60 Journal of Agricultural Economics 62

Koonan S., 'India's sui generis system of plant variety protection' (2014), available at http://www.quno.org/sites/default/files/resources/QUNO\%20India\%20-

\%20plant\%20variety\%20protection\%20-\%202014.pdf

Lesser W., 'Valuation of Plant Variety Protection Certificates' (1994) 16 Review of Agricultural Economics 231

Lence S.H., Hayes D.J., Alston J.M. and Smith J.S., 'Intellectual Property in Plant Breeding: Comparing Different Levels and Forms of Protection' (2016) 43 European Review of Agricultural Economics 1

Lesofe I., 'Finding the Right Balance Between the Enforcement of Competition Law and The Protection of Intellectual Property Rights' (2017), available at: http://www.compcom.co.za/wpcontent/uploads/2017/09/Paper_Competition-and-IP-Law_Itumeleng-Lesofe_Final_24082017.pdf

Li W., 'Patenting Genes in China, U.S., and the EU: How Does It Differ? Can It Get Out of Control?' (2016) 35 Biotechology Law Report 165

Lianos I., 'Brands, Product Differentiation and EU Competition Law' in Desai D., Lianos I and Weber Waller S (eds.), Brands, Competition Law and IP (Cambridge University Press 2015)

Liu C. and Zhang W., 'Recent Advances in Protection of New Varieties of Plants', Lexology (19 July 2016)

Llewelyn M, 'The Legal Protection of Biotechnological Inventions: An Alternative Approach', (1997) 19 European Intellectual Property Review 115

López A., 'Innovation and Appropriability, Empirical Evidence and Research Agenda' in The Economics of Innovation (WIPO 2009), available at www.wipo.int/ipdevelopment/en/economics/pdf/wo_1012_e_ch_1.pdf.

Malla S. and Gray R., 'An Analytical and Empirical Analysis of the Private Biotech R\&D Incentives. Selected Paper' (2000) Annual Conference of the Agricultural and Applied Economics Association, Tampa, Florida

Malla S, Gray R. and Phillips P., 'Gains to Research in the Presence of Intellectual Property Rights and Research Subsidies’ (2004) 26 Review of Agricultural Economics 63

Mansfield E., 'Patents and Innovation: An Empirical Study' (1986) 32 Management Science 173 
Marra M.C, and Piggott N.E., 'The value of non-pecuniary characteristics of crop biotechnologies: A new look at the evidence' in. Just R.E, Alston J.M., and Zilberman D. (eds.) Regulating agricultural biotechnology:Economics and policy (NewYork: Springe 2006)

Maskus K.E., Private Rights and Public Problems - The Global Economics of Intellectual Property in the 21st Century (Peterson Institute for International Economics 2012)

Mazucatto M., The Entrepreneurial State: Debunking Public vs. Private Sector Myths (Anthem 2013)

McDougall P, 'The Cost and Time Involved in the Discovery, Development and Authorisation of a New Plant Biotechnology Derived Trait' (2011) available at https://croplife.org/wpcontent/uploads/pdf_files/Getting-a-Biotech-Crop-to-Market-Phillips-McDougall-Study.pdf

Merges R.P. and Nelson R., 'On the Complex Economics of Patent Scope' (1990) 90 Columbia Law Review 839

Metzger A., 'Patents on Native Traits: What Scope of Protection?' in Matthews D. and Zech H. (eds), Research Handbook on Intellectual Property and the Life Sciences (Edward Elgar 2017)

Mitra J., Tait J., and Wield D., 'From Maturity to Value-added Innovation: Lessons from the Pharmaceutical and Agro-biotechnology Industries' (2011) 29(3) Trends in Biotechnology 105

Minssen $\mathrm{T}$ and Nordberg A, 'The Impact of Brocolli II \& Tomato II on European patents in conventional vreeding, GMO's and Synthetic Biology: The grand finale of a juicy patents tale?' (2015) 34 Biotechnology Law Report 81

Mogues T., Yu B., Fan S. and McBride L., 'The Impacts of Public Investment In and For Agriculture: Synthesis of The Existing Evidence' (2012) ESA Working Paper No. 12-07, available at http://www.fao.org/docrep/016/ap108e/ap108e.pdf

Mokyr J., The Lever of Riches: Technological Creativity and Economic Progress (Oxford Univertsity Press 1992)

Moschini G, 'Competition in the US Seed Industry and the Role of Intellectual Property' (2010) 25 Choices Mag 1

Moser P., 'Patents and Innovation in Economic History' (2016) 8 Annual Review of Economics 241

Moser P., Ohmstedt J. and Rhode P.W., 'Patent Citations - An Analysis of Quality Differences and Citing Practices in Hybrid Corn' (2016), available at SSRN: https://ssrn.com/abstract=1888191 or http://dx.doi.org/10.2139/ssrn.1888191

Moser P. and Rhode P.W., 'Did Plant Patents Create the American Rose?' in Lerner J. and Stern S. (eds.) The Rate and Direction of Inventive Activity Revisted (2011 University of Chicago Press)

Moser P. and Wong P., 'Competition and Innovation: Did Monsanto's Entry Encourage Innovation in GMO Crops?' April 3, 2015. 
Moss D. L., 'Transgenic Seed Platforms: Competition Between a Rock and a Hard Place?' AAI Submission, October 23, 2009

Muir W.M. et al, 'Genome-wide assessment of worldwide chicken SNP genetic diversity indicates significant absence of rare alleles in commercial breeds' (2008) 105(45) PNAS

Murray F. and O'Mahony S., 'Exploring the Foundations of Cumulative Innovation: Implications for Organization Science' (2007) 18 Organization Science 1006

Naseem A., Oehmke J., Schimmelpfennig D., 'Does Plant Variety Intellectual Property Protection Improve Farm Productivity? Evidence from Cotton Varieties' (2005) 8 Agbioforum 100

National Research Council. The Impact of Genetically. Engineered Crops on Farm Sustainability in the United States. Washington, DC: National Academies Press. 2010

Netnou-Nkoana N.C., Jaftha J.B., Dibiloane M.A. and Eloff J., 'Understanding of the Farmers' Privilege Concept by Smallholder Farmers in South Africa' (2015) 111 South African Journal of Science

Nordhaus W., 'An Economic Theory of Technological Change' (1969) 59 The American Economic Review 18

Nuffield Council on Bioethics, Genome Editing: An Ethical Review (September 2016)

O'Connor S.M., 'IP Transactions as Facilitators of the Globalized Innovation Economy' in Dreyfuss R.C., Zimmerman D.L. and First H. (eds), Working Within the Boundaries of Intellectual PropertyInnovation Policy for the Knowledge Society (Oxford University Press 2010)

Ordover J.A., 'Economic Foundations and Considerations in Protecting Industrial and Intellectual Property’ (1984) 53 Antitrust Law Journal 503

Ostrom E., Governing the Commons: The Evolution of Institutions for Collective Action (Cambridge University Press 1990)

Pardey P., Chan-Kang C., Beddow J., and Dehmer S., 'Long-Run and Global R\&D Funding Trajectories: The U.S. Farm bill in a Changing Context' (2015) 97(5) America Journal of Agricultural Economics 1312

Pardey P., Koo B., Drew J., Horwich J., Nottenburg C., 'The Evolving Landscape of Plant Varietal Rights in the United States 1930-2008' (2013) 31 Nature biotechnology 25

Perrin R., Kunnings K., Ihnen L., 'Some Effects of the U.S. Plant Variety Protection Act of 1970.' Research Report No. 46, Department of Economics and Business Economics (1983 North Carolina State University, Raleigh)

Peschard K., 'Seed Wars and Farmers' Rights: Comparative Perspectives from Brazil and India' (2017) 44 The Journal of Peasant Studies 144

Peschard K., 'Farmers' Rights and Food Sovereignty: Critical Insights from India', (2014) 41 The Journal of Peasant Studies 1085 
Petit N., 'Significant Impediment to Industry Innovation: A Novel Theory of Harm in EU Merger Control?' (2017) ICLE White Paper 2017-1

Phillipson M., 'Agricultural Law: Containing the GM Revolution' (2001) 48 Biotechnology and Development Monitor 2

Piergiovanni R., and Santarelli E., 'The More You Spend, the More You Get? The Effects of R\&D and Capital Expenditures on the Patenting Activities of Biotechnology Firms' (2013) 94(2) Scientometrics 497

Piggott N.E., and Marra M.C., 'Biotechnology adoption over time in the presence of non-pecuniary characteristics that directly affect utility: A derived demand approach', (2008) 11(1) AgBioForum 58

Pollack A., 'Monsanto and DuPont Settle Fight Over Patent Licensing' Times (26 March 2013) New York Times

Pray C., Ohmhke J. and Naseem A, 'Innovation and Dynamic Efficiency in Plant Biotechnology: An Introduction to the Researchable Issues,' (2005) 8 AgBioForum 52

Prifti V., 'The Breeding Exemption in Patent Law: Analysis of Compliance With Article 30 of the TRIPS Agreement' (2013) 16 The Journal of World Intellectual Property 218

PWC, Animal health: Strategy Playbook for an Evolving Industry, (August, 2015)

Reichman J. H., Uhlirch P. F. and Dedeurwaerdere T., Governing Digitally Integrated Genetic Resources, Data, and Literature: Global Intellectual Property Strategies for a Redesigned Microbial Research Commons (Cambridge University Press 2016)

Renwick A., Mofakkarul I., and Thompson S., 'Power in Global Agriculture: Economics, Politics, and Natural Resources' (2012) 2(1) International Journal of Agricultural Management

Rodrigues R.L., Lage C.L.S. and Vasconcellos A.G., 'Intellectual Property Rights Related to the Genetically Modified Glyphosate Tolerant Soybeans in Brazil' (2011) 83 Anais da Academia Brasileira de Ciências 719, available at: https://dx.doi.org/10.1590/S0001-37652011000200029

Rosegrant M., Kasryno F. and Perez N.D., 'Output Response to Prices and Public Investment in Agriculture: Indonesian Food Crops' (1998) 55 Perez Journal of Development Economics 333

Roucan-Kane M., and Gray A., 'The US Seed Industry: An Exploration of Statistics Highlighting the Economic Activity pf the US Row Crop Seed Industry', (2009) Purdue University, Department of Agricultural Economics, Working Paper \#09-08

Samuelson P., 'Intellectual Property Arbitrage: How Foreign Rules Can Affect Domestic Protections' (2004) 71 University of Chicago Law Review 223

Schimmelpfennig D. E., Pray C. and Brennan M., 'The Impact of Seed Industry Concentration on Innovation: A Study of US Biotech Market Leaders' (2004) 30 Agricultural Economics 157

Schumpeter J., The Theory of Economic Development (London, Transaction Publishing 2005, first published by Harvard University Press in 1934) 
Schumpeter J., Capitalism, Socialism and Democracy (1942, published by Harper \& Brothers 1950)

Scotchmer S., Innovation and Incentives (MIT Press 2004)

Scotchmer S., 'Standing on the Shoulders of Giants: Protecting Cumulative Research and the Patent Law' (1991) 5 Journal of Economic Perspectives 29

Shi, G., and Chavas J.-P., 'On pricing and vertical organization of differentiated products' (2009) Staff Paper No. 535. University of Wisconsin-Madison. Madison, WI. 2009.Available online at http://www.aae.wisc.edu/pubs/sps/pdf/stpap543.pdf

Solberg Ø. and Breian L., 'Commercial Cultivars and Farmer's Access to Crop Diversity: A Case Study from the Nordic Region' (2015) 24 Agricultural and Food Science 150

Solow R.M., 'Technical Change and The Aggregate Production Function' (1957) 39 The Review of Economics and Statistics 312

Stallman J., Impacts of the 1930 Plant Patent Act on Private Fruit Breeding Investment. (1986, Pd.D. Dissertation, Michigan State University)

Stiegert K., Guanming S., Chavas, J-P., 'Innovation, Integration, and Biotech Revolution: The Case of U.S. Seed Markets', (2010) 25(2) Choices

Stiegert K., Guangming Shi W., and Chavas J-P, 'Innovation, Integration and the Biotechnology Revolution in the US Seed Markets' (2010) 25(2) The Magazine of Food, Farm and Resource Issues Quarter 2

Strba S.I., 'Legal and Institutional Considerations for Plant Variety Protection and Food Security in African Development Agendas: Solutions from WIPO?' (2017) 12 Journal of Intellectual Property Law \& Practice 191

Tepperman A. and Sanderson M., 'Innovation and Dynamic Efficiencies in Merger Review' (Canada, Competition Bureau 2007), available at www.competitionbureau.gc.ca/eic/site/cb-bc.nsf/vwapj/crafinal-report-on-efficiencies-2007-04-09-e.pdf/\$FILE/cra-final-report-on-efficiencies-2007-04-09e.pdf

Teece D.J., Pisano G. and Shuen A., 'Dynamic Capabilities and Strategic Management' (1997) 18 Strategic Management Journal 509

Teece D.J., 'Profiting from Technological Innovation: Implications for Integration, Collaboration, Licensing and Public Policy' (1986) 15 Research Policy 285

Thomson R., 'The Yield of Plant Variety Protection' (2015) 97 American Journal of Agricultural Economics 762

Trade Research Niche Area, Faculty of Economic and Management Sciences, North West University, 'South Africa's Agricultural Trade Competitiveness Diagnostics (June 2013)

Uhlirch P.F., Designing the Microbial Research Commons (National Academies Press 2011) 
Venegas V.B., 'Shifting Towards a Dynamic Efficiency Test?: Evaluating Licensing Agreements under Antitrust Law' in Anderman S. and Ezrachi A. (eds) Intellectual property and Competition Law - New Frontiers (Oxford University Press 2011)

Würtenberger G., 'Protection of Plant Innovations' in Matthews D. and Zech H. (eds), Research Handbook on Intellectual Property and the Life Sciences (Edward Elgar 2017) 


\title{
Chapter 2: Mergers and Product Innovation: Seeds and GM Crops
}

\author{
Pierre Régibeau ${ }^{2251}$ and Katharine E. Rockett ${ }^{2252}$
}

\subsection{Introduction}

One approach attempts generality using formal modelling to draw broad lessons about the link between merger and innovation in an effort to define a benchmark position. This literature has generated some useful initial recommendations; however, the models often are incomplete descriptions of the relevant features of markets and the merging firms within them, so drawing policy advice could be premature. A clear step forward would be to develop the theory further, but this will take time and so does not address current policy challenges.

A second approach is to argue for the burden of proof to fall on the merging parties as a way to summarise the scepticism in the literature without making bold policy moves, while at the same time recommending a thorough review of the facts in each case. This is also a useful step, but could be made more useful by putting more form on this factual review. As a first step toward doing this, some others have made conceptual recommendations on factors to consider or areas in which argumentation would be welcome. While these contributions are useful, they have remained at a high level, moving them a step away from implementation by practioners. This highlights a potential area of contribution in this literature that could have a nearer term solution.

Finally, some have recommended analysis of markets that are alternative to product markets, including technology and innovation markets. Again, this is useful conceptually but the definition of these markets can be difficult to pin down. As before, there is a clear area where development is needed in the literature.

In light of this current state of knowledge on the analysis of mergers and innovation, our paper has two main purposes. Firstly, we develop what we hope to be a more "policy-maker friendly" typology of the effects of mergers on innovation investments by outlining simple components that can be combined into a decision rule. Such an exercise has several benefits: it provides a step by step understanding of the many effects at play, makes it possible to distinguish between first and second order effects, and finally helps to compare the innovation dimension of mergers to the more traditional pricing/output dimension. Having identified the effects at play we are then in a position to ask whether there are indeed circumstances where an a priori - rebuttable - presumption about the link between mergers and innovation would be justified.

Our second objective is to use this typology of effects in order to better understand the innovation dimension of mergers in the GM/seed industry as a specific case of interest. This industry has a concentrated core, which makes it a potentially fertile ground to investigate mergers that could be of concern to competition authorities. It is without question an important contributor to the BRIC economies, which are a focus of the work in this volume. The industry and the recent mergers within it share special features that make it a nice counter-point to the theoretical models that have been proposed as generalizable to mergers: to the extent that this industry provides special features, we would want to allow for any policy recommendations to take those into account in any merger

${ }^{2251}$ Charles River Associates, London

${ }^{2252}$ Department of Economics, university of Essex and CEPR 
analysis to be undertaken. These features include a heavy regulatory framework that leads to economies of scale and scope in GM applications but also a natural synergy between chemical and GM innovations that could bias the choice of applications to fall in specific areas. This means that the diversity in applications that could result from the economies of scope at the regulatory level may not emerge. To the extent that the BRIC countries could benefit from some of the more far-flung applications, these two features may not overall be beneficial to BRIC economies. To the extent that merger would be justified, then, by the economies at the regulatory (or marketing level), the complementarity may work in the opposite direction. Second, there is also a natural complementarity in seeds production as germplasm is an important "stock" from which innovations flow. This generates a natural vertical linkage that can also affect innovation production in terms of volume and application.

The Chapter is structured as follows. Section 2 reviews the economic literature very briefly. In fact, the literature is huge, so this is a highly selective treatment. The overall message, however, should be to communicate the early nature of the theoretical results, some of the measurement issues that dog this area of work and increase the ambiguity of its recommendations, and the typologies that have been put forward before to address policy making in the face of this ambiguity. Section 3 proposes our typology and then we develop an algorithm in Section 4 to create a clear decision framework to approach merger and innovation. Section 5 examines patent data in the GM food sector and discusses the special features of this industry. Section 6 concludes and outlines next steps in this evolving area of work.

\subsection{Review of the economic literature}

\subsubsection{Competition Policy and Innovation}

This Chapter takes as a starting point that the uses of intellectual property is a valid area to which to apply competition policy analysis. We have developed this point elsewhere: while intellectual property may generate stronger externalities than some other types of property, the tool of intellectual property rights provides a forum for addressing these externalities and does so by its unique rights design. This design anticipates, clearly, that intellectual property rights have the potential to be profitable and so allow their creators to recoup their investment. At the same time, the specifics of the design can, and have, adjusted in response to changes in this anticipated return for a variety of reasons, including regulatory reasons. In this light, there is no need for any strong exception to be made in competition policy for intellectual property ${ }^{2253}$.

This does not give much guidance, however, in light of the fact that competition policy certainly affects innovation incentives and innovation can be of benefit to final consumers. Hence, the interaction of competition policy and innovation is an important area to understand and incorporate into policy design. Ideally, to be most efficient, any tool that affects innovation incentives should act only in the case where innovation occurs. It is not clear, however, that competition policy is well adapted to do this, as it often affects both the pre- and post- innovation settings of a firm: if firms are allowed to merge, the merged entity will be present in the pre-innovation state and the post-

${ }^{2253}$ For example, specific exceptions have been made in the pharmaceutical sector for a variety of reasons. For a development of this argument, see Regibeau and Rockett (2007). 
innovation state and will be subject to any requirements of competition policy in both states equally. This could be good for innovation incentives if the policy means that the firm will appropriate more of the gains to any innovation that follows, but bad if it means that the firm has a more protected and profitable position in the absence of innovation.

Competition clearly needs to work hand in hand with other innovation oriented policies, such as intellectual property protection so that it does not negate but instead reinforces the potential appropriability or other benefits that these sister policies afford. Hence, the set of policies must work together to guarantee an outcome that will incentivise innovation. The most recent revision of the US horizontal guidelines (2010) and the equivalent EC Merger Regulations (2004) also require innovation effects to be included in the potential set of harms ${ }^{2254}$ but does not provide further tools to diagnose when this will be the case. Hence, the precise nature of the innovation-merger interface is a live competition policy issue. We need to keep in mind that while this paper and much of the discussion of the innovation-merger link focuses on mergers and competition policy, this occurs in the context of an overall regulatory, legal, and institutional structure that also affects innovation sometimes more directly - and interacts with the merged firm as well.

We then move on to an issue that has received a great deal of attention: the relation between market structure and innovation, but which is not necessarily directly relevant to the analysis of mergers since merger involve the analysis of combinations of entities rather than simple changes in concentration, ie changes in the number of potentially identical entities. We then consider mergers more specifically, observing that a series of approaches have been attempted to capture what policy makers need to know about the role of mergers in innovation incentives and innovation ability. This includes work that recommends that the facts of each merger need to be reviewed on a case by case basis but with some distribution of the burden of proof; work that develops simple theoretical benchmarks as a starting point to create a benchmark position for policy-makers; and work that advocates some concepts to guide the analysis of innovation incentives and effects but does not necessarily go far enough to provide an accessible guide. Whatever system is advocated based on the current state of debate needs to be readily understandable by a wide variety of professionals involved in mergers. For this it needs to be simple, in keeping with the historical philosophy and approach of competition analysis, and applicable as a decision-making methodology. We attempt a move in this direction after setting the scene in this literature review.

\subsubsection{Innovation and Market Structure}

One way to approach the question of whether merger increases or decreases innovation incentives is to look at the relation between market structure and innovation, where attempts have been made to find the "optimal" degree of concentration to generate high levels of innovation. Changes in concentration are not, of course, the same as a merger since changes in concentration in these models amount to a change in the number of competitors while a merger transforms the merging firms. At the same time, much of the debate on merger and innovation has taken concentration and innovation as a starting point in the same way as one might take the tools of market structure analysis in terms

${ }^{2254}$ See US Department of Justice and Federal Trade Commission (2010), especially page 23, for US guidelines. Shapiro (2012) provides case discussions related to these guidelines and to innovation. See also European Commission (2004) for regulation and European Commission (2016) for a brief review of the application of innovation concerns in competition policy and merger. 
of price and quantity effects to raise questions about whether a merger concentrates an industry excessively according to basic concentration measures. We begin, then, with a review of the main findings of this literature, including a nod to its long history going back to the mid-twentieth century.

The controversy about which market structure generates the most innovation traces its roots back to the work of Joseph Schumpeter (1942), who postulated that, the large firm operating in a concentrated market is "the most powerful engine of progress and... long run expansion of output...". He suggested that the superiority of the large firm over the "atomistic" firm was due to a combination of several factors: the need for at least a transient profit gain to create a return to the investment in innovation; the reduction in uncertainty that can accrue to a firm that dominates its market and so need not take into account rivals' strategic behaviour; and the relative lack of financial constraints of large firms. While this view set the static efficiency losses of concentration against dynamic efficiency gains of concentration, early estimates in the mid-twentieth century suggested that these static efficiency losses were relatively small compared to the longer term gains from innovation in economic growth ${ }^{2255}$. This work also paved the way for innovation effects to be an argument for concentration, which ran against anti-trust orthodoxy of the time. More precisely, the market structure that may generate the greatest consumer gains in terms of prices and output may not be the one that generate greatest gains in product quality or "new things".

The results of the literature on innovation and market structure are not so clear cut, however. First, it is not always clear whether concentrated markets themselves affect innovation or whether the larger firms that often are associated with such markets are the root cause of any benefits. Indeed, empirical work attempting to verify that innovation increases more than proportionately with firm size has been inconclusive ${ }^{2256}$ so that the size-innovation linkage is unclear. Early work on whether innovation increased with market concentration was no more definitive as the relation appeared to be non-linear with moderate concentration levels being optimal (Scherer, 1967).

One issue bedevilling any progress was how innovation should be measured. Output based measures such as patent counts risk over-counting relatively insignificant innovations unless weights are applied to attempt to correct for this while input based measures such as R\&D personnel and $\mathrm{R} \& \mathrm{D}$ expenditures risk measuring effort rather than what society presumably cares about, which is results. Work by Lanjouw and Schankerman (2004) suggests that many of the indexes to measure innovation are related, but there are many qualifications to this and the performance varies across field $^{2257}$. A second measurement issue was how to address endogeneity: does size generate innovativeness or do more innovative firms tend to grow? Does concentration generate innovativeness, or does innovation result in growth by innovators and exit by those who cannot keep up? More recent techniques in econometric analysis have helped to address this, but have not been able to generate a definitive answer ${ }^{2258}$.

\footnotetext{
${ }^{2255}$ See Harberger 1954, and Cowling and Mueller, 1978, although more recently critiqued by Aidt and Hillman 2008. ${ }^{2256}$ See for example, Cohen (2010) and Katz and Shelanski (2007) for references on this and discussion.

${ }^{2257}$ Citations-weighted patents perform relatively well in their work. See Lanjouw and Schankerman (2004) for careful and insightful analysis.

${ }^{2258}$ See Doraszelski and Jaumandreu (2013) for a recent contribution that maps out some of the challenges of endogeneity in the relation between research and development activities and productivity of firms, which is one outcome of innovation advances. References contained in this paper include many other important works that have generated advances on isolating causation. For an alternative treatment of endogeneity see Schankerman and Van Reenen (2013) and references therein.
} 
Finally, the simple rate of innovation may not tell the entire story: Cohen (2010) finds that the type of innovation tends to differ across larger and smaller firms with larger firms conducting more process and incremental innovation whereas smaller firms conduct more product innovation. To the extent that both types of innovation are necessary to progress consumer surplus in the longer run, it is not the size of a single firm but its size as part of the overall mix in the industry that matters to consumer welfare. To the extent that industries with moderate concentration levels tend to include a mix of firm sizes, it is not clear what precise control variable - size or concentration - is generating the favourable innovation results.

The ambiguity in the link between market structure and innovation can be traced back to the theoretical ambiguity of two effects that influence innovativeness in opposite directions, and which are rooted in the discussions that Schumpeter's work engendered. On the one hand, a larger firm tends to "replace its own profits" when it innovates. A firm that cannibalises an existing highly profitable position by replacing its products by better versions of the same has little to gain, net, from its innovative activity compared to a firm that enters "de novo" in the industry. This "replacement effect" can suggest that more concentrated markets would have lower levels of innovation. Arrow (1962) formalised the argument, using the example of a process innovation that lowered marginal cost to argue that a competitive market would generate little profit to a non-innovative firm but that an innovator can effectively use the price of non-innovative rivals as a "price umbrella" that it can undercut slightly while retaining high sales and a healthy margin. This could be called an "efficiency effect" that drives innovation as opposed to a "replacement effect" that could stall it. Together, replacement and efficiency effects suggest that more competitive product market structures should generate more innovation.

On the other hand, a second effect argues in the opposite direction. A firm that is already dominant has a strong incentive to maintain that dominance and the profits it generates, rather than allow entry that could potentially make the industry more competitive. Gilbert and Newbery (1982) point out that when a firm is facing a potential challenge to its dominance by an outsider, the "insider" firm maintaining its dominance has more to lose than a challenger has to gain by coming into the industry. This is because the challenger would be entering an already contested market while the insider would be defending a market that is not currently contested. This "strategic effect" means that an existing dominant firm would have a greater incentive than a challenger to innovate ${ }^{2259}$ : dominance, not competition, engenders innovation.

The incentive to "escape competition" and the effect of "establishing or defending dominance" by innovating were combined in a classic paper by Aghion et al (2005). This paper assumes a very particular balance of these effects to obtain the result that the relation between concentration and innovation follows the shape of an "inverted U", that was found in earlier empirical results. It is worthwhile detailing this paper, as it should be clear what a fine balance it strikes in order to generate the theory that allows us to interpret the contention that moderate concentration levels and innovation go hand in hand.

Aghion and co-authors assume that innovation takes a specific form: it must be "step by step", for example slowly chipping away at the marginal cost of producing output. This means that

2259 See Tirole (1997) for an outline of these effects. Vickers (1985) presents a theoretical model of "leapfrogging" behaviour and "increasing lead" behaviour in various industry settings that investigates the strategic incentive for a leader to maintain a lead, finding that the type of competition (Cournot or Bertrand) matters to the answer. Schmutzer (2013) revisits this issue in recent two-stage work. 
innovators cannot "leap ahead" with a drastic innovation but instead must draw even with competitors before drawing ahead with a series of incremental innovations. Imitation, at the same time, is assumed to be ready enough that followers are at most one step behind at any time: the lead can never become overwhelming. As such, it assumes a particular intellectual property rights regime and a particular type of innovative "technology". Finally, it is assumed that the profitability of a firm depends solely on its lead: a firm that draws even with a competitor may earn more than a firm that is behind, but a leader earns more than a firm that has drawn even. All of these assumptions are important to generating the final result of an inverted $U$ relationship between innovation and market structure. Indeed, Gilbert (2006), discussing the theoretical literature on the link between competition and innovation, points out that the relationship is complex and depends on many factors. As one varies these factors, the conclusions change. He sums this up by saying that it is not so much that we don't know what the linkage is between competition and innovation but rather that we have a plethora of models that emphasise different environments and that environment is, in fact, important to the way the linkage works overall.

Despite this fine balance in Aghion's work, then, he and coauthors manage to capture many of the threads of the competition and innovation literature in a single setting that is internally consistent and yields empirical results that tend to be robust to some degree. The incentives for the two innovative effects: escaping competition and catching up to a leader (or maintaining a lead) depend on the level of "competition" in the industry, which translates roughly to the intensity of rivalry in the "head to head" state where firms draw even. As competition rises, innovation comes mainly from the incentive to escape this intense head to head competition; as competitive rivalry falls, innovation is increasingly generated by followers attempting to earn greater profits by moving toward a head-to-head state (which is profitable if rivalry is not too intense). Because both low and high competition industries generate innovation, albeit for different reasons, it is unclear which degree of rivalry dominates overall in generating innovative output. Indeed, the most innovative industry in this model is an intermediate structure. A nice feature of the theoretical analysis is that it separates out the effects of the intensity of rivalry from the product market structure ${ }^{2260}$. The model also allows rivalry to act as both a spur for innovation and a brake, as it can discourage laggards as well as force head to head firms to surge forward.

The paper verifies these results empirically on UK data from 1968-1997 drawing an analogy between product market competition and rivalry, albeit at the 2-digit SIC code level, with citationweighted patents as the index of innovative output, noting that different industries have different "sweet spots" in concentration levels. On some level, their empirical result has been verified in a wide number of settings since the publication of this work and using a wide number of techniques ${ }^{2261}$ At the same time, the exact "peak" of the inverted U varies across industries and across time, which makes it difficult to implement except in extreme situations of monopoly or very close to monopoly. If this is the case, then while it does an excellent job at isolating underlying behavioural drivers, it stops short of giving a well-defined policy direction: a relationship between competition and innovation that changes direction from positive to negative at some point, but where that point is not well defined, is a significant step away from policy.

\footnotetext{
${ }^{2260}$ As has been noted by others, the intensity of competition is not synonymous with product market structure and so should not be treated so (Gilbert, 2006).

${ }^{2261}$ See Aghion et al (2015) for a review of the recent literature.
} 
Even on its own terms, it also leaves other questions unanswered, some of which have been address elsewhere at least in part. The first and most vexing is whether, as a general issue, maximising innovation rates is what is best socially. Indeed, there is no theoretical clarity on whether private incentives to innovate are too low or too high socially without intervention. A firm that innovates "steals business" from a rival. This means that the private sector will have excessive incentives to innovate from a social perspective since society should not care which particular firm innovates - what matters is that consumers have access to an improved product or service regardless of source. From the firm's perspective, however, it matters very much whether it - or a rival receives that business and so the business stealing effect is a wedge between private firm incentives and social incentives for innovation. On the other hand, it is also the case that any innovation produces some surplus that is not fully captured by the firm in the form of spillovers to other firms or simply generating value for consumers that is not fully incorporated into price ("consumer surplus"). Hence, private incentives to innovate may be too low (because firms do not capture the full value of their innovations) or too high (because firms innovate to steal business from each other) compared to the social optimum. Without firm guidance on where innovation rates are compared to the social optimum, we cannot use the "inverted U" result as a complete guide on where we would "prefer" industry rivalry to be. As an empirical issue, Bloom et al (2013) address this in a recent paper. In their careful analysis, positive spillovers from innovation dominate, so that their view is that the private incentives to innovate are socially insufficient overall. They qualify this by noting that smaller and larger firms do not fall at the same point on the trade-off, since smaller firms tend to produce niche products, which tend to produce smaller spillovers.

The second question is that while Aghion et al's argument is compelling, it is not the only explanation for why innovation rates might be highest at moderate concentration levels. As was mentioned above, Gilbert (2006) points to a number of other confounding factors that can be present in any particular case and it is not clear that the controls in the "inverted U" literature have adequately taken these concerns into account. For example, Darwinian effects have been pointed to by Lee (2005, 2009) and are not an emphasis here. Recent work has gone farther to examine the role of management practices in differences in productivity across firms ${ }^{2262}$ and resulting industry productivity levels of survivors from "Darwinian selection", but again are not really addressed here. If the observed changed in rivalry in an industry has come about due to a reduction in regulation, is a high innovation rate due to a loosening of past constraints or due to the level of rivalry? Is it because moderate levels of rivalry tend to be associated with a mix of firm sizes? To the extent that differently sized firms might create different types of innovation, is it this mixture that is really behind the results? In short, the model does what models do well: they simplify the problem to isolate the role of certain effects and then observe the role of those effects in a general setting. When we move to decisions on specific cases, however, we need to aggregate all the effects into a decision that is suited to the specifics of the case at hand. While the controls are very careful in this empirical tradition, the interpretation the results for the purposes of deciding specific cases are unclear since they attempt something different: they attempt general behavioural truths. A step needs to be made to clarify how the general translates to the specific. As we noted above, the results do not lead to a well defined policy position for the bulk of cases.

2262 See Kortum and Lerner 1997, Bloom and Van Reenen, 2007, Aghion et al (2013), Bloom (2010) and Bloom et al (2015) for example. The measurement of management practices is very difficult, as this literature emphasises, so the results are still evolving rapidly in this area. 


\subsubsection{Innovation and Mergers}

\subsubsection{Moving from Market Structure to Merger:}

As we have noted, while the preceding literature can be relevant to the discussion, it is not definitive. First, an "inverted U" empirical relation between market structure as a proxy for rivalry and innovation, relies for its theoretical justification on a specific balance of forces. Second, the empirical work points to industry-specific effects that significantly affect the balance of effects. Third, the nature of innovation that will be generated is clear as is its market effect in this theoretical framework: a merger of interest may instead involve only roughly defined ideas of exactly what the nature of future innovations will be and how they will affect existing or future product markets ${ }^{2263}$.

Fourth, and most importantly merger is not the same as a change in market structure (although it may accompany one) and merger policy is not the same as changes in concentration. This point was made by Whinston in his 2012 discussion of the Shapiro (2012) contribution that we will focus on here. Whinston illustrates his argument by quoting his own work with Segal (2007), where he notes that while primitives (such as the elasticity of demand) make a large difference to the "Aghion style" of analysis, one would be mistaken to modify competition policy to reinforce these primitives. Instead, modelling merger itself and how it works provides targeted answers to the question of how merger should be handled that can be more definitive.

The specific framework in which merger occurs can narrow down the analysis, which can in turn yield more definitive answers. Merger involves a specific approval framework that allows tools, including remedies, that are not included in the theory we have presented; it involves options to promote innovation that need to be considered in comparison to or possibly in conjunction with merger (such as cross licensing or research joint ventures), it involves a change in management that can have important positive or negative effects on the merged parties' innovation rates; it involves a change in size of the resulting firm; it involves entry effects and possibly other effects not mentioned here. While the relation between market structure and innovation might be a good starting point, then, it is only a starting point. To make a judgement about how merger and innovation interact, we need to go farther, to delve into the precise issues involved in mergers rather than industry concentration. This does not mean that precise way these mergers are evaluated do not depend on market structure or other situational "triggers". Katz and Shelanski (2007) suggest, for example, that the burden of proof might shift to show that merger would or would not have positive innovation effects depending on market structure considerations. One must recognise, however, that the "inverted U" literature does not provide a strong guide to this since the position of the "peak" of the inverted $U$ is unclear across industries and circumstances. Finally, the possibility of remedies means that the choice set of policy makers may be considerably wider than to simply "allow or not allow" a merger: remedies allow for merger to be allowed under certain conditions. This enriches the set of

\footnotetext{
2263 The literal effect of merger in the Aghion et al model is to shut down innovation completely. This follows from design features of the model that allow for a "clean" presentation but illustrate that the application to merger of the framework is not straightforward. In other matters related to this discussion, Segal and Whinston (2007) study a model of "exchanges of leadership" through innovation, finding that the presence of an entrant serves as a spur for innovation. This paper suggests that exclusionary practices can harm innovation, a point reinforced by Raskovich and Miller (2010).
} 
possibilities to be considered. All of these point to the need of analysis that is more tailored to the issue of merger per se.

\subsubsection{Formal modelling of Merger and Innovation: First Steps}

We have said that the literature linking innovation and market structure does not give much guidance both because of the nature of its results and the fact that they are not well linked to the nature of merger as a combination of firms, even though one could consider pursuing the possibility of market structure triggers. A more targeted approach needs to be considered. One way forward would be to use a case by case analysis of the facts with each case simply treated as unique. It would be helpful, however, to have more definitive red lines that could allow authorities to decide on a limited set of issues for which to request fact-based analysis or have some overarching rules. This could also allow for more certainty for the merging parties and could reduce the cost of the cases for authorities and parties alike.

Two recent papers have attempted formal modelling to address the merger and innovation per se, both of which emphasise that internalising externalities is the essence of the merger's effect on innovation ${ }^{2264}$. This allows the papers to address squarely the combination effect of mergers rather than rely on market structure to address merger indirectly. Federico, Langus and Valetti, (2017a, 2017b), points out that when firms combine, they coordinate prices (ie, internalise a negative pricing externality), which raises innovation incentives (all else equal) by improving overall profitability ${ }^{2265}$. The merger also allows the firms to internalise negative innovation externalities by internalising what would otherwise be a business stealing effect (in both innovative and non-innovative states). This can lower innovation rates for the entire industry if the concentration levels are already relatively high since business stealing has a powerful effect in their specification (for example, if the firms are in highly substitutable product areas). In a similar vein, Motta and Tarantino (2016) examine an industry where prices and investments are two choice variables, finding that mergers that are profitable generally are not good for consumer surplus. The paper has a similar "feel" in that it emphasises the role of mergers in internalising a (negative) pricing and a business stealing innovation externality, although the modelling of R\&D differs from stochastic to deterministic. Their model also includes regularity assumptions on the reactions of non-merging competitors that guarantee that the direction of travel for the merging firm is the same as the industry as a whole, which means that merger decreases both the merging entity's innovation and that of the industry as a whole. While this result becomes ambiguous under modest changes to the model (such as sequential rather than simultaneous setting of prices and investment or quality improvement rather than cost reductions) they can show that the result does survive for set of specific function forms.

As a stylised models, both approaches contribute an outline of underlying effects that could inform a set of considerations that could give form to an approach that goes beyond case-by-case analysis. Indeed the three concepts behind these works two of which, innovation competition and product market competition, are outlined above and a third, appropriability conditions, which is included but analysed only secondarily in these papers, are used to organise the economics literature

\footnotetext{
${ }^{2264}$ Earlier related models include Yi (1999), Kleer (2012), and Ishida et al (2011). These are not as general as the frameworks discussed here.

2265 They qualify this by noting that since the price coordination occurs both before and after the innovation, the effect is not obvious a priori where the markets of the merging firms are linked.
} 
in Annex 4 of the European Commission's recent Dow-Dupont decision ${ }^{2266}$. The actual analysis of the merger's effect on innovation carries on after this enumeration of general considerations to focus more on specific issues that were raised in the course of the arguments.

The paper by Federico et al (2017) can be viewed as an illustration of how these three general considerations can work together in a specific framework to draw a conclusion, but equally shows that the way these are drawn together is crucial to the result. This is also clear from earlier synthesis work, such as that of Gilbert (2006). Our synthesis treatment includes these considerations, but nests them within a methodology as a guide to decision making. We also disaggregate the general concepts to allow for more straightforward and targeted measurement. We detail our arguments below.

Haucap and Stiebale (2016) add empirical work to a theoretical model of merger. They begin by noting that the effect of merger on the innovation of non-merging firms is not, in fact, mentioned as a consideration in the US horizontal merger guidelines. This is an important issue, and is certainly not the spirit of the two theoretical contributions we have just mentioned. It is worthwhile to underline, as Haucap and Steibale do, that the effect on the entire industry is potentially the salient point for overall consumer welfare. In their empirical work, they study a sample of recent European pharmaceutical cases, finding that merger tends to be accompanied with a secular decline in innovation. This can lend some empirical support to these relatively stark theoretical models that generate an unambiguously negative result for merger's overall innovative effect.

If we use Haucap and Steibale's empirical work to justify these approaches, the difficulty is that the empirics are based on an industry with very long lead times so that diagnosing innovation effects of merger is fraught: getting the lag structure right is crucial, as the observed reduction in innovation could have been the reason for the mergers in the first place. Furthermore, the term necessary to observe long term effects does not necessarily elapse in their observation set. Overall, while the Haucap and Steibale work is careful, using state of the art difference-in-differences technology, it is not clear that this technique solves the problem of establishing the correct lag structure. For example, the merging firms may be precisely those susceptible to weakness in an environment with changing research technology, as was present in the 1990s and 2000s in this industry.

From a purely theoretical viewpoint, the models are very restrictive. As in the Aghion et al paper, innovation is incremental not transformative. Entry and exit do not occur so Darwinian effects will not tend to be present. Neither is fully dynamic. These models are, then, first steps at organising ideas in this sense: they may be good models for some innovative situations but are not general enough to be a full guide to policy. Furthermore, if one were to use them as a guide in certain cases, there are some pressing concerns. First, innovation is taken as given in these models within the timeframe with no exit and no postponement. If innovation considerations are likely to make merger approval harder as matter of policy, then postponement or exit as a prelude to merger could become likely. Second the competitive environment in these models is quite specific and, as the Motta and Tarantino extensions suggest, they do not necessarily generalise. One has to be conscious of "doing no harm" when applying such stylised frameworks. It is for this reason that we take a modified approach to generating guidance, below.

Katz and Shelanski (2007) review the literature and find as we do that there is ambiguity in the recommendations or that the results are too early for implementation. In the face of this, they

${ }^{2266}$ See European Commission (2017). 
suggest that merger policy adopt a generally neutral stance toward innovation (except in the extreme case of merger to monopoly) and instead conduct a case-by-case review. Such a case-by-case approach would allow cases that have not yet been treated, such as drastic changes in the structure of the industry due to merger-induced changes in innovation, to be taken into account. As they point out, pre-merger market shares may be completely irrelevant post-merger if such innovation occurs and may, indeed, be the reason the merger has been proposed in the first place. At the same time, the case-by-case review would normally need some guidance so that each case can be decided. In this sense, one would like to go farther to establish from the literature how to approach a case, even if each is viewed as unique. There is a thin line between this approach and the formal but restrictive models we reviewed above, and we attempt in our framework, below, to tread this line.

\subsubsection{The Impact of the Conditions of Merger}

The literature has pointed out some specific pitfalls in the analysis of mergers, and these could perhaps serve as a guide to decision-making. One is that the effects that Schumpeter originally quoted in favour of innovation by large firms need not operate for large firms that are created by mergers. Some mergers severely restrict liquidity and so could mean that even though the firm is larger, it is not necessarily more liquid or generally financially stronger. Hence, Schumpeter takes firm size as initially given, and not the method by which is it achieved. Indeed, Aghion et al (2005) stand this argument on its head by arguing that the threat of bankruptcy that could be present in a merger that takes on a great deal of debt. They argue that this could be a significant stimulus for innovation. This is supported also by Hall's (1990) earlier work that suggests that the method of financing an acquisition has more to do with the innovative outcomes than the fact of acquisition itself.

Katz and Shelanski (2007) point out that the institutional setting matters ${ }^{2267}$. This is clear from the

Aghion et al (2005) paper, where imitation possibilities affect the balance of innovation incentives: a firm can only be "so far" ahead in their framework and this matters to the results. As a result, the intellectual property regime, the legal framework for licensing agreements, and other technology policy can matter to how we approach mergers. As shown by Aghion et al (2015), and again following in the inverted $U$ tradition, strong patent rights can be complementary to a competitive product market structure in driving innovation in a step-by-step innovation as described above: the strong protection increases the duration of the rents a firm earns by escaping competition and so improves innovation in this case ${ }^{2268}$. Indeed, the "escape competition" possibility is what allows their model to have a complementarity link whereas earlier work of Romer (1990) and Aghion and Howitt(1992) showed what appeared to be the opposite.

Institutions and regulation can also allow firms ample opportunities to combine innovative efforts without merger. If this is the case it may be less crucial that mergers accommodate innovation: other techniques such as research joint ventures or cross licensing can be accessed to generate the

\footnotetext{
2267 While we focus on patents as the relevant setting here, the argument can be made much more broadly. See for example, the work of Griffith and co-authors (2010) evaluating a swathe of product market reforms their effect on the profitability of innovation and productivity growth. Overall, she finds that reforms that put pressure on profitability tend to be associated with a positive innovation effect.

2268 The paper presents their work as a way to reconcile the relatively ambiguous results on the link between the strength of patent protection and innovative activity overall with the theoretical justification of the incentive effect of temporary profits to spur innovation. See comments by Lerner (2009). The linkage between innovation and growth is discussed with references in Aghion et al (2015).
} 
innovation gains that a full merger might also generate without necessarily changing firm structure or the attendant pricing incentives. Indeed, Motta and Tarantino (2016) explicitly compare merger to other combinations that fall short of merger in their formal treatment. Finally, verification matters: even if there are potential innovation gains from a merger, if these gains are not readily verifiable it is unclear to what extent this can reasonably be taken into account in any decision regarding the merger.

\subsubsection{The Ambiguous Results of the Empirical Work on Merger and Innovation}

In empirical work studying mergers and innovation specifically, generally merger and innovation are not highly related empirically at a general level: individual variation in circumstance seems more salient than the overall effect and the empirical results tend to vary by study ${ }^{2269}$. The style of the studies that address this question differ a lot and the differences in technique may be related to the different answers.

To select just a few to outline the range of relationships that have been found between innovation and merger, Gautam and Katila (2001) in a study of acquisitions in the chemical industry, find that increasing size of the acquiring firm's knowledge base is positive for innovation while increasing size of the acquired firm's knowledge base is overall a negative, making not so much size but size plus the role in the acquisition play a key role. Bertrand and Zuniga (2006) find ambiguous results that vary by industry, by whether the merger is cross-border or not, and overall show little effect of merger on R\&D 2270 . Orgnaghi (2009), Szucs (2014), and Haucap and Steibale (2016) are generally negative on the effect of merger on innovation, with the last of these papers focussing on the effect on the entire industry and not just the merging firms. Cassiman et al (2005) find that the effects on innovation depend on whether the merging firms possess complementary or substitute technologies with greater gains for complements and when the firms are not product market rivals. ${ }^{2271}$ More recent work by Entezarkheir and Moshiri (2017) on a panel of publicly-traded US firms from 1980-2003 find a positive relation between merger and innovation but find significant cross-industry variation.

As a general comment on this literature, the timeframe of analysis often is quite short, often only a few years. It is not clear that one would see significant innovation effects, at least in innovation outputs, over such a short period and certainly not in certain industries such as pharmaceuticals where lead times are very long.

The issue of appropriate timeframe is particularly concerning when the amount of disruption associated with the process of merger itself may affect innovation and may do so more in precisely the cases where the potential gains are greatest. For example, in older work Hitt, Hoskissen et al (1991) find that mergers of firms that are not product market rivals may have worse "integration"

\footnotetext{
${ }^{2269}$ See Veugelers (2006) for a literature review emphasising the role of differences and individual circumstance in driving the results of merger and innovation empirically.

${ }^{2270}$ Bertrand et al (2007) expands on this argument with a focus on affiliates. Steibale and Reize (2011) expand on the issue of where innovation is affected (acquirer/acquiree) in the FDI context.

${ }^{2271}$ Other papers showing that "fit" matters include Gautam and Katila 2001 and Cassiman et al 2005. While the last result of Cassiman and co-authors seems helpful, this is not clear: socially speaking redundant R\&D efforts are not a benefit. If firms with substitute technologs and who are product market rivals and therefore reduce their redundant R\&D, this can be a social positive. As pointed out by Katz and Shelanski (2007), however, it may still be best for consumers to have even redundant R\&D go forward unless the expense is such that the firm elects not to pursue R\&D effort at all.
} 
effects on innovation than mergers among product market rivals ${ }^{2272}$ In related empirical work, Hall (1990) also finds results indicating that there is a "learning" benefit to a vigourous merger strategy: some firms with a high propensity to merge appear to perform better on research measures than those who have a lower propensity to merge. In other words, we should consider when we evaluate effects how good a firm is at executing mergers and choosing merger partners.

\subsubsection{Which market should competition policy be concerned about?}

The market structure literature relates product market structure to the incentives to innovate. On the other hand, it has been proposed that one way to incorporate innovation into merger concerns is to evaluate "innovation markets" and evaluate the effect of a change in concentration in those markets. There are several problems with using innovation market structure as a way of judging the innovation incentives of a merger. First, defining an innovation market can be challenging: potential competitors in an innovation market may not be those who currently are active in that market, as defined by production of existing patent or other innovative output measures. In other words, the most dangerous potential rival may be one who has an excellent idea, but who has not even put it into practice. In this sense, the definition of competitors in an innovation market may be much harder than the definition of the relevant competitors in a product market. Innovation market considerations can then, if nothing else, introduce uncertainty into the merger review process that could create difficulties of its own for users.

Second, even if one could define the innovation markets unambiguously, the literature on the link between innovation market structure and innovation rates does not deliver robust predictions. The structure of theoretical models is that of "R\&D races". Such races are quite technical to analyse, and generating predictions often involves quite specific assumptions about competitors, the "technology" by which innovations are obtained by the racing parties, the information available to them on the progress of competitors towards innovative output, distance to technological frontier and other elements ${ }^{2273}$. The results are sensitive to these assumptions, but the precise conditions of real R\&D "races" are likely to diverge from those chosen in models that have been published. This suggests that bespoke modelling would need to be undertaken to know how particular innovation markets are affected by merger. It may also be the case that particular innovations would not be affected in the same way: at the very least, the information available on competitor progress is likely to differ across technologies and across time ${ }^{2274}$.

\subsubsection{Approaching Merger and Innovation with Some Key Principles}

\footnotetext{
2272 Ernst and Vitt, 2000, show in case studies that key innovators often leave firms upon merger, R\&D Management but Healy, Papelu and Ruback 1992 do not find this.

2273 See Harris and Vickers (1987) for a theoretical treatment of the differential behaviour of leaders and followers in a patent "race". More recent work, referenced in part in Aghion et al (2015), discussed differences in behaviour. across leaders and followers in the context of distance from a technological frontier.

${ }^{2274}$ Katz and Shelanski (2007) discuss the difficulties of defining a market where innovation is present in some depth, critiquing using predicted price movements as a method because of the difficulty of comparing price movements in future - let alone products - in an innovative environment to price movements and product substitution possibilities today. This is clearly particularly serious where innovation is "disruptive" rather than incremental as in the Aghion et al framework. They also discuss the merits of evaluating "technology markets" separate from "product markets".
} 
Two pieces have attempted to tread the same line as we do between the formalism but specificity of the theoretical treatments the mild but perhaps not sufficiently directive neutral recommendation of Katz and Shelanski.

Baker (2007) has gleaned four key principles from the state of the literature to consider in evaluating the effect of any proposed merger on innovation, which are summarised in Shapiro's (2012) review: (1) competition among firms seeking to develop the same new product or process encourages innovation; (2) competition among firms producing an existing product encourages them to find ways to lower their costs or improve their products; (3) firms that expect to face more product market competition after innovating have less incentive to invest in $R \& D$; and; (4) a firm will have an extra incentive to innovate if doing so discourages its rivals from investing in R\&D.

These are reasonable, but not the only rules one could propose. Shapiro (2013) goes on, for example, to propose some rules of his own: to wit that analysis should be organised around three concepts: (1) contestability, ie the prospect of gaining or protecting profitable sales by providing greater value to customers, spurs innovation; (2) appropriability, the ability to capture the social benefits to innovative effort, spurs innovation; and (3) synergies, a combination of complementary assets that enhances innovation capabilities, can spur innovation. Shapiro links these general concepts to the work we have reviewed above in some detail, making the point that competition is often a misleading concept to use in evaluating innovation incentives, as what matters is the "before versus after" comparison of the firm's situation. This may be quite unrelated to competition as the latter is often measured in concentration ratios or HHI and instead may be determined more by imitation possibilities (which may or may not be related to product market structure) or rivalry (which also may or may not be related to standard measures of product market structure).

Shapiro, in line with Katz and Shelanski, sees certain "typical" cases arising for merger and innovation analysis. These usually involve a small number of firms that are either product market rivals or are incumbent and entrant in a market. In some cases, they are two potential competitors who are developing products for a market but have not yet entered. In all these cases, the issue is to analyse the incentive to innovate, which Shapiro's classification suggests is addressed by considering contestability and appropriability, and the ability to innovate, which he suggests boils down to an analysis of synergies. He goes on to outline the 2010 revisions of the US horizontal guidelines, which incorporate innovation concerns, and some cases to illustrate how his three concepts do a good job of organising the arguments in these cases.

Whether this is the best classification to communicate with the plurality of those who need to understand and apply merger analysis, however, is less clear. These are difficult and high level concepts and may not be understood similarly across the wide constituencies that must use them: lawyers, judges, businesspeople and politicians. As such, even though the concepts of "incentive and ability" to innovate are clear, the jump to contestability, appropriability, and synergy and exactly what these concepts mean is less clear.

Overall, then, we see from this review that the literature on market structure and innovation delivers some empirically verified and insightful results on desirable levels of concentration for innovative production, but that these results do not carry over perfectly to merger and may, indeed, be quite different from what a model explicitly characterising merger might generate. The differences across industry of the basic empirical results, and the differences between merger and changes in concentration are manifold, including the financing of the merger, the size and organisation effects, and the context of the merger. At present there are both arguments for a benchmark approach coming 
from those with simple theoretical presentations, and more case-by-case analysis by those who view the complexities of specific mergers as key.

In the next two sections, we will try to develop the last of the various approaches here, where a set of guiding principles that map how the decision should be undertaken is proposed. The closest to our approach is Shapiro (2012), with Katz and Shelanski's (2007) approach also somewhat related, and Baker (2007) linked as well. We then move on to discussing some special features of the industry and setting of interest, GM crops in the BRIC countries, in the last section of the paper.

\subsection{Main economic effects and a proposed typology}

We now turn to a review of the basic effects in merger and propose a typology that captures them as way of organising thoughts on the interaction between merger and innovation in a directive but not restrictive manner. This is in the spirit of the typology of Shapiro (2013), with some differences in selection and breadth that we argue makes the classification useful. Our approach will be to map out a decision framework, which distinguishes our approach from his. In order to conduct the analysis we will build up the analysis in a step by step way, so that layers of effects are added. These layers need to be combined, which we do at the end of the analysis. Many of the effects underlined in the models and approaches discussed above will be found here. The aim here, however, is to provide an analysis that is neither too high level nor too specific in order to fashion a tool that is more useful in policy

The main economic principles underlying the relationship between mergers and innovation are relatively straightforward. When competition authorities consider the traditional static effects of mergers, they focus on three dimensions: the substitutability or complementarity of the products involved, productive efficiencies (and the likely pass-through of these to consumers) and the reaction of non-merging firms. We see no reason to deviate from this approach when looking at the potential effects of mergers on innovation. We will therefore ask whether the innovative activities of the merging parties are complementary or substitutes, whether the merger gives rise to material efficiencies in the innovation process and what the impact of the merger on rivals' innovation might be.

Of course, from a policy point of view, it is useful to link these broad principles to observable. In particular, competition authorities like to be able to get a broad preliminary view of the likely effects of a merger by looking at the current pattern of prices and sales. This approach is well established for the assessment of static effects and is embodied in the use of "summary measures" such as Herfindahl indices or measures of upward pressure on prices. It is these measures - and the economic theory on which they rely - that support the universally accepted presumption that mergers between significant "players" and mergers that occur in already highly concentrated markets are especially likely to lead to higher prices. The question then seems to be whether we can establish a similar link between the current state of the market and the likely dynamic effects of concentrations.

\subsubsection{Static Effects}

In order to draw a useful analogy between static and dynamic effects, it is important to go back to the economic foundation of the notions of "substitutability" and "complementarity". The notion of substitutability goes back to consumer preferences: if acquiring more of a given product can 
compensate the consumer for having less of another, then the products are substitute. It is because of this primitive - and very intuitive meaning of "substitution" that economic textbooks and competition authorities can go on to define substitutability between two products A and B in terms of a price experiment: if an increase in the price of good $\mathrm{A}$ leads to an increase in the demand for good $\mathrm{B}$, then A and B are said to be (gross) substitutes. In the same vein, A and B are said to be complements if an increase in the price of $\mathrm{A}$ leads to a decrease in the demand for $\mathrm{B}$.

The implication of the concept of substitution for merger regulation is straightforward. If firm A produces a product which is a substitute for the product of firm B then an increase in the price of good A leads to higher sales for good B. in the pre-merger situation, firm A does not take this effect into account: what happens to the profits of its rivals is of no concern as long as its own profits are not affected. After the merger, however, firm A and B act to maximise their joint profits. The fact that an increase in the price of good A increases the demand for good B then means that the price increase is more likely to be profitable than before the merger. This is why mergers between producers of substitutes are expected to raise the prices of the merging parties. By contrast, a merger between producers of complements would be expected to lead to lower prices for the merging parties. For a long time, such price effects were the main source of concerns about mergers.

A further complication comes from the fact that a merger also changes the decisions of nonmerging parties. Does the fact that the merged parties raise their prices (or decrease their levels of production) lead other rivals to raise their prices (decrease their own output) or does it lead them to decrease their prices (increase their own output)? Unfortunately, economic theory does not have a general answer to this question. If the products of the merged entity and those of its rivals are strategic complements then less aggressive behaviour on the part of the merged entity also leads to less aggressive behaviour on the part of its rivals. The rivals' reaction then compounds the negative effect of the merger. If the products are strategic substitutes, then the merger leads rival to behave more aggressively. i.e. to cut prices or expand output. This reaction is good for consumers. While economic theory does not allow us to determine on an ex ante basis whether we are in a world of strategic substitutes or strategic complements, it does nevertheless throw us a lifeline: under rather general circumstances, the reactions of rivals are a second order effect. In particular the more aggressive behaviour of rivals when goods are strategic complements usually does not suffice to overcome the negative effect coming from the merged parties' own behaviour: these reactions are only a mitigating factor $^{2275}$.

Perhaps because of how difficult it is to pin down the sign and magnitude of such second order effects, competition authorities have increasingly relied on so called measures of upward price pressures which focus on the behaviour of the merged entity and ignore the reaction of rivals ${ }^{2276}$.

\subsubsection{Dynamic Effects arising from the product markets}

The role of substitution in the analysis of the effect of mergers on incentives to innovate is complicated by the fact that, in the vertical chain of activities, innovation occurs "upstream" of price and output decisions. This means that incentives to innovate are affected not only by the degree of substitution between the innovative activities of the merging parties, it also depends on the effect of

\footnotetext{
2275 See Fudenberg and Tirole (1984) for a discussion of these effects. Bulow Genakopoulos and Klemperer (1985) coined strategic substitutes and strategic complements as phrases to describe the effects outlined in the 1984 paper. 2276 See Farrell and Shapiro (2010) for details.
} 
the merger on the level of prices (outputs) for the final products. For expositional purposes, then, we will first ignore the price/output effects of the merger and turn to the interaction between innovation and price/output decisions later on.

The fact that innovation activities take place "upstream" from price/output decisions also means that we need to distinguish between two types of substitution. At the level of innovation markets the concept of substitution/complementarity is technical. A and B's innovative activities are substitutes if an increase in A's innovation decreases the net technical contribution of B's innovation and complements if an increase in A's innovation enhances the value technical merit of B's innovation. So, for example, we would expect A and B's innovation to be substitutes if they both work on a given approach to the development of a malaria vaccine but we would expect them to be complements if A works on a technology to improve a mobile telecommunication standards and B develops more advanced mobile applications which are enabled by the new standard.

At the level of the technology and product markets, the notion of substitution or complementarity is the same as for price/output decisions. A's innovation is a substitute for B's innovation is it helps A steal sales from B and B's own innovation helps steal sales from A.

\subsubsection{Mergers without Price Effects}

Assume for now that prices are fixed. If it helps, we can imagine that prices (for example) are regulated. This means that investing in innovation is beneficial because it increases the demand for the innovator's product(s) at these fixed prices. Let us now distinguish between different post-merger scenarios.

\section{Scenario 1: Independent R\&D Programs and No Sharing of Results}

In this scenario, the merging parties remain separate. Each formerly independent entity follows its own innovation policy without any coordination. Moreover, the results from the separate innovation programs are not shared. The only impact of the merger is that the levels of investment in innovation at each of the formerly separate entities are determined with the goal of maximising joint profits ${ }^{2277}$. Under such circumstances, the relevant notion of substitution is substitution between the products sold in the downstream market and the analogy with price or output decisions is complete. If the innovations conducted by firms A and B are substitutes, then an increase in A's investment in innovation takes business away from B. Before the merger, A does not consider this externality. After the merger, A takes this negative effect on B's profits into account. Hence the merger reduces the levels of investment in innovation just as it led to higher prices or lower output levels. If the innovation pursued by A and B are complements, then an increase in A's innovation also increases the value of B's innovation and, hence, increases B's sales and profits. In that case, the merger leads to higher levels of innovation. As we will argue further below, the fact that this effect of mergers on innovation corresponds so exactly to the main static effect of mergers is useful because it implies that there is no need to worry about this type of dynamic effects unless the merger raises significant static concerns in the first place. Moreover, this close relationship between static and dynamic effect also

${ }^{2277}$ One could imagine, for example, that levels of funding are set so that a common goal is met, but there is no "on the ground" coordination of activities. Contrast to scenario 2, which could include a more complete coordination of the research activity beyond mere funding levels. 
implies that traditional remedies (e.g. divestments of some products) designed to alleviate static concerns would also deal with this type of dynamic issue.

There is not anything very different in terms of the reaction of rivals either. If the merged firm's investment in innovation is a strategic substitute for the investment of rivals then a decrease in the merged entity's investment in innovation leads to higher investments by rivals. The effect is reversed if we have strategic complements. The only slight difference between innovation investment decisions and price/output decisions is that economic theory provides us with even less of a guide as to whether we are in a world with strategic substitutes or strategic complements. Indeed, one can easily have situations where the investments of one firm are strategic substitutes and those of the other are strategic complements. Moreover, whether we face strategic substitutes or strategic complements depends in a complex manner on the appropriability regime and the pay-off of R\&D "races". ${ }^{2278}$ In our view, this additional complexity is one more reason for ignoring the second order effects coming from the reaction of rivals. There is simply no point in considering effects of which we cannot possibly determine the magnitude or even the sign in a reliable manner.

\section{Scenario 2: Independent R\&D Programs and Sharing of Results}

We modify our previous scenario to allow for the sharing of results between the two parts of the merged entity. This introduces the useful distinction between R\&D investment and R\&D outcome. The difference between the two comes from three sources: uncertainty, duplication and diffusion. We begin with diffusion.

Diffusion is an issue because the knowledge created by innovation is a public good. While a new production line can only be used by one firm at a time, the knowledge required to offer new products can be disseminated at no or very low cost. Let us first assume that the knowledge obtained from investing in $R \& D$ is fully appropriable, i.e. that the entity which obtained the knowledge can fully exclude others from using it. Let us say that firm A is the investor. Before the merger, A considers the benefits of having the additional knowledge - and the new products or product improvements that it entails - while its rivals do not. This is equal to the fixed price-cost margin times the additional sales realised due to the innovation. After the merger, the innovation can be applied to firm $\mathrm{A}$ and to firm B. In one extreme case, where the innovation leads to a new product, the diffusion of knowledge between A and B does not matter: the benefits to the firm as a whole is still equal to the net additional sales generated by the products tie the price-cost margin. However, as soon as the innovation can help improve some of the products of each of the two parties, then sharing the knowledge creates additional profits for the merged entity as a whole. Hence intra-firm diffusion extends the scale of application of innovation. This scale effect has two consequences. Firstly it implies that, for a given level of investment in $R \& D$, the resulting innovation diffuses more broadly and is therefore more useful to consumers. Secondly, the ability to exploit innovation on a greater scale makes it more valuable and increases the merged entity's incentives to invest in R\&D. These two effects are beneficial to consumers and do not exist for price/quantity decisions. In this restricted sense then, mergers are less likely to have adverse effects on innovation that on price/quantity decisions.

\footnotetext{
${ }^{2278}$ In particular, in R\&D races, the slope of R\&D "reaction functions" depends crucially on whether the benefits of
} "forging ahead" exceed the benefits of "catching up". On this topic, see Vickers (1985) and Harris and Vickers (1987). 
The magnitude of this knowledge-diffusion effect depends both on the size of the merging parties and on the degree of substitution between their innovative activities in the innovation market. The larger the merging parties, the greater the benefits from using a given stock of knowledge on a larger scale. The closer the substitution between the innovation efforts of the two entities, the less additional knowledge is gained by sharing results and hence the smaller the magnitude of the effect.

\section{Scenario 3: Integrated R\&D Programs}

We now turn to duplication. A merged entity might also have the opportunity to better coordinate its research programs in order to avoid duplication. The potential importance of this coordination benefit depends crucially on the nature of the R\&D process. If we are in an environment where research can be directed effectively, then most overlap between the outcomes of two research programs can be avoided. If the environment is such that the nature of $R \& D$ outcomes is highly uncertain, then the scope for effective $R \& D$ coordination would be small.

As we show formally in the appendix, coordination between the R\&D programs of the two merging parties has an ambiguous effect on the total investment in innovation but unambiguously improves the innovation outcome (i.e. the quality of the products). The intuition is the following. Imagine that one of the research programs (say A) proceeds just as before the merger, while the other is directed to avoid any duplication ${ }^{2279}$. Given knowledge sharing within the firm, B gets the benefit of the duplicated innovation it would have obtained on its own before the merger "for free". This means the, de facto, investment in A creates a positive spillover for B. This leads to greater innovation investment in A. For B, any level of its own investment now corresponds to a higher level of total quality than without coordination, since it now gets the "spillover" from A. As there are decreasing marginal returns to quality, this implies that $B$ invests less in $R \& D$ then without coordination. In fact one can show that B invests exactly the amount needed to reach the same overall quality level as in the absence of coordination. The overall effect then is an increase in the quality of product A and no change in the quality of product $\mathrm{B}$. We conclude that the ability to coordinate research programs is another source of merger-specific improvement in the innovation outcomes of the merging parties.

Contrary to the knowledge sharing effect discussed in the previous section, the strength of this coordination effect increases with the degree of substitution of the two entities' efforts in the innovation market: the closer the research, the greater the potential for inefficient duplication.

\subsubsection{Price Effects}

A distinctive feature of investments in innovation is that they take place "upstream" of pricing/output decisions. As such innovation decisions depend not only on the expected equilibrium prices - and hence on the expected profit margins - but on how innovation itself would affect these prices. It is this difficulty that makes finding general results on merger and innovation particularly hard - much harder than for static effects. A formal analysis of how allowing for endogenous prices affects incentives to innovate can be found in the appendix. However, the results are rather intuitive and can therefore be presented informally here.

${ }^{2279}$ This is of course unlikely to be the optimal manner of coordinating. This example is used only to show simply that coordination has benefits for innovation outcomes. 
In the absence of merger-specific efficiencies, mergers lead to higher prices for the products of the merging parties. This means that the corresponding profit-margins also increase, making any gain in sales due to innovation more profitable than before the merger. This effect leads unambiguously to more investment in innovation by the merging parties.

When investing in innovation, the firm should anticipate how successful innovation would change the equilibrium prices of all industry participants. Two types of price changes matter. Firstly, investing in A will lead to a higher price for the merged entity's products. This makes gaining sales through innovation more profitable and hence leads to an additional merger-specific increase in incentives to innovate compared to the situation with fixed prices that we studied above. Secondly, the merging party should anticipate that investing in innovation will lead rivals to actually decrease their prices (to compensate for their higher quality handicap), which hurts the merged entity's profits. In the pre-merger situation, firm A only considered the negative effect of this price reaction by rivals on its own profits. After the merger, the effect on the profits of product B are also taken into account. So, with endogenous prices, there is also an additional negative effect of the merger on the parties' incentives to innovate. It is not generally possible to determine the net effect of these two types of price changes. As discussed in the appendix, we can only suppose that the net effect is more likely to be negative if non-merging rivals are more important. ${ }^{2280}$

\subsubsection{Efficiencies}

\subsubsection{Economies of scale and Complementarities in the Innovation Markets}

Since we focus on product innovation, the efficiencies that are relevant to our analysis are those that makes it possible to obtain a given level of expected product improvements at a lower cost. Since we have already discussed the benefits of information sharing and the avoidance of overlap the only traditional efficiency-enhancing factors that we are left with are economies of scale and complementarities at the level of the research activities. Economies of scale need no elaboration. These are economies of scale arising in the innovation market only. Economies of scale stemming from the ability to apply a given knowledge base to a broader product line have already been accounted for under our "knowledge sharing" effect. By complementarities we mean the ability to combine different research skills, knowledge base and research equipment. This type of efficiencies are similar to the productive efficiencies those that are usually assessed as part and parcel of the evaluation of the static effects of a merger.

\subsubsection{Legal Uncertainty and Patent Thickets}

Patent rights are probabilistic and imprecise ${ }^{2281}$. They are also very numerous. This means that there can be considerable uncertainty as to whether a given product infringes on some legitimate IPR held by another party. In such an environment, a firm which invests in innovation is potentially

\footnotetext{
2280 This is just a conjecture. As non-merging rivals become more important, the effect of their price reaction on the merging parties increase. However, at the same time, rivals might find it less necessary to adjust their prices in reaction to the merging parties' investments if these parties account for a small share of the market. So, this conjecture might actually be fragile.

${ }^{2281}$ See Ayres and Klemperer (1999) and Lemley and Shapiro (2005) for independent and alternative presentations of this concept.
} 
exposed to hold up as IPR holders attempt to enforce undetected or imprecise IPRs after the firm has sunk its own investment. This has a chilling effect on innovation. If broad cross-licensing agreements aimed at restoring legal certainty are not forthcoming then a merger between two IPR-holding parties has an additional pro-innovation effect.

A related but distinct issue is that of patent thickets. Patent thickets arise when IPRs held by a significant number of different entities read on a potential new product. The best-known example is probably that of mobile phones where thousands of patents held by a significant number of different firms must be clear in order to produce an attractive non-infringing product. In a sense, this is a third type of complementarity between the innovations pursued by different entities. We have discussed the role of product market substitution, and the role of complementarities in the innovation markets. Patent thickets relate to complementarity in the production of the products. As always with complementarity, internalisation improves efficiency. A merger between two firms involved in the same "thickets" would then offer an efficiency benefit. Moreover, the anticipation of this greater ex post efficiency should improve the innovation incentives of all firms involved in the thicket, including non-merging parties. The magnitude of this effect depends on the number and significance of the thickets where the merging parties overlap as well as on their joint importance within any given thicket: the more thickets with overlap, the greater the economic significance of these thickets and the larger the merging parties' joint share of the thicket patents, the greater the expected benefit from the merger.

\subsubsection{Horizontal effects on innovation markets}

Concerns can also arise if the merging parties enjoy strong positions in the innovation market, i.e. if they seem likely to jointly account for a large share of future innovations in a given technological area. The source of this consistent success in the innovation markets matter. In particular - absent overlap in the corresponding downstream markets, which we have already discussed, A merger between two firms with a major presence in innovation markets should not raise concerns unless they control inputs that are crucial to innovation and - as one would normally expect - the merger would increase their incentives to withdraw these inputs from others. In that sense, "horizontal" concerns in the innovation market are truly "vertical" concerns at heart. They are therefore further discussed in the next section.

\subsubsection{Vertical effects}

Two main types of vertical effects are relevant for the innovation dimension of mergers: a traditional foreclosure effect affecting the innovation market and the fact that future innovation typically relies on past innovation and the knowledge/information that it generates.

\subsubsection{Foreclosure in the Innovation Market}

Innovation activities require inputs. These include specialised personnel, specialised equipment and, some times, materials or organisms on which research can be performed and into which it might be embedded. Specialised labour does not necessarily move easily between employers, especially if there is significant teamwork involved. Some specialised research equipment might be expensive and 
time-consuming to replicate and form quasi-essential facilities (e.g. particle accelerators) or it might be covered by patents. Some research requires access to genetically engineered laboratory animals or appropriate plants/seeds. In all of these situations, the merger might increase the parties' joint incentives and/or ability to foreclose rival research activities. Potentially, this type of vertical issue could be addressed by imposing divestments of some of the parties' research capacities, where "capacity" refers to the hard to imitate or access research inputs discussed above. Note that such divestments only make sense to address these potential negative vertical effects of the merger on innovation. It is of little use to handle the product-market related effects analysed in section 3.2. It would therefore be wrong to think of such divestment as a necessary part of merger remedies whenever innovation effects might matter.

\subsubsection{Sequential innovation}

In most industries, today's innovations rely on previous discoveries. When the pace of technological progress is at least reasonably fast, some of these past innovations are still proprietarily held. As discussed in the ample literature on sequential innovation ${ }^{2282}$ this can result in hold-up issues that leads to lower levels of cumulative innovation. Integration between firms involved at different stages of this dynamic innovation process reduces the severity of the hold-up problem, leading to higher levels of innovation. The importance of this effect increases with the speed of technological progress, imperfections in the technology markets (i.e. obstacles to licensing) and the extent to which current innovation relies on past innovation. All three of these factors can be assessed in the context of a specific industry or transaction. In particular, the extent of interdependence between current and past innovation can be evaluated based on patent citation studies with particular attention to the citation pattern between the merging parties.

\subsection{Linking the effects to market structure ${ }^{2283}$}

In the previous section we went through the main effects that help explain how a merger between to innovative firms would likely influence their level of investment in R\&D and the corresponding level of innovation. While this analysis helps us clarify matters and make it possible to draw a point per point comparison with the more traditional static concerns of merger review, it does not by itself links the likely effect of mergers to observable features of the industry (except substitution/complementarity). In particular, we have not yet discussed how the strength of the various effects identified above relate to the pre-merger market structure.

For the static effects of mergers, the link is relatively straightforward. For simplicity, consider an industry made up of identical single-product firms. Other things equal, increasing the number of firms in the market decreases the "diversion ratio" between the merging parties A and B so that the first order effect of the merger becomes smaller. The link between the reaction of rivals and market structure is much less certain. However, as rivals' reaction is of second order, it makes sense to have

${ }^{2282}$ See Scotchmer $(1991,2004)$, and Rockett (2010) for a survey.

2283 In this section, we will adopt the "old" approach linking pre-merger market structure to likely merger effects. We are fully aware of the drawbacks of this approach pointed in Farrell and Shapiro (XXX) and the literature that this paper spurred. However, as our main purpose is to present a simple typology of effects, the endogeneity considerations considered in this literature would overly complicate matters. 
a rebuttable presumption that a merger leads to lower levels of static consumer welfare and to be especially suspicious of mergers taking place in an already highly concentrated market.

Does a similar presumption make sense for innovation? Just as in the case of static effects, the direct innovation-decreasing effect identified in our scenario 1 above depends on the diversion ratio between the merging parties. Again, all else equal, a more diluted industry means a lower diversion ratio and hence a lower negative effect of the merger. As rivals' reactions are still of second order - and their sign is even harder to assess than for price/quantity decisions - these two traditional effects would indeed argue for an equivalent dynamic presumption that mergers lead to lower investment in innovation and to worse innovation outcomes from the point of view of consumers.

However, we also saw that link between merger and innovation involves a number of additional effects which are not present for the simpler static price/output decisions. Two of these effects, the diffusion of knowledge between merging partners and the avoidance of duplication lead to better innovation outcomes after the merger. The third broad class of effects relates to the fact that changes in the quality/features of the merged entity's products also lead to different equilibrium prices. As we have just seen, the net impact of this "equilibrium price effect" cannot be determined with any generality. However, if anything, it seems more likely to have a net positive effect on innovation post-merger than a net negative one.

One might of course hope that one could find conditions under which these specific dynamic effects are small enough so that the static presumption that mergers decrease consumer welfare could be extended to a dynamic context. In particular, might we still think that the effect of mergers on innovation is more likely to be negative if the pre-merger environment is highly concentrated and the merging parties are large? Unfortunately such a convenient extension is not warranted. This is not only because, as we have seen, the link between innovation and endogenous prices seems likely to account for increased innovation post-merger even in highly concentrated environments but because the benefits from information sharing are larger the larger the merging parties are. We therefore conclude that there should not be a (rebuttable) presumption that mergers lead to less innovation even if the initial situation is highly concentrated and the merging parties are large.

We can however identify a number of factors that make it more likely that a given merger would increase or decrease innovation. The first factor - as for static effects - is the computation of the relevant "diversion ratios" and profit-margins which can be combined into a dynamic equivalent of our traditional measures of upward pressure on prices. The profit margins are the same price-cost margins used for static UPPs. The diversion ratios would refer to the proportion of the sales gained by A following an innovation which come at the expense of B. As we do for price/output decisions, one could start from a neutral symmetric benchmark where all of A's rivals account for the same share of the diversion and modify this analysis if we have reasons to believe that the products of the merging parties are especially close substitutes. Once the size of this negative effect on innovation is estimated, we have a better idea of how big pro-innovation effects need to be to overcome it.

A practical approach might then be to make the strongest possible case for positive innovation effects and check what the total magnitude of these countervailing forces might be. One would start from the projected price effect from the merger. This gives us a projected increase in price cost margins. From this, one can compute the likely increase in investment based on some assumed elasticity of quality improvement to investment. Such an assumption is not very different from assumptions on demand elasticities that we routinely make. The next step would be to assess the extent of overlap between the innovative activities of the two parties. This could be based on a review 
of their patent portfolios and research projects. The greater the overlap, the larger the gains from reducing it and hence the better the innovation outcome. Again some quality to investment elasticity is needed to help translate these gains into innovation outcomes. Finally, an examination of patent portfolios could also give us an estimate of the potential for innovation sharing between the two parties. One subtlety in this respect is that, since we only care about merger-specific information sharing, technologies that are already licensed by one of the parties to the other should be eft out of this exercise. From this cumbersome but feasible exercise we could get an upper bound of the mergerspecific increase in innovation incentives and outcomes. If it falls significantly short of the direct harmful effects discussed above, then innovation issues compound the concerns about the merger and call for specific remedies. If the orders of magnitude are broadly similar, then the authority is better off focussing on the traditional static effect. If the positive effects on innovation dwarf the negative effects then the conventional "thresholds" used in assessing the static losses from the proposed transaction should be adjusted upward'

The following table summarises our discussion so far.

Table 1: Main Innovation Effects of Mergers

\begin{tabular}{|c|c|c|c|c|c|c|}
\hline \multirow[t]{2}{*}{ Effect } & \multicolumn{2}{|l|}{ Static } & \multicolumn{4}{|c|}{ Innovation } \\
\hline & $\begin{array}{l}\text { Effect on } \\
\text { Consumers }\end{array}$ & $\begin{array}{l}\text { Link to } \\
\text { Market } \\
\text { Concentr } \\
\text { ation and } \\
\text { Size of } \\
\text { Merging } \\
\text { Parties }\end{array}$ & $\begin{array}{l}\text { Effect on } \\
\text { Investm } \\
\text { ent }\end{array}$ & $\begin{array}{l}\text { Effect } \\
\text { on } \\
\text { Innova } \\
\text { tion } \\
\text { Outco } \\
\text { mes }\end{array}$ & $\begin{array}{l}\text { Link to } \\
\text { Market } \\
\text { Concent } \\
\text { ration } \\
\text { and Size } \\
\text { of } \\
\text { Merging } \\
\text { Parties } \\
\end{array}$ & $\begin{array}{l}\text { Substitutio } \\
\text { n/ } \\
\text { Compleme } \\
\text { ntarity }\end{array}$ \\
\hline $\begin{array}{l}\text { Cannibalisation } \\
\text { of Sales between } \\
\text { merging parties }\end{array}$ & $\begin{array}{l}\text { Higher } \\
\text { Prices / } \\
\text { Lower } \\
\text { Quantities }\end{array}$ & $\begin{array}{l}\text { Harm } \\
\text { increases } \\
\text { with } \\
\text { concentrat } \\
\text { ion and } \\
\text { size/625lo } \\
\text { seness of } \\
\text { the parties }\end{array}$ & $\begin{array}{l}\text { Lower } \\
\text { levels }\end{array}$ & $\begin{array}{l}\text { Less } \\
\text { Innovat } \\
\text { ion }\end{array}$ & $\begin{array}{l}\text { Harm } \\
\text { increases } \\
\text { with } \\
\text { concentr } \\
\text { ation and } \\
\text { size/clos } \\
\text { eness of } \\
\text { the } \\
\text { parties }\end{array}$ & $\begin{array}{l}\text { Harm } \\
\text { stronger if } \\
\text { greater } \\
\text { substitution } \\
\text { in } \\
\text { downstream } \\
\text { markets }\end{array}$ \\
\hline $\begin{array}{l}\text { Reaction of } \\
\text { Rivals }\end{array}$ & $\begin{array}{l}\text { Ambiguous } \\
\text { Second- } \\
\text { order }\end{array}$ & $\begin{array}{l}\text { Ambiguo } \\
\text { us }\end{array}$ & $\begin{array}{l}\text { Ambiguo } \\
\text { us } \\
\text { Second- } \\
\text { order }\end{array}$ & $\begin{array}{l}\text { Ambig } \\
\text { uous } \\
\text { Second } \\
\text {-order }\end{array}$ & $\begin{array}{l}\text { Ambiguo } \\
\text { us }\end{array}$ & $\mathrm{NA}$ \\
\hline $\begin{array}{l}\text { Knowledge } \\
\text { Sharing }\end{array}$ & NA & NA & $\begin{array}{l}\text { Increases } \\
\text { investme } \\
\mathrm{nt}\end{array}$ & $\begin{array}{l}\text { More } \\
\text { Innovat } \\
\text { ion }\end{array}$ & $\begin{array}{l}\text { Positive } \\
\text { effect } \\
\text { increases } \\
\text { with the } \\
\text { size of }\end{array}$ & $\begin{array}{l}\text { Benefits } \\
\text { stronger if } \\
\text { less } \\
\text { substitution } \\
\text { in }\end{array}$ \\
\hline
\end{tabular}




\begin{tabular}{|c|c|c|c|c|c|c|}
\hline & & & & & $\begin{array}{l}\text { the } \\
\text { merging } \\
\text { parties }\end{array}$ & $\begin{array}{l}\text { innovation } \\
\text { markets }\end{array}$ \\
\hline $\begin{array}{l}\text { Coordination of } \\
\text { Investments }\end{array}$ & NA & NA & $\begin{array}{l}\text { Ambiguo } \\
\text { us }\end{array}$ & $\begin{array}{l}\text { More } \\
\text { Innovat } \\
\text { ion }\end{array}$ & $\begin{array}{l}\text { No } \\
\text { obvious } \\
\text { link }\end{array}$ & $\begin{array}{l}\text { Benefit } \\
\text { stronger if } \\
\text { less } \\
\text { substitution } \\
\text { in } \\
\text { innovation } \\
\text { markets }\end{array}$ \\
\hline $\begin{array}{l}\text { Indirect Price } \\
\text { Effect }\end{array}$ & NA & NA & $\begin{array}{l}\text { Ambiguo } \\
\text { us but } \\
\text { more } \\
\text { likely to } \\
\text { be } \\
\text { positive } \\
\text { if } \\
\text { merger- } \\
\text { specific } \\
\text { price } \\
\text { increases } \\
\text { are large }\end{array}$ & $\begin{array}{l}\text { Ambig } \\
\text { uous } \\
\text { but } \\
\text { more } \\
\text { likely } \\
\text { to be } \\
\text { positive } \\
\text { if } \\
\text { merger- } \\
\text { specific } \\
\text { price } \\
\text { increas } \\
\text { es are } \\
\text { large }\end{array}$ & $\begin{array}{l}\text { Conjectu } \\
\text { re: } \\
\text { positive } \\
\text { effect } \\
\text { more } \\
\text { likely if } \\
\text { merging } \\
\text { parties } \\
\text { large } \\
\text { compare } \\
\text { d to the } \\
\text { market }\end{array}$ & $\begin{array}{l}\text { Stronger } \\
\text { likelihood } \\
\text { of positive } \\
\text { effect if } \\
\text { products of } \\
\text { the merging } \\
\text { entities are } \\
\text { closer } \\
\text { substitutes }\end{array}$ \\
\hline $\begin{array}{l}\text { Economies of } \\
\text { scale and } \\
\text { complementarity } \\
\text { in Innovation } \\
\text { markets }\end{array}$ & $\begin{array}{l}\text { Similar } \\
\text { efficiencies } \\
\text { at the } \\
\text { production/d } \\
\text { istribution } \\
\text { levels }\end{array}$ & $\begin{array}{l}\text { Stronger if } \\
\text { merging } \\
\text { partners } \\
\text { are larger }\end{array}$ & $\begin{array}{l}\text { Ambiguo } \\
\text { us }\end{array}$ & Higher & $\begin{array}{l}\text { Stronger } \\
\text { if } \\
\text { merging } \\
\text { parties } \\
\text { are large }\end{array}$ & Obvious \\
\hline $\begin{array}{l}\text { Complementarit } \\
\text { y from } \\
\text { Sequential } \\
\text { Innovation } \\
\end{array}$ & NA & NA & $\begin{array}{l}\text { Ambiguo } \\
\text { us }\end{array}$ & Higher & NA & NA \\
\hline Patent thickets & NA & NA & Higher & Higher & NA & $\begin{array}{l}\text { Stronger if } \\
\text { the merging } \\
\text { parties } \\
\text { overlap in } \\
\text { several } \\
\text { significant } \\
\text { thicket and } \\
\text { their joint } \\
\text { share of }\end{array}$ \\
\hline
\end{tabular}




\begin{tabular}{|l|l|l|l|l|l|l|}
\hline & & & & & $\begin{array}{l}\text { patents in } \\
\text { the thicket is } \\
\text { large. }\end{array}$ \\
\hline Legal Certainty & NA & NA & Higher & Higher & NA & $\begin{array}{l}\text { Stronger if } \\
\text { substitution } \\
\text { in } \\
\text { innovation } \\
\text { and product } \\
\text { markets }\end{array}$ \\
\hline
\end{tabular}

\subsection{A competition policy algorithm}

Our arguments in sections 3 and 4 have strong implications for dealing with the innovation aspect of mergers. As we have seen, the main negative effect of mergers on innovation works through the same channels as the standard static effects. This immediately implies that, if there are no significant static concerns (or if these concerns can be remedied) and there are no significant vertical issues affecting the innovation market, then, as the additional innovation effects should be favourable to the merger, one can dispense with that part of the review.

What if there are significant static effects from the mergers? Two main principles apply. Firstly, remedying the static effects should also remedy the main negative, innovation-related effects of the merger since those work through the main channels. Secondly, the presence of innovation effects operating through overlap in the product lines of the merging parties make finding appropriate remedies more pressing: while remedies that would ensure that prices do not increase by more than $2 \%$ might be considered sufficient in that absence of an innovation dimension to the merger, they would not be if they also leave a $2 \%$ decrease in innovation. The criteria for what constitutes satisfactory downstream remedies should therefore be tighter if innovation issues also appear to be material.

If static effects (magnified by their dynamic equivalent) cannot be fully remedied or if there are significant concerns about foreclosure in innovation markets then analysing the additional positive effects of the merger on innovation becomes indispensable to reach a fair decision about clearance. In that case as well, the burden of proof should be on the merging parties since the size of "additional" effects such as knowledge sharing and the avoidance of duplication depends on the nature of R\&D activities and their internal organisation, which are both factors on which the parties should have much better information than the regulator.

Based on these principle, we can propose a policy algorithm illustrated in the flow chart below. 


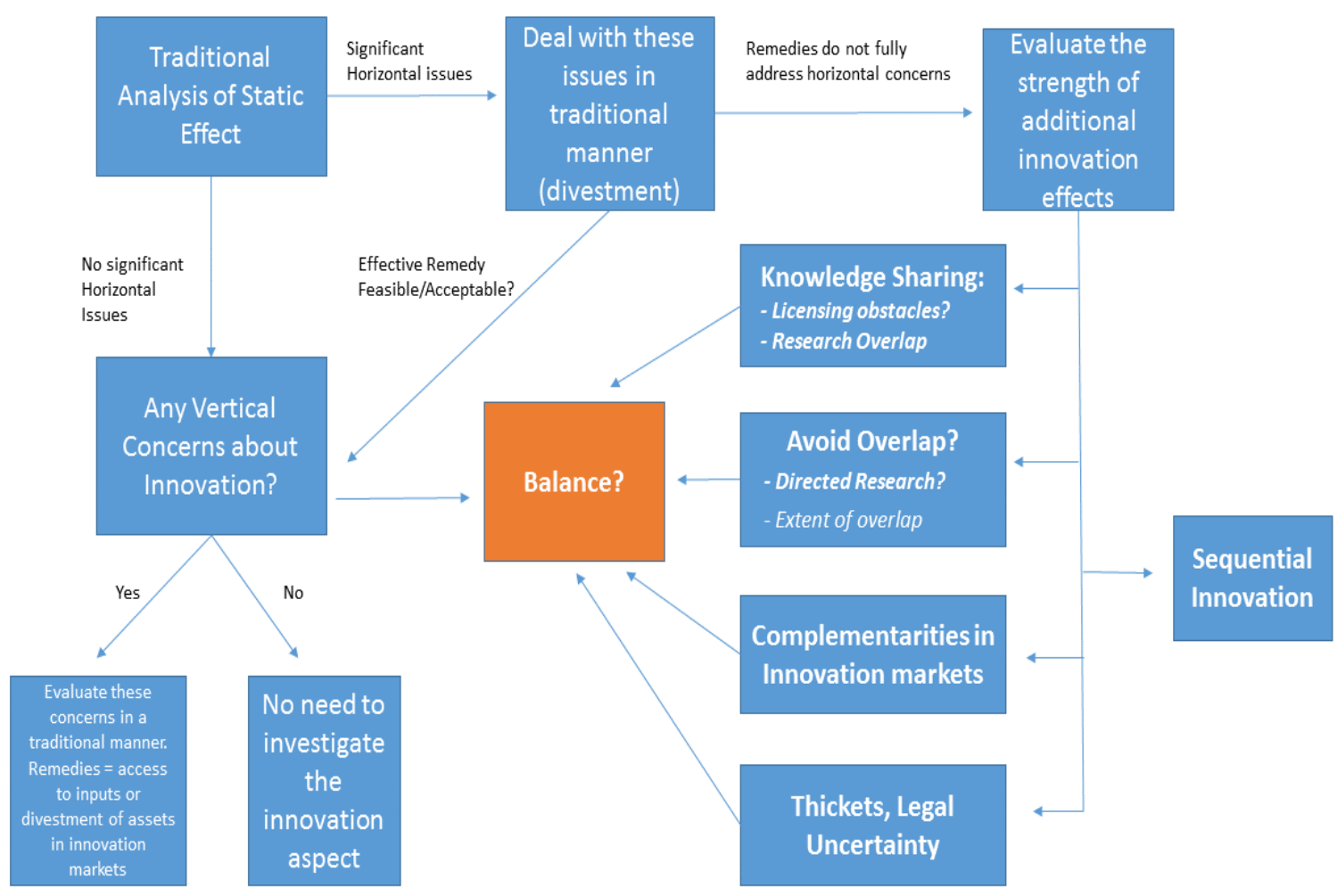

In a sense, this algorithm can be seen as proceeding from a (refutable) presumption that mergers are bad for innovation. After all we argue that significant static issues imply significant dynamic issues, that mergers might create some vertical concerns in innovation market and that the burden of providing evidence of the positive effects of the merger on innovation should mostly be on the merging parties. However, the policy algorithm presented above has several features that go beyond such a presumption. In particular, there is the crucial observation that, once the static aspects of a merger have been addressed, the main negative dynamic issues should also have been resolve unless one can document some legitimate "vertical" concern in the innovation markets.

\subsection{The GM crops and seed industries: main features and past mergers}

\subsubsection{Product and industry characteristics}

Crops are grown from seeds. To be successful, farmers must ensure that they obtain seeds of good quality which are well-adapted to the environment in which they will be used. As pathogens, fungi, insects and other pests are an endemic problem, farmers are also interested in obtaining plants that are as robust as possible to these hazards and/or plants on which effective chemical or biological defensive substances can be used without adversely affecting the yield and quality of the crop harvest. Pathogens and pests are not the only major obstacles. By drawing water and nutrients away from the crop, weeds also hurt the farmer's output. Hence, again, farmers seek seeds for crops that do not suffer too much from such competition and/or crops which are resistant to the use of herbicides to control the weeds. The ability to draw nutrients from the ground is also crucial. This makes the development of plants with efficient root systems economically important. Here too, there is a potential complementarity with bio-chemical products as plants can be designed to be especially receptive to specific types of fertilisers. In the same vein, plants can also differ in their ability to deal 
with the presence of undesirable compounds - such as salt or heavy metals - in the soil. A fourth factor is the general climate. Crops are crucially affected by the availability of water, the average temperature and the variability of these two variables. Hence, using seeds that yield drought-resistant crops, for example, can make the difference between success and failure. The commercial success of crops also depends on their nutritional content (if meant for consumers), biological content (if meant for material extraction), their texture, their presentation and their ability to survive the modern distribution system with little deterioration. Again, seeds for a similar crop can differ markedly in these respects.

New varieties of seeds are obtained in two main manners. The first, traditional approach, is through cross-breeding existing varieties or mutant varieties thereof. This traditional approach can itself be assisted by some expertise at the genetic level in order to help identify the types of plants worth breeding together and/or select the plants to keep breeding through the program, for example. However, genetic engineering is not used to directly insert foreign genes into the seed. By contrast, "GM" crops involve the insertion of foreign genes into a host plant with the goal of modifying one or more of the plant's "traits". There are of course various possible combinations of these two approaches, but the distinction still remains important, as the expertise involved in the two processes is rather different.

Economically, GM crops and, for lack of a better term, "non-GM" crops are substitutes. For example, herbicide resistant plant can be obtained by inserting genes into a plant genome but it can also be bred from parents demonstrating a promising natural resistance. The substitution between different crops (wheat, corn, soybean and so on) depends on the intended use, with greater substitution for animal feed that for products meant for final consumers. There is nothing specific to GM or non-GM crops in this respect. Finally, the different traits possessed - or imparted to - a given plant/seed are a priori neither substitute nor complements: herbicide resistance is generally unrelated to the control of ripening. However, these characteristics are "bundled" within a single seed so that, when it comes to designing a seed that respond to the specific need of a specific type of farmer operating in a specific region, the traits embedded in the seed are effectively complements.

\subsubsection{Mergers and the direction of innovation}

Mergers can affect not only the level of innovation but also the direction of innovation. The complementarity between seeds, GM modification and products like pesticides and herbicides has implications for innovation. As shown in Harhoff et al. (2001), firms that sell herbicides and pesticides have an incentive to devote more resources to the development of plant traits that pairs them more closely with their proprietary products. This indeed seems to be one of the main reasons why traits such as herbicide or pesticide resistance were developed earlier and more intensively than other traits such as drought resistance. This bias towards plant traits that complement the companies' other products is not socially desirable. It leads to the relative neglect of other aspect of innovation.

Some crop traits have wider applications than others. In particular, traits aimed at tailoring a seed to particular local conditions have lower scale than others such as some types of herbicide resistance. Because of the public good nature of innovation, private companies privilege the development of traits (and plants) with broad applications. There is no obvious efficiency here: investing more on innovation which can be used on a large scale than on innovation with more limited applications makes sense both privately and socially. However, from the point of view of specific 
country - and BRICs in particular, this scale concern can be acute as it often leaves such countries short of the type of technology (environmental stress, sugar cane varieties,...) that fits their need. It is legitimate for the Competition Authorities of a given country to take its specific need into account when reviewing a merger. In this respect, a merger between two companies can increase the relevant scale of commercialisation of innovation directed towards less popular traits or plants if both parties are active in the corresponding downstream markets.

\subsubsection{Past mergers}

The pattern of substitution and complementarity in the (GM) crop/seed industry is reflected in the evolution of the market structure and the type of mergers that we have observed. Initially, three main types of companies joined the industry in the late 1980s to early 2000s: seed companies - who were already long-standing players - chemical companies, driven by the desire to promote their herbicide, pesticides, fertilisers and other products and pharmaceutical/biological companies looking to leverage their budding expertise in genetic engineering.

The tables below, based on Lianos with Katalevsky (2017), summarises some of the main acquisitions in the industry. In the first table, we colour-code the expertise of each of the acquiring firm: green from main expertise, yellow for a lesser but still significant involvement. We then count the number of acquisitions that fall within each of the expertise categories.

Table 2: name

\begin{tabular}{|l|l|l|l|l|l|l|l|}
\hline Acquirer & & $\begin{array}{l}\text { GM } \\
\text { Crops }\end{array}$ & $\begin{array}{l}\text { Seeds/ } \\
\text { Breeding }\end{array}$ & Chemicals & Pharma & $\begin{array}{l}\text { Bio Crop } \\
\text { Protection }\end{array}$ & Misc \\
\hline Bayer & & & & & & Check & \\
\hline & Acquisitions & 1 & 9 & 8 & 0 & 4 & 4 \\
\hline Monsanto & & & & & & & \\
\hline & Acquisitions & 6 & 13 & & & 2 & 5 \\
\hline Dupont & & & & & & & \\
\hline & Pioneer & & & 0 & 0 & 0 & 0 \\
\hline & & 1 & 9 & 0 & 0 & 0 & 1 \\
\hline Syngenta & & & & & & & \\
\hline & & 0 & 20 & 1 & 0 & 3 & 7 \\
\hline Villmorin & & & & & & & \\
\hline & & 0 & 27 & 0 & 0 & 0 & 1 \\
\hline
\end{tabular}

source?

A striking feature of the table is that, with the exception of Bayer, which acquired a number of other chemical manufacturers, the acquisitions relate to firms which are active in complementary activities. Indeed, by far the dominant pattern is the acquisition of seeds companies by firms coming either from the chemical or the pharmaceutical side of the industry. As such, the presumption should be that these acquisitions are more likely to lead to increased innovation than to reduce it. The review of such transactions should then concentrate on the typical static effect, with a possibility for the parties to 
argue for some innovation-related benefits. However, as discussed in section 5.4. below, this does not mean that this type of acquisition, if they persist would necessarily remain benign.

Moreover, as shown in table XXX, a breakdown of Bayer and Monsanto's acquisitions according to the focus of the targets on certain crops shows a bias toward Soybean, Cotton and Cornrelated acquisitions. One would therefore also need to look at the overall presence (seeds, GM, complementary products) of the newly formed entities in the markets for these specific crops. While one should also investigate the "trait" dimension of the acquisitions, we do not have the information necessary to do so.

Table 3: the trait dimension of the acquisitions

\begin{tabular}{|l|l|l|l|l|l|l|l|l|}
\hline Acquirer & & Soybean & Wheat & Rice & Cotton & Corn & Rape & $\begin{array}{l}\text { Other } \\
\text { Specific } \\
\text { Plants/Crops }\end{array}$ \\
\hline Bayer & & & & & & & & \\
\hline & Acquisitions & 7 & 1 & 1 & 4 & 1 & 1 & 2 \\
\hline Monsanto & & & & & & & & \\
\hline & Acquisitions & 4 & 1 & & 3 & 4 & 2 & 4 \\
\hline
\end{tabular}

source?

\subsubsection{Vertical dimensions}

So far, our analysis has neglected two indirect but potentially important effects of mergers on innovation in the (GM) crop industry: the complementarity between seeds and GM R\&D and the potential bundling of seeds and chemical products.

Research into genetic modification of crops only produces revenues once it is incorporated into seeds that can be sold commercially. While a GM innovator could in principle license its discovery to companies controlling seeds, such licensing is typically less profitable than direct application to the relevant seed. Moreover, the very development of the technology allowing the modification of a given trait benefits from the availability of a broad variety of seeds on which to experiment. ${ }^{2284}$ In practice, then, this means that GM research is facilitated by having a large variety of seeds on which experiments can be conducted and to which the GM technology can eventually be applied. As we have seen above, this seems indeed to be a major factor being the acquisition of so many seed companies by chemical firms. As long as each potential GM innovator still has access to a critical mass of seeds, we would expect such mergers to be welfare improving as they allow the internalisation of complements. However, as the share of the (proprietary) seed markets controlled by some companies grows, one might be concerned that additional mergers between these companies and seed companies would eventually limit the availability of seeds to rival GM innovators to the point where it negatively affects their continued ability to innovate at the same pace. To assess the likelihood of such an "innovation foreclosure" theory of harm, it is useful to look at the share of the proprietary seed market controlled by the main companies.

2284 The importance of this factor would depend on the state of the "experimental exemption" doctrine in the relevant jurisdictions. See MIstali and Adachi (2010) and references therein. 
Table 4: the share of the proprietary seed market controlled by the main companies

\begin{tabular}{|l|l|l|}
\hline & $\mathbf{2 0 0 7}$ & $\mathbf{2 0 1 2}$ \\
\hline Monsanto & $23 \%$ & $27 \%$ \\
\hline Dupont-Pioneer & $15 \%$ & $17 \%$ \\
\hline Syngenta & $9 \%$ & $9 \%$ \\
\hline Limagrain & $6 \%$ & $5 \%$ \\
\hline Lands O' Lakes & $4 \%$ & $4 \%$ \\
\hline KW SAG & $3 \%$ & $4 \%$ \\
\hline Bayer & $2 \%$ & $3 \%$ \\
\hline
\end{tabular}

Source: $x x x$

The shares controlled by the larger owners like Monsanto, are inching towards the levels at which Competition Authorities would consider that there might be an ability and possible incentive to engage in some form of foreclosure. Of course, the numbers above cut across all types of seed so that concentration levels are bound to be higher for some given crops and/or traits. In our opinion, then, we have likely reached the point where further acquisitions of seed companies by Monsanto should not be waived through without a proper investigation of potential foreclosure effects on the GM innovation of rivals.

The second "vertical" concern comes from the practice of tying certain types of seeds to certain types of products, e.g. refusing to supply seeds unless they are used together with a specific herbicide...owned by the same company. This is a more traditional merger-related foreclosure concern. It should either be addressed ex post as a matter of antitrust or - maybe preferably - be the object of "cease and desist" commitments as part of the merger review process. Again, the market shares shown in the table above are probably not yet at the level for which such concerns would be found to be founded, but we are getting into an areas where such effects would need to be considered.

\subsection{BRICS: special concerns}

Our analysis of merger and innovations and the specific characteristics of the (GM) crop industry applies fully to mergers affecting BRICS countries either as consumers or a host to some of the relevant activities. However, merger enforcement in the crop industry also raises issues that are either specific to the BRICS or are at least more acute.

In our opinion, the most significant differences stem from the different needs of BRIC countries in terms of crop-related innovation. Growing conditions in China, India and Brazil are notably distinct from conditions in the large markets of North America and Europe. There is therefore a natural tendency for traits suiting those specific conditions and the type of crops that the climate favour to be relatively neglected in the innovation efforts of private firms. In a similar vein, production technologies vary across countries. For some crops at least the capital intensive methods found in Northern America are not appropriate in some BRICS locations. This again creates a need for a somewhat different type of research. The effect of a particular merger on the direction of innovation of the merged entity is therefore of greater importance for BRICS countries than for North America or Europe. 
We saw above that, because of expanding scale, a merger between two firms that are active in the type of downstream products needed by BRICS should increase the parties' incentive to invest in BRICs-compatible product. In this sense, Brics might benefit from the innovation-related effects of mergers more than the US, Canada or Europe. There might be countervailing effects however. In particular, the consequences of the acquisition of a local firm by a large foreign company might be uncertain. Local companies not only have local market expertise, their own innovation, IPRs and products tend to be geared towards local need. It is therefore crucial to determine why the acquisition is taking place. If the main driver is to access the name, local reputation and distribution channels of the local firm, then one might fear that the local firm's focus on local needs might be quickly eroded once it becomes part of a large group. If, on the other hand, the rationale for the acquisition is to obtain access to the company's IPRs, its research expertise or even its stock of locally adapted seeds, then one would expect that the acquisition would lead to an increase in innovation targeted at some local needs.

While resistance to chemical compounds and compatibility with chemical fertilisers is of course useful in BRICS countries, they might still be relatively less important than for markets like the US and Canada, where the type of crops, the climate and the farming techniques are quite different. In this respect, the acquisition of a target by a large Agro-chemical group might lead to a greater emphasis on these types of traits than was the case when the target was independent. In this sense then, continued acquisitions of seeds or GM companies by large agro-chemical firms is likely to also have a downside in terms of the type of innovation that it encourages.

We have already discussed the possible "vertical" issues that could arise because of the acquisition of seed companies. The shares of the privately owned seed market that we referred to did not account for the specific needs of the BRICS' agricultural sectors. Clearly then, data for a more "BRICS-relevant" basket of seeds should be obtained in order to assess the vertical theories of harm that we discussed.

It is interesting that, as noted in Chapter I of Part III and Chapter 1 of Part IV until the recent mega-merger wave in agrochem there has not yet been a merger case in the BRICS where innovation was a significant issue. This is somewhat surprising since, if anything we would expect BRICS countries to be particularly concerned about innovation as it has been shown to be a major engine of growth for countries at this stage of economic development. ${ }^{2285}$ This is especially so for countries, like Brazil, where trade in agricultural products is an important aspect of the overall growth strategy.

A final issue for innovation and merger that is specific to the BRICs is that patent coverage and enforcement might differ significantly from what is found in North America or Europe. As we have seen in the literature survey, this can matter in some frame works: if competition and strong patent rights are complementary in inducing innovation in the Schumpeterian world set out by Aghion et al in a series of papers (but not in other worlds, as he points out), then we can expect the surrounding intellectual property environment to affect the optimal approach to innovation from society's perspective. Contrary to what one might think, this does not really question our reliance on US patent data in our short empirical analysis. In that analysis, patents are used only to give us an idea of the overall intensity and direction of research. It therefore makes sense to use a jurisdiction where large industry participants patent extensively. Of course, differences in the treatment of IPR might also be a reason why the current innovation strategies of large crop companies appears to neglect the specific

${ }^{2285}$ See Aghion et al (2015) and related discussion in our literature review. 
needs of BRICS markets, with consequences for what we observe in the data. In that sense then competition policy and merger reviews are complements when it comes to trying to address this imbalance. Chapter 1 of Part IV details some differences in patentability between the BRICs and Europe that could imply different optimal competition policy responses, when placed in the context of the literature we have reviewed, above. ${ }^{2286}$

\subsection{An empirical examination}

\subsubsection{Using patent data to assess innovation: methodology and limitations}

Innovation is notably hard to measure. Essentially one has a choice between input measures such as firm's investment in innovation and outcome measures. Input measures are unreliable as the "R\&D" expenditures reported often include expenses that are only remotely related to what economists would consider to be "investments in innovation". Moreover, even such imperfect measures are not easily available, especially if some companies are privately held. Outcome data is not much better. Ideally, we would want measures of the improvement in product quality and/or the lowering of production costs. These simply do not exist. A common fall-back option is then to rely on the number and type/quality of patents obtained by a given company ${ }^{2287}$. While this is often the best measure available, it has its own drawbacks.

The main drawback of patent data as a measure of innovation is that there is a difference between the propensity to innovate and the propensity to patent. Simply put, not all useful innovation are patented and many useless findings are. This discrepancy between patenting and innovation would not be a special concern for our purpose if the distance between patent measurements and innovation was not itself affected by the merger: the same bias would apply before and after the merger so that a comparison of patenting pre and post-merger would still be informative as to the merger-related change in innovation. Unfortunately, there are reasons to believe that mergers can themselves affect the wedge between propensity to innovate and propensity to patent. Two examples will help illustrate the issue.

The first example comes from the limited nature of our data. We only record patents, not plant protection rights. If a company - say a seed company - relied primarily on non-patent rights before the merger, it might well be that, post-merger, the acquiring firm's extensive patent experience translates into more patenting for the same level of innovation. In this case, relying on patent data to assess the effects of the merger on innovation would paint too rosy a picture: the data might show an increase in patenting which does not correspond to any increase in innovation or even masks a decrease in innovation performance.

The second example shows how our re and post-merger comparison might be biased by strategic patenting behaviour. Patents exist not only to protect the technology embedded in the firm's products. It is also there to exclude others from using technologies that the firm is not using or to serve as bargaining chips in licensing negotiations. The more strong competitors the firm faces, the stronger the incentives to use patents defensively or as bargaining chips. If the firm acquires another

${ }^{2286}$ Chapter 1 of Part IV of this Report.

${ }^{2287}$ For example, see Valentini (2012). 
significant rival, the number of strong competitors decreases, possibly leading to less patenting overall, even though the total level of innovation might not have changed.

While we should be aware of such potential biases, the stark reality is that patent information is essentially the only publicly available, sufficiently reliable source of information on innovation that can be collected and used within the tight deadline faced in merger reviews and without investing huge resources.

\subsubsection{The data}

We rely on two data sets. The first one is the USPTO data on patents granted. Our second source is ESPACENET. We focus on separate issues in the two sections, and so our selection of patents is somewhat different even within these different sources. The two sections should be complementary, however, building a picture of innovation performance generally in the first treatment and more specifically in a limited number of patents that we suggest may have special relevance to the BRIC countries in the second. Our analysis in both sections is preliminary, with the data serving to raise as much as answer questions.

\subsubsection{US Patents}

The advantage of using US patents is that we look at patents over time under a single, fairly stable review regime. Biases include a greater propensity of firms to patent into their own jurisdiction. This bias should not matter when we look at mergers/acquisitions between two US-based firms but it might matter when the acquiring firm or main merging party is based in the US, since it might have a greater propensity to file protect the innovation of the acquired/joined firm under the US patent system.

The following table give us the total number of US patents for the main firms in the industry. These are patents relating to the GM Crop/seed business broadly understood but excluding patents on non-biological herbicides and pesticides. We also report the total number of such patents. The numbers are presented for four time periods; 1995 -1999, 2000 - 2004, 2005 - 2009 and 2010 - 2015. Table?

\begin{tabular}{|l|l|l|l|l|l|l|l|l|}
\hline & \multicolumn{2}{l}{$\mathbf{1 9 9 5}-\mathbf{1 9 9 9}$} & \multicolumn{2}{l}{$\mathbf{2 0 0 0 - 2 0 0 4}$} & \multicolumn{2}{l|}{$\mathbf{2 0 0 5}-\mathbf{2 0 0 9}$} & \multicolumn{2}{l|}{$\mathbf{2 0 1 0 - 2 0 1 4}$} \\
\hline & $\begin{array}{l}\text { Non- } \\
\text { GM }\end{array}$ & GM & $\begin{array}{l}\text { Non- } \\
\text { GM }\end{array}$ & GM & $\begin{array}{l}\text { Non- } \\
\text { GM }\end{array}$ & GM & $\begin{array}{l}\text { Non- } \\
\text { GM }\end{array}$ & GM \\
\hline Monsanto & 50 & 64 & 53 & 106 & 176 & 153 & 833 & 177 \\
\hline Bayer & 0 & 7 & 0 & 19 & 14 & 33 & 18 & 55 \\
\hline Dupont & 3 & 2 & 0 & 4 & 0 & 16 & 0 & 18 \\
\hline Syngenta & 0 & 0 & 19 & 37 & 109 & 60 & 231 & 48 \\
\hline Novartis & 18 & 37 & 17 & 24 & 0 & 0 & 0 & 0 \\
\hline Zeneca & 10 & 45 & 0 & 26 & 0 & 0 & 0 & 0 \\
\hline De Kalb & 46 & 5 & 87 & 27 & 5 & 7 & 0 & 0 \\
\hline Pioneer & 196 & 51 & 269 & 130 & 535 & 180 & 1379 & 222 \\
& & & & & & & & \\
\hline Seminis & 1 & 2 & 6 & 12 & 2 & 3 & 109 & 2 \\
\hline
\end{tabular}




\begin{tabular}{|l|l|l|l|l|l|l|l|l|}
\hline Aventis & 0 & 0 & 0 & 40 & 0 & 3 & 0 & 0 \\
\hline Rhone & 0 & 12 & 0 & 12 & 0 & 0 & 0 & 0 \\
\hline
\end{tabular}

The table reveals two main trends: the concentration of GM patents has increased over time and the number/proportion of "non-GM" patents has literally exploded from 2005 to 2014. The first trend tells us that we have reached a point where Competition Authorities should worry about concentration in both innovation and technology markets if any merger between firms significantly involved in GM-crop innovation is proposed. The second trend is at least consistent with the prediction that merging entities with complementary research programs (GM firms and seed companies) should lead to an increase in innovation. This increase is especially noticeable for Dupont - Pioneer and Monsanto - Seminis. The lack of effect for Bayer might be a reflection of its greater focus on chemical acquisitions. In this respect, collecting information on crop-related chemical patents would be useful.

The next table shows the patents on non-biological pesticides, fungicides and herbicides divided between patents that mention prominently the modification of a specific trait and those which do not. This classification helps us get an idea of the split between more basic and more applied research. Interestingly, there is no trend. One might have expected to find a natural "lifecycle", where there is more general innovation in early years, followed by more applied research but, apparently, broad innovation is still thriving in the industry.

Table 6

\begin{tabular}{|l|l|l|l|l|l|l|l|l|}
\hline & \multicolumn{2}{|l}{$\mathbf{1 9 9 5}-\mathbf{1 9 9 9}$} & \multicolumn{2}{l|}{$\mathbf{2 0 0 0}-\mathbf{2 0 0 1}$} & \multicolumn{2}{l|}{$\mathbf{2 0 0 5}-\mathbf{2 0 0 9}$} & \multicolumn{2}{l|}{$\mathbf{2 0 1 0 - 2 0 1 4}$} \\
\hline & Traits & Methods & Traits & Methods & Traits & Methods & Traits & Methods \\
\hline Monsanto & 28 & 36 & 51 & 55 & 49 & 154 & 52 & 105 \\
\hline Bayer & 5 & 2 & 15 & 4 & 25 & 8 & 39 & 16 \\
\hline Dupont & 0 & 2 & 2 & 2 & 9 & 7 & 11 & 7 \\
\hline Pioneer & 29 & 22 & 38 & 92 & 71 & 109 & 114 & 108 \\
\hline Novartis & 22 & 15 & 16 & 10 & 0 & 0 & 0 & 0 \\
\hline Syngenta & 0 & 0 & 31 & 11 & 35 & 25 & 26 & 22 \\
\hline Zeneca & 25 & 20 & 12 & 14 & 0 & 0 & 0 & 0 \\
\hline DeKalb & 1 & 4 & 2 & 25 & 1 & 6 & 0 & 0 \\
\hline Seminis & 2 & 0 & 10 & 2 & 1 & 2 & 1 & 1 \\
\hline Aventis & 0 & 0 & 13 & 27 & 2 & 1 & 0 & 0 \\
\hline Rhone & 2 & 10 & 3 & 9 & 0 & 0 & 0 & 0 \\
\hline
\end{tabular}

Tables XXX show the specific traits covered by patents, while Table XXX organises patents according to the type of traits which are modified. The following tables organises patents according to the plants or crops to which they apply. These tables gives us an idea of the type of innovation and products for which concentration is higher than what overall patent numbers would led us to believe.

In terms of traits, the data confirm that chemical companies have a disproportionate tendency to produce patents specifically related to the control of weeds, insects and other pests. We also find 
some high concentrations in some categories such as insect/nematode resistance where three firms account for the bulk of patents.

$1995-1999$

\begin{tabular}{|l|l|l|l|l|l|l|l|l|}
\hline & Herbicide & Pest/disease & Insect & Fungi & Virus & $\begin{array}{l}\text { Starch/ } \\
\text { Sugar }\end{array}$ & $\begin{array}{l}\text { Drought/ } \\
\text { Salt }\end{array}$ & Others \\
\hline Monsanto & 5 & 0 & 10 & 1 & 6 & 5 & 0 & 2 \\
\hline Bayer & 0 & 4 & 0 & 1 & 0 & 0 & 0 & 0 \\
\hline Dupont & 0 & 0 & 0 & 0 & 0 & 0 & 0 & 0 \\
\hline Pioneer & 0 & 2 & 2 & 1 & 3 & 1 & 0 & 19 \\
\hline Syngenta & 0 & 0 & 0 & 0 & 0 & 0 & 0 & 0 \\
\hline Novartis & 1 & 9 & 3 & 4 & 1 & 0 & 0 & 4 \\
\hline Zeneca & 1 & 4 & 1 & 9 & 0 & 4 & 0 & 5 \\
\hline DeKalb & 0 & 0 & 0 & 0 & 0 & 0 & 0 & 1 \\
\hline Seminis & 0 & 0 & 0 & 0 & 1 & 0 & 0 & 1 \\
\hline Aventis & 0 & 0 & 0 & 0 & 0 & 0 & 0 & 0 \\
\hline Rhone & 2 & 0 & 0 & 0 & 0 & 0 & 0 & 0 \\
\hline
\end{tabular}

$2000-2004$

\begin{tabular}{|l|l|l|l|l|l|l|l|l|}
\hline & Herbicide & Pesticide & $\begin{array}{l}\text { Insect/ } \\
\text { nematodes }\end{array}$ & Fungi & Virus & $\begin{array}{l}\text { Starch/ } \\
\text { Sugar }\end{array}$ & $\begin{array}{l}\text { Drought/ } \\
\text { Salt }\end{array}$ & Others \\
\hline Monsanto & 3 & 1 & 32 & 4 & 2 & 5 & 0 & 5 \\
\hline Bayer & 2 & 1 & 3 & 0 & 0 & 4 & 0 & 5 \\
\hline Dupont & 0 & 0 & 0 & 1 & 0 & 1 & 0 & 0 \\
\hline Pioneer & 0 & 16 & 3 & 0 & 0 & 4 & 0 & 14 \\
\hline Syngenta & 4 & 3 & 10 & 7 & 0 & 1 & 1 & 4 \\
\hline Novartis & 4 & 4 & 6 & 0 & 0 & 1 & 0 & 1 \\
\hline Zeneca & 1 & 1 & 2 & 3 & 0 & 3 & 0 & 2 \\
\hline DeKalb & 0 & 0 & 1 & 0 & 0 & 0 & 0 & 1 \\
\hline Seminis & 0 & 0 & 0 & 0 & 7 & 2 & 0 & 1 \\
\hline Aventis & 3 & 3 & 4 & 0 & 0 & 2 & 0 & 1 \\
\hline Rhone & 1 & 2 & 0 & 0 & 0 & 0 & 0 & 0 \\
\hline
\end{tabular}

$2005-2009$

\begin{tabular}{|l|l|l|l|l|l|l|l|l|}
\hline & Herbicide & Pesticide & $\begin{array}{l}\text { Insect/ } \\
\text { nematodes }\end{array}$ & Fungi & Virus & $\begin{array}{l}\text { Starch/ } \\
\text { Sugar }\end{array}$ & $\begin{array}{l}\text { Drought/ } \\
\text { Salt }\end{array}$ & Others \\
\hline Monsanto & 5 & 5 & 26 & 2 & 0 & 2 & 1 & 8 \\
\hline Bayer & 5 & 0 & 8 & 2 & 0 & 9 & 0 & 1 \\
\hline Dupont & 3 & 2 & 2 & 1 & 0 & 1 & 0 & 0 \\
\hline Pioneer & 4 & 11 & 17 & 8 & 0 & 12 & 3 & 16 \\
\hline Syngenta & 3 & 18 & 28 & 5 & 2 & 2 & 2 & 1 \\
\hline Novartis & 0 & 0 & 0 & 0 & 0 & 0 & 0 & 0 \\
\hline Zeneca & 0 & 0 & 0 & 0 & 0 & 0 & 0 & 0 \\
\hline
\end{tabular}




\begin{tabular}{|l|l|l|l|l|l|l|l|l|}
\hline DeKalb & 0 & 0 & 0 & 0 & 0 & 0 & 0 & 1 \\
\hline Seminis & 0 & 0 & 0 & 0 & 1 & 0 & 0 & 0 \\
\hline Aventis & 2 & 0 & 0 & 0 & 0 & 0 & 0 & 0 \\
\hline Rhone & 0 & 0 & 0 & 0 & 0 & 0 & 0 & 0 \\
\hline
\end{tabular}

$2010-2014$

\begin{tabular}{|l|l|l|l|l|l|l|l|l|}
\hline & Herbicide & Pesticide & $\begin{array}{l}\text { Insect/ } \\
\text { nematodes }\end{array}$ & Fungi & Virus & $\begin{array}{l}\text { Starch/ } \\
\text { Sugar }\end{array}$ & $\begin{array}{l}\text { Drought/ } \\
\text { Salt }\end{array}$ & Others \\
\hline Monsanto & 5 & 3 & 19 & 0 & 2 & 0 & 9 & 16 \\
\hline Bayer & 20 & 1 & 7 & 0 & 0 & 5 & 3 & 1 \\
\hline Dupont & 3 & 2 & 1 & 0 & 0 & 0 & 0 & 5 \\
\hline Pioneer & 12 & 7 & 30 & 9 & 1 & 5 & 9 & 41 \\
\hline Syngenta & 5 & 14 & 1 & 0 & 0 & 0 & 0 & 5 \\
\hline Novartis & 0 & 0 & 0 & 0 & 0 & 0 & 0 & 0 \\
\hline Zeneca & 0 & 0 & 0 & 0 & 0 & 0 & 0 & 0 \\
\hline DeKalb & 0 & 0 & 0 & 0 & 0 & 0 & 0 & 0 \\
\hline Seminis & 0 & 0 & 0 & 0 & 0 & 0 & 0 & 1 \\
\hline Aventis & 0 & 0 & 0 & 0 & 0 & 0 & 0 & 0 \\
\hline Rhone & 0 & 0 & 0 & 0 & 0 & 0 & 0 & 0 \\
\hline
\end{tabular}

The tables on patent by plant type also reveal high concentrations for specific plants such as corn and cotton. We also note that the bulk of plant-specific efforts is devoted to very few crops. This supports our claim that research in the industry might be biased away from some of the specific needs of BRICS countries so that special attention to the research composition effects of mergers might be called for.

$1995-1999$

\begin{tabular}{|l|l|l|l|l|l|l|l|l|l|l|}
\hline & $\begin{array}{l}\text { Soybea } \\
\mathbf{n}\end{array}$ & $\begin{array}{l}\text { Cor } \\
\mathbf{n}\end{array}$ & $\begin{array}{l}\text { Whea } \\
\mathbf{t}\end{array}$ & $\begin{array}{l}\text { Ric } \\
\mathbf{e}\end{array}$ & $\begin{array}{l}\text { Cotto } \\
\mathbf{n}\end{array}$ & $\begin{array}{l}\text { Suga } \\
\mathbf{r}- \\
\text { Cane }\end{array}$ & $\begin{array}{l}\text { Tomat } \\
\mathbf{o}\end{array}$ & $\begin{array}{l}\text { Fruit } \\
\mathbf{s}\end{array}$ & $\begin{array}{l}\text { Vegetabl } \\
\text { es }\end{array}$ & $\begin{array}{l}\text { Other } \\
\text { s }\end{array}$ \\
\hline $\begin{array}{l}\text { Monsan } \\
\text { to }\end{array}$ & 3 & 0 & 0 & 0 & 2 & 0 & 3 & 1 & 0 & 1 \\
\hline Bayer & 0 & 0 & 0 & 0 & 0 & 0 & 1 & 0 & 0 & 0 \\
\hline Dupont & 0 & 1 & 0 & 0 & 0 & 0 & 0 & 0 & 0 & 0 \\
\hline Pioneer & 0 & 7 & 0 & 0 & 0 & 0 & 0 & 2 & 1 & 2 \\
\hline $\begin{array}{l}\text { Syngent } \\
\text { a }\end{array}$ & 0 & 0 & 0 & 0 & 0 & 0 & 0 & 0 & 0 & 0 \\
\hline Novartis & 0 & 1 & 1 & 0 & 0 & 0 & 0 & 0 & 0 & 0 \\
\hline Zeneca & 0 & 1 & 0 & 0 & 0 & 0 & 2 & 1 & 0 & 3 \\
\hline DeKalb & 0 & 1 & 0 & 0 & 0 & 0 & 0 & 0 & 0 & 4 \\
\hline Seminis & 0 & 0 & 0 & 0 & 0 & 0 & 0 & 0 & 0 & 0 \\
\hline Aventis & 0 & 0 & 0 & 0 & 0 & 0 & 0 & 0 & 0 & 0 \\
\hline Rhone & 0 & 0 & 0 & 0 & 0 & 0 & 0 & 0 & 0 & 0 \\
\hline
\end{tabular}




\begin{tabular}{|l|l|l|l|l|l|l|l|l|l|}
\hline & Soybean & Corn & Wheat & Rice & Cotton & $\begin{array}{l}\text { Sugar- } \\
\text { Cane }\end{array}$ & Fruits & Vegetables & Others \\
\hline Monsanto & 3 & 0 & 0 & 0 & 2 & 0 & 4 & 0 & 0 \\
\hline Bayer & 0 & 0 & 0 & 0 & 2 & 0 & 0 & 0 & 1 \\
\hline Dupont & 0 & 1 & 0 & 0 & 0 & 0 & 0 & 0 & 0 \\
\hline Pioneer & 1 & 24 & 0 & 0 & 0 & 0 & 0 & 0 & 8 \\
\hline Syngenta & 0 & 3 & 1 & 0 & 0 & 0 & 0 & 0 & 2 \\
\hline Novartis & 0 & 3 & 0 & 0 & 0 & 0 & 0 & 0 & 1 \\
\hline Zeneca & 0 & 0 & 0 & 0 & 0 & 0 & 1 & 0 & 3 \\
\hline DeKalb & 0 & 12 & 0 & 1 & 0 & 0 & 0 & 0 & 5 \\
\hline Seminis & 0 & 0 & 0 & 0 & 0 & 0 & 0 & 0 & 3 \\
\hline Aventis & 0 & 0 & 0 & 0 & 0 & 0 & 0 & 0 & 2 \\
\hline Rhone & 0 & 1 & 0 & 0 & 0 & 0 & 0 & 0 & 1 \\
\hline
\end{tabular}

$2005-2009$

\begin{tabular}{|l|l|l|l|l|l|l|l|l|l|}
\hline & Soybean & Corn & Wheat & Rice & Cotton & $\begin{array}{l}\text { Sugar- } \\
\text { Cane }\end{array}$ & Fruits & Vegetables & Others \\
\hline Monsanto & 2 & 11 & 4 & 4 & 4 & 0 & 0 & 0 & 3 \\
\hline Bayer & 0 & 3 & 0 & 1 & 1 & 0 & 0 & 0 & 1 \\
\hline Dupont & 0 & 4 & 0 & 0 & 0 & 0 & 0 & 0 & 0 \\
\hline Pioneer & 2 & 35 & 0 & 0 & 0 & 0 & 0 & 0 & 0 \\
\hline Syngenta & 0 & 3 & 0 & 3 & 1 & 0 & 0 & 0 & 2 \\
\hline Novartis & 0 & 0 & 0 & 0 & 0 & 0 & 0 & 0 & 0 \\
\hline Zeneca & 0 & 0 & 0 & 0 & 0 & 0 & 0 & 0 & 0 \\
\hline DeKalb & 0 & 4 & 0 & 0 & 0 & 0 & 0 & 0 & 2 \\
\hline Seminis & 0 & 0 & 0 & 0 & 0 & 0 & 0 & 0 & 1 \\
\hline Aventis & 0 & 0 & 0 & 0 & 0 & 0 & 0 & 0 & 1 \\
\hline Rhone & 0 & 0 & 0 & 0 & 0 & 0 & 0 & 0 & 0 \\
\hline
\end{tabular}

$2010-2014$

\begin{tabular}{|l|l|l|l|l|l|l|l|l|l|}
\hline & Soybean & Corn & Wheat & Rice & Cotton & $\begin{array}{l}\text { Sugar- } \\
\text { Cane }\end{array}$ & Fruits & Vegetables & Others \\
\hline Monsanto & 8 & 25 & 0 & 4 & 5 & 0 & 0 & 1 & 8 \\
\hline Bayer & 0 & 2 & 0 & 3 & 16 & 0 & 0 & 0 & 4 \\
\hline Dupont & 2 & 6 & 0 & 0 & 0 & 0 & 0 & 0 & 0 \\
\hline Pioneer & 7 & 46 & 0 & 0 & 0 & 0 & 0 & 0 & 7 \\
\hline Syngenta & 0 & 5 & 0 & 1 & 0 & 2 & 0 & 0 & 6 \\
\hline Novartis & 0 & 0 & 0 & 0 & 0 & 0 & 0 & 0 & 0 \\
\hline
\end{tabular}




\begin{tabular}{|l|l|l|l|l|l|l|l|l|l|}
\hline Zeneca & 0 & 0 & 0 & 0 & 0 & 0 & 0 & 0 & 0 \\
\hline DeKalb & 0 & 0 & 0 & 0 & 0 & 0 & 0 & 0 & 0 \\
\hline Seminis & 0 & 0 & 0 & 0 & 0 & 0 & 0 & 0 & 1 \\
\hline Aventis & 0 & 0 & 0 & 0 & 0 & 0 & 0 & 0 & 0 \\
\hline Rhone & 0 & 0 & 0 & 0 & 0 & 0 & 0 & 0 & 0 \\
\hline
\end{tabular}

\subsubsection{Espacenet}

\section{The Data}

We now turn to the alternative data. As above, while the data are not sufficient for a formal analysis, but they do serve to generate some issues and questions that should be investigated further as modelling of innovation and merger develops.

We focus on the area of GM crops as it is both relevant to the BRICs in terms of economic activity and is a relatively well defined and narrow area of innovation. This reduces the scope of our analysis to a manageable number of data points so that we can hope to understand our data set well and the issues it raises before passing to larger data set analysis in future work. We eliminate patents related to purely chemical compounds in insecticides and herbicides, even if these could also be used with GM crops, and also do not look at ancillary patents on implements used with crops. We are interested in patents affecting the plants themselves. We also restrict information to those patents that were published in any area related to the BRICs or the BRICs themselves, as an indicator of which patents viewed as directed at their specific needs and possible implementation within those markets. This gives us a more limited dataset but perhaps one that reflects more the "local" benefit of the BRIC countries.

As in the USPTO data case, we focus our initial review on raw patent counts without citation weighting, despite its limitations. As we have explained, this is because the point of the exercise is merely to generate questions that may merit further investigation. The focus of this section is to point out if there are any striking differences in this alternative dataset compared to the broader USPTO approach. Finally, we include patent applications (which may or may not have ended up as patent grants) as a measure of research activity in this dataset. While this opens the data to a variety of strategic and administrative effects that could, for example, result in multiple applications and withdrawals, our view is that as a complement to the USPTO patent grant data this can be useful as part of our first look, however "raw" the figures are at this point.

\section{Some Preliminary Observations}

Restricting attention to firms that are listed as merging in Lianos' compilation of BRIC mergers for this industry and reproduced in Appendix B of this chapter, we first note that many of the merging firms (particularly the seed firms) do not hold patents that fall within this dataset. For a company such as Seedworks, this is clear as their focus is on hybridisation (which falls outside our data selection). Indeed, many of the seed firms are listed with a specialty in hybridisation. In fact, the reasons for some of these mergers were not necessarily for production of more patents, but for 
application of existing techniques to a wider germplasm portfolio ${ }^{2288}$. For others, such as Misung, while there are patents listed but none that applies to plants directly.

Table 7: Total Patents Recorded for Merging Firms*

\begin{tabular}{|l|l|}
\hline Name & Total Datapoints \\
\hline Monsanto & 155 \\
\hline Bayer & 82 \\
\hline Syngenta & 104 \\
\hline Devgen & 22 \\
\hline Agventure & 1 \\
\hline Bilag & 1 \\
\hline Mitsui & 3 \\
\hline Pioneer & 234 \\
\hline Others (27 firms) & 0 \\
\hline
\end{tabular}

* Start date of data collection for each firm differs somewhat, as each becomes merger-active at a different point in Lianos' table, reproduced in Appendix B of this chapter. We collected data from ten years before the first of the relevant merger dates in his table, and continue throughout (as the last date of merger was within ten years of the present). The data reported here terminate in 2016, as the final year is currently incomplete

For those with a patent portfolio, we see representation over the entire period we record data for each firm. This period differs somewhat, as is noted after the table, above. Furthermore, a zero entry does not mean that the firm did not patent: it may very well have patented, but those patents may not have fit our search criteria. We keep those criteria fixed so that our data is comparable across firms and across time, but do not attempt to be fully inclusive. This section is based on a highly selective, but still we feel useful, exercise.

Table 8: Total Datapoints per year for merging firms with patents in dataset

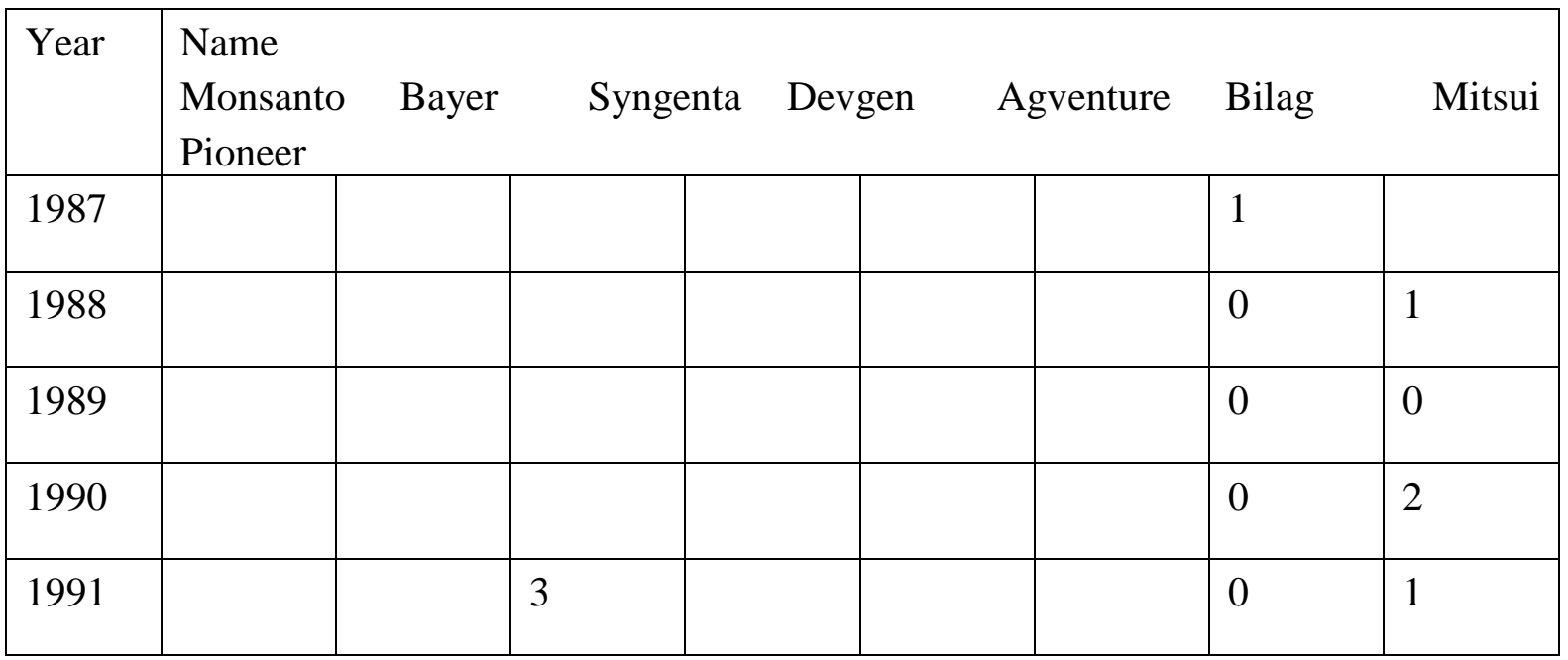

2288 For example, see Monsanto's press release on the benefits of the Agroeste Sementes acquisition, http://news.monsanto.com/press-release/monsanto-company-acquires-agroeste-sementes-brazilian-corn-seed-company . 


\begin{tabular}{|l|l|l|l|l|l|l|l|l|}
\hline 1992 & & & 2 & & & & 0 & 2 \\
\hline 1993 & & & 1 & & & 0 & 0 & 6 \\
\hline 1994 & & 1 & 1 & & & 0 & 0 & 3 \\
\hline 1995 & 7 & 1 & 3 & & & 0 & 0 & 5 \\
\hline 1996 & 3 & 2 & 5 & & & 0 & 0 & 5 \\
\hline 1997 & 5 & 2 & 6 & & & 0 & 0 & 10 \\
\hline 1998 & 1 & 3 & 5 & & & 0 & 0 & 7 \\
\hline 1999 & 2 & 3 & 10 & 1 & & 0 & 1 & 12 \\
\hline 2000 & 4 & 2 & 15 & 6 & 0 & 0 & 0 & 11 \\
\hline 2001 & 9 & 8 & 10 & 0 & 0 & 0 & 0 & 7 \\
\hline 2002 & 4 & 5 & 9 & 0 & 0 & 0 & 0 & 6 \\
\hline 2003 & 6 & 3 & 1 & 0 & 0 & 0 & 0 & 3 \\
\hline 2004 & 15 & 1 & 5 & 0 & 0 & 0 & 0 & 9 \\
\hline 2005 & 9 & 3 & 1 & 0 & 0 & 0 & 0 & 5 \\
\hline 2006 & 8 & 1 & 3 & 1 & 0 & 0 & 0 & 8 \\
\hline 2007 & 11 & 5 & 2 & 4 & 0 & 1 & 0 & 13 \\
\hline 2008 & 6 & 3 & 5 & 1 & 0 & 0 & 0 & 9 \\
\hline 2009 & 4 & 3 & 2 & 0 & 0 & 0 & 0 & 15 \\
\hline 2010 & 4 & 2 & 5 & 1 & 1 & 0 & 0 & 20 \\
\hline 2011 & 5 & 9 & 2 & 0 & 0 & 0 & 1 & 9 \\
\hline 2012 & 2 & 9 & 3 & 1 & 0 & 0 & 0 & 13 \\
\hline 2013 & 2 & 5 & 4 & 1 & 0 & 0 & 0 & 11 \\
\hline 2014 & 12 & 3 & 1 & 4 & 0 & 0 & 0 & 21 \\
\hline 2015 & 17 & 3 & 0 & 0 & 0 & 0 & 0 & 14 \\
\hline 2016 & 19 & 5 & 0 & 2 & 0 & 0 & 0 & 6 \\
\hline
\end{tabular}


The number of patents per firm, year in and year out, seems relatively stable per firm. There does not appear to be any large jump - up or down - upon a merger event, although with the small numbers of patents involved per year and per firm, this type of jump would be quite difficult to eyeball. This might bear investigation with a somewhat less "raw" dataset: there are some years with standout numbers that may be the result of particular merger events or may be the result of other strategic or operational decisions or even random variation in research productivity. What seems most surprising, however, is the lack of "churn" in the larger players in this industry. This is at odds with the bulk of the theoretical models reviewed in the literature review, with the exception of Vickers (1985), where certain industry structures could lead to increasing dominance rather than churn.

Given that churn may be an important feature of innovative systems, especially when one considers Schumpeterian "creative destruction", this bears investigation before carrying over the results of the general literature on innovation and merger to this industry or to the BRICs. If the industry is exhibiting a feature not predicted generally by these models or compatible with them, then it suggests that current analysis is missing something important. Again, this points to further investigation.

In terms of overall productivity of the firms that merge compared to those that have not but that trigger the same set of keywords and satisfy the other search criteria we used on Espacenet - our "control" group - we see that this alternative group is responsible for a generally growing number of total patents over the time period. Compared to the merging firms in terms of innovation totals, we see that the merging firms' productivity is relatively stable over the period post-2000 whereas the non-merging firm group increases production considerably in the table below. The non-merging firm totals are influenced by entry as well as productivity, of course, whereas the bulk of the merging firms' production is from firms that reached a relatively mature status pre- 2000 .

Taking this one step farther, however, if one considers any firm that has a patent included in our non-merging firm dataset as a "potential innovator", we see the set of potential innovators rising sharply over time and the average number of patents per potential innovator is falling. Clearly, there is considerable variance across firms, however, with some patenting only once while others remain active so that a comparison of averages is somewhat unfair: a full comparison of merging and nonmerging groups would require us to compare like with like, and this would require some case study development (since the numbers are small). The point of this observation should be that there are many entities capable of research in this area, as represented by patent applications, even if few appear to commercialise ultimately and few are relatively high research producers. In this sense, the set of potential innovators is large (assuming smaller producers can ramp up) even if the set of potential commercialisers is small. This may be due to the regulatory demands of this industry upon commercialisation.

Table 9: Total Patents Recorded for Merging and "Non-Merging" Firms*

\begin{tabular}{|l|l|l|}
\hline Year & Merging firms (total) & Non-merging firms \\
\hline 2000 & 38 & 179 \\
\hline 2001 & 41 & 283 \\
\hline
\end{tabular}




\begin{tabular}{|l|l|l|}
\hline 2002 & 24 & 223 \\
\hline 2003 & 13 & 282 \\
\hline 2004 & 30 & 261 \\
\hline 2005 & 18 & 353 \\
\hline 2006 & 21 & 330 \\
\hline 2007 & 36 & 286 \\
\hline 2008 & 24 & 422 \\
\hline 2009 & 24 & 495 \\
\hline 2010 & 33 & 695 \\
\hline 2011 & 26 & 649 \\
\hline 2012 & 28 & 863 \\
\hline 2013 & 24 & 958 \\
\hline 2014 & 41 & 792 \\
\hline 2015 & 34 & 876 \\
\hline 2016 & 32 & 871 \\
\hline
\end{tabular}

*These are taken from 2000 to ensure a constant selection of firms for the merging group.

We also note that the mergers identified by Lianos generally do not conform to the mould set out in the literature review's articles of mergers of equals, both of whom have strong incentives to take the industry leadership in any given product areas, and where there are few impediments to commercialisation separate from those of innovation. In this industry, many of the mergers have been to obtain resource access (germplasm) for the innovators and have not been among equals in terms of innovative or commercial capabilities.

Moving on to look more precisely at the composition of the patent portfolios across traits and crops, we also see general stability although with significant differences in areas of focus possible across firms. As in the case of US patents, most patents are centred in the area related to herbicide or resistance to certain pests and pesticides or insects and insecticides. Drought, or salt resistance features were less represented, but protein content features were, via Monsanto and Pioneer. In terms of crops, while much activity was in sorghum, maize, soy, rice and wheat, the areas of coffee and cocoa were much less represented. Again, the focus differed across firms with some both holding far more relevant patents and having a much broader portfolio of traits and plants in their research portfolio.

The participation in some of the ancillary areas (like drought resistance) looks more like the work of a firm doing monitoring activity to keep a participation in an area that by and large is being 
pushed forward by others. This draws attention to a potential difference between this data set's lessons and those of the theoretical literature. In the data, it looks like there are areas where firms might well prefer to be second movers or otherwise "bit players". In the models of innovation we saw in the literature review, there is generally a first mover advantage: firms do not aspire to be second. As was pointed out in an early paper by Katz (1987) this need not be the case: a race can turn into a waiting game under certain conditions, including favourable licensing terms and favourable imitation possibilities. These are conspicuously lacking in the models we reviewed, above, but there is some evidence that the second mover position can be quite profitable in some $\operatorname{areas}^{2289}$. We present, below, figures for two of the highly productive patenters in this dataset as illustration.

Table 10: Trait Production: Entire Dataset, by firm*

\begin{tabular}{|c|c|c|c|c|c|c|c|c|}
\hline \multirow[t]{2}{*}{ Name } & \multicolumn{8}{|l|}{ Trait } \\
\hline & $\begin{array}{l}\text { Herbici } \\
\text { de } \\
\text { Resistan } \\
\text { ce }\end{array}$ & $\begin{array}{l}\text { Drought } \\
\text { Resistan } \\
\text { ce }\end{array}$ & $\begin{array}{l}\text { Protei } \\
\mathrm{n} \\
\text { Conte } \\
\mathrm{nt}\end{array}$ & $\begin{array}{l}\text { Pest/Pestic } \\
\text { ide } \\
\text { Resistance }\end{array}$ & $\begin{array}{l}\text { Insect/Insecti } \\
\text { cide } \\
\text { Resistance }\end{array}$ & $\begin{array}{l}\text { Salt } \\
\text { Toleran } \\
\text { ce }\end{array}$ & $\begin{array}{l}\text { Miner } \\
\text { al } \\
\text { Conte } \\
\text { nt }\end{array}$ & $\begin{array}{l}\text { Nemato } \\
\text { de } \\
\text { Resistan } \\
\text { ce }\end{array}$ \\
\hline $\begin{array}{l}\text { Monsan } \\
\text { to }\end{array}$ & 57 & 10 & 113 & 34 & 44 & 14 & 0 & 16 \\
\hline Bayer & 33 & 1 & 55 & 9 & 22 & 7 & 1 & 2 \\
\hline $\begin{array}{l}\text { Syngent } \\
\mathrm{a}\end{array}$ & 22 & 6 & 63 & 22 & 31 & 9 & 1 & 12 \\
\hline Devgen & 1 & 1 & 14 & 16 & 15 & 0 & 0 & 11 \\
\hline $\begin{array}{l}\text { Agvent } \\
\text { ure }\end{array}$ & 0 & 1 & 1 & 0 & 1 & 0 & 0 & 2 \\
\hline Mitsui & 1 & 0 & 2 & 0 & 0 & 0 & 0 & 0 \\
\hline Pioneer & 30 & 52 & 130 & 59 & 77 & 17 & 77 & 8 \\
\hline
\end{tabular}

* Note that many traits may be present in a single patent's claims, so this table should not sum up to the total number of patents. Bilag excluded from this table, as claims are missing from the relevant Espacenet files.

Table 11: Plant Production: Entire Dataset, by firm*

\begin{tabular}{|l|l|l|l|l|l|l|l|l|l|l|l|l|}
\hline Name & \multicolumn{10}{|l|}{ Plant } \\
& $\begin{array}{l}\text { Sorghu } \\
\mathrm{m}\end{array}$ & $\begin{array}{l}\text { Maiz } \\
\mathrm{e}\end{array}$ & $\begin{array}{l}\text { So } \\
\mathrm{y}\end{array}$ & $\begin{array}{l}\text { Ric } \\
\mathrm{e}\end{array}$ & $\begin{array}{l}\text { Whe } \\
\text { at }\end{array}$ & $\begin{array}{l}\text { Cotto } \\
\mathrm{n}\end{array}$ & $\begin{array}{l}\text { Sug } \\
\text { ar }\end{array}$ & $\begin{array}{l}\text { Rap } \\
\mathrm{e}\end{array}$ & $\begin{array}{l}\text { Potat } \\
\text { o }\end{array}$ & $\begin{array}{l}\text { Coff } \\
\text { ee }\end{array}$ & $\begin{array}{l}\text { Coc } \\
\text { oa }\end{array}$ & $\begin{array}{l}\text { Toma } \\
\text { to }\end{array}$ \\
\hline $\begin{array}{l}\text { Monsan } \\
\text { to }\end{array}$ & 29 & 44 & 86 & 78 & 77 & 81 & 52 & 21 & 37 & 5 & 1 & 42 \\
\hline Bayer & 7 & 17 & 20 & 18 & 12 & 25 & 11 & 16 & 9 & 0 & 0 & 8 \\
\hline
\end{tabular}

\footnotetext{
${ }^{2289}$ See Lieberman and Montgomery (1988) and later follow up work for an early study of first versus second mover advantages. There is also anecdotal evidence for this. One well-studied case is that of GE's second mover position in CT Scanners, unseating EMI. See Bartlett (1983).
} 


\begin{tabular}{|l|l|l|l|l|l|l|l|l|l|l|l|l|}
\hline $\begin{array}{l}\text { Syngent } \\
\text { a }\end{array}$ & 25 & 39 & 29 & 37 & 32 & 22 & 23 & 1 & 19 & 0 & 0 & 22 \\
\hline Devgen & 5 & 3 & 5 & 5 & 3 & 4 & 3 & 3 & 5 & 2 & 0 & 5 \\
\hline $\begin{array}{l}\text { Agventu } \\
\text { re }\end{array}$ & 0 & 0 & 0 & 0 & 0 & 0 & 0 & 0 & 2 & 0 & 0 & 0 \\
\hline Mitsui & 0 & 0 & 0 & 1 & 0 & 0 & 0 & 0 & 0 & 0 & 0 & 0 \\
\hline Pioneer & 122 & 185 & $\begin{array}{l}12 \\
0\end{array}$ & 115 & 121 & 81 & 48 & 41 & 40 & 1 & 5 & 43 \\
\hline
\end{tabular}

*Note that many traits may be present in a single patent's claims, so this table should not sum up to the total number of patents. Bilag excluded from this table, as claims are missing from the relevant Espacenet files.

Table 12: Monsanto Trait Production By Year

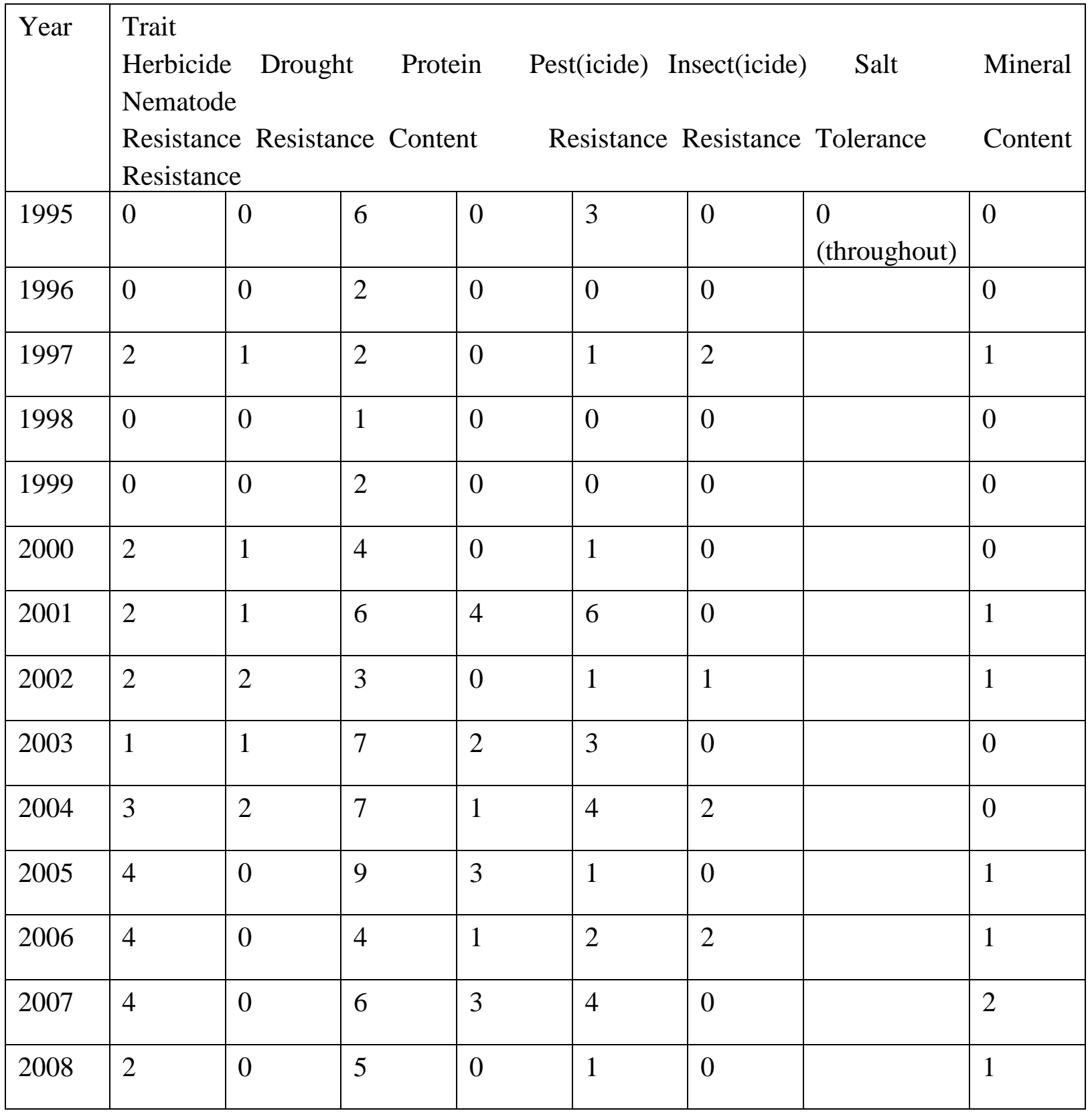




\begin{tabular}{|l|l|l|l|l|l|l|l|l|}
\hline 2009 & 2 & 1 & 3 & 0 & 2 & 0 & 1 \\
\hline 2010 & 2 & 0 & 1 & 0 & 1 & 1 & 0 \\
\hline 2011 & 1 & 0 & 5 & 1 & 1 & 0 & 1 \\
\hline 2012 & 0 & 0 & 2 & 1 & 1 & 0 & & 0 \\
\hline 2013 & 0 & 0 & 1 & 0 & 0 & 0 & & 0 \\
\hline 2014 & 7 & 0 & 10 & 4 & 2 & 3 & & 2 \\
\hline 2015 & 10 & 1 & 13 & 3 & 2 & 1 & & 1 \\
\hline 2016 & 8 & 0 & 16 & 9 & 8 & 2 & & 2 \\
\hline
\end{tabular}

Monsanto: Crop Production Per Year*

\begin{tabular}{|c|c|c|c|c|c|c|c|c|c|c|c|c|}
\hline \multirow{2}{*}{$\begin{array}{l}\text { Year } \\
1995\end{array}$} & \multicolumn{3}{|c|}{$\begin{array}{l}\text { Crop } \\
\text { Sorghum Maize } \\
\text { Coffee Cocoa }\end{array}$} & $\begin{array}{c}\text { Soy } \\
\text { Tomato }\end{array}$ & & \multicolumn{2}{|c|}{ Wheat } & Cotton & & \multicolumn{2}{|c|}{ Rape } & Potato \\
\hline & 1 & 1 & 2 & 1 & 2 & 1 & 1 & 0 & 4 & 0 & 0 & 2 \\
\hline 1996 & 0 & 3 & 2 & 2 & 3 & 2 & 2 & 1 & 3 & 0 & 0 & 2 \\
\hline 1997 & 0 & 2 & 1 & 1 & 0 & 2 & 2 & 2 & 0 & 0 & 0 & 1 \\
\hline 1998 & 0 & 0 & 1 & 0 & 0 & 1 & 0 & 0 & 1 & 0 & 0 & 1 \\
\hline 1999 & 0 & 2 & 1 & 2 & 2 & 1 & 1 & 1 & 1 & 0 & 0 & 0 \\
\hline 2000 & 0 & 0 & 4 & 2 & 3 & 3 & 0 & 2 & 4 & 0 & 0 & 4 \\
\hline 2001 & 5 & 1 & 7 & 6 & 7 & 7 & 5 & 4 & 4 & 0 & 0 & 6 \\
\hline 2002 & 0 & 2 & 2 & 1 & 0 & 2 & 2 & 0 & 0 & 0 & 0 & 1 \\
\hline 2003 & 4 & 1 & 3 & 4 & 4 & 3 & 2 & 2 & 2 & 1 & 1 & 2 \\
\hline 2004 & 0 & 9 & 6 & 8 & 7 & 7 & 3 & 0 & 3 & 0 & 0 & 2 \\
\hline 2005 & 3 & 4 & 7 & 5 & 5 & 5 & 3 & 0 & 3 & 0 & 0 & 3 \\
\hline 2006 & 1 & 4 & 4 & 4 & 4 & 3 & 1 & 1 & 1 & 0 & 0 & 1 \\
\hline 2007 & 3 & 3 & 5 & 4 & 4 & 5 & 3 & 2 & 2 & 0 & 0 & 4 \\
\hline 2008 & 1 & 2 & 3 & 3 & 3 & 3 & 0 & 1 & 0 & 0 & 0 & 1 \\
\hline 2009 & 1 & 2 & 2 & 1 & 1 & 2 & 1 & 0 & 1 & 0 & 0 & 1 \\
\hline
\end{tabular}




\begin{tabular}{|l|l|l|l|l|l|l|l|l|l|l|l|l|}
\hline 2010 & 0 & 2 & 1 & 1 & 1 & 2 & 1 & 0 & 0 & 0 & 0 & 0 \\
\hline 2011 & 1 & 0 & 3 & 4 & 2 & 2 & 2 & 0 & 1 & 0 & 0 & 1 \\
\hline 2012 & 0 & 0 & 1 & 1 & 1 & 1 & 0 & 0 & 0 & 0 & 0 & 0 \\
\hline 2013 & 0 & 1 & 0 & 0 & 0 & 0 & 0 & 0 & 0 & 0 & 0 & 1 \\
\hline 2014 & 3 & 2 & 7 & 7 & 7 & 8 & 4 & 1 & 2 & 1 & 0 & 2 \\
\hline 2015 & 2 & 1 & 12 & 12 & 12 & 11 & 11 & 0 & 1 & 0 & 0 & 2 \\
\hline 2016 & 3 & 2 & 12 & 8 & 8 & 9 & 7 & 3 & 3 & 3 & 0 & 3 \\
\hline
\end{tabular}

*Note: If a plant (or a trait) is not mentioned in a patent, it does not trigger the keyword search that would make it included in this table. This does not mean that the patent does not apply to the plant or trait: it just means that the trait or plant is not singled out separately as an application.

Table 13: Pioneer Trait Production By Year*

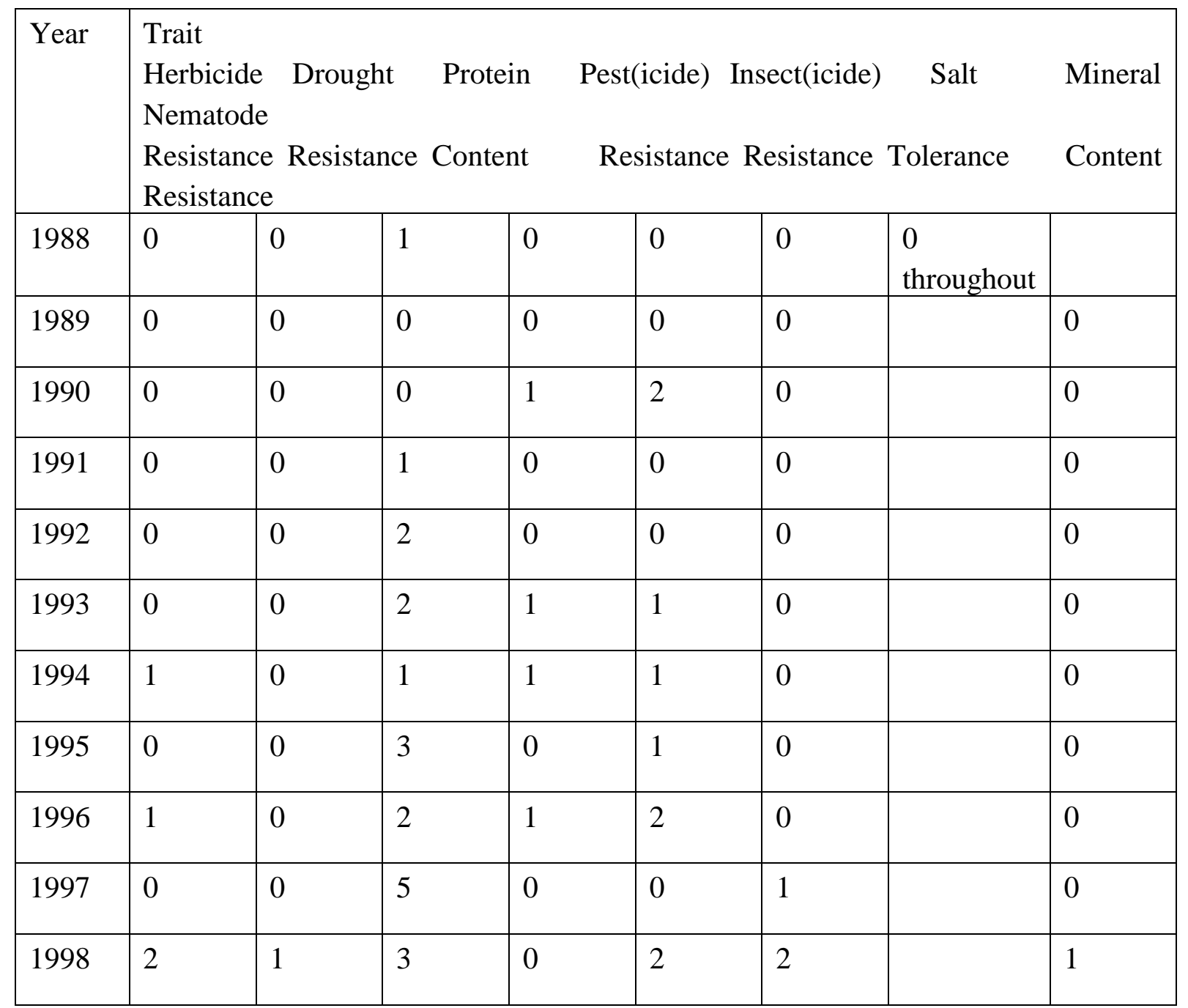




\begin{tabular}{|c|c|c|c|c|c|c|c|}
\hline 1999 & 0 & 0 & 10 & 0 & 0 & 0 & 1 \\
\hline 2000 & 1 & 0 & 9 & 0 & 1 & 0 & 1 \\
\hline 2001 & 1 & 0 & 6 & 0 & 0 & 0 & 0 \\
\hline 2002 & 1 & 0 & 6 & 0 & 1 & 0 & 0 \\
\hline 2003 & 0 & 0 & 1 & 0 & 0 & 0 & 0 \\
\hline 2004 & 2 & 3 & 3 & 0 & 3 & 2 & 0 \\
\hline 2005 & 1 & 2 & 1 & 0 & 3 & 2 & 0 \\
\hline 2006 & 5 & 6 & 4 & 3 & & 5 & 2 \\
\hline 2007 & 2 & 0 & 4 & 5 & 6 & 0 & 0 \\
\hline 2008 & 0 & 2 & 8 & 5 & 0 & 0 & 0 \\
\hline 2009 & 1 & 1 & 11 & 9 & 7 & 0 & 1 \\
\hline 2010 & 0 & 5 & 10 & 12 & 10 & 0 & 0 \\
\hline 2011 & 0 & 3 & 6 & 3 & 4 & 0 & 0 \\
\hline 2012 & 1 & 7 & 6 & 2 & 4 & 1 & 0 \\
\hline 2013 & 2 & 3 & 7 & 1 & 4 & 0 & 2 \\
\hline 2014 & 4 & 10 & 8 & 6 & 8 & 2 & 0 \\
\hline 2015 & 2 & 4 & 6 & 7 & 7 & 0 & 0 \\
\hline 2016 & 3 & 4 & 1 & 4 & 4 & 2 & 0 \\
\hline
\end{tabular}

*Please see note accompanying Monsanto trait and plant tables as it also applies here: these tables signal when a trait or plant is specifically singled out as part of the patent, and does not mean that other patents that are quite general in their application do not apply to the trait or plant in question.

Table 14: Pioneer: Crop Production Per Year*

\begin{tabular}{|l|l|l|l|l|l|l|l|l|l|l|l|l|}
\hline Year & \multicolumn{10}{|l|}{$\begin{array}{l}\text { Crop } \\
\text { Sorghum Maize Soy Rice Wheat Cotton Sugar Rape Potato } \\
\text { Coffee Cocoa Tomato }\end{array}$} \\
\hline 1990 & 2 & 2 & 2 & 2 & 2 & 0 & 0 & 0 & 0 & 0 & 0 & 2 \\
\hline 1991 & 1 & 1 & 1 & 1 & 1 & 0 & 0 & 0 & 0 & 0 & 0 & 1 \\
\hline
\end{tabular}




\begin{tabular}{|c|c|c|c|c|c|c|c|c|c|c|c|c|}
\hline 1992 & 2 & 2 & 2 & 2 & 2 & 0 & 0 & 1 & 0 & 0 & 0 & 2 \\
\hline 1993 & 1 & 4 & 1 & 1 & 1 & 1 & 0 & 1 & 0 & 0 & 0 & 1 \\
\hline 1994 & 1 & 2 & 1 & 1 & 1 & 1 & 0 & 1 & 0 & 0 & 0 & 1 \\
\hline 1995 & 2 & 4 & 1 & 1 & 1 & 1 & 0 & 1 & 0 & 0 & 0 & 1 \\
\hline 1996 & 1 & 2 & 1 & 1 & 1 & 1 & 0 & 0 & 1 & 0 & 0 & 0 \\
\hline 1997 & 2 & 5 & 3 & 3 & 2 & 0 & 0 & 0 & 0 & 0 & 0 & 0 \\
\hline 1998 & 4 & 5 & 3 & 3 & 4 & 1 & 0 & 0 & 0 & 0 & 0 & 0 \\
\hline 1999 & 5 & 8 & 5 & 4 & 4 & 2 & 0 & 0 & 0 & 0 & 0 & 0 \\
\hline 2000 & 5 & 7 & 6 & 6 & 6 & 4 & 0 & 0 & 0 & 0 & 0 & 0 \\
\hline 2001 & 4 & 6 & 3 & 4 & 4 & 3 & 0 & 0 & 1 & 0 & 0 & 0 \\
\hline 2002 & 3 & 4 & 2 & 3 & 3 & 1 & 0 & 0 & 0 & 0 & 0 & 0 \\
\hline 2003 & 1 & 2 & 1 & 2 & 1 & 1 & 0 & 0 & 0 & 0 & 0 & 1 \\
\hline 2004 & 2 & 7 & 1 & 3 & 2 & 0 & 0 & 0 & 0 & 0 & 0 & 0 \\
\hline 2005 & 2 & 3 & 2 & 2 & 2 & 2 & 0 & 0 & 0 & 0 & 0 & 0 \\
\hline 2006 & 1 & 6 & 5 & 2 & 2 & 2 & 0 & 0 & 0 & 0 & 0 & 0 \\
\hline 2007 & 6 & 10 & 7 & 6 & 6 & 6 & 3 & 2 & 3 & 0 & 0 & 3 \\
\hline 2008 & 7 & 7 & 8 & 7 & 7 & 7 & 6 & 6 & 6 & 0 & 0 & 6 \\
\hline 2009 & 11 & 11 & 11 & 11 & 11 & 9 & 9 & 7 & 9 & 0 & 0 & 7 \\
\hline 2010 & 9 & 13 & 10 & 8 & 14 & 7 & 5 & 4 & 4 & 0 & 1 & 4 \\
\hline 2011 & 8 & 9 & 6 & 8 & 8 & 5 & 1 & 4 & 1 & 0 & 0 & 1 \\
\hline 2012 & 11 & 12 & 9 & 9 & 9 & 8 & 6 & 2 & 4 & 0 & 1 & 2 \\
\hline 2013 & 5 & 8 & 6 & 4 & 4 & 1 & 0 & 0 & 0 & 0 & 1 & 0 \\
\hline 2014 & 11 & 18 & 12 & 8 & 9 & 6 & 6 & 3 & 3 & 1 & 0 & 3 \\
\hline 2015 & 9 & 13 & 6 & 8 & 9 & 8 & 8 & 6 & 7 & 0 & 1 & 6 \\
\hline 2016 & 4 & 6 & 3 & 3 & 3 & 3 & 2 & 2 & 1 & 0 & 1 & 1 \\
\hline
\end{tabular}


In sum, we see that the data points to several features that should be analysed to see how they affect the general "pro-competitive" slant of the merger and innovation literature. We see surprisingly little churn in both volume and application of research, surprisingly little keenness in some traits that may suggest a second mover advantage, and considerable narrowing of the competitive field when moving from those who appear research active and those who are active to a level of commercialisation.

Separate from GM crop considerations, if we step back and think that the patents in this dataset are intended to be filtered for those with special applicability to BRIC countries, we need to question whether any second mover advantage could be due to differences in strength of intellectual property protection. The current research shows that there is a link between this and optimal level of competitive pressure to generate innovation (Aghion et al (2015)) and older papers indicate that weak intellectual property protection can result in second mover advantages rather than first mover advantages (Katz 1985), so investigating merger policy in the presence of weaker intellectual property rights could also bring the analysis more in line with the data.

\subsubsection{A first look at some major mergers}

Ideally an empirical study of the link between merger and innovation would compare the chosen measure of innovation before and after the merger, controlling for all other factors that might also have affected the measure of innovation.

Unfortunately, this approach is hard to apply to mergers in the GM Crop/Seed business, for two main reasons. The first reason is the relative dearth of "mega mergers", i.e. mergers that are substantial enough to be likely to leave a trace in the data. Bayer-Monsanto would qualify, but we do not have a "post-merger" period to use for comparison purpose. For Monsanto, the acquisition of DeKalb and Seminis would be likely candidates. The DeKalb transaction suffers from the opposite problem: it occurred early enough that the pre-merger period might not be sufficiently informative. Seminis, on the other hand, seems "just right" a it occurred in 2005. The acquisition of Pioneer by Dupont in 1999 is another merger worth looking at.

Another limitation comes from the time and resources limit that we faced in developing this study. In principle, we would have liked to gather information not only on GM Crops and plant patents but also on patents obtained on complementary products such as pesticides, herbicides and fertilisers. At this stage, we do not have information on these complementary products. This is an issue for the Monsanto-Seminis and Dupont-Pioneer acquisitions since we observe only one type of innovation. We simply point here to some interesting initial observations that warrant, in our view, further work.

The graph below illustrates a first attempt at detecting a possible effect of major mergers on innovation. The numbers underlying the graph are computed as follows. For Monsanto, Bayer and Dupont, we add the patents registered under their name as well as the patents registered under the names of the major acquisition (DeKalb, Seminis, Aventis/Rhone Poulenc, Pioneer). For Syngenta, which was not involved in any major acquisition, we simply add the Syngenta and Novartis numbers. The vertical lines show the dates of the major acquisitions.

If we take Syngenta as a reference for the evolution of innovation in a firm which was not affected by major mergers, it seems pretty clear that Monsanto and Dupont experienced significantly faster innovation growth soon after their major merger. This is what we would expect from the 
acquisition of a major seed company. By contrast Bayer, whose main acquisition was of Aventis, a firm with a similar profile, shows no such bounce, which is again in line with expectations. This is not definitive, but it is suggestive that more work in the area of analysing certain mergers could yield insights and perhaps insights that differ across industries and countries. We believe that this indicative graphic warrants further investigation.

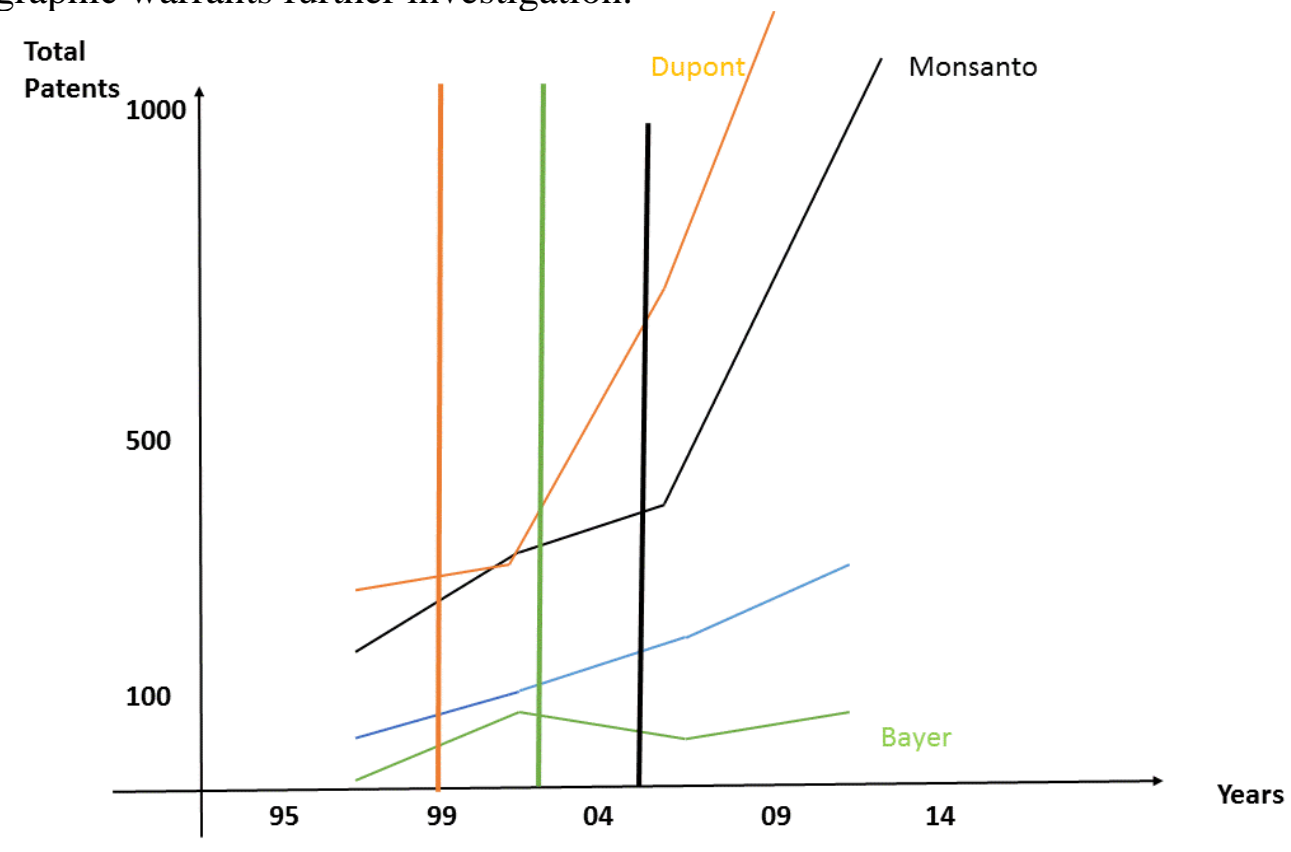

Figure 1

\subsection{Conclusion}

We began with a review of the economics literature that is relevant to mergers and innovation. We find that the literature illustrates several points. First, the material on the inverted $U$ relation between rivalry (read market structure for empirical work) and innovation is not directly relevant to merger and, to the extent it establishes a starting point to "trigger" investigations, that starting point is not well defined since it varies considerably across industry and across the institutional conditions of merger and the way merger is accomplished (such as its financing). Second, the theoretical work specifically on merger and innovation is based on restrictive and recent models that have yet to be shown to be robust. At the same time, it should be clear from this work that there should be no "get out of jail free" card based on innovation. Third, the work on creating conceptual maps for policy purposes from the literature has been helpful in the sense of organising what is a large number of sometimes contradictory factors, but could be made more user-friendly.

In light of this current state of knowledge, our paper has two main purposes. Firstly, we have presented what we hope to be a more "policy-maker friendly" typology of the economic effects of mergers on innovation investments by outlining simple components and combining these into a decision rule. Such an exercise has several benefits: it provides a step by step organisation of the many effects at play, makes it possible to distinguish between first and second order effects, and finally helps to compare the innovation dimension of mergers to the more traditional pricing/output dimension. Having identified the effects at play we are then in a position to ask whether there are 
indeed circumstances where an a priori - rebuttable - presumption about the link between mergers and innovation would be justified. Our main conclusion in this respect is that, indeed, mergers between parties with material overlap in the products and technology markets can be assumed to have a negative effect on innovation. However, such effects can be addressed through the kind of remedies which are traditionally used to handle the likely effects of mergers on prices and levels of output. In that sense, dynamic issues can remain mostly in the background as long as traditional static issues are addressed successfully. There are however additional channels through which a merger can affect innovation. We have argued that most of those effects are favourable to innovation. Nonetheless, a merger can also lead to "vertical" issues in the innovation market where the combination of crucial inputs held by the parties could harm the innovation efforts of their rivals. When such a concern can be documented, there is a trade-off between this negative effects and a whole set of positive effect linked to scale effects, improved coordination of investment and the complementary nature of successive innovations. When assessing this trade-off, the merging parties should be responsible for bringing evidence in support of these positive effects.

We have made some progress on our second objective of using this typology of effects in order to better understand the innovation dimension of mergers in the GM/seed industry as a specific case of interest. The industry and the recent mergers within it share special features that make it a nice counter-point to the theoretical models that have been proposed as generalizable to mergers: to the extent that this industry provides special features, we would want to allow for any policy recommendations to take those into account in any merger analysis to be undertaken. These features include a heavy regulatory framework that leads to economies of scale and scope in GM applications but also a natural synergy between chemical and GM innovations that could bias the choice of applications to fall in specific areas. This means that the diversity in applications that could result from the economies of scope at the regulatory level may not emerge. To the extent that the BRIC countries could benefit from some of the more far-flung applications, these two features may not overall be beneficial to BRIC economies. To the extent that merger would be justified, then, by the economies at the regulatory (or marketing level), the complementarity may work in the opposite direction. Second, there is also a natural complementarity in seeds production as germplasm is an important "stock" from which innovations flow. This generates a natural vertical linkage that can also affect innovation production in terms of volume and application.

We see in our initial data work that there are indicators that the orientation of innovation is indeed related to complementarities and this narrowing of focus in the larger firms combined with the regulatory barriers to overcome for commercialisation may mean that the diversity of applications of this technology that reach the market may be biased, possibly in directions that are not helpful to the BRIC countries. Furthermore the heavy merger activity with seed companies conceivably relates to the innovation complementarities here of germplasm and GM applications, but creates vertical integration issues that need to be considered. The local effects that we found in our data related to the BRIC countries per se were not the same as the general effects on innovation at a global level, suggesting that innovation effects may be very widespread geographically, and suggesting that any mitigating factors for innovation effects might rely on data drawn from a wide set of activities undertaken by the firm. We have emphasised that our results are very preliminary and have left detailed application of our framework to specific mergers for future work. At the same time, our data review indicates that this exercise could be enlightening and worthy of the time and effort it would require. 
Tables and Figures

Table 1: Main Innovation Effects of Mergers......534

Table 2: NO NAME or source....539

Table 3: the trait dimension of the acquisitions (source needed).....540

Table 4: the share of the proprietary seed market controlled by the main companies (source needed)..........541

Table 5: NO NAME..........545

Table 6: NO NAME.....545

Table 7: Total Patents Recorded for Merging Firms...550

Table 8: Total Datapoints per year for merging firms with patents in dataset.....551

Table 9: Total Patents Recorded for Merging and "Non-Merging" Firms

Table 10: Trait Production: Entire Dataset, by firm.....554

Table 11: Plant Production: Entire Dataset, by firm.....555

Table 12: Monsanto Trait Production By Year......555

Table 13: Pioneer Trait Production By Year.....557

Table 14: Pioneer: Crop Production Per Year* 
Figure 1: no name......561 


\section{References}

Aghion, Philippe, Nick Bloom, Richard Blundell, Rachel Griffith, and Peter Howitt. 2005. "Competition and Innovation: An Inverted- U Relationship." Quarterly Journal of Economics 120(2): 701- 28.

, and Rachel Griffith. 2005. Competition and Growth: Reconciling Theory and Evidence. Cambridge, MA: MIT Press.

, Christopher Harris, Peter Howitt, and John Vickers. 2001. "Competition, Imitation and Growth with Step- by- Step Innovation." Review of Economic Studies 68:467-92

, Peter Howitt, Susanne Prantl. 2015. "Patent Rights, Product Market Reforms, and Innovation.” Journal of Economic Growth 20: 223-262.

, John Van Reenen and Luigi Zingales. 2013. Innovation and Institutional Ownership. American Economic Review 103(1): 277-304.

Aidt, Toke, Arye Hillman. 2008. "Enduring Rents.” European Journal of Political Economy 24: 545553.

Arrow, Kenneth. 1962. "Economic Welfare and the Allocation of Resources to Invention." In The Rate and Direction of Inventive Activity: Economic and Social Factors, edited by the UniversitiesNational Bureau Committee for Economic Research and the Committee on Economic Growth of the Social Science Research Councils, 609-26. Princeton, NJ: Princeton University Press.

Ayres, Ian and Paul Klemperer. 1999. "Limiting Patentees' Market Power Without Reducing Innovation Incentives: The Perverse Benefits of Uncertainty and Non-Injunctive Settlements." Michigan Law Review 97(2): 985-1033.

Baker, Jonathan. 2007. "Beyond Schumpeter vs. Arrow: How Antitrust Fosters Innovation.” Antitrust Law Journal 74:575- 602

Bartlett, Christopher. 1983. "EMI and the CT Scanner (A)." Harvard Business School Case 383-194. (Revised November, 2001)

Bertrand, Olivier, Pluvia Zuniga. 2006. "R\&D and M\&A: Are Cross-Border M\&A Different? An Investigation of OECD Countries." International Journal of Industrial Organization. 24(2). 401-423 Bertrand, Olivier, Katariina Hakkala \& Pehr-Joahn Norback. 2007. "Does the Entry Mode of FDI Matter for Affiliate R\&D?" Research Institute of Industrial Economics working paper 693.

Bloom, Nicholas. 2010. "Why Do Management Practices Differ Across Firms and Countries?" Journal of Economic Perspectives 24:203-24.

, Carol Propper, Stephan Seiler, John Van Reenen. 2015. "The Impact of Competition on Management Quality: Evidence from Public Hospitals.” Review of Economic Studies 82(2): 457489.

, Mark Schankerman, and John Van Reenen. 2013. "Identifying Technology Spillovers and Product Market Rivalry." Econometrica 81 (4): 1347-1393.

, and John Van Reenen. 2007. "Measuring and Explaining Management Practices Across Firms and Countries.” Quarterly Journal of Economics 122:1351- 408.

Bulow, Jeremy, John Geanakopoulos, and Paul Klemperer. 1985. "Multimarket Oligopoly: Strategic Substitutes and Complements." The Journal of Political Economy 93(3): 488-511.

Cassiman, Bruno, Massimo Colombo, Paola Gerrone, Reinhilde Veugelers. 2005. "The Impact of M\&A on the R\&D Process: An Empirical Analysis of the Role of Technological and Market Relatedness." Research Policy 34: 195-220. 
Cohen, Wesley. 2010. "Fifty Years of Empirical Studies of Innovative Activity and Performance." In Economics of Innovation. B. Hall and N. Rosenberg Eds. Amsterdam: North Holland. Chapter 4. Council Regulation (EC) No 139/2004 of 20 January 2004 (the EC Merger Regulation), Official Journal L 24, 29.01.2004, p. 1-22.

Cowling, Keith, Dennis Mueller. 1978. "The Social Costs of Monopoly Power." The Economic Journal 88 (352): 727-748.

Doraszelski, Ulrich, Jordi Jaumandreu. 2013. "R\&D and Productivity: Estimating Endogenous Productivity." Review of Economic Studies 80(4): 1338-1383.

Entezarkhier, Mahdiyeh and Saeed Moshiri. 2017. "Mergers and Innovation: Evidence from a Panel of US Firms." Economics of Innovation and New Technology: 1-22.

European Commission Decision Case M.7932 Dow/Dupont. 27/3/2017. Available at: http://ec.europa.eu/competition/mergers/cases/decisions/m7932_13668_3.pdf

Farrell, Joseph and Carl Shapiro. 2010. "Antitrust Evaluation of Horizontal Mergers: An Economic Alternative to Market Definition." The B.E. Journal of Theoretical Economics 10(1) (Policiesperspectives): Article 9.

Federico, Giulio, Gregor Langus, Tommaso Valletti. 2017a. "A Simple Model of Mergers and Innovation" Economics Letters 157 (2017) 136-140. Also see working paper version for more detailed presentation at: CESifo working paper series 6539.

--- 2017b "Horizontal Mergers and Product Innovation: An Economic Framework" SSRN working paper 2999178. July 10. Available at: https://ssrn.com/abstract=2999178

Fudenberg, Drew and Jean Tirole. 1984. "The Fat-Cat Effect, the Puppy-Dog Ploy and the Lean and Hungry Look." American Economic Review Papers and Proceedings 74(2): 361-366.

Gilbert, Richard. 2006. "Looking for Mr. Schumpeter: Where Are We in the Competition- Innovation Debate." In Innovation Policy and the Economy, vol. 6, edited by Adam Jaffe, Josh Lerner, and Scott Stern, 159-215. Chicago: University of Chicago Press.

Gilbert, Richard, and David Newbery. 1982. "Preemptive Patenting and the Persistence of Monopoly." American Economic Review 72:514- 26.

Gautam Ahuja \& Riita Katila. 2001. "Technological Acquisitions and the Innovation Performance of Acquiring Firms: A Longitudinal Study.” Strategic Management Journal. 22: 197-220.

Griffith, Rachel, Richard Harrison, and Helen Simpson. 2010. "Product market reform and innovation in the EU." Scandinavian Journal of Economics 112(2): 389-415.

Hall, Bronwyn. 1990. "The Impact of Corporate Restructuring on Industrial Research and Development." Brookings Papers on Economic Activity, Microeconomics 85.

Harberger, Arnold. 1954. "Monopoly and Resource Allocation." The American Economic Review (Papers and Proceedings of the Sixty-Sixth Annual Meeting of the American Economic Association). 44(2):77-87.

Harhoff, Dietmar, Pierre Regibeau, Katharine Rockett. 2001. "Some Simple Economics of GM Foods." Economic Policy 16(33): 264-299.

Harris, Christopher, and John Vickers. 1987 "Racing with Uncertainty." Review of Economic Studies 54(1): 1-21.

Haucap, Justus and Joel Stiebale. 2016. "How Mergers Affect Innovation: Theory and Evidence from the Pharmaceutical Industry." Dusseldorf Institute for Competition Economics Discussion Paper 218. April. Available at: 
http://www.dice.hhu.de/fileadmin/redaktion/Fakultaeten/Wirtschaftswissenschaftliche_Fakultaet/DI CE/Discussion_Paper/218_Haucap_Stiebale.pdf

Healy, Paul, Krishna Papelu, and Richard Ruback. 1992. "Does Corporate Performance Improve after Mergers?” Journal of Financial Economics 31(2): 135-175.

Hitt, Michael A., Robert E. Hoskisson, R. Duane Ireland, Jeffrey S. Harrison. 1991. "The Effect of Acquisitions on R\&D Inputs and Outputs,.” Academy of Management Journal 34(3): 693-706.

, Robert E. Hoskisson, Richard A. Johnson, Douglas D. Moesel. 1996. "The Market for

Corporate Control and Firm Innovation.” Academy of Management Journal 39(5): 1084-1119.

Lemley, Mark and Carl Shapiro. 2005. "Probabilistic Patents." The Journal of Economic Perspectives 19(2): 75-98.

Katz, Michael, and Carl Shapiro. 1987. "R\&D Rivalry with Licensing or Imitation." American Economic Review 77(3): 402-420. , and Howard Shelanski. 2007. "Mergers and Innovation.” Antitrust Law Journal 74:1-

85.

Kortum, Sam and Josh Lerner. 1997. "Stronger Protection or Technological Revolution: What is Behind the Recent Surge in Patenting?" NBER working paper 6204.

Lanjouw, Jennifer, and Mark Schankerman. 2004. "Patent Quality and Research Productivity: Measuring Innovation with Multiple Indicators.” The Economic Journal 114: 441-465.

Lee, Chang- Yang. 2005. “A New Perspective on Industry R\&D and Market Structure.” Journal of Industrial Economics 53:101- 22.

2009. "Competition Favors the Prepared Firm: Firm's R\&D Response to Competitive Market Pressure.” Research Policy 38:861- 70.

Lerner, Josh. 2009. "The empirical impact of intellectual property rights on innovation: Puzzles and clues." American Economic Review 99(2): 343-348.

Lieberman, Marvin and David Montgomery. 1988. "First Mover Advantages." Strategic Management Journal 9(S1): 41-58.

Lopez, A. L., and Vives, X., 2016. Cross-Ownership, R\&D Spillovers and Antitrust Policy. CESifo Working Paper 5935.

Mermelstein, B., Nocke, V., Satterthwaite, M. A., and Whinston, M. D., 2014. "Internal versus External Growth in Industries with Scale Economies: A Computational Model of Optimal Merger." NBER Working Paper 20051 (April).

Misati, Evans and Kiyoshi Adachi. 2010. "The Research and Experimentation Exceptions in Patent Law: Jurisdictional Variations and the WIPO Development Agenda". UNCTAD-ICTSDPolicy Brief 7. Available at: https://www.ictsd.org/downloads/2011/12/the-research-and-experimentationexceptions-in-patent-law-jurisdictional-variations-and-the-wipo-development-agenda.pdf

Motta, Massimo, Tarantino, Emanuele, 2016. The Effect of a Merger on Investments, CEPR DP11550. October.

Nocke, V., and Whinston, M. D., 2010. Dynamic Merger Review. Journal of Political Economy, 118(6): 1201-1251.

Ornaghi, Carmine and Juan Correa. 2014. Competition and Innovation: Evidence from US Patent and Productivity Data.” Journal of Industrial Economics 62(2):258-285.

Raskovich, Alexander, and Nathan Miller. 2010. "Cumulative Innovation and Competition Policy." Antitrust Division, US Department of Justice, EAG Discussion Paper 10- 5, September. Available at: https://www.justice.gov/sites/default/files/atr/legacy/2015/02/18/262643.pdf 
Rockett, Katharine. 2010. "Property Rights and Invention.” In Economics of Innovation. B. Hall and N. Rosenberg Eds. Amsterdam: North Holland. Chapter 7.

Scherer, Frederic M. 1967. "Market Structure and the Employment of Scientists and Engineers." American Economic Review 57: 524 -531.

Schmutzler, Armin. 2013. "Competition and investment - A unified approach.” International Journal of Industrial Organization 31 (5):477-487.

Schumpeter, Joseph. 1942. Capitalism, Socialism and Democracy. New York: Harper \& Brothers. (available in the Taylor and Francis e-library, 2003, at http://cnqzu.com/library/Economics/marxian\%20economics/Schumpeter,\%20Joeseph-

Capitalism,\%20Socialism\%20and\%20Democracy.pdf

Scotchmer, Suzanne. (1991). "Standing on the Shoulders of Giants: Cumulative Research and Patent Law." The Journal of Economic Perspectives 5(1): 29-41.

(2003) Innovation and Incentives. MIT Press, Cambridge, MA.

Shapiro, Carl, 2012. Competition and Innovation. Did Arrow Hit the Bull's Eye? In: Lerner, Josh, Stern, Scott (Eds.), The Rate and Direction of Inventive Activity Revisited. University of Chicago Press, pp. 361-404.

Stiebale, Joel and Frank Reize. 2011. "The impact of FDI through mergers and acquisitions on innovation in target firms." International Journal of Industrial Organization 29:155-167.

Syverson, Chad. 2004. "Market Structure and Productivity: A Concrete Example." Journal of Political Economy 112:1181-222.

- 2011. "What Determines Productivity?" Journal of Economic Literature 49 (2): 326- 65.

Szucs, Florian. 2014. "M\&A and R\&D: Asymmetric effects on acquirers and targets?" Research Policy 43 (7):1264-1273.

Tirole, Jean. 1997. The Theory of Industrial Organization. Cambridge, MA: MIT Press.

United States Horizontal Merger Guidelines (August 19, 2010), available at: https://www.ftc.gov/sites/default/files/attachments/merger-review/100819hmg.pdf

Valentini, Giovanni, 2012. "Measuring the Effect of M\&A on Patenting Quantity and Quality", Strategic Management Journal, 33:3, pp. 336 -346.

Veugelers, Reinhilde. 2006. "Literature review on M\&A and R\&D.” In Mergers and Acquisitions The Innovation Impact, edited by B. Cassiman and M.G. Colombo. Edward Elgar, 37-62.

Vickers, John. 1985. "Pre-emptive patenting, joint ventures, and the persistence of oligopoly." International Journal of Industrial Organization 3 (3):261-273.

Vives, Xavier. 2008. "Innovation and Competitive Pressure." Journal of Industrial Economics 61:419-469.

Whinston, Michael. 2012. "Comment on Competition and Innovation: Did Arrow Hit the Bull's Eye?”. The Rate and Direction of Inventive Activity Revisited. Josh Lerner and Scott Stern, Editors. Chicago: University of Chicago Press: 404-410.

Yi, Sang-Seung. 1999. "Market structure and incentives to innovate: The case of Cournot oligopoly." Economics Letters 65 (3):379-388. 


\section{Appendix A: formal analysis of the innovation effects of a merger}

Two firms A and BBB merge. Competition is in prices. For simplicity we assume that each firm sells a single product, hence innovation takes the form of product improvements, $P_{i}$ is the price charged by firm I, with $i=A, B$. We define as $P$ as the vector of the other firms' prices. There are no production costs. By investing $I_{i}$, firm i improves its quality from a benchmark of zero to $Q_{i}=$ $Q\left(I_{i}\right), Q^{\prime}>0, Q^{\prime \prime}<0$ with a probability equal to $\alpha$. If two firms A and B succeed in their innovation effort, part of their innovations might overlap in the sense that a firm with its own acquired knowledge no longer needs the knowledge obtained by the other firm. We define the overlap as a fraction $\omega$ of the smaller of the two quality improvements. Hence, if we have $Q_{A}>Q_{B}$, B has a quality improvement $(1-w) Q_{B}$ which A does not have and $\mathrm{A}$ has an improvement $Q_{A}-w Q_{B}$ that $\mathrm{B}$ does not have.

\section{Fixed price}

\section{$\underline{\text { No Coordination, No Sharing of Information }}$}

Before the merger, the profit maximisation problem of firm $I$ is

$$
\operatorname{Max}_{I_{i}} P_{i} D_{i}\left(P_{i}, P_{j}, P ; Q_{i}, Q_{j}, Q\right)-I_{i}
$$

The corresponding first order condition is

$$
P_{i} \frac{\partial D_{i}}{\partial Q_{i}} \frac{\partial Q_{i}}{\partial I_{i}}-1=0
$$

After $A$ and $B$ merge, the maximisation problem is

$$
\operatorname{Max}_{I_{A}, I_{B}} P_{A} D_{A}\left(P_{A}, P_{B}, P ; Q_{A}, Q_{B}, Q\right)-I_{A}+P_{B} D_{B}\left(P_{B}, P_{A}, P ; Q_{B}, Q_{A}, Q\right)-I_{B}
$$

The corresponding first order conditions are

$$
\begin{aligned}
& P_{A} \frac{\partial D_{A}}{\partial Q_{A}} \frac{\partial Q_{A}}{\partial I_{A}}+P_{B} \frac{\partial D_{B}}{\partial Q_{A}} \frac{\partial Q_{A}}{\partial I_{A}}-1=0 \\
& P_{B} \frac{\partial D_{B}}{\partial Q_{B}} \frac{\partial Q_{B}}{\partial I_{B}}+P_{A} \frac{\partial D_{A}}{\partial Q_{B}} \frac{\partial Q_{B}}{\partial I_{B}}-1=0
\end{aligned}
$$

Comparing the FOCs before and after merger shows that they differ only because of an additional term equal to

$$
P_{B} \frac{\partial D_{B}}{\partial Q_{A}} \frac{\partial Q_{A}}{\partial I_{A}} \text { or } P_{A} \frac{\partial D_{A}}{\partial Q_{B}} \frac{\partial Q_{B}}{\partial I_{B}}
$$

In the post-merger conditions. If the products produced by $\mathrm{A}$ and $\mathrm{B}$ are substitutes, then this term is negative: improving the quality of good A steals sales from good B. Indeed this term could easily be couched in terms of diversion ratios and profit margins. Therefore investments in innovation are unambiguously lower after the merger.

\section{No Coordination, Sharing of Information}

We need to define the amount of transferable information between the R\&D programs of the two firms. We simply assume that a proportion $\gamma$ of the improvement in one product is transferable to the other product. Essentially $\gamma$ is a measure of post-merger internal spillovers. The size of the parameter depends on the technological closeness of the products involved as well as on the type of innovation 
pursued. The closer the products are technology and the more "upstream oriented" the research is, the larger we would expect the parameter $\gamma$ to be.

The pre-merger first order conditions are the same as before. Post-merger we have

$$
\begin{aligned}
& Q_{A}=Q_{A}\left(I_{A}\right)+\gamma Q_{B}\left(I_{B}\right) \\
& Q_{B}=Q_{B}\left(I_{B}\right)+\gamma Q_{A}\left(I_{A}\right)
\end{aligned}
$$

Hence the profit-maximisation problem is

$$
\begin{aligned}
\operatorname{Max}_{I_{A}, I_{B}} P_{A} D_{A}( & \left.P_{A}, P_{B}, P ; Q_{A}\left(I_{A}\right)+\gamma Q_{B}\left(I_{B}\right), Q_{B}\left(I_{B}\right)+\gamma Q_{A}\left(I_{A}\right), Q\right)-I_{A} \\
& +P_{B} D_{B}\left(P_{B}, P_{A}, P ; Q_{B}\left(I_{B}\right)+\gamma Q_{A}\left(I_{A}\right), Q_{A}\left(I_{A}\right)+\gamma Q_{B}\left(I_{B}\right), Q\right)-I_{B}
\end{aligned}
$$

The corresponding first order conditions are

$$
\begin{aligned}
& P_{A}\left[\frac{\partial D_{A}}{\partial Q_{A}} \frac{\partial Q_{A}}{\partial I_{A}}+\frac{\partial D_{A}}{\partial Q_{B}} \gamma \frac{\partial Q_{A}}{\partial I_{A}}\right]+P_{B}\left[\frac{\partial D_{B}}{\partial Q_{A}} \frac{\partial Q_{A}}{\partial I_{A}}+\frac{\partial D_{B}}{\partial Q_{B}} \gamma \frac{\partial Q_{A}}{\partial I_{A}}-1=0\right. \\
& P_{B}\left[\frac{\partial D_{B}}{\partial Q_{B}} \frac{\partial Q_{B}}{\partial I_{B}}+\frac{\partial D_{B}}{\partial Q_{A}} \gamma \frac{\partial Q_{B}}{\partial I_{B}}\right]+P_{A}\left[\frac{\partial D_{A}}{\partial Q_{B}} \frac{\partial Q_{B}}{\partial I_{B}}+\frac{\partial D_{A}}{\partial Q_{A}} \gamma \frac{\partial Q_{B}}{\partial I_{B}}-1=0\right.
\end{aligned}
$$

The first expression can be re-arranged as follows

$$
P_{A}\left[\frac{\partial D_{A}}{\partial Q_{A}} \frac{\partial Q_{A}}{\partial I_{A}}\right]+P_{B}\left[\frac{\partial D_{B}}{\partial Q_{A}} \frac{\partial Q_{A}}{\partial I_{A}}\right]-1+\gamma \frac{\partial Q_{A}}{\partial I_{A}}\left[\frac{\partial D_{A}}{\partial Q_{B}}+\frac{\partial D_{B}}{\partial Q_{B}}\right]=0
$$

The first three terms correspond to the effects that we have already identified in the previous subsection. The additional effect of information sharing is captured in the last part of the expression. The two terms in bracket have opposite signs: an improvement in the quality of product B increases the demand for B and decreases the demand for A. It seems reasonable - in line with traditional practice in models of oligopoly, to assume that the "own effect" of a change in the quality of B is larger in absolute value than the "cross-effect". This mean that the sum of the two terms in bracket is positive and the diffusion of innovation enabled by the merger leads the merged entity to invest more heavily into innovation. Moreover, because information exchange leads to a broader application of the innovation for any given levels of investment we can also conclude that the diffusion of innovation enabled by the merger leads to larger superior innovation outcomes.

\section{Coordinated Investment in Innovation}

We now abstract from innovation-sharing and focus on duplication. The effect of duplication depends on the appropriability regime. For simplicity we limit ourselves to the situation where innovation is not excludable, i.e. two firms making the same discovery can each exploit that discover In the absence of exclusivity, the pre-merger situation is the same as in our base case so that the FOC for firm i can be written as:

$$
P_{i} \frac{\partial D_{i}}{\partial Q_{i}} \frac{\partial Q_{i}}{\partial I_{i}}-1=0
$$

So, in the pre-merger word, investment levels of $I_{A}$ and $I_{B}$ would lead to quality levels of $Q_{A}\left(I_{A}\right)$ and $Q_{B}\left(I_{B}\right)$ respectively with an overlap equal to $\omega \operatorname{Min}\left[Q_{A}, Q_{B}\right]$. After the merger, the same levels of investments could be reallocated. The merged entity could keep $I_{A}$ at the pre-merger level, giving $Q_{A}\left(I_{A}\right)$. To reach the same level of quality for $\mathrm{B}$, it would then need to invest $I_{B}^{o}$ such that $Q_{B}\left(I_{B}^{o}\right)=$ $(1-\omega) Q_{B}\left(I_{B}\right)$, leaving additional resources equal to $I_{B}-I_{B}^{O}$ available to obtain further quality improvements either for A or for B. This effect can only lead to better innovation outcomes, even though it might no lead to greater total investment in innovation. Keeping other things equal (in particular, ignoring the other effects of the merger), if investing a given sum to get given levels of product improvements is worth it, then investing a smaller sum to obtain the same improvements is 
also worth it. So the level of realised innovation cannot fall because of coordination. Indeed, because avoiding overlap also increases the marginal productivity of innovation investment, coordinating R\&D programs must lead to higher levels of realised innovation. However, this does not imply that total investment goes up since, as the marginal productivity of investment decreases the level of realised innovation. To see this, neutralise all other merge effects and assume that the revenues linked to qualities are equal to $R_{A}\left(Q_{A}\right), R_{B}\left(Q_{B}\right)$ respectively with $R_{i}^{\prime}>0, R_{i}^{\prime \prime}<0$. Before the "merger", the firms faced the following maximisation problem:

$$
\operatorname{Max}_{I_{i}} R\left(Q_{i}\left(I_{i}\right)\right)-I_{i}
$$

With the following corresponding first order conditions:

$$
R^{\prime}\left(Q_{i}\left(I_{i}\right)\right) \frac{\partial Q_{i}}{\partial I_{i}}-1=0
$$

After the "merger", we have

$$
\operatorname{Max}_{I_{A}, I_{B}} R\left(Q_{A}\left(I_{A}\right)\right)+R\left(Q_{B}\left(I_{B}\right)+\omega Q_{A}\left(I_{A}\right)\right)
$$

This specification assumes that A pursues research as usual while B is steered away from areas of overlap. While this might not be the most efficient organisation of research it at least gives us a lower bound on what the merged entity should be able to achieve. The First order conditions are:

$$
\begin{gathered}
R^{\prime}\left(Q_{A}\left(I_{A}\right)\right) \frac{\partial Q_{A}}{\partial I_{A}}-1+R^{\prime}\left(Q_{B}\left(I_{B}\right)+\omega Q_{A}\left(I_{A}\right)\right) \omega \frac{\partial Q_{A}}{\partial I_{A}}=0 \\
R^{\prime}\left(Q_{B}\left(I_{B}\right)+\omega Q_{A}\left(I_{A}\right)\right) \frac{\partial Q_{B}}{\partial I_{B}}-1=0
\end{gathered}
$$

Comparing these FOCs to the FOCs without coordination, we see that coordination leads to greater investment in product A since it de facto produces a "spillover" in favour of good B. The FOC for investment in B has the same functional form as without coordination. However, because of the spillover from A, the level of quality reached for any given investment in B is higher under coordination. Given that there are decreasing returns to quality, this implies that there is less investment in B when R\&D programs are coordinated to avoid overlap. However, for both FOC to be satisfied we need $Q_{B}\left(I_{B}\right)+\omega Q_{A}\left(I_{A}\right)$ to be equal to the level of quality reached without coordination. Overall then the form of cooperation that we have considered leaves to more investment in A, less investment in B, the same level of quality for B but a higher level of quality for A. This is therefore an additional positive effect of the merger on the innovation outcome for the merging parties.

\section{endogenous prices}

So far, we have taken the prices as exogenous. Let us now define the equilibrium prices as a function of the qualities obtained by all parties as

$$
P_{i}^{*}\left(Q_{i}, Q_{j}, Q\right)
$$

Pre-merger, the innovation investment problem of firm $\mathrm{i}$ is

$$
\operatorname{Max}_{I_{i}} P_{i}^{*}\left(Q_{i}, Q_{j}, Q\right) D_{i}\left(P_{i}^{*}, P_{j}^{*}, P^{*} ; Q_{i}, Q_{j}, Q\right)-I_{i}
$$

The corresponding first order condition is

$$
\left[P_{i}^{*} \frac{\partial D_{i}}{\partial Q_{i}}-1\right]+D_{i}^{*} \frac{d P_{i}^{*}}{d Q_{i}}+P_{i}^{*}\left[\frac{\partial D_{i}}{\partial P_{i}^{*}} \frac{d P_{i}^{*}}{d Q_{i}}+\frac{\partial D_{i}}{\partial P_{j}^{*}} \frac{d P_{j}^{*}}{d Q_{i}}+\frac{\partial D_{i}}{\partial P^{*}} \frac{d P^{*}}{d Q_{i}}\right]=0
$$

Using the envelope theorem, we have 


$$
\left[P_{i}^{*} \frac{\partial D_{i}}{\partial Q_{i}}-1\right]+P_{i}^{*}\left[\frac{\partial D_{i}}{\partial P_{j}^{*}} \frac{d P_{j}^{*}}{d Q_{i}}+\frac{\partial D_{i}}{\partial P^{*}} \frac{d P^{*}}{d Q_{i}}\right]=0
$$

The first term in bracket is the first order condition that we obtained when prices were exogenous. The second term captures the (effect of an increase in quality on the equilibrium prices of the rival firms and hence on the demand for the product of firm i. If, as one would generally expect, an increase in the quality of product I leads to a decrease in the equilibrium prices of other products, then this second term is negative, i.e. a single product firm will invest less in innovation if prices are endogenous than if they are fixed.

We can now consider the post-merger situation. The maximisation problem is

$$
\begin{gathered}
\operatorname{Max}_{I_{A}, I_{B}} P_{A}^{*}\left(Q_{A}, Q_{B}, Q\right) D_{A}\left(P_{A}^{*}, P_{B}^{*}, P^{*} ; Q_{A}, Q_{B}, Q\right)+P_{B}^{*}\left(Q_{B}, Q_{A}, Q\right) D_{B}\left(P_{B}^{*}, P_{A}^{*}, P^{*} ; Q_{B}, Q_{A}, Q\right)-I_{A} \\
-I_{B}
\end{gathered}
$$

The first order condition for $I_{A}$ is:

$$
\begin{aligned}
\frac{\partial Q_{A}}{\partial I_{A}} \frac{d P_{A}^{*}}{d Q_{A}}\left[D_{A}+\right. & \left.P_{A}^{*} \frac{\partial D_{A}}{\partial P_{A}}\right]+P_{A}^{*} \frac{\partial Q_{A}}{\partial I_{A}}\left[\frac{\partial D_{A}}{\partial P_{B}} \frac{d P_{B}^{*}}{d Q_{A}}+\frac{\partial D_{A}}{\partial P} \frac{d P^{*}}{d Q_{A}}+\frac{\partial D_{A}}{\partial Q_{A}}\right]+\frac{\partial Q_{A}}{\partial I_{A}} \frac{d P_{B}^{*}}{d Q_{A}}\left[D_{B}+P_{B}^{*} \frac{\partial D_{B}}{\partial P_{B}}\right] \\
& +P_{B}^{*} \frac{\partial Q_{A}}{\partial I_{A}}\left[\frac{\partial D_{B}}{\partial P_{A}} \frac{d P_{A}^{*}}{d Q_{A}}+\frac{\partial D_{B}}{\partial P} \frac{d P^{*}}{d Q_{A}}+\frac{\partial D_{B}}{\partial Q_{A}}\right]-1=0
\end{aligned}
$$

It is important to be clear as to the comparison we now engage into. We start by assuming that we are at the pre-merger level of prices and at the pre-merger level of investment, so that the pre-merger FOCs for both the investment decision and the pricing decisions are satisfied and evaluate the postmerger investment FOC at that point. Because the price setting FOC is satisfied, our post-merger FOC can be rewritten as:

$$
P_{A}^{*} \frac{\partial Q_{A}}{\partial I_{A}}\left[\frac{\partial D_{A}}{\partial P_{B}} \frac{d P_{B}^{*}}{d Q_{A}}+\frac{\partial D_{A}}{\partial P} \frac{d P^{*}}{d Q_{A}}+\frac{\partial D_{A}}{\partial Q_{A}}\right]+P_{B}^{*} \frac{\partial Q_{A}}{\partial I_{A}}\left[\frac{\partial D_{B}}{\partial P_{A}} \frac{d P_{A}^{*}}{d Q_{A}}+\frac{\partial D_{B}}{\partial P} \frac{d P^{*}}{d Q_{A}}+\frac{\partial D_{B}}{\partial Q_{A}}\right]-1=0
$$

Comparing the FOCs before and after merger we see that the post-merger FOC has an added set of terms. So the first term minus 1 would be equal to zero but not the second term. The sign of this second term will then determine whether investment incentives are higher after the merger. The sign of this term is the sign of the bracketed part of it. The first term in brackets is positive: an increase in the quality of good A leads to a higher price for A, and this increases the demand for product B. By contrast, the second term is negative: a higher quality for A leads to lower prices at non-merging entities and this decreases the demand for product $\mathrm{B}$. The third term is an old acquaintance: it is the direct cannibalisation of B's sales due to the improvement of the quality of product A. This effect already existed in our model with fixed prices. As before, it leads to less investment in innovation. Hence the additional effect of allowing for endogenous price is the sum of the other two terms in the bracket. As those two terms have opposite signs, can we say anything about the likely net effect? It seems reasonable to assume that the indirect effect through the price of non-merging parties would become relatively more important as the number and significance of these parties increases compared to the significance of merging party B. If that conjecture is correct then introducing price endogeneity would be more likely to lead to lower innovation by the merging parties when the merging parties account for a relatively low share of the industry.

So far, we have compared the FOCs at the pre-merger price and investment equilibrium. However, we also know that, for any level of investment, the equilibrium prices of the merging parties 
will be higher after the merger. The main effect of this price effect is to increase the profit margins of the merging parties. As the result, the value of gaining extra sales by improving the product is higher post-merger. This implies higher investment in innovation.

Overall then, introducing endogenous pricing adds to main effects to the merger: an own price effect that leads to higher innovation and an indirect effect on the price of other parties which can either increase or decrease innovation, with a decrease more likely if the merging parties are relatively small. 
Appendix B: Mergers

Bayer's recent $M \& A$ activity

\begin{tabular}{|c|c|c|c|}
\hline Year & $\begin{array}{l}\text { Company } \\
\text { purchased/target }\end{array}$ & $\begin{array}{l}\text { Main } \\
\text { Geographical } \\
\text { markets involved }\end{array}$ & $\begin{array}{l}\text { Product/Main activity of } \\
\text { target company }\end{array}$ \\
\hline 2015 & SeedWorks India Pvt. Ltd & India & $\begin{array}{l}\text { Breeding, production and } \\
\text { marketing of hybrid seeds of } \\
\text { tomato, hot pepper, okra and } \\
\text { gourds }\end{array}$ \\
\hline 2015 & $\begin{array}{l}\text { proPlant Gesellschaft für } \\
\text { Agrar- und } \\
\text { Umweltinformatik mbH }\end{array}$ & Germany & $\begin{array}{l}\text { Agricultural digitalization: } \\
\text { provider of plant health } \\
\text { diagnosis and infection level } \\
\text { warning service }\end{array}$ \\
\hline 2014 & Biagro Group & Argentina, Brazil & $\begin{array}{l}\text { Production and distribution of } \\
\text { biological seed treatment } \\
\text { solutions }\end{array}$ \\
\hline 2014 & Granar S.A. & Paraguay & $\begin{array}{l}\text { Breeding, production and } \\
\text { marketing of improved seed } \\
\text { (especially soybean seed) } \\
\text { adapted to the growing } \\
\text { conditions in subtropical } \\
\text { regions }\end{array}$ \\
\hline 2014 & $\begin{array}{l}\text { E. I. DuPont de Nemours } \\
\text { and Company } \\
\text { (acquisition of land } \\
\text { management assets) }\end{array}$ & $\begin{array}{lr}\text { United } & \text { States. } \\
\text { Canada, } & \text { Mexico, } \\
\text { Australia, } & \text { New } \\
\text { Zealand } & \end{array}$ & $\begin{array}{l}\text { Forestry and range \& pasture } \\
\text { business segments }\end{array}$ \\
\hline 2013 & $\begin{array}{l}\text { PROPHYTA Biologischer } \\
\text { Pflanzenschutz GmbH }\end{array}$ & Germany & $\begin{array}{l}\text { Supply of biological crop } \\
\text { protection products }\end{array}$ \\
\hline 2013 & $\begin{array}{ll}\text { Wehrtec } & \text { Tecnologia } \\
\text { Agricola Ltda } & \end{array}$ & Brazil & Production of soybean seed \\
\hline 2013 & Agricola Wehrmann Ltda & Brazil & Soybean business \\
\hline 2013 & $\begin{array}{l}\text { Melhoramento Agropastoril } \\
\text { Ltda }\end{array}$ & Brazil & Soy Germplasm Bank \\
\hline
\end{tabular}




\begin{tabular}{|c|c|c|c|}
\hline 2013 & FN Semillas S.A. & Argentina & $\begin{array}{l}\text { Breeding, production and } \\
\text { marketing of improved } \\
\text { soybean seeds }\end{array}$ \\
\hline 2012 & Abbott \& Cobb Inc. & $\begin{array}{lr}\text { United } & \text { States, } \\
\text { Mexico, } & \text { Australia } \\
\text { and Asia } & \end{array}$ & $\begin{array}{l}\text { Watermelon and melon seed } \\
\text { business }\end{array}$ \\
\hline 2012 & AgraQuest, Inc. & $\begin{array}{l}\text { United States, } \\
\text { Global }\end{array}$ & $\begin{array}{l}\text { Supply of innovative } \\
\text { biological pest management } \\
\text { solutions based on natural } \\
\text { microorganisms }\end{array}$ \\
\hline 2011 & $\begin{array}{l}\text { Hornbeck Seed Company, } \\
\text { Inc. }\end{array}$ & United States & $\begin{array}{l}\text { Supply of soybean, rice, and } \\
\text { wheat varieties; in-house } \\
\text { soybean } \\
\text { breeding program and a } \\
\text { proprietary } \\
\text { soybean germplasm. }\end{array}$ \\
\hline 2011 & Raps GbR & Germany & $\begin{array}{l}\text { Oilseed rape seed business } \\
\text { and breeding material }\end{array}$ \\
\hline 2009 & Athenix Corporation & United States & $\begin{array}{l}\text { Herbicide tolerance and insect } \\
\text { control trait development } \\
\text { platform, particularly for corn } \\
\text { and soybeans }\end{array}$ \\
\hline 2007 & $\begin{array}{l}\text { Stoneville Pedigreed Seed } \\
\text { Company }\end{array}$ & United States & Cotton seed production \\
\hline 2006 & $\begin{array}{l}\text { California Planting Cotton } \\
\text { Seed Distributors, Inc. }\end{array}$ & United States & $\begin{array}{l}\text { Development, production, } \\
\text { and distribution of cotton } \\
\text { planting seeds }\end{array}$ \\
\hline 2006 & Reliance Genetics LLC & United States & Cotton production \\
\hline 2005 & $\begin{array}{l}\text { Associated Farmers } \\
\text { Delinting, Inc. (acquisition } \\
\text { of intangible assets and the } \\
\text { property, plant and } \\
\text { equipment required for the } \\
\text { production of cotton seeds) }\end{array}$ & United States & Cotton seed production \\
\hline 2004 & Gustafson & $\begin{array}{l}\text { United States, } \\
\text { Canada and Mexico }\end{array}$ & $\begin{array}{l}\text { Manufacture and marketing } \\
\text { of seed treatment products } \\
\text { and related technical } \\
\text { equipment. }\end{array}$ \\
\hline 2004 & $\begin{array}{l}\text { Bilag Industries Private Ltd, } \\
\text { India (shares buy-back in a } \\
\text { joint venture) }\end{array}$ & India & $\begin{array}{l}\text { Manufacture } \\
\text { agrochemicals }\end{array}$ \\
\hline
\end{tabular}




\begin{tabular}{|c|c|c|c|}
\hline 2002 & $\begin{array}{l}\text { Aventis } \quad \text { CropScience } \\
\text { Holding S.A. }\end{array}$ & Global & $\begin{array}{l}\text { Crop protection, } \\
\text { biotechnology and } \\
\text { agrochemical specialties }\end{array}$ \\
\hline 2001 & $\begin{array}{l}\text { Syngenta AG } \\
\text { (acquisition of corn } \\
\text { herbicide MIKADO }{ }^{\circledR)}\end{array}$ & Europe & Crop protection and herbicide \\
\hline 2000 & $\begin{array}{l}\text { Novartis } \\
\text { (acquisition of FLINT }{ }^{\circledR} \text { line } \\
\text { of crop fungicides) }\end{array}$ & Global & Crop protection \\
\hline 2000 & $\begin{array}{l}\text { Misung Ltd. } \\
\text { (acquisition of remaining } \\
\text { interest of Joint Venture) }\end{array}$ & South Korea & $\begin{array}{l}\text { Development and marketing } \\
\text { of a wide range of crop } \\
\text { protection products }\end{array}$ \\
\hline 1999 & pbi Home \& Garden Limited & United Kingdom & $\begin{array}{l}\text { Supply of plant protection } \\
\text { products and Fertilisers for } \\
\text { amateur gardeners }\end{array}$ \\
\hline 1998 & $\begin{array}{l}\text { Zeneca } \\
\text { (acquisition of seed } \\
\text { treatment business) }\end{array}$ & United Kingdom & Crop protection \\
\hline
\end{tabular}




\begin{tabular}{|c|c|c|c|}
\hline Year & $\begin{array}{l}\text { Company } \\
\text { purchased/tar } \\
\text { get }\end{array}$ & $\begin{array}{l}\text { Main } \\
\text { Geographical } \\
\text { markets } \\
\text { involved }\end{array}$ & Product/Main activity of target company \\
\hline 2016 & Vitalfields & Europe & $\begin{array}{l}\text { Digital agriculture innovation and farm } \\
\text { management software }\end{array}$ \\
\hline 2016 & $\begin{array}{l}\text { TargetGene } \\
\text { (acquisition of } \\
\text { undisclosed } \\
\text { equity stake) }\end{array}$ & Israel & Genome-editing technologies \\
\hline 2014 & $\begin{array}{l}\text { BioAgAllicanc } \\
\text { e }\end{array}$ & United States & $\begin{array}{l}\text { Alliance with Novozyme to work on } \\
\text { microbial solutions }\end{array}$ \\
\hline 2013 & Agradis, Inc. & United States & $\begin{array}{l}\text { Development of sustainable agricultural } \\
\text { solutions. Includes a collection of microbes } \\
\text { that can improve crop productivity }\end{array}$ \\
\hline 2013 & $\begin{array}{l}\text { Rosetta Green } \\
\text { Ltd }\end{array}$ & Israel & $\begin{array}{l}\text { Identification and use of unique genes to } \\
\text { guide key processes in major crops } \\
\text { including corn, soybeans and cotton }\end{array}$ \\
\hline 2013 & $\begin{array}{l}\text { Grass Roots } \\
\text { Biotechnology }\end{array}$ & United States & $\begin{array}{l}\text { Gene expression and other agriculture } \\
\text { technologies }\end{array}$ \\
\hline 2013 & $\begin{array}{l}\text { Dieckmann } \\
\text { GmbH \& CO. } \\
\text { KG }\end{array}$ & Germany & Breeding of oilseed rape and rye seeds \\
\hline 2013 & $\begin{array}{l}\text { The Climate } \\
\text { Corporation }\end{array}$ & United States & Weather data analysis \\
\hline 2012 & $\begin{array}{l}\text { Precision } \\
\text { Planting, Inc. }\end{array}$ & United States & Planting technology development \\
\hline 2012 & Beeologics & Israel & $\begin{array}{l}\text { Development of biological tools to provide } \\
\text { targeted control of pests and diseases }\end{array}$ \\
\hline 2011 & $\begin{array}{l}\text { Divergence, } \\
\text { Inc. }\end{array}$ & United States & $\begin{array}{l}\text { Research and development services for } \\
\text { genomics and informatics on agriculture } \\
\text { and infectious diseases, as well as products } \\
\text { for the control of parasites }\end{array}$ \\
\hline 2011 & Pannon Seeds & Hungary & Seed processing plant \\
\hline 2010 & Anasac & Chile & Corn and soybean processing plant \\
\hline 2009 & Westbred & United States & Focus on wheat germplasm \\
\hline
\end{tabular}




\begin{tabular}{|c|c|c|c|}
\hline 2009 & $\begin{array}{l}\text { MDM } \\
\text { (acquisition of } \\
\text { equity stake) }\end{array}$ & Brazil & Cotton seed business \\
\hline 2008 & $\begin{array}{l}\text { Aly } \\
\text { Participacoes } \\
\text { Ltda }\end{array}$ & Brazil & $\begin{array}{l}\text { Sugarcane breeding and research and } \\
\text { development in plant applied genomics }\end{array}$ \\
\hline 2008 & Marmot, S.A. & $\begin{array}{l}\text { Guatemala, } \\
\text { Central America, } \\
\text { and South } \\
\text { America }\end{array}$ & $\begin{array}{l}\text { Hybrid corn seed production and provider } \\
\text { of corn, sorghum, forage sorghum, } \\
\text { soybeans, and pastures (grass-type seeds) }\end{array}$ \\
\hline 2008 & $\begin{array}{ll}\text { De } & \text { Ruiter } \\
\text { Seeds } & \text { Group } \\
\text { B.V. } & \end{array}$ & Europe, Global & $\begin{array}{l}\text { Breeding and production of hybrid } \\
\text { vegetable seeds (including crops such as } \\
\text { tomatoes, cucumbers, melons, peppers and } \\
\text { rootstock). Provider of products to growers } \\
\text { within the protected-culture vegetable seed } \\
\text { market. }\end{array}$ \\
\hline 2008 & $\begin{array}{l}\text { Evogene Ltd } \\
\text { (acquisition of } \\
\text { equity stake) }\end{array}$ & Israel & Focus on crop productivity \\
\hline 2007 & $\begin{array}{l}\text { Agroeste } \\
\text { Sementes }\end{array}$ & Brazil & Hybrid corn seed production \\
\hline 2007 & $\begin{array}{l}\text { Delta and Pine } \\
\text { Land Company }\end{array}$ & United States & $\begin{array}{l}\text { Commercial breeding, production and } \\
\text { marketing of cotton planting seed. Also } \\
\text { breeding, production and marketing of } \\
\text { soybean planting seed. }\end{array}$ \\
\hline 2005 & $\begin{array}{l}\text { Emergent } \\
\text { Genetics, Inc. }\end{array}$ & $\begin{array}{l}\text { United States, } \\
\text { India }\end{array}$ & Cotton seed business \\
\hline 2005 & $\begin{array}{l}\text { Icoria } \\
\text { (agricultural } \\
\text { division) }\end{array}$ & United States & Biotechnologies \\
\hline 2005 & Seminis, Inc. & $\begin{array}{l}\text { United States, } \\
\text { Global }\end{array}$ & $\begin{array}{l}\text { Development, growth and marketing of } \\
\text { fruit and vegetable seeds }\end{array}$ \\
\hline 2004 & $\begin{array}{l}\text { Channel Bio } \\
\text { Corporation }\end{array}$ & United States & $\begin{array}{l}\text { Production and marketing of seeds } \\
\text { (specialising in corn) }\end{array}$ \\
\hline 1998 & $\begin{array}{l}\text { Plant Breeding } \\
\text { International } \\
\text { Cambridge } \\
\text { Ltd. and PBI } \\
\text { Saatzucht } \\
\text { GmbH }\end{array}$ & Europe & $\begin{array}{l}\text { Production and marketing of new and } \\
\text { improved crop varieties. Includes } \\
\text { significant breeding programs for winter } \\
\text { wheat, barley, oil seed rape, beans, peas and } \\
\text { potato }\end{array}$ \\
\hline
\end{tabular}




\section{Dupont Pioneer's recent M\&A activity}

Table . Mergers and acquisitions of DuPont Pioneer (1995-2015)

\begin{tabular}{lllll}
\hline & $\mathbf{1 9 9 5 - 2 0 0 5}$ & $\mathbf{2 0 0 6 - 2 0 1 0}$ & $\mathbf{2 0 1 1 - 2 0 1 5}$ & Subtotal \\
\hline Number of Deals & 1 & 10 & 1 & $\mathbf{1 2}$ \\
\hline $\begin{array}{l}\text { of which } \\
\text { seeds, agriculture products (crops, }\end{array}$ & & & \\
$\begin{array}{l}\text { cereals, etc.) } \\
\text { traditional Fertilisers / pesticides / }\end{array}$ & 7 & 1 & 9 \\
$\begin{array}{l}\text { chemicals } \\
\text { biotech (pesticides, other) }\end{array}$ & - & & - \\
others (IT software) & - & 1 & - & 1 \\
Total transaction volume*, USDm n/a & n/a & - & 2 \\
\hline *based on publicly disclosed & & & \\
information & & &
\end{tabular}

Pioneer Hi-Bred International was acquired by El DuPont de Nemours \& Co in 1999. Since then this division manages the agriculture business of Dupont. By the end of 2014 the annual net sales figure of the division reached almost USD 11.3bn. Unlike its rivals, mostly Monsanto and Syngenta, Pioneer Hi-Bred was less acquisitive. We identified 11 deals where Pioneer was buyer of the seeds assets (Table 3). Most acquisitions were announced in 2008-2011 and completed in 20102014. Two of the acquisitions are software deals (Farms Technology,LLC which provides Internetbased procurement applications and Map Shots, Inc., which is active in precision agriculture software sales).

The majority of DuPont Pioneer's transactions (9 out of 11 deals) are acquisitions of seeds producers: two of them based in India, one in South Africa, and the rest were US incorporated seed companies. In 2008 DuPont launched the PROaccess platform which enables the company to sell its seeds to more growers through a network of distributors via special distribution agreements. Over the period 2008-2011, Pioneer acquired many of its partners of PROaccess platform including AgVenture, Hoegemeyer Hybrids, NuTech Seed, Seed Consultants, Terral Seed (all deal announced in 2010), and Doebler's Pennsylvania Hybrids (2011). No transaction data was disclosed on any of DuPont's deals.

Interestingly, Pioneer Hi-Bred was more involved in divestments than in acquisitions over the period under review. In 2014 the company sold pesticides business assets to its rivals such as Bayer, Sumimoto Chemicals, Mitsui, S\&W Seed, and Syngenta. Over the last 5 years Pioneer continued to sell pesticides and chemical assets while acquiring mostly seeds companies. 


\section{Syngenta's recent M\&A activity}

Table . Mergers and acquisitions of Syngenta (2000-2015)

\begin{tabular}{|c|c|c|c|c|}
\hline & $2000-2005$ & 2006-2010 & 2011-2015 & Subtotal \\
\hline Number of Deals & 6 & 16 & 8 & 30 \\
\hline of which & & & & \\
\hline $\begin{array}{l}\text { seeds, agriculture products (crops, } \\
\text { cereals, etc.) }\end{array}$ & 5 & 11 & 4 & 20 \\
\hline traditional Fertilisers / pesticides / & & & & \\
\hline chemicals & - & - & - & - \\
\hline biotech (pesticides, other) & - & 1 & 2 & 3 \\
\hline $\begin{array}{l}\text { others (IT, peat, distribution, animal } \\
\text { feed, etc.) }\end{array}$ & 1 & 4 & 2 & 7 \\
\hline Total transaction volume*, USDm & 654,28 & 607,62 & 741,57 & 2003,47 \\
\hline
\end{tabular}

Syngenta emerged as a spin-off, after the merger between the agrochemical business of pharmaceutical corporation AstraZeneca and the seeds and crop protection business of Novartis. Between 2000 and 2015 Syngenta continued steady M\&A activity; however the company pursued smaller size targets compared to Monsanto. Its biggest deal was acquisition of a Belgian biotech company Devgen (closed in 2014) for USD 512,6m. 


\section{Vilmorin's recent $M \& A$ activity}

\begin{tabular}{|c|c|c|c|}
\hline 2010 & SuTarim & Turkey & Vegetable Seeds \\
\hline 2010 & Trinity Growers & UK & Vegetable Seeds \\
\hline 2010 & Mesa Maize & United States & Vegetable Seeds \\
\hline 2010 & Trio Research & United States & Field Seeds \\
\hline 2010 & Sementes Guerra & Brazil & $\begin{array}{l}\text { Maize assets included in Limagrain } \\
\text { Guerra do Brasil }\end{array}$ \\
\hline 2010 & Brasmilho & Brazil & $\begin{array}{l}\text { Maize and sorghum seeds, } 100 \% \\
\text { acquisition completed in } 2012\end{array}$ \\
\hline 2010 & Atash Seeds & India & Bought additional $38.74 \%$ share \\
\hline 2010 & Trigen Seeds & United States & Wheat research program bought \\
\hline 2010 & Arcadia Biosciences & United States & Field Seeds \\
\hline 2010 & BSF Ag Research & United States & Field seeds \\
\hline 2010 & Genesis Seed Research & United States & Field seeds \\
\hline 2010 & Clovis Matton & Belgium & Field seeds \\
\hline 2011 & VCC Japan & Japan & \\
\hline 2012 & Boreal Plant Breeding & Finland & $\begin{array}{l}\text { Partnership, breeding of field seeds for } \\
\text { Northern Europe }\end{array}$ \\
\hline 2012 & Genetica Agricola & Brazil & Field seeds \\
\hline 2012 & Campbell Soup Group & United States & $\begin{array}{l}\text { Tomato and pepper breeding and sales } \\
\text { business }\end{array}$ \\
\hline 2012 & Century Seeds & India & Vegetable seeds \\
\hline 2012 & Eurodur & France & Field seeds \\
\hline 2013 & Link Seed & South Africa & Maize seeds \\
\hline 2013 & Bisco Bio Sciences & India & Corn, sorghum, millet, and rice \\
\hline 2013 & Geneseed & Brazil & Field seeds \\
\hline 2013 & KSP & Brazil & Field seeds \\
\hline 2013 & CCGL & Brazil & Field seeds \\
\hline 2013 & Shamrock & $\begin{array}{l}\text { US and } \\
\text { Mexico }\end{array}$ & Vegetable seeds \\
\hline 2013 & Eureka Seeds & United States & Field seeds \\
\hline 2014 & Seed Co & Zimbabwe & Field seeds \\
\hline 2014 & Seed Asia & Thailand & Field seeds \\
\hline 2014 & Greenland & Poland & Garden Products \\
\hline
\end{tabular}




\section{PART V: Country Reports}

\section{Chapter 1: Brazil 2290}

\section{Murilo Lubambo}

\subsection{The Food Value Chain}

Brazil plays a major role in the world food value chain, as one of the greatest producers of agricultural and livestock products. It is the world `s largest supplier of coffee beans, oranges and sugar cane. It has been among the top five leading producers and suppliers of corn, dry beans, soybeans, tropical fruits, meat, milk and beer. ${ }^{2291}$

Brazil went through a liberalisation programme in the early 90s. Despite that, some claim that the Brazilian economy remains comparatively closed compared to other emerging economies: its integration in Global Value Chains is lower than the average. ${ }^{2292}$ This may be explained by the persistence of a strategy of industrial policy which promotes domestic production of inputs in key sectors and intermediate products, relying on subsidies and local content rules.

The primary sector of the economy accounts for 5.2\% of the Brazilian GDP. ${ }^{2293}$ Brazilian agriculture is highly developed in certain geographical areas, supplying the internal and export markets. Some recent reports have assessed the performance of Brazilian agriculture. ${ }^{2294}$ According to the OECD, "Brazil is projected to maintain its role as a leading supplier to international food and agriculture markets over the next decade while also meeting the needs of an expanding and increasingly wealthy population."2295 There is strong institutional support to the development of agriculture research and technology through the public entity EMBRAPA. ${ }^{229}$ In other areas, however, agriculture remains inefficient and without any expressive technical developments. The large-scale farming is generally carried out in very large estates. Reports say that around $45 \%$ of rural land is concentrated in estates over 1000 hectares (ha), which represents less that $1 \%$ of total number of rural estates. ${ }^{2297}$

The export-oriented markets attract a great deal of intermediaries in the agriculture wholesale and trading sectors. The concerns about the appeal of the products abroad has naturally led to the development of certain voluntary, higher quality standards. In general, the best products (eg fruits from the Northeast of the country) end up in developed markets. The expansion of the agricultural frontier towards the Equatorial forest and the Northeast of the country raises concerns in terms of

\footnotetext{
${ }^{2290}$ This fiche reflects the law as it was on $31^{\text {st }}$ August 2017 and consider events which took place until this date.

${ }^{2291} \mathrm{http} / / /$ www.fao.org/faostat/en/\#rankings/countries_by_commodity

${ }^{2292}$ Araújo, S. and D. Flaig (2016), "Quantifying the Effects of Trade Liberalisation in Brazil: A Computable General Equilibrium Model (CGE) Simulation”, OECD Economics Department Working Papers, No. 1295, OECD Publishing, Paris. http://dx.doi.org/10.1787/5jm0qwmff2kf-en

${ }^{2293} \mathrm{http}: / /$ databank. worldbank.org/data/reports.aspx source=2\&series=NV.AGR.TOTL.ZS\&country=BRA

${ }^{2294}$ OECD (2015), Innovation, Agricultural Productivity and Sustainability in Brazil, OECD Food and Agricultural Reviews, OECD Publishing Paris. DOI: http://dx.doi.org/10.1787/9789264237056-en; OECD (2015), "Brazil”, in Agricultural Policy Monitoring and Evaluation 2015, OECD Publishing, Paris

2295 OECD/Food and Agriculture Organization of the United Nations (2015), OECD-FAO Agricultural Outlook 2015, OECD Publishing, Paris. http://dx.doi.org/10.1787/agr_outlook-2015-en Chapter 2 Brazilian agriculture: Prospects and challenges p. 61

2296 https://www.embrapa.br/en/quem-somos

${ }^{2297}$ https://www.oxfam.org.br/sites/default/files/arquivos/relatorio-terrenos_desigualdade-brasil.pdf p. 8
} 
environmental sustainability. The market for inputs is key to keep up with this expansion. Producers of agricultural machines, seed developers and multipliers, livestock genetics, feed and fertilising companies, all play a role in this process.

There is a striving food processing industry, concentrated in South and Southeast of the country. In this intermediary sector, important domestic and the conglomerate multinational groups interact. In some sectors (orange juice and meat) there is a high degree of verticalisation. The whole agribusiness chain (considering inputs, agriculture and livestock, industry and related services) accounts for $21.35 \%$ of the GDP. ${ }^{2298}$

Moreover, large national and international groups are active in the wholesale and retail markets. In 2015, the Brazilian food retail market has achieved R \$ 315.8 billion (around US\$ 80 billion) in revenues, which represent $5.89 \%$ of the GDP. ${ }^{2299}$ The increase of the medium class meant a diversification of the diet of the average Brazilian. More products were in demand and the industry and retail have had to adapt to new choices and tastes.

There has been a special concern with family, small sized agricultural production and how to integrate those in the value chains. ${ }^{2300}$ It represents around $70 \%$ of the food consumption of the internal market. ${ }^{2301}$ Land reform is a pressing and ongoing concern. ${ }^{2302}$ The support of the Worker's Party ("PT" in the Portuguese acronym) by the Landless Workers Movement ("MST" in the Portuguese acronym) meant a relative decrease in the number of protests. ${ }^{2303}$ Despite the peak in 2003-2006, it fell in 2007-2010. ${ }^{2304}$ The recent political instability is likely to raise again the level of tension and may lead to more invasions or occupations of land owned by companies, for instance, to protest against transgenic seeds and pesticides. ${ }^{2305}$

As to the fight against poverty, the Zero Hunger programme was the first landmark social programme of the former Worker`s Party government. It consisted initially in a national wide set of policies to eradicate hunger in the territory. Some of its components were progressively, and more successfully, translated into the programme Bolsa Familia, which quickly gained prominence. It mainly consists in a monthly allowance given to the women, heads of poor families in need, provided that they fulfill some conditions (eg keep children at school, pre-natal care...). The Bolsa Familia programme was key to consolidate the Worker`s Party label as a socially oriented political group. Discounting some excesses in the marketing of the policies in order to garner prestige and political gains, its merits were widely recognized from a technical perspective, nationally and internationally. In fact, it achieved consistent results in line with the recommendations of the United Nations Food and Agriculture Organisation. ${ }^{2306}$ FAO is currently headed by a Brazilian, Dr. Jose Graziano, former Extraordinary Minister for Food Security. He was elected and re-elected with the support of several countries, which recognised in him the merits of the Brazilian policies.

\footnotetext{
2298 http://www.cepea.esalq.usp.br/upload/kceditor/files/Pib_Cepea_1994_2015_V2.xlsx

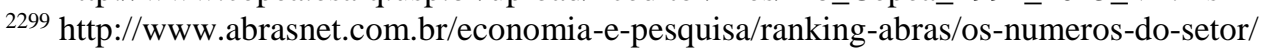

${ }^{2300}$ Formerly a Ministry, the Secretary for Family Farming and Rural Development is now located in the Ministry of the Civil Cabinet, which is closer to the Office of the President.

2301 http://www.brasil.gov.br/economia-e-emprego/2015/07/agricultura-familiar-produz-70-dos-alimentos-consumidospor-brasileiro

2302 The National Institute for Colonisation and Agrarian Reform (INCRA), also linked to the Civil Cabinet, is responsible to carry out land reform in Brazil.

${ }^{2303} \mathrm{http}$ ://oglobo.globo.com/politica/mst-governo-lula-teve-20-menos-de-invasoes-de-terra-que-de-fh-2832226

$2304 \mathrm{https} / /$ www.oxfam.org.br/sites/default/files/arquivos/relatorio-terrenos_desigualdade-brasil.pdf

${ }^{2305} \mathrm{http}$ ://g1.globo.com/pernambuco/noticia/2013/10/agricultores-ocupam-unidade-de-empresa-que-produztransgenicos.html

${ }^{2306}$ See the FAO report on the Brazilian initiatives http://www.fao.org/3/a-i5335o.pdf
} 


\subsection{Regulatory Framework of the Food Sector in Brazil}

\subsubsection{General Introduction}

The justifications for the existence of regulation in the food sector are varied and go much beyond the inability of the marketplace to deal with structural problems. ${ }^{2307}$

Agriculture is a sensitive market given its specific characteristics, eg the risk of crop destruction and the exogenous determination of prices. The cyclical nature of production, the longterm response that is needed to increase demand, subject to sudden and dramatic supply shocks requires some level of government intervention and coordination in order to avoid crises of over or under-production.

Other segments of the food chain require regulation or intervention. Food processing requires the definition of health and hygiene standards. Retail requires regulation for reasons of information asymmetry of final consumers. Inputs, such as seeds and pesticides, require safety standards. This flows under the umbrella of the regulations of risk and protection of vulnerable parties. It involves decisions on how to evaluate information, how to balance costs and benefits and how to value, manage and assess risks. ${ }^{2308}$

One could argue that in developing or emergent economies, such as Brazil, regulation and competition in the agriculture and food chain sectors should be carefully designed and analysed, given their impact in nutrition and health for the population that cannot afford the importation of food products. It could be argued that regulation should be adequate to the particular situation and development needs of the country. This forms part of the government duty to fulfil its social commitments to ensure the right to food. In this sense, access to food and water should be a key concern for regulators. Issues of unequal bargaining power, such as in the case of small farmers and cooperatives, may also require special legislation.

\subsubsection{The legal nature of the Regulation of the food sector}

In fact, the Brazilian Constitution recognises the right to food as a fundamental right, ${ }^{2309}$ and this is explicit since 2010. While this recognition was the result of the approval of the Constitutional Amendment $\mathrm{n}$. 64, from a bill introduced in 2003, a fundamental right to food (and water) could always be derived from the principle of human dignity, the right to life and the right to health. ${ }^{2310}$ The Constitution also provides the legal basis for the regulation of food supply and stocks and the inspection of food and beverages. ${ }^{2311}$ The Constitution and the Civil Code ensure freedom of contract and the Consumer Code establishes special rights to consumers in contracts.

\footnotetext{
${ }^{2307}$ For a classic text, see Stephen Breyer, Regulation and Its Reform (Reprint edition, Harvard University Press 1984) Chapter I.

${ }^{2308}$ For an exposition see Viscusi, Regulating the Regulators, University of Chicago Law Review.

Vol. 63, No. 4. (Autumn, 1996), pp. 1423-1461.

${ }^{2309}$ See art. 5, art. 6. See also art. 7, IV, art. 208, VII, art. 227 (caput),

${ }^{2310}$ Lubambo de Melo, Murilo Otavio "Direito Fundamental à Água” in Anais do II Congresso Jurídico de Estudantes de Direito, 2003, Recife, 2003.

${ }^{2311}$ See art. 23, VIII and art. 200 VI.
} 
The result of the liberalisation programme was the creation of a model of regulatory reform based on independent regulatory agencies, set up from 1998. They exert regulatory powers in each of the areas reserved for them. In the health and food safety area, the main body is the Brazilian Health Regulatory Agency - ANVISA, the powers of which are described later.

The different aspects of the regulation of the food chain in Brazil are expressed in the form of infra-constitutional norms such as laws, decrees, ministerial regulations and agency resolutions. The federal norms must be published in Diário Oficial (Official Gazette) and most of them are available online. The system of federalism also leaves to States and municipalities the regulation of same aspects of the production and consumption with a local interest.

Brazil is also part of Mercosur, together with Argentina, Paraguay, Uruguay and Venezuela (currently suspended). It is an imperfect customs union, with a common external-tariff on nonmember countries, despite several exceptions. This institutional set-up enhances cooperation in terms of agricultural policy and provides for an exchange of regulatory initiatives. The respective ministers of agriculture have a forum to meet in the political level, whereas working sub-group $\mathrm{n} 8$ provides a technical arena for discussions. ${ }^{2312}$ However, Mercosur`s normative reach and impact in relation to internal regulations for food is rather limited, except indirectly, by means of the treaties related to consumer protection and intellectual property.

\subsubsection{Stakeholders and Policy Framing}

Several players in the food chain interact in the process of setting up the regulation of the sector. It is indeed necessary to know which are the key interests influencing regulators and how interests should be balanced and taken into account. ${ }^{2313}$

The economic players in the market (farmers, cooperatives, food processors/manufacturers, industrial groups, traders and retailers) are the primary addressees of the regulations. The government, with its bureaucratic institutions and agencies, has its own policy interests and agenda. One could add the role of the national confederations of agriculture, industry and services. More specific to food products, the Brazilian Sugarcane Industry Association, the Association of Exporters of Citric Juices and the Brazilian Association of Slaughterhouses are examples of active and politically influential entities in the primary sector. The Brazilian Association of Food Industry (ABIA) and the Brazilian Association of Supermarkets (ABRAS) are powerful associations that gather interests and lobby for the regulation of their sectors. Small farmer's associations were important stakeholders in relation to land access and seeds, especially during the time when the Worker`s Party ruled. Civil entities, such as Proteste and the Brazilian Institute for Consumer Defence (IDEC), are active in consumer rights and constantly monitor and pressure for an adequate regulation of labelling.

Lobbying is exerted towards the activities of the Parliament (for bills), of the executive power (for decrees and ministerial regulations) and of the independent administrative authorities. Regulatory agencies constantly carry out public consultations on new regulations, in which several stakeholders take part.

2312 http://www.mercosur.int/innovaportal/file/492/1/estructura.noviembre_es.pdf

2313 Tony Prosser, “Theorising Utility Regulation” Modern Law Review. n 62, March 1999, 206-209 


\subsubsection{Courts and Regulations}

Federal courts in Brazil have the power to review administrative acts by federal authorities and to issue injunctions against those acts. State courts also review acts by state entities. There are Regional Courts of Appeals and further recourse to the Superior Court of Justice (STJ) or the Supreme Court (STF) in certain cases. Therefore, all the decisions taken by administrative agencies such as ANVISA, CADE and other federal and state authorities are subject to judicial review, as will be illustrated. This involves an assessment of the legality of the act and the proportionality of the decision. Courts have the power to annul administrative acts, such as general resolutions and individual orders.

\subsection{Production}

\subsubsection{Acquisition of Land by Foreigners}

The importance of a regulatory framework for investments in the food sector has been emphasised in several arenas. The Federal Constitution establishes a general principle of non-discrimination for investments, except for specific sectors clearly defined. This means that the Brazilian legal system ensures equitable treatment for both national and foreign investors. There are also measures taken for national security reasons. An example of that are the restrictions on rural land ownership by foreigners, through the imposition of conditions and limits.

Both the Law 5,709 of October 1971 and the Law 8,269 of February $1993^{2314}$ apply to land purchases and land leases by foreigners and, more controversially, to Brazilian companies controlled by foreigners. The following limits are established:

- Foreigners may acquire or lease up to three 'special modules' without seeking approval. Each 'special module' ranges from 5 to 100 hectares depending on the region.

- For foreign natural persons, there is a limit in acquisition or lease of fifty modules.

- For foreign juridical persons, there is a limit in acquisition or lease of one hundred modules.

- Acquisitions over twenty modules require approval by National Institute for Colonisation and Agrarian Reform.

- Foreign companies can only acquire rural land for agricultural, cattle-raising, industrial or development projects.

- No more than $25 \%$ of the rural areas of any municipality may be owned by foreigners, and no more than $10 \%$ may be owned by foreigners of the same nationality.

Following concerns of "land grabbing" in the aftermath of the global food price hikes of 2007$2008^{2315}$, Brazil published on 23 August 2010 a Presidential Order, approving a Government Legal Opinion (Parecer CGU/AGU No. 01/2008) providing that on rural land-ownership and leases, Brazilian companies that are controlled by foreigners are also subject to the legal regime applicable to foreign companies. There have been claims that this reinterpretation of the laws hampered the development of investments in agriculture by foreign companies in Brazil.

After that, the State of São Paulo's Internal Affairs Division of Justice issued a legal opinion to all land registries of Sao Paulo which seems contrary to the Federal Government Opinion. In 2016,

$2314 \quad$ Available at: http://www.planalto.gov.br/ccivil_03/leis/L8629.htm

http://www.planalto.gov.br/ccivil_03/leis/L5709.htm

and 2315 OECD Chapter 2, p. 91-92 
the Supreme Court of Brazil suspended the effects of the State's legal opinion. ${ }^{2316}$ There is also a pending claim by the influential Rural Society of Brazil to reinstate that Brazilian companies, controlled or not by foreigners, should not be subject to the restrictions, based on the principle of equality. They argue that agribusiness needs scale and volume of resources in order to attract investments.

\subsubsection{Agricultural Policy and Food Supply}

Law 8,171 of 17 January $1991^{2317}$ sets out the Brazilian agricultural policy, which is supply-oriented by promoting food supply as one of its main tenets. It establishes the principles for research and technical assistance, rural credit and insurance, agricultural inspection, and the production, deposit and sale of stocks. When it comes to agricultural products, basic foodstuffs (eg. rice, beans, wheat) should be given special attention with regard to the minimum price policy.

The National Food Supply Company (CONAB) is a public enterprise responsible for the management of food supply stocks in Brazil. Created in 1990, it regulates the supply of the Brazilian internal market. CONAB manages the supply of food stocks and implements the policy of minimum price of the federal government and other mechanisms to sustain agricultural products prices. The programmes of acquisition of foodstuffs by the federal government consists in the purchase of foodstuffs in order to level off the rent of small producers, that is, family farmers and their cooperatives. However, the programme has been subject to successive budget cuts and was granted 340 million reais in 2017 (around 100 million USD). ${ }^{2318}$

CONAB also organises the national framework of warehouses and the wholesale of food products. In order to do that, it gathers detailed data and statistics on prices and crop production. As a public company, it establishes internal rules to organise its activities and procedures. CONAB is responsible for the delivery of food kits to communities affected by climate disasters. It carries out the sale of public stocks by legal means, including through electronic auctions and the programme for spot market sales focussed on micro producers (farming and livestock).

Box I analyses and justifies the available mechanisms for agricultural price support in Brazil:

\section{Box I: Mechanisms for agricultural price support in Brazil}

"Market price support aims to reduce price volatility, protect farmers' incomes, improve the availability of food supplies and offset the additional costs of producers in regions that are distant from the main markets and ports. There are also specific programmes that target small-scale agriculture, with some purchases being distributed via food programmes.

Minimum guaranteed prices are reviewed annually, covering thirty-three crops. They are announced regionally through the PGPM (Política de Garantia de Preços Mínimos) by the Secretary of Agricultural Policy (SPA) operated by the National Food Supply Agency (Companhia Nacional de Abastecimento, CONAB). This mechanism covers a great variety of crops from rice, wheat, maize, cotton, soybeans, to regional crops like cassava, beans, açaí, guaraná, sisal, and a few livestock products like cow and goat milk, and honey. Other price support mechanisms for commercial

\footnotetext{
2316 http://www.conjur.com.br/2016-set-13/stf-suspende-parecer-compra-terra-rural-estrangeiro

2317 Available at: http://www.planalto.gov.br/ccivil_03/leis/L8171.htm

$2318 \mathrm{http} / / /$ www.canalrural.com.br/noticias/rural-noticias/orcamento-programa-aquisicao-alimentos-cai-65687
} 
agriculture are the direct government purchases (Aquisição do Governo Federal, AGF) and the provision financing of storage by the FEPM (Financiamento para Estocagem de Produtos Agropecuários integrantes da Política de Garantia de Preços Mínimos) former Empréstimo do Governo Federal-EGF. The [Secretariat of Family Farming and Agrarian Development] supports the development of family farming, and makes use of the minimum prices policy. Instruments that support prices and target small-scale agriculture are government purchases similar to AGF (Programa de Aquisição de Alimentos, PAA) and the minimum prices programme for family farms, (Programa de Garantia de Preços para a Agricultura Familiar, PGPAF). Under PAA, CONAB makes direct acquisitions from family farms at market prices, with the product either going into stock or distributed as part of a food programme. The PGPAF ensures that small-scale farmers receive a guaranteed price based on the average regional production cost of family farms."

Source: OECD/Food and Agriculture Organization of the United Nations (2015) 2319

States and municipalities also possess regulatory powers. To illustrate, States can establish periods of non-cultivation of soybeans, beans and others to avoid the proliferation of plagues, any violation being subject to sanctions. In addition, States are responsible for regulating the State`s central food services for the wholesale supply of horticultural products from small farmers and cooperatives.

\subsubsection{Production and Trade}

The Ministry of Agriculture, Livestock and Food Supply (MAPA) formulates and carries out the government's policy in relation to agriculture and agribusiness. It regulates, classifies and inspects agricultural products in Brazil, including imported foodstuffs. MAPA coordinates the national system for agricultural and livestock protection, in which state entities also play a role.

It has a stable structure of civil servants, led by a minister, politically appointed by the President. The main Secretariats dealing with food related regulation are the following: Secretariat of Agricultural Protection (SDA); Secretariat of Agriculture and Livestock Development and Cooperativism (SDC); and Secretariat of International Agribusiness Relations (SRI). ${ }^{2320}$ Connected to MAPA, apart from the Coffee Policy Council, there is the Agribusiness Council, which gathers the Sectoral Consultative Chambers for more than 30 products or chains. Since March 2017, the Ministry of Industry, Foreign Trade and Services has been responsible for fisheries and aquaculture, previously under the MAPA structure.

Rural debt remains a challenge in Brazil. As underlined by the WTO Trade Policy Review Report, Brazilian authorities generally justify the rural credit system, as a means to correct a market failure resulting in insufficient credit allocation to medium, small and micro producers, and the financing mechanism, due to the importance of family farming on the supply for internal consumption, thus, food security. ${ }^{2321}$

Agricultural foreign trade policy, as part of the foreign trade policy, is defined by the Foreign Trade Chamber, the council of which is composed by seven Ministries and which may issue

${ }^{2319}$ OECD-FAO Agricultural Outlook 2015, OECD Publishing, Paris. P. 94 http://dx.doi.org/10.1787/agr_outlook-2015en

${ }^{2320}$ Food and Agriculture US Report p. 3

2321 WTO TPR 2013, parag. 4.31, p. 124 
Resolutions. In addition, both the Ministry of Industry, Foreign Trade and Services, the Ministry of Finance, through its Secretariat of Federal Revenue, and the Central Bank have a role in the administration of import and export of products for commercial use, including foodstuffs.

\subsection{Access to Seeds}

\subsubsection{Seeds Market}

Brazil has a solid seed industry. The value of the domestic market was estimated in $\mathrm{R} \$ 10$ billion (around US\$ 3 billion) in 2015. Soybeans and corn seeds constitute 74\% of the market in Brazil, as shown in the chart below: 2322

\section{Seeds Market in Brazil - 2015}

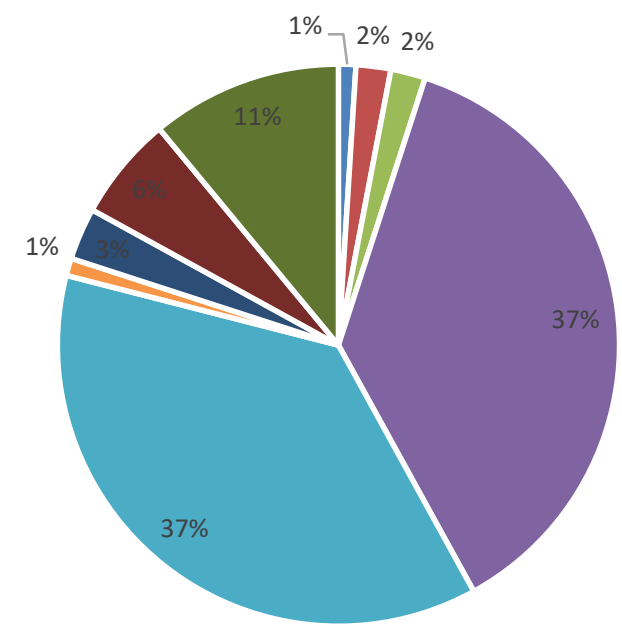

- Cotton

- Rice

- Beans

- Corn

- Soybeans

- Sorghum

- Wheat

- Vegetables

- Fodder Plant

Source: Chart adapted from the 2015 Report of the Brazilian Association of Seeds and Seedlings ${ }^{2323}$

\subsubsection{Food Security}

Law 11,346 of 15 September, $2006^{2324}$ establishes the National System for Nutritional and Food Security in order to ensure the human right to adequate food. It emphasises the sovereign right of states to make decisions on food production and consumption.

The system is managed by several institutions from the public sphere as well as private entities. The National Council for Nutritional and Food Security is the main body to set guidance and priorities for the food policy. It was regulated by the Decree 7,272 of 25 August, 2010, ${ }^{2325}$ which sets out the National Policy for Food Security. An executive chamber is responsible for specific measures of monitoring and assessing the policy and drafting four-year long plans.

\footnotetext{
${ }^{2322}$ See Dow/Dupont merger analysis in the Report of the Commissioner Burnier, p. 23-24, AC 08700.005937/2016-61.

${ }^{2323}$ Available at: http://www.abrasem.com.br/wp-content/uploads/2013/09/Anuario_ABRASEM_2015_2.pdf

${ }^{2324}$ Available at: http://www.planalto.gov.br/ccivil_03/_ato2004-2006/2006/lei/111346.htm

2325 Available at: http://www.planalto.gov.br/ccivil_03/_ato2007-2010/2010/decreto/d7272.htm
} 
The chamber approved in May 2016 the Plan for 2016/2019, in which the United Nations participated through the Centre of Excellence against Hunger of the World Food Programme. ${ }^{2326}$ There are 9 challenges, 121 goals and 99 measures, with specific indexes. Since this policy was highly linked with the Worker`s Party agenda, there are doubts on the extent to which the current government will stick to it.

\subsubsection{Protection of Seeds}

The Brazilian Entreprise for Agriculture Research, EMBRAPA, is a public company founded in 1973. EMBRAPA has almost 10.000 employees and an annual budget of around 3 billion reais (roughly 900 million USD). ${ }^{2327}$ It undertakes high-profile research and development activities and technology transfer in agriculture and livestock. It develops and markets seeds in cooperation with research centres and governments and offers products in competition with other national and international companies. EMBRAPA is the owner of relevant patents and software registers, in sole or co-ownership, in Brazil and abroad and have made hundreds of requests, still under analysis. ${ }^{2328}$ It also coordinates the national system of research in which federal states entities participate.

The Brazilian Plant Variety Protection Act (Law 9,456 of 25 April, 1997) ${ }^{2329}$ protects conventional plant breeding techniques, which are not subject to patent protection conferred by the Brazilian Industrial Property Law (Law 9,279 of 14 May, 1996). ${ }^{2330}$ Patent law in Brazil is only available to transgenic microorganisms and the processes which lead to production of transgenic seeds, plants and its parts (organs, tissues or cells), not to the final product itself. ${ }^{2331}$

The plant variety protection extends up to 15 years. In case of vine, fruits, forestry and ornamental trees, it extends up to 18 years. Box II summarises the main features of the Brazilian system:

\section{Box II: Brazilian Plant Variety Rights Regime}

\section{"Definition}

According to PVP Law, plant variety consists in a variety of any plant genus or species that is clearly distinguishable from other known plant varieties by a minimum margin of descriptors and by its own denomination, is homogenous and stable in its descriptors throughout successive generations and belongs to a species useful in farming and forestry, being described in a publicly available and accessible specialized publication, including the component lines of hybrids.

Only a new plant variety or an essentially derived variety of any genus or species is eligible for protection. New plant variety, according to PVP Law, means a variety that has not been offered for sale in Brazil for more than 12 months prior to the date of the application for protection and, with due regard to the period for commercialization in Brazil, has not been offered for sale in other

\footnotetext{
${ }^{2326}$ http://www.cfn.org.br/wp-content/uploads/2016/05/PLANSAN-2016.pdf

${ }^{2327}$ Available at: https://www.embrapa.br/en/quem-somos

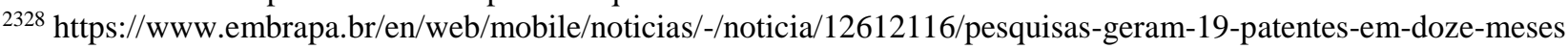

${ }^{2329}$ Available at: http://www.planalto.gov.br/ccivil_03/leis/L9456.htm

2330 Available at: http://www.planalto.gov.br/ccivil_03/leis/L9279.htm

${ }^{2331}$ Rodrigues, Roberta L, Lage, Celso L. S, \& Vasconcellos, Alexandre G. (2011). Intellectual property rights related to the genetically modified glyphosate tolerant soybeans in Brazil. Anais da Academia Brasileira de Ciências, 83(2), 719730. https://dx.doi.org/10.1590/S0001-37652011000200029
} 
countries, with the breeder's authorization, for more than six years for tree and vine species and for more than four years for other species.

How To Protect

The application for protection of a new plan variety shall be formalized in a request signed by the natural or legal person who has bred the plant variety or his agent and endorsed by the competent agency. Such application shall include at least the requirements established in Article 14 of the PVP Law.

Every plant variety shall have a denomination that identifies it, serves as its generic designation and conforms to the following criteria for the purposes of protection: (a) it must be unique, and not expressed in the form of numerals only; (ii) it must consist of a designation that is different from that of a pre-existing plant variety; and (iii) it must not mislead as to the essential characteristics or origin of the variety."

Source: Intellectual Property Guide Brazil 2014, IPO 2332

The National System of Seeds and Plant Seedlings was set out by Law 10,711 of 5 August, 2003. ${ }^{2333}$ It establishes a system of certification for seed varieties, which could be done by research institutes and agricultural commissions. Some claim that these entities are heavily influenced by seed breeding companies. ${ }^{2334}$ The registration requirements do not apply to agriculture farming, which receives special treatment. They can cultivate with local or creole seeds without the need to register. They can multiply, sell and distribute the seeds or seedlings among themselves but not to the general market. Seed networks with local seed banks explore the local varieties, which, some claim, are more adaptable to the specific environments. ${ }^{2335}$

The National Program of Seeds and Plant Seedlings for Agriculture Farming was launched in the context of preserving food security through the distribution of seeds. The federal government can also acquire local seeds in the Programa de Aquisição de Alimentos - PAA, described above, which are distributed to farmers afterwards, at no cost.

Law 10,831 of 23 December, $2003^{2336}$ recognised organic farming. Decree 7,794 of 20 August, $2012^{2337}$ sets out the National Policy for Agroecology and Organic Production, which explicitly recognises the role and importance of local varieties.

\subsubsection{GMOs}

Brazil is the second largest producer of genetically modified (GM) crops in the world after the US: in the 2014/2015 planting season, around $90 \%$ of the soybean and corn crops was genetically modified. ${ }^{2338}$

\footnotetext{
2332 https://www.gov.uk/government/uploads/system/uploads/attachment_data/file/456358/IP_Guide_Brazil.pdf

2333 Available at: http://www.planalto.gov.br/ccivil_03/leis/2003/L10.711.htm

${ }^{2334}$ https://www.ileia.org/2016/04/16/seed-banks-national-policy-brazil/

2335 https://www.ileia.org/2016/04/16/seed-banks-national-policy-brazil/

2336 Available at: http://www.planalto.gov.br/ccivil_03/leis/2003/L10.831.htm

${ }^{2337}$ Available at: http://www.planalto.gov.br/ccivil_03/_ato2011-2014/2012/decreto/d7794.htm

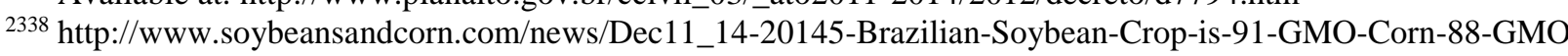


Law 11,105 of 24 March, 2005, ${ }^{2339}$ sets up an institutional framework to manage the biosafety policy. It defines the regulation of genetically modified organisms (GMOs), including seeds and grains, such as soybeans, corn and sugarcane. The law sets out authorization, inspection and monitoring procedures for research and commercial release, production and marketing rules, cultivation regimes and restrictions on GMOs in foodstuffs.

The National Biosecurity Council (CNBS) is a ministerial body responsible for setting the guidelines of the biosafety policy. The National Technical Commission for Biosafety (CTNBio), under the umbrella of the Ministry of Communications, Science and Technology, is a multidisciplinary collegiate authority, of a consultative and deliberative nature, for the provision of technical advice and support to the Federal Government in the formulation, updating and implementation of the policy for GMOs and their derivatives. Moreover, it establishes technical safety standards and technical opinions concerning the authorisation for activities which involve research and commercial use of GMOs and their derivatives, based on the evaluation of the sanitary risks to human health and the environment.

In October 2016, the CTNBio has approved the biosafety certificates for the importation of three varieties of genetically modified corn, two from Monsanto and one from Syngenta. The corn would be destined to be used as animal feed and should not be cultivated. This comes in the context of problems related to corn stocks and low supply. This decision has not come out without protest. Representatives of the small-scale family agriculture sector and some experts expressed concerns as to the depth and accuracy of the analysis and the possible risks of deviation in the use of the corn. ${ }^{2340}$

Moreover, the first genetically modified sugarcane has been developed by the Sugarcane Research Centre and, pending authorization, will be released in the crop 2017/2018. ${ }^{2341}$ In 2016, the CTNBIO has also authorised the production of new soybeans GMOs resistant to herbicide DICAMBA, developed by Monsanto. ${ }^{2342}$ This is part of the strategy to release the third generation of GM soya, with several products to be commercially released by $2020 .{ }^{2343}$

The Law 11,105, in its article 6, VII, sole paragraph, prohibits the development and sale of seeds genetically modified to become sterile after the second generation. Nevertheless, many law bills have been proposed to eliminate or condition this prohibition. They originate from representatives of the agribusiness and are to the benefit of seed breeding companies, which support these initiatives. ${ }^{2344}$ In case they are adopted, this would increase small farmer`s dependence on those companies, since they generally save grown seeds to cultivate the next crop.

\subsection{Consumers' interests}

\subsubsection{Food and Health Surveillance}

\footnotetext{
${ }^{2339}$ Available at: http://www.planalto.gov.br/ccivil_03/_ato2004-2006/2005/lei/111105.htm $2340 \quad$ https://www.brasildefato.com.br/2016/10/28/milho-transgenico-aprovado-pela-ctnbio-jamais-foi-testado-emcondicoes-brasileiras/

${ }^{2341} \mathrm{http}: / / \mathrm{www} . c a n a l$ rural.com.br/noticias/agricultura/cana-transgenica-tera-uso-comercial-liberado-64892

$2342 \mathrm{http}: / /$ sfagro.uol.com.br/ctnbio-aprova-soja-transgenica-resistente-ao-herbicida-dicamba/

2343 http://zh.clicrbs.com.br/rs/noticia/2016/12/monsanto-prepara-terceira-geracao-de-soja-transgenica-8814192.html

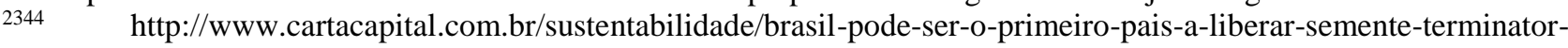
9110.html ; see also http://outraspalavras.net/brasil/ruralistas-tentam-aprovar-sementes-estereis/
} 
The Brazilian Health Regulatory Agency (ANVISA) is a regulatory agency characterised by its administrative independence, which is ensured by its financial autonomy and the mandate terms for its board of directors, composed by five members. Its creation and regulatory powers were defined by the Law 9,782 of 26 January 1999.

The agency is monitored by the Ministry of Health. It exercises health surveillance on the production and marketing of products and services, including technologies, processes and ingredients that pose health risks. ${ }^{2345}$ It is competent to regulate the importation of products and to perform sanitary inspections at the points of entry to the territory.

ANVISA has the power to issue general regulations in the form of Resolutions and individual decisions to prohibit the sale of products and to determine the recollection from the market of unsafe foodstuffs.

In 2016, ANVISA put in force a new regulation (Resolution 26/2015) for foodstuffs labelling. The industry is now under an obligation to include information in clear language on all ingredients which may produce allergies. This generated some judicial claims by stakeholders such as milk producers' associations. Recently, the Federal Court of Appeals for the $1^{\text {st }}$ Region confirmed that the Resolution applies to both domestically produced and imported products. ${ }^{2346}$ There has been a public consultation on labelling related to lactose and lactose $\operatorname{diet}^{2347}$ and also a related children's food, who may be oversensitive to some minerals. ${ }^{2348}$

Some sanitary and phytosanitary (SPS) regulations in Brazil are also exercised by the Ministry of Agriculture, Livestock and Food Supply (MAPA). Its Secretariat of Agricultural Protection (SDA) is responsible for the protection of animal and plant health. It is responsible for the SPS aspects of production and international trade of livestock, fruits, vegetables, grains, veterinary drug, plants and pesticides. ${ }^{2349}$ The proposals for negotiation of SPS measures are put forward by the Secretariat of International Agribusiness Relations, which also follows the WTO notification procedures in the area.

In March 2017, there was a blow to the confidence of the Brazilian agriculture protection system after the Federal Police uncovered a nation-wide scheme of corruption on the inspection of meat and meat products in "Operation Weak Flesh" (Operação Carne Fraca) ${ }^{2350}$ This involved MAPA`s state representatives and federal inspectors who apparently received advantages in exchange of turning a blind eye on inspection procedures of meat-packing establishments. Several countries announced a temporary ban of importation of meat from Brazil, but have progressively resumed imports, given the assurances by the Brazilian government that the problem was under control and that the authorities involved were being investigated. ${ }^{2351}$

\subsubsection{Pesticides and Additives}

\footnotetext{
$2345 \mathrm{http} / / /$ portal.anvisa.gov.br/contact-us

2346 http://www.justicaemfoco.com.br/desc-noticia.php?id=118360\&nome=Rotulagem-em-produtos-alergenicos-seaplica-tanto-aos-produtos-nacionais-quanto-aos-importados

2347 http://www.brasil.gov.br/saude/2016/09/anvisa-ira-consultar-populacao-sobre-rotulagem-de-alimentos-com-e-semlactose

${ }^{2348}$ http://www.brasil.gov.br/saude/2016/06/anvisa-abre-consulta-sobre-limite-toxicologico-em-comida

${ }^{2349}$ WTO TPR Brazil 2013 p. 65

2350 http://www.reuters.com/article/us-brazil-corruption-food-exports/operation-weak-flesh-takes-bite-out-of-brazilsmeat-exports-idUSKBN16V281

${ }^{2351} \mathrm{http} / / / \mathrm{www}$. reuters.com/article/us-brazil-meat-idUSKBN17823W
} 
Several institutions are involved in the approval of food additives and agricultural chemicals (pesticides and herbicides), under Law 7.802 of July 11 1989. ${ }^{2352}$ Apart from the ones already referred to above (i.e. MAPA and ANVISA), there is the Brazilian Institute for the Environment and Natural Resources (IBAMA), which forms part of the structure of Ministry of Environment. Box III summarises the main features of this regulation:

\section{Box III: Brazilian regulation of pesticides}

"ANVISA defines food additives as any ingredient without nutritional benefits deliberately added to food to modify its physical, chemical, biological and sensorial characteristics during any stage processing, storage, handling, transportation, etc. Before approved for consumption, any food additive is analyzed separately in order to prove its technological need and safety. This analysis includes: the relation of the additive to the product it will be incorporated to; its functionality; studies and toxicological data which allows an adequate risk assessment; studies on estimates of potential ingestion; regulatory framework from other countries; and, international benchmark.

Depending on its nature, the approval or incorporation of the additive to the food regulatory framework may occur with restrictions of use. In this case ANVISA will establish maximum limits for the active substance for the specific food product in which the additive will be incorporated. If the additive is approved but a safety tolerance is not set, the additive may be used at the level required to obtain desired result. [...]

Brazil follows international standards on tolerances of pesticides, herbicides and fungicides on agricultural products, and uses Codex Alimentarius as a general reference. The Codex Alimentarius Committee of Brazil (CCAB) represents the country in international Codex Committees and advocates for the use of Codex standards in the country.

Based on Codex norms, registration of agricultural chemical is held by a three party committee (MAPA, IBAMA, and ANVISA). ANVISA provides toxicological analysis and establishes maximum tolerance levels while IBAMA evaluates environmental impact. MAPA is the initial point of contact in the product registration process and also the party that deliberates final approval after receiving inputs from ANVISA and IBAMA. In order to improve the inspection of pesticides and contaminants on vegetables in Brazil, in 2009 the National Program for Pesticides and Contaminants Detection was created. The program collects samples of domestic and imported fruit and vegetables, such as papaya, apple, pineapple, lettuce, rice, peanut, banana, lemon, acid lime, mango, melon, corn, strawberry, pepper, tomato and grape. Imported products must comply with the same requirements established for local products."

Source: Food and Agriculture, US Report p. 10-11 2353

In addition to the Pest Risk Assessment (PRA), MAPA and ANVISA sets out registration and inspection requirements for importing meat, dairy, seafood products and plant products, animal feed and alcoholic and non-alcoholic beverages. ${ }^{2354}$

2352 http://www.planalto.gov.br/ccivil_03/leis/L7802.htm

2353 Brazil: Food and Agricultural Import Regulations and Standards - Narrative. 11 January 2016 Available at: https://www.fas.usda.gov/data/brazil-fairs-country-report-0

${ }^{2354}$ For details, see Food and Agriculture US Report p. 10-15. 


\subsubsection{Standards and Local Interests}

The Institute of Metrology, Standardisation and Industrial Quality (INMETRO) is responsible for the definition of standards. INMETRO is the focal enquiry point in Brazil in relation to the technical barriers to trade (TBT) committee of the WTO. In the food area, it sets out regulations on packaging and containers, when it comes to the quality and safety of their conditioning. It conducts tests and is responsible for the accuracy of weights and measurements. It delegates some of its powers to entities in the federal states.

Technical rules, comprising standards and specifications for packaging and containers are set out by the Brazilian Association of Technical Norms (ABNT). It is a member of the International Organization for Standardisation (ISO) and other regional entities. It carries out the certification for consumer packaging (paper and carton boxes, plastic bags, steel sheet, aluminium cans, tetrapak, PET bottles) and regulates the recycling of packaging and containers for food products. ${ }^{2355}$

Municipalities can also regulate public food markets in the exercise of its police powers. They can impose sanitary inspection taxes. They can also regulate the opening and closing times of markets and supermarkets. ${ }^{2356}$ In 2015/2016, several municipalities adopted local laws prohibiting the production or sale of foie gras (goose fat spread). In Sao Paulo, this local law was annulled by the State Court, which found it contrary to the State constitution.

\subsubsection{Alcoholic Beverages and Consumption}

Consumption of alcohol is permitted and socially acceptable in Brazil. As to spirits, Cachaça do Brasil (sugar cane liqueur) has been recognised as a geographical indication since 2001, under the terms of the TRIPS agreement. The regulation of its use was finally completed in $2016 .^{2357}$

Brazil is a great worldwide producer of beer, though consumption per capita is low. The norms in relation to the classification, production and inspection of beverages are set by Law 8,918 of 14 July, 1994, regulated by the Decree 6,871 of 4 June, 2009. ${ }^{2358}$

Specific regulation aims at ethical considerations in advertisement in order to avoid overconsumption and consumer deception. The National Council for Advertisement Self-Regulation - CONAR - is an example of self-regulation in the area. It has the power to send warnings and require the removal of poster and TV shots. It has analysed several beer advertisements on ethical grounds, including excessive sensuality and undue suggestion to sexual prowess, social success and popularity derived from beer consumption.

\footnotetext{
2355 Food and Agriculture US Report. p. 9

http://www.stf.jus.br/portal/jurisprudencia/listarJurisprudencia.asp?s1=645.NUME.\%20NAO\%20S.FLSV.\&base=base Sumulas

2357 http://www.agricultura.gov.br/comunicacao/noticias/2016/10/cachaca-com-indicacao-geografica-ganharegulamento

$2358 \quad$ Available at:

http://www.planalto.gov.br/ccivil_03/leis/L8918.htm and http://www.planalto.gov.br/ccivil_03/_Ato2007-2010/2009/Decreto/D6871.htm
} 
Laws 11,705 of 19 June, 2008 and 12,760 of 20 December, $2012^{2359}$ have established stricter terms of alcohol in the blood while driving ("zero tolerance" approach). The measures have significantly reduced road accidents and deaths in Brazil.

\subsubsection{Consumer Protection System}

Law 8,078 of 11 September, $1990,{ }^{2360}$ sets out the norms for consumer protection and defence. Articles 6(I) and (III) of the Law state that the protection of the consumer's life, health, and safety against risks arising from practices when buying harmful or dangerous products and services is a basic consumer right. They should be given adequate and clear information about different products and services, with correct specifications for quantity, characteristics, composition, quality and price, as well as any risks involved. ${ }^{2361}$ It provides a list of criminal offences, the penalties of which may be higher, if they are related to foodstuffs.

The National Secretariat for Consumer Policy (SENACON) is part of the Ministry of Justice. Together with the State and local consumer agencies (many of them referred to as PROCONs), civil entities and public prosecutors and defenders, they form the National System for Consumer Protection. They are responsible for enforcing these regulations. SENACON is also responsible for coordinating and promoting the recall of products, including foodstuffs. This is the case when companies identify a risk for human health or incorrect labelling in foodstuffs already released for sale. For example, SENACON promoted the recall of tomato sauces of a brand produced by Heinz, which had surpassed the maximum tolerable of rodent hair. ${ }^{2362}$ Moreover, it monitored the recall of peanut sweets and pasta products which had not included the correct information on the presence of gluten. ${ }^{2363}$ Finally, in March 2017, SENACON determined the recall of products originating from some meatpacking companies involved in the meat inspection probe (Operation Weak Flesh), referred above. ${ }^{2364}$

The Secretariat also possesses the power to impose sanctions against the enterprises. To illustrate, in 2015, SENACON confirmed the imposition in 2013 of a fine to Parmalat and others for incorrect labelling of its UHT milk in relation to fat, carbohydrates and protein levels in breach of ANVISA and MAPA regulations. ${ }^{2365}$

GMO labelling in Brazil is mandatory since the Decree 4,680 of 24 April 2003. ${ }^{2366}$ The label consists of a transgenic symbol in the shape of a triangle with the letter T inside the triangle. ${ }^{2367}$ Under

\footnotetext{
$2359 \quad$ Available at: http://www.planalto.gov.br/ccivil_03/_ato2007-2010/2008/lei/111705.htm and http://www.planalto.gov.br/ccivil_03/_ato2011-2014/2012/lei/112760.htm

${ }^{2360}$ Available at: http://www.planalto.gov.br/ccivil_03/leis/L8078.htm

${ }^{2361} \mathrm{http}$ ///brasilcon.org.br/arquivos/arquivos/cdc-en.pdf Art. 31 provides that: "The offer and the presentation of products and services must contain information that is clear, direct, precise, comprehensive, and in the Portuguese language regarding the characteristics, qualities, quantity, composition, price, warranty, validity and origin, among other pieces of information, as well as any risks that the product or service may pose to the consumer's health and safety." [emphasis added]

2362 http://justica.gov.br/noticias/pelo-de-roedor-provoca-recall-de-molho-de-tomate-heinz

$2363 \mathrm{http}: / /$ justica.gov.br/noticias/senacon-alerta-para-recall-de-macarroes-barilla

$2364 \mathrm{http} / / /$ justica.gov.br/noticias/senacon-divulga-desdobramentos-da-operacao-carne-fraca

$2365 \mathrm{http}: / /$ www.jurisway.org.br/en/article.asp?id_dh=11579

${ }^{2366}$ Available at: http://www.planalto.gov.br/ccivil_03/decreto/2003/d4680.htm
}

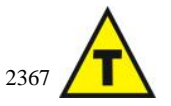


the labelling regulations, consumers must be informed if more than one percent $(1 \%)$ of a food product for human or animal consumption is produced from or contains GMOs.

In January 2016, Nestle, Pepsico and Bimbo were fined for non-disclosing the presence of transgenic organisms in some of their products. ${ }^{2368}$ The products ranged from salty snacks, biscuits and cakes. The total fines reached around 1 million dollars. The authorities considered that these companies had violated the right to information and consumer choice.

\subsection{Competition Law}

\subsubsection{Competition Law and Food Value Chains}

Competition law in Brazil has gone through some important changes in the past five years. The New Law 12,529 of 30 November, $2011^{2369}$ came into force on May 29, 2012, replacing the old Law 8,884, of 1994.

It was the culmination of a reform, the objective of which was to improve effectiveness of the enforcement of competition law. It set out a single authority system under the umbrella of the Administrative Council for Economic Defence - CADE, with a subsidiary role by the Ministry of Finance in the promotion of competition. It established a pre-merger notification system with changes in the notification criteria, the notification criteria being defined by articles art. 88 of the Law and CADE's Resolution n. 2/2012. CADE was given new powers to investigate, prosecute and sanction anticompetitive conduct. There were also some changes in the leniency and settlement regime. CADE`s Superintendence (SG) assesses concentrations and investigates conducts, while CADE`s Tribunal renders the final decisions in the relevant cases. The drivers of the reform were the rationalisation of bureaucratic and business costs, already pointed out by the OECD in its peer review reports. ${ }^{2370}$

A reform started to be envisaged in 2003 , in the context of doubts on how a newly elected Worker's Party government would deal with competition law. Thus, the reform was an opportunity for the agenda setting of the new government at the time. The process of diffusion/transplantation explored the social capital ${ }^{2371}$ of a generation of lawyers and government officials with access to more "modern" systems. The new competition law bill benefitted from seven years of interaction between the executive and the legislative branches. Intense lobbying from companies and associations also took place. Throughout this period, there was unstable support to the bill by politicians. There was specific pressure in the process of approval, which may be evidenced by some amendments to address particular situations. A compromise was reached with regulators to raise the notification thresholds as soon as the new law came into force. There was also a political compromise to reduce the amount of possible fines (percentage-wise and on a turnover basis).

\footnotetext{
2368 http://www.ibtimes.com/gmo-labeling-requirements-brazil-fines-nestle-pepsico-failing-disclose-genetically2259921

${ }^{2369}$ Available at: http://www.planalto.gov.br/ccivil_03/_ato2011-2014/2011/Lei/L12529.htm

${ }^{2370}$ OECD Peer Review (2005) Available at: http://www.oecd.org/daf/competition/45154362.pdf ; (OECD Peer Review (2010) Available at: http://www.oecd.org/daf/competition/35445196.pdf

2371 Yves Dezalay, Dealing in Virtue: International Commercial Arbitration and the Construction of a Transnational Legal Order / Yves Dezalay \& Bryant G. Garth; Foreword by Pierre Bourdieu (University of Chicago Press 1996); Yves Dezalay and Bryant G Garth, The Internationalization of Palace Wars: Lawyers, Economists, and the Contest to Transform Latin American States (1 edition, University Of Chicago Press 2002).
} 
Competition policy in Brazil is enforced by a centralised administrative system, relying also on the judiciary's and public prosecutors' cooperation to strengthen enforcement (dawn raids, extension of the geographical reach of the law). Decisions are subject to a broad scope of judicial review not only at the first instance but also with several instances of appeal. CADE is placed inside the bureaucracy of the federal government, but has the powers of an independent agency. It decides how it will spend its resources, but it may be subject to budget constraints and cuts from the Central Federal Administration.

Among the challenges for the future, one may cite the backlog of cases. It is necessary that CADE speeds up the analysis and investigation of anticompetitive conducts. There is also a pressing need for guidelines on fines and remedies, the standard of proof, and vertical conducts ${ }^{2372}$. The following years will be an important test for institutional resilience. There are pending cases with the highest economic and political profile ever. They are derived from the Lava Jato (Car Wash) investigations, which uncovered an extensive corruption scheme involving top politicians and large companies, engaged in cartel and bid-rigging practices. ${ }^{2373}$

Competition law in Brazil does not include any a priori sectorial exclusions or exemptions. ${ }^{2374}$ Therefore, mergers in the food chain are scrutinised in the same way as all the other economic sectors, if they reach the turnover requirements of the law. Likewise, conducts in the food sector are analysed irrespective of the level of the chain or its vertical/horizontal nature. The next sections report on relevant cases under merger control and conducts decided with regard to each product.

\subsubsection{Merger Cases}

\subsubsection{Agricultural Machines}

In February 2016, CADE was notified of the acquisition of the control of Precision Planting, a subsidiary of Monsanto, by John Deere. ${ }^{2375}$ In November 2016, CADE`s Superintendence decided that the merger was complex. The Superintendence`s report indicated that the transaction could lead to high horizontal concentration in the aftermarket of sales of seeders to rural producers. Also, there was vertical integration between the seeders and its components. It was considered that there were incentives and capacity to discriminate in the aftermarket. There were also concerns related to exchange of sensitive information between John Deere and its competitors. The efficiencies were not deemed to be sufficient to compensate for the competitive harms.

SG`s opinion was that the ,merger should not be approved in that manner. Given its global scope, the transaction had to be analysed in several jurisdictions. Due to the lack of progress in the approval by the American authorities, the parties decided to abandon the request, which was discontinued by CADE.

\footnotetext{
${ }^{2372}$ See, D. Geradin \& C. M. da Silva Pereira Neto, For a Rigorous Effects' Based Analysis of Vertical Restraints Adopted by Dominant Firms, (2012) http://www.cedes.org.br/pesquisas/vertical_restraints.pdf .

2373 https://www.theguardian.com/world/2017/jun/01/brazil-operation-car-wash-is-this-the-biggest-corruption-scandalin-history

${ }^{2374}$ There are, however, some particularities of regulated sectors such as telecommunication; oil and gas; electricity; surface, civil and air transportation; and health. See OECD, Competition Law and Policy in Brazil - A Peer Review (OECD Pub 2010). In the case of banking, there is a pending discussion in the Supreme Court of whether the Central Bank would be the authority with exclusive competence to analyse mergers in the financial sector. There is also one exemption regarding submissions of consortiums formed to participate in public bids (art. 90, sole paragraph).

${ }^{2375}$ AC 08700.000723/2016-07, discontinued.
} 


\subsubsection{Fertilisers}

In 2014, CADE assessed the dissolution of a joint venture (Fosbrasil) between ICL and VALE. ${ }^{2376}$ As a result, ICL would control the totality of Fosbrasil, which produced phosphoric acid used as an input to ICL the production of phosphate salts and fertilisers. The report of the authority indicated that vertical integration would result from the operation. Due to the high market shares, CADE decided that Fosbrasil had both the incentives and the capacity to discriminate against its competitors, such as refusing to sell its inputs to producers of phosphate salts. The final decision was approval with the restrictions described in the negotiated agreement with the parties to ensure supply on a nondiscriminatory basis.

\subsubsection{Seeds}

In 2006, CADE analysed the agreement between Monsanto, FMT and Unisoja for the licensing and sale of soybean seeds with the gene Roundup Ready. ${ }^{2377}$ The report of the authority indicated that Monsanto and FMT had almost $40 \%$ of the market of soybeans and that Monsanto had signed agreements with other companies. Therefore, CADE concluded that there was a risk of market foreclosure for other developers if the exclusivity clause remained. The authority approved the transaction with the conditions of changing three clauses of the contract in order to allow the parties to carry out research and development independently and to produce seeds with technologies other than Monsanto's.

In 2008, CADE reviewed the acquisition by Monsanto of Agroeste Sementes. ${ }^{2378}$ The report of the authority indicated some horizontal concentration in the market for hybrid corn, involving the technology, the incorporation into the seeds, the multiplication and the sale. Monsanto was a market leader in all types of corn seeds and the variation of the HHI was significant. Although barriers to entry were high, the authority considered that rivalry in the market (Syngenta, Pioneer and Dow) was enough to curb any anticompetitive effects. There was though a non-competition clause that required adjustment. The final decision was approval of the transaction with the condition of restricting the non-competition clause to five years.

In 2014, CADE assessed the licensing agreement granted by Monsanto to Bayer, through which the latter would develop and sell soya seeds with the Intacta technology. ${ }^{2379}$ The report of the authority indicated that there was the risk that Monsanto would exert undue control and influence on Bayer in the soya market. It considered that some clauses of the agreement would be detrimental to the competition and had to be changed. CADE imposed restrictions on the agreement such as the exclusion of a preference option and of provisions related to the exchange of commercial information. The transaction was approved with those restrictions.

\subsubsection{Livestock Genetics Industry}

${ }^{2376}$ AC 08700.000344/2014-47, decided on 16 December 2014.

${ }^{2377}$ AC 08012.003997/2003-83, decided on 15 March 2006.

2378 AC 08012.012229/2007-44, decided on 23 April 2008.

${ }^{2379}$ AC 08700.004957/2013-72, decided on 23 January 2014. 
In 2011, CADE scrutinised the acquisition by Cobb of Hybro business owned by Hendrix Genetics. $^{2380}$ The report of the authority indicated that there was horizontal concentration in the international market for poultry genetics and in the national market of poultry genetics replication. There was also vertical integration between those sectors. Entry barriers were moderate and rivalry was not sufficient to cub the exercise of market power. Efficiencies were mostly considered to be positive. However, the main concern was that investment in technology could be hindered.

The transaction was approved with the imposition of behavioural commitments. They included obligation to keep active the acquired genetic lineages. If parties considered they were not commercially viable, they would be obliged to transfer them, sell them by auction or give access to third parties that would keep the same commitments.

\subsubsection{Fruits and Vegetables}

In 2011, CADE analysed the merger of the orange juice businesses of Fisher and Citrovita (Votorantim). ${ }^{2381}$ The report of the authority indicated that there was horizontal concentration in the markets of unprocessed orange and frozen orange juice. In the latter, despite the high market shares, rivalry was deemed to be able to prevent the exercise of market power. In the former market, it considered that the merger would increase the purchase power of oranges by the parties. The vertical relation would be reinforced, so there was a risk of market foreclosure for independent orange farmers. Efficiencies were not considered sufficient to balance the competitive concerns to farmers and national consumers.

The merger was approved with the condition of signing a performance agreement. The agreement required that the parties provide to their orange suppliers annual data on harvest, crops and orange juice processing, such as prices and amounts. This would be in force until the creation of the association of orange farmers and processors.

In 2014, CADE evaluated the constitution of the Council of Producers and Exporters of Orange Juice. ${ }^{2382}$ Its aim was to improve conditions for the purchase of oranges, given the concentration of the market in the processing sector. The report of the authority indicated that the Council should be organised following some criteria, such as membership and information sharing. If the rules are not followed, the incorporation will be prohibited. The final decision was approval with conditions.

With regard to vegetables, CADE assessed, in 2015, the acquisition of assets of Brasfrigo by Goias Verde. ${ }^{2383}$ The report of the authority indicated that there was horizontal concentration in the markets of canned corn, peas, and other vegetables and some vertical integration in tomato related products. The report emphasised that the combined market share was not high enough to raise competition concerns (slightly over $20 \%$ in the market of canned corn, and below $20 \%$ in other markets). However, the operation had only been notified after CADE`s investigation, which constituted gun jumping, in accordance to the new law.

Because of that, the final decision was approval with the following restrictions, in agreement with the companies:

${ }^{2380}$ AC 08012.007776/2008-99, decided on 23 February 2011.

${ }^{2381}$ AC 08012.005889/2010-74, decided on 12 December 2011.

2382 AC 08012.003065/2012-21, decided on 12 February 2014.

${ }^{2383}$ AC 08700.010394/2014-32, decided on 22 April 2015. 
- Recognition of the infringement of gun-jumping

- Payment of R \$3.000.000,00

- Refrain from use of the brand "Jurema" for two years.

\subsubsection{Coffee}

In 2012, CADE evaluated the acquisition by 3 Coracoes of Veloso e Tavares. ${ }^{2384}$ The report of the authority indicated that some horizontal concentration would result from the transaction in the market of toasted coffee, cappuccino and coffee filters. However, the combined market shares were not sufficient to raise any competitive concerns (below 20\% in toasted coffee, and between 40-50\% in cappuccino, but with a very low HHI increase). There was a non-competition clause which needed adjustment as to the geographical scope and language. The final decision was approval with the restriction of changing the non-competition clause.

\subsubsection{Chocolate and Confectionary}

The multinational Nestlé acquired Garoto, a top Brazilian producer of chocolates. In 2004, the final report of the authority indicated that in confectionary and chocolate powder, the resulting horizontal concentration was not relevant. ${ }^{2385}$ On the other hand, there was high horizontal concentration in chocolate coatings and chocolates in general. It considered that there were high barriers to entry in the market due to brand loyalty and industrial secrets. Also, rivalry was not capable of preventing the exercise of market power. CADE concluded that that the efficiencies were not sufficient to address the competition concerns. The final decision, taken by majority, was the prohibition of the merger. One commissioner dissented and voted for the approval with conditions. However, the operation had already taken place under the post-merger approval procedure.

The decision was challenged in courts for more than a decade. In October 2016, Nestlé finally presented a proposal for a judicial settlement. CADE considered that the package for sale offered by Nestle was adequate. The market for chocolate coatings was not a problem anymore. As to the market of chocolates in general, the package allowed a prospective buyer to operate independently and in a satisfactory way. In 18 October 2016, CADE accepted the agreement, which ended this long dispute.

\subsubsection{Meat and Poultry}

In 2009, the merger of Sadia and Perdigão, two Brazilian top players in the food industry - and historical rivals - into Brasil Foods took place. They represented together between $50 \%$ and more than $80 \%$ of sales in the Brazilian market of processed food in each market. In 2011, CADE undertook an extensive analysis of all the relevant markets. ${ }^{2386}$ The report indicated that the operation could lead to high horizontal concentration, especially in the markets of margarine, sausages, ham, hamburgers, lasagnes, frozen pizza, kebabs and meatballs. There was also vertical integration and concerns on the increase of the purchase bargaining power. Entry and rivalry were not capable of compensating the market power created. The claimed efficiencies were not sufficient.

\footnotetext{
${ }^{2384}$ AC 08012.004527/2011-47, decided on 12 September 2012.

${ }^{2385}$ AC 08012.001697/2002-89 and AC 08700.003861/2016-30, decided on 04 February 2004.

${ }^{2386}$ AC 08012.004423/2009-18, decided on 13 July 2011.
} 
The reporting Commissioner voted for the prohibition and disapproval of the merger. The other Commissioners (majority) voted for its approval with several restrictions. The restrictions involved, among others:

- the suspension for 5 years of brands such as Perdigao and Batavo in some markets;

- the sale of "fight brands" such as Doriana, Light, Texas, Patitas, Rezende and Wilson;

- the sale of unprocessed meat businesses;

- the sale of assets and distribution centres.

In this context, BRF`s competitor, Marfrig, bought several distribution centres, production plants, slaughterhouses, farms, hatcheries and more than 10 brands.

In 2013, CADE evaluated the acquisition by JBS of the assets of the major slaughterhouse Bertin and of assets from several other companies in 2012. ${ }^{2387}$ Some transactions had not been notified in due time and others not at all. Due to that, $\mathrm{CADE}$ imposed a fine of $\mathrm{R} \$ 7,4$ million for the delay. The report of the authority indicated that the merger should go forward, but identified the need for market monitoring. Moreover, JBS had to adjust its non-competition clauses. In addition, it had to inform the authority of any acquisition, rent or lease of slaughterhouses, either active or inactive, for the following 30 months. The final decision was approval with restrictions.

In 2014, CADE scrutinised the acquisition by BRF Foods of a minority participation (16\%) in the capital of Minerva. ${ }^{2388}$ In exchange, Minerva acquired BRF`s livestock activity in the State of Mato Grosso do Sul. The report of the authority indicated that the operation would be pro-competitive in the market of livestock bovine meat. On the other hand, it would raise concerns in the market for processed food (healthy hams, processed chicken products, meatballs, kebabs and bacon) due to horizontal concentration. Both parties brought efficiency gains from the minority participation. The final decision was approval with the condition of selling specific assets (not published). This was reached by means of a negotiated agreement with the parties.

Also, in 2014, CADE analysed the rental by JBS of three units of cattle slaughtering from Rodopa in the States of Mato Grosso do Sul, Sao Paulo and Goias. ${ }^{2389}$ The report of the authority indicated that the operation could lead to high horizontal concentration and vertical integration in a relevant market composed by small slaughterhouses. The final decision was approval with conditions. Among them, there was the obligation to keep the operations of the acquired units, to reactivate some closed units, and not acquire units in states in which it had high market shares. This was reached by means of a negotiated agreement with the parties. The parties did not comply with some of the obligations so, in October 2016, a fine was imposed and a new deadline was set.

JBS, one of the world's biggest meat-packing firms, is being investigated in the Lava-Jato (Car Wash) proceedings. The concerns are related to the fraudulent concession of subsidised loans for the expansion of the JBS group by the National Bank for Social and Economic Development (BNDES) and illegal measures taken by the administration for the benefit of the group. ${ }^{2390}$ Because of that, all the acquisitions involving JBS are being carefully scrutinised.

From 2016, CADE has evaluated the acquisition by JBJ Agropecuaria of Fratelli Dorazio Alimentos and Mataboi. ${ }^{2391}$ Due to the delay in the notification, CADE considered that the parties

${ }^{2387}$ AC 08012.008074/2009-11 and others, decided on 17 April 2013.

2388 AC 08700.000658/2014-40, decided on 20 August 2014.

2389 AC 08700.010688/2013-83, decided on 20 August 2014.

2390 https://www.bloomberg.com/news/articles/2017-05-25/brazil-s-car-wash-scandal-reveals-a-country-soaked-incorruption

2391 AC 08700.007553/2016-83, final decision pending. 
engaged in gun-jumping, fined the company in $\mathrm{R} \$ 664.000$ and set a firewall within the merged company until a final decision is reached. In March 2017, CADE`s Superintendence considered that the transaction was complex and undertook an extensive analysis of all the relevant markets. Due to the family relations between the controlling shareholder of JBJ and the controlling shareholders of JBS, CADE's SG evaluated the risk of coordinated action. In June 2017, it considered that high horizontal concentration would arise in the markets of cattle slaughtering in the State of Goias and in the national market of unprocessed meat. The failing firm defence was not accepted. It recommended the imposition of remedies and sent the case to CADE`s tribunal, which will soon reach a final decision.

\subsubsection{Beer and Soft Drinks}

In 2000, CADE analysed the merger between Antartica and Brahma, two major players in the beer and soft drinks markets, into AMBEV. ${ }^{2392} \mathrm{CADE}$ decided that there was high horizontal concentration in the beer market in five regional markets. Rivalry and entry were not capable of curbing market power. There were no compensating efficiencies to balance the increase in the dominant position. CADE decided that AMBEV should sell the brand Bavaria together with five processing units and assets to produce beer in each of the affected markets. It should provide for temporary sharing of the distribution network for the brand sold. The final decision was approval with the restrictions contained in the agreement. A dissenting commissioner voted for the prohibition of the operation.

In 2004, CADE analysed licensing by Pepsico to AMBEV (via CBB) for the production and sale of Gatorade, with the respective transfer of assets. ${ }^{2393}$ The report of the authority indicated that horizontal concentration would arise in the market for artificial isotonic beverages. The combined market would be very high (95\%) given that CBB already produced the isotonic Marathon. Barriers to entry were high due to the loyalty to the brand. Besides, there would be no effective rivalry in the market. Efficiencies related to production and sale strategies and marketing were not sufficient to curb the exercise of market power.

CADE decided for the sale of the brand Marathon by means of a public auction. The acquiring company would be able to use the distribution channels of the seller. A dissenting commissioner voted for the full prohibition of the operation. The final decision was approval by majority with the conditions set out in the performance agreement between CADE and CBB. Marathon was successfully sold to Energia Online Ltda.

In 2008, CADE evaluated the acquisition by Coca Cola and FEMSA of Del Valle Mexico. ${ }^{2394}$ The report of the authority indicated some horizontal concentration in the markets of ready-to-drink juices. The added market shares were expressive, but entry and rivalry would be enough to curb anticompetitive effects for the supermarket sales. The report then analysed the specificities of the distribution chains in the retail for cold juices. There was also a non-competition clause that required adjustment. The final decision was approval with the condition of restricting the scope of the noncompetition clause to the relevant market. Also, by a close majority, it decided that the parties should abstain from tying practices in relation to prepared juices in the cold market.

2392 AC 08012.005846/1999-12, decided on 30 March 2000.

${ }^{2393}$ AC 08012.000212/2002-30, decided on 14 July 2004.

${ }^{2394}$ AC 08012.003001/2008-44, decided on 18 June 2008. 
In 2012, CADE assessed the distribution contract through which Probiotica would distribute AMBEV`s Gatorade products for 3 years. ${ }^{2395}$ The report of the authority indicated that there was no horizontal concentration in the markets of food supplements for physical activities and artificial sports drink. This led to the conclusion that the acts would not raise competitive problems. However, there was a non-competition clause that required adjustments. The final decision was approval with the condition of changing the non-competition clause, restricting it to the sale channels through which Probiotica distributed Gatorade.

\subsubsection{Dairy}

In 2011, CADE evaluated the acquisition by Laticinios Bom Gosto of shares and quotas in the companies Lider, Santa Rita, Menpar, Cedrolat, CBL and of assets from Parmalat. ${ }^{2396}$ They were notified after investigation for non-submission. Therefore, a fine for the delay was imposed. The report of the authority indicated horizontal concentration in the markets of milk cream; ultra-hightemperature milk; cheese; creamy cheese; butter; powdered milk; milk drinks; milk caramel; condensed milk and prepared juices. However, the concentration in those markets was below 20\%, so there were no competitive concerns to address. The final decision was approval with a restriction in one of the transactions, consisting in the adjustment of the temporal aspect of the non-competition clause.

CADE analysed in 2012 the acquisition by Avex (BrFoods) of Argentinian enterprises of the Danica Group, in the margarine market. ${ }^{2397}$ The report of the authority indicated no horizontal concentration resulting from the operation, since Danica only operated in Argentina. It highlighted that BRFoods could not use the Danica brand in Brazil, due to previous commitments with CADE. The final decision was approval with the restriction of non-use or introduction of new margarine brands in the Brazilian market, in line with the decision on the creation of BRFoods.

\subsubsection{Retail}

Several decisions resulted in an intervention in the retail sector in Brazil. In 2004, CADE analysed the acquisition by Bompreco of six supermarket units in Bahia. ${ }^{2398}$ The report of the authority indicated some horizontal concentration in the retail supermarket business in Salvador and Lauro de Freitas. In the latter case, the resulting market shares were high (over 50\%). Entry would be possible only in relation to small supermarkets. Rivalry was not considered sufficient to prevent the exercise of market power. Efficiencies in relation to cost reductions and technical progress were not deemed to counter-balance the anticompetitive effects. The final decision, taken by majority, was approval with the condition that Bompreco sold the unit in the city Lauro de Freitas-BA in three months. If not sold, the unit would have to be publicly auctioned.

\footnotetext{
${ }^{2395}$ AC 08012.005575/2012-33, decided on 21 November 2012 and 03 April 2013.

${ }^{2396}$ AC 08012.003820/2010-14; AC 08012.003821/2010-51; AC 08012.003822/2010-03; AC 08012.003824/2010-94, decided on 19 January 2011.

${ }^{2397}$ AC 08012.011550/2011-98, decided on 09 May 2012.

2398 AC 08012.005104/1999-51, decided on 02 June 2004, available at http://anexos.radaroficial.com.br/0481696497dc9650bd77f8f366916888.pdf
} 
In 2007, CADE evaluate the constitution of Sendas Distribuidora, owned by Sendas and CDB (Pão de Açucar Group), involving several supermarkets and brands. ${ }^{2399}$ The report of the authority indicated that the operation resulted in horizontal concentration in several markets, among them retail in a local and neighbourhood levels. In several markets, the rivalry and entry were capable of compensating the market power created. In the market of Cabo Frio/RJ, the high variation of the HHI led to the conclusion that the analysis should be deepened. The majority considered that entry and rivalry would not be enough to balance the market power. The final decision was taken by majority and resulted in the approval with the condition of selling the assets related to the supermarket in Cabo Frio/RJ in 60 days.

Also in 2007, CADE analysed the acquisition by Bompreco of five supermarkets of Carrefour, including all the respective assets, workers and food products. ${ }^{2400}$ The report of the authority indicated that horizontal concentration in some markets would result from the operation. Specially in the market of Petrolina-PE, the high market share and the absence of probable entry or rivalry led to the conclusion that a restriction was necessary. Efficiencies were considered vague and not fully proven. The final decision was approval with the restriction that Bompreco should sell one of its supermarkets in the city of Petrolina.

In 2008, CADE decided on the rental by CBD (Pão de Açucar Group) of the assets related to five supermarkets of Rossi. ${ }^{2401}$ The report of the authority indicated that the merger resulted in horizontal concentration in the supermarket retail business in several localities. In the cases where concentration was over $30 \%$, rivalry and entry were capable of compensating the market power created. The final decision was approval with the condition of restricting the scope of the noncompetition clause to specific neighbourhoods, when it came to the city of Guarulhos.

In 2016, CADE assessed the joint venture agreement between Dia World Trade and IRTS (Casino Group) to constitute ICDC, which would provide international services on top and coordination for private label. ${ }^{2402}$ Both groups operated in the retail market for food products. The Brazilian Association for Food Industry had been accepted as a third party. CADE defined that the market for services on top and analysed it on the international and national basis. It defined the market shares to conclude that the resulting HHI was high enough to justify a more detailed analysis. It carried out an analysis of rivalry to conclude that both Wal Mart and Carrefour were capable of exercising a balance to the market power of the JV companies. Also, the compensatory power of manufacturers was strong enough. CADE considered there were enough guarantees that sensitive market information would not be discussed in the JV. Efficiencies on global operations would result in better quality of the services provided, since both groups covered different countries. The final decision was approval without restrictions.

\subsubsection{Conduct Cases}

\subsubsection{Soybeans}

2399 AC 08012.009959/2003-34, decided on 24 October 2007.

${ }^{2400}$ AC 08012.003972/2001-18, decided on 12 December 2007.

${ }^{2401}$ AC 08012.010903/2007-56, decided on 17 September 2008.

${ }^{2402}$ AC 08700.003252/2016-81, decided on 05 August 2016. 
The Minister of Agriculture made a request for the opening of preliminary proceedings against the non-governmental organization Focus on Sabbatical. The allegations were that the NGO was offering to soybean producers in Brazil US\$ 165 to every non-farmed hectare. The aim was to reduce supply and force an increase in prices in the world market for soybeans.

In 2005, CADE decided that in theory the conduct could be a violation of the antitrust law related to the destruction or abandonment of crops ${ }^{2403}$ However, there was no sufficient evidence of the infringement, given the low representativeness of the NGO and the fact that it was not duly established in Brazil. CADE discontinued the proceedings.

\subsubsection{Meat and Poultry}

CADE investigated a buyer cartel to purchase meat composed by the largest meat-packing firms of the country. In 2007, CADE decided that there was enough material evidence of the conduct. ${ }^{2404}$ It fined all the companies. One of the companies and its managers signed a cease-and-desist agreement and voluntarily paid its fines with a reduction.

In the poultry sector, an ex officio investigation began after the authority found out that the president of the Brazilian Association of Poultry Farming recommended that the sector reduced its production in $20 \%$ in order to avoid a decrease in prices. The declaration was published in public reports. In 2010, CADE considered that the conduct was illegal. ${ }^{2405}$ The Association and its president entered into a cease-and-desist agreement and paid a fine of almost 1 million reals (around half a million dollars).

\subsubsection{Fish and Seafood}

CADE investigated a claim of abuse of petition (sham litigation) in the market of sardines in brine. Ampex, an importer of sardines, argued that Gomes da Costa and Coqueiro (Pepsico), by means of their trade unions, were trying to avoid that Ampex consolidated its market position. They had made several requests to administrative authorities to increase taxes of imported sardines and to prevent the inclusion of the species imported by Ampex in the list of authorised products in Brazil.

In 2011, CADE considered that there was no sham litigation. ${ }^{2406}$ All the claims were a legitimate exercise of petition rights. It closed the investigation of the preliminary proceedings.

\subsubsection{Orange}

Since 1999, Brazilian authorities had been investigating a cartel for the purchase of oranges. ${ }^{2407}$ The companies and the association involved signed in November 2016, seven cease-and-desist agreements by which they recognised the cartel. ${ }^{2408}$ The resulting fine was 301 million BRL (around 90 million dollars). The processing companies fixed prices and established quotas to purchase orange

\footnotetext{
2403 AP $08001.003383 / 2002-40$, decided on 28 September 2005, available at: http://anexos.radaroficial.com.br/314000986b81bfa079a872fe1ba19e01.pdf

${ }^{2404}$ PA 08012.002493/2005-16, decided on 28 November 2007.

${ }^{2405}$ PA 08012.003623/2009-53; RQ 08700.002933/2009-01, decided on 10 June 2010.

${ }^{2406}$ AP 08012.006484/2010-53, decided on 31 August 2011.

${ }^{2407}$ PA 08012.008372/1999-14, 08012.001255/2006-66 e 08012.010505/2007-30, decided on 23 November 2016.

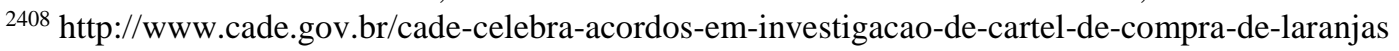


from farmers. Evidence was obtained from dawn raids, which were target of several judicial measures. This was an important decision considering that, in 2006, CADE had rejected an agreement in the case. The decision constitutes an affirmation of the autonomy and independence of CADE given that the companies were powerful and had good relations with political groups in Brazil. Among those involved, there was the family of a wealthy business with considerable influence over several politicians. ${ }^{2409}$

\subsubsection{Chocolate}

Proceedings were initiated against the Brazilian Association for the Chocolate and Confectionary Industry for sharing information about price increases during Easter in 2009. ${ }^{2410}$

In 2013, the Association and its directors concluded with CADE a cease-and-desist agreement through which it ensured that it would not share information on prices, costs or levels of production in the market nor dates or percentage of price increases. They also paid an amount of $\mathrm{R} \$ 96.000,00$ (around 40 thousand dollars) related to the infringement.

\subsubsection{Cereals}

In 2013, CADE decided on the determination of the infringement and imposition of fines to several bakeries and its owners for the fixing of the price of bread in the town of Sobradinho, in the surroundings of the city of Brasilia. ${ }^{2411}$ The case started in 2001 from a complaint made by the State Police who had arrested bakery owners during a meeting organised by the trade association at a local restaurant.

CADE decided that there was sufficient evidence of the infringement, which included the agenda for the meeting, with an item named "price of bread", identical posters with the new prices to be announced to consumers, and several oral testimonies. CADE concluded that the meeting was part of a strategy to align market practices.

Fines were imposed to 18 bakeries and 19 individuals, totalling 650 thousand reals. (approximately US\$200,000.00).

\subsubsection{Salt}

CADE has been investigating a cartel in the national market for salt, involving companies, its managers and trade associations. ${ }^{2412}$ The investigation began after a complaint of predatory pricing on imports on preliminary proceedings. In turn, this led to information about a possible cartel. CADE collected further evidence from dawn raids. In 2014, Salina Branco and its managers opted for a settlement and paid R \$ 5,5 million. The decision was to approve the cartel settlement due to its convenience and legality. The proceedings continue in relation to the other parties. CADE`s

\footnotetext{
2409 https://www.bloomberg.com/news/articles/2015-01-27/brazil-orange-baron-becomes-billionaire-as-florida-outputsours

${ }^{2410}$ PA 08012.001772/2009-88 and RQ 08700.011043/2012-87, decided on 03 July 2013.

${ }^{2411}$ PA 08012.004039/2001-68, decided on 22 May 2013.

${ }^{2412}$ PA 08012.001022/2008-25; PA 08012.005882/2008-38 and RQ 08700.002238/2014-06, decided on 26 November 2014.
} 
Superintendence recommended to the Tribunal their condemnation and imposition of fines. The final decision is pending in the Tribunal.

\subsubsection{Dairy}

In 2017, CADE condemned and fined several milk producers, including cooperatives, and a trade union of milk producers in Brazil in the state of Rio Grande do Sul for the organisation of a cartel. ${ }^{2413}$ According to the decision, the producers gathered to define the price of milk and put pressure on small producers to align their behaviour with the market leaders.

\subsubsection{Beer}

AmBev, formed in 1999 and currently part of the AB Inbev group, abused its dominant position by engaging in exclusionary practices, relating to the beer sold to small points of sale. AmBev established a loyalty programme called "Tô Contigo" ("I'm WITH you"), which awarded "points" redeemed into prices to dissuade retailers from selling competing brands. In 2009, the report of the authority concluded that AmBev was dominant in the upstream market of beer in each of the five regions of Brazil. The downstream product market was defined as ready-to-drink cool bottled beer (0.6L), sold in bars and small stores. Geographically, the downstream market was defined as local, since consumers tend to move around locally to consume cool beer. CADE found that the discounts, conditioned on exclusivity or $90 \%$ market share, were a very powerful inducement for points of sale to prefer AmBev's porfolio against its rivals. It enabled AmBev to leverage its dominant position.

In July 2009, CADE decided that the conduct was an abuse of dominance and ordered AmBev to change its programme. ${ }^{2414}$ The fine for abuse of dominance was $1.5 \%$ of the turnover. ${ }^{2415}$ Following the decision, AmBev brought judicial proceedings. In 2015, CADE and AmBev concluded a judicial agreement, which resulted in the reduction of the fine. Additionally, CADE ordered SDE to open administrative proceedings against AmBev managers for their purposeful role in the conduct. These proceedings were settled administratively in July 2014.

In another case, CADE analysed whether AmBev had created difficulties for its competitors by adopting a new $630 \mathrm{ml}$ bottle to distribute its beers. The investigation started with a complaint from the Association of Soft Drinks claiming that the introduction of the new bottle increased the costs of rivals. They could not recycle the bottles for reuse, considering that the sharing of $600 \mathrm{ml}$ bottles was the standard practice in the industry. In 2010, AmBev and CADE concluded a cease-and-desist agreement by which AmBev would progressively abandon the use of the bottles in some states. It also agreed to exchange $630 \mathrm{ml}$ bottles for the standard $600 \mathrm{ml}$ ones at the request of its rivals.

In 2015, AmBev and CADE concluded a cease-and-desist agreement related to proceedings investigating its exclusive supply and freezer policy with points-of-sale (retail). The case had initiated by a complaint of the rival Kaiser. AmBev agreed to limit the amount and the volume of sales of beer to points of sale with which it could have formal or de facto exclusivity in a given region. It also

\footnotetext{
${ }^{2413}$ PA 08012.010744/2008-71, decided on 18 January 2017.

${ }^{2414}$ PA 08012.003805/2004-10 and PA 08012.010028/2009-74, decided on 22 July 2009.

${ }^{2415}$ For more details, see Murilo Lubambo \& Fernando Furlan, "The Companhia de Bebidas das Américas - AmBev Loyalty Rebates Case” International Antitrust Bulletin, American Bar Association, Section of Antitrust Law, vol 4, p. 13 (2010).
} 
agreed to change its freezer policy. It could not require exclusivity in exchange for the loan of the freezer. The report of the authority concluded that the agreement was adequate and convenient.

\subsection{Superior Bargaining Power}

\subsubsection{Contract Law}

In Brazilian law, there is no concept of abuse of economic dependence. Contracts between businesses are regulated ${ }^{2416}$ by the Civil Code, since the enactment of the New Civil code in 2002 (hereinafter "BCC"). The BCC unified the regulation of commercial contracts, previously regulated by the Commercial Code, with the general law of obligations. Brazilian contract law is centred upon the principle of bargaining power, though several limitations are possible, especially through the application of general concepts, such as good faith and public interest. ${ }^{2417}$ In fact, the founding principle of objective good faith is now expressed in art. 422 of BCC and serves as an interpretative tool and as an element of creation of legal duties. ${ }^{2418}$ Also, the social function of contracts is now explicit in art. 421 and has been discussed and applied by courts. ${ }^{2419}$

In particular, Brazilian scholars envisage the judicial intervention in cases of contractual imbalances as connected to the constitutional principle of social justice. ${ }^{2420}$ However, the recourse to constitutional principles may be justified only in particularly serious cases.

Nonetheless, some argue that contract law can be used against opportunistic and exploitative behaviour of the dominant party of the contract. ${ }^{2421}$ The concept of vulnerability has been raised as a basis for intervention in order to avoid excessive advantages to one of the parties. ${ }^{2422}$ In this regard, Iwasa reports that:

Castello Miguel classified those interventions in two types: the first one aims to protect interests that are external to the contracting parties and are related to collectivity (e.g., social function of the contract and the environment). The second type aims to protect the interests of the parties of the contract and its application is justified only when there is an inequality of bargaining power between parties. If there is a balance between them, they are presumably able to protect their own interests and avoid the violation of social values such as the principle of equality. Consequently it

\footnotetext{
${ }^{2416}$ Article 966 defines 'business proprietor' as “anyone who engages, on a professional basis, in organised economic activity for the production or trade of goods or services", see Leslie Rose, O Código Civil Brasileiro em Inglês/ The Brazilian Civil Code in English (Renovar 2008) 188.

${ }^{2417}$ Luciana Iwasa, 'A Comparative Evaluation of the Legislative Controls on Unfair Terms and Exemption Clauses in Consumer and Business Contracts in England and Brazil' (phd, Aston University 2013) 72 <Available at: http://eprints.aston.ac.uk/19144/> accessed 25 August 2015.

${ }^{2418}$ Caio Mário da Silva Pereira, Instituições de Direito Civil (16a-25a edição, Forense 2012) 17-19.

2419 Nelson Nery Júnior and Rosa Maria Andrade Nery, Código Civil Comentado (8 ed rev, ampl e atualizada até 12072011, Editora Revista dos Tribunais 2011) 538-543.

2420 Ibid referring to Paula Castello Miguel, Contratos entre Empresas (Revista dos Tribunais 2006) 86-93 and André Osório Gondinho, 'Codificação e Cláusulas Gerais' (2000) Rio de Janeiro: Padma, n. 2 Revista Trimestral de Direito Civil 3

${ }^{2421}$ Ibid, referring to Humberto Theodoro Júnior, O Contrato e seus Princípios (3rd edn, Aides 2001) 17.

2422 Lobo, Paulo. "Contratante Vulneravel e Autonomia Privada" in https://jus.com.br/artigos/25358/contratantevulneravel-e-autonomia-privada accessed 8 May 2017.
} 
is possible to contend that interventions in $B 2 B$ contracts are generally of the first type; whereas the second type may be more relevant to small businesses contracts. ${ }^{2423}$

It seems possible for Brazilian judges to treat specific cases involving abuse of superior bargaining power, using different provisions of Brazilian contract law, in particular: Art. 122 regarding potestative clauses; Art. 157 on the concept of damage; Art. 187 on the abuse of right; Art. 317 on the adjustment of a disproportional obligation; Art. 413 on the equitable reduction of the penal clause; Art. 478 and art. 480, respectively on the termination and on the reduction of obligations for excessive onerousness; and Art. 884 on enrichment without a cause (different from the common law institute of unjust enrichment).

As in the Roman law tradition, Brazilian contract law generally provides for nullity of the contract as a consequence of several vitiating factors: mistake and ignorance (art. 138); wrongful conduct ("dolo") (art. 145); coercion (art. 151); state of peril (art. 156) and fraud (art. 158). Art. 157 of the new civil code also sets out the vitiating factor of lesion, which "occurs when a person, in pressing need or through lack of experience, assumes an obligation that is manifestly disproportionate to the value of its counterpart.",2424

However, in case of B2B contracts, it is generally assumed that both parties enter the contract with the minimum knowledge available to avoid substantial mistakes, at least as intended in the Roman law doctrine. Moreover, only in fringe cases will it be possible to envisage coercion, as general contract law principles tend to strictly interpret the physical harm element. By contrast, the objective good faith has the function of a general clause, which is however limited by the substantiation of the fraudulent intent of the party covering a dominant position.

Finally, the Brazilian law on unfair contracts addresses solely consumer protection, leaving therefore out of its reach $\mathrm{B} 2 \mathrm{~B}$ contracts.

\subsubsection{Competition Law}

Brazilian law does not explicitly contemplate any rule on abuse of economic dependence, abuse of superior bargaining power or the concept of obligatory trading partner. ${ }^{2425}$ However, thanks to the loose wording of the competition law provisions, CADE maintains that it would be possible to sanction an undertaking for abuse of superior bargaining power, as the "claim could be based on any of these effects / purposes, even though there is not a clear definition of the infraction"2426.

Article 36 of the Brazilian Competition Act provides for all the types of anticompetitive conduct sanctioned by the law:

"The acts which under any circumstance have as an objective or may have the following effects shall be considered violations to the economic order, regardless of fault, even if not achieved:

I - to limit, restrain or in any way injure free competition or free initiative;

II - to control the relevant market of goods or services;

III - to arbitrarily increase profits; and

\footnotetext{
${ }^{2423}$ Iwasa, referring to Paula Castello Miguel, Contratos entre Empresas (Revista dos Tribunais 2006) 124-125.

${ }^{2424}$ Leslie Rose, O Código Civil Brasileiro em Inglês/ The Brazilian Civil Code in English (Renovar 2008$) 41$.

${ }^{2425}$ ICN, ‘Report on Abuse of Superior Bargaining Position’ (2008) 10.

2426 ibid 12.
} 


\section{$I V$ - to exercise a dominant position abusively".}

The following indents of Article 36 better define these four broad violations, presenting examples of classical conducts that may be considered violations whenever they produce the effects above. However, none of these definitions refers to an abuse of superior bargaining power or to other similar non-structural power type of infringement. One could argue that indent III (arbitrary increase of profits) could base such a claim, dispensing with the analysis of restraint of competition, control of markets or abuse of dominance. However, CADE has been quite reluctant to refer to this indent to base infringements.

Article 36, $\S 2$ adopts indeed a structural approach to the definition of dominance stating that:

"A dominant position is assumed when a company or group of companies is able to unilaterally or jointly change market conditions or when it controls $20 \%$ (twenty percent) or more of the relevant market, provided that such percentage may be modified by Cade for specific sectors of the economy".

In fact, the broad scope of the law could encompass those kinds of abuses. On the other hand, CADE has been careful to not intervene in the freedom of contract, in relation to conduct within the sphere of private relations. In 2009, for instance, CADE analysed whether AMBEV had imposed quotas, engaged in resale price maintenance with its distributors and sold directly to supermarkets, among other practices. ${ }^{2427} \mathrm{CADE}$ decided that there was no infringement related to the distribution network, since those were private matters and discontinued the proceedings.

Nonetheless, CADE has already examined cases dealing with abuse of economic dependence and has reasoned about the connection between dependency and market power.

As Berardo and Becker state, "CADE highlighted that dependency, i.e. one seller depending exclusively or almost exclusively on purchases made by one purchaser, does not in itself necessarily correspond to buying power, which obviously depends on aggregate market output and purchases." 2428 .

In this regard, for example, the competition authorities investigated a complaint by a cooperative of milk producers in Minas Gerais. The cooperative was an intermediary in the sale of milk to Itambe, a large company which sold milk in Brazil. It complained that Itambe engaged in market division and discriminatory practices towards its suppliers, which depended on the sale to Itambe. In the end, the proceedings were discontinued by CADE for lack of evidence. ${ }^{2429}$

All in all, no infringement has ever been found based exclusively on economic dependence, devoid of general market conditions.

Finally, another way that competition enforcement could possibly deal with the situation is in the scope of the analysis of mergers. CADE's Resolution No. 10, adopted November 2014., mentioned nterdependence as a criterion for the mandatory notification of certain contracts. ${ }^{2430}$ If an

\footnotetext{
${ }^{2427}$ PA 08012.004363/2000-89, decided on 28 October 2009.

2428 Jose Carlos da Matta Berardo, and Bruno Bastos Becker, in Pierre Kobel, Pranvera Këllezi and Bruce Kilpatrick (eds), Antitrust in the Groceries Sector \& Liability Issues in Relation to Corporate Social Responsibility (2015) 101. ${ }^{2429}$ AP 08012.010986/2006-01, decided on 12 March 2011.

2430 "[The Resolution] sets out the situations in which notification to CADE is required for associative agreements. According to the resolution, associative agreements are those in force for a period longer than two years, in which there is horizontal or vertical cooperation or risk sharing that represent a relationship of interdependence among the contracting parties. The resolution also defines that a relationship of interdependence fits into two different hypothesis. : When companies are horizontally related in the object of the contract, interdependence occurs if the joint participation of the companies in the market affected by the contract equals or exceeds $20 \%$ of the market share. When companies are vertically related in the object of the contract, on the other hand, interdependence occurs if at least one of them holds a
} 
associative contract between companies is of mandatory notification, CADE could impose restrictions upon its presentation to avoid the abuse of economic dependence. However, Resolution 10 was revoked and substituted by Resolution 2017, which narrowed the scope of associative contracts with mandatory notification

\subsection{Agricultural Subsidies}

Brazil recognises that agriculture is a sensitive market given its specific characteristics, eg the risk of crop destruction and the exogenous determination of prices.

Brazilian authorities have justified justify the rural credit system, as a means to correct a market failure resulting in insufficient credit allocation to medium, small and micro producers, and the financing mechanism, due to the importance of family farming on the supply for internal consumption, thus, food security. ${ }^{2431}$

\subsubsection{Mechanisms and Institutions for Support}

Box I analyses and justifies the available mechanisms for agricultural price support in Brazil:

\section{Box I}

"Market price support aims to reduce price volatility, protect farmers' incomes, improve the availability of food supplies and offset the additional costs of producers in regions that are distant from the main markets and ports. There are also specific programmes that target small-scale agriculture, with some purchases being distributed via food programmes.

Minimum guaranteed prices are reviewed annually, covering thirty-three crops. They are announced regionally through the PGPM (Política de Garantia de Preços Mínimos) by the Secretary of Agricultural Policy (SPA) operated by the National Food Supply Agency (Companhia Nacional de Abastecimento, CONAB). This mechanism covers a great variety of crops from rice, wheat, maize, cotton, soybeans, to regional crops like cassava, beans, açaí, guaraná, sisal, and a few livestock products like cow and goat milk, and honey. Other price support mechanisms for commercial agriculture are the direct government purchases (Aquisição do Governo Federal, AGF) and the provision financing of storage by the FEPM (Financiamento para Estocagem de Produtos Agropecuários integrantes da Política de Garantia de Preços Mínimos) former Empréstimo do Governo Federal-EGF. The [Secretariat of Family Farming and Agrarian Development] supports the development of family farming, and makes use of the minimum prices policy. Instruments that support prices and target small-scale agriculture are government purchases similar to AGF (Programa de Aquisição de Alimentos, PAA) and the minimum prices programme for family farms, (Programa

participation of $30 \%$ or more in the affected markets. In this case, the resolution requires, additionally, that at least one of the following conditions is met: (i) the contract establishes revenue or loss sharing; (ii) the contract results in a relationship of exclusivity. The resolution brought both clarification and legal certainty to a much-debated issue within the legal community", see OECD, Annual Report on Competition Policy Developments in Brazil (OECD 2014) 4 $<$ Available http://www.oecd.org/officialdocuments/publicdisplaydocumentpdf/?cote=DAF/COMP/AR(2015)19\&docLanguage=En

${ }^{2431}$ WTO , Brazilian Trade Policy Review, 2013, wT/TPR/S/283 parag. 4.31, p. 12417 May 2013 
de Garantia de Preços para a Agricultura Familiar, PGPAF). Under PAA, CONAB makes direct acquisitions from family farms at market prices, with the product either going into stock or distributed as part of a food programme. The PGPAF ensures that small-scale farmers receive a guaranteed price based on the average regional production cost of family farms."

Source: OECD/Food and Agriculture Organization of the United Nations (2015) $)^{2432}$

The National Food Supply Company (CONAB) is a public enterprise responsible for the management of food supply stocks in Brazil. Created in 1990, it regulates the supply of the Brazilian internal market. CONAB manages the supply of food stocks and implements the policy of minimum price of the federal government and other mechanisms to sustain agricultural products prices. The programmes of acquisition of foodstuffs by the federal government consists in the purchase of foodstuffs in order to level off the rent of small producers, that is, family farmers and their cooperatives. However, the programme has been subject to successive budget cuts and was granted 340 million reais in 2017 (around 100 million USD). ${ }^{2433}$

\subsubsection{Level of Support and Crops}

The most up-to-date document describing the level of subsidies in Agriculture is the 2017 WTO Secretariat Report of the Brazilian Trade Policy Review. ${ }^{2434}$ Box II highlights some of the findings:

\section{Box II}

"4.20. During the review period, Brazil continued to provide a broad range of assistance to its agricultural sector, inter alia, in the form of administered interest rate or concessional credit lines, price support mechanisms, and insurance premium subsidies. ...

4.21. Domestic support to agricultural producers remains at a low level compared with OECD countries. ${ }^{19}$ According to the OECD, Brazil's total support estimate (TSE) to agriculture averaged $0.35 \%$ of GDP in 2012-15 (0.55\% in 2008-10), well below the OECD average of $0.7 \%$ (Table 4.2). Support to farmers as measured by the producer support equivalent (PSE) was 3.2\% of gross farm receipts in the period, below the OECD average of $17.6 \% .{ }^{20}$ Support peaked in 2014 and fell in 2015 as both market price support (MPS) and payments based on input use (credit and insurance subsidies) declined. The MPS reduction was due to the minimum guaranteed prices increasing at a slower pace than inflation, and the depreciation of the R $\$$ relative to the US\$.

$[\ldots]$

4.22. According to Brazil's WTO notifications on domestic support measures during the review period, the current total aggregate measure of support (AMS) stood at US\$213.7 million in 2010/11 (wheat, sisal) and US\$7.7 million 2011/12 (sisal) (above its de minimis level but much below its final

${ }^{2432}$ OECD-FAO Agricultural Outlook 2015, OECD Publishing, Paris. P. 94 http://dx.doi.org/10.1787/agr_outlook-2015en

${ }^{2433}$ http://www.canalrural.com.br/noticias/rural-noticias/orcamento-programa-aquisicao-alimentos-cai-65687

2434 WTO, Brazilian Trade Policy Review, 2017 WT/TPR/S/358/Rev.1, 18 October 2017 available at: < https://www.wto.org/english/tratop_e/tpr_e/tp458_e.htm> 
bound level of U\$912.1 million), and then fell to zero (i.e. below its de minimis level) in 2011/12 and remained at this level in 2013/14 and 2014/15."

Source: WTO TRP 2017 (2017)

No export subsidies for agriculture have been granted in the recent past. ${ }^{2435}$

\subsubsection{Forms of Support}

\subsubsection{Minimum Prices Guarantees}

The table below details the operations of the mechanism of minimum price guarantees in 2013-16 by programme and crops:

\section{Table I}

( $\mathrm{R} \$$ million $)$

\begin{tabular}{|c|c|c|c|c|c|}
\hline & & 2013 & 2014 & 2015 & 2016 \\
\hline \multicolumn{6}{|c|}{$\begin{array}{l}\text { Disbursement } \\
\text { (purchase) }\end{array}$} \\
\hline \multirow{5}{*}{$\mathrm{AGF}^{2436}$} & Total & 79 & 84 & 0 & 0 \\
\hline & Edible beans & 0 & 72 & 0 & 0 \\
\hline & & & & & \\
\hline & Maize & 79 & 4 & 0 & 0 \\
\hline & Wheat & 0 & 8 & 0 & 0 \\
\hline \multirow{3}{*}{$\mathrm{COV}^{2437}$} & Total & 1,395 & 0 & 0 & 0 \\
\hline & Coffee & 1,029 & 0 & 0 & 0 \\
\hline & Maize & 366 & 0 & 0 & 0 \\
\hline \multirow[t]{4}{*}{ PEP } & Total & 0 & 0 & 0 & 9 \\
\hline & Wheat & 0 & 0 & 0 & 9 \\
\hline & Total & 484 & 631 & 15 & 69 \\
\hline & Cotton & 0 & 244 & 0 & 0 \\
\hline
\end{tabular}

${ }^{2435}$ WTO notifications G/AG/N/BRA/36, 27 January 2015, and G/AG/N/BRA/39, 12 January 2016.

${ }^{2436}$ See above.

${ }^{2437}$ Public Option Contracts (COV) "The Government offers option contracts to producers and cooperatives through public auctions. Winning bidders acquire the right to sell their products to the Government at a future date, for a predetermined "execution price" (a minimum price plus storage and financial costs). If the execution price is lower than the market price on the due date, the option contract is not used. When it deems convenient, the Government may transfer its obligation to buy to another party. The scheme may be used for any product covered by the PGPM.” TPR Brazil p. 105 


\begin{tabular}{|l|l|l|l|l|l|}
\multirow{5}{*}{ PEPRO $^{4400}$} & Maize & 455 & 256 & 0 & 0 \\
\cline { 2 - 6 } & Grapes & 11 & 0 & 0 & 0 \\
\cline { 2 - 6 } & Natural rubber & 0 & 3 & 15 & 0 \\
\cline { 2 - 6 } & Orange & 18 & 47 & 0 & 0 \\
\cline { 2 - 6 } & Wheat & 0 & 81 & 0 & 69 \\
\hline Total & & 1,958 & 715 & 15 & 78 \\
\hline
\end{tabular}

Source: CONAB, prepared by MAPA.

\subsubsection{Agriculture Insurance and Environmental Requirements}

\section{Box III}

"4.40. Agricultural insurance support continued to be provided to producers through four main programmes, either in the form of insurance premium subsidies covering the difference between a fixed premium and market rates through a discount in the fee to farmers (fixed percentage), or by compensating farmers for production losses due to natural disasters. ... The operation of these risk management programmes is currently shared among federal institutions, including some Ministries and the Central Bank. During the review period, a number of initiatives to improve the effectiveness of the rural insurance premium programme (PSR) included: the development of a model contract to facilitate collective negotiation for producers; greater dissemination of the programme availability; disclosure of statistical information on the programme; risk analysis; greater involvement of the private sector through advisory committees; and, the creation of a productivity register for a better estimation of risk (March 2016). Resources allocated to all agricultural insurance programmes amounted to R $\$ 700$ million (US $\$ 210$ million) in the 2015/16 agricultural plan; subsidy rates ranged from $35 \%$ to $100 \%$ of the premium, depending on the sector and the risk coverage. ${ }^{41} \ldots$

4.42. Agricultural zoning requirements continue to link agricultural support to environmental sustainability. They condition producers' eligibility for concessional credit and subsidized insurance programmes. Compliance with zoning applies to all concessional credit and all insurance premium subsidies for any product covered by the zoning (Section 4.2.4.1)."

Source: WTO TPR 2017 (2017) fn ommited

\subsection{Conclusion}

\footnotetext{
2438 Agricultural Products' Sale Option Private Premium (PEPRO) "This scheme offers producers and cooperatives the possibility to sell their product at a premium, equal to the difference between reference and market prices, fixed through an auction. In contrast to the PEP, premiums are paid directly to producers.” TPR Brazil p. 105
} 
To sum up, Brazil has a wide network of regulations in the food sector. It is spread in several levels of hierarchy, organs and autonomous agencies, as described. The rationale of the regulation generally follows the classic framework of regulation of production and trade for economic reasons, regulation for social purposes, including food safety, and risk regulation. Consumer protection and competition enforcement in the food market are essential to maintain the functioning of market, to the benefit of the citizens. Compared to other BRICs countries, CADE has been quite active in its enforcement activities in this area. Contract law can be also a tool to tackle some issues affecting food chains.

\section{References}

Araújo, S. \& Flaig, D. "Quantifying the Effects of Trade Liberalisation in Brazil: A Computable General Equilibrium Model (CGE) Simulation" (2016) OECD Economics Department Working Papers, No. 1295, OECD Publishing, Paris, Available at: <http://dx.doi.org/10.1787/5jm0qwmff2kfen>.

OECD, Innovation, Agricultural Productivity and Sustainability in Brazil, (2015) OECD Food and Agricultural Reviews, OECD Publishing Paris. Available at: <http://dx.doi.org/10.1787/9789264237056-en>.

· OECD, "Brazil", in Agricultural Policy Monitoring and Evaluation 2015 (2015) OECD Publishing, Paris.

OECD/Food and Agriculture Organization of the United Nations, "Chapter 2 - Brazilian agriculture: Prospects and challenges" in OECD-FAO Agricultural Outlook 2015, (2015) OECD Publishing, Paris. Available at: 〈http://dx.doi.org/10.1787/agr_outlook-2015-en>.

Breyer, S. Regulation and Its Reform (1984) Harvard University Press.

Viscusi, WK. Regulating the Regulators (1996) 63 (4) University of Chicago Law Review 1423.

Lubambo de Melo, MO. "Direito Fundamental à Água” in Anais do II Congresso Jurídico de Estudantes de Direito (2003) Recife.

Prosser, T. “Theorising Utility Regulation” (1999) 62 (2) Modern Law Review 196.

WTO, Brazilian Trade Policy Review - TPR WT/TPR/S/283 (2013).

Rodrigues, R L; Lage, C L S \& Vasconcellos, A. G. "Intellectual property rights related to the genetically modified glyphosate tolerant soybeans in Brazil" (2011)83(2) Anais da Academia Brasileira de Ciências, 719 Available at: 〈https://dx.doi.org/10.1590/S0001-37652011000200029>.

Fonseca, F. \& Berk, C. Brazil: Food and Agricultural Import Regulations and Standards Narrative. USDA FAIRS Country Report. Available at: <https://www.fas.usda.gov/data/brazil-fairscountry-report-0>.

OECD, Brazil - Peer Review of Competition Law and Policy (2005) Available at: 〈http://www.oecd.org/daf/competition/45154362.pdf>.

OECD, Brazil - Peer Review of Competition Law and Policy (2010) Available at: 〈http://www.oecd.org/daf/competition/35445196.pdf>. 
- Dezalay, Y \& Garth, B G, Dealing in Virtue: International Commercial Arbitration and the Construction of a Transnational Legal Order (1996) University of Chicago Press.

- Dezalay, Y. \& Garth, B G, The Internationalization of Palace Wars: Lawyers, Economists, and the Contest to Transform Latin American States (2002) University of Chicago Press.

- Lubambo, M. \& Furlan, F. "The Companhia de Bebidas das Américas - AmBev Loyalty Rebates Case" International Antitrust Bulletin, American Bar Association, Section of Antitrust Law, vol 4, p. 13 (2010).

- $\quad$ Rose, L. O Código Civil Brasileiro em Inglês/ The Brazilian Civil Code in English (2008) Editora Renovar.

- Iwasa, L. 'A Comparative Evaluation of the Legislative Controls on Unfair Terms and Exemption Clauses in Consumer and Business Contracts in England and Brazil' (2013) PhD, Aston University, Available at: <http://eprints.aston.ac.uk/19144/> accessed 25 August 2015.

Pereira, C M S Instituições de Direito Civil (2002) 16th-25th ed, Forense.

- $\quad$ Nery Júnior, N. \& Nery, R M A Código Civil Comentado (2011) 8 ed, Editora Revista dos Tribunais.

Lobo, P. "Contratante Vulnerável e Autonomia Privada" (2013) Available at: $<$ https://jus.com.br/artigos/25358/contratante-vulneravel-e-autonomia-privada $>$ accessed 8 May 2017.

International Competition Network, 'Report on Abuse of Superior Bargaining Position’ (2008).

Berardo, J C M \& Becker B B, "Brazil” in Kobel, P, Këllezi, P \& Kilpatrick, B (eds), Antitrust in the Groceries Sector \& Liability Issues in Relation to Corporate Social Responsibility (2015) 95.

OECD, Annual Report on Competition Policy Developments in Brazil (2014) Available at: $<$ http://www.oecd.org/officialdocuments/publicdisplaydocumentpdf/?cote=DAF/COMP/AR(2015) $19 \&$ docLanguage $=\mathrm{En}>$. 


\title{
Chapter 2: Russian Federation
}

\author{
By Ekaterina Perevoshchikova ${ }^{2439}$, Maxim Bashkatov, Katya Semenova \& Georgy Tyulyaev ${ }^{2440}$
}

\subsection{General Overview and Legal Framework}

\subsubsection{Domestic aspects and institutional framework}

The Federal Antimonopoly Service of the Russian Federation (hereinafter - "FAS") as the national competition authority plays a prominent role in monitoring and ensuring the protection of competition in the Russian food market. This is evidenced by the increasing number of inquiries and investigations carried out by FAS, as well as by the variety of areas which have become the object of its scrutiny.

The task of FAS is protection of competition and creation of favorable conditions for competition in the products markets (including the agricultural products and food markets). ${ }^{2441}$ This task is performed through different instruments including monitoring of the prices for socially important alimentary products, ${ }^{2442}$ especially in periods of significant price increase (as was the case in autumn 2014 - winter 2015), investigation of abuse of dominance and concerted practices; control on economic concentration at all levels of the food supply chain; control on the fairness and transparency of the procedures of granting subsidies to agricultural producers; giving clarification and recommendations to state and municipal bodies on the application of legislation having effect on competition, etc.

It is noteworthy that FAS's mandate has been significantly expanded during last years ${ }^{2443}$ and now encompasses not only protection of competition, but also various spheres of economic regulations. Thus, FAS regulates and oversees the activities of natural monopolies; performs control over the public procurement procedures and foreign investments in the Russian Federation; oversees compliance with the regulations on advertising activities. ${ }^{244}$ The Order of the President of the Russian Federation dated 21 July 2015 No.373 conferred to FAS significant powers in the sphere of tariff (price) regulations. On the one hand, this gives FAS more flexibility in its choice of remedies and broader approach to tackling particular market problems; on the other hand, this might lead to the tendency to administrative regulation of the markets instead of creating the system of economic incentives to promote competition. ${ }^{2445}$

\footnotetext{
${ }^{2439}$ Centre for Law, Economics \& Society, UCL Faculty of Laws.

${ }^{2440}$ HSE Skolkovo Institute for Law and Development.

${ }^{2441}$ Mission of the FAS at <fas.gov.ru/about/mission.html> accessed 26 December 2016; 'Regulations on the Federal Antimonopoly Service of the Russian Federation'adopted by the Decree of the Government of the Russian Federation dated 30 June 2004 No. 331.

${ }^{2442}$ Paragraphs 5,6 of Article 8 of the Federal law "On the Basic Principles of State Regulation of Trading Activities in the Russian Federation" dated 28 December 2009 N 381-FZ and "The List of Certain Types of Socially Important Essential Alimentary Products...' adopted by the Decree of the Government of the Russian Federation dated 15 July 2010 No. 530.

2443 Thus, during last 20 years the number of laws, for overseeing of which FAS is responsible, increased from 3 to 16 according to Sergey Titov, 'FAS Reform: Struggle for the Agency' (November 27, 2014) 3725 Vedomosti< www.vedomosti.ru/politics/articles/2014/11/27/borba-za-sluzhbu> accessed 20 April 2017.

2444 'Regulations on the Federal Antimonopoly Service of the Russian Federation' adopted by the Decree of the Government of the Russian Federation dated 30 June 2004 No. 331.

2445 Sergey Titov, 'FAS Reform: Struggle for the Agency' (November 27, 2014) 3725 Vedomosti < www.vedomosti.ru/politics/articles/2014/11/27/borba-za-sluzhbu> accessed 20 April 2017.
} 
In its activities FAS is subject to Russian competition law, which comprises two principal legal acts.

The first one is the Federal law "On Protection of Competition" dated 26 July 2006 N 135FZ (hereinafter - the "Federal law "On Protection of Competition"), whose goals are to secure the single economic area; free movement of goods; freedom of economic activity; protection of competition, and creating conditions for effective functioning of product markets. ${ }^{2446}$

The FAS investigations are mainly based on the following provisions of the Federal law "On Protection of Competition":

(vi) Article 10 - prohibition of abuse of dominant position;

(vii) Article 11 - prohibition of written or oral agreements between competitors (cartels) / "vertical" agreements, which lead or might lead to a restriction of competition ;

(viii) Article 11.1 - prohibition of concerted actions, which lead to restriction of competition;

(ix) Article 15 - prohibition of adoption of acts or performance of actions by state bodies, which lead or may lead to prevention, restriction or elimination of competition;

(x) Article 16 - prohibition of anticompetitive agreements or concerted actions by state authorities; between the state authorities and economic entities if they lead or may lead to the prevention, restriction or elimination of competition.

The second important legislative act is the Federal law "On the Basic Principles of State Regulation of Trading Activities in the Russian Federation" dated 28 December 2009 N 381-FZ (hereinafter - the "Federal law "On the Trading Activities"), which was adopted with the view to rebalancing relationships between food retail chains and food suppliers. Article 9 of the said Federal Law sets forth the rights and obligations of parties to a food supply contract including, inter alia, mandatory disclosure of information about selection criteria of potential counterparties and the essential terms of a food supply contract; the 5\% cap on the volume-based remuneration for the purchase of goods under a food supply contract; prohibition of bundling of purchasing of food products from the supplier with rendering to the latter by the buyer services aimed at promoting and advertising food products; etc.

Article 13 of the Federal law "On the Trading Activities" sets antimonopoly requirements for economic entities involved in trading activities for sale of food products through organising a retail chain and economic entities supplying food products to retail chains including prohibition to:

1) create discriminatory conditions as defined in the Federal law "On Protection of Competition";

2) prevent entry to / exit from the product market for other economic entities;

3) violate price setting procedures established by normative legal acts;

4) impose "unfair" conditions on the counterparty (e.g. exclusivity of supplies, return to the supplier of food products, which were not sold upon certain term, etc.). ${ }^{2447}$

\footnotetext{
${ }^{2446}$ Article 1 of the Federal law "On Protection of Competition".

2447 “Article 13. Antimonopoly Rules for Economic Entities Involved in Trading Activities and Economic Entities Supplying Food Products

1. Economic entities, involved in trading activities for sale of food products through organization of a retail chain, and economic entities, supplying food products to retail chains, are prohibited from:

1) Creating discriminatory conditions defined in accordance with the Federal law "On Protection of Competition";

2) Preventing entry/exit of another economic entity tolfrom the market;

3) Violating price setting procedures established by normative legal acts;

4) Imposing upon a counterparty the following conditions:
} 
Article 15 of the Federal law "On the Trading Activities" sets antimonopoly requirements for state and local authorities in the area of regulations of trading activities, including prohibition of restrictions on free movements of goods between different regions or between districts within one region; restrictions on free selection of counterparties; imposing price regulation on the economic entities, etc.

Provisions of both acts are subject to FAS enforcement. According to last publicly available official statistics on investigation of the cases on violation of the Federal law "On Protection of Competition", the Federal law "On the Trading Activities" in agricultural markets, ${ }^{2448}$ the majority of investigated cases referred to an unjustified increase of prices for food products. Among them, out of 321 antitrust cases brought by regional departments of FAS from August 2010 to January 10, 2012, setting of monopolistic prices constituted 104 cases; refusals to deal and concerted actions aimed at price increase constituted 159 cases; anticompetitive actions of state and local authorities constituted 52 cases.

The interplay between the Federal law "On Protection of Competition" and the Federal law "On the Trading Activities" was not initially clear. The amendments introduced to the Federal law "On the Trading Activities" in July 2016 aimed, inter alia, to eliminate the discrepancies between two legal acts and bring the Federal law "On the Trading Activities" in compliance with the main concepts and principles of antimonopoly regulations in the Russian Federation. ${ }^{2449}$ Importantly, FAS clarified that Article 13 of the Federal law "On the Trading Activities" was applicable to all cases of violation of its requirements by retail chains and food suppliers regardless of their market shares. ${ }^{2450}$ Therefore, there is no need to establish dominance in order to apply Article 13 the Federal law "On the Trading Activities". However, its application should be in line with the Federal law "On Protection of Competition" and the clarifications of FAS related to the Article 10 of the said law [abuse of

a) Prohibiting the economic entity from entering into food supply contracts with other economic entities involved in similar activities, as well as food supply contracts with other economic entities on similar or other conditions;

b) On liability for failure to comply with the obligations of the economic entity for supplies of food products on conditions that are more favourable than conditions for other economic entities involved in similar activities;

c) On providing information by the economic entity to the counterparty about contracts concluded by the economic entity with other economic entities involved in similar activities;

f) On reducing the prices by the economic entity, supplying food products, to the level, when with mark-up (surcharge) added, the price shall not exceed the minimum price for such goods supplied to the economic entities involved in similar activities ("most favoured nation clause");

i) On returning the food products, not sold during the designated period, to the economic entity that had supplied such goods, except when returning such goods is allowed or is provided for by laws of the Russian Federation;

j) Other conditions not relevant to the subject matter of the contract or substantially similar to the conditions provided for by sub-clauses " $a$ " - " $i$ " of this Article;

5)Performing wholesale trade under a commission agent agreement or a mixed agreement with elements of a commission agent agreement.

2. An economic entity can present evidence that its actions (omissions) specified in Part 1 of this Article (except actions specified in Paragraph 4 Part 1 of this Article) can be allowed under Part 1 of Article 13 of the Federal Law "On Protection of Competition" as of 26 July 2006 No.135-FZ”.

${ }^{2448}$ Report on investigation of the cases on potential violations of the Federal law "On Protection of Competition", the Federal law "On the Trading Activities", the Code of Administrative Offences by territorial departments of FAS as of 10.01.2012 <fas.gov.ru/documents/documentdetails.html?id=1524> accessed 05 January 2017.

2449 Paragraph 4 of the "Clarification of the FAS of Russia on some issues of application of the Federal Law dated 28.12.2009 No. 381-FZ "On the Basic Principles of State Regulation of Trading Activities in the Russian Federation" as amended by the Federal Law dated 03.07.2016 No. 273-FZ" <fas.gov.ru/documents/documentdetails.html?id=14896> accessed 05 January 2017.

${ }^{2450}$ Provided that the threshold equal to 400 million RUB of the annual turnover of the economic entity (its group) / retail chain is met: ibid. 
dominance]. ${ }^{2451}$ Meanwhile, breaches of Article 9 of the Federal law "On the Trading Activities" fall outside the scope of competition law and enforcement of the said provisions does not require compliance with the procedures of investigation of antitrust violations. ${ }^{2452}$

The courts play an important role in the application of competition law to food supply chains in Russia through individual cases review and the general interpretation of competition rules. Russian commercial courts undertake a close scrutiny of FAS decisions, including the correct definition of product and geographical markets in abuse cases when assessing if there is sufficient evidence of anticompetitive agreements and that the distinction between agreements and concerted practices was duly observed. Commercial courts may strike down decisions of FAS due to incorrect definition of the product market (generally too narrow); ${ }^{2453}$ because the FAS' decision blurred the distinction between an agreement (cartel) and concerted actions set forth by Articles 11 and11.1 of the federal Law "On Protection of Competition" respectively, because of the failure to prove existence of an agreement between alleged participants of the cartel; ${ }^{2454}$ or the failure to prove the fact of setting a monopoly price in compliance with paragraph 1 Article 6 of the Federal law "On Protection of Competition". 2455

FAS has defined priorities in the promotion of competition in the Russian federation by publishing the 'National Plan on Development of Competition in 2017-2018'. This focuses on a number of industries including agriculture (agro-technologies, digital agricultural platforms, modern genetics, and plant protection agents) ${ }^{2456}$. Upon adoption of the National Plan by the Order of the President of the Russian Federation, the specialised ministries and agencies should devise and implement on its basis the "road maps" of development of competition in the corresponding sectors of the economy. Thus, the draft 'Road Map on Development of Competition in Agricultural Industry in 2017-2018' puts particular emphasis on increasing the availability of the transport infrastructure for the agricultural producers; development of exchange trading and off-exchange online trading of agricultural products; promotion of competition in the seed market by stimulating the domestic supply of seeds and establishment/upgrading the agricultural genetics centers. ${ }^{2457}$

\footnotetext{
${ }^{2451}$ Letter of the Federal Antimonopoly Service dated 05.09.2016 No.AK / 60976/16 "Clarification of the FAS of Russia on some issues of application of the Federal Law dated 28.12.2009 No. 381-FZ "On the Basic Principles of State Regulation of Trading Activities in the Russian Federation" as amended by the Federal Law dated 03.07.2016 No. 273FZ <fas.gov.ru/documents/documentdetails.html?id=14793> accessed 05 January 2017.

${ }^{2452}$ Letter of the Federal Antimonopoly Service dated 05.09.2016 No.AK / 60976/16 "Clarification of the FAS of Russia on some issues of application of the Federal Law dated 28.12.2009 No. 381-FZ "On the Basic Principles of State Regulation of Trading Activities in the Russian Federation" as amended by the Federal Law dated 03.07.2016 No. 273FZ <fas.gov.ru/documents/documentdetails.html?id=14793> accessed 05 January 2017.

${ }^{2453}$ See, for example, decision of the First Commercial Court of Appeal dated 28 March2016 on the case №A798318/2015 on complaint of CJSC "Tander"; decision of the Commercial Court of Volgo-Vyatsky Region dated 24 October 2016 on the case №A79-11990/2015 on complaint of the State unitary agricultural enterprise "Ulyanovskoye". ${ }^{2454}$ Decision of the Commercial Court of Povolzhskiy region dated 04 October 2016 on the case № A65-20903/2015 on complaint of LLC “Agrotorg”, CJSC “Tander", CJSC “TD "Perekrestok", LLC “Ashan”, and others.

${ }^{2455}$ Decision of the Commercial Court of the Northern-Caucasus region dated 26 November 2015 on the case № A63803/2015 on complaint of CJSC "Stavropolsky broiler" and LLC "Ptizecombinat".

${ }^{2456}$ FAS Press release 'National Plan on Development of Competition in 2017-2018 must enhance the national economic framework' (10 November 2016) // FAS. URL: https://fas.gov.ru/press-center/news/detail.html?id=47744.

${ }^{2457}$ The draft 'Plan ("Road Map) of on Development of Competition in Agricultural Industry in 2017-2018', < http://fas.gov.ru/upload/other/\%D0\%94\%D0\%BE\%D1\%80\%D0\%BE\%D0\%B6\%D0\%BD\%D0\%B0\%D1\%8F\%20\%D 0\%BA\%D0\%B0\%D1\%80\%D1\%82\%D0\%B0\%20\%D0\%BF\%D0\%BE\%20\%D0\%BA\%D0\%BE\%D0\%BD\%D0\%BA \%D1\%83\%D1\%80\%D0\%B5\%D0\%BD\%D1\%86\%D0\%B8\%D0\%B8\%20\%D0\%B2\%20\%D0\%90\%D0\%9F\%D0\%9A \%2015.02.2017.docx>accessed 20 April 2017.
} 


\subsubsection{International Cooperation}

The Russian competition authority is integrated into the international competition law system through Russia's participation in the Eurasian Economic Union (hereinafter - the "EEU"). The foundation document of the EEU is the Treaty on the Eurasian Economic Union (Astana, 29 May 2014), which sets forth the general principles and rules of competition in the EEU, powers of the Eurasian Economic Commission in the field of competition law and rules of the interaction between national competition authorities of the EEU member states, as well as between the Eurasian Economic Commission and national competition authorities of the EEU member states.

The main goal of the EEU in the field of competition is the establishment of the common competition policies and rules in the territory of the EEU. This is achieved through:

(i) harmonisation of the competition law and policies of the EEU member states;

(ii) control over protection of competition in the cross-border markets. ${ }^{2458}$

In 2013 the Supreme Eurasian Economic Council adopted the Model Law on Competition, ${ }^{2459}$ which has become an important tool of harmonisation of competition law within the EEU and was transposed into the national competition policies of a number of the EEU member states. ${ }^{2460}$

In addition, the Eurasian Economic Commission has powers to (i) conduct antitrust investigations with regard to violations of the general rules of competition in the EEU established in Article 76 of the Treaty on the Eurasian Economic Union, (ii) adopt legally binding decisions and (iii) impose fines on undertakings in case such violations have or might have negative impact on the competition in the cross-border markets. ${ }^{2461}$ The cross-border markets mean the product markets, which geographic boundaries include the territories of two or more EEU member states. ${ }^{2462}$ The Eurasian Economic Commission is authorised to investigate the violation of the competition rules in cross-border markets when additional criteria established by the Eurasian Economic Commission are met (for example, participants of an anticompetitive agreement reside in at least two different member states, the certain market share threshold is exceeded, etc). ${ }^{2463}$ Decisions and actions of the Eurasian Economic Commission in the field of competition can be appealed to the Court of the Union, which is a permanent judicial body of the EEU.

FAS has collaborated with the Eurasian Economic Commission on a number of cross-border competition cases with a view to level the playing field for competitors in cross-border EEU markets. Thus, the Eurasian Economic Commission and the FAS assessed the cross-border (RussianBelorussian) market of apatite concentrate in order to ensure equal wholesale prices of apatite

\footnotetext{
${ }^{2458}$ Article 74 of the Treaty on the Eurasian Economic Union (Astana, May 29, 2014, amended May 08, 2015); 'Competition Policy within the Eurasian Economic Union', <fas.gov.ru/international-partnership/eaes.html> accessed 20 April 2017.

${ }^{2459}$ Decision of the Supreme Eurasian Economic Council dated October 24, 2013 No.50 "On the Model Law "On Competition", accessed at https://docs.eaeunion.org/docs/ru-ru/0047311/scd_25102013_50.

${ }^{2460}$ Denis Gavrilov and Alina Chernyaga, 'Antitrust Regulation in the Eurasian Economic Union' (December 13, 2016), the International Centre for Trade and Sustainable Development, <www.ictsd.org/bridges-nеws/антимонопольноерегулирование-в-евразийском-экономическом-союзе> accessed 20 April 2017.

${ }^{2461}$ Annex 19 to the Treaty on the Eurasian Economic Union (Astana, 29 May 2014, amended 08 May 2015) 'Protocol on the General Principles and Rules of the Competition', para 9.

2462 Decision of the Supreme Eurasian Economic Council dated 19 December 2012 No.29 "On the Criteria of Defining a Market as Cross-Border”, para 2, <docs.eaeunion.org/docs/ru-ru/0044093/scd_20122012_29> accessed 20 April 2017.

${ }^{2463}$ Decision of the Supreme Eurasian Economic Council dated 19 December 2012 No.29 "On the Criteria of Defining a Market as Cross-Border”, para 2, <docs.eaeunion.org/docs/ru-ru/0044093/scd_20122012_29> accessed 20 April 2017. paras 4-5.
} 
concentrate for both Russian and Belorussian manufacturers. ${ }^{2464}$ The EEU and Russian competition authorities also carried out the investigation into vertical agreements between the major manufacturer of mining equipment Caterpillar and its dealers, which resulted in amendments of the relevant agreements. ${ }^{2465}$ During the period of 2016 - first half of 2017 the Eurasian Economic Commission resolved 16 complaints on violation of the competition rules in cross-border markets which resulted in 9 investigations. ${ }^{2466}$ On 27 September 2017 the Eurasian Economic Commission adopted its first prohibition decision with regard to the abuse of dominance in the cross-border market of grainoriented electrical steel by PJSC "Novolipetskiy Metallurgical Complex" and LLC "VIS-Steel" which resulted in a total fine of over 217 million RUB. ${ }^{2467}$ In general, the Eurasian Economic Commission favours a 'soft' approach in the form of voluntary commitments to remedy violations of competition rules and make use of instruments of prevention and consultations to deter antitrust violations. ${ }^{2468}$ In line with this the Commission continuously works on formalising several codes of good practice (including the Code for Retail Chains). ${ }^{2469}$ This means a closer cooperation between the Eurasian Economic Commission and FAS in the future and greater role for the EEU competition rules and practices in protection and promotion of competition in the Russian Federation.

\subsection{Competition Issues on Different Levels of the Food Supply Chain}

\subsubsection{Factors of Production}

Within the factors of production, the main competition law concerns expressed by FAS refer to the high dependency on import supplies of genetic materials and seeds, underdevelopment of domestic seed farming industry and necessity of import substitution in this important segment. ${ }^{2470}$

Seed farming is considered to be the most profitable segment of the global fresh fruit and vegetables production chain: the volume of the global fruit and vegetable seeds market exceeds 6 billion USD and is expected to reach 13 billion USD by $2018 .{ }^{2471}$ Despite this, Russia almost has had no participation in the selection, seed farming, and development of new products, mostly due to a lack of necessary support to Russian R\&D in this area (see the section IP Rights of this report). ${ }^{2472}$

Among the measures suggested by FAS to improve the situation in this area are the state support for the establishment of agricultural genetics centers; the market launching of selection inventions, the IP rights involved belonging to the state; and the application of competition law to the practices of abuse of intellectual property rights as an instrument of monopolisation of the agricultural markets. 2473

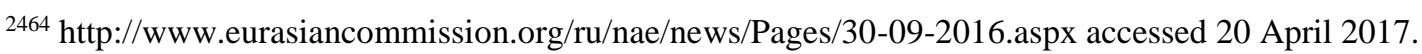

$2465 \mathrm{http}: / / \mathrm{www}$.eurasiancommission.org/ru/nae/news/Pages/29-07-2016-4.aspx accessed 20 April 2017.

$2466 \mathrm{http}: / /$ www.eurasiancommission.org/ru/nae/news/Pages/25-08-2017-2.aspx accessed 25 October 2017.

${ }^{2467} \mathrm{http}: / /$ www.eurasiancommission.org/ru/nae/news/Pages/27-09-2017-1 aspx accessed 25 October 2017.

$2468 \mathrm{http} / / / \mathrm{www}$.eurasiancommission.org/ru/nae/news/Pages/25-08-2017-2.aspx accessed 25 October 2017.

${ }^{2469} \mathrm{http}$ ://www.eurasiancommission.org/ru/nae/news/Pages/30-09-2016.aspx accessed 20 April 2017.

${ }^{2470}$ FAS press releases dated 07 December 2016 at <fas.gov.ru/press-center/news/detail.html?id=48110> accessed 24 December 2016 and 07 July 2016 at <fas.gov.ru/press-center/news/detail.html?id=46335> accessed 24 December 2016.

${ }^{2471}$ Meshkova T.A., Moiseichev E. Russia's Experience of Foresight Implementation in Global Value Chain Research // Journal of Innovation and Entrepreneurship. 2016. Vol. 5. N 9. p. 8.

2472 Meshkova T.A., Moiseichev E. Russia's Experience of Foresight Implementation in Global Value Chain Research // Journal of Innovation and Entrepreneurship. 2016. Vol. 5. N 9. p. 8.

${ }^{2473}$ FAS press release dated 07 July 2016 at <fas.gov.ru/press-center/news/detail.html?id=46335> accessed 24 December 2016.
} 
The concentration in the market of seeds raises additional competition concerns, as "there are significant risks to competition inherent to the formed structure of the seed market". ${ }^{247}$ In 2016 FAS of Russia approved two mergers in the seeds market: the merger between Dow Chemical and DuPont and the acquisition of LLC Syngenta by ChemChina. ${ }^{2475}$ Both transactions have been cleared unconditionally based on traditional approaches to merger control (such as definition of product markets, in which parties to merger are active, and their market shares). ${ }^{2476}$ However, the head of the Department of control on chemical industry and agro-production remarked that

"there is an issue of updating approaches to the analysis of transactions in the market for genetic materials. We should take into account the specifics of their functioning and their influence on the global food markets, as well as assess the risk of restricted access to innovative products and technologies for potential competitors". ${ }^{247}$

In accordance with the commitment decision adopted by the EU Commission in March 2017, which addressed concerns that the merger between Dow Chemical and DuPont would significantly reduce competition in markets for existing pesticides, as well as stifle innovation in the pesticides sector ${ }^{2478}$ DuPont committed to divest a significant part of its existing pesticide business, including its R\&D arm. On 26 May 2017 FAS cleared unconditionally acquisition by the US company FMC Corporation of the JSC "DuPont Chimprom" 2479 which formed a part of the transfer of pesticide production and R\&D division of DuPont to FMC following DuPont's divestiture commitments.

The similar commitment have been offered to the EU Commission by ChemChina in the view of its acquisition of the Swiss company Syngenta, one of the global players in the market of pesticides and plant growth regulators. ${ }^{2480}$ Despite both companies' presence in the Russian market for pesticides, according to experts, the merger is unlikely to change the dynamics of the market in Russia, unless in the short-term perspective, while in long-term it might contribute to expansion of ChemChina in Russia. ${ }^{2481}$

There are signs of the further consolidation also in the market of animal genetics and breeding. On April, 25th 2017 FAS cleared unconditionally the merger between Cypriote GP CY Holding Ltd (which allegedly acts in the interests of Cobb-Vantress, Inc., the global producer of poultry breed) ${ }^{2482}$ and LLC "Broiler Buduschego", ${ }^{2483}$ the leading Russian supplier of the poultry breed material currently controlling up to $40 \%$ of the Russian market of the breed material for broiler producers.

${ }^{2474}$ FAS press release dated 07 December 2016 at <fas.gov.ru/press-center/news/detail.html id=48110> accessed 24 December 2016.

${ }^{2475}$ Decision of FAS of Russia dated 13 July 2016 № CП/47456/16 (on Syngenta) and Decision dated 10 July 2016 № ЦА/49718/16 (on Dow Chemical and DuPont).

${ }^{2476}$ FAS press release dated 07 July 2016 at <fas.gov.ru/press-center/news/detail.html?id=46335> accessed 24 December 2016.

2477 Decision of FAS of Russia dated 13 July 2016 № CП/47456/16 (on Syngenta) and Decision dated 10 July 2016 № ЦА/49718/16 (on Dow Chemical and DuPont).

2478 European Commission - Press release as of 27 March 2017 'Mergers: Commission clears merger between Dow and DuPont, subject to conditions', <europa.eu/rapid/press-release_IP-17-772_en.htm> accessed 02 September 2017.

2479 Decision of FAS dated 26 May 2017 N CП/35465/17, <solutions.fas.gov.ru/ca/upravlenie-kontrolya-himicheskoypromyshlennosti-i-agropromyshlennogo-kompleksa/sp-35465-17> accessed 02 September 2017.

${ }^{2480}$ European Commission - Press release as of 05 April 2017 'Mergers: Commission clears ChemChina acquisition of Syngenta, subject to conditions', <europa.eu/rapid/press-release_IP-17-882_en.htm> accessed 04 September 2017.

2481 'ChemChina has got permission for acquiring Syngenta', <sugar.ru/node/18283> accessed 02 September 2017.

2482 Anatoliy Kostyrev, 'Samuel Lipman is tired of poultry farming' (Kommersant No. 74 dated 27 April 2017), https://www.kommersant.ru/doc/3282845 accessed 19 April 2017.

${ }^{2483}$ Decision of FAS of Russia dated 25 April 2017 № ЦА/27771/17 http://solutions.fas.gov.ru/ca/upravlenie-kontrolyahimicheskoy-promyshlennosti-i-agropromyshlennogo-kompleksa/tsa-27771-17 accessed 19 April 2017. 
The merger puts the foundation for further expansion of Cobb-Vantress into the Russian market of the animal breed materials. ${ }^{2484}$

\subsubsection{Right of Access of Farmers to the Plant Varieties and Animal Breeds in Russia}

The legal basis for the production, harvesting, processing, storage, sale, transportation and use of seeds of agricultural and forest plants is set forth by the Russian law "On Seed Breeding" dated 17 December 1997 N 149-FZ (hereinafter - the "Russian Law "On Seed Breeding").

The Russian law is based on the provisions of the International Convention for the Protection of New Varieties of Plants (hereinafter - "UPOV Convention"), which aim is to encourage the development of new varieties of plants by codifying and protecting intellectual property for plant breeders. Russia acceded to the said Convention on 24 April 1998 and since that its domestic laws should abide by the basic concepts of plant variety protection established by UPOV Convention.

According to the Russian Law "On Seed Breeding" the use of the new variety of plants is allowed after this variety had been included in the State Register of the Plant Variety Admitted to Use. ${ }^{2485}$ The breeder of a new variety of plant should be registered by the designated State Commission of the Russian Federation for Testing and Preservation of Plant Varieties. ${ }^{2486}$ Upon registration the breeder incurs obligations of maintaining (preserving) the variety in accordance with the characteristics indicated in the variety description as of the date of registration in the State Register of the Plant Variety Admitted to Use. ${ }^{2487}$ According to the Civil Code of the Russian Federation (hereinafter the "Civil Code"), the exclusive right to the variety of plants is recognized and protected subject to its state registration in the State Register of Protected Varieties of Plants and Animal Breeds and is confirmed by the patent. ${ }^{2488}$ The intellectual property rights for new variety of plants belong to the owner of such patent including its production and reproduction; conditioning for the purpose of propagation; offering for sale; selling or other marketing; import to or export from the territory of the Russian Federation. ${ }^{2489}$ However, in line with the provisions of Article 15 of UPOV Convention, there are certain exceptions to the breeder's right, including compulsory exceptions set forth by UPOV Convention: $:^{2490}$

(i) acts done privately and for non-commercial purposes (e.g. for subsistence farming),

(ii) acts done for experimental purposes,

(iii) use of protected varieties for the purpose of breeding other varieties, as long as the new varieties are not "essentially derivative" of the protected variety.

Additional exceptions set forth by the Civil Code to protect the right of farmers (so-called "farmer's privilege") include:

(iv) use of the products of the harvest obtained by farmers in their own holding, for two years for propagating purposes within their own holdings, if the variety of plants is included the

\footnotetext{
2484 Anatoliy Kostyrev, 'Samuel Lipman is tired of poultry farming' (Kommersant No. 74 dated 27 April 2017), https://www.kommersant.ru/doc/3282845 accessed 19 April 2017.

${ }^{2485}$ Article 6 of the Russian Law "On Seed Breeding".

2486 'Provisions on the Registration of the Originator of the Variety of the Plant' adopted by the Decree of the Ministry of Agriculture and Food Production of the Russian Federation as of 10 February 1999 N 50, paras 1, 6.

${ }^{2487}$ Provisions on the Registration of the Originator of the Variety of the Plant' adopted by the Decree of the Ministry of Agriculture and Food Production of the Russian Federation as of 10 February 1999 N 50, para 7.

${ }^{2488}$ Article 1414 of the Civil Code.

${ }^{2489}$ Article 1421 of the Civil Code.

${ }^{2490}$ Article 1422 of the Civil Code.
} 
specified list of varieties adopted by the Government of the Russian Federation ${ }^{2491}$ (this provision corresponds to the optional exception established by paragraph 2 Article 15 of the UPOV Convention);

(v) reproduction of commercial animals for their use in the own holding (the farmer's privilege applied mutatis mutandis to animal breeds).

In addition, subparagraph 6 Article 1422 of the Civil Code sets forth the principle of exhaustion of the breeder's right in line with Article 16 of the UPOV Convention. This provision allows any acts with seeds, plant material, breed material and commercial animals, which have been sold or otherwise marketed by the breeder or with his consent, apart from:

- further propagation of plant seeds or animal breeds;

- an export of material of the variety, which enables the propagation of the variety, into a country which does not protect varieties of the plant genus or species to which the variety belongs, except where the exported material is for final consumption purposes.

As evidenced by the case law, the exhaustion of the breeder's right is quite often used as a defence against claims of unauthorised use of protected seeds in farming activities. ${ }^{2492}$

Article 1423 of the Civil Code sets forth compulsory licensing of the rights for varieties of plants or animal breeds. According to it, after three years from the date of grant of the patent for the variety of plants, any person who wishes and is prepared to use the variety of plants, ${ }^{2493}$ in case the patent holder refuses to license it for the production or sale of seeds or breed material on conditions consistent with established practice, has the right to bring an action to court to force the patent holder to grant to the plaintiff a non-exclusive license to use this variety of plants or animal breed in the territory of the Russian Federation. The conditions of the compulsory license, including the consideration to be paid, should be defined by the court. The aggregate consideration should be no less than consideration paid under the license agreement in similar circumstances. The burden of proof that there are justifiable reasons why the license should not be granted to the plaintiff lies with the patent holder.

Despite the provisions of Article 1423 of the Civil Code entered into force more than 10 years ago, the Russian case law on granting compulsory licenses for varieties of plants or animal breeds is scarce. ${ }^{2494}$ In fact, the compulsory license for varieties of plants remains rather theoretical opportunity than the practical solution for agro-producers. ${ }^{2495}$

\footnotetext{
${ }^{2491}$ The order of the Government of the Russian Federation dated 04 October 2007 N 643 sets forth the list of some staple varieties like wheat, rye, potato, buckwheat, peas, etc.

${ }^{2492}$ See, for instance, the decision of the Federal Commercial Court of the Far-Eastern Region dated 14 May 2009 on the case N A04-1065/2008; the decision of the Sixth Court of Appeal dated 16 July 2010 on the case N A04-1211/2010; the decision of the Fifteenth Court of Appeal dated 02 December 2009 on the case N A32-15389/2009.

2493 The preparedness means the technical ability to use the license (for instance, possession of the agricultural land plot, relevant equipment, etc.) - see the commentary to Article 1423 of the Civil Code at http://stgkrf.ru/1423 accessed 13 September 2017.

${ }^{2494}$ Thus, there is only one case available in the public data base on refusal to grant compulsory license for varieties of plants, which is decision of the Nineteenth Commercial Court of Appeal dated 30 June 2015 on the case N A08-3816/2014 in which both the court of the first instance and the court of appeal dismissed the claim on the ground that (i) the offer to conclude the license agreement was sent before expiry of three year period from the date of grant of the patent, and (ii) the offer of the plaintiff did not contain all substantial conditions of the license agreement required by law.

${ }^{2495}$ Karina Safaryan, Innovation Business, Practical Aspects of Assets Evaluation (FBGOU VPO "The Russian Academy of National Economy and Public Service under the President of the Russian Federation" 2012) https://profilib.com/chtenie/20893/karina-safaryan-innovatsionnyy-biznes-prakticheskie-aspekty-otsenki-aktivov25.php accessed 11 September 2017.
} 


\subsubsection{Markets of Fertilisers in Russia}

Regarding Fertilisers, in 2014 FAS released the Analytical report on the conditions of competition in the market of Fertilisers where it established that in 2011-2012 the market was characterised by the low degree of concentration and vigorous competition in the market of nitrogenbased chemical Fertilisers (the most massively used by agricultural producers) and much higher degree of concentration and suppressed competition in the markets of potassium and phosphate chemical Fertilisers. ${ }^{2496}$ The main reasons are high barriers to entry to the market and presence of only two producers of raw materials for potassium and phosphate chemical Fertilisers in the Russian Federation - OJSC "Uralkaliy" (for potassium Fertilisers) and OJSC "Apatit" (for phosphate Fertilisers). FAS also noted that the exportation of the Fertilisers exceeds several times supplies to the domestic market, which is explained, inter alia, by low demand for Fertilisers in the Russian market due to insufficient financial resources of Russian agricultural producers. ${ }^{2497}$ As a result, FAS urged the necessity of regular monitoring of the pricing and competition conditions in the market of Fertilisers. $^{2498}$

The transparency of pricing in the market of Fertilisers remained a concern for FAS in 20152016 and in October 2016 FAS announced its plans to introduce the exchange trading of Fertilisers in Russia. ${ }^{2499}$ The main rationale was to prevent the establishment of monopoly prices for Fertilisers and improve the logistics and planning components in the market of Fertilisers. The announced launching of exchange trading is scheduled for autumn $2017 .^{2500}$

\subsubsection{Agricultural Production (Farming)}

Prior to 1993, the Russian agricultural industry was based on a system governed by the Ministry of Trade and supervised by a number of state agencies. The producer supplied commodities to wholesale intermediaries which, in turn, distributed the goods to industrial processors or to territorial departments of the Ministry of Trade.

The opening up to the global market and the dissolution of the Soviet regime brought the restructuring of the industry, which was intensified following the 1998 financial crisis. The agricultural sector has been consolidated progressively under the aegis of few national incumbents. In particular, Gazprom became the largest agricultural holding, controlling 91 agricultural firms through 25 of its subsidiaries. ${ }^{2501}$

\footnotetext{
${ }^{2496}$ Analytical report on the conditions of competition in the market of Fertilisers, Federal Antimonopoly Service of Russia (2014), <fas.gov.ru/documents/documentdetails.html?id=1851,13> accessed 20 December 2016.

2497 Analytical report on the conditions of competition in the market of Fertilisers, Federal Antimonopoly Service of Russia (2014), <fas.gov.ru/documents/documentdetails.html?id=1851,13> accessed 20 December 2016., 14.

${ }^{2498}$ Analytical report on the conditions of competition in the market of Fertilisers, Federal Antimonopoly Service of Russia (2014), <fas.gov.ru/documents/documentdetails.html?id=1851,13> accessed 20 December 2016., 15.

${ }^{2499}$ FAS press release dated 29 October 2016 at <fas.gov.ru/press-center/news/detail.html?id=47589>.

2500 Interview with the Deputy Head of FAS Andrey Tsyganov at "RIA News", < ria.ru/interview/20161228/1484793637.html>; the latest announcements mention the launch of exchange trading by the end of 2017 - http://мниап.pф/en/news/FAS-Rossii-planiruet-do-konca-2017-goda-zapustit-birzevuu-torgovlumineralnymi-udobreniami/.

2501 Johan F. M. Swinnen, and others, The Dynamics of Vertical Coordination in Agrifood Chains in Eastern Europe and Central Asia: Implications for Policy and World Bank Operations (The World Bank, 2011), 91.
} 
The rationale of the regional authorities for assisting the creation of agrofirms and large regional holdings was "to actively employ methods of state control to preserve and develop the agroindustrial sector of the region, to rehabilitate bankrupt agricultural enterprises, to provide the enterprises with fixed and current assets, and to restore the broken integration links". 2502 The Orel region was intended to become a model for developing a regional agricultural sector under market conditions but with a strong supervisory role for the state. The creation of huge agro-holdings in Russia has significantly affected the performance of the farms. Interestingly, the results appear to be quite mixed. ${ }^{2503}$ Gataulina et al.'s (2004) study finds that vertical integration has contributed to:

- A better supply of inputs to farms.

- Growth in output and productivity.

- Poor financial results.

- "Important heterogeneity among the farms. Some of the integrated farms with good management seem to have performed very well" 2504 .

However, on the other hand, Gataulina et al found out that the profitability of such agroholdings worsened by almost 20 percent during 1999-2002. The negative trend in profitability also affected other vertically integrated agricultural enterprises to the extent that, for instance, in 2002 among 149 agro-holdings in the Belgorod region only 39 were profitable. ${ }^{2505}$

In the field of agricultural production, one of the most important goals of the state policy declared since the adoption of the Food Security Doctrine in 2010, and re-enforced after the introduction of import limitations for agricultural products from the Western countries in the summer 2014 , is the "sustainable development of domestic production of food and raw materials, which is sufficient to guarantee the country's food independence". ${ }^{2506}$ In line with this goal, different measures of state support for domestic agricultural producers have been introduced, starting from direct subsidies to farmers to the creation of state-owned grain companies and the interventional reserve for grains as a mechanism of direct regulation of the market in order to stabilise the prices for the most important food products.

FAS plays a quite an active role in this area. On the one hand, it monitors compliance of state and local bodies with the procedures of granting subsidies to agricultural producers and detects abusive practices related to it. Thus, control on the procedures of granting subsidies to farmers was one of the priority activities of FAS in $2015 .{ }^{2507}$ As a result, more than fifty investigations were opened on the alleged violation of the Federal law "On Protection of Competition" by regional state bodies (see an example of the case in Box 1). The violations were mostly related to illegal discrimination among the recipients of subsidies (for instance, by setting an additional criteria, such as having registered office in the region granting a subsidy or obligation to sell all the grains harvest

\footnotetext{
${ }^{2502}$ Johan F. M. Swinnen and others.

${ }^{2503}$ Johan F. M. Swinnen, and others, The Dynamics of Vertical Coordination in Agrifood Chains in Eastern Europe and Central Asia: Implications for Policy and World Bank Operations (The World Bank, 2011), 91.

${ }^{2503}$ Johan F. M. Swinnen, and others, The Dynamics of Vertical Coordination in Agrifood Chains in Eastern Europe and Central Asia: Implications for Policy and World Bank Operations (The World Bank, 2011), 91.

${ }^{2504}$ Johan F. M. Swinnen, and others, The Dynamics of Vertical Coordination in Agrifood Chains in Eastern Europe and Central Asia: Implications for Policy and World Bank Operations (The World Bank, 2011), 91.; Gataulina and others.

${ }^{2505}$ Johan F. M. Swinnen, and others, The Dynamics of Vertical Coordination in Agrifood Chains in Eastern Europe and Central Asia: Implications for Policy and World Bank Operations (The World Bank, 2011), 91.

${ }^{2506}$ Paragraph 3 of the Food Security Doctrine adopted by the Order of the President of the Russian Federation dated 30 January 2010 N 120.

${ }^{2507}$ FAS press release dated 12 February 2016 at <fas.gov.ru/press-center/news/detail.html?id=44712> accessed 20 December 2016.
} 
of the current year to the entities registered and having processing capacities in the territory of the specified region $)^{2508}$ and violation of the order of granting state preferences set forth by Chapter 5 of the Federal law "On Protection of Competition" (for instance, by retroactively amending the legal normative act stipulating the procedure of granting subsidies in order to make a pre-defined recipient eligible for them). ${ }^{2509}$

\section{Box 1: Decision by FAS of Russia dated 17 August 2016 on the case №1-00-187/00-06-15}

In this case, FAS proved the existence of an oral agreement between the Government of Belgorod region, the Department of agricultural and industrial complex of Belgorod region, the Fund of promotion of products manufactured in Belgorod region and the group of companies affiliated to the same natural person in violation of Article 16 of the Federal law "On Protection of Competition" (prohibition of anticompetitive agreements or concerted actions by federal, regional or local state authorities; between these authorities and economic entities if they lead or may lead to restriction or elimination of competition).

The Fund of promotion of products manufactured in Belgorod region was established in order to promote the products of Belgorod agricultural producers. Under control of the Government of Belgorod region, the Department of agricultural and industrial complex of Belgorod region, the Fund collected funds from the agricultural producers, who had previously received subsidies from the budget under the program of state support of agriculture in Belgorod region. In fact, almost $100 \%$ of money received as subsidies was transferred by the agricultural producers to the said Fund. The Government of Belgorod region forced the agricultural producers to perform payments to the Fund through setting the lower rent rates for agricultural land plots owned by Belgorod region for those producers who transferred money to the Fund. In 2014 the Fund allocated all its budget (in the form of subsidies and loans on preferential terms) to the companies which constituted the same group and were affiliated to $\langle\ldots\rangle$ (a natural person).

FAS established that in 2014 the Government of Belgorod region, the Department of agricultural and industrial complex of Belgorod region, the Fund of promotion and economic entities affiliated to $\langle\ldots\rangle$ entered into an oral agreement aimed at giving preferences to the economic entities affiliated to $\langle\ldots\rangle$ compared to other participants of the relevant market in violation of Article 16 of the Federal law "On Protection of Competition".

On many occasions, in addition to taking prohibition decisions and imposing fines, FAS issues obligatory requirements to insert amendments into the regional legal acts and plays an active role in the preparation of the said amendments.

On the other hand, FAS performs the traditional monitoring of antitrust violations by market participants in the form of anticompetitive agreements and/or abuse of dominance. Antitrust instruments constitute one of the measures of the state's agricultural policy, along with, for example, granting subsidies to agricultural producers or tariff and non-tariff regulation of the agricultural

\footnotetext{
${ }^{2508}$ Decision by FAS of Russia dated 02 December 2014 on the case №1-15-11/00-06-14; Decision by FAS of Russia dated 27 November 2015 on the case № 1-00-122/00-06-15; Decision by FAS of Russia dated 27 November 2015 on the case № № 1-00-121/00-06-15; Decision by FAS of Russia dated 28 July 2015 on the case №1-15-42/00-06-15.

${ }^{2509}$ Decision by Chuvashia FAS dated 16 December 2015 on the case № 43/05-AM3-2015; Decision by Chuvashia FAS dated 10 December 2015 on the case № 36/05-AM3-2015.
} 
markets. ${ }^{2510}$ Russian competition law currently does not set forth any specific exemptions from antitrust scrutiny for the agricultural sector. Therefore, the general exemptions contained in Article 13 of the Federal law "On Protection of Competition" and the Decree of the Government of the Russian Federation dated 16 July 2009 N 583 "On the Cases of Permissibility of Agreements between Economic Entities" apply to the agricultural sector with regard to the conditions of exemption of vertical agreements, $R \& D$ agreements and agreements on collaborative use of the R\&D results. ${ }^{2511}$

It is noteworthy that by 2013 "the Russian markets of the agricultural produce and food [were] evaluated as low-concentrated and highly competitive", ${ }^{2512}$ which means that the majority of producers were small and medium enterprises and none of them can impose a monopolistic price for farming output. ${ }^{2513}$ The main reasons of low concentration includes low barriers for entry, insignificant economies of scale and high transportation costs limiting the optimal size of the production unit, etc. ${ }^{2514}$ Moreover, the share of small private farm holdings have been historically high in Russia (though with stable tendency to decrease since its peak in 2002) (2515 $^{2}$ and in 2009 accounted for milk - over $50 \%$; potato - over $80 \%$ and vegetables - over $75 \%$. $^{2516}$

However, later reports notice the process of horizontal and vertical consolidation of agroproduction and establishment of large agro-holdings and more intense cooperation between small agro-businesses ${ }^{2517}$ for instance in the markets of sunflower oil, milk and milk products in some regions, and baker's yeast. ${ }^{2518}$ The majority of agro-holdings have stemmed from the large food processing enterprises; they have complex horizontally and vertically integrated structure and are usually quite diversified, rather than specialised (see example in Box 2). As of 2014, the share of agro-holdings in the Russian food production market was estimated at $15-20 \% .{ }^{2519}$ The increasing

\footnotetext{
${ }^{2510}$ Article 6 of the Federal Law dated 29 December 2006 N 264-FZ “On Development of the Agriculture”.

${ }^{2511}$ Considering also that (i) vertical agreements are exempted if the market share of each party to such agreement in the relevant market does not exceed 20\% (paragraph 2 Article 12 of the Federal law "On Protection of Competition"), and (ii) some agreements between undertakings (such as related to price discrimination or imposing the "unfair" or irrelevant contract terms) are exempted if none of the undertakings holds a dominant position in the relevant market and their aggregate turnover from the sale of goods does not exceed $400 \mathrm{mln}$. RUB for the last calendar year (paragraph 3 Article 12 of the Federal law "On Protection of Competition").

2512 Competition Issues in Food Chain Industry 2013, OECD, 15 May 2014, Directorate for Financial and Enterprise Affairs, Competition Committee DAF/COMP (2014) 16, 330.

2513 Competition Issues in Food Chain Industry 2013, OECD, 15 May 2014, Directorate for Financial and Enterprise Affairs, Competition Committee DAF/COMP (2014) 16, 330.; see also Tatyana Vorozheikina, 'State Regulation of the Fragmented Industries' (2011) Bulletin of the Russian University of Economics 4, 108.

${ }^{2514}$ Competition Issues in Food Chain Industry 2013, OECD, 15 May 2014, Directorate for Financial and Enterprise Affairs, Competition Committee DAF/COMP (2014) 16, 330.

${ }^{2515}$ T.Kozhevnikova, V. Ryabikh, E.Mezhueva, 'Prospects of Development of Enterprises of the Agricultural Industry in Russia in the Context of the World Economic Crisis' (2014) Social and Economics Phenomena and Processes 3 42, 46, <cyberleninka.ru/article/n/perspektivy-razvitiya-apk-regiona-v-kontekste-mirovogo-agrarnogo-krizisa> accessed 26 December 2016.

2516 Tatyana Vorozheikina, 'State Regulation of the Fragmented Industries' (2011) Bulletin of the Russian University of Economics 4, 113.

2517 KPMG Report, "The agricultural and food value chain: Entering a new era of cooperation" (2013), 22, <assets.kpmg.com/content/dam/kpmg/pdf/2013/06/agricultural-and-food-value-chain-v2.pdf> accessed 20 December 2016; T.Kozhevnikova, V. Ryabikh, E.Mezhueva, 'Prospects of Development of Enterprises of the Agricultural Industry in Russia in the Context of the World Economic Crisis' (2014) 1 Social and Economics Phenomena and Processes 345, <cyberleninka.ru/article/n/perspektivy-razvitiya-apk-regiona-v-kontekste-mirovogo-agrarnogo-krizisa> accessed 26 December 2016.

2518 Competition Issues in Food Chain Industry 2013, OECD, 15 May 2014, Directorate for Financial and Enterprise Affairs, Competition Committee DAF/COMP (2014) 16, 331).

${ }^{2519}$ T. Kozhevnikova, V. Ryabikh, E.Mezhueva, 'Prospects of Development of Enterprises of the Agricultural Industry in Russia in the Context of the World Economic Crisis' (2014) Social and Economics Phenomena and Processes 3 42,
} 
concentration in the agricultural production sector is also evidenced by the decreasing number of agricultural enterprises (see Table 2a), which is a consequence of aggregation of enterprises and insolvency of small farms due to their unprofitability and inefficient business model. ${ }^{2520}$ Unfortunately, more specific numbers related to market shares and levels of concentration in the Russian agricultural production sector are currently not available.

Table 2a

\begin{tabular}{|c|c|c|c|c|c|c|}
\hline \multirow{2}{*}{ Types of Economic Activity* } & \multicolumn{5}{|c|}{$\begin{array}{l}\text { Number of economic entities, thousands, } \\
\text { (in } \% \text { to the total) }\end{array}$} & \multirow{2}{*}{$\begin{array}{l}\text { Change, } \\
\% \\
(2014 \text { to } \\
2013)\end{array}$} \\
\hline & 2007 & 2009 & 2011 & 2013 & 2014 & \\
\hline $\begin{array}{l}\text { Total for the Russian } \\
\text { Federation }\end{array}$ & 4506,6 & 4771,9 & 4823,3 & 4886,4 & 4886,0 & 100,0 \\
\hline Agriculture, hunting and forestry & $\begin{array}{l}261,5 \\
(5,8)\end{array}$ & $\begin{array}{l}222,1 \\
(4,7)\end{array}$ & $\begin{array}{l}193,4 \\
(4,0)\end{array}$ & $\begin{array}{l}169,4 \\
(3,4)\end{array}$ & $\begin{array}{l}149,6 \\
(3,1)\end{array}$ & 88,3 \\
\hline
\end{tabular}

Source: FAS, 'Report on the Conditions of Competition in the Russian Federation' (2015), available at http://fas.gov.ru.

\section{Box 2: Agrocomplex}

On 24 November 2016 FAS cleared unconditionally merger between "Agrocomplex named after N.I.Tkachev" and "ParusAgroGroup" which resulted in "Agrocomplex" owning K600 ha of the farming land and becoming one of the four largest agro-holdings in Russia. This was a part of the long-lasting consolidation process. Thus, in 2015 "Agrocomplex" acquired fourteen farms with total area K170 ha from the agro-holding Valinor. In 2016 the company acquired Pavlovskiy sugar plant, Poultry factory "Akashevskaya" and rice assets of agro-holding "Rasguliay". Currently "Agrocomplex" is a very diversified vertically integrated agro-holding producing all range of agro-products starting from grains and animal feed to animal farming to meat processing and production of rice, bread, sugar, dairy and oil. However, upon merger assessment, FAS has come to conclusion that merger would not lead to restriction of competition, as the share market of "Agrocomplex" post-merger would constitute only $10 \%$ in Krasnodar region, 5,2\% in Stavropol region and 3,7\% in Rostov region.

Source: FAS press release dated 07.12.2016 accessed at http://fas.gov.ru/press-center/fas-inmedia/detail.html?id=48093 and the web site of "Agrocomplex" http://zao-agrokomplex.ru/.

It should also be noted that the majority of agricultural markets in Russia are regional, as the major share of the products are consumed within the same region where they have been produced. ${ }^{2521}$

46, <cyberleninka.ru/article/n/perspektivy-razvitiya-apk-regiona-v-kontekste-mirovogo-agrarnogo-krizisa> accessed 26 December 2016.

FAS, 'Report on the Conditions of Competition in the Russian Federation' (2015), 40, <fas.gov.ru/about/list-ofreports/report.html?id=1685> accessed 19 December 2016.

${ }^{2521}$ Tatyana Vorozheikina, 'State Regulation of the Fragmented Industries' (2011) Bulletin of the Russian University of Economics 4, 108. 
Therefore, the level of concentration varies from one region to another (as it will be illustrated in the next section with regard to processing of raw milk).

In general, the agricultural producers represent a weaker level of the food supply chain and can hardly dictate the conditions of sales to the manufacturers and wholesalers, as evidenced by some FAS cases. Thus, in a number of similar cases FAS established that buyers of raw milk in different areas of Altay region violated subparagraph 1 of paragraph 1 Article 11 of the Federal law "On Protection of Competition" by entering into agreements on setting artificially low prices of purchase for raw milk from individual farms. ${ }^{2522}$ FAS pointed out that the relationships between sellers and buyers of raw milk are unequal, with buyers having superior bargaining power. The farmers do not have opportunity to influence the purchase prices of raw milk and accept the prices set by the buyers. As a remedy, FAS imposed on the buyers the obligation to conduct an independent pricing strategy. This case might be considered as an example of abuse of collective dominance in very fragmented oligopsony markets.

\subsubsection{Processing and Wholesale}

The conditions of competition on the level of processing and wholesale represent a much more important concern for FAS than the production level. This is evidenced by the regular monitoring performed by FAS of different product markets and the numerous investigations resulting from the sector inquiries and received complaints. The processing and wholesale segment is characterised by the higher degree of concentration and greater bargaining power of manufactures and wholesalers towards the farmers. Therefore, the abuse of dominance (including collective dominance) and anticompetitive agreements are the most frequent practices detected by FAS at this level.

In the end of 2014-2015, during the outburst of prices for certain food products following the introduction of import limitations, FAS revealed numerous abuses related to unjustified increases of the wholesale prices for bread and cereals. ${ }^{2523}$ FAS established the presence of cartels on the local or regional level, ${ }^{2524}$ and violations of paragraph 1 Article 13 of the Federal law "On the Trading Activities" by creating discriminatory pricing conditions for buyers. ${ }^{2525}$ On some occasions, the manufacturer managed to put forward an economic justification of the price increase by providing evidence of an increase of the company's costs (see Box 3). ${ }^{2526}$

\section{Box 3: Decision by FAS of Komi Republic dated 16 September 2015 on the case № A25-} 11/14.

FAS investigated the economically and technologically unjustified increase of the wholesale prices for the socially important alimentary products (rye bread, wheat bread) by LLC "Syktyvkarskiy chlebokombinat" (manufacturer and wholesaler). FAS established that the latter held a dominant

\footnotetext{
${ }^{2522}$ Decisions of UFAS of Altay Region on the cases №19-ФAC22-AM/06-15, 14-ФAC22-(AM)/06-15, 20-ФAC22AM/07-15, 15-ФАС22-AM/06-15, 18-ФАС22-AM/06-15.

${ }^{2523}$ FAS press release dated 23 January 2015 at <fas.gov.ru/press-center/news/detail.html?id=34353> and 03 February 2015 at <fas.gov.ru/press-center/news/detail.html?id=34384>.

${ }^{2524}$ Decisions by UFAS of Kurskiy region dated 21 July 2016 on the cases №03-05/21-2016A and №03-05/22-2016A.

2525 Decision by Pensenskiy UFAS dated 16 January 2015 on the case № 2-15/02-2014; Decision by Tatarstan UFAS dated 16 March 2015 on the case №05-841/2014.

${ }^{2526}$ Decision by UFAS of Komi Republic dated 16 September 2015 on the case № A25-11/14.
} 
position in the wholesale market of rye-wheat bread and the wholesale market of wheat bread in the territory of several Komi municipalities as its market share exceeded 50\%, market shares of its competitors are insignificant, and there were significant barriers for entry.

Under subparagraph 1 paragraph 1 Article 10 of the Federal law "On Protection of Competition" actions (lack of action) of an economic entity holding a dominant position, which result or can result in prevention, restriction or elimination of competition are prohibited, including, inter alia, establishment and maintaining of monopolistically high price for a commodity. Pursuant to paragraph 1 Article 6 of the Federal law "On Protection of Competition" monopolistically high price is the price set by a dominant undertaking, if that price exceeds both the sum of costs required for the production and sale of such product and mark-up, and the price, which was formed under conditions of competition on merit in the comparable product market.

LLC "Syktyvkarskiy chlebokombinat" has provided evidence that increase of prices for bread by $21,1 \%$ from 01.10 .2014 was caused by the increase of the company's costs, including raw materials by $2,3 \%$, fuel and energy by $20,1 \%$, salary by $14 \%$, overhead costs by $55,4 \%$. The increase of the overhead costs resulted from development and maintenance of its own retail chain. According to clarification of the tax authority, the costs of performing one type of economic activity (such as retail) could be included in the overall expenditures of the company (reflected in the wholesale prices). Therefore, the wholesale prices for rye bread and wheat bread set by LLC "Syktyvkarskiy chlebokombinat" are economically substantiated and do not constitute monopolistically high prices.

The market of milk was also under constant monitoring of FAS. Thus, in 2004-2005 FAS performed an investigation of the market of the milk processing, in which it established that markets of processing of raw milk were regional and can be divided into four types: oligopsony, highly concentrated, medium concentrated and low concentrated (see Table 3a). ${ }^{2527}$ The narrow geographic definition of the markets is determined by high transportation costs and high costs of equipment (first of all, refrigerators) for farmers, which results in high dependency of the latter from local milk processing factories. ${ }^{2528}$ In some regions (Udmurt Republic, Komi Republic, Sakhalin Region, Archangelsk Region, Bashkiria, etc) the monopoly position of the milk processing factories is exacerbated by historically established production chains when back in Soviet times there was only one processing factory for each agricultural zone. ${ }^{2529}$

Table 3a

\begin{tabular}{|l|l|l|l|}
\hline N & Type of the Market Structure & $\begin{array}{l}\text { Share of } \\
\text { Regions }\end{array}$ & Examples of Regions \\
\hline 1 & Oligopsonic & 8,3 & Orel, Stavropol, Volgograd, Chita \\
\hline 2 & Highly concentrated & 47,9 & $\begin{array}{l}\text { Amur, Astrakhan, Murmansk, Magadan, } \\
\text { Sakhalin, Kurgan, Yaroslavl, Kirov, Tula, }\end{array}$ \\
\hline
\end{tabular}

${ }^{2527}$ FAS, 'Analysis of the Market of Services Provided by Dairy Producers and Other Economic Entities to Suppliers of Raw Milk', <fas.gov.ru/documents/documentdetails.html?id=1250> accessed 20 April 2017.

${ }^{2528}$ FAS, 'Analysis of the Market of Services Provided by Dairy Producers and Other Economic Entities to Suppliers of Raw Milk', <fas.gov.ru/documents/documentdetails.html?id=1250> accessed 20 April 2017., 5.

${ }^{2529}$ FAS, 'Analysis of the Market of Services Provided by Dairy Producers and Other Economic Entities to Suppliers of Raw Milk', <fas.gov.ru/documents/documentdetails.html?id=1250> accessed 20 April 2017., 7. 


\begin{tabular}{|l|l|l|l|}
\hline & & & $\begin{array}{l}\text { Lipetsk, Tver, Chelyabinsk, Kaliningrad, } \\
\text { Smolensk, Komi, Tatarstan, Karelia, } \\
\text { Karachayevo-Cherkassia, Adygheja, } \\
\text { Bashkiria }\end{array}$ \\
\hline 3 & Medium concentrated & 31,25 & $\begin{array}{l}\text { VoronezhRegion, Tambov, Kemerovo, } \\
\text { Samara, Pensa, Kostroma, Omsk, } \\
\text { Ulyanovsk, Sverdlovsk Region, } \\
\text { Mordovija, Altay. }\end{array}$ \\
\hline 4 & Low concentrated & 12,5 & $\begin{array}{l}\text { Belgorod Region, Saratov, Vladimir, } \\
\text { Ryasan, Ivanovo, Nizhny Novgorod. }\end{array}$ \\
\hline
\end{tabular}

Source: FAS, 'Analysis of the Market of Services Provided by Dairy Producers and Other Economic Entities to Suppliers of Raw Milk' (2004 - I half of 2005), available at http://fas.gov.ru/

FAS has also investigated abuse of dominance cases in the market of raw milk processing and imposed liability on some raw milk processors like JSC "DANON RUSSIA" and OJSC "Zolotiye Luga" for abuse of dominance in the form of unjustified price differentiation for suppliers of raw milk. ${ }^{2530}$ Thus, DANON RUSSIA bought raw milk from its suppliers on the basis of standard contracts, whose price consisted of basic price and various surcharges related to the quality of milk. The basic price consisted of the basic regional price (depending on supply-demand conditions in the region) and the price adjustment on the basis of a complex assessment of each supplier. Therefore, the basic price for each individual supplier was different and dependent on the volume of supplied raw milk, the schedule of milk delivery, category of the supplier, duration of relationships with the buyer, etc. The suppliers with similar characteristics where included in the same price groups "clusters". FAS established that such non-transparent price setting was detrimental to competition between suppliers, who could not understand clearly the factors, which they were assessed upon, and, therefore, could not devise the long-term commercial strategies. Thereby DANON RUSSIA created unequal conditions, under which some suppliers received a higher price for their supplies without objective justification.

FAS conducted investigations of the sharp increase of wholesale prices in the markets of vegetables and fruits, ${ }^{2531}$ fish, ${ }^{2532}$ meat and poultry ${ }^{2533}$ establishing either the existence of a cartel or of an abuse of dominance. Multiple cases were initiated in the regional wholesale markets of sugar. ${ }^{2534}$ In one of the cases FAS established the coordination of economic activity of CJSC "TPK "Agro-Trade" and LLC "Buinskiy sugar" (two wholesalers) in the market of sugar by the third company, "Holding company "Ak-Bars", which gave mandatory indications to wholesalers regarding prices and volumes of supplies, as well as the range of clients. ${ }^{2535}$ The coordination resulted or might result in setting economically unjustified (monopolistic) wholesale prices for sugar in Tatarstan

\footnotetext{
${ }^{2530}$ Decision by Saint-Petersburg UFAS dated 30 June 2015 on the case №K06-23/15 (DANON) and decision by UFAS of Tumenskiy region dated 21 Decemeber 2015 on the case № K15/71-10 ("Zolotiye Luga").

2531 See, for example, Decision by Kemerovo UFAS dated 20 November 2015 on the case N16/A-10-2015.

2532 Decision by Tatarstan UFAS dated 15 September 2015 on the case №05-828/2014.

${ }^{2533}$ Decision of UFAS of Stavropol region dated 10 December 2014 on the case №91.

${ }^{2534}$ See, for example, Decision by Tatarstan UFAS dated 30 November 2015 on the case №05-157/2015 (A05-1396/2015); FAS press release dated 23 January 2015 at <fas.gov.ru/press-center/news/detail.html?id=34353>.

2535 Decision by Tatarstan UFAS dated 30 November 2015 on the case №05-157/2015 (A05-1396/2015); FAS press release dated 23 January 2015 at <fas.gov.ru/press-center/news/detail.html?id=34353>.
} 
region. The coordination of economic activity of undertakings by the third party, which does not form a group with any of the coordinated undertakings and is not active in any of the markets, where the coordinated activity is performed, is prohibited by paragraph 5 Article 11 of the Federal law "On Protection of Competition" within the horizontal agreements (cartel) framework. The FAS rejected the arguments of "Holding company "Ak-Bars" that for establishing of coordination the presence of an anticompetitive agreement between the coordinated undertakings (the "rim" in the "hub-andspoke" conspiracy) should be proved and pointed out that "coordination is the unilateral actions of the coordinator... which in itself are prohibited regardless the grounds of performing of such actions". ${ }^{2536}$ Therefore, no proof of existence of the "rim" is necessary, as long as the coordination resulted in actual or potential anticompetitive effects specified in Article 11 of the Federal law "On Protection of Competition".

All the above food products are included in the list of "socially important" products, which are subject to regular monitoring according to the Plan of the actions of FAS of Russia to implement the Decree of the President of the Russian Federation dated 06 August 2014 №560 "On the Application of Certain Special Economic Measures in order to Ensure the Security of the Russian Federation" aimed at the prevention of unjustified increase of the prices in the food markets. ${ }^{2537}$

Apart from monitoring and investigations, FAS pointed out to the necessity of structural measures, such as tightening control over the economic concentration on the processing level (for example, in the market of processing of raw milk) ${ }^{2538}$ or the strengthening of the position of farmers in contract negotiations with processors through, for instance, stimulating the cooperation between suppliers. $^{2539}$

The development of agricultural cooperations has been consistently declared as one of the priorities of the state agricultural policies in general, as well as of the FAS priorities in agricultural sector. ${ }^{2540}$ The agricultural cooperation is exempted from the restrictions imposed by Article 14 of the Federal law "On the Trading Activities" on dominant retail chains, whose market share exceeds $25 \%$ in the relevant geographic market often defined as narrow as local district (see the section "Retail"). ${ }^{2541}$ Agricultural cooperatives receive state support in the form of subsidies provided from the federal and regional budgets for development of technical infrastructure, acquisition of equipment, organising of distributing and logistics centers, etc. As a result, the number of agricultural cooperatives has increased from 2006 to 2013 by five times and as of 01 January 2014 amounted to $6913 .^{2542}$

\footnotetext{
2536 Decision by Tatarstan UFAS dated 30 November 2015 on the case №05-157/2015 (A05-1396/2015); FAS press release dated 23 January 2015 at <fas.gov.ru/press-center/news/detail.html?id=34353>.

${ }^{2537}$ Decree of the FAS dated 14 August 2014 N 525/14 "On Adoption of the Plan of the Actions of FAS of Russia on Implementation of the Decree of the Government of the Russian Federation dated 07 August 2014 N 778 "On Measures on Implementation of the Decree of the President of the Russian Federation dated 06 August 2014 №560 "On the Application of Certain Special Economic Measures in order to Ensure the Security of the Russian Federation".

${ }^{2538}$ FAS press release dated 20 May 2016 at <fas.gov.ru/press-center/news/detail.html?id=45796>.

${ }^{2539} \mathrm{FAS}$ press release dated 20 May 2016 at $<$ fas.gov.ru/press-center/news/detail.html?id=45796>.

2540 'Strategy of the Sustainable Development of the Agricultural Territories of the Russian Federation to 2030' adopted by the Decree of the Government of the Russian Federation dated 02 February 2015 N151-r; FAS press release dated 27 February 2017 at <fas.gov.ru/press-center/news/detail.html?id=49039>.

${ }^{2541}$ Paragraph 1 Article 14 of the Federal law "On the Trading Activities".

2542 'Strategy of the Sustainable Development of the Agricultural Territories of the Russian Federation to 2030' adopted by the Decree of the Government of the Russian Federation dated 02 February 2015 N151-r; FAS press release dated 27 February 2017 at <fas.gov.ru/press-center/news/detail.html?id=49039>.
} 


\subsubsection{Retail}

Over the last few years the food retail sector in Russia has witnessed various changes including "the growth of the number of retail trade chains" 2543 and an increase of the market share of top ten retail chains ${ }^{2544}$ at the expense of regional chains and local retailers. ${ }^{2545}$ This raises the justified concerns of FAS, as the strengthened position of the large retail chains often results in abusive practices against suppliers and end consumers.

In its investigations in the food retail market, FAS predominantly enforces Articles 9 and 13 of the Federal law "On the Trading Activities" and Articles 10 and 11 of the Federal law "On Protection of Competition".

In February 2017 the territorial department of FAS conducted the market investigation with regard to compliance of supply contracts between food retail chains and their suppliers with the requirements of the Federal law "On the Trading Activities" (as amended by the Federal law dated 03 July $2016 \mathrm{~N} \mathrm{273-FZ).}{ }^{2546}$ FAS conducted altogether 701 inspections of the food retailers and established that out of 11266 supply contracts around 11\% (1 261 contracts) are non-compliant with the requirements of the Federal law "On the Trading Activities". ${ }^{2547}$ Thus, the most frequent violations of the Federal law "On the Trading Activities" included:

- stipulating the terms of delayed payment exceeding the terms set forth by the law (paragraph 7 of Article 9); ${ }^{2548}$

- payment of remuneration for the purchase by a retailer from its suppliers certain quantities of the food products ("quantity rebates"), ${ }^{2549}$ if such remuneration exceeds permitted $5 \%$ of the price of purchased products or if the remuneration is paid for purchase of socially important products (paragraph 4 and 5 of Article 9); ${ }^{2550}$

\footnotetext{
${ }^{2543}$ Competition Issues in Food Chain Industry 2013, OECD, 15 May 2014, Directorate for Financial and Enterprise Affairs, Competition Committee DAF/COMP (2014) 16, 330).

25442015 was marked by the record increase of top ten retailers' market share from $21,6 \%$ to $24,3 \%$ according to INFOLine, <www.marketch.ru/marketing_marginalia/obzor_rynka_fmcg_po_itogam_2015_goda> accessed 20 April 2017. This trend is expected to continue.

${ }^{2545}$ Due to decrease of demand, the revenue of the local retailers plummeted by $27 \%$ on average in 2015 (see Ischenko N, 'The Largest Retailers Have Significantly Increased Their Market Share', "Vedomosti” N3989 dated 25 December 2015 at <www.vedomosti.ru/business/articles/2015/12/25/622565-seti-narastili-dolyu>).

${ }^{2546}$ Report of FAS dated 27 March 2017 "On the results of inspections of supply contracts between retail chains and food suppliers with regard to their compliance with the requirements of Federal Law "On the Basic Principles of State Regulation of Trading Activities in the Russian Federation" dated 28 December 2009 N 381-FZ", <fas.gov.ru/documents/documentdetails.html?id=15105> accessed 01 September 2017.

${ }^{2547}$ Report of FAS dated 27 March 2017 "On the results of inspections of supply contracts between retail chains and food suppliers with regard to their compliance with the requirements of Federal Law "On the Basic Principles of State Regulation of Trading Activities in the Russian Federation" dated 28 December 2009 N 381-FZ", <fas.gov.ru/documents/documentdetails.html?id=15105> accessed 01 September 2017.

${ }^{2548} 34 \%$ of the total amount of violations - ibid. Report of FAS dated 27 March 2017 "On the results of inspections of supply contracts between retail chains and food suppliers with regard to their compliance with the requirements of Federal Law "On the Basic Principles of State Regulation of Trading Activities in the Russian Federation" dated 28 December 2009 N 381-FZ", <fas.gov.ru/documents/documentdetails.html?id=15105> accessed 01 September 2017.

${ }^{2549}$ In the latest clarification of the Federal law "On the Trading Activities" as of 09 June 2017 № AK/39035/17 FAS has stated that paragraph 12 of Article 9 of the Federal law "On the Trading Activities" does not preclude the parties from including in a supply contract with a retailer condition on reduction of the price of supplied goods for a specified period provided that the retailer will fully pass on this price reduction to the consumers. Such condition does not fall under $5 \%$ restriction specified in paragraph 4 of Article 9 of the Federal law "On the Trading Activities".

${ }^{2550} 22 \%$ of the total amount of violations - Report of FAS dated 27 March 2017 "On the results of inspections of supply contracts between retail chains and food suppliers with regard to their compliance with the requirements of Federal Law
} 
- violation of the procedure of disclosing information on selection of the counterparties by a retailer (paragraph 1, 2 of Article 9). ${ }^{2551}$

Other violations of the Federal law "On the Trading Activities" established by FAS include, inter alia:

- including provisions on rendering by the retailer to its supplier of the advertising, marketing, promotional or similar services in the food supply contract or forcing a supplier to enter into a contract for rendering paid services aimed at promoting food products while concluding or implementing the food supply contract (paragraph 12 of Article 9); ${ }^{2552}$

- stipulating the slotting allowance - payment for the right to supply goods to the retail chain or the payment for the modification of the assortment of goods (paragraph 13 of Article 9, previously Article 13); ${ }^{2553}$

- including in a food supply contract restrictions regarding the assignment of rights under the contract (paragraph 10 of Article 9; previously subparagraph 1a paragraph 1 Article 13); ${ }^{2554}$

- stipulating different terms of payment for supply of similar goods in the contracts (subparagraph 1 paragraph 1 Article 13); ${ }^{2555}$

- stipulating different terms of responsibility in contracts for the supply of similar goods (subparagraph 1 paragraph 1 Article 13); ${ }^{2556}$

- stipulation of the cost of marketing services as a percentage of the goods supplied to the retailer and setting the different prices of marketing services in contracts with suppliers of similar goods (subparagraph 1 paragraph 1 Article 13); ${ }^{2557}$

- violation of the order of price setting defined by legal acts (subparagraph 3 paragraph 1 Article 13); ${ }^{2558}$

- refusal of a retailer to enter into a contract with a supplier (provided that the supplier corresponds to the selection criteria) or unjustified deferral of considering a commercial offer of the latter (subparagraph 2 paragraph 1 Article 13); ${ }^{2559}$

\footnotetext{
"On the Basic Principles of State Regulation of Trading Activities in the Russian Federation" dated 28 December 2009 N 381-FZ", <fas.gov.ru/documents/documentdetails.html?id=15105> accessed 01 September 2017.

. See also Decision by Voronezh UFAS dated 25 December 2015 on the case №606-13T; Decision by Kaluga UFAS dated 27 October 2015 on the case №05-01т/2015; etc.

${ }^{2551} 12 \%$ of the total amount of violations - ibid.

${ }^{2552}$ For example, Decision by Kurgan UFAS, 31 December 2015, case №44.

${ }^{2553}$ Decisions by Saint-Petersburg UFAS dated 18 September 2015 on the case №K06-36/15 and dated 23 June 2015 on the case № K06-7/15.

${ }^{2554}$ For example, decisions by Bashkortostan UFAS dated 21 May 2015 on the case № T-13/13-15 and dated 19 May 2015 on the case № T-14/13-15.

${ }^{2555}$ For example, Decision by Lipetzk UFAS dated 05 August 2015 on the case №91.

${ }^{2556}$ For example, Decision by Karachaevo-Cherkessia UFAS dated 22 May 2015 on the case №27.

${ }^{2557}$ For example, Decision by Saratov UFAS dated 25 September 2015 on the case №36/tr; Decision by Moscow UFAS dated 03 April 2015 on the case № 5-9-3/00-18-14.

${ }^{2558}$ For example, Decisions by Yakutsk UFAS dated 28 May 2015 on the case №02-46/15A and dated 29 June 2015 on the case №02-20/15A.

${ }^{2559}$ For example, Decision by Karachaevo-Cherkessia UFAS dated 22 May 2015 on the case №27; Decision by Krasnodar UFAS dated 10 June 2015 on the case №384/2014; Decision by Tatarstan UFAS dated 16 March 2015 on the case №05$841 / 2014$.
} 
- prohibiting a supplier under the food supply contract from concluding analogous contracts with other buyers (organisations) carrying out the same trading activities within the specified territory (subparagraph 4 paragraph 1 Article 13); ${ }^{2560}$

- including in the food supply contract the condition on returning to the supplier alimentary products which were not sold after a certain period (subparagraph 4 paragraph 1 Article 13); ${ }^{2561}$

- selling of food products to the entity performing trading activities through the retail chain via a commission/agent agreement unless such agreement is concluded by entities within one group (the aim of this provision is to limit the number of intermediaries between food suppliers and end users which might lead to unjustified increase of prices) (subparagraph 5 paragraph 1 Article 13). ${ }^{2562}$

The latest investigations of violations of the Federal law "On the Trading Activities" initiated by FAS involve the major Russian retailers (such as retail chains "Metro", "Lenta", Magnit (CJSC "Tander"), Diksi and Seventh Continent) who have included in their supply contracts discriminating conditions, namely different terms of payment of remuneration and charges, which put suppliers of analogous goods in unequal position. The investigations are pending. ${ }^{2563}$

The threshold below which the practices of food retail chains are unlikely to raise competition concerns is two-folded. On the one hand, in accordance with paragraph 2 of Article 5 of the Federal law "On Protection of Competition", the economic undertaking cannot be considered dominant if its market share does not exceed 35\%. ${ }^{2564}$ On the other hand, food retail chains are exempted from the restrictions imposed by Article 13 and 14 of the Federal law "On the Trading Activities" if the annual turnover of the retail chain (its group) does not exceed 400 million rubles. ${ }^{2565}$ Therefore, even if the retail chain cannot be considered dominant due to its low market share in the relevant product market, it still can be caught by the competition law prohibitions set forth in Article 13 of the Federal law "On the Trading Activities".

In addition, Article 14 of the Federal law "On the Trading Activities" sets forth the important restriction on the territorial expansion of retail chains. Thus, the food retail chain, whose market share exceeds $25 \%$ of the volume of all food products sold during the previous year in the territory of the region or local district, is not allowed to acquire or lease additional premises for trading within the relevant territory on any ground, including commissioning of new objects. The transaction performed in violation of this restriction is null and void, and FAS is entitled to bring an action for closing the store opened in violation of Article 14 of the Federal law "On the Trading Activities". Regional departments of FAS perform regular monitoring of market shares of the largest retail chains. Thus, in 2010 the market share of the large retailer X5 in Saint-Petersburg was found to be 35\% and the

\footnotetext{
${ }^{2560}$ For example, Decision by Vologda UFAS dated 25 October 2016 on the case №1-13ТД/16.

${ }^{2561}$ For example, Decision by Smolensk UFAS dated 16 December 2015 on the case №05-09/04-15/T.

${ }^{2562}$ For example, Decision by Ulyanovsk UFAS dated 31 August 2015 on the case №12222/04-2015.

${ }^{2563}$ Press-releases 'Moscow Region FAS has initiated procedures against retail chains for imposing discriminatory terms on their suppliers' as of 12 August, 20 August and 27 August 2017, <fas.gov.ru/presscenter/news/detail.html?id=51317>; <fas.gov.ru/press-center/news/detail.html?id=51243>; <fas.gov.ru/presscenter/news/detail.html?id=51420> accessed 01 September 2017.

${ }^{2564}$ With some exceptions set forth in paragraphs 3 and 6 of the said Article.

2565 Paragraph 4.1. of Article 1 of the Federal law "On the Trading Activities".
} 
latter lost right to expand within the territory of the city until 2013, when its market share dropped to $22,86 \% .^{2566}$

The cases of violation of the Federal law "On Protection of Competition" by retail chains include the establishment and maintaining of monopolistically high prices for a commodity (subparagraph 1 paragraph 1 Article 10), ${ }^{2567}$ setting different prices (tariffs) for analogous good unless it is economically, technologically or otherwise justified (subparagraph 6 paragraph 1 Article 10) ) $^{2568}$ and entering into anticompetitive agreements, which lead or could lead to setting and maintenance of the prices (paragraph 1 Article 11$)^{2569}$ and/or reducing the sales volume / termination of sales of the products (paragraph 4 Article 11 ) $^{2570}$. There is evidence that the competition in the retail market in Russia is to the great extent based on price (especially against the fall in real incomes of customers in 2014-2015); ${ }^{2571}$ thus, even a small unilateral increase of the price of a product could result in a critical loss of customers and switching to a cheaper product. ${ }^{2572}$ Therefore, retailers often resort to parallel increases of the prices for the staple products, which was particularly the case during the volatile economic situation in the end of 2014-beginning of 2015. However, proving the existence of agreement aimed at setting the prices often poses practical challenges for FAS.

For instance, Tatarstan FAS investigated significant simultaneous increase of retail prices for buckwheat in the supermarkets of LLC “Agrotorg", CJSC "Tander", CJSC "TD "Perekrestok", LLC "Ashan" and others in the territory of Tatarstan in the period from November 2014 to January $2015 .^{2573}$ It established that the increase in the retail prices did not correspond to an increase in wholesale prices for the product and resulted in significant increases of the mark-up of retailers (up to 10 times in certain cases), which provided evidence of an anticompetitive agreement under paragraph 1 Article 11 of the Federal law "On Protection of Competition”. As a proof of the existence of an agreement, FAS considered that a consistent significant increase of retail prices by independent retailers (provided that their costs remain stable) has no other economically viable explanations, rather than as an agreement. However, the commercial courts did not uphold the position of FAS, pointing that FAS provided no evidence of the awareness of the participants of the alleged cartel of each other's pricing strategies or communications between them that could constitute the agreement. $^{2574}$

According to subparagraph 1 paragraph 13 of Article 9 of the Federal law "On the Trading Activities" food retail chains are prohibited to require from their suppliers payment for the right to supply food products to the existing or newly opened retail facilities. According to FAS, prohibition of slotting allowances covers not only explicit cases, but also payments for any services delivered by the retail chain, which are imposed on suppliers by the retails chain and do not have the economic justification other than payment for access to the shelf space. However, commercial courts, without

\footnotetext{
${ }^{2566}$ Elena Donbrova and Amera Karlos, "The market share of retailers X5, "Lenta" and "O'key" exceeded the threshold set by law', (13 February 2017) Delovoy Peterburg, <www.dp.ru/a/2017/02/12/Retejleri_s_polovinoj> accessed 20 April 2017.

2567 Decision by Chuvashiya UFAS dated 08 July 2015 on the case №19/04-AM3-2015.

2568 Decision by Chuvashiya UFAS dated 08 July 2015 on the case №19/04-AM3-2015.

${ }^{2569}$ For example, Decision by Tatarstan UFAS, 18June 2015, case №05-827/2014.

${ }^{2570}$ Decision by Yamalo-Nenetsk UFAS dated 27 April 2015 on the case № 02-01/11/03-2015.

${ }^{2571} \mathrm{http}: / /$ www.marketch.ru/marketing_marginalia/obzor_rynka_fmcg_po_itogam_2015_goda/

$2572 \mathrm{http} / / / w w w . v e d o m o s t i . r u / b u s i n e s s / a r t i c l e s / 2015 / 12 / 25 / 622565$-seti-narastili-dolyu/

2573 Decision by Tatarstan UFAS dated 18.06.2015 on the case №05-827/2014.

${ }^{2574}$ Judgement of the Eleventh Commercial Court of Appeal dated 14 June 2016 on the case №A65-20903/2015; Ruling of the Supreme Court of the Russian Federation dated 30 January 2017 № 306-КГ16-19447.
} 
rejecting the FAS standpoint entirely, require more thorough proof that payment for the services rendered by the retail chain (such as services for promotion of goods) is in fact slotting allowance (see Box 4). Meanwhile, the additional services rendered by the food retail chain to its suppliers (like promotional, marketing, logistics, packaging services) are subject to the stringent rules: (i) they should be rendered on the basis of the separate agreement, and (ii) the aggregate amount of payment for such services together with payment for the purchase by a retailer from its suppliers certain quantities of the food products should not exceed $5 \%$ (earlier 10\%) of the price of the purchased goods. ${ }^{2575}$

\section{Box 4: Decision by FAS of Saint-Petersburg dated 23 June 2015 on the case № K06-7/15}

FAS made an inquiry into the supply contracts of the retail chain "Lenta" and established that all the suppliers have entered into additional service agreements, under which specific remuneration was to be paid by the suppliers in exchange for their promotion and advertising. Moreover, supply agreements include "retro-bonus" paid to LLC "Lenta" for purchasing of a certain volume of goods from the supplier (not exceeding 10\%). FAS established that the overall amount of payments performed by the suppliers to LLC "Lenta" varied from $24 \%$ to $53 \%$ of the product turnover and was considered unprofitable for suppliers. FAS came to conclusion that remuneration paid to "Lenta" under agreements for promotion of goods was, in substance, the payment for the right to supply the goods to the supermarkets of LLC "Lenta" and, as such, was in breach of the Federal law "On the Trading Activities".

The commercial courts overturned the FAS decision due to the lack of evidence of the violation committed. During the new trial, the Commercial Court of Saint-Petersburg pointed out that FAS did not prove that in that case payment for the services for promotion of the goods in the retail chain "Lenta" was in fact payment for the right to supply goods to the retail chain; that the services were imposed on suppliers as a condition for entering into supply contracts with "Lenta"; that they were unprofitable for suppliers and economically unjustified. ${ }^{2576}$

\subsubsection{Private Labels}

The share of private labels in the line of products of retailers is growing steadily during last several years. Thus, by 2017 the share of private labels of the big retailers has reached $10-17 \%$ in their overall turnover, ${ }^{2577}$ which are still less than the share of private labels in many foreign countries (30$35 \%) .{ }^{2578}$ The difference in price between private labels and analogous brands reaches $20-30 \%$ and

\footnotetext{
2575 Paragraphs 4 and 11 of Article 9 of the Federal law "On the Trading Activities".

2576 Judgement of the Commercial Court of the Northern-Western District dated 24 October 2016 on the case №A56$60406 / 2015$.

2577 According to RBK and Kommersant the share of private labels of "Piatorochka" amounts to 17\% of its turnover; "Diksi" - 15,5\%; "Lenta" - 12\%; "Magnit" - 11\%; "Metro Cash and Carry" - 10,9\% (Anastasiya Demidova, "Food retail chains are selling their names' (23 March <www.rbc.ru/newspaper/2017/03/23/58d267cb9a7947df5d18c78d> accessed 21 April 2017; Julia Bezrukova,'The retail chains use private labels to increase their income' (09 August 2016, Kommersant), https://www.kommersant.ru/doc/3059373 accessed 20 April 2017. 2578 ibid.
} 
many consumers switch to private labels in the low price categories where the brand is not of the utmost importance (sugar, cereals, milk, soft drinks, etc). ${ }^{2579}$

The effect of private labels on supply side is ambiguous. On the one hand, as the trading space in supermarkets is limited, the small, less known brands tend to be replaced with private labels, which results in higher barriers to enter the market and foreclosure of small and medium suppliers. On the other hand, the retail chains usually do not manufacture private labels and contract them to smaller producers, which might be advantageous for the latter, as small producers usually do not have enough resources for marketing and promotion of their own brands. ${ }^{2580}$ However, producers of private labels often have to accept unprofitable trading conditions and sell their goods with very low or even zero margin, ${ }^{2581}$ due to the bargaining power of the big retail chains.

Russian competition law and law on trading activities do not contain direct prohibition against private labels. However, this practice has attracted some attention of the competition authority. Back in 2011 during the expert panel on retail industry FAS announced that it was planning to investigate the practice of the "brand squeezing", by which FAS meant using private labels as leverage to force independent producers to drop prices of their brands. ${ }^{2582}$ The outcome of the investigation is unclear.

\subsubsection{Code of Good Practices in Food Retail}

Development of good business practices plays significant role in the retail sector. Thus, in December 2012 seven leading industry associations (AKORT, Rusbrand, Soyuzmoloko (association of milk producers), Rusprodunion, National Meat Association, Fish Union, Association of Producers and Consumers of Oil and Grease), the Russian Chamber of Commerce and Association of Consumers of the Russian Federation signed the "Code of Good Practices of Relationships between Retail Chains and Suppliers of Consumer Goods" (hereinafter - the "Code of Practices"). ${ }^{2583}$ The main goals of the Code of Practices are:

- improvement of interactions between retail chains and suppliers based on the principles of good faith in order to establish the balance of commercial interests of the parties;

- increase of efficiency of interactions between retail chains and suppliers in order to optimise the costs along all supply chain;

- promotion of competition and compliance of all market participants with the ethical rules of market behaviour;

- satisfying the customers' demand for high quality consumer goods.

The good practices include transparency of selection process and equal rights of suppliers to enter into a supply contract with the retail chain; predictability and economic justification of any price modification under the supply contract; the transparent procedure of introducing consumer goods to and removing it from the assortment matrix of the retail chain; procedures of exchange of documentation between the parties of the supply contract; implementation of promotion campaigns

\footnotetext{
2579 Julia Bezrukova, 'The retail chains use private labels to increase their income' (09 August 2016, Kommersant).

2580 The Center of Monitoring of the Market Environment, 'Analysis of Position of the Large Retail Chains in the Food Retail Market of Saint-Petersburg and Practices of their Interaction with Food Producers' (2005, S.-Petersburg) 6, accessed at fas.gov.ru/files/8797/SPb_Ritail2005.doc.

${ }^{2581}$ Anastasiya Demidova, 'Food retail chains are selling their names' (23 March 2017, RBC).

2582 FAS press release 'Brand Squeezing' dated 28 October 2011, <fas.gov.ru/press-center/fas-inmedia/detail.html?id=9994> accessed 11 September 2017 .

${ }^{2583}$ Accessed at http://www.codeofconduct.ru/ and http://fas.gov.ru/documents/documentdetails.html?id=1643.
} 
and category management, etc. If the dispute on implementation or interpretation of the Code of Practices arises, the parties may decide to bring the dispute in front of the special Commission on Implementation of the Code of Practices, which should resolve the dispute within 15 working days upon receipt of all necessary documents. FAS is highly supportive to the wider implementation of the Code of Practices. For instance, in 2014 FAS issued the letter approving the draft addendum to the standard supply contract / contract on promotion of consumer goods stipulating that during performance of the said contract the parties would abide by the Code of Practices. ${ }^{2584}$

\subsubsection{Regulation of Retail Prices and Mark-Up for Food Products}

One of the issues arisen in 2015 and addressed by FAS was the setting of a maximum retail markups for certain types of food products by regional state authorities in order to restrain the outburst of prices and maintain stability in food markets. Generally speaking, the Russian legislation does not provide for state regulation of food prices (except for cases determined according to the Article 8 of the Federal Law "On the Trading Activities"). The cases when the regional state bodies are authorised to set the regulated prices and mark-ups include, inter alia, mark-ups for food products traded in the Far North of Russia and equivalent regions with the restricted terms of shipment of goods. ${ }^{2585}$ FAS pointed out that the introduction of the state regulation of prices for certain types of food products (including the maximum retail mark-ups) by regional state bodies in cases, which are not listed in the Decree of the Government of Russian Federation dated 07 March 1995 No. 239, (even in the form of recommended mark-ups if recommendations are adopted by market participants) could constitute a violation of Article 15 of the Federal law "On Protection of Competition". ${ }^{2586}$ Such regional legal acts should be abolished as inconsistent with federal legislation.

\subsection{State Regulation of Food Supply Value Chains in Russia}

Agriculture is an important economic sector in terms of number of the people employed in it which constitutes $9.7 \%$ of the active population. ${ }^{2587}$ The share of agriculture value added in the GDP is relatively low and amounts to $4 \%$ with the actual slow growth by $1.3 \%$ on average between 2000 and $2010 .{ }^{2588}$ The agrarian system is characterized by the co-existence of large commercial producers with small farmers that produce predominately for their own consumption and informal markets. ${ }^{2589}$

State support to agriculture has increased steadily in Russia during last decade intending to partially fill the gap in agricultural public policy created after the collapse of state-owned agroholdings prevailing in the Soviet Union and the failure of the state to support market reforms in the agricultural industry in 1990s. ${ }^{2590}$ The WTO accession generates a number of challenges, mostly

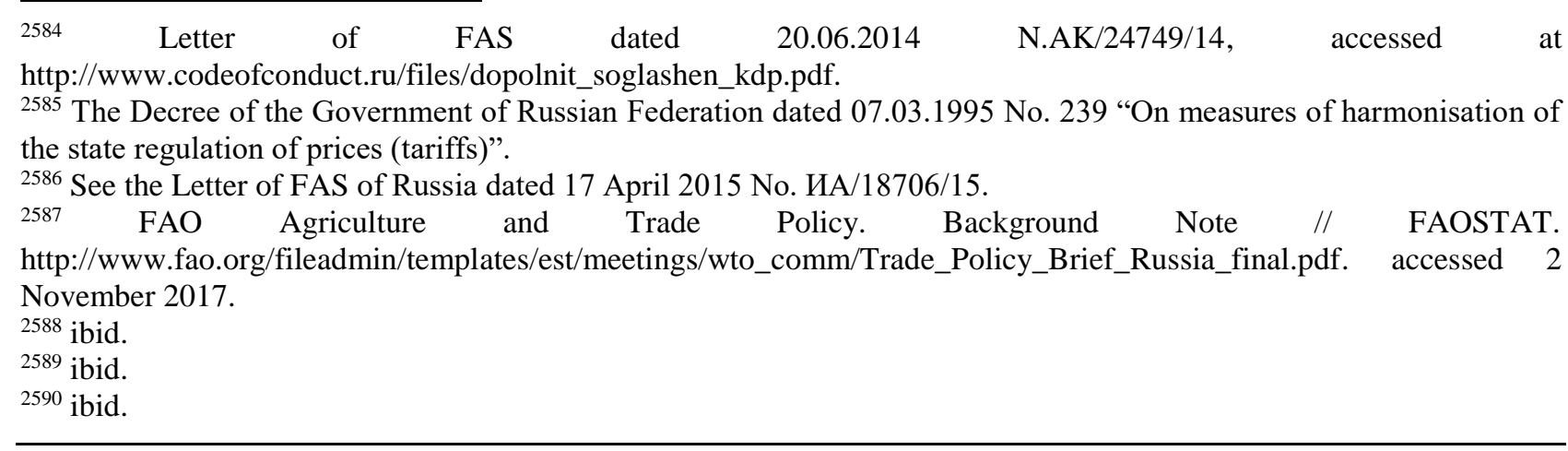


related to market access for meat and meat products, but Russia is not facing an eminent obligation to lower domestic support as measured by AMS. The AMS commitments for the period 2012-15 are well above the current level of support. However, after 2015 adjustments will have to be made to maintain the level of domestic support and eventually reduce it to the average level in the 2006-08 period (US $\$ 4.4$ billion per year). The main challenge for the Russian Government with respect to WTO commitments on agriculture will be finding new ways to foster long- term growth and competitiveness of the sector through less trade-distorting types of measures consistent with the WTO obligations. $^{2591}$

\subsubsection{Agricultural Policy and Food Supply}

The agricultural policy in Russian Federation is defined under the Federal Law "On development of agricultural industry" dated 29 December 2006 N 264-FZ (hereinafter - the "Law on Agricultural Industry"). This Federal Law governs the relations arising between the citizens and agricultural producers, other citizens, legal entities, public authorities in the sphere of development of agricultural industry. The Law on Agricultural Industry establishes the legal basis of the state social and economic policy in the sphere of development of agricultural industry, which is defined as economic activity on production of agricultural goods, rendering services for providing the population with Russian food products, and providing the industry with agricultural inputs and assistance to the sustainable development of the rural territories. ${ }^{2592}$

Under Article 3 of the Law on Agricultural Industry, agricultural producers are defined as an organisation or an individual entrepreneur performing production of agricultural goods, their primary and subsequent (industrial) processing according to the list approved by the Government of the Russian Federation and sale of these products provided that the share of the income from sale of the above agricultural goods constitutes at least seventy percent in the total income of agricultural producers from sales of goods (performance of works, services) for each calendar year.

Agricultural producers are also represented by: ${ }^{2593} 1$ ) citizens engaged in personal subsidiary farming according to the Federal Law "About Personal Subsidiary Farming" dated 07 July 2003 No. 112-FZ; 2) the agricultural cooperatives of consumers (processing, trading, providing services (including credit services), supplying, procurement) created according to the Federal Law "About Agricultural Cooperation" of dated 08 December 1995 No. 193-FZ (hereinafter - the Federal Law "About Agricultural Cooperation").

The Ministry of Agriculture is the federal body authorised to set forth the key priorities in the agricultural policy. The Ministry is, in particular, responsible for: ${ }^{2594}$

(i) Drafting and implementing government policy and legal regulation of the agriculture and related industries, including livestock farming (inter alia, breeding of domesticated fish species included in the State Register of Protected Varieties of Plants and Animal Breeds), veterinary services, including pharmaceuticals, crop production, phytosanitary control, soil improvement and fertility, regulation of the farm products, raw materials, and food markets, the food and food processing

\footnotetext{
${ }^{2591}$ ibid.

${ }^{2592}$ Article 1 of the Law on Agricultural Industry.

2593 Article 3 of the Law on Agricultural Industry.

${ }^{2594}$ Paragraph 1 of the Regulations on the Ministry of Agriculture of the Russian Federation adopted by the Decree of the Government of the Russian Federation dated 12 June 2008 No. 450.
} 
industry, the production and distribution of tobacco products, and the sustainable development of rural areas.

(ii) Drafting state policy and legal regulation in the fisheries industry, including fishing and fish farming (aquaculture), conservation of aquatic biological resources, the manufacture, processing and sale of fish and other products derived from aquatic biological resources, the industrial activities on fishing vessels; the protection, research, preservation and replacement of marine wildlife and protection of their natural habitats, excluding aquatic biological resources in federal protected nature areas and listed in the Red Book of the Russian Federation; ensuring the safe operation of fishing vessels, as well as emergency and rescue work in fishing areas during fishing expeditions; and the supervision and control over aquatic biological resources and protection of their natural habitats in Russia's inland waters.

(iii) Drafting and implementing state policy and legal regulation in the field of land relations (regarding agricultural land plots), ensuring state monitoring of such land.

(iv) Providing state services related to agriculture, including the sustainable development of rural areas.

(v) Managing state property belonging to enterprises and organisations subordinate to the ministry.

According to Article 10 of the Law on Agricultural Industry, the Ministry is obliged to prepare and publish the national report related to state agricultural policy (hereinafter - the "National Report"). The Government of the Russian Federation adopts the National Report and sends it to the Federal Assembly.

The National Report sets forth:

(i) The outcomes of the realisation of the state programme on agricultural development for the previous year;

(ii) Key figures of performance of agricultural industry in accordance with the goals and objectives set up under the national program (index of gross production in agricultural and food industries, investments in agriculture, incomes of citizens of rural areas; figures on the staple food consumption per capita per year; net inflow from exports of food products; share of the national food products in the consumers market; cost effectiveness of agricultural industry; technical equipment in agricultural industry; price parity index and index of increase of the volume of social services provided to citizens i rural areas).

(iii) Agriculture development forecasts for the forthcoming year and proposals to amend the national programme if necessary.

The "State Program on Agricultural Development and Regulation of Agricultural Products, Commodities and Food Markets, 2013-2020" (hereinafter - the "State Programme") has been drafted by the Ministry of Agriculture of the Russian Federation pursuant to Article 8 of the Law on Agricultural Industry.

The strategic aims of the State Programme include:

1) Ensuring food security of Russia within the parameters of the Food Security Doctrine of the Russian Federation.

2) Increasing competitiveness of Russian agricultural products on domestic and foreign markets within the framework of Russia's WTO membership.

3) Improving the financial stability of agricultural producers.

4) Promoting the sustainable development of rural areas. 
5) Regenerating and using lands and other agricultural resources more efficiently, making production environment-friendly.

To achieve these goals, the State Programme addresses the following tasks within the framework of federal targeted programmes, sub-programmes and key measures:

1) Incentivising production of the main types of agricultural products and food products;

2) Implementing anti-epizootic measures with regard to quarantinable and especially dangerous animal diseases;

3) Supporting the development of infrastructure of the agricultural and food market;

4) Making agricultural products, commodity and food market regulation more effective.

5) Supporting small businesses;

6) Ensuring the effectiveness of state authorities' activities in the sphere of agricultural development and regulation of agricultural product, commodity and food markets.;

7) Increasing cost-effectiveness in agriculture to ensure its sustainable development;

8) Improving life standards in rural areas;

9) Encouraging innovation in the agricultural industry;

10) Promoting biotechnology;

11) Creating conditions for the efficient use of agricultural lands;

12) Promoting the amelioration of agricultural lands;

13) Economic regulation of the use of land, water and other renewable natural resources in agricultural production, increasing soil fertility to the optimal level in each specific zone.

The State Programme consists of six sub-programmes and four federal targeted programmes:

1) The sub-programmes are "Developing Crop Farming and the Processing and Sale of Crop Farming Products"; "Developing Animal Breeding and the Processing and Sale of Animal Breeding Products"; "Developing Beef Cattle Breeding"; "Supporting Small Businesses"; "Technical and Technological Modernisation, Innovative Development"; "Ensuring the Implementation of the State Programme".

2) The federal targeted programmes: "Social Development of Rural Areas to 2013"; "Sustainable Development of Rural Areas in 2014-2017 and to 2020 (draft)"; Preservation and Restoration of Agricultural Soil Fertility and Agricultural Landscapes as the National Asset of Russia in 20062010 and to 2013; "Developing Agricultural Land Amelioration in Russia in 2014-2020" (draft).

3) Total federal funding for the state programme is 1.5097 trillion rubles (in current prices), including 158.9 billion rubles in 2013, 162 billion rubles in 2014, and 175.4 billion rubles in 2015 .

4) The sub-programmes to develop crop farming and animal breeding are based on a scheme that includes not only agricultural production but also processing of agricultural products, infrastructure development and market regulation.

5) Implementation of the State Programme and its sub-programmes and federal targeted programmes will be evaluated by the criteria established in the State Programme, which include:

a. Index of agricultural production by farms of all categories (in comparable prices).

b. Index of crop farming production (in comparable prices).

c. Index of animal breeding production (in comparable prices).

d. Index of food production, including beverages (in comparable prices).

e. Index of the actual amount of investment in the fixed agricultural assets. 
f. Cost-effectiveness of agriculture.

g. Average monthly wages in the agricultural industry (at agricultural enterprises other than small businesses).

The State Program outlines two sets of priorities. However, the so called "second level" of priorities may not be given significant financial support.

The first level of priorities includes: $:^{2595}$

1) In the production sphere - development of the cattle industry (production of meat and milk) as the core (strategic) sub-industry that use the "competitive advantages of the country", ${ }^{2596}$ such as availability of significant agricultural lands.

2) In the economic sphere - increase of returns of agricultural producers.

3) In the social sphere the priorities are very general: sustainable development of rural territories as the precondition for preservation of labour resources and the territorial integrity of the country and creation of conditions for economic and physical availability of food for the socially disadvantaged groups of population (based on the rational norms of consumption).

4) In the sphere of development of production potential - reclamation and irrigation of agricultural land, recovery of non-used arable land and other agricultural lands.

5) In the sphere of institutional development - development of integration links in the agroindustrial complex and establishment of food sub-complexes, as well as territorial vertically integrated agribusiness, so called "clusters".

6) In the sphere of science and human resources, the Program's priority is to "provide for a innovative agro-industrial complex".

The second level of priorities includes: ${ }^{2597}$

1) Development of import-substitution industries, including vegetable and fruits production.

2) Ecological safety of agricultural and food products.

3) Increase of exports of agricultural products, raw agricultural materials and food products, if and when the domestic markets are saturated.

4) Minimising the cost of logistics and supporting the competitiveness of production, considering at the same time the rational location and specialisation of agricultural and food industries by zones and regions of the country.

The State Program supports the Russian agriculture compliance with WTO requirements and considers relevant plans of actions of the Russian Government, business, and the Ministry of Agriculture. Implementation of the State Programme will make possible to achieve the main indicators outlined by the Food Security Doctrine of the Russian Federation by $2020 .{ }^{2598}$ The annual allocations for the State Programme in eight years will grow slowly, at 4.6 percent, from 159 billion rubles ( $\$ 5.3$ billion) in 2013 to 218 billion rubles ( $\$ 7.27$ billion). The Program envisages that in the first 2 years (2013 and 2014) the budget allocations will be almost flat, and they will accelerate in 2015-2018. According to industry analysts, the cuts in budget funds compared to the Ministry of

2595 Agriculture Development Program 2013-2020 // USDA Foreign Agricultural Services. 2012. https://gain.fas.usda.gov/Recent\%20GAIN\%20Publications/Agriculture\%20Development\%20Program\%2020132020_Moscow_Russian\%20Federation_11-6-2012.pdf accessed 2 November 2017.

2596 ibid.

2597 ibid.

2598 Agricultural Development and Regulation of Agricultural Products, Commodities and Food Markets, 2013-2020 // Government Decisions. The Russian Government <http://government.ru/en/docs/3360/> accessed 2 November 2017. 
Agriculture's draft were caused primarily by federal budget constraints and uncertainties, and only partially by Russia's WTO obligations, since the most drastic cuts were in spheres in the "green box" that can have unlimited domestic support. ${ }^{2599}$

Regulations on disclosure and agricultural policy have been elaborated by the Eurasian Economic Commission. Namely, Regulations have been adopted by a decision of the Eurasian Economic Commission "On Requirements for the Sub-System of Agricultural Industry of the Participating States in the framework of integrated reference system of the Eurasian Economic Union and the rules on formation thereof". The sub-system shall guarantee storage of the data on median retail prices, median consumer prices and median contract prices of the key categories of agricultural products, food production and manufacturing in the Eurasian Economic Union. ${ }^{2600}$

The Russian Ministry of Industry and Trade (Minpromtorg) is responsible for working out an agenda for agricultural industry and trade activities. For instance, the Order of Minpromtorg dated 25 December 2014 N 2733 set forth the "Strategy of Development of Trade in the Russian Federation for 2015-2016 and up to the year 2020". The Strategy devises the optimal tools for the development of retail food marketing. Namely, it instigates interaction between distributors and farmers with the help of wholesaling centers and large-scale trade networks. Trade networks ought to minimise costs of both farmers and retailers and shorten the median term of production cycle. Local wholesale markets and small businesses shall uphold large-scale retail networks. That will guarantee the access of consumers to food products distributed on different tiers. Small-scale wholesale distributors shall interlink different tiers of market and foster cooperation between small and medium entrepreneurs. ${ }^{2601}$

\subsubsection{Production and Trade}

Basic legal provisions on state policies in the field of production and trade of food products are established under the Federal law "On the Trading Activities". ${ }^{2602}$ Article 17 sets up the measures to be undertaken in order to foster trade activities in the domain of agriculture. The regional state authorities work out an agenda to instigate investment projects concerning the establishment of new supply centers, which receive and store agricultural products, form consignments of goods for households, maintain wholesale and retail trading activities. The agenda shall include the provisions in order to support agricultural households and consumers' co-operatives, which run trading activities, sale and purchase of agricultural products in rural areas. ${ }^{2603}$

According to Article 5 of the Federal law "On the Trading Activities" the Government of the Russian Federation is responsible for:

(i) State policy in the domain of trade activities.

(ii) Adoption of calculation and assessment methods for the regional state authorities authorised to establish standards on the minimal sale premises per population of certain regions.

\footnotetext{
${ }^{2599}$ Agriculture Development Program 2013-2020 // USDA Foreign Agriculture Service. 2012 https://gain.fas.usda.gov/Recent\%20GAIN\%20Publications/Agriculture\%20Development\%20Program\%2020132020_Moscow_Russian\%20Federation_11-6-2012.pdf accessed 2 November 2017.

${ }^{2600}$ EEC Collegium Decision No. 18 "On Requirements for an Agricultural Subsystem within the Framework of Integrated Information System of the Eurasian Economic Union and the Rules for its Joint Creation".

${ }^{2601}$ The Order of the Russian Ministry of Industry and Trade dated 25 December 2014 N 2733 "On Strategy of Development of Trade in the Russian Federation in 2015-2016 and by 2020".

${ }^{2602}$ Federal law "On the Basic Principles of State Regulation of Trading Activities in the Russian Federation" dated 28 December 2009 N 381-FZ.

${ }^{2603}$ ibid.
} 
(iii) Adoption of calculation and assessment methods of net overall volume of sales within the regions of the Russian Federation (including federal Moscow and Saint-Petersburg, municipal areas and city districts).

Article 9 of the Federal law "On the Trading Activities" regulates the rights and obligations of the parties to supply agreement, retailers and distributors. Namely, it establishes the rules on mandatory disclosure of information, obligations of the parties to supply agreement, remuneration of the retailers and distributors. Supply agreements may preclude the parties from assignment of rights and liability for violation thereof. Additional services (e.g. preparation, packing of goods) can be rendered on the basis of additional service agreements. Solicitation of additional services or conditions is prohibited as well as abuse of rights.

The obligations of legal entities and individual entrepreneurs are also regulated under Article 11 of the Federal law N 51-FZ "On sanitary and epidemiological welfare of population". Business entities are obliged to guarantee safety for human health, control quality of services and food products during production, transportation, storage and sale 2604 .

\subsubsection{Food Security}

The international legal regulation of food security is based on the norms of "General Declaration on Abolition of Hunger and Undernourishment", approved by the resolution 3348 (XXIX) of UN General Assembly on 17 December 1974, Rome Declaration of the World Summit on food security, which took place on 16-18 November 2009, as well as other documents, including those prepared by the UN Food and Agricultural Organization (FAO) ${ }^{2605}$.

Basic requirements in respect of food safety in Russia are set up by the Federal Law "On Quality and Safety of Food Products" dated 02 February 2000 No. 29 FZ. The Federal Service for Supervision of Consumer Rights Protection and Human Welfare (Rospotrebnadzor) controls the enforcement of legal rules regarding food quality. Namely, Rospotrebnadzor enacts orders, which set forth methodological requirements for the classification of households and quality of food products. $^{2606}$

The Federal Service for Veterinary and Phytosanitary Supervision (Rosselkhoznadzor) is the governmental federal organ carrying out functions of control and supervision in the field of veterinary science. It establishes and lifts phytosanitary quarantine zones; controls the use of pesticides and agrochemicals; maintains soil fertility; it is responsible for selection achievements, protection, reproduction and use of objects of animal world (hunting resources) and aquatic biological resources, and it also carries out the functions on protecting the population from animal infectious diseases. Federal Service for Veterinary and Phytosanitary Supervision is under control of the Ministry of Agriculture of the Russian Federation. ${ }^{2607}$

The important provisions on food security are set forth by the Order of the President of the Russian Federation on "Doctrine of Food Security of the Russian Federation" (hereinafter - the

\footnotetext{
${ }^{2604}$ Federal Law "On Sanitary and Epidemiological Welfare of Population" as of 30 March 1999 N 52-FZ.

${ }^{2605}$ Legal coverage for food security of Russia: national and international legal aspects // European Congress on Rural Law - 11-14 September 2013. Lucerne (Switzerland).

${ }^{2606}$ See e.g.: The Order of the Federal Service on Surveillance for Consumer Rights Protection and Human Well-Being dated 30 September 2015 No. 1008 "On Methodological Requirements".

2607 Federal Service for Veterinary and Phytosanitary Supervision // Official site. http://www.fsvps.ru/fsvps/main.html?_anguage=en accessed 2 November 2017.
} 
"Food Security Doctrine"). ${ }^{2608}$ The Food Security Doctrine was approved on 01 February 2010. The Doctrine does not have the status of mandatory legal act, but may be considered only as an outline of the goals and objectives for agricultural production and policy. ${ }^{2609}$ The Food Security Doctrine's goals are to guarantee reliable food supplies for the population, develop agriculture and fisheries, respond swiftly to internal and external threats to the stability of food market, and participate effectively in international cooperation on food security. The Food Security Doctrine identifies risks and threats to Russia's food security, key directions of the national economic and social policies in this area, and mechanisms and resources for ensuring food security. The Food Security Doctrine sets the criteria for food security assessment. Thus, it establishes that the share of the following domestically produced food products in the total volume of food resources in the internal market should constitute: grain - not less than 95 percent; sugar - not less than 80 percent; vegetable oil not less than 80 percent; meat - not less than 85 percent; milk - not less than 90 percent; fish - not less than 80 percent; and potatoes - not less than 95 percent. ${ }^{2610}$

The major tasks in providing for food security regardless of changes in internal or external conditions are:

(i) Timely prognosis, identification and prevention of external and external threats to food security, minimisation of their adverse effects due to permanent readiness of the system of food supply, formation of strategic reserve of food products.

(ii) Sustainable development of the national production of food and raw food necessary to support food independence of the country.

(iii) Achieving and maintaining physical and economic access to safe food for every citizen in amount and variety of products, which meet reasonable standards of food consumption to provide active and healthy lifestyle.

(iv) Ensuring food security. ${ }^{2611}$

The Chief State Medical Officer, who prescribes sanitary rules for business entities involved in trading activities, specifies the requirements for sale of food products. The sanitary rules cover activities of households, food markets and warehouses notwithstanding their legal form of incorporation. The rules include the requirements for acquisition / acceptance and storage of food products and regulations for sale. ${ }^{2612}$ The Chief State Medical Officer enacts the rules on food value and safety of food staples. The rules are targeted at legal entities, individual entrepreneurs and citizens involved in production, importing, and sales of food products. They regulate the services in the field of retail marketing and public catering. For example, under the Order of the Chief State Medical

${ }^{2608}$ The Order of the President of the Russian Federation dated 30 January 2010 No. 120 "On Adoption of the Food Security Doctrine of the Russian Federation".

2609 Food Security Doctrine Adopted // USDA Foreign Agricultural Services. URL: https://gain.fas.usda.gov/Recent\%20GAIN\%20Publications/Food\%20Security\%20Doctrine\%20Adopted\%20_Moscow _Russian\%20Federation_2-11-2010.pdf.

${ }^{2610}$ The Food Security Doctrine // The President of Russia. <http://en.kremlin.ru/catalog/glossary/37> accessed 2 November 2017.

2611 'Russia's doctrine of food security signed; possible implications for biotechnology', Wageningen University \& Research (02.02.2010) <http://library.wur.nl/WebQuery/file/cogem/cogem_t4c6a3a1a_001.pdf> accessed 28 October 2017.

${ }^{2612}$ The Order of the Chief State Medical Officer of the Russian Federation of dated 07 September 2001 No. 23 "On Adoption of Sanitary Rules" (SP 2.3.6.1066-01). 
Officer dated 14 November 2001 No. 36 the legal entities and individual entrepreneurs involved in producing and trading of food products are obliged to disclose information on food products that contain genetically modified organisms (GMO). ${ }^{2613}$

However, in 2016 the Federal law dated 03 July 2016 No. 358-FZ "On Amendments to Certain Legislative Acts of the Russian Federation regarding the Improvement of State Regulation in the Field of Genetic Engineering" prohibited domestic sales and import of genetically modified organisms. ${ }^{2614}$ The cultivation and breeding of genetically modified plants and animals is prohibited, except for cases where they will be used in testing and scientific research. ${ }^{2615}$ The current legislation allowed the use of genetically modified seeds in agriculture and required special labelling of food that was produced with GMOs. Because the introduction of GMO registration procedures has been postponed until July 2017, however, there was a de facto moratorium on production of genetically modified food and punishment for violation of the rules regulating GMO production was not foreseen. ${ }^{2616}$.

The further regulations can be specified with the enactments of the executive. Interaction between business entities, associations and state authorities can be settled under industry agreements governing agricultural policy and overall agenda in the sphere of food production. ${ }^{2617}$

Russian legislation provides for the liability for administrative offences and crimes committed by the economic entities.

The grounds for liability are set up under Article 26.1 of the Federal law "On quality and safety of Food Products". Legal entities, individual entrepreneurs, who conduct trading activities or manufacturing / production of food products, can be held liable for misconduct in accordance with civil, administrative or criminal liability rules. ${ }^{2618}$

The rules on administrative liability for administrative offences committed by entities, which are engaged in trade activities, are set up under Articles 14.41, 14.42 of the Code of Administrative Offences of the Russian Federation (hereinafter - the "Code of Administrative Offences"). Article 14.40 of the Code of Administrative Offences implies liability for infringing the antimonopoly rules established by federal law while exercising trading activity. ${ }^{2619}$

In accordance with Article 14.41 failure of an economic agent, engaged in trade activities by way of setting up a trade network, to supply information about the terms and conditions for selecting

\footnotetext{
${ }^{2613}$ The Decree of the Chief State Medical Officer of the Russian Federation dated 14 November 2001 No. 36 "On Adoption of Sanitary Rules" (SP 2.3.2.1078-01).

2614 Amalia Zatari, 'Putin signed the law on GMO prohibition', (04 July 2017, RBC) <www.rbc.ru/politics/04/07/2016/577aa7bb9a794761a21c8d57> accessed 28 October 2017.

2615 'Moscow Bans GMO: Russia, the World's Largest GMO-free Territory, Platform for the Development of Organic Agriculture' (2016)Global Research <http://www.globalresearch.ca/moscow-bans-gmo-russia-the-worlds-largest-gmofree-territory-platform-for-the-development-of-organic-agriculture/5548448> accessed 2 November 2017; 'Russian State Duma Passes Total Ban on GMO Crops and Animals' (2016) Sustainable Pulse $<$ http://sustainablepulse.com/2016/06/25/russian-parliament-passes-total-ban-on-gmo-crops-and-

animals/\#.WPoJRxFZdp1> accessed 2 November 2017; 'Where are GMOs grown and banned?', GMO FAQ. Agricultural biotechnology frequently asked questions. <https://gmo.geneticliteracyproject.org/FAQ/where-are-gmosgrown-and-banned/> accessed 2 November 2017.

2616 Russia: Full Ban on Food with GMOs // Library of Congress. 2016. URL: http://www.loc.gov/law/foreignnews/article/russia-full-ban-on-food-with-gmos/; Law Proposal № 714809-6. On amending of the certain enactments on genetic engineering // ASOZD (the Automated System for Legislative Procedures). URL: http://asozd2.duma.gov.ru/main.nsf/\%28SpravkaNew\%29? OpenAgent\&RN=714809-6\&02.

2617 "The Industry Agreement on the Agroindustrial Sector of the Russian Federation in 2015-2017”, December 16, 2014.

${ }^{2618}$ Federal Law dated 2 January 2000 N 29-FZ "On Quality and Safety of Food Products".

2619 "Code Of Administrative Offences Of The Russian Federation " dated 30 December 2001 No. 195-FZ.
} 
a contractor for concluding a contract for supply of food products and about the substantial terms of such contract, which is requested by a contractor - shall entail the imposition of an administrative fine. Failure of an economic agent, engaged in supplying food products, to provide information about the terms and conditions for selecting a contractor for concluding a contract for supply of food products and about the major terms of such contract, as well as information on the quality and safety of food products to be supplied which is requested by a contractor shall also entail imposition of a fine.

Article 14.42 of the Code of Administrative Offences sets forth liability for failure to satisfy the requirements established by federal law for the terms and conditions of concluding a contract for supply of food products while exercising trade activities.

Finally, Article 283 of the Criminal Code of the Russian Federation prescribes criminal liability for production, storage, carriage or sale of goods and products, fulfilment of works or rendering of services, which do not meet safety standards.

\subsection{IP Rights}

\begin{tabular}{|l|l|l|}
\hline Russia & $\begin{array}{l}\text { a. General applicable IP } \\
\text { rights: Part IV of the Civil } \\
\text { Code of the Russian }\end{array}$ & $\begin{array}{l}\text { a. UPOV Convention for the protection of } \\
\text { new varieties of plants; }\end{array}$ \\
Federation (as amended on \\
01 July 2017); 2620 \\
of Intellectual Property Rights (TRIPS \\
b. IP-related laws: \\
- Federal Law No. 135-FZ \\
Aated 26 July 2006 “On \\
Protection of Competition" \\
(as last amended on 29 July \\
2017); \\
- Federal Law No. 149-FZ \\
dated 17 December 1997 \\
"On Seed Breeding" (as \\
last amended on 3 July \\
2016).
\end{tabular}

\subsection{Seed Markets}

\subsubsection{Mergers in Agriculture}

\footnotetext{
${ }^{2620}$ Part IV of the Civil Code "codifies fundamental rules and principles of intellectual property law". For specific provisions on IP Rights in agriculture, see Chapter 73 'Selection Achievements'.

For other general provisions relating to intellectual property provided for in the Civil Code, see:

-Part I, Chapter 2, Articles 2, 8 \& 3; Chapter 3, Articles 18 \& 26; Chapter 4, Articles 64; Chapter 6, Articles 128 \& 129 ; Chapter 16, Article 256

-Part II, Chapter 38, Articles 769, 773 \& 772; Chapter 45, Article 855; Chapter 54, Article 1028.

${ }^{2621} \mathrm{http}: / / \mathrm{www} . u p 0 v$. int/en/publications/conventions/1991/act1991.htm.
} 
The markets of agricultural production have recently seen the highest growth rate amongst economic markets. ${ }^{2622}$ The highest growth was supported by the low volatility in the demand for food. ${ }^{2623}$ However, the growth rate may significantly decrease due to a drop in purchasing power and the depletion of production capacity reserves, significantly affecting the investment attractiveness of the agricultural sector. ${ }^{2624}$

Nevertheless, mergers and acquisitions still occur in the regions. Usually, these M\&As happen due to the inefficiency of the absorbed farms: farms failed to switch to new technologies in time, they have low yields, high production costs, and cannot stand competition. Thus, market players are consolidating. ${ }^{2625}$ However, M\&As do not often decrease the number of economic entities: absorbed companies remain independent legal entities and only ownership changes. ${ }^{2626}$

The main reasons encouraging Russian entrepreneurs to launch M\&A are sale of distressed assets and presence of private investors, which increases competition for capital. Companies with a high degree of diversification are considering the possibility of selling inefficient assets to focus their efforts on developing their core business. Another incentive for M\&As is the need to preserve and increase the market share, as well as to improve the profitability of the business. ${ }^{2627}$

Moreover, it is easier to buy a strategic asset than make expensive $R \& D$, introducing innovative technologies on its own. Limited access to capital markets reinforces the trend towards creating strategic alliances.

Alliances and joint ventures are becoming increasingly attractive forms of cooperation for Russian and global companies in current economy. Alliances may preserve business or expand business geography and facilitate access to innovative technologies.

Alliances have several advantages in comparison with joint ventures, since they increase the market share of business and give access to more technological and efficient processes without affecting the autonomy of the company.

Sale of mortgages constitutes another popular tool. The most famous example of mortgages sale is the purchase of shares and debts of Razgulay Group (one of the ten largest agricultural companies in Russia) by the agricultural holding Rusagro (one of the largest owners of farmland in the country, controlling almost 500 thousand hectares) ${ }^{2628}$. Deals like the sale of mortgages of Razgulay Group outline an important trend: liquidity of assets makes it no longer profitable for banks to hold pledges and try to sell them at a price higher than the market price.

\subsubsection{Antimonopoly regulation and sale models in Agriculture}

\footnotetext{
2622 Development of agriculture in Russia: perspectives and obstacles // KP.ru. $2016 . \quad$ URL: https://www.kp.ru/guide/razvitie-sel-skogo-khozjaistva-v-rossii.html; FAS Report on Competition in 2016 (2017).

${ }^{2623}$ Plotnikova I.A., Orlova E.R. Agricultural markets in Russia: analysis of contemporary obstacles // Vestnik MIEP. 2015. Vol. 19. N 2. pp. 64-72.

2624 ibid.

2625 Tumalanov N.V. Change of competitive environment in perspective of agricultural markets // Modern Competition. 2012. Vol. 3. N 33. P. 80-83.

2626 ibid.

2627 ibid.

${ }^{2628}$ Burlakova E. "Rusagro would cover expenses for "Razgulay Group" buyout in a 2 year period" // Vedomosti. 2016. URL: $\quad$ https://www.vedomosti.ru/business/articles/2016/08/29/654748-rusagro-okupit-zatrati-na-pokupku-aktivovrazgulyaya; "Razgulay Group" was adjudged bankrupt // Interfax. 2017. URL: http://www.interfax.ru/business/559781.
} 
Patent protection for seed companies switched the sales model from seed sales contract to seed licensing agreements. Nevertheless, the transition to the licensing model was not possible, because the licensing model was based on the plant variety protection law ${ }^{2629}$, which allows farmers to save and re-seed the seeds, even if the seed company holds intellectual property rights on the seeds. Moreover, plant variety law is usually more restrictive in terms of licensing practices and the evidence of the infringement of these rights (given that protection is provided for the phenotypic characteristics of the variety). Biotechnological patents do not impose these restrictions and hence acts as a key license model. Therefore, seed companies prefer biotechnological patents rather than plant variety patents.

Nowadays the main sale model is licensing agreements with detailed contract clauses on the use of seeds, in particular, clauses that prohibit farmers to save and re-seed the seeds. Such contract clauses allow patent holders to control farmers via contractual obligations. An example of this control is the so-called "Technology Transfer Agreement", under which Monsanto sells branded Roundup Ready seeds. This agreement has very restrictive clauses on farmers' rights to save and re-seed the seeds, because it prohibits subsequent re-use of the seeds. Violation of this clause can be considered as a breach of contract, entailing draconian sanctions: a farmer violating the clause must pay 120 times the price paid for the technology as well as pay legal costs. To control farmers, Monsanto also stipulates the right of Monsanto employees to carry out a permanent check of farmer fields. An arbitration clause forms also the part of the agreement.

Biological tools to protect intellectual property rights are another model to control seed industry. For example, male cytoplasmic sterilization is the most efficient biological tool, because it allows the production of hybrid seeds deprived of the opportunity for self-reproduction. These biological tools are patented and all patents are owned by a limited number of seed companies.

This sophisticated legal and biological environment turns the part of the value chain into a closed system. It relies on the self-contained complex practices of contracting and applies sophisticated technological security arrangements.

Nevertheless, antitrust legislation in the Russian Federation lacks any efficient instruments, which can help to resist any negative consequences for competition in the seed market resulting from the abuse of IP rights. For instance, under Article 10 of the Federal law "On protection of competition" abuse of IP rights by a dominant undertaking does not affect actions in respect of enforcement of exclusive rights on intellectual property and means of identification, individualising food products or associated services. Moreover, in accordance with Article 11 of the Federal law "On Protection of Competition" anticompetitive agreements are prohibited..

\subsection{Consumers' Interests}

\subsubsection{Food and Health Regulation}

The food and health regulation in the Russian Federation are implemented by the Federal Service for Supervision of Consumer Rights Protection and Human Welfare (Rospotrebnadzor), which is accountable to the Government of the Russian Federation.

${ }^{2629}$ Federal Law dated 17 December 1997 N 149-FZ “On Seed Breeding”. 
The Rospotrebnadzor carries out its activities in accordance with the Decree of the Government of the Russian Federation dated 06 April 2004 No. 154 "Questions of the Federal Service for Supervision of Consumer Rights Protection and Human Welfare" and on the basis of the Regulations on the Federal Service for Supervision of Consumer Rights Protection and Human Welfare, approved by the Decree of the Government of the Russian Federation dated 30 June 2004, No. 322.

As follows from Article 1 of the Regulations, the Rospotrebnadzor is a federal governmental body responsible for the development and implementation of the state policy and normative legal regulation in the sphere of consumer protection, and for the development and approval of state sanitary epidemiological rules and hygienic standards. Moreover Rospotrebnadzor is responsible for the organization and implementation of the state sanitary-epidemiological control and supervision in the field of consumer protection.

Rospotrebnadzor is also authorised to impose sanctions against the enterprises. For example, recently Rospotrebnadzor confirmed the imposition of a fine on the global retail company "Ashan" for violation of sanitary epidemiological norms. The total fines reached around $\$ 500$ thousand. ${ }^{2630}$

The Federal service of Veterinary and Phytosanitary Supervision implement additional oversight in this area. According to the "Regulations of the Federal Service of the Veterinary and Phytosanitary Supervision" dated 14 September 2016 No.633, this service is a federal governmental body responsible for the control and supervision in the field of veterinary, sales of medicines for veterinary use, quarantine and protection of plants, and the safe use of pesticides and agrochemicals. The Service is accountable to the Ministry of Agriculture of the Russian Federation and carries out the state supervision of the quality and safety of seeds. ${ }^{2631}$

\subsubsection{Pesticides and Additives}

The pesticide market in Russia is one of the largest in the world. It has already reached a volume of 1.2 billion dollars, but its growth continues. ${ }^{2632}$ It is worth noting that the Russian market of plant protection products today is dominated by imported products, the majority of which are counterfeit. ${ }^{2633}$ This requires the state to establish strict regulatory policies in this area.

According to the Federal Law dated 19 July 1997 No. 109-FZ "On the Safe Management of Pesticides and Agrochemicals", pesticides are chemical or biological preparations used to control pests and diseases of plants, weeds, pests of stored agricultural products, domestic pests and external parasites of animals, as well as to regulate plant growth, pre-harvesting leaves (defoliants), preharvesting plants (desiccants).

The use of pesticides and agrochemicals in Russian Federation is allowed only after they have past the registration tests and have been issued the registration certificate by the authorised state body. In the case of registration of a new kind of pesticide, the application for registration should pass the following steps:

\footnotetext{
2630 The amount of fines for violations in "Ashan" exceeded 25 million rubles. http://www.ntv.ru/novosti/1522316/ accessed 29 October 2017.

${ }^{2631}$ The Order of the Rosselkhoznadzor dated 14 September 12016 No. 663. http://fsvps.ru/fsvps/laws/4593.html\#3.

2632 'Until the thunder breaks out' (2014) Expert Online <expert.ru/2014/02/26/poka-grom-ne-gryanet> accessed 29 October 2017.

2633 'Market, crisis, counterfeit' (2 June 2016) Agroxxi <www.agroxxi.ru/associacija-evropeiskogo-biznesa/rynok-kriziskontrafakt.html> accessed 29 October 2017.
} 
(i) Registration tests of pesticides and agrochemicals, organised by the federal executive agency;

(ii) Expertise of the results of registration tests of pesticides and agrochemicals;

(iii) State registration of pesticides and agrochemicals for 10 years; ${ }^{2634}$

(iv) Finally, a pesticide or agrochemical is included in the State Register of Pesticides and Agrochemicals, which are approved for use in the territory of the Russian Federation.

\subsubsection{Standards and Local Interests}

The list of product standards, which are used in Russia, contains the following:

- Documents of the national standardisation system which establish the general characteristics of the object of standardisation, as well as rules and general principles with respect to the object of standardisation.

- All-Russian classifiers are standardisation documents that distribute technical, economic and social information in accordance with its classification (classes, groups, types, etc.) and are mandatory for use in government information systems and in inter-agency exchange of information in accordance with the procedure established by federal laws and other normative legal acts of the Russian Federation;

- standards of organisations - documents on standardisation, approved by a legal entity, as well as by an individual entrepreneur to improve production and ensure product quality, perform work, provide services, including technical conditions.

\subsubsection{Alcoholic Beverages and Consumption}

The history of production and consumption of alcohol products, covering the period from the pre-revolutionary time to the present, indicates that the increase in the consumption of alcoholic beverages and the change in the structure of its consumption toward stronger alcohol products were due to the lack of unified approaches to the regulation of alcohol production, shifting priorities in the sphere of economic interests to the detriment of public health. ${ }^{2635}$

In Russia in 1914 - 1917 the lowest level of alcohol consumption was observed compared to Europe, and amounted to 0.831 of absolute alcohol (anhydrous alcohol) per capita. However, the mid-1970s marked beginning of a significant increase in its consumption. By the beginning of the 1990 s, the consumption of registered alcoholic products per capita amounted to 5.41 of absolute alcohol (anhydrous alcohol) per year, and by 2008 it had increased to $101 .{ }^{2636}$

However, taking into account the alcohol-containing products and spirits of domestic production that are not allowed for consumption, the actual consumption of alcoholic products per capita currently stands at about 181 per year. ${ }^{2637}$

According to World Health Organisation experts, exceeding the permissible level of alcohol consumption (at the rate of 81 of absolute alcohol (anhydrous alcohol) per year per capita) is extremely dangerous for the health of the nation: consumption of each litre in excess of this limit

\footnotetext{
${ }^{2634}$ Federal Law dated 19 July 1997 No. 109-FZ "On the Safe Management of Pesticides and Agrochemicals". http://base.garant.ru/11900732/

${ }^{2635} \mathrm{http}: / /$ www.fsrar.ru/policy_of_sobriety/koncepcia

$2636 \mathrm{http}: / /$ www.fsrar.ru/policy_of_sobriety/koncepcia

${ }^{2637}$ http://www.fsrar.ru/policy_of_sobriety/koncepcia
} 
reduces the life duration by 11 months for men and by 4 months for women. ${ }^{2638}$ According to the world statistics, the alcohol consumption leads for nearly 2 million deaths and $4 \%$ of diseases worldwide every year. ${ }^{2639}$

First of all, it is noteworthy that the Government Decree No. 2128-r dated 30 December2009 adopted the "Concept of Implementing the State Policy on Reducing Alcohol Abuse among the Population of the Russian Federation for the Period up to 2020".

The main source of legal regulation of production and sale of alcoholic products is the Federal Law "On State Regulation of Production and Turnover of Ethyl Alcohol, Alcoholic and AlcoholContaining Products and on Limiting Consumption (Drinking) of Alcohol Products" dated 22 November 1995 No. 171-FZ (hereinafter - the "Law on Production and Turnover of Alcohol"). According to paragraph 7 of Article 2 of the Law on Production and Turnover of Alcohol, alcoholic products mean food products produced with or without the use of ethyl alcohol, produced from food raw materials, and (or) alcohol-containing food products, with the content of ethyl alcohol more than 0.5 percent of the volume of the end products. Alcoholic products are divided into such types as spirits (including vodka), wine, fruit wine, liqueur wine, sparkling wine (wine), wine drinks, beer and beverages, made on the basis of beer, cider, pear cider, mead.

According to paragraph 2 of article 18 of the Law on Production and Turnover of Alcohol, to be eligible for selling alcoholic products, organisations must have a license for this type of activity.

Sale of alcoholic products is prohibited for minors. The sale and repeated sale of alcoholic products to a minor entails administrative and criminal liability, respectively (Part 2.1 of Article 14.16 of the Code of Administrative Offenses of the Russian Federation, Article 151.1 of the Criminal Code of the Russian Federation) ${ }^{2640}$.

In general, the state control (supervision) of the production and turnover of ethyl alcohol, alcohol and alcohol-containing products, as well as state supervision over the use of the main technological equipment for the production of ethyl alcohol, which is subject for state registration, includes:

1) licensing control over the production and turnover of ethyl alcohol, alcohol and alcohol-containing products;

2) state supervision over compliance with the mandatory requirements for ethyl alcohol, alcohol and alcohol-containing products, which are established by international treaties of the Russian Federation, federal laws, and other regulatory legal acts of the Russian Federation, which are adopted in accordance with these laws;

3) state supervision over the use of the main technological equipment for the production of ethyl alcohol, which is subject for the state registration.

\subsubsection{Consumer Protection System}

The contemporary history of the development of consumer protection in the Russian Federation started with the adoption of the Federal Law "On Protection of Consumer Rights" dated

\footnotetext{
$2638 \mathrm{http} / / / \mathrm{www}$.euro.who.int/en/health-topics/disease-prevention/alcohol-use

$2639 \mathrm{http}: / / \mathrm{www}$.euro.who.int/en/health-topics/disease-prevention/alcohol-use

2640"The Criminal Code of the Russian Federation" of 13.06.1996 N 63-FZ. URL: http://www.consultant.ru/document/cons_doc_LAW_10699/. Code of the Russian Federation on Administrative Offenses of 30.12.2001 N 195-FZ. URL: http://www.consultant.ru/document/cons_doc_LAW_34661/.
} 
07 February 1992 No. 2300-1 (hereinafter - "Federal Law “On Protection of Consumer Rights").In addition, the Civil Code of the Russian Federation, the "Guidelines for the Protection of Consumer Interests" (adopted on 09 April 1985 by Resolution No. 39/248 at the 106th Plenary Meeting of the UN General Assembly), and more than 20 federal laws adopted directly in compliance with the requirements of the Law "On Protection of Consumer Rights" further specify the provisions about consumer protection. Moreover, in order to provide consistency of the case law in the field of consumer rights protection, the Plenum of the Supreme Court of the Russian Federation issued the Resolution No. 17 of 28 July 2012 "On consideration by courts of civil cases on consumer rights disputes" where it clarifies a number of issues regarding the implementation of the the Federal Law "On Protection of Consumer Rights". This multitude of legal sources for consumer protection rights may lead to inconsistencies and legal uncertainty, which along with the direct violations of consumer rights by unscrupulous representatives of the business, may have led to the growth of distrust from the part of citizens. ${ }^{2641}$

The state body in the area of protection of consumer rights is the Federal Service for Supervision of Consumer Rights Protection and Human Welfare (Rospotrebnadzor), which was created in 2004.

\subsection{Superior Bargaining Power}

\subsubsection{Superior Bargaining Power in Russian Contract Law}

Russian contract law deals with the superior bargaining power concept as a part of the general mechanism to protect weaker parties in contracts. For a long time the protection of the weaker party has been based only on special legislation on consumer rights and Article 428 of the Civil Code on adhesion contracts. Nevertheless, even then, Russian legislation has included traditional means to protect the weaker party that is affected by the monopolist. This refers to a general prohibition of abuse of rights under Article 10 of the Civil Code, which authorises the court not to protect the right in the case of its abuse and Article 169 of the Civil Code which specifies the invalidity of a legal transaction made with a purpose contrary to the basis of the legal order or morality. Article 428 gives the right to the party adhering to the contract to demand the rescission or change of it if the terms of such an adhesion contract, determined by another party in standard forms, are unfair and burdensome.

However, the enforcement of these rules has been relatively rare. Only in cases when an adversely affected party is an end consumer, courts tend to apply special legislative provisions on consumer rights protection, in particular Paragraph 1 of Article 16 of the Federal Law "On Protection of Consumer Rights". This Paragraph establishes the mandatory nature of the rules set by the said law and stresses the general principle the contracts with consumers, whose provisions adversely affect consumers rights compared to the federal law, are null and void. Courts have tended to apply this rule in the majority of cases when the contract does not contradict the law but contains provisions which could be interpreted as unfair and too burdensome for one of the parties.

So, from a paternalistic point of view, the extension of the described protection to B2B transaction cannot be presupposed. Entrepreneurs (Russian law deals with this legal definition while

2641 "On Actual Aspects of Consumer Rights Protection in the Russian Federation". URL: http://council.gov.ru/activity/activities/roundtables/59611/. 
describing actors with a special legal capacity) should incur all legal and economic consequences of their strategic decisions because of the implied entrepreneurial risk. So, as a general proposition, the law shall not interfere in relative contractual relationships. But, from a different point of view, a blatant violation of bargaining capability cannot be ignored by courts as this might reflect the abuse of civil law rights of the party to a commercial contract.

The Supreme Commercial Court (hereinafter - the "SCC") summarised the case law of lower state commercial courts to make Article 428 the center of protection of the weaker party in contract law. On 14 March 2014 it rendered a Ruling № 16 "On the Freedom of the Contract and Its Limits" (hereinafter - the "Ruling") which opened the door for a new non-standard approach to interpretation of the contract law provisions.

Firstly, the SCC stated that not only physical persons can be protected through the application of Article 428 (contract of adhesion). A previous version of this Article (existing as amended now) excluded contracts between legal entities from the scope of application.

Secondly, the SCC expanded the sphere of application of this Article. Previously it had dealt only with contracts of adhesion (that means a "contract whose terms are determined by one of the parties in printed forms or other standard forms and that may be accepted by the other party not otherwise than by adhering to the proposed contract as a whole"), but the Court interpreted it as to be applied to all other contracts, "if one contracting party which has developed and proposed a draft contract containing clearly burdensome terms substantially violating the balance of interests (unfair contract terms), and if at the same time the other contracting party was in a position effectively complicating for him renegotiation of such terms (weaker party)". ${ }^{2642}$ To apply the contract of adhesion regime the court does not have to establish that the disputed contract was a standard one, but rather defines the factual balance of the bargaining capabilities of the parties and finds out whether the adherence to the offered terms was forced. ${ }^{2643}$

Thirdly, the SCC established what the unfair contract term is. These terms are supposed to be legally valid and binding but clearly onerous (burdensome), causing a serious imbalance in the parties' interests. The court shall evaluate provisions of this kind in aggregate with the other terms of the agreement and related transactions, since advantages under some contractual conditions may, therefore, compensate for disadvantages under others. So, the onerous character of the concrete term shall be established as related to concrete cases, but not as being based on some abstract criteria. ${ }^{2644}$

Fourthly, the status of the so called weaker party was clarified - it is the contracting party, which was in no position to negotiate the terms because of inequality in bargaining power. ${ }^{2645}$ It is important that courts shall analyse the actual (real) state of bargaining power in the deal, taking into account whether submission to the contract was compulsory and other related circumstances: the standard of professionalism of the parties in the concrete sphere, competition on the given market and the possibility of concluding an alternative transaction. ${ }^{2646}$ That means that the SCC entitled the weaker party to claim its counter-party for disproportion in bargaining power on the ground of competition level.

\footnotetext{
${ }^{2642}$ Paragraph 9 of the Ruling.

${ }^{2643}$ Paragraph 10 of the Ruling.

${ }^{2644}$ Paragraph 10 of the Ruling.

2645 Paragraph 10 of the Ruling.

${ }^{2646}$ Paragraph 10 of the Ruling.
} 
Finally, the mechanism of the weaker party protection was sufficiently developed. Article 428 of the Civil Code states that the affected party can claim for amendment or rescission of the adhesion contract (in our situation - of such a contract with unfair terms) by bringing an action to court. Consequently, the weaker party is stimulated to file the suit even if losses caused by the mentioned unfair terms have not yet been sustained. The SCC pointed that alternatively, instead of claiming for contract amendment, the weaker party can object to the enforcement of terms resulting from the superior bargaining power of the other party. This sort of objection is based on Articles 10 and 169 of the Civil Code described above. Since compulsion in negotiations through superior bargaining power of one of the parties is to be regarded as acting in bad faith, the legal mechanism of objection under the civil law looks quite flexible and procedurally viable.

Over the past several years of its application, the approach reflected in the Ruling has been developed in a fairly large number of cases. Commercial courts turn to a new understanding of adhesion contract cautiously. For example, they interfere into B2B transactions on the basis of Article 428 of the Civil Code only in exceptional cases, which are when the imbalance in superior bargaining power was clearly disproportional. ${ }^{2647}$

However, there were several gaps in the existing approach to unequal bargaining power of parties to commercial contracts. Firstly, there are different approaches in judicial practice to cases when the party to the contract was offered the draft of the agreement, but did not make any effort to negotiate the terms of it. The Russian legal scholars suggest that only if such an adhering party is a consumer his or her lack of initiative could be excused and therefore could be granted protection. On the other hand, with regard to B2B transactions, the party claiming for application of Article 428 shall demonstrate initiative in negotiations, otherwise he or she cannot claim for such sort of protection.

Secondly, it is important to clarify whether it is possible to identify the weaker bargaining party when the mentioned imbalance in bargaining power could have been evaded through an alternative transaction with another market actor - "Best Alternative to a Negotiated Agreement" (BATNA). In other words, whether developed competition on certain market prevents application of the defence against the unfair contract terms just described, or whether actors shall have access to it even in the situation when an alternative deal is also possible.

The Ruling states that the court shall consider all attending factors, such as the possibility to negotiate the terms in concrete situations and facts of compulsion to the deal, but also the level of competition on the particular market and the possibility of an alternative transaction. Though the correlation between these various strands of the case law has not been revealed by now, the issue can be raised whether it is possible to argue that the adherence to the contract was compulsory and the party joined it is a weaker party when the hypothetical chance to enter into a substitutable agreement still exists. It may be argued that the consumer could receive the protection in all cases and the entrepreneur (a market professional actor) would obtain it while bargaining on a highly monopolised market.

The third aspect is closely connected with a Russian economic peculiarity. One of the largest economic spheres in Russia is the public procurement sector. Entering into the contract for public procurement inherently means that the party submits the terms which could be negotiated in minor detail. Does it mean that such a submitting person will be named the weaker party in all the cases?

${ }^{2647}$ Resolution of Plenum of SAC of the Russian Federation dated 14 March 2014 N 16 "On Freedom of Contract and its Limits" 
Shall there be some sort of presumption concerning the inability to conclude the alternative deal and to prevent losses caused by the superior bargaining power of the public counterparty? Russian commercial courts are likely adopt the approach by which the compulsory character of negotiation with a public body should be established regarding all the attending factors: for instance, the chance to argue the disputed unfair term, the possibility of alternative transactions, etc. This means that a legally binding procedure of bargaining specified in statutory law does not presuppose that there is no space for unfair contract terms and superior bargaining power enforced in bad faith.

On 08 March 2015 the Federal Statute No. 42-FZ 'On Amendments to the First Part of the Civil Code' was enacted. Among other changes to the Civil Code, this statute has amended Article 428 of the Civil Code in line with the Ruling № 16 of the Supreme Commercial Court.

Subparagraph 3 of Article 428 of the Civil Code provides that the courts may address the "weak party" aspect in many commercial disputes. Now, Article 428 specifies that:

"Rules provided under sub-paragraph 2 of this Article [428] shall be applied also to contracts that are not contracts of adhesion but where conditions of such agreements are determined by one of the parties while the other party due to obvious inequality in bargaining power is put in a position that substantially prevents it from negotiating other content of the certain contract terms".

The new wording rises a lot of questions since it does not provide guidance as to what should constitute an "obvious inequality in bargaining power" and does not set forth any criteria for "substantial" prevention from negotiation of alternative conditions of the agreement except for the provisions of the Ruling № 16 of the Supreme Commercial Court (which remains in force, even though the SCC was abolished as a judicial forum and it's the legal status of the Ruling seems uncertain). These doctrines are new to Russian civil law and it may take courts years to adopt a uniform approach to the issue of unequal bargaining power.

As it was stressed above, Russian contract law enables the assessment of the level of competition on a certain market in order to determine whether it is possible to apply the superior bargaining power concept. Moreover, in certain cases courts used Article 428 of the Civil Code as an additional criterion to qualify the dominant position of the market actor and then to enforce the competition law mechanism.

Thus, the Ruling of State Commercial Court of Cassation of Severo-Kavkazsky Region dated 10 June 2011 on the case №A53-16802/2010 refers to Article 428 of the Civil Code when assessing the imposition of disadvantageous contract conditions or conditions unrelated to the subject of the contract. In the Rulings of the State Commercial Court of Cassation of Ural Region dated 28 May 2012 №Ф09-3773/12 on the case №A60-29999/2011 and dated 16 August 2011 №F09-4957/11 on the case №A60-816/2011 the court refers to Article 428 of the Civil Code to assess the contract concluded by the parties. The position of the counterparties to the contract in these cases is clearly dominant, since they are natural monopolies.

The Ruling of the Fifth State Commercial Court of Appeal dated 15 June 2010 №05AП$3380 / 2010$ on the case №A51-5351/2010 refers to Article 428 of the Civil Code 8 to assess the contract concluded by the parties. The position of the supplier is recognised as dominant, because it is the only provider of access to the cable TV market in the municipality (village).

The Ruling of Seventeenth State Commercial Court of Appeal dated 10 February 2015 № 17АП-10443/2014-ГК on the case №A50-8350/2014 refers to Article 428 of the Civil Code when assessing whether the imposition of disadvantageous contract conditions or contract conditions 
unrelated to the subject took place. The position of the group of entities was recognised to be dominant by FAS.

\subsubsection{Superior Bargaining Power under Competition Law}

Article 5 of the Federal law "On Protection of Competition defines dominance as follows:

"The position of an economic entity (except financial organisations) is recognized as dominant, when:

1) its share in the certain product market exceeds fifty percent unless in the course of investigation of the case of violation of the antimonopoly legislation or in the course of exercising state control over economic concentration it would be established that despite the excess of the aforementioned quantity position of the economic entity in the goods market is not dominant;

2) its share in the certain product market is less than fifty percent in case the dominance of this economic entity was established by the antimonopoly body based on its stable or insignificantly changing share in the market as compared to the shares of its competitors in this product market; opportunities for access to this product market of new competitors, or based on other criteria characterising the product market".

The evaluation of bargaining power of market actors or the assessment of economic dependence that might be established between some of them seems not to be a factor triggering the application of Russian competition law rules. ${ }^{2648}$

However, Article 10 of the Federal law "On Protection of Competition, although it targets only undertakings having a dominant position as defined by Article 5 thereof, can be potentially applied to anticompetitive conduct tending to exploit a superior bargaining position, such as the following:

"[...] 3) imposing contractual terms upon a counterparty which are unprofitable for the latter or not connected with the subject of agreement (economically or technologically unjustified and (or) requirements for transferring financial assets, other property, including property rights, which are not provided for directly by federal laws, statutory legal acts of the President of the Russian Federation, statutory legal acts of the Government of the Russian Federation, statutory legal acts of the authorised federal executive authorities or judicial acts, as well as consent to conclude a contract only on condition of including in it provisions concerning the goods in which the counterparty is not interested and other requirements);

4) economically or technologically unjustified reduction or cutting off the production of goods if there is demand for the goods or orders for their delivery are placed and there is possibility of its profitable production, as well as if such reduction or cutting off the production of goods are not provided for directly by the Federal Laws, statutory legal acts of the President of the Russian Federation, statutory legal acts of the Government of the Russian Federation, statutory legal acts of the authorized federal executive authorities or judicial acts;

5 ) economically or technologically unjustified refusal or evasion form concluding a contract with individual purchasers (customers) in the case when there are possibilities for production

\footnotetext{
2648 At first glance, Russian competition law seems to be solidly based on structural underpinnings of the analysis of
} dominance. 
or delivery of the relevant goods as well as if such a refusal or evasion is not provided for directly by federal laws, statutory legal acts of the President of the Russian Federation, the Government of the Russian Federation, authorised federal executive authorities or judicial acts".

In the same vein, the Russian antitrust authority has openly stated that they reject the application of a notion of abuse of superior bargaining power independently from the analysis of the market power of the dominant firm, as "only a company(s) with substantial degree of market power can effectively exploit vertically integrated upstream and downstream trade partners and, therefore, general behavioral legal provisions for market dominant firms suffice". ${ }^{2649}$

Nonetheless, Article 13 of the Federal law "On the Trading Activities", which deals exclusively with the supply of food products, set forth the types of conduct that may fall foul of competition regulation (for detailed analysis see the section "General Overview and Legal Framework" and "Retail"). Some of these types of conduct, such as creating and imposing discriminatory conditions to contractual counterparties, seem to operate independently from the assessment imposed by Article 5 of the Federal law "On Protection of Competition" and may be used in dealing with superior bargaining power of big food retail chains. Hence, it is possible to argue that, at least potentially, the FAS is enabled to deal with cases of abuse of superior bargaining power, although solely in the market of supply of food products.

\subsection{Agricultural Subsidies}

During last years the agricultural development has been marked by the significant increase of the state support of the agricultural producers. ${ }^{2650}$

Legal framework for the state support of the agriculture includes the following legal acts:

\subsubsection{Federal Law dated 29 December 2006 N 264-FZ “On Development of the}

\section{Agriculture".}

Paragraph 1 of Article 6 of the said Federal Law sets forth that granting budget subsidies to agricultural producers constitutes one of the measures of the state's agricultural policy. Article 7 specifies the measures of the state support of the agriculture including indirect support, development of the agricultural infrastructure and informational support, inter alia:

1) ensuring the availability of credit resources for agricultural producers including farmers and agricultural cooperatives (by partial reimbursement of the interest rates payable by agricultural producers);

2) development of the risk insurance system in agriculture;

3) development of breeding livestock;

4) development of elite seed production;

5) ensuring the production of animal farming (dairy, meat, etc.);

\footnotetext{
2649 ICN, 'Report on Abuse of Superior Bargaining Position' <www.internationalcompetitionnetwork.org/uploads/library/doc386.pdf> accessed 29 October 2017.

(2008) $\quad 17$ 2650 'Development of the Agriculture in Russia: Reality and Perspectives' (Komsomolkaya Pravda, 29 July 2016) (https://www.kp.ru/guide/razvitie-sel-skogo-khozjaistva-v-rossii.html
} 
6) ensuring the development and maintenance of perennial plantations;

7) renewal and upgrade of fixed assets of agricultural producers;

8) improving soil fertility;

9) ensuring sustainable development of rural areas, including the construction and maintenance of roads connecting the rural areas;

10) provision of consulting assistance to agricultural producers, training of specialists for agriculture, etc.

\subsubsection{State programmes aimed at subsidising agricultural producers:}

- The State Programme on Agricultural Development and Regulation of Agricultural Products, Commodities and Food Markets, 2013-2020 (hereinafter - the "State Programme on Agricultural Development") is the main legal act governing the implementation of the state support of agricultural producers;

- The Federal Targeted Programme "Sustainable development of rural areas for 2014-2017 and for the period until 2020";

- Federal Scientific and Technical Program for the Development of Agriculture for 2017-2025;

- Federal Targeted Program "Development of Amelioration of Agricultural Land in Russia for 2014-2020"; etc.

Each of the programmes establishes certain subsidies to the budgets of subjects of the Russian Federation for implementation the measures for achievement of specific goals of the programme.

The regions of the Russian Federation are entitled to adopt and implement their own regional programmes of the state support of the agricultural entrepreneurship or specific sectors of agriculture. They are funded from the regional budget and are overseen by the regional agencies authorised in the field of regulation of agriculture.

Institutions in charge implementing the subsidies regime for agriculture are:

\section{Government of the Russian Federation:}

- adopts the State Programme on Agricultural Development, other targeted programmes and many regulatory legal acts establishing, for instance, the conditions of granting the subsidies for the regional budgets for covering the costs of implementing the state support measures within the specific region;

- $\quad$ specifies the list of products whose producers and initial processors are entitled to the state subsidies; ${ }^{2651}$

(ii) Ministry of Agriculture of the Russian Federation is the main public body responsible for: ${ }^{2652}$

- implementing the State Programme on Agricultural Development;

\footnotetext{
2651 The Order of the Government of the Russian Federation dated 28 November 2016 No.2524-p.

${ }^{2652}$ Regulations on the Ministry of Agriculture of the Russian Federation adopted by the Order of the Government of the Russian Federation dated 12 June 2008 No.450.
} 
- drafting and presenting the national report on the progress and outcome of implementation of the State Programme on Agricultural Development;

- devising and implementing measures to support small and medium-sized agricultural businesses aimed at their development, including development and implementation of relevant departmental target programs;

- drafting and implementing the plans of allocation subsidies to the regional budgets for implementation of the State Programme on Agricultural Development and state targeted programmes;

- coordinating the actions of the regions of the Russian Federation aimed at implementation of the state programmes.

(iii) Regional bodies authorised to implement the agricultural policies are responsible for implementation of the State Programme on Agricultural Development and state targeted programmes and for allocation of subsidies to the end beneficiaries within the relevant region.

(iv) Federal Antimonopoly Service monitors compliance of state and local bodies with the procedures of granting subsidies to agricultural producers and detects abusive practices related to it. Thus, control on the procedures of granting subsidies to farmers was one of the priority activities of FAS in $2015 .{ }^{2653}$ As a result, more than fifty investigations were opened on the alleged violation of the Federal law "On Protection of Competition" by regional state bodies authorised to implement the agricultural policies. The violations were mostly related to illegal discrimination among the recipients of subsidies (for instance, by setting an additional criteria, such as having registered office in the region granting a subsidy or obligation to sell all the grains harvest of the current year to the entities registered and having processing capacities in the territory of the specified region $)^{2654}$ and violation of the order of granting state preferences set forth by Chapter 5 of the Federal law "On Protection of Competition" (for instance, by retroactively amending the legal normative act stipulating the procedure of granting subsidies in order to make a pre-defined recipient eligible for them). ${ }^{2655}$

The state support of agricultural producers takes the following forms:

(i) Preferential lending (one of the main forms of subsidising agricultural producers). It includes partial reimbursement by the state of the interest rates on short-term investment loans granted to agricultural producers, organisations and individual entrepreneurs that produce, process and / or sell agricultural products, so that the actual payable rate constitutes no more than 5\%. ${ }^{2656}$ The list of purposes for which a subsidised loan can be

\footnotetext{
${ }^{2653}$ FAS press release dated 12 February 2016 at $<$ fas.gov.ru/press-center/news/detail.html?id=44712 $>$ accessed 20 December 2016.

${ }^{2654}$ Decision by FAS of Russia dated 02 December 2014 on the case №1-15-11/00-06-14; Decision by FAS of Russia dated 27 November 2015 on the case № 1-00-122/00-06-15; Decision by FAS of Russia dated 27 November2015 on the case № 1-00-121/00-06-15; Decision by FAS of Russia dated 28 July 2015 on the case №1-15-42/00-06-15.

${ }^{2655}$ Decision by Chuvashia FAS dated 16 December 2015 on the case № 43/05-AM3-2015; Decision by Chuvashia FAS dated 10 December 2015 on the case № 36/05-AM3-2015.

${ }^{2656} \mathrm{http}: / / \mathrm{mcx} . r \mathrm{activity} / \mathrm{state}-\mathrm{support} / \mathrm{measures} / \mathrm{preferential-credit/}$
} 
taken is quite broad: renewal of the technopark, purchase of fertilisers and pesticides, for processors - purchase of domestic agricultural raw materials. ${ }^{2657}$

(ii) Unified regional subsidy is granted to regions for implementation of the regional programmes of the state support.

(iii) Partial compensation of direct costs incurred for construction and modernisation of agro-industrial facilities, as well as for the purchase of machinery and equipment. The eligible beneficiaries are enterprises that began construction and (or) modernisation of storage tanks, potato storage and vegetable storage facilities, greenhouses, dairy farms, pig breeding farms, animal breed and seed selection centers, and wholesale distribution centers.

(iv) Subsidies aimed at increasing productivity in dairy cattle breeding, which are provided by partial reimbursing of the costs of agricultural producers for 1 kilogram of cow and (or) goat's milk sold in the market and (or) shipped for their own processing needs.

(v) Subsidies to producers of agricultural equipment.

(vi) Partial reimbursement of the costs of agricultural producers for payment of insurance premiums. This form of support arose in response to the law on compulsory agricultural insurance and encompasses reimbursement of costs for payment of insurance premiums under the insurance of risks of plant harvesting and livestock.

(vii) Grants to agricultural cooperatives for acquiring of equipment and development of facilities and resources.

(viii) One-off subsidies for setting a farm and acquiring necessary equipment, land plots, seeds, livestock, feed, etc.

(ix) Subsidies for untied support of plant production. The subsidy is intended to compensate agricultural producers (except for citizens who run a personal subsidiary farm) for the part of their costs of agro-technological works and depends on the crop acreage.

In general, after Russia's accession to WTO in 2012, the untied forms of the state support of producers' income are replacing tied price support, because they do not contradict the WTO rules that strictly regulate state subsidies to producers. ${ }^{2658}$ In fact, the above-mentioned reimbursement of the interest rates on investment loans should be attributed to the untied support as well. Another type of the untied support is subsidies for the payment of the first installment (advance payment) under the leasing agreement for the purchase of agricultural equipment and transport. Finally, tax incentives and preferential tax regimes for agricultural producers constitute another wide-spread form of the untied state support. ${ }^{2659}$

The wide range of crops/agricultural sectors can benefit from the subsidies including: In animal breeding: ${ }^{2660}$

- dairy cattle breeding;

- livestock breeding;

- meat cattle breeding;

- increasing the number of reindeer, marals and meat horses;

\footnotetext{
${ }^{2657}$ https://rynok-apk.ru/articles/plants/subsidiya-v-pomoshch/

${ }^{2658}$ Vasily Erokhin, Establishing Food Security and Alternatives to International Trade in Emerging Economies (2017 IGI Global), 69.

${ }^{2659}$ https://rynok-apk.ru/articles/plants/subsidiya-v-pomoshch/

2660 https://rynok-apk.ru/articles/plants/subsidiya-v-pomoshch/
} 
- increasing the breeding stock of sheep and goats,

- production and sale of fine wool and semi-fine wool.

In plant production:

- laying and maintenance of vineyards;

- purchase of seeds;

- plant production in the territories with conditions adverse to the agriculture;

- acquisition of elite seeds;

- laying and maintenance of perennial fruit and berry plantings.

The overall philosophy of the state support of the agricultural sector is reflected mostly in the State Programme on Agricultural Development, which emphasises as its primary objectives the increase in production outputs of the main types of agricultural products; modernisation and renewal of the technological base of agricultural industry and even increase in export of Russian agricultural products. The sustainable development of rural territories and providing the full employment of the rural populations is specified among its objectives and is the focus of the separate state programme. However, the number of unsolved problems indicates that the state support in this direction is suboptimal. Thus, the average salary of employees in the farming industry remains very low; ${ }^{2661}$ there are still difficulties in acquiring land plots to set up individual farms; significant upfront investments are necessary to receive the state subsidies. ${ }^{2662}$ The full implementation of the Federal Targeted Programme "Sustainable development of rural areas for 2014-2017 and for the period until 2020" might help to solve some crucial problems of rural territories and stimulate inflow of human resources to the agricultural sector.

2661 'Development of the Agriculture in Russia: Reality and Perspectives' (Komsomolkaya Pravda, 29 July 2016) (https://www.kp.ru/guide/razvitie-sel-skogo-khozjaistva-v-rossii.html.

2662 https://rynok-apk.ru/articles/plants/subsidiya-v-pomoshch/ 


\section{References}

Agricultural Development and Regulation of Agricultural Products, Commodities and Food Markets, 2013-2020 // Government Decisions. The Russian Government <http://government.ru/en/docs/3360/>.

Agriculture Development Program 2013-2020 // USDA Foreign Agricultural Services. 2012. https://gain.fas.usda.gov/Recent\%20GAIN\%20Publications/Agriculture\%20Development\%20Progr am\%202013-2020_Moscow_Russian\%20Federation_11-6-2012.pdf.

'Analysis of the Market of Services Provided by Dairy Producers and Other Economic Entities to Suppliers of Raw Milk' (FAS), <fas.gov.ru/documents/documentdetails.html?id=1250>;

ФАС России, 'Анализ рынка услуг, предоставляемых молочными комбинатами и иными хозяйствующими субъектами, поставщикам сырья для производства молочной продукции'.

Analytical report on the conditions of competition in the market of Fertilisers, Federal Antimonopoly Service of Russia (2014), <fas.gov.ru/documents/documentdetails.html?id=1851,13>;

Аналитический отчет по результатам анализа состояния конкурентной среды на рынке минеральных удобрений, ФАС России (2014).

Bezrukova J,'The retail chains use private labels to increase their income' (09 August 2016, Kommersant), https://www.kommersant.ru/doc/3059373;

Юлия Безрукова, 'Сети используют товары под собственным брендом, чтобы увеличить доходы’ (9 августа 2016 года) Коммерсант.

Burlakova E. "Rusagro would cover expenses for "Razgulay Group" buyout in a 2 year period" // Vedomosti. 2016. URL: https://www.vedomosti.ru/business/articles/2016/08/29/654748-rusagrookupit-zatrati-na-pokupku-aktivov-razgulyaya;

Екатерина Бурлакова, «Русагро» окупит затраты на покупку активов «Разгуляя» за два года, (28 августа 2016) Ведомости.

Center of Monitoring of the Market Environment, 'Analysis of Position of the Large Retail Chains in the Food Retail Market of Saint-Petersburg and Practices of their Interaction with Food Producers' (2005, S.-Petersburg) 6, accessed at fas.gov.ru/files/8797/SPb_Ritail2005.doc;

АНО "Центр Исследований Рыночной Среды", 'Анализ положения крупных торговых сетей на розничном рынке продовольствия Санкт-Петербурга и практики их взаимодействия с предприятиями - поставщиками продовольствия'.

Clarification of the FAS of Russia on some issues of application of the Federal Law dated 28.12.2009 No. 381-FZ "On the Basic Principles of State Regulation of Trading Activities in the Russian Federation" as amended by the Federal Law dated 03.07.2016 No. 273-FZ < fas.gov.ru/documents/documentdetails.html?id=14896>; 
Разъяснения ФАС России по некоторым вопросам применения Федерального закона от 28.12.2009 № 381-Ф3 «Об основах государственного регулирования торговой деятельности в Российской Федерации» в редакции Федерального закона от 03.07.2016 № 273-Ф3.

Competition Issues in Food Chain Industry 2013, OECD, 15 May 2014, Directorate for Financial and Enterprise Affairs, Competition Committee DAF/COMP (2014).

Demidova A, 'Food retail chains are selling their names' (23 March 2017) RBC www.rbc.ru/newspaper/2017/03/23/58d267cb9a7947df5d18c78d;

Анастасия Демидова, 'Продуктовые сети торгуют именем' (23 марта 2017) РБК.

Development of agriculture in Russia: perspectives and obstacles // KP.ru. 2016. URL: https://www.kp.ru/guide/razvitie-sel-skogo-khozjaistva-v-rossii.html.

Donbrova E and Karlos A, "The market share of retailers X5, "Lenta" and "O'key" exceeded the threshold set by law', (13 February 2017) Delovoy Peterburg, www.dp.ru/a/2017/02/12/Retejleri_s_polovinoj;

Елена Домброва, Амера Карлос, 'Рыночная доля ретейлеров Х5, "Лента" и "О'Кей" в Петербурге превысила установленный законом предел' (13 февраля 2017 года) Деловой Петербург.

Draft 'Plan ("Road Map) of on Development of Competition in Agricultural Industry in 2017-2018'; План развития конкуренции («дорожная карта») в агропромышленном комплексе Российской Федерации на 2017 - 2018 годы.

European Commission - Press release as of 27 March 2017 'Mergers: Commission clears merger between Dow and DuPont, subject to conditions', <europa.eu/rapid/press-release_IP-17772_en.htm>.

European Commission - Press release as of 05 April 2017 'Mergers: Commission clears ChemChina acquisition of Syngenta, subject to conditions', <europa.eu/rapid/press-release_IP-17-882_en.htm> accessed 04 September 2017.

FAO Agriculture and Trade Policy. Background Note // FAOSTAT. http://www.fao.org/fileadmin/templates/est/meetings/wto_comm/Trade_Policy_Brief_Russia_final. pdf.

FAS press release 'Brand Squeezing' dated 28 October 2011, <fas.gov.ru/press-center/fas-inmedia/detail.html?id=9994>;

Пресс-релиз ФАС 28 октября 2011 'Выдавливание брендов’.

FAS press release dated 12 February 2016 at <fas.gov.ru/press-center/news/detail.html?id=44712>.

FAS press release dated 20 May 2016 at <fas.gov.ru/press-center/news/detail.html?id=45796>; 
Пресс-релиз ФАС 20 Мая 2016, 'ФАС России рассказала о ситуации на молочном рынке РФ’.

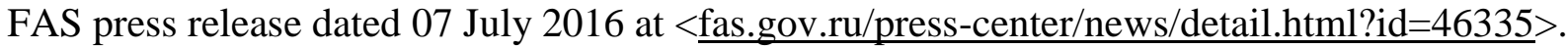

FAS press release dated 29 October 2016 at $<$ fas.gov.ru/press-center/news/detail.html?id=47589 $>$.

FAS Press release dated 10 November 2016 'National Plan on Development of Competition in 20172018 must enhance the national economic framework';

Пресс-релиз ФАС 'Национальный план развития конкуренции призван улучшить экономическую ситуацию в стране' (10 Ноября 2016 );

FAS press release dated 07 December 2016 at <fas.gov.ru/press-center/news/detail.html?id=48110>.

FAS press release dated 27 February 2017 at <fas.gov.ru/press-center/news/detail.html?id=49039>; Пресс-релиз ФАС 27 Февраля 2017, 'В рамках Экспертного совета при ФАС России внесены предложения в проект «дорожной карты» развития АПК'.

FAS Press-releases 'Moscow Region FAS has initiated procedures against retail chains for imposing discriminatory terms on their suppliers' as of 12 August, 20 August and 27 August 2017, <fas.gov.ru/press-center/news/detail.html?id=51317>; $\quad$ fas.gov.ru/presscenter/news/detail.html?id=51243 $>$; $\langle$ fas.gov.ru/press-center/news/detail.html?id=51420 $>$.

Пресс-релизы ФАС 12 августа, 20 августа и 27 августа 2017 года 'Московское областное УФАС возбудило дело в отношении торговых сетей за создание дискриминационных условий для поставщиков' .

FAS Report on Competition in 2016 (2017).

Food Security Doctrine Adopted // USDA Foreign Agricultural Services. URL: https://gain.fas.usda.gov/Recent\%20GAIN\%20Publications/Food\%20Security\%20Doctrine\%20Ad opted\%20_Moscow_Russian\%20Federation_2-11-2010.pdf.

Gavrilov D and Chernyaga A, 'Antitrust Regulation in the Eurasian Economic Union' (December 13, 2016), the International Centre for Trade and Sustainable Development, www.ictsd.org/bridgesnews/антимонопольное-регулирование-в-евразийском-экономическом-союзе;

Денис Гаврилов, Алина Черняга, 'Антимонопольное регулирование в Евразийском экономическом союзе', the International Centre for Trade and Sustainable Development https://www.ictsd.org/bridges-news/мосты/news/антимонопольное-регулирование-вевразийском-экономическом-союзе.

ICN, 'Report on Abuse of Superior Bargaining Position' (2008) 17 www.internationalcompetitionnetwork.org/uploads/library/doc386.pdf.

Interview with the Deputy Head of FAS Andrey Tsyganov at "RIA News", < ria.ru/interview/20161228/1484793637.html>; 
Интервью с Заместителем руководителя ФАС России Андреем Цыгановым "РИА-Новости" 28 декабря 2016 года 'Андрей Цыганов: можем начать торговлю удобрениями на бирже осенью 2017 года'.

Ischenko N, 'The Largest Retailers Have Significantly Increased Their Market Share', "Vedomosti" N3989 dated 25 December 2015 at <www.vedomosti.ru/business/articles/2015/12/25/622565-setinarastili-dolyu>).

Наталья Ищенко, 'Крупнейшие продовольственные сети существенно нарастили долю рынка', Ведомости N3989, 25 декабря 2015 года.

Kostyrev A, 'Samuel Lipman is tired of poultry farming' (Kommersant No. 74 dated 27 April 2017), https://www.kommersant.ru/doc/3282845;

Анатолий Костырев, 'Самюэль Липман устал от птицеводства' (Коммерсант No. 74 от 27 Апреля 2017 года).

Kozhevnikova T, Ryabikh V, Mezhueva E, 'Prospects of Development of Enterprises of the Agricultural Industry in Russia in the Context of the World Economic Crisis' (2014) 1 Social and Economics Phenomena and Processes 3;

Т. Кожевникова, В.Саяпин, Н.Рябых, "Перспективы развития АПК региона в контексте мирового аграрного кризиса" (2014) 1 Социально-экономические явления и процессы 3.

KPMG Report, "The agricultural and food value chain: Entering a new era of cooperation" (2013), 22, 〈assets.kpmg.com/content/dam/kpmg/pdf/2013/06/agricultural-and-food-value-chain-v2.pdf>.

Legal coverage for food security of Russia: national and international legal aspects // European Congress on Rural Law - 11-14 September 2013. Lucerne (Switzerland).

Letter of the Federal Antimonopoly Service dated 05.09.2016 No.AK / 60976/16 "Clarification of the FAS of Russia on some issues of application of the Federal Law dated 28.12.2009 No. 381-FZ "On the Basic Principles of State Regulation of Trading Activities in the Russian Federation" as amended by the Federal Law dated 03.07.2016 No. 273-FZ http://fas.gov.ru/documents/documentdetails.html?id=14793;

Разъяснения ФАС России по некоторым вопросам применения Федерального закона от 28.12.2009 № 381-Ф3 "Об основах государственного регулирования торговой деятельности в Российской Федерации" в редакции Федерального закона от 03.07.2016 № 273-Ф3 http://fas.gov.ru/documents/documentdetails.html?id=14793.

'Market, crisis, counterfeit' (2 June 2016) Agroxxi www.agroxxi.ru/associacija-evropeiskogobiznesa/rynok-krizis-kontrafakt.html.

'Market Survey Following the Results of 2015', INFOLine, <www.marketch.ru/marketing_marginalia/obzor_rynka_fmcg_po_itogam_2015_goda> ;

'Обзор рынка FMCG по итогам 2015 года', INFOLine. 
Meshkova T.A., Moiseichev E. Russia's Experience of Foresight Implementation in Global Value Chain Research // Journal of Innovation and Entrepreneurship. 2016. Vol. 5. N 9.

Mission of the FAS at $\leq$ fas.gov.ru/about/mission.html $>$.

'Moscow Bans GMO: Russia, the World's Largest GMO-free Territory, Platform for the Development of Organic Agriculture' (2016) Global Research <http://www.globalresearch.ca/moscow-bans-gmo-russia-the-worlds-largest-gmo-free-territoryplatform-for-the-development-of-organic-agriculture/5548448>.

'On Actual Aspects of Consumer Rights Protection in the Russian Federation'. URL: http://council.gov.ru/activity/activities/roundtables/59611/.

Plotnikova I.A., Orlova E.R. Agricultural markets in Russia: analysis of contemporary obstacles // Vestnik MIEP. 2015. Vol. 19. N 2.

'Razgulay Group was adjudged bankrupt' // Interfax. 2017. URL: http://www.interfax.ru/business/559781.

'Суд признал банкротом группу "Разгуляй"' (24 апреля 2017, Interfax).

Report on investigation of the cases on potential violations of the Federal law "On Protection of Competition", the Federal law "On the Trading Activities", the Code of Administrative Offences by territorial departments of FAS as of 10.01.2012<fas.gov.ru/documents/documentdetails.html?id=1524>;

Справка о рассмотрении дел, возбужденных по выявленным признакам нарушения Закона о защите конкуренции, Закона о торговле, Кодекса об административных правонарушениях территориальными управлениями ФАС России.

'Report on the Conditions of Competition in the Russian Federation' (2015) FAS, <fas.gov.ru/about/list-of-reports/report.html?id=1685>;

ФАС России, 'Доклад о состоянии конкуренции за 2015 год’.

Report of FAS dated 27 March 2017 "On the results of inspections of supply contracts between retail chains and food suppliers with regard to their compliance with the requirements of Federal Law "On the Basic Principles of State Regulation of Trading Activities in the Russian Federation" dated 28 December 2009 N 381-FZ”, < fas.gov.ru/documents/documentdetails.html?id=15105>;

Доклад ФАС России о результатах проверок договоров поставки между торговыми сетями и поставщиками продовольственных товаров на соответствие требованиям Федерального закона от 28.12.2009 № 381-Ф3 "Об основах государственного регулирования торговой деятельности в Российской Федерации".

'Russia: Full Ban on Food with GMOs' // Library of Congress. 2016. URL: http://www.loc.gov/law/foreign-news/article/russia-full-ban-on-food-with-gmos/. 
'Russia's doctrine of food security signed; possible implications for biotechnology', Wageningen University \& Research

<http://library.wur.nl/WebQuery/file/cogem/cogem_t4c6a3a1a_001.pdf>

(02.02.2010)

'Russian State Duma Passes Total Ban on GMO Crops and Animals' (2016) Sustainable Pulse $<$ http://sustainablepulse.com/2016/06/25/russian-parliament-passes-total-ban-on-gmo-crops-andanimals/\#.WPoJRxFZdp1>.

Safaryan K, Innovation Business, Practical Aspects of Assets Evaluation (FBGOU VPO "The Russian Academy of National Economy and Public Service under the President of the Russian Federation” 2012) https://profilib.com/chtenie/20893/karina-safaryan-innovatsionnyy-biznesprakticheskie-aspekty-otsenki-aktivov-25.php;

Карина Сафарян, 'Инновационный бизнес: практические аспекты оценки активов' (ФГБОУ ВПО "Российская академия народного хозяйства и государственной службы при Президенте Российской Федерации", 2012).

Swinnen J F M, and others, The Dynamics of Vertical Coordination in Agrifood Chains in Eastern Europe and Central Asia: Implications for Policy and World Bank Operations (The World Bank, 2011).

Titov S, 'FAS Reform: Struggle for the Agency' (November 27, 2014) 3725 Vedomosti < www.vedomosti.ru/politics/articles/2014/11/27/borba-za-sluzhbu>;

Сергей Титов, 'Полномочия ФАС предложено ограничить' (27 ноября 2014) N3725 Ведомости.

'The amount of fines for violations in "Ashan" exceeded 25 million rubles' http://www.ntv.ru/novosti/1522316/ accessed 29 October 2017.

'The Industry Agreement on the Agroindustrial Sector of the Russian Federation in 2015-2017', December 16, 2014.

Tumalanov N.V. Change of competitive environment in perspective of agricultural markets // Modern Competition. 2012. Vol. 3. N 33.

'Until the thunder breaks out' (2014) Expert Online <expert.ru/2014/02/26/poka-grom-ne-gryanet>.

Vorozheikina T, 'State Regulation of the Fragmented Industries' (2011) Bulletin of the Russian University of Economics 4

Т.Ворожейкина, "Государственное регулирование фрагментированных отраслей" (2011) Вестник Российской экономической академии 4.

'Where are GMOs grown and banned?', GMO FAQ. Agricultural biotechnology frequently asked questions. <https://gmo.geneticliteracyproject.org/FAQ/where-are-gmos-grown-and-banned/. 
Zatari A, 'Putin signed the law on GMO prohibition', (04 July 2017, RBC) www.rbc.ru/politics/04/07/2016/577aa7bb9a794761a21c8d57. 


\section{Chapter 3: India}

Amber Darr

\subsection{Introduction}

On $3^{\text {rd }}$ November 2017, the Government of India (the Government) launched the 'World Food India' initiative in a bid to attract investment of USD 10 billion in the Indian Food Processing sector. The Government's avowed aim in doing so is to transform the Indian food economy and to double farmers' income. ${ }^{2663}$ The Government's focus on the Food Processing sector is both timely and appropriate. The Indian food industry comprises 32 per cent of the country's total food market. It is one of the largest industries in India and is ranked fifth in terms of production, consumption, export and expected growth. It contributes around 8.80 and 8.39 per cent of Gross Value Added in Manufacturing and Agriculture sectors respectively, constitutes 13 per cent of India's exports and six per cent of total industrial investment. ${ }^{2664}$

The Indian food industry is also significant from a global perspective. India's food and grocery market is the world's sixth largest, with retail contributing 70 per cent of the sales. Although the online food ordering business in India is in its nascent stage, it has witnessed exponential growth in recent years: the online food delivery industry has grown at 150 per cent year-on-year with an estimated Gross Merchandise Value of US\$ 300 million in 2016. With online food delivery players like FoodPanda, Zomato, TinyOwl and Swiggy building scale through partnerships, the Government believes that the organized food business not only has huge potential but also a promising future. The Government has also announced that the Global e-commerce giant, Amazon is planning to enter the Indian food retailing sector by investing US\$ 515 million in the next five years and the US-based food company Cargill Inc, aims to double its branded consumer business in India by 2020. ${ }^{2665}$

In launching the World Food India initiative the Government implies that bolstering the Food Processing and Retail sectors will automatically benefit the Agriculture sector which not only feeds these sectors but also constitutes approximately 17.32 percent of India's GDP ${ }^{2666} \&$ employs 54.6 percent of the Indian population. ${ }^{2667}$ However, the Agriculture sector continues to be affected by many challenges that hinder it from realizing its true potential. Even in the new millennium, when technology has touched every aspect of Indian lives, a majority of Indian farmers continue to deploy antiquated agrarian practices. Although the Government has taken some initiatives in this regard, it is understood that more needs to be done in this regard. ${ }^{2668}$ Further, businesses and related infrastructure across the Agriculture Value Chain remain underdeveloped and the sector is unable to attract investment due to structural inefficiencies and lack of economically remunerative business models. ${ }^{2669}$

\footnotetext{
2663 http://www.thehindu.com/business/Industry/india-to-attract-10-billion-in-food-processing-sector-in-3-yearsgovt/article19974041.ece (accessed 4 November 2017).

${ }^{2664} \mathrm{https}$ ://www.ibef.org/industry/indian-food-industry.aspx (accessed 4 November 2017).

2665 Ibid.

$2666 \mathrm{http}: / /$ statisticstimes.com/economy/sectorwise-gdp-contribution-of-india.php (accessed 4 November 2017)

${ }^{2667} \mathrm{http}: / /$ eands.dacnet.nic.in/PDF/State_of_Indian_Agriculture,2015-16.pdf (accessed 4 November 2017).

2668 The Government's information and communications technology (ICT) initiatives are discussed more fully in appropriate sections later in the fiche.

2669 Ashish Iyer and Abheek Singhi 'Indian Agribusiness: Cultivating Future Opportunities' Boston Consulting Group (2012).
} 
In order to support investment in the Food Processing and Retail sectors and thereby, at least indirectly to help the Agriculture sector, the Government proposes to launch a 'Food Regulatory Portal'. This is planned as a single interface for food business to cater to both domestic operations and food imports. The Government expects the portal to be a 'game changer' for effective and transparent implementation of Food Safety Laws in the country. ${ }^{2670}$ Establishing such a portal is likely to be challenging given the complexities of the food value chains in India as well as the number of regulatory laws and institutions that presently govern the food sector. This fiche begins by describing the food value chain(s) in the country and proceeds to outline the relevant laws and institutions and identify the legal challenges that are likely to arise at different points in these chains and the considerations that may be taken into account in dealing with the Indian food sector.

\subsection{The Indian Food Value Chain(s)}

\subsubsection{The Basic Indian Food Value Chain ${ }^{2671}$}

The basic structure of a Food Value Chain may be represented as follows:

Figure 1: Basic Structure of the Food Value Chain

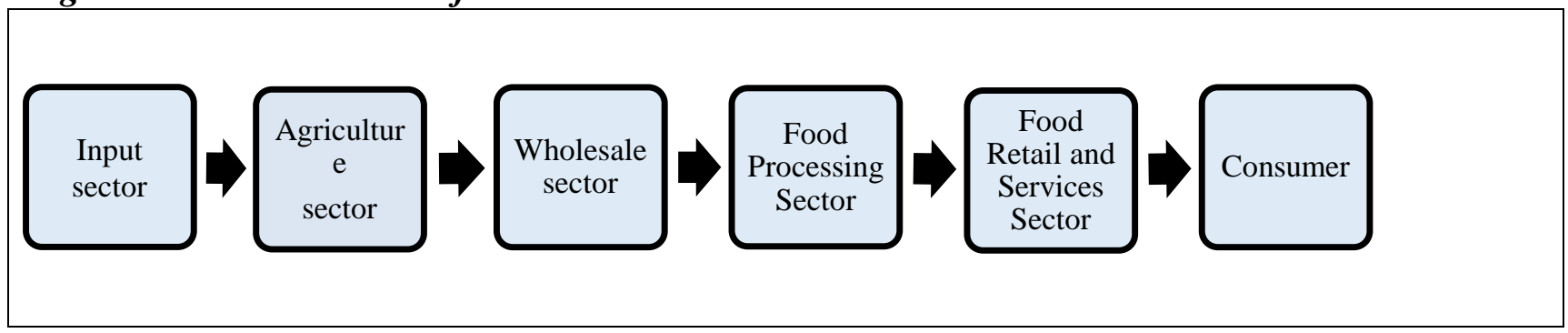

Authors' compilation

In India, this basic representation of the Food Value Chain is complicated due to the distinct value chains that exist in the Agriculture and the Food Processing sectors and the interconnections between the two as well as their independent connections with the Retail sector. In order to unpack these complexities, it is important to first describe each sector in the basic Food Value Chain:

\subsubsection{The Input Sector}

The Input sector comprises seeds, Fertilisers, pesticides, agricultural machinery, electricity and water and crop insurance and is populated by Government agencies as well as private companies. This sector forms the base of all food value chains whether Agriculture, Food Processing or Retail.

\subsubsection{The Agriculture Sector}

According to a strict definition, the Agriculture sector comprises all farmers whether individual, organized as co-operatives or corporate entities, engaged in the production of fruits, vegetables and

\footnotetext{
2670 See n. 2663.

${ }^{2671}$ This section is based upon information derived from Saurabh Kumar, Aparna Sharma 'Agricultural Value Chains in India: Prospects and Challenges' C CUTS International 2016.
} 
other crops. However, individual farmers and smallholders comprise the greatest portion of this sector and over 54.6 per cent of the rural households depend on agriculture as their principal means of livelihood. ${ }^{2672}$ Agriculture also contributes approximately 17.32 percent to India's GDP. The Indian agriculture industry can be classified into four major product groups — food grains, fruits and vegetables, dairy, and meat. These product groups together account for approximately 85 percent of private final consumption expenditure on food. ${ }^{2673}$ The Agriculture sector has the option of supplying to wholesalers, food-processing companies, retailers or consumers.

\subsubsection{The Wholesale Sector}

The Wholesale sector comprises traders, middlemen and government purchase centers. This sector is fed solely by the Agriculture sector but may have onward connections with food processing companies, retailers or consumers. The value added by this sector is limited in that it acts merely as a conduit for the produce of the agriculture sector.

\#

\subsubsection{Food Processing Sector}

The Food Processing sector may be categorized into (a) Primary processing, which includes cleaning, grading, sorting, packing etc. of agricultural products to make agriculture products fit for human consumption. Finished products in this case include packed milk, fruits \& vegetables, milled rice, flour, pulses, spices and salt largely unbranded, and, (b) Value-added or secondary/tertiary processing, which includes dairy products (ghee, cheese and butter), bakery products, processed fruits $\&$ vegetables, juices, jams, pickles, confectionery, chocolates and alcoholic beverages. These products undergo higher level of processing through which agricultural products are converted into new or modified products.

\subsubsection{Food Retail and Services sector}

The Retail sector is populated by a variety of players ranging from hypermarkets, supermarkets, corner grocery shops and local vendors. The inclusion of Food services to this sector brings the restaurant, fast food industry as well as online food delivery industry within its fold.

\subsubsection{Consumers}

Consumers, though not strictly a sector in the food value chains, represent the end-point of the food value chains and may include both the sophisticated urban consumer as well as her more traditional counterpart, the rural consumer. Consumers not only avail of the food sector but also play an important role in shaping it, to the extent that consumer preferences shape policy decisions and market choices. Arguably, the rise of an urban middle class in India has played in a considerable part in developing the nature of products produced by the Food processing industry as well as expanding

2672 See n. 2667.

2673 See n. 2669, 22. 
the retail options for customers whether through establishing modern fast food outlets to promoting online delivery services.

\subsubsection{An Integrated Model of the Food Value Chain}

\section{Figure 2: The Integrated Food Value Chain}

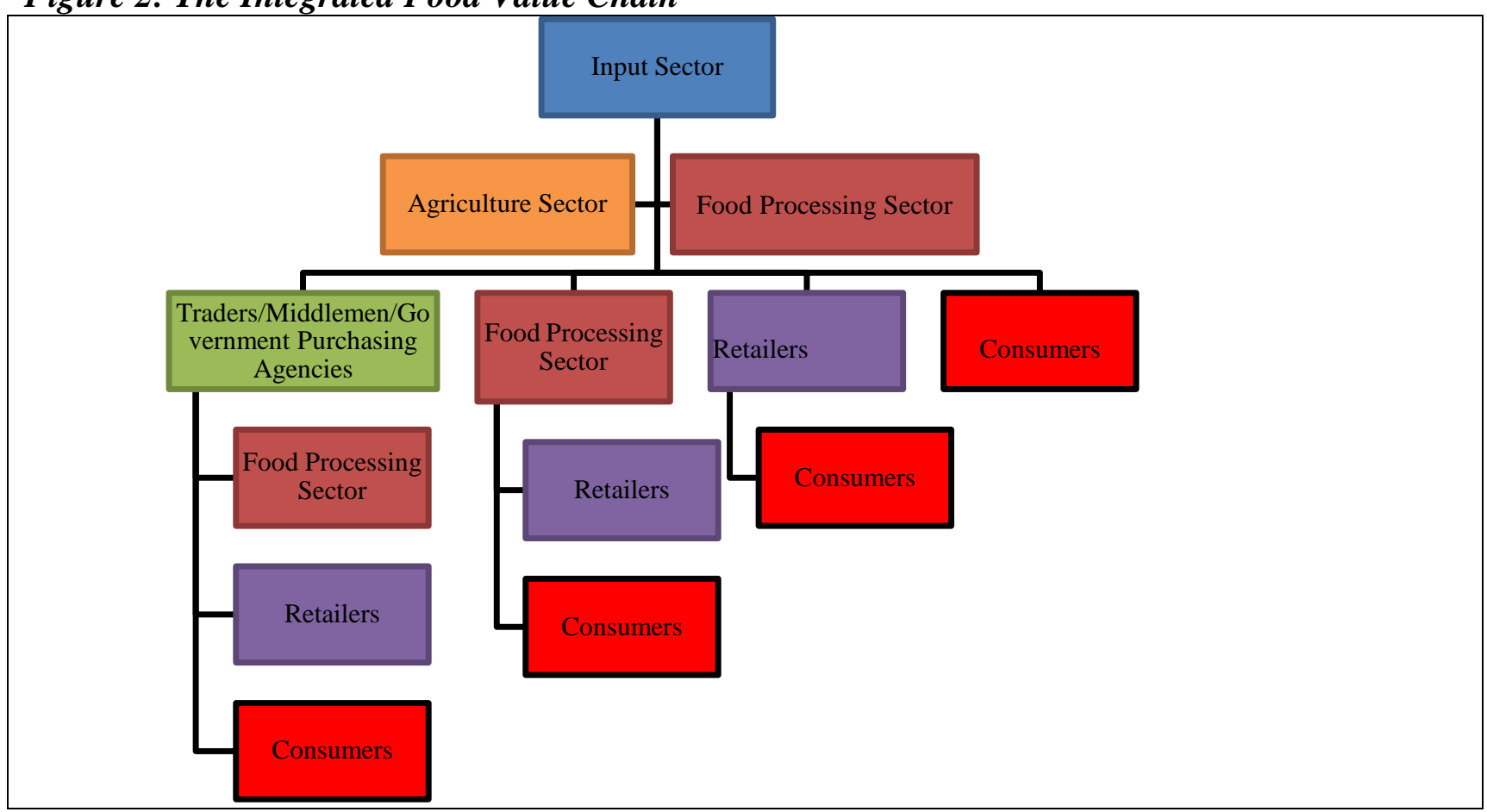

Source: Author's compilation

Figure 2, outlines the interconnections and linkages between the different Food sectors in India. The Input sector may supply to the Agriculture sector or directly to the Food Processing Sector. Further, the Agriculture sector may supply its produce to wholesalers, food processing companies, and retailers or even directly to consumers. Whilst the food-processing sector may be fed directly by the Input, Agriculture or Wholesale sector, its onward link is only with the Retail sector.

Different laws and institutions regulate different sections in these value chains. Legislation in respect of the Agriculture sector is the domain of the States rather than of the Centre (or the Union as it is referred to in the Constitution. These terms are used interchangeably throughout, as appropriate). ${ }^{2674}$ Therefore, whilst the Centre may draft model laws and urge the States to adopt laws in accordance with these model laws, it does not have the constitutional authority to legislate in this regard. In April 2017, the Central Government (Agriculture Ministry) had drafted a new model Agricultural Produce Market Committee (APMC) Act proposing single-point levy of market fee across a State and a united single trading license for cost-effectiveness of transactions, ${ }^{2675}$ whilst in

\footnotetext{
2674 Constitution of India, Seventh Schedule, State List, Item 14: Agriculture, including agricultural education and research, protection against pests and prevention of plant diseases. In terms of Article 246 (3) of the Constitution, States have the exclusive power to legislate in respect of items listed in the State List.

2675 http://www.thehindubusinessline.com/economy/policy/ministry-comes-up-with-model-apmc-act-to-integrate-agrimarkets/article9660628.ece (accessed 4 November 2017).
} 
its recent budget speech, the Government has announced a move to table a draft contract farming law. ${ }^{2676}$ However, the extent to which these laws are adopted, depends on individual States.

Trade and commerce in, and the production, supply and distribution of foodstuffs, including edible oilseeds and oils, is a Concurrent subject and therefore, either the States or the Centre may legislate in this regard. ${ }^{2677}$ Intra-state trade and commerce is the domain of the Centre and only the Centre Legislature may legislate on this topic. ${ }^{2678}$ Further, although the Indian Constitution does not explicitly provide for the protection of consumers, several items in the Union and the Concurrent Legislative Lists allow both the Union and the Provincial legislature to legislate in this regard. ${ }^{2679}$

\subsection{The Legal and Regulatory Framework for Food Value Chain(s)}

In 1991, India adopted a liberal economic policy and for the first time in its independent history, opened itself to the global trade and investment. ${ }^{2680}$ Investors were initially attracted to India due to the low cost of labour combined with a weak legal and regulatory infrastructure. ${ }^{2681}$ However, as the magnitude of investment in the country grew, so did the demand for more stringent legal and regulatory protection. The Government, therefore, took it upon itself to frame appropriate polices to facilitate India's transition from a protected to a competitive market economy and embarked on a process of drafting and adopting a modern legal framework and acquiring a new generation of regulatory institutions for implementing this legal framework throughout the country. ${ }^{2682}$ As part of this process, India adopted a number of laws and regulations for the food sector, which are not always in complete harmony with each other. This section outlines the most significant legislation and instruments in respect of the different sectors within the Indian food sector:

\subsubsection{The Input sector}

Legislation governing the input sector includes the Essential Commodities Act 1955 and the Seeds Act $1966 .{ }^{2683}$

\subsubsection{The Essential Commodities Act 1955}

The Essential Commodities Act (ECA) and the Orders issued under it (for example, the Seeds (Control) Order 1983, the Seed Control Order (Amendment) 1983 and the Fertiliser Control Order

https://timesofindia.indiatimes.com/india/centre-to-come-out-with-draft-model-law-on-contractfarming/articleshow/60455065.cms (accessed 4 November 2017).

2677 Constitution of India, Seventh Schedule, Concurrent List, Item 33 read with Article 246 (2).

${ }^{2678}$ Constitution of India, Seventh Schedule, Union List, Item 42 read with Article 246 (1).

${ }^{2679}$ See for example in the Union List, Item 50 ('Establishment of standards of weight and measure'); Item 51 ('Establishment of standards of quality for goods to be exported out of India or transported from one State to another'); and in the Concurrent List, Item 18 ('Adulteration of foodstuffs and other goods').

2680 Jagdish Bhagwati India In Transition: Freeing The Economy Oxford University Press, Delhi (C) 1992.

${ }^{2681}$ To understand this underlying phenomenon, see Ronald B. Davies and Krishna Chaitanya Vadlamannati 'A Race to the Bottom in Labour Standards? An Empirical Investigation' Journal of Development Economics 2013 (103) 1-14. For another perspective see Dr. Valpy Fitzgerald's 'Regulatory Investment Incentives' OECD, 2001 (https://www.oecd.org/daf/inv/investmentstatisticsandanalysis/2510459.pdf accessed 4 Nov 2017).

${ }^{2682}$ Vijay Vir Singh and SiddhartaMitra, Regulatory Management and Reforms in India, Background Paper for OECD, CUTS International, page 4.

${ }^{2683}$ Information in respect of these laws has been taken from http://nsai.co.in (accessed 6th January 2017). 
1985) govern a number of agricultural inputs including seeds and Fertilisers. The aim of this Act is to regulate the supply and distribution of, trade and commerce in these essential commodities.

In terms of this Act, the Central Government has the power to control production, supply, distribution, etc., of essential commodities on grounds specified in the Act (section 3) and orders issued by the Government in exercise of this power override anything contained in any other legislation (section 6). The Government also has the power to confiscate essential commodities (section 6A) after following the procedure provided in the Act.

Further, under this Act, the Government has almost unlimited power to pass certain Control Orders and take other action in respect of essential commodities. An example of this was the issuance by the Government of the Cotton (Price) Control Order in September 2015. In terms of this Order, the Government fixed Bt cottonseed prices at Rs 800 for 450 grams, compared with the then current rates that ranged from Rs 830 to Rs $1,000 .{ }^{2684}$ Monsanto indirectly challenged this Control Order before the Delhi High Court in a breach of contract suit filed by it against Nuziveedu Seeds Limited. However, in its decision dated $28^{\text {th }}$ March 2017 the Delhi High Court ruled in favour of the Defendant, Nuziveedu Seeds Limited and required Monsanto to renegotiate the trait fee in accordance with local laws ie the Control Order. ${ }^{2685}$

\subsubsection{The Seeds Act 1966}

The Seeds Act (SA) and the Rules framed under it ie the Seed Rules 1968 and the Seeds (Amendment) Rules 1973 and 1974 provide for constituting the Central Seed Committee to advise the Central and State Governments on matters arising from the administration of the Act (section 3). The Act also establishes Central and State seed laboratories (section 4) and a Seed Certification Agency (section 8); confers powers on the Government to notify different kinds and varieties of seeds (section 5) and to specify minimum limits of germination and purity of these seeds (section 6).

The Act confers powers on the Certification Agency to certify different kinds and varieties of seeds on an application from an interested party (section 9) and to revoke such certification upon grounds specified in the Act (section 10). Further, the Act empowers State governments to appoint seed analysts (section 12) and seed inspectors (section 13) and specifies the powers of and procedure to

\footnotetext{
${ }^{2684}$ https://nsai.co.in/editor/fmanage/userfiles/Newsletter/December_Newsletter.pdf (accessed 7 November 2017).

2685 The Plaintiffs in this case were Monsanto Technology, Monsanto Holdings Private Limited and Mahyco Monsanto Biotech, all part of a multi-national agrochemical and agricultural biotechnology corporation and a leading producer of genetically engineered seeds. The Plaintiffs filed a case against Nuziveedu Seeds Limited, Prabhat Agri Biotech Limited and Pravardhan Seeds Private Ltd. (Defendants), which are Indian agribusiness companies that market seeds and supply hybrid seeds to Indian farmers. The Plaintiffs alleged that the Defendants continued to market and sell Genetically Modified Hybrid Cotton Planting Seeds despite the termination of sub-license agreements between the Plaintiffs and the Defendants. The Plaintiffs also alleged violation of intellectual property rights of their registered patent (IA 214436) and their trademark sub-licenses for 'Bollgard' and 'Bollgard II'. The Plaintiffs alleged trademark infringement and 'passing off' by the Defendants when they sold their products with labels of 'Bollgard'. The Plaintiffs wanted to initiate a permanent injunction against the Defendants, along with disclosures, recalls of infringing products and award of damages. The High Court was of the opinion that the termination of the contract by the Plaintiffs was incorrect. The Judge stated: "the Plaintiffs were duty bound to consider the request of the defendants as made by the communications beginning July 2015 , for modification of the terms as to the rate of trait fee payable under the 2015 sub-license agreements for which the mechanism had earlier been agreed upon in the form of Article 11.03. Since the plaintiffs did not adhere to their obligation under the contract, the demand of payment under the contract terms being not lawful, it apparently being higher than the trait fee permitted by the law in force, the defendants could not have been found to be in default or to have breached their obligations within the meaning of Article 9.02." http://www.invntree.com/blogs/delhi-high-court-makes-a-decision-inhybrid-cotton-seeds-case accessed 4 November 2017.
} 
be followed by these analysts and inspectors (sections 14 and 15). The Act also restricts the export and import of notified kinds and varieties of seeds (section 17) and provides for the recognition of seed certification agencies of foreign countries (section 18). The Act was amended in 1972 to provide for establishing of a Central Certification Agency. ${ }^{2686}$

In 2004, the Government had proposed a new Seeds Act, which was tabled before the Parliament as the Seeds Bill 2004. However, the bill was seen as being detrimental to farmers' interests and was criticised for creating an unnecessary parallel system of registration and was not passed into law. ${ }^{2687}$ In 2014, the Government revived the bill after a decade, but it was again put on hold in 2015 after the backlash against the provisions relating to genetically modified (GM) seeds. Whilst certain scholars are of the view, that this bill, if passed, is likely to 'improve the innovation incentives facing seed companies ${ }^{\prime 2688}$ the fate of the bill remains uncertain.

\subsubsection{The Agriculture sector}

The Agriculture sector in India has received considerable legislative attention since the country's independence from British Rule in 1947. India undertook extensive land reform and in its first legislative move in this regard, abolished intermediaries so that farmers could be brought into direct control of their land. India also carried out tenancy reforms to protect the rights of farmers, placed limits on land holdings and consolidated land holdings and established the Food Corporation of India with the mandate to devise effective price support operations for safeguarding the interests of the farmers; ensure distribution of food grains throughout the country for public distribution system; and maintain satisfactory level of operational and buffer stocks of food grains to ensure national food security. ${ }^{2689}$ However, given the country's constitutional infrastructure, the majority of these initiatives are required to be implemented by State governments rather than the Central Government and, therefore, their impact varies from State to State. ${ }^{2690}$ Some of the most significant pieces of Central legislation in respect of the Agriculture sector are detailed below:

\subsubsection{The Protection of Plant Varieties \& Farmer Rights Act 2001}

The Protection of Plant Varieties \& Farmer Rights Act 2001 (PPV\&FRA) provides, among other things, for the establishment of an effective system for protection of plant varieties and the rights of farmers and plant breeders and to encourage development of new varieties of plants.

This Act was passed in pursuance of India joining the World Trade Organization (WTO) in 1995 and its signing of WTO's Trade-Related Aspects of Intellectual Property Rights (TRIPS) agreement, which brought intellectual property to the forefront of the Indian seed industry. Article 27.3 (b) of this agreement requires signatory countries to provide protection for plants in the form of

\footnotetext{
2686 The Seeds (Amendment) Act 1972.

${ }^{2687}$ Laurence R. Helfer, Graeme W. Austin Human Rights and Intellectual Property: Mapping the Global Interface Cambridge University Press 2011, 409-415.

${ }^{2688}$ David J. Spielman, Deepthi E. Kolady, Anthony Cavalieri, N. Chandrasekhara Rao 'The Seed and Agricultural Biotechnology Industries in India: An Analysis of Industry Structure, Competition, and Policy Options' Food Policy 45 (2014) 88-100.

2689 Section 13, Food Corporation of India Act 1964.

2690 Maitreesh Ghatak, Sanchari Roy 'Land Reform and Agricultural Productivity in India: a Review of the Evidence' Oxford Review of Economic Policy, Volume 23, Number 2, 2007, 251-269.
} 
patents, or with a system created specifically for the purpose ("sui generis"), or some combination thereof. Following the enactment of the PPV\&FRA, the Government established the PPV\&FR Authority (section 3), to carry out the purposes of the Act and to maintain a Plant Varieties Register (section 12). The Authority became operational in 2005 and began processing applications for varietal registration in $2007 .{ }^{2691}$

The PPV\&FRA requires that the breeder or any other person entitled to produce, market and sell seeds of a registered variety must make such seeds or propagating materials available to farmers "in a timely manner" to "satisfy their requirements" and "at a reasonable market price". ${ }^{2692}$ The Act also provides protection to farmers who have developed different varieties of plants (section 39). In terms of the Act, farmers have the right to 'save, use, sow, resow, exchange, share or sell' farm produce including seeds of a protected variety in the same manner as they were entitled to prior to the Act, however, without the right to sell branded seed of a protected variety. Farmers are also entitled to recognition and reward in cases where the genetic material they preserved and improved is used in developing new varieties. Further, in terms of the Act, farmers have the right to claim compensation from the breeder, if the variety they had purchased from him fails to perform as per the disclosure made by the breeder. Finally, farmers are immune from infringement legal action, if such infringement was innocent.

The Act also sets out provisions for the grant of compulsory license in respect of certain plant varieties (section 47). The Authority has the power at any time, after the expiry of three years from the date of issue of a certificate of registration of a variety, to grant to any person a compulsory license to undertake production, distribution and sale of the seed or other propagating material of a registered variety, provided that such person is able to demonstrate that the reasonable requirements of the public for seed or other propagating material of the variety have not been satisfied or that the seed or other propagating material of the variety is not available to the public at a reasonable price.

\subsubsection{The Patents Act 1970 (as amended in 1999, 2002 and 2005)}

The Patent's Act (PA) defines 'inventions' for the purposes of the Act (section 3). For agricultural purposes it is relevant to note that the Act excludes from this definition methods of agriculture or horticulture (section 3h) and plants and animals in whole or any part including seeds, varieties and species and essentially biological processes for production or propagation of plants and animals (section $3 \mathrm{j}$ ). The Act provides the procedure for processing domestic and foreign patent applications and stipulates the protection allowed to patent holders.

Although the PA did not initially allow for patenting in the Agriculture sector, it was amended in 2002 and 2005 in order to bring India into compliance with the Trade- Related Aspects of Intellectual Property Rights (TRIPS) Agreement. The 2002 amendment made microorganisms and any method of treatment for plants patentable. However, plants, animals, parts thereof, and essentially biological processes were excluded from this definition and still cannot be patented in India. ${ }^{2693}$

\footnotetext{
${ }^{2691}$ Deepthi Elizabeth Kolady, David J. Spielman and Anthony Cavalieri 'The Impact of Seed Policy Reforms and Intellectual Property Rights on Crop Productivity in India' Journal of Agricultural Economics, Vol. 63, No. 2, 2012, 361384.

${ }^{2692}$ Protection of Plant Varieties and Farmers' Rights Rules, 2003 (as amended in 2012), Rule 36A.

${ }^{2693}$ See n. 2688, 94.
} 
The 2002 amendment to the PA is wide in its scope because it does not to define the term 'micro-organism' and also does not prohibit the patentability of any seeds or plants derived from patented microorganisms. However, section 3(d) of the amended PA limits the scope of patent protection by stipulating that the mere discovery of a new form of a known substance, which does not result in the enhancement of the known efficacy of that substance, is not patentable. Similarly, it stipulates that the mere discovery of any new property or new use for a known substance or of the mere use of a known process, machine or apparatus unless such known process results in a new product or employs at least one new reactant, is not patentable. However, the amended PA does not clarify as to how the 'enhancement of the known efficacy of a substance' may be established. ${ }^{2694}$ The 2005 amendment introduced the term 'inventive step' in section $2 \mathrm{ja}$ and defined it as 'a feature of an invention that involves technical advance as compared to the existing knowledge or having economic significance or both and that makes the invention not obvious to a person skilled in the art.' Given the broad definition of the term inventors may apply for a patent on a product or process, on the grounds that it is economically significant, even if it does not involve any technical advance. ${ }^{2695}$

\subsubsection{The Biological Diversity Act 2002}

India adopted the Biological Diversity Act 2002 (BDA) after it had become a signatory to the Convention on Biological Diversity adopted by the United Nations Conference on Environment and Development adopted in Rio de Janeiro in 1992. ${ }^{2696}$ The BDA was enacted on $5^{\text {th }}$ February 2003 with the object of conservation of biological diversity, sustainable use of its components and fair and equitable sharing of the benefits arising out of the use of biological resources, knowledge and for matters connected therewith or incidental thereto. ${ }^{2697}$

In 2003 India established the National Biodiversity Authority in pursuance of the Act with the mandate to facilitate, regulate and advise on behalf of the Government on issues relating to the conservation and sustainable use of biological resources and fair and equitable sharing of benefits arising out of the use of biological resources. The Government also established State Biodiversity Boards (SBBs), which focus on advising the State governments, subject to any guidelines issued by the Central Government, on matters relating to the conservation of biodiversity, sustainable use of its components and equitable sharing of the benefits arising out of the utilization of biological resources. The SBBs also regulate by granting of approvals or otherwise, requests for commercial utilization or bio-survey and bio-utilization of any biological resource by Indians. ${ }^{2698}$

The local level Biodiversity Management Committees (BMCs) are responsible for promoting conservation, sustainable use and documentation of biological diversity including preservation of habitats, conservation of land races, folk varieties and cultivars, domesticated stocks and breeds of animals and microorganisms and chronicling of knowledge relating to biological diversity. ${ }^{2699}$

\footnotetext{
${ }^{2694}$ Jagjit Kaur Plahe 'The Implications of India's Amended Patent Regime: stripping away food security and farmers' rights? Third World Quarterly, 30:6, 1197-1213, 1203-1204.

2695 Ibid.

2696 Pratibha Brahmi, R. P. Dua and B. S. Dhillon 'The Biological Diversity Act of India and Agro-biodiversity Management' Current Science, Vol. 86, No. 5, 10 March 2004.

${ }^{2697} \mathrm{http} / / / \mathrm{www}$. wipo.int/wipolex/en/text.jsp?file_id=185798 (accessed $15^{\text {th }}$ May 2017)

${ }^{2698} \mathrm{http} / / /$ nbaindia.org/content/22/2/1/aboutnba.html (accessed 5 November 2017).

2699 ibid.
} 
Further legislation that is likely to have an impact on the Agriculture sector includes the Disaster Management Act 2005, ${ }^{2700}$ Multi-state Co-operative Societies Act 2002; ${ }^{2701}$ Information Technology Act 2000 (as amended by the 2008 Amendment Act); ${ }^{2702}$ The Dangerous Machines (Regulation) Act $1983,{ }^{2703}$ and Insecticides Act 1968. ${ }^{2704}$

\subsubsection{Proposed Laws}

Given the growth of contract farming in recent times in which the supplier agrees with the farmer not only on price, quantity and time of the performance, but also establishes the standards that farmers have to follow in production ${ }^{2705}$ the Central Government is considering regulating relationships between agricultural producers and suppliers or wholesalers. In its recent budget speech, the Government has announced a move to table a draft contract farming law. However, given that this is a matter for the States, the enactment and effect of these laws is likely to vary. Though Punjab had enacted a law on contract farming in 2013, it has so far not implemented it. States like Gujarat, Haryana, Karnataka, Maharashtra and Madhya Pradesh have done this for select crops through amendments to their existing laws on agricultural marketing. ${ }^{2706}$

\subsubsection{The Wholesale, Food Processing and Food Retail and Services sectors.}

\subsubsection{The Bureau of Indian Standards Act 2016}

This Bureau of Indian Standards Act (BISA) provides for the establishment of a national standards body for the harmonious development of standardisation, conformity assessment and quality assurance of goods, articles, processes, systems and services and for matters connected therewith or incidental thereto. The Act applies to all articles including any substances, artificial or natural, or partly artificial or partly natural, whether raw or partly or wholly processed or manufactured or handmade in India or imported into India (section 2(1)).

\footnotetext{
${ }^{2700}$ Section 2(d) of the Act defines disaster as a catastrophe, mishap, calamity or grave occurrence in any area, arising from natural or man-made causes or by accident or negligence which results in substantial loss of life or human suffering or damage to and destruction of property or damage to or degradation of environment and is of such a nature or magnitude as to be beyond the coping capacity of the community of the affected area.

${ }^{2701}$ This Act governs all co-operative societies with objects not confined to one state, which were incorporated before or after the coming into force of the Act.

2702 This Act provides legal recognition to transactions carried out by means of electronic data interchange and other means of electronic communications, which involve the use of alternatives to paper based methods of communication and storage of information and facilitates electronic filing of documents with government agencies.

${ }^{2703}$ This Act provides for the regulation of trade and commerce in and production supply distribution and use of the product of any industry producing dangerous machines with a view to securing the welfare of labour operating such machine and for payment of compensation for the death or bodily injury suffered by any labourer while operating any such machine etc.

${ }^{2704}$ This Act regulates the import, manufacture, sale, transport, distribution and use of insecticides with a view to prevent risk to human beings or animals.

${ }^{2705}$ Most notably, Pepsi is involved in contract farming for potatoes to procure a particular quality input for its chips. Through contract farming, Pepsi is providing the required seeds, Fertilisers and other inputs to farmers so that it sources the desired quality of produce. See n. 2669, 14.

2706 See n. 2676.
} 


\subsubsection{The Food Safety and Standards Act 2006}

The Food Safety and Standards Act (FSSA) overrides all other food related laws in India such as the Prevention of Food Adulteration Act 1954, Fruit Products Order 1955, Meat Food Products Order 1973, Vegetable Oil Products (Control) Order 1947, Edible Oils Packaging (Regulation) Order 1988, Solvent Extracted Oil, De- Oiled Meal and Edible Flour (Control) Order 1967, Milk and Milk Products Order 1992. ${ }^{2707}$ The aim of this Act is to lay down the basic framework for regulating the manufacture, storage, distribution, sale and import of food products to ensure availability of safe and wholesome food for human consumption. The Act addresses the entire gamut of food related issues with the primary objective of providing safe, hygienic and quality food to the people. ${ }^{2708}$

\subsubsection{The Legal Metrology Act 2009}

The Legal Metrology Act (LMA) and the Legal Metrology (Packaged Commodities) Rules 2011 (as amended in 2016) establishes and enforces the standards of weights and measures, regulates trade and commerce in weights, measures and other goods which are sold and distributed by weight, measure or number. ${ }^{2709}$ It also stipulates requirements to be complied with by manufacturers, packers or importers in the sale and distribution of packaged commodities. ${ }^{2710}$ This Act has repealed and replaced the Standard of Weights and Measures Act 1976 and the Standards of Weights and Measures (Enforcement) Act 1985.

\subsubsection{Consumers Related Laws}

\subsubsection{Consumer Protection Act $1986^{2711}$}

The purpose of the Consumer Protection Act (CPA) is to provide for better protection of the interests of consumers and for that purpose to make provision for the establishment of consumer councils and other authorities for the settlement of consumers' disputes and for matters connected therewith (Preamble).

The Act provides for the establishment of Central and State Consumer Protection Councils (sections 4 and 7 respectively). The objects of the Central and State Councils are to promote and protect the rights of the consumers such as, the right to be protected against the marketing of goods and services which are hazardous to life and property; the right to be informed about the quality, quantity, potency, purity, standard and price of goods or services, as the case may be so as to protect the consumer against unfair trade practices; the right to be assured, wherever possible, access to a variety of goods and services at competitive prices; the right to be heard and to be assured that consumer's interests

\footnotetext{
${ }^{2707}$ In terms of Section 89 of the FSSA, 2006 the provisions of the Act are to have effect notwithstanding anything inconsistent therewith contained in any other law for the time being in force or in any instrument having effect by virtue of any law other than this Act."

2708 This Act is discussed in more detail in section 9 below in relation to Unfair Trading Practices.

${ }^{2709}$ Preamble to The Legal Metrology Act, 2009.

${ }^{2710} \mathrm{http}: / / \mathrm{www} . \mathrm{metrologycentre.com/codes/acts.html.}$

${ }^{2711}$ http://ncdrc.nic.in/bare_acts/Consumer\%20Protection\%20Act-1986.html\# (accessed 5 November 2017).
} 
will receive due consideration at appropriate forums; the right to seek redressal against unfair trade practices or restrictive trade practices or unscrupulous exploitation of consumers; and the right to consumer education (sections 6 and 8 respectively).

The Act applies to all goods and services unless specifically exempted by the Central Government. It covers all sectors, private, public and co-operative. The Act allows damages to consumers, establishes simple, speedy and less expensive adjudicatory procedures and requires states to establish a Consumer Disputes Redressal Forum to be known as the "District Forum" and a Consumer Disputes Redressal Commission to be known as the "State Commission". It also provides for the establishment of a National Consumer Disputes Redressal Commission to be established by the Central Government (section 9). ${ }^{2712}$

\subsubsection{Competition Act $2002^{2713}$}

The Competition Act (CA) replaces the Monopolies and Restrictive Trade Practices Act 1969. The Act establishes the Competition Commission of India (section 8) and allows aggrieved persons to bring anti-competitive agreements (section 3) and instances of abuse of dominant position to the notice of the Commission (section 4). The underlying ethos of the Act, enunciated in its Preamble, is to prevent practices having adverse effect on competition, to promote and sustain competition in markets, to protect the interests of consumers and to ensure freedom of trade carried on by other participants in markets, in India. The Commission approaches all complaints filed before it with these objectives in mind and particularly focuses on ensuring consumer welfare. The Commission also has the power to take suo motu notice if it believes that circumstances warrant doing so (section 19). The Commission has the power to impose penalties if it finds a party to be engaged in anti-competitive practices or otherwise infringing the Act (section 27). In addition to addressing anti-competitive agreements and abuses of dominant position, the Commission also regulates mergers to ensure that these do not have an adverse effect on competition in the Indian markets. Until May 2017, appeals from orders of the Commission used to lie to the Competition Appellate Tribunal. However, these appeals now lie to the National Company Law Appellate Tribunal (NCLAT). Appeals from orders of NCLAT lie to the Supreme Court of India.

\subsection{Relevant Government Ministries, Departments and Regulatory Bodies}

The Indian food sector is governed by a number of government ministries, departments and regulatory that exercise their powers under the various laws referred to in the preceding section. The most significant ministries and the relevant departments and regulatory bodies, organised under these ministries, are as follows.

\subsubsection{Ministry of Agriculture and Farmers Welfare}

This Ministry comprises the departments of Agricultural Research and Education, Agriculture, Cooperation and Farmers Welfare and Animal Husbandry, Dairying and Fisheries. The Ministry is

2712 This Act is discussed more fully in section 9 in relation to Unfair Trade Practices.

2713 The Competition Act $2002 \quad$ (as $\quad$ amended $\quad$ in

http://www.cci.gov.in/sites/default/files/cci_pdf/competitionact2012.pdf (accessed 5 November 2017). 
engaged in the management and development of Indian agriculture. The Ministry's mandate includes evolving new strategies in the field of agriculture particularly through technological research. To this end, the Ministry manages the Indian Council of Agricultural Research, the Indian Agricultural Statistics Research Institute and the Indian Agricultural Research Institute. ${ }^{2714}$

The Ministry also administers a number of laws relating to the Input and Agriculture sectors through its various divisions and directorates which include the Crops Division (Directorate of Pulses Development, Directorate of Jute Development, Directorate of Rice Development, Directorate of Wheat Development, Directorate of Sugarcane Development, Directorate of Millets Development, Directorate of Tobacco Development and Directorate of Cotton Development); Integrated Nutrients Management Division, Technology Mission on Oilseeds \& Pulses Division and the Directorates of Oilseeds Development, Plant Protection, Quarantine and Storage. ${ }^{2715}$

\subsubsection{Ministry of Chemicals and Fertilisers}

This Ministry functions through two departments, the Department of Chemicals and Petrochemicals and the Department of Fertilisers. The Department of Fertilisers is particularly relevant for the food sector and concentrates in developing and promoting fertiliser industries. It comprises four divisions, the Fertiliser Projects and Planning Division, Fertiliser Imports, Movement and Distribution Division, Administration Division and Finance and Accounts Division. ${ }^{2716}$

\subsubsection{Ministry of Commerce and Industry}

This Ministry comprises two departments, the Department of Commerce and the Department of Industrial and Policy Promotion, both of which are mandated to work for the betterment of economic growth in the country. The ministry is divided into eight divisions and works through several different offices, boards, commissions and councils. The most relevant division from the perspective of the Food sector is the Export Products (Agriculture) Division which has the mandate to contribute towards formulating the Export Policy of Agriculture Products and also facilitating and promoting exports of agricultural and allied products (other than plantation crops like tea, coffee and spices and marine products). ${ }^{2717}$ This division also takes care of issues arising from Sanitary and Phytosanitary and Technical Barriers to Trade issues and Biotechnology matters. The Division also exercises administrative control over the Agricultural \& Processed Food Products Export Development Authority (APEDA); ${ }^{2718}$ the Coffee Board, Spices Board, Tobacco Board, the Cashew Export

\footnotetext{
2714 http://www.mapsofindia.com/government-of-india/central-government-ministries/ministry-of-agriculture.html (accessed 9th January 2017)

$2715 \mathrm{http}: / /$ goidirectory.nic.in/ministries_index.php?ct=1 (accessed 9th January 2017).

2716 http://www.mapsofindia.com/government-of-india/central-government-ministries/ministry-of-chemicalsFertilisers.html (accessed 9th January 2017).

${ }^{2717} \mathrm{http}: / /$ commerce.nic.in/DOC/InnerContent.aspx?Id=83. (accessed 5 November 2017).

2718 APEDA was established by the Central Government under the Agricultural and Processed Food Products Export Development Authority Act 1985. Government officers from many different Ministries are represented as Members in APEDA and it is responsible for export promotion and development of scheduled products including fruits, vegetables and their products, meat and meat products, poultry and poultry products, dairy products, confectionery, biscuits and bakery products, honey, jaggery and sugar products, cocoa and its products, chocolates of all kinds, alcoholic and nonalcoholic beverages, cereal and cereal products, groundnuts, peanuts and walnuts, pickles, papads and chutneys, guar gum, floriculture and floriculture Products, herbal and medicinal plants. APEDA is also responsible for monitoring the import of sugar. http://apeda.gov.in/apedawebsite/about_apeda/About_apeda.htm. (accessed 5 November 2017).
} 
Promotion Council of India (CEPCI) and the Indian Oilseeds \& Produce Export Promotion Council (IOPEPC). The Ministry also has administrative control of the Directorate General of Foreign Trade (DGFT). The DGFT was established in 1991 to express the commitment of the Government towards economic liberalization. ${ }^{2719}$ It is tasked to regulate and promote foreign trade in the country. In carrying out its mandate, the DGFT is required to take into consideration developments in international trade and to ensure India's compliance with its WTO obligations.

The Marine Products Export Development Authority is an autonomous body established in 1972 under the Ministry's Department of Commerce. It is responsible for the development of the marine products industry with special reference to exports. ${ }^{2720}$ Further, it is engaged in granting extension packages to fishermen, farmers and workers engaged in various stages of processing of marine products. The Authority also works to establish the presence of Indian seafood in major international markets by co-branding Indian products with major buyers and by marketing products abroad. The Authority also issues registration Certificates and Registration cum Membership Certificates (RCMC Certificates) on-line through its Regional Offices. It processes Subsidy Applications and disburses subsidies and conducts Lab testing over the computer. It has also introduced an e-procurement system.

The mandate of the Ministry of Commerce was recently expanded when on 24th May 2017 the Union Cabinet approved the phasing out of the Foreign Investment Promotion Board (FIPB), which had been established under the Ministry of Finance to clear applications for Foreign Direct Investment (FDI) in the retail sector in India. The relevant Government announcement stated that after abolishing of the FIPB, the work relating to processing of applications for FDI and approval of the Government thereon under the extant FDI Policy would be handled by the concerned Ministries/Departments in consultation with the Department of Industrial Policy \& Promotion (DIPP) of the Ministry of Commerce, which will also issue the Standard Operating Procedures for processing applications and decisions of the Government under the extant FDI policy. This move was undertaken to increase the flow of FDI to India. ${ }^{2721}$

\subsubsection{Ministry of Food Processing Industries}

The functions of the Ministry may be broadly classified under policy support and development activities. Policy support includes formulation and implementation of policies for Food Processing sector with overall national priorities and objectives and facilitating creation of an environment conducive for the healthy growth of the sector.

The development activities espoused by the Ministry include continued emphasis on creation of World Class Infrastructure for growth of Food Processing sector through Mega Food Parks, Integrated Cold Chain; modernization of abattoirs and providing assistance under various Plan

\footnotetext{
2719 http://dgft.gov.in/ (accessed 5 November 2017).

${ }^{2720} \mathrm{http}: / /$ commerce.nic.in/DOC/InnerContent.aspx $? \mathrm{Id}=219$.

${ }^{2721} \mathrm{http} / / /$ pib.nic.in/newsite/PrintRelease.aspx?relid=162097 (accessed 5 November 2017). The government of India has taken various initiatives to improve the retail industry in India. For example, it has allowed has allowed 100 per cent FDI in online retail of goods and services through the automatic route, thereby providing clarity on the existing businesses of e-commerce companies operating in India. It is also considering changing the FDI rules in food processing, in a bid to permit e-commerce companies and foreign retailers to sell Made in India consumer products. (http://www.mondaq.com/india/x/628322/Inward+Foreign+Investment/India+announces+new+Foreign+Direct+Invest ment+Policy+2017+2018) accessed 5 November 2017.
} 
Schemes to the sector; widening the $\mathrm{R} \& \mathrm{D}$ base in food processing by involving various $\mathrm{R} \& \mathrm{D}$ institutes and supporting various R \& D activities; Human Resource Development to meet the growing requirement of managers, entrepreneurs and skilled workers in the food processing industry; assistance for setting up analytical and testing laboratories and active participation in the laying down of food standards and their harmonization with international standards and continuation of intensive consultation with industry, academia, scientists and representatives of state governments for smoother and inclusive growth of the sector. ${ }^{2722}$ Most recently, the Ministry has launched the World Food India initiative.

\subsubsection{Ministry of Consumer Affairs, Food and Public Distribution}

This Ministry is responsible for the equitable spread of essential edible commodities at fair monetary values. It comprises the Department of Consumer Affairs and the Department of Food and Public Distribution. The Department of Consumer Affairs controls, among others, the Bureau of Indian Standards, ${ }^{2723}$ the National Consumer Co-operative Federation and the National Consumer Disputes Redressal Commission whereas the Department of Food and Public Distribution performs the task of managing the food distribution system in India with the prime objective of setting up and managing a fair commodity pricing system for farmers. The Department also administers the Public Distribution System, which distributes essential commodities such as rice, wheat, kerosene and sugar through a nation wide network of Fair Price Shops. The Food Corporation of India reports to this Department.

The Department of Food and Public Distribution is also tasked to ensure food security for the country through timely and efficient procurement and distribution which includes the procurement of food grains, building up and maintenance of food stocks, their storage, movement and delivery to distributing agencies and monitoring their production, stock and price levels. ${ }^{2724}$ The Department aims to give incentives to farmers by offering them fair value of their produce under the Minimum Support Price Mechanism, distributing food grains to families living below the official poverty line and by insuring poor households against the risk of hunger under Antyodaya Anna Yojana (AAY) programme, establishing grain banks in food scarce areas and involving Panchayati Raj Institutions in the Public Distribution System.

The policy objectives of this Department are to implement the National Food Security Act, 2013, to undertake price support operations through efficient procurement of wheat, rice and coarse grains, to strengthen the Targeted Public Distribution Systems, to develop and promote the sugar industry, to develop warehousing sector and improve public service system. ${ }^{2725}$ To this end, the Department formulates sugar policy and fixes the Fair and Remunerative Price (FRP) of sugarcane payable by Sugar factories. It develops and regulates the sugar industry with particular focus on technology. The Department also formulates policies for the import and export of food grains and edible oils.

\footnotetext{
2722 http://mofpi.nic.in/about-us/goals-and-roles (accessed 5 November 2017).

${ }^{2723}$ The Bureau of Indian Standards (BIS) is a standard setting organization formed under the Bureau of Indian Standards Act 1986. It is the national standards body in India and works towards the harmonious development of standardization, marking and quality certification. There are several food items, which are under the mandatory certification of BIS, like milk products, infant milk substitute, packaged drinking water, complementary foods, and hexane - food grade. http://www.bis.gov.in (accessed 5 November 2017).

${ }^{2724}$ http://dfpd.nic.in/about-us.htm. (accessed 5 November 2017).

2725 http://dfpd.nic.in/vision-mission.htm. (accessed 5 November 2017)
} 
In 2014, the Government set up a High Level Committee under Mr. Shanta Kumar (Union Minister of Consumer Affairs and Public Distribution from 1999 to 2002) to suggest restructuring or unbundling of the Food Corporation of India with a view to improve its operational efficiency and financial management. The Government also asked the Committee to suggest measures for overall improvement in management of foodgrains by the Food Corporation; to suggest reorienting its role and functions of in Minimum Support Price operations, storage and distribution of foodgrains and food security systems of the country; and to suggest cost effective models for storage and movement of grains and integration of supply chain of foodgrains in the country. ${ }^{2726}$

\subsubsection{The Ministry of Health and Family Welfare}

This Ministry is relevant from the point of view of the Food sector as it has been designated as the relevant ministry for administering the Food Safety and Standards Act 2006 through the Food Safety and Standards Authority of India (FSSAI) established under the FSSA. The main purpose of FSSAI is to stipulate scientific standards for food items and to regulate their manufacture, storage, distribution, sale, and import to ensure availability of safe and wholesome food for human consumption. ${ }^{2727}$ The national level authority has its head office in Delhi and the State Food Safety Authorities enforce provisions of the Act at the state level.

\subsubsection{Ministry of Corporate Affairs}

This Ministry is relevant for being the nodal ministry for the Competition Commission of India and for administering the Competition Act 2002 under which the Commission has been established.

\subsection{Categories of Regulation and their Impact}

\subsubsection{Categories of Regulation}

\subsubsection{Private Regulation}

Private regulation emerged in India as a response to international developments and the inability or incapacity of public bodies to cater to these. Some of these private regulations had their genesis in consortia while others emerged from the efforts of the NGOs and civil society groups. Regardless, however, a great many of these private regulations, especially those developed by the corporate sector, are primarily market-oriented and designed to address the level of economic development in the country. For example, regulations governing the Indian wet retail market may not be adequate according to US consumption standards however, these are considered appropriate from the point of view of Indian consumers because anything more stringent would render the products too expensive for their consumption. There is also some disparity between regulations for products intended for domestic consumption and export products. Whilst regulations adopted in respect of products intended for domestic consumption tend to be designed keeping in mind the ultimate affordability of

\footnotetext{
${ }^{2726}$ Report of the High Level Committee on Reorienting the Role and Restructuring of Food Corporation of India (C 2015 http://fci.gov.in/app2/webroot/upload/News/Report\%20of\%20the\%20High\%20Level\%20Committee\%20on\%20Reorie nting\%20the\%20Role\%20and\%20Restructuring\%20of\%20FCI_English_1.pdf (accessed 7 November 2017). ${ }^{2727}$ http://fssai.gov.in/home (accessed 5 November 2017).
} 
the products, those adopted in respect of products intended for the export market are more likely to conform to international standards. ${ }^{2728}$

\subsubsection{Government Regulation}

The Government is the most significant source of regulations for the Indian food sector. The regulatory requirements prescribed by the Government pertain, among other things, to the procurement of various licenses and permits with regard to business operations of persons and entities engaged at different stages of the food sector, particularly in respect of exports and imports. In recent years, the Government has also prescribed safety and quality standards, however, as in the case of private regulation, the regulations prescribed by the Government are not at the level of regulations prevailing in industrialized economies. Further, the effectiveness of even these Government regulations remains doubtful due to inadequate and/or cumbersome implementation infrastructure. ${ }^{2729}$ The Maggi Noodles case is an interesting example of lack of enforcement of food safety standards. In 2015, the FSSAI banned Maggi Noodles from the Indian market after finding excessive lead in them, there was some evidence that a large number of people still continued consuming these noodles. ${ }^{2730}$

In the food export sector, the Government has allowed the foreign partners of export oriented Indian companies to set the standards. Although this has resulted in high profits for certain Indian food exporters it has also meant that the standards are not uniform throughout the sector and India's inability to comply with international food safety standards has impeded food exports from India. ${ }^{2731}$

\subsubsection{Impact of Regulations}

The impact of regulations depends on large measure on the ability and capacity of the relevant regulatory institutions to enforce these regulations. However, there are certain factors that even though are extraneous to the regulatory institutions, have nevertheless the power to obstruct if not altogether block their actions.

\subsubsection{Courts and Regulation}

In exercise of their powers of judicial review and in the wake of "judicial activism" in India, Indian courts, have recommended amendments to legislation, at times suggesting specific regulatory measures that may be adopted while at other times issuing policy advice and requiring concrete

\footnotetext{
${ }^{2728}$ Rajesh Mehta 'International Food Safety Standards and India's Food Exports- An Analysis Based on Gravity Model Using Three-Dimensional Data’ Discussion Paper \# 169 (C) Research and Information System for Developing Countries 2010.

${ }^{2729}$ FICCI Report on Food Safety and Standards Act- Challenges in the Implementation of the Act, 2006, Food Defense Awareness Workshop, February 2013, http://ficci.in/events/21353/ISP/7th8th\%20workshop\%20on\%20challanges\%20of\%20FSSA-2006\%20at\%20Jaipur.pdf; FICCI Food Retail Chain Report, http://www.ficci.in/events/21274/ISP/finalfoodRetailChainReport.pdf.

${ }^{2730}$ Nestle's Maggie noodles still had $10.9 \%$ of market share after the ban and after the company called off its products from the market. "Maggi regains top spot in noodles market with 57\% share in June", live Mint, August 23, 2013, http://www.livemint.com/Companies/yjum6G5Wnr29NPb8p9TpgN/Maggi-regains-top-slot-in-noodles-market-with57-share-in-J.html.

${ }^{2731}$ International Food Safety Standards and India's Food Exports- An Analysis Based on Gravity Model Using ThreeDimensional Data, Rajesh Mehta, September 2010, Research and Information System for Developing Countries.
} 
administrative actions in pursuance of such advice. ${ }^{2732}$ Further, in some cases, the Supreme Court of India has also issued directions to the concerned central authorities with regard to proper implementation of regulations and has suggested strategies for doing so. ${ }^{2733}$ The Supreme Court of India has also maintained that the food value chain related laws have to be interpreted in light of the relevant provisions of the Indian Constitution. ${ }^{2734}$

The 2015 decision of the Indian Supreme Court in an appeal filed before it by the Food Safety and Standards Authority of India (FSSAI) against the decision of the Bombay High Court is an important example of the role that Courts may play with regard to enforcement of regulations. In 2013 FSSAI had issued an advisory issued by that asked manufacturers to get recipe-by-recipe clearance for their products even if the ingredients were already approved or deemed safe. Under the regime prior to this advisory, manufacturers were only required to obtain product approval if they were adding a new ingredient or introducing an additive. However, the 2013 advisory broadened the requirement of approval to cover all products even if they were using approved ingredients or additives within permissible limits. The Maharashtra-based Vital Nutraceuticals and the Indian Drug Manufacturers' Association challenged this advisory before the Bombay High Court. However, in its 2014 decision the Bombay High Court struck down the advisory on the ground that FSSAI did not have the authority to issue such an advisory without following due process. ${ }^{2735}$ FSSAI appealed to the Supreme Court, however, the Supreme Court also dismissed FSSAI's product approval mechanism and agreed with the Bombay High Court that FSSAI did not have the authority to issue advisories without following the procedure provided for framing regulations as prescribed under the FSSA. Subsequently, FSSAI announced that it would not longer continue with the product approval system prescribed in the advisory. Although certain industry observers hoped that new regulations that FSSAI may make in this regard would bring India closer to the global practice where companies do not require approval from regulators to launch a product, while also paving the way for adopting the international practice of registration of food processing enterprises and setting up a random inspection system others were concerned about the uncertainty that may result due to discontinuation of the advisory. ${ }^{2736}$

At the time of writing this, the Supreme Court is also hearing an appeal in respect of the Maggi Noodles case. ${ }^{2737}$ Nestle India had challenged FSSAI's order banning Maggi Noodles for containing excessive lead before the Bombay High Court. ${ }^{2738}$ In its 2015 decision, Bombay High Court ruled in favour of Nestle arguing that FSSAI had acted hastily in banning the noodles and had directed Nestle to have the noodles tested from several laboratories. In June 2017, Nestle started selling the noodles again after obtaining satisfactory results from these lab tests. However, in July 2017 FSSAI moved

\footnotetext{
${ }^{2732}$ Swami Achyutan and Tirth \& Ors vs Union Of India \& Ors (Writ Petition (C) No. 159 OF 2012; decided on August 5, 2016).

${ }^{2733}$ Centre For Public Interest Litigation vs Union Of India \& Ors (Writ Petition (C) No. 681 OF 2004 (decided on 23 October 2013), para 24.

2734 Ibid,para 22.

2735 https://economictimes.indiatimes.com/news/politics-and-nation/supreme-court-junks-fssai-plea-against-bombayhigh-court-order-on-2013-advisory/articleshow/48545611.cms (accessed 5 November 2017).

2736 http://www.livemint.com/Politics/Zdb1HmUtuCIjP3tHAGa6mL/FSSAI-scraps-product-approvals-after-SCquestions-procedure.html (accessed 5 November 2017).

2737 See n. 2730.

${ }^{2738}$ WPL No. 1688 of 2015 Nestle India Limited v Food Safety and Standards Authority of India and others.
} 
the Supreme Court against the order of the Bombay High Court. It will be interesting to see how the Supreme Court reacts in this regard. ${ }^{2739}$

\subsubsection{Other Factors Affecting the Impact of Regulation}

The regulatory framework of the contemporary Indian food sector suffers from various anomalies, with the result that incentives available to private players in the food sector are not always in alignment with public and social policy. ${ }^{2740}$ The situation is exacerbated by the legal and regulatory framework, which, until recently, imposed too many hurdles in the way of entry for new entrants. ${ }^{2741}$ An important reason for this gap between the regulatory framework and the social realities and priorities of the country is that the regulatory framework although ostensibly 'made in India', is mostly 'imported' from other countries or international standard setting organisations without the required degree of attention to the indigenous realities and needs of the country. ${ }^{2742}$ India also adopted a considerable amount of regulation due to its membership of the WTO and the need to remain in compliance with the international obligations imposed by it rather than due to an indigenous demand for the regulation. This externally dictated regulation has remained under utilized in the country if not altogether ignored.

Interestingly, alongside borrowing regulations from elsewhere, policy makers in India are also working on expanding the scope of food value chain related regulations at a considerable pace and to encompass issues such as the price of farm output and input, setting safety and risk assessment standards etc. This approach towards food regulation is not without its consequences: for instance, Monsanto threatened to leave India and also withdrew the application it had filed before the Genetic Engineering Appraisal Committee (GEAC) $)^{2743}$ in terms of which it was seeking approval for its next generation Roundup Ready cotton seeds technology, citing uncertainties in business and regulatory environment as its reasons for doing so particularly in the wake of intervention on the part of the Indian government in setting not only Maximum Sale Price of Bt Cotton seeds but also the price of its components namely Seed Value and Trait Value. ${ }^{2744}$

Whilst the government withdrew the price setting notification under pressure from the biotech body Association of Biotechnology Led Enterprises (ABLE-AG) whose members include Monsanto, Mahyco, Bayer, Syngenta, DuPont Pioneer etc., ${ }^{2745}$ the Order issued by it in exercise of its powers under section 3 of the Essential Commodities Act 1955 to 'provide an effective system for fixation

2739 http://www.livemint.com/Companies/1JKHsutTXLWtTcVwdIDg0H/The-Maggi-ban-How-Indias-favouritetwominute-noodles-lost.html and http:/food.ndtv.com/food-drinks/fssai-moves-supreme-court-against-lifting-ban-onmaggi-noodles-1244235 (accessed 8 November 2017).

2740 Shahidur Rashid, Ashok Gulati, Ralph Cummings Jr. (ed) From Parastatals to Private Trade: Lessons from Asian Agriculture (C) 2008 International Food Policy Research Institute http://base.dnsgb.com.ua/files/book/Agriculture/Business-in-Agriculture/From-Parastatals-to-Private-Trade.pdf (accessed 5 November 2017).

${ }^{2741}$ Doing Business in India: 2015 Commercial Guide for US Companies, US and Foreign Commercial Service and US Department of State, 2015. http://photos.state.gov/libraries/india/13974/PDFS/2015CCG.pdf. (accessed 5 November 2017).

${ }^{2742}$ See Agricultural Legislations, http://www.icar.org.in/files/Agril-Legislation.pdf, February 28, 1976 at page 31.

${ }^{2743}$ Genetic Engineering Appraisal Committee (GEAC) is responsible for the approving the production, sale, import and use of substance and products that contain genetically engineered or modified organisms.

${ }^{2744}$ Cotton Seed Price (Control) Order, 2015. Also see n. 2685.

2745 Notification S.O.1813(E) dated May 18, 2016, Department of Agriculture, Cooperation \& Farmers Welfare, Ministry of Agriculture \& Farmers Welfare Government of India. 
of maximum sale price of cotton seeds to ensure their availability to the cotton farmers at uniform as well as fair, reasonable and affordable prices' still remains in force. ${ }^{2746}$

Domestic politics also plays a role in the impact of regulation. India often resorts to politically inspired policy instruments to address socio-economic distortions arising from the implementation of weak and largely ineffective regulatory framework in the food sector. However, in doing so, efficiency of the food sector is compromised on the altar of political expediency. Further, the drafting of policy instruments is mostly entrusted to the Indian bureaucracy, which has limited technical knowledge of the subjects in question and is even otherwise considered to be hampered by a certain degree of inefficiency and even corruption. ${ }^{2747}$

For the food sector regulatory framework to achieve its goals in India, it is necessary for the government to set aside sufficient resources for regulatory authorities entrusted with the task of implementing this framework and to allow for the judicious and efficient use of these resources. ${ }^{2748}$

\subsection{Stakeholders in Food Sector Regulation in India}

The dynamics of policy-making and legislation involve a variety of stakeholders who have a vested interest in advancing their particular concerns and demands through the power corridors in the Parliament. ${ }^{2749}$ The number of stakeholders along the food value chain is ever increasing. ${ }^{2750}$ From research laboratories where new food technologies take birth to the farm and then to the table a diverse group of people become engaged with the food value chain and bring their expertise, influence and preferences to bear on the manner in which the chain functions. The three most important stakeholders in the Indian food sector are farmers, food processors/manufacturers and consumers. This section examines the situation of each of these stakeholders and highlights their concerns.

\subsection{1. $\quad$ Farmers}

A review of policy debates, both inside and outside of the Parliament as well as newspaper reports indicates that all public, social and economic discourse is farmer centric. In addition to the rhetoric, the Government has taken considerable measures to improve the economic and social condition of the farmers by launching ICT initiatives.

At the Central Government level plans included alternate delivery channels spanning Rural Knowledge Centres (RKCs), ICT-based extension, farmer-to- farmer extension, and simultaneous promotion of NGOs and the private sector. The scheme--'Mass Media Support to Extension' aims to utilize the television and radio infrastructure for producing and broadcasting agricultural programmes

\footnotetext{
${ }^{2746}$ Gazette Notification No. G.S.R.936(E) dated 07-12-2015 under section 3 of the Essential Commodities Act, 1955.

${ }^{2747}$ Doing Business in India: 2015 Commercial Guide for US Companies, US and Foreign Commercial Service and US Department of State, 2015. http://photos.state.gov/libraries/india/13974/PDFS/2015CCG.pdf; UK Department of International Trade 2016 https://www.gov.uk/government/publications/exporting-to-india/exporting-to-india. (accessed 5 November 2017).

2748 FSSAI to invest Rs500 crore to upgrade labs, will partner with private firms, live Mint, April 15, 2016, http://www.livemint.com/Companies/1nveH8rGscyryXWSicxQzM/FSSAI-to-invest-Rs500-crore-to-upgrade-labs-willpartner-wi.html.

${ }^{2749}$ Rahul Sharma, A Case For Lobbying, The Hindu, May 30, 2013 http://www.thehindu.com/opinion/op-ed/a-case-forlobbying/article4763497.ece.

${ }^{2750}$ Competition and Regulation in India, 2009 - Leveraging Economic Growth Through Better Regulation, Pradeep S Mehta, CUTS International.
} 
for supporting other extension efforts. Further, in order to promote e-governance in agriculture at the centre and provide support to states/UTs for the same, the Department of Agriculture and Cooperation is implementing a central sector scheme, 'Strengthening/Promoting Agricultural Information Systems'. ${ }^{2751}$

At the State level perhaps the most significant initiative as been the 'E-Choupal'Initiative' which makes use of the physical transmission capabilities of current intermediaries - aggregation, logistics, counter-party risk and bridge financing with a blend of click \& mortar capabilities, village internet kiosks managed by farmers themselves, to enable the agricultural community to access ready information in their local language on the weather $\&$ market prices, disseminate knowledge on scientific farm practices \& risk management, facilitate the sale of farm inputs and purchase farm produce from the farmers' doorsteps .'E-Choupal' services today reach out to more than 3.5 million farmers growing a range of crops - soyabean, coffee, wheat, rice, pulses, shrimp - in more than 38,000 villages through nearly 6500 kiosks across nine states namely Madhya Pradesh, Haryana, Uttaranchal, Karnataka, Andhra Pradesh, Uttar Pradesh, Maharashtra, Rajasthan and Kerela. ${ }^{2752}$

Regardless, however, the economic and social condition of farmers in India fails to improve if it does not actually deteriorate. The Indian farmer gets the least share of the retail price of the food product paid by the end consumer even though it is the farmer who provides the basic food item, which is later processed for end consumption. ${ }^{2753}$ The reasons for the powerlessness of farmers despite their numbers and significance in the food value chain are manifold. India has approximately $159,591,855$ hectares of agricultural land divided into 138,348,461 land holdings. ${ }^{2754}$ This means that approximately $90 \%$ of farmers in India have less than two hectares of land to their name. ${ }^{2755}$ The fragmentation of land is compounded by lack of awareness and education and financial stress, which makes the farmer the most vulnerable stakeholder in the Indian food value chain. ${ }^{2756}$ The small size holdings also imply that individual farmers exercise very low bargaining power when it comes to lobbying and asserting their rights before the Government. Farmers also have low bargaining power with respect to private sector corporations due to almost zero holding capacity, low to non-existent financial reserves for sustenance, limited access to the market, knowledge and information vacuum and, in some cases, due to the perishable nature of their produce and absence of affordable storage facilities.

The problems faced by farmers in India are exacerbated by the fact that more than half of India's agricultural households are debt ridden, with $42 \%$ of them owing money to the banking

\footnotetext{
${ }^{2751}$ Bibhu Santosh Behera, T.K.Das, ,K.J., Jishnu, R.A.Behera, A.C.Behera, S.Jena 'E-Governance Mediated Agriculture for Sustainable Life in India' Procedia Computer Science 48 (2015) 623 - 629.

2752 Ibid.

2753 See The Statement of Managing Director, Gujarat Co-operative Milk Marketing Federation Ltd, which owns the Amul brand in 'Amul says FDI in retail will hurt farmers', The Hindu, December 4, 2011 http://www.thehindubusinessline.com/economy/agri-business/amul-says-fdi-in-retail-will-hurtfarmers/article2687070.ece.

2754 Statistics from Indian Government Census with 2010-2011 as reference year. http://agcensus.dacnet.nic.in/NL/nettabledisplay2a.aspx.

${ }^{2755}$ National Sample Survey Office (NSSO) 70th Situation of Agricultural Households in India, http://mospi.nic.in/mospi_new/upload/KI_70_33_19dec14.pdf.

${ }^{2756}$ See International assessment of Agricultural Knowledge Science And Technology for Development, 2009, Global Report, Mcntyre Baverly etc. al. Washington D.C. USA.
} 
institutions and $26 \%$ to conventional moneylenders. ${ }^{2757}$ In many situations, farmers are forced to sell their produce at a price, which is lower than the cost of the production simply to make ends meet.

In addition to the ICT initiatives, the Government has sought to help farmers through setting of minimum support price (MSP) and by procurement by Government agencies. The rationale of the MSP is to ensure that farmers are not compelled to sell their produce below support price either due to exploitation by large market players or due to a bumper harvest. The MSP is effective mainly for four crops: wheat, paddy, cotton (modestly) and sugarcane (for which mills are legally obligated to buy cane from farmers at prices fixed by government). However, the impact of MSP and procurement varies from State to State and its actual benefit to farmers remains fluctuating at best. ${ }^{2758}$ India has also enacted the Right to Fair Compensation and Transparency in Land Acquisition, Rehabilitation and Resettlement Act 2013. Although the avowed aim of the Act is to provide just and fair compensation to the affected families whose land has been acquired, or is proposed to be acquired, or families that are affected by such acquisition, it is argued that the Act favours landowners to the detriment of impoverished landless farmers. ${ }^{2759}$

India also has an endemic farmer suicide problem. A large number of qualitative studies, argue that the liberalization of the agricultural sector in the early-1990s led to an agrarian crisis which rendered farmers with certain socioeconomic characteristics-cash crops cultivators, with marginal landholdings, and debts-particularly vulnerable to the risk of committing suicide. A 2014 study of farmer suicides in India suggested clear policy implications: it suggested that if the State were able to reduce the proportion of marginal farmers, cash crops, or indebted farmers by one per cent, the suicide rates-suicides per 100,000 per year- would be reduced by $0.437,0.518$ and 0.549 respectively, when all other variables are held constant. The study also noted that despite more than six decades of trying, the majority of Indian States have been unable to enact meaningful land reforms, largely because of the strength of the rural elite at the local level. It, therefore, suggested that while redistribution of land is a desirable policy prescription, it is perhaps not a realistic one. It argued that State interventions to stabilize the price of cash crops and relieve indebted farmers may be more effective at reducing suicide rates in India. ${ }^{2760}$

An important factor in the continued occurrence of farmer suicides is that agriculture is no longer considered a viable occupation. Farmers often need loans to run their farms and find themselves unable to repay these loans. ${ }^{2761}$ The Intelligence Bureau has suggested termed loan waiver and relief packages for farmers to ease their situation. However, it is unlikely that credit facilities alone would ease the farmers' general situation. Furthermore, farmers in India often choose private moneylenders in order to procure easy loans. These moneylenders charge interest at the rate of $25 \%$ to $50 \%$, which then becomes impossible for farmers to repay. The Intelligence Bureau has also

\footnotetext{
2757 The Hindu, More than 50\% of farm households in debt, 27 June 2015, http://www.thehindu.com/news/national/morethan-50-of-farm-households-in-debt/article6711414.ecehttp://www.thehindu.com/news/national/more-than-50-of-farmhouseholds-in-debt/article6711414.ece.

2758 Shoumitro Chatterjee, Divesh Kapoor 'Understanding Price Variation in Agricultural Commodities in India: MSP, Government Procurement, and Agriculture Markets' (C) India Policy Forum July 12-13, 2016 http://www.ncaer.org/events/ipf-2016/IPF-2016-Paper-Chatterjee-Kapur.pdf (accessed 5 November 2017).

${ }^{2759}$ Samanta, D., \& Shireesh 'Social Impact Assessment of Projects involving Land Acquisition in India: Implications of RFCTLARR Act, 2013'. Journal of Management and Public Policy, (2015). 7(1), 27-35.

${ }^{2760}$ Kennedy and King Globalization and Health 2014, 10:16 http://discovery.ucl.ac.uk/1468922/1/1744-8603-10-16.pdf (accessed 5 November 2017).

2761 Intelligence Bureau Report December 19, 2014; See Aman Sharma, December 23, 2014 Economic Times at http://economictimes.indiatimes.com/news/politics-and-nation/intelligence-bureau-raises-red-flag-on-farmer-suicidesin-its-report-to-pmo/articleshow/45610775.cms.
} 
pointed out that the farmer suicide rates are higher for farmers who cultivate crops that need high financial investment (in seeds and fertilisers etc.) to produce high yields. ${ }^{2762}$ The situation of the farmers is detrimental to agriculture itself as outstanding loans and rising debt leads to low crop yield, poor procurement rate of crops and successive crop failure.

Contract farming has often been offered as a solution to the dire straits Indian farmers find themselves in. However, the extent to which contract farming may improve the lot of the farmers is unclear. In 1989, PepsiCo started the trend of contract farming in India by engaging in tomato farming in Hoshiarpur, Punjab. However, this experiment proved to be disastrous. ${ }^{2763}$ It was also widely believed that "contract farming actively promoted through change of law will mean that the farmer loses his independence and rights over the land." ${ }^{2764}$ Further, given the very low bargaining power of farmers India, it is likely that companies will either force one-sided contracts on them or will fail to honor the commitments made in these contracts. ${ }^{2765}$ Needless to say it would be difficult, if not impossible for farmers to enforce contracts against companies due to their lack of power and the exorbitant legal cost such an action is likely to entail. ${ }^{2766}$

\subsubsection{Food Processors and Manufacturers}

Indian food processors assert their rights and issues through the All India Food Processors' Association (AIFPA), which was established in 1943 by highly motivated and visionary food processors engaged mainly in processing fruits and vegetables. Subsequently, AIFPA expanded to include food processors from other sectors of the industry and now includes a cream of processors involved in processing of fruits \& vegetables, meat and poultry, fish, milk \& milk products, cereals and pulses manufacture of a wide range of food products such as juices and nectars, jams and jellies, breads, biscuits and confectionery, various milk products, ready-to- eat foods, sweets and confectionery, various ethnic delicacies etc. Member food processors account for a large percentage of the total production of the food processing industry in India as well as that of total exports of processed food products.

AIFPA's objectives include the promotion, encouragement and support of the Indian Food Processing Industries and raising the industry's technical standards, product quality and safety to match global standards; active participation in evolving quality standards \& safety measures under the Food Safety and Standards Act 2006, and seeking redressal of the problems of the food industry that impedes their growth and development. AIFPA is duly recognized by the Government as a nodal agency and interacts closely with various government bodies, such as the Union Ministry of Food Processing Industries; Union Ministry of Health \& Family Welfare; Union Ministries of Finance, Agriculture, Commerce and Civil Supplies; National Horticulture Board (NHB), Ministry of Agriculture, Govt. of India; Agricultural and Processed Food Products Development Authority

\footnotetext{
2762 Government of India, Ministry of Home Affairs, Lok Sabha, Un-starred Question No. 107, 24.022015 http://mha1.nic.in/par2013/par2015-pdfs/ls-240215/107.pdf.

${ }^{2763}$ Lok Sabha Debate, Lok Sabha Debates Further Discussion Regarding Widespread Distress Among The Farmers ... on 24 August, 2006 an> Title: Further discussion regarding widespread distress among the farmers in the country raised by Shri Mohan Singh on the 17th August, 2006.

2764 Ibid.

${ }^{2765}$ Aloy Dutta et al., A Case Study of Pepsico Contract Farming For Potatoes, IOSR Journal of Business and Management, PP 75-85, 2016

2766 Ibid.
} 
(APEDA), Ministry of Commerce, Govt. of India; Bureau of Indian Standards (BIS) \& its variations sectional committees on subjects affecting the industry; Empowered Committee of State Finance Ministers on Value Added Tax (VAT), GST etc. and Quality Council of India. ${ }^{2767}$

Certain foreign and domestic groups also exert considerable influence in the food processing industry. Some of the most successful conglomerates in the Indian Food Processing Industry include:

a) Indo Nissin Foods Ltd. Nissin Food entered India in 1988 through a joint venture with Brooke Bond India Ltd. (Brooke Bond later merged with Hindustan Unilever Limited 'HUL') to form Indo Nissin Foods Ltd. However, the agreement was terminated in 1998 and HUL pulled out its stake from the company and discontinued the distribution of Indo Nissin products. Nissin Food then decided to distribute the products through Marico Industries. Nissin Food manufactures noodles and a variety of home foods. 'Top Ramen' is its most significant brand in India with approximately 20 per cent market share in the instant noodle market. Indo Nissin uses the technology of its parent company for manufacturing its products. The company's production facilities are located near Delhi and in Bangalore.

b) Perfetti Van Melle India. This is a 100 per cent subsidiary of the global conglomerate and started operations in India in 1992 by setting up its factory. It launched its first brand in the Indian market in 1994. It leads the Indian sugar confectionery market with more than 25 per cent of the value share of the market. In the last 12 years, the company's portfolio has grown from a single brand to 15 brands. The company strives to leverage the international brand portfolio in India, while adapting flavors and blends to suit local tastes.

Domestic players in this industry include Dabur India Limited (fruit juice, cooking pastes, coconut milk, tomato puree, lemon drink, chilli powder and honey); Gits Food Products Pvt. Ltd. (sweet mix, namkeens, snack mix meal mix, pure ghee, dairy whitener and milk powder); Godrej Industries Ltd. (edible oils, vanaspati, bakery fats, fruit drinks, fruit nectar, fruit juices and tomato puree); Haldiram Marketing Pvt. Ltd. (sweets, namkeens, syrups, crushes, chips and papads); MTR Foods Ltd. (readyto-Eat curries and rice, Ready-to-Cook gravies, frozen foods, ice creams, instant snack and dessert mixes, spices such as turmeric, coriander, black pepper, pickles and papads); Parle Agro Private Ltd. (fruit drinks and mineral water); Milkfood (milk powder, baby food, cheese and other milk products).

Significant overseas players in the industry are Hindustan Unilever Limited (tea, instant coffee, biscuits, ice-creams, salt, wheat flour, instant drinks, soups, jam and squash); Britannia Industries Ltd. (biscuits, flavored milk, dairy whitener, ghee, bread, cake and rusk); Agro Tech Foods (wheat flour, edible oil, vanaspati, popcorn, french fries and green peas); ITC Ltd. (wheat flour, salt, ready-to-eat meals, biscuits, confectioneries, snacks and cooking paste); Nestle India Pvt. Ltd. (instant coffee, condensed milk, dairy whitener, infant food, chocolates and confectioneries); Pepsico India Holdings (soft drink, fruit juice and chips); Cadbury India Ltd. (chocolates, hard boiled confectionery, malt foods, cocoa powder). ${ }^{2768}$

Some of the major investments in this sector in the recent past are:

\footnotetext{
2767 http://www.aifpa.net (accessed $15^{\text {th }}$ May 2017)

${ }^{2768}$ This information is derived from report on Food Processing Market and Opportunities prepared by KPMG for India Brand Equity Foundation and issued by IBEF. https://www.ibef.org/download/Food_Processing_270608.pdf (accessed 15th May 2017).
} 
a) US-based food company Cargill Inc, aims to double its branded consumer business in India by 2020 , by doubling its retail reach to about 800,000 outlets and increasing its market share to become national leader in the sunflower oil category which is likely to make the company be among the top three leading brands in India

b) Mad Over Donuts (MoD), outlined plans of expanding its operations in India by opening nine new MoD stores by March 2017.

c) Danone SA plans to focus on nutrition business in India, by launching 10 new products in 2017, and aiming to double its revenue in India by 2020 .

d) Uber Technologies Inc. plans to launch UberEATS, its food delivery service in India, with investments made across multiple cities and regions.

e) Di Bella, the Australia-based coffee chain, plans to invest Rs 67 crore (US\$ 10 million) for setting up 20 new outlets in Mumbai, besides entering Delhi and Bangalore by 2017.

f) KKR \& Co LP, the US-based private equity firm, plans to invest about Rs 520 crore (US\$ 77.38 million) in the dairy company Kwality Ltd, which will be used to strengthen its milk procurement infrastructure and increase processing capacity.

g) Henry Ford Health Systems (HFHS), a US-based health and wellness group, plans to enter India by signing a franchise partnership with Chandigarh-based hospitality and food services firm KWalls Hospitality, and setting up 'Culinary Wellness' branded stores across the country.

h) Mondelez International, the US-based confectionery, food, and beverage major, inaugurated its new manufacturing plant in Andhra Pradesh which is valued at Rs 1,265 crore (US\$ 190 million), with an annual production capacity of 250,000 tonnes.

i) Pure Circle, a Malaysia-based natural sweetener producer, plans to invest around Rs 1,300 crore (US\$ 200 million) in India to set up a manufacturing plant and make the country its regional production and export hub in the next five years.

j) Swiggy, a food delivery start-up owned by Bundl Technologies Private Limited, has raised Rs 230.34 crore (US\$ 33.80 million) in a Series $C$ funding round, with its existing investors SAIF Partners, Accel Partners, Norwest Venture Partners and Apoletto Asia Ltd contributing 79 per cent of the new funds raised.

k) Gujarat Cooperative Milk Marketing Federation (GCMMF), popularly known as 'Amul', plans to invest Rs 5,000 crore (US\$ 733.6 million) to establish ten new processing plants as well as expand the current capacity to touch 32 million litres per day (MLPD) capacity by 2020 .

1) Private Equity (PE) firm India Value Fund Advisors (IVFA) plans to invest around US\$ 100-150 million in the food business in India over the next two years.

m) Zomato, a restaurant search and discovery platform, has raised US\$ 60 million from the Singapore government-owned investment company Temasek, along with existing investor Vy Capital, in order to explore new business verticals.

n) ITC Limited plans to invest Rs 800 crore (US\$ 117.4 million) to set up a world-class food processing facility in Medak, a district located in Telangana. The company has also formulated plans to enter the dairy market. ${ }^{2769}$

o)

${ }^{2769}$ https://www.ibef.org/industry/indian-food-industry.aspx (accessed 15th May 2017). 


\subsubsection{Consumers}

Indian consumers may make their presence felt through consumer organisations that are essentially advocacy groups seeking to protect people from corporate abuse including unsafe products, predatory lending, false advertising, astro-turfing and pollution. Consumer organisations exert pressure via protests, campaigning or lobbying. They may engage in single-issue advocacy or set themselves up as consumer watchdogs. Consumer organizations have also operated in the area of food safety. However, campaigning in this area is complicated since scientific, dietary or medical evidence is normally more complex than in other arena. Whilst the aim of consumer organizations may be to establish and to attempt to enforce consumer rights, these have also been effective simply by using the threat of bad publicity to keep companies' focus on the consumers' point of view. Some of the most significant consumer organisations in India are:

\subsubsection{CERC (Consumer Education and Research Centre)}

This is the leading consumer rights organisation in India and is set up as a non- profit, nongovernment body, dedicated to the protection and promotion of consumer interests through active use of research, media, law, advocacy and information dissemination. CERC does not belong to any political party, nor does it subscribe to any political ideology. CERC is recognised as a research institute by the Government and as a consumer organisation by the State government of Gujarat. The United Nations has recognised CERC as one of the approved non-government organisations.

\subsubsection{FEDCOT (Federation of Consumer Organisations in Tamil Nadu)}

FEDCOT is a nation-wide non-governmental organisation that is voluntary, non-profitable, nonpolitical, civic-minded, secular and registered under the Societies Act 1860 to work for the promotion and development of consumers' interest and their welfare. It is an umbrella body of more than 350 registered consumer associations in Tamil Nadu and Pondicherry. It is one of the largest consumer organisations in the country and in Asia, which works at grass-roots level. It embraces people from different walks of life. It is significant that 60 per cent of the member councils are in rural areas. FEDCOT claims to be a consumer movement of the people, by the people and for the people and to be concerned with human values.

\subsubsection{Citizen Consumer and Civic Action Group (CAG)}

This is a non-profit, non-political and professional organisation that works towards protecting citizens' rights in consumer and environmental issues and promoting good governance processes including transparency, accountability and participatory decision-making. CAG takes up and prioritizes issues affecting common citizens such as extreme pollution, lack of access to information, poor quality health care and civic amenities.

\subsubsection{Consumer Guidance Society of India (CGSI)}


This is a consumer rights organisation based in Mumbai, India. It was founded by nine women in 1966 to fight against sub-standard products, high prices, hazardous drugs, never ending shortage of goods and many other unjust practices. It became the first consumer rights organisation to conduct formal product testing in 1977. CGSI publishes a magazine, 'Keemat'.

\subsubsection{Consumer Unity of Trust Society International (CUTS)}

CUTS began its journey in 1983 in Rajasthan, from a rural development wall newspaper 'Gram Gadar'. This monthly communication initiative is still published regularly and has been instrumental in providing a forum to the rural population for voicing its issues and concerns. In 1983, CUTS operated on a zero budget out of a garage at Jaipur. Today, its annual budget exceeds US $\$ 2.5 \mathrm{mn}$ or Rs13crores. The organisation consists of five programme centres and one resource centre in India. It has its headquarters at Jaipur and offices in Chittorgarh, Calcutta and New Delhi, two resource centres in Africa (at Lusaka, Zambia and Nairobi, Kenya) and one resource centre in London, UK. CUTS' current staff strength is over 130 persons, of which one third are females working also at managerial levels.

CUTS is registered since 1984, under the Rajasthan Societies Registration Act, 1958. It is governed by a 12-member Executive Committee, which is elected every three years from a general body of 350 life members and 150 institutional members. With the vision of "Consumer sovereignty in the framework of social justice and equality, within and across borders" the activities of CUTS, as a research, advocacy and networking organisation working on several areas of public interest, are divided into: Consumer protection; International trade and development; Competition, investment and economic regulation; Human development, and Consumer safety.

\subsubsection{Mumbai Grahak Panchayat (MGP)}

MGP is a registered voluntary consumer organization established in 1975. It has more than 20,000 members in and around Mumbai to whom it supplies about 75 essential commodities at their doorstep, every month. MGP's joint purchase and distribution system has been acclaimed by Consumers International, which supports, links and represents consumer organizations all over the world. To enable consumers to exercise their choice, especially before festivals, MGP also has Consumer Plazas at different locations in the city which it runs for 10 days every year and sells items like readymade clothes, bed sheets, bags, sarees, utensils, crockery at reasonable rates.

MGP's Consumer Protection Wing has filed a number of public interest petitions to protect consumers' interests. MGP's Consumer Education Wing organizes consumer awareness camps, workshops and seminars for students and teachers. MGP's Study and Research Wing undertakes consumer research and provides the base for launching various consumer interest campaigns. It also sends an in-house newsletter 'Grahak' to its members, free of cost. A number of priced publications are also available. MGP has a number of Complaint Guidance Centres all over Mumbai, which give free guidance to consumers. MGP also has a new Environment Wing, which looks after matters of environmental interest. ${ }^{2770}$

2770 https://consumergoods.indiabizclub.com/info/consumer_protection_act/consumer_organisations (accessed 15th May, 2017) 


\subsection{Intellectual Property Rights and the Agriculture Sector in India}

\subsubsection{Positive Impact of India's IPR regime}

The three main laws governing intellectual property rights in the Agriculture sector in India are the Protection of Plant Varieties and Farmers' Rights Act 2001 (PPV\&FRA), the Patents Act 1970 (PA) and the Biological Diversity Act 2002 (BDA). ${ }^{2771}$

As a result of the successive policy changes in Intellectual Property, India's seed industry has expanded substantially. From 1987 onwards, policy reforms have encouraged several large firms (both foreign and domestic) to enter the seed industry. ${ }^{2772}$

As of 2005, India's commercial seed market has accounted for $25 \%$ of the total potential seed market in the country, whereas the varietal seeds farmers retain from the previous crops accounted for the remaining $75 \%$, indicating significant room for commercial growth. Although public research organizations and State Seed Corporations still play a role in the industry, the private sector has grown in importance in recent decades. As of 2005, the ratio of seed sales by volume between the private and public sectors stood at 76-24 denoting a strong private sector presence in the market. State Seed Corporations are now mostly confined to distributing certified seeds in the high-volume, low-value segment of the varietal wheat, rice, pulses and cottonseed markets. The private sector, on the other hand, has made sizable inroads in the higher value segment of the seed market, first with the development and dissemination of vegetable hybrids, then with hybrids of sorghum and pearl millet, followed by maize, cotton and, most recently, rice. ${ }^{2773}$

The private sector has not only invested heavily in new crops and technologies, but has also pursued legal IPR protection under the PPV\&FRA. In 2008-2009, 64\% of the 460 PVP applications received by the PPV\&FR Authority were from the private sector, with the remaining $36 \%$ from the public research system and farmers themselves. The largest number of applications was for crops where hybrids, particularly private hybrids, are predominant such as cotton, maize and rice. ${ }^{2774}$

The combination of supportive policy changes and enforceable (biological) IPRs has encouraged greater private investment in hybrid crop (maize and pearl millet) improvement, ultimately leading to increases in yield levels. The statistical evidence pointing to structural changes in yield trends when viewed alongside the well-documented historical evidence on changes in the public and private sectors' roles in crop-specific research, development and delivery - suggests that India has leveraged both public science and private investment to accelerate productivity growth with respect to these two crops. ${ }^{2775}$

\subsubsection{Challenges Remaining}

On the whole, public policies in India have provided mixed signals to private investors in the innovation and product markets. Whilst the promulgation of the PPV\&FRA and the approval of genetically modified Bt cotton in 2002 have been supportive measures, and have signaled India's

\footnotetext{
${ }^{2771}$ See section 3(b)(i), (ii) and (iii) above.

2772 See n.2691, 364.

2773 Ibid.

2774 Ibid, 365.

2775 Ibid, 378.
} 
openness to private investors by ensuring that innovators would be allowed to recoup their research investments in cultivar improvement, and encouraging $R \& D$ at the technological frontier, a third policy shift - the 2010 moratorium on the commercial release of Bt brinjal - has dampened these innovation incentives.

The realization of India's Agriculture sector potential - and expansion beyond the current level of concentration -will likely occur when firms can overcome barriers to entry that currently inhibit innovation at the cutting edge. The major barriers are largely related to the high costs, time delays, and uncertainty associated with regulatory approval for GM crops and IPR enforcement for private cultivars. Uncertainty in the current regulatory system is probably the greatest constraint for India's seed and agbiotech industries. Although the National Biotech Development Strategy 2007 and the National Biotechnology Regulatory Authority of India (NBRAI) Bill of 2009 aim to streamline regulatory agencies and processes, the uncertainty is persistent and largely unaddressed. This uncertainty is likely exacerbated by the slow progress of the 2004 Seed Bill through Parliament, which, if passed, is expected to improve the innovation incentives available to seed companies.

\subsection{Competition Law and the Indian Food Value Chain}

It is expected that " $(\mathrm{t})$ he food industry, which is currently valued at US\$ 39.71 billion will grow at a Compounded Annual Growth Rate (CAGR) of 11 per cent to reach US\$65.4 billion by 2018."2776 The size of food market calls for addressing competition concerns by legislation, compliance and enforcement. Not only is the size of the food market growing but also its contours have evolved from traditional villages to a more dynamic and urbanized setting and now cover a broad spectrum of commercial activities.

With the advent of globalization and increasing investments, the Indian food sector has given rise to much competition-related skepticism. For instance, the UK Department for International Trade has observed that India is a price competitive market where consumers, mostly prefer lower prices to quality and durability. ${ }^{2777}$ The nature of India's economic system and widespread poverty in the country is the main reason behind this preference. However, the situation is aggravated by lack of awareness regarding other factors that may influence consumer behavior and highlight the multifaceted nature of consumer welfare. India being one of the world's largest consumer markets which is mostly characterized by static competition, is prone to falling prey to the anti-competitive activities of big companies.

\subsubsection{The Rationale for Competition Law}

As the Consumer Price Index keeps moving upward and the rate of inflation keeps soaring, the competition concerns gain consumer-oriented dimensions. While prices of food items in India have been rising ${ }^{2778}$ the Government has been making an effort to align itself with the liberalized policy

\footnotetext{
${ }^{2776}$ http://indiainbusiness.nic.in/newdesign/index.php?param=industryservices_landing/337/1 July 2016.

2777 UK Government's Department for International Trade, Doing business in India: India trade and Export Guide, https://www.gov.uk/government/publications/exporting-to-india/exporting-to-india.

${ }^{2778}$ See Rahul Anand et al, Understanding India's Food Inflation: The Role of Demand and Supply Factors, International Monetary Fund, WP/16/2 (2016), https://www.imf.org/external/pubs/ft/wp/2016/wp1602.pdf
} 
regime around the world and to serve the more organized industrial lobby, ${ }^{2779}$ often at the expense of the middle and poor class which is directly affected by the rising prices.

The introduction of the Competition Act in 2002 and its operationalization in 2009 has added an important dimension to regulating the food sector in India. The aim of the Act is to provide for the establishment of a Commission to prevent practices which have or are likely to have an adverse effect on competition; to promote and sustain competition in the markets; to protect the interests of consumers, and to ensure freedom of trade carried on by other participants in the markets and for addressing all matters incidental thereto. Given this mandate it is likely that at least some portion of all stages of the food value chain in India ranging from inputs, agriculture to manufacturing and consumption fall within the ambit of the Indian Competition Law. ${ }^{2780}$

In a note submitted by it to the OECD, the Competition Commission of India has expressly acknowledged the applicability of the Indian Competition Law to all markets at different stages along the food value chain. ${ }^{2781}$ However, the Commission has also observed that due to the complex legislative structure of the Indian food value chain, matters arising from practices along this chain do not often make it to the Commission. ${ }^{2782}$ According to the Commission other factors due to which food sector complaints are not often filed before it include lack of or limited awareness of Competition Law amongst consumers and the disorganized nature of several segments of the food supply chain. ${ }^{2783}$

\subsubsection{Landmark Cases relating to the Food Value Chain(s)}

\subsubsection{Suo Motu Case 1 of $2010-$ In Re Sugar Mills decided on 30.11.20112784}

In this case, the Commission took note of a news article "Cartelization by Industry to push up Sugar Prices: Traders" 2785 which suggested that the Indian Sugar Mills Associations and the National Cooperative Sugar Mills Federation were involved in anticompetitive practices by colluding with each other to increase ex-factory price of sugar by 4-6 per cent. ${ }^{2786}$ The Commission referred the matter

${ }^{2779}$ See Sarah Joseph, Neoliberal Reforms and Democracy in India, Economic and Political Weekly, Vol. 42, No. 31 (Aug. 4-10, 2007), pp. 3213-3218.

${ }^{2780}$ Competition Issues in Food Chain Industry 2013, OECD, 15 May 2014, Directorate for Financial and Enterprise Affairs, Competition Committee DAF/COMP (2014)16 - A note by Competition Commission of India at page 221. Agricultural co-operatives are included in the definition of 'person' in the Indian Competition Act. See 1. 2(l)(v) 'an association of persons or a body of individuals, whether incorporated or not, in India or outside India; is icep' 2(1)(viii) 'a cooperative society registered under any law relating to cooperative societies' and 2(x) 'every artificial juridical person, not falling within any of the preceding sub-clauses. There is nothing to suggest that these are assessed differently. While section 54 allows the Central Government to exempt, this power has not been exercised in respect of agricultural cooperatives.

2781 Ibid.

2782 Ibid at Page 2171

2783 The Commission has also alluded to lack of capacity on its part to deal with matters related to the food sector and has stated that India "expects to obtain knowledge and information from counterpart jurisdiction on this sector." Elsewhere in the note, however, the Commission has stated that "Government investment policies on the subject would be playing crucial role in increased competitiveness in this sector and the Commission is fully equipped to handle issues of competition scrutiny in this sector." Furthermore, in the two cases cited by the Commission in this note, the Commission has commented that the policies framed by the Government are anti-competitive.

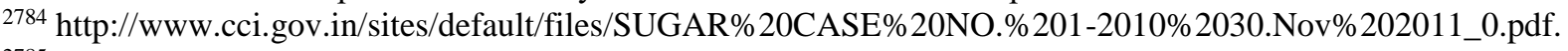

2785 The Economic Times, 26.07.2010.

2786 There are about 50 million sugarcane farmers and 5 million sugar mill workers in India. The Industries (Development and Regulation) Act, 1951, placed the sugar industry in the First Schedule (Item No. 25) to the Act, which meant that no sugar mill could be set up without a license of the Central Government. Sugar and sugarcane are Essential Commodities under the Essential Commodities Act 1955 and in exercise of the powers conferred under Section 3 of the Essential 
for investigation, to the Director General Investigations (DG) who concluded in his report that the sugar mills, acting through their associations or federations, had formed cartel to fix the price of sugar in violation of Section 3(3) (a) and (b) of the Competition Act 2002. ${ }^{2787}$

In evaluating the DG's report, the Commission expressed the view that "since sugar is under control either through a mechanism of control over prices or control over release/supply, the industry is not operating within the free market and market dynamics are not able to drive the industry. The behavior of such an industry is determined not fully by market forces but by the controls and regulations of the government." the Commission also observed that "...in such a regulated sector as sugar industry, the possibility of successful cartelization of sugar prices is remote because the releases in the market are not in the hands of sugar mills and additionally there is pressure to make timely payment of sugarcane." 2788 The Commission further observed that "the sugar industry is not free from control and is at present highly controlled and regulated" and that "sugar prices are not a mere function of demand and supply and there are complex forces at play which distort and in a way proscribe the market from working in a competitive and free manner."2789

The Commission also took note of the observations of the High Level Committee on Competition Policy ${ }^{2790}$ which had found that "restrictions on sugarcane prices and procurement, production capacities, dual pricing of sugar (levy and non-levy), restraints of exports and imports and many other like restrictions have enabled the inefficient producers of sugar to continue and prevent the rise of a competitive sugar industry." ${ }^{2791}$ The Commission therefore recommended that the government, after taking into account all aspects, needs to put such measures in place as may be necessary for the overall social and economic welfare, and may frame a policy which allows market and competitive forces to play a bigger role in the sector. The Commission further sated that competition in the sector may not only enable the efficient firms to perform better but also may ultimately bring benefits to the consumers since efficient firms in a competitive environment may not only compete for greater share of the market but also incentivize consumers through better product and lower prices. ${ }^{2792}$

Commodities Act, 1955, the Central Government has issued the Sugar (Control) Order, 1966 and the Sugar (Control) Order 1966. In addition to the above, the Executive or the Parliament, as the case may be, has also passed Levy Sugar Supply (Control) Order, 1979, Sugar (Packaging and Marking) Order, 1970, Levy Sugar Price Equalization Fund Act, 1976, Sugar Cess Act, 1982, Sugar Development Fund Act, 1982 and Sugar Development Fund Rules 1983. The price of sugarcane is announced by the Central Government on the recommendations of the Commission for Agricultural Costs and Prices (CACP) after consulting the State Governments and associations of sugar industry. The amended provisions of the Sugarcane (Control) Order, 1966 provides for fixing fair and remunerative price of sugarcane on the basis of various considerations such as price at which sugar produced by sugarcane is sold etc. In the case of sugarcane, the statutory minimum price has been replaced by Fair and Remunerative Price (FRP), in terms of which farmers are not required to wait for the end of the season or for any announcement of the profits by the sugar mills or the Government. This practice absolutely negates market forces and places an obligation on the government to provide support to the sugarcane farmers. The new system also assures the margins on account of profit and risk to farmers in all the years, irrespective of whether the sugar mills generate profits or not and is not dependent on the performance of any individual sugar mill. In order to ensure that higher sugar recoveries are adequately rewarded and considering variations amongst sugar mills, the FRP is linked to a basic recovery rate of sugar, with a premium payable to farmers for higher recoveries of sugar from sugarcane. ${ }^{2787}$ Para 32 of the Judgment.

${ }^{2788}$ Para 5.40 of the Judgment.

${ }^{2789}$ Para 7 of the Judgment.

${ }^{2790}$ Raghavan Committee Report.

${ }^{2791}$ Para 8 of the Judgment.

${ }^{2792}$ Para 9 of the Judgment. 
In this case, the Commission took note of reports published in various newspapers and journals (eg Wall Street Journal dated 23 December 2010) highlighting the unusual rise in price of onions during December 2010. After examining these newspaper reports the Commission formed the view that this was a fit case for investigation and referred the matter to the Director General Investigations (DG). ${ }^{2793}$ After investigation, the DG concluded that the cause of the unusual price hike in onions was the result of unseasonal and erratic rainfall which had adversely impacted the seasonal onion crop and resulted in reduced supply of onions in the market. ${ }^{2794}$ However, the DG also observed that "although implicit understanding among the traders to raise prices in the wake of scarcity to make profits for themselves cannot be ruled out, evidence of cartelization and organized collusion among the traders or among any other player in the whole supply chain could not be found."

The DG also appeared to overstep his mandate when he recommended that, "policy measures are required to increase farm productivity, improve supply bottlenecks and augment the storage facilities. It has also been brought that there could be possibility of manipulation of prices through acts like mixing poor quality onions with higher quality onions and a system of grading may be introduced in onion." 2795 The DG further suggested that "reforms in the existing structure of APMC

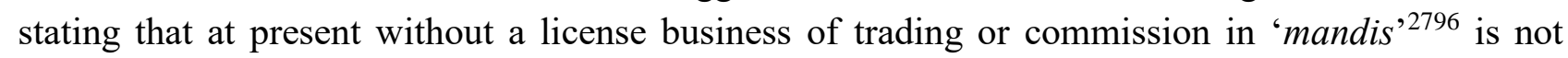
possible, which in a way prohibits new players from emerging at the market place."2797

The Commission agreed with the DG's investigation report and ruled out existence of any cartelization or collusion among onion traders/commission agents. However, one member, wanted the matter to be re-investigated and, therefore, the Commission ordered a study to be carried out in this regard. 2798

3.8.2.3 Suo Motu case No. 2 of 2011-Re Aluminum Phosphide Tablets Manufacturers order dated 23.04.2012

In this case, the Commission took notice of an alleged anti-competitive agreement amongst the manufacturers of Aluminum Phosphide tablets on the basis of a letter from the Food Corporation of India (FCI), which used these tablets for the preservation of central pool food grains in the country. Based on the information provided to it, the Commission formed the view that this was a fit case for further investigation and forwarded it to the Director General Investigations (DG). After examining extensive relevant evidence, the DG concluded in his report that the manufacturers of the tablets had 'acted in a concerted manner to eliminate competition among themselves by indulging in collusive bidding in the tender for procurement of goods by FCI in 2009 and collectively boycotting the etenders floated by FCI in 2011' in violation of section 3 of the Competition Act. ${ }^{2799}$

\footnotetext{
${ }^{2793}$ Para 3 of the Judgment.

${ }^{2794}$ Para 5.39 of the Judgment.

2795 Para 5.40 of the judgment.

${ }^{2796}$ The hindi word for wholesale markets.

${ }^{2797}$ Para 5.40 of the judgment

${ }^{2798}$ CCI Market Study on Competitive Assessment of Onion Markets in India - done by Agricultural Development and Rural Transformation Center, Institute for Social and Economic Change (ISEC) Bangalore (2012), available at http://www.cci.gov.in/images/media/completed/AO.pdf.

${ }^{2799}$ Para 4.26 of the judgment.
} 
After considering the DG's report and hearing the parties concerned, the Commission came to the conclusion that the conduct of three manufacturers of the tablets was in violation of section 3 of the Act due to the parties having engaged in collusive bidding. ${ }^{2800}$ The Commission imposed a penalty at the rate of $9 \%$ on the average of 3 years turnover of these three parties. The Commission also directed the parties to cease and desist from engaging in manipulating the process of bidding. ${ }^{2801}$

The Respondents in this case ie the three aggrieved parties, filed an appeal before the now defunct Competition Appellate Tribunal. ${ }^{2802}$ By its order dated 29 October 2013, the Tribunal substantially reduced the penalty imposed by the Commission on the ground that the Commission had failed to provide justification for fixing it at $9 \%$ of the average turnover of the Respondents.

\subsection{Unfair Trading Practices}

\subsubsection{Legislation governing Unfair Trading Practices}

In India, unfair trading practices are covered under the Consumer Protection Act 1986 (CPA) and may include unfairly refusing a transaction, discriminating against a transacting party, unfairly excluding competitors, unfairly soliciting customers, unfairly coercing customers, trading with a transacting party by unfairly taking advantage of one's bargaining position, trading under terms and conditions which unfairly restrict business activities of a transacting party, disrupting business activities of another enterprise, and unfair provision of capital, assets, manpower, etc. Section 2(1)(r) of CPA defines unfair trading practices to mean a trade practice, which, for the purpose of promoting the sale, use or supply of any goods or for the provision of any service, adopts any unfair method or unfair or deceptive practice. The Consumer Protection Act addresses these practices through its threetier quasi-judicial system comprising the District Forums, the State Commission or the National Commission and finally the Supreme Court of India. ${ }^{2803}$

Until 2002, the Monopolies and Restrictive Trade Practices Act (MRTPA), which was enacted to prevent monopolies and restrictive trade practices, was the foremost legislation for dealing with unfair trade practices in the country. In 2002, the Competition Act, repealed the MRTPA, and cases pending before the MRTP Commission were transferred to the Competition Commission of India. Although section 4(2) of the Competition Act states that the imposition of unfair or discriminatory conditions or prices in the purchase or sale of goods or services may be deemed to be an abuse of a dominant position, section 66(4) transferred the authority to deal with the unfair trade practices to the National Commission established under CMA which was already dealing with such practices.

Two exceptions in this regard were provided in (a) section 66(3) in terms of which all cases pertaining to monopolistic or restrictive trade practices pending before the MRTP Commission on or before the commencement of the Competition Act, including such cases, in which any unfair trade practice had also been alleged, were to stand transferred to the Competition Commission and were to be adjudicated by that Commission in accordance with the provisions of the repealed Act as if that Act had not been repealed, and (b) section 66(5) in terms of which cases pertaining to unfair trade practices referred to in clause (x) of subsection(1) of section 36A of the MRTPA and pending before

\footnotetext{
${ }^{2800}$ Para 7.40 and 7.41 of the judgment.

${ }^{2801}$ Para 8.2 and 8.3 of the judgment.

${ }^{2802}$ In May 2017, the Comeptiotn Appellate Tribunal was abolished and the National Company Law Appellate Tribunal was given the additional mandate to hear appeals from the decisions of the Commission.

${ }^{2803}$ See section 3(d)(i).
} 
the MRTP Commission were to stand transferred to the Competition Commission, and the Competition Commission was directed to dispose of such cases as if they were cases filed under that Act.

The most important sector specific legislation in respect of unfair trading practices is the Food Safety and Standards Act 2006 (FSSA). ${ }^{2804}$ The Act consolidates and repeals various acts and orders that had until its enactment handled food related issues in various Ministries and Departments. It also seeks to consolidate the laws relating to food and to curb food adulteration by prescribing higher penalties for violation of food laws. FSSA aims to ensure availability of safe and wholesome food for human consumption and the enforcement of food safety standards and seeks to regulate the law relating to advertising and unfair trade practices in the food sector. As per new rules issued under the FSSA, a penalty may be levied on, and prosecution undertaken against restaurants found violating the provisions of FSSA. The provisions of the FSSA apply to all types of food businesses - from a roadside food stall to a five-star hotel.

The two most important provisions of the FSSA in this regard are, (i) section 18(f) which states that the Food Safety and Standards Authority (formed under the FSSA) shall, while framing regulations or specifying standards under the Act, ensure prevention of fraudulent, deceptive or unfair trade practices which may mislead or harm the consumer, and (ii) section 24 which states that no misleading or deceiving advertisement may be made in respect of any food item and that any person who makes any such advertisement or engages in any unfair trade practice for the purpose of promoting the sale, supply, use and consumption of articles of food, or adopts any unfair or deceptive practice including the practice of making any statement, whether orally or in writing or by visible representation, which falsely represents that the foods are of a particular standard, quality, quantity or grade-composition, makes a false or misleading representation concerning the need for, or the usefulness of, or gives to the public any guarantee of the efficacy of a food product, that is not based on an adequate or scientific justification thereof shall be liable to be penalized in an amount commensurate with the nature of the violation. The FSSAI also lays down science based standards for articles of food and for the manufacture, storage, distribution, sale and import of foods and to ensure availability of safe and wholesome food for human consumption. FSSAI hears complaints relating to the food sector from the consumers.

Also in pursuance of the Act, food safety committees have been established in each State. Such food safety committees meet each month and discuss the development in each state to learn from the best practices as well as to decide on future course of action.

\subsubsection{Instances of Unfair Trading Practices in Food Processing Industry ${ }^{2805}$}

There has been a global concern about food safety and unfair trade practices in quality and quantity of the food products and of the deliberate addition of chemicals like additives, adulterants and food colours, for the purpose of disguising inferior commodities, or contaminating the food products during production, processing, packaging and storage. There has also been concern regarding the adulteration of food items by addition of harmful substances like poisonous chemicals and copper in milk, alcohol, rice, etc. which has caused health hazards at mass levels.

\footnotetext{
2804 See section 3.3(ii) above.

2805 http://www.cuts-ccier.org/pdf/Unfair_Trade_Practices_and_Institutional_Challenges_in_India-An_Analysis.pdf (accessed 15th May 2017)
} 
In India, in 2011, the water purifier 'Pureit' (a brand of Hindustan Unilever) made a false claim that it could "destroy one crore viruses in one litre of water" and announced that the National Institute of Virology (NIV) had confirmed these claims. This claim and announcement agitated the Pune-based NIV and it issued a legal notice to HUL for making unsubstantiated claims. In a letter to HUL dated 2 June 2011, the director of NIV explained the details of the tests conducted by NIV and explained to HUL that its advertisements were not based on facts. It requested HUL to refrain from twisting and misrepresenting the facts and threatened it with legal action if it failed to take immediate corrective measures in this regard.

Another example of such unfair trade practices in food industry was seen when the Consumer Guidance Society from Vijaywada, Andhra Pradesh filed a case in the District Forum (established under CPA) against Amway India Enterprises. ${ }^{2806}$ It was argued that Amway was offering a variety of consumer goods and food products including dietary supplements or sale through network marketing and at exorbitant prices. It was further argued that some of the products marketed by Amway were misbranded and that some of them were also adulterated. The District Forum held that Amway had adopted unfair trade practices in advertising and selling their products. The District Forum directed Amway to remove the adulterated and misbranded products from the market and not to indulge in such unfair trade practices in future. The Forum also directed Amway to issue a corrective advertisement regarding the products, which had been misbranded and misrepresented and imposed exemplary damages of Rs. 100,000.00 to be deposited in the Consumer Welfare Fund and Rs. 2,000.00 cost to be paid to the Consumer Education Society.

\subsection{Superior Bargaining Power}

In 1987, the Supreme Court acknowledged the emergence of the theory of unequal bargaining power in the sphere of contract law, in terms of which the test of the reasonableness or fairness of a contract clause was examined on the touchstone of the bargaining power of the parties to the contract. ${ }^{2807}$

In other cases, the Supreme Court has held that Article 14 of the Indian Constitution guarantees equality before and equal protection under law to all persons and has further held that this principle calls upon all Courts to strike down an unfair and unreasonable contract term between parties that do not enjoy parity in bargaining power. In this regard, the Supreme Court specifically referred to a situation where the weaker party had entered into a contract because it was the only option available to it to acquire the goods and services. The Supreme Court also held that the principle of superior bargaining power was applicable to the State in its industrial and commercial role. ${ }^{2808}$ In certain cases, the High Courts of India have held that the question of unequal bargaining power is related to the notion of free will i.e. whether the parties to the contract entered into it per their own free will. ${ }^{2809}$ The High Courts have also hesitated to find unequal bargaining power unless it is supported by evidence of fraud, mistake or duress that may be deemed to vitiate consent. ${ }^{2810}$

\footnotetext{
${ }^{2806}$ Consumer Guidance Society v. Amway India Enterprises, C.C. 140 of 2007, decided 16th October 2007.

${ }^{2807}$ Central Inland Water Transport Corporation Ltd. \& Another. etc. vs. Brojo Nath Ganguly \& Another. 1986 AIR 1571 , 1986 SCR (2) 278 at para 2.3. Foreign jurisprudence and common law played key role in the establishment of the jurisprudence of unequal bargaining power in India. For example, Gillespie Brothers \& Co.Ltd. v. Roy Bowles Transport Ltd., [1973] 1 Q.B. 400; Lloyds Bank Ltd. v. Bundy, [1974] 3 All. E.R. 757; A. Schroeder music Publishing Co. Ltd. v. Macaulay (Formerely Instone), [1974]1 W.L.R. 1308; and Levison\&Anr. v. Patent Steam Carpet Co. Ltd., [1978] 1. ${ }^{2808}$ Such contracts are not covered by the "undue influence" doctrine as provided for under the Section $16(1)$ of the Indian Contract Act.

${ }^{2809}$ Unikol Bottlers Ltd. vs Dhillon Kool Drinks And Ors, decided on 7 February, 1994 (Delhi High Court) at Para 31. ${ }^{2810}$ Ibid at Para 36.
} 
In respect of cases relating to the Indian food value chain, contracts entered into between the companies and farmers may qualify as cases relating to unequal bargaining power particularly because more often than not, farmers are unlikely to even be aware of the terms they are agreeing to. The farmers' lack of awareness and lack of resources required for hiring a lawyer aggravates the situation and tilts the contract in favour of large corporate party that is likely to have drafted the contractual provisions and is even otherwise able to obtain legal advice. Such cases may also be considered from the point of view of abuse of dominant position under Competition Law.

Indian private law belongs to the common law tradition and, as such, applies many of its principles.

Thus, Indian contract law provides for all the general remedies to the defects of consent such as mistake, misrepresentation, fraud, coercion, undue influence. A situation of unequal bargaining power between parties does not affect the validity of the contract even if it results in an agreement, which contains blatantly unequal provisions. ${ }^{2811}$ In order to have the agreement voided, the claimant has to prove that the contract was concluded in defect of consent. ${ }^{2812}$

However, evidence of the unconscionable conduct reverts the burden of proof on the party that has a "dominating position" and that has presumably exerted undue influence. For this reason, in the case seminal case Inland Water v. Brojo the Indian Supreme Court referred to the doctrine of public policy to annul unfair and unreasonable contract clauses made in a situation of unequal bargaining power. ${ }^{2813}$ Based on this precedent, specific clauses may be expunged from the contract if they are affected by procedural or substantial unfairness in the sense that they confer an unjust advantage or unjust disadvantage on any one party.

\subsection{Interface between Competition Law, IP Rights, Unfair Trading Practices and Superior Bargaining Position}

\subsubsection{Competition Law and IPRs ${ }^{2814}$}

The inherent conflict between Competition Law and Intellectual Property Rights arises from the fact that whilst Competition Law checks the abuse of dominant power, IP Law effectively creates dominance, if not monopolies by granting exclusive license to the right holders and by allowing them to exploit the result of their inventions albeit for a limited period of time.

This inherent conflict between anti-monopoly legislation and and IPRs predates the Competition Act. Cases involving IP Rights had even arisen before MRTP Commission, which was the predecessor to the present Competition Commission. Specifically, the MRTP Commission had held in Vallal Peruman and Others versus Godfrey Phillips India Limited (1994) and Manju Bharadwaj v. Zee Telefilms Limited (1996) that a trademark owner may be deemed to have engaged in unfair trade practices by the misuse, manipulation, distortion, contrivance or embellishment of ideas and in doing so, may expose himself to an action.

The Competition Act appears to codify the thinking of the MRTP Commission. In terms of section 3(1) and (2) of the Act, any agreement in respect of production, supply, distribution, storage, acquisition or control of goods or provision of services, which causes or is likely to cause an

\footnotetext{
${ }^{2811}$ Nilima Bhadbhade, Contract Law in India (Kluwer Law International 2010) 130.

${ }^{2812}$ Kesavulu Naidu v. Arithulai Ammal (1912) 36 ILR Mad 533.

${ }^{2813}$ Central Inland Water Transport Corporation Ltd. v. Brojo Nath Ganguly AIR 1986 SC 1571.

2814 https://www.esciencecentral.org/journals/interface-between-competition-law-and-intellectual-property-rights-acomparative-study-of-the-us-eu-and-india-ipr.1000115.php?aid=26445 (accessed 15 ${ }^{\text {th }}$ May 2017).
} 
appreciable adverse effect on competition within India is prohibited and may be deemed to be void. However, in terms of section 3(5), nothing in section 3, restricts the right of any person to restrain any infringement of, or to impose reasonable conditions, as may be necessary for protecting any of his rights which have been or may be conferred upon him under the Copyright Act 1957; the Patents Act 1970; the Trade and Merchandise Marks Act 1958 or the Trade Marks Act 1999; the Geographical Indications of Goods (Registration and Protection) Act 1999; the Designs Act 2000; and the Semi-conductor Integrated Circuits Layout-Design Act, 2000 (37 of 2000). Further, section 4(2)(b) of the Competition Act states that an enterprise may be deemed to abuse its dominant position, if it limits or restricts technical or scientific development relating to goods or services to the prejudice of consumers.

However, the Competition Commission has not been consistent in its interpretation and enforcement of provisions relating to IP Rights. Unlike the EC in the European Union, and the FTC and DOJ in the USA, which frequently issue guidelines with regard to treatment of IPRs, the only comparable document in India is the Advocacy Booklet on IPRs published by the Commission. However, rather than elaborating the Commission's approach to different types of agreements and forms of conduct, the Booklet only illustrates different licensing terms that are restrictive or likely to be anticompetitive. This lack of guidance is reflected in the Commission's tendency to intervene in IP related issues without any consistent basis or method and its uncertain application of legal provisions. $^{2815}$

In Department of Agriculture, Cooperation \& Farmers Welfare v M/s Mahyco Monsanto Biotech (India) Limited, which is a case concerning Monsanto's licensing of its Bt cotton technology, the Commission while ordering a detailed investigation into the matter, held that the 'agreements entered into by Monsanto with the sub-licensees appeared to be causing appreciable adverse effect on competition in the Bt cotton technology market' and the 'termination conditions are found to be excessively harsh and do not appear to be reasonable as may be necessary for protecting any of the IPR rights, as envisaged under Section 3(5) of the Act'. Interestingly, the Commission did not examine Monsanto's conduct under the standards applicable to unilateral abuse of dominance under section 4 of the Competition Act. ${ }^{2816}$

In other cases such as the Shri Shamsher Kataria v. Honda Siel Cars ${ }^{2817}$ the Commission conflated sections 3 and 4. First, the Commission concluded that the automobile manufacturers (OEMs) had violated section 4(2)(c) of the Act by denying market access to independent workshops and by excluding competitors by means other than legitimate competition. The Commission reasoned that the OEMs had strengthened their dominant position by becoming the only source of supply of these spare parts in the aftermarket, and the independent service providers had been effectively restricted from competing with the authorized dealers of the OEMs. Next the Commission evaluated these agreements under section 3, concluding that the restrictions placed on the Original Equipment Suppliers (OESs) violated sections 3(4)(b), 3(4)(c), and 3(4)(d) read with section 3(1) of the Act because they adversely affected competition in the automobile sector. However, its only basis for this finding was that (i) the choice between authorized dealer or independent retailer should be left to the consumer, and (ii) there is a requirement for the creation of a collaborative space between the

${ }^{2815}$ Yogesh Pai and Nitesh Daryanani 'Patents and Competition Law in India: CCI's Reductionist Approach in evaluating Competitive Harm' Journal of Antitrust Enforcement, 2017, 5, 299-327, 304.

${ }^{2816}$ Order dated 10 February 2016 in Reference Case No 2 of 2015.

${ }^{2817}$ Samsher Kataria v Honda Siel Cars India Ltd. \& Ors., Case No 03/2011. 
independent repairers, OESs, and auto manufacturers so they can effectively counter the use of spurious spare parts and provide the consumer with competitive and efficient repair and maintenance options. 2818

The Commission also considered whether agreements between OEMs and OESs and between OEMs and their authorised dealers were eligible for an exemption under section 3(5). However, the Commission rejected the OEMs argument that measures for protecting its IP are exempt from antitrust scrutiny under section 3(5), holding that the OEMs had failed to provide sufficient evidence of the existence of any IP rights in the spare parts. Further, while examining the OEMs conduct under section 4, the Commission held that they could not rely on the defence that they were protecting their IP rights, because there is no equivalent to section 3(5) under section 4. In its order in December 2016, the now defunct Competition Appellate Tribunal has broadly confirmed the approach of the Commission. ${ }^{2819}$

The reaction of the Courts to the interventions of the Commission appears to be largely deferential and in petitions filed before the Courts challenging the jurisdiction of the Commission with respect to IP matters, the Courts have decided in favour of the Commission. For instance, in the case of Amir Khan Productions Private Limited v. Union of India, the High Court ruled that the Commission has the power to deal with intellectual property cases; what can be contested before Copyright Board can also be contested before the Competition Commission and the Competition Act has overriding effect over other legislations for the time being in force. ${ }^{2820}$

\subsubsection{Superior Bargaining Power and Competition Law}

Although there is no specific rule on abuse of superior bargaining power in the Competition Act, such a rule may be inferred from the provisions relating to abuse on dominant position. In terms of section 4.2 (a), dominant position means a position of strength, enjoyed by an enterprise, in the relevant market, in India, which enables it to operate independently of competitive forces prevailing in the relevant market, or to affect its competitors or consumers or the relevant market in its favour. In considering dominance, the Commission is required to take into consideration certain factors which may be deemed to be indicative of the bargaining power of an enterprise including the market share of the enterprise; the size and resources of the enterprise; the size and importance of the competitors;

\footnotetext{
2818 See n. 2815, 309-310.

2819 Toyota Kirloskar (Pvt.) Ltd. v Competition Commission of India (Appeal No 60/2014).

${ }^{2820}$ In Amir Khan Private Limited versus Union of India, Federation of Indian Chambers of Commerce \& Industry (FICCI) filed information against united producers/distributors forum (hereinafter called as UPDF) and others for market cartel in films against the Multiplexes. In order to raise their revenue, UPDF refused to deal with multiplex owners. Multiplex business is 100 percent dependent upon films. So this is refusal to deal and anti-competitive. The UPDF and others hold almost 100 percent share in Bollywood film industry. UPDF was indulged in limiting/controlling supply of films in the market by refusal to deal with Multiplexes. It is violation of Section 3(3) of Competition Act 2002 . The Commission prima facie found there is anticompetitive agreement and there is abuse of dominant position also. So the Commission directed Director General (hereinafter called as DG) to inquire into the matter. The Director General inquired into the matter and submitted a report that there is cartel. The Commission issued a show cause notice. UPDF instead of answering to show-cause notice, approached the Bombay High Court. UPDF contended that films are subject to copyright protection. Therefore Copyright Board has the jurisdiction to deal with matter. The Bombay High Court discussed the matter in great detail. The court ruled that Section 3(5) provides that Section 3(1) shall not take away the right to sue for infringement of patent, copyright, trademark etc. All the defences which can be raised before Copyright Board can also be raised before the Commission. Competition law does not bar application of other laws. Matter is presently sub judice before the Commission
} 
the economic power of the enterprise eg commercial advantages over competitors; and the countervailing buying power. ${ }^{2821}$

The Commission has referred to the concept of superior bargaining power in a 2012 market study in which it investigated the onion market and found that, due to large storage capacity, traders had become highly concentrated locally and were able to exert superior bargaining power at the national level. The Commission further found that this allowed them to vertically integrate several other market actors, especially agents and logistic companies. In view of these factors the Commission stated that "(s)uch multiple roles by select few big traders have brought inequality between traders. So big have become very big which has created monopolistic conditions."2822 The Commission also noted that contract farming can represent a viable solution to the problems of the Indian agricultural market, as it would allow the parties to the contract to bypass highly concentrated traders and set a balanced and fair contractual framework between farmers and retailers. ${ }^{2823}$

In a number of its orders, the Commission has identified the existence of unequal bargaining power between parties to contracts, ${ }^{2824}$ whereas in several other cases parties themselves have pressed this principle. ${ }^{2825}$ Regardless, however, the Commission has not decided any of its cases on the basis of superior bargaining power.

In the case of Indian Sugar Mills Association \& Another vs. Indian Jute Mills Association \& Others. ${ }^{2826}$, the Commission considered allegations of violation of section 3 made by the Indian Sugar Mills Association against the Indian Jute Mills Association. The Sugar Mills Association contended that the Government had made it mandatory on the Sugar Mills to use Indian made jute bags for the packaging of sugar and, therefore, there was an anti-competitive agreement between the members of the Jute Mills Association and the Gunny Trade Association for fixing the sale price of jute packaging material. In pursuance of this agreement, the Gunny Trade Association issued a daily price bulletin for jute bags and members of the Jute Mills Association and Gunny Trade Association duly followed it. After a detailed investigation and hearings, the Commission found the Gunny Trade Association and the Jute Mills Association to be in violation of section 3 of the Act. ${ }^{2827}$

In this order, the Commission also observed that “...although no contravention of section 3 or 4 has been found against the Ministry of Textiles...the policy of the Ministry and ... [the] placing [of] statutory requirement on the Sugar Mills to undertake sugar packaging using jute bags produced in India only, is undoubtedly against the principle of competitive neutrality as the entities manufacturing matching products are denied access to that segment of packaging products... Furthermore, such a policy/provision not only restricts the choice of customers like the Sugar Mills but it may also lead to escalation in the cost ultimately borne by the end consumer, i.e., common people." The Commission then called upon the Ministry of Textiles "to reassess the whole situation in view of the current market situation and strive to remove the distortions which militate against the

\footnotetext{
${ }^{2821}$ Section 19(4) of the Competition Act.

2822 Competition Commission of India, Competitive Assessment of Onion Markets in India (2012) 28 <Available at: http://www.cci.gov.in/images/media/completed/AO.pdf >. 2823 ibid 31.

${ }^{2824}$ Belaire Owners' Association Vs. DLF Limited, HUDA \&Ors. (Case No. 19/2010) - Abuse of Dominant Position in Real Estate Industry.

${ }^{2825} \mathrm{M} / \mathrm{s}$ Rajarhat Welfare Association \&Anr. v/s DLF Commercial Complexes Ltd. \&Ors. (Case No. 10 of 2011 , Dated: 25.05.2011) at Para 2.6; Case No. $13 \& 21$ of 2010 and Case No. 55 of 2012 at par 5.24.

${ }^{2826}$ CCI, Case No. 38/2011.

${ }^{2827}$ Para 200 of the judgment
} 
principle of competitive neutrality." 2828 This observation by the Commission indicates a paradigm shift in the approach as more heed was paid to the competition concerns and the consequential economic implications rather than on the fate of the ailing jute industry of India.

More recently, in the Monsanto case ${ }^{2829}$, the Commission received a reference from the Department of Agriculture, Cooperation and Farmers Welfare, Ministry of Agriculture and Farmers Welfare and from private seed companies against Mahyco Monsanto Biotech (India) Limited alleging, inter alia, Mahyco's contravention of the provisions of Sections 3 and 4 of the Act. The Ministry had made the representation on basis of information received from various stakeholders' groups including farmers' associations and political movement bodies, National Seeds Association of India.

This case also reflects a situation where a large corporate entity such as Monsanto has been utilizing its superior bargaining power to charge heavy royalties to Indian companies, which had obtained licenses for its genetically modified seed. However, the final burden of the high royalty was borne by the consumers, which in this case means the farmers. The Commission found that there was a prima facie case against Monsanto and observed that lack of competition is taking toll of the agriculture. The Commission has referred to the matter to its Director General Investigations and the matter is still pending a final decision.

\subsubsection{Dealing with Unfair Trade Practices under Competition Law}

Although the Indian Competition Act does not explicitly deal with unfair trading practices, the Commission has taken up unfair trade practices in pursuance of its provisions dealing with abuse of dominant position. Cases taken up against coal companies ${ }^{2830}$ and builders ${ }^{2831}$ are particularly notable in this regard.

\subsection{Agricultural Subsidies}

Agriculture subsidies in India are managed by the government, primarily through the Ministry of Agriculture, which plays a diverse role in this regard, through its trade and domestic policies. These policies are mostly implemented by departments and institutions set up under the central government and at times by institutions under the state governments. The ethos behind this support is to generate self-sufficiency in the agricultural sector, create employment and improve the income of the farm households. ${ }^{2832}$ The overall aim of the Indian agricultural policy is to protect farmers from international price volatility. ${ }^{2833}$

\footnotetext{
${ }^{2828}$ Para 201 of the judgment.

${ }^{2829}$ Reference Case No. 2 of 2015 \& Case No. 107 of 2015.

$2830 \mathrm{http}: / / \mathrm{www}$.business-standard.com/article/economy-policy/unfair-trade-practices-7-coal-india-related-cases-beforecci-113111000209_1.html (accessed 15th May 2017). 2831

http://www.mondaq.com/india/X/568058/Antitrust+Competition/CCIs+Whip+On+DLF+Cease+And+Desist+Unfair+Tr ade+Practices (accessed 15th May 2017).

${ }^{2832}$ Harshal A Salunkhe and Binod B Deshmush, 'The Overview of Government Subsidies to Agriculture Sector in India' (2012) 1 IOSR Journal of Agriculture and Veterinary Science 43.

${ }^{2833}$ Kathleen Mullen, David Orden and Ashok Gulati, 'Agricultural Policies in India' (International Food Policy Research Institute (IFPRI) 2005).
} 


\subsubsection{India's trade policies}

The Agricultural \& Processed Food Products Export Development Authority (APEDA) is an autonomous organization established under the Department of Commerce. It is responsible for the promotion of export of agricultural commodities and for providing subsidies to exporters of certain specified products. ${ }^{2834}$

The main incentive schemes established by the government include:

Vishesh Krishi and Gram Udyog Yojana (VKGUY): The incentive under this scheme is granted in the form of duty credit scrip @ 5\% of FOB value of the exports.

Incremental Export Incentivization Scheme (IEIS): The incentive under this scheme is in the form of Duty Credit Scrip for export of agricultural products excluding sugar and food grains. ${ }^{2835}$

To further encourage exports of value-added agricultural products, the Indian government has also established agricultural export zones (AEZs). The purpose of the AEZs is to source raw agricultural products and complete the processing and packaging of their products within a geographical region. This "cluster approach" involves states identifying the regions in which products with export potential are being produced. Through December 2002, the Government had approved 41 AEZs in 17 states. According to the APEDA website, today there are approximately 60 AEZs in 20 states in India. ${ }^{2836}$ The central government contributes approximately 30 percent of the total funding for AEZs, while the state governments and private bodies supply 15 percent and 55 percent, respectively.

\subsubsection{Domestic policies}

Domestic polices include price support programmes, direct payments, and input subsidies to influence the cost and availability of farm inputs like credit, fertilizers, seeds, irrigation water, etc. ${ }^{2837}$ In India, domestic support for agriculture has been provided mainly through two channels: Minimum Support Price (MSP) guarantees for basic staple commodities and provision of inputs subsidies. In addition, a complex array of other policy instruments has been employed. ${ }^{2838}$

\section{(a) Market Support Price}

Basic staples in India continue to be subject to MSP guarantees. These commodities include paddy rice, wheat, coarse cereals, maize, barley, pulses, sugarcane, cotton, groundnuts, jute, rapeseed/mustard, sunflower, soyabean, safflower, toria, tobacco, copra, sesamum, and niger seed. The stated objectives of the agricultural price policy are to ensure remunerative prices to the farmers, even out effects of seasonality, and promote agricultural diversification although the guaranteed prices can be below prices prevailing in markets.

Recommendations concerning the MSP levels are made by the Commission for Agricultural Costs and Prices (CACP). ${ }^{2839}$ In formulating its recommendation, the CACP considers a number of

\footnotetext{
2834 “India : Subsidy on Agricultural Goods" Publication info: MENA Report ; London (Aug 27, 2013).

2835 "India : Subsidy on Agricultural Goods" Publication info: MENA Report; London (Aug 27, 2013).

${ }^{2836} \mathrm{http}: / /$ apeda.gov.in/apedawebsite/trade_promotion/Agri_Export_Zone.htm (accessed 17 November 2017).

${ }^{2837}$ Salunkhe and Deshmush (n 1).

${ }^{2838}$ Mullen, Orden and Gulati (n 2). 20

${ }^{2839} \mathrm{http}$ ://cacp.dacnet.nic.in (accessed 17 November 2017).
} 
factors, including input/output price parity, trends in market prices, demand and supply, inter-crop price parity, effects on industrial cost structure, effects on general prices, cost of living, international market prices, and the terms of trade. CACP recommendations have generally been followed but the MSP can vary from the CACP recommended prices. ${ }^{2840}$

\section{(b) Market Intervention Scheme}

For horticultural and other agricultural commodities not covered by the MSP, there is a Market Intervention Scheme (MIS) of somewhat ad hoc support measures. Under the MIS, if the price of a commodity falls below a specific "economic" level the Government can intervene, at the request of the state governments, by purchasing the product at intervention prices that do not exceed the cost of production. Losses incurred in implementing the MIS are shared equally between the central and state governments. Since 1998, the MIS has been used to support a number of horticultural products, including oranges, coriander seed, apples, oil palm, potatoes, red chilies, areca nut, ginger, and onions. ${ }^{2841}$

(c) Input Subsidies

Subsidies to farmers resulting from interventions in fertilizers, electrical power and irrigation began to increase in the mid 1980s, and have continued to climb in current and constant (real) value. The Government claims to be gradually moving towards a more deregulated regime while emphasizing the need for investment in power, irrigation and rural infrastructure.

\section{Seeds}

Many schemes such Rashtriya Krishi Vikas Yojna, Macro Management Agriculture, Integrated Scheme for oilseeds, pulses, oil palm and maize (ISOPOM); Technology missions for cotton, National food security Mission etc. provide for subsidized seeds. Some of them also provide incentives for investment in Seed manufacturing infrastructure and upgradations.

New Policy on Seed Development (NPSD) includes permitting 100 per cent foreign direct investment (FDI) under the automatic route. The thrust is also on creating a seed bank. There are three stages in seed production cycle. At the first stage the 'Indian Council of Agricultural Research' (ICAR), National Seeds Corporation (NSC) or state farms corporations (SFCs) develop Breeder seeds. In the second stage, the NSC, SFCs or State seeds corporations develop Foundation Seeds and then finally seeds certified by the state agricultural universities or private organizations authorized by ICAR, Certified Seeds, are produced and distributed to all farmers. The National Seeds Company (NSC) formed in 1963 has a central role in development of seed industry in India. It implements a number of subsidy schemes (including ISOPOM discussed above) and is also involved in export of seeds, especially to SAARC nations and African countries. It also maintains a SAARC seed bank in which it maintains an inventory of large quantities of various seeds in order to tackle shortages that may arise due to natural calamities or for other reasons.

\footnotetext{
${ }^{2840}$ Mullen, Orden and Gulati (n 2). 21

2841 ibid.
} 
From 2016-17, new initiatives like distribution of seed minikits, subsidy on production of quality seed, creation of seed hubs, strengthening breeder seed production programme and strengthening/establishing production units of bio-fertilizers and bio-control agents at ICAR institutes and State Agriculture Universities (SAUs), cluster frontline demonstrations through grass root level farm science centres, Krishi Vigyan Kendra (KVKs) are being undertaken under the National Food Security Mission to increasing productivity and production of pulses in the country. ${ }^{2842}$

\section{Fertilizers}

To promote the use of fertilizers by farmers, the central government provides a fertilizer subsidy to the producers of fertilizers. In 2017-18, Rs 70,000 crore has been allocated for fertilizer subsidy, which is the second biggest expenditure on subsidy after food subsidy. ${ }^{2843}$ Allocations for fertilizer subsidy have been increasing at an annual rate of $11.4 \%$ between 2000 and 2016. Currently the amount of subsidy to be given is determined based on the cost of production of the fertilizer company. Companies with a higher cost of production receive greater subsidies. This reduces the companies' incentive to reduce their cost of production. Although the consumption of urea has been increasing over the past decade, no new domestic production capacity has been added in the past 15 years. ${ }^{2844}$ A Committee that examined the role of Food Corporation of India recommended that cash transfers should be made to farmers to replace the current fertilizer subsidy regime. This would allow farmers to choose fertilizers in the combination best suited to their needs, and help them to fix the fertilizer imbalance in soil. In the Union Budget 2016-17, it was announced that a direct benefit transfer program for fertilizers would be launched on a pilot basis in a few districts across the country. In July 2016, the government announced that it would be conducting pilot studies of direct benefit transfers in 16 districts in 2016-17.

A retention price system (RPS) for fertilizers was introduced in 1977 to insulate farmers from rising prices of fertilizers and to ensure the availability of this input. The difference between the "retention price" or normal cost of production (plus 12-percent post-tax return on investment) and the "notified sales price" (minus a distribution margin) is paid to manufacturers based on specific plants. A subsidy is also paid to cover the cost of transportation to the farming areas where fertilizer utilization is concentrated. Since there is a uniform issue (sales) price for domestic and imported fertilizers, the government also bears the net cost between the delivery cost of imported fertilizers and the price paid by farmers. ${ }^{2845}$ Originally nitrogenous, phosphatic and potassic fertilizers were included under the price control subsidy program. However, in 1992 phosphatic and potassic fertilizers were decontrolled. Their prices rose dramatically leading to a fall in usage. To make these fertilizers available to farmers at lower prices, and to encourage balanced use among fertilizers, the central government has continued to provide "a concession" (subsidy) for decontrolled phosphatic and potassic fertilizers. ${ }^{2846}$ While the budgetary expenditure on fertilizer subsidies is large, a portion of the subsidy supports an inefficient fertilizer industry, rather than providing farmers with low cost inputs. ${ }^{2847}$

\footnotetext{
2842 'Agriculture Report 2016-2017' (c) Department of Agriculture, Cooperation and Farmers Welfare, 24.

${ }^{2843}$ Tanvi Deshpande State of Agriculture in India $@ 2017$ PRS Legislative Research. 10

2844 Ibid.

${ }^{2845}$ Mullen, Orden and Gulati (n 2).

2846 ibid.

2847 ibid.
} 


\section{Wheat and Rice}

When world cereal prices were at very low levels in the late 1990s, India increased the domestic support prices for wheat and rice, which led to increased production and procurement. Consequently, India's food grain stocks grew to unusually large levels compared to usual carry-over quantities. In November 2000, the Government initiated a policy of subsidies to export cereals, by offering wheat for export at a price "equal to the economic cost minus two years carrying cost but not lower than the central issue price for [those below the poverty line] BPL". The subsidy was expanded to rice the following year.

\section{Electricity}

Underpricing or provision of free electricity to agricultural users is possibly the largest subsidy. Industrial and commercial power consumers pay a price higher than the unit price of electricity to compensate for the losses on agricultural power supply. These subsidies are charged to the state budgets. There is some evidence of agricultural electricity being siphoned off for other uses as it is not metered and is determined on a residual basis.

\section{Irrigation}

Irrigation subsidies charged against state budgets remain the mainstay of Indian agricultural system. In most states, the pricing of canal water does not cover more than 20 per cent of the operation and maintenance, let alone recover capital costs. Other irrigation subsidy programs include the Accelerated Irrigation Benefit Programme (AIBP) to assist States complete ongoing irrigation projects. Beginning in 1999-2000 minor irrigation schemes in the north-east region, hill States and drought prone regions were included in the AIPB. From 2002, approved medium and major irrigation projects that can be completed within one year are funded under the AIPB's fast track programme.

\section{Credit}

Credit subsidy to Indian agriculture can be perceived to consist of two components: (a) interest subsidy that accrues to agriculture due to concessional rate of interest that is charged from the sector vis a vis others of the economy; and (b) default subsidy which accrues to the agriculture in the form of bad debts which will never be paid back to lending institutions. ${ }^{2848}$ Credit subsidies are given through the banking system and is available for short term loans provided for production purpose for a period of one year. ${ }^{2849}$ Nationalised Banks are authorised only to offer interest subvention provided by the Government of India through the Reserve Bank of India (RBI). Co-operative Banks may offer both interest subvention and interest subsidy and it is given through the National Bank for Agriculture and Rural Development (NABARD). ${ }^{2850}$

${ }^{2848}$ Ashok Gulati 'Input Subsidies in Indian Agriculture: A Statewise Analysis' (1989) Economic and Political Weekly, Vol. 24, No. 25, A57-A65.

2849 'Agriculture Subsidies in India' Shodhganga 62-63.

2850 Ibid. 
In recent years India has been concerned that the reduction of its agriculture subsidies in the face of continued support of their agriculture sector in the developed countries would make the Indian agricultural produce less competitive internationally. This will also encourage dumping of artificially cheaper products in India, which in turn will have an adverse impact on the livelihood of Indian farmers. ${ }^{2851}$ Regardless, however, India has been under pressure from the WTO to rationalize its support to the agriculture sector.

India initially reported its fertilizer, electricity, irrigation, seed and credit to the WTO under nonproduct specific support commitments. India's support to its agricultural sector is covered by the domestic support categories that are exempt from reduction commitments under the WTO's Agreement on Agriculture. ${ }^{2852}$ The BJP-led government has toughened its stance on food subsidies since it came to power in 2014. The government indicated in the notification to WTO that another $\$ 14.7$ billion was spent on public stockholding for food security purposes, another 'green box' complaint element that was $\$ 13.8$ billion in FY 2011. India provided statistics to show that it was spending consistently lesser on research between 2011-12 and 2013-14 but increasingly more on advisory services. ${ }^{2853}$

\subsection{Conclusion}

The Indian Central Government disposes of important powers to regulate the food sector. ${ }^{2854}$ However, it is a different issue whether such powers are being exercised effectively or not. In the context of India, it is important to understand that most of the food related laws pertain to food safety and standardization, whilst different laws govern the various aspects of commercial operations of food processing companies. Whilst some effort has been made to introduce technology in the Agriculture sector, a great deal more needs to be done especially given the small individual land holdings, the poor economic condition of the farmers and the farmers' lack of awareness about new technologies. There have been efforts by the government to educate these farmers but financial constraints faced by the farmers has prevented them from taking advantage of this offer. The enormity of the tragedy of the farming sector is evident from the high rate of suicides of farmers, however, its impact is felt throughout the food value chain which remains unable to realise its true potential.

\footnotetext{
${ }^{2851}$ Yogesh Bandhu 'Trade Competitiveness, Subsidies and Barriers to Trade: Implication for Indian Agriculture' Online at https://mpra.ub.uni-muenchen.de/22802/ MPRA Paper No. 22802, posted 25. May 2010 01:04 UTC.

2852//economictimes.indiatimes.com/articleshow/59623742.cms?utm_source=contentofinterest\&utm_medium=text\&ut m_campaign=cppst (accessed 12 November 2017).

${ }^{2853}$ Ibid.

${ }^{2854}$ Essential Commodities Act 1955.
} 


\section{References}

Baverly M, et al. 'International assessment of Agricultural Knowledge Science And Technology for Development' (2009) Global Report Washington D.C. USA.

Behera BS, Das TK, Jishnu KJ, Behera RA, Behera AC, Jena S (2015) 'E-Governance Mediated Agriculture for Sustainable Life in India' Procedia Computer Science 48, 623 - 629.

Bhagwati J, India In Transition: Freeing The Economy (1992) Oxford University Press, Delhi.

Brahmi P, Dua RP, Dhillon BS, 'The Biological Diversity Act of India and Agro-biodiversity Management' (2004) Current Science, Vol. 86, No. 5, 659.

Chatterjee S, Kapoor D, 'Understanding Price Variation in Agricultural Commodities in India: MSP, Government Procurement, and Agriculture Markets' (2016) India Policy Forum

Competition Commission of India, 'Competitive Assessment of Onion Markets in India' (2012)

Davies RB, Vadlamannati KC, 'A Race to the Bottom in Labour Standards? An Empirical Investigation' (2013) Journal of Development Economics (103) 1-14.

Dutta A, et al., 'A Case Study of Pepsico Contract Farming For Potatoes' (2016) IOSR Journal of Business and Management, 75-85

FICCI 'Report on Food Safety and Standards Act- Challenges in the Implementation of the Act, 2006' (2013) Food Defense Awareness Workshop

Fitzgerald V, 'Regulatory Investment Incentives' (2001) OECD

Ghatak M, Roy S, 'Land Reform and Agricultural Productivity in India: a Review of the Evidence' (2007) Oxford Review of Economic Policy, Volume 23, Number 2, 251-269

Helfer LR, Graeme WA, Human Rights and Intellectual Property: Mapping the Global Interface (2011) Cambridge University Press

Iyer A, Singhi A 'Indian Agribusiness: Cultivating Future Opportunities' (2012) Boston Consulting Group

Joseph S, 'Neoliberal Reforms and Democracy in India' (2007) Economic and Political Weekly, Vol. 42, No. 31, 3213-3218

Kennedy J, King L, 'Globalization and Health' (2014) 10:16

Kolady DE, Spielman DJ, Cavalieri A 'The Impact of Seed Policy Reforms and Intellectual Property Rights on Crop Productivity in India' (2012) Journal of Agricultural Economics, Vol. 63, No. 2, 361384.

Kumar S, 'Report of the High Level Committee on Reorienting the Role and Restructuring of Food Corporation of India (C) 2015

Kumar S, Sharma A ‘Agricultural Value Chains in India: Prospects and Challenges' (2016) CUTS International. 
Mehta M 'International Food Safety Standards and India's Food Exports- An Analysis Based on Gravity Model Using Three-Dimensional Data' Discussion Paper \# 169 (2010) Research and Information System for Developing Countries

Mehta PS,_Competition and Regulation in India, 2009 - Leveraging Economic Growth Through Better Regulation' CUTS International

OECD 'Competition Issues in Food Chain Industry 2013' (2014) Directorate for Financial and Enterprise Affairs, Competition Committee

Pai Y, Daryanani N, 'Patents and Competition Law in India: CCI's Reductionist Approach in evaluating Competitive Harm' (2017) Journal of Antitrust Enforcement Vol 5, 299-327

Plahe JK, 'The Implications of India's Amended Patent Regime: stripping away food security and farmers' rights?' Third World Quarterly, 30:6, 1197-1213, 1203-1204.

Raghavan SVS, 'Report of the High Level Committee on Competition Policy and Law' (1999)

Rahul A et al, 'Understanding India's Food Inflation: The Role of Demand and Supply Factors' (2016) International Monetary Fund

Rashid S, Gulati A, Cummings Jr R. , (ed) From Parastatals to Private Trade: Lessons from Asian Agriculture (2008) International Food Policy Research Institute

Samanta, D., Shireesh 'Social Impact Assessment of Projects involving Land Acquisition in India: Implications of RFCTLARR Act, 2013' (2015) Journal of Management and Public Policy, 7(1), 2735 .

Singh VV, Mitra S, 'Regulatory Management and Reforms in India. Background Paper for OECD' (C), CUTS International.

Spielman DJ, Kolady DE, Cavalieri A, Rao NC, 'The Seed and Agricultural Biotechnology Industries in India: An Analysis of Industry Structure, Competition, and Policy Options' (2014) Food Policy 45 $88-100$. 


\section{Chapter 4: China}

Qiang Yu ${ }^{2855}$, Bo Wang \& Ye Huilin ${ }^{2856}$

\subsection{China's agricultural policy and food value chain}

The term "food value chain" refers to segments of independent but inter-related processes of food supply, from food production, to consumer purchase. Although there are thousands of years of history of agriculture and food processing in China, analysis and regulation of the power and structure within a specific segment of the food value chain and the inter-relationship between different segments and the over-all chain only began quite recently. China's food production and supply system has undergone reforms since 1978, when there was a shift from the communist system (planed production and supply, with no market mechanism) to a system based on demand-supply relationships, that is, a market mechanism. The main reason for these agro-food product supply system reforms was that the planned agro-food product supply system was inefficient and unable to provide enough food for the growing Chinese population. ${ }^{2857}$ This major policy shift proved to be effective. According to an official document, China has successfully tackled hunger problems and increased the level of peasants' income, as well as providing food for $22 \%$ of the world population with its own capacity, namely, $6 \%$ of the world's water resource and $9 \%$ of the world's arable land. ${ }^{2858}$

The Chinese government attaches great importance on agricultural issues. Being a traditional agrarian country, China has an over 5,000-year history of agriculture-prioritize policy. The emphasize on the food-supply security and rural social stability have long been Chinese central government's priorities. Such importance and priorities are influenced by the economic realities, the historical and cultural traditions, as well as the ideology of the Communist Party of China (CPC). Firstly, the majority of the Chinese population lives in the rural area (although the number is constantly decreasing as the consequence of economic development and urbanization, the rural population still amounts $50.32 \%$ as of $2011^{2859}$, over 348 million peoples directly working on agricultural industry as of December $2006^{2860}$ ). Secondly, the stability and the well-beings of the rural society and farmers has long been the decisive factor of the tradition Chinese society, the issues of land annexation and land-lost peasants are the recurring inducements of Civil wars and revolutions. The patriarchal society and its related small scale natural peasant economy are the fundamental social structure of the ancient China. Consequently, the ancient dynasties have all adopted the ideology and policy of Physiocracy and commerce restriction. Chinese governments therefore view agricultural issues as the matters of national stability and security, even matters of government's legitimacy. Thirdly, the CPC's main supporters during the Chinese civil war are the mass public in Chinese rural areas. The CPC got support of them by implementing land reform policy which enable peasants to have their own lands and free them from exploitations by landlords. Mao's most important strategy to achieve national success is "encircling the cities from the rural areas and taking the political power by armed

\footnotetext{
${ }^{2855}$ HSE Skolkovo Institute for Law and Development.

${ }^{2856}$ Centre for Law, Economics and Society, UCL Faculty of Laws.

${ }^{2857}$ Exceeding 1.37 billion. http://www.stats.gov.cn/tjsj/zxfb/201604/t20160420_1346151.html.

$2858 \mathrm{http}: / / \mathrm{www} . \mathrm{mlr} . \mathrm{gov} . \mathrm{cn} / \mathrm{zt} / 38$ thdiqiuri/2.htm.

2859 第六次人口普查数据

2860 第二次全国农业普查数据
} 
forces”(农村包围城市, 武装夺取政权). The CPC's most important strike (also a proved failure) towards communist economy was the agricultural collectivization during 1950s to 1970s. The "Chinese economic miracle" was also kicked off by Deng Xiaoping's agricultural reforming policy. Until today, agriculture is still not only a sector/industry of Chinese economy, but a comprehensive issue of national security and stability. The Three Rural Issue (the issues of agriculture, rural areas and farmers, 三农问题) is still one of the top priority of Chinese central government's agenda. Moreover, some serious food security cases happed in the recent 20 years have forced Chinese government to address the issue with utmost importance. In a nutshell, from seeds to final goods, the whole food value chain is regarded as vital to national security and prosperity, and therefore, highly regulated. This fact may be better illustrated while comparing China to the countries with less population or with more developed industrial structure.

China's success in the food production and supply system is primarily the result of a proactive policy on the food production process. This policy has been extended to the external sphere when negotiating China's international treaties. China has sought reservations when it signed World Trade Organization (WTO) agreements with other countries on agricultural issues. ${ }^{2861}$ China is a founding member of the Food and Agriculture Organization of the United Nations (FAO). China joined the the International Plant Protection Convention on 20 October 2005, without reservations.

In domestic legislation, when drafting the Anti-Monopoly Law (AML), a separate provision was added to provide exemptions for anticompetitive behaviour, such as sharing production facilities and co-operative production among farmers. A major reason explaining China's proactive policy on the production segment in food production is the Great Chinese Famine of 1959 to 1961 and other famines that have occurred historically in China. During the Great Chinese Famine, about 30 million Chinese people died and it is estimated that it also led to about 33 million lost or postponed births. ${ }^{2862}$ The so named "Three-Year Disaster", ${ }^{2863}$ remains one of the worst catastrophes in world history. As a result, China has sought self-sufficiency on food production. The Chinese government has pursued a self-sufficiency oriented agricultural policy, rather than focusing on imports or exports and all means to improve food outputs have been implemented. This has further influenced the diversification of peasants and food suppliers. There have been some military units with the specific mission to conduct farming work and provide foodstuffs on the market, have, a typical example being Xinjiang Production and Construction Corp. (a unit in Heilongjiang being reformed in 1976), but their role in the food supply in China is quite limited ${ }^{2864}$.

Although China's Reform or “open-up” policy “搞活、放开” marked by the transition from the communist collective farm model to the "household contract responsibility system" since 1978, and the deregulation of the agro-foods sector, after China joined the WTO, has led to great successes in the production of agro-food products, there have also been adverse consequences in other segments of the food value chain, namely regarding food distribution. As an increasing number of people moved to urban areas, and became consumers, the number of people in food production positions fell. By 2011, the urban population exceeded the sub-urban population, ${ }^{2865}$ and it has continued to

\footnotetext{
2861 Protocol on the Accession of the People's Republic of China 2001. http://unpan1.un.org/intradoc/groups/public/documents/APCITY/UNPAN002123.pdf.

2862 Ashton Basil, Hill Kenneth, Piazza Alan, Zeitz Robin, Famine in China, 1958-61, Population and Development Review 10:613-645 1984.

2863 三年自然灾害.

2864 http://www.xjbt.gov.cn/.

2865 http://www.gov.cn/jrzg/2012-08/14/content_2204179.htm.
} 
increase. With the deepening of the "open-up" policy, food production became more professionalized and is no more simply subsistence agriculture. This trend indicates that the consumption market is increasingly important and food distribution has become a major issue in China, second only to food production aiming to mitigate problems of food scarcity.

Deregulation of the food consumption markets and the processing and distribution segments of food value chains have increasingly led to problems. The increased demand from Chinese consumers attracted international food suppliers. With the increasing amount of food imports, problems have arisen sequentially or simultaneously regarding food quality, different food standards, excessive pricing, etc. With the fragmentation of the production segment, some domestic food distribution entities began to hoard food or raw material and sell them at unreasonably high prices. There have also been cases regarding illegal pricing of soybeans and garlic (which will be introduced in the following Section). ${ }^{2866}$

Along with the rapid development of this huge consumption market, economic dependence problems between suppliers and dealers, market structure problems, and anticompetitive overcharging by suppliers and dealers has appeared in many segments of the food value chain; increasing concentration, both vertically and horizontally. In 2010, the wholesaler Hubei Salt Group Ltd was found to be abusing its dominance over retailers; in 2014, a rice vermicelli processing factory organised a cartel to raise the price of rice vermicelli above a competitive level and was, therefore fined 10,000 RMB. ${ }^{2867}$ As a trend, since 2008, market concentration has become increasingly prominent, with at least 60 merger or acquisition cases relating to all segments of the agro-food industry, involving both domestic and international firms.

\subsection{Bodies regulating the food value chains}

Food value chains cover a wide range of independent but related sectors, subject to regulation from numerous regulatory bodies. The regulation of food value chains in Mainland China is especially complex. The market is comprises approximately 1.5 billion food consumers and agro-food production constitutes $8.6 \%$ of China's gross domestic product (about 10.84 trillion USD in 2016). ${ }^{2868}$ Together with the nation's legal and policy support and protection, the number of regulatory bodies regulating food value chains is beyond the scope of this report. Consequently, only the main regulatory bodies are introduced below.

Summarily, the food value chains regulating system could be categorized into 3 parts.

- As for the top tier, the agencies responsible for macro-economic control and regulation, i.e. the National Development and Reform Commission, has its significant influence on the overall policies regulating food value chains. Moreover, the Commission has some specific authorities influencing agriculture and food industry. Thorough its price regulating, foreign investment regulation and antitrust powers, as well as it's subsidy State Administration of Grains, the Commission plays an important role in Chinese food value chains regulation. On a separate note, observers of this topic should also pay attention to the CPC's office of rural policy (中央农村工作领导小组办公室). That office is, however, beyond the scope of this fiche.

\footnotetext{
${ }^{2866}$ Soybeans(豆你玩); garlic(蒜你狠).

2867 http://www.ndrc.gov.cn/fzgggz/jgjdyfld/fjgld/201402/t20140228_588558.html.

2868 http://www.stats.gov.cn/tjsj/zxfb/201701/t20170120_1455942.html
} 
- Secondly, there is a dedicated ministry of agricultural issues in the Chinese bureaucracy. The Ministry of Agriculture is responsible for several important matters concerning food industry. Moreover, there is a state agency regulating food and drug quality and security, since its crucially importance to the nation.

- Thirdly, ministries and agencies responsible for general market supervision, intellectual property protection, commerce and trade regulation, import and export administration also have their respective authorities over food value chains.

- Additionally, since the food industry is tightly connected with the land policy and the deeply involvement of state owned enterprises in the value chains. The Ministry of Land and Resources (MLR, 国土资源部) and the State-owned Assets Supervision and Administration Commission (SASAC，国有资产监督管理委员会) also have indirect influence on food value chains. Other governmental ministries and agencies, may also have their influence when concerns specific issues.

1. The National Development and Reform Commission (NDRC, 国家发展和改革委员 会)

The NDRC is the competent authority for the macro control and regulation of the Chinese economy, it is also the authority responsible for national and industrial reform policies formulation. Considering Chinese central government's long-standing agenda of promoting market economic-oriented reform, the NDRC is indeed the most powerful department within the State Council and the whole administrative system. Among its multiple duties, "to formulate and coordinate the implementation of the overall national economic and social development strategy, mid and long-term agendas and annual plan", "to promote the industrial restructuring, research and coordinate issues of fundamental importance in agriculture industry; to coordinate specialised agricultural projects and policies", "to formulate national import and export plan of important agricultural and industrial products, to supervise and adjust the implementation of the plans", "to manage the state reserves of food, cotton, sugar, petrol and medicine" are all of relevance to the agriculture and food industry, and to be more precisely, food value chain. Besides, it is also worth mentioning that NDRC is also the price regulating authority and one of the foreign investment policy formulating authority.

There are some NDRC's affiliations important to the food value chains regulation.

(1) Principally, and most significantly, the State Administration of Grain (SAC, 国家粮食局) is the very authority responsible for national grain distribution, agricultural industry guidance and supervision, and the central food reserve administration. The responsibilities and authorities of the SAC include the supervision and administration of grain production, procurement, marketing, storage, logistics, processing and quality inspection, as well as the related scientific research, agricultural informationalisation, and international affairs. The principal functions of the SAG include: 2869

- Entrusted by the NDRC, to study and formulate mid-term and long-term strategies of national grain macro-control, overall balance of supply and demand, grain distribution, grain import and export and deployment of national grain reserves; and to develop and implement the programs for the reform of national grain distribution system.

- To draft laws and statutes, relevant policies, rules and regulations for the nation's grain

${ }^{2869}$ http://www.chinagrain.gov.cn/english/General\%20Situation2.html 
distribution and national grain reserves management, and supervise the enforcement; to formulate plans of building facilities for grain distribution, storage and processing; and to raise proposals in regard of setting a framework for grain protective procurement price, protection price and limited market price.

- To standardize and manage the quality of grain products in coordination with the State Bureau of Quality and Technology Supervision; and to establish technical criteria for grain storage and transportation, and supervise the implementation.

- To steer the management of national grain distribution and personnel training of grain sector; to guide and promote technical reform and the spread of new technology; to take charge of relevant financial work; to promote foreign exchanges and cooperation; and to handle the statistic work of grain industry.

- To formulate technical norms for the management of national grain reserves and supervise the implementation; to propose the scale and overall layout of national grain reserves as well as plans for procurement, marketing, import and export of national grain reserves, and supervise the implementation; to supervise and examine the stock, quality and security of national grain reserves.

- To undertake other tasks assigned by the State Council and the NDRC. In accordance with relevant regulations of the State Council, the SAG is also responsible for guiding the business of China Grain Reserves Corporation.

In addition to the SAC, some other sub-sectors of the NDRC also have authorities over some issues concerning the agriculture economy and the food industry.

(2) The Department of Rural Economy (农村经济司) is responsible for formulating general plans of rural economic development and agricultural policy. The Department of Rural Economy is responsible for analyzing the development of agriculture and rural economy; making policy recommendations on rural economic development strategies and the reform of rural economic system, coordinating major issues concerning agriculture and rural economic and social development; coordinating and balancing the development plans and policies for agriculture, forestry, water conservancy and meteorology; making proposals on layout of major projects, and coordinating the implementation of these proposals. ${ }^{2870}$

(3) The Department of Price (价格司) is responsible for forecasting price changes, recommending objectives, policies and reform plans for price adjustment; formulating price and fee-charging policies and regulations; putting forward the scope, principles and measures of price management, making recommendations on revision of government pricing catalog; setting and adjusting prices and fees administered by the central government; and organizing cost investigation concerning major agricultural products, commodities and services. The Department of Price has important functions in Chinese agricultural industry regulation. For example, it publishes the minimal grain (wheat, rice etc.,) procurement prices on a yearly basis; it also frequently conducts cost investigations of agricultural products and publishes its guidance on such investigations. ${ }^{2871}$

(4) The Bureau of Price Supervision and Antimonopoly (价格监督和反垄断局) is one of the three Chinese antitrust enforcement agencies. Its jurisdiction covers unilateral, collective

2870 http://njs.ndrc.gov.cn/jgsz/

${ }^{2871}$ http://en.ndrc.gov.cn/mfod/200812/t20081218_252212.html 
anticompetitive cases concerning price behaviours. The bureau is also the statutory authority of implementing the Chinese Price Law. The Bureau of Price Supervision and Anti-Monopoly is responsible for drafting administrative laws and regulations of price supervision and inspection; guiding and organizing price supervision and inspection, and handling activities and cases related to commodity price, service price and fee collection involving violation of price-related laws by central government agencies, handling price monopoly activities and reconsideration cases and appeals concerning the punishment of price violations. ${ }^{2872}$

(5) The Department of Foreign Capital and Overseas Investment (利用外资和境外投资司) has its influence on agricultural and food industry by formulating policies to promote, permit or forbid foreign investments on this very sector. As a crystal example, transgenic breeding is explicitly forbidden from foreign investments; the breeding of new varieties and the manufacturing of seeds are restricted from foreign investments, foreign investment is only allowed to invest in the companies controlled by Chinese and obtain clearances of governmental authorities; on the other hand, some of the sectors in agriculture and food manufacturing are listed as sectors encouraged for foreign investment. ${ }^{2873}$ This department is also responsible for regulating Chinese outbound investments.

2. The Ministry of Agriculture (MOA, 农业部)

Among all the regulatory bodies, most segments of food value chains are governed by the Ministry of Agriculture of the PRC. There are also agricultural departments of local governments responsible for regulating regional food value chains. According to ALPRC Article 9,

"People's governments at all levels shall assume unified responsibility for work in respect of agriculture and development of the rural economy and make arrangements for the relevant departments and all sectors of society to do a good job in all fields of endeavor for the development of agriculture and for provision of services to the development of agriculture. The competent administrative department for agriculture under the State Council shall be in charge of work in agriculture and economic development in the rural areas throughout the country. The competent administrative department for forestry under the State Council and relevant departments shall, within the scope of their respective duties, be in charge of work related to agriculture and development of the rural economy. The competent administrative department for agriculture under the local people's governments at or above the county level shall be in charge of work related to agriculture and development of the rural economy including crop-planting, animal breeding and fishery, within their own administrative regions, while the competent administrative departments for forestry shall be in charge of forest work within their own administrative regions. The relevant departments under the local people's governments at or above the county level shall, within the scope of their respective duties, be responsible for work related to services for agricultural production and operation within their own administrative regions."2874

The MOA's statutory responsibilities include: ${ }^{2875}$

- To research into and work out development strategies and long-term and mid-term development plans of agriculture and rural economy, to organize their implementation after

\footnotetext{
2872 http://en.ndrc.gov.cn/mfod/201207/t20120719_492595.html

2873 外商投资产业指导目录， 2017 http://wzs.ndrc.gov.cn/zcfg/201706/W020170628553908627683.pdf

2874 http://www.npc.gov.cn/englishnpc/Law/2007-12/12/content_1383785.htm.

2875 http://english.agri.gov.cn/aboutmoa/mandates/
} 
approvals; to draw up agricultural development plans and supervise their implementation.

- To study on and draw up agricultural industry policies, direct the rational structural adjustment of agricultural industries, rational allocation of agricultural resources and improvement of produce quality; to put forward policy suggestions regarding prices of agricultural products and means of agricultural production, tariff adjustment, circulation of agricultural staples, rural credit, taxation and rural financial subsidies; to organize the drafting of laws and provisions regarding various agricultural industries such as crop production, animal husbandry, fishery, rural and township enterprises.

- To make researches for and put forward suggestions regarding further system reforms of rural economy; to guide the building of socialized agricultural service system and the building of rural collective economic and cooperative organizations; to stabilize and improve basic rural business running system, policies, adjust rural economic relations, guide and supervise the alleviation of farmers' burdens and transfer of land-use rights.

- To research and formulate guidelines and policies regarding industrialized management of agriculture and the system building and development plans of agricultural staple produce market and promote the agricultural integration of pre-production, in-production and postproduction; to organize the "shopping basket program" and the market system building of means of agricultural production; research into and put forth suggestions concerning the import and export of major agricultural products and means of agricultural production; to forecast and publicize rural economic information on supply and demand of various agricultural products and means of agricultural production.

- To organize the zoning of agricultural resources, ecological agriculture and sustainable agricultural development; to guide the exploitation of agricultural land, fishery waters, grasslands, shoals and swamps suitable for agricultural purposes and the exploitation of rural regenerative energy as well as the protection and management of resources of biological species of agriculture; to be responsible for the protection of ecological environment of fishery waters and aquatic wild animals and plants; to safeguard the state's fishery rights and execute the supervision and management rights of fishing vessel inspections, fishery administration and fishing ports on behalf of the state.

- To formulate development plans and related policies regarding agricultural scientific research, education, technology extension and their building of rank and files, and implement the strategy of revitalizing agriculture through science and education; to organize the selection and application of major scientific research and technology extension projects; to guide the development work of agricultural education and agricultural professional skills.

- To draw up technical standards for various agricultural industries and organize their implementation thereof; to organize the implementation of quality supervision and certification of various agricultural products and green food products and the protection of new varieties of agricultural plants; to organize and coordinate the monitoring and defining of quality of agricultural inputs such as seeds, chemicals and veterinary drugs, and of related law supervision and executions; to organize the registration of domestic manufactured as well as imported seeds, chemicals, vet drugs and related Fertilisers, etc. and the safety supervision of agricultural machines.

- To draft laws and provisions on animal and plant diseases prevention and quarantine, sign inter-governmental agreements and accords and formulate related standards; to organize 
veterinary administrations and veterinary medical products administration and inspection; to organize and supervise domestic animal and plant disease prevention and quarantine, publicize epidemic information and organize the work of eradication.

- To undertake foreign-related agricultural affairs and organize related international economic and technical exchanges and cooperation.

- To guide the work of directly affiliated public institutions and the reform of enterprises affiliated to the Ministry; to supervise the value retention and increment of state-owned assets of enterprises affiliated to the Ministry; in accordance with authorizations, to administer the personnel affairs, payrolls, institutional establishments and stuffing of the directly affiliated institutions; to guide related social groups for the benefit of development of agricultural economy.

The MOA has many internal departments. A large number of these departments are of responsibilities of food supply chains regulation.

(1) Department of Bureau of Market and Economic Information (市场与经济信息司) ${ }^{2876}$ :

(2) The Department of Crop Production (种植业管理司). ${ }^{2877}$

(3) The Department of Livestock Production (畜牧业司) $)^{2878}$

(4) The Bureau of Quality and Safety Supervision for Agro-products (农产品质量安全监管 局 $)^{2879}$

(5) The Bureau of Seed Management (种子管理局). ${ }^{2880}$

(6) The Bureau of Fisheries (渔业渔政管理局) $)^{2881}$

In addition to the departments and bureaus listed above, the MOA also has a bureau responsible for the management of state farms and land reclamation (农垦局), a department responsible for farm mechanization (农业机械化司), a bureau responsible of promoting agro-product manufacturing and township enterprises (农产品加工局及乡镇企业局) and a department responsible for supervising agricultural technology development (科教司)。Moreover, there are agricultural academic research institutions such as the Chinese Academy of Agricultural Science (中国农业科学院) and the Chinese Academy of Fishery Science (中国水产科学院) also affiliated to the MOA. Most agricultural industrial associations are also under the supervision and direction of the MOA, such as China AgriProduce Marking Association (中国农产品市场协会), China Seed Association (中国种子协会), China Vegetable Association (中国蔬菜协会), China National Association for Seed Trade (中国种 子贸易协会), China Association for Plant Nutrition and Fertilisers (中国植物营养与废料协会) and Dairy Association of China (中国奶业协会).

3. China Food and Drug Administration (CFDA, 国家食品药品监督管理总局) ${ }^{2882}$

The China Food and Drug Administration is a ministerial governmental agency responsible for Chinese food and drug safety regulation. The establishment of this specific administration in 2012 is a significant landmark implicating the food safety and quality regulation in China has been emphasized.

4. State Administration for Industry and Commerce (SAIC, 国家工商行政管理总局)

\footnotetext{
2876 http://www.scs.moa.gov.cn/jieshao/jigou/scltcscs/.

${ }^{2877}$ http://english.agri.gov.cn/aboutmoa/departments/201301/t20130115_9512.htm

2878 http://english.agri.gov.cn/aboutmoa/departments/201301/t20130115_9514.htm

${ }^{2879} \mathrm{http}: / /$ english.agri.gov.cn/aboutmoa/departments/201301/t20130115_9519.htm

$2880 \mathrm{http} / / /$ english.agri.gov.cn/aboutmoa/departments/201301/t20130115_9520.htm

${ }^{2881} \mathrm{http}$ ///english.agri.gov.cn/aboutmoa/departments/201301/t20130115_9518.htm

2882 http://eng.sfda.gov.cn/WS03/CL0756/
} 
The State Administration for Industry and Commerce is the competent authority in charge of market supervision, regulation and related administrative law enforcement. The SAIC and its local subsidiaries are responsible for law enforcements in enterprise registration, antitrust and anti-unfair competition, advertising industry, consumer protection and trademark protection.

Among its broad statutory responsibilities. The following points about food value chains are worth mentioning.

- The SAIC and local AIC system is in charge of enterprises registration. All kinds of undertakings, including foreign-invested enterprises, joint ventures and agricultural cooperatives fall inside of its jurisdiction.

- The SAIC and local AIC system is responsible for enforcing Chinese Anti-unfair Competition Law (AUCL，中华人民共和国反不正当竞争法) to investigate and punish economic irregularities such as unfair competition and commercial Bribery; and Chinese Anti-Monopoly Law (AML，中华人民共和国反垄断法) with regard to monopolistic agreements, abuse of market dominant position, and practices to eliminate or restrict competition through abuse of administrative power (excluding price monopoly, which falls into the jurisdiction of the NDRC).

- The SAIC system is responsible for trade mark registration and protection.

Among the SAIC's internal departments and bureaus, the Anti-monopoly and Anti-unfair competition Bureau (反垄断与反不正当竞争执法局), the Trade Mark Office (商标局), the Consumer Protection Bureau (消费者权益保护局) are important agencies while regulating enterprise's market behaviours, undertakings in food value chains are by all means under their authorities. ${ }^{2883}$

5. Other market regulating ministries and administrations.

The 4 ministries aforementioned are the main branches for food value chains regulation. However, there are other ministries may also have influences.

(1) Ministry of Commerce (MOFCOM or MOC, 商务部). Being the ministry responsible for international and domestic trade regulation and the international economic cooperation, the MOFCOM has a broad and strong voice over import and export regulation and other matters. The Anti-Monopoly Bureau (反垄断局) under MOFCOM is the authority responsible for merger review and clearance under the troika enforcement structure of the AML.

(2) State Intellectual Property Office (SIPO, 国家知识产权局). SIPO is the competent agency for patent application and protection. Under its sub-organisations, there is a dedicated division responsible for drug and biology innovation.

(3) The National Health and Family Planning Commission (国家卫生计生委), which monitors and assesses food safety risks and develops national food safety standards;

(4) the General Administration of Quality Supervision, Inspection and Quarantine (AQISQ, 国家质检总局), which regulates imported and exported food.

(5) Antimonopoly and Anti-unfair Competition Enforcement Bureau Department for Market Circulation of Food: It has responsibility to (i) draft detailed measures and practice directions for regulating safety of food in market circulation, (ii) Implement safety surveillance, quality monitoring and related market entry rules for food in market circulation, and (iii) respond to significant emergencies of food safety in marketplaces, and investigate into severe food safety

${ }^{2883} \mathrm{http}: / /$ www.saic.gov.cn/english/aboutus/Departments/index.html 
cases and mete out appropriate punishments thereof. ${ }^{2884}$

\subsection{Regulatory framework for the food value chains}

The basic regulatory framework and the basic economic order within and between the segments of food value chains have been set by a number of laws and national policies. As the food value chain is a novel concept to both Chinese academics and regulators, there is no specific law or policy that regulates it as an integrated phenomenon. All established policies and laws regulate only one or a few segments of a food value chain. The regulation of different segments of a food value chain differs substantially. Due to historical (famines) and factual (large population but limited natural resources) reasons, the Chinese government focuses on the production segments of the food value chains via both law and national policy, whereas regulation of the other segments of food value chains has basically relied on a number of laws. The following Sections will introduce the policies implemented within the supply segments of the food value chain.

\subsubsection{National policy regarding the supply segments of the food value chains}

As introduced in the previous paragraphs, it is reasonable and necessary for the Chinese government to emphasise the food production segments of food value chains. Under this policy, a stable food production system became the general aim of the legislation (as provided for by Article 3 of Agriculture Law of the People's Republic of China). This general aim comprises three basic specific aims. To achieve these aims, since 1982, the Chinese central government has issued its so-called "No. 1 Central Document" as an annual policy declaration. ${ }^{2885}$

The No.1 Documents put great importance on larger-scale household agriculture operations (for example, family-run farms and farmer co-operatives); and encourage and support the transfer of rural land to specialised farmers, family-run farms, and farmer co-operatives.

To achieve this aim, innovation of financial products and services to farmers is encouraged. Agricultural subsidies continue to support the modernisation of agricultural technologies and grain production. A mixture of minimum purchase price, temporary reserve measures and target price subsidy aims to secure the supply of wheat, rice, corn, soybean, rapeseed, cotton and sugar, and prevent volatile price fluctuations. The No. 1 Documents stress the importance of developing high efficient water saving irrigation and the improvement of agricultural logistics (trade market centres, wholesale and retail distribution, cold chain logistics and online settlements) to facilitate the "NorthSouth" and "West-East" distribution of food. Commercial investment is encouraged in greenhouse production, food processing, and livestock farming, but not in large industrial scale crop farming. Instead of following the US and South American model of large agricultural farms, China maintains a large rural population that is encouraged to be active in large-scale household agriculture. However, as a result of the shortage of agricultural land in China (China has 9\% of the total arable land in the world and $21 \%$ of the world's population), imports are an important source of food security.

\footnotetext{
${ }^{2884} \mathrm{https}: / /$ www.jetro.go.jp/ext_images/world/asia/cn/ip/law/pdf/origin/2008080758891502.pdf and http://www.gov.cn/zhengce/content/2016-10/10/content_5116652.htm（国务院办公厅矢于印发国家工商行政管理总 局主要职责内设机构和人员编制规定的通知)

${ }^{2885} \mathrm{http}: / /$ www.moa.gov.cn/ztzl/yhwj2014/. Interrupted from 1987 to 2003.
} 
The Opinions of the State Council on Accelerating the Development of the Modern Crop Seed Industry of 10 April 2011 state that the crop seed industry is a key national industry. Its modernisation is accelerated for the long-term social stability and food security of China. To achieve this objective, China will insist on independent innovation through international co-operation in the crop seed industry, in particular with respect to advanced breeding technology, to improve the domestic crop seed industry's competitiveness. As a result, foreign investment in the seed business in China is only allowed by way of a joint-venture in which the Chinese partners have a controlling interest.

The first and primary basic aim of the Chinese agricultural policy is to achieve security of food supply. As universally known, China is the largest developing country in the world, and has the largest population. ${ }^{2886}$ This has exerted considerable pressure on the country's food production capacity, which is based on limited natural resources and less-advanced production technology. Despite these issues, the Chinese government still insists on implementing a challenging agriculturalfood policy: supplying about $95 \%$ domestic needs for agro-food products. ${ }^{2887}$

To guarantee the achievement of the first aim, a series of measures have been implemented by the central government, both from the overarching agro-food level and from the more sectorialspecific level (“十八亿亩红线”). At the overarching agro-food level, the central government has, to date, offered support and subsidies for agricultural insurance, with specific programs for corn, rice, wheat, cotton, potatoes, oil-bearing crops, sugar crops, breeding sows, fattening swine, cows, natural rubber, forest, highland barley and Tibetan sheep, totaling 15 types of products. The central government offers compensation to crop farming insurance; the central and western regions receive compensation of $40 \%$ of the fiscal expenditure on crop farming insurance, the eastern region receives $35 \%$, the Xinjiang Production and Construction Corporation, the central reclamation area, Grain Storage Company North, China National Agricultural Development Corporation receive 65\%, and provincial governments receive at least $25 \%$. In addition to providing policy support for the development of peasant cooperatives, the central government also encourages cooperative economic development in rural areas; supports the development of large-scale production, specialised production, and modern management; and allows direct financial support to be offered to eligible cooperatives unions. In 2015, in addition to continuing the established affirmative policy, the central government adopted a series of measures to further advance the healthy development of the peasant cooperatives.

Each year, nearly all specific agro-food sectors receive policy support. In the grain sector, to prevent peasants from being hurt by low prices, in 2015, the central government continued a policy that has been implemented for a long time: the minimum purchase price policy toward wheat and rice. In 2015, the minimum purchase prices were: $118 \mathrm{RMB} / 50$ kilograms for wheat, $135 \mathrm{RMB} / 50$ kilograms for spring rice, $138 \mathrm{RMB} / 50$ kilograms for autumn indica rice, and $155 \mathrm{RMB} / 50$ kilograms for japonica rice. In the animal genetics breeding sector, the central government has operated a highgrade breed subsidy policy since 2005. In 2014, the central government invested 1.2 billion RMB mainly subsidising farm(er)s buying high grade breeding swine (cattle) semen or high-grade antelope, breeding rams and yaks. The standards are: (1). for standard animals, 40 RMB per swine, 30 RMB per cow or breeding cow, and 20RMB per other species of breeding cow. (2). for high grade breeds, $800 \mathrm{RMB}$ per sheep and 2000RMB per cow. In 2015, the above subsidies were continued. In addition,

\footnotetext{
${ }^{2886}$ Exceeding 1.37 billion. http://www.stats.gov.cn/tjsj/zxfb/201604/t20160420_1346151.html

${ }^{2887} \mathrm{http}: / /$ www.npc.gov.cn/huiyi/cwh/1116/2010-08/27/content_1592133.htm
} 
seed embryos were introduced into the subsidy list: the standard is 5,000 RMB per embryo. The central government also provides animal epidemic prevention subsidies. In mainland China, these subsidies are available for: (1). the widely used animal diseases compulsory immunisation vaccines, covering highly pathogenic avian influenza, highly pathogenic blue-ear swine disease, foot and mouth disease, swine fever, and small ruminant animal disease; (2). the culling of animals and poultry infected with diseases, including: highly pathogenic avian influenza, foot and mouth disease, highly pathogenic blue-ear swine disease, small ruminant animal disease, and brucellosis and tuberculosis in dairy cows; (3). animal epidemic prevention, to which the central government provided a 0.78 billion RMB in 2015; (4). the harmless treatment of dead swine on farms, with a standard subsidy of 80 RMB per dead swine; (5). the harmless treatment of dead swine in processing factories, with a standard subsidy of 80 RMB per dead swine; (6) a diesel subsidy in the fishery sector, which is the largest subsidy in that sector; and (7) conservation of fishery resources, with the central government offering 0.4 billion RMB in 2015.

Increasing the income of peasant is the second basic-aim of the national agro-food policy as increased income stimulates peasant to remain in the agro-food sector, which is beneficial for a stable supply of agro-food products. As food consumers, the peasants (about half of China's population) directly benefit from this policy and can, in turn, contribute to balanced and stable food value chains. To achieve this aim, the central government implements various policies, including compensation and price limits on certain agro-food facilities. The central government offers compensation for buying and renewing machines related to the production of agro-food products. First, it offers a machinery purchase subsidy, which was paid to all domestic farms and individuals in 2015. The subsidy includes 11 general categories, which can be divided to 43 sub-categories. The subsidy amounts are fixed: general agricultural machine, not exceeding 50,000 RMB; milking machine/drying machine, not exceeding 120,000 RMB; large tractor, non-tillage planter, harvester, large seed soaking pre-germination machine, and combined harvesters, not exceeding 150,000 RMB; super-large tractor, not exceeding 250,000 RMB; sugarcane harvester, not exceeding 400,000 RMB; cotton picking machine, not exceeding 500,000 RMB. Second, there is a subsidy against the discard and replacement of agricultural machine. A pilot subsidy program was conducted in 2015 in the following provinces and cities: Hebei, Shanxi, Heilongjiang, Jiangsu, Zhejiang, Anhui, Jiangxi, Shandong, Henna, Hubei, Hunan, Guangxi, Shanxi, Gansu, Xinjiang, Ningbo, Qingdao. A subsidy against discard and replacement is offered simultaneously. The standards are: tractors - 500-11,000 RMB per machine; combined harvesters - 3,000-180,000 RMB per machine. Third, the central government offers a subsidy for not increasing the amount of fertilisers and pesticides used in food production. Since 2014, the central government has offered a subsidy for advanced planting and nourishing technology with 3000,000 RMB has offered in five provinces for adopting a technology that plants corn and adds fertilisers concurrently. In 2011, the central government started pilot work on using low-toxicity biological pesticides. In 2015, the central government offered 960,000 RMB to support the adoption of these pesticides in 42 farms located across the country.

The third basic aim, namely the efficiency of agro-food production (in some circumstances called competitiveness of agro-food production), is a policy that originated from many economic changes within the agro-food sector. There have been great changes in the production, supply, and consumption segments of food value chains since China's agricultural policy reform began in 1978 . Both production and distribution became more market-oriented, and are typically governed by market mechanisms. Competition became a main market mechanism in the production and distribution of 
products in Chinese food value chains. China has already witnessed both domestic and international competition within the supply segments of food value chains, and there will be more international competition after the expiration of China's agro-food protection agreements with WTO members. There are also other important reasons for implementing an efficiency-oriented policy, including, for example, the lack of arable land and other resources. For all these reasons, a high-efficiency production system is required in China's agro-food sectors.

The central government, therefore implements all-encompassing affirmative policies to address the efficiency issue. First, a high breed seeds subsidy is available. In 2015, the central government reserved a financial subsidy of 20.35 billion RMB for various agricultural plants, comprising rice, wheat, corn, cotton, soybeans, canola, barley, potato, and peanut. The relevant standards are: wheat, corn, soybeans, canola and barley - $10 \mathrm{RMB} / \mathrm{mu}^{2888}$; Tibetan wheat $15 \mathrm{RMB} / \mathrm{mu}$; Tibetan rice/cotton - $15 \mathrm{RMB} / \mathrm{mu}$; potato $100 \mathrm{RMB} / \mathrm{mu}$; and peanut - $500 \mathrm{RMB} / \mathrm{mu}$. Second, the government offers a subsidy for standardisation of animal genetics breeding, to which 3.8 billion RMB were allocated in 2014. 2.5 billion RMB to the swine sector, 1 billion RMB to the cow sector, and the remainder to sheep and cattle sectors. In 2015, the subsidy was continued, except for small-sized swine feeding. Third, there is a subsidy for training agricultural workers, for which the central government devoted 1.1 billion RMB for training peasants. This subsidy covers four provinces, including 20 cities, it ensured that 10,000 young peasants obtain necessary technological skills and experience. Fourth, financial support is offered through financial departments of the country, which has adopted many supporting policies, such as granting peasant credit loans, supporting mergers between small-sized agricultural farms and factories, helping to establish closer economic connections among all segments of food supply chains (downstream firm, farm and upstream firm), promoting modern agriculture projects, and supporting the establishment of wholesale markets, retail markets, and storage facilities. Fifth, support measures for household farms were adopted by the central government in 2015 . These measures cover many aspects, including, for example, financial direct subsidies, tax incentives, loans, insurance, and mortgage guarantees

\subsubsection{National laws regarding the various segments of the food value chain}

\subsubsection{Basic laws for the production and supply segments of the food value chain}

\subsection{Agriculture Law of the People's Republic of China 1993( 中华人民共和国农业法)}

Agriculture Law of the People's Republic of China (ALPRC) is the basic law for both Chinese agriculture and the production and supply segments of the food value chains. For Chinese agriculture, the law applies to all general and specific sectors that relate to agricultural and food production. Article 2 ALPRC provides that "For the purpose of this Law, agriculture consists of the industries of crop-planting, forestry, animal breeding and fishery, including the services before, during and after the production process directly related with the above". ${ }^{2889}$ Article 1 ALPRC provides that agriculture is the foundation of all sectors of the country's economy. In specific, it provides that "This Law is

2888 "mu" is a Chinese land measurement unit.

${ }^{2889}$ Article 2 of ALPRC. http://www.npc.gov.cn/englishnpc/Law/2007-12/12/content_1383785.htm. 
enacted with a view to consolidating and strengthening the position of agriculture as the foundation of the national economy, deepening the reform in rural areas, developing the productive forces of agriculture, pushing forward the modernization of agriculture, safeguarding the legitimate rights and interests of peasants and agricultural production and operation organizations, increasing the income of peasants, enhancing their scientific and cultural qualification, promoting the sustained, steady and sound growth of agriculture and the rural economy, and attaining the objectives of building a welloff society in an all-round way." ${ }^{2890}$ Besides the above issues, ALPRC provides many basic principles and conventions that apply to the agro-food sectors. Article 3 states the following:

"The State gives first priority to agriculture in the development of the national economy. The main objectives in developing agriculture and the rural economy are to establish a rural economic system that meets the demand for the development of the socialist market economy, to continuously emancipate and develop the productive forces in the countryside, to enhance the quality and efficiency of agriculture as a whole, to ensure the supply and quality of agricultural products, to satisfy the need of developing the national economy, of an increased population and of enhancing people's lives, to increase the income of peasants and raise their living standards, to promote the transfer of the surplus rural labor to non-agricultural industries and to cities and towns, to narrow the difference between town and country and between regions, to build a prosperous, democratic and culturally advanced new socialist countryside, and to gradually bring about the modernization of agriculture and the countryside". 2891

ALPRC also provides the fundamental conventions on using arable lands for production. Under Chinese law, all arable lands belong to the country or collective peasants. All peasants rent (or through contractual management) land from these two types of owners, known as "Household Contracted Management". ${ }^{282}$ Against this operating system, Article 5 ALPRC provides that "The State, for a long time to come, stabilizes the two-tier management system that combines unified with separate management on the basis of household contractual management, develops systems for commercialized services, expands the actual strength of collective economy, and guides the peasants onto the road of common prosperity." ${ }^{2893}$ For the food supply issue, it further provides that "The State adopts measures to ensure that agriculture plays a better role in many fields such as in the supply of food, industrial raw materials and other farm products, in the maintenance and improvement of the ecological environment and in the promotion of the rural economic and social development."2894

ALPRC provides the basic operating conventions for agricultural production, as well as governmental encouragement of cooperative production among peasants and all the other segments of food value chains. Article 10 ALPRC stipulates that

"The State applies the contractual management system in respect of land in rural areas, protects, in accordance with the law, the long-term stability of the relationship of land contract in rural areas, and protects the right of peasants to use their contracted land. The Land Administration Law of the People's Republic of China and the Law of the People's Republic of China on Land Contract in Rural Areas shall be applicable to matters such as the mode and

\footnotetext{
${ }^{2890}$ http://www.npc.gov.cn/englishnpc/Law/2007-12/12/content_1383785.htm.

${ }^{2891} \mathrm{http} / / / w w w . n p c . g o v . c n / e n g l i s h n p c / L a w / 2007-12 / 12 /$ content_1383785.htm.

2892 家庭承包经营.

2893 http://www.npc.gov.cn/englishnpc/Law/2007-12/12/content_1383785.htm.

${ }^{2894}$ http://www.npc.gov.cn/englishnpc/Law/2007-12/12/content_1383785.htm.
} 
term of contractual management of rural land, the rights and obligations of the party giving out the contract and the contractor, and protection and transfer of the right to land contractual management. The rural collective economic organizations shall, on the basis of the household contractual management and in accordance with law, manage the collective assets, provide their members with services in respect of production, technology, information, etc., make arrangements for rational development and use of collective resources and build up economic strength". 2895

According to Article 11, "The State encourages peasants to voluntarily organize themselves into various kinds of specialized cooperative economic organizations on the basis of household contractual management. Specialized cooperative economic organizations of peasants may take diversified forms and shall be established and registered in accordance with the law. No organizations or individuals may infringe upon the property of such organizations or their right of decision-making in management." 2896 Article 13 provides that

"The State takes measures to develop industrial management of agriculture in various forms, and encourages and supports peasants and agricultural production and operation organizations in their efforts to develop integrated operation of production, processing and marketing. The State provides guidance and support to enterprises, scientific research institutions and other organizations which are in the service of production, processing and circulation of agricultural products through concluding contracts or establishing different kinds of enterprises with peasants or farmers specializing in cooperative economic organizations, in their efforts to form benefit communities that jointly share profits and undertake risks, in order to push forward the industrial management of agriculture and give impetus to the development of agriculture." 2897

Article 14 states that "Peasants and agricultural production and operation organizations may, in accordance with the law and administrative regulations, establish trade associations of different kinds of agricultural products in order to provide their members with services related to production, marketing, information, technology, training, etc., to play the role of coordination and self-discipline, to submit applications for relief measures for trade in agricultural products and to safeguard the interests of their members and trade." 2898

ALPRC provides the basic mechanisms for processing and circulating agro-food products, devoting more than three articles to provide that the purchases and sale of agro-food products shall follow market mechanisms, namely, the competition mechanism. Articles 26, 27, and 30 provide that it is the central government's responsibility to establish and maintain the market mechanism and to provide the corresponding environment. According to Article 26,

"The purchase and sale of agricultural products shall be regulated by market forces. The State exercises the necessary macro-economic control over in the purchase and sale of key agricultural products which have a bearing on the national economy and the people's livelihood, establishes a system for storage regulation at the central and local levels and

\footnotetext{
2895 http://www.npc.gov.cn/englishnpc/Law/2007-12/12/content_1383785.htm.

$2896 \mathrm{http} / / / \mathrm{www} . n p c . g o v . c n /$ englishnpc/Law/2007-12/12/content_1383785.htm.

${ }^{2897} \mathrm{http} / / / \mathrm{www} . n p c . g o v . c n /$ englishnpc/Law/2007-12/12/content_1383785.htm.

${ }^{2898}$ http://www.npc.gov.cn/englishnpc/Law/2007-12/12/content_1383785.htm.
} 
improves the storage and transportation system, in order to guarantee supply and stabilize the market." 2899

It is provided in Article 27 that

"The State gradually establishes a unified, open, competitive and orderly market system for agricultural products and formulates plans for the development of a wholesale market for agricultural products. The State gives support to the rural collective economic organizations and specialized cooperative economic organizations of peasants in their efforts to build up wholesale markets and rural fairs for agricultural products. Administrative departments for industry and commerce under the people's governments at or above the central government level and the relevant departments shall, in compliance with their respective duties and in accordance with the law, administer the wholesale markets for agricultural products, standardize the order of trade and prevent local protectionism and unfair competition". ${ }^{2900}$

Article 30 provides that the State encourages the development of import and export trade of agricultural products. ${ }^{2901}$ This provision guarantees that domestic agro-food product supply is exposed to international competition. ${ }^{2902}$ In addition to these provisions, ALPRC also provides specific ways to facilitate the adoption of the general operating mechanism. Article 28 stipulates that "The State encourages and supports the circulation of agricultural products in various forms. It supports the peasants and the specialized cooperative economic organizations of peasants to engage in purchase, wholesale, storage, transportation and retail of agricultural products and other intermediary activities in accordance with the relevant regulations of the State. It encourages the supply and marketing cooperatives and other agricultural production and operation organizations engaged in the purchase and sale of agricultural products to provide market information and open up circulation channels for agricultural products in the service of the purchase and sale of such products. People's governments at or above the county level shall take measures and urge the relevant departments to ensure unblocked transportation of agricultural products and to reduce the circulation costs for such products. The relevant administrative departments shall simplify formalities to facilitate the transportation of fresh and live farm products, they are not allowed to detain the means of transport for fresh and live farm products except where otherwise provided for in laws and administrative regulations". 2903

Article 29 provides that

"The State supports the development of the processing of agricultural products and the food industry in order to increase the added value of the products. People's governments at or above the county level shall formulate plans for the development of the processing of agricultural products and the food industry, provide guidance to the enterprises engaged in the processing of agricultural products, helping them form a rational regional layout and structure of scale, and support the specialized cooperative economic organizations of peasants and enterprises town and township enterprises in their efforts to engage in processing and comprehensive development and utilization of agricultural products. The State establishes well-defined

\footnotetext{
${ }^{2899}$ http://www.npc.gov.cn/englishnpc/Law/2007-12/12/content_1383785.htm.

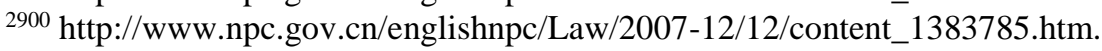

${ }^{2901} \mathrm{http} / / / w w w . n p c . g o v . c n / e n g l i s h n p c / L a w / 2007-12 / 12 /$ content_1383785.htm.

2902 The State may take the necessary measures when the import of certain agricultural products has already occasioned or is likely to occasion serious effect detrimental to the production of relevant agricultural products at home.

${ }^{2903}$ http://www.npc.gov.cn/englishnpc/Law/2007-12/12/content_1383785.htm.
} 
quality standards for processed agricultural products, improves the means of inspection and testing and tightens control and supervision over quality safety during the processing of agricultural products, in order to guarantee food safety". ${ }^{2904}$

In addition to the various institutions and mechanism that target the establishment of a rural economic system that meets the demand for the development of the socialist market economy, ${ }^{2905}$ ALPRC also includes provisions relating to the continuousl emancipation and development of the productive forces in the countryside, in order to enhance the quality and efficiency of agriculture as a whole, and to ensure the supply and quality of agricultural products, ${ }^{2906}$ ALPRC provides many measures to guarantee stable food supply and safety. Article 31 provides that the State may adopt measures to protect and enhance the comprehensive capacity for grain production, steadily to raise grain production level and to ensure gain safety. ${ }^{2907}$ Article 33 states that

When the market price of grain is too low, the State Council may decide to introduce the protective price system for some varieties of grain. Protective prices shall be determined on the principle that they are conducive to the protection of the peasants' interests and to the stable production of grain. When peasants sell their grains in accordance with the protective price system, no purchasing units entrusted by the State may refuse to purchase them. People's governments at or above the county level shall make arrangements for departments of finance, banking, etc. as well as purchasing units entrusted by the State to raise enough funds in time for the purchase of grain. No departments, units or individuals may withhold or misappropriate such funds." 2908

Article 35 provides that "The State establishes a risk fund for grain, which shall be used to support grain storage, stabilize grain markets and protect the interests of peasants."2909

As the production and supply of agro-food products depend heavily on natural environments and resources, and the sole application of market mechanisms may harm the supply of food, thus affecting the public interest, and further all the other segments of the food value chains ALPRC provides many corresponding measures, both at the central government and local government levels to ensure a sufficient level of support. Hence, Article 37 provides that

"The State establishes a sound network for support and protection of agriculture, and takes such measures as financial investment, preferential taxation and banking assistance to support, in terms of fund input, scientific research and popularization of technology, education and training, supply of the means of agricultural production, market information, quality standard, test and quarantine, commercialized services and disaster relief, peasants and agricultural production and operation organizations in their efforts to develop agricultural production, in order to help increase the income of peasants. On condition that the relevant international treaties which China has concluded or has acceded to are not contravened, the State pursues a policy in support of the income of peasants, and the specific measures thereof shall be worked out by the State Council." 2910

Furthermore, Article 40 stipulates that

\footnotetext{
${ }^{2904}$ http://www.npc.gov.cn/englishnpc/Law/2007-12/12/content_1383785.htm.

${ }^{2905}$ Article 3 of ALPRC. http://www.npc.gov.cn/englishnpc/Law/2007-12/12/content_1383785.htm.

${ }^{2906}$ Article 3 of ALPRC. http://www.npc.gov.cn/englishnpc/Law/2007-12/12/content_1383785.htm.

${ }^{2907} \mathrm{http}: / / w w w . n p c . g o v . c n /$ englishnpc/Law/2007-12/12/content_1383785.htm.

${ }^{2908}$ http://www.npc.gov.cn/englishnpc/Law/2007-12/12/content_1383785.htm.

2909 http://www.npc.gov.cn/englishnpc/Law/2007-12/12/content_1383785.htm.

${ }^{2910} \mathrm{http}: / / w w w . n p c . g o v . c n /$ englishnpc/Law/2007-12/12/content_1383785.htm.
} 
"The State, through taxation, pricing, credit and other means, encourages and guides peasants and agricultural production and operation organizations to increase investment in agricultural production and operation and in capital construction such as small irrigation and water conservancy projects. The State encourages and supports peasants and agricultural production and operation organizations to raise agricultural funds in various forms on a voluntary basis and in accordance with law."'2911

According to Article 44,

"The State encourages the supply and marketing cooperatives, rural collective economic organizations, specialized cooperative economic organizations of peasants, other organizations and individuals to develop diversified forms of undertakings that provide commercialized services before, during and after the process of agricultural production. People's governments at or above the county level and the relevant departments under them shall take measures to provide support to undertakings that render commercialized services to agriculture. The departments for agriculture, industry and commerce, transportation and public security and other relevant departments shall take measures to give support to units that provide transregional commercialized services to agriculture". ${ }^{2912}$

Article 45 provides that "The State establishes a sound rural financial network, improves the rural credit system and tightens supervision over rural finance. The financial institutions concerned shall take measures to increase input to credit, improve financial services in the countryside and extend credit in support of agricultural production and operation conducted by peasants and agricultural production and operation organizations. Rural credit cooperatives shall adhere to their aims of serving agriculture, the peasants and economic development in rural areas and, in providing credit services, give priority to production and operation conducted by local peasants. The State, by taking such measures as discount, encourages financial institutions to provide credit to the peasants and agricultural production and operation organizations engaged in agricultural production and operation." 2913 Article 46 provides that "The State establishes a sound insurance system for agriculture. The State gradually establishes a sound policy-related insurance system for agriculture. It encourages and supports peasants and agricultural production and operation organizations to form mutual-aid cooperative insurance organizations in the service of agricultural production and operation, and encourages commercial insurance companies to conduct insurance business in agriculture. The principle of voluntariness shall be practised in agricultural insurance. No organizations or individuals may compel peasants or agricultural production and operation organizations to buy agricultural insurance." 2914 Article 47 provides that "People's governments at all levels shall take measures to increase the capabilities of fighting against natural disasters in agriculture, do a good job of preventing and fighting against disasters and providing disaster relief, help victims to restore production, and encourage them to support themselves by engaging in production and give each other assistance; and they shall give relief and help to the victims who lack the basic living guarantee." 2915

\footnotetext{
${ }^{2911}$ http://www.npc.gov.cn/englishnpc/Law/2007-12/12/content_1383785.htm.

$2912 \mathrm{http}: / /$ www.npc.gov.cn/englishnpc/Law/2007-12/12/content_1383785.htm.

2913 http://www.npc.gov.cn/englishnpc/Law/2007-12/12/content_1383785.htm.

2914 http://www.npc.gov.cn/englishnpc/Law/2007-12/12/content_1383785.htm.

2915 http://www.npc.gov.cn/englishnpc/Law/2007-12/12/content_1383785.htm.
} 
ALPRC takes special care to incentivise peasants to produce and supply agro-food products. Specifically, Article 72 provides that: "In the course of the agricultural and rural economic restructuring, the industrialization of agricultural operation and the transfer of the right to land contractual management, no people's government at any level, rural collective economic organization or villagers committee may infringe upon the peasants' right to land contractual management, interfere with the items of production and operation arranged by the peasants themselves, or compel the peasants to buy the means of production designated by it or to sell their agricultural products through the channels designated by it." 2916 Article 75 provides that "When purchasing agricultural products, no purchasing units may force down the grade or price or withhold any fees from the money paid. Where taxes are to be withheld or collected by an agent, as provided for by laws and administrative regulations, the provisions of the said laws and regulations shall be abide by. Where a dispute arises over the grade of quality of agricultural products between the unit purchasing the agricultural products and the seller of the products, they may entrust a statutory qualified authority for quality inspection of agricultural products with the inspection of the products."2917

\subsection{Fisheries Law of the People's Republic of China 1986 (FLPRC)( 中华人民共和国渔 业法) and Animal Breeding Law of the People's Republic of China 2006 (AHLPRC)( 中华人民共和国畜牧法)}

FLPRC and AHLPRC are the basic laws that apply to the production and supply segments of fisheries and livestock farming.

From a broader view, FLPRC is an extension of ALPRC, because it sets the basic market order and operating system for the production of fisheries in China. FLPRC provides the basic order for both the aquaculture and capture fishery production activities such as aquatic animal and aquatic plants within PRC jurisdiction. Article 2 provides that "All productive activities of fisheries, such as aquaculture and catching or harvesting of aquatic animals and plants, in the inland waters, tidal flats, territorial waters and exclusive economic zones of the People's Republic of China and in all other sea areas under the jurisdiction of the People's Republic of China shall be conducted in accordance with this Law". ${ }^{2918}$ To enhance, protect, increase, develop and to proceed to the rational utilization of fishery resources, the FLPRC sets a very strict licensing system: namely, both the breeding and the fishery must be licensed by the PRC government. According to Article 10

"Any unit or and individual that wishes to use the water areas or tidal flats owned by the whole people of China and designated for aquaculture according to national plans shall apply to the administrative department for fisheries under the local people's government at or above the county level. An aquaculture permit shall be issued after examination by the people's government concerned, allowing the applicant to use certain water areas or tidal flats for aquaculture. Specific measures for examining and issuing aquaculture permits shall be formulated by the State Council. The water areas and tidal flats owned by the collective or by the whole people but used by agricultural collective economic organizations may be contracted out to individuals or collectives for aquaculture". ${ }^{2919}$

\footnotetext{
2916 http://www.npc.gov.cn/englishnpc/Law/2007-12/12/content_1383785.htm.

2917 http://www.npc.gov.cn/englishnpc/Law/2007-12/12/content_1383785.htm.

2918 http://www.npc.gov.cn/englishnpc/Law/2007-12/12/content_1383934.htm.

${ }^{2919}$ http://www.npc.gov.cn/englishnpc/Law/2007-12/12/content_1383934.htm.
} 
The right to use water areas is subject to revocation if it meets the conditions of Article 11 of FLPRC. ${ }^{2920}$ Similarly, Article 15 FLPRC provides that "The import and export of fry and fingerling of aquatic animals shall be subject to examination and approval by the administrative department under the State Council or such departments under the people's governments of provinces, autonomous regions or municipalities directly under the Central Government". ${ }^{2921}$ Misuse of governmental licences is punishable by administrative sanctions. Article 32 further stipulates that "For water areas that are used for fisheries and that also serve the purposes of water storage, regulation and irrigation, the competent department concerned shall fix the lowest water level required for fisheries". ${ }^{2922}$

AHLPRC is designed to standardize "the production and operation in animal breeding (protection and utilization of the genetic resources, breeding, raising, operation and transportation of livestock and poultry $)^{2923}$, to guarantee the quality and safety of livestock and poultry products, to protect and make rational use of the genetic resources of livestock and poultry, to safeguard the lawful rights and interests of the producers and operators in animal breeding and to promote sustained and healthy development of animal breeding". ${ }^{2924}$ This law specifically clarifies the government's responsibility to design and maintain markets for livestock farming and product circulation, in which market mechanisms should be followed. To fulfill theirtasks, in livestock and poultry breeding, The administrative department for animal breeding and veterinary medicine under the people's government at or above the county level shall, in accordance with the development plan for animal breeding and in compliance with market demands, give guidance to and support the restructuring of animal breeding, promote the production of livestock and poultry and enhance the market competition of livestock and poultry products". It is also mentioned in the same provision that "The State assists capital construction projects in pastoral areas of grasslands, such as erecting fences, building water conservancy projects, improving the grassland and building bases of forage grass and feeds, in order to optimize the composition of livestock herds, improve the strains, transform the mode of production, promote the rearing of livestock in pens or sties, and rotated grazing in demarcated areas, gradually bring about a balance between pastures and livestock and improve the ecological environment of grasslands". ${ }^{2925}$ In livestock trading and transport, "People's governments at or above the county level shall promote the building of a trading market of livestock and poultry characterized by openness, uniformity and orderly competition"; 2926.2927

\subsection{Land Administration Law of the People's Republic of China (LALPRC) 1986( 中华人 民共和国土地管理法), Law of the People's Republic of China on Land Contract in Rural Areas 2002 (LPRCLCRA) (中华人民共和国农村土地承包法), Grassland Law of the People's Republic of China 2002 (GLPRC) (中华人民共和国草原法), Seed Law of the People's Republic of China 2015 (SLPRC)( 中华人民共和国种子法)}

\footnotetext{
${ }^{2920}$ http://www.npc.gov.cn/wxzl/gongbao/2000-12/06/content_5004465.htm.

${ }^{2921} \mathrm{http} / / / \mathrm{www} . n p c . g o v . c n /$ englishnpc/Law/2007-12/12/content_1383934.htm.

2922 http://www.npc.gov.cn/englishnpc/Law/2007-12/12/content_1383934.htm.

${ }^{2923}$ Article 2 of AHLPRC. http://www.npc.gov.cn/englishnpc/Law/2007-12/13/content_1384134.htm.

${ }^{2924}$ Article 1 of AHLPRC. http://www.npc.gov.cn/englishnpc/Law/2007-12/13/content_1384134.htm.

2925 Article 35 of AHLPRC. http://www.npc.gov.cn/englishnpc/Law/2007-12/13/content_1384134.htm.

${ }^{2926}$ Article 50 AHLPRC. http://www.npc.gov.cn/englishnpc/Law/2007-12/13/content_1384134.htm.

${ }^{2927}$ Article 51 AHLPRC. http://www.npc.gov.cn/englishnpc/Law/2007-12/13/content_1384134.htm.
} 
There are few basic laws that govern the primary production segments of the food value chains. These elements cover either the original production materials or the basic economic relationship between the owners' of these inputs and their tenants or purchasers.

LALPRC is enacted "for the purpose of strengthening land administration, maintaining the socialist public ownership of land, protecting and developing land resources, making rational use of land, effectively protecting cultivated land and promoting sustainable development of the society and the economy". ${ }^{2928}$ This legislation emphasises that "The People's Republic of China practises socialist public ownership of land, namely, ownership by the whole people and collective ownership by the working people", something that is also provided for by Chinese constitutional law. ${ }^{2929}$ LALPRC provides that the State applies a system of control over the purposes of the use of land rigidly restricting the conversion of land for agriculture to land for construction also binding all units and individuals to use land in strict compliance with the purposes of use defined in the overall plans for land utilization. ${ }^{2930}$ LALPRC also provides for the renting (or the contractual management system) of arable lands, Article 15 specifically stipulating the following:

"State-owned land may be operated under a contract by units or individuals for crop cultivation, forestry, animal breeding or fishery. Land owned by peasant collectives may be operated under a contract for crop cultivation, forestry, animal breeding or fishery by units or individuals that do not belong to the economic organizations of the said collectives. The party that gives out the contract and the party that undertakes it shall sign a contract in which they stipulate the rights and obligations of both parties. The duration of such contract shall be provided for by the contract. The units or individuals that contract to operate the land shall have the obligation to protect such land and make a rational use of it in conformity with the purposes of use provided for in the contract. Land owned by peasant collectives shall be operated under a contract by units or individuals that do not belong to the economic organizations of the said collectives, with the agreement of at least two-thirds of the members of the villagers' assembly or of the representatives of villagers, and the matter shall be submitted to the township (town) people's government for approval."2931

With regard to the contractual management institution provided by LALPRC, LPRCLCRA was enacted in order to specify its application in rural areas. ${ }^{2932}$ LPRCLCRA provides in its Article 1 that, first of all, the peasants own long-term and guaranteed land-use rights. ${ }^{2933}$ Article 20 then provides that the duration of a contract for arable land shall be 30 years, the term of contract for grassland ranges from 30 to 50 years and the term of contract for forestland ranges from 30 to 70 years; but may be longer for specific types of forest, upon approval by the competent administrative department under the State Council"; ${ }^{2934}$ The State applies the contractual management system in respect of land in rural areas. Land contract in rural areas takes the form of household contractual management within the collective economic organizations in the countryside, while such land in rural areas as barren

\footnotetext{
${ }^{2928}$ Article 1 of LALPRC. http://www.npc.gov.cn/englishnpc/Law/2007-12/12/content_1383939.htm

${ }^{2929}$ Article 2 of LALPRC. http://www.npc.gov.cn/englishnpc/Law/2007-12/12/content_1383939.htm

${ }^{2930}$ Article 4 of LALPRC. http://www.npc.gov.cn/englishnpc/Law/2007-12/12/content_1383939.htm

${ }^{2931}$ http://www.npc.gov.cn/englishnpc/Law/2007-12/12/content_1383939.htm

${ }^{2932}$ Article 2 LPRCLCRA. For purposes of this Law, land in rural areas includes the arable land, forestlands and grasslands owned collectively by the peasants and by the State and used collectively by the peasants according to law, as well as other lands used for agriculture according to law.

${ }^{2933} \mathrm{http} / / / w w w . n p c . g o v . c n / e n g l i s h n p c / L a w / 2007-12 / 06 /$ content_1382125.htm

${ }^{2934}$ Article 20 of LPRCLCRA. http://www.npc.gov.cn/englishnpc/Law/2007-12/06/content_1382125.htm
} 
mountains, gullies, hills and beaches, which are not suited to the form of household contract, is contracted in such forms as bid invitation, auction and public consultation. ${ }^{2935}$. Furthermore, LPRCLCRA stipulates that

"The State protects, in accordance with the law, the long-term stability of the relationship of land contract in rural areas. After the land in rural areas is contracted, the nature of ownership of the land shall remain unchanged. The contracted land may not be purchased or sold."2936

Article 5 LPRCLCRA provides that "Members of the collective economic organizations in rural areas shall, according to law, have the right to undertake rural land contracts with their own collective economic organizations that give out the contracts. No organizations or individuals may deprive the members of the rural collective economic organizations of their right to undertake contracts or illegally restrict such right." 2937 The situation that contracted land may not be purchased or sold prevents the free movements of the basic production material and is therefore contrary to the market mechanism within the production and supply segments of the food value chain. As a result, LPRCLCRA uses four articles to provide for the circulation of the right to contact management of the contracted land. Article 10 provides the principle for this circulation noting that "The State protects the circulation of the right to land contractual management, which is effected according to the law, on a voluntary basis and with compensation". ${ }^{2938}$ Article 32 provides the forms of the circulation of the contact management of the contracted land, which may be achieved through subcontracting, leasing, exchanging, transferring or other means. ${ }^{2939}$ Article 42 provides that "For the purpose of developing the agricultural economy, the contractors may, of their own free will, jointly pool their rights to land contractual management as shares to engage in cooperative agricultural production". 2940

Quite similarly to LALPRC and LPRCLCRA, GLPRC provides for the ownership of grassland and the corresponding utility institutions. GLPRC was drafted to protect, develop and rationalize the "use of grasslands, improving the ecological environment, maintaining the diversity of living things, modernizing animal breeding and promoting the sustainable development of the economy and society". ${ }^{2941}$ GLPRC clarifies that

"The grasslands are owned by the State, with the exception of the grasslands owned by collectives as provided for by law. With respect to the State-owned grasslands, the State Council shall exercise the right of such ownership on behalf of the State. No unit or individual may take illegal possession of, trade in or illegally transfer in other forms the grasslands". ${ }^{2942}$ In addition to this, GLPRC indicates the specific bodies entitled to utilize or to rent (or through contractual management) grassland. Article 10 states that "The State-owned grasslands may, in accordance with the law, be assigned for use to the units under the ownership by the whole people and to collective economic organizations. All units that use the grasslands shall fulfil the duty of protecting, developing and rationally using the grasslands". ${ }^{2943}$ According to Article 11 "With respect

\footnotetext{
2935 Article 3 of LPRCLCRA. http://www.npc.gov.cn/englishnpc/Law/2007-12/06/content_1382125.htm

${ }^{2936}$ Article 4 of LPRCLCRA. http://www.npc.gov.cn/englishnpc/Law/2007-12/06/content_1382125.htm

2937 http://www.npc.gov.cn/englishnpc/Law/2007-12/06/content_1382125.htm

${ }^{2938} \mathrm{http} / / /$ www.npc.gov.cn/englishnpc/Law/2007-12/06/content_1382125.htm.

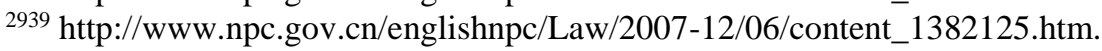

$2940 \mathrm{http} / / / w w w . n p c . g o v . c n / e n g l i s h n p c / L a w / 2007-12 / 06 /$ content_1382125.htm.

${ }^{2941}$ Article 1 of GLPRC. http://www.npc.gov.cn/englishnpc/Law/2007-12/13/content_1383951.htm.

${ }^{2942}$ Article 9 of GLPRC. http://www.npc.gov.cn/englishnpc/Law/2007-12/13/content_1383951.htm.

2943 http://www.npc.gov.cn/englishnpc/Law/2007-12/13/content_1383951.htm.
} 
to the State-owned grasslands, for which the right of use is not assigned, the people's governments at or above the county level shall register such grasslands and shall be responsible for their protection and control. With respect to the grasslands owned by collectives, the people's governments at or above the county level shall register such grasslands, issue to the collectives the certificates of ownership after verification to and establish their right of ownership of such grasslands. Where the ownership of grasslands is changed in accordance with the law, the formalities for registration of shall be completed". ${ }^{2944}$ GLPRC also provides the specific form of renting grassland and the circulation of the right to contract management of grassland. Article 13 provides that

"The grasslands owned by collectives or the State-owned grasslands which have been assigned for use to collective economic organizations may be contracted for management by households individually or jointly within the said collective economic organizations. No adjustment may be made to the grasslands used by the contractors within the term of contractual management of the grasslands; where appropriate adjustments need be made to a few pieces of grasslands, the matter shall be subject to agreement by two-thirds or more members of the villagers' (herdsmen) assembly, or two-thirds or more villagers' (herdsmen's) representatives, of the collective economic organization concerned and shall be reported for approval to the township (town) people's government and the competent administrative department for grasslands under the people's government at the county level. Where grasslands owned by a collective or the State-owned grasslands which are assigned for use to a collective economic organization in accordance with the law are contracted to units or individuals other than the ones of the said organization, the matter shall be subject to agreement by two-thirds or more members of the villagers' (herdsmen) assembly, or twothirds or more villagers' (herdmen's) representatives, of the collective economic organization concerned and shall be reported for approval to the township (town) people's government". ${ }^{2945}$ The circulation of the right to contract management of grassland is provided for by Article 15: "The right to contractual management of grasslands is protected by the law, and it may be transferred in accordance with the law according to the principles of voluntariness and compensation. The transferee of the right to contractual management of grasslands shall have the capability to pursue animal breeding and shall fulfil the obligations of protecting, developing, and rationally using the grasslands in adherence to the purpose of use as agreed upon in the contract. The transfer of the right to contractual management of grasslands shall be subject to agreement by the party contracting out the grasslands. The term of transfer agreed upon in the transfer contract by the contractor and the transferee may not exceed the remaining period of the original contract." 2946

SLPRC covers many key issues on the protection and utilization of seeds, such as "protecting and making rational use of germ plasm resources, standardizing variety selection and cultivation, as well as seed production and business operation and the administration thereof, protecting the right to new varieties of plants, safeguarding the lawful rights and interests of seed producers, traders and users, improving the quality of seeds, pushing forward the industrial management of seeds, developing modern seed industry, guaranteeing grain safety of the state, and promoting the development of agriculture and forestry." ${ }^{2947}$ It is worth noting that in the 2015 revision, the portions of the "regulation

\footnotetext{
2944 http://www.npc.gov.cn/englishnpc/Law/2007-12/13/content_1383951.htm.

2945 http://www.npc.gov.cn/englishnpc/Law/2007-12/13/content_1383951.htm.

${ }^{2946}$ http://www.npc.gov.cn/englishnpc/Law/2007-12/13/content_1383951.htm.

${ }^{2947}$ Article 1 of SLPRC. http://en.pkulaw.cn/display.aspx?cgid=259498\&lib=law
} 
of New Plant Varieties" are incorporated into the revised law and penalties for violations are also strengthened.

For the protection of germ plasm resources, Article 25 provides that "The State shall establish a new plant varieties protection system, whereby the rights of new plant varieties shall be granted by the administrative department for agriculture or for forestry under the State Council to those varieties listed in the national protected plant varieties catalog, cultured or discovered in the wilderness and then selected and bred, characterized by novelty, uniqueness, uniformity and stability and appropriately named. The legal rights of the new plant variety owner shall be protected. Other terms shall be implemented in accordance with this Law, related laws and regulations such as the new plant variety content and belonging, granting conditions, application and acceptance, review and approval, duration, cessation and invalidation, etc. The State encourages and supports seed scientific and technical innovation, new plant variety breeding and result transformation. Where the variety is granted new plant variety right and popularized, the breeder shall be entitled to obtain corresponding appropriate economic profits according to the laws." Article 28 provides protection for owners of new plant varieties "The entity which or the person who is granted with variety right has an exclusive right in their protected variety. No other entity or individual shall, without permission from the owner of the variety rights, produce, reproduce or sell the propagation material of the protected variety, or repeatedly use the propagation material of the protected variety for commercial purposes in the production of the propagation material of another variety. Except as otherwise provided in this Law, related laws and regulations." Article 73 stipulates the liabilities for breach of the new plant varieties: "If the parties fail to perform the agreement or no agreement is reached through the mediation, the owner or stakeholder of the new plant variety right may file a lawsuit to the people's court according to law. The indemnity of infringing new plant variety right shall be determined in accordance with the right holder's actual losses resulted from infringement; in case actual losses are difficult to determine, the indemnity can be determined in accordance with the infringer's benefits gained from infringement; in case both right holder's losses and infringer's benefits are difficult to determine, the indemnity can be appropriately determined with reference to the times of the new plant variety right license fee. The indemnity shall include right holder's reasonable expenses to cease infringement. In case new plant variety right is seriously infringed, the indemnity can be between one times and three times of the value determined by above-mentioned method. Where the right holder's losses, infringer's benefits, and new plant variety right license fee are all difficult to determine, the people's court can determine an indemnity under RMB 3 million in accordance with such factors as the type of new plant variety right, infringement nature and circumstances. When settling a case regarding infringement of the new plant variety right, the administrative departments of agriculture and forestry under the people's government at or above county level may order the infringer to cease the infringing act and confiscate the illegal gains and the seeds to safeguard public benefits. In case the amount is less than RMB 50,000, a fine between RMB 10,000 and RMB 250,000 will be imposed; if such amount is more than RMB 50,000, a fine of 5 times to 10 times as that of the amount will be imposed".

For the production of seeds, the former seed production license and seed operation license are merged into one Seed Production and Operation License. Article 31 stipulates that "The seed production and business license for seed import and export shall be subject to examination by administrative departments of agriculture and forestry of the people's governments of the provinces, 
autonomous regions, municipalities directly under the State Council, and be issued by the administrative departments of agriculture and forestry under the State Council. The production and operation licenses for enterprises engaged in businesses including major crop hybrid seeds and parent seeds, tree seeds of improved variety, as well as the enterprises with integrated business in breeding, production and marketing, eligible for requirements of the administrative departments for agriculture and forestry under the State Council shall be subject to examination by the people's government administrative departments of agriculture and forestry at county level, and be issued by the administrative departments of agriculture and forestry of the people's governments of the provinces, autonomous regions, municipalities directly under the State Council. The license of production and business of any seeds other than those listed in the two preceding paragraphs shall be issued after examination by administrative department for agriculture or for forestry under the people's government at or above the county level where the seed producer or trader is located. The seed production and business license is not required for the persons that only produce non-major crop seeds or non-major forest tree seeds."

Seed is a special commodity; special principle in the accounting legal responsibility process of a trade is deserved. Article 46 provides that "Where seed users suffer losses due to seed quality problems, or inauthentic information on seed label and instructions, the seed user could claim compensation from the traders selling the seeds, or claim compensation from seed producers or other traders. The amount of such compensation shall include purchase price of the seeds, losses of anticipated profits, and other relevant losses. Where the liability rests on seed producers or other traders, the trader selling the seeds that have paid the compensation shall have the right to recover the paid compensation from other producers or traders. Where the liability rests on the trader selling the seeds, the seed producers or other traders trader who have paid the compensation shall have the right to recover the paid compensation from the trader selling the seeds."

SLPRC also provides that seeds import and export shall be based on administrative licensing. Article 58 provides that "Those engaged in seed imports or exports shall in addition to the seed production and business license, obtain the seed import and export permit in accordance with related laws and regulations of the state. The State Council shall set the limits of authority for examining and approving the introduction of the seeds of crops and forest trees from abroad, and formulate measures for validation of the import and export of such seeds and administrative measures for the introduction of transgenic plant varieties." Article 60 provides exception to article 58, "Where seeds are imported for producing seeds for other countries, such imports may be exempt from the restriction provided in Paragraph 1, Article 58 of this Law, provided that a contract is signed for producing seeds for foreign countries. The imported seeds are only to be used for the production of hybrid seeds, and the products are not allowed to be sold at domestic markets. The crop seeds or forest tree seeds introduced from abroad for experiment shall be planted in isolation, and no harvests therefrom may be sold as commodity seeds."

\subsection{Grain Law of the People's Republic of China (draft for public comments) 2015 $(G L P R C d p c)$ (中华人民共和国粮食法(征求公众意见稿))}


GLPRCdpc will be the law that will govern grain production, distribution and consumption across the country (provided by Article 2) for many categories of foodstuff. According to Article 2 of the draft law, grain refers to"cereals and their processed products, beans and root crops." 2948

GLPRCdpc went to public comments phase in 2012. The legislators attached an important instruction on the legislative purpose, regarding its application scope and principles:

"grain is a special commodity and material of strategic importance crucial to the national economy and people's livelihood. The Draft for Opinions makes it very clear that safeguarding national grain security is the fundamental purpose of the legislation of the grain law. To achieve national grain security, we should not only maintain stable grain production and ensure domestic grain supply from various sources, but we should also strengthen our regulation and supervision on grain distribution, maintain market stability and safeguard the market order. Rational utilization and conservation of grain should also be advocated at the consumption end. Hence the Draft for Opinions provides that this act applies to grain production, distribution, and consumption in China. In line with the definition of grain stipulated in the Regulations on Grain Distribution and Medium to Long-term Planning for National Grain Security, the Draft for Opinions stipulates that grain refers to cereals and their finished grain, beans and tubers. Given that edible vegetable oil is an important life necessity for rural and urban residents and that the state has rendered similar support to the production and distribution of rapeseed oil, sunflower seed oil etc. to cereals, the Draft for Opinions provides that this act also applies to the production, distribution, and consumption of edible vegetable oil and oil seeds. Besides, in view of both of the similarities and differences between tubers and cereals and in light of such realities, the Draft for Opinions stipulates this act also applies to all activities in the production, distribution, and consumption of tubers except for the provisions of purchase certificates and storage filing." 2949

GLPRCdpc covers many segments of food value chain, the key relevant contents being: (1). institutions on building capacity for comprehensive grain production as wellas institutions about protecting incentives for grain production; (2). institutions on regulatory control and stock reserve management for grains; (3) institutions on market-oriented allocation of grain resource or; safeguarding grain distribution.

The institutions on building capacity for comprehensive grain production and the institutions on protecting incentives for grain production were provided for in Chapter 2 and Chapter 3 respectively, generally they are consistent with ALPRC and Chinese agricultural policy. The reference to institutions with the aim to build capacity for comprehensive grain production stresses government's role in overall planning, direction and support. Asit is indicated in Article 11 GLPRCdpc,

"The State shall strengthen the integrated planning for grain production capacity building, focus the support efforts on main grain producing regions, improve grain production conditions, build reliable commodity grain production bases, and, in preservation of ecological system, duly and appropriately develop backup producing regions with resource

\footnotetext{
2948 Non-official translation offered by United States Department of Agriculture Foreign Agricultural Service. https://gain.fas.usda.gov/Recent\%20GAIN\%20Publications/Grain\%20Law\%20(draft)_Beijing_China\%20\%20Peoples\%20Republic\%20of_12-18-2014.pdf

2949 Non-official translation offered by United States Department of Agriculture Foreign Agricultural Service. https://gain.fas.usda.gov/Recent\%20GAIN\%20Publications/Grain\%20Law\%20(draft\%20for\%20public\%20comments) _Beijing_China\%20-\%20Peoples\%20Republic\%20of_3-6-2012.pdf.
} 
advantages and production potential. The people's governments above the county level shall formulate a grain production plan based on eco-system, water resources, land, and agricultural and climatic resources and conditions. The medium to long-term plan for national food security and grain production layout and construction projects shall go through a validation process with regard to water resources". 2950

Institutions about protecting incentives for grain production provide government's role in institutional construction, establishing production-facilitating systems and financial input. Besides, article 16 GLPRCdpc stipulates that it is the government's role to establish agro-food related systems in order to prevent agricultural meteorological disasters: ${ }^{2951}$

Many institutions for regulatory control and stock reserve management for grains were designed in order to maintain the stability of the supply and price of grain. From the grain regulation perspective, many institutions were designed to control grain import and export, as well as the aquiiation of domestic grain firms. Article 52 GLPRCdpc refers to the macro-control of grain import and export, specifically, noting that "Based on domestic grain supply and demand situation and the need of macro-control, the State shall adjust domestic grain surplus and deficiency through grain import and export and adopt a quota system to manage import and export of major grain varieties". ${ }^{2952}$ Article 59 provides the review procedure of grain related acquisitions: "The enterprises that are newly established or that are merged or acquired with domestic grain production and operation shall be reviewed in accordance with relevant state regulations if national food security is involved." 2953 The GLPRCdpc also stipulates that the government shall provide support to grain supply from many aspects, including tax, finance and insurance. For instance, Article 53 provides that "The State shall implement a grain risk fund system that rationally determine the use and scope of the grain risk fund based on the nation's financial situation and the need of macro-control. The fund shall be earmarked to specified uses in a bid to support grain production and distribution and stabilize the grain market." ${ }^{2954}$ Article 55 stresses the government's role in offering financial support, noting that

"The State shall take such measures as finance, banking, and tax to support grain operators undertaking policy-related grain operation. Policy banks shall ensure the supply of credit fund required in the course of grain production and storage in accordance with relevant state regulations. Financial institutions of commercial nature are encouraged to provide loans to

\footnotetext{
2950 Non-officialtranslation offered by United States Department of Agriculture Foreign Agricultural Service. https://gain.fas.usda.gov/Recent\%20GAIN\%20Publications/Grain\%20Law\%20(draft)_Beijing_China\%20\%20Peoples\%20Republic\%20of_12-18-2014.pdf.

2951 Non-officialtranslation offered by United States Department of Agriculture Foreign Agricultural Service. https://gain.fas.usda.gov/Recent\%20GAIN\%20Publications/Grain\%20Law\%20(draft)_Beijing_China\%20\%20Peoples\%20Republic\%20of_12-18-2014.pdf.

2952 Non-officialtranslation offered by United States Department of Agriculture Foreign Agricultural Service. https://gain.fas.usda.gov/Recent\%20GAIN\%20Publications/Grain\%20Law\%20(draft)_Beijing_China\%20\%20Peoples\%20Republic\%20of_12-18-2014.pdf.

2953 Non-officialtranslation offered by United States Department of Agriculture Foreign Agricultural Service. https://gain.fas.usda.gov/Recent\%20GAIN\%20Publications/Grain\%20Law\%20(draft)_Beijing_China\%20-

\%20Peoples\%20Republic\%20of_12-18-2014.pdf.

2954 Non-officialtranslation offered by United States Department of Agriculture Foreign Agricultural Service. https://gain.fas.usda.gov/Recent\%20GAIN\%20Publications/Grain\%20Law\%20(draft)_Beijing_China\%20\%20Peoples\%20Republic\%20of_12-18-2014.pdf.
} 
operation such as grain purchase and storage. The operators undertaking policy-oriented grain operation shall strictly follow relevant state policies and regulations."2955

Finally, the GLPRCdpc puts in place a grain reserve system. Article 56 provides that

"The State shall implement a grain reserve system at the central and local government levels.

The central grain reserve shall be used mainly to adjust the overall grain supply and demand at the national level in a bid to stabilize the grain market and deal with severe natural disasters or other emergencies. Unless approved by the State Council, no institutions or individuals shall be allowed to use the central grain reserves. The State Council shall issue the regulations on the management of central grain reserve. The grain reserve of local governments shall be used mainly to adjust the grain supply and demand within the region in a bid to stabilize the local grain market and deal with serious natural disasters or other emergencies in the region. The State Council shall determine the scale of local grain reserve and the People's Governments at the provincial level shall determine the specific varieties, layout, and management methods. The regulations of local grain reserves are formulated by local governments. The central and local grain reserve shall be kept at a reasonable level and the function positioning, variety structure, and layout shall be coordinated and supplemented". ${ }^{2956}$ Furthermore, according to Article 58, "The State shall establish a minimum and maximum stock level system for grain operators. The grain operators engaging in grain procurement, processing, and marketing as well as feed and industrial grain enterprises shall be obliged to maintain a no-less-than minimum stock level in the event of surplus in the grain market and dramatic price declines or to maintain a no-more-than maximum stock level in the event of deficit in the grain market and dramatic price increases." 2957

Institutions on market-oriented allocation of grain resources and institutions on safeguarding grain distribution are two of the key issues regulated by the GLPRCdpc, with the aim to meeting the need of establishing and improving socialist market economy, consolidating the results of marketoriented reform of grain distribution system and ensuring the fundamental role of market mechanism in the allocation of grain resources. The Draft for Opinions stipulates that the state adopts a marketoriented management system under macro regulation for the production, distribution, and consumption of grain. Grain purchase, storage, processing, transport, wholesale, retail and etc. is open to the public. It is stated that all market players shall perform the same obligations, make their own decisions, and take full responsibilities for their profits and losses as well as self-development. Furthermore, relevant associations in the grain industry should strengthen self-discipline and improve service in a bid to maintain order in the grain market. ${ }^{2958}$

\footnotetext{
2955 Non-officialtranslation offered by United States Department of Agriculture Foreign Agricultural Service. https://gain.fas.usda.gov/Recent\%20GAIN\%20Publications/Grain\%20Law\%20(draft)_Beijing_China\%20\%20Peoples\%20Republic\%20of_12-18-2014.pdf.

2956 Non-officialtranslation offered by United States Department of Agriculture Foreign Agricultural Service. https://gain.fas.usda.gov/Recent\%20GAIN\%20Publications/Grain\%20Law\%20(draft)_Beijing_China\%20$\%$ 20Peoples\%20Republic\%20of_12-18-2014.pdf.

2957 Non-officialtranslation offered by United States Department of Agriculture Foreign Agricultural Service. https://gain.fas.usda.gov/Recent\%20GAIN\%20Publications/Grain\%20Law\%20(draft)_Beijing_China\%20-

\%20Peoples\%20Republic\%20of_12-18-2014.pdf.

2958 Unofficial translation offered by United States Department of Agriculture Foreign Agricultural Service. https://gain.fas.usda.gov/Recent\%20GAIN\%20Publications/Grain\%20Law\%20(draft\%20for\%20public\%20comments) _Beijing_China\%20-\%20Peoples\%20Republic\%20of_3-6-2012.pdf.
} 
Chapter 4 of the draft law provides more information on these two institutions. Article 25 specifies that the State shall

"nurture and develop a unified, open, and competitive grain market system and prohibit any regional blockade in grain distribution. The government shall establish a unified, standardized, and bidding-based grain transaction system in order to intensify the construction of the market for grain procurement, wholesaling, and retailing, and regulate the development of a grain futures market". 2959

The various institutions on grain distribution are made explicit in Articles 26, 28 and 32. Article 26 provides for the adoption of the licensing system for grain procurement. Specifially, it requires that "The operators engaging in grain procurement activities shall meet the following requirements: (1) Have necessary capital for operation; (2) Own necessary grain storage facilities and equipment; (3) Be equipped with relevant ability on grain quality inspection and storage; (4) Keep a good record of operations, management, and credit without any illegal operation. When processing a grain procurement license, the grain administration department shall inquire about the credit record of the license applicant or require him/her to provide credit reports issued by qualified institutions". ${ }^{2960}$ Article 28 of the draft law provides that "Operators engaging in grain storage shall report to the grain administration departments and meet the following requirements: (1) Have fixed location for operation; (2) Possess necessary facilities and equipment suitable for storage activities; (3) Equipped with technicians holding a national vocational certificate on grain inspection and storage. The previous provision shall not apply to grain operators that engage in storage activities for self-use or temporary storage for re-sale purposes". ${ }^{2961}$ Besides, Article 32 provides all the forbidden issues that relate to operators engaging in grain procurement, wholesaling, and retailing activities: "(1) Default on payment to grain peasants; (2) Fabricate and spread false information to disturb market order; (3) Collude with each other and manipulate market prices; (4) Maliciously hoard grain and whoop up the prices; (5) Raise or depress prices in disguise through means such as intentional upgrading or downgrading; (6) Short weigh, adulterate or sell shoddy products; (7) Monopolize the market or conduct unfair competition; (8) Other activities in violation of state regulations". ${ }^{2962}$

\subsubsection{Basic laws for the distribution and consumption segments of the food value chains}

The distribution and purchase of production materials, services and foods must also conform to a number of laws and international trade agreements, which are integrated parts of the economic order within the agro-food sectors and food value chains.

\footnotetext{
2959 Non-officialtranslation offered by United States Department of Agriculture Foreign Agricultural Service. https://gain.fas.usda.gov/Recent\%20GAIN\%20Publications/Grain\%20Law\%20(draft)_Beijing_China\%20\%20Peoples\%20Republic\%20of_12-18-2014.pdf.

2960 Non-officialtranslation offered by United States Department of Agriculture Foreign Agricultural Service. https://gain.fas.usda.gov/Recent\%20GAIN\%20Publications/Grain\%20Law\%20(draft)_Beijing_China\%20\%20Peoples\%20Republic\%20of_12-18-2014.pdf.

2961 Non-officialtranslation offered by United States Department of Agriculture Foreign Agricultural Service. https://gain.fas.usda.gov/Recent\%20GAIN\%20Publications/Grain\%20Law\%20(draft)_Beijing_China\%20-

\%20Peoples\%20Republic\%20of_12-18-2014.pdf.

2962 Non-officialtranslation offered by United States Department of Agriculture Foreign Agricultural Service. https://gain.fas.usda.gov/Recent\%20GAIN\%20Publications/Grain\%20Law\%20(draft)_Beijing_China\%20\%20Peoples\%20Republic\%20of_12-18-2014.pdf.
} 
Price Law of the People's Republic of China (PLPRC) 1998 provides that the State practices and gradually perfects the price mechanism shaped mainly by the market under macroeconomic regulation and control. Specifically, Article 3 provides that

"Determination of prices shall be in line with the law of value, prices of most commodities and services shall be the market-regulated prices and prices of an extremely small number of commodities and services shall be the government-guided prices or the government-set prices. Market-regulated prices mean those prices determined autonomously by the operators and formed through market competition. The operators referred to in this Law mean the legal persons, other organizations or individuals engaging in the production and management of commodities or provision of paid services. Government-guided prices mean those prices determined to guide the operators by the competent departments of price of the government or other departments concerned, the baseline prices and their range of fluctuations in accordance with the pricing authority and scope in pursuance of the provisions of this Law. Government-set prices mean those prices determined by the competent departments of price of the government or other departments concerned in accordance with the pricing authority and scope in pursuance of the provisions of this Law". 2963

Article 6 further provides that "Market regulated prices shall be practised and determined autonomously by the operators in pursuance of this Law for commodity prices and services prices except those to which government-guided prices and government-set prices shall apply pursuant to the provisions of Article 18 of this Law". 2964

Both Article 3 and Article 6 provides that the government may enforce government-guided prices or government-set prices when necessary for the prices of the following commodities and services. According to the National Development and Reform Commission, many agro-food products are subject to government-set prices. Some of them appear in the below form:

State Development Planning Commission (Now NDRC) and the State Council list on commodities that apply government-set prices ${ }^{2965}$.

\begin{tabular}{|c|c|c|c|}
\hline & $\begin{array}{l}\text { Types } \\
\text { commodities }\end{array}$ & Substances of pricing & Departments \\
\hline 1 & $\begin{array}{l}\text { Important } \\
\text { commodities that are } \\
\text { reserved by the } \\
\text { central government }\end{array}$ & $\begin{array}{l}\text { Reserved grain, edible vegetable oil, cotton } \\
\text { purchasing and selling prices, the reserve } \\
\text { price of the reserved sugar in auction, prices } \\
\text { of purchasing and selling reserved fertiliser, } \\
\text { purchasing and selling prices of natural silk } \\
\text { (from silkworm) }\end{array}$ & $\begin{array}{l}\text { State Development Planning } \\
\text { Commission and other related } \\
\text { departments }\end{array}$ \\
\hline 2 & Partial Fertilisers & $\begin{array}{l}\text { bench mark price and its floating range for } \\
\text { factory sales, port settlement prices }\end{array}$ & $\begin{array}{l}\text { State Development Planning } \\
\text { Commission }\end{array}$ \\
\hline
\end{tabular}

\footnotetext{
2963 http://english.mofcom.gov.cn/article/policyrelease/Businessregulations/201303/20130300046121.shtml ${ }^{2964}$ http://english.mofcom.gov.cn/article/policyrelease/Businessregulations/201303/20130300046121.shtml 2965 http://www.sdpc.gov.cn/zwfwzx/zfdj/djfw/200507/t20050707_130525.html.
} 


\subsection{Law of the People's Republic of China on the Protection of Consumer Rights and Interests 1994 ( 中华人民共和国消费者权益保护法)}

The law provides the basic law for protecting consumers and the principle for trade. In particular Article 2 provides that "The rights and interests of consumers in purchasing and using commodities or receiving services for daily consumption shall be under the protection of the present Law, or under the protection of other relevant laws and regulations in absence of stipulations in this Law". ${ }^{2966}$ Article 3 stipulates that "Business operators shall, in their supply of commodities produced and sold by them or services to consumers, abide by the present Law, or abide by other relevant laws and regulations in absence of stipulations in the present law". ${ }^{2967}$ Article 4 provides that "In transactions between business operators and consumers a principle of voluntariness, equality, fairness, honesty and credibility shall be followed". ${ }^{2968}$ With respect to peasants, their rights as a group of consumers were confirmed by the law. Article 54 provides that "The present Law shall be applicable mutatis mutandis to peasants' purchase or application of means of production used directly in agricultural production". ${ }^{2969}$ This article indicates that the purchase of production materials by agricultural workers receive special protection.

\subsection{Foreign Trade Law of the People's Republic of China (1994)（中华人民共和国对外 贸易法)}

Importation and exportation of food are regulated by a number of Chinese laws, in particular the Foreign Trade Law of the People's Republic of China (FTLPRC) which governs this economic activity, although it provides exceptions or reservations for issues relating the food value chains. Articles 4 and 14 FTLPRC provide basic rules for the importation and exportation of most commodities. Article 4 provides that "The State applies a unified system of foreign trade, encourages the development of foreign trade and preserves a fair and free foreign trade order". ${ }^{2970}$ Article 14 stipulates that the State permits free import and export of goods and technologies unless the laws or administrative regulations provide otherwise. ${ }^{2971}$ Exceptions for agro-food products are provided in Articles 14 and 16. Following the general exception in Article 14, Article 16 specifies that the State may, if necessary, restrict or prohibit the import or export of agricultural, animal breeding and fishery products of any form in accordance with the provisions of international treaties or agreements signed or acceded to by the People's Republic of China". ${ }^{2972}$

The international treaties and agreements are mainly referred to at the Protocol on the Accession of the People's Republic of China. Article 7 FTLPRC provides the non-tariff measures that the Chinese government may take regarding agro-food products: "In implementing the provisions of Articles III and XI of the GATT 1994 and the Agreement on Agriculture, China shall eliminate and shall not introduce, re-introduce or apply non-tariff measures that cannot be justified under the

\footnotetext{
${ }^{2966} \mathrm{http} / / /$ www.china.org.cn/china/LegislationsForm2001-2010/2011-02/14/content_21917139.htm

${ }^{2967} \mathrm{http} / / /$ www.china.org.cn/china/LegislationsForm2001-2010/2011-02/14/content_21917139.htm

${ }^{2968} \mathrm{http} / / / \mathrm{www}$. china.org.cn/china/LegislationsForm2001-2010/2011-02/14/content_21917139.htm

${ }^{2969} \mathrm{http} / / / \mathrm{www}$. china.org.cn/china/LegislationsForm2001-2010/2011-02/14/content_21917139.htm

${ }^{2970} \mathrm{http} / / / \mathrm{www} . \mathrm{npc}$. gov.cn/englishnpc/Law/2007-12/12/content_1383624.htm

${ }^{2971} \mathrm{http} / / / \mathrm{www} . n p c . g o v . c n /$ englishnpc/Law/2007-12/12/content_1383624.htm

2972 http://www.npc.gov.cn/englishnpc/Law/2007-12/12/content_1383624.htm
} 
provisions of the WTO Agreement. For all non-tariff measures, whether or not referred to in Annex 3, that are applied after the date of accession, consistent with the WTO Agreement or this Protocol, China shall allocate and otherwise administer such measures in strict conformity with the provisions of the WTO Agreement, including GATT 1994 and Article XIII thereof, and the Agreement on Import Licensing Procedures, including notification requirements". ${ }^{2973}$ Article 9 states when and how the Chinese governments can influence the price of agro-food products "The goods and services listed in Annex 4 may be subject to price controls, consistent with the WTO Agreement, in particular Article III of the GATT 1994 and Annex 2, paragraphs 3 and 4 of the Agreement on Agriculture. Except in exceptional circumstances, and subject to notification to the WTO, price controls shall not be extended to goods or services beyond those listed in Annex 4, and China shall make best efforts to reduce and eliminate these controls". ${ }^{2974}$ Article 12 includes Chinese government's commitments and obligations as contained in China's Schedule of Concessions and Commitments on Goods and stipulates that China shall not maintain or introduce any export subsidies on agricultural products and that, under the Transitional Review Mechanism, it shall notify fiscal and other transfers between or among state-owned enterprises in the agricultural sector (whether national or sub-national) and other enterprises that operate as state trading enterprises in the agricultural sector. ${ }^{2975}$

\subsection{Protection of Intellectual Property Rights}

Patent law excludes patent protection for plant variety, only have patent protection for the processes used in the manufacturing of animal and plant varieties. ${ }^{2976}$

Regulations of the PRC on protection of New Varieties of Plants 1997(amended on March 1, $2013)^{2977}$ is administrative regulations. The hierarchy is lower than Laws issued by NPC. The protection of varieties of plants are general between UPOV Convention 1978 and UPOV Convention 1991(have not reach the minimum protection of 1991 UPOV). The protection of plant variety in the Regulations only covers the botanical genus and species in the national catalogue of protected plat varieties, rather than all plant genera and species. ${ }^{2978}$ The Regulations grant " 15 years of protection for variety rights, and 20 years for vines, forest trees, fruit trees and ornamental plants and 15 years for other plants." 2979 The regulation grant an exclusive right to produce or sell for commercial purposes the propagating material of the protected variety, or use for commercial purposes in a repeated manner in the production of the propagating material of another variety. ${ }^{2980}$ Seed Law of the People's Republic of China (SLPRC) (Amended in 2015) ${ }^{2981}$ includes a new chapter: chapter IV Protection of New Varieties. Generally, SLPRC extended the exclusive right to produce, propagate, or sell the propagating material of the protected variety of plants without the consent from right

\footnotetext{
2973 https://www.wto.org

2974 https://www.wto.org

2975 https://www.wto.org

2976 Patent Law of the People's Republic of China [Revised], 2008, see http://www.wipo.int/edocs/lexdocs/laws/en/cn/cn028en.pdf Article 25

2977 Regulations of the PRC on protection of New Varieties of Plants (hereinafter Regulations) see http://www.wipo.int/wipolex/en/details.jsp?id=15503

2978 Regulations Article 13, Article 27

2979 Regulations Article 34

2980 Regulations Article 6

2981 see: http://www.npc.gov.cn/englishnpc/news/Legislation/2015-11/05/content_1950421.htm The full text of SLPRC2015 is not available from official source. The English edition of SLPRC in NPC database has not been revised.
} 
holders. SLPRC does not require the commercial purpose, and only requires commercial purpose when the propagating materials are used for the production of the propagating material of another variety. 2982

In terms of farmers' right to access seed, Article 10 of Regulations: if farmers harvest the material of the protected variety on their own holdings and use for propagating purpose by farmers on their own holdings. The same article is also included in SLPRC $2015^{2983}$. The legislation limits farmer's right to the self-use and self-propagating extent. Also, the SLPRC and Regulation entitled Ministry of Agriculture to grant compulsory licensing to implement the variety rights for the sake of national or public interest. ${ }^{2984}$

China ratified the Cartagena Protocol on Biosafety on 8 June 2005, effective from 6 September 2005.

China has traditionally cautiously reviewed the introduction and development of Genetically Modified Organisms (GMOs) and GM products. The authorities actively promote fundamental research but strictly control the planting of GM crops. In theory, crops that pass the safety tests are considered safe and can be planted. To date, China has approved seven GM crops of which only Bt Cotton is grown on a large scale. In addition, China has approved four imported GM crops (cotton, soybean, corn and canola) as raw materials for processing but they cannot be imported as seeds.

Nestle was involved in the first GM labelling case in China. In 2003, Ms Yanling Zhu sued Nestle for not labelling GM ingredients in its cocoa powder product "Qiaobanban", and claimed compensation of the product price and an order for Nestle to label GM ingredients on its packaging. The full case report is not publicly available. The Court appointed the Shanghai Academy of Agricultural Science to test the cocoa product for GM ingredients: The result was negative when using the Protocol of the Quantitative PCR Analysis included in the recommended industrial standards issued by the Ministry of Agriculture. However, the sample tested positive on GM glyphosate-resistance soybean with the Nested PCR analysis provided by international standards. The GeneScan Analytics GmbH also confirmed the existence of a GM ingredient. The court ruled in favour of Nestle and no GM labelling was required. The case shows that Chinese courts rule on the basis of domestic standards.

\begin{tabular}{|c|c|c|c|}
\hline Seeds & $\begin{array}{l}\text { Regulations of the People's } \\
\text { Republic of } \\
\text { China, the Protection of } \\
\text { New Varieties of Plants of } \\
1 \text { October } 1997^{2985} \text {.中华人 } \\
\text { 民共和国保护植物新品 } \\
\text { 种条例 }\end{array}$ & $\begin{array}{l}\text { a. UPOV Convention for } \\
\text { the protection of new } \\
\text { varieties of plants; }{ }^{2986} \\
\text { b. Agreement on Trade- } \\
\text { Related Aspects of } \\
\text { Intellectual Property }\end{array}$ & $\begin{array}{l}\text { Ministry of Agriculture } \\
\text { (MOA): } \\
\text {-Regulation of the People's } \\
\text { Republic of China on } \\
\text { Protection of New Varieties } \\
\text { of Plants (2014 Revision) }\end{array}$ \\
\hline
\end{tabular}

\footnotetext{
2982 SLPRC 2015 Article 28

${ }^{2983}$ SLPRC 2015 Article 29

${ }^{2984}$ SLPRC 2015 Article 30, Regulation Article 11,

also see Implementing Rules for the Regulations of the People's Republic of China on the Protection of New Varieties of Plants (Agriculture Part) (consolidated version of April 25, 2014) http://www.wipo.int/wipolex/en/details.jsp?id=15183 Article 12

$2985 \mathrm{http}: / /$ www.wipo.int/wipolex/en/text.jsp?file_id=360025.

$2986 \mathrm{http} / /$ www.upov.int/en/publications/conventions/1991/act1991.htm . China has only signed the 1978 UPOV Convention, not the 1991.
} 


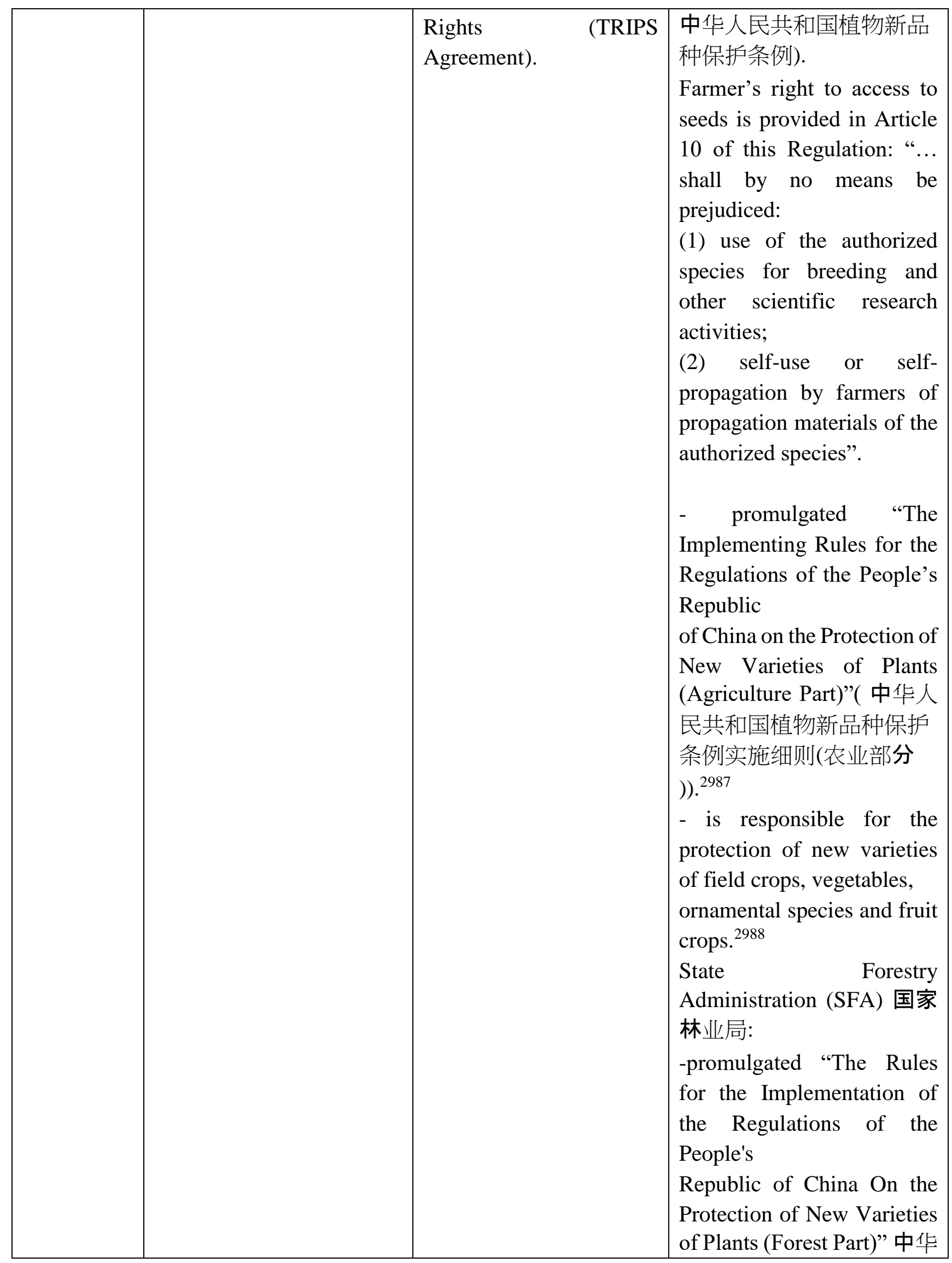

$2987 \mathrm{http}: / /$ www.cnpvp.cn/en/index.html.

${ }^{2988}$ In October 2011, the protection of plant varieties under the authority of MOA covered 80 genera and species, see http://www.cnpvp.com/english/Introduction\%20of\%20the\%20Network.htm. 


\begin{tabular}{|c|c|c|c|}
\hline & & & $\begin{array}{l}\text { 人民共和国植物新品种保 } \\
\text { 护条例实施细则(森林部分 } \\
)^{2989} \text {; } \\
\text { - responsible for the } \\
\text { protection of new varieties } \\
\text { of forest trees, bamboo and } \\
\text { woody rattan, woody } \\
\text { ornamental plant (including } \\
\text { woody flower e.g. roses), } \\
\text { fruit tree (dry fruit), woody } \\
\text { oil-bearing plants, plants } \\
\text { used for beverage, plants } \\
\text { used for condiment and } \\
\text { woody herbs as well as other } \\
\text { plants which are in } \\
\text { conformity with Article } 2 \text { of } \\
\text { the Regulations. }\end{array}$ \\
\hline $\begin{array}{l}\text { Animal } \\
\text { genetics }\end{array}$ & $\begin{array}{l}\text { The Patent Law, } 1993^{2991} \\
\text { 专利法 }\end{array}$ & $\begin{array}{l}\text { Convention on Biological } \\
\text { Diversity, 1992生物多样 } \\
\text { 性公约 } \\
\text { The Agreement on Trade- } \\
\text { Related Aspects of } \\
\text { Intellectual Property } \\
\text { Rights (TRIPS), } 1994\end{array}$ & $\begin{array}{l}\text { State Science and } \\
\text { Technology Commission } \\
\text { ("SSTC") 国家科学技术委 } \\
\text { 员会 } \\
\text { the China Food and Drug } \\
\text { Administration (CFDA) 中 } \\
\text { 国食品药品监督管理局 }\end{array}$ \\
\hline
\end{tabular}

\subsection{Competition law, superior bargaining power, and food value chains}

\subsubsection{Competition laws and the food value chains}

Anti-monopoly Law of the People's Republic of China (AML) $2008^{2992}$ 中华人民共和国反垄 断法. AML governs four general issues: (1), abuse of dominant position; (2), abuse of administrative monopoly; (3), anticompetitive collaboration and agreements; (4), merger and acquisition. However, Article 56 AML provides that the AML does not apply to the association or cooperation by agricultural producers or rural economic organizations in their business activities of production, processing, sale, transportation, storage of farm products, etc. ${ }^{2993}$

The competition law exemption for agro-food sectors generally targets the provisions

\footnotetext{
2989 http://www.cnpvp.net/index/index_en.aspx.

${ }^{2990}$ In October 2011, the protection of plant varieties under the authority of SFA covered 78 genera and species, see http://www.cnpvp.com/english/Introduction\%20of\%20the\%20Network.htm.

${ }^{2991} \mathrm{http}: / /$ www.wipo.int/wipolex/en/details.jsp?id=6503

2992 http://english.mofcom.gov.cn/article/policyrelease/Businessregulations/201303/20130300045909.shtml

${ }^{2993} \mathrm{http} / / /$ english.mofcom.gov.cn/article/policyrelease/Businessregulations/201303/20130300045909.shtml
} 
included in AML Chapter 2. Article 16 forbids industrial organisations from organising concerted anticompetitive practices, while Article 13 forbids competitors from collaborating: specifically, prohibiting them from concluding the following monopoly agreements: " (1) on fixing or changing commodity prices; (2) on restricting the amount of commodities manufactured or marketed; (3) on splitting the sales market or the purchasing market for raw and semi-finished materials; (4) on restricting the purchase of new technologies or equipment, or the development of new technologies or products; (5) on joint boycotting transactions; and (6) other monopoly agreements confirmed as such by the authority for the enforcement of the Anti-monopoly Law under the State Council. For the purposes of this Law, monopoly agreements include agreements, decisions and other concerted conducts designed to eliminate or restrict competition."2994 Article 14 forbids anticompetitive collaborations between suppliers and dealers, specifically "(1) on fixing the prices of commodities resold to a third party; (2) on restricting the lowest prices for commodities resold to a third party; and (3) other monopoly agreements confirmed as such by the authority for enforcement of the Antimonopoly Law under the State Council.",2995

Provisions against Pricing Abuse ${ }^{2996}$ 反价格垄断规定is a department regulation enacted pursuant to AML. It primarily forbids anticompetitive pricing collaboration, price related administrative abuse, and pricing abuses. It also repeats Article 56 AML, negating the application of section 1 of Article 3: "a price fixing agreement reached by business operators". ${ }^{2997}$

Specialized Peasants' Cooperatives constitutes the main form of conducting joint or coordinated actions that are provided for by Article 56 AML. These are protected and governed by Law of the People's Republic of China on Specialized Farmers Cooperatives (LPRCSFC) 2006. According to Article 2 LPRCSFC, specialized farmers' cooperative are defined as

"mutual-help economic organizations joined voluntarily and managed in a democratic manner by the producers and operators of the same kind of farm products or by the providers or users of services for the same kind of agricultural production and operation. Specialized farmers cooperatives mainly serve their members, offering such services as purchasing the means of agricultural production, marketing, processing, transporting and storing farm products, and providing technologies and information related to agricultural production and operation". 2998

Agro-food production constitutes the starting point of any food value chain. As it is dependent on environment and fragile in nature, it is a standard international custom for this segment of food value chain to receive support from the government. As evidenced by the agro-food exceptions provided for in the aforementioned laws, LPRCSFC provides legal protection to farmers' cooperation, which is important for maintaining stable product supply and distribution, which in turn benefits peasants themselves and stabilises the food value chain. Article 6 LPRCSFC provides that "The State protects the lawful rights and interests of the specialized farmers cooperatives and their members, and no units or individuals may infringe upon such rights and interests". ${ }^{2999}$ LPRCSFC provides that governments shall provide specialized farmers' cooperative financial and tax support, in specific, Article 51 provides that: "The policy-oriented financial institutions of the State shall adopt diversified means to

\footnotetext{
${ }^{2994}$ http://english.mofcom.gov.cn/article/policyrelease/Businessregulations/201303/20130300045909.shtml

$2995 \mathrm{http}: / /$ english.mofcom.gov.cn/article/policyrelease/Businessregulations/201303/20130300045909.shtml

${ }^{2996} \mathrm{http} / / / \mathrm{www} . g o v . c n / f l f g / 2011-01 / 04 /$ content_1777969.htm

${ }^{2997}$ http://www.gov.cn/flfg/2011-01/04/content_1777969.htm

${ }^{2998} \mathrm{http} / / /$ www.npc.gov.cn/englishnpc/Law/2008-01/02/content_1388023.htm

${ }^{2999} \mathrm{http} / / /$ www.npc.gov.cn/englishnpc/Law/2008-01/02/content_1388023.htm
} 
provide funds through various channels in support of the specialized farmers cooperatives. The specific supportive policies shall be formulated by the State Council. The State encourages the commercial financial institutions to provide financial services to the specialized farmers cooperatives by diversified means". ${ }^{3000}$ Article 52 provides that "The specialized farmers cooperatives shall enjoy preferential treatment in taxation prescribed by the State in respect of agricultural production, processing, circulation and services and other economic activities involving agriculture. Other preferential taxation policies in support of the development of specialized farmers cooperatives shall be formulated by the State Council". ${ }^{3001}$ Despite of this, LPRCSFC specifies many provisions that specialized farmers cooperatives shall obey. Article 7 provides that "In production and operation, specialized farmers cooperatives shall obey the relevant laws and administrative regulations, observe social and business ethics, and act in good faith." ${ }^{3002}$ It is noted that although Chinese competition law offers exemptions for "association or cooperation by agricultural producers or rural economic organizations in their business activities of production, processing, sale, transportation, storage of farm products, etc", ${ }^{3003}$ the other three main areas that governs by Chinese competition law receive no exemption. There has, thus, been competition law enforcement in each of these three areas, namely distribution cartels, merger control, and abuse of a dominant position in the agricultural sector. These cases will be introduced in the following paragraphs. Regarding superior bargaining power, which is an academic and legislative frontier, it is not yet certain whether abuse of superior bargaining power to harm food production, distribution, and consumption constitutes an infringement of Chinese competition law, nor whether such abuse would also be subject to competition law exemption. Regulation of superior bargaining power in China will be introduced in the following section.

\subsubsection{Regulation of superior bargaining power and food value chains}

Abuse of superior bargaining power to gain unfair profits began to emerge in China more than a decade ago. Along with the application of market mechanisms within the territory, from around 2006, abuse of superior bargaining power started to be considered a serious legal problem, with the adoption of a number of department regulations in order to regulate it.

On 3 March 2006, Ministry of Commerce (MOFCOM) launched a draft department regulation soliciting comments and entitled 'Administrative Measures for the Sales Promotion Acts of Retailers' ${ }^{3004}$. Article 4 of the draft provides that: "A retailer, when undertaking sales promotion activities, shall follow the principles of lawfulness, fairness and good faith and observe the commercial ethics, and may not undertake any sales promotion activity in violation of social moralities, disturb the market competition order and the social public order or impair the lawful rights and interests of consumers and other business operators". 3005

On 13 Oct 2006, MOFCOM, the Ministry of Public Security, the State Administration for Industry \& Commerce, the State Administration of Taxation, the State Development \& Reform Commission (incl. former State Development Planning Commission) jointly enacted a department regulation entitled Administrative Measures for Fair Transactions between Retailers and suppliers

\footnotetext{
3000 http://www.npc.gov.cn/englishnpc/Law/2008-01/02/content_1388023.htm.

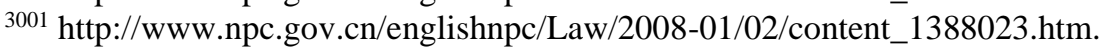

3002 http://www.npc.gov.cn/englishnpc/Law/2008-01/02/content_1388023.htm.

3003 Article 54 of AML. http://www.china.org.cn/china/LegislationsForm2001-2010/2011-02/14/content_21917139.htm.

3004 http://www.mofcom.gov.cn/article/bh/200604/20060401951577.shtml.

3005 http://www.mofcom.gov.cn/article/bh/200604/20060401951577.shtml.
} 
零售商供应商公平交易管理办法. ${ }^{3006}$ Article 6 of the regulation specifies five specific forms of abuse of superior bargaining power, providing that "No retailer may conduct any of the following unfair transactions by abusing its superior bargaining power: (1) (when) It signs with a supplier a contract on the supply of a particular commodity, in which both parties agree to the specifications, type, pattern, etc., but later it refuses to accept the commodity, with, however, the exception where the supplier should be liable for the matter, or the supplier so agrees, and where the retailer will bear the losses incurred therefrom; (2) It requires any supplier to bear the liability for the wasting of any commodity un-stipulated in advance; (3) There is no advance stipulation of conditions for removing any commodity from the shelf or counter, or where the conditions for removing any commodity from the shelf or counter are not met, but the retailer removes the commodity provided by the supplier from the shelf or counter without any justifiable reason, except that the retailer does so under any law, regulation, or under an administrative decision made by the administrative organ; (4) It forces any supplier to refund the sales profit unconditionally, or it sets a certain sales volume as the precondition for return of sales profit, but charges the supplier refund of profit in the case of failure to reach the stipulated sales volume; or (5)It forces any supplier to purchase any commodity it designates or accept any service it designates". 3007

With the increasing number of cases, these department regulations gradually lost their effectiveness. Therefore, legislators are compelled to address the superior bargaining power abuse problem with national laws.

Article 17 of the Anti-Monopoly Law (AML) (中华人民共和国反垄断法) (implemented in 2008) provides that the assessment of the existence of a dominant position depends on many factors, beyond market shares, such as the extent to which other undertakings rely on the undertaking in question, thus indirectly referring to situations of economic dependence ${ }^{3008}$. However, to our knowledge, there have not been any cases implementing the dependence perspective in interpreting Article 18 AML.

In 2011, MOFCOM and other four ministries issued a Work plan against large scale retailers and suppliers' illegal charge .(清理整顿大型零售企业向供应商违规收费工作方案) The work plan expressed concerns over the abuse of superior bargaining power of large-scale retailers, including supermarkets, general stores and electronic stores.$^{3009}$ The main part of the work addressed three superior bargaining power abuse issues: product promotion, abusive prices and the display of the price tag in retail.

In 2015, a draft version of the Commodity Circulation Law of the People's Republic of China 中华人民共和国商品流通法 ${ }^{3010}$ was published soliciting comments. Article 2 of the draft law clarified the scope of the legislation's application: "The Law applies to the commodity circulation within the territory of the People's Republic of China. For the purpose of the Law, commodity circulation refers to trade activities such as wholesale, retail and logistics of commodities and other relevant services." No exemption for agro-food issues is mentioned in the draft law. Articles 41 and 42 prohibit the abuse of superior bargaining power concerning commodity circulation and services between retailers and suppliers. Specifically, Article 41 provides that "During commodity circulation,

\footnotetext{
${ }^{3006} \mathrm{http} / / / \mathrm{www} . \mathrm{mofcom} . \mathrm{gov} . \mathrm{cn} / \mathrm{article/b/c/200610/20061003442804.shtml.}$

$3007 \mathrm{http} / / /$ www.mofcom.gov.cn/article/b/c/200610/20061003442804.shtml.

3008 Article 10, SAIC Rules on Abuse of Dominance; Article 18, NDRC Rules on Anti-Price Monopoly Conduct.

${ }^{3009}$ See, http://www.mofcom.gov.cn/article/h/redht/201112/20111207899504

3010 http://tfs.mofcom.gov.cn/article/as/201503/20150300928533.shtml. The law is still in the legislation process at the time of writing.
} 
retailers and suppliers are prohibited to abuse superior bargaining power, to hinder fair trade, to harm each other's legitimate rights. Retailers are those who supply commodity to consumers. Suppliers are those who supply commodity to retailers, including manufacturers and others who supply the retailers. Superior bargaining power refers to one trading party's advantage over its trading parties, . The advantage is formed due to one party's economic reliance on its trading party. This economic reliance restraints one trading party's ability to choose more trading parties, to contract negotiation and to establish trading conditions." Furthermore, Article 42 provides that "Service fee between retailers and suppliers shall be based on negotiation, and shall go through formal agreements. Imposing fees that are not directly related to the commodity or are not based on service constitutes abuse of superior bargaining power."

On 25 February 2016, the Legislative Affairs Office of the State Council published the amending draft of the Anti-Unfair Competition Law of the People's Republic of China (AUCL) 中华 人民共和国反不正当竞争法. The AUCL added the abuse of superior bargaining power as a prohibited act and no exemption for agro-food issues is mentioned in the draft amendment.

The draft amendment defines superior bargaining power as where "in a certain transaction, a business operator holds a comparatively advantageous position as to capital, technology, market access, sales channel and raw material purchase etc., which renders the trading counterparty to be dependent on this business operator, (this manifested by) the difficulty (it has) to switch to other business operators". AUCL Article 6 also identifies five forms of abuse of superior bargaining power as unfair trade: (1). restricting a trading counterparty to certain trading partners without any justifiable reasons; (2). restricting a trading counterparty to designated products without any justifiable reasons; (3). restricting a trading counterparty to certain trading conditions when dealing with other operators without any justifiable reasons; (4). charging unreasonable fees or unreasonably requesting other economic benefits from trading counterparties; and (5). imposing other unreasonable conditions.

\section{Article 6, AUCL Draft Amendement ${ }^{3011}$}

"An undertaking shall not engage in any of the following conduct of unfair trading by taking advantage of its comparative advantage position:

(1) Without justifiable reasons, restricting counterparties' trading partners;

(2) Without justifiable reasons, restricting counterparties to purchase certain designated products;

(3) Without justifiable reasons, restricting the trading terms and conditions between counterparties and other undertakings;

(4) Abusively overcharging or unreasonably demanding counterparties to offer other economic interests; or

(5) Attaching other unreasonable trading terms.

'Comparative advantage position' in this Law refers to an advantageous position in a specific transaction held by an undertaking in terms of capital, technology, market access, distribution channel and material procurement, etc. and its trading counterparty is reliant on such undertaking and is difficult to switch to other undertakings."

${ }^{3011}$ Unofficial translation prepared by the Anjie Law Firm. The translation was used by the ABA as an appendix of its Opinion.

See https://www.americanbar.org/content/dam/aba/administrative/antitrust_law/at_comments_20160324_china.authche ckdam.pdf 
About a year before publishing the draft AUCL, an amendment of the AML was initiated in 2015 by the National Development and Reform Commission; one of the main issues touched upon by the amendment is whether the provision on superior bargaining power should be added to the AML. The draft amendment (to which SAIC contributed) was published by the Legislative Affairs Office of the Administration in February 2016 for public consultation.

The majority of Chinese scholars agree to include a SPB clause in the national law, but in the AML, instead of the AUCL. The inclusion of a provision to govern superior bargaining power into the AML has long been suggested by the majority of Chinese scholars and the recent amendments ignited again the debate. Most Chinese scholars support the view that superior bargaining power (SPB) should be regulated by Chinese Antimonopoly Law (AML) ${ }^{3012}$. Prof. Guangyao XU has noted that it is not necessary to include the SPB clause into the Chinese unfair competition law, because SPB touches upon the same issues as those dealt by the concept of dominant position, or it constitutes a form of dominant position. He also noted that AML offers sufficient mechanisms for the regulation of SPB. ${ }^{3013}$ Dr. Qiang YU notes that SPB should be regulated by AML, noting the importance of addressing SPB in the AML on the basis of a global value/supply chain approach. ${ }^{3014}$ Prof. Xiaoye WANG has also criticised the inclusion of a provision on SPB into Chinese unfair competition law, in view of the fact that AML can regulate some of the SPB-abuse practice, but with limited scope and effectiveness and that the regulation of other types of SPB-abuses must rely on contract law, commercial law and sectoral-specific regulations. ${ }^{3015}$ Judge Li ZHU, suggests that the most of the concerns about the abuse of SPB could be addressed by the AML or the contract law, it is therefore unnecessary to include such a clause in the AUCL. Moreover, the risk of that clause being misused or abused is imminent and significant. ${ }^{3016}$ One should also note the position of Prof. Yanbei MENG who considers that it is baseless to include the regulation of SPB into Chinese Anti-Unfair Competition law. She explained that the regulation of SPB is contrary to the objectives of the AUCL. What's even worse, according to her, if the regulation of SPB was included into the law, anticompetitive effects will be exempt from being punished. ${ }^{3017}$

At the opposite side, Prof. Jian LI expresses some reticence in introducing a provision on SBP in AML. According to him, the theory of SPB has major defects, and its inclusion into competition law will produce negative implications to the theoretical analysis and legal practice for both antitrust law and unfair competition law. ${ }^{3018}$ For professor Jian Li, the inclusion of SPB into AML will be problematic in view of the fact that AML is market structure based, while SPB is economic

\footnotetext{
3012 See, for instance, 孟雁北, 滥用相对经济优势地位行为的反垄断法研究, 法学家, 2004 年第6 期; 徐士英、 唐茂军, 滥用相对支配地位行为的法律规制研究, 东方法学》, 2008 年第3 期 http://qiduojun.csu.edu.cn/shichangguizhifa/512.html (explaining that that Article 18 AML should offerr the basis for relevant regulation)

3013 许光耀, “相对优势地位”与“市场支配地位”的法理辨析一一对《反不正当竞争法（征求意见稿）第6条的不 同解释》，价格理论与实践，2016年第5期。

3014 于强, 滥用优势地位与反垄断法的适用, 竞争政策研究, 2016年第4期。

3015 王晓晔，论滥用“相对优势地位”的法律规制，现代法学，2016年第5期。

3016 朱理, 滥用相对优势地位问题的法律规制——虚幻的敌人与真实的危险, 电子知识产权, 2016年第6期。 3017 孟雁北, 论反不正当竞争立法对经营自主权行使的限制一一以《反不正当竞争法（修订草案送审稿）为研 究样本, 中国政法大学学报, 2017年第2期。

3018 李剑, 相对优势地位理论质疑, 现代法学, 2005年第3期。
} 
dependence based. Its inclusion may improperly expand the regulatory scope of AML and finally protect competitors and not competition. ${ }^{3019}$

Professor Xianlin WANG, however, strongly suggests that a SPB clause should be included in the AUCL. He argues that the superior bargaining position is neither regulated by the AML (which covers the dominance regulation), nor the contract law. For example, some big retailers may impose significant tax and unfair fee on its small suppliers. For those non-dominant, but relatively superior retailers, it is important to regulate their behaviour by introducing such a SPB clause in the AUCL. ${ }^{3020}$ Prof. Xianlin WANG has recently repeated his position on the inclusion of SPB into Chinese Antiunfair Competition Law explaining that if the regulation of SPB was excluded from the the draft law, no law can be used for governing it, taking the position that it is preferable in the long-run that the regulation of SPB should be included into Chinese Anti-unfair Competition Law. ${ }^{3021}$ Prof. Mingyu LV has also pointed out that the provision on SPB can be included into Chinese Anti-Unfair Competition Law if the wording of the clause was adjusted. ${ }^{3022}$

Relations between the amendment of the AUCL and that of the AML remain subtle at present. However, there is no theoretical foundation for introducing regulatory provisions on superior bargaining power into the AUCL, whereas there are extensive theoretical and factual reasons for adding such a provision into the AML. The key issues that need to be discussed are whether the regulation of superior bargaining power will be subject to AML exemption and, in the case of exemption being applied to agro-food sectors, which segments of supply chains will be affected. The proposed amendment of the AUCL was reviewed by the Chinese National People's Congress for the first time in February 2017. Entrusted by and on behalf of the Premier, the head of SAIC gave a supporting explanation to the Congress on this session. The Congress published the bill it reviewed for public comments after the first reading. It is in this draft that the SPR provision was deleted. Since the first reading draft was prepared and proposed by the Administration for parliamentary review, it should be the Administration who may remove the SPR clause.

After the first reading and the Congress's first round of public consultation, the Law Committee of the Congress made some revisions to the first reading bill. The Congress then deliberated the bill for the second time in August 2017. The vice-chair of the Law Committee of the Congress explained why certain changes were made in that session. The Congress published the version used for the second reading, in which the SPR clause is still excluded. It will be another round of deliberation of the bill before the final vote on the amendment. For most of the cases, the bill does not incur any substantial changes after the second reading. However, if there is a disagreement among the legislators, the bill may also be revised significantly. Additional rounds of deliberations may be organised after the three readings. Procedurally, it is still uncertain if the SPR clause will be included in the amended AUCL.

In any case it seems highly unlikely that a clause on Superior Bargaining Power will be included in the AUCL this time, in view of various objections to it by a number of scholars. The rationale against such inclusion seems to relate, inter alia, to possible worries of false positives, and to the theoretical and institutional division between the AML and the AUCL.

\footnotetext{
3019 李剑，论结构性要素在我国反垄断法中的基础地位，政治与法律，2009年第10期。

${ }^{3020}$ 王先林，对《反不正当竞争法（修订草案送审稿）》的两点解读，中国工商报，2016年3月2日。

3021 戴龙等, “《反不正当竞争法》修订的重大问题学术研讨会”综述，竞争政策研究，2016年第4期。

3022 孟雁北, 《反不正当竞争法 (修订草案)》研讨会综述, 竞争政策研究, 2017年第2期。
} 


\subsection{Competition Law Enforcement in specific segments of the food value chain}

\subsubsection{Fertilisers}

Uralkali Open-end Corporate, Silvinit Open-end Corporate $2011^{3023}$

乌拉尔开放型股份公司吸收合并谢尔维尼特开放型股份公司

MOFCOM reviewed the merger declaration of Uralkali Open-end Corporate's (Uralkali) and Silvinit Open-end Corporate (Silvinit), and decided to approve this merger. However, restrictive conditions were imposed pursuant to the AML and other relevant regulations. After analysing in depth the impact of this merger on market competition pursuant to Article 27, MOFTOM held that an unfavourable impact of eliminating and restricting competition may result in the Chinese potassium chloride fertiliser market. This is because the global potassium chloride fertiliser market is highly concentrated; more specifically, three giant firms hold more than $80 \%$ of the market share and the merging firms are two of them. Moreover, the two firms dominate the Chinese potassium chloride fertiliser market (as they hold more than 50\% market share). Consequently, MOFCOM required the merged entity to offer non-discriminatory treatment to Chinese consumers.

\subsubsection{Beans}

\section{Marubeni Corporation, Gavilon Holdings, LLC $2012^{3024}$}

丸红公司收购高鸿公司

On 19 June 2012, MOFCOM received a notification concerning the acquisition of $100 \%$ of the equity in Gavilon Holdings, LLC ("Gavilon") by Marubeni Corporation ("Marubeni"). After reviewing the case, MOFCOM decided to approve this acquisition with restrictive conditions pursuant to AML Article 30. MOFCOM examined this acquisition and analysed, in-depth, its impact on competition in accordance with the AML and its supporting regulations. It ultimately held that the acquisition may have the effect of eliminating or restricting competition in the import market for soybeans in China.

China is the world's largest importer of soybeans. The amount imported into China in 2012 accounted for $60 \%$ of the total trading volume globally and $80 \%$ of the total supply in China. Marubeni exports $99 \%$ of its soybeans to China. Gavilon disposes of important capabilities in the procurement, storage, and logistics of soybeans in North America. Therefore, this acquisition would combine Gavilon's strength in the soybeans market in North America with Marubeni's comprehensive advantage in the export market of soybeans to China. In addition, it was considred that the acquisition would also improve Marubeni's capability to export soybeans to China, and potentially enhance Marubeni's power to control the import market of soybeans in China, potentially eliminating or restricting competition. Currently, China is heavily reliant on importing soybeans, as the domestic soybean-consuming market is highly fragmented, with small-sized businesses lacking bargaining power. This acquisition could further undermine the bargaining power of these small soybean businesses in the downstream market. The post-merger firm could further enhance its power to control the import market of soybeans in China, thereby further increasing the cost of market entry. Ultimately, this merger would have harmed downstream competition and, in turn, consumers.

\footnotetext{
${ }^{3023}$ http://fldj.mofcom.gov.cn/article/ztxx/201106/20110607583288.shtml
} ${ }^{3024} \mathrm{http} / / /$ fldj.mofcom.gov.cn/article/ztxx/201304/20130400100376.shtml 
Upon assessing, Marubeni's remedy proposal submitted on 17 April 2013, MOFCOM held that it could reduce the adverse effects on competition resulting from this acquisition and, consequently, decided to approve this acquisition with the following restrictive conditions.

(i) Within six months after this decision becomes effective, Marubeni shall establish two independent legal entities together with two independent operation teams responsible for the export and sale of soybeans into China. Marubeni will export and sell soybeans into China through its soybean subsidiary. Gavilon will export and sell soybeans into China through its soybean subsidiary. All these actions are subject to reporting to the supervision trustee and receive the approval of MOFCOM.

(ii) Marubeni's soybean company and Gavilon's soybean company, in respect of matters including, but not limited to, the appointment and dismissal of personnel, procurement, marketing, sale, pricings, etc, shall remain separate and independent firms. To ensure the enforcement of the principles of fairness and reasonableness, Marubeni and Gavilon shall formulate safeguarding measures in advance, which shall be carried out after reporting to the supervision trustee and upon the approval of MOFCOM.

(iii) Upon completion of this acquisition, Marubeni's soybean company shall not purchase soybeans from Gavilon's American Asset (the facility located in the U.S.A., which is solely controlled by Gavilon and engaged in product procurement and export), unless conducted under fair market conditions. Upon the completion of the acquisition, if Marubeni's procurement and export assets located in the U.S.A. are transferred and incorporated into Gavilon, Marubeni's obligation to procure soybeans based on the principles of fairness and reasonableness shall be extended to such assets. To ensure the enforcement of the principles of fairness and reasonableness, Marubeni and Gavilon shall formulate safeguarding measures (including the possibility of setting up a firewall between Marubeni's soybean company and Gavilon's American Asset) in advance, which shall be carried out after reporting to the supervision trustee and upon the approval of MOFCOM.

(iv) Marubeni's soybean company and Gavilon's soybean company shall not exchange competitive information with each other. "Competitive information" refers to any information that may lead Marubeni's soybean company and Gavilon's soybean company to coordinate their respective business behaviours, which includes, but is not limited to, the sales price of soybeans in China, information relating to the commercial terms for procurement and sales, cost, existing or potential customers, negotiation with customers and customers lists, marketing and strategic plans, etc. To ensure the achievement of the above goal, Marubeni and Gavilon shall formulate safeguarding measures in advance, especially by setting up a firewall between Marubeni's soybean company and Gavilon's American Asset to ensure that they would not exchange competitive information. Such measures shall be carried out after reporting to the supervision trustee and upon the approval of MOFCOM.

JCCE, Inner Mongolian Zhalute Banner Hongye Grain and Oil Trading Co., Ltd., Taonan Ji Dou Economics Trade Co.,Ltd, and Other firms(109 firms) $2010^{3025}$

吉林玉米中心批发市场有限公司联合内蒙古扎鲁特旗正达粮油贸易有限公司、吉林省洮南市 吉豆经贸有限公司

${ }^{3025}$ http://jjs.ndrc.gov.cn/gzdt/201007/t20100702_358457.html. 
On 17 October 2009, JCCE ${ }^{3026}$, Inner Mongolian Zhalute Banner Hongye Grain and Oil Trading Co., Ltd., Taonan Ji Dou Economics Trade Co.,Ltd, spread wrong statistical data predicting that the amount of mung bean output within the main production areas (within Mainland China) would fall $64.05 \%$ in 2009 compared to that in 2008. According to this data, JCCE and 109 other firms concerted to raise the price of mung beans nationwide, which is a violation of PLPRC. Consequently, JCCE received a fine of one million RMB, while Inner Mongolian Zhalute Banner Hongye Grain and Oil Trading Co., Ltd., Taonan Ji Dou Economics Trade Co.,Ltd received fine of half a million RMB each.

\subsubsection{Salt}

\section{Inner Mongolia Chifeng Salt Company 2014}

\section{内蒙古赤峰盐业公司垄断行为案}

In September 2014, Chifeng Salt Industry Company and its subsidiaries engaged in discriminatory treatment between different retailers. Specifically, Chifeng Salt Industry Company supplied only a few but expensive types of salt products to Chifeng. As the only edible salt wholesaler in Chifeng, Chifeng Salt Industry Company's conduct amounted to abuse of dominance through discriminatory treatment, including a refusal to deal. The Inner Mongolia AIC found that such conduct violated Article 17 of the AML and constituted an abuse of market dominance. The AIC imposed financial penalties of CNY 2,988,358, which included CNY 1,940,544 in disgorgement and CNY 1,047,814 in fines.

\section{Hunan Yongzhou Salt Company 2015}

湖南盐业永州市分公司搭售案

During January 2014 and March 2015, the company had engaged in tie-in sales of unpopular salt products in the course of wholesale of popular salt products, which had wide-ranging impact and caused actual harm on the part of retailers and consumers. The Hunan AIC found that the company violated the (5) provision in first paragraph of Article 17 of the AML and therefore imposed a fine of CNY 272,000 (USD 39,172) and disgorgement of CNY 698,000. The fine is equivalent to $1 \%$ of the company's sales in 2014.

\subsubsection{Garlic}

Zhongmu County Cold Storage Association 20103027

中牟县冷藏保鲜协会

On 16 March 2010, Zhongmu County Cold Storage Association issued an executive document ordering its members to set the price of garlic storage service to $260-320 \mathrm{RMB} / \mathrm{ton}$, with no members allowed to lower it. Consequently, NDRC fined Zhongmu County Cold Storage Association for 80.000 RMB for violating PLPRC.

\subsubsection{Sugar}

\footnotetext{
3026 吉林玉米中心批发市场有限公司

${ }^{3027}$ http://jjs.ndrc.gov.cn/gzdt/201007/t20100702_358457.html
} 
Guangxi Phoenix Biochemical Ltd., Guangxi Nanhua Sugar Ltd. and other firms $2011^{3028}$ 广西凤糖生化股份有限公司和广西南华糖业集团有限公司

Between 2010 and 2011 Guangxi Phoenix Biochemical Ltd., Guangxi Nanhua Sugar Ltd. and other firms hoarded huge quantities of sugar and sold their sugar at unreasonably high prices, which were found to constitute violations of PLPRC. Consequently, NDRC imposed administrative fines to these firms and required them to sell 170,000 tons of sugar priced not higher than 7,000RMB/ ton before 15 October 2011.

\subsubsection{Rice vermicelli}

Nanning Xianyige Food Factory $2014^{3029}$

南宁市鲜一阁食品厂

On 1 December 2009, the director of Nanning Xianyige Food Factory - Zhihe Que, organised a cartel to raise the price of rice vermicelli within the geographic market of Nanning City. On 1 January 2010 , Zhihe Que and 17 other rice vermicelli suppliers raised their price in a concerted way. Several weeks later, Zhihe Que organised another similar cartel in the adjacent city of Liuzhou. NDRC fined Nanning Xianyige Food Factory and the two other main organising factories 300,000 RMB. Some of the cartel members received fines between 30,000 RMB and 80,000 RMB each, while others only received an administrative warning. NDRC did not publish the legal basis for these decisions.

\subsubsection{Beverages}

Coca-Cola, Huiyuan $2009^{3030}$

\section{可口可乐公司收购中国汇源公司}

On September 18, 2008, the MOFCOM received notification materials for the merger of Coca-Cola Co. and China Huiyuan Co. Through its review, MOFCOM found that this merger would have an adverse impact on competition. Given Coca-Cola's dominant position in the carbonated-beverage market, it could easily leverage the combined marketing power of a merged company to dominate China's juice-beverage market by bundling products or offering special incentives and exclusive arrangements. Coca-Cola Co. then submitted a preliminary resolution proposal and a revised proposal. After assessment of the same, MOFCOM concluded that the revised proposal still could not effectively alleviate this merger's adverse impact on competition. Therefore, pursuant to AML Article 28, MOFCOM decided to block the merger.

\subsubsection{Milk}

\section{Speedfresh Resale Price Maintenance}

\section{上海领鲜物流维持转售价格案}

On $27^{\text {th }}$ December 2016, Price Bureau of Shanghai DRC imposed a CNY 1.978 million fine in total as $1 \%$ of the relevant turnover of Shanghai Speedfresh and ordered it to stop illegal conducts of implementing vertical monopoly agreements which fixed the resale prices.

\footnotetext{
${ }^{3028}$ http://jjs.ndrc.gov.cn/gzdt/201110/t20111009_437580.html.

3029 http://www.ndrc.gov.cn/fzgggz/jgjdyfld/fjgld/201402/t20140228_588558.html.

3030 http://fldj.mofcom.gov.cn/article/ztxx/200903/20090306108494.shtml
} 


\subsubsection{Milk Powder}

\section{Infant Formula RPM}

\section{合生元等乳粉企业限制竞争行为案}

On $7^{\text {th }}$ August 2013, the NDRC imposed sancations on Biostime, MeadJohnson, Dumex, Abbott, Friso, Anumum, Wyeth, Beingmate and Meiji for the conclusion and implementation of monopoly agreements which fixed the resale prices.

\subsubsection{Alcohol}

\section{Kweichow Moutai and Wuliangye}

\section{茅台、五粮液限制转售价格案}

On 22 February 2013, Guizhou Provincial Pricing Administration released the decision to impose a penalty of RMB 247 million (about USD 39.8 million) on Kweichow Moutai, the most famous Chinese state-owned producer of premium liquor, for administering resale price maintenance ("RPM"). On the same day, Sichuan PDRC released its decision to penalize Wuliangye, another state-owned premium liquor producer, in an amount of RMB 202 million (about USD 32.6 million) for RPM as well. Both agencies are local counterparts of the National Development and Reform Commission, which is charged with the responsibility to enforce against price-related monopoly agreements, including RPM under AML. The case has made a huge stir, because this was the first time the Chinese AML enforcement agencies penalized RPM under the AML.

\subsubsection{Beer}

\section{InBev, Anheuser $2008^{3031}$}

\section{英博集团公司收购 $\mathrm{AB}$ 公司}

On 18 November 2008, MOFCOM published its decision to approve InBev NV/ SA's proposed US\$52 billion acquisition of Anheuser-Busch Companies Inc, subject to conditions. This was the first merger decision under the AML to be published and the first merger to be conditionally approved under the AML. The decision did not set out any detailed analysis of the transaction, mainly because the AML was enacted at the same year and there was no tradition of publishing detailed competition analysis.

MOFCOM stated that, although the transaction may not eliminate or restrict competition in China's beer market, it could nevertheless potentially lead to adverse effects on China's beer market in the future if the market power of the post-merger firm was abused. Therefore, MOFCOM approved this transaction with the following conditions:

- Anheuser-Busch's existing $27 \%$ stake in Tsingdao Brewery must not be increased;

- InBev shall notify MOFCOM promptly if there are any changes in its controlling shareholders or the shareholders of such controlling shareholders;

- InBev shall not increase its existing $28.56 \%$ stake in Zhujiang Brewery; and

${ }^{3031}$ http://fldj.mofcom.gov.cn/article/ztxx/200811/20081105899216.shtml 
- InBev shall not hold any stake in China Snow Breweries or Beijing Yanjing Brewery, and two other major breweries in China.

- InBev shall notify MOFCOM before seeking to take any such steps and to obtain MOFCOM's prior approval.

Anheuser-Busch InBev, SAB Miller2016 3032

百威英博啤酒集团收购英国南非米勒酿酒公司股权

MOFCOM received the notification for antitrust review of the concentration of brewers for the proposed acquisition of SABMiller plc (SABMiller) by Anheuser-Busch InBev SA/NV (AB InBev). Upon review, MOFCOM decided to approve this concentration of business operators with restrictive conditions pursuant to Article 30 of the AML.

$\mathrm{AB}$ InBev and SABMiller are mainly engaged in the production and sales of beer. As beer differs significantly from white spirits, wines and other alcoholic beverages in terms of ingredients, brewing process, alcohol content and consumer preference, beer was defined as a separate relevant product market.

According to Article 27 of the Anti-monopoly Law, MOFCOM conducts in-depth analysis of the concentration's effect on the market, taking into account the concentration of relevant market, the market share and control power of the operators concerned in the concentration, the difficulty of market entry, the effect on the consumers and other business operators and other factors, and believes that the concentration has the effect of eliminating or restricting competition in the relevant market. MOFCOM found that (i) the Transaction would have further enhanced the control power of AB InBev in the relevant market, (ii) the Transaction would reduce the competition between the two leading competitors in the Chinese beer market, (iii) the Transaction would increase the entry barriers in the relevant market, (iv) the Transaction would harm the interests of downstream distributors.

In summary, the merger would further enhance its power on the relevant market, reducing competition between the two close leading competitors in the market, raising entry barriers to the market, therefore harming the interests of the downstream dealers. MOFCOM considered that the merger would have the effect of eliminating or restricting competition on the relevant market, and consequently harm the interests of the Chinese consumers.

After assessment, MOFCOM concluded that the final proposals of the restrictive conditions submitted by AB InBev and SABMiller on 14 July 2016 and 21 July 2016 respectively would be able to remove the negative effect that the Transaction has on competition.

Given that the transaction will have the effect of eliminating and restricting the competition in the relevant market, according to MOFCOM [2008] No.95 Announcement, MOFCOM decided to conditionally clear the Transaction based on the final proposal of the restrictive conditions submitted by $A B$ InBev and SABMiller and require $A B$ InBev and SABMiller to fulfill, among others, the following obligations:

- To divest the $49 \%$ interest held by SABMiller in CR Snow.

- To sell the 49\% interest in CR Snow to CRB strictly in accordance with the Agreement submitted to MOFCOM by AB InBev.

3032 http://fldj.mofcom.gov.cn/article/ztxx/201607/20160701369044.shtml 
MOFCOM can monitor the implementation of commitments through a monitoring trustee or on their own. ${ }^{3033}$

\subsection{Agricultural Subsidies}

The Chinese Communist Party issued a "No. 1 Document" in early 2004 that gave top priority to the policy goal of increasing rural incomes. A whole range of policies has been introduced, but the two most prominent are direct subsidies for farmers and elimination of taxes on farmers. The stated goal of the policies is to raise the income of farmers, but the document also emphasizes the importance of increasing grain production.

\section{Direct Subsidies Paid to Farmers}

After several years of experimenting, China introduced its first nationwide direct subsidies for farmers during 2004. China's Finance Ministry reported the total grain subsidies at 11.6 billion RMB. China allocated 10.28 billion RMB ( $\$ 1.25$ billion) from provincial "grain risk funds" to directly subsidize farmers in 13 major grain-producing provinces. Officials in 16 of China's other provinces, municipalities, and autonomous regions provided an additional 1.3 billion RMB ( $\$ 158$ million) in subsidies to farmers in grain-producing counties under their jurisdiction. Local authorities were urged to ensure that subsidies reached farmers before the 2004 spring crops were sown. Information about the subsidies was widely published in news media to ensure that farmers knew how much they were entitled to receive. Each province could set its own method for granting subsidies. The standard practice seems to be to pay farmers a set amount, generally around 10 RMB per mu (approximately $\$ 7.33$ per acre), for area planted in grain. The method for calculating a farmer's acreage base apparently varies from province to province, or even from county to county within the same province. In most cases, the payment appears to be based on historical production records. In a few areas, payments were tied to actual production or marketing of grain. The subsidy varied across both regions and commodities. Subsidies were not implemented in several poor western provinces or on the island province of Hainan. In some areas, reductions in agricultural tax were given in lieu of cash payments. The subsidies amount to roughly $\$ 2-\$ 5$ per ton of output. The subsidies per farm were also small since the average farm plants only 3-4 mu of each crop.

The grain subsidies represent a small portion of the value of grain production in China. Grain production figures for China's 2004 harvest were not yet available at the writing of this report, but China's rice, wheat, and corn production are currently forecast by USDA at approximately 400 million tons. At an average farm price of 1,500 RMB per ton, the RMB 11.6 billion in subsidies would be equal to less than 2 percent of the gross value of grain production.

\section{Agricultural Taxes Eliminated}

Another highly visible measure intended to increase farm incomes is the elimination of agricultural taxes. China has had an agricultural tax throughout its recorded history, and the current agricultural 
tax law dates back to the 1950s. Before 2004, Chinese farmers were typically assessed an agricultural tax based on the normal productive value of their land, an agricultural specialty product tax, and a myriad of additional local taxes and fees to fund road construction, schools, and various other projects and services undertaken by village and township authorities. The heavy tax burden on farmers has been the source of widespread dissatisfaction and occasionally outright rebellion by farmers. The government has been calling for local governments to reduce excessive fees and taxes and has carried out experimental reforms since 2001. Agricultural taxes were assessed differently in each locality, but the typical arrangement was to collect 7 percent of the normal value of production from a household's land, based on each family's allotted land area and an historical average price and yield. An additional surcharge of 20 percent was assessed to fund village administrative expenses, bringing the total tax to 8.4 percent. Some additional taxes were allowed, notably a tax on nongrain specialty crops and a "herding tax" on grazed livestock in grassland areas. In 2004, the "No. 1 Document" stipulated that the agricultural tax would be eliminated in 5 years. The tax was reduced by 3 percentage points in 2004 and an additional 1 percentage point per year in subsequent years. China also eliminated the specialty crop tax (with the exception of tobacco) and taxes on grazing livestock. China's State Council singled out Jilin and Heilongjiang Provinces for complete elimination of the agricultural tax in 2004. Provincial authorities were given the go-ahead to cut taxes even faster, if possible. Five other wealthy provinces and municipalities (Beijing, Tianjin, Shanghai, Zhejiang, and Fujian) eliminated the tax in 2004, and Tibet eliminated its grazing tax. Later in the year, the government decided to speed up elimination of the agricultural tax and announced in January 2005 that 25 of China's 31 provinces, municipalities, and autonomous regions would eliminate the agricultural tax in 2005. In 2003, the National Bureau of Statistics reported revenue from the agricultural tax at RMB 33.6 billion ( $\$ 4$ billion), specialty crop taxes at RMB 9 billion ( $\$ 1$ billion), and herding taxes at RMB 149 million ( $\$ 18$ million), a combined total of RMB 42.7 billion ( $\$ 5$ billion). Other news reports indicate that agricultural tax revenues totalled RMB 60 billion ( $\$ 7$ billion) before the tax-elimination policy was implemented. These figures are equal to just 2-3 percent of all taxes collected in China.

However, many rural local governments depend heavily on agricultural taxes to finance basic education and other local government activities. News reports indicate that the central government will transfer funds to local governments to make up for lost tax revenue, but no details have been announced about how this transfer is to be accomplished. Agricultural Inputs Subsidized Seeds and agricultural machinery also are subsidized under new policies. Subsidies for high-quality seeds, including high-oil soybeans, special-use corn and wheat, and high-quality rice varieties, are paid to seed supply companies, which are expected to pass on the subsidies to farmers. Targets of 10 million $\mathrm{mu}$ (1.65 million acres) of acreage planted in high-quality seeds were set for each of 13 provinces (the same provinces receiving direct subsidies for farmers). In Heilongjiang Province, the subsidy for improved corn and soybean seeds was set at 10 yuan per mu and the subsidy for rice seed was 15 yuan per mu. According to a Xinhua News Agency report in August 2004, 1.6 billion yuan ( $\$ 193$ million) in seed subsidies had been paid since October 2003. China also allocated an additional 40 million yuan ( $\$ 5$ million) to subsidize purchases of farm machinery in 66 large grain-producing counties of 16 provinces. Subsidies can cover up to 30 percent of the purchase price.

Farmers pay the subsidized price. After the sale, dealers collect the subsidy from provincial government offices overseeing farm mechanization. 


\section{Prices Set By Markets}

Over the past several years, China has been abolishing procurement of grain at "protection prices" (support prices at which government-sponsored marketing bureaus procure a set quota of grain from farmers), a policy introduced during the late 1990s when market prices for grain were falling from historical highs reached in 1996. By 2003, protection prices remained for only grain in important production areas, and most of those were eliminated in 2004. In 2004, the government maintained minimum "protection prices" for only rice, spurred by concerns about rising rice prices and spot shortages of rice in 2004. The setting of protection prices for rice reflects the political sensitivity of rice, the staple food grain throughout much of China. However, market prices rose 40-50 percent between 2003 and 2004 to levels well above the protection price. Grain prices are now mostly set in open markets, and government procurement prices appear to be following market prices.

\section{Grain Marketing Liberalized}

In addition to agricultural subsidies and tax reduction, China is privatizing the domestic grain marketing system, making large public investments in agricultural infrastructure, stepping up efforts to prevent loss of agricultural land to urban uses, and encouraging rural financial institutions to loan more money to farmers. China is encouraging better market infrastructure. In 2004, China resumed futures trading of corn (it had been suspended in the late 1990s), introduced a new futures contract for imported soybeans (futures contracts for domestic soybeans have been traded for a number of years), and began cotton futures trading at the Zhengzhou commodities exchange. In June 2004, China announced new regulations designed to liberalize grain markets by reducing the dominant role played by government-sponsored enterprises in domestic grain trade (Xinhua Domestic News Service). These regulations seem to be the culmination of a steady rollback of the monopoly power of government sponsored grain bureaus that had been under way for several years. While the marketing regulations appear to promote open competition, the key players in grain marketing are former government grain bureau procurement stations that were privatized by selling them to their managers. They still have close ties to government. These companies have access to governmentdirected grain procurement loans and government-owned storage and processing facilities, while small private grain traders have difficulty obtaining bank loans and have limited storage capacity (Zhong). The regulations stipulate that the government can intervene in grain markets when prices are rising rapidly and that government departments have responsibility to ensure that grain supply and demand is balanced (the "governors' responsibility system" introduced in 1995). Early assessments by observers report that grain markets are more competitive and open. Private and individual grain merchants are playing a greater role in grain procurement, state-owned enterprises are improving service and working with village brokers to purchase grain, and farmers have more alternatives for grain marketing (Hebei Rural Survey Team; Heilongjiang Rural Survey Team, November 11, 2004).

\section{Rural Infrastructure Investment Increased}

China is also working to improve the livelihoods of agricultural producers by increasing agriculturalrelated public investments. The government planned to increase its financial support for agricultural 
infrastructure in 2004 to 150 billion RMB ( $\$ 18.1$ billion), up from 120 billion RMB ( $\$ 14.5$ billion) in 2003. Projects include spending on infrastructure, such as improved irrigation facilities, rural roads, methane production facilities, rural hydroelectric plants, pasture enclosures, research, and construction of agricultural high technology parks. The Ministry of Water Resources reported investment in irrigation projects of RMB 58 billion ( $\$ 7$ billion) during the 8 months from September 2003 to May 2004, an 11.7-percent increase over the previous year (Xinhua News Agency). Research has shown that such investments have been the most important source of China's agricultural productivity growth. Historically, little of China's infrastructure expenditure has actually reached farmers. A survey by the Development Research Center of China's State Council found that only 30 percent of funds appropriated for agriculture are spent on agricultural production. In the past, much of the expenditure on agriculture was used for operating expenses by various levels of government to purchase automobiles, pay for banquets, or otherwise misappropriated.

\section{More Loans for Farmers}

China is also seeking to boost farm investment by making more small loans to farm households through its vast system of 35,000 rural credit cooperatives (RCCs). During the 1990s, farm loans were frequently squeezed out by loans to rural factories and local governments. RCCs are now under pressure to make more loans to farm households. Many rural communities have adopted a micro-loan classification system that evaluates all households in a village and classifies each household into one of four or five loan-eligibility categories. Government reports indicate that new RCC agricultural loans totalled $\$ 23.4$ billion during the first 9 months of 2004, an increase of 27.8 percent from yearearlier amounts. These loans are small, nearly all under $\$ 2,500$, and short-term (mostly 3-6 months). They are used for input purchases as well as modest investments, such as well-digging, livestock and fertilizer purchases, planting orchards, and greenhouse construction. China's state-owned policy banks are also increasing loans to agricultural processing companies that meet criteria for size, management, facilities, and technology set by national or provincial governments. These "dragon head" enterprises receive favourable loan terms from state banks with the expectation that they will provide farmers with profitable outlets for farm products. The Agricultural Development Bank of China (ADBC) launched a specialized lending program targeted at "dragon head" agricultural enterprises in 2002, and lending grew to RMB 40 billion ( $\$ 4.8$ billion) in 2003. The China Development Bank, Agricultural Bank of China, and RCCs also make preferential loans to these enterprises, but the total amount is not known (Xinhua News Agency).

\section{References}

Ashton, B., Hill, K., Piazza, A., \& Zeitz, R. 'Famine in china, 1958-61' (1984) 10 Population and Development review, 613-645.

于强, 滥用优势地位与反垄断法的适用, 竞争政策研究, 2016年第4期。( $Y u, \quad Q$, , “The application of Anti-Monopoly Law to the abuse of Superior Bargaining Position' (2016)4 Competition Policy Research, 64-75) 
国家统计局《2015年全国1\%人口抽样调查主要数据公报》(2016) available at < http://www.stats.gov.cn/tjsj/zxfb/201604/t20160420_1346151.html> (People's Republic of China National bureau of Statistics, 'Main data communique of $1 \%$ national population sampling survey in 2015 ' (2016))

国家统计局《2016年国民经济实现“十三五”良好开局》(2017)available ～ａt http://www.stats.gov.cn/tjsj/zxfb/201701/t20170120_1455942.html >(China National bureau of Statistics, 'National Economy Has Achieved a Good Start of $13^{\text {th }}$ Five-year Plan' (2017))

孟雁北，《反不正当竞争法（修订草案）》研讨会综述，竞争政策研究，2017年第2期。 (Meng, Y., 'A Summary of the seminar on Anti-Unfair Competition Law (Revised Draft)' (2017)2 Competition Policy Research, 81-85)

孟雁北, 滥用相对经济优势地位行为的反垄断法研究, 法学家, 2004 年第6 期 ; (Meng, Y., 'An antitrust study on the abuse of superior bargaining power' (2004)6 The Jurist, 82-88)

孟雁北，论反不正当竞争立法对经营自主权行使的限制一以 以反不正当竞争法（修订草案 送审稿）为研究样本，中国政法大学学报，2017年第2期。(Meng, Y., 'The restriction on exercising the autonomy of operation from Unfair Competition Legislation -- Taking the Anti-Unfair Competition Law (Revised Draft for review) as the research sample' (2017)2 Journal of China University of Political Science and Law, 135-145)

徐士英、唐茂军，滥用相对支配地位行为的法律规制研究, 东方法学, 2008 年第3 期available at http://qiduojun.csu.edu.cn/shichangguizhifa/512.html (Xu, S., and Tang, M., 'The study on the legal regulation of the abuse of Superior Bargaining Power'(2008)3 Oriental Law, 35-45)

戴龙等，“《反不正当竞争法》修订的重大问题学术研讨会”综述，竞争政策研究，2016年第 4期。(Dai, L. etl, 'A summary of the seminar on the major issues in the revision of Anti-Unfair Competition Law' (2016)4 Competition Policy Research)

朱理，滥用相对优势地位问题的法律规制——虚幻的敌人与真实的危险，电子知识产权， 2016年第6期。(Zhu, L., 'The legal regulation of the abuse of Superior Bargaining Position- An illusory enemy and the real danger' (2016)6 Electronic Intellectual Property, 31-39)

李剑, 相对优势地位理论质疑, 现代法学, 2005年第3期。( $\mathrm{Li}, \mathrm{J}$. , 'Questioning the theory of superior bargaining power' (2005)3 Modern Law Science, 101-107)

李剑，论结构性要素在我国反垄断法中的基础地位，政治与法律，2009年第10期。(Li， J., 'The Basic Position of Structural Elements in China Anti-Monopoly Law' (2009)10 Politics and Law, 121-129)

王先林，对《反不正当竞争法（修订草案送审稿）》的两点解读，中国工商报，2016年3月2 日。(Wang, Xianlin, 'Two point to analyse the Anti-Unfair Competition Law (Revised Draft for review)' (2016)3 China industry \& commerce news ) 
王晓晔，论滥用“相对优势地位”的法律规制，现代法学，2016年第5期。(Wang, Xiaoye, “The legal regulation of the abuse of Superior Bargaining Power' (2016)5 Modern Law Science, 79-92)

许光耀，“相对优势地位”与“市场支配地位”的法理辨析一一对《反不正当竞争法（征求意见 稿）》第6条的不同解释，价格理论与实践，2016年第5期。(Xu, G., 'Jurisprudential Analysis of 'Superior Bargaining Power' and 'Market Dominant Position'-A different interpretation of the article 6 in Anti-Unfair Competition Law(Exposure draft)' (2016)5 Price:Theory \& Practice, 43-45 ) 


\section{Chapter 5: South Africa}

\section{Dennis Davis \& Liat Davis (University of Cape Town)}

\subsection{The Food Chain(s) in South Africa}

The annual growth of the South African population stands at $1.6 \% .^{3034}$ Therefore, the country is expected to grow to over 80 million people by $2035 .{ }^{3035}$ In order to cater for this increase, food production must more than double using the same or fewer natural resources.

The increasing problem of food security is exacerbated by the state of the agricultural sector. The contribution of agriculture to total Gross Domestic Product (GDP) has been declining since 1960 when the sector contributed $11.223 \%$ to $2.44 \%$ in $2016 . .^{3036}$

Due to the increase in population farmers are under pressure to intensify their agricultural outputs to meet the increasing food demands. Farmers have not been able to keep up with this demand as they have to deal with increasing resource scarcity and limited direct investment in the agricultural sector. Consequently, the country has become a net importer of key food items, including wheat and meat. ${ }^{3037}$ Rice, sugar and poultry, which are part of the national food basket, are among the top seven products imported in terms of quantity. The country also imports considerable amounts of processed foods. ${ }^{3038}$

South Africa has become a net importer of various agricultural products and foods. At the same time, the South African food market is significant, estimated to be worth over R200 billion, with the fresh-produce sector commanding a $15 \%$ share. ${ }^{3039}$

Bulk products with far longer shelf-life - sugar, flour and long-life milk for example - are under growing threat from imports. ${ }^{3040}$ Although local production of these products may be competitive, the cost of transport, logistics and delivery time regularly allow for imported products to be supplied at a considerably cheaper price and sometimes more expeditiously. ${ }^{3041}$

Local producers of bulk agricultural commodities are significantly constrained by the lack of an effective rail transport system. ${ }^{3042}$ Morris and Kaplan note that the "high inland transport costs alone may result in imported product being landed cheaper, at the coast." 3043

Over $60 \%$ of the South African population now lives in urban areas ${ }^{3044}$ and with the rural population depending more on purchasing their food, the role of formal and informal food retailers in providing access to food is becoming increasingly recognised. ${ }^{3045}$ In 2013 it was reported that there were approximately 33 hypermarkets, which is the equivalent of 330 supermarkets, and 1352 actual

\footnotetext{
${ }^{3034} \mathrm{http}: / / \mathrm{www}$. infomineo.com/south-africas-agriculture/

$3035 \mathrm{http} / / / \mathrm{www}$.infomineo.com/south-africas-agriculture/

$3036 \mathrm{http}: / /$ data.worldbank.org/indicator/NV.AGR.TOTL.ZS?locations=ZA

3037 file:///C:/Users/K1634807/Downloads/wwf006_ffl_report_low_res\%20(1).pdf

3038 file:///C:/Users/K1634807/Downloads/wwf006_ffl_report_low_res\%20(1).pdf

$3039 \mathrm{http}: / /$ awsassets.wwf.org.za/downloads/safl_the_future_of_south_africas_food_system.pdf

${ }^{3040}$ D. Kaplan \& M. Morris, Potential for Developing Local Suppliers in the Retail Sector Report for Trade and Industrial Policy Strategies (TIPS), May 2017.

${ }^{3041}$ Ibid..

3042 Ibid..

3043 Ibid.,.

3044 World Bank data: Available at: http://data.worldbank.org/indicator/SP.URB.TOTL.IN.ZS

$3045 \mathrm{http} / / /$ awsassets.wwf.org.za/downloads/safl_the_future_of_south_africas_food_system.pdf
} 
supermarkets, amounting to almost 1700 supermarket equivalents in South Africa. ${ }^{3046}$ The make up less than $2 \%$ of food retail outlets, yet have an estimated retail share of 50-60\%. ${ }^{3047}$

In South Africa, only $13 \%$ of the land is arable, with only $3 \%$ considered to be high-potential agricultural land. ${ }^{3048}$

Significant changes in food consumption have taken place since the 1970s. Amongst others, there has been an increase in supermarkets, while rising urbanisation and growing per capita incomes are expected to "double the demand for high-value foods such as dairy, meat, fresh fruits, vegetables and processed, packaged and prepared foods. Total food expenditure has increased for fruit and vegetables and processed foods such as spaghetti and over-ready meals, while expenditure on maize and wheat flour has declined." 3049

The structure of the consumer goods retail sector has undergone a transition since 1994. During the apartheid era between 1948 to 1994, South Africa's population went through an enforced process of segregation, with white people principally living in first-world suburban areas, and black people being removed to "townships", quasi-independent rural homelands. ${ }^{3050}$ These townships had no commercial districts and white-owned businesses were not legally permitted to trade in such areas.

These structures impacted significantly on the structure of the route-to-market, as the township markets represented a large consumer base for FMCG companies, however reaching them was not easy. ${ }^{3051}$ As a result, there was a rise of township entrepreneurs, particularly in the informal retail sector, running small local supermarkets and spaza shops. In order to service these independent retailers, a channel emerged consisting of large wholesalers and cash and carry's established near commuter hubs. ${ }^{3052}$

Due to local and international pressure, after democratisation trade liberalisation was deliberately increased. ${ }^{3053}$ In the first year after the dawn of democracy, the ANC developed the Reconstruction and Development Programme (RDP) which advocated removing controls and levies, and "'unsustainable subsidies to the large-scale farm sector', and committed to a land redistribution target of $30 \%$ of land under white ownership."

Since 1994, with the lifting of trade restrictions significant developments took place in the route-to market. For example, corporate retail moved into townships and former homelands, led by Shoprite, Boxer and SPAR, with everyone following suit, including Pick $\mathrm{n}$ Pay and even Woolworths. ${ }^{3054}$ Furthermore, regional malls opened in most major townships.

\footnotetext{
3046 http://awsassets.wwf.org.za/downloads/safl_the_future_of_south_africas_food_system.pdf

$3047 \mathrm{http}: / /$ awsassets.wwf.org.za/downloads/safl_the_future_of_south_africas_food_system.pdf

3048 http://awsassets.wwf.org.za/downloads/wwf006_ffl_report_low_res.pdf

${ }^{3049}$ L.C. Ronquest-Ross, N. Vink \& G. O. Sigge, "Food Consumption changes in South Africa since 1994" in South African Journal for Science, Vol 111, No. 9/10, September/October 2015.

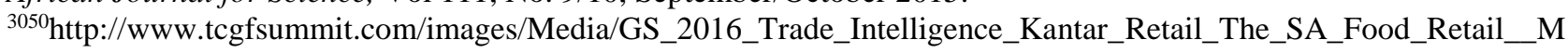
arket.pdf

${ }^{3051}$ http://www.tcgfsummit.com/images/Media/GS_2016_Trade_Intelligence_Kantar_Retail_The_SA_Food_Retail_M arket.pdf

${ }^{3052}$ http://www.tcgfsummit.com/images/Media/GS_2016_Trade_Intelligence_Kantar_Retail_The_SA_Food_Retail_M arket.pdf

${ }^{3053}$ Reconstruction and Development Programme www.sahistory.org.za; chapter 2.4

${ }^{3054}$ http://www.tcgfsummit.com/images/Media/GS_2016_Trade_Intelligence_Kantar_Retail_The_SA_Food_Retail_M arket.pdf
} 
As a result of these changes many South African operated independent and informal retailers in the townships were unable to compete with these supermarket chains and consequently went out of business. This in turn put significant pressure on the wholesalers who supplied them. ${ }^{3055}$

In response to these changes wholesale operators restructured their business in the following ways $^{3056}$ :

a. Using a hybrid model whereby they started operating as both retailer and wholesaler under one umbrella. This has seen the growth of Retail Cash \& Carry stores which sell products in single units, shrinks as well as in cases catering for the needs of traders, hawkers as well as individual shoppers. Makro, IBC Group members, Elite Star members, Jumbo $\mathrm{C} \& \mathrm{C}$ are some examples of these stores.

b. Using a redistribution model by increasing telesales capabilities, taking telephonic and electronic orders, and providing a product distribution service for their commercial (independent retail) customers.

c. Some of the wholesale cash and carry operators saw wholesale as unsustainable and as a result shifted from having wholesale only members to focusing on growing their franchise retail members. In so doing, they used their wholesale outlets as distribution centres for franchise retail members.

These models subsequently evolved. Today suppliers are able to reach consumers through the formal supermarket value chain. Under this format, products flow from supplier to distribution centre or end consumers directly buy the products from supermarkets. ${ }^{3057}$ There has been significant investment in distribution centres. All supermarket chains have numerous distribution centres. ${ }^{3058}$ Increasingly, supermarkets are switching to their own centralised distribution centres instead of storeto-store procurement. ${ }^{3059}$ Corporate or franchise stores find it cheaper to procure their products from distribution centres than individually negotiating and purchasing products directly from main suppliers. ${ }^{3060}$ This is due to scale economies and associated discounts and rebates that can be guaranteed by the suppliers when distribution centres buy products in bulk. ${ }^{3061}$

Alternatively, suppliers sell products through independent retailers who are generally small businesses which target lower income customers in "peri-urban, township, industrial and central business district areas of cities." 3062 They follow the hybrid format which includes 'cash and carrys' that have both wholesale and retail offerings in addition to "numerous informal spaza shops, spazarettes and superettes." ${ }^{3063}$ An alternate model is in the form of buying group-led independent

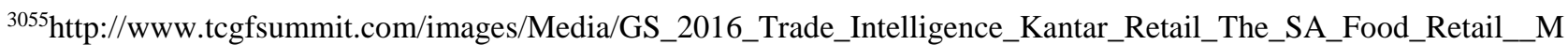
arket.pdf

${ }^{3056}$ http://www.tcgfsummit.com/images/Media/GS_2016_Trade_Intelligence_Kantar_Retail_The_SA_Food_Retail_M arket.pdf

3057 Centre for Competition, Regulation and Economic Development, "The Global Food Value Chain and Competition Law and Policy in BRICS countries: Insights from selected value chains in South Africa”, Working Paper 21/2017. ${ }^{3058}$ Ibid..

${ }^{3059}$ R. das Nair, \& S. Chisoro, 'The Expansion of Regional Supermarket Chains. Changing models of retailing and the implications for local supplier capabilities in South Africa, Botswana, Zambia, and Zimbabwe', UNU-WIDER Working Paper 2015/114.

3060 Ibid.

3061 Ibid..

${ }^{3062}$ Centre for Competition, Regulation and Economic Development, "The Global Food Value Chain and Competition Law and Policy in BRICS countries: Insights from selected value chains in South Africa”, Working Paper 21/2017.

${ }^{3063}$ Centre for Competition, Regulation and Economic Development, "The Global Food Value Chain and Competition Law and Policy in BRICS countries: Insights from selected value chains in South Africa”, Working Paper 21/2017.
} 
retailing. Buying groups are separate, independent entities that play an integral role in supporting independent retailers. ${ }^{3064}$ Although each independent retailer that forms part of a buying group is owned by different individuals, the stores may be branded under a common name. Buying groups will buy large quantities from suppliers for the entire group which they promote on behalf of the independent retailers, and provide important skills development to retailers in their group. ${ }^{3065}$ South Africa has five main buying groups, namely, Unitrade Management Services, Buying Exchange Company, Independent Buying Consortium, Independent Cash \& Carry Group and Elite Star Trading. ${ }^{3066}$

\subsection{The food market in South Africa}

The value of the South African food market is estimated at R460 - R470bn. ${ }^{3067}$ Food is defined in this case to include edible groceries, non-edible groceries, commodities, tobacco, perishables, cosmetics, bakery, red meat, fruit and vegetables, cigarettes, but excludes food services. ${ }^{3068}$

The difference between the South African food retail and other African countries is the highly developed and competitive formal retail market which make up almost $70 \%$ of total food sales. ${ }^{3069}$

South Africa has a large informal trade sector which is serviced by hawkers, small local supermarkets and spaza shops. Informal traders largely purchase goods from wholesale outlets which make up approximately $30 \%$ of food retail sales. ${ }^{3070}$ However, some manufacturers, like Coca-Cola and Pioneer Foods, supply directly to independent and informal traders as well. ${ }^{3071}$

The agro-processing sector in South Africa is highly concentrated implying that entry and active participation of small and medium enterprises remains limited. ${ }^{3072}$

In 2013 imports and exports of processed products were respectively valued at R70 and R47 billion. There has been a negative trade balance in respect of processed foods as the country imports more than it exports. Higher demand for processed products has been triggered by the growth of the middle class. ${ }^{3073}$

The National Development Plan (NDP) "identifies historically high levels of concentration in agricultural value chains, high and increasing levels of vertical integration between agriculture and agro-processing, access to infrastructure (specifically irrigation and farming equipment) and lack of access to consumer markets as significant constraints to entry and growth in the sector." 3074

\footnotetext{
${ }^{3064}$ Centre for Competition, Regulation and Economic Development, "The Global Food Value Chain and Competition Law and Policy in BRICS countries: Insights from selected value chains in South Africa", Working Paper 21/2017. 3065 Ibid.

3066 Ibid.

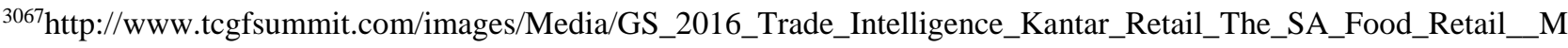
arket.pdf

3068http://www.tcgfsummit.com/images/Media/GS_2016_Trade_Intelligence_Kantar_Retail_The_SA_Food_Retail__M arket.pdf

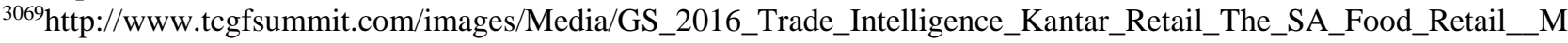
arket.pdf

${ }^{3070} \mathrm{http} / / /$ www.tcgfsummit.com/images/Media/GS_2016_Trade_Intelligence_Kantar_Retail_The_SA_Food_Retail_M arket.pdf

${ }^{3071}$ http://www.tcgfsummit.com/images/Media/GS_2016_Trade_Intelligence_Kantar_Retail_The_SA_Food_Retail_M arket.pdf

3072 Briefing Note on the Agro-processing sector in South Africa.

${ }^{3073}$ Ibid.

${ }^{3074 h t t p s: / / s t a t i c 1 . s q u a r e s p a c e . c o m / s t a t i c / 52246331 e 4 b 0 a 46 e 5 f 1 b 8 c e 5 / t / 57 d 03334 d 1758 e 630 e 04 a 79 b / 1473262401284 / ~}$

Agroprocessing+Sector+Study_07092016.pdf
} 
Food processing (excluding beverages and tobacco) accounted for " $14.3 \%$ of total manufacturing value add in 2014 and was the largest manufacturing sub-sector by some distance, with the next largest category being coke and petroleum products. Food processing is also the largest manufacturing employer and accounts for $13.6 \%$ of total manufacturing employment, with 183161 jobs in 2014."3075

South Africa accounted for almost $60 \%$ of processed fruit in Sub-Saharan Africa by volume in 2011, with raisins, juice, and canned fruit the most significant products. ${ }^{3076}$

Supermarkets are directly involved in all stages of the value chain - including primary production and packing, cold chain management and storage; transport; export; and sometimes even the final distribution. ${ }^{3077}$ Visser notes that supermarkets effectively control value chains: "their ability to set prices and determine the quality, processes and social standards under which goods are produced ...."3078 She indicates further that retailers' have the ability to set "farm gate prices, such that most of the rent on the final retail price of (fresh) agricultural product accrues to them." In South Africa, producer-cooperatives that export get approximately $28-30 \%$ of the final retail price, whereas supermarket retailers get about $35-40 \%$. $^{3079}$

Visser notes that of the 2011 final retail price for table grapes exported to the UK, supermarkets capture $42 \%$, distributors capture $32 \%$, while growers receive $18 \%$ (and $26 \%$ if they pack their own fruit). ... Apart from low prices, retailers' poor purchasing practices also increased producer vulnerability. Retailers often do not provide written contracts or guarantees of purchase beyond a verbal agreement; and they often buy fruit on 'consignment' - with no prices agreed on until very close to the point of final delivery." 3080

Labour costs are a major consideration in production costs and as a result farmers mechanise where possible. ${ }^{3081}$ For example, wine harvesting machines are able to replace up to seventy workers per twelve hour shift. ${ }^{3082}$ By 2014 approximately 58\% of hectares belonging to (mostly larger) producers in its study group were mechanically harvested. ${ }^{3083}$ By contrast, the scope for mechanisation is far more limited for easily perishable crops, for as Visser states "[w] here producers cannot mechanise, they tend to use 'labour augmenting technologies', such as pre-cutters to prune vineyards. In pack houses, however, up to $40 \%$ of workers can be replaced by mechanisation and pack house modification (Meyer 2012), so pack house mechanisation could result in job losses for almost 10000 seasonal workers and 2300 permanent workers." 3084

The National Development Plan (NDP) emphasises the need of securing small business access to domestic value chains in order to facilitate "market entry in a highly concentrated

\footnotetext{
${ }^{3075} \mathrm{https} / /$ static1.squarespace.com/static/52246331e4b0a46e5f1b8ce5/t/57d03334d1758e630e04a79b/1473262401284/ Agroprocessing+Sector+Study_07092016.pdf

3076 file:///Users/marbo/Downloads/chapter-6-kickstarting-agroprocessing-value-chains.pdf

${ }^{3077}$ M. Visser 'Going nowhere fast? Changed working conditions on Western Cape Fruit and Wine Farms. Working Paper 41. Institute for Poverty, Land and Agrarian Studies; September 2016, available at http://www.plaas.org.za/sites/default/files/publications-pdf/WP41\%20Visser.pdf , at 14

3078 Ibid., at 14.

${ }^{3079}$ Ibid., at 15. See also S Barrientos and M Visser South African Horticulture: Opportunities and Challenges for economic and social upgrading in value chains: Working Paper 12: Durham North Carolina: Capturing the Gains.

3080 Visser at 16

3081 Visser at 17

3082 Visser at 18

3083 Visser at 16

3084 Visser at 17
} 
environment." 3085 The NDP encourages retailers to preferentially procure from small businesses with the aim of stimulating local producers and to "develop suppliers within the region in support of regional industrialisation objectives." 3086 Pursuant to this objective, legislative interventions have taken place. These include the Competition Act (1998), the Preferential Procurement Framework Act (2000) and the Revised Preferential Procurement Regulations (2011), and the Broad-Based Black Economic Empowerment Act (2003) and regulations.

Von Broembsen indicates that the NDP underlines that the production of commodity foodstuffs is highly concentrated among a few large suppliers. Although small and sometimes informal suppliers take part in non-value add commodities, such as fresh produce, the majority of mass-consumed goods are produced by large suppliers; and often "supply chains are vertically integrated, as big retailers create their own brands and private labels." ${ }^{3087}$ As a result of the considerable volumes that are produced suppliers are able to cut their margins per unit, which results in small and even medium sized competitors being squeezed out. ${ }^{3088}$

South Africa has seen the growth of private label products in supermarkets. Every major supermarket has a range of their own brand/private label products. ${ }^{3089}$ The majority of Woolworths' products are private labels. Shoprite has 'Ritebrand' and 'Housebrand' ranges in Checkers, which cover approximately 300 products. ${ }^{3090}$ Pick n Pay's private label is "No Name" brand and it is looking to expand its private label range. Food Lover's Market has "Freshers" and "Food Lovers Signature". SPAR has its own private label products. SPAR does not allow major suppliers to manufacture its own private label products but rather allows new and smaller suppliers to enter the supermarket supply chain. ${ }^{3091}$

Morris and Kaplan note that Shoprite Checkers currently has about $8 \%$ of turnover as private label and this will soon double. ${ }^{3092}$ South African supermarkets are moving in the direction of private labels as it is seen as key to their competitive edge in that it develops brand loyalty. ${ }^{3093}$ Moreover, this furnishes supermarkets with more leverage with the large suppliers who have branded products. ${ }^{3094}$ This is manifest in a recent example where Pick n Pay's branded tomato sauce which within a few weeks of introduction claimed $15 \%$ of the overall local market. ${ }^{3095}$

Private labels operate differently for large and smaller volume producers. ${ }^{3096}$ The use of private label by Pick $\mathrm{n}$ Pay and Shoprite, for example, often involves engaging large brand manufacturers to supply a specific large volume order which will be packaged in accordance with the

\footnotetext{
${ }^{3085}$ Cited by M. von Broembsen, 'You can't bite the hand that feeds you': Contracts between SME suppliers and the large supermarkets $\quad$ Econ3x3 (May 2017), available at http://www.econ3x3.org/sites/default/files/articles/Von\%20Broembsen\%202017\%20Small\%20business\%20and\%20su permarket\%20supply\%20chains.pdf , at 2

3086 Ibid

3087 Ibid., at 3.

3088 Ibid

3089 R. Das Nair \& S. Chisoro, "The expansion of regional supermarket chains and implications for local suppliers", WIDER Working Paper 2017/26. The data available is incomplete and what follows is based on the best available data. 3090 Ibid.

3091 Ibid..

${ }^{3092}$ D. Kaplan \& M. Morris, Potential for Developing Local Suppliers in the Retail Sector Report for Trade and Industrial Policy Strategies (TIPS), May 2017.

3093 Ibid.

${ }^{3094}$ Kaplan, D \& Morris, M, Potential for Developing Local Suppliers in the Retail Sector Report for Trade and Industrial Policy Strategies (TIPS), May 2017.

3095 Ibid..

3096 Ibid..
} 
private label specifications. ${ }^{3097}$ Large supermarkets have sufficient influence to negotiate optimal deals under such circumstances. This notwithstanding, they are dependent on large brand manufacturers to supply the best quality. ${ }^{3098}$ For small supermarkets, such as Food Lovers Markets, order sizes are limited - "if they use a large branded manufacturer it would be on the basis of picking up over runs, and the power relations then are too asymmetric." 3099 As a result, small supermarkets opt for engaging with, and seeking out, small specialist manufacturers supplying their private label products. $^{3100}$

The growing trend to using private labels has implications for local producers. Such producers are able to focus solely on product, while functions like packaging, distribution, marketing is taken care of by the supermarkets. ${ }^{3101}$ The potential exists for suppliers and supermarkets to form long standing relationships and to improve the quality of the product. Moreover, it means that "the volume requirements for the local producer are somewhat reduced."

Significant downsides also exist as the local producer relies on a sole customer making it potentially vulnerable. ${ }^{3102}$ Although volumes are reduced, "they are still large - private label or house brands provide an entry for new producers but rarely for small producers." ${ }^{3103}$ For example, Pick n Pay branded tomato sauce is supplied by a new but large well-capitalised food producer. ${ }^{3104}$ In addition, private labels compete with branded products. The large food processors in South Africa Tiger Brands, Pioneer and others - are often "reluctant to supply products that compete with their own branded products." 3105 This is decidedly so, as supermarkets want to provide the private label products at considerably lower prices. ${ }^{3106}$

\subsection{Inputs to Primary Production:}

The total expenditure in 2013 on farms was R178.5 billion, with inputs accounting for 130.1 billion (73 percent); animals, R27.6 billion (15 percent); and salaries and wages, R20.7 billion (12 percent). ${ }^{3107}$ The major input costs were R20.6 billion for animal feed ( 20 percent of the total); R10.2 billion ( 8 percent) for repairs, maintenance and licences; R10 billion ( 8 percent) for fertilisers; and R8.3 billion (6 percent) for fuel. ${ }^{3108}$ Other significant inputs include depreciation, packing materials, contractors, seed and planting materials, and animal and crop remedies. ${ }^{3109}$

The various inputs have their own dominant corporations. "The commercial animal feed sector tends to be vertically integrated, especially within the large poultry producers." 3110 Feed is a major source of profit for the poultry companies. The vertically integrated companies produce feed

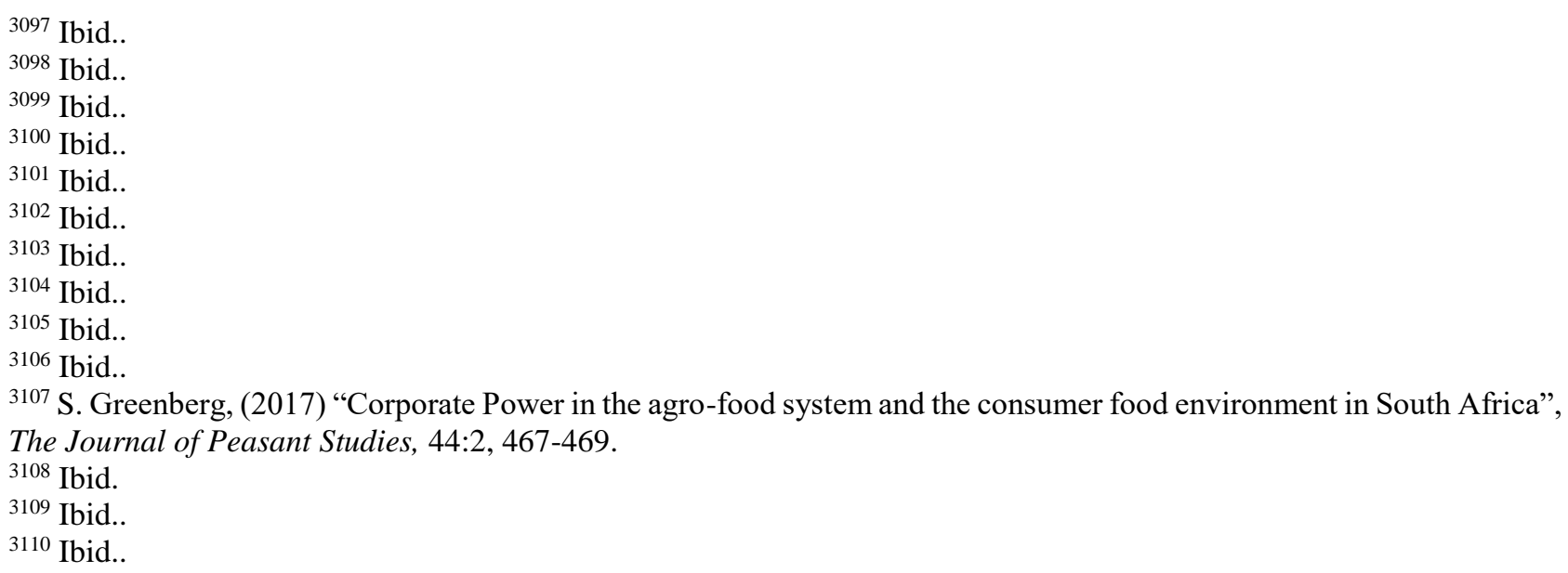


for their "internal operations as well as for sale to others. Animal feed tends to employ far fewer workers than poultry operations. Animal feed accounts for a small share of overall revenue produced by the vertically integrated poultry producers, but animal feed operations account for most of the operating profit." 3111

Agricultural machinery is mainly imported "with domestic and multinational corporations operating as agents and after-sales support, sometimes with exclusive brand rights in South Africa and regionally." 3112 According to the DTI in 2014 the imported agricultural machinery was valued at R6.5 billion.

A high proportion of fertiliser raw materials and finished product are imported. ${ }^{3113}$ Prior to the 1980s the fertiliser industry was built under state protection. After deregulation, the industry could not sustain itself and as a result factories were closed and South Africa became a net importer of fertiliser from around $2000 .{ }^{3114}$ In 2000 fertiliser imports were valued at R858 million, rising to R7.4 billion in 2014.

In 2009 and 2010, the Competition Commission intervened in the nitrogenous fertiliser value chain. Prior to the intervention, several anticompetitive practices existed in the fertiliser market. Penalties were imposed for collusion, which led to the restructuring of the fertiliser industry.

An ex-post assessment of the competition authorities' intervention into the South African nitrogenous fertiliser industry was conducted. The assessment found that post-intervention many positive outcomes have been observed including new entry, increased customer choice and price competition as well as significant customer savings. The assessment noted that there had been entry and expansion in the downstream level of the value chain. Firms that were traders, previously reliant on Sasol for input supplies, expanded and acquired their own plants, thereby increasing the numbers of players at that level of the value chain. Moreover, there had been entry by smaller blenders and traders. The entry of new players into this level of the value chain has increased competition while simultaneously increasing the security of supply of fertiliser domestically. ${ }^{3115}$

Despite the competitive gains resulting from the competition authorities' intervention in the fertiliser industry, the assessment noted some further market developments, both negative and positive. There has not been any entry in the production of ammonia and Sasol remains the sole producer of ammonia in South Africa. ${ }^{316}$ There has been an increase in the importation of cheaper low quality fertiliser and depressed margins in the industry. ${ }^{3117}$ The exit of Sasol from the downstream level of the value chain may potentially reduce the pro-competitive benefits that arose from the increased competition at the upstream level. Moreover, there is the concern about the lack of growth of the smaller blenders and traders after significant market entries post intervention, as some of them have failed to stabilize and register growth in the market.

In 2013/2014 commercial agricultural production was valued at R208.3 billion. Primary agricultural production can be divided into three broad areas: animal production ( 46 percent of gross

\footnotetext{
3111 Ibid.

3112 Ibid.

3113 Ibid.

3114 Ibid.

3115 S. Grimbeek, Giya, G. \& Mahlalela, Q. (2017). "The Impact of Competition in the fertiliser industry after the Sasol divestiture of blending facilities in 2010.” Competition Commission of South Africa Working Paper No. 1.

3116 Ibid.

3117 Ibid.
} 
value in 2013/2014), field crops (28 percent) and horticulture (26 percent). ${ }^{3118}$ According to Stephen Greenberg, at the heart of the agro-food system South Africa has a grain-livestock complex. The combined poultry (meat and eggs), maize, cattle and dairy represented R104.4 billion of the total value of commercial primary production in 2014. ${ }^{3119}$ Beyond this, the grain-livestock complex extends upstream, "where animals purchased and animal feed alone had a combined value of R54.2 billion in 2014; maize is the major commercial seed type, the sector uses a large share of fertiliser and machinery, etc." ${ }^{3120}$ Downstream, the grain-livestock complex "extends into grain storage and handling, processing and further value addition." 3121

\subsection{Supermarkets:}

Over the past two decades there has been a significant spread of South African supermarkets into southern Africa. This has had important consequences for consumers, local supplier capabilities, and the competitive landscape. ${ }^{3122}$ This is due to the fact that supermarkets offer a wider range of grocery retail products at relatively cheaper prices, "given economies of scale and global sourcing strategies, compared to local, independent retailers." 3123

Morris and Kaplan note that there are two significant trends in the supermarket environment that have implications for local production. ${ }^{3124}$ The first is a trend towards fresh products. This trend is not circumscribed to higher income groups as it is now widespread for almost all income groups. ${ }^{3125}$ This notwithstanding, very poor consumers who lack refrigeration and storage are limited in partaking in this trend. ${ }^{3126}$

This trend to fresh produce also favours local production. In all the supermarkets, fresh products were overwhelmingly supplied locally - "[t] he two largest supermarket chains gave the figure of 97\%." ${ }^{3127}$ The exceptions being some high-end products such as Italian meats; French cheese and olive oil. ${ }^{3128}$

Local supply is somewhat restricted by seasonality. ${ }^{3129}$ The introduction of new varieties has however allowed for "the exploitation of different climatic zones in South Africa such that local supply now caters for a much larger part of the year." 3130 For example, Woolworth's now obtains avocados for 9 months of the year from South Africa - "whereas local supply was formerly only 3 months." 3131

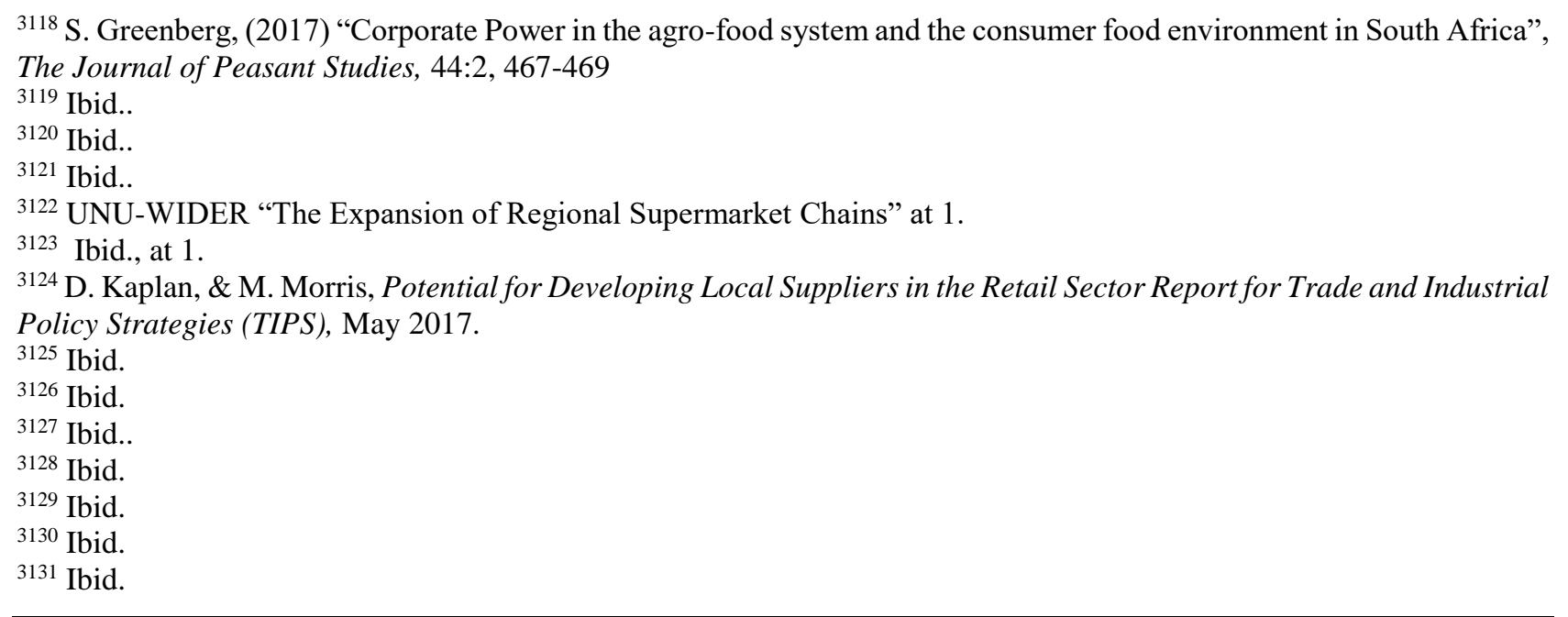


Some fresh produce is supplied from elsewhere in Southern Africa. However, this is restricted by the difficulty of obtaining permits. ${ }^{3132}$ Morris and Kaplan's report indicates that permits are being widely used to restrict entry into the South African market.

The second trend is towards private label. ${ }^{3133}$ Although this trend allows new producers to enter the market, new entrants still have to supply at volume in respect of the large supermarkets. ${ }^{3134}$ This makes it hard for small producers to enter the market.

Successful new entrants are regularly bought out by the local large branded suppliers who are intent on protecting their local market dominance. ${ }^{3135}$ The limited entry of new local suppliers and the concentration of local suppliers with strong brands, has led some supermarkets to look for "exclusive supply" via importation. ${ }^{3136}$ This is particularly the case for large volume supermarkets.

By contrast, the Woolworths favours a local production model as they see such a model as providing them with far more control over the ultimate quality of the product. ${ }^{3137}$ The considerable control that Woolworths exercises over the production processes is conducted in such a way as if the supplier were a subsidiary. ${ }^{3138}$ According to Von Broembsen "Woolworths assigns a food technologist to work with individual suppliers to help them improve recipes and to gain the technological know-how to improve products."3139

Only $10-12 \%$ of Woolworth's processed foods are imported. ${ }^{3140}$ In the main, these are foods that cannot be produced in South Africa. The packaging of these imported products is often done locally. 3141

Although the growth of supermarkets have improved competitive pricing and accessibility to an expansive range of products, it has created challenges for local suppliers to enter the supermarket value chain. ${ }^{3142}$

Moreover, "strategic behaviour of supermarkets with market power such as entering into exclusive supply agreements with large suppliers, and into exclusive leases with prime retail centres and shopping malls, has competition implications on new entrants, independent retailers, and small suppliers." 3143

Von Broembsen indicates that the estimates of supermarkets aggregate share of the South African food retail market differ, from a total market share of the four big South African, in 2002, supermarkets of approximately 60 per cent share of the total retail food market in 2002 to a far more substantial share of the market of 93.8 per cent in 2006. The Competition Commission in 2015 estimated that supermarkets capture 90 percent of the South African food market. ${ }^{3144}$

\footnotetext{
3132 Ibid.

3133 Ibid.

3134 Ibid.

3135 Ibid.

3136 Ibid.

${ }^{3137}$ Ibid.

${ }^{3138}$ Von Broembsen at 15.

${ }^{3139}$ Von Broembsen at 10.

${ }^{3140}$ Kaplan, D \& Morris, M, Potential for Developing Local Suppliers in the Retail Sector Report for Trade and Industrial Policy Strategies (TIPS), May 2017.

${ }^{3141}$ D. Kaplan \& M. Morris, Potential for Developing Local Suppliers in the Retail Sector Report for Trade and Industrial Policy Strategies (TIPS), May 2017.

3142 UNU-WIDER “The Expansion of Regional Supermarket Chains" at 1.

${ }^{3143}$ UNU-WIDER “The Expansion of Regional Supermarket Chains” at 1.

3144 von Broembsen at 4.
} 
Shoprite/Checkers and Pick n Pay, the two key chains, hold the largest share of the market from between 24 and 40 per cent each. ${ }^{3145}$ However the different supermarkets service different markets: Shoprite targets low-income consumers, whereas Checkers serves the higher income market. Spar and Pick n Pay target both, whereas Woolworths only targets high-income consumers. Pick n Pay competes with Shoprite Checkers for the mass market, and with Woolworths for the upper income markets. ${ }^{3146}$

As South Africa has a growing middle class, the consequence thereof is that a greater amount of middle class consumers constitute the market retail thus generate a greater demand for luxury foods. Further the consumers diets have changed. ${ }^{3147}$ Fewer vegetables are consumed by the middle class who purchase more protein and highly processed foods. ${ }^{3148}$

In terms of the supermarkets' procurement system, two of the retailers in recent years have shifted from a regional to a central procurement system, which results in significant cost implications for suppliers that do not have a powerful brand. ${ }^{3149}$ In the past, suppliers had negotiated with a regional buyer and delivered goods to different regions. Procurement has now become centralised with buyers in Johannesburg making procurement decisions for the whole country. ${ }^{3150}$

Another feature of the procurement structure is that all deliveries at Pick $n$ Pay occur on a first-come, first-serve basis. As Van Broembsen notes "[s]mall suppliers sometimes spend hours in the receiving depot queue - 'you might only have a couple of boxes, but have to wait in the queue behind big trucks delivering mass orders... because Pick n Pay has no incentive to make it efficient.' In relative terms this implies a larger cost for a small supplier."3151

The majority of South African food imports which are likely to be on the shelves of supermarkets are deep-sea imports which are not sourced from SADC countries. ${ }^{3152}$ By contrast this is not the case with South African food exports, the majority of which go to the SADC region. ${ }^{3153}$ The spread of supermarkets can account for the growth in food exports to the SADC region, given that they are an important route to market. ${ }^{3154}$ "Poultry and preparations of cereal, flour, starch, milk, pasta, and biscuits show the highest average annual growth rate in exports with an average annual growth rate of 23.6 per cent and 20 per cent respectively over an 11-year period during 2003-14. Cereals (wheat, rice, rye, barley, oats, maize, corn), sugar and confectionery, and miscellaneous edible preparations (yeast, baking powders, soya sauce, tomato ketchup, soups) record the highest growth in absolute terms. These trends concur with past studies that the growth of supermarkets in food retailing is associated with increased sales of processed, dry, and packaged foods such as noodles, milk products, and grains. A key reason for this is that supermarkets have the advantage of economies of scale and such dry products have a longer shelf life. ${ }^{3155}$

The following diagram illustrates the supply chain of grocery products ${ }^{3156}$ :

\footnotetext{
3145 von Broembsen at 5.

3146 von Broembsen at 5.

3147 Von Broembsen at 3.

3148 ibid

3149 von Broembsen at 5.

3150 ibid

3151 von Broembsen at 6.

${ }^{3152}$ UNU-WIDER "The Expansion of Regional Supermarket Chains" at 25.

${ }^{3153}$ UNU-WIDER “The Expansion of Regional Supermarket Chains” at 25.

${ }^{3154}$ UNU-WIDER "The Expansion of Regional Supermarket Chains" at 25.

${ }^{3155}$ UNU-WIDER “The Expansion of Regional Supermarket Chains” at 25.

${ }^{3156}$ Illustration from UNU-WIDER “The Expansion of Regional Supermarket Chains" at 12.
} 


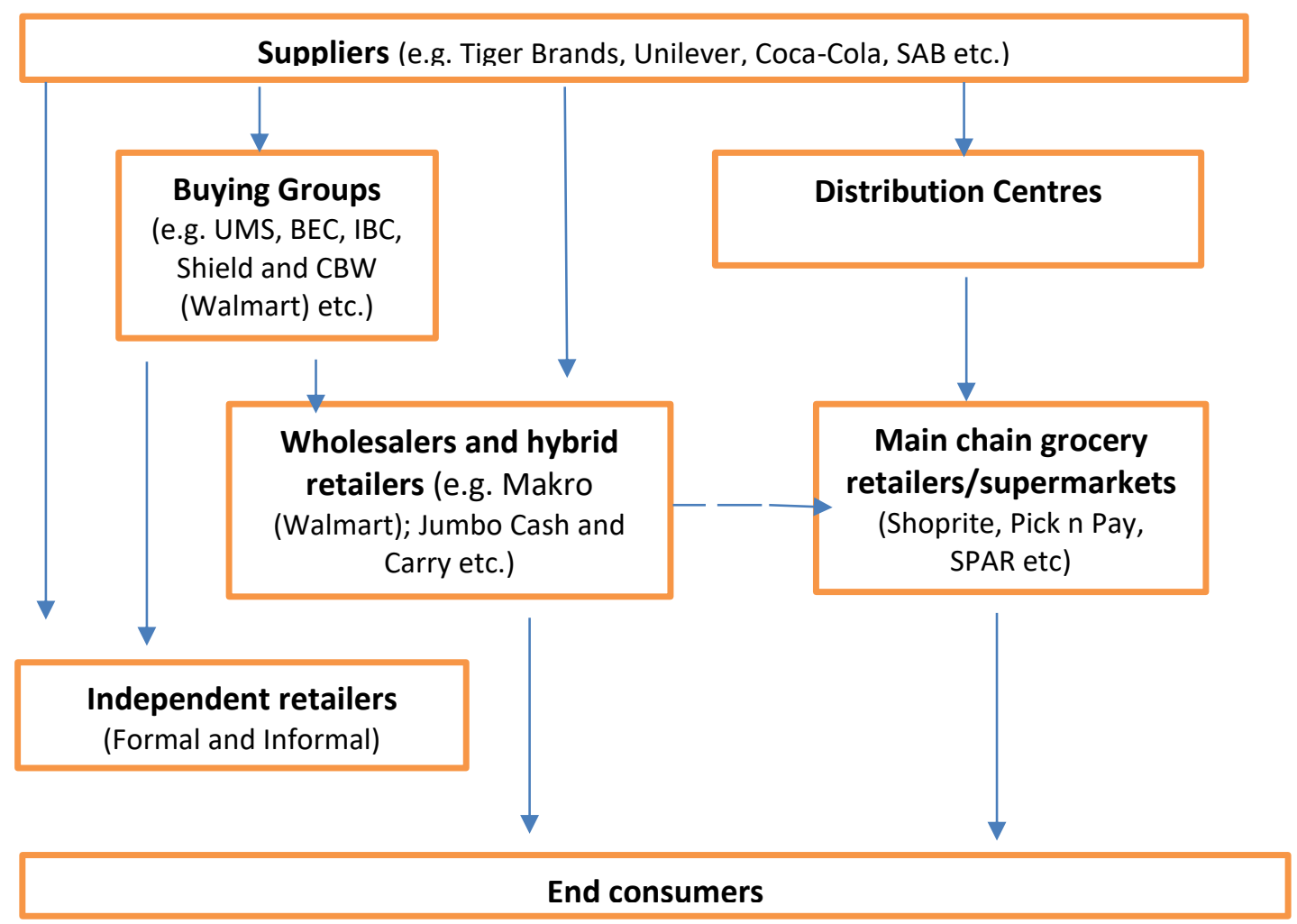

What this diagram shows is that buying groups occupy a similar space for independent retailers as distribution centres do for the major supermarkets. ${ }^{3157}$

\subsection{Regulatory Framework:}

Prior to the agricultural sector in South Africa being deregulated, the state extensively regulated the production and marketing of most agricultural products. The state supported farmers through legislation, investment in research and development, infrastructure, land tenure, the securing of input supply, extension of services and the settlement of farmers, and the protection of domestic markets from international competition. ${ }^{3158}$

A comprehensive system of support for white farmers was developed which included the establishment of the Land and Agricultural Bank, and the Co-operative Societies Acts of 1922 and 1939 as well as the Marketing Act of 1937 (consolidated in 1968). ${ }^{3159}$ The Marketing Act instituted a system of controls which regulated the movement, pricing, quality standards and marketing supply of the majority of agricultural production. ${ }^{3160}$ Marketing schemes ("control boards") controlled approximately $80 \%$ of agricultural products which involved various arrangements whereby the control boards would set prices, control marketing and remove surpluses. ${ }^{361}$ Under the first democratic government liberalisation which had started in the 1980s continued. The Marketing of Agricultural Products Act 47 of 1996 abolished control boards.

\footnotetext{
${ }^{3157}$ UNU-WIDER "The Expansion of Regional Supermarket Chains” at 12. DBSA: Midrand. March 2010

${ }^{3159} \mathrm{http} / /$ www.tandfonline.com/doi/full/10.1080/03056244.2013.854034?src=recsys \&

$3160 \mathrm{http} / / / \mathrm{www}$. tandfonline.com/doi/full/10.1080/03056244.2013.854034? src=recsys \&

${ }^{3161} \mathrm{http} / / / \mathrm{www}$. tandfonline.com/doi/full/10.1080/03056244.2013.854034?src=recsys\&
}

${ }^{3158}$ I. Gouws and T. Lamprecht citing Vink, N. \& Van Rooyen, J. 2009. 'The economic performance of agriculture in South Africa since 1994: Implications for food security', Development Planning Division Working Paper Series No.17, 
South Africa's agriculture sector is regulated by the National Department of Agriculture, Forestry and Fisheries (DAFF).

\subsubsection{Food and Safety Standards:}

The Department of Health (DOH), Department of Agriculture, Forestry and Fisheries (DAFF) and the Department of Trade and Industry (DTI) are responsible for developing and enforcing food safety in South Africa. "Six Acts and regulations promulgated in terms of the Act govern the production, manufacture, transport and labelling of food manufacture." $" 3162$

These include:

- The Foodstuffs, Cosmetics and Disinfectants Act (Act No. 54 of 1972). This Act governs the manufacture, sale and importation of foodstuffs, cosmetics and disinfectants. "It controls what goes into foods, rather than regulating the hygiene of food preparation." 3163

- The Health Act (Act 63 of 1977) and various regulations which include hygiene specifications relating to foodstuffs.

- The International Health Regulations Act (Act 28 of 1974)

- The Agricultural Products Standards Act, 1990 (Act 119 of 1990).

- The Meat Safety Act, 2000 (Act 40 0f 2000)

- The Standards Act, 1993 (Act 29 of 1993).

\subsubsection{Seed Regulation:}

South Africa's seed industry is regulated as following:

- The Plant Improvement Act 53 of 1976 (as amended) deals with the registration of varieties, premises, certification, labelling, minimum quality standards, prohibition on the sale of uncertified seeds and requirements for seeds. Section 26 of the Act regulates the importation of plants whilst section 27 deals with exporting them. The Act provides for the registration of establishments where plants and propagation material are sold and packed. The Directorate of Plant and Quality Control is responsible for the enforcement thereof.

- The Plant Breeders' Rights Act 15 of 1976 (as amended) deals with plant breeders' rights, the protection of such rights, the issue of licences in respect of exercising those rights and the registration of plant breeders. The Directorate of Plant and Quality Control is responsible for the enforcement thereof.

South Africa has been a member of the UPOV Convention since 1977. The Plant Breeders' Rights Act gives effect to South Africa's obligations under the UPOV Convention consequently affording protection to intellectual property for new plant varieties.

The farmers' privilege is contained in section 23 of the Act, which provide that farmers' privilege is provided to "a farmer who on land occupied by him or her uses harvested material obtained on such land from that propagating material for purposes of propagation: Provided that

\footnotetext{
3162 von Broembsen at 16.
}

3163 von Broembsen at 17. 
harvested material obtained from replanted propagating material shall not be used for purposes of propagation by any other person other than that farmer." This excludes the exchange of protected varieties among farmers. ${ }^{3164}$

The Act is to be replaced by a new Plant Breeders' Rights Bill which has already been approved by Parliament. ${ }^{3165}$ According to the African Centre for Biodiversity the new Bill substantially strengthens the rights of breeders and weakens the rights of farmers.

The African Centre for Biodiversity purports that South Africa does not have any law in place to allow farmers the rights to replant, exchange or sell farm-saved seed. The 1976 Act allows farmers to only replant farm-saved seed from protected varieties on their own holdings.

According to Biowatch SA, "current legislation exclusively protects the rights of the commercial breeder and seed sector, which is dominated by a handful of multinational corporations." "3166 As an illustration, the laws governing the seed sector "prevent the cultivation and sale of non-certified seed varieties, thereby destroying the market value of non-certified seeds and promoting reliance on varieties sold by registered commercial seed producers." 3167 This in turn creates a bias towards "monoculture" as the exemplar of agricultural production which favour largescale commercial seed producers at the expense of smallholders. ${ }^{3168}$

Biowatch SA notes that the research that is available indicates that smallholders rely on farmsaved seed for $60-70 \%$ of their seed needs. ${ }^{3169}$ Saving seed allows smallholders to save money and to deliver food security to their families and communities. ${ }^{3170}$

- The Agricultural Pests Act 36 of 1983 (as amended) dealing with phytosanitary issues. It provides measures for the prevention of agricultural pests. The Directorates of Plant and Quality Control and of Resource Conservation are responsible for the enforcement thereof.

- The Genetically Modified Organisms Act 15 of 1997 (as amended) which deals with the requirements for genetic modification.

- There are also secondary acts which impact on seeds such as the Fertilisers, Farm Feeds, Agricultural Remedies, and Stock Remedies Act 36 of 1947 (as amended). This Act regulates the registration of Fertilisers, stock feeds, agricultural remedies, stock remedies, sterilising plants and pest control operators. It also provides for the control over the acquisition, disposal, sale and use of Fertilisers, farm feeds, agricultural

\footnotetext{
3164 N.C. Netnou-Nkoana, Jaftha JB, Dibiloane MA, Eloff J. "Understanding of the farmers' privilege concept by smallholder farmers in South Africa”, S Afr J Sci. 2015;111(1/2), Art. \#2013-0344, 5 pages. http://dx.doi.org/10.17159/ sajs.2015/2013-0344

3165 African Centre for Biodiversity, Concerns with the Revised Plant Breeders' Rights Act, March 2017, accessed at: https://acbio.org.za/wp-content/uploads/2017/03/Lobby-paper-PBR.pdf

3166 Wynberg, R., van Niekerk, J., Williams, R., and Mkhaliphi, L., 2012. Policy Brief. Securing Farmers' Rights and Seed Sovereignty in South Africa. Biowatch South Africa and the Environmental Evaluation Unit, University of Cape Town.

3167 Ibid..

3168 Ibid.

3169 Biowatch South Africa, Submission on the Plant Breeders' Rights (PBR) Bill, 18 April 2017. Accessed at http://www.biowatch.org.za/docs/subs/2017/Submission_PlantBreedersRightsBill_042017.pdf

3170 Wynberg, R., van Niekerk, J., Williams, R., and Mkhaliphi, L., 2012. Policy Brief. Securing Farmers' Rights and Seed Sovereignty in South Africa. Biowatch South Africa and the Environmental Evaluation Unit, University of Cape Town.
} 
remedies and stock remedies. The Directorate of Agricultural Production Resources and Livestock Improvement is responsible for the enforcement thereof.

\subsubsection{Regulating contracts between retailers and SMEs through legislation:}

The Consumer Protections Act 68 of 2008 (CPA) and the National Credit Act 34 of 2005 (NCA) regulate contracts between consumers and retailers. The legislation and regulations provide for a variety of consumer rights, including a right to information; and an institutional enforcement mechanism, including a Commission, provincial structure and a Consumer Goods and Services Ombudsman. ${ }^{3171}$

\subsection{Production}

\subsubsection{Land Reform:}

Land reform was a prominent feature in the negotiations that brought the end of apartheid. Since 1994, South Africa began redressing past injustices through land reform in the agricultural sector. Section 25 of the South African Constitution forms the basis of the land restitution and redistribution programme. In response to these constitutional imperatives, the South African government initiated a land reform programme which aimed at redistributing $30 \%$ of white owned commercial agricultural land by 2014 to black South Africans as well as settling all redistribution claims by $2005 .{ }^{3172}$ To date, all land claims have still not been settled and in 2014 less than $10 \%$ of the redistribution target had been achieved.

The redistribution of agricultural wealth to previously disadvantaged people had been pursued through the liberalisation and deregulation agenda. This has resulted in "increased efficiency through vertical integration, and elaborate value chains at the expense of addressing the needs of the poor and the landless." 3173 Although some argue that the system has contributed towards keeping food prices affordable, "it has also constrained the entrance of new farmers and entrepreneurs into the system along the entire food value chain and has done little to redistribute agricultural wealth."3174

The debate around land reform fits into the larger issue about the need for agrarian reform that will include marginalised farmers and communities in the country's food system. ${ }^{3175}$ Small farmers, manufacturers and retail outlets are faced with high barriers to entry to be part of the commercial formal food system in South Africa. The old agrarian and land system has essentially been left unchanged.

In South Africa, only 13 per cent of the land is arable with only 3 per cent of that arable land considered to be high-potential land. In 2012, it was shown that 87 per cent of the arable land was

\footnotetext{
${ }^{3171}$ Von Broembsen at 26. Although not legislation or regulation, in the most recent iteration of The Department of Trade and Industry's Industrial Policy Action Plan (IPAP), there are initiatives underway to increase the participation of small farmers and suppliers. IPAP 2017/2018 notes the need to get commitments from the main retailers to develop a procurement charter, to facilitate supplier development programmes and to facilitate easier access to outlets. This is however yet to be implemented.

3172 HJ Kloppers and GJ Pienaar, "The Historical Context of Land Reform in South Africa and Early Policies", Potchefstroom Electronic Law Journal, 2014 Vol 14 No 2.

$3173 \mathrm{http} / / /$ awsassets.wwf.org.za/downloads/safl_the_future_of_south_africas_food_system.pdf

$3174 \mathrm{http} / / /$ awsassets.wwf.org.za/downloads/safl_the_future_of_south_africas_food_system.pdf

$3175 \mathrm{http}: / /$ awsassets.wwf.org.za/downloads/safl_the_future_of_south_africas_food_system.pdf
} 
still owned by white commercial farmers. ${ }^{3176}$ "This is indicative of South Africa's dualistic agrarian structure that comprises about 35000 large-scale, mostly white commercial farmers who produce must of the country's marketed output, and a much larger number (approximately 4 million) of smallscale, black farmers who are largely confined to the former Bantustans." ${ }^{3177}$ Beneficiaries of the land reform process have been faced with difficulties around developing or maintaining effective production on the newly acquired land and they have received limited government support. ${ }^{3178}$

Notwithstanding the rhetoric favouring small-scale agriculture, since the end of apartheid neither the land reform programme nor the agricultural restructuring process has actually facilitated the realisation of this objective. ${ }^{3179}$ On the contrary, the government has been accused of "pandering to agribusiness by pushing a contract farming model to integrate selected small-scale black farmers into corporate value chains, which has left the fundamental corporate-driven agrarian and agri-food structure intact." 3180

\subsubsection{Acquisition of Agricultural Land:}

The transfer of immovable property is regulated by the Deeds Registries Act 47 of 1937. Currently there is no restriction on the ownership of land or the acquisition of land by a foreign party. However, the new Land Holdings Bill will dramatically change this. The Bill proposes that foreign nationals and entities will not be entitled to own agricultural land in South Africa, but will be allowed to enter into a long term lease for a minimum period of 30 years.

\subsubsection{Consumer Interests:}

\subsubsection{GMO's:}

South Africa's regulatory regime governing aspects of GMO use is fairly vigorous as it includes, contained use, trial release, commercial release, and transboundary movement. The primary legislation is the Genetically Modified Organisms Act of 1997 and its Regulations. The Act was amended in 2006, however the amendment only took effect in 2010, in part to give effect to the Cartagena Protocol on Biodiversity which South Africa ratified in 2003. ${ }^{3181}$ There are additional laws which impose further rules on GMO-related activities, such as the National Environmental Management: Biodiversity Act, the Consumer Protection Act, and the Foodstuffs, Cosmetics and Disinfectants Act. ${ }^{3182}$

The Department of Agriculture, Forestry and Fisheries (DAFF) administers the GMO Act. The Department is responsible for promoting responsible GMO-related activities; limiting harm to the environment as well as to human and animal health; and establishing standards for conducting risk assessments for GMO-related activities. ${ }^{3183}$

\footnotetext{
3176 http://awsassets.wwf.org.za/downloads/safl_the_future_of_south_africas_food_system.pdf

$3177 \mathrm{http} / / /$ awsassets.wwf.org.za/downloads/safl_the_future_of_south_africas_food_system.pdf

$3178 \mathrm{http} / / /$ awsassets.wwf.org.za/downloads/safl_the_future_of_south_africas_food_system.pdf

$3179 \mathrm{http} / / /$ awsassets.wwf.org.za/downloads/safl_the_future_of_south_africas_food_system.pdf

$3180 \mathrm{http} / / /$ awsassets.wwf.org.za/downloads/safl_the_future_of_south_africas_food_system.pdf

$3181 \mathrm{https} / / / \mathrm{www}$. loc.gov/law/help/restrictions-on-gmos/south-africa.php\#_ftn6

3182 https://www.loc.gov/law/help/restrictions-on-gmos/south-africa.php\#_ftn6

3183 https://www.loc.gov/law/help/restrictions-on-gmos/south-africa.php\#_ftn6
} 
The GMO Act establishes three institutions with specific functions - the Registrar, the Executive Council and the Advisory Council. Some of the Executive Council's functions include determining whether an applicant for a permit should submit a risk assessment and an environmental impact assessment as well as approve applications for the use of facilities for conducting GMOrelated activities in consultation with the Advisory Committee.

The Registrar is responsible for administering the GMO Act. The Registrar's functions include examining applications, issuing permits and amending or withdrawing permits. Furthermore, the Registrar is required to keep a register of all the facilities involved in the contained use or the trial release of GMO's and the names and addresses of all individuals involved in GMO-related activities.

The Advisory Committee is a national advisory body on all matters concerning or related to the GMOs. The Committee is required to advise on all aspects relating to the introduction of GMOs into the environment, the contained use, the importation and exportation; and on proposed regulations and written guidelines.

Once the GM crop is released, the impact on the environment is monitored by the South African National Biodiversity Institute established under the National Environmental Management: Biodiversity Act ${ }^{3184}$

South Africa was the first country in Africa to approve commercial production of genetically modified crops. The first approval for the commercial use of a genetically modified crop was in 1997 for Monsanto's MON810 Yield Guard insectresistant maize. ${ }^{3185}$ According to the United Nations, South Africa currently has 2.3 million hectares of GM crops under cultivation of which 4.3 per cent in GM cotton, 17.7 per cent is GM soybean and 78.0 per cent is GM maize. ${ }^{3186}$ South Africa is the ninth largest producer of GM crops in the world. ${ }^{3187}$

Maize is the staple foodstuff for the majority of South Africans, and it is also used as livestock feed. ${ }^{3188}$ Approximately $90 \%$ of South Africa's maize crop is genetically modified ${ }^{3189}$, yet the change to GM maize was never properly publicised and the majority of South African's do not know that they are consuming a GM product. ${ }^{3190}$

At least $85 \%$ of the seed business for the big commodity crops are owned by Monsanto and DoPont/Pioneer Hi Bred/Pannar. ${ }^{3191}$

Bt maize varieties in South Africa are expensive. Bt maize is sold at approximately double the price of popular non-GM hybrids and "five times that of the price of popular open pollinated varieties." 3192 Furthermore, because commercialised Bt maize varieties are developed to give high yields under optimal agricultural conditions smallholders suffer as they do not have the economy to provide such an optimal environment, and commonly farm on lands which are not well-suited for

\footnotetext{
${ }^{3184}$ No. 10 of 2004.

3185 http://www.biowatch.org.za/list.php?cat=GM\%20crops

$3186 \mathrm{http}$ ///unscn.org/files/Publications/Country_Case_Studies/UNSCN-Country-Case-Study-South-Africa-FINAL.pdf

3187 African Centre for Biodiversity, The Bayer-Monsanto merger: Implications for South Africa's agricultural future and its smallholder farmers. ” February 2017.

3188 http://www.biowatch.org.za/list.php?cat=GM\%20crops

3189 African Centre for Biodiversity, The Bayer-Monsanto merger: Implications for South Africa's agricultural future and its smallholder farmers. " February 2017.

$3190 \mathrm{http}: / /$ www.biowatch.org.za/list.php?cat=GM\%20crops

${ }^{3191}$ African Centre for Biodiversity, The Bayer-Monsanto merger: Implications for South Africa's agricultural future and its smallholder farmers. " February 2017.

3192 Fischer K, Van den Berg J, Mutengwa C. Is Bt maize effective in improving South African smallholder agriculture? S Afr J Sci. 2015;111(1/2), Art. \#a0092, 2 pages. http://dx.doi. org/10.17159/sajs.2015/a0092
} 
agriculture. ${ }^{3193}$ Consequently, planting the Bt maize that is currently available involves the risk that input costs will not be covered within one year. ${ }^{3194}$

According to Biowatch numerous field trials have been approved for additional forms of GM maize, GM soya, GM cotton as well as GM sugar-cane, GM potato and GM cassava. ${ }^{3195}$ At the laboratory level (in universities and research institutes) research is being conducted on "drought tolerant GM maize and pharmaceutical production from GM maize and GM tobacco".3196

Biowatch notes that the principle of "substantial equivalence" has been proposed in justifying the lack of environmental and food safety tests on GM food crops. ${ }^{3197}$ For example, in South Africa food safety tests do not need to be conducted for GM soya as it is considered to be substantially the same as natural soya. ${ }^{3198}$ Biowatch contends that no subsequent studies have been conducted since the principle was adopted despite there being evidence that it impacts on both human and animal health. This suggests that approximately $70 \%$ of South Africa's major food staple is now genetically modified, without it being tested for possible health effects. ${ }^{3199}$

Farmers are faced with serious consequences when pollen from a field of genetically modified maize contaminates nearby fields of traditional maize or organically grown maize. ${ }^{3200}$ Affected farmers are not able to sue the GM seed producer responsible for contamination but rather the GM patent holder can sue the farmer if any GM material is found to be present in their crop without a GMO licence fee being paid. ${ }^{3201}$

Biowatch notes that saving seeds for replanting, or exchanging seeds with other farmers is a traditional right for farmers. However, these practices are effectively put to an end with GMO seed patents. In the case of GM maize, GM soya and GM cotton the control and ownership of the seeds passes entirely to multinational corporations that hold patents, like Monsanto. ${ }^{3202}$

It is a requirement that foodstuffs obtained through certain techniques of genetic modification be labelled as such before they are put on sale in the marketplace. The Consumer Protection Act imposes additional labelling requirements. It requires that "[a]ny person who produces, supplies, imports or packages any prescribed goods must display on, or in association with the package or those goods, a notice in the prescribed manner and form that that discloses the presence of any genetically modified ingredients or components of those in accordance with applicable regulations."

\subsubsection{Food Safety:}

The Department of Health is responsible for ensuring food safety in South Africa. As part of its functions, it oversees the administration of food legislation, which includes publicizing regulations

\footnotetext{
${ }^{3193}$ Fischer K, Van den Berg J, Mutengwa C. Is Bt maize effective in improving South African smallholder agriculture? S Afr J Sci. 2015;111(1/2), Art. \#a0092, 2 pages. http://dx.doi. org/10.17159/sajs.2015/a0092

${ }^{3194}$ Fischer K, Van den Berg J, Mutengwa C. Is Bt maize effective in improving South African smallholder agriculture? S Afr J Sci. 2015;111(1/2), Art. \#a0092, 2 pages. http://dx.doi. org/10.17159/sajs.2015/a0092

$3195 \mathrm{http}: / /$ www.biowatch.org.za/list.php?cat=GM\%20crops

$3196 \mathrm{http} / / /$ www.biowatch.org.za/list.php?cat=GM\%20crops

${ }^{3197} \mathrm{http}: / /$ www.biowatch.org.za/list.php?cat=GM\%20crops

3198 http://www.biowatch.org.za/list.php?cat=GM\%20crops

$3199 \mathrm{http}: / / \mathrm{www}$. biowatch.org.za/list.php?cat=GM\%20crops

${ }^{3200} \mathrm{http}: / / \mathrm{www}$. biowatch.org.za/list.php?cat=GM\%20crops

${ }^{3201} \mathrm{http}: / /$ www.biowatch.org.za/list.php?cat=GM\%20crops

$3202 \mathrm{http}: / /$ www.biowatch.org.za/list.php?cat=GM\%20crops
} 
for food safety, labelling food, and evaluating risk assessments for the DAFF that are related to agricultural chemicals and food produced through biotechnology. ${ }^{3203}$

\subsubsection{Food Security:}

South Africa is considered to be food secure at a national level, in terms of aggregate food availability. The National Development Plan indicates that being food secure at a national level means that it "earns a trade surplus from agricultural exports and is able to cover the cost of food imports from those exports."

The same cannot be said at a household and community level. Household food security is determined by the ability to access food as opposed to its availability. According to Statistics South Africa, the Household Food Insecurity Access Scale which is directed to determine household access to food revealed that the percentage of South African households with inadequate or severely inadequate access to food decreased from 23.9\% in 2010 to $22.3 \%$ in 2016. During that period the percentage of individuals that were at risk decreased from $28.6 \%$ to $24.9 \%$. Between the period of 2002 and 2016, the percentage of households that experienced hunger decreased from $23.8 \%$ to $11.8 \%$ while the percentage of individuals who experienced hunger decreased from $29.3 \%$ to $13.4 \% .{ }^{3204}$

The National Development Plan was published in 2012 with the aim of eliminating income poverty by 2030 . The Plan proposes a commitment to household food and nutrition security involving both public and private sector action. The Plan takes into account that low-income households spend approximately 35 per cent of their money on food whereas upper-income households spend 3 per cent.

In 2013, Cabinet passed the South African National Food and Nutrition Security Policy which was gazetted on 22 August 2014. The Policy sets out five pillars for achieving food security, namely: improved nutritional safety nets; improved nutrition education; the alignment of investment in agriculture towards local economic development; improved market participation of the emerging agricultural sector; and food and nutrition security risk management

\subsection{Competition Law}

\subsubsection{Competition Law and Food Value Chains}

The specific context of competition law needs examination with the context of the history of South African agriculture. The agriculture industry in South Africa has a long history of intense state intervention. The apartheid government extensively regulated the production and marketing of agricultural products through state sanctioned 'control boards' established by the Marketing Act of 1937. Agricultural co-operatives were appointed and functioned as regional monopolies. ${ }^{3205}$ The cooperatives played an important role in providing inputs and services such as storage, packaging and processing, as well as representing the broad interests of white farmers. ${ }^{3206}$ Farmers were paid fixed

\footnotetext{
${ }^{3203}$ https://www.loc.gov/law/help/restrictions-on-gmos/south-africa.php\#_ftn6

${ }^{3204}$ StatsSA, General Household Survey, 2016.

3205 https://www.oecd.org/daf/competition/CompetitionIssuesintheFoodChainIndustry.pdf

${ }^{3206} \mathrm{http}: / /$ www.compcom.co.za/wp-content/uploads/2014/09/Sept-08-Newsletter-29.pdf
} 
prices on delivery of their produce, they were given price protection, subsidised finance and export subsidies.

In order to address the legacy of a concentrated and closed economy with limited competition, the first democratic government liberalised the sector with the aim of promoting market efficiency and competitiveness. The competition legislation which was introduced was presented both as part of a standard microeconomic reform agenda to ensure liberalised markets work, and as a tool to address the market power of entrenched business which derived its power from apartheid-era policies favouring the white minority. ${ }^{3207}$ Consequently, the Competition Act was negotiated in the context of liberalisation, albeit through the prism of Apartheid history.

Thus, the balance between addressing the legacy of apartheid and the liberalisation agenda is manifest in the combination of the relatively expansive objectives of the Act. ${ }^{3208}$ There is an emphasis on the ability of small and medium sized enterprises as well as historically disadvantaged persons to participate in the economy. Further, the Act aims to regulate the transfer of economic ownership in keeping with the public interest and to promote employment and advance the social and economic welfare of South Africans. Effects-based tests are specified in the Act for evaluating mergers and most anti-competitive conduct. ${ }^{3209}$ In general, a consumer welfare standard is applied to determination of abuse of dominance and merger cases. The Competition Appeal Court has taken account of dynamic efficiency to allow the merger between Pannar \& Pioneer ${ }^{3210}$ finding that as consequence of innovation, improved competition with Monsanto could take place. In addition public interest factors like employment, the ability of small business controlled or owned by Black South Africans to become competitive are important factors in a merger inquiry.

With liberalisation the agricultural sector was restructured. There was a decrease in the number of farmers by approximately $25 \%$ from 1996, with consolidation to form larger farms at high levels of mechanisation. ${ }^{3211}$ Moreover, there was a shift in patterns, with less land used for crops such as maize and wheat, as lower-yielding land was no longer used following the ending of the regulated prices guaranteed to farmers. Agricultural employment in 2011 was around $40 \%$ lower than in the mid 1990s. ${ }^{3212}$

Since the liberalisation of the sector, food value chains concentration levels have remained consistently high, especially for most of staple food products, with the exception of poultry where new entry has created a more competitive environment for local consumers. ${ }^{3213}$ On the whole, there are high concentration levels in the manufacture and supply of inputs such as fertiliser as well as in processing, packaging and retail. ${ }^{3214}$ "The actual farming is relatively unconcentrated, meaning farmers are price takers on both sides." 3215

The agricultural cooperatives converted into private companies and through mergers and acquisitions they extensively consolidated into "large agro-processing concerns, commodity traders

\footnotetext{
3207 http://www.tandfonline.com/doi/full/10.1080/03056244.2013.854034?src=recsys\&

${ }^{3208} \mathrm{http}: / /$ www.tandfonline.com/doi/full/10.1080/03056244.2013.854034? src=recsys \&

${ }^{3209} \mathrm{http} / / /$ www.tandfonline.com/doi/full/10.1080/03056244.2013.854034?src=recsys \&

${ }^{3210}$ Pioneer Hi-Bred International Inc \& Pannar Seed (Pty) Ltd v Competition Commission 173/CAC/Nov11

${ }^{3211} \mathrm{http}: / /$ www.tandfonline.com/doi/full/10.1080/03056244.2013.854034? src=recsys\&

$3212 \mathrm{http}: / / \mathrm{www}$. tandfonline.com/doi/full/10.1080/03056244.2013.854034? src=recsys \&

$3213 \mathrm{https} / /$ www.oecd.org/daf/competition/CompetitionIssuesintheFoodChainIndustry.pdf

${ }^{3214} \mathrm{http}: / / \mathrm{www} . c o m p c o m . c o . z a / w p-c o n t e n t / u p l o a d s / 2014 / 09 / S e p t-08-N e w s l e t t e r-29 . p d f$

$3215 \mathrm{http}: / /$ www.compcom.co.za/wp-content/uploads/2014/09/Sept-08-Newsletter-29.pdf
} 
and suppliers of farming requisites." 3216 Today multinational traders occupy a significant role in local trading of agricultural commodities. ${ }^{3217}$

\subsubsection{Main competition law cases}

\subsubsection{Main Merger Cases:}

\subsection{Seed Industry}

In Pioneer Hi-bred International Inc and Another $v$ Competition Commission and Another [2012] ZACAC 3 the South African Competition Commission prohibited the proposed merger by PioneerHi-Bred International (Pioneer), a US-based multinational seed producer of the South African seed company Pannar Seed (Pty) Ltd. The Tribunal upheld the Commission's finding however on appeal to the Competition Appeal Court (CAC) in 2012 the merger was approved. The Commission and Tribunal had found that the merger would substantially reduce competition in the maize seed markets which could not be outweighed by pro-competitive gains that may arise from the merger. The Tribunal regarded this as a three to two merger as the market only consisted of the two firms in question and one other. Moreover, the approach of the Tribunal was effectively to compel Pannar to seek a partnership with another company, not presently competing in the market.

The CAC held that the reasons advanced by the Tribunal do not justify its rejection of the merger because the demise of Pannar is inevitable which will then reduce the market from three to two in any case. The Appeal Court cautioned the Tribunal from speculating that the target firm ought to enter into partnership with another firm as such an approach constitutes an intrusion into the management and control of private companies. The CAC held that the merger would increase competition which would result in long-term dynamic efficiency improvements in the nature and quality of seed production.

\subsection{Cereals}

The leading breakfast cereal manufacturer in South Africa, Pioneer Food Group (Pioneer), planned Pioneer Foods (Pty) Ltd \& Future Life Health Products (Pty) Ltd Case No: LM017 May15 to merge with Future Life Health Products (Future Life), a smaller food manufacturer. The Competition Commission recommended that the merger be approved without conditions. However, the Tribunal approved the merger with conditions. The Commission examined whether the parties competed in the market for breakfast cereal, or whether the target sold a distinct, 'functional food'. The Competition Tribunal found that a single market existed, primarily because the target sold at prices close to cereals rather than to supplements, which were three times more expensive, and because all the major retailers stocked both products next to one on grocery shelves. The Tribunal further stated that the products represented each other's closest substitute. ${ }^{3218}$

\footnotetext{
$3216 \mathrm{http}: / / \mathrm{www}$. tandfonline.com/doi/full/10.1080/03056244.2013.854034? src=recsys\&

${ }^{3217} \mathrm{http} / / / \mathrm{www}$. tandfonline.com/doi/full/10.1080/03056244.2013.854034? src=recsys\&

${ }^{3218}$ In food and agro-processing the dominant firms within this market have a market share of $60.5 \%$ and the $\mathrm{HHI}$ in this sector is 2861. Presentation by Dr Liberty Mcube Chief economist of the Competition Commission at Commissions annual conference $1 / 9 / 2017$.
} 
The Tribunal imposed certain behavioural conditions on the merging parties. The founding shareholder of the acquiring undertaking would control pricing and marketing of cereal products. The exchange of proprietary information would be limited and a restriction was placed on the cross appointment of board members. The Tribunal intended for the conditions to deter coordinated effects, and limited their duration to five years. The Tribunal also determined that the acquirer could not reduce investment in the target for two years.

\subsection{Poultry}

In Astral Foods Limited and National Chick Limited (2) (69/AM/Dec01) [2003] ZACT 8 the acquirer supplied breeding stock to the South African broiler industry, holding a 69\% market share. Its closest competitor, Cobb, had a market share of $26 \%$, but mostly supplied Rainbow Farms. The acquirer supplied $38 \%$ of its parent stock (of chickens) ["PP"] to in-house broilers, and $62 \%$ to independent broilers. The transaction involved horizontal and vertical elements, horizontal because both parties manufactured animal feed, vertical because the target produced day-old chicks.

The Competition Tribunal found the vertical issues raised by the merger most disconcerting because a dominant supplier was buying its largest independent customer, and entry barriers into both markets were high. The transaction reduced the share of PP available to independent broiler breeders from $60 \%$ to $40 \%$, and they separately lacked the capacity to expand quickly to support the entry of Cobb. The transaction further could permit the acquirer to price discriminate in favour of its own operations downstream. Over the short-term, Cobb could not make-up the hypothetical diversion in production. On the other hand, the acquirer argued that it earned the highest margins upstream and thus had an incentive to maximize output rather than to foreclose downstream. Moreover, Cobb had $50 \%$ of the international market and could grow in South Africa over the medium term, particularly in response to price increases.

Because of the risk of short-term foreclosure, the Tribunal imposed the following conditions. The acquirer could not discriminate when supplying its own operations over independent customers, and it could not demand exclusivity as a condition to supplying independent customers.

As to the horizontal aspects of the merger, it would create a dominant feed producer in a particular region in South Africa, while removing an effective competitor from the market. The acquirer agreed to divest its Nurex division.

\subsection{Fish}

\section{Oceana Group Limited and Another v Competition Commission [2014] ZACAC 3:}

Foodcorp wanted to sell its fishing operations, including its quota and fish processing plants, to Oceana because it considered them to no longer be core to its future strategic investment and Foodcorp's fishing rights, including the survival of its entire fishing business, were under threat from the Department of Agriculture, Fisheries and Forestry as a result of its reduced empowerment shareholding.

The Competition Commission's main concern had to do with the sale of the canned pilchards. Oceana's Luck Star brand enjoyed 73\% market share and Foodcorps Glenryck had a market share of $8.2 \%$. Lucky Star with access to Foodcorp's fishing rights would result in a very dominant player in 
the downstream canned pilchards market. As a result, the parties proposed excluding the Glenryck brand from the transaction.

The Commission found that the proposed transaction resulted in horizontal effects in respect of the harvesting, processing and marketing of pilchards. It found that the merging parties pilchard brands were the closest competitors in the market with a combined market share of $80 \%$, compared to $10 \%$ of its next closest competitor. Consequently, the Commission found that there was a high barrier to entry at the harvesting level; high capital requirements at the processing level; with no other effective competing brand at the marketing level. Moreover, the virtual removal of an effective competitor at each level of the value chain, would result in a substantial reduction in the vertically integrated market. the Commission found that access to sufficient local quota was vital to the support of the canned pilchards brand, and therefore the disposal of Glenryck without access to Foodcorp's quota would lead to the removal of an effective competitor from the market. The Commission thus approved the merger subject to a condition that Glenryck be disposed of to a third party, together with Foodcorp's fish quota.

The merging parties consequently appealed the Tribunal's decision to the CAC. The Court found that the Tribunal had drawn inferences from speculative evidence, which ultimately led to conclusions that were not based on the facts. The CAC therefore overturned the Tribunal's decision and approved Oceana's acquisition of the Foodcorp fishing business, subject to the condition proposed by the merging parties that Foodcorp retain and continue to operate the Glenryck brand in accordance with good business practice. Further, the CAC emphasised that the transaction had a significant public interest consideration in that the continued existence of the Foodcorp fishing business under Oceana would result in the survival of the Laaiplek processing facility and the employment associated therewith for approximately 1000 employees in a highly impoverished region, who would otherwise have been retrenched.

\subsection{Infant Milk Formula}

In Nestle SA and the Infant Nutrition Business of Pfizer Inc Case No: 65/LM/Jul12 (015248) Nestle produced, marketed, and sold food and beverage products worldwide. It acquired Pfizer Nutrition, specifically its infant nutrition business. The Competition Commission identified horizontal overlap as both parties were involved in infant nutrition, however their products were complementary rather than competitive. The Commission nevertheless found a "highly concentrated" market with only three competitors: (1) Nestle with greater than a 70\% market share; (2) Pfizer with less than 10\%; and (3) Aspen with a 20\% share. The Commission also determined that healthcare professionals constituted a significant route to market and that they tended to recommend the same baby food brands to customers, who also were loyal. This made entry difficult.

The Competition Tribunal ordered the following rebranding remedies as conditions to approving the merger. Nestle had to sell and provide (1) a 10-year license to use the Pfizer trademarks on certain baby food products currently active in South Africa, and agree to a subsequent 10-year "blackout" period during which it could not use the trademarks, so as to incentivize investment; (2) an exclusive 10-year license to use Pfizer's product formulations; (3) a non-exclusive perpetual license relating to know-how to develop and manufacture the divested products; (4) a license to access pipeline products; (5) access to clinical and product trial results; and (6) other related conditions. 
The Tribunal approved of the rebranding remedy relative to a permanent divestiture because rebranding maintained pre-merger competitive restraints while potentially creating a viable competitor over the medium-term. It also reduced risk to reputational damage, insufficient investment and free-riding, collusion, and coercion from split ownership of the brands in different jurisdictions and either a contractual or customer relationship in South Africa.

\subsection{Retail}

Minister of Economic Development and Others v Competition Tribunal and Others, SACCAWU $v$ Wal-Mart Stores and Another [2012] ZACAC 2 was a critical case for the development of the public interest criteria.

In 2010 Wal-Mart made an offer to acquire 51\% of Massmart's ordinary share capital. At the time Massmart employed 27000 employees in 14 countries in Sub-Saharan Africa. The transaction was notified to the Competition Commission which recommended its approval without conditions. However, trade unions and government opposed the deal before the Competition Tribunal. The Tribunal approved the merger subject to the voluntary conditions offered by the parties.

The case was appealed to the CAC. The uncontested evidence before the Court was that prices of goods sold by Walmart would be lower, and in many cases significantly lower than those offered by existing firms operating in the South African market. Walmart had no presence in South Africa or indeed Africa before the merger. In turn, Massmart, at the most, held 25\% of certain segments of the relevant market and was smaller than the two key competitors, Checkers and Pick n Pay.

The entire dispute turned on whether the merger can or cannot be justified on public interest grounds. A key argument was the detrimental effect that the merger would have on small and medium sized South African enterprises which supplied which supplied products to the relevant supermarket chains and the consequent loss of employment.

The CAC permitted the merger subject to certain conditions. Pursuant to that order the Court ordered the commission of a study "to determine the most appropriate means together with the mechanism by which local suppliers may be empowered to respond to the challenges posed by the merger and thus benefit thereby."

The Court held that the public interest provision in the Competition Act could not be employed as a surrogate for a coherent industrial policy. The challenges posed by globalisation had to be met by a comprehensive policy designed by the State to deal with the challenges that globalisation in general and global value chains in particular posed to the domestic South African economy. The Court held that a programme be developed and adequately funded to empower local, micro, small and medium sized enterprises, which may be affected by the merger.

\subsection{Beverages}

Coca-Cola Beverages Africa Ltd \& Various Coca-Cola \& Related Bottling Operations Case No: LM243Mar15 raised the possibility of broader public interest grounds being developed by the Competition Tribunal.

The Tribunal considered the transaction as having two components, Bottling and Branding. The acquiring firms include SAB Miller and the company that owns the Coke trademarks. The 
acquired firms consist of processors, including bottling companies. The transaction creates one bottling entity.

The parties believed that the transaction enhances access to investment resources, creates scope for reinvestment in various initiatives, and improves distribution capacity. As to the impact on competition, the primary relationship between the parties is vertical. The Competition Commission found that the transaction would have a neutral effect on competition because the acquiring companies already have integrated the bottling operations of the acquired companies.

The transaction also consisted of horizontal overlap in the carbonated drinks, fruit juice, and water product markets. The Commission found that the transfer of brands would have little competitive impact. The Commission further discussed subsidiary concerns under the heading of "public interest", which included black empowerment, limiting job losses for three years while contributing funds to retaining, and creating a separate fund for disadvantaged farmers and suppliers.

The Competition Tribunal found that the proposed merger could have a negative effect on the current local producers of tin cans, glass packaging, sugar crates in South Africa. It also found that fruit juice concentrate of a particular brand (Appletiser), being sourced outside South Africa rather than in the country as was the case pre merger created a difficulty for the merger.

An undertaking was thus made an order of the Tribunal that the production of Appletiser would be maintained in South Africa, that at least $20 \%$ of the equity in Appletiser SA be sold to a black controlled company. Further, the merging parties were to invest no less than R400 m in developing the downstream and retail components of the South African soft drink market for 25000 black retailers of the merging parties' products

Conditions also included ensuring that small retail outlets supplied with fridges by Cola-Cola were not required to exclusively sell Coca-Cola products but be free to sell competing products. The agreement opens fridge space in coolers owned or supplied by Coca-Cola to smaller retailers. Ten percent of fridge space will be available to rival products from smaller producers in retail establishments where only Coca-Cola supplied coolers are available.

This opens the market to new entrants and small bottlers, helping to avoid restrictive business practices that keep small and medium-sized businesses out of markets. The Commission noted that similar commitments had been agreed to by TCCC in other countries in relation to exclusionary conduct investigations. ${ }^{3219}$

In Pick n Pay and Fruit \& Veg City 2014/09 MR 022007 the Commission recommended to the Tribunal that Pick n Pay should be prohibited from acquiring Fruit \& Veg City. Pick n Pay and Fruit \& Veg city are competitors in the retail market for fresh food. The Commission analysed the market from both a national and local perspective. At the national level, the combined market share of the parties in the retail fruit and vegetable market would have been $58 \%$. The parties also had significant market share in various local markets. Fruit \& Veg City was identified as a significant competitive restraint to Pick n Pay.

The Commission took the view that the proposed acquisition would result in the removal of an effective competitor and that the acquisition of Fruit \& Veg City would not just limit the competition in the market, but would weaken future competition in the market. the Commission was of the view that the merger would harm consumers directly, as prices were likely to increase and consumer choice would decrease after the merger.

${ }^{3219}$ Press Release by Coca-Cola Company 10 May 2016 
In The SPAR Group Ltd \& Florida Foodliner (Pty) Ltd Case No: 020925; The acquiring undertaking conducts a wholesaling operation, buying cheap and selling various goods to SPAR Guild members. It also runs distribution centres where it stores and ships "dry goods, perishable goods, liquor, general merchandise, [and] personal care goods," again to members. The acquiring undertaking lastly owns and manages nine retail centres. The acquired undertaking operates retail supermarkets selling "fresh and processed foodstuffs, toiletries, household products," etc., in addition to retail liquor stores.

The acquirer simply seeks to expand its retail operations. The transactions present both horizontal and vertical issues. Horizontal overlap occurs at the retail level of food, groceries and liquor. Vertical overlap exists as well because the SPAR Group supplies goods to acquired undertakings. In the retail market for liquor, the parties do not compete in the same geographic market. Likewise, in the retail market for groceries the parties do not compete in the same geographic market. the Competition Commission thus concluded that the transaction does not pose horizontal concerns. The Tribunal agreed with this finding.

Addressing the vertical issue, the Commission stated that while the target undertaking purchases between $92 \%$ and $96 \%$ of its products from the acquirer, the transaction does not risk foreclosure because competitive conditions do not change.

\subsubsection{Conduct Cases}

Liberalisation increased competition in formally regulated markets, however it inadvertently increased the incentives for firms to participate in cartels. As a result, after liberalisation many formerly price regulated industries turned to illegal collusion. ${ }^{3220}$ For example, the wheat value chain was highly regulated by the state from 1937 to 1996. The Wheat Board "was the sole buyer and seller of wheat at predetermined prices." ${ }^{3221}$ It was expected that with liberalisation millers would compete. However, instead of competing the millers replaced state regulation with private regulation. ${ }^{3222}$ In 2007 the bread, flour and maize meals cartels were uncovered.

\subsection{Fertiliser}

The Competition Commission alleged that defendant Foskor charged excessive prices for the sale of phosphoric acid. Animal feed producers originally notified the Commission of the possibility of an abuse, as phosphoric acid constitutes an input to both livestock and poultry feed. Foskor charged prices in South Africa by taking the export price as the base and adding $75 \%$ of the freight rate shipping phosphoric acid to India. Foskor also contracted with Sasol to produce phosphoric acid on behalf of Foskor. Their combined production accounted for over $80 \%$ of total local production

\footnotetext{
3220

http://www.oecd.org/officialdocuments/publicdisplaydocumentpdf/?cote=DAF/COMP/GF/WD(2015)23\&docLanguage $=$ En

3221

http://www.oecd.org/officialdocuments/publicdisplaydocumentpdf/?cote=DAF/COMP/GF/WD(2015)23\&docLanguage $=$ En

3222

http://www.oecd.org/officialdocuments/publicdisplaydocumentpdf/?cote=DAF/COMP/GF/WD(2015)23\&docLanguage $=$ En
} 
capacity of phosphoric acid. Foskor sold $95 \%$ of its product abroad; the entire domestic market would have accounted for $35.7 \%$ of Foskor's total sales. Foskor also produced phosphate rock to supply the South African fertiliser industry.

The Commission determined that Foskor possessed the ability to sustain prices "substantially in excess" of the competitive level, to "the very limit" of its monopolistic power in the local market, and that the price that Foskor charged was "excessive and detrimental to consumers". To respond to the Commission's concerns, Foskor eliminated the 75\% shipping rate from the local phosphoric acid price, thereby substantially lowering prices. Foskor additionally committed to adopt a competition law compliance program. The Commission initially did not demand that Foskor pay damages, but later required Foskor to pay 6,481,889.65 rand in administrative penalties.

The Commission also found that the agreement with Sasol divided markets by allocating customers and particular types of goods. The Commission granted Foskor conditional immunity for this conduct and settled with Sasol.

In 2009 and 2010, the Competition Commission intervened in the nitrogenous fertiliser value chain. Prior to the intervention, several anticompetitive practices existed in the fertiliser market. These practices can be divided into two mutually reinforcing categories. ${ }^{3223}$ The first pertains to practices that emanated from Sasol's dominance and desire to maintain such dominance, whilst the second pertains to collusive practices among the major fertiliser blenders and distributors.

Prior to the Commission's intervention in the nitrogenous fertiliser value chain, Sasol was the sole supplier of ammonia in South Africa. Ammonia is the main input in the production of nitrogenous Fertilisers. In 1999 Sasol became the monopoly supplier of ammonia in South Africa when the production facilities of African Explosives and Chemical Industries ("AECI") were closed down.

Omnia, Foskor and Kynoch (Yara) are suppliers of imported ammonia. Each of these firms supply ammonia through their shared ownership of the Richards Bay ammonia import facility. They each own shares of $25 \%$, with Sasol forming the fourth shareholder.

The ammonia that is produced by Sasol and imported by Omnia, Foskor and Kynoch (Yara), is used to produce ammonium nitrate, which in turn is used in the production of Fertilisers. ${ }^{3224}$ Prior to the Commission's intervention in 2009 and 2010, Sasol, Omnia and AECI were the firms that were involved in the manufacture of ammonium nitrate as they had the necessary infrastructure to produce it.

At the downstream level of the value chain there are blenders and traders, such as Nutri-Flo and Profert, which prior to the Commission's intervention sourced input from Sasol to create blended Fertilisers in order to on-sell to farmers. In 2003 and 2004 respectively, they both laid complaints alleging that they were subject to exploitative and exclusionary conduct on the part of Sasol. They alleged that Sasol, acted in concert with Omnia and Kynoch (Yara), which had the effect of depressing the ability of the complainants to achieve a competitive outcome in the market for the blending and distribution of nitrogenous-based Fertilisers. Furthermore, it was alleged that the interdependence between Sasol, Omnia and Kynoch (Yara) frustrated market participants such as Nutri-Flo and Profert from expanding their businesses and effectively competing.

3223 This discussion draws on S. Grimbeek, Giya, G. \& Mahlalela, Q. (2017). "The Impact of Competition in the fertiliser industry after the Sasol divestiture of blending facilities in 2010." Competition Commission of South Africa Working Paper No. 1.

${ }^{3224}$ Ibid.. 
In 2005, at the time of the Commission's investigations, it was observed that Sasol produced more than $40 \%$ of the country's ammonium nitrate. As a result of the collusive agreements entered into between Sasol, Omnia and Kynoch, Omnia's incentive to effectively utilize its ammonium nitrate plants was significantly reduced.

The Commission also noted that Omnia supplied very little ammonium nitrate to the open market due to its vertical integration. Moreover, Omnia was reliant on imported ammonia for its operations. The fundamental problem with that arrangement was the reliability of the rail wagons in transporting ammonia up from the Richards Bay import facility. Under an agreement with Kynoch (Yara), ammonium nitrate was produced by AECI, however that ceased in 2004. As a result, smaller players who required ammonium nitrate had to rely solely on Sasol. At present Sasol remains the main supplier of ammonium nitrate in South Africa.

In short, the Commission's investigations revealed that Sasol had been abusing its dominance upstream, charging prices as if the products had been imported. In addition, Sasol was found to be in a cartel with two other major producers of intermediate fertiliser products, Omnia and Kynoch. ${ }^{3225}$

Upon the consolidation of its findings in 2005, the Commission referred the matter to the Competition Tribunal Sasol reached agreements with the Commission, which effectively imposed behavioural and structural conditions on Sasol. ${ }^{3226}$ On 20 July 2010 the Tribunal confirmed the settlement order in terms of which Sasol undertook to provide fertiliser on an ex-works basis and further not to discriminate across customer types (i.e. blenders, traders and end users) and across geographic regions. Sasol also undertook to divest five of its blending plants, thus limiting its present in the downstream market.

\subsection{Bread Cartel}

Up until 1991 the bread industry was highly regulated. As a result of this regulated environment, "regular meetings took place between bread producers largely, through an industry association, the Chamber of Baking ("the Chamber") to whom all of the bakers belonged." 227 Although the legislative impediment to competition was removed with deregulation, the bread producers continued interacting with regard to their common issues. Moreover, the Chamber continued to operate as a forum for information sharing.

There are four "primary bakeries who enjoy a combined market share of between 50-60 per cent of the domestic bread market in South Africa. Blue Ribbon owned by Premier Foods, Albany Bakeries owned by Tiger Consumer Brands, Sasko and Duens Bakeries owned by Pioneer Foods and Sunbake Bakeries owned by Foodcorp. The remainder of the market is served by smaller independent bakeries. The four primary plant bakeries are all vertically integrated. Their milling operations account for more than 90 per cent of all milled wheat. As milling companies they sell flour to the

\footnotetext{
${ }^{3225}$ G. Makhaya \& S. Roberts (2013) "Expectations and outcomes: considering competition and corporate power in South Africa under democracy," Review of African Political Economy.

3226 S. Grimbeek, Giya, G. \& Mahlalela, Q. (2017). "The Impact of Competition in the fertiliser industry after the Sasol divestiture of blending facilities in 2010.” Competition Commission of South Africa Working Paper No. 1. 3227

http://www.oecd.org/officialdocuments/publicdisplaydocumentpdf/?cote=DAF/COMP/GF/WD(2015)23\&docLanguage $=$ En
} 
independent bakeries. Plant bakeries and independent bakeries produce similar products and are competitors with each other." 3228

The Competition Commission received information in 2006 about an alleged bread cartel operating in the Western Cape Province. After an initial investigation, the Commission initiated a complaint against Pioneer Foods, Tiger Brands and Premier Foods, all of whom had allegedly been involved in the cartel.

During the Commission's investigation, Premier Foods applied for leniency indicating its willingness to fully cooperate with the Commission on its role in the cartel. It disclosed that Premier Foods, Tiger Brands and Pioneer Foods had been operating a bread cartel in the Western Cape by fixing selling prices and other trading conditions. Further, it revealed that a bread cartel had been operated in other parts of the country and they had also entered into agreements which involved the division of markets by allocating territories. Based on that information the Commission proceeded to initiate another investigation. Thereafter the Commission referred both the Western Cape and National complaint to the Tribunal.

Tiger Brands corroborated the information provided by Premier Foods. Tiger Brands provided additional evidence on the bread cartel, including information that the cartel was also fixing flour and maize meal prices. In November 2007 the Tribunal imposed a fine of R98 million on Tiger Brands for its role in the bread cartel. Foodcorp, a respondent in the national complaint, entered into a settlement agreement with the Commission and in 2009 the Tribunal confirmed the settlement agreement and imposed a fine of R45 million on Foodcorp. By contrast, Pioneer Foods denied that it was involved in a Western Cape Cartel.

After contested proceedings whereby the Commission alleged that Pioneer Foods' bread baking divisions engaged in price fixing and market allocation, per se offenses, Pioneer admitted to price fixing and market allocation in the Western Cape but only to the discount granted to agents or resellers setting the price of toaster bread, as competition primarily occurred through discounting downstream in this market. The three leading bakeries had capped the discount to agents at 90 cents per loaf, and agreed not to supply new distributors.

The Tribunal refused to impose fines on Pioneer's international turnover, but only its bread and bakery turnover in regions where it acted anti-competitively. To impose a fine on turnover in another product market, the Tribunal would require the monopolist to extend leverage on market power. The Tribunal found as aggravating circumstances the regressive impact of higher bread prices, the removal of capacity from markets, and Pioneers' insistence on defending egregious conduct for which strong evidence existed.

\subsection{Wheat Flour Cartel}

The four major firms that operate in the wheat milling industry in South Africa control nearly 97 per cent of the wheat flour market. these firms are Premier Foods, Tiger Brands, Pioneer Foods and Foodcorp. The four firms are further vertically integrated in baking and production of other foodstuffs such as cereals and pasta.

3228

http://www.oecd.org/officialdocuments/publicdisplaydocumentpdf/?cote=DAF/COMP/GF/WD(2015)23\&docLanguage $=$ En 
The flour industry in South Africa is highly concentrated and is characterised by "multimarket contact, homogenous products and a history of collusion, both at the level of milled wheat and in the main end consumer product, bread." ${ }^{3229}$ The firms have extensive presence in a number of geographic markets and are also active on the downstream level of the value chain.

The Commission's investigations revealed that at various stages between 1999 and 2007 private meetings and telephonic discussions took place between the wheat milling firms. During these meetings they agreed to fix the price of both wheat and white maize products and to create uniform price lists for wholesale, retail and general trade customers. Moreover, they agreed on the timing of the price increases and the implementation thereof. The agreements were used to secure coordination at both national and regional levels and were mutually reinforcing.

In 2010 the Tribunal confirmed a consent agreement between the Commission and Pioneer Foods regarding Pioneer Foods' involvement in the milling cartels. Pioneer admitted that it had engaged in price fixing and market allocation in the wheat and maize milling markets, that it exchanged information with competitors through industry associations and received cost and market share information in return, and that it lowered price to keep rivals from expanding in certain regions of South Africa. Pioneer committed (1) to cooperate in the Commission's investigations by providing evidence and testifying, (2) to set-up a competition law compliance program, (3) to cease committing the conduct that the Commission found troublesome, including threatening price wars against rivals, (4) to lower the price of wheaten flour and bread products, which must equate to a reduction in gross profits of 160,000,000 rand, and (5) not to decrease the level of capital expenditure as a result of the following fine; rather to increase that expenditure by 160,000,000 rand. Pioneer lastly agreed to pay an administrative penalty of 500,000,000 rand.

\subsection{Milk Cartel}

In 2004 the Commission received information alleging the existence of a cartel fixing the price of fresh milk. An investigation was initiated and the Commission found evidence of price fixing for raw and processed milk by Clover, Parmalat, Ladismith Cheese, Woodlands Dairy, Nestle, Lancewood and Milkwood Dairy. In 2006 the Commission referred the complaint to the Tribunal. "The complaint related to collusion and/or price fixing at the milk procurement level, including exchange of information and exchanging milk between regions between processors instead of entering each other's regions to procure milk, as well as price fixing in the sale of processed milk and dairy products." 3230 Moreover, there was a complaint relating to exclusive dealing in inducing suppliers not to deal with competitors.

The Competition Commission held that defendant Lancewood had perpetrated a horizontal conspiracy that directly or indirectly fixed the procurement prices of milk and set other trading conditions. The conspiracy members at both the field office and management levels exchanged price information by phone, email, or in person, including pricing data for procurement and retail sales, set prices based on hypothetical scenarios circulated among the group, and reported price movements

3229

http://www.oecd.org/officialdocuments/publicdisplaydocumentpdf/?cote=DAF/COMP/GF/WD(2015)23\&docLanguage $=\mathrm{En}$

3230

http://www.oecd.org/officialdocuments/publicdisplaydocumentpdf/?cote=DAF/COMP/GF/WD(2015)23\&docLanguage $=$ En 
based on past, present, and future pricing. Lancewood received economic pricing reports that detailed the factors used to set pricing by competitors and the different prices paid by processors, and that further requested a response based on Lancewood's corresponding pricing information. Lancewood once requested and received aggregated pricing data from an independent third-party targeted at an area where it did not compete. Lancewood admitted to exchanging pricing information and agreed to pay an administrative penalty of 100,000 rand. It further committed to instituting a competition law compliance program and to cooperating with the Commission's prosecution of other conspiracy participants.

\subsection{Poultry Cartel}

The Competition Commission initiated an investigation regarding complaints on anti-competitive conduct in the market of poultry breeding stock and broiler production, poultry products as well as poultry feed. The investigations were initiated against the South African Poultry Association ("SAPA"), Animal Feed Manufacturers Association, Rainbow Chickens Ltd, Pioneer, Country Bird Holdings Ltd and Afgri Ltd.

The Commission's investigation involved market allocation specifically against Pioneer and Rainbow; exclusive supply agreements against all broiler producers (including Astral); tying allegations against certain breeding stock suppliers and information exchange against all of the respondents through their membership in SAPA. After its investigation the Commission decided not to refer the complaint to the Tribunal subject to undertakings by the respondents regarding future exchanges of information.

The Commission initiated an investigation into alleged price fixing against Rainbow, Astral, Country Bird Holdings and Afgri. The Commission received a leniency application from Pioneer in respect of cartel behaviour in the market of fresh poultry products in the Western and Eastern Cape. This matter formed part of the Commissions R960 million settlement with Pioneer on all outstanding cases. ${ }^{3231}$ Subsequently, Astral admitted to collusive behaviour in that market and settled with the Commission.

\subsection{Packaging}

The Competition Commission alleged that defendant Rooibos had entered into exclusive supply agreements with the four main rooibos packers that required the packers to buy all or "a substantial amount" of their rooibos requirements from defendant, thereby preventing the packers from obtaining rooibos upstream from other suppliers. Rooibos also offered volume discounts "based on targets" to induce packers not to buy rooibos from defendant's rivals. The Commission further found that Rooibos had dominance in the upstream market for "the processing and supply of bulk rooibos to packers," that the exclusive agreements had foreclosed rivals upstream and had maintained dominance, and that the volume discounts had produced a similar effect.

Rooibos agreed not to enter into any further exclusive agreements, not to offer individualized discounts, not to offer discounts above a threshold that apply to the entire volume purchased, not to

3231 "Competition Dynamics and regional trade flows in the poultry sector: the case of South Africa, Botswana, Namibia and Zambia". 
lower price on incremental sales below the average variable cost to produce that portion of output, and only to offer discounts on equivalent terms to all customers. The Commission agreed not to impose an administrative penalty.

\subsection{Agricultural Subsidies}

Prior to the deregulation of the sector in the 1990s, the Agricultural sector in South Africa was supported by a system and framework of regulation that included the establishment of the Land Bank, the enactment of the Agricultural Marketing Act of 1937, Land Acts of 1913 and various other components of agricultural policy which included control boards (price setting of agricultural commodities), investments in R\&D, access to extension services and infrastructure (Kirsten, Van Zyl and Van Rooyen, 1994). In line with other apartheid era policies, this framework served to support a number of agricultural products produced by a small proportion of market participants, mainly white commercial farmers and large processors, at the expense of black farmers and processors.

Field crops such as maize and sugar received the most support although subsidies were also directed towards wheat products and the dairy industry. Other sectors such as horticulture and poultry received little support during this period. The support to field crops largely comprised protection from foreign competition, subsidies and in the case of maize, access to productive technology. The maize farmers' access to this technology is largely considered to be responsible for the high level of production of the maize industry even today despite the reduction in the amount of land on which maize seed is planted.

The maize sector was also one of the most significant lobby groups in the agricultural sector. They used their political influence to, amongst other things, strengthen the position of (white commercial) farmers to gain access to resources (Kirsten et al. 1994). It is no surprise that until 1995, maize was a dominant product in South Africa's export basket largely due to the subsidies received (Edwards, Kirsten and Vink, 2007). Today, South Africa remains a net exporter of maize although this has reduced over time, partly due to the redistribution of land and drought conditions experienced. A further protection the maize industry benefited from was a guaranteed payment from the state should export losses be incurred by the maize board. These guaranteed prices were largely responsible for the substantial amount of land dedicated to maize production in earlier years.

Like for other products, the protection in the sector was facilitated by control boards and agricultural cooperatives. With the deregulation of the sector in the 1990s in which the control boards were dismantled, new systems began to emerge in which the agricultural market system was more self-regulating.

Between the 1960s and 1990s, the support received by maize and wheat crops went beyond subsidies and extended into financing and processing, which contributed to the creation of a powerful lobby group for farmers in this sector (Tregurtha, Vink and Kirsten, 2010). It also resulted in the control of key infrastructure such as the operation and ownership of grain silos, constructed with state support. The power of the lobby groups and cooperatives extended to capacity payments, handling, debt relief and tax concessions (Armin and Bernstein, 1995). This created significant distortion or direct government intervention across agricultural products.

The sugar industry is another field crop that received significant state support and in which there has been limited reform since even before the 1990s (Edwards, Kirsten and Vink, 2007). It is still a key sector identified for targeted interventions based on its value-add, export performance and 
economy-wide multiplier effects, in accordance with the 2016/17-2018/19 IPAP iteration (the dti, 2016 - see table 1 below). The industry is yet to be deregulated and remains highly protected. The industry is regulated in terms of the Sugar Act of 1978 and Sugar Industry Agreement (SIA) of 2000, binding on all sugarcane growers and producers of sugar products (DAFF, 2016), in addition to other underlying domestic policies and regional agreements regulating the industry.

The sugar industry benefits from tariff protection on sugar imports when the world sugar price drops below a pre-determined dollar-based reference price, a tariff is placed on imports. ${ }^{3232}$ The dollar-based reference price for sugar is periodically reviewed by International Trade Administration Commission (ITAC) (das Nair et al., 2017). The tariff protection is not without its challenges as it is considered to benefit the larger millers and harm the rest of the sector. It also appears to penalise domestic and industrial consumers because it does not differentiate between different types and qualities of sugar (das Nair et al., 2017; Barnes et al. 2015).

The sugar sector receives additional protection under the Sugar Act and Sugar Industry Agreement (SIA) in which local and export quotas or volumes produced are determined. In addition, the Sugar Act and SIA determine sugarcane prices using the Division of Proceeds (DoP) ${ }^{3233}$ formula. The rationale for the setting of prices is to protect growers from low global sugar prices and from the buying power of millers. The Sugar Act and SIA are currently under review by the dti, including consideration of the potential for anticompetitive outcomes (Canegrowers, 2014).

The agricultural policies that subsequently developed for field crop other than sugarcane aimed firstly to correct injustices of past policy, largely through land reform; secondly to make the sector more labour-intensive and lastly to increase competitiveness internationally. The passing of the Marketing of Agricultural Products Act in 1996 heralded the new liberalised agricultural system in which marketing boards were dismantled and statutory export monopolies ended (Greenberg, 2017). This Act essentially created a 'free market' system for food and effectively removed government's control over prices and subsidies in the agricultural sector.

Table 1 below outlines the key policy changes from the 1980s to present.

\section{Table 1: Key policy changes in the agriculture and agro-processing sectors}

\begin{tabular}{|l|l|}
\hline Deregulation and policy reform (from 1980's) \\
\hline - & Deregulation of marketing \\
\hline - & Liberalisation of price control \\
\hline - & Change in direct budgetary expenditure on agriculture \\
\hline - & Scrapping of Land Acts (in 1991) \\
\hline - $\quad$ Tariffication of farm commodities \\
\hline Subsequent policies (since 1990's to 2007) \\
\hline - Land reform \\
\hline - Institutional restructuring \\
\hline - & Promulgation of Marketing of Agricultural Products Act (no 47 of 1996) \\
\hline
\end{tabular}

\footnotetext{
3232 See das Nair et al. 2017 for details of how the dollar reference price works.

${ }^{3233}$ See das Nair et al. (2017)
} 
- Trade policy (quantitative restrictions, duties, price controls, import/export permits replaced by tariffs $)^{3234}$

- Labour market reform

- Bilateral and regional trade agreements (SACU, SADC and TDCA ${ }^{3235}$ )

Policies from 2007

- Industrial Policy Action Plan (IPAP) (2012-2017) ${ }^{3236}$

- Agricultural Policy Action Plan (APAP) (2015-2019) ${ }^{3237}$

- National Policy Framework on the development of small and medium agro-processing enterprises (2015)

Source: Edwards, Kirsten and Vink (2007); IPAP iterations; (DAFF, 2014), (DAFF, 2016)

A key outcome of the policy changes was the redistribution of land from field crop production to the production of horticultural products and to pastoral use. The shift to horticultural production was largely driven by export demand following trade liberalisation. The amount of land dedicated to maize production was significantly reduced by about a million hectares while the land dedicated to pasture increased by about 700,000 hectares.

Between 1939 and 1997, the fruit and nut industry was regulated by the citrus board through agricultural marketing boards. The board determined the volumes of fruit allocated to each processor as well as the quantity to be sold in the fresh market. The sector was deregulated post-1997 with the closing of the marketing boards. The Industrial Policy Action Plan (IPAP) from 2010-2017 and the Agricultural Policy Action Plan (APAP) from 2014-2019 now identifies fruit as a strategic sector in the agro-processing value chain with high growth potential and labour absorptive capacity. The action plans aim to grow the fruit sector by improving access to export markets, growing exports in existing markets, assisting firms with complying with standards and investing in critical infrastructure.

A number of initiatives/support systems have been set to achieve this goal:

- the dti established a National Food Control Agency to address fragmentation and duplication of roles in food safety regulation in 2010.

- the dti established a Public Private Partnership (PPP) fruit caning initiative in partnership with South Africa Fruit \& Vegetable Canners' Association (SAFVCA), in 2005, to improve competitiveness and ensure the long-term sustainability of the fruit and vegetable canning industry.

- the dti assisted the industry to access new markets in China and India between 2010 and 2011 and grow sales in these markets.

\section{Table 2: Agricultural and agro-processing subsidies in IPAP and APAP}

\footnotetext{
3234 The sugar industry was the only industry not subjected to this process of liberalisation.

3235 Southern Africa Customs Union, Southern Africa Development Community, and Trade, Cooperation and Development Agreement (with the European Union).

3236 IPAP agriculture and agro-processing policies include industrial financing, procurement, trade policies, competition policy, demand side skills strategies, development of special economic zones and a regional agricultural plan

3237 The APAP is focussed on key action programmes in 11 sectors: poultry/soya beans/maize integrated value chain, red meat, wheat, fruit and vegetables, wine industry, sugar, biofuels, forestry, small-scale fisheries, Aquaculture Competitiveness Improvement Programme (ACIP).
} 


\begin{tabular}{|c|c|c|c|c|c|}
\hline Form of subsidy & Level of support & $\begin{array}{l}\text { Areas/crops to } \\
\text { benefit }\end{array}$ & Philosophy & $\begin{array}{l}\text { Institutions in } \\
\text { charge }\end{array}$ & Year \\
\hline $\begin{array}{l}\text { Agro-Processing } \\
\text { Support } \quad \text { Scheme } \\
\text { (APSS) }\end{array}$ & $\begin{array}{l}20 \% \text { to } 30 \% \text { cost- } \\
\text { sharing grant }\end{array}$ & Agro-processing & $\begin{array}{l}\text { Increased capacity, } \\
\text { employment creation, } \\
\text { modernised } \\
\text { machinery and } \\
\text { equipment, } \\
\text { competitiveness and } \\
\text { productivity } \\
\text { improvement and } \\
\text { broadening } \\
\text { participation }\end{array}$ & DTI & $2017 / 18$ \\
\hline $\begin{array}{l}\text { Aquaculture } \\
\text { Development and } \\
\text { Enhancement } \\
\text { Programme }\end{array}$ & $\begin{array}{l}\text { Cost-sharing grant of up } \\
\text { to a maximum of } \mathrm{R} 30 \\
\text { million }\end{array}$ & Aquaculture & $\begin{array}{l}\text { Develop emerging } \\
\text { agriculture farmers; } \\
\text { Increase production; } \\
\text { Sustain and create } \\
\text { jobs; } \\
\text { Encourage } \\
\text { geographical spread }\end{array}$ & DAFF, DTI & Current \\
\hline $\begin{array}{lr}\text { Agricultural } & \text { Broad- } \\
\text { Based } & \text { Black } \\
\text { Economic } & \\
\text { Empowerment } & \\
\text { (AgriBEE) } & \end{array}$ & Up to $\mathrm{R} 5 \mathrm{~m}$ & Agriculture & $\begin{array}{l}\text { Skills development in } \\
\text { agriculture, } \\
\text { transformation }\end{array}$ & DAFF & $2003-2007$ \\
\hline $\begin{array}{l}\text { Comprehensive } \\
\text { Agricultural Support } \\
\text { Programme (CASP) }\end{array}$ & & $\begin{array}{l}\text { Agricultural } \\
\text { support services }\end{array}$ & & DAFF & Since 2004 \\
\hline $\begin{array}{l}\text { The Micro } \\
\text { Agricultural } \\
\text { Financial Institutions } \\
\text { of South Africa } \\
\text { (MAFISA) }\end{array}$ & Up to $\mathrm{R} 500,000$ & $\begin{array}{l}\text { Agriculture, } \\
\text { forestry and } \\
\text { fisheries }\end{array}$ & $\begin{array}{l}\text { Purchase of } \\
\text { production inputs } \\
\text { (fertilizers, seeds, } \\
\text { pesticides etc.); } \\
\text { Purchase of small } \\
\text { equipment and } \\
\text { implements such as } \\
\text { Knapsack spray, bird } \\
\text { drinkers and feeders, } \\
\text { wheelbarrow, spades } \\
\text { etc.; } \\
\text { Purchase of breeding } \\
\text { livestock, } \\
\text { medication, feed, } \\
\text { branding material }\end{array}$ & DAFF & Current \\
\hline $\begin{array}{l}\text { Ilima-Letsema } \\
\text { programme }\end{array}$ & & Agriculture & Increased production & DAFF & 2016 \\
\hline $\begin{array}{l}\text { Provide hatcheries } \\
\text { for SMMEs }\end{array}$ & & Aquaculture & Increase seed supply & $\begin{array}{l}\text { DAFF, } \\
\text { Department of } \\
\text { Science and } \\
\text { Technology } \\
\text { (DST), } \\
\text { Distributed } \\
\text { Wind Energy } \\
\text { Association } \\
\text { (DWEA) }\end{array}$ & $2011 / 12$ \\
\hline $\begin{array}{l}\text { Establishment of } \\
\text { small-scale millers }\end{array}$ & & Milling & $\begin{array}{l}\text { Increase competition } \\
\text { and reduce prices }\end{array}$ & $\begin{array}{l}\text { Industrial } \\
\text { Development } \\
\text { Corporation } \\
\text { (IDC), } \\
\text { Economic } \\
\text { Department of } \\
\text { Development }\end{array}$ & $2014 / 15$ \\
\hline
\end{tabular}




\begin{tabular}{|c|c|c|c|c|c|}
\hline & & & & $\begin{array}{l}\text { (EDD), NMC, } \\
\text { Provincial } \\
\text { Departments of } \\
\text { Economic } \\
\text { Development, } \\
\text { Foundation for } \\
\text { African } \\
\text { Business \& } \\
\text { Consumer } \\
\text { Service } \\
\text { (FABCOS) }\end{array}$ & \\
\hline $\begin{array}{l}\text { Agro-processing } \\
\text { competitiveness fund } \\
\text { established from } \\
\text { fined levied against } \\
\text { Pioneer for its role in } \\
\text { the bread cartel }\end{array}$ & $\mathrm{R} 250 \mathrm{~m}$ & $\begin{array}{l}\text { Various food value } \\
\text { chains }\end{array}$ & $\begin{array}{l}\text { promote } \\
\text { competitiveness, } \\
\text { employment and } \\
\text { growth in food value } \\
\text { chains. It will provide } \\
\text { finance on favourable } \\
\text { terms to small and } \\
\text { medium enterprises. }\end{array}$ & IDC & \\
\hline $\begin{array}{l}\text { Establishment of a } \\
\text { feed mill }\end{array}$ & $\mathrm{R} 28 \mathrm{~m}$ & Feed mill & $\begin{array}{ll}\text { Increase } & \text { feed } \\
\text { production } & \end{array}$ & DTI & $2015 / 16$ \\
\hline $\begin{array}{ll}\text { Establishment } & \text { of } \\
\text { incubator farm }\end{array}$ & $\mathrm{R} 20 \mathrm{~m}$ & Barley & $\begin{array}{ll}\text { Increase } & \text { barley } \\
\text { production } & \\
\end{array}$ & DTI, FABCOS & $2015 / 16$ \\
\hline $\begin{array}{l}\text { Bronkhorstspruit } \\
\text { soya crushing facility }\end{array}$ & R1bn & Soya & $\begin{array}{l}\text { Facilitate import } \\
\text { substitution of soya } \\
\text { cake, increase local } \\
\text { soya bean cultivation, } \\
\text { create at least } 48 \\
\text { permanent jobs and } \\
\text { have an indirect } \\
\text { employment impact } \\
\text { of more than } 1000 \\
\text { jobs. }\end{array}$ & DTI, IDC & 2013 \\
\hline $\begin{array}{l}\text { Agroprocessing } \\
\text { facility }\end{array}$ & $\mathrm{R} 86 \mathrm{~m}$ & Multi-user facility & $\begin{array}{l}\text { It is designed to } \\
\text { enable small, micro } \\
\text { and medium } \\
\text { enterprises } \\
\text { (SMME's) to expand } \\
\text { their processing and } \\
\text { value-addition } \\
\text { activities in the } \\
\text { Eastern Cape. } \\
\text { Provides affordable } \\
\text { industrial space for } \\
\text { many small-to- } \\
\text { medium companies. } \\
\text { It would also create } \\
\text { thousands of } \\
\text { employment } \\
\text { opportunities to the } \\
\text { NMB community. }\end{array}$ & $\begin{array}{l}\text { DTI, Coega } \\
\text { Development } \\
\text { Corporation }\end{array}$ & $2015 / 16$ \\
\hline $\begin{array}{l}\text { Manufacturing } \\
\text { Competitiveness } \\
\text { Enhancement } \\
\text { Programme (MCEP) }\end{array}$ & $\begin{array}{l}\text { R5.8bn over } 3 \text { years. } \\
\text { Production Incentive } \\
\text { (administered by the dti) } \\
\text { - Capital Investment } \\
\text { - capped at R30 } \\
\text { million }\end{array}$ & $\begin{array}{l}\text { A range of sectors } \\
\text { falling under the } \\
\text { SIC } 3 \text { classification. } \\
\text { Agroprocessing } \\
\text { industry was the } \\
\text { major recipient in } \\
2015 . \\
\text { industries Agro- } \\
\text { supported include } \\
\text { dairy, bread, }\end{array}$ & $\begin{array}{l}\text { The MCEP } \\
\text { comprises two sub- } \\
\text { programmes: } \\
\text { Production Incentive } \\
\text { (PI) and the Industrial } \\
\text { Financing Loan } \\
\text { Facilities }\end{array}$ & DTI, IDC & Since 2009 \\
\hline
\end{tabular}




\begin{tabular}{|c|c|c|c|c|c|}
\hline & $\begin{array}{l}\text { - Green Technology } \\
- \text { capped at R20 } \\
\text { million } \\
\text { - Enterprise } \\
\text { Competitiveness } \\
\text { Improvement - } \\
\text { capped at R10 } \\
\text { million } \\
\text { Feasibility Studies - } \\
\text { capped at R8 } \\
\text { million } \\
\text { Cluster } \\
\text { Competitiveness } \\
\text { Improvement } \\
\text { capped at R50 } \\
\text { million } \\
\text { Industrial Financing } \\
\text { Loan } \\
\text { (administered by IDC) } \\
\text { Pre and post } \\
\text { dispatch; Working } \\
\text { Capital } \\
\text { Industrial Policy } \\
\text { Niche Project } \\
\text { Funding }\end{array}$ & $\begin{array}{l}\text { milling, beverages, } \\
\text { meat, etc }\end{array}$ & & & \\
\hline $\begin{array}{l}\text { Establishment of e- } \\
\text { centre }\end{array}$ & & Agro-processing & $\begin{array}{l}\text { To create a shared } \\
\text { space in which } \\
\text { produce can be } \\
\text { marketed } \\
\text { internationally. }\end{array}$ & $\begin{array}{l}\text { dti, EDD and } \\
\text { Cape Agulhas } \\
\text { Municipality }\end{array}$ & $2015 / 16$ \\
\hline $\begin{array}{lr}\begin{array}{l}\text { Establishment } \\
\text { domestic }\end{array} & \text { of } \\
\text { business hub } & \end{array}$ & & Agro-processing & $\begin{array}{l}\text { stimulate the local } \\
\text { economy, create } \\
\text { employment, } \\
\text { optimise agricultural } \\
\text { potential and agro- } \\
\text { processing a } \\
\text { creating a central } \\
\text { processing and } \\
\text { marketing hub }\end{array}$ & $\begin{array}{l}\text { dti, LIV } \\
\text { foundation, } \\
\text { DAFF, KZN } \\
\text { Provincial and } \\
\text { Local } \\
\text { government and } \\
\text { Department of } \\
\text { Rural } \\
\text { Development } \\
\text { and Land } \\
\text { Reform } \\
\text { (DRDLR),. }\end{array}$ & $2015 / 16$ \\
\hline $\begin{array}{ll}\text { Agricultural } & \text { Policy } \\
\text { Action Plan } & \end{array}$ & $\begin{array}{l}\text { Import tariffs } \\
\text { AGRI BEE Charter } \\
\text { Government Preferential } \\
\text { Procurement Policy } \\
\text { Infrastructural } \\
\text { development } \\
\text { Supplier development } \\
\text { programmes } \\
\text { Support for R\&D } \\
\text { Land allocation } \\
\text { Acquisition of new } \\
\text { technology } \\
\text { Skills development }\end{array}$ & 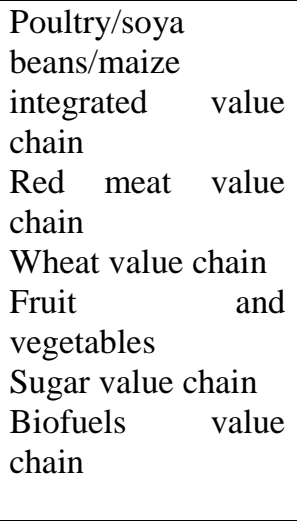 & $\begin{array}{l}\text { Meet the objectives } \\
\text { of the National } \\
\text { Growth Plan (NGP), } \\
\text { National } \\
\text { Development Plan } \\
\text { (NDP) and Industrial } \\
\text { Policy Action Plan } \\
\text { (IPAP): } \\
\text { - Contribution to } \\
\text { food security } \\
\text { Job creation }\end{array}$ & $\begin{array}{l}\text { DTI, DAFF, } \\
\text { Agricultural } \\
\text { Research } \\
\text { Council (ARC), } \\
\text { DRDLR, } \\
\text { National } \\
\text { Agricultural } \\
\text { Marketing } \\
\text { Council } \\
\text { (NAMC), } \\
\text { Agriculture } \\
\text { Sector } \\
\text { Education }\end{array}$ & $2015-2019$ \\
\hline
\end{tabular}




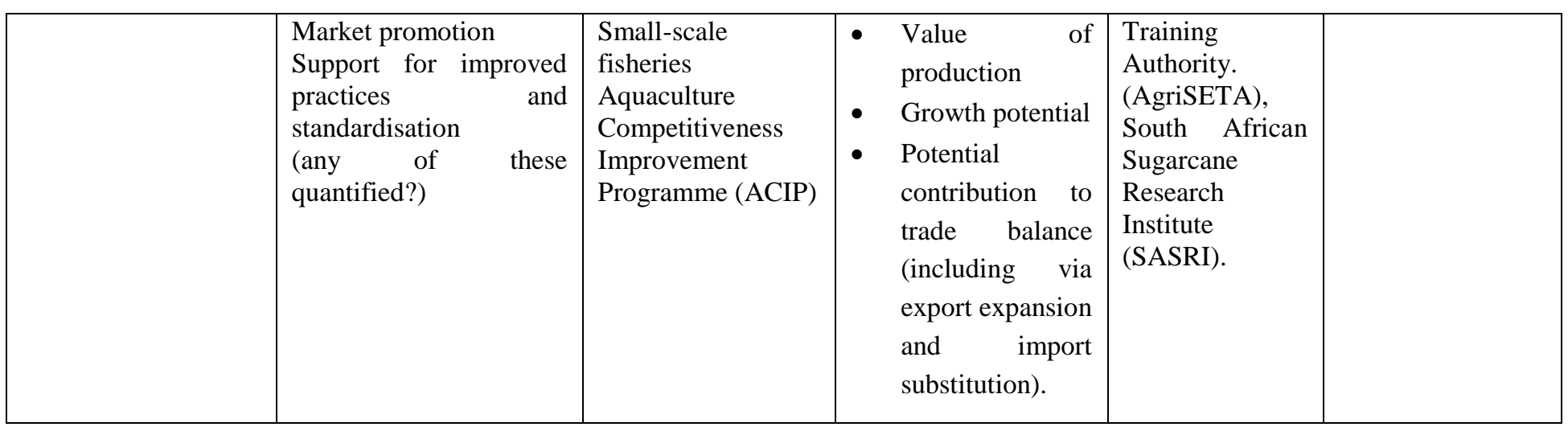

- IPAP 2011-2013 developed a Food Processing Strategy and Action Plan to facilitate the building of strong local brands that can compete in world markets.

- IPAP 2015 and 2016 highlighted plans to establish a targeted shared infrastructure programme through the South Africa products hub aimed at increasing exports. The hub involved sharing of facilities and services such as transport, storage and packaging for firms located in the same area. Furthermore, the programme enabled farmers in the same sector to procure inputs in bulk and market their produce to international markets.

- Beyond infrastructure support, IPAP 2016-2017 plans to develop an agro-processing supplier development programme in partnership with large retailers and agri-processors to provide shelf space and support to emerging and marginalized producers and farmers.

- IPAP 2016-2017 focuses on identifying and extending support to high-growth and high-value niche sectors with export potential such as blueberries and other fruit varieties that constitute high-value products with demand in developed export markets. Support for niche sectors includes market information and marketing, dissemination of new technologies, removing of unnecessary regulatory and infrastructural barriers and delays, and provision of finance.

The dairy sector was also highly regulated prior to the 1990s. The Dairy Industry Control Board was established in 1930. The Dairy Industry Control Act in 1930 and The Marketing Act of 1937 allowed for extensive state intervention in the dairy industry (Kassier et al., 1992; Scrimegour and Sheppard, 1998; Groenewald, 2000). The Marketing Acts of 1937 and 1968 set out to stabilise the incomes of South Africa's milk producers by regulating the flow of milk and by restricting perceived 'harmful competition' between market participants (Groenewald, 2000).

More recent policies as outlined in the IPAP 2015 and 2017/18-2019/20 have focused on developing and facilitating small-scale dairy processors to increase South Africa's exports of processed milk products and help new entrants to become more competitive in the global dairy market. They also aim to develop models for small dairy producers to become bottlers and distributors, including improving access to appropriate cold chain technologies and retail outlets.

Although difficult to comprehensively map out and quantify the full magnitude of support given to the different crops over time, an initial attempt is made in Table 2 below for the support mechanisms by the Department of Trade and Industry (DTI) and the Department of Agriculture, Forestry and Fisheries (DAFF), as well as other institutions, in more recent years.

\subsection{Conclusion}


Competition law in South Africa has concentrated mainly exclusively, upon mergers, not unexpectedly in a sector of the economy under significant economic pressure as described above.

However, the inquiry into this sector has been extended recently as a result of the Competition Commission having established a market inquiry in November 2015 into the grocery retail section. It is designed to focus on the role of supermarket chains in townships, particularly in peri urban and rural areas. Its report once completed, will throw further light on the role of supermarket chains in the promotion or retardation of small and medium sized businesses and the relationship of the retail sector to the pressing question of the supply of food to the South African population. ${ }^{3238}$

\section{References}

African Centre for Biodiversity, The Bayer-Monsanto merger: Implications for South Africa's agricultural future and its smallholder farmers (February 2017).

Armin, N., \& Bernstein, H. (1995). The Role of Agricultural Co-operatives in Agriculture and Rural Development. LAPC: Policy Paper 32.

Barnes, J., Francis, D., \& Hartogh, T. (2015). Economic impact assessment of the revision of the South African sugar Act. B\&M Analysts DAFF. (2014). Agricultural Policy Action Plan (APAP) 2015-2019. Pretoria : Department of Agriculture, Forestry and Fisheries.

Barrientos, S. and M Visser South African Horticulture: Opportunities and Challenges for economic and social upgrading in value chains: Working Paper 12: Durham North Carolina:

Capturing the Gains (2012), available at http://www.capturingthegains.org/publications/workingpapers/wp_201212.htm .

Canegrowers. (2014). Report of the Board of Directors 2014/15. South African Cane Growers Association.

Centre for Competition, Regulation and Economic Development, 'The Global Food Value Chain and Competition Law and Policy in BRICS countries: Insights from selected value chains in South Africa', Working Paper 21/2017.

DAFF. (2014). Agricultural Policy Action Plan 2015-2019. Pretoria: Department of Agriculture, Forestry and Fisheries.

DAFF. (2016). National Policy Framework on the support and development of small and medium agro-processing enterprises in South Africa. Department of Agriculture, Forestry and Fisheries.das Nair, R., Nkhonjera, M., \& Ziba, F. (2017). Growth and development in the sugar to confectionery value chain. Centre for Competition, Reguation and Economic Development, Working Paper 2016/17.

das Nair, R \& S. Chisoro, 'The Expansion of Regional Supermarket Chains. Changing models of retailing and the implications for local supplier capabilities in South Africa, Botswana, Zambia, and Zimbabwe', UNU-WIDER Working Paper 2015/114.

Edwards, L., Kirsten, J., \& Vink, N. (2007). Distortions of agricultural incentives in South Africa: 1944-2005. World Bank Agricultural Distortions Working Paper 38.

\footnotetext{
${ }^{3238}$ The inquiry has conducted some public hearings but has produced no report as at the time of the completion of this paper. It has provided transcripts of the hearings conducted on the Competition Commission's website www.compcom.co.za / retail market inquiry
} 
Fischer K, Van den Berg J, Mutengwa C. Is Bt maize effective in improving South African smallholder agriculture? S Afr J Sci. 2015;111(1/2), Art. \#a0092, 2 pages. http://dx.doi. org/10.17159/sajs.2015/a0092

Greenberg, S., 'Corporate Power in the agro-food system and the consumer food environment in South Africa', (2017) 44(2) The Journal of Peasant Studies, 467-469.

Groenewald, J.A, The Agricultural Marketing Act: a post mortem, (2000) 68(3) South African Journal of Economics, 364.

Grimbeek, S., Giya, G. \& Mahlalela, Q, 'The Impact of Competition in the fertiliser industry after the Sasol divestiture of blending facilities in 2010'. Competition Commission of South Africa Working Paper No.1 (2017).

Kaplan, D. \& M. Morris, Potential for Developing Local Suppliers in the Retail Sector Report for Trade and Industrial Policy Strategies (TIPS), May 2017.

Kassier, W.E., de Wet, G.L., du Toit, C.M., Kugel, H.W.L., van Zyl, J, Vink N \& van der Merwe BK. (1992). Report of the Committee of Inquiry into the Marketing Act, Pretoria, South Africa.

Kirsten, J.F., Van Zyl, J. \& Van Rooyen, J. (1994). South African agriculture in the 1980s. South African Journal of Economic History, 9(2), pp.19-48.

Makhaya, G. \& S. Roberts ;'Expectations and outcomes: considering competition and corporate power in South Africa under democracy', (2013) 40(138) Review of African Political Economy 556-571.

Netnou-Nkoana, N.C., Jaftha JB, Dibiloane MA, Eloff J. 'Understanding of the farmers' privilege concept by smallholder farmers in South Africa', (2015) 111 (1/2) South African Journal for Science, Art. \#2013-0344, 5 pages. http://dx.doi.org/10.17159/ sajs.2015/2013-0344

Ronquest-Ross, L.C., N. Vink \& G. O. Sigge, 'Food Consumption changes in South Africa since 1994' (2015) 111 (9/10) South African Journal for Science, Art. \#2014-0354, 12 pages. http://dx.doi.org/10.17159/ sajs.2015/20140354.

Scrimegour, F. \& Sheppard, R. (1998). An economic analysis of the deregulation of selected Israeli, South African and South American producer boards. MAF Policy Information Paper No. 20.

Tregurtha, N., Vink, N., \& Kirsten, J. (2010). Presidency Fifteen Year Review Project: Review of Agricultural Policies and Support Instruments in South Africa 1994-2009. Pretoria: Trade and Industrial Policy Strategies`.

Vink, N. \& Van Rooyen, J., 'The economic performance of agriculture in South Africa since 1994: Implications for food security’, Development Planning Division Working Paper Series No.17, DBSA: Midrand. March 2010.

von Broembsen, M., 'You can't bite the hand that feeds you': Contracts between SME suppliers and the large supermarkets, Econ3x3 (May 2017), available at http://www.econ3x3.org/sites/default/files/articles/Von\%20Broembsen\%202017\%20Small\%20busi ness\%20and\%20supermarket\%20supply\%20chains.pdf .

Wynberg, R., van Niekerk, J., Williams, R., and Mkhaliphi, L.. Policy Brief. Securing Farmers' Rights and Seed Sovereignty in South Africa. (Biowatch South Africa and the Environmental Evaluation Unit, University of Cape Town, 2012). 


\title{
PART VI: Case studies
}

\section{Chapter 1: Insights from selected value chains in South Africa ${ }^{3239}$}

\author{
Teboho Bosiu, Reena das Nair and Anthea Paelo
}

\subsection{Introduction}

This paper is South Africa's contribution to the BRICS Working Group on Food and Agroprocessing's overarching report on 'The Global Food Value Chain and Competition Law and Policy in BRICS countries'. The Working Group's overarching report aims to first provide an overview of key developments in various segments of global food value chains in the BRICS countries and to then focus in more detail on the impact of the recent consolidation in plant protection and seeds segments of value chains.

This paper contributes to the overarching report by providing an overview of developments and competition concerns in the following food and food-related segments in South Africa:

1. Seeds

2. Fertilisers

3. Animal feed and poultry

4. Maize and wheat milling

5. Dairy

6. Retail

These value chains were selected because of their importance as critical inputs into food production and given their significance as part of a typical food basket for consumers in southern Africa. These foods are increasingly retailed through supermarkets in the region. The selected value chains are also important because they have the potential to promote value addition and industrialisation in the region.

We employ a framework that allows for the evaluation of competition and regulatory dynamics in agro-processing value chains using a regional value chain approach, alongside the global value chain (GVC) approach which has been employed for a range of products including agricultural commodities and cash crops. The motivation for this approach is provided in Section 2.

This rest of this paper is structured as follows. Section $\mathbf{3}$ provides a brief background of the history and evolution of the broader food sector in South Africa. This is important to understand some of the outcomes we see in food markets today, including the competition problems. This section also introduces more recent developments in food value chains in South Africa, such as rising levels of institutional shareholders, growth of agri-investment companies, increase in financialization and greater cross-ownerships within and across food value chains. It further highlights the growing internationalisation of food markets in South Africa. These developments have implications on the strategies of lead firms in food value chains and how they compete.

Sections 4 to 9 then assess each of the selected value chains focusing on mapping out the value chain; assessing ownership patterns, levels of concentration and performance in terms of production, trade and investments; and reviewing competition interventions and impacts thereof. While the key

3239 The views expressed in this paper are those of the authors and not of the Competition Commission of South Africa. 
historic competition interventions in each sub-sector are discussed, the decisions over the past five years are tracked and implications on competitive rivalry, development and upgrading opportunities within the value chain are assessed. The implications of global mega-mergers and global cartels for South Africa are also considered.

\subsection{A value chain approach in conjunction with industrial organisation principles}

A GVC approach provides valuable insights into the interaction between producers, intermediate players and retailers in food value chains, the governance of these chains, as well as an understanding of the distribution of rents and power dynamics at each level. The governance includes a range of mechanisms for vertical control and coordination. Such analyses can then potentially set the foundation for designing appropriate tools for competition law interventions (Lianos and Lombardi, 2016 a, b; Davis et al, 2016). It is an area where competition authorities in developing countries are becoming increasingly interested in to foster conditions where markets can work better for investment, value added and a share of the rents for the producers in those countries.

\subsubsection{Regional value chains?}

While a GVC approach in evaluating dynamics in agro-processing markets provides useful insights, research in several value chains in southern Africa has shown that this approach has greater applicability when further refined to a regional value chain level, at least with regard to a number of important agro-processing activities through to retail.

Increasing regional integration and consolidation of global value chains has seen new patterns of trade and investment emerge. Multinational enterprises, in search of fewer, larger and more capable suppliers are likely to turn to more regional sourcing (Cattaneo et al. 2010; Gereffi and FernandezStark, 2011) and are increasingly investing in regional operations. Emerging economies in southern Africa and an increase in regional trade agreements further promotes regional value chains. ${ }^{3240}$ This is evident in the recent increase in intra-regional trade in processed foods and diversified manufactured products. An assessment of value chains that is either too narrow in that it only looks at national dynamics or too wide in that it only looks at global dynamics leaves out a critical geographic area over which production is happening- the southern African region. This therefore has strong implications for growth and industrialisation of the region as a whole.

There are several reasons why assessing value chains, including agro-processing value chains, from a regional perspective in southern Africa is relevant.

First, as highlighted, recent trade data from South Africa shows that exports of processed/prepared food products are increasingly going to the rest of Africa (Figure 1). We note however that the sharp spike in shares into the rest of Africa between 2009 and 2010 is likely to be an adjustment in reporting of exports to Southern African Customs Union (SACU) countries. This implies a considerable under-reporting of exports to Africa in earlier years. ${ }^{3241}$ In any case, it is clear that the rest of Africa is the most important 'market' for South African exports of processed/prepared

3240 Only a few studies have looked at regional value chains in southern Africa (see Keane, 2015, Farole, 2015 and Morris et al. 2012), and even fewer have looked at selected value-chains in depth (Fessehaie et al, 2015; 2016; Ncube et al, 2016). ${ }^{3241}$ Prior to 2010 exports of food-stuffs by South Africa to other SACU countries were not recorded as exports. 
foodstuffs. Further, this is being driven by exports to southern African countries (Figure 2). The southern African region as a whole therefore is an important market for South Africa. Other studies have also identified substantial gains from intra-regional trade in agro-processing products and South Africa has been identified as being a key driver of regional value chains as a market and as a source of inputs (AfDB et al. 2014; Jensen and Sandrey, 2015).

\section{Figure 3: Shares of South Africa's exports of processes/prepared foodstuffs by destination}

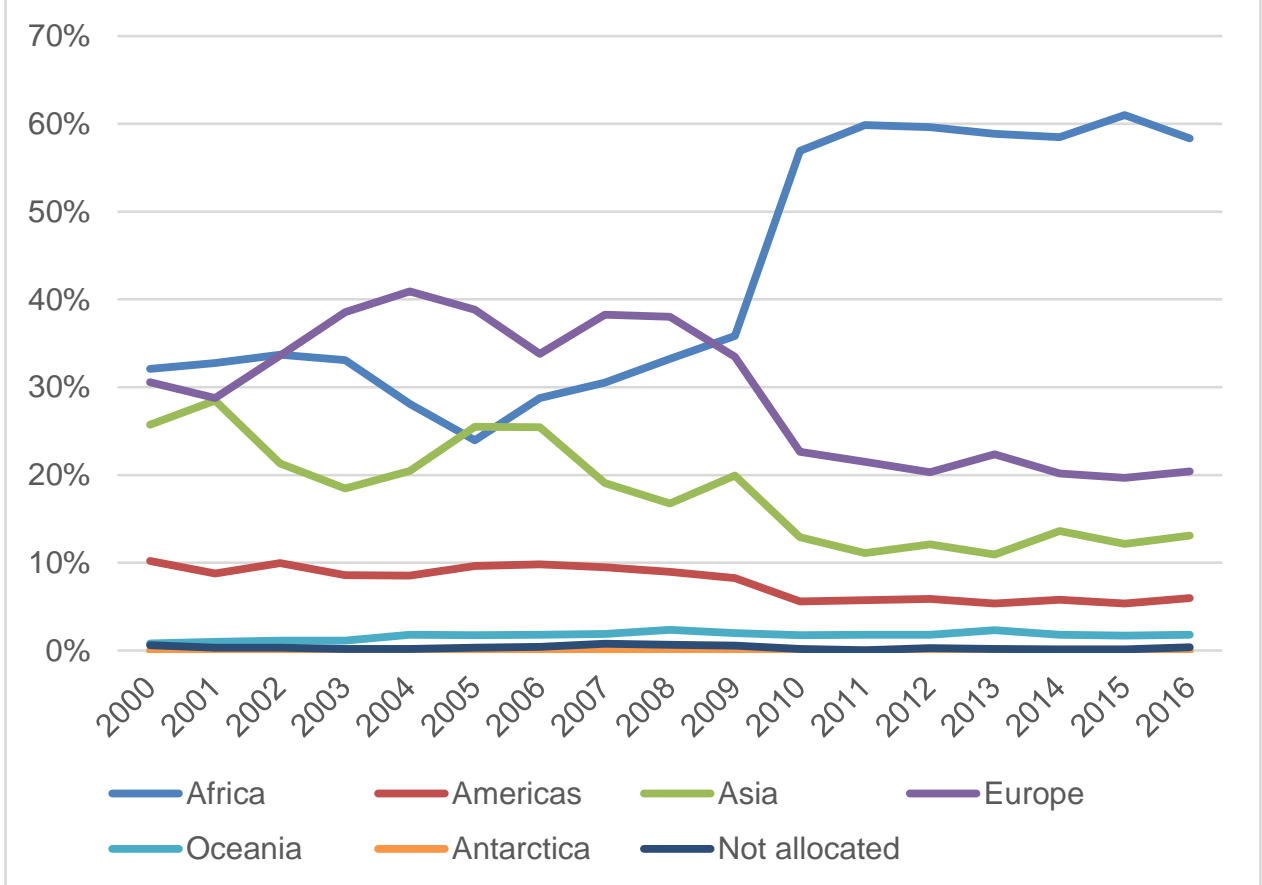

Source: Calculations from Quantec data. The 2009-2010 jump is largely due to reporting adjustments for exports to $S A C U$.

Figure 4: South Africa's exports of processes/prepared foodstuffs to Africa are driven by exports to SADC and SACU exports

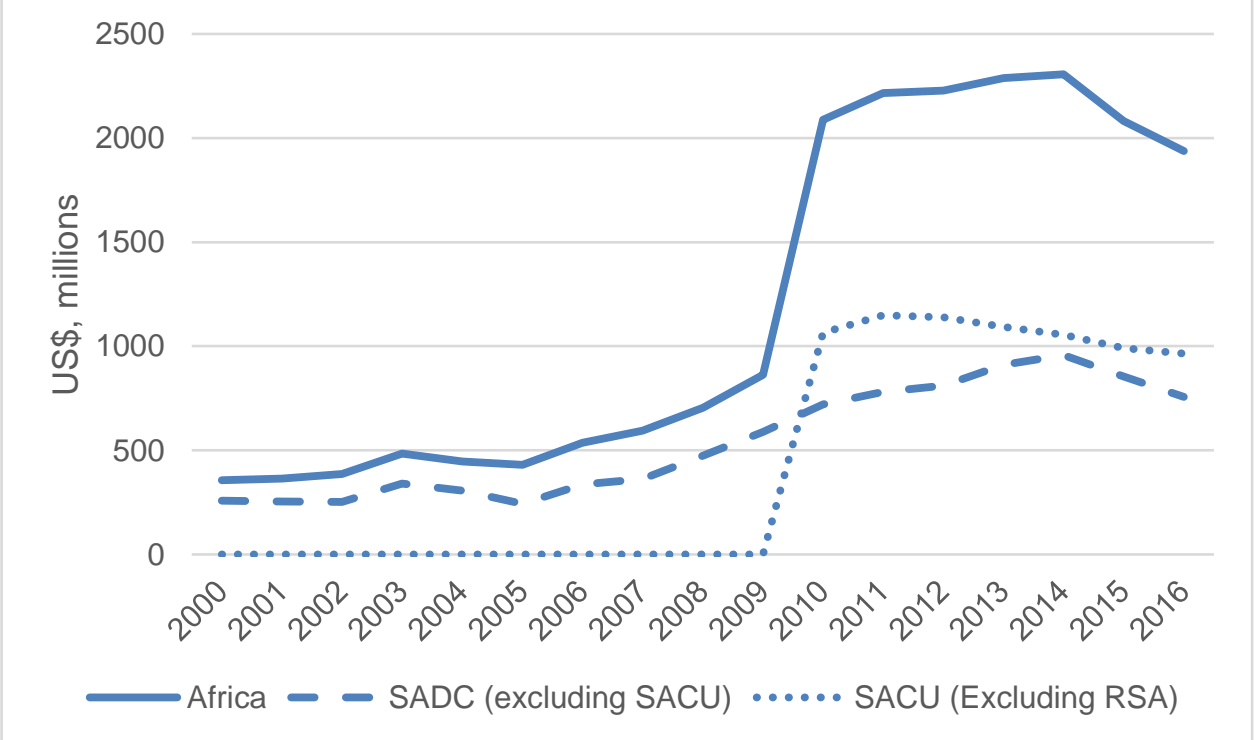

Source and notes (as above) 
There are obvious transport cost advantages for South African suppliers supplying the region as opposed to deep sea markets. In addition, the spread of supermarkets and the related investments in logistics and distribution centres have lowered costs for supply within the region.

The movement of processed food in the region has been driven in the last two decades by the rapid expansion of South African supermarket chains. The two main South African supermarket chains, Shoprite and Pick n Pay jointly have almost 400 stores in 16 African countries, majority of which are in southern African countries. In most countries, a handful of supermarket chains dominate the formal retail sector. These chains target, through different formats, high-end affluent consumers in urban areas as well as lower income consumers in peri-urban and rural areas.

The processed and packaged food products sold in supermarket chains located outside of South Africa are largely imported from South Africa and deep-sea suppliers. For example, it is estimated that more than $80 \%$ of the products sold in supermarkets in Zambia are imported, mostly from South Africa (Ziba and Phiri, 2016). The region as a whole has a net trade deficit in food products, due in large part to the deficit of South Africa, meaning opportunities for suppliers in the southern African region to build scale, capabilities and competitiveness through supplying supermarkets in the region. There are also opportunities for South African suppliers to grow their exports into the region through the expanding network of supermarket chains. Supermarkets therefore can be a strong catalyst to stimulate food processing and light manufacturing industries in southern Africa. The development of such industries is squarely in line with the Southern African Development Community's 'Industrialisation Strategy and Roadmap, 2015-2063' (das Nair and Chisoro, 2016). The relationships and balance of power between retailers and suppliers in the region is therefore important for agro-processing value chains.

Second, there is potential for firms to build capabilities for global competitiveness through competing regionally (Fessehaie and Morris, 2013; Kaplinsky and Morris, 2015). Upgrading in regional value chains is likely to be easier than in global value chains as these chains are likely to be less tightly governed or controlled (Keane 2015). According to UNCTAD (2013:92): "Regional value chains present opportunities for improving productivity...both for domestic firms with export potential and those that produce goods predominantly demanded at the national and regional levels. For domestic firms...regional value chains give them the opportunity to upgrade and achieve international competitiveness, thereby making it easier to connect with GVCs." (cited in Keane, 2015).

Third, given existing regional integration agreements and policies (in the case of southern Africa, the SADC free trade agreement, SACU etc.), there is greater scope for collaborative efforts, including by governments, in supporting upgrading and developing value chains. In this context, the political and economic realities and the respective country policies are important.

Finally, a few large regional players in agro-processing value chains dominate not just South African, but also regional markets in terms of ownership, production and investment. In the case of key processed food products for instance, South African multinationals like RCL Foods Limited, Country Bird Holdings Limited and Astral Foods Limited are key players across the region in poultry; Illovo Sugar and Tongaat Hullet dominate the region in sugar and Tiger Brands and Pioneer Foods lead in milling. These firms are also often vertically integrated. Understanding strategies, investment decisions and relationships in the value chain is important in evaluating relative bargaining power.

At the retail end, it is the same handful of South African supermarket chains that collectively dominate the formal retail sector in many southern African countries. This allows upgrading 
opportunities for suppliers as these supermarkets have a greater incentive to develop suppliers that can supply their stores throughout the region with products of the required quality, consistency and characteristics. But there are also clear concerns of abuse of buyer power that arise given the market power of large supermarket chains as this paper highlights.

\subsubsection{Competition policy and links to industrial and other policies}

Understanding strategies of the large lead firms that control regional food and agro-processing value chains is critical for formulating effective policy interventions. This requires mapping out the structure of each value chain beyond national borders where appropriate and evaluating the balance of power at each level. From a BRICS perspective, it is also useful to be able to compare the relative experiences of other BRICS countries to southern Africa's in similar value chains.

The overviews suggest that in agro-processing value chains the power often rests with firms that control key inputs (for instance, in poultry and sugar, but also in other sectors such as fertiliser); with firms that have economies of scale advantages (in animal feed and poultry, but also in sectors like dairy) and with firms that control important routes to market (the supermarket chains). This is not to suggest that there have been no competition concerns at other levels, for instance, at the processing level (e.g. in milling and baking, and in dairy). However even in these cases, the lead firms exert considerable control over the entire value chain including through substantial vertical integration.

Competition policy is only one of the tools available to improve competitiveness and to promote growth in these value chains. While it can be effective in curbing anti-competitive conduct and maintaining competitive rivalry between existing players, it cannot actively introduce new players into a value chain. In South Africa, inclusive participation in the economy is a key objective of several economic policies, including competition policy. This is where well-designed industrial and agricultural policies can help, in conjunction with competition policy. But this requires coordination between government departments and players in the value chain, nationally and regionally, to ensure 'optimal' competition at each level. Coordination is essential for investment in production capacity and development of capabilities and it includes supporting long-term competitiveness of the whole value chain. The coordination required extends to the governance of the value chain to ensure that large or lead firms do not continue to extract the maximum rent that they can, and that new entrants are allowed the opportunity to participate. Competition authorities and other relevant government departments in the southern African region can be part of supporting dynamic regional value chains, and improved global competitiveness of regional producers through, for example, coordinating on how competition concerns are collectively tackled in the region.

In the supermarket sector for instance, intervention can take the form of more organized, sustainable and regionally focused efforts to increase the participation of suppliers. These interventions could aim to, in addition to reducing bargaining power imbalances, build capabilities of suppliers. Successfully developing supplier capabilities requires a much larger, long-term and commercially-oriented approach by supermarkets in partnership with governments. This can be done through the creation of supplier development programmes like the Massmart/Walmart programme (discussed in section 9). Voluntary or mandatory codes of conduct between suppliers and supermarkets can also be a useful way to control the exertion of buyer power, level the playing field and reduce information asymmetries between suppliers and supermarkets. Such codes of conduct 
can be encouraged by national governments, and harmonised across the region given that it is largely the same retailers that operate in the different countries in the region. There are initiatives underway currently to develop such a code of conduct (discussed in Section 9 and 10).

\subsection{Brief background on the history and evolution of food sectors in South Africa}

\subsubsection{History of protection in the food sector}

The history of the development of the food sector in South Africa is important to understand some of the outcomes we see today.

The former Union of South Africa established a comprehensive support system for white farmers through the Land and Agricultural Bank, and the passing of the Co-operative Societies Acts of 1922 and 1939. The support measures included the provision of agricultural finance, inputs, extended land tenure, and marketing services (Vink and Kirsten, 2000).

The Marketing Act of 1937 (consolidated in 1968) became the cornerstone of agricultural policy governing the marketing of the majority of agricultural production in South Africa. The main provisions of the Act included those giving powers to the Control Boards for the following functions: the imposition of levies; the authority to buy a product at determined prices or on such basis the Minister may approve ('surplus removal'); sales through a marketing board ('single channel marketing schemes'); and, fixing prices and margins (Kassier, 1992: 7-8). State intervention into the agricultural sector continued in much the same fashion over the next few decades, characterized by single marketing channels and tightened controls over prices and the movement of produce, as well increased subsidies to white farmers (Kirsten and van Zyl, 1996).

With regard to the main grain crops, the Maize and Wheat Boards were the intermediaries between the farm gate and the processing levels. The industry operated through a single marketing channel, with producer cooperatives providing for input procurement and marketing of produce. Over time cooperative activities extended to other production functions (such as financing and processing), importantly becoming a powerful collective bargaining tool for famers (Tregurtha et al., 2010). A key activity of the cooperatives included the operation and ownership of grain silos, constructed with massive state support extending to infrastructure, capacity payments, handling, debt relief and tax concessions (Amin and Bernstein, 1995; LAPC, 1994). These effectively became regional monopolies as they were appointed as agents by the respective boards (Vink, 2012). The cooperatives and the control boards were also exempted from competition law (Kassier, 1992).

The deregulation by the new Marketing Act of 1996 abolished the control boards and fully liberalized all markets except for sugar (Vink and Van Rooyen, 2009; Sandrey and Vink, 2007). The process included the establishment of the National Agricultural Marketing Council (NAMC), and followed trade liberalisation. The aim was to promote improved marketing of agricultural products and market access to all market participants (Vink and Kirsten, 2002).

Liberalisation generally meant decreased support. There have been the expected changes in land use, with a declining area planted with maize, and changes in the composition of output (Tregurtha et al., 2010). Poultry production and horticulture, which had not been supported, have both performed relatively well (Sandrey and Vink, 2007), although still with ongoing imports as we note in the case of poultry in Section 6. 
However, several competition concerns that have arisen since liberalisation stem from conduct that has continued post liberalisation as illustrated by the maize and wheat cartel discussed in Section 8.

The main historic changes in the food sector over time is depicted in the Figure 3 below.

\section{Figure 5: Key historic changes in the food sector in South Africa}

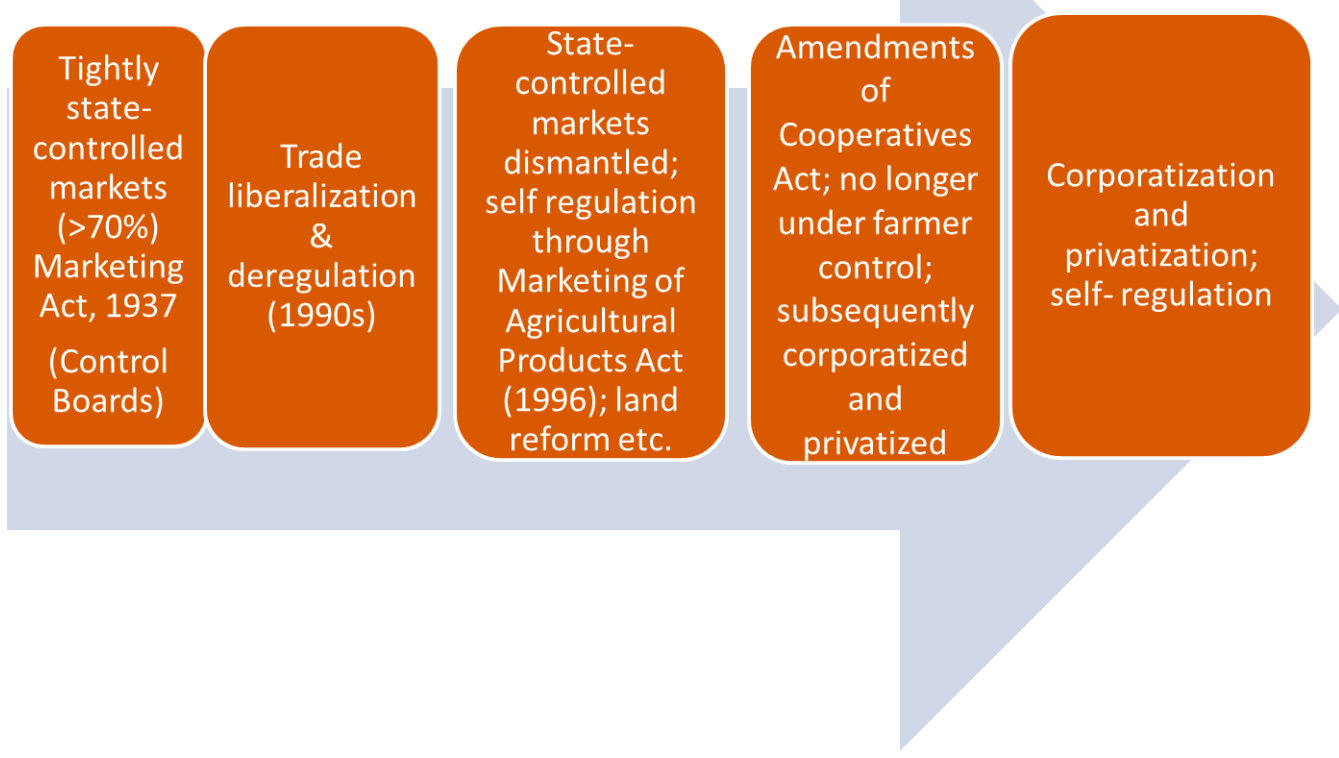

Source: Authors' illustration

\subsubsection{Recent developments in the food sector in South Africa}

While the history is important in understanding some of the outcomes, more recent developments in the food sector also have implications on ownership, market power, control and incentives to compete. This sub-section provides a very brief overview of recent developments in food value chains in South Africa.

\section{Increasing financialisation and growth of agri-investment companies}

Along with rising corporatisation, which has resulted in powerful corporate players shaping the availability, affordability and acceptability of foods (Greenberg, 2017), there has been increasing financialisation of the food sector. The rise of controlling institutional shareholders has given significant power to financial actors in agri-food markets, of which principal institutional investors include insurance companies and pension funds (Clapp, 2012). Large food corporations, such as Tiger Brands, Pioneer Foods and Shoprite have institutions such as the Public Investment Corporation (PIC) $)^{3242}$ (the largest investment fund in South Africa) as their controlling shareholder giving the PIC effective control over investment decisions (Greenberg, 2017). Similarly, as noted in Section 5.5, the

${ }^{3242}$ The PIC has a key mandate to manage the pension funds of government employees. 
Government Employees Pension Fund (GEPF) recently acquired a key player in the fertiliser industry.

Agri-investment companies in South Africa have also been on the rise. JSE-listed investment company, Remgro, for example, holds shares in the agro-food system ${ }^{3243}$ with major interests in RCL Foods and Unilever, as well as in several other strategic economic sectors. This potentially weakens the influence of other actors over agro-food system outcomes and gives such conglomerates an opportunity to maintain or establish positions of power (Clapp, 2012).

Such agri-investment companies are typically large conglomerates with controlling and passive shareholdings in numerous sectors. This increasing web of cross-ownership can have an impact on incentives to effectively compete (for cross ownerships in seeds, for instance, see Section 4.4).

\section{Rising internationalisation}

There has also been increasing global ownership of previously local companies in the South African food sector. In the sugar industry, for instance, Illovo is now a subsidiary of Associated British Foods, while the largest agri-services and grain storage company in South Africa, Afgri, is now owned by Canadian investment group, AgriGroupe. US giant Walmart took over Massmart in the retail sector. This has implications on the strategies of the firms (such as procurement strategies and business models adopted from home countries) and their conduct.

\section{Technology revolution}

Advances in technology have eroded the sectoral boundaries that previously existed between manufacturing and agriculture (Page, 2014). The confines between agriculture and industry, and essentially processed and unprocessed agricultural products, are becoming less distinct - partly a result of the global agricultural sector employing more capital and sophisticated technology, giving scope to rising productivity, transforming global competition and the structure of production. The global agricultural value chain for horticultural crops provides a useful example of agro-industry activities that require technologies and complex industrial processes (keeping products fresh, packaging and innovation are all value adding activities). This means that industrial policies and agricultural policies of a country need to closely speak to each other.

\subsection{Assessment of the Selected Value Chains}

A recent study by the Bureau for Food and Agricultural Policy (BFAP) in South Africa highlights the high input costs faced by maize farmers in South Africa relative to other maize producing countries, including Brazil. Figure 4 below shows the 'establishment costs' in South Africa to produce a tonne of maize compared to costs incurred by farmers in the US, Argentina, Brazil and Ukraine. As evident, South African farmers face higher input costs and a key contributor is fertiliser costs. This adds to food inflation given that maize meal is a staple food in South Africa and raises serious concerns about the affordability of basic foods for poor consumers. Sections 4 and 5 below evaluate two of these inputs in more detail - seeds and fertilisers.

${ }^{3243}$ See Mondliwa, Nhundu, Paelo, Thosago, \& Vilakazi (2017) for a detailed assement of Remgro’s investment strategies 
Figure 6: BFAP estimation of maize establishment cost (US\$ per ton maize produced)

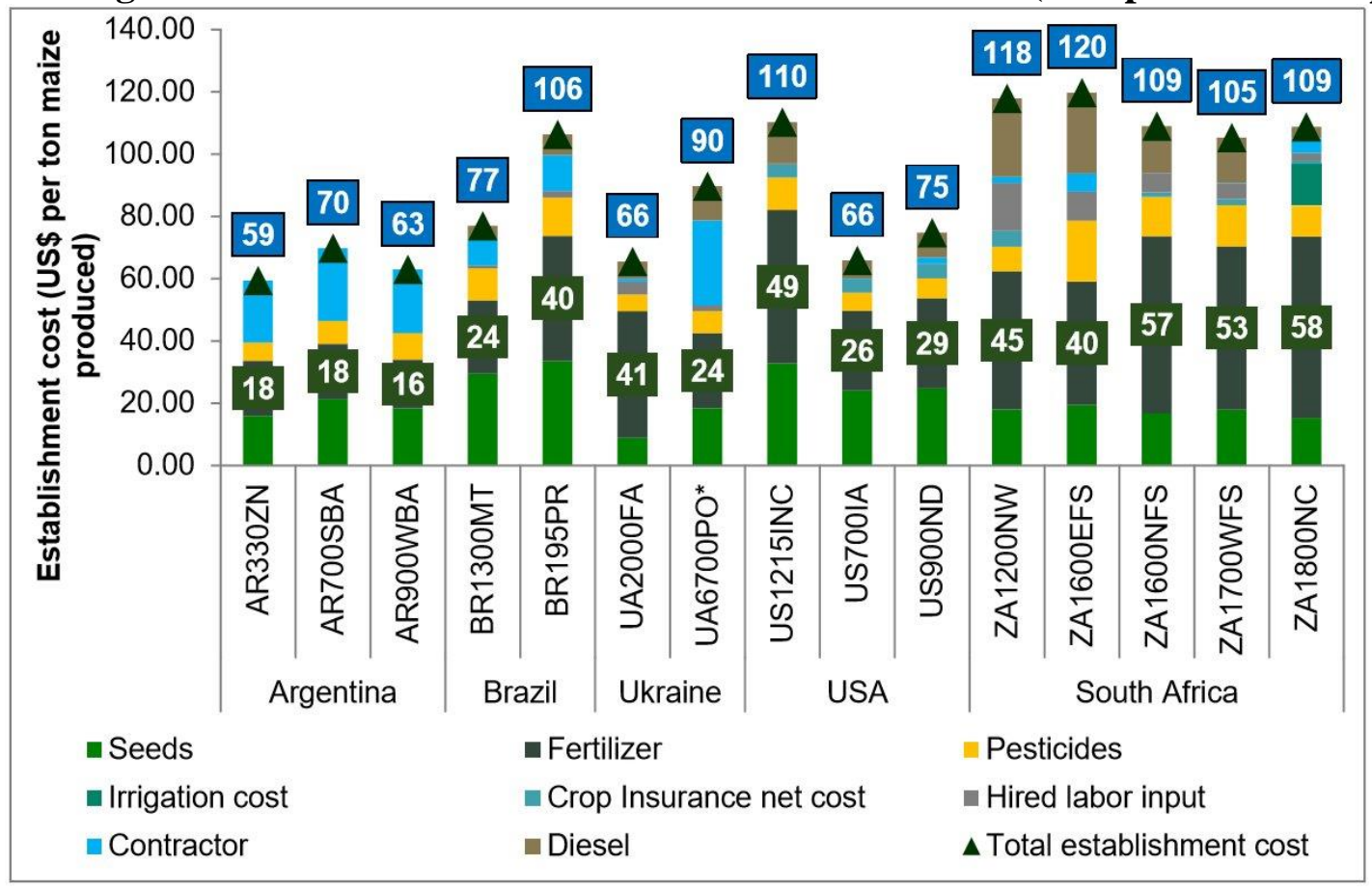

Source: Reproduced from BFAP (2016) - Policy Brief on the 2015/2016 drought

\subsubsection{Seeds Value Chain}

1.4.1.1.A mapping of the key players and ownership structures

The seed market in South Africa is made up of three main categories of agricultural seeds: agronomical seeds, horticultural seeds and forage seeds (Table 1). As of 2014/2015, agronomical seeds made up about $74.5 \%$ of the total market retail value of the whole seed industry with horticultural crops accounting for $16 \%$ while forage and pasture seeds accounted for $9 \%$ (SANSOR, 2015). ${ }^{3244}$

Table 1: Composition of seed markets in South Africa, 2014/15

\begin{tabular}{|l|l|l|l|}
\hline Seed type & $\begin{array}{l}\text { Total Market value } \\
\text { based on Retail } \\
\text { Selling Price (R } \\
\text { Millions) }\end{array}$ & $\begin{array}{l}\text { Share of seed } \\
\text { market (2014/15) }\end{array}$ & $\begin{array}{l}\text { Share of seed } \\
\text { market (2010) }\end{array}$ \\
\hline Agronomical seeds & 4121.69 & $74.5 \%$ & $73 \%$ \\
\hline Horticultural seeds & 887.64 & $16.1 \%$ & $18.5 \%$ \\
\hline Forage and pasture seeds & 521.20 & $9.4 \%$ & $7.5 \%$ \\
\hline Total & $\mathbf{5 5 3 0 . 5 3}$ & $\mathbf{1 0 0 \%}$ & $\mathbf{1 0 0 \%}$ \\
\hline
\end{tabular}

Source: SANSOR ( 2015) and DAFF (2015)

3244 Agronomical seeds include maize, soya bean, wheat, sunflower, barley, sorghum etc.; Horticultural crops largely consist of vegetables and fruit e.g. spinach, squash, sweet corn, tomato etc. 
The seed value chain consists of three main levels: 1) Research and Development; 2) Production/multiplication of seeds; 3) Processing/ packaging and distribution (Figure 5). Research and development involves the innovation required to develop seeds with high yield rates and with resistance to disease, drought and other environmental stresses. Under research and development, there are three main components necessary: a diverse germplasm pool, advanced breeding technologies and trait selection or development. Germplasm contains the genetic material from which seed characteristics such as the amount of crop yield and reaction to the environment are determined (Competition Tribunal, 2010). The breeding technologies are the processes and technology used to improve the qualities of the seed. The biotech traits are specific genes taken from other organisms used to create additional improved qualities to the seed such as pesticide resistance.

Seed companies can be involved in at least one of these stages of the research, development and breeding of seeds. Once this process is complete and a viable seed has been created, the seeds then go into the production and multiplication stage of the value chain. The end products are then processed, packed, stored and distributed to consumers. Depending on the type of seeds developed, the seeds then go to the milling, fertiliser or animal feed sectors.

\section{Figure 7: Value chain of the commercial seed market}

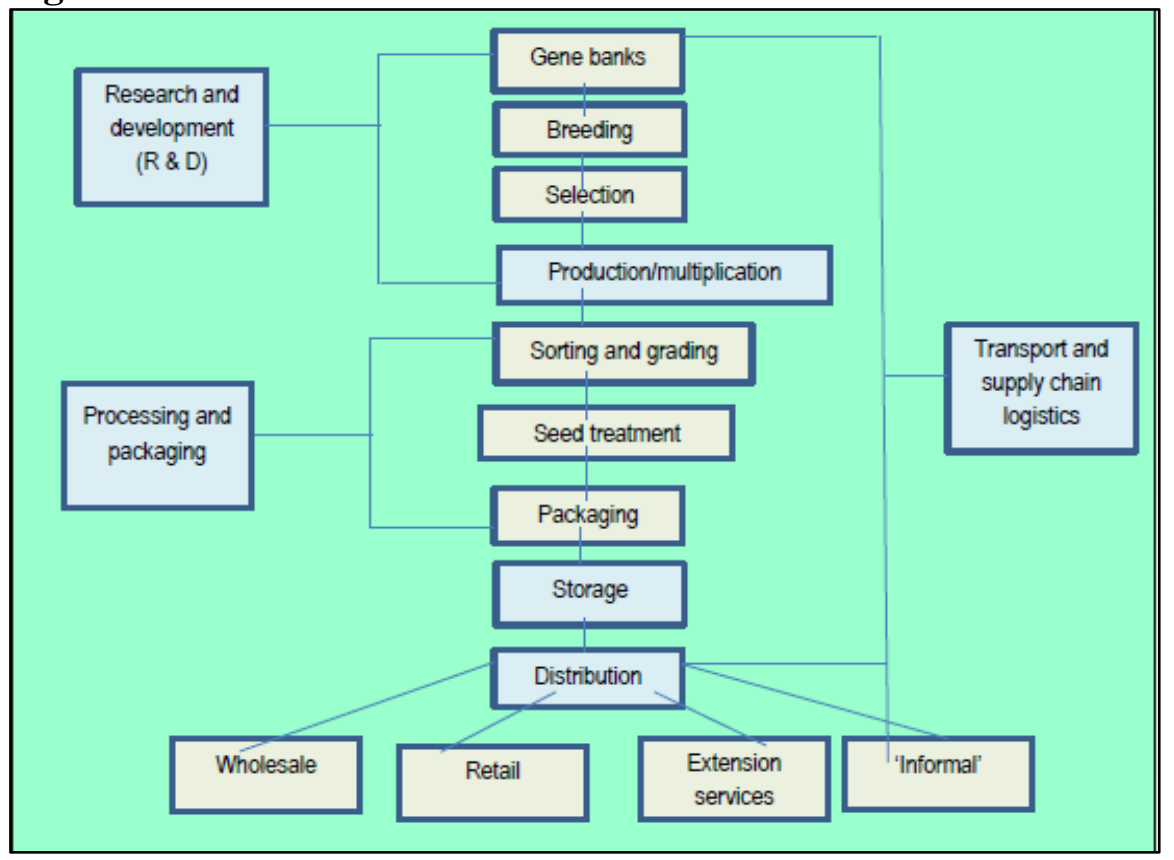

Source: (DAFF, 2015)

The seed market globally and nationally is highly concentrated and has continued to consolidate over the last five years. Globally, only seven firms control about $71 \%$ of the global seed market (ETC Group, 2015). In South Africa, the seed market is even more concentrated with only two main players in the market: Monsanto and Pioneer Hi-Bred International.

Monsanto is the largest seed firm in South Africa. It has the highest amount of sales for maize seed and supplies $90 \%$ of commercially planted soybean in South Africa (African Centre for Biodiversity, 2017a). It began operations in South Africa in 1968 and is part of a global group involved in the research, manufacture, production and distribution of seeds, herbicides and vegetables (Who Owns Whom, 2017a). In the 1990s, it acquired Sensako and Carnia, two local seed companies, 
providing it with a major stake in the South African market. Sensako's acquisition alone gave Monsanto $45 \%$ of the agrochemical market for field crops. In 2005, Monsanto acquired Seminis, the world's largest fruit and vegetable seed company which gave it ownership of plant breeders' rights to a range of South African seed varieties (Pollack, 2005; African Centre for Biodiversity, 2017a). In May 2017, the Competition Commission conditionally approved a merger in which Bayer Aktiengesellschaft (Bayer) acquired Monsanto Corporation (Monsanto) (Competition Commission South Africa, 2017a) (see section 4.4) on discussion of mergers concerning Monsanto).

Pioneer Hi-Bred International Inc (Pioneer) is a subsidiary of E.I. DuPont De Nemours \& Co (DuPont), a diversified bio-chemical company listed on the New York Stock Exchange. Its main activities include research, product development of commercial seeds as well as the production and distribution of seed varieties such as alfalfa, canola, corn, inoculants, mustard, pearl millet, rice, sorghum, soya beans, sunflower and wheat. In 2012, Pioneer acquired Pannar Seed, a South African company involved in research and development of seeds in South Africa. Pannar had been in operation since 1958. The acquisition gave the firm, a post-merger market share of $48 \%$ of the hybrid maize seed market.

In July 2017, the Competition Commission also conditionally approved DowDuPont Inc. (DowDuPont) acquisition of Dow Chemical Company (Dow) and E.I. du Pont de Nemours and Company (DuPont) (Competition Commission South Africa, 2017b). Dow is a global diversified chemicals company involved in the research, development, production and distribution of plastics and chemicals, agricultural sciences including seeds, hydrocarbon and energy products and services.

Bayer's merger with Monsanto would raise their combined market share to 29\% while Dow's merger with DuPont (Pioneer) would give it a 25\% market share (ETC Group, 2015). Together these companies would hold a 54\% market share of the global seed market.

\subsubsection{Regulation and barriers to entry}

Several acts and regulation govern the seed industry. Some of the main regulations include: ${ }^{3245}$

- The Plant Improvement Act, 1976 (Act No. 53 of 1976);

- The Plant Breeders' Rights Act, 1976 (Act No. 15 of 1976);

- The Agricultural Pests Act, 1983 (Act No. 36 of 1983);

- The Genetically Modified Organisms Act, 1997 (Act No. 15 of 1997);

- Various secondary acts such as the Fertilisers, Farm Feeds, Agricultural Remedies, and Stock Remedies no. 36 of 1947 (as amended).

Due to the high level of research and innovation involved in the seed industry, seed companies are given plant breeders rights or patents to enable them to gain returns from their investments. These Plant Breeders Rights (PBRs) and patents, may however, have the additional impact of raising barriers to entry. PBRs are often offered with regards to hybrid varieties and give the breeder a 20 year exclusive commercial production of the protected hybrid variety (Competition Tribunal, 2010). The rights protect the variety and not the method in which the seed is obtained which means that a farmer can save and reuse the seeds. There are certain requirements that need to be fulfilled in order for the breeder to gain a PBR over a seed variety which include distinctness, uniformity, stability and novelty (Competition Tribunal, 2010). Patents are offered with respect to GMs as genetic

3245 SANSOR website. 
modifications is essentially the creation of a wholly new crop (Competition Tribunal, 2010). Patent protection can extend beyond the seed product to include the process as well. Under the patent, farmers are only permitted to use the seed to plant one crop and not reused. Companies often use contracts to enforce these conditions and have been known to make unannounced inspections of crop fields. PBRs and patents serve to bolster the market power held by the seed companies.

The extended periods required to develop the seed and to gain regulatory approval for seed development also acts as a significant barrier to entry (African Centre for Biodiversity, 2017a), As discussed above, there are three components of the breeding level of the value chain, a germplasm pool, advanced breeding technologies and biotech traits. With regards to the pool of germplasm, a number of years are required to develop competitive amounts of germplasm to enable breeding of seeds. Pannar took about 52 years to develop its pool of germplasm specifically suited for the South African region (Competition Tribunal, 2010). Prior to the merger between Pioneer and Pannar, Pioneer had been present in South Africa for 18 years but was yet to develop germplasm suited to the regions of South Africa or Africa (Competition Tribunal, 2010). Further, a Greenfields entrant would require at least eight years gain regulatory approval for trait development and then a further three to five years to get approval for the use of the traits within South Africa (Competition Tribunal, 2010). Given the time required for an entrant to develop and market a commercially viable seed, an entrant would struggle to compete effectively with the incumbents in the market. The costs of research can be prohibitive. The second component of advanced breeding technologies as well as the development of biotech traits requires substantial capital investment. While, both of these components can be accessed through contracts and licensing with large companies such as Monsanto, it also means that companies are forced to source essential inputs from their rivals which has its own competition concerns.

A combination of these barriers to entry means that there is unlikely to be a Greenfields entrant into the seed development market. The present structure of two seed companies with substantial market power raises a number of competitive concerns especially since seeds remain a key input in the food value chain.

\subsubsection{Performance of the seed industry in South Africa}

\subsection{Production}

An analysis of agronomic seed groups, which accounts for over $70 \%$ of the seed market, shows that maize makes the greatest share of the retail price value in the market with $88.63 \%$ (Table 2). This includes both white maize (generally used for human consumption) and yellow maize (generally used for animal consumption). Soya bean and wheat have next highest market value although together their share is less than $10 \%$.

Table 2: Top 10 South African commercial agronomic seed crops by value, 2014/15

\begin{tabular}{|l|l|l|}
\hline Crop & Value (R'000) & \% of total market value \\
\hline Total maize & 56655954 & $88.63 \%$ \\
\hline Soya bean & 3941814 & $6.17 \%$ \\
\hline Wheat & 1705729 & $2.67 \%$ \\
\hline Dry bean & 761219 & $1.19 \%$ \\
\hline
\end{tabular}




\begin{tabular}{|l|l|l|}
\hline Sunflower & 351412 & $0.55 \%$ \\
\hline Barley & 310194 & $0.49 \%$ \\
\hline Grain sorghum & 111635 & $0.17 \%$ \\
\hline Other & 43165 & $0.07 \%$ \\
\hline Groundnut & 39456 & $0.06 \%$ \\
\hline Total market & $\mathbf{6 3 9 2 0 5 7 8}$ & $\mathbf{1 0 0 \%}$ \\
\hline
\end{tabular}

Source: DAFF (2015)

In terms of production, growth has been inconsistent with an increase in the 2011/12 season before production dropped again (

Figure 8).

Figure 8: Total agronomic seed production (tons), 2010/11 - 2014/2015

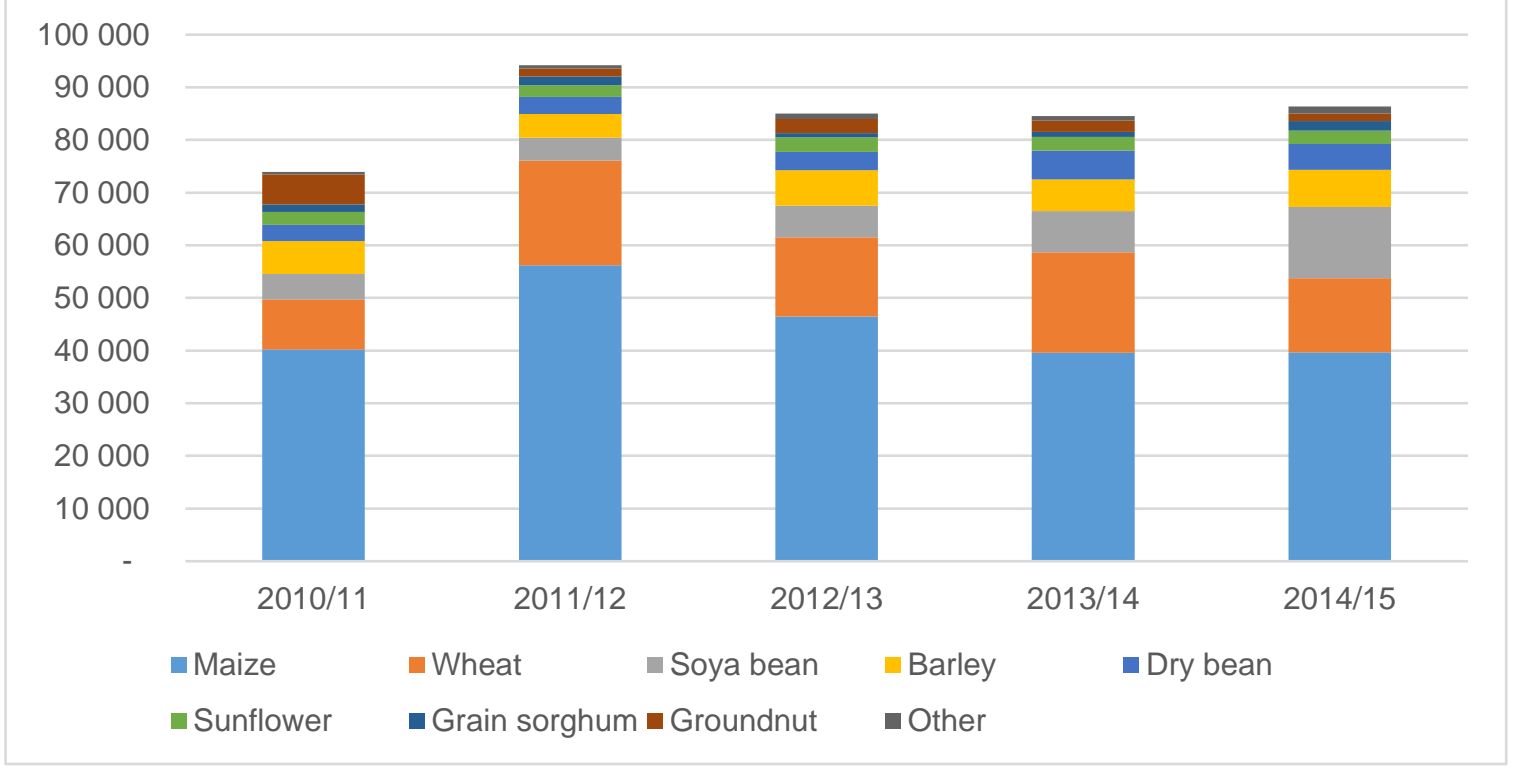

Source: DAFF (2015)

Although production has dropped over the last five years, yield rates particularly for maize, wheat and grain sorghum have been rising over the last twenty years. By contrast, yield rates for groundnuts, soya bean and sunflower have remained largely constant over the same period of time (Figure 9). Perhaps unsurprisingly, the main seeds in which the large seed firms mentioned above are invested in are for maize, wheat and grain sorghum. Substantial investment has likely been made into the development of new varieties of these seeds resulting in higher yield rates. 
Figure 9: Yield rates for main agronomical seeds (1990/91 -2016/17)

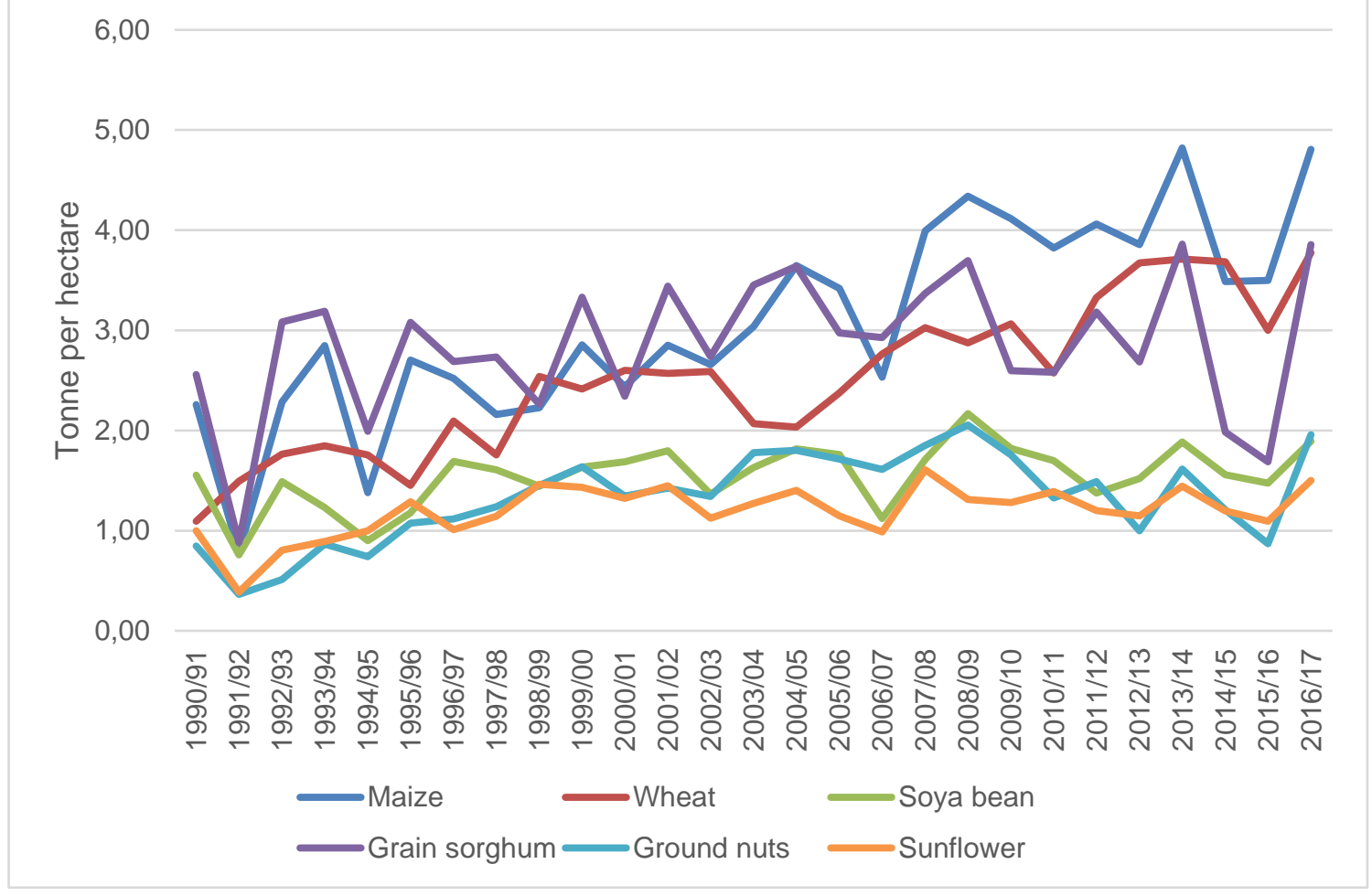

Source: DAFF (2017)

\subsection{Exports and Imports}

Exports of agronomic seeds have declined steadily between 2010/11 and 2014/15 largely due to the decline in maize seed which accounts for the bulk of agronomic seeds. (Figure 10). The decline was particularly sharp between 2011/12 and 2012/2013, likely due to drought conditions that persisted into the 2014/15 season.

Figure 10: South Africa's agronomic seeds exports, 2010/11-2014/15

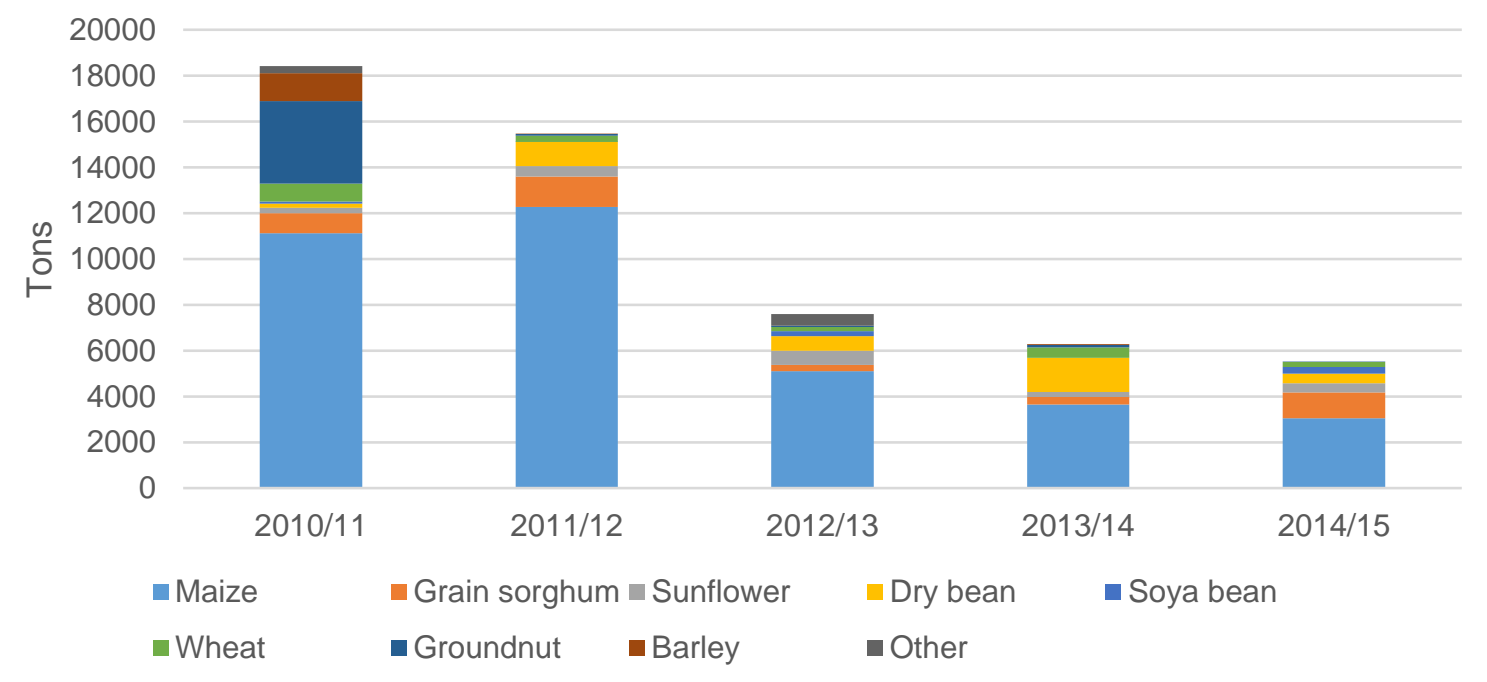

Source: DAFF (2015) 
Maize seed exports dropped significantly from the 2011/2012 financial year coinciding with high increase in prices (Table 3). The high prices however may have been reflective of low supply of maize.

Imports of agronomic seeds into South Africa have also been inconsistent. There were significant imports in 2012 contributed largely by imports of maize seed and grain sorghum. This dropped the following year (Figure 9).

\section{Figure 11: Imports volume of agronomic crops seeds, 2011-2015}

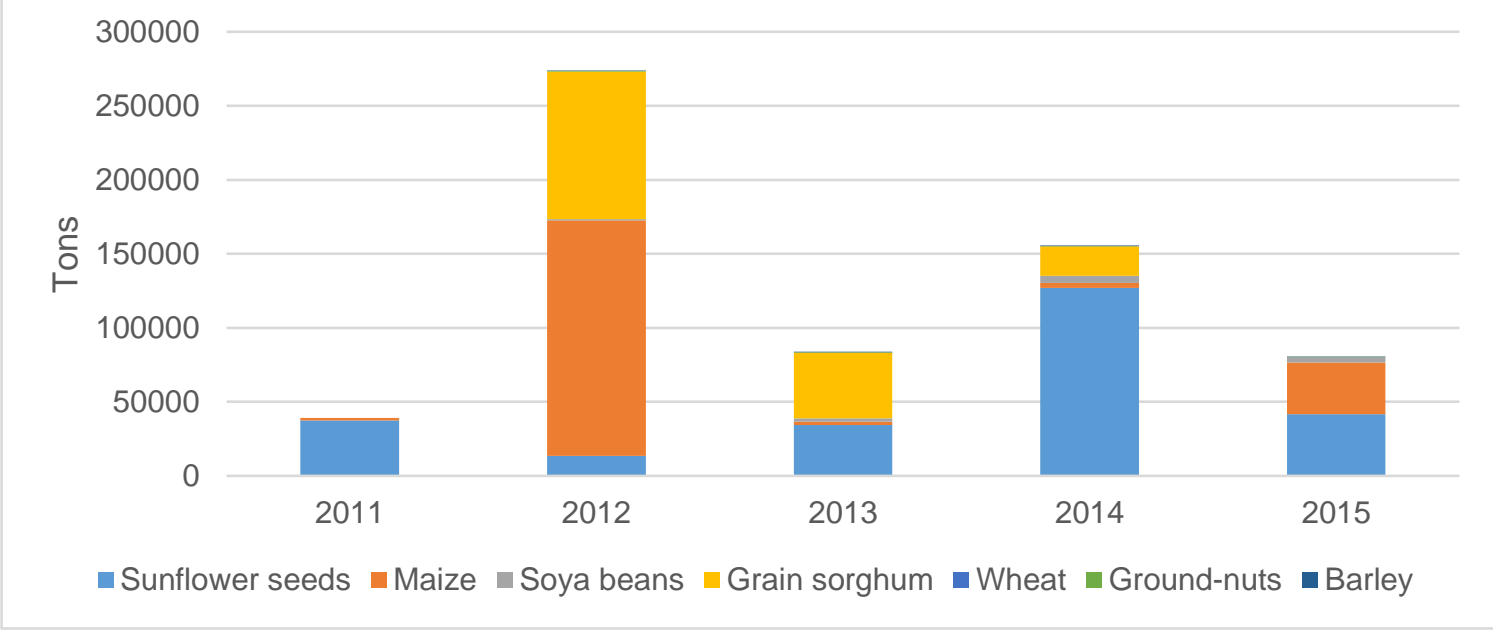

Source: DAFF (2015)

\subsection{Prices}

Prices have generally been on the rise for the period 2013 - 2015. Except for the 60,000-kernel bag of yellow maize seeds, different varieties of agronomical seeds both GM and non-GM have experienced an increase in prices (Table 3). It is not yet clear why prices of the 80,000-kernel bag of yellow maize seeds have increased while that of the 60,000-kernel bag of yellow maize seeds have deceased. This will be investigated further.

There have been increases in prices for grain sorghum seed as well as the GM white maize seeds variety. These are the two product markets in which both Pioneer and Pannar were operating in and which were considered for purposes of the Pioneer/Pannar merger (Competition Tribunal, 2010). The conditions imposed on the merging parties upon approval of the merger included undertakings that prices for all Pannar maize hybrids and for Open-Pollinated Varieties (OPVs) were not to exceed inflation for a period of three sales season (see section 4.4.1). While the price increases for GM white maize seeds have not been substantially greater than inflation, the increase for grain sorghum seeds have been.

It is important to note however that average prices alone may provide an inaccurate picture of the trends in the market. In the hybrid maize market, in particular, due to high levels of innovation, there are new varieties of seed released regularly. ${ }^{3246}$ These seeds may have better characteristics including higher yield rates and faster rates of maturity. This in turn attracts greater demand and

3246 Telephonic Interview with the Agricultural Research Council, conducted on 21 September 2017. 
higher prices even as the prices of older varieties drop. In a market as concentrated as this, concerns arise as to whether the pricing of new varieties is competitive or set to extract maximum rents. The same competition concerns arise as to the levels of innovation and new products released into the market.

Table 3: Average Rand price of agronomical seeds (2013-2015)

\begin{tabular}{|c|c|c|c|c|c|}
\hline & Cultivars/weight & 2013 & 2014 & 2015 & $\begin{array}{l}\text { \% change } \\
(2013-15)\end{array}$ \\
\hline \multirow{2}{*}{$\begin{array}{l}\text { White maize seeds (60 } \\
000 \text { kernels/bag) }\end{array}$} & Non-GM & 1233 & 1310 & 1350 & $9.5 \%$ \\
\hline & GM & 1900 & 2167 & 2353 & $23.8 \%$ \\
\hline \multirow{2}{*}{$\begin{array}{l}\text { Yellow maize seeds (60 } \\
000 \text { kernels/bag) }\end{array}$} & Non-GM & 1488 & 1653 & 1755 & $17.9 \%$ \\
\hline & GM & 2298 & 2638 & 1765 & $-23.1 \%$ \\
\hline \multirow{2}{*}{$\begin{array}{l}\text { White maize seeds (80 } \\
000 \text { kernels/bag) }\end{array}$} & Non-GM & 2042 & 2151 & 2266 & $10.9 \%$ \\
\hline & GM & 2821 & 2970 & 3129 & $10.9 \%$ \\
\hline \multirow{2}{*}{$\begin{array}{l}\text { Yellow maize seeds ( } 80 \\
000 \text { kernels/bag) }\end{array}$} & Non-GM & 2014 & 2156 & 2364 & $17.3 \%$ \\
\hline & GM & 2699 & 2852 & 3030 & $12.2 \%$ \\
\hline \multirow[t]{2}{*}{ Grain sorghum seeds } & $20 \mathrm{Kg}$ & 1150 & 1336 & 1476 & $28.3 \%$ \\
\hline & $25 \mathrm{Kg}$ & 1287 & 1568 & 1750 & $35.9 \%$ \\
\hline Soya bean seeds & $25 \mathrm{Kg}$ & 594 & 659 & 690 & $16.1 \%$ \\
\hline \multirow[t]{2}{*}{ Sunflower seeds } & 150DP/bag & 1476 & 1501 & 1566 & $6.0 \%$ \\
\hline & 180DP/bag & 1499 & 1681 & 1785 & $19.0 \%$ \\
\hline
\end{tabular}

Source: (DAFF, 2015)

1.4.1.4.Trends in concentration and outcomes of key competition cases

As mentioned above, the global seed industry is highly concentrated and continues to consolidate. The highly concentrated nature of the global market is replicated in the South African market. There are two main companies that own significant portions of the registered varieties. In the maize market, for both yellow and white GM maize seeds, Du Pont Pioneer and Monsanto own $80 \%$ of the seed varieties in the market (Table 4).

Table 4: Number of maize registered varieties owned by major seed companies in South Africa, November 2016

\begin{tabular}{|l|l|l|l|l|}
\hline \multicolumn{2}{|l|}{ Maize variety } & Du Pont Pioneer/Pannar \% & Monsanto \% & Total \% \\
\hline \multirow{2}{*}{$\begin{array}{l}\text { Yellow } \\
\text { maize }\end{array}$} & GM & 71.6 & 12.7 & $\mathbf{8 4 . 8}$ \\
\cline { 2 - 5 } & Hybrid & 56.4 & 5.8 & $\mathbf{6 3 . 4}$ \\
\cline { 2 - 5 } & OPV & 14.3 & 0 & $\mathbf{1 4 . 3}$ \\
\hline \multirow{3}{*}{$\begin{array}{l}\text { White } \\
\text { maize }\end{array}$} & GM & 80.3 & 8.6 & $\mathbf{8 8 . 9}$ \\
\cline { 2 - 5 } & Hybrid & 41.8 & 6.2 & $\mathbf{4 8}$ \\
\cline { 2 - 5 } & OPV & 6.9 & 3.4 & $\mathbf{1 0 . 3}$ \\
\hline
\end{tabular}

Source: African Centre for Biodiversity (2017)

Three main types of seed systems exist in South Africa: Open-Pollinated Varieties (OPVs), hybrids and Genetically Modified (GM) seeds. OPVs refer to seeds that are a result of random crosspollination (Grain SA, 2011). While the yield potential is less than other varieties, the costs are low 
and the seed can be recycled. They also have a broader genetic base and are resistant to environmental stresses. They are also not subject of Plant Breeders' Rights IPBRs) or other Intellectual Property (Competition Tribunal, 2010). Hybrid seeds are the result of cross-pollination and breeding between the first generation progeny of two unrelated plants of related species (Grain SA, 2011). These seeds usually have higher yields but are often more expensive and cannot be recycled (Competition Tribunal, 2010). GMs are completely new strands of crops created by breeding a particular gene sequence taken from an unrelated species and combining it with the genes of the seed to be modified (Competition Tribunal, 2010).

Overall, OPVs account for the majority of the seed systems making up about $56 \%$ of the total seed market. However, in the maize seed market (which makes up at least $70 \%$ of total seed industry turnover), hybrid maize makes up $80 \%$ of the total maize seed sold and $56 \%$ of the value of the total seed market (Competition Tribunal, 2010; DAFF, 2015). This is important because it means that the firms involved in the production of maize seed and hybrid maize seed, in particular, are in the more profitable portion of the value chain. Commercial breeders often have little incentive to develop OPVs over hybrids because they are less profitable (Competition Tribunal, 2010). The average bag of hybrid seeds can be as much as five times more expensive than OPVs (Competition Tribunal, 2010).

For the hybrid varieties, the Du Pont Pioneer and Monsanto own 63.4\% of the varieties of yellow maize and $48 \%$ of the varieties of white maize. Du Pont Pioneer and Monsanto, by contrast, own less than $15 \%$ of the OPV seeds of both yellow and white maize, giving credence to the fact that there may be less incentive to develop these seeds as they are less profitable.

Monsanto and Du Pont Pioneer also have ownership of a substantial portion of the other registered agronomic seed varieties. Their ownership stands out in particular for wheat as well as for GM and non-GM cotton seed varieties (Table 5). The three major players - Monsanto, Du Pont Pioneer Pannar, and Karoo Seed own nearly $70 \%$ of the top eight crop varieties (African Centre for Biodiversity, 2017a).

Table 5: Percentage of registered seed varieties owned by merging parties in South Africa, November 2016

\begin{tabular}{|l|l|l|l|}
\hline Seed variety & Du Pont Pioneer \% & Monsanto \% & Total \% \\
\hline Soya GM & 34.9 & 4.6 & 39.5 \\
\hline Soya non-GM & 11.4 & 2.9 & 14.3 \\
\hline Wheat & 19.0 & 54.3 & 73.3 \\
\hline Cotton GM & & 84.6 & 84.6 \\
\hline Cotton non-GM & - & 66.7 & 66.7 \\
\hline Other agronomic & 37.4 & 0.5 & 37.9 \\
\hline
\end{tabular}

Source: (African Centre for Biodiversity, 2017b)

In terms of market shares calculated for antitrust purposes in 2010, the Competition Commission prior to the Pioneer/Pannar merger found that Monsanto, Pannar and Pioneer had $90 \%$ of maize, wheat and sorghum seed markets (Competition Tribunal, 2010). The firms' ownership of patents served to bolster their market shares in these markets. Prior to the merger, the market shares in the hybrid maize market which made the largest percentage of the seed market were 50\% to Monsanto, $30 \%$ to Pioneer and 18\% to Pannar (Competition Tribunal, 2010). Pannar's market share in the hybrid 
maize market had been declining steadily from about $60 \%$ in the 1990 s to $51 \%$ in the 2000 s to $18 \%$ in 2010. Smaller companies including Linkseed, K2 Agri and Agricol had a combined market share of less than 5\% in 2010 (Competition Tribunal, 2010).

The concentration in the sector is underlined by the number of active breeders in South Africa. The maize market is dominated by the private sector with 26 active breeders out of 27 being private entities (African Centre for Biodiversity, 2017a). The soya bean market has only seven active breeders, sunflower has ten and wheat, nine. Even in these markets, the private sector dominates with only two public sector breeders, sunflower and wheat markets combined had only 26 active breeders. Monsanto, Pannar and Dupont-Pioneer together employ $80 \%$ of private sector maize breeders, $100 \%$ of soybean and 100\% of sunflower breeders in the country (African Centre for Biodiversity, 2017a).

A major concern with the continued consolidation of the sector is that Monsanto, DuPont Pioneer and Dow Chemicals, which recently merged with Du Pont Pioneer, share the same institutional investors (Lianos and Katalevsky, 2017). For instance:

- BlackRock Inc. controls 5.97\% of Monsanto, 6.31\% of Dupont and 6.58\% of Dow Chemical;

- The Vanguard Group controls 6.82\% of Monsanto, 6.99\% of Dupont and $6.65 \%$ of Dow Chemicals;

- The State Street Corp. controls $4.59 \%$ of Monsanto, $4.91 \%$ of Dupont and $3.97 \%$ of Dow Chemicals.

The challenge with having the same investors in competing firms is the potential for collusion. The investors have access to information on all three companies that would not have been otherwise accessible that would enable them to take part in parallel exclusion or cumulative foreclose (Lianos and Katalevsky, 2017). Parallel exclusion refers to conduct by several firm that block entry by new participants in the sector while cumulative foreclosure effect arises as a result of a network of agreements, exclusive obligations and non-compete clauses. In a sector where firms depended on contracts to access GM seeds or biotech traits in research and development, foreclosure is possible and even facilitated by shared ownership of institutional investors (see also Seldeslachts et al., 2017).

\subsection{Competition cases and historical interventions}

In 2010, a merger between Pioneer Hi-Bred International (Pioneer), a US-based, vertically-integrated commercial seed company and Pannar Seed Limited (Pannar), a South African seed company was prohibited by the Competition Commission of South Africa. The merger would increase Pioneer's stake in Pannar from 20\% to $80 \%$. An appeal made by the parties at the Competition Tribunal was subsequently dismissed when the Tribunal upheld the Commission's decision to prohibit the merger. A further appeal to the Competition Appeal Court (CAC) resulted in an approval of the merger with conditions. An attempt by the Competition Commission to appeal the decision at the Supreme Court of Appeal (SCA) was dismissed in June 2012.

The Commission's case largely centred on the breeding and commercialisation of hybrid maize seed, a highly concentrated market in South Africa which made up a significant portion of the annual turnover of the South African seed industry. The market was made up of three main players: Monsanto with a 50\% market share, Pioneer with around 30\% and Pannar third with around 15\%. Pannar's market share in the hybrid maize market had been declining steadily from about $60 \%$ in the 1990 s to $51 \%$ in the 2000 s to $18 \%$ in 2010 . 
Both Pioneer and Pannar are involved in the breeding and selling of hybrid maize seed. Three components are required for the breeding of hybrid seed varieties namely a diverse pool of local seed germplasm; advanced breeding technologies and biotech traits. The main reason stated for Pannar's steady decline was the lack and inability to grow their advanced breeding technologies making them less able to compete with companies such as Monsanto. A merger with Pioneer would enable Pannar to access these advanced breeding technologies necessary to compete in the market. In turn, Pioneer could benefit from Pannar's deep and gains arguments.

The Competition Commission prohibited the merger on the basis that it would result in a duopoly and may result in price increases, incentivise collusive behaviour and raise barriers to entry. There were also public interest concerns in South Africa losing its sovereignty in the seed industry to foreign companies. GMOs were also likely to proliferate the market at the expense of non-GMOs that were cheaper, recyclable and preferred by smaller farmers. The Commission determined that the efficiency gains were insufficient to counteract the competitive concerns raised by the merger.

The Tribunal agreed with the approach by the Competition Commission. The Competition Appeal Court, however, took a different approach, accepting the parties' argument that the Competition Commission did not fully consider the counterfactual of what would happen should the merger not go ahead. The parties suggested that should the merger not take place, Pannar would eventually leave the market making obsolete the wide pool of germplasm Pannar holds. The Competition Commission's suggestion that Pannar merges with another international company other than Pioneer was found to be unfeasible as the international companies had to have capabilities in developing seed for a particular region. Other companies such as Syngenta and Dow were found to be incompatible in this regard.

The Appeal Court also criticised the approach that the Commission and Tribunal used in analysing the efficiencies argument presented by the merging parties. The Commission had focussed on quantification of the efficiencies but the Appeal Court argued that verification rather than the precise quantification of efficiencies should have been used, arguing that the Tribunal should have looked at long term efficiency gains rather than short term static gains. The merger was approved with a number of conditions:

- Prices for all Pannar maize hybrids and for OPVs were not to exceed inflation for a period of three sales seasons.

- For a period of three sales seasons, there would be no increase in prices of the Developing Farmer Products and thereafter, actual selling prices of the products would not increase beyond CPI on an annual basis for a further five sales seasons.

- Pannar customers will continue to receive discounts from the date of closing.

- Concerning employment, there would be no job losses or retrenchments for a period of two years.

- The parties committed to establishing an International Research and Technology Hub in South Africa by 2016.

- Establish and participate in community programs and partnerships in the interest of farmers.

- Maintain the same maize hybrids currently marketed and sold.

- Main developing farmer products in sufficient commercial quantities for developing farmer and to maintain breeding programs related to sunflower, grain sorghum, forage sorghum, wheat, dry beans and soybeans for five years. 
- To licence the plant materials in the genetic material list to public institutions on a nonexclusive and perpetual basis.

The Competition Commission of South Africa is currently carrying out an ex-post assessment of the merger to determine its impact on markets. This will include an assessment of maize prices as well as levels of innovation. The assessment is important for understanding the impact of the continuing trends of concentration in the food value chain on food prices and accessibility.

\subsection{Recent mergers and acquisitions}

Four main mergers have taken place in the industry for the period under review (last 5 years). (Table 6). All four involved large companies with significant global market share signalling substantial consolidation of the sector. The mergers were all approved with conditions although the first merger, Pioneer/Pannar was prohibited twice as discussed above before it was approved following an appeal by the parties at the Competition Court of Appeal.

Table 6: Main mergers and acquisitions in the seed industry

\begin{tabular}{|c|c|c|c|c|c|}
\hline Year & $\begin{array}{l}\text { Primary } \\
\text { Acquiring Firm }\end{array}$ & $\begin{array}{l}\text { Primary } \\
\text { Target Firm }\end{array}$ & Size & Status & Conditions \\
\hline 2012 & $\begin{array}{l}\text { Pioneer Hi-Bred } \\
\text { International Inc. }\end{array}$ & $\begin{array}{l}\text { Pannar Seed } \\
\text { (Pty) Ltd }\end{array}$ & I & $\begin{array}{l}\text { Approved } \\
\text { with } \\
\text { conditions } \\
\end{array}$ & $\begin{array}{l}\text { Discussed in section } 4.4 .1 \\
\text { above. }\end{array}$ \\
\hline 2016 & $\begin{array}{l}\text { China National } \\
\text { Agrochemical } \\
\text { Corporation }\end{array}$ & Syngenta AG & I & $\begin{array}{l}\text { Approved } \\
\text { with } \\
\text { conditions }\end{array}$ & $\begin{array}{l}\text { Merging parties are not to } \\
\text { relocate their manufacturing } \\
\text { plant from North West } \\
\text { Province in South Africa for a } \\
\text { certain period of time. }\end{array}$ \\
\hline 2017 & DowDuPont Inc. & $\begin{array}{l}\text { Dow Chemical } \\
\text { Company and } \\
\text { E.I. du Pont de } \\
\text { Nemours and } \\
\text { Company } \\
\text { (DuPont) }\end{array}$ & $\mathrm{L}$ & $\begin{array}{l}\text { Approved } \\
\text { with } \\
\text { conditions }\end{array}$ & $\begin{array}{l}\text { Dow will make available } 81 \\
\text { maize hybrids and } 7 \text { maize } \\
\text { inbred lines to other third } \\
\text { parties for licensing in South } \\
\text { Africa. } \\
\text { Dow is to register its } \\
\text { PowerCore and Enlist } \\
\text { biotechnology traits in } \\
\text { South Africa within } 2 \text { years of } \\
\text { approval of the merger. }\end{array}$ \\
\hline 2017 & $\begin{array}{l}\text { Bayer } \\
\text { Aktiengesellschaft }\end{array}$ & $\begin{array}{l}\text { Monsanto } \\
\text { Corporation }\end{array}$ & I & $\begin{array}{l}\text { Approved } \\
\text { with } \\
\text { conditions }\end{array}$ & $\begin{array}{l}\text { The merged entity to divest } \\
\text { and sell the entire global } \\
\text { Liberty Link trait technology } \\
\text { and the associated Liberty } \\
\text { branded agro-chemicals } \\
\text { business of Bayer. }\end{array}$ \\
\hline
\end{tabular}




\begin{tabular}{|l|l|l|l|}
\hline $\mid$ & $\mid \begin{array}{l}\text { The potential buyer of the } \\
\text { divested businesses has to } \\
\text { commercialize the divested } \\
\text { products in South Africa, or } \\
\text { alternatively, license the } \\
\text { divested business to South } \\
\text { African third party to } \\
\text { commercialize anywhere in } \\
\text { the world should the } \\
\text { purchaser be unable to do so. } \\
\text { Limit retrenchment and } \\
\text { support emerging farmers. }\end{array}$ \\
\hline
\end{tabular}

Source: Competition Commission website.

\section{China National Agrochemical Corporation and Syngenta AG}

In June 2016, China National Agrochemical Corporation (CNAC), an international company based in China and involved in the development, manufacture and sale of agrochemicals notified the Competition Commission of its intention to merge with Syngenta, another international company with its headquarters in Switzerland. Syngenta is involved in seeds and crop products in over 90 countries. The companies' activities overlap in the market for the manufacture and supply of agrochemicals or crop protection products, namely fungicides, insecticides, herbicides (selective and nonselective) and seed treatment products (Competition Commission, 2017).

Although both companies are involved in seed production, they do not operate in the seed market in South Africa. The Competition Commission therefore assessed the effects in the following markets: insecticides, non-selective herbicides, selective herbicides, fungicides and seed treatment, finding that the merger was unlikely to substantially prevent or lessen competition in the mentioned markets as there were a number of other suppliers of the same products. The Commission did find that there were some public interest concerns with regards to employment, particularly if the parties were to import all its product rather than use the manufacturing plant in the North-West Province. The Commission therefore approved the merger on condition that the manufacturing plant in the North West not be moved for a certain period of years.

DowDuPont Inc. and Dow Chemical Company and E.I. du Pont de Nemours and Company (DuPont)

DowDuPont Inc. (DowDuPont) is an international company with its headquarters in the USA and involved in the research, development, production and distribution of plastics and chemicals, agricultural sciences including seeds, hydrocarbon and energy products and services received approval from the Competition Commission to merge with the DuPont Group. The group is involved in the research development, production distribution and sale of chemical products, polymers, agrochemicals, seeds, food ingredients amongst other products (Competition Commission South Africa, 2017b). The Commission found that there was no overlap in the commercialisation of hybrid and GM hybrid maize in South Africa but that the merger would likely result in the removal of 
potential competitor as Dow had had prior intentions to enter the South African commercial maize see market. To address this concern, the conditions placed by the commission involved Dow making available 81 maize hybrids and seven maize inbred lines to other third parties as well as registering its PowerCore and Enlist biotechnology traits in South Africa within two years of approval of the merger.

The Commission had also found that the merger was likely to lead to the substantial reduction of competition in the market and development of insecticides for certain fruits and vegetables. To remedy this, the Commission required DuPont to divest its global insecticide business Liberty Link technology and the associated Liberty branded agro-chemicals business to a third party.

\section{Bayer Aktiengesellschaft and Monsanto Corporation}

In May 2017, the Commission conditionally approved the merger between Bayer Aktiengesellschaft (Bayer) and Monsanto Corporation (Monsanto) (Competition Commission South Africa, 2017a). The Commission found that there were competition concerns in the market for the supply of GM cottons seeds as Monsanto is already a monopoly in South Africa with regards to this market. It would also result in the removal of a potential competitor, not only in the development and production of seed traits but also in the development of herbicides. The cross-licensing agreements that characterised the market also made it conducive for coordinated conduct. The Commission therefore required the companies post-merger to divest of global Liberty Link trait technology and the associated Liberty branded agro-chemicals business of Bayer. The new buyer would be required to commercialise the divested products within South Africa or to license the business to a South African third party. Additional conditions related to maintain employment and providing support to emerging farmers.

While not all the mergers discussed above were in the same market they occurred in parallel or complementary product markets in the agricultural sector which raises concerns around a few firms dominating key segments of agricultural value chains. Such large-scale mergers are approved in South due to the limited competitive effects on a national level. However, there are long term anticompetitive effects of the increased concentration and consolidation of the sector on a global level including impacts on Research and Development ( $\&$ \& ), prices and innovation. There is a need, therefore, for such large-scale mergers in already concentrated sectors to be assessed more broadly. In this respect, there is a role for closer collaboration between the different BRICS authorities to ensure that approvals of mergers in certain jurisdictions do not have inadvertent long-term impacts on others and that conditions imposed are consistent across jurisdictions with regards to certain aspects, for instance, innovation and R \& D.

\subsubsection{Fertiliser Value Chain}

1.4.2.1.A mapping of the value chain and key players ${ }^{3247}$

Fertiliser is a key input into agricultural value chains. The estimated value of the overall fertiliser industry in South Africa was around R10bn in 2016. ${ }^{3248}$ The industry supplies around 2 million tons of fertiliser products to the local market, with the maize industry consuming between $40 \%$ and $50 \%$ of this. A major challenge for the industry is the changing weather patterns due to climate change.

3247 This section draws mostly from Grimbeek et al (2017) and the recent report by Who Owns Whom (2017), as well as Ncube et al (2017) and Vilakazi (2017).

3248 Who Owns Whom report (2017). 
This is evident from the decrease in fertiliser usage due to the drought experienced in 2015 and 2016 in South Africa.

The fertiliser industry consists of three main segments: nitrogen $(\mathrm{N})$; phosphate $(\mathrm{P})$; and potash (K). In South Africa, manufacturing of inputs into fertilisers is dominated by Sasol, Foskor and Omnia. Sasol remains the largest producer of chemical inputs into fertiliser, and Foskor focuses on the mining of phosphate rock and the production of phosphoric acid and phosphate-based fertilisers. Another source of inputs is ArcelorMittal as several by-products (i.e. blast furnace slag and steelmaking slag) from the production of steel are sold into the fertiliser value chain. Thus, the individual markets for $\mathrm{N}, \mathrm{P}$ and $\mathrm{K}$ are highly concentrated.

The location of input materials largely influences the manufacture of fertilisers. An important node of manufacturing activity is in Sasolburg where Sasol and Omnia production plants are situated. ArcelorMittal is also located close to these companies. Foskor mines and processes phosphate rock in Phalaborwa, Limpopo Province, which is then carried by rail to the production facility in Richards Bay in KwaZulu-Natal. The production facility is strategically located in Richards Bay since Foskor imports some raw materials to combine with mined products (i.e. phosphate rock) and then exports phosphoric acid.

Figure 10 shows the nitrogenous fertilisers value chain. We focus more on nitrogenous fertilisers due to their significant usage $(67.9 \%$ consumed in 2015 , Table 7$)$ relative to the other fertilisers and given the competition concerns in this market. Nitrogenous fertilisers include Limestone Ammonium Nitrate (LAN), Ammonium Nitrate Solutions (ANS), and urea. Ammonia, which is produced by Sasol at its Secunda and Sasolburg plants, is the key input into the production of nitrogenous fertilisers. Other suppliers of imported ammonia in South Africa are Omnia, Foskor and Kynoch. However, Sasol remains the dominant supplier of ammonia in South Africa. Urea is largely imported given that it is made from ammonia in a different production process, one that is not undertaken in South Africa.

Table 7: Consumption by Fertiliser type

\begin{tabular}{|l|l|l|l|}
\hline \multicolumn{4}{|l|}{ Consumption (\%) } \\
\hline Year & Nitrogen & Phosphate & Potash \\
\hline 2011 & 69.8 & 13.5 & 16.7 \\
\hline 2012 & 69.8 & 13.8 & 17.1 \\
\hline 2013 & 69.7 & 13.3 & 16.8 \\
\hline 2014 & 67.9 & 16.8 & 18.5 \\
\hline 2015 & 67.9 & 15.1 & 16.6 \\
\hline
\end{tabular}

Source: Who Owns Whom (2017b)

In the upstream level, as seen in the diagram, Sasol is the monopoly local producer of ammonia to independent manufacturers of fertilisers and is also active throughout the rest of the value chain. In fact, prior to $2009^{3249}$, Sasol was the sole supplier of ammonia in South Africa. Sasol became the monopoly supplier of ammonia in South Africa in 1999 following the closure of African Explosives and Chemical Industries (AECI)'s production facilities. Sasol's produces ammonia from its coal-to-

${ }^{3249}$ The Competition Commission intervened in 2009 and 2010 leading to noticeable reconfigurations. This is described further in the section 5.5.1. 
liquid fuel processes, and from natural gas (about 50\%) imported from Mozambique. Post 2009, Omnia has undertaken significant investments into the rail wagons required to transport imported ammonia, as well as investments into expansion of its nitric acid plants. However, Omnia's imports of ammonia are strictly for internal use in its own downstream operations and are not available for use by third parties.

The ammonia produced by Sasol (and that imported by Omnia, Foskor and Kynoch) is then used to produce ammonium nitrate, used in the production of fertilisers or explosives. Sasol, Omnia and AECI have the necessary infrastructure, in particular nitric acid plants, to produce ANS. LAN production, which is produced by reacting ANS with limestone to stabilise it, forms solid fertilisers. LAN is produced by both Sasol and Omnia.

\section{Figure 12: Nitrogenous Fertiliser Value Chain}

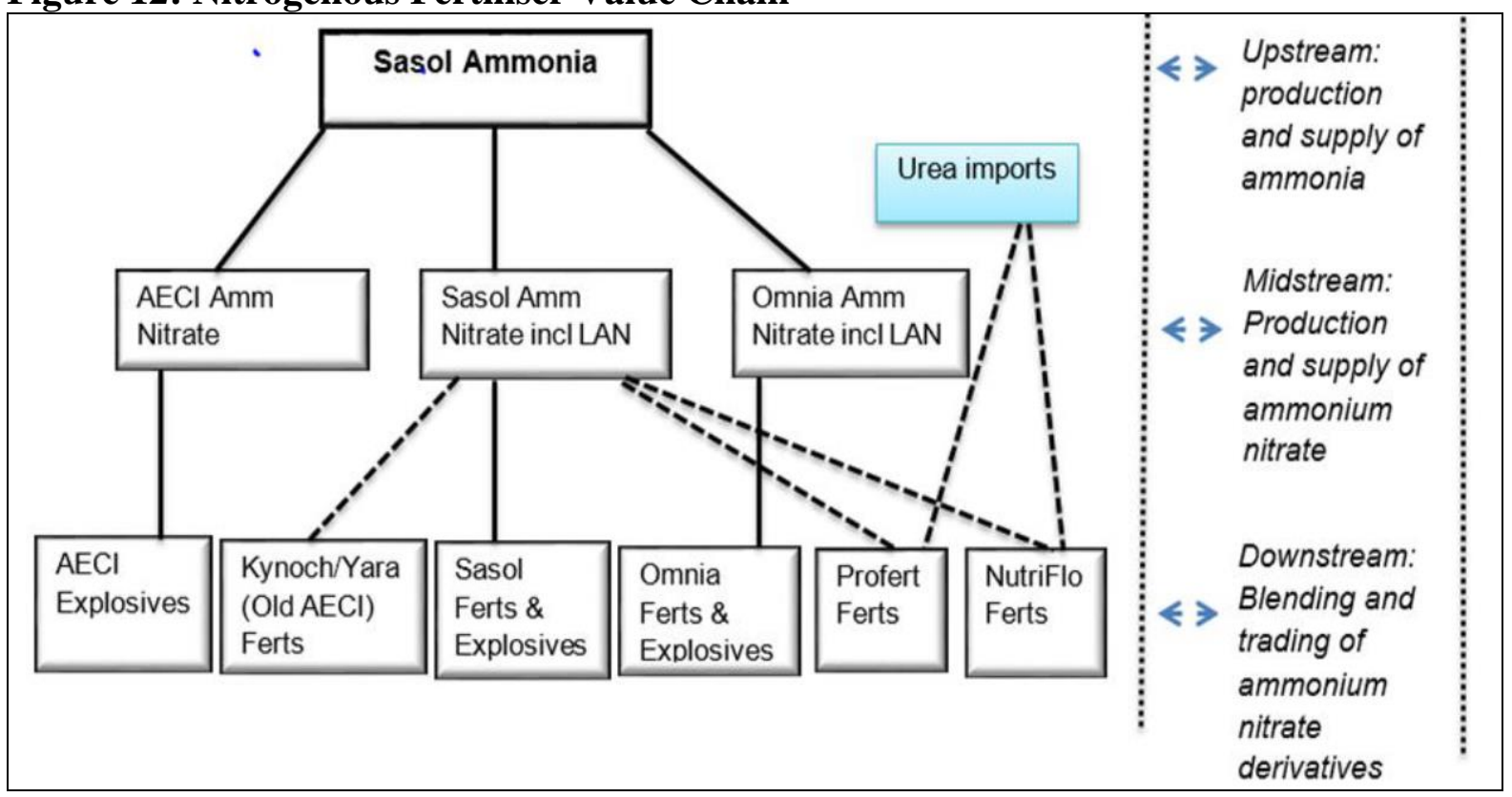

Source: Grimbeek et al, 2017

The midstream segment of the value chain mainly involves the production of ammonium nitrate. This segment is also highly concentrated. Prior to 2009, Sasol, Omnia and AECI were the firms involved in the manufacture of ammonium nitrate, which all owned nitric acid and ammonium nitrate plants. In 2005 Sasol produced more than $40 \%$ of the country's ammonium nitrate. Omnia supplied very little ammonium nitrate to the open market due to its vertical integration. Furthermore, the collusive arrangement ${ }^{3250}$ between Sasol, Omnia and Kynoch, reduced Omnia's incentive to effectively utilise its ammonium nitrate plants. AECI produced ammonium nitrate under an agreement with Kynoch which ceased in 2004. Smaller players requiring ammonium nitrate were therefore effectively dependent on Sasol. Currently Sasol still remains the main supplier of ammonium nitrate in South Africa.

The downstream segment involves the blending and trading of ammonium nitrate derivatives. In general blending provides a means for growers to receive the correct ratio of nitrogen, phosphorus, potash, and micro nutrients. Ammonium nitrate in fertiliser production can either be mixed with water to form ANS or combined with limestone/ calcium to form LAN or Calcium Ammonium Nitrate

${ }^{3250}$ See section 5.5 .1 below 
(CAN). Apart from Kynoch and Omnia, other downstream players include Nutri-Flo and Profert Holdings. Omnia leads the downstream fertiliser market with a $45 \%$ market share for LAN, followed by Kynoch Fertiliser and Profert Holdings with an estimated $15 \%$ market share each. ${ }^{3251}$

The industry value chain thus reflects a range of organisational forms, ranging from vertically integrated companies to companies involved in blending, distribution or retail only. Moreover, several smaller players have emerged since the Competition Commission's intervention in 2009, with some involved in retail and wholesale of fertiliser directly to farmers or co-operatives. Co-operatives have become an important source of fertiliser sales. They purchase, store and distribute fertiliser for their farmer members. Thus, farmers are able to collectively negotiate better prices for fertilisers. The fertiliser industry however still remains highly concentrated. And interestingly, government remains a significant shareholder in the fertiliser sector, specifically in Sasol and Foskor where the Industrial Development Corporation (IDC) held in $8.2 \%$ and $59 \%$ respectively in $2013 .{ }^{3252}$

\subsubsection{Regulatory framework}

A range of legislation is used to regulate the fertiliser industry. These include;

- Fertilisers, Farm Feeds, Agricultural Remedies \& Stock Remedies Act No. 36 of 1947

- Agricultural Products Standards Act No.119 of 1990

- National Regulations for Compulsory Specifications Act No. 5 of 2008

- Marketing of Agricultural Products Act No. 47 of 1996

- National Environmental Management Act No. 107 of 1998

- National Environmental Management: Air Quality Act No. 39 of 2004

- Environment Conservation Act No. 73 of 1989

- Foodstuffs, Cosmetics and Disinfectants Act No. 54 of 1972

- Medicines and Related Substances Control Amendment Act No. 101 of 1965

Additionally, the National Treasury is expected to release a revised Carbon Tax Bill in 2017. Furthermore, a revised regulation for the carbon offset allowance, which enables firms to reduce their carbon tax liability will be published by mid-2017. There are currently no import tariffs on imports of fertiliser.

\subsubsection{Performance of the Fertiliser industry}

\subsection{Consumption}

The domestic industry has an estimated value of about R10bn, a decline from R14bn in 2009. The decline since 2009 saw the value of the industry reaching R7.5bn in 2015, before picking up to R10bn in 2016 (Who Owns Whom, 2009; 2015; and 2017b). The consumption of fertiliser has also been declining since 2011 (Table 8). About 1.9 million tonnes of fertiliser were consumed in 2015, reduction from 2.1 million tonnes in 2014. The reduction in consumption is attributable to drought conditions in South Africa, and possibly due to pricing concerns as shown in the following subsection.

${ }^{3251}$ Who Owns Whom report (2017)

3252 Who Owns Whom report (2017) 
Table 8: Fertiliser consumption (in tonnes)

\begin{tabular}{|l|l|}
\hline Year & Consumption (tonnes) \\
\hline 2011 & $2,002,071$ \\
\hline 2012 & $2,052,858$ \\
\hline 2013 & $1,991,370$ \\
\hline 2014 & $2,198,230$ \\
\hline 2015 & $1,978,407$ \\
\hline
\end{tabular}

Source: FERTASA

\subsection{Prices}

The prices of fertiliser in South Africa are substantially higher than the rest of the world. In 2015, the average cost of fertiliser used in the production of maize was $78 \%$ higher in South Africa than in other international maize producing countries (Figure 11). The maize industry consumes about $40 \%$ to $50 \%$ of total fertiliser consumption in South Africa. The high costs of fertiliser are partly a reflection of high concentration levels resulting in uncompetitive pricing of fertiliser products. As discussed in section 5.5.1 below, there have been a number of cases brought to the Competition Commission against Sasol in 2004. The cost of certain fertilisers is also however determined by the costs of importing, including all the related transport and distribution costs and the trader and agrodealer margins. For instance, transport costs can account for $50 \%$ of the delivered price to farmers when including all the related costs and margins. ${ }^{3253}$ The other reason for high domestic prices is the difference in suitability and availability of natural resources like soil quality and climate when compared to countries such as Brazil, Argentina, the US and Ukraine. ${ }^{3254}$ For instance there is evidence of considerable acidification and nutrient depletion in South African soils, which means the country requires more Fertilisers given the poorer quality of soil.

Figure 13: Fertiliser cost: International key maize producing countries vs. South Africa

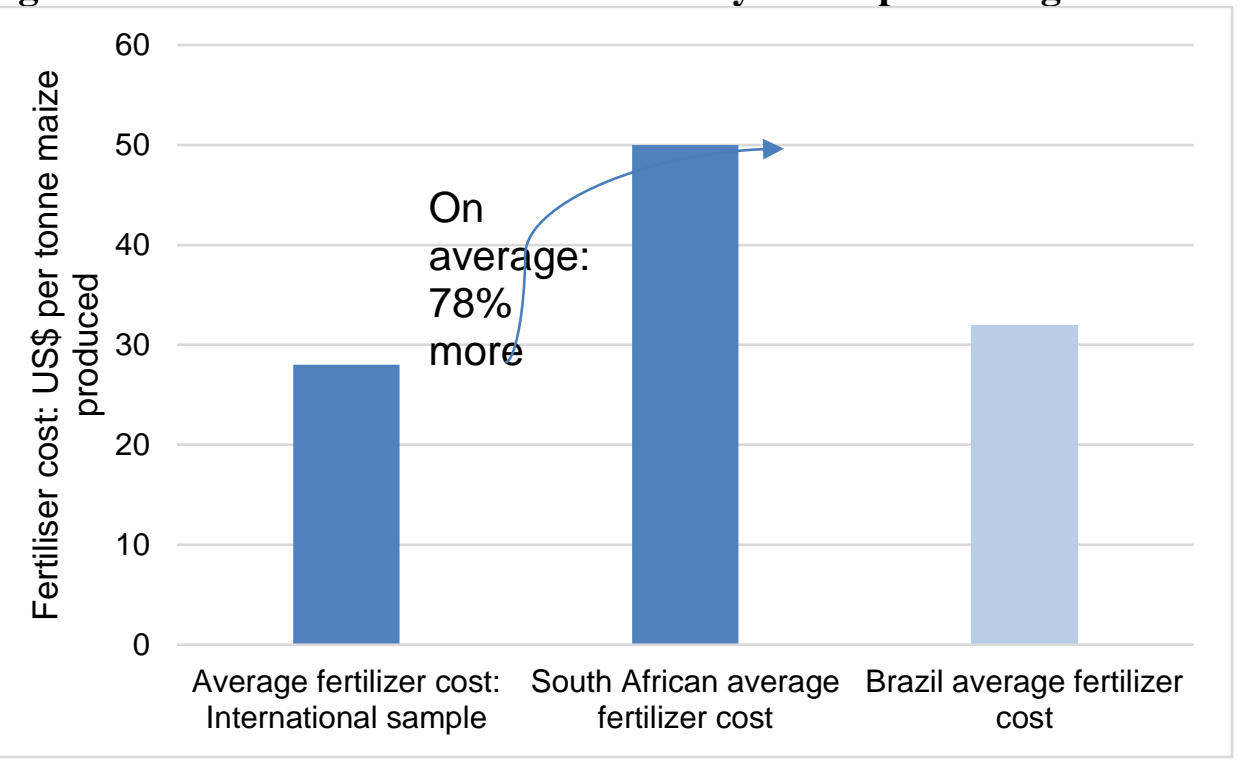

Source: Reproduced from BFAP \& Agri Benchmark, 2015

\footnotetext{
3253 See Ncube, Roberts and Vilakazi (2016)

${ }^{3254}$ BFAP (2015)
} 
Figure 12 below shows the overall inland and coastal monthly price trends for Sasol's Limestone Ammonium Nitrate between 2005 and 2015. Inland regions include North West, Northern Cape, Eastern Cape, Mpumalanga, Gauteng and Limpopo. Coastal region refers to KwaZulu Natal. Preintervention and post-intervention periods refer to periods in relation to the Competition Commission's intervention in the fertiliser industry cartel between Sasol, Omnia and Kynoch, discussed further in section 5.5.1. Overall prices comprise average prices to blenders, traders, and farmers. Notably, fertiliser prices rose dramatically in 2008 due to a combination of factors such as increased demand as a result of higher food prices and increased energy costs which are particularly important in producing nitrogenous fertilisers. The high price increases slowed down after 2009.

Figure 14: Overall Inland and Coastal Monthly Price Trends for LAN (Jan 2005-June 2015)

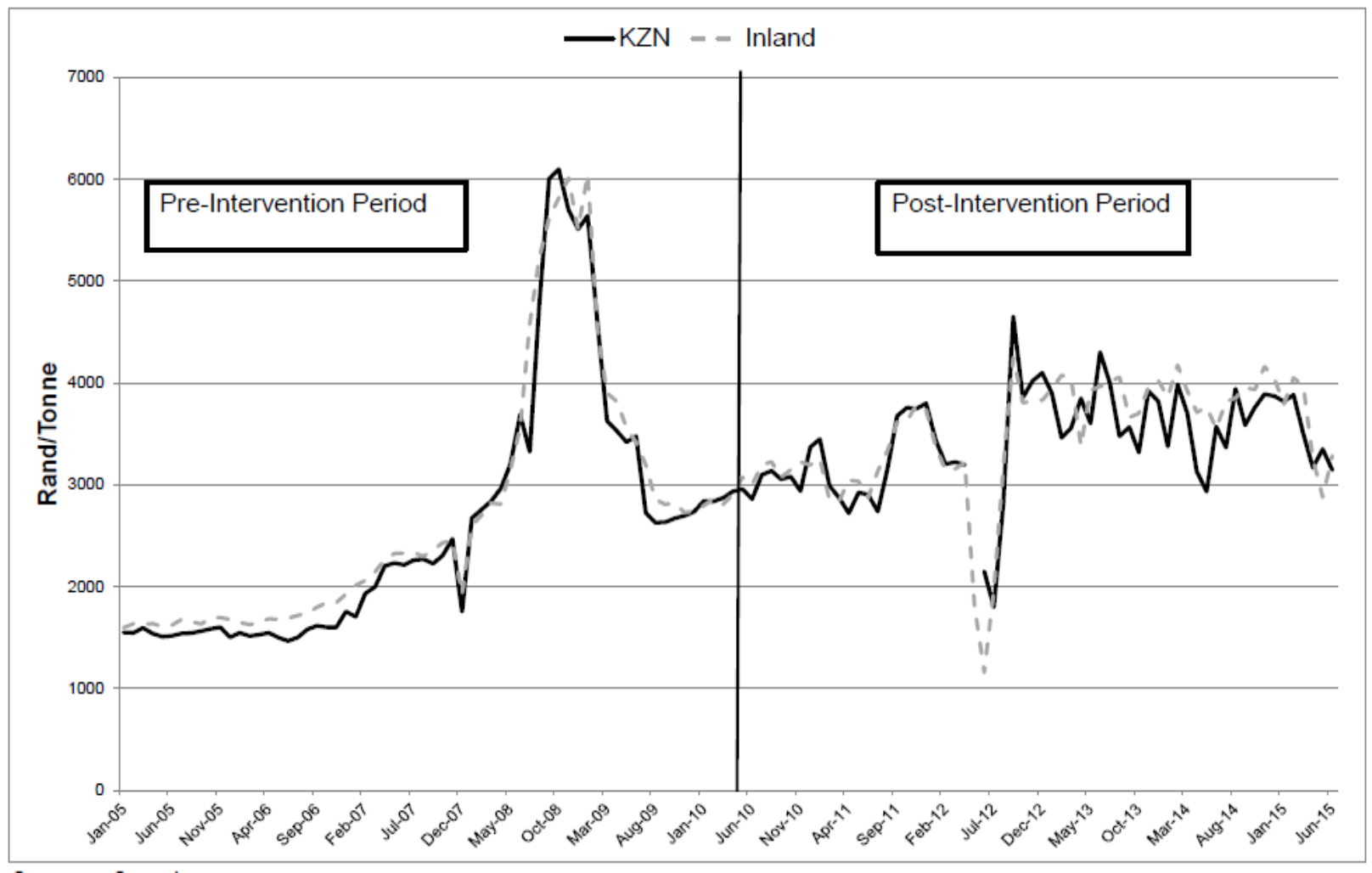

Source: Grimbeek et al, 2017

Generally, inland prices were higher than coastal prices in the pre-intervention period, driven by the cartel conduct. Under normal circumstances it would be expected of Sasol to charge higher prices for the inland region since inland customers are located much closer to Sasol's production facilities compared to coastal customers. Further, the cartel allowed Sasol to price lower in the coastal region where it faced competition from imports. In the post-intervention period, inland prices are generally relatively lower than coastal prices. Thus, the intervention by the Competition Commission which mandated no price discrimination across customers between inland and coastal regions appears to have yielded the desired effects. A more detailed analysis of the Commission's intervention is presented in section 5.5.1.

\subsubsection{Key investments}


There have been noticeable episodes of investment in the fertiliser sector. An important one being in the Free State where Westfert has created a facility to house 200,000 tons of fertiliser. ${ }^{3255}$ The facility is apparently the fourth-largest dome structure in the world and has significant capacity to improve the logistics of moving fertilisers to farms.

The other important investment (worth R1.35bn) is that involving Kropz SA (Pty) Ltd through the continuation of the development of its Elandsfontein Phosphate Project ${ }^{3256}$. Approximately 95\% is being spent within the South Africa, with effort taken to maximise direct benefit to local businesses in the Saldanha Bay Municipality. Kropz is miner of fertiliser feed minerals that includes a Black Economic Empowerment partner, Africa Rainbow Minerals (ARM).

Post 2009 Omnia expanded its operations for the production of ammonium nitrate by undertaking a large investment in a new nitric acid plant. This facility has the capacity to produce $40 \%$ more nitric acid per annum compared to Omnia's first nitric acid plant's capacity of 73000 tons which was in operation pre-2009. ${ }^{3257}$ Omnia has also invested in the new rail wagons to ensure more reliability and efficiency in the importation of ammonia.

Other investments in the downstream segment involved several acquisitions of Sasol's plants following Sasol's divesture of its blending businesses post-2009, as a result of the intervention by competition authorities. This is discussed further in section 5.5.1. Profert acquired Sasol's Potchefstroom and Bellville plants in Cape Town in March and August 2011 respectively. GWK, an agricultural cooperative that is also involved in the blending and distribution of granular and liquid fertiliser products, acquired Sasol's Durban plant in June 2011. Kynoch acquired both Sasol's Kimberley and Endicott plants.

\subsubsection{Trends in concentration and outcomes of key mergers}

As highlighted in previous sections, the fertiliser industry is highly concentrated. Moreover, there are signals of further consolidation and/or integration evidenced by recent merger activity in the sector. In 2016 for instance, South African fertiliser producer Omnia Holdings agreed to acquire an oil products and lubricants supplier as part of its strategy to expand its chemical business. Table 9 lists other mergers and acquisition between 2010 and 2017. (note: there have been mergers in the organic fertiliser segment which are not presented here). Of interest is the recent large acquisition by the Government Employees Pension Fund (GEPF) of ETG (Kynoch) which was unconditionally approved in 2017. This is an example of growing institutional investors in food value chains.

Table 9: Mergers and Acquisitions (2010 - 2017)

\begin{tabular}{|l|l|l|}
\hline Date & Acquiring firm & Target firm \\
\hline 2010 & Kynoch Fertiliser & Yara South Africa \\
\hline \multirow{3}{*}{2011} & Profert & Sasol's Potchefstroom and Bellville plants \\
\cline { 2 - 3 } & GWK & Sasol's Durban plant \\
\cline { 2 - 3 } & Kynoch Fertiliser & Sasol's Kimberley and Endicott plants \\
\hline 2012 & Gromor & National Plant Food \\
\hline 2013 & Grinrod & NWK Ltd \\
\hline
\end{tabular}

${ }^{3255}$ Who Owns Whom report (2017)

${ }^{3256}$ Kropz website

${ }^{3257}$ Grimbeek et al (2017) 


\begin{tabular}{|l|l|l|}
\hline 2014 & Export Trading Group (ETG) & Kynoch Fertiliser \\
\hline 2015 & Rolfes & Ag-Chem \\
\hline 2017 & $\begin{array}{l}\text { Government Employees Pension } \\
\text { Fund (GEPF) }\end{array}$ & ETG (Kynoch) \\
\hline
\end{tabular}

Source: Who Owns Whom (2017b); Grimbeek et al (2017)

Several mergers and acquisitions also took place internationally. This suggests increased consolidation of global fertiliser markets. Key deals include the following:

- PotashCorp of Saskatchewan and Agrium which would create a new US\$36bn player. The merger however occurs in a context where both companies have reported losses, and where the potash price has been lower.

- The US agrochemical company, Brandt, acquired the Spanish agrochemical and fertiliser company, Tratamientos Guadalquivir.

- Belgian specialty chemicals distributor Azelis acquired the Italian specialty chemical distributor for agrochemical and fertiliser formulations, Ametech.

Although it is not clear if these companies have operations in South Africa, some of them have footprint in Africa. Tratamientos Guadalquivir's website indicates that the company services the Middle East and African markets as well. Azelis has footprint in Ivory Coast and Morroco. Nonetheless, South Africa imports fertilisers from some of the countries in which these companies are based. For instance, the third largest source of South African phosphatic fertiliser imports is Spain, which hosts Tratamientos Guadalquivir, a producer of phosphatic fertilisers amongst a range of products.

\subsection{Overview of competition interventions}

The key competition cases in the South African fertiliser market include the abuse of dominance case brought against Sasol as well as the collusive case between Sasol, Omnia and Kynoch. In 2003 and 2004, Nutri-Flo and Profert filed complaints with the Commission alleging that Sasol, acting in concert with Omnia and Kynoch (Yara), engaged in a range of anticompetitive practices. The complainants alleged that the conduct negatively affected the ability to achieve a competitive outcome in the market for the blending and distribution of nitrogenous based fertilisers. The abuse of dominance practices by Sasol involved exclusionary pricing, excessive pricing and price discrimination. Nutri-Flo and Profert further submitted that the collusive relationship between Sasol, Omnia and Kynoch prevented them from expanding their businesses and competing effectively.

Subsequently Sasol admitted in 2009 to having acted in concert with Omnia and Kynoch (Yara) through agreements on various pricing formulae for, and discounts to, products manufactured or supplied by itself, Kynoch (Yara) and Omnia, thereby contravening section 4(1)(b) of the Act. Sasol paid an administrative penalty of approximately R250 million. Sasol reached an agreement with the Commission in respect other contraventions.

In order to limit Sasol's presence in the downstream market and reduce its ability to manipulate market conditions, agreements were reached between Sasol and the Commission that resulted in the imposition of a series of behavioural and structural conditions on Sasol. For instance, Sasol undertook to provide fertilisers on an ex-works basis and to further not discriminate across customer types (i.e. blenders, traders and end- users) and across geographic regions (i.e. inland and 
coastal regions). Moreover, with regards to the structural conditions, Sasol undertook to divest five of its blending plants.

In other important rulings, the Competition Commission entered into a consent agreement with Foskor, to end an agreement between Foskor and Sasol that reduced options for buyers of phosphates. A case of price fixing against the Fertiliser Association of Southern Africa (FERTASA) and five agricultural lime manufacturers was referred to the Competition Tribunal in 2014, following an investigation that revealed that the manufacturers made use of FERTASA to fix commissions paid to agents. Furthermore, a group of 58 farmers won a case against Sasol in March 2015, where Sasol was accused of fixing fertiliser prices between 1996 and 2004. Following the Tribunal's intervention in 2009, the group of farmers affected by Sasol's actions lodged a private legal case seeking financial compensation from the company, resulting in a confidential settlement between Sasol and the farmers. ${ }^{3258}$

\subsection{Ex-post assessment of the Competition Commission's intervention in $2009^{3259}$}

There has not been any entry in the production of ammonia and Sasol remains the sole producer of ammonia in South Africa. This can be explained by the significant capital outlay required in building an ammonia plant. However, we note that there has been an increase in the importation of ammonia since 2010. Prior to the intervention, Omnia was restricted from importing Ammonia as per the agreement with Sasol. Post intervention, Omnia had to seek alternative sources of raw materials for their plants, in the form of imports. Omnia's entry into the market provides some competition to Sasol as it increases the number of competitors in the upstream market from one to two. However, the bulk of Omnia's production is dedicated towards internal consumption. The Commission's intervention has also resulted in increased supply of nitrogenous fertilisers. As mentioned above, Omnia's new ammonium nitrate facility has the capacity to produce $40 \%$ more nitric acid per annum compared to its first nitric acid plant's capacity of 73000 tons.

One of the other impacts of the Competition Commission rulings is that there are now more blending and trading companies, particularly as a result of the divestiture of most of Sasol's blending facilities. Atlas Organic Fertilisers (Pty) Ltd and Aquasol Nutri are two examples of additional blending companies in the sector. Moreover, the firms that were previously reliant on Sasol input supplies have subsequently expanded and acquired their own blending plants. Further, the divestiture of Sasol's blending facilities implies increased competition along the nitrogenous fertiliser value chain, given that the level of Sasol's vertical integration along the value chain has been reduced. Sasol's operations at the retail level of the industry have also declined. The intervention also decreased the magnitude of price increases in the post-intervention period, thereby generating substantial customer savings of between R1 billion and R10.5 billion from 2010 to $2015^{3260}$. That is, post-intervention prices increased by less than they would have increased absent the intervention by competition authorities.

This finding by the Commission is based on various assumptions and scenarios as follows. The first scenario assumes that post-intervention prices would have continued to increase at the pre-

\footnotetext{
3258 Farmer's Weekly. Available at: https://www.farmersweekly.co.za/agri-news/south-africa/sasol-settles-fertiliserprice-fixing-case-with-farmers/. See also Who Owns Whom (2017)

${ }^{3259}$ Following the judgements on the abuse of dominance and cartel cases involving Sasol, Omnia and Kynoch.

${ }^{3260}$ See Grimbeek et al (2017)
} 
intervention annual average rate (excluding the years 2008 and 2009) had the authorities not intervened. Building on the first, the second scenario tries to smooth the prices in 2008 and 2009 to account for outliers observed due to economic crisis. In the third scenario, the calculation of average annual prices in the pre-intervention period includes 2008 and 2009. Scenario four applies the Producer Price Index (PPI) to calculate prices, starting from the year 2009. These scenarios result in four possible values of consumer savings ranging from R1 billion and R10.5 billion as mentioned above.

\subsection{Regional and global collusive practices}

The Sasol cartel in South Africa specifically had a structure known as 'The Export Club', which was used to share information on sales of fertiliser in order to coordinate bids to the southern Africa region. Thus, major importers of South African fertilisers such as Zambia, Zimbabwe, Namibia and Botswana were negatively impacted, effectively limiting the growth of agricultural sectors in these countries. This has reciprocal effects on South Africa since its growth linked to the growth of the region, mainly because the country supplies many of the agricultural input products (incl. capital equipment) to the region. This illustrates the importance of considering the regional dimension to competition enforcement, and a regional value chain approach to sector analyses. Moreover, cartel cases busted in South Africa present an opportunity to other competition authorities to investigate and establish impact in their respective jurisdictions. In Zambia for instance, Omnia Fertilisers Zambia Limited and Nyiombo Investments Limited were also found to have rigged government contracts for fertiliser supply between 2007 and 2011.

Globally there is prevalence of government sanctioned export cartels. The following examples are found in potash, phosphates and nitrogenous fertilisers. In potash, two dominant cartels account for $80 \%$ of reserves. These are Canpotex (includes North American PotashCorp, Agrium and Mosaic) and BPC (joint venture between Russian and Belarusian potash producers, Uralkali, Silvinit and Belaruskali). Uralkali has exited the cartel in 2013. Canpotex controls over a third of the global potash production capacity. In phosphates, there is PhosChem, a USA Webb-Pomerene export cartel (includes PotashCorp and Mosaic), and OCP of Morocco, a government owned monopoly over phosphate mining. There is also likely collusion in nitrogenous fertiliser market based on studies of observable pricing trends.

Global fertiliser cartels impact South Africa because the country is still a net importer of certain phosphatic, nitrogenous and potassium fertilisers. Other BRICS member-states including Brazil, India and China are directly affected since they are major destinations of Canpotex's potash. ${ }^{3261}$ Evidently, these cartels have significant global market shares and influence, which might prove challenging for national competition authorities to prosecute given political economy dynamics, especially since these cartels are sanctioned by governments in their countries of origin. In Canada for instance, a proposed acquisition of PotashCorp by BHP Billiton was blocked by government on the grounds that it would reduce government's revenues from the Canpotex cartel since BHP Billiton intended to exit the Canpotex partnership. ${ }^{3262}$ Again, collaborative efforts between

\footnotetext{
3261 Canpotex website

${ }^{3262}$ See Krugel, Lauren (2010-08-19). "Small Sask. potash producers bask in glow of BHP bid for Potash Corp." Yahoo! Finance. Canadian Press
} 
competition authorities at regional and global levels remain crucial in this segment, particularly collaboration between the BRICS countries' competition authorities.

\subsection{Barriers to entry}

There are barriers to entry for manufacturing of fertilisers, significant amongst them being high levels of capital requirements. For instance, the manufacturing process for synthetic production of chemicals used in fertilisers is estimated to require about R200m working capital. ${ }^{3263}$ Other barriers, such as compliance with relevant legislation, are found in blending fertiliser variants. Thus, a relatively less sophisticated company may find regulatory requirements challenging to meet. Nonetheless, bio-fertilisers require a much lower capital investment and face lower regulatory barriers, providing an opportunity for smaller businesses in the sector to develop niche products.

\subsubsection{Animal Feed to Poultry Value Chain ${ }^{3264}$}

\subsubsection{A mapping of the key players and ownership structures}

The animal feed to poultry value chain is an important part of the agricultural sector in South Africa. In 2014, broiler production alone accounted for almost $15 \%$ of all agricultural production in terms of value and 33\% of all animal products produced in South Africa (SAPA, 2014). In fact, the poultry industry provides $65 \%$ of all animal protein (excluding milk) consumed in South Africa. Poultry consumption reached almost $38 \mathrm{~kg}$ per capita in 2014 with beef consumption a distant second at $18 \mathrm{~kg}$ per capita (SAPA, 2014). Poultry meat has consistently been the lowest cost source of animal protein since 2009.

The poultry value chain has multiple levels - from the production and processing of agricultural commodities through to a quasi-industrial process of batch production of the rearing, processing, to the distribution of poultry in fresh and frozen form (McCleod et al. 2009). (Figure 13). The value chain approach is particularly important from a competition perspective when considering that many cases of anti-competitive behaviour emerged around the difficulty to accessing key inputs, and the existence of exclusive supply agreements along the value chain. The value chain starts with the two main inputs - animal feed and breeding stock (Figure 13). Animal feed, which is generally made from milled maize and soybean or sunflower, accounts for between 50 and 70 per cent of the total input costs (Bagopi et al. 2014). Animal feed production is carried out in the feed mills where the main ingredients (maize and soya), including vitamins and antibiotics, are combined to produce stock feed.

\footnotetext{
3263 Who Owns Whom report (2017)

${ }^{3264}$ This section draws largely from the research project conducted by CCRED in 2016 and titled "Competition, barriers to entry and inclusive growth: Agro-processing", as well as from the recent working papers (Ncube et al., 2017; Ncube et al., 2016; and Ncube and Zengeni, 2016)
} 
Figure 15: Animal feed to poultry value chain

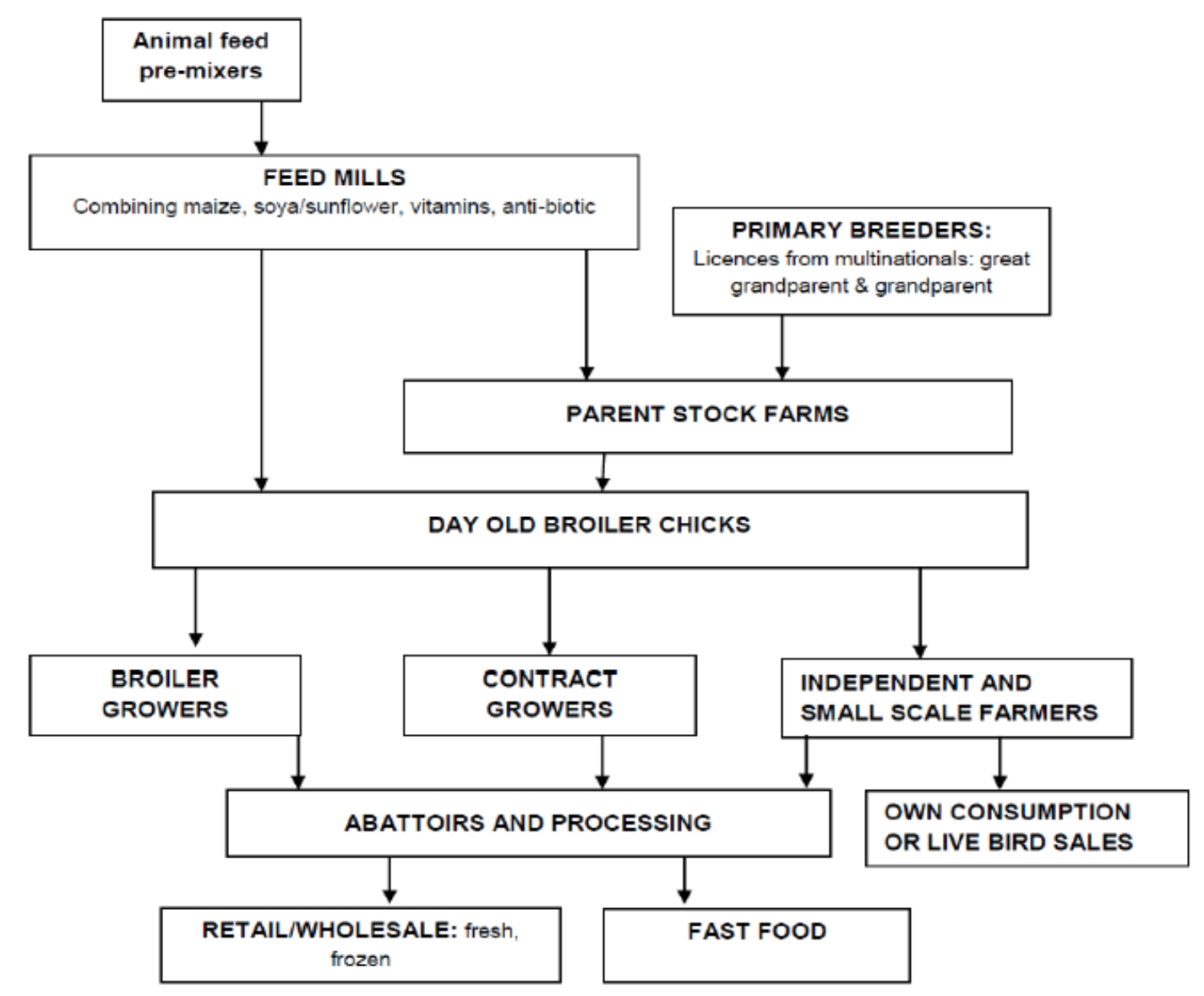

Source: Bagopi et al. (2014)

There are only two main firms providing poultry breeding stock to South Africa, Aviagen which is privately owned by German-based EW Group, and Cobb-Vantress Inc, a USA-based multinational. This highlights the global dimension of the poultry value chain. Typically, the holder of the intellectual property such as Aviagen and Cobb-Vantress would sell grandparent stock to a distributor (usually through a franchise arrangement) who will then breed parents to supply day-old parent stock. The customers of this parent stock are either fully integrated broiler producers who sell their product to the retail market or they are day-old broiler chick producers who in turn supply independent broiler producers. Once the day-old chicks are fully grown (between 32 and 42 days old) they are taken to slaughter at an abattoir and processed for sale in the retail market and fast food restaurants. In some cases, the chickens are sold live. This is normally the case with small-scale farmers. Vertical integration with key inputs such as animal feed is also a key characteristic in poultry value chain globally particularly for the larger players. This is important for the co-ordination of production, especially for those firms operating on a large scale.

In South Africa, the great majority of poultry is produced by large-scale commercial players who are also generally vertically integrated with key inputs such as animal feed, all the way to slaughtering operations (DAFF 2014). The two main producers are Rainbow Chicken and Astral. The poultry production of these two companies represents 46 per cent of total broiler meat production (Table 10). The other key producers are Country Bird Holdings Limited (CBH), Quantum, and 
Daybreak. Smaller players such as Sovereign Foods and new entrant Grain Field Chickens (GFC) make up the rest of the production.

Table 10: Market shares of leading poultry producers (2014 production volumes)

Source: DAFF, 2014

\begin{tabular}{|l|l|}
\hline Company & Market share (\%) \\
\hline Rainbow Chicken & 24 \\
\hline Astral & 22 \\
\hline Country Bird Holdings & 7 \\
\hline Tydstroom & 6 \\
\hline Fouries & 6 \\
\hline Daybreak & 5 \\
\hline Others & 25 \\
\hline
\end{tabular}

Rainbow Chicken, Astral and CBH are the only holders of exclusive commercial genetic breeding licenses in South Africa. Astral holds a license for the Ross 308 breed, Rainbow Chicken for the Cobb 500, while CBH holds a license for Abor Acres breed (Quantum also holds a license for the Cobb breed but it is only for internal production and not for commercial sales like the other licenses held by Rainbow, Astral and $\mathrm{CBH}$ ). All the three breeds are provided by multinationals Aviagen and Cobb-Vantress. That is, Ross 308 and Abor Acres are provided by Aviagen, while Cobb 500 is provided by Cobb-Vantress. As a result, any producer seeking to participate within the poultry value chain in South Africa would need to purchase breeding stock from Rainbow Chicken, Astral or CBH, whether for their own production or for commercial sales. The industry is thus characterised by high levels of concentration at the upstream level, and highlights the importance of scale in the poultry value chain.

Rainbow Chicken is the fully integrated poultry-producing subsidiary of RCL. RCL Foods is a diversified food company made up of four subsidiaries - Foodcorp, Rainbow, TSB Sugar and Vector Logistics. Rainbow Chicken manufactures its own feed through its feed division Epol. The company also has business interests in Zambia and Botswana.

Astral has poultry operations in South Africa, Mozambique, Swaziland and Zambia and feed mills in South Africa, Mozambique and Zambia. In Zambia, Astral has introduced a new broiler breed, Lohmann Meat, through its breeder farm and hatchery division, Tiger Chicks. Lohmann Meat is also owned by Aviagen. In Mozambique, Astral recently constructed a hatchery called Mozpintos and is currently constructing a breeder farm. Astral has also been engaged in expansion activities in South Africa through the purchase of other poultry operations.

Quantum is a former subsidiary of Pioneer and consists of three integrated business units, Tydstroom (broiler business), Nulaid (eggs and commercial laying hens), and Nova Feeds (animal feed). The company recently disposed of the abattoirs of its Tydstroom unit, effectively exiting from the broiler meat production business. It is now in an agreement with Astral to supply it with 550,000 live birds per week to its Western Cape abattoir and another agreement with Sovereign Foods to supply 250,000 live birds per week to its Gauteng abattoir. Quantum also has broiler and layer breeding operations in Zambia and Uganda and acquired a commercial egg business in Zambia in 2013. 
Country Bird Holdings (CBH) is a holding company formed in 2005 incorporating integrated poultry and stock feed business operations in South Africa, operating as Supreme Poultry (Pty) Ltd and Nutri Feeds, and poultry breeding operations in the region operating as Ross Africa Limited. CBH currently operates in South Africa, Botswana, Zambia, Namibia, Zimbabwe, and Mozambique. The company's poultry breeding operations in Botswana and Zambia operate under the Ross subsidiaries and the animal feed production operates under the Master Farmer subsidiary. CBH's Mozambique operations are still to be incorporated but they will include a fully integrated poultry business. In Zimbabwe, CBH operates the Kentucky Fried Chicken franchise.

Grain Field Chicken (GFC) is a fully integrated division of the Vrystaat Koöperasie Beperk (Pty) Ltd (VKB) which is based in the eastern Free State, established in 2010. VKB is a farmerowned agricultural company which specialises in the storage and marketing of agricultural products. GFC sources its maize and soybean from VKB. This has given it a unique competitive advantage, ensuring that GFC has not had to import maize or soybean for their animal feed needs so far. Thus, VKB has created an almost fully self-sufficient business in GFC. They buy maize from VKB farmers, have a stake in a soya oil crushing plant, and also own an abattoir. The GFC abattoir currently slaughters approximately 750000 chickens per week. This is half of the production of Daybreak, one of the smaller vertically integrated players. VBK also has 22 VKB retail outlets and 41 NTK outlets through which they market their agricultural produce, including the broilers. It also supplies the Boxer Group of supermarkets and there are prospects of supplying SPAR supermarkets (Coleman, 2013). Through a contract with Eagle's Pride, GFC uses both Cobb and Ross birds, with Cobb making up $85 \%$ of the day-old chicks that they purchase. The main markets of GFC are in Gauteng and KZN.

As can be seen, all these producers are integrated with feed and broiler production, and processing, which includes abattoirs (Table 11). It is also important to note that the animal feed companies that are vertically integrated with the poultry companies shown in Table 2 -Nutri Feeds (Pty) Limited, Epol, Meadow Feeds, and Nova Feeds - along with Daybreak are the top five producers of animal feed in South Africa (Louw et al. 2013).

However, the recent restructuring indicates that non-vertically integrated companies can also be competitive. The changes in Pioneer to form Quantum involved the closure of their abattoir and an agreement with Astral for supply of live birds (Magwaza, 2014). In the case of Grain Field Chickens, the breeding stock is sourced from specialised breeding business Eagle's Pride, and independent out-growers are used for broiler rearing. Apart from Quantum, all the producers shown in Table 11 also have breeding facilities. Moreover, a number of the players, especially large South African poultry companies, have operations in more than one country in the region. This emphasises the important regional dimensions of the value chain.

\section{Table 11: Company structure of main integrated poultry firms in South Africa}

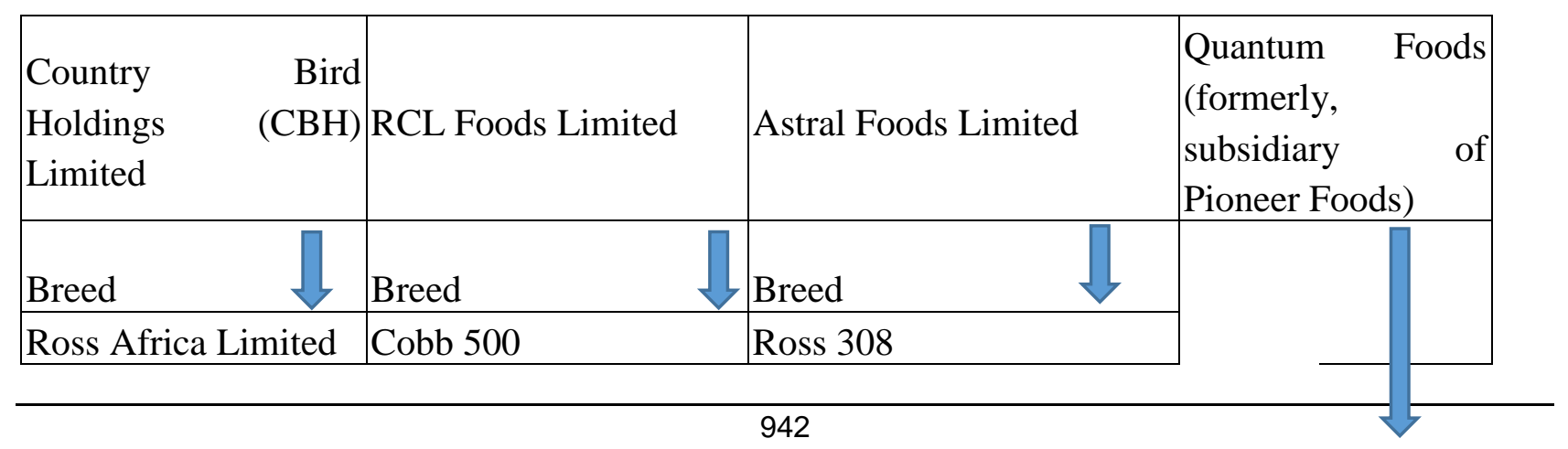




\begin{tabular}{|c|c|c|c|c|c|c|}
\hline Feed & Feed & DOC & Feed & DOC & Feed & DOC \\
\hline$\left|\begin{array}{lr}\text { Nutri } & \text { Feeds } \\
\text { (Pty) } & \text { Limited }\end{array}\right|$ Ross & Epol & $\begin{array}{l}\text { Rainbow } \\
\text { Chicken }\end{array}$ & Meadow Feeds & $\begin{array}{l}\text { National } \\
\text { Chicks }\end{array}$ & $\begin{array}{l}\text { Nova } \\
\text { Feeds }\end{array}$ & $\begin{array}{l}\text { Bergvlei } \\
\text { Chicks }\end{array}$ \\
\hline $\begin{array}{l}\text { Broiler } \\
\text { processing }\end{array}$ & Broiler pro & essing & $\begin{array}{l}\text { Broiler } \\
\text { processing }\end{array}$ & & & \\
\hline $\begin{array}{l}\text { Supreme Poultry } \\
\text { (Pty) Limited }\end{array}$ & Rainbow & & Astral & & & \\
\hline
\end{tabular}

Source: Ncube, Roberts and Zengeni (2016)

DOC: Day Old Chicks

\subsubsection{Regulatory framework}

As with the rest of the agro-processing sector, the poultry industry in South Africa is subject to domestic regulation specific to food, which at times has an effect of creating structural barriers to entry. Aside from market conduct/economic regulation governed by the Competition Act, regulations affecting the sub-sector include licensing, food safety, quality and environmental laws (Banda, et al, 2015). Non-economic regulations include the Department of Agriculture Forestry and Fisheries' regulation of animal feed. The department's regulation is concerned with monitoring quality and assessing whether the feed formulation matches the need of the animals. The feed is regulated by the Fertilisers, Farm feeds, Agricultural Remedies and Stock Remedies Act 36 of 1947, Act 37. The registration of feed involves a four-stage process, namely, verification, technical screening, assessment and approval.

Though feed manufacturers acknowledge that a registration process is necessary to ensure the quality of feed produced, it may be restrictive to new entrants. Small animal feed producers find it costly to test feed in laboratories. This restricts smaller firms from producing feed for sale in the open market. However, these costs are not prohibitive for a feed manufacturer or poultry producer who plans to enter at significant scale.

Other non-economic regulations include ${ }^{3265}$ :

- Labelling and Advertising of Foods (R429 of 29 May 2014)

- Foodstuffs, Cosmetics and Disinfectants Act, 1972 (Act No.54 of 1972)

- Agricultural Product Standards Act 1990, (Act No.119 of 1990)

- Good Manufacturing Practice

- South African National Standards SANS 885:2011

- South African Poultry Association (SAPA) Code of Practice for Broiler Production 3266

1.4.3.3.Performance of the South African poultry industry

1.4.3.3.1. Production

3265 Government gazette (2014, vol. 587, No. 37695).

${ }^{3266}$ SAPA website 
The animal feed to poultry value chain in South Africa has seen high levels of growth over the last decade. The production of broiler meat has increased from 928000 tons in 2004 to 1.7 million tons in 2014 (Table 12). This growth has been driven in large part by increases in the scale of production of the larger poultry producers, together with the growth in local consumption from $23 \mathrm{~kg}$ per capita in 2003 to almost 38kg per capita in 2014. For example, Astral increased broiler production from 2.1 million birds per week in 2006 to 4.4 million birds per week in 2014 (Astral Foods 2006, 2014). CBH's production has increased from 1.2 million birds per week in 2008 (CBH, 2008) to 1.5 million birds per week in 2014. Interestingly, the production of the largest producer - Rainbow Chickens has not increased as much as that of Astral, increasing from 4 million birds per week in 2004 to just 4.5 million birds per week in 2015 (Rainbow Chicken, 2005). As previously noted, Rainbow Chicken and Astral account for $46 \%$ of total broiler meat production (DAFF, 2014).

One of these major producers - $\mathrm{CBH}$ - is a relatively new entrant into the poultry industry. The story behind CBH's entry and growth highlights how competition law can open access to markets (see section 1.4.3.5. below).

Table 12: Broiler meat production and consumption in South Africa (thousands of tonnes)

\begin{tabular}{|l|l|l|}
\hline Year & Production & Consumption \\
\hline 2004 & 928 & 1082 \\
\hline 2005 & 1019 & 1204 \\
\hline 2006 & 1143 & 1383 \\
\hline 2007 & 1200 & 1470 \\
\hline 2008 & 1276 & 1508 \\
\hline 2009 & 1358 & 1558 \\
\hline 2010 & 1430 & 1645 \\
\hline 2011 & 1478 & 1753 \\
\hline 2012 & 1499 & 1836 \\
\hline 2013 & 1529 & 1899 \\
\hline 2014 & 1711 & 2023 \\
\hline 2015 & 1726 & 2170 \\
\hline 2016 & 1677 & 2199 \\
\hline
\end{tabular}

Source: DAFF (2014); Lovell (2012); SAPA (2015, 2017)

While entry by vertically integrated players has grown the number of independent players in the market, growth has also been driven by the increase in the number of contract growers. Broiler production by contract growers has increased over the years and is currently at approximately 60$80 \%$ of total broiler production. The shift towards a greater reliance on contract growing has largely been as a result of an increasing desire by the major poultry producers to shift costs associated with owning large pieces of farm land from themselves to the contract growers.

The entry of contract growers has been partly facilitated by the sale of the poultry farms by the major poultry producers to new contract farmers, like in the case of Daybreak Farms which sold off seven of its farms to black poultry producers. The current Daybreak Farms is the result of the divestiture of Afgri Poultry from the Afgri group of companies. Afgri Poultry was sold to the AFPO 
Consortium, through a transaction which was funded by the Public Investment Corporation (PIC). The divestiture was in line with Afgri's strategic decision to focus on its core grain businesses. ${ }^{3267}$

Contract growing also creates more opportunities for entry given the low cost of capital required to start up in comparison with other stages of the value chain which require a significantly higher level of expertise. The increasing prevalence of contract growers is also important in the context of inclusive growth. Ease of entry means more people can become contract growers thereby creating employment. However, while there has been entry at the contract growing level, the entry of $\mathrm{CBH}$ and the GFC illustrate that in order for entry to result in large scale production and to be considered a serious competitor in the poultry industry, it has to be at multiple levels of the value chain. Thus, while contract growing is an important means by which potential poultry farmers can enter the poultry value chain, the recent episodes of entry raise important questions about its effectiveness as a possible avenue of inclusive growth, particularly in the context of the Department of Trade and Industry's vision of creating Black Industrialists.

\subsection{Prices of poultry}

Fresh chicken prices are generally higher than prices of frozen chicken, however the latter are higher after accounting for brining (Figure 14). Frozen chicken (after accounting for brining) is more expensive than fresh chicken but only by a very small amount after 2011 . The reduction in frozen chicken prices of about $20 \%$ (R5) in early 2008, occurred around about the same time that Country Bird exited from the Elite joint venture with Astral and introduced a new breed, Arbor Acres. ${ }^{3268}$ The introduction of the breed not only led to increased production but it also increased rivalry in the provision of breeds. ${ }^{3269}$ It is likely that this rivalry affected the pricing of frozen chicken (which is the largest consumed category locally), resulting in the dip in chicken prices in 2008 and the price moderation between 2008 and 2011.

Poultry prices started increasing following the spike in feed prices in 2012 (Figure 14). Interestingly, a similar spike in the price of feed in 2014 did not result in an associated increase in chicken prices. This is likely due to increased import penetration in 2014 (Figure 15) which squeezed local poultry producer margins as feed cost increases could not be passed onto consumers. A similar fluctuation in imports in the last quarter of 2012 saw a concurrent decline in local poultry prices. Notably, frozen chicken prices are mostly affected by imports than fresh chicken prices, as imports come in frozen form, making them compete directly with frozen chicken produced locally.

\footnotetext{
3267 See http://www.afgri.co.za/afgri-strengthens-focus-on-grain-business-through-sale-of-poultry-business-and-picprovides-funding-for-transaction/

${ }^{3268}$ See section 6.5 below

${ }^{3269}$ Ncube et al, 2016.
} 
Figure 16: South African Quarterly Feed and Poultry Prices (2008 - 2015)

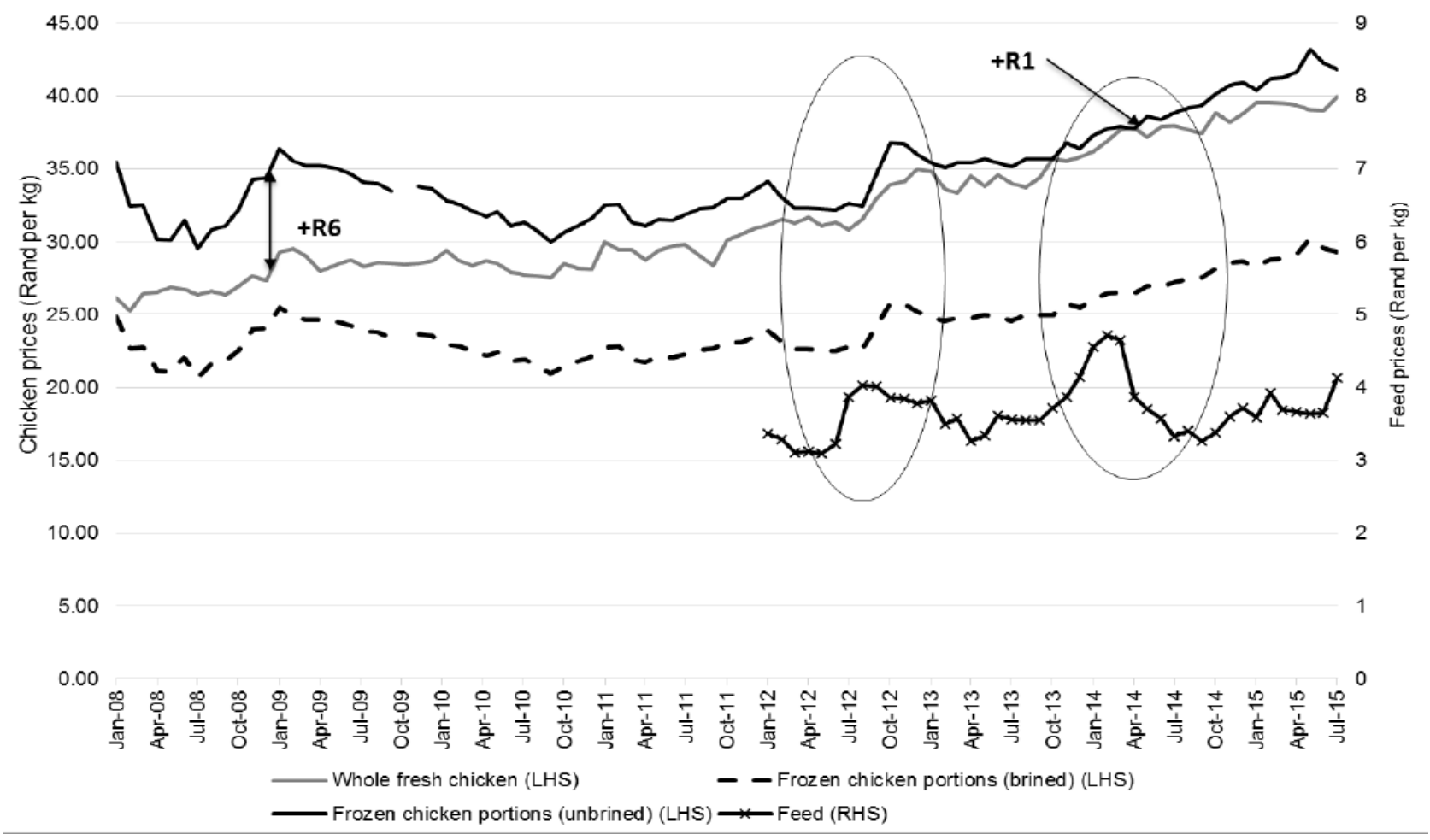

Source: Ncube et al., 2016

\subsection{Import and exports}

There was a significant spike in the South African poultry imports in the third quarter of 2012 (Figure 15). The end of 2012 saw imports increasing from US $\$ 80$ million to US $\$ 140$ million, a 75 per cent increase from one quarter to the next. These led to applications for anti-dumping duties against Brazil in 2013 (ITAC, 2013), which was the major source of South African imports prior 2012.

After the imposition of anti-dumping duties on Brazilian imports, there was a decline - albeit with fluctuations - in the value of imports (Figure 15). The anti-dumping tariffs - ranging from 12 to 82 per cent - were imposed on whole birds, boneless cuts, bone-in portions, and offal imported from Brazil (ITAC 2013). Thereafter, there was a switch towards imports from the EU, where the dumping duties did not apply as a result of the free trade agreements with South Africa (Kwaramba and Tregenna 2014). 
Figure 17: South Africa poultry trade flows (2010Q1 - 2016Q4)

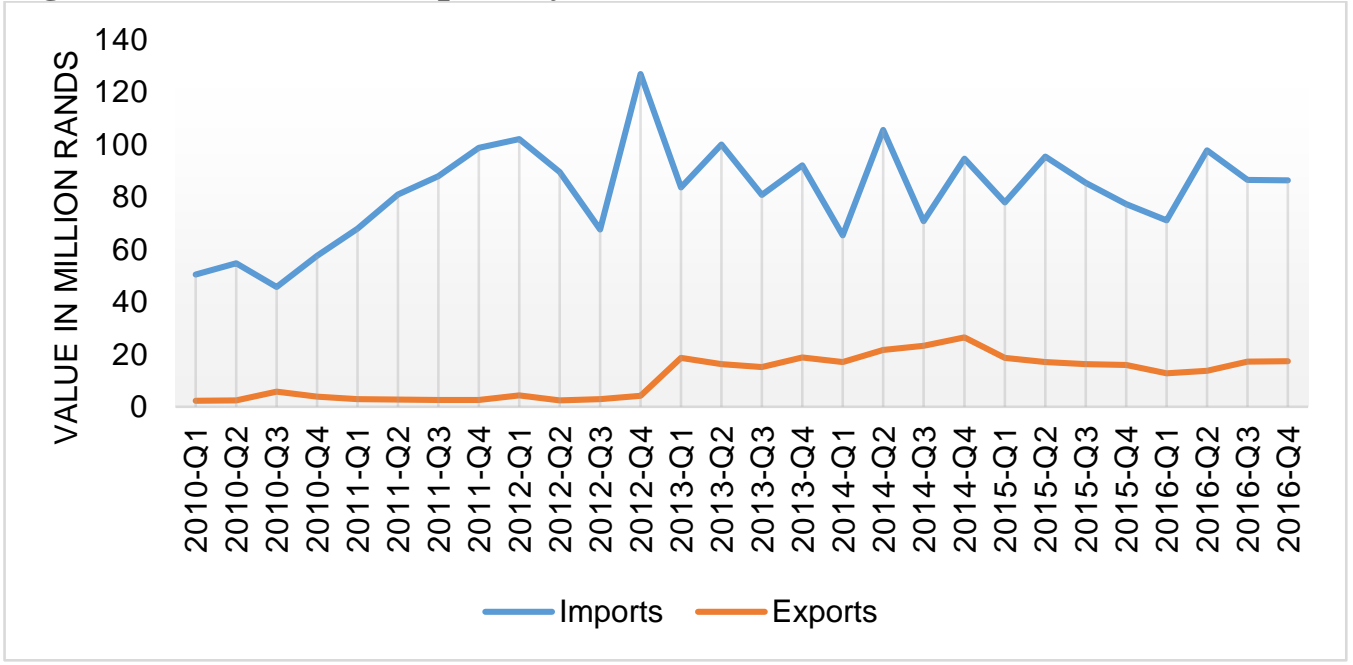

Source: Trade Map (ITC 2010-2016)

A smaller spike at the beginning of 2014 was due to an increase in imports from Europe, even though only increasing to the levels at the end of 2011. This increase led to another bid for an anti-dumping investigation being submitted by SAPA to ITAC in 2014. ITAC made a final determination on 27 February 2015, recommending the imposition of anti-dumping duties of 31.30-73.33 per cent on Germany, 3.86-22.81 per cent on the Netherlands, and 12.07-30.99 per cent on the United Kingdom (ITAC 2015). In its determination on this matter, ITAC indicated that though the poultry industry suffered material injury from dumping, other factors also contributed to its performance such as rising production costs related to feed, fuel, electricity and labour costs (ITAC 2015).

South Africa also has a combination of anti-dumping duties, tariffs, and a quota for imports from the United States. Recently, there has been a battle between South Africa poultry producers and American poultry producers as the latter threatened to have benefits of the African Growth and Opportunity Act (AGOA) repealed if access is not granted to American poultry farmers (Mnyandu, 2015). The resultant solution was a duty-free quota of poultry imports from the USA of 65000 tons available on a twelve-month basis from 1 April 2016 (DTI, 2016).

The issue of imports is important to South African producers because it reflects different chicken consumption patterns found in North American and EU countries when compared to South Africa. In the South African market, bone-in portions are the most widely consumed, generally in the form of IQF portions (SAPA, 2014). In contrast, high-income overseas markets mostly consume fillets such as breast portions that are sold at a premium. Since bone-in portions are not in high demand in overseas markets, they are then sold in other markets, such as South Africa, for a lower price. It is alleged that overseas players, including Brazilian producers, make their margins on fillet meat and sell bone-in portions at costs that allow them to cover the tariffs and logistical costs of shipping the meat to South Africa.

Other important imports in the poultry value chain include animal feed imports. Feed is the largest cost of producing chicken, accounting for 50-70 per cent of the cost of producing a chicken $^{3270}$, with maize and soybean being the two key inputs in the production of feed. South Africa

${ }^{3270}$ Ncube et al, 2017 
is less competitive in the cost of both day-old chicks and animal feed, when compared with countries such as Brazil and Netherlands (Table 13). Brazil price of feed is $45 \%$ cheaper than South Africa.

Table 13: Prices of feed and day-old chicks in selected countries in US\$ per kilogram of live weight

\begin{tabular}{|l|l|l|l|l|}
\hline & South Africa & Netherlands & United Kingdom & Brazil \\
\hline Day-old chicks & 0.21 & 0.19 & 0.23 & 0.14 \\
\hline Feed & 0.89 & 0.84 & 0.92 & 0.66 \\
\hline
\end{tabular}

The data above is for 2013 for Netherlands, United Kingdom and Brazil. It was converted to US\$ using an exchange of $£ 1=U S \$ 1.32$. South Africa data is for 2012.

Source: Zengeni, 2017

South African imports of oilcakes used in the production of animal feed, mostly made up of soybean oilcake, are larger than the imports of poultry. Argentina is the main source of South Africa's imports, accounting for 54 per cent of the total share of oilcake imports in 2014. However, the implementation of Department of Trade and Industry's soybean strategy (DTI, 2012) has meant investment in processing capacity and has reduced imports of soybean meal from 2012. ${ }^{3271}$ Through this strategy and financing from the Industrial Development Corporation in 2013, South African soybean crushing capacity has been substantially expanded to approximately 2.1 million tons per year.

South Africa is still constrained in soya production albeit being a surplus producer of maize. The country is generally reliant on imported soya with Argentina being the main source of South African soya cake (Ncube et al, 2016). Figure 16 below compares soya bean prices per ton in South Africa, Argentina, Brazil and Zambia. South African soya prices generally reflect the Argentina and Brazil prices which are the main sources of imports. The Zambian prices have been on a downward trend since 2010 reflecting the increase in production that the country is currently experiencing. Moreover, the Zambian prices are below the South African prices in 2013, 2014 and 2016, thus showing the increasing competitiveness of Zambia as a soya producing country.

${ }^{3271}$ Ncube et al, 2016 
Figure 18: Soya prices per ton U\$

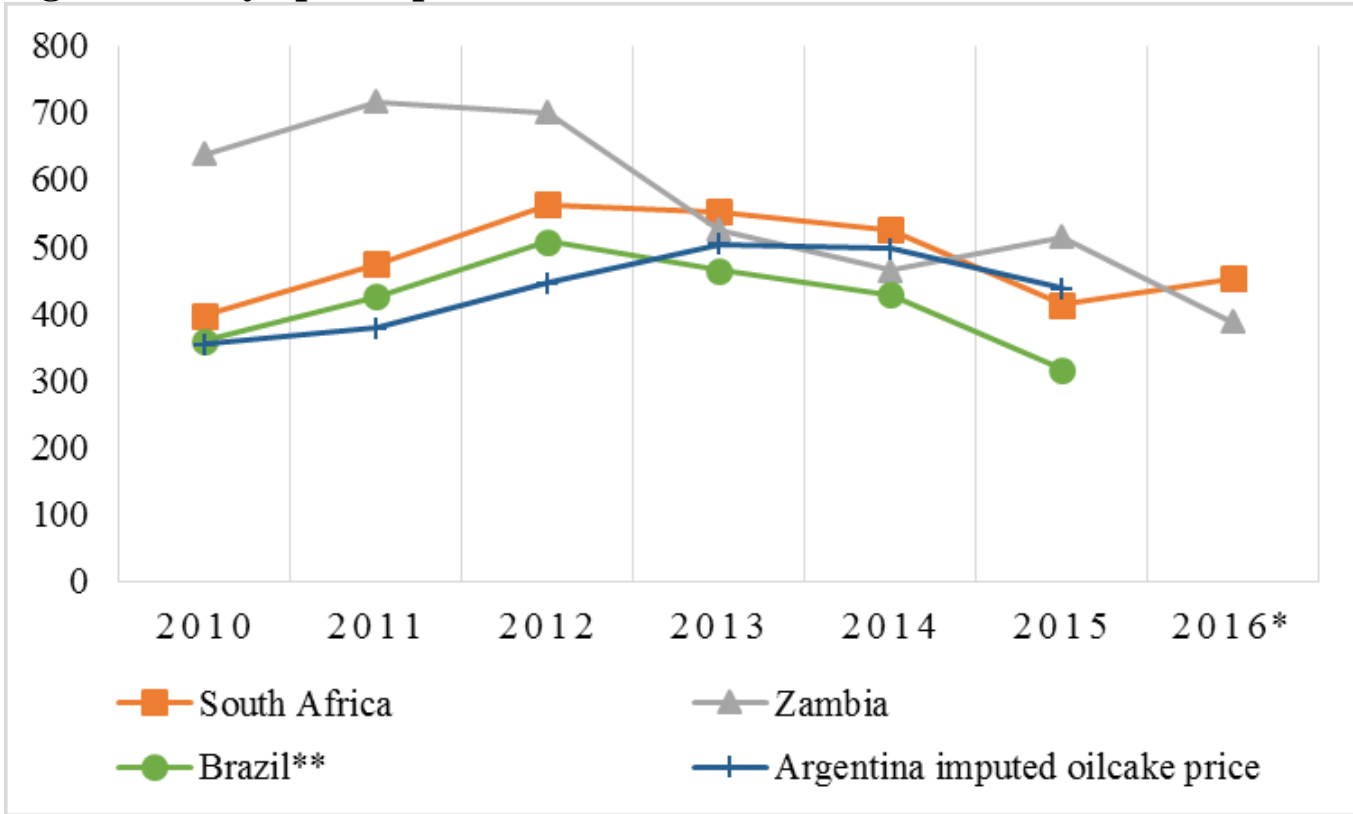

*The 2016 prices are up to September and July 2016 for Zambia and South Africa.

Source: Zengeni, 2017

Despite the decrease in Zambian prices, these are still at times higher than the imputed price of the processed product imported from Argentina (Figure 16), raising important questions about the conditions that would be necessary for Zambia to reach the scale and cost structure to enable importsubstitution from deep-sea sources for both soybeans and oilcake. Necessary conditions include, amongst others, investment to support agriculture production and storage facilities. The need to invest in storage facilities is important, given that one of the largest feed producers in Botswana indicated the poor quality of soybeans from Zambia was due to a lack of storage (Ncube et al., 2017). The potential to replace deep-sea soya imports from South America into South Africa's poultry feed sector by imports from Zambia is recognised in the latest iteration of the Department of Trade and Industry's Industrial Policy Action Plan (IPAP), reinforcing the importance of developing regional value chains. "A team is now working with the regional soya and poultry industry and logistics providers to focus on the price points required to enable processed soya to be landed at prices that are competitive with or better than deep-sea imports" (IPAP, 2017/18 - 2019/20).

South Africa's exports of poultry have been substantially lower, mainly to the Southern African Customs Union (SACU). At the beginning of 2013, poultry exports increased from US\$4.7 million in the fourth quarter of 2012 to US\$22 million in the first quarter of 2013 and remained at around these levels thereafter (Figure 15 above). The increase was largely due to a sharp recorded increase in exports to Lesotho and Namibia as a result of the improvement in the recording of intraSACU trade from 2013 and under-reporting before that point (Ncube et al, 2016).

\subsection{Key investments}

Due to high levels of integration, investments in the poultry value chain are very costly and typically require huge capital outlays to sustain the high working capital requirements. Importing grandparent 
stock can cost up to R8 million a flock (Grimbeek and Lekezwa, 2013), and it can take anything from 15 to 24 months from receipt of grandparent stock to produce the first commercial-level day old chick (Bagopi et al., 2014; SAPA, 2014i). Due to this lengthy production cycle, new poultry producers require up to two years' worth of capital to sustain their business before they earn revenue from the sale of their first commercial broilers.

Notwithstanding, the South African poultry industry has experienced investments in different stages of the value chain, evidenced by the expansion of operations by existing firms as well as the entry of new firms. For instance, in 2014, CBH had acquired a loan of $\$ 25$ million from the International Finance Corporation (IFC) for the installation of soya deactivation plants at two of its feed mills, and increasing its broiler processing capacity in South Africa (IFC, 2013). The loans were also for increasing day-old chick production in Botswana and Zambia.

The entry of Grain Fields Chicken (GFC) saw a total investment of R350 million, with the abattoir alone costing R200 million to construct. The establishment of GFC occurred through a joint venture between VBK and the Industrial Development Corporation (IDC). VKB borrowed approximately R88 million from the IDC which the IDC sourced from the Department of Labour's Unemployment Insurance Fund as well as from the Agro Processing Competitiveness Scheme (IDC, 2014). The role of development finance from the IDC has played a crucial role, however the 'patient' nature of the total capital expenditure contributed even more to GFC's successful entry. For instance, GFC had four successive years of significant losses before making a profit in its fifth year of operation. The diverse operations of its parent company, VKB, assisted in sustaining the business owners during this time.

Other investments involve the 2006 acquisition of Daybreak Farms at a cost of R120 million, which marked Afgri's re-entry into the broiler business. At the time, Daybreak was a fully integrated broiler producer, processor and distributor of poultry products in South Africa. Afgri saw its participation in the broiler business as a strategic investment to ensure the growth of its animal feed business. Accordingly, the acquisition of Daybreak saw Afgri embark on a significant drive to increase the production capacity of its new broiler business. Afgri undertook an estimated expenditure of R410 million to expand their broiler business. The expansion increased weekly production capacity from approximately 325000 birds to 650000 birds per week in 2009. Afgri's expansion of its broiler business continued in 2010 with the acquisitions of Midway Chix, a Limpopo-based hatchery with capacity to produce 875000 chicks per week as well as the acquisition of another broiler producer, Rossgro Chickens, with a capacity of 350000 chickens per week. It also secured broiler supply from local growers located near the old Daybreak farm in Delmas, Mpumalanga. The overall production capacity of Afgri Poultry increased rapidly to over 1 million birds per week.

There have also been significant investments by South African firms in the region. For instance, in Mozambique, Astral recently constructed a hatchery called Mozpintos and is currently investing in a breeder farm. In Zambia, it has introduced a new broiler breed, the Lohmann Meat. $\mathrm{CBH}$ has also been expanding into the rest of the southern African region and other parts of Africa. It has expanded its operations in Ghana, Nigeria, Zambia, Mozambique, Botswana and Swaziland. It has also recently received conditional competition approval from the Botswana Competition Authority to acquire the KFC business in Botswana (Botswana Competition Authority, 2015).

\subsubsection{Trends in concentration and outcomes of key cases in South Africa}


To reiterate, the poultry value chain is highly concentrated, typically at each stage of the value chain. At the feed stock level, the five major producers - Nutri Feeds (Pty) Limited, Epol, Meadow Feeds, Nova Feeds and Daybreak - account for almost 50 per cent of the total animal feed production in South Africa. The breeding stock level is also highly concentrated, with only three playersRainbow Chicken, Astral and $\mathrm{CBH}$. These companies hold exclusive commercial genetic breeding licenses. As a result, any producer seeking to participate within the poultry value chain in South Africa would need to purchase breeding stock from Rainbow Chicken, Astral and CBH, whether for their own production or for commercial sales.

In the early 2000s, the breeding stock market was effectively a duopoly. Astral had a market share of $69 \%$ of breeding stock, while its main competitor, Rainbow Chicken, had a market share of $26 \%$ of the great grandparent market. This changed around 2007 due to the introduction of a new breed by $\mathrm{CBH}$ (discussed in section 4.5 below). At the downstream level, the two major poultry producers - Rainbow Chicken and Astral—produce 46 per cent of total broiler meat production (DAFF 2014).

The poultry industry has continued to consolidate, as well as vertically integrate, increasing concentration levels, as evidenced by mergers and acquisition activity in the past 7 years (Table 14). Table 15 outlines the mergers which were approved conditionally. The overall competitive effect of these mergers is mixed. On one hand, there has been rationalisation and acquisitions to ensure security of supply to manage processing costs (Pioneer). On the other hand, there have been acquisitions as part of expansion into new geographic markets (Astral and Rainbow). While these mergers may not immediately raise competition concerns, concerns about market power in local and regional markets arise should the trend of acquisitions continue.

Table 14: Merger Activity in the Poultry Sector (2010 - 2016)

\begin{tabular}{|c|c|c|c|c|}
\hline Case No. & Primary Acquiring Firm & Primary Target Firm & Size & Status \\
\hline 2010May5134 & $\begin{array}{l}\text { Country Fair Foods, a division } \\
\text { of Astral Operations Limited }\end{array}$ & $\begin{array}{l}\text { Vredebest (Pty) Ltd and Byways } \\
\text { Poultry Farm (Pty) Ltd }\end{array}$ & $\mathrm{S}$ & Approved \\
\hline 2010Sep5336 & Daybreak Farms (Pty) Ltd & Rossgro Chickens (Pty) Ltd & $\mathrm{L}$ & Approved \\
\hline 2011Apr0016 & Astral Operations Ltd & $\begin{array}{l}\text { The Abbatoir business operated } \\
\text { by Corpclo } 2410 \text { (Pty) Ltd }\end{array}$ & $\mathrm{I}$ & Approved* \\
\hline 2011Jun0102 & Afgri Operations Limited & Pride Milling Company (Pty) Ltd & $\mathrm{L}$ & Approved \\
\hline 2011Nov0375 & $\begin{array}{l}\text { Rainbow Farms (Pty) Ltd and } \\
\text { Vector Logistics (Pty) Ltd }\end{array}$ & $\begin{array}{l}\text { Bushvalley Chickens Partnership } \\
\text { and Rodev Chickens (Pty) Ltd }\end{array}$ & $\mathrm{I}$ & Approved \\
\hline 2012Jun0356 & Pioneer Foods (Pty) Ltd & $\begin{array}{l}\text { Lohmann Breeding SA (Pty) Ltd } \\
\text { and Avichick (Pty) Ltd }\end{array}$ & $\mathrm{I}$ & Approved \\
\hline 2012Ju10370 & Pioneer Foods (Pty) Ltd & $\begin{array}{l}\text { DFC Breeder Farm (Pty) Ltd and } \\
\text { DFC Broiler Farm (Pty) Ltd }\end{array}$ & $\mathrm{I}$ & Approved \\
\hline 2012Nov0653 & Pioneer Foods (Pty) Ltd & Amaqanda Farms (Pty) Ltd & $\mathrm{S}$ & Approved \\
\hline 2013Oct0481 & $\begin{array}{l}\text { AgriGroupe Holdings (Pty) } \\
\text { Ltd }\end{array}$ & AFGRI Limited & $\mathrm{L}$ & Approved \\
\hline 2015Jun0312 & $\begin{array}{l}\text { VKB Agriculture Proprietary } \\
\text { Limited, Louis Dreyfus }\end{array}$ & $\begin{array}{l}\text { The Kromdraai Group of } \\
\text { Companies }\end{array}$ & $\mathrm{L}$ & Approved* \\
\hline
\end{tabular}




\begin{tabular}{|l|l|l|l|l|} 
2015Jul0435 & Sovereign Foods & $\begin{array}{l}\text { Quantum Foods Proprietary } \\
\text { Limited }\end{array}$ & I & Approved \\
\hline 2015Nov0647 & $\begin{array}{l}\text { Quantum Foods Proprietary } \\
\text { Limited }\end{array}$ & $\begin{array}{l}\text { Olifantskop Feeds Proprietary } \\
\text { Limited }\end{array}$ & I & Approved \\
\hline 2016Feb0052 & AFGRI Operations Limited & $\begin{array}{l}\text { Pride Milling Company } \\
\text { (Proprietary) Limited }\end{array}$ & L & Pending \\
\hline 2016Aug0411 & VKB Landbou (Pty) Limited & $\begin{array}{l}\text { Lomina Vyf (Pty) Ltd trading as } \\
\text { Farmpak }\end{array}$ & I & Approved \\
\hline 2016Aug0410 & $\begin{array}{l}\text { Country Bird Holdings } \\
\text { Proprietary Limited }\end{array}$ & $\begin{array}{l}\text { Sovereign Food Investments } \\
\text { Limited }\end{array}$ & I & Approved* \\
\hline The Humansdorp Co- & $\begin{array}{l}\text { Operative Limited and } \\
\text { Umtiza Farmers Corp Limited } \\
\text { and the business of UFC Trust }\end{array}$ & I & Approved \\
\hline
\end{tabular}

*Approved with conditions (outlined in Table 15 below)

Source: Competition Commission website

Table 15: Mergers approved with conditions

\begin{tabular}{|l|l|}
\hline Merger (Case No.) & Conditions \\
\hline Astral vs Corpclo (2011Apr0016) & $\begin{array}{l}\text { The Corpclo shareholders shall continue to } \\
\text { source, on average over a period of } 6 \text { months, no } \\
\text { less than 90,000 day-old chicks per week from } \\
\text { Stonor. }\end{array}$ \\
$\qquad \begin{array}{l}\text { Transparent prices and terms and conditions for } \\
\text { each for dealings between Astral and Corpclo. }\end{array}$ \\
$\begin{array}{l}\text { All discounts and incentive schemes offered by } \\
\text { the Astral Group will be communicated separately } \\
\text { from the day-old chick and broiler feed prices, and } \\
\text { will not be designed so as to compel the Corpclo } \\
\text { shareholders to source broiler feed and day-old } \\
\text { chicks from the Astral Group to the exclusion of } \\
\text { competitors. }\end{array}$ \\
$\qquad \begin{array}{l}\text { The Corpclo shareholders will report to the } \\
\text { Commission every three months on their } \\
\text { obligation to procure from Stonor. }\end{array}$ \\
\hline VKB vs Kromdaai (2015Jun0312) & $\begin{array}{l}\text { Merging parties shall not retrench any employees } \\
\text { at the merged entity as a result of the merger } \\
\text { VKB shall give first preference to the affected } \\
\text { employees should positions arise at VKB for a }\end{array}$ \\
\hline
\end{tabular}




\begin{tabular}{|l|l|}
\hline CBH vs Sorereign (2016Aug0410) & $\begin{array}{l}\text { period of } 12 \text { months after the approval of the } \\
\text { merger }\end{array}$ \\
\hline $\begin{array}{l}\text { no merger-specific job losses for an indefinite } \\
\text { period; }\end{array}$ \\
$\begin{array}{l}\text { the introduction of a 4\% B-BBEE shareholding in } \\
\text { Sovereign Foods within } 2 \text { years of CBH acquiring } \\
\text { substantial shareholding in Sovereign Foods. }\end{array}$ \\
\hline
\end{tabular}

Source: Competition Commission website

Adding County Fair as part of Astral together with Astral's acquisition of National Chicken (Natchix) in 2002 and Earlybird Farms in 2004 increased the total Astral's group broiler production to just below that of Rainbow. Rainbow has also expanded their operations through strategic acquisitions of Vector Logistics in 2004 which resulted in the company becoming even more vertically integrated in the poultry supply chain ${ }^{3272}$.

There have been further 9 cases of notified mergers and acquisitions in animal feed and poultry between 2010 and 2015. Pioneer made two acquisitions in 2012, both of which included broiler breeding and layer operations. Pioneer's primary rationale for these acquisitions was the need to ensure increased throughput for its existing abattoirs. Pioneer also acquired Amaqanda farms, which appears to have been a previous contract egg producer for Pioneer.

Astral's acquisition in early-2011 of broiler breeding farms and abattoir facilities in the KwaZulu-Natal region was done primarily to expand its footprint into a new geographic area. Astral Foods (County Fair) also acquired three broiler farms in the Western Cape, near Paarl. The Commission held that the transaction will not lessen competition significantly, as these farms previously provided most of their production to the Astral group. Rainbow's acquisition of a processing facility in the Tzaneen area in September 2011 was also aimed at entering a new geographic market.

Large poultry mergers reported in the 2010-2015 period involved the acquisitions by Afgri of Midway Chix, a Limpopo-based hatchery with capacity to produce 875000 chicks per week, and Rossgro Chickens, with a capacity of 350000 chickens per week. However, on 1 April 2015, Afgri divested its poultry operations together with the Kinross Animal Feeds Mill to AFPO Consortium (Pty) Ltd; a transaction funded by the Public Investment Corporation (PIC). Following this transaction, Agfri Poultry was renamed Daybreak Farms. Daybreak Farms is the first fully blackowned vertically integrated poultry firm with the scale (at broiler production and feed level) to potentially compete against the larger incumbents.

The features of the poultry business thus mean that the sector is dominated by a small number of large vertically integrated businesses. The businesses also generally have strategic linkages into related areas of agricultural value chain such as maize and soya production, milling and storage, and logistics. The concentrated nature of the sector means there is likely to be scope for the exertion of market power, whether unilaterally or through coordinated arrangements. The behaviour of the large producers influences the space for smaller entrepreneurial producers and the spread of activities.

${ }^{3272}$ See cases 113/LM/Nov05, 74/LM/Sep04, 57/LM/Aug04 ,69/AM/Dec01 


\subsubsection{Overview of other competition interventions}

Despite the highlighted episodes of entry, the South African poultry industry is still highly concentrated, with significant barriers to entry. Furthermore, local producers and suppliers of parent stock have exclusive supply agreements with overseas suppliers. For instance, as a result of the high barriers to entry and limited countervailing power due to lack of alternatives, the duopoly of Rainbow Farms (Rainbow) and Astral dominated the market in South Africa for many years due to the fact that they were the only commercial suppliers of parent breeding stock.

Several competition cases in the poultry sector illustrate the potential for incumbents to raise entry barriers and exclude smaller rivals. The case brought by $\mathrm{CBH}$ against Astral demonstrates the importance of obtaining a high performing breed, and highlights how competition law can open access to markets ${ }^{3273}$. CBH was a major poultry producer in Zimbabwe and Botswana before entering South African poultry market in 1992, through a joint venture with Astral and National Chick Limited (Natchix) known as the Elite Joint Venture.

One of the terms of the joint venture was obliging $\mathrm{CBH}$ to source at least $90 \%$ of its breeding stock from Elite, effectively preventing $\mathrm{CBH}$ from trading with Astral's rivals. CBH lodged a complaint of exclusionary abuse with the Competition Commission in 2007, following which $\mathrm{CBH}$ exited the Elite joint venture shortly thereafter to establish a rival breeding business with the new breed known as Arbor Acres, also sourced from Aviagen. This saw the entry of a third breed into the South Africa market to challenge the Astral/RCL duopoly. Astral has since settled the allegations with the Commission, admitting to the contravention of section 8(c) and 4(1) (b) (i) for which it was fined R16.7.3 million.

Incumbents can thus foreclose downstream rivals from inputs, and this might require rivals to enter at both upstream and downstream levels, substantially increasing the entry costs. In the Elite case, the fact that Rainbow was vertically integrated effectively meant there were no good competitors to Astral and its Ross breed. Similarly, there could be customer foreclosure where incumbents control abattoirs which are required to buy and process the birds from independents. Nonetheless, it does not appear as if there have been cases reported in this regard.

There have also been cases of collusive conduct penalised across the animal feed to poultry value chain between 2010 and 2016 (Table 16). ${ }^{3274}$ In 2013 Astral, through its subsidiary County Fair, admitted to entering into an agreement with a competitor (Pioneer through its division known as Tydstroom Poultry) to fix the prices of fresh poultry in the Western Cape for a period between 2003 and 2007. Astral was subsequently charged an administrative penalty of over R16 million. There were also several cases in grain storage, which will be discussed in section 5 below.

\section{Table 16: Cartels in the Animal to Poultry Value Chain $\left(2010\right.$ - 2016 $\left.{ }^{3275}\right)$}

\begin{tabular}{|l|l|l|l|l|}
\hline Cartel & Firms involved & Date & Case No. & Penalty \\
\hline & Wes Enterprises, & & & \\
Animal feed & MGK Operating Company & 2013 & $017517 / 017509$ & R 34355.43 \\
\hline
\end{tabular}

\footnotetext{
${ }^{3273}$ Competition Tribunal $(2011,2013)$.

3274 This only shows cases that were successfully penalized. There several other cases that were not referred and penalized by the Competition Tribunal.

3275 There is no record of other cartels penalized beyond 2013
} 


\begin{tabular}{|l|l|l|l|l|} 
& $\begin{array}{l}\text { Astral Operations, } \\
\text { Tydstroom }\end{array}$ & 2013 & 015891 & $\begin{array}{l}\mathrm{R} \\
894.47\end{array}$ \\
\hline Poultry & $\begin{array}{l}\text { Astral Operations, } \\
\text { Country Bird }\end{array}$ & 2013 & No.74/CR/JUN08 & No penalty \\
\hline
\end{tabular}

Source: Competition Tribunal

The Commission has also investigated a case of market allocation, exclusive supply agreements and information exchange against all members of the South African Poultry Association (SAPA) under a single case (no. 2009Apr4389). The Commission's investigation focused on the largest players which are all integrated up to the feed level, namely Rainbow Chickens, Astral, Pioneer and CBH. The allegations included market allocation by Pioneer and Rainbow; exclusive supply agreements involving all broiler producers; tying allegations against certain breeding stock suppliers; and information exchange against all the companies. However, following undertakings by the respondents, the Commission took a decision not to refer the exclusive supply agreement as well as information exchange allegations. Thus, the Commission did not prosecute Astral for the abovementioned conducts.

At the feed level, the Commission uncovered collusive conduct and penalised two companies - Wes Enterprises and MGK Operating Company - for fixing the prices of animal feed. The Commission's investigation revealed that Wes Enterprises entered into an agreement with MGK's retail division to supply MGK with its products which MGK would then sell in its retail stores to farmers countrywide. Wes also issued its distributors with the price list that indicated the price at which distributors can obtain the products from Wes as well as the suggested prices to farmers.

A post-intervention assessment of the competition concerns highlighted above indicates some positive results. The Astral/CBH ruling has led to the introduction of a new breed in the South African poultry value chain, effectively increasing rivalry in the supply of breeding stock. This saw increase in production volumes accompanied by the decline in margins of major producers from around the time restrictions on $\mathrm{CBH}$ ended in 2007 (Ncube et al, 2016). Further, following the unearthing of the animal feed cartel, there is clear decline in feed prices from late 2013/early 2014 (Figure 14 above). On the other hand, the conditions imposed on some of the mergers have mainly aimed at addressing public interest concerns only, particularly the potential loss of employment. While these have helped in safeguarding jobs that would have otherwise been lost as a result of the mergers, they trend towards increasing concentration and vertical integration remains a concern.

However, in the Astral/Corpclo merger, the Commission did find the potential for the merged entity to foreclose rivals in the supply of day old chicks and animal feed. The undertakings by the merging parties to ensure transparent prices and the agreement that discounts and incentives would not be designed so as to compel Corpclo to source feed and day-old chicks from Astral to the exclusion of competitors, have helped to alleviate the foreclosure concerns.

\subsubsection{Dairy Value Chain}

\subsubsection{A mapping of the key players and ownership structure}

The dairy value chain (Figure 17) involves a number of activities including the production and marketing of raw milk, pasteurized milk and cream, fermented milk, long-life milk and cream, 
yoghurt, cheese and its by-product whey, milk powder, sweetened and unsweetened concentrated milk, butter and butter oil (ghee).

Figure 19: Dairy industry marketing channels

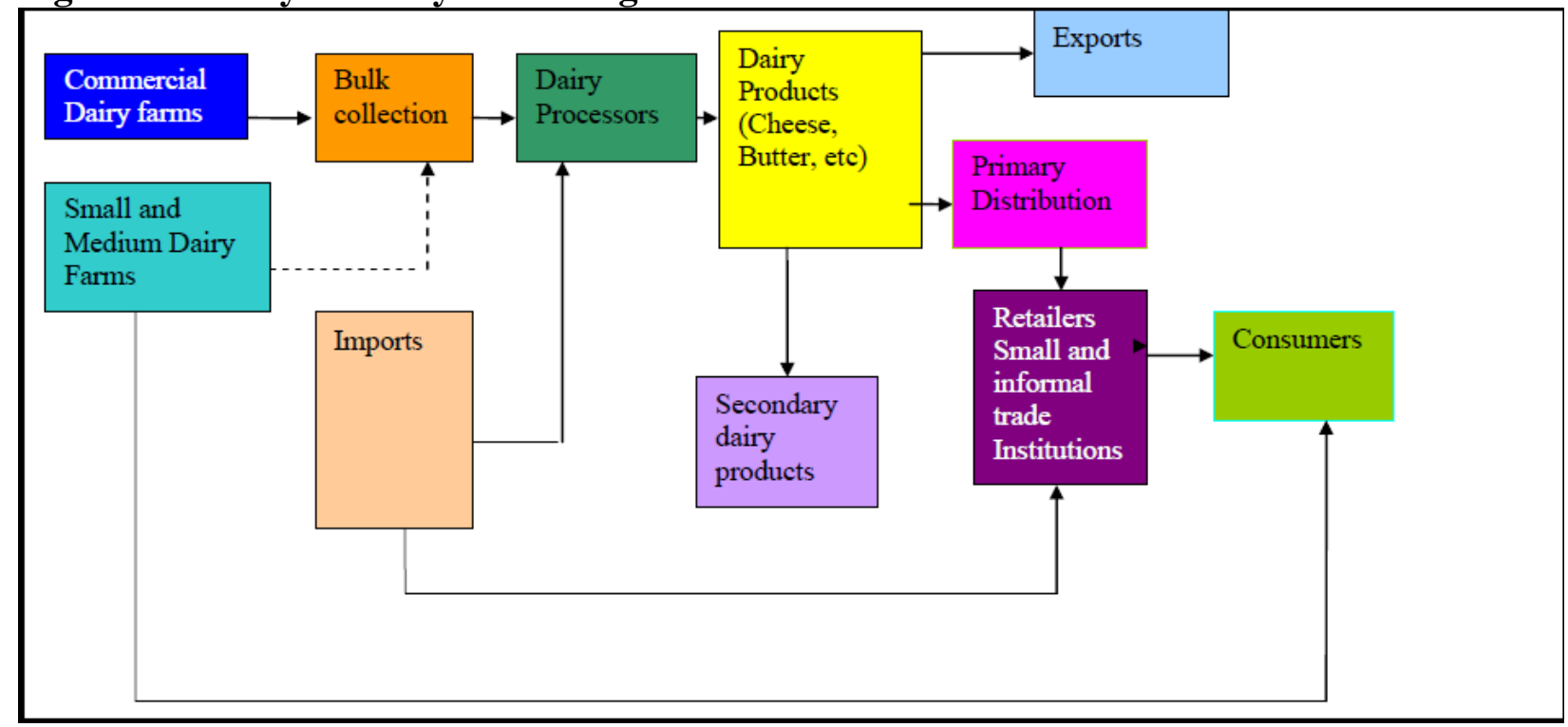

Source: Department of Agriculture Forestry and Fisheries (2012a)

There are two main sources of raw milk for processing: commercial dairy farms and small and medium dairy farms. Milk from commercial dairy farms usually goes straight into bulk collection for dairy processors who then produce dairy products such as cheese, butter and yoghurt. The products are then either exported or channelled into primary distribution which goes to retailers and smaller in formal trade institutions which then goes to consumers. Small and medium dairy farms either supply consumers (producer-distributors) or contribute to the bulk collection of milk (Midgley, 2016). Dairy processors can also import raw milk to use in their production processes.

The dairy sector in South Africa consists of a number of large players. Figure 18 below contains the market shares of different companies in the dairy sector based on retail value. In 2016, the firms with the highest market shares in terms of retail value were Clover (17.5\%), Lactalis the maker of popular Parmalat brand (14.6\%) and Dairybelle ${ }^{3276}$ with $5.4 \%$. What stands out about the sector is the presence of multinational company with operations in a number of countries within and outside Africa at various levels of the value chain including in the packaging and transport logistics of dairy products.

3276 DairyBelle was liquidated in May 2017, See: http://www.iol.co.za/capetimes/news/dairybelles-assets-to-beauctioned-off-9456293 
Figure 20: Company market shares of dairy products based on retail value, 2011 -2016

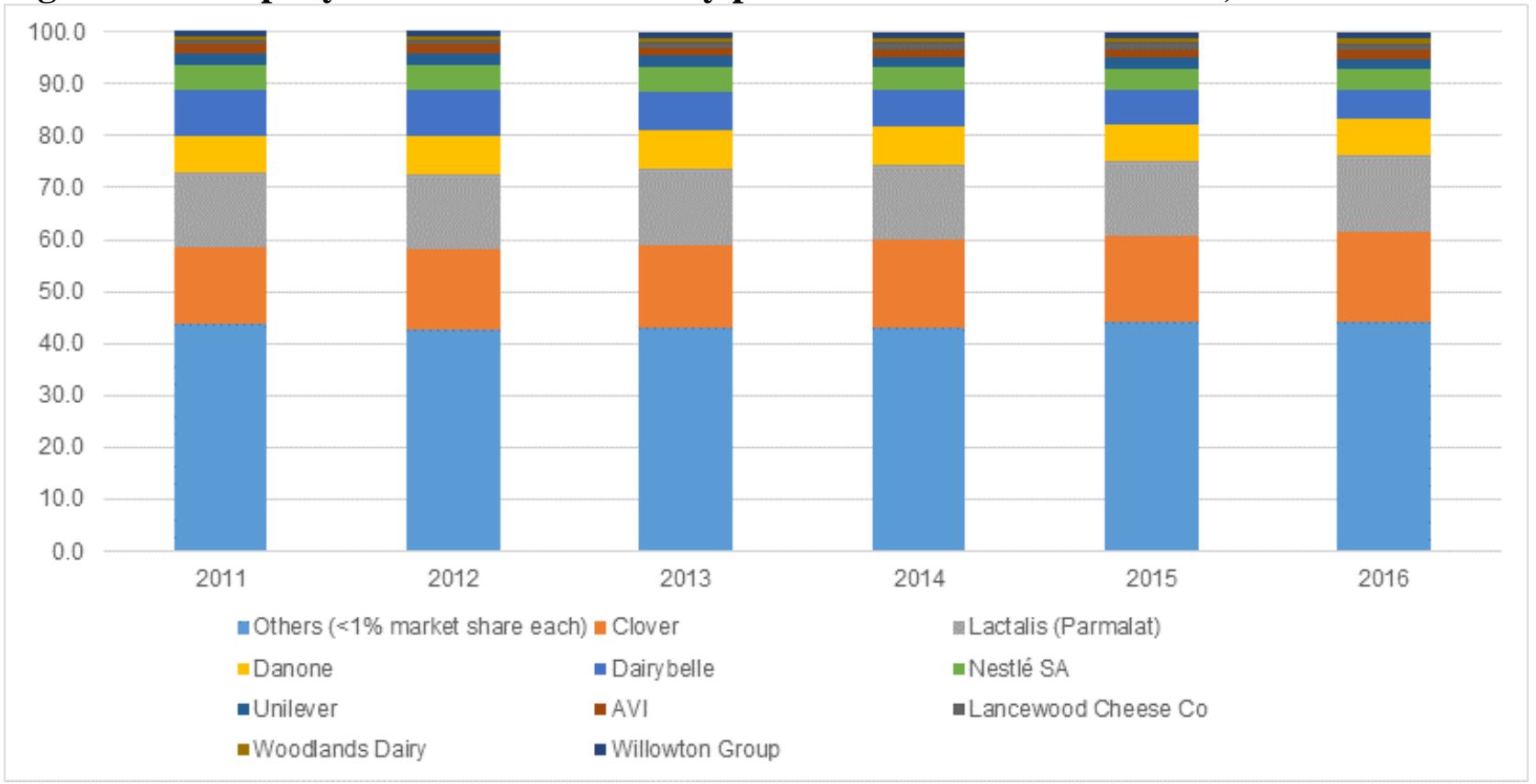

Source: Euromonitor (2017)

An analysis of market shares at an aggregate dairy product level gives the appearance of a very competitive sector with several players. However, an analysis by type of dairy products provides a different picture with one or two companies having significant market shares. Euromonitor (2017) provides markets shares by different type of dairy products: Cheese; drinking milk products; yogurt and sour milk products and other products.

For drinking milk products, Clover has the highest market share in terms of retail value with $35.5 \%$, more than twice the market share of its next competitor. Pick ' $n$ ' Pay and Parmalat follows with $11.9 \%$ and $11.6 \%$ respectively (Figure 21 ). Together these three companies hold $59 \%$ of the market share. In terms of cheese products, Parmalat has the highest market share of $28 \%$. Dairybelle and Clover follow with market shares of $15 \%$ and $11 \%$ respectively. These three again hold a combined market share of $54 \%$ of the market. However, the market shares held by the incumbents may be underestimated because they most likely produce the house brand milk products sold by Pick n Pay and other retail supermarkets.

For yoghurt and sour milk products, Danone is the dominant player, holding $41 \%$ of the market share, several times the market share of its closest competitors Parmalat and Clover each with $6 \%$ market share. For other milk products including chilled desserts and coffee whiteners, Nestlé leads with a $35 \%$ market share followed by National Brands with $18 \%$ and Danone with $10 \%$. Clover continues to lead drinking milk products and accounted for $36 \%$ value share in 2016, a share three times that of its closest competitor. Clover, Parmalat, Danone and Dairybelle make repeated appearances in terms of high market share of the different types of products. 
Figure 21: Market shares of various dairy products, 2016

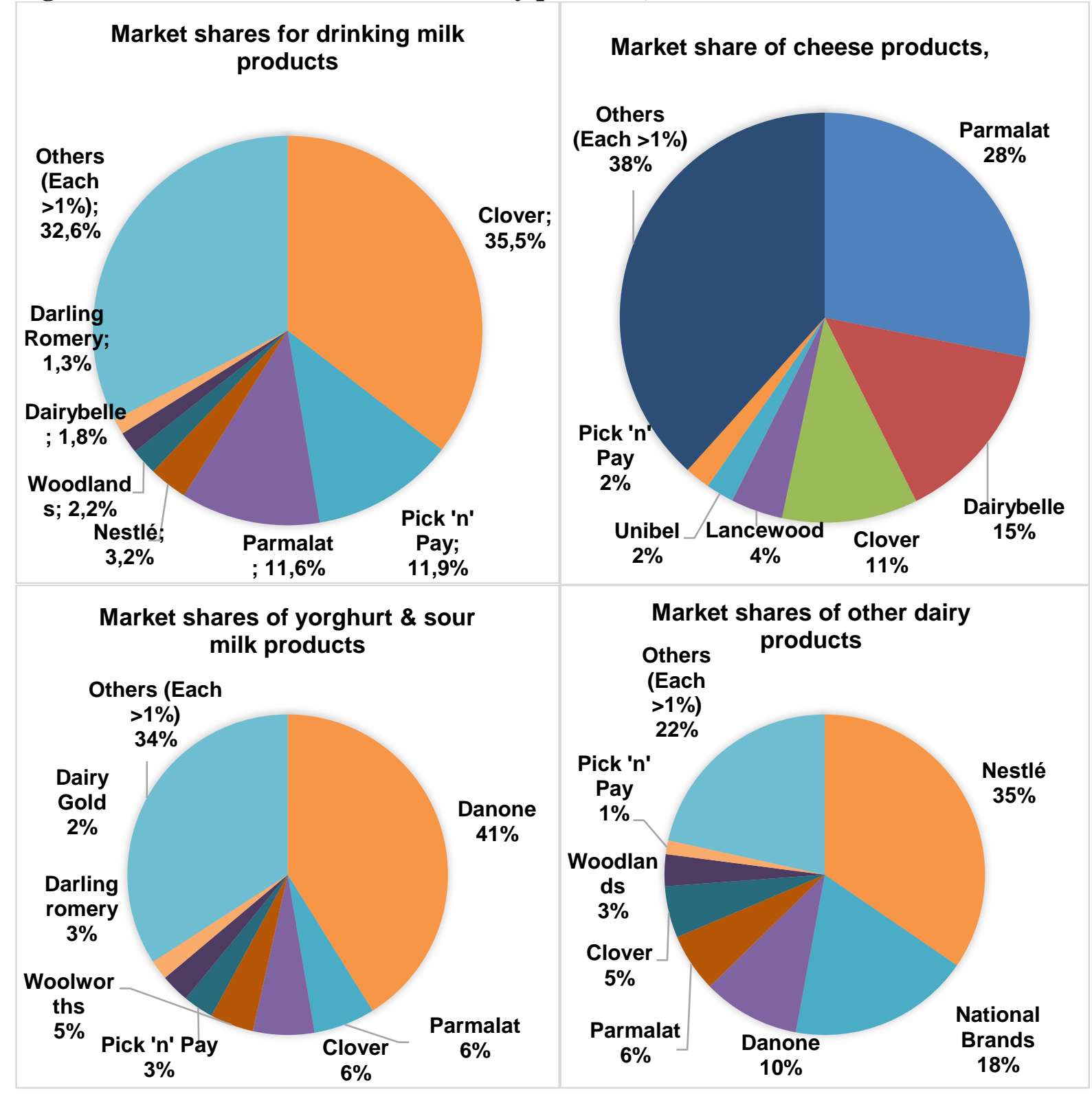

Source: Euromonitor (2017)

Note: Drinking milk products include flavoured milk drinks, milk, powder milk and milk alternative while other dairy products include Chilled and shelf desserts, chilled snacks, coffee whiteners, condensed milk, cream and fromage frais and quark.

Clover SA (Pty) was established in 1994 but originated from a butter factory formed as early as 1898 in KwaZulu-Natal Midlands (Ncube et al., 2016). The company produces a number of dairy products including milk, cheese, cream, condensed milk, flavoured milk drinks, juice and bottled water (Euromonitor, 2017). In 1998, Clover and Danone formed the joint-venture Danone Clover (Pty) Ltd in which Clover supplied Danone with a number of service the production of yoghurt and other sour milk products. The joint venture came to an end in 2010 when Danone Clover became Danone Southern Africa (Pty Ltd taking over the Danone brand in yoghurt and sour milk drinks (Euromonitor, 2017). Clover maintained an agreement with Danone in which Clover would continue to produce Danone's yoghurt products which expired in December 2014. In 2003 the company listed 
on the Johannesburg Stock Exchange (JSE). Clover diversified its product offering by acquiring Real Juice Co Holdings (Pty) Ltd from AVI Ltd in 2012 and acquiring the yoghurt and long-life/UHT milk business of Dairybelle in 2014 for ZAR 200 million (Clover, 2014). Clover also provides distribution and logistics services which incidentally contributes $50 \%$ of the company's revenue despite making up about $30 \%$ of Clover's operations (Ncube et al., 2016).

Parmalat began operations in South Africa in 1998 and is a subsidiary of Lactalis, a French dairy company, the largest in the world by turnover (Ncube et al., 2016). Some of its products include Parmalat Everfresh UHT milk, Steri Stumpie flavoured drinking milk, milk powder, cheeses under the brand names Simonsberg, Melrose and Bonnita brands, Bonnita-branded butter, yoghurt. maas, and custard, and Aylesbury ice cream. It also produces a range of fruit juices under the PureJoy brand. Parmalat operates a UHT milk processing plant and UHT warehouse in Parow (Western Cape) and in Port Elizabeth (Eastern Cape). Its annual milk demand amounts to approximately 400 million litres (Ncube et al., 2016).

Nestlé South Africa was first established in South Africa in 1866 although it was only formally registered in 1916. It has eight manufacturing facilities and three distribution centres across the country. Nestlé's dairy segment comprises concentrated dairy products such as KLIM, Nespray and Nido instant milk powder, evaporated milk, and condensed milk. It also produces dairy-based powdered beverages such as Milo, Nesquik and Nestlé Hot Chocolate. Nestlé does not produce fresh or UHT milk in South Africa. Nestlé procures its own raw milk, but outsources the conversion of raw milk into milk powder to other processors including Clover and Parmalat. They pay a conversion cost to these processors and use the milk powder in the production of their dairy-based beverages (Ncube et al., 2016).

Danone entered the South African market when it created a joint venture with Clover SA. ${ }^{3277}$ In 2010, Danone acquired 100\% of the joint-venture creating Danone Southern Africa which also operates in Botswana, Namibia, Angola, Lesotho, Swaziland and Mozambique. The company specializes in the production of fresh dairy products and desserts. Some of its brands include Nutriday, Ultra Mel, Yogi Sip, Inkomazi and Activia. The company has two manufacturing facilities based in Gauteng which makes use of 5\% of all milk produced in South Africa.

Woodlands Dairy first began operations in 1995 when it packaged milk from the Woodlands Farm. They now manufacture a range of concentrated dairy products including cheese, butter, cream, amazi, flavoured milk, and extended shelf-life fresh milk in addition to packaging private label UHT milk for Spar and Woolworths (Ncube et al., 2016). ${ }^{3278}$ It is based in Humansdorp in the Eastern Cape. Its majority-shareholder, with a $75 \%$ stake in the company, is Gutsche Family Investments (GFI). The remaining 25\% of Woodlands Dairy is held by African Pioneer Limited and Nozala Investments (Pty) Ltd.

\subsubsection{Regulatory framework}

The South African dairy industry is regulated primarily by the Department of Agriculture, Forestry and Fisheries (DAFF) although certain regulation pertaining to the dairy industry is regulated by other government departments including the Department of Trade and Industry (DTI) and Department of

3277 Danone website.

3278 Woodlands Dairy website. Available at http://www.woodlandsdairy.co.za/ 
Health (DOH). Some of the main legislation governing the sector include the following (Dairy Standard Agency, 2016):

- Foodstuffs, Cosmetics and Disinfectants Act, 1972 (Act 54 of 1972) - governing most the health-related aspects in the industry

- The Animal Diseases Act, 1984, Act 35 of 1984

- Export: Veterinary procedural Notice 20/2010-01 Standards for the registration of a veterinary approved dairy establishment for export.

- Agricultural Product Standard Act, 1990, Act 119 of 1990

- South African Bureau of Standards compulsory and non-compulsory standards relating to Food safety and Quality

- International Standards Organisation requirements and guidelines

- Codex standards relating to production of various products and processes along the value chain

Other than the above legislation, there are also guidelines for the operation of the sector. These include $^{3279}$ :

- Code of Practice for Milk Producers

- Code of Practice for the Secondary Industry

- Documentation Development

- Guidelines for the interpretation of quality problems in milk

- Guide to Dairy Product Labelling

- International Dairy Federation/Food Agriculture Organisation (IDF/FAO) Guideline Documentation on: Animal Production and Health; Guide to Good Farming Practice 2004

New dairy regulation R260 was introduced by the Department of Agriculture, Forestry and Fisheries and implemented in March 2016. The regulation requires firms to indicate ingredients lists, batch codes and best by/use by/sell by dates on packaging. It further added restrictions with fat content categorization (Euromonitor, 2017). Products with 4.5\% fat are considered high fat products, 3.34.5\% fat as full fat, $1.5 \%-3.3 \%$ as medium fat, $1.5-3.3 \%$ fat as low fat and products containing 0.5$1.5 \%$ fat as fat-free (Euromonitor, 2017). These appear not to be prohibitive. While strict, it just requires companies to change their labelling. Few companies changed their recipes to fit the new categories.

\subsubsection{Performance of the South African dairy sector}

\subsection{Production and trade in the dairy sector}

As of 2014, whole fresh cow milk was the third largest agricultural product in terms of tonnage and fifth highest in terms of value (Midgley, 2016). Milk production has grown consistently over the years with an average annual growth rate of just over 2\% from 1960 million litres in 2000 to 2780 litres in 2014 (Figure 22). The number of producers has by contrast dropped, from 5980 in 2000 to 1890 in 2014, pointing towards a trend of fewer farms with larger herds and production capacity.

${ }^{3279}$ Dairy Standard Agency website. 
Figure 22: Milk Production in South Africa (2000 - 2014)

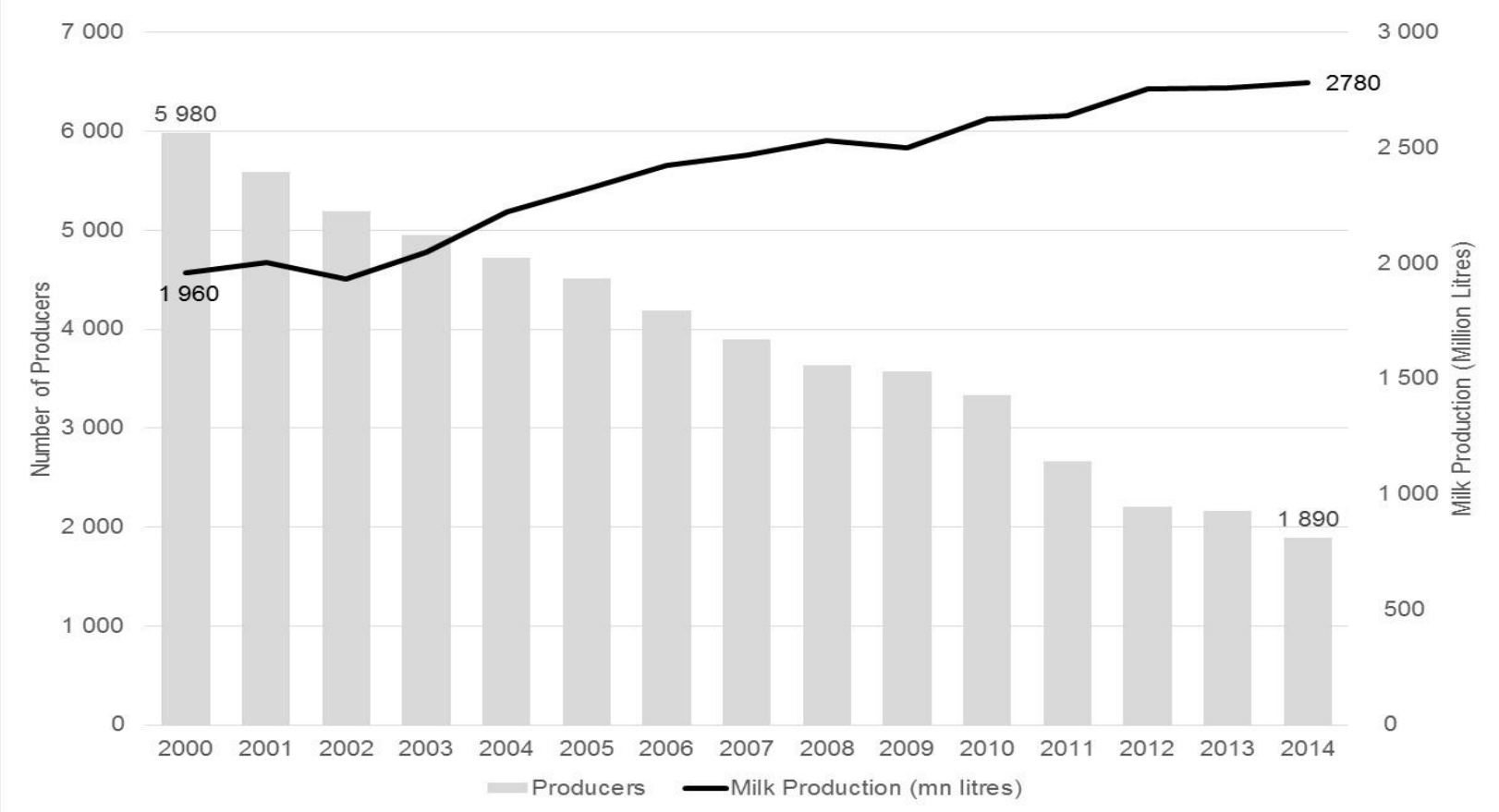

Source: Milk Producers' Organisation

The emergence of these large commercial farms also points towards the growing consolidation and concentration of the sector discussed further in section 7.4. The large farms producing more than 5000 litres of milk per day currently supply about $80 \%$ of the total milk production in South Africa (Ncube et al., 2016). The economies of scale characterised by such large production can raise the barriers to entry for smaller entrants into the sector.

\subsection{Prices in the Dairy sector}

Average prices for dairy products have been consistently increasing between 2011 and 2016 for different dairy products particularly for fresh and long-life milk (Table 17). Prices for Fresh milk rose by $9 \%$ and $10 \%$ on average for full cream and low fat milk respectively for the period under review.

Table 17: Average Domestic Prices for Dairy Products, 2011 - 2016

\begin{tabular}{|l|l|l|l|l|l|l|l|l|}
\hline Product & Unit & $\mathbf{2 0 1 1}$ & $\mathbf{2 0 1 2}$ & $\mathbf{2 0 1 3}$ & $\mathbf{2 0 1 4}$ & $\mathbf{2 0 1 5}$ & $\mathbf{2 0 1 6}$ & $\begin{array}{l}\text { CAG } \\
\text { R }\end{array}$ \\
\hline Fresh Full Cream Milk & 1 Litre & 8.53 & 9.38 & 10.09 & 11.35 & 12.13 & $\begin{array}{l}12.9 \\
6\end{array}$ & $9 \%$ \\
\hline $\begin{array}{l}\text { Long Life Full Cream } \\
\text { Milk }\end{array}$ & 1 Litre & 9.55 & $\begin{array}{l}10.2 \\
2\end{array}$ & 10.87 & 11.98 & 12.77 & $\begin{array}{l}13.4 \\
3\end{array}$ & $7 \%$ \\
\hline Fresh Low Fat Milk & 1 Litre & 8.74 & 9.79 & 10.78 & 12.48 & 13.38 & $\begin{array}{l}14.3 \\
6\end{array}$ & $10 \%$ \\
\hline Long Life Low Fat Milk & 1 Litre & 9.61 & $\begin{array}{l}10.4 \\
1\end{array}$ & 11.00 & 12.06 & 12.68 & $\begin{array}{l}13.3 \\
0\end{array}$ & $7 \%$ \\
\hline
\end{tabular}




\begin{tabular}{|l|l|l|l|l|l|l|l|l|}
\hline Plain Yoghurt & $\begin{array}{l}500 \\
\text { Gram }\end{array}$ & $\begin{array}{l}12.8 \\
1\end{array}$ & $\begin{array}{l}13.5 \\
8\end{array}$ & 14.08 & 14.84 & 15.54 & $\begin{array}{l}15.8 \\
0\end{array}$ & $4 \%$ \\
\hline Flavoured Yoghurt & $\begin{array}{l}500 \\
\text { Gram }\end{array}$ & $\begin{array}{l}12.4 \\
0\end{array}$ & $\begin{array}{l}11.9 \\
4\end{array}$ & 13.88 & 14.59 & 15.38 & $\begin{array}{l}16.0 \\
8\end{array}$ & $5 \%$ \\
\hline Cheddar Cheese & $\begin{array}{l}\text { Per } \\
\text { Kilogra } \\
\text { m }\end{array}$ & $\begin{array}{l}87.3 \\
7\end{array}$ & $\begin{array}{l}94.3 \\
2\end{array}$ & $\begin{array}{l}103.4 \\
9\end{array}$ & $\begin{array}{l}111.8 \\
7\end{array}$ & $\begin{array}{l}119.5 \\
2\end{array}$ & $\begin{array}{l}98.7 \\
5\end{array}$ & $2 \%$ \\
\hline Sour Milk & 1 Litre & $\begin{array}{l}10.9 \\
1\end{array}$ & $\begin{array}{l}12.0 \\
0\end{array}$ & 12.72 & 13.26 & 13.76 & $\begin{array}{l}15.2 \\
6\end{array}$ & $7 \%$ \\
\hline Custard & 1 Litre & $\begin{array}{l}21.4 \\
4\end{array}$ & $\begin{array}{l}22.0 \\
7\end{array}$ & 22.71 & 23.93 & 24.67 & $\begin{array}{l}25.5 \\
5\end{array}$ & $4 \%$ \\
\hline
\end{tabular}

Source: Stats SA (Statistics South Africa). (n.d)

The difference between retail and producer prices (farm to retail price spread) displayed in Figure 23 below rose from R5.44 per litre in January 2010 to R8.95 in July 2017. In 2015, retail prices dropped following a fall in producer prices in previous months. This was likely due to the drought that affected milk produced. Retail prices in 2016 rose significantly and disproportionately from the growth in producer prices.

Figure 23: Monthly milk producer and retail prices, $2010 \quad-\quad 2016^{3280}$

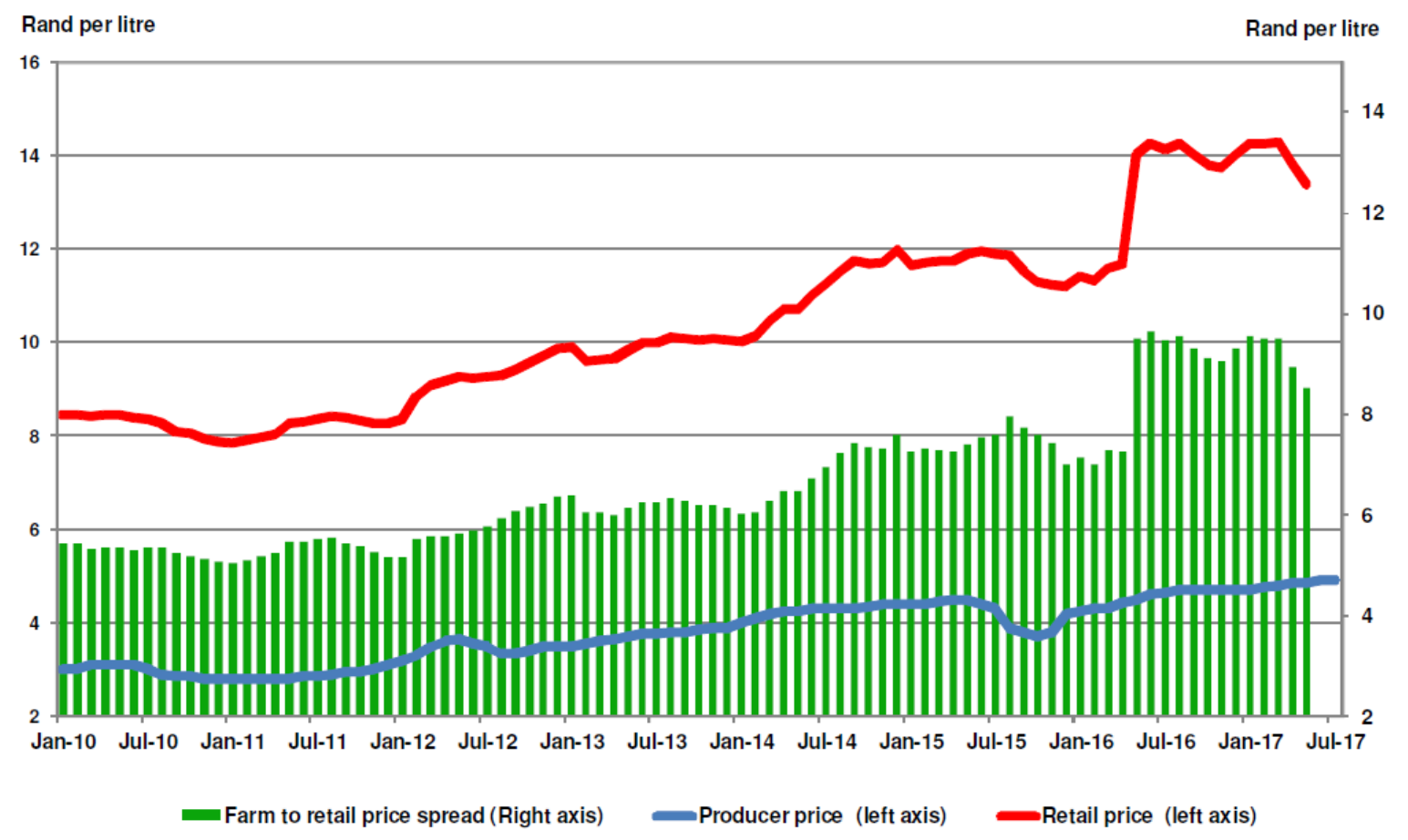

Source: (MPO, 2017)

\subsection{Imports and exports}

3280 The retail prices reflected in the figure are of fresh milk per litre for milk packaged in 2-litre plastic containers and are compared to producer prices. 
In terms of trade data, exports have grown with a CAGR of $21 \%$ while the CAGR for imports was $6 \%$. Exports experienced particularly strong growth in 2010. This dropped in 2015. Between 2009 and 2012, imports were experiencing consistent growth but the value of imports began to drop in 2013 (Figure 24).

Figure 24: Total South African Imports and Exports of Dairy products, 2006 - 2016

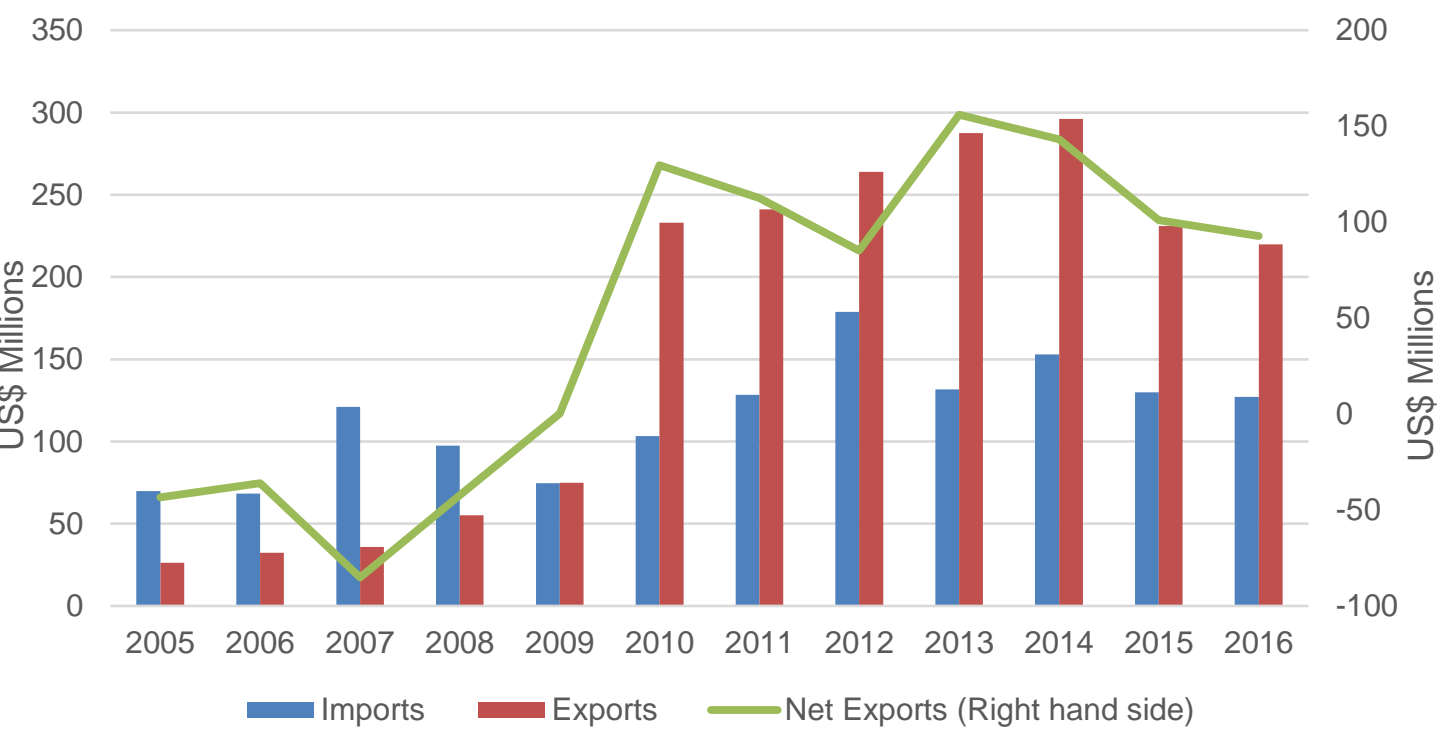

Source: UN Comtrade data. Note: net exports are on the RHS axis

From 2010 onwards, exports of dairy products have been significantly higher than imports in to the region. A large proportion of these exports have been to the SADC region (Figure 25). In 2009, while there is a large spike in exports of the main categories of dairy products, as previously noted, this spike is exacerbated by SACU exports now being included in SA's export data figures. There is growth of exports into the SADC region nonetheless, and this is likely due to the growing trend of expansion of South African retail chains into southern Africa (das Nair and Chisoro, 2016). 
Figure 25: Dairy Exports form SA to SADC (2005 - 2016)

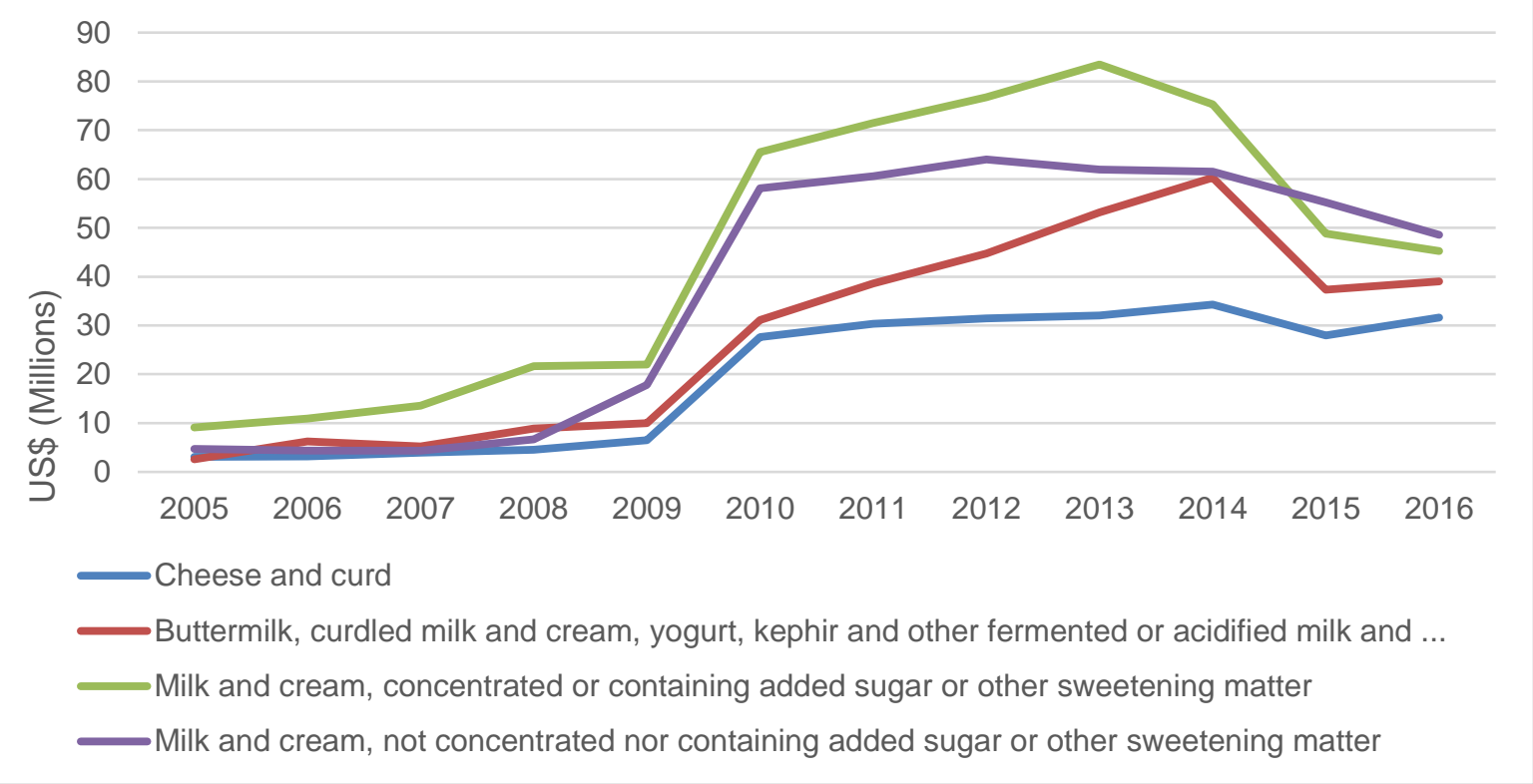

Source: UN Comtrade data

1.4.4.4.Trends in concentration and outcomes of key competition cases

\subsection{Overview of competition interventions}

At the lower levels of the value chain, there has been considerable consolidation. At the primary level, as of January 2016, there were 1683 milk producers, a decline of 54\% from 3665 in January 2008 (Milk Producers' Organisation, 2016). The reduction in the number of milk producers, however did not result in a similar decline in milk production but rather coincided with increased productivity by large scale farmers (Figure 22). At the secondary level, the number of producer-distributors dropped from 178 in September 2008 to 115 in April 2016 while the number of milk buyers dropped from 163 to 150 during the same period (Milk Producers' Organisation, 2016). While there are about 150 milk buyers in the country, the four largest milk buyers (which are also the main processors, (Clover, Nestlé, Parmalat, and Woodlands) purchase more than $50 \%$ of the total milk production (Ncube et al., 2016).

The continued concentration in the sector particularly amongst the milk buyers has resulted in the substantial bargaining power being held by a small number of buyers. It is perhaps in response to this that the South African Milk Co-operative (Samilco) made up of dairy farmers applied for an exemption from the Competition Commission in August 2013 to enable their members to participate in collective price negotiations with milk processors. The exemption was to allow for the possible sharing of sensitive information during the collective negotiations. ${ }^{3281}$ The exemption was amended in October 2014 to include an "equalization mechanism". Under the equalization mechanism, a farmer who produced milk in excess of the amount required in a stipulated contract would redistribute the milk to farmers who had been unable to meet their contract volumes enabling them to satisfy their contracts. Before this mechanism was implemented, the farmer who produced excess

3281 The initial exemption application was published in the Government Gazette, No. 36760. http://www.gov.za/sites/www.gov.za/files/36760_gen856.pdf 
milk would generally sell it to the processors at lower prices than the contract price. In this way, the farmers could meet their volumes at the higher contract prices. The exemption highlights the existence of the asymmetric bargaining power in the industry and is also reflected in the complaint the MPO brought against the major retail chains in 2009, alleging that the supermarkets used their bargaining power to suppress prices at the farm. ${ }^{3282}$

Concentrated sectors such as this one are often characterized by concerns of collusive and anti-competitive conduct. At least four cases have been brought against the dairy industry since the early 2000s and include most of the main players identified above.

In 2006, the Competition Commission of South Africa brought four main charges against Clover South Africa, Parmalat, Ladismith Cheese, Woodlands Dairy, Nestlé, Lancewood and Milkwood Dairy for collusive conduct, the price fixing and the use of exclusive supply agreements between 1 January 2002 and 30 March 2006. The charges concerned the following:

- The information exchange between the processors which allowed them to agree on the purchase price of raw milk.

- Milk supply and exchange agreements between Clover, Parmalat, Woodlands and Nestlé in which they agreed to sell their surplus milk to one another, rather than to sell it to end users at lower prices which kept retail prices high.

- Exclusive agreements between Clover and Parmalat and milk producers in which the producers were compelled to supply their total milk production exclusively to Clover and Parmalat and not to rivals. This prevented the producers from accessing more competitive prices from third parties or for smaller processors to access milk supplies.

- Price-fixing of UHT milk by Clover and Woodlands, and by Woodlands and Milkwood. Woodlands and Milkwood were also alleged to have engaged in market division

The case, however, was dismissed in 2011 on procedural grounds. There were apparent irregularities in the way in which the Competition Commission had initiated and investigated the case. The Commission withdrew the case in late 2011.

A more recent competition case has involved an investigation into alleged abuse of dominance by Parmalat. The case was initiated in November 2014 and concerns a bonus scheme Parmalat implement with the aim to reward milk producers in the Eastern and Western Cape for continuous uninterrupted 12 months' supply of milk to Parmalat. In August 2016 however, the Commission decided to drop the complaint against Parmalat finding that there was insufficient evidence to illustrate that competition between milk processors had been substantially lessened as a result of Parmalat's bonus scheme (Competition Commission South Africa, 2016).

\subsection{Recent cases (2011- 2016)}

At least six mergers took place in the sector for the period under review, the majority of which involved Clover, the largest dairy processor in South Africa (Table 18). The mergers involved Clover's attempt to expand into new or niche markets: In all four cases, Clover is expanding into new or niche markets; an expansion into juice in June 2012, into yogurt distribution in November 2014, and an expansion into Ayrshire milk production in December 2014 via the acquisition of Nkunzi Milkway. Acquisition of businesses in adjacent or niche segments appears to be the main

3282 https://mg.co.za/article/2009-07-04-supermarket-chains-investigated 
means by which firms can obtain access to new and niche markets cost effectively (Ncube et al., 2016).

Table 18: Mergers and Acquisitions in the Dairy Sector (2011 - 2016)

\begin{tabular}{|c|c|c|c|c|c|}
\hline Year & $\begin{array}{l}\text { Primary } \\
\text { Acquiring Firm }\end{array}$ & $\begin{array}{ll}\text { Primary } & \text { Target } \\
\text { Firm } & \\
\end{array}$ & Size & Status & Conditions \\
\hline 2012 & Clover SA (Pty) Ltd & $\begin{array}{l}\text { Real Juice Co. } \\
\text { Holdings (Pty) Ltd }\end{array}$ & I & $\begin{array}{l}\text { Approved } \\
\text { conditionally }\end{array}$ & $\begin{array}{l}\text { Extension } \\
\text { agreements } \\
\text { independent } \\
\text { distributors }\end{array}$ \\
\hline 2014 & $\begin{array}{l}\text { Clover S.A. (Pty) } \\
\text { Ltd }\end{array}$ & $\begin{array}{l}\text { Dairybelle's } \\
\text { Yoghurt/UHT Milk } \\
\text { Businesses }\end{array}$ & $\mathrm{L}$ & $\begin{array}{l}\text { Approved } \\
\text { conditionally }\end{array}$ & $\begin{array}{l}\text { Continue to provide } \\
\text { Danone with secondary } \\
\text { distribution services } \\
\text { until June } 2015 \\
\text { No retrenchments } \\
\text { should result from this } \\
\text { merger. } \\
\text { Clover to create an } \\
\text { employee grant of R30 } \\
\text { 000 to fund business } \\
\text { opportunities in the } \\
\text { event of retrenchments. }\end{array}$ \\
\hline 2014 & $\begin{array}{l}\text { Clover S.A. (Pty) } \\
\text { Ltd }\end{array}$ & $\begin{array}{l}\text { Nkunzi Milkyway } \\
\text { (Pty) Ltd }\end{array}$ & I & $\begin{array}{l}\text { Approved } \\
\text { conditionally }\end{array}$ & $\begin{array}{l}\text { Clover will invest in } \\
\text { production capacity } \\
\text { and facility upgrades }\end{array}$ \\
\hline 2016 & $\begin{array}{l}\text { Bongicel } \\
\text { Proprietary Ltd }\end{array}$ & $\begin{array}{l}\text { Lusitania Food } \\
\text { Products } \\
\text { Proprietary Ltd } \\
\end{array}$ & $\mathrm{L}$ & Approved & \\
\hline 2016 & Nestle S.A. (Nestle) & $\begin{array}{l}\text { P\&R Ice Cream } \\
\text { Public Ltd Co. }\end{array}$ & $\mathrm{L}$ & Approved & \\
\hline
\end{tabular}

Source: Competition Commission website.

The Competition Commission's efforts to address competition concerns are illustrated clearly in the merger between Clover and Dairybelle. Clover issued a notice to terminate its provision of secondary distribution services of Danone yoghurt products. ${ }^{3283}$ Prior to the merger, Clover was not in the yoghurt business, the issuance of the termination notice could be considered anti-competitive as Clover, now a rival would refuse Danone access to essential distribution services. The CCSA's condition in this regard ensured that Clover continued to provide this essential service.

3283 Competition Commission Media Release 16 October 2014. Available here: http://www.compcom.co.za/wpcontent/uploads/2014/09/Commission-recommends-approval-of-the-acquisition-of-Dairybelles-businesses-by-Cloverwith-conditions.pdf 
The other conditions related to the above mergers appear to mostly concern public interest issues such as employment. In the Clover/Real Juice merger, the condition related to the continued use of independent suppliers particularly with regards to distribution of its juice products rather than Clover's use of its own distribution network, largely to maintain employment. Similarly the condition in the Clover/Nkunzi case relating to improved production capacity was a commitment that Clover would not shift production from Nkunzi's Silverton facility in Pretoria to its Clayville facility in Johannesburg thereby resulting in retrenchments (Hancock, 2015). Nkunzi was one of only six suppliers of Ayrshire milk, a niche product with only one buyer in Woolworths SA.

\subsection{Barriers to entry}

One of the major barriers to entry in the industry is the significance of logistics in the sector. In addition to producing milk, entrants must be able to transport highly perishable raw milk to the processing plant. This is costly especially because raw milk is low in value relative to the volume. Furthermore, daily output of milk is uncertain and fluctuates daily, as a result, tanker routes must be planned daily in order to ensure that the largest volume of milk is collected over the shortest possible distance to enable efficiency. The fact that there is no return load further increases the price. This challenge exists further down the value chain during transport of finished products from the processor to distribution centres and to stores. Managing this logistics process efficiently is often a significant challenge for entrants.

Another important part of the value chain is packaging and labelling of the processed products. Packaging costs represent approximately $17 \%$ of the cost of finished products. The packaging used for fresh and UHT milk is either imported or priced at import parity prices which contribute to the significant costs. Due to the absence of supply of this product and high levels of concentration in the packaging market, this cost can form a significant barrier to entry for new processing firms.

The lack of capital is another barrier especially considering the costs required to take a product from its raw milk state to processing, packaging and finally distribution. While incentive programmes such as the Department of Trade and Industry's Manufacturing Competitiveness Enhancement Programme (MCEP) were available, many of the applicants complained about the lengthy and burdensome process involved in acquiring the funding. In many cases, consultants had to be hired to guide the firms through the process which further added to their costs.

\section{Mode of entry}

The main means of entry into the sector appears to be through the acquisition of smaller firms in new or niche markets as illustrated by Clover in the section below. However, dairy firms appear to be entering the processing level of the value chain through the establishment of their own milk processing plants. For instance, in 2015, the acquisition of Honeydew Dairies in KwaZulu-Natal by Dairy Day. Farmers in the Port-Elizabeth region in the Eastern Cape also established Coega Dairy in 2015. 


\subsubsection{Milling Value Chain}

1.4.5.1.A mapping of the key players and ownership structures

The maize and wheat value chains form an important part of the food processing sector as main sources of food for the economy. It is also a sector that has been characterized by cartel conduct from established incumbents after the liberalisation of the sector. Anti-competitive conduct has been present from storage and trading through processing (milling) to collusion in final product prices of bread and white maize products.

The figure below illustrates the main areas of the maize value chain (Figure 24). Farmers and producers source their seeds from input suppliers. Their harvest is then transported to silo owners of which there is a limited number due to the expense required to construct a silo. There have in fact been no new constructions of silos since before the 1990s. From the silos, the products are then transported to traders, to exporters or to the local market for sale. At the local market, the products are sold to the animal feed industry, to maize millers or to other millers such as wet milling and brewing. The products are then exported or sold to the wholesale/retail market where it is accessed by the final consumer. 


\section{Figure 26: Maize Market Value Chain}

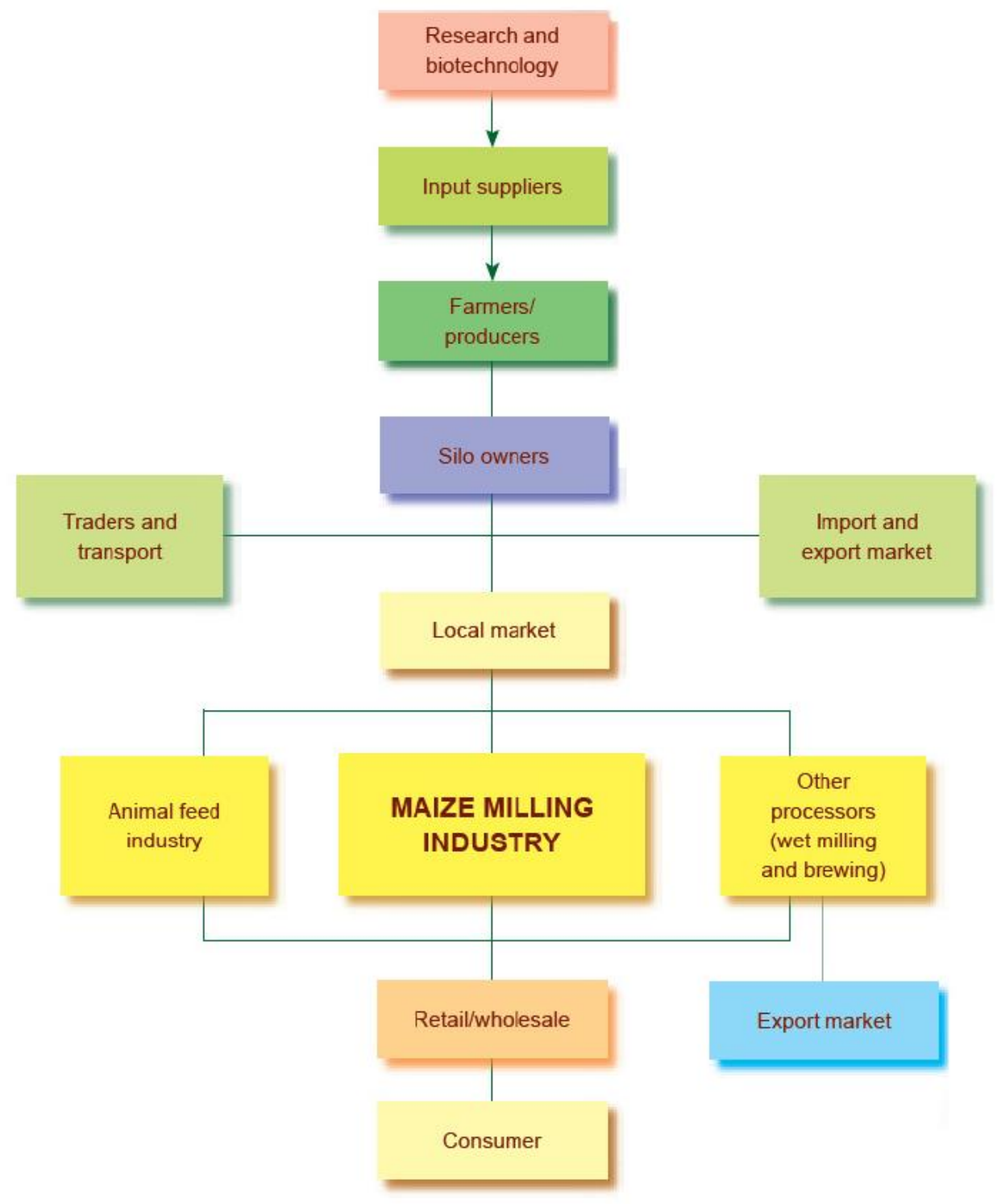

Source: Louw et al. (2010)

There are four main players in the maize meal and wheat value chains: Tiger Brands Ltd, Pioneer Foods, Foodcorp (now RCL Foods) and Premier (Ncube et al., 2016).

Tiger Consumer Brands Ltd was founded in 1921 and listed on the Johannesburg Stock exchange in 1925. The company manufactures and distributes products in several FMCG products including packaged food, home and personal care products, baby care products and soft drinks (Euromonitor 2017; Ncube et al. 2016). It also has substantial market share in a number of food segments including baked goods (25.3\%), Breakfast cereals (23.1\%), Confectionery (23.2\%).

Pioneer Foods is a result of a merger between Bokomo (a milling company formed in 1920) and Sasko (a wheat producer formed in 1929). It was listed on the Johannesburg Stock Exchange in 2008. It is one of the largest manufacturers and distributors of packaged food, non- alcoholic drinks, and related products in South Africa (Euromonitor, 2017).

RCL Foods (previously Foodcorp (Pty) Ltd) is one of the largest food producers in South Africa. It made up of four subsidiaries Foodcorp, Rainbow Chicken, TSB and Vector which involve poultry production, sugar production, milling and baking as well as a logistics division among other 
consumer products. ${ }^{3284}$ Its product range includes peanut butter, pet food, mayonnaise, edible oils, bread and bakery products, canned pilchards as well traditional South African products such as rusks and white maize meal (Euromonitor 2017; Ncube et al. 2016).

Premier Foods was founded in 1882 in Port Elizabeth as a fast-moving consumer goods company. It operates 16 bakeries, 5 wheat mills, 2 maize mills, a sugar confectionery plant and 24 distribution depots in South Africa, Swaziland and Lesotho. It also has a home and personal operation based in the United Kingdom. ${ }^{3285}$

An analysis of company market shares of baked goods by retail value, Pioneer Foods and Tiger Brands have the highest shares with a $30 \%$ and $25 \%$ respectively. Company market shares have been maintained over the last six years (Figure 27).

Figure 27: Company market shares for baked goods by retail sales value, 2011 - 2016

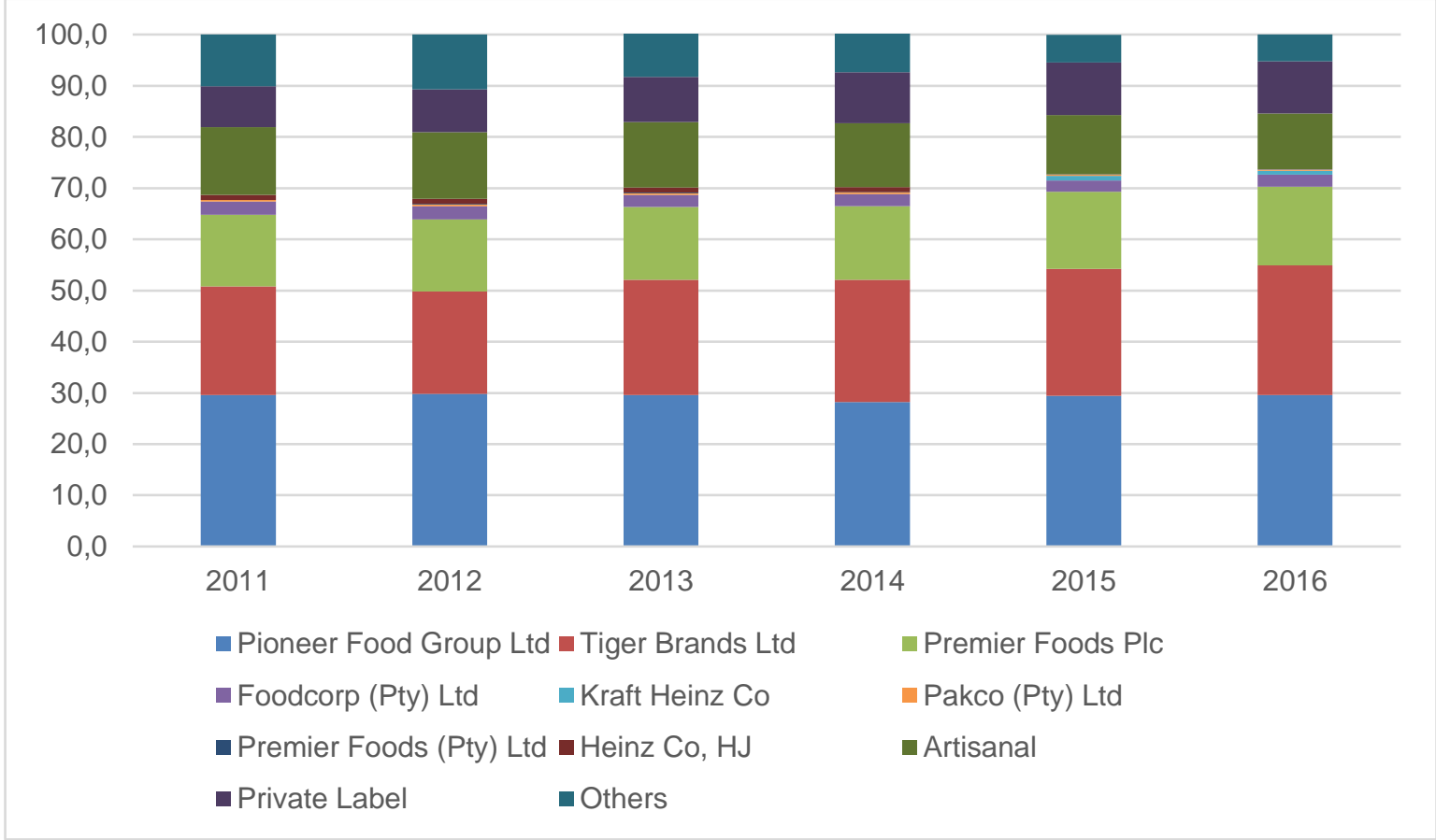

Source: Euromonitor (2017)

Note: The baked goods category includes bread, cakes, dessert mixes, frozen baked goods and pastries

\subsubsection{Regulatory framework}

Some of the main regulations governing the milling sector are as follows ${ }^{3286}$ :

- Consumer Protection Act - Labelling of GMO's

- Act 36 of 1947 Fertilisers, Farm Feeds, Agricultural Remedies and Stock Remedies. Proposed Repeal of Regulation R2054 (\% moisture on Hominy Chop).

- Act No. 119 of 1990 Agricultural Products Standards Act as amended by Act No. 129 of 1993 and Act N. 63 of 1998 - Maize Product Standards Act

- Draft wheat grading regulations (noting the removal of the Cultivar list)

\footnotetext{
${ }^{3284}$ RCL Foods website.

3285 Premier website.

${ }^{3286}$ National Chamber of Milling website.
} 
- Act 47 of 1996 Marketing of Agricultural Products Act as amended by Act No. 59 of 197 and Act No. 52 of 2001.

- Act No. 54 of 1972 Foodstuffs, Cosmetics and Disinfectants - No. R 2003 Regulations relating to the Fortification of certain food stuffs.

Most of the regulation has to do with correct labelling of GMO products, health fortifications grading of the milling products as well as food safety concerns.

\subsection{Performance of the South African Milling sector}

\subsection{Production}

Maize production has generally been growing over the last 30 years although there has been a decline in the area of land on which maize is grown (Figure 26). Between 1994 and 2017, there was a 36\% decline in the size of area on which maize was planted. Part of this was due to the withdrawal of government subsidies that resulted in higher costs of production for farmers (Kirsten, Edwards and Vink, 2009). However, maize production grew by $8 \%$ during the same period, likely due to an increase in crop yields from 2.8 tons/ha to 4.8 tons/ha. The dip in production in 2015 was likely a result of the drought experienced in 2015.

Figure 28: Maize Production in South Africa (1981 - 2017) $)^{3287}$

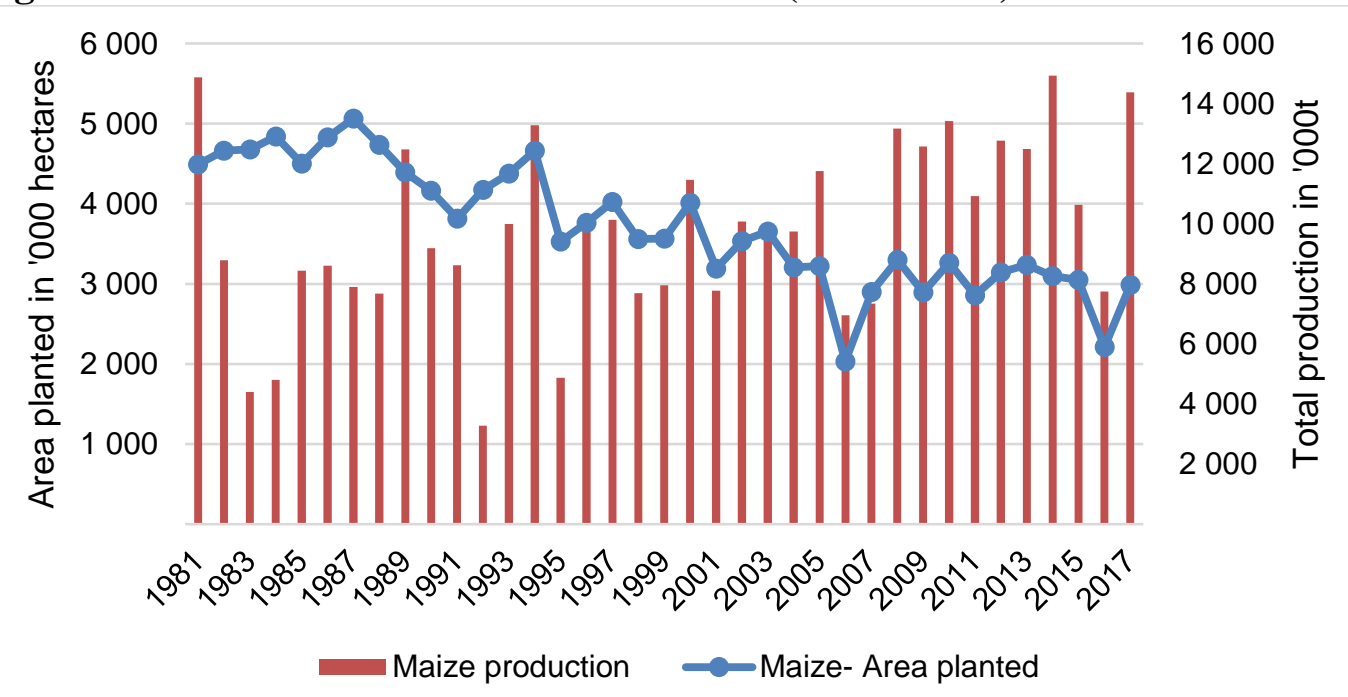

Source: Authors' illustration based on data from DAFF (Department of Agriculture, Forestry and Fisheries) (n.d.)

There appears to be some reduction in wheat production. Between 1994 and 2017, wheat production declined by $3 \%$ while wheat land use dropped by $53 \%$ (Figure 27 ).

3287 The DAFF Marketing year of May to April is used. 
Figure 29: Wheat Production in South Africa (1981 - 2017) $)^{3288}$

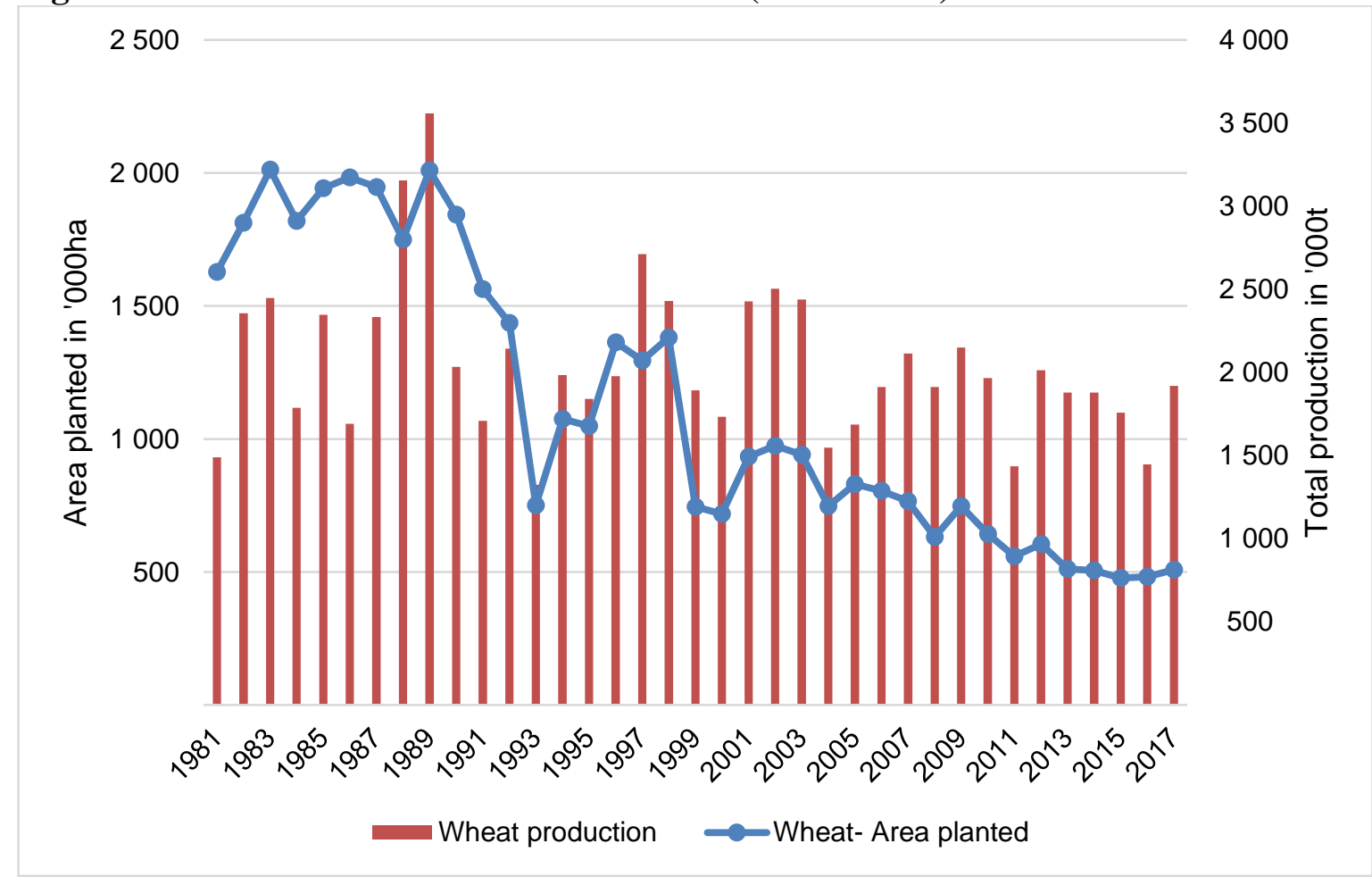

Source: Authors' illustration based on data from DAFF (Department of Agriculture, Forestry and Fisheries) (n.d.)

The reduction in the area planted seems to point to the emergence of a small number of large farms as was the case in the dairy sector. It supports the notion of the increasing consolidation and concentration of different agricultural value chains. Where these farms are vertically integrated with upstream and downstream activities such as the development of seeds, their production wholesale and retail trading, this can be problematic in terms of raising barriers to entry and creating dominant players.

\subsection{Imports and exports}

Volumes of export of maize have fluctuated erratically between 1981 and 2017. Wheat, however, has remained relatively stable. Low wheat exports are likely due to the low wheat production in the country (Figure 28).

\footnotetext{
3288 The DAFF Marketing year of May to April is used.
} 
Figure 30: Volume of Maize and Wheat Exports

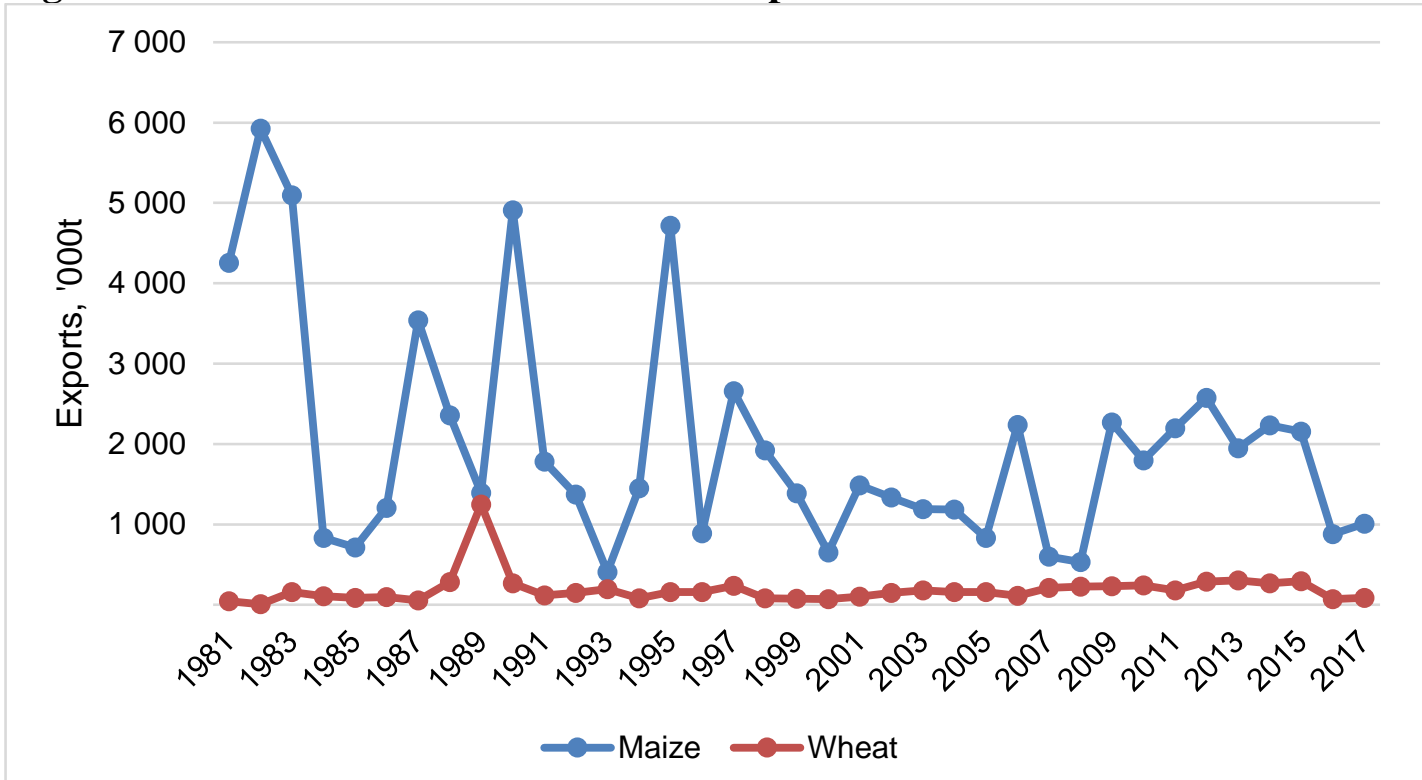

Source: Authors' illustration based on data from DAFF (Department of Agriculture, Forestry and Fisheries) (n.d.)

In value, wheat has the highest value in terms of imports and exports. There was a dip in trade for both wheat and maize in 2009, likely due to the financial crisis. The market recovered in 2010 before experiencing another dip in 2015 likely due to drought conditions (Figure 29).

Figure 31: Value of Exports and Imports (2005 - 2016)

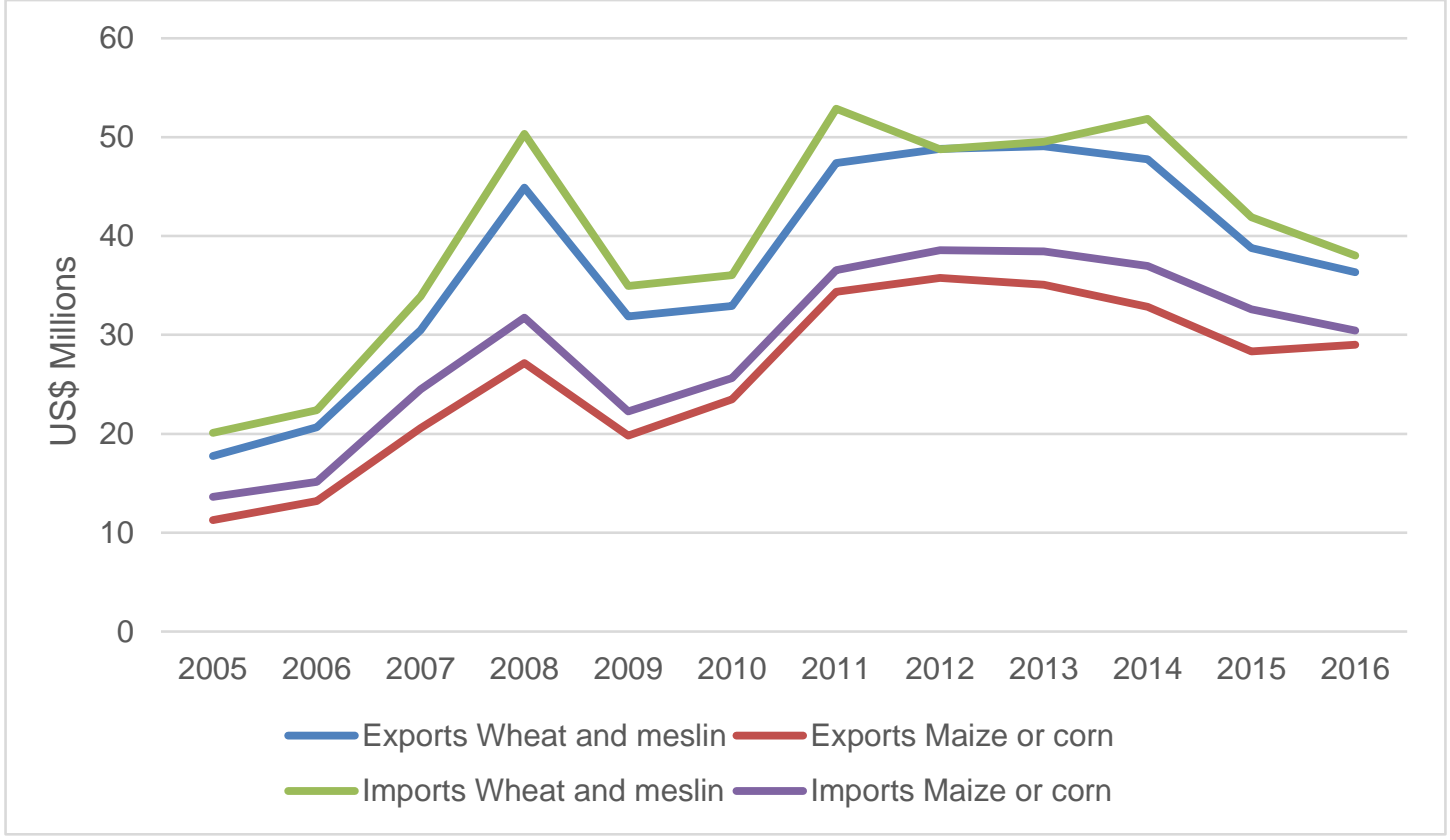

Source: UN Comtrade data

1.4.5.2.1.3.Prices 
Retail prices for both white and brown bread prices have steadily risen between 2008 and 2016 (Figure 32). ${ }^{3289}$ This price increase has been disproportionate to the price of wheat which accounts for on average $18 \%$ of production costs of white bread and $20 \%$ for brown bread. Retail flour prices (since producer prices were unavailable as a time series), on average accounted for $41 \%$ of the price of white bread and $42 \%$ for the price of brown bread.

\section{Figure 32: Bread and wheat prices (2008-2016)}

Comparison of wheat and bread price, $700 \mathrm{~g}$ of white bread

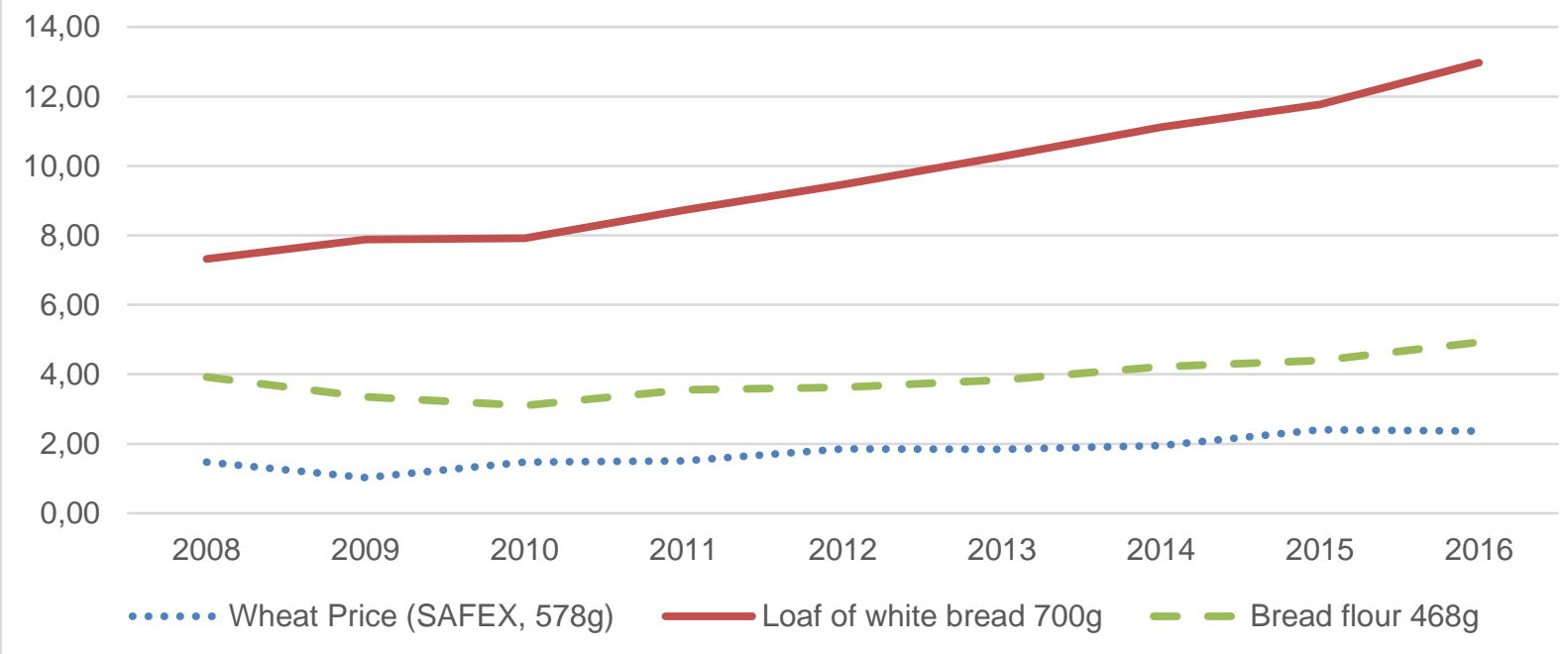

Comparison of wheat and bread price, $700 \mathrm{~g}$ of brown bread

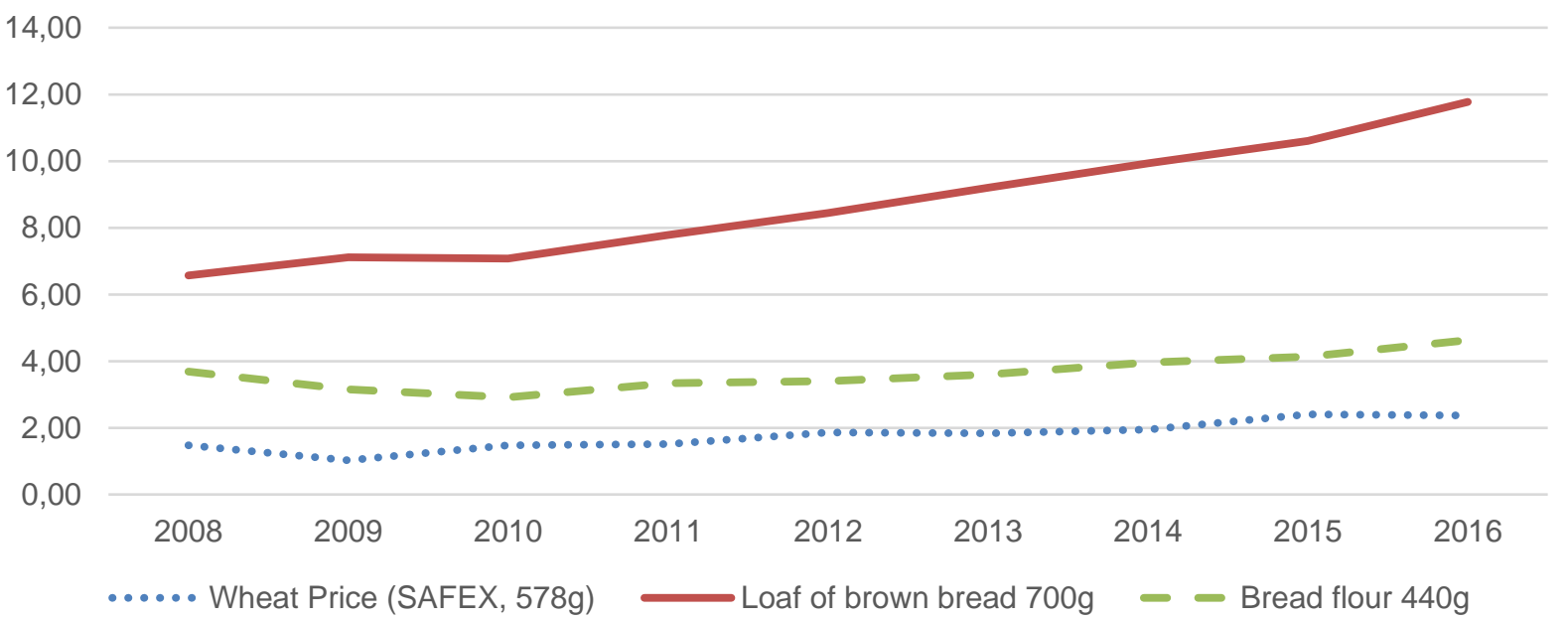

Source: Authors' illustration based on data from NAMC (National Agricultural Marketing Council) (n.d.)

Notably, the wheat price dropped between 2009 and 2010 coinciding with signing of agreements by the milling companies implicated in the bread and milling cartels (Mncube, 2014b). However, bread prices soon rose and remain high despite the limited growth of input prices perhaps reflecting the market power at the baking level of the value chain. It could also be due to the low price elasticity of

${ }^{3289}$ The 2009 NAMC Input Cost Monitor reports that $468 \mathrm{~g}$ of flour is required to produce 1 loaf of white bread and $439.6 \mathrm{~g}$ of flour produces 1 loaf of brown bread. The wheat to flour conversion ratio for is $76 \%$ for white bread flour and $81 \%$ for brown bread flour (i.e. 1 ton of wheat produces $760 \mathrm{~kg}$ of white flour and $810 \mathrm{~kg}$ of brown flour). 
demand for bread although there are a number of other costs involved that make up the retail price including marketing to build brand awareness (Ncube et al., 2016). The large vertically integrated firms such as Pioneer foods are able to benefit from flour price and retail price spread as well as from their brand power making entry difficult.

\subsection{Key investments}

In terms of storage, the control boards in partnership with the state managed the storage infrastructure by determining on their establishment, location and capacity. A total of 266 silos were constructed, 220 in the northern parts of the country with a total capacity of around 15.5 million tons and 46 silos were constructed in the Western Cape with a capacity of just under 1 million tons (NAMC, 2004). The silos were operated as local monopolies and owned by farmers in their vicinity. The cooperatives were not to compete with each other. ${ }^{3290}$ Once the sector was deregulated the silos, they were transferred to newly privatized agro-conglomerates. It costs about R10m to construct a silo with a capacity of 8000 tons which has acted as a disincentive. In the last 20 years, no new silos have been constructed. The history of control and information exchanged in the sector has contributed to the collusion cases that have been investigated in the sector.

A number of new investments have been made in the sector. Some of them include:

In 2013, Oos Vrystaat Kaap Operations Limited (OVK), an agricultural cooperative located in Ladybrand (Free State), commissioned a new state-of-the-art wheat mill in 2013. The mill has a capacity of $150 t$ per day and was built at a cost of R40 million. The facility produces white bread flour, brown bread flour, and brown bread flour mix for the "Power" and "Super Bake" brands (Booysen, 2013). Also in 2013, Afgri constructed a wheat milling plant in Harrismith in the Free State. The mill produces cake flour, bread flour, and specialised products used in the baking, pizza, and pasta industries (Ncube et al., 2016).

In 2014, Lethabo Milling commissioned a new maize mill in Ventersburg with a throughput of about 3000 tons per month. The funding used to construct the new mill was from the Massmart Supplier Development Fund, one of the conditions the Competition Commission placed on the approval of the Walmart/Massmart merger. Bakhresa, a diversified Tanzanian firm involved in food products, beverages, and transport and packaging obtained a $\$ 25 \mathrm{mn}$ loan from the International Finance Corporation in June 2014 to refurbish the Union Mill in Durban and build a plant with a capacity to mill 750 tons of wheat per day. Another wheat mill, Westra owned by agricultural cooperative GWK due to start operating late in 2015 (Ncube et al., 2016).

\subsubsection{Trends in concentration and outcomes of key competition cases}

\subsection{Overview of competition interventions}

Stemming from the history of collusion in the sector, there have been a number of cartels related to the milling sector. A brief description of these cartels is provided below.

\section{The storage cartel}

\footnotetext{
${ }^{3290}$ For a description of the silo industry, see Competition Commission vs Senwes, Competition Tribunal Case Number 110/CR/Dec06
} 
There were two competition cases that the Competition Commission dealt with in relation to storage. The first involved Senwes Limited, a 106-year old entity and former cooperative with physical silo operations in the Free State, Northern Cape, North West and Gauteng. Senwes controls about 25\% of the country's storage capacity and handles about $30 \%$ of the country's summer grain production. ${ }^{3291}$ Senwes also traded grain alongside commodity traders and farmers. Early in 2003, Senwes changed its storage policy in a way that raised competing traders' costs relative to Senwes' own traders and essentially made it unviable for competitors to trade grain in competition with Senwes. The Tribunal confirmed that this conduct constituted a margin squeeze in contravention of section 8 (c) of the Competition Act and that Senwes had abused its unilateral market power in grain storage to exclude competing traders. It however, did not receive a penalty as this was its first offence.

The second case involved collusion amongst private silo owners who had continued to collectively agree on dairy storage tariffs for grain within the silo industry. The sixteen silo owners implicated and the silo industry association, the then Grain Silo Industry (Pty) Ltd (now Agbiz Grain), entered into a consent agreement with the Commission in 2011, admitting to the collusive determination of silo tariffs. ${ }^{3292}$

\section{The maize and wheat milling cartels}

In 2006, the Commission uncovered cartel conduct in the wheat and milling levels of the value chain. The cartel involved collusive agreements at the milling level and into the downstream markets for wheat flour, maize meal and bread.

The regional cartels were coordinated nationally by large vertically integrated miller that collected information through the National Chamber of mining. At the baking level, pricing, trading conditions and even maximum allowable discounts were coordinated by large vertically integrated bakers and facilitated by the Camber of baking that enable them to monitor each other's market shares, pack size by category level, customer channel at provincial level. (Kalicharan, 2010).

\section{The bread cartel}

The bread cartel, as mentioned above, was an extension of the cartel at the milling level. It involved four of the four major bread producers: Premier, Tiger Brands, Foodcorp and Pioneer. Premier Foods provided assistance to the Commission during the investigation and was granted leniency. Tiger Brands and Foodcorp entered into consent agreements in 2007 and 2009 respectively, paying administrative penalties while Pioneer initially disputed the extent of its involvement, eventually entering into a consent agreement with the Competition Commission in 2010 (Grimbeek and Lekezwa, 2013).

Pioneer also admitted to taking part in anticompetitive and exclusionary conduct in the Western Cape (Mncube, 2014a). An independent bakery in Mossel Bay (Mossel Bay Bakery) laid a complaint that alleged that Pioneer had threatened to initiate a price war unless the bakery raised the price of its bread. Pioneer was also at the time selling its bread at predatory prices especially since

\footnotetext{
${ }^{3291}$ Senwes website. Available at http://www.senwes.co.za/

3292 Tribunal Case Number 43/CR/Jun11
} 
the bread it sold in Mossel Bay was transported from Worcester and yet was cheaper in Mossel Bay than in Worcester. Pioneer also admitted to having acted anti-competitively at various point by launching "fighting brands" through which it sold bread at very low prices to deter new entrants or persuade competitors to increase the price of their bread. Pioneer's behaviour served to create a reputation of a fierce competitor in order to discourage entry or influence its rivals to maintain high prices.

\subsection{Recent cases (2011- 2016)}

For the period under review, there were four large mergers that took place, in addition to other smaller cases (Table 19). In the grain value chain, two of the transactions involved acquisitions by Afgri, namely the 2011 acquisition of a yellow maize milling plant (Pride Milling) and the November 2013 acquisition of four grain storage silos to extend Afgri's storage capacity in Limpopo, Gauteng, and the North West. The third transaction involves the acquisition of various Eastern Cape-based bakeries by the Premier Group which extended Premier's footprint into a new province alongside the intermediate mergers described above.

The fourth grain-related merger involved the acquisition of the Kromdraai Group of companies, which are involved in the wheat-to-bread value chain, by global commodity illustrating the trend of further consolidation. Here global commodity traders are integrating into processing and storage levels of the grain value chain.

A number of entrants in maize and wheat milling have attempted to participate at small (micro), medium, and large scale with varying degrees of success. Entry at the medium and larger scale appears to mostly be driven by agricultural cooperatives or firms that are already involved in milling elsewhere in the country.

Table 19: Mergers in the Milling Sector (2011 -2016)

\begin{tabular}{|c|c|c|c|c|}
\hline Case Number & Primary Acquiring Firm & $\begin{array}{l}\text { Primary Target } \\
\text { Firm }\end{array}$ & Size & Status \\
\hline 2011Mar5685 & Tiger Brands Limited & $\begin{array}{ll}\text { Davita } & \text { Trading } \\
\text { (Pty) Ltd } & \\
\end{array}$ & $\mathrm{L}$ & Approved \\
\hline 2011Jun0081 & $\begin{array}{l}\text { Tiger Consumer Brands Limited and } \\
\text { Tiger Food Brands Intellectual } \\
\text { Property Holding Company (Pty) Ltd }\end{array}$ & $\begin{array}{l}\text { Unilever ple and } \\
\text { Unilever South } \\
\text { Africa (Pty) Ltd }\end{array}$ & I & Approved \\
\hline 2012Dec0721 & $\begin{array}{l}\text { Tiger Consumer Brands Limited and } \\
\text { Tiger Food Brands Intellectual } \\
\text { Property Holding Company (Pty) Ltd }\end{array}$ & $\begin{array}{l}\text { The Mrs H.S. Ball's } \\
\text { Chutney Business, } \\
\text { which Is a part of } \\
\text { Unilever Plc. and } \\
\text { Unilever South } \\
\text { Africa (Pty) Ltd }\end{array}$ & I & Approved \\
\hline 017434 & Premier Group Limited & $\begin{array}{l}\text { Eastern } \\
\text { Bakeries }\end{array}$ & $\mathrm{L}$ & Approved \\
\hline 2014Nov0682 & Premier Group (Pty) Ltd & $\begin{array}{l}\text { Mister } \quad \text { Bread } \\
\text { Milling (Pty) Ltd }\end{array}$ & I & Approved \\
\hline
\end{tabular}




\begin{tabular}{|c|c|c|c|c|}
\hline 2015Apr0205 & Pioneer Foods Proprietary Limited & $\begin{array}{l}\text { Future Life Health } \\
\text { Products } \\
\text { Proprietary Limited }\end{array}$ & $\mathrm{L}$ & Approved \\
\hline 2016Jan0022 & Acorn Agri (Pty) Ltd & $\begin{array}{l}\text { Conafex Cape } \\
\text { Holdings Ltd and } \\
\text { Grassroots Group } \\
\text { Holdings (Pty) Ltd }\end{array}$ & I & Pending \\
\hline 2016Feb0052 & AFGRI Operations Limited & $\begin{array}{l}\text { Pride Milling } \\
\text { Company } \\
\text { (Proprietary) } \\
\text { Limited } \\
\end{array}$ & $\mathrm{L}$ & Pending \\
\hline 2016Feb0058 & Africum Limited & $\begin{array}{l}\text { Agrifriend } \\
\text { Equipment } \\
\text { Proprietary Limited }\end{array}$ & I & Approved \\
\hline 2016Sep0499 & Sun Village Supermarket (Pty) Ltd Ltd & $\begin{array}{l}\text { Alpha Bakery } \\
\text { Confectionary (Pty) } \\
\text { Ltd, in respect of } \\
\text { the businesses } \\
\text { known as Sun } \\
\text { Village } \\
\text { SUPERSPAR } \\
\end{array}$ & I & Approved \\
\hline 2016Nov0629 & K2016491554 (Proprietary) Limited & $\begin{array}{l}\text { Awesome Snacks } \\
\text { (Proprietary) } \\
\text { Limited }\end{array}$ & I & Approved \\
\hline 2016DEC0015 & Puratos Group NV & $\begin{array}{l}\text { Bidvest Bakery } \\
\text { Solutions } \\
\text { Proprietary Limited } \\
\end{array}$ & I & $\begin{array}{l}\text { Approved } \\
\text { with } \\
\text { conditions }\end{array}$ \\
\hline
\end{tabular}

\subsubsection{Barriers to entry}

The main barriers to this entry are access to capital, access to markets and the barriers that resulted from high levels of vertical integration in the sector. Using a case study of an entrant into the sector, Nkhonjera, et al (2016) showed the difficulty in accessing funding for entry and expansion in the sector. Lethabo Milling took about four years to get funding and required about ZAR 9.8 million to refurbish the facility and purchase inputs. The funding was obtained through the programme set up following the Walmart/Massmart merger. Massmart provided additional support which included training, waiving of listing fees and assisting with the pricing model.

In addition to the capital, an entrant requires access to markets and branding. Even if an entrant is able to access funding and produce an item, they need access to good shelf space in retail chains in order for consumers to see and access their product. However, there are certain costs attached to acquiring such shelf space which as explained in the retail section (Section 9) can be restrictive. The market is also highly contested due to customer loyalty to particular brands. An entrant, therefore, has to invest significantly in advertising and promotions. Here again, Lethabo Milling was able to benefit from access to good shelf space from Massmart. 
Small millers have found alternative ways to access the markets by supplying their products to local municipal market and informal shops such as spazas. Buyers also travel to the mills to purchase the flour ensuring that the millers have lower operational costs and that there is a better cash flow. Because they eliminate transport costs, these millers are able to sell a $20 \mathrm{~kg}$ bag of flour for as much as $20 \%$ less than traditional suppliers.

Furthermore, entrants are likely to be competing with companies that are vertically integrated across the value chain and therefore have access to inputs and more efficient processes than entrants. New firms will likely be competing against their suppliers. They also do not benefit from the economies of scale and scope that the vertically integrated agro-conglomerates are able to enjoy.

\subsubsection{The role of retail in food value chains}

\subsubsection{Mapping the retail landscape}

The value chain for food products in South Africa is depicted in Figure 31 below. Suppliers can access consumers through the formal supermarket value chain, where products flow from supplier to distribution centre or directly through supermarkets to the end consumer. Alternatively, suppliers can sell via independent retailers who are typically small businesses, targeting lower income customers in peri-urban, township, industrial and central business district areas of cities. They include cash and carrys that have both wholesale and retail offerings (hybrid format) as well as numerous informal spaza shops, spazarettes and superettes. Suppliers typically sell to wholesalers or buying groups, who in turn sell to independent retailers. Around 30-40\% of grocery retail market is served by independent retailers while the balance is served by a handful of large multinational supermarket chains (discussed in Section 9.3).

Buying groups in South Africa are separate, independent entities that play an important role in supporting independent retailers. While each independent retailer that is part of a buying group is owned by an individual, the stores may be branded under a common name. Buying group-led independent retailing is an important alternative model in South Africa. These groups have reduced certain barriers to entry faced by independent retailers (see Section 1.7.5.5.). They assist in lowering costs given that they buy large volumes from suppliers for the group, they advertise and promote on behalf of independent retailers and they offer important skills development and training to retailers in their group. The main buying groups in South Africa are Unitrade Management Services, Buying Exchange Company, Independent Buying Consortium, Independent Cash \& Carry Group and Elite Star Trading. They also provide an alternative route to market for suppliers.

The modernisation of supermarkets in South Africa has seen significant investments in distribution centres (DCs). All supermarket chains have multiple DCs and invest annually in the upkeep and expansion of these centres. The centres serve not only their South African stores, but also their regional stores in southern Africa.

\section{Figure 33: Role of retail in food value chains in South Africa}




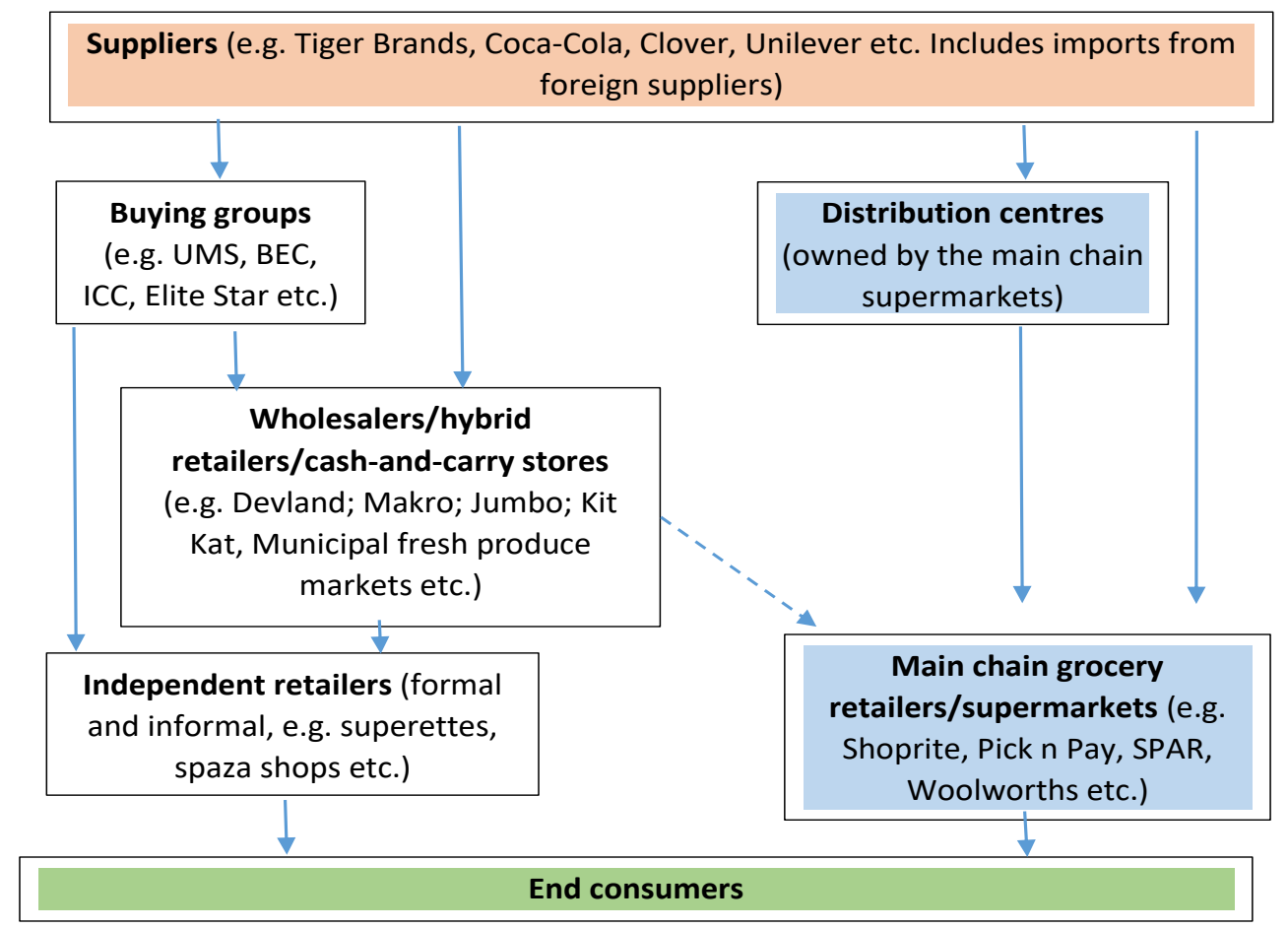

Source: das Nair and Chisoro (2016)

\subsection{Significance of retail in South Africa}

In terms of the contribution to GDP in South Africa, wholesale and retail trade fall under the broad 'Trade, catering and accommodation services' category. This broad sector has remained fairly constant in terms of percentage contribution to actual GDP (at 2010 constant prices) at around 14$15 \%$, and is the third largest contributor to GDP (Figure 32).

Figure 34: Contribution of trade (including retail), catering and accommodation sector to GDP in South Africa 


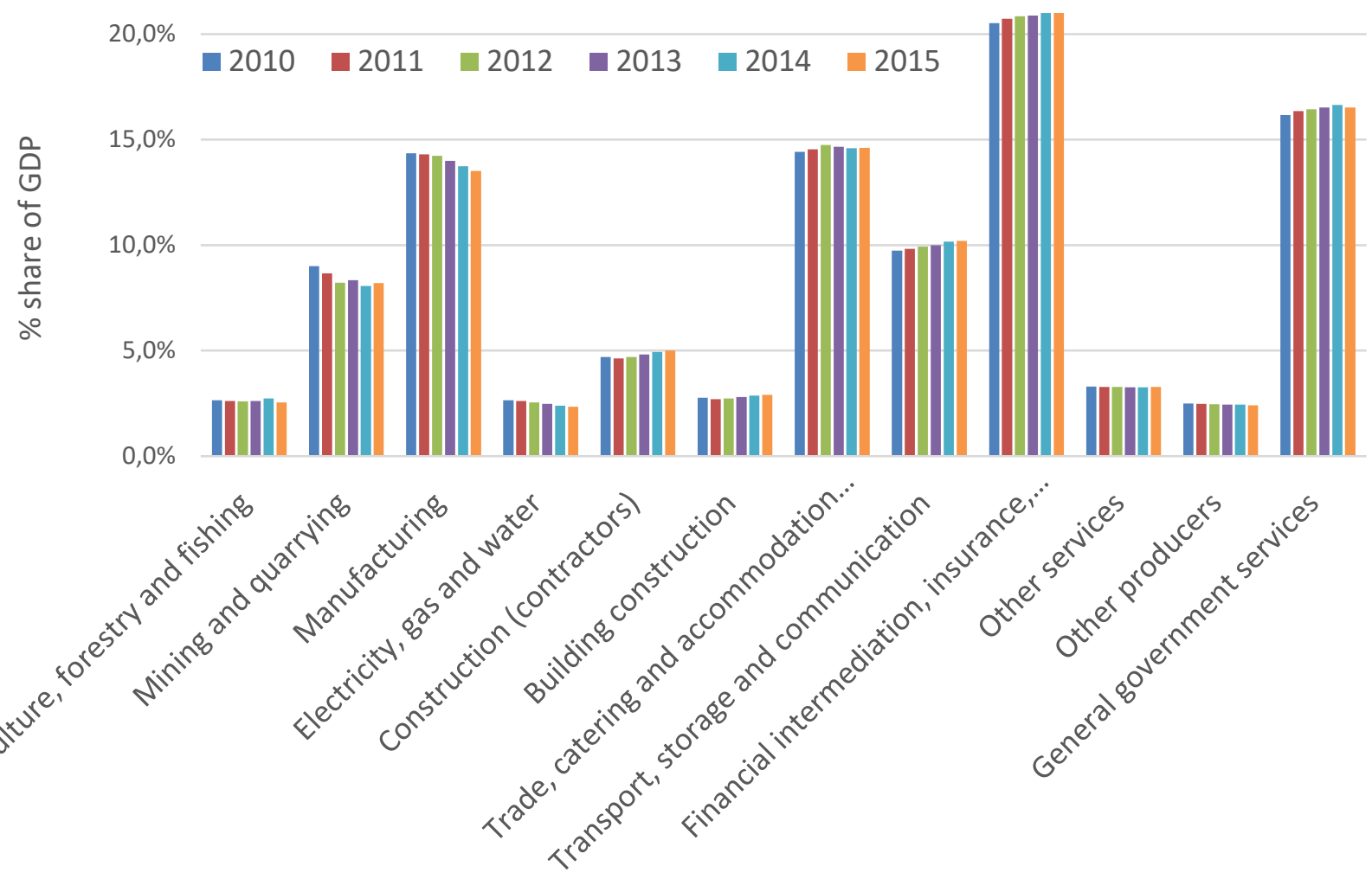

Source: Quantec, \% shares based on Rand millions at constant 2010 prices

Within this broad category however, wholesale and retail trade has grown by around $34 \%$ between 2005 and 2015 (Figure 33).

Figure 35: Growth of wholesale and retail trade sector, Rand millions at constant 2010 prices

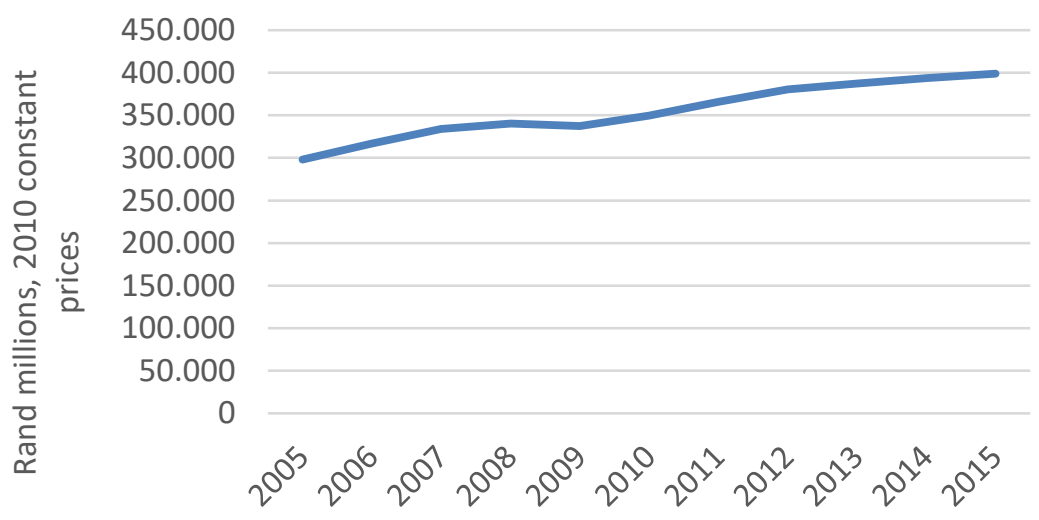

Source: Quantec, Easy Data

Figure 34 shows that retailers, which include supermarkets, are the third largest sector in terms of number of listed firms in the Johannesburg Stock Exchange (JSE) Top 40 ranked by turnover, with six firms featuring in the Top 40. 
Figure 36: Number of firms by sector in JSE Top 40 (turnover), 2015

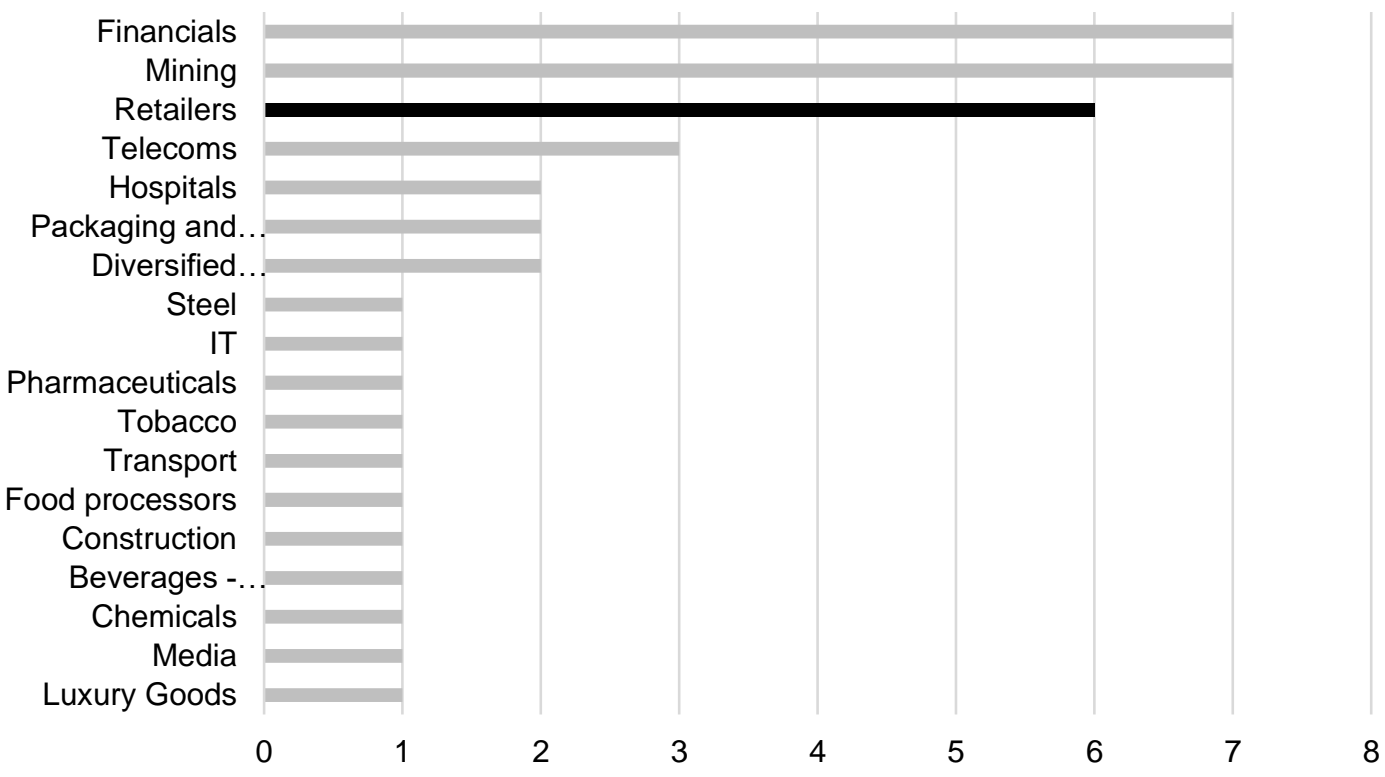

Source: I-Net BFA. Note: 2016 data is only available for some companies

Five of the six retailers in the JSE TOP 40 by revenue are supermarkets (the sixth being Steinhoff, a furniture retailer). Turnover for the listed supermarkets has increased significantly between 2010 and 2015 highlighting the growth of supermarkets (Table 20).

Table 20: JSE Top 40 by turnover (R billion), 2010 and 2015

\begin{tabular}{|c|c|c|c|c|}
\hline & Company & Sector & $\begin{array}{l}2015 \\
\text { Turnover }\end{array}$ & $\begin{array}{l}2010 \\
\text { Turnover }\end{array}$ \\
\hline 1. & Glencore Plc & Mining & 2653 & 1813 \\
\hline 2. & BHP Billiton Plc & Mining & 636 & 404 \\
\hline 3. & Anglo American Plc & Mining & 318 & 184 \\
\hline 4. & British American Tobacco Plc & Tobacco & 299 & 153 \\
\hline 5. & SABMiller Plc & Beverages - Brewers & 269 & 131 \\
\hline 6. & Sanlam & Financials & 239 & 123 \\
\hline 7. & The Bidvest Group & Diversified industrials & 205 & 110 \\
\hline 8. & Sasol & Chemicals & 185 & 122 \\
\hline 9. & MTN Group & Telecoms & 147 & 115 \\
\hline 10. & Old Mutual Plc & Financials & 145 & 70 \\
\hline 11. & Steinhoff International N.V. & Retailers & 137 & 48 \\
\hline 12. & Richemont SA & Luxury Goods & 136 & 51 \\
\hline 13. & Mondi Limited & Packaging and paper & 115 & 55 \\
\hline 14. & Shoprite Holdings & Retailers (supermarket) & 114 & 67 \\
\hline 15. & Imperial Holdings & Transport & 110 & 54 \\
\hline 16. & Massmart Holdings & $\begin{array}{l}\text { Retailers } \\
\text { supermarkets) }\end{array}$ & 85 & 47 \\
\hline 17. & Vodacom Group & Telecoms & 77 & 59 \\
\hline
\end{tabular}




\begin{tabular}{|l|l|l|l|l|}
\hline 18. & Datatec & IT & 75 & 29 \\
\hline 19. & Sappi & Packaging and paper & 75 & 46 \\
\hline 20. & The SPAR Group & Retailers (supermarket) & 73 & 35 \\
\hline 21. & Naspers & Media & 73 & 28 \\
\hline 22. & Anglogold Ashanti & Mining & 67 & 262 \\
\hline 23. & Pick n Pay Stores & Retailers (supermarket) & 67 & 55 \\
\hline 24. & Standard Bank Group & Financials & 65 & 38 \\
\hline 25. & Barloworld & Diversified industrials & 63 & 42 \\
\hline 26. & Anglo American Platinum & Mining & 60 & 46 \\
\hline 27. & Woolworths Holdings & Retailers (supermarket) & 57 & 26 \\
\hline 28. & Liberty Holdings & Financials & 54 & 22 \\
\hline 29. & Aveng & Construction & 44 & 34 \\
\hline 30. & FirstRand & Financials & 40 & 18 \\
\hline 31. & Barclays Africa Group & Financials & 39 & 23 \\
\hline 32. & Kumba Iron Ore & Mining & 36 & 39 \\
\hline 33. & Aspen Pharmacare Holdings & Pharmaceuticals & 36 & 10 \\
\hline 34. & MMI Holdings & Financials & 35 & 10 \\
\hline 35. & Mediclinic International & Hospitals & 35 & 17 \\
\hline 36. & Netcare & Hospitals & 34 & 22 \\
\hline 37. & Impala Platinum Holdings & Mining & 32 & 25 \\
\hline 38. & Telkom SA SOC & Telecoms & 32 & 37 \\
\hline 39. & Tiger Brands Limited & Food processors & 32 & 19 \\
\hline 40. & ArcelorMittal SA & Steel & 31 & 30 \\
\hline
\end{tabular}

Source: INET BFA. Note: 2016 data is only available for some companies so has not been reported

In terms of their JSE market capitalisation in 2015/2016, Woolworths and Shoprite are the largest supermarket chains in the retail industry in South Africa (Table 21). The relative market shares of key retailers are discussed below.

Table 21: Supermarket groups ranked by JSE market capitalization, March 2016

\begin{tabular}{|l|l|}
\hline & $\begin{array}{l}\text { Market capitalisation as reported in } \\
\text { annual reports (ZAR billions) }\end{array}$ \\
\hline $\begin{array}{l}\text { Woolworths } \\
\text { Holdings }\end{array}$ & 74.2 \\
\hline Shoprite Holdings & 109.9 \\
\hline SPAR Group & 34.5 \\
\hline Pick n Pay Stores & 34.4 \\
\hline Massmart Holdings & 32.6 \\
\hline Choppies Limited & 4.3 \\
\hline
\end{tabular}

Source: INETBFA

1.4.6.1.2. Key players and market shares 
Shoprite and Pick n Pay are the largest supermarket chains in South Africa, with around $30 \%$ of the national market each (in terms of store numbers), while SPAR is the next largest with around $20 \%$ of the market. This is followed by Woolworths, with the rest mainly held by Fruit and Veg City, and new entrants in food - Game through Foodco (which following the Walmart acquisition diversified into grocery retail offerings) and Cambridge Foods (also Walmart), and Botswana-owned Choppies $^{3293}$ (Figure 35).

Figure 37: Market Share of Grocery Retailer in South Africa, 2016 based on store numbers

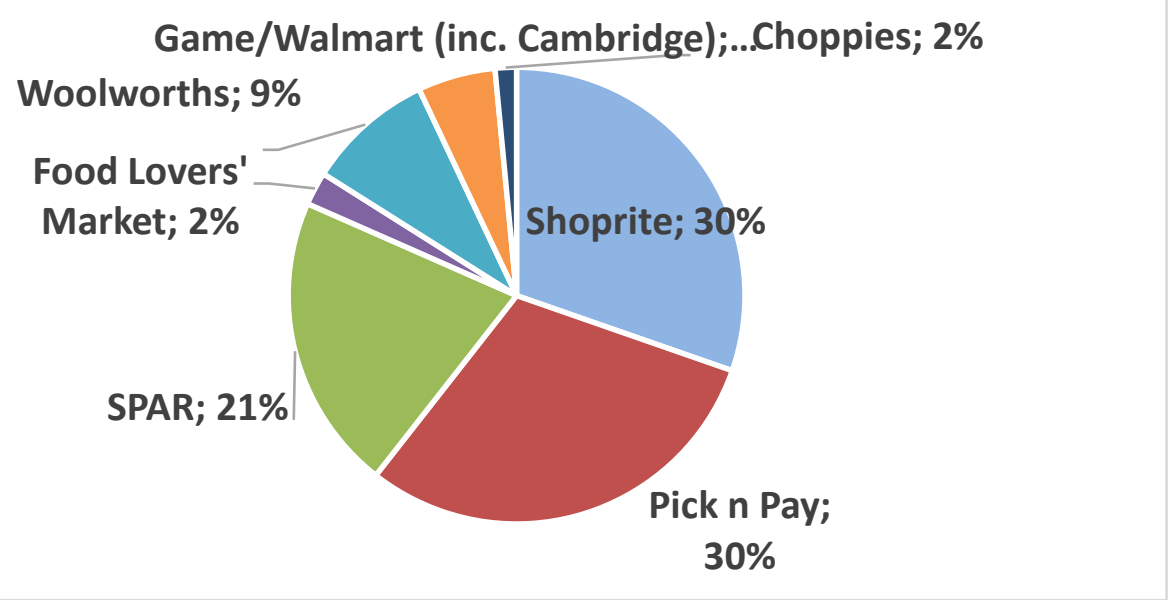

Source: Annual Reports and interviews

Note: Only the grocery retail stores are counted. Revenue or sales data by country for each supermarket is a better measure of relative size in each country. This data is however not consistently publicly available per country for all supermarkets.

\subsubsection{Policy and regulatory frameworks}

There is currently no specific policy for the retail sector in South Africa. While subject to regulation on health and safety, standards etc., there is no regulator for market conduct other than the competition authorities and the Consumer Protection Commission. This has led to concerns about behaviour that the narrow tools available in competition law have been unable to address (discussed below), although the CCSA is trying to address some of these concerns through the Grocery Retail Market Inquiry.

The Department of Trade and Industry (DTI) has however in its latest Industrial Policy Action Plan (IPAP) (2017/2018) iteration identified the need to intervene in the retail sector to increase the participation of small farmers and suppliers. ${ }^{3294}$ IPAP 2017/2018 notes the need to get commitments from the main retailers to develop a procurement charter, to facilitate supplier development programmes and to facilitate easier access to outlets. This is yet to be implemented.

1.4.6.2.1. Nature of competitive rivalry and a review of competition concerns in South Africa 1.4.6.2.1.1.Nature of competition

\footnotetext{
${ }^{3293}$ For descriptions of these players, see das Nair and Chisoro 2015 and 2016.

${ }^{3294} \mathrm{http}: / /$ www.thedti.gov.za/DownloadFileAction?id=1171
} 
A supermarket offering today is much more than a 'basket of goods' at a specific price. Supermarkets offer consumers a wide selection of products under one roof that is convenient, easily accessible, has secure parking options, is open for long hours in addition to a range of other ancillary services. ${ }^{3295}$ Modern retailers are thus said to offer a "Price-Quality-Range-Service" (PQRS) package (Dobson, 2015). This can greatly reduce overall costs for consumers, including transport, time, search, information and storage costs. The offering includes an 'overall customer experience', which brings in elements of accessibility, ambiance, range and variety (Nooteboom, 1980; Betancourt, 2006; Basker and Noel, 2013). In providing these offerings, modern retailers differentiate between themselves through store formats (González-Benito et al. 2005) such as supermarkets, hypermarkets, convenience stores, cash and carrys, discount stores etc.

Competition within same format supermarkets ('intra-format') depends on how similar the offerings of supermarkets are in terms of product and service range; and how prepared consumers are to substitute between offerings ('closeness of competition'). The competitive reaction to lost market share between same format stores can be through increasing promotional activity and price discounting (Dobson, 2015; Ellickson and Misra, 2008). All the supermarket chains in South Africa, except for Woolworths, have extended their offering to target customers across the full range of income groups. Woolworths has a single format offering that targets high income consumers. For the other supermarkets, there has been a focus on increasingly targeting low-income consumers, either by opening new stores (like Shoprite's Usave) or by acquiring existing stores (like Pick n Pay's Boxer and Spar's SaveMor) in peri-urban, township and rural areas. Most of the supermarket chains have also diversified their formats to include hypermarkets, convenience stores, express stores at fuel forecourts and fast food offerings. On the upper-income end, Shoprite competes with Pick n Pay and Food Lovers' Market and is increasingly targeting Woolworths' clientele through its Checkers offering. Supermarkets thus compete to offer a full suite of formats, where similar formats compete more vigourously.

Intra-format competition is especially seen in the offering of lower-priced house brands (das Nair and Chisoro, 2016; 2017). There is also a degree of inter-format competition with vertically integrated wholesalers and retailers, buying group led-independent retailers and general independent retailers. There is also a degree of inter-format competition with vertically-integrated wholesalers and retailers, buying group-led independent retailers and general independent retailers.

Whilst there may be some competition between existing supermarket chains, there has been limited entry of new supermarket chains with formats that compete directly with the incumbents in the region. The South African supermarket industry remains concentrated with the top 4 - Shoprite, Pick n Pay, SPAR and Woolworths - collectively dominating markets. It was several years before FVC gained traction to become an effective rival. The other significant new players, Choppies and Game, only entered almost two decades after FVC. This is reflective of the high barriers to entry into the industry. From an IO perspective, supermarkets have been characterised as natural oligopolies, where a few powerful chains offer quality products and low prices (Ellickson, 2013). This stems from Sutton's (1991) endogenous sunk cost model of competition. In this model, market structure is determined by competition to provide higher quality and wider service offerings. In turn, as the market grows, existing firms expand sunk cost investments to remain competitive. Such investments limit the number of firms that can profitably enter even large or fast-growing markets. There may be a small

${ }^{3295}$ Money transfer, credit, mobile telephony, pharmaceutical and delivery services etc. 
but vibrant set of fringe players that grow alongside large supermarket chains, but these do not compete on quality and variety in the same way that large chains do, and can grow without investing in large sunk investments as demand grows (Ellickson, 2013). This ties in with the observation in South Africa of a few large supermarket chains collectively dominating markets, with limited competition from a fringe of independent retailers.

Modern supermarket chains do indeed heavily invest in infrastructure. Investments include those in supply chains, centralised distribution centres (DCs), IT systems and transport fleets to get a wide range of products on shelves at the lowest possible costs (Harvey, 2000). Supermarkets in South Africa are increasingly moving towards centralised DCs instead of store-to-store procurement as they modernise. While offering numerous cost saving benefits, including scale and scope economies, investing in DCs also substantially raises barriers to entry (Basker and Noel, 2013). Given high entry barriers and sunk costs, supermarkets can be characterised as having become increasingly oligopolistic over time where there are a few large, powerful chains. These chains tend to have both significant market power (oligopoly) and buyer power (oligopsony), with a consequent high degree of control over entire value chains (Dobson, 2015).

\subsection{2..Competition concerns at a horizontal level}

The strategic behaviour of incumbents with market power further creates barriers to entry. A historic concern in South Africa is the practice of supermarkets entering lease agreements with property owners in shopping centres that contain exclusivity clauses ('exclusive leases'). This prevents new retailers and specialist stores like butcheries and bakeries from locating in lucrative spaces, limiting their ability to grow. Physical location and attractive store sites are important if an entrant is to become an effective competitor. Property developers provide supermarkets with these sites, with the most desirable sites being located inside shopping centres where customer traffic is dense. Exclusive leases signed between property developers and anchor tenants, which are often supermarkets, grant them rights to operate as the sole supermarket in the mall.

From the property owners' point of view, incumbent supermarkets are 'must have' anchor tenants to secure financing from banks given the high footfall they attract. Although banks do not necessarily insist on exclusivity clauses in leases, they do require anchor tenants before they approve finance to guarantee returns. The typical argument by anchor supermarkets for exclusive leases is that they are crucial for the development of the mall and property developers would not construct a mall without commitments from the supermarket. This highlights their strong bargaining position.

In practice, leases in South Africa typically last ten years, but anchor tenants have several options for renewal resulting in exclusivity that spans decades. While exclusive leases might arguably be justified in the initial phases of investment to allow anchor supermarkets to recoup investments, gain footfall and establish markets, it is hard to see how they can be reasonable for extended periods of time. It also appears that small property developers, particularly in rural areas, who do not have bargaining power against major supermarkets are more inclined to succumb to exclusive leases to kick-start developments. Lack of competition has far-reaching consequences in rural areas where pricing is a key factor for low-income consumers and where the nearest alternative supermarket is further away than in urban areas, increasing transport and search costs. 
The CCSA has received complaints about exclusive leases over the years (including from FVC and Walmart), and in 2015 announced a market inquiry into the retail sector considering this issue amongst others (the Grocery Retail Market Inquiry). The inquiry is on-going. ${ }^{3296}$

Internationally, the UK Competition Commission required phasing out exclusive leases in its Groceries Market Investigation Order of 2010 following recommendations from the former Office of Fair Trading. In Australia, following an inquiry by the competition authority, the major supermarket chains voluntarily provided court-enforceable undertakings which phased out exclusive leases.

Interviews in South Africa revealed that such leases are still prevalent. ${ }^{3297}$ This was also strongly highlighted in the recent Gauteng leg of hearings of the retail inquiry in June 2017, where both buying groups and independent specialist retailers gave submissions on how difficult it is to get mall space from property developers/owners on competitive terms to the big supermarket chains. The hearings revealed how before the construction of the mall even commenced, space was already allocated to the bigger players, and that existing businesses in the area were often not even notified of the construction. Their inability to locate in the mall and the rental terms they are faced with often puts them on a back foot in terms of participating and growing. ${ }^{3298}$

Some of the South African supermarkets appear to have 'exported' the practice of entering into exclusive leases to the countries to which they have internationalised. In Botswana, the competition authority has reached a settlement with a supermarket that required exclusive leases, resulting in the removal of the clause and an undertaking that it would not continue with this practice. In Zambia, some supermarkets attested to having exclusive leases with shopping malls. Others claimed that these leases no longer exist but did so prior to the CCPC discouraging such conduct.

Another avenue in which competition between supermarkets may be dampened is when a dominant supermarket uses its buyer power to enter into exclusive supply agreements with key suppliers, preventing them from supplying 'must-have' products to rival supermarkets. In South Africa, suppliers interviewed generally noted that supermarkets did not impose exclusivity conditions in their trading terms (where, if on the supermarket's supplier list, they are prevented from supplying rival supermarkets). This bears out in practice in that most suppliers usually sell to multiple supermarkets. The exception to this is in the supply of house brands. Certain suppliers are developed exclusively by supermarkets to supply house brands and these suppliers are typically not permitted to sell the brand to other supermarkets. There were no major concerns raised about this in the four countries. ${ }^{3299}$ Aside from a few instances in the supply of house brands, suppliers were free to supply any supermarket chain, new entrant chain, or independent retailer. However, even if suppliers are free to supply independent retailers, the various costs imposed on them by large supermarkets may negatively affect the trading terms with independent retailers as compensation for these higher costs (the waterbed effect). In South Africa, it is often difficult for independent retailers, wholesalers, or

\footnotetext{
3296 The transcripts of the Gauteng hearings are available at http://www.compcom.co.za/transcripts-3/. Transcripts from the Cape Town hearings are available at http://www.compcom.co.za/transcripts-2/.

${ }^{3297}$ A range of factors affect whether exclusive leases are insisted upon in South Africa. These include shopping centre size, whether the centre is a new or existing centre, whether the centre is in a rural or urban area, or whether it is a corporate or franchise store.

3298 The transcripts where these issues were raised are available at http://www.compcom.co.za/transcripts-3/.

3299 There are other ad hoc instances where supermarkets require exclusive commitments from suppliers. For instance, in Zimbabwe, when supermarkets are running promotions, they may require a temporary exclusive commitment from a supplier for certain products.
} 
buying groups to get similar trading terms to what the large supermarket chains get for seemingly equivalent transactions.

The extent that this 'waterbed effect' has a negative impact on independent retailers in South Africa was clearly highlighted by buying groups, UMS and Elite Star Trading, at the Gauteng leg of the CCSA's retail inquiry hearings. These buying groups made submissions to the panel on the entrenched commercial relationship between suppliers and the big supermarket chains resulted in highly skewed trading terms in favour of the supermarket chains, even for the same volumes of product bought. These buying groups highlighted that they could not secure equal rebates and volume discounts as the big supermarkets could from suppliers, and that there could be up to a $20-25 \%$ price difference from what the buying groups had to pay versus what the big supermarkets pay. This immediately places the buying group supported independent retailers on an unlevel playing field and makes them less competitive. ${ }^{3300}$

\subsection{Implications on suppliers - main vertical competition concerns}

Given the market power of the large supermarket chains, suppliers, particularly small- and mediumsized suppliers, are often not able to secure attractive trading terms to enable long-term participation in supermarket value chains, investment and growth. Over and above demanding lower costs and higher standards from suppliers, supermarkets in South Africa often impose a range of other costs through trading terms. Large supermarket chains in many cases are able to control pricing in their trading terms by controlling elements such as listing fees, rebates, advertising and slotting allowances, promotion fees, payment period terms, settlement discounts, and new store openings fees (Reardon and Gulati 2008). This unilateral control of trading terms is reflective of the buyer power of large supermarket chains globally (Clarke et al. 2002).

Supplier interviews revealed that the large supermarket chains generally dominate the negotiations of trading terms. Contracts between suppliers and supermarkets are usually evergreen, with the trading terms typically renegotiated on an annual basis. Given that majority of the same retailers that operate in South Africa also operate in the other countries, the practices in the different countries in the region are generally similar.

The South African supermarkets often require suppliers to pay listing fees to be listed in their books. According to supermarkets, given vigorous competition for shelf space, payment of listing fees shows the supplier's commitment and confidence in their ability to supply supermarkets and in the quality of their product. Examples of listing fees in South Africa range from USD 350 to USD 3,500 for a single product line for a limited time period, or 12-15 per cent off the list price, to as high as USD 17,000 to USD 20,000 for till positions for a limited time period.

Access to good shelf space (including in gondola ends during promotions) is critical for suppliers to successfully sell their products. For new entrants and small suppliers, it is a constant battle to access prime shelf space that is usually taken up by dominant suppliers. Similarly, access to cooler/refrigeration space is important for suppliers of cold products (such as soft drinks, ice creams, and frozen products). There have been numerous competition cases globally that have recognized the

3300 http://www.compcom.co.za/wp-content/uploads/2017/06/6-June-Competition-Commission-Retail-EnquiryTranscript-1-1.pdf 
harm to competition of dominant suppliers imposing exclusivity on cooler space. ${ }^{3301}$ Recently in South Africa, a settlement was reached in the SAB Miller/Coca-Cola bottlers merger which included, among other things, an undertaking to allow 10 per cent of Coca-Cola fridge space in small retail outlets to stock competitors' carbonated soft drink products.

Settlement discounts are also given to supermarkets for paying the supplier within the number of days stipulated in the trade agreement, which varies depending on the supplier. In South Africa, it is commonly 15-30 days from statement and the discount for paying within this period is usually in the range of $2.5-5$ per cent off the list price.

Long payment periods put considerable pressure on suppliers' cash flow and working capital, which is problematic for small suppliers. There are allegations suggesting that suppliers are subsidising supermarkets with these long payment periods and that this money was a cheaper way for supermarkets to replenish stock rather than to seek other sources of finance (such as bank loans) to do so. These remain unsubstantiated however and requires further investigation.

Supermarkets sometimes require advertising discounts off the purchase price for indirectly advertising on behalf of suppliers when they advertise the supermarket chain generally. However, not all suppliers are required to pay such fees, especially those that heavily invest in advertising their own brands. Suppliers pay supermarkets to participate in different promotions and to get special shelf space for these promotions. ${ }^{3302}$ Promotion fees can range from USD 2,500 to USD 7,000 in South Africa, depending on the scale of the promotion and the size of the outlet. Suppliers can also run promotions at their own cost in the supermarket premises.

An important factor in supplying supermarkets is the ability to supply products at the lowest cost, to supply at the required quality, and to consistently supply the required volumes across all outlets. This is difficult for small and medium suppliers, or new entrants, who have not yet gained scale. ${ }^{3303}$ However, for franchise stores such as SPAR, small suppliers with limited scale are able to participate in the value chain as there is less of a requirement to have consistency across all the franchises given individual ownership of stores. A supplier can just supply a single SPAR store. The Fruit and Veg City model of procurement, which is predominantly from municipal fresh produce markets, also allows small farmers who cannot get into formal supermarket supply chains a chance to participate in retail markets. Similarly, buying group-led independent retailers also offer small to medium sized suppliers an alternative to supplying formal supermarket chains and usually impose far less stringent terms on them. This highlights the importance of alternative and diverse models of retail.

Other costs that suppliers occur include the basic legal standards that suppliers have to adhere to, such as South African Bureau of Standards (SABS). Further, there is a range of food safety, health and safety, environmental, packaging, and labelling standards.

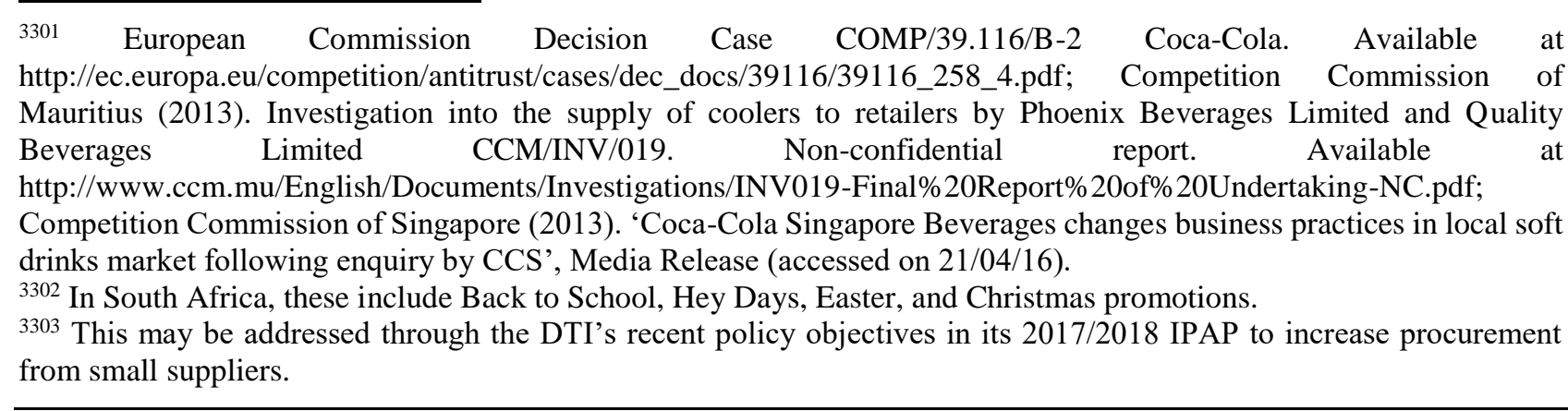


Over and above these basic legal requirements, supermarkets impose private standards on suppliers. In South Africa, supermarkets sometimes insist that suppliers have Hazard Analysis and Critical Control Point (HACCP) accreditation. HACCP is an internationally recognized system for reducing the risk of safety hazards in food. The HACCP system requires that potential hazards are identified and controlled at specific points in the process including biological, chemical, or physical hazards.

In some cases, supermarkets impose higher accreditation standards than HACCP, such as Food Safety System Certification (FSSC 22000) which is also an international accreditation. In other cases, suppliers are taking it upon themselves to get higher accreditations to have a competitive edge over rivals. Regardless of accreditation, it appears that retailers typically send their own auditors to audit the supplier at the supplier's cost. Estimates from suppliers are that HACCP can cost as much as USD 5,500 and FSSC 22000 can cost up to USD 13,800 per annum, with additional USD 6,900 annual fees for maintenance.

Other private standards include sustainability requirements. For instance, Woolworths requires that its food suppliers farm sustainably under its 'Farming for the Future' initiative in addition to other sustainability requirements. Shoprite's fresh produce arm, Freshmark, has its Good Manufacturing Practices standard for all pack-house facilities. Most supermarkets require Halaal and Kosher certifications in South Africa. In the poultry industry, almost all producers are Halaal approved, and abattoirs need to be approved by the government. Supermarkets also impose private standards on house brands for many of these products. In addition, supermarkets are increasingly requiring barcoding on the packaging of products in the countries assessed. Other global initiatives, such as GlobalG.A.P. (Good Agricultural Practice), also have implications for local suppliers trying to export to international markets (see das Nair and Chisoro 2016).

The costs of adhering to all these standards and audits are borne entirely by the supplier, making it increasingly costly to supply formal supermarket chains. Independent retailers on the other hand often have lower, if any, private standards. Independent retailers therefore provide an avenue through which new suppliers can start building scale

There has been growth in private label products in supermarket shelves in South Africa recently. Every major supermarket chain has a range of own brand/private label products. ${ }^{3304}$ Many suppliers of branded products also manufacture and sell private labels to supermarkets. Supplying house brands is a way in which suppliers can get their products on supermarket shelves. Suppliers can use this as a stepping stone to get onto supermarkets' preferred supplier lists especially for suppliers that have not yet built a brand name. House brands also confer some bargaining power to supermarkets over large, multinational suppliers. However, concerns were highlighted around suppliers being 'forced' into supplying house brands at lower margins than their own branded products and this was used as a tool to negotiate down prices for branded products.

\subsection{Outcomes of key competition cases}

\footnotetext{
3304 Majority of Woolworths' products are private labels. Shoprite has its 'Ritebrand' and 'Housebrand' ranges in Checkers, which covers around 300 products. Pick n Pay has its 'No Name' brand and is looking to further expand the private label range. Food Lover's Market produces its own house brands 'Freshers' and 'Food Lover's Signature'. SPAR also has its own branded products. SPAR does not allow major suppliers to manufacture its own private label products, thus allowing new and small suppliers to enter the supermarket supply chain.
} 
There have been very few major competition cases in the retail sector, other than mergers. In 2007, the Competition Commission recommended that the Competition Tribunal prohibit the large merger between Pick n Pay and FVC on grounds that the merger would result in the removal of an effective competitor in the retail market for fresh food. The Commission found that FVC was a growing effective competitor to Pick n Pay and the other major retailers, and would provide an even greater product offering in the future. Allowing the merger would therefore stifle both current and future competition. It appears that the Commission was correct in its prediction of FVC's future growth. FVC subsequently showed impressive growth. Turnover has grown steeply from R1.6 billion in 2006 to R15 billion in 2015, with a growth rate well ahead of the major listed food retailers. ${ }^{3305} \mathrm{FVC}$ 's turnover grew by approximately $21 \%$ per year, compared to the $15 \%$ growth rate of the other major supermarkets. $^{3306}$ The number of stores has also grown particularly between 2006 and 2012. ${ }^{3307}$

The second key retail merger involved the take-over of Massmart by Walmart. The merger between Walmart and Massmart was ultimately approved with several conditions. Created as part of the conditions imposed by the Competition Appeal Court, the merged firm had to set up a Supplier Development Fund (SDF) and make available ZAR 240 million over a period of five years to develop suppliers. This stemmed from concerns that Walmart would divert its sourcing away from local suppliers and to its massive global supplier base. This raised public interest concerns around local supplier participation and development. The other key conditions involved employment.

The SDF has been operating for approximately 4 years. Massmart worked with TechnoServe, a non-profit organisation, to upskill and train farmers to supply fresh produce to its stores, in addition to providing preferential finance terms and inputs. The retailer invested R40 million in smallholder farming to support Massmart's move into fresh produce and grocery market. However, this programme was relatively unsuccessful and has been discontinued due to several setbacks:

- Small farmers were vulnerable to crop disease and weather and could not afford insurance leading to huge crop losses. Massmart ended up covering their costs and purchasing seeds for new crop;

- Massmart entered into pricing agreements with farmers but did not require exclusivity arrangements. The result was that farmers would supply other retailers who offered better prices than Massmart. In the end, Massmart only received suppliers' produce when the market price was low (below the contract price) thereby incurring losses.

- Massmart was required to provide support in terms of farming equipment, logistics, pack houses, extension services (soil science and Fertilisers) and carry out significant investment in attaining food safety requirements. Massmart underestimated the cost of these investments and they were not financially prepared to carry out such investments.

There were however some successful initiatives on the manufacturing/processing side of the initiative (e.g. Lethabo Milling, The Noodle Factory, Thistle Bakery and Marble Gold). The Noodle Factory based in Cape Town has been listed with Makro for 13 years supplying an Indonesian noodle brand called Alhami. The firm has started supplying other retail chains such as Fruit \& Veg City and

\footnotetext{
${ }^{3305}$ Growth rates of the major listed supermarket chains were reported at about $15 \%$ per year between 2006 and 2012 , while that of FVC was $20 \%$ per year. http://www.financialmail.co.za/business/2012/07/18/fruit-veg-city-grows-marketshare, accessed 15/01/2015.

3306 http://www.financialmail.co.za/moneyinvesting/2013/10/31/woolworths-rides-high-in-sa-food-sector, accessed 25 August 2015

3307 See also http://www.entrepreneurmag.co.za/advice/success-stories/entrepreneur-profiles/fruit-and-veg-city-michaeland-brian-coppin/, accessed 25/08/2015
} 
Shoprite Checkers. Thistle Bakery based in Kempton Park is a baked goods manufacturer receiving financial assistance from the SDF. Thistle Bakery supplies baked goods under Massmart's Marketside private branding to 32 Game stores. ${ }^{3308}$

Lethabo Milling, a maize milling company based in Free Sate received financial assistance as part of the programme. Lethabo received a R1.6 million grant from Massmart towards refurbishing its plant. The support extended to an offtake agreement with Massmart which helped Lethabo further secure a loan from a commercial bank. Lethabo has a guaranteed route to market through supplying Massmart stores in South Africa and has received additional support for training, waived listing fees, fast-track payments (7-day payment period as opposed to 30-day payment terms), and assistance with pricing models. Lethabo Milling is still receiving assistance from the SDF following the challenges brought about by the drought resulting is escalating grain prices. The programme is assisting by providing revolving credit for the miller's operations and assisting with negotiations to secure access to grain supply with Farmwise Grains.

Massmart discontinued investment in direct farming projects given the difficulties faced and because it was not a market leader in the category of fresh produce. Therefore, it could not influence the end selling price of fresh produce, resulting in a squeeze in profits for products produced by farmers under the programme. Massmart has since shifted its supplier development programmes to focus on building supplies category where it is regarded as a market leader. The current Massmart model focuses on established business that can be up-scaled quickly in FMCG, General Merchandise, DIY and Building, where it makes mutual commercial sense for both Massmart and the supplier. ${ }^{3309}$

A brief look at the recent merger activity involving supermarkets in the past three years shows that the large supermarket chains have been buying up smaller independent retailers (Table 22). This is consistent with the concerns around the growing market share of chain supermarkets and increasing market power. All these mergers were approved by the Commission without any conditions, except for the merger involving Shoprite and Stone Acres SuperSpar. The conditions were however on employment issues under public interest criteria. ${ }^{3310}$

Table 22: Merger cases involving grocery retail in South Africa

\begin{tabular}{|l|l|l|l|}
\hline Year & Acquiring firm & Target firm & Status \\
\hline 2014 & $\begin{array}{l}\text { Shoprite Checkers } \\
\text { (Pty) Ltd }\end{array}$ & $\begin{array}{l}\text { The assets and liquor license of the Stone } \\
\text { Acres SuperSpar and Tops, Mafikeng of } \\
\text { Klipakkers (Pty) Ltd }\end{array}$ & $\begin{array}{l}\text { Approved with } \\
\text { conditions }\end{array}$ \\
\hline 2015 & $\begin{array}{l}\text { Cambridge Foods } \\
\text { Gree } \\
\text { (Proprietary) Limited }\end{array}$ & $\begin{array}{l}\text { Powersave Wholesalers CC t/a } \\
\text { Powersave Cash \& Carry and as Reezas } \\
\text { Supermarket CC t/a Savemore } \\
\text { Supermarket }\end{array}$ & Approved \\
\hline 2015 & The Spar Group Ltd & $\begin{array}{l}\text { Florida Foodliner (Pty) Ltd, Florida } \\
\text { Junction Superspar and Florida Junction } \\
\text { Tops@Spar, and Memoire Trading 130 }\end{array}$ & Abandoned \\
\hline
\end{tabular}

\footnotetext{
3308 Supplier Development Programme Massmart Report (2015).

${ }^{3309}$ Supplier Development Programme Massmart Report (2015).

3310 http://www.gov.za/sites/www.gov.za/files/37912_gen658.pdf
} 


\begin{tabular}{|c|c|c|c|}
\hline & & $\begin{array}{l}\text { Pty Ltd, Gordon Road Superspar and } \\
\text { Gordon Road Tops@ Spar }\end{array}$ & \\
\hline 2015 & $\begin{array}{l}\text { The Spar Group } \\
\text { Limited }\end{array}$ & $\begin{array}{l}\text { Florida Foodliner (Pty) Ltd, in respect of } \\
\text { the business known as Florida Junction } \\
\text { SUPERSPAR and Florida } \\
\text { JunctionTops@Spar and Memoire } \\
\text { Trading } 130 \text { (Pty) Ltd, in respect of the } \\
\text { business known as Gordon Road } \\
\text { SUPERSPAR and Gordon } \\
\text { RoadTops@Spar }\end{array}$ & Approved \\
\hline 2015 & The Spar Group Ltd & $\begin{array}{l}\text { Mqanduli Traiding Store CC, In respect } \\
\text { of the business known as Nozukile } \\
\text { SUPERSPAR and Nozukile Tops at Spar }\end{array}$ & Approved \\
\hline 2015 & The Spar Group Ltd & $\begin{array}{l}\text { Kwankcenke Trading cc known as } \\
\text { Engcobo SUPERSPAR and Ndu's Spar } \\
\text { CC }\end{array}$ & Approved \\
\hline 2015 & $\begin{array}{l}\text { Pick 'n Pay Retailers } \\
\text { (Pty) Ltd }\end{array}$ & Trio Belville (Pty) Ltd & Approved \\
\hline 2016 & The Spar Group Ltd & $\begin{array}{l}\text { Kayur Superstore (Pty) Ltd in respect of } \\
\text { the business knows as Gateway } \\
\text { SuperSpar and Gateway Tops at Spar }\end{array}$ & Approved \\
\hline 2016 & $\begin{array}{l}\text { Choppies } \\
\text { Supermarkets South } \\
\text { Africa (Pty) Ltd }\end{array}$ & $\begin{array}{l}\text { Retail Business of Jwayelani Retail } \\
\text { Proprietary Limited }\end{array}$ & Approved \\
\hline 2016 & $\begin{array}{lr}\text { Sun } & \text { Village } \\
\text { Supermarket } & \text { (Pty) } \\
\text { Ltd Ltd } & \\
\end{array}$ & $\begin{array}{l}\text { Alpha Bakery Confectionary (Pty) Ltd, } \\
\text { in respect of the businesses known as Sun } \\
\text { Village SUPERSPAR }\end{array}$ & Approved \\
\hline 2016 & The Spar Group Ltd & $\begin{array}{l}\text { Algoa Supermarket (Pty) Ltd, in respect } \\
\text { of the businesses known as Algoa SPAR } \\
\text { and Tops and Aspen SPAR and Tops }\end{array}$ & Approved \\
\hline 2016 & The Spar Group Ltd & $\begin{array}{l}\text { Andramaria Supermarket CC, in respect } \\
\text { of the business known as Rant en Dal } \\
\text { SUPERSPAR and Tops at SPAR }\end{array}$ & Approved \\
\hline
\end{tabular}

Source: Competition Commission website

In terms of abuse of dominance and cartel cases in the retail sector, there have been no major historic or recent finalised cases, but the grocery retail inquiry could potentially recommend further investigations to be initiated. ${ }^{3311}$ Unlike the Kenyan Competition Act for instance which has been amended to include abuse of buyer power specifically, the South African competition law is a blunt instrument to deal directly with issues of buyer power (hence there is an inquiry in this area). The dominance threshold for a single supermarket is often not met and the burden of proof for small

3311 There have only been two failures to notify merger transactions by Fruit and Veg City that were considered in 2016. 
retailers to show a substantial lessening of competition is prohibitively high. Therefore only a few cases are successfully prosecuted. This may call for an amendment of the Act, which is something that is being considered currently and/or other measures, such as codes of conduct that govern the behaviour or retailers specifically, something that DTI is currently considering.

\subsubsection{Barriers to entry}

The main structural barriers to entry in this sector are a function of the inherent characteristics of supermarket chains. Some of the biggest barriers are the substantial investments required in distribution centres and logistics networks as part of the supply chain of supermarkets, as well as scale and scope economies in having multiple stores. Investments in distribution centres by the largest supermarkets Shoprite and Pick $\mathrm{n}$ Pay have been significant and give an indication of the orders of magnitude involved. Shoprite invests annually in distribution centres, related equipment and vehicles. It invested around R400mill in 2014 and over R650mill in 2015 (an increase of 63\%). In 2015, this was around 14\% of total capital expenditure. Pick n Pay invested R628 million in 2010 in one of its largest distribution centres in Longmeadow, as well as another similar investment in its Philippi distribution centre in 2012.

The lack of access to distribution centres and logistics networks places independent retailers and new entrants at a considerable competitive disadvantage. Suppliers often provide additional discounts for sales to distribution centres even for the same volumes of product. These include distribution, warehouse and pallet discounts, which could amount to up to $10 \%$ off the price of products. Investments in distribution centres therefore can contribute to levelling the playing fields with respect to sourcing for smaller players who have access to them (das Nair and Chisoro, 2015). Advertising costs are also a significant barrier to expansion for supermarkets and independent retailers. Independent retailers have found ways of partially overcoming this through the buying groups they are affiliated with. These groups undertake advertising and promotions, including through the use of knock-and-drop advertising and direct marketing on behalf of independent retailers. Other major barriers for small players include lack of business management skills, retail capabilities and access to finance.

Access to finance and lack of retail skills were also key barriers identified in the southern African countries. Other areas where government assistance was sought include rehabilitation of infrastructure (such as rail, road, and energy infrastructure), better access to agricultural extension services, greater protection from imports, regularly reviewed 'sensitive product' industries, and facilitation of access to export markets.

\subsection{Conclusions and recommendations}

This paper, through a RVC lens, has assessed developments in the following selected key food value chains in southern Africa:

1. Seeds

2. Fertilisers

3. Animal feed and poultry

4. Maize and wheat milling

5. Dairy 


\section{Retail}

An RVC approach is strongly advocated for in evaluating market outcomes as a complementary tool to traditional industrial organisation approaches to competition matters. In many of the value chains assessed, it is the same multinational players that operate across countries and the conduct of these firms with market power tends to be similar in the different countries. A RVC approach further provides useful insights into bottlenecks in the value chain that can span across countries in the region, and provides insights into opportunities for upgrading. Bilateral or multilateral efforts by competition authorities and other government departments of the respective countries may be required to address these. Understanding the governance role of large lead firms in value chains also adds to assessments of market power that competition authorities can benefit from.

The cooperation of competition authorities within the region is therefore vital to successfully detect and prosecute anticompetitive behaviour. This requires constant monitoring of trends and market outcomes through, for instance, a 'market observatory' platform, coordinated and shared between national and regional competition authorities.

The history of development of food markets in South Africa has resulted in many legacy competition concerns, but the paper has highlighted more recent trends that affect competitive dynamics that should not be ignored. The increased financialisation, cross-ownerships and internationalisation of large lead local firms in the food sector affects the strategies and incentives to effectively compete. Mergers that involve institutional players may not, on the face of it, present direct competition concerns, but in the long run may result in diminished incentives to compete. These trends in food markets are not unique to South Africa. Again, there is a role for competition authorities globally, especially BRICS countries' authorities, to cooperate and collaborate on matters that have global impacts.

The role of the retail level of the value chain for the development of food markets cannot be underestimated. Large retail chains with significant market power (as is the case in southern Africa) influence the participation and development of suppliers. Effective competition at this level is important to reduce effects of abuse of buyer power on suppliers. It is therefore important to foster a competitive environment for a diversity of retail models and to keep retail spaces open to entrants to allow them to gain a foothold in the market. Competition authorities need to engage with local government/municipalities to ensure that urban planning policies open up retail space. This should include planning and licence conditions that ban exclusive leases or limit the duration of these to no more than 5 years on exceptional grounds.

To further curb abuses of buyer power may require a multi-pronged approach. Amending the Competition Act to more effectively address abuses of buyer power by including lessening, preventing or distorting competition as tests for anticompetitive effects under the abuse of dominance provisions is one approach. Initiatives to amend the Act are currently underway and the experiences in the retail sector can provide useful insights to this process on the limitations of the Act as it currently stands. Powers can also be given to the Grocery Retail Market Inquiry undertaken by the Competition Commission to make orders based on its findings. A complementary approach involves setting up a code of conduct that governs the relationship between supermarkets and suppliers. ${ }^{3312}$ Given the multinational nature of supermarkets in the region, such a code can be harmonised across

3312 In the UK for example, the Groceries Supply Code of Practice was set up specifically to oversee the relationship between supermarkets and their suppliers following an inquiry by the former Office of Fair Trading. 
the region. Policy can also require that supermarkets support local small and medium sized suppliers through investing in formal supplier development programmes. Both a code of conduct and supplier development initiatives are currently being considered by the Department of Trade and Industry in its industrial policy going forwards. 


\section{References}

AfDB (African Development Bank), Organisation for Economic Co-operation and Development, and United Nations Development Programme (2014). African Economic Outlook 2014: Global Value Chains and Africa's Industrialisation. Paris: UN Economic Commission for Africa.

African Centre for Biodiversity (2017a) The BAYER-MONSANTO merger: Implications for South Africa's agricultural future and its smallholder farmers. Available at: https://acbio.org.za/thebayer-monsanto-merger-implications-for-south-africas-agricultural-future-and-its-smallholderfarmers/ (Accessed: 17 August 2017).

African Centre for Biodiversity (2017b) The Three Agricultural Input Mega-mergers: Grim reapers of South Africa's food and farming systems. Johannesburg. Available at: https://acbio.org.za/wpcontent/uploads/2017/04/Mega-Mergers-Bayer-Monsanto.pdf (Accessed: 17 August 2017).

Amin, N \& Bernstein, H, (1995). The Role of Agricultural Co-operatives in Agriculture and Rural Development. LAPC: Policy Paper 32.

Astral Foods (2006). Annual report. Available at: http://www.astralfoods.com/PDF/Annual\%20Report\%202006/Astral\%20Annual\%20Report.pdf (accessed 8 March 2016)

Astral Foods (2014). Annual report. Available at: http://www.astralfoods.com/pdf/astral_ar2014.pdf (accessed 8 March 2016)

Bagopi, E., E. Chokwe, P. Halse, J. Hausiku, M. Humavindu, W. Kalapula, and S. Roberts, (2014). 'Competition Dynamics and Regional Trade Flows in the Poultry Sector: The Case of South Africa, Botswana, Namibia, and Zambia'. Paper presented at the Pre-ICN Forum, 22 April, Palmeraie Golf Palace. Marrakech: International Competition Network. Available at: http://agriprofocus.com/upload/post/2014_Poultry_Trade_flows_in_S_Africa_Botswana_Namibi a_Zambia_ICN_Confpaper1443600533.pdf (accessed 26 January 2016).

Banda, F., Robb, G., \& Roberts, S. (2015). Review Paper Two: the links between competition policy, regulatory policy and trade and industrial policies. Centre for Competition Regulation and Economic Development Working Paper 2015/5

Basker, E., and M. Noel (2013). Competition Challenges in the Supermarket Sector with an Application to Latin American Markets. Report for the World Bank and the Regional Competition Centre for Latin America. Mexico, DF: CRCAL.

Betancourt, R. (2006). The Economics of Retailing and Distribution. Edward Elgar Publishing.

Booysen, V. (2013) 'Nuwe koringmeule open by Clocolan', Netwerk 24, 29 April. Available at: http://www.netwerk24.com/Sake/Nuwe-koringmeule-open-by-Clocolan-20130429.

Botswana Competition Authority (2015). Available at: http://www.competitionauthority.co.bw/sites/default/files/Merger\%20Decision\%20No\%20\%2036 \%202015-KFC\%20and\%20Callus\%20\%20Pty\%20Ltd.pdf (accessed 8 March 2016)

Cattaneo, O., G. Gereffi and C. Staritz. (2010). Global Value Chains in a Postcrisis World: A Development Perspective. Washington, DC: The World Bank.

CBH (Country Bird Holdings) (2008). Annual report. Available at: http://www.sharedata.co.za/Data/009085/pdfs/CBH_ar_08.pdf (accessed 8 March 2016) 
Clapp, J. (2012). The financialisation of food: who is being fed? Rio de Janeiro, Brazil: Paper presentedat the International Society for Ecological Economics Conference

Clarke, R., Davies, S., Dobson, P. \& Waterson, M., (2002). Buyer power and competition in European food retailing. Cheltenham: Edward Elgar.

Clover (2014) Clover acquires Dairybelle's Yoghurt and UHT assets - Clover. Available at: http://www.clover.co.za/news/post_3848-clover-acquires-dairybellersquos-yoghurt-and-uhtassets/success (Accessed: 24 July 2017).

Coleman, A. (2013, February 2). Value-adding in the eastern Free State. Retrieved from Farmer's Weekly http://www.farmersweekly.co.za/article.aspx?id=34977

Competition Commission South Africa (2016) 'Statement on the decisions of the Competition Commission - 17 August 2016'. Available at: http://www.compcom.co.za/wpcontent/uploads/2016/01/Commission-Statement-17-August-2016-Final-1.pdf (Accessed: 28 July 2017).

Competition Commission (2017) 'Notification to Approve with Condition the Transaction involving China National Agrochemical Corporation and Syngenta AG'. Pretoria: Government Gazette. Available at: http://0discover.sabinet.co.za.ujlink.uj.ac.za/webx/access/ggaz_pdf/2017/jan/gg40645_nn155.pdf (Accessed: 25 August 2017).

Competition Commission South Africa (2017a) 'Commission conditionally approves Bayer and Monsanto Transaction'. Pretoria: Competition Commission South Africa. Available at: http://www.compcom.co.za/wp-content/uploads/2017/01/Commission-Conditionally-ApprovesBayer-Transaction-Final.pdf (Accessed: 21 August 2017).

Competition Commission South Africa (2017b) 'Dow, DuPont Merger Approved with Conditions'. Pretoria: Competition Commission South Africa. Available at: http://www.compcom.co.za/wpcontent/uploads/2017/01/Du-Pont-media-release-5-July-2017.pdf (Accessed: 21 August 2017).

Competition Tribunal (2010). 'Pioneer Hi-Bred International Inc and Pannar Seed (Pty) Ltd v. Competition Commission'. Case 81/AM/Dec10, 9 December 2011, Pretoria. Available at: http://www.comptrib.co.za/assets/Uploads/81AMDec10.pdf

Competition Tribunal (2011). 'The Competition Commission v. Astral Operations Ltd, Elite Breeding Farms, and Ross Poultry Breeders (Pty) Ltd'. Case 74/CR/Jun08, 30 June 2008, Pretoria. Available at: http://www.saflii.org/za/cases/ZACT/2011/83.html (accessed 9 November 2015).

Competition Tribunal (2013). 'The Competition Commission v. Astral Operations Limited'. Case 015891, 5 November, Pretoria. Available at: http://www.comptrib.co.za/assets/Uploads/015891.pdf (accessed 9 November 2015).

DAFF (Department of Agriculture, Forestry and Fisheries) (2014). A Profile of the South African Broiler Market Value Chain. South Africa: DAFF. Available at: http://www.nda.agric.za/doaDev/sideMenu/Marketing/Annual\%20Publications/Commodity\%20P rofiles/Livestock/Broiler\%20market\%20value\%20chain\%20profile\%202014.pdf (accessed 7 December 2015).

DAFF (Department of Agriculture, Forestry and Fisheries) (2014). A Profile of the South African Broiler Market Value Chain. Pretoria: DAFF. Available at: www.nda.agric.za/doaDev/sideMenu/Marketing/Annual\%20Publications/Commodity\%20Profiles /Livestock/Broiler\%20market\%20value\%20chain\%20profile\%202014.pdf (accessed 7 December 2015). 
DAFF (Department of Agriculture, Forestry and Fisheries) (2015). A Profile of the South African Broiler Market Value Chain. South Africa: DAFF. Available at: http://www.nda.agric.za/doaDev/sideMenu/Marketing/Annual\%20Publications/Commodity\%20P rofiles/field\%20crops/Broiler\%20market\%20value\%20chain\%20profile\%202015.pdf (accessed 30 January 2017).

DAFF (2015) Grain Seeds Market Analysis Report. Pretoria. Available at: http://www.nda.agric.za/doaDev/sideMenu/Marketing/Annual Publications/Commodity Profiles/field crops/South African Grain Seeds Market Analysis Report 2015.pdf (Accessed: 16 August 2017).

DAFF (2017) 'Abstract of Agricultural Statistics 2017'. Pretoria: Department of Agriculture, Forestry and Fisheries.

Dairy Standard Agency (2016) Combined List of Acts, Regulations and Standards relating to Food Safety and Quality Aspects of Milk and Other Dairy Products. Available at: http://dairystandard.co.za/images/downloads/DSA_list_of_combined_dairy_legislation_and_stan dards_Oct_2016.pdf (Accessed: 18 July 2017).

Das Nair, R. \& Chisoro, S. (2015). The expansion of regional supermarket chains: Changing models of retailing and the implications for local supplier capabilities in South Africa, Botswana, Zambia, and Zimbabwe. UNU-WIDER Working Paper 2015/114

...(2016). The expansion of regional supermarket chains and implications for local suppliers: A comparison of findings from South Africa, Botswana, Zambia and Zimbabwe. UNU-WIDER Working Paper 2016/169

...(2017). The expansion of regional supermarket chains: Implications on suppliers in Botswana and South Africa. UNU-WIDER Working Paper 2017/26

Department of Agriculture Forestry and Fisheries (2012) A Profile of the South Africa Dairy Market Value Chain. Available at: http://www.nda.agric.za/docs/AMCP/Dairy2012.pdf (Accessed: 18 July 2017).

Dobson, P. (2015). Structural Issues in the Groceries Sector: Merger and Regulatory Issues. Background paper by the OECD Secretariat - Latin American Competition Forum, Session I DAF/COMP/LACF (2015)13.

DTI (Department of Trade and Industry) (2012). 'Strategy for the Development of the Soybean Sector in South Africa'. South Africa: Agro-Processing Unit, Industrial Development Policy Development Division, DTI (accessed via private communication).

DTI (Department of Trade and Industry) (2016). 'Press Statement on President Obama's 11th January 2016 Proclamation'. Available at: http://www.thedti.gov.za/editmedia.jsp?id=3627 (accessed 15 December 2016).

Edwards, L, Kirsten, J, Vink, N, (2009). 'South Africa'. In Anderson, K and WA Masters (eds) Distortions to agricultural incentives in Africa, Washington DC, World Bank, 147-174.

Ellickson, P.B. and Misra, S. (2008), Supermarket Pricing Strategies., Marketing Science, 27(5), pp. 811-828.

Ellickson, P.B (2013). Supermarkets as a Natural Oligopoly. Economic Inquiry. Vol. 51, No. 2, April 2013, 1142-1154 
Ensor, L. (2015, June 9). AGOA comprise mixed blessing for SA. Retrieved from Business Day : http://www.bdlive.co.za/business/trade/2015/06/09/agoa-compromise-mixed-blessing-for-sa

ETC Group (2015) 'Breaking Bad: Big Ag Mega-Mergers in Play Dow + DuPont in the Pocket? Next: Demonsanto?', ETC Group Communiqué, (115). Available at: http://www.etcgroup.org/sites/www.etcgroup.org/files/files/etc_breakbad_23dec15.pdf (Accessed: 16 August 2017).

Euromonitor (2017) Packaged Food in South Africa. Euromonitor International. Available at: http://www.euromonitor.com/packaged-food-in-south-africa/report

Farole, T. (2015). Factory Southern Africa? SACU in Global Value Chains. World Bank Group Working Paper

Fessehaie. J., Rustomjee, Z. and L. Kaziboni (2016). Can mining promote industrialization? A comparative analysis of policy frameworks in three Southern African countries. WIDER Working Paper 2016/83, CCRED.

Fessehaie, J. and M. Morris (2013). Value Chain Dynamics of Chinese Copper Mining in Zambia: Enclave or Linkage Development? The European Journal of Development Research, Palgrave Macmillan, vol. 25(4), pages 537-556, September.

Gereffi. G., and K. Fernandez-Stark (2011). Global Value Chain Analysis: A Primer. Centre on Globalization, Governance \& Competitiveness (CGGC).

González-Benito, O., P. A. Munoz-Gallego and P. K. Kopalle (2005). Asymmetric competition in retail store formats: Evaluating inter- and intra-format spatial effects. Journal of Retailing, 81 (1, 2005) 59-73.

Greenberg, S. (2017). Corporate Power in the agro-food system and the consumer food environment in South Africa. Journal of Peassant Studies, 1-31.

Grimbeek, S., \& Lekezwa, B. (2013). The Emergence of More Vigorous Competition and the Importance of Entry - Comparative Insights from Flour and Poultry. CCRED Working Paper $2013 / 1$

Grain SA (2011) 'Hybrid or Open Pollinated Variety Seed - Weigh up the Options', Pula Imvula, (August). Available at: http://www.nampo.co.za/documents/Pula imvula August - English.pdf (Accessed: 16 August 2017).

Hancock, T. (2015) Tribunal approves Clover and Nkunzi merger with conditions, Engineering News. Available at: http://www.engineeringnews.co.za/article/tribunal-approves-clover-andnkunzi-merger-with-conditions-2015-04-24 (Accessed: 24 August 2017).

Harvey, M. (2000). Innovation and competition in UK supermarkets. Supply Chain Management: An International Journal, 5(1), 15-21.

IDC (Industrial Development Corporation). (2014, March 03). Grain Field Chicken impresses President Zuma. Available at: http://www.idc.co.za/home/media-room/articles/666-grain-fieldchicken-impresses-zuma.html (accessed 8 March 2016)

IFC (International Finance Corporation) (2013). Country Bird: Environmental \& Social Review Summary. Available at: http://ifcext.ifc.org/ifcext/spiwebsite1.nsf/ProjectDisplay/ESRS32653 (accessed 8 March 2016)

ITAC (International Trade Administration Commission of South Africa) (2015). 'Investigation into the Alleged Dumping of Frozen Bone-in Portions of Fowls of the Species Gallus domesticus, Originating from Germany, The Netherlands and the United Kingdom: Final Determination'. ITAC 
Report 492. Available at: http://www.itac.org.za/upload/document_files/20150306125607_ReportNo-492.pdf (accessed 15 December 2016).

ITAC. (2013). Report No. 442: Increase in the rates of customs duty on frozen meat of fowls of the species gallus domesticus, whole bird, boneless cuts, bone-in portions, carcasses and offal.

Jensen, H.G., and R. Sandrey (2015). 'African Agricultural Trade: Recent and the Future'. African Journal of Agricultural and Resource Economics, 10(2): 146-57.

Kalicharan, A. (2010) Founding Affidavit for the Wheat Milling Cartel. Pretoria.

Kaplinsky, R. and M. Morris. (2015). "Thinning and Thickening: Productive Sector Policies in The Era of Global Value Chains." European Journal of Development Research. Nature Publishing Group, 1-21. doi:10.1057/ejdr.2015.29.

Kassier, WE. (1992). Report of the Committee of Inquiry into the Marketing Act. Pretoria, Department of Agriculture.

Keane, J. (2015). Firms and Value Chains in Southern Africa. World Bank Working Paper. London: World Bank.

Kirsten, JF \& Van Zyl, J (1996). The contemporary agricultural policy environment: undoing the legacy of the past. OUP, Cape Town.

LAPC (Land and Agricultural Policy Centre) (1994). Food security and staple foods: Policy Issues for South Africa. Policy Paper 4 for MERG, Braamfontein, Johannesburg: LAPC.

Lianos, I. and Katalevsky, D. (2017). Merger Activity in the Factors of Production Segments of the Food Value Chain: - A Critical Assessment of the Bayer / Monsanto merger. 1/2017.

Lianos, I and C. Lombardi (2016 a). Superior Bargaining Power and the Global Food Value Chain: The Wuthering Heights of Holistic Competition Law? Concurrences ( $\left.\mathrm{N}^{\circ} 1\right), 2016$

Lianos, I and C. Lombardi (2016 b). Discussion paper on Global Food Value Chains (CLES \& HSE, 2016).

Louw, A., Geyser, M., Troskie, G., van der Merwe, M., Scheltema, N. and Nicholson, R. (2010) Determining the factors that limit agro-processing development in the wheat milling and baking industries in rural areas in South Africa. Pretoria: Pretoria. Available at: http://www.namc.co.za/upload/all reports/Maize Milling Report.pdf (Accessed: 13 August 2017).

Louw, A., J. Schoeman, and M. Geyser (2013). 'Pork and Broiler Industry Supply Chain with Emphasis on Feed and Feed-Related Issues'. Journal of Agricultural Economics and Development, 2(4): 134-46.

Magwaza, N. (2014, April 4). Broilers for Astral, tight focus for Pioneer. Retrieved from Business Report : $\quad$ http://www.iol.co.za/business/news/broilers-for-astral-tight-focus-for-pioneer1.1670923\#.VlrB-XYrK00

McCleod, A., O. Thieme, and S.D. Mack (2009). 'Structural Changes in the Poultry Sector: Will There Be Smallholder Poultry Development in 2030?'. World's Poultry Science Journal, 65(2): 191-200.

Midgley, S. J. E. (2016) Commodity Value Chain Analysis of Dairy. Available at: http://awsassets.wwf.org.za/downloads/wwf_pfu_commodity_report__dairy_lowres_.pdf (Accessed: 24 July 2017).

Milk Producers' Organisation (2016) Lacto Data. 1. Available at: http://www.milksa.co.za/sites/default/files/BIPLAC024 May 2016.pdf (Accessed: 24 July 2017). 
Mncube, L. (2014a) 'Strategic Entry Deterrence: Pioneer Foods And The Bread Cartel', Journal of Competition Law \& Economics, 9(3), pp. 637-654.

Mncube, L. (2014b) 'The South African Wheat Flour Cartel: Overcharges at the Mill', Journal of Industry, Competition and Trade.

Mnyandu, E. (2015). 'Davies Off to Washington to Defuse Poultry Spat'. Business Report, 2 April. Available at: http://www.iol.co.za/business/markets/davies-off-to-washington-to-defuse-poultryspat-1.1840292\#.Ve6StxGqqko (accessed 7 December 2015)

Mondliwa, P., N. Nhundu, A. Paelo, M. Thosago, \& Vilakazi, T (2017). Growth and Strategies of Large and Leading Firms - Remgro Limited Company Assessment. CCRED Working Paper $11 / 2017$

Morris, M., R. Kaplinsky, and D. Kaplan (2012). One Thing Leads to Another: Promoting Industrialisation by Making the Most of the Commodity Boom in sub-Saharan Africa. Raleigh, NC: Lulu.com.

MPO (2017) Dairy Market Trends - July 2017. Available at: http://www.mpo.co.za/wpcontent/uploads/2017/05/Key-market-signals-July-2017.pdf (Accessed: 30 August 2017).

NAMC (2004) Wheat Strategy. (April 2004). Retrieved from National Chamber of Milling. NAMC.

Ncube, P., Nkhonjera, M., Paremoer, T. and Zengeni, T. (2016) Competition, barriers to entry and inclusive growth - Agro-processing. 3/2016. Johannesburg. Available at: http://static1.squarespace.com/static/52246331e4b0a46e5f1b8ce5/t/56f12ea43c44d828f69521f1/1 458646697706/Nicholas+Nhundu_+Barriers+to+Entry+and+Inclusive+Growth+in+Retail+Banki ng.pdf

Ncube, P., S. Roberts, and T. Zengeni (2016). Development of the Animal Feed to Poultry Value Chain across Botswana, South Africa, and Zimbabwe. UNU-WIDER Working Paper 2016/2. Helsinki: UNU-WIDER. Available at: www.wider.unu.edu/sites/default/files/wp2017-4.pdf (accessed 17 March 2017).

Ncube, P. and Zengeni, T. (2016). Growth and Entry in a Concentrated Industry: The Case of the SA Poultry Industry. Economic Research Advisory Network (ERAN) First Annual Conference, East London, South Africa.

Ncube, P., S. Roberts, T. Vilakazi (2016). Regulation and Rivalry in transport and fertiliser supply in Malawi, Tanzania and Zambia. Competition in Africa: Insights from Key Industries. Ed. Simon Roberts Human Sciences Research Council

Ncube, P., S. Roberts, and T. Zengeni (2017). The Southern African Poultry Value Chain: Regional Development versus National Imperatives. UNU-WIDER Working Paper. Helsinki: UNUWIDER.

Ncube, P., S. Roberts, T. Zengeni, and P. Samboko (2017). Identifying Growth Opportunities in the Southern African Development Community Through Regional Value Chains: The Case of the Animal Feed to Poultry Value Chain. UNU-WIDER Working Paper 2017/4. Helsinki: UNUWIDER. Available: www.wider.unu.edu/sites/default/files/wp2017-4.pdf (accessed 17 March 2017).

Nooteboom, B. (1980) Retailing: Applied Analysis in the Theory of the Firm. Amsterdam: J.C. Gieben.

Page, J. (2014). Can Africa Industrialise. Journal of African Economics, (21)2:, 86-125. 
Pollack, A. (2005) Monsanto Buying Leader in Fruit and Vegetable Seeds - The New York Times, The New York Times. Available at: http://www.nytimes.com/2005/01/25/business/monsantobuying-leader-in-fruit-and-vegetable-seeds.html?mcubz=3 (Accessed: 21 August 2017).

Rainbow Chicken Limited (2005). Annual report. Available at: http://www.sharedata.co.za/Data/000389/pdfs/RAINBOW_ar_mar05.pdf (accessed 8 March 2016)

Reardon, T. \& Gulati, A. (2008). The rise of supermarkets and their Development Implications, International Experience Relevant for India. International Food Policy Research Institute (IFPRI) and Michigan State University. IFPRI Discussion Paper 00752.

Sandrey, R, and Vink, N. (2007). The deregulation of agricultural markets in South Africa and New Zealand: a comparison. Agrekon, 46(3), 323-350.

SANSOR (2015) SANSOR Annual Report 2014/2015. Available at: http://sansor.org/wpcontent/uploads/2012/08/SANSOR-web-entire-doc-small-z.pdf (Accessed: 16 August 2017).

SAPA (South Africa Poultry Association) 2014. South Africa Poultry Association 2014 industry profile. Available at: https://www.sapoultry.co.za/pdf-docs/sapa-industry-profile.pdf (accessed 07 January 2017).

Seldeslachts, J., Newham, M., Banal-Estanol, A. (2017): Changes in common ownership of German companies, DIW Economic Bulletin, ISSN 2192-7219, Vol. 7, Iss. 30, pp. 303-311

Sutton, J. (1991). Sunk Cost and Market Structure: Price Competition, Advertising, and the Evolution of Concentration. MIT Press, Cambridge.

Tregenna, F. and Kwaramba, M. (2014). An institutional analysis of the International Trade Administration Commission of South Africa. Journal of Economic and Financial Sciences, 7(Special issue 1), pp.641-660.

Tregurtha, N, Vink, N, Kirsten, J. (2010). Presidency Fifteen Year Review Project: Review of Agricultural Policies and Support Instruments in South Africa 1994-2009. Trade and Industrial Policy Strategies, Pretoria.

Vink, N \& Kirsten, J (2000). Deregulation of agricultural marketing in South Africa: lessons learned. Briefing Paper prepared for the Free Market Foundation.

Vink, N \& Kirsten J (2002). Pricing behaviour in the South African food and agricultural sector. Report to National Treasury.

Vink, N \& Van Rooyen, J (2009). The economic performance of agriculture in South Africa since 1994: Implications for food security. Development Planning Division Working Paper Series No. 17, DBSA: Midrand.

Vink, N. (2012). The long-term economic consequences of agricultural marketing legislation in South Africa. South African Journal of Economics, 80(4): 553-566.

Who Owns Whom (2017a). Monsanto South Africa (Pty) Ltd, Who Owns Whom - African Business Information. Available at www.whoownswhom.co.za

Who Owns Whom (2017b). The Fertiliser and Nitrogen Compounds Industry. Who Owns Whom. Available at www.whoownswhom.co.za

Zengeni, T. (2017). The Impact of Poultry Imports on South Africa's Poultry Industry. 2nd Annual Economic Research Advisory Network (ERAN) 2017 Conference, Free State, South Africa.

Zengeni, T. (2014). 'The Competitiveness and Performance of the Zimbabwe Poultry Industry'. Unpublished Masters dissertation. Johannesburg: University of the Witwatersrand. 
Ziba, F. and M. Phiri (2016). The Expansion of Regional Supermarket Chains: Implications for Local Suppliers in Zambia. Zambia Institute for Policy Analysis and Research (ZIPAR). UNU-WIDER. 


\section{Chapter 2: GM Cotton Seeds: Emerging Jurisprudence vis--à-vis Competition, Price Control and Patent Licensing in India}

Ujjwal Kumar (CUTS)

\subsection{Background}

The first (and so far the only) genetically modified (GM) crop that has been approved for commercial release in India is Bt Cotton. The approval was given to Monsanto's BG-I ${ }^{3313}$ cotton technology for commercial release in 2002 and to BG-II in 2006. While Monsanto never applied for patent in India for BG-I, its BG-II was granted patent ${ }^{3314}$ in India in March, 2009.

'Monsanto Inc. is a major global player in agricultural products, including developer and licensor of GM traits and has a 100 percent subsidiary in India in form of Monsanto Holdings Private Limited (MHPL). Maharashtra Hybrid Seeds Company (MAHYCO) is an Indian company, engaged in R\&D, production, processing and marketing of seeds. MHPL holds 26\% stake in MAHYCO. Mahyco Monsanto Biotech (India) Limited (MMBL), a 50:50 joint venture formed between MHPL and MAHYCO, is engaged in sublicensing of the patented Bt cotton technology of Monsanto Inc. in India., 3315

\section{Figure 1: The Monsanto Group}

Monsanto Inc. (USA)

$100 \%$

50:50

MMBL (India)

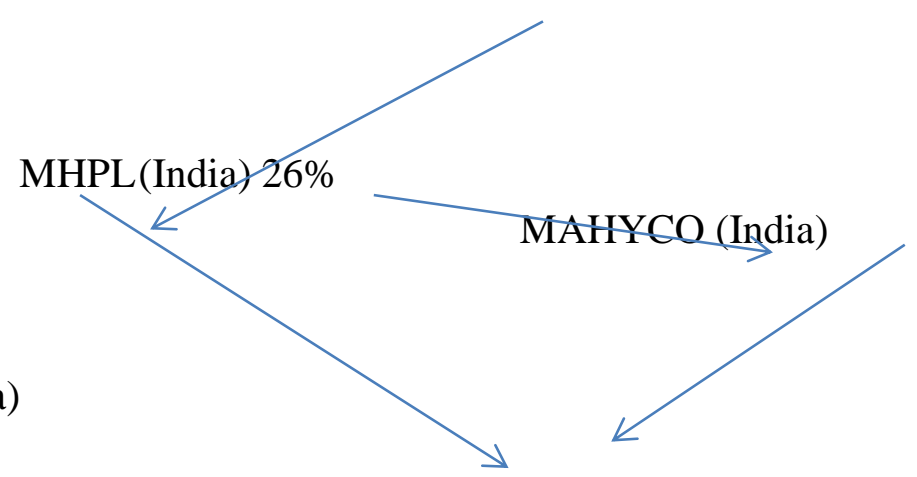

Many Indian seed companies (around 50) have entered into sub-licensee agreements with MMBL for procuring its Bt cotton technology in consideration of an upfront one time non-refundable fee (Rs.5mn) and recurring fee called as 'Trait Value'. The 'Trait Value' is the estimated value for the trait of insect resistance conferred by the Bt gene technology and is to be paid to MMBL on the basis of MRP of $450 \mathrm{gm}$ seed packet in advance for each crop season.

This "fixation or determination of GM trait value and its licensing" has been the trigger for various interventions by central and state governments and central point of almost all (mostly ongoing) disputes between Monsanto and its licensees. Because of these disputes several important

\footnotetext{
3313 Bollgard is the brand owned by Monsanto Inc. BG-I contain one Bt gene stacked with the base cotton variety and BG-II contains two Bt genes.

3315 CCI order dated 10.02.2016 on Reference Case No. 2 of 2015 \& Case No. 107 of 2015
} 
issues - scientific, environmental, regulatory, socio-economic, political-economy - emerged or reemerged.

This Chapter, however, has limited scope. Part I contains factual illustrations on the following three recent developments:

- Dispute before the Competition Commission of India (CCI) alleging inter alia abuse of dominance by the Monsanto group;

- Notification of Cotton Seeds Price (Control) Order, 2015 empowering Central Government to fix price for Bt Cotton seeds, including the trait value; and

- Issuance of Draft Licensing and Formats for GM Technology Guidelines, 2016 by the Central Government.

The Part II of the Chapter analyses and examines the following three contentious issues arising out of the above-said developments (with concluding remarks included within each analysis):

- Does the CCI have jurisdiction on the matters related with patent technology and its licensing?

- Can and should government intervene into regulation of licensing agreement of a proprietary technology using ECA, and consequently fix trait value as well as issue licensing guidelines?

- Should gene patents be licensed on FRAND terms in seed sector?

\subsection{Recent Developments}

\subsubsection{Competition Enforcement ${ }^{3316}$}

The fixation of trait value had been a matter of dispute in the erstwhile competition authority the MRTPC, which had observed in an interim order in May 2006, that "There is a basic difference between royalty and trait value ... and are not synonymous... In any case the lumpsum payment of Rs.50 lakhs may be considered as royalty for the same, but the future payments on sale cannot be termed as royalty". ${ }^{3317}$

Later when the MRTPC was dissolved, the matter was transferred to the Competition Appellate Tribunal (COMPAT) as per the new Competition Act. The COMPAT disposed of the matter in December 2009 viewing the fact that the parties to the dispute had reached an agreement and a new price (Rs.750/pack) had been fixed for Bt Cotton seeds. However, it was categorically stated by COMPAT that "...if there may be future modifications in the prices the same may give rise to further cause of action". 3318

In November 2015, the Central Government made a reference ${ }^{3319}$ to CCI alleging certain anticompetitive practices on the part of MMBL. In December 2015, three private seed companies (Informants), whose licenses were terminated by MMBL, also moved to CCI raising allegations of anti-competitive practices by MMBL. Later few more private seed companies joined as informants.

\section{Box 1: Allegations against MMBL and its defence before CCI}

The Central Government's allegations against MMBL are:

3316 This section is largely based on the CCI Order dated 10.02.16 on Reference Case No. 2 of 2015 \& Case No. 107 of 2015

3317 CCI, $\quad$ Case $\quad$ No. $\quad 02 / 2015 ; \quad$ p7;

http://www.cci.gov.in/sites/default/files/Ref\%20Case\%20022015\%20\%26\%20others.pdf (accessed on 17.01.17)

3318 Ibid p 8

${ }^{3319}$ Under Section 19(1) of the Competition Act 
- Abuse of dominant position by charging unreasonably high trait fees for Bt cotton seeds

- Creating a monopoly through restrictive (licensing) agreements for unjust enrichment by charging high trait value from its licensees and ultimately from farmers

- Its sub-licensing agreements with the Indian seed manufacturing companies are anticompetitive

The private seed companies' allegations are:

- The sub-license agreements between MMBL and the seed companies are one-sided, arbitrary and onerous as well as it is restrictive if sub-licenses want to deal with new technology provider

- Linkage of the trait value to the MRP of seed packets is without any economic justification and as such is unfair

- MMBL has not entered into any sub-license with MAHYCO and MHPL, hence they are not subject to unfair conditions. This amounts to discriminatory conduct on part of MMBL.

MMBL, on the other hand, contended that these allegations are emerging from contractual dispute between the parties and has no competition issue involved. MMBL justified the trait value by stating that they are entitled to reward for innovation and claimed that the trait value charged from Indian seed companies is lowest in the world. On restrictiveness, MMBL submitted that the sub-licensees are only required to intimate it regarding proposed negotiations with any of the sub-licensor's competitor and the same is not abusive or unreasonable. To counter the allegation regarding discriminatory treatment and leveraging of its dominant position, MMBL contended that the market share of MAHYCO and MHPL in the cotton seed market has reduced from 13 percent to 7 percent since 2013.

Broadly, there were two issues before the CCI to decide for the purpose of initiating a thorough investigation:

- Whether the conducts of MMBL amounts to "abuse of dominance" ${ }^{3320}$ within the meaning of the Competition Act?

- Whether, sub-license agreements between the Licensees and MMBL are "anti-competitive agreements" 3321 within the meaning of the Competition Act?

After detailed deliberations the CCI came to conclusion that the "provision of Bt cotton technology in India" is the relevant market for the purpose of analysis. It also figured out that there also exist entry barriers in the form of rigorous regulations and requirement of huge investment.

Does MMBL enjoy a dominant position? The CCI found that there were few other companies offering single gene Bt Cotton technology. However, for the two gene Bt cotton technology (BGII), MMBL is the only player. In addition, out of $1128 \mathrm{Bt}$ Cotton hybrids approved by the GEAC (till May 2012), 986 were having Bt technology sub-licensed by MMBL. The CCI also found that the MMBL's Bt cotton technology was used in more than 99 percent of area under Bt cotton cultivation. Therefore, for CCI the dominant position of MMBL in the relevant market is apparent.

\footnotetext{
${ }^{3320}$ Under Sections 4(2)(a)(i), 4(2)(a)(ii), 4(2)(b), 4(2)(c) and 4(2)(e) of the Act

${ }^{3321}$ Under Sections 3(1) and 3(4) of the Act
} 
Is such alleged dominance by MMBL being abused? The sub-license agreements contain certain terms and conditions that appeared to the CCI as being abusive, stringent and restrictive as well as unfair. For instance, the termination of a license would have the effect of denial of market access to the seed manufacturers, given their dependence on MMBL for Bt cotton technology. These conditions also amount to restriction of development of alternate Bt cotton technologies.

\section{Box2: Restrictive conditions in the Licensing Agreement}

The sub-licenses between MMBL and seed companies have been alleged to contain the following abusive and restrictive terms $\&$ conditions:

- License requires the sub-licensee to intimate MMBL within 30 days from date of undertaking development of hybrid cotton based on a trait obtained from a competitor of MMBL, failing which may trigger termination of the license with immediate effect

- The consequences of such termination require the sub-licensee to immediately cease selling the GM cotton seed produced under the agreement and immediately destroy all such seeds

- The sub-licensee shall immediately destroy all parent lines or other cotton germplasm which has been modified to contain the Monsanto's technology

- MMBL is empowered to terminate the sub-license agreement with immediate effect, if at any time, any laws in the territory restrict the sub license fees (trait value) payable by the sub-licensee

According to the CCI, the termination of license, while the matter was still sub-judice, and invoking stringent termination conditions, prima facie points towards MMBL using its dominance in the upstream market to protect its presence in the downstream market through its group entities. MMBL also could not provide evidence to get rid of the allegations of discriminatory conduct favouring its groups companies. As any discrimination has the potential to distort the level playing field in the downstream Bt cotton seeds market, CCI felt the need for further examination.

As regards the allegations of "anti-competitive agreements," the CCI observed that the notification requirements coupled with the stringent termination conditions in the sub-license agreement entered into between MMBL and the aggrieved seed manufacturers were in the nature of refusal to deal and exclusive supply agreements within the meaning of S.3(4)(b) and 3(4)(d) of the Act.

To the CCI, the termination conditions were found to be excessively harsh and did not seem to be reasonable as may be necessary for protecting any of the IPR rights, as envisaged under S.3(5) of the Act. Such agreements discourage and serve as a major deterrent for the sub licensee from exploring dealing with competitors. The agreements thus, have the effect of foreclosing competition in the upstream Bt Technology market which is characterised by high entry barriers.

The CCI came to the conclusion that there exists a prima facie case of contravention of the provisions of S.3(4) and S.4 of the Act by the Monsanto Group and consequently directed the Director General to conduct an investigation into the whole matter. As of now, the DG is yet to complete the investigation. 
One Member ${ }^{3322}$ of the CCI, however, did not agree with the conclusion reached by the majority. Even if MMBL holds a dominant position vis-à-vis BG-II, there is no prima facie case for abuse of such dominance. The dissenting note says, “...it is not a violation of any provision of the Act, though it may have competition concerns. The remedy lies elsewhere. The decision of the Central Government to fix trait fee and prescribe terms of licensing under the Essential Commodities Act, 1955 could be one." 3323

In the meantime, MMBL moved to the Delhi High Court ${ }^{3324}$ asking it to stop the CCI from investigating. MMBL's main contention is that the CCI has no jurisdiction in respect of any matter related to IPRs, including rights pertaining to licensing of patents, which falls within exclusive jurisdiction of the patent authority, civil courts as provided under the Patents Act, 1970. The Court ${ }^{3325}$ refused to stay the investigations but directed CCI not to pass any final order. The matter is still sub judice.

However, in another case (Ericsson case; discussed below) with similar issues, the Delhi HC has ruled that CCI does have jurisdiction.

\subsubsection{Cotton Seeds Price (Control) Order, 2015}

The Cotton Seeds Price (Control) Order, 2015 (CSPCO) was issued by the Ministry of Agriculture and Farmers Welfare (MoAFW), India on $7^{\text {th }}$ December 2015 in exercise of the powers conferred by Section 3 of the Essential Commodities Act, 1955 (ECA). ECA is "an Act to provide, in the interest of the general public, for the control of the production, supply and distribution of, and trade and commerce, in certain commodities". As per S.2(a)(ix) of ESA, "cotton seed" forms an "essential commodity'.

According to the S.3 of ECA, "if the Central Government is of opinion that it is necessary or expedient so to do for maintaining or increasing supplies of essential commodity or for securing their equitable distribution and availability at fair prices, ..., it may, by order, provide for regulating or prohibiting the production, supply and distribution thereof and trade and commerce therein". Accordingly the CSPCO has been issued "to provide for an effective system for fixation of sale price for cotton seeds to ensure their availability to the farmers at fair, reasonable and affordable prices".

\section{Box 3: Important features of CSPCO, 2015}

The CSPCO was issued on farmers demand and it was necessitated because of fixation of sale price by multiple authorities that resulted in different prices in different states. This Order is for uniform regulation across India of the sale price of cotton seeds with the existing and future GM technologies.

The Controller under the Seed (Control) Order 1983 shall be the competent authority under CSPCO as well and shall have the power to regulate the sale price of cotton seed. The Controller shall advise the Government on the following:

\footnotetext{
3322 M.S. Sahoo

${ }^{3323}$ CCI Order dated 10 February 2016, Case No. 02/2015

${ }^{3324}$ Writ petition (civil) No. 1776/2016 and WP(C) No.1777/2016

3325 Vide its Order dated $29^{\text {th }}$ February 2016
} 
- Regulation of sale of Cotton Seeds at notified Maximum Sale Price (MSP)

- Prescription of licensing guidelines and format for all the GM Technology Licensing Agreements

- Any other matter referred to him for advice by the Government.

The CSPCO empowers the Government to notify MSP of cotton seeds from time to time. In determining the MSP the Government would have to take into consideration

- seed value

- license fee (trait value)

- trade margins

- other taxes.

The Government, while fixing the MSP, shall also fix and regulate the Seed Value and License Fee including royalty or trait value. For the purpose of fixing MSP, the Government may constitute a Committee, which shall have recommendatory power.

The fixed MSP would be notified on or before 31st March of every year applicable for the next financial year. "MSP fixation along with fixation of its components" shall be binding on all stakeholders including the Licensor and the Licensee, notwithstanding anything contained in any contract or instrument to the contrary. And importantly, the Government may also prescribe, by notification, a format for License Agreements.

The CSPCO further states that "any person who contravenes any of the provisions of this Order or fails to carry out any direction or requisition made thereunder, shall be punishable under section 7 of the ECA. This section prescribes imprisonment or fine or both.

After adhering to the recommendations of a nine-member Committee for the purpose of fixing MSP of Bt cotton seeds, in March 2016, the Government notified the MSP of Bt cotton seeds. The MSP of Bt Cotton seed (packets of 450gms) for financial year 2016-17 for the whole of India was fixed for BG-II at Rs.800, which included a cap of Rs.49 on Trait Value. It remained the same for 2017-18.

Furthermore, invoking the powers conferred by the CSPCO, the M/o AC\&FW issued a Notification on $18^{\text {th }}$ May 2016 containing "Licensing and Formats for GM Technology Agreement Guidelines", which was subsequently revoked and was published for comments. These guidelines are discussed below in details.

Meanwhile, within days of issuance of the CSPCO, MMBL filed a writ petition in Delhi HC challenging inter alia the provisions empowering the Govt. to determine royalty fee/trait value, as illegal and unconstitutional. MMBL submitted that the Government is unfairly regulating and expropriating its IPRs and freedom to negotiate and contract the terms of its licensing agreements with its sub-licensees. While the petition is still sub judice, the Court did not grant any stay.

Subsequently, the Association of Biotechnology Led Enterprises Agriculture Group (ABLE-AG), of which MMBL is a member, also filed a writ petition in Karnataka High Court, reportedly on same grounds as those raised by MMBL in Delhi HC. The Karnataka HC first granted a stay vide its $21^{\text {st }}$ March Order, but in May, 2016 it revoked its stay order. The matter is pending in both the high courts. 


\subsubsection{Licensing and Formats for GM Technology Agreement Guidelines}

Invoking the powers conferred by the CSPCO, the M/o A\&FW issued a Notification on $18^{\text {th }}$ May 2016 containing "Licensing and Formats for GM Technology Agreement Guidelines, 2016"3326. But due to opposition and viewing its wide implications, the notification was rescinded on $24^{\text {th }}$ May 2016 , and had been put as draft for comments. So far there has been no development on this.

The central philosophy, encompassing the issuance of the Guidelines \& Formats, is that the protection and management IP of a transgenic plant variety per se is governed by the PPVFR Act and not the Patents Act, even though biotechnology inventions are patentable.

\section{Box 4: Relevant features of the Draft GM Licensing Guidelines and Format}

The central philosophy, encompassing the issuance of the Guidelines \& Formats, can be read into the following paragraphs from the (draft) notification:

"...section 3 of the Patents Act, 1970 excludes a method of agriculture or horticulture and plants and animals in whole or any part thereof other than microorganisms but including seeds, varieties and species and essentially biological processes for production or propagation of plants and animals from the inventions...

...even though biotechnology inventions are patentable, once the GM Traits developed through biotechnology are transferred into a variety ("transgenic variety"), the transgenic variety per se cannot be patented; the seeds carrying such trait also cannot be patented and hence, the plant varieties including transgenic varieties carrying the GM Traits can be protected only under the Protection of Plant varieties and Farmer's Rights Act, 2001...

...the transgenic varieties become the intellectual property of the breeder or company who has developed it...

...based on the existing intellectual property rights regime for biotechnology, plants and varieties in the seed industry, it is felt necessary to prescribe the licensing guidelines so that all seed companies have access to the GM Traits without any restraint and at the same time biotech trait development is adequately rewarded under the fair, reasonable and non-discriminative mechanism (FRAND mechanism)..."

With respect to fixation of trait value, the guidelines states taking into account the following additional factors:

- year of patenting and commercialisation of the trait in India

${ }^{3326}$ http://egazette.nic.in/WriteReadData/2016/169713.pdf 
- efficacy of trait and gradual reduction in trait value from the year of commercial use in India

Post-notification of the guidelines, the maximum trait value may be up to 10 percent of MSP of GM Cotton seed (as fixed by the Government) for the initial period of five years from commercialisation. From sixth year the trait value shall taper down by 10 percent of initial trait value every year.

The Guidelines further states: "as the GM Traits are expected to have a limited period of efficacy, any GM Trait which loses its efficacy as reported by States and verified by the Indian Council of Agricultural Research (ICAR) shall not be eligible for any trait value whatsoever. Presence of the trait in the seed after the loss of efficacy shall not be a reason for claiming any trait value merely on the basis of patent for the technology which is used to develop the trait."

If new GM Traits commercialised after the publication of these Guidelines, the mutually agreed upfront fee will be subject to maximum ceiling not exceeding Rs. $2.5 \mathrm{mn}$ payable in two equal annual instalments.

In addition, the guidelines also provide certain clarifications/principles to be part of any GM licensing agreement. For instance:

- The Agreement shall be based on principles of equity and FRAND terms

- The GM Trait transfer will be on non-exclusive basis covering entire India

- The GM Technology used for developing the GM Trait shall be the property of Licensor, but the commercial exploitation rights and IPRs under PPVFR Act of transgenic cotton varieties developed by Licensee under this agreement shall rest with Licensee

- Although Licensee cannot transfer the GM Trait under the Agreement to any party without prior approval of the Licensor, the Licensee may license the transgenic variety developed by them under the agreement, having IPRs under the PPVFR Act, to any other company

- The Licensor shall transfer GM Trait to the licensee within 15 days of receipt of first instalment of upfront fee

- The Licensor shall not put any restrictive condition in the Agreement restraining licensee to get similar or other GM Traits or any other technology from other technology developers/licensor

- The Licensor shall also permit the Licensee to stack any other appropriate GM Trait from any other Licensor or trait developer as and when required so as to provide better agronomic value to the farmers

The GM Licence Guidelines requires that the licensor cannot refuse the grant of license to obtain approved GM Trait by any eligible seed company. That means the access to GM trait shall not become a barrier to entry into market. If the licensor does not award such license within 30 days of a request, 
the Licensee is deemed to have obtained the license for the GM Trait as per FRAND mechanism and the licensor shall abide the Guidelines.

\subsection{Examining Contentious Issues}

From the above descriptions at least three key contentious issues arise:

- Does the CCI have jurisdiction on the matters related with patent technology and its licensing?

- Can and should government intervene into regulation of licensing agreement of a proprietary technology using ECA, and consequently fix trait value as well as issue licensing guidelines?

- Should gene patents be licensed on FRAND terms in seed sector?

\subsubsection{CCI's jurisdiction}

The Patents Act bestows rights on a patent holder to prevent third parties from making, using, offering for sale, selling or importing the products using the said patent without its consent. The Act also presents a framework for exercise of such rights and remedies in cases of abuse of the patent rights. Therefore, it is generally contended that such matters pertaining to patents and licensing need to be dealt under the Patents Act and not under the Competition Act.

The Delhi High Court considering precisely the same issue related with the jurisdiction of the $\mathrm{CCI}$ in the case Telefonaktiebolaget LM Ericsson vs. Competition Commission of India \& Another ${ }^{3327}$ held that CCI has the jurisdiction to entertain cases related to 'abuse of dominance' and 'anticompetitive agreements' even when the product concerned is patented. The following paragraphs summarise the logic and reasoning given by the Court.

The Section 62 of the Competition Act states that "the provisions of this Act shall be in addition to, and not in derogation of, the provisions of any other law for the time being in force". Also S.60 of the Act says, "the provisions of this Act shall have effect notwithstanding anything inconsistent therewith contained in any other law for the time being in force". Therefore, mere plain reading of these two provisions, it is evident that the intention of the Parliament in enacting the Competition Act was not to curtail or whittle down the full scope of any other law, as the Act would be "in addition to, and not in derogation of" any other Act.

The Court also observed that the remedies as provided under Section 27 of the Competition Act for abuse of dominant position are materially different from the remedy as available under Section 84 (Compulsory License) of the Patents Act. It is also apparent that the remedies under the two enactments are not mutually exclusive; in other words grant of one is not destructive of the other. Thus, it may be open for a prospective licensee to approach the Controller of Patents for grant of compulsory licence in certain cases. The same is not inconsistent with the CCI passing an appropriate order under Section 27 of the Competition Act.

Furthermore, the provisions of Sections 21 and 21A of the Competition Act indicate that the intention of the Parliament was not to abrogate any other law but to ensure that even in cases where CCI or other statutory authorities contemplate passing orders, which may be inconsistent with other statutes, the opinion of the concerned authority is taken into account while passing the such orders. These provisions clearly indicates the Competition Act co-exist with other regulatory statues and be

${ }^{3327}$ W.P.(C) 464/2014; Judgement delivered by Delhi High Court on 30.03.2016 
harmoniously worked in tandem with those statues and as far as possible, statutory orders be passed which are consistent with the concerned statutory enactments including the Competition Act.

The Court also observed that the operative width of the two enactments is different. Whereas the Patents Act provides specific remedy to the 'person' seeking relief, the orders passed by CCI are in 'rem' (i.e. against or about a 'thing'). While the doors are open for the parties to initiate proceedings related with a patented product under the Patents Act, the jurisdiction of the CCI cannot be curtailed and hence any proceeding initiated on such product under the Competition Act are maintainable. Unless until, contrary view is given by the Supreme Court, this may be taken as settled.

\subsubsection{Government Intervention under ECA}

Although Essential Commodities Act, 1955 does not expressly provide for regulation of trait value, it gives wide powers to regulate or prohibit any class of commercial or financial transactions relating to foodstuffs or cotton textiles in public interest. The Indian Patents Act also does not supersede or eclipse the provisions of ECA vis-à-vis patented products. Thus, as per the rules of interpretations, both the enactments should be read together unless there is an express provision to the contrary.

The Karnataka High Court while revoking its earlier stay order (discussed above), had observed: "it is prima facie seen that the source of power to fix the maximum sale price including trait value is available and such step is taken to see that the essential commodity is made available at a fair price to farmers... to continue the interim order would not be in public interest... it is the government's duty to ensure production and supply of cotton seeds at a fair price and the interim order was hampering this". 3328

On the process of price fixation, the Court further observed that "it cannot be stated as arbitrary fixation at this stage since the documents produced on behalf of the government indicates that a committee was constituted to consider the price fixation and after providing opportunity to all the concerned parties, the price has been fixed, which has been notified" ${ }^{3329}$.

It may be noted that before governments began to intervene in controlling MSP of cotton seeds, trait value/license fee used to constitute around 67 percent of the retail price ${ }^{3330}$, making it evident that higher license fees was leading to higher seed prices. In 2006, Indian farmers were paying about Rs. 1600 to Rs. 1700 for 450 gram of Bt cotton seed, of which Rs.1250 was going to MMBL as trait value $\mathrm{e}^{3331}$.

Even the noted agriculture scientist, Dr MS Swaminathan has advocated for price control, saying "the government should have authority to use price controls in certain situations, but not to usurp the role of the market" 3332 . He further warns: "High seed prices and trait fees will come in the way of social inclusion on technological access - and social inclusion is fundamental to growth of the sector". 3333

\footnotetext{
3328 The Mint, 05-05-16

${ }^{3329}$ Financial Express, 05-05-16

3330 Manjunatha et al:: Need for Government Intervention in Regulating Seed Sale Price \& Trait Fee; Journal of Intellectual Property $\quad$ Rights, $\quad$ Vol 20, November $\quad 2015, \quad$ p385; http://nopr.niscair.res.in/bitstream/123456789/33583/1/JIPR\%2020(6)\%20375-387.pdf

${ }^{3331}$ Chaturvedi, Sachin; Technological Change and New Actors: Debate on Returns and Regulations; RIS, 2010

${ }^{3332}$ Seeds of Strife, Down to Earth, $31^{\text {st }}$ August 2010; http://www.downtoearth.org.in/news/seeds-of-strife-1737 ${ }^{3333}$ Ibid
} 
Table 1: Snap Shot of Price Control Initiatives by Various State Governments

\begin{tabular}{|l|l|l|}
\hline Price Control Initiatives & $\begin{array}{l}\text { Concerned } \\
\text { State }\end{array}$ & Current Status \\
\hline $\begin{array}{l}\text { Executive Order fixing the price at } \\
\text { Rs. } 650 \text { and Rs. 750 }\end{array}$ & Madhya Pradesh & $\begin{array}{l}\text { High Court (HC) quashed } \\
\text { the order (2008) }\end{array}$ \\
\hline $\begin{array}{l}\text { Ordinance issued notifying fixed } \\
\text { price for Bt cotton (BG- Rs. 650 } \\
\text { and BG II Rs. 750) }\end{array}$ & Maharashtra & $\begin{array}{l}\text { The Ordinance lapsed and } \\
\text { was re-issued on May 9, } \\
2009 . \text { Challenged in HC, } \\
\text { decision awaited. }\end{array}$ \\
\hline $\begin{array}{l}\text { Ordinance issued notifying fixed } \\
\text { price for Bt cotton (BG- Rs. 650 } \\
\text { and BG II Rs. 750) }\end{array}$ & Gujarat & $\begin{array}{l}\text { The Ordinance was replaced } \\
\text { with an Act. Challenged in } \\
\text { HC, decision awaited. }\end{array}$ \\
\hline $\begin{array}{l}\text { Ordinance issued notifying fixed } \\
\text { price for Bt cotton (BG- Rs. 650 } \\
\text { and BG II Rs. 750) }\end{array}$ & Andhra Pradesh & $\begin{array}{l}\text { The Ordinance was replaced } \\
\text { with an Act. Challenged in } \\
\text { HC, decision awaited. }\end{array}$ \\
\hline
\end{tabular}

Source: RIS Discussion Paper \#168 3334

Be that as it may, there have been backlash also on the CSPCO under the ESA. Monsanto warned by saying: "It is difficult. . . to justify bringing new technologies into India in an environment where such arbitrary and innovation-stifling government interventions make it impossible to recoup research and development investments. . . and where sanctity of contracts is absent". 3335

Similarly, Ashok Gulati has stated: “...This one will hit India's credibility in protecting IPR and, no wonder, most global seed companies feel hesitant in bringing their latest technologies to India precisely for this reason. Our public research is pitiable. Look at the entire ICAR budget for the country, which was around Rs.4840cr (USD0.8bn) in 2014-15. But Monsanto alone spent USD1.7bn in R\&D in 2014." 3336

Would government move really hit India's credibility in protecting IPRs, and consequently discourage investment and transfer of technology? In this regard, it must be noted that under IP policy 'agriculture' and 'health' have been looked upon differently since long, not only in India but in many other countries. These formed one of the most contentious items during Uruguay Round of trade negotiations and the trend continues in any other international negotiation.

Contrary to what Monsanto Inc. has observed, Boeing in its submission to the United States Trade Representative (USTR) has said: "the Boeing Company conducted a detailed review and determined that India maintains adequate Intellectual Property Rights legal framework for the company's aerospace and defence products... Boeing continues to have a positive experience with Indian customers, partners, and suppliers on IPR protection... ${ }^{3337}$ Indian IPR laws are comparable to IPR regulations in developed countries as India is signatory to all major conventions and treaties on this subject". 3338

Similarly, Honeywell International is on record saying: "India's IPR framework was one of the key enablers in the establishment of Honeywell's engineering and technology presence." 3339

\footnotetext{
${ }^{3334}$ Supra17

${ }^{3335}$ Financial Times, 14.03.2016

${ }^{3336}$ Indian Express, 14.03.16

3337 The Hindu Business Line, 15.04.2016

3338 The Economic Time, 13.05.2016

3339 ibid
} 
Therefore, India's IP regime is very much conducive to attract R\&D investments in the country. It does have differentiated approach for seed and pharmaceutical sectors, but the same is akin to the policy space provided under international agreements. More so, the Central Government has shown much restraint in intervening into matters of patented technology and has a National IPR Policy to facilitate investment in innovation.

Since 1988, when the seed industry was liberalised through New Policy on Seed Development, there has been tremendous growth of private (both domestic and foreign) seed companies. By 2010 more than 80 percent of turnover in seed business came from private seed companies. ${ }^{3340}$ About 90 percent of new varieties that has been registered under PPVFR Act are hybrids developed by private seed companies. ${ }^{3341}$

Similarly, the National Seed Policy, 2002, recognises the importance of GM technology, when it says: "Biotechnology will be a key factor in agricultural development in the coming decades. Genetic engineering/ modification techniques hold enormous promise in developing crop varieties with a higher level of tolerance to biotic and abiotic stresses. A conducive atmosphere for application of frontier sciences in varietal development and for enhanced investments in research and development is a pressing requirement. At the same time, concerns relating to possible harm to human and animal health and bio-safety, as well as interests of farmers, must be addressed".

The point is that the policy environment for foreign investment in Indian seed sector, in general, and GM seed sector, in particular, is quite conducive. And few government regulations to safeguard national/farmers' interests do not create such a bad situation for investment and technology transfer. The Indian seed market remains more liberalised than that of China, which severely restricts FDI and trading in certain types of seeds. ${ }^{3342}$

Farmer groups have been the main demanders for price regulation of $\mathrm{Bt}$ cotton seed and so far various State Governments have been fulfilling this demand. But when due to fixed MSP (without capped trait fee), the domestic seed companies (sub-licensee companies) found their profits getting significantly squeezed, they began to put pressure on respective state governments. Subsequently, Telangana/Andhra Pradesh began intervening into fixing 'royalty/trait value'. This triggered similar actions by cotton growing states, which in turn led to number of court cases.

While one set of court cases were initiated challenging the said move of the state governments, another set of court cases were initiate between few sub-licensees and MMBL, whether to pay according to government fixed trait value or as prescribed by the license contract between the two parties. Most of these cases are still pending. The Central Government, in the meantime, decided to issue CSPCO, assuming itself the responsibility of price control of Bt cotton seeds, including fixing trait value/fee.

It may also be pertinent to note here that most stakeholders (farmers groups, state governments etc.) have been demanding inclusion of price control under the new Seed Bill (introduced twice in the Parliament, 2004 and 2010). ${ }^{3343}$ Major part of the Bill, if it becomes an Act, would be implemented by State Governments, where chances of adhering to populist measures are much

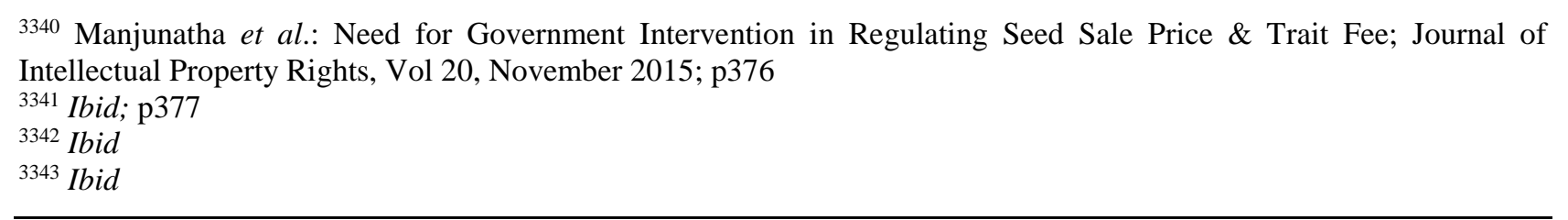


higher. Almost all the private seed companies (domestic and foreign) are opposed to this approach of price control - directly under an Act, implemented by state governments ${ }^{3344}$.

If at all a price control regime is needed, the seed companies would rather prefer a softer law approach under an administrative Order, implemented by Central Government. Under this approach it is easier to amend and withdraw notifications than that under the former approach.

Therefore, the present move by the Central Government in fixing MSP of Bt cotton seeds, including royalty/trait value, vide an administrative order, tends to bring more certainty, transparency and homogeneity as far as policy environment is concerned. The emerging price control pattern in GM cotton looks like: patent holder (say Monsanto) would negotiate "royalty/trait fee" for transferring its patented technology (say BG-III) with GOI. Once that is done, GOI would notify the MSP of such GM cotton seed for whole of India.

This emerging pattern seems to present a middle path, from regulation and competition perspective. On the one extreme is a situation where a patent holder using its dominance in the market negotiates with domestic seed companies individually, having weak bargaining power, resulting in unreasonable MRP. On the other extreme is a situation where state governments in their populist zeal intervening to control the price, including royalty fee, and reducing it to such lower level that neither patent holders nor (sub)licensees are happy.

\subsection{Patents and gene-editing}

Patents on life forms had been a subject matter of contentious debate since the Uruguay Round of trade talks, mainly because of its effect on pharmaceutical (health) and seed (agriculture) sectors. After intense negotiations, the text in the TRIPs Agreement, that finally emerged in form of Article 27(3)(b), excluded plants and animals from patentable subject matter. The TRIPs Agreement gave choice to Member states to exclude from patentability: (i) plants and animals, and (ii) essentially biological processes for the production of plants and animals. But it required Members to provide patent protection for: (i) microorganisms, and (ii) non-biological and microbiological processes for the production of plants and animals. However, the Agreement provided for review of the Article 27(3)(b), which is still pending and the issue can re-emerge any time in future.

Using the flexibility, the Indian Patents Act excluded from patentability: (1) discovery of any living thing or non-living substance occurring in nature ${ }^{3345}$, and (2) plants and animals in whole or any part thereof other than micro-organisms but including seeds, varieties and species and essentially biological processes for production or propagation of plants and animals ${ }^{3346}$.

Therefore, patents related to genes can be contested on at least two grounds. First, does the isolation of gene amount to a 'discovery'; and second, whether genes are 'parts of plant or animal'. More or less, such contentions are found in most jurisdictions, including that of developed countries. For instance, in the case of the Association for Molecular Pathology v. Myriad Genetics Inc. (2013), the Supreme Court of the United States ruled that isolated DNA is not patentable subject matter under

\footnotetext{
${ }^{3344}$ It should be noted that "Agriculture, including agricultural education and research, protection against pests and prevention of plant diseases" is a State Subject under the Constitution of India, which enables the State Government to regulate Bt Cotton seed price.

3345 Section 3(c)

${ }^{3346}$ Section 3(j)
} 
United States law, and that such isolated nucleotide sequences are barred by the 'product of nature' exclusion to patentability.

The US Supreme Court, however, did allow that DNA manipulated in a lab is eligible to be patented because DNA sequences altered by humans are not found in nature. Thus complimentary DNA (cDNA) sequences can be patented in the US. The Court held: "A naturally occurring DNA segment is a product of nature and not patent eligible merely because it has been isolated, but cDNA is patent eligible because it is not naturally occurring."

The same gene patent of Myriad Inc. was also subject of litigation in Australia. Unlike the US law, where "laws of nature, natural phenomena and abstract ideas" are exceptions to patentability, under the Australian law an invention is prima facie patentable if it is a 'manner of manufacture'.

The High Court of Australia (the apex court), in D'Arcy v. Myriad Genetics, held that a gene's substance is information embodied in arrangements of nucleotides and hence is not a manner of manufacture. The information is not 'made' by human action. Disallowing the Myriad patent, the Court observed that "while the invention claimed might be, in a formal sense, a product of human action, it was the existence of the information stored in the relevant sequences that was an essential element of the invention as claimed". Thus, the key element of isolated DNA - the genetic information itself - is not patentable in Australia.

Although it was human gene that was involved in the above said Myriad cases, the rulings does/would have effects on the patents pertaining to agricultural biotechnology. The Indian Patent Office (IPO) has also granted multiple patents claiming isolated genetic material and nucleotide sequences $^{3347}$. The Bt Cotton Technology was granted patent in India in 2009.

The "Guidelines for Examination of Biotechnology Applications for Patent" (GEBAP), published by the IPO in 2013, explicitly states that "products such as microorganisms, nucleic acid sequences, proteins, enzymes, compounds, etc., which are directly isolated from nature, are not patentable subject-matter".

\section{Box 5}

\section{Guidelines for Examination of Biotechnology Applications for Patent: Relevant Features}

The GEBAP, which is meant for patent examiners and are non-binding in nature, has cautioned saying:

“...there are some issues relating to patentability of biotechnological inventions which are of serious concern to the users of Patent System such as novelty, obviousness, industrial applicability, extent of disclosure and clarity in claims. In addition, a few special issues have also evolved such as those relating to moral and ethical concerns, environmental safety, issues relating to patenting of Expressed Sequence Tags of partial gene sequences, cloning of farm animals, stem cells, gene diagnostics, etc. Thus, the patenting of inventions in the field of biotechnology poses challenges to the applicants for patents as well as to the

3347 Jefferson, David J. and Padmanabhan, Meenu S., Recent Evolutions in Intellectual Property Frameworks for Agricultural Biotechnology: A Worldwide Survey; Asian Biotechnology and Development Review, Vol.18 No.1; RIS 2016 
Patent Office... These guidelines are intended to help the examiners and controllers of the Patent Office so as to achieve uniformity and consistency"

\begin{abstract}
"biotechnology deals with living subject matters and involves alteration of genomic materials of an organism. Such change may influence or may have a deep impact upon the environment or the human, animal or plant life or may involve serious questions about morality. Hence, adequate care should be taken while examining the inventions vis-à-vis their primary or intended use or commercial exploitation and it should be carefully dealt so that the subjectmatter must not be contrary to public order, morality or causes serious prejudice to human, animal or plant life or health or to the environment."
\end{abstract}

As far as biotech patents in India are concerned, till 2002, patents were not granted for inventions relating to (a) living entities of natural or artificial origin, (b) biological materials or other materials having replicating properties, (c) substances derived from such materials and (d) any processes for the production of living substances/entities including nucleic acids.

In 2002, the Calcutta High Court, in its decision in Dimminaco AG v. Controller of Patents and Designs opened the doors for the grant of patents to inventions where the final product of the claimed process contained living microorganisms. The court held that a new and useful art or process is an invention, and where the end product (even if it contains living organism) is a new article, the process leading to its manufacture is an invention. That there was no statutory bar in the patent statute to accept a manner of manufacture as patentable even if the end product contained a living organism.

In 2002, the Patents Act was amended and biochemical, biotechnological and microbiological processes were included within the scope of chemical processes for the grant of patent. The definition of "invention" was also changed to "any new product or process involving an inventive step and capable of industrial application" thereby deleting the word "manner of manufacture" as mentioned in the earlier Act. The 2005 amendment of the Patents Act paved the way for the grant of product patents in any field of technology including biotechnology with certain exceptions.

Although, microorganisms are excluded from non-patentability list, a conjoined reading with Section 3 (c) of the Act implies that only modified microorganisms, which do not constitute discovery of living thing occurring in nature, are patentable subject matter under the Act. ${ }^{3348}$

Be that as it may, India does not provide for patents on seeds. Using TRIPS flexibility, India provides protection to the new plant varieties via a sui generis legislation Protection of Plant varieties and Farmer's Rights Act, 2001 (PPVFR Act). Under this law, like plant breeders, farmers also have 'rights', inter alia to save, exchange and sell (in non-branded form) seeds from their fields, even if the same is protected under the Act. India is not a member of UPOV, mainly because of farmers' rights under PPVFR Act; even though the concept of Plant Breeders' Rights (PBRs) is largely based on those provided under UPOV.

Private seed companies mostly develop hybrid varieties, which though can be re-sown but yield declines substantially. Therefore, farmers would need to buy every season. This gives protection to the investments of seed companies.

${ }^{3348}$ Guidelines for Examination of Biotechnology Applications for Patent, 2013 
Bt cotton seed, however, presents a special case where the 'Bt cotton technology' is patented, while the new varieties in which Bt gene has been inserted are provided with PBRs under the PPVFR Act. According to the draft GM License Guidelines (discussed above) in such a situation the IP protection of the GM seed would be per se under PPVFR, which does not pose much hurdles in the access of patented GM traits. A case for licensing under FRAND term has been made. This apparently goes against the rights of patent holders under the Patents Act, and hence presents a conflicting situation between the two IP legislations.

The National Seed Association of India (NSAI), body of domestic seed companies (of which most Bt licensees are members), however, goes a degree further. According to the NSAI interpretation, all breeders and researchers - public or private - have "right to access to trait" and the trait owner can be compensated under benefit sharing scheme provided by the PPVFR Act. (See Box 6 for details.)

\section{Box 6: Stated position of NSAI}

The position of NSAI with respect to the application of right legislation for fixation of trait value can be read into the following paragraphs, taken from their letter to Niti Ayog. Excerpts:

We would like to reiterate that as per the Indian IPR laws which are TRIPS compliant, the seeds and plants cannot be patented. Monsanto obtained patents in India for cotton transformation and event identification based on their patents of US under PCT. However, it can be noted that the claims granted to them by the Indian patent office does not cover any IP rights to Monsanto on seeds and plant varieties as specifically prohibited under Section 3(j) of the Indian Patents Act, 1970. The IPR for seeds and plant varieties are covered by a sui generis enactment known as Protection of Plant Varieties and Farmers' Rights (PPVFR) Act, 2001 in India. Therefore, the subject of Bt cotton seeds is entirely covered only under this enactment.

As per the provisions under Section 30 of PPVFR Act, all the breeders in public, private seed companies or research institutes have a right to use any protected variety including a transgenic variety carrying a transgenic trait for developing new varieties which are registerable for IP protection under Section 18 of the Act and can enjoy IP protection under Sections 24 and 28 which includes rights to exclusive commercialisation.

The developer of a trait like Monsanto is also provided rights under Section 26 to claim benefit share which has to be determined only by the PPVFR Authority. All the breeders who used such trait are liable to pay a trait value as determined by the Authority under the benefit sharing agreement. The Authority is also empowered to facilitate recovery of the benefit share amount in case the breeders fail to pay to the trait developer.

The provisions of the PPVFR Act are balanced taking care of the interest of the trait developers, breeders, seed companies and the farmers. The trait developer 


\begin{tabular}{l} 
can make claims and justify such claims so that the Authority can fix appropriate \\
trait value. \\
NSAI recommended to the Department of Agriculture \& Cooperation to issue \\
guidelines under the PPVFR Act so that the PPVFR Authority determines the \\
trait value which the breeders have to mandatorily pay for using such trait for \\
developing new varieties. As access to trait is provided as a right under PPVFR \\
Act, no licensing of a trait is required under the law. This is part of the IP \\
legislation of India and therefor there may not be any need to use the provisions \\
of the Essential Commodities Act, 1955. \\
\hline Source: Letter from NSAI to Niti Ayog; dated 09.09.2016, Ref: NSA/2016/107
\end{tabular}

In light of the interpretations presented by the D/o Agriculture Cooperation and Farmers' Welfare and the NSAI, it becomes apparent that there is an inherent tension between the two legislations Patents Act, 1970 and the PPVFR Act, 2001 - demanding legal clarity on the issue. In addition, as the two laws are under the jurisdiction of two different departments/ministries (viz. DAFW and DIPP) matter could become worse.

The National Intellectual Property Rights Policy, 2016 (adopted by the Cabinet on $12^{\text {th }}$ May 2016) clearly visualise such situations when it says:

"Intellectual property in India is regulated by several laws, rules and regulations under the jurisdiction of different Ministries/Departments. A number of authorities and offices administer the laws. The legal provisions need to be implemented harmoniously so as to avoid conflict, overlap or inconsistencies among them. It is necessary that the authorities concerned administer the laws in coordination with each other in the interest of efficient administration and user satisfaction. Legal, technological, economic and socio-cultural issues arise in different fields of IP which intersect with each other and need to be addressed and resolved by consensus in the best public interest." (emphasis added)

Furthermore, the Objective 3 of the National IPR Policy, 2016 is "to have strong and effective IPR laws, which balance the interests of rights owners with larger public interest". Under this objective, the Policy inter alia envisages "identifying important areas of study and research for future policy development", which includes: (1) Interplay amongst IP laws, and between IP laws and other laws to remove ambiguities and inconsistencies; and (2) IP interface with competition law and policy.

Therefore, to resolve the said conflict "by consensus in the best interest of public"; studies should be conducted to remove ambiguities and inconsistencies and also stakeholder consultations in different parts of the country. Further, studies on the IP interface with competition law and policy in the GM Cotton Seed sector may also be conducted with the aims to make policy recommendations vis-à-vis balance of the rights and obligations, which may include licensing on FRAND terms.

\section{References}

Manjunatha et al.: Need for Government Intervention in Regulating Seed Sale Price \& Trait Fee; Journal of Intellectual Property Rights, Vol 20, November 2015, pp 375-387; http://nopr.niscair.res.in/bitstream/123456789/33583/1/JIPR\%2020(6)\%20375-387.pdf 
Jefferson, David J. and Padmanabhan, Meenu S., Recent Evolutions in Intellectual Property Frameworks for Agricultural Biotechnology: A Worldwide Survey; Asian Biotechnology and Development Review, $\quad$ Vol.18 No.1; $\quad$ RIS https://www.researchgate.net/publication/294728197_Recent_Evolutions_in_Intellectual_Property Frameworks_for_Agricultural_Biotechnology_A_Worldwide_Survey

CCI Order dated 10 February 2016, Case No. 02/2015 http://www.cci.gov.in/sites/default/files/Ref\%20Case\%20022015\%20\%26\%20others.pdf

George, Mathews P.; http://spicyip.com/2016/03/monsanto-case-ip-and-competition-lawdimensions.html

Guidelines for Examination of Biotechnology Applications for Patents, IP India, March 2013

The Cotton Seeds Price (Control) Order, 2015

Licensing and Formats for GM Technology Agreement Guidelines, 2016

National Intellectual Property Rights, 2016 


\section{Chapter 3: New forms of financing the agricultural sector in Brazil: The experience of the soybean chain}

Sylvia Saes (USP, Brazil), Rodrigo Lanna F. da Silveira (Unicamp, Brazil), Beatriz Saes (USP, Brazil)

\subsection{Introduction}

Since the late 1980s, Brazilian agricultural chains have undergone profound transformations resulting from structural economic changes. On one hand, the opening up of the national market from the 1990s contributed to the concentration and internationalization of input companies. On the other, increased exports, coupled with technological progress, stimulated the expansion of production to the frontier areas, constituting also a concentrated industry structure based on the use of modern inputs. The new forms of financing required by the emerging agriculture producers were not met by the State, whose role in the economy was already decreasing. From the late 1980s and early 1990s, the private sector gradually assumed functions previously carried out by the State, such as the financing of agricultural production, the provision of information, and the development of mechanisms to stabilize production.

Our paper aims to analyze the evolution and recent trends in the organization of agricultural markets and their implications for agricultural chains' actors and for the financing of agriculture. We seek to shed light on the relationships between soybean farmers and agro-industries, focusing on the Central-West region of Brazil, which is characterized as the main agriculture frontier in the late 20th century, and is also currently the region with the highest grain production in the country.

The paper is organized as follows. Section 2 begins with a brief contextualization of the structural change in Brazilian agriculture. In addition, we present the main aspects of the consolidation of Brazilian exported-oriented soybean agriculture. Section 3 focusses on the central role of the new organizational forms of Brazilian soybean chains to explain the sector performance. Section 4 presents our final considerations regarding these new trends of the organization in the agricultural chains. The study notes that while these new forms of financing enable the market to function properly, they also represent a way for input and processors firms to appropriate margin on both sides of the production chain.

\subsection{Structural change in Brazilian agriculture}

\subsubsection{The effects of the Brazilian crisis of the 1980s on rural credit}

The Brazilian industrialization policies between 1930s and 1970s, characteristic of the import substitution model, ${ }^{3349}$ had important consequences for the agricultural sector. Especially from the 1960s, in addition to supplying a growing urban population, the performance of domestically-oriented agriculture was seen as functional to national industrialization since it was an essential factor in keeping real wages in urban areas at low levels. As a result, the rigidity of agricultural supply was seen as one important cause for the emerging inflationary process. Because the advance of industrialization also depended on the expansion of the capacity to import machinery and equipment,

3349 The import substitution model is a model of late industrialization that existed in Latin America approximately between the 1930s and 1960s. It was based on the protection of national industrial sectors in order to reduce the import coefficient of these economies. For more information, see Hirschman (1968). 
the investment in the development of new crops and the modernization of agriculture was seen as a means of diversifying the export basket, still heavily dependent on coffee and sugarcane. ${ }^{3350}$

In 1965, based on the hypothesis that technology diffusion was fundamental to agricultural development, the National System of Rural Credit (NSRC) was created to provide subsidized financing to producers for the acquisition of modern inputs. The Minimum Price Guarantee Policy from 1966 sought to guarantee minimum income to producers and reduce future price uncertainty, as well as indicate which production should increase in order to supply the domestic market. Finally, in the 1970s, the special programs for occupancy of the Cerrado biome promoted the development and modernization of agriculture in Brazil's Central-West. Their main effect was to expand the agricultural frontier in the country through grain production (Souza et al., 1999, Coelho, 2001).

The Brazilian external debt crisis in the 1980s, followed by low economic growth and increasing inflation, definitively compromised the import substitution model and the agricultural policies associated with it. In particular, World Bank credit supports to Brazil from 1982 were provided with specific conditions related to deregulation of national markets and public debt reduction. From 1987, economic policy reforms that promoted trade liberalization, deregulation, and privatization of Brazilian companies were reflected in important changes for the agricultural sector, including a more export-oriented strategy (Farina, 2001).

By the late 1970s, the NSRC had consolidated two main sources of financing: the required ratio on demand deposits ${ }^{3351}$ and funds from the National Treasury. The required ratio on demand deposits provided between $10 \%$ and $15 \%$ of total rural credit in the 1970s, while the resources from the National Treasury accounted for about 85\% (Coelho, 2001). However, the price inflation from the late 1970s undermined the volume of demand deposits available to rural credit, despite the increased level of deposit liabilities to be used by the NSRC. In the face of rising inflation, the population had to leave their money in savings to protect their wealth, with the result that from 1972 to 1989 , the ratio of money resources (money and demand deposits) to total financial resources in commercial banks fell from 37\% to only 7.8\% (Araújo, 2011).

Furthermore, the extinction of the Bank of Brazil's Movement Account in 1986, from which the State could fulfill its economic policy objectives based on automatic monetary supplies, significantly reduced the rural credit available from the National Treasury (Saes and Silveira, 2014). Just before the extinction of the Movement Account (1985), the National Treasury provided around $90 \%$ of total resources granted by rural credit. By the late 1980s, it provided less than $30 \%$ (Coelho, 2001). This drastic rupture of public financing channels of agriculture in the 1980s is described by Figure 1.

\section{Figure 1. Annual credit from the National System of Rural Credit and Brazilian grain production}

\footnotetext{
${ }^{3350}$ It is also important to observe that, as in other countries, agriculture policies were designed to deal with the specific characteristics of national agriculture, including the uncertainties associated with the dependence on environmental and climatic factors.

${ }^{3351}$ A minimum percentage of demand deposits that commercial banks are required to lend to agriculture.
} 


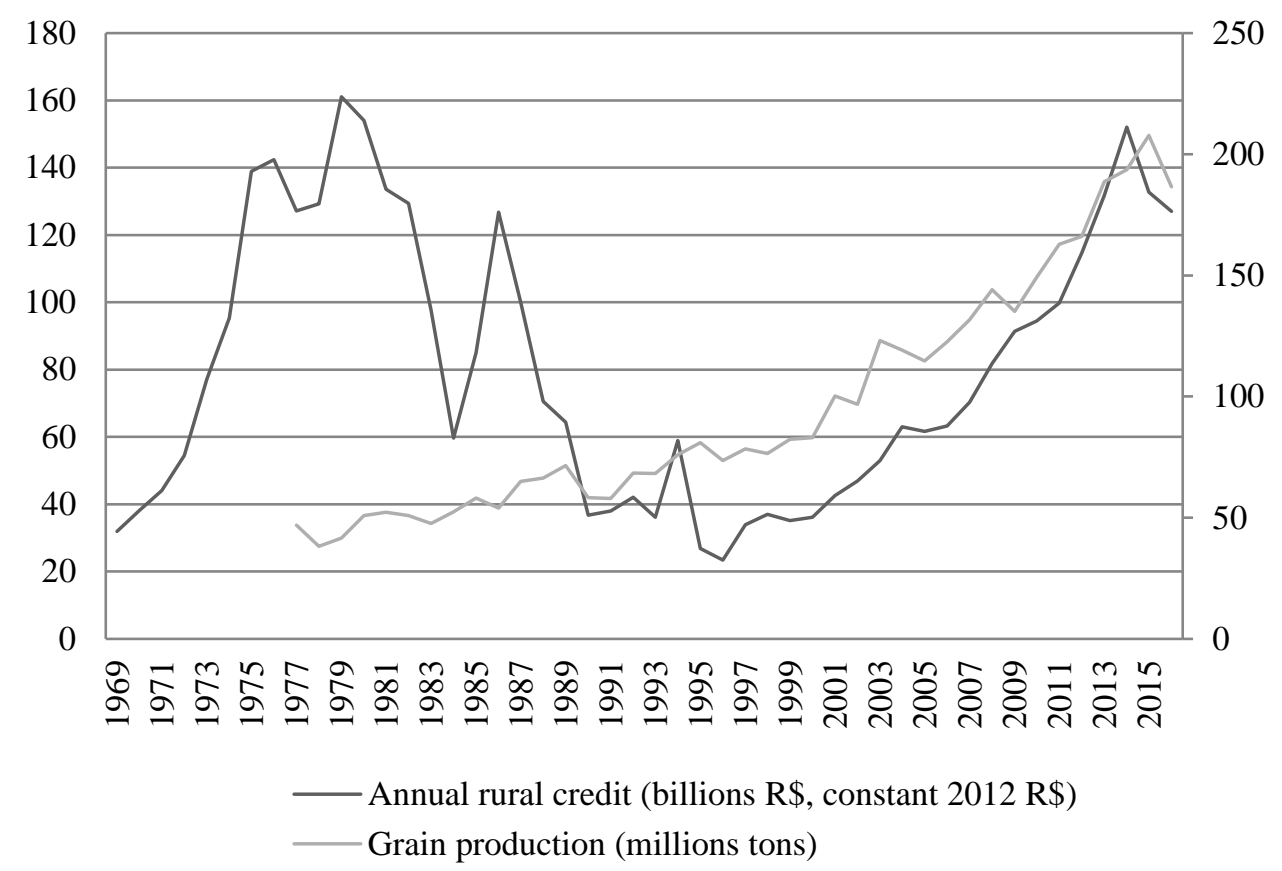

Source: Central Bank of Brasil (Department of Regulation, Supervision and Control of Operations of Rural Credit and Proagro-DEROP_Department of Regulation, Supervision and Control of Rural Credit Operations and Proagro-DEROP) and Conab (Brazilian Food Supply Company).

It is true that after reaching its lowest level in 1996, the amount of annual rural credit began to recover, and in the 2000s underwent significant growth. The stabilization of prices following the Real Plan in 1994 dramatically reduced the subsidy embedded in the interest rates of the rural credit, ${ }^{3352}$ but also increased the available volume of demand deposits. The required ratio on demand deposits had an increasing role in rural credit, reaching $28 \%$ of the total by 2016 (Figure 2). Also, the Rural Savings Account, created in 1986 in response to the financing crisis, has grown significantly, taking the place of the National Treasury as the most important financing source. ${ }^{3353}$ In its first year of operation (1987), the credit from Rural Savings already represented 23\% of total credit, and although it has undergone several cycles in the 1990s and 2000s, its participation reached $34 \%$ in 2016. Likewise, BNDES has become an important financing source since 1991, mainly through the FINAME line (Financing of Machinery and Equipment) (Coelho, 2001, Araújo, 2011, BCB, 2017).

In the meantime, Law 11,076 created new agribusiness financing securities in 2004, aiming to expand the participation of the private sector in financing agribusiness, thus reducing the role of the federal government. Although the spread of these new securities is relatively recent, we can see in Figure 2 that the Agribusiness Credit Bill (LCA) already represented 8\% of total rural credit in $2016 .{ }^{3354}$ The LCA is a nominative and freely negotiable security representing the promise of payment in cash originated from businesses between rural producers - or their cooperatives — and

\footnotetext{
3352 Between 1973 and 1993, real interest rates were often negative due to high inflation rates (Araújo, 2011).

${ }^{3353}$ Despite the drastic reduction of its role as a lender, the National Treasury from the mid-1990s began to concentrate its resources on the equalization of interest rates (by paying the banking system the difference between the interest rate it would like to receive and the one set by the NSRC). Therefore, the National Treasury, even if indirectly, also stimulated the increase of rural credit supply (Ramos and Martha Junior, 2010).

3354 The other securities created by Law 11,076 are Certificate of Agricultural Deposit (CDA), Agricultural Warrant (WA), Agribusiness Receivables Certificate (CRA), and Agribusiness Credit Rights Certificate (CDCA).
} 
third parties. They are issued exclusively by a financial institution, public or private, and are income tax-free, which make them more attractive for investors.

\section{Figure 2. Rural Credit by financing sources in 2016}

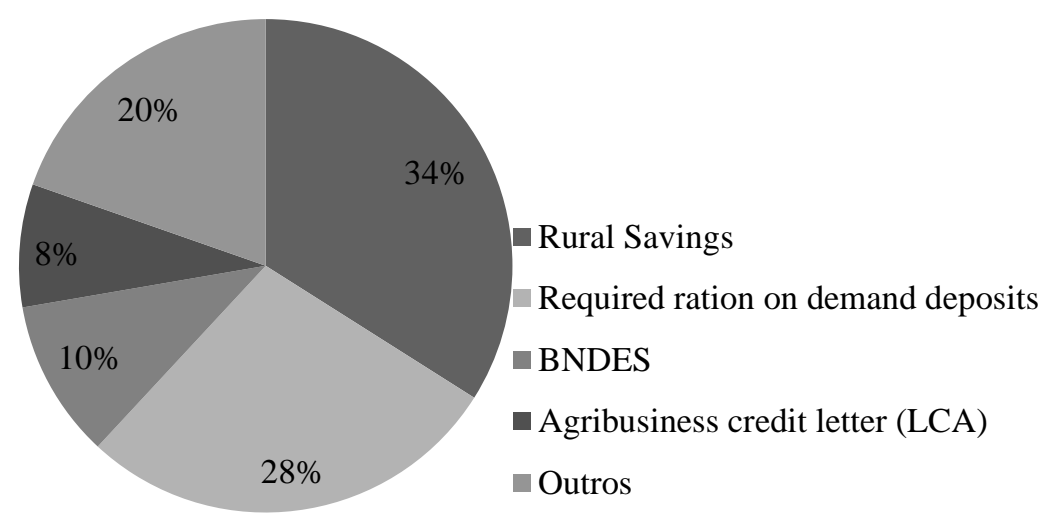

\section{Source: Central Bank of Brazil}

Even with the recovery of rural credit from 1996, it remained far short of the financing needs and growth of Brazilian agricultural production. While annual rural credit only returned to 1970s levels by 2015 , grain production showed a significant and steady growth throughout the period-from less than 50 million tons to about 200 million tons (Figure 1). Thus, in relative terms the recovery of rural credit was much less vigorous, either for grains or in agriculture in general. In addition, the importance of diversifying the beneficiaries of financing was recognized in recent decades. From the mid-1990s, there was an important effort to undo distortions and imbalances that had been produced by the rural credit policy, since mainly a small number of large producers were able to appropriate the subsidized credits. In this sense, the National Program for the Strengthening of Family Agriculture (PRONAF) was instituted in 1996 with the purpose of financing agricultural and non-agricultural activities operated by family farmers. ${ }^{3355}$

Another interesting aspect of Figure 1 is the apparent non-correlation between rural credit and grain production. Indeed, the granting of subsidized credit had been of great importance for the expansion of grain production in the 1970s. However, the abrupt reduction in the supply of credit during the following decade did not have a negative effect on the upward trend in grain production. In order to understand how grain production, and particularly soybean production, was not negatively affected by the scarcity of rural credit, we will present in the next section the transformations of the sector in the last decades, which were determinant for the emergence of alternative sources of financing to official rural credit.

\subsubsection{Consolidation of Brazilian exported-oriented soybean agriculture}

\footnotetext{
${ }^{3355}$ In the 2000s, Pronaf's share of the total volume of rural credit was around $11 \%$. Nevertheless, some studies point to a still unequal distribution of rural credit, in which small producers, landless farmers, and other disarticulated groups find many obstacles to access credit (see Belik, 2015).
} 
Although the first soybean crops in Brazil date from the end of the 19th century, it was only in the 1960s that its production became significant, concentrated mainly in the southern region of the country. Since the 1970s, soybeans have been the fastest growing grain crop in both Brazil and the world. In Brazil, the production growth since 1980 has been over 500\%, and made this crop the main Brazilian agribusiness. Figure 3 shows this important growth, which resulted from both a significant expansion of cultivated land and increasing productivity over time, insofar as production increased more sharply than planted area.

\section{Figure 3. Brazilian soybean production, exports and planted area}

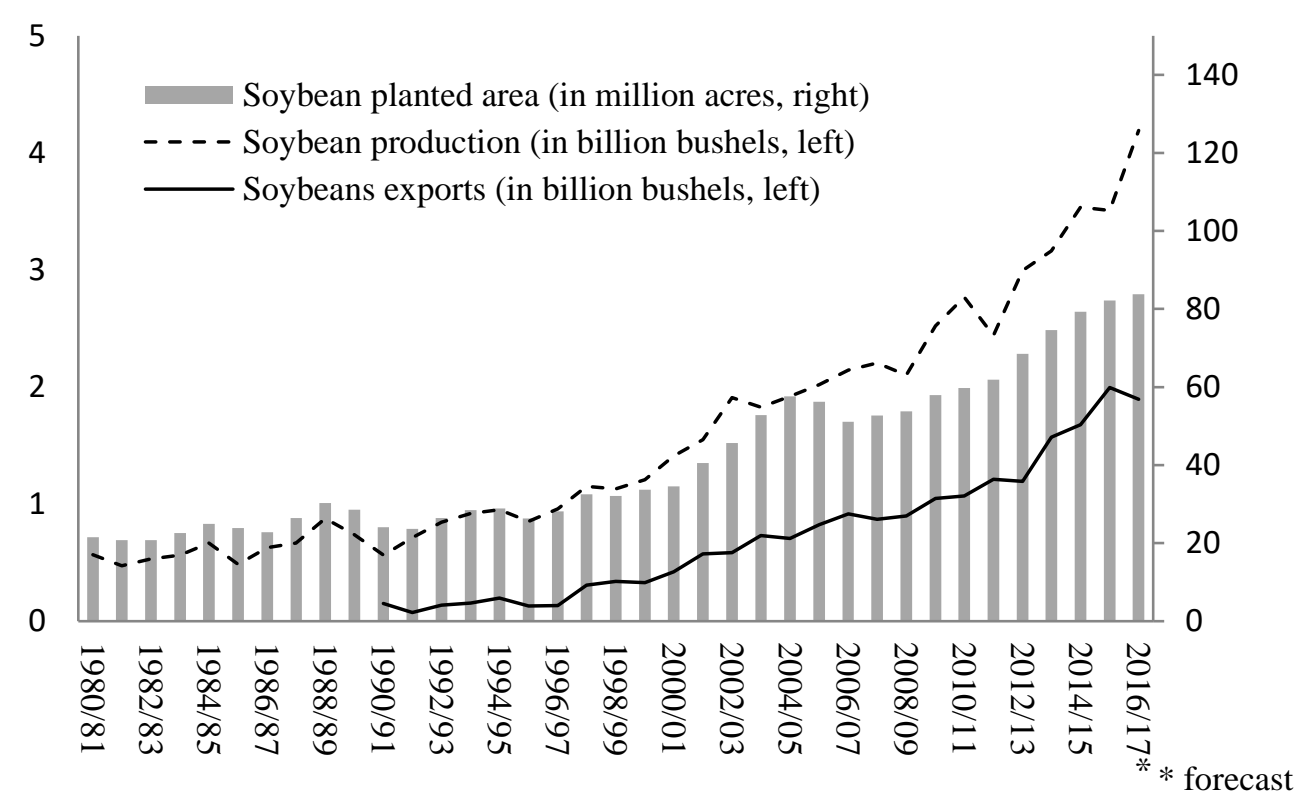

Source: Conab (Brazilian Food Supply Company) and UN Comtrade Database.

Many factors contributed to this rapid rise in soybean cultivation. First, as already emphasized, it was fundamental to grant a large volume of credit subsidized through the National Rural Credit System from 1965 onwards. Particularly throughout the 1970s, subsidies increased significantly due to the inflationary process, reaching the maximum level of $-38.5 \%$ (measured by the difference between the interest rate and the inflation rate). On the other hand, the Minimum Price Guarantee Program (PGPM) had the role of eliminating price risks for the producer by setting a guaranteed price before planting, to take effect after harvest. The system was operated from two main instruments: Federal Government Loans (EGF) and Federal Government Acquisitions (AGF). The first, which made it possible to stock the crop in the harvest/off season, was the main financing instrument for marketing in agriculture and was especially important for soybeans - about 55\% of EGFs between 1975 and 1983 were destined for soybeans. AGFs, in turn, were important in stimulating the advancement of the agricultural frontier, since they involved subsidies to transport costs (Coelho, 2001).

Even more important for the advancement of the agricultural frontier were the special programs for the occupation of the Cerrado (Brazilian savannah). The POLOCENTRO (Program for Development of the Cerrados), implemented between 1975 and 1982, was intended to stimulate a rapid development and modernization of the Brazilian Center-West region by granting subsidized 
credit for both agriculture and infrastructure (mainly roads and electrification). The main beneficiaries were large and medium producers, and except for areas of livestock pasture, the most cultivated product was soybeans. The Program involved a significant area: during its term, 6 million acres of Cerrado were converted into cultivated land, but directly and indirectly, the Program reached more than 9 million acres. Of no less importance was the participation of the Brazilian Agricultural Research Corporation (EMBRAPA), which promoted the development of agronomic research and appropriate technologies for the Cerrado (Coelho, 2001, Dall'Agnol et al., 2007). The success of these policies that aimed to promote the advancement of the agricultural frontier can be seen in the change in distribution of soybean production among Brazilian regions throughout the 1970s and 1980s (Figure 4).

Figure 4. Regional distribution of Brazilian soybean production (in million bushels)

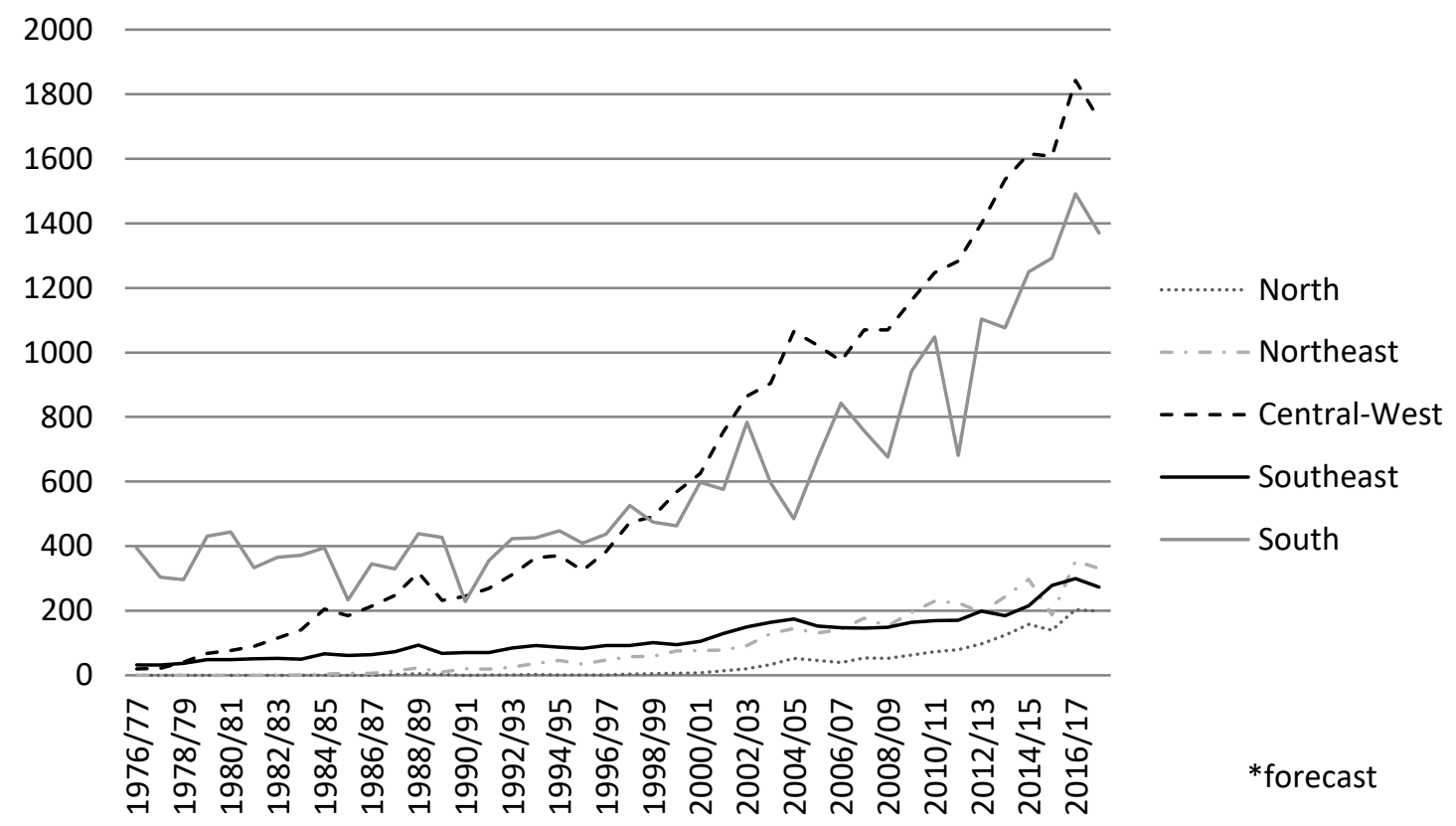

Source: Conab (Brazilian Food Supply Company)

The advance of soybean cultivation to the Center-West region was accompanied, as shown in Figure 3, by the expansion of exports from the 1990s. It is possible to say that Resolution 155 of the National Council of Foreign Trade (CONCEX) of 1988, which put an end to the qualitative and quantitative restrictions on rice, maize, and soybean exports, marks the beginning of a growing orientation of soybean cultivation towards the external market (Souza et al., 1999). Especially in the Center-West region, production growth was also directly related to the development of so-called export corridors, based on waterways and railroads located in the central and northern regions of the country (Fearnside, 2001).

In this context, despite the scarcity of rural credit and the weakening of PGPM, the warming of the international market certainly contributed to the expansion of the production of this crop. And, despite the appreciation of the Brazilian currency (Real) in the second half of the 1990s, exports continued to expand significantly. A factor that contributed to this was the introduction of the Kandir Law (Complementary Law 87) in 1966, which promoted the exemption of the ICMS tax on Brazilian 
exports of basic and semi-processed products, thus stimulating exports of grains. In the 2000s, this process was further stimulated by the great expansion of Chinese demand for commodities in the international market.

However, greater trade liberalization and the expansion of soybean exports alone are not sufficient to explain how the rural credit crisis did not significantly affect the growing performance of soybeans. Certainly fundamental was the expansion of the participation of foreign capital in the sector, with important consequences for the organization of the sector and for relations among the agents of the soybean production chains. As Jank et al., (2001) shows, the liberalization of foreign investments throughout the 1990s led to a rapid internationalization and concentration, through mergers and acquisitions, of the Brazilian agro-industrial chains. Increasing foreign investment, promoted mainly by multinational corporations, was seen as an opportunity both to penetrate the domestic market and to take advantage of the recent liberalization of international trade.

In the soybean chain, there has been a rapid concentration since 1995 as a result of the acquisition of 12 large national companies by four multinationals: Bunge, Louis Dreyfus Commodities, Archer Daniels Midland (ADM), and Cargill (collectively known as ABCD) (Jank et al., 2001). These four trading companies alone acquired almost $60 \%$ of all grains exported by Brazil in 2003. Although in recent years Asian trading companies have increased their share of the Brazilian grain market, the ABCD still play a decisive role in the negotiation of soybean crops (see Bonato, 2016). In Brazil, trading companies have always been more important in the Cerrado, where soybean cultivation is more recent and to some extent has progressed with the entry of these multinationals. In traditional farming areas located in southern Brazil, cooperatives played a greater role in the acquisition of soybeans (Lazzarini and Nunes, 1998).

On the other hand, the input industry for soybean cultivation was also affected by the economic transformations underway in the 1990s. In the previous decades, the genetic material for the crop was developed mainly by public institutions such as EMBRAPA and by some domestic private companies. The entry of multinational biotechnology companies in the country only occurred after the sanction of the Law of Protection of Cultivars (Law 9.456) of 1997, which protected the intellectual property rights of cultivars. Since 1997, the multinational Monsanto has acquired several national companies and developed the RR (Round-Up Ready) GM soy, consolidating itself as the leading producer of genetically modified seeds (Lazzarini and Nunes, 1998). In 1998, the National Technical Biosafety Commission (CTNBio) concluded that the use of the genetically modified Roundup Ready cultivar does not pose environmental or health risks, authorizing the planting of transgenic soybeans in Brazil. In the 2016/17 crop, it was estimated that $96.5 \%$ of soybean production was GM, equivalent to 32.7 million hectares (Celeres, 2017).

The dependence of domestic production on the use of inputs produced by large technology companies, coupled with the change in Brazilian agricultural policy, especially concerning the financing instruments, resulted in a new organization and coordination of agro-industrial systems, characterized by the greater participation of the input industry. In addition to determining more complex relationships between the productive segments, this general process delineates and influences a large part of the determinants of the return margins of the producer segment.

\subsection{New organizational forms of Brazilian soybean chains}


In the last decades, as mentioned in the previous section, important changes in institutional, organizational, and competitive environments have been observed in the soybean agro-industrial chain in Brazil. As a consequence, a new scenario has arisen involving different forms of commercialization of the production and financing of the agricultural activity. Two main factors explain this process: the first is based on the gradual exit of the State as a financier of agricultural activity, given the fiscal crisis of the State in the 1980s. Part of this role has been transferred to the private sector, promoting changes in the pattern of financing of national agriculture.

The second factor is the increase in competition and market concentration in the input and grain processing sectors. Large multinational companies, with the objective of expanding market share and/or guaranteeing grain provision, have developed and implemented new contractual arrangements with producers, bringing innovations in the forms of commercialization and financing of the activity.

The first milestone of this changing scenario occurred in the 1980s, when so-called "trocatroca" ("swap") and "green soy" contracts were first observed in the Central-West region of Brazil. The first represents an agreement in which the producer receives inputs (seeds, Fertilisers, and pesticides) from a company before planting, and undertakes to pay with sacks of soybeans obtained at harvest. The second consists of an early sale of the production to a grain trader or mill. The producer receives a set amount of resources from the company at the time of planting and delivers part of its production, tied to the financial volume captured, during the harvest period (Terra, 2012).

This framework of innovations has gained new shape since 1994, with the creation of the Rural Product Certificate (CPR). Defined as an exchange note, tradable in the market, the CPR consists of a promise of future delivery of a certain agricultural product. Upon the issuance of this paper, carried out by a rural producer (or a cooperative/producers' association), a commitment is made to the issuer, and there is a duty to settle on maturity. At first, this repayment occurred only by physical delivery. In addition to eliminating the risk of a lack of funds for planting costs, the producer manages the price and marketing risk of the product. However, the reliance on physical delivery represented an obstacle to the expansion of the negotiation of the CPR, since it prevented the participation of potential financiers not interested in receiving the agricultural product. In 2001, in order to attract new agents in this market, the financial CPR was developed (Silva and Lapo, 2012). In this contract, instead of delivering the goods to the counterparty, the producer liquidates the security in cash at a certain price, which can be fixed (defined at the time of the transaction) or indexed by an indicator relative to the spot or futures market. However, it should be noted that in the financial $\mathrm{CPR}$, the producer has the risk of commercialization of the product, and there is also the price risk when considering the modality with fixed price quotation.

\section{Figure 5. Modalities of Rural Product Certificate (CPR).}



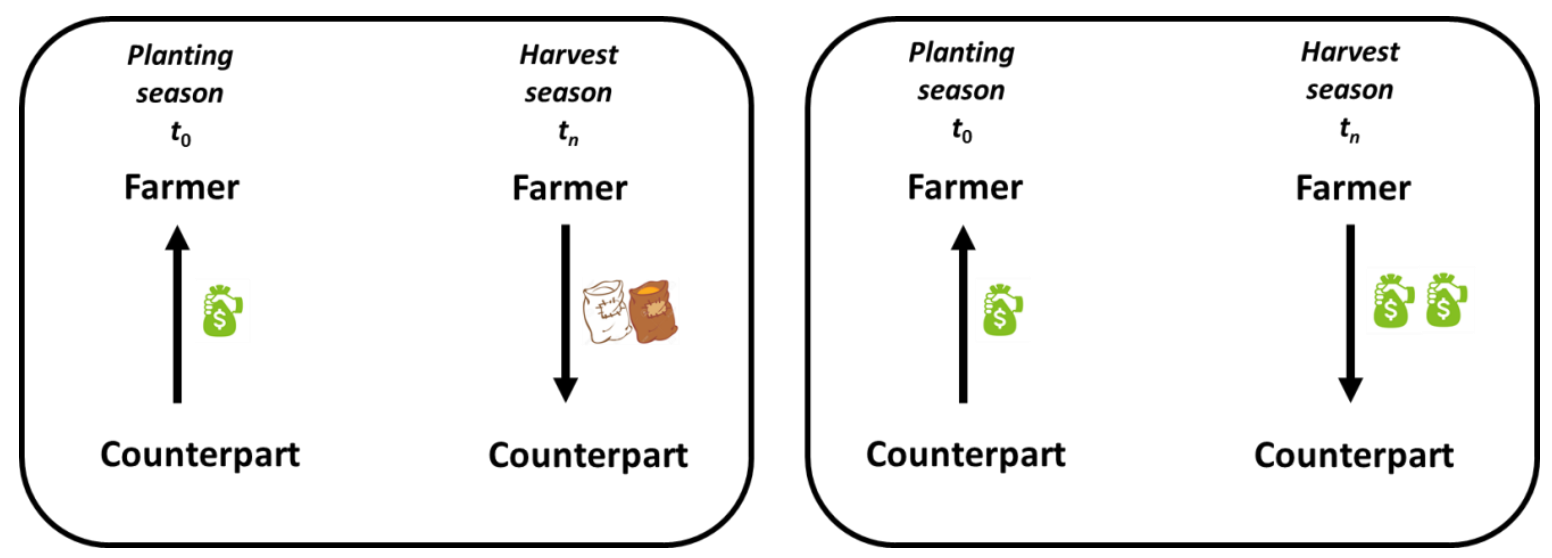

(a) Physical CPR (b) Financial CPR

New forms of fundraising were created in 2004 with the creation of five titles: Agricultural Deposit Certificates (CDA), Agricultural Warrant (WA), Agribusiness Credit Letters (LCA), Agribusiness Credit Rights Certificates (CDCA), and Agribusiness Receivables Certificates (CRA). In general, these securities are based on agricultural products or agricultural debt securities. In addition, they have the function of increasing fundraising in the financial market directed to different agents that operate in the agribusiness. Table 1 presents a summary of the characteristics of these securities. While the CDAs and WAs have a unique focus on agricultural producers (with the goods deposited in the warehouse), the LCAs, CDCAs, and CRAs allow the collection of resources by different agribusiness agents, being backed by credit rights (CPRs, Rural Promissory Notes, CDAs, WAs, and export contracts, among others).

Of note in this set of securities is the growth in funding through CRAs, given the possibility, since 2012, of public offers. According to Aoun (2012), the issuance of these bonds goes through three stages: i) agribusiness agents (producers, cooperatives, and companies) buy inputs from a supplier, using CPRs as collateral; ii) the company supplying the inputs issues CDCAs, these being backed by the CPRs; and iii) securitization companies buy discounted CDCAs and then issue CRAs to investors. For the latter, the advantage lies in the fact that there is no levy of income tax on earnings, besides the existence of attractive profitability. On the other hand, when the transaction matures, because the payment of receivables occurs directly from agribusiness agents to investors, the latter are exposed to credit risk. Large agribusiness companies, such as Monsanto, Bayer, Bunge, and Syngenta, have used this tool to raise funds. 
Table 1. Characteristics of the CDA, WA, ACL, CDCA, and CRA

\begin{tabular}{|c|c|c|}
\hline Title & Definition & Issuer \\
\hline CDA & $\begin{array}{l}\text { Title based on the promise of } \\
\text { delivery of a product deposited in } \\
\text { warehouse }\end{array}$ & $\begin{array}{l}\text { Warehouse at the request of the } \\
\text { depositor of the agricultural product }\end{array}$ \\
\hline WA & $\begin{array}{l}\text { Title that grants the right to pledge } \\
\text { on the underlying asset to CDAT }\end{array}$ & $\begin{array}{l}\text { Warehouse at the request of the } \\
\text { depositor of the agricultural product }\end{array}$ \\
\hline CDCA & $\begin{array}{l}\text { Representative title of promise of } \\
\text { payment, with credit rights backed } \\
\text { (denominated receivables), }\end{array}$ & $\begin{array}{l}\text { Agricultural cooperatives or legal } \\
\text { entities engaged in commercialization, } \\
\text { processing or industrialization of } \\
\text { agricultural products or inputs } \\
\text { (including machinery) }\end{array}$ \\
\hline LCA & originating in businesses carried out & Public or private financial institutions \\
\hline CRA & & $\begin{array}{l}\text { Agribusiness receivables securitization } \\
\text { companies }\end{array}$ \\
\hline
\end{tabular}

Source: Silva (2006)

In this context of transformations and creation of new titles involving the agribusiness, contractual arrangements have developed in which large multinational companies advance resources or inputs to producers, becoming an important alternative for financing the agricultural activity. Contractual variations are observed in relation to the price setting, the payment term, and the agents (Leme and Zylberstajn, 2008).

An example of such arrangements is based on the "harvest term" sales mechanism, performed between soybean producers and input suppliers. The latter deliver seeds, Fertilisers, and pesticides to the producers who, after approximately six months (with the commercialization of the grain), make the payment. Silva and Lapo (2012, p. 7) point out that the concession of inputs "can occur through direct sales to the producer (from the manufacturer itself) or between the manufacturer and the input distributor (resale or cooperative), who will then pass the harvest term condition to the producer (their client)."

Another modality of production financing, which has been particularly widespread in the grain market of Brazil's Central-West for the costing of soybeans and winter corn, is called a barter. This consists of a triangular operation between producer, input company, and trading company (agribusiness or exporter). As can be seen in Figure 6, the producer receives the input (technological package) from the supplier/company before planting, and is committed to delivering a portion of its production to a trading company as a form of payment. The latter agent, when selling the grain, makes the payment to the input company. The collateral for these operations is generally the CPR, which is issued by the producer.

\section{Figure 6. Exchange operation (barter)}




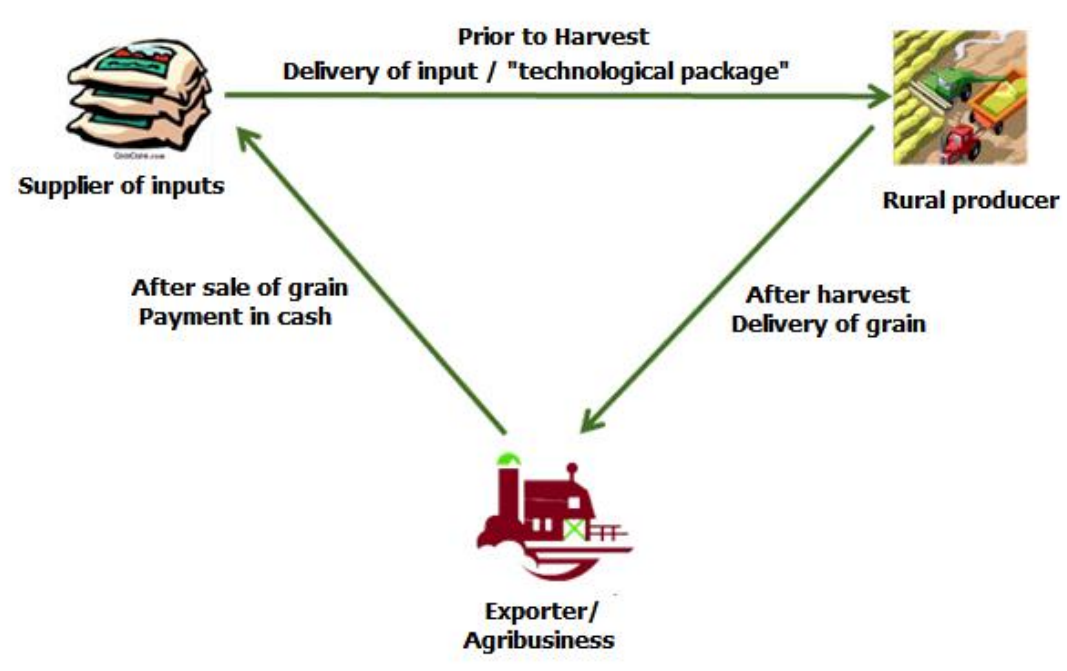

Source Silva (2012).

The mechanism described above illustrates a more complex organizational form in which coordination between different actors in the chain (from input to export companies) is required. In recent years, agricultural machinery companies (especially manufacturers of tractors and harvesters), such as Case New Holland and AGCO Corp., have also made barter operations available to soybean producers in Brazil, with Cargill partnering. The barter service is offered in Brazil by large companies such as Bayer, Pioneer, Monsanto, Syngenta, Cargill, ADM, Adama, Bunge, and Louis Dreyfus (Clarifi, 2017). In addition, Banco do Brasil, the country's leading rural credit bank, has developed a barter model in which the bank advances resources, with CPRs as collateral. Thus, the risk of the operation, which was concentrated in the input suppliers, is transferred to the bank. In order to obtain funds for such an operation, the bank uses LCA emissions as collateral.

On the one hand, these operations allow management of the risk of lack of resources for the farmer's activity. As Silva (2012, p. 69) mentions, "the producer receives the input and markets his production without the need for financial disbursement." Such operations are still capable of generating benefits related to the risk price management (grain price, input price, and exchange rate), as well as reducing the need to stock the products and ensuring greater practicality and time savings in the establishment of contracts between the agents involved (Arakawa, 2014, Leme and Zylbersztajn, 2008). On the other hand, since some large companies act simultaneously in the input sector (especially in the field of Fertilisers) and as buyers of grain, this operation represents a way of appropriating margin of both sides of the supply chain, besides being a form of increasing market share (Silva, 2012). Bertrand et al. (2005) observe the fragilities of these contractual arrangements due to the dependence from the producer to the input and trading companies. In addition, the producer ends up with short-term obligations at higher interest rates compared to government credit.

As already mentioned, rural credit arising from these contractual arrangements with the private sector has been gaining importance in the grain supply chain in Brazil. Buainain et al. (2014) analyze data from the Agrosecurity consultancy company, which points out that in the 2009/10 harvest, $47 \%$ of the resource requirements for the Central-West producers were supplied by companies in the sector, and only $24 \%$ originated from loans from banks and credit unions. In the South, there is an inverse participation: $45 \%$ of the funding needs come from financial institutions and $27 \%$ from input and trading companies. Equity in both regions corresponds to approximately one-third of the capital requirements for the cost of the activity. 
Figure 7. Distribution of resource sources for funding in the Center-West and Southern regions of Brazil in the 2009/2010 harvest.

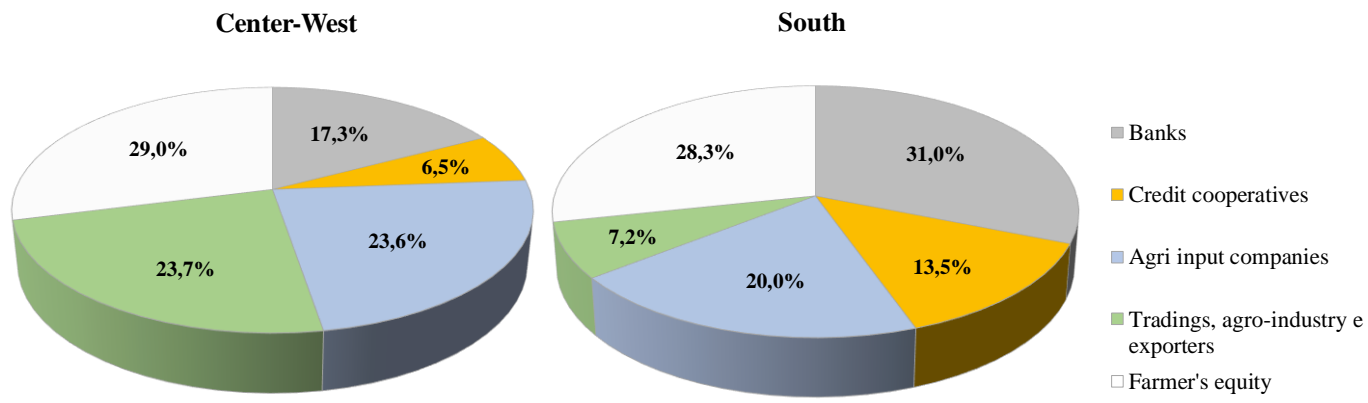

Source: Silva (2012)

According to the Matogrossense Institute of Agricultural Economics (IMEA), between 2008 and 2017, resources for crops in Mato Grosso do Sul - Brazil's largest soybean producing state, responsible for approximately one third of national production - came primarily from multinationals and resellers (43\%), followed by equity (33\%), and loans from the banking system (24\%).

In this context, Leme and Zylberstajn (2008), based on interviews with 200 soy producers in the states of Mato Grosso and Goias, studied the factors determining the choice of soybean producers for contractual arrangements with companies to purchase Fertilisers. The results showed that producers who opted for exchange operations, had the perception that such transactions generated savings in time and resources, as well as solving problems of lack of own capital for acquiring the input. In addition, higher-yielding, more risk-averse, and more reliable soy producers had a greater tendency to adopt such contractual arrangements.

Figure 8. Participation of resource modalities in the financing of soybean producers in the state of Mato Grosso between 2008 and 2017

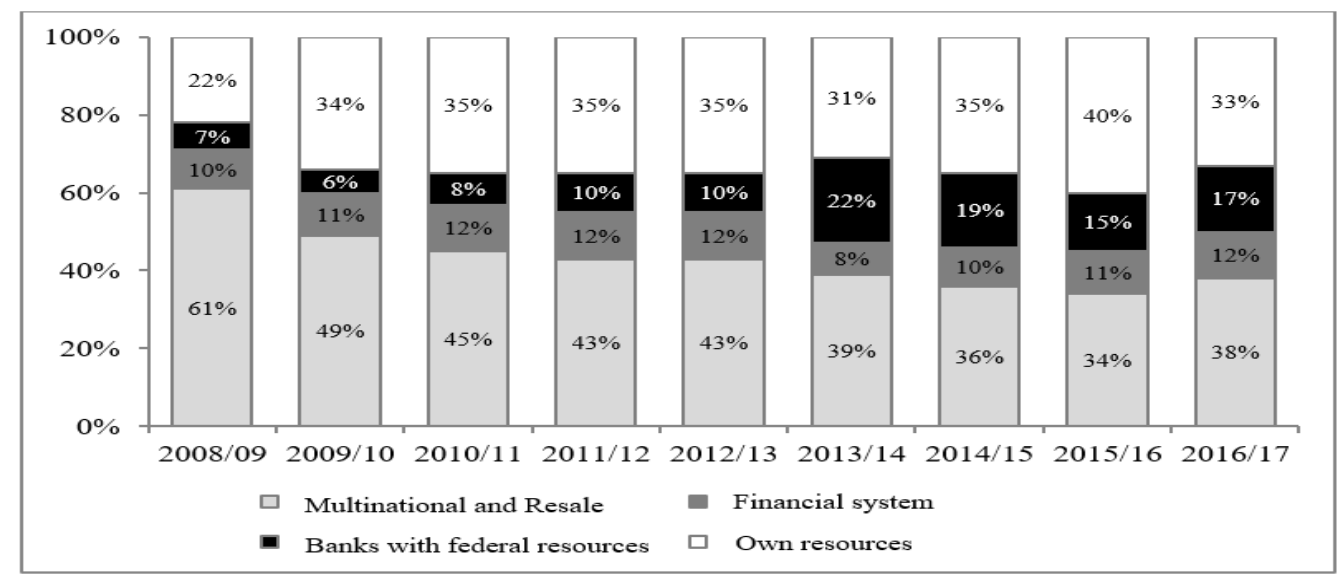

Source: IMEA (2017) 
Thus, changes in the institutional and competitive environments of the soybean agro-industrial chain in Brazil have led to new forms of grain commercialization and financing of production costs. Such innovations have allowed a reduction of the transaction costs among the agents of the chain, besides being arrangements that guarantee, in general, less exposure to the risks of price and commercialization to the producer. It should be noted, however, that given the high interest rates that these contracts charge, these operations are especially used by producers in periods of low availability of rural credit from the federal government and own resources (as in 2016/17 given the 2015/16 crop failure).

\subsection{Conclusions}

This study aimed to explore how soybean production in Brazil has become one of the most important in the world in terms of quantity and productivity, despite having to deal with severe restrictions in state financing since the 1980s.

Throughout the text it is possible to emphasize that, in seeking to understand the logic of the relationship between business strategy and the organization of agricultural supply chains, one must take into account the institutional and competitive environments that surround them, particularly with regard to the deregulation of markets and increasing industrial concentration.

It was observed that the new configuration of financing for the sector came into being first through the previous support of public policy in the years of abundant subsidized credit, which allowed the opening of border areas to large properties, and second, due to investments in agricultural technology, with emphasis on the research by EMBRAPA - Brazil`s Research Corporation. No less important was the restructuring of the downstream and upstream segments of the production segment, previously marked by more competitive characteristics but subjected to mergers and acquisitions, resulting in a strong concentration of this market. The concentration of the processing segment has led to a greater need to acquire inputs by promoting more "tied" contracts, which determine the consolidation of new patterns of financing of agricultural production, with a strong role in obtaining input and guaranteeing the "fidelity" of supply.

In addition to generating more complex relationships among the productive segments, these new configurations, in determining the property rights of resources, show how the distribution of income occurs in the value chain.

As a result of this process, there is no denying the creativity of companies to adopt, test, and improve different forms of financing that have enabled the sector to obtain competitive gains, becoming the top soy exporter in the world. However, it should be emphasized that these new forms also represent the dependence of the producer on the trading companies, which end up appropriating margins from both sides of the supply chain operation.

\section{References}

Aoun, S. Financiamento da produção agrícola: expansão do mercado de derivativos. Análises e Indicadores do Agronegócio, v. 7, n. 9, 2012.

Arakawa, H. H. Percepção do produtor agrícola em relação às operações de barter: um estudo da região de Lucas do Rio Verde (MT). Dissertação (Mestrado em Economia Aplicada) - Escola Superior de Agricultura Luiz de Queiroz, Universidade de São Paulo, Piracicaba, 2014. 
Araújo, P. F. C. Política de crédito rural: reflexões sobre a experiência brasileira. Textos para Discussão CEPAL-IPEA, 37. Brasília, DF: CEPAL. Escritório no Brasil/IPEA, 2011.

BCB - Central Bank of Brazil. Matriz de dados do crédito rural. Available at: http://www.bcb.gov.br/pt-br/\#!/c/MICRRURAL/.

Belik, W. O Financiamento da Agropecuária Brasileira no Período Recente. Texto para discussão, Instituto de Pesquisa Econômica Aplicada. Brasília: Rio de Janeiro: Ipea, 2015.

Bertrand, J-P.; Cadier, C.; Gasques, J. G. O crédito: fator essencial à expansão da soja em Mato Grosso. Cadernos de Ciência \& Tecnologia, v. 22, n. 1, p. 109-123, 2005.

Bonato, G. Tradings do ABCD perdem espaço no mercado brasileiro de grãos para rivais da Ásia. Notícias de Negócios. Reuters. 23 de março de 2016. Disponível em: http://br.reuters.com/article/businessNews/idBRKCNOWP2BM?sp=true.

Buainain, A. M.; Santana, C. A. M.; Silva, F. P.; Garcia, J. R.; Loyola, P. O tripé da política agrícola brasileira: Crédito rural, seguro e Pronaf. In: Antônio Márcio Buainain; Eliseu Alves; José Maria da Silveira; Zander Navarro (Org.). O mundo rural no Brasil do século 21: a formação de um novo padrão agrário e agrícola. 1ed.Brasília: Embrapa, 2014.

Celeres. $3^{\circ}$ levantamento de adoção da biotecnologia agrícola no Brasil, safra 2016/17. Impresa, 18 de abril de 2017. Available at: http://www.celeres.com.br/3o-levantamento-de-adocaoda-biotecnologia-agricola-no-brasil-safra-201617/.

Clarif. Barter como modelo de negócio. 25 de outubro de 2017. Disponível em: www.clarif.com.br.

Coelho, C.N. 70 anos de política agrícola no Brasil (1931-2001). Revista de Política Agrícola, Ano X, n.3. Ministério da Agricultura, Pecuária e Abastecimento, jul/ago/set. 2001.

Dall'Agnol, A., Roessing, A.C., Lazarotto, J. J., Hirakuri, M. H., Oliveira, A. B. O complexo agroindustrial da soja brasileira. Circular Técnica Embrapa, Londrina, n. 3, p. 1-12, set. 2007.

Farina, E. M. M. Q.; Azevedo, P. F.; Saes, M. S. M. Competitividade: Mercado, Estado e Organizações. São Paulo: Singular, 1997. 283 p.

Farina, E.M.M.Q. Challenges for Brazil's food industry in the context of globalization and Mercosur consolidation. International Food and Agribusiness Management Review, 2(3/4): 315-330, 2001 .

Fearnside, P. M. Soybean cultivation as a threat to the environment in Brazil. Environmental Conservation, v. 28, n. 1, p. 23-38, 2001.

Hirschman, A. O. The political economy of import-substituting industrialization in Latin America. The Quarterly Journal of Economics, v. 82, n. 1, p. 1-32, 1968.

Instituto Matogrossense de Economia Agropecuária - Imea. Composição do funding do custeio da soja para safra 2016/17 em Mato Grosso. Imea, 2016.

Jank, M. S., M. F. P. Leme, A. M. Nassar, and P. F. Filho. Concentration and internationalization of Brazilian agribusiness exporters. International Food and Agribusiness Management Review, v. 2, n. 3/4, p. 359-374, 2001.

Lazzarini, S.G., Nunes, R. Competitividade do sistema agroindustrial da soja. In: Farina, E.M.M.Q.; Zylbersztajn, D. Competitividade no Agribusiness Brasileiro. São Paulo: PENSA/USP/IPEA, 1998. p.194-420. 
Leme, M. F. P.; Zylbersztajn, D. Determinantes da escolha de arranjos institucionais: evidências na comercialização de fertilizantes para soja. Revista de Economia e Sociologia Rural, v. 46, n. 2, p. 517-546, 2008.

Ramos, S. I., Martha Junior, G.B. Evolução da política de crédito rural brasileira. Planaltina, DF: Embrapa Cerrados, 2010.

Saes, M. S. M.; Silveira, R. L. F. Novas formas de organização das cadeias agrícolas brasileiras:Tendências recentes. In A. M. Buainain et al., eds. O mundo rural no Brasil do século 21. Brasília: EMBRAPA, 2014.

Silva, F. P.; Lapo, L. E. R. Modelos de financiamento da cadeia de grãos no Brasil. In: $2^{\mathrm{a}}$ Conferência em Gestão de Risco e Comercialização de Commodities. BM\&FBOVESPA, São Paulo, 2012.

Silva, G. de S. Novos instrumentos de financiamento do agronegócio brasileiro e uma análise das alternativas de investimentos para o CDA/WA. 2006. Dissertação (Mestrado em Economia Aplicada) - Escola Superior de Agricultura Luiz de Queiroz, Universidade de São Paulo, Piracicaba, 2006.

Souza, E. L. L.; Saes, M. S. M.; Nunes R. Mudanças institucionais e desempenho da produção de milho e soja. Gestão \& Produção, v.6, n.3, p. 185-200, 1999.

Terra, L. U. A Cédula de Produto Rural (CPR) como alternativa de financiamento e hedging de preços para a cultura da soja. Dissertação (Mestrado em Engenharia de Produção) - Universidade Federal de Santa Catarina, 2002.

Zylbersztajn, D., Jank, M. S. Agribusiness in Mercosur: building new institutional apparatus, (1998) 14(4) Agribusiness 257. 